$94^{1}$

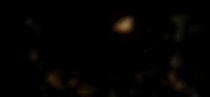

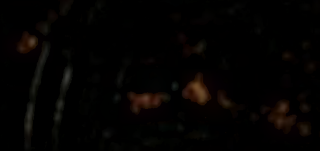
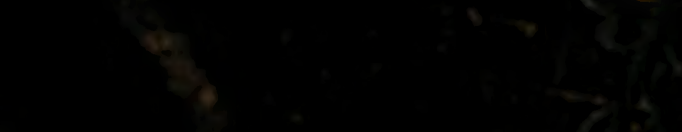


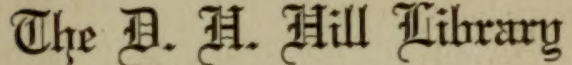

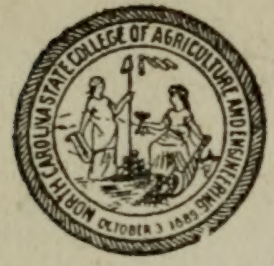

sAcIAL COLLCTIONS

Zurth Carolina State College

S511
583

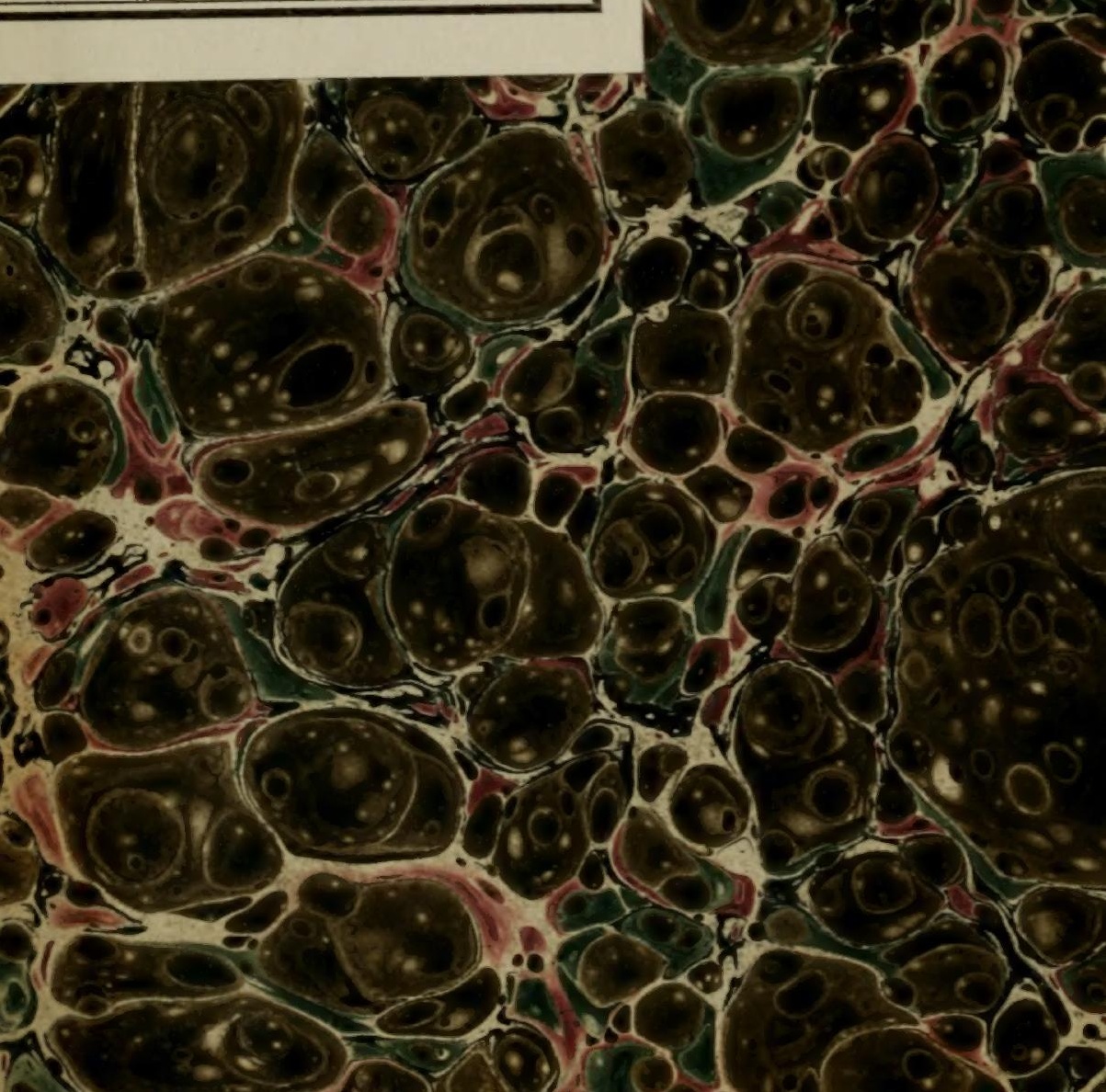





\section{.}

$=$

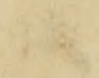



Digitized by the Internet Archive in 2010 with funding from NCSU Libraries 




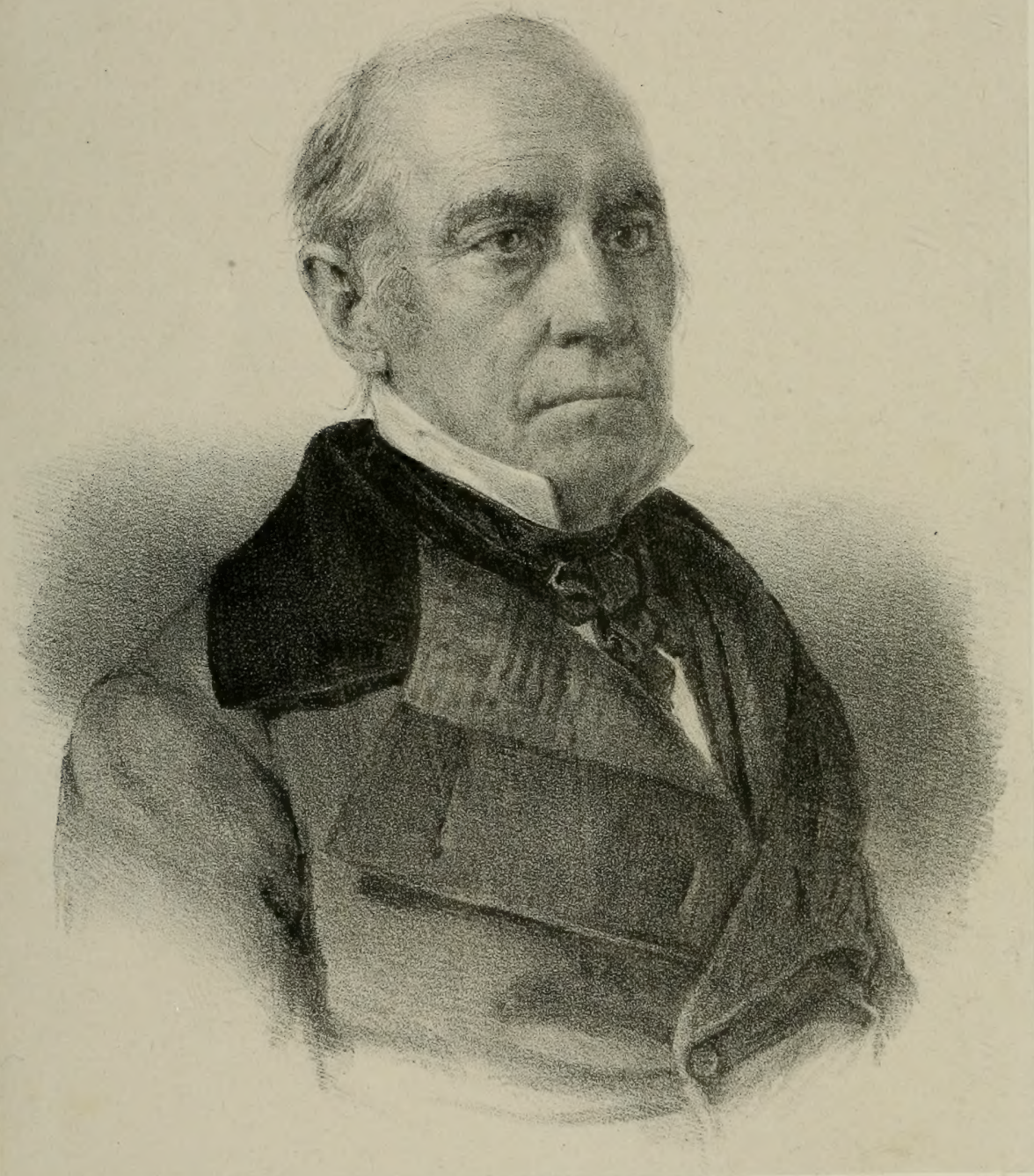




\section{BOOK OF THE FARM :}

DETAILING THE LABORS OF THE

FARMER, STEWARD, PLOWMAN, HEDGER, CATTLE-MAN, SHEPHERD, FIELD-WORKER, AND DAIRYMAID.

\section{BY HENRY STEPIIENS.}

WITH FOUR HUNDRED AND FIFTY ILLUSTRATIONS.

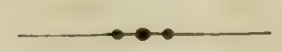

TO WHICH ARE ADIED

EXPLANATORY NOTES, REMARKS, ETC.

BY JOHN S. SKINNER,

EDITOR OF THE FARMER' LIBRARY.

VOLUME I.

NEW YORK :

C. M. SAXTON, AGRICULTURAL BOOK PUBLISHER. 1851. 



\title{
BOOK OF THE FARM.
}

\section{OF THE DIFFICULTIES WHICH THE YOUNG FARMER HAS TO ENCOUNTER AT THE OUTSET OF LEARNING PRACTICAL HUS- BANDRY.}

\author{
"One, but painted thus. \\ Would be interpreted a thing perplex'd \\ Beyond self-explication."
}

THE young farmer, left to his own guidance, when beginning to learn his profession, encounters many perplexing difficulties. The difficulty which at first most prominently obtrudes itself on his notice consists in the distribution of the labor of the farm; and it presents itself in this way :He observes the teams employed one day in one field, at one kind of work, and perhaps the next day in another field, at a different sort of work. He observes the persons employed as field-workers assisting the teams one day, and in the next, perhaps, working by themselves in another field or elsewhere. He observes those changes with attention, considers of their utility, but cannot discover the reasons for making so very varied arrangements; not because he entertains the least doubt of their propriety, but, being as yet uninitiated in the art of farming, he cannot foresee the purpose for which those labors are performed. The reason why he cannot at once foresee this is, that in all cases, excepting at the finishing operations, the end is unattained at the time of his observation.

The next difficulty the young farmer encounters is in the variety of the labors performed. He not only sees various arrangements made to do the same sort of work, but various kinds of work. He discovers this difference on examining more closely into the nature of the work he sees performing. He observes one day the horses at work in the plow in one field, moving in a direction quite opposite, in regard to the ridges, to what they were in the plow in another field. On another day he observes the horses at work with quite a different implement from the plow. The field-workers, he perceives, have laid aside the implement with which they were working, and are performing the labor engaged in with the hand. He cannot comprehend why one sort of work should be prosecuted one diy, and quite a different sort of work the next. This difficulty is inexplicable for the same reason why he could not overcome the former one : because he cannot foresee the end for which those varieties of work are performed. No doubt he is aware that every kind and variety of work which are performed on a farm, are preparatives to the attainment of certain crops ; but what portion of any work is intended as a certain part of the preparation for a particular crop, is a knowledge which he cannot acquire by intuition. Every preparatory work is thus perplexing to the young farmer. 
Field work being thus chiefly anticipatory, is the circumstance which renders its object so perplexing to the learner. He cannot possibly perceive the connection between preparatory labors and their ultimate ends; and yet, until he learn to appreciate their necessary connection, he will remain incapable of managing a farm. It is in the exercise of this faculty of anticipation or foresight that the experienced and careful farmer is con tradistinguished from the ignorant and careless. Indeed, let the experi ence of farming be ever so extensive, or, in other words, let the knowledge of minutiæ be ever so intimate, unless the farmer use his experience by foresight, he will never be enabled to conduct a farm aright. Both foresight and experience are acquired by observation, though the former is matured by reflection. Observation is open to all farmers, but all do not profit by it. Every farmer may acquire, in time, sufficient experience to conduct a farm in a passable manner; but many farmers never acquire foresight, because they never reflect, and therefore cannot make their experience tell to the most advantage. Conducting a farm by foresight is thus a higher acquirement than the most intimate knowledge of the minutiæ of labor. Foresight cannot be exercised without the assistance of experience; though the latter may exist independently of the former. As the elements of every art must first be acquired by observation, a knowledge of the minutiæ of labor should be the first subject for acquirement by the young farmer. By carefully tracing the connection betwixt com. bined operations and their ultimate ends, he will acquire foresight.

The necessity of possessing foresight in arranging the minutiæ of labor, before the young farmer can with confidence undertake the direction of a farm, renders farming more difficult of acquirement, and a longer time of being acquired, than most other arts. This statement may appear incredible to those who have been accustomed to hear of farming being easily and soon learned by the meanest capacity. No doubt it may be acquired in time, to a certain degree, by all who are capable of improvement by observation and experience ; but, nevertheless, the ultimate ends for which the various kinds of field-work are prosecuted, are involved in obscurity to every learner. In most other arts no great space usually elapses between the commencement and completion of the piece of work, and the piece is worked at until finished. The beginner can thus soon perceive the connection between the minutest portion of the work in which he is engaged, and the object for which it is intended. There is in this no obscurity to perplex his mind. He is purposely led, by degrees, from the simplest to the most complicated parts of his art, so that his mind is not bewildered at the outset by participating in a multiplicity of works at one time. He thus begins to acquire true experience from the outset.

The young farmer has no such advantages in his apprenticeship. There is no simple, easy work, or one object only to engage his attention at first. On the contrary, many minutiæ connected with the various works in progress, claim his attention at one and the same time, and if the requisite attention to any one of them be neglected for the time, no other opportunity for observing it can occur for a twelvemonth. It is a misfortune to the young farmer, in such circumstances, to be thrown back in his progress by a trifling neglect. He cannot make up his lee-way until after the revolution of a year. And though ever so attentive, he cannot possibly learn to anticipate operations in a shorter time, and therefore cannot possibly understand the drift of a single operation in the first year of his apprenticeship. The first year is generally spent almost unprofitably, and certainly unsatisfactorily to an inquisitive mind. But attentive observation during the first year will enable him, in the second, to anticipate the successive 
operations ere they arrive, and arrange every minutia of labor as it is required. Many of the events of the first year, which had left no adequate impression of their importance on his memory, crowd upon his observa. tion in the second, as essential components of recognized operations. A familiar recognition of events tends, in a rapid degree, to enlarge the sphere of experience and to inspire confidence in one's own judgment; and this quality greatly facilitates the acquisition of foresight.

Let it not be imagined by those who have never passed through the perplexing ordeals incident to the first year of farming, that I have described them in strong colors, in order to induce to the belief that farming is an art more difficult of attainment than it really is. So far is this from being the case, I may safely appeal to the exporience of every person who had attained manhood before beginning to learn farming, whether $I$ have not truly depicted his own condition at the outset of his professional career. So that every young man learning farming must expect to meet vith those difficulties.

\section{OF THE MEANS OF OVERCOMING THOSE DIFFICULTIES.}

"We can clear these ambiguities."

ROMEO AND JUZIET.

Experience undoubtedly dissipates doubt and removes perplexity; but experience, though a sure and a safe, is a slow teacher. A whole year must revolve ere the entire labors of a farm can be exhibited in the field, and the young farmer satisfactorily understand what he is about; and a whole year is too much time for most young men to sacrifice. Could the young farmer find a monitor to explain to him, during the first year of his apprenticeship, the purpose for which every operation on a farm is performed,-foretell to him the results which every operation is intended to effect,-and indicate to him the relative progress which all the operations should make, from time to time, toward the attainment of their various ends, he would thereby acquire a far greater quantity of professional information, and have greater confidence in its accuracy, than he could possibly obtain for himself in that anxious period of his novitiate. Such a monitor would best be an experienced and intelligent farmer, were he duly attentive to his pupil. Farmers, however, can scarcely bestow so much attention as would be desired by pupils at all times; because the lapses of time occasioned by necessary engagements, in the fulfilment of which farmers are sometimes obliged to leave home, produce inattention on the part of the farmer; and inattention and absence combined constitute sad interruptions to tuition, and cannot always be avoided by the most painstaking farmer. But a book might be made an efficient assistant-monitor. If expressly written for the purpose, it might not only corroborate what the farmer inculcated, but serve as a substitute in his temporary absence. In this way tuition might proceed uninterruptedly, and the pupil never want a monitor upon whom he could confidently rely. Were a book, purposely so arranged, put into the hands of young farmers so circumstanced, the usual deprecations against recommending the acquirement of practical farming from books alone would not here apply. I would give no such counsel to any young farmer; because books on farming, to be really serviceable to the learner, ought not to constitute the arena on which to study farming-the field being the best place for perceiving the fitness of labor 
to the purposes it is designed to attain-but as monitors for indicating the best modes of management, and showing the way of learning those modes most easily. By these, the practice of experienced farmers might be communicated and recommended to beginners. By consulting those which had been purposely written for their guidance, while they themselves were carcfully observing the daily operations of the farm, the import of labors-which are often intricate, always protracted over considerable portions of time, and necessarily separated from each other-would be acquired in a much stiorter time than if left to be discovered by the sagacity of beginners.

It is requisite to explain that, by the phrase "young farmer," I mean the young man who, having finished his scholastic and academical education, directs his attention, for the first time, to the acquirement of practical farming; or who, though born on a farm, having spent the greater part of his life at school, determines, at length, on following his father's profession. For the latter class of young men, tuition in farming, and information from books, are as requisite as for the former. Those who have constantly seen farming from infancy can never be said to have been young farmers; for, by the time they are fit to act for themselves, they are proficients in farming. Having myself, for a time, been placed precisely in the position of the first description of young men, I can bear sincere testimony to the truth of the difficulties I have described as having to be encountered in the first year of apprenticeship. I felt that a guide-book would have been an invaluable monitor to me, but none such existed at the time. No doubt it is quite reasonable to expect of the farmer ability to instruct the pupils committed to his charge in a competent manner. This is certainly his duty; which, if rightly performed, no guide-book would be required by pupils; but very few farmers who receive pupils undertake the onerous task of instruction. Practical farming they leave the pupils to acquire for themselves in the fields, by imperfect observation and slow experience, as they themselves had previously done ; theoretical knowledge, very few, if any, are competent to impart. The pupils, being thus very much left to their own application, can scarcely avoid being beset with difficulties, and losing much time. At the same time it must be acknowledged that the practice gained by slow experience is, in the end, the most valuable and enduring. Still, a book on farming, expressly written to suit his circumstances, might be a valuable instructor to the young farmer; it might guard him against the difficulties which learners are apt to encounter; and it would recompense him for loss of time, by imparting sound professional information.

Such a book, to be really a useful instructor and correct guide, should, in my estimation, possess these necessary qualifications. Its principal matter should consist of a clear narrative of all the labors of the farm, as they occur in succession; and it should give the reasons fully for which each piece of work is undertaken. While the principal operations are narrated in this way, the precise method of executing every species of work, whether manual or implemental, should be minutely detailed. The construction of the various implements by which work is performed-the mode of using them-the accidents to which each is liable-should be circumstantially described. A seasonable narrative of the principal operations will show the young farmer that farming is really a systematic business, having a definite object in view, and possessing the means of attaining it. The reasons for doing every piece of work in one way, rather than another, will convince him that farming is an art founded on rational and known principles. A description of the implements, and of the method of using them, will give him a closer insight into the nature and fitness of (8) 
field-work for attaining its end, than by any other means. A perusal of these narratives, all having a common object, will impart a more comprehensive and clearer view of the management of a farm in a given time, than he could acquire by himself from witnessing ever so many isolated operations. The influence of the seasons on all the labors of the field is another consideration which should be attended to in such a book. In preparing the ground, and during the growth of the crops, the labor appropriated to each kind of crop terminates for a time, and is not resumed until a fit season arrive. These periodical cessations from labor form natural epochs in the progress of the crops toward maturity, and afford convenient opportunities for performing the work peculiarly appropriate to each epoch; and, since every operation of the farm is made to conform with its season, these epochs correspond exactly with the natural seasons of the year. I say with the natural seasons, in contradistinction to the common yearly seasons, which are entirely conventional. This necessary and opportune agreement between labor and the natural seasons induces a corresponding division of the labors of the farm into four great portions, or scasons, as they are usually termed. Lahor should, therefore, be described with particular reference to its appropriate season.

[Reflecting on the preceding chapters with a view to give them practical bearing on our own country, one is led to remark that the struggles which ensued immediately after the establishment of our National Ind ependence, and which had for their object the settlement of the great working principles of the Constitution, produced intense political excitement throughout the country. Unfortunately, this rage for politics, dignified in its commencement by great national aims, settled down into a sort of political monomania; and hence these struggles have become perennial, but with sad degeneracy as to motive. Anxiety about the great administrative principles of the Government has been superseded by an abiding and unquenchable thirst for office, for the sake of official emolument and power. $\$ 25,000,000$ constitute the annual premiums to be contended for and distributed among party competitors, sufficiently numerous and active, and so widely dispersed among the people as to draw off their minds from the practical bearing of public legislation and its indissoluble connection with the landed interest of the country. Thus bas it happened that, while the People of the United States-landholders in very large proportion-pay annually, and, as it would seem, willingly, so many millions to provide for military instruction and to maintain military institutions, little or nothing is done by their Representatives for the diffusion of agricultural knowledge, or for the construction of highways or conveniences to develop and improve the industrial resources of the country!

If the people-the cultivators of the soil-would force their legislators to appropriate, for the dissemination of agricultural knowledge through all the common schools of the country, one-tenth of that which the landholders now pay for prolonged debates and useless legislation, and for the pay and maintenance of the military machinery of the Government, our young men destined for farming might enter on their career in full possession of the know-ledge recommended in the precediug chapters; and such knowledge could not fail to be followed by an immense increase in all the fruits of productive industry, as well as in that additional security for the public peace and prosperity which is the natural fruit of superior intelligence. The young men of the country would then enter upon life with a well-founded conviction that farming, truly, "is an art, founderl on rational and known principles."

With these views it was that Wadsworth and Van Rensselaer, of New-York, exerted their infinence for the establishment of Common Schoois, in all of which the Sciences connected with Agriculture ought now to have preference and prominence over all others. The spontaneons and nnassisted growth of agricultural schools, which may now be seen springing up in various sections of the country, clearly indicates that public sentiment is, fortunately, beginning to gather force and to take a right direction on this great subject of popular agricultural education-giving reason to hope that, eventually, even those who deny that the Government possesses any constitutional control over it, will at least agree that if public treasure is to be collected and appropriated to the diffusion of any sort of knowledge, or the construction of any sort of road. or survey or map, or the publication of any sort of book, it were far better for the interests of the people of the United States, and of humanity, that such expenditures should be applied to the dissemination of that sort of (9) 
knowledge, and to the construction of that sort of road, or map, or book, which shall have a tend ency to increase the "staff of life"-to make bread abundant-and provide, in a word, the materials of manufactures-the elements of commerce-and the basis, not so much of military glory, as of national prosperity.

There seems, in truth-and every Christian will hail all such omens with delight-to be a growing conviction that, as the field of Science enlarges, the practical man cannot fulfil his calling, whatever that calling may be, without some acquaintance with those branches of Science which bear upon it. The Divine, the Lawyer, the Physician, the Merchant-and he, still honored and rewarded above the best, whose art it is to destroy his fellow-man-are all of them acting upon this principle. The advance of Science in all other pursuits, except farming, is making empiricism in them degrading and unprofitable. Yet the follower of each of them was once an empiric. The Farmer alone is so still. Does not, then, the advance of Science-may we not say, his own character and self-respect-require him, too, to be a man of certainty-independent on, or rather a controller of, circumstances?

Ed. Farm. Lib.]

\section{OF THE RIND OF INFORMATION TO BE FOUND IN EXISTENT WORKS ON AGRICULTURE.}

"Tire the hearer with a book of words."

MUCH A do ABOUt Nothing.

UNLESS the business of a farm be treated in books somewhat in the manner thus described, I consider it impossible for a young farmer to derive from them the requisite information for conducting a farm, even though he should be constantly resident upon it. By even the most careful perusal of books, which relate methods of cultivating crops and treating live stock in the most general terms and in detached sections having no relative connection with each other, the young farmer will never, in my opinion, understand how to apportion labor and modify its application to the raising of crops and rearing of live-stock, in accordance with the nature of the season. He will never learn to know by perusing a narrative couched in the most general terms, when an operation is really well performed; because, to be able to judge of the quality of work, all its minutiæ ought previously to have been fully and carefully detailed to him. Narratives couched in general terms, to the exclusion of essential minutiæ, will never impart that precision of ideas which the mind should possess in conducting any piece of field work; and without precision of ideas in regard to labor, no man will ever be able to conduct a farm aright. But to be told how to conduct a farm aright, is the chief motive of the young farmer for consulting a book at all.

Now, on examining works of any pretensions which have, for years past, been written on practical Agriculture, none will be found to have been written and arranged on the principles I have recommended, and much less for the special benefit of beginners in farming. All are so arranged as to constitute books of reference for experienced, rather than as guides for young farmers. Yet, how few of the former will condescend to consult agricultural works! The aversion of experienced farmers to to consult books on Agriculture has long been proverbial.* No doubt this

["This aversion cuubiless arises in a great measure from the neglect of parents to have Agriculture and studies nearly akin to it made $a$ part of the education of their aons. Amusements followed, courses of reading indulged in, and habits contracted when we are young, continue to have their influence over ns in after life, and to possess attraction, if only by forco of early asso. ciation, while he who grows to man's cstate in ignorance of that great perennial source of enjoy(10) 
aversion may be explained; but whether the explanation is to be found in a general indifference to book-farming, or in the quality of the books themselves, or in both circumstances combined, it is not easy to determine. The aversion, however, appears to be felt more toward systematic than periodical works on Agriculture. The latter class receives favor because, possibly, they may contain something that is not generally known, and their information bears the character of freshness. As to young farmers, if they cannot find books suited to their particular state of knowledge, they have no alternative but to peruse those that are extant.

For the sake of the young farmer, the usual contents of agricultural books require farther consideration. Let any systematic work on practical Agriculture be examined, and it will be found to contain an arrangement of the various particulars of farming, somewhat in this order. The soil and the various methods of working it are first described. The implements are then most probably particularized, or their description deferred to a later portion of the work. The methods of raising and securing the different kinds of crops are then detailed; and the treatment of live-stock is delayed to the last. We suppose that no satisfactory reasons can be given for adopting this particular arrangement of subjects. It is, perhaps, considered a simple arrangement, because it proceeds from what is considered the elementary process of preparing the soil, to the more complicated process of cultivating the plants for which the soil has been prepared. But the simplicity of the arrangement, I apprehend, is to be found rather in what is assumed than what is apparent; for plowing land is not a more simple process, or more elementary than sowing seed. Indeed, some sorts of plowing require far greater dexterity and ingenuity in the performance than any process connected with the production of crops. Perhaps it is considered a natural arrangement, because the ground is first prepared, and the crop is then sown. The ground, it is true, must be partially, if not wholly, prepared before the crop be put into it; but, in the cultivation of the summer crops, much of the labor bestowed on the land is performed while the crops are in a rapid progress toward maturity.

Although the seasons visibly influence the operations and products of the farm, systematic works on Agriculture scarcely disclose the subdivision of the year into seasons, much less the very different operations performed in different seasons, and still less the difference of character of the same season in different years. For all that is given in them by way of advice, every operation may as well be performed in one season as in another. No doubt, reference is made, and cannot altogether be avoided being made, to the season in which the piece of work described should be performed; but the reference seems to allude to the season more as an accidental concomitant, than as constituting the sole influential power that

ment, the love of books, very rarely contracts a fondness for them in after life. To put them in his way, when his habits are already fixed, and expect to force them on his attention, is like attempting to espalierise trees already half grown: hence the force of the maxim that you sbould "bring ap the child in the way he should go." The boy should be led, while yet a boy, to take pleasure in books, and especially in such books as are best calculated to store his mind with the practice, and to embellish it with the literature of his particular calling. All that can enlighten Agriculture and instruct in the natural history and properties of whatever belongs to the country, should, at ceuntry schools, take the place of the antiquated trash which continues to form the bulk of Common School education, with the exception, in a great and honorable measure, of the schools in New.York, Massachusetts, and some other Northern States, where the subject has attracted the earnest regards of able, benevolent and conscientious men, who so well deserve and no rarely receive the tribute due to the real benefactors of mankind. 
regulates the order of time in which the work should be performed. The allusion to the season, in short, only forms an isolated hint, which, being singly repeated in a number of places, it is impossible for the reader te keep in mind the particular operation that should be performed in its own season. This apparent neglect of the great influential power which regulates all farm business, constitutes an insuperable objection to describing, in an uninterrupted narrative, a piece of work which is performed at intervals. Such a dissertation might bewilder the reader on its perusal, but could not satisfy the mind of the young inquiring farmer.

But the minuter arrangements in the books I am remarking on, are fully more objectionable than the general. The entire process usually adopted for working the land for a particular crop, is described in an uninterrupted narrative, before a description of the nature of the crop is given for which the soil is preparing; and, in consequence, before the connection between the preparation and the crop can be understood by the young farmer. This is not the usual procedure on farms, and cannot therefore be accounted natural; and it certainly tends to mislead the beginner. The usual practice is, that the land destined for any particular crop is prepared to a certain degree, at stated times, in accordance with the natural seasons, and between those times many operations intervene which bear no relation to that particular crop. Every operation thus occupies a portion of time, intermittent in its season, and cannot truly be described in a continued dissertation. The finishing operation of every crop is always deferred until the appropriate season.

The descriptions of implements are very unsatisfactory, and their construction, for the most part, is very imperfectly represented. None trace their action from the first start to the entire completion of the work. Implements of husbandry having, only a few years ago, been made in the rudest manner, their actions were necessarily imperfect, and their absolute weight a serious drag on the draught. They are now constructed on true principles of mechanical science-are light in motion, perfect in action, and elegant in form. It is remarkable that a correct description of improved implements has not ere this been undertaken by some skillful machinist.*

Some works treat first of the science of Agriculture, and then of the practice, as if the science of the art had been ascertained by studying abundance of facts derived from practice; or, as if its science already possesses such a superiority as to be allowed the precedence of practice. Others make science follow practice, as if the science had been derived from the practice described; whereas what is offered as science is generally presented in isolated speculations, volunteered chiefly by theorists unacquainted with the practice of Agriculture. Some authors theorize on agricultural subjects from as slight a foundation of facts as in the experimental sciences, although they profess to give no preference to science over practice. Theorizing writers, however, sometimes throw out hints which, when improved by more practical experimenters, really lead to useful results; but whatever may be the origin of the hints of theorists, the ability to give a convincing and philosophical reason for every operation in husbandry, is an accomplishment which every young farmer should endeavor to attain. Efforts to discover reasons for practice derived from

["It is to he presumed that when this was written, the author had not seen " RANsome's Boor or THE Implements of Agriculture." It contains drawings and deseriptions of all the implements of A griculture employed in England. Such of them as are adapted to our country will be given in the FARMers' IIBRARY AND MONTHLY JouRnal of Agriculture, as two of the harrows were in Vol. 1. pp. 591-2.

(12)

Ed. Farm. Lib.] 
principles applicable alike to science and good husbandry, is a healthful exercise of the mind, and tend to render it capable of accommodating practice to existing circumstances. Conformity of practice with the season exhibits in the farmer superior ability for conducting farming operations : like the experienced mariner, who renders every change in the gale subservient to the safety of his ship, navigation itself not being more dependent on weather than is farming. By pursuing a course of observation and investigation such as this, the mind of the young farmer will soon become scientifically enlightened; but books on farming usually afford no assistance in pursuing such a course of study.

The treatment of live-stock is usually deferred to the conclusion in works on Agriculture, as if it were either the most important, or the most complicated, occupation of the farm. Breeding for the improvement of a particular race of animals, and judicious crossing betwixt two fixed races, are indeed occupations which tax the judgment severely; but the ordinary treatment of live-stock is as easily managed as most of the operations of the field. The complete separation, moreover, made in books betwixt live-stock and field-operations, is apt to impress the mind of the inexperienced reader that no necessary connection subsists betwixt stock and crop, whereas neither can be treated with advantage either to the farmer or themselves, unless both are attended to simultaneously.

From what I have stated regarding the arrangement of the subjects in systematic works on Agriculture, it will be observed that they are hetter adapted for reference than tuition. They form a sort of dictionary or cyclopedia, in which the different subjects are treated independently of each other, under different heads, though they may not be placed in alphabetical order. Being strictly works of reference, they may be consulted at any time; and are only valuable as such, in proportion to the accuracy of the information they contain; and being such, they are unfitted to impart agricultural knowledge suited to beginners; because, 1st, operations are not described in the order in which they occur on the farm; $2 \mathrm{~d}$, the descriptions omit many of the minutiæ of management, and yet constant attention to these constitutes an essential characteristic of a good farmer; 3d, they contain no precautionary warnings against the probability of failure in operations from various incidental causes, which ought to be anticipated, and attempted to be shunned; and, 4th, they afford no idea of the mode of carrying on various operations simultaneously in the different departments of management. Such works, therefore, impart no notion of how to set about to conduct a farm; and yet, without this essential information, to obtain which the earnest young farmer toils incessantly, they can render him no assistance as guides. Indeed, the authors of such works do not profess to be teachers of young farmers.

Experience has made me well acquainted with the nature of the diffculties tyros in Agriculture have to contend with; and I clearly see that the books on farming extant are incompetent to assist them in overcoming those difficulties. I consider it, therefore, very desirable that a work should be written for the express purpose of presenting facilities to young farmers in the acquirement of their profession. This opinion $I$ have entertained for many years, and see no cause to change it for all the works on Agriculture that have been published of late years. To me it is matter of surprise that such a work has never been written by any of the prominent writers on Agriculture in this prolific age of books, when assistance in the acquirement of learning is proffered in so many shapes to the youths of all classes. In most other branches of art, there is no want of facilities in books for acquiring their elementary principles and practice. @3, 
On the kindred art of gardening, in particular, every possible variety of publication exists, from the ponderous folio to the tiny duodecimo, containing all the minutiæ of practice and the elucidation of principles. It is difficult to account for the want of solicitude shown by agricultural writers, for the early advancement of the young farmer. Perhaps many of them have never experienced the irksome difficulties of acquiring a practical knowledge of Agriculture, and therefore cannot extend their sympathies to those who have; perhaps the exhibition of an intimate acquaintance with the minutiæ of farming appears too trivial an accomplishment to arrest the attention of general writers; perhaps they think when a young man begins to farm, it is sufficient for him to have a steward in whose skill he can confide; perhaps the tuition of young farmers is beneath their dignity, and they would rather aspire to the higher object of instructing experienced men; or perhaps they have never condescended to trouble themselves with practical farming, which, to judge of their lucubrations by the sterlingness of their practical worth, many of them, I dare say, never have.

\title{
4. OF THE CONSTRUCTION OF "THE BOOK OF THE FARM."
}

\author{
"A book? O rare one! \\ Be not as is our fangled world, a garment \\ Nobler than that it covers: let thy effects \\ So follow, to be most unlike our courtiers, \\ As good as promise."
}

Crmbeline.

A воок for the special purpose of instructing young farmers, such as it should be, and such as they are entitled to expect from the hands of experienced agriculturists, is yet a desideratum in the agricultural literature of this country. I am disposed to question the ability of any one man to write such a work, as its accomplishment would require a rare combination of qualities. The writer would require, as a primary qualification, to be a highly experienced agriculturist, able to indite lucid instructions for conducting a farm. He should also be a clear-headed mechanician, to describe with minute distinctness the principles and construction of agricultural implements. He should, moreover, be an accomplished man of science, to explain to conviction the rationale of every operation. Onerous as the task thus appears, I shall, nevertheless, attempt to write such a book. With adequate assistance, I trust I shall be able to overcome, at least, the practical difficulties of the undertaking; and, as to the scientific part, men of science have not yet brought Science to bear upon Agriculture in so satisfactory a manner as to justify them in contemning the rational explanations given of the various operations by practical men.Could I but succeed in arranging the various operations as they successively and actually occur on a farm, in so lucid a manner as that any young farmer might comprehend the exact purport of each piece of work, as it developed itself in the field, I should certainly do him essential service.In accomplishing this, it is scarcely possible to invest with sufficiently attractive interest the descriptions of the minute details of the various operations, so that their aptitude to the purpose intended may be appreciated. Careful attention to these details-in themselves, I own, irksome-will the sooner enable the young farmer to understand thoroughly the connection of successive operations ; and by the understanding of which he will be forewarned of the approach, and be able to ascertain the import, of the 
yarticular end for which they are preparatory. Besides showing by anti cipation the successive operations as they arrive, could I also give clear descriptions of the labor performed for each crop, as it is carried on simul. taneously on a farm, I should achieve a still greater service of or the young iarmer. He would then clearly comprehend a difficult department of his art.

To accomplish these ends, I purpose to arrange the matter in the fol.

wing manner, and for the following reasons. The entire business of a arm necessarily occupies a year; but that year embraces in some years more, and in others less, than twelve months. The agricultural year, moreover, both in its commencement and termination, does not correspond with that of the calendar; and those periods are determined in this way. The beginning and ending of every agricultural year are entirely dependent on the duration of the life of cultivated vegetables, which constitute the chief product of the farm. In the temperate regions if the globe, vegetable life becomes dormant, or extinct, according as the vegetable is perennial or annual, at the beginning of winter. The beginning of winter is therefore chosen, in the temperate zones, to commence the agricultural year, and, of course, the labors of the farm; and, when winter again approaches, the labors of the field have performed their annual revolution. The same sort of work is performed year after year. To understand those labors throughout the year is the chief aim of the young farmer; and to describe them to him satisfactorily is the principal object of this book.

Two modes of describing farm-business may be adopted. One is to arrange it under different heads, and describe all similar operations under the same head, as has hitherto been done in systematic works on Agriculture. The other mode is to describe the operations as they actually occur, singly, in succession, as is to be done in this work. Both methods describe the general farm business, and both may be consulted for any particular part of the business. But how the relative position of any particular part of the business stands in regard to, and influences any other, can only be shown by the latter method, and it does so at a glance of the eye. Moreover, as some parts of farm business commence, and others terminate, at one or other period of the year, the latter method can clearly indicate, what the other cannot so well do, in which period any particular operation is commenced, continued, or terminated; and it gives the details of each operation much more minutely than the other method.

The agricultural year, like the common year, is distinctly and conveniently divided into seasons, which regulate all farm work. I have given the seasons as full an influence over the arrangements of the matter in this book as they really possess over the business-matter of the farm. The whole business-matter is divided into four parts, each bearing the name of the season that influences the operations that are performed in it. By this arrangement every operation, whether requiring longer or shorter time for completion, is described as it takes its turn in the fields. The work that occupies only a short time to begin and complete, in any one season, is described in a single narrative. Very few of the operations of a farm, however, are begun and completed in one of the seasons; some extending over the whole four, and most into two or three. Any piece of work that extends over almost all the seasons can, nevertheless, be described with great accuracy ; for although, in its progress toward completion, it may altogether occupy an extended range of time, each season imposes a peculiar kind of operation toward the advancement of the work; which peculiar operation ceases, and a different kind is entered upon, at 
the season which concludes the work. These cessations of labor, connerted with the same work which extends over several seasons, are thus nut mere conveniences, but necessary and temporary finishings of work, whirr it would be improper to resume but at a subsequent and appropriate sea son. In this way all the more extensive pieces of work are gradually advanced, in progressive steps, season after season, until their completion: while the smaller are concurrently brought onward and completed, each in its proper season.

Before proceeding farther, let me guard the young farmer against imbibing a misconception regarding the length of the seasons. In the year of the calendar, each season extends over a period of three calendar months; and the same three months every year compose the same season, whatsoever may be the nature of the weather. Every season of the calendar is thus of the same length. The seasons of the agricultural year, though bearing the same names as those of the calendar, are, on the other hand, not of the same length every year, but their duration is regulated by the state of the weather. The agricultural seasons have characteristic signs to distinguish them. The spring revives the dormant powers of vegetables; the summer enlarges their growth; the autumn develops the means of reproduction; and the winter puts a stop to vegetable energy. In the year of the calendar these characteristics are assumed to last just three months in each season; but in the agricultural year, notwithstanding that the characteristics of one season extend over or are contracted within three months, still that season bears its proper name, whether it encroaches on or is encroached upon by another season. The spring, for example, may be encroached on by the protraction of winter on the one hand, and the earliness of summer on the other; a case in which results both a late and short spring - a state of spring which creates very bustling work to the farmer. So with the rest of the seasons. This elastic property in the agricultural seasons contradistinguishes them from the seasons of the calendar which possess no elasticity. The commencement, continuance, and termination of field work being, therefore, entirely dependent on the seasons of the agricultural year-and those seasons, in their turn, being as dependent on the weather-it follows that field operations are entirely dependent on the state of the weather, and not on the conventional seasons of the calendar. Whether an agricultural season be long or short, the work that properly belongs to it must be finished in it while it lasts. If it be of sufficient length, the work to be performed, admitting of a considerable latitude of time, may be well finished; and, if not so finished, the crop runs the risk of failure. Should any season happen to be shortened by the weather, by the preceding season encroaching upon it, the work should he so far advanced during the preceding prolonged season that, when the proper season for its completion arrives-as arrive it will-the finishing may be accomplished before its expiring. Should any season be curtailed by the earliness of the succeeding one, and the weather improve, as in the case of summer appearing before its time, no apprehension need be entertained of accomplishing the finishing work in a satisfactory manner; but should the weather prove worse, as in the premature approach of winter upon autumn, then extraordinary exertions are required to avert the disastrous consequences of winter weather upon the crops. The unusual protraction of any of the seasons in which a work should be completed is attended with no risk, except that too frequently. from the consciousness of having plenty of time in complete the work, unnecessary delay is permitted, until the succeeding season unexpectedly makes its appearance. In such cases, procrastination is truly the thief of 
time. During the protraction of a season, much time is often wasted in waiting for the arrival of the succeeding one, in which a particular work is most properly finished; but, in a contracted season, a great part of the work is hurriedly gone through, and of course slovenly performed. The most perfect field-work is performed when the agricultural and conventional seasons happen to coincide in duration.*

The greatest difficulty which the farmer experiences, when first assuming the management of a farm, is in distributing and adjusting labor. To accomplish this distribution and adjustment correctly, in reference to the work, and with ease as regards the laborer, a thorough knowledge is requisite of the quantity of work that can be performed in a given time by all the instruments of labor, animal and mechanical, usually employed. It is the duty of the young farmer to acquire this knowledge with all diligence and dispatch; for a correct distribution of the instruments of labor enables the work to be performed in the most perfect manner in regard to the soil-with the smallest exertion as regards physical force-and with the greatest celerity in regard to time; and, in the adjustment of those instruments, every one should just perform its own share of work. These essential particulars I shall point out, in their connection with the work in hand. In descanting on the distribution of labor, I shall incur the hazard of being prolix rather than superficial. The general reader may dislike the perusal of minute details; but the ardent student will recieve with thankfulness the minutest portion of instruction, especially as he can only otherwise acquire this kind of instruction by long experience. The distribution and adjustment of labor is a hranch of farm management that has been entirely overlooked by every writer on systematic Agriculture.

Constant attention on the part of the young farmer to the minutiæ of labor evinces in him that sort of acuteness which perceives the quickest mode of acquiring his profession. The distribution of the larger pieces of work may proceed satisfactorily enough under the skill of ordinary work-people; but the minuter can best be adjusted by the master or steward. The larger operations would always be left in a coarse state, were the smaller not to follow, and finish them off neatly. There are many minor operations, unconnected with greater, which should be skillfully performed for the sake of their own results; and they should be so arranged as to be performed with neatness and dispatch. Many of them are frequently performed concurrently with the larger operations ; and, to avoid confusion, both their concurrent labors should harmonize. Many of the minuter operations are confined to the tending of live-stock, and the various works performed about the farmstead. Attention to minutiæe constituting the chief difference betwixt the neat and careless farmer, I have be-

[* Erery young farmer may lay it down as a good rule to endeavor in all his work to be a little before the best manager in his neighborhood, "Drive your work or your work will drive you," says Dr. Franklin, and "Time enough ahways proves little enough." The best way, as a general rule, and which is a cardinal one with all successful farmers, is to begin early-get your land in the most perfect tilth-plant and sow as early as the season will admit, but let nothing tempt you to plow stiff or clay land when wet enough to bake into clods-endeavor to be the first to harvest and bouse your crops, and then prepare and send them at once to market, and sell them for the best price you can get. By that means you keep your work before you, avoid much mortification, and save your crop from waste and depredation by rats that gnaw, and thieves that "break in and steal."

N. B.-It is doubtful if any farmer ever yet lost anything by cutting his wheat too early and too green-not that it conld not be done, but probably never is done-while millions have been lost by leaving it too long in the field

(17)......2

Ed. Farm. Lib.] 
stowed due consideration on them. They form another particular which has been too much overlooked by systematic writers on Agriculture.

Implements of husbandry may be considered the right hand of the farmer; because, without their aid, he could not display the skill of his art. Modern mechanical skill has effected much by the improvement of old, and the invention of new implements. Modifications of construction and unusual combinations of parts are frequently attempted by mechanics; and, though many such attempts issue in failure, they nevertheless tend to divulge new combinations of mechanical action. It is desirable that all mechanists of implements should understand practical Agriculture, and all farmers study the principles of mechanics and the construction of machines, so that their conjoined judgment and skill might be exercised in testing the practical utility of implements. When unacquainted with farming, mechanists are apt to construct implements that are obviously unsuited to the work they are intended to execute; but having been put together after repeated alterations, and, probably, at considerable expense, the makers endeavor to induce those farmers who are no adepts at mechanics to give them a trial. After some unsatisfactory trials they are thrown asideWere farmers acquainted with the principles of mechanics, the discrimination which such knowledge would impart would, through them, form a barrier against the spread of implements of questionable utility, and only those find circulation which had been proved to be simple, strong, and efficient.* It may be no easy matter to contrive implements possessing all those desirable qualities; but, as they are much exposed to the weather, and the ground upon which they have to act being ponderous and uncouth, it is necessary they should be of simple construction. Simplicity of construction, however, has its useful limits. Most farm operations being of themselves simple, should be performed with simple implements; and all the primary operations, which are simple, requiring considerable power, the implements executing them should also be strong; but operations that are complicated, though stationary, require to be performed with comparatively complicated machinery, which, being stationary, may be used without derangement. Operations that are both complicated and locomotive should be performed with implements producing complicated action by simple means, in order to avoid derangement of their constituent parts.This last is a difficult, if not impossible problem, to solve in practical mechanics. The common plow approaches more nearly to its practical solution than any other implement; yet that truly wonderful implement, executing difficult work by simple means, should yet be so modified in construction as to permit the plowman to wield it with greater ease. These considerations tend to show that the form and construction of implements of husbandry, and the circumstances in which they may be used, are still subjects affording ample scope upon which mechanical skill can exercise itself.

Implements have not received in works on Agriculture that consideration which their importance demands. The figures of them have been made by draftsmen who have evidently had no accurate conception of the

[* Who can deny that the principles of Mechanics, as far as all agricultural machinery is concerned, onght to take the place of some other things on which so much time is bestowed in all our country schools? Should any boy, who is to be a farmer, come to the possession of his estate without having been made to understand the principles of action-for example, of the wedge, the screw, the inclined plane, and the lever? How plainly such principles are illustrated by men of science, and how easily they may be comprehended by the commonest capacity, may be seen in the December and January (1845-6) Numbers of the Monthly Journal of Agriculture. 
functions of their constituent parts. The descriptions given of those constituent parts are generally meager, and not unfrequently erroneous; and as to the best mode of using implements, and the accidents to which they are liable, one would never discover that there was any peculiarity in the one, or liability to the other. In order to avoid both these classes of errors, much care has been bestowed in this work in delineating the figures, and giving descriptions of all the implements requisite for conducting a farm.

To ensure accuracy in these respects, I consider myself fortunate in having acquired the assistance of Mr. James Slight, Curator of the Machines and Models in the Museum of the Highland and Agricultural Society of Scotland, whose high qualifications as a describer and maker of machines are duly appreciated in Scotland. His son George, yet a very young man, is a beautiful delineator of them, as the drawings of the cuts and engravings in the work amply testify. And having myself paid close attention to the applicability of most of the implements used in farm operations, I have undertaken to describe the mode of using them-to state the quantity of work which each should perform, the accidents to which each is liable, and the precautions which should be used to avoid accidents. With our united efforts, I have confidence of giving such an exposé of farm implements as will surpass every other work of the kind. We have the advantage of having the field to ourselves. To assist the right understanding of the implements, they are represented by figures.

So much for the practical, and now for the scientific portion of the work. Agriculture may, perhaps, truly be considered one of the experimental sciences, as its principles are, no doubt, demonstrable by the test of experiment, although farmers have not yet been able to deduce principles from practice. It is remarkable that very few scientific men have, as yet, been induced to subject agricultural practice to scientific research; and those of them who have devoted a portion of their time to the investigation of its principles have imparted little or no satisfactory information on the subject. This unfortunate result may probably have arisen from the circumstance that Agriculture has so intimate a relation to every physical science that, until all those relations are first investigated, no sufficient data can be offered for a satisfactory scientific explanation of its practice. The difficulty of the investigation is, no doubt, much enhanced by husbandry being usually pursued as a purely practical art, because the facility of thus pursuing it successfully renders practical men indifferent to Science. They consider it unnecessary to burden their minds with scientific research, while practice is sufficient for their purpose. Could the man of practice, however, supply the man of science with a series of accurate observations on the leading operations of the farm, the principles of those operations might be much elucidated; but I conceive the greatest obstacle to the advancement of scientific Agriculture is to be sought for in the unacquaintance of men of science with practical Agriculture. Would the man of science become acquainted with practice, much greater advancement in scientific Agriculture might be expected than if the practical man were to become a man of science, because men of science are best capable of conducting scientific research, and, being so qualified, could best understand the relation which their investigations bore to practice; and, until the relation betwixt principles and practice is well understood, scientific researches, though perhaps important in themselves, and interesting in their results, tend to no practical utility in Agriculture. In short, until the facts of husbandry be acquired by practice, men of science will 
in vain endeavor to construct a satisfactory theory of Agriculture on the principles of the inductive philosophy.

If this view of the present position of the science of Agriculture be correct, it may be expected to remain in a state of quiescence until men of science become practical agriculturists, or, what would still prolong its state of dormancy, until farmers acquire scientific knowledge. It is a pity to damp the ardor of scientific pursuit where it is found to exist; but, from what I have observed of the scanty services science has hitherto conferred on Agriculture, and knowing the almost helpless dependency of farming on the seasons, I am reluctantly impelled to the belief that it is less in the power of science to benefit Agriculture, than the sanguine expectations of many of its true friends would lead farmers to believe. It is wrong to doubt the power of science to assist Agriculture materially; and it is possible, in this age of successful art, that an unexpected discovery in science may yet throw a flood of light on the path of the husbandman; but I am pretty sure, unless the man of science become also the practical husbandman, it will be difficult, if not impossible, for him to discover which department of the complicated art of husbandry is most accessible to the research of science.

Hitherto, as it appears to me, Agriculture has derived little benefit from the sciences, notwithstanding its obvious connection with many of them. A short review of the relation which the physical sciences bear to Agriculture will render this opinion more reasonable. In the first place, the action of the electric agency in the atmosphere and on vegetation is yet as little understood in a practical sense as in the days of Franklin and of Ellis. No doubt, the magnetic and electric influences are now nearly identified; but the mode of action of either, or of both, in producing and regulating atmospherical phenomena, is still ill understood; and, so long as obscurity exists in regard to the influence of their elementary principles, the history of atmospherical phenomena cannot advance, and the anticipations of atmospherical changes cannot be trusted.

Geologists, at first engaged in ascertaining the relative positions of the harder rocks composing the crust of the earth, have only of late years directed their attention to the investigation of the more recent deposits; but, even with these, they have afforded no assistance in the classification of natural soils and subsoils. They have never yet explained the origin of a surface-soil, almost always thin, though differing in thickness, over subsoils composed of different kinds of deposits. They have never yet ascertained the position and structure of subsoil deposits, so as to inform the farmer whether land would be most effectually drained with drains running parallel with, or at right angles to, the courses of valleys and rivers.

Systematic botany can only be useful to Agriculture in describing the natural plants which are indigenous to different soils. Botanists have successfully shown the intimate relation subsisting betwixt plants and the soils on which they grow; but much yet remains to be ascertained of the relation betwixt different soils and trees, and the effects of different subsoils on the same kind of tree. Planting cannot be pursued on fixed principles, if planters are unacquainted with this knowledge; and, until a fixed and generally received classification of soils and subsoils is determined on, it is impossible to comprehend, by description, what particular soil or soils the plants referred to affect.

Botanical physiology has developed many remarkable phenomena, and explained most of the important functions of plants-investigations which tend to give a clearer insight into the growth of crops. In this department of science, too much discussion to be of benefit to Agriculture has, (20) 
as I conceive, been expended on what really constitutes the food of plants. Whether the food is taken up by the plant in a gaseous, a solid, or a liquid state, may in itself be a very interesting inquiry, but it tends to no utility in Agriculture so long as no manures are supplied to crops in a gaseous or liquid state. All that can practically be done in supplying food to plants, is to observe the increased quantity of their secretions in a given condition from an increased given quantity of manure. Thus may the increased quantities of mucilage, farina, gluten, in the various cultivated plants, be observed. It is of little moment to the farmer whether the manure administered is taken up by the crops in a gaseous, liquid, or solid state, since all these secretions are elaborated from the same manure. The anatomical structure of plants, the situations, soils, and manures which crops affect, the secretions which they elaborate, and the prolificacy and value of their products, are the results that most interest the farmer; and, if botanical physiologists desire to benefit Agriculture they must direct their attention to the emendation and increase of products. Again, the results from the cross impregnation of plants of the same kind, so as to produce valuable permanent varieties, may confer as valuable a boon on Agriculture as the successful crossings of different breeds of livestock have already conferred by increasing their value. Many varieties of plants having their origin in this way have been brought into notice, and some are now established and extensively cultivated; but most of the varieties in use have been obtained from casual impregnations effected by Nature herself, and not by the efforts of man to obtain varieties possessing superior properties, as in the case of the doinesticated animals. Thus botanical physiology might confer great benefit on Agriculture, if its views were directed to increasing the prolificacy of valuable plants already in cultivation, and introducing others that would withstand the modes of culture and changes of climate incidental to this country.

But there is one view in which botanical physiology may be of use to Agriculture, and that is, in ascertaining correctly the nature, properties, and relative values of plants. To show the importance of such an investigation, a case may here be specified. A variety of rye-grass, called Italian, has been lately introduced into this country. It is found to be a very free grower in this climate; and it is highly acceptable to all kinds of live-stock, whether in a green or dried state. Could this grass be rendered certainly perennial, it would be an invaluable acquisition to the pastures of this country. Its character, however, is rather capricious, for in some places it disappears after two years' cultivation, while in others it displays undiminished vigor of growth for four or five years, and may perhaps continue so to do for an indefinite period of time. Judging by these various results, it is probable that there is more than one variety of the plant, and distinguishing varieties seem to be known to foreigners. Keeping in view the existence of varieties, if different varieties were affected differently by the same locality, there would be nothing in the phenomenon to excite surprise; but when the same variety, derived from the same stock, and placed in similar circumstances, exhibits different instances of longevity, there must be characteristics of the plant still unknown to cultivators. In this dilemma, the assistance of the botanical physiologist would be desirable to discover those latent characteristics. It would be desirable to know the conditions that regulate the existence of plants into permanent and temporary varieties-a property of plants at present involved in mystery. Hitherto, no practical explanation of the subject has been proffered to the farmer; and so long as he shall be permitted to discover the true properties of plants for himself, 
botanical physiology cannot be regarded by him as of much use to Agriculture.

The Italian rye-grass exhibits in its nature an anomaly that no other variety of rye-grass does. The annual rye-grass, as it is commonly called, is seldom seen in the ground, even to the extent of a few plants, in any kind of soil, and under any treatment, after the second year; and the perennial is as seldom observed to fail in any circumstances, except when it may have been too closely cropped by sheep to the ground too late in autumn, when it generally dies off in the following spring. But the Italian may be annual or perennial in the same circumstances. Farmers cannot account for such an anomaly. High condition of good soil may tend to prolong, while the opposite state of poor soil may tend to shorten, its existence. But why those circumstances should not produce the same effects on all varieties of rye-grass, it is for science to explain.

Entomology might be made to serve Agriculture more than it has yet done. In this department of science farmers might greatly assist the entomologist, by observing the minute, but varied and interesting, habits of insects. The difficulty of comprehending the true impulses of insects, as well as of identifying species in the different states of transformation, render the observations of farmers less exact than those of entomologists who have successfully studied the technicalities of the science. The field of observation in the insect creation being very wide, and there being comparatively but few explorers in it, a large portion of a man's life would be occupied in merely observing species and their habits, and a much larger in forming general deductions from repeated observation. The result would be, were farmers to study entomology, that a long period must elapse ere the habits of even the most common destructive insects, and the marks of their identity, would become familiarized to them. In consequence of this obstacle to the study of the farmer, the obligation ought to be the greater to those entomologists who daily observe the habits of insects in the fields and woods, and simplify their individual characteristics; and at the same time devise plans to evade their extensive ravages, and recommend simple and effective means for their destruction. The English farmer, living in a climate congenial to the development of insect life, painfully experiences their destructive powers on crops and woods; and, although in England entomologists are ever vigilant and active, yet their efforts easily to overcome the tenacity of insect life, with a regard to the safety of the plant, have hitherto proved unavailing.*

Chemistry is somehow imagined to be the science that can confer the

[*W riters on Entomology, though they have described the structure and habits of insects, have probably done little to preveni their ravages. The mischief done by the Hessian Fly has been mitigated by the labors of those whose studies have enabled them to indicate the period of their nidification, or egg-laying; and thus teaching the farmer to delay his time of sowing-whereby, however, his crop is necessarily diminished. But it does not follow that because a knowledge of the physiology and habits of insects may lead to no practical remedy against their ravages, that their natural history should not be studied. All such studies form a part, and an elegant part too, of agricultural literature, and deserve, therefore to be cultivated by every country gentleman. KOLlaR on the Insects injurious to Farmers and Gardeners, and HARRIS on the Insects injurious to Vegetation in Massachusetts, ought assuredly to form a part of every farmer's library. There are books enough of the most entertaining character, closely allied to his own profession, sufficient to beguile and improve every leisure hour the country gentleman can command, and it behooves every farmer to supply them to his sons. The time is coming, may we not hope, when to be a good farmer will carry with it the presumption of being a man of various and elegant, as well as of practical knowledge-when the agriculturist, ceasing to be a mere empiric, will know as well the why and the wherefore as the how and the when. The foundation for all this, it cannot be too often repeated, must be laid ir our schools.

(22)

Ed. Farm. Lib.] 
greatest benefits on Agriculture. This opinion seems confirmed in the minds of most writers and agriculturists, and especially the English, most probably from the circumstance of an eminent chemist having been the first to undertake the explanation of agricultural practice on strictly scientific principles. Sir Humphry Davy has, no doubt, been the cause of bestowing on that science the character, whose influence was imagined to be more capable of benefiting Agriculture than its eulogists have since been able to establish. He endeavored to explain with great acuteness many of the most familiar phenomena of Agriculture, when in possession of very limited acquaintance with practical facts; and the result has been, that while his own chemical researches have conferred no practical benefit on Agriculture- his conclusions being in collision with practice-the field of observation and experiment which he explored and traversed has since been carefully avoided by succeeding chemists, in the conviction, no doubt, that wherein he failed they were not likely to succeed. The idea seemed never to have struck them that Sir Humphry had attempted to enforce a connection betwixt Chemistry and Agriculture which both were incapable of maintaining. Viewing the relation betwixt them merely in a practical point of view, I can see no very obvious connection betwixt tilling the soil and forcing crops by manure for the support of man and beast-which is the chief end of Agriculture-and ascertaining the constituent parts of material bodies, organic and inorganic-which is the principal business of Chemistry. A knowledge of the constituent parts of soils, or plants, or manures, now forms a necessary branch of general chemical education, but how that knowledge can improve agricultural practice, has never yet been practically demonstrated. No doubt, Chemistry informs us that plants will not vegetate in pure earths, and that those earths constitute the principal basis of all soils; but as pure earths are never found in soils in their ordinary state, farmers can have no chance of raising crops on them. It may be true, as Chemistry intimates, that plants imbibe their food only when in a state of solution; but what avails this fact to Agriculture, if fact it be, when manures are only applied in a solid state? It may be quite true, as Chemistry declares, that plants cannot supply, from their composition, any substance they have not previously derived from the air, earth, or decomposed organic matter; but of what practical use to Agriculture is this declaration, as long as farmers successfully raise every variety of crop from the same manure? Chemistry may be quite correct in its views with regard to all these particulars, but so is practice, and yet both are very far from agreeing; and as long as this constitutes the only sort of information that Chemistry affords, it is unimportant to the farmer. He wishes to be shown how to render the soil more fertile, manures more effective, and crops more prolific, by the practical application of chemical principles.

There are many writers, I am convinced, who recommend the study of Chemistry to farmers little acquainted with the true objects of chemical research, and not much more with practical Agriculture. At all events, they expatiate, only in vague generalities, on the advantages of analyzing soils, manures, \&c. but do not attempt to demonstrate how any practice of husbandry may certainly be improved by the suggestions of Chemistry. The truth is, until chemists become thoroughly acquainted with agricultural facts, they cannot see the bearings of chemical principles on agricultural practice, any more than the most uncouth farmer; and until they prove the farmer's practice in any one instance wrong, and are certain of its being put right by their suggestions, there is no use of lauding Chemistry as a paramount science for Agriculture.

(23) 
In this view of the science, I would rather underrate the ability of Chemistry to benefit Agriculture than excite the fallacious hopes of the farmer by extolling it with undue praise. At the same time, were a chemist to recommend suggestions promising a favorable issue, that might tend to excite a well-grounded hope in chemical assistance, and I am sure the suggestions would even be fairly tried by farmers who entertain pretty strong suspicions against science. If, for example, on carefully analyzing a plant in common culture, it was found to contain an ingredient which it could not obviously have derived from the manure or the soil, were a suggestion made to mix a quantity of that particular ingredient with the soil or manure, it would at once be cheerfully put to the test of experiment by farmers. If, on the other hand, were the same chemist to suggest making heavy clay land friable by the mechanical admixture of sand, the physical impracticability of the proposal would at once convince the farmer that the chemist had no adequate notion of farm work. And yet propositions as absurd as this have frequently been suggested to farmers by writers who are continually maintaining the ability of Chemistry to henefit Agriculture. But let me appeal to facts-to ordinary experience.

I am not aware of a single agricultural practice that has been adopted from the suggestions of Chemistry. I am not speaking unadvisedly while making this unqualified statement. In truth, I do not know a single operation of the farm that has not originated in sheer practice. But is it not somewhat unreasonable to expect improvement in agricultural practice, and still more, an entirely improved system of Agriculture, from the suggestions of Chemistry? Some chemical results may appear to bear analogy to certain operations of the farm, such as the preparation of manures; but such analogies, being chiefly accidental, are of themselves insufficient grounds upon which to recommend chemical affinity as the principle which ought to regulate a system of practically mechanical operations. How can the most familiar acquaintance with the chemical constituents of all the substances found on a farm, suggest a different mode of making them into manure, inasmuch as practice must first pronounce the treatment to be an improvement, before it can really be an improvement, whatever Chemistry may suggest? Besides, Chemistry, with all its knowledge of the constituent parts of substances, cannot foretell, more confidently than practice, the results of the combinations with the soil, of the substances analyzed among themselves, and the combined effects of these and the soil upon cultivated plants. I am aware that hints may be suggested by science which may prove beneficial to practice; but unless they accord with the nature of the practice to which they are proposed to be applied, they are certain of proving unserviceable. Many hints thrown out at random have frequently been put to the test of experiment; but to experimentize on hints is quite a different thing in farming from that sort of farming which is proposed to be entirely based on theoretical suggestions, whether of Chemistry or of any other science.

For these reasons, I conceive, Chemists would be more usefully employed in following than in attempting to lead practical Agriculture. If it were practicable, it would certainly be very desirable for the farmer to be assured that his practice was in accordance with chemical principles; if, for example, it could be explained on chemical principles why a certain class of soils is better suited to a certain kind of crop than other classes, and $w h y$ animal manure is better suited than vegetable to a certain kind of crop; when Chemistry shall explain why certain results are obtained by practice, it will accomplish much, it will elucidate that which was before obscure in principle. Were chemists to confine the first stage of 
their investigations of agricultural matters to this extent, farmers would be much gratified with the assurance of their practice being in unison with the principles of chemical science; and this would tend more than any other circumstance to inspire them with confidence in the utility of that science. This is the position which Chemistry, in my opinion, should occupy in relation to Agriculture; for how successful soever it may be in assisting other arts, such as dyeing, soap-making, and ink-making, it assists them both by synthesis and analysis; whereas it can only investigate agricultural subjects by analysis, because every substance employed in Agriculture, especially a manure, is used by farmers in the state it is found in the markets, without reference to its chemical constituent parts ; and, when used, should an analytical or synthetical process go on among those parts, or with the soil, with which they are intimately brought into contact, the process going on in the soil would change the chemical composition of the whole, and place them beyond the reach of chemical research. The investigation of the soil after the removal of the crop might then be curious, but nothing more.* In this investigation the farmer, the vegetable physiologist, and the chemist, would all disagree as to the extent of the infuence exercised by the favorite substance of each in producing the

[* In all these views we cannot agree, but the author would seem to be supported in thein by David Law, Esq. Professor of Agriculture in the University of Edinbargh, who says in reference to the use of chemistry in analyzing soils, "The ehemist may draw useful conclusions from a careful analysis of the matter of the soil, and may from time to time be able to communicate results that may be serviceable to the practical farmer; but it is not necessary for the ends of practice that the farmer himself should be a chemist. The farmer cannot arrive at the science of mineral analysis, without a knowledge of chemistry and the business of the laboratory, which he can rarely acquire, and which it is in no degree necessary to his success as a farmer that he should be possessed of."

Mr. Colmas, too, whose judgment and zeal in the canse of education and science as applied to Agriculture are so well known, seems to think the actual importance of chemistry, in its connection with that pursuit, 80 far, has been overrated. He says "the application of sulphuric acid to bones seems as yet to be the only case of the application of chemical science to the improvement of Agriculture upon scientific principles, and this affords strong grounds to hope for much more."

In relation to agricultural sehools, Mr. Colman's Report may be read with profit. One ought to take for granted that it, too, will be in all our country schools. On the principle that the Father who wished to beget in his sons a capacity for labor, told them he had buried his treasure in the garden, without telling the spot, leaving them to dig it all over, we recommend the reader not to adopt, in extenso, the opinions of these two distinguished authors, until he shall have read carefully Davy and Boussingault and Liebig and Petzholdt and Johnstone, and then form bis own judgment. Surely every young Farmer should know enough of chemistry to be able, as he may by a very simple process, to analyze his own soil that be may know in what most important ingredients it is redundant or deficient, to the end that having learned from analysis made by professional chemists the ingredients which make the necessary food for certain crops, he may be able to supply such as are needful in the soil, or to avoid the expense of applying others, in which he finds his land to be redundant. Mr. Colman, in his personal observations or European Agriculture, vol. 1, part 3, gives us the best accounts of the practical working and benefit of $\mathrm{Ag}$. ricultural schools in Ireland, and of the one then about to be established at Cirencester, England. Referring to the school at Larne, he says :

"It was from this establishment that a detachment of five pupils was sent for examination to the great meeting of the Agricultural Society of Scotland the last autumn, where their attainments created a great sensation, and produced an impression, on the subject of the importance of agricultural education, which is likely to lead to the adoption of some universal system on the subject.

"I shall transcribe the acconnt given of the occasion: "Five boys from the school at Larne were introduced to the meeting, headed by their teacher. They seemed to belong to the better class of peasantry, being clad in bomely garbs; and they appeared to be from twelve to fifteen years of age. They were examined, in the first instance, by the inspector of achoole, in grammar, geography, and arithmetic : and soarvely a single question did they fail to answer correctly. They were then examined, by an agricultural professor, in the scientific branches, and by two (25) 
crop. In settling the question, however, the farmer would have the same advantage over his rivals, in taking possession of the crop as the reward of his practical skill, as the lawyer who, in announcing the judgment of the court to two contending parties, gave a shell to each, and kept the oyster to himself.

Of all the sciences, mechanics have proved the most useful to Agriculture. If implements may be characterized as the right hand of Agriculture, mechanical science, in improving their form and construction, may be said to have given cunning to that right hand; for, mechanical science, testing the strength of materials, both relatively and absolutely, employs no more material in implements than is sufficient to overcome the force of resistance, and it induces to the discovery of that form which overcomes resistance with the least power. Simplicity of construction, beauty of form of the constituent parts, mathematical adjustment, and symmetrical proportion of the whole machine, are now the characteristics of our implements; and it is the fault of the hand that guides them, if field-work is not now dexterously, neatly, and quickly performed. In saying thus much for the science that has improved our implements to the state they now are, when compared with their state some years ago, I am not averring they are quite perfect. They are, however, so far perfect as to be correct in mechanical principle, and light in operation, though not yet simple enough in construction. No doubt many may yet be much simplified in construction; and I consider the machinist who simplifies the action of any useful implement, thereby rendering it less liable to derangement, does a good service to Agriculture as the inventor of a new and useful implement.

These are the principles which determine the arrangement adopted in this book. In applying these principles, as the seasons supremely rule the destiny of every farming operation, so to them is given full sway over the whole arrangement. This is accomplished by describing every operation in the season it should be performed, and this condition necessarily implies the subdivision of the arrangement into four seasons. Authors of Farmers' Calendars divide their subject-matter into calendar or fixed months, being apparently inattentive to the infuences of the seasons. Such an arrangement cannot fail to create confusion in the minds of young farmers; as any operation that is directed to be done in any month, may not in every year, be performed in the same month, on account of the fluctuating mature of the seasons.

In adopting the seasons as the great divisor of the labors of the farm, the months which each season occupies are not specified by name, because the same season does not occupy the same number of months, nor even exactly the same months, in every year. The same work, however, is performed in the same season every year, though not, perhaps, in the same month or months.

In arranging the seasons themselves, the one which commences the agricultural year, which is Winter, has the precedence. The rest follow in the natural succession of Spring, Summer, and Autumn; in which last all farming operations, having finished their annual circuit, finally terminate. A few remarks, illustrative of its nature, and the work performed in it, are

practical farmers in the practical departments of Agriculture. Their acquaintance with these was alike delightful and astonishing. They detailed the chemical constitution of the soil and the effect of manures, the land best fitted for green crops, the different kinds of grin, the dairy, and the system of rotation of crops. Many of these answers required considerable exercise of reflection; and as previous concert between themselves and the gentlemen who exsmined them was out of the question, their acquirements seemed to take the meeting by surprise; at the same time they afforded the utmost satisfaction, as evincing how much could be done by a proper system of training." 
given at the commencement of each season. By comparing these intro. ductory remarks, one with the others, the nature of the principal operations throughout the year may be discovered; and, by perusing them in succession as they follow, an epitome of the entire farm operations for the year may be obtained.

Throughout the four seasons, from the commencement of winter to the end of autumn, the operations of the farm, both great and small, are described in a continued narrative. This narrative is printed in the larger type (long primer). The reader will soon discover that this narrative does not extend uninterruptedly through the whole pages-portions of smaller type (brevier) intervening, and apparently interrupting it. On passing over the small type, it will be perceived that it is really written, and may be perused without interruption. The object of this plan is to permit the necessary descriptions of all the operations, performed in succession throughout the year, to be read in the large type, to the exclusion of every other matter that might distract the attention of the reader from the principal subject. A peristrephic view, so to speak, of the entire operations of the farm is thus obtained. The leading operations, forming the principal subjects of the narrative, are distinguished by appropriate titles in CAPITALs placed across the middle of the page. The titles are numbered, and constitute, in the aggregate, a continuous succession, running through all the seasons. The leading operations thus easily attract the eye. Wood-cut figures of implements, and other objects, requiring no detailed descriptions, and representing at once their form and use, are inserted in the paragraph which alludes to thein in the narrative.

Implements that require detailed descriptions to explain, and complicated figures to represent them; reasons for preferring one mode to another of doing the same kind of work; and explanations of agricultural practice on scientific principles-together constituting the subsidiary portion of the work-are given in paragraphs in the medium-sized type (brevier), and this matter is that which apparently interrupts the principal narrative. Each paragraph is numbered within parentheses, the same as in the principal narrative, and these paragraphs carry on the numbers arithmetically with the paragraphs of the principal narrative. When references are made from the large to the small type, they are made in corresponding numerals. The words most expressively characteristic of the illustration contained in the paragraph are placed in italics at or near the beginning of it.

Marking all the paragraphs with numerals greatly facilitates the finding out of any subject alluded to-saves repetition of descriptions when the same operation is performed in different seasons-and furnishes easy reference to subjects in the index.

Wood-cut figures of the intricate implements and other objects requiring detailed descriptions, are placed among the descriptions of them in the brevier type. The portraits of the animals given are intended to illustrate the points required to be attended to in the breeding of the domesticated animals. The portraits are taken from life by eminent artists. The wood-cuts are enumerated as they occur in the order of succession, whether they belong to the large or the small type, and each wood-cut is designated by its distinctive appellation-both the numeral and appellative being requisite for quick and easy reference.

The matter in the small type appears somewhat like foot-notes in ordinary books ; but, in this instance, it differs in character from foot-notes, inasmuch as it occurs in unbroken pages at the end of the description of every leading operation. By this plan the principal narrative is not inter- 
fered with, and both it and its illustrations may be perused before the succeeding leading operation and its illustrations are taken into consideration. This plan has the advantage of relieving the principal narrative of heavy foot-notes - the perusal of which, when long, not only seriously interrupts the thread of the narrative, but causes the leaves gone over to be turned back again; both interferences being serious drawbacks to the pleasant perusal of any book.

Foot-notes required either for the principal narrative or illustrations are distinguished by the usual marks, and printed at the bottom of the page in the smallest type used in this work.

The paragraphs containing the matter supplied by Mr. Slight are enclosed within brackets (thus, [ ]), and attested by his initials, J. S.

[The additions by John S. Skinner are designated by his title of " $E d$ itor of the Farmers' Library."]

\section{OF THE EXISTING METHODS OF LEARNING PRACTICAL HUS- BANDRY.}

"I have vowed to hold the plow for her sweet love three year."

LOVE's LABOR LOST.

1 HAvE hinted that there are three states, in one of which the young farmer will be found when beginning to learn his profession. One is when he himself is born and brought up on a farm, on which, of course, he may acquire a knowledge of farming intuitively, as he would his mother tongue. Another is when he goes to school in boyhood, and remains there until ready to embark in the active business of farming; the impressions of his younger years will become much effaced, and he will require to renew his acquaintance with farming as he would of a language that he had forgotten. Young men thus early grounded generally make the best farmers, because the gxeat secret of knowing practical farming consists in bestowing particular attention on minor operations, which naturally present themselves to the youthful mind before it can perceive the use of general principles. Farmers so brought up seldom fail to increase their capital; and, if their education has been superior to their rank in life, frequently succeed in improving their status in society. It is to the skillful conduct and economical management of farmers so situated, that Scotland owes the high station she occupies among the agricultural nations of the world.

The third state in which the learning of farming is requisite is when a young man who has been educated and entirely brought up in a town, or perhaps passed his boyhood in the country, but may have bestowed little attention on farming, wishes to learn it as his profession. In either of these cases, it is absolutely necessary for him to learn it practically on a farm ; for total ignorance of his business, and entire dependence on the skill and integrity of his servants, will soon involve him in pecuniary difficulties. To meet the wishes of seekers of agricultural knowledge, there are farmers who receive pupils as boarders, and undertake to teach them practical husbandry.

The chief inducement, as I conceive, which at first prompts young men who have been nurtured in towns to adopt farming as a profession, is an undefined desire to lead a country life. The desire ofien originates in this way. Most boys spend a few weeks in the country during the school 
vacation in summer, on a visit to relations, friends, or school companions. To them the period of vacation is a season of true enjoyment. Free of the task-in the possession of unbounded liberty-untrammeled by the restraints of time, and partaking of sports new to them and solely appertaining to the country, they receive impressions of a state of happiness which are ever after identified with a country life. They regret the period of return to school-leave the scene of those enjoyments with reluctance-and conceive that their happiness would be perpetual, were their hearts wedded to the objects that captivated them. Hence the desire to return to those scenes.

It is conducive to the promotion of Agriculture that young birds of fortune are thus occasionally ensnared by the love of rural life. They bring capital into the profession; or, at all events, it will be forthcoming when the scion of his father's house has made up his mind to become a farmer. Besides, these immigrations into farms are requisite to supply the places of farmers who retire or die out. Various motives operate to bring farms into the market. Sons do not always follow their father's profession, or there may not be a son to succeed, or he may die, or choose another kind of life, or may have experienced ill treatment at home, or been guilty of errors which impel him to quit the paternal roof. For these drains, a supply must flow from other quarters to maintain the equilibrium of agricultural industry. This young race of men, converted into practical farmers, being generally highly born and well educated, assume at once a superior status in, and improve the tone of, rural society. Though they may amass no large fortunes, they live in good style. In the succeeding generation, another change takes place. Unless he is well provided with a patrimony, the son seldom succeeds his father in the farm. The father finds he cannot give the farm free of burdens to one son in justice to the rest of the family. Rather than undertake to liquidate such a burden by means of a farm-that is, from land that is not to be his own-the son wisely relinquishes farming, which, in these circumstances, would be to him a life of pecuniary thralldom.

The young man who wishes to learn farming practically on a farm, should enter upon his task at the end of harvest, as immediately after that the preparatory operations commence for raising the next year's crop; and that is the season, therefore, which begins the new-year of farming. He should provide himself with an ample stock of stout clothing and shoes, capable of repelling cold and rain, and so made as to answer at once for walking and riding. From the outset, he must make up his mind to encounter all the difficulties I have described under the first head. Formidable as they may seem, I encourage him with the assurance that it is in his power to overcome them all. The most satisfactory way of overcoming them is to resolve to learn his business in a truly practical manner. Merely being domiciled on a farm is not of itself a sufficient means of overcoming them, for the advantages of residence may be squandered away in idleness, by frequent absence, by spending the hours of work in the house in light reading, or by casual and capricious attendance on field operations. Such habits must be eschewed, before there can be a true desire to become a practical farmer. Every operation, whether important or trifling, should be personally attended to, as there is none but what tends to produce an anticipated result. Attention alone can render them familiar; and, without a familiar acquaintance with every operation, the management of a farm need never be undertaken.

$M u c h$ assistance in promoting this attention should not be expected from the farmer. No doubt it is his duty to communicate all he knows to (29) 
his pupils; and, as I believe, most are willing to do so; but, as efficient tuition implies constant attendance on work, the farmer himself cannot constantly attend to every operation, or even explain any, unless his attention is directed to it; and much less will he deliver extempore lectures at appointed times. Reservedness in him does not necessarily imply unwillingness to communicate his skill; because, being himself familiar with every operation that can arrest the attention of his pupils, any explanation of minutiæ at any other time than when the work is in the act of being performed, and when only it could be understood by the pupils, would only serve to render the subject more perplexing. In these circumstances the best plan for the pupil to follow is to attend constantly, and personally observe every change that takes place in every piece of work. Should the farmer happen to be present, and be appealed to, he will, as a matter of course, immediately clear up every difficulty in the most satisfactory way; but should he be absent, being otherwise engaged, then the steward or grieve, or any of the plowmen, or shepherd, as the nature of the work may be, will, on inquiry, afford as much information on the spot as will serve to enlighten his mind until he associates with the farmer at the fireside.

To be enabled to discover that particular point in every operation which, when explained, renders the whole intelligible, the pupil should put his hand to every kind of work, be it easy or difficult, irksome or pleasant.Experiences acquired by himself, however slightly affecting his mind-desirous of becoming acquainted with every professional incident-will solve difficulties much more satisfactorily than the most elaborate explanations given by others. The larger the stock of these personal experiences he can accumulate, the sooner will the pupil understand the purport of every thing that occurs in his sight. Daily opportunities occur on a farm for joining in work, and acquiring those experiences. For example, when the plows are employed, the pupil should walk from the one to the other, and observe which plowman or pair of horses perform the work with the greatest apparent difficulty or ease. He should also mark the different styles of work executed by each plow. A considerate comparison of these particulars will enable him to ascertain the best and worst specimens of work. He should then endeavor to discover the cause why different styles of work are produced by apparently very similar means, in order to enable himself to rectify the worst and practice the best. The surest way of detecting error and discovering the best method is to take hold of each plow successively, and he will find, in the endeavor to maintain each in a steady position, and perform the work evenly, that all require considerable labor-every muscle being awakened into energetic action, and the brow most probably moistened. As these symptoms of fatigue subside with repetitiors of the exercise, he will eventually find one of the plows more easily guided than any of the rest. The reasons for this difference he must himself endeavor to find out by comparison, for its holder cannot inform him, because he professes to have-indeed, can have-no knowledge of any other plow but his own. In prosecuting this system of trials with the plows, he will find himself becoming a plowman, as the mysteries of the art divulge themselves to his apprehension; but the reason why the plow of one of the men moves more easily, does better work, and oppresses the horses less than any of the rest, is not so obvious; for the land is in the same state to them all-there cannot be much difference in the strength of the pairs of horses, as each pair are generally pretty well matched-and, in all probability, the construction of the plows is the same, if they have been made by the same plow-wright, yet one plowman evi(30) 
dently exhibits a decided superiority in his work over the rest. The inevitable conclusion is, that plowman understands his business better than the others. He shows this by trimming the irons of his plow to the state of the land, and the nature of the work he is about to perform, and by training his horses more in accordance with their natural temperament, whereby they are guided more tractably. Having the shrewdness to acquire these essential accomplishments to a superior degree, the execution of superior work is an easier task to him than inferior work to the other plowmen. This case, which I have selected for an example, is not altogether a supposititious one; for, however dexterous all the plowmen on a farm may be, one will always be found to show a superiority over the rest.

Having advanced thus far in the knowledge and practice and capability of judging of work, the pupil begins to feel the importance of his acquisition; and this success will fan the flame of his enthusiasm, and prompt him to greater acquirements. But even in regard to the plow, the pupil has muck to learn. Though he has picked out the best plowman, and knows why he is so, he is himself still ignorant of how practically to trim a plow, and to drive the horses with discretion. The plowman will be able to afford him ocular proof how he places (tempers) all the irons of the plow in relation to the state of the land, and why he yokes and drives the horses as he does in preference to any other plan. Illiterate and unmechanical as he is, and his language full of technicalities, his explanations will nevertheless give the pupil a clearer sight into the minutice of plowing than he could acquire by himself as a spectator in an indefinite length of time.

I have selected the plow as being the most useful implement to illustrate the method which the pupil should follow, in all cases, to learn a practical knowledge of every operation in farming. In like manner, he may become acquainted with the particular mode of managing all the larger implements which require the combined agency of man and horse to put into action; as well as become accustomed to wield the simpler implements used by the hand easily and ambidexterously, a great part of farm-work being executed with simple but very efficient tools. Frequent personal attendance at the farm-stead, during the winter months, to view and conduct the threshing-machine, while threshing corn, and afterward to superintend the winnowing-machine, in cleaning it for the market, will be amply repaid by the acquisition of essential knowledge regarding the nature and value of the cereal and leguminous grains. There is, moreover, no better method of acquiring an extensive knowledge of all the minor operations of the farm, than for the pupil personally to superintend the labors of the field-workers. Their labors are essential, methodical, almost always in requisition, and mostly consisting of minutiæ; and their general utility is shown, not only in their intrinsic worth, but in relation to the labors of the teams.

The general introduction of sowing-machines, particularly those which sow broadcast, has nearly superseded the beautiful art of sowing corn by hand.* Still a great deal of corn is sown by the hand, especially on small

\footnotetext{
* It were to be wished that this remark were more applicable to the U. S. Since the introduction of an English sowing-machine near Wilmington, Delaware, and the improvement on it, as it is alleged, by PenNock, it may be expected that this operation, recommended as well by its neatness as by its economy, will be extended through the country. It will be seen on referring to the June, 1846, Monthly Journal of Agriculture (which, be it always understood, is published along with the Farmers' Library) that Mr. Jones, a very observing and diligent practical Farmer, gives it as his opinion that the use of Pennock's drill or sowing-machine effects a saving or increase of 25 per cent.
} 
farms, on which expensive machines have not yet found their way. In the art of hand-sowing, the pupil should endeavor to excel, for, being difficult to perform it in an easy and neat manner, the superior execution of it is regarded as an accomplishment. It is, besides, a manly and healthful exercise, conducive to the establishment of a robust frame and sound constitution.

The feeding of cattle in the farm-stead, or of sheep in the fields on turnips, does not admit of much participation of labor with the cattle-man or shepherd; but nevertheless, either practice will form an interesting subject of study to the pupil, and without strict attention to both, he will never acquire a knowledge of fattening live-stock, and of computing their value.

By steadily pursuing the course of observation which I have thus chalked out, and particularly in the first year of his apprenticeship, the pupil in a short time, will acquire a considerable knowledge of the minutiæ of labor; and it is only in this way that the groundwork for a familiar acquaintance with them can be laid. A truly familiar acquaintance with them requires years of experience. Indeed, observant farmers are learning some new, or modifications of some old, practice every day, and such new-like occurrences serve to keep alive in them a regard for the most trivial incident that happens on a farm.

In urging on the pupil the necessity of putting his hand to every kind of labor, I do not mean to say he should become a first-rate workman. To become so would require a much longer time than he could spare in a period of pupilage. His personal acquaintance with every implement and operation should, however, enable him by that time to decide quickly whether work is well or ill done, and whether it has been executed in a reasonable time. No doubt this extent of knowledge may be acquired in time, without the actual labor of the hands; but, as it is the interest of the pupil to learn his profession not only in the shortest possible time, but in the best manner, and as these can be acquired sooner through the joint coöperation of the head and hands, than by either singly, it would seem imperative on him to begin to acquire his profession by labor.

Other considerations regarding the acquisition of practical knowledge deserve the attention of the pupil. It is most conducive to his interest to learn his profession in youth, and before the meridian of life has set in, when labor of every kind becomes irksome. It is also much better to have a thorough knowledge of farming, before engaging in it on his own account, than to acquire it in the course of a lease, during which heavy losses may be incurred by the commission of comparatively trivial errors, especially at the early period of its tenure, when farms in all cases are most difficult to conduct. It is an undeniable fact, that the work of a farm never proceeds so smoothly and satisfactorily to all parties engaged in its culture, as when the farmer is thoroughly master of his business. His orders are then implicitly obeyed, not because they are pronounced more authoritatively, but because a skillful master's plans and directions inspire that degree of confidence in the laborers as to believe them to be the

The spread of improved agricultural implements is proverbially slow over the world, but less 80 in this, probably, than in any other part of it, owing to the freedom of our institutions, the frequent and extensive intercourse of our people and their aptness both at invention and imitation. But even here the adoption of the costly machinery of improved construction in England, is much restrained by the want of capital, which counteracts even our greater necesaity for all labor-saving contrivances. All associations or uses of capital, therefore, to supply means to the industrious and frugal agriculturist, on fair terms and for periods corresponding with the nature of his pursuits, would deserve to bo rewarded with honor and with profit. 
best that could be devised in the circumstances. Shame is often acutely felt by servants, on being detected in error, whether of the head or heart, by so competent and discriminating a judge as a skillful master; because rebuke from such a one implies ignorance or negligence in those against whom it is directed. The fear of having ignorance and idleness imputed to them, by a farmer who has become acquainted with the capabilities of work-people by dint of his own experience, and can estimate their services as they really deserve, urges laborers to do a fair day's work in a workmanlike style.

Let the converse of all these circumstances be imagined; let the losses to which the ignorant farmer is a daily prey, by many ways-by hypocrisy, by negligence, by idleness, and by dishonesty of servants-be calculated, and it must be admitted that it is infinitely safer for the farmer to trust to his own skill for the fulfillment of his engagements, than entirely to depend on that of his servants, which he will be obliged to do if they know his business better than he himself does. No doubt a trustworthy steward may be found to manage well enough for him-and such an assistant is at all times valuable-but, in such a position, the steward himself is placed in a state of temptation, in which he should never be put; and, besides, the inferior servants never regard him as a master, and his orders are never so punctually obeyed, where the master himself is resident. I would, therefore, advise every young farmer to acquire a competent knowledge of his profession, before embarking in the complicated undertaking of conducting a farm. I only say a competent knowledge; for the gift to excel is not imparted to all who select farming as their profession; "it is not in man who walketh to direct his steps" aright, much less to attune his mind to the highest attainments.

Before the pupil fixes on any particular farm for his temporary abode, he should duly consider the objects he wishes to attain. I presume his chief aim is to attain such an intimate knowledge of farming as to enable him to employ his capital safely in the prosecution of the highest department of his profession. This will, probably, be best attained by learning that system which presents the greatest safeguards against unforeseen contingencies. Now, there is little doubt that the kind of farming which cultivates a variety of produce is more likely to be safe, during a lease, in regard both to highness of price and quantity of produce, than that which only raises one kind of produce, whether wholly of animals, or wholly of grain. For, although one kind of produce, when it happens to be prolific or high priced, may, in one year, return a greater profit than a variety of produce in the same year, yet the probabilities are much against the frequent recurrence of such a circumstance. The probability rather is that one of the varieties of produce will succeed, in price or produce, every year; and, therefore, in every year there will be a certain degree of su:cess in that mode of farming which raises a variety of produce. Take, as an example, the experience of late years. All kinds of live-stock have been reared with profit for some years past; but the case is different in regard to grain. Growers of grain have suffered greatly in their capital in that time. And yet, to derive the fullest advantages from even the rearing of stock, it is necessary to cultivate a certain extent of land upon which to raise straw and green crops for them in winter. Hence, that system is the best for the young farmer to learn, which cultivates a relative proportion of stock and crop, and not either singly. This has been characterized as the mixed system of husbandry. It avoids, on the one hand, the monotony and inactivity attendant on the raising of grain, and subdues, on the other, the roving disposition engendered in the tending of live-stock in a $(33) . . . . .3$ 
pastoral district; so it blends both occupations into a happy union of cheerfulness and quiet.

Most farmers in the lowlands of Scotland practice the mixed husbandry, but it is reduced to a perfect system nowhere so fully as in the Border Counties of England and Scotland. There many farmers accept pupils, and thither many of the latter go to prepare themselves to become farmers. The usual fee for pupils, in that part of the country, is one hundred pounds $[\$ 500]$ per annum for bed and board, with the use of a horse to occasional markets and shows.* If the pupil desire to have a horse of his own, about thirty pounds a-year more are demanded. On these moderate terms, pupils are generally very comfortably situated.

I am very doubtful of it being good policy to allow the pupil a horse of his own at first. Constant attention to field-labor is not unattended with irksomeness; and, on the other hand, exercise on horseback is a tempting recreation to young minds. It is enough for a young man to feel the removal of parental restraint, without also having the dangerous incentive of an idle life placed at his disposal. They should consider that, upon young men arrived at the years when they become farming pupils, it is not in the power, and is certainly not the inclination, of farmers to impose ungracious restraints. It is the duty of their parents and guardians to impose these; and the most effectual way that I know of, in the circumstances, to avoid temptations, is the denial of a riding-horse. Attention to business in the first year will, most probably, induce a liking for it in the second; and, after that, the indulgence of a horse may be granted to the pupil with impunity, as the reward of diligence. Until then, the horse occasionally supplied by the farmer to attend particular markets, or pay friendly visits to neighbors, should suffice ; and, as that is the farmer's own property, it will be more in his power to curb in his pupils any propensity to wander abroad too frequently, and thereby preserve his own character as a tutor.

Three years of apprenticeship are, in my opinion, requisite to give a pupil an adequate knowledge of farming-such a knowledge, I mean, as would impress him with the confidence of being himself able to manage a farm; and no young man should undertake such a management until he feels this confidence in himself. Three years may be considered by many as too long a time to spend in learning farming; but, after all, it is much less time than that given to many other professions, whose period of apprenticeship extends to five and even seven years; and, however highly esteemed those professions may be, none possess a deeper interest, in a national point of view, than that of Agriculture. There is a condition attendant on the art of farming-which is common to it and gardening, but inapplicable to most other arts-that a year must elapse before the same work can again be performed. Whatever may be the ability of the learner

[" A gentleman of ample fortune, residing at Paterson, New-Jersey, has lately, with his son's entire concurrence and desire, sent him to reside with a Scotch farmer, of Shields, near Ayr; to whom he pays one hundred pounds sterling a year-say $\$ 500$ - for board and education as a farmer. Mr. Turnant (that appears to be the name) is Vice President of the Ayrshire Agricultural Society ; and is, withal, a gentleman, and lives as such. The young man alluded to keeps no horse, but is fully instructed in all the departments of Agriculture. We mention this particular case of a young gentleman, not urged by necessity, betaking himself to Agriculture as a profession, with the acquiescence of his father, to show that public sentiment is taking a right turn, and that those who have been so assiduously laboring to elevate this pursuit in the pablic esteem have not entirely lost their labor, but may hope yet to see practical Agriculture followed as an intellectual occupation-one in which success may warrant the presumption of some merit besides the mere faculties of imitation and plodding industry. 
to acquire farming, time must thus necessarily elapse before he can have the opportunity of again witnessing a bygone operation. There is no doubt of his natural capacity to acquire, in two years, the art to manage a farm, but the operations necessarily occupying a year in their performance, prevent that acquisition in less time than three. This circumstance, of itself, will cause him to spend a year in merely observing passing events. This is in his first year. As the operations of farming are all anticipatory, the second year may be fully employed in studying the progress of work in preparation of anticipated results. In the third year, when his mind has been stored with all the modes of doing work, and the purposes for which they are performed, the pupil may attempt to put his knowledge into practice ; and his first efforts at management cannot be attempted with so much ease of mind to himself as on the farm of his tutor, under his correcting guidance.

This is the usual progress of tuition during the apprenticeship of the pupil; but, could he be brought to anticipate results while watching the progress of passing events, one year might thus be cut off his apprenticeship. Could a book enable him to acquire the experience of the second year in the course of the first, a year of probationary trial would be saved him, as he would then acquire in two what requires three years to accomplish. This book will accomplish no small achievement-will confer no small benefit on the agricultural pupil-if it accomplish this.

\title{
6. OF THE ESTABLISHMENT OF SCIENTIFIC INSTITUTIONS OF
} PRACTICAL AGRICULTURE.

\author{
"Here let us breathe, and happily institute \\ A course of learning and ingenious studies." \\ TAMING OF THE SHREW.
}

Although I know of no existing plan so suited to the learning of practical farming as a protracted residence on a farm, yet I feel assured a more efficient one might easily be proposed for the purpose. An evident and serious objection against the present plan is the want of that solicitous superintendence over the progress of the pupils, on the part of the farmer, which is implied in his receiving them under his charge. The pupils are left too much to their own discretion to learn farming effectually. They are not sufficiently warned of the obstacles they have to encounter at the outset of their career. Their minds are not sufficiently guarded against receiving a wrong bias in the methods of performing the operations. The advantages of performing them in one way rather than another are not sufficiently indicated. The effects which a change of weather has in altering the arrangements of work fixed upon, and of substituting another more suited to the change, is not sufficiently explained. Instead of receiving explanatory information on these and many more particulars, the pupils are mostly left to find them out by their own diligence. If they express a desire to become acquainted with these things, no doubt it will be cheerfully gratified by the farmer; but how can the uninitiated pupil know the precise subject with which to express his desire to become acquainted?

In such a system of tuition, it is obvious that the diligent pupil may be (35) 
daily perplexed by doubtful occurrences, and the indifferent pupil permit unexplained occurrences to pass before him, without notice. Reiterated occurrences will, in time, force themselves upon the attention of every class of pupils : but, unless their attention is purposely drawn to, and explications proffered of, the more hidden difficulties in the art of farming, they will spend much time ere they be capable of discovering important occult matters by their own discernment.

It is in this respect that farmers, 'who profess to be tutors, show, as 1 conceive, remissness in their duty to their pupils ; for all of them can impart the information alluded to, and give, besides, a common-sense explanation of every occurrence that usually happens on a farm, otherwise they should decline pupils.

It is obvious that pupils should not be placed in this disadvantageous position. They ought to be taught their profession; because the art of husbandry should be acquired, like every other art, by teaching, and not by intuition. On the other hand, pupils in this, as in every other art, ought to endeavor to acquire the largest portion of the knowledge of external things by their own observation; and they should be made aware, by the farmer, that he can at most only assist them in their studies; so that, without much study on their parts, all the attention bestowed on their tuition by the most pains-taking farmer will prove of little avail. Practical experience forms the essential portion of knowledge which farmers have to impart, and it is best imparted on the farm; but they have not always the leisure, by reason of their other avocations, to communicate even this on the spot in its due time. More than mere practical knowledge, however, is requisite to satisfy the mind of the diligent pupil. He wishes to be satisfied that he is learning the best method of conducting a farm : he wishes to be informed of the reasons why one mode of management is preferable to every other: he wishes to become familiar with the explanations of all the phenomena that are observable on a farm.

To afford all the requisite information to the pupil in the highest perfection, and to assist the farmer in affording it to him in the easiest manner, I propose the following plan of tuition for adoption, where circumstances will permit it to be established. The more minutely its details are explained, the better will it be understood by those who may wish to form such establishments.

Let a farmer of good natural abilities, of firm character, fair education, and pleasant manners-leasing a farm of not less than five hundred acres, and pursuing the mixed system of husbandry-occupy a house of such a size as would afford accommodation to from ten to twenty pupils. The farm should contain different varieties and conditions of soil-be well fenced, well watered, and not at an inconvenient distance from a town.

With regard to the internal arrangements of the house, double-bedded rooms would form suitable enough sleeping apartments. Besides a diningroom and drawing-room, for daily use, there should be a large room, fitted up with a library, containing books affording sound information on all agricultural subjects, in various languages-forming at one time a lecture-room for the delivery of lectures on the elementary principles of those sciences which have a more immediate reference to Agriculture, and at another a reading or writing room or parlor for conversations on farming subjects.There should be fixed, at suitable places, a barometer, a sympiesometer, thermometers (one of which should mark the lowest degree of temperature in the night), a rain-gauge, an anemometer, and a weathercock. No very useful information, in my opinion, can be derived by the farmer from a bare register of the hights and depths of the barometer and thermometer. 
A more useful register for him would be that of the directions of the wind, accompanied with remarks on the state of the weather, the heat of the air as indicated by the feelings, and the character of the clouds as expressed by the most approved nomenclature. The dates of the commencement and termination of every leading operation on the farm should be noted down, and appropriate remarks on the state of the weather during its performance recorded. A small chemical laboratory would be useful in affording the means of analyzing substances whose component parts were not well known. Microscopes would be useful in observing the structure of plants and insects, for the better understanding of their respective functions.

The slaughter-house required for the preparation of the meat used by the family should be fitted up to afford facilities for dissecting those animals which have been affected by peculiar disease. Skeletons and preparations for illustrating comparative anatomy could thus be formed with little trouble. A roomy dairy should be fitted up for performing experiments on the productive properties of milk in all its various states. A portion of the farm-offices should be fitted up with apparatus for making experiments on the nutritive properties of different kinds and quantities of food, and the fattening properties of different kinds of animals. A steelyard, for easily ascertaining the live-weight of animals, is a requisite instrument.The bakery, which supplies the household bread, would be a proper place for trying the relative panary properties of different kinds of flour and meal. Besides these, apparatus for conducting experiments on other subjects, as they were suggested, could be obtained when required.

Another person besides the farmer will he required to put all this apparatus into use. He should be a man of science, engaged for the express purpose of showing the relation betwixt science and Agriculture. There would be no difficulty of obtaining a man of science, quite competent to explain natural phenomena on scientific principles. For that purpose, he would require to have a familiar acquaintance with the following sciences: With meteorology and electricity, in order to explain atmospherical phenomena, upon the mutations of which all the operations of farming are so dependent: with hydrostatics and hydraulics, to explain the action of streams and of dammed-up water on embankments, to suggest plans for the recovery of land from rivers and the sea, and to indicate the states of the weather which increase or diminish the statical power of the sap in vegetables: with botany and vegetable physiology, to show the relations between the natural plants and the soils on which they grow, with a view to establish a closer affinity between the artificial state of the soil and the perfect growth of cultivated plants; to exhibit the structure of the different orders of cultivated plants; and to explain the nature and uses of the healthy, and the injurious effects of the diseased secretions of plants: with geology, to explain the nature and describe the structure of the superficial crust of the earth, in reference to draining the soil ; to show the effects of subsoils on the growth of trees; to explain the effects of damp subsoils on trees, and of the variations of the surface of the ground on climate: with mechanics, to explain the principles which regulate the action of all machines, and which acquirement previously implies a pretty familiar acquaintance with the mathematics: with chemistry, to explain the nature of the composition of, and changes in, mineral, vegetable, and animal substances: with anatomy and animal physiology, to explain the structure and functions of the animal economy, with a view to the prevention of disease, ineidental to the usual treatment of animals, and to particular localities.All young men, educated for what are usually termed the learned professions - theology, law, and medicine-are made acquainted with these sci- 
ences, and a young man from either faculty would be competent to take charge of such an establishment. Of the three I would give preference to the medical man, as possessing professionally a more intimate knowledge of chemistry, and animal and vegetable physiology, than the others. But the most learned graduate of either profession will display his scientific acquirements to little advantage in teaching pupils in Agriculture, unless he has the judgment to select those parts of the various sciences whose principles can most satisfactorily explain the operations of Agriculture.Ere he can do this successfully, he would, I apprehend, require to know Agriculture practically, by a previous residence of at least two years on a farm. Without such a preparation, he would never become a useful teacher of agricultural pupils.

On the supposition that he is so qualified, his duty is to take the direct charge of the pupils. His chief business should be to give demonstrations and explanations of all the phenomena occurring during operations in the farm field. The more popular demonstrations on botany, animal and vegetable physiology, and geology, as also on meteorology, optics, and astronomy, whenever phenomena occur which would call forth the application of the principles of any of those sciences, would be best conducted in the fields. In the library, short lectures on the elementary principles of science could be regularly delivered-conversations on scientific and practical subjects conducted-and portions of the most approved authors on Agriculture, new and old, read. These latter subjects could be most closely prosecuted when bad weather interrupted field-labor. In the laboratory, slaughter-house, farmstead, and dairy, he could command the attendance of the pupils, when any subject in those departments was to be explained.

The duty of the farmer himself, the governor or head of the establishment, is to enforce proper discipline among the pupils, both within and without doors. He should teach them practically how to perform every species of work, explain the nature and object of every operation performing, and foretell the purport of every operation about to be performed. For these important purposes he should remain at home as much as is practicable with his avocations abroad.

The duties of the pupils are easily defined. They should be ready at all times to hear instruction, whether in science or practice, within or without doors. Those pupils who wish to study practice more than science, should not be constrained to act against their inclinations, as science possesses little allurement to some minds; and it should be borne in mind by the tutors, that practical farming is what the pupils have chiefly come to learn, and that practice may prove successful in after life without the assistance of science, whereas science can never be applied without practice.

The duty common to all, is the mutual conducting of experiments, both in the fields and garden; for which purpose both should be of ample dimensions. All new varieties of plants might be first tried in the garden, until their quantity warranted the more profuse and less exact, though more satisfactory culture of the field. On ridges in the fallow-field, with different kinds and quantities of manure, and different modes of working the soil and sowing the seeds, experiments should be continually making with new and old kinds of grains, roots, tubers, bulbs, and herbaceous plants. In course of time, the sorts best suited to the locality will show themselves, and should be retained, and the worthless abandoned. In like manner, experiments should be made in the crossing of animals, whether with the view of maintaining the purity of blood in one, the improvement of the blood of another, or the institution of an entirely new blood. In either class of experiments, many new and interesting facts 
regarding the constitutional differences of animals, could not fail to be elicited.

Any farmer establishing such an institution, which could only be done at considerable expense, in fitting up a house in an adequate manner, and securing the services of a man of science, would deserve to be well remunerated. I before mentioned that one hundred pounds a year as board were cheerfully given by pupils to farmers under ordinary circumstances. In such an institution, less than one hundred and fifty pounds a year would not suffice to remunerate the farmer. Supposing that ten pupils at that fee each, were accommodated on one farm, the board would amount to fifteen hundred pounds a year. In regard to the expense of maintaining such an establishment, with the exception of foreign produce and domestic luxuries, all the ordinary means of good living exist on a farm. The procuring of these necessaries and luxuries and maintaining a retinue of grooms and domestic servants, together with the salary of an accomplished tutor, which should not be less than three hundred pounds a year besides board, would probably incur an annual disbursement of a thousand pounds a year. The farmer would thus receive five hundred pounds a year for risk of the want of the full complement of pupils, and for interest on the outlay of capital. Such a profit may be considered a fair, but not an extravagant remuneration for the comfortable style of living and superior kind of tuition afforded in such an establishment.

Were the particulars pitched at a lower scale, a profit might be derived from ten pupils, of not less a sum than that derived from the usual board of one hundred pounds a year. Were two hundred a year exacted, pupils of the highest class of society might be expected. Were different institutions at different rates of board established, all the classes of society would be accommodated.

Would farmers who have accommodation for conducting such an institution, but duly consider the probable certainty of obtaining a considerable increase to their income, besides the higher distinction of conducting so useful an institution, I have no doubt many would make the attempt. There are insuperable obstacles to some farmers making the attempt; but there are many who possess the requisite qualifications of accommodation in house and farm locality, personal abilities, influence, and capital, for instituting such an establishment. But even where all these qualifications do not exist, most of the obstacles might be overcome. In the case of the house, it could be enlarged at the farmer's own expense, for the landlord cannot be expected to erect a farm-house beyond the wants of an ordinary family; nor, perhaps, would every small landed proprietor permit the unusual enlargement of a farm-house, in case it should be rendered unsuitable to the succeeding tenant. To avoid this latter difficulty, the farmer who could afford accommodation to the fewest number, could receive the highest class of pupils, were his own education and manners competent for the highest society, while those who had more accommodation could take a more numerous and less elevated rank of pupils. In either way the profit might be equally compensatory.

In regard to other considerations, a tutor entirely competent could not at once be found. It may safely be averred, that a really scientific man, thoroughly acquainted with the practice of Agriculture, is not to be found in this country. But were a demand for the services of scientific men to arise from the increase and steady prosperity of such establishments, no doubt, men of science would qualify themselves for the express purpose. As to pupils, the personal interest of the farmer might not avail him much at first in influencing parents in his favor, but if he possess the reputa- 
tion of being a good farmer, he would soon acquire fame for his institution. I have no doubt of an eminent farmer entirely succeeding to his wishes, who occupies a commodious house, on a large farm, in an agricultural district of high repute, and possessing sufficient capital, were he to make the experiment by engaging a competent scientific tutor, and teaching the practical department himself. Such a combination of alluring circumstances could not fail of attracting pupils from all parts of the country, who were really desirous of learning Agriculture in a superior manner.

There might still be another, though less attractive and efficacious, mode of accomplishing a similar end. Let a scientific tutor, after having acquired a competent knowledge of practical Agriculture, procure a commodious and comfortable house in any village in the vicinity of some large farms, in a fine agricultural district. Let him receive pupils into his house, on his own account, in such numbers and at such fees as he conceives would remunerate him for his trouble and risk. Every thing relating to science within doors, could be conducted as well in such a house as in any farm-house; and as to a field for practice, let the tutor give a douceur to each of the large farmers in his neighborhood, for liberty for himself and pupils to come at will and inspect all the operations of the farms. In this way a very considerable knowledge of farming might be imparted. Having every article of consumption to purchase at marketprice, such an establishment would cost more to maintain than that on a farm; but, on the other hand, the salary of the tutor would in this case be saved, and there would be no farmer and his family to support. To assist in defraying the extra expenses of such an establishment, let the tutor permit, for a moderate fee, the sons of those farmers whose farms he has liberty to inspect, and of those who live at a distance, to attend his lectures and readings in the house, and his prelections in the fields. A pretty extensive knowledge of and liking for the science of Agriculture might thus be diffused throughout the country, among a class of young farmers who might never have another opportunity of acquiring it, because they would never become permanent inmates in any such establishment.

I have known a mode of learning farming adopted by young farmers of limited incomes, from remote and semi-cultivated parts of the country, of lodging themselves in villages in cultivated districts adjacent to large farms, occupied by eminent farmers, and procuring leave from them to give their daily personal labor and superintendence in exchange for the privilege of seeing and participating in all the operations of the farm.

There are still other modes than those described above of learning farming, which deserve attention, and require remark. Among these the only one in this country, apart from the general practice of boarding with practical farmers, is the Class of Agriculture in the University of Edinburgh. This chair was endowed in 1790 by Sir William Pulteney, with a small salary, and placed under the joint patronage of the Judges of the Court of Session, the Senatus Academicus of the University of Edinburgh, and the Town Council of the City of Edinburgh. The first professor elected by the patrons to this chair in 1791, was the late Dr. Coventry, whose name, in connection with the Agriculture of the country, stood prominent at one time. He occupied the chair until his death in 1831. His prelections, at the earlier period of his career as a professor, were successful, when his class numbered upward of seventy students. When I attended it, the number of students was upward of forty. Dr. Coventry was a pleasing lecturer, abounding in anecdote, keeping his hearers always in good humor, courting interrogation, and personally showing great kindness to every student. At the latter period of his in$(40)$ 
cumbency, the class dwindled away, and for some years before his death he delivered a course of lectures only every two years. He delivered, I understand, thirty-four courses in forty years.

The present Professor Low succeeded Dr. Coventry. Since his installation into the chair, he has rekindled the dying embers of the agricultural class, by delivering an annual course of lectures suited to the improved state of British Agriculture, and by forming a museum of models of agricultural implements, and portraits of live-stock illustrative of his lectures, of the most extensive and valuable description. In Dr. Coventry's time there was no museum deserving the name, and seeing this, Professor Low had no doubt been impressed with the important truth, that without models of the most approved implements, and portraits of the domesticated animals, serving to illustrate the principal operations and breeds of animals to be seen on the best cultivated farms, and pastoral districts, a mere course of lectures would prove nugatory. This museum is attached to the University, and to show the zeal and industry by which the present Professor has been actuated in its formation, the objects in it must be worth more than $£ 2,000$. The funds which obtained those objects were derived from the revenues under the management of the Board of Trustees for the encouragement of Arts and Manufactures in Scotland. This Board was instituted by the 15 th Article of the Treaty of Union between Scotland and England. Besides forming the museum, Professor Low has, during his yet short incumbency in the chair, already contributed much important matter to the agricultural literature of the country, by the publication of his Elements of Practical Agriculture, which contain almost the entire substance of his lectures, and the series of colored portraits of animals taken from the pictures in the museum, now coming out periodically in numbers.

There has lately been appointed a lecturer on Agriculture in Marischal College, Aberdeen, at a salary of $£ 40$ a year. Being but an experiment, the appointment, I believe, has only been made for three years.

There is no public institution in England for teaching Agriculture.*Some stir is making in the establishment of an Agricultural College in Kent, the prospectus of which I have seen; and, some time ago, I saw a statement which said that provision exists for the endowment of a chair of Agriculture in one of the Colleges of Oxford.

An agricultural seminary has existed at Templemoyle, in the county of Londonderry, Ireland, for some years. It originated with the members of the North-west of Ireland Farming Society, and the first intention was to form it on such a scale as to teach children of the higher orders every science and accomplishment, while those of the lower orders, the sons of farmers and tradesmen, were to be taught Agriculture. But the latter arrangement only has been found to be practicable. In a statement circulated by a member of the committee, I find that "the formation of this establishment has caused its founders an expenditure of above $£ 4,000$ of which about $£ 3,000$ were raised at its commencement by shares of $£ 25$ each, taken by the noblemen, gentlemen, and members of the North-west Society. The Grocers' Company of London, on whose estate it is situated, have been most liberal in their assistance, and have earned a just reward in the improvement of their property, by the valuable example the farm of Templemoyle presents to their tenantry.

"In sending a pupil to Templemoyle, it is necessary to have a nomina-

[ The one at Cirencester, mentioned by Mr. Colman, is probably now in operation. 
tion from one of the shareholders, or from a subscriber of $£ 2$ annually.The annual payment for pupils is $£ 10$ a year, and for this trifling sum they are found in board, lodging, and washing, and are educated so as to fit them for land-stewards, directing agents, practical farmers, schoolmasters, and clerks. From fifteen to seventeen is the age best suited to entrance at Templemoyle, as three years are quite sufficient to qualify a student possessed of ordinary talents, and a knowledge of the rudiments of reading and writing, to occupy any of the above situations.

"Upward of two hundred young men, natives of sixteen different counties in Ireland, have passed or remain in the school. Of these, between forty and fifty have been placed in different situations, such as land-stewards, agents, schoolmasters, and clerks, or employed on the Ordnance Survey. Nearly one hundred are now conducting their own or their fathers' farms, in a manner very superior to that of the olden time.*

"The school and farm of Templemoyle are situated about six miles from Londonderry-about a mile distant from the mailcoach-road leading from Londonderry to Newtonlimavady. The house, placed on an eminence, commands an extensive and beautiful view over a rich and highly cultivated country, terminated by Lough Foyle. The base of the hill is occupied by a kitchen and ornamental garden, cultivated by the youths of the establishment, under an experienced gardener. The house and farm-offices behind contain spacious, lofty, and well ventilated schoolrooms ; refectory ; dormitories; apartments for the masters, matron, servants, \&c. Each pupil occupies a separate bed; the house can accommodate seventy-six, and the number of pupils is sixty. They receive an excellent education in reading,

[" It may be of practical service in the United States to give here the general regulations of the "Larne" School, of which Mr. Colman seems to think so favorably. He says they were given to him in printed form by the intelligent principal. Ed. Farm. Lib.

"1. As the great object is to make the boys practical farmers, one-half of them will be at all times on the farm, where they will be employed in manual labor, and receive from the head farmer such instructions, reasons, and explanations. as will render the mode of proceeding, in all the various operations performed on the farm, sufficiently intelligible to them. Every pupil is to be made a plowman, and taught, not only how to use, but how to settle the plow-irons for every soil and work, and to be instructed and made acquainted with the purpose and practical management of every other implement generally used. And all are to be kept closely to their work, either by the head farmer or his assistant, or, in their unavoidable absence, by the monitor placed in charce of them.

"2. Their attention is to be drawn to stock of all kinds, and to the particular points which denote them to be good, bad, indifferent, hardy, delicate, good feeders, good milkers, \&c.

" 3 . At the proper season of the year, the attention of the boys is to be directed to the making and repairing of fences, that they may know both how to make a new one, and, what is of great advantage, how to repair and make permanent those of many years' standing.t

" 4. The head farmer will deliver evening lectures to the pupils on the theory and practice of Agriculture, explaining his reasons for adopting any crop, or any particular rotation of crops, as well as the most suitable soil and the most approved modes of cultivating for each; the proper management and treatment of working, feeding, and dairy stock; the most approved breeds, and their adaptation to different soils. He will point out the best method of reclaiming, draining, and improving land; and will direct attention to the most recent inventions in agricultural implements, detailing the respective merits of each.

"5. After the boys have been taught to look at stock on a farm with a farmer's eye, the committee propose that they should in rotation attend the head farmer to fairs and markets, in order to learn how to buy and sell stock. At the same time, the committee expect the head farmer will make his visits to fairs as few as possible, as his attention to the pupils of the establishment is al. ways required, and he should therefore be as seldom as possible absent from Templemoyle.

"An annual examination of the school is held before the committee and subscribers. and conducted by examiners totally independent of the school. The examination is attended by the lead. ing gentlemen in the neighborhood, and many of these take a part in the examination, by either asking or suggesting questions-a practice which is deserving of recommendation, as adapted to give additionalwalue and dignity to the examination.

"Such are some of the principal regulations of the school, which I have copied, that ite man. agement might be fully understood."]

† This, of course, applies principally to live fences, or hedges. It could at present have little pertinency to the United States, where certainly there is very little mystery in making the fences, and as littlo babor expended in keeping them in repair.

(42) 
writing, arithmetic, book-keeping, mathematics, land-surveying, and geography. This department is managed by an excellent head-master, and assistant-master, both resident in the house. The pupils are so classed that one-half are receiving their education in the house, while the remainder are engaged in the cultivation of a farm of 165 Scotch acres, in the management of which they are directed by the head-farmer, an experienced and clever man, a native of Scotland, who has a skillful plowman under him. The pupils who are employed one part of the day on the farm are replaced by those in the school, so that the education always advances in and out of doors pari passu."*

In enumerating the means of obtaining agricultural knowledge in this country, I cannot omit mentioning those coässistant institutions, the Veterinary Colleges. Their great object is to form a school of veterinary science, in which the anatomical structure of quadrupeds of all kinds-horses, cattle, sheep, dogs, \&c.-the diseases to which they are subject, and the remedies proper to be applied for their removal, might be investigated and regularly taught; in order that, by this means, enlightened practitioners of liberal education, whose sole study has been devoted to the veterinary art in all its branches, may be gradually dispersed over all the kingdom. The Veterinary College of London was instituted in 1791, according to the plan of Mr. Sain Bel, who was appointed the first professor. Parliamentary grants have been afforded at times to aid this institution, when its finances rendered such a supply essential. It is supported by subscription. Every subscriber of the sum of $\mathfrak{£ 2 1}$ is a member of the society for life.Subscribers of two guineas annually are members for one year, and are equally entitled to the benefits of the institution. A subscriber has the privilege of having his horses admitted into the infirmary, to be treated, under all circumstances of disease, at 3s. $6 \mathrm{~d}$. per night, including keep, medicines, or operations of whatever nature that may be necessary; likewise of bringing his horses to the college for the advice of the professor gratis, in cases where he may prefer the treatment of them at home.tUntil last year, care was chiefly bestowed in this institution on the horse, when the Royal Agricultural Society of England, deeming it as important for the promotion of Agriculture to attend to the diseases of the other animals reared on farms as well as the horse, voted $£ 300$ a year out of their funds for that purpose.

The Veterinary College of Edinburgh had its origin in the personal exertions of its present professor, Mr. William Dick, in 1818, who, after five years of unrequited labor, fortunately for himself and the progress of the veterinary science in Scotland, obtained the patronage of the Highland and Agricultural Society of Scotland, who have afforded him a small salary since 1823. Since then the success of his exertions has been extraordinary-not fewer than from seventy to one hundred pupils attending the college every session, of whom about twenty every year, after at least two years' study of practical anatomy and medicine, become candidates for the diploma of veterinary surgeon. Their qualifications are judged of after an examination by the most eminent medical practitioners in Edinburgh.The students enjoy free admission to the lectures on human anatomy and physiology in Queen's College, by the liberality of its professors. Through the influence of the Highland Society, permission has been obtained for the graduates to enter as veterinary surgeons into her Majesty's cavalry regiments, as well as those of the Honorable East India Company.

In recommending farmers to attend lectures on veterinary science, it

- Irish Farmer's Magazine, No. 51.

† Beauties of Kingland and Wales, vol. x, Part IV. p. 181.

(43) 
must not be imagined that I wish them to become veterinary surgeons.Let every class of people adhere to their own profession. But there is no doubt that a knowledge of veterinary science is of great use to the farmer, not in enabling him to administer to the diseased necessities of his livestock-for that requires more professional skill and experience than any farmer can attain to, and is the proper province of the regularly bred veterinary surgeon-but to enable him readily to detect a disease by its symptoms, in order to apply immediate checks to its progress until he can communicate with and inform the veterinary surgeon of the nature of the complaint, whereby he may bring with him materials for treating it correctly on his arrival. The death of a single animal may be a serious loss to the farmer; and if, by his knowledge of the principles of the veterinary art, he can stay the progress of any disease, he may not only avert the loss, but prevent his animal being much affected by disease. Disease, even when not fatal to animals, leaves injurious effects on their constitutions for a long time.

With regard to attending lectures on Agriculture, I should say, from my own experience, that more benefit will be derived from attending them after having acquired a practical knowledge of husbandry than before; because many of the details of farming cannot be comprehended, unless the descriptions of them are given where the operations themselves can be referred to.

Abroad are several institutions for the instruction of young men in Agriculture, among which is the far-famed establishment of Hofwyl, in the canton of Berne, in Switzerland, belonging to M. de Fellenberg.* This establishment is not intended so much for a school of Agriculture, as that of education and moral discipline. All the pupils are obliged to remain nine years, at least until they attain the age of twenty-one-during which time they undergo a strict moral discipline, such as the inculcation of habits of industry, frugality, veracity, docility, and mutual kindness, by means of good example rather than precepts, and chiefly by the absence of all bad example. The pupils are divided into the higher and lower orders, among the former of whom may be found members of the richest families in Germany, Russia, and Italy. For these the course of study is divided into three periods of three years each. In the first, they study Greek, Grecian history, and the knowledge of animals, plants, and minerals ; in the second, Latin, Roman history, and the geography of the Roman world; and, in the third, modern languages and literature, modern history to the last century, geography, the physical sciences, and chemistry. During the whole nine years they apply themselves to mathematics, drawing, music, and gymnastic exercises. The pupils of the canton of Berne only pay M. de Fellenberg 45 louis each, and do not cost their parents above 100 louis or 120 louis a year. Strangers pay him 125 louis, including board, clothing, washing, and masters.

The pupils of the lower orders are divided into three classes according to their age and strength. The first get a lesson of half an hour in the morning, then breakfast, and afterward go to the farm to work. They return at noon. Dinner takes them half an hour, and after another lesson of one hour, they go again to work on the farm until six in the evening. This is their summer occupation; and in winter they plait straw for chairs, make baskets, saw logs and split them, thresh and winnow corn, grind colors, knit stockings; for all of which different sorts of labor an

[* For a valuable notice of this institution, see the Report of Professor BACHE, on his return from Europe-having been sent by the Girard College, on a tour of observation, and to purchase a library (we believe) for that institation.

[Ed. Farm. Lib. 
adequate salary is credited to each boy's class until they are ready to leave the establishment. Such as have a turn for any of the trades in demand at Hofwyl, wheelwright, carpenter, smith, tailor or shoemaker, are allowed to apply to them. Thus the labor of the field, their various sports, their lessons, their choral songs, and necessary rest, fill the whole circle of the twenty-four hours; and judging from their open, cheerful, contented countenances, nothing seems wanting to their happiness.

It is admitted that, on leaving the establishment, the pupils of the higher classes are eminently moral and amiable in their deportment, that they are very intelligent, and that their ideas have a wide range; and though they may not be so advanced in science as some young men brought up elsewhere, they are as much so as becomes liberal-minded gentlemen, though not professors. The pupils of the lower classes leave at the age of twenty-one, understanding Agriculture better than any peasants ever did before, besides being practically acquainted with a trade, and with a share of learning quite unprecedented among the same class of people; and yet as hard-working and abstemious as any of them, and with the best moral habits and principles. It seems impossible to desire or imagine a better condition of peasantry.

As all the instruction at this establishment is conveyed orally, a great many teachers are required in proportion to the number of the pupils. In 1819 , there were thirty professors for eighty pupils. This entails a considerable expense upon M. de Fellenberg, who besides extends the erection of buildings as he finds them necessary. He is, however, upon the whole, no loser by the speculation. Each pupil of the lower orders costs him $£ 56$ a year to maintain and educate, which is $£ 38$ s. a year beyond the value of his work, and yet the investment is a profitable one, yielding something more than $8 \frac{1}{4}$ per cent. interest, net of all charges. "The farm is undoubtedly benefited by the institution, which affords a ready market for its produce, and perhaps by the low price at which the labor of the boys is charged. But the farm, on the other hand, affords regular employment to the boys, and also enables M. de Fellenberg to receive his richer pupils at a lower price than he could otherwise do. Hofwyl, in short, is a great whole, where one hundred and twenty or one hundred and thirty pupils, more than fifty masters and professors, as many servants, and number of day-laborers, six or eight families of artificers and tradesmen, altogether about three hundred persons, find a plentiful, and in many respects a luxurious subsistence, exclusive of education, out of a produce of one hundred and seventy* acres; and a money income of $£ 6,000$ or

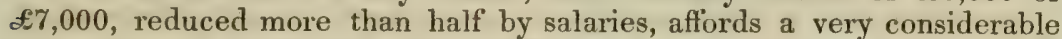
surplus to lay out in additional buildings." $\dagger$ It seems that, since 1807 , two convents, one in the canton of Fribourg, and the other in that of Thurgovie, have formed establishments analogous to those of M. de Fellenberg.t

The celebrated German institution for teaching Agriculture is at Möeglin, near Frankfort on the Oder. It is under the direction of M. Von Thaër. There are three professors besides himself-one for mathematics, chemistry, and geology ; one for veterinary knowledge; and a third for botany and the use of the different vegetable productions in the materia medica, as well as for entomology. Besides these, an experienced agriculturist is engaged, whose office it is to point out to the pupils the mode

* This is the number of Acres in the farm as stated in the Edinburgh Review for October, 1819; but a correspondent in Hull's Philanthropic Repertory for 1832, makes it 250 acres.

$\dagger$ Edinburgh Review, No. 64.

t Ebel, Manuel du Voyageur en Suisse, tome it.

(45) 
of applying the sciences to the practical business of Husbandry. Such a person would be difficult to be found in this country. The course commences in September, the best season, in my opinion, for commencing the learning of Agriculture. During the winter months the time is occupied in mathematics, and in the summer the geometrical knowledge is practically applied to the measurement of land, timber, buildings, and other objects. The first principles of chemistry are unfolded. Much attention is paid to the analyzation of soils. There is a large botanic garden, with a museum containing models of implements of husbandry. The various implements used on the farm are all made by smiths, wheelwrights and carpenters residing round the institution; the workshops are open to the pupils, and they are encouraged by attentive inspection to become masters of the more minute branches of the economy of an estate.

As the sum paid by each pupil, who are from twenty to twenty-four years of age, is 400 rix-dollars annually (equal to about $£ 60$ sterling, if the rix-dollar is of Prussian currency), and besides which they provide their own beds and breakfasts, none but youths of good fortune can attend at Möeglin. Each has a separate apartment. They are very well-behaved young men, and their conduct to each other, and to the professors, is polite even to punctilio.

The estate of Möeglin consists of twelve hundred English acres. About thirty years ago it was given in charge by the King of Prussia to M. Von Thaër, who at that time was residing as a physician at Celle, near Luneburg, in Hanover, with the view of diffusing agricultural knowledge in Prussia, which it was known M. Von Thaër possessed in an eminent degrte, as evinced by the translations of numerous agricultural works from the English and French, by his management in setting an example to the other great landed proprietors, and stimulating them to adopt similar improvements. His Majesty also wished him to conduct a seminary, in which the knowledge of the sciences might be applied to Husbandry, for the instruction of the young men of the first families.* When M. Von Thaër undertook the management of this estate, its rental was only 2,000 rix-dullars a year $(£ 300)$, and twenty years ago the rental had increased to 12,000 rix-dollars $(£ 1,800)$. This increased value, besides the buildings erected, has arisen from the large flocks of sheep which in summer are folded on the land, and in winter make abundant manure in houses constructed for their lodging.

These particulars are taken from Mr. Jacob's travels, who visited Möeylin in 1819 , and who, in considering of the utility of such an institution in this country, makes these remarks on the personal accomplishments of M. Von Thaër. "We have already carried the division of labor into our Agriculture, not certainly so far as it is capable of being carried, but much farther than is done in any other country. We have some of the best sheep farmers; of the best cattle and horse breeders; of the best hay, turnip, potato, and corn farmers in the world; but we have perhaps no one individual that unites in his own person so much knowledge of chemistry, of botany, of mathematics, of comparative anatomy, and of the application of these various sciences to all the practical purposes of Agriculture as Von Thaër does; nor is the want felt, because we have numbers of individuals who, by applying to each branch separately, have

\footnotetext{
L* For his biography and a general account of his writings, and the whole of his great work on "The Principles of Agriculture," see the Farmers' Libraky, commencing with Num. ber 3 , Vol. I. The whole has been published, and may be had, bound by itself, and ought andoubtedly to be atandard book in every school in the United States.

Ed. Farm. Lib.]
} 
reached a hight of knowledge far beyond what any man can attain who divides his attention between several objects. In chemistry we have now most decidedly the lead. In all of botany that is not mere nomenclature, it is the same. In mechanics we have no equals. There are thus abundant resources, from which practical lessons may be drawn, and be drawn to the greatest advantage; and that advantage has excited, and will continue to excite, many individuals to draw their practical lessons for each particular branch of Agriculture, from that particular science on which it depends; and thus the whole nation will become more benefited by such divisions and subdivisions of knowledge, than by a slight tincture of all the sciences united in the possession of some individuals."*

France also possesses institutions for the teaching of Agriculture. The first was that model farm at Roville, near Nancy, founded by M. Mathieu de Dombasle.t Though it is acknowledged that this farm has done service to the Agriculture of France, its situation being so far removed from the centre of that country, its influence does not extend with sufficient rapidity. Its limited capital does not permit the addition of schools, which are considered necessary for the instruction of young proprietors who wish to manage their own properties with advantage, and of agents capable of following faithfully the rules of good Husbandry.

To obviate the disadvantages apparent in the institution of Roville, " a number of men distinguished for their learning and zeal for the prosperity of France, and convinced of the utility of the project, used means to form an association of the nature of a joint-stock company, with 500 shares of 1,200 francs each, forming a capital of 600,000 francs $(£ 25,000)$. The first half of this sum was devoted to the advancement of superior culture, and the second half to the establishment of two schools, one for pupils who, having received a good education, wish to learn the theory and the application of Agriculture, and of the various arts to which it is applicable; and the other for children without fortune, destined to become laborers, instructed as good plowmen, gardeners, and shepherds, worthy of confidence being placed in them." + This society began its labors in 1826 by purchasing the domain of Grignon, near Versailles, in the valley of Gally, in the commune of Thiverval, and appointing M. Bella, a military officer who had gained much agricultural information from M. Vón Thaër during two years' sojourn with his corps at Celle. M. Bella traveled through France, in the summer of 1826 , to ascertain the various modes of culture followed in the different communes. Grignon was bought in the name of the king, Charles $X$. who attached it to his domain, and gave the society the title of the Royal Agricultural Society for a period of forty years. The statutes of the society were approved of by royal ordinance on the 23d May, 1827, and a council of administration was named from the list of shareholders, consisting of a president, two vice-presidents, a secretary, a treasurer, and directors.

The domain, which occupies the bottom and the two sides of the valley, in length 2,254 metres (a metre being equal to 3 feet and $11 \frac{1}{2}$ lines), is divided into two principal parts; the one is composed of a park of 290 hectares ( 387 acres), inclosed with a stone wall, containing the mansionhouse and its dependencies, the piece of water, the trees, the gardens, and the land appropriated to the farm; the other, called the outer farm, is composed of 176 hectares ( 234 acres), of uninclosed land, to the south of the park.

* Jacob's Travels in Germany. \&c. pp. 173-188.

+ Annales de Roville.

$\$$ Rapport General aur la ferme de Grignon, Juin, 1828, p. 3.

(47) 
With regard to the nature of the schools at Grignon, this account has been published: "The council of administration being occupied in the organization of regular schools, has judged that it would be convenient and useful to open, in 1829 , a school for work-people, into which to admit boys of from twelve to sixteen years of age, to teach them reading, writing, arithmetic, and the primary elements of the practice of geometry. The classes to meet two hours every day in summer, and four hours in winter, the rest of the time to be employed in manual work. The fee to be 300 francs the first year, 200 francs the second, and 100 francs the third. After three years of tuition the fee to cease, when an account is to be opened to ascertain the value of their work against the cost of their maintenance, and the balance to go to form a sum for them when they ultimately leave the institution."

"Meanwhile, as the director has received several applications for the admission of young men, who, having received a good education, are desirous of being instructed in Agriculture, the council has authorized the conditional admission of six pupils. But as there are yet no professors, the pupils who are at present at Grignon can only actually receive a part of the instruction which it is intended to be given. They every day receive lessons from the director on the theory of Agriculture, besides lessons on the veterinary art, and the elements of botany, from the part of the veterinary school attached to the establishment; also lessons of the art of managing trees and making plantations, given by a forester of the crown forests, and some notions of gardening by the gardener. During the rest of the time, they follow the agricultural labors and other operations of the establishment. They pay 100 francs a month, including bed, board, and washing.

"Several proprietors who occupy farms, having expressed a desire to see young farm-servants taught the use of superior implements, and the regular service on a farm, the director has admitted a few, lessening the fee to the payment of board and lodging. There are two just now. To such are given the name of 'farm pupils.' "*

The course of education proposed to be adopted at Grignon, is divided into theoretical and practical. The course to continue for two years. In the first year to be taught mathematics, topography, physics, chemistry, botany and botanical physiology, veterinary science, the principles of culture, the principles of rural economy applied to the employment of capital, and the interior administration of farms. The second year to comprehend the principles of culture in the special application to the art of producing and using products; the mathematics applied to mechanics, hydraulies, and astronomy; physies and chemistry applied to the analysis of various objects; mineralogy and geology applied to Agriculture; gardening, rural architecture, legislation in reference to rural properties, and the principles of health as applicable both to man and beast.

There are two classes of pupils, free and internal. Any one may be admitted a free pupil that has not attained twenty years of age, and every free pupil to have a private chamber. The pupils of the interior must be at least fifteen years of age.

The fee of the free pupils is 1,500 francs a year; that of the pupils of the interior 1,300 francs. They are lodged in the dormitories in box-beds; those who desire private apartments pay 300 francs more, exclusive of furniture, which is at the cost of the pupils.t

There is an agricultural school at Hohenheim, in the Duchy of Wir-

* Annales de Grignon, 21 livraison, 1829, p. 48.

† Annales de Grignon, 3d Livraison, 1830, p. 138.

(48; 
temberg, and another at Flottbeck in Flanders, belonging to M. Voght. An account of both these institutions is given by M. Bella, in the third number of the Annales of Grignon. There are, I understand, schools of Agriculture, both in St. Petersburg and Moscow, but have not been so fortunate as to meet with any account of them.

It appears to me from the best consideration $I$ can give to the manner in which Agriculture is taught at these schools, that as means of imparting real practical knowledge to pupils, they are inferior to the usual mode adopted in this country, of living with farmers. In reference to the results of the education obtained at Möeglin, Mr. Jacob says : "It appeared to me that there was an attempt to crowd too much instruction into too short a compass, for many of the pupils spend but one year in the institution, and thus only the foundation, and that a very slight one, can be laid in so short a space of time. It is, however, to be presumed, that the young men come here prepared with considerable previous knowledge, as they are mostly between the ages of twenty and twenty-four, and some few appeared to be still older." **

Although the pupils are kept at Hofwyl for nine years, and are fined if they leave it sooner, it is obvious that the higher class of them bestow but little attention on farming, and most on classical literature. And the particulars given in the elaborate programme of the school of Agriculture at Grignon, clearly evince that attention to minute discipline, such as marking down results, and to what are termed principles, which just mean vague theorizings, form a more important feature of tuition than the practice of husbandry. The working pupils may acquire some knowledge of practice by dint of participating in work, but the other class can derive very little benefit from all the practice they see.

\title{
7. OF THE EVILS ATTENDANT ON LANDOWNERS NEGLECTING TO
}

\section{LEARN PRACTICAL AGRICULTURE.}

\author{
Save men's opinions, and my living blood- \\ To show the worid I am a gentleman."
}

RICHARD II.

There would be no want of pupils of the highest class for institutions such as I have recommended for promoting agricultural education, did landed proprietors study their true interests, and learn practical Agriculture. Besides the usual succession of young farmers to fill the places of those who retire, and these of themselves would afford the largest proportion of the pupils, were every son of a landowner, who has the most distant prospect of being a landed proprietor himself, to become an agricultural pupil, in order to qualify himself to fulfill all the onerous duties of his station, when required to occupy that important position in the country, that class of pupils would not only be raised in respectability, but the character of landed proprietors, as agriculturists, would also be much elevated. The expectant landlord should therefore undergo that tuition, though he may intend to follow, or may have already followed, any other profession. The camp and the bar seem to be the especially favorite arenas upon which the young scions of the gentry are desirous of displaying their

* Jacob's Travels in Germany, \&c. p. 185.

$(97) \ldots \ldots . .4$ 
first acquirements.* These professions are highly honorable, none more so, and they are, no doubt, conducive to the formation of the character of the gentleman; but, after all, are seldom followed out by the young squire. The moment he attains rank above a subaltern, or dons his gown and wig, he quits the public service, and assumes the functions of an incipient country gentleman. In the country he becomes at first enamored of field sports, and the social qualities of sportsmen. Should these prove too rough for his taste, he travels abroad peradventure in search of sights, or to penetrate more deeply into the human breast. Now, all the while he is pursuing this course of life, quite unexceptionable in itself, he is neglecting a most important part of his duty-that of learning to become a good landlord. On the other hand, though he devote himself to the profession of arms or the the law, either of which may confer distinction on its votaries; yet if either be preferred by him to Agriculture, he is doing much to unfit himself from being an influential landlord. To become a soldier or a lawyer, he willingly undergoes initiatory drillings and examinations; but, to become a landlord, he considers it quite unnecessary, to judge by his conduct, to undergo any initiatory tuition. That is a business, he conceires, that can be learned at any time, and seems to forget that it is his profession, and does not consider that it is one as difficult of thorough attainment as ordinary soldiership or legal lore. No doubt the army is an excellent school for confirming, in the young, principles of honor and habits of discipline; and the bar for giving clear insight into the principles upon which the rights of property are based, and into the true theory of the relation betwixt landlord and tenant; but while these matters may be attained, a knowledge of Agriculture, the weightiest matter to a landlord, should not be neglected. The laws of honor and discipline are now well understood, and no army is required to inculcate their acceptableness on good society. A knowledge of law, to be made applicable to the occurrences of a country life, must be matured by long experience; for, perhaps, no sort of knowledge is so apt to render landed proprietors litigious and uncompromising with their tenants as a smattering

[* So is it in the United States; and who can wonder at it, secing that the bar and the habit of public speaking acquired at it open the broadest and easiest road to public distinction, while the military is almost the only life commission bestowed by the Government. Having once received that, the officer is placed for the remainder of his days beyond the reach of political vicissitude. Even his education has been at the public expense, and having once received his sword, he has only to keep his head above ground and he is sure of promotion and of increased pay. Courage in the line of his profession is, properly, sure of honors and rewards; while the same virtue in civil life offers no immunity against proscription and party despotism. All liberty of thought is deemed to be incompatible with party loyalty. This preference and elevation of the military over civil virtues is but a servile prejudice derived from despotic Governments, where rulers, cut off from sympathy with and dependence on the people, have to rely on the military arm for support on all occasions of popular commotion and outbreak under irremediable oppression. Nor will civil virtues and the capacity to promote the substantial interests of the people enjoy that eminence in the public esteem, and that encouragement and reward which it should be the care of a republican government to bestow, until the mass of the cultivators of the soil become more generally and thoroughly instructed, not only in the practical principles of their calling, but in the preference which they have a right to assert as due from Government to the landed interest-an interest on which all others live, and without which they would all dwindle and perish, as does the misletoe when the oak on which it grows falls under the strokes of the woodman's ax.

When will agricultarists force a system of legislation in which honor shall be rendered to the men of the country for talents and civil virtues; and military and other parasitical institutions and classes be reluctantly tolerated and supported as necessary evils, or at least as mere appendages in the great machinery of Government?

(98) 
of law. Instances have come under my own notice, of the injurious propensities which a slight acquaintance with law engenders in landed proprietors, as exhibited on their own estates, and at county and parochial meetings. No class of persons require Pope's admonition regarding the evil tendency of a "little learning" to be more strongly inculcated on them, than the young barrister who doffs his legal garments, to assume in ignorance the part of the country squire :

"A little learning is a dangerous thing !
Drink deep. or taste not the Pierian spring;
There shallow draughts intoxicate the brain."

I do not assert that a knowledge of military tactics, or of law, is inconsistent with Agriculture. On the contrary, a competent knowledge of either, and particularly of the latter, confers a value on the character of a country gentleman versant with Agriculture; but what I do assert most strongly is, that the most intimate acquaintance with either will never serve as a substitute for ignorance of Agriculture in a country gentleman.

One evil arising from studying those exciting professions before Agriculture is, that, however short the time spent in acquiring them, it is sufficiently long to create a distaste to learning Agriculture practically, for such a task can only be undertaken, after the turn of life, by enthusiastic minds. But as farming is necessarily the profession of the country gentleman, for all have a farm, it should be learned, theoretically and practically, before his education should be considered finished. If he so incline, he can afterward enter the tented field, or exercise his forensic eloquence, when the tendency which I have noticed in these professions will be unable to efface the knowledge of Agriculture previously acquired. This is the proper course for every young man destined to become a landed proprietor to pursue, and who wishes to be otherwise employed as long as he cannot exercise the functions of a landlord. Were this course always pursued, the numerous engaging ties which a country life never fails to form, rendered more interesting by a knowledge of Agriculture, would tend to extinguish the kindling desire for any other profession. Such a result would be most desirable for the country ; for only contemplate the effects of the course pursued at present by landowners. Does it not strike every one as an incongruity for a country gentleman to be unacquainted with country affairs? Is it not "passing strange" that he should require inducements to learn his hereditary profession-to know a business which alone can enable him to maintain the value of his estate, and secure his income? Does it not infer a species of infatuation to neglect becoming well acquainted with the true relation he stands to his tenants, and by which, if he did, he might confer happiness on many families; but to violate which, he might entail lasting misery on many more? In this way. the moral obligations of the country gentleman are too frequently neglected. And no wonder, for these cannot be perfectly understood, or practiced aright but by tuition in early life, or by very diligent and irksome study in maturer years. And no wonder that great professional mistakes are frequently committed by proprietors of land. Descending from generalities to particulars, it would be no easy task to describe all the evils attendant on the neglect of farming by landowners; for though some are obvious enough, others can only be morally discerned.

1. One of the most obvious of those evils is, when country gentlemen take a prominent share in discussions on public measures connected with Agriculture, and which, from the position they occupy, they are frequently called upon to do, it may be remarked that their speeches are usually introduced with apologies for not having sufficiently attended to agricultural 
matters. The avowal is candid, but it is any thing but creditable to the position they hold in the agricultural commonwealth. When, moreover, it is their lot or ambition to be elected members of the legislature, it is deplorable to find so many so little acquainted with the questions which bear directly or indirectly on Agriculture. On these accounts, the tenantry are left to fight their own battles on public questions. Were landowners practically acquainted with Agriculture, such painful avowals would be spared, as a familiar acquaintance with it enables the man of cultivated mind at once to perceive its practical bearing on most public questions.

2. A still greater evil consists in their consigning the management of valuable estates to the care of men as little acquainted as themselves with practical Agriculture. A factor or agent, in such a condition, always affects much zeal for the interest of his employer; but it is "a zeal not according to knowledge." Fired by this zeal, and undirected, as it most probably is, by sound judgment, he soon discovers something at fault among the poorer tenants. The rent, perhaps, is somewhat in arrear-the strict terms of the lease have been deviated from-things appear to him to be going down hill. These are fruitful topics of contention. Instead of being "kindly affectioned," and thereby willing to interpret the terms of the lease in a generous spirit, the factor hints that the rent must be better secured, through the means of another tenant. Explanation of circumstances affecting the condition of the farmer, over which he has perhaps no control-the inapplicability, perhaps, of the peculiar covenants of the lease to the particular circumstances of the farm-the lease having perhaps been drawn up by himself, or some one as ignorant as himself-are excuses unavailingly offered to one who is confessedly unacquainted with country affairs, and the result ensues in interminable disputes betwixt him and the tenants. With these the landlord is unwilling to interfere, in order to preserve intact the authority of the factor; or, what is still worse, is unable to interfere, because of his own unacquaintance with the actual relations subsisting betwixt himself and his tenants, and, of course, the settlement is left with the originator of the disputes. Hence originate actions at law, criminations and recriminations-much alienation of feeling; and at length a settlement of matters, at best, perhaps, unimportant, is left to the arbitration of practical men, in making which submission the factor acknowledges as much as he himself was unable to settle the dispute. The tenants are glad to submit to arbitration to save their money. In all such disputes they, being the weaker parties, suffer most in purse and character. The landlord, who should have been the natural protector, is thus converted into the unconscious oppressor, of his tenants. This is confessedly an instance of a bad factor; but have such instances of oppression never occurred, and from the same cause, that of ignorance in both landlord and factor?

A factor acquainted with practical Agriculture would conduct himself very differently in the same circumstances. He would endeavor to prevent legitimate differences of opinion on points of management terminating into disputes, by skillful investigation and well-timed compromise.He studies to uphold the honor of both landlord and tenants. He can see whether the terms of the lease are strictly applicable to prevailing circumstances, and judging thereby, checks every improper deviation from appropriate covenants, while he makes ample allowance for unforeseen contingencies. He can discover whether the condition of the tenants is influenced more by their own doings, than by the nature of the farms they occupy. He regulates his conduct toward them accordingly; encour(100) 
aging the industrious and skillful, admonishing the indolent, and amending the unfavorable circumstances of the farms. Such a man is highly respected, and his opinion and judgment are greatly confided in by the tenantry. Mutual kindliness of intercourse always subsists between them. No landlord, whether himself acquainted or unacquainted with farming, but especially the latter, should confide the management of his estate to any other kind of factor.

3. Another obvious evil is one which affects the landed proprietor's own comfort and interest, and which is the selection of a steward or grieve for conducting the home-farm. In all cases it is necessary for a landowner to have a home-farm, and to have a steward to conduct it. But the steward of a squire, acquainted and unacquainted with farming, is placed in very dissimilar circumstances. The steward of a squire acquainted with farming, enjoying good wages, and holding a respectable and responsible situation, must conduct himself as an honest and skillful manager, for he knows he is superintended by one who can criticize his management well. A steward in the other position alluded to, must necessarily have, and will soon take care to have, everything his own way. He soon becomes proud in his new charge, because he is in the service of a squire. He soon displays a haughty bearing, because he knows he is the only person on the farm who knows anything about his business. He becomes overbearing to the rest of the servants, because, in virtue of his office, he is appointed purveyor to the entire establishment; and he knows he can starve the garrison into a surrender whenever he pleases. He domineers over the inferior work-people, because, dispensing weekly wages, he is the custodier of a little cash. Thus advancing in his own estimation step by step, and finding the most implicit reliance placed in him by his master, who considers his services as invaluable, the temptations of office prove too powerful for his virtue, he aggrandizes himself, and conceals his malpractices by deception. At length his peculations are detected, by perhaps some trivial event, the insignificance of which had escaped his watchfulness. Then loss of character and loss of place overtake him at once.Such flagrant instances of unworthy factors and stewards of country gentlemen, are not supposititious. I could specify instances of both, whose mismanagment has come under my own observation. Both species of pests are engendered from the same cause-the ignorance of landowners in country affairs.*

4. Another injurious effect it produces is absenteeism. When farming possesses no charms to the country gentleman, and field-sports become irksome by monotonous repetition, his taste for a country life declines, and to escape ennui at home, he banishes himself abroad. If such lukewarm landed proprietors, when they go abroad, would always confide the management of their estates to unexceptionable factors, their absence would be little felt by the tenants, who would proceed with the substantial improvement of their farms with greater zest under the countenance of a sensible factor, than of a landlord who contemns a knowledge of Agriculture. But it must be admitted that tenants farm with much greater confidence under a landlord acquainted with farming, who is always at home, than under the most unexceptionable factor. The disadvantages of absenteeism are only felt by tenants left in charge of a litigious factor, and

[* With obvious allowance for difference of circumstances, some of these remarks may be made to apply to gentlemen, more especially in the South, who devolve their affairs too much on their managers or overseers; and to merchants, and other gentlemen of fortune, who cannot reside through the year on their estates.

(101)

Ed. Farm. Lib.] 
it is always severely felt by day-laborers, tradesmen, and shop-keepers in villages and small country towns.

Now, all these evils-for evils they certainly are-and many more I have not touched upon, would be avoided, if landowners would make it a point to acquire a knowledge of practical Agriculture. This can best be done in youth, when it should be studied as a necessary branch of education, and learned as the most useful business which country gentlemen can know. It will qualify them to appoint competent factors-to determine upon the terms of the lease most suited to the nature of each of the farms on their properties, and to select the fittest tenants for them. This qualification could not fail to inspire in tenants confidence in their landlords, by which they will be encouraged to cultivate their farms in the best manner for the land and for themselves, in even the most trying vicissitudes of seasons; and without which confidence the land, especially on estates on which no leases are granted, would never be cultivated with spirit. It confers on landlords the power to judge for themselves of the proper fulfillment of the onerous and multifarious duties of a factor. It enables them to converse freely in technical terms with their tenants on the usual courses of practice, to criticize work, and to predicate the probability of success or failure of any proposed course of culture. The reproving or approving remarks of such landlords operate powerfully with tenants. How many useful hints is it all times in the power of such landlords to suggest to their tenants or managers, on skillfulness, economy, and neatness of work; and how many salutary precepts may they inculcate on cottagers, on the beneficial effects of parental discipline and domestic cleanliness! The degree of good which the direct moral influence of such landlords among their tenantry can effect, can scarcely be over estimated; its primary effect being to ensure respect, and create regard.The good opinion, too, of a judicious factor is highly estimated by the tenantry; but the discriminating observations of a practical and well-disposed landlord go much farther in inducing tenants to maintain their farms in the highest order, and to cherish a desire to remain on them from generation to generation. Were all landlords so actuated-and acquaintance with farming would certainly prompt them thus to act-they could at all times command the services of superior factors and skillful tenants.

They would then find there is not a more pleasing, rational, and interesting study than practical Agriculture; and soon discover that to know the minutiæ of farming is just to create an increasing interest in every farm operation. In applying this knowledge to practice, they would soon find it to operate beneficially for their estates, by the removal of objects which offend the eye or taste, and the introduction of others that would afford shelter, promote improvement, and contribute to the beauty of the landscape of the country around.

These maxims of Bacon seem not an inapt conclusion to our present remarks: "He that cannot look into his own estate at all, had need both choose well those whom he employeth, and change them often, for new are more timorous and less subtle. He that can look into his estate but seldom, it behoveth him to turn all to certainties."* [Essays, p. 106.]

[ It has doubtless already occurred to the reader that some of the preceding observations do not apply to our country, but where they are not exactly applicable, they are mixed up with others that may be applied, or from which hints may be drawn. In republishing an author, we should remember the anecdote told by Doctor Franklin when Members of Congress were pick. ing holes in the Declaration of Independence-how a party from the country criticized a hatter's sign with the picture of a hat, and under it, "Hats sold here for cash, by John Smith." One said the sign showed it was hats, and nothing else; another, that it was useless to say sold, be(102) 


\title{
8. EXPERIMENTAL FARMS AS PLACES FOR INSTRUCTION IN
}

\section{FARMING。}

\author{
"Things done without example, in their issue \\ HENRY VIII
}

IT seems to be a favorite notion with some writers on agricultural subjects, that, of all places for learning farming, experimental farms are the best. They even recommend the formation of experimental farms, with the view of affording to young men the best system of agricultural education. They go the length of confidently asserting that all the field operations and experiments, on experimental farms, could be conducted by pupils. And they are nearly unanimous in conceiving that 200 acres would be a large enough extent for an experimental farm, and that on such a farm 100 pupils could be trained to become farmers, stewards and plowmen.

A very slight consideration of the nature of an experimental farm, will serve to show how unsuitable such a place is for learning farming. The sole object of an experimental farm is, to become acquainted with the best properties of plants and animals by experiment, and thereby to ascertain

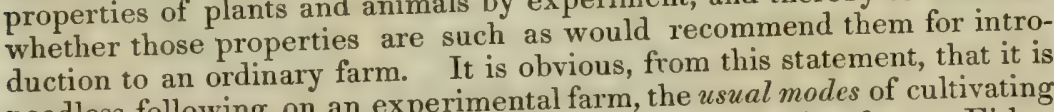
needless following, on an experimental farm, the usual modes of cultivating the ordinary plants and rearing the ordinary animals of a farm. Either new plants, and other modes than the usual ones of cultivating and rearing the ordinary plants and animals, should be tried on an experimental farm, otherwise it would not be an experimental farm, or of more use than an ordinary farm. In witnessing new or unusual modes of culture, the pupil would thus learn nothing of the particulars of ordinary farming. Extraordinary modes of cultivating ordinary plants, by changes in the rotation or of manure, and the risk of failure in both-for failure is a neces-
sary condition of experiment pupils with experimental schemes, instead of guiding them to the most
s. approved plan of cultivating each sort of plant. To confound the mind of a beginner, by presenting before it various modes of doing the same thing, injury. Were a pupil, who had been trained up on an ordinary farm, to have opportunities of witnessing varieties of experiments conducted on an experimental farm, he might then derive benefit from numerous hints which would be suggested in the course of making the experiments. But if pupils would be unfavorably placed on an experimental farm, by remaining constantly on it, much more would the farm itself be injured, by having its experiments performed by inexperienced pupils. So far from pupils being able to conduct experiments to a satisfactory issue, the most cause it might be inferred they were not to be given away; the third was for striking out here, as the place would be presumed to be where the sign was hung out; the fourth said all would know that when the hats were sold the money was to be paid; and a fifth insisted that the name. of the seller was entirely superfluous-until they struck out all except the picture of the hat. So we must be cautious in striking out too freely from an author, because what might seem superflu. on to most readers may for peculiar reasons be acceptable or useful to others; and these observations will apply to other sections of the work, though they may not be repeated. 
experienced cultivators are at times baffled by unforeseen difficulties; and so far would such experiments inspire confidence in farmers, that they would assuredly have quite an opposite tendency. So far, therefore, would the services of pupils in any degree compensate for the extraordinary outlay occasioned on experimental farms, by unsuccessful or unprofitable experiments, that even those of the most experienced cultivators would most probably produce no such desirable result; for no experimenter can command success, and failure necessarily implies extraordinary outlay. So far, therefore, could the services of pupils accomplish what those of experienced cultivators could not command, that their very presence on an experimental farm, with the right of coöperating in the experiments, would be a constant source of inconvenience to the experienced experimenters.

But, besides these objections, the mode of conducting experiments on so small farms as those recommended by most writers, would be quite unsuitable to pupils desirous of learning farming. Where varieties of culture on various sorts of plants are prosecuted on a small extent of ground, only a very small space can be allotted to each experiment. It is true that, should any of the varieties of plants be new to this country, the seed of which at first being of course only obtainable in small quantities, to procure such being a primary object with the promoters of experimental farms the space required for them at first must be very small. But although each lot of ground should be small, the great varieties of seeds cultivated in so many different ways, will nevertheless require a great number of lots, which altogether will cover a considerable extent of ground. How all these lots are to be apportioned on 200 acres, together with ground for experimenting on different breeds of animals, and different kinds of forest trees, is more than I can imagine. It would require more than double that extent of ground to give mere standing-room to all the objects that should be cultivated on an experimental farm, and over and above which, 100 pupils on such a farm would form a perfect crowd. Besides, the lots being so small, would require to be worked with the spade instead of the plow; and this being the case, let the experiments on such a farm be ever so perfectly performed, they could give pupils no insight whatever into real farming, much less secure the confidence of farmers.

It is the pleasure of some writers on experimental farms, to institute a comparison, or even strict analogy, betwixt them and experimental gardens. As the latter have improved the art of gardening, they argue, so would the former improve Agriculture. But the truth is, there can be no analogy betwixt the introduction into common gardens of the results obtained in experimental gardens, and the results of experiments obtained in such sma!l experimental farms as recommended by agricultural writers, introduced into the common field culture of a farm; because, the experiments in an experimental garden having been made by the spade, may be exactly transferred into almost any common garden, and, of course, succeed there satisfactorily; whereas the experiments made by the spade in a small experimental farm, cannot be performed with the spade on a common farm; they must there be executed by the plow, and, of course, in quite different circumstances. The rough culture of the plow, and most probably in different circumstances of soil, manure, and shelter, cannot possibly produce results similar to the culture of the spade, at least no farmer will believe it; and if they put no confidence in experiments, of what avail will experimental farms be ? Announcements of such results may gratify curiosity, but no benefit would be conferred on the country (104) 
by experiments confined within the inclosures of an experimental farm. No doubt, a few of the most unprejudiced of the farmers will perform any experiment, with every desire for its success, and there is as little doubt that others will follow the example; and some will be willing to test the worth of even a suggestion; but as these are the usual modes by which every new practice recommends itself to the good graces of farmers, no intervention of an experimental farm is therefore required for their promulgation and adoption. It is the duty of the promoters of experimental farms to disseminate a proved experiment quickly over the country, and the most efficient mode of doing so is to secure the confidence of farmers in it. To ensure their confidence, it will be necessary to show them that they can do the same things as have been done on the experimental farm by the usual means of labor they possess, and they will then show no reluctance to follow the example. Take the risk, in the experimental farm, of proving results, and show the intrinsic value of those results to the farmers, and the experiments, of whatever nature, will be performed on half the farms of the kingdom in the course of the first season.

For this purpose it is necessary to ascertain the size an experimental farm should be, which will admit of experiments being made on it, in a manner similar to the operations of a farm. The leading operation, which determines the smallest size of the fields of an experimental farm, is plowing. The fields should be of that size which will admit of being plowed in ordinary time, and at the same time not larger than just to do justice to the experiments performed in them. I should say that five acres imperial is the least extent of ground to do justice to plowing ridges along, across, and diagonally. Three acres, to be of such a shape as not to waste time in the plowing, would have too few ridges for a series of experiments, and to increase their number would be to shorten their length, and lose time in plowing. But even five acres are too small to inclose with a fence; ten acres, a good size of field for small farms, being nearer the mark for fencing. Taking the size of an experimental plot at five acres, the inclosure might be made to surround the divisions of a rotation; that is, of a rotation of four years, let twenty acres be inclosed; of five years, twenty-five acres, \&c.; but in this arrangement the experiments would only prove really available to small tenants, who frequently cultivate all their crops within one fence, and the subject thus experimented on would not be individually inclosed within a fence, as is the case with crops on larger farms.

The whole quantity of land required for an adequate experimental farm may thus be estimated. New varieties of seeds would require to be increased by all the possible modes of reproduction. Old varieties should undergo impregnation-be subjected to different modes of culture-be preserved pure from self-impregnation-and be grown in different altitudes. Each variety of seed already cultivated, such as wheat, barley, oats, potatoes, turnips, \&c., to undergo these various modifications of treatment on five acres of land, would, including the whole, require an immense extent of ground, and yet, if each kind did not undergo all these varieties of treatment, who could then aver that all our seeds had been subjected to satisfactory field experiments? Only one kind of grain, treated as variedly as might be, on five acres for each modification of treatment, would occupy seventy acres; and were only five kinds of seed taken, and only five varieties of each, and the whole cultivated on both low and high ground, the quantity of ground required altogether would be 3,500 acres. The extent of ground thus increases in a geometrical progression, (105) 
with an increase of variety of plants. Besides, the numerous useful grasses, for the purposes of being cut green, and for making into hay, would require other 1,000 acres. The whole system of pasturing young and old stock on natural and artificial grasses in low grounds and on high altitudes, and in sheltered and exposed situations, would require at least 3,000 acres. Then, experiments with forest-trees, in reference to timber and shelter in different elevations and aspects, would surely require 1,000 acres. Improvements in bog and muir lands should have other 1,000 acres. So that 9,500 acres would be required to put only a given proportion of the objects of cultivation in this country to the test of full experiment.Such an extent of ground will, no doubt, astonish those who are in the habit of talking about 200 acres as capable of affording sufficient scope for an experimental farm. Those people should be made to understand that the plow must have room to work, and that there is no other way of ex- perimentizing satisfactorily for field culture, on an experimental farm, but by affording it a real field to work in. If less ground be given, fewer subjects must be taken; and if any subject is rejected from experiment, then the system of experimentizing will be rendered incomplete. The system of experimentizing should be carried out to the fullest extent of its capability on experimental farms, or it should be left, as it has hitherto been, in the hands of farmers. The farmers of Scotland have worked out for themselves an admirable system of husbandry, and if it is to be improved to a still higher pitch of skill by experimental farms, the means of improvement should be made commensurate with the object, otherwise there will be no satisfaction, and certain failure; for the promoters of experimental farms should keep in mind that the existing husbandry, improved as it is, is neither in a stationary nor in a retrograding, but in a progressive state toward farther improvement. Unless, therefore, the proposed experiments, by which it is intended to push its improvement still farther toward perfection, embrace every individual of the multifarious objects which engage the attention of agriculturists, that one may be neglected which, if cultivated, would have conferred the greatest boon on Agriculture. I come, therefore, to this conclusion in the matter : that minute experiments on the progressive developments of plants and animals are absolutely requisite to establish their excellence or worthlessness, and these can be performed on a small space of ground; but to stop short at this stage, and not pursue their culture on a scale commensurate with the operations of the farm, is to render the experimental farm of little avail to practical husbandry, and none at all to interest the farmer.

So large an extent of farm would most probably embrace all the varieties of soil. It should, moreover, contain high and low land, arable, bog, and muir land, sheltered and exposed situations, and the whole should lie contiguous, in order to be influenced by the climate of the same locality. It would scarcely be possible to procure such an extent of land under the same landlord, but it might be found in the same locality on different estates. Such a farm, rendered highly fertile by draining, manuring, liming; and labor, and plenished, as an experimental farm should be, with all the varieties of crop, stock, implements, and woods, would be a magnificent spectacle worthy of a nation's effort to put into a perfect state for a national object. What a wide field of observation would it present to the botanical physiologist, containing a multiplicity of objects made subservient to experiment! What a laboratory of research for the chemist, among every possible variety of earths, manures, plants, and products of vegetation! What a museum of objects for the naturalist, in which to observe the living habits and instincts of animals, some useful to man, and others (106) 
injurious to the fruits of his labor! What an arena upon which the husbandman to exercise his practical skill, in varying the modes of culture of crops and live-stock! What an object of intense curiosity and untatisfying wonder to the rustic laborer! But, above all, what interest and solicitude should the statesman feel the appliance of such a mighty engine, set in motion, to work out the problem of agricultural skill, prosperity, and power.*

\title{
9. OF THE KIND OF EDUCATION BEST SUITED TO YOUNG
}

\section{FARMERS.}

\begin{abstract}
"Between the physical sciences and the arts of life there subsists a constant mutual interchange of good offices, and no considerable progress can be made in the one without, of necessity, giving rise to corresponding steps in the other. On the one hand, every art is in some measure, and many entirely, dependent on those very powers and qualities of the materiul world which it is the object of physical inquiry to investigate and explain." Herschel.
\end{abstract}

WITH respect to the education of young farmers, no course of elementary education is better than what is taught at the excellent parochial schools of this country. The sons of farmers and of peasants have in them a favorable opportunity of acquiring the elements of a sound education, and they happily avail themselves of the opportunity; but, besides elementary education, a classical one sufficiently extensive and profound for farmers may there also be obtained. But there are subjects of a different nature, sciences suited to the study of maturer years, which young farmers should make a point of learning-I mean the sciences of Natural Philosophy, Natural History, Mathematics, and Chemistry. These are taught at colleges and academies. No doubt these sciences are included in the curriculum of education provided for the sons of landowners and wealthy farmers; but every class of farmers should be taught them, not with a view of transforming them into philosophers, but of communicating to them the important knowledge of the nature of those phenomena which daily present themselves to their observation. Such information would make them more intelligent farmers, as well as men. The advantages which farmers would derive from studying those sciences will be best understood by pointing out their nature.

It is evident that most farming operations are much affected by external influences. The state of the weather, for instance, regulates every field operation, and local influences modify the climate very materially. Now it should be desired by the farmer to become acquainted with the causes which give rise to those influences, and these can only be known by comprehending the laws of Nature which govern every natural phenomenon. The science which investigates the laws of these phenomena is called Natural Philosophy, and it is divided into as many branches as there are classes of phenomena. The various classes of phenomena occur in the earth, air, water, and heavens. The laws which regulate them, being unerring in their operation, admit of absolute demonstration; and the science which affords the demonstration is called Mathematics. Again, every object, an imate or inanimate, that is patent to the senses, possesses an individual identity, so that no two objects can be confounded together. The science which makes us acquainted with the marks for identifying individuals is

* Paper by me on the subject in the Quart. Jour. of Agri., vol. vii. p. 538.

(107) 
termed Natural History. Farther, every object, animate or inanimate, cognizable by the senses, is a compound body made up of certain elements. Chemistry is the science which makes us acquainted with the nature and combinations of those elements. We thus see how generally applicable those sciences are to the phenomena around us, and their utility to the farmer will be the more apparent, the more minutely each of them is in. vestigated. Let us take a cursory view of each subdivision as it affects Agriculture.

Mathematics are either abstract or demonstrative. Abstract mathematics "treat of propositions which are immutable, absolute truth," not liable to be affected by subsequent discoveries, "but remains the unchangeable property of the mind in all its acquirements." Demonstrative mathematics are also strict, but are "interwoven with physical considerations" - that is, subjects that exist independently of the mind's conceptions of them or of the human will; or, in other words still, considerations in accordance with nature. Mathematics thus constitute the essential means of demonstrating the strictness of those laws which govern natural phenomena. Mathematics must, therefore, be first studied before those laws can be understoodTheir study tends to expand the mind-to enlarge its capacity for general principles, and improve its reasoning powers.

Of the branches into which Natural Philosophy is divided, that which is most useful to farmers is Mechanics, which is defined to be "the science of the laws of matter and motion, so far as is necessary to the construction of machines, which, acting under those laws, answer some purpose in the husiness of life." Without mechanics, as thus defined, farmers may learn to work any machine which answers their purpose; but it is only by that science they can possibly understand the principles upon which any machine is constructed, nor can any machine be properly constructed in defiance of those principles. Both machinists and farmers ought to be versed in mechanical science, or the one cannot make, and the other guide, any machine as it ought to be ; but, as I have had occasion to express my sentiments on this subject already, I shall abstain from dilating farther upon it here. Mathematical demonstration is strictly applicable to mechanics, whether as to the principles on which every machine operates, or the form of which it is constructed. The principles of mechanics are treated of separately under the name of Dynamics, which is defined to be " the science of force and motion."

Pneumatics is the branch of natural philosophy which is next to mechanics in being the most useful to the farmer to know. It "treats of air, and the laws according to which it is condensed, rarefied, gravitates." The states of the air, giving a variable aspect to the seasons, as they pursue their " appointed course," endue all atmospherical phenomena with extreme interest to the farmer. Observation ałone can render variety of phenomena familiar; and their apparent capriciousness, arising most probably from the reciprocal action of various combinations of numerous elements, renders their complicated results at all times difficult of solution; for all fluids are susceptible of considerable mutations, even from causes possessing little force; but the mutations of elastic fluids are probably effected by many inappreciable causes. Nevertheless, we may be assured that no change in the phenomena of the atmosphere, however trivial, takes place but as the unerring result of a definite law, be it chemical or physical.

Closely connected with pneumatics, in 80 far as the air is concerned, are the kindred natural sciences of electricity and magnetism. These agencies, though perfectly perceptible to one or more of the senses, and evidently (108) 
constantly at work in most of the phenomena of the atmosphere, are mysteriously subtle in their operations. It is extremely probable that one or both are the immediate causes of all the changes which the atmosphere is continually undergoing. It is hardly possible that the atmosphere, surrounding the globe like a thin envelop, and regularly carried round with it in its diurnal and annual revolutions, should exhibit so very dissimilar phenomena every year, but from some disturbing cause, such as the subtile influences of electricity, which evidently bear so large a share in all remarkable atmospherical phenomena. Its agency is the most probable cause of the irregular currents of the air called winds, the changes of which are well known to all farmers to possess the greatest influence on the weather.

Natural History comprehends several branches of study. Meteorology consists of the observation of the apparent phenomena of the atmosphere. The seasons constitute a principal portion of these phenomena. The clouds constitute another, and are classified according to the forms they assume, which are definite, and indicative of certain changes. The winds constitute a third, and afford subject for assiduous observation and much consideration. Attention to the directions of the wind and forms of the clouds will enable farmers to anticipate the kind of weather that will afterward ensue in a given time in their respective localities. The prevalence of the aqueous meteors of rain, snow, hail, and ice, is indicated by the state of the clouds and winds.

Hydrography is the science of the watery part of the terraqueous globe. It makes us acquainted with the origin and nature of springs and marshes, the effects of lakes, marshes, and rivers, on the air and on vegetation in their vicinity; and the effects of sea air on the vegetation of maritime districts.

Geology is the knowledge of the substances which compose the crust of the earth. It explains the nature and origin of soils and subsoils; that is, the manner in which they have most probably been formed, and the rocks from which they have originated; it discovers the relative position, structure, and direction in which the different rocks usually lie. It has as yet done little for Agriculture; but a perfect knowledge of geology might supply useful hints for draining land, and planting trees on soils and over subsoils best suited to their natural habits, a branch of rural economy as yet little understood, and very injudiciously practiced.

Botany and botanical physiology, which treat of the appearance and structure of plants, are so obviously useful to the agricultural pupil, that it is unnecessary to dilate on the advantages to be derived from a knowledge of both.

Zoology, which treats of the classification and habits of all animals, from the lowest to the highest organized structure, cannot fail to be a source of constant interest to every farmer who rears stock. There are few wild quadrupeds in this country; but the insect creation itself would employ a lifetime to investigate.

Anatomy, especially comparative anatomy, is highly useful to the farmer, inasmuch as it explains the functions of the internal structure of animals upon which he bestows so much care in rearing. Acquainted with the functions of the several parts which constitute the corporeal body, he will be the better able to apportion the food to the peculiar constitution of the animal; and also to anticipate any tendency toward disease, by a previcusly acquired knowledge of premonitory symptoms. Comparative anatomy is most successfully taught in veterinary schools.

The only other science which bears directly on Agriculture, and with (109) 
which the pupil farmer should make himself acquainted, is Chemistry; that science which is cognizant of all the changes in the constitution of matter, whether effected by heat, by moisture, or other means. There is no substance existing in nature but is susceptible of chemical examina. tion. A science so universally applicable cannot fail to arrest popular attention. Its popular character, however, has raised expectations of its power to assist Agriculture to a much greater degree than the results of its investigations yet warrant. It is very generally believed, not by practical farmers, but chiefly by amateur agriculturists, who profess great regard for the welfare of Agriculture, that the knowledge derived from the analysis of soils, manures, and vegetable products, would develop general principles which might lead to the establishment of a system of Agriculture as certain in its effects as the unerring results of science. Agriculture, in that case, would rank among the experimental sciences, the application of the principles of which would necessarily result in increased produce. The positive effects of the weather seem to be entirely overlooked by these amateurs. Such sentiments and anticipations are.very prevalent in the present day, when every sort of what is termed scientific knowledge is sought after with an eagerness as if prompted by the fear of endangered existence. This feverish anxiety for scientific knowledge is very unlike the dispassionate state of mind induced by the patient investigation of true science, and very unfavorable to the right application of the principles of science to any practical art. Most of the leading agricultural societies instituted for the promotion of practical Agriculture, have been of late assailed by the entreaties of euthusiastic amateur agriculturists, to construct their premiums to encourage only that system of Agriculture which takes chemistry for its basis.

These are the physical sciences whose principles seem most applicable to Agriculture; and being so, they should be studied by every farmer who wishes to be considered an enlightened member of his profession. That farmers are quite competent to attain to these sciences, may be gathered from these observations of Sir John Herschel : "There is scarcely any well-informed person who, if he has but the will, has not the power to add something essential to the general stock of knowledge, if he will only observe regularly and methodically some particular class of facts which may most excite his attention, or which his situation may best enable him to study with effect. To instance one subject which can only be effectually improved by the united observations of great numbers widely dispersed: Meteorology, one of the most complicated but important branches of science, is at the same time one in which any person who will attend to plain rules, and bestow the necessary degree of attention, may do effectual service." But in drawing our conclusions, great caution is requisite ; for, "In forming inductions, it will most commonly happen that we are led to our conclusions by the especial force of some two or three strongly impressive facts, rather than by affording the whole mass of cases a regular consideration; and hence the need of cautious verification. Indeed, so strong is this propensity of the human mind, that there is hardly a more common thing than to find persons ready to assign a cause for every thing they see, and in so doing, to join things the most incongruous, by analogies the most fanciful. This being the case, it is evidently of great importance that these first ready impulses of the mind should be made on the contemplation of the cases most likely to lead to good inductions. The misfortune, however, is, in natural plilosophy, that the choice does nnt rest with us. We must take the instances as Nature presents them. Even if we are furnished with a list of them in tabular order, we must under(110) 
stand and compare them with each other, before we can tell which are the instances thus deservedly entitled to the highest consideration. And, after all, after much labor in vain, and groping in the dark, accident or casual observation will present a case which strikes us at once with a full insight into the subject, before we can even have time to determine to what class its prerogative belongs."**

Many farmers, I dare say, will assert it to be far beyond the reach of their means, and others beyond their station, to bestow on their sons so learned an education as that implied in the acquirement of the sciences just now enumerated. Such apprehensions are ill-founded; because no farmer that can afford to support his sons at home, without working for their bare subsistence, but possesses the means of giving them a good education, as I shall immediately prove ; and no farmer, who confessedly has wealth, should grudge his sons an education that will fit them to adorn the profession they intend to follow.

It cannot be denied that a knowledge of mathematics and natural philosophy greatly elevates the mind. Those farmers who have acquired these sciences, must be sensible of their tendency to do this; and they will therefore naturally wish their sons to enjoy what they themselves do. Those who of themselves do not know these sciences, on being informed of their beneficial tendency, will probably feel it to be their duty to educate their sons, and thereby put it in their power to raise themselves in society and at the same time shed a lustre on the profession of which they are members. The same species of reasoning applies to the acquirement of the peculiar accomplishments bestowed on the mind by a knowledge of natural history and chemistry. Neither the time nor expense of acquiring such an education is of that extent or magnitude as to deter any farmer's son from attempting it, who occupies a station above that of a farm steward. Besides these considerations, a good education, as the trite saying has it, is the best legacy a parent can leave his child; and, on this account, it is better for the young farmer himself to bestow on him a superior education, in the first instance, with a part even of the money destined by his father to stock him a farm, than to plenish for him a larger farm, and stint his education. The larger farm would, no doubt, enable the half-educated son to earn a livelihood more easily; but the well-educated one would be more than compensated in the smaller farm, by the possession of that cultivated intelligence which would induce him to apply the resources of his mind to drawing forth the capabilities of the soil, and making himself an infinitely superior member of society. Were industrious farmers as eager to improve their sons' minds by superior education, as they too often are to amass fortunes for them-a boon unprofitably used by uncultivated minds-they would display more wisdom in their choice. No really sensible farmer should hesitate to decide which course to take, when the intellectual improvement of his family is concerned. He should never permit considerations of mere pelf to overcome a sense of right and of duty. Rather than prevent his son having the power to raise himself in his profession, he should scrupulously economize his own expenditure.

I shall now show that the time occupied in the acquisition of those sciences which are expedient for the farmer to learn, is not lost when compared with the advantages which they may bestow: Part of three years will accomplish all, but three years are doubtless an immense time

* Discourse on the Study of Natural Philosophy, pp. 133, 182

(111) 
for a young man to lose! So it would be ; but, to place the subject in its proper light, I would put this statement and question for considerationWhether the young farmer's time, who is for years constantly following bis father's footsteps over the farm, and only superintending a little in his absence, while the father himself is, all the time, quite capable of conducting the farm, is not as much lost, as the phrase has it, as it would be when he is occupied in acquiring a scientific education at a little distance from home? Insomuch as the young man's time is of use to the farm, the two cases are nearly on a par; but, in as far as both cases affect himself, there is no question that science would benefit him the more-no question that a superior education would afterward enable him to learn the practical part of his profession with his father, with much greater ease to himself. The question is thus narrowed to the consideration of the alternative of the cost of keeping the son at home, following his father as idly as his shadow, or of sending him to college. Even in this pecuniary point of view, the alternative consists merely of the difference of maintenance at home, and that in a town, with the addition of fees. That this difference is not great, I shall now show.

Part of three years, as I have said, would accomplish all amply, and in this way: the first year to be devoted to mathematics, the second to natural philosophy, and the third to natural history and chemistry; and along with these principal subjects, some time in both years should be devoted to geography, English grammar and composition, book-keeping, and a knowledge of cash transactions. The two months' vacation in each year could be spent at home. There are seminaries* at which these subjects mayt be studied, at no great distance from every farmer's home. There are, fortunately for the youths of Scotland, universities, colleges, and academies, in many parts of the country. Edinburgh, Glasgow, Aberdeen, and St. Andrews, can boast of well-endowed universities and colleges; while the academies at Dundee, Perth, Ayr, Dollar, and Inverness, have been long famed for good tuition.

\section{OF THE DIFFERENT KINDS OF FARMING.}

"I'll teach you differences."

$$
\text { LEAR. }
$$

Perhaps the young farmer will be astonished to learn that there are many and various systems of farming; yet so in reality is the case, and moreover that they all possess very distinctive characteristics. There are six kinds of farming practiced in Scotland alone; and though all are pursued under some circumstances common to all, and each kind is perhaps best adapted to the particular soil and situation in which it is practiced; yet it is highly probable that one of the kinds might be applicable to, and profitably followed, in all places of nearly similar soil and locality. Locality, however, determines the kind of farming fully more than the soil ; the soil only entirely determining it when of a very peculiar consistence. The comparative influence of locality over soil in determining this point will be better understood after shortly considering each kind of farming. 
1. One kind is wholly confined to pastoral districts, which are chiefly situated in the Highlands and Western Isles of Scotland-in the Cheviot and Cumberland hills of England-and very generally in Wales. In all these districts, farming is almost restricted to the breeding of cattle and sheep; and, as natural pasture forms the principal food of live-stock in a pastoral country, very little arable culture is there practiced for their behoof. Cattle and sheep are not always both reared on the same farm. Cattle are reared in very large numbers in the Western Isles, and in the pastoral valleys among the mountain-ranges of England, Wales, and Scotland.* Sheep are reared in still greater numbers in the upper parts of the mountain-ranges of Wales and of the Highlands of Scotland; and on the green round-backed mountains of the south of Scotland and the north of England. The cattle reared in pastoral districts are small sized, chiefly black colored, and horned. Those in the Western Isles, called "West Highlanders," or "Kyloes," are esteemed a beautifully symmetrical and valuable breed of cattle. Those in the valleys of the Highland moun tains, called "North Highlanders," are considerably inferior to them in quality, and smaller in size. The black-faced, mountain, or heath, horned sheep, are bred and reared on the upper mountain-ranges, and fattened in the low country. The round-backed green hills of the south are mostly stocked with the white-faced, hornless, Cheviot breed,; though the best kind of the black-faced breed is also reared in some localities of that district, but seldom both breeds are bred by the same farmer. Wool is a staple product of sheep pastoral farming.

Pastoral farms are chiefly appropriated to the rearing of one kind of sheep, or one kind of cattle; though both classes of stock are bred where valleys and mountain-tops are found on the same farm. The arable culture practiced on them is confined to the raising of provisions for the support of the shepherds and cattle-herds; and perhaps of a few turnips, for the support of the stock during the severity of a snow-storm; but the principal artificial food of the stock in winter is hay, which in some cases is obtained by inclosing and mowing a piece of natural grass on a spot of good land, near the banks of a rivulet, the alluvial soil along the river sides being generally of fine quality. All pastoral farms are large, some containing many thousands of acres-nay miles in extent; but from 1,500

[* In the United States the mountain ranges running from east to west may be considered our "pastoral" or grazing districts.

The farther we go east the more are such lands devoted to sheep husbandry, while in the west and south-west they are given up to the rearing of cattle, to be sold, as lean or stock cattle, to the grazier, who sometimes buys and carries them through the winter on wheat straw, and fattens them on grass against the next autumn. But more generally they are sold in spring, grazed through the summer, and fattened on corn the following winter. Thus prepared for market, they are either killed and packed in the West, or driven thence in spring and summer to the easteru markets. For our pastoral or grazing districts, a comparatively smaller and more thrifty race of cattle, weighing, when at market, from 500 to 700, is most advantageous for all parties, as, with but little exception they have to "shift for themselves" throughout the year, and often get no special feeding.

It is as true now as it was in the time of Sir John Sinclair, that where the surface is barren and the climate rigorous, it is essential that the stock bred and maintained there should be enabled to sustain the severities and vicissitudes of the weather as well as scarcity of foood, or any other circumstance in its locality and treatment that might subject a more delicate breed to injury. For the purposes of the cattle breeder in the mountains, it is probable that the hardy middle sized North Devon would be found most eligible; or if it should be deemed expedient to try a foreign cross which we have not tried, obvious reasons saggest that the Polled, or Galloway, and the Scotch Highland races should be had recourse to.

Ed. Farm. Lib.]

(113)...... 5 
to 3,000 acres is perhaps an ordinary size.* Locality determines this kind of farming.

The stocking of a pastoral farm consists of a breeding stock of sheep or cattle, and a yearly proportion of barren stock intended to be fed and sold at a proper age. A large capital is thus required to stock at first, and afterward maintain such a farm; for, although the quality of the land may not be able to support many heads of stock per acre, yet, as the farms are large, the number of heads required to stock a large farm is very consid. erable. The rent, when consisting of a fixed sum of money, is of no great amount per acre, but sometimes it is fixed at a sum per head of the stock that the farm will maintain.

A pastoral farmer should be well acquainted with the rearing and management of cattle or sheep, whichever his farm is best suited for. A know ledge of general field culture is of little use to him, though he should know how to raise turnips and make hay.

2. Another kind of farming is practiced on carse land. A carse is a district of country, consisting of deep horizontal depositions of alluvial or diluvial clay, on one or both sides of a considerable river; and may be of great or small extent, but generally comprehends a large tract of country. In almost all respects, a carse is quite the opposite to a pastoral district. Carse land implies a flat, rich, clay soil, capable of raising all sorts of grain to great perfection, and unsuited to the cultivation of pasture grasses, and, of course, to the rearing of live-stock. A pastoral district, on the other hand, is always hilly - the soil generally thin, poor, and various, and commonly of a light texture, much more suited to the growth of natural pasture grasses than of grain, and, of course, to the rearing of live-stock. Soil decides this kind of farming.

Being all arable, a carse farm is mostly stocked with animals and implements of labor; and these, with seed-corn for the large proportion of the land cultivated under the plow, require a considerable outlay of capital.Carse land always maintains a high rent per acre, whether it consists solely of money, or of money and corn valued at the fiars prices. A carse farm, requiring much capital and much labor, is never of large extent-seldom exceeding 200 acres.

A carset farmer requires to be well acquainted with the cultivation of grain, and almost nothing else, as he can rear no live-stock; and all he requires of them are a few milch cows, to supply milk to his household and farm-servants, and a few cattle in the straw-yard in winter, to trample down the large quantity of straw into manure-both of which classes of cattle are purchased when wanted.

3. A third sort of farming is that which is practiced in the neighborhood of large touns. In the immediate vicinity of London, farms are appropriated to the growth of garden vegetables for Covent-Garden market; and, of course, their method of culture can have nothing in common with either pastoral or carse farms. In the neighborhood of most towns, garden vegetables, with the exception of potatoes, are not so much cultivated as green crops, such as turnips and grass, and dry fodder, such as straw and hay, for the use of cow-feeders and stable-keepers. The practice of this kind of farming is to dispose of all the produce, and receive in return manure for the land. And this constitutes this kind of farming a retail trade like that in town, in which articles are bought and sold in small quantities, mostly \# It is to be regretted that neither the Old nor the New Statistical Account of Scotland gives the least idea
of the size of the farms in any of the parishes described.

[t What we call a grain-farmer.

(114)

Ed. Farm. Lib. 1 
for ready money.* When there is not a sufficient demand in the town for all the disposable produce, the farmer purchases cattle and sheep to eat the turnips, and trample the straw into manure, in winter. Locality decides this kind of farming.

The chief qualification of an occupant of this kind of farm is a thorough acquaintance with the raising of green crops-potatoes, clover, and turnips; and his particular study is the raising of those kinds and varieties that are most prolific, for the sake of having large quantities to dispose of, and which, at the same time, are most suitable to the wants of his customers.

The capital required for a farm of this kind, which is all arable, is as large as that for a carse farm. The rent is always high per acre, and the extent of land not large-seldom exceeding 300 acres.

4. A fourth kind of farming is the dairy husbandry. It specially directs its attention to the manufacture of butter and cheese, and the sale of milk. Some farms are laid out for the express purpose; but the sale of milk is frequently conjoined with the raising of green crops, in the neighborhood of large towns, whose inhabitants are whence daily supplied with milk, though seldom from pasture, which is mostly appropriated as paddocks for stock sent to the weekly market. But a true dairy-farm requires old pasture. The chief business of a dairy-farm is the management of cows and of their produce; and whatever arable culture is practiced thereon is made entirely subservient to the maintenance and comfort of the dairy stock.The milk, where practicable, is sold; where beyond the reach of sale, it is partly churned into butter, which is sold either fresh or salted, and partly made into cheese, either sweet or skimmed. No stock are reared on dairyfarms, as on pastoral, except a few quey (heifer) calves, occasionally to replenish the cow stock; nor aged stock fed in winter, as on farms in the vicinity of towns. The bull calves are frequently fed for veal, but the principal kind of stock reared are pigs, which are fattened on dairy refuse.Young horses, however, are sometimes successfully reared on dairy-farms. Horse labor being comparatively little required thereon, mares can carry their young, and work with safety at the same time; while old pasture, spare milk, and whey afford great facilities for nourishing young horses in a superior manner. Locality has decided this kind of farming on the large scale.

The purchase of cows is the principal expense of stocking a dairy-farm ; and as the purchase of live-stock in any state, especially breeding-stock, is always expensive, and live-stock themselves, especially cows, constantly liable to many casualties, a dairy-farm requires a considerable capital. It is, however, seldom of large extent-seldom exceeding 150 acres. The arable portion of the farm supplying the green crop for winter food and litter, does not incur much outlay, as hay - that obtained from old pasture grass -forms the principal food of all the stock in winter. The rent of dairyfarms is high.

A dairy-farmer should be well acquainted with the properties and management of milch cows, the manufacture of butter and cheese, the feeding of veal and pork, and the rearing of horses; and he should also possess as much knowledge of arable culture as to enable him to raise those kinds of

[" The facilities afforded by steam for the quick transportation of perishable articles-such as fruit and milk, and the more delicate vegetables-has had the effect of opening market gardens at a comparatively great distance from the large towns. A railroad or a steamboat will bring these articles into market, from a distance of fifty miles, with as little delay, and less injury by transportation, than an ordinary conveyance would bring them ten miles. Obvious as is this fact, it is deemed proper to mention it, that it may not be lost sight of in the purchase of farms. 
green crops, and that species of hay, which are most congenial to cows for the production of milk.

5. A fifth method of farming is that which is practiced in most arablo districts, consisting of any kind of soil not strictly carse land. This method consists of a regular system of cultivating grains and sown grasses, with the partial rearing, and partial purchasing, or wholly purchasing, of cattle ; and no sheep are reared in this system, they being purchased in autumn, to be fed on turnips in winter, and sold off fat in spring. This system may be said to combine the professions of the farmer, the cattle-dealer, and the sheepdealer.*

To become a farmer of this mixed husbandry, a man must be acquainted with every kind of farming practiced in the country. He actually practices them all. He prosecutes, it is true, each kind in a rather different manner from that practiced in localities where the particular kind is pursued as the only system of farming; because each branch of his farming must be conducted so as to conduce to the welfare of the whole, and, by studying the mutual dependence of parts, he produces a whole in a superior manner.This multiplicity of objects requires from him more than ordinary attention, and much more than ordinary skill in management. No doubt, the farmers of some of the other modes of farming become very skillful in adapting their practice to the situations in which they are actually placed, but his more raried experience increases versatility of talent and quickness of discernment; and, accordingly, it will be found that the farmers of the mixed husbandry prove themselves to be the cleverest and most intelligent agriculturists of the country.

\section{OF CHOOSING THE KIND OF FARMING.}

*Choice, being mutual act of all our souls, makes merit her election. ${ }^{n}$

Tronlez aNd Cressida.

THESE are the various kinds of farming pursued in this kingdom; and, if there be any other, its type may, no doubt, be found in the mixed system just described. One of these systems must be adopted by the aspirant pupil for his profession. If he succeed to a family inheritance, the kind of farming he will follow will depend on that pursued by his predecessor, which be will learn accordingly; but if he is free to choose for himself, and not actually restricted by the circumstances of peculiar locality, or soil, or inheritance, then I would adrise him to adopt the mixed husbandry, as containing within itself all the varieties of farming which it is requisite for a farmer to know.

If he is at liberty to take advice, I can inform him that the mixed husbandry possesses advantages over every other; and practically thus : in pastoral farming, the stock undergoes minute examination, for certain purposes, only at distantly stated times; and owing to the wide space over which they have to roam for food in pastoral districts, comparatively less attention is bestowed on them by shepherds and cattle-herds. The pastoral farmer has thus no particular object to attract his attention at home between those somewhat long intervals of time; and in the mean while time is apt to hang heavy on his hands. The carse farmer, after the la. bors of the field are finished in spring, has nothing but a little hay-making

[* Which, in our country, are often combined. 
and much bare-fallowing in summer, to occupy his mind until the harvest. Dairy-farming affords little occupation for the farmer in winter. The farmer in the vicinity of large towns has almost nothing to do in summer, from turnip-seed to harvest. Mixed-husbandry, on the other hand, affords abundant and regular employment at all seasons. Cattle and sheep feeding, and marketing grain, pleasantly occupy the short days of winter. Seedsowing of all kinds affords abundant employment in spring. The rearing of live-stock, sale of wool, and culture of green crops, fill up the time in summer until harvest; and autumn, in all circumstances, brings its own busy avocations at the ingathering of the fruits of the earth. There is, strictly speaking, not one week of real leisure to be found in the mixed system of farming-if the short period be excepted, from assorting lambs in the beginning of August to putting the sickle to the corn-and that period is curtailed or protracted, according as the harvest is early or late.

If the young farmer is desirous of attaining a knowledge of every kind of farm work-of securing the chance of profit every year-and of finding regular employment at all seasons in his profession, he should determine to follow the mixed husbandry. It will not in any year entirely disappoint his hopes. In it, he will never have to bewail the almost total destruction of his stock by the rot, or by the severe storms of winter, as the pastoral farmer sometimes has. Nor can he suffer so serious a loss as the carse farmer, by his crop of grain being affected by the inevitable casualties of blight or drouth, or the great depression of prices for a succession of years. Were his stock greatly destroyed or much deteriorated in value by such casualties, he might have the grain to rely on; and were his grain crops to fail to a serious extent, the stock might insure him a profitable return. It is scarcely within the bounds of probability that a loss would arise in any year from the total destruction of live-stock, wool, and grain. One of them may fail, and the prices of all may continue depressed for years; but, on the other hand, reasonable profits have been realized from them all in the same year. Thus, there are safeguards against a total loss, and a greater certainty of a profitable return from capital invested in the mixed, than in any other kind of husbandry at present known.

\section{OF SELECTING A TUTOR-FARMER FOR TEACHING FARMING,}

"These are their tutors, bid them use them well."

TAMING OF THE SHREW.

After resolving to follow farming as a profession, and determining to learn the mixed, as the best system of husbandry, it now only remains for the young farmer to select a farmer who practices it, with whom he would wish to engage as a pupil. The best kind of pupilage is to become a boarder in a farmer's house, where he will not only live comfortably but may learn this superior system of husbandry thoroughly. The choice of locality is so far limited, as it must be in a district in which this particular system is practiced in a superior manner. The qualifications are numerous. The farmer should have the general reputation of being a good farmer; that is, a skillful cultivator of land, a judicious breeder, and an excellent judge of stock. He should possess agreeable manners, and have the power of communicating his thoughts with ease. He should occupy a good farm, consisting, if possible, of a variety of soils, and situate in a

(117) 
tolerably good climate, neither on the top of a high hill, nor on the confines of a large moor or bog, but in the midst of a well cultivated country. These circumstances of soil and locality should be absolute requisites in a farm intended to be made the residence of pupils. The top of a hill, exposed to every blast that blows, or the vicinage of a bog, overspread with damp vapor, would surround the farm with a climate in which no kind of crop or stock could arrive at a state of perfection; while, on the ther hand, a very sheltered spot in a warm situation, would give the puvil no idea of the vexations experienced in a precarious climate. His inexperience in these things will render him unfit to select for himself either a qualified farmer, or a suitable farm; but friends are never wanting to render assistance to young aspirants in such emergencies, and if their opinion is formed on a knowledge of farming, both of the farm and the personal qualifications of the farmer they are recommending, some confidence may be placed in their recommendations.

As a residence of one year must pass over ere the pupil can witness the course of the annual operations of the farm, his engagement at first should be made for a period of not less than a year; and at the expiring of that period he will, most probably, find himself inadequate to the task of managing a farm. The entire length of time he would require to spend on a farm, must be determined by the paramount consideration of his having acquired a competent knowledge of his profession.

\section{OF THE PUPILAGE.}

"A man loves the meat in his youth that he cannot endure in his age."

Much Ado about Nothina.

Having settled these preliminaries with the tutor-farmer, the pupil should enter the farm-the first field of his anticipations and toils in farming-with a resolution to acquire as much professional knowledge, in as short a time as the nature of the business which he is about to learn will admit of.

The commencement of his tuition may be made at any time of the year; but since farming operations have a regular beginning and ending every year, it is obvious that the most proper time to brgin to view them is at the opening of the agricultural year, that is, in the beginning of winter. It may not be quite congenial to the feelings of him who has perhaps been accustomed to pass his winters in a town, to participate for the first time in the labors of a farm on the eve of winter. He would naturally prefer the sunny days of summer. But the beginning of winter being the time at which every important operation is begun, it is essential to their being understood throughout, to see them begun, and in doing this, minor inconveniences should be willingly submitted to, to acquire an intimate knowledge of a profession for life. And, besides, to endeavor to become acquainted with complicated operations, after the principal arrangements for their accomplishment have been completed, is purposely to invite wrong impressions of them.

There is really nothing disagreeable to personal comfort in the business of the farm in winter: On the contrary, it is full of interest, inasmuch as the well-being of living animals then comes home to the attention more forcibly than the operations of the soil. The totally different and wellmarked individual characters of different animals, engage our sympathies (118) 
in different degrees; and the more so, perhaps, of all of them, that they appear more domesticated when under confinement than at liberty to roam about in quest of food and seclusion. In the evening, in winter, the hospitality of the social board awaits the pupil at home, or at a friend's house, after the labors of the day are over. Neighbors interchange visits at that social season, when topics of conversation common to all societies are varied by remarks on professional occurrences and management, elicited by the modified practices of the different speakers, from which the pupil may pick up much useful information. Or should society present no charms to him, the quieter companionship of books, or the severer task of study, is at his command. In a short time, however, the many objects peculiar to the season which present themselves in the country in winter, cannot fail to interest him.

The very first thing to which the pupil should direct his attention on entering the farm, is to become well acquainted with its physical geography-that is, its position, exposure, extent; its fences, whether of wall or hedge ; its shelter, in relation to rising grounds and plantations; its roads, whether public or private; its fields, their number, names, sizes, relative positions, and supply of water; the position of the farm-house and steading of farm-stead. Familiar acquaintance with all these particulars will enable him to understand more readily the orders given by the farmer for the work to be performed in any field. It is like possessing a map of the ground on which certain plans of operations are about to be undertaken. A plan of the farm would much facilitate an introduction to this familiar acquaintance. The tutor-farmer should be provided with such a plan to give to each of his pupils, but if he have it not, the pupil himself can set about constructing one which will answer his purpose well enough.

\section{OF DEALING WITH THE DETAILS OF FARMING.}

"Oh! is there not some patriot . .
To teach the lab'ring hands the sweets of toil ?
Yes, there are such."

TromsoN.

Tне principal object held in view, while making the preceding observations, was the preparation of the mind of the young person, desirous of ibecoming a farmer, into such a state as to enable him, when he enters a farm as a pupil, to anticipate and overcome what might appear to him great difficulties of practice, which, with an unprepared mind, he could not know existed at all, far less know how to overcome ; but, on being informed that he must encounter them at the very outset of his career, he might use the means pointed out to him for meeting and overcoming them. These difficulties have their origin in the pupil seeing the operations of the farm, of whatever nature, performed for the first time, in the most perfect manner, and always with a view to accomplishment at some future period. The only mode of overcoming such difficulties, and thereby satisfying his mind, is for the pupil to ascertain by inquiry the purport of every operation he sees performing; and though he may feel that he does not quite comprehend that purport, even when informed of it, still the information will warn him of its approaching consummation, and he will not, therefore, at any time thereafter be taken by surprise when the event actually arrives. If I show the pupil the importance of making inquiry regarding the purport of 
every operation he sees performing, I see no better mode of rendering all farming operations intelligible to his mind. In order to urge him to become familiar with the purport of everything he sees going on around him, I have endeavored to point out the numerous evils attendant on farmers, landowners, and emigrants neglecting to become thoroughly acquainted with practical husbandry, before attempting to exercise their functions in their new vocations. And, in order that the young person desirous of becoming a farmer may have no excuse for not becoming well acquainted with farming, I have shown him where, and the manner how, he can best become acquainted with it; and these are best attained, under present circumstances, by his becoming an inmate for a time in a farm-house with an intelligent farmer. Believing that the foregoing observations, if perused with a.willing mind, are competent to give such a bias to his mind as to enable the pupil, when he enters a farm, to appreciate the importance of his profession, and thereby create an ardent desire for its attainment, I shall now proceed to describe the details of every operation as it occurs in its due course on the farm.

The description of these details, which are multifarious and somewhat intricate, will compose by far the most voluminous portion of this work, and will constitute the most valuable and interesting part of it to the pupil. In the descriptions, it is my intention to go very minutely into details, that no circumstance may be omitted in regard to any of the operations, which may have the appearance of presenting a single one to the notice of the pupil in an imperfect form. This resolution may invest the descriptions with a degree of prolixity which may, perhaps, prove tiresome to the general reader; but, on that very account, it should the more readily give rise to a firm determination in the pupil to follow the particulars of every operation into their most minute ramifications; and this because he cannot be too intimately acquainted with the nature of every piece of work, or too much informed of the various modifications which every operation has frequently to undergo, in consequence of change in the weather, or the length of time in which it is permitted by the season to perform it. Descriptions so minute will answer the purpose of detailed instructions to the pupil; and, should he follow them with a moderate degree of application through one series of operations, he will obtain such an insight into the nature of field labor as will ever after enable him easily to recognize a similar series when it is begun to be put into execution. Unless, however, he bestow consider able attention on all the details of the descriptions, he will be apt to let pass what may appear to him an unimportant particular, but which may be the very keystone of the whole operation to which they relate. With a tolerable memory on the part of the pupil, I feel pretty sure that an attentive perusal of the descriptions will enable him to identify any piece of work he afterward sees performing in the field. This achievement is as much as any book can be expected to accomplish.

In describing the details of farming, it is necessary to adhere to a determinate method; and the method that appears to me most instructive to the pupil is to follow the usual routine of operations pursued on a farm. It will be requisite, in following that routine implicitly, to describe every operation from the beginning; for it must be impressed on the mind of the pupil that farm operations are not conducted at random, but on a tried and approved system, which commences with preparatory labors, and then carries them on with a determinate object in view throughout the seasons, until they terminate at the end of the agricultural year. The preparatory operations commence immediately after harvest, whenever that may happen, and it will be earlier or later in the year according as the season is early or (120) 
late; and as the harvest is the consummation of the labors of the year, and terminates the autumnal season, so the preparatory operations begin with the winter season. Thus the winter season takes the precedence in the arrangements of farming, and doing so, that should be the best reason for the pupil commencing his career as an agriculturist in winter. In that season he will have the advantage of witnessing every preparation as it is made for realizing the future crops-an advantage which he cannot enjoy if he enter on his pupilage at any other season; but it is a great advantage, inasmuch as every piece of work is much better understood, when viewed from its commencement, than when seen for the first time in a state of progression.

Having offered these preliminary remarks respecting the condition of the agricultural pupil when about to commence learning his profession, I shall now proceed to conduct him through the whole details of farming, as they usually occur on a farm devoted to the practice of the mixed, or, in other words, of the most perfect system of husbandry known; while, at the same time, he shall be made acquainted with what constitute differences from it in the corresponding operations of the other modes of farming, and which are imposed by the peculiarities of the localities in which they are practiced. These details I shall narrate in the order in which they are performed, and for that purpose will begin with those of Winter-the season which commences the agricultural year-for the reason assigned in the paragraph immediately preceding this one. 


\title{
W IN T E R.
}

\author{
"All nature feels the renovating force \\ Of WINTER, only to the thoughtless eye \\ In ruin seen. The frost-concocted glebe \\ Draws in abundant vegetable soul, \\ And gathers vigor for the coming year." \\ THOMSOR.
}

THE subjects which court attention in Winter are of the most interesting description to the farmer. Finding little inducement to spend much time in the fields at this torpid season of the year, he directs his attention to the more animated portions of farm-work conducted in the steading, where almost the whole stock of animals are collected, and where the preparation of the grain for market affords pleasant employment for work-people within doors. The progress of live-stock to maturity is always a prominent object of the farmer's solicitude, but especially in winter, when the stock are comfortably housed in the farmstead, plentifully supplied with wholesome food, and so arranged in various classes, according to age and sex, as to be easily inspected at any time.

The labors of the field in winter are confined to a few great operations. These are, plowing the soil in preparation of future crops, and supplying food to the live-stock. The plowing partly consists of turning over the ground which had borne a part of the grain crops ; and the method of plowing this stubble land-so called because it bears the straw that was left uncut of the previous crop-is determined by the nature of the soil. That portion of the stubble land is first plowed which is intended to be first brought into requisition for a crop in spring, and the rest is plowed in the same succession that the different crops succeed each other in the ensuing seasons. The whole soil thus plowed in the early part of winter in each field (where the farm is subdivided with fences), or in each division (where there are no fences), is then neatly and completely provided with channels, cut with the spade in suitable places, for the purpose of permitting the water that may fall from the hearens to run quickly off into the ditches, and thereby to maintain the soil in as dry a state as is practicable until spring. Toward the latter part of winter, the newest grass land-or lea,* as grass land is generally termed-intended to bear a crop in spring, is then plowed; the oldest grass land being earlier plowed, that its toughness may have time to be meliorated by spring by exposure to the atmosphere. .... When the soil is naturally damp underneath, winter is the season selected for removing the damp by draining. It is questioned by some farm-

[* Every agricultural student and reader would do well to notice these peculiar terma em. ployed by English agricultural writers, because it is in that country, above all others, that the pirit of investigation is constantly at work. It is there that the progress of discovery is most steady, and publication most prompt and diffusive, and that, above all, in our own mother tongre. 
ers whether the winter is the best season for draining, as the usually rainy and otherwise unsettled state of the weather then renders the carriage of the materials for draining very laborious. On the other hand, it is maintained by other farmers that, as the quantity of water to be drained from the soil determines both the number and size of the drains, these are thus best ascertained in winter; and, as the fields are then most free of crop, they are in the most convenient state to be drained. Truth may perhaps be found to acquiesce in neither of these reasons, but rather in the opinion that draining may be successfully pursued at all seasons..... Where fields are uninclosed, and intended to be fenced with the thorn-hedge, winter is the season for performing the operation of planting it. Hard frost, a fall of snow, or heavy rain, may put a stop to the work for a time, but in all other states of the weather it may proceed in perfect safety..... When meadows for irrigation exist on any farm, winter is the season for beginning the irrigation with water, that the grass may be ready to mow in the early part of the ensuring summer. It is a fact well worth keeping in remembrance, in favor of winter irrigation, that irrigation in winter produces wholesome, and in summer unwholesome, herbage for stock. On the other hand, summer, not winter, is the proper season for forming water-meadows..... Almost the entire live-stock of an arable farm is dependent on the hand of man for food in winter. It is this circumstance which, bringing the stock into the immediate presence of their owner, creates a stronger interest in their welfare then than at any other season. The farmer then sees them classed together in the farmstead according to their age and sex, and delights to contemplate the comparative progress of individuals or classes among them toward maturity. He makes it a point to see them provided at all times with a comfortable bed or lair, and a sufficient supply of clean food at appointed hours in their respective apartments. The feeding of stock is so important a branch of farm business in winter that it regulates the time for prosecuting several other operations. It determines the quantity of turnips that should be carried from the field for the cattle in a given time, and causes the farmer to consider whether it would not be prudent to take advantage of the first few dry fresh days to store up a quantity of them, to be in reserve for the use of the stock during the storm that may be at the time portending-for storms like other

"Coming events east their shadows befor :"

It also determines the quantity of straw that should be provided from the stack-yard, in a given time, for the use of the animals ; and upon this, again, depends the supply of grain that can be sent to the market in any given time. For although it is certainly in the farmer's power to thresh as many stacks as he pleases at one time, provided the machinery for the purpose is competent for the task-and he is tempted to do so when prices are highyet, as new threshed straw forms superior provender for live-stock confined in the farmstead, its supply, both as litter and fodder, is therefore mainly dependent on its use by the' stock; and as its consumption as litter is greater in wet than in dry weather, and wet weather prevails in winter, the quantity of straw used in the course of that season must always be very considerable, and so, therefore, must the quantity of grain ready to be sent to market. All the stock in the farmstead in winter, that are not put to work, are placed under the care of the cattle-man.... The feeding of that portion of the sheep-stock which are barren, on turnips in the field, is a process practiced in winter. This forms fully a more interesting object of contemplation to the farmer than even the feeding of cattle-the behavior of sheep in any circumstances being always fascinating. Sheep being 
put on turnips early in winter, a favorable opportunity is thereby afforded the farmer, when clearing the field partially of turmips for the sheep (in a manner that will afterward be fully described to the pupil), to store a quantity of them for the cattle in case of an emergency in the weather, such as rain, snow, or frost. This removal of the surplus turnips that are not used by the sheep confined on the land renders sheep-feeding a process which, in part, also determines the quantity of that root that should be carried from the field in a given time.... The flock of ewes roaming at large over the pastures requires attention in winter, especially in frosty weather, or when snow is on the ground, when they should be supplied with hay, or turnips when the former is not abundant. The shepherd is the person who has charge of the sheep flock.... The large quantity of straw used in winter causes, as I have said, a considerable quantity of grain to be sent at that season to market. The preparation of grain for sale constitutes an important branch of winter farm-business, and should be strictly superintended. A considerable portion of the labor of horses and men is occupied in carrying the grain to the market-town, and delivering it to the purchasers-a species of work which jades farm-horses very much in bad weather. .... In hard frost, when the plow is laid to rest, or when the ground is covered with snow, and as soon as,

$$
\text { " } \text { A beaten path afford," }
$$

the farm-yard manure is carried from the courts, and deposited in a large heap, in a convenient spot near the gate of the field which is to be manured with it in the ensuing spring or summer. This work is carried on as long as there is manure to earry away, or the weather continues in either of those states..... Of the implements of husbandry, only a few are put in requisition in winter: the plow is in constant use when the weather will permit ; the threshing-machine enjoys no sinecure; and the cart finds periodic employment.

The weather in winter is of the most precarious description, and, being so, the farmer's skill to anticipate its changes in this season is severely put to the test. Seeing that all operations of the farm are so dependent on the weather, a familiar acquaintance with the local prognostics which indicate a change for the better or worse is incumbent on the farmer. In actual rain, snow, or hard frost, none but in-door occupations can be executed; but, if the farmer have wisely "discerned the face of the sky," he can arrange the order of these indoor operations, so as they may be continued for a length of time, if the storm threaten a protracted endurance, or be left without detriment, should the strife of the elements quickly cease.

The winter is the season for visiting the market town regularly, where the surplus produce of the farm is disposed of-articles purchased or bespoke for the use of the farm, when the busy seasons arive-where intermixture with the world affords the farmer an insight into the actions of mankind-and where selfishness and cupidity may be seen to act as a foil to highten the brilliancy of honest dealing.

Winter is to the farmer the season of domestic enjoyment. The fatigues of the long summer-day leave little leisure, and much less inclination, to tax the mind with study; but the long winter evening, after a day of bracing exercise, affords him a favorable opportunity, if he have the inclination at all, of partaking in social conversation, listening to instructive reading, or hearing the delights of music. In short, I know of no class of people 
more capable of enjoying a winter's evening in a rational manner, than the family of the country gentleman or the farmer.*

Viewing winter in a higher and more serious light-in the repose of nature, as emblematical of the mortality of man-in the exquisite pleasures which man in winter, as a being of sensation, enjoys over the lower creation-and in the eminence in which man, in the temperate regions, stands, with respect to the development of his mental faculties, above his fellow-creatures in the tropics : in these respects, winter must be hailed by the dweller in the country, as the purifier of the mental as well as of the physical atmosphere.

On this subject, I cannot refrain from copying these beautiful reflections by a modern writer, whose great and versatile talents, enabling him to write well on almost any subject, have long been known to me. "Winter," says he, "is the season of Nature's annual repose-the time when the working structures are reduced to the minimum of their extent, and the energies of growth and life to the minimum of their activity, and when the phenomena of nature are fewer, and address themselves less pleasingly to our senses than they do in any other of the three seasons. There is hope in the bud of Spring, pleasure in the bloom of Summer, and enjoyment in the fruit of Autumn; but, if we make our senses our chief resource, there is something both blank and gloomy in the aspect of Winter.

"And if we were of and for this world alone, there is no doubt that this would be the correct view of the winter, as compared with the other seasons; and the partial death of the year would point as a most mournful index to the death and final close of our existence. But we are beings otherwise destined and endowed-the world is to us only what the lodge is to the wayfaring man; and while we enjoy its rest, our thoughts can be directed back to the past part of our journey, and our hopes forward to its end, when we shall reach our proper home, and dwell there securely and forever. This is our sure consolation-the anchor of hope to our minds during all storms, whether they be of physical nature, or of social adversity.

"We are beings of sensation certainly ; many and exquisite are the pleasures which we are fitted for enjoying in this way, and much ought we to be grateful for their capacity of giving pleasure, and our capacity of receiving it; for this refined pleasure of the senses is special and peculiar to us out of all the countless variety of living creatures which tenant the earch around us. They eat, they drink, they sleep, they secure the succession of their race, and they die; but not one of them has a secondary pleasure of sense beyond the accomplishment of these very humble ends.t We

$L^{*}$ Especially if reared in a love of books, and the stady of the natural history of all around them.

Ed. Farm. Lib.]

[ + It strikes us as a gloomy and mistaken view to say that in the whole range and variety of creation, man should be the only being endowed with susceptibility to social pleasures. Who has not witnessed with admiration not merely the force of conjugal, parental and filial ties between animals and birds, but the social affections also-the sentiments of friendship ani hospitality, of jealousy. revenge, and of triumph! We may mention an instance under our own observation, of friendship a it hospitality displayed between two dogs. A lady residing in Baltimore petted a magnificent Newfoundland dog, Pelham, while her mother, residing at Annapolis, bestowed her friengship on a small terrier, whose name was Guess. 'A steamboat plied between the two cities, and Pelham often accompanied his mistress on her visits to her mother, and there formed an intimacy with Guess. When the boat was leaving for Baltimore. Guess was sure to accompany his mistress to see her friends off; and on one occasion was left on boald and carried to Baltimore, where he was landod among strangers, not knowing where to put his head. Pel(125) 
stand far higher in the mere gratifications of sense; and in the mental ones there is no comparison, as the other creatures have not an atom of the element to bring to the estimate.

"The winter is, therefore, the especial season of man-our oton season, by way of eminence; and men who have no winier in the year of the region in which they are placed, never of themselves display those traits of mental development which are the true characteristics of rational men, as contrasted with the irrational part of the living creation. It is true there must be the contrast of a summer, in order to give this winter its proper effect, but still, the winter is the intellectual season of the year-the season during which the intellectual and immortal spirit in man enables him most triumphantly to display his superiority over 'the beasts that perish.' "**

\section{OF THE STEADING OR FARMSTEAD.}

"When we see the figure of the house, then must we rate the cost of the erection."

Henry IV. Part II

(1.) BEFORE proceeding to the consideration of the state in which the pupil should find the various fields at the beginning of winter, it will tend to perspicuity in the furnishing of a farm to let him understand, in the first instance, the principles on which a steading, or onstead, or farmstead, or farm-offices, or farmery, as it has been variously styled, intended for a farm conducted on the mixed husbandry, should be constructed, and also to enumerate its constituent parts. This explanation being given, and got quit of at once, the names and uses of the various parts of a farmstead will at once become familiarized to him. And before beginning with the description of anything, I may here express it as my opinion that my descriptions of all the farm operations will be much more lucid and graphic if addressed personally to the pupil.

ham by chance met him in the street, was transported with joy at the sight of him. learned how by accident he had arrived, and soon persuaded him to go home with him, where he knew his mistress would kindly entertain him for her mother's if not for his own sake, until the boat should return. It was an instance of cordial hospitality such as towns' gentlemen are not alucays ready to reciprocate with their friends from the country.

No one, in fact, can be at a loss for examples to show that Providence has kindly blessed inferior beings with capacity for other than mere brutal enjoyments. The congregation of various birds is a remarkable indication of the spirit of sociality among the feathered tribe of creation; so animals herd logether under the same love of company. The strongest fences cannot confine some horses in a field alone. Cattle will not fatten in the finest pastures without society; nor is this propensity confined to animals of the same species. A charming naturalist says he knew a doe, then atill alive, that was brought up from a little fawn among dairy cows. With them it went afield, and with them it returned to the cow-yard. The dogs of the house took no notice of the deer, being used to her; but if strange dogs came by, a chase ensued, and while the master would look un and smile to see his favorite securely leading her pursuers over hedge, or gate, or stile, till she returned to the cows, they, with fierce lowings and menacing horns, would drive the assailants quite out of the pasture.

This complete degradation of all other created things, placing such a vast abyss between them and man, seems to detract from the benevolence of a common Father over all. Let us felicitate nurselves on the superiority of our physical structure and reasoning faculties, and the improvements and the power thence derived; but let us also remember in humility if not in shame, that of all animals, not one is more prone than man, to the wanton abuse of his strength.

* Mudie's Winter, Preface, p. 3-5.

Ed. Farm Lib.] 



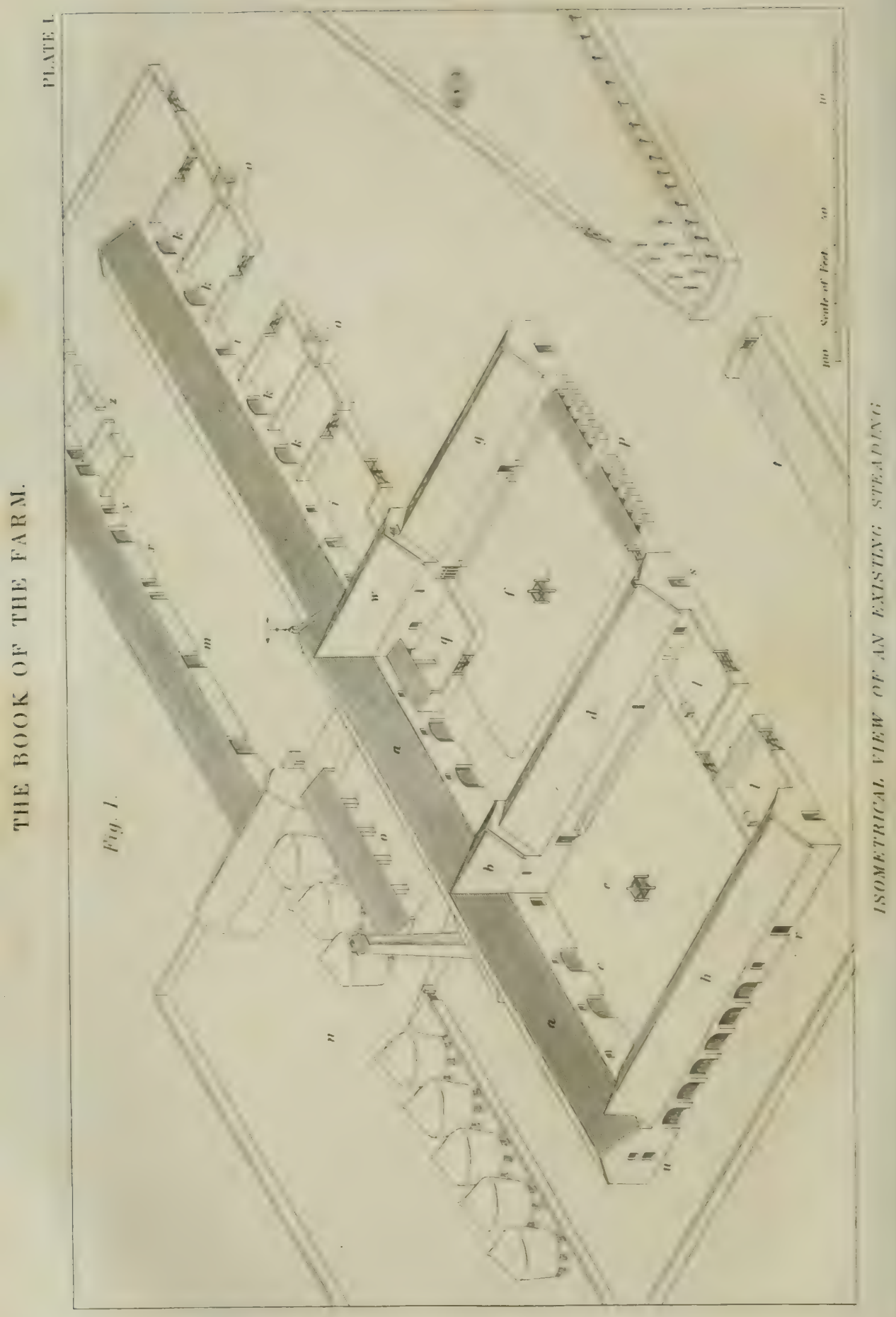


(2.) To present a description of a steading in the most specific terms, it will, in the first place, be necessary to assume a size which will afford accommndation for a farm of given extent. To give full scope to the mixed husbandry, I have already stated that a farm of 500 imperial acres is required. I will therefore assume the steading, about to be described, to be suited to a farm of that extent. At the same time you should bear in mind that the principles which determine the arrangement of this particular size, are equally applicable to much smaller, as well as much larger steadings; and that the mixed husbandry is frequently practiced on farms of much smaller extent.

(3.) It is a requisite condition to its proper use, that every steading be conveniently placed on the farm. To be most conveniently placed, in theory, it should stand in the center of the farm ; for it can be proved in geometry that of any point within the area of a circle, the center is the nearest to every point in its circumference. In practice, however, circumstances greatly modify this theoretical principle upon which the site of all steadings should be fixed. For instance, if an abundant supply of water can be easily obtained for the moving power of the threshing-machine, the steading may be placed, for the sake of thus economizing horse labor, in a more remote and hollow spot than it should be in other circumstances. If wind is preferred, as the moving power, then the steading will be more appropriately placed on rising ground. For the purpose of conveying the manure down hill to most of the fields, some would prefer the highest ground near the center of the farm for its site. Others, on the contrary, would prefer the hollowest point near the center, because the grain and green crops would then be carried down hill to the steading, and this they consider a superior situation to the other, inasmuch as the grain and green crops are much more bulky and heavy than the manure. In making either of these choices, it seems to be forgotten that loads have to be carried both to and from the steading; but either position will answer well enough, provided there be no steep ascent or descent to or from the steading. The latter situation, however, is more consonant to experience and reasoning than the other; though level ground affords the easiest transit to wheelcarriages. It is also very desirable that the farm-house should be so situated as to command a view of every field on the farm, in order that the farmer may have an opportunity of observing whether the labor is prosecuted steadily ; and if other circumstances permit, especially a plentiful supply of good water, the vicinity of the farm-house should be chosen as the site for the steading; but if a sacrifice of the position on the part of either is necessary, the farm-house must give way to the convenience of the steading.

(4.) As a farm of mixed husbandry comprises every variety of culture, so its steading should be constructed to afford accommodation for every variety of produce. The grain and its straw, being important and bulky articles, should be accommodated with room as well after as before they are separated by threshing. Room should also be provided for every kind of food for animals, such as hay and turnips. Of the animals themselves, the horses being constantly in hand at work, and receiving their food daily at regular intervals of time, should have a stable which will not only afford them lodging, but facilities for consuming their food. Similar accommodation is required for cows, the breeding portion of cattle. Young cattle, when small of size and of immature age, are usually reared in inclosed open spaces, called courts, having sheds for shelter and troughs for food and water. Those fattening for sale are cither put into smaller courts with troughs called hammels, or fastened to stakes in byres or feed- 
ing-houses, like the cows. Young horses are reared either by themselves in courts with sheds and mangers, or get leave to herd with the young cattle. Young pigs usually roam about everywhere, and generally lodge among the litter of the young cattle, while sows with sucking pigs are provided with small inclosures, fitted up with a littered apartment at one end, and troughs for food at another. The smaller implements of husbandry, when not in use, are put into a suitable apartment; while the carts are provided with a shed, into which some of the larger implements which are only occasionally used, are stored by. Wool is put into a cool, clean room. An apartment containing a furnace and boiler to heat water and prepare food when required for any of the animals, should never be wanting in any steading. These are the principal accommodations required in a steading where live-stock are cared for; and when all the apartmeuts are even conveniently arranged, the whole building will be found to cover a considerable space of ground.

(5.) The leading principle on which these arrangements is determined is very simple, and it is this: 1 . Straw being the bulkiest article on the farm, and in daily use by every kind of live-stock, and having to be carried and distributed in small quantities by bodily labor though a heary and unwieldy substance, should be centrically placed, in regard to all the stock, and at a short distance from their respective apartments. The position of its receptacle, the straw-barn, should thus occupy a central point of the steading; and the several apartments containing the live-stock should be placed equidistant from the straw-barn, to save labor in the carrying of straw to the stock. 2. Again, applying the principle, that so bulky and heavy an article as straw should in all circumstances be moved to short distances, and not at all, if possible, from any other apartment but the straw-barn, the threshing-machine, which deprives the straw of its grain, should be so placed as at once to throw the straw into the strawbarn. 3. And, in farther application of the same principle, the stack-yard containing the unthreshed straw with its corn, should be placed contiguous to the threshing-machine. 4. Lastly, the passage of straw from the stack-yard to the straw-barn through the threshing-machine being directly progressive, it is not an immaterial consideration in the saving of time to place the stack-yard, threshing-mill, and straw-barn in a right line.

(6.) Different classes of stock require different quantities of straw, to maintain them in the same degree of cleanliness and condition. Those classes which require the most should therefore be placed nearest the strawbarn. 1. The younger stock requiring most straw, the courts which they occupy should be placed contiguous to the straw-barn, and this can be most effectually done by placing the straw-barn so as a court may be put on each side of it. 2. The ulder or fattening cattle requiring the next largest quantity of straw, the hammels which they occupy should be placed next to these courts in nearness to the straw-harn. 3. Horses in the stables, and cows in the byres, requiring the smallest quantity of straw, the stables and byres may be placed next farthest in distance to the hammels from the straw-barn. The relative positions of these apartments are thus determined by the comparative use of the straw. 4. There are two apartments of the steading whose positions are necessarily determined by that of the threshing-machine; the one is the upper-luan, or threshingbarn, which contains the unthreshed corn from the stack-yard, ready for threshing by the mill; and the other the corn-barn, which is below the mill, and receives the corn immediately after its separation from the straw by the mill to be cleaned for market. 5. It is a great convenience to have the granaries in direct communication with the corn-barn, to save (12:8) 
the labor of carrying the clean corn to a distance when laid up for future use. To confine the space occupied by the steading on the ground as much as practicable for utility, and at the same time insure the good condition of the grain, and especially this latter advantage, the granaries should always be elevated above the ground, and their floors then form convenient roofs for either cattle or cart-sheds. 6. The elevation which the granaries give to the building should be taken advantage of to shelter the cattle-courts from the north wind in winter; and for the same reason that shelter is cherished for warmth to the cattle, all the cattle-courts should always be open to the sun. The courts being thus open to the south, and the granaries forming a screen from the north, it follows that the granaries should stretch east and west on the north side of the courts; and, as has been shown, that the cattle-courts should be placed one on each side of the straw-barn, it also follows that the straw-barn, to be out of the way of screening the sun from the courts, should stand north and south, or at right angles to the south of the granaries. 7. The fixing of the strawbarn to the southward of the granaries, and of course to that of the threshing-machine, necessarily fixes the position of the stack-yard to the north of both. Its northern position is highly favorable to the preservation of the corn in the stacks. 8. The relative positions of these apartments are very differently arranged from this in many existing steadings; but I may safely assert, that the greater the deviation from the principle inculcated in paragraphs (5) and (6) in the construction of steadings, the less desirable they become as habitations for live-stock in winter.

(7.) This leading principle of the construction of a steading which is intended to afford shelter to live-stock during winter, is as comprehensive as it is simple, for it is applicable to every size of steading. Obviously correct as the principle is, it is seldom reduced to practice, possibly because architects, who profess to supply plans of steadings, must be generally unacquainted with their practical use. There is one consideration upon which architects bestow by far too much attention-the constructing of steadings at the least possible cost; and, to attain this object by the easiest method, they endeavor to confine the various apartments in the least possible space of ground, as if a few square yards of the ground of a farm were of great value. No doubt, the necessity of economy is urged upon them by the grudging spirit of the landlord when he has to disburse the cost, and by the poverty of the tenant when that burden is thrown upon him. Now, economy of construction should be a secondary consideration in comparison with the proper accommodation which should be afforded to live-stock. Suppose that, by inadequate accommodation, cattle thrive by $10 \mathrm{~s}$. a-head less in the course of a winter than they would have done in well constructed courts and hammels (and the supposition is by no means extravagant),

- and suppose that the farmer is prevented realizing this sum on three lots of $t$ wenty cattle each of different ages, there would be an annual loss to him of $£ 30$, from want of proper accommodation. Had the capital sum, of which the annual loss of $£ 30$ is the yearly interest, been expended in constructing the steading in the best manner, the loss would not only have been averted, but the cattle in much better health and condition to slaughter, or to fatten on grass. Economy is an excellent rule to follow in farming, but it should never be put in practice to the violation of approved principles, or the creation of inconveniences to live-stock, whether in the steading or out of it. I regret to observe both errors too prevalent in the construction of steadings. For example: It is undeniable that as cattle occupy the courts only in winter, when the air, even in the best situations, is at a low temperature, and the day short, they should in such circum(129)......6 
stances enjoy as much light and heat from the sun as can be obtained. It is quite practicable to afford them both in courts facing fully to the south, where these influences may be both seen and felt even in winter. Instead of that, cattle-courts are very frequently placed within a quadrangle of buildings, the southern range of which, in the first instance, eclipses the winter's sun of eren his diminished influence; and the whole of which, besides, converts the chilling air, which rushes over the corners of its roof into the courts, into a whirlwind of starvation, which, if accompanied with rain or sleet, is sure to engender the most insidious diseases in the cattle. Beware, then, of suffering loss by similar fatal consequences to your cattle; and, to prompt you to be always on your guard, impress the above simple principle of the construction of steadings firmly upon your minds. Rest assured that its violation may prove in the end a much greater loss by preventing the cattle thriving, than the paltry sure saved at first in the outlay of the buildings can possibly ever recompense you for that loss.

(8.) Fig. 1, Plate 1. gives an isometrical view of an existing steading suitable for the mixed husbandry, somewhat though not on the precise principles which I have inculcated just now, but rather on the usual plan of huddling together the various parts of a steading, with a view of saving some of its original cost.* There are many steadings of this construction tn be found in the country, but many more in which stalls for feeding cattle are substituted for hammels. The north range $a$ a represents the granaries with their windows, $b$ the upper harn, $c c$ the arches into the sheds for cattle under the granaries. The projecting building $d$ in the middle is the straw-barn, which communicates by a door in each side with the court $e$ or $f$ for the younger cattle. The projecting building $g$, standing parallel with the straw-barn on the right hard side of the court $f$, is the stahle for the work-horses; and the other projecting building $h$, also parallel with the straw-barn on the left-hand side of the court $e$, is the cart-shed. The cow-byres $i$, and hammels $k$ for feeding cattle, are seen stretching to the right in a line with the north range $a$, but too far off from the straw-barn $d: l$ are hammels for a bull and queys: $m$, sheds for shepherds' stores: $n$, stack-yard with stacks : $o$, turnip stores : $p$, piggeries : $q$, calves' court : $r$, implement-house: $s$, boiling-house : $t$, horse-pond : $u$, hen-house : $v$. liquid manure tank: $w$, hay-loft : $x$, out-houses: $y$, slaughter-house : and $z$, hammels for young horses. This is a common disposition of the prin-

[* The reader will, probably, find nothing in "THE Bоoк of THE FARM" which, at first view, may seem more obnoxious than this to the appearance of being on a scale of accommodation and expense unsuired to American farmers and American husbaudry. And yet, when he comes to examine the observations of the Author in all their details, they will be found to be replete with practical instruction and directions, which may be beeded with profit in the construction and arrangement of all huildings, on whatever scale, designed for the shelter of domestic animals, the care and distribution of their food, and the preservation of farm vchicles and implements-such buildings as in England are termed the "steading or farmstead."

Some there may be, and doubtless are - such as wealthy merchants on retiring from the cares and vicissitudes of commerce-who unite the means with the desire to have their farmstead as inmplete as the best architectural design and materials can make it. To all such the plans here presented may eerve as models, while they. and others with less means at command, may so modify them as to suit all difference of circumstances-avoiding snme portions, and yet seeing much in parts of them that is eligible and in accordance with their own views and means.

But, without desiring to prejudice the judgment of the reader, we may ask him at least to ad. mit, in the costliness of the illustrations connected with this part of the Book of the Farm, some evidence that the Publishers desire not to shnn any outlay that may be necessary to make the Farucrs' Library worthy of public patronage, and fitted to fulfill their own promiser. 

cipal parts of a modern improved steading; and a slight inspection of the plate will convince you that in the arrangement of its different apartments is exhibited much of the principle which I have been advocating. Many modifications of this particular arrangement may be observed in actual practice:-1. such as the removal of the straw-barn $d$ into the north range $a$, and the placing of hammels, such as $k$, into the courts $e$ and $f$, and the conversion of one of the sheds $c$ into cart-sheds. 2. Another modification encloses a large court divided into two, within a range of buildings forming three sides of a quadrangle, and retaining the north range for the granaries, of a higher altitude than the rest. 3. While another comprises two large courts, each surrounded by three sides of a quadrangle, the range in the middle occupied by the threshing-mill and straw-barn being retained at a higher altitude than the rest. 4. Another completes the quadrangle around one court. 5. While another surrounds a large court, divided into two, with a quadrangle. 6. And the last modification surrounds two separate courts, each with a quadrangle, having a common side. These modifications are made to suit either large or small farms; but they all profess to follow the same plan of arrangement. In truth, however, so varied is the construction of steadings, that, I dare say, no two in the country are exactly alike. Modifications in their construction in obedience to influential circumstances may be justifiable, but still they should all have reference to the principle insisted on above.

(9.) Fig. 2, Plate II. contains an engraving of a ground-plan of the steading represented by the isometrical view in Plate I. It is unnecessary for me to describe in detail all the component parts of this plan, as the names and sizes of the various apartments are all set down. A short inspection will suffice to make you well enough acquainted with the whole arrangement. This plan has been found, by extensive use, to constitute a commodious, convenient, and comfortable steading for the stock and crop of 500 acres, raised by the mixed husbandry; and those properties it possesses in a superior degree to most similar existing steadings of the same extent in this country, and in a much greater degree than any of the modified plans to which I have just alluded.

(10.) The steading I would desire to see erected would be exactly in accordance with the principle I have laid down. I do not know one, nor is there probably in existence one exactly on that principle, but I have seen several, particularly in the north of England, which have impressed me with the belief that there is a construction, could it be but discovered, which would afford the most excellent accommodation, the greatest convenience, and the utmost degree of comfort to live-stock; and live-stnck being the principal inhabitants of steadings, too much care, in every respect, cannot, in my opinion, be bestowed on the construction of their habitations, so as to insure them in the inclement season the greatest degree of comfort. I shall describe both an isometrical view and ground-plan of a steading of imaginary construction, in strict accordance with the above principle-the principle itself having been brought out by the promptings of experience. I shall minutely describe these plans, in the sanguine hope that the obvious advantages which they exhibit will recommend their construction for adoption to all proprietors and tenants who feel desirous of obtaining a plan of a steading for crop and stock, the arrangements of which have been suggested by matured practical experience. The size of these particular plans is not suited to any farm, whereon the mixed husbandry is practiced, of less extent than 500 acres; because, in order to illustrate their principle, it was necessary to fix on some definite size, that the relative sizes and positions of the different apartments might be defini- 
tively set down; but the whole arrangement of the apartments is suited to any size of plan, as the size and number of the apartments may be enlarged or diminished according to the extent of the farm.

(11.) Fig. 3, Plate III. represents an isometrical vievo of such a steading, and keeping the principle upon which it is constructed in mind, you will find that this view illustrates it in every respect that has been stated. 1. A $\mathrm{A}$ is the principal or north range of building, of two stories in hight, standing east and west. It contains two granaries, $\mathrm{A}$ and $\mathrm{A}$, the upperbarn $\mathrm{C}$, which is also the site of the threshing-machine; the corn-barn being immediately below it is of course invisible, the sheds D D are under the granaries; $\mathbf{E}$ is the engine-house, and $\mathrm{F}$ the steam-engine furnacestalk, where the power employed to impel the threshing-machine is steam, $\mathrm{G}$ the implement-house entering from the west gable, and $H$ the hayhouse, under a granary. These several apartments, while occupying the north range, are greatly serviceable in sheltering the young stock in the large courts $I$ and $K$ from the north wind. 2. Immediately adjoining to the south of the corn-barn, upper-barn, and threshing-machine, is the straw-barn L, standing north and soutb, contiguously placed for the emission of straw from either side into the courts $\mathbf{I}$ and $\mathbf{K}$. 3 . It is also conveniently situated for supplying straw to the feeding hammels $\mathrm{M}$, to the right or eastward of the large court $K$, and equally so for supplying it to those at $\mathrm{N}$, to the left or westward of the large court $I .4$. It is accessibly enough placed for supplying straw to the work-horse stable $\mathrm{O}$, and the saddle-horse stable $P$, to the right or eastward in a line of the principal range $A$. It is equally accessible to the cow-byre $Q$, and calves'-cribs $R$, to the left or westward, in a line of the principal range $A$. S is the stackyard, from which the stacks are taken into the upper-barn C, by the gangway $T$; $\mathrm{C}^{*}$ is the boiling-house; $V$ the cart-shed, opposite and near the work-house stable $\mathrm{O}$; $\mathrm{W}$ is the wool-room, having a window in the gable, and its stair is from the straw-barn $\mathrm{L} ; \mathrm{XX}$ comprise two small hammels for bulls; $\mathrm{Y}$ is the servants' cow-house, in the hammels $\mathrm{N}$; $\mathrm{Z}$ is the gighouse, adjoining to the riding-horse stable P. $a$ are four sties for feeding pigs therein; $b$ is a small open court, with a shed for containing young pigs after they have just been weaned; $c$ are two sties for brood-sows while lying-in. $d$ are three apartments for the hatching and rearing of fowls. $e$ and $f$ are turnip-stores for supplying the hammels $M ; g$ is the turnip-store for supplying the large court $\mathrm{K} ; h$, that for small hammels $\mathbf{X}$, and the servants' cow-house $\mathbf{Y}$; $i$, that for the large court $\mathrm{I}$; and $p$ and $q$ are those for the hammels $\mathbf{N} . \quad k$ is the open court and shed, with water-trough for the calves; l the open court, with water-trough for the cows. $m$ is the turnip-shed for the cow-house $\mathrm{Q}$, and calves'-cribs $\mathrm{R}$. $n$ is the hay-stack built in the stackyard $\mathrm{S}$, near the hay-house $\mathrm{H}$. $o$ and $o$ are straw-racks for the center of the large courts $I$ and $K . \quad u$ is the rentilator on the roof of the hoiling-house $U ; r$ that on the cow-house $Q$; $s$, that on the calves'-cribs $\mathrm{R} ; t$ and $u$, those on the roof of the work-horse stable $\mathrm{O}$; and $y$, that on the riding-horse stable $\mathrm{P} . \quad x$ is the liquid manurewell to which drains converge from the various parts of the farmstead. $\boldsymbol{z}$ are feeding-troughs, dispersed in the different courts and hammels. $v$ is the open court for the servants' cows. And $f^{\prime}$ and $f^{\prime}$ are potato stores.

(12.) A very little consideration of the arrangement just now detailed, will suffice to show you that it completely illustrates the principle I have been advocating for the construction of farmsteads. Still, looking at the isometrical view, in fig. 3 , Plate III., it will be observed that the threshingmachine $\mathrm{C}$-the machinery for letting loose the straw-is situated in the middle of the groat range $\mathrm{A}$, ready to receive the unthreshed crop behind (132) 
from the stack-yard $\mathrm{S}$, and as ready to deliver the straw threshed into the straw-barn L standing before it. The store of straw in L, being placed exactly in the center of the premises, is easily made available to the large courts $I$ and $K$ and the sheds $D$ and $D$ by its four doors, two on each side. The straw can be carried down the road on the right of the straw-barn $\mathbf{L}$, to the hammels $\mathbf{M}$; and along the farther end of the court $\mathbf{K}$, through the gate at $\mathrm{H}$ to both the stables $\mathrm{O}$ and $\mathrm{P}$. It can with as much facility be carried across the eastern angle of the large court I, through the gate at the bull's hammels $\mathrm{X}$, to the range of hammels at $\mathrm{N}$, and to the servants' cow-house $\mathrm{Y}$, by its door near the turnip-store $h$. It can also be carried right across the same court $I$, through the gate behind $Y$ to the cow-house $\mathrm{Q}$, and the calves'-cribs $\mathrm{R}$. The hammels $\mathrm{X}$, the pigs in $a b$ and $c$, and the fowls in $d$, can easily be supplied with straw. You may observe in the arrangement of these apartments, that the stables $\mathrm{O}$ and $\mathrm{P}$, and the cow-house $Q$, and the calves'-cribs $R$, are situated behind the hammels $\mathrm{M}$ and $\mathrm{N}$, and they are there for these reasons: Hammels for feeding cattle requiring much more straw than stables and byres, according to the foregoing theory, should be placed near the straw-barn; and hammels, moreover, being only occupied in winter by stock, should derive, during that season, the fullest advantage that can be given them of the light and heat of the sun. The servants' cow-byre $Y$ heing placed nearer the straw-barn than the hammels $\mathrm{N}$, may seem to contravene the principle laid down; but the cow-byre, if desired, may be remnved to the other end of the hammels, though in the case where young horses and queys in calf are intended to occupy the small hammels $\mathrm{N}$, it may conveniently remain where it is, as they do not require so much straw as cows. If these hammels are to be destined to the accommodation of feeding stock, then the byre ought to be removed to the extreme left of the building. This form of steading is amply commodious, for it can accommodate all the working and breeding stock, together with four generations of young stock in different stages of growth. A more convenient arrangement than this for a farmstead, as I conceive, can scarcely be imagined, and all the parts of it are of such a magnitude as not only to afford ample room for every thing accommodated within it, but with proper fittings up, the arrangement is capable of conferring great comfort on its inmates. Its commodiousness will be the more apparent after the ground-plan has been considered in detail.

(13.) Fig. 4, Plate IV. is the ground-plan of the steading, of which the preceding plate that has just been described is the isometrical view. The straw-barn $\mathrm{L}$ is seen at once, running north and south. It is purposely made of the hight of the upper barn to contain a large quantity of straw, as it is often convenient in bad weather to thresh out a considerable quantity of corn, when no other work can be proceeded with, or when high market prices induce farmers to reap advantage from them. There is another good reason for giving ample room to the straw-barn. Every sort of straw is not suited to every purpose, one sort being best suited for litter, and another for fodder. This being the case, it is desirable to have always both kinds in the barn, that the fodder-straw may not be wasted in litter, and the litter-straw given as fodder to the injury of the bestial. Besides, the same sort of straw is not alike acceptable as fodder to every class of animals. Thus wheat-straw is a favorite fodder with horses, as well as oat-straw, while the latter only is acceptable to cattle. Barleystraw is only fit for litter. To give access to litter and fodder straw at the same time, it is necessary to have a door from each kind into each court. Thus four doors, two at each side near the ends, are required in a large (133) 
straw-barn. Slit-like openings should be made in its side-walls, to admit air and promote ventilation through the straw. A sky-light in the roof at the end nearest the threshing-machine, is useful in giving light to those who take away and store up the straw from the threshing-machine when the doors are shut, which they should be whenever the wind happens to blow too strongly through them into the machine against the straw. Instead of dividing straw-barn doors into two vertical leaves, as is usually done, they should be divided horizontally into an upper and a lower leaf, so that the lower may always be kept shut against intruders, such as pigs, while the upper admits both light and air into the barn. One of the doors at each end should be furnished with a good stock-lock and key and thumblatch, and the other two fastened with a wooden hand-bar from the inside. The floor of the straw-barn is seldom or never flagged or causewayed, though it is desirable it should be. If it were not so expensive, the asphaltum pavement would make an excellent floor for a straw-barn. Whatever substance is employed for the purpose, the floor should be made so firm and dry as to prevent the eartl rising and the straw moulding. Mouldy straw at the bottom of a heap superinduces throughout the upper mass a disagreeable odor, and imparts a taste repugnant to every animal. That portion of the floor upon which the straw first alights on sliding down the straw-screen of the threshing-machine, should be strongly boarded to resist the action of the forks when removing the straw. Blocks of hard-wood, such as the stools of hard-wood trees, set on end, causewaywise, and sunk into the earth, form a very durable flooring for this purpose. Stone flagging in this place destroys the prongs of the pitchforks. The straw-barn should communicate with the chaff-house by a shutting door, to enable those who take away the straw to see whether the chaff accumulates too high against the end of the winnowing-machine. The communicacation to the wool-room in this plan is by the straw-barn, by means of the stair $c^{\prime}$, made either of wood or stone. The straw-barn is represented 72 feet in length, 18 feet in breadth, and 15 feet in hight to the top of the side walls.

(14.) $\mathrm{C}$ is the corn-barn. Its roof is formed of the floor of the upper barn, and its hight is generally made too low. The higher the roof is the more easily will the corn descend to be cleaned from the threshing-machine down the hopper to the winnowing-machine. Nine feet is the least hight it should be in any instance. The plan gives the size of the corn-barn as 31 feet by 18 feet, but taking off 5 feet for partitioning off the machinery of the threshing-mill, as at $s$, the extent of the workable part of the barnfloor will be 26 feet by 18 feet. In that space I have seen much barnwork done, but it could be made more by diminishing the size of the shed $D$ of the court $K$. The corn-barn should have in it at least two glazed windows to admit plenty of light in the short days of winter, and they should be guarded outside with iron stanchions. If one window cannot be got to the south, the door when open will answer for the admission of sunshine to keep the apartment comfortably dry for the work-people and the grain. The door is generally divided into upper and lower halves, which, as usually placed, are always in the way when the winnowingmaahine is used at the door. A more convenient method is to have the door in a whole piece, and when opened, to fold back into a recess in the outer wall, over the top of which a plinth might project to throw off the rain. In this case the ribets and lintel must be giblet-checked as deep as the thickness of the door, into which it should close flush, and be fastened with a good lock and key, and provided with a thumb-latch. The object of making the corn-barn door of this form is to avoid the inconvenience of its opening into the barn, where, unless it folds wholly back on a wall, is (134) 
frequently in the way of work, particularly when winnowing roughs, and taking out sacks of corn on men's backs. As to size, it should not be less in the opening than $7 \frac{1}{2}$ feet in hight and $3 \frac{1}{2}$ feet in width. A light half-door can be hooked on, when work is going on, to prevent the intrusion of animals, and the wind sweeping along the floor. The floor of the corn-barn is frequently made of clay, or of a composition of ashes and lime; the asphaltic composition would be better than either; but in every instance it should be made of wood-of sound, hard red-wood Drahm battens, plowed and feathered, and fastened down to stout joists with Scotch flooring sprigs driven through the feather-edge. A wooden floor is the only one that can be depended on being constantly dry in a corn-barn; and in a barn for the use of corn, a dry floor is indispensable. It has been suggested to me that a stone pavement, square-jointed, and laid on a bed of lime over 9 inches of broken stones; or an asphaltum pavement, laid on a body of 6 inches of broken stones, covered with a bed of grout on the top of the stones, would make as dry and more durable barn-fioor than wood, and which will not rot. I am aware that stone or asphaltum pavement is durable, and not liable to rot; but there are objections to both, in a corn-barn, of a practical nature, and it is certain that the best stone pavement is not proof against the undermining powers of the brown rat; while a wooden floor is durable enough, and certainly will not rot, if kept dry in the manner I shall recommend over the page. The objections to all stony pavements as a barn-floor are, that the scoops for shoveling the corn pass very harshly over them-that the iron nails in the shoes of the work-people wear them down, and raise a dust upon them-and that they are hurtful to the bare hands and lighter implements, when used in taking up the corn from the floor. For true comfort in all these respects in a barn-floor, there is nothing like wood. The walls of this barn should be made smooth with hair-plaster, and the joists and flooring forming its roof cleaned with the plane, as dust adheres much more readily to a rough than to a smooth surface. The stairs to the granaries $s$ and $s$ should enter from the corn-barn, and a stout plain-deal door with lock and key placed at the bottom of each. And at the side of one of the stairs may be inclosed on the floor of the barn a space, $t$, to contain light corn to be given to the fowls and pigs in summer when this sort of food is scarce about the steading.

(15.) As the method of hanging doors on a giblet-check should be adopted in all cases in steadings where doors on outside walls are likely to meet with obstructions on opening inward, or themselves becoming obstructive to things passing outward, the subject deserves a separate notice. In fig. 5, $a$ is a strong door, mounted on crooks and bands, fully open, and thrown back into the recess of the wall $b$; the projecting part of the lintel $c$ protecting it effectually from the rain ; $d$ is the gibletcheck in the lintel, and $e$ that in the ribets, into which the door shuts flush; $f$ is the light Fig. 5.

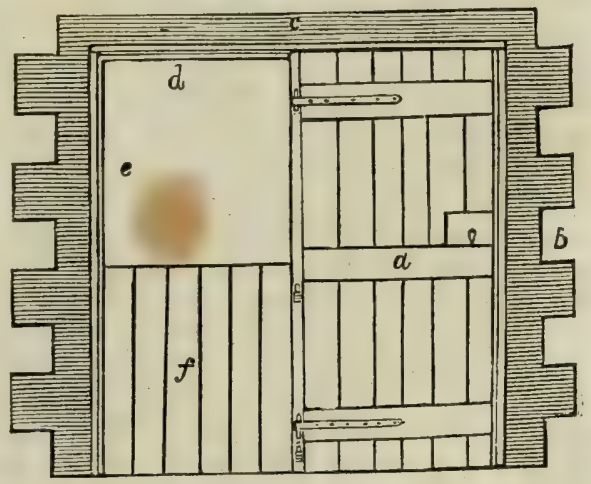

THE CORN-BARN DOOR.

movable door used when work is going on in the corn-barn.

(135) 
(16.) The wooden floor of the corn-barn is liable to decay unless precautions are used to prevent it, but a much too common cause of its destruction is vermin - such as rats and mice. It is discreditable to farmers to permit this floor to remain in a state of decay for any length of time, when an effectual preventive remedy is within their reach; and the more certainly preventive that remedy is, the more it should be appreciated. I used a most effectual method of preventing the destructive ravages of either vermin or damp, by supporting the floor in the particular manner represented in fig. 6. The earth, in the first instance, is dug out of the barn to the depth of the foundations of the walls, which should be two feet below the door soles; and, in the case of a new steading, this can be done when the foundations of the walls are taken out. The ground is then spread over with

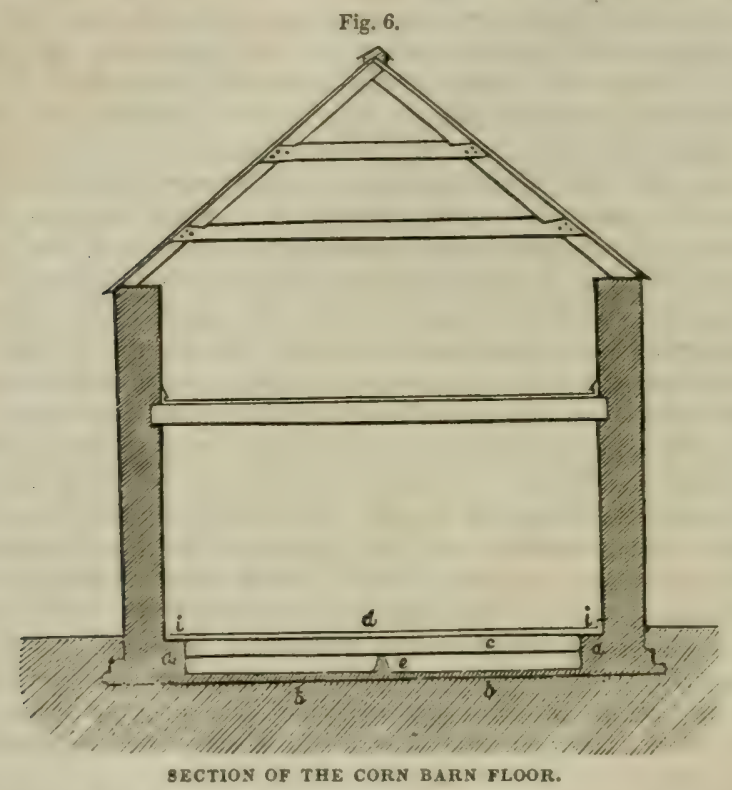

a layt $;$ of sand, sufficient to preserve steadiness in the stout rough flags $b b$, which are laid upon it and jointed in strong mortar. Twelve-inch thick sleeper walls $a a$, of stone and lime, are then built on the flags, to serve the purpose of supporting each end of the joists of the floor. The joists $c$, formed of 10 by $2 \frac{1}{2}$ inch plank, are then laid down 16 inches apart, and the spaces between them filled up to the top with stone and lime. The building between the joists requires to be done in a peculiar way. It should be done with squared rubble stones, and on no account should the mortar come in contact with the joists, as there is nothing destroys timber, by superinducing the dry rot, more readily than the action of mortar upon it.For this reason great care should be observed in building in the joists into the walls-in placing the safe-lintels over the doors and windows, the stones being dry-bedded over them-and in beam-filling between the couple-legs. The floor $d$ is then properly laid on a level with the doorsole, and finished with a neat skifting board $i i$ round the walls of the barn. By this contrivance the vermin cannot possibly reach the floor but from the flags, which are nearly 2 feet under it. A hewn stone pillar $e$, or even two, are placed on the flags under each joist to support and strengthen the (136) 
floor. This construction of floor admits of abundance of air above and below to preserve it, and affords plenty of room under it for cats and dogs to hunt after the vermin. This figure also gives a section of the building above the corn-barn, including the floor of the upper barn, the outside walls, and the coupling, slating, and ridging of the roof of the middle range of building.

(17.) The chaff-kouse, $r$, stands between the corn and straw barns. It is separated from the former by a wooden partition, and from the latter by a stone-wall. Its hight is the same as that of the corn-barn, the floor of the upper barn forming a roof common to both. It is 18 feet in length and 14 feet in width. It contains the winnowing-machine or famers of the threshing-machine, from which it receives the chaff. It has a thin door with a thumb-latch into the straw-barn, for a convenient access to adjust any of the gearing of the fanners; as also a boarded window hung on crooks and bands, fastened in the inside with a wooden hand-bar, and looking into the large court K ; but its principal door, through which the chaff is emptied, opens outward into the large court I. This door should be giblet-checked, and fastened from the inside with a wooden hand-bar. The space between the head of the fanners and the wall should be so boarded up as not to interfere with the action of the fanner-belts, but merely prevent the chaff being scattered among the machinery, and any access by persons being effected by the machinery into the upper barn.

(18.) D D are two sheds for sheltering the cattle occupying the courts I and $K$ from rain and cold, by night or day, when they may choose to take refuge in them. The shed of the court $I$ is 52 feet in length by 18 feet in width, being a little longer than that of the court $K$, which is 47 feet in length and 18 feet in width, and their hight is 9 feet to the floor of the granaries, which forms their roof. The access to these sheds from the courts is by arched openings of 9 feet in width, and $7 \frac{1}{2}$ feet in hight to the top of the arch. There should be a rack fastened against one of the walls of each shed to supply fodder to the cattle under shelter in bad weather, as at $h^{\prime}$. As when a large number of cattle are confined together, of whatever age, some will endeavor to obtain the mastery over the others, and to prevent accidents in cases of actual collision, it has been recommended to have two openings to each shed, to afford a ready means of egress to the fugitives; and, as a farther safety to the bones and skins of the unhappy victims, the angles of the hewn pillars which support the arches should be chamfered. In my opinion, the precaution of two openings for the reason given is unnecessary, inasmuch as cattle, and especially those which have been brought up together, soon become familiarized to each other; and two openings cause draughts of air through the shed. If holes were made in the faces of the pillars opposite to each other in the openings, so as bars of wood could be put across them, the cattle could at any time be kept confined within the sheds. This might at times be necessary, especially when the courts are clearing out of the manure. The shed of the court $K$ has a door $d^{\prime}$ in the back wall for a passage to the work-people when going from the corn to the upper barn, by the gangway $T$.

(13.) $\mathbf{E}$ is the engine-house for the steam-engine, when one is used. It is 18 feet in length and 8 feet in width, and the granary-floor above forms its roof. It has a window looking into the large court I, and a door into the boiler and furnace-house $\mathrm{F}$, which house is 24 feet in length and 8 feet in width, and has an arched opening at the left or west end. The chimney-stalk is 6 feet square at the base, and rises tapering to a hight of 45 feet. If wind or horses are preferred as the moving power, the windmilltower or horse-course would be erected on the site of F.

(137) 
(20.) $\mathrm{G}$ is the implement-liouse for keeping together the smaller implements when not in use, when they are apt to be thrown aside and lost.The intrinsic value of each implement being small, there is too generally less care bestowed on them than on those of more pecuniary value; but in use each of them is really as valuable as the most costly, and even their cost in the aggregate is considerable. The implement-house is 18 feet in length by 14 feet in width, and its roof is formed of the granary-floor.This house should be provided with a stout plain-deal door with a good lock and key, the care of which should only be entrusted to the farm-steward. It should also have a partly glazed window like that of the cowhouse, as sometimes this apartment may be converted into a convenient work-shop for particular purposes. The floor should be flagged, or laid with asphaltum pavement. Besides the implements, this apartment may contain the barrel of tar, a useful ingredient on farms where sheep are reared, and where cart-naves require greasing ; the grindstone, a convenient instrument on a farm on many occasions for sharpening edge-tools, such as scythes, axes, hay-knife, dung-spade, \&c. A number of wooden pins and iron spikes, driven into the walls, will be found useful for suspending many of the smaller articles upon. The walls should be plastered.

(21.) $H$ is the hay-house at the east end of the north range $A$, and corresponding in situation to the implement-house. It is 18 feet in length, 17 feet in width, and its roof is also formed of the floor of the granary above. Its floor should be flagged with a considerable quantity of sand to keep it dry, or with asphaltum. It should have a giblet-checked door to open outward, with a hand-bar to fasten it by in the inside; it should also have a partly glazed window, with shutters, to afford light when taking out the hay to the horses, and air to keep it sweet. As the hay-house communicates immediately with the work-horse stable $\mathrm{O}$ by a door, it can find room for the work-horse corn-chest $y$, which may be there conveniently supplied with corn from the granary above by means of a spout let into the fixed part of the lid. For facilitating the taking out of the corn, the end of the chest should be placed against the wall at the side of the door which opens into the stable, and its back part should be boarded up with thin deals to the granary-floor, to prevent the hay coming upon the chest. Its walls should be plastered. This hay-house is conveniently situated for the haystack $n$ in the stack-yard $\mathrm{S}$.

(22.) The form of the corn-chest, $y$, is more convenient and takes up less room on the floor, when high and narrow, than when low and broad.When of a high form, a part of the front should fold down with hinges, to give easier access to the corn as it gets low in the chest. Part of the lid should be made fast, to receive the corn-spout from the granary, and to lighten its movable part, which should be fastened with a hasp and padlock, and the key of which should be constantly in the custody of the farmsteward, or of the man who gives out the corn to the plowmen, where no farm-steward is kept. A fourth part of a peck-measure is always kept in the chest, for measuring out the corn to the horses. You must not imagine that, because the spout supplies corn from the granary when required, it supplies it without measure. The corn appropriated for the horses is previously measured off on the granary-floor, in any convenient quantity, and then shoveled down the spout at times to fill the chest; besides, lines can be marked on the inside of the chest indicative of every quarter of corn which it can contain.

(23.) $\mathrm{O}$ is the stable for the work-horses. Its length, of course, depends on the number of horses employed on the farm; but in no instance should its width be less than 18 feet, for comfort to the horses themselves, and con- 
venience to the men who take charge of them. This plan, being intended for a definite size of farm, contains stalls for 12 horses, and a loose box besides-the whole length being 84 feet. Few stables for work-horses are made wider than 16 feet, and hence few are otherwise than hampered for want of room. A glance at the particulars which should be accommodated in the width of a work-horse stable will show you at once the inconvenience of this narrow breadth. The entire length of a work-horse is seldom less than 8 feet; the extreme width of the hay-rack is about 2 feet; the harness, hanging loosely against the wall, occupies about 2 feet; and the gutter occupies 1 foot: so that in a width of 16 feet there are only 3 feet left from the heels of the horses to the harness, on which to pass backward and forward to wheel a barrow and use the shovel and broom. No wonder, when so little space is left to work in, that cleanliness is so much neglected in farm-stables, and that much of the dung and urine are left to be decomposed and dissipated by heat in the shape of ammoniacal gas, to the probable injury of the breathing and eye-sight of the horses, when shut up at night. And, what aggravates the evil, there seldom is a ventilator in the roof; and, what is still worse, the contents of the stable are much contracted by the placing of a hay-loft immediately above the horses' heads.Whatever may be the condition of a work-horse stable in reference to size and room, its walls should always be plastered with good haired plaster, as forming the most comfortable finishing, and being that most easily kept clean..... Some people imagine that twelve horses are too great a number to be in one stable, and that two stables of six stalls each would be better. Provided the stable is properly ventilated, there can no injury accrue to a larger than to a smaller number of horses in a stable; and, besides, there are practical inconveniences in having two work-horse stables on a farm. The inconveniences are that neither the farmer nor farm-steward can personally superintend the grooming of horses in two stables; that the orders given to the plowmen by the steward must be repeated in both stables; and that either all the plowmen must be collected in one of the stables to receive their orders, or, part of them not hearing the orders given to the rest, there cannot be that common understanding as to the work to be done which should exist among all classes of work-people on a farm.

(24.) Another particular in which most work-horse stables are improperly fitted up, is the narrowness of the stalls, 5 feet 3 inches being the largest space allowed for an ordinary sized work-horse. A narrow stall is not only injurious to the horse himself, by keeping him peremptorily confined to one position, in which he has no liberty to bite or scratch himself, should he feel so inclined, but materially obstructs the plowman in the grooming process, and while supplying the horse with food. No work-horse, in my opinion, should have a narrower stall than 6 feet from center to center of the travis, in order that he may stand at ease, or lie down at pleasure with comfort. If " the laborer is worthy of his hire," the work-horse is deserving of a stall that will afford him sound rest.

(25.) It is a disputed point of what form the hay-racks in a work-horse stable should be. The prevailing opinion may be learned from the general practice, which is to place them as high as the horses' heads, because, as it is alleged, the horse is thereby obfiged to hold up his head, and he cannot then breathe upon his food. Many more cogent reasons, as I conceive, may be adduced for placing the racks low down. 'In the first place, a work-horse does not require to hold his head up at any time, and much less in the stable, where he should enjoy all the rest he can get. $2 . \Lambda$ low rack permits the position of his neck and head, in the act of eating, to be more like the way he usually holds them, than when holding them up to a (139) 
high one. 3. He is not nearly so liable to pull out the hay among his feet from a low as from a high rack. 4. His breath cannot contaminate his food more in a low than in a high rack, because the greatest proportion of the breath naturally ascends; though breathing is employed by the horse to a certain degree in choosing his food by the sense of smell. 5 . He is less fatigued eating nut of a low than from a high rack, every mouthfull having to be pulled out of the latter, from its sloping position, by the side of the moutb turned upward. 6. Mown-grass is much more easily eaten out of a low than a high rack. 7. And lastly, I have heard of peas falling out of their straw, when eaten out of a high rack, into the ears of the horse, and therein setting up a serious degree of inflammation.

(26.) The front rail of the lou-rack should be made of strong hard-wood, in case the horse should at any time playfully put his foot on it, or bite it when groomed. The front of the rack. should be sparred for the admission of fresh air among the food, and incline inward at the lower end, to be out of the way of the horses' fore-feet. The bottom should also be sparred, and raised about 6 inches above the floor, for the removal of hay seeds that may have passed through the spars. The corn-trough should be placed at the near end of the rack, for the greater convenience of supplying the corn. A spar of wood should be fixed across the rack from the front rail to the back wall, midway between the travis and the corntrough, to prevent the horse tossing out the fodder with the side of his mouth, which he will sometimes be inclined to do when not hungry. The ring through which the stall collar-shank passes, is fastened by a staple to the hard-wood front rail. I have lately seen the manger in some workhorse stables in steadings recently erected made of stone, on the alleged score of being more easily cleaned than wood after the horses have got prepared food. From my own observation in the matter, I do not think wood more difficult of heing cleaned than stone at any time, and especially if cleaned in a proper time after being used-daily, for instance. As plow men are proverbially careless, the stone-manger has perhaps been substituted on the supposition that it will bear much harder usage than wood; or perhaps the landlords, in the several instances in which stonemangers have been erected, could obtain stone cheaper from their own quarries than good timber from abroad: but either of these reasons are poor excuses for the carelessness of servants on the one hand, or the parsimony of landlords on the other, when the well-being of the farmers' most useful animals is in consideration; for, besides the clumsy appearance of stone in such a situation, and its comfortless feel and aspect, it is injurious to the horses' teeth when they seize it suddenly in grooming, and it is impossible to prevent even some work-horses biting any object when groomed; and I should suppose that stone would also prove hurtful to their lips when gathering their food at the bottom of the manger. I have no doubt that the use of stone-mangers will have a greater effect in grinding down the teeth of farm-horses, than the "tooth of old Time" itself.

(27.) The hind posts of travises should be of solid wood rounded in front, grooved in the back as far as the travis boards reach, sunk at the lower ends into stone blocks, and fastened at the upper ends to battens stretching across the stable from the ends of the couple legs, where there is no hay-loft, and from the joists of the flooring where there is. The head-posts are divided into two parts, which clasp the travis boards between them, and are kept together with screw-bolts and nuts. Their lower ends are also sunk into stone blocks, and their upper fastened to the battens or joists. The travis boards are put endways into the groove in the hind-post, and pass between the two divisions of the head-post to 
the wall before the horses' heads; and are there raised so high as to prevent the contiguous horses troubling each other.

(28.) The floor of all stables should be made hard, to resist the action of the horses' feet. That of a work-horse stable is usually causewayed with small round stones, embedded in sand, such as are to be found on the land or on the sea-beach. This is a cheap mode of paving. When these cannot be found, squared blocks of whinstone (trap rock, such as basalt, greenstone, \&c.) answer the purpose fully better. Flags make a smoother pavement for the feet than either of these materials, and they undoubtedly make the cleanest floor, as the small stones are very apt to retain the dung and absorb the urine around them, which, on decomposi tion, cause filth and constant annoyance to horses. To avoid this inconvenience in a great degree, it would be advisable to form the gutter behind the horses' heels of hewn freestone, containing an entire channel, along which the urine would flow easily, and every filth be completely swept away with the broom. The channel should have a fall of at least $1 \frac{1}{2}$ inch to the 10 feet of length. The paving on both sides should incline toward this gutter, the rise in the stalls being 3 inches in all. In some stables, such as those of the cavalry and of carriers, the floor of the stalls rise much higher than 3 inches, and on the Continent, particularly in Holland, I have observed the rise to be still more than in any stables in this country. Sorne veterinary writers say that the position of the feet of the horse imposed by the rise, does not throw any unnecessary strain on the back tendons of the hind-legs. ${ }^{*}$ This may be, but it cannot be denied that in this position the toes are raised above the hecls much higher than on level ground. I admit that a rise of three inches is necessary in stalls in which geldings stand, as they throw their water pretty far on the litter; but in the case of mares, even this rise is quite unnecessary. It is indisputable that a horse always prefers to stand on level ground, when he is free to choose the ground for himself in a grass-field, and much more ought he to have level ground to stand on in a stable, which is his place of rest.

(29.) Fig. 7 gives a view of the particulars of such a stall for workhorses as I have described. $\quad a \quad a$ are the strong hind-posts ; $b \quad b$ the headposts, both sunk into the blocks $c c c c$, and fastened to the battens $d d$, stretching across the stable from the wall $e$ to the opposite wall; $f f$ the travis-boards let into the posts $a a$ by grooves, and passing between the two divisions of the posts $b b$; the boards are represented high enough to prevent the horses annoying each other; $g g$ curb-stones set up between the hind and fore posts $a$ and $b$, to receive the side of the travis-boards in gruoves, and thereby secure them from decay by keeping them beyond the action of the litter; $h$ is the sparred bottom of the hay-rack, the upper rail of which holds the ring $i$ for the stall collar-shank; $k$ the cornmanger or trough; $l$ the bar across the rack, to prevent the horse tossing out the fodcier; $m$ the pavement within the stall; $n$ is the freestone gutter for conveying away the urine to one end of the stable; $o$ the pavement of the passage behind the horses' heels; $p$ are two parallel spars fastened over and across the battens, when there is no hay-loft, to support trusses of straw or hay, to be given as fodder to the horses in the evenings of winter, to save the risk of fire in going at night to the straw-barn or hayhouse with a light.

(30.) The harness should all be hung against the wall behind the horses, and none on the posts of the stalls, against which it is too frequently placed to its great injury, in being constantly kept in a damp state by the

- Stewart's Stable Èconomy, p. 17.

(141) 
horses' breath and perspiration, and apt to be knocked down among the horses' feet. A good way is to suspend harness on stout hard-wood pins driven into a strong narrow board, fastened to the wall with iron holdfasts; but perhaps the most substantial way is to build the pins into the wall. The harness belonging to each pair of horses should just cover a space of wall equal to the breadth of the two stalls which they occupy, and when windows and doors intervene, and which, of course, must be left free, its arrangement requires some consideration. This mode of arrangement I have found convenient. A spar of hard-wood nailed firmly across the upper edge of the batten $d$, fig. 7 , that supports both the posts

Fig. 7.

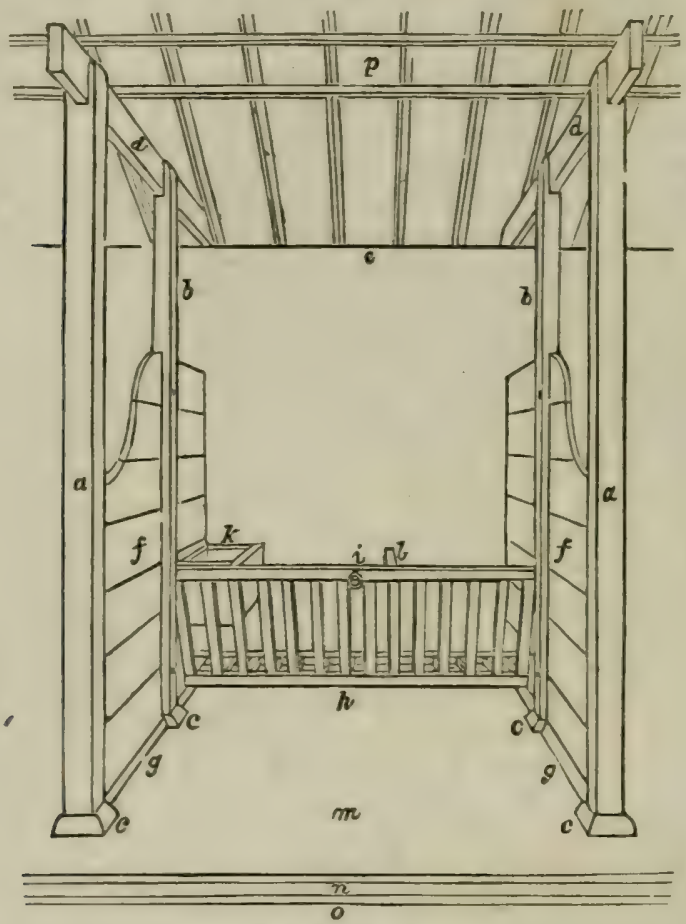

STALL FOR WORK-HORSE STABLE.

of a stall, will suspend a collar on each end, high enough above a person's head, immediately over the passage. One pin is sufficient for each of the cart-saddles; one will support both the bridles, while a fourth will suffice for the plow, and a fifth for the trace-harness. Thus 5 pins or 6 spaces will be required for each pair of stalls, and in a stable of 12 stalls, deducting a space of 13 feet for 2 doors and 2 windows in such a stable, there will still be left, according to this arrangement, a space for the harness of about 18 inches between the pins. Iron hooks driven into the board betwixt the pins will keep the cart-ropes and plow-reins by themselves. The curry-comb, hair-brush, and foot-picker may be conveniently enough hung up on the hind-post betwixt the pair of horses to which they belong, and the mane-comb is usually carried in the plowman's pocket.

(31.) Each horse should be bound to his stall with a leather stall-collar, having an iron-chain collar-shank to play through the ring $i$ of the hay(142) 
rack, fig. 7, with a turned wooden sinker at its end, to weigh it to the ground. Iron-chains make the strongest stall-collar-shanks, though certainly noisy when in use; yet work-horses are not to be trusted with the best hempen cords, which often become affected with dry-rot, and are, at all events, soon apt to wear out in running through the smoothest stallrings. A simple stall-collar, with a nose-band, and strap over the head, is sufficient to secure most horses; but as some have a trick of slipping the strap over their ears, it is necessary to have either a throat-lash in addition or a belt round the neck. Others are apt, when scratching their neck with the hind-foot, to pass the fetlock joint over the stall-collar-shank, and finding themselves thus entangled, to throw themselves down in the stalls, bound neck and heel, there to remain unreleased until the morning, when the men come to the stable. By this accident, I have seen horses get injured in the head and leg for some time. A short stall-collar-shank is the only preventive against such an accident, and the low rack admits of its being constantly used.

(32.) The roof of a work-stable should always be open to the slates, and not only that, but have openings in its ridge, protected from the weather by a particular kind of wood-work, called a ventilator. Such a thing as a ventilator is absolutely necessary on the roof of a work-horse stable. It is distressing to the feelings to inhale the air in some farm stables at night, particularly in old steadings economically fitted up. It is not only warm from confinement, moist from the evaporation of perspiration, and stifling from sudorific odors, but cutting to the breath, and pungent to the eyes, from the decomposition of dung and urine by the heat. The windows are seldom opened, and many can scarcely be opened by disuse. The roof in fact is suspended like an extinguisher over the half stifled horses. But the evil is still farther aggravated by a hay-loft, the floor of which is extended over and within a foot or less of the horses' heads. Besides the horses being thus inconvenienced by the hay-loft, the hay in it, through this nightly roasting and fumigation, soon becomes dry and brittle, and contracts a disagreeable odor. The only remedy for these inconveniences in workhorse stables is the establishment of a complete ventilation through them.

(33.) Fig. 8. represents one of these ventilators, in which the Venetian blinds $a$ are fixed, and answer the double purpose of permitting the es-

Fig. 8.

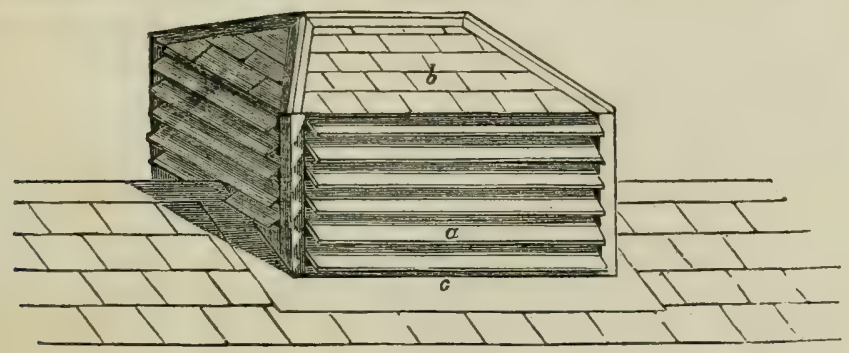

A VENTILATOR.

cape of heated air and effluvia, and of preventing the entrance of rain or snow. The blinds are covered and protected by the roof $b$, made of slates and lead; $c$ is an apron of lead. Such a ventilator would be more ornamental to the steading than fig. 8 , and more protective to the blinds, if its roof projected 12 inches over. One ventilator of the size of 6 feet in length, 3 feet in hight in front, and 2 feet above the ridging of the roof, 
for every four horses in a work-horse stable, may perhaps suffice to maintain a complete ventilation. But openings in the roof will not of themselves constitute ventilation, unless there be an adequate supply of fresh air from below, to enforce a current; and this supply should be obtained from openings in the walls, including the chinks of doors and windows when shut, whose gross areas should be equal to those of the ventilators. The openings should be formed in such situations, and in such numbers, as to cause no draught of cold air to be directed against the horses. They might conveniently be placed, protected by gratings of iron on the outside to prevent the entrance of vermin, in the wall immediately behind the harness, through which the air would pass, and cross the passage toward the horses; and the air on thus entering the stable should be made to deflect to both sides of each opening, by striking against a plate of iron placed before the opening, at a short distance from the wall. I observe other forms of ventilators in use in steadings, one consisting of large lead pipes projected through the roof, with the ends turned down; and another having a portion of the slating or tiling raised up a little, and there held open. Either of these plans is much better than no ventilation at all, and I dare say either mode may be cheaply constructed; but neither is so effectual for the purposes of ventilation as the one I have figured and described.

(34.) Besides the ordinary stalls, a loose-box, $u$, will be found a usefu? adjunct to a work-horse stable. A space equal to two stalls should be railed off at one end of the stable, as represented at $u$ on the plan, fig. 4 , Plate IV. It is a convenient place into which to put a work-mare when expected to foal. Some mares indicate so very faint symptoms of foaling that they frequently are known to drop their foals under night in the stable, to the great risk of the foal's life, where requisite attention is not directed to the state of the mare, or where there is no spare apartment to put her into. It is also suitable for a young stallion, when first taken up and preparing for traveling the road; as also for any young draught-horse taken up to be broke for work, until he become accustomed to a stable. It might be, when unfortunately so required, converted into a convenient hospital for a horse, which, when seized with an unknown complaint, might be confined in it, until it is ascertained whether the disease is infectious, and then he should be removed to an out-house. Some people object to having a loose-box in the stable, and would rather have it out of it; but the social disposition of the horse renders one useful there on the occasions just mentioned. It is, besides, an excellent place in which to rest a fatigued horse for a few days.

(35.) Adjoining to this I have placed the stable for riding-horses, as at $P$ on the plan, fig. 4, Plate IV, not that those stables should always be togethcr, for the riding-horse stable can be placed at any convenient part of the farmstead or near the farm-house. It may be fitted up in the form of three stalls of 6 feet each, or two loose-boxes of 9 feet each, according to inclination, that is, a size of 18 feet square will afford ample room for all the riding-horses a farmer will require. The high rack is always put up in riding-horse stables, to oblige the horse to keep up his head, and maintain a lofty carriage with it. The long manger, stretching from one travis to another, is frequently used where the high rack is approved of. But the neatest mode of fitting up the stall of a riding-horse stable is with a hay-crib in one of the comers, and a corn-box in the other, both being placed at convenient hights from the ground. The stall-posts in ridinghorse stables are fastened into the ground in a boly of masonry, and not to the roof, as that should be made as lofty as the hight of the lialks of the (144) 
couples will admit, and it should be lathed, and all the walls plastered, for the sake of appearance, warmth, and cleanliness. The corn-chest may be placed either in the recess of the window, where its lid might form a sort of table, or in a corner. One door and a window are quite enough for light and entrance. The door should open outward on giblet-checked ribets, and provided with a good lock and key, and spring-latch with a handle, so as not to catch the harness. The hight and width of both riding and work-horse stable-doors are usually made too low and too narrow for the easy passage of ordinary sized horses in harness; $7 \frac{1}{2}$ feet by $3 \frac{1}{2}$ feet are of the least dimensions they should ever be made. A ventilator is as requisite in a riding as a work-horse stable, and, to promote ventilation, the under part of the window should be provided with shutters to open. The neatest floor is of droved flags; though I have seen in stables for riding-horses very beautiful floors of Dutch clinkers.

(36.) The lowest part of a high rack is usually placed about the hight of a horse's back, in contact with the wall, and the upper part projecting about 2 feet from it. This position is objectionable, inasmuch as the angle of inclination of the front with the wall is so obtuse as to oblige the horse to turn up the side of his mouth before he can draw a mouthfull of provender out of it, though the front be sparred at such a width as to permit hay and grass to pass easily through. A better plan is to have the front nearly parallel with the wall, and the bottom sparred to admit the falling out of dust and seeds.

(37.) The long manger, which is always used with the high rack, is chiefly useful in permitting the corn to be thinly spread out, and making it more difficult to be gathered by the lips of the horse, and on that account considered an advantageous form of manger for horses that are in the habit of bolting their corn. I doubt whether horses really masticate their corn more effectually when it is spread out thin, though no doubt they are obliged to take longer time in gathering and swallowing it, when in that state.

(38.) The hay crib fixed up in one corner of the stall, usually the far one, is not large enough to contain fodder for a work-horse, though amply so for a riding-horse. A work-horse will eat a stone of hay of $22 \mathrm{lbs}$. every day, which, when even much compressed, occupies about a cubic foot of space. To make a quadrifid hay-crib contain this bulk, would require the hay to be hard pressed down, to the great annoyance of the horse, and the danger of much waste by constant pulling out. Plowmen require no encouragement by small racks to press fodder hard into racks. This they usually do, with the intention of giving plenty of it to their horses; but were racks generally made capacious enough, they would have less inducement to follow a practice which never fails to be attended with waste of provender. Such hay-cribs are usually made of iron.*

[ Not so yet in the United States, although iron is being more and more substituted for wood, for various purposes, and would be for many more, if iron-masters were farmers, or, vice versa, to make both more familiar with the numerous purposes to which it might be economically applied.

Among those who will read this, there are yet doubtless some who well remember when rope traces and wooden mould-boards and hay-forks were used almost exclusively. Iron might be employed to advantage for a great variety of new uses. It needs for this and other improve. ments that Americans be brought, as they will be by degrees, to disburden themselves of the party demagogues by whom they are ridden, and learn, instead of being absorbed by party politics, to turn their attention and studies to their own true and peculiar interests.

Few things serve better to distinguish the habits and even the character of the progeny from the parent stock-the Americans from their English ancestors-than the more perfect finish and durability of all their mechanical works, machinery and buildings.

(193) ...... 
(39.) With regard to the relative advantages of stalls and loose-boxes in riding-stables, there is no doubt that, for personal liberty and comfort to the horse, the latter are much to be preferred, as in them he can stand, lie down, and stretch him out in any way he pleases; but they require more litter and a great deal of attention from the groom to keep the skin of the horse clean, and preserve the horse-clothes from being torn-considerations of some importance to a farmer who has little use for a regularlybred groom to attend constantly on his riding-horse; unless he be a sportsman.*

(40.) The floor of the riding-horse stable may be paved either with small stones, and a gutter of freestone to carry off urine, like the workhorse stable, or, what is better, with jointed flags; but the neatest form of floorings is of jointed droved flags, grooved across the passage from the door to the stalls, to prevent the slipping of the horses' feet. This plan has also the advantage of being the cleanest as well as the neatest, but it is obviously more suited to the stables of the landlord than the tenant.

(41.) If you use a wheeled vehicle of any kind, the coach-house should adjoin the riding-horse stable. Of 18 feet square in size it will contain two light-wheeled carriages, and afford ample room besides for other purposes, such as the cleaning of harness, \&c. As the utmost precautions of ventilation and cleanliness cannot prevent deposition of dust in a ridinghorse stable, the harness should be placed beyond its reach in the coachhouse, where it should be hung upon pins against a boarded wall. To keep it and the carriages dry in winter, there should be a large fire-place in the coach-house. The floor should be flagged, and the roof and walls lathed and hair-plastered. A door should open from the riding-horse stable, provided with lock and key, and the large coach-housè door should open outward on a giblet-check, and be fastened with bolts and a bar in the inside. $\mathrm{Z}$ in plan fig. 4, Plate IV. is the coach-house, with the large fire-place $i$ in it. Coach-houses having to be kept dry in winter, to prevent the moulding of the leather-work, are frequently kept so by stoves, which, when not in use in summer, become rusted and out of working or: der; and when again lighted in that state, never fail to smoke and soil every thing with soot. $\dagger$

There things are made to endure; here they are made to answer the purposes of the day. There railroads often cost one hundred and fifly thousand dollars a mile! but when they are done, they are done! On the other hand, Americans beat the world in ingenuity and in readiness to imitate and improve. Short apprenticeships, slighted and imperfect structures, unseasoned and perishable materials hastily put together, and even the restless and roaming temper of our popalation, may be regarded as the natural growth of our freer and looser form of government, and we must take the bitter with the sweets.

Ed. Farm. Lib.]

[" "Horse cloths" or coverings are not generally used or needed on American farms. Horses are in no danger from cold. Stables should be always dry, but well ventilated, and care should always be tuken, when horses are heated, not to leave them at rest, in a cold wind or current of air uncovered. No man of any consideration or mercy would do it, or allow it to be done.

Ed. Farm. Lib.]

[ $\dagger$ This suggestion of a fire-place in a coach-house may be regarded as another English refinement, and like many things in this book, which must be published (from their inseparable connection with others that are practicable and expedient) is not therefore to be considered as recommended for imitation.

A fire-place in a house connected with the farmstead, to prevent the mould on harness, which in England is the result of the dampness of the climate, implies more capital and more careful eervants than we have at command in this country. Approved English or foreign servants, as they are styled abroad, on coming to America either go at once, with their means, and for a few dollars, several hundred miles west, and there buy government lands at $\$ 125$ an acre, or they (194) 



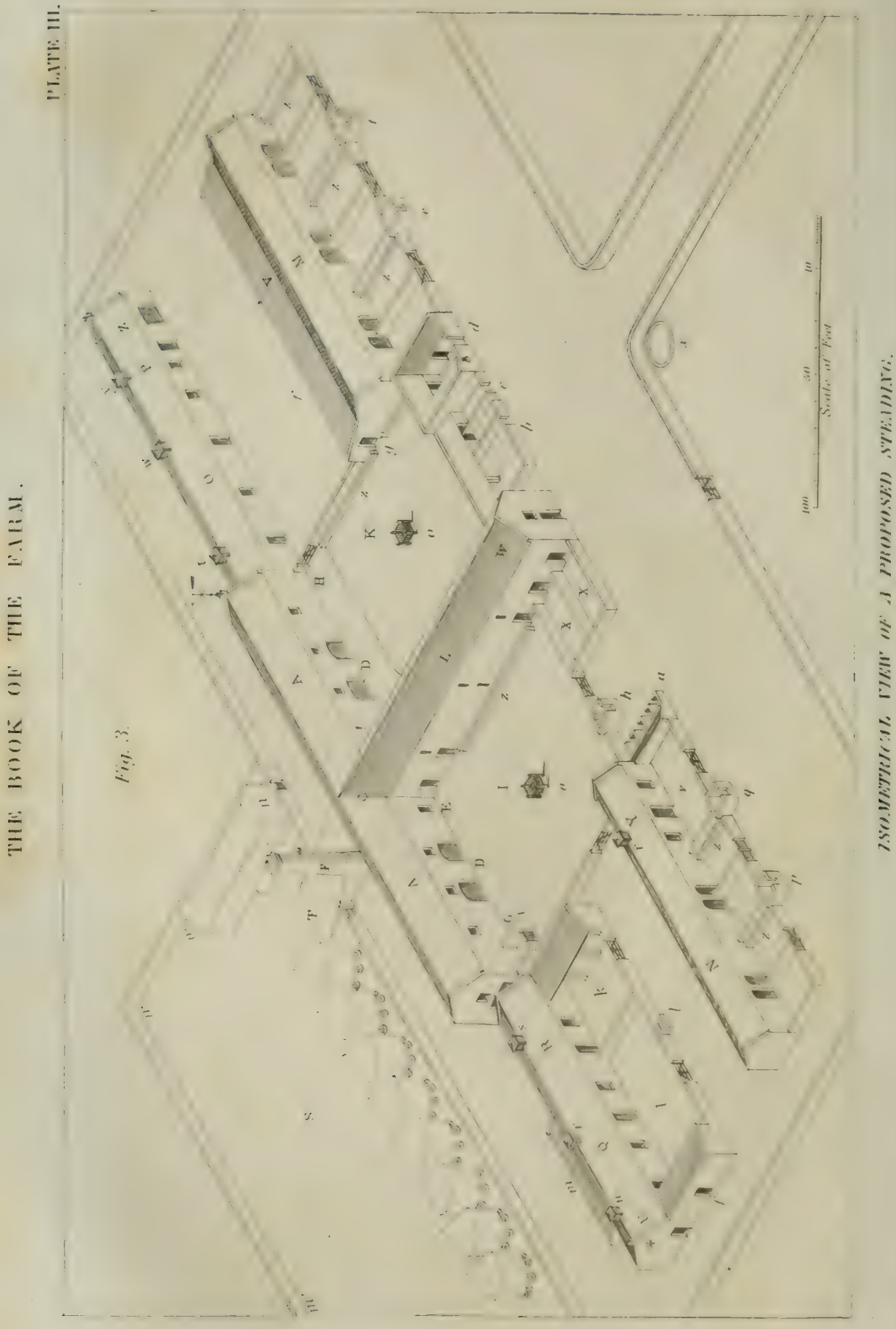


(42.) The cow-house or byre, Q, is placed on the left of the principal range, in a position corresponding with that of the work-horse stable. It is 53 feet in length and 18 feet in width. The stalls of a cow-house, to be easy for the cows to lie down and rise up, should, in my opinion, never be less than 5 feet in width. Four feet is the more common width, but that is evidently too narrow for a large cow, and even 7 feet are considered by some people as a fair-sized stall for two cows; though, in my opinion, every cow should have a stall for herself, for her own comfort when lying or standing, and that she may eat her food in peace.* The width of the byre should be 18 feet; the manger is 2 feet in width, the length of a large cow about 8 feet, the gutter 1 foot, leaving 7 feet behind the gutter for the different vessels used in milking the cows and feeding the calves. The ceiling should be quite open to the slates, and a ventilator, moreover, is a useful apparatus for regulating the temperature and sup plying fresh air to a byre. A door, divided into upper and lower halves, should open outward to the court on a giblet-check, for the easy pasage of the cows to and from the court, and each half fastened on the inside with a hand-bar. Two windows with glass panes, with the lower parts furnished with shutters to open, will be quite sufficient for light, and, along with the half-door, for air also. The walls should be plastered for comfort and cleanliness.

(43.) The stalls are most comfortably made of wood, though some recommend stone, which always feels hard and cold. Their hight should be 3 feet, and in length they should reach no farther than the flank of the cow, or about 6 feet from the wall. When made of wood, a strong hardwood hind-post is sunk into the ground, and built in masonry. " Between this post and the manger should be laid a curb-stone, grooved on the upper edge to let in the deals of the travis endways. The deals are held in their places at the upper ends by a hard-wood rail, grooved on the under

remain in the towns, under much higher wages than the American Farmer can afford to give, taxed as he is to support enormously expensive military and civil establishments. Who would believe, for example, that in Maryland the farmers and planters, asking so little, and getting so much less, from Government, pay 100 men \$4 per day each, and even the postage on all their political and private as well as public correspondence, for the space of three months every year, to make nevo laws and patch up old ones !

Woald any cultivated agricultural community, educated as they ought to be, with an under. standing of their own true interests and just power, submit for one year to be thus humbugged and fleeced?

Ed. Farm. Lib.]

[* This would all be very well if the American farmer had capital to build, for better accommodation, on any scale, however expensive. But where he is forced, according to a common saying, to "cut his coat according to his cloth," less roomy stalls must answer. In our best dairy establishments, as at Morrisania and others, the partition between the stalls is usually very short, just sufficient to prevent the heads of the cows from coming in contact, leaving the space open between their bodies, the width of the stall being often not more than three feet in the clear, and these seem to answer well.

In some of these best milk establishments, strong $t u b s$, which are easily removed to be cleaned or filled, are in use for giving short provender, cut hay or straw, or corn fodder, as the case may be, wet and mixed with bran shorts or meal of some sort, leaving the long provender to go into the manger, which runs from one end of the stable to the other, sometimes resting on the floor. These tubs are filled in the feeding passage, from which also the long provender is supplied to the mangers. Usually this feeding passage is between two rows of stalls in which the cows stand with their heads to the passage. We shall hereafter give exact plans, where it may be deemed necessary, on a scale suited to American farmers; but it is deemed best here not to disturb the copy before us, as every part in the plan has some connection with some other part. From the whole the reader proposing to build may easily select such portions as he may like, and re-com. bine them to meet and satisfy his own views.

Ed. Farm. Lib.]

$(195 ;$ 
side, into which the ends of the deals are let, and the rail is fixed to the back of the hind-post at one end, and let into the wall at the other, and there fastened with iron holdfasts. Stone travises are no doubt more durable, and in the end, perhaps, more economical, where flag-stones are plentiful; but I would in all cases prefer wood, as feeling warmer, being more dry in winter, and less liable to injure the cows coming against them, and within doors will last a long time. The plan of the stalls may be seen at $\mathrm{Q}$ and $\mathrm{Y}$ in the plan fig. 4, Plate IV.

(44.) The mangers of byres are usually placed on a level with the floor, with a curb-stone in front to keep in the food, and paved in the bottom.This position I conceive to be highly objectionable, inasmuch as, when breaking the tumips, the head of the animal is depressed so low that an undue weight is thrown upon the fore-legs, and an injurious strain induced on the muscles of the lower jaw. A better position is, when the bottom of the manger, made of flag-stones or wood, resting on a building of stone and mortar, is raised about 20 inches from the ground, and a plank set on edge in front to keep in the food. This plank should be secured in its position with iron rods batted into the wall at one end, and the other end passed through the plank to a shoulder, which is pressed hard against the plank on the opposite side by means of a nut and screw. This form of manger may be seen in fig. 18, p. 110. In this position of the manger, the cow will eat with ease any kind of food, whether whole or cut, and all feeding-byres for oxen should also be fitted up with mangers of this construction. Mangers are generally made too narrow for cattle with horns, and the consequence is the rubbing away of the points of the horns against the wall.

(45.) The method of supplying green food to cattle in byres may be va. rious, either by putting it into the manger from the inside, or from the outside through holes in the wall made exactly opposite their heads. Either way is equally serviceable to the cattle, but the latter is the more convenient for the cattle-man. Its construction may be easily understood by fig. 9 , which represents the door shut in the opening of the wall on the outside. But, convenient as this mode of supplying food is, I prefer giving it by the stall, when that is as wide as 5 feet, because, in cold weather in winter, the draught of air occasioned by the opening of the small doors at the heads of cows may en-

Fig. 9.

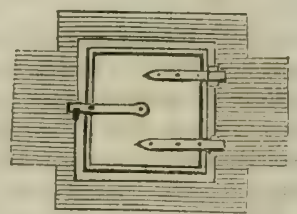

DOOR THROUGH WHICH TO SUPPLY MANGERS WITH TURNIPS.

danger their health. There is another method by having a passage of 3 feet in width betwixt the stalls and the wall, from which both turnips and fodder may be supplied to the cows. In this case the space behind the cows is reduced to 4 feet in width.

(46.) The floor of byres should be paved with small round stones, excepting the gutter, which, being as broad as an ordinary square-mouthed shovel, should be flagged at the bottom, and formed into the shape of a trough by two curb-stones. A gutter of this form can be quickly cleaned out. A similarly formed gutter, though of smaller dimensions, should run from the main one through the wall to the court, to carry off the urine.The causewaying of the stalls of a cow-house should go very little farther up than the hind-posts, because, in lying down and rising up, cattle first kneel on their fore-knees, which would be injured in the act of being pressed against any hard substance like stones. This inner part of the stall should be of earth, made softer by heing covered with litter. The urine gutters may be seen in the plan at $Q$ and $Y$ in fig. 4, Plate IV. 
(47.) Fig. 10 represents a section of a travis and manger of a byre, where $a$ is the wall, $b$ the building which supports the manger $c$, having a front of wood, and bottomed with either flags or wood, $d$ the hard-wood hindpost, sunk into the ground, and there built in with stones and mortar, $e$ the hard-wood top-rail, secured behind the post $d$, and let into and fixed in the wall $a$ with iron holdfasts, $f$ the stone curb-stone, into which the tra-

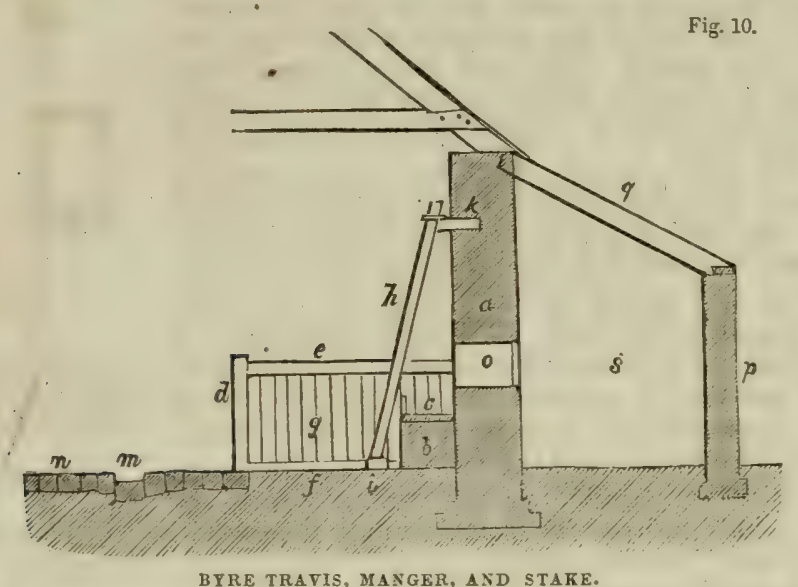

vis-board is let; $g$ the boarding of wood, let endways into the curb-stone below, and into the top-rail above, by a groove; $h$ is a hard-wood stake, to which the cattle are fastened by binders, the lower end of which is let into a block of stone $i$, and the upper fastened by a strap of iron to a block of wood $k$ fixed into the wall $a ; m$ is the gutter for the dung, having a bottom of flag-stones, and sides of curb-stones; $n$ the paved floor; $o$ the opening through the wall $a$ by which the food is supplied into the manger $c$ to the cattle, from the shed $s$ behind. This shed is 8 feet wide, $p$ being the pillars which support its roof $q$, which is just a continuation of the slating of the byre roof, the wall $a$ of which is 9 feet, and the pillars $p 6$ feet, in hight. But where no small doors for the food are used, the shed $s$, pillars $p$, and roof $q$, are not required-a small turnip store being sufficient for the purpose, and to which access may be obtained by the back door, seen in $Q$, at the right hand of the stalls in fig. 4, Plate IV. Fig. 11.

(48.) Cattle are bound to the stake in various ways. 1. One way is with an iron chain, commonly called a binder or seal. This is represented in fig. 11, where $a$ is the large ring of the binder which slides up and down the stake $h$, which is here shown in the same position as it is by $h$ in the section of the stall in fig. 10. The iron chain being put round the neck of the beast, is fastened together by a broad-tongued hook at $c$, which is put into any link of the chain that forms the gauge of the neck, and cannot come out again until turned on purpose edgeways in reference to the link of which it has a hold. This sort of binder is in general use in the midland and northern counties of Scotland. 2. Another method of binding is with the baikie, which is made of a piece of hard wood $e$, fig. 12,

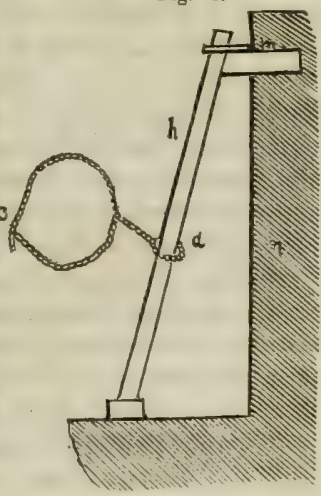
(197) 
standing upright and flat to the neck of the beast; a rope $g$, fastens the lower end of it to the stake, upon which it slides up and down by means of a loop which the rope forms round the stake. This rope passes under the neck of the animal, and is never loosened. Another rope $k$, is fastened at the upper end of the piece of woode, and, passing over the neck of the animal, and round the stake, is made fast to itself by a knot and eye, and serves the purpose of fastening and loosening the animal. The neck being embraced between the two ropes, moves up and down, carrying the baikie along with it. This method of binding animals to the stake, though quite easy to the animals themselves, has this objectionable property, which the seal has not, of preventing the animals turning round their heads to lick their bodies, which they can do with the seal pretty far back, and yet are unable to turn round in the stall. The seal being made of iron, is more durable than the baikie. The top of the stake of the seal is inclined toward the wall $n$, and fixed as represented by $m$ in fig. 11 ; the baikie stake is held perpendicular, and is fixed to a $\log$ of wood $m$, fig. 12 , stretching parallel to the wall $o$, across the Fig. 12.

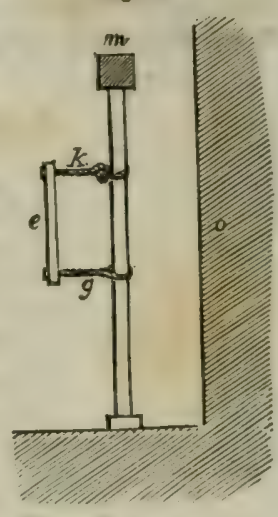

A BAIKIE. byre, of which log the cross section only is here shown. The seal-stake is placed in an inclined position to allow its top to be fastened to the wall, and in regard to it the animal is comparatively loose; but as the neck is always held close to the baikie-stake, that stake must be placed in a perpendicular position to allow the animal to move its neck up and down to and from the manger.

(49.) This construction of the byre with its fittings up, is quite as well suited to fatten oxen as to accommodate milch cows. Feeding byres are usually constructed much too small for the number of oxen confined in them. When stalls are actually put up, they seldom exceed 4 feet in width; more frequently two oxen are put into a double stall of 7 feet, and not unfrequently travises are dispensed with altogether, and simply a triangular piece of boarding is placed across the manger against the wall, to divide the food betwixt such pair of oxen. In double stalls, and where no stalls are used, even small-sized oxen, as they increase in size, cannot all lie down together to chew their cud and rest, whereas, the fatter they become, they require more room and more rest ; and large oxen are hampered in them from the first. In such confined byres, the gutter, moreover, is too near the heels of the oxen, which prevents them standing back when they desire. Short stalls, to be sure, save the litter being dirtied, by the dung dropping from the cattle directly into the gutter, and this circumstance no doubt saves trouble to the cattle-man; but in such a case the litter is saved by the sacrifice of comfort to the animals. Such considerations of economy are quite legitimate in cowkeepers in town, where both space and litter are valuable, but that they should induce the construction of inconvenient byres in farmsteads indicates either parsimony on the part of the landlord or ignorance on that of the architect; and no farmer who consults the well-being of his animals, and through them his own interest, should ever originate such a plan, or sanction it where he finds it to exist. The truth is, these confined structures are ordered to be erected by landlords unacquainted with Agriculture, to save a little outlay at first. Expenditure to them is a tangible object; but in dealing thus with their tenants, they seem not to be aware they are acting with short(198) 
sightedness toward their own interests ; for want of proper accommodation in the farmstead certainly has, and should have, a considerable influence on the mind of the farmer, when valuing the rent of the farm he wishes to occupy. Should you have occasion to fit up a byre for the accommodation of milch cows or feeding oxen, bear in mind that a small sum saved at first, may cause you to incur a yearly loss of much greater amount than the saving, by not only preventing your feeding cattle attaining the perfection which a comfortable lodging would certainly promote in them; but in affecting the state of your cows by want of room, the calves they bear in such circumstances are sure to prove weak in constitution.

(50.) Immediately adjoining the cow-house should be placed the calves' house. This apartment is represented at $\mathrm{R}$ of the plan in fig. 4 , Plate IV. fitted up with cribs. It is 35 feet in length, and 18 feet in width, and the roof ascends to the slates. Calves are either suckled by their mothers, or brought up on milk by the hand. When they are suckled, if the byre be roomy enough, that is, 18 feet in width, stalls are erected for them against the wall behind the cows, in which they are usually tied up immediately behind their mothers; or, what is a less restrictive plan, put in numbers together in loose boxes at the ends of the byre, and let loose from both places at stated times to be suckled. When brought up by the hand, they are put into a separate apartment from their mothers, and each confined in a loose-box or crib, where the milk is given them. The superiority of separate cribs over loose boxes for calves is, that calves are prevented sucking one another, after having got their allowance of milk, by the ears, or teats, or scrotum, or navel; by which malpractice, when unchecked, certain diseases may be engendered. The crib is large enough for one calf at 4 feet square and 4 feet in hight, sparred with slips of tile-lath, and having a small wooden wicket to afford access to the calf. The floor of the cribs may be of earth, but the passage between them should be flagged or of asphaltum. Abundance of light should be admitted, either by windows in the walls, or sky-lights in the roof; and fresh air is essential to the health of calves, the supply of which would be best procured by a ventilator, such as is represented in fig. 8, p. 95 , already described. There should be a door of communication with the cow-house, and another in two divisions, an upper and a lower, into a court furnished with a shed, as $k$ in fig. 4, Plate IV. which the calves may occupy until turned out to pasture. The cribs should be fitted up with a manger to contain cut turnips, and a high rack for hay, the top of which should be as much elevated above the litter as to preclude the possibility of the calves getting their feet over it. The general fault in the construction of calves' houses is the want of both light and air-light being cheerful to creatures in confinement, and air particularly essential to the good health of young animals. When desired, both can be excluded. The walls of the calves' house should be plastered, for the sake of neatness and cleanliness. Some people are of opinion that the calves' house should not only have no door of communication with the cow-house, but should be placed at a distance from it, in order that the cows may be beyond the reach of hearing the calves. Such an objection could only have originated from an imperfect acquaintance with the nature of these animals in the circumstances. A young cow even that is at once prevented smelling and suckling her calf, does not recognize its voice at any distance, and will express no uneasiness about it after the first few minutes after parturition, and after the first portion of milk has been drawn from her by the hand.

(51.) The front of one of these calves' cribs is represented by fig. 13, ip (199i 
which $a$ is the wicket-door which gives access to it, $b b$ are the hinges, and $c$ is a thumb-catch to keep the door shut. You will observe that this kind of hinge is very simple and economical. It consists of the rails of the wicket being a little elongated toward $b$, where they terminate in a semi-circular form, and the lower face of which is shaped into a pin which fills and rotates in a round bole made in a billet of wood, seen at the lower hinge at $b$, 'securely screwed to the upright door-post of the crib. Another billet $d$ is scre,pred immediateIy above the fower rail $b$, to prevent the $\alpha^{\prime}$, or being thrown of the hiurs, oy any accident. 'ross-tavied iron hinges, of khe liģhroess suited to such Fig. 13. doors would soon break by rusting in the dampness usually occasioned by she r,resth of a number of calves confined within the same apartment.

I's'. A pretty large court should be attached to the cow-house, in which we rows can walk about for a time in the best part of the day in winter, wrsing in the sun when it shines, rubbing against a post that should be ver up for the purpose, drinking a little water provided for them in a trough $v$; and licking themselves and one another. Such a court is, besides, necessary for containing the manure from the byre, and should have a gate by which carts can have access to the manure : $l$ is such a court on the plan, fig. 4, Plate IV. being 58 feet in length by 30 feet in width.

(53.) $k$ in the plan, fig. 4, Plate IV. is the court attacherl to the calves' house, 30 feet in length by 25 feet in width, in which should be erected, for shelter to the calves in cold weather, or at night before they are turned out to pasture, or for the night for a few weeks after they are turned out to pasture, a shed $k, 30$ feet in length by 12 feet in width, fitted up with mangers for turnips, and racks for hay. A trough of water, $w$, is also requisite in this court, as well as a gateway for carts by which to remove the dung.

(54.) On the left of the cow-house is the boiling-house U, for cooking food in, and doing everything else that requires the use of warm water.The boiler and furnace $b^{\prime}$ should be placed so as to afford access to the boiler on two sides, and from the furnace the vent rises to the point of the gable. A fire-place $a^{\prime}$ is useful for many purposes, such as melting tar, boiling a kettle of water, drying wetted sacks, nets, \&c. One door opens into the byre, and another, the outer one, is in the gable, through which access to the byre may be obtained, or, if thought better, through the gate and court of the byre. There should be a window with glass, and shutters in the lower division, to open and admit air, and a ventilator $u, f i g .3$, Plate III. on the roof may be advisable here as a means at times to clear the house of steam. The walls of the boiling-house should be plastered. As proximity to water is an essential convenience to a boiling-house, water is quite accessible in the trough of the cows' court $l$, or, what is still better, in a trough connected with it outside, as at $l^{\prime}$, in fig. 3 , Plate III. or. $w$, in fig. 4, Plate IV.

(55.) Windows should be of the form for the purpose they are intended to be used. On this account windows for stables, and for other apartments, (200) 
should be of different forms. 1. Fig. 14 represents a window for a stable The opening is $4 \frac{1}{2}$ feet in hight by 3 feet in width. The frame-work io composed of a dead part $a$ of 1 foot in depth, 2 shutters $b b$ to open on hinges, and fasten inside with a thumb-catch, and $c$ a glazed sash 2 feet in hight, with 3 rows of panes. When panes are made under 8 inches square, there is a considerable saving in the price of glass. The object of this form of a stable window is, that generally a great number of small articles are thrown on the sole of a work-horse stable window, such as shortends, straps, \&c. which are only used occasional$\mathrm{ly}$, and intended to be there at hand when wanted. The consequence of this confused mixture of things, which it is not easy for the farmer to prevent, is that, when the shutters are desired to be

Fig. 14.

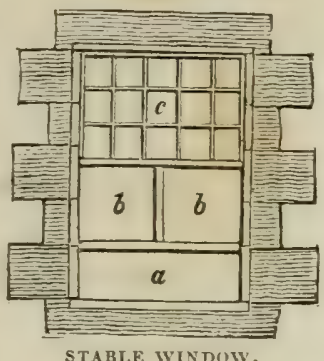

STABLE WINDOW. opened, it is scarcely possible to do it without first clearing the sole of everything; and, rather than find another place for them, the window remains shut. A press in a wall might be suggested for containing these small articles; but in the only wall, namely, the front one of the stable $\mathrm{O}$, in which it would be convenient to make such a press, all its surface is occupied by the harness hanging against it; and besides, no orders, however peremptory, will prevent such articles being, at throng times, thrown upon the window-soles; . and where is the harm of their lying there at hand, provided the windows are so constructed as to admit of being opened when desired? When a dead piece of wood, as $a$, is put into such windows, small things may remain on the sole, while the shutters $b b$ are opened over them. 2 . In other apartments, such as byres, corn-barn, calves' house, boiling-house, implement-house, hayhouse, where there is no chance of an accumulation of sundry articles in the window-sole, the shutters of the windows, if desired, may descend to the bottom of the frame, as in fig. 15. The size of the window may still be the same, $4 \frac{1}{2}$ feet in hight and 3 feet in width. The frame consists of two shutters a a 2 feet in hight, with a glazed sash $c 2 \frac{1}{2}$ feet in hight, having 4 rows of panes.-

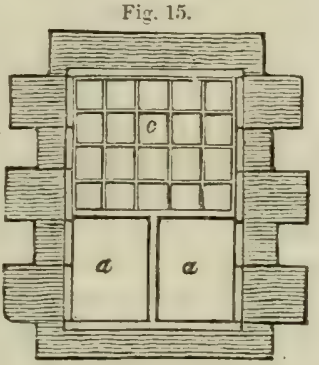

BYRE, \&C. WISDOW. Such a form of window will admit a great deal of light and air.

(56.) The upper barn B, as seen in fig. 16, occupies the whole space above the corn-barn and chaff-house. It is 32 feet in length and 30 feet in breadth, and its roof ascends to the slates. It has a good wooden floor like the corn-barn, supported on stout joists. It contains the principal machinery of the threshing-machine, and is wholly appropriated to the storing of the unthreshed corn previous to its being threshed by the mill. For the admission of barrows loaded with sheaves from the stack-yard, or of sheaves direct from the cart, this barn should have a door toward the stack-yard of 6 feet in width, in two vertical folds to open outward, on a giblet-checkone of the folds to be fastened in the inside with an iron cat-band, and the other provided with a good lock and key. It is in this barn that the corn is fed into the threshing-mill; and, to afford light to the man who feeds in, and ample light to the barn when the door is shut-which it should be when the wind blows strongly into it-a sky-light should be placed over the head of the man. The large door should not be placed immediately behind the man who feeds in, as is frequently the case in farmsteads, to his (201) 
great annoyance when the sheaves are bringing in. There should be slits in the walls for the ventilation of air among the corn-sheaves, which may not at all times be in good order when taken into the barn. A hatchway

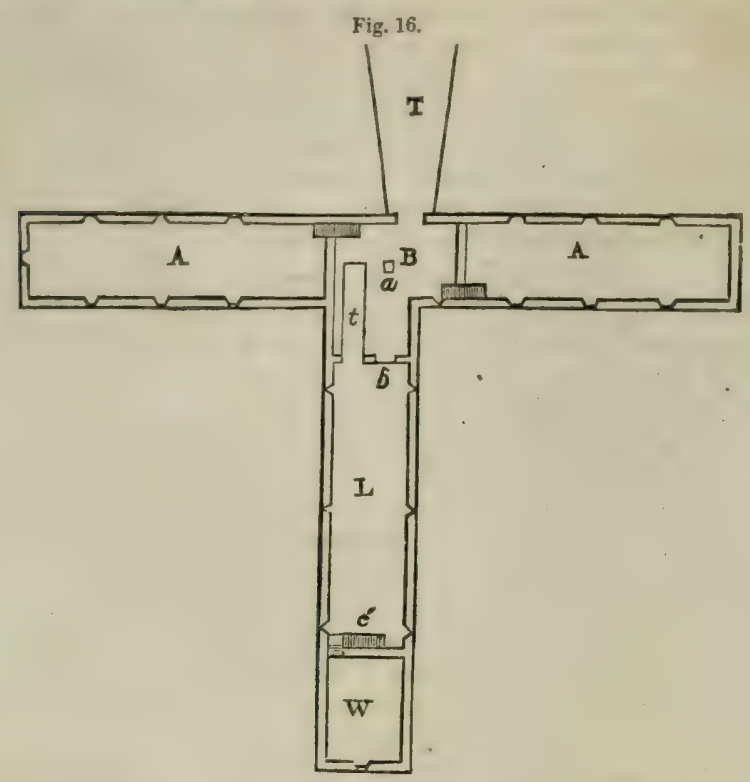

PLAN OF UPPER BARN, GRANARIES, AND WOOL-ROOM.

$a, 3$ feet square, in the floor, over the corn-barn below, is useful when any corn or refuse has to be again put through the mill. Its hatch should be furnished with strong cross-tailed hinges, and a hasp and staple, with a padlock and key, by which to secure it from below in the corn-barn. An opening $b$, of 4 feet in hight and 3 feet in width, should be made through the wall to the straw-barn, for the purpose of receiving any straw from it that may require to be put through the mill again. This opening sbould be provided with a door of one leaf, or of two leaves, to fasten with a bar, from the upper barn. The threshing-machine is not built on the floor, but is supported on two very strong beams extending along the length of the barn: $t$ is the site of the threshing-machine in the figure.

(57.) Immediately in connection with the upper barn is the gangway, $\mathrm{T}$, fig. 4, Plate IV. and fig. 16. It is used as an inclined plane, upon which to wheel the corn-barrows, and form a road for the carriers of sheaves from the stack-yard. This road should at all times be kept hard and smooth with small broken stones, and at the same time sufficiently strong to endure the action of barrow-wheels. Either common asphaltum or wood pavement would answer this purpose well. 'To prevent the body of the gangway affecting the wall of the corn-barn with dampness, it should be kept apart from that wall by an arch of masonry. Some farmers prefer taking in the corn on carts instead of by a gangway, and the carts in that case are placed alongside the large door, and emptied of their contents by means of a fork. I prefer a gangway for this purpose; because it enables the farmer to dispense with horse-labor in bringing in the stacks if they are near at hand, and they should always be built near the upper-barn for convenience. Barns in which flails alone are used for (202) 
threshing the corn, are made on the ground, and the barn-door is made as large as to admit a loaded cart to enter and empty its contents on the floor.

(58.) In fig. 16, AA are two granaries over the sheds DD, implementhouse $\mathrm{G}$, and hay-house $\mathrm{H}$, in fig. 4, Plate IV. That on the left is 76 feet in length and 18 feet in width, and the other 65 feet in length and 18 feet in width. The side walls of both are 5 feet in hight. Their roofs ascend to the slates. Their wooden floors should be made strong, to support a considerable weight of grain; their walls well plastered with hair plaster; and a neat skifting-board should finish the flooring. Each granary has 6 windows, three in front and three at the back, and there is one in the gable, at the left hand over the door of the implement-house. These windows should be so formed as to admit light and air very freely, and I know of no form of window so capable of affording both, as this in fig. 17, which I have found very serviceable in granaries. The opening is $4 \frac{1}{2}$ feet in length and 3 feet in hight. In the frame $a$ are a glazed sash 1 foot in hight, composed of two rows of panes, and $b$ Venetian shutters, which may be opened more or less at pleasure : $c$ shows in section the manner in which these shutters operate. They revolve by their ends, formed of the shape of a round pin, in holes in the side-posts of the frame $d$, and are kept in a parallel position to each other by the bar $c$, which is attached to

Fig. 17.
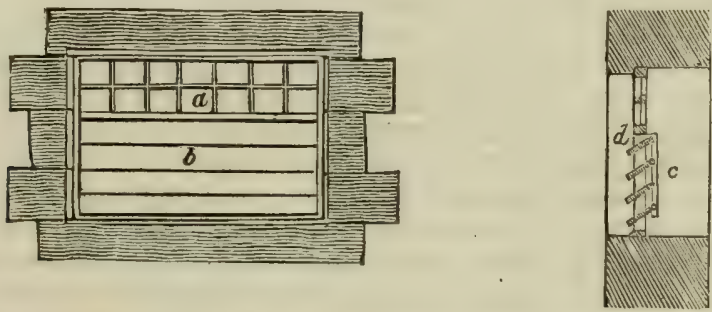

GRANARX WINDOW AND SECTION OF SHUTTERS.

them by an eye of iron, moving stiff on an iron pin passing through both the eye and bar $c$. The granary on the right hand being the smallest, and immediately over the work-horse corn-chest, should be appropriated to the use of horse-corn and other small quantities of grain to be first used. The other granary may contain seed-corn, or grain that is intended to be sold when the prices suit. For repairing or cleaning out the threshing-machine, a large opening in the wall of this granary, exactly opposite the machinery of the mill in the upper barn, will be found convenient. It should be provided with a large movable board, or folding doors, to close on it, and to be fastened from the granary. This opening is not shown in fig. 16.

(59.) At the end of the straw-barn $\mathrm{L}$ is the wool-room W, fig. 16, its site being indicated by $W$ on the roof of the isometrical view, fig. 3 , Plate III. It just covers the small hammels $X$, and is therefore 25 feet in length and 18 feet in breadth. It enters from the straw-barn $\mathrm{L}$ by means of the stone or wooden trap-stair $c^{\prime}$. Its floor should be made of good wood, its walls and roof lathed and hair-plastered. Its window should be formed like that of the byres, with a glazed sash above, and opening shutters below. A curtain should be hung across the window to screen the light and air from the wool when desired. The door need not exceed 6 feet in hight, but should be $3 \frac{1}{2}$ feet in width, to let a pack of wool pass easily (203) 
through. As the wool is most conveniently packed in this room, there should be provided in the roof two strong iron hooks, for suspending the comers of the pack-sheet in the act of packing it, and another from which to susperd the beam and scales for weighing the fleeces. Although the wonl will usually occupy this room only when the cattle are in the field, yet in case it should be found expedient to keep it over year, or have animals in the small hammels $\mathrm{X}$ in summer, and in case their breath should ascend into the wool through any openings of the joinings of the deals of the floor, it will be a safe precaution for preserving the wool in a proper state, to have the roof of the hammels below lathed and plastered. This room could he entered by a door and stone hanging-stair in the gable.

(60.) $\mathrm{M}$ and $\mathrm{N}$ in the plan, fig. 4, Plate IV. are hammels for the feeding of cattle, rearing of young horses, and tending of queys in calf until they are tied up in the cow-house. 1. Hammels consist of a shed, and an open court, communicating by a large opening. The shed part need not be so wide as the rest of the apartments in the farmstead, in so far as the comfort of the animals is concerned; and in making them narrower considerahle saving will be effected in the cost of roofing. 2. There is no definite rule for the size of hammels ; but as their great convenience consists in conferring the power to assort cattle according to their age, temper, size and condition, while at liberty in the fresh air, it is erident that hammels should be much smaller than courts, in which no assortment of animals can be attempted. 3. The courts of hammels, from which the dung is proposed to be taken away by horse and cart, should not be less than 30 feet in length by 18 feet in breadth, and their entrance gates 9 feet in width; and this size of court will accommodate 4 oxen that will each attain the weight of 70 stones imperial. This is the size of the courts of the bammels M. Should it not be thought inconvenient to take the dung out of the courts with barrows, then they need not be made larger than 20 feet in length by 17 feet in width, and this is the size of the courts of the hammels $\mathbf{N}$, which will accommodate 3 oxen of the above size. 4. The sheds to both sizes of courts need not exceed 14 feet in width, and their length will be equal to the width of the courts. Of these dimensions 4 oxen in the larger will have just the same accommodation as 3 oxen of the same size in the smaller hammels. 5. All hammels should have a trough, $z$, for turnips, fitted up against one of the walls of the court. The side-wall is the most convenient part, when a large gate is placed in front, through which the carts are backed to clear away the dung from the courts. In the case of the smaller courts, the turnips may be supplied to the trough over the top of the front wall. 6. To give permanency to hammels, the shed should be roofed as effectually as any of the other buildings, thongh to save some expense at first, many farmers are in the habit of roofing them with small trees placed close together on the tops of the walls of the sheds, and of building thereon either straw, corn, or beans. This is certainly an excellent place upon which to stack beans or peas; but the finished building is that which should be adopted in all cases. Temporary erections are constantly needing repairs, and in the end actually cost more than work substantially executed at first. 7. The division betwixt the shed and court forms the front wall of the shed, through which an opening forms the door betwixt them. This door, 6 feet in width, should always be placed at one side and not in the middle of the hammel, to retain the greatest degree of warmth to the interior of the shed. The corners of its scutcheon should be rounded off to save the cattle being injured against sharp angles. The divisions betwixt the respective courts should be of stone and lime walls, 1 foot in thickness, and 6 feet in hight. Those with(204) 
in the sheds should be carried up quite close to the roof. Frequently they are only carried up to the first balk of the couples, over which a draught of air is generated along the inside, from shed to shed, much to the discomfort of the animals ; and this inconvenience is always overlooked in hammels which are built with the view of saving a little cost in building up the inside division walls to the roofs. 8. Racks for fodder should be put up within the sheds, either in the three spare corners, or along the inner end. 9. In my opinion there is no way so suitable for feeding oxen, bringing up young horses in winter, or taking care of heifers in calf, as hammels; and of the two sizes described above, I would decidedly prefer the smaller, as permitting the fewer number of animals to be put together. 10. XX are two small hammels at the end of the strawbarn $\mathrm{L}$ for accommodating a bull, or stallion, or any single animal that requires a separate apartment for itself. These are each 18 feet in length and 12 feet in width within the sheds, the roofs of which are formed of the floor of the wool-room W; and 29 feet in length and 12 feet in width in the courts. The doors into them should be made to open outward, on giblet-checks. The courts are furnished with turnip-troughs, $z$, and one water-trough, $w$, will serve both courts, as shown in the plan, figure 4, Plate IV. A rack should be fitted up for fodder in the inside of each shed.

(61.) It should be observed that a part of the hammels $N$ is fitted up as a byre $Y$. This byre is intended to accommodate the servants' cows.There are 8 stalls -6 for the plowmen's, 1 for the farm-steward's, and 1 for the shepherd's cows-and they are nearly 5 feet in width. The length of the byre is 38 feet, and its width is only 14 feet, which gives a rather small space behind the cows; but, as servants' cows are generally small, and the milk from them immediately carried away, if there is just sufficient room for feeding and milking them, and adequate comfort to the cows themselves a large space behind them is unnecessary. This byre has a ventilator $r^{\prime}$ The cows are furnished with an open court $v, 38$ feet in length and 20 feer in width, and a water-trough $w$.

(62.) I and $\mathrm{K}$ of the plan, fig. 4, Plate IV. are two large courts for young cattle, both in the immediate vicinity of the straw-barn $\mathrm{L}$, and both having a shed D under one of the granaries; $I$ is 84 feet in length and 76 feet in width, and K 84 feet in length and 77 feet in width. Troughs for turnips should be fitted up against one or more of the walls surrounding the courts in the most convenient places, such as at $z$ in both courts. Besides racks for fodder, $h^{\prime}$, against one of the walls within the sheds D D, there should racks be placed in the middle of the conrts, that the cattle may stand around and eat out of them without trouble. The square figures $o o$ in the middle of the courts $I$ and $K$ indicate the places where the racks should stand, and their form may be seen at $o o$ in the isometrical view, fig. 3, Plate III. Around two sides of $\mathrm{K}$ is a paved road $e^{\prime}, 13$ feet in width, for carts going to be loaded with grain at the door of the corn-barn C. Though the cattle have liberty to walk on this pavement, it should be kept clean every day. Such courts are quite common in steadings for the rearing of young cattle in winter, and even for feeding large lots of cattle together, as is practiced by most farmers who do not rear calves; but, for my part, I prefer hammels for all classes and ages of cattle; for, although cattle are restricted in them in regard to space, still the few in each hammel have plemty of room to move about. There is no hardship to the animals in this degree of confinement, while they have the advantage of quietness among them. selves in the open air, produced by being assorted according to temper, size, sex, and age. On abolishing large courts altogether out of steadings, (205) 
I would substitute in their place hammels of different sizes, and convert the cattle-sheds $\mathrm{D}$ and $\mathrm{D}$ into cart-sheds and receptacles for the larger class of implements. It is probable that the use of large courts will not soon be dispensed with in farmsteads, and for that reason $I$ have retained them in the plan; but I have no doubt that a period will arrive when farmers, to insure to themselves larger profits from cattle, will see the advantage of taking the utmost care of them, from the period of their birth until disposed of in a ripe condition at an early age; and then hammels will be better liked than even courts are at the present day, and farmers will then universally adopt them.

(63.) Fig. 18 represents a trough for turnips suited both for hammels and courts, where $a$ is the wall against which the trough is built, and $b$ a build-

Fig. 18.

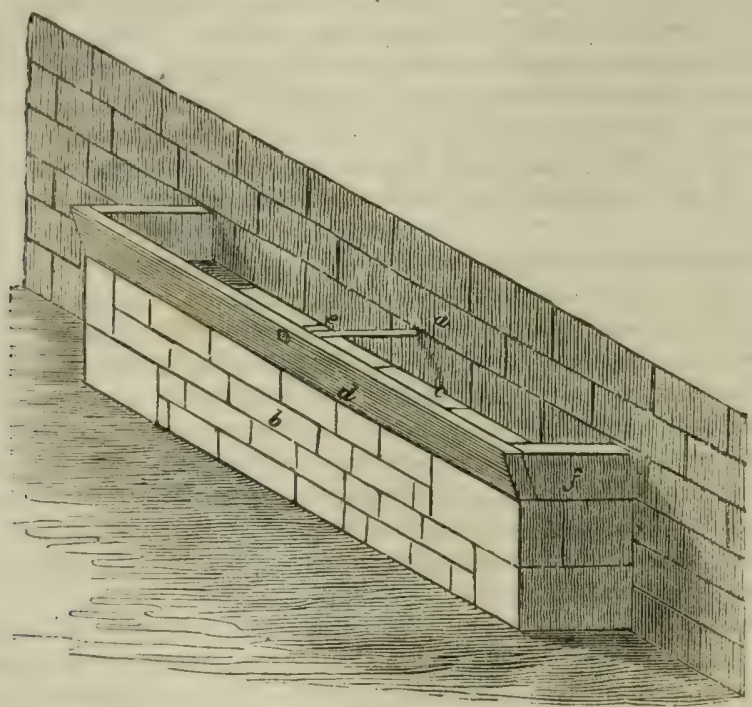

TURNIP TROUGH.

ing of stone and lime 2 feet thick. The lime need not be used for more than 9 inches in the front and sides of the wall, and the remaining 15 inches may be filled up with any hardmaterial; $c$ is the flagging placed on the top of the wall, and forming the bottom of the trough. Some board the bottom with wood, where wood is plentiful, and it answers well enough; but, of course, flags, where easily obtained, are more durable, though wood is pleasanter for the cattle in wet and frosty weather in winter. $d$ is a plank, 3 inches thick and 9 inches in depth, to keep in the turnips. Oak planking from wrecks, and old spruce trees, however knotty, I have found to make cheap and very durable planking for the edging of turnip troughs. The planks are spliced together at the ends, and held on edge by bars of iron $e$ batted with lead into the wall, in the manner already described in $(44$,$) p. 100$; and the figure clearly shows this mode of fastening the plank. The masonry represented in the figure is finer than need be for the pur. pose; and the trough, though here shown short, may extend to any length along the side or sides of a court.

(64.) The straw-racks for courts are made of various forms. 1. On farms of light soils, where straw is usually scarce, a rack of the form of (206) 
fig. 19, having a movable cover, will be found serviceable in preserving the straw from rain, where $a a$ is the bottom inclined upward to keep the straw always forward to the front of the rack in reach of the cattle.Through the apex of the bottom, the shank' which supports the movable cover $b$ passes, and this cover protects the straw from rain. The shank with its cover is worked up and down, when a supply of straw is given, by a rack and pinion $c$, to which pinion is attached the lying shaft, on which is shipped a handle $d$. A rack of this kind is made of wood, and should be 5 feet square, and 5 feet in hight to the top of the corner posts; and sparred all round the sides, as well as the bottom, to keep in the straw. 2. A more common kind of rack is represented by fig. 20, which is of a square form, and sparred all round the sides to keep in the straw. The cattle draw the straw through the spars as long as its top is too high for them to reach over it; but after the dung accumulates, and the rack thereby becomes low, the cattle get at the straw over the top. This kind is also made of wood, and should be 5 feet square and 4 feet in hight.3. Fig. 21 represents a rack made of malleable iron, intended to supply the straw to the cattle always over its top, and is therefore not sparred,

Fig. 19.

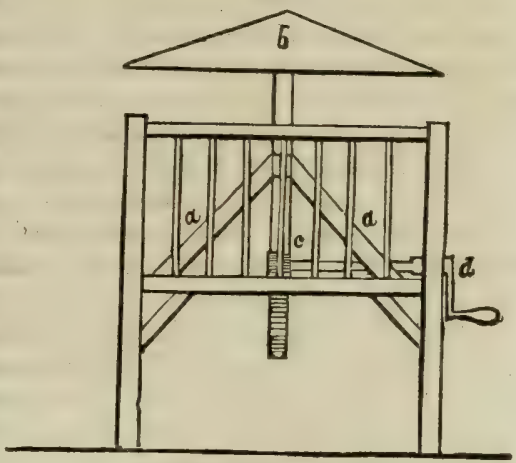

COVERED STRAW-RACK. but rodded, in the sides, to keep in the straw. In use it remains constantly on the ground, and not drawn up as the dung accumulates, as in the case of the other kinds of racks described. This kind is $5 \frac{1}{2}$ feet in length, $4 \frac{1}{2}$ feet in breadth, and $4 \frac{1}{2}$ feet in hight; the upper rails and legs are made of iron 1 inch square, and the other rails $\frac{3}{4}$ inch. Iron is, of course, the most durable material of which straw-racks for cattle can be made.

(65.) There are few things which indicate greater care for cattle when housed in the farmstead, than the

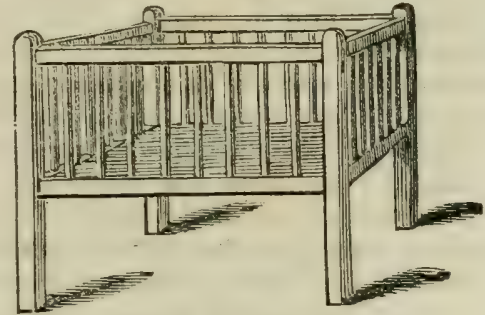

WOODEN STRAW-RACK.
Fig. 20.

Fig. 21.

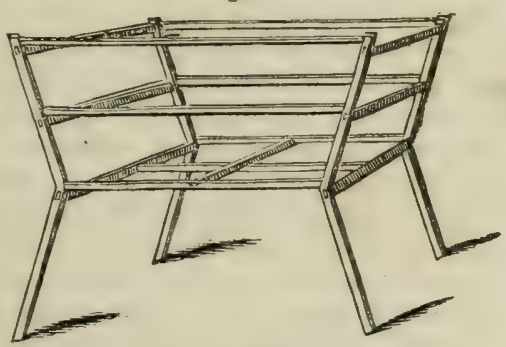

IRON STRAW-RACK. erection of places for storing turnips for their use. Such stores are not only convenient, but the best sort of receptacles for keeping the turnips clean and fresh. They are seen in the isometrical view, fig. 3 , Plate III. and in the plan, fig. 4, Plate IV. at $e$ and $f$ for the use of the hammels $\mathbf{M}$; at $g$ for that of the court $K$; at $h$ for the hammels $X$, and servants' cowhouse $\mathrm{Y}$; at $i$ for the use of the court $\mathrm{I}$; at $m$ for that of the cow-house $\mathrm{Q}$, and calves' cribs $\mathbf{R}$; and at $p$ and $q$ for the hammels $N$. The walls of these turnip-stores should be made of stone and lime, 8 feet by 5 feet in(207) 
side, and 6 feet in hight, with an opening in front, 2 feet and upward from the ground, for putting in and taking out the turnips thereat; or they may be made of wood, where that is plentiful, with stont upright posts in the four corners, and lined with rough deals. They may be covered with the same material, or with straw, to protect the turnips from frost. They should be placed near the apartments they are intended to supply with turnips, and at the same time be of easy access to carts from the roads. These receptacles may, of course, be made of any convenient form.

(66.) The supply of water to all the courts where as many turnips as they can eat are not given to the cattle, is a matter of paramount consideration in the fitting up of every farmstead. In the plan, fig. 4, Plate IV. troughs for water are represented at $w$, in the large courts $I$ and $K$, in those of the cow-houses $l$ and $v$, and calves' cribs $k$, as well as in those of the bulls' hammels $X$. The troughs may be supplied with water either directly from pump-wells, or by pipes from a fountain at a little distance-the former being the most common plan. As a pump cannot conveniently be placed at each trough, there is a plan of supplying any number of troughs from one pump, which I have found to answer well, provided the surface of the ground will allow the troughs being nearly on the same level, when placed within reach of the animals. The plan is to connect the bottoms of any two or more troughs, set on the same level, with lead pipes placed under ground; and, on the first trough being supplied direct from the pump, the water will flow to the same level throughout all the other troughs. There is, however, this objection to this particular arrangenent, that, when anv one of the troughs is emptying by drinking, the water is drawn off from: the rest of the troughs, that it may maintain its level throughout the whole; whereas, if the trough which receives the water were placed a few inches below the top of the one supplying it, and the lead pipe were made to come from the bottom of the supply trough over the top of the edge of the receiving one, the water would entirely be emptied from the trough out of which the drink was taken, without affecting the quantity in any of the others. 1. To apply these arrangements of water-troughs to the plan fig. 4. Plate IV. Suppose that a pump supplies the trough $w$, in the court I, direct from a well beside it-a lead pipe passing, on the one hand, from the bottom of this trough under ground to the bottom of the trough $w$, in the court $\mathrm{K}$, and, on the other hand, to that of the trough $w$ in the calves' court $k$, and thence to that of the trough $w$ in the court $l$ of the cow-house $\mathrm{Q}$; and, in another direction, to the bottom of the trough $w$ in the court $v$ of the servants' cow-house $\mathrm{Y}$; and suppose that the troughs in $\mathrm{K}$ and $k$ and $l$ and $v$ are placed on the same level as the supply trough in the court $\mathbf{I}$, it is obvious that they will all be supplied with water as long as there is any in the supply trough, and the emptiness of which will indicate that the water from it had been drawn off by the other troughs, and that the time had fully arrived when it was necessary to replenish the trough in the court I direct from the pump. The supply trough, in such an arrangement, should be larger than either of the other troughs. The trough of the bulls' hammels $\mathrm{X}$ might be supplied by a spout direct from the pump in the court I. In this way a simple system of watering might be erected from one pump to supply a number of troughs in different courts. It may be proper to illustrate this mode of connecting water-troughs by a figure. Let $b$, fig. 22 , be the supply trough at the pump, and $f$ the receiving one, and let both be placed on the same level; then let $g$ be a lead pipe connecting the lottoms of both troughs, the ends of which are protected by hollow hemispherical drainers, such as $c$. It is here obvious, from the law which regulates the equilibrium of fluids, that the water, as supplied by the pump to $(208)$ 
$b$. will always stand at the same hight in $f$. 2. I shall now illustrate the other method of supplying troughs also by a figure. Let $a$, fig. 22 , be the supply trough immediately beside the pump; let $b$ be the trough in any other court to be supplied with water from $a$, and for that purpose it should be placed 3 inches below the level of $a$. Let a lead pipe $d$ be fastened to the under side of the bottom of $a$, the orifice of which, looking upward, to be protected by the hemispherical drainer $c$. Let the lead pipe $d$ be passed under ground as far as the trough $b$ is situated from $a$, and emerge out of the ground by the side of and over the top of $b$ at $e$. From this construc-

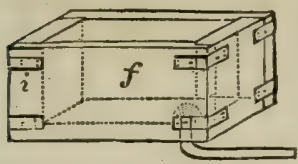

Fig. 22.
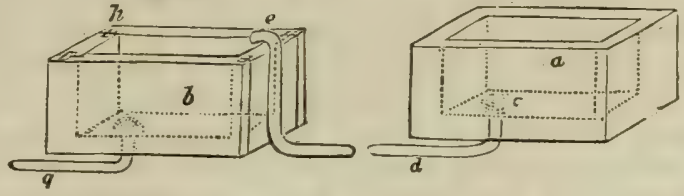

WATER-TROUGHS

tion it is clear that, when $a$ is filling with water from the pump, the moment the water rises to the level of the end of the pipe at $e$, it will commence to flow into $b$, and will continue to do so until $b$ is filled, if the pumping be continued. The water in $a$, below the level of the end of the pipe at $e$, may be used in $a$ without affecting that in $b$, and the water in $b$ may be wholly used without affecting that in $a$. 3. Water-troughs may be made of various materials; the form of $a$ is that of one hewn out of a solid block of freestone, which makes the closest, most durable, and best trough; that of $b$ is of flag stones, the sides of which are sunk into the edges of the bottom in grooves filled with white lead, and there held together with iron clamps $h$. This is a good enough kind of trough, but is apt to leak at the joints. Trough $f$ is made of wood dove-tailed at the corners, and held together by clamps of iron $i$. These troughs may be made of any size and proportions. 4. In some steadings, the water-troughs are supplied from a large cistern, somewhat elevated above their level, and the cistern is filled with water from a well either by a common or a forcepump. But, in this arrangement, either a cock, or ball and cock, are requisite at each trough: in the case of a cock, the supply of water must depend on the cock being turned on the trough in due time; and, in that of a ball and cock, the supply depends on the cistern being always supplied with water from the pump. There is great inconvenience and expense in having a ball and cock at each trough. 5. In steadings where there is an abundant supply of water from natural springs, accessible without the means of a pump, lead pipes are made to emit a constant stream of water into each trough, and the surplus is carried away in drains, perhaps to the horse-pond. 6. There is still another mode which may be adopted where the supply of water is plentiful, and where it may flow constantly into a supply-cistern. Let the supply-cistern be 2 feet in length, 1 foot wide, and 18 inches in depth, and let it be provided with a ball and cock, and let a pipe proceed from its bottom to a trough of dimensions fit for the use of cattle, into which let the pipe enter its end or side a little way, say 3 inches, below the mouth of the trough. Let a pipe proceed from this trough, from the bend of the pipe, as from the bend of the right-hand pipe $e$ at the bottom of the trough $b$, fig. 22 , to another trough, into whose end it enters in like manner to the first trough, and so on into as many succeeding troughs, from trough to trough, on the same level, as you require; and the water will rise in each as high as the mouth of the pipe, and, when with(209) $\ldots . . .8$ 
drawn by drinking from any one of them, the ball and cock will replenish it direct from the supply-cistern; but the objection to a ball and cock applies as strongly to this case as to the other methods, although there is economy of pipe attending this method.

(67.) In most farmsteads a shed for carts is provided for, though many farmers are too regardless of the fate of these indispensable machines by permitting them to be exposed to all vicissitudes of weather. The cart-shed is shown at $\mathrm{V}$ in the isometrical view fig. 3, Plate III. and by $\mathrm{V}$ in the plan fig. 4, Plate [V. immediately behind the hammels M, facing the workhorse stable $\mathrm{O}$, and looking to the north, away from the shrinking effects of the sun's heat. It is 80 feet in length, 15 feet in width within the pillars, and 8 feet in hight to the slates in front. The ronf slopes from the back-slating of the hammels, and is supported at the eave by a beam of wood resting on 7 stone and lime pillars, and a wall at each end. The pillars should be of ashler, 2 feet square, and rounded on the corners, to avert their being chipped off with the iron rims of the wheels by the carelessness of the plowmen, when backing the carts into the shed. For the same purpose, a pawl-stone should be placed on each side of every pillar. This shed is longer than what is actually required where double-horse carts are only used, 6 ports being sufficient for that number, but singlehorse carts are now so much in use, that more of these are required, perhaps not fewer than 8. Two single-horse carts can stand in each port, one in front of the other. Any spare room in the shed may be employed in holding a light cart, the roller, the grass-seed machine, the turnip-sowing machine, the bodies of the long carts, and other articles too bulky to be stowed into the implement-house G.

(68.) Though swine are usually allowed to run about the steading at pleasure, yet, to do them justice, they should be accommodated at times with protection and shelter, as well as the rest of the live-stock. Piggeries or pig-sties are therefore highly useful structures at the farmstead. They are of three kinds: 1. Those for a brood-sow with a litter of young pigs. This kind should have two apartments, one for the sow and the litter to sleep in, covered with a roof, and entered by an opening, the other an open court in which the feeding-trough is placed. For a breeding-sty each apartment should not be less than 6 feet square. This kind of sty is represented by $c c$ in the plan, fig. 4, Plate IV. and at $c$ in the isometrical view, fig. 3 , Plate III. 2. Those for feeding-pigs: these should also have two apartments, one with litter for sleeping in, covered by a roof and entered by an opening; the other an open court for the troughs for food. A sty of 4 feet square

Fig. 23.

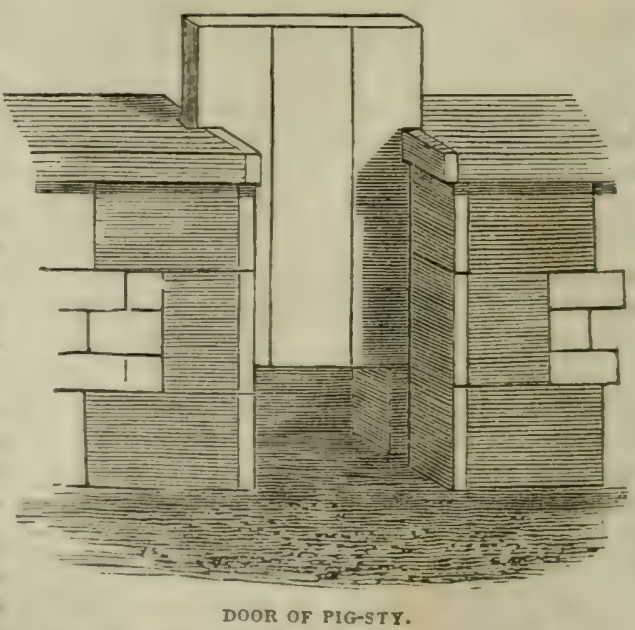

in each apartment, will accommodate 2 feeding-pigs of 20 stones each. Of this kind of sty 4 are represented at $a$ in the isometrical view, fig. 3 , 
Plate III. and in the plan fig. 4, Plate IV. These two sorts of sties may each have a roof of its own, or a number of them may have a large roof over them in common. The former is the usual plan, but the latter is the most convenient for cleaning out, and viewing the internal condition of the sties. 3. The third kind is for the accommodation of weaned young pigs, when it is considered necessary to confine them. These should have a shed at one end of the court, to contain litter for their beds. The court and shed are represented at $b$ in the plan, fig. 4, Plate IV. and isometrical view, fig. 3 , plate III. They extend 25 feet in length and 21 feet in width. 4. The floors of all these kinds of sties should be laid with stout flags to prevent every attempt of the swine digging into the ground with their snouts. 5. As swine are very strong in the neck, and apt to push up common doors, the best kind of door which I have found for confining them by, is that formed of stout boards, made to slip up and down within a groove in hewn stones forming the entrance in the outside wall. This form of door may be seen in fig. 23 , and seems to require no detailed description.

(69.) Domestic fowls require accommodation in the steading as well as other stock. 1. They should be provided with houses for hatching their eggs in, as also for roosting in undisturbed, and both kinds should be constructed in accordance with the nature of the birds, that is, those fowls which roost on high should be kept in a different house from those which rest on the ground. The roosts should be made of horizontal round spars of wood, and spaces of 18 inches cube should be made of wood or stone at a hight of 1 foot or 18 inches from the ground, to contain the straw nests for those which are laying. The hatching-houses should be fitted up with separate compartments containing large nests elevated only 3 or 4 inches above the level of the floor. 2. The foundations should be of large stones and the flooring of strong flags, firmly secured with mortar above a body of small broken stones, and the roofs completely filled in under the slates to prevent the possibility of vermin lodging either above or below ground. 3. Good doors with locks and keys should be put on the houses, windows provided for the admission of light and air, and an opening made in the outer wall of the roosting-house, 4 feet above the ground, to admit the fowls which roost on high by a trap-ladder resting on the ground, as at $d$ in fig. 3 , Plate III. The roof should be water-tight at all times, and lathed and plastered in the inside, for warmth and cleanliness. The fowls' house may be seen at $d$ in the isometrical view, fig. 3, Plate III, and in the plan, fig. 4, Plate IV. 4. It is not absolutely necessary that either the hen-houses or pig-sties should be placed where they are represented in the plan; but as they do not there interrupt the free entrance of the sun into the court $K$, and therefore do not interfere with the comfort of more important stock, they are there of easy access, themselves quite exposed to the sun, which they should always be, and they square up the front of the farmstead. The hen-house has been recommended by some people to be built near the cow-byre to derive warmth from it; but all the heat that can be obtained from mere juxtaposition to a byre is quite unimportant, and not to be compared to the heat of the sun in a southern aspect.

(70.) $\mathrm{S}$, in both the plan, fig. 4, Plate IV. and isometrical view, fig. 3, Plate III. is part of the stack-yard. 1. As most of the stacks must stand on the ground, the stack-yard should receive that form which will allow the rain-water to run off and not injure their bottoms. This is done by ridging up the ground. The minimum breadth of these ridges may be determined in this way. The usual length of the straw of the grain crops can be conveniently packed in stacks of 15 feet diameter; and as 3 feet is (211) 
little enough space to be left on the ground between the stacks, the ridges should not be made of less width than 18 feet. 2. The stack-yard shouid be inclosed with a substantial stone and lime wall of $4 \frac{1}{2}$ feet in hight. In too many instances the stack-yard is entirely uninclosed and left exposed to the depredation of every animal. 3. It is desirable to place the outside rows of the stacks next the wall on stools or stathels, which will not only keep them off the wet ground, should they remain a long time in the stackyard, but in a great measure prevent vermin getting into the stacks. These stathels are usually and most economically made of stone supports and a wooden frame. The frame is of the form of an octagon, under each angle and centre of which is placed a support. The frame-work consists of pieces of plank, $a$, fig. 24 , one of which is 15 feet, and the others $7 \frac{1}{2}$ feet in length, 9 inches in depth, and $2 \frac{1}{2}$ inches in thickness; and the supports consist of a stone, $b$, sunk to the level of the ground, to form a solid foundation for the upright support, $c, 18$ inches in hight, and 8 inches square, to stand upon, and on the top of this is placed a flat rounded stone

Fig. 24.

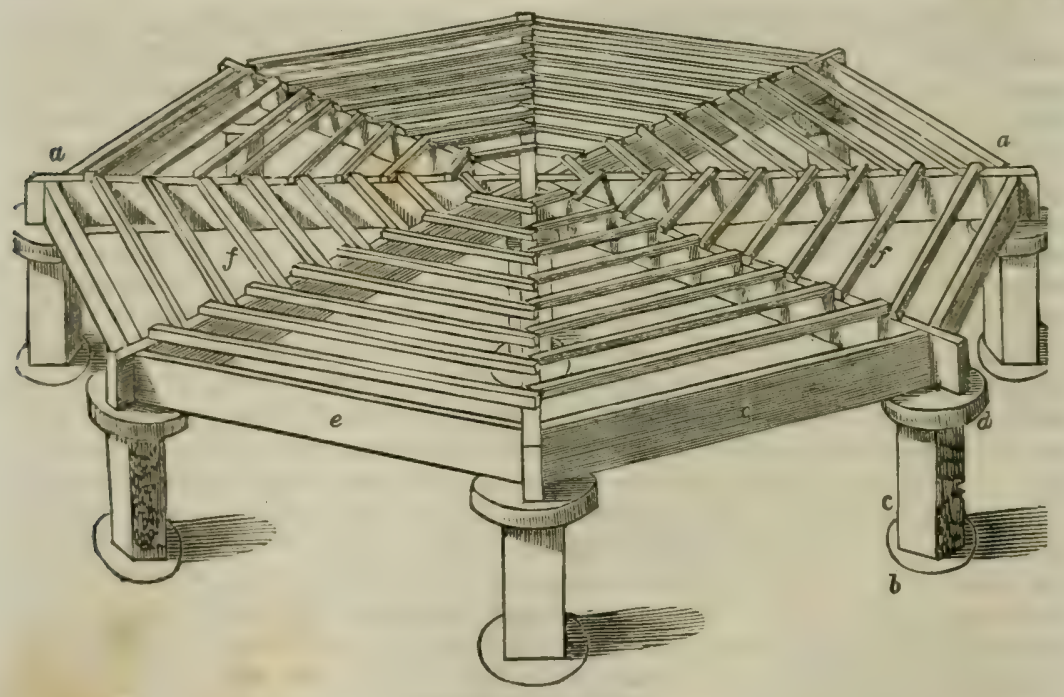

A STATHEL FOR STACKS.

or bonnet, $d$, of at least 2 inches in thickness. The upright stone is bedded in lime, both with the found and bonnet. All the tops of these stone supports, 8 in number around the ninth in the center, must be on the same level. Jpon them are placed on edge the scantlings $a, 9$ inches in depth, to each side of which are fastened with strong nails the bearers $e e$, also 9 inches in depth and 2 inches in thickness. In this way each support bears its share of the frame-work. The spaces between the scantlings $a$ are filled up with fillets of wood, $f f$, nailed upon them. If the wood of the frame-work were previously preserved by Kyan's process, it would 'Tast perhaps twenty years, even if made of any kind of home timber, such as larch or Scotch fir. 4. There should be a wide gateway into the stack-yard, and where the corn is taken on carts to the upper barn to be threshed, the same gateway may answer both purposes, but where there is a gangway to the upper barn, the gate may be placed in the most convenient side of the stack-yard. Where carts are solely used for taking (212) 
in the corn to the upper barn, the rows of stacks should be built so widely asunder as to permit a loaded cart to pass at least between every two rows of stacks, so that any particular stack may be accessible at pleasure. When a gangway is used, this width of the arrangement of the stacks is not necessary, the usual breadth of 3 feet between the stacks permitting the passage of corn-barrows, or of back-loads of sheaves. Thus, where a gangway is used, the stack-yard is of smaller area to contain the same bulk of grain. 5. Stack-stools, or stathels, or staddles, as they are variously called, are sometimes made of cast-iron; but these, though neat and efficient, are very expensive and liable to be broken by accidental concussion from carts. Stacks on stathels are represented in fig. 3 , Plate III. by figures of stacks, and in fig. 4, Plate IV. by circles. Stathels should also be placed along the stack-yard wall from $m^{\prime}$ to $n^{\prime}$ and from $n^{\prime}$ to $\theta^{\prime}$ in fig. 3, Plate III.

(71.) A pigeon-house is a necessary structure, and may be made to contribute a regular supply of one of the best luxuries raised on a farm. As pigeons are fond of heat at all seasons, there seems no place in the farmstead, especially in winter, better suited for the accommodation of their dwelling than the upper part of the boiling-house. A large pigeon-house is not required, as. with ordinary care, pigeons being very prolific breeders, a sufficien: number for the table may be obtained from a few pairs of breeding r,yrds. I have known a pigeon-house not exceeding 6 feet cube, and not very favorably situated either for heat or quietness, yield 150 pairs of pigenss in a season. For a floor, a few stout joists should be laid on the tops of the walls. The flooring should be strong and close, and the sides front and roof, in the inside, lathed and plastered. A small door will wutfice for an entrance, to which access may be obtained from the boil,yg-house by a ladder. The pigeon-holes may be seen in the gable of tne boiling-house $U$, in the isometrical view, fig. 3, Plate III. They may be formed of wood or stone, and should always be kept bright with white paint. The cells in this sort of pigeon-house should be made of wood, and placed all round the walls. I think that 9 inches cube are large enough for the cells. Another site for a pigeon-house may be chosen in the gable of the hay-loft above the riding-horse stable, in fig. 1, Plate I.

(72.) Although potatoes are best kept in winter in pits, yet an apartment to contain those in use for any of the stock, will be found very convenient in every steading. For convenience the potato-store should be near the place of their consumption or their preparation into food. In the latter case, proximity to the boiling-house is convenient. 1. Accordingly one potato-store will be found at $f^{\prime}$, just at the door of the boiling-house $U$, in the isometrical view, fig. 3 , Plate III. and plan fig. 4 , Plate IV. It is 30 feet in length and 10 feet in width, and its door being placed in the center, two kinds of potatoes may conveniently be stored in it at the same time, without the chance of admixture. The door should be provided with a good lock and key. 2. Another store of potatoes may be placed in the apartment $f^{\prime}$ next the cart-shed $V, 18$ feet by 15 feet, to supply them to the feeding beasts in the hammels $M$, or to the young stock in the courts; but should this apartment not be required for this, it can be used for any other purpose.

(73.) Rats and mice are very destructive and dirty vermin in steadings, and particularly to grain in granaries. Many expedients have been tried to destroy them in granaries, such as putting up a smooth triangular board across each corner, near the top of the wall. The vermin come down any part of the walls to the corn at their leisure, but when disturbed run to the corners, up which they easily ascend, but are prevented gaining the top (213) 
of the wall by the triangular boards, and on falling down either on the corn or the floor, are there easily destroyed. But preventive means in this case are much better than destructive, inasmuch as the granaries are thereby always kept free of them, and consequently always sweet and clean. 1. The great means of prevention is, to deprive vermin of convenient places to breed in above ground, and this may be accomplished in all farmsteads by building up the tops of all the walls, whether of partitions or gables, to the sarking, or the slates, or tiles, as the case may be, and beam-filling the tops of the side walls, between the legs of the couples, with stone and mortar; taking care to keep the mortar from contact with the timber. These places form the favorite breeding-ground of vermin in farmsteads, but which delightful occupation will be put a stop to there, when occupied with substantial stone and mortar. The top of every wali, whether of stables, cow-houses, hammels, and other houses, should be treated in this manner; for, if one place be left them to breed in. the young fry will find access to the corn in some way. The tops of the walls of old as well as of new farmsteads can be treated in this manner, either from the inside, or, if necessary, by removing the slates or tiles until the alteration is effected. One precaution only is necessary to be attended to in making beam-fillings, especially in new buildings, which is, to leave a little space under every couple face, to allow room for subsidence or the bending of the couples after the slates are put on. Were the couples, when bare, pinned firmly up with stone and lime, the hard points would act as fulcra, over which the long arm of the couple, while subsiding, with the load of slates new put on, would act as a lever, and cause their points to rise, and thereby start the nails from the wall plates, to the imminent risk of pushing out the tops of the walls, and sinking the top of the roof. 2. But besides the tops of the walls, rats and mice breed under ground, and find access into apartments through the floor. To prevent lodgment in those places also, it will be proper to lay the strongest flagging and causewaying upon a bed of mortar spread over a body of 9 inches of small broken stones, around the walls of every apartment on the groundfloor where any food for them may chance to fall, such as in the stables, byres, boiling-house, calves'-house, implement-house, hay-house, pig-sties, and hen-house. The corn-barn has already been provided for against the attacks of vermin; but it will not be so easy to prevent their lodgment in the floors of the straw-barn and hammels, where no causewaying is usually employed. The principal means of prevention in those places are, in the first place, to make the foundation of the walls very deep, not less than two feet, and then fill up the interior space hetween the walls with a substantial masonry of stone and lime mixed with broken glass; or perhaps a thick body of small broken stones would be sufficient, as rats cannot burrow in them as in earth.

(74.) It is very desirable, in all courts occupied by stock, to prevent the farther discharge of rain-water into them, than what may happen to fall upon them directly from the heavens. 1. For this purpose all the eaves of the roofs which surround such courts should be provided with rain-water spouts, to carry off the superfluous water, not only from the roofs, but to convey it away in drains into a ditch at a distance from, and not allow it to overflow the roads around, the farmstead. 2. With a similar object in view, and with the farther object of preserving the foundations of the walls from damp, drains should be formed along the bottom of every wall not immediately surrounding any of the courts. These drains should be dug 3 inches below the foundation-stones of the walls, a conduit formed in them of tile and sole, or flat stones, and the space above (214) 
the conduit to the surface of the ground filled up with broken stones. These broken stones receive the drop from the roofs, and carry away the water; and, should they become hardened above the drains, or grown over with grass, the grass may be easily removed, and the stones loosened by the action of a hand-pick. Rain-water spouts should be placed under the fronteaves of the building $\mathrm{AA}$, and on both sides of the straw-barn $\mathrm{L}$, and along the front-eaves of the stables $O$ and $P$, of the byre $Q$, calves' cribs $R$, and of the hammels $M$ and $N$. These lines of eaves may easily be traced in the isometrical view, fig. 3 , Plate III. The spouts may be made either of wood or cast-iron, the latter being the more durable, and fastened to the wall by iron holdfasts. Lead spouts are, I fear, too expensive for a steading, though they are by far the best. The positions of the rain-water drains around the steading may be traced along the dotted lines, and the courses the water takes in them are marked by arrows, as in the plan, fig. 4, Plate IV.

(75.) But it is as requisite to have the means of conveying away superfluous water from the courts, as it is to prevent its discharge into them. 1. For this purpose, a drain should enter into each of the large courts, and one across the middle of each set of hammels. The ground of every court should be so laid off as to make the lowest part of the court at the place where the drain commences or passes; and such lowest point should be furnished with a strong block of hewn freestone, into which is sunk flush an iron grating, having the bars only an inch asunder, to prevent the passage of straws into the drain. Fig. 25 gives an idea of such a grating, made of malleable iron, to bear rough usage, such as the wheel of a cart passing over it; the bars being placed across, with a curve downuard, to keep them clear of obstructions for the water to pass through them. A writer, in speaking of such gratings, says, "they should be strong, and have the ribs well bent upward, as in that form they are not so liable to be choked up."* This remark is quite true in regard to the form gratings should have in the sewers of towns, for with the ribs bent downward in such a place, the accumulated

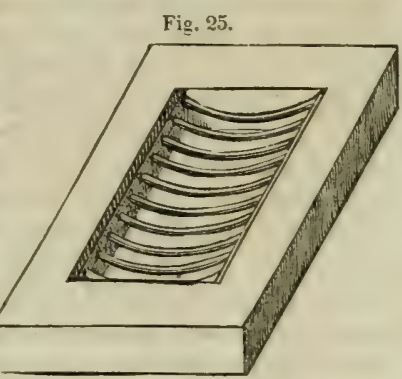

DRAIN GRATING. stuff brought upon them by the water would soon prevent the water get ting down into the drains ; but the case is quite different in courts where the straw covers the gratings from the first, and where being loose over the grating whose ribs are bent downward, it acts as a drainer, but were the gratings bent upward, as recommended, the same straw, instead of acting as loose materials in a drain through which the water percolates easily, would press hard against the ribs, and prevent the percolation of water through them. Any one may have perceived that the straw of dunghills presses much harder against a raised stone in the ground below it, than against a hollow. The positions of these gratings are indicated in the plan, fig. 4, Plate IV. by $x$ in the different courts; and in fig. 2, Plate II. they are seen at the origin of all the liquid manure drains, in the form of small dark squares. 2. Drains from the courts which convey away liquid manure as well as superfluous water, should be of a different construction from those described for the purpose of carrying away rainwater. They should be built with stone and lime walls, 9 inches high and 6 inches asunder, flagged smoothly in the bottom, and covered with

* Highland and Agricultural Society's Prize Essays, rol. viii. p. 375. (215) 
single stones. Fig. 26 shows the form of this sort of drain, and sufficiently explains its structure. As liquid manure is sluggish in its motion, the drains conveying it require a much greater fall in their course than rain-water drains. They should also run in direct lines, and have as few turnings as possible in their passage to the reservoir or tank, which should be situate in the lowest part of the ground, not far from the steading, and at some convenient place in which composts may be formed. One advantage of these drains being made straight is, that, should any of them choke up at any time by any obstruction, a large

Fig. 26.

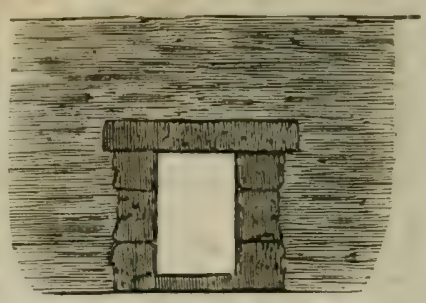

LIQUID MANURE DRAIN. quantity of water might be poured down with effect through them, to clear the obstruction away, as none of them are very long. These drains may be seen in the plan, fig. 4, Plate IV. to run from $x$ in their respective courts in straight lines to the tank $k^{\prime}$. It would be possible to have a tank in each set of hammels and courts, to let the liquid manure run directly into them; but the multiplicity of tanks which such an arrangement would occasion, would be attended with much expense at first, and much inconvenience at all times thereafter in being so far removed from the composts. Were the practice adopted of taking the liquid manure to the field at once, and pouring it on the ground, as is done by the Flemish farmers, then a tank in every court would be convenient.

(76.) The liquid manure tank should be built of stone or brick and lime. Its form may be either round, rectangular, or irregular; and it may be arched, covered with wood, left open, or placed under a slated or thatched roof-the arch forming the most complete roof, in which case the rectangular form should be chosen. I have found a tank of an area of only 100 square feet, and, a depth of 6 feet below the bottoms of the drains, contain a large proportion of the whole liquid manure collected during the winter, from courts and hammels well littered with straw, in a steading for 300 acres, where rain-water spouts were used. The position of the tank may be seen in the plan, fig. 4, Plate IV. at $k^{\prime}$. It is rectangular, 34 feet in length and 8 feet in width, and might be roofed with an arch. The tank $x$, in the isometrical view, fig. 3 , Plate III. is made circular, to show the various forms in which tanks may be made. A cast-iron pump should be affixed to one end of the tank, the spout of which should be as elevated as to allow the liquid to run into the bung-hole of a large barrel placed on the framing of a cart.

(77.) Gates should be placed on every inclosed area about the steading. Those courts which require the service of carts should have gateways of not less width than 9 feet; the others proportionally less. 1. The more common form of gate is that of the five-barred, and which, when made strong enough, is a very convenient form. It is usually hung by a heelcrook and band. I am not fond of gates being made to shut of themselves, particularly at a steading; for, whatever ease of mind that property may give to those whose business it is to look after the inclosure of the courts, it may too often cause neglect of fastening the gate after it is shut; and, unless gates are constantly fastened. where live-stock are confined, they may nearly as well be left altogether open. The force of the contrivance of gates to shut of themselves has often the effect of knocking them to pieces against the withholding-posts. 2. Sometimes large boarded doors are used as gates in courts, and especially in a wall common to two courts. They (216) 
are, at best, clumsy looking things, and are apt to destroy themselves by their own intrinsic weight. 3. Sometimes the gate is made to move up like the sash of a window, by the action of cords and weights rumning over pulleys on high posts-the gate being lifted so high as to admit loaded carts under it. This may be an eligible mode of working a gate betwixt two courts in the peculiar position in which the dung accumulating on both sides prevents its ordinary action, but in other respects it is of too complicated and expensive a construction to be frequently adopted. I shall have occasion afterward to speak at large on the proper construction of gates.

(78.) I wish to suggest some slight modifications of this plan of a steading, as they may more opportunely suit the views of some farmers than the particular arrangements which have been just described. 1. I have already suggested that, if the large courts $I$ and $K$ are to be dispensed with and hammels adopted in their stead, the hammels M could be produced toward the left as far as the causeway $e^{\prime}$, on the right hand of the strawbarn L; and so could the hammels $\mathrm{N}$ be produced toward the right as far as the south gate of the court I. By this arrangement the cart-shed $V$, and store-houses $g$ and $f^{\prime}$, would be dispensed with, and the cattle-sheds D D converted into cart-sheds and a potato-store. 2. The piggeries $a, b$, and $c$, could then be erected in the middle of the court at $K$, and the hen-houses in the middle of the court $\mathrm{I}$, respectively, of even larger dimensions than I have given them in the places they occupy. 3. If desired, the workhorse stable $O$ might be separated from the principal range $A$ by a cartpassage, as is the case with the byre-range $Q$, by which alteration the hayhouse and stable would have doors opposite, and the present north door of the hay-house dispensed with. It would be no inconvenience to the plowmen to carry the hay and corn to the horses across the passage. 4. If the stable were disjoined, the right-hand granary may have a window in the east gable, uniform with that in the west over the implement-house G. 5. It may be objected to the boiling-house $U$ being too far removed from the work-horse stable $\mathrm{O}$. As there is as little inherent affinity betwixt a boiling-house and byre as betwixt one and a stable, the boiling-house might be removed nearer to the stable, say to the site of the riding-horse stable $\mathrm{P}$, and the coach-house $\mathrm{Z}$ could then be converted into a potato-store, with a common door. 6. The gig-house and riding-horse stable could be built anywhere in a separate range, or in conjunction with the smithy and carpenter's shop, should these latter apartments be desired at the steading.7. The servants' cow-byre $Y$ could be shifted to the other end of the ham mel range $\mathrm{N}$, to allow the hammels to be nearest the straw-barn. 8. Any or all of these modifications may be adopted, and yet the principle on which the steading is constructed would not be at all affected. Let any or all of them be adopted by those who consider them improvements of the plan represented on Plate IV.

(79.) As I have mentioned both a smithy and carpenter's shop in connection with the steading, it is necessary to say a few words regarding them. It is customary for farmers to agree for the repairs of the iron and wood work of the farm with a smith and carpenter respectively at a fixed sum a-year. When the smithy and carpenter's shops are near the steading, the horses are sent to the smithy, and every sort of work is performed in the mechanic's own premises; but when they are situate at such a distance as to impose considerable labor on horses and men going to and from them, then the farmer erects a smithy at the steading for his own use, fitting it up with a forge, bellows, anvil, and work-bench. Such a smithy, to contain a pair of draught-horses when shoeing, would require to be 24 feet in length and 15 feet in width, with a wide door in the center, $7 \frac{1}{2}$ feet high, and a (217) 
glazed window on each side of it. As the time of a pair of horses is more valuable than that of a man, a smithy is often erected at the steading, while the carpenter's shop is at a distance.

(80.) All the roads around the steading should be properly made of a thick bed, of not less than 9 inches, of small broken whinstone metal, carefully kept dry, with proper outlets for water at the lowest points of the metal bed, and the metal occasionally raked and rolled on the surface until it becomes solid.

(81.) The best way of building such a steading as I have just described is, not to contract for it in a slump sum; because, whatever alterations are made during the progress of the work, the contractor may take advantage of the circumstance, and charge whatever he chooses for the extra work executed, without your having a check upon his charges. Nor, for the same reasons, should the mason, carpenter, or slater work be contracted for separately in the slump. The prices per rood or per yard, and the quantities of cach kind of work, should be settled beforehand between the employer and contractor. The advantage of this arrangement is, that the work is finished according to the views and tastes of the individual for whose use the farmstead has been built-he having had the power of adopting such slight modifications of the plan, during the progress of the work, as experience or reflection may have suggested. The contractor is paid according to the measurement of the work he thus executes. A licensed surveyor, mutually chosen by both parties, then measures the work, and calculates its several parts according to the prices stipulated for betwixt the contractor and his employer, and draws up a report of the value of each kind of work, the total sum of which constitutes the cost of the farmstead. Installments of payment are, of course, made to the contractor at periods previously agreed upon. This plan may give you no cheaper a steading than the usual one of contracting by a slump sum, but cheapness is not the principal object which you should have in view in building a steading.Your chief object should be the convenience of your work-people, and the comfort of your live-stock. This plan enables you to erect a steading in accordance with your own views in every respect; and you can better judge, in the progress of the work, of the fitness of the plan for the accommodation required, than by any study of the plans on paper-which, upon the whole, may appear well enough adapted to the purposes intended, but may, nevertheless, overlook many essential particulars of accommodation and comfort.

(82.) What I mean by essential particulars of accommodation and comfort in a steading are such as these: In giving a foot or two more length to a stable or byre, by which each animal may have two or three inches more room laterally, more ease would be given to it, and which is a great comfort to working stock: A window, instead of looking to the cold north, may be made with as much ease to look to the warm south: A sky-light in the roof, to afford a sufficient light to a place that would otherwise be dark: An additional drain to remove moisture or effluvia, which, if left undisturled, may give considerable annoyance: A door opening one way instead of the other, may direct a draught of air to a quarter where it can do no harm: These little conveniences incur no more cost than the incongruities of arrangement which are often found in their stead, and though they may seem to many people as trifles unworthy of notice, confer, nevertheless, much additional comfort on the animals inhabiting the apartments in which they should be made. A door made of a whole piece, or divided into leaves, may make a chamber either gloomy or cheerful; and the leaves of a door formed either vertically or horizontally, when (218) 
left open, may either give security to an apartment, or leave it at liberty to the intrusion of every passer by. There are numerous such small conveniences to be attended to in the construction of a steading before it can be rendered truly commodious and comfortable.

(83.) Before the prices of work to be executed can be fixed on between the employer and contractor, minute specifications of every species of work should be drawn up by a person competent for the task. A vague specification, couched in general terms, will not answer; for when work comes to be executed under it, too much liberty is given to all parties to interpret the terms according to the interest of each. Hence arise disputes, which may not be easily settled even on reference to the person who drew up the specifications, as he possibly may by that time have either forgotten his own ideas of the matter, or, in adducing his original intentions under the particular circumstances, may possibly give offence to one party, and injure the other; and thus his candor may rather widen than repair the breach. Whatever are the ideas of him who draws up the specification, it is much better to have them all embodied in the specifications, than to have to explain them afterward.

(84.) The principle of measuring the whole work after it has been executed, is another consideration which it is essential you should bear in mind. It is too much the practice to tolerate a very loose mode of measuring work; such as measuring voids, as the openings of doors and windows are termed, that is, on measuring a wall, to include all the openings in the rubble-work, and afterward to measure the lintels and ribets and corners. In like manner, chimney-tops are measured all round as rubble, and then the corners are measured also as hewn work. Now the fair plan obviously is to measure every sort of work as it stands by itself; where there is rubble let it be measured for rubble, and where there is hewn work let it be measured for as such. You will thus pay for what work is actually done for you, and no more; and more you should not pay for, let the price of the work be what it may. This understanding regarding the principle of measurement should be embodied in the specifications.

(85.) To see if the principle I have endeavored to enforce in the arrangement of the componeut parts of a steading for the mixed husbandry be applicable to steadings for other modes of husbandry, you have only to apply it to the construction of steadings usually found in the country.

(86.) In pastoral farms, the accommodation for stock in the steading is generally quite inadequate to give shelter, in a severe winter and spring, to the numbers of animals reared on them. For want of adequate accommodation, many of both the younger and older stock suffer loss of condition-a contingency much to be deprecated by the store-farmer, as the occurrence never fails to render the stock liable to be attacked by some fatal disease at a fu-

Fig. 27.

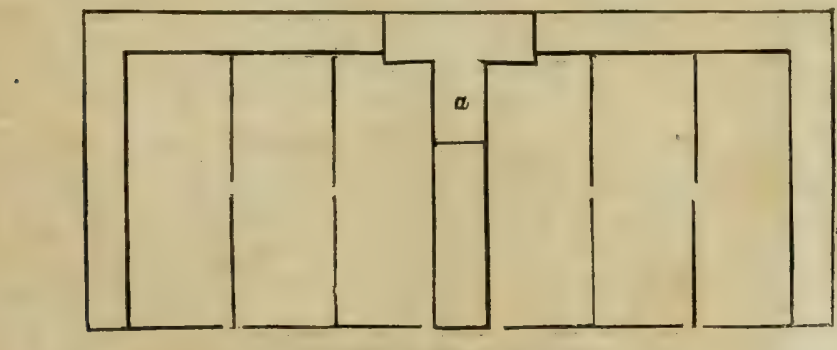

PASTORAL FARM-STEADING.

ture period. In the steadings of such farms, the numerous cattle, or still more numerous sheep, as the stock may happen to be, should have shelter. The cattle should be boused in (219) 
sheds or hammels in stormy weather, supplied with straw for litter and provender, or, what is still better, supported on hay or tumips. For this purpose their sheds should be quito contiguous to the straw-bam. Sheep should either be put in large courts beduled with straw, and supplied with hay or turnips, or so supplied in a sheltered spot, not far distant from the steading The particular form of steading suitable to this species of farm seems to be that which embraces three sides of a donble rectangle, having the fourth side open to the south, each rectangle enclosing a large court, divided into two or more parts, on each side of the straw-burn, which should form a side common to both rectangles. This form answers to the molification pointed out at 3, in paragraph (8.) p. 82, and it is shown in fig. 27, where $a$ is the struw-barn, with hut the courts placed on each side of it.

(87.) In the steadings of carse farms, comfortable accommodation for stock is male a matter of secondary import. In them it is not unusual to see the cattle-courts facing the north. As there is, however, great abundauce of straw on such farns, the stock seem to be warm enough lodged at night. Where so much straw is required to be made into manure, the courts and stables should be placed quite contigurus to the straw-ban. The form of steading most suitable to this kind of farn seems to be that of three sides of a rectangle, embracing a large court, divided into two or three parts, facing the south, and having the upper and corn-barn projecting behind into the straw-yard, as described in modificution $2,(8$.$) p. 82$, and shown in fig. 28 , where $a$ is the straw-barn, near the courts, and contiguous to which should be the byres and stables.

(88.) In farms in the neighborhood of towns, the cowhouses, feeding-byres, or hammels, being the only means of converting the straw into manure, which is reserved for home use from the sale of the greatest part to the cowfeeders and stablers in towns, should be placed nearest the straw-barn. The very confined state in which cows are usually kept in the byres of such farms, and especially in those near the largest class of towns, makes them very dirty, the effects of which must injure the quality of the dairy produce. In constructing a steading for a farm of this kind, such an inconvenience should be avoided. The most convenient form of steading is that of the three sides of a rectangle, embrucing within it a set of feeding-hammels facing the south; the threshing-mill and straw-barn being in the north range, the work-horse stable in one of the wings, and the cow-byre in the other, from both of which the dung may be wheeled into their respective contiguous dunghills, as is described in modification 1, (8.) p. 82 , and shown graphically in fig. 29 , where $a$ is the strawbarn, on both sides of which are the byres and stable, and $c$ are hammels inclosed within the rectangle.

Fig. 28.

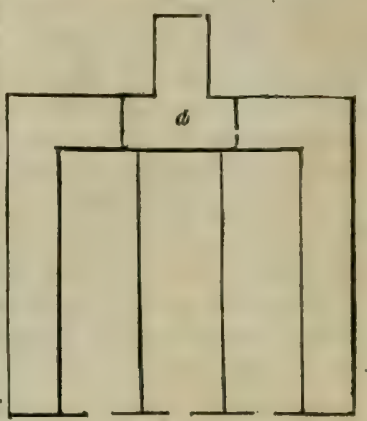

CARSE FARM-STEADING.

(89.) In dairy farms, the cows being the greatest means of making manure, their byres, as well as the hammels for the young horses and young queys, and the sties for the swine, should be those most contiguous to the straw-barn. It should be the particular study of the dairy-farmer to make the byre roomy and comfortable to the cows, the thriving state of that portion of his stock being the source from which his profits are principally derived. The form of steading recommended for farms in the neighborhond of towns seems well adapted to this kind of farming, in which the hammels could be occupied by the young horses and young queys, and beside which the pig-sties could also be placed, such as are shown in fig. 29, where $\mathrm{c}$ are the hammels, and $e$ the hog-sties, but which may be placed elsewhere if desired.

(90.) It may prove of service to inquire whether this principle of constructing steadings for every sort of farm is inculcated by the most recent or authoritative writers on Agricul. ture. 1. In the collection of designs of farm-buildings, in the Prize Essays* of the Highland and Agricultural Society of Scotland, the absolute necessity for the contiguity of cattle-sheds, hammels, and stables to the straw-barn, is a matter not sufficiently attended to. When hammels are placed in front of the principal buildings, as in No. 1 of the designs, doors are required in the back of the hammels for taking in the straw. These doors not only incur ad. ditional cost in the making, but, being placed in the shed, induce the animals to escape through them, and, when open, occasion an uncomfortable draught of air. The openings, too, betwixt the sheds and courts of the hammels being placed in the center, cold easily circulates through the sheds. And the separation of the calves'-house from the cow-byre as in

* Prize Essays of the Highland and Agricultural Society, vol. viii. p. 365. 
design No. 2, must be very inconvenient in rearing calves. 2. In "British Husbandry," the principle of constructing a steading is thus laid down: "The position of a threshing-mill should decide that of almost every other office; for it cuts, or ought to cet, the hay into chaff, together with much of the straw; and the house that immediately receives this chaff ought to be so placed as to admit of a convenient delivery to the stalls and stables. Thus the strawbarn, chaff-house, ox-stalls, and horse-stables, with the hay-stacks and the sheep-yard (if there be any), should be dependent on the position of the threshing mill, as they will be attended with waste and expense of labor." If the chaff-cutting machine is to be employed for preparing much of the straw for the use of the stock, it should be placed in the straw-barn, otherwise the straw must be carried to it, which would entail a considerable deal of labor. It is thus the position of neither the chaff-cutting or threshing-machine that should determine the site of the rest of the steading. The threshing-machine cannot conveniently be placed near the centre of a steading, because it would then be necessarily removed to a distance from the stack-yard, and the carriage of the sheaves from which would also entail considerable labor. In the examples of existing steadings given in this recent work from pages 85 to 109 , being chiefly the plans of steadings on the properties of the Duke of Sutherland, the position of the straw-barn seems in them to be considered a matter of secondary importance.In the plans in pages $85,86,100,103,107,108$, and 109 , the straw-barn is surely placed at an inconvenient distance from the apartments occupied by the live-stock, and the carriage of straw from it to them must "be attended with waste and expense of labor." 3. Professor Low inculcates the principle more correctly where he says, "Barns, being the part whence the straw for fodder and litter is carried to the stables, feeding-honses, and sheds, they should be placed so as to afford the readiest access to these different buildings. It is common to place them as near the centre of the range as the general arrangement of the other buildings will allow." + This is quite correct in principle; but, in referring to the figure, it is said that, "In the design of the figure, in which are represented the barns, this principle of arrangement is observed;" yet, on inspecting the figure at p. 624 , it will be observed that the feeding-hammels are placed at a greater distance from the straw-barn than even the pig-sties and poultry-yards. It does not appear that the yard behind the sties is intended to be occupied by anything but manure; so, if the hammels had occupied the more eligible site of the hog-sties, they would not have interposed betwixt the sun-light and any stock. It may also be observed that the cow-houses, which require less straw than feeding stock, are placed nearer the straw-barn than the hammels on the right. 4. Mr. Loudon, in treating of the "fundamental principles for the construction of the various parts which compose a farmery," recommends the houses for the various kinds of stock to be constructed according to the size and shape of the animals to be accommodated; and, assuming the horse, the ox and the sheep to be of the form of a wedge, he draws these two conclusions : "First, that the most economical mode of lodging the first two of these quadrupeds must be in houses the walls of which form concentric circles, or segments of circles parallel to each other; . . . . and, secondly, that in all open yards where quadrupeds are allowed to run loose, and eat from racks and mangers, .... when the rack or manger is to be in a straight line, the breadth of the broad end of the wedge must be allowed for each animal; and, when it is to be curved, the radius of the curve must be determined by the breadth of the smaller end of the wedge.From this theory it may also be deduced that there must be one magnitude, as well as one form, more economical than any other, for lodging each of these animals; and that this magnitude must be that circumference of a circle which the narrow ends of the wedges completely fill up, and no more." $\ddagger$ And figures are given of both curved and straight mangers and racks, to illustrate these principles. Now, independent of the acknowledged inconveni ence of accommodating any circular or curved form of apartment or building in a steading, as is universally felt in regard to the usually circular form of the horse-course of a threshing mill, the very data on which this theory is founded are incorrect ; for, although it is true that many horses and oxen are of the form of a wedge, yet the higher bred and better stock, to which all improving breeders are desirous of assimilating their own, are not wedge-shaped. The Clydesdale draught-horse, the short-horn ox, and the Leicester sheep, the nearer they attain perfect symmetry of form, the nearer they approach the form of a parallelopipedon, instead of a wedge, in the carcass. This theory is, therefore, not universally applicitile.Indeed, Mr. Loudon afterward says (p. 375) that "these principles for the curvilinear arrangement of stalls, racks, and troughs, we do not lay down as of very great importance, but rather with a view to induce the young architect to inquire into the reasons of things, and to endeavor in everything to take principles into consideration rather than precedents." The object is laudable, but its aim will scarcely be attained by the young architect having his attention directed to questionable data. He is at all times much more disposed to follow his own crude fancies, in the construction of steadings, than to improve on precedents suggested by the farmer's experience.

(91.) It may be interesting to inquire why the quadrangular form of steading was so much in vogue some years ago. It was, doubtless, adopted on account of its compactness of form,

* British Husbandry. vol. i. p. 97. $\dagger$ Low's Elements of Practical Agriculture, 2d edition, p. 623.

† Loudon's Encyclopædis of Architecture, p. 373.

(221) 
admitting it to be erected at a considerable saving of expense, at a time-during that of the war-when building-materials of every kind, and wages of every description of artisans, were very high. I do not believe that the value of all the ground on which the largest steading could stand formed any inducement for the adoption of the compact form of the quadrangle, but rather from the wish of the landlord to afford no more than bare accommodation to the tenant's stocking. An economical plan, furnished by an architect, would thus weigh more strongly with him than a mere regard for the comfort of his tenant's live-stock, whose special care he would consider more a tenant's than a landlord's business. It is not so easy to account for the tenant's acquiescence in such a form of steading; for, although it must be owned that, at that period, very imperfect notions were entertained of what were requisite for the comfortable accommodition of animals, yet the tenant's own interest being so palpably involved in the welfare of his stock, might bavetaught him to desire a more comfortable form of steading. Thus an imperfect state of things originated in the parsimnny of landlords, and was promoted by the heellessness of tenants. The consequences were that cattle were confined in courts inclosed all around with high buildings, eating dirty turnips off the dunghill, and wading or standing mid-leg deep in dung and water; and frequently so crowded together, and stinted of food, that the most timid among them were daily deprived of their due proportion of both food and shelter. Is it any matter of wonder that cattle at that time were unequally and imperfectly fed? In the steadings of the smaller tenants, matters were, if possible, stili worse. The state of the cattle in them was pitiable in the extreme, whether in the courts, or while "cabined, cribbed, and coufined" in the byres. Though those in the latter were, no doubt, under the constant shelter of a roof, they were not much better off as to cleanliness and food; and much worse off for want of fresh air, and in a state of body constantly covered with perspiration. But these unmerited hardships, which the cattle had to endure every winter, have been either entirely removed or much ameliorated, within these few years, by the adoption of conveniences in the construction of steadings on the part of landlords, and superior management, acquired by experience, on the part of tenants.Troughs are now erected along the walls of courts, at convenient places, for holding turnips, now given clean to the cattle. Rain-water spouts are now put along the eaves of the houses surrounding the courts. Drains are now formed to carry off the superfluous moisture from the courts. The courts themselves are opened up to the meridian sun, and really made comfortable for cattle. And hammels are now built for cattle in steadings where they were before unknown. Still, notwithstanding the decided improvement which has undoubtedly taken place in the construction of steadings, there are yet many old steadings which have not been ameniled, and too many modern ones erected in which all the improvements that might have heen have not been introduced. Should it be your fate to take a farm on which an old steading of the quadrangular form is standing, or a new one is proposed to be built, in repairing the one, and constructing the other, be sure never to lose sight of the leading principles of construction inculcated above, and insist on their being put into practice. A little pertinacity on your part on this point will, most probably, obtain for you all your wishes, and their attainment to the full will vindicate you in offering a higher rent for the farm, without incurring risk of loss.

(92.) It is now time to enter minutely into the specifications upon which every kind of work in the construction of a substantial steading should be executed, and those below will be found applicable to every size and plan of steading. As they accord with my own experience and observation in these matters, and hoth have been considerable, I offer them with the greater degree of confidence for your guidance. They embrace the particulars of masonwork, carpenter-work, slater-work, plumber-work, smith-work, and painter and glazierwork; but they are not drawn up in the formal way that specifications are usually done, the various subjects as they are specified being illustrated by examples and the elucidation of principles.

(93.) Of the specifications of mason-trork, the first thing to be done is the digging of the foundations of the valls. When the site of the steading is not obliged to be chosen on a rock, the depth of the foundarions of all the outside walls should never be less than 2 feet. Judging by usual practice, this may be consiclered an inordinate depth, and as incurzing much expense in building an unnecessary yuantity of foundation walls, which are immediately after to be buried out of sight; but this depth is necessary on account of the drains which should be mule around the outside walls, to keep all the floors dry in winter, and it is scarcely possible to keep them dry with drains of less depth than 27 inches, which afford the water a channel of ouly 3 inches below the bottom of the foundations. The groundfloor of dwelling-houses may be kept in a dry state by elevating it a cousiderable hight above the ground; but such an expedient is impracticable in a steading where most of the apartments, being occupied by live-stock, must be kept as near as possible on a level with the groumd; nnd it is not wood-floors alone that must be kept dry, but those of sheds. barns, and byres, whether made of composition, or causeway, or earth. The injurious effects of damp in the floors of stables, byres, and hammels, on the condition of the animals inlabiting them in winter, or of bans on the state of the straw, corn, or hay in them, are too much overlnoked. Its malign influences on the health of animals, or in retarding their thriving, not being apparent to the senses at first sight, are apt to be ascribed to constitutionul defect $\{222 ;$ 
in the animals themselves, instead of, perhaps, to the truer cause of the unwholesome state of the apartments which they occupy. The truth is, the floor of every apartment of the steading, whether accommodating living creatures, or containing inanimate things, cannot be too dry; and, to render them as much so as is practicable, there seems no way of attaining the end so effectually as to dig the foundations of the walls deep, and to surround them with still deeper drains. This position I shall here endeavor to prove to you satisfactorily. There are many substances upon which walls are usually founded, which, from their nature, would make walls constantly damp, were expedients not used to counteract their natural baleful properties. Amorphous rocks, such as granite, which are impervious to water; whinstone rocks, which; though frequently containing minute fissures, being delinquescent, become very damp in wet weather; clay, and tilly clay even more than the unctuous, retains a great deal of water-all these substances form objectionable ground upon which to found any building. Stratified rocks, such as sandstone, not retaining the water long, form drier substances for a foundation than any of the amorphous rocks or clays. Pure sand is not always dry, and it is apt to form, in some situations, an insecure foundation. Pure gravel is the driest of all foundations, but not the most secure. From the nature of these various substances, excepting the gravel, it would appear that no wall founded on them can assuredly be kept dry at all seasons; and therefore drains are necessary to render and keep them dry at all seasuns. Moreover, a foundation made in a bank of even the driest gravel will prove damp, unless the precaution of deep draining betwixt the foundation and the rise of the bank is resorted to. Rather than choose a site for your steading which is overhung by a bank, make a deeper foundation on more level ground, and drain it thoroughly, or even build some hight of waste wall, and fill up a part of the ground that is low around the steading. I have experienced the bad effects of digging a foundation for a steading in a rising ground of tolerably dry materials,and also the good effects of filling up low ground at a part of another steading, and have found the air in the apartments of the latter, at all seasons much more agreeable to the feelings than in the former. The bad effects of the former I endeavored to counteract by deep draining, though not so effectually as in the latter case. I am therefore warranted in concluding that dry apartments are much more healthy for animals, and better for other things, than are those which feel cold and damp. A circling, however, of substantial drains around the steading, between it and the bank, will render the apartments to the feelings, in a short time, in a comparatively comfortable state.

(94.) The outside walls should be founded with stones 3 feet in length, 2 feet in breadth, and 8 or 9 inches in thickness, so laid, in reference to the line of foundation, as to form a scarcement of 6 inches on each side of the wall above them. The low walls may stand on one course of such foundation, while the higher walls should have two such courses.

(95.) All the walls, both external and internal, should be built of the best rubble-20ork, the stones being squared, laid on their natural beds, closely set in good lime mortar, and well headed and packed. Headers should go through the thickness of the walls at not more than 5 feet apart in every third course. The walls should only be built one course in hight on side, before the other side is brought up to the same level, the first of the courses to go through two-thirds of the wall, besides the headers or band-stones.

(96.) The external walls should be 2 feet in thickness, and the incernal division-walls, as also the walls composing the fronts and subdivisions of the courts and hammels, 1 foot. The low external walls should be raised 9 feet, and the high external walls of the middle range, as well as that of the straw-barn, 15 feet above the ground. All the gables of the external walls, and all the intermal division walls, should rise to the pitch of their respective roofs, and be entirely filled up to the sarking or tiles, as the case may be. The front and side walls of the large courts and bulls' hammels, and the subdivision walls of the courts of the hammels, should be raised 6 feet, and the front walls of the hammels, as also those of the cows' and calves' courts and pig-sties, 5 feet above the ground. All the walls which carry rnofs should be beam-filled with rubble-work, with the precaution given in (73.) p. 118.

(97.) The external fronts of all the outside walls, as well as those of the front walls of the courts and hammels, should be faced with hammer-dressed rubble in courses, not exceeding 6 inches in thickness, with the vertical and horizontal joints raised or drawn in hollow. The tops of the front and subdivision walls of the courts and hammels should be finished with a coping of hammer-dressed round-headed stones, 12 inches in diameter, firmly set close together in good lime mortar.

(98.) To test if rubble masonry is well built, step upon a leveled portion of any course, and, on setting the feet a little asunder, try by a searching motion of the legs an $\mathrm{l}$ feet whether any of the stones ride ujon others. Where the stones ride, they have not been properly bedded in mortar. To ascertain if there are any hollows, pour out a bucketfull of water on the wall, and those places which have not been sufficiently packed or hearted with small stones, will immediately absorb the water.

(99.) The width of all the doors should be 3 feet 6 inches, and their hight 7 feet, with the exception of those of the work-horse stable, corn-barn, straw-barn, and saddle-horse stable, which should be 7 feet 6 inches. The width of the arches of the cattle-courts shonld be 9 feet; that of those of the hammels 6 feet, and that of the ports of the cart-sherl 8 feet, and all 7 feet 6 inches in hight. The width of all the windows should be 3 feet, and their hight (223) 
4 feet, with the exception of those of the granaries, which should be 4 feet in width and 3 feet in hight. The windows should have a bay inside of 6 inches on each side. Slits of 1 foot 3 inches in hight and 3 inches in width in front, with a bay inside like the windows, sbould be left in the walls of the straw and upper barns for the admission of air to the straw and the "com in the straw. All the voids should have substantial discharging arches over the timber-lintels to be able to support the wall above, even although the timber-lintels should fail.

(100.) All the door-soles should be laid 3 inches above the ground or causeway, and those of the stables and byres and calves'-house should be beveled in front, that the feet of the animals going out and in may not strike against them.

(101.) The corners of the buildings should be of broached ashler, neatly squared, 2 feet in length, 12 inches of breadth in the bed, and 12 to 18 inches in hight, having 1 inch chisel draught on both frouts. The vindows and doors should have ashler ribets - the outbands 2 feet in length, and the inbands at least two-thirds of the thickness of the walls, and both 12 inches of breadth in the beds, and 14 or 15 inches in hight. They should have 1 inch of the front, 5 inches of ingoings, and 4 inches of checks, clean droved. The tails of the outhand ribets should be squared and broached. The doors of the work-horse and saddle-horse stables, upper and corn barns, hay-house and bulls' hammels, should have droved giblet-checks, to permit them opening outward. The window-sills should be droved, projecting $1 \frac{1}{2}$ inches, and $6 \mathrm{t}$ or 7 inches in thickness. The lintels of both the doors and windows should have 1 inch of the front, 5 inches of ingoings clean droved, and be from 14 to 15 inches in hight.The skeros sliould be broached when such are used, having 1 inch chisel-draught on both margins of the front, and the inner edge with a 4 -inch check-plinth, having an inch back-rest under it. The holes in the byre-roall, through which the turnips are supplied, should be 20 inches square, with ashler ribets, flush sills and lintels, having broached fronts and droved giblet-checks to receive their shutters. The side corners of the arched openings of the cattle-courts and hammels, and those of the ports of the cart-shed, should be regular out and in. band, 2 feet in length, 12 inches of breadth in the bed, and 12 inches in hight, and dressed in a manner similar to the other comers, but should be chamfered on the angles. The arches should be elliptical, with a rise of 2 feet, with broached soffits on both fronts, an inch-droved margin, and radiated joints. In the plan, fig. 4, Plate IV. the cart-shed ports are not arched, there being no room for such a finishing in the peculiar form of the roof. The pillars of the cart-shed, the byre, turnip-shed, and calves'-shed, should be 2 feet square in the waist, of broached ashler, with inch-droved margins, and built of stones 12 inches in hight. Those of the two former should have a droved base course, 12 inches in depth, with $1 \frac{1}{2}$ inches washing, chamfered on the angles. The tops of the walls of the pig-sties, calves'-shed, hen-house, and potato-store, should have a 6 -inch droved plinth, 12 inches in the bed. The fire-places in the boiling-house and coach-house should have a pair of droved jambs and a lintel, 3 feet 6 inches of hight in the opening, and a droved hearth-stone 5 feet in length and 3 feet in breadth. The boiler should have a hearth-stone 4 feet 6 inches in length, and 2 feet 6 inches in breadth, and it should be built with fire-brick, and have a cope of 4 inches in thickness of droved ashler. The flues from both the fire-places and the boiler should be carried up 12 inches clear in the opening, and should have chimney-stalks of broached ashler, 2 feet in hight above the ridges of the respective roofs, 2 feet square, and furnisbed with a droved check-plinth and block 12 inches in depth. The gates of all the cattle and hammel courts should be hung on the droved ashler corners when close to a house, but on droved built pillars when in connection with low court-walls. The riding-horse stable, if laid at all with flags, should bave them 4 inches thick, of droved and ribbed pavement behind the travisposts, having a curved water-channel communicating with a drain outside. The travis-posts of the work-horse stable should be provided with droved stone sockets, 12 inches in thick. ness, and 18 inches square, founded on mbble-work, and a droved curb-stone should be put betwixt the stone sockets of each pair of head and foot travis-posts, provided with a groove on the upper edge to receive the under edge of the lower travis-board. For the better riddance of the urine from the work-horse stable, there should be a droved curved vater-chan$n e l, 6$ inches in breadth, wrought in freestone, all the length of the stable, with a fill at least of $1 \frac{1}{2}$ inches to every 10 feet of length. The water-channel in the cow-byres and feeding. houses should be of droved curb-stones, 6 inches thick, 12 inches deep, and laid in the bottom with 3 -inch thick of dnovea pavement, placed 6 inches below the top of the curb-stones. If stone is preferred for vater-troughs, which it should always be when easily obtained, the tronghs should not be of less dimensions than $3 \frac{1}{2}$ feet in length, 2 feet in breadth, and 18 inches in depth over all; or they may be made of the same dimensions of pavement-flags put together with iron-batts. Wood may be substituted for stone when that cannot be easily obtained. The liquid-manure drain should be 9 inches in hight and 6 inches in width in the clear, with droved flat sills and hammer-dressed covers. A stone 2 feet in length, 18 inches in breadth, and 8 or 9 inches in thickness, with an opening through it, giblet-checked, will contain a grating 15 inches in length and 9 inches in breadth, with the bars one inch asunder, at the ends of the liquid-manure drains in the courts. The liquid-manure tank, sunk into the ground, will be strong enough with a 9-inch brick or nubble wail of stone and lime-mor tar, having the bottom laid with jointed flag-pavement. If the ground is gravelly, a puddling

$(224)$ 
of clay will be requisite behind the walls, and below the pirement of the bottom. The bottom of the feeling-tronghs in the byres, courts, and hummels, should be of 3-inch thick of flag-pavement, jointed and scabbled on the face, or of wood. All the window-sills in the in. side should be finished with 3 -inch droved or scabbled pavement.

(102.) The walls in the front of the courts are intended to be quite plain; but, should you prefer ornamental structures, their tops may be finished with a 6 -inch droved cope, 15 inches in breadth, with a half-inch washing on both fronts; and with a droved base-course 12 inches in depth, having a washing of $1 \frac{1}{2}$ inches. The pillars of the gates to the larger courts may be of droved ashler, in courses of an octagonal form, of 15 inches in thickness, and 2 feet by 2 feet, with 12-inch base, and a 12-inch checked plinth and block, built at least 18 inches higher than the wall. And if you prefer an outside hanging-stair to the upper-barn instead of the gangway, or to the wool-room, the steps should be droved 3 feet 6 inches clear of the wall, with 6 inches of wallhold. And, farther, you may substitute droved crow-steps on the gables for the broached skews, with an inch back-rest under them. These crowsteps, in my opinion, are no ormaments in any case in a steading. They are only suited to a lofty, castellated style of building.

(103.) The floors of the cow-byres, work-horse stable, stalls of the riding-horse stable, passage of the calves'-house, coach-house, boiling-house, implement-house, hay-house, and turnip and potato stores, should be laid in causeway with whinstone, or with small land stones, upon a solid stratum of sand, with the precaution of a bed of broken stones under the flagging as formerly recommended in (73.) p. 118. A causeway, 13 feet in breadth, should also be made in the large court $K$ to the corn-barn door, round to the gate at $H$, for the use of loaded carts from the barn, with a declivity from the wall to the dung area of 2 inches in the 10 feet. Causeways are usually formed in steadings with round hard stones found on the land, or in the channels of rivers, or on the sea-shore, imbedded in sand. In those situations the stones are always hard, being composed of water-worn fragments of the primitive and secondary as well as of trap-rocks; but round boulders of micaceous sandstone, usually found in gravel pits, are unfit for the purpose of causeways, being too soft and slaty. A more perfect form of causeway is made of squared blocks of trap, whether of basalt or greenstone, imbedded in sand, such as is usually to be seen in the streets of towns. The ready cleavage of trap-rocks into crinvenient square blocks renders them valuable dépôts, where accessible, of materials for causeways and road metal. The floors of the pig-sties and poultry-yards should be laid with strong, thick-jointed stones umbedded in lime mortar, having broken glass in it, upon a bed of 9 inches thick of small broken stones, to withstand not only the digging propensities of the pigs on the surface, but also to prevent vermin gaining access from below through the floor to the poultry. The areas of the cattle-courts, and floors of the sheds, hammels, and cart-shed, will be firm enough with the earth beaten well down.

(104.) There is a plan of making the floors of out-houses, recommended by Mr. Waddell of Berwickshire, which deserves attention. It is this: Let the whole area of the apartment be laid with small broken stones to the depth of 9 inches. Above these let a solid body of masonwork, of stone and lime properly packed, be built to the hight of 12 or 14 inches, according to the thickness of the substance which is to form the upper floor. The lime, which is applied next the walls, shonld be mixed with broken glass. If a composition is to form the floor, it should be laid on 3 inches in thickness above the masonry; but if asphaltum, 1 inch thick will suffice, the difference in the hight being made up in the masonry. ${ }^{*}$ This plan of Mr. Waddell's seems well adapted for making a solid and secure foundation against vermin, for the causewaying of the several apartments mentioned above; but it is not so well adapted for wood-floors either as a preservative against damp, or preventive against vermin, as the plan described at p. $88,(16$.

(105.) While treating of the subject of causewaying, I may as well mention here the various sorts of flooring and pavement which may be formed of other materials than those already mentioned; and the first is concrete, which forms a very good flooring for indoor use. It is formed of a mixture of coal-ashes obtained from furnaces, and from a fourth to a third part or more, according to its strength, of slaked lime, and worked into the form of paste with water. A coating of clay of 2 or 3 inches is first laid on the ground leveled for the purpose, and upon the clay, while in a moist state, the concrete is spread two or three inches in thickness, and beaten down with a rammer or spade until the under part of the concrete is incorporated with the upper part of the clay. The surface of the concrete is then made smooth by beating with the back of a shovel, and when left untouched for a time, that substance assumes a very hard texture. This is a cheap mode of flooring, labor being the principal expense attending it.

(106.) A nother sort of pavement is that of asphaltum, suitable either for indoor use, or for outdonr purposes, where no cartage is to be employed upon it. It is a composition of bitumen, obtained from coal-tar after the distillation of naphtha, and small clean gravel. When applied, the bitumen and gravel in certain proportions are melted together in a pot over a fire, and when sufficiently liquified and mixed, the composition is poured over the surface of the ground to be paved, which is previously prepared hard and smooth for the purpose,

- Prize Essays of the Highland and Agricultural Society, vol. viii. p. 373.

(225)......9 
about an inch or more in thickness, and is spread even and smoothed on the surface with a heated irun roller. When completely dry, the asphaltum becomes a perfect pavement, as hard as stone, and entirely impervious to water. It would form an excellent flooring for the straw-barn, 6crvants'-bouse, boiling-house, potato-stores, and the passages in the cow-byre and calves'-house. It might also make noofing to out-houses, where there is no chance of the roof being shaken. As made at the Chemical Works at Bonnington near Edinburgh. it costs $5 d$. per square foot when laid down, which makes it an expensive mode of paving. Whether this usphalte will bear heat, or the trampling of horses' feet, I do not know; but it seems there is a sort of asphaltum pavement in France which will bear $100^{\circ}$ of heat of Fahrenheit, and is employed in flooring the cavairy barracks of that country. The sub stance of which this pavement is made, is called "The Asplaltic Mastic of Seyssel," and for the manufacture and sale of which a company has been formed in Paris to supply pave ment for various purposes. The substance is a nutural asphaite found at Pyrimont, at the foot of the eastern side of Mount Jura, on the right bank of the river Rhone, one league north of Seyssel. In chemical composition this asphalte contains 90 per cent. of pure car bonate of lime, and 9 or 10 per cent. of bitumen. To form the asphalte into a state fit for use, it is combined with mineral pitch, obtained at the sune place, in the proportion of 93 per cent. of the asphalte to 7 per cent. of the mineral pitch. The pitch when analyzed contains of resinous petroliferous matter from 69 to 70 per cent. and of carbon from 30 to 35 per cent. The preparation of this asphalte being tedious, its cost is greater than that mentioned above. For foot-pavements or floors it is about $6 \frac{1}{2} \mathrm{~d}$. and for roofs $8 \frac{1}{4} \mathrm{~d}$. per square foot.*

(107.) Another mode of causewaying is with blocks of wood, commonly called 2000 . pavement. Portions of the streets of London have been laid with this kind of pavement, the blocks having been previously subjected to the process of $\mathrm{hyanizing}$, and they are found to make a smooth, clean, quiet, and durable causewaying. This would be a dexirable method of paving the road round the large court $K$, Plate IV. the straw-barn, work-horse stable, hay-house, cow-byres, passage in the calves'-house, riding-horse stable, coach-house, and potato-stores. It would be expedient, when used in a stable or byre, usat some other substance than sand be put between the blocks, for that is apt to absorb urine too readily. Gront formed of thin lime and clean small gravel, or asphalte poured in between the blocks, might repel moisture. This latter expedient has already been tried, as may be seen at page 14 of Mr. Simm's observations on asphalte. There are various methods of disposing of the blocks of wood so as to make a steady and durable pavement. 1. The earliest plan adopted in Loudon, in 1838, was that of Mr. Stead, a specimen of laying which I had an oppor tunity of seeing in the Old Bailey, London, in 1839. It consisted of hexagunal blocks of wood set on eud upon a sandy substratum. The blocks had the Kyan stamp on their side Since then the substratum upon which the blocks rest has been made of Roman cement and what is called Thames ballast, which I suppose means Thames river sand. The cost of this mode is $9 \mathrm{~s}$. the square yard for 6 -inch blocks, aud 28 . the yard for the concrete. $\approx$. Another plan is that of Mr. Carey, which consists of setting cubical blucks on end, a mere modification of that of Mr. Stead. The cost is for 8-inch blocks 12s. 6d.; 9-inch blocks 13s. 6d.; and 10 -inch blocks 14s. $6 \mathrm{~d}$. the square yard. 3. Mr. Grimmans's is another mode of woodpaving. It consists of the blocks forming oblique parallelopipedons at su angle of $77^{c}$, and they are so cut as to set from right to left and from left to right, presenting a sort of herringbrne work. The blocks are chamfered at the edges to prevent the slipping of horses' feet. With the concrete of Roman cement and Thames ballast, this paving is charged 12s. the square yard. 4. Mr. Rankin's method secures the safety of the horses' feet in slipping, but is too elaborate a mode for general adoption. It consists of a number of small blocks, cut out of the same piece of wood, lying above oue another in a complicated fashion. With con crote, its cost is $16 \mathrm{~s}$. the square $y$ ard. 5. Of all the modes of wocd-paving yet invented, that of the Count de Lisle is the best. It consists of placing beside each other oblique cubes of 6 inches, having an inclination of $63^{\circ} 26^{\prime} 58-10^{\prime}$, a number derived by calculation from the stereotomy of the cube. "These blocks are cut and drilled by machinery, mathematically alike; aud are so placed in the street that they rest upon and support each other from curb to curb, each alteruate course having the angle of inclination in opposite directions. These course's are connected to each other, side and side, by dowels, which occupy the exact centers of two isosceles [equilateral ?] triangles, into which each block is divisible. This arrangement affords the means of connectung every block with four others, and prevents the possibility of one being forced below the level of another. Pressure and percussion are therefore distributed, in effect over large surfaces, and a perfect cohesion established. Fior is this cobesion advantageous only as a means of resistance against superincumbent force. It is of equal value in withstanding any effort to break up the unifornity of surface by undue expansion. The concrete foundation having a slight elliptical curve given to it, and the wood-paving being so laid as to correspond with that curve, for the purposes alike of strength and surface drainage, there is naturally a slight tension on the dowels in an upward direction, which the pressure from above tends to relieve; while the lower ends of the blocks abut 80 closely together in ome direction, and every block is so kept in its position by two

* Simm's Practical Observations on the Asphaltic Mastic or Coment of Seyssel, p. 3. (226) 
dowels on each side in the other direction, that the whole mass will take any increased curve consequent upon expansion, without the slightest risk of either partial or general dis. placement." There is much facility in replacing these blocks, especially since "the doweling of them together at the manufactory in panels of 24 each, 6 in length by 4 in width, the blocks at the sides of which being connected by iron cramps. Thus prepared, the process of covering a street is exceedingly rapid and simple. One end of a panel is cut off at an angle to agree with that of the curb and the curve of the street, and is then abutted against it; each panel containing four courses in alternate angles, another dove-tails precisely with the first, and thus panel after panel is laid until the street is crossed, and the last cut off to abut against the other curb." To prevent slipping. grooves are cut across the street at about 6 inches apart, and others are formed along the street, to prevent rutting, and the joinings of the longitudinal grooves are broken. The substratum upon which this mode of wood-paving is made to rest is a concrete formed of "blue lias lime, a metallic sand, and Thames ballast," which becomes permanently solid and impervious to water after two or three days, by the oxidation of the metallic sand. The cost of this mode is 13s. the square yard for 6-inch blocks and concrete complete, and 6d. a yard every year for keeping it in perfect repair for 10 or 20 years; 128. fir 5 -inch blocks; 11 s. for 4 -inch blocks, and proportionately for repairs.

(108.) Of these various modes of wood-paving, the following are the quantities of each which have been tried in London up to November, 1841, viz:

Of Stead's hexagons................. 8,710 sq. Jds. | Of Grimman's oblique parallelopipedons.650 sq. yds. De Lisle's oblique cubes............. 19.838 ...

Carey's squares.................. $1,750 \quad \ldots$

The Metropolitan Wood-paving Company have adopted De Lisle's system.

(109.) As to the durability of wood-paving, it is reasonable to suppose that "a structure of wood, instead of resisting the pressure or percussion of passing vehicles, like such an incompressible substance as granite, yields to it sufficiently to counteract friction, from its inherent property of elasticity. Hence in Whitchall, where the blocks have been down about two years, they are not reduced in depth $\frac{1}{8}$ of an inch on an average; and this reduction, being more the result of compression than of abrasion, is not likely to continue even at that ratio ; for the solidity of the blocks is increased even if the volume be thus slightly reduced. Indeed, paradoxical as it may at first appear, the traffic, which is destructive of wood-paving in one way, contributes to its preservation in another; and may thus be explained: The woud-paving is put down in a comparatively dry state, and, if it were always perfectly dry, would be much more susceptible of destruction from accidental or mechanical, as well as from natural causes. But, soon after it is constructed, it becomes perfectly saturated from rain and other causes, and continual pressure forces more and more water into the blocks, until every pore is completely filled. In this state, the water assists in supporting superincumbent weight, while it effectually preserves the wood from decay. For, in fact, of the 6 sides of a block of the given form, only the upper one is exposed to the action of the atmosphere; below the surface the whole mass is as thoroughly saturated as if it were immersed in water; and the surface itself becomes so hardened by pressure and the induration of foreign substances, such as grit and sand, as to be impervious to the action of the sun, especially in a northern climate; and that water is a preservative against decay may be proved in a variety of cases. . . . . . Dry rot, therefore, can never affect good wood-paving, nor can any other secondary process of regetation, in conseguence of the preservative qualities of water -the shutting out, in short, if atmospheric influence; and it is questionable if, under other circumstances, the inceseant vibration to which the blocks are suljected, by traffic, would not have a strong preservative tendency."

(110.) On the comparative cost of laying down and maintaining wood-paving with other sorts, a statement which has been made regarding wood-paving and paving with granite, in the parish of St. Mary le Strand, in London, for the last 7 years, tells in favor of the wood. It is this :

Granite-paving and concrete cost......................... £0 $12 \quad 6$ the square yard.

Repairs for 7 years at $3 \mathrm{~d}$. the yard............................

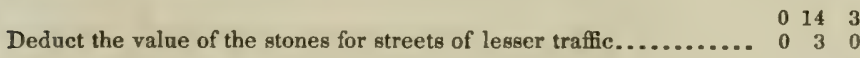

Actual cost of 7 years...............................

- $\quad \ldots$

$\ldots$

Wood-paving cost ....................... £0 130 the sq. yd.

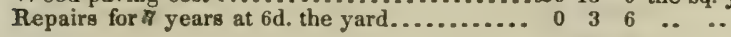

Deduct value of the wood for paving streets of

lesser traffic.

$\begin{array}{lllll}0 & 16 & 6 & \ldots\end{array}$

$\begin{array}{lllll}0 & 3 & 0 & \ldots & \ldots\end{array}$

\begin{tabular}{rrrrr}
0 & 12 & 6 & $\ldots$ & $\ldots$ \\
\hline 0 & 2 & 3 & $\ldots$ & $\ldots$
\end{tabular}

Giving an apparent advantage of $2 \mathrm{~s} .3 \mathrm{~d}$. the square yard to the granite-paving for the first 7 years; hut, were the comparison continued for an indefinite period onward, it would be (227) 
found that the same blocks of wood would last longer than the same blocks of granite, and hence the wood would be chenper in the long run.

(111.) On comparing its cost with macadamization, it is found that macadamized roads of much truftic, such as Oxfond-street, Piccadilly, cost from 28. 6d. to 3s. the square yard every year, besides the expense of the original formation: whereas wood-paving can be laid down and kept in repair for a rent-charge of $2 \mathrm{~s} .3 \mathrm{~d}$. the square yard every year-being a saving of from 10 to 30 per cent. per annum."

(112.) I have dwelt the longer on the subject of wood-paving, because I am persuaded that it would make a much more durable road about steadings, and to the fields of farms, than the materials usually employed for such purposes; and, as to their comparative condition under traffic, there would be a decided superiority on the side of the wood-paving, for farm roals are usually in the most wretched state of repair-every hour of time and every ton of metal expended on them being grudged, as if they were an item with which the farmer had nothing whatever to do. I do not say that wood-paving would be cheap where wood is scarce and carriage long, and of course dear; but in those parts of the country where larchwool is in abundance, and where it realizes low prices, it might be, I conceive, profitably employed in not only making farm roads, but in paving every apartment in the steading.

(113.) Another method still of cansewaying is with Dutch clinkers-a kind of very hard brick male in Holland, of about the breadth and thickness of a man's hand. They are used in paving roads and streets in that country. They are set lengthways on edge and imbedded in sami, and are laikl so as to form a slight arch across the road. Most of the great roads in Holland are paved with this brick, and more beantiful and pleasant roads to travel on cannot be found anvwhere, except perhaps in the heat of summer, when they become oppressively hot. I hal an opportunity of seeing a part of the road near Haarlem laid with these clinkers, and observed, as a part of the process, that, as a certain piece of the causewaying was finished, bumlles of green reeds were laid lengthways across the road over the new laid bricks, to temper the pressure of the wheels of carriages upon the bricks on going along the roads, until the bricks shonld have subsided firmly into the stratum of sand. As these clinkers are small, they can be laid in a variety of forms, some as a beautiful kind of Mosaic work. The import duty on Dutch clinkers was reduced to 3s. per 1,000 on 1 st January, 1834; in 1819 it was 16s. 8d.t The present price of clinkers (1842) in London is 35s. the 1,000.

(114.) Fine smooth durable pavement is made of the beautifully stratified beds of the inferior gray sandstone, a rock nearly allied to graywacke. It is a rock of fine texture, hard, and perfectly impervious to water. It occurs in abundance in the south-east part of Forfarshire, and, being chiefly shipred at Arbroath in that county, it has received the appellation of "Arbronth Pavement." Hard Hags from the counties of Caithness and Orkney also form very durable, though not always smooth, pavement. Some, however, of this, as well as of the Arbroath pavement, requires very little, if any, dressing with tools on the face. The Caithness pavement is cut on the edge with the saw, the Arbroath pavement with common masuns' tools. In a paper read to the British Association at their meeting at Glasgow in 1840, I'rufessor Traill described this flag as belonging to the red sandstone series, although its appearance as pavement would lead one to suppose it to belong to an older formation. Pavenent is also formed of the stratified portions of the sandstone of the coal-formation. Most of the foot-pavement of the streets of Edinburgh is of this kind. Its face requires to be wrought with tnols, and its texture armits water. Arbroath pavement costs from 2d. to 4d. per syuure font at the quarry, according to thickness. Both it and Caithness pavement cost $10 \mathrm{~d}$. and common stone pavement $6 \mathrm{~d}$. per foot in Edinburgh. When jointed and droved, the cost is 9.l. per square font additional.

(115.) In connection with the subject of masonry, I may advert to the sinking of wells for a supply of water. 1. In trap and other amorphous rocks, little water may be expected to be fomil, and the labor of sinking by blasting with gunpowder renders a well sunk in these sulstinces a very expensive undertaking. When there is probability of finding water in strutified rocks unler trap, the latter may be penetrated by boring with a jumper, with the view of forning an artesian well; but before such a project is undertaken, it should be ascertained beforelumel that stratified rock or diluvium exists below the trap, and that the dip of cither is toward the site of the well. Of so much importance is one good well on a farm, that a consjderable expense should be incurred rather than want, at any season, so es. sential a beverage as water to mund beast. When insuperable objects exist against finding water on the spot, perhaps the better plan will be either to go a distance to a higher elevation, where a common well may succeed in finding water, and then convey it to the steading by a wood or iron or lead pipe; or to descend to a lower site and throw the water up to the steading by means of a force-pump. Either of these plans may be less expensive, or more practicable than the boring through a hard rock to a great depth. The well in Bumborough Castle, in Northumberland, was sunk upward of 100 feet through trap to the sandstone below; and at Dundee, a bore was made through trap, 300 feet, to the inferior sandstone below, by means of a steam-engine, to olvtain water for a spinning-mill. 2 . In gravel and sand, a well may be ounk to a considerable depth before finding water. Being 
desirous of a supply of water to three adjoining fields of dry turnip land, resting on a dee? bed of pure gravel, and which had no watering-pool. I fixed on the most likely spot to contain water, near the foot of a rising ground of diluvial clay, in which to dig a well, and it happened to be a spot common to all the fields. After persevering to the depth of 22 feet without success, at the imminent hazard of overwhelming the men with gravel, as a despairing effort, at night-fall I caused a foot-pick to be thrust down into the bottom of the pit as far as the handle, and on withdrawing the instrument, water was seen to follow it. Next morning three feet more were dug, when the water excavating the gravel around the bottom of the pit rendered farther digging a dangerous operation for the men, so the ring of the well was there begun to be built with stones. The water afterward would rise no higher in the well than the level where it was first found, but the supply, nevertheless, was sufficient for the use of three fields. On finding water in this case, in the midst of very hopeless symptoms, I would recommend perseverance to diggers of wells, and success will most probably reward their efforts. 3. In very unctuous clay, such as is found in carse land, water is difficult to be obtained by digging to ordinary depths; but as such a country is usually situate near a large river, or on the side of a broad estuary, by digging to the depth of the bed of the river, some sand will most probably be found through which the water will find its way to the well; and though brackish in the estuary, it may come into the well sweet enough for all domestic purposes. 4. Wells dug in stratified rocks, such as sandstone, may be supplied with water at a moderate depth, perhaps 6 or 8 feet; but among regular strata there is as much risk of losing water as there is ease in obtaining it. To avoid disappointment, it will be necessary to puddle the seams of the rock on that side of the well in which it dips downward. 5. The substance which most certainly supplies water on being dug into is diluvial clay, a substance which forms the subsoil of the greatest extent of arable land in this kingdom. This clay is of itself impervious to water, but it is always intersected with small veins of sand frequently containing mica, and interspersed with numerous small stones, on removing which, water is found to ooze from their sites, and collect in any pit that is formed in the clay to receive it. The depth to be dug to secure a sufficiency of water may not be great, perhaps not less than 8 feet or more than 16 feet; but when the clay is homogeneous and hard, and there is little appearance of water, digging to upward of 40 feet in depth will be required to find water. I knew a remarkable instance of a well that was dug in such clay in Ireland, in which 40 feet were penetrated before any water was found; but immediately beyond that depth, so large a body of pure water was found in a small vein of sand, that the diggers escaped with difficulty out of the well, leaving their tools behind. A force-pump was obtained to clear the well of water, in order to allow the ring to be built; but it was unable to reduce the bulk of water, so that the ring remains unbuilt to this day; the water always stands within three feet of the top of the well, and the clay is not much affected by it. 6. Suppose, then, that this wall is to be dug in clay containing small stones and veins of sand. Let a circle of 8 feet in diameter be described on the surface of the ground, from whose area let the ground-soil be removed to be used elsewhere. After throwing out a depth of 8 or 9 feet with the spade, let a winch and rope and bucket be set up to draw the stuff out of the well. While the digging is proceeding, let a sufficient quantity of flat stones be laid down near the winch, by which to let them down to build the ring. A depth of $\mathbf{1 6}$ feet will most probably suffice, but if no water is found, let the digging proceed to the requisite depth. A ring of 3 feet in diameter will be a large enough bore for the well, the rest of the space to be filled up with dry rubble masonry, and drawn in at the top to 2 feet in diameter. Whenever the building is finished, the water should be removed from the well with buckets, if the quantity is small, and with a pump if it is large, to allow the bottom to be cleared of mud and stones. A thick flat stone, reaching from the side of the ring to beyond the center, should be firmly placed on the ground at the bottom of the well, for the wooden pump to stand upon, or for the lead pipe to rest on. If a wooden pump is used, a large flat stone, having a hole in it to embrace the pump, should be laid on a level with the ground upon the ring of the well; but if a lead pipe is preferred, the flat stone should be entire and cover the ring, and the clayey earth thrown over it. The cost of digging a well in clay, 8 feet in diameter and 16 feet deep, and building a ring 3 feet in diameter with dry rubble masonry, is only $£ 5$, exclusive of carriage and the cost of the pumps. A wooden-mounted larch pump of from 15 to 20 feet in length costs from $£ 3$ to $£ 310$ s. and a lead one $£_{2} 10$ s. with 1s. 2d. per lineal foot for pipe of the depth of the well. The wooden pump will last perhaps twenty years, and the lead one a lifetime, with ordinary care, and the lead at all times is worth something.

(116.) The making of the well naturally suggests the subject of water. The different kinds of water receive names from the sources from which they are derived. 'Thus there is sea-vater, the water of the ocean ; rain-water, the water which falls from the atmosphere; river-water, the water which flows in the channels of rivers; spring-water, the water as it naturally issues from the ground; well-water, the water collected in wells; pond-water, the water collected in an artificial hollow formed on the surface of the ground; and marshwater, the stagnant water collected in swamps and bogs. All these sorts of water possess different properties, acquired from the circumstances from which each is derived.

(117.) Pure water is not found in nature, for all the sorts of water accumulated on or near (229) 
the surface of the earth, though differing in purity in regard to each other, are none of them pure in the chemical sense of the term; that is, free of the arlmixture of other matter, such as gases, salts, earth. Pure water is colorless, and insipid to the taste. Its specific gravity is 1.000 ounces per cubic foot. It is made the standard of gravity, 1 being its equivalent mark. It is an inelastic fluid. It consists of hydrogen and oxygen, the combination by weight being 8 of oxygen and 1 of hydrogen-by volume, 1 of oxygen to 2 of hydrogenand by equivalent or atom, 1 of hydrogen with 1 of oxygen; its chemical symbol being $\mathrm{H}+\mathrm{O}$ or HO. Pure water is obtained by the distillation of rain or river water, and, to re. tain it so, it must be kept in closed botules filled to the stopper, as it has a strong aftiuity for common air, oxygen, and carbonic acid gas.

(118.) Water from the condensed vapor of fresh water is the purest that can be obtained by natural means. Hence, rain-water collected after rain has fallen for a time, at a hight above the ground, in the country, and at a distance from any dwelling of man, or new-fallen. melted snow, is the purest water that can be collected in a natural state; but, nevertheless, it is not pure, inasmuch as it coutaius oxygen, nitrogen, carbonic acid, and earthy matter, which it has met with in the atmosphere, besides nearly as much common air as it can absorb. Procured from the roofs of buildings, rain-water is always contaminated with many additional impurities, derived from the channels through which it has flowed. It is generally very dark-colored, and, when allowed to stand, deposits a quantity of earthy ingredients. It is not in a proper state for domestic purposes until it has got quit of as much of these impurities as it can by deposition.

(119.) Rain-water for domestic purposes is collected in eisterns. The form of a rain-tcater cistern, represented by fig. 30 , I have found an useful one for allowing the undisturbed de position of impurities, and at the same time the quick flowing off of the purer water, without disturbing the deposition. Let $a b b c$ be a cistern of stone or wood, placed as: a convenient spot of the steading or farm-house, for the re ception of rain-water. I have found that such a cistern, of the capacity of 12 cubic feet, holds a sufficient quantity of rain-water for the domestic purposes of an ordinary family. A cistern of 2 feet square at the base, and 3 feet in hight, will just contain that quantity; bnt, as the size of au ordinary wash-tub is 2 feet in diameter, the space betwixt $d$ and $d$ must be male 2 feet 6 inches at least, and the hight of the cistern $b$ could be 2 feet; but if more water is required than 12 cubic feet, then the hight should be 3 feet, which gives a capacity to the cistern of 18 cubic feet. Suppose the cistern represented in the figure to contain 18 cubic feet, then the area of $a$ will be $2 \mathrm{f}$ feet square, and $b 3$ feet in hight, supported on two upright stones $d d$ of the brealth of the cisteru and 2 feet high. The cistern may either be mule of a block of freestone hewn out to the dimensions, or of flags, of which the sides are let into grooves in the bottom and into each other, and imberled in white-lead, and fastened together with irou clamps, having a stone movable cover $c$. Or it may be formed of a box of wood, securely fastened at the comers to be water-tight, with a cover of wook, and resting on the stone supports $d d$. Stone being more durable, is, of course, preferable to wood for a cistem that stands out in the opm air. A hollow cupper cylinder $g$ is fastened perpendicularly into the bottom $a$, having its lower end projecting 1 inch

Fig. 30 .

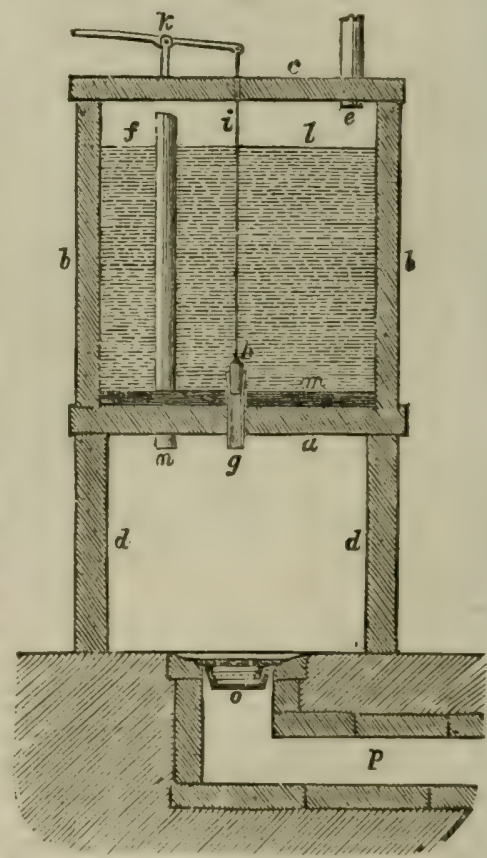

RAIN-WATER CISTERX.

below, and its upper 3 inches above, the respective surfaces of the bottom. The upper end of the copper cylinder is formed to receive a ground truncated cone of copper called a plug or stopper, which is moved up and down with the lever $k$, by means of the stout copper rod $i$. The plug must be made watertight with grease, the rod of which passes through a hole in the cover, to be connected with the lever, whose support or fulcrum is fixed on the cover. These parts are all male of copper, to withstand rusting from the water, with the exception of the lever, which may be of iron, painted. The rain-water is supplied to the cistern by the pipe $e$, which descends from the rain-water conductor, and is let throngh a hole in the cover. The water is represented standing as high as $l$, but, in case it should rise to overflow, it can pass off by the lead waste-pipe $f$, which is secured and movable at pleasure in a ground. (230) 
washer $n$, whose upper end is made flush with the upper surface of the bottom $a$. After the water has entered the cistern, it gets leave to settle its sediment, which it may do to the hight of the upper end of $g$. The sediment is represented by $m$, and, when it accumulates to $h$, the cover $c$ should be taken off, and the waste-pipe $f$ removed, and it can then be cleaned completely out by the washer $n$. The waste water runs away through the air-trap $o$, and along the drain $p$. It is more convenient to have two small than one large cistern, as, while the water is rising in the one, that in the other gets leave to settle. The cost of such a cistern, with droved stones, and to contain 18 cubic feet, with the proper mountings, may be about $\mathfrak{£ 5}$. I think it right to say, in commendation of this form of water-cistern, that in no case have I known the water about the plug to be frozen-in consequence, perbaps, of the non-conducting power of the mud in the bottom of the cistern. The rod $i$ has sometimes be come fast th the ice on the top of the water, but a little boiling water poured down by the side of the rod through a funnel soon freed it from restraint.

(120.) Rain-water, besides containing gases in solution, becomes impregnated with many saline substances in its passage through the ground; and hence the water of springs and riv. ers always contains many ingredients. The purest spring-water is that which has passed through gravelly deposits, such as of granite, sandstone, quartz; because the component parts of those stony substances being insoluble, the water cannot take up much of them. In the same way the water of old wells is purer than that of new, because the long continued action of the water has removed or gradually dissolved the soluble matters in the same passages through the ground to the well. "The matters generally contained in spring, well, and river water," says Mr. Reid, "are carbonate of lime, sulphate of lime, muriate of lime, sulphates of potash and soda, muriate of soda, and sometimes a little magnesia. "In rainwater,' says Dr. Murray, 'the muriates I have found generally to form the chief impreguation, while in spring-water the sulphates and carbonates are predominant, and in the former the alkalies,' potash and soda, 'are in larger quantity, while the earths, particnlarly lime, are more abundant in the latter.' $" * *$ It is in its combination with one or more of these salts that water becomes hard, chiefly with the sulphate of lime or gypsum, and the carbonate of lime or limestone. Water is said to be hard when it will not dissolve but decompose soap. Soft water, on the other hand, does not decompose, but combines easily with sonp and dissolves it. Hard water is not so fit as soft for many culinary purposes, such as making tea and boiling vegetables. It is, therefore, of importance for you to know when water is in a hard or soft state. By placing a few thin slices of white soap in a clean tumbler of the water to be examined, its hardness will be indicated by vhite flahes ur curdy particles around the soap, the effect of decomposition-the acids of the salts in the water combining with the alkali of the soap and leaving the fatty matter. A very small quantity of either of the salts enumerated above will render water hard. Water can dissolve 1-500 part of its weight of gypsum; but, according to Dr. Dalton, 1-1000 part is sufficient to render it hard; and Mr. Cavendish says that 1200 grains of water containing carbonic acid will hold in solution 1 grain of limestone. Limestone is insoluble in pure water; but water containing carbonic acid in solution can dissolve it.

(121.) "To discover whether the hardness be owing to the presence of limestone or gypsum, the following chemical tests," says Mr. Reid, "may be applied. A solution of the nitrate of barytes will produce a white precipitate with water containing either gypsum or limestone; if limestone have been present in the water the precipitate will be dissolved, and the liquid rendered clear on adding a few drops of pure nitric acid; if the presence of gypsum caused the precipitate, this will not be dissolved by the nitric acid. A solution of the sugar of lead may be used in the same way, but the nitrate of barytes is preferred." $t$

(122.) As to a practical remedy for hard water, bniling will remove the lime. The carbonic acid in excess in the water is converted into the gaseous form, and the carbonate of lime then becoming insoluble, falls to the bottom of the vessel. Hence the incrustation of tea-kettles. If the hardness is caused by gypsum, a little pearlash or soda (carbonate of potash or carbonate of soda) will remove it, and the lime of the water will also be precipitated with the carbonic acid of the pearlash or soda.

(123.) River-water is always softer than spring or well water, because it deposits its earthy ingredients when flowing in contact with common air, which it absorbs in considerahle quantity. By analysis, the water of the river Clyde yielded 1-35 of its bulk of gases, of which 19-20 were common air. "All that is necessary," remarks Mr. Reid, "in order to render river-water fit for use is to filter it. This is rather a mechanical than a chemical operation, and is done by causing the water to pour through several layers of sand, which intercepts the muddy particles as the liquid passes through. Filtering stones, made of some porous material, such as sandstone, and hollowed out so as to be capable of containing a considerable quantity of water, have sometimes been employed to purify water. Compressed sponges have also been employed for this purpose. Sand and charcoal form the chiet elements in the construction of the filters now so much employed for purifying water, the powdered charcoal acting not only mechanically in detaining any muddy particles, but having a chemical effect in sweetening the water (rendering it fresh) if it be at all trinted, or even in retarding putrefaction, if it have any tendency that way." + 
(124.) Water, as a beverage, wonld be insipid or even nauseous without the gases and saline matters usually found in it. They give a natural seasoning and a sparkling appearance to it, thereby rendering it agreeable to the taste. Every one knows the mawkish taste of boiled water when drank alone.

(125.) As I am on the subject of water, a few words should here be said on the making of horse-ponds. The position of the horse-pond will be seen in figs. 1 and 2, in Plates $\mathrm{I}$. and II. When a small stream passes the steading, it is easy to make a pond serve the purpose of horses drinking and washing in it, and the water in such a pond will always be pure and clean. But it may happen, for the sake of convenience, when there is no stream, that a pond should be dug in clay, in which case the water in it will always be dirty and offensive, unless means are used to bring water by a pipe from a distance. If the subsoil is gravelly, the water will with difficulty be retained on it, on which account the bottom should be puddled with clay. Puddling is a very simple process, and may be performed in this manner: Let a quantity of tenacious clay be beaten smooth with a wooden rammer, mixing with it about one-fourth part of its bulk of slaked lime, which has the effect of deterring worms making holes in it. After the mass has lain for some time souring, let large balls of it be formed and thrown forcibly on the bottom of the pond, made dry for the purpose, and beaten down with the rammer or tramped with men's feet, until a coating 6 or 7 inches in thickness is formed, or more, if there is plenty of clay. Then let a quantity of clean gravel be beaten with the rammer into the upper surface of the clay hefore it has had time to harden. Should the pond be large, and the weather at the time of making it so dry as to harden the clay before its entire bottom can be covered with it, let the puddling and graveling proceed together by degrees. Above the coating of gravel, let a substantial causeway of stones and sand be formed to resist the action of the horses' feet, and which, if properly protected at the ends, and finished on the open side of the pond, will withstand that action for a long time. I have seen a sort of pond recommended to be made, into which the horses enter at one end, and pass through it by the other. This is a convenient shape of pond, in as far as it admits of the uninterrupted passage of the horses throngh the pond, hut it is liable to serious objections. Being contracted laterally, the pair of horses which first descend to drink will occupy the greatest proportion of its whole hreadih, and, while in that position, the succeeding pair must drink the muddy water at their heels: and, as the contracted form precludes easy turning in the deepest part of the water, none of the rest of the horses can be permitted to hlock up the opposite or open end of the pond. A murh better form of pond, I conceive, is with an open side, having the opposite side fenced, and the water supplied clean at the upper end, and made to flow immediately awav lw lite lower. At such a pond a number of horses can stand in a row to drink at the same time, aml easily pass each other in the act of washing the legs after drinking. As to the depth, no horse-pond should ever exceed the hight of the horses' knees. The water should on no account reach their bellies: for althoush I am quite aware of plowmen being desirous to wate their horses deep, and of even wishing to see their sides laved with water, to save themselves some trouble in cleaning, that is no reason why you should run the risk of endangering the health of your norses by making the pond deeper than the knee.

(126.) With regard to the kind of stone which should bn emploved in the hnilding of a steading, it must be determined by the mineral product of the lucalitv in which it is pro. posed to erect it. In all localities where stone is accessible, it should be preferred to every other material; but where its carriage is distant, and of course expensive, other materials, such as brick or clay, must be taken. In large flat tracts of country, stone is generally at too great a distance; but in those situations, clay being ahundant. hrick may be easily made, and it makes an excellent building material for walls, and far surerior to the old-fashioned clay walls which were in vogue before brick became so universally used for building. Of stone, any kind may be used that is nearest at hand, though some rocks are much better adapted for building purposes than others. 1. Of the primitive rocks, gray granite forms a beautiful and durable stone, as is exemplified in the buildings in Aluerdeenshire, Cornwall, and Newry in Ireland. Gneiss, micaslate, and clayslate, do not answer the purpose well. They give a mugh edgy fracture, frequently rise too thin in the bed, especially in the case of clayslaie; are not unfrequently curved in the bed, and at the same time difficult to be dressed with the hammer. 2. Of the transition series, gravwacke makes a beautifinl build. ing-stone, as may be seen in the houses at Melrose. The old red sandstone, though a good building-stone, has a disagreeably sombre aspect, as seen at Arbroath; but the inferior gray sandstone which prevails in the neighborhood of Dundee, is a beautifial and duratse build. ing-stone. 3. All the sandstones of the coal formation form excellent materials for building, as is exemplified in Edinburgh and many other places. 4. The limestone, from marble to the mountain carboniferous limestone, make fine building-stone, as at Plymouth; but in case of fire they are apt to be cntcined by heat, as exemplified in the cathedral at Armagh, before it was repaired. And 5. Even the trap-rocks are employed in building houses where sandstones are scarce. Though the two classes of rock are frequently located together. Whinstone is objectionable, inasmuch as it throws out dampness in wet weather, and the walls require to be lathed and plastered on the inside, to render the house even comfortable. Frequently where whinstone is near at hand, and sandstone can be obtained at a little distance, 
the latter is employed as corners, ribets and lintels, though the contrast of color betwixt them is 100 violent to be pleasant to the eye. If sandstone, therefore, can be procured at a reasonable cost of carriage, you should give it the preference to whinstone, fur the sake of comfort to your live-stock in their habitations in wet weather. You may, indeed, choose to incur the expense of lathing and plastering all the insides of the walls of the steading; but a lathed wall in any part of a steading would be apt to be broken by every thing that came against it, and is, on that account, an unsuitable finishing for a steading. 6. The worst sort of building-stone are landfast boulders of the primitive and trap rocks, which, although reduceable by gunpowder, and manageable by cleavage into converient shaped stones, incur great labor in their preparation for building; and even after the stones are prepared in the best manner they are capable, their beds are frequently very rough, and jointings coarsi:, and the variety of texture and color exhibited by them, render them at the best unsightly objects in a building. They are equally unsuitable for dry-stone dykes as for buildiugs, for in the case of dykes, they must be used very nearly in their natural state, as the usual charge for such work will not bear labor being bestowed on the preparation of the material. Still, after all, if no better material for building houses is near at hand than those boulders, they must be taken as the only natural product the country affords. There is a cliss of boulders, composed chiefly of micaceons sandstone, found in banks of gravel, which aiswer for drystone dykes admirably, splitting with ease with a hand-pick into thin layers, and exhibiting a rough surface on the bed, very favorable to their adherence together in the wall. This species of building material is abundant in Forfarshire, where specimens of dry-stone building may be seen of a superior order. In these remarks of the general choice of buildingstones by Mr. G. Smith, architect in Edinburgh, there is much truth: "The engineer and architect," says he, "go differently to work in choosing their stones. The former, in making his experiments for his piers and bridges, selects the strongest and hardest as most suited to resist great pressure. The latter, for his architectural decorations, chooses not only the most beautiful as to texture and uniformity of color, but those which may be easily cut into the most delicate mouldings, and which, moreover, will stand the winter's frost and the summer's heat. It may be remarked that the hardest stones are not always those which hold out the best against the effects of the weather."*

(127.) I may here observe, in concluding my observations on the specifications of masonry, that any lime that is used on a farm, for the purpose of steeps for grain or for mortar, gets leave to lie about in the most careless manner, either under a shed, or at some place contiguous to water, where it had been made up into mortar. In either case there is waste of a useful article; and in many parts of the country, where carriage is far distant, it is a highpriced article. The lime that is to be used in a dry state should be kept under cover; and all that is required in a season could be held in a cask or small hogshead to stand in a corner of the cart-shed or potato-store, but not in the straw-barn, where a little damp may cause it to ignite the straw. With regard to mortar, no more should be male at a time than is used, or it should be carefully heaped together in a convenient place, and covered with turf.

(128.) In Sweden, mortar is made and kept in a convenient form of cart, represented by fig. 31 , a practice which might with propriety be followed in this country. The cart con.

Fig. 31.

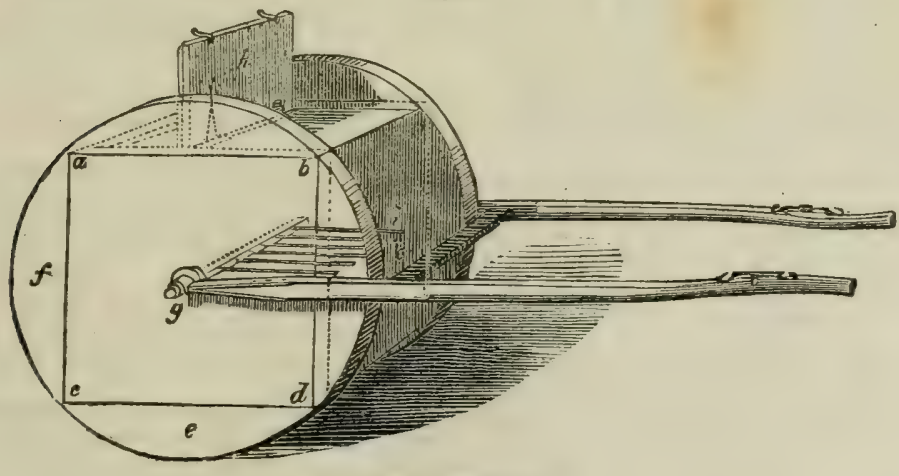

SWEDISH MORTAR-CART.

sists of a cube $a b c d$ of a side of 3 feet made of 2 -inch thick battens. The wheels are formed of the two sides of the cube, on which are fixed circular segments such as $e$ and $f$, made of strong battens 3 inches thick, secured by a screw at each end into the side of the

* Prize Eigays of the Highland and Agricultural Society. vol. x. p. 85. 
cube, and the circles are shod with iron as conmon wheels. The axle $g$, inside and outside, is closely passed through the cube, so as not to allow any of the mortar to come out. The axle moves in a small iron nave attached to the shafts of the cart. On it are screwed iron bars $i$. which pass through one of the sides of the cube, and fastened to it by screws $k$. The use of these bars is to break the mortar when too tough; and if one set of bars is found insufficient for that purpose, similar ones should be put throngh the opposite side of the cube. A lid $h$ is well secured to the cube by hinges, and kept fast by means of a hasp. When the shafts are drawn, the whole cart revolves with the wheels.

(129.) The lime is put into the cart by the lid, and sprinkled over with a little water, about half a gallon of which to the bushel of lime will be enough the first time. The cart is then driven mound a while; and when the driver, who must often look to the mortar, finds that all the water is imbibed, a little more must be poured in, and the cart again driven round. Water is poured in in small quantities until the lime forms coagulated masses or balls, and then it is worked until no dry lime is seen in the mass. The success of making good mortar dipeuds on the skill of the driver, who will soon learn to do it well after a cart. ful or two of driving. Three bushels of lime and sand can be prepared in this way in a short time, but the saud should not be put in till after the lime has been sufficiently wrought with water.*

(130.) Of the specification of carpenter-work, the first timber that is used in building con sists of sufe-lintels, which should be 4 inches thick, of such a breadth as to cover the spas: they are placed over, and they should have a solid bearing at both ends of 12 inches.

(131.) The scantlings or couples for the roofs vary in size with the breadth of the build. ing. When the building is 18 feet wide, the scantlings shonld be 8 inches wide at bottom, 7 inches at top, and $2 \frac{1}{2}$ inches thick. Those for 15 feet wide buildings should be $7 \frac{1}{2}$ inches wide at bottom, and $6 \frac{1}{2}$ inches at top. All scantlings should be placed 18 inches apart from center to center, upon wall-plates 8 inches wide by 11 inches thick, firmly secured to bondtimber built into the tops of the walls. These dimensions of scantlings are suitable for a roof of blue slates. For a tile-roof the scantlings are placed 2 feet apart from center to center.For roofing with gray-slates, which are very heavy, the scantlings should be 3 inches thick. With tiles and gray-slates the rools require a higher pitch than with blue slates, and this is given by making the scantlings 1 font longer.

(132.) The balks of an 18 feet wide building should be $7 \frac{1}{2}$ inches broad by $2 \frac{1}{2}$ inches thick, and, for the 15 feet one, 7 inches by $2 \frac{1}{2}$ inches. In both cases the balks should be of the length of one of the scantlings, which will bring its position so low down on the scantlings as to be only a little more than 3 feet above the wall-heads. It is generally supposed that one balk is sufficient for the support of the scantlings; but it will be seen in fig. $6, p .88$, that I have represented a vertical section of the principal range of the steading with two halks, because I wonld always prefer two balks to one, and the only objection to the two is the expense. When two balks are employed, the lower one will be about 2 feet, and the upper one about 5 feet, above the wall-heads.

(133) If a slated roof is adopted, there should be a ridge-tree 10 inches broad by 2 inches thick, and the tops of the scantlings should be bound with collar-pieces, 5 inches broad and 2 inches thick, half checked into the scantlings. If a tile-roof is preferred, it is sufficient that the tops of the scantlings be checked in with collar-pieces, as just described.

(134.) The whole rouf should be covered with sarking, 8 inch thick, and clean jointed. A tile-roof requires tile-lath, $1 \frac{1}{1}$ inches square, and 11 inches apart, excepting at the eaves, which should have a boarding from 12 inches to 15 inches broad, and inch thick for slates. Tile-lath is also employed with gray-slates.

(135.) The peands and flankers should be 9 inches broad at bottom, and 7 inches at top, and 3 inches thick, properly backed to receive the sarking or tile-lath of the respective sorts of roofis.

(136.) The joists of the flooring in the part of the buildings that is 18 feet wide should be 10 inches deep by $2 \frac{1}{2}$ inches in thickness, placed 18 inches asunder from center to center, and having a wall-hold or rest of 12 inches at each end. When the bearings of joists exceed 8 feet, it is a more secure and economical plan to have beams, instead of battens, laid across the building, 13 inches deep, and 6. inches in width, with a wall-hold of 12 inches at each end. Upon these should rest joists 7 inches deep, and $2 \frac{1}{2}$ inches in breadth, and not more than 16 inches apart from center to center, dove-tailed into the beams with a hold of 9 inches at each exd. These joints are best cut out of Memel log of first or second quality, the difference of price between the two qualities being $2 \mathrm{~d}$. the cubic foot.

(137.) The floors of the upper and corn-barn and granaries should be of $1 \frac{1}{4}$ inches thick, of red or white wood battens, grooved and tongued, and well srasoned when wrought and laid. The under side of the floor, and the joists which support the floor of the upper-barn, forming the roof of the corn-barn, should be clean dressed. to prevent the adherence of dust.

(138.) In some parts of the country, and especially in East-Lothian, the floor of the cornbarn is made of composition; but, in order to leave a part of the floor clean, upon which to winnow the grain, a space, 12 feet square, is usually left in the middle of the floor. This

* Quarterly Journal of Agriculture, vol. xi. p. 245 .

(234) 
space is laid with sleeper-joisting, 7 inches deep by $2 \frac{1}{2}$ iuches thick, and 18 inches apart from conter to center, supporting a flooring of deal 2 inches thick, grooved and tongued. As a precaution against vermin, as well as the enjoyment of cleanliness while winnowing and othorwise haudling the grain, I would always recommend an entire wooden floor for the cornbarn, to be laid down in the manner described in (16.) and represented in fig. 6, p. 88

(139.) The windows of the stables should be of the form of fig. 14, p. 105. Those of the other apartments of the steading, with the exception of the granaries, should be of the form of fig. 15, p. 105; and those of the granary should be of the form of fig. 17, p. 107. The astragals, if not made of wood, may be of cast-iron or zinc. Cast-iron astragals cost 1s. and zinc $9 \mathrm{l} d$. the square foot.

(140.) The exterior doors, $7 \frac{1}{2}$ feet high, should be of $1 \frac{1}{4}$ inch deal, grooved, and tongued, and beaded, having three back-bars, 7 inches broad by $1 \frac{1}{4}$ inches thick; those of the cornbarn, cow-byre, and boiling-house, being in two horizontal leaves, that of the upper-barn in two vertical leaves, and those of the rest of the apartments being entire.

(141.) If desired, small windows of one or two rows of panes may be placed above all the outside doors; in which case, the voids of these doors should be made proportionally high, say 8 feet.

(142.) The inside doors should be 7 feet high, of 3 inch deal, with three back-bars 6 inches broad and 1 inch thick, grooved, and plowed, and beaded. They should have checks 6 inches broad by $2 \frac{1}{2}$ inches thick, and keps and facings $4 \frac{1}{2}$ inches broad by 3 inch thick.

(143.) The travis boarding of the work-horse stable should be $1 \frac{1}{2}$ inches thick, $9 \frac{1}{2}$ feet long, 7 feet 6 inches high at the fore and 4 fiet 6 inches high at the heel posts, doweled in the joints with oak pins, and of an ogee form on the top, let into a 2 -inch deep groove in the heel-post, and coped with beading. The heel-posts should be 6 inches square, beaded, the fore-posts, on both sides, 5 inches by $2 \frac{1}{2}$ inches, and both fixed at the top to runtrees, 6 inches deep by 2 inches broad. The side walls of the end-stalls should be finished in the same manner, and firmly secured to wall-straps and bond-timbers.

(144.) The travis-boarding of the riding-horse stable should be of the same strength as just described; but the heel-posts should be turned 5 feet high above the ground, with moulded caps and balls, and let from 18 inches to 2 feet into the ground, through a stone frame 18 inches square and 12 inches thick, firmly built with stone and mortar. The foreposts should be 3 inches in diameter on both sides to the hight of the travis-boarding. Heelposts are also made of cast-iron, which cost $22 \mathrm{~s}$. eacts.

(145.) The hay-racks of the work-horse stable should have a hard-wood rail, 3 inches deep by $2 \frac{1}{2}$ inches wide, and the spars of fir, 2 inches broad by $1 \frac{1}{2}$ inches thick, placed $2 \frac{1}{2}$ inches apart. These spars should be put on both front and bottom.

(146.) The hay-racks of the riding-horse stable should be of hard-wood, and placed high up, with rails, 3 inches deep by $2 \frac{1}{2}$ inches wide, and turned rollers, 2 inches of diameter, set $2 \frac{1}{2}$ inches apart. Cast-iron racks are frequently used in the corner of the stall, and they cost 10 s. each.

(147.) The mangers of the riding-horse stable should be of rounded battens in front, of full breadth of the stalls, placed at a convenient hight above the floor, and bottomed and lined with $1 \frac{1}{4}$-inch deal.

(148.) In the work-horse stable, corn-boxes are placed in the near angle of the hay-racks.

(149.) The stalls of the cow or feeding byres should be made of $1 \frac{1}{4}$-inch deal, beaded, grooved, and tongued. They should be 6 feet long, and 4 feet high, with 1 -inch beaded coping, let into stakes or heel-posts, 5 inches to 6 inches diameter, and held to the wall at the head with a 2-inch fillet, and iron hold-fast on each side. The heel-posts should either be taken to the hight of the byre-wall, and secured to runtrees, 6 inches deep by 2 inches broad, or fastened into the ground with masonry like those of the riding-horse stable.

(150.) The doors of the feeding-holes of the byres should be of 3 -inch deal, of two thicknesses, crossed.

(151.) The slairs from the corn-barn to the granaries, if of wood, should have 11 inches of tread and 7 inches of hight of steps. A stair or trap of similar dimensions may lead to the wool-room.

(152.) The floors of the granaries, upper and corn-barns, and wool-room, should have an angular skirting, 3 inches by 3 inches, around them.

(153.) Should the upper-barn, or granaries, or wool-room, be ascended by outside stone stairs, they should be furnished with plain $\frac{3}{4}$-inch iron railing, carried around the outer erlge of the steps and platform, with a hard-wood hand-rail, or be inclosed with $\frac{3}{4}$-inch deal lining, the whole hight above the steps, and properly framed.

(154.) The interior of the hen-house should be fitted up with rough s-inch deal shelves and divisions, and roosting-trees 3 inches deep by 2 inches broad.

(155.) The doors of the hen-house should be of 1 -inch deal, beaded, grooved and tongued.

(156.) Wooden ventilators should be placed upon the roof above every altemate pair of horses and cattle, of the form and dimensions of fig. 8, p. 95; or they may consist of 3 -inch deal, 6 inches square, in an opening abnve every alternate stall, and furnished on the upper part above the roof, with bent tuhes of lead, 6 lbs. to the square foot, or with zinc ones of the same dimensions. The zinc ventilators vary in price, according to size, from $4 \mathrm{~s}$. to 78. each. (235) 
(157.) The ceilings of the stables, boiling-house, granaries, wbere tile are used for roofing, wool-room, and hen-touse, should be lathed with Baltic split-lath 3-16 of an inch in thickness. "Laths are sold by the bundle. which is generally called a hundred; but 7 score, or 140 , are computed in the 100 for 3 -feet laths: 6 score, or 120, in such as are 4 feet; and for those which are denominated 5 feet, the common 100 , or 5 score." $\quad$ Lath is also made of home wood, usually Scots fir, sawn up into s-irch plank, and split irregularly with the ax. and, when nailed on, the splits are kept open by means of a wedge. The duty on foreign lath-wood is trom $f+5 \mathrm{~s}$. to $f 312 \mathrm{~s}$. and on that from the colonies from $15 \mathrm{~s}$. to $25 \mathrm{~s}$. on the bulk of 6 feet wide by 6 feet high, according to the length of the timber.

(158.) The riding-horse stable should have saddle-brackets of 3 -inch deal, firmly supported, and two pins let iuto rails 6 inches wide and $1 \frac{1}{2}$ inches thick, for each horse. The workhorse stable should have two similar rails, with large and small pins for each horse.

(159.) Every court and hammel should be provided with a gate, the forms and dimen. sions of which I will afterward give, when I cone to speak of the subject of gates in general, in spring.

(160.) The entrance to the piggeries should be furnished with doors of 1-inch deal, of two thicknesses. crossed. as represented in fig. 23, p. 114.

(161.) All the varieties of fir timber imported into the country are employed in the building of-steadings, and those kinds are most used in localities which are obtained from the nearest sea-ports. For example, along the cast coast of this country Memel logs and Baltic battens are used for all rough purposes, wbile on the west coast no timber is to be seen in: the construction of steadings but what is brought from America. 1. Norway and St. Petersburg baitens being cut to proper lengths and breadths, form cheap and very durable timber for all farm purposes. The price is, for red from $3 \mathrm{~d}$. to $3 \frac{1}{2} \mathrm{~d}$., for white from $2 \frac{5}{8} \mathrm{~d}$. to 3d. the lineal foot. The Norway battens are a shade cheaper. The red or white-wood batteus make excellent floors, and plain deal doors for iuside use. Such flooring is beautifully dressed by planing machinery at Mr. Burstall's mills at Leith. 2. Memel logs are admira. bly fitted for joisting, windows, uutside doors, and all outside work, it being composed of strong and durable fibre, surrounded with resinous matter. It sells for from 2s. $4 \mathrm{~d}$. to $2 \mathrm{~s}$. $6 \mathrm{~d}$. the cubic foot. The greatest objection to its use for small purposes is its knottiuess, on which account the Norway battens make handier small scantlings and cleaner donr-work. 3. The American red-pine is excellent timber, being clean, reedy, and resinous. It is seldom or never of so large dimensions as Memel log. It fetches from 28 . to 2s. $2 \mathrm{~d}$. the cubic foot. It is fitted for beams, joists, scantlings, windows, and outside doors. 4. American yellow-pine is well suited to all inside work, and especially that which requires the highest finish, such as bound-donrs, window-fittings, and mantel-pieces. There is no wood that receives paint so well. The logs are generally of immense sizes, affording great economy of timber in cutting them up. Its price is, for small sizes 1s. $8 \mathrm{~d}$. and for large 28. 3d. the cubic foot. 5. Swedish 11 -inch plank is good and useful timber, but its scantlings are not very suitable for farm-buildings. I have seen stout joists for granaries made of it, with a s draught taken off the side for sarking. It forms excelient planking for wheeling upnn, and for gangwavs. It sells, the white-wood for from $5 \mathrm{~d}$. to $6 \mathrm{~d}$. and the red from $6 \mathrm{~d}$. to $7 \mathrm{~d}$. the lineal foot.

(162.) In the interior of the country, at a distance from sea-ports. home timber is much used in farm buildings. Larch forms good scantlings and joists, ard is a durable timber for rough work, and so does well grown Scots fir of good age, and cut down in the proper season; but its durability is not equal to larch, or generally any good foreign timber for rough purposes. $t$

(163.) All the timber I have referred to is derived from the trees belonging to the natural order of Conifera, or cone-bearing trees. 1. The Scots fir, Pinus sylvestris, is a well known tree in the forests of this country, and few new plantations are made withont its aid, as a nurse for hard-wood trees. In favorable situations it grows to a large size, as is evidenced in the Memel $\log$, which is just the produce of the Scuts fir from the forests of Lithuania. I have seen Scots fr cut down at Ardovie, in Forfarshire, of as good quality and useful sizes as the best Memel. 2. The Swedish plank is of the spruce, Abies excelsa, or communis $\rightarrow$ tree which, as it is treated in this country, comes to little value, being rough and full of $\mathrm{knots.}$ Inspection of a cargo from Sweden, which arrived at Hull in 1808 , convinced Mr. Pontey that the white deal, which fetched at that time from $£ 14$ to $£ 1510$ s. the load of 50 cubic feet, was of common spruce, the jlanks having been recently sawn, and a small branch left attached to one of them. $\$ 3$. Whether the Norway pine is the same species as the pine found in some of the forests of the north of Scotland, I do not know. I observe that some writers speak of the Norway batten as of the Norway spruce, called by them Pinus Abies.

\footnotetext{
- McCulloch's Dictionary of Commerce, art Lath.
}

I In rol. ix. p. 165, of the Prize Esays of the Highland and Agricultural society, you will find a long aco count of the Larch Plantations of Atholl, drawn up by me from the papers of the late Duke of Athcll; and in vol. xii p. 122, of the same work, is an account of the aative pine forests of the north of \&cotland, by Mr John Grigor, Forres.

I Pontey's Profitable Planter, p. 41, 4th edition, 1814 ; and at p. 56 he reletee an anecdote of a person who though long accustomed to attend on eawyers, was deceived by nome scots fir. which he coneidered excel lens foreign plank. 


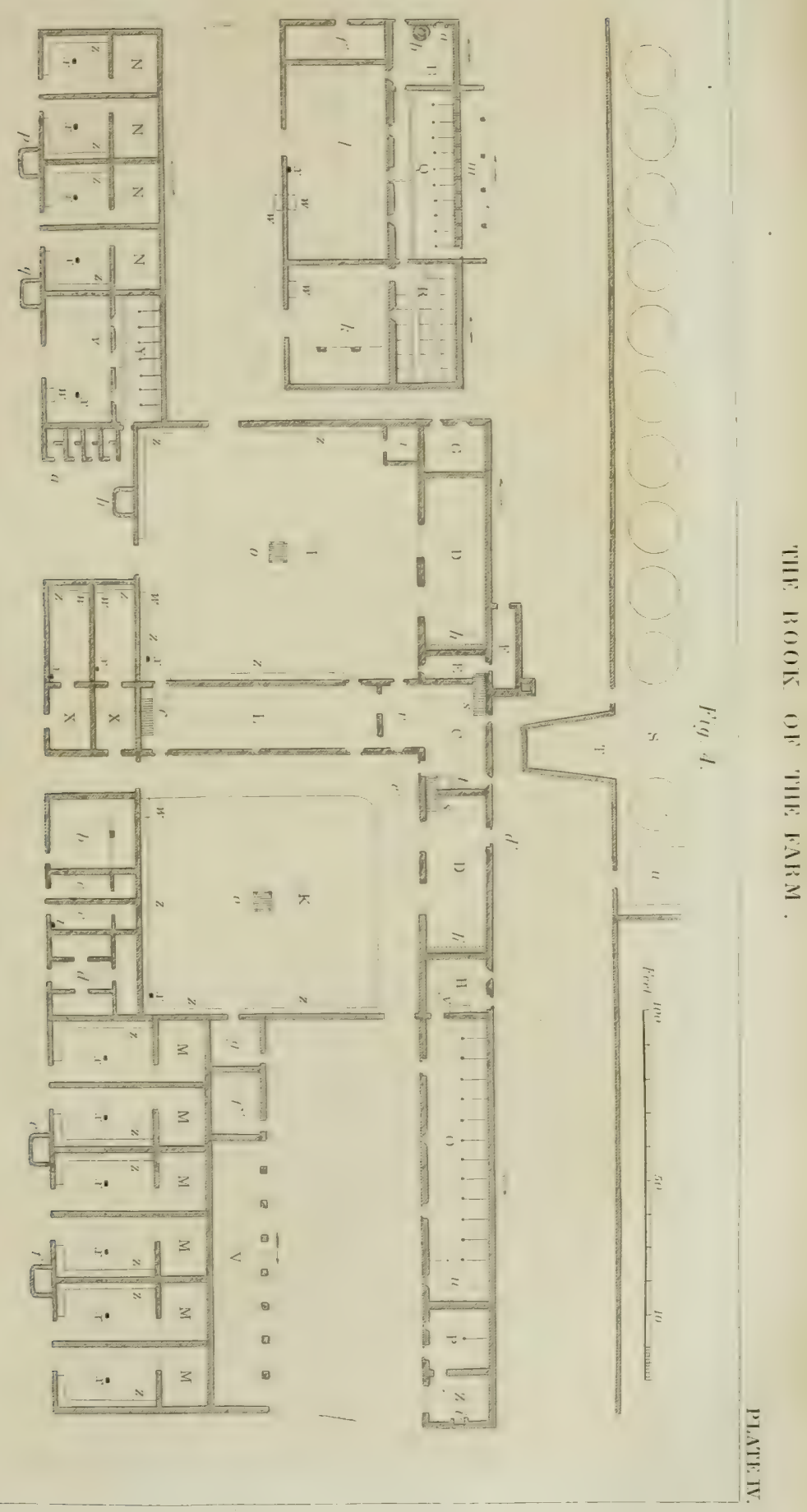



It may be that the white-wood battens are derived from that tree; but the red-wood kind has, very probably, the same origin as the red-wond of the north of Scotland, which is from a variety of the Pinus sylvestris, or horizontalis of Don. ${ }^{*} 5$ : The red pine of Canada is the Pinus resinosa. 6. And the yellow pine is the Pinus variabilis or Pinus mitis of Michaux, which towers in lofty hight far above its compeers. It grows to the gigantic hight of 150 feet, and must require great labor to square it to the sizes found in the British market, large as these sizes unquestionably are. 7. The larch, Larix europaa, is a native of the ravines of the Alps of the Tyrol and Switzerland, where it shoots up, as straight as a rush, to a great hight.

(164.) In regard to the composition of wood, and its chemical properties, "It is considered by chemists that dry timber consists, on an avernge, of 96 parts of fibrous and 4 of soluble matter in 100 ; but that their proportions vary somewhat with the seasons, the soils, and the plant. All kinds of wood sink in water when placed in a basin of it under the exhausted receiver of an air-pump, showing their specific gravity to be greater than 1,000," and varying from 1.46 (pine) to $1.53(o a k$ ). . . "Wood becomes snow-white when exposed to the action of chlorine; digested with sulphuric acid, it is transformed first into gum, and, by ebullition with water, afterward into grape sugar. . . . . Authenreith stated, some years ago, that he found that fine sawdust, mixed with a sufficient quantity of wheat Hour, made a cohesive dough with water, which formed an excellent food for pigs-apparently showing that the digestive organs of this animal could operate the same sort of change upon wood as sulphuric acid does. . . . The composition of wood has been examined by Messrs. Gay-Lussac and Thenard, and Dr. Prout. According to Dr. Prout, the oxygen and hydrogen are in the exact proportions to form pure water; according to the others, the hydrogen is in excess." +

(165.) "When minutely divided fragments of a trunk or branch of a tree," as M. Raspail observes, " have been treated by cold or boiling water, alcohol, ether, diluted acids and alkalies, there remains a spongy substance, of a snow-white color when pure, which none of these reägents have acted on, while they have removed the soluble substances that were associated with it. It is this that has been called woody-matter, a substance which possesses all the physical and chemical properties of cotton, of the fibre of flax, or of hemp.'

(166.) "On observing this vegetable caput mortuum with the microscope, it is perceived to be altogether composed of the cells or vessels which formed the hasis or skeleton of the living organs of the vegetable. They are either cells which, by pressing against each other, give rise to a net-work with pentagonal or hexagonal meshes; or cells with square surfaces; or else tubes of greater or less length, more or less flattened or contracted by drying-sometimes free and isolated, at other times agglomerated and connected to each other by a tissue of elongated, flattened, and equilateral rells; or, lastiy, tubes of indefinite length, each containing within it another tube formed of a single filament spirally rolled up against its sides, and capable of being unrolled under the eye of the observer, simply by tearing the tube which serves to support it. We find the first in all young organs, in annual and tender stems, in the pith of those vegetables that have a pith, and always in that of the monocotyledons. It is in similar cells that the fecula is contained in the potate. The second is met with in all the trunks and woody branches of trees. The tubes and the spirals (trachea) are found in all the phanerogamous plants. These are the organs which constitute the fibre of hemp, of flax, \&c."

(167.) "Experiment in accordance with the testimony of history, proves that, if excluded from the contact of moist air, woody matter, like most of the other organized substances, may be preserved for an indefinite period." The plants found in coal mines, the wood, linen cloths, bandages, and herbs and seeds found in the coffins of Egyptian mummies, have all their characters undecayed, and yet these tombs are in many cases nearly 3000 years old. "But, if the woody matter be not protected against the actinn of air and moisture, the case is very different. By degrees its hydrogen and oxygen are disengaged, and the carbon predominates more and more. Thus the particles of the texture are disintegrated gradually, their white color fades, and passes through all the shades till it becomes jet-black; and if this altered woody matter be exposed to heat, it is carbonized without flame, because it does not contain a sufficient quantity of hydrogen. Observe, also, that the cells of woody matter contain different sorts of substances tending to organize, and that these are mixed and modified in many different ways." . . . "Woody matter, such as I have defined it, being formed of one atom of carbon and one atom of water, as soon as it is submitted to the action of a somewhat elevated temperature, without the contact of air, experiences an internal reäction, which tends to separate the atom of water from the atom of carbon. The water is vaporized, and the carbon remains in the form of a black and granular residue." $\ddagger$

(168.) Now, if any means could be devised by which the substances in the cells of wondy matter could be deprived of their tendency to organize, when in contact with common air, wood might be rendered as permanently durable, and even more so, than the grains of wheat which have been found undecayed in Egyptian mummies. This discovery seems to

- See Quarterly Journal of Agriculture, vol, xi. p. 530 . † Ure's Dictionary of the Arts, art. Wood.

+ Raspail's Organic Chemistry, translated by Henderson, pp. 141-164.

$$
\text { (237) }
$$


have been made by Mr. Kyan. In contemplating the probability of the use of home timber being much extended in the construction of steadings, when the young woods at present growing shall have attained their full growth, it may be proper that the growers of wond, and the farmers on the estates on which wood is grown, be made aware of this mode of preventing timber being affected by the dry-rot. What the true cause of dry-rot is, has never yei been deternined, but it frequently shows itself by a species of mildew, which covers the timber, and the action of which apparently causes the wood to decay, and crumble down into powder. The mildew, however, is neither the dry-rot nor its cause, but its effect. It is distinctly seen by the microscope to be a fungus; and as the fungus itself is so minute as to require the aid of the microscope to be distinctly seen, its seeds may be supposed to be so very minute as to be taken up by the spongeoles of trees. But whatever may be the cause of dry-rot in timber, there is not a doubt now of the fact, after years of successful experience, that the process discovered by Mr. Kyan of simply steeping tinber in a solution of corrosive sublimate, bi-clsloride of mercury, preserves timber from dry-rot.

(169.) The principle upon which the chemical action of the corrosive sublimate upon vegetable matter, preserves the timber is easily explained. All plants are composed of cellular tissues, whether in the bark, alburnum, or wood. The tissue consists, as you have seen. of various shaped cells; and although they may not pass uninterruptedly along the whole length of the plant, as M. de Candolle maintains, yet air, water, or a solution of any thing, may be made to pass through the cells in their longitudinal direction. Experiments with the air-pump have proved this beyond dispute. Those cells, and particularly those of the alburnum, coutioin the sap of the tree, which, in its circulation, reaches the leaves, where its watery particles fly off, and the enlarging matter of the tree, called the albumen, remains. Albumen is the nearest approach in vegetables to animal matter, and is, therefore, when by any natural means deprived of vitality, very liable to decomposition, particularly that which is connected with the alhurnum, or sap-wood. Now, corrosive sublimate has long been known to preserve animal matter from decay, being used to preserve anatomical preparations; and even the delicate texture of the brain is preserved by it in a firm state. The analogy between animal and regetable albumen being established, there seems no reason to doubt the possibility of corrosive sublimate preserving both substances from decay; and, accurdingly, the experiments of Mr. Kyan. with it, on albuminous and saccharine solutions, have confirmed the correctness of this conjecture. The prior experiments of Fourcroy, and especially those of Berzelius, in 1813, had established the same conclusions, though neither of these eminent chemists had thought of their practical application to the preservation of timber. Berzelius found that the addition of the bi-chloride (corrosive sublimate) to an albuminons solution produced a proto-chloride of mercury (calomel), which readily combined with albumen, and produced an insoluble precipitate. This precipitate fills up all the cellular interstices of the wood, and becomes as hard as the fibres."*

(170.) Even after timber has been subjected to this process, it is requisite to give the air free access to it by means of ventilation, and for that purpose, where timber is covered up, which it is not likely to be in a steading, small openings, covered and protected by crst-iron gratings in frames, should be made through the outside walls.

(17i.) With regard to the expense of this process, which is a material consideration to those who have large quantities of timber to undergo the treatment, it costs for steeping $£ 1$ the load of 50 cubic feet. But persons having tanks for their own use only, and not for the purposes of trade, pay 5s. for each cubic foot of the internal sontents of the tank. A tank, fitted up to steep large scantlings and logs, costs about $£ 50$, nd the process may cost $3 \mathrm{~d}$. or less the cubic foot to those who construct a tank for themsel es.

(172.) Other means have been devised for preserving timber from decay, such as pyroligneous acid, derived from the smoke of burning wood; naphtha, obtained by distillation of coal-tar; and in 1839 a patent was taken out by Sir William Burnett, of the medical department of the Nayy, for steeping wood in a solution of the chloride of zinc ; $\dagger$ but experiment has not yet had time to decide whether any of these methods possesses any superiority over the valuable process practiced by Mr. Kyan.

(173.) The pine tribe, of which I have been speaking as of 80 much use in our farm buildings, is also highly useful in the arts. It is from the Pinus sylvestris and the Abies excelsa that tar is obtained in the largest quantities, for the use of all nations; and it is a substance which is of great utility in a farm, though not requisite in large quantity. The tar of the north of Europe is of a much superior description to that of the United States. It is ob. tained by a process of distillation, which consists of burning, in a smothering manner, roots and billets of fir-timber, in pits formed in rising ground for the purpose, and covered with turf.

(174.) The quantity of tar imported into this country in 1837 , was 11,480 lasts, of 12 barrels per last, each barrel containing $31 \frac{1}{2}$ gallons. The duty is 158 . per last, 12s. upon tar from the British possessions, and 2s. 6d. per cwt. upon Barbadoes tar. "Tar produced or manufactured in Europe is not to be imported for houne consumption, except in British ships,

* See paper hy me on this subject in vol. viil. p. 385 of Quarterly Journal of Agriculture.

+ Repertory of Patent Inventions, New Serieg, vol. xii. p. 346. (238) 
or in ships of the country of which it is the produce, or from which it is imported, under penalty of forfeiting the same, and $£ 100$ by the master of the ship."*

(175.) Besides tar, most of the pines afford one or other of the turpentines. Common tur pentine is extracted by incision from the Abies excelsa and the Pinus sylvestris.

(176.) Of the specifications of plumber-work, the kind of work done after the carpentry the flanks and peands should be covered with sheet-lead, weighing $6 \mathrm{lbs}$. to the square foot, 18 inches broad. The ridges should be covered either with droved angular freestone ridgestones, or with 6 -lb. lead, 18 inches broad, supported on $2 \frac{1}{2}$ inches in diameter of ridge-rolls of wood. Platforms and gutters should have 7-lb. lead. In cisterns, it should be 8-lb. in the bottom and 6-lb. in the sides. Rain-water spouts of $4 \frac{1}{2}$ inches in breadth, and conductors of $2 \frac{1}{2}$ or 3 inches diameter, should be of $6-1 b$. lead.

(177.) The lead of commerce is derived from the ore galena, which is a sulphuret, yield. ing about 87 per cent. of lead and 13 of sulphur. Galena is found in greatest quantity in transition rocks, and of these the blackish transition limestone contains the largest. The ore is more frequent in irregular beds and masses than in veins. The galena lead-mines of Derbyshire, Durban, Cumberland, and Yorkshire, are situate in limestone, while those of the Leadhills, in Scotland, are in graywacke. Great Britain produces the greatest quantity of lead of any country in the world, the annual produce being about 32,000 tons, of which the English mines supply 20,000. The rest of Europe does not supply 50,000 tons. The export of lead has fallen off considerably, and its price has experienced a corresponding depression for some years past, on account of the greatly increased production of the lead-mines of Adra in Granada, in Spain.t

(178.) As zinc has been substituted in some cases for lead in the covering of buildings, although sufficient experience has not yet been obtained as to their comparative durability, it may be proper to give here the sizes and prices of covering flanks, peands and ridges with zinc. The flanks are covered with zinc, weighing 16 ounces to the square foot, at a cost of $6.3 \mathrm{~d}$. the square foot. The peands and ridges are covered with 12 .inch sheet zinc, weighing 13 ounces in the square foot, at a cost of $7 \mathrm{~d}$. the square foot. The zinc covers for the peands and ridges are so prepared that they clasp by contraction, and thereby hold fast by the wooden ridge-rolls, and this is so easily done that any mechanic may put them on. Where soldering is required in zinc-work, such as the laying on of platforms on roofs, the cost of the sheet of 18 ounces to the square foot is enhanced to $9 \mathrm{~d}$. the square foot. Zinc in all jobs costs about half the price of lead.

(179.) Zine is not very suitable for gutters and platforms, on account of its thinness-the wood below warping in warm weather, and tearing up the sheets of zinc.

(180.) Zinc is an ore which occurs in considerable quantity in England. It is found in two geolngical localities, in the mountain limestone and in the magnesian limestone. It occurs in veins, and almost always associated with galena or lead-glance. It is of the greatest abundance in the shape of a sulphuret or blende, or black-jack, as the miners call it. There is also a siliceous oxide of zinc, and a carbonate, both called calamine. In North America, the red oxide of zinc is found in abundance in the iron mines of New-Jersey. The zinc of commerce is derived, in this country, from the blende and calamine. It is naturally brittle, but a process has been discovered by which it is rendered malleable, and it retains its ductility ever after. It is this assumed ductility which renders the metal useful for domestic purposes. "It is extensively employed for making water-cisterns, baths, spouts, pipes, plates for the zincographer, for voltaic batteries, filings for fire-works, covering roofs, and a variety of architectural purposes, especially in Berlin; because this metal, after it gets covered with a thin film of oxide or carbonate, suffers no farther change frum long exposure to the weather. One capital objection to zinc as a roofing material is its combustibility." $\ddagger$

(181.) The most malleable zinc is derived from Upper Silesia, under the name of spclter, which is sent by inland traffic to Hamburgh and Belgium, where it is shipped for this country. The quantity imported in 1831 was 76,413 cwt. and in 1836 it had fallen off to 47,406 cwt. A considerable portion of these quantities was exported to India and China, amounting, in 1831 , to $62,684 \mathrm{cwt}$. The duty is $£ 2$ a ton on what is formed into cakes, and $10 \mathrm{~s}$. per cwt. on what is not in cakes.

(182.) The slater-work is then executed. Of its specifications, if blue slates are to be employed, they should be selected of large sizes, well squared, and have an overlap of 3 , gradually diminishing to the ridge, and well bedded and shouldered with plaster-lime. The slutes are fastened to the sarking with malleable iron nails, weighing $15 \mathrm{lbs}$. to the 1000 , after being steeped when heated in linseed oil. These nails cost $3 \mathrm{~s}$. 4d. the 1000,1300 being required for a rood of 36 square yards. Cast-iron nails were used for slating until a very few years ago, and which were also boiled in oil.

(183.) Slating is performed by the rood, and from 1000 to 1200 blue slates should cover a rood. The cost of the slates, in towns, including carriage, and putting them on with nails, is $£ 44 \mathrm{~s}$, the rood.

* McCulloch's Dictionary of Commerce, art. Tar.

$\uparrow$ See Ure's Dictionary of the Arts, and McCulloch's Dictionary of Commerce, arte. Lead.

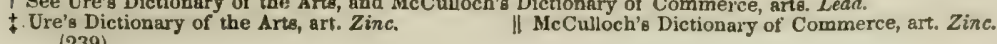
(239) 
(184.) Blue slate is derived from the primitive mok clay-slate. It nccurs in large quantities through the mountainous parts of the kingdom. Good slate should not absorb water, and it should be so compact as to resist the action of the atmosphere. When it imbibes moisture, it becomes covered with mose, and then rapidly decays.

(185.) The principal blue slate quarries in Great Brituin are in Wales, Lancashire, Westmoreland, Cumberland, Argyle, and Perthshires. The most extensive quarry is in Caemarvonshire, in Wules, near the town of Bangor, on the Penrlyyn estate. It employs 1500 men and boys. The Welsh slate is very large and smooth, and much of it is fit for putting into frames for writing-slates. When used very large, being thin, it is apt to warp on change of temperature. The English slates at Ulverstone, in Lancashire, and in the counties of Westmoreland and Cumberland, are not so large as the Welsh, but equally smooth and good.The Easdale slates, in Argyleshire, are small, thick, waved on the surface, and contain many cubical crystals of iron-pyrites, but its durability is endless. Being a small and heavy slate, it requires a stout roofing of timber to support it. The Ballihulish slates are rather smoother and lighter than the Easdale, though also small, and containing numerous crystals of ironpyrites, and is equally durable. The slates in Perthshire are of inferior quality to either of these. "The ardesia of Easdale," says Professor Jamesan, "was first quarried about 100 years ago; but was for a long time of little importance, as sandstone flags and tiles were generally used for roofing houses. As the use of slates became more prevalent, the quarries were enlarged, so that 5,000,000 slates are annually shipped from this island. The number of workmen is at present (in 1800) about 300, and they are divided into quarriers and daylaborers. The quarriers are paid annually at a certain rate for every 1000 slates, from $10 \mathrm{~d}$. to $15 \mathrm{~d}$. I believe, as their work has been attended with more or less difficulty. The davlaborers are employed in opening new quarries, and have from $10 \mathrm{~d}$. to 18. a day."

(186.) Slates are assorted into sizes at the quarry. The sizes at Bangor vary from 36 inches in length to $5 \mathrm{f}$ inches in breadth. Their weight varies from 82 to $12 \mathrm{cwt}$. the 1000 , and the prices from $140 \mathrm{~s}$. to $10 \mathrm{~s}$. the 1000 for the smaller, and from $55 \mathrm{~s}$. to $35 \mathrm{~s}$. the ton for the larger sizes.

(187.) Cisterns, with sides and ends 1 inch thick, 1s. 10d. the cubic foot contents.

(188.) The export of slates from. England to foreign ports has increased from 2,711 tons in 1828 , to 6,061 tons in 1832 . That of framed slates has decreased in number, in the same period, from 37,034 to 15,420 .

(189.) The shipping expenses of slates at Bangor are $6 \mathrm{~d}$. the ton, and bills of lading 3s. $6 \mathrm{~d} . \dagger$

(190.) When the mof is to be covered with tile, it should be laid with lath 14 inches square to a gauge of 10 or 11 inches. There should be 3 or 4 courses of slates along all the eaves. The flanks, peands and ridges should be covered with tile. The whole under joints of the tiling should be pointed with plaster-lime.

(191.) Tiling is executed by the rood of 36 square yards; and, as pan-tiles are obliged 0 be made of a certain size, namely, $13 \frac{1}{2}$ inches long, $9 \frac{1}{2}$ inches wide, and $\frac{1}{2}$ inch thick, by 17 th Geo. III. c. 42 , under a penalty of $10 \mathrm{~s}$. for every 1000 , a rood will just contain 576 tiles.Tiles should be smooth on the surface, compact, and ring freely when struck, when they will resist water. When they imbibe moisture by porosity, they soon decay in winter by the effects of rain and frost.

(192.) There were, in 1830, 5,369 brick and tile manufacturers in England and Wales, and 104 in Scotland, and must have greatly increased since.

(193.) The duty on tiles was abolished in 1833 , the revenue derived from that source being very trifling. The duty on foreign pan-tiles is $£ 15$ the 1000 . The export of tiles is inconsiderable, not having exceeded, in $1830,803,742 . \ddagger$

(194.) Gray-slates require the roof to be lathed in the same manner as tile, but, not being of an uniform size like tile, they are assorted to sizes in the quarry. The larger and heavier slates are put next the eaves, and gradually diminish in size to the ridge. The course at the eaves is laid double, slate above slate. Every slate is hung upon the lath by a wooden pin being passed through a hole at the upper end, and, on being laid on, the slates are mado to overlap \&t least $\frac{1}{3}$. Gray-slates should either be bedded and shouldered in plaster-lime, or laid on moss, the latter making the warmer roof.

(195.) Gray-slates are pretty smooth on the surface, and, when so compact in texture as to resist moisture, form a durable though very heavy roof.

(196.) The flanks are made of slate, but the ridge is covered with droved angular ridgestone of freestone. A s this species of roofing is not adapted to pavilion roofs, the peands should be covered with lead, but the safest form of roof with gray-slates is with upright gables.

(197.) The cost of gray-slating depends on the locality where it is wished to be done. At Edinburgh it costs $\mathcal{E} 6$ a mod; whereas in Forfarshire, the matrix of the grap-slate, it can be done, exclusive of carriage, for $£ 210 \mathrm{~s}$. the rond. 'In Forfarshire the slates cost $£ 4$ per

- Jameson's Mineralogy of the Scottish Ieles, vol. i. p. 195.

+ McCulloch's Dictionary of Commerce, art. Slates. (240) 
per 1.000; 360 are required for a rood; the putting them on, including dressing, holing, pins for the slates, and nails for the laths, costs only 15s.; and with moss for bedding ls., and lime for teething $3 \mathrm{~s} ., 22 \mathrm{~s}$. the rood. The droved angular freestone ridging-stone, includiing carriage, costs $6 \mathrm{~d}$. a lineal foot, or $10 \mathrm{~s}$. the rood.

(198.) Gray-slates are obtained in best quality from gray slaty inferior sandstone belonging to the old red sandstone series. They are derived from the same quarries as the farfamed Arbroath pavement, being, in fact, formed by the action of frost on pavement, set on edge for the purpose. A mild winter is thus unfavorable to the making of slates. From Carmylie to Forfar, in Forfarshire, is the great field for the supply of gray-slates; and as blue-slates can only be obtained there by sea and long land carriage, and there is little clay fit for tiles, they constitute the chief roofing of cottages and small farm-houses in that part of the country, their aspect being cold and unpicturesque, though snug enough.

(199.) Of all sorts of slating, there is none equal to blue-slate for appearance, comfort, and even economy in the long run. When a blue-slate roof is well executed at first, with good materials, it will last a very long time. Tile roof's are constantly requiring repairs, and the employment of gray-slate is a sacrifice of, and a burden upon, timber. Of the blue-slate the Welsh give the cheapest roofing, being larger and much lighter than Scotch or English slates.

(200.) As the plaster-woork of a steading does not require to be of an omamental nature, its specifications should be simple. The ceilings of the riding-horse stable, boiling-house, wool-room, hen-house, and granaries, when tile-roofing is employed, should be finished with two coats of the best haired plaster, hard rubbed in. The walls of the granaries, corn-barn, work-horse stable, cow-byre, boiling-house, calves'-house, wool-room, gig-house, and henhouse, should be finished with one coat, hard rubbed in. The walls of the riding-horse stable shonld have three coats, hard rubbed in. Plaster-work is measured by the square yard, and costs for one coat $3 \mathrm{~d}$., for two coats from $4 \mathrm{~d}$. to $41 \mathrm{~d}$., and for three coats from $5 \mathrm{~d}$. to $6 \mathrm{~d}$. the square yard.

(201.) It is necessary to say something regarding the specifications of smith-10ork, although there is not much of this kind of work required in a steading. All the ontside doors, including those on the feeding-holes at the byre, should be hung with crooks and bands; the crooks should be fastened into the ingoings of the ribets with melted lead. The larger crooks and bands cost $10 \mathrm{~s}$. and the smaller $5 \mathrm{~s}$. the pair. The inside doors should be hung with $\mathrm{T}$ hinges, 18 inches long, and the opening parts of the windows with 9-inch $\mathrm{T}$ hinges. The former are 1s. and the latter $9 \mathrm{~d}$. a pair. The outside doors should have good 10-inch stock-and-plate locks, which cost $2 \mathrm{~s} .6 \mathrm{~d}$. each, except. where there are more than one outside door to the same apartment, in which case all the doors but one can be fastened by bars from the inside. The inside doors should have the same sort of locks; the common stock-lock, which cost 1s. 6d. each, not being worthy of commendation. Thumb-latches are convenient for opening and keeping shut doors that do not require to be constantly locked, such as the doors of the corn-barn, granary, boiling-house, cow-byre, and hen-house. These latches cost from $5 \mathrm{~d}$. to $7 \mathrm{~d}$. each. A wooden bar of hard wood, to open and shut from both sides, is a convenient mode of fastening inside doors. The upper barn-door, of two vertical leaves, requires an iron stay-band to fasten it with. The doors of the riding-horse and workhorse stables should be provided with sunk flush ring-handles and thumb-latches, to be out of the way of catching any part of the harness. The mangers of the riding-horse stable, and the upper rail of the hay-rack of the work-horse stable, should be provided with rings and staples for the stall-collar shanks to pass through. These cost 1d. each.

(202.) Various descriptions of nails are used for the different parts of work in a steading. The scantlings of the roofs are fastened together with double-doubles, which cost 5s. per 1,000. Deals of floors are fastened down with flooring-nails, 16-lb. weight, and 4s. $6 \mathrm{~d}$ per 1,000. The bars of the plain-deal doors are put on with $10-1 \mathrm{~b}$. nails, which cost $3 \mathrm{~s}$. $6 \mathrm{~d}$. the 1,000. For finishing, single-flooring nails at 2s. 6d., and 2-inch springs at 2s. to $2 \mathrm{~s}$. $3 \mathrm{~d}$. the 1,000 are used.

(203.) As a security against robbery, iron stancheons, $\frac{7}{8}$ inch in diameter, should be fixed on the outside of the low windows of the corn-barn and implement-house. Such stancheons cost $3 \mathrm{~d}$. per pound.

(204.) Iron is chiefly found among the members of the coal formation, in bands composed of nodules, which are called compact clay-ironstone, a carbonate of iron. It is abundant in the west of Scotland and in South Wales. Its annual worked production is probably not less than $1,000,000$ tons.*

(205.) The windows of all the apartments should be glazed with best $2 \mathrm{~d}$ crown-glass, fastened in with fine putty. Glazing is executed for $2 \mathrm{~s}$. the square foot.

(206.) A skylight in blue slating is made of a frame fastened to the sarking. In the roofing, tiles are made on purpose to hold a pane of glass. In gray-slating, a hole is made in the slate to suit the size of the pane. A dead skylight of zinc, to answer any kind of roofing, costs $4 \mathrm{~s}$.

(207.) There is a duty of 73s. $6 \mathrm{~d}$. the cwt. on good window, and 30s. on broad or inferior window-glass, which is returned in drawback on exportation to foreign countries. When

\footnotetext{
+ Ure's Dictionary of the Arts, art. Iron.
} 
glass intended for exportation is cut into panes, it must be in panes of less than 8 incnes in il. . ile to enable it to claim the drawback.

(1) 3.) Glass of small sizes, though of good quality, such as is fit for glazing hot-houses and forcisg-frames, costs only from $8 \mathrm{~d}$. to $10 \mathrm{~d}$. the square foot; while in ordinary sized panes it costs 18. $3 \mathrm{~d}$., and in still larger sizes it is charged 1s. $6 \mathrm{~d}$. the square foot. I am not sure but the sort fit for hot-houses would answer the purpose of glazing the windows of a steading.

(209.) "The reseurches of Berzelius having removed all doubts concerning the acid character of silica, the general composition of glass presents now no difficulty of conception. This substance consists of one or more salts, which are silicates with bases of potash, soda, lime, oxide of iron, alumina, or oxide of lead; in any of which compounds we can substitute one of these bases for another, provided that one alkaline base be left. Silica, in its turn, may be replaced by the boracic acid, without causing the glass to lose its principal characters."

(210.) Rain-water spouts, or mus as they are techuically termed, may be made of wood, cast-iron, lead, or zinc. Wooden ones may be made out of the solid or in slips nailed to. gether. When made out of the solid, with iron hold-fasts, they cost 1s. and when pieced together $6 \mathrm{~d}$. the lineal foot. The conductors from both kinds cost. $8 \mathrm{~d}$. the lineal foot. Wooden spouts should be pitched inside and painted outside. Cast-iron ones are heavy, but they cost no more than $2 \mathrm{~s}$. a yard if of $4 \frac{1}{2}$ inches diameter, and the conductors, of from 2 to 4 inches diameter, from 8s. to 18s., of 9 feet in length each. Lead makes the best spout, hut it is very expensive, being 1s. $6 \mathrm{~d}$. a foot. Zinc ones, on the other hand, are very light. Stout 4 -inch zinc spouts cost $9 \frac{1}{2} \mathrm{~d}$. the foot, and a $2 \frac{1}{2}$ pipe as colductor, $7 \frac{1}{2} d$. the foot. The lowest part of this pipe is made strong enough to resist accidents. Every sort of water-spout should be cleaned at least once a year, and the wooden ones would be the better for an annual coat of paint.

(211.) The ontsides of all the outside doors and windows, all the gates of the courts and hammels, and the water-troughs in the various courts, if made of wood, should receive three coats of good paint. Painting costs $3 \mathrm{~d}$. or $4 \mathrm{~d}$. the square yard, but three coats can be done for $8 \mathrm{~d}$. the square yard. The best standing colors, and they happen to be the cheapest too, are gray, stoue, or slate-blue ; the last seems to be most commonly preferred. Green is dear and soon fades, and red seems very distasteful in buildings. But the truth is, that white-lead and oil are the principal ingredients in paint, and all the coloring matter has no power to preserve timber from the effects of the weather. A substance called lithic paint has receutly been found to answer well for country purposes. The lithic, which costs $\approx \frac{1}{2} d$. per lb. is ground to powder, and mixed, in a certain proportion, with cold coal-tar, and the mixture is applied with a brush. This paint deprives the coal-tar of its noxious smell, and hardens it into a durable paint in a few days.

(212.) White lead of commerce is a carbonate of lead, or ceruse, as it is called, artificially formed from pure lead. It has long been made with great success at Klagenfurth, in Carinthia, and large quantities are made in England. The compound is 1 equivalent of lead, 1 of oxygen, and 1 of carbonic acid; or by analysis, of lead $77 \cdot 6$, oxygen 6 , and car bonic acid $16^{\circ} 4$ in 100 parts. White lead, when it enters the buman system, occasions dreadful maladies. Its emanations cause that dangerous disease the colica pictonum, afterward paralysis, or premature decrepitude and lingering death. All paints are ground into fine powder in a mill, as being a safer plan for the operator, as well as more expeditious, than by the hand. $t$

(213.) I have said (81.), (82.), (83.), that when the building of a steading is to be mea. sured, the work that has actually been executed should alone be measured, and no allonances, as they are called, should on any account be permitted to increase the amount of cost. The correctness of this rule will appear obvious, and its adoption reasonable, after you have learnt the sort of claims for allowances made by tradesmen in various sorts of work.

(214.) In the first place, in regard to masoniry, double measure is claimed on all circular work. Claims are made for allowance on all levelings for joists, bond-timbers, and wallheads. The open spaces or voids left in the walls for doors and windows, are claimed to be measured along with rubble-work. Girthing around the external walls of rubble-work is claimed in measurement, the effect of which is, to measure the square pieces of building in each corner twice over. Scontions of all voids are claimed to be measured over and above the rubble-work. The ashlar for the hewn-work is first measured with the rubble, and then at is claimed to be measured by itself. In like manner, chimney-tops are first measured as rubble, and then claimed to be measured again as ashlar. In short, wherever any sort of mason-work differs from the character of the general work under the contract, allowances are claimed.

(215.) In regard to carpentry, the claims are equally absurd. For the cuttings connected with the peands and flanks of roofs, 18 inches of extra measurement are claimed. The same extent is claimed for angles in the flooring, and in all such unequal work. In windowmaking a clain is made for 3 inches more than the hight, and 4 inches more than the width of windows, which is more than the voids; whereas the measurement should be confined

- Ure's Dictionary of the Arts, art. Glass. (290)

† Ibid. arts. White-lead, Paine. 
to the mere daylight afforded by the windows. In many instances $1 \frac{1}{2}$, and even double measure, is claimed for round work, according to its thickness. Where plain deal is cleaned on both sides, such as the under part of the floor of the upper-barn, which forms the roof of the corn-barn, or shelving, $1 \frac{1}{2}$ measure is claimed.

(216.) In slating, claims are made on the making of peands and flanks, from 18 inches to 3 feet in width, and for eaves, from 12 inches to 18 inches in width, more than the actual work done. For all circular work, such as the slating of a round horse-course of a threshing-machine, double measure is claimed.

(217.) In plaster-work, double measure is claimed for all circular work. There is an allowance made in plastering which is, however, quite reasonable, and that is, in the case where new work is joined to old, an allowance of one foot is made around the new work, as the old part has to be wetted and prepared for its junction with the new.

(218.) A perusal of these statements naturally suggests the question, how could such claims have originated? If a workman execute the work he agreed to undertake, and gets payment for what work he executes, he is not entitled to ask more. But what proves an aggravation of such demands is, that modes of measurement differ in different counties-that different allowances are made on different kinds of work - and that those allowances differ in different counties. So it appears that those allowances are based on no principle of equity But it may be urged in justification of these allowances that the prices of work, as usually estimated, are too low to remuuerate the contractor for his labor, and that allowances are therefore requisite to insure him against loss. To this specious statement it may be replied by asking, why should any honest contractor estimate work at such rates that he knows will not remunerate him? A rogue will do so, because he wishes to have possession of a job at all hazards, in order to make up his foreseen loss by exorbitant claims for allowances. If employers will not pay sufficiently for good work, as is alleged against them, and perhaps with truth, let them understand that they shall receive insufficient work as an equivalent for their stinted money. But it is very unfair to take advantage of an honorable employer, hy capricious and absurd allowances, when he is all the while desirous to pay his workmen well for their labor. So much dependence is sometimes placed on allowances by contractors, that I have heard of a case where a surveyor was obliged to reduce the claims made against a single steading, to the extent of $£ 800$ ! Such a fraudulent system ought to be entirely abolished, and it is quite in the power of those who employ tradespeople to abolish it

(219.) It would be completely abolished were contracts to contain stringent clauses prohibiting all allowances whatsoever; and to consist of detailed measurements, and specified prices for every species of work to be executed. If more work happens to be executed than was expected, its value can easily be ascertained by the settled measurements and prices, and if less, the contractor is still paid for what he has actually executed. Were such a form of contract uniformly adopted, proprietors and farmers could measure the work done as well as any surveyor, whose services might, in that case, be dispensed with; but, what would be still better, the measurements of the surveyor could be checked by the proprietor or the tenant if either chose to take the trouble of doing it. Where any peculiar kind of work is desired to be executed, it could be specified in a separate contract.

(220.) Having thus amply considered all the details which should form a part of all specifications of the different kinds of work required to build a steading, I shall now give the particulars which should be specified in all contracts, and that these may not be imaginary, but have a practical bearing, I shall take the steading as shown in the plan, fig. 4, Plate IV. as the example. In order that the data furnished in the proposed specifications shall be generally applicable, I shall first give the measurements of the various kiuds of work proposed to be executed-then the quantity of materials required for constructing the sameand lastly, the prices paid for the different sorts of work in Edinburgh, both including and excluding the cost of carriages, that you may have a criterion by which to judge of the cost of doing the same kind of work in other parts of the country. You may reasonably believe that the prices of labor and materials are higher in Edinburgh than in the country; but, on the other hand, you must consider the superiority of the workmanship obtained in so large a town. These must affect the total amount of the estimate to a certain extent, but to what exact per centage I cannot say. I am told that carpenter-work is very little dearer in Edinburgh than in the country, but that mason-work, smith-work and plaster-work are all considerably higher; but of smith-work, as I have already said, little is required in building a steading.*

[* Now, although the suggestions and reasoning of this chapter apply to a country where the kind and cost of the materials, and yet more the cost of labor, differ very materially from such as are in use or paid in this country, yet the reasoning and the rules laid down are of universal ap. plication; and how would it be possible to omit them, without impairing essentially the value of the work in hand?

All who have had much experience in building have found it to be difficult to guard againt imposition; and this is especially the case with men who have not been qualified, either by eds. cation or experience, to judge for themselves. By education we mean instruction at school ot (291) 
Measurement of the Plas of a Proposed Steading in Fig. 4, Plate IV.

\section{Mason-acork.}

6225 Cubic yards of Foundations, and wheeling the earth not farther than 60 yards distance

$207 \quad$ Drains with sills and covers

85 Cubic roods of Rubble-walls, 2 feet thick.

47 Division rubble-walls, 12 to 15 inches thick, including dykes.

42 Lineal feet of Chimney-vents.
$400 \quad$..

$\begin{array}{rll}400 & \cdots & \text { Cormers of buildings. } \\ 80 & \text {-. } & \text { Comers for archways. }\end{array}$

$50 \quad \quad \ldots \quad$ Arched lintels for archways.

$1528 \quad$.. Ribeto, sills, lintels, and steps.

$75 \quad$... Arched lintels over doors.

$24 \quad$ - R R R $\quad$ Congens of archways to granary.

80 .. C Comers, sills, and lintels of feeding-holes of byres.

60 -. Corners of gateways to courts.

$286 \quad$-. C Corners or hammer-dressed scontions for gates in dykes.

$20 \quad$-. Coping of chimney-stalks.

110 .. Ashlar pillars for sheds, from 18 to 20 inches square.

$294 \quad$.. Skews on gables.

$1671 \quad \ldots \quad$ Semi-circular hammer-dressed coping on dykes.

$100 \quad$.. Guters in byres.

$94 \quad$.. Coping round liquid manure tank.

$300 \quad \ldots \quad$ Steps of stairs to granaries.

45 ‥ Brick stalk for steam-engine, 6 feet square at the base.

152 Square roods of Rubble-causew ay.

287 Lineal yards of Causewayed gutters around the buildings outside.

2 Pairs of jambs and lintels.

Building in boiler, including boiler and furnace complete.

17 Droved stones, with gratings for liquid manure drains.

8 Water-troughs in courts.

31 Stonee for heel-posts of stalls.

31 Stones for curbs of stall-boardings.

Carpenter-work.

540 Square feet of 4 -inch thick safe lintels.

2768 Square yards of Roofing, with balks and sarking.

583 Joisting and flooring of granaries and corn-barn

762 Lineal feet of Ridge-batkens.

$\begin{array}{rll}192 & \text {-. } & \text { Dressed beams for pillars of roofs of sheds. } \\ 1141 & \text {. } & \text { Door-checks or fixings, } 6 \frac{1}{2} \text { inches by } 2 \frac{1}{2} \text { inches. }\end{array}$

1366 .. Door-keps or stops and facings.

2132 Square feet of $1+$-inch deal doors.

1360 ... $1 \frac{1}{2}$-inch divisions of gtalls.

829 Lineal feet of Heel and fore-posts.

18 .. Manger in riding-horse stable

18 -. Hay-rack in ditto.

96 .. Hay-racks, low, in work-horse stable.

84 ... Fecding-troughs in byres.

$670 \quad \ldots \quad \ldots \quad \ldots \quad$ courts,

36 ... Racks in cattle-sheds.

432 Square feet of Daylight of windows.

760 .. Sparred divisions of cribs for calves.

669 Lineal feet of Rian-water spouts.

$87 \quad \cdots \quad$ Conductors from ditto.

10 Small doors of feeding-holes of byre.

14 Corn-boxes for work-horee stable.

2 Square racks for center of courts.

1 Corn-chest for work-horses.

1 ... for riding-horse stable.

7 Luffer-board ventilators for roofs.

8 Sparred gates, from 9 feet to 10 feet wide.

12 ... 55

Rails, harness-pins, and saddle-trees.

Stathel-frames for stacks.

Pump with mounting.

Slater-work.

77 Square roods of Blue-slating, gray-slating, or tiling.

elsewhere in the rules of mensuration and the principles of mecbanics far enough to know-what every achool-boy might easily be taught-enough of architecture to know the names of every part and piece of timber employed in building, and the manner of measuring carpenters' and brick. layers' and plasterers' work-a sort of useful practical information which any young man might acquire in a few days of earnest. ardent study.

One important point to be guarded against is the liability to be imposed upon by exorbitant charges for every, the very slightest addition to, or departure from the plan of bailding agreed upon. If auch chapters as these have no other effect, we may hope they will assist in impress. ing upon the mind of the farmer the obligation he is under as a parent and 8 friend, to see that his son is so educated as to enable him to form his own correct opinion, to the end that while be should be at all times ready to do full justice, and even to be as liberal as he can afford to be to mechanics, he shall be prepared to detect and resist all attempts at imposition. 


\section{Plumber-work.}

1084 Square feet of Lead on ridges, flanks, and peands. 669 Lineal feet of Lead rain-runs or spouts.

Plaster-work.

1507 Square yards of 1at, $2 \mathrm{~d}$, and $3 \mathrm{~d}$ coat plaster.

22 Stock-and-plate locks.

Smith-10ork.

28 Pairs of crooks and bands.

9 Pairs of cross-tailed hinges.

35 small.

2 Sets of fastenings for double doors.

3 Locks for small courts.

10 Pairs of crooks und bands for feeding-holes.

10 Sneck-fastenings for ditto.

33 Thumb-latches.

18 Manger-rings.

17 Seals for fastening cows, or feeding cattle.

Stanchions for windows.

Cast-iron runs and conductors,

-. travis-posts,

Cast-iron runs and conductors,
$\ldots \quad$ travis-posts,
$\ldots \quad$ hay-racks for riding-horse stable,
B.erindow-sashes,
Boiler and furnace.

Mounting for gates.

\section{Quantites of Materials and Numbers of Carriage in Steading.}

$108 \frac{1}{2}$ Cubic roods of 2-feet walls, each rood ccntaining 36 cubic yards of building, requiring 40 cart loads of rubble-stones, 2 cart-loads of lime. and 4 or 5 cart-loads of sand, besides water

710 Ashlar corners.

1004 Ribets.

100 Sills and lintels, from $4 \mathrm{ft}$. to $4 \frac{1}{2}$ ft. long.

20 ... $\quad 30$ inches long.

31 Steps, from $3 \frac{1}{2}$ feet to 4 feet long.

$60 \ldots 4 \quad \ldots 5 \quad \ldots$

20 Lineal feet of Coping of chimney-stalks.

2 Pairs of chimney-jambs, 3 t ft. by $2 \mathrm{ft}$. long.

2 Lintels for ditto, from $3 \frac{1}{2}$ ft. to $4 \mathrm{ft}$. long.

110 Ashlar stones for pillars, from 18 inches to 20 inches square.

294 Lineal feet of Skews.

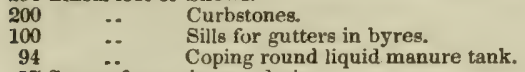

17 Stones for gratings to drains.

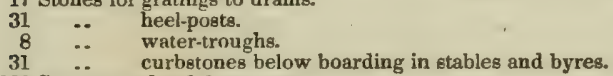

100 Square roods of Causeways.

136 Loads of Timber.

326 Square feet of Glass for windows.

On ascertaining the quarry mail, or prime cost of the stones, and the cost of carriage, in the locality in which you intend to build your steading, the cost of each of the above quantities of materials will easily be ascertained.

(221.) The following schedule gives the prices of those materials in Edinburgh, and they are stated both inclusive and exclusive of carriages.

\section{Mitson-work.}

\begin{tabular}{|c|c|c|c|c|c|}
\hline \multicolumn{3}{|c|}{$\begin{array}{l}\text { Including } \\
\text { Carriage. }\end{array}$} & \multicolumn{3}{|c|}{$\begin{array}{l}\text { Exclud'g } \\
\text { Carriage. }\end{array}$} \\
\hline L. & s. & & L. & s. & \\
\hline 0 & 0 & 6 & 0 & 0 & 4 \\
\hline 10 & 0 & 0 & 8 & 0 & 0 \\
\hline 8 & 8 & 0 & 7 & 0 & 0 \\
\hline 5 & 0 & 0 & 4 & 6 & 0 \\
\hline 0 & 3 & 0 & 0 & 2 & 4 \\
\hline 0 & 5 & 0 & 0 & 4 & 0 \\
\hline 0 & 0 & 3 & & & \\
\hline 0 & 1 & 9 & 0 & 1 & 6 \\
\hline 0 & 3 & 0 & 0 & $\overline{2}$ & 6 \\
\hline 0 & 5 & 0 & 0 & 4 & 8 \\
\hline 0 & 0 & 6 & & & \\
\hline 0 & 1 & 2 & 0 & & 0 \\
\hline 0 & 1 & 0 & 0 & & 10 \\
\hline 0 & 2 & 6 & & & \\
\hline 0 & $\tilde{\mathbf{2}}$ & 0 & & & \\
\hline 0 & 2 & 0 & & & \\
\hline
\end{tabular}

Digging foundations. .........

Rubble-foundations, reduced to 2 feet thick . . . . . . . . . . per rood of 36 cubic yards.

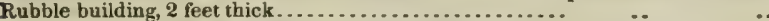

.. 18 inches thick and under, reduced to

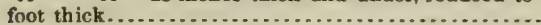

Rubble drains, with dressed flags, sills and covers, 12 inches square in

the opening. ........................................ per lineal yard

Ditto, 15 inches by 18 inches in the opening..................... ...

Hammer-dressed coursed work, with raised or hollow joints.......... per square foot.

Where bricks are used for building the walls, the prices are for-

24 thick brick on edge walls. . . . . . . . . . . . . . . . . . . . . . . . . . per square yard

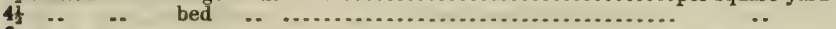

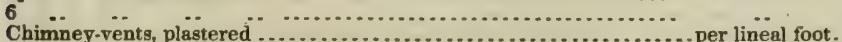

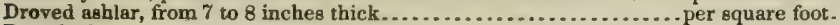

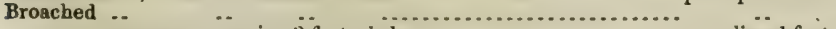

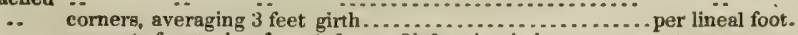
.. supports for stacks, from i feet to $2 \frac{1}{2}$ feet in girth..........

Droved ribets, front and ingoing with broached tails, 2 feet long and 1

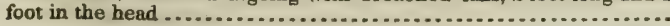

$$
\therefore \quad\left|\begin{array}{lll}
0 & 2 & 0 \\
0 & 2 & 6
\end{array}\right|
$$

(293) 


Mason-roork (continued).

Droved projecting sills, 7 inches thick.

per lineal foot.

Sills and lintels dreszed similar to the ribets.

Droved skew s, ourse for chimney-stalks, 6 inches deep......................

Broached

Corners for coach-house doors, with droved giblet-checks .............. per lineal foot.

Elliptical arched lintels for ditto. .

Segmental

Broached pillare for cart-sheds, sc. ................................. per square foot.

Droved jambs and lintels

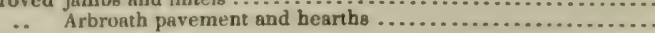

.. freestone pavement................................

Broached

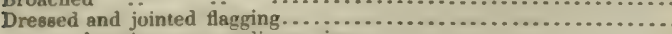

.. hanging steps, ordinary sizes ......................... per lineal fnot.

- common steps,

.. plats of hanging stairs, single measure........................ per equare yard

.. $\quad$ tone-skirtinge, $4 t$ inches deep............................... per lineal foot.

.. ridge-etones, common form...........................

.. socket-stones for travis-posts.................................each.

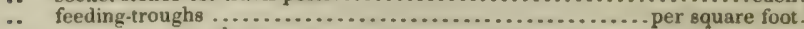

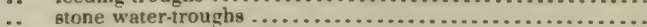

Curb-stones for gutters in byres............................. per lineal foot

Droved curb stones for otalls

Semi-circular coping for dykes, hainmer-dressed, from 12 inches to 1

inches diameter.

Square dressed whinstone-causeway..................per rood of 36 square yards

Rubble causewuying...

When ornamental masonry is introduced into steadings, these are the prices:

Droved base-course and belts, 12 inches deep..................... per lineal foot.

-. wall-head plinths, 6 inches thick

.. cumices, 9 to 10 , 6 inches thick ......................

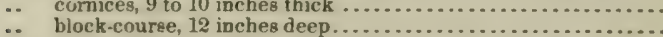

.. checked plinth and block for chimney-gtalks, 1 foot deep.....

Polished hanging steps, ordinary sizes..........................

Polished plats of hanging stairs, single measure........................ per square foot

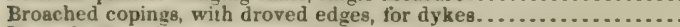

Droved pillars for small gates to hammels, \&c.....................

Building in boiler and furnace complete.

Bricks

.

Rubble atones .............................................. per load

\section{Carpenter-work.}

Safe-lintels and rough beams . per cubic foot

Dressed beams.

Scantling for roufs, 7 inches by $2 \frac{1}{2}$ inches, and 18 inches from center

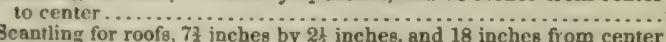
to center.

Balks, 6 inches by 2 inches, and 18 inches from center to center....

Galks, 6 inches by 2 inches, and 18 inches from center to center...

Wall-plates for roofing, 7 inches by $1+$ inches.. ...... per lineal foot.

Ridge trees, 10 inches by 2 inches.

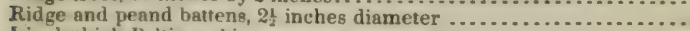

finch thick Baltic sarking..

Tile-Inth, $1 \frac{1}{6}$ inches square, and ii inches apart

Bond timber $3 t$ inches by 1 t incheg, and on inches

Baltic split lath, 3-16 inch thick...

Plain joisting 7 in by 2 in

7 in. by $2 t$ in. and 18 inches from center to center.

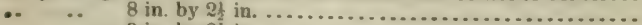

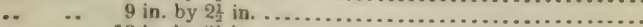

- $\quad$ - $10 \mathrm{in.by}$.

$$
\cdots \quad 12 \text { in. by } 2 . \text { in. }
$$

$1+$ Batten flooring, mooved and tongued.

Door-cherkg, 6 inches by 21 inelhes

Cherked winkw

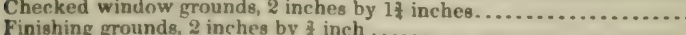

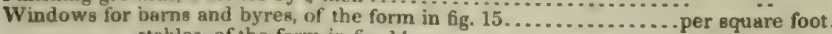

$$
\text { .. gtables, of the form in fig. } 14 \ldots
$$

per square yard.

-

yer square yard

$\cdots$

$\cdots$

..

$\ldots$

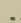

$\ldots$ per lineal foot

1f Travis-boarding for riding-horse and work-horse stables, doweled.

1 travis-boards, grooved and tongued and beaded, for byres

It-inch deal lixing, grooved and tongued, for end stalls of riding-horse stable, with

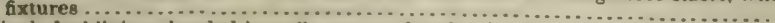

\&-inch deal linings, beaded in walls, over and under the mangers in the riding-horge

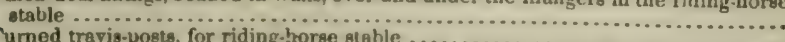

Beaded travis-poste, fore-posts, and runtrees, for work-horse stable, reducad to 3

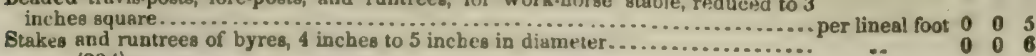
(294) 


\section{Carpenter-nork (continued).}

Hard-wcod himh hay-racks, with turned rollers 2 inches diameter and $2 \frac{1}{2}$ inches

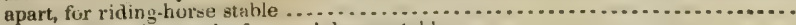

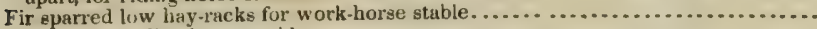

Mangers for riding-horge stable.

It-inch deal beaded outside doors, with 3 back

Including Carriage.

$\begin{array}{llll} & \text { I. } & 8 . & \text { D. } \\ \cdots & 0 & 3 & 0 \\ \cdots & 0 & 1 & 0 \\ \cdots & 0 & 1 & 6\end{array}$

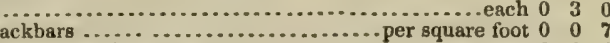

inside doors, with three 1-inch buckbars.....................

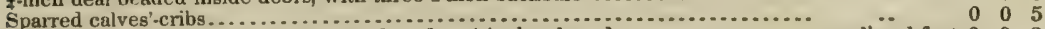

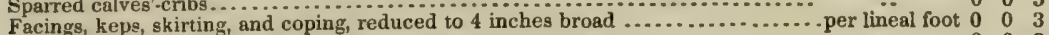

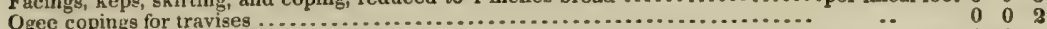

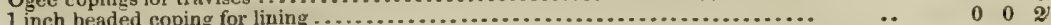

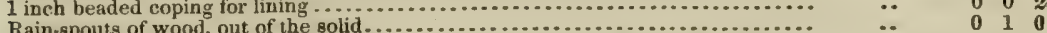

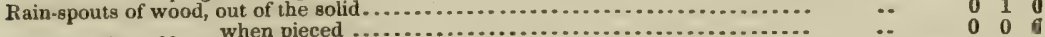

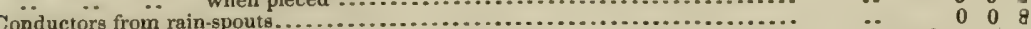

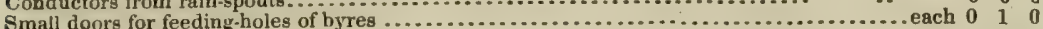

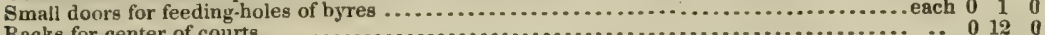

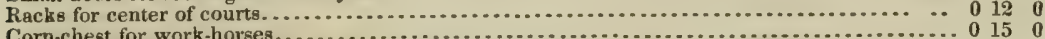

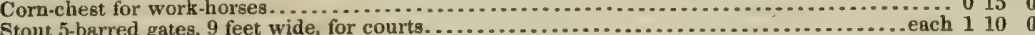

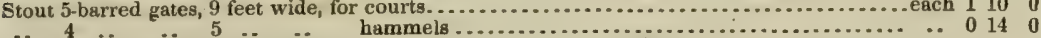

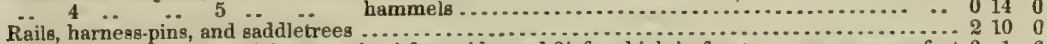

Luffer-board ventilators, 6 feet long by 4 feet wide, and $2 \frac{1}{2}$ feet high in front....... per square foot 0

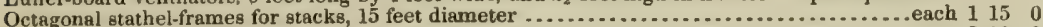

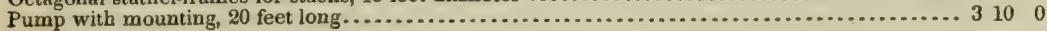

\section{Slater-work.}

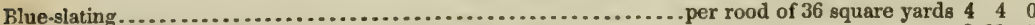

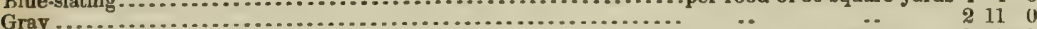

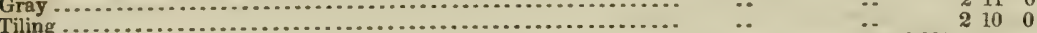

Blue slates ............................................................... per 1,000 310

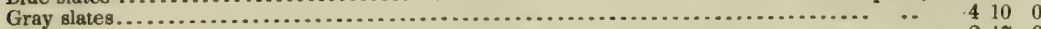

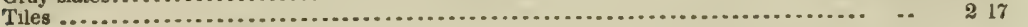

Plumber-woork.

6-1b. per square foot lead on peands, flanks and ridges (25s. per cwt.) ......... per square foot $0 \quad 1 \quad 3 \frac{3}{2}$

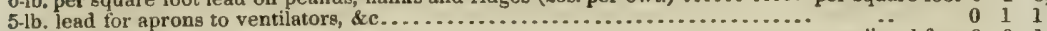

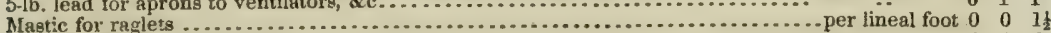

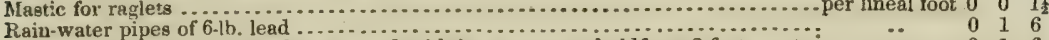

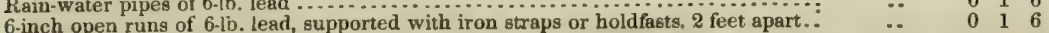

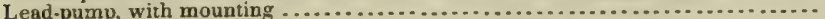
Lead-pipe for ditto

\section{Smith-work.}

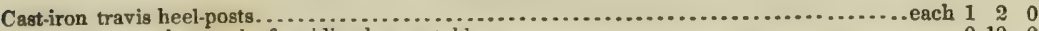
$\begin{array}{ll}\ldots & \text { corner hay-racks for riding-horse stable } \ldots \ldots \ldots \ldots \ldots \ldots \ldots \ldots \ldots \ldots \ldots \ldots \ldots \ldots \ldots \\ \ldots\end{array}$

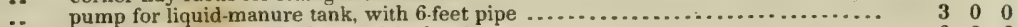

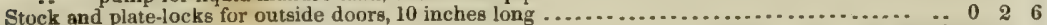

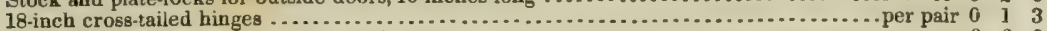

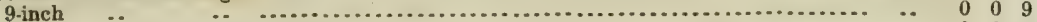

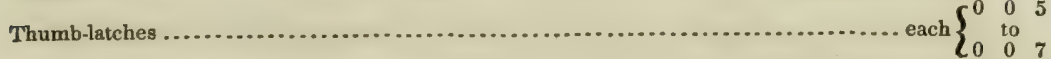

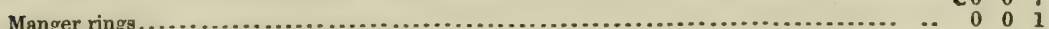

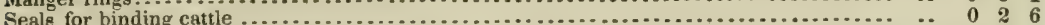

Cast-iron rain-spouts, $4 \frac{1}{2}$ inches diameter .................................. per lineal yard 0 . 0

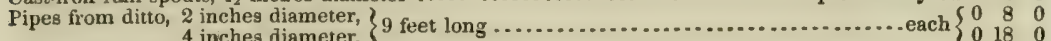

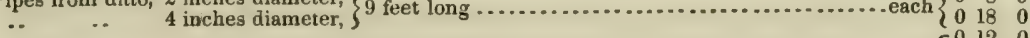

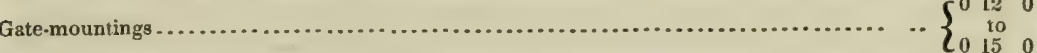

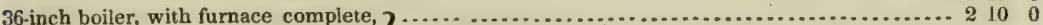

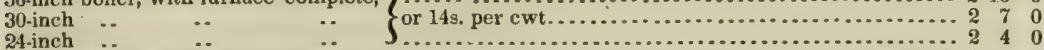

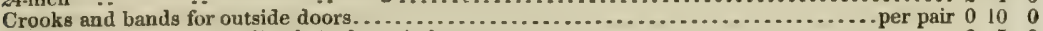
feeding-hole doors in byres ................................... 0 . 0 5 0

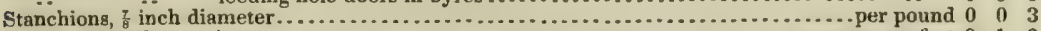
Cast-iron window sashes.............................................. per square foot 010

\section{Plaster-2oork.}

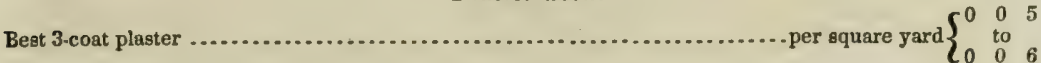

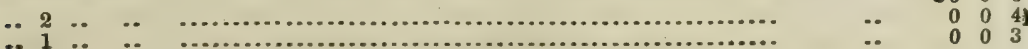

\section{Glazier-work.}

Best second crown-glass in small pane per square foot $0 \quad 0 \quad 10$

.. .. .. large panes.

Painter-work.

White lead. colored gray, atone, or slate-blue, 3 coats (295) 
(222.) There is a simple rule for d termining the pitch which a roof should have for tho various sorts of sliting. In blue-slating the rule is, that the roof should be in hight 1 of the breadth of the building. Sunp sse that a building is 18 feet inside in width like the middle range of the steading, the walls are each two feet thick, which gives a breadth of 22 feet over walls. Deduct 6 inches on each wall for an escarpment on its top, upon which the scantlings or couple-legs rest upon the wall-plates, and 1 of 21 feet gives 7 feet for the hight of the roof ahove the walls. Old fashioned houses have a pitch of the square, that is, the hight is equal to half the breadth, which, in the supposed case, would be $10 \mathrm{~s}$ feet. In gray slating the pitch is fixed at 1 foot below the square, or the hight would be $3 \frac{1}{2}$ feet. In tiling, the pitch may be lower than even in blue slating, and it is determined according to circumstances; and even blue slate roofs are made as low in the pitch as $\frac{1}{4}$ of the breadth, that is with large Welsh slates. Taking the rise at 7 feet, the scantlings should be 13 feet long each, and the balk, of course, as long. Taking the rise at $9 \frac{1}{2}$ feet, the scantlings should be 14 feet long. (131.) and (132.), p. 138.

(223.) A liquid mauure tank can be constructed at little cost. An excavation being made in clay, a lining should be built all round. The lining may be either of r ubble masonry, of stone and mortar, or of brick and mortar. If the subsoil is not of a retentive nature, a plas. tering of Roman cement will suffice to render the building retentive. A 9-inch wall, or a brick in length, will make a lining of sufficient strength to contain the liquid. The tank should be covered over in any of the various ways I have mentioned in ( 76.$)$, and paved in the bottom with flags or bricks secured by cement. A cast-iron pump should be inserted at one end of the tank when it will be ready for use.

(224.) The cost of constructing such a tank, with brick in length and cement, will be somewhat as under, exclusive of drains:

$$
\begin{aligned}
& \text { Feet. Inches. }
\end{aligned}
$$

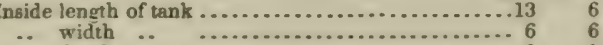

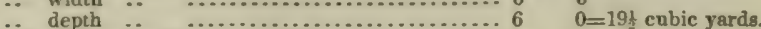

Cutting the bed of the tank, at $3 d$, per cubic yard ........................... \&0 $\quad 7 \quad 6$

Building wall, including bricks and mortar ............................... $6 \quad 8 \quad 0$

Plastering and cement ............................................. 0160

Covering with flags ...................................................... 2150

Total .......................................................... $\overline{\$ 10 \quad 6 \quad 6}$

Such a size of tank is said to be sufficient for a farm of from 150 to 200 acres. A receptacle of a more simple and unexpensive nature might be constructed, which would answer some of the ends of a more complete tank. It might be made under a shed, and composed of walls of clay, and covered with slabs of boarding. The expense of such a receptacle would be somewhere as under, the dimensions being as in the preceding case:

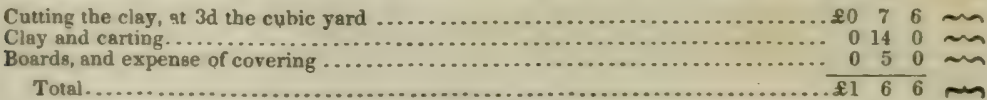

Sucn a tank, however, would suffer in frost or drouth. A cask sunk into the ground, with open channels to it, forms a sufficient tank for a cottager."

[" There are few instances in which gross neglect of valuable resources within their reach is so glaring on the part of American agriculturists as in the general failare to collect an abundant supply of water for all purposes from the roofs of their houses, and especially where these are of any considerable size, and yet more when they are so contiguous that the rain which falls on several of then might be collected into one common reservoir.

Having ascertained, as any one may do by reference to meteorological tables kept anywhere in his County or State, what is the annual quantity of rain-water which falle in that region, it is easy to calculate what measure of water may be gathered into a cistern from roofing of a given sur. face. Waistell arges the importance of placing sponts round all the buildings of the farm, observing that, besides the value of the supply of water thus obtained, the buildings will be benefited by the walls and foundations being kept drier than when the water from the roof is suffered to fall upon them. He states that the quantity of water that falls annually in his connty opon overy 100 superficial feet, or 10 feet square, of building, is about 1,400 imperial zallons.

In Mississippi, from dire necessity, such cisterns are in common use; but how many farmers over the country might, in this way, save the immense labor bestowed and the time lost in bringing water by hand from a distance, and in sending their domestic animals to it, while the remedy is so close at hand! By a simple process of filtration, and the use of ice, water so collected makea the purest and best drinking-water.

The tank or cistern may be puddled round with clay, to avoid the expense of Roman cement.

But the yet more valuable use of tanks is the one referred to by our author for collecting the (296) 


\section{THE FARM-HOUSE.}

"Do you but mark how this becomes the house."

LEAR.

(225.) In alluding to the farm-house at all, it is not my intention to give a full plan of one, as I have given of the steading; because its internal arrangements are generally left to the fancy of architects or of its occupiers, and with little regard to their adaptation to a farm. Any specific plan which I would recommend of a farm-house would therefore, I fear, receive little attention from either landlord or tenant. But the part of it which is exclusively devoted to labor has so intimate a connection with the management of the farm that I must give my opinion upon it. The part I mean includes the kitchen and dairy, and their accompanying apartments. Now, it may frequently be seen in the plans furnished by architects, that, to give the farm-house a fashionable and airy appearance, the working portion of it is too often contracted and inconveniently arranged. The principle of its construction should be to make this part of the house thoroughly commodious in itself, and at the same time prevent its giving the least annoyance to the rest from noise or disagreeable effluvia, which cannot at all times be avoided in the labors of the kitchen. Both objects would be accomplished by placing it independent of the main body of the house, and this is best effected by a jamb. Whatever may be the external form given to the house, the relative positions of its two parts may easily be preserved, whether in the old-fashioned form of a front tenement and back jamb, or the more modern and beauteous form of the Elizabethan style.

(226.) The ground-plan which I recommend of the kitchen and the other parts of the farm-house in which work is performed, may be seen in fig. 32 , where $a$ is the kitchen, 18 feet in length, 16 feet in breadth, and 10 feet in hight, provided with a door to the interior of the house, in the wall nearest to you, another to the kitchen pantry $k$ and dairy $m$, and a third to the scullery $d$ and porch $p$. It contains two windows, one on each side of $g$ on the lefi, a large kitchen range, oven, and furnace-pot at $b$, a commodious lock-up closet $c$, a wall-press $h$, and a dresser and table $g$. There is a stair at $c$ to the servants' and other apartments above, and which also leads to the principal bed-rooms in the upper story of the house. Beyond the kitchen is the scullery $d$, which contains a large furnace-pot $e$, a sink in the window $f$, a wall-press $h$, and a dresser $g$. This apartment is 18 feet

liquid manure; and we are assured that in France and Germany, and more especially in Belgium, where manure is saved as we save dollars, a manure-tank is considered as indispensable as any other part of the steading or farm-buildings.

Their size will depend, of course, on the number of animals which the system be pursues may invite the farmer to keep. Instead of making them round or oval, it is contended that the best way is to make them into cubes or squares. A tank, says DE RHAM, for a farm of 200 acres of arable land, should be 15 feet wide, 15 deep, and 45 long-giving 3 cubes of 15 feet of liquid.The rule in Germany is to have tanks large enough to contain ten times as many hogsheads as there are heads of cattle on the place. But as we shall, in the Journal of AGriculturs, treat more fully of this subject, we need not prolong this note. Of the expense of construction, every one must judge for himself, according to the price of labor and materials; but of this we are sure, that these must be exorbitant, where the profit does not very soon afford ample remuneration.

Ed. Farm. Lib. 
in length, 10 feet in breadth, and 10 feet in hight. A door from it, and another fiom the kitchen, open on a lobby common to both, and which lobby gives access by another door to the principal kitchen entrance-door

Fig. 32.

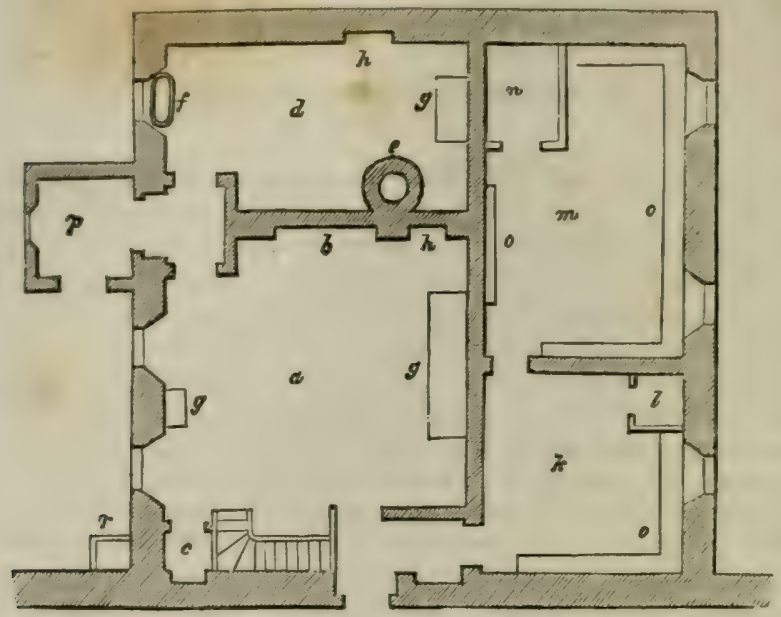

GROUND PLAN OF A KITCHEN, \&C. OF A FARM-HOUSE.

through the porch $p$. The porch $p, 6$ feet square, is erected for the purpose of screening both the kitchen and scullery from wind and cold, and it contains the back entrance-door, and is lighted by a window. On the outside, and in front of the porch-door, is $r$, the rain-water cistern, fig. $30, \mathrm{p}$. 134. On going to the right from the kitchen to the kitchen-pantry $k$, is a wall-press in the passage. The pantry $k$ is provided with a door; a window, which should look to the east or north; a larder $l$, and abundance of shelving at $o$; it is 12 feet square, having a roof of 10 feet in hight. Within this pantry is the milk-house or dairy $m$, having two windows also facing to the north or east; a lock-up closet $n$, and shelving $o$ around the walls; it is $18 \frac{1}{2}$ feet in length, 12 feet in breadth, and 10 feet in hight.

(227.) These are the different apartments, and their relative positions, required for conducting the business of a farm within the house, and in the fitting up of which are many particulars which require attention. The floor of the kitchen should be of flagged pavement polished, that it may be cleaned with certainty and ease. The outside wall and ceiling should be lathed, and all the walls and ceiling plastered with the best hair-plaster. Iron hooks, both single and double, should be screwed into the joists of the roof, from which may be suspended hams or other articles. The dressers $g$ are biest made of plain-tree tops and black American birch frames, the chairs of the latter wood, and the stools of common fir. In case of accidents, or negligence in leaving them unfastened at night, it would be well to have the lower sashes of the windows of the kitchen and scullery fast, and the upper ones only to let down for the occasional admission of fresh and the escape of heated air.

(228.) In the scullery, the sink $f$ should be of polished free-stone, made to fit the window-void, with a proper drain from it, provided with a cesspool. The floor should be of the same material as that of the kitchen, for the sake of cleanliness. The outside wall and ceiling should be lathed, and all the walls and roof plastered. There should be a force-pump in (298) 
the scullery to fill a cistern with water at the upper part of the house, to contain a constant supply for the sink. A boiler behind the kitchen fire, provided with a small cistern and ball-cock and ball in connection with the upper cistern, for the supply of cold water into the boiler; and a cock fiom it in the kitchen, and another from it in the scullery, for drawing off warm water when required, could be fitted up at no great cost, and would be found a most serviceable apparatus in a farm-house.

(229.) The large furnace-pot $e$ should be built in with fire-brick surrounded with common brick, plastered, and protected with cloth on the outside, rubbed hard into the plaster, and the mouth of the pot protected with a 4 -inch pavement polished. To carry off the superfluous steam, a lead-pipe should be fastened into a narrow, immorable portion of the potlid, and passed through the wall into the flue. An iron bar should project from the stone-wall about 3 feet or so above the furnace-pot, having a horizontal eye at its end directly over the center of the pot, to be used when making the porridge for the reapers' morning meal in harvest, as shall be described afterward. The dresser $g$ should be of the same material as that of the kitchen. There should be iron hooks fastened into the roof for hanging any article thereon. Shelving is also useful in a scullery.

(230.) The outside walls and ceiling of the kitchen-pantry should be lathed, and all the walls and ceiling plastered. The flooring should be of the same material as that of the kitchen, or of hard brick. The shelving $o$ should be of wood of several tiers, the lowest row being $3 \frac{1}{2}$ feet above the floor. The movable portion of the window should be protected with fly zinc-gauze, and so also the side and door of the larder $l$. A few iron hooks in the roof will be found useful for hanging up game or fowls. A set of steps for reaching above an ordinary hight is convenient in a pantry.

(231.) The outside walls and ceiling of the milk-house should be lathed, and the walls and roof plastered. The flooring should be of polished pave. ment, for the sake of coolness. The windows should be protected in the movable part with fly zinc-gauze, which is much better than wire-gauze; and the side and door of the lock-up closet $n$ should also be lined with zinc-gauze. The best shelving for a milk-house is marble; and, though this substance may appear extravagant in a farm-house, the price of marble is now so much reduced that it is worth the extra expense, the import of foreign marble being now free. Marble is always cool, and easily cleaned and freed of stains. Scottish marble is hard and unequal of texture. The gray-veined marble from Leghorn is therefore preferable, though the black marble of the county of Galway in Ireland is equally good; but the gray color has a coolness and freshness about it in a dairy, which the black does not possess. Polished pavement is the next best material for coolness, but it is very apt to stain with milk or butter, and the stains are difficult of removal. I speak from experience, and know the labor required to keeping stone-shelving in a milk-house always sweet and clean; and, let me say farther, unless it is so kept, any other material is preferable to it. If marble be rejected on account of expense, I would recommend stout shelving of beech or plane-tree, as being smooth, and hard, and easily kept clean. This shelving should be 2 feet broad, $1 \frac{1}{2}$ inches thick, and, to be convenient, should not exceed the hight of 3 feet from the floor.

(232.) It is necessary to make the wall which separates the kitchen and scullery fiom the milk-house and pantry of brick or stone, to keep the latter apartments more cool, and less likely to be affected by the heat and vapor, which must, of necessity, sometimes escape from the former. It would, no doubt, be convenient for the removal of dishes to have a door communicating between the scullery and milk-house; but it is much bet(299) 
ter to avoid every risk of contamination from a place which must at times be filled with vapors injurious to milk-a substance which is at all times delicately susceptible of injury.

(233.) The windows of all the apartments should be provided with shutters on the inside; and it may be a safe precaution against nocturnal intruders to protect those of the milk-house and pantry with iron stancheons on the outside, as they should, occasionally at least, be left open even all night.

(234.) On this side of the kitchen will be observed a stair. It is 4 feet in width, and intended to lead to the story above the kitchen floor, as also to the upper story of the principal part of the house. The story above the kitchen may be subdivided in this way. Let a continuation of the brick or stone wall which separates the kitchen and scullery from the milk-house and kitchen-pantry be carried up, in the form of a partition of lath and plaster, to the roof of the second story, which may be 9 feet in hight, as seen on the right of $g$, fig. 33 . The wall of the kitchen flue $b$ should, of

Fig. 33.

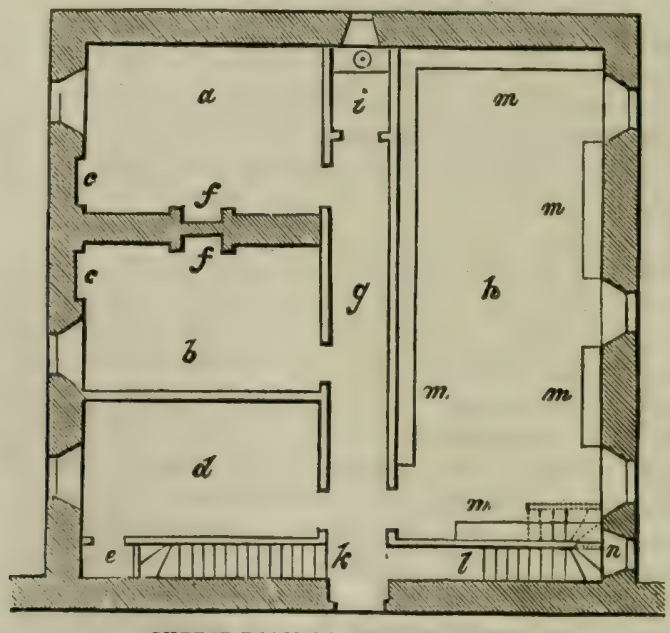

CHEESE-ROOM \&C. OF FARM-HOUSE.

sourse, be carried up to a chimney-stalk above the ridging, containing at least 4 flues from below-one of the kitchen fire, one of the small furnacepot of the kitchen, one of the oven, and one of the large furnace-pot in the scullery; but there should also be one from the room above the scullery, and one from one of the rooms above the kitchen; and, to render both kitchen and scullery as wholesome by ventilation as possible, there should be a small flue from the ceiling of each to carry off heated air and vapor. The kitchen-stalk would thus contain 6 flues from below and 2 from above.

(235.) The upper story should be partitioned off in the way as seen in fig. 33. Let the apartment $a$ above the scullery be fitted up with a fireplace $f$ as a bed-room for the female servants, having a closet $c$ in the outer wall. After taking off a passage $g$ of $3 \frac{1}{2}$ feet in width along the whole length of this part of the house, this room will be 14 feet long and 10 feet wide. The space above the kitchen may be divided into 2 bed-rooms-one $b, 14$ feet in length, by 9 feet in width, and 9 feet in hight, with a fire-place $f$ and window, and closet $c$. This might he occupied as a sitting-room and bed-room by the housekeeper, if the services of such a person are re(300) 
quired; if not, it might serve as a large store-room, with a fire-place which would be useful for various purposes. The other room $d, 14$ feet in length by 8 feet 3 inches in width, and 9 feet in hight, having a window in it, but no fire-place, might be fitted up as a bed-room for occasional stranger ser 2 ants. This latter apartment has a closet $e$ in it, 3 feet in width by 2 feet in depth, directly above the lock-up closet $c$ off the kitchen.

(236.) At the end of the passage is a water-closet $i$, lighted by a window in the gable of the jamb. The size of the water-closet is 5 feet 3 inches by $3 \frac{1}{2}$ feet. Its cistern is supplied with water from the cistern that supplies the sink in the scullery, and its soil-pipe could descend in an appropriate recess in the wall. The window of the water-closet could give light to the passage $g$ by a glass-window above the water-closet door, or the passage could be lighted by a cupola in the roof, or it could be lighted from the cheese-room $h$ by two windows in the lath and plaster wall, each of which could have a pane to open into the cheese-room for the purpose of ventilation.

(237.) The entire space above the kitchen-pantry and milk-house may be appropriated to a cheese-room $h, 29$ feet 3 inches in length on the floor, 12 feet in width, and 9 feet in hight, having 3 windows in it. Besides the floor, proper shelving $m$ should be put up for the accommodation of the cheese, in its various stages toward maturity; and the lower halves of the windows should be provided with Venetian shutters, outside of the glass, to regulate the air into the room when the windows are opened.

(238.) If there is sufficient room in the roof above these various apartments for a garret, access can be obtained to it by a stair at $l$, which would have to return upon itself in ascending the 9 feet, the hight of the story; and both this stair and the one $k$ down to the kitchen could be lighted by the window $n$. If there is no garret, then the cheese-room will be 32 feet 3 inches in length, by dispensing with the stair $l$. The window $n$ could then be also dispensed with.

(239.) These dimensions of kitchen and other apartments would be suited to the farm-house of a farm of from 500 to 1000 acres, under the mixed husbandry. The milk-house may, perhaps, be large enough for even a dairy-farm of ordinary extent; but should it be too small for that purpose, it might easily be enlarged by increasing either or both the length and breadth of the building.

(240.) In regard to the relative positions which the farm-house and steading should occupy, it has been remarked by a recent writer, that "It is generally advised that the farm-house should be placed directly in front: to which, however, it may be objected that it casts a shade over the southern entrance of the yard if very near, and if too far off, its distance will be found to be inconvenient. Perhaps the best situation is on one side of the farm-yard, with the common parlor and kitchen opening nearly into it: farmers may talk as they like about unhealthy odors arising from the stables and yards, but there never was any one injured by them, and they cannot keep too close an eye upon their servants and stock." If farmers "cannot keep too close an eye upon their servants and stock," and if the position of their houses will enable them to do so, they should do something more than place them "on one side of the farm-yard:" they must remain constantly in them, and cause "their servants and stock " to be continually in sight in the farm-yard, otherwise their watching will be of no avail ; for when the servants come to know that the house has been placed there merely to watch their proceedings, they at least, if not the stock, can and will easily avoid the par. ticular place constantly overlooked by the house. The truth is, and every farmer knows it that it is not the spot occupied by his house, whether here or there, that maintains his ar: thority over his servants; he knows that he himself must be "up and doing" in the fields in the farm yard, every where- "be stirring with the lark,"

"From morn to noon, from noon to dewy eve"-

ere he can ascertain whether his servants are doing their work well, and his stock thriving

* British Husbandry, vol. 1. p. 86.

(301) 
well. Inconvenience to himself in going a great distance betwixt his house and the steading, will induce the farmer to place his house near rather than at a distance from the steading. He wishes to be within call-to be able to be on the spot in a few seconds, when his presence is required in the farm-yard, the stable. the byre, or the barn; but more than this he does not want, and need not care for. Place your house, therefore, if you bave the choice, on some pleasant spot, neither "direct in front" nor much in the near of the steading. If there be no snch spot at hand, make one for your house, place it there, and dwell in it, with the comfortable assurance that your servants will not regard you the less, or your stock thrive the worse, because you happen to live beyond the influence of the " unhealthy odors arising from your stables and yands "-odors, by the way, of the unpleasantuess of which I never heard a farmer complain. No one of that class but a sloven would place bis house beside a dunghill.

\title{
17. THE PERSONS WHO LABOR THE FARM.
}

\author{
"Jokn. \\ 1.abor in thy rocation. \\ Geo. Thou hast bit it; for there 's no better sign of a brave mind than a hard hand." \\ Hexar VI. Part 11.
}

(241.) Тнове who labor a farm form the most important part of its material; they are the spirit that conducts its operations. You should, therefore, become early acquainted with those functionaries. They are the farmer himself, the steward or grieve, the plowman, the hedger or laborer,* the shepherd, the cattle-man, the field-worker, and the dairy-maid. These have each duties to perform, which, in their respective spheres, should harmonize and never interfere with each other. Should any occurrence happen to disturb the harmony of lahor, it must arise from some misapprehension or ignorance in the interfering party, whose aberrations must be rectified by the presiding power. I shall consider the duties in the order I have mentioned the respective agents.

(242.) And first, those of the farmer. It is his province to originate the entire system of management - to determine the period for commencing and pursuing every operation-to issue general orders of management to the steward, when there is one, and if there be none, to gire minute instructions to the plowmen for the performance of every separate field operation-to exercise a general superintendence over the field-workersto observe the general behavior of all-to see if the cattle are cared forto ascertain the condition of all the crops-to guide the shepherd-to direct the helger or laborer-to effect the sales of the surplus produce-to conduct the purchases conducive to the progressive improvement of the farm-to disburse the expenses of management-to pay the rent to the landlord-and to fulfill the obligations incumbent on him as a residenter of the parish. All these duties are common to the farmer and the steward engaged to manage a farm. An independent steward and a farmer are thus so far on the same footing; but the farmer occupies a loftier station. He is his own master-makes bargains to suit his own interests-stands on an equal footing with the landlord in the lease-has entire control over the servants, hiring and discharging them at any term he pleases-and possesses power to grant favors to servants and fiends. The farmer has not all those duties to perform in any one day, but in the course of their proper fulfillment, daily calls are made on his attention, and so large a portion of his time is occupied by them, that he finds little leisure to go far from home, except in the season when few operations are performed on a

[* Altogether inapplicable to our country. (302)

Ed. Farm.L.ib.] 
farm, viz. the end of summer. These are the professional duties of the farmer; but he has those of domestic and social life to fulfill, like every other member of society. If a farmer fulfills all his duties as he ought to do, he cannot be said "to eat the bread of idleness."

(243.) The duty of steward, or grieve,* as he is called in some parts of Scotland, and bailiff in England, consists in receiving general instructions from his master the farmer, which he sees executed by the people under his charge. He exercises a direct control over the plowmen and fieldworkers; and unreasonable disobedience on their part of his commands is reprehended as strongly by the farmer as if the affront had been offered to himself: I say unreasonable disobedience, because the farmer is the judge of whether the steward has been reasonable in his demands. It is the duty of the steward to enforce the commands of his master, and to check every deviation from rectitude he may observe in the servants against his interests. Although he should thus protect the interests of his master from the attacks of any servant, yet it is not generally understood that he has control over the shepherd, the hedger, or the cattle-man, who are stewards in one sense, over their respective departments of labor. The farmer reveals to the steward alone the plans of his management; intrusts him with the keys of the corn-barn, granaries and provision-stores; delegates to him the power to act as his representative on the farm in his absence; and takes every opportunity of showing confidence in his integrity, truth and good behavior. When a steward conducts himself with discretion in his master's absence, and exhibits at all times a considerate mind, an active person, and an honest heart, he is justly regarded as a valuable servant.

(244.) Personally, the farm-steward does not always labor with his own hands; verifying, by his judicious superintendence, on a large farm at least, the truth of the adage, that "one head is better than two pair of hands." He should, however, always deliver the daily allowance of corn to the horses. He should, moreover, be the first person out of bed in the morning, and the last in it at night. On most farms he does work: he sows the seed-corn in spring, superintends the field-workers in summer, tends the harvest-field and builds the stacks in autumn, and threshes the corn with the mill, and cleans it with the winnowing-machine, in winter. On some farms he even works a pair of horses, like a common plowman; in which case he cannot personally sow the corn, superintend the workers, build the stacks, or thresh the corn, unless another person takes charge of his horses for the time. This is an objectionable mode of employing a steward; because the nicer operations-such as sowing corn, \&c. or the guidance of his horses-must be intrusted to another, and most likely inferior, person. But in by far the greatest number of cases, the steward does not work horses; on the contrary, when a plowman qualifies himself to become a steward, it is chiefly with the view of enjoying immunity from that species of drudgery. In any event, he should be able to keep an account of the work-people's time, and of the quantity of grain threshed, consumed on the farm, and delivered to purchasers.

(245.) Stewards are not required on all sorts of farms. On pastoral farms his species of service would be of no use, as it is on arable land that these are really required. Anywhere, his services are the most valuable where the greatest multiplicity of subjects demand attention. Thus, he is a more useful servant on a farm of mixed husbandry, than on one in the neighborhood of a town, or on a carse farm. But even on some farms of

[* Overgeer or Manager. (303) 
mixed culture, the services of a steward are dispensed with altogether; in which case the farmer himself gives his orders directly to the plowmen, or indirectly through the hedger or cattle-men, as he may choose to appoint to receive his instructions. In such a case the same person is also intrusted to corn the horses; for the plowmen themselves are never intrusted with that business, as they are apt to abuse such a trust by giving too much corn to the horses, to their probable injury. The same person performs other parts of a steward's duty ; such as sowing corn, superintending field-workers, and threshing corn; or those duties may be divided betwixt the cattle-man and hedger. On the large farm in Berwickshire on which I learned farming, there was no steward, the cattle-man delivering the master's orders and corning the horses, and the hedger sowing the corn, building the stacks, and threshing the corn. The object of this arrangement was to save the wages of a steward, when the farmer himself was able to undertake the general superintendence. I conducted my own farm for several years without a steward.

(246.) The duties of a plowman are clearly defined. The principal duty is to take charge of a pair of horses, and work them at every kind of labor for which horses are employed on a farm. Horse-labor on a farm is various. It is connected with the plow, the cart, sowing-machines, the roller, and the threshing-mill, when horse-power is employed in the threshing of corn; so that the knowledge of a plowman should comprehend a variety of subjects. In the fulfillment of his duties, the plowman has a long day's work to perform ; for, besides expending the appointed hours in the fields with the horses, he must groom them before he goes to the field in the morning and after he returns from it in the evening, as well as at mid-day between the two periods of labor. Notwithstanding this constant toil, he must do his work with alacrity and good will; and when, from any cause, his horses are laid idle, he must not only attend upon them as usual, but must himself work at any farm-work he is desired. There is seldom any exaction of labor from the plowman beyond the usual daily hours of work, these occupying at least 12 hours a day for 7 months of the year, that being a sufficient day's work for any man's strength to endure. But occasions do arise which justify the demand of a greater sacrifice of his time, such as seed-time, hay-time, and harvest. For such encroachments upon his time, many opportunities occur of repaying him with indulgence, such as a cessation from labor, especially in bad weather. It is the duty of the plowman to work his horses with discretion and good temper, not only for the sake of the horses, but that he may execute his work in a proper manner. It is also his duty to keep his horses comfortably clean. Plowmen are never placed in situations of trust; and thus, having no responsibility beyond the care of their horses, there is no class of servants more independent. There should no partiality be shown by the master or steward to one plowman more than to another, as it is the best policy to treat all alike who work alike. An invidious and reprehensible practice exists, however, in some parts of the country, of setting them to work in an order of precedency, which is maintained so strictly as to be practiced even on going to and returning from work-one being appointed foreman, whose movements must guide those of the rest. Should the foreman prove a slow man, the rest must not go a single bout more than he does; and, if he is active, they may follow as best they can. Thus, while his activity confers no benefit to the farmer beyond its own work, his dullness discourages the activity of the others. This consideration alone should be sufficient ground for farmers to abolish the practice at once, and put the whole of their plowmen on the same footing. I soon saw the evils attending the (304) 
system, and put an end to it on my own farm. When one plowman displays more skill than the rest, it is sufficient honor for him to be intrusted to execute the most difficult pieces of work; and this sort of preference will give no umbrage to the others, as they are as conscious of his superiority in work as the farmer himself can possibly be. The services of plowmen are required on all sorts of farms, from the carse-farm to the pastoral, on which the greatest and the least portion of arable culture are practiced.

(247.) The services of a shepherd, properly so called, are only required where a flock of sheep are constantly kept. On carse-farms, and those in the neighborhood of large towns, he is of no use; nor is he required on those farms on which sheep are bought in to be fed off in winter. On pastoral farms, on the other hand, as also those of the mixed husbandry, his services are so indispensable that they could not be conducted without him. His duty is to undertake the entire management of the sheep; and, when he bestows the pains he should on his flock, he has little leisure for any other work. His time is occupied from early dawn, when he should be among his flock before they rise from their lair, and during the whole day, to the evening, when they again lie down for the night. To inspect a large flock at least three times a day, over extensive bounds, implies a walking to fatigue. Besides this daily exercise, he has to attend to the feeding of the young sheep on turnips in winter, the lambing of the ewes in spring, the washing and shearing of the fleece in summer, and the bathing of the flock in autumn. And, over and above these major operations, there are the minor ones of weaning, milking, drafting, and marking, at appointed times; not to omit the unwearied attention to be bestowed, for a time, on the whole flock, to evade the attacks of insects. It will readily be seen, from this summary of duties, that the shepherd has little time to bestow beyond the care of his flock. As no one but a shepherd, thoroughly bred, can attend to sheep, there must be one where a standing sheep-flock is kept, whatever may be the extent of farm. On a small farm, his whole time may not be occupied in his profession, when he can make as well as mend nets, prepare stakes for them, and assist the hedger (if there be one) to keep the fences in repair; or he may act as groom, and take charge of the horse and gig, and go errands to the post-town; or he may undertake the duties of steward. On large pastoral or mixed husbandry farms, more than one shepherd is required. The establishment then consists of a head shepherd, and one or more young men training to be shepherds, who are placed entirely under his control. The office of head shepherd is one of great trust. Sheep being individually valuable, and in most instances consisting of large flocks, a misfortune happening to them, from whatever cause, must incur great loss. On the other hand, the care and skill of the shepherd may secure a good return for the capital invested in sheep. The shepherd acts the part of butcher in slaughtering the animals used on the farm. The only assistance which he depends upon in personally managing his flock is that of his faithful dog, whose sagacity in that respect is little inferior to his own.

(248.) The services of the cattle-man are most wanted at the steading in winter, when the cattle are all housed. He has the sole charge of them. It is his duty to clean out the cattle-houses, and supply the cattle with food, fodder, and litter, at appointed hours every day, and to make the food ready for them, should prepared food be given them. The business of tending cattle being matter of routine, the qualifications of a cattle-man are not of a high order. In summer and autumn, when the cows are at grass, it is his duty to bring them into the byre or to the gate of the field, as the case may be, to be milked at their appointed times; and it is also 
his duty to aseertain that the cattle in the fields are plentifully supplied with food and water. He should see the cows served by the bull in due time, and keep an account of the cows' reckonings of the time of calving. He should assist at the important process of calving. As his time is thus only occasionally employed in summer, he frequently undertakes the superintendence of the field-workers. In harvest, he is usefully employed in assisting to make and carry food to the reapers, and may lend a hand at the taking in of the corn. As cattle occupy the steading in winter on all kinds of farms, the services of the cattle-man appear indispensable; but all his functions may be performed by the shepherd, where only a small flock of sheep are kept. The office of the cattle-man is not one of trust nor of much labor. An elderly person answers the purpose quite well, the labor being neither constant nor heavy, but well-timed and methodical. The cattle-man ought to exercise much patience and good temper toward the objects of his charge, and a person in the decline of life is most likely to possess those qualities.

(249.) Field-workers are indispensable servants on every farm devoted to arable culture. They mostly consist of young women in Scotland, but more frequently of men and boys in England; and yet there are many manual operations much better done by women than men. In hand-picking stones and weeds, in filling drains, and in barn-work, they are far more expert, and do them more neatly, than men. The duties of field-workers, as their very name implies, are to perform all the manual operations of the fields, as well as those with the smaller implements, which are not worked by horses. The manual operations consist chiefly of cutting and planting the sets of potatoes, gathering weeds, picking stones, collecting the potato crop, and filling drains with stones. The operations with the smaller implements are pulling turnips and preparing them for feeding stock and storing in winter, performing barn-work, carrying seed-corn, spreading manure upon the land, hoeing potatoes and turnips, and weeding and reaping corn-crops. A considerable number of ficld-workers are required on a farm, and they are generally set to work in a band. They work most steadily under superintendence. The steward, the hedger, or cattle-man, should superintend them when the band is large; but, when small, one of themselves, a staid person, who is capable of taking the lead in work, may superintend them well enough, provided she has a watch to mark the time of work and rest. But field-workers do not always work by themselves; being at times associated with the work of the horses, when they require no particular superintendence. On some farms, it is considered economical to lay the horses idle, and employ the plowmen at their labors rather than engage field-workers. This may be one mode of avoiding a little outlay of money; but there is no true economy in allowing horses "to eat off their own heads," as the phrase has it ; and, besides, plowmen cannot possibly do light work so well as field-workers. In manufacturing districts field-workers are scarce; but were farmers generally to adopt the plan of employing a few constantly, and hire them for the purpose by the half year, instead of employing a large number at times, young women would be induced to adopt field-labor as a profession, and become very expert in it. It is steadiness of service that makes the field-workers of the south of Scotland so superior to the same class in other parts of the country.

(250.) The duties of the dairy-maid are well defined. She is a domestic servant, domiciliated in the farm-house. Her principal duty is, as her name implies, to milk the cows, to manage the milk in all its stages, bring up the calves, and make into butter and cheese the milk that is obtained from the cows after the weaning of the calves. The other domestics gen(306) 
erally assist her in milking the cows and feeding the calves, when there is a large number of both. Should any lambs lose their mothers, the dairymaid should bring them up with cow's milk until the time of weaning, when they are returned to the flock. At the lambing season, should any of the ewes be scant of milk, the shepherd applies to the dairy-maid to have his bottles replenished with warm new milk for the hungered lambs. The dairy-maid also milks the ewes after the weaning of the lambs, and makes cheese of the ewe-milk. She should attend to the poultry, feed them, set the brooders, gather the eggs daily, take charge of the broods until able to provide for themselves, and see them safely lodged in their respective apartments every evening, and let them abroad every morning. It is generally the dairy-maid, when there is no housekeeper, who gives out the food for the reapers, and takes charge of their articles of bedding. The dairy-maid should be an active, attentive, and intelligent person.

(251.) These are the duties of the respective classes of servants found on farms. You may not require all these classes on your farm, as you have seen that some sorts of farms do not require the services of all. You have seen that a pastoral-farm has no need of a steward, but of a shepherd; a carse-farm no need of a shepherd, but of a steward; a farm in the neighborhood of a town no need of a hedger, but of a cattle-man; and, on a dairy-farm, no need of a shepherd, but of a dairy-maid; but, in the case of a farm of mixed husbandry, there is need of all these classes.

(252.) And now that you have seen how multifarious are the duties of them all, you will begin to perceive how intricate an affair mixed husbandry is, and how well informed a farmer should be of every one of these varieties of labor, before he attempts to manage for himself. To give you a stronger view of this, conceive the quantity and variety of labor that must pass through the hands of these various classes of work-people in the course of a year, and then imagine the clear-headedness of arrangement which a farmer should possess, to make all their various labors coincide in every season, and under every circumstance, so as to produce the most desirable results. It is in its variety that the success of labor is attained: in other words, it is in its subdivision that the facility of labor is acquired, and it is by the intelligence of the laborers that perfection in it is attained. And vain would be the endeavors of any farmer to produce the results he does, were he not ably seconded by the general intelligence and admirable efficiency of bis laborers.

\title{
18. THE WEATHER IN WINTER.
}

\author{
"See, Winter comee to rule the variedyear, \\ Sullen and sad, with all his rising train; \\ Vapors, and clouds, and storms. Be these my theme."
}

Thomson.

(253.) As the weather, at all seasons, has undeniably a sensible power to expedite or retard the field operations of the farm, it becomes an incumbent duty on you, as pupils of Agriculture, to ascertain the principles which regulate its phenomena, in order to anticipate their changes and avoid their injurious effects. It is, no doubt, difficult to acquire an accurate knowledge of the laws which govern the subtile elements of Nature; (307) 
but experience has proved that accurate observation of atmospherical phenomena is the chief means which we possess of becoming acquainted with those laws.

(254.) In saying that the weather has power to alter the operations of the farm, I do not mean to assert that it can entirely change any great plan of operations that may have been determined on, for that may be prosecuted even in spite of the weather; but there is no doubt that the weather can oblige the farmer to pursue a different and much less efficient treatment toward the land than he desires, and that the amount and quality of its produce may be very seriously affected by the change of treatment.For example, the heavy and continued rain in autumn 1839 made the land so very wet that not only the summer-fallow, but the potato-land, could not be seed-fumowed; and the inevitable consequence was that sowing of the wheat was postponed until the spring of 1840 , and in many cases the farmers were ohliged to sow barley instead of wheat. The immediate effect of this remarkable interference of the weather was restriction of the breadth of land appropriated to autumnal wheat, and the consequent extension of that intended for barley and spring wheat-a change that caused so much work in spring that it had the effect of prolonging the harvest of 1840 beyond the wished-for period, and of otherwise deranging the calculations of farmers.

(255.) Now, when such a change is, and may in any season be, imposed upon the farmer, it becomes a matter of prudence as well as of desire to become so acquainted with usual atmospherical phenomena as to anticipate the nature of the weather that is to come. If he could anticipate particular changes of weather by observing peculiar phenomena, he could arrange his operations accordingly. But is such anticipation in regard to the weather attainable? No doubt of it; for, although it is not as yet to be expected that minute changes of the atmosphere can be anticipated, yet the lind of weather which is to follow-whether rainy or frosty, snowy or fresh-may be predicted. We all know the prescience actually attained by people whose occupations oblige them to be much in the open air and to observe the weather. In this way shepherds and sailors, in their respective circumstances, have acquired such a knowledge of atmospherical phenomena as to be able to predict the advent of important changes of the atmosphere; and to show that the sort of knowledge acquired is in accordance with the circumstances observed, it is obvious that, even among these two classes of observers, great difference of acquirements exists on account of diversity of talent for observation. For example: A friend of mine, a commander of one of the ships of the East India Company, became so noted, by olsservation alone, for anticipating the probable results of atmospherical phenomena in the Indian seas, that his vessel has frequently been seen to ride out the storm, under bare poles, while most of the ships in the same convoy were more or less damaged. As an instance of similar sagacity in a shepherd, I remember in the wet season of 1817 , when rain was predicted as inevitable by every one engaged in the afternoon of a very busy day of leading in the corn, the shepherd interpreted the symptoms as indicative of wind and not of rain, and the event completely justified his prediction.

(256.) I conceive that greater accuracy of knowledge in regard to the changes of the weather may be attained on land than at sea, because the effect of weather on the sea itself enters as an uncertain element into the question. It is generally believed, however, that seamen are more proficient than landsmen in foretelling the weather; and, no doubt, when the imminent dangor, in which the lives of seamen are jeopardized, is consid(308) 
ered, the circumstance may reasonably be supposed to render them peculiarly alive to certain atmospherical changes. To men, however, under constant command, as seamen are, it is questionable whether the ordinary changes of the atmosphere are matters of much interest. In everything that affects the safety of the ship, and the weather among the rest, every confidence is placed by the crew in the commanding. officer, and it is he alone that has to exercise his weather wisdom. On the other hand, every shepherd has to exercise his own skill in regard to the weather, to save himself, perhaps, much unnecessary personal trouble, especially on a hillfarm. Even the young apprentice-shepherd soon learns to look out for himself. The great difference in regard to a knowledge of the weather betwixt the sea-captain and the farmer, though both are the sport of the same elements, consists in this, that the captain has to look out for himself, whereas the farmer has his shepherd to look out for him: the seafaring commander himself knowing the weather, directs his men accordingly; while the farmer does not know it nearly so well as his shepherd, and probably even not so well as his plowmen. See the effects of this difference of acquirement in the circumstances of both. The captain causes the approaching change to be met by prompt and proper appliances; whereas the farmer is too frequently overtaken in his operations from a want of the knowledge probably possessed by his shepherd or plowmen. You thus see the necessity of farmers acquiring a knowledge of the weather

(257.) It being admitted that prescience of the state of the weather is essential to the farmer, the question is, how the pupil of Agriculture is to acquire it? No doubt it can best be attained by observation in the field; but as that method implies the institution of a scries of observations extending over a long period of years, a great part of the lifetime of the pupil might pass away ere he could acquire a sufficient stock of knowledge by his own experience. This being the case, it is but right and fair that he should know what the experience of others is. This I shall endeavor to communicate, premising that he must observe for himself, after being made acquainted with the manner of conducting his own observations.

(258.) The simplest way for me to communicate what has been established in regard to the observation of atmospherical phenomena, is, in the first place, to describe to you the various instruments which have, from time to time, been contrived to indicate those phenomena; and to put these instruments into a right use, you should become well acquainted with their respective modes of action, which are all dependent on strictly scientific principles. All the instruments required are the barometer, thermometer, weathercock, hygrometer, and rain-gauge. The principles upon which these instruments operate shall be separately explained; the phenomena of the clouds and winds, upon which the diversity of the states of the atmosphere appear so much to depend, shall be described; and the efficacy of the electric agency, which seems to affect so many of the phenomena observed, shall be noticed. The general principles of atmospherical phenomena being thus considered in this place, I shall have no more occasion to recur to them, but will only have to notice the characteristic phenomena of each season as they occur.

(259.) Atmospherical phenomena being the great signs by which to judge of the weather, instruments are used to detect their changes which cannot be detected by the senses. These instruments possess great ingenuity of construction, and they all indicate pretty accurately the effects they are intended to recognize. But though they tell us nothing but the truth, such is the minute diversity of atmospherical phenomena that they do not tell us all the truth. Other means for discovering that mus: bo (309) 
used; and the most available within our reach is the converting of the phenomena themselves into indicators of atmospherical changes. In this way we may use the transient states of the atmosphere, in regard to clearness and obscurity, dampness or dryness, as they affect our senses of sight and feeling, the shapes and evolutions of the clouds, and the peculiar state of the wind, into means by which to predicate the changes of the weather. But this kind of knowledge can only be acquired by long observation of natural phenomena.

(260.) The most important instrument, perhaps-the most popular, certainly-for indicating the changes of the atmosphere, is the barometer, an instrument so universally known and used by farmers, that a particular description of it is here unnecessary. This instrument is formed to be placed either in a fixed position or to be portable. As it is only used in the portable shape to measure the altitude of mountains, the method of using it need not be here described. For a fixed position, the barometer is made either of the figure of an upright column or of a wheel. Whether it is because that the divisions on the large circular disk, pointed out by the long index of the wheel-barometer, are more easily observed than the varieties of the column of mercury in the perpendicular one, is the reason which renders the wheel-barometer more popular among farmers, I know not; but were they to consider that its indications cannot be so delicate as those of the upright form, because of the machinery which the oscillations of the mercury have to put in motion before the long index can indicate any change, the upright form would always be preferred. It is true that the tube of the upright barometer is generally made too small, and is perhaps so made to save mercury and make the instrument cheaper; but a small tube has the disadvantage of increasing the friction of the mercury in its passage up and down the tube. On this account the mercury is apt to be kept above its proper level when falling, and to be depressed below its proper hight when rising. To obviate this inconvenience, a tap of the hand against the case of the instrument is required to bring the mercury to its proper position. The tendency of the mercury to rise may be observed by the convex or raised form of the top of the column; and the hollow or concave form indicates its tendency to fall.

(261.) In observing the state of the barometer, too much regard should not be had to the numerals and words usually written on the graduated scale, placed along the range of the top of the column of mercury; because it is the rising or falling of the mercury alone that is to be taken as indicative of a change of weather, whatever may be its actual hight in the tube. The greatest hight attained by the column is entirely determined by the hight of elevation of the place of observation above the level of the sea. The higher the place is above the sea, the mean hight of the column will be the lower. For example, on comparing two barometers at the same time, at two places of different hights in the same part of the country, and subject to the same climate, one may stand as high as 30 inches, and the other only at $29 \frac{1}{2}$ inches. According to the usual markings of barometers, the mercury at the first place would stand at "Fair," whereas, at the other place, it would be at "Changeable." This difference of the mercury is in itself important, but it does not axise from any difference in the state of the air, as indicative of a change of weather, but merely from the difference of elevation of the two places above the level of the sea. The mercury is as near its greatest hight at $29 \frac{1}{2}$ inches at the higher place, as it is at 30 inches at the lower place, in reference to their respective positions above the sea; and this being the case, and other circumstances equal, it will be the same weather at both places. This differ(310) 
ence of the hight of the mercury is explained in this way. The barometer being the instrument which indicates the weight or pressure of the atmosphere, as its name implies, it is found on trial that the mercury stands highest at the level of the sea, and that it descends as elevation above the sea increases. The depression has been found by experiment to be $\frac{1}{10}$ of an inch for about every 88 feet of elevation, or more correctly as given in this table.*

Table showing the Number of Feet of Altitude corresponding to Depressions OF THE BAROMETER.

\begin{tabular}{|c|c||c|c|}
\hline Depression. & $\begin{array}{c}\text { Altitude in } \\
\text { feet. }\end{array}$ & $\begin{array}{c}\text { Depression. } \\
\text { Altiude in } \\
\text { feet. }\end{array}$ \\
\hline-1 & 87 & -6 & 527 \\
-2 & 175 & -7 & 616 \\
-3 & 262 & -8 & 705 \\
-4 & 350 & -9 & 795 \\
-5 & 439 & 1 inch. & 885 \\
\hline
\end{tabular}

(262.) It becomes, then, a matter of some importance for you, in order to place explicit reliance on the changes indicated by your barometer, to ascertain the hight of your farm above the level of the sea. If you know that by other means, namely, by trigonometry, then the allowance in the table will give you its true elevation; but should you not be acquainted with its elevation, which is usually the case with farmers, the mean hight of the barometer can be ascertained by a series of simple observations, made at a given time, over a year or more. For example, "the sum of one year's observations, made at 10 A. M. and 10 P. M. in 1827, was 21615.410 inches, and this number divided by the number of observations, 730 , or twice the number of days in that year, gave 29.610 inches as the mean hight or changeable point of the barometer." $\dagger$ Now, taking the mean hight of the barometer at 29.948 inches at the mean level of the sea, where the atmosphere always indicates the greatest density, deduces from nine years' observations at the mean temperature of the air, with a range from 28 inches to 31 inches, it is seen that the instance adduced above of $29 \cdot 610$ inches gives 338 of an inch less than the mean, which, by the table, indicates an elevation of the place of observation of about 265 feet above the mean level of the sea. It is from the mercury being above or below this point of 29.610 inches in the supposed place of your farm, that you are to conclude what weather may be expected at that place, from the changes of the barometer. From the want of this knowledge, farmers are generally led into the mistake of supposing that the words "Fair," "Change," "Rain," engraved on the scale of the barometer, indicate such weather in all places, when the mercury stands at them. The best way to correct this mistake is to have the words engraved at the hights truly applicable to the particular place of observation. Notwithstanding this source of common error, the barometer is a generally useful instrument, inasmuch as its indications foretell the same results at all seasons, with perhaps only this exception, those of the effects of heat in summer, which cannot of course be noticed in winter.

(263.) The general indications of the barometer are few, and may easily be remembered. A high and stationary mercury indicates steady, good weather. A slow and regular fall indicates rain; and, if during an $\mathbf{E}$. wind, the rain will be abundant. A sudden fall indicates a gale of wind, and most probably from the W. Good, steady weather must not be expected in sudden depressions and elevations of the mercury. A fine day 
may intervene, but the general state of the weather may be expected tc be unsteady. An E. or N. E. wind keeps up the mercury against all other indications of a change. A W or S. W. wind causes a fall when the wind changes from E. or N. E.; but, should no fall take place, the maintenance of the hight, in the circumstances, is equivalent to a rise, and the reverse of this is equivalent to a fall. The quantity affected by these particular causes may he estimated at $\frac{2}{10}$ of an inch." The barometer, at sea, is a good indicator of wind, but not of rain. When the barometer is used within doors, the best situation for it is in any room where the temperature is equal, and not exposed to sunshine. The cost of a perpendicular barometer of gond workmanship is from $£ 111$ s. 6 d. to $£ 212 \mathrm{~s}$. 6d. according to taste and finish; that of a wheel-barometer from $£ 228$. to $£ 55$ s. The barometer was invented by Torricelli, a pupil of Galileo, in 1643 .

(264.) Among the variable causes which affect the barometer is the direction of the wind. The maximum of pressure is when the wind is $\mathbf{N}$. E. decreasing in both directions of the azimuth till it reaches the minimum between S. and S. W. This difference amounts 10 above $\frac{3}{10}$ of an inch at London. The variation occasioned by the wind may be owing to the cold which always accompanies the E. winds in spring, connected as they probably are with the melting of the snow in Norway; but it is not unlikely to be owing, as Mr. Meikle suggests, to its opposition to the direction of the rotation of the earth, causing atmospherical accumulation and pressure, by diminishing the centrifugal force of the aerial particles.t

(265.) The accidental variations of barometric pressure are greatly influenced by latitude. At the equator it may be said to be nothing, hurricanes alone causing any exception. The variability increases toward the poles, owing probably to the irregularity of the winds beyond the tropics. The mean variation at the equator is 2 lines, $t$ in France 10 lines, and in Scotland 15 lines, throughout the year-the quantity having its monthly oscillations. These do not appear to follow the parallels of latitude, but, like the isothermal lines, undergo inflections, which are said to have a striking similarity to the isoclinal magnetic lines of Hanstcen. If so, it is probably by the medium of temperature that these two are connected.More lately, M. Kämtz has pointed out the connection of the winds with such changes, and he has illustrated the influence of the prevalent aerial currents which traverse Europe, though not with apparent regularity, yet, at least, in subjection to some general laws.||

(266.) The sympiesometer was invented by Mr. Adie, optician in Edinburgh, as a substitute for the common barometer. Its indications are the same, with the advantage of having a longer scale. For the measurement of hights this instrument is very convenient, from its small size admitring of its being carried in the coat-pocket, and not being subject to the same chances of accident as the portable barometer. The hight is given in fathoms on the instrument, requiring only one correction, which is performed by a small table engraved on its case. It is stated to be delicately sensible of changes at sea, particularly of gales. Not being an instrument which has been brought into general use, though Professor Forbes is convinced it might be, I need not allude to it farther here.ई

(267.) The next instrument which claims our attention is the thermometer. As its name implies, it is a measurer of heat. It is undoubtedly the most perfect of our meteorological instruments, and has been the means

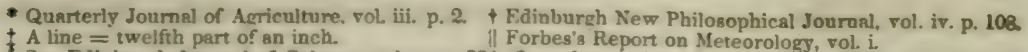

11 Forbes's Report on Meteorology, vol $i$.

See Edinburgh Journal of Scien
New Series, vol. iv. pp 91 and 329. (312) 
of establishing the most important facts to science; but, being a mere measurer of temperature, it is incapable of indicating changes of the atmosphere so clearly as the barometer, and is therefore a less useful instrument to the farmer. Regarding the ordinary temperature of the atmosphere, the feelings can judge sufficiently well; and, as the condition of most of the productions of the farm indicates pretty well whether the climate of a particular locality can bring any species of crop to perfection, the farmer seems independent of the use of the thermometer. Still, it is of importance for him to know the lowest degree of temperature in winter, as certain kinds of farm produce are injured by the effects of extreme cold, of which the feelings are incapable, from want of habit, of estimating their power of mischief. For this purpose, a thermometer self-registering the lowest degree of cold will be found a useful instrument on a farm. As great heat does no harm, a self-registering thermometer of the greatest heat seems not so useful an instrument as the other two.

(268.) "The thermometer, by which the temperature of our atmosphere was determined," says Mr. John Adie, of Edinburgh, "was invented by Sanctario, in 1590. The instrument, in its first construction, was very imperfect, having no fixed scale, and air being the medium of expansion. It was soon shown, from the discovery of the barometer, that this instrument was acted upon by pressure as well as temperature. To separate these effects, alcohol was employed as the best fluid, from its great expansion by heat, but was afterward found to expand unequally. Reaumur first proposed the use of mercury as the expansive medium for the thermometer. This liquid metal has great advantages over every other medium; it has the power of indicating a great range of temperature, and expands very equally. After its introduction, the melting point of ice was taken as a fixed point, and the divisions of the scale were made to correspond to $1^{\frac{1}{0}} \frac{0}{00}$ th parts of the capacity of the bulb. It was left for the ingenious Fahrenheit to fix another standard point, that of boiling water under the mean pressure of the atmosphere, which is given on his scale at $212^{\circ}$; the melting point of ice at $32^{\circ}$. This scale of division has almost universally been adopted in Britain, but not at all generally on the Continent. The zero of this scale, though an arbitrary point adopted by Fahrenheit, from the erroneous idea that the greatest possible cold was produced by a mixture of common salt and snow, has particular advantages for a climate like ours; besides being generally known, the zero is so placed that any cold which occurs very rarely causes the mercury to fall below that point, so that no mistake can take place with regard to noting minus quantities.The only other divisions of the thermometer between the two fixed points in general use are those of Reaumur and the centesimal: the former divides the space into 80 equal parts; the division of the latter, as indicated by its name, is into 100 parts. In both these scales the zero is placed at the melting point of ice, or $32^{\circ}$ Fahrenheit."* The self-registering thermometers were the invention of the late Dr. John Rutherfurd, and his are yet the best. The tube of the one for ascertaining the greatest degree of heat is inclined nearly in a horizontal position and filled with mercury, upon the top of the column of which stands an index, which, on being pushed upward, does not return until made to descend to the top of the mercury by elevating the upper end of the thermometer. This index was first made of metal, which became oxydized in the tube, and uncertain in its motions. Mr. Adie, optician in Edinburgh, improved the instrument, by introducing a fluid above the mercury, in which is floated a glass index, which is free

* Quarterly Journal of Agriculture, vol. iii. D. 5. (313) 
from any action, and is retained in its place by the fluid. "The other thermometer, for registering the lowest degree," says Mr. John Adie, "is filled with alcohol, having an index of black glass immersed in the liquid. This index is always carried down to the lowest point to which the temperature falls; the spirit passes freely upward without changing the place of the index, so that it remains at the lowest point. This instrument, like the other, turns upon a center, to depress the upper end, and allow the index, by its own weight, to come into contact with the surface of the spirit, after the greatest cold has been observed, which is indicated by the upper end of the index, or that farthest from the bulb. In both cases the instruments are to be left nearly horizontal, the bulb end being lowest. This angle is most easily fixed by placing the bulb about $\frac{3}{4}$ of an inch under the horizontal line."*

(269.) Thermometers of all kinds, when fixed up for observation, should be placed out of the reach of the direct rays of the sun or ot any reflected heat. If at a window or against a wall, the the: nometer should have a northern aspect, and be kept at a little distance from either; for it is surprising through what a space a sensible portion of heat is conveyed from soil and walls, or eren from grass illuminated by the sun. The maxima of temperature, as indicated by thermometers, are thus generally too great; and from the near contact in which thermometers are generally placed with large ill-conducting masses, such as walls, the temperature of the night is kept up, and the minima of temperature are thus also too high. The price of a common thermometer is from $5 \mathrm{~s} .6 \mathrm{~d}$. to $14 \mathrm{~s}$. and of Rutherfurd's minimum self-registering thermometer 10 s. $6 \mathrm{~d}$.

(270.) Many highly interesting results have been obtaicred by the use of the thermometer, and among the most interesting are those regarding the mean temperature of different localities. In prosecuting this subject, it was found that a diurnal oscillation took place in the temperature as well as the pressure of the atmosphere, and that this again varies with the seasons. Nothing but frequent observations during the day could ascertain the mean temperature of different places; and, in so prosecuting the sub. ject, it was discovered that there were hours of the day, the mean temper. ature of which, for the whole year, was equal to the-mean of the whole 24 hours, which, when established, would render all future observations less difficult. The results exhibit an extraordinary coincidence.

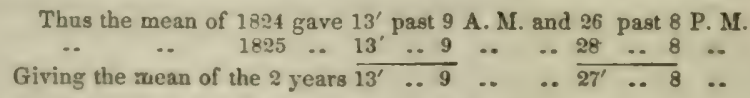

These results were obtained from a series of observations made at Leith Fort in the years 1824 and 1825 by the Royal Society of Edinburgh.t Some of the other consequences deducible from these observations are, "that the mean hour of the day of minimum temperature for the year is 5 A. M., and that of maximum temperature $40^{\prime}$ past $2 \mathrm{P}$. M.; that the deviation of any pair of hours of the same name from the mean of the day is less than half a degree of Fahrenheit, and of all pairs of hours, $4 \mathrm{~A}$. M. and P. M. are the most accurate; that the mean annual temperature of any hour never differs more than 30.2 from the mean of the day for the whole year; that the mean daily range is a minimum at the winter solstice, and a maximum in April; and that the mean daily range in this climate is $6^{\circ} .065 . " \ddagger$ The mean temperature at Leith Fort for the mean of the two years, at an elevation of 25 feet above the mean level of the 
sea was found to be $48^{\circ} .36$. The mean, taken near Edinburgh, at an altitude of 390 feet above the mean level of the sea, at 10 A. M. and P. M., with a common thermometer, and with the maximum and minimum results of self-registering thermometers, gave these results when reduced to the mean level of the sea: With the self-registering thermometers $48^{\circ} .413$, and with two observations a day with the common thermometer $48^{\circ} .352$, which correspond remarkably with the observations at Leith Fort. These observations were taken at $10 \mathrm{~A}$. M. and $10 \mathrm{P} . \mathrm{M}$., which were found to be the particular hours which gave a near approximation to the mean temperature of the day ; but had they been made at the more correct periods of $13^{\prime}$ past $9 \mathrm{~A}$. M. and $27^{\prime}$ past $8 \mathrm{P}$. M., it is probable that the results with those at Leith Fort would have corresponded exactly.* The mean temperature of any place may be ascertained pretty nearly by observing the mean temperature of deep-seated springs, or that of deep wells. Thus the Crawley Springs, in the Pentland Hills, which supply Edinburgh with abundance of water, situated at an elevation of 564 feet above the level of the sea, give a mean temperature of $46^{\circ} .3$, according to observations made in 1811 by Mr. Jardine, civil engineer, Edinburgh; and the Black Spring, which is 882 feet above the level of the sea, gave a mean temperature of $44^{\circ} .9$, by observations made in the course of 1810-11-15-18-19. A well in the Cowgate of Edinburgh gave a mean temperature of $49^{\circ} .3$, by observations made every month in the year 1794 , of which the temperature of the month of June approached nearest to the mean temperature of the year, being $49^{\circ} .5 . \dagger$

(271.) The measurement of the humidity of the atmosphere is a subject of greater importance in a scientific than in a practical poist; for however excellent the instrument may be for determining the degree of humidity, the atmosphere has assumed the humid state betore any indication of the change is noticed on the instrument, and in this 1 espect it is involved in the same predicament as the thermometer, which only tells the existing heat, and both are less useful on a farm than the barometer, which indicates an approaching change. No instrument has yet been contrived by which the quantity of moisture in the air can be ascertained from inspection of a fixed scale, without the use of tables to rectify the observation. The instrument used for ascertaining the moisture of the air is appropriately termed a hygrometer. Professor Leslie was the first to construct a useful instrument of this kind. His is of the form of a differential thermometer, having a little sulphuric acid in it; and the cold is produced by evaporation of water from one of the bulbs covered with black silk, which is kept wetted, and the degree of evaporation of the moisture from the bulb indicates the dryness of the air.

(272.) Another method of ascertaining the moisture of the atmosphere, is by the dew-point hygrometer of Professor Daniells; but this instrument is considered rather difficult of management, except in expert hands.

(273.) The best hygrometer is that of Dr. Mason, which consists of two thermometers, fastened upright to a stand having a fountain of water in a glass tube placed betwixt them, and out of which the water is taken up to one of the bulbs by means of black floss silk. When the air is very dry, the difference between the two thermometers will be great; if moist, less in proportion; and when fully saturated, both will be alike. The silk that covers the wet bulb, and thread which conveys the water to it, require renewal about every month, and the fountain is filled when requisite with distilled water, or water that has been boiled and allowed to cool,

* Quarterly Journal of Agriculture, vol. iii. p. 9. (315)

† Bid. p. 10-11. 
by immersing it in a basin of the water till the aperture only is just upon the surface, and the water will flow into it. For ordinary purposes of observation, it is only necessary to place the instrument in a retired part of the room away from the fire, and not exposed to weather, open doors, or passages; but for nice experiments the observations should always be made in the open air and in the shade, taking especial care that the instrument be not influenced by the radiation of any heated bodies, or any currents of air. When the hygrometer is placed out of doors in frosty weather, the fountain had better be removed, as the freezing of the water within may cause it to break; in this case a thin coating of ice may soon be formed on the wet bulb, which will last a considerable time wet, and be rewetted when required.

(274.) Very simple hygrometers may be made of various substances, to show whether the air is more or less humid at any given time. One substance is the awn of the Tartarian and wild oats, which, when fixed in a perpendicular position to a card, indicates, by its spiked beard, the degree of humidity. A light hog's bristle split in the middle, and riding by the split upon the stem of the awn, forms a better index than the spike of the awn itself. To adjust this instrument, you have only to wet the awn and observe how far it carries round the index, and mark that as the lowest point of humidity, and then subject the awn to the heat of the fire for the highest point of dryness, which, when marked, will give betwixt the two points an arc of a circle, which may be divided into its degrees. I have used such an instrument for some time. When two or more are com parc ' together, the mean of humidity may be obtained. The awns can be rene,sed at pleasure. With regard to confiding in the truth of this simple hygrometer, the precaution of $\mathrm{Dr}$. Wells is worth attention. " $\mathrm{Hy}$ grometers formed of animal and vegetable substances," he says, "when exposed to a clear sky at night, will become colder than the atmosphere, and hence by attracting dew, or, according to an observation of Saussure, by merely cooling the air contiguous to them, mark a degree of moisture beyond what the atmosphere actually contains. This serves to explain an ohservation made by M. de Luc, that in serene and calm weather, the humidity of the air, as determined by a hygrometer, increases about and after sunset with a greater rapidity than can be attributed to a diminution of the general heat of the atmosphere."* The principle of this sort of hygrometer may serve to explain a remarkable natural phenomenon. "Hygrometers were made of quills by Chiminello, which renders it probable that birds are enabled to judge of approaching rain or fair weather. For it is easy to conceive that an animal having a thousand hygrometers intimately connected with its body, must be liable to be powerfully affected, with regard to the tone of its organs, by very slight changes in the dryness or humidity of the air, particularly when it is considered that many of the feathers contain a large quantity of blood, which must be alternately propelled into the system, or withdrawn from it, according to their contraction or dilatation by dryness or moisture." $\dagger$ Does Virgil allude to a hygrometric feeling in birds when he says-

\footnotetext{
"Wet weather seldom hurts the most unwise, So plain the signs, such prophets are the skies: The wary crane foresees it first, and sails Above the otorm, and leaves the lowly vales." $\ddagger$
}

(275.) The Weather-cock is a very useful instrument to the farmer. It should be erected on a conspicuous part of the steading, which may readily

* Wells on Dew, p. 64. † Edinburgh Encyclopøedia, art. Hygrometry. † Dryden's Virgil, i. Georgics, 514 (316) 
be observed from one of the windows of the farm-house. Its position on the steading may be seen in fig. 1 , Plate I., and fig. 3 , Plate III. Its car dinal points should be marked with the letters N. E. S. W., to show at a glance the true points of the compass. The vane should be fitted up with a ball or box containing oil, which may be renewed when required. There is not a neater or more appropriate form for a vane than an arrow, whose dart is always ready to pierce the wind, and whose butt serves as a governor to direct it to the wind's eye. The whole should be gilt, to prevent the rusting of the iron. Mr. Forster had such a vane erected at his place of residence, which had a small bell suspended from its point which struck upon the arms pointing to the direction of the compass, and announced every change of wind.* Such a contrivance may be considered a conceit, but it has the advantage of letting you know when the wind shifts much about, as when it does there is as little chance of settled weather as in the frequent changes of the barometer. A better contrivance of the bell would be to have a hammer suspended from the dart by a supple spring, and a bell of different tone attached to each of the arms which indicate the point of the compass, and the different toned bells, when struck, would announce the direction in which the wind most prevailed. Besides bells, there is a contrivance for indicating the directions of the wind by an index on a vertical disk, like the dial-plate of a clock, an instance of which may be seen in the western tower of the Register-House in Edinburgh. This would be a very convenient way of fitting up a weather-cock.

(276.) With regard to the origin of the name of weather-cock, Beckmann says that vanes were originally cut out in the form of a cock, and placed on the tops of church spires, during the holy ages, as an emblem of clerical vigilance.t The Germans use the same term as we do, wetterhahn; and the French have a somewhat analogous term in coq de clocher. As the vane turns round with every wind, so, in a moral sense, every man who is " unstable in his ways," is termed a weather-cock.

(277.) In reference to the wind is another instrument called the anemometer, or measurer of the wind's intensity. Such an instrument is of little value to the farmer, who is more interested in the direction than the intensity of the wind, as it is that property of it which has most effect in promoting changes of the weather. It must be admitted, however, that the intensity of the wind has a material effect in modifying the climate of any locality, such as that of a farm elevated in the gorge of a mountain pass. Still, even there its direction has more to do in fixing the character of the climate than the intensity; besides, the anemometer indicates no approach of wind, but only measures its force when it blows, and this can be sufficiently well appreciated by the senses. The mean force of the wind for the whole year at $9 \mathrm{~A}$. M. is 0.855 , at $3 \mathrm{P} . \mathrm{M}$. 1.107 , and at $9 \mathrm{P}$. M. 0.605 .

(278.) The best instrument of this class is Lind's anemometer, which, although considered an imperfect one, is not so imperfect, according to the opinion of Mr. Snow Harris, of Plymouth, who has paid more attention to the movements of the wind than any one else in this country, as is generally supposed. Lind's anemometer "consists of two glass tubes about 9 inches long, having a bore of $\frac{4}{10}$ of an inch. These are connected, at their lower extremities, by another small tube of glass, with a bore of $\frac{1}{10}$ of an inch. To the upper extremity of one of the tubes is fitted a thin metallic one, bent at right angles, so that its mouth may receive horizontally the current of air. A quantity of water is poured in at the mouth, till the 
tubes are nearly half full, and a scale of inches and parts of an inch is placed betwixt the tubes. When the wind blows in at the mouth, the column of water is depressed in one of the tubes, and elevated in the same degree in the other tube; so that the distance between the surface of the fluid in each tube is the length of a column of water, whose weight is equivalent to the force of the wind upon a surface equal to the base of the column of fluid. The little tube which-connects the other two is made with a small aperture, to prevent the oscillation of the fluid by irregular blasts of wind. The undulations produced by sudden gusts of wind would be still more completely prevented by making the small tube, which connects the other two large ones, of such a length as to be double between the other two, and be equal to the length of either. The same effect might also be produced by making a thin piece of wood float upon the surface of the fluid in each tube."*

(279.) Another meteorological instrument is the rain-gauge. This instrument is of no use to the farmer as an indicator of rain, and, like some of the rest which have been described, only professes to tell the quantity of rain that actually has fallen in a given space, yet even for this purpose it is an imperfect instrument. "The simplest form of this instrument," says Mr. John Adie, "is a funnel, with a cylindrical mouth, 3 or 4 inches high, and having an area of 100 square inches, made of tinned iron or thin copper. It may be placed in the mouth of a large bottle for receiving the water, and, after each fall, the quantity is measured by a glass jar, divided into inches and parts. A more elegant arrangement of the instrument is formed by placing the funnel at the top of a brass cylindrical tube, having at one side a glass tube, communicating with it at the under part, with a divided scale placed alongside of it. The area of the mouth is to that of the under tubes as $10: 1$; consequently 1 inch deep of rain falling into the mouth will measure 10 inches in the tubes, and 1 inch upon the scale will be equal to a fall of $\frac{1}{10}$ of an inch, which quantities are marked upon the scale, and the water is let off by a stop-cock below. The instrument should be placed in an exposed situation, at a distance from all buildings and trees, and as near the surface of the ground as possible. . . . In cases of snow-storms, the rain-gauge may not give a correct quantity, as a part may be blown out, or a greater quantity have fallen than the mouth will contain. In such cases, the method of knowing the quantity of water is to take any cylindrical vessel, such as a case for containing maps, which will answer the purpose very well; by pressing it perpendicularly into the snow, it will bring out with it a cylinder equal to the depth. This, when melted, will give the quantity of water by measurement. The proportion of snow to water is about $17: 1$, and hail to water $8: 1$. These quantities, however, are not constant, butdepend upon the circumstances under which the snow or hail has fallen, and the time they have been upon the ground." The cost of a rain-gauge, according as it is fitted up, is $£ 15 \mathrm{~s} . £ 212 \mathrm{~s} .6 \mathrm{~d}$. and $£ 44$ s.

(280.) These are the principal instruments employed by meteorologists to ascertain atmospherical changes, and seeing their powers and uses, as now described, you can select those which appear to you most desirable to possess. Of them all, only two are indicators of approaching changes, the barometer and the weather-cock; and these, of good construction, you will of course have, whichever of the others you may choose to possess.

(281.) Besides these two instruments, there are objects in nature which indicate changes of the weather. Of these the Clouds are eminent premon-

* Edinburgh Encyclopwedia, art. Anemometer.

1 Quarterly Journal of Agriculture, vol, iii. p. 13.

† Sce Thomson's History of the Royal Society. (318) 
itors. It may at first sight be supposed that clouds, exhibiting so great a variety of forms, cannot be subject to any positive law; but such a supposition is erroneous, because no phenomenon in nature can possibly occur, but as the effect of some physical law, although the mode of action of the law may have hitherto eluded the acutest search of philosophical observation. It would be unphilosophical to believe otherwise. We may therefore depend upon it, that every variety of cloud is an effect of a definite cause. If we cannot predict what form of cloud will next ensue, it is because we are unacquainted with the precise process by which they are formed. But observation has enabled meteorologists to classify every variety of form under only three primary figures, and all other forms are only combinations of "two or more of these three.*

(282.) 1. The first simple form is the Cirrus, a word which literally means a curl, or lock of hair curled. 2. The second is the Cumulus, or heap. 3. And the third is the Stratus, or bed or layer. Combinations of these three give the four following forms, the names of which at once indicate the simple forms of which they are composed. 1. One is Cirro-Cumulus, or combination of the curl and heap. 2. Another is the Cirro-Stratus, or combination of the curl and stratus. 3. A third is the Cumulo-Stratus, or combination of the heap and the stratus. 4. And, lastly, there is the combination of the Cumulo-Cirro-Stratus, or that combination of all the three simple forms, which has received the name of Nimbus or rain-cloud. The English names usually given by writers to some of these forms of clouds. are very singular, and seemingly not very appropriate. The curl is an appropriate enough name for the cirrus, and so is the rain-cloud for the nimbus; but why the heap should be called the stacken-cloud, the stratus the fall-cloud, the curled heap the sonder-cloud, the curled stratus the wane-cloud, and the heaped stratus the twain-cloud, is by no means obvious, unless this last form, being composed of two clouds, may truly be denominated a twain-cloud; but, on the same principle, the cirro-cumulus, and the cirro-stratus, and the cumulo-stratus, may be termed twain-clouds. We must, however, take the nomenclature which the original and ingen ious contriver of the classification of clouds, Mr. Luke Howard, of Lon don, has given.

(283.) The first form of clouds which demands your attention is the Cirrus or curl-cloud. This is the least dense of all clouds. It is composed of streaks of vapor of a whitish color, arranged with a fibrous structure, and occurring at a great hight in the atmosphere. These fibrous streaks assume modified shapes. Sometimes they are like long naruw rods, lying quiescent, or floating gently along the upper region of the atmosphere.At other times one end of the rod is curled up, and spread out like a feather; and, in this shape, the cloud moves more quickly along than the other, being evidently affected by the wind. Another form is that familiarly known by the "gray mare's tail," or "goat's beard." This is more affected by the wind than even the former. Another form is in thin fibrous sheets, expanded at times to a considerable breadth, like the gleams of the aurora borealis. There are many other forms, such as that of net-work, bunches of feathers, hair, or thread, which may respectively be designated reticulated, plumose, comoid, and filiform cirri.

(284.) In regard to the relative hights at which these different forms of cirri appear, I would say that the fibrous rod assumes the highest position

[" For farther observations on the "Means of Prognosticating the W eather," see last number of Jour. of Ag., page 137. For a valuable work on this subject, as applicable to our own country, the reader is referred to Forry on the Climate of the United States. (319) 
in the air; the rod with the turned-up end the next highest; the bunch of feathers is approaching the earth; the mare's tail is descending still farther; and the sheet-like form is not much above the denser clouds. Sometimes the fibrous rod may be seen stretching between two denser clouds, and it is then supposed to be acting as a conductor of electricity between them.

(285.) As to their relative periods of duration, the fibrous rod may be seen high in the air for a whole day in fine weather; or it vanishes in a short time, or descends into a denser form. When its end is turned up, its existence is hastening to a close. The plumose form soon melts away; the gray-mare's tail bears only a few hours of pretty strong wind; but the broad sheet may be blown about for some time.

(286.) 'The sky is generally of a gray-blue when the fibrous rod and hooked rod are seen; and it is of the deepest blue when the plumose watery cirrus appears. It is an observation of Sir Isaac Newton, that the deepest blue happens just at the changes from a dry to a moist atmosphere.

(287.) The cirrus cloud frequently changes into the complete cirro-cumulus, but it sometimes forms a fringed or softened edge to the cirro-stratus; and it also stretches across the heavens into the density of a cirro-stratus. Of all the seasons, the cirrus appears least frequently in winter.

(288.) The Cumulus may be likened in shape to a heap of natural meadow hay. It never alters much from that shape, nor is it ever otherwise than massive in its structure; but it varies in size and color according to the temperature and light of the day, becoming larger and whiter as the heat and light increase; hence it generally appears at sunrise, assumes a larger form by noon, often screening the sun from the earth, and then melts away toward night. On this account it has received the designation of the "cloud of day." Its density will not allow it to mount very high in the air; but it is, nevertheless, easily buoyed up for a whole day by the vapor plane above the reach of the earth. When it so rests it is terminated below by a straight line. It is a prevailing cloud in the daytime at all seasons, and is exceedingly beautiful when it presents its silvery tops tinted with sober colors against the bright blue sky. Cumuli sometimes join together and as suddenly separate again, though in every case they retain their peculiar form. They may often be seen floating in the air in calm weather, not far above the horizon; and they may also be seen driving along with the gale at a greater hight, casting their fleeting shadows on the ground. When in motion, their bases are not so straight as when at rest. Cumuli, at times, disperse, mount into the air, and form cirri, or they descend into strati along the horizon; at others a single cumulus may be seen at a distance in the horizon, and then increasing rapidly into the storm-cloud, or else overspreading a large portion of the sky with a dense veil. Does the poet allude to the cumulus, as seen in a summer afternoon, in these breathing words?

\footnotetext{
"And now the mists from earth are clouds in heaven, Clouds slowly castellating in a calm

Sublimer than a storm; which brighter breathes

O'er the whole firmament the breadth of blue,

Because of that excessive purity

Of all those hanging snow-white palaces,

A gentle contrast, but with power divine."
}

(289.) The Stratus is that bed of vapor which is frequently seen in the valleys in a summer evening, permitting the trees and church spires to stand out in bold relief; or it is that horizontal bank of dark cloud seen to 
rest for a whole night along the horizon. It also forms the thin dry white fogs which come over the land from the sea with an east wind in spring and summer, wetting nothing that it touches. When this dry fog hangs over towns in winter, which it often does for days, it appears of a yellow hue, in consequence, probably, of a mixture with smoke. It constitutes the November fog in London. The stratus is frequently elevated by means of the vapor plane, and then it passes into the cumulus. On its appearing fiequently in the evening, and its usual disappearance during the day, it has been termed the "cloud of night." Having a livid gray color when the moon shines upon it, the stratus is probably the origin of those supposed spectral appearances seen at night by superstitious people in days of yore. The light or dry stratus is most prevalent in spring and summer, and the dense or wet kind in autumn and winter.

(290.) "Cirrus," remarks Mr. Mudie, " is the characteristic cloud of the upper sky; and no cloud of denser texture forms, or is capable of being sustained there. Cumulus is, in like manner, the characteristic cloud of the middle altitude; and although it is sometimes higher and sometimes lower, it never forms at what may be called the very top of the sky, or down at the surface of the ground. Stratus is the appropriate cloud of the lower sky, and it is never the first formed one at any considerable elevation; and, indeed, if it appears unconnected with the surface, it is not simple stratus, but a mixed cloud of some kind or other."*

(291.) The forms of the clouds which follow are of mixed character, the first of which that demands our attention is a compound of the cirrus and cumulus, or cirro-cumulus, as it is called. The cirrus, in losing the fibrous, assumes the more even-grained texture of the cumulus, which, when subdivided into small spherical fragments, constitute small cumuli of little density, and of white color, arranged in the form of a cirrus or in clusters. They are high in the air, and beautiful objects in the sky. In Germany this form of cloud is called "the little sheep;" which idea has been embodied by a rustic bard of England in these beautiful lines :

\footnotetext{
"Far yet above these wafted clouds are seen

(In a remoter sky, still more serene,)

Others, detached in ranges through the air.

Spotless as snow, and countless as they 're fair ;

Scattered immensely wide from east to west,

The beauteous 'semblance of a flock at rest." $\dagger$
}

Cirro-cumuli are most frequently to be seen in summer.

(292.) Another form of cloud, compounded of the cirrus and stratus, is called cirro-stratus. While cirri descend and assume the form of cirrocumuli, they may still farther descend and take the shape of cirro-stratus, whose fibres become dense and decidedly horizontal. Its characteristic form is shallowness, longitude, and density. It consists at times of dense longitudinal streaks, and the density is increased when a great breadth of cloud is viewed horizontally along its edge. At other times it is like shoals of small fish, when it is called a "herring sky ;" at others, mottled like a mackerel's back, when it is called the " mackerel-back sky." Sometimes it is like veins of wood, and at other times like the ripples af "sand left by a retiring tide on a sandy beach. The more mottled it is, the cirro-stratus is higher in the air, and the more dense and stratified, the nearer it is the earth. In the last position, it may be seen cutting off a mountain top, or stretching behind it, or cutting across the tops of large cumuli. Sometimes its striated lines, not very dense, run parallel over the zenith, whose opposite ends apparently converge at opposite points of the hori-

* Mudie's World. (321) ......12

$\dagger$ Bloomfield 
zon, and then they form that peculiar phenomenon named the "boat," or "Noah's ark." At times cirro-strati cut across the field of the setting sun, where they appear in well-defined dense striæ, whose upper or lower edges, in reference to their position with the sun, are burnished with the most brilliant hues of gold, crimson, or vermilion. Sometimes the cirrostratus extends across the heavens in a broad sheet, obscuring more or less the light of the sun or moon, for days together, and in this case a balo or corona is frequently seen to surround these orbs. In a more dense form, it assumes the shapes of some small long-bodied animals, and even like architectural ornaments; and in all its mutations it is more varied than any other form of cloud. The streaked cirro-strati are of frequent occurrence in winter and autumn, whereas the more delicate kinds are most seen in summer.

(293.) A third compound cloud is formed of the cumulus and stratus, called cumulo-stratus. This is always a dense cloud. It spreads out its base to the stratus form, and, in its upper part, frequently inosculates with cirri, cirro-cumuli, or cirro-strati. In this form it is to be seen in the plate of the three cows. With all or either of these it forms a large massive series of cumulative clouds which hang on the horizon, displaying great mountain shapes, raising their brilliantly illuminated silvery crests toward the sun, and presenting numerous dusky valleys between them. Or it appears in formidable white masses of variously defined shapes, towering upward from the horizon, ready to meet any other form of cloud, and to conjoin with them in making the dense dark-colored storm-cloud. In either case, nothing can exceed the picturesque grandeur of their towering, dazzling forms, or the sublimity of their masses when surcharged with lightnings, wind, and rain, and hastening with scowling front to meet the gentle breeze, and hurrying it along in its determined course, as if impatient of restraint, and all the while casting a portentous gloom over the earth, until bursting with terrific thunder, scorching with lightning some deroted object more prominent than the rest, deluges the plain with sweeping flonds, and devastates the fields in the course of its ungovernable fury. A tempest soon exhausts its force in the temperate regions; but in the tropics it rages at times for weeks, and then woe to the poor mariner who is overtaken by it at sea unprepared. Of the cumulo-stratus the variety called "Bishops' wigs," as represented near the horizon in the plate of the draught-mare, may be seen at all seasons along the horizon, but the other and more imposing form of mountain scenery is only to be seen in perfection in summer, when storms are rife. It also assumes the shapes of larger animals, and of the more gigantic forms of nature and art. Is the cumulo-stratus the sort of cloud described by Shakspeare as presenting these various forms?

\footnotetext{
"Sometime, we see a cloud that's dragonisb ;

A vapor, sometime, like a bear or lion,

A tower'd citadel, a pendant rock.

A forked mountain or blue promontory

With trees upon't, that nod unto the world,

And mock our eyes with air :

That, which is now a horse, even with a thought,

The rack dislimns, and makes it indistinct,

As water is in water."
}

(294.) The last compound form of cloud which I have to mention is the cirro-cumulo-stratus, called the nimbus or rain-cloud. A showery form of the cloud may be seen in the plate of the draught-horse. For my part I cannot see that the mere resolution of a cloud into rain is of sufficient im-

- Arthony and Cleopatra.

$(322)$ 
portance to constitute the form into a separate and distinct cloud; for rain is not so much a form as a condition of a cloud, in the final state in which it reaches the earth. Any of the three compound forms of clouds just described may form a rain-cloud, without the intervention of any other. Cirro-strati are often seen to drop down in rain, without giving any symptoms of forming the more dense structure of the nimbus; and even light showers fall without any visible appearance of a cloud at all. The nim. bus is most frequently seen in summer and autumn.

(295.) There is a kind of cloud, not unlike cumuli, called the scud, which is described usually by itself as broken nimbus. It is of dark or light color, according as the sun shines upon it, of varied form, floating or scudding before the wind, and generally in front of a sombre cumulo-stratus stretching as a background across that portion of the sky, often accompanied with a bright streak of sky along the horizon. The ominous scud is the usual harbinger of the rain-cloud, and is therefore commonly called " messengers," "carriers," or "water-wagons."

(296.) On looking at the sky, forms of clouds may be observed which cannot be referred to any of those, simple or compound, which have just been described. On analyzing them, however, it will be found that every cloud is referable to one or more of the forms described. This defectiveness proves two things in regard to clouds. 1. That clouds, always presenting forms which are recognizable, must be the result of fixed laws.2. That the sagacity of man has been able to classify those forms of clouds in a simple manner. Without such a key to their forms, clouds doubtless appear, to common observers, masses of inexplicable confusion. Clouds thus being only effects, the causes of their formation and mutations must be looked for in the atmosphere itself; accordingly, it has been found that, when certain kinds appear, certain changes are taking place in the state of the atmosphere; and beyond this it is not necessary for a common observer to know the origin of clouds. It is sufficient for him to be aware of what the approaching change of the atmosphere will be, as indicated by the particular kind of cloud or clouds which he observes; and in this way clouds become guides for knowing the weather. In endeavoring thus to become a judge of the weather, you must become an attentive observer of the clouds. To become so with success in a reasonable time, you must first make yourself well acquainted with the three simple forms, which, although not singly visible at all times, may be recognized in some part of those compound clouds which exhibit themselves almost every day.

(297.) That clouds float at different altitudes, and are more or less dense, not merely on account of the quantity of vapor which they contain, but partly on account of their distance from vision, may be proved in various ways. 1. On ascending the sides of mountains, travelers frequently pass zones of clouds. Mountains thus form a sort of scale by which to estimate the altitude of clouds. Mr. Crossthwaite made these observations of the altitude and number of clouds in the course of five years :

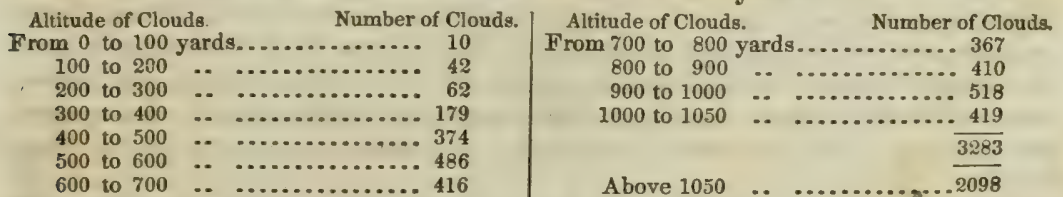

Hence the number of clouds above 1050 yards were, to the number below, as $2098: 3283$, or $10: 16$ nearly. The nomenclature of Howard not having been known at the time, the forms of the various clouds met with at the different altitudes could not be designated. 2. Another proof of a dif(323) 
ference of altitudes in clouds consists in different clouds being seen tc move in different directions at the same time. One set may be seen moving in one direction near the earth, while another may be seen through their openings unmoved. Clouds may be seen moving in different directions, at apparently great hights in the air, while those near the ground may be quite still. Or the whole clouds seen may be moving in the same direction with different velocities. It is natural to suppose that the lighter clouds-those containing vapor in the most elastic state-should occupy a higher position in the air than the less elastic. On this account, it is only fleecy clouds that are seen over the tops of the highest Andes. Clouds, in heavy weather, are seldom above $\frac{1}{2}$ mile high, but in clear weather from 2 to 5 miles, and cirri from 5 to 7 miles.

(298.) Clouds are often of enormous size, 10 miles each way and 2 miles thick, containing 200 cubic miles of vapor; but sometimes are even ten times that size. The size of small clouds may be easily estimated by observing their shadows on the ground in clear breezy weather in summer. These are usually cumuli scudding before a westerly wind. The shadows of larger clouds may be seen resting on the sides of mountain ranges, or spread out on the ocean.

(299.) You must become acquainted with the agency of Electricity before you can understand the variations of the weather. The subject of atmospherical electricity excited great attention in the middle of the last century by the experiments and discoveries of Franklin. He proved that the electric fluid, ${ }^{*}$ drawn from the atmosphere, exhibits the same properties as that obtained from the electrical machine, and thus established their identity. Since that period, little notice has been taken of its powerful agency in connection with meteorology; but brilliant are the discoveries which have since been made in regard to its powers in the laboratories of Davy, Faraday, and others. They have clearly identified electricity with magnetism and galvanism, and, in establishing this identity, they have extended to an extraordinary degree the field of observation for the meteorologist, though the discovery has rendered meteorology much more difficult to be acquired with exactness. But the science should, on that account, be prosecuted with the greater energy and perseverance.

(300.) It must be obvious to the most indifferent observer of atmospherical phenomena, that the electric agency is exceedingly active in the atmosphere, how inert soever may be its state in other parts of the earth. Existing there in the freest state, it exhibits its power in the most sensible manner; and its freedom and frequency suggest the interesting inquiry whence is derived the supply of the vast amount of electricity which seems to exist in the atmosphere?

(301.) Of all investigators of this interesting but difficult inquiry, $M$. Pouillet has directed his attention to it with the greatest success. He has shown that there are two sources fiom which this abundant supply is obtained. The first of these is regetation. He has proved, by direct experiment, that the combination of oxygen with the materials of living plants is a constant source of electricity; and the amount thus disengaged may be learned from the fact that a surface of 100 square metres (or rather more than 100 square yards), in full vegetation, disengages, in the course of one day, as much vitrous electricity as would charge a powerful battery.

(302.) That some iciea may be formed of the sort of action which takes

* "Electricity. though frequentiy called a fluid, has but little claim to that designation; in using it, therefore, let it be always understood in a conventional sense, not as expressing any theoretical view of the physical state of electric matter."

Dr. Golding Bird. (324) 
place between the oxygen of the air and the materials of living plants, it is necessary to attend, in the first place, to the change produced on the air by the respiration of plants. Many conflicting opinions still prevail on this subject; but "there is no doubt, however, from the experiments of various philosophers," as Mr. Hugo Reid observes, "that at times the leaves of plants produce the same effect on the atmosphere as the lungs of animals, namely, cause an increase in the quantity of carbonic acid, by giving out carbon in union with the oxygen of the air, which is thus converted into this gas; and it has been also established that at certain times the leaves of plants produce very opposite effects, namely, that they decompose the carbonic acid of the air, retain the carbon and give out the oxygen, thus adding to the quantity of the oxygen in the air. It has not yet been precisely ascertained which of these goes on to the greater extent; but the general opinion at present is, that the gross result o the action of plants on the atmosphere is the depriving of it of carbonic acid, retaining the carbon and giving out the oxygen, thus increasing the quantity of free oxygen in the air." "*

(303.) It being thus admitted that both carbonic gas and oxygen are exhaled by plants during certain times of the day, it is important to ascertain, in the next place, whether electricity of the one kind or the other accompanies the disengagement of either gas. Toward this inquiry $\mathbf{M}$. Pouillet instituted experiments with the gold-leaf electroscope, while the seeds of various plants were germinating in the soil, and he found it sensibly affected by the negative state of the ground. This result might have been anticipated during the evolution of carbonic gas, for it is known by experiment that carbonic gas, obtained from the combustion of charcoal, is, in its nascent state, electrified positively, and, of course, when carbonic gas is evolved from the plant, the ground should be in a state of negative electricity. M. Pouillet presumed, therefore, that when plants evolve oxygen, the ground should be in a positive state of electricity. He was thus led to the important conclusion, that vegetation is an abundant source of electricity. $\dagger$

(304.) The second source of electricity is evaporation. The fact of a chemical change in water by heat inducing the disengagement of electricity, may be proved by simple experiment. It is well known that mechanical action will produce electricity sensibly from almost any substance. If any one of the most extensive series of resinous and siliceous substances, and of dry vegetable, animal and mineral produce, is rubbed, electricity will be excited, and the extent of excitation will be shown by the effect on the gold-leaf electroscope. Chemical action, in like manner, produces similar effects. If sulphur is fused and poured into a conical wine-glass, it will become electrical on cooling, and affect the electroscope in a man ner similar to the other bodies mechanically excited. Chocolate on congealing after cooling, glacial phosphoric acid on congealing, and calomel when it fixes by sublimation to the upper part of a glass vessel, all give out electricity; so, in like manner, the condensation as well as the evaporation of water, though opposite processes, gives out electricity. Some writers attribute these electrical effects to what they term a change of form or state; but it is obvious that they may, with propriety, be included under chemical action. This view is supported by the fact of the presence of oxygen being necessary to the development of electricity. De la Rive, in bringing zinc and copper in contact through moisture, found that the zinc became oxidized, and electricity was evolved. 'When he pre-

- Reid's Chemistry of Nature. $(325 ;$

† Leithead on Electricity. 
vented the oxidation, by operating in an atmosphere of nitrogen, no electric excitement followed. When, again, he increased the chemical action by exposing zinc to acid, or by substituting a more oxidable metal, such as potassium, the electric effects were greatly increased. In fact, electrical excitation and chemical action were observed to be strictly proportional to each other. And this result is quite consistent with, and is corroborated by, the necessary agency of oxygen in evolving electricity from vegetation." But more than all this, "electricity," as Dr. G. Bird intimates, " is not only evolved during chemical decomposition, but during chemical combination; a fact first anmounced by Becquerel. The truth of this statement has been, by many, either altogether denied or limited to the case of the combination of nitric acid with alkalies. But after repeating the experiments of Becquerel, as well as those of Pfaff, Mohr, Dalk, and Jacobi, I am convinced that an electric current, certainly of low tension, is really evolved during the combination of sulphuric, hydrochloric, nitric, phosphoric, and acetic acids, with the fixed alkalies, and even with ammonia." $\dagger$

(305.) As evaporation is a process continually going on from the surface of the ocean, land, lakes, and rivers, at all degrees of temperature, the result of its action must be very extensive. But how the disengagement of electricity is produced, either by the action of oxygen on the structure of living plants, or by the action of heat on water, is unknown, and will perhaps ever remain a secret of Nature. It is easy, however, to conceive how the electricity produced by these and other sources must vary in different clinates, seasons and localities, and at different hights in the atmosphere.f

(306.) It thus appears that the sources of electricity are found to be evolved in every possible form of action. It is excited by almost every substance in nature, by friction, which is a mechanical action; it is as readily evolved by chemical action, as you have just learned; as also in the cases of condensation and evaporation of liquids; and it has also been proved to be excited by vital action, as in the case of vegetation; and as the action of oxygen is the same in the animal as in the vegetable function, it is as likely that the respiration of animals produces electricity as that of vegetables. When the sources of this mysterious and subtle agent are thus so numerous and extensive, you need not only not be surprised at its extensive diffusion, but the universality of its presence indicates that its assistance is necessary to the promoting of every operation of Nature. Its identity in all cases is also proved by the fact, that though the means employed for its excitation are various, its mode of action is always the same. In every case of excitation, one body robs the other of a portion of its electricity, the former being plus or positive, the other minus or negative in its natural quantity. "The two species, or negative and positive electricity," says Dr. Bird, "exist in nature combined, forming a neutral combination (in an analogous manner to the two magnetic fluids) incapable of exerting any obvious physical actions on ponderable matter: by the process of friction, or other mechanical or chemical means, we decompose this neutral combination, the negative and positive elements separate, one adbering to the surface of the excited substance, the other to the rubber; hence in no case of electrical excitation can we obtain one kind of electricity withont the other being simultaneously dereloped. We do not observe any fiee electricity on the surface of metallic bodies submitted to friction, in consequence of their so readily conducting electricity that the

* I.eithead on Electricity.

† Bird' Elemente of Natural Philosophy.

\$ Forbeg's Report on Meteorology, vol. i. (326) 
union of the negative and positive fluids takes place as rapidly as they are separated by the friction employed."*

(307.) The natural state of every body in regard to its electricity is thus in a state of quiescence or equilibrium, but this equilibrium is very easily disturbed, and then a series of actions supervene, which illustrate the peculiar agency of electricity, and continue until the equilibrium is again restored.

(308.) The force of the electrical agency seems to be somewhat in the proportion to the energy with which it is roused into action. Dr. Faraday states, that one grain of water "will require an electric current to be continued for $3 \frac{3}{4}$ minutes of time to effect its decomposition; which current must be strong enough to retain a platina wire $\frac{1}{10}$ of an inch in thickness red-hot in the air during the whole time." "It will not be too much to say, that this necessary quantity of electricity is equal to a very powerful flash of lightning." $\dagger$ When it is considered that, during the fermentation and putrefaction of bodies on the surface of the earth, water is decomposed, and that to effect its decomposition such an amount of electric action as is here related is required to be excited, we can have no difficulty in imagining the great amount of electricity which must be derived from the various sources enumerated being constantly in operation.

(309.) In mentioning the subject of electricity, I will take the opportunity of expressing my opinion that the electrometer is a meteorological instrument of much greater utility to you than some of the instruments I have described; because it indicates, with a great degree of delicacy, the existence of free electricity in the air ; and as electricity cannot exist in that state without producing some sort of action, it is satisfactory to have notice of its freedom, that its effects, if possible, may be anticipated. The best sort of electrometer is the "condensing electroscope:" it consists of a hollow glass sphere on a stand, inclosing through its top a glass tube, to the top of which is affixed a flat brass cap, and from the bottom of which are suspended two slips of gold-leaf. At the edge of the flat brass cap is screwed a circular brass plate, and another circular brass plate, so as to be parallel to the first, is inserted in a support fixed in a piece of wood moving in a groove of the stand which contains the whole apparatus. This is a very delicate instrument, and, to keep it in order, should be kept free of moisture and dust.

(310.) In regard to the usual state of the electricity in the atmosphere, it is generally believed that it is positive, and that it increases in quantity as we ascend. In Europe the observations of M. Schübler of Stuttgardt, intimate that the electricity of the precipitating fluids from the atmosphere is more frequently negative than positive, in the proportion of $155: 100$; but that the mean intensity of the positive electricity is greater than that of the negative in the ratio of $69: 43$; and that different layers or strata of the atmosphere, placed only at small distances from each other, are fiequently found to be in different electric states.f It appears, also, from recent observations of M. Schübler, that the electricity of the air, in calm and serene weather, is constantly positive, but subject to two daily fluctuations. It is at its minimum at a little before sunrise; after which it gradually accumulates, till it reaches its first maximum a few hours afterward -at 8 A. M. in May; and then diminishes until it has descended to its second minimum. The second maximum occurs in the evening about $t$ wo hours after sunset ; and then diminishes, at first rapidly, and next in slower brogression during the whole of the night, to present again on the follow-

* Bird's Elements of Natural Philosophy.

† Forbes's Report on Meteorology, vol. i.

† Faraday's New Researches, 8vo edition. (327) 
ing day the same oscillations. It is probable that the exact time of its increase and decrease is influenced by the seasons. The intensity increases from July to January, and then decreases; it is also much more intense in the winter, though longer in summer, and appears to increase as the cold increases." These fluctuations may be observed throughout the year more easily in fine than in cloudy weather. "Among the causes modifying the electric state of the atmosphere," observes Dr. Bird, " must be ranked its hygrometric state, as well as probably the nature of the effluvia which may become volatilized in any given locality. Thus, Saussure has observed that its intensity is much more considerable in elevated and isolated places than in narrow and confined situations; it is nearly absent in houses, : : ?der lofty trees, in narrow courts and alleys, and in inclosed places. In some places the most intensely electric state of the atmosphere appears to be that in which large clouds or dense fogs are suspended in the air at short distances above the surface of the earth; these appear to act as conductors of the electricity from the upper regions. Cavallo ascertained, from a set of experiments performed at Islington in 1776 , that the air always contains free positive electricity, except when influenced by heavy clouds near the zenith. This electricity he found to be strongest in fogs and during frosty weather, but weakest in hot weather, and just previous to a shower of rain; and to increase in proportion as the instrument used is raised to a greater elevation. This, indeed, necessarily happens," continues Dr. Bird, "for as the earth's surface is, cœteris paribus, always negatively electrified, a continual but gradual combination of its electricity with that of the air is constantly taking place at its surface, so that no free positive electricity can be detected within 4 feet of the surface of the earth." $\dagger$

(311.) A comparative view of the fluctuations of the barometer and electrometer may tend to show that in their mode of action all the physical agencies may be governed by the same law. The mean results of manv observations by various philosophers are as follows:

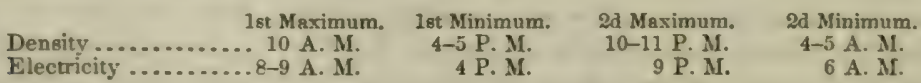

(312.) These are all the general remarks which are called for at present on the subject of atmospherical electricity. As electrical phenomena exhihit themselves most actively in summer, observations on particular ones will then be more in season than in winter; and the only electrical excitation that is generally witnessed in winter is the aurora borcalis or northern lights, or " merry dancers," as they are vulgarly called. It mostly occurs in the northern extremity of the northern hemisphere of the globe, where it gives almost constant light during the absence of the sun. So intense is this radiance, that a book may be read by it, and it thus confers a great blessing on the inhabitants of the Arctic Regions, at a time when they are benighted. The aurora borealis seems to consist of two varieties; one a luminous, quiet light in the northern horizon, gleaming most frequently behind a dense stratum of cloud; and the other of vivid coruscations of almost white light, of a sufficient transparency to allow the transmission of the light of the fixed stars. They are sometimes colored yellow, green, red, and of a dusky hue. The coruscations are generally short, and confined to the proximity of the northern horizon; but occasionally they reach the zenith, and even extend to the opposite horizon; their direction being from N. W. to S. E. It seems now undeniable, that the aurora borealis 
frequently exercises a most marked action on the magnetic needle; thus affording another proof of the identity of the magnetic and electric agencies.

(313.) It is not yet a settled point among philosophers, whether the aurora borealis occurs at the highest part of the atmosphere, or near the earth. $\mathrm{Mr}$. Cavendish considered it probable, that it usually occurs at an elevation of 71 miles above the earth's surface, at which elevation the air must be but $\frac{1}{148567}$ time the density of that at the surface of the earth, a degree of rarefaction far above that afforded by our best constructed air-pumps. Dr. Dalton conceives, from trigonometrical measurements made by him of auroral arches, that their hight is $\mathbf{1 0 0}$ miles above the earth's surface. His most satisfactory measurement was made from that of the 29th March, 1826. As the peculiar appearance of aurora and its coruscations precisely resemble the phenomena which we are enabled to produce artificially by discharges of electricity between two bodies in a receiver through a medium of highly rarefied air, the opinion of Lieut. Morrison, R. N. of Cheltenham, a profound astronomer and meteorologist, is deserving of attention, as regards the position of the aurora at the time of its formation. He states that long, light clouds ranging themselves in the meridian line in the day, at night take a fleecy, aurora-like character. "I believe," he says, " that these clouds are formed by the discharges and currents of electricity, which, when they are more decided, produce aurora." Mr. Leithead conjectures that the aurora becomes "visible to the inhabitants of the earth upon their entering our atmosphere." If these conjectures are at all cor . rect, the aurora cannot be seen beyond our atmosphere, and therefore cannot exhibit itself at the hight of 100 miles, as supposed by Dr. Dalton, since the hight of the atmosphere is only acknowledged to be from 40 to 50 miles. This view of the hight of the aurora somewhat corroborates that held by Rev. Dr. Farqharson, Alford, Aberdeenshire, and which has been strongly supported by Professor Jameson. $\dagger$

(314.) There are other atmospherical phenomena, whose various aspects indicate changes of the weather, and which, although of rarer occurrence than the clouds or electricity, are yet deserving of attention when they appear. These are, Halos around the disks of the sun and moon; Coronæ or broughs, covering their faces; Parhelia, or mock suns; Falling Stars; Fire-balls; and the Rainbow. Of these, the halo and corona only appear in winter; the others will be noticed in the course of the respective seasons in which they appear.

(315.) A halo is an extensive luminous ring, including a circular area, in the center of which the sun or moon appears. It is formed by the intervention of a cloud between the spectator and the sun or moon. This cloud is generally the denser kind of cirro-stratus, the refraction and reflection of the rays of the sun or moon at definite angles through and upon which, is the cause of the luminous phenomenon. The breadth of the ring of a halo is caused by a number of rays being refracted at somewhat different angles, otherwise the breadth of the ring would equal only the breadth of one ray. Mr. Forster has demonstrated mathematically the angle of refraction, which is equal to the angle subtended by the semidiameter of the halo.f Halos may be double and triple; and there is one, which Mr. Forster denominates a discoid, halo, which constitutes the boundary of a large corona, and is generally of less diameter than usual, and often colored with the tints of the rainbow. "A beautiful one appeared at Clapton on the 22d December, 1809, about midnight, during the passage of a

\footnotetext{
* Leithead on Electricity.

† Encyclopædia Britannica, 7th edition, art. Aurora Borealis.

‡ Forster's Researches into Atmospherical Phenomena.
} (329) 
cirro-stratus cloud before the moon."* Halos are usually pretty correct circles, though they have been observed of a somewhat oral shape; and they are generally also colorless, though they sometimes display faint colors of the rainbow. They are most frequently seen around the moon, and acquire the appellation of lunar or solar halos, as they happen to accompany the particular luminary.

(316.) The corona or brough occurs when the sun or moon is seen through a thin cirro-stratus cloud, the portion of the cloud more immediately around the sun or moon appearing much lighter than the rest. Coronæe are double, triple, and even quadruple, according to the state of the intervening vapors. They are caused by a similar refractive power in vapor as the halo; and are generally faintly colored at their edges. Their diameter seldom exceeds $10^{\circ}$. A halo frequently encircles the moon, when a small corona is more immediately around it.

(317.) Hitherto I have said nothing of rain, snow, wind, or hail-phenomena which materially affect the operations of the farmer. Strictly speaking, they are not the cause, but only the effects, of other phenomena; aud on that account, I have purposely refrained alluding to them, until you should have become somewhat acquainted with the nature of the agencies which produce them. Having heard of these, I shall now proceed to examine particularly the familiar phenomena of rain, snow and wind. Rain and wind being common to all the seasons, it will be necessary to enter at once into a general explanation of both. Snow is peculiar to winter, and will not again require to be alluded to. And hail will form a topic of remark in summer.

(318.) You must be so well acquainted with the phenomenon of rain, that no specific definition of it is here required to be given. It should, however, be horne in mind, that the phenomenon has various aspects, and the variety indicates the peculiar state of the atmosphere at the time of its occurrence. Rain falls at times in large drops, at others in small, and sometimes in a thick or thin drizzle; but in all these states, it consists of the descent of water in drops from the atmosphere to the earth. In reflecting on this phenomenon, how is it, (you may ask yourselves) that the air can possibly support drops of water, however minute? The air cannot support so dense a substance as water; and it is its inability to do so, that causes the water to fall to the ground. The air, however, can support vapor, the aggregation of the particles of which constitutes rain or water. Vapor is formed by the force of the heat of the sun's rays upon the surface of land, sea, lakes and rivers; and from its easy ascent into the atmosphere, it is clear that water is rendered lighter than air by heat, and, of course, vastly lighter than itself. The weight of one cubic inch of distilled water (with the barometer at 30 inches, and the thermometer at $62^{\circ} \mathrm{Fahrenheit)}$ is 252.458 grains ; that of 1 cubic inch of air is 0.3049 of a grain ; of course, vapor must be lighter than this last figure. Heat has effected this lightness by rendering vapor highly elastic; and it is not improbable that it is electricity which maintains the elasticity, after the vapor has been carried away beyond the influence of its generating heat, and there keeps it in mixture with the air. The whole subject of evaporation is instructive, and will receive our attention in summer, when it presents itself in the most active condition to our view, and is intimately connected with the phenomenon of dew.

(319.) The quantity of vapor in the atmosphere is variable. This Table shows the weight in grains of a cubic foot of vapor, at different temperatures, from $0^{\circ}$ to $95^{\circ}$ Fahrenheit :

- Former' Researches into Atmospherical Phenomena. (330) 


\begin{tabular}{|c|c|c|c|c|c|c|c|}
\hline $\begin{array}{c}\text { Tempera- } \\
\text { ture. }\end{array}$ & $\begin{array}{c}\text { Weight in } \\
\text { grains. }\end{array}$ & $\begin{array}{c}\text { Tempera- } \\
\text { ture. }\end{array}$ & $\begin{array}{c}\text { Weight in } \\
\text { grains. }\end{array}$ & $\begin{array}{c}\text { Tempera- } \\
\text { ture. }\end{array}$ & $\begin{array}{l}\text { Weight in } \\
\text { grains. }\end{array}$ & $\begin{array}{c}\text { Tempera- } \\
\text { ture. }\end{array}$ & $\begin{array}{l}\text { Weight in } \\
\text { grains. }\end{array}$ \\
\hline 0 & 0.8 .56 & 24 & $1 \cdot 961$ & 48 & $4 \cdot 279$ & 72 & $8-924$ \\
\hline 1 & 0.892 & 22 & $2 \cdot 028$ & 49 & $4 \cdot 407$ & 73 & $9-199$ \\
\hline 2 & 0.928 & 26 & $2 \cdot 096$ & 50 & $4 \cdot 535$ & 74 & $9-484$ \\
\hline 3 & $0-963$ & 27 & $2 \cdot 163$ & 51 & $4-684$ & 75. & $9-780$ \\
\hline 4 & $0-999$ & 28 & $2 \cdot 229$ & 52 & $4-832$ & 76 & $10 \cdot 107$ \\
\hline 5 & $1-034$ & 29 & $2 \cdot 295$ & 53 & $5 \cdot 003$ & 77 & $10 \cdot 387$ \\
\hline 6 & $1 \cdot 069$ & 30 & $2 \cdot 361$ & 54 & $5 \cdot 173$ & 78 & $10 \cdot 699$ \\
\hline 7 & $1 \cdot 104$ & 31 & $2 \cdot 451$ & 55 & $5 \cdot 342$ & 79 & $11 \cdot 016$ \\
\hline 8 & $1 \cdot 139$ & 32 & $2 \cdot 539$ & 56 & $5 \cdot 511$ & 80 & $11 \cdot 333$ \\
\hline 9 & $1 \cdot 173$ & 33 & $2 \cdot 630$ & 57 & $5 \cdot 679$ & 81 & $11 \cdot 665$ \\
\hline 10 & $1 \cdot 208$ & 34 & $2 \cdot 717$ & 58 & $5 \cdot 868$ & 82 & $12 \cdot 005$ \\
\hline 11 & $1 \cdot 254$ & 35 & $2 \cdot 805$ & 59 & $6 \cdot 046$ & 83 & $12 \cdot 354$ \\
\hline 12 & $1 \cdot 308$ & 36 & $2 \cdot 892$ & 60 & $6-222$ & 84 & $12 \cdot 713$ \\
\hline 13 & $1-359$ & 37 & $2 \cdot 979$ & 61 & $6-399$ & 85 & $13 \cdot 081$ \\
\hline 14 & $1 \cdot 405$ & 38 & $3 \cdot 066$ & 62 & $6 \cdot 575$ & 86 & $13 \cdot 458$ \\
\hline 15 & $1 \cdot 451$ & 39 & $3 \cdot 153$ & 63 & $6 \cdot 794$ & 87 & $13 \cdot 877$ \\
\hline 16 & $1 \cdot 497$ & 40 & $3-239$ & 64 & $7 \cdot 013$ & 88 & $14 \cdot 230$ \\
\hline 17 & $1 \cdot 54 I$ & 41 & $3-371$ & 65 & $7 \cdot 230$ & 89 & $14 \cdot 613$ \\
\hline 18 & $1 \cdot 586$ & 42 & $3 \cdot 502$ & 66 & $7 \cdot 447$ & 90 & $15 \cdot 005$ \\
\hline 19 & $1 \cdot 631$ & 43 & $3 \cdot 633$ & 67 & $7-662$ & 91 & $15 \cdot 432$ \\
\hline 20 & $1 \cdot 688$ & 44 & $3 \cdot 763$ & 68 & $7 \cdot 899$ & 92 & $15-786$ \\
\hline 21 & $1 \cdot 757$ & 45 & $3 \cdot 893$ & 69 & $8 \cdot 135$ & 93 & $16 \cdot 186$ \\
\hline 22 & $1 \cdot 825$ & 46 & 4-022 & 70 & $8-392$ & 94 & $16 \cdot 593$ \\
\hline 23 & $1-893$ & 47 & $4-151$ & 71 & $8 \cdot 658$ & 95 & $17 \cdot 009$ \\
\hline
\end{tabular}

Dr. Dalton found that the force of vapor in the torrid zone varies from 0.6 of an inch to 1 inch of mercury. In Britain it seldom amounts to 0.5 of an inch, but is sometimes as great as 0.5 of an inch, in summer; whereas, in winter, it is often as low as $0 \cdot 1$ of an inch of mercury. These facts would enable us to ascertain the absolute quantity of vapor contained in the atmosphere at any given time, provided we were certain that the density and elasticity of vapors follow precisely the same law as that of gases, as is extremely probable to be the case. If so, the vapor will vary from $\frac{1}{60}$ to $\frac{1}{100}$ part of the atmosphere. Dalton supposes that the medium quantity of vapor in the atmosphere may amount to $\frac{1}{70}$ of its bulk.**

(320.) The theory propounded by Dr. Hutton, that rain occurs from the mingling together of great beds of air of unequal temperatures differently stored with moisture, is that which was adopted by Dalton, Leslie, and others, and is the current one, having betr illustrated and strengthened by the clearer views of the nature of deposition which we now possess.

(321.) On the connection of rain with the fall of the barometer, Mr. Meikle has shown that the change of pressure may be a cause as well as an effect; for the expansion of air accompanying diminished pressure, being productive of cold, diminishes the elasticity of the existing vapor, and causes a deposition. $\dagger$

(322.) M. Arago has traced the progress of decrease in the annual amount of the fall of rain from the equator to the poles; and these are the results obtained by various observers at the respective places:

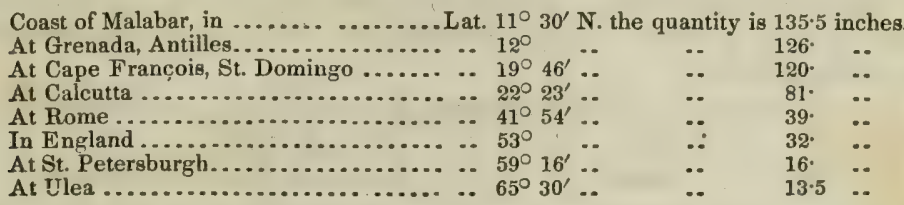

On the other hand, the number of rainy days increases from the equator to the poles, according to the observations of M. Cotte. Thus : 


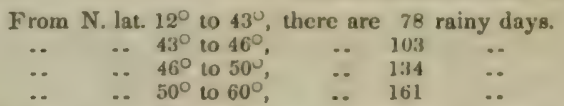

(323.) There is a great variation in the quantity of rain that falls in the same latitude on the different sides of the same continent, and particularly of the same island. 'Thus, to confine the instances to our own island, the mean fall of rain at Edinburgh, on the east coast, is 26 inches; and at Glasgow, on the west coast, in nearly the same latitude, the amount is $\mathbf{4 0}$ inches. At North Shields, on the east coast, the amount is 25 inches; while at Coniston in Lancashire, in nearly the same latitude on the west coast, it is as great as 85 inches.*

(324.) A remarkable variation takes place in the fall of rain at different Tights; the quantity of rain that falls on high ground exceeding that at the level of the sea. This fact may be easily explained by the influence of a hilly country retaining clouds and vapor. At Lancaster, on the coast, the quantity that falls is 39 inches; and at Easthwaite, among the mountains in the same county, the amount is 86 inches. By a comparison of the registers at Geneva and the convent of the Great St. Bernard, it appears that at the former place, by a mean of 32 years, the annual fall of of rain is 30.70 inches; while at the latter, by a mean of 12 years, it is 60.05 inches. Dr. Dalton clearly points out the influence of hot currents of air ascending along the surface of the ground into the colder strata which rest upon a mountainous country. The consequence is, that although neither the hot nor the cold air was accompanied with more moisture than could separately be maintained in an elastic state, yet when the mixture takes place, the arithmetical mean of the quantities of vapor cannot be supported in an elastic state at an arithmetical mean of the temperatures; since the weights of vapor which can exist in a given space increase nearly in a geometrical ratio, while the temperatures follow an

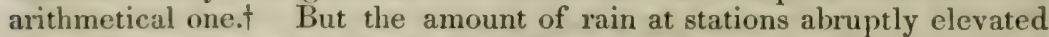
above the surface of the earth, diminishes as we ascend. For example, at Kinfauns Castle, the seat of Lord Gray, on the Tay, in Perthshire, by a mean of 5 years, 22.66 inches of rain fell; while on a hill in the immediate neighborhood, 600 feet higher, no less than 41.49 inches were collected, by a mean of the same period. This is an instance of a high elevation rising pretty rapidly above the castle, but in a natural manner ; and it is adduced as a contrast with an artificial elevation of a rain-gauge at the observatory at Paris, when the rain that fell on the town, at a vertical hight of 28 metres (rather more than as many yards), was 50.47 inches, white, according to the observation of M. Arago, it was 56.37 inches in the court below. $f$

(325.) The variation in the amount of rain in the scasons follows, in a great measure, the same law as that propounded by Dalton in reference to the lights of mountains. The greatest quantity of rain falls in autumn, and the least in winter. Thus, according to M. Flaugergues, taking the mean amount as 1 -

\begin{tabular}{|c|c|c|c|c|c|}
\hline In spring, & .." & 0.2217 & .. & -- & March, April and May. \\
\hline In summer, & -. & 0.2001 & $\cdots$ & .. & June, July and August. \\
\hline In autumu, & $\cdots$ & 0.3845 & $\cdots$ & -. & September, October and November. \\
\hline
\end{tabular}

It may be useful to give the proportional results of each month. Again, taking the mean amount of the year as 1 , the proportional result for

\footnotetext{
* Table of the quantity of Rain that falls in different parts of Great Britain. By Mr. Joseph Atkin.
} con, Harraby, near Carlisie.

† Manchester Memoiru, New Series vol. v. † Forbes's Report on Meteorology, vol. 1 (332) 


\begin{tabular}{|c|c|}
\hline is & \\
\hline .0 .0541 & August. \\
\hline March.... & September. \\
\hline. $.0 \cdot 0802$ & October.... \\
\hline. $.0 \cdot 0847$ & November................. \\
\hline June........................0.0765 & December ................. \\
\hline
\end{tabular}

As M. Flaugergues observes, the maximum belongs to October and the minimum to February, and May comes nearest to the mean of 40 years.* Taking these proportional results by the months which constitute the seasons of the agricultural year as I have arranged them, the mean of the seasons will be respectively thus :

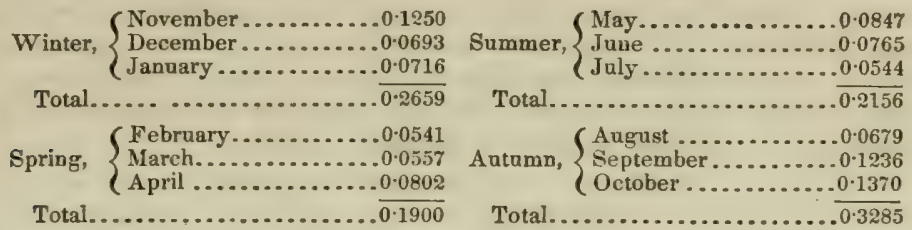

This method of division still gives the maximum of rain to autumn, though it transfers the minimum from the winter to the spring; which, as I think, approaches nearer to the truth in reference to Scotland than the conclusions of M. Flaugergues, which specially apply to France.

(326.) The last table but one gives the proportional amount of rain that fell, in a mean of 40 years, in each month. It may be useful to know the mean number of rainy days in each of the months. They are these :

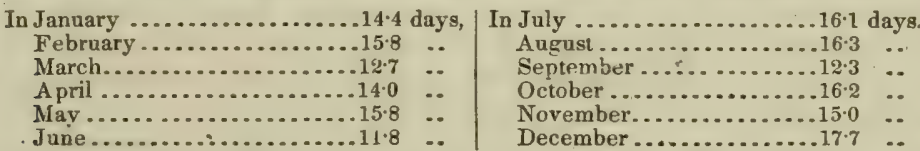

These tables show that though the number of rainy days is nearly equal in the vernal and autumnal equinoxes, the quantity of rain that falls in the autumn is nearly double of that in spring. If this last table is arranged according to the months of the agricultural seasons, the number of rainy days in each season will stand thus :

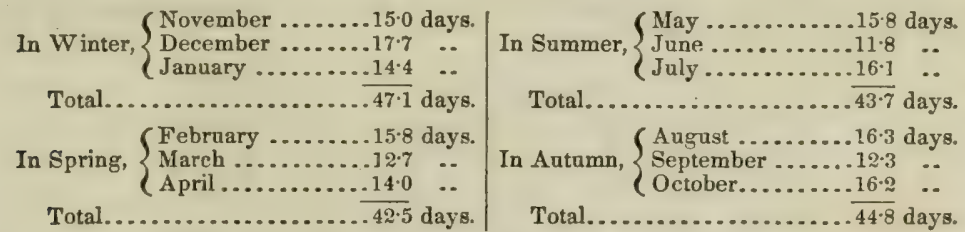

In all 178.1 days of rain. This arrangement shows that the greaiest number of rainy days is in the agricultural winter, and the least number in the spring, which seems to agree with experience.

(327.) Mr. Howard remarks, that, on an average of years, it rains every other day; and, by a mean of 40 years at Viviers, M. Flaugergues found 98 days of rain throughout the year.t

(328.) With regard to the question, Whether more rain falls in the night than in the day? Mr. Howard's statement bears, that of 21.94 inches-a mean of 31 lunar months-rain fell in the day to the amount of 8.67 inches, and in the night to 13.27 inches. Dr. Dalton also says, that more rain falls when the sun is under the horizon than when it is above it.f

\footnotetext{
* Encyclopædia Metropolitana, art. Meteorology.

Inid.

$\ddagger$ Ibid. (333)
} 
(329.) It has not been ascertained whether, on the whole amount over the globe, rain is increasing or diminishing in quantity. As M. Arago justly observes, it is very difficult to know how many years of observations are necessary to get a mean value of the fall of rain, the amount being extremely variable. There are, no doubt, several causes which may tend to change the amount of rain in any particular spot, without forming part of any general law, such as the destruction or forming of forests, the inclosure and drainage of land, and the increase of habitations. M. Arago has shown that the fall of rain at Paris has not sensibly altered for 130 years, and that although an increase was supposed to have been proved at Milan, by observations for 54 years, yet the extremes of the annual results between 1791 and 1817 were 24.7 and 58.9 inches. The observations of M. Flaugergues, at Viviers, establish an increase there in 40 years. The number of rainy days throughout the year is 98 , but dividing the 40 years into decades, the number sensibly increases. Thus-

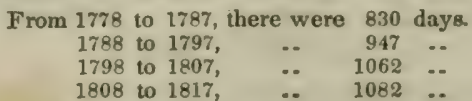

But this result must arise from local circumstances, as at Marseilles there has been a striking decrease in 50 years.

(330.) Notwithstanding the enormous annual fall of rain at the equator, particular instances of a great depth of rain in a short time have occasionally occurred in Europe, which probably have seldom been equaled in any other part of the globe. At Geneva, on the 25th October, 1822, there fell 30 inches of rain in one day. At Joyeuse, according to M. Arago, on the 9th October, 1827, there fell 31 inches of rain in 22 hours." With regard to remarkable variations in the quantity of rain in different places, among the Andes it is said to rain perpetually; whereas in Peru, as Ulloa affirms, it never rains, but that for a part of the year the atmosphere is obscured by thick fogs called garuas. In Egypt it hardly ever rains at all, and in some parts of Arabia it seldom rains more than two or three times in as many years, but the dews are heavy, and refresh the soil, and supply with moisture the few plants which grow in those sunny regions.

(331.) According to a statement of observations by $\mathbf{M r}$. Howard, there appears a relation to exist betwixt the winds and the annual amount of rain. This is his statement:

\begin{tabular}{|c|c|c|c|c|c|c|}
\hline \multirow{2}{*}{ YeAR. } & \multicolumn{4}{|c|}{ WIND. } & \multirow{2}{*}{$\begin{array}{l}\text { Calm } \\
\text { daye. }\end{array}$} & \multirow{2}{*}{$\begin{array}{l}\text { Annual } \\
\text { rain in } \\
\text { inches. }\end{array}$} \\
\hline & N. E. & E. S. & SW & W. N. & & \\
\hline 1807 & 61 & 34 & 113 & 114 & 43 & $20-14$ \\
\hline 1808 & 82 & 38 & 108 & 103 & 35 & $23-24$ \\
\hline 1809 & 68 & 50 & 123 & 91 & 33 & $25 \cdot 28$ \\
\hline 1810 & 81 & 72 & 78 & 83 & 41 & $28 \cdot 07$ \\
\hline 1811 & 58 & 59 & 119 & 93 & 36 & $24 \cdot 64$ \\
\hline I 812 & 82 & 66 & 93 & 91 & 34 & $27 \cdot 24$ \\
\hline 1813 & 76 & 53 & 92 & 124 & 20 & $23 \cdot 56$ \\
\hline 1814 & 96 & 65 & 91 & 96 & 17 & $26 \cdot 07$ \\
\hline 1815 & 68 & 36 & 121 & 107 & 33 & $21 \cdot 20$ \\
\hline \multirow[t]{2}{*}{1816} & 64 & 66 & 106 & 102 & 28 & $32 \cdot 37$ \\
\hline & 74 & 54 & 105 & 100 & 32 & $25 \cdot 18$ \\
\hline
\end{tabular}

The remarks which this statement seems to warrant are, that in regard to the E. winds, in the dry year 1807 , the class of N.-E. winds is nearly double of the class of E.-S. winds; in 1815 , the next driest year, is the same result; and in 1808 , the next driest to that, the result is rather more than double. Still farther in regard to $\mathrm{E}$. winds, in the wettest year,

* Forbes's Report on Metcorology, vol i.

(334) 
1816, the class of E.-S. winds exceeds that of N. E.; in 1814 they were $\frac{2}{3}$ of the latter; in $1812, \frac{3}{4}$, and $1810, \frac{7}{8}$. With regard to the class of W. winds, the class of W. N. winds falls off gradually from 1807 to 1810 inclusive, while the annual amount of rain increases from year to year, and in three of the six remaining years the amount is drier than the average in the dry years, and wetter than the wet ones.

(332.) Mr. Howard says, that 1 year in every 5 in this country may be expected to be extremely dry, and 1 in 10 extremely wet.

(333.) The mean annual amount of rain and dew for England and Wales, according to the estimate of Dr. Dalton, is 36 inches. The mean quantity of rain falling in 147 places, situated between north lat. $11^{\circ}$ and $60^{\circ}$, according to Cotte, is 34.7 inches. If the mean fall over the globe be taken at 34 inches, it will, perhaps, not be far from the truth.*

(334.) The influence of the lunar periods on the amount of rain deserves attention. Professor Forbes believes that there is some real connection between the lunar phases and the weather. M. Flaugergues, who has observed the weather at Viviers with the greatest assiduity for a quarter of a century, marked the number of rainy days corresponding with the lunar phases, and found them at a maximum at the first quarter, and a minimum at the last.

(335.) It almost always happens that rain brings down foreign matter from the air. It is known that the farina of plants has been carried as far as 30 or 40 miles, and the ashes of volcanoes have been carried more than 200 miles. We can conceive that when the magnitude of the particles of dry substances is so reduced as to render them incapable of falling in any given velocity, that their descent may be overcome by a very slight current of the air; but even in still air a spherc of water of only the almost inconceivable size of $\frac{1}{600000}$ part of an inch in diameter falls 1 inch in a second, and yet particles of mist must be much larger than this, otherwise they could not be visible as separate drops; the least drop of water that is discoverable by the naked eye falls with a velocity of 1 foot in the

[* It is scid that, on an average, half as much more rain falls in England than on the Continent of Europe. In Ireland, says Doctor KANE, a very able and profound writer on the Industrial Resources of that country, there is probably not more rain than in England, but there is more damp. Long since, Arthar Young, he says, noticed the difficulty of drying agricultural produce in Ireland, and to this humidity he attributed the rapid vegetation which clothes that island with natural herbage, even where there is scarcely a trace of soil, and causes it to be likened to an "emerald" set in the ring of the sea. Like causes produce like effects in our country-hence on the hills and small mountains about Lebanon, N. Y. the Messrs. Tilden carry through the driest summers their flock of 1,000 of the best Saxonies in the finest condition; those hills are ever green. The average quantity that falls over the entire surface of Ireland is put down at 36 inches. Thus, if all that falls in the year were collected at one time, it would cover the whole Island to the depth of 3 feet; and as the area of Ireland amounts to $80,208,271$ square acres, containing $100,712,631,640$ square yards, there are this number of square yards of water precipitated on the island in every year.

For youthfal readers we may be allowed in this place to transcribe from the admirable author above mentioned the following brief and simple explanation of the origin and formation of clouds, rain and rivers, and "water power:"

"The land being placed on the surface of our globe at a level superior to that of the ocean, by which its coasts are washed, there is produced continually, by atmospherical conditions, a circ $\mathbf{z}$. lation of the mass of water, which, evaporating from the surface, ascends as vapor to the higher and colder regions of the air, where it is condensed into clouds. These float until the electrical cozdition which characterizes their peculiar molecular state being dissipated, they fall as rain. as hail, or snow, and the water thus regaining the solid or liquid form, tends continually by its gravity, to a lower level, until it gains the general mass of ocean from whence it had been originally derived. The rain or snow thus falling into the interior and elevated districts of country, forms at first rivulets, then streams, finally rivers; and the force of the descending water is capable of giving motion to machinery : it is the source best known, and most simply applicable, of voaler poncer."

Ed. Farm. Lib.] 
second, when the air is still. Although it is probable that the resistance opposed to the descent of small bodies in air, may be considerably greater than would be expected from calculation, still the wonder is how they are supported for any length of time.* In this difficulty there is much inclination to call in the aid of electricity to account for the phenomenon. Mr. Leithead accounts for it in this way: "When the earth is positive and the atmosphere negative, the electric fluid, in endeavoring to restore its equilibrium, would cause a motion among the particles of the air in a direction from the earth toward the higher region of the atmosphere; for the air being a very imperfect conductor, the particles near the earth's surface can only convey electricity to the more remote particles by such a motion. This wonld, in effect, partly diminish the downward pressure of the air, which is due to its actual density;" and, in doing this, might it not, at the same time, counteract in some degree the gravity of any substance in the air by surrounding it with an electrical atmosphere? "When, on the contrary," continues Mr. Leithead, "the earth is negative and the air positive, this motion of the particles will be reversed; thus increasing the pressure toward the earth, and producing the same effect as if the air had actually increased in density ;" $\dagger$ and would it not thereby be more capable of supporting any foreign body in it ?

(336.) Rain falls at all seasons, but snow only in winter, and it is just frozen rain; whenever, therefore, there are symptoms of rain, snow may be expected if the temperature of the air is sufficiently low to freeze vapor. Vapor is supposed to be frozen into snow at the moment it is collapsing into drops to form rain, for we cannot suppose that clouds of snow can float about the atmosphere any more than clouds of rain. Snow is a beautifully crystalized substance when it falls to the ground, and it is probable that it never falls from a great hight, otherwise its fine crystalline configurations could not be preserved.

(337.) The forms of snow have been arranged into five orders. 1. The lamellar, which is again divided into the stelliform, regular hexagons, aggregation of hexagons, and combination of hexagons with radii, or spines and projecting angles. 2. Another form is the lamellar or spherical nurleus with spinous ramifications in different places. 3. Fine spicula or 6-sided prisms. 4. Hexagonal pyramids. 5. Spicula, having one or both extremities affixed to the center of a lamellar crystal. There are numerous varieties of forms of each class.t All the forms of crystals of snow afford most interesting objects for the microscope, and when perfect no objects in nature are more beautifully and delicately formed. The crystals ramify from a center, or unite with one another under the invariable angle of $60^{\circ}$, or its complemental angle of $120^{\circ}$. The lamellated crystals fall in calm weather, and in heavy flakes, and are evidently precipitated from a low elevation. The spiculæ of 6 -sided prisms occur in heavy drifts of snow accompanied with wind and intense cold. They are formed at a considerable elevation; and they are so fine as to pass through the minutest chinks in houses, and so hard and firm that they may be poured like sand from one hand into another, with a jingling sound, and without the risk of being melted. In this country they are most frequently accompanied with one of the varieties of the lamellar crystals, which meet their fall at a lower elevation; but in mountainous countries, and especially above the line of perpetual slow, they constitute the greatest bulk of the snow, where they are ready at the surface to be blown about with

* Polehampton's Gallery of Nature and Art. vol. iv.

+ Leithead on Electricity, p. 374. This explanation Mr. Leithead also gives to account for the changes in the density of the atmosphere, as indicated by the oscillations of the barometer.

1 Encyclopædia Metropolitana, art. Meteorology. (336) 
the least agitation of the air, and lifted up in dense clouds by gusts of wind, and precipitated suddenly on the unwary traveler like a sand-drift of the torrid zone. These spiculæ feel exceedingly sharp when driven by the wind against the face, as I have experienced on the Alps. How pow erless is man when overtaken in such a snow-storm, as

Beneath the shelter of the shapeless drift,
Thinking o'er all the bitterness of death!" *

The other forms of snow are more rare.

(338.) All other things being equal, Professor Leslie supposes that a flake of snow, taken at 9 times more expanded than water, descends three times as slow.

(339.) From the moment snow alights on the ground it begins to undergo certain changes, which usually end in a more solid crystalization than it originally possessed. The adhesive property of snow arises from its needly crystaline texture, aided by a degree of attendant moisture which afterward freezes in the mass. Sometimes, when a strong wind sweeps over a surface of snow, portions of it are raised by its power, and, passing on with the breeze under a diminished temperature, become crystalized, and, by attrition, assume globular forms. Mr. Howard describes having seen these snow-balls, as they may be termed, in January, 1814 ; and Mr. Patrick Shirreff, when at Mungoswells, in East Lothian, observed the like phenomenon in February, 1830. I observed the same phenomenon in Forfarshire, in the great snow-storm of February, 1823.

(340.) During the descent of snow, the thermometer sometimes rises, and the barometer usually fails. Snow has the effect of retaining the temperature of the ground at what it was when the snow fell. It is this property which maintains the warmer temperature of the ground, and sustains the life of plants during the severe rigors of winter, in the Arctic Regions, where the snow falls suddenly, after the warmth of summer; and it is the same property which supplies water to rivers in winter, from under the perpetual snows of the alpine mountains. While air, above snow, may be $38^{\circ}$ below zero, the ground below will only be at zero.t Hence the fine, healthy, green color of young wheat and young grass, after the snow has melted off them in spring.

(341.) In melting, 27 inches of snow give 3 inches of water. Rain and snow-water are the softest natural waters for domestic purposes; and are also the purest that can be obtained from natural sources, provided they are procured either before reaching the ground, or from newly fallen snow. Nevertheless, they are impregnated with oxygen, nitrogen, and carbonic acid, especially with a considerable quantity of oxygen; and rainwater and dew contain nearly as much air as they can absorb.\| Liebig maintains that both rain and snow-water contain ammonia.

(342.) Snow reflects beautifully blue and pink shades at sunset, as is observed with admiration on the Alps of Switzerland. It also reflects so much light from its surface as to render traveling at night a cheerful occupation; and in some countries, as in Russia and Canada, it forms a delightful highway when frozen.

(343.) Hoar-frost is defined to be frozen dew. This is not quite a correct definition; for dew is sometimes frozen, especially in spring, into globules of ice which do not at all resemble hoar-frost-this latter substance being beautifully and as regularly crystalized as snow. The formation of hoar-frost is always attended with a considerable degree of cold, 
because it is preceded by a great radiation of heat and vapor from the earth, and the phenomenon is the more perfect the warmer the day and the clearer the night bave been. In the country, hoar-frost is of most frequent occurrence in the autumnal months and in winter, in such places as have little snow or continued frost on the average of seasons; and this greatly from great radiation of heat and rapor, at those seasons occasioned by a suspension of regetable action, which admits of little absorption of moisture for vegetable purposes. *

(344.) Dr. Farquharson, Alford, Aberdeenshire, has paid great attention to the subject of hoar-frost or rime, which frequently injures the crops in the northern portion of our island long before they are ripe. The results of his observations are very instructive. 1. He has observed that the mean temperature of the day and night at which injurious hoar-frosts may occur, may be, relatively to the freezing-point, very high. Thus, on the wights of the 29th and 31st August, 1840, the leaves of potatoes were injured, while the lowest temperatures of those nights, as indicated by a self-registering thermometer, were as high as $41^{\circ}$ and $39^{\circ}$ respectively.2. Hoar-frost, at the time of a high daily mean temperature, takes place only during calm. A very slight, sieady breeze will quickly melt away frosty rime. 3. The air is always unclouded, or nearly all of it so, at the time of hoar-frost. So incompatible is hoar-frost with a clouded state of the atmosphere, that on many occasions, when a white frosty rime has been formed in the earlier part of the night, on the formation of a close cloud at a later part, it has melted off before the rising of the sun. 4. Hoarfrosts most frequently happen with the mercury in the barometer at a high point and rising, and with the hygrometer at comparative dryness for the temperature and season; but there are striking exceptions to these rules. On the morning of the 15 th September, 1810 , a very injurious frost occurred, with a low and falling barometric column, and with a damp atmo. sphere. 5. In general, low and flat lands in the bottom of valleys, and grounds that are in land-locked hollows, suffer most from hoar-frost, while all sloping lands, and open uplands, escape injury. But it is not their relative eleration abore the sea, independently of the freedom of their exposure, that is the source of safety to the uplands; for, provided they are inclosed by higher lands, without any wide, open descent from them on some side or other, they suffer more, under other equal circumstances, than similar lands of less altitude. 6. A rery slight inclination of the surface of the ground is generally quite protective of the crops on it from injury by hoar-frost, from which flat and hollow places suffer at the time great injury. But a similar slope downward in the bottom of a narrow, descending hollow does not save the crop in the bottom of it, although those on its side-banks higher up may be safe. 7. An impediment of no great hight on the surface of the slope, such as a stone-wall fence, causes damage immediately above it, extending upward proportionally to the hight of the impediment. A still loftier impediment, like a closely-planted and tall wood or belt of trees, across the descent, or at the bottom of sloping land, causes the damage to extend on it much more. 8. Rivers have a bad repute as the cause of hoar-frosts in their neighborhood, but the general opinion regarding their eril influence is altogether erroneous; the protective effect of running water, such as waterfalls from mill-sluices, on pieces of potatoes, when others in like low situations are blackened by frost, is an illustration which can be referred to. 9. The severity of the injury by hoar-firost is much influenced by the wetness or dryuess of the soil at the

- Mudie's World. 
place; and this is exemplified in potatoes growing on haugh-lands, by the sides of rivers. These lands are generally dry, but bars of clay sometimes intersect the dry portions, over which the land is comparatively damp.Hoar-frost will affect the crop growing upon these bars of clay, while that on the dry soil will escape injury; and the explanation of this is quite easy. The mean temperature of the damp lands is lower than that of the dry, and, on a diminution of the temperature during fiost, it sooner gets down to the freezing point, as it has less to diminish before reaching it.10. Hoar-frost produces peculiar currents in the atmosphere. On flat lands, and in land-locked hollows, there are no currents that are at all sensible to the feelings; but on the sloping lands, during hoar-frosts, there is rarely absent a very sensible and steady, although generally only feeble, current toward the most direct descent of the slope. The current is produced in this way. The cold first takes place-on the surface of the ground, and the lower stratum of air becoming cooled, descends to a lower temperature than that of the air immediately above, in contact with it. By its cooling, the lower stratum acquires a greater density, and cannot rest on an inclined plane, but descends to the valley; its place at the summit of the slope being supplied by warmer air from above, which prevents it from getting so low as the freezing temperature. On the flat ground below, the cool air accumulates, and commits injury, while the warmer current down the slope does none; but should the mean temperature of the day and night be already very low before the calm of the evening sets in, the whole air is so cooled down as to prevent any current down the slope. Injury is then effected both on the slope and the low ground; and hence the capricious nature of hoar-frost may be accounted for.*

(345.) Frost has been represented to arise from the absence of heat; but it is more, for it also implies an absence of moisture. Sir Richard Phillips defines cold to be "the mere absence of the motion of the atoms called heat, or the abstraction of it by evaporation of atoms, so as to convey away the motion, or by the juxtaposition of bodies susceptible of motion. Cold and heat are mere relations of fixity and motion in the atoms of bodies." $\neq$ This definition of heat implies that it is a mere property of matter-a point not yet settled by philosophers; but there is no doubt that, by motion, heat is evolved, and cold is generally attended by stillness or cessation of motion.

(346.) Frost generally originates in the upper portions of the atmasphere, it is supposed, by the expansion of the air carrying off the existing heat, and making it susceptible of acquiring more. What the cause of the expansion may be, when no visible change has taken place, in the mean time, in the ordinary action of the solar rays, may not be obvious to a spectator on the ground; but it is known, from the experiments of Lenz, that electricity is as capable of producing cold as heat, to the degree of freezing water rapidly.ț

(347.) The most intense frosts in this country never penetrate more than one foot into the ground, on account of the excessive dryness occasioned in it by the frost itself withdrawing the moisture for it to act upon. Frost cannot penetrate through a thick covering of snow, or below a sheet of ice.

(348.) Ice is water in a solid state, superinduced by the agency of frost. Though a solid, it is not a compact substance, but contains large interstices filled with air or other substances that may have been floating on the surface of the water. Ice is an aggregation of crystals subtending with one another the angles of $60^{\circ}$ and $120^{\circ}$. It is quickly formed in shallow, but

\footnotetext{
* Prize Essays of the Highland and Agricultural Society, vol. xiv.

† Phillips's Facts. (387)
} 
takes a long time to form in deep water, and it cannot become very thick in the lower latitudes of the globe, from want of time and intensity of the frost. By 11 years' observations at the Observatory at Paris, there were only 58 days of frost throughout the year, which is too short and too desultory a period to freeze deep water in that latitude.

(349.) The freezing of water is effected by frost in this manner. The upper film of water in contact with the air becomes cooled down, and when it reaches $39^{\circ} .39$ it is at its densest state, and of course sinks to the bottom through the less dense body of water below it. The next film of water, which is now uppermost, undergoes the same condensation, and in this way does film after film in contact with the air descend toward the bottom, until the whole body of water becomes equally dense at the temperature of $39^{\circ} .39$. When this vertical circulation of the water stops, the upper film becomes frozen. If there is no wind to agitate the surface of the water, its temperature will descend as low as $28^{\circ}$ before it freezes, and on freezing will start up to $32^{\circ}$; but, should there be any wind, then the ice will form at once at $32^{\circ}$, expanding at the same time $\frac{1}{9}$ larger than in its former state of water.

(350.) It is worth while to trace the progress of this curious phenonue non-the expansion of ice. In the first place, the water contracts in bulk by the frost, until it reaches the temperature of $39^{\circ} .39$, when it is in its state of greatest density, and then sinks. It then resists the freezing power of frost in a calm atmosphere, until it reaches $28^{\circ}$, without decreasing more in bulk, and it remains floating on the warmer water below it, which continues at $39^{\circ} .39$. When so placed, and at $28^{\circ}$, it freezes, and suddenly starts up to the temperature of $32^{\circ}$, and as suddenly expands $\frac{1}{9}$ more in bulk than at its ordinary temperature, and of course more than that when in its most condensed state at $39^{\circ} .39$. It retains its assumed enlarged state of ice until it is melted.

(351.) So great is the force of water on being suddenly expanded into ice, that, according to the experiments of the Florentine Academy, every cubic inch of it exerts a power of $27,000 \mathrm{lbs}$. This remarkable power of ice is of use in Agriculture, as I shall illustrate when I come to speak of the effects of fiost on plowed land.

(352.) It is obvious that no large body of fresh water, such as a deep lake or river, can be reduced in temperature below $39 \circ .39$, when water is in its densest state, as what becomes colder only floats upon and covers the denser, which is at the same time warmer, portion; and as ice is of larger bulk, weight for weight, than water, it must float above all, and, in retaining that position, prevent the farther cooling of the mass of water below $39^{\circ} .39$. On the other hand, sea-water freezes at once on the surface, and that below the ice must retain the temperature it had when the ice was formed. Frost in the polar regions becomes suddenly intense, and the polar sea becomes as suddenly covered with ice, without regard to the temperature of the water below. The ice of the polar sea, like the snow upon the polar land, thus becomes a protective mantle against the intense cold of the atmosphere, which is sometimes as great as $57^{\circ}$ below zero.In this way, sea animals, as well as land vegetables, in those regions, are protected against the effects of the intensest frosts.

(353.) Ice evaporates moisture as largely as water, which property preserves it from being easily melted by any unusual occurrence of a high temperature of the air, because the rapid evaporation occasioned by the small increase of heat superinduces a greater coldness in the body of jce.

(35t.) The great cooling powers of ice may be witnessed by the simple experiment of mixing $1 \mathrm{lb}$. of water at $32^{\circ}$ with $1 \mathrm{lb}$. at $172^{\circ}$, the mean (388) 
temperature of the mixture will be as high as $102^{\circ}$; whereas $1 \mathrm{lb}$. of ice at $322^{\circ}$, on being put into $1 \mathrm{lb}$. of water at $172^{\circ}$, will reduce the mixture to the temperature of ice, namely, $32^{\circ}$. This perhaps unexpected result arises from the greater capacity of ice for caloric than water at the temperature of $32^{\circ}$; that is, in other words, more heat is required to break up the crystalization of ice than to heat water.

(355.) It may be worth while to notice that ponds and lakes are generally frozen with different thicknesses of ice, owing either to irregularities in the bottom, which constitute different depths of water, or to the existence of deep springs, the water of which, as you have seen, seldom falls below the mean temperature of the place, that is, $40^{\circ}$. Hence the un known thickness of ice on lakes and ponds, until its strength has been ascertained; and hence also the origin of most of the accidents on ice.

(356.) The phenomenon of Fog or Mist occurs at all seasons, and it appears always under the peculiar circumstances explained by Sir Humphry Davy. His theory is, that radiation of vapor from land and water sends it up until it meets with a cold stratum of air, which condenses it in the form of mist-which naturally gravitates toward the surface. When the radiation is weak, the mist seems to lie upon the ground; but when more powerful, the stratum of mist may be seen elevated a few feet above the ground. Mist, too, may be seen to continue longer over the water than the land, owing to the slower radiation of vapor from water; and it is generally seen in the hollowest portions of ground, on account of the cold air, as it descends from the surrounding rising ground and mixes with the air in the hollow, diminishing its capacity for moisture.

(35\%.) Mist also varies in its character according to its electric state; if negatively affected, it deposits its vapor more quickly, forming a heavy sort of dew, and wetting everything like rain ; but if positively, it continues to exist as fog, and retains the vapor in the state in which it has not the property of wetting like the other. Thin, hazy fogs occur frequently in winter evenings after clear cold weather, and they often become so permanently electric as to resist for days the action of the sun to disperse them. Thick, heavy fogs occur also in the early part of summer and autumn, and are sometimes very wetting.

(358.) The fogs in hollows constitute the true stratus cloud. We see vapor at a distance in the atmosphere, and call it cloud; but when it sinks to the earth, or will not rise, and we are immersed in it, we call it mist or fog. When immersed in a cloud on a mountain, we say we are in a mist; but the same mist will be seen by a spectator, at a distance in the valley, as a beautiful cirro-stratus resting on the mountain.

(359.) The magnifying power of mist is a well-known optical illusion.Its concealing and mistifying effects may have been observed by every one; and its causing distant sounds to be heard as if near at hand, may also have been noticed by many. The illusive effects of mist are very well described in these lines:

\footnotetext{
"When all you see through densest fog is seen, When you can hear the fishers near at hand Distinctly speak, yet see not where they stand, Or sometimes them and not their boat discern, Or half concealed some figure at the stern; Boys who, on shore, to sea the pebble cast, Will hear it strike against the viewless mast; While the stern boatman growls his fierce disdain At whom he knows not, whom he threats in vain."
}

- Crabbe 


\section{CI.IMATE.}

" Retwixt th' extremes, two happier climates hold, The temper that partakes of hot and cold.

DAYDEN.

(360.) This seems a favorable opportunity for saying a few words on climate - a most interesting subject to the farmer, inasmuch as it will enable him to discover the favorable and unfavorable particulars connected with the site of the farm which he may wish to occupy. 'This is a point, in looking at farms, which I am afraid is entirely overlooked by farmers, much to their disappointment and even loss, as I shall have occasion to observe when we come to be on the outlook for a farm. Meantime let us attend to a few general principles.*

[* It would be vain to attempt to make notes on a subject so comprehensive, with a view to adapt the observations of the author in hand to any peculiar circumstances as connected with the climate of the United States, and its connection with the health and agricultural industry of its in. babitants. To do so, it would be necessary to write a book, and that has been done already by the late Samuex Forry, M. D., with a degree of ability and in a spirit that do bonor to bis memory.

The meteorological phenomena established by observations at our military posts, taken and sollected and published under the direction of our accomplished Surgeon General L Awsor, form the basis of Dr. Forry's book on "The Climate of the United STATES," published in 1842.

Well aware that terrestrial temperature, in its effect on the animal and vegetable kingdom, is modified as well by local causes as by the position of the sun, the author of this highly interesting and valuable work has adopted a classification of climates based on physical geography, without reference to latitude.

The military posts from which the facts are supplied for the basis of his deductions, are divided iato Northern, Middle, and Southern. The first embracing posts on the coast of New-England, extending as far south as the harbor of New.York-posts on the northern chain of lakes. and posts remote from the northern and inland seas. The Middle embracing the Atlantic coast from Delaware Bay to Suvannah, and interior stations. And the Southern, the posts on the Lower Mississippi, and posts in the peninsula of East Florida. The last comprebending a region characterized by the predominance of low temperature-the Southern a high temperature, and the Middle phenomena vibrating to both extremes.

It is to be lamented that a sufficient number of thermometrical observations have not been made through the range of our mountain regions, to determine more exactly the influence of altitude as well as of latitude; but as at such interior and elevated points we have no occasion for military stations, it would not accord with the policy of this Republican Goverument to make provision for the collection of facts to enlighten and give more activity and profit to mere industrial pur. suits. Tabular abstracts presented in the work of Dr. Forry embrace the condensed results of observations made at various posts between $24^{\circ} 33^{\prime}$ and $46^{\circ} 39^{\prime}$ of north latitude, and between $67^{\circ} 4^{\prime}$ and $95^{\circ} 43^{\prime}$ of longitude west of Greenwich, embracing an extent of $22^{\circ} 6^{\prime}$ of latitude and $28^{\circ} 39^{\prime}$ of longitude.

To any one having a just appreheusion of what is needed to a rational education of young men intended to be cultivators of the soil, with a knowledge of subjects which it becomes every gen. tleman to know something about, we need not say how proper and useful it would be to place such books as this in all our country schools. This we can aver with the less hesitation, inasmuch as, in the attempt to extract some passages for the edification of young readers, we find it difficult to make choice of a portion, where all is alike instructive. On the general subject of climate, perhaps the best paper is to be found in the Encyclopødia Britannica, art. Climate. In that article. Professor Leslie estimates that the diminution of temperature of $1^{\circ}$ of F alsrenheit's scale corresponds to an extent of 300 feet. But this, says Brande, will hold true only of moderate eleva(390) 
(361.) Climate may be divided into general and local. The former affects alike all places in the same parallel of latitude; it is measured from the equator to the polar circles in spaces, in each of which the longest day is half an hour longer than that nearer the equator; and from the polar circles to the pole, it is measured by the increase of a month. It is obvious that the breadth assumed for those spaces is quite arbitrary, and it is equally clear that each space is subject to a different temperature. In fact, a difference of temperature constitutes the chief distinction in the general climate of places; and it is this great distinction which has given rise to the division of zones on the surface of the globe into the torrid, temperate. and frigid-names indicative of different degrees of temperature.

(362.) The torrid zone embraces that space of the globe on both sides of the equator in which the sun passes across the zenith during the year. Being under the perpendicular direction of the sun's rays, this is the hottest portion of the globe. It comprehends $23 \frac{1}{2}{ }^{\circ}$ on each side of the equator, or $47^{\circ}$ in all.

(363.) The temperate zones extend $43^{\circ}$ on each side of the torrid, and being acted upon by the sun's rays in an oblique direction, are not so

tions. At the altitude of 1 mile, $2 \mathrm{~m} .3 \mathrm{~m} .4 \mathrm{~m}$. and 5 miles, the increase of elevation corresponding to $1^{\circ} \mathrm{Fahr}$. will be respectively $295,277,252,223$, and 192. Configuration, too, has a powerful influence on temperature. The form of the limits of any large mass of land, as determined by its contact with the ocean-that is to say, the greater or less extent of coast it possesses in proportion to its area-exercises, says Brande, and as is well known, a considerable influence on climate. The small amount of variation in the temperature of the ocean tends to equalize the periodic distribution of heat among the different seasons of the year; and the proximity of a great mass of water moderaies, by its action on the winds, the heat of summer and the cold of winter. Hence the great contrast between the climate of islands and of coasts, and the climate of the interior of vast continents. Europe presents a remarkable example of this. From Orleans and Paris to London, Dublin, Edinburgh, and even farther north, the mean temperature of the year diminishes very little, notwithstanding the increase of latitude; while in the eastern part of the Continent each degree of latitude, according to Humboldt, produces a variation of $1^{\circ} .1 \mathrm{Fahr}$. in the mean temperature.

We must take room here for another extract from Forry :

"Where, indeed, do we not meet the evidences of design? As temperature decreases pro gressively with the elevation of land, great varieties of vegetation are presented in the same region. While the flowers of spring are unfolding their petals on the plains of Northern France, Winter continues his icy reign upon the Alps and Prrenees. By this beneficent appointment of Nature, the torrid zone presents many habitable climates. On the great table-plain of Mexico and Gautemala, a tropical is couverted into a temperate clime. As the vernal valley of Quito lies in the same latitude as the destructive coasts of French Guiana, so the interior of Africa may possess many localities gifted with the same advantages. In our own country, reference has already been made to the marked contrast between the Atlantic Plain and the parallel mountain ridges; but it is in the geographical features of Columbia, in South America, that we find most strikingly displayed the physical phenomenon of hight producing the effect of latitude-a change of climate, with all the consequent revolutions of animal and vegetable life, induced by local position. It is on the mountain slopes of from 3,000 to 7,000 feet, beyond the influence of the noxious mias. mata, that man dwells in perpetual summer amid the richest vegetable productions of Nature.In the mountains of Jamaica, at the hight of 4,200 feet, the vegetation of the tropics gives place to that of temperate regions; and here, while thousands are cut off annually along the coast by yellow fever, a complete exemption exists. In these elevated regions, the inhabitants exhibit the ruddy glow of health which tinges the countenance in northern climes, forming a striking contrast to the pallid and sickly aspect of those that dwell below. In ascending a lofty mountain of the torrid zone, the greatest variety in vegetation is displayed. At its foot, under the burning sun, ananas and plantains flourish; the region of limes and oranges succeeds; then follow fields of maize and luxuriant wheat; and, still hisher, the series of plants known in the temperate zone. The mountains of temperate regions exhibit, perhaps. less variety, but the change is equally striking. In the ascent of the Alps, having once passed the vine-clad belt, we traverse in succes. sion those of oaks, sweet chesnuts, and beeches till we gain the region of the more hardy pines and stunted birches. Beyond the elevation of 6,000 feet, no tree appears. Immense tracts are then covered with herbaceous vegetation, the variety in which ultimately dwindles down to mosses and lichens, which struggle up to the barrier of eternal snow. In the United States proper. we have at least two summits, the rocky pinnacles of which shoot np to the altitude, perhaps, of 6,500 feet. Of these, Mount W ashington, in New.Hampshire, is one. Encircling the base is a 
warm in any part of them as the torrid, and the temperature of their several parts, of course, decreases as they are situated farther from the torrid. Besides this, these zones being entirely intercepted by the torid, the temperature of their northern and southern divisions is hotter and colder as the sun is farther off or nearer to the northern or southern extremes of his declination.

(364.) The frigid zones extend from the temperate to the poles. They are intercepted by both the torrid and temperate zones. The sun's rays affect them at a still more oblique angle than the temperate, and, of course, their mean temperature is yet lower than theirs. They are so far removed from the sun, that in winter the sun is never seen in them above the horizon, while in summer he is never under the horizon; and it is this accumulation of the sun's rays in summer that in a degree compensates for the

heavy forest-then succeeds a belt of stunted firs - next a growth of low bushes - and still farther up only moss or lichens, or lastly a naked surface, the summits of which are covered, during ten months of the year, with snow. Of the snow-capped peaks of Oregon, we possess no precise knowledge."

As it is, even if it were proper to make more extended extracts, we have room only for the fol. lowing-recommending the book itself to every one who would desire to possess some acquaintance with a matter that equally affects his own health and the growth of every thing around him to which his labor is applied, and on which he depends for his subsistence; for truly the investi. gation of the laws of climate embraces almost every branch of natural philosophy-constituting, as it does, according to the broad and true definition of Dr. F., "the aggregate of all external physical circumstances appertaining to each locality in ils relation to organic nature."

Here it may be proper, for the information of the useful reader, to state, as it may serve him in his readings in relation to the geography of climate, that writers illustrating the general laws of temperature have drawn around the globe a series of curves or lines of equal annual tempera. ture, called isothermal lines; lines of equal summer called isothermal lines, and lines of equal winter called isochemical curves. It is pleasing, says Dr. F., to contemplate such a division of the earth-each isothermal belt, as well as those of summer and winter temperatures, representing zones, in which we may trace the causes of the similarity or diversity in animal and vegetable productions; and then again he says, to determine the influence of these zones respectively upon the animal economy in health, and the agency exercised in the cessation of disease, bave proved investigations still more interesting.

"For full mental and corporeal development, the due succession of the seasons is requisite.Those countries which have a marked spring, summer, autumn, and winter, are best adapted by this agreeable and favorable vicissitude for developing the most active powers of man. It is, according to Malte-Brun, between the 40th and 60th degrees of north latitude," that we find the nations most distinguished for knowledge and civilization, and the display of courage by sea and by land. In countries which have no summer, the inhabitants are destitute of taste and geniue; while, in the regions unfavored by winter, true valor, loyalty and patriotism are almost unknown. To this all-pervading agency of atmospheric constitution, must be referred, in a considerable de. gree, the superiority of the warlike nations of Southern Europe over the effeminate inbabitants of Asia ; and to the same cause. in connection with others, is to be ascribed the subsequent con. quest of the former by the formidable hordes which issued from Nurthern Europe. And in regard to the political horizon of North America, if we look upon history as philosophy teaching by example, it requires not the gift of divination to forenee the destiny of Mexico and the States south of it, whose inhabitants, enervated by climate, conjointly with other causes, will yield, by that necessity which controls all moral laws, to the energetic arm of the Anglo-Saxon race. The future history of these States would seem to be typified in that of Texas.

"One of the inost interesting problems in history is the geographical distribution of the human family ; for the oldest records seldom allude to an uninhabited country. From remote ages, it is well known that the inhabitants of every extended locality have been marked by certain physical, moral and intellertual peculiarities, serving, no lesg than particularity of language, to distinguish them from all other people; but how far this result ought justly to be ascribed to the agevcy of elimate is still an undetermined point. It may, however, with good reason, be assumed that the physical charanteristics which distinguish the primitive races of the human family; usually classed under five varieties, exist independent of external causes; while the various families or nations composing each race owe their similarity of physical and moral character, and of langunge, to the influence of climate, habits of life, and various collateral circumstances. Political institutions and

* This limitation, no doubt well adapted to Europe, is inapplicable to the United States. This is apparene from the fact that the isothermal lines, in being traced around the globe, suffer great dcprcseion, as will be shown, on the Atlantic region of North America. 'The $32 \mathrm{~d}$ and the $46 \mathrm{th}$ prallels would consequently form a reasonable boundary. 
entire deprivation of them in winter, and has the effect of raising the mean temperature of those zones to a hight in which both human life and vegetation may exist. The frigid zones extend $47^{\circ}$.

(365.) The three zones occupy these relative proportions of space:

The torrid...............470

The temperate ............ $86^{\circ}$

The frigid.............. $477^{\circ}$

$\overline{180^{\circ}}$ from pole to pole.

" The climates of different parts of the earth's surface are unquestionably owing, in great measure, to their position with respect to the sun. At the equator, where the sun is always nearly vertical, any given part of the surface receives a much greater quantity of light and heat than an equal portion near the poles; and it is also still more affected by the sun's vertical rays, because their passage through the atmosphere is shorter than that of the oblique rays. As far as the sun's mean altitude is concerned, it appears from Simpson's calculations, that the heat received at the equator in the whole year is nearly $2 \frac{1}{2}$ times as great as at the poles; this proportion being nearly the same as that of the meridian heat of a vertical sun, to the heat derived, at $23 \frac{1}{2}$ from the poles, in the middle of the long an-

social organization even struggle successfully against climatic agency; for beroes, men of genius and philosophers have arisen both in Egypt, under the tropics, and in Scandinavia, under the polar circle. Climate, however, modifies the whole nature of man. The powerful influence of locality on human organization is apparent at once in surveying the external characters of the different nations of any quarter of the earth. Even in casting one's eve over our National Legislature, the diversity of physiognomy, caused by endemico-epidemic influences, is so obvious that the general countenance of each State's delegation aords a pretty sure criterion to judge of its comparative salubrity. We can at once distinguih the ruddy inhabitant of that mountain chain where health and longevity walk hand in hand, where Jefferson and Madison inspired its cheerful and invigorating breezes, from the blanched resident of our southern lowlands-those fair and inviting plains, whose fragrant zephyrs are laden with poison, the dews of whose summer evenings are replete with the seeds of mortality. As in the smiling, but malarial, plains of Italy-

"In florid beauty groves and fields appear;

Man seems the only growth that dwindles here."

"Nothing is more obvious, as a general law, than that the animal and vegetable kingdoms have been adapted to particular climates-the effects of which, for example, in cold and warm countries, upon the same animal, are so great that the fleece of the same species of sheep in the former is soft and silky, and, in the latter, coarse, resembling hair.

"As regards vegetation, it is in tropical countries, beneath a vertical sun, that it displays its utmost glory and magnificence. It is there, amid eternal summer, that we find groves ever verdant, blooming, and productive. Advancing to the north or south, we soon discover forests, which, denuded of their leaves, assume, during half the year, the appearance of death; and, still approach ing the poles, we meet vegetable life under a variety of stunted forms, which are ultimately saperseded by a few coarse grasses and lichens.

"In Agriculture, England has been, and to a certain extent still is, our principal school of in struction; but her lessons must be corrected by observing the difference of climate and collateral circumstances. To effect this purpose, a comparative view of the meteorology of the two coun. tries would avail much. But the science of meteorology concerns more particularly the horticulturist; for Agriculture has for its object the fertilization of the soil and the growth and nourishment of indigenous plants, and such as have, by a long course of treatment. become inured to the climate; while horticulture aims not only at a knowledge of the constitution of soils, but aspires to the preserving and propagating of exotic vegetation.

"So closely identified is this science with the every-day occurrences of life, that man is by nature a meteotologist. The shepherd and the mariner, in ages remote, when philosophy had not yet asserted its noble prerogative of releasing the mind from the bondage of superstition, were wont to look with awe upon the face of heaven as an index to prognosticate future results from present appearances, and to read upon it 'times and seasons.' "

Can we doubt but that we have sufficiently exposed the interesting character of this snkject, and its bearing on Agriculture, to show that climate is one of the topics which ought to be treated in a Book of the Farm, and one with which every instructor of youth, and every gentleman and political economist, ought to make himself acquainted so far as that may be done, as it may by giving an hour a day, for a few weeks, to the perusal of works which illustrate the researches of those who have devoted attention to the subject?

Ed. Farm. Lib.] 
nual day at the poles. But the difference is rendered still greater by the effect of the atmosphere, which intercepts a greater proportion of the heat at the poles than elsewhere. Bouguer has calculated, upon the supposition of the similarity of the effects of light and heat, that, in lat. $45^{\circ}, 80$ parts of 100 are transmitted at noon in July, and 55 only in December.It is obvious that, at any individual place, the climate in summer must approach in some degree to the equatorial climate, the sun's altitude being greater, and in winter to the climate of the polar regions."

(366.) From what has just been observed, it is obvious that the temperature of the air diminishes gradually from the equator to the poles; and it also becomes gradually colder as we ascend in hight above the surface of the ground. Here, then, are two elements by which to judge of the general climate of different latitudes. Moreover, the diminution of heat from the equator to the poles is found to take place in an arithmetical progression-that is, the annual temperature of all the latitudes are arithmetical means between the mean annual temperature of the equator and the poles. This law was first discovered by M. Meyer, but by means of an equation which he founded on it, and afterward rendered more simple, Mr. Kirwan calculated the mean annual temperature of every degree of latitude between the equator and the poles. The results were, that the mean temperature at the equator is $84^{\circ}$, that at the poles $31^{\circ}$, and that in $\mathrm{N}$. lat. $54^{\circ}, 49^{\circ} .20$.

(367.) From Mr. Kirwan's calculations of the mean temperatures of every month, it appears that January is the coldest month in every latitude, and that July is the warmest month in all latitudes above $48^{\circ}$. In lower latitudes, August is the warmest month; while the difference in temperature between the hottest and coldest months increases in proportion to the distance from the equator. Every habitable latitude enjoys a mean heat of $60^{\circ}$ for at least two months ; and this heat seems necessary for the production of corn. Within $10^{\circ}$ of the poles the temperature differs little, and the same is the case within $10^{\circ}$ of the equator. The mean temperature of different years differs very little near the equator, but it differs more and more as the latitudes approach the poles.

(368.) As the temperature of the atmosphere constantly diminishes on ascending above the level of the sea, the temperature of congelation must be attained at a certain hight above every latitude; consequently, mountains which rear their heads above that limit must be covered with perpetual snow. The elevation of the freezing region varies according to the latitude of the place, being at all times highest at the equator, and lowest at the poles. In the higher regions of the atmosphere, especially within the tropics, the temperature varies but little throughout the whole year; and hence, in those brilliant climates, the line of perpetual congelation is strongly and distinctly marked. But, in countries remote from the equator, the boundary of frost descends after the heat of summer as the influence of winter prevails-thus varying its position over a belt of some considerable depth.

(369.) But beyond the line of congelation is another which forms the boundary of the ascent of visible vapor, and this point it is obvious must be less liable to change than the point of congelation. At the equator the highest point of vapor is 28,000 feet, at the pole 3,432 feet, and in N. lat. $54^{\circ}$ it is 6,647 feet. In tracing this point successively along every latitude, we learn that heat diminishes, as we ascend, in an arithmetical progression. Hence it follows that the heat of the air above the surface of the earth is

* Polehampton's Gallery of Nature and Art, vol. ir.

(394) 
not owing to the ascent of hot strata of air from the surface, but to the conducting power of the air itself.*

(370.) The question of local climate presents a much greater interest to the farmer than that of the general climate of the country which he inhalits. Local climate may be defined to signify that peculiar condition of the atmosphere in regard to heat and moisture which prevails in any given place. The diversified character which it displays has been generally referred to the combined operation of several different causes, which are all reducible, however, to these two: distance from the equator, and hight above the level of the sea. Latitude and local elevation form, indeed, the great basis of the law of climate; and any other modifications have only a partial and very limited influence.t

(371.) The climate of every individual country may be considered local in reference to that of all other countries in the same degrees of latitude. Islands are thus warmer than continents. The E. coast of all countries is colder than the $W$., though the latter is moister. Countries lying to the windward of great ranges of mountains or extensive forests are warmer than those to leeward $f$ Small seas are warmer in summer and colder in winter than the standard portion of great oceans, as they are in some degree affected by the condition of the surrounding land. Low countries are warmer than high, and level plains than mountainous regions. Plains present only one species of climate, which differs in its seasonal characters alone, but mountains exhibit every variety, from their latitude to the pole along the meridian of the quadrant. In this way, high mountains, situate in the tropics, present every variety of climate. "If we take each mount ain," says Mr. Mudie, "which rises above the line of perpetual snow, as the index to its own meridian, we shall find that each one expresses, by its vegetation, all the varieties of climate between it and the pole; and thus these lofty mountains become means of far more extensive information than places which are situated near the main level of the sea, and more especially than plains, which, when their surfaces are nearly flat, have no story to tell, but the same uniform and monotonous one, for many miles." But although the high tropical mountains are thus indices of climate reaching fiom the equator to the pole, they are not subject to the seasonal differences which the climates are along the meridian of the quadrant. " Although," continues Mr. Mudie, "the temperature does ascend and descend a little, even upon the mountains immediately under the equator, and although the seasonal change becomes more and more conspicuous as the latitude increases, either northward or southward, yet, within the whole tropical zone, the seasonal difference is so slight that there is no marked summer or winter apparent in the native and characteristic vegetation.

- From the small change of seasons in this region, they are almost all plants of uniform growth throughout the year, and have no winter for repose; so that, at great elevations, their growth is at all times much slower than that of plants in polar latitudes, during the perpetual sunshine of the summer there. . . . Say that the altitude of the mountain uuder the equator, upon which the seasonal action is displayed, is a little more than

$\left\lfloor\mp \overline{M r}\right.$. Jefferson considered the difference as equal to $3^{\circ}$ of latitude-for example, that the calture of cotton might be carried $3^{\circ}$ farther north on the Mississippi than on the Atlantic ; and Volney ascribed this to the influence of south-west winds carrying the warm air of the Gulf of Mexico up the valley of the Mississippi ; but Forry contests the truth of the theory of these philosophers, by a train of reasoning, for which we regret we have not room. The reader is referred to the whole of section 3 , part 1 , of his work.

Ed. Farm. Lib.]

* For tables of the altitudes of the points of congelation and vapor, see Encyclopædia Britannica, 7th edi tion, art. Climare.

(395) 
3 miles. Then, estimating in round numbers, 1 foot of altitude on the mountain will correspond to about 16,000 feet on the meridian; that is, a single foot of elevation on the mountain is equivalent, in difference of temperature, to about 3 miles, or more nearly 3 minutes of a degree in latitude, and therefore 20 feet are equal to a whole degree; and when one once arrives at the mean temperature of London, 400 feet more of elevation will hring one to the climate of Lapland."*

(372.) From these facts and reasonings, it appears that a slight difference of elevation in a mountainous district of this country, which stands upon so high a parallel of latitude, may make a considerable difference of climate, and that, other things remaining the same, that farm which is situated on a high elevation has a much greater chance of being affected by changes of climate than one at a lower level. Yet certainly local circumstances have a material effect in rendering the general position of any farm less desirable, such as vicinity to a lake or marsh, or a leeward position to a hill or large wood in reference to the direction from which the wind generally blows, as these tend to lower the temperature below that of the mean of the country. So, in like manner, any position in a long, narrow valley, or on the side of a large, isolated hill, or in a pass betwixt two mountains separating plains, is more subject to the injurious effects of wind than the mean of the country, as the wind acquires an accelerated motion in such localities. An elevated table-land is subject to a lower temperature and higher winds than a plain of the same extent on a lower level; hence most situations among hills are colder and more windy than on plains. On the other hand, the being on the windward side of a hill or large wood, or on flat ground backed with hills and woods to the N. and E., or being in the midst of a cultivated country, all insure a higher temperature and less injurious winds than the mean of the country. An extensive plain or valley, through which no large river passes, or in which no large lake or wood exists, is subject to very little violent wind. In the former exposed situations, the snow lies long, and the winds are cutting keen; while in the more sheltered positions the snow soon disappears, and the wind is less violent and keen. All these differences in circumstances have a sensible effect on the local climate of every country, and in a small one like Great Britain, varied as it is in its physical geography, and surrounded on all sides by water, they have the effect of dividing the country into as many climates as there are varieties of surface and differences of position in regard to the sea. These local influences, in most seasons, have a greater effect on the time of growth, quantity and quality of the produce of the earth, than the general climate of the country; although, no doubt, the latter exercises such a predominating influence in some seasons, by excessive heat or rain, as to overcome all local influences, and stamp an universality of character over the season. "According to Cotte's aphorisms, local heat hecomes greater on plains than on hills; it is never so low near the sea as in inland parts ; the wind has no effect on it; its maximum and minimum are about 6 weeks after the solstices, it varies more in summer than in winter; it is least a little before sunrise ; its maxima in the sun and shade are seldom on the same day; and it decreases more rapidly in autumn than it increases in summer." $\dagger$

(373.) Besides all these causes, there is another phenomenon which bas a material effect on local climate, and that is, the darting of cold pulsations downward from the upper regions of the atmosphere, and of warm pulsations upward from the earth. This is a different phenomenon from ra-

* Mudie's World.

† Polehampton's Gallery of Nature and Art, vol. iv 
diant heat. These pulsations of temperature are detected by a new instrument called the athrioscope; and although the experiments with it have as yet not been sufficiently numerous to insure implicit confidence in its results, yet the experience of all who have paid attention to the varieties of circumstances which affect climate, can tell them that many causes are evidently at work in the atmosphere, to produce effects which have not yet been recognized by the instruments in common use. "The æthrioscope opens new scenes to our view. It extends its sensations through indefinite space, and reveals the condition of the remotest atmosphere. Constructed with still greater delicacy, it may perhaps scent the distant winds, and detect the actual temperature of any quarter of the heavens. The impressions of cold which arrive from the north will probably be found stronger than those received from the south. But the facts discovered by the rthrio. scope are nowise at variance with the theory already advanced on the gradation of heat from the equator to the pole, and from the level of the sea to the highest atmosphere. The internal motion of the air, by the agency of opposite currents, still tempers the disparity of the solar impressions; but this effect is likewise accelerated by the vibrations excited from the unequal distribution of heat, and darted through the atmospheric medium with the celerity of sound. Any surface which sends a hot pulse in one direction, must evidently propel a cold pulse of the same intensity in an opposite direction. The existence of such pulsations, therefore, is in perfect unison with the balanced system of aerial currents. The most recondite principles of harmony are thus disclosed in the constitution of this nether world. In clear weather, the cold pulses then showered entire from the heavens will, even during the progress of the day, prevail over the influence of the reflex light, received on the ground, in places which are screened from the direct action of the sun. Hence at all times the cool ness of a northern exposure. Hence, likewise, the freshness which tempers the night in the sultriest climates, under the expanse of an almost azure sky. The coldness of particular situations has very generally been attributed to the influence of piercing winds which blow over elevated tracts of land. This explication, however, is not well founded. It is the altitude of the place itself above the level of the sea, and not that of the general surface of the country, which will mould its temperature. A cold wind, as it descends from the high grounds into the valleys, has its capacity for heat diminished, and consequently becomes apparently warmer. The prevalence of northerly above southerly winds may, however, have some slight influence in depressing the temperature of any climate. In our northern latitudes, a canopy of clouds generally screens the ground from the impressions of cold. But within the Arctic Circle, the surface of the earth is more effectually protected by the perpetual fogs which deform those dreary regions, and yet admit the light of day, while they absorb the frigorific pulses vibrated from the higher atmosphere. Even the ancients had remarked that our clear nights are generally likewise cold. During the absence of the sun, the celestial impressions continue to accumulate; and the ground becomes chilled to the utmost in the morning, at the very moment when that luminary again resumes its powerful sway. But neither cold nor heat has the same effect on a green sward as on a plowed field, the action being nearly dissipated before it reaches the ground among the multiplied surfaces of the blades of grass. The lowest stratum of air, being chilled by contact with the exposed surface, deposits its moisture, which is either absorbed into the earth, or attracted to the projected fibres of the plants, on which it settles in the form of dew or hoarfrost. Hence the utility, in this country, of spreading awnings at night, (397) 
to screen the tender blossoms and the delicate fruits from the influence of a gelid sky; and hence, likewise, the advantage of covering walled trees with netting, of which the meshes not only detain the frigorific pulses, but intercept the minute icicles, that, in their formation, rub the air of its culd. It has often been observed as an incontrovertible fact, that the clearing of the ground and the exteusion of Agriculture have a material tendency to ameliorate the character of any climate. But whether the sun's rays be spent on the foliage of the trees, or admitted to the surface of the earth, their accumulated effects, in the course of a year, on the incumbent at mosphere, must continue still the same. The direct action of the light would no doubt more powerfully warm the ground during the day, if this superior efficacy were not likewise nearly counterbalanced by exposure to the closer sweep of the winds, and the influence of night must again reestablish the general equilibrium of temperature. The drainage of the surface will evidently improve the salubrity of any climate, by removing the stagnant and putrefying water ; but it can have uo effect whatever in rendering the air milder, since the ground will be left still sufficiently moist for maintaining a continual evaporation, to the consequent dissipation of heat."*

(374.) The particulars of the geographical distribution of plants and animals tend to show the action of general climate on the regetable and animal functions ; the effects of latitude and of elevation above the earth's surface being similar upon both, although most sensibly felt in the vegetable economy. M. Humboldt, the celebrated philosophical traveler, paid great attention to this subject, and, from his own researches, constructed tabular views of the range of animal and vegetable being in both conditions of the globe; but as his observations are more particularly applicable to America, it is not necessary to repeat them here, interesting as they really are." $\dagger \ddagger$

(375.) It has been said already, that "the effect of elevation is equiva lent to latitude; but it must be recollected that plants will not thrive equally in places with the same mean temperature. Some require a strong ephemeral heat. Hence, in judging of the aptitude of any place for rearing particular plants, we must comprare the mean temperature of the summer, as well as of the whole year, before we decide. Thus, we are enabled to explain why the pistacio nut ripens in Pekin, but wili not ripon in France, where the isothermal line for the whole year is the same. But though the Chinese winter be more severe than that of France, the summer heat is far greater. Innumerable other instances might he adduced of the same fact. The moisture of a climate has much influence upon its vegetation. Water is the vehicle of the food of plants, and perhaps yields a great proportion of it; so, if moisture be deficient, plants die; but they require water in very different proportions. Those with broad, smoroth, soft leaves, that grow rapidly and have many cortical pores, require much water to maintain their vitality; on the other hand, plants with few cortical pores, with oily or resinous juices and small ronts, will generally thrive best in dry situations. Exposure to light is necessary for most plants. The green color of plants is only formed in light, as is shown hy blanching: and light appears to be the cause of certain muvements which are remarked in the flowers of most plants, and in other parts of some

[ $\$$ Doctor Forry has shown that Humbold:'s observations on the physical distribution of plants " convey very erroneous impressions, from the circumstauce, mostly. that his limits of the Old World are confined to Western Europe, and of the New World to Eastern America." See Forry on the Climate of the United Stater, page 76.

|Ed. Farm. Lib.

* Fincyclopzedia Britunnica, ith edition. art. Cimate.

I See Fidinburgh Philosophical Journal, rols. iij. iv, and $\mathrm{v}$. ¡398j 
delicately organized individuals, which open and close their leaves according to the degree of light. This last property is chiefly seen in tropical plants. Light appears to be necessary to the decomposition of carbonic acid, and the fixation of carbon in their tissues; and it is indispensable to the right performance of the function of reproduction. The influence of soil on vegetables is seen in the preference which many plants have for a calcareous soil ; some affect silicious sands, others clay retentive of water; some plants thrive best in the clefts of slaty rocks; some delight to dwell amid granitic rocks; and others on a saliferous soil. Earthy matters enter largely into the composition of some vegetables; and in the epidermis of the gramineæ, silica is invariably found. The presence of animal matters in soils is necessary to many plants, and is generally nutritive to all. Iron and copper are found in small quantities in some plants. The sta. tions of particular plants have often been determined by these peculiarities of soil; and when a soil and climate are equally suitable for many social plants, we find them growing together, until the strongest obtains the mastery, and chokes the others. The common heath appears to have usurped, in Europe, a space once occupied by other genera, if we may judge from what generally happens on exterminating heath; for then other plants very speedily make their appearance, the seeds of which seem to have long preserved their vitality in the earth, and only to have wanted room to spring into visible existence. A continuation of these causes no doubt influences the distribution of particular species." .... "On comparing the two Continents, we find in general, in the New World under the equatorial zone, fewer Cyperaceæ and Rubiaceæ, but more Compositæ; under the temperate zone, fewer Labiatæ and Cruciferæ, and more Compositæ, Ericeæ, and Amentaceæ, than in the corresponding zones of the Old World. The families that increase from the equator to the pole, according to the method of fractional indications, are Glumeaceæ, Ericeæ, and Amentaceæ. The families which decrease from the pole to the equator, are Leguminosæ, Rubiaceæ, Euphorbiaceæ, and Malvaceæ. The families that appear to attain their maximum in the temperate zone are Compositæ, Labiatæ, Umbelliferæ, and Cruciferæ."*

(376.) In regard to the geographical distribution of animals, the slightest acquaintance with zoology is sufficient to show that animals do not indiscriminately spread themselves over every part of the habitable globe. "But the natural limitation of species has been, in some measure, affected by human agency. The domesticated animals have been, by man, imported from different parts of Asia into Europe, and finally into America. At the discovery of that continent, it was without the horse, the cow, the sheep, the hog, the dog, and our common poultry, all which are spread over it in innumerable herds, and in some places have relapsed into the wild state, in countries well suited for their subsistence.t The same use-

[ + The first neat cattle, a bull and three heifers, were imported into New-England by Edward Winsboro, one of the founders and then Governor of the Plymouth Colony. They were brought over in the ship Charity, in March, 1624. For the first four years the settlers of the old Colony lived without milk. The first notice of horses is 20 years afterward, in 1644. Before the intro. duction of horses it was, we are told, no uncommon thing for people to ride on bulls. For this we have the authority of a forthcoming work on the Lives of the Governors, by $J_{A C O B}$ B. MOORE, a victim of political proscription, removed for opinion's sake from a sabordinate post in a Department, though possessing qualities to administer it far superior to its head and to most of its members. With his virtues and talents, in the army he would, at his age, be enjoying a high position and the certainty of yet higher promotion and higher pay for life. As this work carefully eschews party politics, we do not name any party thus prostituting the powers of the Govera.

* Encyclop»dia Britannica, 7th edition, art. Physical Geography. (399) 
ful animals have been, by Europeans, within the last half century, carried to the larger islands of the Pacific, where they were previously unknown. How many insects may have been propagated by the cargoes of our ships in distant lands, it is easier to conjecture than to estimate; how many have been imported with the cerealea and other graminex of Europe into newly discovered regions, it is impossible to say. Human agency has sumetimes been the means of propagating in Europe disgusting or destructive species from foreign regions. Thus, the commerce of the Dutch wafted the Teredo navalis to the dyke-defended coasts of Holland, to the imminent hazard of that country; the brown rat and the blatta, which now infest this country, are helieved to be importations from the East Indies; and the white bug, that now lays waste our orchards, is stated to have reached us with American fruit-trees."

(377.) The definitions of the limits of the zoological divisions on the globe has first been attempted by Mr. Swainson, an eminent English naturalist. "He contends that birds of any district afford a fairer criterion of the limits of a geographical distribution than any other class of animals. Quadrupeds he believes to be too much under the dominion of man, and liable to have their geographic limits disturbed by human interference; and the other classes of animals are either too numerous or too few, to afford the means of determining the limits of such divisions; while birds, though seemingly fitted by nature to become wanderers, are surprisingly steady in their localities, and even in the limits of their annual migrations. These migrations are evidently caused by scarcity of food. Thus, our swallows leave us when their insect-food begins to fail, and they naturally pursue that route which is shortest, and affords subsistence by the way. The distance from the shores of the Baltic to Northern Africa is not half so great as between England and America ; and during the migration over land, the winged travelers find food and resting-places as they proceed to more genial climates." $\dagger \ddagger$

(378.) Before concluding the subject of climate, I may advert to the very generally received opinion among farmers and others who are much exposed in the air, that the weather of Great Bitain has changed materially within the memory of the present generation. I am decidedly of this opinion; and I observe that Mr. Knight, the late cminent botanical physiologist, expressed himself on this subject in these words: "My own habits and pursuits, from a very early period of my life to the present time (1829), have led me to expose myself much to the weather in all seasons of the sear, and under all circumstances; and no doubt whatever remains on my mind, but that our winters are generally a good deal less severe than formerly, our springs more cold and ungenial, our summers, particularly the

ment, meaning only to refer to and to denounce the anti-republican policy which everywhere gives the most invidious preference to the military over civil virtues; and $s 0$ will it ever be antil the sons of the cultivators of the soil are differently educated from what they have been.

Ed. Farm. Lib.]

[ $\mathrm{A}$ work of great and curious research has been published lately in France, by Marcel De Serres, with accompanying maps, on the canses of the migrations of divers animals and particulariy of birds and fishes. We lament the want of time to translate, and of room to append eome extracts. It is another of that catalogue of books which should go to make ap the library of the country gentleman-by which we mean, once for all, not the man of fine apparel or of ample fortane, for these may belong to the fool, the upstart, or the demagngue. We mean the man of kind and geatle nature, who would not wantonly give pain to a fly, and who is eager to acquire and willing to impart information; men whose gracefulness is in the heart and feeling, rather than in exterior pomp or ostentatious display of wealth, Several such "country gentlemen," in our estimation, have we lately seen and "eaten salt" with, in their vorking clothes. Ed. Farm. Lib.]

* Encrelopæedia Britannica, 7th edition, art. Physical Geography. (400)

+ Ibid. 
latter part of them-as warm at least as they formerly were, and our autumus considerably warmer." He adds, that "I think that I can point out some physical causes, and adduce rather strong facts in support of these opinions."

(379.) Of the physical causes of these changes, Mr. Knight conceives that the clearing of the country of trees and brushwood, the extension of arable culture, and the ready means afforded by draining to carry off quickly and effectually the rain as it falls, have rendered the soil drier in May "than it could have been, previously to its having been inclosed and drained and cultivated; and it must consequently absorb and retain much more of the warm summer rain (for but little usually flows off) than it did in an uncultivated state; and as water, in cooling, is known to give out much heat to surrounding bodies, much warmth must be communicated to the ground, and this cannot fail to affect the temperature of the following autumn. The warm autumnal rains, in conjunction with those of summer, must necessarily operate powerfully upon the temperature of the succeeding winter." Hence, a wet summer and autumn are succeeded by a mild winter; and when N. E. winds prevail after these wet seasons, the winter is always cloudy and cold, but without severe frosts; probably, in part, owing to the ground upon the opposite shores of the Continent and of this country being in a similar state. The fact adduced by Mr. Knight in support of this opinion is that of the common laurel withstanding the winter, notwithstanding its being placed in a high and exposed situation, and its wood not being ripened in November.

(380.) "Supposing the ground," continues Mr. Knight, "to contain less water in the commencement of winter, on account of the operations of the drains above mentioned, as it almost always will and generally must do, more of the water afforded by the dissolving snows and the cold rains of winter will be necessarily absorbed by it; and in the end of February, however dry the ground may have been at the winter solstice, it will almost always be found saturated with water derived from those unfavorable circumstances; and as the influence of the sun is as powerful on the last day of February as on the 15th day of October, and as it is almost wholly the high temperature of the ground in the latter period which occasions the different temperature of the air in those opposite seasons, I think it can scarcely be doubted, that if the soil have been rendered more cold by having absorbed a larger portion of water at very near the freezing temperature, the weather of the spring must be, to some extent, injuriously affected." Hence, the springs are now more injurious to blossoms and fruits than they were thirty years ago. Hence, also, the farmers of Herefordshire cannot now depend on a crop of acorns from their extensive groves of oaks.* +

[ + On this question of the stability of climates in Europe and America, and the influence of calti-ation on temperature, the reader should not rest satisfied until he turns to the array of his. 1. cal facts and thermometrical data adduced by Doctor Forry in refutation of the theories main-

a' zed by the philosophers of the Old and of the New World-among the latter Jefferson and Hush, the latter of whom says: "From the accounts which have been handed down to us by ow ancestors, there is reason to believe that the climate of Pennsylvania has undergone a materia change. The springs are much colder, and the autumns more temperate, insomuch that cattle are not housed so soon by one month as they formerly were. Rivers freeze later and do not remain so long covered with ice." Doctor F. gives tables of thermometrical observations made at Philadelphia three years successively, at intervals of 25 years, from 1793 to 1824 , and during thirty-three years at Salem, Mass., to show a remarkable uniformity of mean temperature. The following table, by Forry, exhibits the duration of winter at the City of New-York :

+ Knight's Horticultural P\&pers.

(401).....14 


\title{
20. OBSERVING AND RECORDING FACTS.
}

\begin{abstract}
"Facts are to the mind the same thing as food to the body. On the due digestion of facts depend the strength and wisdom of the one, just as rigor and health depend on the other. The wisest in council, the ablest in debate, and the most agreeable companion in the commerce of human life, is that man who has qsimilated to his understanding the greatest number of facts."

BuNKz.
\end{abstract}

(381.) THese words of "the greatest philosophical statesman of our country," as Sir James Mackintosh designated Burke, convey to the mind but an amplification of a sentiment of Bacon, which says that "the man who writes, speaks, or meditates, without being well stocked with facts as landmarks to his understanding, is like a mariner who sails along a treacherous coast without a pilot, or one who adventures on the wide ocean without either a rudder or a compass." The expression of the same sentiment by two very eminent men, at periods so far asunder and in so very different conditions of the country, should convince you of the universal application of its truth, and induce you to adopt it as a maxim. You can easily do so, as there is no class of people more favorably situated for the observation of interesting facts than agricultural pupils. Creation, both animate and inanimate, lies before you ; you must be almost always out of doors, when carrying on your operations; and the operations themselves are substantial matters of fact, constantly subject to modification by the state of land and the atmosphere. It is useful to observe facts and to

\begin{tabular}{|c|c|c|c|}
\hline First ice formed. & $\begin{array}{l}\text { First snow fell. } \\
\text { Nov. } 3\end{array}$ & $\begin{array}{c}\text { Last ice formed. } \\
\text { April } 10\end{array}$ & $\begin{array}{l}\text { Last snow fell. } \\
\text { April } 30\end{array}$ \\
\hline ..... Nov. 3 & Dec. 12 & April 10 & Mar. 17 \\
\hline $333 \ldots \ldots \ldots \ldots$. O. . . 31 & Dec. 15 & Mar. 29 & Mar. 1 \\
\hline $34 \ldots \ldots \ldots \ldots \ldots$ Oct. 30 & Nov. 15 & May 15 & April 25 \\
\hline $35 \ldots . . . . .$. & Nov. 27 & A pril 18 & April 16 \\
\hline $36 \ldots \ldots \ldots \ldots \ldots \ldots$ Oct. 26 & Nov. 24 & A pril 12 & April 13 \\
\hline $37 \ldots \ldots \ldots \ldots$ Oct. 14 & Nov. 14 & May 1 & April 4 \\
\hline $38 \ldots \ldots \ldots \ldots$ Oct. 31 & Oct. 31 & April 17 & April 24 \\
\hline $339 . \ldots \ldots \ldots \ldots$ & Nov. 10 & Mar. 31 & April 17 \\
\hline Oct. 26 & Nov. 18 & Mar. 26 & A pril 1 \\
\hline
\end{tabular}

The state of the weather as indicated by the course of the winds, and the proportion of fair and cloudy days, based upon three years' observations, are shown in the following table :

\begin{tabular}{|c|c|c|c|c|c|c|c|c|c|c|c|c|c|}
\hline \multirow{3}{*}{$\begin{array}{l}\text { Places of } \\
\text { Observation. }\end{array}$} & \multicolumn{8}{|c|}{ WINDS. } & & \multicolumn{3}{|c|}{ WEATHER. } & \multirow{3}{*}{ 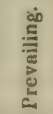 } \\
\hline & 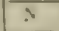 & $\mathrm{NW}$ & $\mathrm{NE}$ & E: & $\mathrm{SE}$ & s & $15 w$ & IV & & fair & $|c|^{\prime} d y$ & rain & \\
\hline & days & $\overline{\text { days }}$ & days & $\overline{\text { days }}$ & $\overrightarrow{\text { dajs }}$ & $\overline{\mathrm{d} x y s}$ & $\overline{\text { days }}$ & $\overline{\text { day } 8}$ & 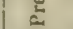 & $\overline{\text { days } 3}$ & $\overline{d a y s}$ & $\overrightarrow{\text { daye }}$ & \\
\hline$\overline{\mathrm{FT}}$. MaI & $\overline{1.55}$ & $\overline{2 \cdot 86}$ & $9 \cdot 08$ & $\overline{1-03}$ & $\overline{10 \cdot 83}$ & $\overline{1 \cdot 11}$ & $\overline{2 \cdot 64}$ & $\overline{1-33}$ & $\overline{S E}$ & $\overline{19-02}$ & $\overline{5 \cdot 19}$ & $\overline{6 \cdot 22}$ & Fair \\
\hline FT. KING. & 1.62 & $\mid 2-79$ & $3-46$ & $3 \cdot 54$ & $4 \cdot 37$ & $5 \cdot 63$ & $5-96$ & $3 \cdot 08$ & S IV & $25 \cdot 75$ & $2 \cdot 88$ & $1 \cdot 89$ & Fair \\
\hline FT. B R & $1 \cdot 53$ & $|3-72|$ & $5 \cdot 58$ & $\mid 2-89$ & $4 \cdot 44$ & $|2 \cdot 75|$ & $6 \cdot 42$ & $|3 \cdot 17|$ & $\mathrm{S} \mathrm{W}^{\mathrm{T}}$ & $20-33$ & $4 \cdot 47$ & $5 \cdot 64$ & Pair \\
\hline K FY W EST & $3 \cdot 20$ & $3 \cdot 13$ & $10 \cdot 50$ & $|5 \cdot 37|$ & $5 \cdot 37$ & $|0.54|$ & 1.67 & 0.38 & $N \mathrm{E}$ & $21 \cdot 54$ & $3 \cdot 08$ & $5 \cdot 92 \mid$ & F air \\
\hline
\end{tabular}

We must dismiss the snbject, for the want of room, with the following summary observation of a writer who, had he lived, had given earnest of his capacity to malse such contributions to the stock of science as would have done yet more honor to himself and his country :

"No accurate thermometrical observations yet made in nny part of the world, warrant the conclusion that the temperature of a locality undergoes changes in any ratio of progression; but conversely, as all facts tend to establish the position that climates are stable, we are led to believe that the changes or perturbations of temperature to which a locality is subject, are produced by some regular oscillations, the periods of which are to us unknown. That climates are suscepti. ble of melioration by the extensive changes produced on the surface of the earth by the labors of man, has been pointerl out already; hut these effects are extremely subordinate, compared with the modification induced by the otriking features of physical geography - the oceau, lakes. moun tains, the opposite coasts of continents, and th s- prolongation and enlargement toward the polea.

(402) 
familiarize yourself with them, as, when accumulated, they form the stores from which experience draws its deductions. Never suppose any fact too trivial to arrest attention, as what may at first seem trivial, becomes, in many instances, far from being so ; it being only by the comparison of one circumstance with another, that their relative value can be ascertained; and familiar knowledge alone can enable you to discriminate between those which influence others and those which stand in a state of isolation. In this point of view, observation is always valuable; because at first the pupil must necessarily look upon all facts alike, whatever may ultimately be found to be their intrinsic or comparative importance. The unfoldings of experience alone can show to him which classes are to be regarded by themselves, and which are not only connected with, but form the character of others. Remember, also, that to observe facts correctly is not so easy a matter as may be at first supposed; there is a proper time for the commencement of the investigation of their history, which, if not hit upon, all the deductions will be erroneous; and this is especially the case when you are performing experiments instituted for the purpose of corroborating opinions already adopted; for, in this way, many an acute experimentalist has been proselytized into an erroneous system of belief. But as pupils you should have no preconceived notions to gratify, no leanings to any species of prejudice. Look upon facts as they occur, and calmly, cautiously, and dispassionately contrast and compare them. It is only thus that you will be able to discriminate causes from consequences, to know the relative importance of one fact to another, and to make the results of actual observation in the field subservient to your acquiring a practical knowledge of Agriculture.

(382.) The facts to which you should, in the first instance, direct your attention, are the effects of the weather at the time, not only on the operations of the fields and on their productions, but also on the condition of the live-stock. You should notice any remarkable occurrence of heat or cold, rain or drouth, unpleasant or agreeable feeling in the air ; the effects following any peculiar state of the clouds, or other meteors in the air, as storms, aurora borealis, halos, and the like; the particular operation of rain in retarding or materially altering the labors of the field, and the length of time and quantity of rain that it has taken to produce such an effect; as well as the effects on the health or growth of plants, and the comfort and condition of animals. The effects of cold, or snow, or drouth, upon the same subjects, deserve equal attention.

(383.) You should particularly observe the time at which each kind of crop is committed to the ground; how long it is till it afterward appears above it; when it comes into ear; and the period of harvest. Try also to ascertain the quantity of every kind of crop on the ground before it is cut down, and observe whether the event corroborates your judgment. In the same way, try to estimate the. weight of cattle by the eye at different pe riods of their progress toward maturity of condition, and check your tria] by measurements. The very handling of beasts for the purpose of meas uring them will convey to you much information regarding their progress ive state of improvement. When sheep are slaughtered, attend to the weight of the carcass, and endeavor to correct any errors you may have committed in estimating their weights.

(384.) Keep a register of each field of the farm; note the quantity of Iabor it has received, the quantity of manure which has been applied, and the kind of crop sown on it, with the circumstances attending these operations-whether they have been done quickly and in good style, or inters:uptedly, from the hinderance of the weather or other circur rnces; and (403) 
whether in an objectionable or favorable manner. Ascertain, in each field, the number of ridges required to make an acre, and whether the ridges be of equal length or not. By this you will the more easily ascertain how much dung the field is receiving per acre, the time taken to perform the same quantity of work on ridges of different length, and the comparative value of crop produced on an acre in difierent parts of the field. The sub. division of the field into acres in this manner will also enable you to compare the relative values of the crops produced on varieties of soil, if any, in the same field, under the same circumstances of treatment.

(385.) The easiest and most satisfactory mode of preserving and recording all these facts is in the tabular form, which admits of every fact being put down under its own proper head. This form not only exhibits a full exposition of the whole facts at a glance, but admits of every one being recorded with the least trouble of writing. The advantage of writing them down consists not entirely in recording them, but also of impressing them more strongly on the memory.

(386.) The tables should consist of ruled columns, in a book of sufficient size of leaf to contain columns for every subject. 'There should also be a plan of the farm, with every field represented, having its figure, dimensions, and name, the direction of the ridges, and the number of ridges required to make an acre visibly marked upon it. It would be advisable to enter each field into the book, in which could be noted the various sorts of labor it has received, and the produce it has yielded; so that the whole transactions connected with it for the year could be seen at a glance.There should also be a plan of the stack-yard made every year, with each stack represented in it by a circle, the area of which should contain the name of the field upon which the crop in the stack was grown, the quantity of corn yielded by the stack, and in what way the produce was disposed of; and even the cash (if any) which the produce realized, should be marked down. This plan of the stack-yard should be comprehended on a single page of the book.

(387.) To render the whole system of recording facts complete, a summary of them in regard to the weather in each season, together with the produce and value of the crop and stock, should be made up every year to the end of autumn-the end of the agricultural year. In this way, an immense mass of useful facts would be recorded within the narrow compass of a single book. Comparisons could thus be easily made between the results of different seasons, and deductions drawn which could not be ascertained by any other means.

(388.) The only objection you can possibly urge against the adoption of this plan is the time required to record the facts. Were the records to be made twice or thrice a day, like the observations of a meteorological register, the objection would be well founded; because I cannot conceive any task more irksome than the noting down of dry and (in themselves) unmeaning details. But the variations and effects of the weather assume a very different importance, when they possess an overruling influence over the progress of the crops. The recording of these and such like facts can only be required at occasional times, of perhaps an interval of days. The only toil connected with the scheme would be the drawing up of the abstract of the year; but when the task, even if irksome, is for your profes. sional benefit, the time devoted to it should be cheerfully bestowed. 


\section{SOILS AND SUBSOILS.}

"I wander o'er the various mural toil, And know the nature of each different soil."

GAT.

(389.) Having expatiated on every subject with which it seemed to mo expedient that you should be acquainted, to prepare your mind for the ret ception of lessons in practice, we shall now proceed together to study farm ing in right earnest. The first thing, as regards the farm itself, whic. should engage your attention, is the kinds of soil which it contains. ' 1 w become acquainted with these, so as to be able to identify them anywhere. you should know the external characters of every soil usually met with ou a farm; because very few farms contain only one kind of soil, and the gerrerality exhibit a considerable variety.

(390.) Practically, a knowledge of the external characters of soils is a matter of no great difficulty; for, however complex the composition of any soil appears to be, it possesses a character belonging to its kind, which cannot be confounded with any other. The leading characters of ordinary soils are derived from only two earths, clay and sand, and it is the grearer or less admixture of these which stamps the peculiar character of the soil. The properties of either of these earths are even found to exist in wnat seems a purely calcareous or purely vegetable soil. When either eartn is mixed with decomposed vegetable matter, whether supplied naturally or artificially, the soil becomes a loam, the distinguishing character of which is derived from the predominating earth. Thus, there are clay soils and sandy soils, when either earth predominates; and when either is mixed with decomposed vegetable matter, they are then clay loams and sandy loams. Sandy soils are divided into two varieties, which do not vary in kind, but only in degree. Sand is a powder, consisting of small, round particles of silicious matter; but when these are of the size of a hazel-nut and larger-that is, gravel-they give their distinguishing name to the soil ; they then form gravelly soils and gravelly loams. Besides these, there are soils which have for their basis another kind of earth-lime. of which the chalky soils of the south of England consist. But these differ in agricultural character in nothing from either the clay or sandy soils, according to the particular formation from which the chalk is derived. If the chalky soil is derived from flinty chalk, then its character is like that of a sandy soil; but if from the under chalk-formation, its character is like that of clay. Writers on Agriculture also enumerate a peat-soil, derived from peat; but peat, as crude peat, is of no use to vegetation, and, when it is decomposed, it assumes the properties of mould, and should be considered as such; and mould, which forms the essential ingredient of loams, is decomposed vegetable matter, derived either from Nature or from artificial application. So, for all practical purposes, soils are most conveniently divided into clayey and sandy, with their respective loams.

(391.) Loam, in the sense now given, does not convey the idea attached to it by many writers ; and many people talk of it as if it must necessarily consist of clay. Thus, Johnson, in defining the verb " to loam," gives as a synonym the verb "to clay;" and Bacon somewhere says that "the mellow earth is the best, between the two extremes of clay and sand, if it (405) 
be not loamy and binding ;" evidently referring to the binding property of clay. Sir Humphry Davy defines loam as "the impalpable part of the soil, which is usually called clay or loam." And Mr. Reid defines the same substance in these words: "The term 'loam' is applied to soils which consist of ahout one-third of finely-divided earthy matter, containing much carbonate of lime. Other soils are peaty, containing about one-half of vegetable matter." $\dagger$ Professor Low gives a more correct, though, in my opinion, not the exact idea of a loam. "The decomposed orgauic portion of the soil," he truly says, "may be termed mould; but he continues to say, and this is what I doubt, that "the fertility of soils is, coteris paribus, indicated by the greater or smaller proportion of mould which enters into their composition. When soils are thus naturally fertile, or are rendered permanently so by art, they are frequently termed loams." $\ddagger$ You thus see what diversity of opinion exists as to what loam is. Loam, in my opinion, has changed its meaning so far since the days of Johnson, as to consist of any kind of earth that contains a large admixture of decomposed regetable matter-I say a large admixture of vegetable matter, because there is no soil under cultivation, whether composed chiefly of clay or principally of sand, but what contains some decomposed vegetable matter. Lnless, therefore, the decomposed vegetable matter of the soil so preponderates as to greatly modify the usual properties of the constituent earths, the soil cannot in truth be called by any other name than a clayey or sandy soil; but when the regetable matter so prevails as materially to alter the properties of those earths, then a clay loam or a sandy loam is constituted-a distinction well known to the farmer. But, if it is necessary that clay should have a preponderance in loam, then a sandy loam must be a contradiction in terms. Again, a soil of purely vegetable origin-such as crude peat or leaf-mould-cannot be called loam; for admixture of an earth of some sort is required to make loam, under every recorded definition of that term. Nor is the fertility of soils dependent on the greater or smaller proportion of mould or decomposed regetable matter in their composition; for there are soils with apparently very little mould in them, such as sharp gravels, which are highly fertile; and there are moulds, apparently with very little earth in them, such as deaf black mould, which are far removed from fertility. Thus, then, all soils have the properties of clayey or sandy soils, and a considerable quantity of decomposed regetable matter converts them into loam. Hence it is possible for husbaudry to convert an earthy soil into a loam, as is exemplified in the vicinity of large towns.

(392.) A pure clay-soil has very distinctive external characters, by which you may easily recognize it. When fully wetted, it feels greasy to the foot, which slips upon it backward, forward, and sideways. It has an unctuous feel in the hand, by which it can be kneaded into a smooth homogeneous mass, and retain any shape given to it. It glistens in the sunshine. It retains water upon its surface, and makes water very muddy when mixed with it or runs over it, and is long of settling to the bottom. It is cold to the touch, and easily soils the hand and any thing else that touches it. It cuts like soft cheese with the spade, and is then in an unfit state to be worked with the plow, or any other implement. When dry, clay-soi] cracks into numerous fissures, feels very hard to the foot, and runs into lumps, which are often large, and both large and small are very difficult to be broken, and indeed cannot be pulverized. It soils the hand and clothes with a dry, light-colored, soft dust, which has no lustre. It is heary in

* Dary's Agricultural Chemistry, 8ro edit. 1839.

1 Low' Elements of Practical Agriculture, 2d edit

$\uparrow$ Reid's Chemistry of Nature. (406) 
weight, and difficult to labor. It absorbs moisture readily, and will adhere to the tongue. When neither wet nor dry, it is very tough, and soon becomes very hard with a little drouth, or very soft with a little rain. On these accounts, it is the most ticklish of all soils to manage; being, even in its hest state, difficult to turn over with the plow, and to pulverize with other implements. A large strength of horses is thus required to work a clay-land farm ; for its workable state continues only for a short time, and it is the most obdurate of all soils to labor. But it is a powerful soil, its vegetation being luxuriant, and its production great. It generally occurs in deep masses, on a considerable extent of flat surface, exhibiting only a few undulations. It is generally found near a large river, toward its estuary, being supposed to have been a deposition from its waters. Examples of this kind of soil may be seen in Scotland, in the Carses of Gowrie, Stirling, and Falkirk. It may be denominated a naturally rich soil, with little vegetable matter in it, and its color is yellowish-gray.

(393.) When a little sand and gravel are mixed with clay, its texture is very materially altered, but its productive powers are not improved. When such a clay is in a wet state, it still slips a little under the foot, but feels harsh rather than greasy. It does not easily ball in the hand. It retains water on its surface for a time, which is soon partially absorbed. It renders water very muddy, and soils everything by adhering to it; and, on that account, never comes clean off the spade, except when much wetted with water. When dry, it feels hard, but is easily pulverized by any of the implements of tillage. It has no lustre. It does not soil the clothes much, and, though somewhat heavy to labor, is not obdurate. When betwixt the states of wet and dry, it is easily labored, and can be reduced to fine tilth or mould. This kind of soil never occurs in deep masses, but is rather shallow; is not naturally favorable to vegetation, nor is it naturally prolific. It occupies by far the larger portion of the surface of Scotland; much of its wheat is grown upon it, and it may be denominated a naturally poor soil, with not much vegetable matter in it. Its color is yellowishbrown.

(394.) Clay-loam-that is, either of those clays mixed with a large proportion of naturally decomposed vegetable matter-constitutes a useful and valuable soil. It yields the largest proportion of the fine wheats raised in this country, occupying a larger surface of the country than the carse-clay. It forms a lump by a squeeze of the hand, but soon crumbles auwn again. It is easily wetted on the surface with rain, and then feels soft and greasy; but the water is soon absorbed, and the surface is again as soon dry. It is easily labored, and may be so at any time after a day or two of dry weather. It becomes finely pulverized, and is capable of assuming a high temperature. It is generally of some depth, forming an excellent soil for wheat, beans, Swedish turnips and red clover. It is of a deep-brown color, often approaching to red.

(395.) All clay-soils are better adapted to fibrous-rooted plants than to bulbs and tubers; but it is that sort of fibrous root which has also a taproot, such as is found in wheat, the bean, red clover, and the oak. The crops mentioned bearing abundance of straw, the plants require a deep hold of the soil. Clay-soils are generally slow of bringing their crops to maturity, which in wet seasons they never arrive at; but in dry seasons they are always strong, and yield quantity rather than quality.

(396.) A pure sandy soil is as easily recognized as one of pure clay. When wet, it feels firm under foot, and then admits of a pretty whole furrow being laid over by the plow. It feels harsh and grating to the touch. When dry it feels soft; and is so yielding, that every object of the least (407) 
weight sinks in it : it is then apt to blow away with the wind. In an ordinary state, it is well adapted to plants having fusiform roots, such as the carrot and parsnip. It acquires a high temperature in summer. Sandy soil generally occurs in deep masses, near the termination of the estuaries of large rivers, or along the sea shore; and in some countries in the interior of Europe, and over a large proportion of Africa, it covers immense tracts of flat land, and is evidently a deposition from water.

(397.) A gravelly soil consists of a large proportion of sand; but the greater part of its bulk is made up of small rounded fragments of rock brought together by the action of watex. These small firgments have heen derived from all the rock-formations, while the large bowlders, imhedded principally under the surface, have been chiefly supplied by the older formations. Gravelly deposits sometimes occupy a large extent of surface, and are of considerable depth. Such a soil soon hecomes warm, but never wet, absorbing the rain as fast as it falls; and after rain, it feels somewhat firm under foot. It can he easily labored in any weather, and is not unpleasant to work, though the numerous small stones, which are seen in countless numbers upon the surface, render the holding of the plow rather unsteady. As an instance of its dry nature, an old farmer of gravelly soil used to joke with his plowmen, and offer them a "roasted hen" to their dinner on the day they got their feet wet at the plow. This soil is admirably adapted to plants having bulbs and tubers; and no kind of soil affords so dry and comfortable a lair to sheep on turnips, and on this account it is distinguished as "turnip-soil."

(398.) Sandy and gravelly loams, if not the most valuable, are certainly the most useful of all soils. They become neither too wet nor too dry in ordinary seasons, and are capable of growing every species of crop, in every variety of season, to considerable perfection. On this account, they are esteemed "kindly soils." They never occur in deep masses, nor do they extend over large tracts of land, being chiefly confined to the margins of small rivers, forming haughs or holms, through which the rivers meander from their source among the mountains toward the larger ones, or even to the sea; and, in their progress, are apt at times to become so enlarged with rain, both in summer and winter, as to overflow their banks to a limited extent on either side.

(399.) These are all the kinds of soil usually found on a farm ; and of these, the two opposite extremes of the pure clay and the pure sand may most easily be recognized by you. The intermediate shades in the varieties of soil, occasioned by modificatious of greater or smaller quantity of decomposed vegetable matter, it would be impossible to describe. Every soil, however, may be ranked under the general heads of clayey and sandy soils; the gravelly and sandy, as you have learned, constituting differences rather in degree than in kind; and as every soil possesses the property of either clay or sand-be the sand derived from silicious or calcareous deposit-it is useless to maintain the nomenclature of chalky and peaty soils, although these distinctive terms may be retained to indicate the origin of the soils thereby implied by them.

(400.) You are now prepared to consider the question, what constitutes the soil-properly so called? You will perceive the propriety of such a question, when you consider the different ideas entertained of soil by persons of different denominations. The geologist considers the uppermost alluvial cove ng of the earth's crust as the soil, and whatever stratum that rests ipon, as the subsoil. The botanist considers as the soil that portion of the earth's surface which supports plants. People generally consider the ground they walk upon as the soil; but none of these ideas (408) 
define the soil in the agricultural scnse. In that sense, the soil consists only of that portion of the earth which is stirred by the plow, and the sub. soil of that which is found immediately below the plow's course. In this way the subsoil may consist of the same kind of earth as the soil, or it may be quice different, or it may be of rock. As it is of importance for you to keep this distinction of soil and subsoil always in mind, the subject should be illustrated by a figure. Let $a$, fig. 34 , be the surface of the

Fig. 34.

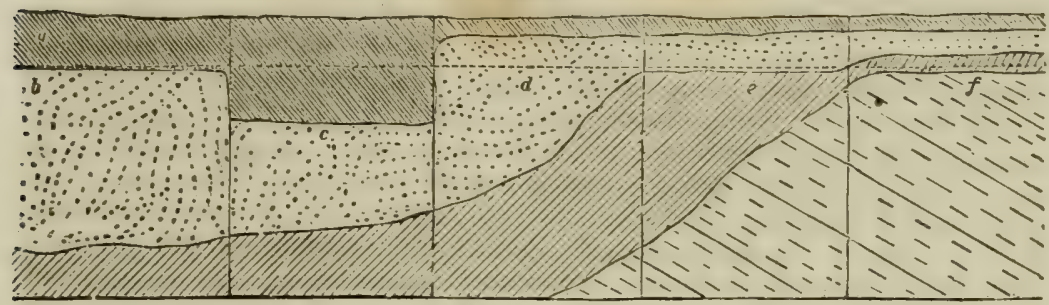

SECTIONS OF SOILS AND SUBSOILS.

ground, the earthy mould derived from the growth and decay of natura] plants; 7 , a dutted line, the depth of the plow-furrow. Now, the plow-sole may either just pass through the mould, as at $b$, when the mould will be the soil, and the earth below it the subsoil: Or it may not pass entirely through the mould, as at $c$, when the soil and subsoil will be similar, that is, both of mould: Or it may pass through the earth below the mould, as at $d$, when the suil and subsoil will again be similar, while neither will be monkl, but earth : $\mathrm{Or}_{r}$ it may move along the surface of $c$, when the soil will be of one kind of earth, and the subsoil of another, that is, either an open subsoil of gravel, or a retentive one of clay: Or it may move upon the surface of $f$, when the soil will be earth, or a mixture of clay, sand and mould, and the subsoil rock. These different cases of soil and subsoil are represented in the figure, each in a distinct sectional division.

(401.) The subsoil, then, in an agricultural sense, is the substance which is found immediately below the line of the course of the plow, be it earth or rock. However uniform in substance, or similar in quality, the subsoil and soil may have been at one time, cultivation, by supplies of vegetable matter, and by presentation of the surface to the action of the air, soon effects a material difference betwixt them, and the difference consists of a change both in texture and color, the soil becoming finer and having a darker tint than the subsoil.

(402.) The nature of the subsoil produces a sensible effect on the condition of the snil atrove it. If the soil is clay, it is impervious to water, and if the sulsoil is clay also, it is also impervious to water. The immediate effect of this juxtaposition is to render both soil and subsoil habitually wet, until the force of evaporation dries first the one and then the other. A retentive subsoil, in the same manner, renders a sandy or gravelly, that is a porous, soil above it habitually wet. On the other hand, a gravelly subsoil, which is always porous, greatly assists to keep a retentive clay soil dry.When a porous soil rests upon a porous subsoil, scarcely any degree of humidity can injure either. Rock may be either a retentive or a porous subsoil, according to its structure; its massiveness throughout keeping ovary soil above it habitually wet; but its stratification, if the lines of stratfcation dip downward from the soil (as at $f$, fig. 34 ), will keep even a reientive soil above it in a comparatively dry state.

(403.) These are the different conditions of st's und subsoils, considered (409) 
pracically. They have terms expressive of their state, which you should keep in remembrance. A soil is said to be stiff or heavy, when it is diffcult to cut through, and is otherwise laborious to work with the ordinary implements of the farm; and all clay soils are more or less so. On the other hand, it is light or free, when it is easy to work; and all sandy and gravelly soils, and sandy and gravelly loams, are so. A soil is said to ts wet, when it is habitually wet; and to be $d r y$, when habitually so. Ali soils, especially clays, on retentive subsoils, are habitually wet; and all soils on porous subsoils, especially gravels and gravelly loams, are habitially dry. Any soil that cannot bring to maturity a fair crop, without ar inordinate quantity of manure, is considered poor; and any one that does so naturally, or yields a large return with a moderate quantity of manure, is said to be rich. Thin, hard clays and ordinary sands are examples of poor soils; and soft clays and deep loams, of rich. A soil is said to be deep, when the surface-earth descends a good way below the reach of the plow; and in that case the plow may be made to go deeper than usual, and yet continue in the same soil; and a soil is thin, when the plow can easily reach beyond it. Good husbandry can, in time, render a thin soil deep; and bad, shallow plowing may cause a deep soil to assume the character of a thin one. A deep soil conveys the idea of a good one, and a thin, or shallow, or ebb, that of a bad. Carse clays and saidy loams are instances of deep soils, and poor clays and poor gravels those of thin. A soil is said to be a hungry one, when it requires frequent applications of a large quantity of manure to bear ordinary crops. Thin, poor gravels are instances of a hungry soil. A soil is said to be grateful, when it returns a larger produce than was expected from what was done for it. All loams, whether clayey, gravelly, or sandy-especially the two last-are grateful soils. A soil is said to be kindly, when every operation performed upon it can be done without doubt, and in the way and at the time desired. A sandy loam, and even a clay loam, both on porous subsoil, are examples of kindly soils. A soil is said to become sick, when the crop that has been made to grow upon it too frequently becomes detoriorated; thus, soils soon become sick of growing red clover and turnips. A sharp soil is that which contains such a number of small, gritty stones as to clear up the plow-irons quickly. Such a soil never fails to be an open one, and is admirably adapted for turnips. A fine, gravelly loam is an instance of a sharp soil. Some say that a sharp soil means a ready one-that is, quick or prepared to do anything required of it ; but I am not of this opinion, because a sandy loam is ready enough for any crop, and it is never caller a sharp soil. A deaf soil is the contrary of a sharp one ; that is, it contains too much inert vegetable matter, in a soft, spongy state, which is apt to be carried forward on the bosom of the plow. A deep, black mould, whether derived from peat or not, is an example of a deaf soil. A porous or open so1? and subsoil, are those which allow water to pass througl them freely and quickly, of which a gravelly loam and gravelly subsoil are examples. A retentive or close soil and subsoil retain water on them; and a clay soil upon a clay subsoil is an instance of both. Some soils are always hard, as in the case of thin, retentive clays when dry, let them be ever so well worked; while others are soft, as fine, sandy loams, which are very apt to become so on being too often plowed, or too much marled. Some soils are always fine, as in the case of deep, easy clay loams; oth srs coarse or harsh, as in thin, poor clays and gravels. A fine clay is smo th when $i_{1}$ a wet state, and a thin clayey gravel is rough when dry. A s 1 is said c are a fine skin when it can be finished off with a beautifully gr anulated surface. Good culture will bring a fine skin on nay soils, and rich sandy (410) 
and clay loams have naturally a fine skin; but no art can give a fine skin to some soils, such as thin, hard clay and rough gravel.

(404.) The colors of soils and subsoils, though various, are limited in their range. Black soils are instanced in crude peat and deep vegetable mould; and white are common in the chalky districts of England. Some soils are blue or bluish-gray, from a peculiar sort of fine clay deposited at the bottom of basins of still water. But the most prevailing color is brown, from light hair-brown to dark chestnut, the hazel-brown being the most favorite color of the class. The sand and gravel loams are instances of these colors. The browns pass into reds, of which there are several varieties, all having a dark hue; such, for instance, are some clay loams. The brown and red soils acquire high degrees of temperature, and they are also styled warm in reference to color. There are also yellow and gray soils, a mixture of which makes a yellowish-gray. They are always cold, both in regard to temperature and color ; and are the opposite, in these respects, to brown and red soils. Color is indicative of the nature of soils. Thus, all yellow and gray colors belong to clay soils. Gray sand and gray stones are indicative of soils of moory origin. Black soils are deaf and inert; the brown, on the other hand, are sharp and grateful, and many of them kindly; while the reds are always prolific. The color of subsoils is less uniform than that of soils-owing, no doubt, to their exclusion from culture. Some subsoils are very party-colored; and the more they are so, and the brighter the colors they sport, they are the more injurious to the soils above them : they exhibit gray, black, blue, green, bright red, and bright yellow colors. The dull red and the chestnut brown subsoils are good; but the nearer they approach to hazel brown the better. Dull browns, reds, and yellowish grays are permanent colors, and are little altered by cultivation; but the blues, greens, bright reds and yellows become darker and duller by exposure to the air and by admixture with manures.

(405.) These are all the remarks required to be made on soils, in as far as practice is concerned; but a great deal yet remains to be said of them as objects of natural history, and subjects of chemistry, and, above all, as the staple of the farm. Part of the natural history, and part of their chem istry, will appear in the paragraphs immediately below, and part of both will deserve our attention when we treat of the fertility of soils; but the management of soils will occupy our thoughts through every season.

(406.) The external characters of minerals established by Werner, and recognized by mineralogists, have never been used to describe agricultural soils. It would, perhaps, serve no practical purpose to do so ; becanse there are naturally such minute shades in the varieties of soils, and those shades are constantly undergoing changes in the course of good and bad modes of cultivation, that definitions, even when establishod, would soon become inapplicable. In respect, therefore, to a scientific classification of soils by external characters, there are as yet no data upon which to establish it, and the only alternative left is to adop such a division as I have endeavored to describe. In adopting that classification I have subt divided it into fewer heads than other writers on the same subject have done. In their subdivisions they include calcareous and peaty soils with the clayey and sandy. Practically,however, calcareous matter cannot be detected in ordinary soils; and, as to chalky soils themselves, their management is so similar to that of light and heavy ordinary soils, according to the formation from which they are derived, that no practical distinction, as I have said, need be drawn betwixt them; and in regard to peaty soils, when reduced to earth, which they easily are by cultivation, they partake of the character of mould. The kind of mould which they form you will learn when I come to treat of the fertility of soils.

(407.) In regard to the relation of soils to the subjacent strata, it is held by a recent practical writer on soils that "the surface of the earth partakes of the nature and color of the subsoil or rock on which it rests. The principal mineral in the soil of any district is that of the geological formation under it; hence we find argillaceous soil resting on the various clay formations-calcareous soil over the cnalk-and oolitic rocks and silicious soils, over the va rious sandstones. On the chalk the sul wite; wn the rarl sundstone it is red; and on tive 
sands and clavs the surface has nearly the same shade of culor as the subsoil." I In nut think that thi description of the position of soils is generally correct, because many instances occur to $\mathrm{m}$ r knowledge of great tracte of soils, including subsoils. having un relatinn th the "geological formation under them." The tine, strong, deep clay of the Carse of Guvvie rests on the old red sandstone, a rock having wothing in common, either in consistence or color, with the clay above it. The large extent of the gray sands of Barrie, and the great. gray gravelly deprosits of the valley of the Lunan. in Furfarshire, both rest on the same formation as the carse clay, namely, the old red sandstone: and so if numerous other examples in Scotland. In fact soils are frequently found of iufinitely diversified character, over extensive districts of rock. whose constitueuts are nearly uniform; and, on the other hand. soils of uniform character occur in districts where the underlying rocks are different as well in their chemical as their geological properties. Thus, an unifurm integument of clay rests upon the gray sandstone to the westward of the Carse of Gownie, in Perthshire, and the same clay covers the Ochil Hills in that county and Fifeshire with an uniform mante-over lislls which are entirely composed of trap. On the other hand, a diversified clay and gravel are found to cover an uniform tract of graywacke in l'ertshire. "We have gray sandstone," says Mr. Buist, aptly, when treating of the geology of the worth-east portion of l'erthshire, "red sandstone, and nock-marl. as it is called, cut by various massy veins of trap or beds of conrlomerate and lime; yet I defy any man to form the smallest guess of the rocks below from the soils above them, though the ground is sufficiently uniform to give fair scope for all to manifest the influence possessed by them. There are lands whose agricultural value has been so greatly modified by the presence or withrlrawal of a bed of gravel between the ara. lile suil and tilly subsoil, which. when present, affords a universal drain, when absent, leaves the land almost unarable. But if we must show a relation betwixt the sandstone and auy of these beds, which of the three," very properiy asks Mr. Buist, "are we to select as having affinity with the rock?"'t

(408.) In passing from practical to scientific opinion on the origin of soils, we find Mr. De la Beche giving his upiniun that "naturally soils are merely decomposed parts of the subjacent ruck, mixed with the decomposed portions of vegetable substances which have grown or fallen upon it, and with a propurtion of amimal substances derived from the droppings of creatures which have fed upon the regetation, from dead insects and worms which once inhabited the surface, and from the decumpusition of animals that have perished on the land, and which have not aitogether been removed by thuse quadrupeds, birds and insects that act as natural scavengers." + This view of the origin of soils seems to corroborate the opiuion of Mr. Iotron. quoted above; but if you look more clusely into the definitions of the terms nsed by buth writers, you will find there is not that identity of opinion between them which appears at first sight. For "the term rock." says Mr. De la Beche, "is applied by geologists, not only to the hard substances to which this uame is commonly giveu, but aiso to those variuns sandis, gravels, shales, marls, or clays, which furm beds, strata, or masses." Tl Taking this correct geulugical definition of rock. Mr. De la Beche's view is quite conect in re. gard to agricullural soils, for they certainly are decompused portions of the ruck, geologically speaking-that is, of thuse " sands, gravels, or clays," upon which they rest; but the inuression leit on the nind of the reader on perusing Mr. Mortou's account of the origin of suils, is tiat the rocky strata. commonly so called, because iudurated, became decomposed to form ssil: and his reference to the various gevlugical formations of England, in explauation of the soils fond above them. warrant the correctness of this impression; but it is this very impression which I wish tn remove from yuur minds, because it conveys, in my opinion, an emvuerus idea of the origin of soils.

(409.) Wu doubt the chernical action of the air, and the physical force of ram, firost, and wiud, pruduce visible effiects upwn the must indurated rocks, but, of course, much greater effects upun incuherent rucks. We know that the action of these agents loads the waters of the Ganges with detritus to the extent of $2 \frac{1}{2}$ per cent. of their volume, which is an enurmous quantity when we cunsider that the water discharged by that river into the sea is 500,905 cubic feet per secund, although this amount fails far short of Major Rennel's statement of 25 per cent. : yet these agents have nut had sufficient power to accumulate, by heir own action un indurated rocky strata. all the deposits of clay, gravel, and sand, found accumulater wo the depth of many feet. Consbined in their action, they could ouly originate a mers $0: 1 \cdot 1 \cdot g$ of soil over the surface of indurated rock, if the rock were situated within the region wf int?-

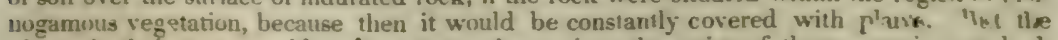
plants, in theil zin, would protect $2 \omega \geqslant$ rocks against the action of thos quncies, and, although they cuild not entirely prevent, they could at least retand, the accumulation of soil beyond what the decay of vegetation supplied. Even in the urpics, where vegetation displays its greatest luxuriance on the globe, the mould dues not increase, though the decay of regetables every year is enormous. "Tito quantity of timber and vegetable matter which grows in a trupical forest in the course of a cantury," says Mr. Lyell, " is enormus, und multitudes of animal skeletons are scattered there during the same period, besides imumerable 
land shells and other organic substances. The aggregate of these materials, therefore, might constitute a mass greater in volume than that which is produced in any coral-reef during the same lapse of years; but, although this process should continue on the land for ever, no mountains of wood or bone would be seen stretching far and wide over the country, or pushing out bold promontories into the sea. The whole solid mass is either devoured by animals, or decomposes, as does a portion of the rock aal soil (into their gaseous constituents) on which the animals and plants are supported. $\because$ These are the causes of the prevention of the accumulation of soils in the tropics. In colder regions a similar result is thus brought about. "It is well known," continues Mr. Lyell, "that a covering of herbage and shrubs may protect a loose soil from being carried away by rain, or even by the ordinary action of a river, and may prevent hills of loose sand from being blown away by the wind; for the roots bind together the separate particles into a firm mass, and the leaves intercept the rain-water, so that it dries up gradually, instead of flowing off in a mass and with great velocity." $\dagger$

(410.) Some other agent, therefore, more powerful than the ordinary atmospherical elements, must be brought to bear upon indurated rocks, before a satisfactory solution of the formation of soils can be given. This other agent is water; but the moment that we assent to the agency of water being able by its great abrasive power and great buoyant property, when in motion, to transport the abraded parts of rocks to a distance, and let them fall on coming in contact with some opposing barrier, that moment we must abandon the idea of soils having been universally derived from the indurated rocky strata upon which they are found to rest. I quite agree with $\mathrm{Mr}$. Buist in the conclusions he has drawn in regard to soils, after he had described their relative positions to the rocks upon which they rest in a large and important district of Perthshire, where he says, "that the alluvial matters of these districts, in general, belong to periods much more remote than those ordinarily assigned to them, and came into existence under circumstances prodigiously different from those which presently obtain : that the present causes-that is, the action of our modern rivers, brooks, and torrents, and of the air and water on the surfaces now exposed to them-have had but little share in modifying our alluvial formations, or bringing them into their present form. The doctrine seems to me most distinctly demonstrable, that wherever gravel or clay beds alternate with each other, and wherever bowlder stones prevail remote from the parent rock, or cnt off from it by high intervening ridges, that, at the time when the surface of the solid rock became covered with such alluvium, much the greater part of it was hundreds of feet beneath the waves. The supposition of the prevalence of enormous lakes, requiring barriers only less stupendous than our highest secondary mountain-ranges, whose outbursts must have swept every movable thing before them, seems far more untenable than the assumption that the present dry land, at the era of bowlders being transported, was beneath the level of the ncean, from which, by slow elevations, it subsequently emerged. Our newer alluvia, again, which are destitute of erratic bowlders in general, such as our Carse of Gowrie and other clays, must have originated when the sea occasionally invaded the land to such moderate extent that the transportation of rocky masses, from great distances from our mountain-land, had been rendered impossible, by the intervention of elevated ridges, or of secondary mountainranges." $\ddagger$ More than this, is it not probable that, when the stratified rocks were being deposited in water, portions of the matter of which they were about to be formed were carried away by currents, and, by reason of the motion given them, were deposited in eddies in a mechanical state, instead of getting leave to assume the crystaline form of indurated stratified rock? May not all diluvium have thus originated, instead of being abraded from solid strata, although it is possible that some portion may have been derived from the abrasion of rocks? It is also quite conceivable that where indurated rocks, such as chalk, and sandstone, and limestone, were left bare by the subsiding waters, and exposed to atmospherica. influences, part of the soil upon them may have been derived at first immediately from them.

(411.) The soil, or incoherent rocks, when complete in all their members, consist of three parts. The oldest or lowest part, not unfrequently termed diluvium, but which is an objectionable term, inasmuch as it conveys the idea of its having been formed by the Noachian deluge, which it may not have been, but may have existed at a much older period of the globe. This cannot be called alluvium, according to the definition of that deposit given by Mr. Lyell, who considers it to consist of "such transported matter as has been thrown down, whether by rivers, floods, or other causes, upon land not permanently submerged beneath the waters of lakes or seas-I say permanently submerged, in order to distinguish between alluviums and regular subaqueous deposits. These regular strata," he continues, "are accumulated in lakes or great submarine receptacles; but the alluvium is in the channels of rivers or currents, where the materials may be regarded as still in transitu, or on their way to a place of rest." $\|$ Diluvium, therefore, should rather be termed subaquebus deposits, and may consist of clay, or gravel, or sand, in deep masses and of large extent. It may, in fact, be transported materials, which, it they had been allowed to remain in their

* Lyell's Principles of (ieology, vol. iii. † Ibid.

$\ddagger$ Prize Essays of the Highland and Agricultural Society of Scotland, vol. xiii.

Lyell's Principles of Geclogy, vol. iii.

(413) 
original site, would have formed indurated aluminous and silicious moks. When such subaqueous deposits are exposed to atmospherical influences, an arable soil is easily formed upion them.

(412.) True alluvial deposits may raise themselves by accumulation above their depositing waters, and art can assist the natural process, by the erection of embankments against the encroachments of these waters, and by the casting out of large ditches for carrying them away, as has been done in several places in the rivers and coasts of our country. Atmospherical influences soon raise an arable soil on alluvium.

(413.) The third member of soils is the upper mould, which has been directly derive? from vegetation, and can only come into existence after either of the other soils has been placed in a situation favorable for the support of plants. Mould, being in contact with air, always exists on the surface, but when either the subaqueous deposit or the alluvium is wanting, the mould then rests upon the one present; or both may be wanting, and then it rests upon the indurated rocky strata.

(414.) When the last case happeus. if the rocky stratum is porous, by means of numerous fissures, or is in inclined beds, the arable soil is an earthy mould of good quality for agricul. tural purposes; such as are the moulds upon sandstones, limestones, and trap, and the upper chalk formation; but if it rest on a massive rock, then the mould is converted into a spongy, wet pabulum for subaquatic plants, forming a marsh, if the site is low, and if high, it is converted into thin peat; and both are worthless soils for Agriculture. When the mould rests immediately upon clay subaqueous deposit, a coarse and rank vegetation exists upon it, and if the water which supports it has no opportunity of passing away, in time a bog is formed by the cumulative growth of the subaquatic mosses.* When mould, on the other hand, is formed on gravelly deposit, the vegetation is short, and dry, and sweet, and particularly well adapted to promote the sound feeding and heaith of sheep. On such cieposits water is never seen to remain after the heaviest fall of rain. When mould rests on alluvial deposit of whatever nature, a rich soil is the consequence, and it will be naturally dry only when the deposit is gravelly or sandy.

(415.) Mr. De La Beche seems to think that farmers do not know the reason why subsoils are favorable or unfavorable to the soil upon them. $t$ I suspect they know more about them than he is aware of. They know quite well that a dry subsoil is more favorable to A griculture than a retentive one; that gravel forms a drier subsoil than clay; and that the reason why these results should be so is, that clay, or a massive rock, will not let water pass through it so easily as gravel, and I presume no geologist knows more of the matter.

(416.) [We must now observe soils and subsoils in another point of view. A practicai outline of the characters of various soils, and the manner in which they may be distinguished one from another, having been already pointed out to you, my intention now is, to consider them scientifically, for the purpose of preparing your minds for following me through the mazy windings of theoretical A griculture, as developed by the joint application of chemistry, mechanical philosophy, and vegetable physiology. Although, to the contemplative and still more to the speculative student, this branch of the subject will exhibit the greatest charms, still I beg you to bear in mind continually, that it is with practice you have to do, and that theory must only be used cautiously as an adjunct to well-studied und assiduously-applied practical knowledge; and although, by so doing, I fully believe you will not only increase greatly your interest in the whole matter, but will likewise proceed with more rapid strides iu the progress of improvement, I feel equally satisfied that an opposite course, viz. the study of theory antecedent to the application of practice, will almost invariably be productive of just the opposite effects, viz. the retardation of your real advance in knowledge, and will. moreover, make you run a rea $t$ risk of becoming speculative men, than which uothing can be more inimical to real improvement.

(417.) Soil, considered scientifically, may be described to be essentially a mixture of an impalpable prowder with a greater or smaller quantity of visible partic'es of all sizes and shapes. Careful examination will prove to us, that although the visible particles have several indirect effects, of so great importance that they are absolutely necessary to soil, still the impalpabie powder is the only portion which directly exerts any influence upon vegetation. This impalpable powder consists of two distinct classes of substances, viz. inorganic or mi:s ral matters, and animal and vegetable substances, in all the various stages of decompositiori.

(418.) A very simple method may be euployed to separate these two classes of particles from each other, viz. the impalpable powder and the visible particles; and, in so doing, we obtain a very useful index to the real value of the soil. Indeed all soils, except stiff clays, can be discrimiuated in this mamer. The greater the proportion of the impalpable matter, the greater, cateris paribus, will be the fertility of the soil. (438.)

(419.) To effect this separation, the following easy experiment may be performed Take a glass tube about 2 feet long, closed at one end; fill it about half full of water, and shake into it a sufficient quantity of the soil to be examined to fill the tube about 2 inches from the bottom; then put in a cork, and having shaken the tube well to mix the earth and water

* For an account of the origin of Boge, see Aiton on Moss.

$\checkmark$ De La Beche, How to observe Geology.

(414) 
thoroughly, set the tube in an upright position, for the soil to settle down. Now, as the larger particles are of course the heavier, they fall first, and form the undermost layer of the deposit, and so on in regular gradation, the impalpable powder being the last to subside, and hence occupying the uppermost portion. Then by examining the relative thickness of the various layers, and calculating their proportions, you can make a very accurate mechanical analysis of the soil.

(420.) The stones which we meet with in soil have in general the same composition as the soil itself, and hence, by their gradually crumbling down under the action of air and moisture, they are continually adding new impalpable matter to the soil, and as I shall show you hereafter the large quantity of this impalpable mineral matter which is annually removed by the crops, you will at once perceive that this constant addition must be of great value to the soil. This, therefore, is one important function performed by the stones of soil, viz. their affording a continually renewed supply of impalpable mineral matter.

(421.) When we come to consider the nourishment of plants, we shall find that their food undergoes various preliminary changes in the soil previous to its being made use of by the plants, and the aid of chemistry will prove to us that the effect is produced by the joint action of air and water ; it follows, therefore, that soil must be porous. Now, this porosity of the soil is in part produced by the presenct of the larger particles of matter, which, being of all varieties of shape, can never fit closely together, but always leave a multitude of pores between them; and in this manner permit of the free circulation of air and water through the soil.

(422.) As the porous nature of soil may, to a certain extent, be taken as an index of its power of retaining moisture, it is advisable to determine its amount. This is effected in the following way: Instead of putting the water first into the tube, as directed above (419), and shaking the soil into it, take a portion of soil dried by a heat of about $200^{\circ} \mathrm{F}$. and shake it into the dry tube, and by tapping the closed end frequently on the table, make the soil lie compactly at the bottom; when you have fully effected this, that is, when farther tapping produces no reduction of bulk, measure accurately the column of soil, cork the tube, shake it till the soil becomes again quite loose, and then pour in the water as directed above (419.) After it has fully subsided, tap the tube as before, and re-measure; the increase of bulk is dependent upon the swelling of each particle by the absorption of water, and hence shows the amount of porosity. In very fertile soil I have seen this amount to one-six th of the whole bulk.

(423.) The functions of the impalpable matter are far more complicated, and will require a somewhat detailed description. In this portion of the soil the mineral and organic matter are so completely united that it is quite impossible to separate them from each other; indeed, there are very weighty reasons for believing that they are chemically combined. It is from this portion of the soil that plants obtain all their mineral ingredients, and likewise all their organic portions, in so far as these are obtained by the ronts; in fact, plants receive nothing from the soil, except water, which has not been associated with that portion which is at present engaging our attention.

(424.) The particles forming the impalpable matter are in snch close apposition that the whole acts in the same way as a sponge, and is hence capable of absorbing liquids and re taining them. It is in this way that soil remains moist so near the surface even after a long continued drouth; and I need not tell you how valuable this property must be to the plants, since by this means they are supplied with moisture during the heat of summer, when otherwise, unless artificially watered, they would very soon wither.

(425.) Another most useful function of this impalpable portion is its power of separating organic matter from water in which it has been dissolved. Thus, for example, if you take the dark brown liquid which flows from a dunghill, and pour it on the surface of some earth in a flower pot, and add a sufficient quantity to soak the whole earth, so that a portion flows out through the bottom of the pot, this latter liquid will be found much lighter in color than before it was poured upon the earth, and this effect will be increased the nearer the soil approaches in its nature to subsoil. Now, as the color was entirely owing to the organic matter dissolved in it, it follows that the loss of color is dependent upon an equivalent lnss of organic matter, or, in other words, a portion of the organic matter has entered into chemical combination with the impalpable mineral matter, and has thus become insoluble in water. The advantage of this is, that when soluble organic matter is applied to soil, it does not all soak through with the water and escape beyond the reach of the roots of the plants, but is retained by the impalpable portions in a condition not liable to injury from rain, but still ca pable of becoming food for plants when it is required.

(426.) Hitherto I have pointed out merely the mechanical relations of the various constituents of soil, with but little reference to their chemical constitution; this branch of the subject, although by far the most important and interesting, is nevertheless so difficult and complex that 1 cannot hope for the practical farmer doing much more than making himself familiar with the names of the various chemical ingredients, and learning their relative value as respects the fertility of the soil; as to his attempting to prove their existence in his own soil by analysis, I fear that is far too difficult a subject for him to grapple with, unless regularly educated as an analytical chemist. 
(427.) Soil, to be useful to the British agriculturist, must contain no less than 12 different chemical substances, viz. silica, alumina, oxide of iron, oxide of manganese, lime, magnesia, putass, sodla, phosphoric acid, sulphuric acid, chlorine, and organic matter : each of these substances must engage our attention shortly: and as I by no means purpose to burden your memuries by relating all the facts of interest cnnnected with them, I shall confine my obser vations almost sulely to their relative importance to plants, and their amount in soil.

(428.) Silica. This is the pure matter of sand, and also constitutes on an average about 60 per cent. of the sarious clays; so that in soil it generally amounts to from 75 to 95 per cent. In its uncombined state, it has no direcl influence upon plants, beyoud its mechanical action, in supporting the rnots, \&c.; but, as it possesses the properties of an acid, it unites with varions alkaline matters in the soil, and produces compounds which are required in greater or less quantity by every plant. The chief of these are the silicates of polass and soda. by which expression is nieant the compounds of silica, or, more properly, silicic acid with the alkalies potass and soda.

(429.) Alumina. This substance never exists pure in soil. It is the characteristic ingredient of clay, althnugh it exists in that compound to the extent of only 30 or 40 per cent. It exerts no direct chemical intluence on vegetation, and is scarcely ever found in the ashes of plants. Its chief value in soil, therefore, is owing to its effects in rendering soil more retentive of moisture. Its amount varies fiom $\frac{1}{2}$ per cent. to 13 per cent.

(430.) Oxide of Iron. There are two oxides of iron found in sorils, namely, the protoxide and peroxide; one of which, the protoxide, is frequently very injurious to vegetation-indeed, so much so, that per cent. of a soluble salt of this oxide is sufficient to render soil almost barren, The peroxide, however, is often found in small quantities in the ashes of plants. The two oxides together constitute from to 10 per cent. of soil. The blue, yel low, red and brown culors of soil are more or less dependent upou the presence of iron.

(431.) Oxide of Manganese. This oxide exists in nearly ail soils, and is occasionally found in plants. It dues not, however, appear to exert any important influence either me chanically or chemically. Its amount varies from a mere trace to about $1 \frac{1}{d}$ per cent. It a sists in giving the black color to soil.

(432.) These 4 substances constitute by far the greatest bulk of every soil, except the chalky and peaty varieties, but, nevertheless, chemically speaking, are of trifling importanco to plants; whereas, the remaining 8 are 80 absolutely essential that no soil can be cultivated with any success unless provided with them, either naturally or artificially. And when you consider that scarcely any of them constitute 1 per cent. of the soil, you will no doubt at first be surprised at their value. The sole cause of their utility lies in the fact that they constitute the ashes of the plants; and as no plant can, by possibility, thrive without its inorganic con stituents (its ashes), hence no soil can be fertile which does not contain the ingredients of which these are made up. I shall not treat of each separately, but will furnish you with one or two analyses of soil to show their importance, and to impress them more fully on your memory. I regret that I must look to foreign works to furnish these analyses; but the truth is, we have not one single published analysis of British soil by a British chemist which is worth recording. Sir Humphry Davy just analyzed soil to determine the amount of the first 4 substances meutioned, and one or two others, and failed to detect 5 or 6 of the most import. ant ingredients. In fact, the only useful analyses we possess are those performed by Spren. gel, and quoted in Dr. I,yon Playfair's second edition of Liebig's Organic Chemistry applied to Agriculture, from which valuable work I quote the following examples.

(433.) Analysis of a very fertile alluvial soil from Honigpolder. Corn had been cultivated upon this soil for 70 years without any manure having been applied to it, but it was now and then allowed to lie fallow:

Eilica with fine silicious sand ..........................64.800

Alumina ............................................. 5.700

Peroxide of iron........................................... 6.100

.. manganese ............................... 0.090

Lime ................................................... 5.880

Magnesia ........................................... 0.840

Potass combined with silica................................. 0.210

Soda combined with silica............................... 0.393

Sulphuric acid combined with lime............................ 0.210

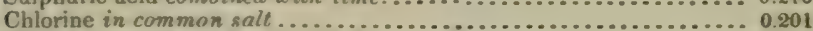

Phosphoric acid combined nith lime...................... 0.430

Carbonic acid combined with lime............................... 3.920

Organic $\{$ Humus ............................................. 5.600

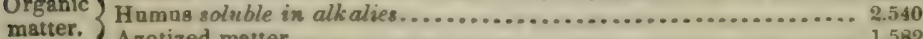

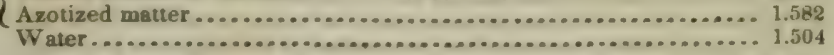

$\overline{100.000^{*}}$

Jiebig's Organic Chemistry applied to Agrieulture, $2 d$ edit.

(4)6) 
434.) Alluvial soil from Ohio, remarkable for its fertility-

Silica with fine silicious sand ............................... 79.538

Alumina ............................................. 7.306

Protoxide and peroxide of iron, with mnch magnetic iron-sand.... 5.824

Peroxide of manganese ................................. 1.320

Lime ................................................. 0.619

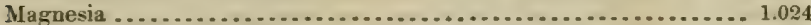

Potass combined with silica ............................. 0.200

Soda ............................................... 0.024

Phosphoric acid combined with lime and iron.................. 1.7.6

Sulphuric acid combined with lime ........................ 0.122

Chlorine in common salt ............................... 0.036

Organic (Humus soluble in alkalies............................... 1.950

Organic $\{$ Humus with azotized matter............................... 0.236

Resinous matter and wax ................................... 0.025

100.000

(435.) Loamy sand from the environs of Brunswick, very barren-

Silica with coarse silicious sand .............................95.843

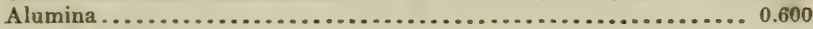

Peroxide of iron ............................................ 1.800

Peroxide of manganese ..................................... trace.

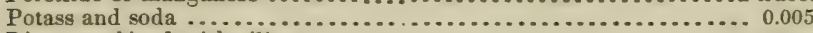

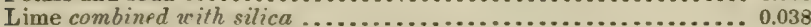

Magnesia combined with silica........................... 0.006

Sulphuric acid.......................................... 0.002

Phosphoriv acid combined with iron...................... 0.198

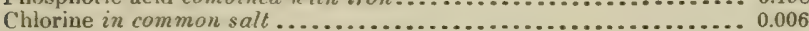

Organic $\{$ Humus ............................................. 0.502

matter, $\{$ Humus soluble in alkalies ...................................... 1.000

100.000

Here the sterility is evidently produced by the small amount of potass, soda, lime, magne sia, and sulphuric acid-all of which are essential for the ashes of most of our usually cultivated crops.

(436.) These analyses will give you some idea of the complex nature of the soil, and the necessity of most minute analysis if we wish to ascertain its real value. The reason for such minuteness in analysis becnmes obvious when we consider the immense weights with which you have to do in practical Agriculture : for example, every imperial acre of soil, considered as only 8 inches deep, will weigh 1884 tons, so that 0.002 per cent. (the amount of sulphuric acid in the barren soil) amounts to $80.64 \mathrm{lbs}$. per imperial acre.

(437.) I have purposely avoided saying anything of the organic matter of soil, as this is a most complicated subject, and will be far better considered under the head of manures.

(438.) All these substances, except the silica contained in the form of sand, constitute the impalpable matter of soil. It is evident, therefore, that this may differ much in chemical constitution without differing in amount, and yet have the greatest influence upon the fertility of the soil ; my design, therefore, of introducing the words "cateris paribus" in paragraph (418) was to induce you to bear in mind that the statement refers solely to soil considered mechanically. For fear of being misunderstood, therefore, I would paraphrase the sen tence thus: IVithout a certain amount of impalpable matter, soil cannot possibly be fertile, yet, while the existence of this material proves the soil to be mechanically well suited for cultivation, chemical analysis alone can prove its absolute value to the farmer.

(439.) Potass and soda exist in variable quantities in many of the more abundant minerals, and hence it follows that their proportion in soil will vary according to the mineral which produced it. For the sake of reference, I have subjoined the following table, which shows the amount per cent. of alkalies in some of these minerals, and likewise a rough calcnlation of the whole amount per imperial acre in a soil composed of these, supposing such a soil to be 10 inches deep.

\begin{tabular}{|c|c|c|c|}
\hline Name c & $\begin{array}{l}\text { Amount per cent. } \\
\text { of Alkali. }\end{array}$ & Name & $\begin{array}{l}\text { Amount per Imperial Acre } \\
\text { in a soil } 10 \text { inches deep. }\end{array}$ \\
\hline & 17.75 & & 927,360 lbs. \\
\hline & 3.31 to & $\mathrm{Pc}$ & 161.000 to 32 \\
\hline & 2.75 to 3.31 & $\mathrm{Po}$ & 80,500 to 161 \\
\hline & 5.75 to 10 . & Potass and Soda & 37,887 to $56.875 \mathrm{lb}$ \\
\hline
\end{tabular}

(440.) From the above table you see the abundant quantities in which these valuable substances are contained in soil; some, however, of you, who are acquainted with chemistry, will naturally ask the question, How is it that these alkalies have not been long ago washed away by the rain, since they are both so very soluble in water? Now the reason of their not having been dissolved is the following; and it may in justice be taken as an example of

$(417) \ldots \ldots 15$ 
those wise provisions of Nature, whereby what is useful is never wasted, and yet is at all times supplied abundantly.

(441.) These alkalies exist in combination with the various other ingredients of the rock in which they oceur, and in this way have such a powerful attraction for each other that they are capable of resisting completely the solvent action of water so long as the integrity of the mass is retained. When, however, it is reduced to a perfectly impalpable powder, this attraction is diminished to a considerable extent, and then the alkali is much more easily dissolved. Now this is the case in soil; and, consequently, while the stony portions of soil contain a vast supply of these valuable ingredients in a condition in which water can do them no injury, the impalpable powder is supplied with them in a soluble state, and hence in a condition available to the wants of vegetation.

(442.) In the rocks which we have mentioned, the alkalies are always associated with clay, and it is to this substance that they have the greatest attraction; it follows, therefore, that the more clay a soil contains, the more alkalies will it have, but at the same time it will yield them less easily to water, and through its medium to plants.-H. R. M.]

\section{PLANTING OF THORN-HEDGES.}

"Next, fenc'd with hedges and deep ditches round, Exclude th' encroaching cattle from thy ground."

DRYDEN'S VIRGIR.

(443.) Iммерiately in connection with the subject of inclosures is the construction of the fences by which the fields are inclosed. There ar only two kinds of fences usually employed on farms, namely, thorn-hedg and stone-dykes. As winter is the proper season for planting, or runnin, as it is termed, thorn-hedges, and summer that for building stone-dykes, I shall here describe the process of planting the hedge, and defer the description of building the dyke until the arrival of the summer season. It may be that the farm on which you have entered as a pupil, or that which you liave taken on lease, may not require to be fenced with thorn-hedges. Still it is requisite that you should be made acquainted with the best mode of planting them.*

[* The dryness of our soil and climate, and yet more the want of persistence which characterizes American agriculturists, and which is so particularly requisite in the formation of a good hedge, will render the rearing of hedges a work of very limited extent and of doubtul success. Moreover, the liability of all estates to be again and again divided and subdivided, will cooperate with other reasons to the same eud. Still, they answer well and are highly ornamental for small inclosures, and for that purpose we are inclined to believe the Maclura, or Osage Orange, will prove valuable as it is beautiful, as any one may see at Mr. Cushing's, near Boston.

As an agricultural topic, we confess we do not regard it as one of general interest, and might have omitted it altogether but for reasons already alleged, in similar cases. The subscriber who reflects that in Stephens's Book of the Farm he is getting a work that would cost him more than $\$ 20$, will be content to put up with some things that may not have for him immediate value.

On large estates in the South, everything forbids the expectation that hedges will ever be resorted to as division fences; and on small ones in the North, stone supplies a more convenient material. Besides, we anticipate the extension of the soiling system, of which one great benefit will be, that cross fences may be dispensed with, and thus one of the greatest burdens on Agriculture be shaken off.

In the old American Farmer much may be found on the subject of hedges. It was very fully treated oy Caleb Kirk, an intelligent practical Quaker farmer of Delaware. But what is now needed to be known by American cultivators who are disposed to make experiments in hedging, is well condensed in the following article from that popular and excellent periodical, the old Albany Cultivator:

Hedees for America.-A great difference of opinion exists in relation to hedges for this country. There have been some very successful attenpts, and there have also been many failures. An examination into the causes of this difference of success, in actual experiments, will doubtless be of use, and enable us to judge whether hedges possess advantages over other kinds of fence (418) 
(444) The proper time for planting thorn-hedges extends from the fall of the leaf, in autumn, to April, the latter period being late enough. 'The state of the ground usually chosen for the process is when in lea. I recom-

in any case. We lately examined several specimens of successful hedge-making. A part of them were made by John Robinson, of Palmyra, N. Y., a vigorous and enterprising English farmer, whose experiments are of several years' continuance. He has over a hundred rods of hedge in different stages of growth, the management or treatment of which appears to be particularly worthy of attention.

The young thorns are set out in the hedge-row at two years of age, after which they are cut off at the surface of the ground the first year, to cause a thick growth of sprouts; they are again cus off the second year, from four to six inches from the ground, according to their hight and vigor. which causes a second crop of thick sprouts at that hight; the third year they are cut off six or eight inches higher. and so on, rising about at that rate until the hedge is five or six feet bigh. This mode of treatment, which is well known and often practiced in England, obviates the necessity of plashing, if it is successfully performed; the successive crops of thick sprouts thus occasioned, densely interlace each other, and the hedge becomes a thick mass of entangled shoots and branches, which cannot be separated. It is in fact precisely similar to the process of felting, but on a larger scale; and when the best specimens thus grown are forcibly shaken at any point, whole rods on either side are shaken with it as in one mass. This felting property thus becomes of more value by far, to the impregnability of the hedge, than the thorns.

One hedge had received three different modes of treatment. A part had been imperfectly cultivated; another portion had been well cultivated for a distance of two feet on each side ; and a third stood on ground wbich was trenched two feet deep before planting. The growth of the second was twice as great as the first, and of the trenched portion still greater. Indeed, one may as well think of raising corn by planting a row in a thick meadow, as to raise a good hedge without keeping the soil constantly mellow about the young trees. A space two feet wide on either side of the hedge is the distance usually kept cultivated.

From six to eight years are needed to make a good, substantial hedge, proof against cattle.

These hedges are set on a bank about eighteen inches above the surface, with a ditch two feet deep serving to carry off surface water on one side. The plants are set six inches apart. If
closer, they do not grow so well.

The greatest difficulty which J. Robinson finds, is protecting the young hedge for several years, until it is proof against cattle. For, although it may be placed along the side of a fence, next to crops, or meadow, yet in the course of rotation it is thrown into pasture, and is thus endangered. A longer course of alternating crops would be the remedy in usual cases.

Hedges for plashing are not subjected to the successive shortening down which has been just described; but the young stems are suffered to grow until several feet high and an inch or more in diameter, when they are cut partly off near the ground and bent over to an angle of forty-five degrees in the direction of the line of the hedge. A thick growth of branches is not needed before this operation. All the large branches should be cut off at the time, but not closely. Young shoots afterward ascend, and growing upright, form cross-bars with the main stems which have been bent over, and interlocking with them produce a sort of lattice-work possessing ultimately great strength. A small portion of the trees are not bent, but remain upright, to stiffen the rest, and slender poles are run along the top, alternating with them, to keep them to their place until the whole is firmly established. These poles being green and of perishable wood, cost little, and rot out when they are no longer needed.

The selection of suitable trees for forming hedges, is of the very first importance. One great reason, without any doubt, why so many have failed in their experiments, is bad selection, or a want of adaptation of certain species to the climate where they were used. The English hawthorn has been found entirely unsuited to most parts of the United States. At Newburgh, accord. ing to A. J. Downing, "its foliage becomes quite brown and unsightly after the first of August." $\mathrm{He}$ also remarks that it is there extremely liable to the attacks of the borer. Farther south, where the summers are longer and dryer, and consequently more dissimilar to those of England, it is of no value whatever. But in the cooler summers of Western New-York, and where, perhaps, the soil may exert also a favorable influence, it has continued to flourish in well-managed hedges for many years. All the hedges of John Robinson, already described, are of this species; a very vigorous hedge, on the grounds of John Baker of Macedon, N. Y., is of the same. We had supposed that moist, rich land wonld be better suited to this thorn than dry upland; but in the experiments of these intelligent farmers it has been found that good fertile upland is incomparably

The sudden failures, however, of this thorn, in some places farther south, should induce its cantious use on a large scale, especially while American species have been found in most parts of the country so much superior. The Washington thorn, (Cratogus cordata) is preferred by some, and possesses the advantage of the seeds vegetating freely the first year. But in Pennsylvania and Delaware, where both this and the Newcastle thorn ( $C$. crus-galli) have been extensively used for many years, the latter has in all cases been found so decidedly superior in hardiness, vigor and freshness of growth, to the former, as to give it eminently the preference. Indeed, the Newcastle thorn appears to be the only American species extensively tried, which has, in all cases whatever, proved to be eatirely free from all disease or defect. It is not improbable, however, that the $W$ ashington thorn may succeed finely so far north as northern or western New.York, where the English species is itself so much more successful than elsewhere. Its easy growth from seed, besides, renders it worthy of trial. There are other trees, doubtless, of value for this purpose. The Buckthorn has been found perfectly hardy and successful around Boston; and the poisonous character of its bark secures it from attacks of the mice. Its thorns are only (419) 
mended lea as the best state for the process, in a paper on thom-hedged which appeared some years ago ;" but experience has since convinced me that this is not the best state of the ground for the purpose; because grass grows up from the turf around the young thorn-plants, and cannot be easily removed, but with the removal, at the same time, of a considerable portion of the earth upon which the young plants rest. A much better time, therefure, is after the ground has been thoroughly fallowed during the summer, that is, after it has been perfectly cleared of all weeds; well stirred and commixed with the plow and the harrow, and pulverized, if need be, with the roller; freshened by lengthened exposure to the air; amply manured with good dung, to promote the growth of the young thorn-plants; and sufficiently limed to prevent worms traversing the soil, and, in conse quence, moles mining in quest of them. If the field in which the line of hedge is proposed to be planted is not intended to be thoroughly fallowedthat is, by a bare fallow or a crop of potatoes or turnips-the part to be occupied by the hedge should be so treated, in order to render the soil as clean, and fresh, and fertile as possible; and the expense incurred by this treatment of the soil will be repaid by the increased health and strength of the hedge for many years thereafter. There is no doubt that lea-sod affords a firmer bed for the young thorn-plants to rest upon than fallowed ground; but it is of much greater importance to secure the ground from weeds, and health and strength to the young plants, than mere firmness of soil under them, but which peculiar advantage may be attained, too, partly by allowing the fallowed ground to consolidate for a time before commencing the operation, and partly by trampling the soil thoroughly while in the act of planting.

(445.) The ground having been thus prepared, the planting of the hedge may be proceeded with forthwith. If its line of direction is determined by existing fences; that is to say, if one side of a field only requires fencing, then the new fence should be made parallel with the old one that runs N. or S., and it may take any convenient course, if its general direction is E. and W. Should a field, or a number of fields, require laying off anew, the $N$. and $S$. fences should run due N. and $S$., for the purpose of

the pointed ends of the branches, which are hardly sufficient to repel all kinds of intruders. Of its treatment by successive heading down, its felting quality, and its capability of plashing, we are not informed, as in nearly if not quite all the specimens we have seen, those operations were omitted.

The expense of a well-made hedge, until it is cattle proof, is about fifty cents per rod. Caleb Kirk, of Delaware, who was thorough and successful in his experiments, gave the following as the cost of an excellent hedge thirteen years old:

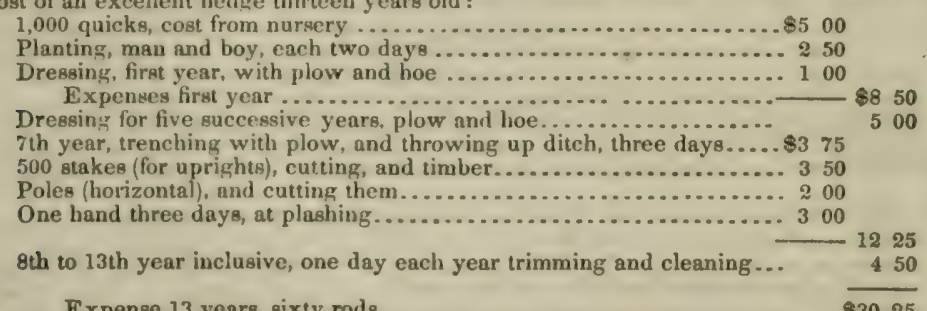

Expense 13 yeara, sixty rods ......................... $\$ 3025$

It may be questioned whether hedges will ever be extensively used where timber or stones are plenty. But as many places are destitute, or likely to become so, experiments to determine their practicability must become very desirable. The disposition to neglect is so prevalent with most farmers, that the great care and attention, and constant culture, so necessary, will not be given, and success cannot take place in such cases. But with skillful management and enterprise they will doubtless be found highly profitable; that if good they will prove a great rural embellish. ment, we all know; and that those who have fruit gardens to protect from rogues, will find them the greatest security, is equally self-evident.]

* It will be found in the Quarterly Journal of Agriculture, vol. i. 
giving the ridges an equal advantage of the sun both forenoon and afternoon. To accomplish this parallelism a geometrical process must be gone through; and to perform that process with accuracy, certain instruments are required.

(446.) In the first place, 3 poles at least in number, of at least $8 \frac{1}{2}$ feet in length, should be provided. They should be shod and pointed with iron at one end, marked off in feet and half-feet throughout their length, and each painted at the top of a different color, such as white, red, blue, green, or black, so as to form decided contrasts with each other when set in line. Three of such poles are required to determine a straight line, even on level ground; but if the ground is uneven, four or more are requisite. These poles will be found of use, not merely in lining off fences, but they will be required every year on the farm, to set off the breadths of the ridges of fields after being fallowed. 2. An optical square for setting off lines at right angles, or a cross-table, for the same purpose, should also be provided. The optical square costs $21 \mathrm{~s}$. and the cross-table 7s. 6d. 3. You should also have an imperial measuring-chain, of 66 feet in length, which costs $13 \mathrm{~s}$., for measuring the breadth or length of the fields, in the process of fencing ; or of drills, drains, and any other species of work set by piece to laborers at other times. Iron pins, for marking the number of chains measured, generally go along with the chain.

(447.) Being provided with these instruments, one line of fence is set off parallel to another in this way. Set off, in the first instance, at right angles, a given distance from near one end of the old thorn-fence, if there be one, or of the ditch, and let this distance be 6 feet from the roots of the thorns, so that a space or scarcement of one foot on the edge or lip of the ditch be left, and there plant one of the poles. About 100 yards' distance plant another pole in the same manner, and so on along the length of the fence from which the distances are set off. If there be no fence to set off the distances from, then let a pole be set perpendicularly up in the line the new fence is intended to occupy, and at noon, in a clear day, observe the direction the shadow of the pole takes on level ground, and that is $\mathrm{N}$. and $\mathrm{S}$; ; or a pocket-compass can give the direction required, deducting the variation of the needle, which in this country is about $270 \mathrm{~W}$.; but the plan with the pole is the simplest and most handy for work-people. Poles, at about 100 yards' distance, should be set up in the line of the shadow; but you should bear in mind that the first two poles should be set up quickly, otherwise a short lapse of time will make a material difference in the line of direction of the shadow. Twenty minutes make a difference of $5^{\circ}$ in the direction of the shadow of the poles, and $5^{\circ}$ at the first pole will make a considerable deviation from the true line of $\mathrm{N}$. and $\mathrm{S}$, at the farthest end of the line of the new fence. Adjust the poles with one another to form the straight line, and this line forms the base line of your operations. This line is $c u$ in fig. 36 , projected by shadow in the manner just described, or set off from the old hedge $a b$. Let $c a^{7}$ and $e$ be 3 poles planted in that line. Let $f$ be the cross-table erected in the line betwixt, and adjusted by looking at the poles $c$ and $d$. Tet $g, h$, and $i$, be poles set and adjusted to one another by the cross-table in the line $f k$, which is the breadth of the field, and which distance is measured by the chain to contain a number of ridges of given breadth, as any fractional part of a ridge left at either side of the field afterward proves inconvenient for work. In like manner, let the line $l p$ be drawn from the cross-table at $l$ by setting the poles $m, n, o, p$. Then set the pole $q$ in a line with the poles $k p$, and measure the distance betwixt $q$ and $u$, along the line $r s t$, with the chain, which distance, if the two previous operations have been accurately (421) 
conducted, should be exactly equal to the distance betwixt $f$ and $k$, or $l$ and $p$; but should it prove greater or less than either, then some error must have been committed, and which can only be rectified by doing the

Fig 36.

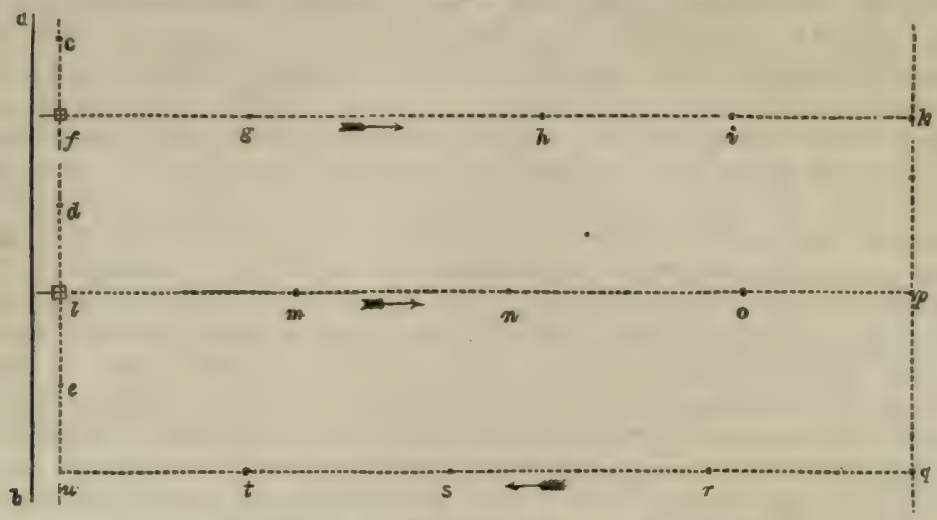

PLAN OF SETTING OFF FENCES PARALLEL TO EACH OTHER.

operation over again. The arrows show the directions in which each line should be measured. Great accuracy should be observed in running these lines of fences parallel, for if a similar error is committed at each successive line of fence, the deviation from parallelism may prove very considerable betwixt the first and last lines. Three poles only being employed to set off the lines $f k$ and $t p$, the ground may be supposed to be nearly level; but wherever such an inequality of ground is found as to cause you to lose sight of 1 of 3 poles, as many should be employed as to have 3 of them in view at one time. This point should be constantly kept in view in setting the poles.

(448.) A line of fence being thus set off, the next process is to plant it with thorns, and for this purpose certain instruments are required. 1. A strong garden line or cord, of at least 70 yards in length, having an iron reel at one end, and a strong iron pin at the other. Its use is to show upon the ground the exact line of the fence betwixt the poles. Its cost is, with a common reel and pin, 4s. 2. A few pointed pins of wood with hooked heads, to keep the cord in the direction of the line of the hedge, whether that follows a vertical curve or a horizontal one, occasioned by the inequalities of the ground. 3. A wooden rule, 6 feet in iength, divided into feet and inches, having a piece of similar wood about 2 feet in length, fastened at right angles to one end. Its use is to measure off short distances at right angles. Any country carpenter can make such a rule. 4. No. 5 spades are the most useful size for hedging, which cost $4 \mathrm{~s}$. 3d. each. 5. A light hand-pick, to loosen the subsoil at the bottom of the ditch and to trim its sides, and it costs $5 \mathrm{~s}$. 6d. or 6s. 6. An iron tramppick to loosen the subsoil immediately under the mould, and raise the bowlder stones that may be found in it. In some parts of the country this pick is unknown, but Fig. 37.

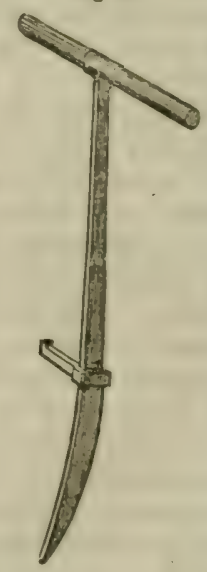

A TRAMP-PICK a more efficient implement cannot be employed for the purpuse. This pick 
stands 3 feet 9 inches in hight. The tramp, fig. 37, is movable, and may be placed on either side, to suit the foot of the workman, where it remains firm at about 16 inches from the point, which gradually tapers and inclines a little forward, to assist the leverage of the shank. The shank is $\frac{3}{4}$ of an inch square under the eye through which the handle passes, and $1 \frac{1}{2}$ inches broad at the tramp, where it is the strongest. It costs 6s. 6d. 7. A ditcher's shovel, fig. 38. Its use is to shovel the bottom and sides of the ditch, and to beat the face of the hedge-bank. It is 1 foot broad and 1 foot long, tapering to a point, with a shaft 28 inches in length, and its cost is, No. 5, 4s. This is a useful shovel on a farm, cleaning up the bottoms of dunghills in soft ground much better than a spade or square-mouthed shovel; and yet in some parts of the country it is an unknown implement. 8. Three men are the most convenient number to work together in running a hedge; and they should, of course, be all well acquainted with spade-work. 9. Should tree-roots be apprehended in the subsoil, a mattock for cutting them

Fig. 38.

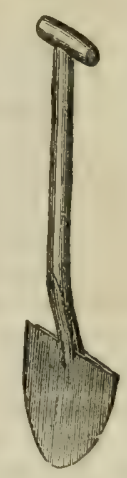

I MITEHER'S SHOVEL. will be required, and it costs $6 \mathrm{~s}$. 6d. 10. A sharp pruning-knife to each man, to prepare the plants for planting, which costs $2 \mathrm{~s}$. to $3 \mathrm{~s}$. each.

(449.) The plant usually employed in this country, in the construction of a hedge, is the common hawthorn. "On account of the stiffness of its branches," says Withering, "the sharpness of its thorns, its roots not spreading wide, and its capability of bearing the severest winters without injury, this plant is universally preferred for making hedges, whether to clip or grow at large."* Thorns ought never to be planted in a hedge till they have been transplanted at least 2 years from the seed-bed, when they will have generally acquired a girth of stem at the root of 1 inch, a length in all of 3 feet, of which the root measures 1 foot, as in fig. 39, which is on a scale of $1 \frac{1}{2}$ inches to 1 foot. The cost of picked plants of that age is $12 \mathrm{~s} .6 \mathrm{~d}$. per 1,000 ; or, as they are taken out of the lines, $10 \mathrm{~s} .6 \mathrm{~d}$. As thorns are always transplanted too thick in the nursery lines, in order to save room, and draw them up sooner to be tall plants, I would advise their being purchased from the nursery at that age, the year before they are intended to be planted in the fence, and of being laid in lines in ample space in garden mould, or any space of ground having a free, deep, dry soil. By such a process the stems will acquire a cleaner bark and greater strength, and the roots be furnished with a much greater number of minute fibres, which will greatly promote the growth of the young

- IV ithering'日 Botany, vol. iii. (423)

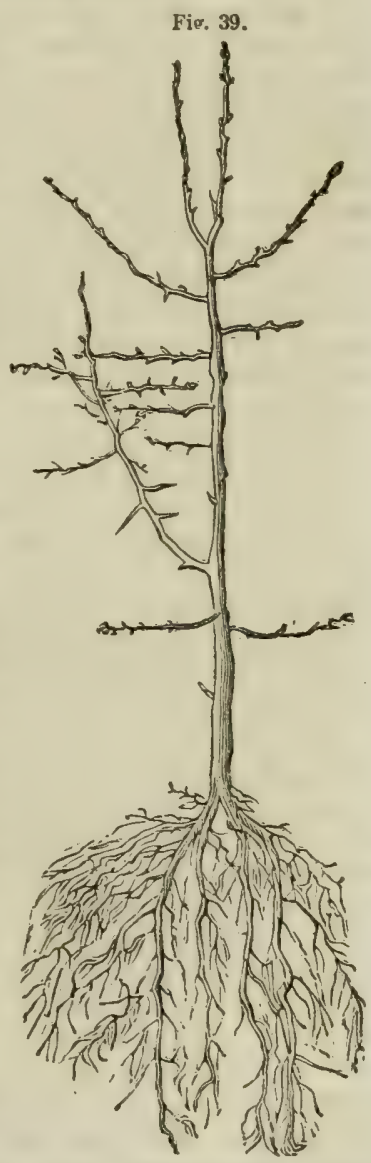

A THORN-PLANT. 
hedge, and thus amply repay the additional trouble bestowed on the care of the plants. But, whether the plants are so treated before they are planted or not, the bundles, containing 200 plants each, should be immediately loosened out on their arrival from the nursery, and sheughed in, that is, spread out upright in trenches in a convenient part of the field, and dry earth well heaped against them, to protect the roots from frost, and to keep them fresh until planted. The plants are taken from the sheughs when wanted.

(450.) If the line of fence is to be straight, which should always be the case if natural obstacles do not interfere to prevent it, let the poles be set up in as'straight a line as possible from one end of the fence to the other. Should the ground be a plain, this line can be drawn straight with the greatest accuracy; but should elevations, or hollows, or both, intervene, however small, great care is requisite to preserve the straightness of the line, because on such ground a straightness of line, determined by poles, is very apt to advance upon the true line in the hollows, and recede from it in the elevations, especially if the inequalities are abrupt. Surveyors use the theodolite specially to avoid this risk of error, but it may be avoided by usiug plenty of poles, so that they may not be set far asunder from one another. In case evil disposed persons shift the poles in the night, and thereby alter the line of fence, pins should be driven at intervals, well into the ground, to preserve the marks of the line. Having set plenty of poles, and so as to please the eye, take the reel and cord, and, pushing its pin firmly into the ground at the end of the line of fence where you wish to begin, run the cord out its full length, with the exception of a small piece of twist round the shank of the reel. Be sure to guide the cord exactly along the bottoms of the poles; and should any obstacle to your doing so lie in the way, such as clods, stones, or dried weeds, remove them, and smooth the ground with the spade; and then, with your face toward the cord, draw it backward toward you with considerable force until it has stretched out as far as it can, and then push the shank of the reel firmly into the ground. As the least obstruction on the ground will cause the cord to deviate from the true line, lift up the stretched cord by the middle about 3 feet from the ground, keeping it close to the sides of the poles, and let it drop suddenly to the ground, when, it is probable, it will lie as straight as practicable. Place a rather heary stone here and there upon the cord to prevent the possilility of its being shifted from its position. With the common spade then cut, or as it is technically termed, rut the line of hedge-bed behind the cord, with your face toward the ditch that is to be, taking care to hold the spade with a slope corresponding to that of the sides of the proposed ditch, and not to press upon, or be too far back from, or cut the cord with the spade. Then take the wooden rule, and placing its cross-head along the cord, set off the breadth of the ditch at right angles to the rutted line $4 \frac{1}{2}$ feet-first, at both ends of the still stretched cord, and then here and there; and mark off those breadths with wooden pins, which will serve to check any important deviation frors the true line at either end of the cord. Now, take up and stretch the cord anew along the other side of the ditch, by the sides of the pins, in the same manner, and with the same precautions as with the hedge-bed, and rut the line with your face toward, and the spade sloping like the side of the ditch. After securing a continuation of the line of the hedge-bed, remove the poles and pins along the length of the cord, and the ditch is thus marked out ready for the formation of the thorn-bed. When about forming the thorn-bed, that end of the line should be chosen for commencing the work which best suits the hand of the workman who is intrusted to 
make it. The rule for this is, whichever hand grasps the eye of the spade should always be nearest the thorn-bed, and the workman should work backward.

(451.) In forming the thorn-bed, raise a large, firm, deep spadeful of earth from the edge of the first rutted line of the hedge, and invert it along that line, with its rutted face toward the ditch. Having placed a few spadefuls in this manner, side by side, beat down their crowns with the back of the spade, paring down their united faces in the slope given to the first rut, and then slope their crowns with an inclination downward and backward from you, forming an inclined bed for the thorn-plant to lie upon as at $b c$, fig. 40 . In like manner, place other spadefuls, to the end of

Fig. 40 .

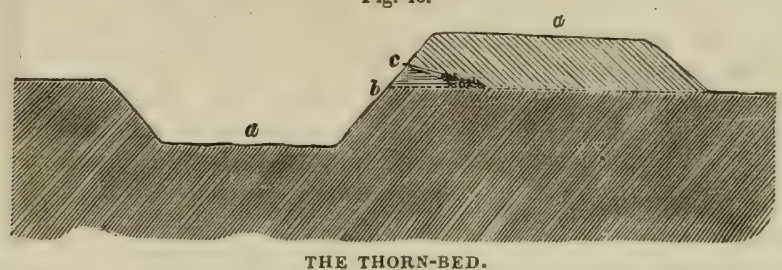

THE THORN-BED.

the thorn-bed last made, taking care to join all the spadefuls so as to make one continued bed, and so on to the whole length of the cord of 70 yards.

(452.) While the principal hedger is thus proceeding with the thorn-bed, his two assistants should prepare the thorn-plants for planting. On receiving the thorn-plants from the nursery, the usual practice is to put the bundles of plants into the soil in some convenient corner of the field, until they are wanted for planting. I have recommended the plants being purchased the year before they are to be planted, and transplanted in wide lines in good garden-mould, to enlarge and multiply the root-fibres. And now that the plants are more particularly to be spoken of, I would farther recommend them to be assorted, according to their sizes, as they are taken out of the bundles, and before being transplanted in the lines. The advantage of this plan is this. Plants should be suited to the situation they are to occupy. On examining the bundles, they will be found to contain both stout and weak plants. The stoutest plants cannot derive sufficient nourishment in the poorer class of soils, however well the soils may have been previously treated for their reception; while weak plants will, of course, thrive well in the better soil. From this circumstance, it may be concluded that weak plants are best adapted to all classes of soils. Not so; for however well weak plants may thrive in all soils, stout plants will grow much more rapidly than weak in good soils; and were all the soils good, the most profitable fence would be obtained from the best and picked plants. But as every farm possesses soils of various degrees of fertility, although the class of its soils may be the same; and as plants in a stout and weak state are usually mixed together, the most prudent practice is to put the weaker plants in the best soil, and the stouter plants in the worse kind of soil, thus giving a chance of success to both sorts of plants and soils. Were the plants assorted when placed in transplanted lines, those could be selected which would best suit the soil which was under operation at the time. But should this trouble not be taken at first, still the plants should be assorted when being prepared for planting, according to the nature of the soil, the weaker being taken for the good soil, and the stronger for that of inferior quality. Want of attention to this adaptation of means to ends is one cause of failure in the rearing of thorn-hedges

(425) 
in many parts of the country; and one of those means consists in trans. planting the weakest plants in good soil, and allowing them to remain there until they had acquired sufficient strength for being planted out. Although the thorn-plant may truly be said to affect every kind of soil in cultivation, yet the plant, in its different states of growth, will thrive better in one condition or kind of soil than in another; and this discrimination should be exercised by the planter, if he would have a good hedge.

(453.) The prepared thorn-plant is represented by fig. 41 ; and it is prepared in this way. Grasp the stem of the full plant, immediately above the root, firmly in the hand, and cut it across with a sharp knife, in an inclination toward the top of the plant at $a$; and the cut thus made will be about 6 inches above the root and fibres. Cut away the long parts of the tap-roots $z$, and any other straggling and injured roots, and even injured fibres; but preserve as many of the fibres entire as possible. Burn the tops thus cut off, or bury them deep in the ground; as they will vegetate, and are easily blown about by the wind, and very troublesome to sheep in the wool. Take great care, in frost, to cover up the prepared roots in earth until they are planted, for roots in the least affected by frost will not vegetate. The safest plan, in frosty weather, is to take but a few plants at a time out of the lines. On

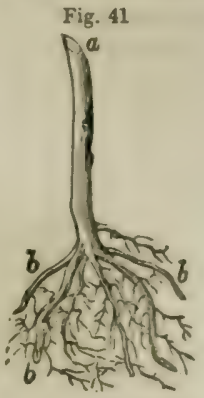

A THORN-PLANT PREPARED FOR PLANTING. the other hand, in dry weather in spring, when the hedge is to be planted in dry ground, put the roots of the prepared plants in a puddle of earth and water, in a shady place, for some hours before laying them in the thorn-bed, and their vegetation will thereby be much facilitated.

(454.) When both the thorn-bed and plants are prepared, the assistants lay the plants in the bed. This is done by pushing each plant firmly into the mould of the bed, with the cut part of the stem projecting not more than $\frac{1}{4}$ of an inch beyond the front of the thorn-bed, and with the root-end lying away from the ditch, at distances varying from 6 to 9 inches ; the 6 inches being adapted to inferior land, and the 9 inches to good soil. While the two assistants are laying the plants, the hedger takes up all the fine mould nearest the thorn-bed, and, dexterously inverting the shovel-fulls of the mould, places them above the laid plants, and secures them in their places. The two assistants having finished laying the thorns, dig and shovel up with the spade all the black mould in the ditch, throwing it upon the roots and stems of the plants, until a sort of level bank of earth is formed over them. In doing this, one of the assistants lifts the soil across the ditch, moving backward, while the other proceeds forward, face to face, shoveling up all the black mould he can find, whether in a loose or firm state, in the ditch. When the hedger has finished covering the plants with mould, and while the assistants are proceeding to clear all the mould from the ditch, he steps upon the top of the mound which they have thrown up above the plants, and, with his face toward the ditch, firmly compresses, with his feet, the mould above the plants, as far as they extend. By the time the compression is finished, all the mould will have been taken out of the ditch. When the thorns have received this quantity of earth above them, they may be considered in a safe state from the frost; but it is not safe, in frosty weather, to leave them, even for a night, with less earth upon them; for plants may not only be frosted in that short space of time; but the earth may be rendered so hard by frost, as to be unfit for working the next day; and should the frost prove severe and the work be altogether suspended, the plants left at all exposed 
will inevitably perish. In frosty weather the plants should not be laid on the thorn-bed in the afternoon, but only in the forenoon, as in the afternoon of a short day there probably will not be time to cover the plants with a sufficient quantity of earth. Indeed, in such weather, when the ground continues hard all day, leave the work off altogether-not only because the earth is then in an unfit state for the work, but the frosted earth is apt to chill the tender fibres. On the other hand, if the weather be fresh and not too wet, such as in spring, the plants may be laid in the afteruoon in safety. In very wet weather, the work should also be suspended, not only on account of the cloggy state of the ground for good work, but the inability of the men to withstand much rain in winter. 'The last operation of the ditch and bank will be more uniform and look better, when a considerable length of it is finished at the same time, than when joinings are visible in it at short intervals; but in frosty or in very wet weather, the sooner a piece of it is finished, the better it is for the cleanliness of the laborers and the condition of the work itself. Fig. 39 shows the progress of hedge-planting to the extent described, where $a$ is the ditch with the mould all taken out, $b$ the thorn-bed sloping inward and downward, $c$ the thom in its bed, with the end of the stem projecting a very little outward, and $d$ the mound above in its compressed state.

(455.) The rule observed for the depth of a ditch that stands well, is $\frac{1}{2}$ its breadth, and the width of the bottom $\frac{1}{6}$ of the breadth at the top. In the case of hedge-planting, the breadth is $4 \frac{1}{2}$ feet; the depth is, of course, 2 feet 3 inches, and the width of bottom 9 inches. The hedge-bank is always broader than the ditch, the soil lying loosely upon it, and in this case is 5 feet; and, of course, the perpendicular hight of the bank is less than the depth of the ditch, being 2 feet. These are, in general, very convenient dimensions for a hedge ditch and bank, where no constant current of water has to be accommodated in the ditch; but should the ditch have to contain a stream of water, though in winter only, it should be made proportionably capacious ; for if not so made at first, it will either have to be made so at last, or the force of the water will assuredly make an adequate course for itself, to the danger of destroying the thorn-bed. Ditches that are brought to a point at the bottom are objectionable in shape for many reasons. They do not afford sufficient materials out of them to form a protective bank or mound for the young thorn-plants; they are easily filled up with the mouldering of earth from the sides and tops, and the decay of vegetables; and when any water gets into them, of which there is every chance when there is an overflow of surfacewater in the field, they soon get filled up in the bottom with mud. Notwithstanding the commendation of such ditches in works of Agriculture,* they should be avoided when there is the probability of the least quantity of water reaching them; and no ditch in connection with a field can be exempt from the intrusion of water.

(456.) When the work has proceeded to this length, the other implements come into use. If the subsoil of the ditch, however, be a tenacious, ductile clay, the spade alone is best to remove it, as picking is useless in such a substance, especially if somewhat moist; for it will raise no more at a time than the breadth of the face of the pick. But if it consists of hard dry clay interspersed with veins of sand and gravel-which com pound forms a very common subsoil in this country-picking is absolutely required; for the spade cannot get through the small stones with effect. In some parts of the country, the handpick is used to loosen such a subsoil, while in others the footpick is employed; and from experience in

* Communications to the Board of Agriculture, vol. ii. Loudon's Encyclopædia of Agriculture.

(427) 
both, I would recommend the latter as being by far the more eflicient implement for such work, and less laborious to the workman. Let one of the assistants loosen the subsoil with the footpick as deep as he can go for the tramp, with the point of the pick away from him; he then pulls the handle toward him, until he brings it down about half way to the ground, and after that he sits on it, and presses it down with the whole weight of his body, until the subsoil gives way and becomes loose, in which state he leaves it before him, and steps backward. When the picker has thus proceerled a short way, the other assistant lifts up what has been loosened with his spade, and throws it upon the top of the mould above the thorn, taking care to place the subsoil so thrown up continuous with the slope backward, given to the face of the bank. He also throws some to the back of the bank, to cover the whole of the black mould with the subsoil; and endeavors to make the shape of the bank uniform. In doing all this, he works backward with his back to the face of the footpicker, but his back would be to the back of a handpicker, standing upon the subsoil which has been loosened by the footpick. He pares down the side of the ditch nearest his right hand, which, in this case, is the opposite one from the hedge. The hedger follows the last assistant, working toward him face to face, and moving forward, shoveling up all the loose earth left by the assistant's spade, throwing it upon the top and front of the mound, making all equal and smooth, and beating the earth firmly and smeoth on the face of the bank. Should the subsoil require no picking at all, the two assistants follow one another, using the spade; and the hedger brings up the rear as before, using the shovel. In this way the hedger throws the earth fully on the face of the bank, even although some should trickle down again into the ditch, rejecting all the larger stones that come in his way, paring down that side of the ditch, giving the proper slope to the bank, and beating the face of the bank with the back of the shovel, and smoothing it downward from its top as far as the black mould is seen on the side of the ditch. The three men thus proceed regularly in their work. Should there be more earth at one place of the ditch than another - which will be the case where there are inequalities in the depth of the ditch-the surplus earth should either be thrown to the back of the bank, rather than its top be made higher at one place than another, or wheeled away to a spot on which a deficiency of earth is apprehended. Besides giving the bank an irregular appearance, it is not desirable to cover the young thorns too heavily with a superincumbent load of earth, so as entirely to exclude the air and moisture from their roots.

(457.) If going along the ditch twice finish the work, the earth in it will have been in a friable state; but with a hard subsoil the work is not so easily done. The handpick is almost always used to raise the last 4 or 5 inches of the bottom of the ditch, and in accomplishing this the same arrangement of the men, and the kind of work performed by each, will have to be gone through; only that, in this case, the assistant uses the hand for the tramp-pick, and works forward. While this last picking and shoveling are proceeding, the hedger again tramps down the top of the bank before throwing up the last portion of earth. The beating with the back of the shovel is absolutely necessary to produce a skin, as it were, on the face of the bank; because the smoothed surface will resist the action of the frost, and thereby prevent the mouldering down of the earth into the ditch. A covering of clay over the bank, and the poorer it is the better for the purpose, is useful in being extremely unfavorable to the vegetation of small seeds. They will readily take root in fine mould, if that formed the external covering, and their eradication afterward would create much (428) 
trouble and cause much waste of earth. The necessity of beating the clay shows the expediency of projecting the plants but a very short way out of the bank, as that process might wound and injure the points of the stems. Indeed, I would prefer their being nearly buried in the bank, so as the young sprouts had to be relieved from captivity, rather than the points should be injured; but the force of vegetation generally accomplishes their release with ease. While the two assistants are preparing the cord for another stretch, and rutting off both sides of the ditch, the hedger pushes back 2 or 3 inches, less or more, of the crest of the bank with his shovel, in oxder to make the finished top parallel with the row of thorns, and after he has gently beaten down the front of the top into a rounded form, the process of planting thorns is finished. Fig. 42 gives an idea of a section of the whole work when finished.

Fig. 42.

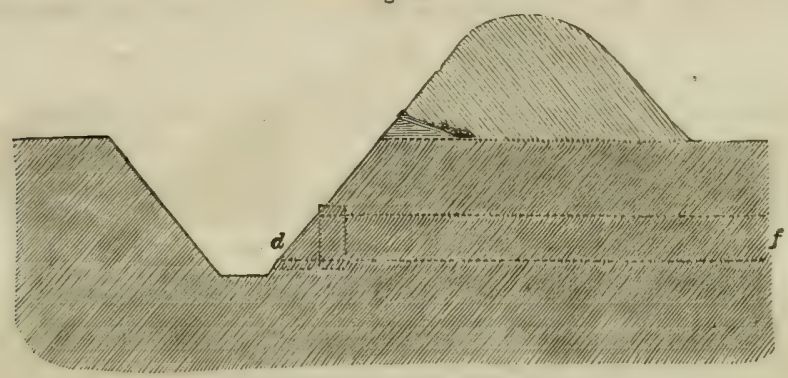

FINISHED HEDGF-BANK.

(458.) Hitherto the work has proceeded quite easily, no obstacles having presented themselves to frustrate or alter the original design of a level fence; but obstacles are sometimes met with, and means should be used to avert or remove them. The obstacles alluded to generally consist of large stones, unequal ground, and stagnant water. 1. Landfast stones are frequently found in clayey subsoils, many of which can be removed with the foot pick, but some are so large and massive as to defy removal but through the assistance of gunpowder. If you should meet with any such enormous masses, and much above ground, it would be better to carry the hedge with a sweep past them, than incur the trouble and expense of re. moving them with the simplest means. If they lie a short way under the thorn-bed, but have plenty of mould over them, they will do no harm to the hedge above them; but should the earth be scanty over them, it will be proper to make the earth deep enough for thorns above them, if that can be easily done, even although an elevation be thereby caused there, above the general line of hedge. 2. With regard to inequality of surface, when the ground dips in the direction of the hedge, and yet when particular undulations in it are so deep and high as to prevent the flow of water over them in the ditch, the higher parts should be cut the deeper and the hollow parts the less, so as a continuous fall may be obtained for the flow of the water along the bottom of the ditch; but the line of the hedge should be placed on the natural surface of the ground, and thereby partake of its undulations. It is in such cases of compromise that the superabundant earth should be wheeled away from the inordinate depths, to make up for the want of earth in the hollows, and thereby equalize the dimensions of the hedge-bank. Should any hollow be so deep as that the hight on either side will not allow the flow of water, a drain should be made from the hollowest part of the bottom of the ditch down the declina(429) 
tion of the adjoining field to some ditch or drain already existing at a lower level. 3. Undulations of the ground cause another inconvenience in hedge-planting, by retaining water in the hollows behind the hedgebank. Such collections of water, though only of temporary existence, injure much any hedge, but especially a young one. The only effectual way of getting rid of them is fortunately a simple one, which is by constructing a conduit through the hedge-bank from each such hollow to the bottom of the ditch; and as these conduits must be founded upon the subsoil, completely under the black mould, and a little above the bottom of the ditch, they are most conveniently built after the ditch has been entirely dug out; and on this account the thorn-bed cannot be formed across these hollows until after the completion of the ditch and hedge-bank on both sides of them. Some taste and dexterity are required in the hedger to fill up the gaps thus left in the planting of the hedge and finishing them neatly afterward. Fig. 43 will give you an idea how to overcome the in-

Fig. 43.

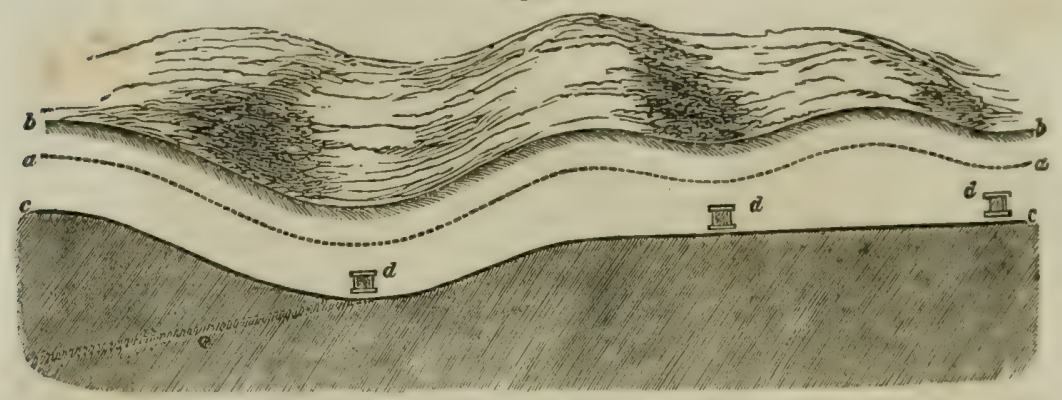

PLAN HOW TO PREVENT WATER LODGING IN HOLLOWS OF FENCES.

convenience created by these hollows, where $a$ is the line of hedge upon the natural surface of the undulating ground, $b$ the top of the hedge-bank parallel to the hedge, $c$ the bottom of the ditch, exposed to view by the entire removal of the ground on this side of the ditch, and which removal also shows the positions of the conduits $d$, which carry the siagnant water away from behind the hedge-bank through below the hedge in the lowest part of the undulations of the ground, and it also shows the position of the drain $e$ through the adjacent ground. It will be observed that the bottrm of the ditch $c$ is not quite parallel with the dotted line of hedge $a$, but srinclined from the right and left, through the hights and hollows of the ground, as to allow the water to flow in a continuous stream toward the lowest part by the drain $e$. Fig. 42 shows by the dotted lines $d$ and $f$ a vertical section of the position and form of the conduits formed across and below the hedge-bed. The ground behind the hedge-bank is represented in fig. 43 as declining toward the hedge, thereby giving a fall to the surface water in the same direction. To give such water an outlet, a drain should be formed along the head-ridge 2 or 3 yards behind the hedgebank, so as to be a little out of the way of the roots of the thorns when they push outward, and in connection with all the conduits $d$. 'This drain should have a conduit at bottom such as drain-tiles afford, and be filled above them with broken stones to about 1 foot from the top.

(459.) In ordinary practice, when two lines of hedges meet, the one terminates against the other, or, crossing each other, form a junction of 4 fields by the corners; and where this latter junction happens, should the land be not of much value, or should the particular situation be much exposed to (430) 
the weather from an obnoxious quarter, it may be advisable to make a clump of planting of a stellar form. It is necessary, in the first place, to ascertain what quantity of ground can be conveniently spared for the purpose; and that should be determined by the value of the ground, or its exposed situation. If the land is valuable; a smaller piece must suffice; but if shelter only, and not ornament, is the chief requisite, then a larger piece should be appropriated; but whatever may be the object of forming such a clump of planting, it is not worth while to inclose a smaller space of ground than $\frac{1}{4}$ of an acre, and the largest need not exceed 1 acre in the low country. Supposing the space is determined on, the inclosure of it is gone about in this manner. Ascertain the point where the two lines of hedges would intersect, and fix a pole there, as at $a$, fig. 44 ; and from it

Fig. 44.

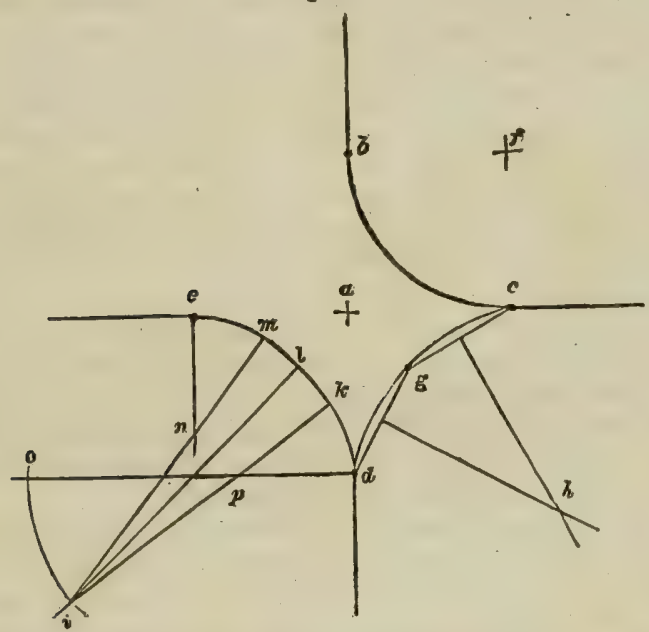

MODES OF DESCRIBING A CURVE IN THE CORNERS OF FIELDS.

measure equal distances with a chain along each line of fence to the points within which is to be included the space of ground allotted for the planting, as from $a$ to $b, a$ to $c, a$ to $d$, and $a$ to $e$. Then there are 3 ways of describing an arc between any two of these outward points. 1. Taking the distance $a b$ from $b$ as a center, sweep an arc, and from $c$ as a center, with the same radius, sweep another arc intersecting that from $b$ in $f$; and then from $f$ as a center, still with the same radius, sweep the arc $c b$. In like manner an arc of the same radius may be swept betwixt $c$ and $d$, $d$ and $e$, and $e$ and $b$. This rule gives no predetermined arch, but it is one which presents a pleasant curve to the eye. 2. Another plan is to fix the hight of the segment which determines the point, beyond which the hedge shall not approach toward $a$. This is done by at once fixing the point $g$, which gives 3 points, $d, g$, and $c$, by which to find the center of the circle $c d$. Join $g d$, which bisect, and from the point of bisection raise a perpendicular; also join $g c$, which bisect, and from the point of bisection raise a perpendicular, and where these two perpendiculars intersect at $h$ as a center, sweep the arc $d c$. This rule is founded on the corollary to the 1st problem of the $3 \mathrm{~d}$ book of Euclid.* A simple rule which practical gardeners employ in drawing one line at right angles to another is this:

* See Duncan's Elements of Plane Geometry. 
From the point of bisection, as above, measure 6 feet along the line toward $c$ or $g$, from the same point also measure outward 8 feet; from the farther end of the 6 feet measure 10 feet, toward the end of the 8 feet, and where these two lines meet, that is the point in a perpendicular direction from the point of bisection, and a line through which, meeting a perpendicular fiom the other point of bisection, intersect at the center $h$ of the circle $d c$. This rule is directly founded on the celebrated 47 th proposition of the 1st book of Euclid. 3. There is still another method of drawing what may be called a compound curve through two given extreme points, and other fixed points between them. The method is chis. Let $d$ and $e$ be the terminations of the straight lines of the fences $d$ and $e$, and $l$ a point in the intended curve any where beyond the straight line hetween $d$ and $e$, and equidistant from $d$ and $e$, but within a quadrant of the two lines of fence; then set off any point $i$ also equidistant from $d$ and $e$, and join $i l$; from any point on the line $i l$, describe an are of such radius as shall pass through $l$, but will fall anywhere beyond $d$ and $e$. Draw $d o$ at right angles to the fence $d$, and make $d o$ equal to $i l$, then find a point $p$ on the line $d o$ equidistant from $o$ and $i$. Join $i p$, and produce it to $k$, and from $p$ as a center describe the arc $d k$. For, $d o$ and $i k$ being equal, and $p o, p i$ being also equal, the remaining $p d$ and $p k$ must be equal to one another and $i p k$ being in a straight line, the circle of which $d k$ is an arc, will touch the larger circle, of which $k m$ is also an arc, according to Euclid, 3d book, 11 prob. In like manner, the arc $e m$ can be described by first drawing $e n$, at right angles to the line of fence $e$, and proceed as before. If the lines of fence run at right angles to each other, the arcs $d k$ and $e m$ will have equal radii. This is, perhaps, too intricate a mode of drawing such curves for practical purposes, but it is well that your ingenuity be exercised in every possible way, so as you may never be at a loss to apply expedients according to circumstances.

(460.) A very common practice-a much too common one-and recommended by almost every writer on planting hedges, is the leaving a broad scarsement in front of the thorn-bed; and the reason given for adopting the plan is, that it is necessary to supply the young thorns with moisture.

Fig. 45 .

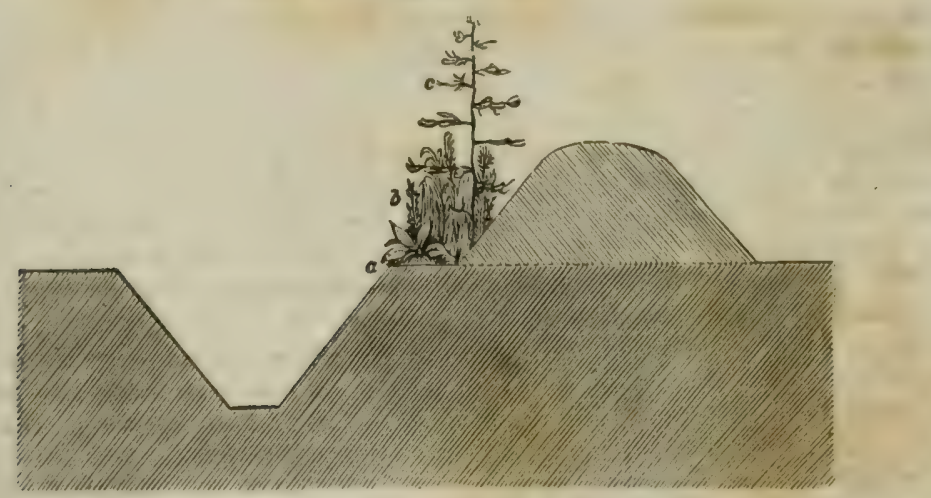

EFFECT OF A HEDGE-BANK WITH SCARSEMENT.

It is alleged that the sloping face of the bank conveys away the rain that falls. What although it does? The young thorn does not require to imbibe moisture by the point of its stem, but by its roots, which it can easily do through the mound, as it is loose enough for the admission of rain.(432) 
But, independently of that, it is obvious that a scarsement is so excellent a contrivance for the growth of weeds, that it is impossible to clean a hedge well where there is one. To be sure, earth from the bottom of the ditch may occasionally be thrown upon the scarsement to smother the weeds, but its accumulation there must be limited to the hight of the thorn-bed. Besides, weeds can grow as well upon this earth as upon the scarsement; and, though they may there be mown down at times, the roots of the perennial ones are quite ready to spring up again in favorable weather. The very figure which a thorn-hedge cuts on a scarsement will at once show the impolicy of placing it in such a position. Thus, in the first place, in fig. $45, a$ is the scarsement, on which there is nothing to hinder the weeds $b$ to grow in great luxuriance, vying in stature and strength with the young plant $c$ itself. How true that there " nothing teems but hateful docks, rough thistles, kicksies, burs, losing both beauty and utility; and our hedges, defective in their natures, grow to wildness."* How is it possible in such a nursery to "deracinate such savagery?" In the next place, such a scarsement holds out a strong temptation to travelers to make it a foot-path, so long as the hedge is young, and when it is situated by the side of a public road. And it invites the poor woman's cow, pasturing on the green road-side, to step upon it and crop the tops of the young hedge along with the grassy weeds; and it makes an excellent run for hares, in the moonlight nights, on passing along which they will not fail to nibble at the young quicks. "Fern is a great enemy to young hedge-plants," says Mr. Marshall; "it is difficult to be drawn by hand without endangering the plants; and, being tough, it is equally difficult to cut it with the hoe ; and, if cut, will presently spring up again ;" and yet, "in a soil free from stones and other obstructions of the spade," he says, "the planting with an offset (scarsement) is perhaps, upon the whole, the most eligible practice." $\dagger$ Where can fern obtain a better site for growing upon than a scarsement of a young hedge? Such are the inconsistencies into which the acutest writers fall when they relinquish the guidance of common sense.

(461.) Where part of a hedge is desired to be carried across a watercourse, an arch or large conduit is often made to span it, and its sides are banked up with sods or earth, and a quantity of mould wheeled upon it, to form the thorn-bed. I have seen such structures, but do not approve of them. If the nature of the ground will at all admit of it, it is far better to plant the thorns on the surface of the natural ground, as near as possible to the water-mark, when the water is flooded. The water-channel, which will probably be dry in summer, when the fields are only used for stock, could be fenced with paling, or, what is a much better fence in such a situation, a stone-wall, if stones can be procured at a reasonable distance, with openings left in it to allow the water to pass through in winter.These openings could be filled up in summer with a few thorns, to keep in sheep. This latter plan is a much better one than the other, for I have found that hedge-banks on a stone-building do not retain sufficient nourishment in summer to support even young thorn-plants.

(462.) If it is desired to plant a thorn-hedge on the top of a sunk fence, or along the edge of a walk by the side of a shrubbery, or to inclose a shrubbery or a clump of trees in pleasure-ground or lawn, the plants may be assorted and prepared as directed above; but instead of raising a mound, which in such situations would not look well, trench a stripe of ground with the spade, in the intended line of the hedge, at least 3 feet in 
breadth, pointing in dung and raking in lime in adequate quantities some time before the time for planting. When that time arrives, stretch the cord in the middle of the stripe, guiding the curves with the wooden pins. First, smoothen the surface of the ground under the cord with a clap of the spade, and then notch deeply with it by the side of the cord, drawing the earth toward you. Into this furrow carefully place the roots and fibres of the thorn-plants, with their cut stems leaning against the cord; and thus, keeping the plants in their places with the left hand, fill up the furrow with earth with a trowel in the right hand. Press the plants firmly against the earth with the outside of the foot placed in a line with the stems, and make the surface level with the spade. After the removal of the cord, press the ground with the row of thorns between your feet, and finish off the work with the rake. In planting ornamental hedges, you should always bear in mind that, for whatever purpose a hedge may be wanted, the thorns should always be planted on the natural surface of the ground; for, if set in traveled earth, unless it is of considerable bulk and depth, they run the risk of either being stunted in growth, or of altogether dying for want of nourishment.

(463.) In setting poles for straight lines, ordinary accuracy of eye will suffice; but in setting them in curves, where geometrical ones cannot be introduced, considerable taste is required by the planner. Such curves can only be formed by setting up large pins, and judge of their beauty by the eye, so that the sweeps may appear naturally to accommodate themselves to the inequalities of the ground, and form, on the whole, a suitable figure for the purpose they are intended to serve. Curves in fields should always be made conformable to the plowing of the adjoining land; for, if such adaptation is not attended to, land may be lost to tillage in the depth or acuteness of the curves. After the large pins are set to show the general form of a long curve, or series of long curves, smaller ones should he employed to fill up the segments between the larger, and the cord then stretched by the side of all the pins, and the beautiful sweep of the curve carefully preserved by the small pins with the hooked heads. If a curved ditch is required, the rutting of the breadth of the ditch, as also the making of the thorn-bed, should follow the cord in its curved position; but great care is required to preserve the two sides of a curved ditch parallel, for if the cross-headed wooden rule is not held at right angles to the line of the hedge, at every point where the breadth of the ditch is measured off-that is, if the cross-head is not held as a tangent to each particular curve-the breadth of the ditch will vary considerably in different places, and, of course, the ditch will there present a twist. There is no error into which laborers are so apt to fall as this: they measure, without thinking of the consequences, at any angle across the ditch; but they should be taught to avoid it, because, if not rectified in time, it will deprive the hedge-bank of essential covering at certain places, on account of the ditch being twisted into broad and narrow portions.

(464.) Where turf is plentiful, it may be employed in this way to fence at once one side of a hedge. Let $a$, fig. 46 , be the turf wall 4 feet high, 18 inches broad at the base, and 1 foot at the top, coped with a large turf; $b$ the stuff thrown out of the ditch $c$, and inclined upward toward the top of the wall. For keeping in Cheviot or Black-faced sheep, or cattle, a stake and single rail of paling $d$, will be required on the top, but not for Leicester sheep. In Norfolk, a high bank is thrown up, without a wall. from 6 to 7 feet in hight from the bottom of the ditch, and the thorn-plants are set into it as at $b$, fig. 46 , among the crude earth taken ont of the bottom of the ditch. As might be expected in such a plan, it is no uncommon sight in that county to see the face of the bank, with the quicks in it, washed down by beating rains; and as the ronts enlarge and the bank moulders down, the young plants hang their heads downward upon the face of the bank. The reason assigned for the adoption of this objectionable practice is, that there is no wood in that county to form temporary fences 
until the thorns shall grow, and that being set upon the top of a steep bank, they are out of the reach of cattle at the bottom of the ditch. Even with a wall like $a$, fig. 46, thorns at $b$ will never grow so vigorously as when placed at $e$; and in dry weather they are soon stinted

Fig. 46.

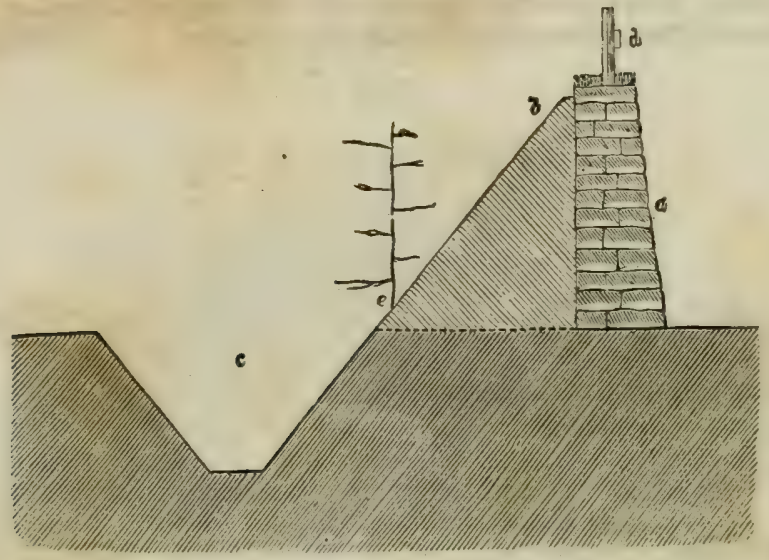

TURF FENCE TO A THORN-HEDGE.

of moisture. Where flat stones are plentiful, a good sheltering fence may be formed by inclnsing a space of a few feet in breadth between two walls, and on filling it with earth, an npright hedge may be planted in it, where it will thrive very well. Such fences may be seen in Devonshire, where flat stones from the primitive clay-slate formations are obtained in abundance. In connection with the mode of fencing considered in this paragraph is one recommended of building a $2 \frac{1}{2}$ feet wall on the top of the bank behind the hedge which had been thrown out of the ditch, and to make its coping of turf. There are objections to this plan ; in the first place, a turf coping on a stone wall never grows well, and in consequence, turf soon becomes there an eyesore. In the next place, a wall founded on earth that has been thrown out of the bottom of the ditch, will not remain even but a very short time, on account of the unequal subsidence of the earth, and the consequent sinking of the stones. A 3 feet stone wall, founded npon the hard ground, on the site of the turf-wall $a$ in fig. 46, with a single railed paling raised behind it, until the hedge get up, would make a far better fence both for sheep and cattle. Another mode of planting a thorn-hedge is to build a stone wall as at $a$, fig. 46, in which are left holes, about the position where the letter $a$ is situate in the figure, through which the thorns grow which have been planted in the bank of earth $b$. This is also an objectionable mode, inasmuch as the plants, whose roots are ramifying in the bank $b$, have no support from that portion of the stem which has to grow in a horizontal direction through the holes of the wall, and the consequence is, that the leverage of the part of the stem which grows upright in the face of the wall is apt to shake the roots, and should the horizontal portion of the stem rest for support upon the wall within the $h$ e, its weight and motion soon bring down the wall, if it is constructed of dry stones, or shatter it, if built with mortar Thorns have been recommended to be planted at the bottom of a wall, as of $a$, fig. 46 , with no bank such as $b$ near it, but baving the ditch $c$ before it as a fence to the hedge, with a paling on its lip. If a stone wall is built in such a situation, there seems no use at all of the hedge as a fence, and if a turf one, then surely thorns will thrive much better with a bank of earth behind them, such as $b$, than at the bottom of a turf wall.

Note-ON Shelters. - The employment of artificial shelters, in fields, for plants, and trees, and animals, is carried to a degree of expense, if not of refinement, in England, which is not likely to be extensively imitated in this country. Fig. 35 represents the form of such shelters better than words could well do it.

Not only all along the sea-board of Long Island, but more or less along all our whole sea-coast, fruit and other trees are liable to be blasted and rendered unproductive by the strong blasts which strike them after acquiring a powerful momentum in sweeping over the ocean.

The wall and the wood on the inside and near to it are of the same hight, but, still farther in, the wood rises considerably higher, owing to the peculiar form of the cope of the wall and the (483) 
shape of the wall itself, being like an isoceles triangle-when the wind strikes ils side, it is reflected upward into the air, at the same angle.

Where such shelters can be provided. they are decidedly useful-as all must have perceived the difference, in early spring, between the advance of vegetation on the south and the north side of every inclosure. Even common garden walls in this way afford opportunities of making beds for early plants, of lettuce, cabbage, radishes, and other vegetables.

[Ed. Farm. Lib

Fig. 35.

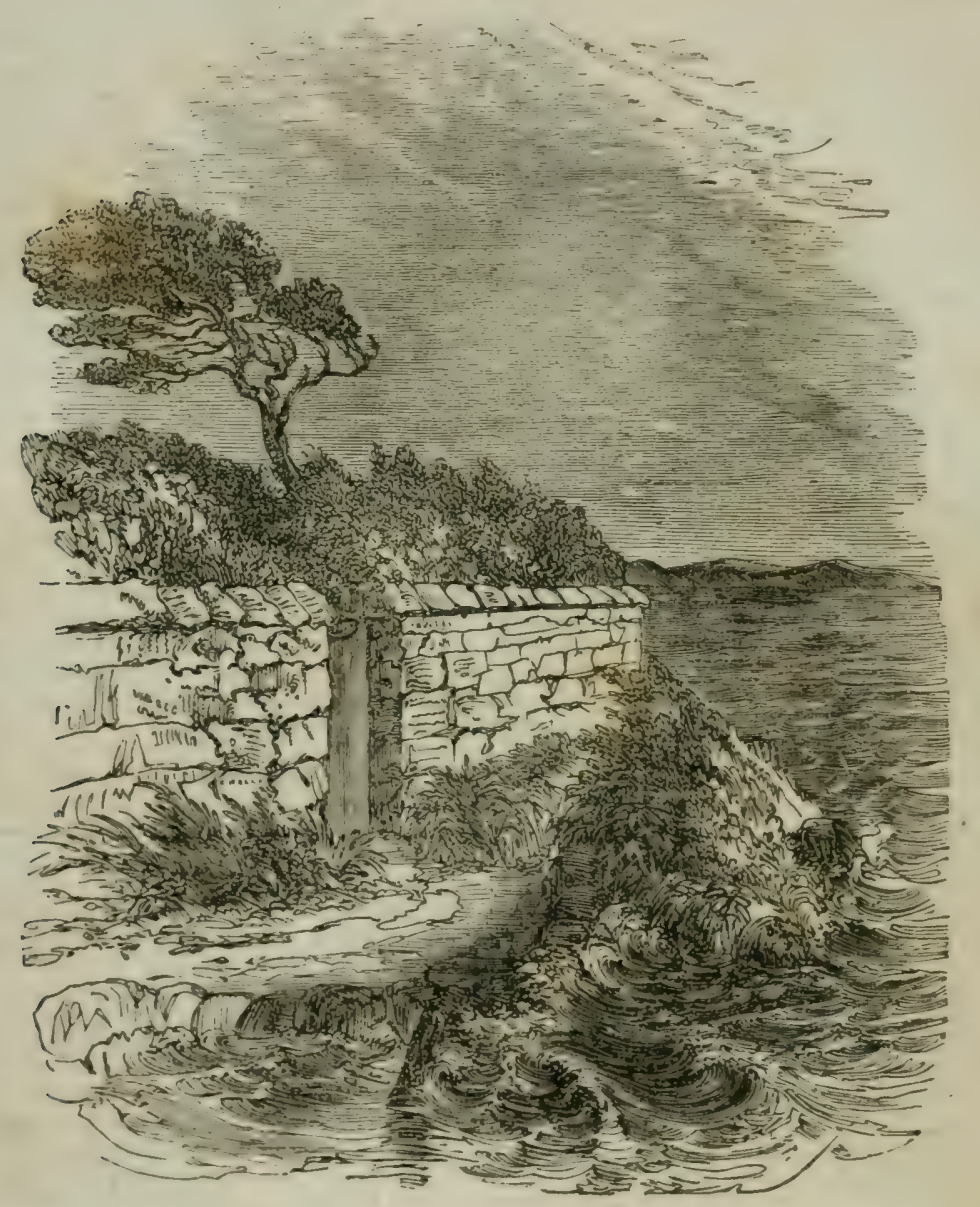






\title{
23. THE PLOW.
}

\author{
"Howsoever any plow be made or fashioned, so it be well tempered, it may the \\ better be suffered."
}

(465.) The plow serves the same purpose to the farmer as the spade to the gardener, both being used to turn over the soil and the object of doing this is, that this form of operation is the only means known of obtaining such a command over the soil as to render it friable and inclose manure within it, so that the seeds sown into it may grow into a crop of the greatest perfection.*

[* What we may lack, if any, of approbation from the farmer, we shall make up in the ap proval we challenge from the plow-maker, for the adoption of all that is said by the author in hand in respect of an implement which is almost as indispensable in the manufacture of crops as the stones in the mill for manufacturing the wheat into flour. As of all implements the plow is the most efficient and labor-saving, so on none has the ingenuity of the farmer and the machinist been so much exercised. It would be hazardous to say, that it has been pushed to its ne plus ultra, and that nothing now remains but to remove the animal and hitch on steam power; but it is not easy to imagine what desideratum remains to be supplied in the construction of the plow. Instead, however, of suppressing anything in the Book of the Farm, we prefer rather to superadd what we find on the subject in a very elaborate essay on the Agriculture of Norfolk, England, to which the Royal Agricultural Society lately awarded a high prize, and paid the compliment of publishing it separately; in extenso, with all its illustrations. Among these aie the representations of the prize plon, which will also be found at the end of this chapter, although we do not perceive any essential difference from or improvement upon the Mid-Lothian plow given by Stephens, the plate of which accompanied our last number, and which is described in this one.

To go back, as our author does, and bring up the history of its progress to its present excellence of construction, from the rude implement in use by the Romans, will need no justification to the reflecting mind, ready as all such minds will be to draw from it the proud conclusion that the march of improvement has been from as humble beginnings to as high reachings in Agriculture as in other arts. Neither can it fail to inspire the hope that much more may yet be achieved in other departments if not in this. None in fact is yet closed to the career of improvement in the estimation of those who are animated by that spirit for going ahead, without which no melioration would occur in any branch of human industry. The French Vigneron, who, better than any one else understands the culture of the vine, says that after ages of observation, the art of adapting each particular species of vine to the soil most congenial to its culture, is yet in its infancy! Let us think so of everything while to improve remains even barely possible!

It may here be mentioned as a cnrious fact that President Jefferson's explanation and diagrams to illustrate them, on the principles of mechanical philosophy involved in the structure of plows, and especially in their mould boards, have been referred to and quoted by writers of the highest authority on that subject in Europe. It is no less curious, that bis son-in-law, Governor Randolph, a man of genius, bas the credit of being the inventor of the hill-side plow, with a shifting mould-board. In Mississippi and the South, where lands seem to be peculiarly subject to injury by washing, owing, perhaps, to the suddenness and violence of their showers, hill-side plowing is very extensively practiced. and with great skill and dexterity, by negro plowmen, as any one may see at Mr. Turnbull's, near Bayou Sara and other places. There, on lands very slightly an. dulating, may be found very perfect and beautiful specimens of this conservative process.

From the "Prize Report" on Norfolk Agriculture.

There is perhaps no implement which has undergone more improvement or more variation than the plow; and a glance at the catalogues which of late years bave emanated from the most celebrated implement-makers, will prove of how vast importance it has been considered to obtain such a construction that while lightness and stiffness were insured, vibration in the beam should be avoided, and a perfect action with economy of power, or a diminution of resistance should be secured, for from such a combination true work can alone result. To obtain these (485) 
(466.) The spade is an implement so simple in construction, that there seems but one way of using it, whatever peculiarity of form it may receive, namely, that of pushing its mouth or blade into the ground with the

great desiderata, appears to have been one of the great objects with Messrs. Ransome, for from no foundry has ever been seen a greater number of these implements, or which combined in harger extent these leading points ; but in every case exhibiting the thought and okill from which they had proceeded. The Reports of the Royal Agricultural Society demonstrate the estimation in which these progressive improvements have been held. It was, however. reserved for these manufacturers to exhibit, at the Southampton meeting of the year 1844, a new plow, which proved itself equally well adapted for light and heavy soils. This implement was chiefly novel in its material, and formation of the handlas and beam. These are constructed of the best wrought iron, combining lightness with adequate strength. The beams are made on the "truss principle" - that is, connecting the two sides together in such a manner as to prevent them from giving way to any amount of force, on whichever side it may be applied. The other new point is the mode of fastening the coulter, which facilitates its being placed in any new position with rapidity and ease. The following cat exbibits the figure of the prize implement, either with two or one wheel, and as a swing plow.
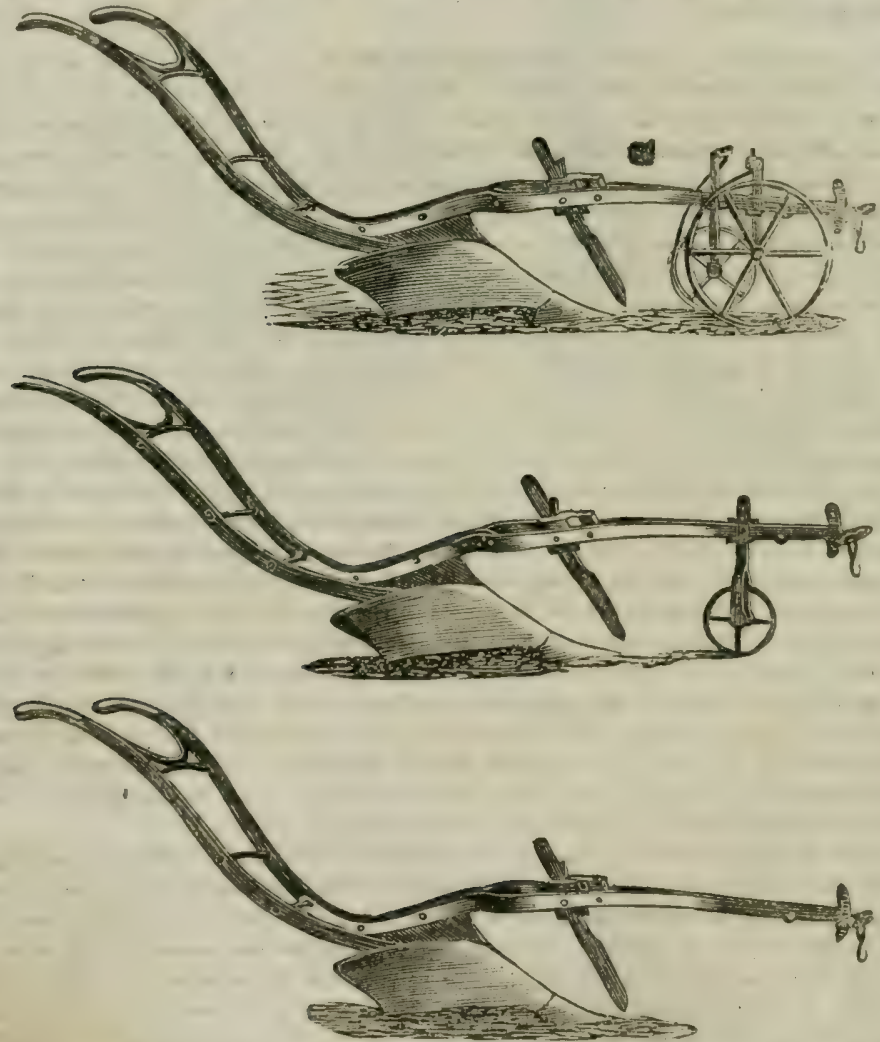

We had seen the plow at work at Mr. Henry Overman's, of Weasenham, in the autumn or 1843 , and the opinion of the judges at Southampton has fully borne out the high opinion that a practical farmer gave us of its capability and excellence.

Among the implements of late invention which have deservedly obtained the inventor great credit, and from their utility have come into considerable use-one more particularly than the other-are the subsoil and subturf plows, the invention of Sir EDWARD STACEY, of Rackheath Hall, Norfolk. Although these implements nre 80 well known, yet any rejort of Norfolk Agriculture would be incomplete were either a notice or a sketch of one of them omitted. Their effects have been found most beneficial on many soils, where the natural tenacity is increased by 8 hard substratum. On one farm where the land was subject to suffer from the rains in the autumn, the subsoil plow was passed up the furrows on a turnip fallow previous to the antumn plowing. The effect was to free the land from a more than ordinary quantity of moisture which happened

(486) 
foot, lifting up as much earth with it as it can carry, and then inverting it so completely as to put the upper part of the earth undermost. This operation, called digging, may be done in the most perfect manner; and any attempt at improving it, in so far as its uniformly favorable results are concerned, seems unnecessary. Hitherto it has only been used by the hand, no means having yet been devised to supply greater power than human strength to wield it. It is thus an instrument which is entirely under man's personal control.

(467.) The effect attempted to be produced on the soil by the plow is an exact imitation of the work of the spade. From the circumstance, however, of the plow being too large and heavy an implement to be wielded by the hand, it is not so entirely under man's control as the spade. To wield it as it should be, he is obliged to call in the aid of horses, which, though not capable of wielding it personally, as man does the spade, ean, nevertheless, through the means of appropriate appliances, such as harness, do so pretty effectually. It is thus not so much man himself as the horses which he employs that turn over the ground with the plow, they, in a great measure, becoming his substitutes in performing that operation; and they are so far his superiors, that they can turn over a greater quantity of the soil with the plow in a given time than he can with the spade. Man, however, has this advantage over horses in turning over the soil, that he can do it well with a very simple instrument-the spade; whereas horses require an instrument of more complex structure-the plow-to perform the same sort of work not so well; and the reason is this, that although the spade is really a very simple instrument, the act of digging with it is

to fall that year, and to benefit materially the following crop of turnips. Sir Edward has already described the utility of the former upon the heath-land attached to his estate, as well as the improvement of his park by the subturf plow, in the journals of the Society

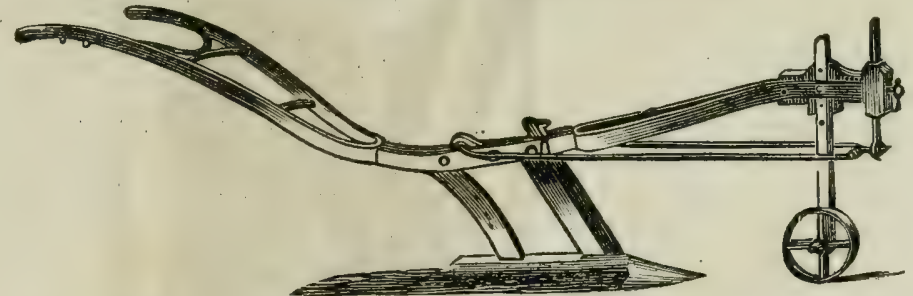

A practice has lately become very prevalent in some parts of the county, to lay the furrows in one direction. This method, if it should be found advantageous, will be greatly aided by Lowcock's new plow: This gentleman is a farmer at Westerland, Devon, and his attention was drawn to its necessity by having found that great injury was sustained in his neighborhood by the currents of air drawn up the furrows when the land was either ridged or thrown into stetches. When the land is laid in one plain surface, it is thought that the seed can be more easily deposited-and that in rainy seasons it will absorb the moisture with greater regularity, and in a dry one would be less injured by drouth. This implement seems to be the combined result of theoretical knowledge and practical experience-Mr. Lowcock farming wet soils.

The mode of adapting it to each furrow is extremely simple. When the plowman has axrived at the end of the furrow, he directs the horses round on the unplowed side of the land, and the dranght chain slides on a rod to the other end. While they are moving, he reverses the handles, where a catch drops into a mortice in the beam, and the plow is again ready. When the share and coulter are at work the mould-board flies into its proper direction, in which place the resistance of the newly-cut furrow keeps it. Presuming the conjectures as to the effect of such a system of plowing to be correct, this will become a very valuable implement in Norfolk. Messrs. Ransome obtained a prize for it at Southampton. (See the opposite page.)

The plows in most general use are the Norfolk and the Swing Plow, which have been ren. dered lighter and steadier than formerly. There are none, perhaps, as a whole, better suited to the soil, although for particular purposes there are sume superior, the Rutland having been found from its length of plat to whelm the olland better; while the Norfolk, from its short breast, lays the earth looser and rougher for the operations of the winter. 


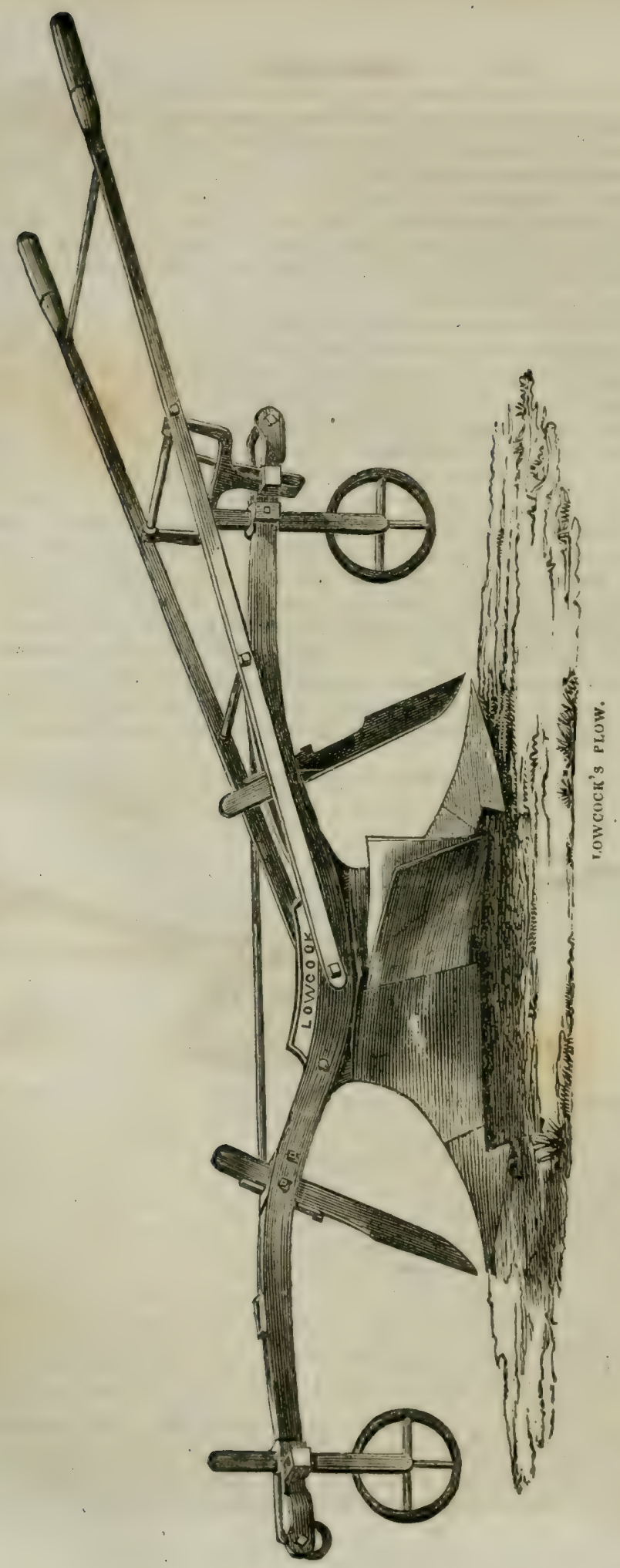


not a simple operation, but requires every muscle of the body to be put into action, so that any machine that can imitate work that has called into requisition all the muscles of the body, must have a complex structure. This would be the case even were such a machine always fixed to the same spot, and, for such a purpose, there is little difficulty in practical mechanics in imitating the work of man's hands, by complicated machinery ; but it is not so simple a problem in practical mechanics, as it at first sight may appear, to construct a light, strong, durable, convenient instrument, which is easily moved about, and which, at the same time, though complex in its structure, operates by a simple action; and yet the modern plow is an instrument possessing all these properties in an eminent degree.

(468.) The common plow used in Scotland is made either wholly of iron, or partly of wood and partly of iron. Until a few years ago it was universally made both of wood and iron, but now it is generally made entirely of iron. A wooden plow seems a clumsier instrument than an iron one, though it is somewhat lighter. The plow is now made wholly of iron, partly from the circumstance of its withstanding the vicissitudes of weather better than wood; and, however old, iron is always worth something; and partly because good ash timber, of which plows were usually made, is now become so scarce in many parts of the country, that it fetches the large price of $3 \mathrm{~s}$. per cubic foot; whereas iron is now becoming more abundant and cheap (204), being no more than $£ 14$ per ton for common cast goods, and from $£ 10$ to $£ 18$ per ton for malleable iron. A wooden plow with iron mountings usually weighs 13 stones imperial, and an iron one for the same work 15 stones. The cost of a wooden one is $£ 316$ s., capable of being serviceable, with repairs, for the currency of a lease of 19 years; that of an iron one $£ 44 \mathrm{~s}$, which will last a lifetime, or at least many years. Some farmers, however, still prefer the wooden one, alleging that it goes more steadily than the iron. Whatever of prejudice there may be in this predilection for the wooden plow, it must be owned that the iron one executes its work in a satisfactory manner. There is, I believe, no great difference of economy in the use of the two kinds of plows.

(469.) The plow, as it is now made, consists of a number of parts, which are particularly described below at (493), fig. 48, and to which you should immediately refer, in order to become acquainted with them. How well soever these different parts may be put together, if they are not all tempered, as it is termed, to one another, that is, if any part has more to do than its own share of the work, the entire implement will go unsteadily. It can be easily ascertained whether a plow goes steadily or not, and the fact is thus practically ascertained; and its rationale will be found below.

(470.) On taking hold of the plow by the handles with both hands, while the horses are drawing it through the land, if it have a constant tendency to go deeper into the soil than the depth of the furrow-slice previously determined on, it is then not going steadily. The remedy for this error is twofold, namely, either to press harder upon the stilts with the hands, and, by their power as levers, bring the sock nearer the surface of the ground, and this is called "steeping;" or to effect the same thing in another way, is to put the draught-bolt of the bridle a little nearer the ground, and this is called giving the plow "less earth." The pressure upon the handles or stilts should first be tried, as being the most ready remedy at your command; but should it eventually fail of effecting the purpose, or the holding the stilts so be too severe upon your arms, the draught-bolt should be lowered as much as required. But should both these attempts at amendment fail, then there must be some error in another part of the plow. On examining the sock, or share, its point may possibly be found to dip too 
much below the line of the sole, which will produce in it a tendency to go deeper than it should. This error in the sock can only be rectified at the smithy.

(471.) Again, the plow may have an opposite tendency, that is, a tendency to come out of the ground. This tendency cannot well be counteracted by the opposite method of supporting the stilts upward with the arms, because in this condition of body you cannot walk steadily, having no support for yourself, but rather affording support to the plow. It is for this reason that a very short man can scarcely hold a plow steary enough at any time; and hence such a man does not make a desirable plowman. The draught-bolt should, in the first instance, be placed farther from the ground, and in so doing the plow is said to get "more earth." Should this alteration of the point of draught not effect the purpose, the point of the sock will probably be found to rise above the line of the sole, and must therefore be brought down to its proper level and position by the smith (525).

(47\%.) You may find it difficult to make the plow turn over a furrowslice of the breadth you desire. This tendency is obviated by moving the draught-bolt a little to the right; but in case the tendency arise from some easual circumstance under ground, such as collision against a small stone, or a piece of unusually hard ground, it may be overcome by leaning the plow a little over to the right, until the obstruction is passed. These expedients are said to give the plow "more land."

(473.) The tendency of the plow, however, may be quite the opposite from this-it may incline to take a slice broader than you want; in which case, for permanent work, the draught-bolt should be put a little farther to the left, and for a temporary purpose the plow may be leaned a little over to the left, and which are said to give the plow "less land."

(474.) These are the ordinary instances of uusteadiness in the going of plows; and, though they have been narrated singly, two of them may combine to produce the same result, such as the tendency to go deeper or come out with that of a narrower or broader furrow-slice. The remedy should first be tried to correct the most obvious of the errors; but both remedies may be tried at the same time, if you apprehend a compound error.

(475.) Some plowmen habitually make the plow lean a little over to the left, thus giving it in effect less land than it would have, were it made to move upon the flat of the sole; and, to overcome the consequent tendency of the plow to make a narrower furrow-slice than the proper breadth, they move the draught-bolt a little to the right. The plowing with a considerable lean to the left is a bad custom, because it makes the lowest side of the furrow-slice, when turned over, thinner than the upper side, which is exposed to view, thereby deluding you into the belief that the land has all been plowed of equal depth; and it causes the horses to bear a lighter. draught than those which have turned over as much land in the same time, with a more equal and therefore deeper furrow-slice. Old plowmen, becoming infirm, are very apt to practice this deceptive mode of plowing.The plow should always move flat upon its sole, and turn over a rectangu. lar furrow-slice; but there are certain exceptions to this rule, depending on the peculiar construction of parts of certain forms of plows, which will be pointed out to you afterward.

(476.) None assume the habit of leaning the plow over to the right, because it is not so easy to hold it in that position as when it moves upon the sole along the land-side.

(477.) Other plowmen, especially tall men, practice the habit of con(490) 
stantly leaning hard upon the stilts, or of steeping; and, as this practice has the tendency to lift up the fore point of the plow out of the ground, they are obliged, to keep it in the ground, to put the draught-bolt farther from the ground than it should be. A little leaning of the hands upon the stilts is requisite at all times, in order to retain a firm hold of them, and thereby have a proper guidance of the plow.

(475.) A good plowman will use none of these expedients to make his plow go steadily, nor will he fall into any of these reprehensible habits.He will temper the irons, so as there shall be no tendency in the plow to go too deep or too shallow into the ground, or make too wide or too narrow a furrow-slice, or cause less or more draught to the horses, or less or more trouble to himself, than the nature of the work requires to be performed in the most proper manner. If he have a knowledge of the implement he works with-I mean, a good practical knowledge of it, for a knowledge of its principles is not requisite for his purpose-he will temper all the parts, so as to work the plow with great ease to himself, and, at the same time, have plenty of leisure to guide his horses aright, and execute his work in a creditable manner. I have known such plowmen, and they invariably executed their work in a masterly way; but I never yet saw a plowman execute his work well, who had not acquired the art of tempering the irons of his plow. Until he learns this art, the best made plow will be comparatively worthless in his hands.

(479.) In the attempt to temper the irons, many plowmen adopt a position of the coulter which increases the draught of the plow. When the point of the coulter is put forward in a line with the point of the sock, but a good deal asunder, to the left or land side, in light land that contains small stones, a stone is very apt to be caught between the points of the coulter and sock, and which will throw the plow out of the ground. This catastrophe is of no great consequence when it occurs on plowing land preparatory to another plowing; but it tears the ground on plowing lea, which must be rectified instantly; and, in doing it, there is loss of time in backing the horses to the place where the plow was thrown out. To avoid such an accident on such land, the point of the coulter should be put immediately above, and almost close upon, that of the sock; and this is the best temper of those irons, in those circumstances, for lea-plowing. In smooth soils - that is, free of small stones-the relation of the coulter and sock to each other is not of much importance in regard to steadiness; but it is the best practice to cut the soil clean at all times, and the practicabil ity of this should be suited to its nature.

(480.) The state of the irons themselves has a material effect on the temper of the plow. If the cutting edge of the coulter, and the point and cutting edge of the sock, are laid with steel, the irons will cut clean, and go long in smooth soil. This is an economical mode of treating plow-irons destined to work in clay-soils. But, in gravelly and all sharp soils, the irons wear down so quickly that farmers prefer irons of cold iron, and have them laid anew every day, rather than incur the expense of laying them with steel, which, perhaps, would not endure work much longer in such soil than iron in its ordinary state. Irons are now seldom if ever steeled; but, whether they are steeled or not, they are always in the best state when sharp, and of the proper lengths.

(4S1.) An imperfect state of the mould-board is another interruption to a perfect temper of the plow. When new and rough, it accumulates the loose soil upon it, whose pressure against the turning furrow-slice causes the plow to deviate from its right course. On the other hand, when the mould-board is worn away much below, it is apt to leave too much of the (491) 
crumbled soil in the bottom of the furrows, especially in plowing loose soils. Broken side-plates, or so worn into holes that the earth is easily pressed through them into the bosom of the plow, also cause rough and unequal work; and more or less earth in the bosom affects the balance of the plow, hoth in its temper and draught. These remarks are made upon the supposition that all plows are equally well made, and may, therefore, be tempered to work in a satisfactory manner; but it is well known that plows sometimes get into the possession of farmers, radically so ill-constructed that the best tempering the irons are capable of receiving will never make them do good work.

(482.) When all the particulars which plowmen have to attend to in executing their work-in having their plow-irons in a proper state of repair, in tempering them according to the kind of plowing to be executed, in guiding their horses, and in plowing the land in a methodical way-when all these particulars are considered, it ceases to surprise that so few plowmen should be first-rate workmen. Good plowmanship requires greater powers of observation than most young plowmen possess, and greater judgment than most will take time to exercise, in order to become familiarized wtth all these particulars, and to use them all to the best advantage. To be so accomplished implies the possession of talent of no mean order. The ship has been aptly compared to the plow, and the phrase, "plowing the deep," is as familiar to us islanders as plowing the land : to be able to put the ship in "proper trim," is the perfection aimed at by every seaman; so, in like manner, to "temper a plow" is the great aim of the good plowman; and to be able to do it with judgment, to guide horses with discretion, and to execute plowing correctly, imply a discrimination akin to sailing a ship.

(483.) [The present age is, perhaps, the most remarkable that time has produced, for the perfection of almost every kind of machine or tool required in the various departments of art and of mauufactures. In that most important of all arts-the production of the raw material of human food-something like a corresponding progress has been effected in its machinery and tools, though certainly not to the same degree of perfection as those employed in most of our inanufactures, whether they be in animal, vegetable, metallic or mineral productions. Various causes exist to prevent, or at least retard, an equal degree of perfection being arrived at in agricultural machinery, among which may be noticed one pervading circumstance, that affects, more or less, almost every machine or implement employed. This circumstance is, that all the important operations of the furn are performed by seasons occu pying comparatively short periods of time, and, should the artisan be endeavoring to produce any new or important machine, he can only make trial of it in the proper season. The imperfection of human perception is too well known to leave us in surprise at the first attempt of any improvement turning out more or less a failure. The artisan, therefore, will in all probability find that his project requires amendment; and, before that can be effected, the season is past in which a second trial could be made, and, consequently, must lie over for a year, in the course of which many circumstances may occur to cause its being forgotten or laid aside. Impediments of this kind do not occur to the inventor or improver of manafacturing 'machinery, where constant daily opportunities are at hand to test the successive steps of his invention. One other general cause, and of another kind, exists, to supersede the necessity, or even the propriety, of employing machinery of such high and delicate firish as we see in the machines of all in-loor manufactures. This is the irregularity of the media on which agricultural machinery is employed, and the numerous changes produced on these media-the soils and produce-by vicissitudes of weather and other causes, which not only affect the operation, but also the existence of many of these machines. From this cause, with its train of incidents, it may be inferred that agricultural machinery and tools must, of necessity, be of simple construction, which embrace nothing but the essentials of usefulness; that they have sufficient strength for their intended purpose, and free of any undue weight; that there should be no redundancy nor misapplication of materials; that all materials $\mathrm{em}$ ployed should be of the best quality, and the workmanship plain and sound. These properties, it must be admitted, are of greater importance to agricultural machinery, in general, than the minute delicacy of construction and finish observable in many of those almost intellectual tools employed in some of the other arts and manufactures.

(484.) Although, therefore, agricultural machines in general do not require a high mechanical finish, yet there are among them those which are based on principles implying a (492) 
knowledge and application of science, as well as mechanical skill, in their construction; and in this class is to be ranked the plow, which, in one word, is the most important of all agricultural machines.

(485.) To the plow, then, our attention is first to' be directed, not only as standing at the head of all its fellows in the ranks of the machinery of the farm, but as being the first imple. ment to which the attention of the farmer is called, in the commencement of this the winter season.

(486.) Before entering on the details of the implement as it now appears, it will be interesting to look back for a moment into its history. With the earliest stages of human industry, the tillage of the ground in some shape must be considered as coeval; and in these early attempts, some implement analogous to a plow must have been resorted to. In all ancient figures and descriptions of that implement, its extreme simplicity is to be remarked; and this is but a natural result; but with the progress of human intellect, are to be also observed deviations from the original simplicity, and an increase in the number of its parts, with a corresponding complexity in its structure. The Roman plows, imperfectly as they are described by different Roman authors, is an example of this. And as an example of apparently very remote origin, the caschrom, or plow used even at this day, in some portions of the Outer Hebrides and in Skye, forms a very curious and interesting antiquarian relic of the ancient Celtic habits. It is formed, as in fig. 47, of one piece of wood, selected fiom its

Fig. 47.

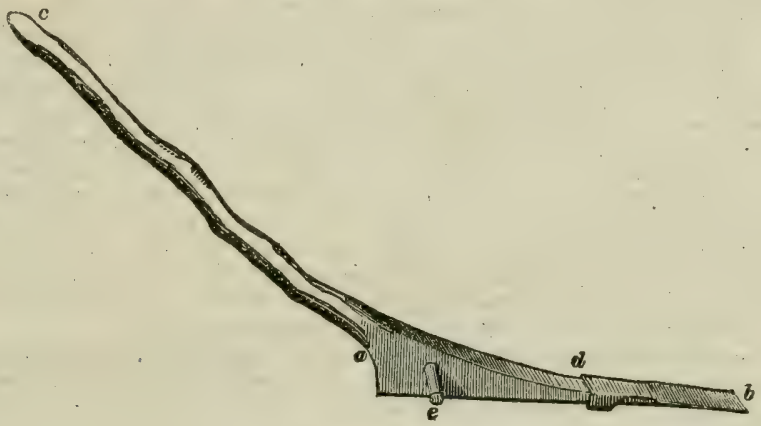

THE CASCHROM.

possessing the natural bend at $a$, that admits of the head $a b$ assuming a nearly horizontat position, when the handle $c$ is laid upon the shoulder of the person who wields the implement. A simple wedge-shaped share, $b d$, is fitted to the fore part of the sole. A wooden peg, $e$, is inserted in the side of the heel at $e$, which completes the implement. On this last member the foot of the operator is applied, to push the instrument into the ground. It is of course worked by the hand alone, and makes simply a rut in the ground. Yet even in this rude implement are to be traced the rudiments of a plow.

(487.) As the cultivation of the soil became more and more an object of industry, corre sponding improvements would naturally follow in the implements by which such operations were performed. But in Britain previous to the beginning of the last century, the plow appears to have continued in a very uncouth state. About that period A griculture seems to have become more an object of improvement. Draining began to be studied, and its effects appreciated. The amelioration of the soil produced by draining would soon call for better modes of dressing such improved soils; hence, still farther improvements in the plow would come into request. In accordance with this, we find the introduction of an improved plow into the northern counties of England, under the name of the Dutch or Rotherham plow. This appears to be the foundation of all the modern improvements, and fiom the circumstance of engineers and mechanics having been brought from Holland to conduct the drain ing of the English fens, there is good reason to conclude that the Rotherham plow was originally an importation from Holland, in a similar manner as the barley-mill was, at a later period, borrowed from that country. About the middle of the past century, the Rotherham plow appears to have been partially introduced into Scotland; but until Mr. James Small took up the subject, and, by his judicious improvements gave a decided character to the plow, little or no progress had been made with it.

(488.) Small appears to have been the first who gave to the mould-board and the share a form that could be partially imitated by others, whereby, following his instructions, mouldboards might be multiplied, each possessing the due form which he had directed to be given to them. It is to be observed, that when Small first tanght the method of construction, mould-boards were really boards of wood, and for their defence, were covered with 
plates of iron. The method of construction being not very clearly defined. and miuld-boards being necessarily constructed by many different hands, the improved syatesn. it may be easily conceived, must have been liable to failure in practice. It was. Iherefire, one of those happy coincidences which now and then secur tor the beuctit of mankind. that the founding of cast-iron was then beginning to become general. T'le firtumate circumstanco was seized. Mould-boards, together with the head or sheath. and the sole and land-side plates, were made of cast-iton: and a model or pattern of these paris having been onco formed, any number of duplicates could be obtained. each pussessing every quality. in point of form, as perfectly as the original model. The plow, thus in a great measure placed boyond the power of uninforned mechanics to maltreat, came rapicily and deservedly into public esteem, under the uame of Small's plow. Though originally produced in Berwickshire, the plow that seems to retain the principal feature of Small's improvenents-llie mould. board-is now found chiefly in East-Lothian, and, as will apjear, ditlers very sensibly from that now generally used in Berwickshire.

(489.) Other writers, about the same period, published unethods fir constructing a mould. boand on just principles. Among these, the method propused by IBailey of Chullingham may be mentioned as approaching very near to the tive therietical firm. Others less perfect have been proposed, which it is not necessary at present to nulice; while several have pub. lished general descriptions of their construction of the phow. but huve withlield the principles on which their mould-boards are formed.

(490.) While these improvements of the past century were going on, the plow was wniversally constructed with wooden framing; but about the beginning of the present century (the precise year cannot now be well defined), malleable iton began to be employed in their fabrication. The application of this makerial in the construction of plows came will si much propriety, that it is now, in Scotland, almost universal. It has many advantages: but the most prominent are its great durability under any expusure. and its letter adaptation to withstand the shocks to which the implement is fiequently liable in the cuurse of working. In a national point of view, it is also deserving of the most extended application, being a produce for which Britain stands unrivaled. This period also. Was productive of an innovation on the form of mould-board and share which had been established by Small. The mould-boards hitherto referred to come under the denomination of concare, or more properly straight-lined; when Mr. Wilkie, Uddingstone, near Glasgow, introduced his new form with convex lines, to be afterward more particularly noticed. and which has been adopted in various districts in Scotland, to the exclusion of the cuncave form.

(491.) At a still later period, a form of plow was brought forward by Mr. Cunningham, Harlaw, near Edinbuph, a practical farmer, in which are combined the properties of Wilkie's, with very slight deviation of form fium that of Small's plow-the principal ditterence being in the furm of the share.

(492.) Having, in this short sketch of the progress of the plow. brought it is the point when it has diverged into three varieties, each of which is held in equal estimation in the respective districts in which it is used, it is a remarkable circumstance that each holds its sway in its peculiar locality, to the almost entire exclusion of its compeers. The first two have undergone numerous slight clunges, forming sub-varieties, but retaining the respective leading features of the concave and convex mould-boards; and, as they have each spread (especially the first) over a wide extent of cumtry, I purpose to distinguish them by the county in which they are chiefly employed. Thus, the Small's pluw shall be denuminated the East-Lnthian, and Wilkie's the Lanarkshire. plow. The third variety is more limited in its range of application, being almost exclusively confined $t$. Mid-Lothian, and the borders of those counties adjoining to it, thoughout which it is known by the name of the Currie plow, but which it is proposed to distinguish here by the name of the Mid-Lothian.

(493.) Before enterng upon the detuiled descipiption, it will be useful to the agricultural student that a nomencluture be given of the various parts of the plow. Thus, fig. 48 , which

Fig. 48.

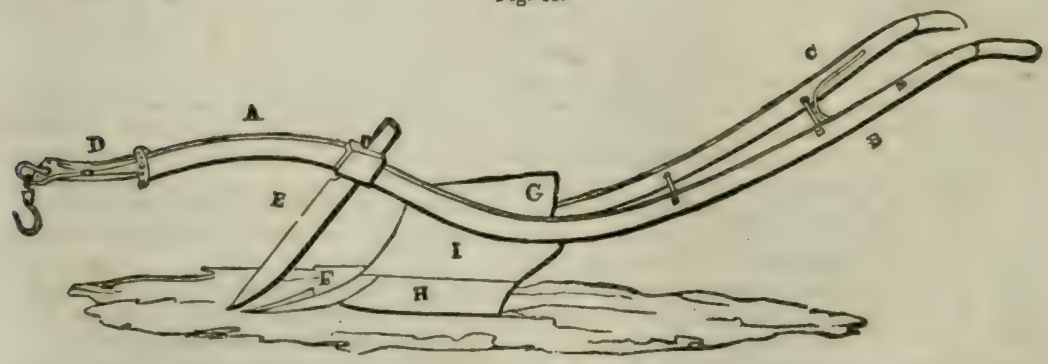




is a view of a plow in perspective, presents that which plowmen and agricultural mechanics denominate the land-side, so called because when in work it is always (except in the case of turn-wrest or right-and-left plows) in contact with the firm or unplowed land. The opposite or right side of the plow, being that which turns over the furrow-slice cut from the firm land, is called the furrow-side. That member of the plow to which the animals of draught are yoked, marked $\mathbf{A}$ in the figure, is the beam. Those parts by which the plowman holds and guides the implement are called the stills or handles, B being the great stilt or left handle, and $\mathrm{C}$ the little stilt or right handle; $\mathrm{D}$ is the muzzle or bridle by which the horses are attached to the beam; $\mathrm{E}$ the coulter is a cutting instrument that st'vers the slice from the firm land, and F the sock or share which cuts the slice below from the subsoil; G is called the urest or mould-board. It is probable that the term wrest applied formerly to only a particular portion of the mould-board-the lower portion in the more ancient plow-which was supposed to wrest or turn aside the slice after being cut by the share; thus we find in the Kent turn-wrest plow that the wrest is a simple straight bar of wood. The mould-board, in the improved implement, receives the slice from the share, turns it gradually over, and deposits it continuously at the proper angle. $\mathrm{H}$ is the sole-shoe on which the plow has its prin cipal support, and on which it moves, and I is the land-side plate, only serving to complete the sheathing of the land-side, presenting a uniform smooth surface to the firm land, and preventing the crumbled earth from falling within the body of the plow. These last parts cover the body-frame from view, which will be exlibited among the details.

(494.) Without entering into a description of all the sub-varieties of these plows, it will be sufficient to attend to the type of each variety, and, first, as to their general qualities and characleristics.

1495.) The East-Lothian plow, figs. 49 and 50, Plate V.-In this plow, the proper lines of the body on the land-side lie all in one plane, which, in working, should be held in the vertical position, or very slightly inclining to the left. The coulter slightly oblique to the land-side plane, the point standing toward the left, the rake of the coulter varies from $55^{\circ}$ to $65^{\circ}$. In the mould-board the vertical sectional lines approximate to straight lines, giving the character of apparent concavity, and it is truncated forward. Share pointed, with a feather or cutter standing to the right, having a breadth of at least $\frac{2}{3}$ the breadth of the furrow, the cutting edge of the feather lying nearly as low as the plane of the sole. The neck of the share is prolonged backward, joining and coinciding with the carve of the mould-board, which curvature is also carried furward on the back of the feather. The character of this plow is to take a furrow of 10 inches in breadth by 7 inches in depth, cut rectangular, leaving the sole of the open furrow level and clean. The resistance to the draught is generally below the average of plows, and this plow is employed for every kind of soil.

(496.) Lanarkshire plow, figs. 51 and 52, Plate IX.-In this plow, the proper lines of the landside lie in different planes; thus when the fore-part of the land-side of the body, taken at the junction of the breast with the beam, is vertical, the hind-part. taken at the heel, overhangs the soleline $\frac{5}{8}$ inch, and the beam, at the coulter-box, lies to the right of a vertical line from the land-side of the sole about 1 inch, the point of the beam being recurved toward the land-side. In working, the fore-part of the body is beld in the vertical line, or slightly inclined to the left. The coulter, by reason of the bend in the beam to the right, and the point being to the left of the land-side, stands very oblique, but nearly coinciding with the land-side, at the hight of 7 inches from the sole. Rake of the coulter from $55^{\circ}$ to $65^{\circ}$. The vertical sectional lines of the mould-board are all convex toward the furrow, giving the mould-board the character of convexity, and it is prolonged forward, covering the neck of the share. Share chisel-pointed, with the feather seldom exceeding $5 \frac{1}{2}$ inches broad, the cutting edge rising from the point at an angle of $8^{\circ}$ till it is 1 inch above the plane of the sole, when it falls into the curve of the mould-board, while the neck passes under the latter. The character of this plow is to take a furrow whose section is a trapezoid, its breadth from $7 \frac{1}{2}$ to 9 inches, and greatest depth $6 \frac{1}{2}$ inches, the sole of the furrow being not level, and deepest at the land-side. In the finished plowing, the laid-up furow-slices have the acute angle upward, giving the character which I call high-crested to the furrow-slice, especially observable in plowing lea. Resistance to the draught about the average, and it is considered to be well adapted to stiff clay, and to lea-land.

(497.) Mid-Lothian plow, figs. 53 and 54, Plate X.-This plow is always worked with a chain bar under the beam. The proper lines of the land-side lie in different planes; thus, when the fore-part of the land-side, taken as in the former case, is vertical. the hind-part, taken at the heel, overhangs the sole line $\frac{3}{8}$ inch, but the beam is continued straight. In working, the land-side is held vertical, or slightly inclined to the left. The coulter stands rather oblique, and the point about $1 \frac{1}{2}$ to 2 inches above the point of the share. Rake of the coulter varying from $56^{\circ}$ to $80^{\circ}$. The vertical sectional lines of the mould-board approximate to straight lines, giving the character of concavity, and the mould-board is prolonged forward, covering the neck of the share. The share is chisel-pointed, with feather seldom exceeding 5 inches broad, and, when trimmed for leaplowing, the cutting-edge rises from the point at an angle of $10^{\circ}$ to a hight of $1 \frac{1}{4}$ inches above the plane of the sole, when it falls into the curve of the mould-board. while the neck passes under it. The character of this plow is to take a furrow-slice whose transverse section is a trapezoid, having an acute angle with a breadth of $8 \frac{1}{2}$ to 9 inches, and nsually from 6 to $6 \frac{1}{2}$ inches in depth. The sole of the furrow is not level, and is deepest at the land-side. In the finished plowing, the laid. up furrow-slices have the acute angle upward, forming a high crest when plowing lea. Resistance to the dranght is about the average, and this plow is considered applicable to every kind of soil, but particularly to plowing 'ea.

(498.) Before entering upon the specific details of the three varieties into which the modern Scotch plows are here divided, it will be necessary to lay donon certain data, on which the detaiis (495) 
of each variety will be baved. F'or this jurpuse, the figures in elevation. figs. 49,51 , and 53 , in the plates of the entire plows about to be described, are sapposed to stand upon level plane, the heel and point of the share tuoching that plane, these being actually the points an which the plow is supported when in motion; this plane shall be called the base line. The fore-part of the land-side of the plow's body-standing in the vertical position, as seen in plan figs. 50, 52 and 54, in the plates -is supposed to be placed upon a similar line, touching the land side of the sole-sboe and the point of the share. The base-line is divided into a scale of feet for the convenience of comparison. The zero of the scale is taken at that part of the plow's body, where a vertical trans. verse section, at right angles to the plane of the land-side, will fall upon a point on the surface of the mould-board, which shall be distant from the land-side plane by a space equal to the greatest breadth of the furrow taken by the respective plows; the hight of this point above the base-line being also equal to the breadth of the slice. Or, the zero is that vertical section of the mould board, which, in its progress under the slice, will just place the latter in the vertical position.The scale, by this arrangement, counts right and left of the zero. The dotted line marked sur. face-line in figs. $49,51,53$, in the plates, represents the depth of the furrow taken by the respect ive plows.

(499.) This zero point has not been fixed on without much consideration; for, having experienced the inconvenience of vague generalities in stating the dimensions of the plow, as given in works on the subject, it has appeared to me desirable that some fixed point should be adopted, and this has been chosen as less liable to change than any other point in the longitude of the plow; all other points of this implement being liable to and may be changed at pleasure, without change of effect. Thus the beam or the handles may be lengthened or shortened, the position of the coulter and the length of the sole may be varied, the mould-board itself may be lenethened or shortened forward without producing any decided change in the working character of the plow, the apparent changes being easily counteracted by a corresponding change in a different direction. The lengthening of the beam, for example, would only require a corresponding cbange in the hight of its extremity above the base line; an alteration in the length of the share, or in the position of the coulter-box, induces only a corresponding change in the angle which the coulter forms with the base line, which angle, in any case, is liable to change from the wearing of the irons themselves, but which can be rectified as required by shifting the draught-bolt in the bridle. The zero point here proposed can, with tolerable exactness, be deternined in any plow with the instruments that every mechanic has in his hands. squares and a foot-rule.

(500.) It may be well, also, to premise farther, in regard to the contour in elevation of the different plows, that although the hights at the different points throughout the beam and handfes are given in detail, as adopted by the best makers, which those onacquainted with the implements may follow with confidence, in the construction of implements of the same character, yet I cannot pass over the circumstance withont noticing that, with the exception of one point-ibe hight of the beam at the dranght-bolt-any part of the contour may be altered to the taste of the maker. and even the point of the beam, as already noticed, may be altered, provided the alteration is continued backward or forward in a certain angle. The change in position in the vertical direction of three other points is limited within a certain range-not from principle. bowever, but for convenience. These points are the hight of the beam at the cowlter-box and at the breast-line of the mould-board; these cannot be brought lorcer than the given dimensions withont subjecting the plow to an unnecessary tendency to choke in foul ground, though they may be raised higher without injury, provided the corresponding parts-the mould-board and body-frame-are altered in proportion. The third point here alluded to is the hight of the handles, which is altogether a point of convenience; but it may be affirmed of this that it is better to be lov than high, since being low places the plow more under the command of the plowman. The different points, as given in plan, being more matters of principle, with exception of the position of the handles, canuot be deviated from without compromising the character of the pluw.

(501.) W ith these preliminary remarks I proceed to the general description of the three varieties, taking first,

(502.) The East-Lothian Plow.-Fig. 49, Plate V. represents an elevation of this plow, on the furrow side, drawn to a scale of 1 inch to 1 foot, and fig. 50 a borizonial plan of the same. It is found with varions shades of difference, but not to the extent or of such a marked character as to require separate description from what follows. The beam and bandles or stilts are almost invariably made of malleable iron, the body-frame being of cast-iron, the latter varying slightly with different makers. In its construction, the beam and left handle are usually finished in one continued bar $\mathrm{ABC}$, possessing the varied curvature exhibited in fig. 49 , as viewed in elevation. When viewed in plan, as in fig. 50 , the axis or central line of the beam and left handle are in a straigbt line-though in this arrangement there are some slight deviations a nong the different makers the point of the beam being in some cases turued more or less to the right or furrow side, and this is found to vary from $\frac{1}{2}$ inch to 2 inches from the plane of the land-side.

(503.) The right handle. DE. is formed in a separate bar, and is attached to the bodr-frame at tts fore end by a bult, as will be shown in detail, and farther connected to the left handle by the bolts FFF, and the stays GG.

(504.) The coulter I is fixed in its box $\mathbf{K}$ by means of iron wedges, holding it in the proper position. Its office being that of a cutting instrament, it is constructed with a sharp edge, and is set at an angle of from $55^{\circ}$ to $65^{\circ}$ with the base-line.

(505.) The mould-board $\mathrm{L}$, which is fixed upon the body-frame, and to the right bandle, is a curved plate of cast-iron, adapted for turning over the furrow-slice. Its fore-edge or breast MN coincides with the land-side of the plow's body; its lower edge $T$ behind stands from 91 to 10 inches diatant from the plane of the land-side, while its upper edge $P$ spreads out to a distance of 19 inches from B, the land-side plane. In this plow the mould-board is truncated in the fore part, and is met by the gorge or neck of the share. the junction being at the line $\mathrm{N}$.

(506.) The share or sock NR is fitted upon a prolongation of the sole-bar of the body-frame, 
termed the head, and falls into the curves of the mould-board, of which its surface forms a continvation.

(507.) The bridle $C$, or muzzle, as sometimes named, is that part to which the draught is applied, and is attached to the point of the beam by two bolts, the one $\mathrm{S}$ being permanent, upon which the bridle turns vertically. The other bolt $U$ is movable, for the purpose of varying the earthing of the plow; the landing being varied by shifting the draught-bolt and shackle $\mathrm{V}$ to right or left. The right and left handles are furnished at $\mathbf{A}$ and $\mathbf{D}$ with wooden helves fitted into the sockets of the handles.

(508.) The general dimensions of the plow may be stated thus; as measured on the base-line: From the zero-point $O$ to the extremity of the heel $\mathrm{T}$, the distance is 4 inches, and from $\mathrm{O}$ for ward to the point of the share $\mathbf{R}$, the distance is 32 inches-giving, as the entire length of sole, 3 feet. Again, from $O$ backward to the extremity of the handles $A^{\prime}$ is 6 feet 2 inches, and forward to the draught-bolt $\mathrm{V}^{\prime} 4$ feet 7 inches, making the entire length of the plow on the base-line 10 feet 9 inches; but, following the sinuosities of the beam and handle, the entire length from $\mathbf{A}$ to $\mathrm{C}$ is about 11 feet 3 inches.

(509.) In reference to the body of the plow, the center of the coulter-box $\mathrm{K}$ is $14 \frac{1}{2}$ inches, and the top of the breast-curve M 9 inches before the zero-point, both as measurerl on the base-line; but, following the rise of the beam, the distance from $M$ to the middle of the coulter-box will be 7 inches.

(510.) The hights at the different points above the base-line are marked on the figure in elevation, along the upper edge of the beam and handle; but the chief points in hight are repeated here, the whole of them being measured from the base-line to the upper edge of the beam and handles at the respective points. At the left handle $\mathrm{A}$ the hight is 3 feet, at the right handle $\mathrm{D}$ 2 feet 9 inches; and a like difference in hight of the two is preserved till the right handle ap. proaches the body at the middle stretcher $\mathbf{F}$; thence the difference increases till it reaches the body. The hight at the point of the beam is 18 inches, and the center of the draught-bolt, at a medium, 17 inches. The lower edge of the mould-board behind, of this plow, at $\mathrm{T}$ is usually set about $\frac{1}{2}$ inch above the base-line, and at the junction with the share about the same hight.

(511.). The dimensions in breadth, from the land-side line, embrace the obliquity that is given to the direction of the beam and handles, compared with the land-side plane of the body taken as the sole. The amount of obliquity, as exhibited by the dotted line AC, fig. 50 , which coincides with the land-side plane of the body, is, that the axis of the beam at the extremity $\mathrm{C}$ stands $1 \frac{1}{6}$ inches to the right, and at the opposite end the left handle $A$ stands about 2 inches to the left of the line. These points may, however, be varied slightly from the dimensions here given. In the first - the point of the beam-it is found in the practice of different makers to range from 1 to 2 inches. In the opinion of some writers and practical men, it is held that the beam should be parallel with the land-side plane of the body. With all deference to such opinions, I apprehend that the direction of the line of draught, in a vertical plane, cannot coincide with the plane of the landside ; for the point of resistance in the plow's body cannot fall in that plane, but will pass through some point to the right of it, and which, from the nature of the subject, cannot be very precisely defined. Both reason and experience, however, point this out to the plow-maker, and especially to the observant plowman. Hence, also, may be remarked, from the instructions laid down by Small* for the formation of the beam-which, in his time. were made of wood-that the land-side of the beam shonld lie in the plane of the land-side of the body; and, as he directed the beam to be $2 \frac{4}{4}$ inches in breadth at that point, its axis must have been $1 \frac{1}{8}$ inches to the right of the landside plane; and, in all cases, it must be admitted that the resultant of the effect will lie in the axis of the point, provided the draught-bolt is placed in that line, But, for very sufficient practical reasons, the draught-bolt has a range from right to left, by which the effects of variation of soil and other causes can be rectified at pleasure.

(512.) A similar difference of opiuion has prevailed in regard to the position of the handles, in reference to the land-side plane. In the plow now under review, the left handle deviates only 2 inches from the line; whereas, as we shall see, another variety has the handle 7 inches to the left of the line; and this deviation has been advocated on the principle of allowing the plowman to walk right in the middle between the handles, his right and left arms being equally extended. ${ }^{\dagger}$ Now I would again submit whether the man who walks with his arms equally extended, and his body equally distant from either handle, or he who is compelled to have one handle always near his body, whereby he can, on any emergency, bring his body instantaneously in contact with the hand, or that which it grasps-which of these men will have the greatest command over the in. strument he guides? Little consideration, I imagine, will be necessary to satisfy the inquirer that the latter will have the advantage.

(513.) The dimensions of the parts of the frame-vork of the plow are: The beam, at its junction with the mould-board at $M$, is from $2 \frac{1}{2}$ to $2 \frac{3}{4}$ inches in depth, by 1 inch in breadth-the same strength being preserved onward to the coulter-box K. From the last point a diminution in breadth and depth begins. which is carried on to the extremity $\mathrm{C}$, where the beam has a depth of $1 \frac{3}{4}$ inches. and a breadth of $\frac{1}{2}$ to $\frac{5}{8}$ inch.

(514.) The conlter-box is formed by pierving an oblong mortise through the bar, which has been previously forged with a protuberance at this place, on each side and on the upper edge; the mortise is $2 \frac{1}{2}$ by $\frac{3}{4}$ inches, and the depth $3 \frac{1}{2}$ inches.

(515.) From the junction with the mould-board at $\mathrm{M}$ backward, the beam decreases gradually till, at the hind palm of the body at $\mathrm{B}$, it is 2 inches in depth, and $\frac{5}{8}$ inch in breadth, where it merges in the left handle A. This last member retains a nearly uniform size throughout of 2 inches by $\frac{3}{8}$ inch. The right handle $\mathrm{D}$ is somewhat lighter, being usually $1 \frac{1}{2}$ inches by $\frac{3}{8}$ inch, and both terminate in welded sockets, which receive wooden helves, of 6 or 8 inches in length. The stretchers FFE, which support and retain the handles at their due distance apart, are in length suited to their positions in the handles, and their thickness is about $\frac{3}{4}$ inch diameter, tapering toward the ends, where they terminate in a collar and tail-bolt, with screwed nut. The up- 
per stretcher has also a semi-circular stay riveted to its middle, the tails of the stays GG terminating like the stretcher with serewed tails and nuts.

(516.) Having given the general dimensions and outline-description of this plow, there remains to be described the details of the bndy-frame and its sheathing, all the figures of which are on a scale of $1 \frac{1}{5}$ inches to 1 foot.

(517.) The body-frame.-The different views of the body-frame are exhibited in the annexed cuts, fig. 55 and 56 , wherein the same letters refer to the corresponding parts in the different

Fig. 55.

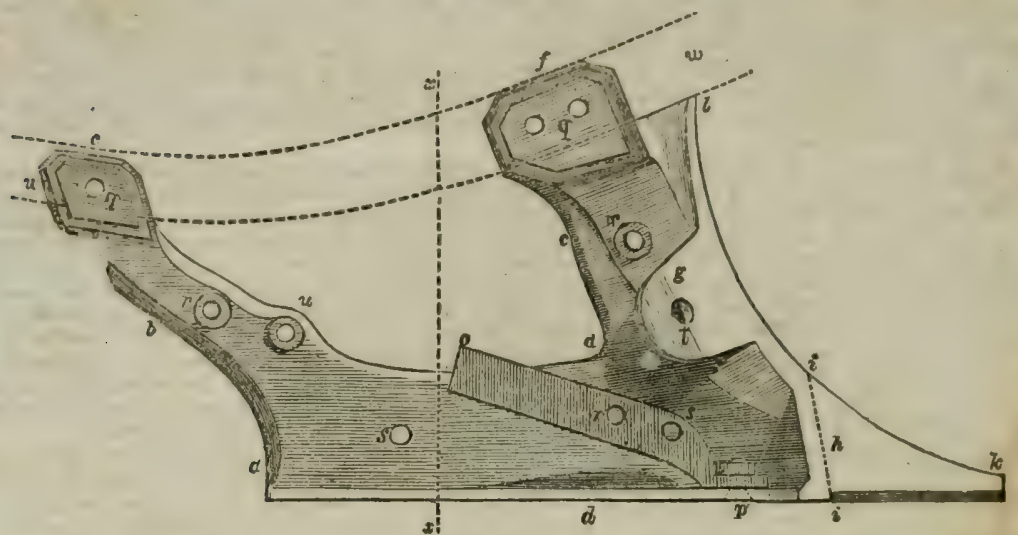

Fig. 56.

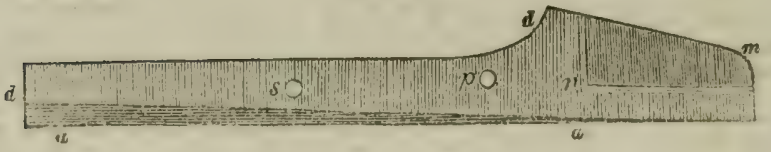

THE DETAILS OF THE BODY-FRAME.

figures. Fig. 55 is an clevation of the furrow-side; fig. 56 a plan of the sole-bar of the frame in. verted; and a vertical section, on the line $x x$, is given in fig. 57 . In all the figures, then, $a a$ is the sole bar, with two arms, $b$ and $c$, extending upward, and having at the lower edre a Hange $d$, running along the right-hand-side. Each of the arms $b c$ terminites in a palm, $e f$, by which it is bolted to the beam. The arm $c$ is furnished, beside, with an oblique palm or ear, $g$, upon which the fore edge of the mould board rests, and to which it is bolted. The sole-bar $a$, with its fiange, terminates forward in the head $h$, which is here made to form the commencement of the twist of the mould-board, and upon which the share is fitted, reaching to the dot. ted line $i i$, fig. 55. The fore edge $k, i, l$ of the frame is worked into the curve anawering to the oblique section of the fore edge or breast of the mould-board, and serves as a support to the latter throughout their junction. The curvature given to the arm $b$ is unimportant to the action of the plow, but the general oblique direction here given to it is well adapted to withstand the thrust con. stantly exerted in that direction when the plow is at work. In fig. 56, the sloping edge $d m$ represents the enlargement of the sole-bar, on which the share is fitted, and where the lower part of the fore edge of the mould board rests. The depressed portion $m n$ is that which is embraced by the flange of the share. In the frame, $O$ is the lower extremity of the right bandle, broken off at $O$, to show the manner in which it is joined to the sole-flange of the frame by the bolt $p$. The bolt-holes $q q$ are those by which the beam is secured to the palms of the frame; $r r$ are those by which the land-side plate is attached; and $s \&$ those of the sole-shoe, $t$ being that which secures the monld-board to the ear, and $u$ that which receives the lower stretcher of the handles. (See fig. 50, Plate V. at F and $\mathrm{O}$.) The letter $v$ marks the second bolt-hole of the mould-board, while its third fixture is effected upon the right hanlle by the intervention of a bracket, or of a bolt and socket, as seen at $\mathrm{O}$, fig. 50, Plate $\mathrm{V}$. The dotted lines $v 0$ wark

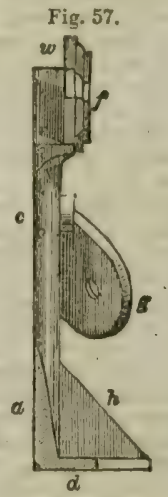

A VERTICAL SECTION OF THE FRAME. the position of the beam when attached to the body, the beum being received into the seats formed on the land-side of the palms $e f$, as seen more distinctiy at $w$, in fig. 57 .

(518.) The body-frame being an important member of the implement, regard is paid to having it as light as may be consistent with a due degree of atrength; hence, in the different parts, breadth has been given them in the direction of the strain, while the thickness is stndiously atten. aated in such places as can be reduced with safety. The least breadth of the sole-bar $a$ is 3 s inches, of the arm $c 4 \frac{1}{2}$ inches, and of $b 2 \frac{1}{4}$ inches. The brendth of the sole-flange is 2 inches, the greatest thickness in any of the parts is $\frac{3}{4}$ inch, and the total weight of the frame is 30 lbs. 
(519.) The share.-Figs. 58-62 are illustrations of the share and its configuration; fig. 58 is a plan, 59 a geometrical elevation of the furrow-side, and 60 a direct end view looking forward, of which $a$ is the boss adapted to the curvature of the mould-board, $b$ the land-side flange which embraces the head on the land-side, $c$ the sole-flange, embracing, in like manner, the head below; and these three parts form the neck or socket of the share, fitting closely upon the head, and being, in effect, part of the mould-board. The part $d e f, f i g .58$, forms the share proper, consist-

Fig. 60 .

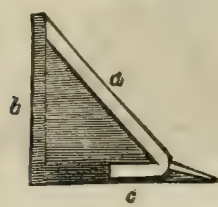

Fig. 59.

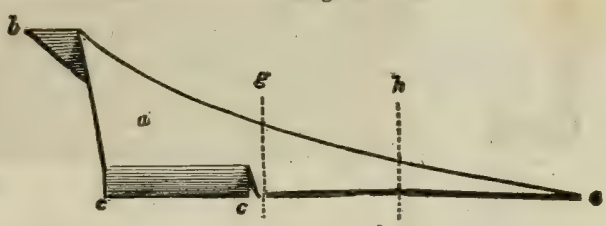

Fig. 61 .
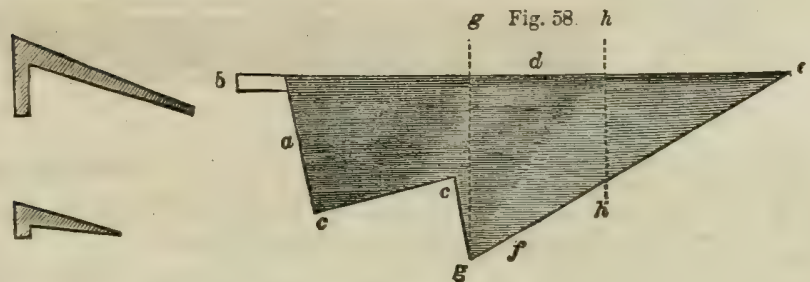

Fig. 62.

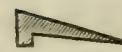

THE DETAILS OF THE SHARE.

ing of $d c e$ the shield, terminating in the point $e$, and of the part $c g e$ the feather or cutter ranning off at the point $e$. The extreme brealth of the share in this plow, measuring from the land. side to the point $g$ of the feather, varies from 6 to $6 \frac{1}{2}$ inches; and its length in the sole, including the neck, is about 16 inches, the feather being 11 inches. The other figures 61 and 62 are transverse sections of the share on the lines $g g$ and $h h$ in the respective figures, exhibiting the structure and relation of the shield and the feather, as well as the position of the cutting edge of the feather in relation to the base-line of the plow represented by the line $A^{\prime} V^{\prime}$, fig. 49 , Plate V. where, as will be observed, the cutting edge, through its entire length, lies within less than $t$ of an inch of the base-line.

(520.) The share is always formed from a plate forged for the express purpose at the iron-mills, and known in the trade by the term sock-plate. Fig. 63 represents the form in which these plates

Fig. 63.

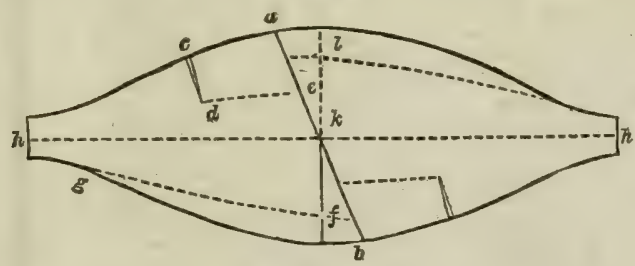

A SOCK-PLATE.

are manufactured, the thickness being from $\frac{1}{2}$ to $\frac{3}{4}$ inches; they are afterward cut in two through the line $a b$, each half being capable of forming a share. To do this, an incision $c d$ is made on the short side to a depth of 2 inches, the part $a c d e$ is afterward folded down to form the soleflange, and the part $b f g$ is, in like manner, folded down to form the land-side flange. The point $h$ is strengthened, when requisite, to receive the proper form of the shield and point, the latter being tipped with steel. The edge $h c$ is extended to the requisite breadth to form the feather. In order to cut a sock-plate at the proper angle, so as to secure a minimum expenditure of labor and material, let a central line $h h$ be drawn upon the plate, and bisect this line in the point $k$, the line upon which the plate should be cut will form angles of $70^{\circ}$ and $110^{\circ}$ nearly, with the line $h h$; or, mechanically, draw $k l$, equal to $5 \frac{1}{2}$ inches, at right angles to $h h$, and $l a$ parallel to $h h$, mark off 2 inches from $l$ to $a$, and, through the points $a k$, draw the line $a b$, which is the proper direction in which the plate should be cut.

(521.) The sole-shoe.-The figures $64-66$ are illustrative of the sole-shoe. Fig. 64 is a plan of the shoe, $a a$ being the sole-flange, and $b b$ the land-side flange. Fig. 65 is an elevation of the same, and fig. 66 a cross section, showing the filling up of the internal angle opposed to where the greatest wear takes place. The thickness of the sole-flange at the heel $a$ is $\frac{7}{8}$ inch, diminishing forward to $\frac{3}{3}$ inch at 3 inches from the point, and thence it is thinned off to prevent obstruction in its progress through the soil. The breadth of the sole is $2 \frac{1}{4}$ inches, and its extreme

(499) 
lergth $20 \frac{1}{2}$ inches. The side-flange is $\frac{1}{2}$ inch thick slong the edge by which it is attached to the sole, diminishing upward to $\downarrow$ inch at the top edge, the hight being $4 \frac{7}{4}$ inches at the heel and 6 inches at the fore end; weight about $14 \mathrm{lbs}$. The upper land-side plate is 18 inches in length on the lower edge, being $1 \frac{1}{1}$ inch longer than the corresponding edge of the sole-plate, the purpose

Fig. 66.

Fig. 65.
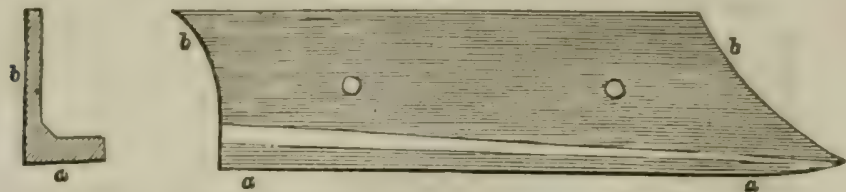

8

b

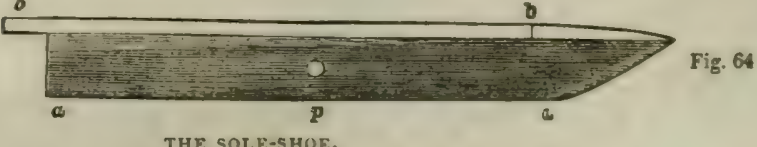

of which will be seen in the figure of the land-side. fig. 71 ; the length on the upper edge is 211 inches. The breadth and the contonr of the upper edge must be adapted to the form that may have been given to the beam. The thickness at the lower edge must agree with that of the sole. plate, and be diminished to $\frac{1}{8}$ inch at the upper edge; weight 9 lbs.

(522.) The couller.-Fig. 67 is an edge and 68 a side view of the coulter of this plow, in which the same letters of reference are applied. The neck $a b$ by which it is aftixed in the coulter-box, is about 10 inches lnng, though it may, with all propriety, be extended to $c$; the neck is usually about 2 inches in brealih and $\frac{3}{3}$ inch in thickness. The blade $b c d$ varies in length according to the variety of the plow to which it belongs, from 18 to 22 inches. The breadth of the blade is usually about 3 inches in the upper part, but is curved off behind and terminating in a noint at $d$. The thickness of the back at the shoulder $b$ is $z$ inch, and tapers gently downward to where the curvature of the back begins; thence it diminishes toward the point to $\frac{r}{8}$ inch or less. It is formed quite flat on the land-side, and on the furrow-side is beveled off toward the eutting edge, where it is about $\frac{2}{8}$ inch in thickness throughout the length of the ellge.

(523.) The bridle-Fig. 69 is a plan. and fig. 70 a corresponding elevation of the bridle, and the mamner of its attachment to the beam, where $a$ is a part of the beam, $b$ the cross-head, and $c c$ the tails of the bridle, with their arc-heads $d$ embracing the beam on the two sides; $e$ is the joint-bolt on which the bridle turns for adjustment to carthing; $f$ is the temper-pin or bolt. and by insertion of it into any one of the holes in the arc-heads, aud passing through the beam, which is here perforated for the parpose, the bridle is lield in auy required position. The draught shackle $g$ is held in its place upon the cross-head $b$ by the draught-bolt $h$ passing through both parts, and the crosi-head heing perforated with five or more holes, the bolt and shackle cau be shifted from right to left, or from left to right. for the proper adjustment of the landing of the plow. To the shackle is appended the swivel-hook $i$, to which is attached the main draught-bar. or swingle-tree of the yoke.

(524.) The land-side-Figs. 71 and 72 are illustrations of the land. side-fig. 71 being an elevation of the body of this plow, represented in the working positions, but with the extremities cut off. The point of the sliare and the heel rest upon the base-line at $a$ and $b$, and the lines of the sole lying between these points form the very obtuse angle which obtains in the sole of this plow; $a c$ is the share. and $d b$ the sole. shoe; $e$ is the land-side plate, and $f g$ a part of the beam. The lines $a d$ and $d b$, together with the base-line, form the very low triangle $a d b$, whose altitude at $d$ does not exceed $\frac{3}{8}$ inch, or by extending the sole-line $b d$. to $h$ the depression $h a$ of the point of the share below this extended line will be $\frac{1}{2}$ inch nearly. Fig. 72 represents a horizontal section of the body, as if cut off at the level of the upper edge of the

Fig. 67. Fig. 68.

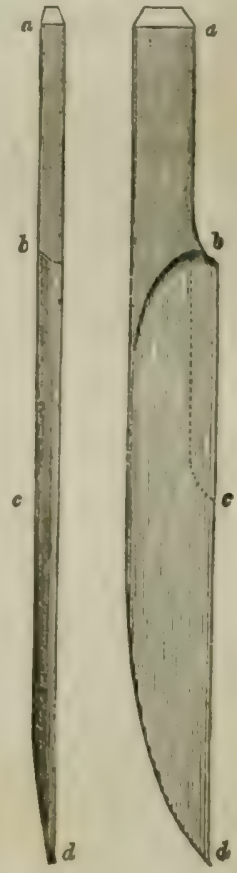

THE COULTER.

sole-shoe. Here $a c$ is the share, $b d$ the solc-flange of the body-frame, the bolt-hole at $b$ being that by which the palm of the right handle is fixed to the Hange; $e$ and $f$ the two arms of the frame, as cut across in the section $g i$, the land-side of the sole-shoe coinciding with the land-side plane, the continuation of this line, $g$ i to $h$, exhibits the inclination of the slare to the land-side, which in this plow may be taken at $\frac{1}{3}$ inch.

(525.) The inclination downward given to the share is intended, and experience confirms the intention, to give steadiness of motion to the implement, by giving it a lengthened base on which (500) 
to etand. It is evident that if a base the converse of this were given to it-convex instead of coneave-so that it should rest on the point $d$, when in motion, the smallest obstruction occurring at the point of the share would give it a tendency to swerve from the horizontal line of progression, and to lose either depth of furrow or be thrown out, thus rendering the management of the plow

Fig. 70

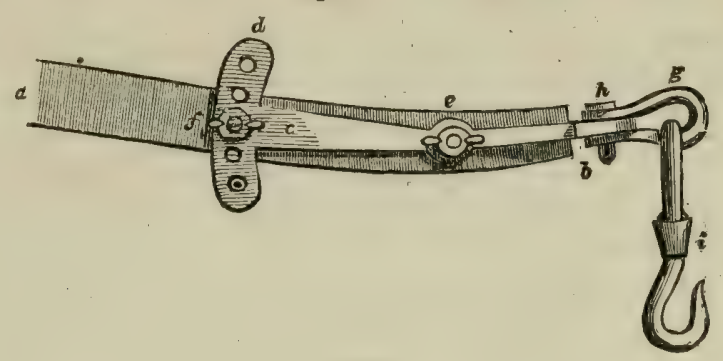

Fig. 69.

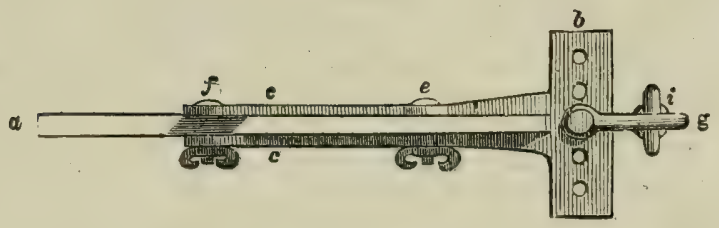

THE BRIDLE.

very difficult and uncertain. Even a perfectly straight base is found not to give the requisite certainty of action, without a greater amount of exertion, as well as closer attention on the part of the plowman. A like reason prevails for this inclination of the share landward, as does for its

Fig. 71.

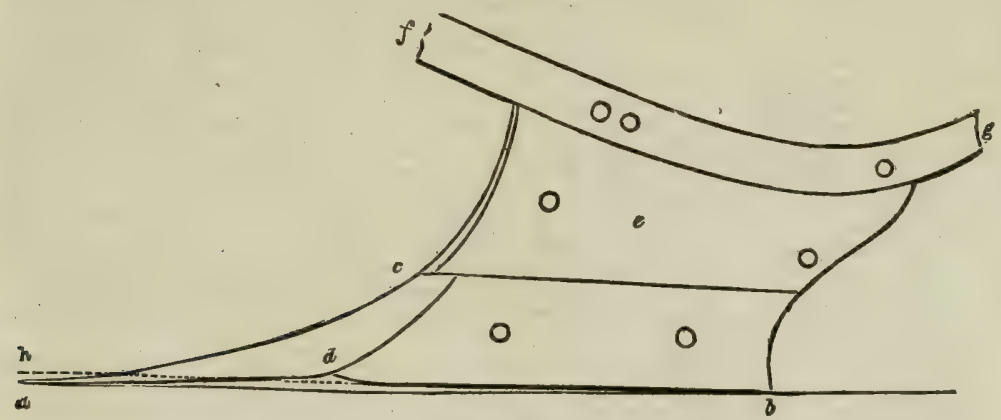

Fig. 72.

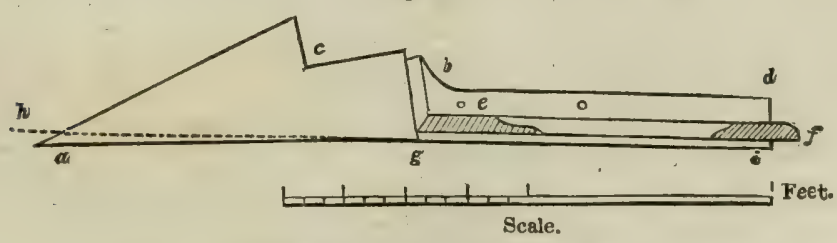

THE DETAILS OF THE LAND-SIDE:

earthward inclination; and, for the steady motion of the plow, the latter is even more necessary than the former; but there is another reason for this landward inclination, which is, that as the plow is seldom held with its land-side truly vertical, but inclining a little landward, and it being desirable to cut the furrow-slice as near as possible rectangular, the coulter has always a slight tendency landward at the point; hence it becomes necessary to give the share a like bias. By this arrangement of the parts, the incision made by the coulter will be nearly vertical. While it is admitted that these inclinations of the share afford certain advantages in the action of the plow, $(501)$ 
it mast not be concenled that the practice is liable to abuse. It has been atated that, if a different arrangement were followed, a greater degree of exertion and of attention ou the part of the plow. man would be called forth; thus, if the sole and land-side of the body were perfectly straight, the plow would present the least possible resistance, buc. as it would thus be so delicately adjusted, the smallest extraneons obstacle would tend to throw it out, unless a constant, naceasing watch is kept on its movements by the plowman. To obviate this, he gets the share set with a strong tendency to earth (for it is this tendency that has most effect;, greater than is requisite; and, to prevent the plow taking a too deep furrow, be counteracts this by adjusting the draught-bolt to tun opposite tendency; the implement will thus be kept in equilibriun, but it is obtained at an additional expenditure of horse-power. Under any such circumstances, the plow is drawa at a disadvantage to the horses. as will be afterward shown, by reason of an obliquity of the line of draught to the direction of motion, and this disadvantage is augmented by every undue tendency given to the parts by which the obliquity of their action is increased; or. if not so increased, the prevention of the increase will induce a deterioration in the work performed. This point I sball be able also to establish when I come to speak of the action of the plow generally. In the mean time, it may be affrmed that all undue inclination given to the share, but especially in its earthing, will either produce an unnecessary resistance to the draught, or it will deteriorate the quality of the plowing. It is, therefore, the interest of the furmer to guard against, and to prevent as much as possible, every attempt at giving any undue bias to this important member of the plow:

(526.) The Lanarkshire Plow.-The Lanarkshire plow, as construeted by Mr. Wilkie, Uddingstone, is represented in Plate IX.; fig. 51 being an elevation. and fig. 52 a plan. Like the former, it now occurs with various shades of difterence, but the leading points remain unchanged; like it, also. its frame-work is invariably made of malleable iron. but, in the construction of this, the application of malleable iron is carried a step farther, as will appear in the details.

(527.) The beam and left handle are usually finished in one continuous bar, $\mathrm{ABC}$, possessing a still more varied carvature than in the former plow, inasmuch as it is curved horizontally as well as vertically. When viewed in plan, and compared with the land-side plane as applied to the sole-sboe, and the fore-part of the body standing vertical, it is found that the beam, where it meets the breast-curve, coincides with the land-side plane, but at the coulter-box it deviates to the right to the extent of $1 \frac{1}{4}$ inches, if measured to the axis of the beam. Instead of continuing to deviate in this direction, the beam returns toward the land-side plane, till at $\mathbf{C}$ it is 1 inch to the right.This formation of the fore-part of the beam gives a position that apparently makes the druught bear from a point within the body of the plow, that may be imagined to approximate to the center of resistance of the body. This is, however, more apparent than real, for the beam in this case acts simply as a bar bent at an angle, and perfectly rigid, on which, suppose a power and resistance applied at its extremities, the resultant of the strain will not follow the axis of the bar through its angular direction, but in the direction of the shortest line between the two points where the power and the resistance are applied. In addition to this horizontal curvature of the beam, it will be observed that the box of the coulter is formed by an increase of thickuess on the right side only, while there is even a slight depression on the left side. This double deviation to the righ: gives an inclination to the plane of the coulter much greater than in any other variety of plow, being about $8^{\circ}$ from the vertical. Though this peculiarity in the form of the beam is one of the most decided characteristics of this plow, as we now find it, it does not appear to have been an original element in Wilkie's plow, for the late Mr. Wilkie says, " the beam, which is $6 \frac{1}{2}$ feet long. is wrought quite straight on the laud-side:" and, from bis data in the same paper, his coulter must have made an angle with the vertical plane of $6^{\checkmark}$, whereas, by the more modern construction, the angle is $8^{\circ}$. Continuing the comparison with the land-side plane, it will be seen that the left handle, at its junction with the tail of the beam, overhangs the land-side plane to the left ty about inch, there being that extent of twist on the surface of the land-side, within the limits of the body, and the same handle continues to recede from that plave till at the helve $\mathrm{A}$ it stands 7 inches to the left. This is also a point in construction of this plow, though it does not bear upon the principle of its actual working. As before observed regarding the position of the plowman in relntion to the bandles (512), this point is one that may be liable to be questioned, but, not being an essential point, its determination is of minor importance.

(528.) The right hundle $\mathrm{DE}$ is formed in one bar, and attached to the body-frame, as will appear in detail : and it is connected to the left bandle by the stretcher bolts F F F. and the stays GG.

(529.) The conlter $\mathrm{I}$ is fixed in its box $\mathrm{K}$; the rake or anglf at which the coulter stands in this plow, as before stated $(266)$, is from $55^{\circ}$ to $65^{\circ}$. The land-side face of the coulter is usually set to form an angle with the land side plane of the plow, horizontally, of about 4 .

(530.) The mould-board $\mathrm{L}$, fixed upon the body-frame and the right handle, is a curved plate of cast-iror: adapted to the turning of the furrew-slice. Its fore-edge or breast MN coincides with the land-side of the body; its lower edge $O$ behind stands from $7 \frac{1}{2}$ to 8 inches distant from the land-side, while its upper edge $\mathrm{P}$ epreads out to 18 inches from $\mathrm{I}$, the land-side. In this plow, the mould board is prolonged forward, covering the neck of the share, meeting the shield at the root of the feather $Q$ of the share. At this point $N Q$, the horizontal breadil of the mould.board is 3 inches: its hight from the base-line, at the same point. is from $2 \frac{1}{4}$ inches to $2 \frac{1}{2}$ inches, according as the inclination of the share varies; the length along the lower edge from $\mathrm{O}$ to $\mathrm{N}$ is 20 inches, and trom P to M 23 inches; the extreme length in a straight line from $P$ to $N$ is 33 inches; and the perpendicular hight from the plane of the base-line to $\mathrm{P}$ is about 11 inches. Slight deviations from these dimensions of the mould.board are to be found in the numerous sub-varieties of this plow.

(531.) The share QR is fitted upon a malleable-iron bead, to be afterward described; the neck passing under the mould-board at NQ. and the shield falling into the curve of the mould-board, terminates forward in the chisel-point $\mathrm{R}$.

(532.) The bridle $\mathrm{C}$ is formed in this plow by the end of the beam being converted into a fork

* Farner's Magazine, vol, xii.

(502) 
or sheers, to which is attached the bridle proper $\mathrm{S}$, by means of the draught-bolt $\mathrm{U}$; the sheers forming an adjustment vertically, while the bridle yields it horizontally, by shifting the draught. shackle at $\mathrm{S}$.

(533.) The right and left handles are each furnished at $\mathbf{A}$ and $\mathbf{D}$ with wooden helves fitted into the sockets of the handles.

(534.) The general dimensions of this plow are: From the zero-point $\mathrm{O}$ to the extremity of the heel $T, 4$ inches, and from $O$ forward to the point $R$ of the share is 29 inches-giving, as the entire length of sole, 2 feet 9 inches. Again, from $\mathrm{O}$ backward to the extremity of the handles, the distance is 5 feet 6 inches, and forward to the draught-bolt $U 4$ feet 4 inches, making the extreme length on the base-line 9 feet 10 inches; but following the sinuosities of the beam and handles, the entire length from $A^{\prime}$ to $U^{\prime}$ is about 10 feet 6 inches. In reference to the body of the plow, the center of the coulter-box is 15 inches, and the point $M$ of the breast-curve $6 \frac{1}{2}$ inches before the zero-point $\mathrm{O}$, both as measured on the base-line; but, following the rise of the beam, the distance from $M$ to the middle of the coulter-box will be $10 \frac{1}{2}$ inches.

(535.) The hights of the different points, as measured from the base line to the upper-line of the beam and handle, are marked on fig. 51 ; a few only of these may be repeated here. At the belve of the left handle, the hight is 3 feet 2 inches; at the same point in the right, it is 3 feet; at the middle stretcher, the difference in hight is only $1 \frac{1}{2}$ inches, but it again increases downward till the right handle meets the sole-bar, to which it is bolted. The hight at the point of the beam is 18 inches. and at the center of the draught-bolt $U$ at a medium 17 inches. The lower edge of the mould-board behind is usually se1 at $\frac{1}{2}$ inch above the plane of the base-line, and at its junction with the share is from $1 \frac{1}{2}$ to $1 \frac{3}{4}$ inches.

(536.) The dimensions of the frame-work of this plow are in general as follows: The beam, at its junction with the mould-board at $M$, is from $2 \frac{1}{2}$ to 3 inches in depth, by from 1 to $1 \frac{1}{8}$ inches in breadth, the same strength being preserved onward to the coulter-box $\mathrm{K}$; and thence, forward to the root of the sheers, a gradual diminution goes on to about 2 inches by $\frac{5}{8}$ inch. The coulter-box is formed, as beiore described, by an oblique mortise being pierced through the beam; which, for this purpose, has been previously forged with a protuberance at this place, to the right side only and upward, giving it a depth of 3 inches. The opening of the conlter-box is about $2 \frac{1}{2}$ by $\frac{7}{8}$ inches. From the junction with the mould-board, the beam begins to diminish also backward till it merges in the left handle, and here it measures only 2 inches in depth by $\frac{3}{4}$ inch in breadth. The left handle, where it joins the tail of the beam, has a depth of $2 \frac{1}{3}$ inches; and here, also, it forks off into the hind branch of the body; and it diminishes in depth backward to $1 \frac{3}{4}$ inches at the commencement of the helve-socket. The right handle, as in the former case, is somewhat lighter, and is connected with the left by means of stretchers, as already described (528); and both terminate in sockets for receiving the wooden helves.

(537.) The body-frame.-This and the succeeding fignres of the details of this plow are on a scale of $1 \frac{1}{2}$ inches to 1 foot. In the frame of the Lanarkshire plow, as usually constructed, those parts which in the East-Lothian plow I have called the body-frame, are here formed in malleable iron. The two bars or branches of the body are welded to, and form prolongations from, the beam and left handle. Fig. 73 is an elevation of this body-frame; $a a$ is a portion of the beam; $b b$ a

Fig. 73.

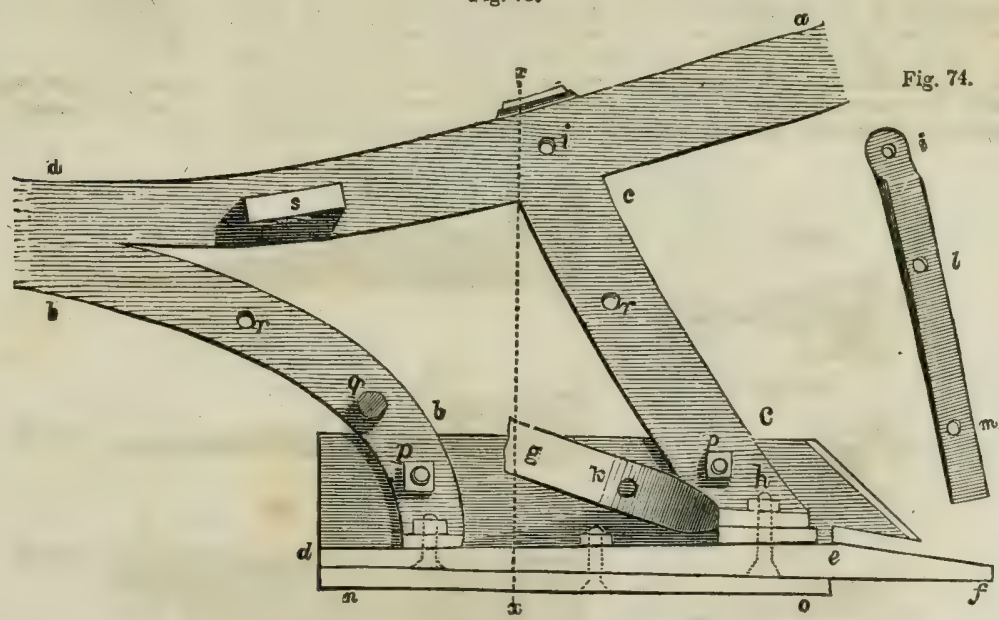

THE DETAILS OF THE BODY-FRAME.

prolongation of the left handle after it merges in the beam, forming the hind-bar of the body-frame; $c c$ is the fore-bar falling from the beam; each of these bars is kneed to the right hand at the bottom, forming a palm by which they are bolted to the sole-bar $d e$. This last terminates forward in the head ef, upon which the share is fitted. The hind-bar is forged to a breadth of 2 inches, its thickness being $\frac{5}{8}$ inch. The fore-bar is about $3 \frac{1}{4}$ inches broad, and $\frac{5}{8}$ inch thick; each being respectively thinner than the beam, at the point where they spring from it, by the thickness of the 
land-side plate. The sole bar $d e$ is made also of malleable iron, and is 15 inches in length in the part from $d$ to $e$, with a breadih of 2 inches swelled at $e$, and depth of 1 inch at $e$. The length from $e$ to $f$ is 8 inches, and in the depth the bar is tapered off from $e$ toward $f$, where the depth is $\frac{3}{b}$ inch. From $c$ it taperg backward to $\frac{1}{2}$ inch at $d$. A portion of the right bandle is exhibited a broken off at $g$; the lower extremity bein 2 twisted $t 0$ a right angle, so as to lie flat on the sole-bar to which it is bolted, along with the palm of the fore-bar at $h$.

(538.j To determine the position of the points in this body-frame, let the zero-point 0 . as already fixed, be marked on the beam at 15 inches behind the center of the coulter-box $\mathrm{K}$, and the whole beam curved agreeably to the dimensions given fig. 32, Plate IX.; then, the hight from the bottom of the sole-bar to the top edge of the beam at the zero-point will be $14 \frac{3}{4}$ inches, as before stated, less the thickness of the sole-shoe at that point, or equal to 14 inches. The fore-part of the sole-bar at $e$ will have its position determined when a straight-edge applied to its lower side from $d$ to $e$, and extending as far as the point of the beam, will place the upper edge of the beam, where it spreads into the sheers, as at C. fig. 51. Plate IX., 18 inches above the straight-edge, or line of the sole-bar. The heel $d$ of the sole-bar will be 4 inches behind the zero, and its point $f 19$ inches before it, the sole-bar being in all 23 inches. The fore-edge of the fore-bar will be 5 inches before the zero at top where it springs from the beam. and 13 inches at bottom, where it joins the sole. bar. The curvature of the fore-bar is only necessary to prevent its lying in the way of the mould. board, and a radius of 18 iuches will effect this.

(539.) The provision for fixing the mould-boord of this plow consists in a gland, fig. 74, fixed on the body-frame and right handle with bolts at $i k$, supporting the forepart of the mould-board by means of bolts at $l \mathrm{n}$. The remaining fixtures is effected by a bracket $\mathrm{H}$, attached also to the right handle, as seen in fig. 52, Plate IX. The shoe, as seen in position, fig. 73 , is marked $n o$, and is secured to the body-frame by the bolis $p p$. The lower stretcher, by which the right handle is connected to the left, is marked $q$. and $r r$ mark the bolts for fixing the land-side plate. Fig. 74, already alluded to, is a front view of the gland on which the fore-part of the mould-board is supported, and this is seen also in profile in fig. 75. which is a transverse section of the body-frame on the line $x x$. In this figure $a$ is the beam, $c$ the forebar with its kneed palm at $h$, under which is thesole-bar $e ; g$ is the broken off part of the right bandle, terminating in the palm iying over that of the fore-bar; and these three parts are secured by one bolt at $h$. The soleshoe is seen at $0 p$, with its land-side flange, which is fixed by the bolt $p$.

(540.) The share-The figures from 76 to 82 are illustrative of the shares of this plow, as adapted to both fallow and lea-plowing, where fig. 76 is a plan, fig. 77 a geometrical elevation of the furrow-side of the share; and fig. 80 a direct end-view looking forward, in all which $a b$ is the neck or socket by which it is attached to the bead; $c$ is the shield, extending over the body and the feather, but for distinction, I shall call the portion $e c f$ in fig. 76 the body, and $b g h$ the feather, $i$ being the point of the share, which in this plow is always chisel-shaped. Fig. 78 is an elevation of the farrow-side of the lea-share, anil fig. 79 a direct end view of the same. These views have the same letters of reference; and exhibit the rise of the cutting edge of the feather above the plane of the base-line, which, when it reaches the maximum hight, stands 1 inches above that plane, which gives an angle equal to $8^{\circ}$ or more with the plane of the sole in a unusverse direction. The extreme breadth of this share at $e y$ is $5 \frac{1}{4}$ to 6

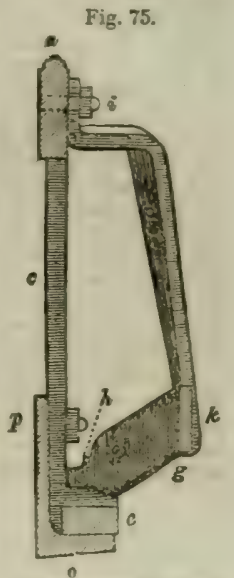

A SECTION OF TEE BODY-FRAMT.

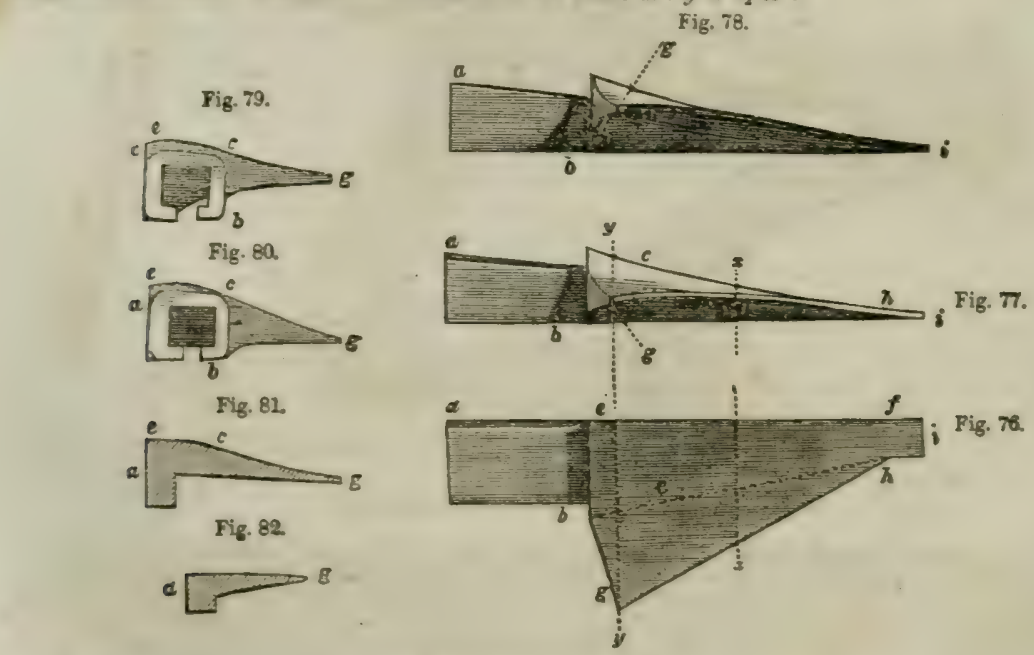

THE DETAILS OF THE SHART. 
inches; the length from the point to the head of the shield $i b, 10$ inches, and again from the point to the extremity of the neck $i a$, is 16 inches. A share thus formed will necessarily cut the furrow lower at the land-side than at the extreme edge of the furrow lower at the land-side, than at the extreme edge of the feather; for, since the share must cut the slice all along its cutting edge at the same instant, that part of the slice which is cut by the chisel-point will be the-lowest pos. sible, and every succeeding point backward will be higher and higher till it reach the apex of the curved feather $1 \frac{1}{4}$ inches above the true plane of the sole. Figs. 79 and 80 exhibit the opening of the neck $a b$, which fits upon the head, and $e c g$ the outline of the posterior end of the shield and feather of the two shares. Figs. 81 and 82 are transverse sections of figs. 76 and 77 on the lines $y y, x x$ respectively.

(541.) The sole-shoe.-Fig. 83 is a plan of the sole-shoe, where $a b$ is the sole-flange with its single bolt-hole, and $c d$ the land-side flange. Fig. 84 is an elevation of the same, as viewed on

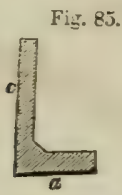

Fig. 84.

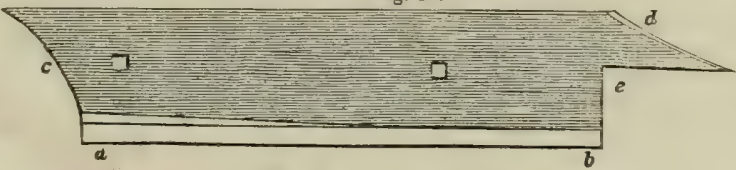

Fig. 83 .

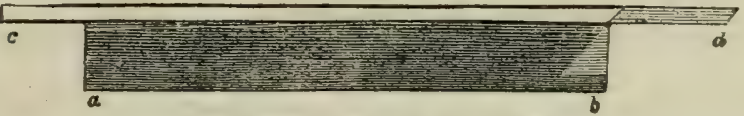

THE DETAILS OF THE SOLE-SHOE.

tne furrow-side, wherein $a b$ is the sole-flange seen edgewise, and $c d$ the side-flange, exlibiting the nutch $e, 2 \frac{1}{2}$ inches long and 2 inches deep, adapted to receive the neck of the share, while the slope $d$ is adapted to the breast-curve of the mould-board. Fig. 85 is a transverse section of the shoe; $a$ the sole, and $c$ the land-side, exhibiting also the filling, in the internal angle, opposite to where the greatest wear takes place on the exterior. The land-side flange is 5 inches in hight, and along the line of junction with the sole it is $\frac{1}{2}$ inch thick, lessening upward to $\frac{3}{g}$ inch at the upper edge; the sole-flange is $\frac{3}{4}$ inch in depth at the heel, diminishing forward to $\frac{1}{2}$ inch at the fore-end. and retaining a uniform breadth of $2 \frac{1}{2}$ inches. The length of the sole-flange is 17 inches, and of the land-side flange to the extreme point 20 inches. The upper land-side plate in this plow is $15 \frac{1}{2}$ inches in length on the lower edge; its upper edge, as exhibited in fir. 90 , corresponds in its outline to the beam, joining flush with the left handle. The thickness at the lower edge agrees with that of the upper edge of the sole-shoe, and is diminished at the upper edge to 1 inch.

(542.) The bridle,-Figs. 86 and 87 are two views of the bridle, the first a plan, the second a

Fig. 87.

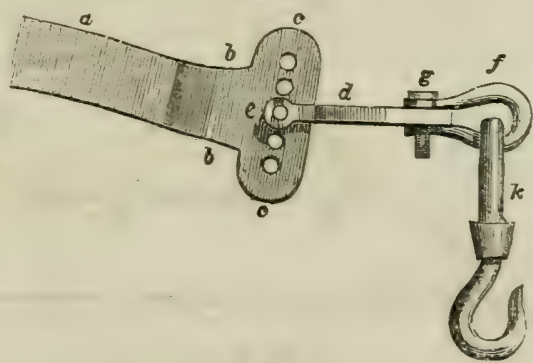

Fig. 86.

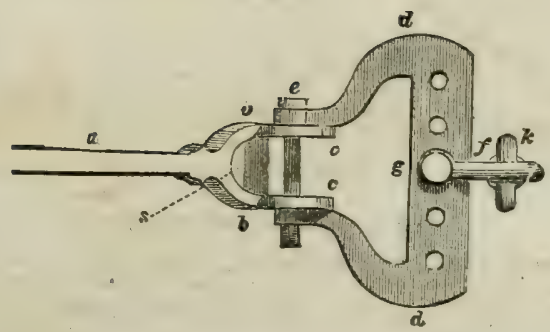


side view, with the same letters to earh. $a$ is a portion of the beam, the extremity of which is forked into the sheers $b b, 2$ inches wide, each cheek of the sheers being also spread ont into cross heads $c c, 5 \frac{1}{3}$ inches long, ench furnished with four or more perforations; they are also prevented from collapsing by the insertion between them of a stretcher 8 . The bridle $d d$ is adapted to the cross-heads of the sheers, and jointed on the draught-bolt $e$. The web $d d$ of the bridle. 9 inclses in length, is also provided with perforations, and fumished with the shackle $f_{1}$ which is attached to it by the bolt $g$. This arrangement affords the usual facility of changing the draugbt. By shifting the bridle on the cross heads of the beam. in the vertical direction. the earthing of the plow is adjusted, and by the same operation on the shackle of the bridle borizontally, the landing is adjusted. The draugbt swivel-hook $k$ is attached to the shackle, as before described, to which are appended the draught.bars afterward described.

(543.) This plow is always provided with a very useful appendage, an iron hammer, fig. 88. The bead and handle are forged in one piece of malleable iron, the latter part being formed into a nut-key. With this simple but useful tool, the plowman has always at hand the means by which he can, without loss of time, alter and adjust the position of his plow-irons-the coulter and shareand perform other little operations, which circumstances or accident may require-for the performance of which most plowmen are under the necessity of taking advantage of the first stone they can find, merely from the want of this simple instrument. The hammer is slung in a staple fixed in the side of a beam in any convenient position, as at $s$ in fig. 73. This little appendage is confidently recommended to all plowmen, as an essential part of the farniture of the plow.

(544.) The plow-staff.-Fig. 89 represents the plow-staff, another and a necessary article of tbe movable furniture of the plow. It is in form of a small shovel, baving a socket, into which a

Fig. 89.

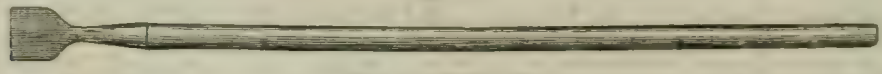

THE PLOW-STAFP.

belve of 5 feet in length is inserted, and in some parts of the country this is furnished with an oblique cross-bead. Its position in the plow is to lie between the handles, and its nse to enable the plowman to remove all exiraneous matter, as earth, stubble, roots, weeds, \&c., that may accumulate upon the mould-board or the coulter. It is common to all plows.

(545.) The Land-Side.-Figs. 90 and 91 are illustrations of the land-side of the body of this plow; fig. 90 being an elevation with the extremities cut off, the point of the share, as before,

Fig. 90.

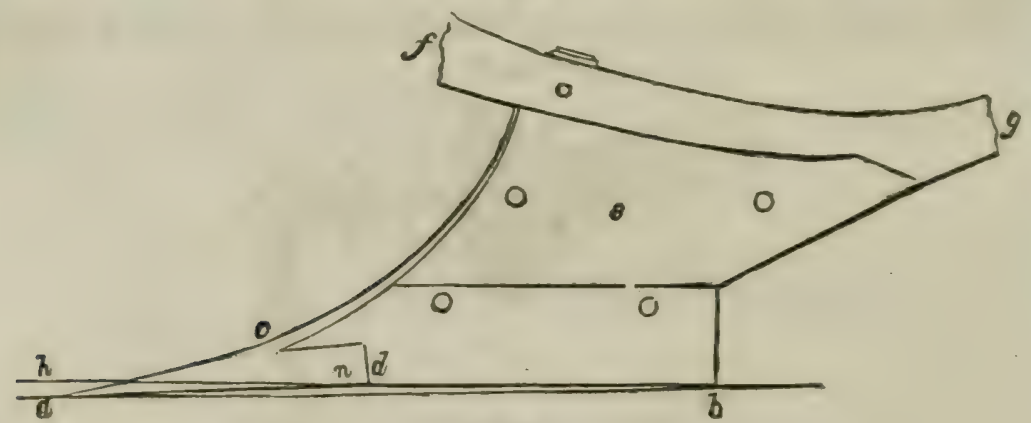

Fig. 91.

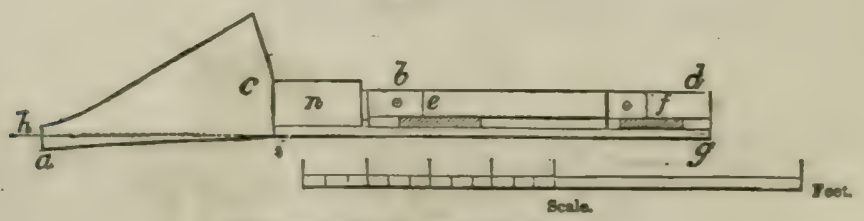

THE DETAILS OF THI LAKD-SIDE.

rests upon the base-line at $a$ and $b$, and the lines of the sole lying between these points form the obtuse angle in the sole.lines; $a c$ is the share, $n$ its neck, and $d b$ the sole-shoe; $e$ is the land-side plate, which is adapted to fill up the entire space between the side-flange of the sole-shoe and the beam; the fore part being adjusted to finish with the edge of the mould.board, while the posteri(506) 
or part may be worked off to the taste of the maker. The lines $a d$ and $d b$, together with the base line. form a very low triangle, $a d b$; the altitude at $d$ being not more than $\frac{3}{8}$ of an inch and by extending the side $b d$ to $h$, the depression $h a$ of the point of the share below the line $b d$ thus extended, will be from $\frac{1}{2}$ to $\frac{3}{4}$ of an inch. Fig. 91 represents a horizontal section of the body, as if cut off at the upper edge of the sole-shoe. Here $a c$ is the share, $n$ its neck; the line $g h$ be ing a continuation of the land-side plane, indicates the inclination landward of the point of the share, which, in this plow, is usually from $\frac{1}{2}$ to $\frac{3}{4}$ inch; $b d$ is the sole-bar, the bolt-hole at $b$ being that by which the right handle is fixed to the bar; $e$ and $f$ the two arms or bars of the body-frame, as cut across in the section; and $g i$ is the land-side flange of the sole-shoe. The line $g i$, continued to $h$, exhibits the inclination of the point of the share to landward of the land-side plane. The same reasoning applies to the inclinations of the share from the sole and land side planes, as has been offered in the case of the East-Lothian plow.

(546.) The Mid-Lothian or Currie Plow.-The Mid-Lothian or Carrie plow is delineated in Plate X., where fig. 53 is an elevation of the furrow-side, and fig. 54 a horizontal plan of the entire plow. This variety of the plow, probably from its more recent introduction, has undergone fewer changes than the two former. In one of its essential parts-the mould-board, little or no difference is to be found in all the range of this variety. In the share, greater changes are ob. servable, and also in the coulter, as shall be noticed in due course. In the majority of these plows, a cast-iron body-frame is employed, and in a!l the mould-board is prolonged forward over the neck of the share; and the draught is applied, through the medium of a chain-bar, placed under the beam. In respect of the mould-board of this plow, it is, in point of curvature, nearly the same as the East-Lothian, though in its prolongation forward, it bears a resemblance to the Lanarkshire, but without possessing that characteristics of that mould-board as will be afterward shown. The share, in so far as it is immediately connected with the mould-board, closely resembles the Lanarkshire, and the external parts of it take also after that plow. The Mid-Lothian plow, therefore, may very appositely be termed a hybrid.

(547.) In the construction of the framework of this plow, the beam and left handle are usually finished in one continued bar, $\mathrm{ABC}$, possessing the varied curvature exhibited in fig. 53. as viewed in elevation. When viewed in plan, as in fig. 54, the axis of the beam lies in one straight line, though in this there are slight shades of variation, with different makers; and the left han. dle, from its junction with the tail of the beam, gradually deviates from the line of the beam's axis. till, at the extremity $\mathrm{A}$, it stands 3 inches to the left of the line of that axis. With reference to the plane of the land-side, also, when the fore part of the body is vertical, the point of the beam is inclined to the right of the plane about $1 \frac{1}{2}$ inches, and the hind part of the body on the land. side overhangs the edge of the sole $\frac{1}{4}$ inch, there being that extent of twist apon the surface of the land-side, within the limits of the body. Some makers of this plow-and they are those of the greatest eminence-adopt the practice also of throwing the coulter-box to the right hand, in the beam, making the beam plain on the land-side, as in the Lanarkshire plow. This, however, is not universal, many still preferring to have the coulter in the axis of the beam In the first case, the land-side of the coulter stands at an angle of about $7^{\circ}$, and the latter about $5^{\circ}$ with the vertical line.

(548.) The right handle DE is formed in a separate bar. and attached to the body-frame at its fore end by a bolt, as will be shown in detail; and it is farther connected to the left handle by the stretcher-bolts F FF, and the stays GG.

(549.) The coulter $\mathrm{I}$ is fixed in its box $\mathrm{K}$ by means of iron wedges, which set and retain it in its proper position. The rake or angle that the cutting edge of the coulter in this plow makes with the base-line, takes a greater range than any of the other two. being from $45^{\circ}$ to $80^{\circ}$. The land-side face, taken horizontally, is usually set to form an angle of $2^{\circ}$ landward, with the landside plane.

(550.) The mould-board L is fixed upon the body-frame, as before described, and is adapted, as in the former cases, to the turning over the furrow-slice. Its fore edge or breast MN coincides with the land-side of the body; its lower edge $O$, behind, stands from $8 \frac{1}{2}$ to 9 inches distant from the land-side; while its upper edge $\mathrm{P}$ spreads out to $19 \frac{1}{2}$ inches from the land-side. It is, as already observed, prolonged forward, covering the neck of the share, and meeting the shield at the root of the feather $Q$. At the point $N Q$, the horizontal breadth of the mould-board is 3 inches, its hight from the base-line, at the same point $\mathrm{N}$, ranges from $2 \frac{3}{4}$ inches to $3 \frac{1}{4}$ inches, according to the degree of inclination that is given to the share; but the real hight from the plane of the soleshoe is $2 \frac{1}{2}$ inches. The length of the mould-board along the lower edge, from $\mathrm{O}$ to $\mathrm{N}$, is 23 inches; from $\mathrm{P}$ to $\mathrm{M}$, along the upper edge, 26 inches; and the extreme length, from $\mathrm{P}$ to $\mathrm{N}$, is $35 \frac{1}{2}$ inches. The perpendicular hight, from the plane of the base-line to the upper edge at $\mathrm{P}$, is about $12 \frac{1}{2}$ inches, though trifling deviations from these dimensions may be found among the makers of this plow.

(551.) The share QR is fitted upon the head, wbich in general is of cast-iron, as afterward described, the neck passing under the mould-board at NQ; and the shield, falling into the curve of the mould-board, terminates forward in the chisel-point $\mathbf{R}$.

(552.) The bridle $\mathrm{C}$ of this plow is formed by a pair of straps $\mathrm{S}$, appended to the point of the beam; and from the lower parts of these, the chain-bar $\mathrm{H}$ passes to the beam, whereon it is fixed, a few inches before the coulterbox $\mathrm{K}$. The bridle proper, $\mathrm{U}$, is attached by the same bolt that connects the chain to the straps. Shifting the straps $\mathrm{S}$ up or down upon the beam, af fords the requisite adjustment vertically, and the bridle $U$ gives the horizontal adjustment.

(553.) The right and left handles are each furuished, at $\mathrm{A}$ and $\mathrm{D}$, with wooden helves. fitted into the sockets of the handles. In this plow, also, there is usually applied a brace-rod $\mathrm{V}$, fixed at the fore end to the tail of the beam, and behind to the right handle by a bolt and nut, for the purpose of supporting the right handle.

(554.) The general dimensions of this plow are-From the zero point $O$ to the extremity of the heel $T$, the distance is 5 inches; and from $O$ forward to the point $R$ of the share, is 29 inches; making an entire length of 34 inches on the sole. Again, from $\mathrm{O}$ backward to the ex(507) 
tremity of the handles $\mathrm{A}^{\prime}$, the distance is 6 feet 2 inches; and forward to the draught-bolt $\mathrm{U}^{\prime}$, 4 feet 3 inches; making the extreme length on the base-line 10 feet 5 inches; but measuring along the sinuosities of the beam and handle, the entire length from $\mathrm{A}$ to $\mathrm{U}$ is 11 feet 6 inches.

(555.) In reference to the body of the plow, the center of the coulter-box is 16 inches, and the point $\mathrm{M}$ of the breast curve $\mathrm{B}$ inches before the zero-point; both as measured on the baseline: but, in following the rise of the beam, the distance from $M$ to the middle of the coulterbox is 11 inches.

(556.) The hights of the different points, from the base-line to the upper edge of the beam and handle, are marked on fig. 53 ; the chief points only being expressed here. At the helve of the left handle, the hight is 3 feet, the right being 2 inches lower; the difference in hight continuing nearly uniform throughout their length. The hight of the point of the beam at $\mathrm{C}$ is 23 inches, and tu the center of the draught-bolt at a medium of $16 \frac{1}{3}$ inches. The lower edge of the mould-board, behiad, is usually set at $\frac{1}{4}$ inch above the plane of the sole; while, at its junction with the share at $\mathrm{N}$, the hight above the base line runs from $1 \frac{1}{2}$ to $1 \frac{3}{4}$ inches.

(557) For the dimensions of all the individual parts of the frame-work of this plow, it is unnecessary to repeat them here, as they correspond so nearly with those already stated in treating of the first two varieties. In this respect, therefore, reference is now made to those before described in paragraphs (513) and (536).

(558.) The body-frame.-The Mid-Lothian, like the East-Lothian plow, is usually constracted with a cast-iron body-frame, differing, however, in some respects, from the latter. Fig. 92 is an elevation of the turrow-side of the body-frame. It consists of a plate or web $a b c d$ of about $\frac{1}{2}$ inch thick, upon which is planted the sole-bar $b$ ef, the beam-flange $a h$, and also the ribs $b i$ and $k l$; these last are for the purpose of strengthening the web. Fig. 93 is a direct view

Fig. 94.

Fig. 92.

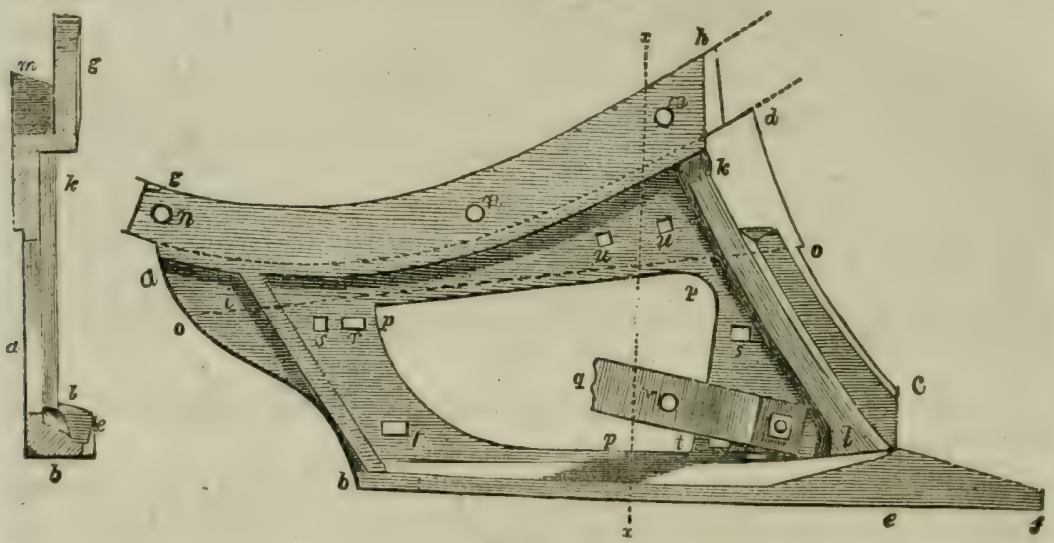

Fig. 93.

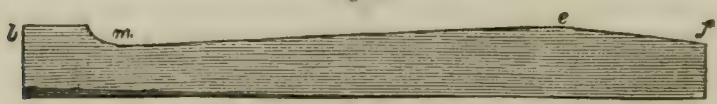

THE DETALLS OF THE: BODY-FRAME.

of the under surface of the sole bar. Its breadth at $b$ and $e$ is $2 \frac{1}{4}$ inches, but from $e$ toward $m$ it is diminished to 2 inches, where the thickness is $\frac{1}{2}$ inch; but at $e$, where the principal strain fallw, through the action upon the share, the depth is increased to 2 inches, from which it tapers forward to $f$, where it measures $1 \frac{1}{4}$ inches in breadth and $\frac{3}{4}$ inch in depth. From $e$ it diminishes also backward; and from $l$ to $b$ a filling piece is inserted in the pattern, in the angle, as scen at $l, \mathrm{fg} .94, \mathrm{t}$ increase the strength. A filling piece is also inserted at $k$, fig. 92 . to sapport that point where the strain from the beam falls upon the body, as well as to give a bearing to the breast of the mould-board. Fig. 94 is a transverse section of the body-frame on the line $x x$, look. ing forward; $a$ is the web, $b e$ the sole-bar, $k l$ one of the ribs in fig. $92, g$ the beam-flange, and $m$ the seat into which the beam is received when applied to the frame, and bolted, as at $n n n$. In the best examples of this body-frame, a part of the land-siae plating is cast along with the frame; the lower edge of this portion is represented by the dotted line 00 , fig. 92 ; and the frame, as here described, is always cast in one piece, but having the perforation $p p p$ alway formed in it. A broken off portion of the right handle is marked $q$. and is formed at the fore part into a palm. by which it is bolted to the web. The bolthole $r$ is the place of insertion of the lower stretcher, which conneets the right handle to the body-frame; $8 \&$ are the bolts of the land-side plate; $t t$ those for the land-side flange of the shoe; $u$ are the bolts for fixing a kneed bracket, on which the upper fore part of the mould-board rests, and is bolted, the lower fixture being at $v$; and a third isobtained through a bracket, bolted upon the right handle, as seen at Y, fig. 54, Plate $\mathrm{X}$. The length of the beam-fiange in this frame is from 19 to $19 \frac{1}{2}$ inches, and the hight and outline of that part are obtained from the hights marked in fig. 53 , Plate $\mathbf{X}$, deducting 1 inch for the thicknesa of the sole-shoe at the heel, and $\frac{1}{2}$ inch at the point.

(508) 
(559.) The sole-shoe.-Fig. 95 is a plan of the sole-shoe; $a b$ the sole-flange 17 inches in length 3 taches in breadth, and 1 inch in depth at $a$ the heel, but diminished to $\frac{1}{2}$ inch at $b ; c d$ is the land side flange, $\frac{1}{2}$ inch in thickness at bottom, and $\frac{3}{8}$ inch at the upper edge, the hight being 4 inches. Fig. 96 is the furrow-side of the shoe, with the same letters of reference; $e$ is the notch at the fore

Fig. 97,

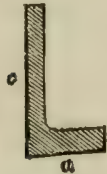

Fig. 96.

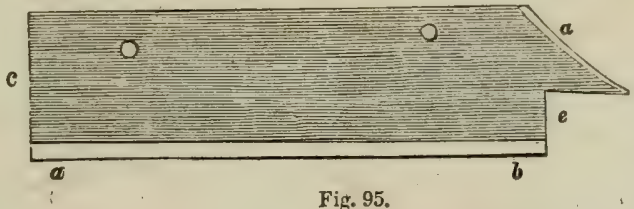

c
Fig. 95.

a

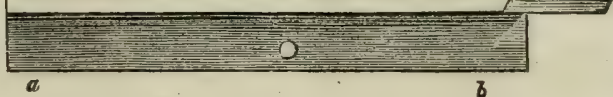

THE DETAILS OF THE SOLE-SHOE.

part, for the passage of the neck of the share ; it is $4 \frac{1}{2}$ inches in length and $2 \frac{1}{2}$ inches in hight, $d$ being the curve adapted to the breast of the mould-board. Fig. 97 is a transverse section of of the shoe, $a$ the sole, and $c$ the side-flange.

(560.) The share.-The share of this plow, in principle and constraction, is the same as that of the Lanarkshire; but in the present case, the head being of cast-iron, the neck is necessarily some what larger. Fig 98 is a plan, in which $a b$ is the neck, $a e d$ the land-side, and $c g e$ the shield; $b f g$

Fig. 98.

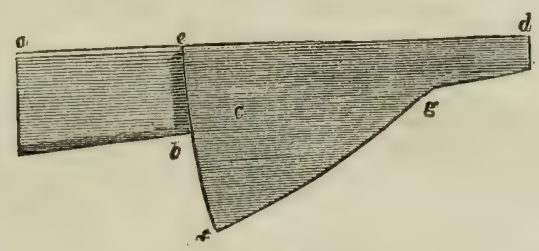

THE SHARE.

is the feather, and $g d$ the point of the share, which, in this plow, is usually chisel-pointed, and longer between the termination of the feather and the point, than in the share of the Lanarkshire plow. In farther illustration of this share, reference is made to that of the Lanarkshire plow, where fig. 78 is a direct view of the furrow-side of the share, exhibiting the rise of the cutting edge of the feather above the base-line, which, in the plows considered the most perfect for plowing lea, amounts to a rise of $1 \frac{1}{4}$ to $1 \frac{1}{2}$ inches. The extreme breadth of this share over the feather ranges from $4 \frac{1}{2}$ to $5 \frac{1}{2}$ inches, the length from the point to the head of the shield, at a maximum, is 11 inches, and including the neck, 17 inches; under the same condition the length from the extreme point to the commencement of the feather at $g$, is about $3 \frac{1}{2}$ inches. Fig. 79 is an end-view of the share looking forward, in which also the same letters are applied; $a b$ is the opening of the neck to receive the head, and $e c g$ shows the ontline of the posterior extremity of the shield and feather. This, like the Lanarkshire plow, is held as peculiarly adapted to the plowing of lea-land; and as the share just described is that which is adapted for that purpose-for the chief and almost sole difference between the adaptation of these plows for lea and stubble land lies in the configuration of the share-it is necessary to advert to the stubble land or fallow-share. In this the chief, indeed the only. difference lies in the formation of the feather, which for stubble land is made broader. and the cutting edge, instead of rising from the point at an angle of $8^{\circ}$, is formed so as to ap. proach to the plane of the sole, or not exceeding an angle of $4^{\circ}$.

(561.) The land-side.-Figs. 99 and 100 are illustrations of the land-side of the body of this plow - the extremities, as in the previous cases, being cut off. Fig. 99 is an elevation. $a b$ is the base-line, $a c$ the share, $n$ its neck, and $d b$ the sole-shoe; $e e$ are the land-side plates-the upper one, as before stated, being cast as a part of the body, and $f g$ is a part of the beam. In the extreme cases of this plow, the altitude of the low triangle $a n b$ is $\frac{3}{4}$ inch; and, when the line of the sole $b n$ is extended to $h$, the depression of the point of the share below that line is found to be about $1 \frac{1}{4}$ inches. Fig. 100 represents a horizontal section of the borly-frame, as if cut off at the upper edge of the sole-shoe; here $a c$ is the share, $n$ its neck, and $b d$ the sole-flange; $c$ and $f$ are the two bars of the body frame, and $g i$ the land-side of the sole. By continuing the line of the land-side to $h$, the inclination of the share landward is found frequently to be 1 inch.

(562.) The bridle.-As has been already noticed, this plow differs from the others in its bridle being connected with a chain bar, passing under and attached to the beam near the coulter-box; and, for the purpose of receiving this equipage, the point of the beam is elevated to the hight of 23

(509) 
inches above the hase-line. The chain is usually a single rod of iron, with a link and shackle be hind, by which it is conuected to the beam, by means of a bolt passing through the shackle and

Fig. 99.

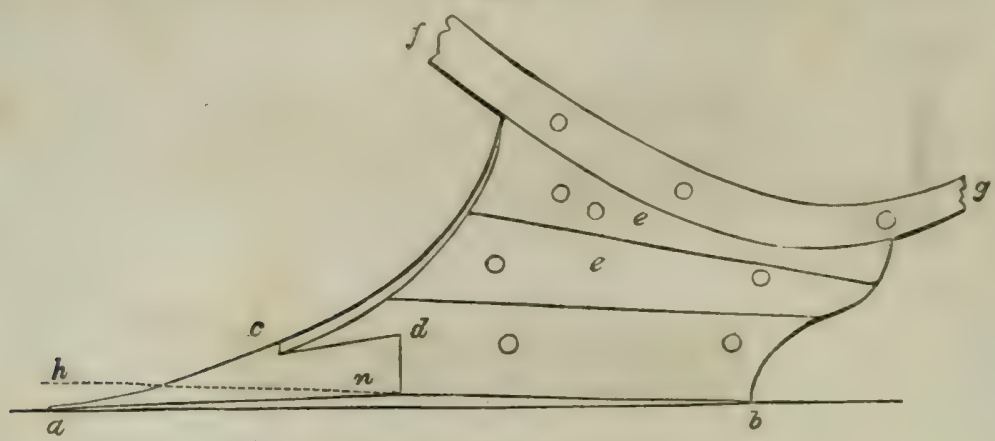

Fig. 100.

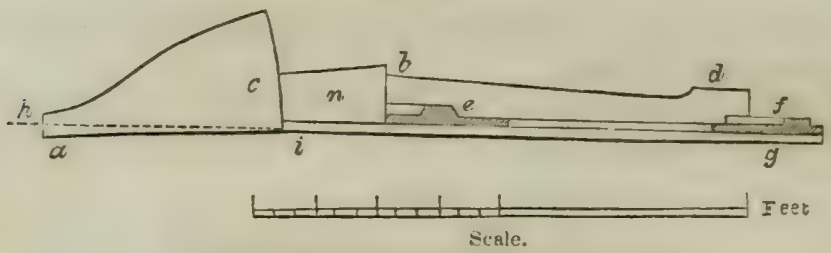

THE DETAILS OF THE LAND-STDE.

the beam at a point about 3 inches before the conlter-box. The bridle, of which fig. 101 is an elevatiou and fig. 102 a plan, cousists of a pair of iron straps $a b, 10$ inches in length, and $1 \frac{1}{1}$ inches

Fig. 101.

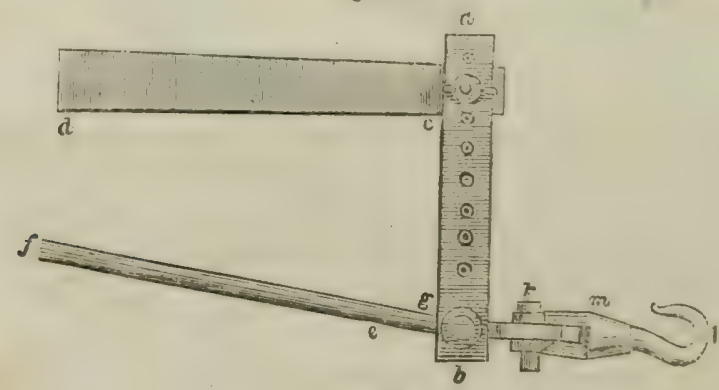

Fig. 102

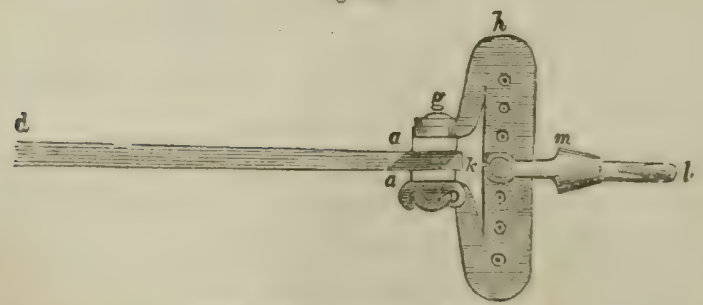

THF DETAILS OF THE BRIDIE.

by $\frac{1}{3}$ inch, each having a number of perforations by which they can be arpended to the point of the beam $c d$, by means of a bolt passing through them and the beam; a strap $a b$ being on each side of it. The fore end of the chain-bar $f c$ is, in like manner, received between.the lower end (510) 
of the straps at $b$, and secured by the draught-bolt $g$. On the same bolt is appended the bridle proper $h i$, the bolt passing through the whole of the parts. The bridle is formed with $\mathrm{a}$ web $h i$ in front, 9 inches in length, and $1 \frac{1}{2}$ inches in breadth, having also a number of perforations for receiving the shackle-bolt $k$. In this equipage, the dranght-swivel hook $l$ and the shackle $m$ are combined in one, which completes the arrangement. This combination of bridle-mounting gives the same facility as before for shifting the direction of the draught-vertically, by raising or low. ering the straps $a b$ on the point of the beam, and horizontally, by shifting the shackle-bolt and shackle $k m$ right and left.

(563.) OF THE ACTION OF THE Plow.-The couller, the share and the mould-board being the principal active parts of the plow, and those which supply the chief characteristics to the implement, it may be useful to the farmer, as well as to the agricultural mechanic, to enter into a more minute descriptive detail of the nature and properties of these members, before entering upon the duties which each in its turn has to perform in the action of cutting and turning over the furrowslice.

(564.) The couller.-The coulter, in its construction, as well as in the duties it has to perform, is the simplest member of the plow. It is a simple bar, in form as represented by figs. 67 and 68 ; varying in length, according to the variety of the plow to which it belongs, from 18 to 22 inches Simple though the form and duties of the coulter may be, there is no member of the plow whereof 4 such a variety of opinions exist as to its position. 1 have shown that, in practice, the rake or angle which its cutting edge makes with the base-line ranges from $45^{\circ}$ to $80^{\circ}$, that of its land-side face from $4^{\circ}$ to $8^{\circ}$ with the vertical, and that the same face, in the horizontal direction, varies from $0^{\circ}$ to $4^{\circ}$ with the land-side. The objects of these variations will be duly pointed out, as mere matters of taste and convention among plowmen. Two points alone, in regard to position, should be considered as standard and invariable. These are, 1st, that the land-side face of the coulter shall be always parallel, in the horizontal direction, to the plane of the land-side of the plow's body ; and, $2 \mathrm{~d}$, that at the hight of 7 inches, or of 6 inches, according to the depth of furrow to which the plow is adapted, the land-side face of the conlter shall be $\frac{1}{4}$ inch to landward, or to the left, of the plane of the land-side of the body. One other point in position is subject to a great diversity of opinion-that is, the position in which the extreme point of the coulter should stand in relation to the point of the share. In respect to landing, or that cause which requires the point of the coulter to be placed to landward of the share, the range of opinion is within moderate bounds, being from 0 to $\frac{3}{4}$ inch ; but, in the vertical direction. the range varies from $\frac{1}{4}$ inch to 2 inches, and in the longitudinal direetion a like difference of opinion exists. Thus Small recommends that the point of the coulter should be 2 or 3 inches in advance of the point of the share, and $\frac{1}{2}$ or 1 inch above the plane of the sole (base-line), while it should be $\frac{1}{2}$ inch or 1 inch to landward of the landside plane.* The first of these propositions, as will be afterward shown, is very much at fault; and the almost universal practice, also, of keeping the two points nearly equal in advance, condemus the practice, and points out equality as the rule. In regard to the position of the point landward, it is liable to considerable variation, partly from the inclination that may be given to the share, and likewise from the degree of obliquity between the coulter and the land-side. This last, indeed, combined with the rule laid down, from the position of the coulter in relation to the landside, at the hight of 6 or 7 inches, is the true source from which the landward relation of the points of the coulter and share can be ascertained; hence, therefore, in whatever variety of the plow, the coulter should have its position in regard to land determined first; and the point of the share should take its position from the coulter. The distance to which the point of the share stands to the right of the coulter should in no case exceed $\frac{1}{2}$ inch, but it were better to confine it to $\frac{1}{4}$ inch. In the vertical position, the advancing of the point of the coulter to, or retiring from, the share, violates no principle in the relation of the parts; but, to place the coulter at an undue distance above the share leaves that portion of the slice uncut that falls between the two points; which must produce an undue resistance, from the part being forcibly pressed asunder, by a process like clipping, through the inclined action of the share upward. The nature of the soil, whether stony or gravelly, or a loam, will, however, always have an effect on this point of the trimming of the plow; and, as no principle is affected, there is no impropriety in giving a latitude in this direction; though I conceive that a distance of 1 inch between the points of the share and coulter ought to be the maximum, except in cases where the nature of the soil may demand a deviation from that distance.

(565.) The office which the conlter has to perform in the action of the plow is simple and uni. form, being merely to make an incision through the soil, in the direction of the furrow-slice that is to be raised. It is a remarkable fact that, in doing this, it neither increases nor decreases the resistance of the plow in any appreciable degree. Its sole use, therefore, is to cut a smooth edge in the slice which is to be raised, and an unbroken face for the land-side of the plow to move against in its continued progress.

(566.) In the early works on the principles of the plow, some misconceptions appear to have been formed of the influence of the coulter, under the supposition that the coulter extending 3 inches in front of the share acted beneficially; and that giving the coulter a great rake, or a low angle with the base, made it cut the soil advantageously, and with less resistance. From a series of experiments. I have satisfied myself that the first of these suppositions is erroneous, and that the projection of the coulter before the share increases the resistance in a very sensible degree. With regard to the second, the resistance seems not to be affected by the angle at which the edge of the coulter stands; and the analogy of a common cutting instrument does not hold in the case of the coulter of the plow. With a razor or a knife in the hand, we make them pass through any object by drawing their cutting edge over the surface to be cut, in the manner as with a saw, which greatly increases the effect without any increase of force; and this holds in all proper cutting instruments; but let the edge of the instrument be placed simply at an angle with the direc. 
tion in which the stroke or cut is to be made, and, in raking the cut, let this oblique position be retained, so that the cutting edge shall proceed parallel to its original position, without any tendency to drawing the edge across the direction of the cut; no saving of force is obtained. This process must be familiar to every one who uses a knife for any purpose whatever. In slicing a loat, the operator is at once sensible that, by moving the knife gently backward or forward, he is required to exert less force, while he at the sane time makes a smoother cut, than he would do by forcing the kuife through the loaf, with its edge either at right angles or obliquely to the direction in which the knife proceeds. The coulter of the plow acts in this last position; its cutting edge etanily abliquety to the direction of motion, but has ne means of drawing or sliding, to cross the forward motion ; it therefore cuts by sheer force of pressure." Where elastic substances occar, an instrument cutting in this manner has some advantages. In the case of fibrous roots, for example, crossing the path of the coulter-the latter, by passing under them, sets their elasticity in action, by which they allow the edge to slide under them to a small extent, and thus produces the sawing effect. In the non-elastic earths, of which soils are chiefly composed, nothing of this kind, it is apprehended, can occur; hence the angle of the coulter, as it affects the force requisite to move the plow, is of little importance.

(567.) I have said that the projection of the coulter in front of the share increases the resistance, and $I$ am borne out in this assertion from the result of experiments not a little inexplicable. On a subject which has of late attracted considerable attention, I was desirous of obtaining information, from experiments alone, on the actual implement : and, to attain this the more fully, I deter. mined on analyzing the resistance as far as possible. W ith this view, a plow was prepared whose coulter descended 7 inches below the line of the sole, and fitted to atand at any required angle.-. This plow, with its sole upon the surface of two-years' old lea, and the couller alone in the soil, the bridle having been adjusted to make it swim without any undue tendency; the force required to draw this experimental instrument, as indicated by the dy namometer, was 26 imperial stones, or $3 \frac{1}{4} \mathrm{cwt}$., and no sensible difference was observed in a range of angles varying from $45^{\circ}$ to $70^{\circ}$. This coulter having been removed, the plow was drawn along the surface of the ficld, when the dynamometer indicated 8 stones, the usual draught of a plow on the surface. Another welltrimmed plow was at work in the same ridge, taking a furrow 10 by 7 inches, and its draught was also 26 stones. On removing the coulter from this plow, and making it take a furrow of the same dimensions, the draught was still the same-namely, 26 stones; the furrow thus taken produced, of course, a slice of very rough plowmanship, and though it exhibited, by a negative, the essential use of the coulter-the clean cutting of the slice from the solid ground-the whole question of the operation and working effects of the coulter are thus placed in a very anomalous position. The question naturally arises, what becomes of the force required to draw the coulter alone through the ground, when, as it appears, the same amount of force is capable of drawing the entire plow, with or without a coulter? A definite and satisfactory answer, it is feared, cannot at present bo given to the question, and, until experiments have been repeated and varied in their mode of ap plication, any explanation that can be given is mere conjecture.

(568.) Since we have seen that the same force is required to dravo the plow without a conlter as with it, and as it has been observed that the work performed without the coulter is very rough, by reason of the slice being in a great measure torn from the solid ground, the breast of the plow being but indifferently adapted for cutting off the slice-it is more than probable that the tearing asunder of the slice from the solid ground requires a certain amount of force above what would be required were the slice previously severed by the vertical incision of the coulter. And though we find that the force requisite to make this incision, when taken alone, is equal to the whole draught, yet there appears no improbability in the supposition that the minus quantity in the one may just equal the plus in the other. Be this as it may, the discovery of the anomaly presents at least a curious point for investigation, and one that may very probably, through a train of careful experiments, point out the medium through which a minimum of draught is to be obtained.

(569.) Regarding the effect of change on the angle of the edge of the coulter, though it does not directly affert the draught of the plow, it is capable of producing practical effects that are of importance. In plowing stubble land, or land that is very foul with weeds, the coulter should be trimmed to a long rake-that is, set at a low angle, say from $45^{\circ}$ to $55^{\circ}$; this will give it a tendency to free itself of the roots and weeds that will collect upon it. by their sliding upward on the edge of the coulter; and, in general, will be ultimately thrown off without exertion on the part of the plowman. The accumulation of masses of such refuse on the coulter greatly increases the labor of the horses. The amount of this increased labor I have frequently nscertained by the dynamometer, and have found it to increase the draught of the plows from 26 stonea, their ordinary draught when clear, up to 36 stones; and, immediately on the removal of the obstruction, the draught has fallen to an average force of 26 stones. It is unnecessary to add that the prevention of such waste of miscular exertion ought to be the care of the farmer, as far as the construction of his machines will admit of.

(570.) To apply a plow, with its coulter set in the position above described, to lea-land with a rough surface, would produce a kind of plowmanship not approved of; every furrow would be bristling with the withered stems of the unconsumed grasses; for, to plow such land with a coulter set in this way, would cause its partially matted surface to present a ragged edge, from the coulter acting upon the elastic fibres and roots of the grasses, pressing them upward before they could be cut through. The ragged edge of the slice thus yroduced gives, when turned over, thit untidy appearance which is often observable in lea plowing. To obviate this the conlter fbould be set at a higher angle, by which it will cut the mat, without tearing it up with a bearded edge. Crack plowmen, when they are about to exhibit a specimen of fine plowing, are so guarded

* An ingenious application of the drawing action here illustrated is to be found in the eubterranean cutters of Mr. Parkes's steam-plow for plowing moss-land.

(512) 


against this defect that they sometimes get their coulter kneed forward under the beam so far as to bring the edge nearly perpendicular. The same cause induces the makers of the Lanarkshire plow to set the coulter with its land-side face, not coincident with the land-side plane horizontally but at an angle with it of $4^{\circ}$, thus placing the right hand face of the coulter nearly parallel to the land-side plawe, and thereby removing the tendency of the ordinary oblique position of the right hand face to produce a rough-bearded edge on the rising slice. The dynamical effect of snch a position will be afterward treated of.

(571.) The shrire.-The structure and position of the different shares having been already point. ed out (519.) (540.) $(560$.$) . and also their relations to the coulter, there remains to make some gen-$ eral remarks on the action of the share, and on the effects resulting from the varieties of that mem. ber of the plow.

(572.) We have seen that the coulter performs but a comparatively small portion of the operation required in the tarning a furrow-slice. The share, however, takes a more important and much more extensive part in the process; on the functions of the share, in short, depends much of the character of the plow. Its duty is very much akin to that of a spade, if pushed horizontally into the soil with a view to lift a sod of earth; but, as its action is continuous, ics form must be modified to suit a continuous action; hence, instead of the broad cutting edge of the spade, which, in the generality of soils, would be liable to be thrown out of its course by obstiacles such as stones, the share may be conceived as a sparde wherein one of its angles has been cut off obliquely, leaving only a narrow point remaining, adapted to make the first impression on the slice. A narrow point being liable to meet obstruction only in the ratio of its breadth to the breadth of the entire share, the chances of its encountering stoncs are extremely few; and though the oblique edge, now called the feather, has a like number of chances to come in contact with stones, yet, from its form, taking them always obliquely, and the direct resistance which the body of the plow meets with on the land-side preventing any swerving to the left, such stones as come in contact with the sloping edge of the feather are easily pushed asile toward the open furrow on the right. The share thus acts by the insertion of its point under the slice intended to be raised, and this is followed up by the feather, which continues the operation bexun by the point, by separating the slice horizontally from the subsoil or the sole of the furrow ; and, simultaneous with this, the coulter separates the slice vertically from the still solid ground. Probably the most natural impression that would occur, at the first thought of this operation, will be that the feather of the share should be of a breadth capable of producing the immediate and entire separation of the slice from the sole; but experience teaches us that such would not fulfill all the requisite conditions of good plowing.The slice must not only be separated; it must be gradually turned upon its edge, and ultimately still farther turned over until that which was the upper surface becomes the lower, lying at an angle of about $45^{\circ}$. It is found that, if the slice were cut entirely off from the sole, the plow would frequently fail in turning it nver to the position just referred to ; it might, in place of this, be only moved a space to the right and fall back, or, at most, it would be liable to remain standing upon its edge; in either case the work would be very imperfect, and it has therefore been found neces. sary to leave a portion, usually from $\frac{1}{2}$ to $\frac{1}{4}$, of the slice uncut by the feather of the share. This portion of the slice is left to be torn asunder from the sole as it rises upon the mould-board, by which means the slice retains longer its hold of the subsoil-turning by that bold, as upon a hinge, till brought to the vertical position, after which it is easily brought into its ultimate place. The breadth of the share is thus, of necessity, limited to $\frac{3}{4}$ the breadth of the slice at a maximum, though its minimum, as will appear, may not exceed $\frac{1}{2}$.

(573.) The disposition of the feather comes next under notice. The feather having to perform the operation of cutting that part of the slice below that lies between the point of the share and the extremity of the feather, it is formed with a thin edge suited to cutting the soil ; but the position of that cutting edge forms a principal feature in distinguishing the varieties of the plow, as before described. This distinguishing character is of two kinds: 1st, that which has the cutting edge lying parallel, or nearly so, to the plane of the sole, as in the East-Lothian plow; and, 2d, that which has this cutting edge elevated as it retires from the point of the share, rising at an angle with the base-line. which is found to vary from $4^{\circ}$ to $8^{\circ}$ as in the Lanarkshire and the Mid-Lothian plows; and all the sub-varieties of these plows have their shares coming under one or other of these two divisions.

(574.) The share, in either of the forms above described, passes under the furrow slice, making a partial separation of it from the sole of the furrow, rising as the share progresses ; the rise, how:ever, being confined entirely to the land-side edge of the slice-the furrow edge, as has been shown, remaining still in connection with the solid ground; and the shield and back of the share being a coutinuation of the mould-board, the latter, in its progress forward, receives the slice from the share and passes it onward, or, more properly speaking, the plow passes under it.

(575) One important consideration remains to be noticed regarding the practical effects of the two forms of feather. In the first, which has the cutting edge nearly parallel with the plane of the sole, the furrow-slice being cut below at one level over the whole breadih of the share and feather, the slice, when exposed in section, will be perfectly rectangular or very slightly rhomboidal, and the sole of the furrow will be perfectly level across. Such a share, then, will lift a slice of any given breadth and depth, which shall contain a maximum quantity of soil, and this problem can only be performed by a share so constructed.

(576.) In the second case, where the feather rises above the plane of the sole at the angles al ready named. the feather is found sometimes to attain a hight of 1 inch and $1 \frac{1}{4}$ inches above that plane. In all such cases, the feather is also narrow; and, supposing that the part of the slice left uncut by it may be torn asunder, in a continuation of the cut so made, the slice will have a depth at its furrow edge less by about $1 \frac{1}{2}$ inches or more than at its land-side edge, as cut by the point of the share. A transverse section of this slice, therefore, fig. 103, would exhibit not a rectangular parallelogram as before, but a trapezoid, whose sides $a b$ and $c d$ might be each 9 inches, and its vides $b d$ and $a c 6$ inches and $4 t$ inches respectively. A slice of this form would, therefore, be 
deficient in the quantity of soil lifted, by a quantity contained in the triangle $d c e$, or about 1.7 part of the enture slice; and this deficiency is left by the share in the bottom of the furrow as part of the solid subsoil. The absolute quantity of soil thus left unlifted by shares of this construction will be found to vary with the elevation that is given to the feather; but, wherever this form of share

Fig. 103.

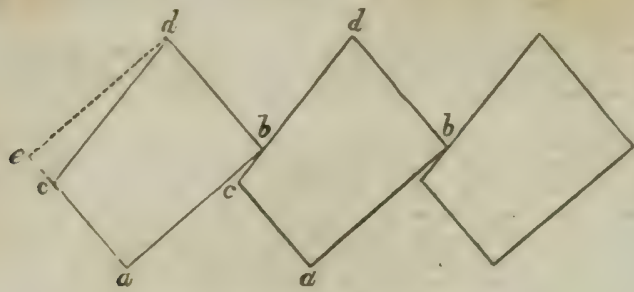

THE CRESTED FERROW-SLICE.

is adopted, results similar to that here described will invariably follow, though they may differ in degree; but the quantity left in the bottom of the furrow will seldom fall short of 10 per cent. of the whole slice. An indirect mode of removing this defect is resorted to in practice, which will be noticed ander the head of mould-board.

(577.) The rule which I wonld recommend to be followed in order to secare the maximum of nsefnl effect in the share, as founded on practice and observation, as well as cumbining the theory of the share and mould-board, is, that the length from the tail of the feather to the point of the share should be from 10 to 11 inches; that the hight of the shield-the surfnce of the share-on the landside, opposite to the tail of the feather, be $2 \frac{1}{2}$ inches above the line of the solo-shoe; that the point of the share be $\frac{1}{2}$ inch below the line of the sole-shoe, and not exceedirg $\frac{1}{2}$ inch to land ward of the land-side plane, this last point being more properly determinable from the coulter: and, lastly, that no part of the edge of the feather should be more than $\frac{3}{8}$ inch above the plane of the sole-shoe, that plane being always understood to be at right angles to the land-side plane.

(578.) The mould board and its action.-Since the time that Small achieved his great improvement in the formation of the mould-board, that member has been gerrerally held as the leading point in the plow. This, in one sense, is no doubt true; for if there is a spark of science required in the construction of the plow, it is certainly the mould-board that most requires it. Yet, for all this, 1 have seen a plow making work little, apparently, inferior to the first rate mould-board plows, that had nothing to enable it to tnrn over the slice but a straight bar of wood.* In this case, however. the work was but apparently well done, there being nuthing to consolidate the slices upon each other as they fell over by their own weight. The real state of the case seems to be this, that the share impresses the furrow-slice with its form and character, and the duty of the monld-board is to transmit and deposit that slice in the best possible manner, and with the least possible injury to the character previously stamped upon it by the share. If this view is correct -and there appears no reason why it should be questioner-the mould-board is only a mediurn through which the slice is conveyed from the share to its destined position. To do this. however, in the most perfect mammer. the mould-board has to perform several highly important functions1st. The trausmission of the slice; 2d, Depositing it in the proper position; and, $3 \mathrm{~d}$, Performing both these operations with the least possible resistance.

(579.) The raising and transmitting the slice have freqner.tly been described as if consisting of three or more distinct movements. With all deference to former writers. I conceive it may be vicwed as having only two movements, namely, eutting the slice by the share and coulter, and transmitting it to its appointed position through the medium of the mould-board. The first has been already discussed: I now proceed to the second.

(580.) The object of every mould board is to transmit the slice in the best manner, and with the least possible expenditure of force; but, as might have been expected, we find considerable difference of opinion on both these points, arising from the variations in the form of the mould-board. In a general way, the trunsmission of the slice may be explained in the following manner:

(581.) In fig. 104, a a represents a vertical section of part of an unbroken ridge of land, and the parallelogram $a b c d$ also a transverse section of an indefinitely short portion of a slice which is proposed to be raised : the breadth $a b$ being 10 inches, and depth $a d 7$ inches; the line $d c$ will be the bottom of the slice. or the line on which it is separated from the sole by the action of the share. The points of the share and coulter enter at $d$; and, in progressing forward, the slice will be gradually raised at $d$, the point $c$ remaining at rest, while the parallelogram revolves upon it as a center. When the share has penetrated to the extent of the feather, the point $d$ of the slice will have been raised $\Omega \frac{1}{2}$ to 3 inches. By the continued progress of the plow, the parallelogram representing the slice will be found in the position ces $f$, and again at $c g h i$. At the fourth stage, when the zero-point of the mould-board has reached the supposed line of section, the slice will have attained the vertical position $c k l \mathrm{~m}$. During these stages of this uniform process, the slice has been turning on the point $c$ as on a pivot, which has retained its original position, while the point $d$, in its successive transitions, has described the quadrant $d e g k$. By the continued progress of the plow, the revolution of the slice will be continued, but it will be observed that, at this stage, it

* A varirty of the Kent turn-wrest plow which I have seen in the poseession of Mr. Hamilton, of Carclule, is an example of this.

(514) 
changes the center of revolution from $c$ to $m$; when the point $k$ will have described the arc $k o$, the slice has then reached the position $m n \circ p$; and ultimately, when the posterior extremity of

Fig. 104.

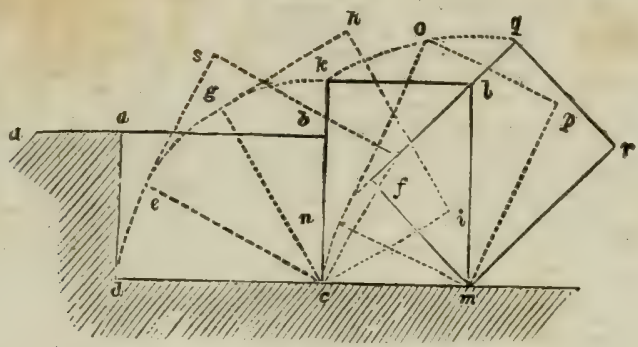

THE TRANSMISSION OF THE FURROW-SLICE.

the mould-board has reached the line of section, the slice will have attained its final position $m f$ $q r$, lying at an angle of $45^{\circ}$, and resting on the previously turned-up slice.

(582.) The process of turning over the slice, therefore, approximates to a uniform motion, provided the parts of the plow destined to perform the operation are properly constructed. The uniformity, however, is not directly as the rectilineal progress of the plow, but must be deduced from a different function to be afterward explained. And, thoush the process here described refers only to an indefinitely short slice, it is only necessary to conceive a continuity of such short slices, going to form an entire furrow-slice. extending to the whole length of the field; and the lengthened furrow-slice, being possessed of sufficient tenacity to admit of the requisite and temporary extension which it undergoes, while the plow is passing under and turning it over, is again compressed into its original length, when laid in its altimate position. The furrow-slice, therefore, under this process, may not inaptly be compared to the motion of a wave in the ocean, keeping in view that the wave of the slice is carried forward in a horizontal direction, whereas the ocean wave is vertical. But in both cases, though the wave travels onward, there is no translation of parts in the direction in which it seems to travel. In the case of the furrow-slice movement, it appears as in the annexed perspective view, fig. 105, where $a b$ is the edge of the land as cut by

Fig. 105.

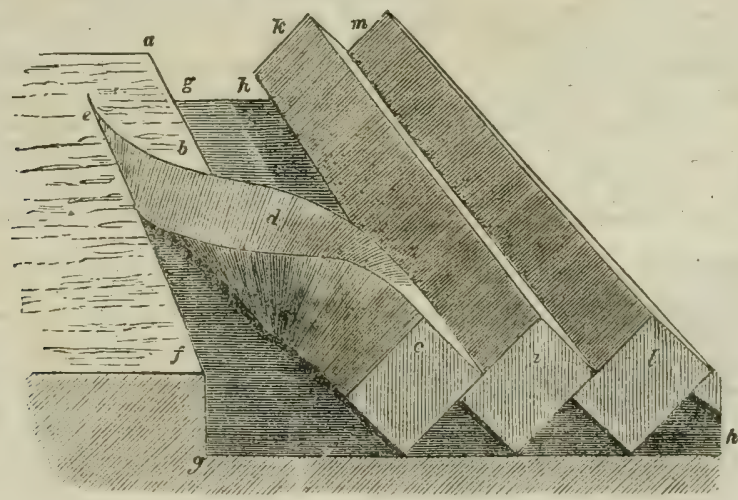

1. VIEW OF THE MOVEMENT OF THE FURROW-SLICE.

the preceding furrow; $c d$ the slice in the act of turning over, but from which the plow has been removed; $e f$, the edge of the land from which the slice $c d$ is being cut; $g h$, the sole of the furrows, and $i k, l \mathrm{~m}$. slices previously laid up. A consideration of this figure will also show that the extension of the slice takes place along the land-side edge $e d$ only, from $e$ to where the backward flexure is given to it when rising on the mould-board, and where it is again compressed into its original length, by the back parts of the mould-board, in being laid down.

(583.) Of the furrow-slice-To accomplish efficient plowing, the furrow-slice should always be of such dimensions and laid in such position that the two exposed faces in a series of slices shall be of equal breadth; any departure from this rule is a positive fault, whether the object be a seed-furrow or intended for amelioration by exposure to the atmosphere. Furrow-slices laid up agreeably to this rule will not only present the maximum of surface to the atmosphere, but they will also contain the maximum of cubical contents, both of which propositions may be illustrated thus by fig. 106 . Let $a b$ represent the breadth of a 10-inch furrow-slice, and describe the semi-circle $a c b$ upon it as a diameter. From the well-known property of the circle, that the an. 
gle in a semi-circle is a right angle. * every triangle formed upon the diameter, as a base, will be right angled, and the only isosceles triansle that can be formed within it will be that which ha the greatest altitude. The trianrle $a c b$ possesses these properties, for produce $c b$ to $d$, making $c d$ equal to $a b$-the breadth of the slice, which must always be equal to the distance between the apices of two contiguons furrows. Complete the parallelogram $a c d e$, which will represent the transverse section of a rectangular slice, whose breadth is 10 inches, and whose two exposed faces $a c$ and $c b$ lie at angles of $45^{\circ}$, and their breadth. as well as the area of the triangle $a b c$, will be a maximum. In order to prove this, let a section of another slice be formed, whose exposed side $a f$ shall be greater than the corresponding side $a c$ of the former, and let this be taken at 8 inches. From $f$. throngh the point $b$, draw $f g$, then will $a f b$ be a right angle as before: $f g$ being also made equal to 10 inches, complete the parallelogram $a f g h$, which will represent the transverse section of a rectangular slice 10 inches by 8 inclues, occupying the same horizontal breadth as before, and whose exposed faces will be $a f$ and $f b$. Draw the line $i c k$ parallel to $a b$, and passing through the apex $c$ of the triangle $a c b$; and the line $i^{\prime} l^{\prime}$ also parallel to $a b$, passing through the apex $f$ of the triangle $a f b$. Here the triangles $a c b$ and $a f b$ stand on equal bases $a b$; but the first lies between the parallels $a b$ and $i c k$. and the second between those of $a b$ and $i^{\prime} k^{N}$; the altitude $f f^{\prime}$. therefore, of the triangle $a f b$, is less than the altitude $c c^{\prime}$ of the triangle $a c b$. And triangles on equal

Fig. 106.

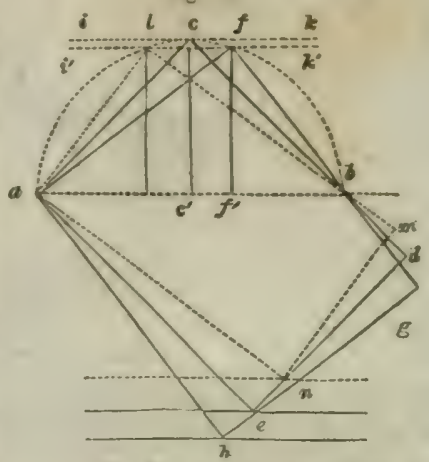

PROPORTIONAL AREAS OF THE FURROWSLICE IN DIFFERENT POSITIONS.

bases being proportional to their altitudes, it follows that the triangle $a f b$ is less than the triangle $a c b$, both in area and periphery. Suppose, again, a slice whose side $a l$ is less than the corresponding side $a c$, and let it be 6 inches: from $l$, through the point $b$, as before, draw $l \mathrm{~m}$. and con. struct the parallelogram a $l m n$, we shall have a transverse section of a third slice of 10 by 6 inches, whose exposed faces $a l . l b$. occupy the same horizontal breadth as before. Here the triangle $a l b$ lies between the parallels $a b$ and $z^{\prime} k^{\prime}$, consequently equal to $a f b$ and less than $a c b$.

(584.) This simple geometrical demonstration, as applicable to the slice, may be corroborated by the nsual formula of the triangle. Thus, the altitude of the triangle $a c b$ is $=\frac{a b}{2}=5$ inches $=c^{\prime} c$, and the side $a c$ or $c b$ is $=\sqrt{a c^{\prime 2}}+c c^{\prime 2}$; or $a c^{\prime}$ and $c c^{\prime}$ being each equal to 5 inches, $a c$ or $c b$ will $=\sqrt{52}+52=7071$ inches. which is the depth dne to a slice of 10 inches in breadth, and the sum of the two exposed faces will be $7.071 \times 2=14.142$ inches.

(585.) In the triangle $a f b, a b=10$ inches and $a f=8$ inches, then $a b 2-a f^{2}=f b^{2}$ and the $\sqrt{f^{2}} 2=6$ inches. The three sides, therefore. of this triangle are 10,8 and 6 inches, and the altitude $f^{\prime} f$ is easily found by the principles of similar triangles. Thus, in the similar triangies $a f f^{\prime}$, $f b f^{\prime}, a b: a f:: f b: f f$. The perpendicular $f f^{\prime}$ is therefore $=4 \cdot 8$ iuches; hence the exposed surfaces are as $14 \cdot 141: 14$, and the altitudes as $5: 4 \cdot 8$. Since it turns out that $a l$ is equal to $f b$. and $a b$ common to both, it follows that $l b$ is equal to $a f$, and the periphery and altitude also equal. and less in all respects than the triangle $a c b$. And so of any other position or dimensions.

(586.) The slice which presents a rectangular section is not the only form which is practiced in modern plowing. Of late years, and since the introduction of the improvements by Wilkie on the plow, a system of plowing has been revivedt in which the great object seems to be that of raising a slice that shall preseut a high shoulder, as it has been called, or which I have ventured to denominate the crested furrov, formerly alluded to. The general impressions that prevail as to the advantages of this mode of plowing are. that the crested furrow afforis a greater surface to the action of the atmosphere, and a greater quantity of cover to the seed in the case of a seed furrow in lea. As there appears to me some degree of fallacy in the reasoninzs on this point among practical men. and as it does not appear to have been hitherto sufficiently investigated, I shall venture a few remarks in the bope of leading others to a more full consideration of the points involved in the subject.

(587.) The crested slice, instead of the rectangular section of the one already described, preneuts a rhomboidal but more frequently a trapezoidal section : indeed the latter may be beld as inseparable from the practice; but in comparing them I shall first take the exposed surface. In fig. 107 , then, let $a b c d$ represent a transverse section of a rectangular slice of 10 by 7 inches, $a e$ the base of the triangle, whose sides $a b, b$ e represent the two exposed sarfaces of the slice when set ap with the sides at angles of $45^{\circ}$ to the horizen. its angle at $b$ being $90^{\circ}$-its altitude $b f$ will be as before $\frac{a e}{2}=5$ inches. Again, let $g h$ be the base of the triangle whose sides $g b, b h$, represent the exposed surfaces of a crested slice- whose base $g h$, equal to $g d$, may be taken at 9 inches, that being the brearth at which such plows take their furrow. Supposing, also. that the cresting is such as to give an altitude $f b$ of 5 inches, as in that of the rectangular slice. we shall have the sides $g b, b h$, from the usual formula, $g f_{2}+f b:=g b 2$, and $g f$ being $4 \frac{1}{2}$ inches $f b=5$

* Euclid, 31, iii.

4 Blith's "English Improver Improved," p. 266, edit. 1652.

(516) 
inches, then the $\sqrt{4 \cdot 5}+5^{2}=6 \cdot 72$ inches $=g b$ or $b h$, being rather more than the best practical authorities for cresting plows give to the depth of a slice; the dimensions recommended being from $8 \frac{1}{2}$ to 9 inches broad, and from 6 to $6 \frac{1}{2}$ inches in depth. It will therefore always tall short in perpendicular hight of the rectangular slice of 10 by 7 inches. But allowing the hight to be the same, we have two triangles. $a \cdot b e$ and $g b h$ of equal hight but of unequal bases; their areas will therefore be unequal and proportional to their bases.

(588.) In bringing these two gystems, however, into practice over any extent of suriace, suppose a ridge of a field, the number of furrows of each required to turn over such ridge, will be exactly in proportion to the length of the base of the triangle, or as 9 to 10 . Heace, though the individual crested slices or triangles have an area less than that of the rectangular slice in the proportion of 9 to 10 ; yet the aggregate area of all the triangles over any given breadth of surface, wherever the number of slices of the one exceeds that of the other in the proportion of 10 to 9 , will be the same, but no more. The imaginary advantage, therefore, of a greater cover to the seed with a crested furrow falls to the ground, provided the comparison is made with a plow that takes a furrow of 10 inches wide by 7 inches deep, sucb as the East-Lothian plow.

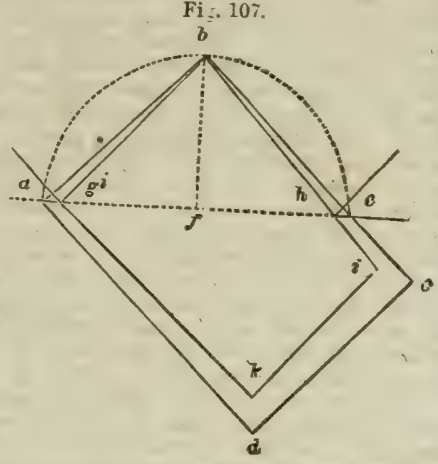

THE COMPARISON OF THE RECTANGULAR A ND CRESTED SLICES.

(589.) It is to be admitted that, were cresting plows that cut their slices 9 inches wide, to take them 7 inches deep, and still preserve the rhomboidal or trapezoidal section, they might, in that case. produce an increase of cover to the seed. as compared with a rectangular slice of 9 by 7 inches. Let us refer again to the last figure, fig. 107, and suppose $g b=7$ inches. $g f$ being, as before, $4 \frac{1}{2}$ iuches, then $g b^{2}-g f^{2}=b f^{2}$ or $b f$ will be equal to $5 \cdot 36$ inches, while, by the same method the rectangular slice of 9 by 7 inches would give $b f$ equal to only 4.39 inches, the crested slice in this case giving a difference of hight of $\cdot 97$ inch. and $\frac{1}{2}$ of this, or 48 inch, of greater cover of seed. But this is not a practicable case, inasmuch as the cresting plow cannot be worked in a furrow of 9 by 7 inches, and lay it at an angle that would give equal exposure to both sides of the slice, whether it possess a rectangular or rhomboidal section. the true depth being 6.36 inches nearly, for a slice whose breadth is 9 inches; and the hight $b$ fof its triangle would be, if rectangular, only 4.5 inches. Compared with itself, therefore, the plow that takes a 9-inch furrow rectangular yields $\frac{1}{4}$ inch less cover to the seed than when it raises the crested slice; but, even with the ad. vantage of the crest, it is not better than the plow that takes a 10 -inch furrow; while, as will appear, the furmer labors under other disadvantages arising from that peculiarity of structure for which it is valued.

(590.) In order to exhibit the difference of effect of the rectangular and the trapezoidal slices, as lifted and laid on each other. by the plow, and as they affect the real intentions of tillage, I shall consider them in separate detail. Fig. 108 is an example of the recangular slice of 10 by 7 inches, $a b c d$ may be taken as a transverse section of the body of the plow, the line $a c$ being the terminal outline of the mouldboard, $a f$ a section of the slice which is just being laid up, and $g h$ a slice previously deposited. In the triangle $i g k$ the base $i k$ is 10 inches, being always equal to the breadth of the slice, the angle at $g$ a right angle, and the sides $i g, g k$ each equal to 7.071 inches, the perpendicular hight $g l$ being 5 inches, as before domonstrated. Fig. 109 is a similar representation, of a cresting-plow, with its effects on the slice and the subsoil ; $k n o p$ is a section of the plow, $k m$ a section of a slice in the act of being deposited on the preceding slice $c l$. Here the slices are trapezoidal. as they are always cut by this species of plow; and from this configuration of the slice, the broader sides are not parallel, nor do the conterminous sides of the adjacent slices lie parallel to each other in the transverse direction. The side $b c$ lying at an angle of $48^{\supset}$ with the base $a b$, while the side

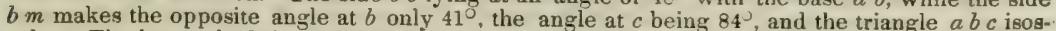
celes. The base $a b$ of the triangle $a b c$ is now supposed to be $8 \frac{1}{2}$ inches-the breadth recommended for a seed-furrow-and the side $a c 6 \frac{1}{2}$ inches, the opposite side $l h$ being $4 \frac{1}{2}$ or 5 inches. The base $a b$, when bisected in $d$. gives $a d=4 \cdot 25$ inches, and since $a c^{2}-a d^{2}=c d^{2}, c d$ will be 4.918 inches, which is less than given by the former demonstration of the crested slice; but $I$ have observed cases still more extreme, where, still referring to the same figure; $a b$ was only $7 \frac{1}{2}$ inches, but the angle at $c$ became so acute as $75^{\circ}$, yet with these dimensions $c d$ is still under $5^{2}$ inches : hence, in all practical cases, with a furrow less than 9 inches in breadth, the result will be a reduction in the quantity of cover for seed.

(59l.) One other point remains to be noticed in reference to the two forms of slice. We have (517) 
seen that the rectangular slice necessarily implies that the bottom of the furrow shall be cut upon a level in its transverse section, fig. 108 ; while the slice that is cut by the cresting-plow leaves the bottom of the furrow with a stoping rise from the land-side toward the furrow.side at every slice, and this rise may range from 1 to 11 inch or more. Returning to fig. 109, the serrated line $f$ ho cxhibits a transverse section of the surface of the subsoil, from which the soil has been turned up by the cresting plow. The triangular epaces ef $g, g h i$ rep. resent the quantity of soil left by such piows at the lifting of each slice. These quantities, which, as before observed. may amount to 1.7 of what the slice ought to be, are thus robbed from it. and left adlsering to the subsoil, except in so far as they may be rubbed down by the ubrading action of the lower edge of the mould-board, as at $f$ and $h$, and the portious of soil so' rubbed oft are thrust into the spaces under the edge of the slices as they are successively laid up. This last process may be readily observed at any time when the plow is working in tough laind or in lea. With a cresting-hlow the spaces $f h$ will be seen more or less filled up with crumbled soil. while with the rectangular plow, the corresponding spaces will be left nearly void. 1 cannot take upon me to say whether or not the filling in of these voids is beneficial to the land in a greater degree than if the 1.7 here left below had been turned up with the slice; but this I ran say, that it is more frequently left adhering to the subsoil than it is to be found stuffed under the edge of the slice. Under any view, the system of the crested furrow-plowing is not unworthy the consideration of the farmer.

(592.) In considering the question, there are two points deserving attention. 1st, The immediate effects upon the labor of men and horses. It may be asserted generally, that all pluws adnpted 10 form a crested furrow are heavier in draught than those that produce the rectangulas furrow. This seems a natural inference from the manner in which they work; the tendency that they all have to under-cut.by the coulter; the narrow feather of the share leaving more resistance to the borly in raising and turning the slice: and not least, the small ridgre left adhering to the bottom of the furrow, if rubbed down and etuffed under the slice, is performed by an unnecessary waste of power, seeing that the mould-board is not adapted for removing such adhering obstructions. 2d, The loss of time and labor arising from the breadth of furrow, compared with those plows that take a 10-jnch furrow. Thus, in plowing an imperial acre with a 10 -inch furrow-leaving nut of view the taking up of closings. turnings, \&c.- the distance walked over by the man and horses will amount to 9.9 miles nearly; with a 9 -inch furrow the distance will be 11 miles; with $8 \frac{1}{2}$-inch furrow, it will be $11 \frac{1}{2}$ miles or thereby: and with a $7 \frac{1}{2}$-inch furrow $13 \frac{1}{4}$ miles nearly.

(593.) It may, therefere be of importance for the agriculturist to weigh these considerations and endeavor to ascertain whether it is more for his interest that his plowing shoula be essentially well done, and with the least expenditure of power and time, or that it should be done more to please the eye, with a ligh surface finish, though this may perhaps be gained at a greater expenditure of power and time; while the essentials may in some degree be imperfectly performed.

(594.) On this part of the subject. I cannot refrain a passing remark on the very laudable exertions that have been made all over the country in producing that emulation among our plowmen which has been so successful in producing excellence in their vocation among that useful class of agricultural laborers, as to give them a preèminence over all ofhers of their class in any country. I mean the institution of plowing-matches. While I offer my humble though ardent wishes for a continuance of the means which have raised the character of the Scottish plowmen. I cannot prevent doubts rising in my mind, that, however good and beneficial these competitions are calcalated to be, if the exertions of the class are properly directed; yet the best exertions of both the promoters and the actors may be frustrated by allowing a false taste to be engendered among these operatives. That such a false taste has taken root I have no doubt; and the results of it are appearing in the spread of opinions favorable to that kind of plowing which to me appears not much deserving of encouragement-the high-crested system. I have observed, at various plowing. matches, that the palm was awarded to that kind of plowmanship which exhibited the highest surface-finish, without reference at all to the ground work of it: and I have compared by artual weight, ail crumbs included, the quantities of soil lifted by plows that gained prizes with others which did not, because their work was not so well dressed un the surface; and I have found that the one to whom the prize was awarded had not lifted so much soit by 1-10 as some of those that were rejected. I am far from intending, by these remarks, to throw discredit on plowing-matches on the contrary, I would see them meet with tenfold encouragement, and would also wish to see many more than is usually met with. of the good and the great of the land, assembled at snch meetings, to encourage and stimulate by their presence the exertions of the competitors in sucl interesting exhibitions. W ith this short digression I leave this subject for the present, with the intention of resuming it in another division of the general subject.

(595.) THE PRINCIPIFS AND FORMATIUN OF THE MOULD.JuARD. -Of the varions individuals who have written upon the plow and the formation of the mould board. Bailey of Chillingham and Small of Berwickshire are perhaps the only two who have communicated their view 8 in a practical shape, and even in their descriptions there is somewhat of ambiguity and ancertainty, but such may be inseparable from the subject. Many other nameless artisans have varied the mould board until almost every county has something peculiarly its own, and each district claims for its favorite all the advantages due to perfection.

$(518 i$ 
(596.) I have been at great pains to analyze a considerable number of these varieties; and as the subject is not uuimportant in a work of this kind, I have selected a few of those best known, and of highest character. as objects of comparison.

(597.) The method atopted to obtain a mechanical analysis of these mould-boards has been simple, but perfectly correct; and as the principle may be applied to the attainment of counter. parts of other objects, perbaps more important than a mould-board, it may be deserving of a place here. As a matter of justice, also, to the fabricators of the different mould-boards here exhibited, I am desirous to show the principle on which these transcripts of their works have been thus brought forward in a new form, and in contrast with each other.

(598.) The instrument employed for this purpose is a double parallelogram or parallel miler, as represented in fig. 110, which is a perspective of the apparatus. The bars $a b, c d, e f$, are

Fig. 110.

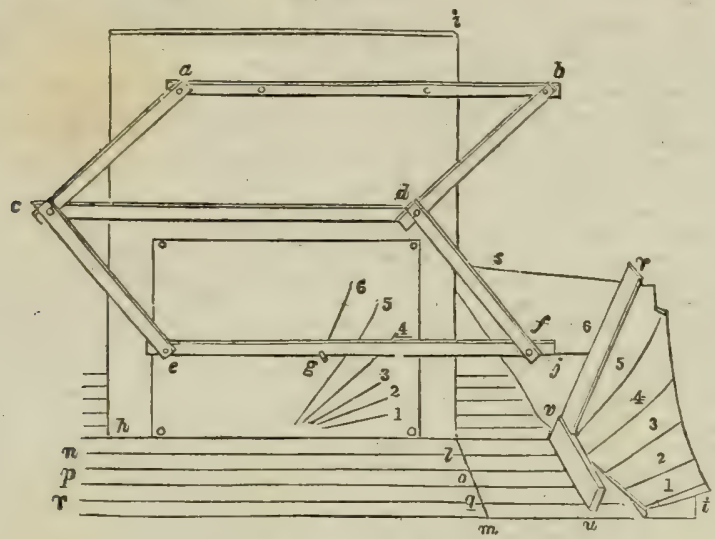

THE PARALIEL RLEER.

slips of hard-wood about 3 feet long, or they may be of any convenient length, and $1 \frac{1}{2}$ inenes broad by $\frac{3}{8}$ inch thick; each of which is perforated at $a, b, c, d, e, f$, the perforations being exactly equidistant in all the bars. Four similar bars, of about half the length, are perforated also at one uniform distance, and the seven bars thus prepared are jointed together upon brass studs, and secured so as to move freely at every joint, but without shake on the studs. The form. when constructed, is that of the two parallelograms $a b c d$ and $c$ def. In the ead of the bar $e f$ a stout wire pointer $j$ is fixed of about 6 inches in length. lying in the plane of the instrument, and parallel to the edge of the bar. In a continuation of this parallel upon the bar $e f$, a socket capable of retaining a pencil or tracer is fixed anywhere at $g$. The instrument so tomed is fixed upon a flat board $h i$, of about 3 feet square, by means of two screw nails passing through the bar $a b$, in a position parallel to the lower edge of the boatd; thus leaving all the other bars at liberty to move upon their joints; which completes the instrument. From the well-known properties of the par. allelogram, as applied to the neutograph and the eidograph, it is unnecessary to demonstrate, that whatever line or figure may be traced with the pointer $j$, will be faithfully repeated by the tracing pencil $g$, upon any substance placed before it, and of the same dimensions as the original.

(599.) Another board or table or a level platform, is now to be selected, and a line $l \mathrm{~m}$, which may be called the fundamental, or leading line, drawn upon it. This line, to an extent of 3 feet or more, is divided into any number of equal parts, but in this case the divisions were 3 inches each; through these points of division are drawn the straight lines $l n, o p, q r$, \&c., indefinitely on each side of the line $l \mathrm{~m}$, and at richt angles to it. The board carrying the instrument is provided with a foot behind, that keeps the face of the board always perpendicular to the platform on which it stands. The plow with the mould-board about to be analyzed is now set upon the table or platform upon which the leading line and the divisions have been laid down; the landside of the plow being set parallel to the leading line, and at any convenient distance from it, suited to the instrument; presentiner the mould in the position $s t$, and so placed in reference to the lines of division that the zero line shall coincide with one of them, provided the extremities do not overreach the divisions eitber way, the laudside of the plow beiug at the same time perpendicular. The instrument is now brought toward one extremity of the mould-board, and placed upon that parallel of the divisions that come nearest to the extremity, as No. 1 in the figure, the edge $l i$ of the instrument coinciding with the leading line $l \mathrm{~m}$. A sheet of paper having been now fixed upon the board $h i$ of the instrument, and a tracing-pencil inserted in the socket $g$, the operation of tracing commences. The tracing point is passed in the vertical direction over the eurface of the mould-board, tracing along a line No. 1; the pencil at the same time tracing a corresponding line No. 1, on the paper, which will be an exact outline of the face of the mouldboard at that division, supposing the mould-board to he cut by a transverse section in that line. The instrument and board are now to be moved one division upon the leading line $l \mathrm{~m}$, the coincidence of the edge $l i$ of the board with that line being still preserved. The tracing point is again made to pass vertically over the face of the mould-board, when the pencil $g$ will trace on (519) 
the paper a second line No. 2. This process, repeated at each successive division, 3, 4. 5, 6 . \&c., the corresponding lines, $3,4,5,6$, dic., on the paper will be traced out, exhibiting a series of perfect sectional lines of the mould-board, each line being that which would arise from an inaginary vertical plane cutting the body of the plow at right angles to its land-side at every 3 inches of its length. To prevent any inaccuracy that misht arise from a misapplication of the tracing point to the oblique surface of the mould-board, a straight-edged ruler, in form of a carpenter's square $u v x_{\text {, }}$ is applied to the mould-board. The stock $n v$ of the square being placed on the platform, and parallel to the line $l \mathrm{~m}$, which brings the edge $v x$ always into the vertical plane, and the iracing rod must be kept in contact with this edge, while it traverses the face of the muuld-board at each successive section.

(600.) This mode of analysia it is to be observed, has not been adopted from its having any re. lation to the principles on which the diflerent mould-boards have been constructed, but because it presents an unerring method of comparing a series of sectional lines of any one mould-board with those of any other: hence it affords a correct system of comparison. But it is not merely \& comparative view that is afforded by it, for in the sequel it will be seen that a ground-work is thus afforded from which the mechanic may at any time or place construct a fac-simile of any mouldboard, the analysis of which has been made after this muner.

(601.) The results of the analysis of a few of the mould boards from the plows of highest character, as taken by this method, are given in the foilowing figures. Plate XI., fig. 111, is a geometrical elevation in a plane parallel to the land-side of the mould-board of the East.Lothian plow $l d$, being its base line. The perpendicular lines of division. commencing from the line 00 the zero, and extending right and left, are she lines of section. Those to the right or fore-end of the mouldboard. marked $a a, b b, \& c$, and those to the left 11,22 . \&c. The curved line $x y z$ represents the path described on the face of the mould-board by the lower land-side edge of the furrow-slice, as the mould-board passes under it; this line I shall rall the line of transit. Fig. 112 is a front view in elevation of the mould-board of the same plow, and corresponding to fig. $111 ; k m$ is the base-line of the plow; $m g$ is the land-side plane in a vertical position, $m$ is also the place of the point of the share, and $h i$ the line of junction between the neck of the share and the mould-board; the remaining lines beyond $h i$ exhibit the outline of all the sections taken by the instrument in reference to the lines in fig. 111 . Thus, $o \circ g \mathrm{~m}$ is the section of the entire body of the plow in the plane of the zero, $\cap$ y $o$ being the ontline of the mould-board at this section, and $y$ the zero-point; $a, g \mathrm{~m}$ the first section forward from the zero, $b b \mathrm{~g} m$ the second, and so on. In like manner, $11 \mathrm{~g} \mathrm{~m}$ is the first section backward from the zera, $22 \mathrm{~g} m$ the second, and so on ; each section so lettered and numbered having relation to the divisions carrying the corresponding letters and no. merals in fig. 111 . The entire series of lines 13,22 . \&c. and $a, b, b$. \&c. thus form a series of profiles of the mould-board, supposing it to be cut vertically by planes at right angles to the landside of the plow. In fig. 112, also, the dotted line $m x y z$ represents the path of the slice or line of transit, as in fig. 111, and $\approx k$ represeuts a transverse section of the slice as finally deposited by the mould board. Figs. 113 and 114 exhilhit, in the same manner, the mould-board of the Currie or Mid.Lothiu plow; the divisional and sectional lines being all laid off in the same manner from the zero as in the example just described of the East-Lothian plow, and the zero-point $y$ in the line $o$ y 0 , which is 9 inches from the plane of the land.side. Fim. 114 bears also the same relation to fig. 113, and as the letters and numerals in these have the same relation and value as in figs. 111 and 112-the East-Lothian-the description given of that applies nut only to the Mid-Lothian, but to the five succeeding figures, viz:

Figs. 115 and 116 represent the Berwickshire plow, being that which has been so successfully adopted by the Marquis of Tweeddale.

Figs. 117 and 118 are of the Lanarkshire plow.

Figs. 119 and 120, Plate XII., are of the Saline or Western Fifeshire plow,

Figs. 121 and 122 are of the FF plow of Messrs. Ransome, of Ipswich.

(602.) With reference to the characters of these different mould-boards, it may be remarked: of the East.Lothian mould-board. fig. 112. Plate XY.. that those portions of the sectional lines lying between the lower edge and the line of transit are essentially straight, the two lines beyond the zero backward excepted, these being slightly concave toward the lower edge: and, although the lines before the zero and above the line of transit are concave, that part of the surface lias no effect upon the furrow-slice. It is, likewise, to be observed that the parallelogram $k y$, which represents a section of the slice when brought to the vertical position, has its upper ansle $y$ onlr touching the zero line, and no other part of the side of the parallelogram in contact with the zero line of sectiou $o y o$; hence the mould-board, by its pressure being exerted chietly agininst the upper edge of the slice, will always have a tendency to abrade the crest of its rectangular slice in its progress over the mould-board.

(603.) In the Mid-Lothinn mould-board, figs. 113 and 114, the lines are also approximating to straight, except in the lower portions of those before the zero, where they produce a couvexity of surface. but this part of the mould-board can have little influence. The chief difference, then, lies in those parts of the sectional lines which lie above the path of the slice, and they also have no effect whatever in the formation or the converance of the slice; neither can the circumstance of elongation forward in this mould-board have any influence, for the same lines are to be found on the necle of the share of the East-Lathian as are here exhibited in the prolongation of the mouldboard. We have, therefore, two plows in which the essential lines of the mould-board are the same, but which produce work of an opposite character. It must be kept in view. however. that in the Mid.Lothian the zero-noint $y$ is only 9 inches from the land-side, while in the East-Lothian it is 10 inches; but the length belind the zero-line being nearly alike in both, and the width at the tail also the same, the difference in distauce of the zero-point from the land-side produces a difference in the effect of the pressure of the mould-board on the edge of the slice. This will be perceived from the relation in which the section $k y$, representing the slice, stands to the zero-line $o y 0$ of the mould board; for in this case the angle at $y$, formed by the side of the parallelogram and the zero-line, is not more than $\downarrow$ of that in the former case. This mould board, therefore, will 

The Western "ifeshire.

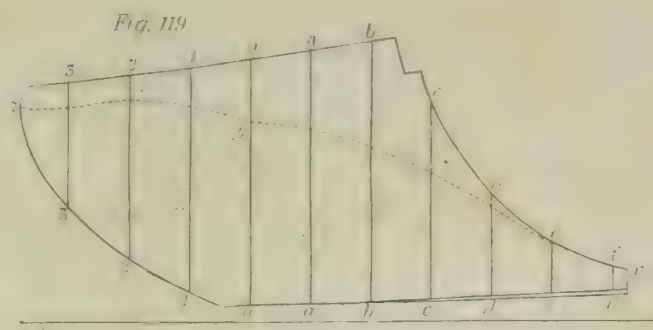

Fio. 131
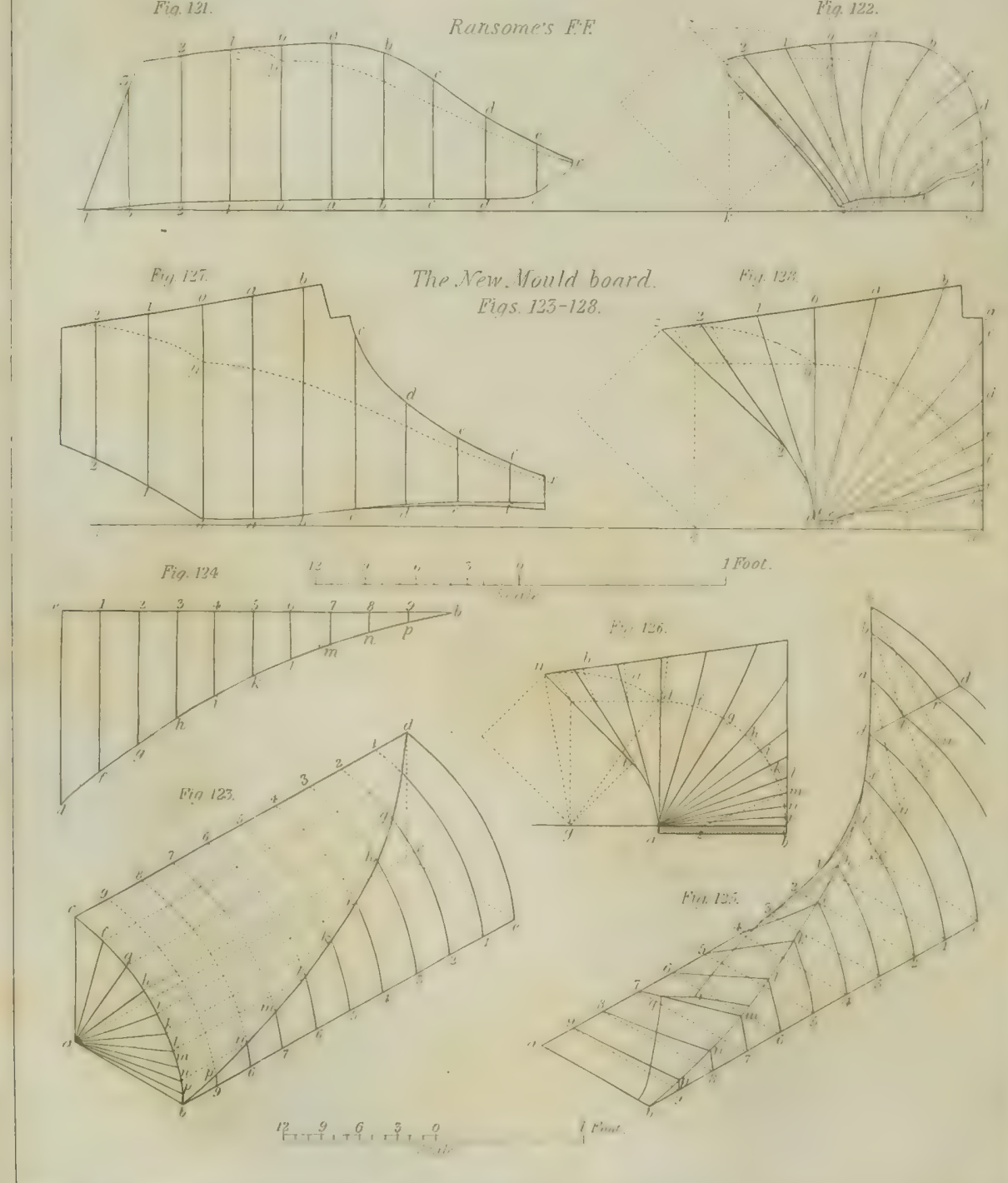

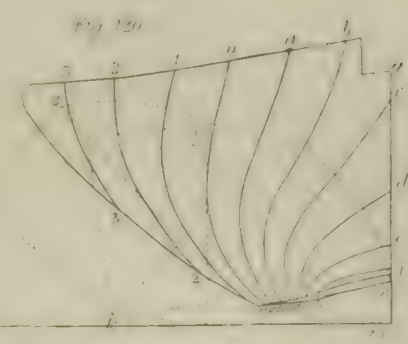

Fig. 122.

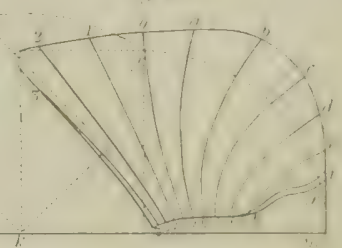

1 Fool.

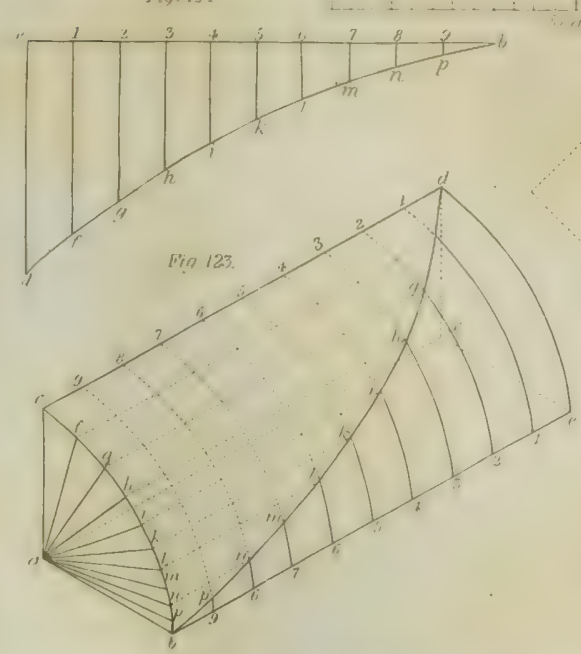

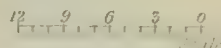

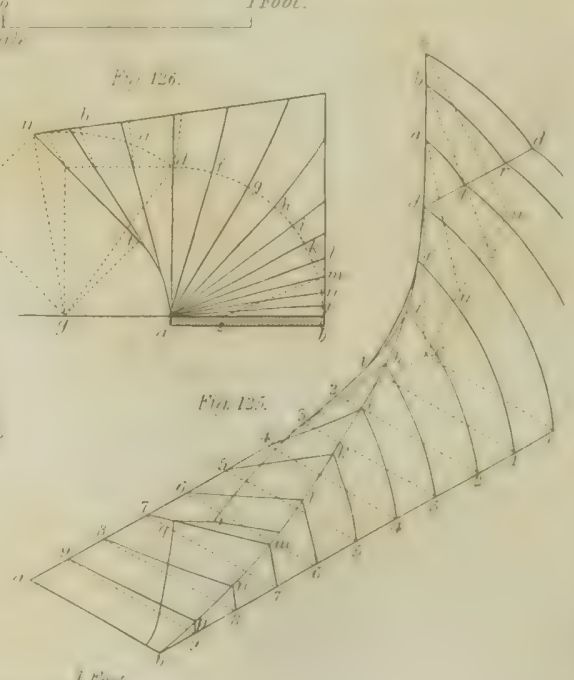
trime. 
sonvey the slice in whatever form it may be cut, with less risk of injury to the crest than can be expected trom the former. But, as these discrepancies cannot produce the marked difference that exists in the appearance of the work performed by these two plows, it is not in the mould. board we are to look for the cause, but in the couformation of the share and the position of the coulter, while the mould-board, from the circumstance last pointed out, is better adapted to convey the slice unaltered.

(604.) The Bertcickshire mould-board, figs. 115 and 116, which is also truncated forward, has the sectional lines, lying before the zero, nearly straight; but, as they approach the zero, they becone gradually and decidedly concave, which increases toward the extremity. This concavity, it will be observed, exists only to a certain extent below the line of transit, and, as the sectional lines approach the line of transit, the curvature is reversed, and the surface becomes convex.This is a form well adapted to deliver a slice free of injury to the edge or crest, for, from the convexity immediately below the line of transit, the mould-board will never press upon nor abrade the edge of the slice, the pressure being exerted always within the extreme edge, as will be seen from the section $k z$ of the slice, as applied at the extremity of the mould-board; though. when in the vertical position, as in $k y$. the section of the slice touches the zero-line at its upper edge, at an angle nearly equal to that in the East-Lothian, showing that it is liable to abrasion until it has yassed that line. But this plow, in practice, sets up a lurrow of the rectangular species, with its angle or crest better preserved than in many others of this class, while, at the same time, it takes out the sole with the characteristic levelness which belongs to the class.

(605.) The Lanarkshire mould-board, figs. 117 and 118, has all its lines convex, the terminal edge excepted, which is nearly straight below, but preserves the convexity as it approaches the line of trausit. Even above the line of transit the convexity is continued, and, though not affect. ing the slice, it gives in appearance a still more decided character of convexity, and, by thus mak ing the upper edge of the mould-board retire, gives a long rake to the breast of the plow. It will be readily conceived that this mould-hoard, from the convexity of all its sectional lines, is essentially formed for turning up a crested furrow, more especially when the torm of its share and the position of its coulter are considered. These last, being formed for culting the slice with a very acute angle, will deliver it to the mould-board; and. from the form of the latter, the slice will pass over it uninjured; for the pressure upon the mould-board will be always greatest upon those parts of the surface of the slice lying within the edge, preventing thereby the abrasion of that tender part. These circumstances are clearly seen from the relation of the section of the slice $k y$ as applied to the zero-line $o$ y $o$, the point of contact lying considerably within the angle at $y$ of the slice; and the same relation holds throughout the entire trausit, up to the delivery of the slice in the ultimate position $k z$

(606.) The Western Fifeshire mould-board, figs. 119 and 120. Plate XII, it will be readily perceived, belongs to the Lanarkshire class; but in this the ronvexity is carried so far to an extreme as to round away the lower parts of the mould-board, till, at the lower edge behind. the width is only 6 inches. The terminal live, also, is prominently convex throughout. It differs also from its original type in having those parts of the sectional lines lying above the line of transit tending to recurvature. This, by carrying forward the apper part of the breast, gives the appearance of greater length to the mould-board; but, besides this, the part lying behind the zero is actually longer than in any of the preceding plows, as will appear from the sectional divisions, figs. 111 , 113 , 115, and 117, Plate XI. As may be anticipated, this variety of the Lanarkshire plow is famed for the acuteness of the furrow which it forms, though, in this respect, it does not excel its prototype. From the way in which the section $k y$ of the slice, when in the vertical position, is applied to tha zero-line, where the point of contact is seen to lie at $\frac{1}{3}$ of its breadth witbin the edge of the slice, it will at once appear how well this mould-board is adapted to transmit an unbroken crest. In every position of its transit up to its ultimate position, the slice will be equally secure from injury in respect to the crest; and, were the crested furrow a true criterion of good plowing, the plow that bears this mould-board, with share and coulter adapted thereto, would be the most perfect ; but there are various and important arguments againgt it.

(607.) In Ransome's Bedfordshire, or F F mould-board, figs. 121 and 122, the sectional lines are of a mixed character; those in the fore part being convex, gradually diminishing in convexity to the zero, behind which they become straight lines, tending to concave-the terminal line being slightly so-but becoming convex at the upper edge. It differs from all the Scotch mould-boards in having the terminal edge lengthened out below, instead of the usual shortening. and in having the breast cut away nearly parallel to the line of transit. The plows mounted with this mould-board are generally worked with cast-iron shares, having a wide-spread feather formed for cutting a level furrow-sole. The furrow usually taken with it is shallow, and, when set up, looks flat in the crest: but the work, so far as it goes, is what may be termed, in plow lansuare. true; that is to say, the slice is rectangular and cut from a level sole. Though the sectional lines before the zero possess a form that would save the slice from abrasion, yet, at the zero-line and behind it, they have the opposite character in the extreme, and we accordjingly find that this mould-board lays a very Hat crested furrow, while the share and coulter are perfectly adapted to cut it rectangular.

(608.) With all the foregoing mould-boards, it will be observed that the section of the furrowslice, in its ulrimate position, seems to encroach upon the tail of the mould-board; and this is to be understood as arising from the circumstance of the slice being represented as incompressible, and unabruded below or above. In practice, the slice is pressed downward on the angle at $k$, and pressed home upon the preceding slice, so as to bring the face of the slice simply in contact with the terminal line of the mould-board instead of the apparent mutual interpenetration exhibited in the figures.

609.) From the examples here given of the forms of mould-boards, and the effects which they produce when combined with any particular form of share and position of coulter, it will be easy to draw a conclusion as to the kind of work that will be performed by any plow that comes nnder our observation, and that without any previous knowledge of its merits; keeping in mind that the 
nltimale form of the furrom will always depend on the form of the share and position of the coulter, that the passage of the slice over the mould-buard will have but a very partial effect on the form of the slice, und that this eflest will be greater or less according to the form of surlace. Thus, a slight convexity of surface, immediately below the line of transit, will with greater certainty secure the uransit of the slice wilbout injury to its edge, than may be expected from a surfare which has a concavity crossing the line of transit. though it may be obtained, as in the Mid. Lothian and East.Lothiai plows, with a straight-lined mould-board; but it will be more certainly obtained if the share is narrow, as in the Mid Lothian; though this last expedient will induce disadvantages in point of draught, and risk of losing the eflect, by uny undue placement of the coulter. These disadvantares maty arise from the conlter not being sufficieutly set to labdward, thereby admitting the breast of the plow to scrape upou the land, and send a small portion of earth along the mould-board, accompanying the edge of the slice, which may have the ctfect of abrading it so mueb at to injure the apperarance of the work, thongh not in fact affecting its efficiency.

(610.) Having thus endeavored to establish some dara by which the agricultural mechanist. whether ameteur or operative, ma be assisted in determining from observation, what practical effects may be expected to result from any form of mould-board and share, I proceed to mention some rules by which he may lorm a mould-bourd on- what I conceive to be the true principle, but upon which may he eneratted such deviatious as taste or.other circumstames may require.

(611.) Those writers who coutributed to the improvement of the plow in the early stages of its modern listory, labored at a time when mould-boards of wood unly were employed. Hence, their instructions related to the formation of that material alone, into mould-boards. Later writers have followed in nearly the sime course, and have given rules for forming a mouldboara, out of a block of wood of suthicient dimensions to contain all the extrenities of the ptoposed fabric. The change now pervaling this branch of mechanics, wherein the introtuction of cast-iron has become universal, preclude's the necessity of falling back upon any of the old rales; what the agricultural mechanic is now required to furnish being not a mould board, bnt. in the language of the foundry, a pattern, from which castings are to be obtained perfect facsimiles of the original pattern, and which may be repeated ad libitum; from this last circum. stance, it follows that the making of a pattern will be a comparatively rare occurrence, and one which he will seldom be called upon to perform. It nevertbeless appears desirable that a knowledge of the construction of such a fabric should be communicated in a nanner that may cnable an ordinarily skilled mechanic to construct a pattern wheu reguired, with accuracy and certainty of effect.

(612.) It has been shown that very considerable discrepancies exist in the form given to mould. boards, and there is no doubt that peculiarities of soil may demand variations in forn ; but the propriety of such wide deviations may be called in question, and the actually required deviation brought within very arrow limits. Ii appears, indeed, that one form may be brought to answer all required purpóses, if aided by a properly adjusted share and coulter.

613.) From a careful study of the foregoing analytical diagrams, and from comparison of nu. merous implements and their practical effects, toyether with a consideration of the dynamical principles on which the plow operates, I-have been led to adopt a theoretical form of mould-bond. which seems to fulfith all the conditions required in the investigation, and which is capable, by very simple modifications of adaptation to the circumstances of the medium on which it works. In the outset, it is assumed that the soil is homoseneous, and that it possesses such a degree of temacity and elasticity as to yield to the passing form of the plow, and to resume, when laid in the due position, that form which was first impressed upon the slice, by the action of the share and coulter; the second consideration being the cutting of a slice from the solid land. In a theoretical view, this must be an operation through its whole depth and breath ; hence the share is con. ceived to be a cutting edge which shall have a horizontal breadth equal to the breadth of the slice that is to be raised, and that the face or land-side of the coulter shall stand at right angles to this. Another consideration is. that the slice now supposed to be cut has to be raised on one side, and turned over through an angle of $135^{\circ}$. the turning over being performed on the lower right-hand edge, as on a hinge, through the first $90^{\circ}$, the remaining $45^{\circ}$ being performed on what was at first the upper right hand edge. (Fig. 104.) The slice, in going throngh this evolution, has to undergo a twisting action, and be again returned to its original form of a right prism. To aceomplish this last process, it is evident that a $n e d \rho e, t u i s t e d$ on its upper surface, must be the agent; and to find the form and dimensions of this wedge, is solving the problem that gives the surface of the mould-board reçuired.

(614.) We have reen, fig. 104, that the slice, in passing through the first $90^{\circ}$, describes the quadrant with its lower edge, and in doing so. we can conceive a continued slice to form the solid of revolution $a b c d e$, fig. 123, which is a quarter of a cylinder, as shown here in isometrical per. spective; the radius $a b$ or $a c$ being equal to the breadih of the slice. We have next to consider the angle of elevation of the twisted wedge; and in doing this, we must not only consider the least resistance, but also the most convenient length of the wedge. In taking a low angle, which would present, of course, proportionally little resistance, it would, at the same time, yield a length of mould board that would be highly inconvenient, seeing that the generating point, in any section of the slice. must ultimately reach the same hight, whether by a low or a higher angle. From experience, we find that, from the point of the share to that point in the plow's body where the slice arrives at the perpendicular position, and which I have named the zero, that 30 inches form a convenient length. The length $c d$ of the solid is therefore made equal to 30 inches or more, and this being divided into 10 equal parta, the parallels $11,22,33$, dc.., are to be drawn upon the cylindrical surface, and between the points $b, d$, a eurve has to be described that shall be the line of transit of the slice. After investigatine the application of various curvns to this purpose, I have found that a circular are is the only one that can be adopted. It presents the least atiainable resistance in the first stages of the ascent, where the force required to raise the slice is the greatest, and in the last stages, where the force of raising has vanished, leaving only what is necessary to turn the slice over, there the resistance is at the greatest; and, above all, the circle being of equal (522) 
flexure throughout. it is in every way best adapted to the objects here required. To determine the radius of curvature of this arc, we must evolve the cylindrical surface $c b d e$, and from it construct the diagram, fig. 121 . Draw $e b$ equal to $c d$ of fig. $123 ; e d$ equal to the length of the arc $c b$ or $d e$. and at right angles to $e b$; divide $e b$ into 10 equal parts, and from the points of division draw the ordinates $1 f .2 \mathrm{~m} .3 h$, \&c., parallel to $e d$; from $b$ set off 10 inches for the length of the share along the line $b e$, which will fall $\mathbb{I}$ inch beyond the division 7 . and at this distance draw the dotted line parallel to $7 \mathrm{~m}$; upon this set off a distance $7 \mathrm{~m}$ of $2 \frac{1}{2}$ inches; and through the three points, $d, m, b$, describe an arc of a circle, whose radius will be found equal to the circum. ference of the crlinder of which $n b \mathrm{c}$. fig. 123, is a quadrant. The circular arc thus found is now to be transferred to the cylindrical surface $c \quad b d e$. The transfer may be performed by drawing the arc on paper, and the paper ther laid over the cylindrical surface in such a manner that the points $b, m, d$, shall be bronght to coincide with the points $b, m, d$ of the cylindrical surface; when the remaining points $f, g, h, i$, or any number more, may be marked on the cylindrical quadrant by pricking through the paper with a pointed instrument at short intervals along the are; or, the length of the ordiuates $1 f, 2 g, 3 h$ of fig. 124 , may be transferred to the correspouding parallels of fig. 123 , when the lengths of the ordinates will cut the parallels in the prints $f, g, h$, $\&$ c. In either case, the curve can now be traced through the points $b, p, n, m$, \&c., on the crliudrical surface. Through the points $b, p, n, m$, \&c., draw the dotted lines $f^{\prime} f^{\prime} \cdot g g^{\prime}, h h^{\prime}$, dic., parallel to $c d$ or $b e$, and from the center $a$ draw the radii $a f^{\prime}, a g^{\prime}, a h^{\prime}$. \&c.; the unequal divisions of the arc $c b$ will thus show the proportional angles of ascent of the slice along the line of transit now found, $b, p, n$, $\& c$. , for each division of the length; while the degree of flexure in the curve or line of transit remains uniform by the same, from any one point, to any other equilistant points.

(615.) To convert the prism thus prepared and lined off into that of the twisted wedge, we have only to cut away that portion of it contained within the boundaries $a, b, c d$. $x$, preserving the ter. minal edges $a b, a x$, and $d x$ : and the prism will thus be resolved into a form represented by a portion $a b d x e$ of fig. 125, also in isometrical perspective. Of this figure, $a b d x$ is the true theoretical surface of the mould board, from the edge $a b$ of the share to the zero-line $d x ; a b e x$ is the sole; the curve $b p n m l$, \&c.. is th line of transit of the slice; and the triangles $1^{\prime} f 1, \Sigma^{\prime} g 2$, $3^{\prime} h 3,4^{\prime} i 4, \& c$., are the vertical planes supposed to cut the solid thus reduced in the divisions 1 , $2,3,4,8 c$., to the hight of the line of transit. as in the analytical sections of the mould.boards.

(616.) The surface now completed can only raise the slice to the perpendicular position; and to complete the operation. we have to carry the twisted wedge back till it shall place the slice at the angle of $45^{\circ}$. To do this we have to extend the original prism, or suppose it to have been at first sulficiently elongated toward $d d^{\prime}$, fig. 125 , and to superimpose upon its flat side the portion $d d^{\prime}$ $u x$, or $a d u$ of fig. 126. The part $d d^{\prime} u x$ is now to be worked off into a part of a new cylindrical surface, whose radius is $y d$ or $y u$, fig. 126 , and upon this surface the line $d u$, fig. 125 , is to be drawn a tangent to the curve $b d$ at $d$. A continuation of the divisions of 3 inches is to be made upon the line $d d^{\prime}$, and the parallels $a^{\prime} q^{\prime}, b^{\prime} r^{\prime}$, and $u d^{\prime}$, continued on the cylindrical surfaces. Whatever portion of the superimposed piece $a d^{\prime} u$ may be fonnd to fall within the small arc $a t$. fig. 126 , is to be cut away, forming a small portion of an interior cylinder concentric to the point $y$. which being done, the remaining portions of the superimposed piece are to be cut away to the dotted lines $d x, a y b z, u u^{\prime}$. of fig. 125, or, what is the same thing, to the lines $d a, a^{\prime} a . b^{\prime} t$. and $u t$, of fig. 126, forming tangents to the curve $a t$, and which will complete the surface of the twisted wedge through its entire length, and to the hight of the line of transit. producing what I conceive to be the true theoretical surface of the mould-board.

(617.) Fig. 126 exhibits distinctly, in the quadrant $o b d$, the inequality of the angles of ascent for the slice, where the radii $a p^{\prime}, a u^{\prime}, a \mathrm{~m}^{\prime}$. \&c., represent the ascents to the corresponding divisions of length in the transit of the slice through the curve $b d u$. which represents the peri phery of the cylindrical surfaces at the line of transit. The parts of the figure lying above that line represent those that must be superimposed above the quadrantal portion of the cylinder, to complete the upper regions of the mould-board; these parts acting merely as a preventive against the overfall of soil into the waste of the plow, are of less importance as to form, than those just described, but are quite necessary in the practice of plowing. The parallelogram $y d$ exhibits the relation in which the furrow-slice stands to this form of mould-board, when the slice has been raised to the perpendicular, and $y \|$ in its ultimate position.

(618.) Although I hold this to be a true theoretical form, it is not in this state fit to be emplored as a practical mould-board; but the steps to render it so are very simple. The broad shovelmouth $a b$, fig. 125 , would meet with obstructions too numerous to admit for a moment of its adoption in practice; but we have only to remove the right-hand portion of the edge $a b$, in the direction $b q$. making the breadth, $q m, 6 \frac{1}{2}$ or 7 inches broad; that portion also contained $7^{\prime} r 3$ is to be cut away, leaving $m r$ about 4 inches broad; $b q r m$ will then represent the share; the mouldboard being thus of the prolonged form in the fore-part. And though this form has no peculiar advantage over the truncated, in respect to working, it is better adapted to admit of the body being constructed of malleable iron, a practice which, though more expensive, is certainly the most preferable, by reason of its greater durability. and being less liable to tracture through the effect of shocks, when stones or other obstructions are encountered.

(619.) Besides the removal of these parts of the theoretical mould-board, other slight modifications are admissible. When the parts have been cut away as described, the edge $b q$ of the share will be found too thick for a cntting edge. If brought to a proper thickness, by removing the parts below, making the edge to coincide with the curved surface; the share so prepared would have the character that belougs to the cresting plows. The lower edge of the mould-board from $r$ to 2 wonld be also rather high, and would present unnecessary resistance to the lower side of the slice; both parts therefore, require to be reduced. The surface of the feather $b q$ is to be $s^{1}$ oped down till it become straight between the points $b$ and $q, q$ not being more than $\frac{1}{4}$ fnch above the plane of the sole, as at the dotted lines $n z$ in fig. 126. The lower edge of the mould-board is also to be rounded off, as showu by the dotted lines along the lower edge from $h$ to $o$ in fig. 128 . To prevent the abrasion of the edge of the slice in passing over the mould-board, it will also be expedient to make 523 j 
the lines from $d$ so $u$, in fig. 126, fall in, from below the line of transit upward as shown by the dotted lines at $d^{\prime}, a^{\prime}, b^{\prime}, \pi$.

(620.) Other modifications may, if required by peculiar taste or otherwise, be given to this form of mould-board. If, after the points bp $n m$, \&ce. have been determined upon the cylindrical surface, fig. 123, or 125. and. in cutting away the parts above $a b$ in the latier figure, instead of reducing the surface to the straight lines $\theta^{\prime} p, 8^{\prime} n, 7^{\prime} m$, \&c. we leave the surface slightly convex ufion all these lines, a surfice will be produced as represented by the dotted sectional lines of fig. 126 , or 128 , and by becoming slightly either recurved above the line of uransit. as in fig. 128, or with continued convexity, as in fig. 118, Plate XI., the surface so pro. duced would deliver the slice without risk of injury to the edge; which. though not of vital importance, is always an object in the estimation of the plowman who perfonns his work with taste. The same modification would also, in the opinion of many agricultural machine-makers, render the mould-hoard more chlieacious in the working of stiff clay soils.

(621.) Fig. 127. Plate XII., represents an elevation of the new mould-board, as now constructed by me, and fis. 128 the analytical sections of the same, taken in the same manuer as described for those preceding, and having the same letters of reference. In the present case, the sectional lines are all straight to the light of the line of transit; above that line and before the zero they are slightly concave, though, as has been shown, this is not imperative; but, bebind the zero, they are cnuvex fiom a little below the line of transit, us shown by the dotted portions of the lines. The parallelogran $k \%$, being a section of the slice when in the vertical position, will be seen to coincide exactly with the zero-line. as it will do through the whole passage of the slice. The litters and zumerals in these two figures have the same reference as in the other figures of the mould board.

(622.j Jurlaing from the trials that have been made of this mould-board, and from the uni form brighlening of its surface after a few hours work, it promises to possess a very uni. form resistance over its whole surface, which is a principal object to be aimed at in the formation of this member of the plow.

(623.) The Monld-board Paltern.-The instructions just given refer solely to the formation of the theoretical surface of the mould-board, including that of the share; but, in the construction of a pattern from which mould-boards are to be cast, the process is somewhat different, thongh based on the principles above laid down.

621.) In proceeding with this, therefore, the quadıant of the cylinder, upon which the whole problem is grounded, may or may not be prepared. If it is to be employed, then the first process is exactly as before described in reference to the quadrant fig. 123, Plate XiII., which must be formed and lined as there described; but the fame process may be pursued from lines alone. without the intervention of the solid, and in the fullowing manner: Having described the quad. rant of a circle, as a $b c$. fic. 123 , of 10 inches radius construct the diagram fig. 124 , as before directed, the entire length $e b$ being 30 inches. divided into equal parts of 3 inches each. The arc $b d$ is then to be drawn through the points $b p n m$, which points. instead of being a transfer, as before described, from the quadrant, may here be drawn at once with a beam-compass touching the thre leading points $b \mathrm{~m} d$. as before, which $w$ ill intersect all the divisions, convertiug them into ordinates $1 f, 2 g, 3 h$. \&c. to the curve $b d$. The lengrhs of these ordinates, from the base-line $e b$, are now to be carefully transferred to the quadrant of the circle $b d$ of fig. 126, aud set off in the circumfirence thereof; thus the point $b$ in fie. 126 corresponds to the wrumation $b$ of the baseline in fig. 124. The first ordinate $g p$ is to be set off on the quadrant from $b$ to $p$, the second ordinate $8 n$ is set off from $b$ to $n$, the third $7 m$ from $b$ to $m$. and so on throu: h the entire quadrant of the circle. The radii $a b, a p$. $a n$. \&c. being now drawn, will furuish the suecessive angles of elevation. with the sole-plane, for each division of the length throughout the quadrant.

(625.) In applying these to the mould-board, i: is to be observed that the first three radii belong to the skare, if it is a prolonged mould-board, or the first five if it is truncated. The quadrant, fig. 126 , with its radii, being thus completely drawn out at full size upon a board, produce the line $b a$ to $y$, and on $y$ as a center. with a radius of 7 inches, describe the are $a t$, and concentric to it the arc $d u$. At an angle of $45^{\circ}$ draw $t u$ a tangent to the arc $a t$, and the point 0 intersection of this tangent with the arc will fix the extreme point $u$ of the mould-board at the hight of the line of transit; which point will be 19 inches from the land sicle plane $b g$, and 12 inches above the plane of the sole, or base-line $y b$. From $d$, lay off divisions of equal parts on the arc $d u$. each equal to $4 \frac{1}{3}$ inches-the diagonal of a square of 3 inches- which completes the lines for the fabrication of the pattern.

(620.) The next step in the operation is that of building $a$ block out of which the pattern is to be shaped. Provide a deal-board of $3 \frac{1}{2}$ feet or thereby in length, with a brearlth of 10 inches; have it dressed of aniform thickness, and at least one edge and end straight and right angled, as seen at $a b c$, in the annexed fig. 129, and $a b$, fig. 126, Plate XII., forming a basement to the block, $a$ being the right angle, and the continuation of the board being hid from view under the superimposed block. Let the edge $a c$ of the board be marked off in equal divisions of 3 inches, agreeing exactly with those of the diagram, fig. 124, marking the divisions with letters

Fig 129.

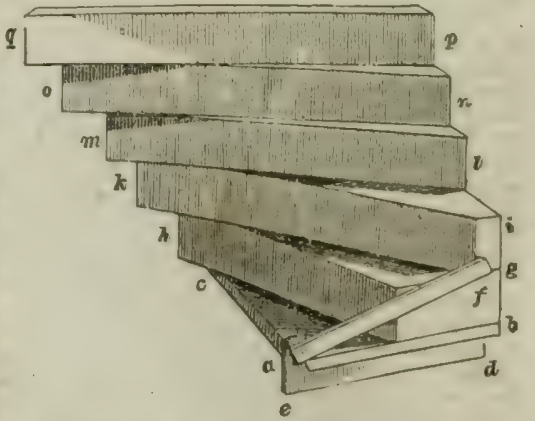

THE BUILDIFG OF THE BLOCK FOR THE MOULDBOARD PATTERN.

or numerals corresponding to the radii of the quadrant, fig, 126, the end $a b$ of the board corre(524) 



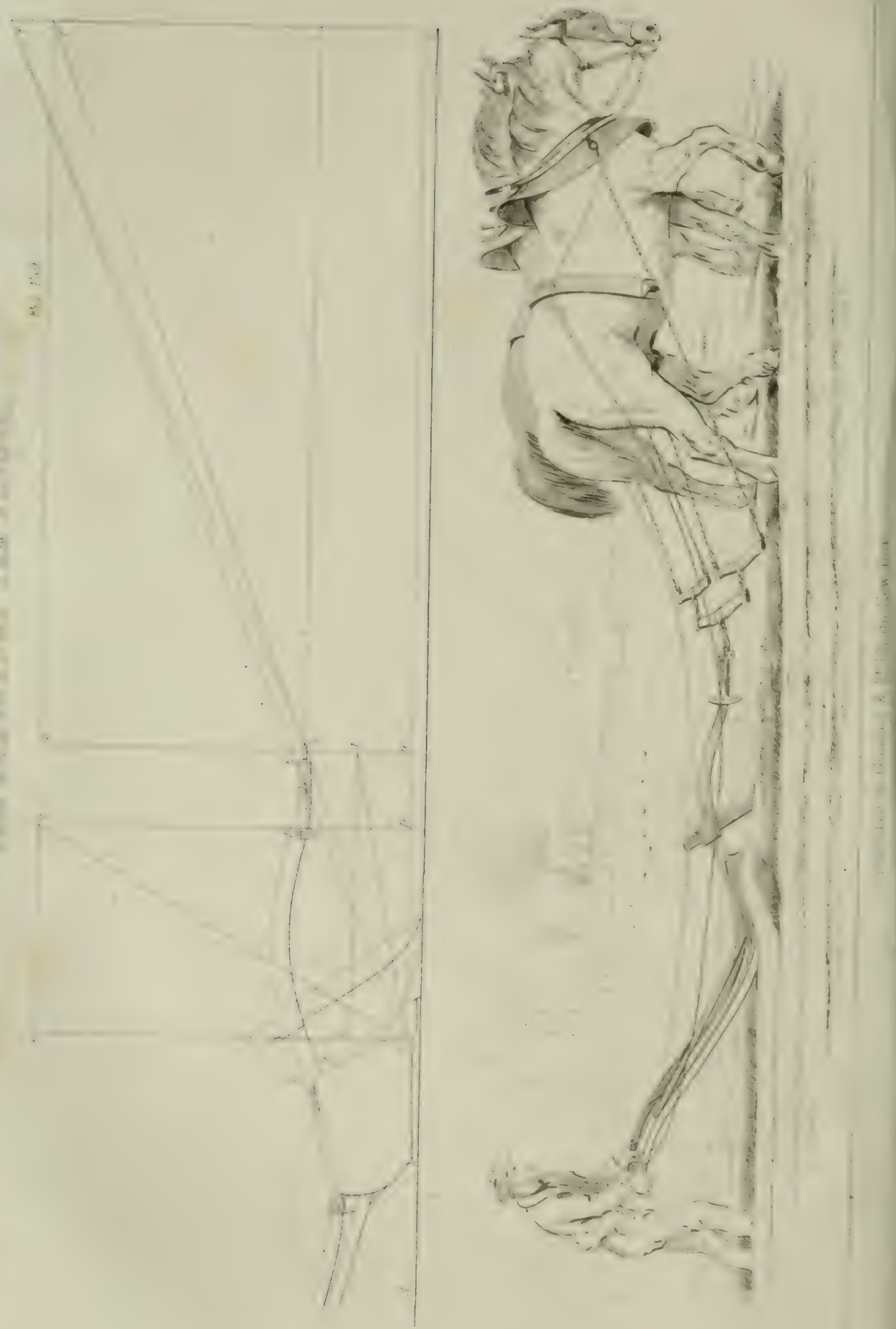


Bponding to the radius $m$ of the quadrant, and to the ordinate $7 m$ of the diagram. Provide also a suit-stock or bevel of the form represented by $d$ e $f$, the stock $d e$ being a straight bar with a head piece at $e$, fixed at riglit angles to the stock, and into this the blade $a f$ is to be jointed, in such a manner that when the blade and stock are set parallel to each other, they shall just receive the thickness of the basement board betwixt them, the length of the blade being equal to the breadth of the slice. Five or more pieces of well-seasoned, clean, 3-inch Memel or yellow-pine deal are now to be prepared, each abont 30 inches in length, and from 6 to 4 inches in breadth. Set the bevel to the angle $b$ a m, fig. 126, and, applying it at the end of the board, as in fig. 129, it will point out the position in which the first block $g h$ must be placed on the board in order that it may fill the lines of the pattern. The farther end of the block, being set in like manner to fall within the lines, it is to be firmly attached to the board with screw-nails. The second block $k:$ is to be joined to the first by the ordinary method of gluing, being set in the same manner as the first to fill the lines of the pattern at both ends, and this requires its being set obliquely to the first. The third block $l m$ is set in like manner, and so on with $n_{0}$ and $p q$. The setting of the different blocks will be much facilitated by having the ends $g$ il $n p$ cut off to the plane of the land-sidethat is, to coincide vertically with the land-side edge of the board, and by keeping in view that the terminal line $c q$ lies at an angle $45^{\circ}$.

(627.) The block being thus prepared, the process of working it off is plain and easily performed in this way. Having set the bevel at the angle $b a \mathrm{~m}$, fig. 126 , which answers to the end $a b$ of the block, the bevel is applied as in the figure, and the surplus wood is cut away to a short distance within the end $a b$ of the board, until the blade of the bevel lies evenly upon the surface, and the kneed head-piece touching the edge of the board. Set the bevel now at the angle $b a h$ and, applying it at the first division on the edge of the board, cut away the surplus wood with a gouge or other tool, in a line parallel to the end of the board, or at right angles to its edge until the $\epsilon$ dge of the blade $a f$ lie evenly on the surface, and the head of the stock touch the edge of the board as before. Repeating this operation at each successive division with the bevel, setting it to the corresponding angle up to the vertical or zero-line, and we have a series of leading lines or draughts, each occupying its true position in the surface of the mould-board to the hight of the line of transit. By continuing these lines, each in the direction already given it, until they terminate in the bieast, or in the upper edge of the pattern, we have a corresponding series of points now determined, in the breast and upper edge; and by removing the surplus wood atill remaining in the spaces between the lines, and reducing the surface to coincide with them, we have the fin. ished surface from the neck of the share up to the zero.

(628.) To complete the after portion of the pattern, we have to form a temporary bevel with a curved blade, adapted to the small arc $a t$, fig. 126 , which blade is prolonged in a tangent $t u$ at the angle of $45^{\circ}$. With the guidance of this bevel, its stock bcing still applied to the board, as in fig. 129. cut away all the wood that occurs to interrupi it behind the zero, until it applies every where behind that line without obstruction. At the third division beyond the zero, the pattern may be cut off in a right vertical, though this is not imperative, as the mould-board may be made considerably longer, and even a little shorter, without at all affecting its operation. At whatever distance in length its terminal edge may be fixed, that portion of the line of transit which lies between the zero and the terminus must leave the original curve $h m, l$, fig. 123, at a tangent, and it will reach the terminus as such, or it will gradually fall into a reëntering carye, according as the terminus is fixed nearer to or farther from the zero-line; the terminus of the line of transit being always 19 inches distant from the land-side plane. That portion of the surface which now remains unfinished between the arcs $a t$ and $d u$, fig. 126, is to be worked off in tangents, applied vertically to the arc $a t$, and terminating in that part of the line of transit that lies between $d$ and $u$. Such portions of the interior cylindrical surface as may have been formed under the application of the temporary bevel to the arc $a t$, are now to be also cut away by a line passing through the junction of the tangents $t a^{\prime}, t b^{\prime}, t u$, with the cylindrical arc $a t$, forming a curved termination in the lower part behind-as seen in fig. $127-$ which completes the surface as proposed.

(629.) The modifications formerly pointed out, paragraphs $(618).(619$,$) and (620$,) may now be made upon the lower and the upper parts of the pattern. The breast-curve and the form of the upper edge will now have assumed their proper curvature; and there only remains to have the whole pattern reduced to its due thicknesses. This, in the fore part, is usually about $\frac{1}{2}$ inch, increasing backward below to about 1 inch, and the whole becoming gradually thinner toward the top edge, where it may be 3-16 inch. The perpendicular hight behind is usually about 12 inches, and at the fore part 14 inches.

(630.) OF ThE Draught of Plows.-From the complicated structure of the plow, and the oblique direction in which circumstances oblige us to apply the draught to the implement. some misconceptions have arisen as to the true nature and direction in which the draught may be applied. The great improver of the plow has fallen into this error, and has, in some measure, been followed by others.* He asserts "that were a rope attached to the point of the share, and the plow drawn forward on a level with the bottom of the furrow, it would infallibly sink at the point." Were this really the case, it would prove that the center of resistance of the plow in the furrow must be somewbere below the level of the sole, which is impossible. As the center of gravity of any body, suspended from a point at, or anywhere near, the surface of that body, wil? always be found in a continuation of the suspending line, supposing it to be a flexible cord, so, in like manner, the c?nter of resistance of the plow will be always found in the direction of the line of draught. Now if, with a horizontal line of draught from the point of the share, it were found that the point of the share had a tendency to sink deeper into the soil, it would be a clear proof that the plow was accommodating itself to the general law, and that the center of resistance is below the line of the sole. The fallacy of this conclusion is so palpable that it would be an act of supererogation to refute it by demonstration, more especially as it never can be of any utility in a practical point of view. I have thought it necessary, however, to advert to it, as it appears to have

* Small's Treatise on Plows. (525) 
aided in throwing a nystery over the mode of applying the line or angle of dranght, which in itself is a sufficieully simple problem.

(631.) The reasoning hitherto adopted on this branch of the theory of the plow seems to be grounded on the two following data : the hight, on au averuge, of a horse's shoulder, or that point in his collar where the yoke is applied: and the length of the draught-chains that will give him ample freedom to walk. It falls out fortunately, too. that the angle of elevation thus produced crosses the plane of the collar as it lies on the shoulders of the horso when in draught, nearly at right angles. It is my purpose, however, in this section to show that /keeping out of view some practical difticulties) the plow may be drawn at any angle, from the horizontal up to a little short of 90 , and that it would require less and less force to draw it as the direction of the line of dranght approached the horizontal line. It would, in all cases, be required that the point of the beam. or rather the draught bolt. should be exactly in the straight liue from the center of resistance to tho point where the motive force would be applied. If this force could be applied in the horizontal direction, we should have the plow drawn by the minimum of force. This position, however. is impracticable, as the line of draught would, in such a case, pass through the solid land of the furrow about to be raised; but it is within the limits of practicability to draw the plow at an angle of 120 , and, as will be demonstrated, the motive force reyuired at this angle would be 1 stone or 14 lbs. less than is required by drawing at the angle of $20^{\circ}$, which may be beld as the average in the ordinary practice of plowing. A plow drawn at this low angle, namely 120 . would have its beam (if of the ordinary length) so low that the draught-bolt would be only 10 inches above the base-line ; and this is not an impracticable hight. though the traces might be required inconveniently long. On the same principle, the angle of draught might be elevated to $60^{\circ}$ or $70^{\circ}$, provided a motive power could be applied at such high angles. In this, as before, the beam and dranghtbolt would have to fall into the line of draught as emanating from the center of resistance. The whole plow, also, under this supposition, would require an almost indefinite increase of weight; and the motive force required to draw the plow at an angle of $60^{\circ}$ would be nearly twice that required in the horizontal direction, or 1 16-18 times that of the present practice, exclusive of what might arise from increased weight. We may therefore conclade that to draw the plow at any angle higher than the present practice is impracticable. and, though rendered practicable, would still be highly inexpedient, by reason of the disadvantage of increased force being thus rendered necessary; unless we can suppose that the applieation of steam or other inanimate power might require it.- Neither would it be very expedient to adopt a lower angle, since it involves a greater lengtb of trace-chains, which, at best, would be rather cumbrous; and it would produce a saving of furce of only one stoue on the draught of a pair of horses. Yet it is worthy of being borne in mind that, in all cases, there is some saving of labor to the horses. whenever they are, by any means, allowed to draw by a chain of increased length, provided the draught-bolt of the plow is broight into the line of draught, and the diaugbtchains are not of such undue weight as to produce a sensible curvature; in other words, to insure the change of angle at the horse's shoulder, due to the increased length of the draughtchain.

(632.) In illustration of these changes in the direction of the draught, fig. 130, Plate XIII. will render the subject more intelligible. Let $a$ represent the body of a plow, $b$ the point of the beam. and $c$ the center of resistauce of the plow, which may be assumed at a hight of 2 inches above the plane of the sole $d e$, though it is liable to change within short limits. The average length of the draught chains being 10 feet, including draught-bars, lrooks, and all that intervenes between the draught-bolt of the plow and the horse's shoulders; let that distance be set off in the direction $b f$, and the average hight of the horse's shoulders where the chains are attached, being 4 feet 2 inches, let the point $f$ be fixed at the hight above the base-line $d e$. Draw the line $f c$. which is the direction of the line of draught acting apon the center of resistance $c$; and if the plow is in proper temper it will coincide also with the draught-bolt of the beam; $e c f$ being the angle of draught, and equal to $20^{\mathrm{P}}$. It will be easily perceived, that. with the same horses and the same length of yoke, the angle $e c f$ is invariable; and if the plow has a tendency to dip at the point of the share under this arrangement, it indicates that the drauglat.bolt $b$ is too high in the bridle. Shifting the bolt one or more holes downward will bring the plow to stoim evenly upon its sole. On the other hand, if the plow has a tendency to rise at the point of the share, the indication from this is, that the draught-bolt $b$ is too lox, and the rectification must be made by raising it one or more holes in the bridle. Suppose, again, that a pair of taller horses were yoked in the plow, the draught-chains, depth of furrow, and soil-and. by consequence, the point of resistance c-remaining the same, we should then have the point $f$ raised suppose to $f^{\prime}$; by drawing the line $f^{\prime} c$, we have e c $f^{\prime}$ as the augle of draft, which will now be $22^{\circ}$; and in this new arrangement, the draught-hall, is found to be beloro the line of draught $f^{\prime} c$; and if the dranght-chains were applied at $b$, in the direction $f^{\prime} b$, the plow would have a tendency to rise at the point of the share, by the action of that law of forces which obliges the liue of draught to coincide with the line which passes through the center of resistance; hence the draught-bolt. $b$ wonld be found to rise to $b^{\prime}$. which would raise the poiut of the share out of its proper direction. To rectify this, then, the draughtbolt must be raised in the bridle by a space equal to $b b^{\prime}$, causing it to coincide with the true line of draught, which would again bring the plow to swim evenly on its sole.

(633.) Regarding the relative forces required to overcome the resistance of the plow, when drawn at different angles of draught, we have first to consider the nature of the form of those parts through which the motive force is brought to bear upon the plow. It has been shown that the tendency of the motive force acts in a direct line from the shoulder of the animal of draught to the center of resistance; and referring again to fig. 130. Plate XIII., were it uot for considerations of convenience, a straight bar or beam lying in the direction $c b$, and attached firmly to the plow' body anywhere between $c$ and. $g$, would answer all the purposes of draught, perbaps, better than the present beam. But the draught not being the end in view, but merely the means by which that end is accomplished, the former is made to subserve the latter: and as the beam. if placed in the direction $c b$, would obstruct the proper working of the plow, we ane constrained to resort to 
anotber indirect action to arrive at the desired effect. This indirect action is accomplished through the medium of a system of rigid angular frame work, consisting of the beam and the body of the plow, or those parts of them comprehended between the points $b, h, c$, the beam being so connected to the body $a h$, as to form a rigid mass. The effect of the motive force applied to this rigid system of parts at the point $b$, and in the direction $b f$, produces the same result as if $c b$ were firmly connected by a bar in the position of the line $c b$, or as if that bar alone were employed, as in the case before supposed, and to the exclusion of the beam $b h$.

(634.) Having thus endeavored to illustrate the causes of the oblique action of the plow, showing that the obliquity is a concomitant following the considerations of convenience and fitness in working the implement, I proceed to show the relative measure of the effects of the oblique action. It is well known that the force of draught required to impel the plow, when exerted in the direction $b f$, may be taken at an average of 24 stones, or $336 \mathrm{lbs}$. Analyzing this force by means of the parallelogram of forces, if we make the line $b f$ to represent $336 \mathrm{lbs}$., the motive force; and complete the parallelogram $b$ if $k$, we have the force $b f$ held in equilibrium by the two forces $i b$ and $k b$; the first acting in the horizontal direction to draw the plow forward, the second acting verically, to prevent the point of the beam from sinking, which it would do were a horizontal force only applied to the point of the beam. The relation of these forces $i b$ and $k b$ to the oblique force will be as the length of the lines $i b$ and $k b$ to the line $b f$, or the line $i b$ will repregent $322 \mathrm{lbs}$, while the oblique force is $336 \mathrm{lbs}$, and the force $k b 95 \mathrm{lbs}$. This last force is represented as lifting the beam vertically by suspension, but the same result would follow if the beam were supported by a wheel under the point $b$; the wheel would then bear up the beara with the same loree as that by which it was supposed to be suspended, $95 \mathrm{lbs}$. But to carry out the sup. position, let the draught now found be applied horizontally from the point $c$. As the plow would then have no tendency either to dip or rise, the force $k b$ vanishes, leaving only the direct hori. zontal force $i b$; hence, were it possible to apply the draaght in a horizontal direction from the point of resistance, the resistance of the plow would be $322 \mathrm{lbs}$. instead of $336 \mathrm{lbs}$.

(635.) But to return to the previous position of the draught, wherein, still supposing it to be in the horizontal direction, and thereby requiring that the point of the beam have a support to prevent its sinking too low. This support may be supposed either a foot, as seen in many both ancient and modern plows, or in the shape of a wheel or wheels, so much employed in many of the English plows. We see at once, under this consideration, the office that a wheel performs in the action of a plow. It has been shown, that whether the plow be drawn in the ordinary direction of draught $b \mathrm{f}$, in which one oblique propelling force only is exerted, or with two antagonist forces, $b i$, in the horizontal direction, and the upholding force, $b k$, in the vertical, we find that, in the latter, the difference in favor of the motive force is only 1-24 of the usual resistance; but the apholding force is equal to $2-7$, while none of these variations has produced any change in the absolute resistance of the plow. The impelling force is theoretically less in the latter case; but since the wheel has to carry a load of $95 \mathrm{lbs}$, we have to consider the effect of this load upon a smail wheel, arising from friction and the resistance it will encounter by sinking less or more into the subsoil. I have ascertained, from experiment, that the difference of force required to draw a wheel of 12 inches diameter, loaded as above described, and again when unloaded, over a tolerably firm soil. is equal to $22 \mathrm{lbs}$, a quantity exceeding $1 \frac{1}{2}$ times the amount of saving that would accrue by adopting this supposed horizontal draught with a wheel. Having thus found the smount of draught at two extremities of a scale, the one, being the oblique draught, in common ase at an angle of $20^{\circ}$, the other deduced from this, through the medium of the established principles of oblique forces, and the latter producing a saving of only 1-24 of the motive force, while it is encumbered with an additional resistance arising from the support or wheel; it necessarily follows that, at all intermediate angles of draught, or at any angle whatever, where the prineiple of the parallelogram of forces finds place-and it will find place in all cases where wheels yielding any support are applied to the plow under the beam-there must necessa. rily be an increase in the amonnt of resistance to the motive force.

(636.) This being a question of some importance, the diagram, fig. 131, will render it more

Fig. 131.

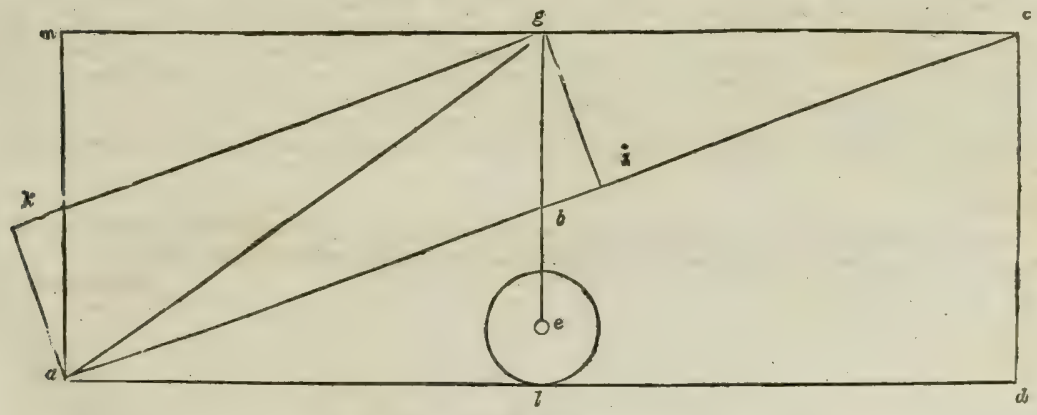

THE DRAUGHT OF WHEEL-PLOWS.

evident. Let $a$ be the point of resistance of a plow's body, $b$ the point of the beam, $c$ the position of the horse's shoulder, and $a d$ the horizontal line; then will $c a d$ be the angle of draught equal to $20^{\circ}$. Let the circle $e$ represent a wheel placed under the beam, which is supported by 
a stem or wheers, here represented by the line $e$ b. In this position the puint of the benm. which is also the point of draught, lies in the line of dranght: the wheel, therefore, bears no loal, but is simply in place, and has no effect on the draught; the motive force, thorefore. montiuues to be $336 \mathrm{lbs}$. Suppose now the point of the beam to be raised to $g$. so that the line of draught $g \mathrm{c}$ may be horizontal; and since the line of draught lies nuw out of the original line $a$ l $c$. and has as. fumed that of $a g c-g$ being now supported on the produced stem $c g$ of the wheel-d raw $g$ perpendicular to $a c$, and complete the parallelogram $a i g k$; the side $a i$ will still represent the original motive force of $336 \mathrm{lbs}$, but, by the change of direction of the lim of Iraught. the ro. quired force will now be represented by the diagonal $a g$ of the parallelugram. equal to abous $351 \mathrm{lbs}$; and $g c$ is a continuation of this force in a horizontal direction. 'Thie draught is therefore increased by $15 \mathrm{lbs}$. Complete also the parallelogram $a / g \mathrm{~m}$. and ns the dingonal $a g-1$ he line of draught last found-is equal to $851 \mathrm{lbs}$, the side $l g$ of the parallohormm will represent the

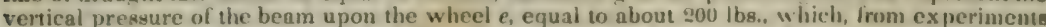
(635), may be valued at $40 \mathrm{lbs}$. of additional resistance, making the whole resistance tu the nontive force $391 \mathrm{lbs}$, and being a total increase arising from the introduclion of a whirl in this position of 5 s lba. Having here derived a maximum-no doubt an extreme case-nnd the usual angle of $20^{\circ}$ as the minimum, we can predicate that. at any angle intermerliate $10 / \mathrm{r} b$ and $/ \mathrm{a} g$. the resistance can never be reduced to the minimum of $3336 \mathrm{lbs}$. Hence it fullowe, as a corullary. that voleds placed unter the beam can never lessen the resistance of the plow: but. on the cun. trary, muat, in all cases, increase the resistance to the motive firre more or less, aceording to the degree of pressure that is brought upon the wheel, and this will lu: proportional to the sine of the angle in the resultant $a g$ of the line of draught.

(637.) The application of a vheel. in the herl of a plow, dix's not come under the same morle of reasoning as that under the beam, the former becoming a part of the busly; from which all tho natural resistance flows; but in viewing it as a part of that body only. we can arrive at certain conclusions which are quite compatible with careful experiments.

(638.) The breadth of the whole rubbing surface in the body of a plow: when iurning a fur. row, is on an average about $17 \frac{1}{2}$ inches, and supposing that surface to the preased nearly equal in all parts, we shall have the sole-shoe, which is about $2 \frac{1}{2}$ inches broad, nceupying 1.7 part of the surface; and taking the entire average resistance of the plow's borly. as belire. at :3:36 lbs., we have 1-7 of this, equal to 48 lbs.. as the greatest amount of resistance produced by the sole of the plow. But this is under the supposition that the resistance arises fiom a uniform degree of friction spread over the whole rubbing surface of the buly: while we have seen. on the contrary, that the coulter, when acting alone, presents a resistance equal in the entire plow. It is only reasonable, therefore, in absence of farther experiments, to conclute that the fore parts of the body-the conlter and share-yield a large proportion of life resistanet when turuing the furrox-slice; but, since we cannot appreciate this with any degree of exactness. let the sole have its fuil share of the resistance before stated, namely, $48 \mathrm{lbs}$. If a wheel is applied at or near tho heel of the plow, it can only bear up the hind part of the sole. and prevent its ordinary friction. which, at the very utmost, cannot be more than $\frac{1}{2}$ of the entire friction due to the entire sole. A wheel, therefore. placed here, and acting under every favoring circumstance, cven to the supposed extinction of its own friction, could not reduce the resisiance by more than $2 /$ Ibs.. being the half of that due to the entire sole, or it is 1.14 of the entire resistance. But we nanuot imagine a wheel so placed. to continue any length of time. without becuming elogged in all directions. thereby greatly increasing its own friction; and when it is considered that the necessarily small portion, of any wheel that can be so applied. will sink into the subsoil. to nn extemt that will still bring the sole of the plow into contact with the sole of the furow. It will thus be found that the amount of reduction of the general resistance will be very much abridged. certainly not fess than one-half, which reduces the whole saving of iraugh to a yuntity not exceeding $1: 2^{\circ}$ llos. nnd even this will be always doubtful, from the ditheuly of keeping such wheels in good working condi. tion. Thig view of a wheel placed at the heel has been contirmed by actual experiments, carefully conducted, wherein Paimer's patent plow with a wheel in the heel (as patented many yenrs ogo), but in this case it was applict on the best principles, gave indreations of increnscil resist. ance from the use of the whel. as compared with the same plow whe the whel was rmoved: the difference having been $1 \frac{1}{2}$ stone in favor of no wheet. I hesitate not. therefore. to say that in no case can wheels be of service toward reducing the resistance of the plow. whether they be placed befure or behind." or in both positions. and the chances are numerous that they shall act in. juriously. That the use of wheels may, under cernain circumstances, bring the implement within the management of less skilful hands ihan is required for the swing plow, must be admitted; but. at the same time. there nay be a question whether, even with that advantage, the practice is com. mendab'e. I should be wanting in candor if, lor myself, I answered otherwise than in the nega. ive.-I. S.]

* The wheel under the beam, for general use, is thought by many not commendable; but tho shell wheel in the land-side is an improvement, as it diminishes or reduces the resistance materially.

Wit.krranv. 
OF MOULD BOARUS.

Fig. 111

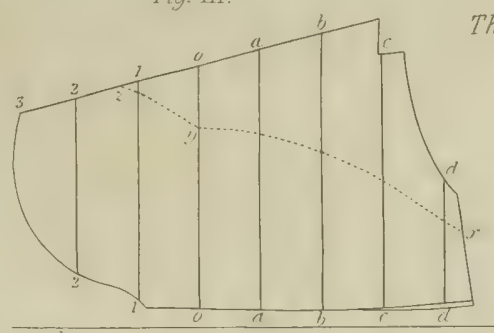

Fick 112.

The East Iothian.

Fig. 113.

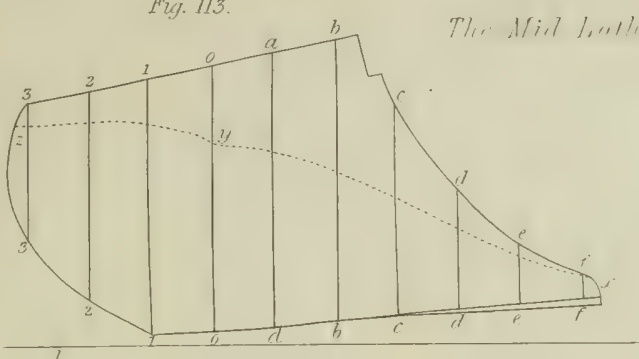

Fig. 114.
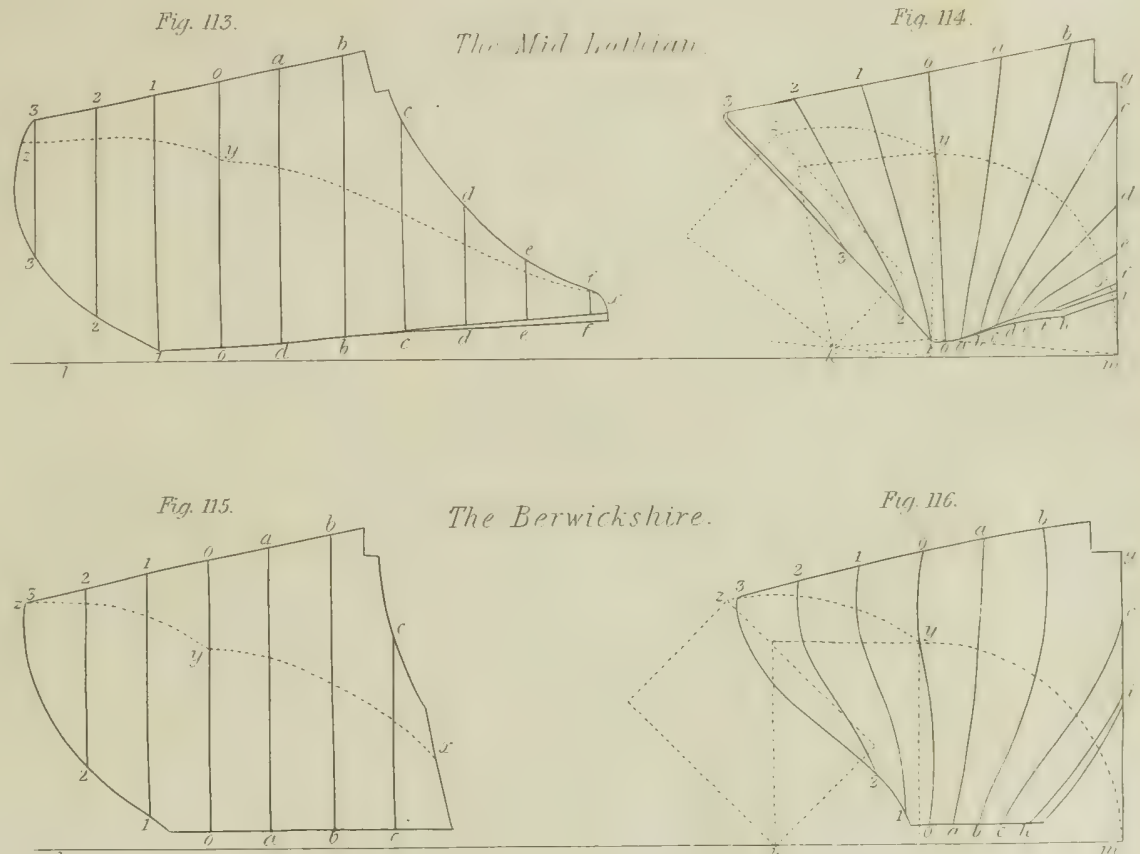

The Berwichshire.

Fin. 116.

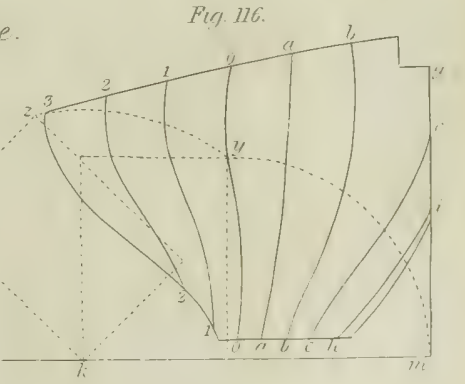

Fig. $11 \%$.

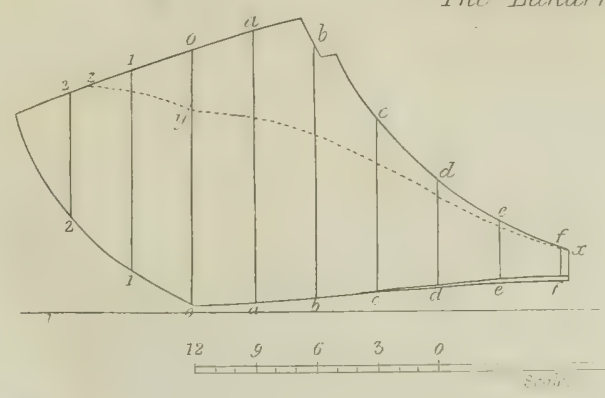

Fin. 178

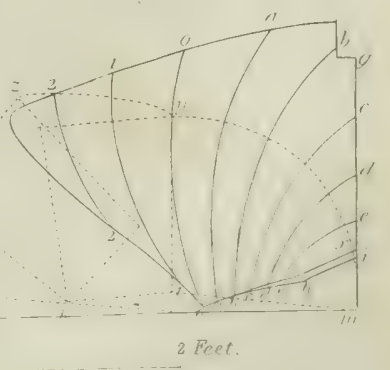





\title{
24. THE VARIOUS MODES OF PLOWING RIDGES.
}

\author{
Drawn by one pair, obedient to the roice, \\ And double rein, held by the plowman's hand, \\ Moves right along, or winds as he directs."
}

Grahax.

(639.) Your knowledge of soils will become more accurate after you have seen them plowed; for as long as a crop, or the remains of one, covers soils, their external characters cannot be fully exposed to view.

(640.) On observing a plow at work, you might imagine that the laying over of a furrow-slice is a very simple process; but it is really not so simple as it appears. You have already seen, in the construction of the plow, that the furrow-slice is laid over by a machine of very complicated structure, though simple in its mechanical action on the soil ; and you may learn, by a single trial, that the plow is not in reality so very easily guided as it appears to be in the hands of an expert plowman. You might also imagine that, as the plow can do nothing else but lay over a furrow-slice, the forms of plowing do not admit of much variety; but a short course of observation will convince you that there are many modes of plowing land.

(641.) The several modes of plowing land have received characteristic appellations, and these are-gathering-up; crown-and-furrow plowing; casting or yoking or coupling ridges ; casting ridges with gore furrows; cleaving down ridges; cleaving down ridges with or without gore furrows; plowing two-out-and-two-in; plowing in breaks; cross-furrowing; angle plowing, ribbing, and drilling; and the preparative operation to all plowing is termed feering or striking the ridges.

(642.) These various modes of plowing are contrived to suit the nature of the soil and the season of the year. Heavy land requires more cautious plowing than light, because of its being more easily injured by rain ; and greater caution is required to plow all sorts of land in winter than in summer. The precautions here spoken of allude to the facilities given to surface water to flow away. The different seasons, no doubt, demand their respective kinds of plowing; but some of the modes are common to all seasons and soils. Attention to all the methods will alone enable you to understand which kind is most suitable to particular circumstances of soil, and particular states of season. To give you an idea of all the modes, from the simplest to the most complicated, let the ground be supposed to be even in reference to the state of its surface.

(643.) The supposed flat ground, after being subjected to the plow, is left in the form of ridges or of drills, each ridge occupying land of equal area, determined by similar lengths and breadths. The ridges are usually made $\mathrm{N}$. and S., that the crop may enjoy the light and heat of the solar rays in an equal degree throughout the day; but they should, nevertheless, traverse the slope of the ground, whatever its aspect may be; and this is done that the surface water may flow easily away.

(644.) Ridges are made of the different breadths of $10,12,15,16$, and 18 feet, in different parts of the country. These various breadths are occasioned partly by the nature of the soil, and partly by local custom. With regard to the soil, heavy land is formed into narrow ridges, to allow the 
rain to flow quickly into the open furrows. Hence, in many parts of England, the ridges are only 10 and 12 feet in width, and in some localities they are in ridglets of 5 or 6 feet. In Scotland, even on the strongest land, the ridges are seldom less than 15 feet; in some localities they are from 16 to 36 feet, and in light soils a not unusual width is 18 feet. In Berwickshire and Roxburghshire, the ridges have for a long period been 15 feet on all classes of soils, being considered the most convenient width for the ordinary manual and implemental operations. In other parts of the country, 16 and 18 feet are more common. Nore than half a century ago, ridges were made very broad-that is, from 24 to 36 feet-high on the top or crown, and crooked like the letter S, from the mistaken notion that the crook always presented some part of the ridge in a right position to the sun-a form which, although it did, would remove other parts as far away from the sun's influence. In the Carse of Gowrie, such broad, crooked ridges still exist; but the usual practice throughout the country is to have ridges of moderate breadth, straight, and lnoking to noon-day. In many parts of Ireland the land is not put into ridges at all, being done up with the spade into narrow stripes called lazy-beds, separated by deep, narrow trenches. Where the plow is used, however, ridges are always formed, though narrow, but usually of 12 feet. For the sake of uniformity of description, let it be understood, when I speak of a riage, that an area of 15 feet of width is meant.

(645.) The first process in ridging up land from the flat surface is called feering or striking the ridges. This is done by planting 3 or more of such poles, graduated into feet and half-feet, as were recommended for setting off the lines of fence (446), and which are used both for directing the plow employed to feer in straight lines, and for measuring off the breadth of the ridges into which the land is to be made up, from one side of the field to the other.

(646.) Land is feered for ridging in this way: Let $a b$, fig. 132, represent the $\mathrm{S}$. and $\mathrm{E}$. fences of a ficld, of which let $x$ be the head-ridge or head-land, of the same width as that of the ridges, namely 15 feet. To mark off its width distinctly, let the plow pass in the direction of $r e$, with the furrow-slice lying toward $x$. Do the same along the other head-land, at the opposite end of the field. Then take a pole and measure off the width of a quarter of a ridge, viz. 3 feet 9 inches, from the ditch lip $a$ to $c$, and plant a pole at $c$. With another pole set off the same distance from the ditch $a$ to $d$, and plant it there. Then measure the same distance from the ditch at $e$ to $f$, and at $f$ look if $d$ has been placed in the line of $f c$; If not, shift the poles a little until they are all in a line. Make a mark on the ground with the foot, or set up the plow-staff, at $f$. Then plant a pole at $g$ in the line of $f d c$. Before starting to feer, the plowman measures off $1 \frac{1}{4}$ ridges-namely, 18 feet 9 inches-from $f$ to $k$, and plants a pole at $k$. He then starts with the plow from $f$ to $d$, where he stops with the pole standiug between the horses' heads, or else pushed over by the tying of the horses. He then, with it, measures off, at right angles to $f c$, a line equal to the breadth of $1 \frac{1}{4}$ ridges, 18 feet 9 inches, toward $t$ until he comes to the line of $k l$, where he plants the pole. In like manner he proceeds from $d$ to $g$, where he again stops, and measures off $1 \frac{1}{4}$ ridges, 18 feet 9 inches breadth, from $g$ toward $v$ at a point in the line of $k 7$, and plants the pole there. He then proceeds toward the other head-ridge to the last pole $c$ from $g$, and measures off $1 \frac{1}{4}$ ridges, 18 feet 9 inches, from $c$ to 7 , and plants the pole at $l$. From $l$ lie looks toward $k$ to see if the intermediate poles are in the line $l \%$; if not, he shifts them to their proper points as he returns to the head-ridge $x$ along the furrow he had made in the line $f c$. (578) 
On coming down $c f$ he obviates any deviation from the straight line that the plow may have made. In the line of $f c$ the furrow-slices of the feering have been omitted, to show you the setting of the poles. It is of much importance to the correct feering of the whole field to have those first two

Fig. 132.

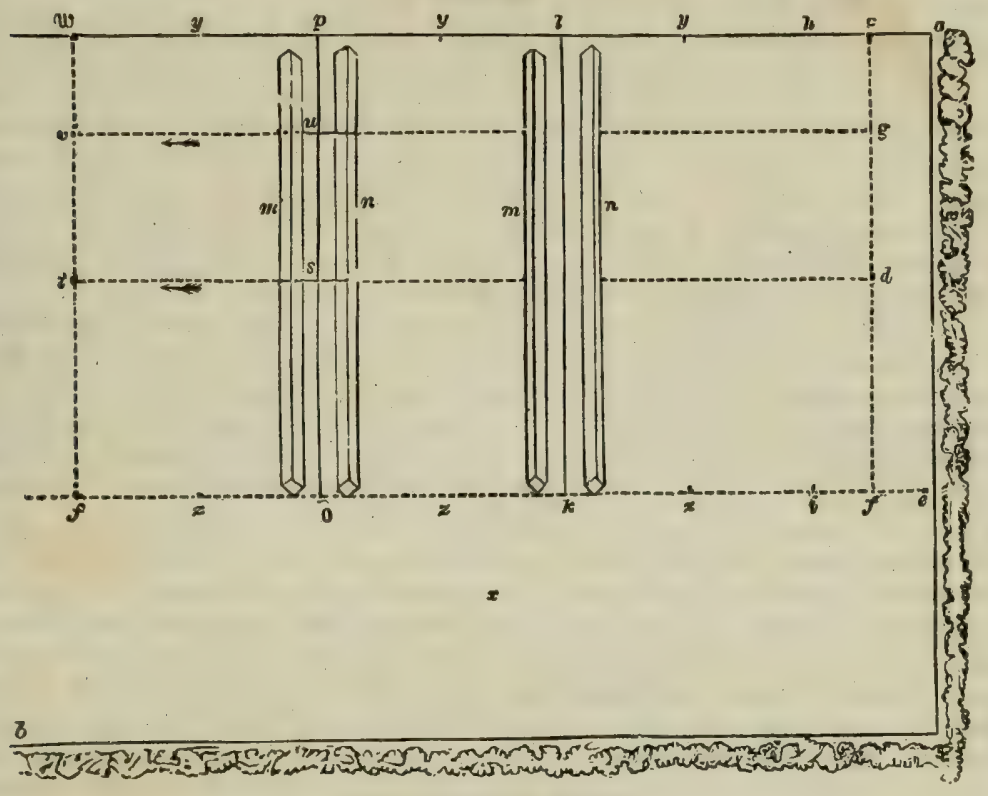

MODE OF FEERING RIDGES.

feerings, $f c$ and $k l$, drawn correctly; and, to attain this end, it is proper to employ two persons in the doing of it-namely, the plowman and the farm-steward, or farmer himself. It is obvious that an error committed at the first feerings will be transmitted throughout the whole field. A very steady plowman and a very steady pair of horses, both accustomed to feer, should only be intrusted with the feering of land. Horses accustomed to feer will walk up of their own accord to the pole standing before them. In like manner the plowman proceeds to feer the line $k l$, and so also the line $o p$; but in all the feerings after the first, from $f$ to $k$, the poles, of course, are set off to the exact breadth of the ridge determined on-in this case 15 feet, such as from $s$ to $t, u$ to $v, p$ to $w$, in the direction of the arrows. And the reason for setting off $c l$ at so much a greater distance than $l_{p}$ or $p w$ is, that the $\frac{1}{2}$ ridge $a h$ may be plowed up first and without delay, and that the rest of the ridges may be plowed by half-ridges. The half-ridge $a h$ is, however, plowed in a different manner from the rest; it is plowed by going round the feering $f c$ until the open furrow comes to $a e$ on the one side and to $h i$ on the other. Then $h i$ constitutes the feering, along with $k l$, for plowing the 2 half-ridges $z i$ and $z k$, which, when done, the open furrow is left in the line $z y$, corresponding to the open furrow left in the line $e a$, and between which is embraced and finished the full ridge of 15 feet $e z$. The half-ridges $z k$ and $z o$ are plowed at the same time by another pair of horses, and the open furrow $z y$ is left between them, and the full ridge $z k z$ is then completed. In like manner the half-ridges $z o$ and $z r$ are afterward plowed by the same horses, and 
the open furrow $z y$ is left between them, and the full ridge $\approx 0 \approx$ is then completed. And so on with every other feering in the ficld. Had the feering been set off the breadth of a half-ridge-that is, $7 \frac{1}{2}$ feet-in the line of $i h$, from $a$ to $h$ and from $e$ to $i$, this half-ridge could only have been plowed by all the furrow-slices being turned over toward $h i$, and the plow returning back empty, thus losing half its time.

(647.) As a means of securing perfect accuracy in measuring off the breadths of ridges at right angles to the feerings, lines at right angles to $f c$ should be set off across the field, from the cross-table and poles set at $d$ and $g$, in the direction of $d t$ and $g v$, and a furrow made by the plow in each of these lines, before the breadths of the feerings are measured along them. Most people do not take the trouble of doing this, and a very careful plowman renders it a precaution of not absolute necessity, but every proficient farmer will always do it, even at the sacrifice of a little time and some trouble, as a means of securing accuracy of work.

(648.) As the plow completes each feering, the furrow-slices appear laid over as at $m$ and $n$. While one plowman proceeds in this manner to feer each ridge across the field, the other plowmen commence the plowing of the land into ridges; and, to afford a number of plowmen space for beginning their work at the same time, the feering-plowman should be set to his work at least half a day in advance of the rest, or more if the number of plows is great or the ridges to be feered long. In commencing to plow the ridges, each plowman takes two feerings, and begins by laying the furrow-slices of the feerings together, such as $m$ and $n$, to form the crowns of the future ridges. In this way one plowman lays together the furrowslices of $f c$ and $k l$, while another is doing the same with those of $o p$ and $r w$. I have already described how the $\frac{1}{2}$ ridge $a h$ is plowed, and stated that the rest of the ridges are plowed in $\frac{1}{2}$ ridges. The advantage of plowing by $\frac{1}{2}$ ridges is, that the open furrows are thereby left exactly equi-distant from the crowns; whereas, were the ridges plowed by going round and round the crown of each ridge, one ridge might be made by one plowman a little broader or narrower than the one on each side of it - that is, broader or narrower than the determinate breadth of 15 feet.

(649.) A ridge, $a$, fig. 133 , consists of a crown $b$, two flanks $c$, two furrow-brows $d$, and two open furrows $a a$. An open furrow is finished at the bottom by two mould or hint-end furrows. (Fig. 134.)

(650.) After laying the feering furrow-slices to make the crowns of the ridges, such as at $f c, k l, \circ p$, and $r w$, fig. 132, the plan to plow up ridges from the flat ground is to turn the horses toward you on the head-ridges, until all the furrow-slices hetween each feering are laid over until you reach the lines $y z$, which then become the open furrows. This method

Fig. 133

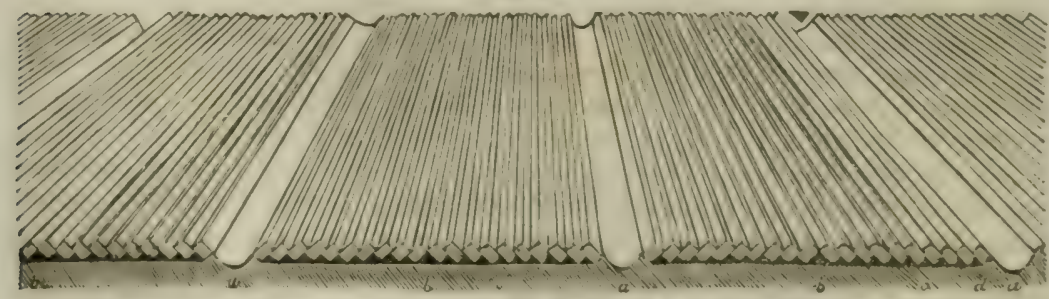

GATHERING UP FROM THE FLAT.

of plowing is called gathering up, or gathering up from the flat, the disposition of whose furrows is shown in fig. 133, where a a a embrace two (580) 
whole ridges, on the right sides of which all the furrows lie one way, from $a$ to $b$, reading from the right to the left; and on the left sides of which all the furrow-slices lie in the opposite direction, from $a$ to $b$, reading fro the left to the right; and both sets of furrow-slices meet in the crow $b \quad b \quad$. The open furrows $a a b$ are finished off with the mould or hint-en furrows, the method of making which is described in the next figure.

(651.) The mould or hint-end furrow is made in this way: When th. last 2 furrow-slices of the ridges $a a$, fig. 134, are laid over, the bottom of the open furrow is as wide as represented by the dotted line $c$, extending

Fig. 134.

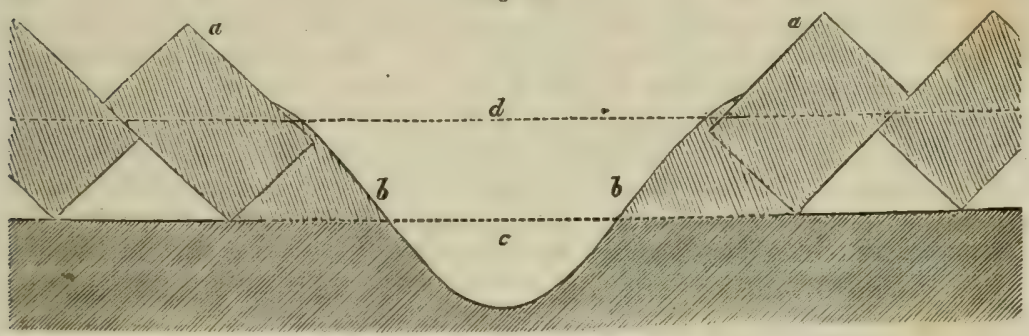

AN OPEN FURROW WITH MOULD OR HINT-END FURROW-SLICES.

from $a$ to $a$. The plow goes along this wide space, and first lays over a triangular furrow-slice $b$ on one side, and another of the same, $b$, on the other side, up against and covering the lower ends of the last furrow-slices $a a$, and by which operation the ground is hollowed out in the shape represented at $c$ by the sole of the plow, The dotted line $d$ shows the level of the ground in its former state, before it was begun to be ridged up, and the furrow-slices $a$ a show the elevation attained by the land above its fermer level by plowing.

(652.) A ridge that has been plowed the reverse to gathering up from the flat is said to be split, which is the short phrase for crown-and-furrow plowing.

(653.) This kind of plowing of crown-and-furrow can easily be performed on land that has been gathered up from the flat. In this case, no feering is required to be purposely made, the open furrows answering that purpose. Thus, in fig. 133, let the furrow-brows $d$ be laid over to meet together in the open furrow $a$, and it will be found that they will just meet, since they were formerly separated in the same spot; and so let each successive furrow-slice be reversed from the position it was laid when gathered up from the flat, and as represented in the figure, then $a$ will become the crowns of the ridges, and $b$ the open-furrows. In this mode, as well as in gathering up, the ridges are plowed by two half-ridges, and in both cases the plowed surface of the ridges is preserved in a flat state; there should be no perceptible curvature of the ground, the open furrow only forming a hollow below the level of the plowed surface. When no surface-water is likely to remain on the land, which is the case with light soils, both these are simple modes of plowing land; and they form an excellent foundation upon which to make drills upon stronger soils for turnips.They are both much practiced in plowing land for barley after turnips.

(654.) But when two plowings are intended to be given to land for barley after turnips, and when it is found inconvenient to cross-furrow the land-which will be the case when sheep on turnips occupy a field of great length in proportion to its breadth, or when the soil or season is too wet to run the risk of letting the land lie any time in a cross-furrow-then the (581) 
land should be feered so as to allow it to be gathered up from the flat, that the crown-and-furrow plowing may afterward complete the ridges. On looking again at fig. 133 , where the ridges are represented complete, it is obvious that, were they plowed from that state into crown-and-furrow, by making the open furrows $a$ a $a$ the future crowns, a half-ridge would be left at each side of the field-a mode of finishing off a field which no considerate farmer adopts, as it displays great carelessness and want of forethought in forming his plans. The land should, therefore, be so feered at first as, to leave a half-ridge next the ditch when gathered up from the flat, and which the subsequent crown-and-furrow plowing will convert into a whole one. Thus, the first feering should be made at e a, fig. 132, and every other should be made at the distance of the width of a ridge, namely 15 feet, from the last one, as at $y z, y z, y z$. On plowing each feering, the open furrows will then be left at $i l, k l, o p$, and $r w$. These open furrows will form the feexings for, and the crowns of, the future ridgeswhich, when plowed, the half ridge from $i$ to $e$ will have to be plowed by itself; thereby, no doubt, incurring some loss of time in laying all the furrow-slices toward the crown $h i$, and returning with the empty plow; but that loss must be endured to get the ridges finished with a perfect form.

(655.) I may mention here, that one stretch of the plow with a furrow is called a landing, and going and returning with a furrow each way is termed a bout.

(656.) Another mode of plowing land from the flat surface is casting or yoking or coupling the ridges. The feering for this mode is done in a different way from either of the two foregoing. The first feering is opened out in the line of $e a$, fig. 132, close to the ditch, and every other is measured off of the width of two ridges from the last-that is, 30 feet asunderas at $y z$, betwixt $k l$ and $o p$, and at half a ridge beyond $r w$. Casting is begun by laying the furrow-slice of the feerings together, and then laying the first furrow-slice toward $e a$, on going up. and toward $y z$, betwixt $l$ and $p$, on coming down the bout; and so on, furrow after furrow, turning the horses on the head-ridges always toward you, until the open furrow is left at $y z$, betwixt $k l$ and $i h$. The effect of casting is to lay the entire furrow-slices of every ridge in one direction, and in opposite directions on adjoining ridges. The proper disposition of the furrow-slices you will see in perspective in fig. 135 , which exhibits three entire ridges, two of them

Fig. 135.

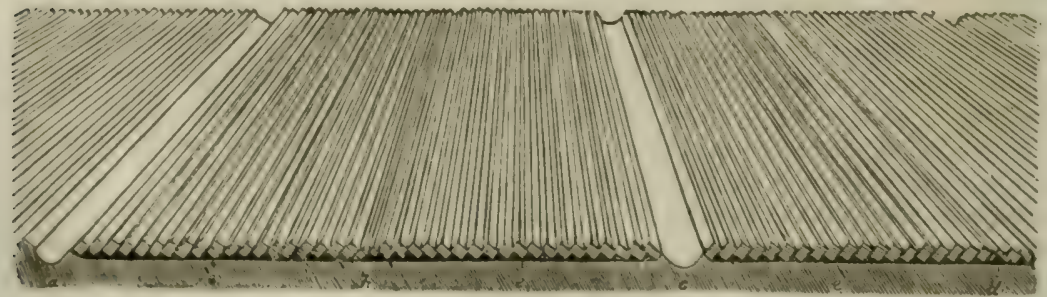

CASTING, YOKING, OR COUPLING RIDGES.

cast or yoked together; that is, the furrow-slices of $a b$ meet those of $c b$ in $b$, which forms the crown of the double ridge, and those of $c d$ lie in the opposite direction from $c b$, and are ready to meet those of the adjoining ridge beyond $d$ at $d$, and they leave the open furrow between them at $c$; and so on, an open furrow between every two ridges. Ridges lying thus yoked can easily be recast, by reversing the furrow-slices of $b c$ and $c d$, thereby converting the open furrow $c$ into a crown of the double ridge, (582) 
and making the crown $b$ an open furrow. Cast ridges keep the land in a level state, and can most conveniently be adopted on dry soils. They form a good foundation for drilling upon, or they make a good seed-furrow on dry land. Lea on light land, and the seed-furrow for barley on the same sort of soil, are always plowed in this fishion. This is an economical mode of plowing land in regard to time, as it requires but few feerings; the furrow-slices are equal, and on even ground; and the horses are always turned inward, that is, toward you. Casting is best performed upon the flat surface, as then the uniform state of both ridges can be best preserved; and should the land be desired to be plowed again, it can be cast the reverse way, and the correct form of the riclges still preserved. In this method of casting, no open furrow is more bare of earth than another.

(657.) Casting ridges is as suitable plowing for strong as light land, provided the ridges are separated by a gore-furrow. A gore-furrow is a space made to prevent the meeting of two ridges, and as a substitute for an upen furrow between them. Its effect is, in so far as the furrow-slices are concerned, like crown-and-furrow plowing, but the difference consists in this, that it turns over a whole ridge, instead of a half-ridge in each feering. It can only be formed where there is a feering or an open furrow. The method of making a gore-furrow is shown in fig. 136. Suppose

Fig. 136.

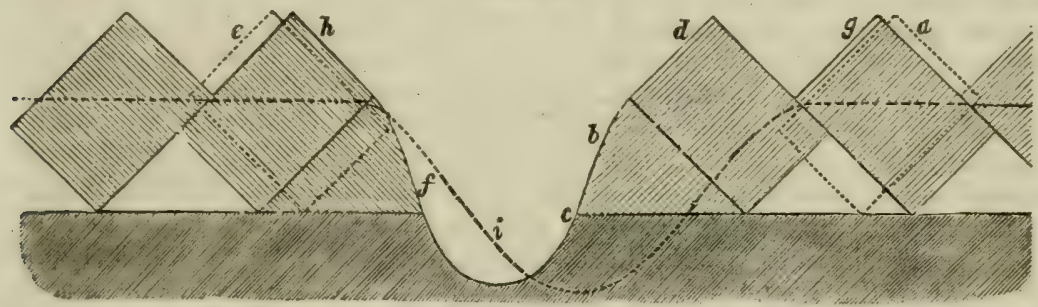

A GORE-FURROW.

that it is proposed to make one in a feering such as is shown by $k$ l and $o p_{p}$ in fig. 132. Let the dotted furrow-slices $a$ and $e$, and the dotted line $i$ represent an open furrow such as in fig. 136, of which $c$ is a point in the middle. Nake the plow pass between the center of the furrow-sole $c$ and the left-hand dotted furrow-slice $e$, and throw up to the right the triangular-shaped mould-furrow-slice $b$. Then turn the horses sharp round toward you on the head-ridge, and lay the dotted furrow-slice $a$ upon $b$, which will then become the furrow-slice $d$, as seen in the fig. at $d$. Again turning the horses sharp round on the head-ridge, take the plow lightly through part of the dotted furrow-slice $e$, and convert it into the triangular shaped mould-furrow-slice $f$, the upper end of $e$ being left untouched; but a portion of $f$ will trickle down toward $i$. Turn the horses from you this time on the head-ridge, and bring down the plow behind $d$, and lay against it the ordinary furrow-slice $g$. Turning the horses again from you on the near head-ridge, lay the ordinary furrow-slice $h$, by destroying the remainder of the dotted furrow-slice $e$ with some more earth, upon the triangularshaped furrow $f$; which, when done, turn the horses from you again on the farther head-ridge for the last time, and come down the open furrow $i$, rubbing the soil up with the mould-board of the plow from $i$ against $f$, and clearing out of the furrow any loose soil that may have fallen into it, and the gorefurrow is completed. The dotted line $i$ shows the surface of the former 
state of the land. A gore-furrow is most perfectly formed and retained in clay soil, for one in tender suil is apt to moulder down by the action of the air into the open furrow, which frustrates the purpose of making it a channel for running water; hut, indeed, on light soils, gore-furrows are of little use, and, of course, seldom formed.

(65S.) When land is cast with a gore-furrow upon gathered ground, it is quite correct to say that the open furrow is more bare of earth than the gore-furrow, as Professor Low intimates, but it is not so correct to say, that "this is an imperfection unavoidable in casting a ridge." "Such a remark is only applicable to cast ridges after they have been gathered up from the flat, and much more so to ridges that have been twice gathered up ; but the imperfection does not belong to casting in its most legitimate form, that is, upon the flat ground. Land, in my opinion, should never be cast upon gathered rilges, to remain in a permanent form, but only for a temporary purpose; as in the process of fallowing, for the sake of stirring the soil and overcoming weeds. For, observe the necessary effect of casting a gathered ridge. Suppose the two gathered ridges between $a$ a $a$, fig. 133 , were desired to be cast together toward the middle open furrow $a$; the effect would be to reverse the position of the furrows from $a$ to $b$, on either side of $a$. They would remain as flat as formerly; but what would be the effect on the furrows on the other halves of the ridges from $b$ to $d$ ? They would be gathered twice, so that the double ridge would have two high furrow-brows by two gatherings, and two low flanks by one gathering. It would, in fact, be unequally plowed, and the open furrow on each side of it would, of course, he bared of earth, having been twice gathered. No doubt, such a distortion might be partially obviated by making the furrow-slices between $a$ and $b$ on each side of the middle open furrow $a$ deeper and larger than those hetween $l$ and $d$, and thus endeavor to preserve a uniform shape to the double ridge; but this would be done by the sacrifice of sterling plowing, and it is much better to confine casting within its own sphere, than practice it in circumstances unfavorable to the land.

(659.) The open furrow in casting does unt necessarily bare the earth more than a gore-furrow. It is broader, certainly, from the circumstance of its furrow-slices being laid from each other; but its furrow-sole is not actually plowed deeper than the gore-furrow. In treating of casting, immediately after showing how ridges may be gathered up nnce and twice, it appears to me that Professor Low seems to intimate, ai page 152 , that land so gathered up may be cast, and preserve its form; but on this $I$ would observe that casting is almost impracticalle after twice gathering; at least it is unadvisable, because, in that case, the effect would be to cleave down the side $b a$, fig. 133 , of the ridge on each side of $a$; that is, to throw them down again to the level of the ground; while it would gather up the other two sides $b d$ thrice, thereby either making the two sides of each ridge of unequal hights, or, to preserve their level, making the furrowslices on the same ridges of unequal sizes-practices both undeserving of commendation under any circumstances. Another author, in speaking of casting ridges together, and showing hrow it may be performed by plowing the furrow-slices of two adjoining ridges in opposite directions, gives the caution that "the inter-furrow, which lies between the two ridges, unavoidably leaves a shoulder or hollow place, of more or less width, according to the expertness of the plowman, in the center of the crown, which defect can only be completely relieved by replowing; " $†$ and informs

" Low's Elemente of Practical Agriculture.

I British llusbandry, vol. ii. $(584)$ 
us that the defect may be partly prevented by using two plows of different mould-boards. I do not see why plowing two furrow-slices into the open furrow in casting should be more difficult or less sterling than in any other mode of plowing. A good plowman will leave in the crown of the ridge, in either case, neither a shoulder nor hollow place, which are certainly not synonymous terms, as they seem to be represented here, but the opposite.

(660.) Nearly allied to casting is a species of plowing called two-outand-two-in, which can be executed on the flat ground, and requires a particular mode of feering. The first feering should be measured off of the breadth of two ridges, or 30 feet, from the ditch $a$ e, fig. 132 ; and every subsequent feering should be measured at 4 ridges breadth, or 60 feet from the last. The land is plowed in this way. Let $a b$, fig. 137, be the

Fig. 137.

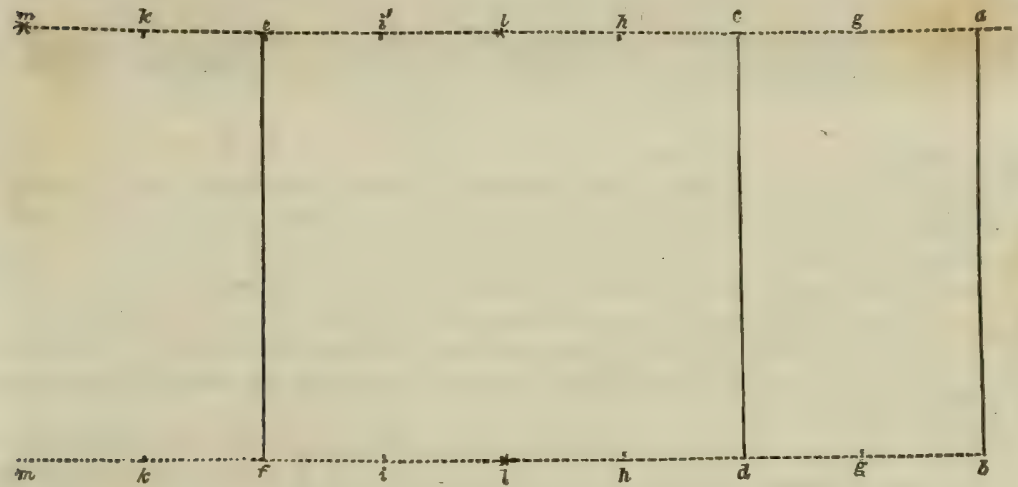

FEERING FOR PLOWING TWO-OUT-AND-TWO-IN.

side of the field, and let $c d$ be the first feering of 30 feet from $a b$; and also, let $e f$ be the next feering of 60 feet. After returning the feering furrow-slices, begin plowing round the feering $c d$, always keeping it on the right hand, and turning the horses from you, that is, outuard, on both the head-ridges, until about the breadth of a ridge is plowed on each side of $c d$. These two ridges may be supposed to be represented by $c g$ on the one side, and $c h$ on the other of $c d$. While this is doing, the two ridges $e i$ and $e k$ are plowed, in like manner, toward ef. At this juncture, open furrows occur at $h h$ and $i i$, embracing between them the breadth of 2 ridges, or 30 feet, from $h$ to $i$. Then let the plowman who has plowed round $c d$, plow $h$ and $i$, always laying the furrow-slices first to $h$ and then to $i$, and turning. his horses toward him, or inward, on both head-ridges, until the ground is all plowed to $l l$, which becomes the permanent open furrow. The next open furrow will be at $m m, 60$ feet or 4 ridges breadth from $l l$. But as yet only 3 ridges have been plowed betwixt $l$ and $a$, the fourth ridge $g a$ being plowed along with the head-ridges $m a$ and $b m$, after all the ridges of the field have been plowed, laving its furrow-slices toward $g g$, and making the open furrow at $a b$. The effect of this mode of plowing is to lay all the furrow-slices in one direction from $a$ to $c$, that is, across the 2 ridges $a g$ and $g c$, and to lay those from $l$ to $c$ in the opposite direction, also across 2 ridges $l h$ and $h c$, and both double ridges meeting in $c d$, which becomes the crown of the 4 ridges $l \hbar, h c, g c$, and $a g$. In like manner all the furrow-slices over the ridges $l i$ and $i e$ on the one hand, and all those over the ridges $m k$ and $k e$ on the other hand, meet (585) 
in their crown at $e f$. In plowing by this mode, every plowman takes in a feering of 4 ridges, which he completes before he goes to another. The reason, I suppose, that this mode of plowing has received the appellation of two-out-and-two-in is, that 2 ridges are plowed toward the feering, and the other 2 from the open furrow.

(661.) The appearance of the ground on being plowed two-out-and-twoin is seen in fig. 138 , where the space from $a$ to $e$ is 60 feet, comprehend-

Fig. 132.

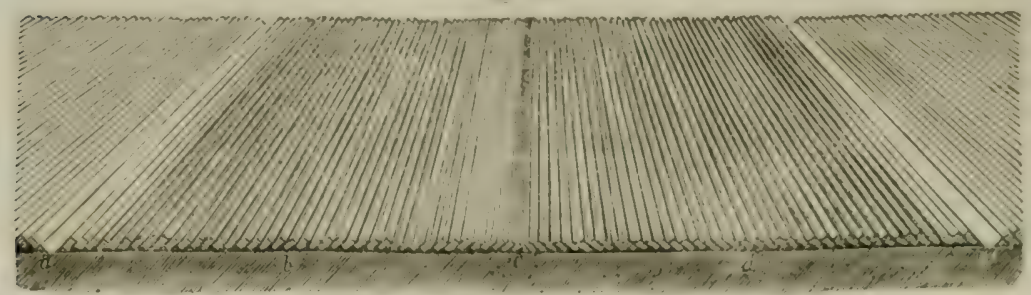

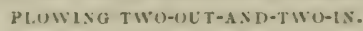

ing 4 ridges, between the open furrows $a$ and $e, 2$ of which ridges, $a b$ and $b c$, have their furrow-slices lying one way, toward the right, and the other $2, e d$ and $d c$, with theirs lying toward the left in the opposite way, both meeting at $c$. which is the crown of the whole break or division of 4 ridges.

(662.) This method of plowing places the land in large flat spaces, and as it dispenses with many open furrows, it is on this account only suitable for light soils, in which it may be practiced for seed-furrowing. It forms an excellent foundation for drilling upon for turnips, or even for potatoes upon gravelly soils.

(663.) The gore-furrow, described in fig. 136, might be judiciously applied to the plowing of land two-out-and-two-in on the stronger classes of soils; but its introduction changes the character of the ridges altogether, inasmuch as the crown $c$ fig. 138 , where the furrow-slices meet, is not only converted into an open furrow, but the actual crown is transferred from $c$ to $b$, and $d$, where the furrow-slices do not meet from opposite directions, but lie across the crowns of their respective double ridges in the same direction. Exactly in a similar manner, when the gore-furrow is introduced into cast ridges, as in fig. 135 , the crowns $b$ and $d$ are converted into open furrows, and transferred to $e$, where the furrow-slices lie across the crowns in the same direction on their respective ridges, instead of meeting there.

(664.) A nearly allied plowing to the last is that of plowing in breaks or divisions. It consists of making feerings at indefinite distances, and plow ing large divisions of land without open furrows. Some farmers plow divisions of 8 ridges or 40 yards; but such a distance incurs considerable loss of time to travel from furrow to furrow at the landings. Instead, therefore, of distances of a given number of ridges being chosen, as is the case in the last mode of plowing, two-out-and-two-in, 30 yards are substituted, and this particular breadth answers another purpose of deviating from the sites of the ordinary ridges, which deviation has the advantage of loosening any hard land that may have been left untouched by the plow in any of the sorts of plowings that have yet been presented to your notice. Land is plowed in breaks only for temporary purposes, such as giving it a tender surface for seed-furrowing, or drilling up immediately. You might easily estimate how much time wuuld be lost in plowing land in breaks, were the feerings made at a greater distance than 30 yards, by looking at fig. 137, where the feerings $c d$ and $e f$ being supposed to be (586) 
60 yards asunder, the plows would have to go round $c d$ and $e f$ until they reached $h$ and $i$ respectively, in doing which they would have to travel in a progressively increasing distance until its extreme point from $h$ to $i$ reached 30 yards for every furrow-slice laid over. Thus is imposed on men and horses a great deal of traveling for the little work actually done.

(665.) Another mode of plowing, which I shall now describe, is twicegathering-up. Its effect may be seen by looking at fig. 139, where it will

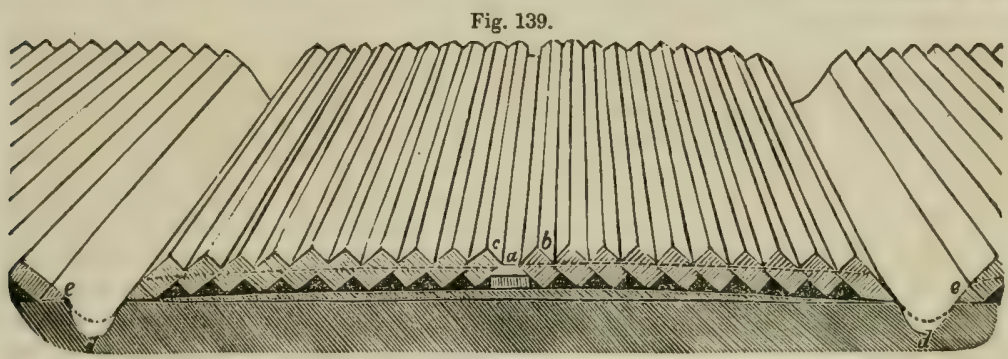

TWICE-GATHERING-UP.

be observed that the furrow-slices rest above the level line of the ground. It may be practiced both on lea and red-land. On red-land that has already been gathered up from the flat, it is begun by making feerings in the crowns of the ridges, as at $b$, fig. 133. The furrow-slices of the feerings are laid together, and the ridges plowed by $\frac{1}{2}$ ridges, in the manner of gathering up from the flat. The $\frac{1}{2}$ ridge left by the feerings at the sides of the field must be plowed by themselves, even at the risk of losing time, because it would not do to feer the first ridge so as to plow the $\frac{1}{2}$ ridge as directed to be done in the first-gathering-up, in fig. 132, around the feering of the $\frac{1}{4}$ ridge $f c$, because the furrows betwixt $f$ and $i$, if plowed in the contrary direction to what they were before, would again flatten the ground, whereas the furrow-slices from $e$ to $f$ and from $z$ to $i$, being plowed in the same direction as formerly, the ground would thereby be raised above the level of $i f$, and disfigure the plowing of the whole ridge $z e$. Gathering up from the flat preserves the flatness of the ground; and the second gathering up would also preserve the land in a flat state, though more elevated, were there depth enough of soil, and the furrow-slices preserved of their proper form, as we have seen in (653), but a roundness is usually given to the ridge in all cases of gathering up furrow-slices toward the crowns, both by the harrowing down of the precipitous furrow-brows and the unequal size of the furrow-slices, from want of soil at the furrowbrows and open furrows. In gathering up lea the second time, no feering is required. The plow goes down a little to the left of the crown of the ridge, and lays over upon the crown a thin and narrow furrowslice upon its back, as $a$, fig. 139 , to serve as a cushion upon which to rest the adjoining furrow-slices. The horses are then turned sharp round from you, and the furrow-slice $b$ is laid over so as to rest at the proper angle of $45^{\circ}$ upon $a$. Turning the horses again sharp round from you, the furrow-slice $c$ is also laid over at the same angle to rest on $a$, but neither $c$ nor $b$ should approach each other so nearly as to cover $a$, but leave a space of about 3 or 4 inches between them. The object of leaving this small space is to form a receptacle for the seed-corn, which, were $i$ and $b$ made to meet a sharp angle, would slide down, and leave the best part of the ridge bare of seed. The crown of the rest of the ridges is treated in the same manner, where in fact is constituted its feering, and the ridges (587) 
are plowed in $\frac{1}{2}$ ridges to the open furrows $d$, which are finished with mould-furrows, but the plowing of these is attended with some difficulty, in order to prevent their gradually mouldering down into the bottom of the open furrows. Twice-gathering-up is only practiced in strong land, and its object is to lift the mould above the cold and wet subsoil. On dry land, no such expedient is required. In fig. 139 the dotted line $e$ is meant to represent the former configuration of the ground, and now it may be seen that the open furrow at $d$ is deeper than it was with once gathering-up.

(666.) The mode of plowing exactly opposite to twice-gathering-up is that of cleaving or throwing down land. The open furrows of twice-gathered-up land constitute deep feerings, which are filled up with furrowslices obtained from the mould-furrows and furrow-brows of each adjoining ridge; and, in order to fill them fully up, the plow should take as deep a hold of the furrow-brow as it can obtain. The furrow-slices are plowed exactly the reverse of those of the twice-gathered-up ridges, and they are also plowed in $\frac{1}{2}$ ridges. The effect of cleaving down is to bring the ground again to the level above which it had been raised by means of the twice-gathering-up. The open furrows are left at the crowns, as at $a$, fig. 139, the mould-furrows of which are seldom stirred, as cleaving down is usually practiced to prepare the land for cross-plowing in the spring. But when heary land is cleaved down in winter, it is always so with gore-furrows; and these, with open-furrows, afford convenient channels, at every half-ridge, for the water to flow off to the ditches. Since twice-gatheringup is only practiced on strong land, and cleaving down only succeeds

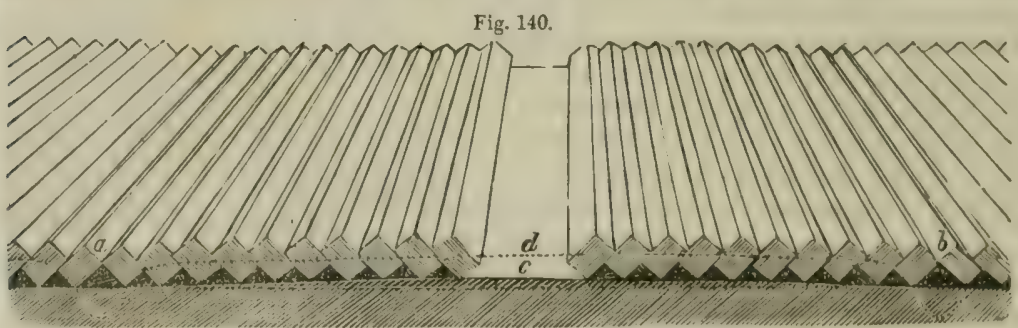

CLEAVING DOWN WITHOUT GORE-FURROWS.

twice-gathering-up, it follows that cleaving down is only practiced on heavy land. The effect produced by cleaving down ground may be seen in fig. 140 , which represents it without gore-furrows $b$ and mould-furrows $c$; but, in fig. 141, the gore-furrows are shown at $a$, and the open and

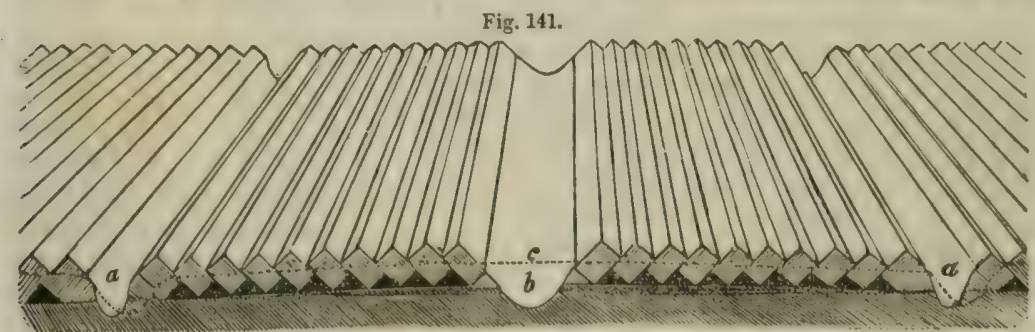

CLEAVING DOWN WITH GORE-FURROWS.

mould-furrows at $b$. The dotted line $d$, in fig. 140 , represents the surface of the former state of the ground, as does the dotted line $c$, in fig. 141.$(588)$ 
Below $a$ and $b$, fig. 140, are shown the former open furrows by the dotted line, as also does the dotted line below $a$, in fig. 141. In both figures, the ground upon which the furrow-slices. rest is made somewhat rounded, to show the effect of twice-gathering it up. In the strict sense, a ridge can only be cleaved after it has been twice plowed. It is, as I think, scarcely correct to say that a ridge is cleaved after one gathering from the flat, for it is then plowed crown-and-furrow. With a strong furrow, a ridge that had been twice-gathered-up can be made flat by one cleaving.

(667.) What is called cross-plowing, or the cross-furrow, derives its name from plowing right across the furrow-slices as they lie in ridges, in whatever form those ridges may have been formerly plowed. Its object is to cut the existing furrow-slices into small pieces, so that the land may be more easily pulverized and prepared for the future crops. It is usually executed in the spring, and should never be attempted in winter, unless the weather continue so long dry and fresh as to allow the land to be again immediately plowed into ridges in any of the safe forms of plowing $I$ have described. Rain, or snow melting on land lying in the cross-furrow, is at once absorbed and retained in it, and in a short time renders it sour. But, even if cross-furrowing were executed in a proper manner in winter, and the land thereafter safely put into ridges, the land would become so consolidated during winter that it would have to be again cross-furrowed in the spring before it could be rendered friable. The object of cross-furrowing being to pulverize land, it is practiced on every species of soil, and exactly in the same manner. It is plowed in divisions, the feerings being made at 30 yards asunder, and these are plowed in the same manner as two-out-and-two-in, by first going round the feering, turning the horses constantly from you, until about $\frac{1}{2}$ of the division is plowed, and then turning them toward you, still laying the furrow-slices over toward the feerings, until your arrival at the open furrow. In cross-plowing, however, the open furrow is never left open, but is again closed by 2 or 3 of the last furrow-slices being returned, and all marks of it obliterated by the plow shoveling the loose soil into the furrows with the mould-board, which is purposely laid over on its side, and retained in that position by a firm hold of the large stilt. The obliteration of the open furrows is necessary to fill up the hollows that would otherwise be left by them across the ridges after they were formed.

(668.) Another mode of plowing, having a similar object to cross-furrowing-namely, of dividing furrow-slices into pieces-is what is called angleplowing or angle-furrowing; and it is so named because the feerings in which it is plowed are made in a diagonal or angular direction across the field. This mode is also plowed in divisions of 30 yards each, and in exactly the same manner as cross-plowing, and with the same precautions as to the season in which it is executed, and the closing of the open furrows. It is never practiced but after cross-plowing, and not always then, but on strong land, or unless the cross-plowing has failed to produce its desired effect of comminuting and stirring up the soil. It is chiefly practiced in bare fallowing, and is therefore mostly confined to strong land.

(669.) I have mentioned a mode of plowing called ribbing (641). In its best form it is usually performed in spring with the small plow, when it will more appropriately fall to be described than in this place; but there is a species of plowing practiced in some parts of the country in autumn or winter which bears the name of ribbing. I notice it because it is practiced in some parts, not with the view of recommending but of reprobating it. It is, I believe, called raftering in England; and is practiced on stubble land, and consists of laying a furrow-slice on its back upon as (589) 
much of the firm soll as it can cover, as seen in fig. 142, where $a$ are the furrow-slices laid over upon the firm soil $b$, and $c$ the plow-tracks. The figure represents it more compact, clean, and regular, than it is usually

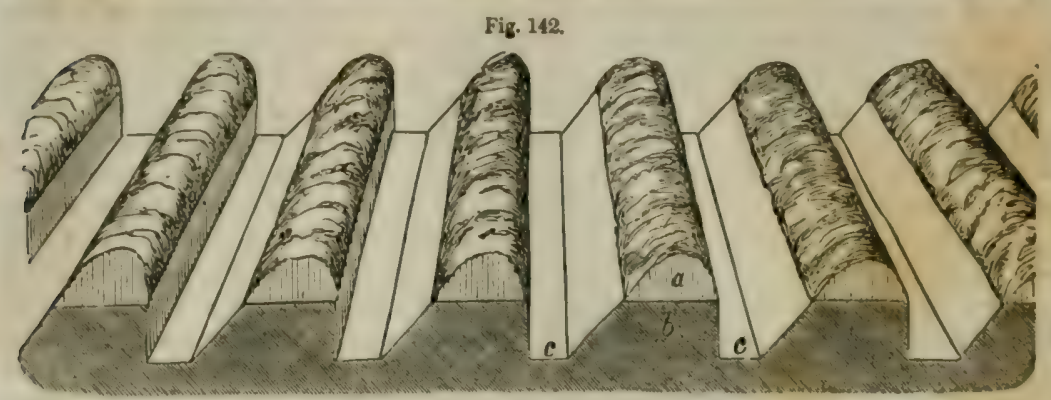

RLB-PLOWING STUBBLE LAND.

found in practice. It is sometimes plowed so as the furrow-slice shall lap and hang over the piece of firm soil upon which it rests, and the plowtracks are often very crooked. The land lies in this state all winter, and is dry enough; but the greatest proportion of the soil remaining unplowed is none the better for this treatment. It has the advantage of being done in a short time, and without care, as it is generally done in a diagonal direction across the ridges, and without any sort of feering. It is chiefly practiced on land in a very foul state, with the view of destroying the weeds, from its being believed that the under surface of the furrow-slice, where the roots of the weeds are most abundant, is thus more exposed to the action of frost than in any other position; and this opinion is no doubt correct; but, if the plowed portion of the ground is in this manner more exposed to the air, it is evident that the unplowed part cannot be exposed at all, and, as the largest proportion of the land is left unplowed, any advantage attending such a mode of plowing must be greatly counterbalanced by iis disadvantages. It is practiced in all sorts of soils. Its practice in Scotland is confined to the north of the Frith of Forth, and even there it is now abandoned on the large farms, though it may still be seen in the fields of the smaller tenants. When a field is so plowed, it has somewhat the appcarance of having been drilled.

(670.) The drilling of land being confined to summer, I shall defer any remarks on that mode of plowing until its proper season arrives.

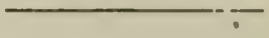

\section{DRAINING.}

"In grounds, by art laid dry, the aqueous bane,
That marred the wholesome herbs, is turned to use;
And drains, while drawing noxious moisture off,
Serve also to diffuse a due supply."

Grahay.

(671.) It is barely possible that the farm on which you learn your pro. fession, or the one you may eccupy on your own account, may not require draining. Nevertheless; you should be made well acquainted with this essential and indispensable practice in hustandry. But the probability is 
that, on whatever farm you may pass your life, some part of it at least, if not the whole, will require draining of one sort or another.*

(672.) Draining may be defined the art of rendering land not only so free of moisture as that no superfluous water shall remain in it, but that no water shall remain in it so long as to injure or even retard the healthy growth of plants required for the use of man and beast.

(673.) On considering this definition, you may reasonably inquire why water in the soil should injure the growth of useful plants, since botanical physiologists tell us that the greatest bulk of the food of plants consists of, or at least is conveyed to them by water. In what way injury should arise, is certainly not very obvious; but observation has proved that stag

[* We have too frequently and too distinctly dwelt upon the importance of divesting land, whether intended for the plow or for grass, of all superfluous moisture, to make it necessary to say more on that point. In England, where the prodigious rental of land, and the value of its products as food for man and beast, instigate the farmer to search for and put in practice every possible mode of angmenting his crops, it is to the condition of the soil with respect to any redundant moisture that he gives his first attention, as we are assured, when examining with a view to rent or purchase.

There the conviction of the importance and the profits of draining, not merely as the basis of permanent improvement, but as a source of immediate remuneration for outlay of capital and labor, is universal; and one of the greatest obstacles at this time to the yet farther progress of ag. ricultural improvement and prosperity in England is, on all hands, admitted to consist in the diff culty of adjusting between landlord and tenant the proportion to be borne by each respectively of the expenses of draining the land, which all admit to be indispensable to the realization of the profits to which the industry and skill of the tenant entitle him. The landlord refuses to grant a long lease, being eager to get the higher rent which a higher state of improvement and productiveness may enable him to exact, while the tenant justly demands a longer lease to warrant him in the expenditures, especially the draining, by which, and his own skillful management, that higher improvement and greater productiveness are to be achieved.

In our country, the same obstacle to plans of improvement, which require time to carry them out and to reap their profits, does not exist, because here almost every man owns the fee simple of the land he cultivates; but here again there are two yet, perhaps, more formidable obstacles to every plan of well-arranged, permanent improvement, involving heavy outlay in the beginning. These are-want of capital, and the facility of procuring cheap land in the Far West. To these, also, may be added a want of enterprise and a want of knowledge. Our young men are not educated in the principles of their profession, as they are for all other professions. Hence, for example, in this very precess of draining, some knowledge of geology and of the plain rules and laws of engineering and hydraulics is needed, to carry it forward upon any extended scale. But how many of our young men, except at the military schools (and these at the farmer's expense), are taught even the simplest elements of these sciences? Scarcely enough geology do they know to distinguish gravel from sand, and either from clay, and not enough of mechanics, bydraulics or engineering, to know how to make or to use a common water-level, to ascertain by what line water may be made to flow. If, then, the reader become impatient at seeing so much on one subject, and especially on perceiving that the execution of the plans laid down by the author would be expensive beyond the means of American farmers, there are yet some considerations to reconcile every reasonable mind. Frirst-He should consider that this is but one chapter of, literal ly, a great BOOK OF THE FARM, so voluminous and comprehensive as necessarily to embrace many things not adapted to all farmers and all localities; and, secondly, that as this work is designed to be studied as well as read, and to serve as well for the young man in his school as for the practical man in the field, it is but fit that the principles as well as the modus operandi of all agricultural processes should be carefully explained; and we may add, after attentive perusal, that in respect of draining, both theory and practice seem here to be so fully described and carefully illustrated as to leave little or nothing to be added in the way of notes.

A long and very valuable essay appears in the last number of the English Farmer's Magazine, on draining as practiced in Aberdeenshire; but we see in it notbing that is not embraced in, if not actually taken from, the work in hand, except some results of particular experiments, and to illustrate the profits of the operation. Well aware are we that they are only our wealthy farmers, such 
nant water, whether on the surface or under the ground, does injure the growth of all the usetul plants. It perhaps altogether prevents or checks perspiration and introsusception; or it may neutralize the chemical decomposition of substances which largely supply the food of plants. Be it as it may, experience assures us that draining will prevent all these bad effects. You may conceive it quite possible for an obvious excess of water to injure useful plants; because you may have observed that excess of water is usually iudicated by the presence, in number and luxuriance, of subaquatic plants, such as rushes (Juncus acutiflorus and J. effusus), \&c., which only flourish where water is too abundant for other plants; and you may even conceive that damp, dark-looking spots in the soil may con-

as have generally acquired fortunes by other pursuits or by inheritance, who can afford sach out lays - such outlays, however, it may be added, as will pay well when they are made under judicious circumstances as to locality and markets. How many thousands of acres are there, for in. stance, along the river and creek shores of the Chesapeake Bay, in Maryland and Virginia, enjoying the advantages of a practical contiguity to the best Atlantic markets, which now produce nothing but coarse grass and malaria, which might, if their owners had the energy, the skill and the capital to drain them, produce crops equal to such as have been produced on the Nansemond (Charles county, Md.) estate of B. O. TAYLOE, Esq.-where, during the past season, under the management of Mr. James K. Nash, a crop of 2,000 barrels of com has been made and housed; and where, on two acres, 125 bushels of good merchantable corn were raised, and that after a fair crop of tobacco the preceding year, and without any unusual application of manure-being $62 \frac{1}{2}$ bashels; which, at the present price, 75 cents, is $\$ 4687 \frac{1}{2}$ an acre.

Need we ask whether such crops, or say 60 bushels to the acre-at 70 cents a bushel. $\$ 42$ would not well remunerate a heavy outlay for draining? And do not such crops and such mauagement better deserve the honors bestowed by Agricultural Societies and Institutes, than mere isolated cases of extraordinary crops, produced at enormous expense, and by the fitul efforts to which the most indolent may sometimes be stimulated, in the hope of winning a V. or an $\mathrm{X}$. ? But again the question recurs, how is the capital to be had by those who are without money, and whose lands might be thus drained?-for the tendency of all our legislation that in any way interferes with or acts upon the use and value of labor and capital, owing to the want of spirit and knowledge on the part of the agriculturists, has a tendency to drive capital as well as enterprise into our large cities, and into channels for the benefit of particular and well-banded classes !

Suppose a field of say ten acres (and how many there are who own such) to be drained so that it would produce even forty bushels of corn to the acre-these, at 60 cents, would give $\$ 24$, the interest on $\$ 400$ at 6 per cent. ; leaving the land worth intrinsically more than 8100 an acre, and two crops would more than pay the cost. Yet there are thousands on thousands of acres in Maryland and Virginia and North Carolina that might be thus drained and rendered thus productive at an expense of $\$ 50$ on acre!

But unfortunately if, perchance, a hard-working farmer, toiling through the year, and conduct. ing his household and all otber affairs with the severest economy. contrives to have a small surplus beyond his outgoings at the end of the year-even he, instead of investing it in draining. his land-in erecting more and hetter buildings-in providing himself with all necessary implements, and otherwise improving his little estate in appearance and fruitfulness - even he, as such a farmer confessed to us last summer in the State of New-York, sends or goes with it to the great, all-ab. sorbing Commercial Emporium, to lend it ont at 7 per cent. on bond and mortgage. Hence it is that while no one knows how much of the State is mortgaged, and while every manufacturing village wears the aspect of youth and healthfulness, and larger cities grow into enornous magnitude-the conntry, at least along the great thoroughfares, as far as one can see, sinks lower and lower in its average products, and puts on the appearance of premature decny and cousumption. All this would be rectified if the education of the rising generation were sucb as it should be, because then we should rear up a race of men who would understam, as, far as the Government is concerned, what is due to their numbers and the products of their industry; and Agriculture would preside where she ought, at the head instead of at the tail of all Cabinet conncils for the general welfare.

Looking carefully through this chapter of the Воок оF TнF FARM, on draining-the mode of eonducting it-the principles by which it is to be guided-the implements employed, and the out- 
tain as much water as to injure plants, though in a less degree; but you cannot at once imagine why land apparently dry should require draining. Land, however, though it does not contain such a superabundance of water as to obstruct arable culture, may nevertheless, by its inherent wetness, prevent or retard the luxuriant growth of useful plants, as much as decidedly wet land. The truth is, that deficiency of crops on apparently dry land is frequently attributed to unskillful hushandry, when it really arises from the baleful influence of concealed stagnant water; and the want of skill is shown, not so much in the management of the arable culture of the land as in neglecting to remove the true cause of the deficiency of the crop, namely, the concealed stagnant water. Indeed, my opinion is-and its conviction has been forced upon me by dint of long

lay, under ordinary circumstances, as compared with the results in the account of profit and losswe see nothing that can be added, except some suggestions as to draining, in a mode and with materials more within the reach of ordinary American farmers, and which appears not to be touched upon in this book. At this there should be the less surprise when we consider that $w o o d$, or young timber-the material to which we refer-is so scarce and dear in England as almost to place it out of question.

In the Eastern States, and along the high lands stretching far away south, stone is at hand in abundance; and in New-York, and so through the States east of the Hudson, the practice of draining is on the increase, and we believe with universal satisfaction as to the advantages; but in a large portion of intervale and alluvial country south of the Hudson, with which we are better acquainted, there is not stone enough in some districts to make the foundation of a chimney. The situation and circumstances are numfrous, however, where farmers are invited by every consideration to drain, with wood (if nothing better), which many of them have at command. We believe we have somewhere before adverted to the instance of a Mr. Suмmers, near Notingham, Maryland, who, without example or instruction, has reclaimed and brought under the plow spots of land which had before been worthless, and which now yield heavy crops; and which, moreover, give to his fields an air of good management, proclaiming that their proprietor has a mind to think, as well as a hand to execute-a consideration which ought to weigh with every farmer of proper spirit, and which it behooves every commonity to commend more fervently than they now commend only, or first and far above all others, those who are most successful in fields of human destruction.

For those who may be inclined-and there ought to be thousands-to drain the boggy spots on their farms by this method, which is within the reach of almost every one, the following observations may prove useful; and the reader will indulge us in this short addition to a long note, when we announce that we shall make no other upon this branch of the Book of the Farm.

"The wood used for this purpose consists of the thinnings of plantations, i.e. the small trees commonly converted into paling. Larch is preferable. on account of its greater durability; but Scotch fir, being the cheapest and most abundant kind in this quarter, is generally used. The drains to be filled with wood are usually thirty-two inches in depth, eighteen inches wide at the top, and about six inches at the bottom. It is essential to the efficiency and durability of wooden drains, that the sides be formed with a proper and regular slope from top to bottom. The small trees-or "spars," as they are designated-are prepared for being put into the drain in the follow. ing manner: A portion of the butt or thick end of each is sawn off for placing transversely in the drain, about six inches above the bottom; the breadth of the drain at this part may be assumed at nine inches, in which case the length of the cross-bars will require to be about fifteen inches, so as to have three inches resting on each side. They are generally about four inches in diameter, and are placed in the drains at intervals of four feet apart; they are forced firmly into their proper position by a few blows of a heavy mallet, the workman taking care that they are all in the same plane or level. Any earth loosened from the sides in striking down the bars is, of course, thrown out as the work is proceeded with. After the butt-ends of the trees (which are divested of their branches in the wood) are severed, and placed transversely in the drains in the manner just described, the remainder of them are laid longitudinally above the bars, three being commonly placed side by side, and covered with the branches and twigs, or with turf, heath, \&c., previous to putting in the earth cast out in opening the drains. It is obvious that this method of draining can be adopted with advautage only in situations where timber is convenient and cheap. and when the subsoil is sufficiently cohesive to afford a proper support to the transverse bars of wood: hence it is inadmissible in the case of boggy lands. The putting in of the wood is accomplished in a very expeditious manner: two persons saw off the butts, and another places them in their proper position in the drain, after which the longitudinal spars are laid on as closely as possible, with the top and butt-ends alternately in the same direction, so as to make them fit the bet- 
and extensive observation of the state of the agricultural soil over a large portion of the country - that this is the true cause of most of the had furming to be seen, and that not one farm is to be found throughout the kingdom that would not be much the better for draining. Entertaining this opinion, you will not be surprised at my urging upon you to practice draining, and of lingering at some length on the subject, that I may exhibit to you the various modes of doing it, according to the peculiar circumstances in which your farm may be placed.

(674.) To the experienced eye, there is little difficulty in ascertaining the particular parts of fields which are more affected than others by superfluous water. They may be detected under whatever kind of crop the field may bear at the time; for the peculiar state of the crop in those

ter. There is thus formed beneath the wood a channel for the passage of water, of about six inches in wilth and the same in depth.

"The cost of this mode of draining obviously depends much on the price of the wood employed. In most parts of this county the spars used for the purpose are obtainable at from $1 \mathrm{~s}$. to $1 \mathrm{~s}$. $6 \mathrm{~d}$. per dozen; and it requires four dozen, averaging twenty feet in length, to do a hundred yards of drain. Drains thus constructed have been known to last for a very long period; on one farm the writer has been assured that drains formed of wood in the manner just described have been in perfect operation for more than thirty years."

In a recent conversation with Mr. HALL, a clear-headed, practical farmer, near Lebanon, N. Y., he remarked that the practice of draining was extending with himself and neighbors, and, where well executed, was attended with double the amount of produce previously obtained. We are indebted to a valued correspondent (one of his young and promising pupils) for the following note on the system of draining pursued by Mr. WILKIssos, of Dutchess county, $\mathbf{N}$. Y. - one of those farmers whom we are pleased to name as among those who bring their minds to reason and reflect on the principles involved in all their agricultural proceedings.

\section{From a Correspondent.}

Dutchess Agricutteral Institute, Aug. 29, 1846.

Dear Sir : Having compared the system of under-draining practiced by Mr. Wilkinson, on the Institute Farm, with that recommended in "Stephens's Book of the Farm," and also with that of many farmers of this State-and being thoroughly convinced that his system is much better adapted to the wants of the farmers of this country generally, on account of the convenience of construction, cheapness, utility, \&c.-I have been induced to give you this article for publication in your Journal. The course he pursues is as follows: In the first place, in laying out the ditehes, he is careful to avoid too grent a descent, that the force of the water running in the ditch may not wash the sides or bottom of it, and thus carry the sediment to some more level portion, where it may collect, and obstruct the water, and render the work valueless. After the ditch is staked out he plows with a common plow the width required and two furrows in depth, ehoveling out the loose earth ench plowing. Then a pair of atrong oxen are attached to a one-handled sub. soil plow, tandem, in siagle yokes, by which the ditch is plowed to the depth required, which is varied ac. cording to circumstances; but the usual depth is from $2 \frac{2}{2}$ to 3 feet, about 20 inches wide at the top, and 1 foot at the bottom. He then commences the filling operation, by drawing small stunes from where they have been previously heaped for the occasion, or the scattering small stones from the adjacent lots. The gtones are drawn by oxen on a low, four-wheeled vehicle, which he calls a truck, or lumber-car, which is about 20 inches high-being a convenient hight for a man to stand beside it on the bank of the ditch, and take the stones from the car and pass them to 8 man in the ditch, who places them by first paving the bottom with those of a medium size, by setting them on the small end as closely as is convenient, selecting the flat ones, or flags, and placing them next to the bank, to prevent it from caving. The largest are next used and throw. in promiscuonsly, taking great care not to throw them against the sides of the ditch. The stone-work is then completed by leveling with the emallest ones that can be procured, not filting it nearer than 1 foot from the surface, thnt the ground may be plowed and aubsoiled as well over the ditches as else. where. Before filling in the earth, the stones are covered with pine shavings very ligbtly, which he obtains from the sash-factory for the cartage.

The advantage in the use of shavings over straw, which is generally used, is that the straw entices the ground-moles into the ditch; they burrow in the stones, and dig through to the aurface, which forms a passage for surfuce-water directly among the stones, and will carry with it quantities of fine mould; thus, by frequent rains, the whole work is rendered valueless.

The filling in of the earth is done with a side-hill plow, the team traveling up and down on the bank of earth, plowing a furrow into the ditch-which, Mr. W. says, facilitates the work 300 per cent. over the old process of shoveling it in.

Where the stones are convenient for filling, and taking the average of eoil for digging, he thinks his ditches of the abore dimensions, completed, cost about 35 cents per rod of $16 \frac{1}{2}$ feet. 
parts, when compared with the others, assists in determining the point. There is a want of vigor in the plants; their color is not of a healthy hue; their parts do not become sufficiently developed; the plants are evidently retarded in their progress to maturity ; and the soil upon which they grow feels inelastic, or saddened under the tread of the foot. There is no mistaking these symptoms when once observed. They are exhibited more obviously by the grain and green crops, than by the sown grasses. In old vasture, the coarse, hard, uninviting appearance of the herbage is quite a sufficient indication of the moistened state of the soil.

(675.) But there appearances of moistened land, which you may easily observe without any previous tuition; and these are most apparent in soil after it has been plowed, and more apparent still in spring, in the month of March, when the winds become dry and keen. Then you may observe, in a dry day, large patches or stripes, or belts of black or dark-brown colored soil, in the face or near the top of an acclivity, while the rest of the field seems quite dry, of a light brown color; or only small spots may be observable here and there; or the flat and hollow parts of the field may be nearly covered with dark-colored soil. You cannot mistake these broad hints of the lurking water below; but, in a few weeks, they may all have disappeared, or be reduced very much in extent, if the weather continues dry, or have become more extended in rainy weather. In the case of their disappearance in dry weather, you may conclude that any wetness of the soil which passes of as the summer advances, can do no harm to cultivated plants, and that the land, in such cases, does not require to be drained. Such a conclusion would be very erroneous : because it is on account of the water remaining in the soil all winter that the crops receive injury in summer. The amount of wetness which you saw pass away first in spring and then in summer, would have done no injury to the crops, for it would be all absorbed, and probably more, in the wants of vegetation; but the wetness remaining in and occupying the pores of the soil and of the subsoil all winter, render the soil so cold, that most of the summer's heat is required to evaporate the superfluous moisture out of it, and, in this very process of drying by evaporation, the heat is dissipated that should be employed in nourishing the crops all summer. No doubt, when the soil and subsoil are put into such a state as that the water that falls upon the soil from the heavens during the winter, on being conveyed quickly away in drains, does take away some of the heat from the soil, but it cannot render it cold or sour. In such circumstances, the natural heat of the weather in spring and summer would have nothing to do but to push forward the growth of the crops to early maturity, io fill them more fully, and make them of finer quality. You thus see how concealed water injures the soil in which it is retained, and you may easilv conceive how it may injure the drier soil around it, by its imbibing the water in contact, by capillary attraction. You thus also see the kind of ground that draining effects in soil so situated. Did the symptoms of wet in spring remain as obvious to your senses throughout the summer, you would have no doubt of the land requiring draining; but you may now admit that you may be deceived by land showing even favorable symptoms of drouth. For all that you yet know to the contrary, water may be lurking under what you imagine to be dry soil. Yes, and it does lurk to a very great extent in this country, and will continue to lurk in humid localities and impervious subsoils, until a vent is given to its egress.

(676.) The phenomenon of the dark spots on fields can be satisfactorily explained. Where the surface of the land is at all permeable to water, and where it rests on beds of different depths, of various lengths and (595) 
breadths, and of diflerent consistence, the water supplied from rain or snow is interrupted in its progress by the retentive heds, and hecomes accumulated in them in larger or smaller quantities, according to their form and capacity; and, at length, the superfluous portion is poured from the surcharged strata, and bursts over retentive heds through the surface-soil in the form of land-springs, at a somewhat lower level. Such springs are either concentrated in me place or diffused over a large extent of surface, according as their outlet happens to be extensive or confined, and deep draining is generally required to remove these; for which purpose, deep drains are cut through alternate beds of retentive and permeable matter, and penetrate into the very seats of the springs. It may happen, however, that the surface is as retentive as the subsoil, in which case the water, not penetrating farther thau the surface-soil, has a free enough passage between the impervinus sulsoil and the loose suil; this state of soil requires mere surtace-draining. Where the upper soil is pervious, and the subsoil uniformly and extensively retentive, water accumulates on the subsoil, to the injury of plants growing on the surface-soil; and to remove water from such a situation, not deep but numerous drains are required to give sufficient opportunities for it to pass away, and such drains are usually formed in the furrows. Where the soil and subsoil are both porous, the water passes quickly through them, and no draining is required to assist it in flowing away, as the entire subsoil constitutes a universal drain. In this state of soil, water is only held in it by capillary attraction, and what is not so supported sinks down through the porous subsoil by its own gravity. Capillary attraction is quite capable of supporting and bringing as much water through a permeable soil and subsoil, from rain above and sources of water from below, as is useful to vegetation, excepting, perhaps, under the extraordinary occurrence of excessive drouth; and of all the sources from which the soil derives its supplies of water, that from springs is the coldest, most injurious to useful plants, and most permanent in its effects: and hence it is that the abstraction of water from the soil by draining does not necessarily interfere with it as a supporter of plants, as a meliorator of the soil, as a menstruum for the food, as a regulator of temperature to plants.

(677.) These states of water in the soil and subsoil indicate that a knowledge of geology might confer a more perfect understanding of the principles of draining; and, fortunately, practice in this department of rural economy has always been consistent with the facts of geology. But a geological drainer is a character who has not yet made his appearance in the world; because no practical drainer or scientific geologist has yet explored that department of geology which is most useful to Agriculture, in such a manner as to assist the art of draining. Most of our arable soils are contained within the newest rock formations, the intricate relations of which present almost insurmountahle obstacles to such a knowledge of them as to be useful in draining. The intricacy of their relations render the operations of draining uncertain; and this uncertainty, I fear, must continue to exist, until the relations of the alluvial rocks are discovered to be as unvarying as those of the more indurated. Perhaps a certainty in the matter is unattainable, because the members of the alluvial formation may not present a strictly relative position to one another. Until the fact, therefore, is ascertained one way or the other, draining must be conducted, in a great measure, by trial or experiment; and in all undertakings on trial, error must be expected to ensue, and unnecessary expense incurred. An unfortunate circumstance, arising from this uncertainty, is the comparative uselessness of the experience acquired in previous operations (596) 
to guide the drainer himself and others, to the means of securing more certain results in their future efforts at draining. No drainer can affirm that the number and depth, and even the direction, of the drains which $\mathrm{h}$ chooses to adopt, are the best suited for drying the field he wishes to drain nor can he maintain that exactly similar arrangements will produce ex actly similar effects in the adjoining or in any other field, at a greater os shorter distance. Every experienced drainer will coincide with the justness of these remarks, and deplore the uncertain nature of his operations; but, nevertheless, the satisfactory consolation is, that as long as he finds draining, even as it is pursued, do good, so long he will continue to practice it. Were geologists to make themselves acquainted with the practical details of draining, and then study that branch of geology which would be of greatest service to draining, it is reasonable to hope that they would confer lasting obligations on the drainer, not only by dixecting him to a well-grounded certainty in his object, but by showing him how to execute his art with greater simplicity. Were they also to direct particular attention to the relation that subsists, if any, between the surface of the earth's crust and the strata immediately subjacent, their investigations might supply valuable materials for a correct nomenclature and classification of soils.

(678.) You thus perceive that a bare recital of the various modes of draining is not alone sufficient to make you an accomplished drainer; for you should know the principles as well as the practice of the art. The principles can enly be acquired by a knowledge of geology, in as far as it has investigated the structure of the alluvial rocks, which are within your reach everywhere, and entirely within your power on your own farm to investigate. This knowledge, even as it is yet known, is requisite ; for any difficulty in draining is found not so much in constructing a drainmost field-laborers can do that-as in knowing where to construct it ; and a correct knowledge of whether the wetness in the land arises from natural springs or from stagnant water under the surface of the soil, can alone direct you to open the kind of drain required. So generally is the practical part of the operation diffused, that every manager of land conceives he knows the whole subject of draining so correctly, that he will commence his operations with the utmost confidence of success; and this confidence has caused much money to be expended in draining, that has in great part been ill directed; not but that its expenditure has done good, but that it has not done nearly all the good that the means employed might have effected. Much money has thus been expended in many places in making a few scattered deep drains, where a greater number of smaller ones would have answered the purpose much better. A degree of success, however, has attended every attempt at draining, and it is this circumstance, more than any other, that has beguiled many into a belief that they are accomplished drainers; for no one, unfit to direct the operation in a proper man ner, would have attempted it at all, unless he had actually experienced in jury from wet land; or have attempted it again, unless his attempts had partially, at least, removed the injury; though the results have not been very successful. Were the efforts of ignorance in draining confined to the squandering of money, they might be compensated for by superior man agement in the other operations of the farm; but, unfortunately, the sinking of valuable capital in injudicious draining cripples the means of the farmer, and at the same time prevents his reaping all the advantages derivable from draining itself. Were draining an operation that could be executed at little cost and trouble, it would be of less importance to urge its prosecution in the most effectual way; but as it is an expensive opera-

(597) 
tion, when conducted in the most economical manner, much consideration should be given to the matter in all its bearings, before attempting to break up ground for draining to any great extent. An examination of the earth's crust, upon which you are to operate, is absolutely necessary to direct your plans aright. Contemplate well, in the first place, the facts which such an examination unfolds to your view, and endeavor by their nature to acquire wisdom to expend your money with prudence as well as skill. Examinations of the soil and subsoil will tell you what kinds require deep draining, and what kinds may be treated with equal success under a different arrangement. Inattention to such distinctions as these has hitherto caused the inordinate application of one general principle, which, as applicable to a particular system, must receive the assent of every drainer who feels the importance of the art, but which, nevertheless, is inapplicable to every case-I mean the system of deep draining.

(679.) You may have observed, from what has been said, that there is more than one species of draining; there is one which draws off large bodies of water, collected from the discharge of springs in isolated portions of ground; and this is called deep or under-draining, because it intercepts the passage of water at a considerable depth under the surface of the ground; and there is another kind which absorbs, by means of numerous channels, the superabundant water spread over extensive pieces of ground under the surface, and has been called surface-draining. This latter kind of draining subdivides itself into two varieties, the one consisting of small open channels formed on the surface of the ground in various directions for the ready use of water flowing upon the land, and this is literally surface-draining. The other is effected by means of small drains constructed at small depths in the ground, at short distances from one another, and into which the water as it falls upon the surface finds its way by its own gravity through the loose soil, and by which it is discharged into a convenient receptacle. But for those two species of surface-drains, the water that falls from above would remain stagnant upon the retentive subsoil at the bottom of the plow-furrow. The former kind of surface-draining is called gaw-cutting, so named from its resemblance to " a mark or crack left in the soil by a stroke or pressure;"** the latter kind derives its name either from the locality which it occupies, or the arrangement of its lines. From its local position, it has been called furrow-draining when it occupies the open furrows of the ridges of a field, though it is not necessary that such drains should always occupy the furrows. It has also been called frequent-draining, from the circumstance of the water finding frequent opportunities of escape; but this name, though the original one, is objectionable, inasmuch as the word may imply that the field requires draining frequently, which it certainly will not. From the arrangement of its lines, it has also been denominated parallel-draining, on account of the usual parallel position of the drains to one another; and yet it is not absolutely necessary to success that they shall be parallel to one another. As by this kind of draining the land is thoroughly or effectually drained, it has been most appropriately called thorough-draining; and this term, as a nomenclature, has the advantage of not committing the drainer to the adoption of any particular form or position of drain, but only to that form or position which renders land thoroughly dry. There are various other modes of draining, such as wedge-draining, plug-draining, mole-draining, each of which will receive consideration in due course.

* See Jamieson's Scottish Dictionary. Gav. $(598)$ 
(680.) The most superficial mode of draining is that effected by open ditches and gaw-cuts, into which the surface-water flows, and is carried off to a distance to some river or lake. This mode of draining does not profess to interfere with any water that exists under the surface of the ground, farther than what percolates through the plowed furrow-slices, and makes its way into the open furrows of the ridges. For the purpose of facilitating the descent of water into the open furrows, the ridges are kept in a bold, rounded form; and that the open furrows may be suitable channels for water, they are carefully water-furrowed, that is, cleared out with the plow after the land has been otherwise finished off with a crop. The gawcuts, small channels cut with the spade, are carefully made through every natural hollow of the ground, however slight each one may be, and the water-furrows cleared into them at the points of intersection. The gawcuts are continued along the lowest head-ridge furrow, and cut across the hollowest parts of the head-ridge into the adjacent open ditch. The recipient ditch forms an important component part of this system of draining, by conveying away the collected waters of the field of which it forms the boundary, and for that purpose is made as much as 4 or 5 feet in depth, with a proportional width. It is immediately connected with a larger open ditch, which discharges the accumulated waters from a number of recipient ditches into the river or lake, or other receptacle which is taken advantage of for the purpose. The large ditch is from 6 to 10 feet in depth, with a proportional width, and, when conveying a full body of water in winter, appears like a small canal. It is evident, from this description, that this is a system of pure surface-drainage, and is only applicable to soils that retain water for a long time on the surface, that is, on very tenacious clays; and, accordingly, it is extensively practiced in such districts as the Carse of Gowrie, where it has been so for a very long period. The large ditches there are called pows, which literally mean mires. The plowmen of the Carse are accustomed to the spade, and are yearly employed, in the proper season, in scouring out the smaller ditches, the larger ones being only scoured occasionally. Whenever a heavy fall of rain occurs in winter or spring, they are employed in clearing out the gaws, and directing the water as fast as possible off the land along the furrows. This operation is a necessary precaution in wet weather upon strong clay land, but it constitutes a very imperfect system of draining, and sacrifices a large extent of goód surface-soil. It would be better, I think, if the Carse farmers were generally to try the effect of covered drains, which would absorb and carry away surplus water equally well as open ones, and save much time in scouring ditches, besides putting the soil into a fitter state to be worked at any season than it can be done under the present system.

(681.) The drains which our forefathers made in loamy snils, resting on a retentive bottom, were placed upon the subsoil immediately under the upper soil, where that was deeper than the plow-furrow; but as the arable portion of the soil, when it is quite of a different nature from the subsoil, is never very thick, the drains were necessarily placed at a small depth; and, the cut being so, experience would soon teach drainers the impropriety of placing the materials which are used to fill a drain within reach of the plow, which consisted of very few stones, often not exceeding three, and those not of large size-one being placed on each side of the cut, and another above them, forming a sort of conduit. These conduits being not far from the surface, of small area, and not very numerous in any one place, a small addition of water would carry, and the moles would force a little earth into them, sufficient to obstruct the flow of water in them; and, of course, any drain in that state would produce the very mis: (599) 
chief it was intended to remedy. Such paltry drains have evidently been formed on the notion that a simple conduit, placed between a porous soil and retentive subsoil, is sufficient to render the soil permanently dry-a notion the fallacy of which the drainers of the present day are well aware. I have met with several such drains in the course of my draining operations, and they were completely choked up; but on being opened, by the cutting of the new drains, clear water flowed out of them for a considerable time. They were all beyond the reach of the plow, in the manner in which the land had been plowed from time immemorial; but the plowing had consisted of a mere skimming of 4 inches of the soil, and on this account the black mould immediately under the plow-track had been com pressed by the sole of the plow into a thin, slaty crust, under which the fine black virgin mould remained untouched, while the plowed surface had become an effete powder by constant cropping.

(682.) Compared with this trifling method, the system of under or decpdraining, being the deepest method of any, is super-excellent. It is technically called Elkington's method, because it was first proposed and practiced by Mr. Joseph Elkington, Princethorp, a farmer in Warwickshire, so long ago as 1764. It is related that he discovered the mode of draining, which has since borne his name, by accident. His fields being very wet, and rotting many of his sheep, he dug a trench 4 or 5 feet deep, with the view of discorering the cause of the wetness. While he was deliberating what was to be done, a servant passed by chance with an iron crowbar for fixing sheep-hurdles with in the ground. Having a suspicion that the drain was not deep enough, and desirous to know the nature of the materials under it, he forced the bar 4 feet below the bottom of the trench, and, on pulling it out, to his astonishment, a great quantity of water welled up through the hole it made, and ran along the drain. He was led to infer from this that large bodies of water are pent up in the bowels of the earth, and are constantly injuring the surface soil, but which may be let off by tapping with an auger or rod. This discovery produced a great sensation at the time, and, in fact, introduced a complete revolution in, this country in the art of draining. It served to establish draining on correct principles. It was as much more effective a method than the old system, in changing the quality of the soil, as blood-letting from a vein by the lancet affects the constitution in a greater degree than the topical application of leeches. But this method soon underwent modifications in practice.Casting a drain and tapping with an auger to catch the spring or bed of water, as in the principle of Artesian wells, was the original plan; but when it was found that water did not in every case follow the auger, as it would not when disseminated through a mass of earth, and not subjected to altitudinal pressure, a modification of the plan was inevitable. It was then attempted to run deep trenches through the lowest part of the damp soil to the highest point where the supply of water was supposed to be, or where it made its appearance, and lead it away as it collected by percolation through the soil and subsoil. In order to embrace the whole damp soil of any locality in the drainage, lateral branches were projected on both sides of the main branch, as far as the apparent dampness extended; and, not to omit the smallest extent of the damp soil, tributary branches were sent off to short distances from the lateral ones. The different branches were made of different sizes, according to the quantity of water which each was supposed to have to convey away. This plan of drains, when projected on the surface, looks like the trunk and branches of a tree in winter deprived of its leaves, and it might therefore be called the ramified or dendritic form. This is the plan that has been very extensively pursued since $(600)$ 
Elkington's time until about 1 S24, since which another system has obtained the preference. Many thousands of acres of land had been drained by that method up to that time, and there is no doubt that the country has derived much benefit from the system. I may mention the fact, as an incentive to important discoveries, and as an instance of disinterestedness, that Elkington willingly communicated all his practice to the late Mr. John Johnstone, the eminent drainer, at the request of the Board of Agriculture, through whose influence the British Parliament voted him a reward of $£ 1,000$.*

(683.) It will much facilitate your conception of this system of draining, if we consider, in the first place, the source from which the water that mars the cultivated soil is derived. When water is evaporated by heat from the sea and land, and conveyed in vapor into an elevated part of the atmosphere, and there retained in an invisible form by the agency of electricity, it remains in that state until a change takes place in the electric equilibrium, when the vapor becomes visible in the form of clouds, which, then becoming independent bodies, become at the same time subject to the laws of physical attraction. Being attracted by the mountains, which are the highest features of the terrestrial portion of the globe, they come into contact with them, give out part of their caloric to them, and, ultimately dissolving, descend upon them in the shape of fog, or rain, or snow. Hence, as you have already seen (324), rain falls much more plentifully upon the mountains than the plains. The rain, as it falls upon the mountains, is absorbed at once by the soil which covers them, and, when it cannot contain any more, the surplus water flows away, and forms streams and rivers.The portion of water retained by the mountain soil undergoes a very different fate. It is conveyed by its own gravity chiefly, and partly by their capillary attraction, among the mineral strata of which the mountain mass is composed, and continues to seek its way through them until, reaching a point beyond which it meets with no resistance, it comes forth to the day in the shape of a strong spring or springs, or, diffused over the whole surface of the mineral mass, it spreads over a large extent of ground. These different destinations of the same water are occasioned by a difference in the nature and positions of the geological formations of the mountain mass. For example, if the whole rising ground, from its base to the summit, is spread over with a saddle-shaped covering of tenacious clay, the water will slide down its face, under the vegetable coating of the surface, as far as the clay descends, which may be to the plain below. This vegetable covering will be permanent grass, if the elevation of the ground is not great; or it will be heath and mosses, if the elevation exceed such a hight as that the mean annual temperature of the air around it does not exceed $40^{\circ} \mathrm{Fah}-$ renheit ; or it may be mould capable of supporting cultivated crops. Thus, in fig. 143, $a$ is the clay over the hill; if rain fall on $a$, it will descend on

Fig. 143.

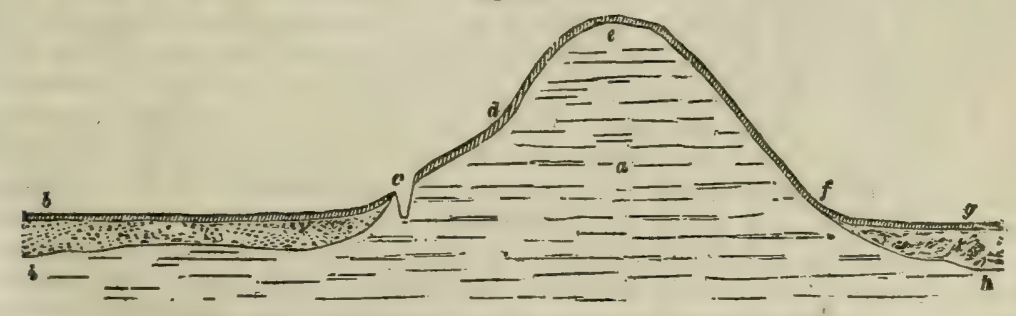

THE ORIGIN OF SPRINGS ON A UNIFORM TENACIOUS SURFACE.

- See Sinclair's Code of Agriculture, notes.

(601) 
the one side to $d$ and on the other to $f$, and, if the temperature of this region is under $40^{\circ}$, def will form the region of heath and mosses. The water will still pass from $d$ to $c$, which is the region of permanent pasture, and it will continue to flow to the plains, to $i$ under $c b$, and to $h$ under $f g$. The vegetable mould may be traced from $b$ by $c, d, e$ and $f$, to $g$. Should the subsoil between the mould $b$ and the clay $i$ be also retentive, then the water will appear at the surface at $c$, and affect all the space from $c$ to $b$; but, should the subsoil from $h$ to $g$ be porous, then the water will continue to flow from $f$ upon the clay $h$, and not affect the surface-mould $f g$.

(684.) Should the mountain, however, consist of concentric layers of different rocks arranged mantle-shaped around it, then the water will descend between the lines of junction of the rocks; and should the masses or beds of rock be of different extents, and thickness, and consistence, which is probable, then the water will either appear at the surface of the ground as a spring, from the subjacent rock of a close texture, or it will descend yet lower, and be absorbed by the subjacent rock of a porous texture. In this manner, the harder rocks cause the springs to appear at a high elevation, while the porous ones convey the water to a lower level, until it meets with a resisting substance to cause it to come to the day. In any case the farmer cannot do anything until the water indicates its presence on the surface of the ground, either at a high or low elevation; and then he should take measures accordingly to remove it.

(685.) To illustrate the cases now alluded to, suppose fig. 144 to repre-

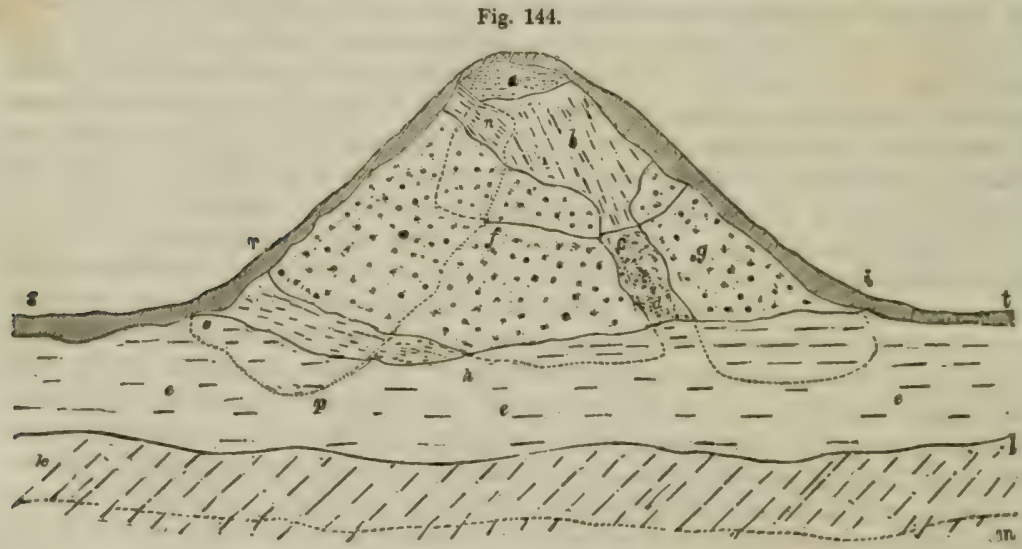

THE ORIGIN OF SPRINGS ON A VARIED SURFACE.

sent a hill composed of different rocks of different consistence. Suppose the nucleus rock $a$ to be of close texture, when the rain falls upon the summit of the hill, which is supposed not to be covered with impervious clay as in the case above, but with vegetable mould, the rain will not be absorbed by $a$, but will pass down by gravity between $a$ and $b$, another kind of rock of close texture. When the rain falls in greater quantity than will pass between these rocks, it will overflow the upper edge of $b$ and pass over its surface down to $c$, but as $c$ is a continuation of the nucleus impervious rock $a$, a large spring will flow down the side of the hill from $c$ and render the ground quite wet to $d$, where meeting another large stratum of impervious rock, it will burst out to-day a large spring at $d$, which will be powerful in proportion to the quantity of rain that falls on the mountain. On flowing down $b$, part of the water will be intercepted by (602) 
the rocks $j$ and $g$, both of which being porous, will absorb and retain it unil surcharged. The surplus water meeting with the impervious rock $e$, will be partly thrust out to-day along the black line $d h$ on the one hand, and $d i$ on the other, when the whole line $h i$ will present a long dark line of wet oozing out of the soil, with the spring $d$ in the center, and which darkness and dampness will extend down the inclined ground as far as the upper line $k l$ of that porous stratum of rock. Part of the water absorbed by the porous rocks $f$ and $g$ will be conveyed under the impervious rock $e$, and come out at their lowest extremities, following the curved dotted lines $h d$ and $d i$, and continue to flow on until it reaches the lowest extremity of $e$ in the dotted line $k l$, where it will be absorbed by the porous rock $m$.

(686.) By such an arrangement of rocky strata on the side of a moun tain range, will be exhibited specimens of both wetness and dryness of soils. The summit $a$ will be wet, and so will the surface of $b$, but the surfaces of $f$ and $g$ will be dry. Again, the surface of $e$ will also be wet, but less so than that of $b$, because part of the water is conveyed by $f$ and $g$ under $e$ to the dry stratum $k l$, which being probably thicker, and, at all events, of greater extent, will be drier than either $f$ or $g$. On another side of the side of the hill another result will take effect. The rain falling on the summit $a$ will descend between $a$ and $n$, as far as the lowest extremity of $n$ along the dotted line $o p$, which being under the impervious rock $e$, the water will continue to flow out of sight until it descends to $k l$, where it will be absorbed by the porous rock $m$, and thus never appear at all either as a spring or a line of dampness. But should the quantity of rain at any time be greater than what will pass between $a$ and $n$, it will overflow $n$ and be absorbed in its descent by the porous rock $f$, which, after becoming surcharged, will let loose the superfluous water in the line $\hbar r$, upon the continuation of the rock $n$, part of which will come to-day along the line $h o$ of the impervious rock $e$, and part conveyed down by $o$ $p$ to the porous rock $k l$, where it will be absorbed. Thus, on this side of the hill, as long as little rain falls, none but its summit will be wet, and all the rest will be dry, though the surfaces of $f$ and $k$ will always be drier than those of $n$ or $e$; but after heavy rains dampness will show itself along the line $h r$, will extend itself even to the line of $k l$, should the rain continue to fall some time.

(687.) The line $s$ by the summit $a$ to $t$ is the mould line pervious to moisture, and which is here represented as is frequently exhibited in nature, namely, a thickness of soil on the southern side of the hill as from $a$ to $i$, and a thickness of soil on the northern basis, as from $r$ to $s$; but a thinness of soil on the southern face, as from $a$ to $r$. It is not pretended that this figure is a truly geological portrait of any mountain. Perhaps no such arrangement of strata actually exists in any single hill, but such overlying and disconnected but conterminous strata do occur over extended districts of hilly country which produce springs much in the way just described. Similar courses of water occur in less elevated districts, though it remains more hidden under the deeper alluvial rocks.

(688.) Now let us apply Elkington's method of draining to these two cases of wetness, and which are of ordinary occurrence. The hill in fig. 143 being supposed to be covered saddle-shaped with an impervious stratum of clay, no water can descend into it, but will flow over it: $a$ is the clay stratum ; $b$ also an impervious stratum, but not so much so as $a$, containing veins of sand and nodules of stones, and forming a very common subsoil of this country. It is clear that the whole extent of ground from $e$ to $b$ will be wet on the surface, and the wetness will not exhibit itself (603) 
in bands, hut he diffused in a uniform manner over the whole surface; but as $b$, in this case, is not so tenacious as $a$, the side of the hill from $c$ te $c$ will always be wetter than the flat ground from $c$ to $b$, because some of the water will he absorbed and kept out of sight in the looser clay $b$. The only method of intercepting the large body of water in its descent down $d$ is to cut the deep drain at $c$, not only sufficiently large to contain all the water that may be supplied from above $c$, but so deep as to catch any oozing of water from $a$ tuward $b$. What the depth of this drain should be it is not easy to deternine without farther investigation, and to enable that investigation to be made, a large drain should be cut on the flat ground in the line from $b$ to $c$, which will also answer the purpose of leading away the water that will be collected by the transverse drain $c$. Suppose the subsoil from $b$ to $i$ is 4 feet thick, then this leading drain should be made $\frac{1}{2}$ foot deeper, namely $4 \frac{1}{2}$ feet, in order that its sole may be placed in impervious matter; and in this case the drain $c$, of the depth of 6 feet, may suffice to keep the flat ground dry. But if from $b$ to $i$ is 8 or 10 feet in depth, then it would be advisable to make the leading drain from $b$ to $c$ at least 6 feet deep, in order to drain a large extent of ground on each side of it, and the drain $c$ may still do at its former depth, namely 6 feet. Should the bottom of the leading drain get softer and wetter as the cutting descends, its depth should either be carried down to the solid clay at $i$, or perhaps it would be well to try auger holes in the bottom, with the view of ascertaining whether the subjacent water migkt not rise to and flow along it. The expedient of boring will be absolutely necessary if the depth from $b$ to $i$ decreases as the distance from the hill increases, for there would be no other way of letting off the water from the basin of the clay from $i$ to $c$. Should the flat ground be of considerable extent, or should the face of the plain undulate considerably from right to left, a leading drain will be required in every hollow; and each of them should be made deeper or shallower according as the subsoil is of a drawing texture or otherwise, bearing in mind that the sole of the drain should, if possible, rest upon an impervious substance, otherwise the water will escape through the pervious matter, and do mischief at a lower level. The subsoil between $g$ and $h$ being supposed to be gravel or other porous substance, it is clear that no drain is required at $f$ to protect the soil between $f$ and $g$, as the porous subsoil will absorb all the water as it descends from $e$ to $f$.

(689.) As to the wet surface of the hill itself $c d e f$, it being composed of impervious clay, must be dried on the principle of surface-draining; that is, if the ground is in permanent pasture for the support of sheep, a number of transverse open sheep drains should be made across the face of the hill, and the water from them conveyed in open ditches into the great drain $c$; or if the ground is under the plow, small covered drains will answer the purpose best; and the contents of these can be emptied into the large drain $c$, and conveyed down the large leading drain to $b$. Thus, in fig. 145, $a b$ is the main drain along the flat ground into which the large drains $c b$ and $d b$ flow. It may be observed here that when one large drain enters another, the line of junction should not be at right angles, but with an acute angle in the line of the flow of water, as at $b$. The open surface-drains in permanent pasture exhibit the form as represented in this figure, where the leaders $e f$ and $g h$ are cut with a greater or less slope down the hill according to the steepness of the acclivity, and the feeders across its face nearly in parallel rows, into their respective leaders. In this way the water is entirely intercepted in its descent down the hill. I may mention that where small drains enter larger, they should (604) 
not only enter with an inclination, as remarked above, but where they come from opposite sides, as in this case, they should enter at alternate distances, as seen in the case of the three drains above $f$, and not as shown

Fig. 145.

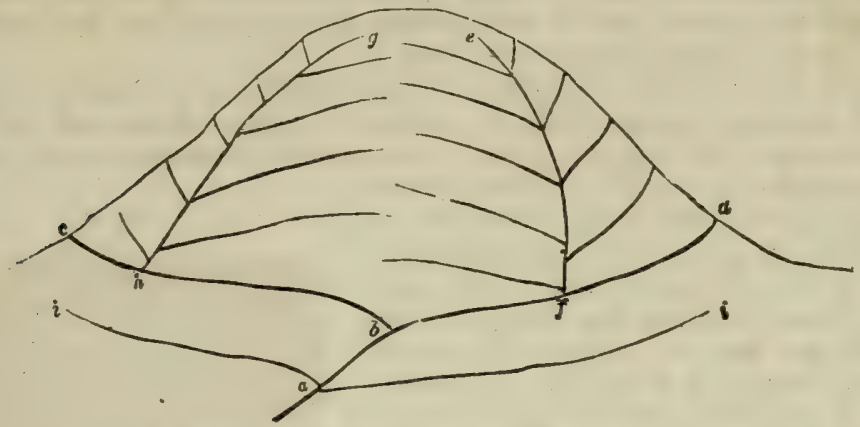

A PLAN OF SHEEP DRAINS ON A HILL OF IMPERVIOUS SUBSOIL

in the fourth and fifth drains. The large drain $c b d$ may either be left open or covered. Should it form the line of separation between arable ground and permanent pasture, it may be left open, and serve to form a fence to the hill-pasture; but should the entire rising ground be under the plow, this, as also the main drain $a b$, and all the small drains, should be covered.

(690.) There are various ways of making small drains in grass. One plan is to turn a furrow-slice down the hill with the plow, and make the furrow afterward smooth and regular with the spade. When the grass is smooth and the soil pretty deep, this is an economical mode of making such drains, which have received the appellation of sheep drains. But where the grass is rough and strong, and swampy places numerous, the plow is apt to choke with long grass accumulnting between the coulter and beam, and makes very rough work, and the horses are apt to overstrain themselves in the swampy ground. The lines of the drains should all be previously marked off with poles before the plow is used.

(691.) A better though more expensive plan, is to form them altogether with the spade. Let $a$, fig. 146 , be a cut thrown out by the spade, 9

Fig. 146.

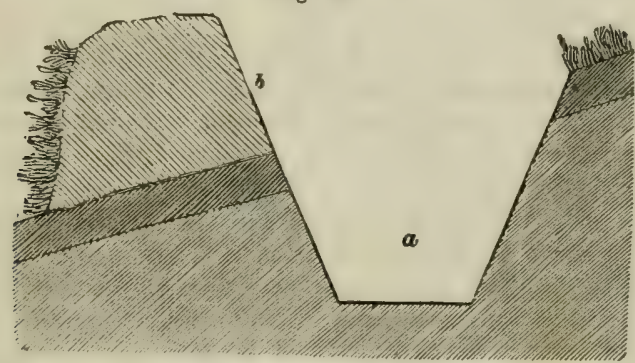

AN OPEN SHEEP DRAIN ON GRASS.

inches wide at bottom, 16 inches of a slope in the high side, and 10 on the low, with a width of 20 inches at top on the slope of the surface of the ground. A large turf $b$ is removed by the spade, is laid on its grassy side downward, on the lowest lip of the cut, and the rest of the earth is placed (605) 
at its back to hold it up in a firm position, the shovelings being thrown over the top to finish the bank in a neat manner. Such a drain catches all the water that descends in the space between it and the drain above, and leads it away to the sub-main drain, such as $e f$ or $g h$, which is of similar construction, but of larger dimensions, running up and down the hill, and the lower end of which finds an entrance into the large main drain at the margin of the arable land.

(692.) Another sort of sheep-drain is formed as represented in fig. 147. A cut is made 6 inches wide at bottom, 16 inches deep, and 18 inches wide at top. The upper turf $a$ is taken out whole across the cut, as deep as the spade can wield it. Two men will take out such a turf better than one. It is laid on iss grassy face upon the higher side of the drain, and the earth pared away from the other side with the spade, leaving the turf of a trapezoidal shape. While one man is doing this, the other is casting out with a narrow spade the bottom of the cut $b$. The earth and shoveling should be spread abroad over the grass; and the large turf $a$ then replaced in its natural position, and tramped down, thereby leaving an open space $b$ below it for the water to pass along. This is not

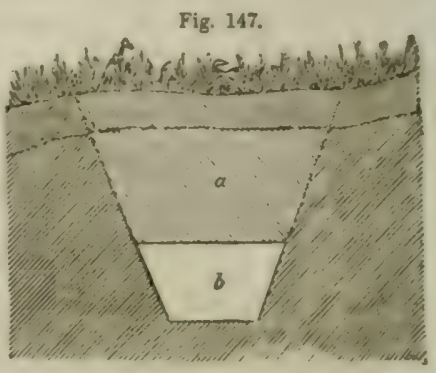

A COVERED SHEEP DRAIN IN GRASS. so permanent a form of sheep drain as the last, nor is it all suitable in pasture where cattle graze, as they would inevitably trample down the turf to the bottom of the drain. It is also a temptation for moles to run along; and when any obstruction is occasioned by them or any other burrowing animal, the part obstructed cannot be seen until the water overflows the lower side of the drain, when the turfs have again to be taken up, and the obstruction removed. It forms, however, a neat drain, and possesses the advantage of retaining the surface whole where sheep alone are grazed. Figs. 146 and 147 are drawn on a scale of $\frac{1}{8}$ inch to 2 inches.

(693.) Having described the various modes of pure surface-draining, and traced the origin of springs, immediately connected with which arises the necessity for the sheep drains just described, I shall now proceed to you the deep, or Elkington's method of draining, which is peculiarly well adapted for draining isolated hollow spots of ground. These are usually formed by water standing in winter on an impervious clay subsoil, the water being either entirely derived from rain-in which case the pool becomes dry in summer-but most frequently partly from rain, and partly from springs in the subjacent strata fed from a higher source. Such pools are drained either by horing holes through the impervious clay into a porous stratum below-should such a stratum exist-or by a deep drain, having an efflux at a lower level.

(694.) I shall give you an account of the successful draining of such a pool. It was covered with water in winter to the extent of about 2 acres, in the center of a field of 25 acres; and though no water was visible in summer, its site was always swampy. It obtained the name of the "Duckmire," wild ducks beiug in the habit of frequenting it every season. On taking a level from its water, it was found that a drain of 10 feet in depth would be required to carry it away in a $2 \frac{1}{2}$-feet-deep drain through the pool. The outlet was on the top of a clay-bank about 150 yards distant from the nearest margin of the pool, rising perpendicularly 40 or 50 feet above the bed of a small river, and was the nearest point for a fall from (606) 
the pool. The operations were performed in summer, when the pool was comparatively dry. The deep cut of 10 feet was first executed; and to render it ever after secure, a cunduit of 9 inches in width by 12 inches in hight was built and covered with land-stones obtained from the field by trench-plowing, above which about 2 feet of stones were placed and covered with turf before the earth was returned into the deep cut. The continuation of the main drain was carried right through the center of the pool, where it could only be formed 30 inches deep, in order to preserve the requisite fall. Another drain, of 3 feet in depth, encircled the area of the pool a little above the water-mark, and was let by each end into the main drain. Both these drains were made 9 inches wide at bottom, to contain a coupled duct of 4 inches in width; and filled with small round stones, admirably adapted for the purpose, none exceeding the size of a goose's. egg, gathered from the surface of the field. The stones were blinded with withered wrack, and the earth returned above them, first with the spade and then with the plow. The pool was at once determined to be drained in this manner, because the high bank of clay above the river-and which formed the entire subsoil of the field-forbade any attempt at boring to a porous stratum below.

(695.). But a difficulty occurred in passing the drain through the center of the pool, which was not foreseen. A complete quicksand was met with, the bottom of which, resting on the clay, was much below that of the deep cut. To have effectually drained the quicksand, the cut should have been made at least 13 feet in depth; so that about 2 feet deep of quicksand were obliged to be left beneath the drain ; and how to construct a lasting drain upon such a foundation, was a puzzling thing, as the wet sand thrown out by the spade was followed by larger quantities sliding down from each side of the drain, and filling up the emptied space.

(696.) It is here worthy of remark, that I committed a mistake in not ascertaining the existence of the quicksand, and of its depth, before beginning to cast the deep main drain; for I had only thought of making such an outlet as would enable me to make a drain of such a depth through the center of the pool as would drain it; whereas I ought to have ascertained in the first place, the nature of the strata under the pool, which would have made me acquainted with the depth of the quicksand; and the drain and outlet should then have been made of the depth to deprive the quicksand entirely of its water. However, as matters were, I was obliged to do the best to form a drain in the quicksand, and this was found to be a rather troublesome operation. Thick tough turfs were provided, to lay upon the sand in the bottom of the drain, and upon these were laid flat stones, to form a foundation on which to build a conduit of stones, having an opening of 6 inches in width and 6 or 7 inches in hight. The back of the conduit, when building, was completely packed with turf, to prevent the sand finding its way into it from the sides of the drain; and the packing was continued behind the few small rubble stones that were placed over the cover of the conduit. A thick covering of turf was then laid over the stones, so that the whole stones of the drain were completely encased in turf, before the earth was returned upon them. The filling up was en. tirely executed with the spade, in case the trampling of the horses should have displaced any of the stones; but these extraordinary precautions were only used as far as the quicksand was found to be annoying. After all the drains were finished, a large quantity of water flowed out of the main drain during the succeeding autumn and winter; but by spring the land was quite dry, the blue unctuous clay forming the bottom of the pool became friable, and on the soil and subsoil being intermixed by deep (607) 
plowing, the new and fresh soil, with proper mungement, ever after bore fine luxuriant crops.

(697.) A 12-acre field of good, deep land on the farm of Frenchlaw, in Berwickshire, was rendered swampy by springs and oozings of water from the surrounding rising ground being retained upon the clay subsoil. A 4-feet drain was formed all round the base of the rising ground, immediately above the line of wet, and several drains of 3 feet in depth were run through the flat part of the field. The outlet was obliged to be cut through a part of a field on the adjoining farm to the depth of 13 feet, conduited and covered over. The swampiness of the ground was completely removed, and the crops ever after were excellent.

(698.) Another application of Elkington's system may be successfully made in draining the springs or oozings of water around gravelly eminences standing isolated in single fields, or across more than one field, upon a bed of clay or other impervious matter. A circumvallation of drain around the base of the eminence, begun in the porous and carried into the impervious substance, having a depth of perhaps from 5 to 7 feet, and connected with a main drain along the lowest quarter of the field, will most effectually dry all the part of it that was made wet by the springs or oozings.

(699.) Bogs and marshes have been drained with great effect by Elkington's method. These almost always rest on basin-shaped hollows in clay; and, when this is of considerable depth, the only way of draining them is by bringing up a deep cut from the lowest ground, and passing it through the dam-like barrier of clay. But it not unfrequently happens that gravel or sand is found at no great depth below the clay on which bogs rest; in which case, the most ready and economical plan is to bore a hole or holes in the first instance through the clay, with an auger 5 inches in diameter; and, after the water has almost subsided, to finish the work by sinking wells through the clay, and filling them up with small stones to within 2 feet of the top.

(700.) I have never seen an instance of the draining of bog by boring or by wells; but the late Mr. George Stephens, land-drainer, instances two or three cases of bogs being successfully drained in Sweden by means of bore-holes and wells in connection with drains; and the late Mr. Johnstone adduces many as successful instances in this country.*

(701.) I have seen extensive and successful effects of drying bogs in Ireland by ordinary drains, especially Carrick Bog, at Castle Rattan, belonging to Mr. Featherstonehaugh, in the county of Meath. The plan consists of dividing the bog into divisions of 60 yards in breadth, by open ditches of 4 feet in depth and 4 feet wide at top, allowance being made for the sliding in of the sides and subsidence by drying, and which movements have the effect of considerably diminishing the size of the drains ; and these ditches are connected by parallel drains at right angles 3 feet 3 inches in deptn, and 18 inches in width. Fig. 148 is a plan of these drains, where $a$ are the large ditches and $b$ the small drains. The ditch $a$ at the bottom is that which takes away all the water to some large ditch, river, or lake. The fall in the ditches and drains is produced by the natural upheaving of the moss above the level of the circumjacent ground, and, of course, this peculiarity causes all the drainage of the bog to flow toward the land.

(702.) The small drains $b$, fig. 148, are made in this manner: A garden line is stretched at right angles across the division from the large open drain $a$ to $a, 60$ yards. The upper rough turf is rutted in a perpendicular direction along the line with a short edging-iron. The line is then shifted

* See Stephens's Practical Irrigator and Drainer. edition of 19:34: and Johnctone's Syatematic Treatige on Draining, tto edition of 1834 -both excellent works on the subject of deep draining. (608) 
18 inches, the width of the top of the drain, and another rut is made by the edging-iron. While one man is employed at this, another cuts out a

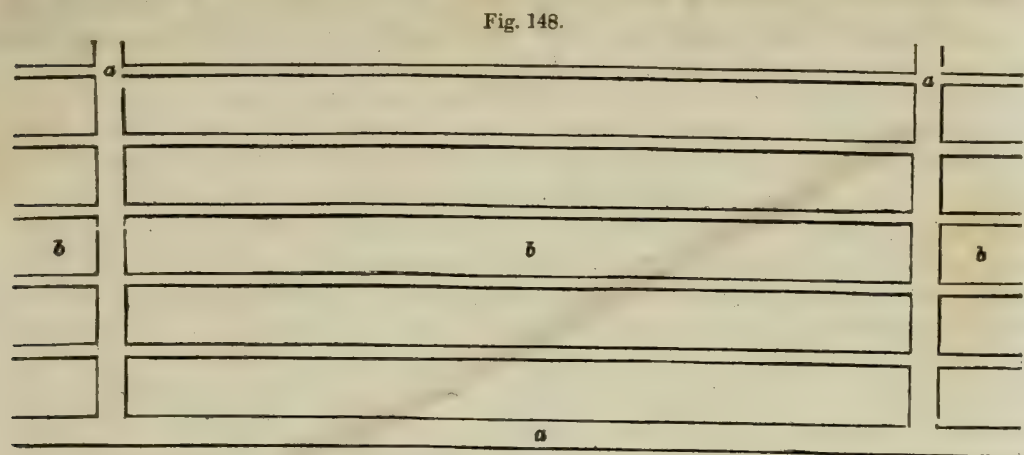

4 PLAN OF DRAINS FOR BOGS AS PRACTICED IN IRELAND.

thick turf across the drain with the broad-mouthed shovel, fig. 149; and, if any inequalities or ruggedness are observed in the wet turf, he makes them smooth and square with a stroke or two with the back of the shovel. The drain is thus left for two months to allow the water to run off, the moss to subside, and the turf to dry and harden.

(703.) At the end of that time the long edging-iron, fig. 150, is employed to cut down the sides of the drain in a perpendicular direction 2 feet 3 inches (see fig. 153), and the flat shovel is also again employed to cut the moss into square turfs, which in this case are not thrown out with the shovel-as on account of their wet state they cannot remain on its clear, wet face, when used so far below the hand-but are seized by another man with the small graip, fig. 151, and thrown on the surface to dry. The

Fig. 149.

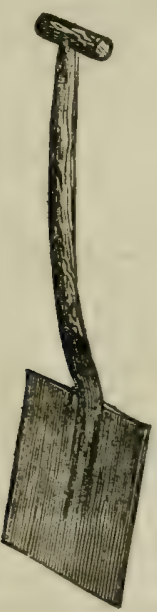

THE BROAD-MOUTHED SHOVEL.
Fig. 150.

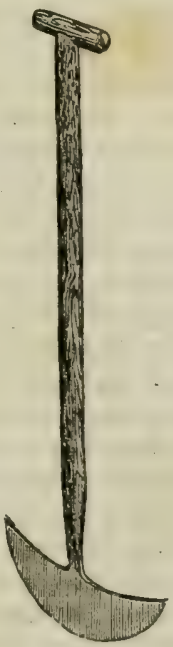

THE LONG EDGINO-IRON.
Fig. 151.

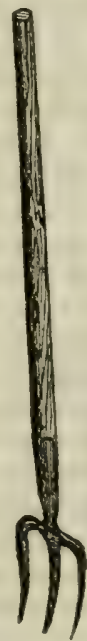

THE SMALL GRAIP.

work is again left for two months more, to allow time for the water to drain off, and the turfs to dry and harden. 
(704.) In these four months the moss subsides about 1 foot. After the two spits of the shovel, the longest edging-iron is again employed to cut down the last spit, which is done by leaving a shoulder $e e, 5$ inches broad, on each side of the drain, fig. 153. The scoop, fig. 152, is then employed

Fig. 15?.

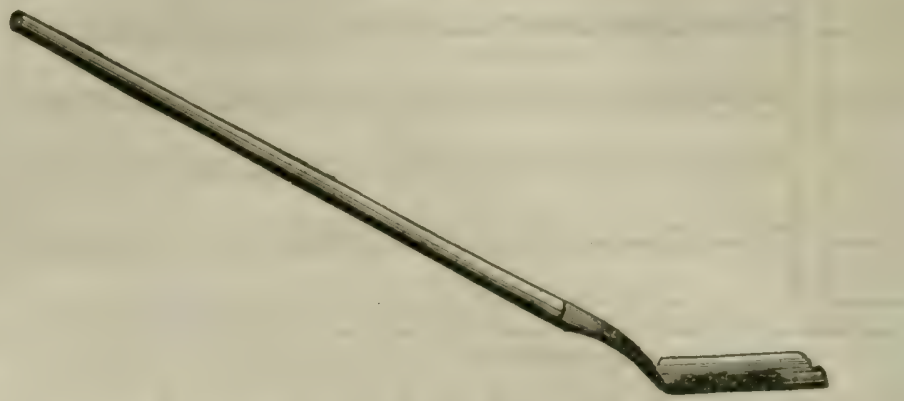

THE BUG JURIS SCUUP.

to cut under the last narrow spit, which is remored from its position by the small graip. The scoop pares, dresses and finishes the narrow bottom of the drain, with a few strokes with its back, making the duct $d 1$ foot deep.

(705.) The filling of the drain is performed at this time, and it is done in this manner. The large turf $b$, fig. 153, which was first taken out, and is now dry, is lifted by the hand and placed, grass side undermost, upon the shoulders $e c$ of the drain, and tramped firmly down with the feet. The second large turf $a$, which is not so dry or light as the first, is lifted by the graip and put into the middle of the drain, and the long, narrow stripes of turf $c e$ separated by the scoop from the bottom, along with other broken pieces, are also placed by the graip along both sides and top of the drain, and all the sods just fill up the subsided drain.

(706.) Fig. 153 represents the drain thus finished, which is well suited for the drying of bog, and in its construction possesses the advantage of having all the materials for filling it upon the spot. It is a wel-known property of dried moss that it resists the action of water with impunity, and the mode just described of making drains affords ample time for the drying and hardening of the turfs cast out of the drains; but it is not requisite for the efficiency of the turfs that they be dried, as they answer the same purpose quite

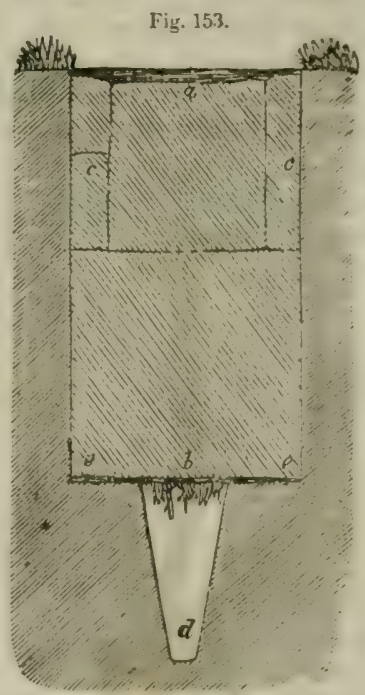

THE SHULLDERED BOG DRAIN. well in a wet state; but the time allowed for the subsidence of the moss itself is a great advantage to the drain, such materials being never again disturbed in a subsided bog drain. A hocr drain requires no other materials, such as wood or tiles, to fill it, there being no material so appropriate or more durable than the moss itself, the slightest subsidence in the drain destroying the continuity of the soles and tiles, whether of wood or clay, while those made of the latter substance will gravitate in the moss by their (610) 
own weight. To expedite the subsidence of the moss, the cutting of the drains is most successfully practiced in summer, when the drouth not only dries the turfs, but gets quit of a large proportion of the water by evaporation. The scale of this figure is $\frac{1}{8}$ to 2 inches, or $\frac{3}{4}$ inch to 1 foot.

(707.) These are all the cases, as I conceive, in which Elkington's method of draining can be applied, and even in them all it will not be attended with certain success, certainly not with equal success. I have frequently made lines of drains across the spouty sloping faces of fields, to the depth of even 6 feet, and never less than 4, without drying more than the breadth which they covered. In these cases I considered the cost of making them just thrown away; while in other cases 4-feet drains have completely removed the spouts, though the subsoil was apparently identically the same in them all. It is possible that the small veins of sand which were intersected by the cutting might, in the unsuccessful cases, dip away from the drains, and the water in them had perhaps ceased to flow in the same direction after their bisection, and in the successful cases the sand veins may have dipped with even a more favorable inclination for discharging their contents into the drains. Whatever difference of distribution there might have been in the component parts of the strata, in these opposite cases, there is little doubt that it was not sufficiently great to be indicated on the surface of the ground; and it is questionable that even the most minute investigation of apparently similar veins of sand, in similar strata, would zequaint us with their real positions, as it is not impossible that the most trifling difference in the relative positions of such veins may produce very lifferent effects upon the course of the water in the subsoil.

(708.) It is now necessary to describe to you the mode to be adopted in forming drains on Elkington's method. Before determining on the direction in which the lines of drains should run in the field proposed to be drained, it has been recommended to sink pits here and there, of such dimensions as to allow a man to work in them easily, and to a depth which will secure the exposure of the subjacent strata and the greatest flow of water, the depth varying perhaps from 5 to 7 feet. A previous examination of the underground is certainly requisite, and pits will certainly acquaint you with the arrangement of the substrata; and, had I pitted the bottom of the pool, the drainage of which I have described above (696), the depth of the quicksand would have been easily ascertained, and the main drain made commensurate with the circumstances of the case. But I agree with the late Mr. Wilson, of Cumledge, Berwickshire, that the driving of lines of drains from the bottom to the top of the field is the most satisfactory method of obtaining an enlarged view of the disposition of the subjacent strata, and, of course, of the depth to which the drains should be sunk.* Such lines of drains will not be useless; on the contrary they will form the outlets of the system of drains connected with each of them, and for that purpose they should be made in the lowest parts of the field.

(709.) Having thus ascertained the nature of the underground, the lines of the drains which run across from the mains should be marked off. This can be done by drawing a furrow-slice along each line; but a neater plan, and one which will not spend the time of horses at all, is to set them off by means of short stakes diviven into the ground, or, if the field is in grass, by small holes made in the ground with three or four notches of the spade, and the turf turned over on its grassy face beside each hole.

(710.) It is very desirable that the stones for filling the drains should be laid down along the lines in the order the drains are to be opened up, not

* Prize Essays of the Highland and Agricultural Society, vol. vii. (611) 
only on account of having them at hand when the filling process is to commence, and of thereby, perhaps, saving the labor of throwing out the earth that may have fallen down from the sides of the drain, when waiting for the stones, and of procuring additional stones for filling up the spaces thus enlarged, but of saving the horses much trouble in backing and forwarding the cart on the ground when it is necessarily much confined at the side of an opened drain. The stones should be laid down on the upper or higher side of the ground, if there be one, that the earth from the drain may be thrown upon the lower side.

(711.) Suppose that it has been determined to make the drains 6 feet deep. For this depth a width at top of 30 inches, and one at bottom of 18 inches, will be quite sufficient for the purpose of drainage, and for room to men to work in easily. This particular, in regard to the dimensions of the contents of a drain, should always be kept in view when cutting one; as even a small unnecessary addition either to the depth or width, and especially to both, of a deep drain, makes a considerable difference in the quantity of matter to he thrown out, and, of course, in the quantity of stones required for again filling up the excavated space. A simple calculation will at once show you the great difference there is in the contents of a drain a little wider and narrower than another; and the difference is much greater than you would imagine at first sight. A drain of the above dimensions-namely, of 6 feet deep, $2 \frac{1}{2}$ feet wide at top, and $1 \frac{1}{2}$ feet at botsom-gives an area by a vertical section of $22 \frac{1}{2}$ square feet, and, in a rood of 6 yards in length, a capacity of 405 cubic feet; whereas a drain of 6 feet deep, 3 feet wide at top, and 2 feet wide at bottom, as recommended in a particular instance by the late Mr. Stephens, ${ }^{*}$ would give a vertical section of 36 square feet, and a capacity of 644 cubic feet, creating more than 50 per cent. of additional work. And you should bear in mind that, provided the parts of a drain are substantially executed, its width, beyond that which will secure efficacy, cannot render it more efficacious. The rule for the width of a drain is very well determined by the ease with which men are able to work at the bottom; and, indeed, men working by the piece, when their work is measured longitudinally, will always prefer narrow to wide drains.

(712.) The cutting of drains should always be contracted for at so much per rood of 6 yards. The size of drain which I have just recommended (711) may be cut for from 1s. $6 \mathrm{~d}$. to 2s. per rood, according to the hardness or other difficulties of removing the subsoil. Where clay is very hard and dry, or very spongy, tough and wet, or where many boulders interfere, the larger sum is not too much; but where the subsoil can be loosened with ordinary picking, and is mixed with small sand veins and stones, the smaller sum will suffice. In such a contract, it should always be understood that the first portion of the earth in the refilling shall be returned into the drain by the contractor, and that he shall provide himself with all the tools necessary for the work.

(713.) The first operation in breaking ground is to stretch the garden line for setting off the width of the top of the drain, 30 inches-the drain being begun at the lowest part of the ground-and each division thus lined off consists of about 4 roods, or 24 yards. Three men are the most efficient number for carrying on the most expeditious cutting of drains.While the principal workman is rutting off the second side of the top of the drain with the common spade, the other two begin to dig and shovel out the mould-earth, face to face, throwing it upon the lower and opposite

- Prize Essays of the IIighland and Agricultusal Socicty, vol. vii.

(612) 
side from the stones. The first spit of the spade most likely removing all the mould, the first man commences the picking of the subsoil with the foot-pick, fig. 37 ; or, if the mould is too deep to be removed by one spit, and requires no picking, the first man digs and shovels out the remainder of it by himself with the spade. The mould is thus all removed from the lined-off break or division of the drain. When the picking commences, one man uses the foot-pick, working backward; another follows him with his back with a spade, and digs out the picked earth; while the contractor comes forward with the shovel, fig. 38, with his face to the last man, and takes up all the loose earth, and trims the sides of the drain. In this way the first spit of the subsoil is removed. Should the drain prove very wet, and danger be apprehended of the sides falling in, the whole division should be taken out to the bottom without stopping, in order to have the stones laid in it as quickly as possible. Should the earth have a tendency to fall in before the bottom is reached, short, thick planks should be provided, and placed against the loose parts of both sides of the drain, in a perpendicular or horizontal position, according to the form of the loose earth, and there kept firm by short stakes acting as wedges between the planks on both sides of the drain, as represented in fig. 154, where $a a$ are

Fig. 154.

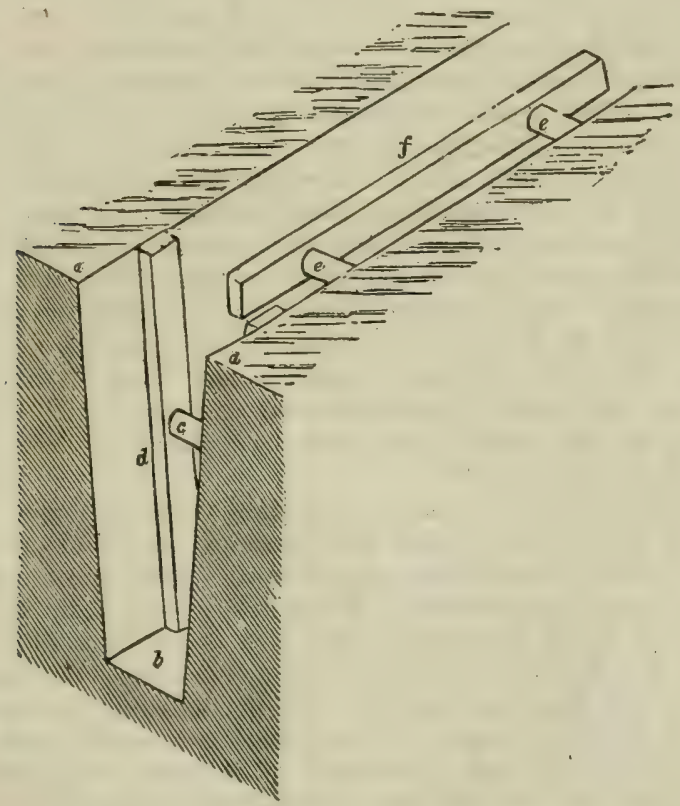

THR POSITION OF PLANKS AND WEDGES TO PREVENT THE SIDES OF DRAINS FALLING IN.

the sides of the drain, $d$ planks placed perpendicularly against them, and kept in their places by the short stake or wedge $c$, and where $f$ are planks placed horizontally and kept secure by the wedges $e \ell$.

(714.) But if the earth in the drain be moderately dry and firm, another division of 4 roods may be lined off at top, and the subsoil removed as low as the depth of the former division. Before proceeding, however, to line off a third division, the first division should be cleared out for the builder of the conduit. The object of this plan is to give room to separate the 
diggers of the earth from the builders of the stones, so as there may be no interference with one another's work, and also to give advantage of the half-thrown-out earth of the second division as a stage upon which to receive the larger stones, such as the covers of the conduit, to their being easily handed to the builder, as he proceeds in the laying of the conduit in the first division. On throwing out the earth to the bottom of the first break, special care should be taken to clear out the bottom square to the sides, to make its surface even, and to preserve the fall previously determined on.

(715.) When a division of the drain has thus been completely cleared out, you yourself, or the farm-steward, should ascertain that the dimensions and fall have been preserved correct as contracted for, before any of the stones are placed in the bottom. I have seen it recommended that the person appointed to build the conduit should ascertain if these particulars have been attended to; but it is always an invidious task for one class of workmen to check the workmanship of another, and on this account such a duty should always be perfurmed by the farmer himself, or by any other authorized person.

(716.) Instead of measuring the dimensions of the drain with a tape-line or foot-rule, which are both inconvenient for the purpose, a rod of the form of fig. 155 will be found most convenient, most certain, and most quickly applied. The rod, divided into feet and inches, is put down to ascertain the depth of the drain, and then turned partially round while resting on its end on the bottom of the drain, until the ends of its arm touch the earth on both sides. If the arms cannot come round square to the sides of the drain, the drain is narrower than intended; and if they cannot touch both sides, it is wider than necessary. When the drain is made narrower than intended, you may take it off the contractor's hands, for the men having been able to work in it with ease to themselves, shows that the width is sufficient ; but if the drain is wider than necessary, you should object to it to prevent similar enlargements in other places, for although the contract may have been formed by the longitudinal measurement, and not by the cubical contents, the larger space involves you in greater expense to fill up with stones.

(717.) All deep drains should be furnished with built con-

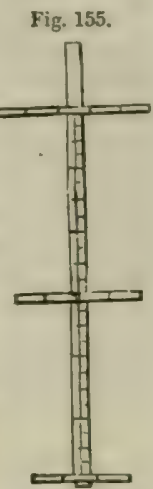

duits, that the water may have a free passage in all circumstances, and thereby escape being choked up, and save the consequent expense of relifting and relaying its materials. The relifting of a drain that has blown, that is, if one in which the water is forced to the surface of the ground, in consequence of a deposition of mud among the stones preventing its flow under ground, is a dirty and disagreeable business for workpeople, and an expensive one for their employer, as it costs at least $9 \mathrm{~d}$., and the filling in again of the earth $1 \mathrm{~d}$. more per rood of 6 yards ;* besides, additional stones are required to fill the enlarged space occasioned by the unavoidable removal of wet earth along with the stones.

(718.) The building of the conduit should be contracted for in a separate stem from the cutting of the drains. If both are undertaken by the same party, there is risk of the two sorts of work being so carried on together, to suit the convenience of the contractor and his men, as to deceive even the inspector; whereas, if each sort is inspected and passed before another 18 allowed to be begun, then both may be executed in a satisfactory manner. The building of the conduit will cost from $1 \mathrm{~d}$. to $2 \mathrm{~d}$. per rood, ac-

- Stephens's Practical Irrigator and Drainer. 
cording to the adaptation of the stones for the purpose.* Flat handy stones can be built firmly and quickly, whereas round shaped ones will require dressing with the hammer to bring them into proper shape, and much pinning to give them stability. The stones are furnished to the builder, and a laborer is also usually provided for him, to supply the stones as he requires them. But circumstances may occur in which it will be more convenient for you to contract with the builder to quarry the stones, supply himself with a laborer and build the conduit, and you to undertake only the carriage of the stones. A dry-stone builder of dykes is a better hand at building conduits for drains than a common mason, as he does not depend upon mortar for giving steadiness to his work.

(719.) Should the ground be firm, and the drain made in summer, and the length of any particular drain not very great, the conduit is most uniformly built when begun at the top and finished at the bottom of the line of drain; but in ground liable to fall down in the sides, or in winter, when the weather cannot be depended upon for two days together, or when the drain extends to many roods in length, the safest plan is to build the con duit immediately after the earth is taken out to the bottom.

(720.) A very convenient article in the building of conduits in a deep drain is a plank of 5 inches in breadth, and of from 6 to 9 feet in length, to put down in the middle of the bottom of the drain, to afford a dry and firm footing to the builder, and to answer the purpose, at the same time, of a gauge of the breadth of the conduit, a space of $\frac{1}{2}$ inch on each side of the plank giving a breadth of 6 inches to the conduit. This plank can be easily removed by two short rope-ends, one attached near each end to an iron staple.

(721.) Suppose the plank set down at the mouth of the drain in the middle of the cut, the dyker begins by leaving a conduit at the mouth of 6 inches wide, having 6 inches of breadth of building on each side of it, and 6 inches high, and using the plank as his foot-board. When the building of these dimensions is finished to the length of the plank, this is carried or pushed by the ropes another length upon the drain, and so on, length after length, until the whole space of drain, when cleared out to the bottom, is built upon. The stones are handed down from the surface to the dyker by the laborer, who, in this case, may be a female fieldworker, until the building is finished. The plank is then removed out of the way, the dyker clears the bottom of the conduit of all loose earth, stones, and other matter, with a hand-draw-hoe 5 inches wide in the face. Immediately after this, he lays the flat covers, which extend at least 3 inches on each side over the conduit, they being from 2 to 3 inches in thickness; and they lie ready for him on the half cast out division of the drain, from which they are handed to him as he works backward. The open space left between the meetings of the covers, which will not probably have square ends, should be covered with flat stones, and the space from the ends of the covers and flat stones to each side of the drain should be filled up and neatly packed with small stones. In this way the dyker proceeds to finish the conduit in every division of drain. To keep the finished conduit clear of all impediments, the dyker makes a firm wisp of wheat or oat straw large enough to fill the bore of the conduit; and which, while permitting the water to pass through, deprives it of all earthy impurities.

(722.) Before the conduit is entirely finished, the drainers throw out the earth of the adjoining division of the drain to the bottom, and the conduit is then built upon it in the same manner as the one just described. Should the laborer have any spare time from supplying the builder with materials,

* Prize Essays of the Highland and Agricultural Society, vol. vii.

$(615)$ 
he throws in stones promiscuously upon the covers, until they reach a hight of 2 feet above the buttom of the drain, where they are leveled to a plain surface. They have been recommended to reach the hight of 4 feet, and when the drain is filled with rubble stones entirely, this hight is desirable, to give the water plenty of room to find its way into it; but with a conduit such as in fig. 156, more than 2 feet secms an unnecessary supply of stones, unless in places where water is more than usually abundant. It has also been recommended to break this upper covering of stones as small as road-metal; " but in deep draining, such as this, there seems no good reason for the adoption of such a practice, while it enhances the cost very considerably. Ordinary land stones or quarry rubbish are quite suitable for the purpose, and should any of the stones be unusually large, they can be broken smaller with a sledge-hammer. This the dyker might be employed in occasionally, as he will break stones much more easily than a laborer, and the work might be included in the contract with him. Should the stones be brought as they are required, the process of filling would be greatly expedited were they emptied at once out of the cart into the drain. This could be done by backing the cart to the edge of the drain, and letting the shafts or movable body of the cart rise so gently as to pour out the stones by degrees. To save the edge of the drain, and break the fall of the stones, a strong, broad board should be laid along the side of the drain, with its edge projecting so far as to cause the stones to fall down into the middle of it. A short log of wood placed in front of the board will prevent the wheels of the cart coming farther back than itself. I am aware that this mode of filling drains has been objected to by a competent authority in these matters, the late Mr. Stephens, as being a dangerous practice for the safety of the drain, especially as stones carry much earth along with them.t But in the case of deep and conduited drains I am sure no danger can arise from its adoption; because I have pursued the plan myself to a large extent with perfect impunity, and can vouch for its experition and economy, and also for its safeness. To prevent the stones doing injury to thin covers, they should not be allowed to fall direct upon them, but upon the end of the stones previously throun in, from which position numbers will roll down of themselves upon the covers without force, and the remainder can be leveled down with the hand before the next cart-load is emptied. There is a very considerable saving in the expense of filling drains in this way, provided it be done in the cautious manner just described, compared with the usual plan of laving down the stones when the drain is ready to receive them, and then throwing them singly in by the hand. Were it convenient to lay the stones down before the drain was begun to be cut, the plan would be inapplicable. As to the stones having earth among them, as much care can be taken to avoid that when they are each thrown or shoveled into the cart, as when put into the drain.

(723.) The leveled surface of the stones should be covered with some dry material before the earth is put over them. The best substance for the purpose is undoubtedly turf, but it is expensive to prepare and carry from a distance; but, should the field be in grass when it is drained, the turf over the drain could be laid aside at hand by the drainers, ana' used for covering the stones. Other materials answer well enough, such as withered wrack, dried leaves, coarse grass, broken moss, tanners' refuse bark, or straw; but I much dislike to see good straw wasted for such a purpose, when manure is usually too scanty upon a farm. The object of placing anything upon the stones is to prevent the loose earth finding its

- Prize Essays of the Highland and Agricultural Society, vol. vij.

$\uparrow$ Quarterly Journal of Agriculture, vol. iii, note. (616) 
way among them; and, although it is not to be supposed that any of the substances recommended will continue long undecomposed, they, however, preserve their consistence until the earth above them becomes so consolilated as to retain its firmness ever afterward. You will learn, in the course "If this article, how stones themselves are prepared to answer the purpose of a covering to those below them.

(724.) After the drain has been sufficiently filled with stones, the earth which wits taken nut of it should be returned as quickly as possible, in case rain fill and wash the earth down its sides among the stones. The filling in of the tirst earth of a deep drain is usually inc'uded in the contract made with the lrainer, and done with the spade, because no horse can assist in that operation until the earth has been put in to such a hight as to enable lim to walk upon it nearly on a level with the ground. The men may either put in all the earth with the spade, or they may put in so much as to allow the plow to do the remainder, but in both cases a little is left elevated immediately over the drain, to subside to the usual level of the ground. There will be much less earth left over the filling than you would imagine from the quantity thrown out at first, and the space occupied by the stones; and it soon consolidates in a drain, especially in rainy weather.

(725.) The section of such a drain as I have been describing is seen in fig. 156, where $a$ is the opening of the conaluit 6 inches square, built with

Fig. 156.

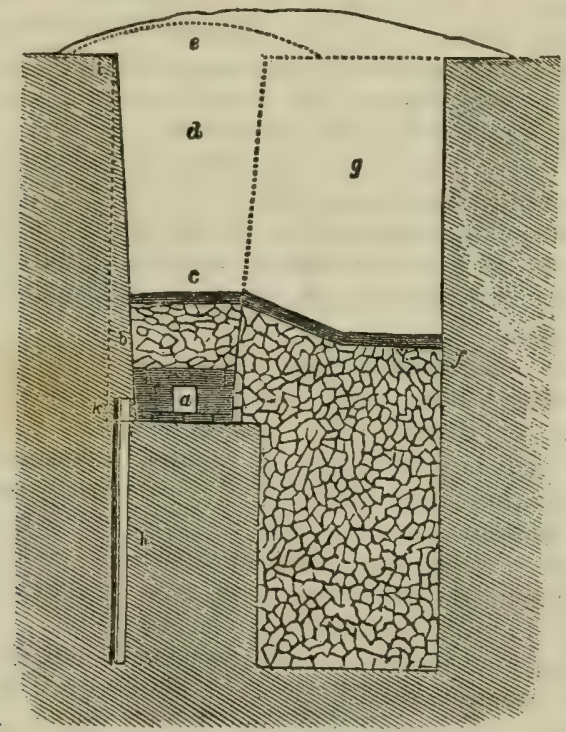

THE DEEP CONDUITED DRAIN, WITH WELL AND AUGER BORE.

dry masonry, and covered with a flat stone at least 2 inches thick; and above it is a stratum of loose round stones $b, 16$ or 18 inches in thickness. The covering above the stones is $c$, and the earth returned into the drain is $d$, with the portion $e$ raised a few inches above the ordinary level of the ground. The mouths of such conduits, when forming outlets, should be protected against the inroads of vermin by close iron gratings.

(7\%6.) Should water be supposed or known to exist in quantity below the reach of even a 6 -feet drain, means should be used to render the drain available for its abstraction, and these means are, sinking wells and boring 
holes into the substrata. A well is made as represented by a part of fig. 1.56, where a pit $g$ of the requisite depth is cast out on the lower side of the drain $a$, if the ground is not level. A circular or square opening, of 3 feet in diameter, or 3 feet in the side, will suffice for a man to work down several feet by the side of the open drain $d$; and, when the stratum which supplies the water is reached, the well should be filled with small stones to about the hight of those in the drain, as at $f$, and the whole area of the drain and well should be covered with dry substances from $f$ to $c$, and the earth is filled in again above all, as at $g$. In making such wells, a small scarcement of solid ground, on a level with the bottom of the building of the conduit $a$, should be preserved, so that the building may have a firm foundation to stand upon, and run no risk of being shaken by the opera tions connected with making the well. I fear this precaution is less attended to in the making of drain wells than it deserves. Such a well should be sunk wherever water has been ascertained to be in quantity at a lower depth than the drain.

(727.) Or the auger may be used instead of the well for the same purpose, by boring through a retentive stratum into a porous, whereby confined water may be brought up into the bottom of the drain, by altitudinal pressure, and escape; or free water may pass down through the bore and be absorbed by the porous stratum below. In the first case, the retreat of the water has to be discovered in making the passage for it to pass away; in the second, it is got rid of by a simple bore. In boring for water at the bottom of a drain, the bore should be made at one side rather than in the middle of the bottom, because any sediment in the water might enter the bore at the latter place and choke it, when the water happened to come up with a small force. In preparation of the bore, let a cut $i k$, fig. 156, be made down the side of the drain, and, inserting the auger at $k$, let the bore be made down through the solid ground, in the direction of $b h$, as far as necessary - the orifice of the bore being made at a little higher level than the bottom of the drain, and an opening left in the building there, to permit the water from the bore to flow easily into and join the water of the drain.

(728.) As boring-irons may be as useful to you for finding water for fields, or for draining a bog, or for ascertaining the depth and contents of a moss, as for ordinary draining, it is proper to give a description of them. The auger, $a$, fig. 157 , is from $2 \frac{1}{2}$ to $3 \frac{1}{2}$ inches in diameter, and about 16 inches in length in the shell, the sides of which are brought pretty close together; and it is used for excavating the earth through which it passes, and bringing it up. When more indurated substances than earth are met with, such as hardened gravel or thin, soft rock, a punch $b$ is used instead, to penetrate into and make an opening for the auger. When rock intervenes, then the chisel or jumper $c$ must be used to cut through it; and its face should be of greater breadth than the diameter of the auger used.There are rods of iron $d$, each 3 feet long, 1 inch square iron, unless at the joints, where they are $1 \frac{1}{2}$ inch and round, with a male screw at one end, and a female at the other, for screwing into either of the instruments, or into one another, to allow them to descend as far as requisite. The short iron key $e$ is used for screwing and unscrewing the rods and instruments when required. A cross-handle of wood $f$, having a piece of rod attached to it, with a screw to fasten it to the top of the uppermost rod, is used for the purpose of wrenching round the rods and auger, when the latter only is used, or for lifting up and letting fall the rods and jumper or punch, when they are used. The long iron key $g$ is used to support the rods and instruments as they are let down and taken up, while the rods are screwed (618) 
on or off with the short key $e$. Three men are as many as can conveni ently work at the operation of boring drains.

Fig. 157.

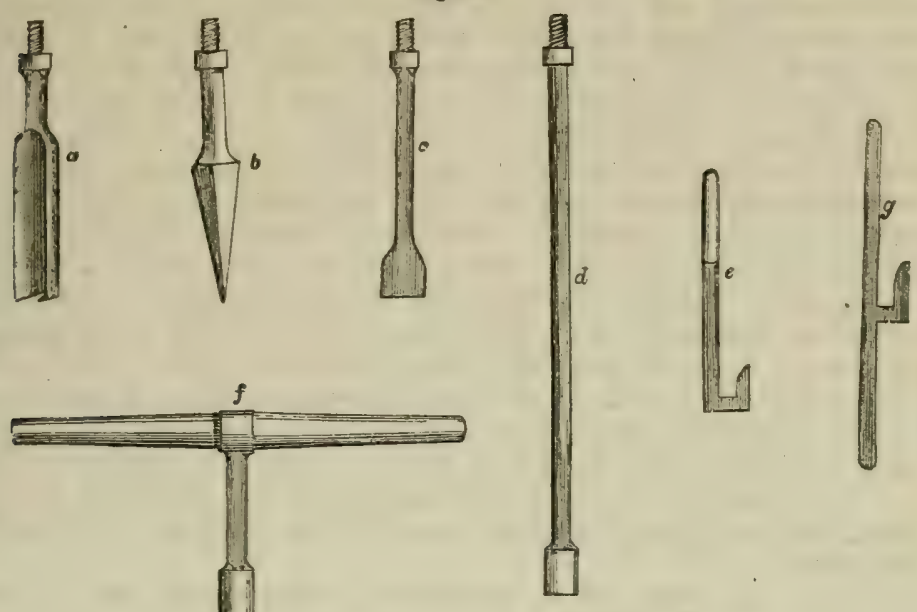

THE INSTREMENTS FOR BORING THE SUBSTRATA OF DEEP DRAINS

(729.) As I have never witnessed the use of the auger in draining, I will give a description of the manner of using it from a competent authority. "Two men," says Mr. Johnstone, "stand above, one on each side of the drain, who turn the auger round by means of the wooden handle; and, when the auger is full of earth, they draw it out, and the man in the bot tom of the drain clears out the earth, assists in pulling it out, and directing it into the hole. The workmen should be cautious, in boring, not to go deeper at a time, without drawing, than the exact depth that will fill the shell of the auger; otherwise the earth through which it is boring, after the shell is full, makes it more difficult to pull out. For this purpose, the exact length of the auger should be regularly marked on the rods from the bottom upward. Two flat boards, with a hole cut into the side of one of them, and laid alongside of one another over the drain, in time of boring, are very useful for directing the rods in going down perpendicularly, for keeping them steady in boring, and for the men standing on when performing the operation."*

(730.) The principles of Elkington's mode of draining seem to depend on these three alleged facts. 1. That water from springs is the principal eause of the wetness of land, which, if not removed, nothing effectual in draining can be accomplished. 2. That the bearings of springs to one another must be ascertained before it can be determined where the lines of drains should be opened; and by the bearings of springs is meant that line which would pass through the seats of true springs in any given locality. Springs are characterized as true which continue to flow and retain their places at all seasons; and temporary springs consist of bursts of water, occasioned either by heavy rains causing it to appear to the day sooner or at a higher level than permanent springs, or by true springs leaking water, and causing it to appear to day at a lower level than themselves; and, if such springs are weak, their leakage may be mistaken for themselves. It is evident that, if drains are formed through these bursts of water, no effect-

- Johnstone on Elkington's Mode of Draining. $(619)$ 
ual draining takes place, and which can only be accomplished by the drain passing through the line of true springs. 3. That tapping the spring with the auger is a necessary expedient, when the dram cannot be cut deep enough to intercept it.* From these three averments it would appear that the seats of true springs are neither at the top nor in the base of a rising ground, but that temporaly springs may be at both; and, of course, the more extensive the hight, the more numerous will be the springs, whether true or temporary. In the case of true springs in the side of rising ground, a system of branched drains will be required to remove them; but, in the case of their being situated near the base, their leakage will originate bogs or swampy grounds; and hence Elkington's mode of draining is only adapted to these peculiarities. It has been very extensively and, I must add, successfully practiced in Scotland, for the removal of both these sources of annoyance to land. The system would have ample scope in Ireland, where bog land still exists to an incredible extent; and in England also, where the regularity of alluvial deposits in many of the western and southern counties might give employment to the auger, to great advantage, in removing the largest proportion of the water which is doing injury; but in Scotland the system of tapping is inapplicable in irregular superficial deposits, though it might be tried in the few bogs which rest on regular strata.

(731.) In so far as the soil of Scotland is affected with water, there is no doubt that it is not now most injured by springs. What injury it suffered in that way has long been removed, by the extensive application of Elkington's mode of draining; and as in the pursuance of that system experience soon indicated that injury was sustained by the land from nther water than that issuing from springs, a modification was introduced into the system, which, not being in accordance with its principles, can excite no surprise that it failed in many instances; and the misguided failures had the effect of bringing disrepute upon otherwise an excellent and efficient mode of draining. The modification I allude to, which brought obløquy upon Elkington's system, was the cutting of deep drains in every direction, irrespective of the arrangement of the subjacent strata, and the filling them nearly full of stones of any size and in any order. Much expense was in the first instance incurred by this practice, and when its effects were not commensurate with the outlay, disappointment was the result, and blame was imputed to the system, instead of to the mode of practicing it.

(732.) The chief injury now sustained by the soil of Scotland arises from the stagnation of rain-uater upon an impervious subsoil. Most of the soil of that country consists of loam, of different consistence, resting on clayey subsoil sufficiently tenacious to retain water, the arable part of which is of unequal depth; where it is shallowest, it is itself injured by the stagnant water immediately below it; and where it is deepest, the plants upon it are injured by chilly exhalations.

(733.) The injury done by stagnant water to arable soil may be estimated by these effects. While hidden water remains, manure, whether putrescent or caustic, imparts no fertility to the soil; the plow, the harrow, and even the roller, cannot pulverize it into fine mould; new grass from it contains little nutriment for live-stock; when old, the finer sorts disappear, and are succeeded by coarse sub-aquatic plants. The stock never receive a hearty meal of grass, hay, or straw, from land in that state; they are always hungry and dissatisfied, and of course in low con-

- Johnstone on Elkington's Mode of Draining. (620) 
dition. Trees acquire a hard bark and stiffened branches, and became a prey to parasitic plants. The roads in the neighborhood are constantly soft, and apt to become rutted; while ditches and furrows are either plashy, or like a wet sponge, ready to absorb water. The air always feels damp and chilly, and, from early autumn to late in spring, the hoar-frost meets the face like a damp cloth. In winter the slightest frost encrusts every furrow and plant with ice, not strong enough to bear one's weight, but just weak enough to give way at every step, while snow lies long lurking behind the sun in corners and crevices; and in summer musketoes, green-flies, midges, gnats, and gadflies, torment the cattle, and the plowman and his horses, from morning to night; while, in autumn, the sheep get scalded heads, and are eaten up by maggots, during the hot blinks of sunshine. These are no exaggerated statements, but such as I have witnessed in every similar situation; and they may be observed in every county in Scotland, in hill, valley, and plain.*

(734.) The only plan of draining fitted to remove the wetness which produces this state of things, is the one which allows stagnant water to flow easily away through moderately deep and numerous drains; for deep drains cannot take away stagnant water from impervious subsoil at the distances they are usually made. This constitutes the second mode of surface-draining alluded to in a former paragraph, (679), and which has now generally obtained the appellation of thorough-draining; and the treatment of which must now receive your attention.

(735.) What should be the exact size of these shallow and numerous drains, is not easily determined. It would be one step toward the settlement of this point were the minimum size determined, which I shall endeavor to do. A drain is not a mere ditch for conveying away water; were it only this, its size would be easily determined by calculation, or experiment, of the quantity of water it would have to convey in a given time. But the principal function of a drain is to draw water toward it from every direction; and its secondary purpose is to convey it away when collected; though both properties are required to be present, to the drain performing its entire functions. These being its functions, it is obvious that the greater the area its sides can present to the matter out of which it draws water, it should prove the more efficacious, and it is also obvious that this efficiency is not so much dependent upon the breadth as upon the depth of the drain, so that, other things being equal, the deeper a drain is, it should prove the more efficient. Now, what are the circumstances that necessarily regulate the depth of drains? In the first place, the culture of the ground affects it; for were land never plowed, but in perpetual pasture, no more earth than would support the pasture grasses would be required over a drain, and this need not, perhaps, exceed 3 inches in depth. The plow, however, requires more room; for the ordinary depth of a furrow-slice is seldom less than 7 inches, and, in crossfurrowing, 8 inches are reached, and 2 inches more than that, or 10 inches in all, may suffice for ordinary plowing; but in some instances, land is plowad with 4 horses instead of 2 , in which case the furrow will reach 12 inches in depth, so that 14 incines of depth will be required to place the materials of the drain beyond the danger of an extraordinary furrow. But farther still, subsoil and trench plowing are sometimes practiced, and these penetrate to 16 inches below the surface, so that 18 inches of earth at least, you thus see, will require to be left on the top of a drain, to place its ma-

- See a paper by me on this subject in vol. vi. of the Quarterly Journal of Agriculture. (621) 
terials beyond the dangers arising from plowing. This depth having been thus determined by reference to practice, it should not be regarded as a source from which a supply of moisture is afforded to the drain by its drawing power, the water only passing through it by absorption; for it is certain that plowed land will absorb moisture, whether there be any drain below it or not. The drawing portion of the drain must, therefore, lie entixely below 18 inches from the surface. Now it will be requisite to make the drain below this as deep as will afford a sufficient area for drawing powers of the lowest degree among subsoils. And what data do we possess to determine this critical point? In the first place, it is evident that a subsoil of porous materials will exhaust all its water in a shorter time than one of an opposite nature. Judging fiom observation, I should say, that 1 inch thick of porous materials will discharge as much water in a given time, as 6 inches of a tilly, or any number of inches of a truly tenacious subsoil. What conclusions, then, ought we to draw from these data? Certainly these, that no depth, beyond the upper 18 inches, farther than what is required for the materials of the drain, will draw water from a truly tenacious subsoil, and that it is therefore unnecessary to go any deeper in such a subsoil; that it is also unnecessary to go any deeper in a subsoil of porous materials, because a small depth in it will draw freely; and that it is only requisite to go deeper in the intermediate kinds of subsoil. Still you have to inquire what should be the specific depths in each of these cases? In the case of really tenacious subsoil, the size of the duct for the water depends on the quantity to pass through it, but, giving the largest allowance of 6 inches with a sole beneath and covering above, 1 foot seems ample depth for these materials to occupy, so that a drain of $2 \frac{1}{2}$ feet seems sufficient for the circumstances attending such a subsoil, that is, its minimum depth, which, in such a case, may also be held to be a maximum. In the case of a porous subsoil, it is absolutely necessary for the preservation of its loose materials in their proper position, to have a lining of artificial materials as far as these extend; and as such a lining can hardly be constructed of sufficient strength of less depth than 1 foot, it follows that $2 \frac{1}{2}$ feet is the minimum depth also in such a subsoil; but there is this difference betwixt this subsoil and the tenacious one, that the porous may be made as deep as you please, provided you apply sufficient materials for the support of the loose materials. With regard to tilly subsoils, since 1 foot is requisite for the safety of the filling materials, it does not seem an overstretch of liberality to give 6 inches more for extension of the drawing surface, so that the minimum depth in this case seems to be 3 feet, and as much more as the peculiar state of the subsoil in regard to tenacity and porosity will warrant you to go. There is another way of arriving at the same conclusions, and it is this.

(736.) It must be admitted by all drainers, that the part of the drain which is intended to draw water under the earth should be occupied with such loose materials as will easily permit the water to pass through them. It is therefore consonant with reason to give a large area to the sides of a drain in a subsoil that draws water rather slowly, and by consequence a smaller area to one in materials that draw freely, while a drain in pure clay will act chiefly as a channel to convey away the water that is permitted to percolate into it through the superincumbent materials. Keeping these important distinctions in subsoils in view, you shall soon learn what use may be made of them in the construction of efficient drains. I guard myself by saying efficient drains; for drains can be ill made, although planned on the most correct principles; and to guard myself against farther misconceptiun, you should bear in mind, that the depths which I have (622) 
just specifed are the minimum depths which are considered suitable for the respective circumstances of the drains.

(737.) Viewing drains as mere channels for the conveyance of water, it is obvious that the quicker they promote its emission, without injuring themselves or the land, they act the more characteristically ; and it is also evident that an open duct will give a freer passage to water than a mass of loose stones, however large or small they may be used. These obvious points being conceded, it follows as a corollary that a drain will act the better of being provided with a duct, along with porous material. Viewing drains as drawers or gravitators of water, it is also clear that the more porous the materials, and the greater the quantity used, they will allow the water an easier passage through them. So, it is also requisite on this account to have a duct for the water to pass quickly away. I wish you to pay particular attention to this mode of reasoning in support of the use of cucts, as I conceive that very erroneous opinions prevail among farmers regarding their utility; but I believe such opinions are prompted more on account of the cost incurred by the use of ducts, than from any valid objection that can be urged against their efficacy.

(738.) There are various substances which may be employed as ducts: 1 st, dry stones, built as you have seen at $a$, in fig. $156 ; 2 \mathrm{~d}$, a coupling of flat stones set up against each other as a triangle, or in a more rude way iwo round stones, set one on each side of the drain, with a flat one, or a large round one, to cover them; $3 \mathrm{~d}$, tiles made for the purpose. One or all of these forms of ducts answer the purpose well, and should be selected according to the facility of obtaining the materials of which they are composed.

(739.) I must now direct your serious attention to another consideration in the construction of drains. It is a well-known fact that, over whatever kind of substance water flows, it has the power of abrading it; for, besides earthy matter, it will in time wear down by friction the hardest rock. This it is enabled to do, not only by its own physical properties, but by the assistance afforded it by the foreign matters which it almost always holds, both in solution and suspension, so that both physically and chemically it has the power to produce destructive effects. It seems, however, to be a very prevalent opinion among farmers, that hard clay can for any length of time withstand the action of water in a drain. They judge of the hardness of the clay from the state it is in when laid bare to the sight on the drain being opened, imagining that it will remain in the same state, but seeming to forget that water can both soften and scrub against substances. Were clay, indeed, always to retain the hardness it at first exhibits, it would require no protection from the abrading action of water; but, when it is known that it cannot possibly remain so, the safest practice is to afford it protection by a covering, which may be fashioned to suit the purpose, such as a flat stone or tile, both of which obtain the name of drain-soles.If water can affect even the hardest clay, it will, of course, have a much greater effect upon softer earth. The effects usually produced by water on clay subsoils are, that the lower stratum of stones and the tiles become imbedded in it to a considerable depth, as has been found to be the case when drains that have blown have been reöpened, and as in the first sets of tile-drains made in Ayrshire. In somewhat softer subsoils, the sandy particles are carried along with the water, and deposited in heaps in the curves and joinings of drains; and, where the subsoil happens to be more sandy than clayey, the foundation which supports the building or tile gives way, and the matter thus displaced forms obstructions at parts which render the drain above them almost useless. Water also carries sand down (6:3) 
the sides of the drain, and, where there is no duct, deposits it among the lowest stratum of stones. You thus see that various risks of derangement occur in a drain, where there are no soles to protect its bottom. On this account, I am a strenuous advocate for drain-soles in all cases; and, even where they may really prove of little use, I would rather use too many than too few precautions in draining, because, even in the most favorable circumstances, we cannot tell what change may take place beyond our view of the interior of a drain, which we are never again permitted, and which we have no desire, to see.

(740.) Porous materials, which are the next things he requires for filling drains, are few at the command of the farmer on his farm, consisting only, 1st, Of small stones gathered from the surface of the land by the hand; $2 d$, Small stones so prepared in a quarry by the use of the hammer; and, $3 d$, Gravel, obtained either from the bed of a river, the sea-beach, or a gravelly knoll.

(741.) Before beginning to break ground for thorough draining, it should be considered what quantity of water the drains will have to convey; and, as the water in the soil is entirely derived from the rain that falls and is absorbed by the soil, its quantity depends upon the climate of the locality in which the drains are desired to be made. Such an investigation is unnecessary in commencing Elkington's mode, as the springs show at once the quantity of water to be conveyed away. In pursuance of the investigation, it is well known that more rain falls on the $W$. than the $E$. coast of this country in the ratio $5: 3$; so that, under the same circumstances of soil, nearly double the number or capacity of drains will be required to keep the soil in the same state of dryness in the western as in the eastern coast. With a view to ascertain the quantity, it has been, in the first instance, "ascertained that the water which flows from a drain is considerably less at any one time than what formerly ran on the surface ;" and this is an expected result, for evaporation and vegetation together must dissipate much of the water that falls on the ground before it sinks into the soil.

(742.) In order, however, to obtain accurate data on this subject, Mr. James Carmichael, Raploch Farm, Stirlingshire, one of the midland coun. ties, and therefore experiencing about the average fall of rain in Scotland, ascertained that, in a "length of 200 yards, and the distance from drain to drain 18 feet, the square feet of surface receiving rain-water for each drain amounts to 10,800 ; this, at 2 inches of rain in 24 hours, will give 1,800 cubic feet of rain-water, and taking the sectional area of the smallest tile of $2 \frac{1}{2}$ by 3 inches at 7.5 inches, and the water moving in this aperture at the rate of 1 mile per hour, the number of cubic feet discharged by the drain in 24 hours will be 6,600 , or nearly four times as much as is necessary to carry off so great a fall of rain as 2 inches in 24 hours;" and this besides what would be carried off by evaporation and absorbed by vegetation. Mr. Stirling, of Glenbervie, also in Stirlingshire, has given similas testimony of his experience in regard to the capability of drains to let off water. "I have only three sets of drains," he says, "in which I know the exact fall in the mains near the mouths and the area drained. The land is mostly stiff clay, having in some places a fall of 1 in 6 , and for 50 yards from the mouths of the mains only 1 in 140 ; is drained at 15 feet; the main-tiles are $2 \frac{3}{4}$ by $3 \frac{1}{2}$ inches, and the rain which falls on 5 superficial roods is discharged at each mouth. I find the tiles nearly $\frac{2}{3}$ full after very heavy rain; therefore that size of tile would, with the same declivity, pass the rain which falls on nearly 2 acres; and, if the fall in the side drains were less, the water would never stand so high in the mains."*

\footnotetext{
* Prize Frsays of the Highland and Agricultural Socinty, vol. xii.
}

(624) 
(743.) It should be borne in mind that these calculations are founded on data obtained from strong clay soil, from which, it may reasonably be suppused, much of the rain that fell had run off, and, consequently, that by a porous soil much more rain will be absorbed; but, although this is doubtless the case, it is obvious that a small orifice will be quite sufficient to carry off much more water than can possibly fall from the heavens in these latitudes in any given time; and that in ordinary rain the drains will be little more than wetted. Still the drainage should be made to carry off the greatest quantity that falls, although it should occur only once in a lifetime.

(744.) Having thus calculated the probably greatest quantity of rain that may fall in the locality of your farm, the next step is to drain each field in succession. It may seem too indiscriminate an instruction to recommend the draining of every field; for it is possible that some of the fields in your farm may be so dry as not to require entire drainage, but it is scarcely possible but that every field will require draining to a certain degree in some part of it. Be that as it may-in pursuing a system of drainage, every field should be thoroughly examined in regard to its state of wetness throughout the year, for that land is in a bad state which is soaking in winter, though it should be burnt up in summer; but the truth is, burning land requires draining as well as soaked land, because drains will supply moisture to burning land in summer, while it will render soaked land dry in winter. Should your farm be pretty level, it natters not at what side you commence operations; but should it have a decided inclination one way, the lowest portion should first be drained; and, if it inclines in more than one direction, then each plane of inclination should have a system of drains for itself. It deserves consideration, however, in choosing the fields for draining, that as drains are more conveniently made at one member of the rotation of crops than another, it may happen that the field ready in this respect for drainage is not the one situate at the lowest part of the farm ; in which case care must be taken to give the water from the drained field such an outlet as will not make the ground below it wetter, and this may be effected either by clearing a ditch along the side of the lower field, or by forming a new ditch, or by leading the water to a ditch, drain or rivulet at some distance.

(745.) The field having thus been fixed upon, the first consideration is the position of those drains that receive the water from the drains that are immediately supplied from the soil; and these are called main drains.In every case they should be provided with a duct, and the ducts may be formed either of stone or of tile-of stone when that material is abundant on the farm, or can be obtained at a short distance-of tile where stone cannot be easily procured; but, if tiles cannot be found at hand, they should be procured from a distance rather than not be obtained at all where stones are scarce.

(746.) Ducts of stone may be formed in various ways-the strongest of which are built with masonry and covered with strong flat stones, as in fig. 156.

(747.) Two flat stones, placed against each other at the bottom of the drain, with another covering, both, as at $a$, fig. 158 , form an equilateral duct of 6 inches in the side, resting on its apex. It should be held down in its position by small stones $b$, gathered from the land, or broken for the purpose, to a hight of 18 inches; then covered with turf or other dry substance $c$, and the earth $d$ returned above them. Where stones are found in sufficient quantity for such a drain, it is highly probable that the subsoil will consist of clay, intermixed with small stones and veins of sand, which, requiring a large area of drawing surface, will fix the depth of the druin

(673).....22 
at 3 feet. In making this form of duct, the drain will require to be 18 inches wide at top, to allow the drainer room to work while standing on the narrow triangular space at the bottom. Placing the apex of the triangle undermost gives the water power to sweep away any sediment along the narrow bottom; but it possesses the disadvantage of permitting the water to descend by its own gravity, between the joining of the stones, to the subsoil, which runs the risk of being softened into a pulp, or of its sandy portion being carried away; and it is possible for a stone to get jammed in the narrow gutter and form a damming.

(748.) Another form of duct, which I prefer to this, and which is also constructed of stone, may be seen beside it in fig. 159 , where $a$ is the duct

Fig. 258.

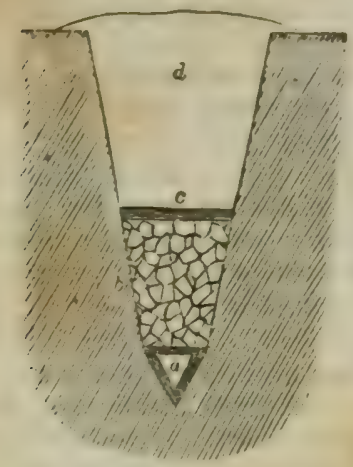

THE TRIANGULAR STONE DECT.
Fig. 159.

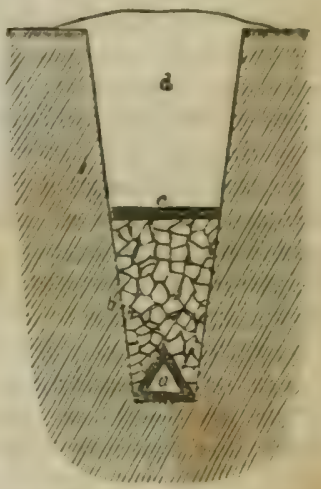

THE COUPLED STONE DTCT.

consisting of a sole lying on the ground, supporting 2 stones meeting at the tnp, forming an equilateral triangle of 6 inches a side. This form encourages a deposition of sediment to a greater degree than the furmer, but it prevents, to any dangerous extent, the descent of the water under the sole. Having a flat bottom, the drain can easily be cast out with a width at top of only 15 inches to a depth of 3 feet. The slanting stones of the duct are held in their position by selected stones being placed on each side, which act as wedges between them and the earth; and the whole structure is retained in its place by 18 inches of small stones above them $b$, corered with turf $c$, and the earth $d$ returned above them.

(749.) A more perfect duct than either of these is made by a tile and sole. In all main drains, formed of whatever materials, capable of conveying a considerable body of water, a sole is alsolutely requisite to protect the ground from being washed away by the water, and a more effectual protection cannot be given to it than by tile and sole. A main-tile, which the tiles in main drains are called, of 4 inches wide and 5 inches high, will contain a large body of water; but should 1 such tile be considered insufficient for the purpose, 2 may be placed side by side, as represented by $a$ and $b$ in fig. 160 . Should a still larger space be required, 1 or 2 soles may be placed above these tiles, and other tiles set on them, as $a$ and $b$ are. Or should a still deeper and heavier body of water be required to pass through a main drain, 1 or 2 tiles can be inverted on the ground on their circular top, as $a$, fig. 161, bearing each a sole $c$ upon its open side, and this again surmounted by another tile $b$ in its proper position. In such an arrangement, there is some difficulty in making the un(674) 
dermost tile $a$ steady on its top; for which purpose, the earth is taken out of a rounded form, and the tile carefully laid and wedged round with stones or earth; but there is greater difficulty in making the uppermost tile $b$

Fig. 160.

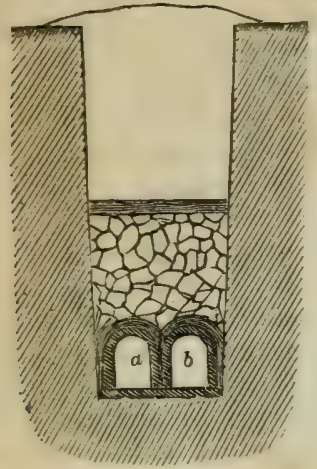

THE DOUBLE TILED MAIN DRAIN.
Fig. 161.

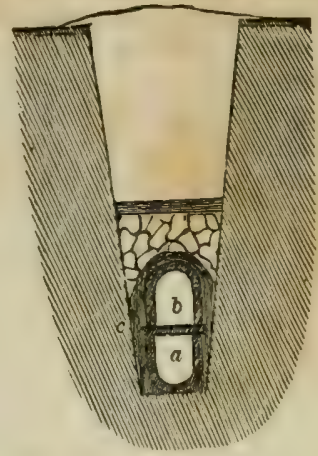

THE INVERTED DOUBJ.E TILED MAIN DRAIN

stand in that position without a sole, as is recommended by some writers on draining, because the least displacement of either tile will cause the upper one to slip off the edge of the under, and fall into it. In the narrowest of these cases of main drains with tiles, the drains can be easily cut at 15 inches wide at top to the depth of 3 feet. Small stones should be put above the tiles, if at all procurable, to the hight of 18 inches above the bottom; if not procurable, gravel will answer the same purpose; and, if both are beyond reach, they should be enveloped with thin, tough turf, as shown afterward.

(750.) Having thus determined on the construction of main drains, according to circumstances in which the water is to be conveyed away, the next thing is to fix the place they should occupy in the field. As they are intended to carry away accumulations of water beyond what they can themselves draw, they should occupy the lowest parts of a field, whether along the bottom of a declivity, the end, or the middle of a field. If the field is so flat as to have very little fall, the water may be drawn toward the main drains by making them deeper than the other drains, and as deep as the fall of the outlet will allow. If the field have a uniform declivity one way, one main drain at the bottom will answer every purpose; but, should it have an undulating surface, every hollow of any extent, and every deep hollow of however limited extent, should be furnished with a main drain. No main drain should be put nearer than 5 yards to any tree or hedge, that may possibly push its roots toward it; but although the ditch of a hedge, whose roots lie in the opposite direction, merely receive the surface-water from the field at the lowest end, it should not be converted into a main drain, that should be cut out of the solid ground, and not be nearer than 3 yards to the ditch lip; and the old ditch should be occupied by a small drain, and filled up with earth from the head-ridge.

(751.) As main-drains thus occupy the lowest parts of fields, the fall in them cannot be so great as in other parts of the field, though it should be kept quite sufficient for drainage. In the case of a level field, the fall may entirely depend on cutting them deeper at the lowest end than at other places ; but, when the fall is small, the duct should be larger than when it is considerable, because the same body of water will require a longer time. (675) 
to flow away. Should the fall vary in the course of the drain, the least rapid parts should be provided with the largest sized tiles; and, in any case, I would recommend an increase of fall on the last few yards tuward the outlet, to expedite the egress of the water, and promote an accelerated specd along the whole length of the drain; but, where the fall is rapid enough throughout, there is the less necessity for an increase of acceleration at the termination. It is surprising what a small descent is required for the flow of water in a well-constructed duct. "People frequently complain," says Mr. Smith, "that they cammot find a sufficient fall, or lerel, as they sometimes term it, to carry off the water from their drains. There are few situations where a sufficient fall cannot be found, if due pains are exercised. It has been found in practice that a water-course 30 feet wide and 6 feet deep, giving a transverse sectional area of 180 square feet, will discharge 300 cubic yards of water per minute, and will flow at the rate of 1 mile per hour with a fall of no more than 6 inches per mile."** On the principle of the acceleration of water from drains, main drains, where practicable, should be 6 inches deeper than those which fall into them; and the greater depth has the additional advantage of keeping the drains clear of sand, mud, or other substances which might lodge, and not only impede but dam back the water in the drains. Should it so happen, from the nature of the ground, that the fall in the main drains is too rapid for the safety of the materials which construct them, it is easy to cut such a length of the proper fall as the extent of the ground will admit-cutting length after length, and joining every two lengths by an inclined plane.The inclined planes could be furnished with ducts like the rest of the drain, or, what is better, in order to break the force of the water, like steps of stairs, of brick or stone masonry, built dry. Fig. 162 will illustrate this method at once, where $a b$ represents the line of the lowest fall that can be obtained for a main drain in a field; but which, you will observe, is very considerable, and much more so than a main drain should have which has to convey, at any time, a considerable quantity of water. To lessen the fall, let the drain be cut in the form represented by the devious line $c h$, which consists of, first, a level part at the highest end $c d$; then of an inclined plane, $d e$; again of a level part, $e f$; again of an inclined plane, $f g$; and, lastly, of a less level part $g h$, to allow the water to flow rapidly away at the outlet; and this part may be parallel with the inclination of the ground.

(752.) The inclined parts may he filled with materials in different ways. One way is with tiles, as seen from $k$ to $l$, where it is olvious that, as draintiles are formed square at the ends, those in the inclined plane $k l$ cannot conjoin with those on the level above and helow, and must, therefore, be broken so as to fit the others at $k$ and 1 . In constructing tiles in this way, it is absolutely necessary that the inclined plane be protected with soles, firmly secured from sliding down, at the lowest end at $l$, by having there a strong stone abutting against the lowermost sole; or a betier plan would be to line the inclined plane with troughs of hewn stone, which will last for ever.

(753.) Instead of tiles, or hewn troughs, stones may form a conduit upon the inclined plane; and ducts of this material, in such a situation, and built dry with selected stones, would certainly he preferable to tiles, even althmugh they could be obtained of the peculiar form required.

(754.) Or the inclined plane could be conduited with brick, as represented from $r$ ' $t$ s. The bricks could be built dry as well as stones, and

* Smith's Remarks on Thorough Draining.

(676) 
could form either a smooth, inclined sole like tile-soles, or a series of steps, as represented in the figure, where they are set two a side lengthways on bed to form the bottom, as at $o$; set on end upon these for the sides of the

Fig. 162.

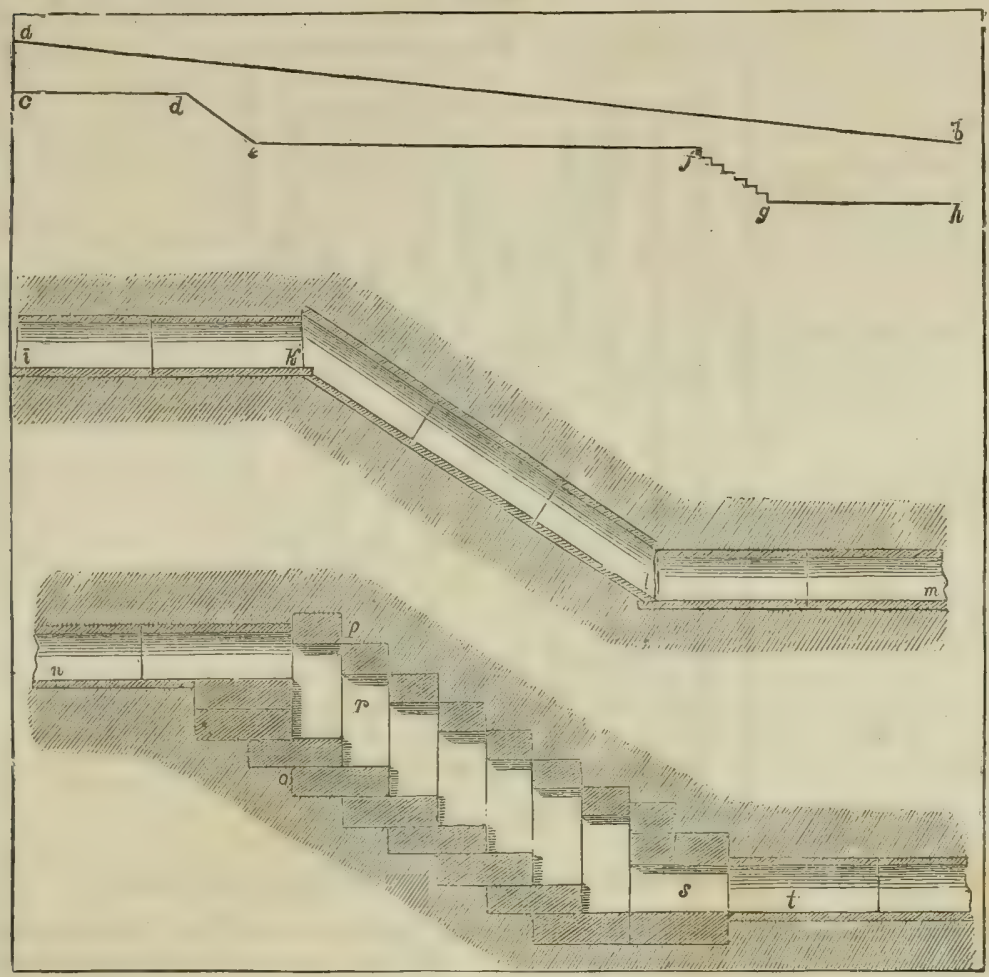

THE DIFFERENT FORMS OF CONDUITS IN THE INCLINED PLAINS OF DRAINS.

conduit, as at $r$; and set lengthways across the conduit upon the upright ones, for the cover, as at $p$. Tiles on the level above connect themselves easily with the bricks, as from $n$; as also on the level below, as at $t$. Should a considerable run of water be expected at times, the step form is preferable to the smooth, in order to break the fall and impede the velocity of the water, especially toward the lower extremity of the drain, where it may acquire too much momentum without a preventive check of this kind. Although much water is expected to flow through the drain, it would not be prudent to build the steps with lime-mortar, as it is too easily removed, and would not prevent the water finding its way to the foundation; but, in every case, it is proper to build the duct on the inclined planes, with selected materials skillfully put together.

(755.) After having fixed the position of the main drains, and determined their levels and depths as here described, the next thing is the laying off of the small drains, which are so placed, or should be so constructed, as to have an easy descent toward the main drains into which they individually discharge their waters. They are usually cut in parallel lines down the declination of the ground; not that all the drains of the same field should be parallel to one another, but only those in the same plane, what(677) 
ever number of different planes the field may consist of. In a field of one plane, there can be no difficulty in setting off the small drains, as they should all be parallel and all terminate in the same main drain, whether the field is nearly level or has a descent. Thus, in fig. 163, a are the

Fig. 163.

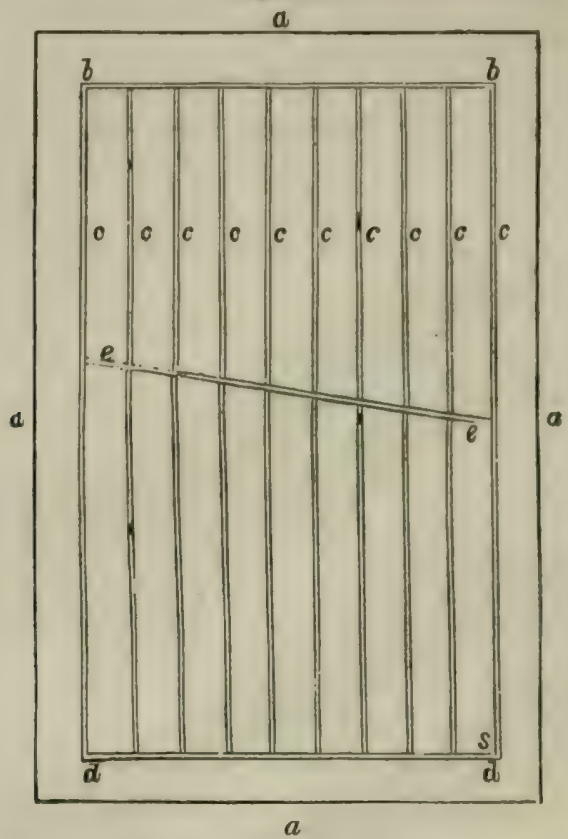

PARALLEL DRAINS IN THE SAME PLANE OF INCLINATION OF THE GROUND.

fences of the field; $d d$ is the main drain, whether the field is a level or inclined toward $d$; and $s$ is its outlet. In this case, all the drains $c$ run parallel to one another, from the one end $b b$, which may be the upper, to the other end $d d$, which may be the lower end; and which convey all the water by the outlet $s$.

Fig. 164.

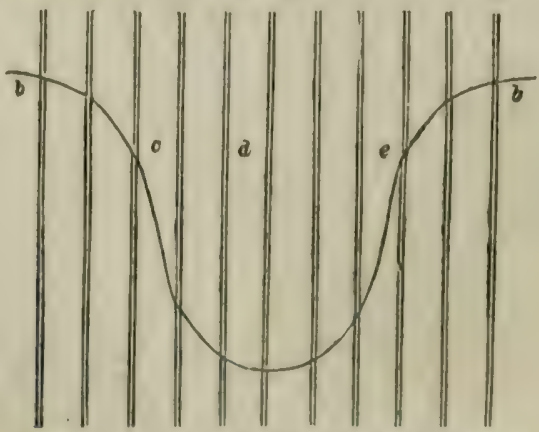

DRAIN IMPROPERLY MADE PARALLEL IRRESPEOTIVE OF THE BLOPE OF THE GROUND.

(756.) But when the field has an undulating surface, though the same principle of parallelism is maintained, a different arrangement is followed (678) 
in regard to it. I have already intimated in a former paragraph (750) that where an undulating surface occurs in a field, a main drain is carried up the hollowest part of it, and the small drains are brought in parallels down the inclination to it. This very favorable arrangement for the speedy riddance of water, after it has reached the drain, is not frequently enough attended to. Thus, the common practice is to run the small drains $b c d e b$, in fig. 164, parallel to one another, throughout the whole field, although its undulating surface, as supposed to be represented by the curved line $b c e b$, would cause the so arranged parallelism of the drains at $c$ and $e$ to run along the sides of the rising ground, where, if any vein of sand occur, it may escape being cut by the drain running parallel along its line either above or below it, instead of being divided across its dip; and even were the sand-vein severed along its length, it would be apt to slip down from the higher side, and render the drain along it inoperative.

(757.) Such drains should be cut, as in fig. 165, up and down the inclined surface $b b$, toward the main drain, which would occupy the line along the

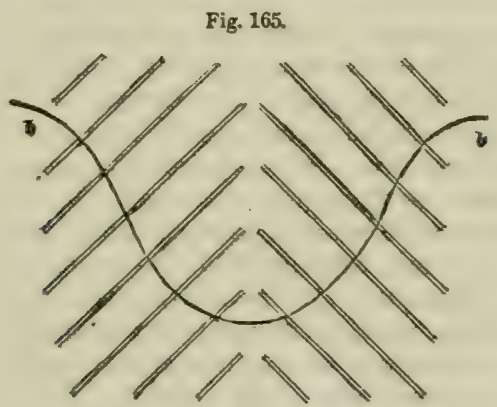

PARALLEL DRAINS IN ACCORDANCE WITH THE SLOPE OF THE GROUND.

points of junction of the drains $b b$. This specific plan is just as easily executed as the other more indiscriminate one of making the direction of every drain of every field alike.

(758.) The next step is to fix the depth of drain most suitable for draining the particular field; and this can only be done by having a thorough knowledge of the nature of its subsoil. I have already given reasons for fixing the minimum depth of drains in the different kinds of subsoil, in paragraph (735); but, as the reasoning given there only establishes the principle, it is not sufficient to determine the most proper depth for every peculiarity of circumstances ; for this must be determined by the nature of the subsoil which guides the whole affair. If the field present an uniform surface, but inclining, let at least 2 exploratory drains be cut from the bottom to the top of the field, if its extent does not exceed 10 acres, and as many more as it is proportionally larger; and if the subsoil of both is found at once tilly, that is, drawing a little water, let the cut be made 3 feet deep without hesitation. On proceeding up the rising ground, the depth may be increased to 4 feet, to ascertain if that depth will not draw a great deal more water than the other. Should the subsoil prove of porous materials, $2 \frac{1}{2}$ feet-the minimum-may suffice; though, on going up the rising ground, it may be increased to 3 feet, to see the effect; but should it, on the other hand, prove a pure tenacious clay, 2 feet will suffice at first, increasing the depth in the rising ground to $2 \frac{1}{2}$ and even 3 feet; for it may 
turn nut that the stratum under the tenacious clay is porous. Where the surface is in small undulations, the drain should be cut right through both the flat and rising parts. In very flat ground, any considerable variation of depth is impracticable, and only allowable to preserve the fall. From such experimental drains data should be obtained to fix the proper dimensions of the other drains.

(759.) If you find the substratum pretty much alike in all the experimental drains, you may reasonably conclude that the subsoil of the whole field is nearly alike, and that all the drains should be of the same depth; but, should the subsoil prove of different natures in different parts, then the drain should be made of the depth best suited to the nature of the subsoil. A correct judgment, howerer, of the true nature of the subsoil, cannot be formed immediately on opening a cut; time must be given to the water in the adjoining ridges to find its way to the drain, which, when it has reached, will satisfactorily show the place which supplies the most water; and, if one set of men open all the cuts, by the time the last ove has been finished, the first will probably have exhibited its powers of drawing ; for it is a fact that drains do not exhibit their powers until some hours after they have been opened. When you are satisfied that the drains have drawn in dry weather as much water as they can, you will be able to see whether or not the shallowest parts have drawn as much as the deepest; and you should then determine on cutting the remainder to the depth which has operated most effectually. If rainy weather ensue during the experiment, still you can observe the comparative effects of the drains, and abide by the results. Never mind though parts of the sides of the cuts fall down during dry or wet weather; they need not be regretted, as they afford excellent indications of the nature of the subsoil, the true structure of which being left by the fall in a much better state for examination than where cut by the spade; and you may then observe whether most water is coming out of the highest or lowest part of the subsoil. It is essential for the duralility of drains to bear in mind that they should always stand, if practicable, upon impervious matter, to prevent the escape of the water from the drain by any other channel than the duct.

(760.) You should be made aware that this is not the usual method adopted by farmers for ascertaining the depth to which drains should be cut. The common practice is, knowing that the field stands on tilly bottom, the drains are made of a predetermined depth, and the contract with the laborers is made on that understanding, be the guess true or false, as it may happen. Now, the considerate plan which I have recommended incurs no additional expense, as all the experimental drains will serve their purpose afterward as well as the others; and, even although they should cost more than the same extent of other drains, the satisfaction afforded to the mind of having ascertained the true state of the subsoil more than compensates for any trifling addition of expense which may have been incurred; and be it remembered that any extra expense consists of only scouring out the earth (if any) that may have fallen down, and of supplying more materials to fill up the chasms thereby occasioned. But the ascertainment of the most proper depths for drains in any sort of subsoil is a much more important matter than many farmers seem, to judge from their practice, to be aware of ; for by neglecting to descend only $\frac{1}{2}$ a foot, nay, perhaps 3 inches more, many of the benefits of draining may be unattained. I quite agree with the late Mr. Stephens on this subject, when he states that "land may be filled full of small drains, so that the surface shall appear to be dry; but the land thus attempted to be drained will never produce a crop, either in quality or quantity, equal to land that has $(680 ;$ 
been perfectly drained,"* where a different kind of draining should have been resorted to.

(761.) A very important particular in the art of thorough draining now claims your attention, which is the determining the distance that should be left between the drains. It is evident that this point can only be satisfactorily determined after the depths of the drains have been fixed upon, as drains in a porous substratum, which draws water from a long distance, need not, of course, be placed so close together as where the substratum yields water in small quantities, and as drains may be of different depths in the same field, according to the draining powers of the substratum, so they should be placed at different distances in the same field. It is the common practice to fix on the open furrows, between the ridges, for the sites of drains, because the hollow of the open furrow saves a little cutting, though such saving is a trifling consideration compared to the advantage of executing the drains in the best manner. For my part, I can see no greater claim for a drain in the furrow than in any other part of the ridge, especially as most of the water should be received from the subsoil rather than the surface, except in pure clay-soils; and it is, of course, as easy to make them in any other part of the ridge as in the open furrow. These observations of Mr. Smith on this subject court remark. "When the ridges of the field," says he, "have been formerly much raised, it suits very well to run a drain up every furrow, which saves some depth of cutting. The feering being thereafter made over the drains, the hollow is filled up, and the general surface ultinately becomes level." This is all very well for the purpose of leveling the ground, but mark what follows! "When the field is again ridged," he continues, "the drains may be kept in the crowns or middle of the ridges; but, if it be intended to work the field so as to altiernate the crowns and furrows, then the ridges should be of a breadth equal to double the distance from drain to drain; and by setting off the furrows in the middle, betwixt two drains, the crowns will be in the same position; so that when the furrows take the places of the crowns, they will still be in the middle betwixt two drains, which will prevent the risk of surface-water getting access to the drain from the water-furrows by any direct opening." $\dagger$ No doubt, it is easy to transpose furrows into crowns, and vice versa; but how would the transposition be effected in these circumstances, since the drains were made in each former furrow, and it is proposed to make the crrwns of the ridges between the drains, the transposition of the crowns could only be effected by adopting the unfarmerlike plan of leaving, in a finished field, a half of the breadth of the ridge adopted at each side; and, rather than practice such slovenliness, would it not be better to cut the drains in the middle of the ridges, and preserve each ridge unbroken?

(762.) With regard to distances between drains, in a partially impervious subsoil, 15 feet are as great a distance as a 3 -feet drain can be expected to draw; and, in some cases, I have no doubt that a 4 -feet one will be required. In more porous matter, a 3-feet drain will probably draw 20 feet, with as great if not greater effect; and in the case of a mouldy, deep soil, resting on an impervious subsoil-which is not an uncommon combination of soils in the turnip-districts of this country - a drain passing through the mould, and resting perhaps 3 or 4 inches in the impervious claywhich may altogether make it 4 feet deep-will draw, I have no doubt, a distance of 30 feet. More than 30 feet distant, I would feel exceeding reluctance to recommend drains being made, unless the circumstances were

* Quarterly Journal of Agriculture, vol. ili. † Smith's Remarks on Thorough Draining, 4th edition. (681) 
remarkably singular, when, of course, a special thing must be done for a special case, such as an entirely porous subsoil containing somewhat indurated portions, when a drain through each of these, at whatever distance. will suffice to keep the whole dry.

(763.) The distance at which ordinary drains in tilly subsoils will not draw is not left to conjecture, but has partially been determined by experiment. Conceiving that a drain in every furrow, in a tilly subsoil, is attended with more expense than any anticipated increase of produce from the soil would. warrant, a tarmer in East Lothian put a drain in every fourth furrow; and that they might, as he conceived, have a chance of drawing at that distance, he caused them to be cut 4 feet deep. A figure will best illustrate the results, where the black lines $a$, fig. 166 , are the
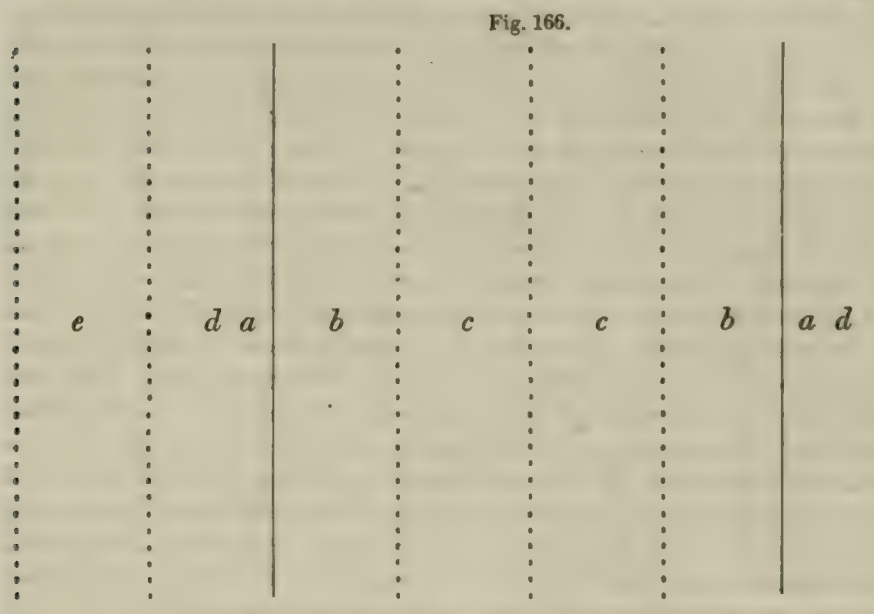

$:$
$\vdots$
$\vdots$
$\vdots$
$:$

THE EFFECTS OF TOO GREAT A DISTANCE BETWIXT DRAINS.

drains between every fourth furrow, and the dotted lines represent the intermediate undrained furrows; and where it is evident, at the first glance, that the drains $a$ have to dry 2 ridges on each side $b c$ and $d e$, of which we should expect that the 2 ridges $b$ and $d$, being nearest to $a$, should be more dried, in the same time, than the 2 farthest ridges $c$ and $e$, and the result agrees with expectation; but still, had the subsoil been of an entirely porous nature, both ridges might have been sufficiently dried by $a$. Trusting to similar contingency, it is not an unusual expectation, entertained by many farmers, that a drain will sufficiently dry 2 ridges on each side, or at least 1 ridge on each side, without ascertaining the exact nature of the subsoil. But mark the results of this particular experiment, which was conducted with the usual expectations. The 2 ridges $b$ and $d$, nearest to $a$, actually produced 9 bushels of corn more per acre than the 2 more distant ridges $c$ and $e$. This is a great difference of produce from adjoining grounds under the same treatment, and yet it does not show the entire advantage that may be obtained by drained over undrained land, because it is possible that the drain $a$ also partially drained the distant ridges $c$ and $e ;$ and this being possible, together with the circumstance that none of the ridges had a drain on each side, it cannot be maintained that either the absolute or the comparative drying power of these 4-feet drains was exactly ascertained by this experiment.* It may be conceived, however, that

- Quarterly Journal of Agriculture, vol. viii. (682) 
if the drains had been put into every other, instead of every fourth, furrow, that the produce of all the ridges would have been alike, inasmuch as every ridge would then have been placed in the same relative position to a drain; and the conjecture seems so reasonable that most farmers, from what I observe of their practice, act upon this plan as from a settled opinion. But such a conjecture, not having been founded upon experience, cannot have the force of an opinion, especially when opposed to the great probability that, coteris paribus, land must. be more effectually drained by a drain in every furrow than at greater distances; as it is not supposable that the open furrows of $b$ and $d$ can be so thoroughly drained as the furrow $a$, which contains the drain itself; because it is obvious that the one side of a ridge should be less effectually drained than the other, which, if of a retentive subsoil, may not be affected at all. All, then, that has been demonstrated by this experiment is this, and the proof I consider is impor tant, that a drain-a deep one though it be-will draw water more effectually across one than across two ridges; and it should be useful to you as a guide against imitating the practice of those who seem to believe that a drain cannot have too much to do.

(764.) While taking this view of the subject, I cannot agree in the advice which Mr. Smith gives when he says, "In cases where time or capital are wanting to complete the drainage at once, each alternate drain may be executed in the first instance, and the remainder can be done in the next time the field is to be broken up."* I would much rather use the words of Mr. Stirling, of Glenbervie, where he says that "I think it a great error to make the half the number of drains required at first, with the intention of putting one between each at a future period. Let what is drained be done as thoroughly as the farmer's exchequer will allow; the farm will be gone over in as short a time, and much more profitably." The reason which Mr. Stirling gives for holding this opinion is a true and practical one-namely, because " a tid (or proper condition of the ground for harrowing) cannot be taken advantage of on the drained furrow until the other is dry, and the benefit of an extended period for performing the various operations of the farm is thus lost." $\nmid$ Every farmer who has studied the influence which soil possesses over crops will be ready to allow that wet soil does much more injury to the dry soil in its neighborhood than dry soil does good to the wet. I would, under every circumstance of season and soil, prefer having the half of my farm thoroughly drained, than the whole of it only half drained.

(765.) At whatever distances drains are placed, they should run nearly at right angles to the main drains. Excepting in confined hollows, having steep ascents on both sides, the drains should run parallel with the ridges, and always parallel with themselves, in the drainage of the same plane of the field. Drains should be carried through the whole length of the field, irrespective of the wet or dry appearances of parts of it; because uniform and complete dryness is the object aimed at by draining, and portions of land that seem dry at one time may be injuriously wet at others, and these may seem dry on the surface when the subsoil may be in a state of injurious wetness.

(766.) Regarding the direction which the drains should run in reference to the inclination of the ground, so as to dry the land most effectually, much diversity of opinion at one time existed; but I believe most farmers are now of the opinion that it should follow the inclination of the ground.The late Mr. Stephens maintained, and as I think erroneously, that as it

* Smith's Remarks on Thorough Draining, 4th edition.

$\uparrow$ Prize Easays of the Highland and Agricultural Society, rol. sit. (683) 
is evident that water within the earth, or on the surface, sceks a level where the finll through the porous subsoil is greatest; therefore a drain mate across the slope or declivity of a field, or any piece of land, will undoubfedly intercept more water than when it is carried straight up the bank or rising ground; and this principle, he says, holds good in every case, whether "the drain be made to receive surface or subterraneous water." I confess I cannot arrive at the conclusion fiom the premises. He reiterates the same opinion more generally, and apparently more practically, in these words: "J)rains winding across the slope or declivity of a field, whatever their mumber or depth may be, their effect upon tenacious or impervious substrata will be much groater than if they were made straight up and down the slope; and when the soil is mixed with thin strata of fine sand, which is the case in nine times out of ten, the eflect will be increased in proportion; and, accordingly, a much less number will answer the purpose, the expense will be greatly lessened, and the land and occupier much more benefited in every respect."* Mr. Smith opposes this opinion, and, what is remarkable, uses the same illustration to refute it, in regard to the property of water and the structure of the substratum, as Mr. Stephens did in support of his views. "Drains," says he, "drawn across a steep, cut the strata or layers of subsoil transversely ; and, as the stratification generally lies in sheets at an angle to the surface (see fig. 169), the water passing in or between the strata, immediately below the bottom of one drain, nearly comes to the surface before reaching the next lower drain. But, as water seeks the lowest level in all directions, if the strata be cut longitudinally by a drain directed down the steeps, the bottom of which cuts each stratum to the same distance from the surface, the water will flow into the drain at the intersecting point of each sheet or layer, on a level with the bottom of the drain, leaving one uniform depth of dry snil."' $f$ Without taking any other element at present into the argument than the single proposition in hydraulics that water seeks the lowest level in all directions, adduced by Mr. Stephens himself, I shall prove the accu-

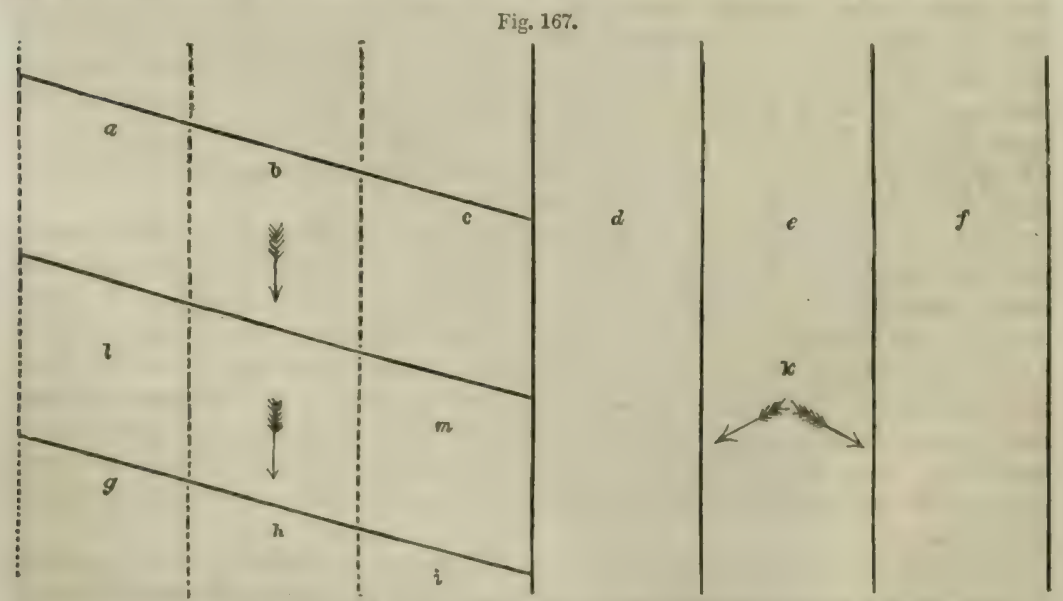

THE COMPARATIVE EFFICACY OF DRAINS ACROSS AND ALONG RIDGES ON A DECIIVITT.

racy of Mr. Smith's conclusions by simply referring to fig. 167 , which represents a part of a ficld all having the same, and that a steep acclivity, and 
which is laid off in the ridges $a b c d e f$, up and down the slope; but the 3 ridges $a b c$ have drains across them, and the other 3 ridges have drains parallel with them, the oblique drains being made at the same distance from each other as the up and down ones, whatever that distance may be. Now, when rain falls on and is absorbed by the ridges $a b c d e f$, it will naturally make its way to the lowest level, that is, to the bottom of the drains; and, as the ground has the same declivity, the water will descend according to the circumstances which are presented to it by the positions of the respective systems of drains. On the ridges $d e f$, having the drains parallel to them, and up and down the inclination of the ground, the water will take a diagonal direction toward the bottom of the drains, as indicated by the deflected arrows at $k$; and as ground has seldom only one plane of declination, such as straight up and down, but more commonly two, another in the direction either from $a$ to $f$ or from $f$ to $a$, it follows that the one side, that is, the lower side of a ridge thus situated, will be sooner drained than the other; but both sides will be soon drained, as may be seen in fig. 168, where $a b$ are vertical sections of small drains, each 30

Fig. 168.

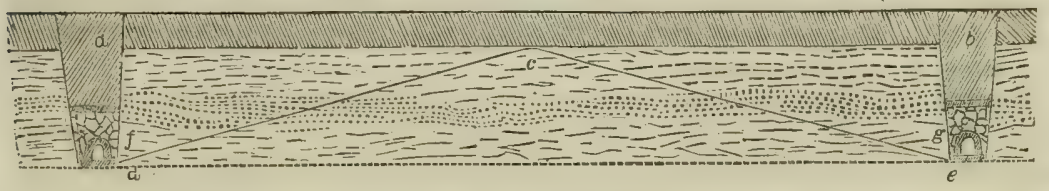

THE DESCENT OF WATER FROM A RIDGE INIU A DRAIN ON EACH SIDE.

inches deep ; $c 1$ frot of mould, in which the rain is absorbed as fast as it falls upon the ridge, 15 feet broad, betwixt $a$ and $b$. On being ahsorbed, the rain, seeking the lowest level, will be hastened toward the drains $a$ and $b$ in the direction of $c d$ and $c e$-that is, by a fall of 30 inches in about 8 feet, which is a rapid fall of rather more than 1 in 3 , and which rapid fall, as is well known, will clear water quickly, and in the clearance of which the drains have only each to draw a distance of half a ridge, or $7 \frac{1}{2}$ feet. Whereas on the ridges $a b c$, which have oblique drains, $a, l, g$, fig. 167 , the water will have to run in the direction of the arrows $b$ and $h$, in doing which it will have to traverse the entire breadth of the ground betwixt $a$ and $l$ or $l$ and $g$, that is, 15 feet, just double the distance the other drains have. But take the superficial view of the case, and suppose that $d, e, f$, and $a, l, g$, are not drains, but open furrows, it is clear that, when rain falls, the water will flow toward $d$, e, or $f$, as indicated by the arrows at $k$-that is, $7 \frac{1}{2}$ feet toward each furrow; whereas the water that falls on $a c, l m$, or $g i$, will have to run across the entire breadth of the ridge from $a$ to $l$, or from $l$ to $g$, that is, 15 feet, just double the distance of the other, before it can reach the open furrows. Or rather take the more profound case, and trace the progress of the water through the substrata. Mr. Thomson, Hangingside, Linlithgowshire, drained 150 acres of land having an inclination varying from 1 in 10 to 1 in 30 . Portions of 3 fields had drains put into them in 1828, 1829 and 1830 , in the oblique direction, and, finding them unsuccessful, he put them in the direction of the slope, like the rest of the fields. "In order," says he, "to ascertain the cause of these failures, a cut was made in the field first referred to, entering at a given point, and carrying forward a level to a considerable depth, when it was clearly seen that the substrata, instead of taking in any degree the inclination of the surface, lay horizontally, as represented in fig. 169. It is therefore obvious," he continues, "that in making drains across a sloping sur(685) 
face, unless they are put in at the precise point where the substrata crop out (and these are exceedingly irregular in point of thickness), they may in a great measure prove nugatory; because, although one drain is near

Fig. 169.

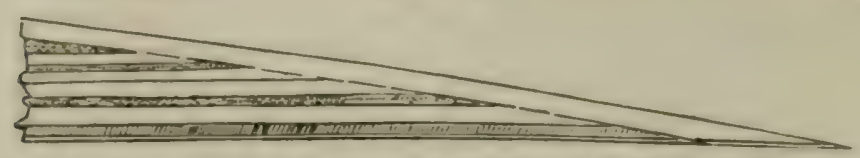

THE CSUAL POSITION OF SCBSTRATA IN REYERESCE TO THE SCRFACE BOLL.

another, from the rise of the ground, none of them may reach the point sought; whereas, in carrying a drain right up the direction of a slope, it is impossible to miss the extremity of every substratum passed through." And although a drain in the oblique direction should cut through a vein of sand as at $f$, fig. 168 , and thereby carry off the water it contains, yet it cannot be denied that the drains $a$ and $b$ will also cut through the said vein-which, when they do, what is there to prevent the water in the vein running toward the drains $a$ and $b$ on each side of the ridge toward $f$ and $g$ ? These observations of Mr. Thomson comoborate Mr. Smith's views, in which I entirely concur.

(767.) In all cases of thorough draining there should a small drain connect the tops of the drains at the upper end of the field. The object of this drain is, in the first instance, to dry the upper head-ridge, and also to protect the upper ends of the ridges from any oozings of water that might come from the fence ditch, or from any rising ground beyond that end of the field. If the fence ditch conveys no current of water, and the hedgeroots lie away from the fiald, and there are no hedge-row trees near at hand, this drain may be made in the ditch itself, and the ends of the furrow-drains brought across the head-ridge to it; but, should water or trees be connected with the ditch, the drain should be made on the head-ridge not nearer than 3 yards from the ditch lip; and it should be of the same depth, though not deeper than the other drains.

(768.) When drains have a course along very long ridges, it is recommended to run a sub-main drain in an oblique direction from side to side, or rather only across all the long ridges of the field, as represented by $e e$ in fig. 163. The length of any drain, it is maintained, should not exceed 200 yards, without a sub-main drain to assist in carrying off the water; and the reasons assigned by Mr. Carmichael for requiring the assistance of such a drain are, "because, if the fall is considerable, the bottom may be endangered by the velocity and volume of water collected during continued rain; or if the declivity be very limited, and the aperture small, the drain is in danger of bursting from an impeded discharge;" but a complete answer to these apprehensions is found in the very next sentence, namely, "the rule is to apportion the area of all drains to their length, declivity, and distance from each other." $\dagger$ It is quite tme what Mr. Smith says on the subject, that "some people are still prone to the practice of throwing in a cross-drain, or to branches going off at right angles, which are of no farther avail in drying the land, while they increase the length of drain without a proportionate increase of the area drained." $\ddagger$ Should the want, howerer, of proper sized tiles, in any particular part of a field, where the quantity of water is greater than over the ordinary surface of the farm,

- Prize Esanys of the Highland and Agricultural Society, vol. xiii. 
induce you to incur the expense of a sub-main drain, rather than run the risk of injuring the land by the dreaded insufficiency of the drains below, it should be directed across the field as shown by $e$ in fig. 163, where, if cut of the same depth as the other small drains, those below should be dis. joined from it by a narrow strip of ground in the line of $e$ to $e$; but a much better plan is to make the sub-main 6 inches deeper than the rest of the drains, where it can be so deepened, and it will intercept the water coming from the ground above, while the drains will pass continuously over it. In such a case, when the sub-main $e$ falls into the small drain $b d$ at the side of the field at $e$, that part of the latter below $e$ to $s$ should be converted into a sub-main, which should be larger than small drains, though sub-mains need not be so capacious as main drains; but, in truth, in such an arrangement as this, sub-mains become mains, inasmuch as they convey as great a quantity of water.

(769.) The experimental cuts having been made, you become acquainted with the nature of the subsoil, and determine upon the depth of the drains; then cutting should be proceeded with forthwith, and this part of the work is best and most satisfactorily done by contracting with an experienced spadesman, at so much per rood of 6 yards.* The rates of cutting are generally well understood in the country. Let me impress upon you, in the matter of making a contract, the great satisfaction you will feel in engaging stout, active and skillful men; for although you may find men able to work a hard day's work, if they are nevertheless unskillful and inexperienced, you will experience many difficulties. Such men willingly take on work at low rates; but you will find it conducive to your interest rather to give such rates as will enable skillful workmen to earn good wages, than save a little money by employing rough, bungling hands; for there is no comparison between the advantages derivable from good and bad work.

(770.) The cutting of the drains is commenced by that of the main drain which terminates at the outlet, and the operation is commenced at the outlet, or lowest part of the field. The commencement of the operation is done in the same way as pointed out in the drains of the Elkington method-namely, by stretching the garden-line, and rutting off the breadth at top with the common spade by the principal man of the party. A second man then removes the top-mould with the spade; and if the subsoil is of strong clay, or tiles alone are to be used in filling the drains, he lays the mould on one side of the drain, and the subsoil on the other. In other kinds of soils and subsoils, and where stones are to be used in conjunction with tiles, the separation of the soils is not necessary. The reasons for this distinction in the use of the soils will be given a little farther on. The principal man, or contractor, follows, and shovels off all the mould, working with his face to the first man. A third man-for the gang or set of drainers should consist of 3 , for expeditious and clean work-loosens the top of the subsoil with the tramp-pick, fig. 37 , and proceeds backward with the picking, while the other men are removing the mould along the break or division measured off by the line, perhaps 60 or 70 yards. The second man then removes the loosened subsoil with the spade in fig. 170 , which is narrower than the common spade, being 6 inches wide at the point, digging with his back to the face of the picker-that is, working backward; and the leading man follows with a narrow-pointed shovel, fig. 38 , called

* It would be extremely convenient and highly satisfactory were the lineal measure of the rood, in which all country work is estimated, fixed of the same length throughout the kingdom, as the great diversities existing in this measure are truly perplexing I cannot gee the utility of a general law on weights and meas ures, if euch anomalies as this, and many others, are allowed to exist.

$$
\text { (607) }
$$


the ditcher's or hedger's shovel, with which he trims the sides of the drain, and shovels out the loose part of the subsoil left by the digger.

(771.) Should the drain be very wet, owing to a great fall of rain, or the cut draw much water from the porosity of the subsoil, to secure a proper consistence to the drain, it is better to leave off the digging at this stage of the work, and proceed to set off another length of line at the top; and, indeed, in such circumstances, it would be expedient to remove the top of the whole length of the particular drain in hand, to allow the water time to run off, and the sides of the drain to harden, as perseverance in digging to the bottom, in the circumstances, would be attended with risk of the sides falling in to a considerable extent. This precaution in digging drains is the more necessary to be adopted in digging narrow shallow drains than deep ones, as planks cannot be used in them to support the falling sides, as in fig. 154, because the men could not find room in small drains to work below the wedges which keep up the planks. Should the ground be firm, or no inconvenient quantity of water be present in the drain, the digging, of course, may properly be proceeded with to the bottom at once.

(772.) To effect this, the picking is renewed at the lower part of the drain, and another spit of earth thrown out with a

still narrower though of the same form of spade as in the last figure, being only 4 inches wide at the point. The leading man trims down the sides of the drain with this spade, and pulls out the remaining loose earth toward him with the scoor such as in fig. 171 ; or throws it out with such a

Fig. 17.

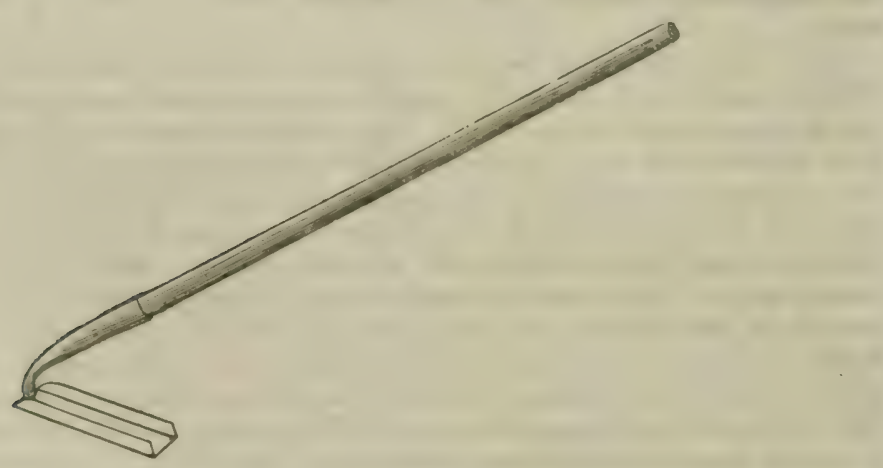

THE EARTH DRAIN SCOOP.

8coop as in fig. 152; and thus finishes the bottom and sides in a neat, even, clean, square, and workmanlike style.

(773.) What with the experimental cuts, and these first two spits of dig. ging below the mould, you will be easily able to determine the drawing property of the subsoil, and, consequently, the depth the drain should go. If the subsoil prove tilly, but still drawing a little water below the mould downward, the drain should certainly he 3 feet deep, and 15 inches wide at top; if of intermixed and minute veins of sand, and otherwise of good dxawing materials, then 30 inches of depth will suffice, and 12 inches of width at top; if of quite impervious clay, 2 feet deep and 10 inches of $(688)$ 
width at top will be found sufficient. It is right to cut the drain a little deeper where there is any sudden rise of the surface, and a little shallower where there are any sudden hollows, than to follow the undulations of the ground where these are trifling. As to the distances betwixt the drains in the first case of a tilly but drawing bottom, 15 feet asunder is, in my opinion, quite wide enough. In the second case of a drawing subsoil, drains at 30 feet asunder will effect as much as in the former case. And, as to pure clays, as 15 feet is too wide a distance, I would prefer 12 feet; but, to suit the ridges, there should be a drain in every open furrow, whatever distance asunder these may be.

(774.) In filling drains, it is a common practice with farmers to put in the materials as the drain proceeds in the digging-which, I conceive, is an objectionable proceeding. I think the whole length of the particular drain in hand should be entirely cleared out to the specified dimensions before the filling commence; because it is necessary, in the first place, that the state of the work be inspected, in accordance with the specification, before taking it off the contractor's hands; and inspection implies measurement of the contents in depth and breadth, and the fall of the bottomwhether it be regular throughout, where the slope of the ground is regular, or sufficient, where the general fall of the ground is small; or whether the fall is preserved in all the places where the ground is irregular. These are not trifling considerations, but essential; so much so, indeed, that the very efficacy of a drain as a conductor of water entirely depends upon them.

(775.) The fall of the ground can at any time be ascertained by the workmen by a simple contrivance. As the bottom of the drain is cleared out, a damming of 4 to 6 inches high will intercept and collect the water seeking its way along the bottom, and by this it can be seen whether the level line of the water cuts the bottom of the drain as far up as it should do according to the specified fall; and a succession of such dammings will preserve the fall all the way up the drain. When the weather is very dry, and a sufficiency of water wanting in the drain to adopt this mode of testing the fall, a few buckets of water thrown in will detect it, and of course it is only on comparatively level ground that such expedients as these are at all required.

(776.) Another reason for filling drains in this shallow mode of draining; where they are necessarily numerous, is from the upper to the lower end -and not from the lower to the upper, as is too commonly the practicethat the bottom of the drain should be cleared out most effectually with the scoop before the materials are put in, and this is best and most easily done down the natural declivity of the ground; and besides, in doing this it is at once seen whether the fall has been preserved, by the following of the water down the declivity. In deep draining the case is otherwise, because in that case the drains being few in number, and each possessing importance, the falls should be previously determined by leveling, and the amount of each leveling marked, by which means they can be preserved as the filling proceeds; and, besides, there would be risk of a deep drain, which may be of considerable length, and take a long time to throw out, falling in, to allow it to remain open for a length of time.

(777.) Of the materials for filling drains, I shall first notice stomes, not only because they have hitherto been the most common material, but have been for the longest time employed for the purpose. Drain stones are usually derived from two sources: 1. From the surface of the land; and when they are small and round, not exceeding the size of a goose's egg, no other material is equal to them in durability for the purposes of a drain;

$(689) . \ldots . .23$ 
and, 2. From the quarry, where they must be broken with hammers, like road-metal, to the smallness of from $2 \frac{1}{2}$ to 4 inches in diameter. It is a pernicious, and, indeed, an obviously absurd practice, to mix promiscuously stones of different sizes in a drain, as such can never assort together, and nothing can be more absurd than to throw in a stone which nearly fills up the bottom of a drain, and is sure to make a dam across it to intercept water. All large land-stones should be broken into small pieces, and any large, angular piece should not be put near the bottom, which should be kept as open as possible. Stones broken in the quarry are always angular, and in so far they are of an objectionable shape; because on fitting together, face to face, they can become a more compact body than round stones possibly can. No doubt, no ordinary pressure upon a body of earth 18 inches deep could squeeze small, broken stones together so as entirely to compress the spaces between them; but gravity, continually acting on loose budies, will in time consolidate small stones more and more; and heavy labor on the surface, and subsidence of water through the earth, assist by their action to produce a similar result; and we all know that macadamization makes a much more compact road than the old fashioned large, round stones.

(778.) Stones should never be broken at the side of the drain. I quite agree with Mr. Stirling when he says that "I prefer breaking stones in a bin. It is more easy to check the size, and it is done cheaper, as otherwise each heap has to be begun on the sward, and many of the stones are forced into the ground, which adds to the difficulty of lifting them. There will be a saving in carting the stones large, but it will be fully balanced by this disadvantage. I would deprecate of all practice that of breaking the stones in the field, and filling by the chain. This may be contracted for

Fig. 172.

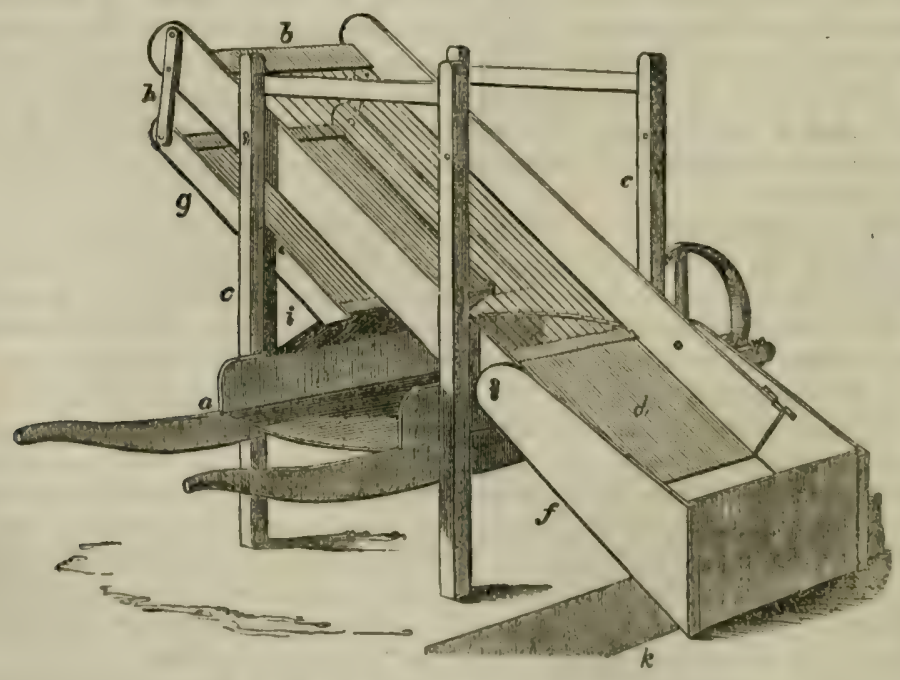

THE DRAIN STONE HARP OR SCREEN.

at a low rate, but it is easy to guess how the contractor makes wages." But although I would greatly prefer small, round stones to angular ones

- Prize Essays of the Ilighland and Agricultural Society, vol. xdi. (690) 
for drains, yet as the places that afford small, round stones naturally are very limited in number, and draining, if confined to such localities, would be as limited, it is far better to take any sort of quarried stones than leave land undrained, and there is no doubt that almost every sort of stones forms an efficient and durable drain if employed in a proper manner.

(779.) As I am acquainted with no drainer who has bestowed so much pains in the breaking, preparing, and putting in stones into drains as $\mathrm{Mr}$. Roberton, I shall describe his method of managing quarried stones; and first in regard to the implements used by him for that purpose. 1. There is a portable screen or harp for riddling and depositing the stones, as seen in fig. 172, which consists of " a wheelbarrow $a$, over and across which is suspended a screen $b$, having the bars more or less apart, according to the description of materials intended to be used. The upper end is hung upon two posts $c c$ about 3 feet above the barrow; the lower end rests upon the opposite side of the barrow. To this lower end is affixed a spout $d$, attached about 10 inches from the lower extremity of which is a board $e$, by means of two arms $f$. Another screen $g$, about one-half the length, and having the bars about half an inch apart, is hung parallel, about 10 inches below the larger one. The upper end of $g$ is fixed by means of two small iron bars $h$ to the upper end of the larger screen; the lower end rests upon a board $i$ sloping outward upon the side of the barrow opposite to that on which the spout $d$ is situate." 2. A movable trough, or, as it is commonly called, a tail-board, a, fig. 173, is attached to the hind part of a

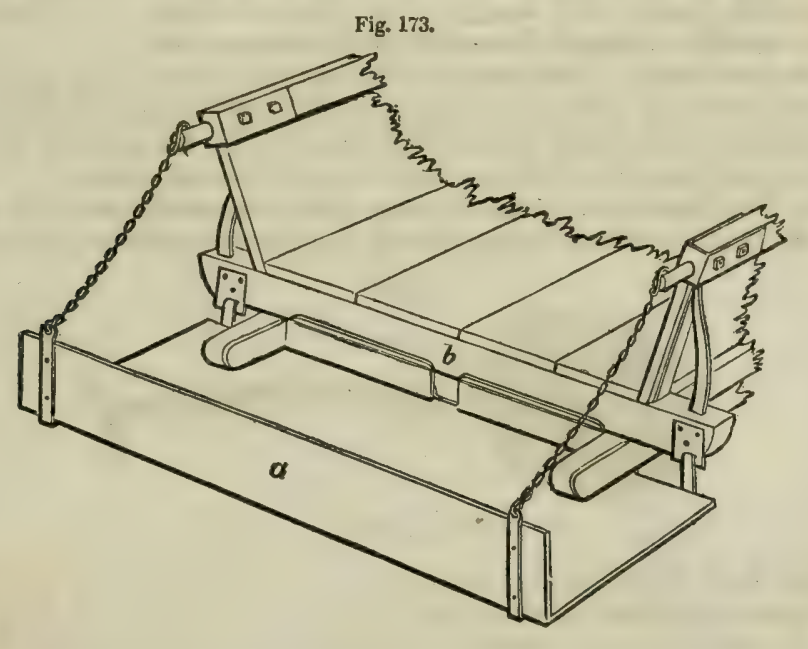

THE TAIL-BOARD TROUGH FOR RECEIVING THE DRAIN STONES IN THEIR FALL.

cart, for the purpose of receiving any stones that may drop while the work men are shoveling them out of the cart. A portion of the hind part of a cart $b$ shows the manner in which it is affixed to it. 3. Fig. 174 is a small

Fig. 174.

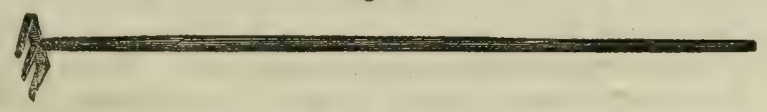

THE DRAIN STONE RAKE.

iron rake, used by the workman in charge of the screen, "for the purpos" (691) 
of making the surface of the larger stones of a uniform hight before being covered with the smaller." 4. Fig. 175 is called a "beater, which is a square piece of wood the width of the drain, used for beating the smaller stones into the interstices of the larger ones, and thus leveling the surface of the drain."*

(780.) The stones are put in in this manner: The earth is all put on one side of the drain. The barrowscreen is placed on the other, so as the board $e$, fig. 172 , attached to the lower end of the spout $d$, shall reach the opposite side of the drain $k$. The cart, with a load of broken stones from the bin, is brought to the same side of the drain as the barrow, and a little in advance, and there the tail-board $a$, fig. 173, is attached to the hinder part of it. The carter then shovels the stones out of the cart, and empties them over the top of the screen. In doing this, some care is requisite; for, if the stones are thrown over the screen with force, they will not alight sooner than half-way down the screen, and thus its screening efficacy will be impaired. The proper method is to rest the shovel on the top of the screen, which part should be shod with plate-iron, and merely turn it over, by which a separation of the stones is at once effected-the larger ones, rolling down, strike against the board $e$, fig. 172, and drop into the middle of the drain, without disturbing the

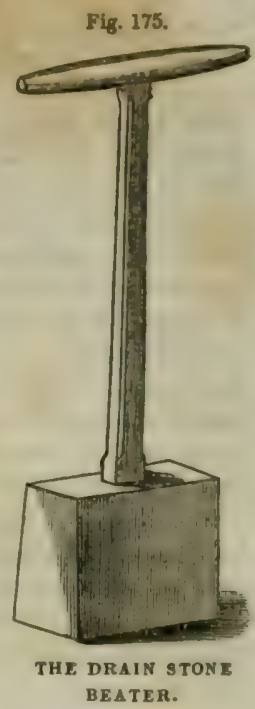
earth on either side. The smaller ones, at the same time, pass through the upper screen $b$, and, being separated from the rubbish by falling on the lower screen $g$, roll down into the barrow $a$, while the rubbish descends to the ground on the side of the barow farthest from the drain.

(781.) The best form of shovel for putting the stones over the top of the screen is what is called a frying-pan or lime shovel, represented by fig. 176,

Fig. 176.

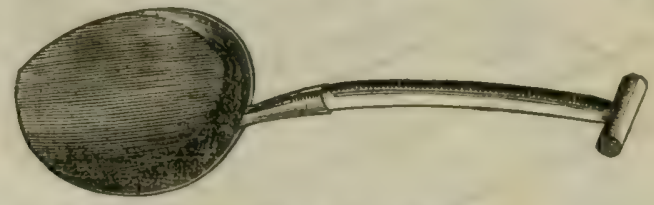

THE FRYTNG-PAN OR LIME-SHOVEL.

the raised back of which keeps the stones in a collected form until they are turned over the screen, and its point secures an easy access along the bottom of the cart under the stones. Such shovels are much in use for spreading lime and shoveling up the bottoms of dunghills in the border counties of Scotland, and they cost 3s. $10 \mathrm{~d}$. each of medium size, ready for use.

(782.) One man takes charge of the filling of the drain. His duties are to move the barrew forward along its side, as the larger stones are filled to the required hight; to level them with the rake, fig. 174 ; to shovel the smaller stones from the barrow, spread them regularly over the top of the larger, and beat them down with the beater, fig. 175, so as to form a close and level surface through which no earth may pass. When the stones are broken in the quarry so as to pass through a ring 4 inches in diameter, a quarter of them is so small, or should be made so small, as to pass through

- Prize Essays of the Highland and Agricultural Society, $\nabla \bullet L$ xiv. (692) 
the wires of the upper screen $b$, fig. 172 , which are $1 \frac{3}{4}$ inches apart; and they then will be found sufficient to give the top of the drain a covering of 2 or 3 inches deep, which, being beaten closely down, requires neither straw, turf, or anything else to cover them.

(783.) With regard to covering with vegetable substances, Mr. Robertun says, with much probable truth, that " the only possible use of a covering of straw or turf is to prevent any of the earth, when thrown back into the drain, getting down among the stones; but it is evident that such a covering will soon decay, and then it becomes really injurious, because, being lighter (and finer) than the soil, it will, when decomposed, be easily carried down by any water that may fall directly upon the drain; and, if the surface of the stones has been broken so small as to provent the drain sustain. ing any injury in this way, then the covering itself must be altogether su. perfluous. But farther, it will be found that the effect of this practice, ir many cases, is still more injurious. When drains are filled in the usua. way, whether with land or quarried stones, a man, or sometimes a woman. is appointed to level the surface and put on the straw or turf; and the per. son appointed to this duty knows that his master expects him to do a cer. tain number of roods per day, and, finding the stones difficuit to break, he too fiequently contents himself with merely leveling the surface, and, by means of the covering, the fault is effectually concealed. By the method, however, of separating the small stones from the large, the whole expense of this sort of breaking is saved, and a covering is given to the drain on which time will produce no change."* I have often grudged fine straw being wasted in covering drains, when less valuable materials might have been collected for the purpose, such as dry leaves, dry quickens, tanner's refuse bark when near towns, coarse bog hay, broken moss, \&c. I never would suffer a particle of good straw to be wasted in covering drains.

(784.) A drain completed in this manner with stones may be seen in fig. 177. The dimensions given by Mr. Roberton are 33 inches deep, 7 inches wide at bottom, and 9 inches wide at the hight of the stones, which is 15 inches; and within these dimensions 15 cubic feet of stones will fill a rood of 6 yards of drain. Mr. Stirling has 30 inches deep in the furrows, 5 inches wide at bottom, and 8 inches wide at 15 inches from the bottom; the contents of a rood of 6 yards being rather more than $12 \mathrm{cu}$ bic feet. The figure here represents a drain 36 inches deep, 9 inches wide at bottom, 12 inches at the top of the stones, and the stones 18 inches deep. These dimensions give cubical contents of $23 \frac{1}{2}$ feet per rood of 6 yards; that is, about half as many stones more than the drains of Mr. Roberton, and of course so much more expensive. I own I am partial to the breadth of the common spade as a gauge for the width of the bottom of a drain that is to be filled with stones, because it gives plenty of room to them to form a durable stony filter, which THE SMALL DEAIN FIILED 7 inches can scarcely do so well, especially when

they are broken to 4 inches in diameter. I am quite persuaded, nevertheless, that the permanency of a drain does not depend so much on the quantity as upon the manner in which the stones are put into it; and $I$ am as well persuaded that it is no matter what description of materials are used, * Prize Essays of the Highland and Agricultural Society, vol. xiv.
(693) 
provided there is alivays left an open and large enough space at the bottom to contain the greatest quantity of water that the drain can possibly have to receive, and provided also that the opening shall be protected from any earth or mud getting in to intercept the flow of water. Yet I agree with Mr. Stirling that our experience is not sufficient to prove what is the smallest size that a drain might be to be permanent. In which uncertainty it should be of sufficient breadth to prevent moles pushing across it; and this consideration regarding moles acquires greater importance the more the land is drained; for, the deeper we contine water under the ground, the deeper will the worms be obliged to go in search of it, and of course the nearer the bottom of the drains will the moles be disposed to burtow in search of their food. Mr. Stirling proposes only to make the bottom of the drain 5 inches, but then he directs the stones to be broken to pass through a ring of $2 \frac{1}{2}$ inches diameter. Such diversity of opinion on the same subject shows you either that experience has not as yet proved what capacity of drain is the best, or that it is immaterial to the draining of land of what breadth drains are made. The principle I maintain in the making of drains is, that, being permanent works, they ought to be made in the most substantial manner. It has not yet been ascertained by experiment what dimensions, in given circumstances, afford sufficient permanency, and until that point has been settled it is wisdom rather to exceed than to curtail the dimensions; and, although in the mean time the wisdom may be "dear bought," the question of cost is a secondary one to efficiency and permanency.

(785.) With regard to the quantity of stones used in such drains, and the time required for putting them in, Mr. Roberton's experience is, in drains of the above dimensions, namely, 33 inches deep, 7 inches wide at bottom, 15 inches filled with stones, and 9 inches wide at the top of the stonesthe cubical contents being 15 feet per rood of 6 yards-supposing that a set of carts, driven by boys or women, are able to keep a man employed in unloading them, and another man taking charge of the screen-barrow, 60 to 70 roods can be filled in a summer day of 10 hours; but, as the lineal length depends on the dimensions of the drain, the work, reduced to cubical contents, gives $3 \frac{1}{2}$ cubic yards per hour. These data were derived from whole pieces of work, such as in $1840 \mathrm{Mr}$. Roberton contracted for, for the execution of 4,000 roods, the filling to commence on the 1st July and to be completed on the 12 th August. There were 2 sets of carts and 2 screens employed, and the contractors had some stones ready and part of the drains half executed by the 1st July. When the filling commenced 66 roods were finished every day-that is, as it happened, a stretch of drain of exactly 400 yards; but, as the weather was very unfavorable for the work, only 3,300 roods, instead of 4,000 , were executed, in which about 2,000 cubic yards of stones were buried. In 1839 , of drains of $2 S$ inches deep, 10 to 12 inches of stones in depth, and about 10 cubic feet contents per rood, 2,100 roods, or from 90 to 110 roods per day, were filled, with 1 set of carts and 1 screen, from 1st July to 5th August.

(786.) In Mr. Stirling's case of the drains mentioned above, namely, 30 inches deep in the furrow, 5 inches wide at bottom, and 8 inches at the top of the stones-which were 15 inches deep, and their cubical contents 12.3 feet per rood of 6 yards, the stones heing supposed to be carted 1 mile2 men filled 60 carts of broken stones each day, allowing for loss of time in backing into the bin of stones; a man emptied a cart-load into the drain in 15 minutes, and was ready to return with the cart in 2 minutes more, the horse being supposed to walk at the rate of 3 miles per hour. In this way, a chain of 22 yards, or 3.66 roods, required 3 carts of stones. 
(787.) So much for stone, and now for the cost of tile-draining. The dimensions of tile-drains depend entirely on the mode they are to be constructed. If no soles are to be employed, they may be the narrower; and if nothing else but tile and sole are to be put into them before the earth is returned, they may be the shallower. If the same rule be followed in regard to them as with stone-drains-that is, if 18 inches of earth should be retained over the hard materials, to give liberty to deep plowing - then 18 inches, added to the tile and covering, is the least depth that a tile-drain should have; and its least breadth is determined by the breadth of sole that is used.

(788.) As the dimensions of these drains depend on the use of soles, the necessity for their adoption should be settled at once. It seems to be the uniform opinion of all writers on tile-draining that, "in hard-bottomed land, the sole-tile is unnecessary; but why unnecessary, as I have before observed, no one has proved to my satisfaction. Water being the substance to whose use drains are appropriated, I may mention, in regard to the quantity that may sometimes be found in drains, that Mr. Stirling has found that, after a very heavy fall of rain, tiles of $2 \frac{3}{4}$ by $3 \frac{1}{2}$ inches are filled with water nearly $\frac{2}{3}$ full; ; and yet writers on draining wish to persuade you that such a body of water will not at all affect a clay subsoil or endanger the stability of tiles. I advise you to believe no such assertions, but take for granted that all drains having an earthy bottom of whatever nature, intended to be occupied by tiles, should have soles, or something equivalent-such as slates-under the tiles, to protect the earth from the destructive effects of water. Mr. George Bell, Woodhouselees, Dumfriesshire, has used Welsh slates instead of tile-soles, and found them equally efficacious and much cheaper.t Gray slate and pavement quarries, such as abound in Forfarshire, would supply an abundance of excellent materials for the soles of drains.

(789.) The breadth of the sole, then, determines the width of the bottom of the drain; and, should the breadth vary in different parts of the country, the width must in practice be made to suit the sole, but it is probable that soles will be made to suit the proper breadth of drains, when that has been determined by experience. But as that point has not yet been determined by experience, and soles are made of sizes most convenient for their manufacture, the drains must continue to be made of the dimensions suited to the materials by which they are to be filled, until a better order of things arrive. I perceive that the breadth of soles made in the neighborhood of Kilmaruock, at the tile-kilns belonging to the Duke of Portland, in Ayrshire, as well as those made by Mr. Boyle, tile-maker in Ayr, is 7 inches; and this breadth is made to answer tiles varying from 4 to 3 inches in width, inside measure. For a 4 -inch tile, a narrower width than 7 inches would not answer; as the tile is $\frac{3}{4}$ of an inch thick, only $\frac{3}{4}$ of an inch is left beyond each side of the tile when placed on the sole, which is as little space as it can stand on securely. For the smaller sized tile of 3 inches, the width is ample; but still it is no disadvantage to a tile to have plenty of room on a sole, as its position can easily be fixed by wedging in stones on each side against the walls of the drain, when stones are used above the tiles; or it leaves sufficient room for a lapping of turf over, and wedging of earth on each side of, the top of the tile. In the case of a 5-inchwide drain at bottom, the smallest size of tile, $2 \frac{3}{4}$ inches wide inside, must be used, as only $\frac{3}{8}$ of an inch would be left on each side of that width of

* Prize Fssays of the Highland and Agricultural Society, vol. xii. (695)

$\uparrow$ Ibid. vol. siii. 
tile. I am aware that to press the tile into the drain, made tight to fit it, without a tile-sole, is a very common practice among drainers; but the practice of pressing hard against the sides of the drain is, in my opinion, objectionable, inasmuch as it is not the hard tile, but the free side of the drain, that draws the water from the land; and to press a hard substance like a tile against the earth in a shallow cut, is very like an attempt to curtail the extent of drawing surface. The inducement to use such expedients would be greatly removed were soles made to suit each description of tile; and, what would be still better, were the sizes of tiles more limited in their range, and more uniformly alike; fur, as at present made, a great diversity of sizes exists throughout the country, in the area of vertical section as well as in length, so that the prices quoted afford no true criterion of their intrinsic worth.

(790.) Soles are usually made flat, but Mr. Boyle makes them curned; not because they are better suited for the purpose, but merely because they are more easily dried in the sheds; but a curved sole is objectionable, as it is more difficult to form a smooth bed for it to lie upon, and it is more apt to break when it happens not to be firmly laid upon its bed than a flat sole.

(791.) As to tiles, their perfect form is thus well described by Mr. Boyle: "All tiles should be a fourth higher than wide; the top rather quickly turned, and the sides nearly perpendicular. Tiles which are made to spread out at the lower edge, and flat on the top, are weak, and bad for conveying water. Some people prefer tiles with flanges instead of soles; but, if placed even in a drain with a considerably hard bottom, the mould. ering of the subsoil by the currents of air and water causes them to sink and get deranged."* Tiles should be smooth on the surface, heavy, firm, and ring like cast-iron when struck with the knuckle. They should be so strong when set as to allow a man not only to stand, but to leap upon them without breaking. The introduction of machinery into the manufacture of drain-tiles, by compressing the clay, and working it thoroughly in a pug-mill to prepare it for being compressed, has greatly tended to increase the strength of tiles. I have seen drain-tiles so rough, spongy, crooked, and thin, as to be shivered to pieces by a night's frost when laid down beside the drain. The use of machinery has caused a great deal more clay to be put into them, and their greater substance has been the cause of improvement in the construction of kilns, in which they are now burned to a uniform texture, as well as some avoidance of breakage in the manufacture; by all which, of course, their cost is lessened. An underburnt as well as an over-burnt tile is bad, the former being spongy and absorbing water, and ultimately falling down; and the latter is so.brittle as to break when accidentally struck against any object.

(792.) The length of drain-tiles varies in different parts of the country. Mr. Boyle's are 13 inches; the Duke of Portland's, in Ayrshire, and Mr. Beart's, Godmanchester, Hertfordshire, 12 inches; and those from the Marquis of Tweeddale's machine, 14 inches, when burnt. If the price is the same per 1,000 , of course the 14 -inch tile is cheaper than the 12 -inch, but otherwise the 12 -inch is the handiest article in the manufacture, as being less apt to waste in handling, and twist when in the kiln; and their number is much more easily calculated in any given length of drain. The following table shows the numbers of tiles required for an imperial acre. of the different lengths made, and placed at the stated distances:

- Prize Essays of the Highlend and Agricultural Society, vol. xii. 1696) 


\begin{tabular}{ccccccccc}
\hline \multicolumn{1}{c}{ Drains at 12 feet apart require 3630} & 3351 & 3111 & 2904 per acre. \\
$\ldots$ & 15 & $\ldots$ & $\ldots$ & 2904 & 2681 & 2489 & 2323 & $\ldots$ \\
$\ldots$ & 18 & $\ldots$ & $\ldots$ & 2420 & 2234 & 2074 & 1936 & $\ldots$ \\
$\ldots$ & 21 & $\ldots$ & $\ldots$ & 2074 & 1314 & 1777 & 1659 & $\ldots$ \\
$\ldots$ & 24 & $\ldots$ & $\ldots$ & 1815 & 1675 & 1556 & 1452 & $\ldots$ \\
$\ldots$ & 27 & $\ldots$ & $\ldots$ & 1613 & 1480 & 1383 & 1291 & $\ldots$ \\
$\ldots$ & 30 & $\ldots$ & $\ldots$ & 1452 & 1340 & 1245 & 1162 & $\ldots$ \\
$\ldots$ & 33 & $\ldots$ & $\ldots$ & 1320 & 1218 & 1131 & 1056 & $\ldots$ \\
& 36 & $\ldots$ & $\ldots$ & 1210 & 1117 & 1037 & 968 & $\ldots$
\end{tabular}

The numbers of each length of tile required at intermediate distances can easily be calculated from these data.

(793.) I give here a representation of a well-formed drain-tile, and how tiles should be set on soles, as in fig. 178, where $a$ and $b$ are two 12-inch

Fig. 178.

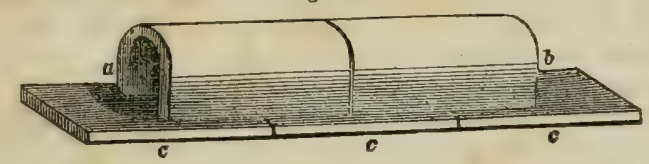

THE RRAIN-TILES PROPERLY SET UPON TILE-SOLES.

tiles, of the correct shape described in paragraph (791) by Mr. Boyle.They are represented as set upon the sole-tiles $c$; and, to insure a continuation of the same relation between tile and sole, the former should stand upon part of two of the latter, making the joinings of the tiles intermediate with those of the soles, the latter being also 12 inches in length. The drain-tiles used for draining the estate of Netherby, in Cumberland, belonging to Sir James Graham, Bart., and represented in vol. vii. p. 392 of the Prize Essays of the Highland and Agricultural Society, are more pointed in the arch than these, but, on that account, are not so strong in the shoulder to bear a weight upon them. It is the practice of some tiledrainers to put a $\frac{1}{2}$ sole under every joining of 2 tiles, leaving the intermediate space of the bottom without any sole, imagining that this will insure sufficient steadiness to tiles on what they call hard clay, while only half the number of soles are used; but I hope I have said enough on the hardness of clay when in contact with water, for you to avoid so precarious a practice.

(794.) There is a mode of joining tiles in drains that meet one another that deserves attention. The usual practice is to break a piece off the corner of 1 or 2 main-drain tiles, where the tiles of the common drains should be connected with them. In breaking off corners, there is risk of breaking the entire tile; and, no doubt, many are broken when subjected to this treatment. Another plan is to set 2 main-drain tiles so far asunder as the inside width of a common-drain tile, and the opening on the other side of the tiles, if not occupied in the same manner by the tiles of another drain, is filled up with pieces of broken tiles or stones, or any other hard substance. It is possible that the broken piece of tile, so placed, may be farther broken or dislodged by the returning of the earth and the action of moles, which may push in earth at that part, and render all above it useless. This is, perhaps, a better plan than running the risk of breaking a number of tiles, and, after all, failing in making the opening suitable for the reception of the adjoining drain-tiles. Both plans, however, are highly objectionable, and should never be resorted to where tiles, formed for the purpose of receiving others in their sides, can be procured. Mr. Boyle, of Ayr, makes main-drain tiles with openings' on purpose to receive the (697) 
shouldered end of the furrow-tiles," and to answer a similar purpose in particular situations, where such tiles cannot be conveniently joined, he makes $\frac{1}{2}$ and $\frac{1}{4}$ lengtbs of main and furrow tiles, which may be so arranged in regard to one another's position as to conjoin the openings of both at the same place. Fig. 179 represents the mode of joining a cummon drain with a main-drain tile, having an opening in its side. The common tile $b$ is not inserted entirely into the main-drain tile $a$, but only placed against it, with a small shoulder, that the openings of both tiles may be always in conjunction.

(795.) The outlet forms the end of the main drain, and its proper place deserves

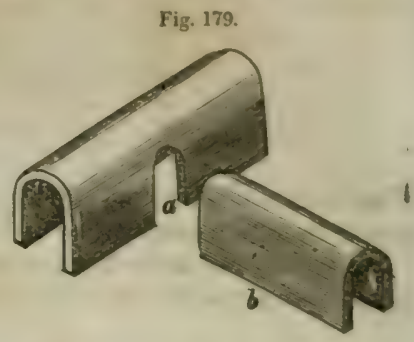

THE JUNCTION OF A COMMON TILE WITH A MAIN-DRAIN ONE. serious cousideration. There should be a decided fall from the outlet, whether it is affected by natural or artificial means. If it be very small-and I have already stated (751) that a small fall is all that is requisite-that is, 1 foot in 150 feet, or 3 feet in the mile, as indicated by the spirit level-the open ditch into which the main drain issues should be scoured deep enough for the purpose, even for a considerable distance; and when this expedient is adopted, it will be requisite to see every year that the outlet is kept open, and the ditch scoured as often as necessary for the purpose.

(796.) It is a frequent charge of neglect against farmers, that they allow open ditches almost to fill up before they are again scoured out; and a not unfrequent excuse for the neglect is, that scouring of ditches to any extent incurs considerable labor and expense. No doult they do, and no wonder, since so much work has to be done, when it is done. Were the ditches scoured out when they actually required it-nay, every year, if that is found necessary for the welfare of stuck, fences, or drains-so little expense would be incurred at one time as to remove every complaint against the labor as a burden; but much better, in every case where it can be done, to incur the expense at once of converting an open ditch into a covered drain, than grudge the expense of keeping it in a proper state.

(797.) Should the fall from the mouth of the main drain to a river be too small, and there be risk, at times, of the overflowings of the river sending back-water into the drain, the drain should be carried down as far by the side of the river as will secure a sufficient fall for the outlet. Rather be at the expense of carrying the drain under a mill-course or rivulet, than permit backwater to enter it.

(798.) A spirit level, such as fig. 150, I have

Fig. 180.

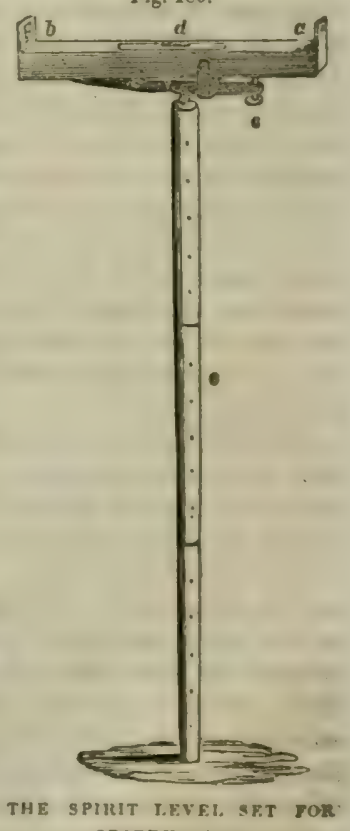

OBSERVATION.

found a very convenient instrument for ascertaining such a point, and generally for taking levels in fields. It is furnished with eye sights $a b$, and

- See Prize Esagy of the Highland and Agricultural Society, vol. xii., Plate L, for figure of this tile. (698) 
when in use is placed into a framing of brass, which operates as a spring to adjust it to the level position $d$, by the action of the large-headed brass screw $c$. A stud is affixed to the framing, and pushed firmly into a gimlet hole in the top of the short rod $e$, which is pushed or driven into the ground at the spot whence the level is desired to be ascertained. I need scarcely mention that the hight of the eye-sight from the ground is deducted from the hight of observation, and which quantity is easily obtained by having the rod marked off in inches and feet; but I may mention that you should use this instrument in all cases of draining on level ground, even where you are confident that you know the fall of the ground, for the eye is a very deceitful monitor for informing you of the levelness of ground. In one case of my own, I was pretty sure by the eye zhat the outlet to a division of drains in a field should fall, at some yards off, into an open ditch, which constantly contained spring water. The contractor of the drains was of the same opinion. On testing with the spirit level, however, we found that the bottom of the outlet would have been 8 inches below the bottom of the ditch instead of above it. As, in this particular case, it would have occasioned a cutting of 200 yards to get a proper fall for the outlet in another direction, I caused a narrow well to be sunk on the spot, 8 feet deep, to the stratum of gravel below, and, on being filled with stones, the gravel absorbed all the water from the drains. Such a spirit level, well finished, costs $15 \mathrm{~s}$. When not in use, the framing is concealed, and the spirit-tube protected by a movable cover; and the whole instrument, being only 8 inches in length, $1 \frac{3}{4}$ inches deep, and 1 inch broad, and light withal, can be easily carried in the pocket, while its rod may be used as a staff.

(799.) It may happen that, through the undulatory nature of the ground, more than one outlet will be required to clear a field of water, that is, one division of drains may be let more easily out in one place, and another division more easily in another. In such a case, it should be well considered whether both outlets should be joined together or carried away separately, the latter being the less objectionable mode.

(800.) The cutting of the main drain should be entirely finished before the tiles are laid in it; and immediately after it is finished, it should be measured with the drain-gauge, fig. 155 , to ascertain if it contains the specified dimensions and fall.

(801.) While the earth is throwing out toward the narrowest side of the head-ridge, that is, next the fence, the carts should be laying down the tiles and soles along the open side next the field; or they can be laid down before the drain is begun to be opened, and after its line of direction has been fixed. To be certain that the number of tiles and soles are laid down, they should each be placed end to end respectively along the whole line, the soles nearest the drain lying against the tiles, among which, of course, broken ones are not counted, though a sole fractured in two will lay down well enough in a good bed between two whole ones. The tiles with the opening in the side, along with its conjunctive small tile, fig. 179, should be laid down at the distances determined on for the small drains to enter the main drain. These preliminary arrangements should be carefully attended to, or much inconvenience may be occasioned in carrying tiles and soles to and fro to the person who lays them in. It is necessary beforehand to instruct the plowman who is to lay them down out of the cart, of the plan, as some mistake will inevitably ensue, if he is merely told to lay down the tiles and soles by the drain; for few plowmen reflect on the consequences of what they are doing. If, by inadvertence to these minutixe of practice, more or fewer tiles or soles are laid down than re 
quired, part of the yoking of a pair of horses lost in laying them down, and part of another is also lost in lealing them away to another place, while the unused tiles are in danger of being broken by frequent lifting, and all this waste of time arising from want of forethought.

(802.) The person intrusted with the laying of the soles and tiles into the drains, should be one who has been long accustomed to that kind of work, and otherwise a good workman, possessing judgment and common sense. If he is not a hired servant, he should be paid by day's wages, that he may have no temptation to execute the work ill; and to enable him to do it well let him take even more time than you imagine is necessary, especially at first, provided he executes what he does to the satisfaction of his employer. You will soon be able to ascertain how much work of this kind a man should do in a day, according to the circumstances of the case, and you can then judge whether he has been putting off his time, and admonish and encourage him accordingly.

(803.) This person should remain constantly at the bottom of the drains; and, to enable him to do so, he should have an assistant, to hand him the materials from the ground. The best assistant he can have, in my opinion, is a female field-worker. Such a one not only receives cheaper wages, but is dexterous in handling light materials, and quite able to lift tiles. soles, and turf easily.

(S04.) Immediately before proceeding to lay the sole-tiles, the man should remove any wet, sludgy matter from the bottom of the drain with a scoop, fig. 171, and dry earth and small stones can be removed with a narrow draw-hoe, as in fig. 181, with a 2 -feet handle $b$, and mouth $a 3$

Fig. 181.

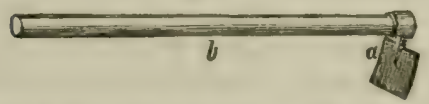

THE NARROW DRAW-HOE FOR DRAINS.

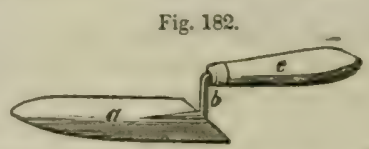

THE TROWEL FOR DRAINS.

inches in width, cost 1s. The sole is firmly laid and imbedded a little into the earth. Should it ride upon any point, such as a small stone or hard lump of eatth, that should be removed; and a very convenient instrument for the purpose, and otherwise making the bed for the soles, is a mason's narrow trowel, as in fig. 182,7 inches long in the blade $a, 5$ inches in the handle $c$, and $1 \frac{1}{2}$ inches at $b$, and if of cast-steel will cost $2 \mathrm{~s}$, of common $1 \mathrm{~s}$. 3d. If a single sole has been determined to be laid on the ground, as in fig. 178 , or a double one side by side, as in fig. 160 , he lays them accord ingly. After laying 3 soles in length, he sxamines to see if they are straight in the face, and neither rise nor fall more than the fall of the drain. As a safe guide to him, in cases where the fall is not decidedly cognizable by the senses, a mason's plumb-level, such as fig. 183 , will be found a convenient instrument. A mark at which the plummet-line $d f$ will subtend an angle with the plumb-line $d e$, equal to the angle of the fall of the drain, should be made on the top of the opening $e$, which, in this case, may be supposed to be where the plumb $f$ at present hangs; by which arrangement it is demonstrable that the angle $e d f$ is always equal to the angle $b a c$, which is the angle of inclination of the fall. The breadth of the sole or soles, as the case may be, should occupy the exact width of the drain, and in the case of a main drain the soles are each 10 inches broad.

(805.) After 3 soles are thus placed, 2 tiles are set upon them, as represented in fig. 178 , that is, the tiles $a$ and $b$ are so placed as that their 
joinings shall meet on the intermediate spaces between the joinings of the sules $c$, and this is done for the obvious reason that, should any commotion disturb one of the soles. neither of the tiles, partially standing upon

Fig. 183.

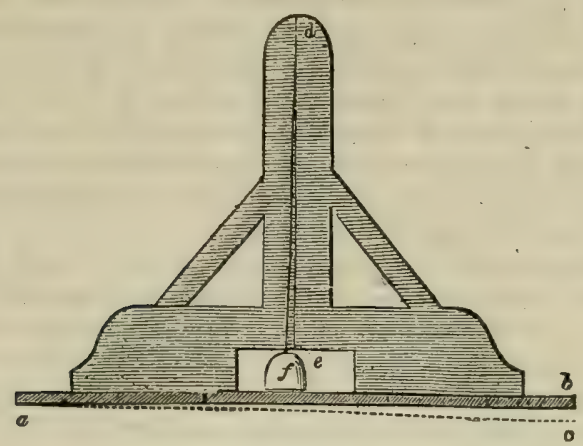

THE DRAINER'S PLUMB-LEVEL.

it, should be disturbed. In ordinary cases of water in a main drain, a tile of 4 inches wide and 5 inches high inside is a good size; and from this size they vary to $5 \frac{3}{4}$ inches in width and $6 \frac{1}{2}$ inches in hight. Although the size of the tile varies, that of the main drain sole is always the same, that is, 10 inches wide and 12 inches long. Taking the useful tile of 4 inches in width and 5 inches in hight, its thickness being $\frac{3}{4}$ inch, there will be a space left in each side of $2 \frac{1}{4}$ inches.

(806.) The covering, of whatever substance, should be laid in a row or in heaps along the line of the tiles. 'Turf is the best covering, and it is put over the tiles saddlewise. If the turf were cut 12 inches broad and 18 inches in length, it would just. lap over the size of tile mentioned above, and rest its end upon the sole on both sides; and, if it be from 2 to $2 \frac{1}{2}$ inches in thickness, the small space left on each side between the turf and the walls of the drain would be filled up. It is as easy to cut the turfs of the exact sizes required as any other, by rutting off the swarded ground in regular breadths; and it would be as easy to cast the turfs in regular oblongs, as in the irregular pieces usually raised according to the whim of the spadesman. The old fauchter-spade of Scotland has long been used to cast turf, but it is a rude instrument at best, and not nearly so gond as the common sparle for a neat job. When cast, the turfs should be laid one above another in neat bundles of 3 or 4 turfs, which can be easily taken up, and placed safely into the cart, and not thrown singly in, to the risk of their being torn, broken, or put out of shape on being doubled up. They should be as carefully taken out of the cart; in the same bundles they were put in, and if not used immediately, should be put in large bundles to keep them supple and moist; but not so kept a long time, in case of their heating and fermenting. If used in summer, in very dry weather, some water should be thrown upon them to keep them inoist, but water in winter might injure their texture by frost. If, on the other hand, they are used immediately, they should be laid down along the outside of the tiles, not in a single row like them, because taking them from the cart and lifting them up again is apt to tear them, but in the small iundles, which are placed as far asunder as the space the turfs would occupy were they laid singly alung in Jine. Judging from the usual treatmeit which it receives, turf seems to be very Iittle valued, be(701) 
ing crumpled up, thrown down, and kicked about, until it becomes much broken and bruised, when it is not nearly so fit for a covering for tile as when raised from the ground. I need scarcely add that smooth turf is much better than tufty or heathery clods. Good turf is an expensive article, and not to be obtained everywhere. A man will cast from 4 to 6 cart-loads, of 1 ton each, per day, according to the smoothness and softness of the ground. Its usual thickness is about 3 inches, when 1 square yard will weigh about $54 \mathrm{lbs}$, and of course 1 ton will cover about 40 square yards, or 40 roods of 6 yards with turfs of 1 foot by $1 \frac{1}{2}$ teet. In the country carriage is the heaviest charge against turf; in towns it is charged from 8 s. to $20 \mathrm{~s}$. a ton, and $8 \mathrm{~s}$. per square yard is charged for casting, carting, and laying turf for greens and borders.

(807.) On being handed to him, the man lays the turf, grass side down, over the tiles in a firm manner, taking care to cause the joinings of the turf to meet as near the middle of the tiles as practicable, and not over the joinings. Were the turf cut of the same breadth as that of the tiles used, the covering of a drain would proceed not only rapidly, but neatly and satisfactorily. He takes care not to displace the tiles in the least when the turf is being put over; and to secure the tiles in their respective places, he puts earth firmly between the covering and the sides of the drain as high as the turf over the tile. This earth is obtained from the soil that was thrown out; and if the subsoil is a strong clay, the surface soil is the best, but a porous subsoil answers the purpose. When all these things which I have described have been done, the drain will appear like the small drain, fig. 151 , where the sole and the tile set upon it, the turf wrapped round the top of the tile, and the stuffing of earth on each side of the tile may all be easily observed.

(808) The preparations for the junction with the small drains should be made luring the completion of the main drain, for if the main tiles are taken up when the small drains are forming, in order to accommodate the small tiles, they will run the risk of being displaced, and of otherwise disturbing the current of water when it is to run in it. Whichever plan is adopted for letting in se small tiles, and be it ever remembered that the tiles with the open side are the best for the purpose, the man should never forget to make the openings at the stated distances the small drains should enter, and for this purpose he should be provided with a 6-feet rod, marked off in feet and inches, to measure the distances as near as he can, in regard to the fitting of the tiles. The covering of turf should, of course, not be put over the openings left for the small tiles, but the openings should not be left wholly unprotected after the main drain is finished, in case any thing should thrust earth or any other substance into the tileduct, that might close up or otherwise injure the drain. A bundle of straw, or rather a turf, until the small drains are connected with them, will be sufficient to protect the openings against injury of this kind.

(809.) The mouth of the main drain at its outlet, whether in a ditch or river, should be protected with masonry, and dry masonry will do. The last sole, which should be of stone, should project as far beyond the mouth as to throw the water either directly upon the bottom, or upon masonry built up by the side of the ditch. The masonry should be founded below the bottom of the ditch, and built in a perpendicular recess in its side, with the outer face sloping in a line with the slope of the ditch. The sloping face can be made either straight, which will allow the water to slip down into the ditch, or like steps of a stair, over which the water will descend with broken force. It would be proper to bave an iron grating on the end of the outlet, to prevent vermin creeping up the drain; not (702) 
that they can injure tiles while alive, but in creeping too far up, they may die, and cause for a time a stagnation of water above them in the drain.

(810.) If the ground fall uniformly toward the main drain over the whole field, the small drains should be proceeded with immediately after the main drain is finished; but should any hollow ground occur in the field too deep for its waters to find their way direct to the main drain, then a sub-main drain should be made along the lowest part of the hollow, to receive all the drainage of the ground around it, in order to transmit it to the main drain. The size of sub-main drains is determined by the extent of drainage they have to effect, and should they have as much to do as the main, they should have the same capacity, but if not, they should have less.

(811.) Sub-main drains are made in all respects in the same manner as main drains; but there may be this peculiarity in regard to them, that they will most probably have to receive small drains on both sides, on account of the position they may occupy in the area of a field, when they will require just double the number of tiles with openings in the side than the main. In order to avoid the interference of sediment from opposite small drains, these should not enter the sub-main directly opposite to each other, nor should their ends enter at right angles, but at an acute angle.

(812.) The sub-main drain should be as far below the small drains as the main itself, when it receives the small drains directly, and for the same reasons; and the main should be as far below the sub-main as the latter is below the small drains. The simple way to effect both these purposes is, to make the main drain deeper after its junction with the sub-main.

(813.) There is nothing now to prevent yuu proceeding with the small drains. In a field having a uniform surface, there is no difficulty or irregularity of work to be encountered in bringing the drains directly down the inclined ground into the main drain. Where sub-mains are employed in particular hollows, the ground comprehending the drainage belonging to each hollow should be distinctly marked off from the rest, that no confusion in the direction of the other small drains may ensue in the execution of the work. These markings should be made in the water-shed of the ground, from which the fall tends toward each sub-main, if more than one is required, and it may also tend toward the main drain. The markings can be made with pins driven in the lines determined by the watershed.

(814.). In commencing the small drains from a fence on one side of the field, supposing that the ridges are 15 feet wide, and keeping in mind that, if the soil of the field is not strong clay, the drains need not be formed in the open furrows, it is requisite to measure the distance of the first drain from the fence, whatever that fence may be, at 16 feet. This space of 16 feet gives 2 feet for the fence-side, 14 feet from the fenceside to the drain, and one foot beyond the drain for the open furrow of the 15-feet ridge. Keeping the distance of every other drain from each other at the breadth of one ridge of 15 feet, or at any other multiple of that breadth, it is clear that every drain will fall within one foot of an open furrow. If the subsoil draws slowly, the drains should not exceed 15 feet asunder, and the depth, I should say, not less than 3 feet.

(815.) I know it is a common impression among farmers, that if a subsoil cannot draw water, there is no use of making drains in it, and this opinion I conceive to be quite correct in regard to pure clay subsoils, which cannot draw water at all. But the view I take of the matter is this, that pure clay subsoils are very limited in extent, and that many clays which seem quite impervious may draw water notwithstanding. Admitting that the subsoil draws water at all, which is the supposition in the (703) 
present case, it is clear that the larger the area is extended for drawing it, the more water will be drawn into the drain. Now, a large area can only be secured by making drains deep and close together; and in the case supposed above, it appears to me that 3 feet in depth, with 15 feet asunder, will not give a greater area than is requisite for drawing water out of such ground. When, on the other hand, the subsoil is free, and discharges water as freely, so large an area is not required to dry the subsoil, and drains of less depth and at greater distance will answer the same purpose as in the other case, such as 30 inches in depth and 30 feet asunder. You must endeavor to make the depths and distances of the small drains suit the nature of the subsoil, for it is impossible for me to lay down here any absolute rule in a matter which admits of such diversity of character.

(816.) Small drains, as well as mains and sub-mains, should be completely cast out, gauged, and examined for the fall, before being attempted to be filled up; and the materials for doing so should be laid down beside them, as well as in the case of mains. The tiles for small drains are smaller than for mains and sub-mains, being 3 inches wide and 4 inches high, inside measurement, which may be considered a large tile in places where those of $2 \frac{3}{4}$ inches wide by $3 \frac{1}{2}$ inches high are used; but so small ones are not made everywhere. There is this consideration in regard to the size of tiles which should be kept in view, that a substantial tile will have the chance of lasting much longer than a slight one, and the probability is, that the larger ones are the more substantial, which, however, may not actually be the case, but it is proper to examine whether they are neavy and firm, before you purchase your tiles. Be guided in your choice of them more on account of substantiality than cheapness, which, as I have said before, is quite of secondary consideration when brought into comparison with durability. Soles will also be required for small drains, for don't give credence to the absurd assumption that clay will retain its hardness at the bottom of a drain, because it happened to be hard when first laid open to the day. Soles for small drains are of different breadths, being 5 inches at one place and 7 inches at another; the former, 5 inches, I should conceive, too narrow for most purposes; for take even the narrowest tiles that are made, $2 \frac{3}{4}$ inches inside-these are moulded at $\frac{6}{8}$ inch thick, and allowing them to shrink $\frac{1}{8}$ in the kiln, their thickness will be $1 \frac{1}{4}$ inches; the outside breadth of the tile being thus 4 inches, leaves only $1 \frac{1}{4}$ inches to divide between the two sides of the tile on a 5 -inch sole, or just $\frac{1}{2}$ an inch on each side, a small enough space, certainly. But as most soles for small drains are made of the same breadth, take a 3 -inch tile, and it will be found by the same mode of calculation that only $\frac{1}{4}$ inch on each side of a 5 -inch sole will be left, which is a much too narrow space to afford perfect steadiness to the tile. I would prefer the 7 -inch soles as made in Ayrshire, and, of course, the breadth of the bottom of the drain should also be 7 inches. In other respects, the filling of the small drains is conducted in the same manner as the mains and sub-mains, and they are finished as represented by fig. 184.

(817.) While casting out the bottom of the end of Fig. 184.

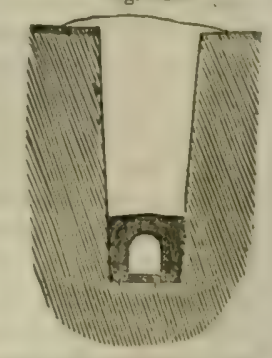
each small drain, care should be taken in communicating it with the main or sub-main with which it is to be connected, that no displacement of tiles takes place in either; and when the bottom is cleared out, the turf or small bundle of straw left in the openings of the sides of the tiles is re(704) 
moved, and the opening examined, and any extraneous matter that may have got into the tiles removed. The places for the entrance of the small drain tiles having been prepared while constructing the main and submains, there will be no difficulty of effecting the junction between the respective sorts of drains. Thus one small drain after another is tnished, until the field, having been begun at one side, is furnished with drains by the time the other is reached. The small drain connecting the tops of all the small drains along the upper end of the field, should not be neglected. (767.)

(818.) The next procedure is the filling up of the drains with the earth that was thrown out of them, which is returned either with the spade or the plow, or both. When drains are furnished with stones, the plow may be used from the first, giving it as much land for the first bout or two as it can work with. If the earth has been thrown out on both sides, a strong furrow on each side of the top of the drain will fill in a considerable quantity of the earth; but, as the earth is generally thrown out on one

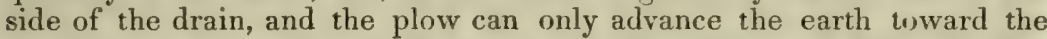
drain while going in one direction, that is, going every other landing empty, or without a furrow, a more expeditious mode of leveling the ground, which, in the considerable lithor of returning the earth into all the small drains of a field, is a matter of some importance, is to cleave down the mound of earth thrown out, and then take in a breadth of land on both sides of the drain, and gather it up twice or thrice toward the middle of the drain, which will constitute a prepared feering, after which the harrows will make the ground sufficiently level. This species of work, however, is only required when much earth has been thrown out, and thrown a distance from the drain, in deep draining; but in thorough-draining, what is accomplished by the plow is done with much less trouble. When the plow alone is used for this purpose, the first two furrows are taken round the mouth of the drain, and fall into it with considerable force; and, where tiles alone are used, such a fall of earth may be apt to break or displace them; and even the steadiest horses, which should only be employed at this work, run the risk of slipping in a hind foot into the drain, which, in attempting to recover, may be overstrained; and such an accident, trifling as it may seem, may be attended with serious injury to the animal. The safest mode, therefore, both for horses and tiles, is, in all cases; to put the first portion of earth into the drain with the spade, and this provision can be made in the agreement with the contractor; and there is this advantage attending the use of the spade that a better choice can be made, if desired, of the earth to be returned, the surface earth may first be put in before the poorer subsoil. (770.)

(819.) In regard to the quality of the earth which is employed to fill up the drains, some considerations are requisite. All deep drains, whether furnished with stones or tiles, should receive their supply of water from below, and not immediately from above through the soil; and all drains that receive their supply of water in this manner should be denominated deep drains, in reference to the nature of their functions, whatever may be their respective depths.

(820.) Were drains entirely filled with loose mould, or other loose materials, it is evident that the rain, percolating directly through them, will arrive in the drain loaded with as many of the impurities that the soil may contain as it could carry along with it in its downward course ; but a primary object with drainers is to prevent impurities getting into the ducts of drains, because in time they might either collect in quantities in the ducts, or fill up the interstices between the stones; and the smaller the 
stones were broken, their upper stratum at least would the more easily be rendered inoperative as a drain. To prevent one and all of these mis chances, the practicable way is to return the clayey subsoil into the drain. where it will again soon consolidate, and resist the direct gravity of rain.

(821.) Keeping these distinctions in view, and applying them first to the case of strong clay soil, such as in the Carse of Gowrie, which does not draw water at all, were they filled up above the tiles with pure clay, the ultimate effect would be that the duct would remain open, but no water would ever enter it. To make them draw at all, there must loose materials be put above the tiles within 2 or 3 inches of the plane upon which the sole of the plow moves; and to obtain the greatest depth of loose materials for such drains, they should be made in the open furrows. As they cannot draw but through the loose materials, and are, in fact, covered ditches, they must receive their supply of water like any other ditch, from above; but here the analogy ceases, for instead of receiving their water direct from the top like a ditch, they should receive it by percolation through the plowed soil, and when the water has descended through the soil, deprived of most of its impurities, it meets the retentive subsoil across the whole area of the ridge, upon which it moves under the arable soil until it meets with the loose materials in the drains, by which it is taken down into the ducts to be conveyed away. The loose materials may be gravel, sand, peaty earth, scorize from furnaces, refuse tanners' bark, and such like.

(S22.) In a subsoil that draws only a little water, were the clayey subsoil returned immediately above the tiles, it would have the effect of counteracting the purpose for which the drains were made, because it would curtail the drawing surface to only the hight of the tiles themselves. The method, therefore, to fill such drains is to put loose materials immediately above the tiles, to a hight not so far as in the case of pure clay drains, but to within $\frac{1}{2}$ a font of the plane of the plow's sole-shoe. Were the drains in such a subsoil, however, filled with stones, the case would be different, for these would secure a sufficient drawing surface, and the clayey subsoil may be returned immediately on their top with perfect propriety.

(S23.) In the case of a free drawing subsoil to the bottom of the drain, the most retentive portion of the earth may be returned immediately above even tiles, for such a subsoil would still draw the moisture toward them; and were stonies used, there would be left ample room for drawing with the most retentive part of the earth returned above them. But should the part of the drain occupied by the tiles or stones be of strong, impervious clay, although the soil above it be of the best drawing materials, as much of the loose subsoil should be placed above the tiles or stones as would give an easy access to the water, and all the space above that may consist of the strongest part of the clay.

(824.) The general rule, then, for filling the drains with the earth that has been thrown nut of them is, that, with the exception of strong clay soils-the drains in which should be filled with porous materials, that the water on the surface may descend through them into the duct below, and be thence carried away-that, with this exception, every kind of drain should be filled near its top with the strongest soil afforded by the drain, in order to prevent the descent of the water into the drain by the top, but rather that the water shall seek its way through the plowed ground, and thence by the porous materials above the duct, and under the clay put in above them into the duct at the bottom. Through such a channel of filtration the water will have every chance of entering the duct in a comparatively pure state.

(706) 
(825.) But the best mode, in my opinion, of draining land of any that has yet been described, has to be brought before your notice, and that is by the union of stones and tiles in the same drain. This method is represented in fig. 185 , where a tile $a$ rests on a sole; small stones are packed around the tile by the hand until they cover it as at $b$; the remaining small stones $c$ are put in by any of the methods described above, but especially by the drain-screen; a covering is either put above them or small stones beaten down, as in the case of the stone drain, with the beater, and the earth returned upon them in either of the modes just described. The width of the bottom is 7 inches, the width of a good sole, width of the top 12 inches, depth $2 \frac{1}{2}$ feet, composed of 18 inches of earth, and 12 inches to the top of the covering of the stones. This drain is constructed very similarly to the tile drains that have been described, by first laying the sole at the bottom and the tile upon it; but instead of covering the tile

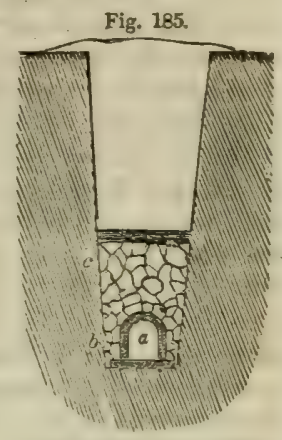

THE TILE AND STONE DRAIN. immediately with turf, small stones are packed by the hand on both sides until they cover its top. As these stones should be packed in as the laying of the tiles proceeds, they should be laid down in heaps, immediately after the tiles have been laid down, as near the drain as possible, so as they may be filled in baskets by the assistant, and handed down in them to the man in the drain. Two baskets are required for this purpose, one to be filled by the assistant when the other is emptying by the drainer. In filling up with stones afterward to their proper hight as to $c$, I would be afraid of using the drain-screen at first, in case the fall of the first stones upon those which were laid in by the hand, as at $b$, should by any chance fracture the tiles below them. I would rather fill up a few yards of the drain as high as required by the hand, and then use the drain-screen to let fall the stones upon the end of those previously filled in, from which they could be shoveled (fig. 38) or raked (fig. 174) down gently upon the stones over the tiles; or the stones could be filled in by the hand at first so high, while laying those at $b$, as to remove all danger from those falling in small quantities from the screen. The filling in from the drain-screen and carts should not be proceeded with until as much of the drain has been laid with tiles and packed in with stones by the hand, as to empIoy at least 2 single horse carts for one yoking, and should the weather seem favorable, not until that number of horses can be employed a whole day, because otherwise the time of the horses would be wasted. If the draining is of such an extent as to keep a pair of horses thus constantly employed, so much the better. In such a case, other hands than those employed in cutting the drain and laying the tiles should be employed in filling in the upper layer of stones with the screen, and beating down the small riddlings as a covering upon them. On the earth being returned into the drain the operation is completed.

(826.) This construction of drain is declared by every writer on and practitioner of draining, to be the ne plus ultra of the art, though I believe very few farmers have adopted it, not because there can the slightest objection be urged against it, but because, in cases where stones have to be quarried and broken, it is an expensive mode, and in other cases stones cannot be obtained at all. The last reason is a very good one, but that of the expense must fall to the ground where there is abundance of stones, as the advantage derived from their use along with the tile will be more 
than counterbalanced by the additional cost. The durability and efficiency of such a drain is undoubted. It is a perfect piece of work, inasmuch as the duct formed of the tile and sole presents the smootbest passage imaginable for carrying off water, and it is proof aganst the efforts of vermin, while the stones not only secure the duct in its place, but impart durability to the whole structure, which at the same time presents an extensive area to the subsoil. What other property that a good drain should have does this one not possess?

(827.) It may be satisfactory to you to have a general idea of thorough draining a field by a sketch of a ground plan, which is represented in fig. 186 , where $a b$ is the main drain formed in the lowest head-ridge; and if the field were of a uniform surface, the drains would run parallel to one another from the top to the bottom into the main drain, as those do from $a$ to $c$, connected as they should be at the top with the drain $d e$ running along the upper head-ridge. But as there may be inequalities in the ground, a very irregular surface cannot be drained in this manner, and must therefore be provided with sub-main drains, as $f g$ and $h i$, which are each connected with a system of drains belonging to itself, and which may differ in character from each other, as $f g$ with a large double set $k l$ in

Fig. 186.

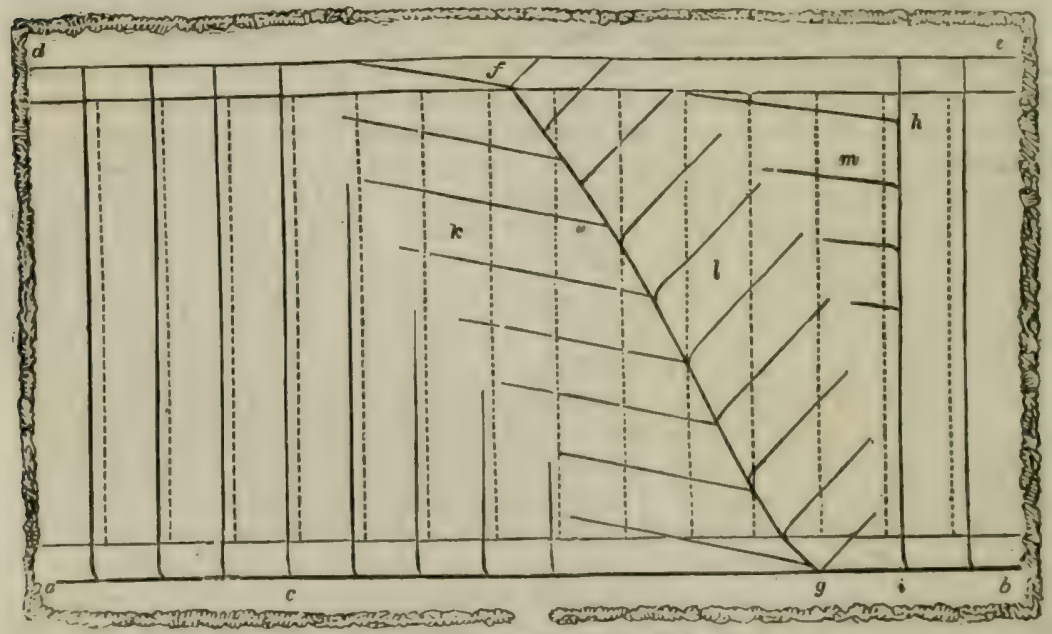

A PLAN OF A THOROUGH-DRAINED FIELD.

connection with it, and $h i$ with only a small single set $m$; the sub-main $f g$ is supposed to run up the lowest part of a pretty deep hollow in the ground, and the drains $k$ and $l$ on either side of it are made to run down the faces of the acclivities as nearly at right angles to the sub-main as the nature of the inclination of the ground will allow, so as always to preserve the natural tendency of water to find its way down the hollow. There is also a supposed fall of the ground from the hight above $l$ toward 7 , which causes the drain at $m$ to run down and fall into what would be a common drain $h i$, were it not, from this circumstance, obliged to be converted into a sub-main. The sub-main $f g$ may be made as large as the main drain $a b$, as both have much to do; but the sub-main $h i$ may be made comparatively smaller, and not larger, firm the top of the field, than a common drain, until it reaches the point $h$, where the collateral drains begin to join it. The main drain should be made larger below $g$ to $i$ than above (708) 
it, and still larger from $i$ to $b$, which is its outlet. It will be observed that all the common drains $a$ and $c$, and at $l$ and $m$, have their ends curved, those at $k$ not requiring that assistance, as they enter more obliquely into the main, from the position of the slope of the ground. The dotted lines represent the upper and lower head-ridges, and the open furrows of the ridges of the field; and it will be observed that the drains are not made to run in the open furrows-that is, the black lines in conjunction with the dotted, but along the furrow-brows of the ridges. This is done with the view of not confounding the open furrows and drains in the figure; but it is a plan which may be followed with propriety in subsoils otherwise than of strong clay; that is, of a light loam resting on a rather retentive subsoil; the water falling upon which should not be drained away by the smal? drains receiving it through their tops, but rather by the absorption of the water toward them from below the plowed soil, as far as the subsoil is porous. A hollow, such as that occupied by the sub-main drain $f g$, alsc indicates that the soil is a loam, and not strong clay. Although the ridges are supposed to be 15 feet wide, and they have been set off here at quarters of an inch, they bear no true relation to the size of the field; so that this diagram should not be considered as showing the relative proportions of the distances betwixt the drains and the size of the field.

(828.) The period of the rotation of cropping at which draining should be executed, requires consideration; but I believe it is now generally allowed to be best performed when the ground is in grass, and before the grass is plowed up. There are several advantages attending this period of cropping over every other. 1. Turf can be obtained at hand for covering the tiles; and although one year's grass may not afford very good turf for the purpose, yet if the turfs are carefully raised by the spade, and as carefully laid aside until used-not heaped upon one another to run the risk of rotting, but set down in a row with the grass-side up-and as carefully handled when about to be used, it will answer very well. In 2 or 3 years old grass, the turf is better; and in old pasture or meadow ground it is as good as can be procured elsewhere. At whatever age the turf is used, it should not be too rough or ton thick, as it will not clap so closely over the tile in either state as it should. Sheep are the best stock for eating down the forage, and preparing the turf for this purpose. 2. Another advantage which grass-land possesses is the firm surface which it presents to cartage of materials, whether stones or tiles. If the stones are put in with the screen, the cart and barrow will pass lightly along the side of the drain ; and if tiles are used, the grass forms clean ground for them to be laid down upon. 3. In grass, the filling in of the earth with the spade makes very neat work.

(829.) When it is determined to drain the land while in grass, the season of the year in which the drains should be opened is thereby in a great degree determined. It would scarcely be prudent to sacrifice the pasturage in summer, and no stock should be allowed to roam about a field that is in the act of being drained, not only on account of the possibility of their injuring themselves by slipping into the drains, but of injuring the drains by breaking down their edges, fracturing the tiles, or displacing the stones. It is therefore expedient to take the use of the summer's grass ; but that the operation may commence soon in autumn, the grass should be by that time eaten down bare by an extra quantity of stock. These preliminary arrangements, then, being made, and the materials laid down as long as the weather is dry and the ground hard, the draining operations may be carried on through the winter, and as far into spring as to give time for the land to be plowed for the reception of the seed. Whether (709) 
there are one or more sets of men engaged in cutting the drains, they should all work in the same field at the same time, as it invariably entails loss of time to drive materials with horses over different fields. With concentrated work, one field is drained after another, and this regularity of the order permits the eating down of the grass in succession, as regularly as the draining proceeds, so that none of the aftermath is sacrificed.

(830.) The next important point for consideration is, whether the great outlay upon land occasioned by draining can be compensated for by increase of produce? for if no increase of produce, adequate to repay the large outlay, can be guarantied, draining will not be persevered in. No one, beforehand, can give such a guaranty; but the experience of enterprising drainers, who have vested their capital in the experiment, has proved that draining - that is, effectual or thorough-draining, by whatever means that object is attained-not only compensates for the outlay incurred, but also improves the quality of the land and everything that grows upon it. Examples of amelioration, as well as of profit, effected by draining, inspiring confidence and stimulating imitation, I shall adduce.

(831.) The existence of moisture in the soil being most easily detected by its injurious effects on the crops usually grown upon it, the benefits of draining are also first indicated by the crops. On drained land, the straw of white crops shoots up steadily from a vigorous braird, strong, long, and at the same time so stiff as not to be easily lodged with wind or rain. The grain is plump, large, bright colored, and thin skinned. The crop ripens uniformly, is bulky and prolific, more quickly won for stacking in harvest, more easily threshed, winnowed, and cleaned, and produces fewer small and light grains. The straw also makes better fodder for live-stock. Clover, in such land, becomes rank, long, and juicy, and the flowers are large and of bright color. The hay from it wons easily and weighs heavy to its bulk. Pasture-grass shoots out in every direction, covering the ground with a thick sward, and produces fat and milk of the finest quality. Tur nips become large, plump, as if fully grown, juicy, and with a smooth and oily skin. Potatoes push out long and strong stems, with enlarged tubers, having skins easily peeled off, and a mealy substance when boiled. Livestock of every kind thrive, become good tempered, are easily fattened, and of fine quality. Land is less occupied with weeds, the increased luxuriance of all the crops checking their growth. Summer fallow is more easily cleaned, and much less work is required to put the land in proper trim for the manure and seed ; and all sorts of manures incorporate more quickly and thoroughly with the soil.

(83\%.) Thorough-drained land is easily worked with all the common implements. Being all alike dry, its texture becomes uniform, and, in consequence, the plow passes through it with uniform freedom; and even where pretty large sized stones are found, the plow can easily dislodge them; and moving in freer soil, it is able to raise a deeper furrow-slice; and the furrow-slice, on its part, though heavy, crumbles down and yields to the pressure and friction of the plow, forming a friable, mellow, richlooking mould. The harrows, instead of being held back at times, and starting forward, and oscillating sideways, swim smoothly along, raking the soil into a uniform surface and entirely obliterating foot-marks. The roller compresses and renders the surface of the soil smooth, hut leaves what is below in a mellow state for the roots of plants to expand in. All the implements are much easier drawn and held; and hence, all the operations can be executed with less labor, and of course more economically (710) 
and satisfactorily on drained than undrained land.* All these effects of draining I have observed from my own experience.

(833.) "It is gratifying," says Mr. James Black, in reference to the ef fects of the Elkington mode of draining on the estate of Spottiswoode in Berwickshire, "to be enabled to state that the general result of the operations has been such as to bear out the calculations of the engineer, and to justify the most sanguine hopes that could have been formed of a valuable improvement. Bursts and springs, which formerly disfigured entire fields, and which rendered tillage precarious and unprofitable, are now not to be seen; and swamps, which were not only useless in themselves, but which injured all the land aronnd them, have been totally removed. The consequence is, that tillage can now in those parts be carried on without interruption, and with nothing beyond the ordinary expenditure of labor and manure; and a sward of the best grasses, raised and continued on spots which formerly only produced the coarsest and least valued herbage."

(834.) But draining has been found beneficial not only to the soil itself, to the processes of laboring it, to the climate in reference to crops, and to the growth of trees, but also to the health of the laboring population. Dr. Charles Wilson, Kelso, when comparing the health of the laboring population of the district of Kelso in two decennial periods, from 1777 to 1787 and from 1829 to 1839 , came to this conclusion in regard to the effect of draining, that "our attention is here justly attracted by the extraordinary preponderance of cases of ague in the first decennium, where they present an average of $\frac{1}{7}$ of all cases of disease coming under treatment; and a closer examination of the separate years shows this proportion rising more than once to even as high as $\frac{1}{5}$; while, in the second decennium, the average proportion is only $\frac{6}{100}$ of the general mass of disease. Ague, then, as is well known to the older inhabitants of the district, was at one time regularly endemic among us; affecting every year a varying, but always a considerable portion of population, and occasionally, in seasons of unusual coldness and moisture, spreading itself extensively as an endemic, and showing its ordinary tendency, under such circumstances, of passing into a continued and more dangerous type. Ague was not usually in itself a disease of great fatality, the deaths recorded at the Dispensary having been only 1.81 per cent. of the cases treated-a sum which denotes its absolute mortality, while its relative mortality was 0.26 , when viewed in connection with that from all other diseases. Still, if we keep in view how frequently it was known to degenerate into fevers of a worse form, and how often it terminated in jaundice, 'obstruction of the viscera of the abdomen,' and consequent dropsies; or even if we take into consideration the frequency of its recurrence, and the lengthened periods during which it racked its victims, we shall see much reason to be thankful that a plague so universal and so pernicious has been almost wholly rooted out from among us. Those who recollect what has been stated of the former swampy nature of the soil in our vicinity, and of the extensive means which have been adopted for its drainage, will, of course, have no difficulty in understanding why ague was once so prevalent, and under what agency it should now have disappeared; and will gratefully acknowledge the twofold value of those improvements which have at once rendered our homes more salubrious and our fields more fruitful." $\dagger$

(835.) But the most palpable advantage of draining land is the profit which it returns to the farmer. A few authenticated instances of the profits actually derived from draining will suffice to convince any occupier of land

* See papers by me on this subject in the Quarterly Journal of Agriculture, vole. vi. and viii.

t Quarterly Journal of Agriculture, vol. xil.

(711) 
of the benefits to be derived from it. "I am clearly of opinion," says Mr North Dalrymple of Cleland, Lanarkshire, "that well authenticated facts on economical draining, accompanied with details of the expenses, value of succeeding crops, and of the land before and after draining, will be the means of stimulating both landlords and tenants to pursue the most important, judicious, and remunerating of all land improvements. The statements below will prove the advantages of furrow-draining; and as to the profits to be derived from it, they are great, and a farmer has only to drain a 5-acre field to have ocular proof upon the point."*

(836.) Without entering into all the minutia of the statements given by Mr. Dalrymple, it will suffice here to exhibit the general results. 1. One field containing 54 Scots acres cost $£ 3037$ s. to drain, or $£ 512$ s.t per acre. The wheat off a part of it was sold for $£ 11$, and the turnips off the remainder for $£ 2513 \mathrm{~s}$. $4 \mathrm{~d}$. per acre. The soil was a stiff chattery clay, and let in grass for $20 \mathrm{~s}$. an acre; but in 1836, after having been drained, it kept 5 Cheviot ewes, with their lambs, upon the acre. 2. Another field of 18 acres cost $£ 59$ s. the acre to drain. The wheat off a part of it fetched $\mathcal{L} 13$, the potatoes off another part $£ 1515 \mathrm{~s}$, and the turnips off the remainder $\$ 21$ per acre. The land was formerly occupied with whins and rushes, and let for 12s. the acre; but when let for pasture after being drained, Mr. Dalrymple expected to get $50 \mathrm{~s}$. an acre for it. It may be mentioned, that the drains made by Mr. Dalrymple were narrow ones, 30 inches in depth, filled 18 inches high with stones or scoria from a furnace, and connected with main drains, 36 inches deep, furnished with tiles and soles.t

(837.) Mr. James Howden, Wintonhill, near Tranent, in East-Lothian, asserts from his experience, that although drains should cost as much as $£ 7$ the acre, yet on damp, heavy land thorough-draining will repay from 15 to 20 per cent. on the outlay.

(838.) A farmer in Lanarkshire, who thorough-drained one-half of a 4 -acre field, and left the other half undrained, in 1838 , planted the whole field with potatoes, and from the drained portion realized $£ 45$, while the undrained only realized $£ 13$ the Scotch acre. $\$$

(839.) A very successful instance of drainage is related to have taken place on the estate of Teddesley Hay, near the River Penk, in Staffordshire, belonging to Lord Hatherton, under the direction of his agent, Mr. Bright. The soil is represented of a light nature, resting on a subsoil of stiff clay. The results are these :

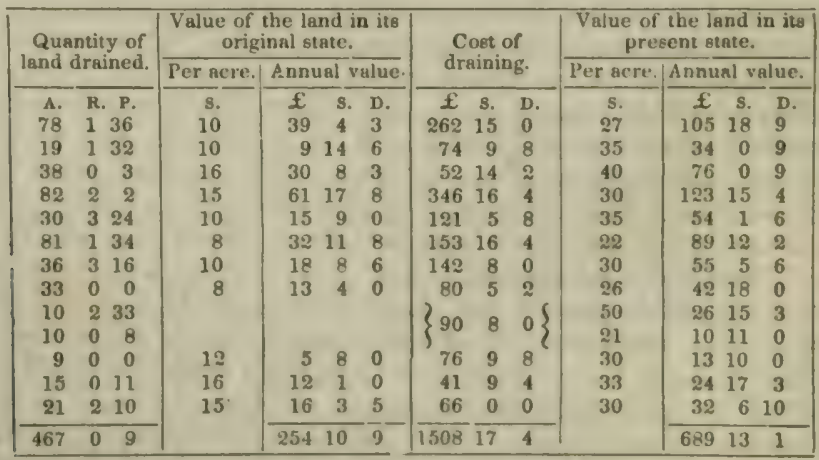

[ $\uparrow$ Calculate the pound at $\$ 480$, and the shilling at 22 cents.

* Quarterly Journal of Agriculture, vol. viii. \$lbid., vol, viii. \|lbjh, vol, viil. \$Ibid, vol. $x$. (712) 
Here is an increase of $£ 435$ 2s. 4 d. a year by draining, with an expenditure

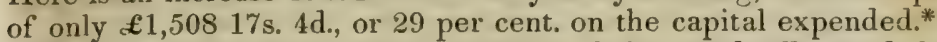

(S40.) Mr. George Bell's experience of the good effects of thoroughdraining on turnips gave, in the instance of Aberdeenshire yellow bullock turnips, which were raised from bone-dust in 1S38, a crop of 16 tons 16 cwt. on 2 acres; whereas the same extent of undrained land only produced 6 tons 4 cwt. the acre. In 1839 the produce of potatoes on drained land was $175 \mathrm{cwt}$. the acre, whereas that on undrained land was only $70 \mathrm{cwt}$.

(841.) Besides the methods of draining land with stones and tiles as have just been described to you at much length, there are other methods which deserve your attentior, because they may be practiced in particular situations in an economical manner. I do not believe that the methods I am about to mention are so effectual as those I have described, still I have no doubt any one of them may be made effectual in situations where the materials recommended are abundant. Besides, it is well to have a choice of methods of performing the same operation, that your judgment may be exercised in adopting the one most advisable in the circumstances in which you are placed; while, at the same time, you should never lose sight of this maxim in Agriculture, that that operation is most economically executed, or, at all events, affords most satisfaction in the end, which is executed in the most efficient manner, both as regards materials and workmanship, and the maxim applies to no operation so strongly as to draining, because of its permanent nature. The mothods of draining which I am about to mention apply to every species of soil, from light loam, the heaviest clay, to bog.

(842.) The fitst method which I shall notice is applicable to a tilly subsoil which dravs water a little. situate in a locality in which flat stones are plentiful and sufficiently cheap. Suppose a piece of land. containing 2 ridges of 15 feet in width. which had been gathered up from the flat, and in this form of plowing, as you have already learned, there is an open furrow on each side of a ridge (650). The drains are made in this manner: Gather up the land twice, by splitting out a feering in the crown of each ridge, and do it with a strong furrow. Should the 4-horse plow have been used for the purpose, the open furrow will be left 16 inches wide at bottom. and if the furrow have been turned over 12 inches in depth, and the furrow-slice laid over at the usual angle of $45^{\circ}$, the tops of the furrow-slices on the furrow-brow will be 32 inches apart, as from $a$ to a. fig. 187. After this plowing the spade takes out a trench from the bottom of the open-furrow 8 inches wide at top $e, 16$ inches deep by $f$, ani 3 inches wide at bottom at $g$. The depth of the drain will thros be 32 inches in all below the crowns of the gathered up ridges. The drain is filled by two flags $h h$ being set up against its sides and meeting in the bottom at $g$; and they are kevt asunder by a large stone of any shape, as a wedge, but large enough to be prevented by $h h$ descending farther than to leave a contuit $g$ for the water. The remainder of the drain is filled to $e$ with small riddled stones with Mr. Robertson's drainscreen or with clean gravel. The stones are covered over with turf and earth like any other drain, or with small stones beaten down firmly. The expense of this method of draining is small : the spade-work may be executed at $1 \mathrm{~d}$. the rood of 6 yards, and of an imperial acre, containing $161 \frac{1}{3}$ of such roods, the cutting will

Fig. 187.

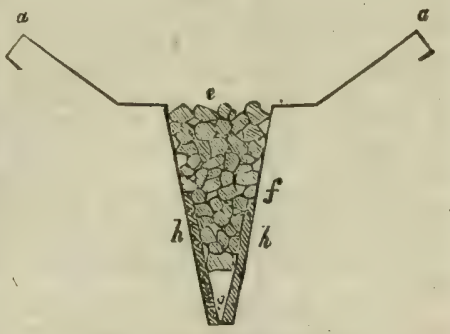

THE FLAT STONE DRAIN.

cost $13 \mathrm{~s} .5 \frac{1}{3} \mathrm{~d}$. The flags, at 1 inch thick and 6 inches broad, will make 15 tons per acre, at $4 \mathrm{~d}$. the ton, will cost 5 s. more. The broken stones, to fill 9 cubic feet in the rood of 6 yards, at $2 \frac{1}{4} d$. per rood, will cost $£ 110 \mathrm{~s} .3 \frac{1}{2} \mathrm{~d}$. more; making in all about $£ 28 \mathrm{~s}$. $8 \mathrm{~d}$. the acre, exclusive of carriage and plowing, which, though estimated, will yet make this a cheap mode of draining land so closely as 15 feet apart. $\dagger$

(843.) The draining of mossy, light soils where peat is plentiful may be effected in this way. The peats are made somewhat of the shape of drain-tiles but more massive, as may be seen in fig. 188. They are laid in the drain one $a$ like a tile-sole, and another inverted upon it, as $b$, like a drain-tile, leaving a round opening between them for the passage of the water. These peats are cut. ont with a spade-tool, contrived some years ago by $\mathrm{Mr}$. Hugh Calderwood, Blacklyres, Ayrshire. The spade is easily worked, and forms a peat with one cut, without any waste of materials; that is, the exterior semi-circle $b$ is cut out of the interior semi-circle of $a$. A man can cut out from 2,000 to 3,000 peats a day with such a spade. The peats are dried in the sun in summer, with their hollow part upon the ground, and are stacked until used; and those used in drains have been found to remain quite hard. The invention of this spade, of which a figure, 189, is here given, tends to make the draining of Moorish soils more practicable than heretofore, and it may be done at 1.5 or 1.4 of the expense of ordinary drain-tiles. The frequent want of clay in upland moory dis-

Fig. 188.
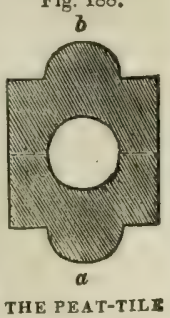

FOR DRAINS. tricts renders the manufacture of drain-tiles on the spot impracticable, and their carriage from a
distance a serious expense.f 
(844.) Sir Joseph Banks alludes to the filling up of drains in bogs, which had been executed at preat expense at Wuburn, by the growth of the marestail (Equsetum palustre). ing the plant. Sir Joseph found "its atem under ground a yard or more in length, and in size like a packthread; from this a root of twice the size of the stem rung horizontally in the ground, taking its origin from a lower root, which strikes down perpendicularly to a depth I have not hitherto been able to trace, as thick as a small finger."* I have frequently met with the roots or stems of the marestail un. der ground, which, on being bisected by the drains, poured out a conetant run of water for some time, but, when fairly emptied of it, and no longer receiving support by a due supply of moisture from above, they withered away. Although there is no doubt chat, in the case mentioned by Sir Joseph Banks, the roots of the marestail penetrated deeper than the drains. yet the circumstance of their sending upward shoots which grew "along the openings left for the passage of water," proves that sufficient moisture had been left near the surface of the bog, notwithstaniiug the draining, to support the plant in life; in short, that the bog had been insufficiently drained, otherwise the rivation of support by moisture to the stems at the surlace would inevitably have destroyed the vitality of the roots below.

(845.) A plan similar to that described in (843) may be practiced on strong clay land. The open furrow is formed in the same manner with the plow, and, being left 16 inches in width, the spade work is conducted in this manner: Leave a scarsement of 1 inch on each side of the open furrow left by the plow, as seen below $a$, fig. 190, and cut out the eartb, 14 inches wide, perpendicularly, and 10 inches deep, as at $b b$. Then cast out from the bottom of this cat, with a spade 3 or 4 inches wide, a cut 5 inches or more in depth $c$, leaving a scarsement of 5 inches on each side of the bottom of the former cut $b b$. The bottom of the small cut will be found to be 32 inches below the crowns of the ridges, when twice gathered up with a strong furrow. The drain is filled up in this way: Take tlagstones of 2 or 3 inches in thickness, as $d$, and place them across the opening of $c$ upon the 5 -inch scarsements, left by the narrow spade; they need not be dressed at the juints, as one stone can overlap the edges of the two adjoining, and they thus form the top of a conduit of pure clay in which the water may flow. As the water is made to flow immediately upon the clay, it is clear that this form of drain cannot be regarded as a permanent one; though a flag or tile sole laid on the bottom of the cut $c$ would render it much more durable. The cutting of this form of drain, the workmen having to shift from one tool to another, will cost $1 \frac{1}{3} \mathrm{~d}$. the rood of 6 yards, which, at 15 feet apart, make 20s. 2d. the acre. The flags for covers will be 12 tons at $4 \mathrm{~d}$. per ton, 48 . more, in all $24 \mathrm{~s}$. $2 \mathrm{~d}$., but with 10 tons of soles the cost will be $3 \mathrm{~s} .4 \mathrm{~d}$. more, or $27 \mathrm{~s}$. 6d. the acre, exclusive of ihe carriage of stones

On examin

Fig. 189. and the labor of the plow. After the joinings of the flags are covered over with turf, the earth may be returned into the drain with the plow, but with precaution, and probably with the previous assistance of the spade; but, after all, the probability is that flat stones canuot be easily obtained in the neighborhood of strong clay, though this form of drain may be adopted in any subsoil wiere tlat stones are abundant. $\dagger$

(846.) A somewhat analogous mode to this last of draining heavy clay land is with the wedge or plug. As this mode of draining requires a very peculiar form of tools, they will be described as required for use.

(847.) The first remarkable implement used in this operation is the bitting-iron, represented by fig. 191, where $a$ is the mouth, $1 \frac{3}{4}$ inches wide; $b$ the bit, 6 inches in length; $c$ the width of the bit, $4 \frac{1}{3}$ inclies.The bit is worked out of the body of the instrument, and laid with the best tempered steel; $e$ is the tramp

of the implement, placed 18 inches $d$ from the mouth $a$; it would perhaps strengthen the power of the implement to have the tramp on the same side as the bit $c$; and $f$ is the helve, which is of the length of that of a common spade.

Fig. 191.

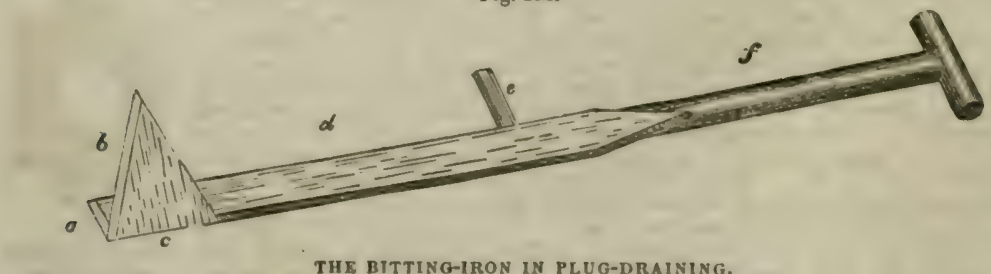

(848.) This species of draining is represented by those who have practiced it to be applicable to all soils that have 8 various and uncertain depth of vegetable mould, incumbent on a subsoil of

* Communications to the Board of Agriculture, vol ii.

† Quarterly Journal of Agriculture, vol, vii.

1714) 
tenacions clay, exceedingly impervious to water, and never dry but by evaporation. It is, how. ever, more suitable to pasture than to arable land, although it will suit all heavy soils that are far removed from stones, or where tiles cannot be conveniently made; but I would remark, on this last observation, that I would advise you to prefer tile draining to this mode, even although the tiles be very dear, either from distance of carriage or difficulty of manufacture on the spot.

(849.) The first process is to remove the surface turf, 12 inches in width and $6 \frac{1}{2}$ inches in depth, with the common spade, and to place it on the right hand side of the workman, with the grass side uppermost. A cut is then made in the clay, on each side of the drain, with an edging.iron. the circular-mouthed spade, as fig. 150 ; bnt a common spade will answer the purpose well enough, and it requires some skill and dexterity to remove this second cut properly. The first cut having been made with the spade 12 inches wide, the second should be made at such an angle down both sides of the drain, 9 inches deep, as that the breadth at the bottom shall be the exact width of the top of the plug $h$, fig. 192-that is, 4 inches wide. Carelessness in expert, or blundering in inexperienced workmen, in this part of the operation, has caused this kind of drain to fail.The bitting-iron then completes the cuttings, by taking out the last cut 9 inches deep. and $1 \frac{3}{4}$ inches wide at the bottom. This instrument is used in this manner: The workman gives its shaft such an angle with the ground line that, when pushed down to the requisite depth, it continues the cut made by the spade or edging-iron used previously, on the right hand side of the drain; and he does exactly the same on the opposite side of the drain, using his foot in both cases on the tramp e, fig. 191. On being forced down on the second side of the drain, the clay, that is now separated all round by the bit $b$, leans against the stem of the iron, and is easily lifted out, so that each bitful of the clay taken out by this instrument will have the form of an oblique parallelopipedon. If this part of the operation is performed inaccurately, the drain cannot succeed, because the angle and depth made by this instrument are of the utmost consequence in forming the bed which is to be occupied by the plug. Considerable accuracy of hand and eye is requisite which, indeed, cannot well be acquired by workmen without much experience, but both may be soon acquired. The clay from the last two cuttings should be placed on the left hand side of the workmen, or the opposite side to that on which the upper turf was laid; and, from the last cutting being uppermost, it will come readily to hand when first returned into the drain. Any loose soil that may happen to remain at the bottom should be carefully taken out by a scoop spade, such as fig. 152, so as to leave the drain perfectly clean before the farther operations are effected.

(850.) The next implement used is the suter or plug, fig. 192, which consists of three or more pieces of wood $i, 8 \frac{1}{2}$ inches in hight, 6 inches in length, 4 inches wide at the top $h$, and $1 \frac{3}{4}$ inches

Fig. 192.

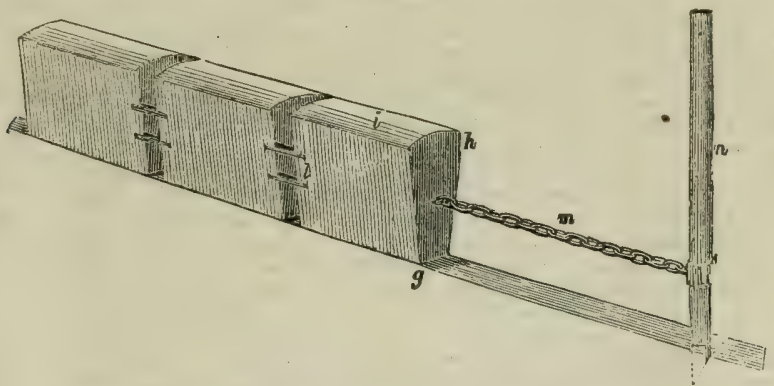

THE SUTERS OR PLUGS IN PLUG-DRAINING.

wide at the bottom $g$, joined together by means of iron links $l$ sunk into the sides which allow them to pass in a cut with a slight curve. A single suter of 18 or 24 inches long wonld answer the same or perhaps better purpose. These dimensions are the guage of the opening of the drain described above.

(851.) The next step in the process is the placing of the plugs on their narrow edges in the bot tom of the drain, which they will exactly fit, if the drains have been properly cut out. The most important part of the process is now to be done. The clay that was last taken out with the bitting-iron is well rammed down upon the plugs, the pieces of the clay being perfectly incorporated into one mass; then the next portion that was cut is returned, and equally well rammed down; and lastly, the turf is placed in the order it was taken out, and fixed in its original position. The whole earth and the turf are rammed down to the full length of the plug, with a rammer made for the purpose. or with such a one as is represented by fig. 175. The operation of ramming being finished, the lever $n$, fig. 192, is then struck into the bottom of the drain, and the plugs drawn forward to within 8 inches of their entire length by the power of the lever on the chain $m$, which is hooked to a staple in the end of the nearest plug. The work of ramming proceeds thus step by atep antil the whole drain is completed.

(852.) The finished drain is represented in section in fig. 193, where $o$ is the duct left in the clay by the plugs, $8 \frac{1}{2}$ inches high; $p$ is the clay that was rammed down above the plugs, 9 inches deep; and $r$ is the returned turf, with the grassy side uppermost, $6 \frac{1}{2}$ inches, which again makes the surface smooth, making a drain of 2 feet in depth. These two figures are drawn to the scale of $\frac{1}{8}$ of an inch to 2 inches.

(853.) Some particulars in the conducting of the work should be attended to. 1. Care should be taken to return all the earth that was cast out of the drain. This is a criterion of good work; (715) 
and for this parpose, the ramming being the most laborious part of the operation, the workmen are apt to execute it in an inefficient unaner, and should there'ore be strictly superintended in its execution. Four men and a boy are the best number of preople for carrying on the work expeditiously; and ouly stout people should be employed, as the ramming is really a laborious process. 2. As few main drains should be made as possible and the open ends of all should be protected against the inroads of vermin; or, what is a better finish, the lowest end of a plug drain should be furnished with tile and oole or stone. The main drains, of course, chould be made larger than the ordinary drains, and they will have to be provided with proportionally larger plugs. The drains slould be at a distance from each other, in proportion to the drawing wature of the subsoil. 3. No stock whatever should be alluwed to enter the ficld while under this treatment, and even not until the earth over the drains has again become somewhat firm. After the drains of a field are all finished, the ground should be rolled with a heavy roller. 4. This sort of drain should not be made in frusty. soowy, or very rainy weather, as the eartl to be rammed in will then be either wo hard, crumbly, or too soft. A strict superintend. ence of the work when it is going on is the only guaranty for effcieucy of work; for, as to the expedient of imposing fines upon poor workmen, they cannot be exacted without hardship, and per. haps injustice.

(854.) Mr. W. S. Evans, of Selkirk House, near Cheltenham, Gioucestershire, executed 300 miles of this kind of drain in 4 years, and is well pleased with its effects upon the land that has been

Fig. 193.

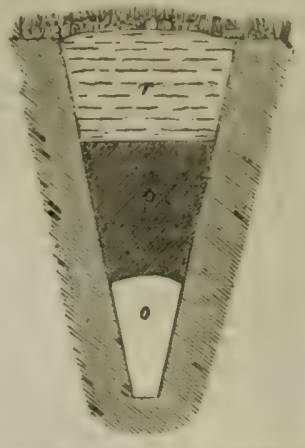

THE SECTION OF A PLUG DRAIN. subjected to it.

(855.) It is not so inexpensive a mode of draining as it at first sight appears, costing $1 \frac{1}{d} \mathrm{~d}$. the lineal yard, or $f 50 \mathrm{~s} .10 \mathrm{~d}$. the acre, according to Mr. Evans's experience; but, according to anotber account, the expense is th. the rood of 6 yards, or $£ 213 \mathrm{~s} .9 \frac{3}{4} \mathrm{~d}$. the acre.

(856.) The principle of this mode of draining is said to have succeeded well on the tops of the Gloucestershire hills, where the bottoms of the drains descend to and are cut through rock, and where the bitting-iron and plug have been laid aside for the pick-ax, the channel formed by which is covered with flat stones, and the whole covered with clay rammed down as before described. This may be a permanent mode of draining; lut in plug-draining in clay, I have no doubt that water will have the effect of softening the sides of the duct, and causing the rammed wedge of elay above to slip downward; and, should the water ever reach to the wedge, the latter will inevitably crumble down, and either entirely fill up, or form a dam across the duct."

(857.) An imperfect form of wedge-draining is practiced in some parts of England on strong clay soils, under the name of sod-draining. It is execated by removing the upper turf with the common spade, and laying it aside, for the purpose of making it the wedge at a sabsequent part of the operation; and, if the turf is tough. so much the better for the durability of the sod-drain. Another spit is made with the narrow spade, fig. 170 , and the last or undermost one is taken out with the narrowest spade, represented in fig. 194, which is only $2 \frac{1}{2}$ inches wide at the mouth: and, as its entire natrowness cannot allow a man's foot being used upon it in the usual manner, a stud or spur is placed in front at the bottom of the helve. upon which the workman's heel is pressed, and pushes down the spade and cuts out the spic. The depth may be to any desired extent. The upper turf is then put in and trampled or beaten down into the narrow drain, in which it becones wedged against the small shoulder left on each side of the drain, before it can reach the narrow channel formed by the last-mentioner? spade, fig. 194 ; and the channel below the turf. being left open, constitutes the duct for the water. It will readily be perceived that this is a temporary form of drain under any circumstances, though it may last some time in grass land, but it seems quite unsuited for arable ground, which is more liable to be affected by dashes of rain than grass land; and. in any situation, the clay in contact with water will run the risk of being so much softened as to endanger the existence of the dust.

(858.) Another method of draining is performed on strong clay land by the mole plow. This implement is almost unknown in Scotland, its use being confined to some parts of England, particularly in those parts where grass land on a clay subsoil abounds. It was, I believe, first introduced to the notice of Scot. tish agriculturists by the Duke of Hamilton, who caused it to be exhibited publicty on the occasion of the Highland and Agricultural Show at Glasgow in 1838. The day after the Show, I saw it exhibited in operation on a farm in the neighborhood of Glasgow, of strong clay land, for it seems to be best suited to operate in that kind of soil. Its object is to make a small opening in the soil at a given distance from the surface, in the form of a mole-run, to act as a duct for the water that may find its way into it ; hence its name of mole.plow. It makes

Fig. 194.

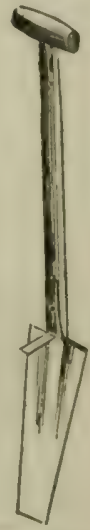

THE NARROWEST SPADE FOR SOD-DRAINS. the pipe or opening in the soil by means of an iron-pointed cone, drawn through the soil by the application of a force considerably greater than that applied to a common plow.

(859.) The mole-plow as a draining machine can never be of much utility in a country like Scotland, whose alluvial formations, though not deficient in extent, are characterized more by the abundance of their stony matters than by their clays as occupying the place of subsoils; and it is only in the few patches of carse land that such clays occur as can be brought ander the action

* Quarterly Journal of Agriculture, vols. iv. and xi 
of the mole plow. In all those subsoils where bowlders occur, whether large or small, the mole plow is so inapplicable, its usefulness is limited to such subsoils as consist of pure alluvial clays. In England, and where extensive flat districts of country occur, there the alluvium may be found which are the proper sphere of action for the mole-plow.

(860.) This plow is of extremely simple construction, as will appear from fig. 195, which is a view of it in perspective. It consists of a beam of oak or ash wood $6 \frac{1}{2}$ feet in length, and meas.

Fig. 195.

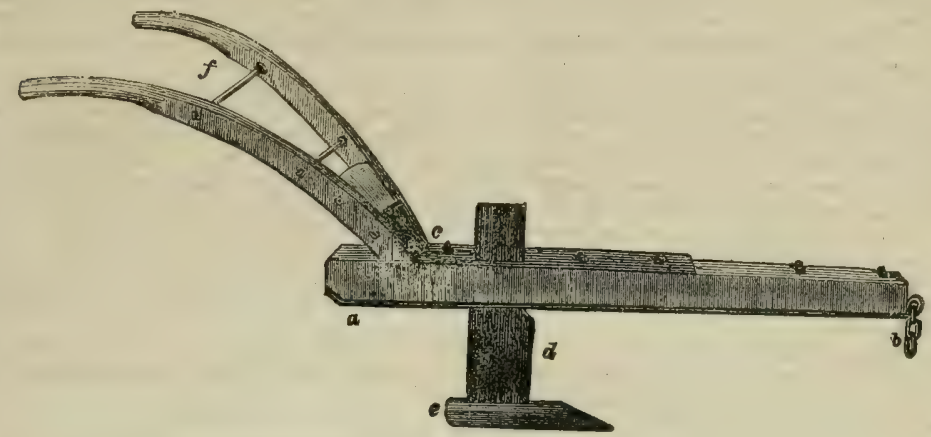

THE MOLE-PLOW.

uring 6 by 5 inches from the butt-end forward to 4 inches square at the bridle $b$. As the beam when in operation lies close upon the ground, and is indeed the only means of regulating the depth at which the conduit is to be formed, the lower side is sheathed all over with a plate of iron about $\frac{1}{2}$ inch thick. This plate at the proper place ( 4 feet 4 inches, or thereby, from the point of the beam) is perforated for the coulter-box; its fore-end is worked into an eye, which serves as a bridle, and is altogether strongly bolted to the beam. At the distance of a foot behind the coulterbox, a strong stub of wood is mortised into the beam at $c$, standing at the rake and spread which is to be siven to the handles. Another plate of iron, of about 3 feet in length and $\frac{1}{2}$ inch thick, is ap;lied on the upper side of the beam; the coulter-box is also formed through this plate, and the hind-part is kneed at $c$, to fit upon and support the stub, to which, as well as to the beam, the plate is firmly bolted. The two stilts or handles $c f$ are simply bolted to the stub, which last is of such breadth is to admit of several bolt-holes, by which the hight of the handles can be adjusted. That which may be termed the head of the plow is a malleable iron plate of about 2 feet in length; that part of it which passes through the beam, and is there fastened by means of wedges like the com. mon coulter, is 7 inches broad and $\frac{3}{4}$ inch thick. The part $d$, below the beam that performs the operation of a coulter, is 9 inches broad, $\frac{3}{4}$ inch thick in the back edge, and thinned off.to a knifeedge in the front. The share or mole is a solid of malleable iron, welded or riveted to the head; jts length in the sole is about 15 inches, and in its cross section (which is a triangle with curved sides and considerably blunted on the angles) it measures about 3 inches broad at the sole, and $3 \frac{1}{2}$ inches in hight. A cylinder is, however, a better form than a triangle; but in either case the forepart of the share is worked into a conical form, the apex being in the line of the sole, or nearly so. This, while it enables the share to penetrate the earth more freely, prevents a tendency to rising out of the ground. 'The tendency to rise is, however, not so great as may be supposed, for the center of motion in this implement being very low, not less than 12 inches under the surface of the ground, and the draft being applied horizontally, there is a strong tendency in the point of the beam and of the share, as in all similar cases of oblique draft, to sink into the ground $(630)-(634)$; the effect of which, if not properly balanced by the effects of form in the parts, will give the moleplow much unnecessary resistance.

(861.) In working this plow, the draft-chain is attached to the bridle-eye at $b$, and it is usually drawn by two horses walking in a circular course, giving motion to a portable horse capstan, that is constructed on a small platform movable on low carriage-wheels, and which is moored by anchors at convenient reaches of 50 to 60 yards. The mechanical advantage yielded by the horse capstan gives out a power of about 10 to 1 , or, deducting friction, equal to a force of about 14 horses.

(862.) When the plow is entered into the soil and moved forward, the broad coulter cuts the soil with its sharp edge, and the sock makes its way through the clay subsoil by compressing. it on all sides; and the tenacity of the clay keeps not only the pipe thus formed open, but the slit which is made by the broad coulter permits the water that is in the soil to find its way directly into the pipe. The plow is found to work with the greatest steadiness at 15 inches below the surface. The upper turf is sometimes laid over beforehand by the common plow, when the moleplow is made to pass along the bottom of its furrow, and the furrow-slice or turf is again carefully replaced. This is the preferable mode of working this plow, as it serves to preserve the slit made by the multer longer open than when it terminates at the surface of the turf, where, of course, it is liable to be soon closed up; but the least trouble is incurred when the plow is made to pass throseb the turf unplowed.

\{ $\left.3 f^{3}\right)$ 'To work the whole apparatus efficiently, 2 horses and 3 men are required; and if the commo estimate of $10 \mathrm{~s}$. a day for 2 horses and 1 man is taken, but which is too high, as you shall (717) 
have occasion afterward $\omega$ learn, and 3s. $6 \mathrm{~d}$. for the other 2 men, an acre of ground can be moles drained for 138. 6d., excluaive of the first cost and tear and wear of this apparatus, the cost of which cannot be less than $£ 50$. At this rate, this is the chespest of all the modes of draining thas you have yet heard of.

(864.) If the mole-plow is put in motion in soft clay, the slit made by the broad coulter will not remain open even for a single day; and, thongh it may again open in severe dronth, it will cloee again whenever the clay becomes moist. This plow seems fitted for action only in pure clay subsoils, and, when such are found under old grase, it may partially drain the ground with comparm tive economy; and, the process being really economical, it may be repeated in the course of year in the same ground. In my estimation, this mode of draining cannot bear a comparison for effeacy to tile-draining, although it is employed in some parts of England, where its effects are highly spoken of."

(865.) It has lately been proposed by Mr. Scot, of Craigmoy, Stewartry of Kirkcudbright, to substitute tubes of larch wood for drain-tiles. in situations where larch is plentiful, and consequently cheap, and drain-tiles dear; and he considers that they would be equally efficient with tiles in many situations, and especially in mossy soils. Were larch tabes confined to draining mossy soils, I conceive they would answer the purpose well, not only on account of their length maintaining their original position in the drain, but on account of the durable nature of larch where water is constantly present, as is instanced in cases of great antiquity, such as the piles of larch upon which the city of Venice is founded. The larch tree that is felled in winter. and allowed to dry with the bark on, is much more durable and useful for every purpose, and infinitely more free of splits and cracks than that which is cut down in sap, and immediately deprived of its bark for tan.

(866.) The tube finished, fig. 196, presents a square of 4 inches outside, with a clear water-way of 2 inches. To those who wish to know how they are made, I refer to Mr. Scot's published statement : $\dagger$ but in doing this $\mathrm{I}$ must remark that the cost of these tubes will exceed that of clay tiles. For, take the cost of drain-tiles at 30 s. per 1000 , including carriage, that will be $1 \frac{1}{2}$ farthings the lineal foot. Now, a lineal foot of larch tube contains say 1 superficial foot of timber at 1 inch thick, which will cost for carriage and sawing the timber 1 farthing; the fitting, boring and

Fig. 196.

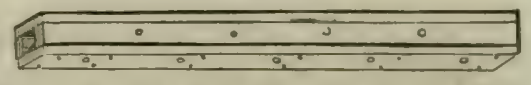

THE LARCH DRAIN-TEBE.

pins will cost other 2 farthings; and the timber, at 6 d. the cubir foot, will increase the cost 2 farthings more, which altogether make the tube more than 3 times dearer than tiles; and, if the cost of the timber is thrown into the bargain, still they will be double the price of tiles.

(867.) The recommendation of wooden tubes for the purpose of draining land reminds nue of many expedients which are practiced to fill drains, among which are brushwond, thorns, trees, and even straw-ropes. With the exception of the trunks of small trees, which, when judicionsly laid down in drains, may last a considerable time, it is not to be imagined that brushwood of any kind can be durable. Hence. drains filled with them soon fall in. It could only be dire necessity that would induce any man to fill drains with straw twisted into ropes; and it could only have been the same eause, in situations where stones were scarce, and at a time when drain-tiles were little known in Scotland, such as was the case during the late war, that could have tempted farm. ers to fill drains with thorns. No doubt, the astringeut nature of thora-wood and bark may preserve their substance from decay under ground for a considerable time, but the sizking of holes in such drains, as I have seen, were infallible symptoms of decay. Only conceive what a mess such a drain must be that is "filled up to the hight of 8 or 10 inches either with brushwood, stripped of the leaves-oak, ash, or willow twigs being the best-and covered with long wheat straw, twisted into bands, which are put in with the hand, and afterward forced down with the spade; care being taken," the only case of it evinced in the whole operation, "that none of the loose mould is allowed to go along with them. The trench is then entirely filled up with earth, the first layer of which is closely trampled down, and the remainder thrown in loosely." $\ddagger$ And jet such is the practice in several of the south-enstern and midland counties of Eugland.

(868.) Of the durability of common brick when used in drains, there is a remarkable instance mentioned by Mr. George Gathrie, factor to the Earl of Stair, on Culhorn, Wigtonshire. In the execution of moderu draining on that estate, some brick-drains, on being intersected. emitted water very freely. According to documents which refer to these drains, it appears that they bad been formed by the celebrated Marshal, Earl Stair, upuard of a hundred years ago. They were found between the veretable mould and the clay upon which it rested, between the "wet and the dry," as the country phrase has it, and about 31 inches below the surface. They presented two forms-one consistiug of 2 bricks set asunder on edge, and the other 2 laid lengthways across them, leaving between them an opening of 4 inches square for water, but having uo soles. The bricks had not sunk in the least through the sandy clay bottom upon which they rested. as they were 3 inclies broad. The other form was of 2 bricks laid side by side, as a sole, with 2 others built on bed on each other at both sides, upon the solid ground, and covered with flat stones, the building being packed on each side of the drain with broken bricks.\|

(869.) Various attempts bave been made to lessen the cost of cutling drains. One of these is to cut the drains narrower than they used to be, for the obvious reason that the drawing power of drains lies more in their depth than breath; and the cubical contents of drains, of any given length, have in consequence been much decreased, and the cost of digging them of course much lessened.

* See the Agricultural Surveys of Middleacx and Essex.

+ Prize Essays of the Ilighland and Agricultural Society, vol. xiv., where the machinery for making these tubes is tigured and minutely described.

t British Husbandry, vol. i.

(i) Prize Essays of the Highiand and Agricultural Society, vol. xiv.

(718) 
(870) An attempt has been made with this view by Mr. Peter McEwan, Blackdub, Stirling. shire. His invention consists of the application of the plow in casting out the contents of drains, and it certainly displays much mechanical ingenuity, and really performs the work with a considerable degree of perfection. This application of the plow, however, is by no means adapted to every species of subsoil-the most common one, of a tilly clay, containing small stones and occasional bowlders, presenting insuperable difficulties to its progress; while in pure unctuous clay it cuts its way with ease, and lays aside the tenacions furrow-slice with a considerable degree of regularity. The instrument has thus a limited application, but a greater objection exists against it, inasmuch as it requires an inordinate amount of power to set it in motion, consisting of that of 12 borses. This circumstance alone still more limits its application, for there are comparatively few farms which employ 6 pairs of borses at work; and besides, it is almost impossible to yoke 12 horses together, so as to derive the amount of labor from them, as when yoked in pairs. It is truly distressing to see the borses with this plow, as I once had the opportunity of witnessing in field, of favorable subsoil, too, in the neighborhood of Glasgow in 1838, on the occasion of the Highland and Agricultural Society's Show.

(871.) Mr. Smith, Deanston, has given a description of Mr. McEwan's draining-plow, which it is not necessary to particularize farther than that the borses go in two divisions, one on each side of the line of draught, yoked to a strong master-tree 10 feet long, arranged so as to have 4 abreast, when 8 horses are used, and 6 abreast when 12 horses are yoked.

(872.) With regard to the state of the work left by this plow, men follow with spades, and take out a bed for tiles or broken stones, and correct any deviation from a uniform fall in the bot tom, occasioned by unevenness of ground. The tiles or stones are then put in the usual manner, and the earth is returned into the drain by the plow.

(873.) This drain-plow is made of two sizes, one weighing $5 \mathrm{cwt}$., costing $£ 11$, the other weighing $4 \mathrm{cwt}$., and costing $£ 88 \mathrm{~s}$, and the bars or swingle-trees, necessary to accompany each plow, are 2 six-horse, 4 three-horse, and a strong chain, the whule costing $f 448$.

(874.) With regard to the length of drain cut by this plow. Mr. Smith estimates the time spent at 2 miles per hour for 8 hours; and allowing $\frac{1}{3}$ of it to be lost in turnings. the actual quantity of work done in 8 hours he takes at 3,126 roods of 6 yards, or about $19 \frac{1}{2}$ acres, at 15 feet asunder, the drains being cut from 18 to 22 inches in depth. This quantity of work is corroborated by $\mathrm{Mr}$. John Glen, Hilton, Clackmannanshire, who states that "we drain 400 Scotch chains in 9 hours," going down bill with the furrow, and ap empty.

(875.) The rate of walking taken by Mr. Smith, at 2 miles the hour, is too great, as the distance traveled in plowing 1 imperial acre of ground, in the usual way, in a day of 10 hours, which constitutes a good rate of work, is $9 \frac{7}{8}$ miles, or only 1742 yards per hour, including of course turnings. There is also a discrepancy in Mr. Glen's atatement of draining nearly half the extent of his land in 9 hours, gning half the time empty, with another statement where he says, "we have used Mr McE wan's drain-plow for the last 4 months, and have drained 837 chains, Scotch measure, with it ": that is, only 2 days' work in 4 months, with 6 horses, the drain being $18 \frac{1}{2}$ inches wide at top, and 8 inches wide at bottom, and from 15 to 17 inches in depth.

(876.) The cost of employing this drain-plow is thus given by Mr. Smith :

12 horses at $4 \mathrm{~s}$. a day each.......................... £2 80

8 men at 2 s. a day each............................. 0160

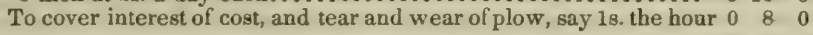

Total.................................. $\overline{£ 3120}$

wkich is only $1 \frac{1}{3}$ farthings per rood of 6 yards.*

1877.) Other plows have been invented for making drains, which have attracted attention, and engaged the advocacy of friends in the immediate locality in which they originated, but seem never to have extended farther.

(878.) In 1832, Mr. Robert Green, a farmer in Cambridgeshire, published an account of a drainplow of his invention. It cuts the ground 23 inches deep and 8 inches wide at top, and 2 inches at bottom, at three cuts; the first being 9 inches, the second 8 inches, and the third 6 inches deep. It is said to take the earth out clean, leaving none to shovel out. It cuts about 500 or 600 poles or rods of the above dimensions, at three times. It requires 4 horses at the first time, and 6 horses the other two, and 2 men and a boy to work them, at $£ 110 \mathrm{~s}$. a day. The price of this plow is quoted at $£ 15$.

(879.) In 1833, Mr. Thomas Law Hodges published an acconnt of a drain-plow invented by Mr. John Pearson, Frotterden, near Cranbrook in Kent. The drain is taken out by it at three turns. Men follow with narrow scoops, and throw out all the loose earth clean, which finishes the drain at 26 inches deep, at an expense of $1 d$. the rod.

(880.) Both these implements are best adapted to strong clay subsoils, and best for plug-draining, especially Pearson's, when, after its operation, a long, narrow plug or slide of wood is used, the clay being rammed down upon which, it is then trawn forward by means of a windlass and rope. This plow is estimated to cost $£ 95 \mathrm{~s}$., but with spades, scoops and rammers, it costs $£ 18 . \pm$

1881.) It may be asserted, withont much fear of contradiction, that improvements by thoronghdraining will never become general, or be made permanent, unless the assistance of the landlord be obtained. When left altogether to the tenant, want of capital and the shortness of the lease will tend at all times to limit the extent- of improvements, and will seldom be made permanent; because the true interest of the tenant is to execute the work only in such a manner as will secure his own temporary purpose. To the proprietor, among the many inducements to improve his estate by draining, the greatest, at least the most satisfactory, is, that it yields an immediate and large return. If he has no spare money, he has only to borrow it at 4 per cent. and lend it,

* Snith's Remarks on Thorough-Draining.

I Green on Underdraining Wet and Cold Land.

1 Hodges on the Use and Advantages of Pearson's urairing. $\mathbf{F l o w .}$ (719) 
ont at 6 per cent., a per centage which no tenant will refuse to pay, and upon a security, too, undoubted-that of his own property. No one will deny that a proprietor is as justly entitled to receive a fair return for money laid out in the improvement of his estate, as he is for that laid ont on the original purchase of it. Hence, I would assume, as a general principle, that for every penny laid out by a proprietor upon ameliorations of any kind, he shall bave an assurance of a return, either immediate or prospective-immediate, in the form of interest or of ariditional rent ; prospective, in the increased value of his property, by which, in after leases, it will yield such an increase of rent as will repay the prrsent outlay. Again, as regards a tenant, I will assume that he will make every improvement th e subject of a calculation of profit or loss for one lease only, and that he will not lay out any moaey merely for the purpuse of making improvements toextend beyoud that period. Let him even have an assurance of a renewal of his lease, still, before that takes place, a valuation will be made of his farm, and in that valuation will be included his im provements; so that, while he originally disbursed the whole expense of them, he will in reality have to pay for them again in the shape of additional rent.

(882.) [The mechanical principles of draining have been already so fully discassed that I need not detain you a moment with their examination; but this will be the best place for considering a most interesting subject connected with soil, upon which the whole necessity of draining depends, I refer to the manner in which an excess of water proves injurious to the fertility of the soil.

(883.) In considering this subject it will be advisable to examine into the effects of water, 1 st apon the mechanical condition of the eoil, and 2d, upon its chemical constituents, reserving the influence which it exerts directly upon vegetation to be discussed on some future occasion.

(884.) If you call to mind what I have said regarding the mechanical constitution of soil (424), you will at once perceive that a soil in situ might not inaptly be compared to a porous solid permeated by innumerable tortuous channels, these channels being formed by the interstutial spaces occurring between the various particles composing the soil.

(885.) If water is added gradually to soil. the first effect will be doubtless to fill these channels, but from the attraction which the various components of soil have for water, they speedily draw it into their pores, and thus empty the channels so that even after a considerable addition, the soil, taken as $a$ whole, does not lose its porosity although each particle has its individual pores filled with water. This is the bealthy condition of soil ; it is what I shall call moist, in contradistinction to wet. Soil in this state can be crumbled down in the hands without making them moddy, al. though it feels distinctly damp, and will lose, when beated to $212^{2} \mathrm{~F}$., from 20 to 50 per cent. of water.

(886.) If now more water should be added, the channels will be again filled, and as the pores of each particle are already saturated with moisture, they can again be emptied only by one of the two following methods: 1st, either very gradually by evaporation from the surface, as in $u n$. drained soil, or, 2d, mach more rapidly and effectually by the channels having communication with some larger channel in a relatively lower level, as is the case in drained soil. Soil in which all the interstices between its particles are more or less filled with water mas be called wet soil, and all such land must be drained before it can be properly and advantageously culivated.

(887.) You will thus perceive that water does no harm, in fact it is absolntely necessary in soil so long as it does not alter its mechanical condition; but whenever it fills up the interstitial channels it becomes injurious for the following reasons: 1st, it prevents the circulation of air through the soil, as this takes place entirely through the medium of these chanaels; $2 d$, it impoverishes the soil by permitting soluble matter to soak through; because until these channels are filled there is no flow of liquid in the soil, except a very gentle current from below upward, produced by capillary attraction toward the drier particles near the surface."

(888.) Again, an excess of water acts most injuriously in soil by reducing its temperature. This is owing to the extremely slight conducting power of water for heat, as compared to earthy matter, assisted also by the cold produced by continued evaporation. According to some experiments which I performed, the diminution of heat produced in this way amounts, in summer. on an average to $6 \frac{1}{2}$ degrees of Fahrenheit, which, according to Sir John Leslie's mode of calcu. lating elevation by the mean temperature, is equivalent to a difference of 1,950 feet. When we consider the effects of elevation upon the nature and amount of produce, we shall have good reaBon to see the baneful effects of such a change as this represents.

(889.) Besides the above injuries inflicted by an excess of water, there are nnmerous effects upon the chemical changes in the soil, and also upon the plants themselves, all of $w$ hich must be considered in their proper place. I trust, however. that what I have advanced will serve to impress sufficiently on your minds the evident necessity of thorough-draining in all situntions where the soil is $w \cdot e l .-H$. R. M.]

(890.) After pointing out the effects of draining in ameliorating the soil and promoting a healthy condition of vegetation. Professor Johuston proceeds to show the effects of water upon clay soil. "I shall add one important remark," he eayg, "which will readily suggest itself to the geologist who has studied the action of air and water on the various clay beds that occur here and there as menabers of the series of stratified rocks. There are no clays which do not cradually soflen under the united influence of air and of running water. It is false economy, therefore, to lay down tiles witbout soles, however hard and stiff the clay subsil may appear to be. In the course of 10 or 15 years, the stiffest clays will soften, so as in allow the tile to sink, and many very much sooner. The passage for the water is thus gradually removed; and when the tile has gunk a couple of inches, the whole must be taken up. Thousands of miles of drains have been thus laid down, both in the low country of Scotland and ia the southern counties of England, which have now become nearly useless; and yet the system stll! goes on. It would appear even

* See Prize Easay on this subject by me in the Prize Essays of the Higbland and Agricultural Snciety, vol. xiii. 
as if the farmers and proprietors of each district, unwilling to believe in or to be benefited by the experience of others, were determined to prove the matter in their own case also, before they will consent to adopt that surer system which, though demanding a slightly greater outlay at first, will return upon the drainer with no after-calls for either time or capital. If my reader," contiuaes the Professor, "lives in a district where this practice is now exploded, and if he be inclined to doubt if other counties be farther behind the advance of knowledge than his own, I would invite him to spend a week in crossing the county of Durham, where be may find opportanities not only of satisfying his own doubts, but of scattering here and there a few words of useful advice among the more intelligent of our practical farmers."*

1892. As the preservation of the fall in a drain on nearly level ground is of great importance in drying it, it may be satisfactory to have a demonstration of the fact that the angle subtended by the plumb-line $d f$, in fig. 183 , is equal to the angle of inclination of the drain $b a c$. The rule is, as radius : $a b$ : : sine of the angle, $b a c: b c$, the hight of the fall: Or, multiply the natural sine of the angle $b a c$ by the length of the fall $a b$, and the same result will be obtained.t

(893.) The Homans practiced draining both with open and covered drains, the former in clay and the latter in porous soils. The instructions given by Palladius for the formation of drains may be received with surprise by modern practicers of the art on account of their correctness, and when their great antiquity is held in remembrance. "If the land is wet," he says, "it may be dried by drains drawn from every part. Open drains are well known: covered drains are made in this manner: Ditches are made across the field 3 feet deep; afterward they are filled half-way up with small stones or gravel, and then filled to the surface with the earth that was thrown out. These covered drains are let to an open one to which they descend, so that the water is carried off, and destroys no part of the field. If stones cannot be got, branches, or straw, or any kind of twigs, may be used in their place." $\ddagger$

[We have omitted some calculations and tabular statements, desigued to illustrate the particular and comparative cost of the several kinds of drains, according to the various materials em. ployed in their formation, and other circumstances affecting the question.

All the elements of these calculations differ so widely from such as would be brought into account in this country, that the publication of them here would afford no reliable or useful data for those who might be disposed to enter on a system of draining, more or less extensive. Having so thoroughly exemplified and explained the principles of draining as conducted in a counrry where they are best understood and recently most exteusively carried out, every reader can best judge for himself as to the cost and the probability of his being adequately remunerated by the results. These questions, as they arise, must depend, in all cases, on the peculiar circumstances that belong to them. As we have before said, the portions of a farm which most generally invite the operation of draining, are low grounds, and usually the most fertile, when divested of surplus moisture; and if any reliable inference is to be drawn from the profits of this operation in Eng. land, such as have been detailed, the increased crops to be expected, would warrant a heavy ontlay, to say nothing of the sanatary effect, which has also been referred to. The reasons here given for not copying all the details, relating merely to the cost of draining by the different methods, and with the materials employed in England, might seem to apply to many others which have been given in respect to other branches of this operation, one of the great sources of the increased productiveness of English Agriculture; but, in the first place, the cases are not exactly parallel; and besides, we are so fully impressed with the importance and the profit of draining rich spots of land in our country, and so well satisfied that in the old States this important item in the management of land is too much overlooked, that it was deemed better to illustrate the subject in all its aspects, even though many of the examples given for that purpose may not be exactly appli. cable to the situation and circumstances of American landholders. For even these examples may present encouragement to justify the operation, in numberless instances where it has been neglected; and at all events, they serve more fully to explain one of the great problems of the day, with which every enlightened agriculturist ought to be familiar in all its phases. $E d$. $F$. Lib.]

* Johnston's Elements of Agricultural Chemistry.

$\dagger$ See the practical application of this rule on a large scale illnstrated in Denton on Model Mapping

Dickson's Husbandry of the Ancients, vol. i. 


\title{
26. YOKING AND HARNESSING THE PLOW, AND OF SWING-TREES.
}

\author{
"No wheels oupport the diving pointed share; \\ No groaning ox is doomed to labor there; \\ No belpmates teach the docile steed his road; \\ Alike unknown the plow-boy and the goad; \\ But, unassisted through each toilsome day, \\ With amiling brow the plowman cleaves his way." \\ BLOOMFIELD.
}

(894.) Havivg inspected the varieties of soil within the sphere of your observation, and been told of the various modes in which the land may be stirred by the plow in winter, it will be proper for you to know the simple and efficient method by which horses are attached to and driven in the plow in Scotland, before the winter-plowing of the soil is begun, and to enable you to conceive the process more vividly, you will find a pretty accurate representation of a plow at work in Plate IIII.*

(895.) The first thing that will strike you is the extreme simplicity of the whole arxangement of the horses, harness, plow, and man, impressing you with the satisfactory feeling that no part of it can go wrong, and afford you a happy illustration of a corr.plicated arrangement performing complicated work by a simple action. On examining particulars, you will find the collar, better seen in fig. 197, around the horse's neck, serving as a padding to preserve his shoulders from injury while pressing forward to the draught. Embracing a groove in the anterior part of the collar, are the haims, composed of two pieces of wood, curved toward their lower extremities, which are hooked and attached together by means of a small chain, and their upper extremities held tight by means of a leather strap and buckle; and they are moreover provided on each side with an iron hook, to which the object of draught is attached. The horse is yoked to the swing-trees by light chains called trace-chains, which are linked on one end to the hooks of the baims, and hooked at the other into the eyes of the swing-trees. A back-band of leather put across the back, near the

[* How little soever may be doing for disseminating in America among the rising generation of agriculturists a knowledge of the principles of their art, it may be said to the credit of the profestion, that in the lightness and perfection of our gearing, and in the manner of attaching and using the motive power employed in the field of Agriculture, we are not behind, if, indeed, we are not in advance, of conntries the most highly improved. Yankee ingenuity, in unrestricted play, under our free Goveranent, has effectcd wonders in the form and structure and economy of agricultural implements and machinery, for saving cost and labor, except. perhaps, such as are of a costly nature, involving too much expense for common use. It is not to be maintained that our materials, especially of leather, or our workmanship in harness manufacture and saddlery, are by any means as perfect as in England; but so little have we m learn from them about "yoking aud harnessing the plow," that we might have ventured to omit this chapter except that we choose, es well to gratify the curiosity as to instruct tho minds of young and inquiring readers. England and Scotland are admitted to be in the van of all European nations in the march of improvement, especially in scientific Agriculture; and he would be deemed but a careless observer who should visit either the one or the other and come bark without being able to tell if there were anything peculiar in their mode of harnessing their teams to agricultural implements. The next best thing to seeing for one's self is to be, as herein, authentically informed. The same reasons, withont feeling the necessity of repeating them, will prompt us to give many other items that might be omit. ted were we to study nothing but practical usefulness and saving to our publishers. 
groins of the horse, supports the trace-chains by means of simple hooks. The bridle has blinders, and while the horse is in draught. it is customary to hang the bearing-reins over the tops of the haims. In some parts of the country there are no blinders; and there is no doubt that many horses so brought up will work very well without them. But in cases of horses of so timid a nature as to be easily frightened at distant objects, and those of so careless a disposition as to look much about them, they are useful in keeping the attention of the horse to his work. You observe there are two horses, the draught of the common plow requiring that number, which are yoked by the trace-chains to the swing-trees, which, on being hooked to the draught-swivel of the bridle of the plow, enable the horses to exercise their united strength on that single point; and being yoked abreast, they are enabled to exert their united strength much more effectually than if yoked atrip-that is, one before the other. The two horses are kept together either by a leather strap, buckled at each end to the bridle-ring, or by a short rein of rope passed from the bridle-ring to the shoulder of each horse, where it is fastened to the end of the trace-chain with a knot. The strap provents the horse separating beyond its length, but allows their heads to move about loosely ; the short reins prevent them not only separating, but keep their heads steady; and on this account, horses fastened with reins can be turned round more quickly and simultaneously than with the strap. The plowman guides the horses with plow-reins, made of rein-rope, which pass from both stilts to the bridle-ring of each horse, along the outermost side of the horse, threading in their way a ring on the back-band and sometimes another on the haims. The reins are looped at the end next the plowman, and conveniently placed for him under the ends of pieces of hard leather screwed to the foremost end of the helves; or small rings are sometimes put there to fasten the reins to. In many places, only one rein is attached to the near-side horse, and in others the horses are guided solely by the voice. It is perfectly obvious that the plowman must have a better and quicker command over his horses with a double than a single rein, and very much more so than by the voice alone.

(896.) Thus harnessed, each horse has not much weight to bear, nor is its harness costly, though made of the strongest harness leather, as this statement will show :

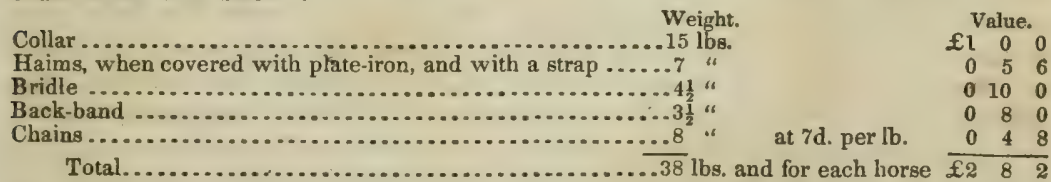

When compared with the weight of English harness, these are little more than feather-weight.

(897.) The collars are differently mounted in the cape in different parts of the country. The use of the cape is to prevent rain falling upon the top of the shoulder, and getting between the collar and shoulder; where, in draught, it would heat and blister the skin. 'In the Lothians, the cape of the form of fig. 197 is both neat and convenient. In Forfarshire, and somewhat more northerly, it is of the form of fig. 198, which lies flatter and comes farther back than the former; and it is certainly a complete protection from rain; but it makes the collar rather heavy, and its own weight is apt to loosen the sewing of white sheep-skin with which it is attached to the body of the collar. Fig. 199 is a form of cape common in England, which answers no purpose of protection from rain, but rather 
to catch the wind, and thereby obstruct the progress of the horse. Such a cape is frequently ornamented with flaring-colored red worsted fringes round the edge, or with large tassels from the corner and middle, or even with bells.

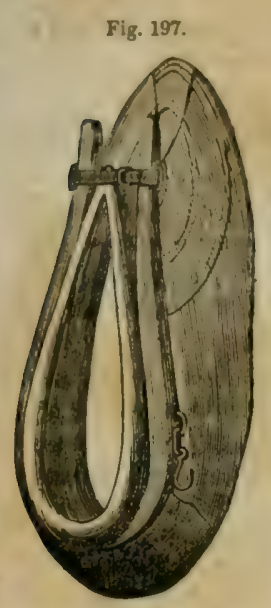

THE LOTHIAN DRAUGHTHORSE COLLAR AND HAIMS.
Fig, 198.

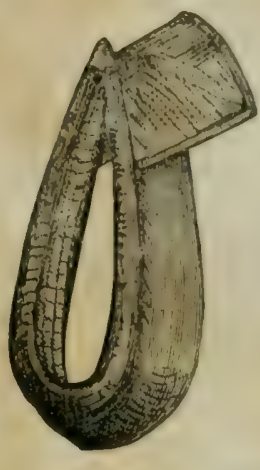

THE FORFARSHIRE

DRAUGHT-HORSE COLLAR.
Fig. 199.

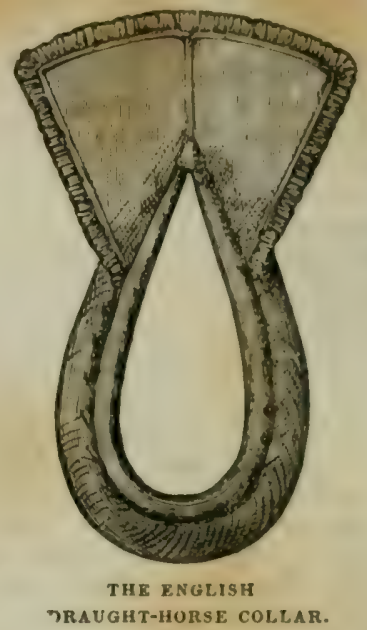

(898.) With regard to ornamenting farm harness, it never appears, in my estimation, to greater advantage than when quite plain, and of good materials and excellent workmanship. Brass or plated buckles and browbands, worsted rosettes, and broad bands of leather tattoved with fillagree sewing, serve only to load and cover the horses when at work, and display a wasteful and vulgar taste in the owner. Whatever temptation there may be in towns to show off the grandeur of teams, you should shun such display of weakness in the country.

(899.) The English farmer is not unfrequently recommended by writers on Agriculture to adopt the 2-horse plan of working the plow; but the recommendation is never accompanied with such a description of the plow as any farmer could understand it who had never seen a plow with 2 horses at work; and it is not enough to tell people to adopt this or that plan, without putting it in their power to understand what is recommended.To enable the English farmer, who may never have chanced to see a twonorse plow at work, and to facilitate the understanding of its arrangements by those who may have seen, but not have paid sufficient attention to it, the figure on Plate XIII. has been executed with a regard to show the just proportions of the various parts of the plow and the harness. The plow has been sufficiently well explained already, and keeping in mind the relative propertions of its parts, those of the horse and harness may be ascertained from this plate; for, so practically correct are those proportions, that any one desirous of mounting a plow in a similar manner may easily do so from this figure before them.

(900.) Although the reins alone are sufficient to guide the horses in the direction they should go-and I have seen a plowman both deaf and dumb manage a pair of horses with uncommon dexterity-yet the voice is a ready assistance to the hands, the intonations of which horses obey with celerity, and the modulations of which they understand, whether express- 
Ive of displeasure or otherwise. Indeed, in some of the midland counties of Scotland, it is no uncommon occurrence to observe the plowmen guiding their horses, both in the field and on the road, with nothing but the voice; but the practice is not commendable, inasmuch as those accustomed to it fall into the practice of constantly roaring to their horses, which at length become regardless of the noise, especially at the plow ; and on the road the driver has no command over them, in any case even of the slightest emergency, when he is obliged to hurry and seize the bridle of the horse nearest to him at the time; and should one or both horses evince restiveness, when he can only have the command of one by the bridle, he runs the risk of being overcome by the other or by the cart.

(901.) The language addressed to horses varies as much as even the dia lects are observed to do in different parts of the country. One word, Wo, to stop, seems, however, to be in general use. The motions required to be performed by the horse at wcrk are-to go forward, to go backward, to go from you, and to come toward you ; and the cessation of all these, namely, to stop or stand still.

To lessen or cease motion.-The word $W_{0}$ is the common one for a cessation of motion; and it is also used to the making any sort of motion slower; and it also means to be careful, or cautious, or not be afraid, when it is pronounced with some duration, such as Wo-o-o. In some parts, as in Forfarshire, Stand has a similar signification; but, to stand without any movement at all, the word Still is there employed. In England, $W_{0}$ is to stop.

To go forward.- The name of the leader is usually pronounced, as also the well-known Chuck, Chuck, made with the tongue at the side of the mouth, while impelling the breath.

To step backward.-Back is the only word I can remember to have heard for this motion.

To come toward you.-Hie is used in all the border counties of England and Scotland; Hie here, Come ather, are common in the midland counties of Scotland. In towns one hears frequently $W y n d$ and Vane. In the west of England $W_{0-e}$ is used.

To go from you.-Hup is the counterpart to hie in the southern counties, while haud aff is the language of the midland counties; and, in towns, Haap is used where wynd is heard, and Hip bears a similar relation to vane. In the west of England Gee agen is used.

In all these cases, the speaker is supposed to be on what is called the near-side of the horse-that is, on the horse's left side. As a single word is more convenient to use than a sentence, I shall employ the simple and easily pronounced words hup and hie, when having occasion to describe any piece of work in which horses are employed.

(902.) [The swingle or swing-trees, whipple-trees, draught-bars, or simply bars-for by all these names are they known-are those bars by which horses are yoked to the plow, harrows, and other implements. In the plow-yoke, a set of swing-trees consists of 3 , as represented in fig. 200 , where $a$ points out the bridle of the plow, $b b$ the main swing-tree attached immediately to the bridle, $c c$ the furrow or off-side little swing-tree, and $d d$ the land or nigh-side little tree, arranged in the position in which they are employed in working. The length of the main-tree, between the points of attachment for the small trees, is generally $3 \frac{1}{2}$ feet, hut this may be varied more or less; the length of the little trees is usually 3 feet between the points of attachment of the tracechain, but this also is subject to variation.

(903.) Swing-trees are for the most part made of wood, oak or ash being most generally used; but the former, if sound English oak, is by much the most durable. though goud Scotch ash is the strongest, so long as it remains sound, but it is liable, by long exposure, to a specres of decay resembling dry-rot. As it is always of importance to know the why and wherefore of everything, I shall here point out how it may be known when a swing-tree is of a proper degree of atrength. A swing-tree, when in the yoke, undergoes a strain similar in practice to that of a beam supported at both ends and loaded at the middle : and the strength of beams or of swing trees in this state is proportional to their breadths multiplied into the square of their depths and divided by their lengths. It is to be anderstood that the depth here expressed is that dimension of the swing-tree (773) 
that lies in the direction of the strain, or what in the language of agricaltural mechanica is called the breadth of the swiug-uree. To apply the above expression to practice-suppose a swing tree

Fig. 200.

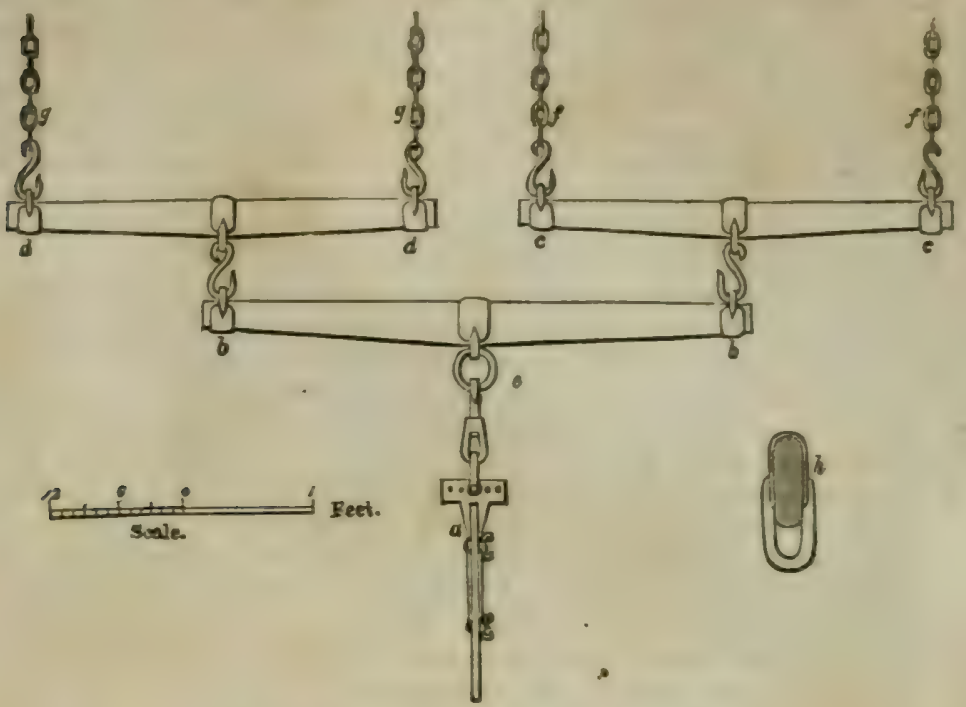

THE SWING-TREES TOR TWO HORSES.

of 3 feet in length between the points of attachment for the dranght, that its breadth is $1 \frac{1}{2}$ inches and depth 3 inches, and another of the same breadth and depth, but whose length is 6 feet, then in the case of the first we have $\frac{1.5 \times 3 \times 3}{3 \text { feet }}=4.5$; and in the second we have $\frac{1.5 \times 3 \times 3}{6}=2.25$ -the strength of these two being as 2 to 1 ; and, to make the 6 feet swing tree of equal strength with the other, the breadth must be increased directly as the length-that is to say, doubled-or the depth increased. so that its square shall be double that of the former. Hence a swing-tree of 6 feet long, and having a breadth of $1 \frac{1}{3}$ inches and depth $4 \frac{1}{2}$ inches, will be equal in strength tc the 3.feet swing-tree with a breadth of $1 \frac{1}{2}$ and depth of 3 inches: but, the depth remaining equal, the breadth is required to be donbled, or made 3 inches for the 6 -feet swing tree.

(904.) To find the absolute strength of a bar or beam, sitante as above described, we have this rale: Maltiply the breadth in inches by the square of the depth in inches, divide the product by the length in feet, and maltiply the guotient by the conetant 660 if for oak, or by 740 if for ashthe product will be the force in pounds that would break the swing-tree or the beam." Here, then, taking the former dimensions as of a small swing-tree, $\frac{1.5 \times 3^{2} \times 740}{3}=3,333 \mathrm{Jba}$ the abBolute force that would break the tree; but, taking into acconnt the defect that all woods are liable to break from crossing the fibres and other contingent defects, we may allow $\frac{1}{2}$ to go for security against such contingencies, leaving a disposable strength eqnal to $1,666 \mathrm{lbs}$. It has been shown (634) that the usual force exerted by a horse in the plow does not exceed $168 \mathrm{lbs}$, but it occasionally rises to $300 \mathrm{lbs}$, and on accidental occasions even to $600 \mathrm{lbs}$.: but this is not much beyond $\downarrow$ of the disposable strength of the 3 feet swing tree when its breadth and depth are $1 \frac{1}{3}$ and 3 inches. The depth of such trees may therefore be safely reduced to $2 \frac{1}{1}$ inches, and still re. tain a gufficient degree of strength to resist any possible force that can come upon it. In the large swing-tree the same rule applies; suppose its length between the points of attachment to be 3 feet 9 inches, its breadth $1 \frac{3}{4}$ inches, and depth $3 \frac{1}{3}$ inches, the material being ash as before; then $1.75 \times 3.5^{2} \times 740$

$375-=4,230 \mathrm{lbs}$; reducing this $\frac{1}{1}$ for security, there remain $2,115 \mathrm{lbs}$, but the greateat force that may be calculated upon from 2 horses is $1,200 \mathrm{lbs}$; we have. therefore, nearly donble security in this aize of large swing-tree.

(905.) In proportioning the strength of swing-trees to any particular draught, let the greatest possible amount of force be calculated that can be applied to each end of the tree, the sum of these will be the opposing force as applied at the middle, and this may be taken as above (904) at 600 lbs. for each horse; but, for security, let it be 3 times or $1.800 \mathrm{lbs}$. each horse $\mathrm{H}$, any unmber of borses being $m \mathrm{H}$; and having fixed upon a breadth $\mathrm{B}$ for the tree, and $\mathrm{L}$ the lengtb, $\mathrm{C}$ being the constant as before, then the depth $\mathrm{D}$ will be found thus: $\frac{\mathrm{L} \times m \mathrm{H}}{\mathrm{B} \times \mathrm{C}}=\mathrm{D}$; ; or, in words, multi-

- Tredgold's Carpentry, art 110. 
ply the length into as many times $1,800 \mathrm{lbs}$. as there are to be horses applied to the tree, divlde the product by the constant ( 740 for ash, or 660 for oak) multiplied into the breadth, the quotient will be the square of the depth, and the square-root of this will be the depth of the swing-tree, with ample allowance for assurance strength. In all cases, the depth at the ends may be reduced to $t$ of that of the middle.

(906.) Wonden swing-trees ought always to be fitted up with clasp and eye mounting of the best wrought-iron, from 2 to $2 \frac{1}{3}$ inches broad, about 3-16 inch thick in the middle parts, and worked off to a thin edge at the sides; the part forming the eye may range from $\frac{1}{2}$ inch diameter in the center eye of the large tree to $\frac{3}{6}$ inch in the end clasps of the small trees; and they are applied to the wood in a hot state, which, by cooling, makes them take a firm seat. In the main tree, the middle clasp has usually a ring or a link $e$ welded into it, by which the set is attached to the hook of the plow's bridle; the two end clasps have their eyes on the opposite edge of the swing-trees, with sufficient opening in the eyes to receive the $\mathrm{S}$ hooks of the small tree. The small are trees furnished with the S hooks, by which they are appended to the ends of the main trees; and end clasps are adapted to receive the hooks of the trace-chains $f f, g g$, a small part only of which are shown in the figure. The detached figure $h$ is a transverse section of a tree showing the form of the clasps, the scale of which is double the size of the principal figure in the cut.

(907.) Though wood has hitherto been the material chiefly used for swing-trees, there have beer some successtul trials of malleable iron for the purpose. These have been variously constructed, in some cases entirely of sheet-iron turned round into a form somewhat resembling the wooden trees; but, in this form, either the iron must be thin, or the bar must be inconveniently heavy; if the former, durability becomes limited, by reason of the oxidation of the iron acting over a large surface, and soon destroying the fabric. Another method has been to form a diamond-shaped truss of solid iron rods, the diamond being very much elongated-its length being 3 feet, and its breadth about 4 inches, with a stretcher between the obtuse angles. A third has been tried, con. sisting of a straight welded tube of malleable iron, about 3 feet long and $\frac{3}{4}$ inch diameter. In this tube, acting as a strut, a tension-rod, also of malleable iron. is applied with a deflection of 4 inches, the extremities of the tension-rod being brought into contact by welding or riveting with the ends of the tubular strut, and eyes formed at the ends and middle for the attachment of the hooks and chains. A tree thus formed is sufficiently strong for every purpose to which it is applied, while its weight does not exceed $7 \mathrm{lbs}$; and the weight of a wooden tree, with its mounting. frequently weighs 8 lbs. The price of a set of common wooden trees, with the iron mounting, is 128, and of the iron trees $18 \mathrm{~s}$.

(908.) The foregoing remarks apply, so far as arrangement goes, to the common 2-horse swing. trees; but the various modes of applying horse-power, both as regards number and position of the horses, require farther illustration. The next I shall notice, therefore, is the 3-horse yoke, of which there are various modes - the simplest of which is, first, a pair, working in the common trees, fig. 200 ; and, for the third horse, a light chain is attached by a shackle to the middle of the main bar $b$. To this chain the third horse is yoked, taking his place in front of the other two, in unicorn fashion. This yoke is defective, inasmuch as there are no means of equalizing the draught of the third horse.

(909.) Perhaps the most perfect method of yoking a 3-horse team, whether abreast or unicornfashion, is that by the compensation levers, fig. 201-a statical combination, which is at once cor-

Fig. 201.

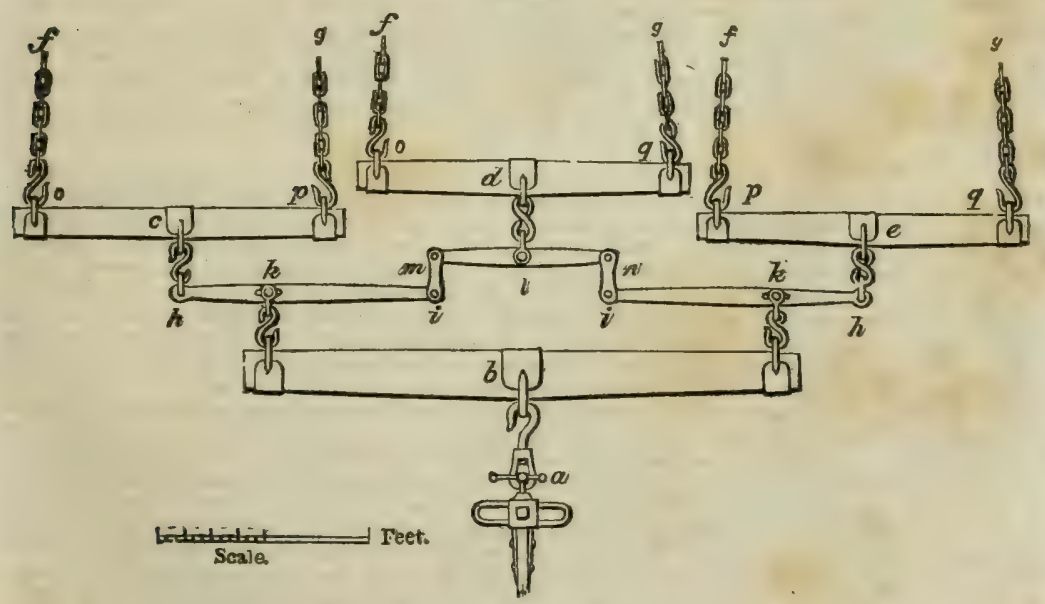

THE SWING-TREES FOR THREE HORSES.

rect in its equalization, scientific in its principles, and elegant in its arrangement : and I have to regret my inability to single out the person who first applied it. The apparatus in the figure is represented as applied to the subsoil-plow $-a$ being the bridle of that plow; $b$ is a main swing- 
tree, 5 feet in length, and of strength proportioned to the draught of 3 horses; and $c d e$ are three small common trees, one for each horse. The trace-chains are here broken off at $f, g$, respectively, but are to be conceived as extending forward to the shoulders of the horses. Between the main swing-tree and the three small ones the compensating apparatus is placed, as in the figure, consisting of three levers, usually constructed of iron. Two of these, $h i$ and $h i$, are levers of the first order, but with unequal arms, the fulcrum $k$ being fixed at $t$ of the entire length from the ontward end of each; the arms of these levers are therefore in the proportion of 2 to 1 , and the entire length of each between the points of attachment is 27 inches. A connecting lever $l$, of equal arms, and 20 inches in length, is jointed to the longer arms iz of the former, by means of the double short links $m, n$. The two levers $h i, h i$, are hooked by means of their shackles at $k$ to the main owing-tree $b$; and the three small swing-treen $c, d, e$, are hooked to the compensation lever at $h$, $h$ and $l$. From the mechanical arrangement of these leverg, if the whole resistance at $a$ be taken at $600 \mathrm{lbs}$, $k$ and $k$ will each require an exertion of $300 \mathrm{lbs}$. to overcome the resistance. B ot these two forees fall to be subdivided in the proportion of the arms of the levers $h i ;$; of each, or 200 lbs., being allotted to the arms $h$, and the remaining 1,100 lbs., to the arms $i$, which brings the gystem to an equilibrium. The two forces $i, i$, being conjoined by means of the connecting levers $m, n$, their union produces a force of $200 \mathrm{lbs}$., thus equalizing the three ultimate forces $h l h$ to 200 lbs. each, and these three combined are equal to the whole resistance $a$; and the 3 horses that are yoked to the swing-tree $c, d, e$, are subjected to equal exertion, whatever may be the amount of resistance at $a$ which has to be overcome.

(910) The judicious farmer will frequently see the propriety of lightening the labor of some in. dividual horse; and this is easily accomplished by the compensation apparatus. For this purpose, one or more holes are perforated in the levers $h i$, on each side of the true falcrum $k$, to receive the bolt of the small shackles $k$. By shifting the shackle and bolt, the relation of the forces $h$ and $i$ are changed, and that in any proportion that may be desired ; but it is necessary to observe that the distance of the additional holes, on either side of the central hole or fulcrum of equilibrium in the system, should be in the same proportion as the length of the arms in which the holes are perforated. Thus, if the distance between those in the short arm is half an inch. those in the longer arm should be an inch. By such arrangement, every increase to the exertion of the power, whether on the long or the short arm, would be equal.

(911.) The same principle of compensation has been applied to varions ways of yoking, one of which is a complicated form of that just described. The main swing-tree and the compensation levers are the same, except that they may be a few inches shorter in all the arms, and the midile one of the three small swing-trees also shorter. The yoking is performed in this manner: The nigh trace-chain of the nigh horse is hooked to the end $o$ of the swing-trce $c$, and his off-side tracechain to the end $o$ of the swing-tree $d$. The middle horse has his nigh-side chajn hooked to the end $p$ of the swing-tree $c$, while his off-side chain goes to the end $p$ of the swing-tree $e$; and the off-side horse has his nigh-side chain attached to the end $q$ of the midclle swing-tree $d$, and his offside to $q$ of the swing tree $e$. This system of yoking is complicated, and though in principle it equalizes the forces so long as all the horses keep equally ahead, yet it is in some degree faulty. Whenever the middle horse gets either behind or before his proper station-or out of that position which keeps all the swing trees parallel to each other-the outside horses have a larger share of the draght upon one ahoulder than upon the other; and, as this produces an unnecessary fatigue to the animal, it should be avoided. Such irregularity cannot occur with the simple mode of giv. ing each horse his own swing-tree.

(912.) A modification of this compensation yoke has been contrived, as I am iuformed, by $\mathrm{Mr}$. Bauchop. Bogend, Stirlingshire. The compensation levers are formed of woor, and in place of the connecting levers $l$, fig. 201, a chain, 2 feet in length, connects the ends $i i$ of the levers $h i$; and in the bight of the chain, as at $k$, a pulley and strap are placed, to which a soam chain is hooked; the palley from it oscillating in the bicht of the chain serves the ame purpose as the connecting lever $l$. In this mode of yoking, the horses work in unicorn-team, the middle horse pulling by the soam-chain.

(913.) In the yoking of 4 horses, various modes are also adopted. The old and simple method is for the plow-horses to draw by a set of common swing-trees, fig. 200 ; and to the center of the main swing-tree at $e$ a soam chain is hooked by means of a shackle or otherwise. The leadinghorses are thus yoked by a second set of common swing trees to the end of the soam This is now seldom employed. but an improved method of applying the soam has heen adopted in its place, which is represented by fig. 202, where $a$ is the bridle of the plow, with its ewivel-hook. A palley $b$ of cast-iron, 6 inches diameter. mounted in an iron frame, of which an edge-view is given at $m$, is attached to the hook of the bridle. A link.chain $c$ is rove through the frame of the palley ; and to one end of it, the short end, is hooked the main swing-tree $d$ of a set of common trees for the plow-horses. The other end of the chain passes forward to a sufficient distance to allow the leading horses room to work; and to it is hooked the second set of common swing-trees at $e$ for the leaders. In the figure, a part of the chain, from $f$ to $g$, is broken off; but the full length is about 11 feet. In this yoke, the trace-chains of the nigh-side hind horse are hooked to the swingtrees at $h h$, and those of the off-side horse at $i i$, the leaders being yoked at $k k$ and $l l$ respectively. In this arrangement, the balance of forces is perfectly preserved; for the hind horses and the leaders, as they pull at opposing ends of the chain passing round a pulley, which must inevitably be always in equilibrium, each pair of horses has an equal share of the draught ; and, from the principles of the common swing-trees through which ench pair acts, the individual horses must have an equally perfect division of the labor, unless this equilibrium has been removed for the purpose of easing a weaker horse. In order in prevent either the hind dorses or the lenders from slipping too much ahead, it is comnon to apply a light check.chain $o$, of about 15 inches long. connecting the two parts of the main-chain. 80 as to allow only a short oscillation round the pulley, wlich is limited by the check-chain. When this is adopted, care should be taken never to allow the checkchain to remain upon the stretch; for, if it do so, the advantage of equalization in the yoke is lost, and it becomes no better than the simple soam. In all cases of using a chain, that part of it which (776) 
passes forward between the hind horses must be borne up by means of attachment to their back bands, or suspended from their collars.

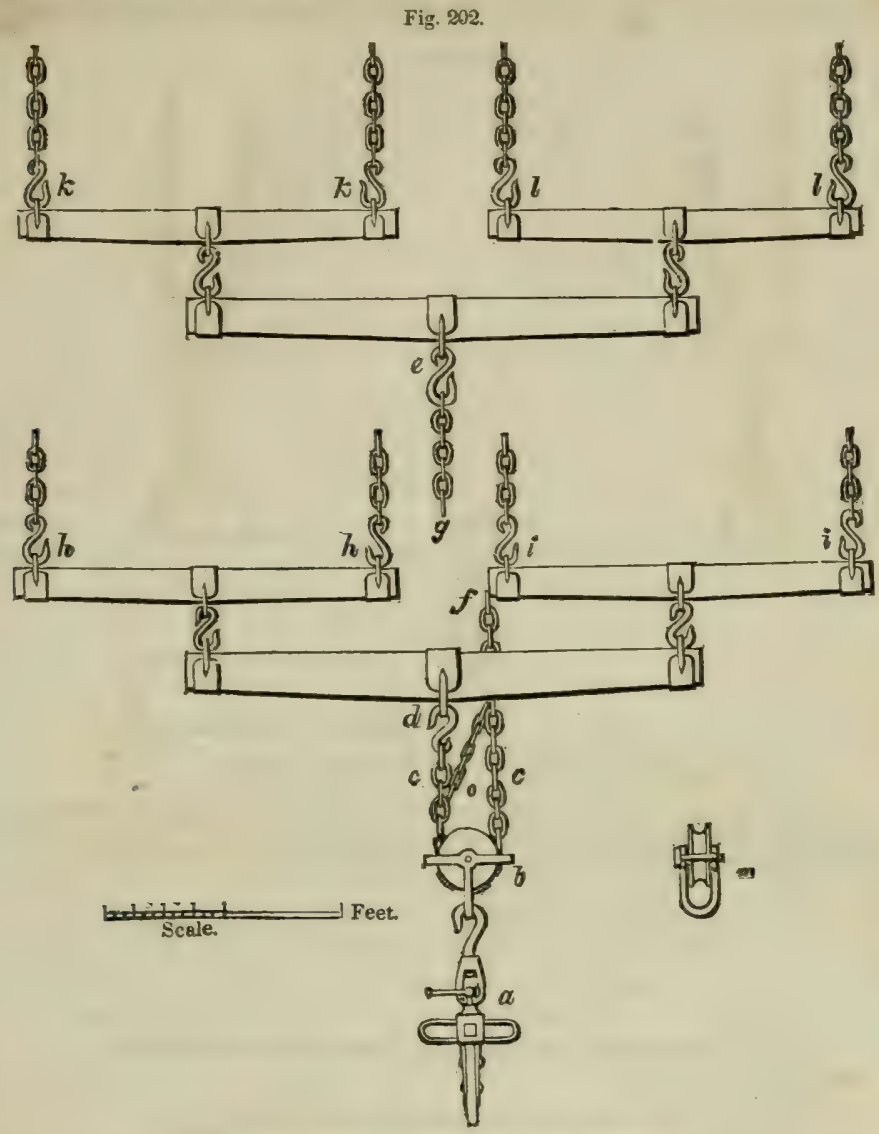

TRE SWING-TREES FOR FOUR HORSES.

(914.) Mr. Stirling, of Glenbervie. Stirlingshire, recommends a method of yoking a team of four horses in pairs, the arrangements of which are represented in fig. $203 ; a$ is part of a main swing. tree of the common length. $b$ a small swing-tree about 4 inches longer than the usual length. but both mounted in the usual form, except that. at each end of the small swing-trees, cast-iron pulleys $c c$, of 3 or 4 inches diameter, and set in an iron frame, are hooked on to the eyes of the swing-tree. The common trace-chains are rove through the frames of these pulleys, as in the figure; the ends $d \boldsymbol{d}$ of the chains are prolonged forward to the proper length for the nigh hind horse, and the ends $e e$ are extended to the nigh leader. At the opposite end of the main swing-tree, which, in this figure, is cut off, the same arrangement is repeated for the off-side horses. The principle of action in this yoke is simple and effective, though different in effect from the former. There the two hind horses are equalized through the medium of their set of common swing-trees. The leading horses are alike equalized by their set, and thus the two pairs balance each other throngh the medium of the soam. Here, on the other hand, the two nigh-side horses have their forces equalized through the trace-chains, which are common to both. by passing over the pulleys $c c$; and the same holds in respect to the two off-sides. The couple of nigh-side and of off-side horses, again, are equalized through the medium of the one set of swing trees. In both. therefore, the principle of equalization is complete, but there is a trifling difference in their economy. In the yoke, fig. 202 , which I call the cross balance yoke, the soam chain and pulley are the only articles required in addition to the every-day gear. In that of fig. 203, which I call the running balance yoke, there is first the set of swing-trees, which, as they have to resist the force of 4 horses, must in all their parts be made stronger than the common set, agreeably to the rules before laid down; and to which are adder the 4 pulleys, all of which are applicable only to this yoke. The trace-chain, though not necessarily stronger than those for common use, is required ahout three times longer than single horse-chains-that is to say, four horses will require the chains of six; but the chains of the 
leaders are more conveniently supported when they pass along the sides of the hind horses, cod it is free of the set of swing-trees which dangle behind the leaders, of the method fig. 202 .

(915.) In cares where 6,8 , and even 12 horses are required, such as for trenching, subsoil.plow. ing, and especially draining with the plow, the yoking is accomplished by modifications and ex-

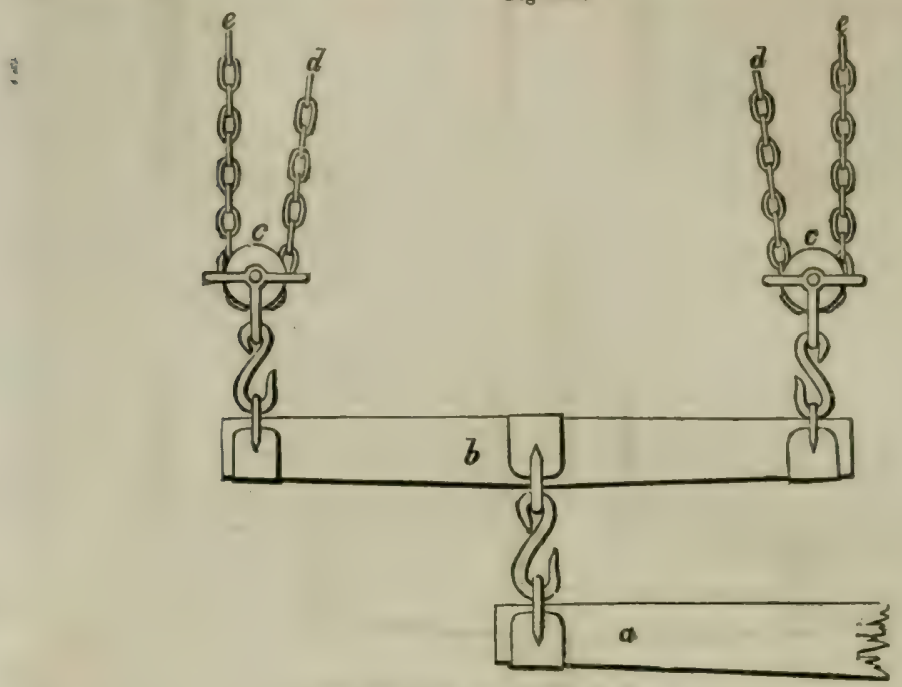

THE SWING-TREES ALSO FOR FOUR HORSES.

tension of the principles here laid down; for example, a team of 6 can be very conveniently applied with equalized effect by employing the compensation levers of fig. 202, along with 3 single swing-trees with pulley at each end and running trace-chains, as in fig. 203.-J. S.]

\section{PLOWING STUBBLE AND LEA GROUND.}

" 'T is time to clear your plowshare in the glebe."

GRAHAM.

(916.) When you take an extensive glance over the fields immediately after harvest, when the crop has been gathered into the stack-yard, you perceive that a large proportion of them are in stubble, while others are occupied by grass, turnips, and young wheat. On examining the stubbled fields particularly, you will observe young grass among the stubble in some fields, and nothing but stubble in others. You could not, of yourself, discover at once that these various states of the fields bear a certain proportion to one another, though they really do; and the cause of their being in those proportions is that they are cultivated under what is termed a "regular rotation of crops," which, when followed out, necessarily causes every field, in its turn, to carry the same series of crops. The numbers composing the series depend on the nature of the soil, and it shall be my duty to make you acquainted with them in due time. Meantime, suffice it to intimate that, when the stubble is in that state, the beginning of the agricultural year is arrived, when certain parts of it must undergo a change and be transformed into those which follow the ones you find them in.Now, that part of the stubble-land which is devoid of any crop is the first (778) 
to undergo a change, and it is effected by the plow, not at random, but by the application of those principles which have already been explained to you when we considered the "various modes of plowing land into ridges," from pages 289 to 302 , where, as you may remember, the mode of plowing was said to be determined by the nature of the soil and subsoil. The stubble-land is generally all plowed before the lea is commenced with, and that part which is to bear the potato-crop next spring is first plowed, then that for the turnip-crop, and last of all for the bare fallow, when there is any

(917.) On clay soil, you will find the stubbled ridges of a rounded form, having been at least twice gathered up, fig. 139 ; and the way to keep them in a dry state during winter, on a considerable declivity, is to cleave them down without a gore-furrow, fig. 140, and without a mould-furrow, fig. 134, or to cleave them down with gore-furrows, fig. 141, and mouldfurrows, when clay-land is flat. On less strong soil, casting with a gorefurrow (657) will preserve land dry whether it be flat or on a declivity.On light loams, casting without gore-furrows, fig. 135, will serve the purpose. And on sandy and gravelly soils, crown and furrow (653) is the most appropriate mode of plowing stubble. It is rare that stubble-land is subjected to any other mode of plowing in winter. Snow should never be plowed in, nor the ground turned over when affected by frost, nor should strong clay soil be stirred when very wet, as it is apt to become very hard in spring, and of course more difficult to work.

(918.) In every variety of soil, plowed in the forms just described for winter, care should be taken to have plenty of channels, or gaws or grips, as they are usually termed in Scotland, cut in the hollowest places, so as surface-water may have them at every point by which to escape into the nearest open ditch. The gaws are first drawn by the plow laying them open like a feering-taking, in all cases, the hollowest parts of the ground, whether these may happen to cross the ridges or go along the open furrows; and they are immediately afterward cleared out with the spade of the loose earth left by the plow, and cast abroad over the surface. The fall in the gaws is made to tend toward a point or points best adapted to carry off surface-water by the shortest route, and do the least injury to the soil. The ends of the open furrows which terminate at the furrow along the side of the lowest head-ridge, as well as this furrow itself, should be cleared out with the spade, and cuts made at the hollowest places across the head-ridge into the ditch. This precaution of gaw-cutting should never be neglected in winter in any kind of soil, the stronger soils requiring more gaws than the lighter; for, as there is no foreseeing the injuries which a single deluge of rain may commit, it is nerer neglected by the provident farmer, though many small farmers, to their own loss, pay little heed to the necessity of its observance.

(919.) With regard to the plowing of lea ground, the most usual form in strong soil is to cast with a gore-furrow, fig. 136; and, on less strong soil, the same form of plowing without a gore-furrow; while, on the lightest soils of all, the crown and furrow is in most common use (653). Gathering up is a rare form of furrow for lea, though it is occasionally practiced on strong soil after gathered up or cast ridges, when it is a rather difficult operation to plow the furrow-brows and open furrows as they should be. The oldest lea is first plowed, that the slices may have time to mellow by exposure to the winter air ; and that which is on the strongest land is for the same reason plowed before that on light. Lea shonld never be plowed in frosty weather, that is, as long as the ground is at all affected by frost, nor when there is rime on the grass, nor when the ground is very soft with rain; because, when ice or rime is plowed down, the non. 
conducting property of grass and earth, in regard to heat and cold, preserves the ice in an unaltered state so long as to chill the ground to a late period of the season; and, when the ground is too soft, the horses rot only cut it into pieces with their feet, but the furrow-slice is apt in be squeezed out of its proper shape by the mould-board. Nor should lea be plowed when hard with drouth, as the plow in that case will take too shallow a furrow-slice, and raise the ground in broad, thin slabs, instead of proper furrow-slices. A semi-moist state of the ground in fresh weather is that which should be chosen for plowing lea. Gaws should not be neglected to be cut after lea-plowing, especially in the fields first plowed, and in strong land, always whether early or late plowed.

(920.) It is a slovenly though too common a practice to allow the headridges to remain unplowed for a considerable time after the rest of the field has been finished plowing, and the neglect is most frequently observed on stubble ground. The reasoning on the matter is that, as all the draughts cannot be employed on the head-ridges, it is a pity to break their number in beginning another entire field; and this reason would be a good one in summer, when there is little chance of bad weather occurring, but in winter it has no force at all, for the gaw-cuts cannot be properly executed until the field is entirely plowed; and to leave a plowed field to the risk of injury from wet weather, even for a day longer than you can help, shows little regard to future consequences, which may turn out far more serious than the beginning to plow a new field without all the draughts. No doubt, when land has been thorough-drained, there is less dread of ill consequences from the neglect of gaw-cutting; but, even in the most favored circumstances of drained land, I think it imprudent to leave isolated hollows in fields-and such are to be found in numbers on every farmwithout the means of getting rid of any torrent of water that may fall at an unexpected time. Let, therefore, as many draughts remain in the field as will plow both head-ridges during the next day at longest; and if they can be finished in one yoking, so much the better.

(921.) With regard to the mode of plowing head-ridges for a winter furrow, some consideration is requisite. In stubble, should the former furrow have been cast with or without a gore-furrow, then, on reversing the casting, a ridge will be left on each side of the field, which will be most conveniently plowed along with the head-ridges by the plow going round parallel to all the fences of the field, and laying the furrow-slices toward them. The same plan could be adopted in plowing lea in the same circumstances. Should the furrow given to the stubble have been a cleaving down with or withnut gore-furrows, then the head-ridges should be cloven down with a gore-furrow along the ends of the ridges, and mould-furrows along their own crowns. On the ridges having been crown and furrowed, the headridges may be gathered up in early and late lea-plowing and in stubble; they may be cloven down without a gore-furrow along the ends of the ridges, especially in the upper head-ridge; and the half ridge left on each side of the field may he plowed by going the half of every bout empty.But a better plan would be, only if the ridges of the field are short, to plow half of each head-ridge toward the ends of the ridges, going the round of the field, and passing up and down upon the half-ridge on each side empty, and then to plow those half-ridges with the other half of the head-ridges in a circuit, laying the furrow-slice still toward the ridges; all which will have the effect of casting the head-ridges toward the ends of the ridges.When the ridges have been plowed in a completed form, a convenient mode of plowing the head-ridges on strong land is to gather them up, first making an open feering along the crowns.

(780) 
(922.) Whatever mode of plowing the land is subjected to, you should take special care that it be plowed for a winter furrow in the best manner. The furrow-slice should be of the requisite depth, whether of 5 inches on the oldest lea, or 7 inches on the most friable ground; and it should also be of the requisite breadth of 9 inches in the former case, and of 10 in the latter; but as plowmen incline to hold a shallower furrow than it should be, to make the labor easier to themselves, there is less likelibood of their making a narrower furrow than it should be-a shallow and broad furrow conferring both ease on themselves, and getting over the ground quickly. A proper furrow-slice in land not in grass, or, as it is termed, in red land, should never be less than 9 inches in breadth and 6 inches in depth on the strongest soil, and 10 inches in breadth and 7 inches in depth on lighter soils. On grass-land of strong soil, or on land of any texture that has lain long in grass, 9 inches of breadth and 5 inches of depth is as large a furrow-slice as may possibly be obtained; but on lighter soil, with comparatively young grass, a furrow-slice of 10 inches by 6 , and even 7 , is easily turned over. At all seasons, but especially for a winter furrow, you should endeavor to establish for yourself a character for deep and correct plowing.

(923.) Correct plowing possesses these characteristics: The furrowslices should be quite straight; for a plowman that cannot hold a straight furrow is unworthy of his charge. The furrow-slices should be quite parallel in length, and this property shows that they have been turned over of a uniform thickness, for thick and thin slices lying together present irregularly horizontal lines. The furrow-slices should be of the same hight, which shows that they have been cut of the same breadth, for slices of different breadths, laid together at whatever angle, present unequal vertical lines. The furrow-slices should present to the eye a similar form of crest and equal surface; because where one furrow-slice exhibits a narrower surface than it should have, it has been covered with a broader slice than it should be; and where it displays a broader surface than it should, it is so exposed by a narrower slice than it should be lying upon it. The furrow-slices should have their back and face parallel, and to discover this property requires rather minute examination after the land has been plowed; but it is easily ascertained at the time of plowing. The ground, on being plowed, should feel equally firm under the foot at all places, for slices in a more upright position than they should be, not only feel hard and unsteady, but will allow the seed-corn to fall down between them and become buried. Furrow-slices in too flat a state always yield considerably to the pressure of the foot; and they are then too much drawn, and afford insufficient mould for the seed. Furrow-slices should lie over at the same angle, and it is demonstrable that the largest extent of surface exposed to the action of the air is when they are laid over at an angle of $45^{\circ}$, thus presenting crests in the best possible position for the action of the harrows. Crowns of ridges formed by the meeting of opposite furrow-slices, should neither be elevated nor depressed in regard to the rest of the ridge, although plowmen often commit the error of raising the crowns too high into a crest, the fault being easily committed by not giving the feered furrow-slices sufficient room to meet, and thereby pressing them upon one another. The furrow-brows should have slices uniform with the rest of the ridge, but plowmen are very apt to miscalculate the width of the slices near the sides of the ridges, for if the specific number of furrow-slices into which the whole ridge should be plowed are too narrow, the last slice of the furrow-brow will be too broad, and will therefore lie over too flat; and should this too broad space be divided into two furrows, each.slice will be too narrow and stand too upright. When the furrow-brows are ill made, (781) 
the mould-furrows cannot be proportionately plowed out ; because, if the space between the furrow-brows is too wide, the mould-furrows must lie made too deep to fill up all the space, and vice versa. If the furrow-slices are laid too flat, the mould-furrows will he apt to throw too much earth upon their edges next the open-furrow, and there make them too high. When the furrow-brows of adjoining ridges are not plowed alike, one side of the open-funow will require a deeper mould-furrow than the other.

(924.) You thus see that many particulars have to be attended to in plowing land into a ridge of the most perfect form. Plowmen differ much in bestowing attention on these particulars; some can never make a good crown, others a good furrow-brow and open-furrow, while others will make them all in a passable, but still objectionable manner. This last class of plowmen, however, is preferable to the other, because the injurious effects of the bad plowing of the former are obvious; whereas the effects of mediocre compared with first-rate plowing are not easy to ascertain, though no doubt the difference of their effects must be considerable in many respects. "It is well known," observes Sir John Sinclair, " that the horses of a good plowman suffer less from the work than those intrusted to an awkward and unskillf 1 hand, and that a material difference will be found in the crops of those ridges tilled by a bad plowman, when compared to any part of the field where the operation has been judiciously performed." Marshall contends that want of good tillage incurs a loss of as much as $\frac{1}{4}$ of the crops throughout the kingdom, $t$ which may be an approximation to the truth in his day; but plowing is certainly now better performed in Scotland than it was, though it must be owned that by fin the greatest part of the process is yet of a mediocre description, and the reasons for the mediocrity of the work are not difficult to find.

(925.) Plowmen cannot learn their profession at a very early age, when cvery profession ought to be acquired to attain a high degree of perfection in it, because plowing requires a considerable amount of physical power, even from the most expert plowmen, and it exacts the greatest exertion of strength by comparison from the youngest in years and the least initiated in the art; and after young men possess sufficient strength to hold the plow, they are left to acquire a knowledge of plowing more through sheer experience than by any tuition given them by those who are better acquainted with the art; and as excellence acquired in it cannot be hequeathed to the rising generation, its knowledge must be acquired $a b$ initio by every generation. For example, to teach boys to plow it has been recommended " to put a cross-bar between the cheeks of the bridle, so as to keep them precisely at the same distance fiom each other, and then setting up a pole at the end of a furrow, exactly measured to the same line as that from which he starts, fixes his eye stcadily upon it, and carries the plow in a direction precisely to that point." $\ddagger$ To do all this implies tha the boy has sufficient strength to hold a plow, which if he have, he will have come the length of a stout lad; and to "fix the eye steadily" upon a pole at a distance, while holding the plow with a staggering gait, and unable for want of breath to speak even a word to the horses, far less to guide them with the reins, is much beyond the power of any lad, instead of a boy; for it would require a very expert plowman to do that, for all that is nothing short of feering, and none but the expertest of the plowmen on a farm is intrusted to feer land; and, besides, no single pole always before the spectator can possibly guide any one in a straight line, for he may imagine he is moving by it in a straight line, while all the while

* Sinclair's Code of Agriculture.

† Marehall's Ciloucestershire, vol, i.

I Britiah Husbandry, vol, ii.

(782) 
he may be deviating very widely from it. The truth is, the young man who is desirous of becoming a plowman in a short time should be taught day by day by an experienced plowman to temper the irons, and guide his plow according to his strength and talents. Very few young men have or are permitted to have such opportunities of learning, and the consequence is, that, as my observation confirms, the best plowmen are generally those who have been taught directly by their fathers, and work constantly upon their fathers' farms.

(926.) Were all the particulars of good plowing mentioned above (923) constantly attended to, there would be no high crowned ridges as at $a$, fig. 204 , by bringing the two feering or the two open furrows too close to-

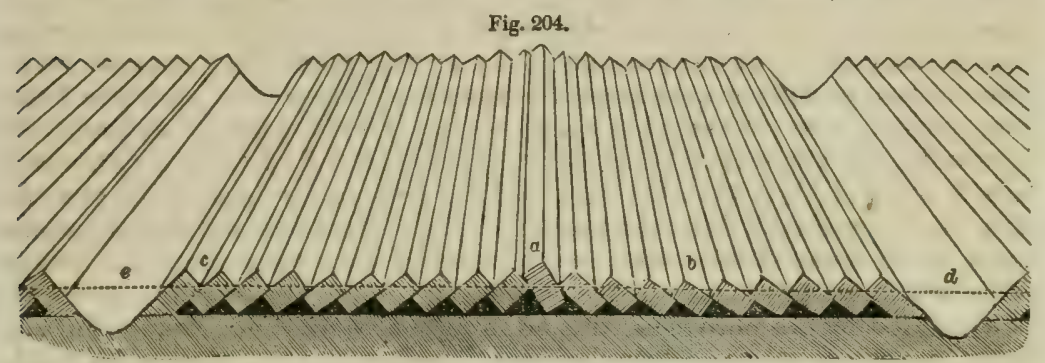

AN EXAMPLE OF BAD PLOWING.

gether, thereby causing the corn sown upon it to slip down both sides, and leave a space bare of seed on the best land of the ridge. There would be no lean flanks as at $b$, by making the furrow-slices there broader than they should be, with a view to plowing the ridge as fast as possible, and thereby constituting a hollow which becomes a receptacle for surface-water that sours the land; or when the soil is strong, it becomes so consolidated, that it is almost sure to resist the action of the harrows, especially when passed across the ridge; or in light soil it is filled up with the loose soil drawn by the harrows from the surrounding hights. There would be no proud furrow-brows as at $c$, by setting up the furrow-slices there more upright than they should be, to the risk of being drawn wholly into the open furrows when the harrows catch them too forcibly on leaving the ridge when cross-harrowed. And there would be no unequal open-furrows, as at $d$, by turning over a flatter mould-furrow on the one side than the other, which cannot fail to retain the greater quantity of seed. To extend this lengthened catalogue of ills accompanying bad plowing, I may mention that every sort of crop grows unequally on an ill-plowed ridge, because the soil is more kindly on the better plowed parts; but the evils of bad plowing are not confined to the season in which it is performed, as it renders land unequal when broken up again, and the thinner and harder portions cannot yield so abundantly as the deeper and more kindly. The line $d e$, fig. 204, shows the position of the surface before the land was plowed, and the furrow-slices, in relation to that line, show the unequal manner in which the ridge had been plowed.

(927.) It seems to be a prevalent opinion among agricultural writers, that land when plowed receives a curvature of surface; whereas, correct plowing, that is, making the furrow-slices on the same ridge all alike, cannot possibly give the surface any other form than it had before it was plowed. If the former surface were curved, then the newly plowed sur-

* Low's Elements of Practical Agricuiture, and British Husbandry, vol. ii. (783) 
face would also be curved; hut if it were flat, the new surface will be flat also. No doubt, in gathering up a ridge, the earth displaced by the plow occupies a smaller area than it did hefore, but as the displacement only elevates it above its former level, the act of elevating it does not necessarily impart any curvature to it. It is quite true, however, that a ridge on being cross-harrowed, becomes curved, inasmuch as it becomes highest at the crown, because the harrows, in crossing, have a tendency to draw the soil toward the open sides of the ridge, that is, into the open furrows, where the least resistance is presented, and which will alter the uniformity of surface left by the plow; but this effect has no connection with the plowing. Seeing this external effect produced without knowing its cause, it is equally true that most plowmen endeavor to give the ridge a curvature, and this they accomplish by what I would designate bad plowing; that is, they give a slight cresting to the crown, which they support with a bout or two of well-proportioned furrow-slices; they then plow the flanks with narrow and rather deep slices set up a little high, to maintain the curvature, for about four bouts more, giving the last of these bouts rather. less depth and hight than the rest, and the remaining three bouts next the furrow are gradually flattened toward the open furrows, which are endea ored to be finished off to the desired curved form by the mould-furrows. This artfulness produces a ridge of pleasing enough curvature, though it is exercised by the plowman with no intention to deceive; he, on the contrary, conceives all the while that he is displaying great skill in his art by so doing, and if he is not instructed better he will continue to practice it as an accomplishment. Such a device, however, sacrifices correct plowing to a fancied superiority of external appearance, as much as the crested furrow formerly spoken of (590), fig. 109. A thoroughly good plowman, and I have known a few, but only a few, of such valuable men, avoids so objectionable a practice, and plows always a true sound furrow, making it larger or smaller as the particular state of the work may require.

(928. Withoat putting much value on the information, it may serve as a fact to refer to, in sase it should be wanted, to state the weight of earth turned over in plowing. If 10 inches are taicen as a fair breadth for a furrow-slice. there will be 18 such slices across a ridge of 15 feet in breadth; and, taking 7 inches as a proper depth for such a furrow-slice, a cross section of the slice will have 70 square inches. A cubic foot of earth is thus turned over in every $24 \frac{1}{2}$ inches and a little more of length of such a slice; and taking 2.7 as the specific gravity of ordinary soil, every 241 inches and a fraction more of such a slice will weigh 12 stones $1 \mathrm{lb}$. imperial.*

(929.) The usual speed of horses at the plow may be ascertained in this way. A ridge of 5 yards in breadth will require a length of 968 yards to contain an imperial acre; and to plow which at 9 bouts, of 10 -inch breadth of furrow-slice, counting no stoppages, will make the horses walk $9 \frac{7}{8}$ miles, which in 10 hours gives a speed of $17 \frac{12}{2}$ yards per hour. Hut as ridges are not made of 968 yards in length, and as horses cannot draw a plow that distance without being af fected in their wind, and as yllowance must be made for time lost in turning at the ends of the ridges, as well as for affording rest to the horses, that speed will have to be considerably increased to do that quantity of work in the time. By experiment it has been found that 1 hour $19 \mathrm{~min}$ ates, out of 8 hours, are lost by turnings while plowing an acre on ridges of $27 \mathrm{~s}$ yards in length. with an 8 .inch furrow-slicet Hence, in plowing an acre on ridges of 250 vards in length. which is the length of ridge I recommended as the best for horses in draught. when speaking of inclosures $(456)$, in 10 hours, with a 10 -inch furrow-slice, the time loat by turnings is 1 hour 22 minutes. I presume that the experiment alluded to does not include the necessary stoppages for rest to the horses. but which should be included; for however easy the length of ridge may be made for draught, horses cammot go on walking in the plow for 5 hours together (one yoking) without takiag occasional rests. Now 250 yards of length of ridgo give nearly 4 ridges to the acre, or 36 bouts: and allowing a rest of one minute in every wher bout. 18 minutes will have to be adided to the 1 hour 22 minutes lost, or very nearly 13 hours of loss of time. out of the 10 hours. for turnings and rest. Thus 18,000 yards will be plowed in 81 hours, or at the rate of 1 mile 422 yards per hour. I think this result is near the truth in regard to the plowing of len in spring; it is ton little in plowing red land in summer, and perhapg too much in plewing slubble land in winter; but, us les plowing is the criterion by which all others are estimated, this result may be taken as a near approximation to the truth.

(930.) The comparative time lost in turning at the ends of long and short ridges may be acen from the following table, constructed from data furnished by the experiment above alluded to:

- Probably meaning $11 \mathrm{lb}$. to the stonc. $-E d . F . L$.

I Sinclaurs Cocle of Agriculture. 
PLOWING STUBBLE AND LEA GROUND.

\begin{tabular}{|c|c|c|c|c|}
\hline Length of ridge. & $\begin{array}{l}\text { Breadth of lurrow- } \\
\text { slice. }\end{array}$ & Time lost in turning. & $\begin{array}{c}\text { Time devoted to } \\
\text { plowing. }\end{array}$ & Hours of work. \\
\hline $\begin{array}{c}\text { Yards. } \\
78\end{array}$ & $\begin{array}{c}\text { Inches. } \\
10\end{array}$ & 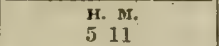 & $\begin{array}{cc}\text { H. } & \text { M. } \\
4 & 4\end{array}$ & $\begin{array}{l}\text { H. } \\
10\end{array}$ \\
\hline 149 & + & 244 & 716 & .. \\
\hline 200 & .. & 21 & 750 & $\ldots$ \\
\hline 212 & .. & $156 \frac{1}{2}$ & $8 \quad 3 \frac{1}{2}$ & $\ldots$ \\
\hline 274 & $\ldots$ & 128 & 833 & $\ldots$ \\
\hline
\end{tabular}

Thus it appears that a ridge of no more than 78 yards in length requires 5 hours 11 minutes of ime to turn at the landings, to plow an acre in 10 hours, with a 10 -inch furrow-slice; whereas a ridge of $2 r_{4}$ yards in length only requires 1 hour 28 minutes for the same purpose, making a difference of 3 hours 43 minutes in favor of the long ridge in regard to saving of time. Consequently, in the case of the shortest ridge, only 4 hours 49 minutes out of the 10 can be appropri. ated to plowing, whereas in that of the long ridge, 8 hours 32 minutes may be devoted to the purpose. Hence so very short ridges require double the time of lnng ones to plow, and are thrs a decided loss to the farmer. This is a subject well worth your experimenting on. by ascertaining the time usually taken in plowing and turning and resting on ridges of different lengtlos, in the different seasons. and in different soils. A watch with a good seconds-hand to mark the time will be required, and the observations should be made unknown to the plowmen, at their usual rate of work; for if you be constantly in the presence of the men, more than the usual work will be done, and less than the usual rests taken.

(931.) There is another circumstance, on some farms, which also greatly affects the speed of horses at work. I mean the great steepness of the gronnd; and it is not unusual to see the ridges traversing such steeps straight up and down. Ridges in such a position are laborious to plow to cart upou, to manure, and for every operation connected with farming. The water runs down the furrows when the land is under the plow. and carries to the bottom of the declivity the finest portion of the soil. In such a position a ridge of 250 yards is much too long to plow without breathing the horses. But although the general rule of making the ridges run $\mathrm{N}$. and $\mathrm{S}$. is the correct one, yet in such a situation as a steep acclivity, they should be made to alope along the face of the hill instead of running right up and down the acclivity, and the slope will not only be easier to labor in every respect, but the soil will be saved being washed so much away in the furrows ; but the direction of the slope should not be made at random : it should go away to the right hand in looking up the acclivity, because the plow will then lay the furrow-slice down the hill when it is in the act of climbing the steep, and on coming down the hill the horses will be the better able to lay the slice even against the inclination of the ground. What the exact length of the ridges on such an acclivity should be, even with the assistance of the slope, I cannot positively say, but should imagine that 100 or 150 yards would be sufficient for the hotses; but, at all events, there can be no doubt that it would be much better for the labor of the farm, as well as for the soil, that there should be 2 fields 100 yards broad each, one higher up than the other, than that the whole ground should be in one field 200 yards in breadth. I have all along been referring to very steep ascents.

(932.) There is still another arrangement of ridges which may materially affect the time required to labor them; I mean that where, by reason of irregularities in the fences or surface of the ground, ridges from opposite directions meet in a common line in the same field; and the question is, Whether the ridges should meet in an imaginary line or at a common head-ridge? Professor Low, when alluding to such an arrangement of ridges, says, that " the part where the opposite sets of furrows meet, may be made an open furrow, or a raised-up ridge or head-land, as circumstances may require."* "When ridges meet from opposite directions, it is clear that they cannot be plowed at the same time without the risk of the lorses encountering one another even upon a head-ridge; and where there is no head-ritge, should one set of ridges be plowed before the other, in the plowing of the second set. the end of the plowed land of the first will be completely trampled down. At the least, therefore, there should be one head-ridge betwixt two sets of ridges, that one set may be plowed before the other. But the most independent way in ail respects with such a form of surface, is to treat it as if each set of ridges belonged to separate fields. and let each have a head-ridge of its own.

(933.) When horses are driven in the plow beyond their step. they draw very unequally together, and, of course, the plow is then held unsteadily. In that case. the plow has a tendency to take too much land; to obviate which the plowman leans the plow over to the left, in which position it raises a thin broad furrow-slice, and lays it over at too low an angle. On the other hand, when the plowman allows the horses to move at too slow a pace, he is apt to forget what he is about. and the furrow-slices most probably will then be made both too narrow and too shallow, and though they may be laid over at the proper angle, and the work appear externally well enough executed. yet there will be a want of mould in the plowed soil.

(934.) [The whole value of plowing, scientifically speaking, depends upon its having the effect of loosening the texture of the soil, and thus permitting a free circulation of air and moisture through its interstices, for the double purpose of increasing the rapidity of the disintegration of its stony portions, and of re-reducing to powder what had formerly been pulverized, but which, from the joint action of pressure, and the binding effect of root-fibres, had become agglutinated together.

(935.) Sufficient has already been said to draw your attention to the point of pulverizing the soil ; in it lies one of the most important secrets of good farming. However well jou may manure your land, however thoroughly you may drain it, you will never obtain the crops it is capa ble of yielding. unless you pulverize it ; nay, so important did Jethro Tull think this, that he felt firmly persuaded that if you pulverized your soil well, you need not manure at all. I need hardly

- Low's Elements of Practical Agriculture.

$(? 85) \ldots . .286$ 
tell you that we shall prove hereafter. Jethro Tull to have carried bis conclasions too far ; but atill so direct and unqualified a statement. from auch a writer, should have its full influtence upon all who wish to learn thoroughly the art of Agriculture. Always bear in mind that the impalpable porcder is the active part of soil, and that no other portion has any direct influence upon vegets. tion, and you will then, at all times, be sufficiently impressed with the necessity of thoroughplowing, harrowing. \&c. ; indeed, you may rest assured that, except upon some few very light sands, you cannot pulverize the soil too much-econemy alone must fix the limit of shis useful operation.

(936.) But were I to stop here, you might naturally suppose that any season of the year would do equally well for plowing, provided it was before seed-time, and that the fixing of the time was regulated entirely with a view to economize labor. It is certainly true that, to a considerable extent, the time of plowing may be varied; but you may rest assured that. as a general rule. the sooner you plow after the removal of the crop, the better condition will your soil be in at the commencement of spring.

(937.) Several chemical processes of considerable consequence as respects the fertility of soil, occur after it has been plowed, which either take place very slowly, or not at all, while it lies unstirred; and. moreover. some of these take place to the greatest advantage during winter.

(938.) This is especially the case with the disintegration of mineral masses. nothing tending so powerfully to reduce even the hardest stones to powder as sudden changes of temperature, combined with the presence of much moisture. During rain or thaw after snow all the clods of earth and the pores of the more loosely aggregated stones become filled with water. which, of course, freezes, if the temperature is sufficiently reduced; and from its expansion during solidification, peculiar property possessed in a marked degree by water, the particles of earth or stone, as the case may be, are pushed so far asunder that, when the thaw returns, it crumbles into fragments, which are again and again acted on until reduced to the state of soil.

(939.) This crumbling by frost is of the greatest importance in the case of stiff clays, for two reasons : 1st, because they are thns reduced much more easy to work: and, $2 d$. which is of far greater consequence, they are enabled to give up their alkalies more readily to water; and clayey minerals are furtunately the quickest to disintegrate, or rather to decompose by the action of the weather; and hence, every means that facilitates that process is valuable, because as we have already seen that those most valuable ingredients of soil, potass and soda, are of no use to plants unless they are soluble in water, and that they do not obtain this property until the mineral with which they have been associated becomes completely decomposed.-H. H. M.]

(940.) [In the previous remarks on the plow were embraced its construction, its principles of action. the principles on which its draught is exerte 1 , and the resistance which it presents to the draught, as also some remarks on the system of plowing that each of the three leading varieties of plows have given rise to; and on this last hranch of the subject I feel constrained to offer some farther reinarks.

(941.) In treating of the form of the furrow-slice I have sufficiently evinced the preference that I give to the rectangular slice; and this I do on the broad principle that derp ploning sught to be the rule, and any other practice the exception. The exception may apply in a variety of cases so well known to practical farmers that it wonld be presumptuous in me to point them out; but our "Book of the Farm" beiug peculiarly addressed to young farmers, the pointing out of a few of these cases of exception becomes more in place.

(942.) Shallow plowing, then. may be admissible in the case of a ficld that has been depastured with sheep, and to be simply turned up for a seed-furrow. The reason usua!ly assigned for this, that the droppings of the sheep forming only a top-dressing, has given rise to the untion that a deep furrow would bary the manure to a depth at which its beneficial effects could not be reached by the plauts of the crop that may be sown upon this field. While I allow that this is an admissible case, the rationale of the reasons assigued for it by practical men. mav, on very fair grounds. be called in question. Thus, it is well known that the roots of vegetables in goneral push !hem. selves out in pursuit of their nutriment, and with an instinctive perseverance they will pass over or through media which afford little or no nutriment, in order to reach a medium in which they can luxuriate at will. With the larger vegetable productions this is romarkably the case; and though, among those plants which the farmer cultivates. the necessity of huntine, as it were, for food cannot occur to a great extent, yet we are well aware that the roots of the cereal grasses may extend from 6 to 12 or more inches; and there is good reason to believe that their length depends upon the depth of the penetrable soil. and that the luxuriance of growth in the plant will in general be proportioned to that depth, soil and climate being the anme.

(943.) Another case of exception to deep plowing, is in some of the courses of fallow plowing. where a deep furrow might be injurious : these occurring in the later courses. And a third is that of a seed-furrow, though in many cases this last is of doubtful reconmendation.

(944.) In some of the clay districts, a system of shallow and narrow plowing is pracliced, under the impression that the exposure of the soil. thus cut up in thin slices, tents more to its ameliom. tion than a system of deep and broad plowing could effect. This supposition may, to a certain extent, be true, as a certain portion of the soil thus trented will undergn a atage of improvenent ; but allowing that it does so, the improvement is but a half measure. Soils of this kind are frequently deep, and. thongh apparently poor, they afford the stamina ont of which may be formed the best artificial soils - the clay loan-which may be brought about by the due application of manure, and a proper. well directed. and continued system of plowing. "On lands of this kind, the system of deep plowing will be always attended with benticial effects; and instead of the appareuty thin and hangry soil which the shallow system is more likely to perpetuate, the result might be a deep and strong clay loam. To effect this, however, there must be no sparing of expense or of labor, the draining must be eflicient, and the manuring. especially with those sub. stances that will teud to sharpen and yield porosity to the slay, must be abondantly anplied.

(945.) The most extensive suite of eases where a departure from the rule is admissible, are those land; where a aaturally thin soil rests on a subsoil of sand or gravel varionsly impregnated (786) 
with oxides of iron. To plow deep at once in such situations would run the risk of serions injury to the sparing quantity of soil naturally existing. But it is to be observed of soils of this kiad, that the subsoil has always a tendency to pan, and if such do exist, the deep system shonld again come into requisition in the form of subsoil plowing, which, by destroying the panthat frequent cause of sterility in soils of this kind-opens a way to the amelioration of both soil and subsoil.

(946.) There appears, in short, every reason for inculcating the system of deep plowing, not only where existing circumstances admit of its adoption, but where its ultimate effects are likely to induce a gradual improvement on the soil and all its products, admitting always that a variation in depth is proper and necessary under the varying circumstances of crops and seasons.

(947.) Though the Scotch swing plow has afforded the principal subject of what has been here given on this implement, it must not be lost sight of that numerous varieties of this important im. plement are to be found in other parts of the kingdom, many of which possess a high degree of excellence; and England is especially remarkable for these varieties. It has been already noticed (487) that the germ of improvement in the Scotch implements appears to have been obtained through England; but, like many other importations from that quarter. the necessities arising from circumstances of climate, of soil, and, perhaps not the least important, the paucity of pecuniary means, obliged the Scottish agriculturist to husband all his resources, and to call forth all his energies. in making the best and most economical use of his new acquisitions, so as in the end to outstrip his more favored brethren of the south. This will be found to have occurred, not only in the plow, but in the introduction of the turnip, of bone manure, and many other simi. lar acquisitions.

(948.) It is remarkable, too, that the decided step taken in Scotland in regard to the rapid extension of the use of the improved plow, was long in retracing its steps back to Erigland, and that the retrograde movement was gradual from the northern counties southward. In nearly half a century, this retrogression appears to have made very slow progress; and, like many other im. provements which linger until some master-mind takes them in hand, the extension of the use of an improved plow met with little encouragement. In due time this subject was taken up by the Messrs. Ransome, of Ipswich; and, through their exertions, such changes have been produced in the plow as place the English agriculiurist in possession of a comamand of these implements in such a variety of forms that no other country can boast of from the hands of one maker.

(949.) The numerous varieties (amounting to at least 100) of the plows constructed by the Messre. Ransome seem to be chiefly adapted to the soils of England, and to the practice of her agriculturists; for we do not find that, when brought into Scotland, and placed in direct competition with the Scotch plow, that they ever gain a preference. There can be no question, however, that some of the varieties of these plows perform well, exhibiting work, when conducted by a skillful band, that for its usefulness may compare with that of any implement now employed. The system of plowing in England being generally of the shallow character, and the morlern plow for the most part of a light construction, adapted to the practice, it has been found that these plows were unable to resist the force required where the deep-plowing system is followed, as in many parts of Scotland. But a more serious objection to the introduction of these plows into Scotland lies in the frequent application to them of wheels. No plowman who has been able to wield the swingplow will ever suffer himself to be incommoded with the addition of wheels to his plow (for he will always consider wheels an inconvenience), and this he does not from a conviction that wheels increase the labor of his horses. but because to himself they appear a source of annoyance; and here it may be farther remarked, as regards wheel-plows, that, since the wheels must always have a tendency to increase the draught $(636)$, and on that account are objectionable, so also, if a plow can be wielded with equal and perhaps better effect without wheels than with them, the excuse that a wheel-plow may be wielded by a man of inferior qualifications is of small value. Any man may be trained to handle a plow, though every man will not be equally successful; and since in the whole of Scotland not a wheel-plow is to be found, except as a curiosity, while her plowing is at least not inferior to that of any part of the kingdom, and as the chances are surely equal that the plowmen are not all equally good, it is evident that plowing can be satisfactorily performed without wheels. If plowing can thus be performed over one part of the kingdom with an implement of the simplest form, and in a satisfactory and economical manner, there can be no necessity for using a more complicated and more expensive machine to perform the same work in another part of the kingdom, where it is at least not better done or done at less expense.

(950.) Having adverted to the plows of England, and particularly to those of the Messrs. Ransome, and though still impressed with the opinion that the simple Scotch swing-plow is preferable as an implement to the wheel-plows in their most improved form, and perhaps even to the swing-plows of England, it is proper to describe generally at least one example out of the many.

(951.) The example chosen for the purpose of illustration is Ransome's F F or Bedfordshire plow, represented in fig. 205. This plow has attained a high character for its general usefulnese, and may be considered as the most perfect of modern English plows.

(952.) Without going into such a minute detail of its parts as has been done in the case of the three leading Scotch plows, I cannot avoid giving a short description of it. Like the greater part of modern English plows, it is constructed partly of wood and partly of iron. The body is of castiron, and is ingeniously formed for the attachment of the beam and handles. These are simply bolted to the body -a practice which leaves the parts in possession of their full strength instead of being weakened by the mortising, as is the case in the joining of the beam and left handle of the Scotch wooden plow. The body-frame rises from the middle of the sole-bar to the full hight of the upper edge of the beam, and the two are bolted together-the body being applied to the land-side of the beam, where ite upper edge is seen at $a b$. The land-sides of the beam and of the body lie, therefore, in one plane behind; but the beam, at the point. lies $1 \frac{1}{2}$ inches to the right of the body-plane. The handles are bolted to a vertical flange that projects from the hind part of the body; and, as an additional security to the right handle, a bar of cast-iron, extending from $a$ to $c$, is laid upon the right-hand side of the beam, as seen in the tigure, and fixed by the same bolts that (787) 
connect the beam and the body. The hind part of this bar is also formed to embrace the root of the right handle, and is also secured by bolts. A farther security is effected by the application of the iron stay-bar $d e$, tying the beam and handles together. When the land-side of the plow is

Fig. 205.

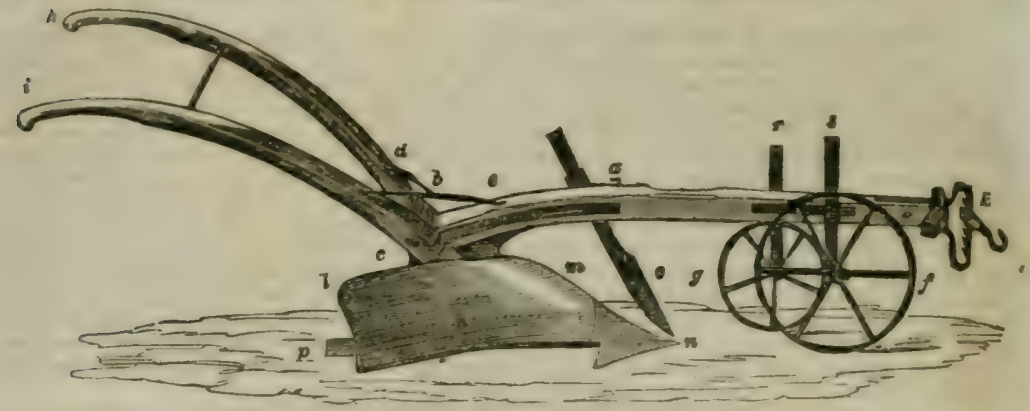

RANSOME'S T F, OR BEDFORDSHIRE PLOW.

vertical, the left handle $h$ stands 10 inches to the left of the line of the land-side, and the width be. tween the handles $h i$ is 26 inches. Following the same rule as has been adopted in giving the details of the Scotch plows, we have the zero of the FF. figs. 121 and 122, Plate XII., at 27 inches behind the point of the share $n$, and the beel $p, 11$ inches behind the zero. The extremity of the handles is 4 feet 3 inches behind, and the point of the beam 4 feet 5 inches before the zero. making the horizontal length of the plow only 8 feet 8 inches. The hight of the handles above the base-line is 2 feet 10 inches: the bight of the body, at the junction $b$ of the bean and handles, is 14 inches: the hight of the beam at the coulter-box is 17 inches, and at the point 16 inches; these hights being all as measured io the upper edge of the beam. The bridle $k$ of this plow is similar to many others of this much-varied member, but differs in the material of which it is composed, being formed of cast-iron. In fig. 148 , the plow is represented with two wheels $f$ and $g$, which are mounted on stems $r s$; these move vertically in separate boxes, one ou each side of the beam, and are held in position by clamp-screws. The larger wheel $f$ rans in the furrow, and bears against the land, thus regulating the landing of the plow, while the wheel $g$ runs upon the land, and regulates the earthing of the plow.

(953.) The active parts of the plow are also peculiar. The mould-board $l \mathrm{~m}$ has been already given in detail in Plate XII.. figs. 121 and 122 ; it is only necessary to add that its form indicates a medium of the convex and concave surfaces, and that its hight points out its inapplicability to deep plowing. The share $n$, as in a large proportion of all plows made by the Messrs. Ransome, is of cast-iron. but is very judicionsly hardened at the point and along the edge of the feather on the lower surface only, which has the effect of throwing all the wear of the metal on the apper sur. face, thereby keeping the edge sharp below so long as the share lasts. This share has freat breadth, being seldom under 7 inches at the broadest part. In the clays and chalky soils of England. the cast-iron share is both ronvevient and economical, though it is doubtul how they might answer in gravelly and stony soils, especially in the latter. The price of a cast-iron share is about 18. $2 \mathrm{~d}$., and an allowance is made for them when worn out and returned of about $6 \mathrm{~d}$. ; their duration may be taken at from 4 to 14 dars, depending much on the texture of the soil. The conlter 0 in this plow, as in most others of the class, is fixed in a metal box bolted in the land-side of the beam. The land-side plane of the conlter, therefore, instead of crossing that of the plow's body, as in the Lanarkshire and other Scotch plows, is parallel to it, and stands altogether to landward of the land-side plane of the plow from top to bottom. and in some cases forms a small angle from the point landward. The body is frequently left entirely open on the land-side, except in 80 far as it is covered by the land-side flange of the sole-shoe, which is not more than 2 inches high, and it stands $1 \frac{1}{2}$ iaches to landward of the body-frame, which last arrangement virtually brings the land-side plane of the body and of the fore part of the beam to coincide.

(954.) Having in a general way described the construction of the frame-work and the acting parts of this plow, there remains for me to say a few words on the wheels with which it is furnished. I have already (636-638) adverted to wheels, as they appear to me to affect the draught of plows, and have expressed myself in sutficiently distinct language to show that, in my opinion. they must in all cases be injorivis, and tend to increase the resistance of the plow to which they are appended. whether they be applied within the body, or under the front, or any other part of the beam. That wheels may be of advantage for the working of a plow in the hands of an anskillfal plowman may be trne ; bu: if this advantage is acquired by a certain additional expenditure of horse power. which, however much the proprietor of the team may blind himself to, will ultimately, though probably unheed,d, tell on his profit and loss account, there will be no gain. bot an ultimate loss. It must be admitted, even by the advocates of the wheel-plow, that thnogh they may be handled with perfert regularity in plowing along ridges, whether the holder be an experienced plowman or not. yet in cross plowing they cannot by any means be brought so hand. ily to follow the andulations of the surface. In leaving one ridge, the share will psss too shallow: and, in entering on the brow of the next, it will go too deep, or at least deeper than the average of the plowing. There is also the element of time. which in all farming operations is an important one; and here wheel-plows ane found to come ahort by about 25 per cent as compared with (788) 
swing-plows. Mr. Pusey, in his paper on the draught of plows, incidentally observes: "While the work of our plowing teams is at best but $\frac{3}{4}$ of an acre upon strong ground (and sometimes as much as 1 acre upon the lightest), the daily task performed by two Scotch horses upon strong land is $1 \frac{1}{4}$ acres."* This deficiency of effect cannot be attributed to want of power in the horses, for English horses are at least not inferior to those emp oyed in Scotland for agricultural purposes; neither cau it be from unskillfulness in the plow men, for even the most skillful seem to come short in this respect, by not being able to plow more than $\frac{3}{4}$ of an acre in a day, while with the swingplow almost any plowman will turn over his acre a day. From the remarks of the same writer, $\dagger$ it is to be inferred that a Scotch swing-plow was iucapable of being ilrawn through a certain clay soil by two horses, while the wheel-plows 'were found to perform the work with tolerable ease, though still a heavy draught. There may be such cases; but trom the conditions of this particular case, where the draught that battled the horses in the swing plow seems not to have exceeded 52 stones, there is an ambiguity in the matter that leads to doubts of the accuracy on the part of the observers of the experiment. We know well that in working the Scctch swing-plow in an 8 or 9 -inch furrow on stiff land, the draught is not untrequently as higb as $7 \mathrm{cwt}$. or 56 stones; but two good horses never shrink from the task; and how a less draught, whatever be the soil, should have baffled the exertions of two good horses in a swing-plow, even in the Oxford clay, requires some farther investigation to be satisfactory.

(955.) Under all the circumstances, then-whether we take expenditure of horse power coma. pared with the small saving in the pay of an inferior workman; the disadvantages attending the more complicated operation of plowing, compared with the celerity with which the swing-plow can be made to accommodate itself to all irregularities of ground; the loss of time. which is equivalent with capital, in plowing a given surface, when compared with the extent turned over by the stving-plow; and the probability that even the solitary instance of an apparent superiority in a wheel-plow may rest upon some oversight in observation-all seem to conspire to produce a conviction that a superiority exists in the swing-plow which is in some measure due to its deserving that appellation from an absence of wheels. And certainly, whatever be the merits of the modern improvements on English plows, they may be ascribed to any other cause than their possessing wheels, in whatever position they may be placed in the plow.

(956.) The plow under consideration is furnished with two wheels, see again fig. 205. The land-side wheel is 12 inches diameter, with a rim not exceeding 1 inch in breadth. The only purpose to which this wheel is applied is to regulate the depth of the furrow, for which purpose it runs upon the solid land. The furrow-wheel is 18 inches in diameter, with a breadth of rim equal to the former; its object is two-fold, serving in some measure to regulate the depth, by running on the bottom of the previously formed furrow, but its chief duty is, by bearing against the edge of the furrow-slice that is about to be raised, to regulate the breadlh of the slice, at the desired hight, by means of pinching-screws.

(957.) It is evident that both wheels perform a duty that either of them alone could do with perhaps equal effect, namely, the regulation of the depth; but the furrow-wheel performs a second office, regulating the breadth. which it can also do without interfering with its other duty. It would appear, therefore, that the land-side wheel may be set aside withont impairing the etficiency of the plow; and we find, accordingly, that these plows are frequently used with only one wheel, which in itself performs both duties.

(958.) The consideration of these wheels, and their effects on the plow, suggests a farther objection to their utility in respect of the increased resistance they produce to the draught. If these wheels are to produce any effect at all, the plow-irons and yoke must be set so as to give the plow a bias both to earth and land. If the plow has not this, then whether it swim evenly, or have a bias, from both earth and land, in either case the wheels are ineflective, as they will neither bear upon the sole nor the edge of the furrow, but let the plow have the bias as proposed to both earth and land, the wheels will then both bear, and exert their efforts by reäction to counteract the tendency of the plow; on the one hand to sink deeper in the furrow, and on the other to cut a broader slice ; and since " action and reätion are alike and in opposite directions," these antagonist forces will be in constant operation to a greater or less amount. Such effects will thereby increase the friction and consequent resistance in proportion to the amount of bias which has been given to the plow; and hence the conclusion is strengthened, that in all cases wheels are incumbrances and sources of increased resistance to the plow.

(959.) Among the numerous makers of plows in England whose works have come under our observation, besides those of Messrs. Ransome, I cannot omit to notice the names of Hart, of $\mathrm{K}$ ing, of Parker, and of Crosskill, all of whom take a high standing as plow-makers after the English fashions, and many of their productions are mounted with wheels. It is unnecessary to repeat any of the observations on that head, but should the preceding remarks come under the observation of any of the makers referred to, or of any other person who may take an interest in the subject, it will be gratifying to find that they endeavor to show how wheel-plows can be rendered more advantageous than swing-plows, and in doing so either practically or demonstratively, in a satisfactory manner. I shall be open to conviction, and ready to yield up that system which appears to me at present as the only tenable one; but it would, of course, be still more satisfactory to learn that these very humble efforts shall be of any use in satisfying those who take the tronble to inquire, that an extended application of the swing-plow practice might either be of individual or geaeral importance.

(960.) Among the other numerous varieties, I cannot pass over the two-furrow plow, which, though seldom, if ever, seen in the hands of a Scotch farmer, is now rather extensively employed in some of the eastern counties of England, but more especially in Lincolnshire. These plows are constructed of a very effective and convenient form by Ransome and others, and are beld to be very economical in point of draught, a pair of good horses being capable of working a twofurrow plow, or in cases of heavier soil three horses; the saving of labor in the one case being

* Journal of the Royal Agricultural Society of England, vol. i.

† Ibid, vol. i.

(789) 
one-half, in the other one-fourth. They are also mounted with wheels, and in the districts where they are employed, and the plowmnn secustomed to the implement, livey muke very fair work. the two furrows being in general laid very nearly alike. It must be cunceded, however, that in the districts where these plows are used, the work is done with a very shallow furrow. seldom exceeding 3 or 4 inches, which may allow of 2 horses taking the drausht. Where the deep. plowing system is fallowed, a two.furtow plow could not be drawn by fewer than 4 bolses, which, as it would afford no saving, but rather the contrary, can never be expedient, or in any way ad. vantageous; for though it may be urged, that when a light furrow only was required the twofurrow plow might offer some advantage, yet if it could not be applicable in every case, the in ference is, that two sets of plows, double and single furrow, must be retained-a practice which cannot, under any circumstances, be recommended. 'The conclusion to be drawn from these remarks is, that though expedients, such as the two-furrow plow, may be very advantageously $\mathrm{em}$ ployed under a particular climate and soil, the practice camnot be held up as one of general application. or that could be rendered economical and advantageous nuder all circumstances. $-J$. S.]

(961.) This seems to me a befitting place to say a lew words on ploning matches. I believe it admits of no doubt that, since the institution of plowing matehes throughout the country, the character of our farm-servants as plowmen has risen to considerable celebrity, not but that individual plowmen could have been found before the practice of matches existed as dexteruus as any of the present dav, but the general diffusion of good plowing must be obvious to every one who has been in the habit of observing the plowed surfnce of the country. 'This improvement is unt to be ascribed to the institution of plowing matches alone, because superior construction of inuplements, better kept, better matched, and superior race of horses : and superior judgment and taste in tield labor in the farmer himself are too important elements in iufluencing the conduct of piowmen to be overlooked in a consideration of this question.

(962.) But be the primary motive for improvement in the most important branch of ficld labor as it may, there cannot be a doubt that a properly regulated emulation amon' workmen of any class, proves a strong incentive to the production of superior workmanship, and the more generally the inducement is extended, the improvement arising from it may be expected to be the more gen. erally diffused; and on this account the plon meluls of the Highland and Agricultural Society of Scotland being open for competition to all parts of scotland every year, have perhaps excited a apirit of emulation among plowmen, by rewarding those who excel, beyond anything to be seen in any other country. Wherever 15 plows can be yathered together for competition at any time and place, there the plowman who obtains the first premium offered by those intereeted in the ex hibition, is entitled to receive, over and above, the Society's plow meda! of silver, bearing a staita. ble inscription, with the gainer's name. About 40 applications are made for the medais every year, so that at least 600 plowmen annually compete for them; but the actual number far exceeds that number; as, in many instances, matches comprehend from 40 to 70 plows, instend of the ninimum number of 15 . The matehes are usually occasioned by the welcome which his neighbors are desirous of giving an incoming tenant to his farm, and its heartiness is shown in the ex tent of the assistance they give him in plowing a field or fields at a time when he has not yet col. lected a working stock sufficient for the purpose.

(963.) Plowing matches are generally very fairly conducted in Scotland. They usually take place on lea ground, the plowing of which is considered the best test of a plowman's skill, theugh I hold that drilling is much more difticult to execute correctly. The best part of the field is usually selected for the purpose, if there be such, and the same extent of ground. usually frum 2 to ridges, according to the length, is allotted to each portion of ground to be plowed. A pin, bearing a number, is pushed into the ground at the end of each lot, of which there are as many marked off as there are plow entered in competition. Numbers corresponding to those on the pins are drawn by the compering plowmen, who take possession of the lots as they are drawn. Ample time is allowed to finisls the lot, and in this part of the arrangements I am of opinion that too much time is usually allowed, to the annoyance of the spectators. Although shortness of time in exe. cuting the same extent of work is not to be compared to excellency of execution, yet it should enter as an important element into the decision of the question of excellence. Every competitor is obliged to feer his own lot, guide his own hoises, and do every other thing connected with the work, such as assorting his horses, and trimming his plow-irons, without the least assistance.

(964.) The judges, who have been brought firm a distance. and have no personal intorest in the exhibition, are requested to inspect the ground after all the plows have been removed, having been kept away from the acene during the time the plows were engaged. Now, this appears to me a very ubjectionable part of the arrangements, and it is made on the plea. that were the judgeg to see the plows at work, some particular ones might be recognized by them as belonging to friends, and their minds might thereby be biased by the circumsinnce. Such a plea pays bat a poor compliment to the integrity of the judge; and any tarmer who accepts of the responsible and honored office of judge, who would allow himself to be influenced by so pitiful a consideration, would deserve not only not to be employed in a similar arbitration ngain, but to be scouted out of aciety. One conseyuence of the exaction of this rule is. that the spectators evince impatience-the spectators. not the plowmen who have been competitors. for they are busily and happily occupied at the time in replenishing the imer mau with rations of elieese and bread and ale providerl to them by the possessor of the fivld who is to enjoy the profits of their labor-while the judges are taking no more than the proper time for deciding the plowing of it may be, $\mathrm{a}$ large extent of ground. The judges onght, theretore, to he present during the whole time devoted to the competition, when they could calml. and certainly ascertain the nature and depth of the fur. row-slices, and have leisure to mature their thoughts on points which may turn the scale against first impressions. 'Thnt the bare inspection of the finished surfuce cannot inform them, in a satiofactory nanner, whether the land has been correctly plowed or not, which can only be done by comparison of the soles of the furrows while the land is plowing, I shall endeavor to make clear to you by figures in a supposed case.

(965.) You have seen the action of different plows, which may be all employed in the same (790) 
match; and you have seen that the East-Lothian form of plow lays over a slice of one form, as in fig. 108, and that the Lanarkshire plow lays over a slice of another form, as in fig. 109, and para. graph (591) acquaints you, that the latter form of slice, namely, that with the high crest and serrated furrow-sole, contains 1.7 less earth than the other. Now, were the surface work only to be judged of, which must be the case when judges are prohibited seeing the work done in the course of execution, the serrated extent of the furrow-sole cannot be ascertained by removing portions of the plowed ground here and there, so well as by constant inspection. As equal plowing consists in turning over equal portions of soil in the same extent of ground, other things being equal, a comparison of the quantity of earth turned over by these two plows may be made in this way: Suppose a space of 1 square yard, turned over by each of the two kinds of plows specified, taking a furrow-slice in both cases of 10 inches in breadth and 7 inches in depth, and taking the specific gravity of soil at $2 \cdot 7$, the weight of earth turned over by the East-Lothian would be 63 stones, while the Lanarkshire plow would only turn over 54 stones, making a difference of 9 stones of 14 lbs. in the small area of one square yard. In these circumstances, is it fair to say, that the horses yoked to the East-Lothian plow have done no more work than those yoked to the Lanarkshire, or that the crop for which the land has been plowed will receive the same quantity of loosened mould to grow in in both these cases? The prohibitory rule against the judges making their inspection during the plowing has been relaxed in stveral instances; but I fear more from the circumstance of the spectators losing their patience, while waiting for the decision after the excite ment of the competition is over, than from regard to the justness of the principle. Thus far is the obvious view of the question regarding the mode in which plowing-matches are usually conducted; but in what follows will be found a more important view as affecting the integrity of good plowing.

(966.) [The primary objects of the institution of plowing-matches must have been to produce the best examples of plowmanship-and by the best, must be understood that kind of plowing which shall not only appear to be well done, but must be thoroughly and essentially well donc. In other words, the award should be given to the plow that produces not only work of a proper surface finish, but which will exhibit, along with the first, the property of having turned up the greatest quantity of soil and in the best manner. That this combination of qualities has ceased to be the object of reward, is now sufficiently apparent to any one that will examine for himself the productions and rewards of recent plowing matches, and the causes of such dereliction are these:

(967.) The introduction by Wilkie of the Lanarkshire plow gave rise, as is supposed, to the high-crested furrow-slice. It cannot be denied that the plows made on that principle produce work on lea land that is highly satisfactory to the eye of a plowman, or to any person, indeed, whose eye can appreciate regularity of form; and, as there are many minds who can dwell with pleasure on the beauty of form, but who do not combine with that idea its adaptation to usefulness, it is no wonder that plows which could thus affect the mind through the sense of sight, should be. come favorites. While the crested system of plowing kept within bounds, it was all very good but in course of time the taste for this practice became excessive; and losing sight of the useful, a depraved taste, of its kind, sacrificed utility to the beautiful, in so far as plowing can be said to produce that impression. This taste came gradually to spread itself over certain districts, and plow-makers came to vie with each other in producing machines that should excel in that particular point of cresting. A keen spirit of emulation among plowmen kept up the taste among their own class, and very frequently the sons of farmers became successful competitors in the matches, which circumstance gave the taste a higher step in the social scale. Thus. by degrees, the taste for this mode of plowing spread wider and wider, until, in certain districts, it came to pervade all classes of agriculturists. At plowing matches in those districts, the criterion of good plowing became generally to be taken entirely from the appearance of the surface; furrow-slices possessing the highest degree of parallelism, exposing faces of equal breadth, and, above all, a high crest, carried off the palm of victory. I have seen a quorum of plow judges " plodding their weary way" for two hours together over a fieid. mcasuring the breadth of faces, and scanning the parallelism of slices, but who never seemed to consider the underground work of any importan.e, in enabling them to come to a decision. Under such a system, it is not surprising that plowmen devote their energies to produce work that might satisfy this depraved taste, and that plow-makers find it their interest to minister to those desires, by going more and more into that construction of parts of the plow that would yield the so much desired results. Thus have those valuable institutions of plowing matches. in the districts alluded to, been unwittingly bronght to engender a practice which. though beautiful as an object of sight, and, when within due bounds, also of utility, has induced a deterioration in the really useful effects of the plow.

(968.) But it is not yet too late to retrieve what has been lost. Let the Highland and Agricultural Society of Scotland, and all local Agriciltural Associations, take up the subject, and institute a code of riles by which the judges of plowing matches shall be guided in delivering their awards. Let these rules direct attention to what is truly beneticial to the land, as well as what may be satisfactory to sight in plowing. When such rules shall have been promulgated from competent authority, we may hope to see plowing matches restored to their pristine integritydoing good to all who are concerned in them, and restoring that confidence in their usefulness which is at present on the wane, but distrust in which has only arisen from an accidental misdirection of their main objects.

(969.) In connection with that part of the subject which has given rise to the foregoing remarks on plowing matches, it is not a little curious to find, that instead of the high-crested furrow being a modern innovation, it is as old as the days of Blith in 1652 ; and he. like the moderns, had entertained the same false notions of its advantages. In his curious work, under the section "How to plow as it may yeeld most mould," he, in his quaint style says : "As for your ordinary scasons of plowing, your land being in good tillage, any well ordered and truly compassed plow will do, you may help yourself sufficiently in the making of your irons, if you would have the edge of your lying furrow lye up hivher, which will yecld most mould, then set your share-phin the shallower, and yet your plow the broader, and hold it the more ashore, the plowman going upon the (i)!i) 
land, and it will lny it with a sharp edge, which is a gallant posture for almost any land, en pecially for the lay turf beyond compare."

(970.) The setting of the share-phin (feather) as bere described, is precisely what is done in the modern plows to make them produce the high-crested furrow (590). Blith seems to consider that holding the plow "ashore" (to landward), aids the effect; it will make a slice thinner at one edge, but not more acute in the crest.-J. S.]

\title{
28. TRENCH AND SUBSOLL PLOWING, AND MOOR-BAND PAN.
}

\author{
"If deep you wish to go, or if the soil \\ Be stitf and hard, or not yet cleared of stones, \\ The Scottish plow, drawn by a team four atrong, \\ Your purpose best will suit ; \\ Graham.
}

(971.) Trenching of land with the spade has been a favorite operation in gardening for many ages; and since the plow became the substitute for the spade in fleld culture, it has been employed for the same purpose, of deepening the friable portion of the soil, and affording to the roots of plants a wider range in which to search for food. It is highly probable, however, that the plow could not have closely imitated the trenching of ground with the spade until after the introduction of the mould-board, which, comparatively speaking, is of very recent date, the ancient plow retaining its primitive simplicity of form until within a few centuries. Indeed, until the muuld-board was added, it was scarcely in the power of the plow to trench the soil, that is, to reverse the position of the furrowslice and mix the upper and lower soils together. When it was added, may now be difficult to ascertain; but fully two centuries ago, Hartlib, in his Legacie, intimates the practice of very deep plowing, with the mould-board in use, when he says: "There is an ingenious yeoman in Kent who hath two plows fastened together very finely, by the which he ploweth two furrows at once, one under the other, and so stirreth up the land 12 or 14 inches deep, which in deep land is good." This is essentially trench-plowing.

(972.) Within a very recent date, it has been recommended to plow land as deep as trenching, but so as to retain the stirred soil below the surfice. Mr. Smith, Deanston, by the invention of his subsoil-plow, has been the means of directing the attention of agriculturists to this peculiar and apparently new process, which has obtained the appellation of sulsoil-plowing. A figure and description of his subsoil-plow is given below. After the introduction of the mould-board, subsuil-plowing could not have been practiced; but prior to that improvement it is not improbable that the process was known and practiced, and so long ago even as by the Romans. It is uncertuin what was the depth of the furrow usually made by the Roman plow, some commentators supposing, from a particular phrase used by Pliny, that it was as much as 9 inches, but at all events he designates a depth of furrow of 3 inches as a mere scarification of the soil. There is no doubt, however, from a passage of Columella, that the Roman farmers occasionally gave a deep furrow to good deep land, when he says : "Nor ought we to content ourselves with viewing the surface, but the quality of the matter below should be diligently inquired into, whether or no it is of earth. It is sufficient for corn if the land is equally good 2 feet deep." If they imagined that corn received benefit from the soil at the

* Blith's Improver Improved, p. 216, edition 1652. (792) 
distance of 2 feet below the surface, they would consider it as an advan. tage to plow as deep as their cattle were capable of, and their plow could go.* As the Roman plow had no mould-board, any deep-plowing effected by it would partake much more of the character of a subsoil than of a trench-plowing.

(973.) The effect of subsoil-plowing being merely to stir the subsoil without affecting its relative position, the best way of performing the operation is, as I conceive, in the following manner: and it may be executed either. in winter or in summer according as it is made to form a part of the spring or summer's operations. It is best executed across the ridges; let, therefore, a feering of 30 yards in width be taken across them with the common plow from the upper fence of the field; and this is most easily effected by opening out feering furrow-slices parallel with and close to the fence, if it be straight, and another at 30 paces distant, and let the subsoil-plow follow in both the open feerings. The plow then closes the feerings, and so plows from one feering to another until the open furrow is formed in the middle of the feered space between them, followed implicitly all the time by the subsoil plow, which is held by one man, and the horses are driven by another. Feering after feering is thus made and plowed with the common plow, and followed by the subsoil until the whole field is gone over, with the exception of about the breadth of a ridge at each side of the field, upon which the horses had tumed, and the neglect of which is probably of no great importance. Fig. 206 is given as

Fig. 206.

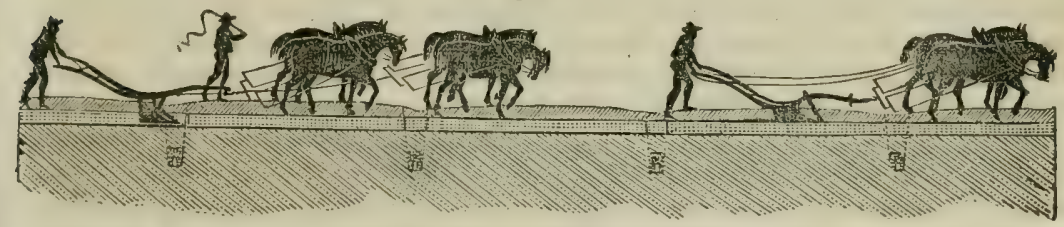

THE TRENCH OR SUBSOIL PLOWING.

a representation of the operation, where the plows and horses appear in black, and where the common plow with 2 horses precedes the subsoil one with 4. The depth taken by the plow is the usual one of 7 inches in stubble, which is seen as the upper furrow, succeeded by the subsoil-plow, which takes usually 9 inches in such a position, and whose furrow is seen in section below that of the other plow, making both furrows 16 inches deep. Care should be specially taken not to allow the subsoil-plow to approach within 2 inches of the covering of any drain, otherwise the drain will be torn up and materially injured. The drains in the figure are supposed to be 36 inches deep, filled 12 inches with tile and sole and small stones, and placed in every open furrow at 15 feet asunder, the curved form of the ground between them representing the ridges. This figure is not meant to give the exactly relative proportions of the different objects composing it.

(974.) The immediate effect of subsoil-plowing being to deepen the friable portion of the soil, it is evident that where the subsoil-plowed soil rests upon impervious or even retentive matter, that the operation will increase the depth, and, of course, the capacity of the soil for holding water, and on this account, in so far as respects itself, the operation after wet weather would do more injury than good to the crops growing upon it.This is a very important fact in regard to the effects of subsoil-plowing,

* Dickson's Husbandry of the Ancients, vol. i.

(793) 
considered in itself, and demands your serious consideration, because a misconception and disbelief of it continues to exist in some parts of the country, especially in England, and injury may thereby be inflicted on land which will require a considerable time to recover. But if injurious effects accompany subsoil-plowing, when it nccasions excess of water, it is evident that were drains formed to give the water an opportunity to escape, it would do no injury to plow land to any depth. The misconception which I have alluded to as existing may not be easily dispelled, as the unusual depth to which subsoil-plowing is executed operates in the first instance as a drier of the surface of the ground, even when there has been no previous draining, and it also renders drained ground drier; and these immediate effects are regarded by improvers of land as all that are required to be effected by the operation, and, consequently, when it is easily ascertained that subsoil-plowing is a much cheaper operation than draining and seems to be equally efficacious, they are content to abide by it alone. I have no doubt that much of the land that has been subsoil-plowed in England has been so in consequence of the adoption of this opinion by farmers, upon whose attention the great comparative economy attending the process was so earnestly pressed some years ago by people of influence. They, however, who understood the nature and capability of subsoil-plowing, and Mr. Smith himself at their head, both published and publicly stated that to employ the subsoil-plow upon land having a retentive subsoil, without draining it in the first instance, would only aggravate the evil they wished to avoid. It is true that the subsoil-plow might penetrate through the retentive matter to an open substratum through which the water would escape; but the chance of meeting with such a rare arrangement of strata, forming the exception to the general structure of clayey subsoil, cannot afford a sufficient excuse for an indiscriminate use of the subsoil-plow.

(975.) It should, therefore, be laid down as a general rule, that no land ought to be subsoil-plowed unless it has been previously drained; for, where the subsoil is so porous naturally as not to require draining, neither will it require subsoil-plowing. After being thoroughly drained, any sort of land may be subsoil-plowed with safety-that is, no harm will accrue from it; but all sorts of land will not derive equal advantage from the operation. Taking it, therefore, for granted that draining should precede the subsoil-plow, the interesting inquiry arises-In what quality of subsoil does subsoil-plowing confer the greatest (if any) benefit to land ?-the correct answer to which can alone determine the extent to which this operation should be carried. In the first place, in pure plastic clay, any opening made by the subsoil-plow passing through it would probably soon collapse together behind the implement. Through such a clay, in a dry state, the operation would be performed with great difficulty, if not prove impracticable. In what is usually called till-that is, clay containing sand veins, small stones, or small boulders-the subsoil-plow will pass sufficiently well, though slowly, and it will displace even pretty large stones, and the clay be afterward kept open for a time. Hardened masses of gravelly clay may be entirely broken up by this operation. I helieve experience has established the effect of the subsoil-plow in these respects. It thus appears that the sphere of the subsoil-plow, as an operation of permanent utility, is limited to the breaking up of hard, gravelly subsoils; because it is scarcely supposable that it can keep pure clay always open, and it cer tainly admits of douht that it will keep a tilly bottom constantly open, as experience has proved that percolation of water through a somewhat porous clay renders it more firm, by the well-known fact that such a soil, returned above a drain, soon becomes as firm as any other part of the field. (794) 
Hard, chalky, gravelly matter, and moor-band pan, are the only subsoils on which one would feel confident that subsoil-plowing would confer perinanent benefit. I say permanent benefit; for I believe it is acknowledged that the process confers an immediate benefit in almost every case in which it has been tried; and on this account its keener advocates have claimed for it much of, if not the entire, advantages derived from its precursor, thorough-draining; and there seems some ground for the claim, inasmuch as subsoil-plowing is executed so soon after thorough-draining that it would be impossible to assert the superior claims of draining, were it not for its occurrence being more common without than with subsoil-plowing; whereas, when the latter is taken by itself, it cuts but a sorry figure. In vindication of his own invention, Mr. Smith endeavors to explain in general terms why indurated subsoil, when drained, should preserve the friability impurted to it by subsoil-plowing. "When drains have been some time executed," he says, "innumerable small fissures will be found in the subsoil, extending from drain to drain; these are caused by the contraction of the substance of the soil arising from its drier state. The contraction being greatest in the stiffest clays, the operation of the subsoil-plow admitting the air to a greater depth, the fissures take place under its operations, and generally reach to the level of the bottom of the drains." This is a natural enough explanation of the almost immediate effect of draining wet subsoils, and also of the almost immediate extension of its effects by a subsequent subsoil-plowing. "These fissures," he continues, "will get more or less silted or glutted up, from time to time, by the minute alluvial particles carried down and left in filtration by the rain-water," which is also a natural effect; but he adds, "the constant expansion and contraction of the unremoved subsoil, by the alternations of wet and dry, has a perpetuai tendency to renew them ;" and it is this effect which I question, because, before such expansion and contraction can be kept up, it must be assumed that the subsoil, after being subsoil-plowed, has no tendency to consolidate into its original state, whether of strong clay or any other substance; and yet the conviction, as [ conceive, of all drainers must be, that every sort of subsoil, except hard rock, consolidates, however well it may have been stirred, though perhaps not to the degree of impermeability it may have possessed before; but, at all events, the more friable it becomes in its condition, it will be the less affected by the "alternations of wet and dry.",*

(976.) It is allowed by all who have used the subsoil-plow that it requires much greater exertion from the horses to work it than the common plow, and that horses do not work well together in it for some time. With regard to the quantity of ground which a plow will subsoil in a day, in a long day in summer, 1 imperial acre may be calculated on being accomplished in favorable circumstances; but should obstructions occur, such as large boulder stones, $\frac{3}{4}$ of an acre is a very good day's work; and in winter $\frac{3}{4}$ is a good day's work without obstructions.

(977.) The great force required to work even the lightest of the Deanston subsoil-plows, which weighs $18 \frac{1}{2}$ stones - the heaviest weighing $28 \frac{1}{2}$ stones of $14 \mathrm{lbs}$. - and the insuperable bar which this circumstance places against its employment on farms working less than 3 pairs of horses, have induced people to contrive what they designate subsoil-plows, to be used as a substitute for the Deanston one; but, in every modification which $I$ have seen proposed, their effect is quite different from what Mr. Smith proposes that his should produce. The Deanston subsoil-plow not only * Smith's Remarks on Thorough Draining. 
penetrates the subsoil to a determinate depth, but, by the simple contriv ance of the feather, the subsoil is not only stirred, but pushed a little aside, and therehy partially mixed with the portion adjoining it. In doing this, there is little doubt that it is the action of the feather which causes the principal weight of the draught complained of in this plow. To avoid this redundancy of draught, as it is supposed to be, a feather is discarded, and simply a large tine bent forward at the point, as in the case of Gabell's subsoil-plow, ${ }^{*}$ or a small scarifier, as in the case of the Charlbury one, $\dagger$ is substituted as its principal feature-a furrow being opened by the common plow preceding, as in the case of the subsoil one. But, as the subsoil plow makes a demand on the horses of the farm for a common plow as well as itself, it is proposed in the Charlbury one to have a small plow Ittached to the beam to lay over the furrow-slice, in orcler to prepare it or the tine or scarifier to pass along. But although a lightness of draught ras been attained in both these instances, and a pair of horses have been said to be able to work Gabell's to the depth of 18 inches, it requires 4 horses to work the Charlbury to 12 inches-which, as a saving of labor, is of no great importance, except as regards the employment of the crimmon plow in preparing the way; for the difference in the nature of the work performed by them differs so widely from that of the Deanston plow, that they cannot be said to be its substitutes, inasmuch as they only make ruts in the subsoil at the distance of the breadth of a furrow-slice from one another-namely, 8 inches at the least, most probably 9 inches, and not improbably 10 inches-and which, of course, leave ribs of hard land standing intouched in the subsoil. It is acknowledged by the proposers of these substitutes that the Deanston is more efficient than either; and, as $\mathrm{Mr}$. Smith's opinion is that the heaviest of his plows does the most satisfactory work, it is clear that they can never be a substitute for his, provided he is correct in his views regarding the utility of thorough sulssoil-plowing, which these substitutes certainly do not even profess to perform. The conclusion I would draw from the inefficiency of these modifications and substitutes for the Deanston subsoil-plow is, that none of them are hikely to be used on farms employing less than 3 pairs of horses, such employment being the only ohject their contrivers had in offering them to public notice.

(978.) A modification has been proposed and practiced in the use of $\mathrm{Mr}$. Smith's own subsoil-plow, which is, that instead of passing it in every furrow of the preceding small plow, it should pass in every other furrow.The advantages said to be derived from this plan are, that it is cheaper, speedier, and the subsoil is not so much lowen, though broken enough io allow the water to escape to the drains; but it is obvious that it is this very defective mode of operation which constitutes the great objection to the English substitution of the Deanston plow.

(979.) Instances are not wanting to prove that benefits have been derived from the conjoint operations of thorough-draining and subsoil-plowing ; but, as in almost every recoried case the combined eflects of both operations are reported, it is impossible to ascertain the advantages derived from each. In a memorandum which I made some time ago, but now forget where the circumstance happened, I find it stated that a field of lea was drained in 1838, and the crop of oats from it in 1839 did not exceed 13 bushels per acre imperial; whereas, after it was subsoil-plowed, another crop of oats in 1840 gave 32 bushels per acre. It is well understood that the first crop of oats from lea newly thorough-drained never vields an increase; but, in this instance, I have no doubt that the second crop of oats

- Journal of the Royal Agricultural Society of England, vol. ii.

t Journal of the Royal Agricultural Society of England, volo. i. ii, and ii.

$\uparrow$ Ibid. rol. i. (796) 
would have been better than the first, without the use of the subsoil-plow, especially if the lea were old. In Mr. Laing's experience on Campend, Mid-I othian, he has "found land to be more thoroughly dried after subsoil-plowing ('especially when there was any approach to clay in the subsoil), with a drain in every alternate furrow, than with a drain in every furrow without it ; in fact, on a stiff clay subsoil I have seen drains of little service, the water for some time standing on the top of them till evaporated, while in the very next field, which had been subsoil-plowed, there was an immense flow of water in every drain, and not a drop to be seen on the surface." Such an effect is not at all surprising, as it is well understood that subsoil-plowing greatly assists thorough-draining at first in drying land; and that effect appears the more striking when the land has not been so well drained as it should have been, which it certainly would not be with a drain in every alternate furrow, when it is so strong as that mentioned by Mr. Laing, where he says of a field of 10 acres that was subsoilplowed in November, 1S36-a wet season, certainly-that it "was at the time, and during the whole operation, so saturated with rain that the horses' feet sunk in the unplowed ground from 4 to 6 inches; which showed, though there was a drain in every alternate furrow, they had not drawn the water from the stiff, retentive subsoil. This circumstance," continues Mr. Laing, "convinced me the more of the necessity of persevering in subsoil-plowing, which alone enabled me to accomplish my object of thoroughly drying the soil."* The conclusion come to is scarcely a fair inference from the premises, which should rather, in the first instance, have brought conviction, from the nature and wet state of the soil, of the necessity of persevering in thorough-draining, by making a drain in every, instead of every alternate, furrow; and it was after thorough-draining had failed, that the drainer would be entitled to say that "subsoil-plowing is an indespensable accompaniment to furnw-draining," "or that it alone enabled him to accomplish his object of thoroughly drying the soil." I cannot refrain from making a passing remark here, that there is a strong propensity in farmers generally to laud the good properties of its auxiliaries at the expense of thorough-draining; and I can only account for the prevalence of the feeling, from the fact being well known to them that it is cheaper to subsoil-plow land than to thorough-drain it, the amount of labor to put it in the condition of being thoroughly dry depending upon its nature.

(9S0.) Mr. Melvin, Ratho Mains, Mid-Lothian, says what will readily be believed in Scotland, that "I have never seen any benefit from the use of the subsoil-plow upon damp-bottomed land that had not been drained;" and after a fair trial in a particular field of deep, soft, damp soil, of both operations conjointly, he expresses himself in terms which place the art of subsoil plowing in nearly its proper position. "Much, no doubt, of the improvement in the condition of this field, is to be attributed to draining, still, the quick absorption of the water in the furrows between the drains (the land being cast), the decided improvement of the drier part, and the uniformly equal crop, sufficiently attest the merits of subsoil-plowing." I have said that, in these remarks, Mr. Melvin has placed subsoil-plowing in necrly, but as I conceive, not altogether its proper position; because the field was drained in the alternate furrows, and the drier part of it was not drained at all. Now, had every furrow been drained, would not the water have been quickly absorbed; and had the drier part been drained, would it have required subsoil plowing at all ?

(9S1.) With regard to the expense of subsoil-plowing, it may be fairly

* Prize Essays of the Highland and Agricultural Society, vol. xii.

(797) 
taken at the cost of 3 pairs of horses and 3 men, and wear and tear of implements per day for every $\frac{3}{4}$ of an acre imperial plowed; and Mr. Pusey instances a case of a farm of not 600 acres of cold clay, the subsoil-plowing of which was estimated to cost $£ 1,300$, but how this sum was made out does not appear.* The returns of the grain crops seem to imply an increase of 25 per cent. at most, and in regard to green crops, an instance is given of a yield of turnips off peaty soil, resting on stiff clay and hard sand and gravel at Drayton in Staffordshire, belonging to Sir Robert Peel, of "four times the quantity in weight ever produced in the same field at any previous time," the large crop alluded to being 27 tons per acre, including tops.t

(982.) With regard to trenching the ground, it has long been practiced by gardeners with the spade, and its ohject is to bury the exhausted soil on the surface with all its seeds of weeds and eggs of insects, and bring up to the surface a comparatively fresh and unexhausted soil, not so rich in manure as the one buried down, but more capable, by its fresh properties, to make a better use of the manure put into it. Trenching with the spade is also practiced on farms on a large scale. From experience in both ways, I can maintain that it is cheaper to trench rough, stony ground with the spade than with the plow, giving consideration to the state of the soil when left by the two implements. The plow with 4 horses will turn over and rip up a strong furrow, and where there are no stones and roots, it will answer the purpose well enough; but where stones, though small but numerous, and if large, are encountered, the furrow becomes very uneven and unequal, the horses jaded, the men fatigued, the implement broken, and the work very imperfectly done. It is the same case with the roots of trees, and even of bushes, against which, when the plow comes, horses pull with vehemence, so as either to injure themselves, or break their tackling. At such work I had two valuable horses so much injured in their wind as to become unfit for ordinary farm work; and finding so I abandoned the plow for this purpose altogether. The same work, on the other hand, can be much better done with the spade, and when it is undertaken by a contractor who remains constantly with the spadesmen, it will be your own fault in superintendence, if the work he ill executed.

(983.) I have found this plan succeed in making good trenching. Let the ground to be trenched be laid off in lots with pins; and let the lots contain equal areas of five yards in breadth. The trench to be 14 inches in perpendicular depth in the solid ground on the average over the lot, the surface being left even with the general inclination of the field that is to be. The 14 inches out of the solid will give a depth of 16 inches in the trenched part of the ground. The contractors should be obliged to remove all stones, large and small, all roots, large and small, and every other thing that it likely to obstruct the future course of the plow, and lay them upon the surface of the trenched ground; and should large boulders be found a little below the surface, these must either be blown to pieces by gunpowder, and the fragments left on the surface, or farther sunk in the earth so as to be out of the reach of the plow in future, according as you find that you may have use for the stones for drains or foundations of fence dykes. The trenching is begun at the utmost limit of the rough ground, by each man rutting some breadths of 12 or 15 inches wide across his lot, and making a trench of the required depth of 14 inches, gauged by a stick kept constantly in his possession to guide him in the depth, that he may not have the plea of ignorance to urge in extenuation of his cupidity. The upper turf or spading is put on its back in the bottom of the trench; the

\footnotetext{
* Journal of the Royal Agricultural Society of England, vol. i.

I Ibid., rol. iii.
} (799) 
soil is then dug and thrown upon it, care being taken to make the new ground level and even; and, lastly, shoveling the loose earth over the surface, leaving no inequalities in the bottom of the new trench. After one set of allotted spaces has been trenched in this way, another is ready marked off by the contractor for the men to enter upon as they finish their lots, and the second set should be marked off either along one end or one side of the field, whichever is found most convenient for the future operations of removing the trenched-up materials to their destination, that a whole piece of ground may be cleared for future operations without interfering with the progress of the trenching, the workmen employed in which should be called upon to do nothing else than their appointed tasks.

(994.) Ground that has lain in this rough state for years will no doubt require draining, and should be drained before or after being trenched, according to circumstances. It should be examined beforehand, by pits sunk here and there, whether the subsoil will afford a sufficient quantity of stones to thorough-drain the ground. If it is supposed or certain that it will, the ground should first be trenched to obtain the stones, and they being on the spot, the drains will be easily filled with them. If the stones be only to that amount as to form an ordinary covering to tiles, then tiles and soles should be used as the principal materials, and, in this case as well as the other, the ground should first be trenched. But if stones are plentiful near at hand, though not in the particular field under improvement, from a quarry hard by, for instance, then the drains should be opened and filled to the requisite depth before the surface of the old ground is broken up, that the cartage of the stones may first be borne by it; and tho trenchers in that case should be obliged to cover the stones of the drains with turf, and level the ground over them as they proceed with the trenching.

(985.) The expense of trenching rough ground at 14 inches deep-and it should never be shallower, in order to insure a good plow-furrow ever after-is from $10 \mathrm{~d}$. to $1 \mathrm{~s}$. per pole, according to the roughness of the ground. I have had very rough ground, consisting of large roots of trees in scattered wood, with brushwood of birch, alder, whin, and broom, and containing as many stones as would have half-drained the ground, trenched 14 inches deep for 1s. per fall, Scntch measure, which is equal to $£ 613 \mathrm{~s}$. $3 \mathrm{~d}$. the imperial acre, or rather more than $9 \frac{1}{2} \mathrm{~d}$. per pole, a large sum, undoubtedly, independent of draining, clearing away rubbish, and other horse and manual labor; but then the ground was rendered at once from a state of wilderness to one in which manure could be applied and covered in with an ordinary furrow-slice of mould. If this is not the cheapest mode, in a pecuniary point of view, of rendering ground available to cultivation, it is at all events the most pleasant to the feelings in the doing, and the most satisfactory when done.

(986.) But there is a mode of trenching ground which is best done with the plow, its object being to imitate the work of the spade by descending deeper than the ordinary depth of furrow, and of commixing part of the subsoil with the surface soil, which has been probably rendered effete by overcropping. Ground can be trenched with the plow in two ways, either with a large-sized common plow drawn by 4 horses in one of the ways pointed out before, fig. 202, or with one plow going before and turning over an ordinary furrow-slice, and another following in the same furrow drawn by 2 or more, usually with 3 horses, or both plows drawn by 3 horses each. It is best performed across the ridges. In either of the above ways the same effect is produced in similar soil, breaking up indurated gravel, deepening thin clays, ameliorating stiff clays by exposure to (799) 
the air, and mixing old and new soils together, the ultimate cffect on all being to deepen that portion of the soil which is used by the cultivated crops.

(957.) In one respect trenching has the same effect as subsuil-plowing, namely, the stirring of the ground to the same depth, the first plow turn. ing over a furrow of 7 inches in deptb, and the second going 8 or 9 inches deeper, making in all a furrow of 15 or 16 inches in depth; but in another respect the two operations leave the soil in very different states-the subsoil-plow stirs the soil to the depth named, but brings none of it to the surface, while the trench-plow does not altogether bring that which was undermost to the surface, but commixes the under and upper suils together. This latter practice has long been known in the midland counties of England, but the former has only been presented to the notice of the Scottish agriculturist since 1529.

(988.) It has been made a question, which is the better mode, if both are not alike, of making the soil fertile? the advocates of subsoil-plowing alleging that it is better to ameliorate the subsoil while under the soil by the admission to it of air and moisture; while those of the trench-plow answer that, if the object of both operations is to ameliorate the subsoil, it will become sooner so by being brought to the surface in contact with atmospheric air and moisture. But, say the promoters of subsoil-plowing, there are subsoils of so pernicious a nature, having the salts of iron and of magnesia in them, that the upper soil would be much injured by its admixture with such substances. No doubt, answer the trench-plowers, if the subsoil that contained these noxious ingredients in a large proportion were brought up in quantity, when compared with the bulk of the upper soil, injury would be done to it for a time, but they say it is not the abuse but the proper use of trench-plowing which they advocate; and of such $a$ subsoil, they would use the discretion to bring up only a little at a time, which they hare it in their power to do, until they accomplish their end, namely, that of ameliorating the whole depth of subsoil. But they maintain that by far the greatest proportion of subsnils do not contain those noxious ingredients; and, besides, the very best and quickest way of getting rid of even these is to bring them at once to the surface, for any of the acids, or the salts of iron, are easily neutralized by the action of lime. which is always applied to the surface; and those of magnesia are most easily reduced on free exposure to the air. And, moreover, they ask, If subsoils shall be ameliorated by air and moisture when stirred by a subsoil, why should they not also be ameliorated when stirred by a trenchplow? And they urge farther, that trenching may be practiced more safely without previous thorough-draining, than subsoil-plowing.

(989.) I have no hesitation in expressing my preference of trench to subsoil-plowing; and I cannot see a single instance, with the sole exception of turning up a very bad subsoil in large quantity, there is any advantage attending subsoil that cannot be enjoyed by trench-plowing; and for this single drawback of a very bad subsoil, trenching has the advantage of being performed in perfect safety, where subsoil-plowing could not be without prerious draining. Mr. Melvin, Ratho Mains, mentions an instance of a field containing both damp and dry ground; the dry was trench-plowed in the autumn of 1836, an inch or two of the sandy gravel being brought up, and "was decidedly increased in fertility," both in the turnip and barley crops which followed." I trench-plowed a field of 25 acres of deep black mould which had been worn out, with a 4-horse plow, taking and clearing a furrow from 14 to 16 inches deep in the solid land, and bringing up almost in every part a portion of the tilly subsoil, which was only

- Prize Essays of the Highland and Agricultural Society, vol, xii $(800)$ 
drained to the extent of a few roods put in the face of a slope exhibiting spouts of water. The turnips that followed were excellent; the barley yielded upward of 50 bushels per acre imperial, and the year after a part was measured off and fenced, containing 6 acres, to stand for hay, which yielded of good hay 1999 stones of $22 \mathrm{lb}$. Another field, the year after, that was not drained, suffered injury after trench-plowing; but that was in consequence of having been caught with a premature fall of rain in the autumn before the trenched land could be ridged up, and it lay in the trenched furrow all winter. It is stated that Mr. Scott, Craiglockart, MidLothian, "trench-plowed in the winter of $1833-4$, with one common plow following another, a field of 20 acres, every two alternate ridges, and he has never observed on any of the crops the slightest difference."* This is, as I conceive, an unsatisfactory mode of testing the value of any sort of plowing land, as it is possible that the untrenched ridges derived a certain and it might be a sufficient advantage, in regard to drying, from the adjoining trenched ridges.

(990.) But while giving a preference to trench-plowing over subsoil, I am of opinion that it should not be generally attempted under any circumstances, however favorable, without previous thorough-draining, any more than subsoil-plowing, but when so drained there is no mode of management, in my opinion, that will render land so soon amenable to the means of putting it in a high degree of fertility as trench-plowing. Mr. Smith himself acknowledges the necessity of trench-plowing land in a rotation or so after the subsoil has been subsoil-plowed, in order to insure to it the greatest degree of fertility.t The experience in trench-plowing after thorough-draining of the Marquis of Tweeddale at Yester, East Lothian, may with great confidence be adduced in favor of the system. I have seen a field on Yester farm under the operation of draining which did not carry a single useful pasture plant, but which afterward admitted of the turnips being drilled across the face of inclining ground, and of presenting to sheep in winter as dry a bed as they could desire; and no farther gone than the spring of 1841, after the Swedish turnip-seed had been sown, a field was trench-plowed with 3 powerful horses in each plow, bringing up white and yellow tilly subsoil as unpromising in appearance as possible. The weather being very dry, this till became so hard that part of the field had to be rolled four times before they were reduced to powder, and after all the operations, there was apparently no sap left in the ground. White turnips were sown, came away, one-half being eaten off by sheep; and when the land was plowed up in spring 1842 , it turned up to appearance a fine rich dark mould, rising in friable clods, and not a particle of till to be seen. No one need be afraid to bring up subsoil of any kind on thorough-drained land after the experience at Yester.

(991.) The advocates of subsoil-plowing seem to lay great stress on the laying of ground quite flat after that operation has followed thoroughdraining, and of showing no open furrows in the field; because a uniform surface is the best for absorbing the rain, and transmitting it in the purest state to the drains. All this, however, is not peculiar to subsoilplowing, for trenched land can be so treated if desired. But as to dispensing with open-furrows, the plan savors more of conceit than of possessing real utility. There is no way that has been contrived of plowing land so conveniently as in ridges, a portion of ground being allotted to each plowman, who is responsible for his own work; and the operations of sowing and reaping are easily marked off in equal distances to the work-people;

* Prize Fssnys of the Highland and Agricultural Society, vol, xil.

$\uparrow$ Smith's Remarks on Thorough Draining.

(801).....88 
and if in conducting all these operations few open-furrows seem desirable, there is the mode of plowing by two-out-and-two-in, fig. 138, which only leaves one open-furrow in every four ridges, and the ground as flat as you please. But the truth is, that a field cannot be plowed without making an open-furrow, but with either one plow making a feering in the middle and turning over the whole ground; or, if more than one plow is employed, they must follow one another in adjoining furrows-a plan inimical to good plowing, inasmuch as no plowman can hold so steady a furrow as when following up his own method of plowing, and few plows are exactly of the same guage on the furrow-sole; or the land must be plowed with a turnwrest plow, beginning at one end and finishing at the other of the field plowing the whole of it itself, or followed by others of the same sort; but where such plows are used for such a purpose, other common plows must be provided on the same farm, as land for turnips or potatoes cannot be drilled up with the turn-wrest plows, as you will learn by-and-by.

(992.) The nature of moor-band pan is given below, and as to its destruction, although I have not had much experience of its obduracy, any case within my experience not exceeding 2 or 3 inches in thickness, which were easily ripped up with the 4 -horse plow, and as easily mouldered down to dust on exposure to the winter's frost ; yet there are places, such as in Aberdeenshire and Morayshire, where it is so deep and hard that extraordinary means are required to break it up. A remarkahle and extensive band of this substance was encountered by Mr. Roderick Gray, Peterhead, when improving a part of the property of the Governors of the Merchants' Maiden Hospital of Edinburgh in that neighborhood. The moory surface was plowed with 4 horses. "At first the plow ran upon the pan, which it seemed impossible to penetrate; various trials were made, and the plan which ultimately succeeded was to have 4 men employed at the plow, and these were engaged as follows: One with a pick and spade made a hole when necessary, until it reached below the pan, and entered the plow at this hole; another held the plow; the third held down the beam, and kept the plow below the pan; and the fourth took care of the horses. In this way the upper stratum and pan were broken, and afterward they were brought into a sort of mould by the grubber and harrows."* However obdurate this substance may be to break up, it will yield to the air and moulder down into an innocuous powder of sand and gravel; but I should suppose that, after the plow was fairly entered below the crust it would not require to be held down.

(993) [In describing the simple construction of the snbsoil-plow, I shall not go to any length into its history. The implement, as now used, is generally know as Smith's subsoil-plow, having been brought into the present form by Mr. Smilh. Deanston Works, who. in the vear 1829, exhib. ited this plow at the Highland and Agricultural Society's Show at Dumfries, and obtained a premiun from the Society for his invention and application of this useful implement. $\dagger$

(994) There is no doubt that plows, acting on the principle of Mr. Smith's. penetrating into, breaking. and stirring op the subsoil, withont bringing it to the surface or mixing it in the first instance with the incumbent soil, have been long known. Mr. Holt, in his View of the A griculture of the County of Lameaster, rendered in 1794 to the Board of Agriculture, when treating of the plows of that county, says: "Another instrument has been lately introduced, whicls Mr. Ec. cleston with propriety calls the Miner. which is a plow-share fixed in a strong beam, without mould boards, and drawn by four or more horses, and follows in the furrow the plow (the com. mon plow) has just made; and. without turnine up the substratum. penetrates into and loosens from 8 to 12 inches deeper than the plow has before gone; which operation, besides draining the land, caukes the water to carry along with it any vitriolic or other noxions matter by the substratum thus loosened. The roots of plants may penetrate deeper; and, in course of tine, that which is but a barren substance may become fertile soil." This is truly the subsoll-plow of Mr. Smith, invented. laid aside, and forgotten for a period of 3.5 years.

(995.) Recent experience points out the reason why the earlier introduction of the subsoil-plow did not meet with the auccess which has attonded Mr. Snith's, which, from the above description appears to be the same implement, for they appear in the essential parts to be almost exactly

- Prize Esaays of the Higbland and Agricultural Society, rol viii. (802)

I It id., vol. viii. 
alike; yet the one has been lost sight of, while the other has come into all that notice which it deserves. The reason is now obvious: Without the necessary improvement of thorough-draining, subsoil-plowing is thrown away; and though thorough, or at least furrow draining, has been practiced in England for a long period, ${ }^{*}$ the idea of combining the two seems not to have occurred to the agriculturists of that day. To Mr. Smith, therefore, is still due the merit of having brought these two powerful auxiliaries of Agriculture in to effective cooperation.

(996.) Since its first appearance in 1829, Mr. Smith's plow has undergone various slight alterations, not affecting, however, its essential character, but chiefly in lightening its constraction. The imploment at first was made of enormous weight, sometimes so much as $5 \mathrm{cwt}$., but a few years' experience served to show that all its objects could be achieved with a plow of little more than half that weight; they are accordingly now generally made from 2 to $3 \mathrm{cwt}$. Fig. 207 represents

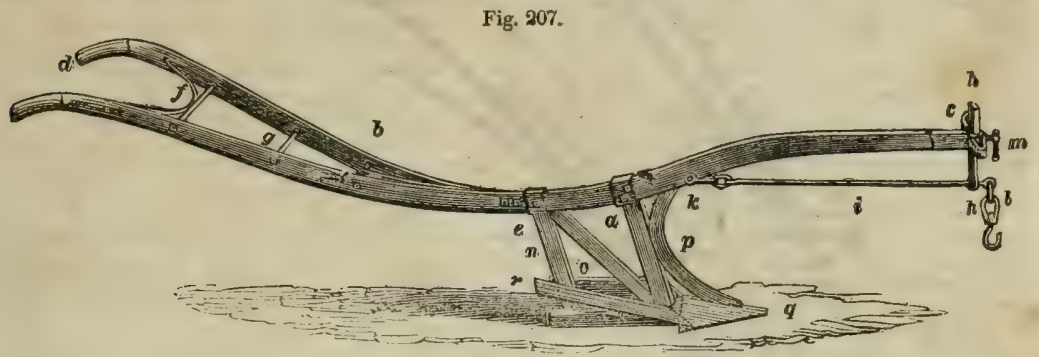

THE DEANSTON SUBSOIL-PLOW.

one of the modifications of the subsoil-plow as now manufactured by James Slight \& Co., Edinburgh. It retains all the acting parts of Mr. Smith's without material change, except in weight, though in other respects it deviates slightly from the original. The beam, which is from 3 to 3 t inches deep at the fore sheath or slot, $a$, and 1 to $1 \frac{1}{4}$ inches thick, extends from $b$ to $c$, a length of 7 feet 4 inches; at $c$, the point, it is diminished to $2 \frac{1}{4}$ by $\frac{3}{4}$ inches, and at $b$ to about the same dimensions. The two handles, extending from $d$ to $e$, are 6 feet 9 inches in length. They are thinned off at $\epsilon$, and bolted, one on each side, to the beam; the depth of the handles is 2 to 21 inches, and are $\frac{3}{9}$ to $\frac{1}{2}$ inch thick, worked into sockets at $d$ in the usual manner for the reception of a wooden helve. The beam and handles are farther connected by stretcher tubes and bolts, the latter passing through all three at $b$, and binding them firmly together; the handles are also farther supported by the stretcher-bolts and bow, $f$ and $g$. The beam is monnted at $c$ with the bridle, which is at least 2 inches by $\frac{1}{2}$ inch, bolted on the point of the beam, being first formed into an oblong loop of 8 inches in length, standing at right angles to the beam, and baving the opening vertical. To the front part of the loop is fitted a stout clasp, the two arms of which embrace the loop above and below. and admit of the slot $h h$ to pass at once through them and the loop. The clasp and slot together have a motion along the loop right and left, and the slot itself has a motion vertically. The chain-bar $i$, is attached to the beam at $k$, and passes through an eye in the lower end of the slot $h$; to the chain-bar is then attached the draught-hook $l$, to which the yoke is applied. The motion above described of the slot $h$, and consequently of the chain-bar and draughthook, afford ready means of adjusting the earthing and landing of the plow, and the position is retained by means of the pinching-screw $m$, which, by being screwed into the clasp, acts against the outside of the loop, drawing the slot and the loop into firm contact. The body consists of the two slots $a$ and $n$, the first about 3 inches broad, the last about $2 \frac{1}{2}$ inches, and each $\frac{3}{4}$ inch thick ; they are welded to a sole-bar 2 inches square, and 30 inches long, flush on the land-side. The head of the slots is worked into a kneed palm, which is strongly bolted to the beam, and the diagonal brace $o$ is fitted in to resist the strain that tends to derange the form of the body. The coulter-bar $p$ is 3 inches broad, $\frac{3}{4}$ inch thick at the back in the upper parts, becoming thinner downward, and is finished with a blunt edge and point; it is simply held in its place by being tongued into the beam, the fore-slot and the share. The share $q$ is made after the same form as that of the common plow, having a feather to the furrow-side, and is spear-pointed. The length of the share is from 14 to 16 inches, and the breadth over the feather about 6 inches. It is fitted upon the prolongation of the sole-bar, and its socket is usually furnished with a short ear, by which it is fixed to the sole-bar to prevent its falling off, as the fixture of the coulter depends upon the share keeping its place. The feather $r$ is a thin-edged bar, 3 inches deep and about $\frac{1}{2}$ inch thick, thinned off on the upper edge ; it is tapered off at the fore end where it joins the share, and is held in contact by being notched into it; but its chief supports are two palms, by which it is bolted to the sole-bar; and a sole-shoe of cast-iron, having a flange rising 6 inches on the landside, completes the subsoil-plow, which, with the exception of the sole-shoe, is constructed entirely of malleable iron. The length of the plow over all is about 13 feet; the length of the sole 3 feet 3 inches; the hight of the handles 3 feet 6 inches; and at the point of the beam 2 feet 4 inches.-J. S.]

(997.) [Not much need be said regarding the efficacy of subsoil-plowing. After what I have stated of the immense value of a mixture of impalpable matter, and larger particles, in the form of a porous mass, I need scarcely say that anything capable of increasing the depth to which this porosity extends, must of necessity be advantageous. This, however, does not show any differ

* See Sir James Graham's observations on the subject in vol. i. of the Journal of the Royal Agriculturel Society of England.

$(803)$ 
ence between subsoil and trench plowiug-in my opinion. the latter is the best in most instances, and this for the following reasons: All subsoils require ameliorating by exposure to air, before they are capable of acting beneficially to plants. This is owing to certain chemical changes which are produced by the joint action of air and water, and it is very evident that all these muat take place much more rapidly when the subsoil, as in trench-plowing, is laid upon the surface of the field, and freely exposed throughout the winter, than when the air is merely admizted more freely by the subsoil being broken up while it still remains under the surface. It may be averred that the trench-plow does not go so deep into the coil as the subsoil.plow ; but still I cannot help thinking that notwithstanding this disadvantage (if any such exists), it is in most cases the most advisable of the two methods, if employed for deepening the soil. Not so, bowever, if used to assist in draining the subsoil. To prove its value for this purpose, 1 would earnestly direct your attention to the following valuable remarks of Professor Johnston: "The sabsoil-plow is an auxiliary to the drain; in very stiff clay subsoils it is most advantageous in loosening the under lay. ers of clay, and allowing the water to find a ready escape downward, and to either side until it reach the drains. It is well known that if a piece of stiff clav be cut into the shape of a brick, and then allowed to dry, it will contract and harden-cut up while $t$ ret, it will only be divided into so many pieces, each of which will harden when dry, or the wbole of which will again attach themselves, and stick together if exposed to pressure. But tear is asunder vchen dry, and it will fall into many pieces, will more or less crumble, and will readily admit the air into its inner parts. So it is with a clay subsoil. After the land is provided with drains, the subsoil being very reten. tive, the subsoil-plow is ased to open it up-to let out the mater, and to let in the air. If this is not done, the stiff under-clay will contract and bake as it dries. but it will neither sufticiently ad. mit the air"-nor let ont the water-" nor open a free passage for the roots. But let this operation be performed when the clay is still too wet, a good effect will follow in the first instance; but after a while the cut clay will again cohere, and the farmer will pronounce subsoiling to be a useless expeuse upon has land. Defer the use of the subsoil plow till the clay is dry-it will then tear and break instead of cutting, and the openness will remain. Once give the air free access, and it, after a time. so modifies the drained clay, that it has no longer an equal tendency to cohere. Mr. Smith of Deanston very judiciously recommends that the subsoil.plow should necer be nsed till at least $a$ year after the land has been thoroughly drained. To attain those benefits which attend the adoption of improved methods of culture, . . let the practical man make his trial in the ways and with the precautions recommended by the author of the method, before he pronounce its condemnation."* Thus you perceive that subsoil-plowing, achen properly per. formed, will always be fouud usefal in assisting the action of drains, but cannot be considered equal to deep or trench plowing, if an alteration is desired in the depth of the soil.

(998.) Another alleged advantage of subsoiling is the breaking in pieces the moor-band pan. I will therefore now say a few words respecting this enemy to good farmers. This ferruginous deposit which so frequently occurs in particular localities between the soil and subsoil is extremely hard and compact, and almost completely impermeable to water. Very much has been written concerning this substance, by persens who have but little knowledge of chemistry, and in their endeavors to prove the manner in which the deposit had been produced, and likewise the cause of its injurious action upon vegetation when newly brought to the surface, have made so many chemical errors that the whole subject appears at first sicht wrapped in doubt, twhereas, we believe that for all practical purposes its nature is already sufficiently well known.

(999.) Monr-band pan belongs to a class of bodies known to chemists under the name of ochrey deposits. These deposits, which so frequently occur in the beds of chalybeate springs, were carefully examined by Berzelias in 1832. and were fonnd to consist of the two oxides of iron i , chemical combination with two new organic acids, which he denominated the crenic and apocrence acids. Feeling certain from various circumstances, that moor-band pan belonged to this class, I undertook an analysis to ascertain whether it contained these acids, and find that in each of two specimens of pan, sent to me for the purpose, there exists a large proportion of crenic acid, in one apocrenic also, and in the other humic acid: there can therefore be no longer any doubt abont the composition of this substance; and. instead of attempting to prove its injurioas effects by relating the difference between the protoxide and peroxide of iron. and the fact of the peroxide being generally combined with water forming hydrale, none of which facts throw the least light upon the subject, we can readily explain all by reference to the chemical properties of the compounds of these two acids with iron. It is well known that iron in solution acts injurinosly apen vegetation; and Berzelius has shown that the crenate and apocrenate of the protox. ide of iron are both soluble in waler; and that the same salts of the peroxide, although of them. selves insoluble, are easily rendered so by ammonia. which substance is always produced in fertile soil : it follows, therefore, that monr-band pan must continue injurious to vegetation so long os the crenates and aporrenates of iron remain undecomposed. In the course of time, various chemical changes are effected by the joint action of air and moisture, which decompose these com. pounds, and give rise to new ones having no injurious effect upon vegetation. $-\mathbf{H}$. R. M.]

\footnotetext{
- Johnston's Elements of Agricultural Chemistry.
} 


\title{
. DRAWING AND STORING TURNIPS, MANGEL-WURZEL, CABBAGE, CARROTS AND PARSNIPS.*
}

\author{
"Beneath dread Winter's level sheets of snow, \\ The sweet nutritious Turnip deigns to grow."
}

BLOOMFIELD.

(1000.) The treatment of live-stock receives early attention among the farm operations of winter; and whether they or land get the precedence depends entirely on the circumstance of the harvest having been completed late or early. If the harvest have been got through early, there is ample time to plow a large portion of stubble-land, in preparation of green crops in spring, before winter quarters are required to be provided for stock; but should it occupy all hands until a late period-that is, until the pas-

[* There are those who think, or affect to think, that nothing of practical Agriculture is to be learned, forsooth, by reading; while another class would maintain that it is all foolishness to read anything relating to the subject, except what may have a direct, immediate bearing on the objects and course of culture in which the reader is himself personally engaged. Such men treat as ridiculous the idea that a farmer should indulge in any curiosity about the crops which serve to make up the wealth, and the course of husbandry that constitutes the field practice of other States of their own country, much more those of foreign countries. Now we confess not to be, or to feel any ambition to be, a member of either of these classes. We confess to being well persuaded that to books we owe the creation and the spread of knowledge; and that the farmer who enter tains right notions of his own respectability, and true position in society, will surely desire to be familiar with the natural and commercial history of all the great staples that serve to employ the industry of mankind, not only in his own but in all countries. There is no reason, that is not insulting and derogatory, why the agriculturist should not possess as general information as he of any other business or pursuit; and, if even there were, it does not follow that he should not possess information as to all the great branches and products of his own profession, even though some of them may never come within the range of his own cultivation, and may even be forbidden, by considerations of climate or other circumstances, from being produced in his own State or country.

Take, for example, this chapter on Turnips, and the uses made of them in England. Every one at all acquainted with agricultural literature knows of how comparatively recent date is the introduction of them, especially in a field crop in England, even as late as the end of the seventeenth century; yet he who has any pretensions to familiarity with the industrial resonrces of the uation from which we sprung, and with which we have the most extensive and important relations, must know that the spread of this single root has had an influence beyond calculation, on the wealth and industry and power of Great Britain. With no great degree of exaggeration it has been said that her national power has its root in the turnip! Now suppose an American traveler, especially an agricultural one, through England, to return without baving made any observation as to the culture and uses of a crop thus influencing the destiny of a great nation ! What would be said of such a dolt? Since, then, all cannot travel who may desire it, is it not the great province of letters - of books - to take the next place, and do the office of traveling ? Too well do we know that there are those who will argue that because we do not and cannot rely on turnips, as the English do, to rear and fatten sheep and cattle-that climate, dearness of labor, want of capital to manure the land sufficiently, and want of the moisture indispensable to bring forward this crop, as well as the possession of Indian com and other crops better adapted to our climate and purposes, all forbid its cuiture to an extent sufficient to render it a great national object, all going to interdict turuip culture ; therefore it is out of place to admit a full exposition of this branch of English husbandry into an American work devoted to American Agricultare. The same cavilers might object that because turnips may never be with us a great staple crop, therefore it was superfluous and ill judged to occupy, in the last number, the little space which served to inform the reader that a good crop of English turnips, say twenty tons to the acre, $(805)$ 
tures have failed to supply stock with the requisite quantity of food-provision for their support should be made in the steading in preference to plowing land. The usual occurrence is, that the harvest is entirely cumpleted before the failure of the pasture; and, accordingly, I have described the methods of plowing the land before taking up the subject of winter treatment of live-stock; and in doing so, have included the plowing of lea after that of stubble-ground, in order to keep all the particulars of winter-plowing together, although the usual occurrence is, that the live-stock are snugly housed in the steading, and the stubble nearly all turned over, before the plowing of lea is commenced, unless there happen to be an old piece of lea to plow on strong land, in which case it should be turned over before the setting in of the winter's frost.

(1001.) Sheep always occupying the fields, according to the practice of this country, the only varieties of stock requiring accommodation in the steading in winter are cattle and horses. The horses consist chiefly of those employed in draught, which have their stable always at hand, and any young horses besides that are reared on the farm. Of the cattle, the cows are housed in the byre at night for some time before the rest of the

would extract and carry off 4,500 pounds of starch and sugar, 540 pounds of gluten, and 45 of oil. We are altogether-with all due deference to such wise and practical men-of a different opinion; and the question is, to which of the classes we have named does the reader belong? In this matter we go in for the "largest liberty." We would open wide to the mind of the young agriculturist the whole field of practical Agriculture in every country. If he is denied the pleasure and benefit of traveling, in person, to enlarge his mind by enlarged observation, there is the greater reason that he should travel in books. For what else was that enlightened observer, Mr. Colman, invited to visit and give us his "Personal Observations of European Agricalture," we would like to know? And what reader of any taste or ambition for knowledge would not rejoice as he reads them, to have been his compagnon de voyage? These are the views onder which we have published, and shall continue to publish, much that may never be put in practice, or that is not practicable in our country exactly in the way, either in detail or extent, that it is done in others. We even think that although a man might not make a pound or a barrel more, for example, of apples, or beets, or barley, or sugar, yet that if our country schools were patron. ized and conducted as they ought to be, and provided with masters as enlightened, because as voll paid and as much honored, as professors of the military art, not a boy would leave school without some knowledge of the native country and the constituent qualities and habits of these and of all other plants and animals. A little insight gained when young, would plant in him an appetite that would prompt to farther inquiry all his life, and the love of reading and research would take the place of sensuality and dissipation that idleness and even leisure moments always engender in men whose vacant minds are insensible to all thirst for knowledge or intellectual recreation. After all, there is one consideration from which we may take some comfort, oven under the mortification of differing from wiser heads, whom we would fain not only please but oblige in all things. No one is obliged to read that for which he has no taste, and from which he may think no advantage (money?) is to be derived; and 80 , in this casc, he who has no curiosity to know how the great branches of turnip and sheep husbandry are connected and carried on, where both constitnte great items in the resources of our great and powerful $m$ sther country, may pass over all that follows on these subjects, to ThE MoNTHLY Journal of AgriCULTURE, where fifty pages of matter await him, in such variety as that he must be hard to please if he cannot find something sufficiently practical and enlightened, were it even on sheep, in the able letters of our friend Mr. RANDALL, which promise to make readers the least familiar an conrant of that subject.

After all, we should be perfectly willing to leave it to the decision of any enlightened and liberat minded render to say whether even this chapter on turnips and sheep feeding does not possess moch intrinsic value and convey information both interesting and practically useful for all agricultural inquirers, except those great would-be monopolists of knowledge, who conccit themBelves to be, in the agricaltural, what the sun is in the natural world, the great fountain of light from which alone the least ray of information is to be derived.

With these explanations we shall be content for the future. (806)

Ed. Farm. Lib.] 
cattle are brought into the steading, in case the coldness of the autumnal dews and frosts should injure their milking properties; so that it is only the younger and feeding cattle that have to be accommodated, and of these the feeding are generally housed before the younger stock, which usually get leave to wander about the fields as long as they can pick up any food. I am only here describing what is the common practice, without remarking whether it is a good or bad one, as the whole subject of the treatment of cattle will very soon engage our attention.

(1002.) By the time the cattle are ready to occupy the steading, turnips should be provided for them as their ordinary food, and the supply at all times sufficient; and it should be provided in this way: The lambs of last spring, and the ewes which have been drafted from the flock as being too old or otherwise unfit to breed from any longer, are fed on turnips on the ground in winter, to be sold off fat in spring. The portion of the turnipground allotted sheep is prepared for their reception in a peculiar manner, by being drawn or stripped, that is, a certain proportion of the turnips is left on the ground for the use of the sheep, and the other is carried away to the steading to be consumed by the cattle. The reason for stripping turnips is to supply food to the sheep in the most convenient form, and, at the same time, enrich the ground for the succeeding crops by their dung, which is applied in such quantity as to prevent the ground being manured beyond what would be proper for the perfect development of the future crops; for it has been found that, were an entire good crop of turnips consumed on the ground, the yield of corn would be scanty and ill-filled. The usual proportion drawn, if a good crop, is $\frac{1}{2}$, but should the soil be in low condition, $\frac{1}{3}$ only is taken away, and should it be in fine condition, $\frac{2}{3}$ or even $\frac{3}{4}$ may be drawn; but, on the other hand, the quantity drawn is dependent upon the bulk of the crop. If the crop is very large, and the ground in very fine condition, $\frac{2}{3}$ may be drawn, but it is rarely the case that the soil is so rich and the crop so large as to make $\frac{1}{2}$ too great a proportion to be left to be consumed. If the crop is poor, $\frac{1}{3}$ only should be. drawn, and a very poor crop should be wholly eaten on, whatever condition the soil may be in. There is another consideration which materially affects the quantity to be left on the ground, which is the occurrence of a poor crop of turnips over the whole farm. Hitherto I have only been speaking of that part of the crop of turnips which is to be appropriated to the use of the sheep, but when the entire crop is bad, that is, insufficient to maintain all the stock fully, then the proportion to be consumed by the sheep and cattle respectively, should be determined at the commencement and maintained throughout the season, that neither class of stock may receive undue advantage. In such a case, it is evident that neither the sheep nor cattle can be fattened on turnips; and other expedients must be resorted to to fatten them, such as either the sheep or cattle should get as many turnips as will feed them, and the other be fed on extraneous matter, or both classes of stock be left in lean condition. When foreign matters for feeding-such as oil-cake-can be procured, the cattle should get the largest quantity of them, and the sheep the largest portion of the turnips ; because oil-cake can be more easily administered at the steading than turnips, and sheep, saving the trouble of manuring the ground afterward, can more easily be supplied with turnips. Thus, then, considerations of the state of soil and crop are required to determine the proportion of the turnip crop that should be drawn; but the standard proportion is $\frac{1}{2}$, and when that is deviated from it should only be from very urgent circumstances, such as those alluded to above.

(1003.) Fig. 208 shows how turnips are stripped in the various propor- 
tions noticed above. When $\frac{1}{2}$ is drawn, it can be done in various ways, but each not alike beneficial to the land; for example, it can be done by leaving 2 drills $a$ and taking away 2 drills $b$; or by taking away 3 drills $e$ and leaving 3 drills $f$; or by taking away 6 drills $i$ and leaving 6 drills $h$;

Fig. 208.
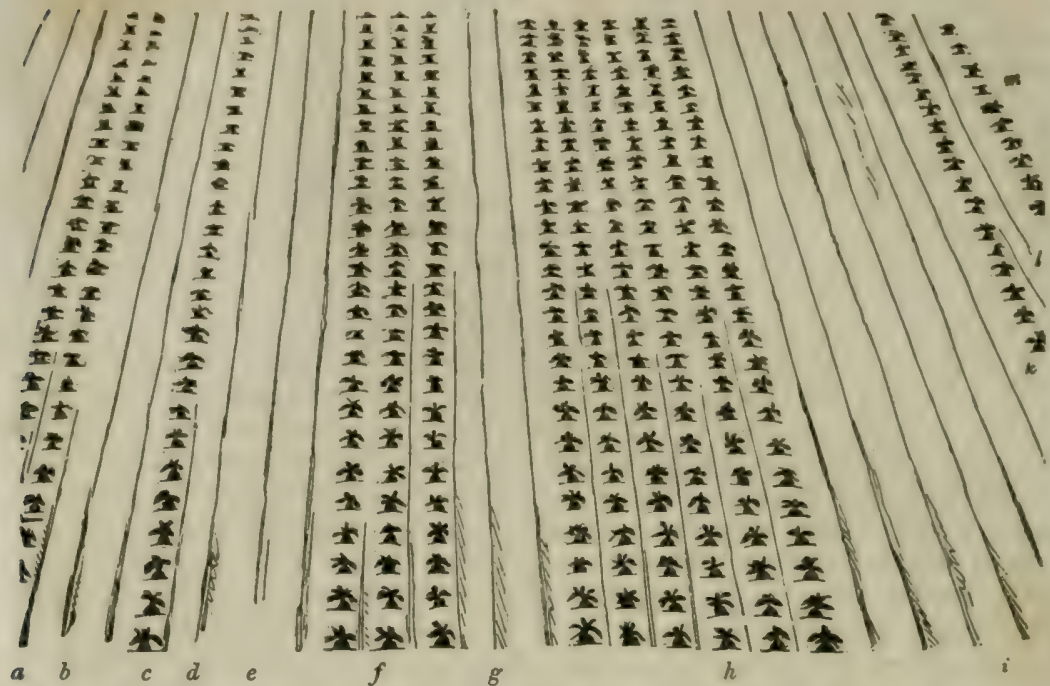

THE METHODS OF STRIPPING THE GROUND OF TURNIPS IN ANY GIVEN PRUPORTIONS

or by taking away 1 drill $l$ and leaving 1 drill $k$; and so on in every other proportion. Though the same result is attained in all these different ways, in so far as the turnips are concerned, there are cogent reasons against them all except the one which leaves 2 drills $a$ and takes away 2 drills $b$; because, when 1 drill only is left, as at $l$, the sheep have not room to stand and lie down with ease between $k$ and $m$, without interfering with the turnips, and, beside, sufficient room is not left for horses and cart to pass along $l$, without injuring the turnips on either side of the horses' feet or the cart-wheels; whereas, when 2 or more drills are pulled, as at $b$, and only 2 left, as at $a$, the sheep have room to stand and eat on either side of the turnips, and the cart can pass easily along $b$ without injuring the turnips; that is, the horse walks up the center hollow of the drills, and a wheel occupies a hollow on each side. Again, when 3 drills are left, as at $f$, and 3 taken away, as at $e$, the sheep injure the turnips of the two nutside rows to reach the middle one at $f$; and much more will they injure those at $h$, when 6 drills are left; and there is, besides, this serious objection to this latter mode, that when practiced on light soils it is observed that the succeeding grain crop is never so good on the ground that has been cleared as where the turuips are left. When other proportions are determined on, $\frac{1}{3}$ may be easily left, by pulling 2 drills, as at $b$, and leaving 1 , as at $c$; or $\frac{1}{4}$ may be left, by pulling 3 drills, as at $e$, and leaving 1 , as at $c$; or $\frac{3}{5}$ may be left, by pulling. 2 , as at $g$, and leaving 3 , as at $f$. There are thus various ways in which the same and different proportions of turnips may be pulled and left on the ground; but in whatever proportion they may be taken, the rule of leaving 2 empty drills for the horses and carts to pass along without injury to the turnips, should never be violated. 
(1004.) But the convenience and propriety of the plan of leaving 2 and taking 2 drills, when the $\frac{1}{2}$ of the crop is to be eaten on, will be best appreciated in witnessing the mode of doing it, as shown in fig. 209, where the drills are represented on a larger scale than in the preceding figure.One field-worker, being a woman, clears the 2 drills at $a$, and another simultaneously the other 2 at $b$; and in clearing these 4 drills, the turnips are thrown into heaps at regular distances, as at $c$ and $d$, among the standing turnips of the 2 drills $e$ and $f$, to the right of one woman and to the left of the other; and thus every alternate 2 drills left unpulled become the receptacle of the turnips pulled by every 2 women. The cart then passes along $a$ or $b$, without touching the turnips either in $e$ or $g$ on the one hand, or in $f$ and $h$ on the other, and it clears away the heaps in the line of $c d$. In the cut the furnips are represented thinner on the ground

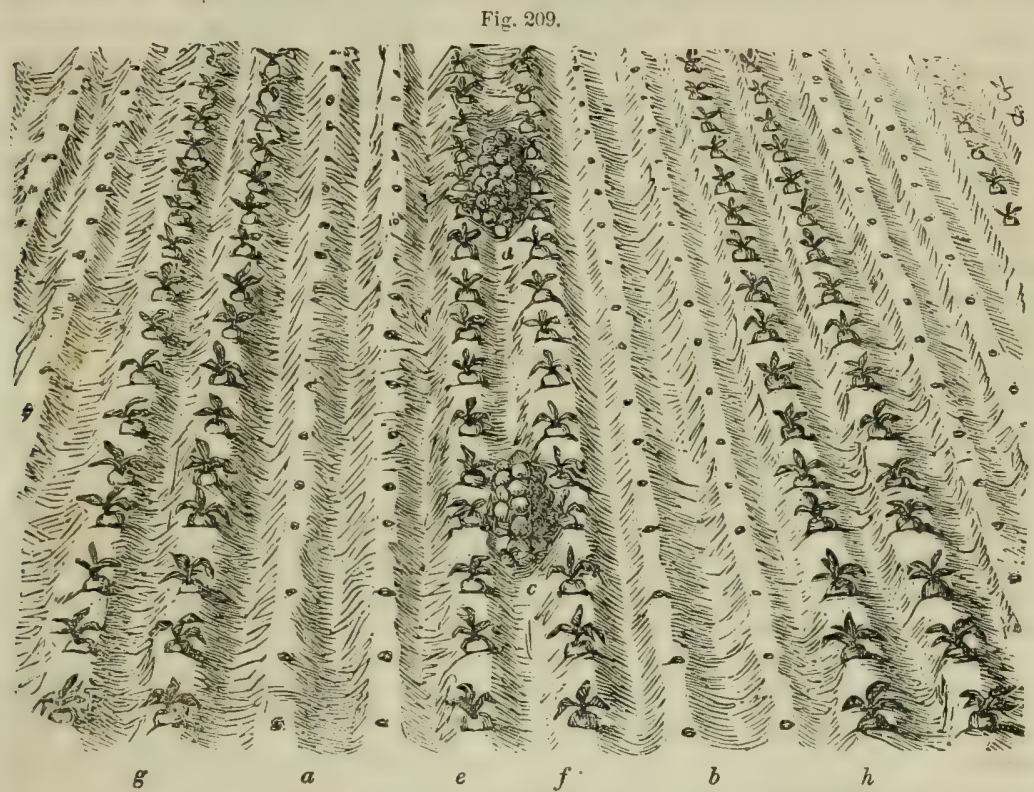

THE METHOD OF PULLING TURNIPS IN PREPARATION FOR STORING.

than they usually are, but the size of the bulb in proportion to the width of the drills is preserved both in the drills and in the heaps. The seats of the pulled turnips are shown upon the bared drills.

(1005.) The usual state in which turnips are thus placed in these temporary heaps, $c$ and $d$, is with their tops on, but the tails are generally taken away. The most cleanly state, however, for the turnips themselves, and the most nutritious for cattle, is to deprive them of both fops and tails.Many, and indeed I may say most farmers are impressed with the idea that tops of turnips make good feeding at the beginning of the season and especially for young beasts. The notion is quite a mistaken one, in regard to the feeding qualities of tops at any season, for there is really no such property in them. No doubt at that season they contain a large quantity of watery juice, which makes cattle devour them with avidity on coming into the steading off bare pasture, and they will even be eaten off before the turnips themselves are touched, when both are presented together; but observation and experience confirm me in the opinion that the time (809) 
bestowed by cattle in consuming the turnip-tops is worse than so much valuable time thrown away; inasmuch as, in their cleanest state, tops are apt to produce a looseness in the bowels, arising partly, perhaps, frum the sudden change of food from grass to such a succulent vegetable; and the complaint is much aggravated by the dirty, wetted, or frosted state in which they are usually given to beasts. This looseness never fails to bring down the condition of cattle so much that a considerable part of the winter passes away before they entirely recover from the shock which their system has thus received. Like my neighbors, I was impressed with the economic idea of using turnip-tops-and I believe it is solely as regards economy, rather than a conviction of their utility, that prompts farmers to continue their use-but their weakening effects upon cattle, especially young ones, caused me to desist from their use; and fortunate was the resolution, for ever aftes their abindonment my cattle throve better and the tops, after all, were not thrown away, as they served to assist the manuring of the field on which they had grown. I have no besitation, therefore, in recommending you to deprive the turnips of both tops and tails before carrying them to the steading for the use of cattle. Sheep are not so easily injured by them as cattle, on account, perhaps, of their costive habit; and perhaps in spring, when turnips are naturally less juicy, tops might be of service to them as a gentle aperient, but then, when they might be most useful, they are the most scanty and fibrous.

(1006.) The tops and tails of turnips are easily removed by means of a very simple instrument. Figs. 210 and 211 represent these instruments, fig. 210 being formed from a portion of an old scythe reaping-hook, with a piece of the point broken off. This is a light instrument, and answers the purpose pretty well; but fig. 211 is still better. It is made of the point of a worn patent scythe, the very point being broken off, and the iron back to which the blade is riveted is driven into a helve, provided with a ferule around the end next the blade. This is rather heavier than the other instrument, and on that account removes the top more easily.

(1007.) The mode of using these instruments in the removal of the tops and tails

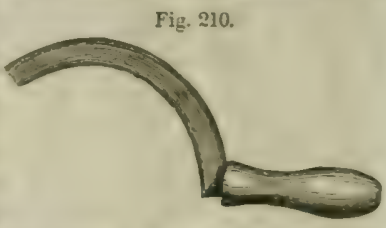

STTRUMENT FOR TOPPING AYD TAILING TURNIPS, MADK OF PART OFAN OLD SCYTHE REAPING-HOOK.

\section{Fig. 211.}

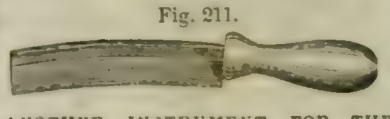

ANOTHER INSTRCMENT FOR THE SAME PLRPOSF, MADE OF A PIECE OF OID PATENT SCYTHE.

of turnips is this. The field-worker moves along between the two drills of turnips which are to be drawn, as from $a$, fig. 209, and pulling a turnip with the left hand by the top from either drill, holds the hulb in a horiznntal position, as represented in fig. 212 , over and hetween the drills $e$ and $f$, fig. 209, and with the hook or knife described above (1006), first takes off the root at $b$ with a small stroke, and then cuts off the top at $a$, between the turnip and the hand, with a sharper one, on which the turnip falls down into the heap $c$ or $d$, whichever is forming at the time. Thus, pulling une or two turnips from one drill, and then as many from the other, the two drills are cleared to the extent desired. Another fieldworker acts as a companion to this one, by going up $b$, pulling the turnips from the drills on either side of her, and dropping them, topped and tailed, into the same heaps as her companion. The tops are scattered over the cleared ground. A left and a right-handed field-worker get on best together at this work.

(1008.) Due care is requisite, on removing the tops and tails, that none 
of the bulb be cut by the instrument, as the juice of the turnip will exude through the incision. Of course, when turnips are to be consumed immediately, this precaution is less necessary; but the habit of slicing off a part or hacking the skin of the bulb indicates carelessness, and should be avoided at all times.

Fig. 212.

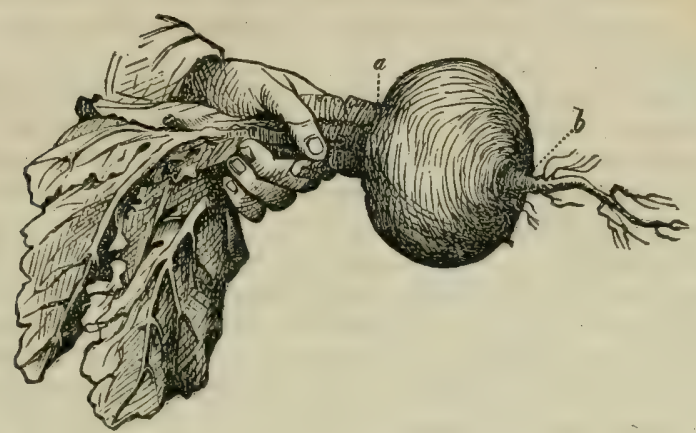

- MODE OF TOPPING AND TAILING TURNIPS.

(1009.) When $\frac{2}{3}$ of the turnips are drawn and $\frac{1}{3}$ left, the field-worker goes up at $b$, fig. $20 \mathrm{~s}$, and, pulling the 2 drills there, drops the prepared turnips between $c$ and $d$, beyond the drill $c$ that is left. When $\frac{3}{4}$ are pulled, as at $e$, and $\frac{1}{4}$ left on the ground, as at $c$, the turnips may still be dropped in the same place between $c$ and $d$, the field-worker pulling all the 3 drills herself, and the horse walking along from $e$ when taking them away. When 3 drills are pulled, as at $e$, and 3 left, as at $f$, which is not so good a plan of leaving the $\frac{1}{2}$ as the 2 and 2 I have described before (1003), the same field-worker pulls all the 3 drills, and drops the turnips along the outside row next herself of those that are left. When $\frac{3}{5}$ are left, as at $f$, and $\frac{2}{5}$ pulled, as at $g$, the field-worker goes up, pulling the 2 drills there, and dropping the turnips between the two rows next her of $f$. When 6 drills are pulled, as at $i$, which is not a good plan for leaving the $\frac{1}{2}, 3$ women work abreast, each pulling 2 drills, and all three drop the turnips into the same heap before the woman in the middle. This plan has the sole advantage of collecting a large quantity of turnips in one place and causing little carting upon the land. When the field is intended to be entirely cleared of turnips, the clearance is begun at the side nearest the gate, and carried regularly on from top to bottom of the field, the nearest part of the crop being taken when the weather is least favorable and the farthest when most so.

(1010.) These last remarks remind me of mentioning that when a field is begun to be stripped for sheep, that part should be chosen which will afford them shelter whenever the weather proves inauspicious. A plantation, a good hedge, a bank sloping to the south, or one in the direction opposite to that from which winds most prevail in the locality, or any marked inequality in the form of the ground, will afford shelter to sheep in case of necessity. On the sheep clearing this part first, it will always be ready for a place of refuge should it be required for protection against a storm. The utility of such shelter you shall be made acquainted with very soon.

(1011.) On removing prepared turnips from the land, the carts should ve filled by the field-workers, as many being employed as to keep the carts (811) 
going, that is, to have one filled by the time another approaches the place of work in the field. If there are more field-workers than will he required to do this, the remainder should be employed in topping and tailing. The topped and tailed turnips should be thrown into the carts by the hand, and not pricked by means of forks or graips; the cart should be placed alongside the drill near two or more heaps; and the carter should manage the horses and assist in the filling, until the turnips rise so high in the cart as to require from him a little adjustment in heaping, to prevent their falling off in the journey.

(1012.) As it is scarcely probable that your field-workers will be so numerous as to top and tail and assist in filling at the same time, so as to keep even 2 carts at work, it will be necessary for them to hegin the pulling so much sooner, whether one yoking, or a whole day, or two days, but so much sooner, according to the bulk of the crop, as to keep the carts going when they begin to drive away the turnips; for it at all times implies bad management to let horses wait longer in the field than the time occupied in filling the cart. And yet how common an occurrence it is to see horses waiting until the turnips are pulled and tailed and thrown into the cart by perhaps only 2 women, the carter building them up not as fast as he can get them, but as slow as he can induce the women to give them ! The driving away should not commence at all until there is sufficient quantity of turnips prepared to employ at least two carts one yoking : and, on the other hand, care should be taken not to allow more turnips than will employ that number of carts for that time to lie upon the ground before being carried away, in case frost or rain should prevent the carts entering the field as long as to endanger the quality of the turnip.

(1013.) Dry weather should be chosen for the pulling of turnips, not only for the sake of cleanliness to the turnips themselves, lut for the sake of the land, which should be cut up and poached by cart-wheels and horses' feet as little as possible; because, when land is much cut up in carrying away turnips, sheep have a very uncomfortable lair, the ruts forming ready receptacles for water, and are not soon emptied. No doubt thoroughdraining assists to make land proof against such a condition; lut let the land be ever so well drained, its nature cannot thereby be entirely changed -clay will always have a tendency to retain water on its surface and soil everything that touches it, when wetted by recent rains; and deep loam and black mould will still be penetrated hy horses' hoofs, and rise in large masses with wheels immediately after rain. No turnips should therefore be led off fields consisting of these sorts of soils, however well drained, immediately after or during severe rain; nor should they be pulled at all, until the ground has again become consolidated.

(1014.) In commencing the pulling of turnips, one of the ficlds intended to support sheep should first be taken, in order to prepare space for them and this is done while all the stock are engaged on pasture, which should not be hared too much, in case the sheep that are to be fed off on turnips fall off in condition upon it.

(1015.) Should the weather prove unfuvorable at the heginning of the season - that is, too wet or too frosty-there should no more turnips be pulled and carried than will suffice for the daily consumption of the catte in the steading; but whenever the ground is dry and firm and the air fresh, no opportunity should be neglected except from other more important operations-such as the wheat-secd-of storing as large a quantity as the time will permit, to be used when the weather proves interruptive to field operations. This is a very important matter, and, as I conceive, much neglected by most farmers, who too frequently place their cattle from (812) 
hand to mouth for food. A very common practice is to employ one or two carts an afternoon's yoking, to bring in as many turnips as will serve the cattle for two or three days at most, and these are brought in with the tops on, after much time has been spent in the field in waiting for the pulling and tailing of the turnips. This slovenly mode of providing provender for cattle should be abandoned. It should be considered a work of the first importance in winter to provide cattle with turnips in the very best condition, independent of the vicissitudes of the weather; and this can only be done by storing a considerable quantity of them in good weather, to be used when the wcather changes to a worse state. When a store is nnce made, the mind becomes easy under the certainty of having, let the weather prove ever so unpropitious, plenty of good food provided at home for the cattle, and having such a provision does not prevent you taking supplies from the field as long as the weather permits the ground to be carted upon with impunity, to be immediately consumed or to augment the store. How much better for all parties-for yourself, for men, horses and cattle-to be always provided with plenty of turnips, instead of being obliged to go to the field for every day's supply, and perhaps under the most uncomfortable circumstances! I believe few farmers would refuse their assent to this truth; and yet, how many violate it in their own practice! The excuses usually made for pursuing the ordinary practice are, that there is no time to store turnips when the potato-land should be plowed up and sown with wheat; that the beasts are yet doing well cnough upon the pasture; and that it is a pity to pull the turnips while they continue to grow. It is proper to bestow all the time required to plow and sow the potato-land; and, after a late harvest, these may have to be done after the pasture has failed; but such an occurrence as the last being the exception to the usual condition of the crops and seasons, ought not to be adduced as an excuse applicable at all times; and as to the other excuses, founded upon the growing state of the turnips and the rough state of the pastures, they are of no force when adduced in compensation for the risk of loss likely to be incurred by a low condition in the stock. Rather than incur such a risk, give up the rough pasture to the sheep, or delay the working and sowing of the potato-land, or sacrifice a portion of the weight of a small part of the turnip crop by pulling it before reaching entire maturity. As for sheep, they are never at a loss for food, being constantly surrounded with turnips as long as the ground is bare.

(1016.) The storing of turnips is very well done in this way: Let a piece of lea ground, convenient of access to carts, be chosen near the steading for the site of the store, and. if that be in an adjoining field, on a 15 -feet ridge, so much the better, provided the ridge runs N. and S. Fig. 213 represents the form of the turnip-store. The cart with the topped and tailed turnips is backed to the spot of the ridge chosen to begin the store, and there emptied of its contents. The ridge being 15 feet wide, the store should not exceed 10 feet wide at the bottom, to allow a space of at least $2 \frac{1}{2}$ feet on each side toward the open furrow of the ridge, for the fall and conveyance of water. The turnips may be piled up to the hight of 4 feet, but will not easily lie to 5 feet on that width of base. In this way, the store may be formed of any length; but it is more desirable to make two or three stores on adjoining ridges than a very long one on the same ridge, as its farthest end may be too far removed for using a wheel-barrow to remove the stored turnips. Assorted straw, that is, drawn out lengthwise, is put from 4 to 6 inches thick above the turnips for thatch, and kept down by means of straw-ropes, arranged lozenge-shaped, and fastened to pegs driven in a slanting direction in the ground, along the base of the straw, 
as may be distinctly seen in the figure. Or a spading of earth, taken out of the furrow, may be placed upon the ends of the ropes to keep them down. The straw is not intended to keep out either rain or air-for both are requisite to preserve the turnips fresh-but to protect them from frost,

\section{Fig. 213.}

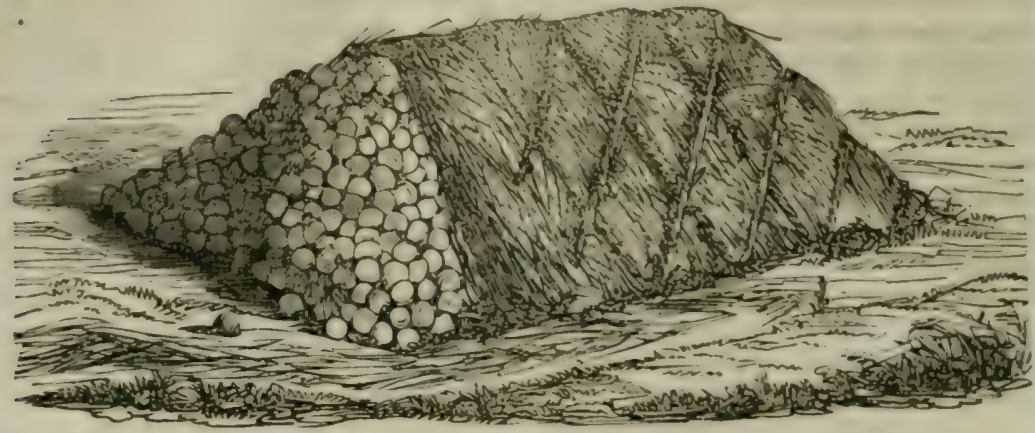

THE TRIANGULAR TURNIP-STORE.

which causes rottenness, and from drouth, which shrivels turnips. To avoid frost the end, and not the side, of the store should be presented to the north, whence frost may be expected to come. If the ground chosen is so flat, and the open furrows are so nearly on a level with the ridges as that a dash of rain would overflow the bottom of the store, a furrow-slice should, in that case, be taken out of the open furrows of the ridges with the plow, or a gaw-cut made with the spade, and the earth used to keep down the ropes.

(1017.) When the turnips are to be used from the store, the straw on the south end is removed, as seen in fig. 213 , and a cart, or the cattle-man's capacious, light wheel-barrow, backed to it; and, after the requisite quantity for the day has been taken out, it should be replaced over the mouth of the store.

(1018.) Some people evince a desire to place the turnip-store in the stack-yard, on account, perhaps, of the straw; hut there is not likely to be sufficient room, especially at the beginning of winter, for the turning of carts in an ordinary-sized stack-yard. I have seen tumips stored up between two stacks, in the early part of the season, but only as a temporary expedient, when there was a scarcity of straw.

(1019.) This is not the only form of store that will preserve turnips fresh and good for a considerable time. I have seen turnips heaped about 3 feet in hight, quite flat on the top, and covered with loose straw, keep very well. Other plans have been devised and tried, such as to pull them from the field in which they have grown, and set them upright with their tops on in another field, in a furrow made with the plow, and then cover the bulbs with the next furrow-slice; and another plan is to pull the turnips as in the former case, and carry them to a bare or lea field, and set them upright beside one another, as close as they can stand, with their tops and roots on. No doubt both these latter plans will keep turnips fresh enough, and an area of 1 acre will, by these methods, contain the growth of 4 or 5 acres of the field in which they had grown; but turnips are certainly not 80 secure from frost in those positions as in a store; an. after the trouble of lifting and carrying them has been incurred, it would be as easy to take them to a proper store at once, where they would be $(814)^{2}$ 
near at hand, and save the farther trouble of bringing them again from the second field. And even if they were so set in a field adjoining the steading, they would occupy a much larger space than any store. Objectionable as these plans are, compared to triangular or flat-topped stores, they are better than storing turnips in houses, where they never fail to sprout on the top and become rotten at the bottom of the bin. Piling them against a high wall, and thatching them like a to-fall, preserves them very little better than in an outhouse. Stored in close houses, turnips never fail to rot at the bottom of the heap; and the heat engendered thereby not only endangers the rest of the heap, but superinduces on its surface a premature vegetation, very exhausting to the substance of the bulbs. Turnips put into pits dug in the ground, and covered with earth, have failed to be preserved. A plan has been recommended to drive stakes $2 \frac{1}{2}$ feet high into the ground, and wattle them together with brushwood, making an inclosure of 3 sides, in the interior of which the turnips are packed, and piled up to a point, and thatched, like the store in fig. 213 ; and the turnips are represented as keeping fresh in such a structure until June; and one advantage attending this plan is said to be, that "where room is rather limited in the rick-yard, one pile of this description will contain 3 times as much as one of those placed on the ground of a triangular shape; and the saving of thatch is also considerable."* But, as it appears to me, the providing of stakes and the trouble of wattling around an inclosure will far more than counterbalance any advantage of space or saving of straw for thatch, compared with the mode I have described in fig. 213; and besides all these inconveniences attending the plan, there is no necessity whatever for having a turnip-store in a rick-yard.

(1020.) With regard to storing mangel-wurzel, this plan seems unexcep tionable. "It should be stored early in November. The best and cheapest mode is to build it up against some high wall, contiguous to your beasts' sheds, not more than 7 or 8 feet deep, carried up square to a certain hight, and then tapering in a roof to the top of the wall; protect the sides with thatched hurdles, leaving an interval between the roots and the hurdles, which fill up with dry stubble (straw); cover the roof with about 1 foot of the same, and then thatch it, so as to conduct all moisture well over the hurdles placed as a protection to the sides. In pulling the plants, care should be taken that as little injury be inflicted upon them as possible. Cleansing with a knife should on no account be permitted, and it is safer to leave some of the leaf on, than, by cutting it too close to impair the crown of the root. The drier the season is for storing the better; although I have never found the roots decayed in the heap by the earth, which, in wet weather, has been brought from the field adhering to them." $\dagger$ Carrots may be stored exactly in the same manner, and so may parsnips. Cabbages are stored by being soughed into the soil, or hung up by the stems, with the heads downward, in a shed. As cabbages are very exhausting to the soil, the plants should be pulled up by the roots when they are gathered, and the stems not merely cut over with a hook or knife, because they will sprout again.

(1021.) All these modes of storing turnips apply to all the varieties of the root usually caltivated, and which are much more numerous than necessary. Mr. Lawson enumerates and describes no fewer than 46 varieties cultivated in the field; namely, 11 of Swedes, 17 of yellow, and 18 of white, the color names being derived as much from the color of the flesh as that of the skin. One kind from each of these classes seems al-

* Journal of the Royal Agricultural Society of England, vol. ii.

† Lawson's Agriculturists' Manual, and Supplement. (815) 
most requisite to be cultivated on every farm, although the yellow is omitted in some districts, and the Swedes in others. Where Swedes are omitted, they have never been cultivated, and where the yellow is the favorite, the Swedes are unknown; for where they are known their culture is never relinquished, and their extension is treading hard upon the yellow, and even curtailing the boundary of the white. The white varieties come earliest into use, and will always be esteemed on account of their rapid growth and early maturity, though unable to withstand the severest effects of frost. It is they which first support both cattle and sheep, being ready for use as soon as the pasture fails; and in storing them, only such a quantity should be prepared as will last to the end of the year. The yellows then follow, and last for about 2 months, that is, to the end of February or thereabout; and the same rule of storing a quantity for a specified time is followed in regard to them as with the whites. Then the Swedes finish the course, and should last until the grass is able to support the cattle, that is, to the end of May, or beginning of June, to which time they will continue fresh in store, if stored in proper time and in the manner recommended above; and the most proper time for storing them is before any vegetation makes its appearance on them in spring, which is generally about the end of March or beginning of April.

(1022.) Of all the 18 varieties of white turnips, I should say that the White Globe (Brassica rapa, depressa, alba, of De Candolle) a, fig. 214,

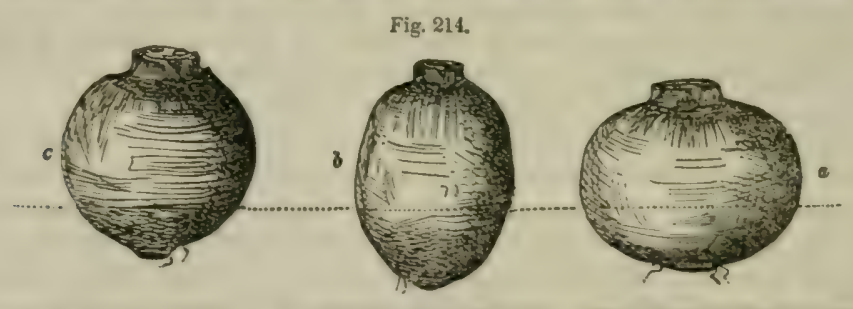

THE WHITE GLOBE TURNIP.

THE PORPLE TOP SWEDISH TURNIP.
THE ABERDEENSHIRE YELLOW BULLOCK TURAIP.

is the best for early maturity, sweetness, juiciness, size of root, weight of crop, and elegance of form. Its form is nearly globular, as its name indicates; skin smooth, somewhat oily, fine, and perfectly white; neck of the top and tap-root small; leaves long (frequently 18 inches), upright, and luxuriant. Though the root does not feel particularly heavy in the hand, it does not emii a hollow sound when struck; its flesh is somewhat firm, fine-grained, though distinctly exhibiting fibres radiating from the center; the juice easily exudes, and the rind is thin. Its specific gravity was determined by Dr. Skene Keith at 0.840 ; and its nutritive properties by Sir Humphry Davy, at 42 parts in 1,000 ; of which were, of mucilage 7 , of sugar 34 , and of albumen or gluten 1." Mr. Sinclair mentions this remarkable fact in regard to the white turnip, that the quantity of nutritive matter contained in different roots of the same variety varies according to the size and texture of their substances. Thus, a root of the white-loaf turnip, measuring $\tau$ inches in diameter, afforded only $72 \frac{1}{2}$ grains; while the same quantity of a root which measured only $t$ inches, afforded 80 grains." So he forms this important conclusion, that "the middle-sized roots of the common turnip are therefore the most nutritious." $\dagger$

(1023.) I suspect that our crops of white globe turnip ordinarily consist

- Dary's Agriculrural Chemistry, edition of 1839.

† Sinclair's Hortus Gramineus iV uburnensis, edition of 1824.

(816) 
of middle-sized bulbs, or they contain many blanks, as the following statement tends to show. Taking the distance between the turnips at 9 inches -being that at which white turnips are usually thinned out-and taking the distance between the drills at 27 inches-the usual one-these distances embrace an area of 243 square inches of ground for each turnip. On each turnip occnpying that area, there should be 25,813 turnips per acre imperial; and taking 30 tons per acre as a fair crop, each turnip will weigh nearly $1 \mathrm{lb} .1 \mathrm{oz}$.! Now, in an ordinary crop of white-globe turnips it is not beyond the truth to take them at 6 inches in diameter overhead; and having the specific gravity of white turnip as mentioned above, a 6 -inch turnip should weigh 6 lbs., and the crop of course be, per acre, 69 tons $2 \mathrm{cwt}$., instead of 30 tons. The inevitable conclusion is, either that blanks, to the enormous extent of being able to contain 39 tons $z$ cwt. of turnips per acre, occur in the ordinary crops of white globes-that is, the number on the acre is only 9,445 turnips, instead of 25,813 ; or the average distance between the turnips may be 20 inches instead of 9 . When actual results fall so very far short of anticipation, the important and interesting inquiry arises, Whether the great deficiency is occasioned by the death of plants after the singling process has been completed? or the average size and weight of each turnio are much less than we imagine? or the distance left by the singling is greater than we desire?-or from all these causes combined? From whichever of these causes, singly or combined, the result arises, it is worthy of serious investigation by the farmer; for the bulk of the crop may really depend more on these less obviuus circumstances than on the mode of culture. Let us see.

(1024.) Weights and sizes of turnips have already been ascertained with sufficient accuracy. The white globes exhibited at the Show of che Highland and Agricultural Society at Inverness in October, 1839, gave a girth varying $28 \frac{1}{2}$ to 34 inches, and a weight varying still more-from 8 lbs. to $15 \frac{1}{2}$ lbs. each root; so that 3 roots of the same girth of $30 \frac{1}{2}$ inches, varied in weight respectively $8 \mathrm{lbs}$., $9 \frac{3}{4} \mathrm{lbs}$., and $14 \frac{1}{2} \mathrm{lbs} .{ }^{*}$ After the statement of these facts, our surprise at realization falling so far short of expectation may be moderated; for we see crops, of apparently the same bulk, weigh differently: and turnips growing on the same field exhibit different fattening properties; and different localities produce turnips of different bulk. Whence arise these various results? These weights are by no means the utmost to which this turnip attains, examples occurring in some seasons of weights from $18 \mathrm{lbs}$. to $23 \mathrm{lbs}$. ; $\dagger$ and I have pulled one from among Swedes, weighing $29 \mathrm{lbs}$., including the top.f From 30 to 40 tons per imperial acre is a good crop of this kind of turnip.

(1025.) Of the yellow turnip, Mr. Lawson has described 17 varieties, of which perhaps the greatest favorite is the green-top Aberdeen Yellow Bullock (Brassica rapa, depressa, flavescens, of De Candolle). This is a good turnip, of the form of an oblate spheroid, as seen at $c$, fig. 214; color of the skin below the ground, as well as of the flesh, a deep yellow orange, and that of the top bright green. The leaves are about 1 foot long, dark green, rather soft, spreading over the bulb, and collected into a small girth at the top of the turnip; the tap-root small. Its specific gravity, as determined by Dr. Keith, is 0.940 ; and its nutritive property, according to Sinclair, is 44 in 1,000 parts, of which $4 \frac{3}{4}$ are of mucilage, $37 \frac{3}{4}$ of sugar, and $1 \frac{1}{2}$ of bitter extract or saline matters. This root feels firm and heavy

\footnotetext{
* Quarterly Journal of Agriculture, vol. $x . \quad$ † Lawson's Agriculturist's Manual.
1 The Norwich Mercury, of July. 1841, makes mention of a turnig-a white one, we presume-exbibited

* Quasterly Journal of Agriculture, vol. x. † †awson's Agriculturist's Manual.
1 The Norwich Mercury, of July. 1841, makes mention of a turnit-a white one, we presume-exbibited at Pakenham market, and sent from Van Diemen's Land in strong brine, which weighed $84 \mathrm{lbs}$, having a girth of 5 feet 2 inches. It is said to have weighed $92 \mathrm{lbs}$. when pulied.
$(865) \ldots \ldots .28$
} 
in the hand, with a skin smooth and fine, flesh firm, but not so juicy, no the rind so thin as the globe.

(1026.) Selected specimens exhibit a circumference of the larger diameter of from 27 to 30 inches, which vary in weight from $6 \mathrm{lbs}$. to $8 \frac{1}{2}$ lbs. each, but specimens may he found weighing as much as from 9 to 11 lbs., and those of the same diameter sometimes show a difference of $1 \mathrm{lb}$. in weight : yellow turnips seldom yield so heary a crop as either the globe or Swedes, 30 tons the imperial acre being a good crop; but their power of fattening is greater than that of white turnips. In some parts of the kingdom, they are grown in preference to Swedes, especially where light soils predominate; but from my own experience in raising Swedes on the driest gravelly soil, of a superior description to the yellow, I believe that if Swedes always received the sort of culture they require, they would in every soil exceed the yellows in weight and nutrition; and a strong proof of the soundness of this opinion may be found in the rapid inroads which they have of late years made, and are making, upon the confines of the yellows.

(1027.) Of the 18 varieties of the Swedish turnip described by Mr. Lawson, the Purple-Top (Brassica campestris, napo-brassica, rutabaga, of De Candolle, has long obtained the preference, and certainly if weight of crop, nutritious property, and durability of texture are valuable properties in a turnip, none can exceed the Swedes. They are of an oblong form, as seen at $b$, in fig. 214 , having the color under ground and of the flesh a deep yellow orange, and the upper part above the ground a dusky purple. The leaves are about 1 foot long, standing nearly upright, of a bluish green color, and growing out of a firm conical base, which forms the neck of the bulb. The skin is somewhat rough, the rind thicker than either of the two former sorts of turnip, and the flesh firm. This turnip feels heavy and very hard in the hand. According to Dr. Kieith, the specific gravity of the yellow Swede is 1,035 , and of the white 1,022 , and Sir Humphry Davy estimates its nutritive property at 64 in 1,000 parts, of which 9 are starch, 51 sugar, 2 gluten, and 2 extract. Dr. Keith states that he found the Swedish turnip heaviest in April, at the shooting out of the new leaves, and that after its flower stem is fairly shot in June, the specific gravity of the root decreases to 0.94 , that exactly of the yellow turnip. This fact shows the relative values of those turnips, and also of the time in spring, namely, before April, for storing the Swedes, after which they should not remain in the ground in a growing state. As Sir Humphry experimented on Swedish turnips grown in the neighborhood of London, where they are confessedly inferior to those in the northern coun ties, his results as to their nutritive properties may be considered below the true mark.

(1028.) Picked specimens have exhibited a girth of from 25 to 28 inches, varying in weight from 7 lbs. to $9 \frac{1}{2} \mathrm{lbs}$., but the weight of this, like all other turnips, is not in proportion to the bulk, as a 25 -inch one gave a weight of $9 \frac{1}{2}$ lbs., while one that measured 26 inches only weighed $7 \mathrm{lbs}$. It is not an uncommon thing, however, to see them from $8 \mathrm{llhs}$. to $10 \frac{1}{2} \mathrm{llhs}$. A crop of from 16 to 20 tons may be obtained by very ordinary culture, but in the neighborhood of large towns, such as Edinburgh, from 28 to 34 tons are obtained on the imperial acre I have heard of 50 or 60 tons boasted of, but suspect that such weights had been calculated for the whole field from very limited and selected spots; nevertheless, a large and equal crop will sometimes be ohtained, under favorable circumstances, for I remember seeing a crop of 50 acres within the policy of Wedderburn, Berwickshire, in 1815, then farmed by Mr. Joseph Tod, Whitelaw, $(866)$ 
on traversing which I could not detect a single turnip of less apparent size than a man's head. The crop was in no part weighed, but it was let to be consumed by cattle and sheep, the half being eaten off by wether sheep at 6 d. a head per week, and realized $£ 21$ per imperial acre! Taking a man's head at 7 inches in diameter, and the specific gravity of a Swedish turnip at $1 \cdot 035$, the weight of each turnip should have been $11 \frac{1}{2} \mathrm{lbs}$, and taking 19,360 turnips per acre, at 12 inches apart, the distance at which Swedish turnips are singled, and 27 inches wide in the drill, the weight of the crop should have been 99 tons 7 cwt. Taking the calculation in another form, let us see the result of $£ 21$ at 6 d. a head per week. That gives 32 sheep to the acre, and taking Mr. Curwen's estimate of a sheep eating 24 lbs. a day, exclusive of 4 lbs. a day of waste, for 180 days, or half a year, the weight of crop by this method should have been 61 tons $14 \mathrm{cwt}$. Statements, however, regarding the quantity of turnips eaten by sheep are various. One given by Sir John Sinclair is a consumption of 21 acres of 44 tons each, by 300 sheep in 180 days, or half a year, which gives 38 lbs. a day for each sheep.* If we take this allowance of 38 lbs. the crop mentioned above should have weighed 85 tons 1 cwt. to have paid £21 per acre! The usual allowance is 16 young sheep to the ordinary acre of 30 tons, which is $23 \frac{1}{3} \mathrm{lbs}$. a day to each, and 10 old sheep, which is $37 \frac{1}{3} \mathrm{lbs}$. to each, and both are probably near the truth; but the exact consumption of food by live-stock is a subject worthy of experimental investigation.

(1029.) The proportion of the top to the ront is less in the Swedish than in other sorts of turnips, as evinced in the experiments of Mr. Isaac Everett, South Creake, Norfolk, which, on a crop of Swedes grown at 18 inches, and 27 inches apart in the rows, of an average of 17 tons 9 cwt., gave 3 tons $3 \mathrm{cwt}$. of tops, on the 15 th December, after which they were not worth weighing; and while mentioning this experiment, I may advert to a fact derivable from it, that tops are lighter in a crop raised on drills than one in rows on the flat surface; that is, while, in the above case, 28 tons $8 \mathrm{cwt}$. of tupped and tailed turnips afforded only 5 tons $10 \mathrm{cwt}$. of tops from the drilled land, those from the rows on the flat surface yielded 6 tons $16 \mathrm{cwt}$. from a crop very little heavier, namely, 28 tons $16 \mathrm{cwt}$.

(1030.) The yellow turnip will continue fresh in the store until late in spring, but the Swedes have a superiority in this respect to all other turnips. The most remarkable instance I remember of Swedes keeping in the store, in a fresh state, was in Berwickshire, on the farm of Whitsome Hill, when in the possession of $\mathrm{Mr}$. George Brown, where a field of 25 acres of excellent Swedes was pulled, rooted, and topped, and stored in the manner already described, in fine dry weather in November. This extensive storing was undertaken to have the field sown with wheat. The store was opened in February, and the cattle partook of the turnips and continued to like them until the middle of June, when they were sold fat, the turnips being then only a little sprouted, and somewhat shriveled, but exceedingly sweet to the taste. There is a property possessed by the Swedish turnip which stamps a great value upon it as a root for feeding stock, which is, the larger it grows the greater quantity of nutritive matter it contains. According to Sinclair, 1,72S grains of large-sized Swedes contained 110 grains of nutritive matter, whereas small-sized ones only yielded 99 grains, $\nmid$ affording a sufficient stimulus to the farmer to raise this valuable root to the largest size attainable.

(1031.) A comparative view of the specific gravity and nutritive proper-

* Sinclair's Account of the Husbandry of Scot'and, vol. di., Aupendix.

† Sinclair's Hortus Graminens WW sburnensis. (867) 
ties of the turnips just described may prove to you both an interesting statement and a memorandum of facts, as far as at present known.

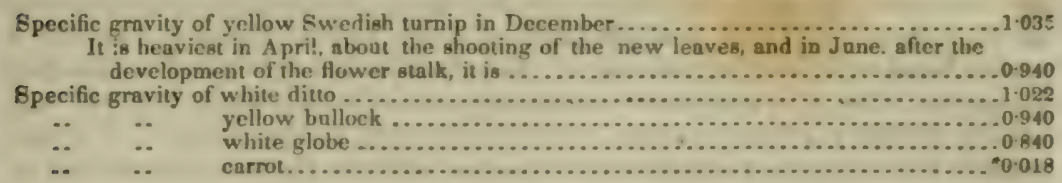

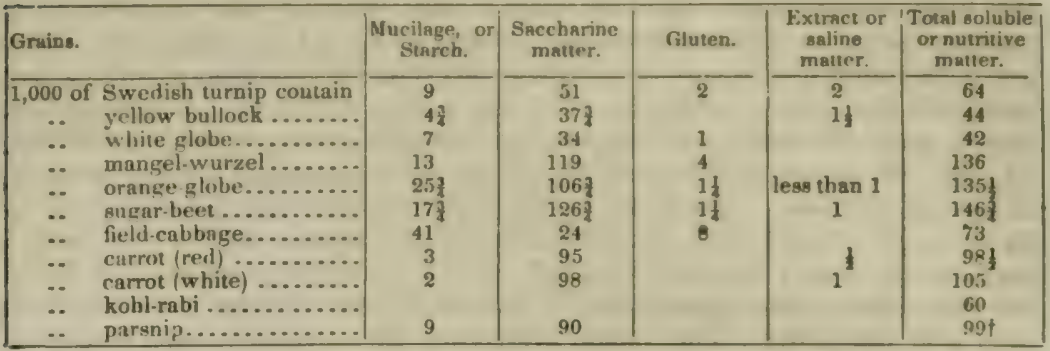

(1032.) A summary of the foregoing results may here be given, thus: A 7 -inch diameter of white turnip affords $72 \frac{1}{2}$ grains, whereas a 4 -inch turnip yields 80 grains of nutritive matter in the same bulk. On the contrary, a large Swedish turnip affords 110 grains, and a small one only 99 grains of nutritive matter in the same bulk. Swedish turnip is superior to cabbage in nutritive matter in the proportion of 110 to $107 \frac{1}{2}$; the white turnip inferior in the proportion of 80 to $107 \frac{1}{2}$; and carrots superior in the proportion of 187 to $107 \frac{1}{2}$. A good crop of Swedes weighs from 30 to 35 tons, of yellow from 30 to 32 tons, and of white globe from 30 to 40 tons the imperial acre. A bushel of turnips weighs from 3 stones to 3 stones 3 lbs. of $14 \mathrm{lbs}$. to the stone, that is, from 42 to $45 \mathrm{lbs}$. the bushel. A young sheep eats about $1 \mathrm{~S}$ lhs., and an old one about $24 \mathrm{lhs}$. of turnips every day ; or, by annther authority, a young sheep eats $23 \mathrm{lbs}$, and an old one $37 \mathrm{lhs}$. a day. The usual allowance to an ordinary crop of turnips is 20 young Black-faced, or 16 Leicester, and 16 old Black-faced and 10 Leicester, or 1 three-year-old ox to the imperial acre; that is, a young Black-faced will consume about $126 \mathrm{lbs}$, an old one $168 \mathrm{lbs}$; a young Leicester $161 \mathrm{lbs}$., an old one $259 \mathrm{lhs}$, and an $\mathrm{x}$ ahout 1 ton of turnips every week. For sheep a crop of turnips of 30 tons will be required, and one of 26 tons will suffice for an ox during 180 days. In making this last estimate, the state of the crop should he taken into consideration, a crop of small yel low or white tumips, if regular, takes longer time to consume in proportion to the bulk than a crop of larger turnips, lut a crop of large Swedish tumips, though apparently thin on the ground, takes a much longer time to he consumed than a thicker crop of small roots. There is no certainty in these calculations; at the same time, they are perhaps near enough the truth to enable you to lay on to turnips such a lot of sheep or cattle as will about consume a crop in a given time.

(1033.) The prices of turnips depend almost entirely un the demand of the locality. In the neighborhood of towns they are always high priced, where an ordinary crop of white will fetch $£ 10$, of yellow $£ 12$, and of Swedes $£ 16$ an imperial acre. They are chiefly purchased by milkmen, or cow-feeders, as they are usually called in Scotland. In the country,

Keith's Agriculturn! Report of Alordeenahire.

t Journal of tbe Royal Auricultural Society of Fingland, vol. ii. ; Sinclaip's Hortus Gramineus Woburnen gis: Dary's Agricuitural Chemistry. (868) 
about $£ 510$ s. for white, and $£ 8$ for Swedish turnips, to be carried off the land, are given; and, when consumed on the ground by sheep, $£ 3$ to $£ 5$ an acre are considered a fair price; and, when on the premises by cattle, $£ 5$ for white, and from $£ 5$ to $£ 7$ per acre for Swedes, with straw. A fairer plan for both the raiser and consumer of turnips is to let them by the week at so much a head of stock put on to consume them. At the usual price of $3 \mathrm{~d}$. per head per week for young sheep, for the ordinary period of 26 weeks, makes a cost for keep of $6 \mathrm{~s}$. $6 \mathrm{~d}$. for the season; and, if it take 16 sheep to consume an acre, tne turnips will realize about $£ 5$ 5s. per acre For old sheep, 6d. per head per week is given, which is just double the cost for the season of the other-namely, 13s. - which, for 10 sheep, will realize $£ 610 \mathrm{~s}$. per acre. For cattle, 5s. per head per week are given, with straw; and, if an ox take 26 weeks to eat an acre, the turnips will realize $£ 610 \mathrm{~s}$. Thus, an acre of turnips that will support 10 old sheep for the season is worth more than one that will support 16 young sheep; but why old sheep should cost more to keep them than young does not appear; it would be fairer for the owner of the sheep to make the rate of keep exactly proportionate between the young and old. In plentiful years $2 \mathrm{~d}$., and in scarce years $4 \mathrm{~d}$. per head are given for young sheep, and other stock in proportion.

(1034.) These three kinds of turnip seem to possess all the properties desiderated by the farmer, and more than these, in my opinion, need not be cultivated; for although, in peculiar seasons, it is possible that, in a particular locality, some other variety may attain greater perfection and prolificacy, yet I believe that, in the long run, these will bear comparison with any variety that has yet been introduced into cultivation, provided they are of pure kinds.

(1035.) There are one or two hybrids of turnips worth mentioning, and which are so named, although it is probable that most of the varieties of turnips in use are natural hybrids. One is called Dale's Hybrid, being a cross betwixt the green-topped Swede and the globe, but whether the white or green-topped globe I do not know. It possesses more of the properties of the yellow turnip than of either of its progenitors; and it has the advantage of arriving sooner at maturity, and may therefore be sown later than the ordinary yellow turnip. The other hybrid is called the Lawtown Hybrid, being a cross between the green-topped Swede and the green-topped globe, the result of which is a heart-shaped, white-fleshed, green-topped turnip, considerably harder than the globes, with its leaves set on like those of the Swedes. The results of these two crosses are-a yellow turnip, Dale's, which arrives sooner at maturity than the older varieties, and a white globe, the Lawtown, which is more hardy than any other variety of white.

(1036.) With regard to the crop afforded by these hybrids, in an experiment made, in 1835 , by Mr. John Gow, Fettercairn, Kincardineshire, the Dale attained to 28 inches in girth, and yielded 23 tons, and the Lawtown to 32 inches in girth, and yielded 27 tons the imperial acre.*

(1037.) Although storing is the proper method of securing turnips for use during a storm of rain or snow, when the turnip-field should not be entered by a cart, yet it is necessary that you should be provided with expedients for obtaining food for your cattle should you be overtaken by a storm, with a scantiness of provision in hand. As both rain and snow exhibit prognostics of their approach, and should these indicate a serious fall or storm, send all the field-workers and plowmen to the turnip-field, and

* Lawson's Agriculturist's Manual.

(869) 
pull the turnips in the form in which the land is in the course of being stripped; and, removing only the tails, throw the turnips into heaps of from 3 to 6 cart-loads each, according to the thickness of the crop, taking care to place the tops of the uppermost turnips on the heap upon the outside, in order to prutect the bulbs from frost, should it come suddenty and unaceompanied with snow. To these heaps rain will do no harm, and they will serve to point out where they are, should snow cover them and the ground. As the turnips gathered in frost or snow should be immediately consumed and not stored, they may be thrown into the cart with a fork or graip, and their tops taken off at the steading, where this process can he done in the severest weather, when women could not stand out in the field to do it.

(1038.) I have given fig. 215 to show you what I conceive to be an illformed turnip, and also one which stands so much out of the ground as to

Fig. 215.

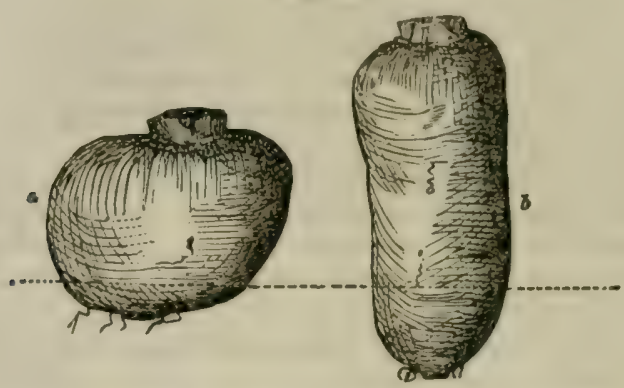

AN ILL-SHAPED TURNIP. THE TANKARD TURNIP.

be liable to injury from frost-where $a$ is an ill-formed turnip, inasmuch as the upper part of it around the top being hollow, rain, snow or rime may lodge there, and find their way into the heart, and corrupt it, as is actually found to take place. All white turnips, when allowed to remain on the ground after they have attained maturity, become soft and spongy, of inferior quality in the heart, and susceptible of putrefaction, which frequently overtakes them in sudden changes from frost to thaw, and reduces them into a saponaceous pulp. This fact supplies a strong reason for storing white turnips after they come to maturity, which state is indicated by the leares losing their green color and becoming flaccid. There are some sorts of white turnips that become spongy in the heart early in the season, and among these I would pronounce the Tankard-shaped, such as is represented by $b$ in fig. 215 ; as are also a flat-shaped red-topped, and a small flattish white turnip, both much cultivated among small farmers, because, being small, they are supposed to require little manure to bring them to maturity, and this class of people are apt to spread manure as thin as possible upon the land, to make it go the farther. I necd scarcely tell you that thrift attends the cultivation of only the hest varieties of turnip. The dotted line in figs. 214 and 215 represents the surface of the ground, by which will be seen the relative depths to which these kinds of turnips descend into the soil when growing.

(1039.) I think it useful to give you a tabular view of the number of turnips there should be on an imperial acre, at given distances between the drills, and between the plants in the drills, and of the weight of the crop at specified weights of each turnip. that you may compare actual receipts with defined data, and endeavor to ascertain whether differences in the crop in these respects arise from defieiency of weight in the turnip itself, or tno much thinning nut of the plants. The distance between the drilis is taken af the usual width of 27 inches: the distance between the plants is what is allowed to the different sorts of turnips; and the imperial acre contains $6,272,640$ (870) 
square inches. On altering the width between the drills, a calculation from these data can easily be made of what ought to be the weight of crop at these given weights of turnips. On comparing a usual crop of 20 tons of Swedes with these data, and keeping in view the distance of 12 inches aimed at between the plants, the inevitable conclusion is that the average weight of each turnip in that crop must be less than 3 lbs., or the distance between the turnips greater than 12 inches.In the one case your skill in raising a crop is almost rendered abortive, and in the other your negligence in wasting space by too much thinning out appears conspicuous. An amendment in both particulars is therefore requisite, and fortunately is attainable in both; for, as you perceive that but a slight difference in either of these particulars makes a great difference in the weight of the crop, your endeavor should be both to make the turnip heavy, and to maintain the desired distance between the plants inviolate. For example, 5.1b. turnips, at 9 inches asunder, give a crop of 57 tons, $12 \mathrm{cwt}$; whereas the same weight of turnip at 11 inches apart gives a crop of 10 tons less. Now, how easy is it for careless people to thin out the plants to 11 instead of 9 inches; and yet, by so doing, a difference of no less than 10 tons, or 18 per cent. on a crop, is sacrificed. And again, a difference of only $1 \mathrm{lb}$. on the turnip-from 4 lbs. to $5 \mathrm{lbs}$. -at 9 inches asunder, makes a difference of 11 tons, or 25 per cent. per acre on the crop! So that a difference of only $1 \mathrm{lb}$. in each turnip, and 2 inches in the distance between them, makes the enormous difference of 21 tons on the whole crop! Who will say, after this, that these particulars do not require the most serious consideration in the treatment of the turnip crop?

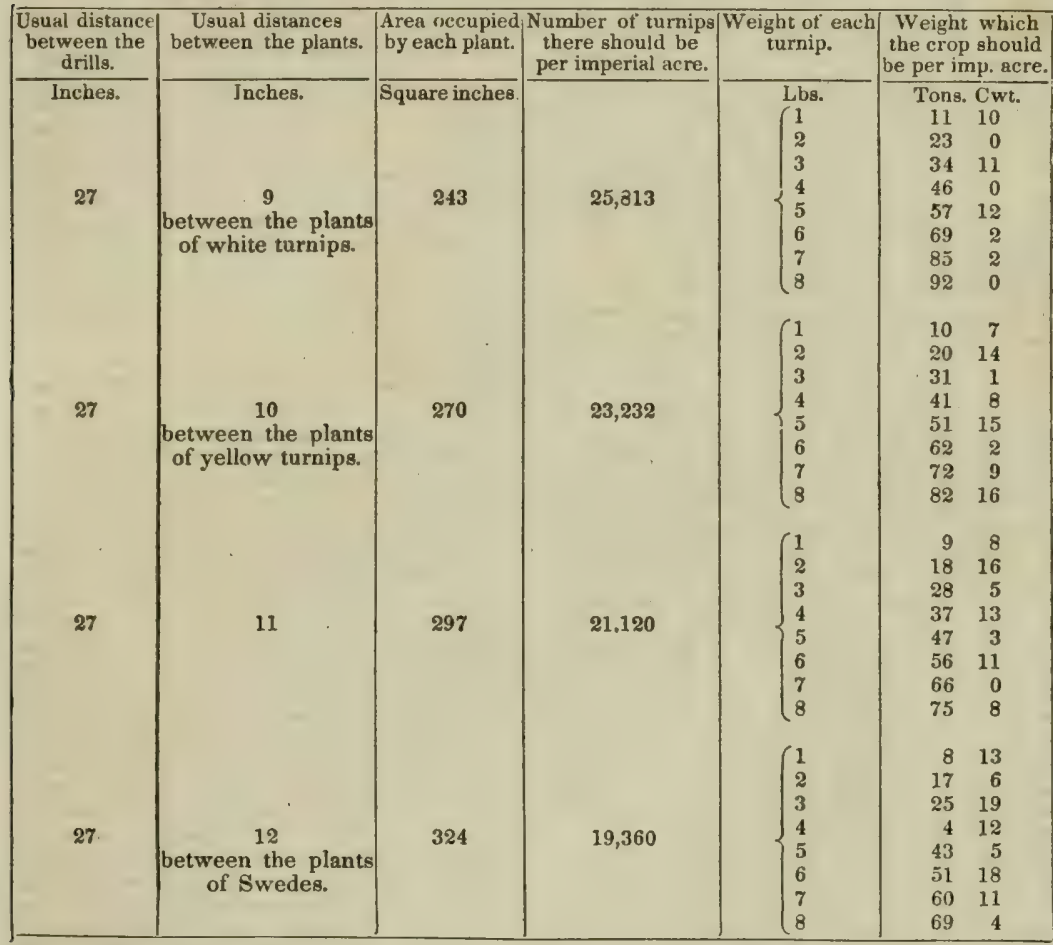

(1040.) On comparing the amount of what the crop should be with instances given in the newspapers of what are considered great crops, it will be seen that these, after all, are no more than what they should be; and they are only the result of what misht be expected to be altained by combined skill and care in culture. In the instances adduced in the Mark-Lane Express in 1840 crops were considered heavy which ranged from 40 to 60 tons per acre; and the Leinster Express of the same year mentions turnips having been raised on Lord Charleville's property in Ireland to a still greater amount-namely, of yellow Aberdeen, 49 tons, $13 \mathrm{cwt}$; of yellow Tancred, 60 tons, $10 \mathrm{cwt}$; of Swedish. 60 tons, $10 \mathrm{cwt}$; ; and of white Tancred, 79 tons, $18 \mathrm{cwt}$. Such statements prove one of two things - enher that large crops of turnips are more easily raised than farmers deem practicable, or great errors have been committed in making out these results. It is quite possible for great errors to be committed in making returns from any other mode of ascertaining the amount of a crop of turnips, than by topping and tailing a whole field, and weimhing every cart-load separately. For example: Suppose that I square yard is measured in a field of turnips in this way-that is, if the distance of 1 yard is measured from a turnip (sce fig. 208) along a drill, then the yard will embrace 5 turnips of white and 4 of Sivedes; whereas, if the measure. ment is begun between two turnips, the same measure will only embrace 4 turnips of white and 3 of Swedes-making, in the former case, a difference in amount of 1 turuip out of every 5 , and in 
the latter, 1 ont of every 4 : and, if the weight of a statute acre has been calculated on sach-like data, the crop will, in the case of the white turnips, be returned 1.5 , and in that of the Swedes beyond the truth. Again, if the yard is placed across two drills, their prodace will be included within the yard, the distance between them being only 27 inches; but, if the yard be placed across one drill only, then its produce alone will be included. as the yard will not reach to the drill on either side; and. if the produce of the whole field is calculated on such data, the result, in the latter mode of measurement, will just give half the amount of the other. Such ways of ascertaining the weight of a crop, when thus plainly stated, appear ridicnlous enongh; but it is an error which country people, who are not aware of the effects of the powers of numbers when muared, are very liable to fall irito. The part of the field, too, from which the data are taken, may make a very great difference in the result over the whole: as. even on true turnip-soil, how different will the size and number of turnips be on a rising knoll and a hollow ! The difference is not very obvious on looking upon the tops alone. but it is made very apparent after sheep have eaten off the leaves, and just begun to break apon the bulbs. The plan, too, of filling one cart-load or so and weighing it, and filling the rest of the cart-loads to a similar extenh without weighing them, is a fallacious one, when the fact is, as shown above, that turnips grown on the same field differ in weight, and therefore a few more or less in a small cart-load will make a considerable difference in the amount over the whole field. I question much whether any person ever weighed every cart-load of turnips as they were brought out of a field. or ever measured many places of the same field, to ascertain the number and weight of turnips in them; aud. onless some plan approaching to either or both of these is adopted, the results obtained will never prove satisfactory. When the trouble of weighing every cart-load is wished to be avoided, the smallest and the largest and the middle-sized turnips should be pulled, topped and cailed, and chosen from every part of the field where a difference of size and number is found to occur. such as in hollows, on knolls, on sloping and level ground, at the top and bottom of the field; and each turnip weighed, and the tops weighed too, eparately if desired, and then the average weight of the turnip nay be relied on. A convenient machine for such a purpose is one of Salter's spring steel-yards, with a basin suspended from it by chains, in which a turnip may be placed with ease and celerity. Besides doing this, the distance from center to center of the tops of the taruips, before they are pulled, should be measured and noted down, and the average distance from tarnip to turnip would then be ascertained. Having thus obtained correct data of the weight and number of turnips within the given limits of a field, the amount of the crop would then be so ascertained as to insure confidence in the result. The average girth of the turnips could be ascertained at the same time if desired; but this is not an essential element in determining the weight of the crop.

(1041.) It may prove interesting to you to know the periods at which the various kinds of turnips in calture were introduced. According to the name given to the plant in this conntry, the Swedes are natives of Sweden; the Italian name Nurani de Laponia intimates an origin in Lapland; and the French names, Chou de Lapone, Chou de Sirede, would indicate an uncertain origin. Sir Jolın Sinclair says: "I am informed that the Swedes were first introduced into Scotland in anno 1781-2, on the recommendation of Mr. Knox, a native of East Lothian, who had settled at Gottenburg, whence he sent some of the seeds to Dr. Hamilton." " There is no doubt they were first introduced into Scotland from Sweden, but I believe their introduction $w$ as prior to the date mentioned. The late Mr. A irth, Mains of Dunn. Forfarshire, informed me that his father was the first farmer who cultivated Swedes in Scotland, from seeds sent lim by bis eldest son then settled in Gottenburg, when my informant, the youngest son of a large family, was a boy of about 10 years of age. This would make the date of their introdaction $17 \tau 7$; and this date is corroborated by the silence preserved by Mr. Wigbt regarding the culture of such a crop by Mr. Airth's father, when he undertook the survey of the state of husbandry in Scotland, in 1773, at the request of the Commissioners of the Annexed Estates, and when he wunld not have failed to report so re. markable a circumstance as the culture of the Swede. Mr. Airth sowed the first portion of seed he received in beds in the garden, and transplanted the plants in rows in the tield. and thas succeeded in raising good crops for some years, before sowing the seed directly in the fields. I havo not been able to trace the history of the yellow turnip; but it is probable that it originated, as is supposed by Professor Low, in a cross between a white and the Swede; and, as its name implies, this may have been in Aberdeenshire. All the white rarietieg of field turnips obtained at first the name of the "Norfolk whites," from the circumstance of their having been first cultivated in that county, to any extent, by Lord Townshend, who, on coming home from being ambaskador to the States-General, in 1730 , paid great attention to their culture, and for which good service he obtained the appellation of "Turuip Townshend." It is rather remarkable that no turnips should have been raised in this country in the fields until the end of the ITth century. when it was lauded as a field-root as long ago as Columella. and in his time even the Gauls fed their eattle on them in winter. The Romans were so well acquainted with turaips that Pliny mentions having ruised them $40 \mathrm{lbs}$ weight $f$ Turnips were cultivated in the gardens in England in the time of Henry VIII.| Dale's hybrid originated in a few ounces of a hybridal seed being sent, in 1822 or 1823, by the late Mr. Sherriff, of Bastleridge, Berwickshin, to Mr. Robert Dale. Libberton West Mains, near Edinburgh, who, by repeated selection and impremation, brought it to what it is, a good yellow turnip. and now pretty extensively cultivated. 8 The Lawtown hybrid originated about 8 or 10 years ago, by Capt. Wright, of Lawtown, in Forfarshire, crossing the green-lopped white with the green-topped Swede, to harden the white; which object proved successful. bat its cultare has not been pushed. By sowing the Swede beside the white Law town, the latter has been converted into a yellow tarnip, possessing the properties of the Swede; and, were the cross still farther pushed, I have no doubt that a distinct variety of the Swede would be obtained. A variety of Swedes was brought into notice, about 4 or 5 years ago, by Mr. Laing, Duddo, Northum.

- Sinclair's Account of the Husbandry of Scotland, vol. i., noke.

i Low's Elements of Practical dericulture.

- Phillips's History of Cultirated Vegetables, rol. it. (872)

$\$$ Dickson's Husbandry of the Ancients, vol. ii. $\$$ Lawson's Agriculturist's Manual. 
berland. who found it among his ordinary Swedes, and observed it by its remarkably elegant form of leaf. which is much notched near the base. It is getting into use, and possesses the valuable property of resisting the effects of spring for at least a fortnight longer than the common varieties, as 1 had a favorable opportunity of observing in Berwickshire late in spring 1841, and on this account may be stored and kept in a fresh state to a very late period of the season.

(1042.) As cabbages are considered good food for cows giving milk, it may be desirable to say a few words as to their use. The varieties of cabbage most suited for field culture are the Drumhead (Brassica oleracen, capitata, depressa), and the great ronnd Scotch or white Strasburg. from which the German sour-krout is chiefly made (Brassica oleracen, capitatn, spherica alba of De Candolle). Of these two, the drum-head is the most productive, and the Scotch stands the winter best. It is alleged by Sinclair that, for the purposes of the dairy, 1 acre of cabbages is wrorth 3 of turnips; but wherein this advantage consists is not stated, which it ought to have been, as he mentions that the nutritive matter contained in Swedish turnips is superior to that in the cabbage, in the ratio of 110 to $107 \frac{1}{2}$. There is no doubt, however, that the taste of milk is less tainted by cabbages than turnips, and I believe more nilk may be derived from them; but there is considerable jifference of opinion with respect to the effects of cabbage on butter and milk, and there is no doubt that a decayed leaf or two in a head of cabbage will impart both to butter and milk a strong. disagreeable taste. " This," says Sinclair, "I have long had an opportunity of proving." If planted in drills usually made for tarnips. these two kinds of cabbage will require to be placed in good roil, 18 inches asunder at least, which will give 12,907 plants to the acre. and, at 24 inches apart, the number of plants will be 9,834 ; and if they at all attain to the weight that cabbages sometimes do-that is, from $18 \mathrm{lbs}$, to $23 \mathrm{lbs}$. each-the lowest number, 18, will give a crop of 78 tons; but the usual crop is from 35 to 40 tons per acre. Their uses are to feed milch cows, to fat ten oxen, and sheep are very fond of them. It is questionable how far their culture should be preferred to turnips, excepting on soil too strong for turnips, as they require a fine, deep. strong soil, and a large quantity of manure-means too valuable to be expended on cabbages, as an economical crop, in Scotland. I have no experience of the cabbage as a food for milch cows or feeding cattle, but know they are much relished by ewes at the season of lambing.

(1043.) The turnip-rooted cabbage (Brassica campestris, napo-brassica, communes of De Candolle) is little known in English culture, though it is cultivated in the fields in France. Iis root is either white or red, and its neck and petioles greenish or purplish. It has a woody, short stem, produced by the formation and decay of the leaves; and. as new leaves are formed by the central bud of the stem, the lower leaves drop off, and thus the top of the bulb assumes the appearance of a stem; and Dr. Neill observes it has a root under ground as sweet as a Swedish turnip. In both these respecte it is very similar to our Swedish turnip. but whether it could be male to assume the form of, or has given origin to, that valuable root, I must leave to be determined by the botanical physiologist

(1044.) The cow-cabbage or Cesareau kale (Brassica oleracea, acephala, arborcscens of De Can. dolle), which created such a noise a few years ago, deserves only a passing notice. "This plant," sayg Don, "is almost similar in habit to the palm kale, but the stem rises to the bight of from 10 to 16 feet, the leaves are not so puckered nor rolled inward at the edges, nor do they hang down so much. The stem is naked and simple, crowned by a head of leaves like a palm-tree. Sixty plauts of this variety are said to afford sufficient provender for one cow for a year: and, as the side leaves are only to be used, it lasts four years without fresh planting. In La Vendee it is said to attain the hight of 12 or 16 feet. In Jersey this plant is sufficiently hardy, and where it grows from 4 to 12 feet. The little farmers there feed their cows with the leaves, plucking them from the stem as they grow, leaving the crown at the top. The stems, being strong, are also used by them for roofing small out-houses. When the gathering of the leaves is finished, at the end of the year. the terminating bud or crown is boiled, and is said to be particularly sweet. It is not suff. ciently hardy to stand the climate of Britain, unless planted in a very sheltered situation." +

(1045.) There is still another variety of the cabbage tribe which deserves notice-the turnip. stemmed cabbage or kohl-rabi (Brassica oleracen, crulo-rapa, alba of De Candolle). The varieties of this plant are numerous, but the best suited for field culture are the large red and green sorts. It is a native of Germanv, where it is much cultivated, as it also is in the low countries and the north of France, where it is chiefly given to milch cows, for which it is well adapted on account of its possessing little of that acridity which is found in the turnip to affect butter and milk. It is taken up before the frost sets in. and stored like potatoes or turnips for winter use. Its habits and produce are similar to the Swedish turnip, the part of the plant resembling which is a swollen bulb at the top of the stem, which, when divested of leaves. may readily be mistaken for a Swedish turnip. Hares are so fond of it, that on farms where they abound, its culture is found to be impracticable. Sir Thomas Tyrwhitt first introduced it into England from Germany $\ddagger$

(1046.) Although the parsnip (Pastinncen sntiva edulis of De Candolle) is too tender a root for general cultivation in this country, it deserves notice on account of its fattening properties when yiven to all domesticated animals. "The parsnip," says Don, "has been partially introduced of late years as a field-plant, and is nearly equal to the carrot in its product of saccharine and nutri. tive matter. Its culture as a field-plant has chiefly been confined to the island of Jersey, where it attains a large size, and is much esteemed for fattening cattle and pigs. It is considered rather more hardy than the carrot, and its produce is said to be greater. . . The variety best suited for the field is the large Jersey. ... In the fattening of cattle, it is found equal, if not superiot, to the carrot, performing the business with as much experition, and affording meat of exquisite flavor, and a highly juicy quality. The animals eat it with much greediness. It is reckoned that 30 perches, where the crop is good, will be sufficient to fatten an ox 3 or 4 years old, when per. fectly lean, in the course of 3 months. They are given in the proportion of about $30 \mathrm{lbs}$. weight

* Sinclair's Hortus Gramineus Woburnensis.

f Don's Feneral Dictionary of Botany and Gardening, vol, i.

† Sinclair's Hortus Gramineus Woburnensis; and Lawson's Agriculturiat's Manual. (873) 
morning, noon and night, the large ones being splis in 3 or 4 pieces, and a little hay supplied in the intervals of those periods. And when given to milch cows with a little hay, in the winter season, the butter is found to be of as fine a color and as excellent a flavor as when feeding in the best pastures. Indeed, the reault of experiment has shown that not only in neat cattle, but in the fattening of hogs and poultry, the animals become fat much souner, and are more healthy, than when fed with any other root or vegetable; and that, besides, the meat is more swert and delicious. The parsuip-leave being more bulky than those of carrots, may be mown off before taking up the roots, and given to cow oxen, or horses, by whom they will be greedily eaten."* The leaves may be greedily eaten when no other green food is presented as a choice to cattle. but I have no doubt that cattle will make very little progress toward condition when using them. The weight of the largest parsnips grown in gardens in Scotland, varies from 10 ounces to 2 lbs. each. $\dagger$

(1047.j The carrot (Dacus carrota sativa of De Candolle) is raised in the fields in meveral yarts of this country. The varieties most suited for field-culture are the large orange, Altringham, long red, and green-top white. In giving a detailed statenent of the general treatment of the crirot, Mr. Burrows says, in regard to their use in winter: "I take up, in the last week of October. with 3-pronged graips, a suflicient quantity to have a store to last me out any considerable fros: or snow that may happen in the winter months. The rest of the crop I leave in the groand. preferring them fresh out of the earth for both horses and bullocks. The carrots keep best in the ground. nor can the severest frosta do them any material injury. The first week in March, it is necessary to have the remaining part of the crop taken up, and the land cleared for barley. The carrots can either be laid in a heap, with a small quantity of straw covered over them. or they may be laid in some empty outhouse or barn. in heaps of many hundred bushels, provided they are put together dry. This latter circumstance it is indispensable to attend to : for if laid together in large heaps when wet. they will certainly sustain much injury. Such as I want to keep for the use of my horses until the months of May and June. in drawing over the heaps (which is necessary to be done the latter end of A pril, when the carrot begins to eprout at the crown very fast), I throw aside the healthy and most perfect roots, and have their crowns cut completely off and laid by themselves. By this means, carrots may be kept the month of June out in a high state of perfection." $\neq$ When the ground is desired to be cleared for wheat, carrots should be taken $\mathrm{a} p$ in autumn, and stored in the manner described for mancel-wurzel (1020), in a dry state, though with fewer precautions against the frost. Arthur Young gives the average produce of an acre of carrots in Suffolk at 350 bushels; but Mr. Burrow s crops averaged upward of 800 bushela, which, taking the bushel at 42 lbs.. will make the former crop 6 tous 11 cw'.. and the latter 15 tons exactly. In the fields in Scotland, the Altringhan carrot has been grown to $1 \frac{1}{2}$ lbs. and in gardens to $2 \frac{1}{2} \mathrm{lbs}$. : and a crop of the large orange carrot, manured with night-eoil, has been raised by Mr. Spiers, of Calcreuch, at the rate of 9 tons the acre-probably the Scoteh acrewhich is equal to 7 tuns $1 \mathrm{cwt}$. the imperial.

(1048.) Varieties of the common putato (Solanum tuberosum) are also used in the feeding of cattle, but as the crop is of more importance as human food, I shall reserve the description of storing them until the proper senson, in autumn, when they are removed from the ground. Meantime, I may mention that the varieties raised exclusively for cattle are the cummon yam, red yam. and ox.noble.

\title{
30. FEEDING SHEEP ON TURNIPS IN WINTER.
}

\author{
"Now, shepherds, to your helpless charge be kind, \\ Battle the raging year, and fill their pens \\ With food at will: lodge them belnw the storm, \\ And wateh them strict; for, from the bellowing East, \\ In this dire season, oft the whirlwind's wing \\ Sweeps un the burden of whole wintry plain \\ At one wide waft. and o'er the bapless tlocks, \\ Ifid in the hollow of two neighboring hills, \\ The billowy tempest whelms."
}

THOMSON.

(1049.) Having prepared room on the turnip land for the sheep intended to be fattened upon turnips, by removing the proportion of the crop in the manner described above, that is, by drawing 2 rows and leaving 2 rows alternately, and having prepared that part of the field to be first occupied by the sheep, which will afford them shelter in case of need, the first thing to be afterward done is to carry on carts the articles to the field requisite to form a temporary inclosure to confine the sheep within the ground allotted them. It is the duty of the shepherd to erect temporary inclosures,

- Don's General Dictionary of Botany and Gardening, rol. i

\$ Communications to the Board of Agriculture, vol. vii. (874) f Lawson's Amriculturist's Manual.

$\oint$ Lawson's Agriculturist's Manual. 
and as, in doing this, he requires but little assistance from other laborers, he bestows as much time daily upon it until finished as his avocations will allow.

(1050.) There are two means usually employed to inclose sheep upon turnips, namely, by hurdles made of wood, and by nets of twine. Of these I shall first speak of the hurdle or flake. Fig. 216 represents 2 hurdles set

Fig. 216.

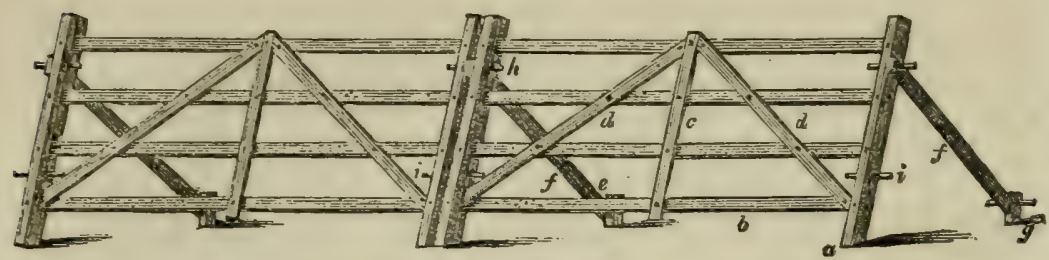

HURDLES OR FLAKES SET FOR CONFINIYG SHEEP ON TURNIPS.

as they should be. The mode of setting them is this; but in doing it, the shepherd requires the assistance of another person,-a field-worker will serve the purpose: The flakes are set down with the lower ends of their posts in the line of the intended fence. The first flake is then raised up by its upper rail, and the ends of the posts are sunk a little into the ground with a spade, to give them a fi:m hold. The second flake is then raised up and let into the ground in the sarne way, both being held in that position by the assistant. One end of a stay $f$ is then placed between theflakes near the tops of their posts, and these and the stay are made fast together by the insertion, through the holes in them, of the peg $h$. The peg $i$ is then inserted through near the bottom of the same posts. The flakes are then inclined backward away from the ground fenced, until their upper rail shall be 3 feet 9 inches above the ground. The stake $e$ is driven into the ground by the wooden mallet, fig. 218 , at such a point as, where the stay $f$ is stretched out from the flakes at the above inclination, that a peg shall fasten stake and stay together, as seen at $g$. After the first two flakes are thus set, the operation is easier for the next, as flake is raised after flake, and fastened to the last standing one in the manner described, unti] the entire line is completed.

(1051.) Various objections can be urged against the use of flakes, the first being the inconvenience of carrying them from one part of a field to another in carts, and of their liability to breakage in consequence; as also the shepherd himself cannot set them up well and speedily without assistance, and even with that they require a good deal of time in setting up. They are also easily upset by a high wind blowing behind them; and, when in use they require almost constant repair and replacing of pegs, stays and stakes; though, when repaired and set carefully by at the end of the season, they will last several years. The mode of making flakes, and their price, are mentioned below.

(1052.) The other method of inclosing sheep on turnips is with nets made of twine of the requisite strength. These nets having square meshes when stretched upon the stakes, usually extend to 50 yards in length, and stand $3 \frac{1}{2}$ feet in hight. They are furnished with a rope along both sides passing through the outer meshes, which are called the "top" and "bottom rope" as the position of either may be at the time. These ropes are wound round the stakes by a peculiar sort of knot called the "shepherd's knot." The stakes are best formed of thinnings of ash-trees that have 
been planted very thick together and grown up long and small, and they should be 3 inches in ditmeter and 4 feet 9 inches long; allowing 9 inches of a hold in the ground, 3 inches between the ground and the bottom of

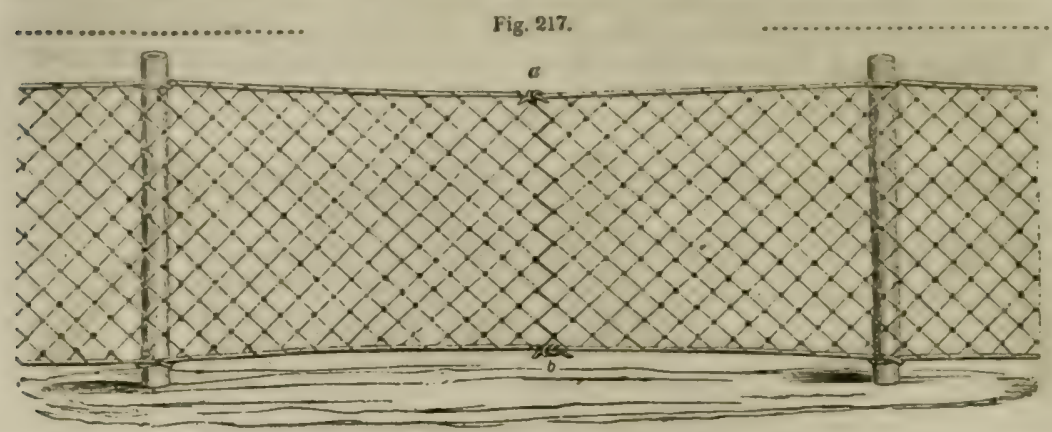

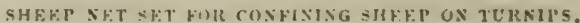

the net, and 3 inches from the top of the net to the top of the stake; or they may be made of larch weclings, 4 inches in diancter and 4 feet 9 inches long; but every kind of wood of which they may he made should be seasoned with the bark on before being cut into stakes. They are pointed at one end with the ax, and that end should be chosen to be poirted which will make the stake stand in the same position as when it was growing in the tree, for its bark, it has been found, is then in the best state for repelling rain.

(1053.) A net is set in this way: If the ground is in its usual soft state, the stakes may simply be driven into the ground with a hard-wood mallet,

Fig. 218.

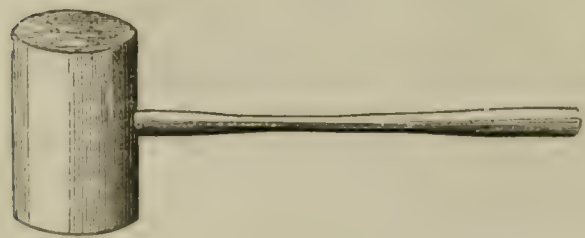

THE SHEPHERD'S WOOD MAT.E.T.
Fiy. 211.

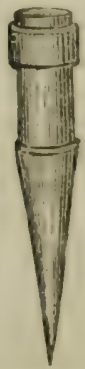

THB DRIVER.

fig. 218 , in the line fixed on for setting the net, at distances of 3 paces asunder. The wool of the apple-tree makes the best mallet, as not being apt to split. Should the soil be thin and the subsoil moderately hard, a hole sufficiently larere for a stake may be made in the subsoil with the tramp-pick, fig. 37 ; hut should the subsoil be so very hard as to require a larger hole to be made than what can ensily he formed by the tramp-pick, or should the ground be so dry and hard as to require the use of any instrument at all, the most efficient one for the purpose is one called a $d r$ ver, fig. 219. It is formed of a piece of pointed hard-wood, strongly shod with iron, and its upper end is protected by a strong ferule of iron to prevent its splitting by the strokes of the mallet. The stakes being thus 
driven so that their tops may not be less than 4 feet high, along as many sides of the inclosure as are required at the place to form a complete fence.

(1054.) A net is set in this manner: Being in a bundle, having been rolled up on the arms and fastened together by the spare ends of the top and bottom ropes, these are unloosened and tied to the stake that has been driven close to the fence, whatever that may be, and then the net is run out in hand toward the right as far as it will extend in a loose manner, on the side of the stakes facing the ground the sheep are to occupy. On coming to the next stake from the commencement, the bottom rope gets a turu to the left round the stake, and the top rope above it a similar turn round the same stake, so as to keep the leading coil of the rope uppermost. The bottom rope is then fastened with the shepherd's knot to the stake, 3 inches from the ground, and the top rope is fastened with a similar knot near the top of the stake, stretcling the net even and upward; and in this way the net is fastened to one stake after another until the whole of it is sct up, as it is called, care being taken to make the top of the net run uniformly throughout its entire length.

(105.5.) The shepherd's knot is made in this way: Let $a$, fig. 220, be the continuation of the rope which is fastened to the first stake, then press the second stake with the hand toward $a$ or the fastened end, and at the same time ighten the turn round the stake with the other hand by taking a hold of the loose end of the rope $d$, and moving it so as to cause it to pass under $a$ at $c$, and screwing it round the stake to $b$, where the elastic force of the stake will secure it tight under $a$ at $b$ when the stake is let go. 'The bottom rope is fastoned first, to keep the net at the proper distance from THE BHEPHERD'S KNOT, в the WHICH A NET IS FASTENED same stake in the same manner. Proceed in this

manner at each successive stake until the whole net is set up. A net may be thus set up either toward the right or the left as the starting point may be situate, but in proceeding in either direction care must be taken to pass the top and bottom ropes round the stakes, so as the leading coil of the rope is always uppermost toward the direction in which the net is to be set up. Thus, in fig. 2:0, the rope $d$ was uppermost until it was passed under $a$, hecause the setting of the net in this case is from right to left, and it continues to be uppermost until it reach the next stake to the left. If both the cord and stake are dry, the knot may slip as son as made, but if the part of the stake at $b$ where the knot is fastened is wetter a little, it will make the rope keep its hold until the cord has acquired the set of the knot. With a new rope that is greasy, and a smooth stake, it is difficult for the knot to retain its hold even with the assistance of water.

(1056.) There are some precautions required in setting a net beside this of the ropes. If the net is new, the cords may be stretched as tight as you please, because they will stretch considerably; but if old, the least damp or rain afterward will stretch them so as to cause them to break. If the net is at all in a damp state, it should be set very tight, because rain cannot make it tighter; and if not set very tight, the first dry weather will so slacken the cords as to loosen all the knots, and make the net slip down the stakes; but even if it should not be slackened to that extent, it will be so slackened as to shake about with the wind, and bag down and touch the ground. Such an occurrence will create the trouble to the shepherd of 
re-setting the whole net, and the best way of avoiding this troulile is to have tho nets in a dry state when they are set. In wet weather shepherds take the opportunity of a dry moment of setting a dry net in autiripation along a new break of turnips, and they also hang up wet nets to dry on the outside of the stakes away from the sheep. Nets should never he wound up in a wet state, even for a short time, as they will soon mould and rot.

(1057.) On commencing the setting of another net, its top and bottom ropes are fastened to those of the last net, and the ends of the nets themselves are brought together by interlacing the meshes of both with a picce of string, as at $a$, fig. 217. Here the knots in the top and bottom ropes are seen, and the twine interlacing the meshes are macle to appear stronger than that of the net only to let it be perceived. Thus one net is set after another, until the whole intended area is inclosed. Where there is a turn in the line of nets in going from one side of the inclosure to another, as seen on the right side of fig. 226, if there is much of the net left at the turn, it should be brought down the next side; in which case the stake at the corner should be driven very securely down, as there will be a considerable strain upon it from the nets pulling from different directions, and this will especially be the case in damp weather. But the safer and perhaps better plan is to take a fresh net at the turn and fasten it to a stake, and run on the other net in its own line until it is suspended either in setting or coiling it around the top of a stake. All surplus ends of nets should be carefully hung upon the back of the stakes when wet, to dry and get the air. Part of the nets will thus cross ridges, and part will run along a ridge. Where they cross ridges that have been but once gathered-up, or plowed crown-and-furrow, the bottom of the nets will be nearly close to the open-furrows, but where they cross a gaw-cut in rather strong land, a stake or two should be made to lie upon the bottom rope to keep it down, for some sheep have a trick of creeping under the net, when they find a suitable opening; and where nets cross ridges which have been twice gathered-up, one stake should be driven at one side of the open-furrow; and another at the crown of the riclge, and the bottom rope will then run nearly parallel to the surface of the ground.

(1058.) In setting nets, in whaterer position, care should be taken to keep each side of the inclosure in the same plane-that is. each side exactly in a straight line, and the surface of its nets perpendicular; and the different lines should meet at right angles to one another, so that every break of turnips occupied by the sheep should either be a rectangle or a square; because the strain upon the ends will then be equalized over the entire cords and stakes of each side, and no undue pressure exerted on any one stake. A shepherd who knows his business so as to pay attention to these particulars, will preserve his nets and stakes a much longer time in a serviceable state, than one who is ignorant or careless about them.

(1059.) The shepherd should al ways be provided with net-twine to mend any holes that may be made in the nets: and where they bappen to be set ucross hare-roads, the hares will invariably keep their runs open; which being the case, it is much better to allow them to remain open, than in filling them up to have them cut through daily.

(1060.) When flakes or nets have been set round the first break, the ground may be considered in a proper state for the reception of sheep; and the ground should be so prepared before the grass fails, that the sheep to be fattened may not in any degree lose the condition they have acquired on the grass; for you should always bear in mind that it is much (878) 
easier to improve the condition of lean sheep that have never been fatter than to regain the condition of those that have lost it. Much rather leave pastures a little rough, than risk the condition of sheep for the sake of eating it down. The rough pasture will be serviceable to the portion of the sheep-stock that are not to be fattened, such as ewes in lamb and aged tups. Let sheep, therefore, intended to be fattened, be put on turnips as early as will maintain the condition they have acquired on the grass. By a break of turnips is meant that part of the crop which is being consumed by the sheep.

(1061.) As the tops of white turnips are long and luxuriant at the commencement of the season, the first break or inclosure should be made smaller than those which succeed, that the sheep may not have too many tops at first on a change of food from grass to turnips, and which they will readily eat to excess, on account of their freshness and juiciness. Let the sheep fill themselves with turnips pretty well before taking them to the next break. The second break may be a little larger than the first, and the third may be of the proper size-that is, contain a week's consumption of food. These considerations will cause the shepherd some trouble for two or three weeks in the beginning of the season; but they are trifling compared with the advantage derived from it by the sheep. Rather let him have the assistance of a field-worker to shift the nets, than neglect the precautions. When the tops wither in the course of the season, and one night of sharp frost may effect that, or after the sheep have been accustomed to the turnip, the danger is over. The danger to be apprehended is diarrhœa or severe looseness of the bowels, which is an unnatural state in regard to sheep, and they soon become emaciated by it; many sink under it, and none recover from such a relaxation of their system until after a considerable lapse of time.

(1062.) Another precaution to be used on this head is, to avoid putting sheep on turnips for the first time in the early part of the day when they are hungry. The danger may be apprehended with tops in a dry state, but when they are wet by rain or snow, or half-melted rime, they are most likely to do the harm. The afternoon, then, when they are full of grass, should be chosen to put the sheep on turnips, and they will immediately begin to pick the tops, but will not have time to injure themselves. Should the weather prove wet at first, and the ground be either somewhat too clayey or soft, and the sheep thereby find an uncomfortable lair, it would be advisable to allow them to rest in an adjoining grass field for a few nights until the ground becomes consolidated (which will soon take place) by their constant and repeated tramplings.

(1063.) Sheep when put on turnips are selected for the purpose. Ewes being at this season with young, whether as a flying or standing flock, are never, in Scotland, put on turnips in winter, but continue to occupy the pastures, part of which, if left on purpose in a rough state, will suffice to support them as long as the ground is free of snow. The reason why great ewes, as ewes in lamb are called, are never put on turnips, is the chance of getting too fat, which if they do, they will produce small lambs and run great risk of being attacked by inflammatory complaints at the lambing time. Tups are most frequently put on turnips, especially tup hoggs, but they are never folded in the same part of the field as the feed. ing sheep, having a snug corner somewhere to themselves, or else the tur. nips are led to them in a sheltered part of a grass field. Young sheep, that is, lambs of the same year, are always put on turnips, whether with the view of feeding them fat at once, or enlarging the size of their bone. Every year a certain number of old ewes, unfit for farther breeding from (879) 
want of teeth, or means of supplying milk, are drafted out of the standing flock to make room for the same number of young females into the ewe flock, and are fattened off upon turnips. It sometimes happens that the castrated male lambs of last year, instead of being sold, have been grazed during the summer, and are fattened off the second season on turnips. All these classes of sheep, of different ages, may be mixed together and occupy the same break of turnips. It is seldom that the last class, namely, the lambs of last year, are kept on to the second year, but the draft ewes are always fed along with the young sheep, and they prove useful in breaking the turnips and eating up the picked shells. A mixture of old and young sheep are less useful to one another when turnips are cut by machines.

(1064.) Since I have had occasion to mention some of the classes of sheep, it may not be out of place here to make you acquainted with the technical names which they receive in respect of age and sex, and which I shall always employ when speaking of them in future. A new-born sheep is called a $l a m b$, and retains that name until it is weaned from its mother and able to support itself. The name is modified according to the sex and condition of the animal: when a female, it is a cwoe-lamb, when a male, a tup-lamb, and the last name is changed to hogg-lamb when the creature undergoes emasculation. After a lamb has been weaned, until the first fleece is shorn from its back, it receives the name of hogg, which cognomen, like that of lamb, is modified according to the sex and condition of the animal; namely, a female is called a euc-hogg, a male a tup-hogg, and a castrated male a wether-hogg. After the first fleece has been shom, another change is made in the nomenclature; the ewe-hogg then becomes a gimmer, the tup-hogg a dinmont or shearling-tup, and the wether-hogg a ditmont, and these names are retained until the fleece is shorn the second time. After this operation another change is effected in all the names, the gimmer being then called a ewe if she is in lamb, but if she has failed being in lambshe is said to be a tup-eill gimmer or barren gimmer, and if she has never been put to the ram she gets the name of yield gimmer. If a ewe who has borne lambs fails again to be in lamb, she is called a tup-eill ewe or barren eure. After the ewe has ceased to give milk, or become dry, she is said to be a yield ewe. The shearling-tup is called a 2-shear tup when the fleece has heen taken off him the second time, and the dinmont commonly a wether, but more correctly a 2-shear wether. After a ewe has been shorn three times she is called a twinter euc, that is, a tu-uinter euce; a tup that has been so treated is called a 3-shear tup; and a wether still a wether, or more correctly a 3-shenr wether, which is an uncommon name among Leicester sbeep, as the castrated sheep of that breed are rarely kept to so great an age. A ewe that has been four times shorn gets the name of a three-uinter ewe or aged cue; a tup is called an aged tup, a name which he retains ever after, whatever his age, but they are seldom, except for special reasons, kept beyond this age; and the wether is now a wether properly so called. A tup and ram are synonymous terms. A ewe when she is removed from the breeding flock is called a draft eue, whatever her age may be, and gimmers that are put aside as untit for breeding from are called draft gimmers, and the lambs, dinmonts, or wethers, that are drafied out of the fat stock are called the sheddings, or tails, or drafts. In England a somewhat different nomenclature prevails. There sheep bear the name of lamb until 8 months old, after which they are called ewe and wether teggs until once clipped. Gimmers are called theaves until they bear the first lamb, when they are named cwes of 4-teeth, next year eures of 6-teeth, and the year after full-mouthed ewes. Dinmonts are called shear $(880)$ 
hoggs until clipped, when they are 2-shear wethers, and ever after they are called wethers.

(1065.) When sheep are on turnips they are invariably supplied with dry fodder, hay or straw-hay being the most nutritious, though most ex pensive; but sweet, fresh oat-straw answers the purpose very wel. Th $\}_{1}:$ fodder is supplied to them in racks. There are various forms of straw. racks for sheep-some being placed so high that sheep can with diffic reach the fodder, and others are mounted high on wheels. The form represented in fig. $221 \mathrm{I}$ have found convenient, containing as much straw at

Fig. 221.

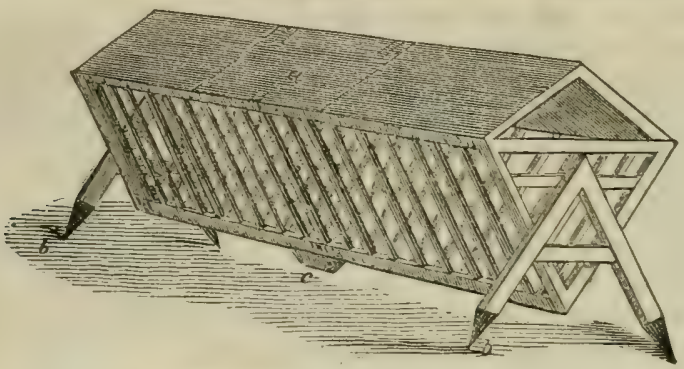

THE SHEEP STRAW OR HAY RACK.

a time as should be given, admitting the straw easily into it, being easily moved about, of easy access to the sheep, and being so near the ground as to form an excellent shelter. It is made of wood, is 9 feet in length, $4 \frac{1}{2}$ feet in hight, and 3 feet in width, having a sparred rack with a double face below, which is covered with an angled roof of boards to throw off the rain. The rack is supported on 2 triangular-shaped tressels $b$, shod with iron at the points, which are pushed into the ground, and act as stays against the effects of the wind from either side. The billet $c$, fixed on the under or acute edge of the rack, rests upon the ground, and, in common with the feet, supports it from bending down in the middle. The lid $a$ is opened on hinges when the fodder is put into the rack. There should at least be 2 such racks in use ; because, when set at an angle to each other against the weather point, the space embraced between them forms an excellent shelter for a considerable number of sheep. (Fig. 226.) Such a rack is easily moved about by 2 persons, and their position should be changed according to a change of wind indicative of storm.

(1066.) It is the duty $f$ the shepherd to supply these racks with fodder, and one or all of them may require replenishment daily. This he effects by carrying a bundle of fodder at any time he visits the sheep. When carts are removing turnips direct from the field, they carry out the bundles; but it is the duty of the shepherd to have them ready for the carters in the straw-barn or hay-house. For shelter alone the racks should be kept full of fodder. Fodder is required more at one time than another; in keen, sharp weather, the sheep eat it greedily, and when turnips are frozen they will have recourse to it to satisfy hunger, and after eating succulent tops they like dry fodder. In rainy, or in soft, muggy weather, sheep eat fodder with little relish; but it has been remarked that they eat it steadily and late, and seek shelter near the racks prior to a coming storm of wind and rain or snow; in fine weather, on the other hand, they select a lair in the more exposed part of their break.

(1067.) Until of late years sheep were allowed to help themselves to tur(881) ......29 
nips in the early part of the season; and in consuming them the tops were first eaten, and then the hulbs were scooped out as far as the ground would permit. When a large proportion of the turnips of the break were thus eaten, the shells, as the bottom part fast in the ground is called, were picked out of the ground with an instrument made for the purpose. Its name is a turnip-picker, and the mode of using it may be seen in fig. 222. Its handle is 4 feet long, and blade 10 inches, including the eye for the handle. By its mode of action, you will see that the tap-root of the turnip is cut through and the shell separated from the ground at one stroke. A very common form of these pickers is with the mouth cleft in two, between which cleft the tap-rout is embraced, and the shell and root are pulled up together. It is found, however,

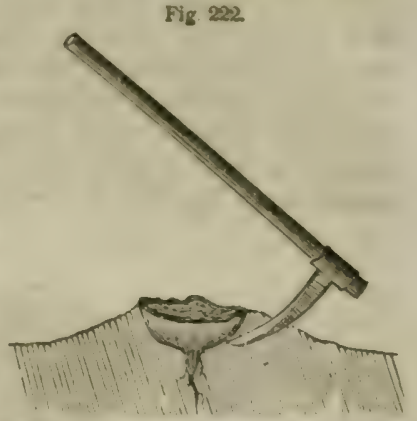

THE TURNIP-PICKRR IN THE ACT OF CUT. TING OFF THE TAP-ROOT AND PULIING UP THE SHFLL OF THE TUKNIP. that the tap-root contains an acrid juice detrimental to the stomach of sheep, so that the better plan is to cut it off and leave it on the ground to rot. The best form of blade may be seen in fig. 223 , and fig. 224 shows the objectionable form of the same instrument.

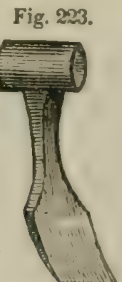

THE BEST FORM OF TURNIP-PICKER.
Fig. 224.

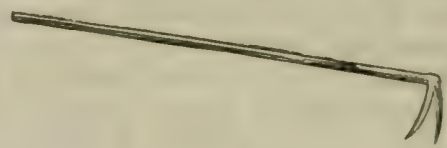

OBJECTIONABLE FORM OF TURNIP-PICKET

(1068.) Only half of the ground occupied by the shells should be piched up at one time, by removing every alternate double row of them, in order to make the sheep spread over a greater space while consuming them.When the ground is dry, the shells should be pretty clean caten up before a new break of turnips is formed; but, a few being left, the sheep will come over the ground again and eat them up, though in a shrireled state, especially in frost, when they are sweeter and softer than turnips.

(1069.) But the more recent and better plan of serving turnips to sheep -and it should be universally adopted-is to cut them into small pieces with a turnip-slicer into troughs conveniently placed for use, while at the same time the sheep have liberty to eat the turnips themselves. A convenient and expeditious form of turnip-slicer is described below at fig. 252, which description you should peruse at once; and a simple form of turnip-

Fig. 225.

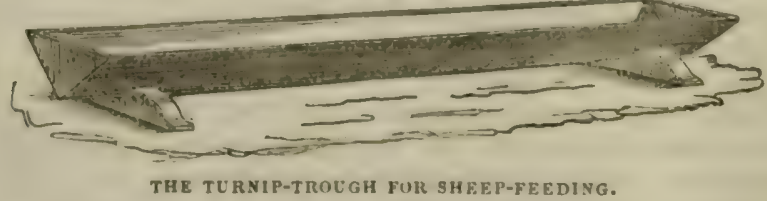

trough is here represented by fig. 225. It is 8 feet long, and made acute (882) 
at the bottom, for the more easy seizure of the pieces of turnip by the mouths of the sheep, by nailing two boards together upon the two triangular-shaped ends, and placing it upon billets for feet. The troughs are set in a line along the outside 2 rows of turnips about to be pulled. The turnip-cutter is wheeled to each trough successively by the field-worker, who works the handle, and its hopper is filled by another worker, who tops and tails the turnips. The sheep range themselves on either side of the trough.

(1070.) I have constructed fig. 226 to give you a bird's-eye view of the manner in which a turnip-field should be fitted up for sheep. There are,

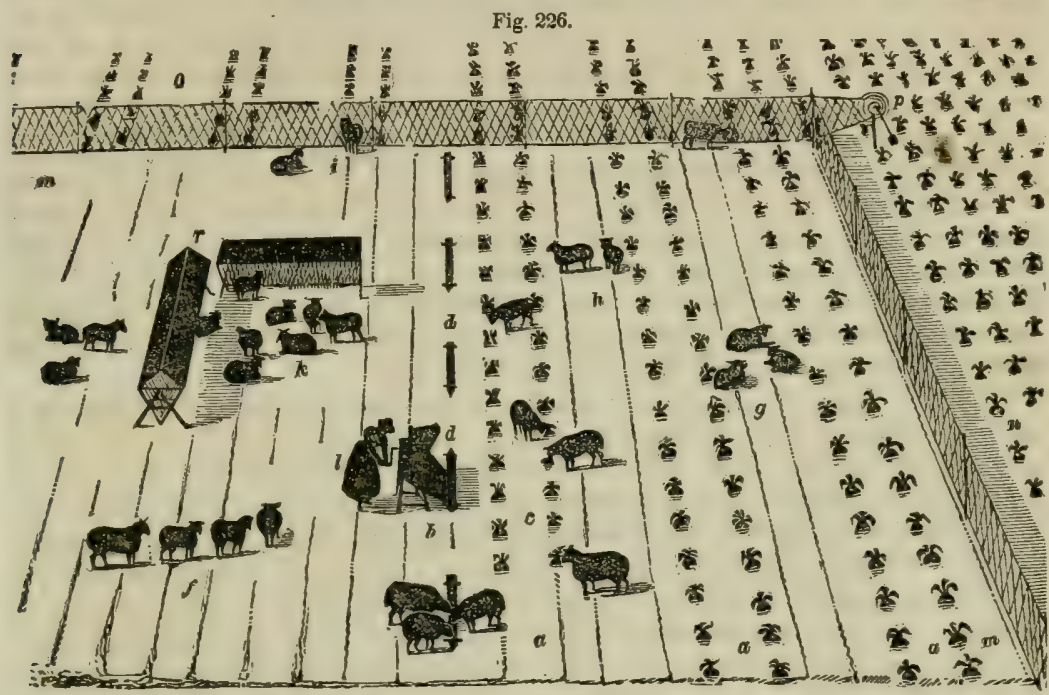

THE MODE OF OCCUPYING TURNIP-LAND WITH SHEFP.

in the first place, the turnips themselves $a$, of which half have been drawn by pulling 2 drills and leaving 2 alternately. The ground upon which they are growing is represented partly bare, because they are supposed to have been pulled up in the progress of the turnip-cutter advancing from one side of the break to the other; and it constitutes the break. As matters are represented, the turnip-slicer $b$ is proceeding up beside the 2 drills $c$, and depositing the cut turnips into one of the small troughs $d$, out of another of which some of the sheep are eating, while others are belping themselves from the bulbs in the drills $c$. The sheep are represented scattered over the ground as they are usually seen, some following one another in a string $f$ toward the place where their food is preparing for them, while others, $g$, are lying resting, regardless of food. Some, $h$, are standing, as if meditating what next to do, and others, $i$, examining the structure of the nets. Some nibble at the dry fodder in the racks $r$, while $k$, a group, lie under their shelter. The field-worker $l$ is slicing the turnips with the machine. Such are the usual occupations of sheep when they have abundance of food at their command. The nets $m$ are represented as inclosing two sides of the break, the other two sides being supposed to be composed of the fences of the field, and not represented. The turnips $n$, to the right of the nets, appear undrawn, while those 0 , above the nets, are stripped, indicating that the progress of the breaks at this time is upward toward the top of the field, in a line with the direction of the drills, (883) 
and, of course, with that of the ridges; and this part of the plan is not a matter of indifference, hecause the breaks should so succeed one another in their passage across the field, as that the land, when cleared of turnips, may be plowed from end to end and ridged up, if desired. In a large field, which engages the sheep for a considerable part of the season, the land is plowed as each stretch of breaks is cleared, in order to preserve the virtue of the manure; and this is of more importance in a large than in a small field, over which a large number of sheep will soon pass. In plowing up land, however, with this intent, care should be taken not to deprive the sheep of any natural shelter they have enjoyed; and to secure this to them as long as practicable, the breaks should be so arranged as to make those first formed along the lowest and most sheltered part of the field, so that the sheep could resort at the bottom of the set of breaks they are occupying, after the first set had been given up and plowed to the top of the field, and so on in succession. Such an arrangement requires more consideration than at first sight may appear, and its neglect may much inconvenience the sheep for want of shelter; and shelter to sheep in winter does not merely imply protection from unusual inclemency of the weather for a night or two, but also preservation of the fleece, and comfort to the flock throughout the season. The remainder of the net along the upper part of the break is represented coiled round the top of a stake at $p$, and there also the mallet and driver await their use.

(1071.) I have already stated that tups or rams are fed on turnips in a separate division from the feeding sheep. Some apportion them in a space in the same, while others give them a break in another field; but I would prefer giving tups turnips in a small grass paddock, and cutting them with the small lever turnip-slicer represented in fig. 246 , and described minutely below. Where the lot of tups is large, say 40 or 50 , it may create, it is true, more trouble to fetch their turnips to them than to inclose them on turnips; but this consideration should be always borne in mind, in regard to tups, that whenever they and female sheep become aware of the presence of each other in the same field, and even in contiguous fields, neither party will rest to feed. The air will carry the scent of their bodies to each other, and, whenever any of the females show a tendency toward coming into season, the scent of the males confirms it, and, becoming restless themselves, they have a tendency to render the rest of the flock so also. And if tups are in a separate fold by themselves, away from the rest of the sheep, they cause as much trouble to the shepherd in visiting them there as a larger flock; whereas, were they near home in a grass paddock, he could visit them frequently in going and coming to his house at his hours of repast.

(1072.) Sheep are sometimes assisted in their feeding on turnips with other substances, such as oil-cake and corn. Either of them is administered in a covered box, to protect it from injury from weather. Such a box is represented in fig. 227 , the construction of which requires no explanation. I have never had any experience of feeding sheep on oil-cake or corn, having mostly farmed turnip-land, upon which sheep never failed to become abundantly fat without any adventitious aid. On deaf and clay soils, however, oil-cake may prove beneficial: and it may be presented in these boxes to sheep on grass in winter as their entire food. Oil-cake luas the effect of keeping the dung of sheep in a moist state. It is supplied them in a bruised state, partly in powder, and partly in bits, as it falls from the oil-cake crusher-a convenient machine, the construction and operation of which will be described when treating of the feeding of cattle. I believe there is little use of measuring the quantity of oil-cake to sheep, (884) 
even when on turnips, as they will eat it when inclined, and some sheep eat it more heartily than others. The discriminating choice of food manifested by sheep is a valuable hint, in fattening them, to supply them with

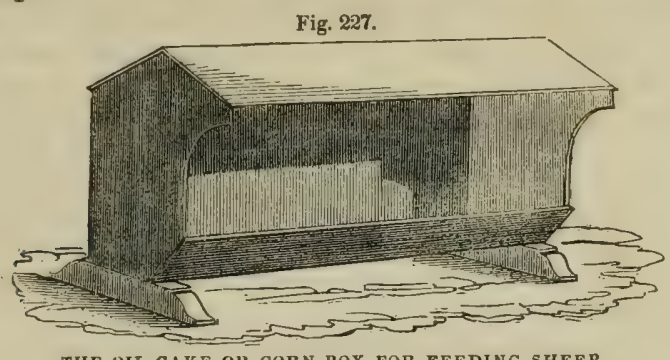

THE OIL-CAKE OH CORN BOX FOR FEEDING SHEEP.

different kinds of food, such as oil-cake, corn, hay, straw, and turnips, at one and the same time, that every sheep may take his choice daily; but, in case such a mode of feeding may be costly, it is worth while to try experiments on the subject, in order to ascertain whether, when a number of articles are presented at the same time to sheep for their choice, less of the most costly kind is not proportionally consumed than when supplied separately. On this principle, corn may be put in one box, and oil-cake in another, and so of other substances; and, although it is an indubitable fact that sheep will feed quite fat upon turnips alone with fodder on turnip-soil, yet they may become sooner ripe upon mixed than simple food; and the time thus gained may more than compensate (or at least compensate) for the cost of the various materials employed in feeding.

(1073.) Salt has been frequently given to sheep on turnips, but with what advantage I have never satisfactorily learned. I have given them it, and the eagerness with which they followed the shepherd when he came at the stated hour to lay down small quantities here and there over the break, upon flat stones, and the relish with which they enjoyed it, was very remarkable; yet the great desire for it continued but a short time, and then every day they took so little that it appeared as if they were trifling with it; and hence I could perceive no benefit they derived from its use. Perhaps the cultivator who paid the greatest attention to the use of salt to animals was the late Mr. Curwen, of Workington Hall, Cumberland, who used to give from 2 to 4 ounces per week to sheep, if fed on dry pastures; but, if feeding on turnips or rape, they were supplied without stint. "It is, in fact, indisputably proved," says Mr. Cuthbert W. Johnson, "that if sheep are allowed free access to salt, they will never be subject to the disease. called the 'rot. Is not this a fact worthy of a farmer's earliest, most zealous attention? Some recent experiments also lead me even to hope that I shall one day or other be able to prove it to be a cure for this devastating disease. I have room but for one fact: Mr. Rusher, of Stanley, in Gloucestershire, in the autumn of 1828, purchased, for a mere trifle, 20 sheep, decidedly rotten, and gave each of them, for some weeks, 1 ounce of salt every morning. 2 only died during the winter; the surviving 18 were cured, and have now, says my informant. lambs by their sides."*

(1074.) There are some inconveniences atcending the feeding of sheep on turnips in winter, which necessarily you should be made aware of. A heavy rain may fall for some days, and render the land quite soft and poachy, though it had been previously thoroughly drained, or even naturally dry. As the wet will, in such a case, soon subside, the removal of the

* Johnson's Observations on the Employment of Salt.

(885) 
sheep for a night and day to an old grass-field will give the land time to become firm; and a small quantity of oil-cake will suffice to support the sheep all the time they will be in the grass-field. A very heary rain may fall in a day, and inundate the lower end of the field with water, which may take some days to subside. The best way of preventing the sheep appronching the inundated part is to fence it off with a net. A fall of snow, accompanied with wind, may cover the sheltered part of the field, and leave the turnips bare only in the most exposed. In this case, the sheep must feed in the exposed part, and the racks placed there for shelter. But the snow may fall heavily, and lie deep over the whole field, and cover every turnip out of reach. Two expedients only present themselves in such a case; the one is to cast the snow from the drills containing the turnips, and pile it upon those which have been stripped. This task cannot be performed by the shepherd alone, or by the field-workers. The plowmen must bring their stable-shovels, fig. 149 or fig. 176, and clear the turnips; but, in doing this in severe frost, too many turnips should not be exposed at one time, in case they become frosted, which they are apt to be when exposed suddenly to frost from under snow. The advantage of casting the snow is that it gives the sheep an immediate access to the turnips; but a disadvantage attends it when the snow lies for a considerable time, all the manure being left by the sheep in the channels cut out of the snow, and, of course, none in those parts upon which the snow has been piled. The best plan to pursue at first, under the circumstances, is, in my opinion, to adopt the other expedient alluded to above-namely, to give the sheep oil-cake in the troughs, fig. 227 , for a time, in a sheltered place of the field, until it is seen whether the snow is likely soon to disappear; and, should it lie longer than afford time to consume the turnips, then the first expedient of casting off the snow may be resorted to at once, and its disadvantages submitted to. In the great fall of snow, in spring 1823 , my turnip-field was covered over 4 feet deep. Having no oil-cake, and finding it impossible to remove the sheep, the snow was cast in trenches, in which they soon learned to accommodate one another, and all throve apace. A fresh fall of snow a few days after came from the opposite quarter, and covered up the trenches, which had to be cleared out again. The snow continued upon the ground until the end of April, and as there was no time after that to put manure on the land which had been covered with piled-up snow-and, indeed, its soft state rendered the operation impracticable-the succeeding crop of barley grew in strips corresponding to the trenches. Even a supply of oil-cake would not, in this case, have superseded the trenching of the snow, to get the turuips eaten in time for the barley-seed.

(1075.) While young sheep and tups are thus provided with turnips during winter, the ewes in lamb find food on the older grass, which, for their sakes, should not be eaten too bare in autumn. Where pastures are very bare, or when snow covers the ground, they should either have a few turnips thrown down to them upon the snow, or, what is better, cloverhay given them in a sheltered situation. The best hay for this purpose is of broad or red clover, and next meadow-hay; but as you can only give the kind you happen to have, much rather give them turnips than hay that has been heated or wetted, or is moulded, as in either of those states it has a strong tendency to engender diseases in sheep, such as consumption of the lungs and rot of the liver; and in regard to great ewes, it is apt to make them cast lamb. If turnips cannot be had, and the hay bad, give them sheaves of oats, or clean oats in troughs, or oil-cake ; but whatever extraneous food is given, do not supply it in such quantity as to fat(886) 
ten the ewes, but only to keep them in fair condition. In the severe snowstorm of 1823, I put my ewes into an old Scots-fir plantation, into which only a small quantity of snow had penetrated, and there supplied them with hay laid on the snow around each tree. A precaution is requisite in using a Scots-fir plantation in snow for sheep; its branches intercepting the snow in its fall to the ground are apt to be broken by its weight, and fall upon the sheep and kill them; and in my case, a ewe was killed on the spot by this cause. The branches should therefore be cleared of the snow around where the sheep are to lodge by shaking them with poles or long forks, assisted by ladders if the case require it. In driving ewes heavy with lamb, through deep snow to a place of shelter, plenty of time should be given them to creep along, in case they should overreach themselves, and the exertion thereby cause them to cast lamb.

(1076.) In some parts of Scotland, and more generally in England, rape as well as turnips is grown for winter food for sheep. The rape (Brassica rapus oleifera of De Candolle) cultivated in this country, is distinguished from the colsat of the Continent by the smoothness of its leaves. It has been cultivated for the fattening of sheep in winter from time immemorial. The green leaves, as food for sheep, are scarcely surpassed by any other vegetable, in so far as respects its nutritious properties; but in quantity it is inferior both to turnips and cabbages. Its haulm may be used as hay with nearly as much avidity as cut straw.* The consumption of rape by sheep should be conducted in exactly the same manner as that of turnips. In England, that intended for sheep is sown broadcast and very thick, in which state it is certainly very suitable for them. In Scotland, it is raised in drills like turnips; and although not so conveniently placed for sheep as the broadcast, the top leaves being somewhat beyond their reach from the bottom of the drill, yet this form permits every cleansing process of the land during summer, and thus renders the culture of rape as ameliorating a crop for land as any other green crops raised for the purpose. It is acknowledged on all hands that, for raising seed for oil, the drill form of culture is far the best.

(1077.) Every kind of sheep, of whatever breed, when kept in the low country, should be treated in winter in the way described above, though the remarks there are meant to apply to the peculiar management of Leicester sheep, which is the usual breed cultivated where sheep form an integral part of the mixed husbandry. Where a Leicester flock is so kept. the ewes are regarded as a standing flock; that is, they bave themselves been bred upon the farm apon which they are supported, and are used as breeders, until considered no longer profitable, when they are fed off. But on many lowland farms, the mixed husbandry is only practiced to a partial extent, no flock. of ewes being kept for breeding, and only wethers intended to fatten on turnips are bought in on purpose. Some farmers, instead of w ethers, buy old ewes, dinmonts, or lambs. When wethers are bought, the breeds generally selected for the purpose are Cheviots and Black-faced from the mountains, where they are bred, and where large standing flocks of ewes are kept for the purpose of supplying the demand for lambs. Turnip-sheep are thus easily obtained at fairs in autumn; but where certain stocks have acquired a good name, purchasers go to the spot and buy them direct from the breeders.

(1078.) Sheep on turnips bave little shelter afforded them but what the fences of the field can give. In some cases, this is quite sufficient; but in others, it is inadequate. Of late years, the subject of shelter has attracted attention, and artificial means have been suggested, consisting of various devices involving different degrees of cost, not merely for protection against sudden outbreaks of weather, but with the view of gradually improving the condition of sheep, both in carcass and wool. It is a natural expectation that a fat carcass should produce more wool, and constant shelter improve its quality.

(1079.) One plan for shelter and comfort, a slight remove from the usual practice, was first tried by Mr. Hunter of Tynefield. in East-Lothian, in 1809, by littering the break occupied by the sheep in the field with straw, and supplying them with turnips upon it. In this way he littered 300 sheep upon 25 acres of turnips, which afforded 36 tons the acre, with the straw of 60 acres of wheat. weighing 1 ton the acre imperial. The sheep were thus treated 5 months on the ground. and fetched $2 \mathrm{~s}$. a head more than those treated in the usual manner. This increase of price is an advantage; but it is not all advantage, as the trouble of learling, at intervals, 60 tons of straw to the field; of leading the same, in the shape of manure, from that field to another; and of carrying the turnips from the drills to the fold, should be deducted from it. When turnips are laid upon

\footnotetext{
* Don's General Dictionary of Botany and Gardening, vol. i.
}

(887) 
straw, sheep cannot bite them easily; and this is an objection to laying down whole turnips tc aheep. on grass, instead of cutting them with a turnip-slicer; and among damp litter, sheep al. most invariably contract foot-rot, as 7 of Mr. Hunter's did."

(1080) Another plan of affording shelter to sheep on turnips is that of movable sheds to lie in.

Fig. 2t4 gives a floor plan of such a shed, 15 feet long, 7 feet wide, with an opening of $t$ of an

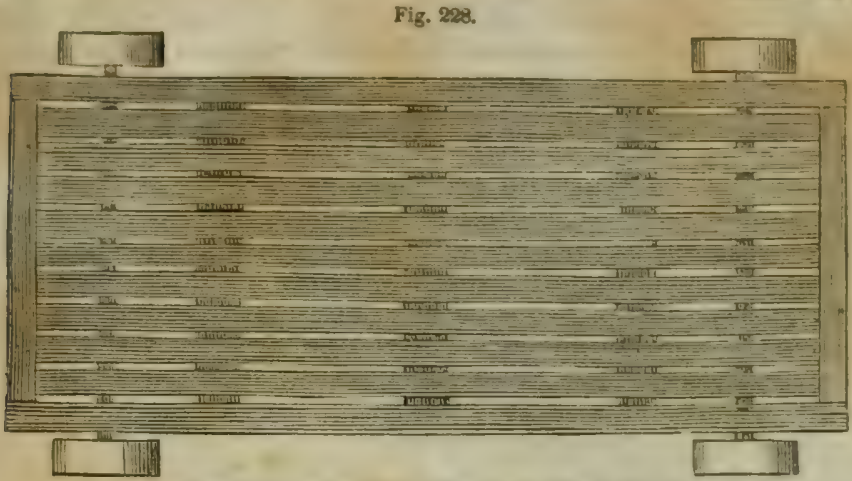

THE FLOOR OF A MOVABLE SHED FOR SHEEP ON TURNIPS.

inch between the floor-deals. The floor-frame rests on 2 axles of iron supported upon 4 iron wheels, 1 foot diameter, which raise it 6 inches above the ground. Fig. 229 gives a side eleva

Fig 229.

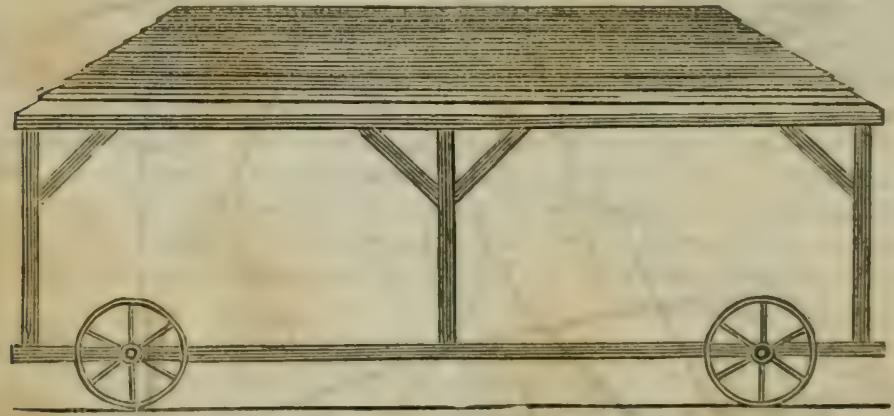

THE SIDE-ELEVATION OF A MOVABLE SHED FOR SHEEP ON TURNIPS.

tion of the shed, with the form of the roof, made of deals, lapping over each other, and elevated 5 feet above the floor; and fig. 230 is an end ele. vation of the same. One side and both ends, when the shed is in use, could be boarded in the quarter from which the wind comes; and if the boards are fastened dead, the shed should be wheeled round to suit the wind: but if boarding is considered too expensive a mode of fitting up such sheds, hurdles clad with thin slabs, or wattled with straw or willow against the ends and side, might answer the same purpose. A horse is required to wheel such a shed to any distance. A shed of the above dimen. sions might accommotate about a score of sheep. and its cost is said to be $\mathrm{fA}_{4}$. But should this constraction be considered too unwieldy, the shed could be made of two pieces of half the size, which would easily be moved about by people, and when placed together on end, would form an entire shed of the proper dimensions. Thus, fig. 231 represents two short floore placed together on 8 wheels; and fig. 232 a side-elevation and roof of two half-sheds, mounted on wheels together. The scale attacher to fig. 232 gives the relative proportions of every part. The cost of 2 half-sheds will of course

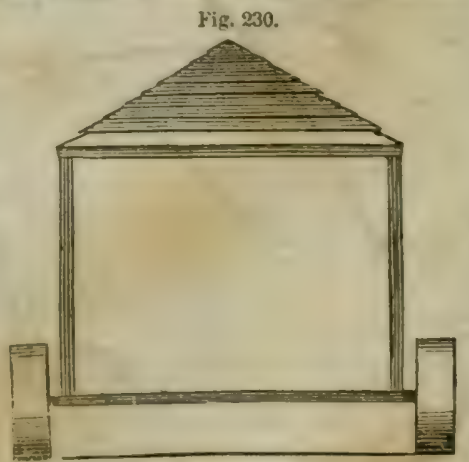

THE END ELEVATION OF A MOVABLE SHED FOR SHEEP ON TURNIPS. be more than a whole one. Whether any one will incur the cost of sheltering sheep on turnipa

- Binclair's Account of the Husbandry of Scotland, vol. it., Appendix.

(888) 
to such sheds is, I conceive, questionable; and it might be some time ere sheep would be in. deced to enter them.*

Fig. 231.
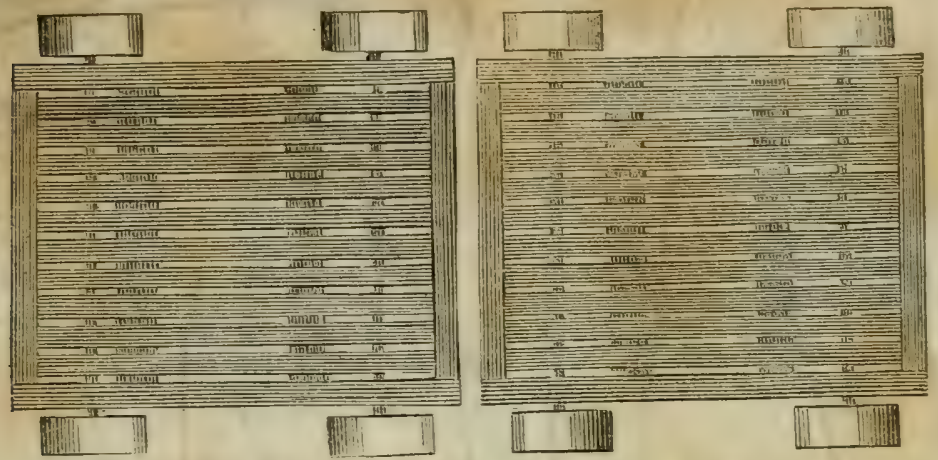

THE FLOUR OF TWO SHORT MOVABLE SHEDS FOR SHEEP ON TURNIPS.

(1081.) A third plan is to erect sheds and courts at the steading, to be littered when required and the sheep daily supplied with cut turnips. This plan, as I conceive, would afford more shelter and protection than by patting down litter, or erecting movable sheds in the field. I re.

Fig. 132.
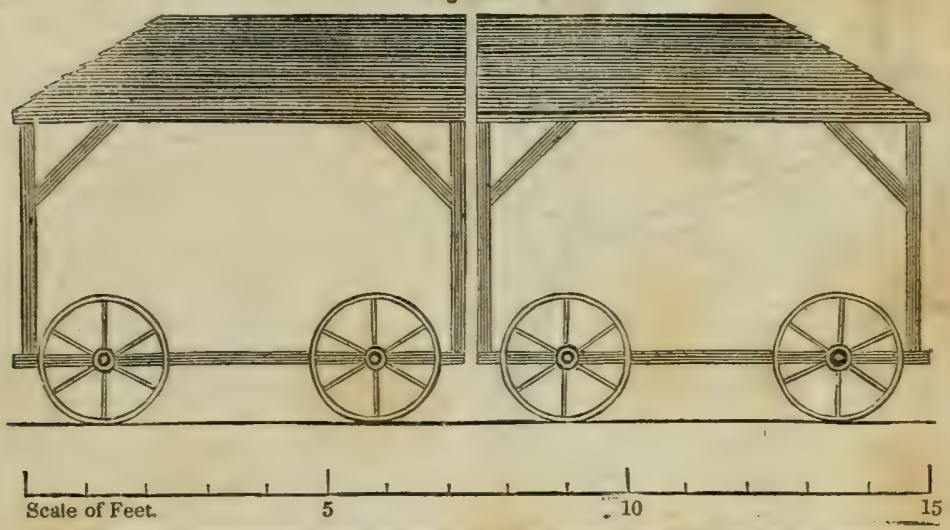

THE SIDE-ELEVATION OF TWO SHORT MOVABLE SHEDS FOR SHEEP ON TURNIPS.

member of seeing, more than 20 years ago, the courts and sheds erected at his steading by the late Mr. Wehster of Balruddery, Forfarshire; so that the recsnt practice and suggestions on the subjed by English sheep-feeders possess at least no novelty. The results of Mr. Webster's experiments, I believe, were not very encouraging. Mr. Childers. M. P. for Malton, fed 40 Leicester wether-hoggs on turnips, 20 in the field and 20 in a shed. The shed consisted of a thatched erection of rough deals, having a floor of slabs raised 18 inches above the ground, with a small court belonging to it. The boarded floor was swept every day, and fresh straw put over the court after every shower of rain. The sheep were divided into as equal lots as could be drawn, the score to be fed in the shed weighing 183 stoues $3 \mathrm{lbs}$,, and those in the field 184 stones $4 \mathrm{lbs}$. Each lot got as many cut turnips as they could eat, which amounted to 27 stones every day; 10 lbs. of lin. sued cake, or $\frac{1}{2}$ lb. to each sheep, per day; $\frac{1}{2}$ pint of barley to each sheep ; and a little bay, and a constant supply of sait. They were fed froral 1st January to lst April; and, on the fourth week, the hoggs in the shed ate 3 stones fewer turnips every day; in the ninth week, 2 stones still fewer und of linseed-cake $3 \mathrm{lbs}$, per day The results were these :

\begin{tabular}{|c|c|c|c|c|}
\hline Date. & 20 shed-hrigge. & Increasc. & :U neld-hosers. & mite age. \\
\hline Jannary 1 & $\begin{array}{l}\text { Sts. lbs. } \\
183 \quad 3\end{array}$ & Sts. Ibs. & $\begin{array}{l}\text { is. Ihs. } \\
\text { jR4 } 4\end{array}$ & sits. bs. \\
\hline February 1 . . . . . . & 2050 & 2111 & 1998 & 15 \\
\hline March $1 . . . \ldots \ldots \ldots \ldots$ & 21510 & 1010 & $208 \quad 2$ & 88 \\
\hline April 1.. & 2399 & 231 : & $220 \quad 12$ & 1210 \\
\hline Total increase.... & & $56 \quad 6$ & & $36 \quad 8$ \\
\hline
\end{tabular}

* Quarterly Journal o Agriculture, vol. xi.

(889) 
"Consequently," says Mr. Childers, "the sheep in the shed, though they consumed nearly 1-5 lesa food, bave made 1 greater progress." * Thus, in 4 months, the shed fed hoggs gained about 1 stone a head more than those in the field, and were worth $8 \mathrm{~s}$. a head more. This experiment of shed-feeding corroborates the ordinary experience in the progress of fattening sheep: namely, that the greatest progress is made at the beginning and end of the season. In the beginning, the fat is laid on in the inside, to fill op; and at the end it is laid on on the outside, after the scquire ment of muscle in the intermediate period.

(1082.) Lord Western pursues the plan of shed-feeding his Anglo-Merino sheep, to the extent of confining them all the year round. His folding-yards are spacious, and surrounded by sbeds, which are only 10 feet wide, and 6 or 7 feet high-built, in the cheapest manner, of timber that would otherwise be burnt. The yards are well littered, and to a considerable depth, and they never heat. After three years' experience, his lordship is "decidedly of opinion that the fatting stock thrive quicker, and the sheep with their lambs also do better than out of doors." Turnips. cabbages and salt constitute their lood. $t$

(1083.) Similar experiments have been tried in Scotland with success. Mr. Wilkin, Tinwald Downs, Dumfriesshre, fed 20 crose-bred Cheviot and Leicester boggs in conrts and shei on tarnips, grass and oil.cake, and their increased ralne over others in the field was estimated at from 22s. to 25s.; and Mr. Jolnn MacBryde, Belkar, fed both Leicester and Cheviot wethers in stalls on turnips, rice, sago, sugar, and linseed-oil, and realized 78. a head more than from those fed in the field $f$ But. in estimating the advantages derived from shed-feeding, the trouble nccasioned in bringing the turnips from, and taking the manure to the field, should always be borne in mind. But should the plan leave no profit. yet if it improve the quality of the wool in its most eseential particulars, it is worthy of consideration.

(1084.) Sheep are not fed on turnips on every hind of farm. Carse-farms are unsuited to this kind of stock; and, where turnips can be raised on them, cattle would be more conveniently fed There being, however, abundance of atraw on clay-farms, sheep might be fed in small courts and sheds at the steading on oil-cake. or any other succedaneum for turnips.

(1085.) On farms in the neighborhoud of large towns, whence a supply of manure is obtained at all times, turnips are not eaten off with sheep; but on those vear small towns they are so employed to manure the land. They are bought in for the purpose, and consist of Cheviot or Black faced wethers, or Leicester hoggs, or draft-ewes, which, if young, feed more quickly than weth ers of the same age.

(1086) On dairy-farms there is as little use for sheep as near towns, except a few wethers to eat off part of the turnips that may bave been raised with bone-dust, or any other specific manure in lien of farm-yard dung.

(1087.) On pastoral farms, sheep are not fattened on turnips; but their treatment in winter pos. sesses exciting interest. There are two kinds of pastoral farms, and as this is the first opportu. nity I have had of considering the peculiarities of their management, 1 shall here make some gen eral remarks on their constitution and fitness for rearing sheep.

(1088.) The tirst thing that strikes you on examining a pastoral country is the entire want of shelter. After being accustomed to see inclosed and protected fields in the low country, the wind ing valleys and round-backed hills of a pastoral one appear, by comparison, naked aud bleak.You are not surprised to find bare mountain-tops and exposed slopes in an alpine country, be cause you scarcely conceive it practicable for man to inclose and shelter elevated mountains; but among green hills and narrow glens, where no natural obstacles to the formation of shelter aeem to exist, but, on the contrary, whose beautiful outlines indicate sites for plantations that would de. light the eye of taste, independent of their utility as shelter to their owner's habitation; and he having experienced their utility in that respect, could vot refuse similar comfort to the dumb and patient creatures dependent on lis bounty. Hence, the hurricane that a planter arrests in its pro gress toward his own dwelling, ceases at the same time to annoy the peace of his flocks and herds. The chief difficulty of forming shelver by planting is the expense of inclosing it: for, as to the value of trees from a uursery, it is a tritle companed to the advantage derived from the shelter where they grow: and yet, in a mountainous country, there is no waut of nuaterials for inclos ing, no want of rock to produce stones for building roush but substantial stone-dykes; labur is but required to remove and put them together; and, as a simple means of their removal, it is surprising what a quantity a couple of men will guarry, and a couple of single-horse carts will convey. in the course of a summer. The carriage, ton. in every instance, could be made down-hill, freah rock being accessible at a higher elevation as the builuing proceeds upward.

(1089.) Sup pose a hill-farm containing 4 square miles, or 2,560 acres, were inclosed with a ring. fence of planting of at least 60 yards in width, the ground occapied by it will amoumt to 174 acres. A 6 -feet stune wall round the inside of the planting will extend to 13.600 roods of 6 yards, which, at 6s. 6d. per rood, will cost $£ 612$. But the sheltered 2.386 acres will be worth more to the ten. ant. and of course to the landlord, than the entire 2,560 acres unsheltered would ever have been while the proprietor will have the value of the wood for the cost of fencing. Besides, it should be borne in mind by the proprietor that planting, as a ring-fence to one farm, shelters one side of 4 other farms of the same size, which is an inducement to extend the benefits of shelter; and these, moreover, can be afforded on a large scale at a cheaper cust than on a small_ so much so that, were neighboring proprietors to undertake simultaneously the sheltering of their farms on : gystematic plan, not only would warmth be imparted over a wide extent of country, but efficient fencing would be accomplished along march fences at half the cost to each proprietor.

(1090.) Low pastoral farms should be stocked with Chevint, and hieh with the more hardy Black-faced, sometimes called the Heath and Mountain Sheep; and, although the genral treatment of both breeds is nearly alike, yet their respective farms are laid out in a diff(r)tut manner. A Cheviot sheep-farm contains from 500 to 2,000 sheep ; that which maintains from 500 to 1,000

- Jonrnal of the Royal Agricuttural Society of Fingland, vol. i.

I Mark-Lane Expreas, $16 i \mathrm{~h}$ Dec. 1839. † \$uarterly Journal of Agriculture, vol. xi. (890) 
is perhaps the highest rented, being within the reach of the capital of many farmers; and one that maintains from 1,000 to 2,000 is perhaps the most pleasant to possess, and, if it have arable land attached to it, will afford pretty good employment to the farmer, though, with good shepherds under him, and no arable farm, he could manage the concerns of 6,000 sheep as easily as those of 500. A shepherd to every 600 Cheviot sheep is considered a fail allowance, where the ground is not very difficult to traverse, and it may be held as a fair stent to put 1,000 sheep on every 1,200 acres imperial.*

(1091.) Every Cheviot sheep-farm should have arable land within it, to supply turnips and hay to the stock, and provision to the people who inhabit it. It is true that all the necessaries, as well as the luxuries, of life may be purchased; but no dweller in the country will hesitate a moment to choose the alternative of raising the necessaries of life and having them at command, to going perhaps many miles to purchase the most trivial article of domestio use. It is not easy to determine the proportion which arable land should bear to pastoral, to supply the requisite articles of provision; but perhaps 2 acres arable to every 20 breeding-ewes the pasture maintains may supply all necessaries. Taking this ratio as a basis of calculation, a pastoral farm maintaining $i, 000$ ewes, a medium number, would require 100 acres of arable land, which would be labored by 2 pair of horses, on a 4-course shift; because, pasture not being required on the arable portinn of the farm, new grass will be its substitute. The farm will thus be divided into 25 acres of green crops, 25 acres of corn after them, 25 acres of sown grasses, and 25 acres of oats after the grass.Manne will be required for 25 acres of green crop, which will partly be supplied by the 100 acres of straw, by bone-dust, and by sheep on turnips after bone-dust. To render the straw into manure there are 4 horses; cows of the faimer, the shepherd, and plowmen; with perhaps a few stirks, the offspring of the cows, and a young colt or two, in the farm-yard. The arable land should have a ring-fence of thorn, if the situation will admit of growth or of stone.

(1092.) The steading for such a farm may be of the form of fig. 28, containing a 4 horse threshing-mill, driven by water if possible, by horses by necessity ; a corn-barn, straw-barn, chaff-house, stable, byre, cart-shed, wool-room, and implement-room for the shepherd's stores.

(1093.) The pasture division of the farm should be subdivided into different lots, varying in number and dimension according to the age and kind of the stock to be reared upon each. The nature of the land determines the age and kind of stock to be reared upon it; for it is found that some land will not suit breeding-ewes, and otbers are unsuitable for hoggs. If the pasture congist chiefly of soft, rough land, hoggs are best adapted for it; but. if short and bare, ewes will thrive best upon it. That farm is best which contains both conditions of pasture, to maintain both breeding and rearing stock. In subdividing a farm into lots. each should, as much as possible, contain within itself the same quality of pasture, whether rough or short; for, should fine and coarse grass be included within the same lot, the stock will remain almost constantly upon the fine, to the risk of even reducing their condition. To the extent of 1.5 of coarse to fine may be permitted within the same lot, without apprehending much detriment to stock. Should a large space of inferior soil lie contiguous to what is much better, they should be divided by a fence, and. if requisite. a different breed of sheep reared upon each. By these arrangements. not only a greater number of sheep may be maintained upon a farm, but the larger number will always be in better condition. $\dagger$

(1094.) The draining of pastoral farms is an operation of great importance, as a superior class of plants will thereby be encouraged to grow in places occupied by coarse herbage, nourished by superabundant and stagnant water. A plan of laying out hill-drains may be seen in fig. 145.Their collected waters may be conveyed away to a contiguous rivulet or hollow in open maindrains, like that in fig. 146. A spouty swamp, of whatever extent, and wherever occurring, should be drained by coupled stone.drains, like fig. 159, cut to the bottom of under water; and the ordiuary drains for conveying the water in the branches should be formed with a cover, like fig. 147 The arable portion of the farm should, of course, be drained by parallel drains, as represented in fig. 186, of the form of coupled drains, like fig. 159; and, if tiles are near as well as stones, like fig. 185. One means of keeping part of the surface dry is to have the channel of every rivulet, how ever tiny, that runs through the farm, scoured every year in those parts where accumulated gravel causes the water, in rainy weatter or at the breaking up of a storm, to overflow its banks; be canse the overflowed water, acting as a sort of irrigation, sets up a fresh vegetation, which is eagerly devoured by sheep in spring, to the risk of their health; and the sand carried by it is left on the grass on the subsidence of the water, much to the injury of the teeth and stomachs of the sheep. The confinement of water within its channels also prevents it leaving the land, where innndated, unduly wet.

(1095.) In recommending a connection of arable with a pasture farm, my object is simply to insure an abundant supplv of provision for sheep in winter. Were our winters so mild as to allow sheep to range over the hills in plenty and safety, no such connection need be formed-or, at least, to a greater extent than would supply provisions to its inhabitants, when situated far from a market. But when we are aware that severe storms at times almost overwhelin a whole flock, and protracted snows and frosts debar the use of the ground for weeks together, it is necessary that provision be made for the support of stock in those calamitous circumstances; and, surely, there is no better or more legitimate mode of supporting them than of raising provision for them upon their own ground. I am quite aware of the folly of trusting to corn in a high district for rent, and am also aware that stock alone must provide that; and I have seen too many instances of failure in trusting to corn and neglecting stock; nevertheless, it cannot be denied that the more stock are provided with food and shelter in winter, the less loss will be incurred during the most inclement season. Let one instance, out of many that could be adduced, suffice to show the com

Little's Practical Observations on Mountain Sheep.

1 A Lammermuir Farmer'a 'Treatise on Sheep in High Districts. The Lammermuir Farmer was the late Mr. John Fairbairn. Hallyburton, a man of good sense and an excellent farmer, and whose acquaintance I was happy to cultivate. 
parative immunity from lose enjoyed, by food and shelter being provided for sheep in winter. In the wet and cold winters of 1816 and 1818 , the extra-that is, the more than usual-loss of sheep and lambs on the farm of Crosscleuch, Selkirkshire, was as follows:

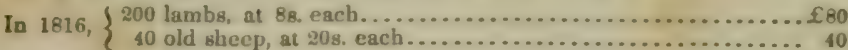

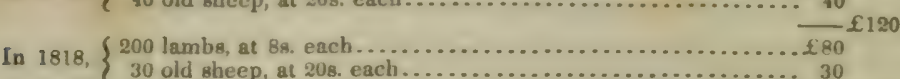

Value of total extra loss.......................

whereas, on the farm of Bowerhope, belonging to the same farmer and on which $\frac{1}{3}$ more sheep are kept, the extra loss in those years was as follow's:

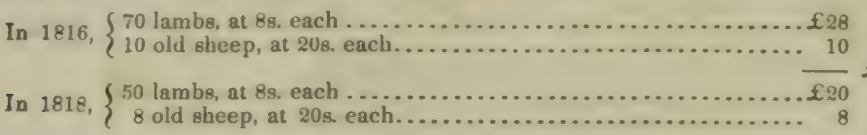

Value of total extra loss......................... £66

Deduct loss on Crosscleuch........................ 230

Value saved on farm of Bowerhope.................. $16 t^{*}$

(1096.) Food and shelter being both necessary for the proper treatment of sheep in winter on pastoral farms, the means of supplying them demand the most serious attention of the store-farmer. During winter, sheep occupy the lower part of the farm. Hoggs are netted on turnips in the early part of the season, and ewes and other sheep subsist on the grass as long as it is green. The division allotted to green crop in the arable part of the farm contains 25 acres, and, allowing 3 acres for potatoes for the use of the farmer and his people, there remain 22 acres for turnips; and as land among the hills is generally dry. turnips grow well upon it; so that 30 double-horse cart. loads to the acre, of $15 \mathrm{cwt}$. each, may be calculated on for a crop. It is judiciously recommended by Mr. Fairbairn to carry off, about the end of October or beginning of November, if the weather is open-that is, fresh-before the grass fails, 4.5 of the turnips, and store them in heaps as in fig. 213, and as described in (1016); and allow the erce-hoggs, retained to maintain the num. ber of the ewe-flock after the draft-ewes have been disposed of, to eat the remaining 1.5 off the ground, with whatever small turnips left when the others were pulled; and, to strip the land in that proportion. 1 drill should be left and 4 carried off. This is. as I conceive, an excellent anggestion for adoption on every hill-farm. especially as it secures the turnips from frost, and, at the same time, gives the entire conmand of them whenever they are required in a storm.

(1097.) It is found that hoggs fall off in condition on turnips in spring, in a high district, if con. fined exclusively upon turnip-land; not certainly for want of food, but probably from too much exposure to cold from want of shelter. They are, therefore, always removed from the turnips in the afternoon to their pasture, where they remain all night, and again brought back to the turnips in the following moruing. It is obvious that this necessary treatnent, under the circumstances, deprives the lanit of much of the manure derivable from the turnips: and hence farni-dung should be put on the land befor: the sowing of the following grain crop, where the previous turuips had been raised with bone-dust. The hoggs continue their daily visit to the land until all the tarnips are consumed; which, amounting in all to $4 \frac{1}{3}$ acres, may last, under the peculiar treatment, 17 score of hoggs-the number kept for refreshing the ewe-stock-about 6 or 7 weeks. After the land has been cleared of the turnips. the horiss should be daily supplied from the store on their pasture with 1 double cart-load to every 8 scores, which will be consumed in about 4 hours; and. after that, they depend on the grass for the remainder of the day. Hound turnips, having no hold of the ground, give way to the upward bite of the sheep with the lower jaw teeth, and prove troublesome to then when laid down upon grass. When taken out of a store, they should therefore always be cut with a slicer. Hogers are treated in this way until Mlarch, or loneer if the weather is bleak: and the advantages of it are that they are maintained in their condition. and become proof against the many diseases which poverty engenders; and their flece weichs $1 \mathrm{lb}$. more at clipping-time. The cost of 8 acres of turnips given to hogrs, valued at $£ 3$ an acre in a high district. is 17 d. each, which is so far counterbalanced by the additional pound of wool which the cost insures, and which is worth from $10 \mathrm{~d}$. to $1 \mathrm{~s}$. per lb. The balance of $5 \mathrm{~d}$. io $7 \mathrm{~d}$. a head, which is the true cost of the keep of the sheep, is a trifle eompared to the advantage of bringing them through the winter in a healthy state and in fair condition.

(1098.) As to the older sheep, they must party depend, in frost and snow, apon the 14 acres of turnips yet in store, and upon hay, and. of course, upon pasture in fresh weather. The hay is ob. tained from the 25 acres of new grass, which may be all made into hay: but allowing 5 acrea for cutting-grass given in suppers to horses and cows, thene remain 20 acres for hay, which, at 120 hay-stones (of $22 \mathrm{lbs}$. to the stone) per acre, give 2,400 hay-stones, or 3.771 stones in perial. The 1,000 ewes will eat $1 / \mathrm{lbs}$. and the hoggs $\frac{1}{\mathrm{l}} \mathrm{lb}$. each every day. besides the two cart-loads of turnips among the lot. At this rate, the hay will last 31 days, which is a shorter time than many storms continue; but if the whole 25 acres of new grass wene made into hay, it would last 40 days. But the rale should be to begin with a full hand of hay at the commencement of farming.

-Napicr' Treatise on Prectical Store-Farming.

(892) 


$$
26
$$




$$
\mathscr{B}
$$


to occupy $\frac{1}{5}$ an acre of ground, to be fenced with a stone-wall 6 feet high, if done by the landlord; but if by the tenant. 3 feet of the wall to be built with stone, and coped other 3 feet with tarf; which last construction, if done by contract, would not cost more than 2s. per rood of 6 yards.

Fig. 235.

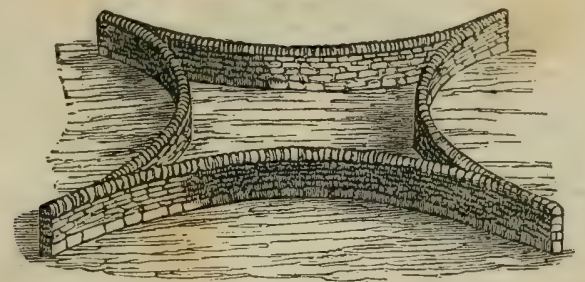

THE FORM OF STELL RECOMMENDED BY MR. FAIRBAIRN.

An objection to this form of stell without a planting is, when the wind strikes into any of the re. cesses, it is arrested in its progress by coming against the perpendicular face of the wall, from which it strikes upward, and then throws down the snow immediately beyond it; where, in this particular form, the drift would be deposited in the inside of the stell ; and hence it is, I presume, that Mr. Fairbairn objects to sheep being lodged in the inside of a stell.* This form, though affording more shelter, seems open to the same objections as may be urged against the forms of the ancient stells, $a, b$, or $c$, fig. 236 , the remains of many of which may be observed among the hills, and might yet screen sheep from a boisterous blast in summer.

\section{Fig. 236.}

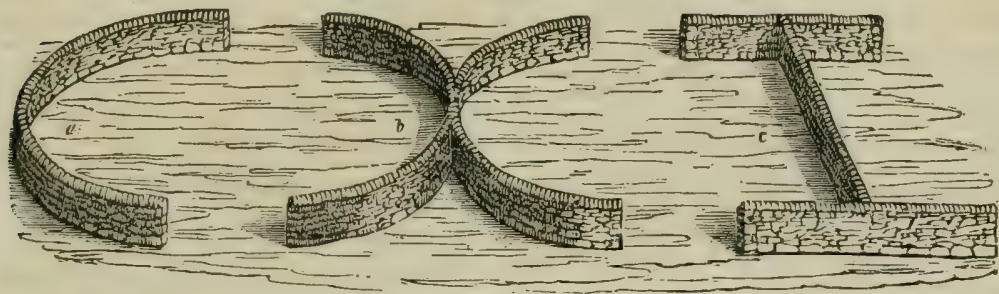

THE ANCIENT STELLS.

(1105.) There is much difference of opinion regarding the utility of sheep-cots on a store-farm.These are rudely-formed houses in which sheep are put under cover in wet weather, especially at lambing time. Lord Napier recommends one to be erected beside every stell, to contain the hay in winter, if necessary; and Mr. Little even advises them to be built to contain the whole hirsel of sheep in wet weather. It seems a chimerical project to house a large flock of sheep for days, and perhaps weeks; and, if even practicable, it could not be done but at great cost. I agree with those who object to sheep-cots in high farms, because, when inhabited in winter, even for one night, by as many sheep as would fill them, an unnatural hight of temperature is occasioned.Cots nuay be serviceable at night when a ewe becomes sick at lambing, or when a lamb has to be mothered upon a ewe that has lost her own lamb, because, these cases being few at a time, the cot never becomes overheated.

(1106.) In an unsheltered store-farm it is found requisite to have 2 paddocks, and the number is sufficient to contain all the invalid sheep, tups, and twin lambs, until strong enough to join the hirsel. Hay should be stacked within, and the turnips stored around the outside walls, or in the planting of the stells. Tups may graze with the hirsel in the early part of the summer; but, as no ordinary dyke will confine them in autumn, they should be penned in one of the stells, on hay or turnips, until put to the ewes.

(1107.) Where a rivulet passes through an important part of the farm, it will be advisable to throw bridges across it at convenient places for sheep to pass along without danger, either to better pasture or better shelter on the opposite bank. Bridges are best constructed of stone, and though rough, if put together on correct principles, will be strong; but, if atones cannot be found fit for arches, they may do for buttresses, and, across these, trees may be laid close, and held together by transverse pieces 6 feet long, which, when covered with tough turf, will form a broad and safe roadway.

(1108.) These are all the remarks that occur to me in reference to the management of a low pastoral farm in winter; and, although many of them are equally applicable to a high store-farm. yet their circumstances are so far different as to warrant modifications of management. There is one circumstance which obviously renders modifications in management necessary, and that is the difference in habit betwixt the Black-faced and Cheviot breeds of sheep, the former being the best suited for a high farm. Some of the hill-farms extend to the highest points of our mountain ranges, to 4.000 feet above the level of the sea, and embracing many thousand acres; and, as land at that

* A Lammermuir Farmer's Treatise on Sheep in High Districts.

(895) 
elevation cannot be expected in yield much nutritious vegetation, many acres in some places are required to support a single sheep, so that a farm containing 1,000 sheep may require from 2,000 to 5.000 acres; but there are few hill-farmers who possess only 1,000 sheep. The circumstance of elevation and seclusion from roads also imposes modifications in the feeding from that pursued in the lower country. The store-farmers of the lower country sell what lambe they can spane, after retaining as many as will keep their ewe-stock fresh. They thus dispose of all their wetherhoggs, the amaller ewe hoggs, and draftewes - which, if parted with at an early age, say 3 years, become more easily fattened on turnips in the low country than wethers of the rame age. Bappose that 1,000 ewes wean 1,000 lambs, 500 of these will be wether and 500 ewe-hoggs; of which latter 17 scone, or 340 , will be retained, and the remaining 160 disposed of. It is the practice of the hill store-farmer, on the other hand, to purchase these lambs-rear them until fit, as wethers, to go to the low country to be fed fat on turnips-and, being a purcbaser of lambs, keeps fewer breeding.ewes than wethers.

(1109.) It seems impracticable to have arable land on a hill-farm-at least, hill-farmers are un. willing to admit that turnips are the best food for their stock in winter. Whatever may prompt them to object to any arable culture on their farms, it would require very cogent reasons to prove that Black ficed sheep would not thrive well on turnips in the hills, if these could be raised in safficient quantity upon the spot. Doubtless on many farms, far removed from the great thoroughfares of the country, it would be very difficult to bring even a favorable spot into culture, and eapecially to raise green crops upon them as they should be; but, on the other band. there are many glens among the hills, not far removed from tolerable roads, in which culture mirht he practiced to great advantage, the produce of which would assist to maintain the condition of the flock thraugh a stormy period of 6 weeks or 2 months.

(1110.) As a corroborative proof of the atility of some culture on hill-farms, it is the practice of mauy hill.farmers to take either turnips or a rough grazing for their stock in the lower part of the country, as nearly adjacent to their homes as food can be procured; and nany lowland-farmers, who possess hill-farms besides, bring down their young sheep to the low country in winter, and put them on turnips. When turnips, however, are taken for this purpose, a considerable expense is incurred, and a rough pasture, though less efficacious than turnips, may bring the stock through the dreary part of winter tolerably well; but the conveniences of home are wanting here, and when snow falls deep, and covers the ground for weeks together, little provision has been made to get at the turnips in the fields; and then whins and bushes afford the only food where there is no hay. but where there is, it is of course given them: bnt then. in this case, there was no use of incurring the expense and enduring the fatisue of the flock going from home, when hay could be given them in their own haunts. Hence the necessity, wherever turnips are, of atoring a large proportion to be used in emergencies. Where a Scots-fir plantation is near a haunt of sheep, they need not starve; for a daily supply of branches. fresh cut from the trees, will not only support them, but make them thrive as heartily as upon hay alone; and, if a small quantity of hay is given along with the fir-leaves, they will thrive better than on bay alone."

(111.) One inducement may make some hill-farmers send their stock to a lower conntry in winter-namely, the want of adequate shelter at home. Their hills are bare of wood, the few trees being confined to the glens, and of course sheep can find no shelter in their usual grounds; and is is ourprising how susceptible of cold even Black-faced sheep are when the atmosphere is becoming moist. They will cover down, creep into corners and beside the emallest bushes for - shelter, or stand hanging their heads and grinding their teeth, having no appetite for food. If a piercing blast of wind follows such a cold day, the chances are that not a few of them perish in the night; and, if thick snow-drift comes on, they drive before it, apparently regardless of consequences, and get into some hollow, where they are overwhelmed. Thus the utility of atells becomes apparent, and many hearty wishes are no doubt expressed for them by the farmer and his shepherd, when too late to save the flock.

(1112.) Much diversity of opinion exists in regard to the best form of stell for high pastures, where wood seldom grows. At such a hight the spruce will not thrive; and the larch, being a deciduous tree, affords but little shelter with its spear-pointed top. There is to tree but the ever. green Scots-fir fit lior the purpose; and, when surrounding a circular stell, such as is represented by fig. 237 , it affords very acceptable shelter to a large number of sheep. In reference to this particular form of stell, it consists of 2 concentric circles of wall. represented by the dark lines in the figure, inclosing a planting of Scots-fir. and having a circular epace $a$ in the center for sheep. which cav be made as largo as to contain any number. This may be denominated an inside atell, in contradistinetion to that in fig. 233 , and has been proved eflicient by the experience of Dr. How. ison. Its entrance, however, is erronecusly made wider at the month than next the interior circle $a$. which has the effect of increasing the velocity of the wind into the circle. or of squeezing the sheep when they enter the passage in numbers. IV ere the passage parallel it would be better, but if wider at the inner end it would be of still better construction.

(1113.) But, where trees camot be planted with any prospect of success, stella nay be formed without them, and indeed usually are; and. of all the forms that have been tried, the circular has obtained the preference on hill-farms; but the difticulty of determining their size ns the best is still a matter of dispute among hill-farmers. Lord Napier thinks that 7 yarde diameter is n good size, aud that the largest should not exceed 10 yards, inside mensure; while Mr. WVilliam Hogg approves of 18 yards. I am inclined to agree with Mr. Hogg. In the first place, the circular form if better than a gquare, a parallelogram. or a cross; because the wind striking ayainst a curved surface, on coming from any quarter, is divided into two columns, each weuker than the undivided mass: wherens, on striking ardinst a straight surface, though its velocity is somewhat checked, it is still undivided, and its force still great, when it rebounds upward with iucreased force, and, curling over the top of the wall, throws down the snow a few yards only bevond it-that is, into the interior of the figure. Any oue who bas noticed the position of drifts of snow on each side

* Little's Practical Obaervations on Mountain Sheep. 
of a straight stone-dyke, will remember that the leeward-side of the dyke is completely filled up. and that on the windward a hollow is left often clear to the ground between the snow and the dyke. Every form of stell, therefore, that presents a straight face to the drift, will be filled up be.

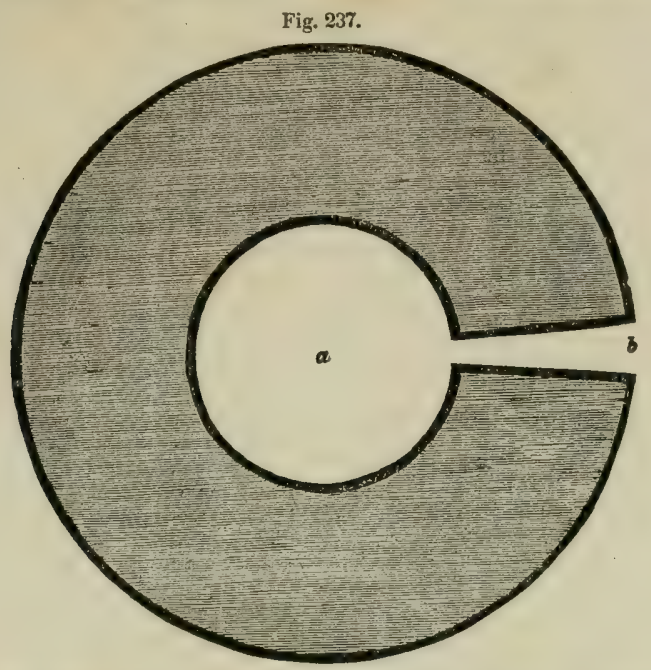

THE INSIDE CIRCULAR STELI, SURROUNDED WITH PLANTING.

hind the front wall, and can be no protection to sheep against being blown over with snow of two curves, that which has the larger diameter will, it is obvious, divide the drift the farther asun. der. A stell of small diameter, such as 7 yards, dividing a mass of drift, the current of air imme. diately over the stell is suddenly cut in two, but to so small a hight that the snow from the air above falls between them into the stell. When, on the other band, a stell of large diameter, as of 18 yards, divides a column of air, this is so much deflected on each side that the current above the stell is widely divided to a considerable hight, and, long before it regains its former state, it has passed over the stell, where it deposits its snow; and hence, near such a stell the snow is found to accumulate in a triangular shape, with its apex away from the stell quite to leeward of the most distant part of the wall, and of course leaves the interior free of snow. Fig. 238 repre-

Fig. 238.

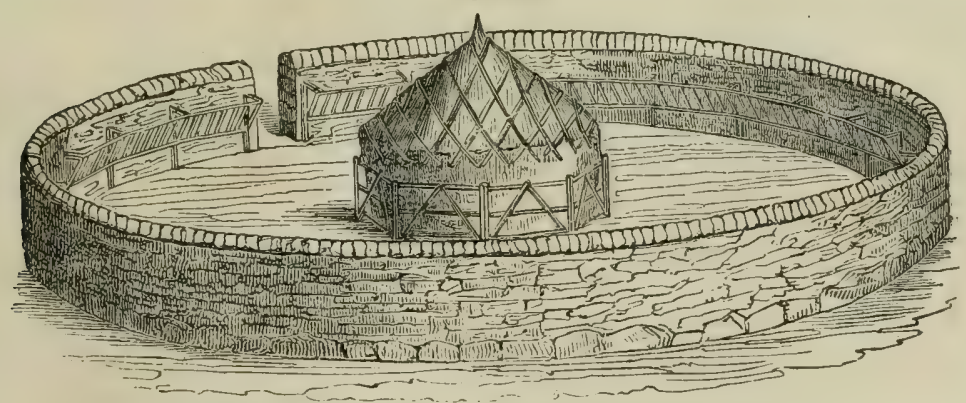

THE CIRCULAR STELL FITTED UP WITH HAY-RACKS.

sents one of 18 yards diameter inside, surrounded by a wall of 6 feet high, the first 3 feet of which may be of stone, and the other 3 feet of turf, and will cost $2 \mathrm{~s}$. $4 \mathrm{~d}$. per rood of 6 yards, if erected by the tenant, but if by the landlord, and wholly of stone and coped, will cost 7s. per rood : this size gives $9 \frac{1}{3}$ roods, which at $7 \mathrm{~s}$. makes its cost $£ 35 \mathrm{~s}$. $4 \mathrm{~d}$., including the quarrying and carriage of the stones-a tritling outlay compared to the permanent advantage derived from it on a hill-farm.The opening into the stell should be from the side toward the rising ground, and its width 3 feet, and of the whole hight of the wall, as seen in the figure; or it is sometimes a square of 3 or 4 feet, on a level with the ground, in which case the stell is entered by stile-steps over the wall. Such a structure should supersede the use of every antiquated form that has been tried, such as the single crescent $a$, fig. 236, double crescent $b$, or double T $c$; and it will easily contain 10 score of sheep for weeks, and even 15 or 16 score may be put into it for a night without being too much crowded together. 
(1114.) Stells should be fitted up with hay-racks all round the inside, as in fig. 238, not in the expensive form of the circle, but of a many-sided regular polygon. It is a bad plan to make sheep eat hay by rotation, as recommended by Lord Napier and Mr. Little, bat condemned by Mr. Fairbairn, for the timid and weak will be kept constantly back, and snfter much privation for days at a time. Let all have room and liberty to eat at one time, and as often as they choose. The hay-stack should be built in the center of the stell, as in fig. 238, where it should be placed on a basement of stone. raised 6 inches above the ground. A small stack. 5 yards in diameter at the base, 6 feet high in the stem, with a top of 6 feet in hight, will contain about 450 hay-stones of hay, which will last 200 sheep 33 days, about the average duration of a long storm; but upon the same base a much greater quantity of hay could be buile. The interior circumference of the stell measures 160 feet round the hay-racks, and if 8 or 9 six-feet flakes were put round the stack, at once to protect the hay and serve as additional hay-racks, that would give 47 feet more, which together afford 1 foot of standing roum to each of 200 sheep at one time, and supersede the objec. tionable plan of feeding them in rotation.

(1115.) Stells form an excellent and indispensable shelter for sheep in a snow.storm, when de. prived of their pasture; but it has occaired to me that, in want of stone-stells, very good stells or chambers might be made of snow of any form or size desired. Even around the space occupied by sheep, after a heavy fall of snow, a stell might be constructed of the snow itself. taken from its interior and piled into walls as wide and bigh as required. Such a construction wnuld remain as long as the storm endured, a new storm could be made available for repairs, and even after the ground was again clear, the snow-walls would remain as screens for some tine after. A small drain or two, in case of a thaw, would convey away the water as the snow melted. As long as the ground continues green, natural shelter is as requisite as stells; these consist of rocks, crags, braes, bushes, heather, and such like. To render these as available to sheep as practicable, the ground should be cleared of all obstructions around them, and bushes planted in places most suited to their growth, such as the whin (LZex europaca), in poor thin clay, and it is a favorite food of sheep in winter: the broom (Genista scoparia), on rich light soil; the juniper (Juniperus communis), in sandy soil; the common elder (Sambucus nigra), in any soil, and it grows well in exposed, windy situations; the mountain ash (Pyrus ancuparia), a hardy grower in any soil; and the birch when bushy (Betula alba), grows in any soil, and forms excellent clumps or hedges for shelter, as well as the hazel (Corylus avcllana), and the common heaths (Erica vulgaris and tetralix), when they get leave to grow in patches to their natural hight in peaty earth.

(1116.) Since hay is the principal food given to sheep in snow or in black frost. it is matter of importance to procure them this valuable provender in the best state and of the best description. It has long been known that irrigation promotes, in an extraordiuary degree, the growth of the nataral grasses; and perhaps there are few localities which possess greater facilities for irrigstion, though on a limited scale, than the Higblaud glens of Scotland. Rivulets meauder there through haughs of richest alluvium, which bear the fiaest description of nataral pastare plants, and yet irrigation is entirely neglected in those regions. Were the rivnlets in winter subdivided into irrigating rills, the prodace of these haughs might be multiplied many fold. It is not my purpose here to describe the management of irrigating meadows-that I will do ere all the winter operations terminate; nor is it my intention to describe the best mode of converting natural grass into hay, for that will form part of our occupation in the summer season : all that is requisite to be said in this place on the subject of irrigated meadows is, that, as they might be formed with great advantage to stock in many places where they are at present neglected, I cannot too earnestly draw the attention of hill-farmers to their utility; and although the localities in which they can be constructed are limited in extent, they will not be the less valuable on that account. One obstruction to their formation is the necessary fencing required around them, to prevent the trespass of stook while the grass is growing for hay. Besiles places for irrigation, there are rough patches of pasture frequently found in the hills, probably stimulated to growth by latent water performing a sort of under-irrigation to the roots of the plants, which should be mown for hay; and to save farther trouble, this bay shonld be ricked on the spot, and surrounded by small hurdles, through which the sheep could feed in frosty weather from the rick, and keep themselves in fair condition. They would assemble round the stacks at stated hours, and, after filling themselves with dry food. again wander over, it may be. the bare but green sward for the remainder of the day, until severe black frost make them frequent the stacks; and when snow comes, the stells would be their place of refuge and support. As the hay in the stacks is eaten in, the flakes should be drawn closer around them, to allow it to approach again within reach of the sheep.

(1117.) [Sheep-flakes or hurdles.-Flakes are constructed in two different forms. The one represented by fig. 216 is the strongest and most durable, but is also the most expensive in first cost. The fisure exhibits 2 flakes joined and supported, in the way they are placed, to form a fence. Fach flake of this construction, with its fixtures, consists of 14 pieces, viz. 2 side-posts $a, 4$ rails $b$, and 3 braces $c d d$. which go in form the single flake; and I stay $f, 1$ atake $g$ or $e$, and 3 pegs $h$ or $i$, which are required for the fixing up of each flake. The scantling of the parts are the side-posts $4 \frac{1}{2}$ feet long, 4 inches by 2 inches. The rails 9 leet long. $3 \frac{1}{5}$ inches broad by 1 inch thick. The braces, 2 diagonals 5 feet 2 iuches lone, $2 \nmid$ inches broad by 3 inch thick, and 1 upright 4 feet lone,

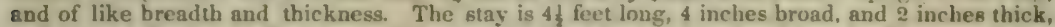
and bored at both ends for the pegs; the stake $1 \frac{1}{2}$ feet long, pointed and bored. The pegs 1 foot long, 1 t inch diameter.

(1i18.) The preparation of the parts consists in mortising the side-posts, the mortises heing neually left round in the ends, and they are bored at cqual distances from the joining and stay pegs. The ends of the rails nre roughly rounded on the edues, which completes the preparation of the parts; and when the flake is completed, its dimensions are 9 feet in length, and 3 feet 4 inches in breadth over the rails; the bottom rail being 9 inches from the foot of the post, and the apper rail 5 inches from the head.

(1119.) The other form of flake, which is by far more extensively employed, though by no (898) 
means the best, consists of the same parts, except that it has always five rails, and the only material difference in the scantling is, that the rails are all $1 \frac{3}{4}$ inches square. An essential differenco also occurs in the preparation or manufacture of this kind of flake. The ends of the rails are all turned round by machinery, and the side-posts are bored for their reception, as well as for the pegs by like machinery. The five rails in the flake are divided in hight as follows: The bottom rail 9 inches from the foot of the posts; the spaces between the first and second and the second and third rails, are each 7 inches, and the two upper spaces are respectively 8 and 9 inches, leav. ing, as before, 5 inches of the post above the upper rail.

(1120.) Flakes of this last description are extensively manufactured in Perthshire, where young larches are abundant, for of that wood they are generally made. Their price, when sold in re. tail by fifties or hundreds, is 1 s. $9 \mathrm{~d}$. to 28 . each flake, including all the parts, sold in pieces ; the expense of putting the parts together is usually 2d. each flake, including nails. The bar-flake first described is not generally to be found in the market, and is chiefly made to order; the price about $28.6 \mathrm{~d}$. each fiake, with fixtures.-J. S.]

(1121.) As hurdles in England are somewhat differently put together, as well as made of a different sort of wood; and as the folding of sheep on turnips is differently managed in that country from what is given above, it seems proper to advert for a little to both these subjects; and first as to the structure of hurdles.

(1122.) Where the common crack-willow (Salix fragilis) will grow, every farmer may have poles enough every year for making 2 or 3 dozen hurdles to keep up his stock. To establish a plantation, large cuttings 9 or 10 feet long should be pushed, not driven, into moist soil, and on being fenced from cattle, will soon shoot both in the roots and head, the latter being fit to be cus every seventh year. Where soil for a willow plantation does not naturally exist, the farmer can buy his hurdles ready-made at $16 \mathrm{~s}$. the dozen; when made at home they cost $4 \mathrm{~d}$. each, and when the shepherd makes them they cost only his time. Hurdie-makers go the round of the country and make at 4d. and mend at $2 \mathrm{~d}$. each, finding their own tools.

(1123.) "A hurdle-maker's tools," says Mr. Main, "are a hand-saw, light hatehet, draw-shave, flamard, a center-bit and stock, a tomahawk, and gimlet. He has also a rending-frame, which in a common tressel $a$, fig. 239 , on which 2 strong poles, $b$, are laid, leaning and connected by 8

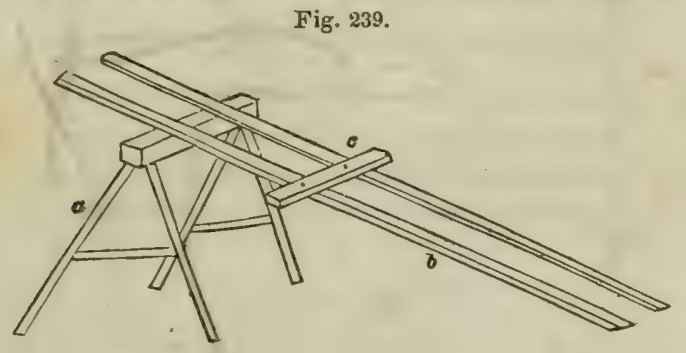

THE RENDING-FRAME IN HURDLE-MAKING.

piece, $c$, called a bridge. Besides this, he has a contrivance for shaving the poles, ac. In doing this, 2 auger-holes are bored in a post, to admit 2 stout square iron stubs, having ears to assist in withdrawing them when done with. The stubs project from the surface of the post about 6 inches, let in about 3 feet from the ground, and 8 inches from each other, though not exactly horizontally, the one nearest the workman being higher than the other, as seen at $a$, fig. 240. The

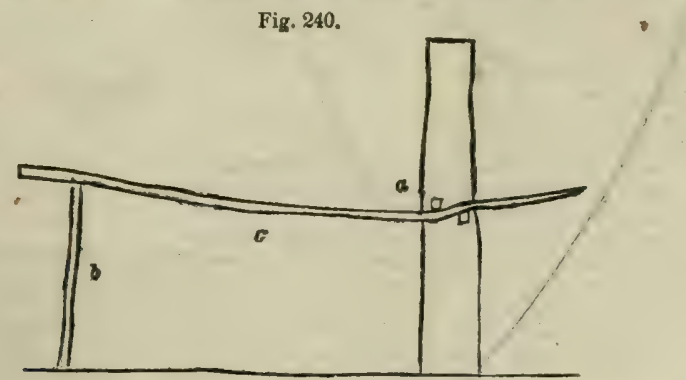

THE POSITION OF THE STUBS AND STANDARD IN HURDLE-MAKING.

ase of these stubs is to hold the poles while they are shaved; being at the same time supported by a standard, $b$, about 3 feet from the post, and having a sharp short spike on the top to steady the pole $c$ under the action of the draw-shave. In the same post a square staple, $a$, fig. 241, in driven, to hold the feet of the heads while they are mortised, assisted by a low stool, $b$.

$(899)$ 
(1124.) "All the things being ready, the poles are prepared for the different purposes to which they can be converted. The butt-end of the pole is first sawed off; $4 \frac{1}{2}$-feet lengtlis make a pair

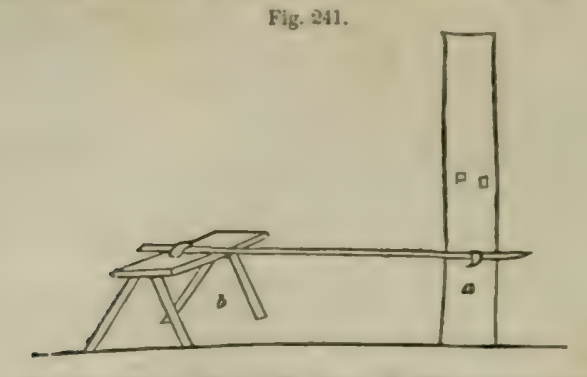

THE SQUARE STAPLE ANT STOOL IN HURDI,EMAKING.

of beads, $a$, fig. $242 ; 9$-feet lengths make a pair of slots, $b$; 5 -feet lengths make a pair of stay-slots $c$ : and $3 \frac{1}{2}$-feet lengths make a pair of uprights, $d$.

Fig. 242.

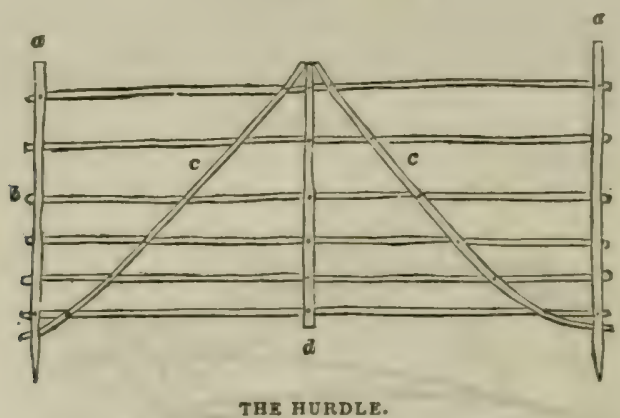

(1125.) "The next proceeding is rending the different pieces, which is dono at the rending. frame, fig. 239. The piece is put over the bridge $c$, with the battend upward. The flamard $a_{v}$ fig. 243-an edge-tool of iron, with a woolen handle-is placed across the pith, and driven down with a wooden baton $b$. When entered down 1 or 2 feet. the pole is brought up to bear upon the bridge. and at the sane time on the under side of the top of the tressel. The pole being kept down by the left hand, while the flamard is cuided by the right, by bending and turning the pole, the cleavage is perfurmed from end to end with great exactness. They next undergo a little ehopping or liewing with the hatchet. to cut off the knobs on the outside, keeping the inside as square as possible. The next uperation is shaving off the bark and all irregularities, and giving each number of the hurdle its proper form.

(1126.) "The maker next proceeds to form the hurdle; 4 low stumps are driven into the ground to mark the length, and 4 other to mark the distance between the upper and lower slots; a pair of heads, one at each end, are laid down in their right position, the Hat or pith side upward; the 6 slots are then laid at due distances upon the heads, and the

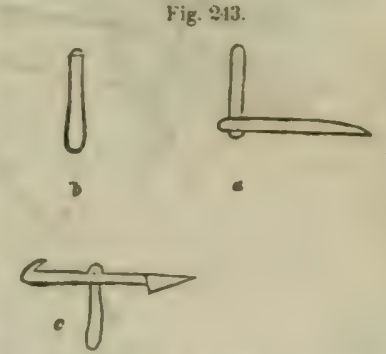

THE FI.AMARN, BATON, AKD TOMAHAWK, IS HIUDLE-MAKINO. latter are scribed to the size of each siot, tu regulate the mortises. The hurdle-maker uses no footrule in his operntions he having rods cut to the different lengths of the respective pieces: ard the entire distances between the slots are arranged by the eye, the lnwer ones being gradually closer together, as seen in tig. 24:2; and the strongest pair of slots are usually chosen for the high. est and lowest of the hurdle. One of the heads is then placed on the staple $a$. fig. 241 , and resting on the top of the mortising-stool $b$, to which it is fixed in an opening by a wedze. The center-bit and etock drilla out a hole at each end of the mortises, and also one for the diagonal-brace glot about 2 incheg below the lowest slot, aud a little out of the line of the mortises above. It will be observed that mortises made by a conter-bi: lenve an intenuediate pisce between the epertures. which is taken out by the tomahawk $c$, fig. 243 , a tool made for the purpose. One end in a sharp stout-poiuted knife. which cuts each side of the middle piece left in the mortise, and the other end hooks out the piecc not dislodged by the knife. The roortising, which with a mallet (900) 
and chisel would take up 1 hour, is done with the center-bit and hawk in 5 minutes. This head is now hammered on to the slots, and the other head is prepared and hammered on in the same way. The top and bottom slots are next nailed to the heads, and then the upright slot exactly in the middle. The 2 stay-slots are cut with a bend at the bottom, and rather sharply pointed; the points are driven through these oblique mortises, and their heads brought up to bear on the top of the upright, and nailed to each slot from top to bottom. The hurdle is then raised on its feet, and the nails clenched, which finishes the business. The gimlet is used for every nail, and a small block of wood placed under each slot while the nail is driven. The nails used are of the best iron, and what are called fine-drawn-not square, but rather flattened, to facilitate clenching, on which much of the strength of the huidle depends; the head of the nail is somewhat large. Their price is 6d. per lb.; 100 poles at 18s. make 36 hurdles, which, including nails and workmanship, cost $\mathcal{~} 1$ 11s. $6 \mathrm{~d}$., or 10s. $6 \mathrm{~d}$. per dozen. Although the horizontal slots are cut 9 feet long, the hurdle, when finished, is only somewhat more than 8 feet, the slot-ends going through the heads 1 or 2 inches; 2 hurdles to 1 rod of 16 feet, or 8 to 1 chain of 22 yards, are the usual allowance.'

(1127.) A larger kind of hurdle, called park hurdles, worth 2s. each, is made for subdividing meadows or pastures, and are a sufficient fence for cattle. From all this it is obvious that. when the small hurdles are used for sheep, the larger class must be obtained to fence cattle; whereas the Scotch flake described above (1117), and in fig. 216, answer both purposes at once, and are therefore more economical.

(1128.) "The hurdles being carted to the field," continues Mr. Main, "are laid down flat, end to end, with their heads next to, but clear of, the line in which they are to be set. A right handed man generally works with the row of hurdles on his left. Having made a hole in the hedge, or close to the dyke, for the foot of the first hurdle, with the fold-pitcher, fig. 244-which is a large iron dibber, 4 feet long, baving a well-pointed, flattened bit, in shape similar to the feet of the hurdles-he marks on the ground the place where the other foot is to be inserted, and there with his dibber he makes the second hole, which, like all the others, is made 9 inches deep. With the left hand the hurdle is put into its place, and held upright while lightly pressed down by the left foot on the lowest slot. This being done, the third hole is made opposite to, and about 6 inches from, the last. The dibber is then put out of hand, by being stuck in the ground near where the next hole is to be made; the second hurdle is next placed in position, one foot on the open hole, and the other foot marks the place for the next hole, and so on throughout the whole row. When the place of the second foot of a hurdle is marked on the ground, the hurdle itself is moved out of the way by the left hand, while the hole is made by both hands. When the whole row is set, it is usual to go back over it, giving each head a slight rap with the dibber, to regulate their hight, and give them a firmer hold of the ground. To secure the hurales steady against the rubbing of the sheep, couplings, or, as they are commonly called, copses, are put over the heads of each pair where they meet, which is a sufficient security. These couplings are made of the twigs of willow, holly, beech, or any other tough shoots of trees, wound in a wreath of about 5 inches diameter.

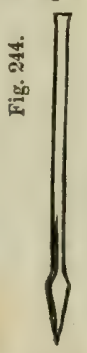

THE FOLD-

PITCHER IN HURDLE-

(1129.) "The number of hurdles required for feeding sheep on turnips is one row the whole length of the ridges of an inclosed field, and as many more as will reach twice across 2 eight-step lands or ridges, or 4 four-step lands-that is, 48 feet, or 3 or 4 ridges of 15 feet. This number, whatever it may be, is suflicient for a whole quadrangular field, whatever nnmber of acres it may contain. The daily portions are given more or less in length, according to the number of the flock. Two of these portions are first set, the sheep being let in on the first or corner piece. Next day they are turned into the second piece, and the cross-hurdles that inclosed them in the first are carried forward, and set to form the third piece. These removes are continued daily till the bottom of the field is reached; both the cross-rows are then to spare, and are carried and set to begin 8 new long-row, close to the off-side of a furrow, and the daily folding carried back over 2 or 4 lands as at first. It is always proper to begin at the top of a field, if there be any difference of the level. in order that the fock may have the driest lair to retire to in wet weather.

(1130.) "When there is a mixed flock-that is, couples, fattening and store sheep-two folds or pens are always being fed off at the same time, which only require an extra cross-row of hurdles. The couples have the fresh pens, while the lambs are allowed to roam over the unfolded turnips, by placing the feet of the hurdles, here and there, far enough apart, or by lamb-hurdles made with open panels for the purpose. The fattening sheep follow the couples, and have the bulbs picked up for them by a boy. The stores follow behind and eat up the shells."* It is never the practice in Scotland to put ewes with their lambs upon turnips, as new grass is considered much better for them, but the only ewe and lamb that can be seen on turnips in winter are of the peculiar breed of Dorsetshire. The store-sheep in Scotland-that is, the ewe-hoggs-are always fed as fully as the wether-hoggs which are intended to be fattened. In England the entire turnip-etock - ewes, lambs and wethers-are all intended for the butcher, and even, if possible, sold refore the turnips are ended. The whole have hay or trough-meat, either in the field or in the sheephouse, on wet or stormy nights. An acre of good turnips maintains 5 score of sheep for 1 week.

(1131.) Nets, by which sheep are confined on turnips in winter, are made of good hempen twine, and the finer the quality of the material, and superior the workmanship bestowed on the manufacture of the twine, the longer will nets last. Being, however, necessarily much exposed to the weather, they soon decay, and, if guided carelessly, can scarcely be tru ted more than a season. No treatment destroys them so rapidly as laying them by for the season in a damp state; and if rolled up wet, even for a few days, they become mildewed, after being affected with which nothing can prevent them rotting. They should never be laid by either damp or dirty, but washed and thoroughly dried in the open air before being rolled up and stowed away. It is alleged by shepherds that nets decay faster in drouth and exposure to dews and light in summer, than in

- Quarterly Journal of Agriculture, vol. iti. 
winter. Several expedients lave been tried to preserve nets from decay-among others, tanning, in imitation of fishermen; but, however well that process may suit nets used in the sea, it make them too hard for the shepherd's use in tying the knots around the atakes. Perhaps a steoping in Kyan's solntion might render then durable, aud preserve their pliability, at the same time. The Company's charge is 58 . per cwt. for nets and cordage. It should be kept in mind that nets made of twine bleached by acids, or other chemical process, should not be submitted to $\mathrm{K}$ yan's solation.

(1132.) Sheep-nels are wrought by hand, at least I have never heard of machinery being yet applied to their manufacture. They are simply made of dead nelling, as it is technically called, which consists of plain work in regular rows, and is wrought by wometa as well as men. A shepberd ought to know how to make nets as well as mend them, which he will not dowell unless he anderstand, in the first place, how to make them.

(1133.) All the instruments required in this sort of net-making are a needle and spool. "Needles are of two kinds - those made alike at each end with open forks, and those made with an eye and tongue at one end and a fork at the other. In both needles the twine is wound on them nearly in the same manner-namely, by passing it alternately between the fork at each end, in the first case, or between the fork at the lower end and round the tongue at the apper end, in the second rase; so that the turns of the string may' lie parallel to the length of the needle, and be kept on by the tongue and fork. The tongue and eye needle is preferable both for making and mending nets, inasmuch as it is not so liable to be hitched into the adjoining meshes in working; but some netters prefer the other kind, as being capable of bolding more twine in proportion to their size." An 8-inch needle does for making nets, but a 4 -inch one is more convenient for mending them.Spools, being made as broad as the length of the side of the mesh, are of ditfiereut breadtbs. Tbey " consist of a flat piece of wood of any given width-of stont wood, so as not to warp-with a portion cnt away at one end, to admit the finger and thumb of the left hand to grasp il conveniently. The twine in netting embraces the spool across the width; and, each time that a loop is pulled taut, half a mesh is completed. Large meshes may be made on small spools, by giving the twine two or more turns round them, as occasion may require." "In charging your needle, take the twine from the inside of the ball. This prevents tangling, which is at once recommendation enough. When you charge the needle with double twine, draw from 2 separate balls." It is almost impossible to describe the art of netting by words. so as to render it intelligible, and I shall not therefore attempt it; but it may be learned from any shepherd. In joiniug the enda of twine together-which, in mending, is necessary to be done-the bend or vearer's kuot is used; and in joining top and bottom ropes together, in setting nets, the reef-knot is best, as the tighter it is drawn the firmer it holds.

(1134.) Sheep-nets run about 50 yards in length when set. and weigh about 14 lbs. Hogg-nets stand $3 \frac{1}{2}$ feet in hight, and dinmonts 3 feet 3 inches, and both are set 3 inches above the ground. Stakes, to have a hold of 9 inches of the ground, bear the net 3 inches from the ground, and be 3 inches above the net-cord, should be $4 \frac{1}{2}$ feet in leugth for the dimmont. and 4 feet 9 inches for the hogg-net. The mesh of the hogg-net is $3 \frac{1}{2}$ inches in the side, and of the dinmont $4 \frac{1}{3}$ inches; the former requires $9 \frac{1}{2}$ meshes in the hight, the latter $8 \frac{1}{2}$. The twine for the hogg-net is rather smaller than that for the dimmont, but the tep and bottom rope of both are alike strong. A bogg-net conte 128., or under $3 \mathrm{~d}$. per yard; a dinmont 10 s., or under $2 \frac{1}{2} \mathrm{~d}$. per yard, on the Border, as at Berwickupon. Tweed ana Coldstream; but they are now sold in the prison of Edinburgh, being the work of the prisoners, at is. $6 \mathrm{~d}$.. or under 2d. per yard; wbile in London the charge is $4 \frac{1}{2} \mathrm{~d}$. per yard.

(1135.) It is generally imagined that nets are not suitable for confining Black taced sheep on turnips, chiefly because they are liable to be entancled in them by their horns: but this objection against the use of nets, is not insuperable, as the following circumstance will show. A farmer, a very extensive feeder of Black-faced sheep, on seeing my Leicester hoggs on turnips contined by nets, expressed a willingness to try the same method of confining his own sheep, adducing the great expense of hurdles as a reason for desiring a change. After getting a pattern net from me to stand 4 feet high, he got others made like it; and so successful was his experiment the first season, that he ever after inclosed a large proportion of his Black-faced sheep by nets. There occurred a few cases of entanglement for some days at first, but as his shepherd was constantly employed among his large flock, and having none else to attend to, no harm arose either to sheep or net, and in a short time the sheep became aware of the trap and avoided it. They never attempted to overleap the aets, though they would never have hesitated to do so over a mach higher wall.

(1136.) [Turnip-Slicers for Sheep.-Nachines for slicing roots, and particularly for the turnip, are constructed in a great variety of forms, but may be classed under two leading groupe-those that cut the turnip simply into circular Jisks, as generally adopted for the feeding of cattle, and those that cut at one operation into oblong rectangular pieces or parallelopipedons, commonly practiced for feeding sheep ; forming a somewhat more complicated class of machine. This last class, as conving first in the order of application, I shall first describe. Turuip-slicers for sheep may be again subdivided into lever and revolving machines: and of the many varieties under these forms, there are the stationary, the portable, the wheelbarrow, and what may be called the locomotive machine. This last being rendered so by its attachment to a cart, and by its own motion thus communicated, performs the operation of glicing while it travels over the field.

(1137. The first introduction of the turnip-slicer is. like many other equally asefal inventions, lost in obscurity, but it is most probable that, like the cultivation of the root itself, it originated in England; and it is likewise probable that the first attempt was the simple chopper still used to chop turnip for cattle. It appears uncertain whether the lever or the revolving slicer came first into use, as does also the time of their introduction. But we have an authentic record of a premium having been offered in 1806 by the Board of Trustees for the Encouragement of Arts and Manufacture's in Scotland, for a revolving turnip-slicer. This svas awarded to Jobn Blaikie car-

- Bachurst's Notes on Nets. (902) 
penter to the late Lord Polwarth, then Mr. Scott of Harden, which is believed to have been the earliest application of that form of the machine in Scotland.

(1138.) Lever Turnip-Slicer for Sheep.-The first of the sheep turnip-cutters that I shail notice, is one of the lever form, but in its mechanical construction may be very aptly called the gridiron turnip-cutter, and is represented in an entire form in fig. 245 , which is a perspective view

Fig 245 .

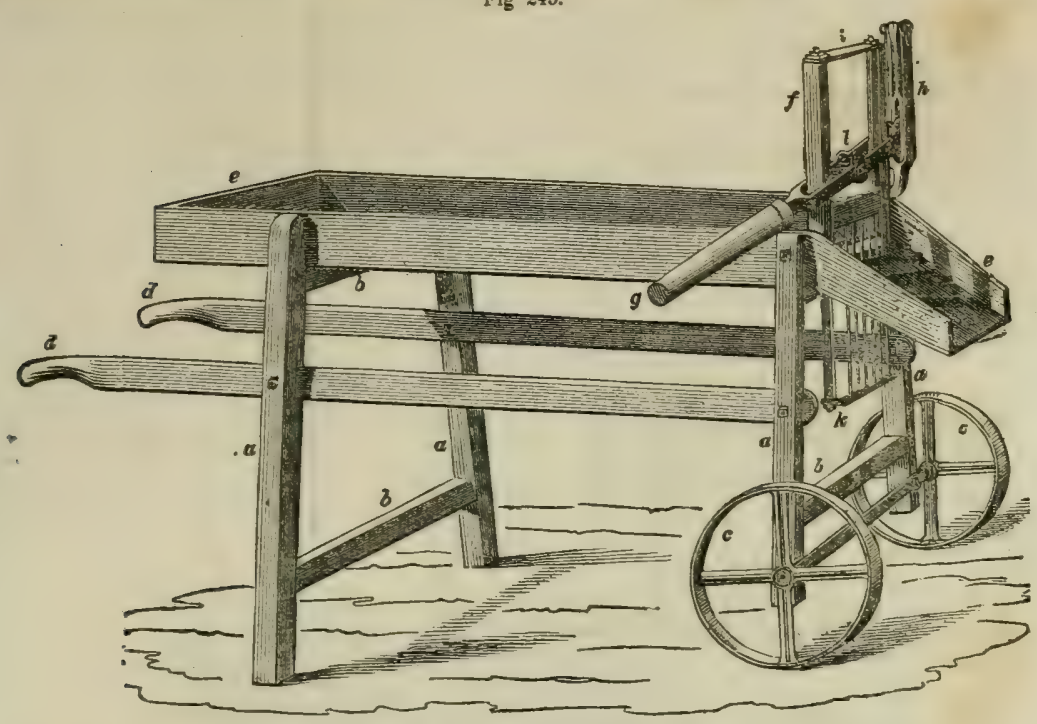

THE LEVER TURNIP-SLICER FOR SHERP.

of the machine. It consists of a wooden frame supporting a trough, together with the cutting apparatus. The frame is formed of the four posts $a, a, a, a$, which are $2 \frac{1}{4}$ inches 8 quare. The front pair stand 15 inches in width, over all at top, the hind pair 19 inches : in both they spread a little below, and are separated to a distance of about 34 inches. Fach pair is connected by cross-rails $b, b$. and they are connected longitudinally by the bars $d, d, 4 \frac{1}{2}$ feet long, which form also the bandles of the wheelbarrow; being bolted to the posts at a suitable hight for that purpose; their scantling is 2 by $1 \frac{1}{2}$ inches. A pair of wheels, $c c$, of cast-iron, 9 to 12 inches diameter, fitted to an iron axle, which is bolted to the front posts, gives it the conveniency of a wheelbarrow. The trough $e$, into which the turnips are laid for cutting, is 4 inches deep, and $3 \frac{1}{2}$ feet long, besides the oloping continuation of it in front of the cutters, for throwing off the sliced turnips. The cutting apparatus consists of a grooved frame of iron $f$, in which the compound cutter moves up and down by means of the lever handle $g$. A forked support, $h$, is bolted by a palm to the farther side of the wooden frame, and at the extremity, $i$, of the fork, a swing link is jointed. The lower end of the link is jointed to the extremity of the lever, which is likewise forked. forming its fulcrum; and the gridiron-cutter, $k l$, is also jointed by its top-bar to the lever at $l$. While the point $l$. therefore, of the cutter moves in a parallel line by its confinement in the grooves of the frame $f$, the fulcrum is allowed to vibrate on the joint $i$ of the swing link-thus allowing an easy vertical motion to the cutter through the full range of its stroke. For the better illustration of the cutting apparatus the following figures are given on a larger scale. Fig. 246 is a front view of the cutter. frame, and fig. 247 a horizontal section of the same, including that of the grooved frame $f$. In fig. $247, a b c$ is a section of the grooved frame, with the cutter-frame set in the grooves. The grooves are $\frac{1}{2}$ inch wide, and the cheeks of the frame $1 \frac{1}{2}$ inches by $\frac{1}{2}$ inch, making the parts $a b c 1 \frac{1}{2}$ inches square; $a d a$ is the bottom bar of the cutting-frame, 1 inch broad, and $\frac{1}{4}$ inch thick, kneed at the ends to receive the lower ends of the cutting-frame: $e$ is the edge view of the slicing-knife, as fixed in the cutter-frame, 4 inches broad by $\frac{1}{8}$ inch thick, and $f f f f f f$ are the vertical or cross cutting-knives, also as seen from above. In fig. 246, $d$ again marks the bottom bar of the cutterframe, $e$ is the slicing-knife, and $f f f f f f$ the shanks of the cross cutting-knives-these are riveted at top into $e$, and at bottom into $d$; $g$ are the side-bars of the cutter-frame, $\frac{3}{4}$ inch by $\frac{1}{2}$ inch, into which the knife $e$ is riveted, and to which the bar $d$ is attached by screw-nuts. The top bar $h$ welded to $g g$ swells out in the middle, where it is perforated for the joint-bolt of the lever, as seen at $l$ in fig. 245 , and forms as a whole the gridiron-cutter.

(1139.) Figs. 248 and 249 are views of the knives on a still larger scale. In the first fig., 248 , together with the portion $f$ broken off, $a a b$ is a cross section of the slicing-knife, and $c d e f$ a cross cutting-knife, with its shank ; here $a d$ is the cutting edge, $c$ being the body, and $e f$ the shank of the knife. The length of the cutting edge $a d$ mav vary from $\frac{1}{3}$ to 1 inch, according to the practice of the feeder, the shank $e f$ being about $\frac{1}{2}$ inch broad, arid the whole $\frac{1}{8}$ inch thick, except the cuting edge, that alone being sharpened and steeled, as wcll as the edgre of the slicing-knife. (903) 
The second fig., 249 , is a section of a cross cutting-knife on the line $x$ of fig. 248. together with a I'art of the shank $e$.

(1140.) The whole length of the cutter-frame. fig. 246 , is about 20 inches, apportioned thus : from the bottom bar, $d$, to the edge of the slicing.knile, 12 inches; breadth of the kuife, as before, \& inches; and from the back of the knite to the top of the frame, 4 inches. The width of the framu

Fig. 216.

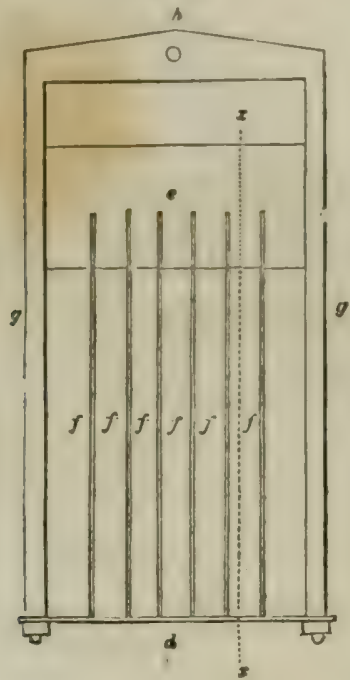

Fig. 247.

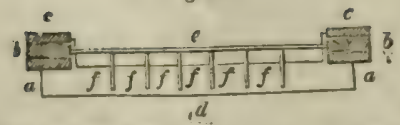

Fig. 249.

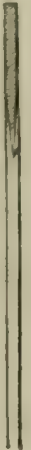

Fig. 248.

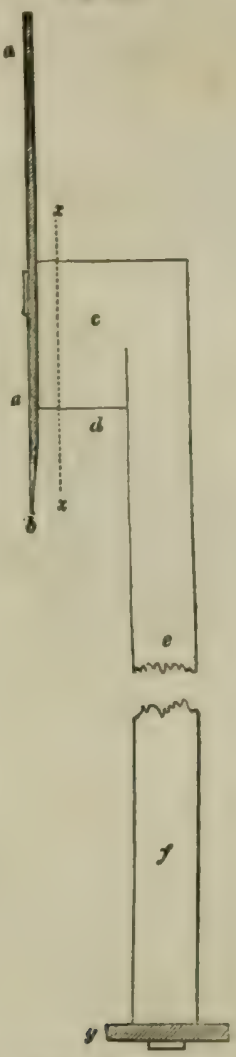

THE FRONT AND SIDE VIEWS OF THE CUTTERS UF THE LEVER TURNIP-SLICER.

-over all may be 9 inches, and the cross-cutters set at from 1 to 11 inches apart. The grooved frame must of course be constructed to receive and admit of the rauge of stroke of the cutterframe. It is to be remarked that the slicing and cross-cutting is performed with this machine by one operation, the slicing edge being only $\frac{1}{2}$ inch in advance of the cross.cutters, as at $b$ in fig. 248 .

(1141.) In operating with this machine, the trough is filled with turnips, and the operator lays bold of the lever $g$. fig. 245 , with the richt hand, while in his left he holds a short baton. Having raised the lever, and with it the cutter-frame, he pushes a turnip with the baton against the gridiron, and bringing down the lever. the knives cut off a slice, and divide it into oblong pieces; these may partly remain between the backs of the crnss-cutters, until the succeeding atroke is effected, when the several portions of this slice will discharge those of the firat. and so on.

(1142.) The principle of the gridiron-slicer is not confined to this particular mode of construction, nor even to a reciprocnting action. Its application to a revolving disk machine was brought forward some years ago by Mr. Hay; but owing probably to its greater expense, has been bat partially aclopted.

(1143.) The gridiron has also been applied in combination with a revolving crank motion; the gridiron reciprocating, and that in a horizontal position. This modification appears to have originated in Roxbarghshire, and appears to posess some advantages, the chief of which is, that, as the roots lie directly upon the gridiron, they are more likely to be regularly sliced than in those machines machines where the roots lie only agaunst the cutters, as in the common vertical disk machines. This mechine is essentially a gridiron turnip-slicer, with a reciprocating motion, de. rived from a rotary motion. The latter is produced by turning a winch handle, the axle of which carries a fly-wheel and two crank levers, or, more properly, the crank of the winch aerves for both; the throw of the handle being 15 inches, while that of the crank is only 7 inches from tho 
axis. A connecting-rod on each side of the machine connects the cranks with the gridiron-cut. ter, producing the reciprocating motion, which is in the horizontal direction; and to render the mation as easy as possible, the frame of the gridiron moves upon slide-rods. From the circum. stance of the motion of the cutter being horizontal, and the turnips lying directly upon the grid. iron, it can be easily constructed to cut both ways, that is, with the out as well as the in stroke; the gridiron for this purpose being furnished at both ends with the slicing-knife and the crosecutting-kuives, as described in (1138) fig. 246. The machinery here described is mounted on a wooden frame, 4 feet 6 inches long. 22 inches wide, and 34 inches bigh, and over the gridiron is placed a square hopper of wood or of sheet-iron, into which the turnips are thrown by an assistant, the machine being driven by a man. A bar of division is placed across in the middle of the hopper, serving as the point of resistance against which the turnips are pressed while the slice is being made; and as the turnips lie on the bars of the gridiron with their full weight, they will for the most part be in a position to secure a slice of uniform thickness being removed. A siight modification has been made on this machine by placing the gridiron on radius bars, making the cutter move in an arc of about two feet radius, instead of moving in a slide as above described. The radius bars produce a lighter motion, but have no effect on the cutting principle.

(1144.) With a view to economy, the regular slicing of turnips is of more importance than many farmers are aware of. When a part of the turnip is cut into very thin, and even into fragments of slices, a very considerable proportion of it goes to waste. In chonsing a turnip-slicer, therefore, one of its points shonld always be, that it should cut as far as possible to a uniform size, whatever that ize may be, and not pass a large proportion of the sliced tarnips in thin-edged slices, or thin and small fragments of slices.

(1145.) Wheel Turnip-slicer for Sheep.-This machine, alluded to in (1136), has, since its introduction, undergone many modifications. From being made entirely of wood, it came to be made entirely of iron; but this last being less convenient for moving about, has induced the more general introduction of a disk of cast-iron, carrying the cutters, mounted on a wooden frame, which is generally again mounted on wheels like a wheelbarrow. Fig. 250 is a perspective of this ma-

Fig. 250.

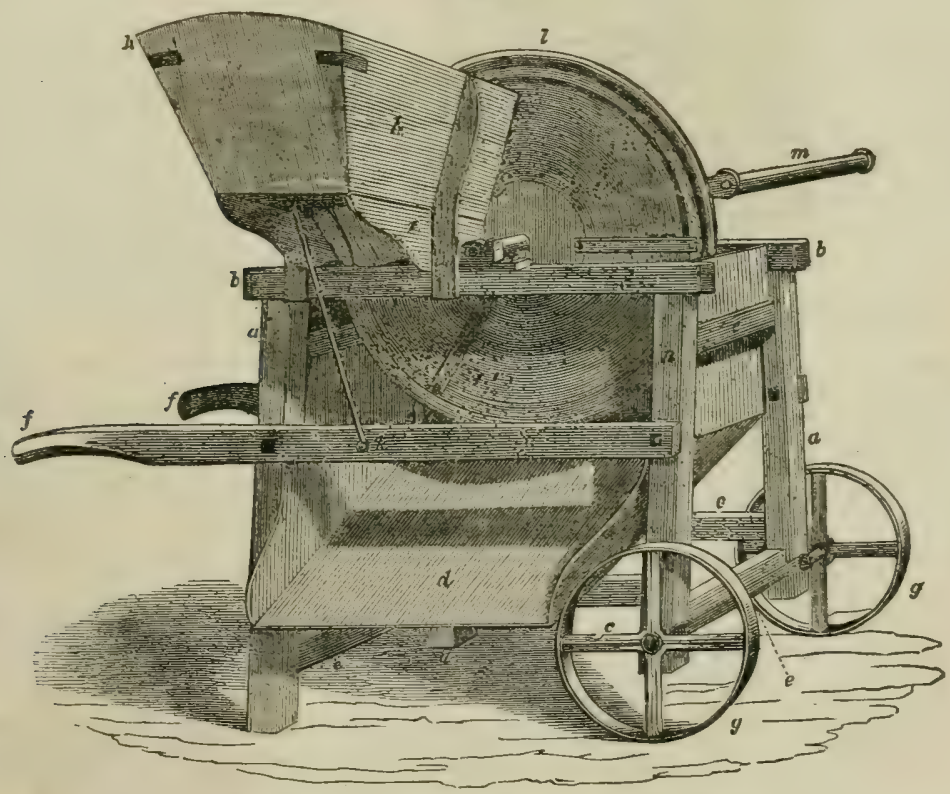

THE WHEELBARROW TURNIP-GLICER FOR SHEEP.

chine; the wooden frame, which is 36 inches long and 15 inches wide over the posts at tol bot fpreads a little wider below, is formed with four posts, $a$ a $a$ a, one of which is only partially seen in the figure; they are $2 \frac{1}{4}$ inches square, and stand about 32 inches in hight. The posts ar: conjected on the sides by top-rails $b b$, and two brace-rails $c c$ below, one of which serves to st pport the spout $d$, which discharges the sliced turnips. The sides of the frame thus formed are convected by cross-rails above and below, $e e e$, and is there furnished with the handle-bars $f f$, bolted to the posts, and projecting a convenient length beyond them at one end. The barrow-wheels $g g$, of 12 inches diameter, are fitted to an iron axle, which is bolted to the posts in front. The hopper $h$ is fixed apon the top-rail by means of a cast-iron sole bolted apon the rail, and is farther sup. ported by a wooden bracket at each side, as seen at $i$, and by the iron stay $k$. The slicing wheel

(905) 
$l$ is a diak of cast-iron, carrying three sets of cutters. The disk is mounted on an axle paseing tbrough its center, where it is fixed, and which is supported on bearings placed on the top-rails, und, when worked, it is turned by the winch-handle $m$, fixed upon the axle. Fig. 251 is a section

Fig. 251.

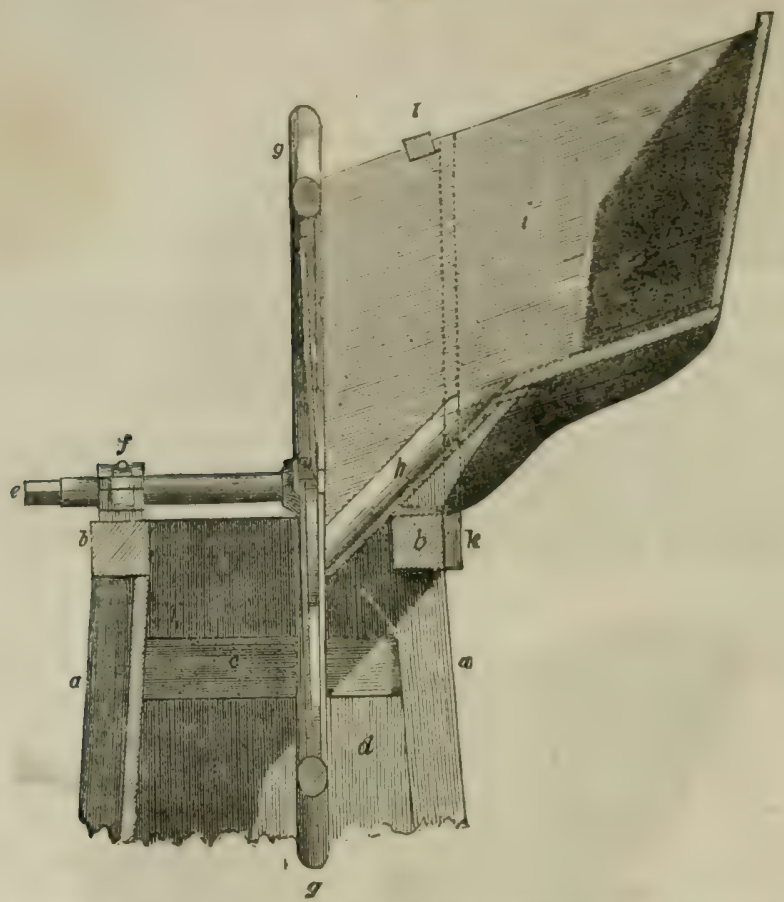

〔THE SECTION OF THE DISK AND HOPPER OF THE WHEELBARROW TERNIP-gLICER.

of part of this machine, cutting it throagh the hopper, and the disk, \&c., to exhibit some of the parts more in detail. $a$ are parts of two of the posts, $b b$ the top-rails, and $c$ one of the end-rails of the frame, covered by the boarding $d$ of the spout. $f$ is one of the pullow-block bearings of the axle, the other being kept out of view by the hopper, and the wiuch-haudle is applied at $e$. $g g$ is the disk shown also in section. The sole of the hopper is repreacuted at $h$; it has a flange between $h$ and $b$, by which it is bolted to the top rail $b ;$ and the sole itself is a cylindrico-concave plate of 12 inches in length at the bottom of the concavity, 9 inches in breadth, and is placed at an angle of $45^{\circ}$. It is also furnished with a flange at ench side, whereby the sides $i$ of the hopper are attached to the sole. $k$ is the foot of one of the brackets referred to in fig. 250, rising in the position of the dotted lines, for supporting the hopper; and / is a light tie-bar, cut by the section, which is applied also to bind the sides of the hopper.

(1146.) The disk or wheel $g g$ is a plate of east iron, 32 inches in diameter aud $t$ inch thick, en. circled by a heavy ring of the same metal, in give it momentum when in action. The face of the disk is divided into three segmental compartme'nts aronnd a plain and central portion, which is 9 inches diameter. This central part lies in the creneral plane of the disk, while the seemental portions diverge from the plane in the direction of the circle. causing them to talie the form of portions of three separate helical or spiral surfaces of 9 inches in breadth. Their divergence from the plnne of the disk does not. however, exceed $\frac{3}{3}$ of an inch at the turmination of a sogment, or such other space as may be deturmined upon for the thickness of the slices. By this construction, three slits are formed in the disk, passing obliquely througb, one at the term. ination of each segment : and the steel slicing knife, 12 inches in length and $1 \frac{1}{2}$ inches in breadih. is fixed by bolts, so as to form the entering edge of each segment, as seen in fig. 250-the flat face of the knile lying in the geveral plane of the disk.The terminal edge of ench segment lies exactly behind the lend. THE WHEELARRow Ternip-sLicen. ing edge of the next, so that, when the slicing-knife is aftixed to a leading edge, the edge of the knife covers $1 \frac{1}{2}$ inches of the length of the preceuting segment. Into the border, which is thus $(906)$

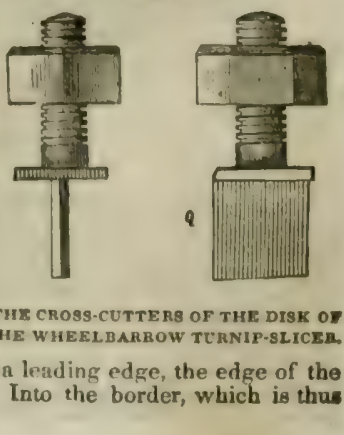


covered by the slicing-kuife, are placed from 6 to 10 lancet shaft-cutters, their length being just equal to the width of the slit, and their distance apart proportioned to the number employed, or the breadth at which the turnips are required to be cross-cut The cross-cutters are formed as represented in fig. 252, where $a$ is an edge, and $b$ a side view of a cutter, with its tail and screwnut, by which it is fixed into the disk.

(1147.) It will be seen that the action of those compound cutters is very similar to that of the gridiron. the slicing and cross-cutting knives acting together, though the slicing-knife is bere also about $\frac{1}{2}$ inch in advance of the cross cutters; and from the construction of the disk, and arrangement of the feeding-hoppers, the turnip is applied with great regularity, and in close contact with the spiral surface of the segments of the disk. The slope of the sole-plate in the hoppers gives the turnip a constant tendency to keep in contact with the surface and the cutters, :bereby securing regular and good performance by the machine.

(1148) The wheel turnip-slicer has been applied in a variety of forms, such as cutting on a horizontal direction, the turnips being placed in a hopper right above the disk; and both vertically and horizontally it has been adopted on the locomotive principle, attached in various modes to a cart. Perhaps the most successful of these modes is that produced at the late Show of Implements at Edinburgh, under the auspices of the Highland and Agricultural Society of Scotland, by Mr. Kirkwood, Tranent. It is a common slicing disk, mounted on a carriage with two wheels, from the axle of which, and by their own resistauce, motion is communicated to the disk by means of a beveled gearing. The carriage is simply hooked on to a cart which couveys the turnips.The cutting process can be stopped at pleasure by means of the common clutch and lever; and the whole machine, being constructed of iron. will be very durable.

(1149.) Cylinder Turnip-Sticers.-Turnip-slicers for sheep have been also constructed in a variety of forms with the cutters set in the surface of a cylinder, and been in use for many years.In Roxburghshire it has been long and successfully employed in the locomotive principle-not driven by any machinery from the cart to which it is attached, but, being simply hooked to the cart, is drawn forward; and the machine being of some weight, and moving upnn wheels of 3 feet or more in diameter, armed with spikes on their tires to prevent them sliding over the surface of the ground, these give motion to the cutting cylinder; while a bos; sitting on the cart which contains the turnips that are to be cut, throws them into the hopper of the machine, from which they are dropped over the surface of the grass on which the sheep are feeding.

(1150.) A modification of the cylinder-slicer was patented in 1839 by Mr. Gardner, Banbury ; the principle of the patent lies in the form and arrangement of the cutters, which are set in three divisions upon the surface of the cylinder. The arrangement of the cutters is peculiar, and diffcult to describe without the aid of a figure. The cylinder on which the cutters are placed is 15 inches in diameter and 12 inches long. Its periphery is divided into 3 compartmente, each forming a portion of a spiral, so that the commencement of one and the ternination of the next leaves a 3 lit across the periphery, corresponding in some degree with that described on the disk of the wheel turnip-cutter. The original cylindrical slicers had the slicing-knife extending in an unbroken edge across the surface of the cylinder, and the cross-cutters placed under and behind it. The improvement on which the patent is based may be described as cutting the slicing-knife into a number of sections, say of $\mathrm{l}$ inch each in length. The two extreme sections remain in the original position on the cylinder. The section next to that on each side is removed backward upon the surface of the cylinder, say $1 \frac{1}{2}$ inches, and there fixed. The section on each side next to those is in like manner set back, and so on till the whole are placed on the surface of the cylinder. By this arrangement, the slicing-cutters form two converging lines, en cchellen. and this is repeated three times on the periphery of the cylinder. The cross-cutters are formed by a part of the slicing. cutter being bent to a right angle with the former.

(1151.) This cylinder machine, by reason of the cutters acting in succession from their position, en echellen. works with great ease and cuts regularly, but, withal, makes the slices too small, and has a tendency to produce waste, though this fault could be easily rectified by enlarging the sections of the knife, and lengthening the cross-cutters. The cylinder is mounted in a wooden frame, and the hopper is so arranged that the turnip, while being cut, tends always to apply itself to the surface of the cylinder.-J. S.]

(1152.) There is a mode of preserving corn for sheep on turnips which has been tried with success in Fife. It consists of a box like a hay-rack, as in fig. 253 , in which the coin is at all times kept closely shut up, except when sheep wish to eat it, and then they get to it by a simple contrivance. The box $a b$ contains the corn, into which it is poured through the small hinged lid $y$. The cover $c d$, concealing the corn, is also hinged, and when elevated the sheep have access to the corn. Its elevation is effected by the pressure of the sheep's fore-feet upon the platform $e f$, which, moving as a lever, acts upon the lower ends of the upright rods $g$ and $h$, raises them up, and elevates the cover $c d$, under which their heads then find admittance into the box. A similar apparatus gives them access to the other side of the box. The whole machine can be moved about to convenient places by means of 4 wheels. The construction of the interior of the box being somewhat peculiar, another, fig. 254, is given as a vertical section of it, where $b$ is the hinged lid by which the corn is put into the box, whence it is at once received into the hopper $d$, the bottom of which being open, and brought near that of the box, a stall space only is left for the corn to pass into the box, the hopper forming the corn-store; $a$ is the cover of the box raised on its hinges by the rod $f$, acted upon by the platform $e f$, fig. 253 ; and. when in this position, the sheep put their beads below $a$ at $c$, and eat the corn at $d$. Machines of similar construction to this have also been devised to serve poultry with corn at will.* It is a safer receptacle for corn in the field than the open oil-cake trough, fig. 230 ; but animals require to be made acquainted with it before they will use it with confidence.

(1153.) It is not my purpose to dilate fully on the diseases of animals, the symptoms and treat$\mathbf{m} \mathbf{n t}$ of which you will find satisfactorily described in the published works of veterinarians; but

- Prize Essays of the Highland and Agricultural Society, vol, vii.

(907) 
nevertncless, it is necesary you should know something of the various diserses animals are liable to, when subjected to the istual treatment of the farm. Were you not warned of the consequences of this, you would not know how to check the progress of disease, but allow it to proceed, until

Fig. 253.

(

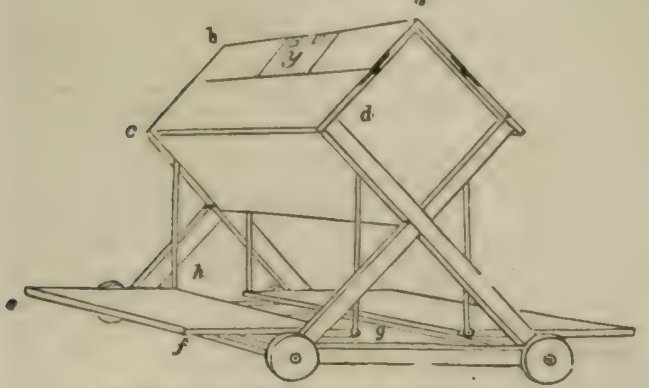

Fig. 254.

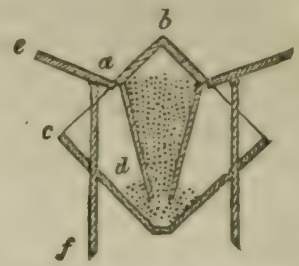

THE VERTICAL SECTION OF THE INTERIOR OF THE COMN-BOX.

THE CORN-BOX FOR SHEEP ON TURNIPS

the life of the animal were endancered. It is, however, not desirable that von should consider yourself as a veterinarian, becuuse, not being a professional man, your practical knowledge will necessarily be confined to the cas's arising from the rasnalties of your own etock, and hence your experience wili never enable you to become so well acquainted with any disease. nor so many, as the professional man, while you would rely so much upon your own knowledgc, crude as it must be, as to undertake the treatment of every case of illness that occurred on your own farm: and thus be prompted to try experiments which may prove dangerous to the safety of the animal, but it is very desirable, because much conducive to your own interest that you should be acquainted with the most easily recognized symptoms of the commonest diseases incidental to domesticated animals, and with the general principles of their treatment. If you but knew how to distinguish botween local and general affections, and to apply the proper preliminary treatment, you would place the afflicted animal in such a state of fafety until the arrival of the veterinary surgeon, as the disease might be easily overcome by him. and your animal restored to health in a short time. Farther than this you have no right to aspire as an amateur veterinarian; for it cannot be too strongly impressed ipon you that, before you can be competent to learn the art of healing, you musi bave an accurate knowledire of the anatomical ftructure and the physiology of the domestic animals. At the same time, as a branch of ceneral knowlertge, veterinary science ought to have your regard, and more especially as your profession places you in a position to occupy the field which affurds the most numerous, varied, and interesting cases for veterinary practice. And besides, you should have "some insight," as Professor Dick suggests, "into a subject with which all whio have any pretension to a knowledge of horse flesh ought to have somp ac. guaintance. And if you bear in mind that, in a compendious view of the principles upon which alone the disease's of domestic animals can be properly treated, you will find an antidote to the quackery by which many valuable animals are sacrificed, and serious expense and vexation occasioned."

(1154.) On this suggestion, I would notice the complaints of sheep, with the view of letting you see their interesting nature, and of the expediency of your becoming acquainted with their principles. The first which presents itself on sheep, in the low country in winter, is purging. occa. sioned by eating too heartily of the tops, when first confined on turnips. At first, the complaint is not alarming, and the physicing may do good ultimately ; but should it increase, or continue beyond the existeuce of the cxciting cause, it may pass into diarrhas, causing prostration of strength, and at last terminate in dysentery. When the purging is moderate, the pain is inconsiderable; but when ascravated, the mucous membrne, which is the seal of the disease, acquires a tendency in inflammation, and griping and colicy pains are the consequence. The disease should not be thousht lizht?y of, but speedily checked. When the green food, as in this case, is obviously at fault, the sheep should be removed to dry pasture until the symptoms disap. pear. One year, I remember, the white turnip tops grew so luxuriantly that when Leicester hogga were put on in October, they were very sonn seized with purging, and the symptoms were much aggravated by alternnte falls of rain and raw frosts. The sheep were removed to a rough, moory pasture, which had been reserved for the ewes; and while there, I caused the field-workers to switch off the turnip tops with sickles, and thus got rid of the cause of complaint. In a short time, the hoggs were rustored to the turnips, and throve apace; thoush the wool behind was much injured by the faeal discharge. And this is one of the losses incurred by such a complaint; and at a season. tow, when it would be improper to clip the solied wool away, to the risk of making the sheep too bare below to lie with comfort apon the cold ground.

(1155.) Sheep are eometimes infested with a species of louse. the Trichodectes spharocephaius, chnracterized by Mr. Denny as having the head nearly orbicular, the clypeus rugulose and ciliated with atiff hairs, and the third joint of the antennx longest and clavate.

(1156.) This animal is perhaps induced to make its appearance by an increase of condition after a considerable period of poverty. It is seldom seen on Leicester sheep, because, perhaps, they are seldon in the state to induce it ; bat hill-sheep are not unfrequently infested by it, and when

* Dick's Manual of Veterinary Scicnce, Preface. 
Bo, it is amazing what numbers of the vermin may be seen upon a single slieep, its powers of reproduction seeming prodigions. It lodges chietly upon and below the neck, where it is most effectually destroyed by mercurial ointnent, which should not, however, be applied, in quantity. in very cold or in very wet weather; and in these circumstances, tobacco-juice and spirit of tar may be safely used. A quart bottle of decoction of tobacco-leaf, containing a wine glass of spiris of tar, is a useful lotion, for many purposes, for a shepherd to have constantly in his possession. Professor Dick says that, in slight visitations of the louse, a single dressing of olive-oil will cause its disappearance.

(115\%.) Another disease to which sheep are subject on passing from a state of poverty to im proved condition is $s c a b$, and hoggs are most susceptitible of it. This disease indicates its existence by causing sheep to appear uneasy and wander about without any apparent object; to draw out locks of wool with its mouth from the affected parts, as the disease increases; and, lastly, to rub its sides and buttocks against every p:ominent object it can find, such as a stone, a tree, a gate post, the nets, and such like. Mr. Youatt says that it arises from an insect, a species of aca rus ; ${ }^{*}$ but whether this be the case or not, one remedy is efficasious, namely, mercurial ointment a weak one of 1 part of the ointment with 5 of lard for the first stage, and the other a stronger, of 1 part of ointment and 3 of lard, for an aggravated case. The ichorous matter from the pustules adheres to and dries upon the wool, and gets the name of scurf, which should first be washed off with soap and water before applying the ointment. 'The scab is a very infectious disease, the whole Hock soon becoming coutaminated; but the infection seems to spread not so much by direct contact as by touching the objects the animals infected have rubbed against. Its direct ef fects are deterioration of coudition, arising firm a restlessness preventing the animal feeding, and loss of wool, large portions not only falling off, but the remainder of the broken fleece becoming almost valueless; and its indirect effects are propasation of the disease constitutionally, and hence the loss to the owner in having a scabbed flock, for no one will purchase fron one to breed from that is known to be, or to bave been, affected by scab. With regard to the very existence of this disease, it is held disgraceful to a shepherd not to be able to detect its existence at a very early stage, and more so to allow it to make head in his flock, however unobservant he may have been of its outbreak. When it breaks out in a standing flock, it must have been latent in its constitution or in the ground, when the shepherd took charge of it, for some shepherds bave only the skill to suppress, not eradicate it ; but it is his duty to examine every sheep of his new charge, and of every one newly purchased; before they are allowed to take to their hirsel, and also to make in quiry regarding the previous state of the ground.

(1158.) On soft ground sheep are liable to be affected with foot-rot, when on turnips. The first symptom is a slight lameness in one of the fore-feet, then in both, and at length the sheep is obliged to yo down, and even creep on its knees, to get to its food. The hoof, in every case, first becomes softened, when it grows misshaped, occasioning an undue pressure on a particular part; this sets up inflammation, and causes a slight separation of the hoof from the coronet; then ulcers are formed below where the hoof is worn away, and then at length comes a discharge of fetid matter. If neglected, the hoof will slough off, and the whole foot rot ofï; which would be a distressing termination with even only one sheep, but the alarming thing is, that the whole flock may be sinilarly affected. and this circumstance has led to the belief that the disease is very contagious. There is, however, much difference of opinion among store-farmers an 1 shepherds on this point. though the opinion of contagion preponderates. For my part, I never believed it to be so, and there never would have been such a belief, had the disease been confined to a few sheep at a time; but though numbers are affected at one time, the fact can be explained from the circum. stance of all the sheep being similarly situate; and as it is the nature of the situation which is the cause of the disease, the wonder is that any escape affection, rather than that so many are affect. ed. The first treatment for cure is to wash the foot clean with soap and water, then pare away all superfluous hoof, dressing the diseased surface with some caustic. the spirit of tar and blue vitriol being most in vogue, but Professor Dick recommends butter of antimony as the best: the affected part being bound round with a rag, to prevent dirt getting into it agrain; and removing the sheep to harder ground, upon bare pasture, and there supplying them with cut turnips. The cure indicates the prevention of the disease, which is careful examination of every hoof before putting sheep upon red land, and paring away all extraneous horn; and should their turnips for the season be upon soft. moist ground, let them be entirely sliced, and let the sheep be coufined npon a small break at a time, and thus supersede the necessity of their walking almost at all upon it for food. I may mention that sheep accustomed to bard ground, when brought upon that which is comparatively much softer, are most liable to foot-rot, and hence the necessity of frequent inspection of the hoof when on soft ground; and as some farms contain a large proportion of this state of land, frequent inspection should constitute a prominent duty of the shepherd.

(1159.) Erysipelatous complaints occur in winter among sheep. "Wildfire, it is said," remarks Professor Dick, "generally shows itself at the beginning of winter, and first attacks the breast and belly. The skin inflames and rises into blisters, containing a reddish fluid, which escapes and forms a dark scab. The animal sometimes fevers. Venesection (blood-letting) should be used, the skin should be washed with a solution of sugar of lead, or with lime-water, and physic given, such as salts and sulphur ; afterward a few doses of nitre."*

(1160.) There is, perhaps, no circumstance upon which an argument conld be better founded in favor of arable land being attached to a hill-farm, for the purpose of raising food to be consumed in stormy weather, than on the fatality of the disease commonly called braxy. It affects young sheep, and chiefly those of the Black-faced breed, which subsist upon the most elevated pasture. Indigestion is its primary cause, exciting constipation, which sets up acute inflammation of the bowels, and death ensues. The indigestion is occasioned by a sudden change from succulent to dry food, and the suddenness of the change is imposed by the sudilen occurrence of frost and nnow, the latter concealing the green herbage which the sbeep have been eating; and obliging 
them to subsiat upon the tops of old heather, and twigs and leaves of bushes that overtop the snow. By this accuunt of the origin of the disease, it is obvious that, were stells provided for shelter, and turnips for food, the braxy would never affect young hill-sheep, at least under the circumstances which usually give rise to it. The Ettrick Shepherd thus describes its symptonas : "The loss of cud is the first token. As the distemper advances, the agony which the animal is suffering becomes more and mure visible. When it etands, it brings all its four feet into the compase of a foot; and sometimes it continues to rise and lie down alternately every two or three minutes. The eyes are heavy and dull, and deeply expressive of its distress. The ears hang dows, and. when more narrowly inspected, the mouth and tongue are dry and parched, and the whic of the eye inflamed. . . The belly is prodigiously swelled, even so much that it sometimes bursts. All the difterent apartments of the stomach are inflamed in some degree." Violent in. fammation succeeds, with a tendency to mortification and sinking, so that, after speedy death, the tonch of the viscera, and even of the carcass, is intolerable. Its effects are so sadden, that a bogg apparently well in the evening will be found dead in the morning. Cure thus seems almost unavailable, and yet it may be effected, provided the symptoms of the disease are observed in time; when, if blood is drawn frecly from any part of the borly, such as by notches made across the ander side of the tail, from the vein under the eye, and that behind the fore arm, and a dose of salts administered in warm water, the animai will most probably recover.t $B$ ut the grand object is prevention of the disease by a timely supply of succulent food; and if tarnips cannot be obtained. it may be worth the store-master's consideration whether oil cake should not be given to the sheep along with hay, during a storm. The laxative property of oil-cake is well established, and its carriage to the remotest hill-farm comparatively easy. Mr. Fairbairn recommends aalt to be given to young sheep, when shifted suddenly from fresh to dry food; and no doubt. as a condiment in support of the healthy action of the stomach, it would prove useful; and more expecially in the case of cattle and sheep, the structure of whose digestive organs renders them peculiarly liable to the effects of indigestion; and on this account it would be a valuable assistant to the more nutritious oil-cake. And instead of entirely acquiescing in the Ettrick Shepherd's rerom. mendation "to pasture the young and old of the flocks all together," as has been done in Peebles. shire, to the eradication, it is said, of the braxy-as being in many cases impracticable and at. tended with no profit, Mr. Fairbairn rather observes, "Let the pasture for a hirsel, as was observed before, be as nearly as possible of one soil. To overlook this is a mighty error, and the eurest means of making the flock unequal. The heath should also be regularly burned, and the sheep never allowed to pasture long upon soft grass." And as a last resource in an attempt to eradicate the disease everywhere, he would have the sheep put on turnips, as "an infallible antidote against the progress of the malady ;" and which he has "invariably found gives a settling stroke to the disease." $\ddagger$ This last remedy doubtless being effective, I would recommend its adoption rather as a preventive than a cure of the disease.

(1161.) The Ettrick Shepherd mentions the existence of 4 kinds of braxy-namely, the bowet sickness, the sickness in the flesh and blond, the dry braxy, and the vater braxy-all originating in the same cause, producing modified effects-namely, a sudden change of food from succulent to dry, inducing constipation of the bowels and consequent inflammation; and they are all a clase of discases allied in their nature to hoven in cattle, and flatulent colic or botts in horses.

\title{
31. DRIVING AND SLAUGHTERING SHEEP.
}

\author{
"Pierced by Roderick's ready blade, \\ Patient the sickening victim eyed \\ The life-blood ebb in crimson tide \\ Down his clogged beard and shaggy limb, \\ Till darkness glazed his eye-balls dim."
}

Scotr.

(1162.) Altrovan it is unusual for farmers who possess a standing flock - and most farmers who practice the mixed husbandry have one-to dispose of their fat sheep in winter-that is, before the turnips are all consumed-yet as farmers, who, having no standing flock, purchase a flying one every year, of sheep in forward condition, and in such numbers as to consume the turnips allotted to them in a short time, do dispose of their fat sheep in winter, it is proper that you should be made acquainted here with the driving of sheep upon roads, and the general practice of the mutton-trade. The sheep most forward in condition in autumn are yeld ewes and wethers, the tup-eill ewes being already fat and sold.

(1163.) Sheep are purchased from farmers both by dealers and butchers.

- Hogg's Shepherd's Guide.

† The Mountrin Shepherd's Manual.

f A Larnmermuir Farmer's Treatise on Sheep in High Disuricts.

(910) 
Dealers buy from farmers in wholesale, and sell to butchers in retail; so they constitute a sort of middle-men; but, unlike most middle-men, their avocation is fully as useful to both parties as to themselves, inasmuch as they purchase at once the whole disposable stock of the farmer, and they assort that stock, and present it at the markets which the different classes of their customers, the butchers, are in the habit of frequenting, in the most suitable form. They thus act the part which the wool-staplers do, in assorting the different qualities of wool between the grower and the manufacturer. They buy either at fairs, or on the farmer's own premises. In the former case they pay ready money, and lift the stock immediately; in the latter they pay at the time the stock is lifted by agreement. In lifting their bargains, they appoint one time among all the places they have purchased, to make up their entire drove; for it is less costly for their people to drive a large one than a small. Dealers chiefly buy at the country fairs, where they have ample choice, and only purchase on the farmer's premises when stock happens to be scarce, and prices likely to advance. Butchers purchase chiefly in the market-towns in which they reside, though they also attend fairs, and pick up a few fat lots which will not bear the long journeys of the dealers; and in this case they pay ready money and lift immediately, as dealers do. But when they purchase on the farmer's premises, they usually lift so many at a time, according to agreement, and pay only for what they lift. Every farmer should avoid this practice, as every time the butcher comes for his lot the sheep have to be gathered, and the whole handled, that he may take away unly those which suit his present purpose ; and this commotion is made most probably every week, the whole stock being disturbed by the shouting of men and the barking of dogs, among whom those of the butcher are not the least noisy or the least active. Farmers take their stock either to fairs or market-towns, and there meet the respective sorts of purchasers, the dealers never appearing as purchasers in towns, the butchers there ruling paramount.

(1164.) When a dealer purchases on the farmer's premises, he lifts his lot at any time of day that best suits his own arrangements. He begins to lift the first lot in the more distant part of the country, and, proceeding on the road in the direction of their destination, he lifts lot after lot until the whole are gathered, to the amount of many hundreds. In this way he may lift a lot in the forenoon on one farm, and another in the afternoon on another; and this is a much more satisfactory way for the farmer to dispose of his stock than the one he allows the butcher to adopt. But when a farmer is to drive his own sheep to market, he starts them at a time when the journey will do them the least injury. Sheep should not begin their journey either when too full or too hungry; in the former state they are apt to purge on the road, in the latter they will lose strength at once.The sheep selected for market are the best conditioned at the time; and, to ascertain this, it is necessary to handle the whole lot, and shed the fattest from the rest; and this is best done about midday, before the sheep feed again in the afternoon. The selected ones are put into a field by themselves, where they remain until the time appointed them to start. If there be rough pasture to give them, they should be allowed to use it, and get quit of some of the turnips in them. If there is no such pasture, a few cut turnips on a lea-field will answer. Here all their hoofs should be carefully examined, and every unnecessary appendage removed, though the firm portion of the horn should not be touched. Every clotted piece of wool should also be removed with the shears. The sheep should also be marked with kieil, or ruddle, as it is called in England-the ochrey-red ironstone of mineralogists, which occurs in abundance near Platte, in Bohe- 
mia.* The keil-mark is put on the wool, and on any part of the body you choose-the purpose being to identify your own sheep in case of any being lost in the fair. The parts usually chosen for marking Leicester sheep are top of shoulder, back, rump, far and near ribs. The mark is made in this way: Take hold of a small tuft of wool at any of the above parts with the right-hand fingers, and seize it between the fore and middle fingers of the left hand, with the palm upward; then color it with the keil, which requires to be wetted, if the wool itself is not damp. Short-wooled sheep are usually risarked on the head, neck, face and rump, or with a bar across the shoulders, and generally too much keil is put upon them. The sheep being thus prepared should have food early in the morning, and be started on their journey about midday - the season, you will remember, being winter. Let them walk gently away; and, as the road is new to them, they will go too fast at first-to prevent which, the drover should go before them, and let his dog bring up the rear. In a short distance they will assume the proper speed, about 1 mile the hour. Should the road they travel be a green one, the sheep will proceed nibbling their way onward at the grass, along both sides; but if a turnpike, especially a narrow one, the drover will require all his attention in meeting and being passed by every class of vehicle, to avoid injury to his charge. In this part of their business, drovers generally make too much ado, both themselves and their dogs; and the consequence is that the sheep are driven more from side to side of the road than is requisite. On meeting a carriage, it would be much better for the sheep were the drover to go forward, instead of sending his dog, and point off, with his stick, the leading sheep to the nearest side of the road; and the rest will follow, as a matter of course, while the dog walks behind the flock, and brings up the stragglers. Open gates to fields are sources of great annoyance to drovers, the stock invariably making an endeavor to go through them. On observing an open gate before, the drover should send his dog behind him over the fence, to be ready to meet the sheep at the gate. When the sheep incline to rest, let them lie down. Before night-fall the drover should inquire of lodging for them for the night, as in winter it is requisite to put them in a grass-field, and supply them with a few turnips or a little hay, the road-sides being bare at that season. If turnips or hay are laid down near the gate of the field they occupy, the sheep will be ready to take the road in the morning; but, before doing this, the drover should ascertain whether the road is infested with stray dogs; if which be the case, the sheep should be taken to the safest spot and watched. Many dogs that live in the neighborhood of droveroads, and more especially village dogs, are in the habit of looking out for sheep to worry, at some distance from their homes. The chief precaution that can be used under such an apprehension is, for the drover to go frequently through the flock with a light, and be late in retiring to rest, and up again early in the morning. This apprehension regarding dogs is not solely in regard to the loss sustained by worrying, but, when sheep have been disturbed by them, they will not settle again upon the road. The first day's journey should be a short one, not exceeding 4 or 5 miles.Upon drove-roads, farms will he found at stated distances with food and lodging for the drover and his flock, at a moderate charge. Allowing 8 miles a day for a winter-day's travel, and knowing the distance of vour market by the destined route, the sheep should start in good time, allowance being made for unforeseen delays, and one day's rest near the market.

\footnotetext{
- Jamernn's Mineralogy, rol iii.
} (912) 
(1165.) The farmers' drover may either be his shepherd, or a professional drover hired for the occasion. The shepherd knowing the flock makes their best drover, if he can be spared so long from home. A hired drover gets $2 \mathrm{~s} .6 \mathrm{~d}$. a day of wages, besides traveling expenses, and he is intrusted with cash to pay all the necessary dues incidental to the road and markets, such as tolls, forage, ferries, and market custom. A drover of sheep should always be provided with a dog, as the numbers and nimbleness of sheep render it impossible for one man to guide a capricious flock along a road subject to many casualties; not a young dog, who is apt to work and bark a great deal more than necessary, much to the annoyance of the sheep, but a knowing, cautious tyke. The drover should have a walking-stick, a useful instrument at times in turning a sheep disposed to break off from the rest. A shepherd's plaid he will find to afford comfortable protection to his body from cold and wet, while the mode in which it is worn leaves his limbs free for motion. He should carry provision with him, such as bread, meat, cheese or butter, that he may take luncheon or dinner quietly beside his flock while resting in a sequestered part of the road, and he may slake his thirst in the first brook or spring he finds, or purchase a bottle of ale at a roadside ale-house. Though exposed all day to the air, and even though he feel cold, he should avoid drinking spirits, which only produce temporary warmth, and for a long time after induce chilliness and languor. Much rather let him drink ale or porter during the day, and reserve the allowance of spirits he gives himself until the evening, when he can enjoy it in warm toddy besine a comfortable fire, before retiring to rest for the night. The injunction to refrain from spirits during the day I know will sound odd to the ear of a Highland drover; but though a dram may do him good in his own mountain-air, and while taking active exercise, it does not follow that it will produce equally good effects on a drove-road in the low country in winter, in raw and foggy weather. I believe the use of raw spirits does more harm than good to all drovers who indulge in the practice. He should also have a good knife, by which to remove any portion of horn that may seem to annoy a sheep in its walk; and also a small bottle of a mixture of tobacco-liquor and spirit of tar, with a little rag and twine, to enable him to smear and bandage a sheep's foot, so as it may endure the journey. He should be able to draw a little blood from a sheep in case of sickness. Should a sheep fail on the road, he should be able to dispose of it to the best advantage; or, becoming ill, he should be able to judge whether a drink of gruel, or a handful of common salt in warm water, may not recover it so as to proceed; but, rather than a lame or jaded sheep should spoil the appearance of the flock, it should be disposed of before the flock is presented in the market.

(1166.) The many casualties incidental to sheep on travel, more especially in winter, require consideration from the farmer before undertaking to send his stock to a distant market-town, in preference to taking them to a fair, or accepting an offer for them at home. A long journey in winter will cost at least 1s. a head, and their jaded appearance may have the effect of lowering their market price $2 \mathrm{~s}$. or $3 \mathrm{~s}$. a head more. Under any circumstances, when you have determined on sending your sheep to a markettown, it is, I believe, the best plan, after the journey, to intrust them to a salesman, rather than stand at market with them yourself, as you cannot know the character of the buyers so well as he does, nor can you know what class of purchasers your lot may best suit. The convenience attending the employment of a salesman is now generally felt, because it not only saves the personal annoyance of attending a market, but your money is remitted to you through a bank in the course of the day. The only pre(961) $\ldots . . .31$ 
caution requisite in the matter is to hecome acquainted with a salesman of judgment; for as to honesty, if he have not that, he is of course quite worthless. In attending country fairs, the case is otherwise; there being no salesman, you yourself must stand by your lot. Before attending the fair, you should make up your mind what to ask for your stock, in accordance with the current market prices; but, notwithstanding this, you may come away with more or less cash than you anticipated, because the actual state of that market will be regulated by the quality and quantity of the stock brought forward, and by the paucity or numbers of buyers who may appear. After your sheep are fairly placed, you should inquire of friends of the state of prices before you sell, and on doing this you will frequently find the market in a most perplexing state from various causes. Thus, there may be too many sheep for the buyers, when the market will be dull, and remain so all day. On the other hand, the stock may be scanty for the buyers, when a briskness may start in the morning and continue even till the whole stock are sold off. There may be briskness in the morning, the buyers purchasing; dullness at midday, buyers declining; and briskness again in the afternoon, buyers again purchasing. There may he excessive dullness in the morning, occasioned by the buyers lying off and beating down prices, and, finding they cannot succeed, buy briskly all the afternoon. There may be dullness in the morning, arising from the dealers finding the condition of the stock below their expectation. The markets are never better for the farmer than when they begin brisk early in the morning, and the stock are all sold off early. These are the vicissitudes of a market; they are interesting, demand attention, and are worth examination. You will frequently observe a trifling circumstance give a decided tone to a market. A dealer, for instance, who generally buys largely, and having bought for many years respectably in that particular fair, will mark the prices of the day by his purchases; so that other people, particularly sellers, observing the prices given by him, will sell briskly and with confidence. There is no use, at any time, of asking a much higher price than the intrinsic value of your stock, or than you will willingly take; for, although your stock may be in particularly fine condition, and of good quality, and therefore worth more than the average price of the market, still their value must conform to the rate of the market, be it high or low, and it is not in your power to control it ; though, if prices dissatisfy you, you have it in your power to take your stock home again. There is a common saying applicable to all public markets, and is now received as a maxim, because indicating the truth, that "the frist offer is the best," that is, the first offer from a bona fide buyer; for there are people to be found in all markets who, having no serious intention of buving at market price, make a point of offering considerably below it, with the view of catching a bargain from a greenhorn, or from one tried of standing longer in the fair, and they sometimes succeed in their wislies; but such people are easily discovered, and therefore cannot deceive any but inexperienced sellers.

(1167.) There are certain rules which, by tacit consent, govern the principles upon which all public markets of stock are conducted, and they are few and simple. There is a custom payable for all stock presented at fairs, exigible by the lord of the manor, or other recognized authority. After entering the field, your stock can take up any unoccupied position you choose, appointed for the particular kind of stock you have to show. No one, on pretence of purchasing, has a right to interfere with a lot which is under inspection by another party. Neither have you any right to show your lot to more than one party at a time, unless each party consent to it. When a bargain is made, there is no necessity for striking hands, or ex(962) 
changing money, as an earnest of it. When a bargain is made, a time may be stipulated by the purchaser for lifting the stock; and, until they are delivered to him or his accredited agents, they continue at the risk of the seller. When counted over before the purchaser, the price becomes immediately due. When the money is paid, there is no obligation on the seller to give a discount off'the price, or a luck-penny, as it is termed; but purchasers sometimes make offers in a way to humor the prejudices of the seller-that is, they offer the price demanded, on condition of getting back a certain sum, or amount of luck-penny, to bring the price down to their own ideas; in such a case, when such an offer is accepted, the seller must return the luck-penny conditioned for, when he receives the money. Sometimes, when parties cannot agree as to price, the offerer proposes to abide by the decision of a third party ; but, in doing this, you virtually relinquish your power over your own stock. Sometimes bills and bank-postbills are tendered by dealers in part or entire payment of what they purchase; but it is in your power to refuse any form of cash but the legal tender of the country, such as Bank of England notes, or gold, or silver. If a bill of exchange or promissory note is proffered instead of ready money, you are quite entitled to refuse the bargain; for the usage of trade in a fair implies the condition of ready money ;* or you may demand a higher price to cover the risk of the bill being dishonored. The notes of any bank you know to be good, you will, of course, not refuse. After the stock are delivered, they are at the risk of the purchaser. Some dealers' top's-men-that is, the men who take charge of their master's lots after delivery-demand a gratuity for their trouble, which you are at liberty to refuse. All these rules, in as far as relates to money and the delivery of stock, apply to the stock purchased by dealers on your own farm. When you purchase stock at a fair, people.will be found on the ground willing to render your drover assistance in taking them out of it, and of setting them fairly on the road. Such people are useful on such occasions, as it may happen, especially in the case of sheep, that one or more may break away from their own flock and $\operatorname{mix}$ with another, when there may not only be difficulty in shedding them out, but those into whose lot yours have strayed may show unwillingness to have their stock disturbed for your sake, though it is in your power to follow your strayed stock, and claim it anywhere by the wool-mark.

(1168.) The way that fat is laid on sheep while on turnips, and the mode of judging of a fat sheep, are these : Hoggs, when put on turnips in winter, are generally lean; for although they had been in good condition as lambs when weaned from their mothers in summer, their growth in stature afterward is so rapid that their flesh is but little intermixed with fat. For the first few weeks on turnips, even in the most favorable circumstances as to quality of food, warmth of shelter, dryness of land, and pleasantness of weather, they make no apparent advancement in condition; nay, they rather seem to fall off, and look clapped in the wool, and indicate a tendency to delicacy, in consequence, I suppose, of the turnips operating medicinally on their constitution as an alterative, if not as a laxative; but immediately after that trying period of young sheep, especially trying in bad weather, is past, when the grass has completely passed through them, and the stomach and intestines have become accustomed to the more solid food of the turnip, their improvement is marked, the wool seeming longer and fuller, the carcass filled out, the eyes clear and full, and the gait firm and steady. They then thrive rapidly, and the more rapidly the drier the weather. 
(1169.) The formation of fat in a sheep destined to be fattened, commences in the inside, the net of fat which envelops the intestines being first formed, and a little deposited around the kidneys. After that, fat is seen on the outside, and first upon the end of the rump at the tail-head, which continues to move on along the back, on both sides of the spine or back-bone to the bend of the ribs, to the neck. Then it is deposited between the muscles, parallel with the cellular tissue. Meanwhile, it is covering the lower round of the ribs descending to the flanks, until the two sides meet under the belly, whence it proceeds to the brisket or breast in front, and the shaw or cod hehind, filling up the inside of the arm-pits and thighs. While all these depositions are proceeding on the outside, the progress in the inside is not checked, but rather increased, by the fattening disposition encouraged by the acquired condition; and hence, simultaneously, the kidneys hecome entirely covered, and the space hetween the intestines and lumbar region or loin gradually filled up by the net and kidney fat. By this time, the cellular spaces around each fibre of muscle is receiving its share, and when fat is deposited there in quantity, it gives to meat the term marbled. These inter-fibrous spaces are the last to receive a deposition of fat; but after this has begun, every other part simultaneously receives its due share, the back and kidneys receiving the most, so much so that the former literally becomes nicked, as it is termed; that is, the fat is felt through the skin to be divided into two portions, from the tail-head along the back to the top of the shoulder, the tail becoming thick and stiff, the top of the neck broad, the lower part of each side of the neck toward the breast full, and the hollows between the breast-bone and the inside of the fore-legs, and between the cod and the inside of the hind thighs, filled up. When all this has been accomplished, the sheep is said to be fat or ripe.

(1170.) When the body of a fat sheep is entirely overlaid with fat, it is then in the most valuable state as mutton; but few sheep lay on fat entirely over their body, one laying the largest proportion on the rump, another on the back; one on the ribs, another on the flanks; one on the parts adjoining the fore-quarter, another on those of the hind-quarter; one more on the inside, and another more on the outside. Taking so many parts, and combining any two or more of them together, you may expect to find, in a lot of fat sheep, a considerable variety of condition, and yet any one is as ripe in its way as any other.

(1171.) Taking these data for your guide, you will be able to detect, by handling, the state of a sheep in its progress toward ripeness. A ripe sheep, however, is easily known by the eye, by the fullness exhihited in all the exterual parts of the particular animal. It may exhibit wants in some parts when compared with others, but you easily see that these parts would never become so ripe as the others; and this arises from some constitutional defect in the animal itself, because, if this were not so, there is no reason why all the parts should not be alike ripe. Whence this defect. arises remains to be consiclered afterward. The state of a sheep that is obviously not ripe cannot altogether be ascertained by the eye; it must be handled, that is, it must be subjected to the scrutiny of the hand. Now, even in so palpable an act as handling discretion is requisite. A full-looking sheep need hardly be handled on the rump, for he would not seem so full unless fat had heen first deposited there. A thin-looking sheep, on the other hand, should be handled on the rump, and if there be no fat there, it is useless handling the rest of the body, for assuredly there will not be so much as to deserve the name of fat. But between these two extremes of condition there is every variety to be met with; and on that 
account examination by the hand is the rule, by the eye alone the exception; but the hand is much assisted by the eye, whose acuteness detects deficiencies and redundancies at once. In handling a sheep the points of the fingers are chiefly employed, and the accurate knowledge conveyed by them through practice of the true state of condition is truly surprising, and settles a conviction in the mind that some intimate relation exists between the external and internal state of an animal. And hence this practical maxim in the judging of stock of all kinds, that no animal will appear ripe to the eye, unless as much fat had previously been laid on in the inside as his constitutional habit will allow. The application of this rule is easy. Thus, when you find the rump nicked on handling, you may expect to find fat on the back; when you find the back nicked, you would expect the fat to have proceeded to the top of the shoulder and over the ribs; and when you find the top of the shoulder nicked, you would expect to find fat on the under side of the belly. To ascertain its existence below, you will have to turn him up, as it is termed; that is, the sheep is set upon his rump with his back down and his hind-feet pointing upward and outward. In this position you see whether the breast and thighs are filled up. Still, ail these alone would not let you know the state of the inside of the sheep, which should, moreover, be looked for in the thickness of the flank; in the fullness of the breast, that is, the space in front from shrulder to shoulder toward the neck; in the stiffness and thickness of the root of the tail, and in the breadth of the back of the neck. All these latter parts, especially with the fullness of the inside of the thighs, indicate a fullness of fat in the inside; that is, largeness of the mass of fat on the kidneys, thickness of net, and thickness of layers between the abdominal muscles. Hence the whole object of feeding sheep on turnips seems to be to lay fat upon all the bundles of fleshy fibres, called muscles, that are capable of acquiring that substance; for as to bone and muscle, these increase in weight and extent independently of fat, and fat only increases their magnitude.

(1172.) I have spoken of the turning up of a fat sheep; it is done in this way: Standing on the near side of the sheep, that is, at its left side, put your left hand under its chin, and seize the wool there, if rough, or the skin, if otherwise; place your knees, still standing, against its ribs, then bowing forward a little, extend your right arm over the far loin of the sheep, and get a hold of its flank as far down as you can reach, and there seize a large and firm hold of wool and skin. By this, lift the sheep fairly off the ground, and turning its body toward you upon your left knee under its near ribs, place it upon its rump on the ground with its back to you, and its hind feet sticking up and away from you. This is an act which really requires strength, and if you cannot lift the sheep off the ground, you cannot turn it; but some people acquire a sleight in doing it, beyond their physical powers. I believe the art consists in jerking the sheep off its feet at once, before it suspects what you are going to do ; for if you let it feel that you are about to lift it as a dead weight, the probability is, that you will not be able to make it lose hold of the ground, as it is surprisinm how dexterously sheep contrive, in the circumstances, to retain hol. the ground with the point of the hoof of the near lind-foot, which, if cannot force away, you cannot turn the sheep. I remember seeing $4 \mathrm{~s}$ herds defeated in the attempt to turn 5 dinmonts belonging to the late Edward Smith, Marledown, Northumberland. None of the shephen even the longest and strongest, could turn all the 5 sheep, and one of them, a short though stout man, could not turn one of them, they were so broad in the back, so round and heavy. The ability to turn a sheep is 
not to be regarded as a feat in a shepherd, but a necessary act in conuec. tion with many important operations, as you shall see afterward.

(1173.) Sheep are easily slaughtered, and the operation is unattended with cruelty. They require some preparation betore heing deprived of life, which consists of food being withheld from them for not less than 24 hours, according to the season. The reasm for fastung sheep before slaughtering, is to give time for the paunch and intestines to empty themselves entirely of food, as it is found when an animal is killed with a full stomach, the meat is morc liable to putrefy, and not so well flavored; and as ruminants always retain a large quantity of food in their intestines, it is reasonable they should fast somewhat longer to get quit of it than auimals with single stomachs. Sheep are placed on their sicle on a stool, called a killing stool, to be slaughtered, and requiring no fastening with cords, are deprived of life by a thrust of a straight knife through the neck, between its bone and the windpipe, severing the carotid artery and jugular vein of both sides, from which the blond flows freely out, and the animal sonn dies. The skin, as far as it is covered with wool, is taken off, leaving that on the legs and head, which are covered with hair, the legs being disjointed by the knee. The entrails are removed by an incision along the helly, after the carcass has been hung up by the tendons of the houghs. The net is carefully separated from the viscera, and rolled up by itself; but the kidney fat is not then extracted. The intestines are placed on the inner side of the skin until divided into the pluck, containing the heart, lungs, and liver; the bag, containing the stomach; and the puddings, consisting of the viscera or guts. The bag and guts are usually thrown away, that is, buried in the dunghill, unless when the bag is retained and cleaned for haggis. The pluck is either fried or made into haggis. The skin is hung over a rope or pole under cover, with the skin-side uppermost, to dry in an airy place.*

[* By the Abbé Comea, a man of great learning and observation, it was remarked that the people of the United States possessed "bacon-stomachs." Their want of relish, not to say their distaste-more especially females-for mutton, is one of the obstacles to the extension of sheep hos bandry in the United States. An opinion generally prevails-borrowed, as many of our opivions are, from England-that mutton does not attain perfection in juiciness and flavor under four or five years; but we are disposed to believe, with an experienced victualer of our acquaintance, and a good judge of mutton, alike in the field and the shambles, that this is a mistake, and that well-fed and fatted mutton is never better than when it gets its full growth, in its second year; nor can the farmer afford to keep it longer, unless the wool would pay for the keep. We have not the epicures and men of wealth who would pay the butcher the extra price, which he must have, that would enable him to pay a remunerating price to the grazier for keeping his sheep two or three years over.

The common mistake in the management of mutton in our country is that we eat it exaclly at the vorong time after it is killed. It should be eaten, ns a fried chicken should, immediately after being killed, and, if possible, before the meat has time to get cold; or, if not, then it should be kept a week or more-in the jee-house, if the weather require-until the time is just at hand when the fibre passes the state of toughness which it takes on at first, and reaches that incipient or preliminary point in its progress toward putrefaction when the fibres begin to give way and the meat becomes iender.

We were gratified lately to see, in a large smokery of Mr. Clements, in Philadelphia, quite a large number of corned legs of mutton, which had been sent in from Ohio. If mutton can be brought into vogue in that shape, it will be an additional inducement for rearing sheep in many gituations removed from available markets.

Who need complain, at a watering.place, if he can secure for his breakfast or his dinner a good mutton-chop, sach as is to be had at Caldwell's White Sulphar Springs, peppered, and broiled. and served up hot, with no gravy but its onon? Can anything be more loothful-more rchole. some?

Ed. Farm. Lib.] 
(1174.) The carcass should hang 24 hours in a clean, cool, airy, dry apartment, before it is cut down. I say cool and $d r y$, for if warm the meat will not become firm, and if-damp a clamminess will cover it, and will never feel dry, and have a fresh, clean appearance. The carcass is divided in two by being sawed right down the back-bone. The kidney-fat is then taken out, being only attached to the peritoneum by the cellular membrane, and the kidney is extracted from the suet-the name given to sheep tallow in an independent state.

(1175.) In almost every town there is a different way of cutting up a carcass of mutton; and, it being here impossible to advert to them all, I shall select those of Edinburgh and London, and distinguish them as the Scotch and English modes. Although the English mode is upon the whole preferable, having been adopted to suit the tastes of a people long acquainted with domestic economy, it must nevertheless be admitted that meat is cut up in Scotland in a cleanly and workmanlike manner; but on the other hand, it will not be denied by those who have observed for themselves, that the beauty and cleanliness of meat, as exhibited in London, call forth the admiration of every connaisseur. The Scotch mode is represented in fig. 255, where, in the hind-quarter, $a$ is the jigot and $b$ the loin, and, in the fore-quarter, $c$ the back-ribs and $d$ the breast. It will be observed that the jigot is cut with a part of the haunch or rump, and the fore-quarter right through the shoulder into 2 pieces. The English mode is represented in fig. 256, where, in the fore-quarter, $a$ is the shoulder, $b$ and $b$ the

Fig. 255 .

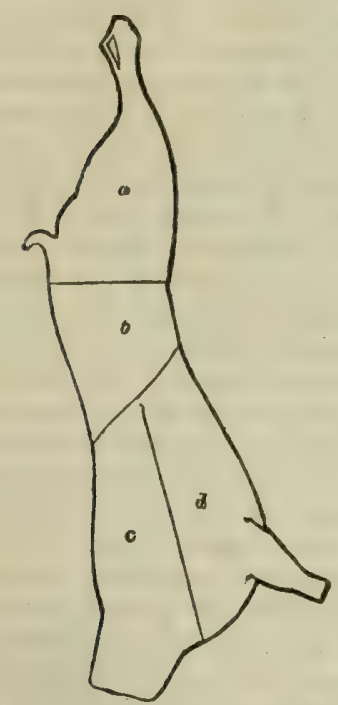

THE SCOTCH MODE OF CUTTING UP A CARCASS OF MUTTON.
Fig. 256.

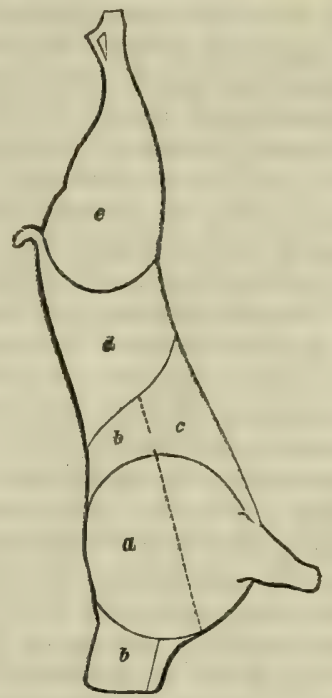

THE ENGLISH MODE OF CUTTING UP A CARCASS OF MUTTON.

neck, and $c$ the breast after the shoulder is removed; and, in the hindquarter, $d$ is the loin and $e$ the leg. The leg here is cut short, without any of the haunch, like a ham; and the shoulder is preserved whole.

(1176.) The jigot $a$, fig. 255, is the handsomest and most valuable part of the carcass, and on that account fetches the highest price. It is either 
a roasting or a boiling piece. Of Black-faced mutton it makes a fine ruast, and the piece of fat in it called the Pope's eye is considered a delicate mor. ceau by epicures. A jigot of Leicester, Cheviot or South-Down mutton makes a beautiful "hoiled leg of mutton," which is prized the more the fatter it is, as this part of the carcass is never overloaded with fat. The loin $b$ is almost always roasted, the flap of the flank being skewered up, and it is a juicy piece. For a small family, the Black-faced mutton is preferable; for a large, the South-Down and Cheviot. Many consider this piece of Leicester mutton roasted as too rich, and, when warm, this is probably the case; but a cold roast loin is an excellent summer dish.The back-rib $c$ is divided into two, and used for very different purposes. The fore-part, the neck, is boiled, and makes sweet barley-broth; and the meat, when well boiled, or rather the whole pottage siminered for a considerable time beside the fire, eats tenderly. The back-ribs make an excellent roast; indeed, there is not a sweeter or more varied one in the carcass, having both ribs and shoulder. The shoulder-blade eats hest cold, and the ribs warm. The ribs make excellent chops. The Leicester and South-Downs afford the best mutton-chops. The breast $d$ is mostly a rnasting piece, consisting of rib and shoulder, and is particularly good when cold. When the piece is large, as of South-Down or Cheviot, the gristly part of the ribs may be divided from the true ribs, and helped separately. The breast is an excellent piece in Black-faced mutton, and suitable to small families; the shoulder being eaten cold, while the ribs and brisket are sweet and juicy when warm. This piece also boils well; or, when corned for 8 days, and served with onion sauce, with mashed turnip in it, there are few more savory dishes at a farmer's table. The shoulder $a$, fig. 256 , is separated before being dressed, and makes an excellent roast for family use, and may be eaten warm or cold, or corned and dressed as the breast mentioned above. The shoulder is best from a large carcass of South-Down, Cheviot or Leicester, the Black-faced being too thin for the purpose; and it was, probably, because English mutton is usually large, that the practice of removing it originated. The neck-piece $b \quad b$ is partly laid bare by the removal of the shoulder, the fore-part being fitted for boiling and making into broth, and the best end for roasting or broiling into chops. On this account this is a good family piece, and in such request among the tradesmen of London that they prefer it to any part of the hindquarter. Heary mutton, such as the Leicester, South-Down and Cheviot, supply the most thrifty neck-piece. The breast $c$ is much the same sort of piece as in the Scotch method, but the ribs are here left exposed at the part from which the shoulder has been removed, aud constitute what are called the spare ribs, which may be roasted, or broiled, or corned. The back end of the breast makes a good roast for ordinary use. The flap of the loin left attached to this piece may be used in making broth. The loin $d$ is a favorite roast in a family; and when cut double, forming the chine or saddle, it may grace the head of the table of any public dinner: Any of the kinds of mutton is large enough for a saddle; but the thicker the meat, of course the larger the slice. The leg $e$ is cut short and roasted. When cut long, taking in the hook-hone, it is similar to a haunch of venison, and roasted accordingly. A fat Black-faced wether yields a good haunch.

(1177.) The different sorts of mutton in common use differ as well in quality as in quantity. The flesh of the Leicester is large, though not coarse-grained, of a lively red color, and the cellular tissue between the fibres contains a considerable quantity of fat. When conked it is tender and juicy, yielding a red gravy, and having a sweet, rich taste; but the fat (968) 
is rather too much and too rich for some people's tastes, and can be pu: aside; and it must be allowed that the lean of fat meat is far better than lean meat that has never been fat. Leicester sheep generally attain to heavy weights-hoggs reaching $18 \mathrm{lbs}$. or $20 \mathrm{lbs}$, and dinmonts $30 \mathrm{lbs}$. per quarter; but the 5 dinmonts which I mentioned before as having defeated the shepherds in turning up, were $55 \mathrm{lbs}$. a quarter overhead, when killed at Newcastle in November, a few weeks after they were shown.

(1178.) Cheviot mutton is smaller in the grain, not so bright of color, with less fat, less juice, not so tender and sweet, but the flavor is higher and the fat not so luscious. The weight attained by a hogg may be taken at $14 \mathrm{lbs}$. or $15 \mathrm{lbs}$., and by a wether at $22 \mathrm{lbs}$; ; but Mr. Fairbairn mentions having fattened 5 wethers in 1818 which averaged $30 \mathrm{lbs}$. a quarter.*

(1179.) Black-faced mutton is still smaller in the grain, of a darker color, with still less fat, but more tender than the Cheviot, and having the highest flavor of all. The ordinary weight of a fat wether is about $18 \mathrm{lbs}$. or 20 lbs. a quarter; but I remember seeing a lot of 5-year-old Black-faced wethers, exhibited at the first Show of the Highland and Agricultural Society at Perth, belonging to Lord Panmure, that averaged $40 \mathrm{lbs}$. a quarter.

(11S0.) The mutton of South-Downs is of medium fineness in grain, color pleasant red, fat well intermixed with the meat, juicy, tenderer than the Cheviot, and of pleasant though not of so high a flavor as the Blackfaced. The ordinary weight may be from $16 \mathrm{lbs}$. to $22 \mathrm{lbs}$. a quarter, but 3 wethers exhibited by Mr. Grantham, at the Show of the Smithfield Club in 1835 , weighed, on the average, $41 \frac{1}{2} \mathrm{lbs}$. a quarter. $\dagger$

(1181.) Tup-mutton of any breed is always hard, of disacreeable flavor, and in autumn not eatable. The mutton of old ewes is dry, hard and tasteless, but of young well enough flarored, but still rather dry. Hogg-mutton is sweet, juicy and tender, but flavorless. And wether-mutton is the meat in perfection, according to its kind.

(1182.) The average quantity of fat afforded by each sheep of every class, sold in any given market in Scotland, is perhaps not great. In Glasgow, for example, where heavy animals of all sorts are generally sold, the fat afforded by all the sheep-consisting chiefly, I presume, of Cheviot and Black-faced-exclusive of lambs, amounting to 57,520 head, sold in 1822 , was only, on the average, 4 lbs. $13 \mathrm{oz}$. per head.f From 8 lbs. to 12 lbs. is the ordinary quantity obtained from Leicester sheep slaughtered on farms of good land; and in Edinburgh I find that $7 \mathrm{lbs}$. is considered an average from Black-faced and Cheviot sheep, which shows that the quality of mutton sold there is better than that in Glasgow.

(1183.) As you may frequently hear it remarked in the course of your experience as a farmer, that 5-year-old mutton is the best, it is worth while considering whether the case can be so. Two subjects of inquiry inmediately present themselves on hearing this remark: one, whether sheep require 5 years to put them in condition for use? and the other is, whether it is treating them properly to postpone putting them in condition for use until they shall attain the age of 5 years? If truth is implied in the first inquiry, then that breed of sheep must be very unprofitable which takes five years to attain its best state; but there is no breed of sheep in Great Britain which requires 5 years to bring it to perfection. Therefore, if truth is implied in the second inquiry, then it must be folly to restrain sheep coming to perfection until they have attained the age of

* A Lammermuir Farmer's Treatise on Sheep in High Districts.

† Cleland's Account of the Highland and Agricultural Society's Show at Glasgow, in 1828. (969) 
5 years. It is not alleged by the lovers of 5 -year-old mutton that it bestows profit on the farmer, for the allegation only insists on its being best at that age. But such an allegation involves one of two absurd conditions in Agriculture; namely, the keeping a breed of sheep that cannot, or the keeping of one that you should not allow to attain to perfection before it is 5 years. Either of these conditions makes it obvious that mutton cannot be in its best state at 5 years. The fact is, the idea of 5 -year-old mutton being super-excellent, is founded on a prejudice, which probably arose from this circumstance : Before winter food which could maintain the condition on stock that had been acquired in summer, was discovered, sheep lost much of their summer-condition in winter, and of course an oscillation of condition occurred year after year until they attained the age of 5 years; when their teeth beginning to fail, would cause them to lose their condition the more rapidly. Hence, it was expedient to slaughter them not exceeding 5 years of age; and, no doubt, at that age mutton would he high flavored that had been exclusively fed on natural pasture and natural hay. But such treatment of sheep camnot now be justified on the principles of modern practice; because both reason and taste concur in mutton being at its best whenever sheep attain their perfect state of growth and condition, not their largest and heaviest; and as one breed attains its perfect state at an earlier age than another, its mutton attains its best before another breed attains its best state, although its sheep may be older; but taste alone prefers one mutton to another, even when both are in their best state, from some peculiar property. The Black-faced sheep, for instance, it is preferred by many, because of the flavor of its mutton; and this property it has most probably acquired from the heathy pasture upon which it is brought up. But if flavor alone is to decide the point, the Welch mutton is much the superior. So far as juiciness is concerned, a Leicester hogg has more of it than any Black-faced sheep; and the darkness of the flesh of the latter arises solely from the breed, as it seems to form the connecting link, in this country, between the sheep and the goat, the latter of which always has dark-colored flesh. Judged by the scale of perfection of growth, Leicester mutton is best in the dinmont; and as it may require five years to bring a Black-faced wether to that state when constantly confined upon the hills, Black-faced mutton may then be considered in its best state, because it is 5-year-old, but so far from being in the condition it would have attained had it been brought down to the low country when a lamb and fed upon the best food, it would still be lean, and, of course, not in a state of perfect growth ; whereas, in the low country, it would attain perfection of growth at 3 years, and then its mutton must be at its brst ; for beyond that age - that is, if kept to 5 years on such food-it would become too fat, and lose much of its delicacy. The cry for 5 -year-old mutton is thus based on very untenable grounds.

(1184). Markets for sheep are held in all large towns, and the butchers in the small ones supply themselves from the farmers. The Edinburgh weekly market, on Wednesday, supplies the Black-faced mutton in perfection, and the Cheviot is also very good. In Morpeth, on Wednesdays, are to be seen Leicesters in the highest state of condition, which are brought up with avidity for the colliers around Newcastle. In London, on Mondays, the South-Downs are seen in great perfection, this being the favorite mutton of the Capital:

(1185). A great trade in the transmission of live-stock and meat from the east coast of Scotland to London, has arisen since the establishment of steam navigation. From inquiry, I found that, in the year ending May 1837, there were shipped 4,221 old sheep, and 11,672 barrel-bulk of meat. (970) 
chiefly mutton, which, at $2 \frac{1}{2}$ cwt. per barrel-bulk, give $29,175 \frac{1}{2}$ cwt.* The meat is sent by butchers at the different shipping ports, and the live-stock by dealers, butchers and farmers. When you determine to send your stock to London, you should, in the first place, establish a correspondence with a live-stock salesman, who will pay all cliarges on board ship and at market, and remit the balance in course of post. The charges consist of freight, which for sheep is $3 \mathrm{~s} .6 \mathrm{~d}$. a herd, commission, hay or grass on board, dues and wharfage, hay or grass on shore, and driving to market. You will, of course, never ship meat, but you should, nevertheless, be well acquainted with all the pieces into which a carcass of beef or mutton is cut up, that you may know whether your stock is of the description to supply the most valuable pieces of meat ; for, without this knowledge, unless, in short, you know the wants of a market, you cannot know whether you are supplying its requirements, or whether your stock ought to realize the top prices.

(1186.) On the supposition that you send sheep to I ondon by steam on your own account, they should be of the following description, to command the best prices, and unless they are so you had much rather dispose of them at home. They should be ripe, compact, and of light weight; carrying a large proportion of lean on the back, loins, and shoulders, with a full, round leg and handsome carcass. Such, from 14 lbs. to $20 \mathrm{lbs}$. 3 quarter, will take readily, but they will draw the most money at from 16 lbs. to $18 \mathrm{lbs}$. The nearer in their form and quality they approach the South-Downs, the more likely to command top prices. True-bred Cheviots and the Black-faced Linton breed approach very near to the South-Down, and command as high a price. Half-breds, between Leicester tups and the above sorts of Cheviot and Black-faced ewes, form valuable sheep. The old Black-faced breed are too thin, and therefore styled goaty in Smithfield, and when only half-fat, or half-meated, as the condition is there termed, fetch middling prices, however good their flavor may be. Purebred Leicesters are too fat, unless sent young, and not exceeding $20 \mathrm{lbs}$. a quarter, but abeve that weight, fetch inferior prices, so much so that a difference of only $1 \mathrm{~d}$. per $1 \mathrm{~b}$. may perhaps constitute all the difference between a profit and loss on their export. This last remark applies to every other breed, and shows the expediency of only exporting the best form of sheep.

(1187.) Never attempt to drive stock on foot on your own account to a distant market, when you have steam-conveyance to the place of destination. A simple comparison of the results of the two methods of traveling will show you at once the advantage of steam-conveyance. It has been ascertained that a journey of 400 miles on land causes a loss of 6 stones out of 40 stones, or 12 per cent.; whereas the loss by steam is only 2 stones out of 50 . But besides this great difference in the loss itself, the state in which the remainder of the flesh is left, it is worth $6 \mathrm{~d}$. a stone less after land travel; and when stock are sent to graze in that state, they require a month to take with the pasture, whereas the steam-carried will thrive again at the end of a fortnight. Besides all these disadvantages of land travel, the juices of the meat of fat stock never recover their natural state, while, by being carried by steam, they do. Were heavy and highconditioned stock to be traveled by land, they would inevitably sink under the attempt, while by steam any degree of condition may be conveyed

\footnotetext{
- See an article on the preparation of live-stock and meat for exportation by steam, in vol. viii. of the Quarterly Journal of Agriculture, drawn up by me on information derived from Mr. Janieg Dickson, in Orkney, who has had great experience in every matter relating to meat and live-stocis; and also from other sources.
} (971) 
with comparative ease. The time, too, spent on a land journey is of consideration, when a more expeditious mode of traveling is in your option.

(1188.) With regard to the relative weights of oflal and meat afforded by sheep, there ane recorded instances of their proportions, and of a fat South-Down wether they were these, namely:

\section{Live veigh, 13 st., $10 \mathrm{lbs}$.}

Orrat.

Lbs. $\mathrm{Oz}$.

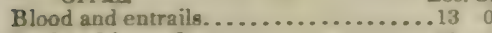

Caul and loose fat..................21

Head and pluck.................. 812

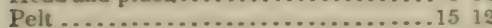

Total. $\overline{5812}$ Mest.

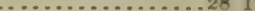

Hind-quarter ...................... 83

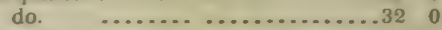

Total...................... $\overline{1134^{*}}$

I mar mention that the carcnss consists of the entire useable meat of the body. which. when sawed down the middle of the back-bone, is divided into two sides, which, when again divided by the 5 th rib. makes the carcass to consist of 4 quarlers. The remainder of the animal consists of offal-namely, of fat, entrails, head and skin. In purchasing fat live-stock, the butcher is snpposed to pay the market value of the carcass, bone and meat to the farmer, reserving the offal to himself for his profit and risk. The relative proportions of mutton and oflal have probably never been absolutely ascertained, as they must differ in different breeds of sheep; but there is little doubt that, in the Leicester breed, the meat bears a hicher proportion to the offal than in any other breed. In the above case, the meat is about $\frac{2}{3}$ and ollal $\frac{1}{3}$ of the whole weight; or. more nearly, the meat is as $123 \frac{1}{2}: 182$. and the offal as $58 \frac{3}{7}: 182$. And in the same breed it bas been said that the proportion of bone is as low as $1 \mathrm{oz}$. to $1 \mathrm{lb}$. Hesh; but I much doubt this, because Mr. Donovan found in a leg of mutton, which is the most fleshy part of the carcass in proportion to the bone in it, weighing $9 \frac{1}{4} \mathrm{lbs}, 16 \mathrm{oz}$. of bone; another of $9 \mathrm{lbs} .6 \mathrm{oz}, 15 \mathrm{oz}$.; and a leg of small Scotch mutton. of only $6 \mathrm{lbs}$, weight, afforded $10 \frac{1}{3} \mathrm{oz}$. of bone.

(1189.) There is a rule mentioned by Mr. Ellman. of Glynde, in Sussex, by which the age of mntton may be ascertained by certain marks on the carcass, and it is an infallible one. He says : "Observe the color of the breast-bone when a sheep is dressed-that is, where the breast-bone is separated-which, in a lamb, or before it is 1 year old, will be guite red; from 1 to 2 years old. the upper and lower bone will be changing to white, and a small circle of white will appear round the edges of the other bones, and the middle part of the breast-bone will yet continue red; at 3 years old, a very small streak of red will be seen in the middle of the 4 midalle bones, and the others will be white; and at 4 years, all the breast-bone will be of a white or gristly color." $t$

(1190.) The experiments of Mr. Donovan prove that meat of all kinds loses a considerable proportion of weight on being cooked. His results on mutton were: 'The average loss on boiling legs of mutton is 10 per cent. : so that, if the butchers' price were $6 \mathrm{~d}$. per lb., the boiled mutton would cost $7 \frac{1}{2} \mathrm{~d}$. The average loss of roasting legs of mution is $27 \mathrm{i}-10$ per cent.; so that, at the butcher's price of $6 \mathrm{~d}$. per lb., the roasted mutton would cost $8 \frac{1}{\mathrm{a}} \mathrm{d}$. per $\mathrm{lb}$. The average loss of roasting shoulders of mutton is 28 per cent.; and, were the butcher's price $5 d$. per $1 \mathrm{~b}$., the roagted shoulder would cost $69-10 \mathrm{~d}$. per lb. The average loss, therefore, in boiling mutton is 10 per cent., and in roasting it 27 85-100 per cent. These results differ considerably from those obtained by Professor Wallace, who, in the case of boiling $100 \mathrm{lbs}$. of mutton, detected a loss of $21 \frac{1}{2}$ per cent., instead of 10 per cent.: and in that of roasting $100 \mathrm{lbs}$, the loss was $31 \frac{1}{2}$ instead of 28 per cent.These discrepancies might, perhaps, be easily explained were we acquainted with every particular connected with both sets of experiments, such as the state of the meat before and after being cooked. In these respects, in his own experiments. Mr. Donovan says: "I used meat of suffi. cirnt bat not unprofitable fatness, such as is preferred by families; the meat was, in all casea, a little rare at its center, and the results were determined with the utmost care." $\neq$

(1191.) Good ham may be marle of any part of a carcass of mutton. though the leg is preferred, and for this purpose it is cat in the English fashion. It should be rabbed all over with good Liv. erpool salt, and a little saltpetre, for 10 minutes. and then laid in a dish and covercd with a cloth for 8 or 10 days. After that it should be rubbed again elightly for about 5 minutes. and then hnng ap in a $d r y$ place, eay the roof of the kitchen, until used. Wether mutton is used for hams, because it is fac and it may be cured any time from November to May; but tup mutton makes the largest and highest flavored bam, provided it be cured in spring, because it is out of season in autumn.

(1192.) There is an economical way of using fat mutton well adapted for the laboring people of - farm. The only time Scotch farm-servants indulge in butcher-mest is when a sheep falls, as it is termed-that is, when it is killed before being affected with an unwholesome disease, and the mutton is suld at a reduced price. Shred down the suet small. removing any flesh or cellular membrane adhering to it; then mix among it intimately $\frac{1}{3} \mathrm{oz}$. of salt and a tea-spoonful of pepper to every pound of suet: pat the mixtare into an earthen jar, and tie ap tightly with bladder. One table-spoonful of seasoned sues will, at any time, make good barley-broth or potato soup for two persons. The lean of the matton may be shred down small, and seasoned in a similar manner, and ased when required; or it may be corned with salt. and used as a joint.

(1193.) Where Leicester sheep are bred. and the farmer kills his own mutton, suet will accu. mulate beyond what can be used for domestic purposes. As long as it is fresh it should be rynd. ed or rendered, as it is termed-that is, prepared for preservation-because the fibrous and fleshy matter mixed with it soon promotes putrefaction. It should be cut in small pieces, removing only fleshy matter. It is then put in an earthern jar, which is placed within a pot containing warm

- Sussex Agricultural Report. † British Husbandry, vol. ii. \$ Donovan's Domestic Economy, vol. ii. (972) 
water, at the side of the fire, merely to simmer, and not to boil. As every portion put in is melt ed, another succeeds, until the whole is melted; and the melted mass should be very frequently gtirred. Suet melts at from $98^{\circ}$ to $104^{\circ} \mathrm{Fabr}$. After being fused a considerable time, the mem. braneous matter comes to the top, and is taken off; and when obtained in quantity, and squeezed, this scum coustitutes the cracklings which are sometimes used for feeding dogs. The purified suet may then be poured through a cullender. into a dish containing a little water, upon which it consolidates into a cake; and the cakes are either sold to the candle-makers or candles taken in exchange. "Many plans for purifying fats," says Ure, "have been proposed. One of the best is to mix 2 per cent. of strong sulphuric acid with a quantity of water, in which the tallow is heated for some time with much stirring, to allow the materials to cool, to take off the supernatant fat, and re-melt it with abundance of hot water. More tallow will thus be obtained, and that considerably whiter and harder than is usually procured by the melters."* Some people melt suet in a pot over the fire, where it is apt to be burnt; and some even fry it in a frying-pan, which may answer for culinary purposes, but cannot, of course, be disposed of to the candle-makers.

13194.) Mutton-suet consists of about 77 parts of stearine and 23 of oleine in every 100 parts.The former is solid, the latter fluid. The specific gravity of suet is 0.936 . When a piece of solid suet is broken, innumerable minute granules separate from the mass; and these, when examined by the microscope, exhibit definite forms, being polyhedral, bonnded within the limits of a sphere, or oblong, of very firm consistence. aud. when measuref, give dimensions varying in length from 1400 to $1-900$, and in breadth from 1-200 to 1-500 part of an inch.t The constituent parts of suet, according to Chevreul, are carbon $78 \cdot 996$, hydrogen $11 \cdot 700$, and oxygen $9 \cdot 304 . \neq$

(1195.) Fat is very generally distributed in the animal frame. It is "abundant under the skin, in what is called the cellular membrane, round the kidners, in the folds of the omentum, at the base of the heart, in the mediastinum, the mesenteric web, as well as upon the surface of the intestines, and among many of the muscles. It varies in consistence, color and smell, according to the animal from which it is obtained. Thus. it is generally flaid in the cetaceous tribes, soft and rank-flavored in the carnivorous, solid and nearly scentless in the ruminants; usually white and copious in well.fed young animals, yellowish and more scanty in the old. Its consistence varies also according to the organ of its production, being firmer under the skin and in the neighborhood of the kidneys than among the movable viscera. Fat forms 1-20 of the weight of a healthy ani$\mathrm{mal}$; but as taken out by the butcher it is not pure, for, being of a vesicular structure, it is always inclosed in membranes, mixed with blood, blood-vessels. lymphatics, \&c."

(1196.) Sheep is one of the most useful, and therefore one of the most valuable, of onr domestic animals; it not only supports our life by its nutritious llesh, but clothes our bodies with its comfortable wool. All writers on diet have agreed in describing mutton as the most valuable of the articles of human fond. "Pork may be more stimulating, beef perhaps more uatritious, when the digestive powers are strong; but, while there is in mutton sufficient nutriment, there is also that degree of consistency and readiness of assimilation which renders it most congenial to the human stomach, most easy of digestion, and most contributable to health. . . . . Of it, almost alone, can it be said that it is our food in sickness as well as in health; its broth is the first thing that an invalid is permitted to taste, the first thilig that he relishes, and is his natural preparation for a return to his common aliment. In the same circumstances, it appears that fresh mutton, broiled or boiled, takes 3 hours to digest; fresh mutton, roasted, $3 \frac{1}{4}$ hours; and mutton-suet, boiled, $4 \frac{1}{2}$ hours.

(1197.) But the products of sheep are not merely useful to man, they also promote his luxuries. The skin of sheep is made into leather, and. when so manufactured with the fleece on, makes comfortable mats for the duors of our rooms, and rings for our carriages. For this purpose the best skins are selected, and sucls as are covered with the longest and most beatiful Heece. Tanned sheep-skin is used in coarse book-binding. White sheep-shin, which is not tanned, but so manufactured by a peculiar process. is used as aprous by many classes of artisans, and, in Agriculture, as gloves in harvest: and, when cut into strips, as twine for sewing together the leathern coverings and stuffings of borse-collars. Morocco leather is made of sheep skins as well as of goats, and the bright-red color is given to it by cochineal. Russia leather is also made of sheep-skins, the peculiar odor of which repels insects from its vicinity, and resists the mould arising from dampthe odor being imparted to it in currying, by the empyrenmatic oil of the bark of the birch tree. Besides soft leather, sheep-skins are made into a fint, flexible. thin substance, known by the name of parchment; and, though the skins of all animals might be converted into writing materials, only those of the sheep and she-goat are nsed for parchment. The finer quality of the substance called vellum is made of the skins of kids and dead-born lambs, and for the manufacture of which the town of Strasburgh has long been celebrater.

(1198.) Mutton-suet is used in the manufacture of common candles, with a proportion of ox-tallow. Minced suet, subjected to the action of high-pressure steam in a digester at $250^{\circ}$ or $260^{\circ}$ Fahr., becomes so hard as to be sonorous when struck, whiter, anil capable, when made into candles. of giving very superior light. Stearic candles, the late invention of the celebrated Guy-Lussac, are manufactured solely from mutton suet.

(1199.) Besides the fat, the intestines of sheep are manufactured into various articles of luxury and utility, which pass under the absurd name of catgut. "All the intestines of sheep," says Mr. Youat, "are composed of 4 coats or layers, as in the horse and cattle. The outer or periloneal one is formed of that membrane by which every portion of the belly and its contents is invested, and confined in its natural and proper situation. It is bighly smooth and polished, and it secretes a watery fluid which contributes to preserve that smoothness, and to prevent all friction and concussion during the different motions of the animals. The second is the muscular cont, by means

* Ure's Dictionary of the Arts, art. Fat.

I Liebig's Animal Chemistry.

+ Raspail's Organic Chemistry.

Edinburgh Encyclopzedia, art. Aliments, as quoted by Youatt on Sheep.

Combe on Digestion and Dietetics.

(973) 
of which the contents of the intestines are gradually propelled from the stomach to the rectum. thence to be expelled when all the useful nutriment is extracted. The muscles, as in all the other intestines, are disposed in two layers, the fibres of the outer coat taking a longitudinal direction, and the inner layer being circular; an arrangement different from that of the muscles of the areo. phagus, and in both beautifully adapted to the respective functions of the tube. The submucous coat comes next. It is composed of numerous glands, surrounded by cellular tissue, and by which the inner coat is lubricated, so that there may be no obstruction to the passage of the food. The mucoss coat is the eoft villous one lining the intestinal cavity. In its healchy state, it is always covered with mucus; and when the glands beneath are stimulated-as under the action of phis, - the quantity of mucus is increased; it becomes of a more watery character; the contents of ilie intestines are softened and diseolved by it; and by means of the increased action of the muscular coat, which, as well as the mucous one, feels the stimulus of the physic, the freces are hurried on more rapidly and discharged." " In the manufacture of some sorts of cords from the intestines of sheep, the outer peritoneal coat is taken off and manufactured into a thread to sew intestines, and make the cords of rackets and battledores. Future washings cleanse the guts, which are then twisted into different-sized cords for various purposes. Some of the best knowu of those purposes are whip-cords, hatters' cords for bow-strings, clock-makers' cord, bands for spinniug-wheels (which have now almost become obsolete), and fiddle and harp strings. Of this last class of cords - the source of one of our highest pleasures - it has long been subject of regret that those manufactured in England should be so inferior in goodness and strenglh to those of Italy; and the rea. son assigned is that the sheep of Italy are both smaller and leaner than those of this country:The difficulty lies, it seems, in making the treble strings from the fine peritoneal coat, their chief fault being weakness, whence the smaller ones are hardly able to bear the stretch required for the higher notes in concert-pitch-maintaining, at the same time, in their form and constraction, that teuuity or smallness of diameter which is required to produce a brilliant and clear tone. $\dagger$ However contemptible this subject may appear in the estination of some, it is worth attending to by those interested in enhancing the profits of our native products, and more especially when it is considered that harp-strings sell as high as from $6 \mathrm{~d}$. to 28 . apiece.

(1200.) While adverting to the uses of the skin of the sheep, it may be useful to give an idea of its physical structure, a knowledge of which being requisite for an acquaintance of the ration. ale of its diseases. "It is composed of 3 textures. Externally is the cuticle or scarf-skin, which is thin, tough. devoid of feeling, and pierced by innumerable minute holes, through which pass the fibres of the wool and the insensible perspiration. It seems to be of a scaly texture; but this is not so evident in the sheep as in many other animals, on account of a peculiar substance, the yolk, which is placed on it to nourish and protect the roots of the wool. It is, however, plainly enough to be seen in the scab and other cutaneous eruptions to which the sheep is liable. Below this is the rete mucosum, a soft structare, its fibres having scarcely more consistence than mucilagre, and being with great difficulty separated from the skin beneath. This seems to be placed as a defence to the termination of the blood-vessels and nerves of the skin, and these are in a manper enveloped and covered by it. The color of the skin. and probably that of the hair or wool also, is determined by the rete $m$ ucosum, or at least the hair and wool are of the same color as this substance. Beneath is the culis or true skin, composed of innumerable minute fibres crossing each other in every direction-highly elastic, in order to fit closely to the parts beneach, and to yield to the various motions of the body; and dense and frm in its structure, that it may resist external injury. Blood-vessels and nerves, coontless in number, pierce it, and appear on its surface under the form of papilla, or minute eminences; while, throngh thousands of orifices, the exhalant ab. sorbents pour out the superfiuous or redundant fluid. The true skin is composed principally or almost entirely of gelatine; so that, although it may be dissolved by long continued boiling, it is insoluble in water at the common temperature. This organization seems to have been given to it not only for the sake of its preservation, while on the living animal, but that it may become afterward useful to man." It would appear that there are circumstances which materially limit the action of the power of excretion and absorption in the skin of the sheep. It is surrounded by a peculiar secretion, adhesive and impenetrable to moisture, the yolk, destined chiefly to preserve the wool in a soft, pliable and healthy state. On this account there can be little perspiration go. ing forward from the skin, and hence few diseases are referable to change in that excretion. Also, there is little radiation of animal heat. both on account of the interposition of the yolk, and of the non-conducting power of the wool. The caloric disengaged from a sheep is only 1-7 part of that from man, though the weight of the animal is $\frac{1}{3}$ of that of man-that is, only half the animal heat radiates irom a sheep, from a given surface, that does from a man. This it is which enables the ewe and its lamb to endure the colds of spring without detriment; and also. when sheep are crowded together in an open fold, no unnatural or dangerous state of heat is thereby produced.\$

* Youatt on Sheep.

1 Ure's Dictionary of the Arts, art. Calgut; also, Lcather, Parchmene.

\$ouatt on Sheep. 


\title{
32. REARING AND FEEDING CATTLE ON TURNIPS IN WINTER.
}

\author{
"The cattle from th' untasted fields return, \\ And ask, with meaning low, their wonted stalls, \\ Or ruminate in the contiguous shade."
}

Thomson.

(1201.) The first thing to be done with the courts in the steading, before being taken possession of by the cattle, is to have them littered plentifully with straw. The first littering should be abundant, as a thin layer of straw upon the bare ground makes an uncomfortable bed; whereas a thick one is not only comfortable in itself, but the lower part of it acts as a drainer to the heap of manure above it. There is more of comfort for cattle involved in this little affair than most farmers seem to be aware of ; for it is obvious that the first layer of litter, when thin, will soon get trampled down, and in rainy weather soon become poached-that is, saturated with wet and pierced with holes by the cattle's feet-so that any small quantity of litter that is afterward laid upon it will but absorb the moisture below it, and never afford a $d r y$ lair to the cattle. On the other hand, when the first layer is thick, it is not poached even in wet weather, because it is with difficulty pierced through by feet, and it instantly drains the moisture that falls upon it, and of course keeps the bedding comparatively dry.

(1202.) There is, however, sometimes a difficulty of obtaining sufficient straw at this season, from various causes, among which may be mentioned a dislike in farmers to thresh a stack or two of the new crop at so early a period, even when there is no old straw or old stack of corn to thresh; but however recently formed the stacks may be, and inconvenient to thresh their produce at the time, it should be done rather than stint the cattle of bedding; and should bad weather immediately set in-an event not unlikely to happen-the cattle may be so chilled in their ill-littered quarters as not entirely to recover from it during the winter; and hence may arise a serious reduction of profit.

(1203.) It may happen, on the other hand, with plenty of old stacks, there may be want of water to drive the threshing-machine; and this is no uncommon predicament at the commencement of winter on many farms which depend upon surface-water for their supply; and a windmill is in no better plight in want of wind. Where such contingencies may happen, a sufficient quantity of litter should be provided for in good time, and there are various ways of doing this. Those who still use the flail may employ it at any season; and those having horse threshing-mills are equally independent. Access to bog-land gives the command of making coarse herbage into hay during summer; but in regard to the use of other products of bog-land for litter, precaution is requisite, for the turfy matter on the top on being used as a bottoming for courts, with the view of sorbing their moisture, will inevitably become as a sponge of water a the first fall of rain, and the cattle will soon render the whole beddir poached mass. I once tried the experiment under the most favorable cumstances of getting the turf well dried, and yet could not get rid of inconvenience of poaching until the courts were entirely cleared of $t]$ contents. Those who are annoyed with ferns in their pastures should them down and won them for litter, and a most excellent foundation $t$ 
make for straw. Those who can cut grass, or gather dry leaves in woods, should do so in summer, or immediately after harvest, for a day or two, with the harvest people. By attending to one or all of these provident measures, a comfortable bed may be provided for cattle at the commencement of the season, under the most unfavorable circumstances in regard to a con mand of straw.

(1204.) Suppose, then, that all the courts and hammels are plentifully littered for the reception of the cattle, the next step is to arrange the different classes of cattle in their respective places. The different classes of cattle are cows, calves of the year, 1-year-olds, 2-year-olds, bulls, heifers in calf, and any extra cattle.

(1205.) Cows occupy the byre Q, fig. 3, Plate III. (42.) Each should always occupy the stall she has been accustomed 20 , and all will then go and come into their stalls without interfering with one another. They- thus learn to become very quiet in the stall, both to the cattle-man who feeds them, and the dairy-maid who milks them. Each stall should have a manger $c$, fig. 10 (47), elevated 20 inches above the floor. lined with wood or stone, and having an edging of plank 8 inches in depth, to keep in the food. The usual plan is to place the mangers of byres on a level with the floor, down to which the cow has to stretch her neck to get to the turnip, or other food, and in doing this she is obliged to support herself almost wholly on one leg. This awkwardness of position is itself a certain proof that the animal is ill at ease while eating. There should be as much room behind the manger to the gutter as to allow the cow to lie at ease, whatever be her size, like a horse in a stall with a low hay-rack. Each stall should have a travis-board to separate it from the next (149). Some people are great advocates for double stalls, both in byres and stables, to hold a pair of animals each. In a byre, that plan is objectionable for several reasons; a cow is a capricious creature, and not always friendly to her neighbor, and one of them, in that case, must be bound to the stake on the same side as she is milked from; to avoid which inconvenience to the dairy-maid, the cow must be put aside nearer her neighbor in the same stall, which may prove unpleasant to both parties, or her neighbor in the adjoining stall be put aside nearer her neighbor, which may prove equally inconvenient. Neither is it a matter of indifference to the cow from which sicle she is milked, for many will not let down their milk if the milk-maid sits down to the unaccustomed side. The safest plan, therefore, in every respect, is for each cow to have her own stall. The floor of the stall should be causewayed only as far as shown at $m$, fig. 10 , and the remainder at $f$ should be of beaten earth, and this plan is intended to save the foreknees of cows from injury. Cattle lie down and rise up by resting on the fore-knees, and when they have to do so on a hard pavement, injury will likely arise to the knees, if the pavement is not always covered with litter. I remember seeing a valuable Short-Horn cow, in Ireland, get injured in the knees from this cause; they swelled so much and continued so long in a tender state that she would not lie down at all; and all the while her owner was not aware of the cause until I suggested it. On the removal of the pavement, and proper treatment of the parts affected, they recovered. Cows are bound to the stake $h$, fig. 10 , either by seal $c d$, fig. 11, or taikie, e $k g$, fig. 12, and either secures the animal sufficiently. The seal is made entirely of iron chain, and slides up and down the inclined stake $h$ by means of the iron ring $d$; the baikie is made partly of wood $e$, and partly of rope $k$ and $g$. Of the two modes of ligature 1 prefer the seal, because its construction permits the animal turning its head so much round as to be able to lick herself as far as the loin, whereas the baikie only admits of (y:6) 
a constrained up and down motion along a perpendicular stake (48); and, besides, it is an impracticable mode of binding in connection with the use of a manger, hecause it prevents the animal stepping back to avoid it.

(1206.) Calves of the year should occupy court K, fig. 3, Plate III. (62.) In such receptacles they are put together male and female, strong and weak, but having plenty of trough room around two of the walls, they can all be amply provided with food at the same time, without the danger of the stronger buffeting about the weaker. The openings into the shed in which they take up their abode at night is at $D$, and in the center of the court stands the straw-rack $o$, formed like fig. 19 where straw is scarce, as on gravelly soils, or like figs. 20 and 21 where it is plenty. The troughs for the turnips are fitted up as in fig. 18, which is there represented as a short one, to show the finishings of the ends, but which, of course, may be extended to any length, as may be seen by $z$ in $K$, fig. 4, Plate IV. There is a water-trough $w$ in the same court, it being essential for young stock to have water at will, and especially when they do not get as many turnips as they can eat. When they do, cattle do not feel the want of water, the juice of the turnip supplying them with sufficient liquid. In the same Plate IV. may be seen the shed D, under the granary, connected with the court $K$, having a straw-rack $h^{\prime}$ fitted up at one end. The turnip-store for this court is at $g$; and $x$ is the mouth of the liquid-manure drain, to carry off any superfluous water. In the calves of the year occupying this court $\mathrm{K}$, where there is a good deal of traffic in going to and from the corn-barn $\mathrm{C}$, the young creatures will become familiarized with the people, and have a chance of getting pickings of corn from the barn.

(1207.) The court I is fitted up precisely with the same conveniences of feeding-troughs $z$, water-trough $w$, straw-racks $h^{\prime}$ and $o$, and turnip-store $i$, as the other court for the 1-year-olds. It will be observed that the shed $D$, in both courts, has two entrances, which is the usual plan; but, in my opinion, the comfort of the cattle is more secured with only one entrance, inasmuch as all draft is prevented; and although the object of two entrances is a laudable one in affording a means of escape to a beast that may be ill-used by the rest, that advantage to one is dearly bought at the sacrifice of comfort to the others, and after all it is doubtful whether the contingency can be avoided in this way.

(1208.) As I have said before (62), I prefer hammels to large courts, for young beasts; because the heifers could be separated from the steers, and each of the classes subdivided to suit color, strength, age, temper, or any other point in which a few agree, and differ from the rest; and it is surprising how much better the same beasts look when assorted. In a large court, all are put together, and, if there be plenty of room for every one to do as it likes, no harm may accrue; but where too many are crowded together, which is almost always the case on farms where winterings are bnught, some will be knocked about and kept back from their meat, and obliged to eat it at untimeous hours; and in either plight will be stinted in their growth and condition. Only one beast so used makes a serious drawback on the value of the lot, for it must be drafted from the rest and sold separately, at a reduced price, to the vexation of the owner, wh $\neq n$ too late to retrieve the loss. Now, no such nccurrence can take place in hammels, where every difference in character, age, and strength of animals, can be nicely assorted; and this is the more requisite in beasts that have been brught in to be fed, than those brought up together at home.

(1209.) The 2-year-olds, intended to be fattened for the butcher, occupy the hammels $\mathbf{M}$, where are inner sheds at $\mathbf{M}$, feeding-troughs $z$, liquidmanure drains $x$, in the courts, and where fodder is supplied in the inside 
of the sheds, in racks, in three of the corners, and the turnip-stores of which are at $e$ and $f$. The sheds heing 14 feet wide and 18 feet long, and the courts 30 feet long by 18 feet in width, each hammel will accommodate 4 steers, not merely at the beginning of the feeding season, but at its end, when they shall have attained the weight of at least 70 stones each imperial.

(1210.) Occasionally the cow stock requires to be renewed, one or two at time, by young heifers; and as these, when in calf, should not of course be fattened, they not be put in the hammels of the feeding-stock of their own age, namely, the 2-year-olds, but have hammels to themselves at $\mathbf{N}$, which are fitted up in precisely the same manner as at $M$, with feedingtroughs $z$, straw-racks in the conner of the sheds, liquid-manure drains $x$, and turnip-stores $p$ and $q$. Their size, inside the shed, is 17 feet long by 14 feet wide, and the court 20 feet long by 17 feet wide, so that each can accommodate 3 heifers in calf. The old cous which these heifers are intended to supersede have to be fattened, and they can be accommodated with one of the hammels at $\mathrm{N}$.

(1211.) The servants' covs are accommodated in the byre $\mathrm{I}$, fitted up in the same manner as the other byre $Q$, having an outer court $\imath$, water-truugh $w$, liquid-manure drain $x$, and turnip-store $h$.

(1212.) When oxen are fattened in byres instead of hammels, they are accommodated in the same manner as the cows are in either $Q$ or $Y$; but instead of each having a stall, they are usually bound up in pairs in double stalls, with a partition in the turnip-trough, placed on the ground, and a travis between every pair. Stalls of this construction are often as narrow as 7 feet, but 8 feet is the more common width. I have already condemned the crowded state in which oxen, fed in byres, are usually placed (49), and shall not again advert to the subject here. When cattle are bound to the stake for the first time, for the season, they are apt to be restless until reconciled to their confinement, which they will be ere long, if provided with plenty of food.

(1213.) Bulls occupy the hammels $\mathbf{X}$, which are fitted up with feeding-troughs $z$, water-troughs $u$, liquid-manure drains $x$, and racks in the comers of the sheds X. More than one bull-calf may be put together; but more than one bull that have served cows are never intrusted together.

(1214.) Having thus accommodated all the cattle, according to their kinds and ages, in their respective places in the oteading, for the winter, let us now attend to the treatment which each class should daily receive during their confinement.

(1215.) And to begin with the cou's. The first piece of wrik connected with the treatment of cows in winter, is to milk them at day-lreak, which camnot he at a very early hour this season. On farms on which cows are bred, they are heavy in calf in winter; so most of them will be dry, and those still yielding milk, being the latest to calve, will give but a scanty supply. It is, therefore, not as milch-cows they are treated at this season. After milking is finished by the dairy-maid, the usual practice is to give the cows, thongh heavy in calf, a feed of cold turnips, on an empty stomach, which I have always considered an injudicious practice; and its injudiciousness is evinced ly the fact of the fotus showing unequivocal symptoms of its existence in the womb, in the same manner as after a drink of cold water in the morning. I would, therefore, give them a mouthfull of fresh oat-straw, to prepare the stomach for the turnips. While amusing themselves with this fudder, the cattle-man, whose duty it is to take charge of all the cattle in the steading in winter, cleans out the (978) 
byre of its litter and dung with the graip, fig. 257, and shovel (fig. 149), and wheelbarrow, and spreads it equally over the court, sweep the gutter and causeway clean with a birch or broom-besom. Having shut the byre-door and left the half-door into the court Fig. 257. open for fresh air, the cattle-man leaves the cows until he has supplied the fattening and young beasts with turnips, which having done, he returns to the cow-byre, bringing litter-straw with him, and gives them their allowance of turnips for the first meal. Cows in calf never get as many turnips as they can eat, the object beirg not to fatten, but support them in a fair condition for calving; for were they fed fat, they would run the risk of life at calving through inflammation, and the calves would be small. It is not easy to specify the number or weight of turnips that should be given to cows; but I conceive that $\frac{1}{3}$ of what a feeding ox would consume will suffice.

(1216.) There are three ways of supplying cows with turnips, either through the openings of the wall at their heads, as at 0 , fig. 10, and through the door, fig. 9 , from the store in the shed $s$, into the trough $c$; or with basketfulls, carried by the stall; or with barrow-loads, wheeled along a passage at their head, as described in (45), and emptied into the same trough $c$ from the same store $s$, as seen in plan at $m$, fig. 4 , Plate IV., by the back-door into the byre.

(1217.) With the willow-basket or skull, is the most common way of serving cows or cattle in byres with turnips. It is about 2 feet in diameter, with holes wrought into each side, under the rim, for handles, and costs about 1s. $6 \mathrm{~d}$.; but they THE GRAIP. are apt to become rotten or broken after the natural sap is dried out of the willows, which is generally in a few months' time, and then they become very brittle. In short, a skull seldom lasts more than a year or two; and as a number of them are required about a steading where a variety of beasts are fed on turnips, their cost, though individually trifling, becomes in the aggregate so considerable as to make its avoidance desirable. A basket of wire or small iron rods has been substituted in some places. A wire basket is represented by fig. 258, where the rim $a b$ $c$, which forms its mouth, is a flat slip of iron about $\frac{3}{4}$ of an inch in breadth, and the keel or bottom $a d c$ is of the same dimensions and materials. Holes are punched through them, at about 3 inches apart from each other. The small iron rods are inserted through them, receiving a bend to suit the form of the basket, and the ends of those attached to the rim $a b c$ are shouldered below, and made fast with a counter-sink rivet above. The spaces left at the ends of the keel, under the rim, at $a$ and $c$, form the handles. The cost is about $2 \mathrm{~s}$. $6 \mathrm{~d}$. each, and with due care-such as the replacement of a rod now and then, when broken-will last from 5

Fig. 258.

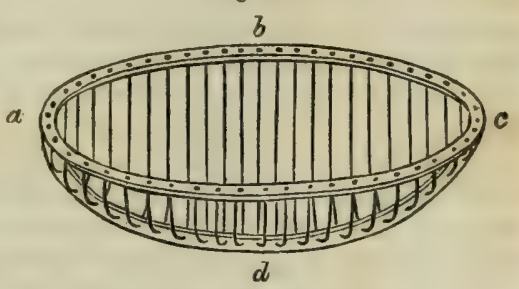

THE WIRE TURNIP-BASKET. to 10 years. Were the keel made straight at $d$, the basket would stand steadier to be filled.*

(1218.) Before the turnips are put into the troughs, the remains of the * Quarterly Jouraal of Agriculture, vol. xi.
(979) 
fodder given in the morning should be strewed down for litter, and the troughs cleaned out. The turnips should always be put into the troughs in a regular order, heginning at the same end of the byre, and finishing at the other, and after the turnips have been given, the cows should be permitted to eat them in quiet, for nothing irritates animals more than to be handled and worked about when feeding. The turnips consumed, and the stalls comfortably littered with straw, the cows will lie down and chew the cud until mid-day, when they should be turned into the court to enjoy the fresh air, lick themselves and one another, drink water from the trough, and bask in the sun. They should go out a while every day, in all weathers, until they calve, except perhaps in a very cold, wet day. One hour may be long enough at a time. In loosening cows from their stalls, a plan requires to be pursued to prevent confusion. In the first place, every cow, in the beginning of the season, should be put in the stall she has occupied since she first became an inmate of the byre; and she will always go to $i$, and no other, avoiding the least collision with the rest. In loosening them from the stalls, they should be so one by one, always beginning at the same end of the byre, and finishing at the other, and not indiscriminately. This will prevent collision on the floor and jamming in the drorway on going out-accidents injurious to animals with young. After their return, they should also be bound in the same regular order from one end of the byre to the other, and this will prevent any one being forgotten to be bound, and to remove every temptation from even a greedy cow running up into another one's stall for the sake of snatching a little of her fond, no food should be lying in the troughs when they return to their stalls; and no food that they like-such as turnips, mangel-wurzel, and the like-should be given them immediately on returning to the byre, because the expectation of receiving it will not only render them impatient to leave the court, but make them restless in the stall until they receive it. This plan, contrary to usual practice, will, it is obvious, suppress all anxiety, and thereby prevent violation of discipline, and, of course, necessity for correction. When subjected to this regular form of discipline, they will soon obey it, and make no confusion, but conduct themselves peaceably. On their return to the byre, let a little fodder be given; and after a lapse of time, say at 3 P. M., give them their evening meal of turnips, after which they should be littered for the night.

(1219.) The treatment of oxen in a byre is different from that of cows; they get as many turnips as they can eat, and are not permitted to leave their stalls until sold off fat. As it is not usual for oxen to be fed in byres and hammels on the same farm, what I have to say in regard to feeding in the byre should be considered in lieu of the plan of what I shall have to say on feeding them in hammels. After the cow-byre doors have been openerl, and the stalls cleared into the gutter of any dung that might annoy the dairy-maid, the cattle-man goes to the feeding-hyre, and, first removing any fodder that may have been left from the previous night, and any refuse of turnips or other dirt, from the troughs, gives the cattle a feed of turnips at once. The quantity to be given at this time should be $\frac{1}{3}$ of what they can eat during the day; for they should be fed 3 times a day-in the morning, at noon, and at sunset; and in distributing the food, the same regularity should be observed as in the case of the cows, that is, the same ox should always be the first supplied, and the same ox the last to receive his portion. When cattle find their food given them in regular order, they never become impatient for their turn. It is a good plan to begin serving at the farthest end of the byre, because then the cattle-man has no occasion to pass and disturb those which have been served; and in the case ‘980) 
of what is called a double-headed byre, in which cattle stand on both sides, tail to tail, both sides should be served simultaneously by alternate beasts, thus still leaving those which have been served undisturbed. With the balf-door left open for the admission of fresh air, and the expulsion of heated air through the ventilators (fig. 8), the cattle-man leaves them to enjoy their meal in quietness.

(1220.) Much has been said on the expediency of wisping and currying cows and fattening-beasts in the byre; and no doubt many satisfactory reasons could be urged in favor of the practice, when they are entirely confined. But, as it occurs to me, animals that are allowed to be at liberty at one part of the day do not require-or at least to a much smaller degree-any artificial dressing, inasmuch as they can dress their own skin, when at liberty, much better than any cattle-man. Nevertheless, where cattle are constantly confined in the byre, as is the case of all beasts fattened in a byre, it seems indispensable for their good health to rub their skin every day by some process; and I believe there are no better instruments for the purpose than a simple curry-comb and a wisp of straw. In performing this operation, however, it should only be done when the cattle are not at food; and you should see to this, for there is a strong propensity in people who have charge of animals to dress and fondle with them when at food; from no desire, I am sure, of tormenting them, but the contrary. Still it is a habit which has a tendency to irritate all animals unnecessarily, and should be prevented; for any one may soon satisfy himself, from observation, that an animal is never more jealous of being approached than when eating his food-as witness the grumble from a dog or the scowl from a horse.

(1221.) Whenever the cattle have eaten their turnips the byre should be completely cleared of the dung and dirty litter with the graip, shovel, besom and barrow belonging to the byre. A fresh foddering and a fresh littering being given, they should be left to themselves to rest and chew the cud, until the next time of feeding, which should be about mid-day, when another $\frac{1}{3}$ of turnips is given to each ox ; after finishing which more fodder should be supplied, and what dung may prove annoying, drawn into the gutter. In the afternoon, before daylight goes, the dung should again be cleared out, and the last supply of turnips for the day, another $\frac{1}{3}$, given to each ox ; and before leaving them for the night, and after the turnips are eaten up, a fresh foddering should be given, and the litter shaken up and augmented where requisite. After eating a little fodder the cattle lie down and rest until visited at night.

(1222.) Where cattle are fattened in hammels, a somewhat different procedure is adopted. While the dairy-maid is milking the cows in the byre, the cattle-man cleans the troughs of the hammels with an old shovel, and gives the first supply of turnips for the day to the cattle; and in doing this he should adopt the same rule as to regularity as with the cows in the byre, always beginning with the same hammel

(1223.) It is now well understood that sliced turnips afford great facilities to cattle in filling their stomachs with food with the least trouble; and the instruments used for this purpose are much simpler than those which have been described for sheep in (1138) and (1145). Not an uncommon instrument for the purpose is an old sharp spade, with which turnips are broken in as many pieces as desired; but it is objectionable, in as far as it breaks them into unequal pieces, the round turnips rolling away from its strokes, and it scatters the hard ones in splinters. Much better instruments will be found in the two hand turnip-choppers described below, figs. 263 and 264. A single perpendicular stroke with either of these instruments 
cuts a turnip into a certain number of pieces ; but in using fig. 263 a little dexterity is required to save its cutting edges from being injured against the bottom of the trough. The dexterity consists in first getting a hold of the turnip with the instrument by a gentle tap, and then lift up the turnip, striking it against the bottom of the trough with a smart stroke, when it will fall into pieces before the knives touch the trough; but the constant exercise of dexterity is scarcely to be looked for in an ordinary cattleman, and, therefore, fig. 264 may be pronounced the more useful instrument of the two, for the studs serve to guard the cutting surface from injury. But where a cattle-man has charge of a large number of cattle receiving cut turnips, a more expeditious process of slicing them is required, and this will be obtained by the use of the lever turnip-slicer, described below in fig. 259. This machine is placed beside the turnip-store, where it slices the turnips into the skull placed under it, and, being light, can easily be carried from store to store, unless where the distance is great, when another machine shonld be provided. It will be observed that all these im. plements cut turnips into large pieces, which are sufficiently small for cattle, sheep requiring theirs cut into long narrow slips, to suit the form of their mouth.

(1224.) Cattle naturally feeling more appetized in the morning than during the day, their morning meal should be large, and while employed at it the cattle-man should furnish their racks with fresh oat-straw, to which they will repair from the tumips, and lie down in the open court or within the shed, according to the state of the weather, and chew their cud with composure. At mid-day their troughs should again be replenished with turnips, and again before daylight is gone. The quantity given at the evening meal partly depends upon the state of the moon; for cattle, as well as sheep, will always feed during the night in moonlight, a habit which I have frequently observed in both animals; and from this fact $I$ conclude that if light were placed beside cattle in the byre, they would also feed during the long winter nights, and, of course, fatten quicker.* The last foddering of straw is given after the evening meal of turuips; and, during the day, whenever the shed or court requires litter, the refuse straw of the foddering may be spread abroad, and in rainy weather it should be brought direct from the straw-barn.

(1225.) The younger cattle in the courts next receive their turnips, and of these the calves should have the precedence, as they take longer time to finish their meal than their older compeers. They occupying the court $\mathrm{K}$, fig. 4, Plate $\mathrm{IV}$., the turnips are wheeled from the store $g$ to the troughs, and there broken with one of the hand turnip-choppers, fig. 263 or 264 , or sliced in the store with the lever-slicer, fig. 259. Their fodder is put hoth in the open straw-rack 0 and that under the shed at $l^{\prime}$, and their litter strewed after the young beasts in the other large court have been served with turnips.

(1226.) Immediately after the calves, the year-olds in the court I are served with turnips, fodder and litter, in the same order. All young beasts should get as many turnips as they can eat; but should the crop prove insufficient for this, let the calves have their full share, and the yearolds rather put on short allowance; but in a case of this kind occurring, the most prudent plan, perhaps, would be to purchase oil-cake for the fattening beasts, to be given along with some turnips, and let all the young

- That highly-prized hind in France, the ortolan, feeds at dawn, and when confined for the purpose of being fattened, an artificial dawn is produced every three hours during the night by artificial light $w$ hen it eats its food, and thereby becomes much sooner fat.

(982) 
beasts have their full share of turnips. To insure them still farther with this, the cows might also have oil-cake.

(1227.) The young heifers in the hammels $\mathrm{N}$, and the bulls in the hammels $X$, next receive their turnips, and as neither of them get as many as they can eat, their proportion is divided into two small meals, one served after all the rest in the morning, and the other before the rest in the evening. Both these classes depending much upon fodder for food, it should be of the sweetest and freshest straw, and supplied at least 3 times a day, morning, noon and evening; and having water at command, and liberty to move about, they will maintain a fair condition. The heifers are supplied from their own turnip-stores $p$ or $q$, and the bulls from that belonging to the servants' cow-byre $h$.

(1228.) With regard to the supply of turnips to the servants' cows, much depends on the terms of the agreement made with the servants. Where a specified number of cart-loads are given, the servant may choose to give them to his cow during the earlier part of the winter or not, because, when she is dry, it is not usual to give her turnips; but if in milk, the servant's family may give what they choose from their own store. On the other hand, if the farmer has agreed to treat the servants' cows in the same manner as his own, then the cattle-man takes charge of them in the manner I have already described (1215).

(1229.) From the beginning of the season until the end of the year, white turnips alone are used, after which, to the end of the winter season, the yellows are brought into requisition, or Swedes where these are not cultivated. When turnips are brought from the field in a very dirty state, which will inevitably be the case in wet weather from clayey soil, they ought to be washed in tubs of water, and when they are so as long as the earth is fresh, they will be the more easily cleansed; and this is not so troublesome and expensive a business as may at first sight appear. A large tub of water, placed at a store when about to be filled with turnips, a field-worker, taking a small fork, picks up a turnip with it, and dashing it about in the water for an instant, pulls it off against the edge of the store or barrow; and in this way cleanses a great number in a short time, much faster than the cattle-man can wheel them away and serve and break them to the beasts. A friend of mine used a very curious mode to wash turnips. Whenever any of the fields of his farm, along which was the lead that conducted the water from the dam to the threshing-mill, were in turnips, he filled the lead pretty full of water, by keeping down the sluice at the mill. He then topped and tailed the turnips in the field, and emptied them into the lead, from a cart when the distance to the turnips was considerable, and from a hand-barrow, carried by field-workers, when they were near. The sluice at the mill was then opened a little, and the gentle current thereby created in the water floated the turnips to the steading, where they were taken out and carried to the stores in barrows. When the turnips were very dirty, they were washed in the lead by a person pushing them about with a pole. That some provision for cleaning turnips is sometimes necessary, is obvious to me, for I have seen very fine cattle getting turnips to eat in such a state that the dirt actually bedaubed them to the very eyes, the tops being left on to make the matter worse. Surely no one will say that filth, in any shape, is beneficial to cattle; not that they dislike to lick earth, but then they do so only when they feel they require it to rectify acidity in the stomach.

(1230.) When turnips have not been stored, and are brought from the field as required, it is highly probable that they will be in a frozen state at times, when, even if broken by the instruments in use, they will be (983) 
masticated by cattle with difficulty, besides the danger they run of being chilled by them; for cattle always have a staring coat after eating frozen turnips. This being the case, means should be taken to thaw them, and the most available is to put them in tubs of cold water for some hours before being given to the cattle. Such expedients, to avoid greater evils, of course always incur expense, and it will be much greater than the comparatively trifling one of storing the same quantity of turnips at the proper season, which, when done, every such petty source of vexation will be removed.

(1231.) It is supposed that a fattening ox, which will attain 70 stones imperial at the end of the season, consumes on an average, during the season, a double horse load of turnips per week, and, as carts are usually loaded in field work in winter, their weight may be estimated at about 12 cwt.; so each ox will consume about $1 \frac{3}{4} \mathrm{cwt}$. or 14 stones a day, or $4 \frac{2}{3}$ stones of each 3 meals, and ahout 16 tons during the season of 26 weeks. The calves may consume $\frac{1}{2}$ or 7 stones, and the 2-year-olds $\frac{3}{4}$, or $10 \frac{1}{2}$ stones a day. 'These comparative statements are given from no authenticated data, for I suppose that no comparative trials with different ages of cattle have ever been made, but only from what I imagine to be near the truth; and some such estimate, at the beginning of the season, is useful to be made, that you may know whether your turnips will answer the stock. It has been correctly ascertained, however, by Mr. Stephenson, Whitelaw, East Lothian, in a careful experiment of 17 weeks, that an ox, yielding under 30 stones of beef, consumes $1 \mathrm{cwt}$, or 8 stones every day;" and if cattle consume food somewhat in proportion to their live weight, in similar circumstances, as is believed, the above ratios may be pretty correct. And yet Mr. Boswell of Kingcausie's four 2-year-olds, fed entirely on turnips, and which increased in live weight, in four months, from 40 to $45 \mathrm{cwt}$., only consumed a little more than 27 tons of yellow bullock turnips, or $8 \frac{1}{2}$ stones each day.t So that Mr. Boswell's cattle, of from 45 to 50 stones each, consumed only a very few more turnips than Mr. Stephenson's, of 28 stones each. Such discrepancies show how little we can yet anticipate when we undertake to fatten cattle. But there is this that may be said in explanation of this difference, which is, however, merely conjectural, that Mr. Stephenson's lightest lot experimented on may have been West Highlanders, Mr. Boswell's Aberdeenshires, and my supposition is made in reference to well-bred Short-Horns. It will be observed that cows receiving $\frac{1}{3}$ of oxen, narnely, $4 \frac{2}{3}$ stones a day, each skullful will contain rather more than $32 \mathrm{lb}$.

(1232.) The most personally laborious part of the duty of a cattle-man in winter is carrying straw in large bundles on his back to every part of the steading. A convenient means of carrying it is with a soft rope about the thickness of a finger, and 3 yards in length, furnished at one end with an iron ring through which the other end slips easily along until it is tight enough to retain the hundle, when a simple loop-knot keeps good what it has got. Provided with 3 or 4 such ropes, he can bundle the straw at his leisure in the harn, and have them ready to lift when required. The iron ring permits the rope to free itself readily from the straw when the bundle is loosened.

(1233.) The dress of a cattle-man is worth attending to, in regard to its appropriateness for his business. Having so much straw to carry on his back, a bonnet or low-crowned hat is most convenient for him; but what is of more importance, when he has charge of a bull, is to have the color

* Prize Essays of the Highland and Agricultural Society, $\nabla 31 . x i i$. (984)

+ Ibid, rol. xi. 
of his clothes of a sombre hue, free of all gaudy or strongly-contrasted colors, especially red, because that color from some cause is peculiarly offensive to bulls. It is with red cloth that the bulls in Spain are irritated at their celebrated bull-baits. Instances are in remembrance of bulls tuming upon their keepers, not perhaps because they were habited in red clothes, but probably because there was some red color about them, or that they contrasted strongly with what their keepers usually wore. It was stated at the time, that the keeper of the celebrated bull Sirius, belonging to the late Mr. Robertson of Ladykirk, had on a red night-cap when he was killed by him. One day, when walking with a lady across a field, for a short cut to a road, my own bull, the one represented in the plate of the Short-Horn bull, than which a more gentle and generous creature of his kind never existed, made toward us, and seemed unusually excited. This conduct did not arise from the circumstance of a stranger being in the field, for many strangers, both male and female, visited him in the field. I could ascribe his extraordinary excitement to no other cause than to the red shawl worn by the lady; for when she left the field he resumed his wonted quietness of conduct. I remember observing him more than usually excited, on another occasion, in his hammel, when his keeper, an aged man who had attended him for years, was beside him on a Sunday afternoon, I ascribed his excited state to the new red nightcap, instead of the usual black hat, which his keeper wore on the occasion; and on my desiring him to throw it away, the animal became again quite quiet. Be the rationale of the thing what it may, it is prudential in a cattle-man to be always habited in a sober suit of clothes.

(1234.) Regularity in regard to time is the chief secret in the successful treatment of cattle. Cattle, dumb creatures though they be, soon understand your plans in regard to what affects themselves, and there is none with which they reconcile themselves more quickly than regularity in the time of feeding; and none on the violation of which they will more readily show their discontent. No cattle-man can keep regular time without a watch; and if he has not one of his own, lend him one that will keep time well. His day's work in winter may be divided thus : Let him be astir and have his breakfast over by daybreak, which cannot he very early at that season. The first thing he should do is to go to the cow-byre, and remove with the graip. into the gutter, any dung that would immediately interfere with the dairy-maid in milking the cows. She should be at the byre in time for this purpose. Leaving her there, he goes to the fattening beasts in the hammels, and first cleans out the same trough, always beginning at the same end, of all refuse, with his shovel; and immediately as he cleans one trough he replenishes it with turnips from the store at hand, and breaks them with any of the instruments used. He thus proceeds from one hammel to another until the six are gone over, or as many as are occupied. It is not an easy matter to say exactly how long time this should take in doing, but say half an hour, 30 minutes. He then proceeds immediately to the calves in the large court, cleans out the dirt from the troughs, replenishes them with fresh turnips from the store, and breaks them; and he does this, having long troughs and fewer turnips, say in 15 minutes. He next goes to the 2-year-old court, and does the same in it; and, having a few more turnips to wheel out of the store and break, he will take a little more time, say 20 minutes. The bulls in the hammels may take 10 minutes to clean out their troughs and supply them with their small quantity of turnips. And the same time, 10 minutes, may suffice to give the heifers a little fresh fodder, for they should not get cold turnips on empty stomachs, more than cows; with another 10 minutes to supply(985) 
ing the old cows, or extra beasts, with turnips. Having thus given all the cattle that are at liberty something to do for some time, he returns to the cow-byre with a bundle of fodder of fresh oat-straw, which he distributes among the cows, and which they pick during the time he is clearing the byre of litter and dung; and to do all this may require 30 minutes. Shutting the principal door of the byre, and leaving the laalf-door to the court open for air, he leaves the cows with the fodder, and cleans out the servants' cow-byre, and folders the cows, which may take other 30 minutes. Taking then a bundle of litter, he goes again to the byre, and spreading any retuse fodder as litter, and cleaning out the troughs, he supplies the cows with their allowance of turnips, and shaking up the straw which he has just brought as litter, he leaves them again to eat and rest awhile. All this may require other 30 minutes; and 10 minutes may suffice to give the heifers their small quantity of turnips, and the old cows their fodder, and 10 minutes more to litter the servants' cows, the servants themselves having supplied the turnips as they choose. All the cattle having now been once fed, brings the time to 25 minutes past $10 \mathrm{~A}$. M., if the operations began at 7 o'clock. The next step to be taken is to supply those which get as many turnips as they can eat, with fodder and litter, and for this purpose he takes the fodder fiesh from the straw-barn, and fills all the straw-racks in the large courts, whether in the open air or under the shed. The old fodiler should be pulled out before the fresh is put in; but this is seldom attended to. He then strews the open courts and sheds with litter where it is chiefly required; namely, along the side of the troughs where the beasts stand to eat the turnips, and where they have lain under the sheds. The hammels are then supplied with fodder and litter, the refuse fodder probahly being sufficient for the latter purpose, as long as the weather is dry. The hulls and heifers should also have fodder and litter. All this business with the straw, and making it up into bundles for the afternoon, may take up 50 minutes, and bring the time to $\frac{1}{4}$ past $11 \mathrm{~A}$. M. What with cleaning out the troughs and supplying the hammels and courts again with turnips of the midlay meal, and letting out all the cows-including those of the servants-into their respective courts, 12 o'clock will have arrived, which is the hour of dinner for all the work-people. The people have an hour to themselves, to $1 \mathrm{P}$. M., to refresh and rest. At 1 P. M. the cattle-man resumes his labors by bunching up uindlings of straw, which are small bundles having a twisted form, of 10 lhs, weight or more each, for each of the cows' supper, and also larger bundles in the ropes for fodder. Having prepared these just now or at any other leisure moment, he takes a bundle of fodder to the byre, supplies the troughs. and brings the cows in from the court, and ties them to their stakes. He does the same with the servants' cows. He then replenishes the straw-racks in the courts and hammels with what little fodder is required. He then litters the sheds comfortably for the night. He lays the windlings of straw in a corner of the servants' cow-hyre for the night's suppering, and he does the same in the other byre; and the reason he does this in preference to letting them remain in the straw-barn is, to avoid the dauger of taking a light into the straw-barn when the windlings are to be used. By the time al: this business with the straw has heen done, it is time to give the cows their second meal of turnips, so that they may have them eaten up before the milk-maid comes again at dusk to milk them. The feeding beasts in the hammels are then supplied with turnips broken for them, then the calves, then the young beasts in the other court, and then the bulls and heifers, in the same order as formerly. He then litters the servants' cows for the night, by which time it will be time for the other cows (986) 
to be milked; immediately after which they are littered for the night, and the doors closed upon them, and thus the labors of the day are finished.

(1235.) In thus minutely detailing the duties of the cattle-man, my object has been to show you rather how the turnips and fodder should be distributed relatively than absolutely; but at whatever hour and minute the cattle-man finds, from experience, he can devate to each division of his work, you should see that he performs the same operation at the same hour and minute every day. By paying strict attention to time, the cattle will be ready for and expect their wonted meals at the appointed times, and will not complain until they arrive. Complaints from his stock should be distressing to a farmer's ears ; for, he may depend upon it, they will not complain until they feel hunger; and if allowed to hunger, they are not only losing condition, but rendering themselves, by discontent, less capable of acquiring it, even should their food happen to be regularly given them for the future. Whenever, therefore, you hear petitioning and impatient lowings from cattle at any steading, you may safely conclude that matters there, in so far as regards the cattle, at least, are conducted in a very irregular manner. The rule, then, simply is, Feed and fodder cattle at fixed times, and dispense their food and fodder in a fixed routine. I had a striking instance of the bad effects of irregular attention to cattle. An old staid laborer who was appointed to take charge of the cattle, was quite able and very willing to undertake the task. He was allowed to take his own way at first; for I had observed that many laboring men display great ingenuity in arranging their work. Lowings from the stock were heard in all quarters, both in and out of doors; and they intimated that my ancient cattle-man was not endowed with the organ of order, while I observed that the poor creature himself was constantly in a state of perspiration. To put an end to this disorderly state of things, I apportioned his whole day's work by his own watch; and on his implicitly following the plan, he was not only soon able to satisfy the wants of every creature committed to his charge, but had abundant leisure besides to lend a hand at anything else that required temporary assistance. His heart overflowed with gratitude when he found he could easily make all the objects of his charge happy; and his kindness to them all was so sincere, that they would have done whatever he liked. A man better suited for this occupation I never saw.

(1236.) Now, you may consider that all these minute details regarding the treatment of cattle are frivolous and unnecessary. But the matter is really not so ; and it is of importance for your own interests to tell you so, for you will admit that where a number of minutiæ have to be attended to, unless taken in some order, they are apt either to be forgotten altogether, or attended to in a hasty manner; and none of these conditions, you will also admit, are conducive to correct management. Observe, then, the number of minute things the cattle-man has to attend to. He has various classes of cattle under his charge-cows, fattening beasts, young steers, calves, heifers, bulls, and perhaps extra beasts besides; and he has to keep all these clean in their various places of abode, and supply them all with food and fodder 3 times in a short winter's day of 7 or 8 hours. Is it possible to attend to all these particulars, as they should be, without a matured plan of operations? The cattle-man requires a plan for his own sake, for were he to do one thing just when the idea struck him, his mind, being guided by no fixed rule, would be as apt to forget as to remember anything he had to do. And besides, the injurious effects which irregularity of attendance tends to produce upon the condition of animals, (987) 
seem to render a plan of operations absolutely necessary to be adopted. Before you can see the full force of this olservation, you require to be told that food given to cattle in an irregular manner-such as too much at one time and too little at another, frequently one day and seldom in anotherand the same with fodder and litter, thus surfeiting them at one time, hungering them at another, and keeping them neither clean nor dirty, never fasls to prevent them acquiring that fine condition which better management insures. And still farther to show you its force, you may not be sensible of any deficiency of condition under the most irregular management, from the want of the means of comparing your beasts with others; but an appeal to figures will show you the risk of loss you are unconsciously incurring. Suppose you have 3 sets of beasts, of different agee, which should get as many turnips as they can eat, and each set to contain 20 beasts; that is, 60 beasts in all. Suppose, moreover, that, by irregular management, each of these beasts acquires only $\frac{1}{2} \mathrm{lb}$. less of live weight every day than they would under proper managenent, this would make a loss of $30 \mathrm{lbs}$. a day of live weight, which, over 180 days, the duration of the fattening season, will make $5,400 \mathrm{lbs}$. of live weight, or (according to the common rules of computation) 3,240 lbs., or 231 stones of beef, which, at $6 \mathrm{~s}$. the stone (not a high price), show a deterioration of $\$ 696 \mathrm{~s}$. in the value of the whole herd at the end of the season. The question, then, resolres itself into this, Whether it is more for your interest to lose this sum annually, or make your cattle-man attend to your beasts according to a regular plan, any form of which it is in your own power to adopt and pursue ?

(1237.) What I have narrated above applies to the ordinary mode of feeding cattle, but extraordinary means are sometimes applied to attain a particular object. You may have, for instance, a pair of very fine oxen which you are desirous of exhibiting at a particular show, not altogether for the sake of gaining the premium offered, but partly for the honor of carrying off the prize from contemporaries. In this case they should have a hammel comfortably fitted up for themselves; that is, possessing all the means of satisfying their wants, both of food and shelter. Your ingenuity should be taxed to derise means that will anticipate every desire; and this you will be the better able to do after you have determined on the sort of food you wish to support them upon. If, regardless of expense, you will present a choice of food, there should be a trough for sliced Swedish turnips-a manger for bean-meal-another for bruised oats-a third for broken oil-cake* - a rack for hay-and a trough for wa-

[" The parts of this disquisition on rearing and feeding cattle on turnips which may seem not to possess practical information or value for the American husbandman, may yet be read with entertainment as affording a familiar view of the details of the most important branch of agricul. tural economy in a country famed for its advancement in the arts as well of tillage as of manu. facture.

Few problems can be of more consequence to a great number of farmers, than the cheapest and best mode of fattening stock. There is a sufficient number of our farmers engaged in it render it a matter of national importance. It opens, as observed by an able writer and practical farmer, a wide field for calculation and inquiry as to the cost per pound, of putting on weight according to the food the animal is fed on.

There is, no doubt, a vast difference in the action of fond, in producing increased weight, de. pending upon its quality and description, the mode in which it is administered, the temper and breed of the animal, and, above all, whether the creature is placed in a cold, damp, and exposed situation, (to which many of our farmers give little or no attention,) or in vice, comfortable, dry and warm quarters.

On this subject we particularly recommend the reader to be on the look-out for, and to read (988) 
ter; for water at will I conceive essential when so much dry food is administered. Then there should be abundance of straw for litter and warmth, and a regular dressing of the skin every day, to keep it both clean and healthy, as fat oxen can reach but very few parts of their bodies with their tongue. So much for winter treatment. In summer they should get cut clover in lieu of the turnips and hay, and all the other auxiliaries to the dry materials and straw, as already stated. But all these will not avail to attain your object, if constant attention be not given, and everything conducted with the utmost regularity in regard to time. True, they get as much as they can eat, but then what they eat should be adminis tered with judgment. It will not suffice to set an adequate portion of each sort of food daily before them, to be taken at will; one or more kinds should be given at stated times, that each may possess the freshness of novelty and variety - not all at one time, but every one at such a time as one or both the animals may incline most to have. All these considerations demand attention, and afford exercise to the judgment. Oxen, when thus fattened, cannot travel any distance on foot; they must be conveyed on carriages built for the purpose, and even on these, if the distance is great, they will fall off in condition, as the confinement in, and motion of, the carriage proving irksome, prevent animals taking their food so heartily as they would do at home. I knew a 3-year-old-off bull that lost 30 stones live weight on being carried partly by steam-ship and partly by railway to a show.

(1238.) The names given to cattle at their various ages are these: A new-born animal of the ox tribe is called a calf, a male being a bull-calf, and a female a quey-calf, heifer-calf, or cow-calf, and a castrated male gets the name of stot-calf, or more commonly, simply a calf. The term calf is applied to all young cattle until they attain a year old, when they are called year-olds or yearlings, saying year-old bull, year-old quey or heifer, year-old stot; stirk is applied to both a young ox and quey, and stot in some places means a bull of any age. In another year they are named 2-year-old bull, 2-year-old quey or heifer, 2-year-old stot or steer. In England females are called stirks from calves to 2-year-old, and the males steers. The next year they are called 3-year-old bull ; females, in England, from 2 to 3-year-old, heifers, in Scotland 3-year-old queys, and when they are kept for breeding, and bear a calf at that age, they get the name of cows, the same as in England, and the males 3-year-old stots or steers. Next year the bulls are aged, the covs retain that name ever after, and the stots or steers are oxen, which they continue to be to any age they are kept. A cow or quey that has been served by the bull is said to be bulled, and are then in calf, and from that circumstance are called in England in calvers.

attentively, a Prize Essay on Fat and Musci.e, that we shall give in an early number, perhaps in our next: which will be the last of the Second Volume.

An important point of the question, says the writer referred to, and one to which Mr. Stephens does not seem to have adverted, is the comparative worth of the manure from the various materials used for feeding. It seems to be admitted, that there is a well grounded preference for that from richly fed animals, and we doubt not that in the farther progress of the application of science to the subject, we shall have an accurately graduated scale of the intrinsic value of manures, from every kind of food, vegetable and animal-frem dry wheat straw to oil-cake, and from fish to fat mutton.

The extent to which oil cake is used as food for beasts in England is entirely justified on the ground of the additional value it imparts to the manure. This is one of the resoarces for feeding our animals and our land that American Farmers seem as yet not to have studied or understood wrth the care we may suppose it deserves from the extent to which it is practiced in other countries.

Ed. Farm. Lib.| 
A cow that has either missed being in calf, or has slipped calf, is said to be eill; and one that has gone dry of milk is called a yeld-cow. A cow giving milk is a milch cow. When 2 calves are born at one birth, they are twins; if three, trins. A twin bull and quey calf are called fres martins, in which case the quey never produces young, but has no marks of a hybrid or mule. Cattle, black cattle, horned-cattle, and neat-cattle, are a?] generic names for the ox tribe, and the term beast is used as a synonym. An ox that has no horns is said to be dodded or humbled. An aged bull that is castrated is called a segg ; and a quey that has had the ovaries obliterated, to prevent her breeding, is called a spayed heifer or quey.

(1239.) Cows are kept on every species of farm, though for very different purposes. On carse and pastoral farms they are merely useful in supplying milk to the farmer and his servants. On dairy farms, they afford butter and cheese for sale. On some farms near large tonns, they chiefly supply milk for sale. And on farms of mixed husbandry, they are kept for the purpose of breed ing young stock.

(1240.) Ov carse and pastoral farms, cows receive only a fow tomips in winter, when they are dry, and are kept on from year to year; but where the farmer supplies milk to his work-people, as a part of wages, they are disposed of in the yeld state. and others in milk, or at the calving, bought in to supply their place, and these receive a large allowance of turaips, with perhaps a little bay. On these farms, little regard is paid to the breed of the cow, the fact of being a good milker being the ouly criterion of excellence.

(1241.) Ou true dairy farms, the winter season is not a favorable one for making butter and cheese for sale; for do what you like to neutralize the effert of the usual rooted green crops on these products, and especially butter, they remain unpalatable to the taste. The cows are therefore in calf during this seasun, and receive the treatment described above until the period of calving in epring.

(1242.) In and near large towns, the dairy-man must always have milk to supply his customera, and it is his interest to render the milk as palatable as possible. For the purpose of maintaining the supply, he buys cows at all seasons, just calved or about to calve. He disposes of the calves, without attempting to fatten them; and to render the milk he sells palatable, he cooks all the food partaken of by the cows. When the cows run dry, they are fattened for the butcher, and not allowed to breed again.

(1243.) The cows in the public dairies in Edinburgh are supported in winter on a variety of substances, namely, turnips, brewers' aud distillers' grains called draff. dreg, malt coming, barley, oats, hay-seeds, chaff, cut hay. One or more of these substances, with turnips, are cooked together, and the usual process in doing this and administering the cooked food, is as follows:Turnips, deprived of tops and tails, and washed clean, are put into the bottom of a boiler, and covered near its top with a quantity of malt comins, cat hay, hay-seeds, chaff, or barley, or more than one of these, as the articles can be procured. IV ater is then poured into the boiler sufficient to boil them, and a lid placed upon it. After being thoroughly boiled and simmered, the mess is put into tubs, when a little pounded rock-salt is strewed over it, and chopped into a mash with a spade. As nuch dreg is then poured upon the mash as to make it lukewarm. and of sach a con. sistence as a cow may drink up. From 1 to $1 \frac{1}{2}$ stable-pailfulls of this mixture-from 40 to 60 pints imperial-according to the known appetite of the cow, is then poured into the trough be. fonging to each. The trough is afterward removed and cleaned, and the manger is rearly for the reception of fodder-hay or straw. This mess is given 3 times a day, after the cows have been milked, for dairy men understand that animals should not be disturbed while eating their food. The times of milking are $6 \mathrm{~A}$. M.. 12 noon. and $7 \mathrm{P}$. M. The sweet milk and cream obtained by these means, aud received direct from the dairy, are pretty good. The former sells in Fdinburgh at $1 d$., aud the latter at $1 \mathrm{~s}$. the imperial pint. Dr. Cleland states the price of sweet milk in Glasgow at $1 \frac{1}{2}$. the imperial pint.

(1244.) It will be observed that none of the articles usually given to cows are so expensive as oil-cake, cabbages, kohl-rabi, or cole-seed. These products were employed by the late Mr. Curwen in his experiments to ascertain the cost of raising milk for supplying the poor, and the results show they ieft him very little profit.*

(1245.) There is litule milk in winter on a farm which supports cows for breeding stock, being only derived from one or two cows that are latest of calving in spring. All the spare milk may probably be eagerly bought by cotters who have no cows: but should that not be the case, a little butter may be made once in ten day's or a fortuight, which if not palatable for the table may be used in making paste, and other culinary purposes. A little saltpetre, dissolved in water, certainly modifirg the rank taste of turnips in boih butter and milk.

(1246.) Cattle are fed on other substances than turnips, either with themselves or in conjunction with turnips. Oil-cake and potatoes are the most common substances used for this purpose. Linseed-oil and linseed have been recommended, and many are fed at distilleries on draff and dreg, as the refuse of distillation are termed; and these are sold to the furmers for the par. pose of feeding. Oats, barley-meal, and bean meal, have also been pressed into the service of feeding cattle.

(1247.) The polatoes used in feeding catle are either the rommon kinds known in humsn food, or others raised on purpose, surh as the yam and ox-noble; and they are given either alter. nately with turnips, or together. In feeding cattle with potatoes of any kind, and in any way,

Curwen's Agricultural Hinzs.

(990) 
there is considerable risk of flatuleney and choking. To prevent the latter, the potatoes should be smashed with a hammer, or with an instrument like a pavior's rammer, and though juice should come out in the operation, no loss is incurred, as it is considered of no service in feeding. To prevent flatulence from potatoes is no easy matter; but a friend of mine used a plan which completely answered the purpose, which was, mixing cat straw with the broken potatoes. The straw obliging the cattle to ehew every moutbfull before being swallowed, may prevent such a large quantity of gas being generated in the paunch as bruised potatoes alone would do, and it is this gas which occasions that distressing complaint called hoven. A farm-steward, who had considerable experience in feeding cattle on potatoes on a led-farm, always placed as many potatoes, whole, before cattle as they could consume, and they never swelled on eating them, because, as be conjectured, and perhaps rightly, they do not eat them so greedily when in their power to take them at will. as when doled out in small quantities. This fact confirms the propriety of mixing cut straw among potatoes that are given in small quantities, in order to satisiying the appetite, and filling the paunch with unfermentable matter. The oniy precaution required in giving a full supply of potatoes is to give only a few and frequently at first, and gradually to increase the quautity.

(1248.) Oil-calce has been long and much employed in England fur the feeding of cattle, and it is making its way in that respect into Scotland. It consists of the compressed husks of linseed after the oil has been expressed from it, and is formed into thin oblong cakes. The cakes are broken into pieces by a machine described in fig. 264. Cattle are never entirely fed on oil-cake, but in canjuncion with other sub tanses, as turnips, potatoes, cut hay, oi cut straw. When given with cut hay or straw, an ox will eat from 7 to 9 ibs. of cake a-day, and the hay or straw induces rumination, which the cake itself is not likely to do. When given with other substances, as tur. nips or potatoes, $3 \mathrm{lbs}$. or 4 lbs. a-day will suffice. A mixture of oil-cake and cut meadow-hay

Fig. 259.

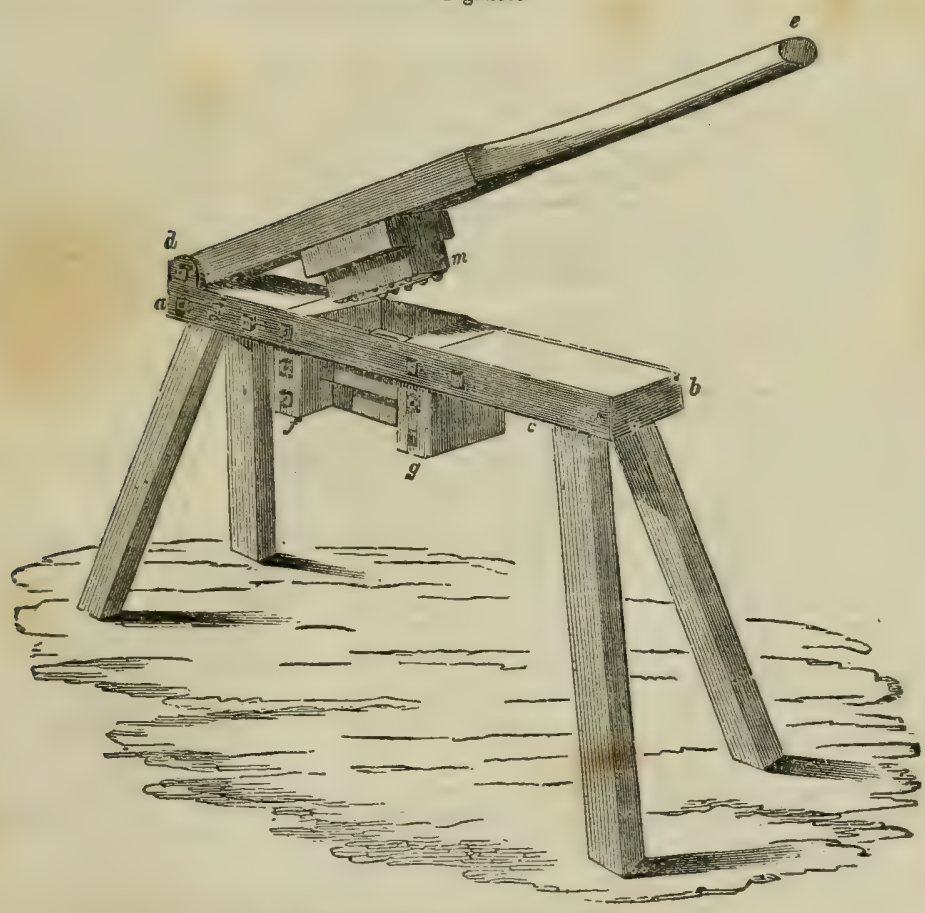

THE LEVER TURNIP-SLICER FOR CATTLE. forms a very palatable and nutritious food for oxen, and is a favorite one in England. Oil-cake
costs from $£ \gamma$ to $£ 10$ a ton.

(1249.) [Turnip-slicers for Cattle. In the description formerly given of machines for cutting tur nips for sheep, that described in (1245) may be again adverted to, fig. 250, the wheel turnip-cutter. This machine is equally well adapted to slice for cattle as for shcep, and is frequently fitted up to slice for cattle only. More frequently it is finished as described with the cross-cutters, fig. 258, and when wanted to slice for cattle, the cross-cutters are removed. This is easily accomplished, by first lifting the slicing-knives from the disk of fig. 250 , then unserewing all the nuts of the crosscutters, and removing them from thcir places. The slicing-knives are then again placed as before, and the machine is prepared to cut the turnips into plain slices. This machine costs from $£ 4$.
4. to 
(1250.) Lever Turnip-slicer. One of the cheapeat and most efficient turnip-slicers is represented in fig. 259. It was brought before the Highland and Agricultural Society of Scotland by Mr Wallace of Kirkconnell, as an improvement on a preexisting machine of the same kind." It has siace undergone some farther improvements in the hands of James Slight and Company, Edinburgh: and for the purpose of regular and perfect slicing of turnips, it may be held as as the best and cheapest now employed. The machine as produced by Mr. W allace, is represented in fig. 259 ; where $a b$ is the stock or sole of the machine, about 34 inches long, 6 inches brosd, and 2 inches in thickness. The sole is in 2 pieces, connected by an iron bar or strap $a c$, which is repeated on the opposite side, and the whule bolted together, as in the figure. The 2 pieces forming the sole are separated longitudinally from each other, so as, with the two side-straps of iron, to form a rectangular opening of 9 inches by 6 inches, bounded on the two ends by the parts of the sole. and on the two sides by the side straps, which, to the extent of the opening, are thinned off to a sharp edge, and thus form the two exterior cutters $d$, $c$, as seen in fig. 260, which is a transverse section through the cradle of the machine. The sole is supported at a hight of 2 feet upon 4 legs, lig. 259 , and the lever $d e$ is jointed at $d$ by means of a bolt passing through it and the ears of the side-straps, as seen at $d$. The lever is 4 feet in longth, its breadth and thickneas equal to that of the sole, but is reduced at the end $e$ to a convenient size for the hand. Two catter blocks $f$ and $g$ are appended to the sole by mortice and tenon, and farther secured by the bolts which pass through the side-strap at that place. Into these blocks the remaining cutters $h h$ and $i$, fig. 260 , are inserted in corresponding pairs, and also secured by bolts; the cutters thus arranged form a cradle-shaped receptacle, into which the turnip is laid $k$ to be sliced. The lever $d e$ is armed with a block of wood $m$, loosely fitted to the cradle; and its lower face is studded with iron knobs, the better to prevent the turnip sliding from under it. The transverse sec. tion $d$ e $f f$, tig. 260 , shows the position of six cutters $d e, h h$, and $i i$, as inserted in the wooden block $d$ e $f f$; and $k l$ is the lever, seen in section, with the block $m$ attached.

(1251.) The late improvement by Messrs. Slight and Company cou. sists in the application of cast-iron knife-blocks, which give greater strength to the machine, and a more ready and secure fixture of the interior kuives, and of introducing 8 cutters instead of 6 , which makes a more convenient size of slice. Fig. 261 is a sertion of the cradle, as it appears with the cast-rron knife-block; $a$ is the body of the blork which is attached to the sole through the medium of a flange behind, and fixed by bolts. The external cutters $b \quad b$ are a part of the side straps, as before; and the interior cutters are fixed in pairs, $c c, d d$, and $e e$, by their respective bolts passing through the cutters and the block.

(1252.) In using this machine, the workman takes hold of the lever at $e$, fig. 259 , with the right hand, and having raised it sufliciently high, he, with the left hand, throws a turnip into the cradle. The lever is now brought down by the -right hand, which, with a moderate impetus, and by means of the block $m$, sends the turnip down upon the cutters. through the openings of which it passes while the cutters are dividing it. and the whole falls away in perfectly uniform slices. In most cases, it is found more convenient to have a boy to throw in the turnips, and this will somewhat expedite the work. One advantage of this turnip-slicer-and it is an important one-is that. with unerring certainty, it cuts every slice of uniform thickness; the slab-stices, indeed, may of course vary, but all are free of the smallest portion of waste. Its cheapness also is of importance, especially when it is considered that, in a given time, it will slice weight for weight of turnips with the most alaborate machine in use, the power applied being also equal. The price is $28 \mathrm{~s}$. to $30 \mathrm{~s}$. It is also extremely portable, and can be carried about by one person. An objection has been urged to this slicer, namely, that the turnips must all be put into it one by one; and it is perhaps unnecessary to remark that this objection applies to all turnip.slicers. For though the hopper of some may be capable of containing a number of turvips at one time, yet that number may be considered as having been deposited there individually. The

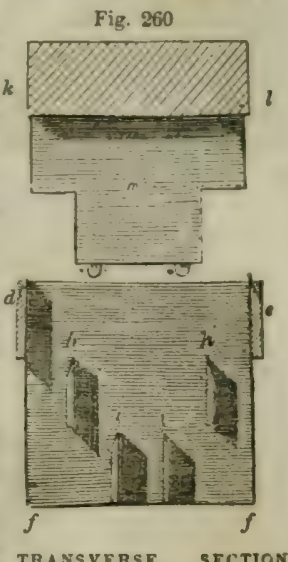

TRANSVERSE SECTION SHOWING THE POSITION OF THE CUTTERS.
Fig. 261 .

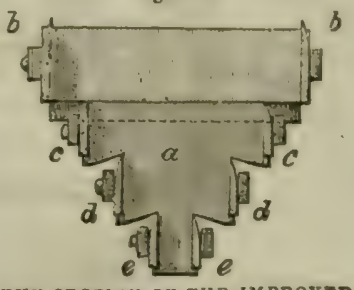

THE SECTIUN OF THE IMPROTID CRADLE. price of the lever turnip-slicer for sheep, as in fig. 245 , is $£ 310 \mathrm{~s}$.

(1253.) Cross Turnip-culter. There is another very simple and useful tumip-cutter, which is frequently used when thin slicing is thought of less importance. but is more especially useful where the cooking system is adopted for either cows or horses, thin slicing being in such cases not called for. This instrument is represented in fig. 262. The cutting part of it consists of 2 steel-edged blades, 8 inches in length and 4 inches in depth. They are slit half-and-half at their middle point, so as to penetrate each other, standing at right angles, forming the cross.cutter. $a$ a a a. They are then embraced in a four-split palm. and riveted. The palm termiuates in a slort shank $e$, which is again inserted into the hooped end of a wooten handle $b .3$ feet in length, which is finished with a crosshead $c$. The price of this instrument is $8 \mathrm{~g}$. 6d. The mode of using it is obvious. It is held by the hand in a vertical position; and when placed upon a curnip, one

- Prize Essays of the Highland and Agricultural Socicty. 
thrust downward cuts it into quarters. This instrument is also varied in its construction, being sometimes made with 3 and even with 4 blades, dividing the turnip into 6 or into 8 portions.

(1254.) Another individual form of the same species is represented by fig. 263. It has two blades $a \quad a$; but they, instead of crossing, stand parallel to each other, and therefore divide the turnips into three portions, resembling slices, of considerable thickness, the mirldle one being $1 \frac{1}{2}$ inches thick. In the construction of this cutter, a blunted stud is formed at the extremities of each blade, and there projects below the cutting edge about $\frac{1}{4}$ inch, serving as guards to save the cutting edges from receiving injury when they have passed through the turnip, or otherwise striking any hard surface. These guards, it may be remarked, would form a useful addition to all this class of cutters. The arms $b$ of the blates rise to a hight of 9 inches, widening upward to $3 \frac{1}{2}$ inches, to give freedom to the midille slice to fall out. The two arms coalesce above, and are then formed into the socket $c$, to receive the handle, which-as in the cross cutter, fig. 262-terminates in a crosshead.

(1255.) Oil-cake Breaker.-Machines for preparing oil.cake for more easy masticatiou by cattle or sheep are made in a variety of forms. One of those forms is similar in principle to that of the early bonecrushing machines; namely, a revolving axle, armed with several series of teeth, which are so arranged as to pass in succession through the interstices of a line of strong teeth or prongs, against which the cakes lies, and is reduced to fragments by the successive action of the revolving teeth. Of this form there are various modifications, all serving the same purpose with nearly equal success.

(1256.) A different form of the machine, and which is held superior in the principle of its construction, is bere exhibited in fig. 264, which is a view of the machine in perspective, wherein $a, a, a, n$, are the fort posts of a wooken frame, on which the machinery is supported. The frame is 39. inches in length and 20 inches in width over the posts at top. the light being 33 inches. $b \quad b$ are two top-rails,

Fig. 262.

Fig. 263.

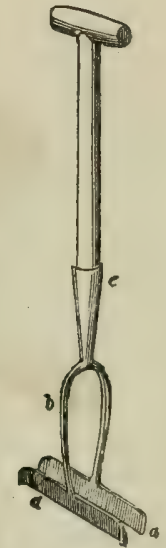

THE HAND TURNIP.

THE HAND TURNIPCHOPPER, WITH PARALLEL BLADES. 34 iuches in length, and the scantling of their timbers should not be less than $2 \frac{1}{4}$ inches square. The posts are supported toward the bottom by the four stay-rails $c, c, c$; and the top-rails are held in position by cross-rails $d$, one only of which is seen in the figure. Of the machinery, the acting parts consist of 2 rollers, studded all over with pyramidal knobs or teeth. These are arranged in zones upon each roller, and having a smooth space or zone between each of the knobbed zones; the knobs of the one roller corresponding to the smooth space in the other. The rollers $e$ and $f$ are constructed with an axle or shaft, that of the first $e$ being 25 inches long, and of the second $f 23$ inches, and each $1 \frac{1}{4}$ inches square. Journals are formed upon these shafts, to run in the bearings which are placed on the top-rails $b b$, as afterward described. In this figure, $g g$ are two pinching screws, which serve to regulate the distance at which the rollers are to work and, consequently, the degree of coarseness to which the cake is to be broken. The wheel $h$, of 20 inches diameter, is placed upon the shaft of the roller $e$, and the pinion $i$, of 3 inches diameter. with its shaft, and the winch-handle $k$, act upon the wheel $h$, giving a very considerable mechanical advantage to the power which is applied to the machine. The Hy-wheel $l$ is likewise placed upon the shaft of the pinion $i$, and is requisite in this machine to enable the power to overcome the unequal resistance of the work. On the farther end of the shaft of each of the rollers, there is mounted a wheel of $4 \frac{1}{2}$ inches diameter, for the purpose of carrying both rollers at the same speed. These wheels, one of which is seen at $m$, are formed with long teeth, to admit of the roller $f$ approaching to or receding from the other, which is stationary in place. A feeding hopper $n$ is placed over the line of division of the two rollers; it is $16 \frac{1}{2}$ inches long, 3 inches wide, and 14 inches deep. In forming the hopper, two upright nieces. 3 inches by 2 in. ches, are bolted to the inside of the top-rail, their position being between the shafts of the 2 rollers, and these form the ends of the hopper. They are then boarded on each side, which completes the machine. The hopper is here represented in section, the near portion of it beung supposed entirely removed, in order to exhibit more distinctly the construction of the rollers.

(1257.) Fig 265 is a farther illustration of the construction of the rollers being a transverse section of the two, $a$ are the shafts, the shaded part $b$ one of the plain disks which go to form the smooth zones on the body of the roller; it is 4 inches diameter and 1 inch thick; $c$ is one of the knobbed disks, its body being of the same diameter and thickness as the former; but having the 4 -sided pyramidal knobs set around it, the diameter, measuring to the apex of the knobs, is ex. tended to 6 inches. One roller for the machine here described requires 5 plain and 6 knobbed disks, beginning and ending with a knobbed disk. In the other the arrangement is reversed, bringing out the alternation of the plain and knobbed zones before alluded to as more distinctly represented in fig. 266, which is a plan of part of the rollers, $c c$ being two of the knobbed disks, and 666 three of the plain. 
(1258.) Fig. 267 represents one of the bearings or plummer hiocks for the journals of the rollera, $a$ is the bed of the plummer-block. $b$ and $c$ the brass bushes, and $d$ the cover. The bush $b$, which corrceponde to the roller e, fig. 264 . is siwnys stationary, while $c$, which is acted upon by the

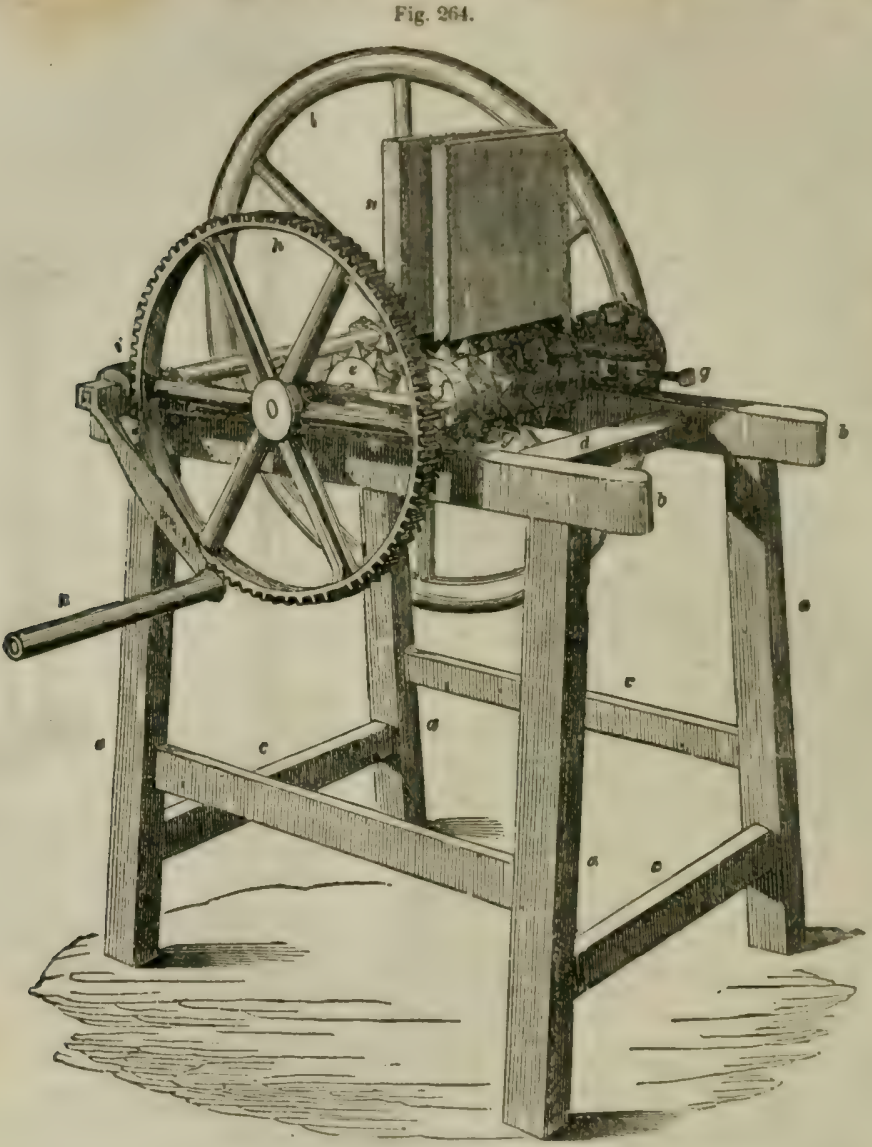

THE OIL-CAKE BREAKER.

screw, is advanced toward, or withdrawn from, $b$, as the size to which the cake is to be broken may require. These plummer-blocks are bolted down to the top-rails of the frame, to which slso the separate bearings of the pinig ghaft are likewise bolted.

Fig. 265.

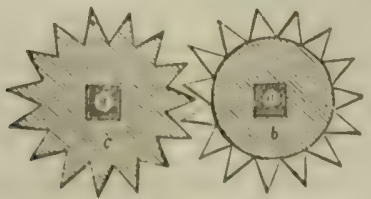

THE TRANSVERSE SECTION OF THE ROLLERS.
Fig. 266.

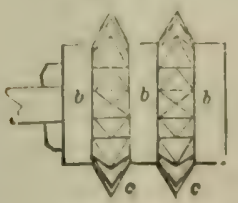

11259. It may be proper to remark here that the machine now deacribed is of a good medium gize, and with a man to drive and a boy to feed in the cakes, it will break about half a ton in an hour. The price is from $\mathrm{fit}$ to $\mathrm{ft} 10 \mathrm{~s}$. The amount of its performance can be augmented or diminished to only a small extent, for as its feed is necessarily confined to one cake at a time, the only change that can be made on its production must depeud upon the celerity of its motions. Hence it is one of those machines that cannot easily be adapted to large and to smaul establieh. (994) 
ments with any view, in this latter case, to amelioration of form; for the almost only means of doing so must be by giving it a quicker or slower motion, which can only affect the expense of construction to a very small amount, so small as hardly to be appreciable. In addition to what is

Fig. 267.

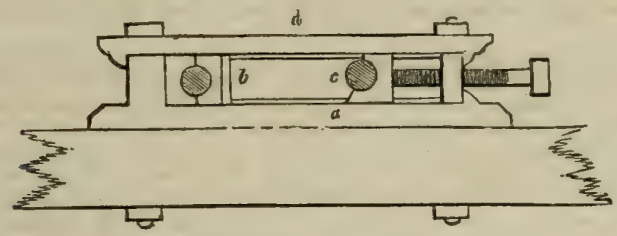

PART OF THE TOP-RAIL, WITH PLUMMER BLOCK.

shown of this machine in fig. 264 , the rollers are frequently covered with a movable wooden case, which gives a more tidy appearance to it, and, moreover, it is always desirable that the frame below should contain a shoot formed of light boarding, that will receive the broken cake from the rollers, and deliver it at one side of the machine into a basket or other ntensil in which it can be removed to the feeding stations.-J. S.]

(1260.) Mr. Brodie, Abbey Mains, East Lothian, made an experiment on feeding cattle, from October, 1836, to June, 1837, on different kinds of food. There were 4 lots of cattle, consisting of 5 each. The first lot was fed on turnips and straw, which, being the usual treatment, formed the standard of comparison. The second lot had half the weight of turnips and $30 \mathrm{lbs}$. of oil-cake a day. A third lot was fed on the last quantity of turnips and bean-meal and bruised oats. And the fourth had distillery grains and ground beans. The value of the cattle, when put up to feed, was $f 11$ a piece, and they were of the Aberdeenshire polled breed. This is a summary of the cost of feeding :

Iot 1. White turnips at 8 s. 4 d., Swedes at $12 \mathrm{~s} .6 \mathrm{~d}$. per ton, cost................ £53 910 Average cost of each beast per week.......................... $0^{0} \quad 6 \quad 3$

Lot 2. Turnips as above, oil-cake, $£ 7$ 15s. per ton, cost ................... $\overline{£ 4816 \quad 0}$

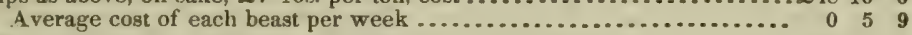

Lot 3. Turnips as above, bean-meal 58., bruised oats $3 \mathrm{~s} .6 \mathrm{~d}$ per bushel, cost ..........£58 $8 \overline{1}$ Average cost of each beast per week .......................... $00^{6} 6$

Lot 4. Turnips and bean-meal, as above, draff 4s. 6d. per quarter, dreg 28. $6 \mathrm{~d}$. per

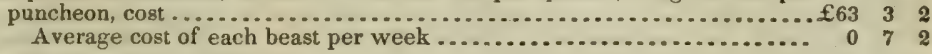

The ultimate results are as follows:

\begin{tabular}{|c|c|c|c|c|c|c|c|}
\hline Lots. & Live weight. & \multicolumn{2}{|c|}{ Beef. } & \multicolumn{2}{|c|}{ Tallow. } & \multicolumn{2}{|c|}{ Hide. } \\
\hline & sts. & & & sts. & Ibs. & sts. & lbs. \\
\hline 1. & 536 & 283 & 3 & 36 & 10 & 27 & 13 \\
\hline 2. & 552 & 295 & 10 & 41 & 6 & 29 & 6 \\
\hline 3. & 517 & 280 & 7 & 37 & 2 & 26 & 13 \\
\hline 4. & 545 & 280 & 0 & 36 & 11 & 25 & 7 \\
\hline
\end{tabular}

"Upon the whole," concludes Mr. Brodie, "it is evident, by these experiments, that feeding wfth turnips as an auxiliary has been the most advantageous mode of using turnips, as, by the above statement, it is apparent that if the cattle of the first lot had only been allowed half the quantity of turnips which they consumed, and had got oil-cake in lieu of the other half, as was given to the second lot, the expense of their keep would have been lessened $£ 413 \mathrm{~s}$., and from saperior quality of beef, their value would have been increased $£ 10$, making together $£ 1413 \mathrm{~s}$. "* "Three remarks occur to me to make on the progress of this expesiment; the first is, that if the cattle had been sold on the 7th April, 1837, when they were adjudged by competent farmers, they would not have repaid the leeder his expenses, as the prime cost of lot first, with the cost of feeding to that time, amounted to $£ 951 \mathrm{~s}$. $8 \mathrm{~d}$., and they were only valued at $£ 82$; lot second cost $£ 9012 \mathrm{~s}$, and they were valued at $£ 8810 \mathrm{~s}$; lot third cost $£ 93 \quad 4 \varepsilon_{\text {. }}$, and were valued at $£ 77$; and lot fourth cost $£ 9748$. 5d.. and their value was only $£ 81$ 108. And this is almost always the result of feeding cattle, because ripeness only exhibits itself toward the end of the feeding season, and it is only after that state of condition is indicated that the quality of the meat improves 60 rapidly as to enbance its value so as to leave a profit. As with sheep so with cattle; with good beasts the inside is first filled up before the outside indicates fineness. Another remark is, that this result should be a useful hint to you to weigh well every consideration before disposing of your fattening beasts in the middle of the feeding season. The last remark I have to make is, that the cattle of lot first, continuing to receive the same sorts of food they had always been accustomed to, throve more rapidly at first than the beasts in the other lots but afterward lost their advantage; thereby corroborating the usual experience of stock not gaining condition immediately on a change of food, even of a better kind, such as from turnips to grass.

(1261.) Mr. Mowbray of Cambus, in Clackmannanshire, made experiments in the winter of 1839-40 on feeding cattle with other than the ordinary produce of the farm, but as the cattle wers

- Quarterly Journal of Agriculture, vol, viii.

(995) 
not all sold at the same time I need not relate the details; and I mention the experiments for the sake of some of the conclusinns that may be deduced from then. It would appear that cntte may be fed on tnrnips and hay as cheaply as on turnips and straw, for this rearon, that when straw is given as fodder, more turnips are consumed, and. therefore, when turnips are scarce, hay may be used with advantage. It also appears that cattle may be fed cheaper on distillery refuse of draff and dreg than on tarnips and straw, but then the food obtained from the distillery requires more time to bring cattle to the same condition, which in some circumstances may be an inconvenience."

(1262.) Linseed oil has been successfully employed to feed cattle by Mr. Curtis of Weat Rud. ham, in Norfolk. The mode of using the oil is this : First ascertain how much cut straw the oxen, intended to be fed. will consume a week, then sprinkle the oil, layer upon layer, on the cut straw, at the rate of 1 gallon per week per ox. The mixture, on being turned over frequently, is kept 2 days before being used, when a slight fermentation takes place, and then the oil will scarcely be discerned, having been entirely absorbed by the straw, which should of course be the best oat straw. This mixture, when compared with oil-cake, has stond its ground. The cost of the oil is not great, its average price being about 34s. the cwt. of $12 \frac{1}{6}$ gallons, a gallon of fine oil weighing $9.3 \mathrm{lb}$., which makes the feeding of an ox cost only $2 \mathrm{~s}$. 10d. per week.t

(1263.) Mr. Curtis has fed cattle for upward of 20 years upon what he calls green malt, which consists of steeping light barley "for 48 hours in soft water, when the water is let oft" and the barley is thrown into a round hoap, in a conical form, till it gets warm and begins to sprout freely. It is then spread out and turned over repeatedly as it grows. The only care required is, that the sprout or future blade does not get cut off, as the malt will then lose much of its nutritious qual. ity." He finds this substance, which costs with its labor 1s. a stone, preferable to oats at 10d. in their natural state. $\neq$

(1264.) A method of feeding cattle has been adopted by Mr. Wames, Jr.. Trimingham, Norfolk, which, in a manner. combines both the substauces used by Mr. Curtis, and dearves atten. tion. The substances consist of linseed-meal and crushed barley. The barley may either be ased malted. that is, in a state of "green malt," as designated by Mr. Curtis, or crushed Alat by braising cylinders. Crushed oats, boiled peas and bean flour may all be substituted for the barley, and used with the linseed meal. The mode of making this compound is thus recommended by Mr. Warnes: "Put $168 \mathrm{lbs}$. of water into an iron cauldron or copper or boiler, and as soon as it boils, not before, stir in $21 \mathrm{lbs}$. of linseed meal; continne stirring it for 5 minutes; then let 53 lbs. of the crushed barley be sprinkled by the hand or one person upon the boiling mucilage, while another rapidly stirs and crams it in. After the whole has been carefully incorporaten, which will not occupy more than 5 minutes, cover it closely down and throw the furnace door open. Should there be much fire, put it out. The mass will continue to simmer, from the heat of the cauldron, till the barley has entirely absorbed the mucilage. The work is then complete, and the food may be used on the following day. When removed into tubs, it must be rammed down to exclude the air, and to prevent its turning rancid. It will be seen that these proportions consist of 3 parts of barley to one of linseed, and of 2 parts of water to 1 of barley and linseed included. Also, that the weight of the whole is 13 stones when put into the cauldron; but after it has been made into compound and become cold, it will be found in general reduced to some. thing less than 15 stones, which will afford 1 bullock for a fortniyht 1 stone per day, containing $11 \mathrm{lbs}$ of linseed. It will keep a long time if properly prepared. The consistency ought to be like that of clay when formed for bricks." In regard to the nutritive properties of this compound Mr. Warnes testifies thus: "The last of my experimental bullocks for 1841 was disposed of at Christmas at 8s.6d. per stone. He weighed 60 stones 5 lbs., of 14 lbs. to the stone, and cost f7 17s. od. thirteen months previously; so that he paid $f 17$ 108. for little more than one year's keepiug. His common focd was turnips or grass; $14 \mathrm{lbs}$ a day of barley or peas compound were given him for 48 weeks, and an unlimited quantity the last 5 weeks: when, considering the shortness of that time, his progress was perfectly astonishing, not only to myself, a constant ob. server, but to many graziers and butchers who had occasional opportunities of examining him. Altogether the weight of compound did not exceed 2 tons 4 cwits, at a cost of only $£ 316 \mathrm{~s}$ per ton."Il

(1265.) This successful result obtained by Mr. Warnes shows that cattle may be profitably fed on prepared food, though the results of several experiments which have been made by farmers in Scotland lead to an opposite conclusion; yet Mr. Warnes's statement contains no comparian, for it is quite possible that the nutritious materials emploved by him, nanely. linseed-meal and bruised barley, would have fed a bullock equally well in their naturally cold state as when cold, after being cooked warm. As to the expediency of cooking food for cattle, Mr. Warneg goes ao far in opinion as to say that " neither oil nor linseed should be used in a crude state, but formed into mucilage by being boiled in wuter:" but this opinion was evidently given when the results obtained by Mr. Curtis on feeding crttle with linseed-oil in a crude state, were unkuown to him : fur although he admits "that linseed-oil will fatten bullocks, experience has placed beyond a doubt. Among the fattest beasts ever sent to the London market from Norfolk wray a lot of Scotch beifers, grazed (?) on linseed-oil and bay." Yet he adds : "But the quamtity given per day, the cost per head, or anything relative to profit or loss, I never heard." I should therefore like to see a comparison instituted between the nutritive properties of linseed.meal and bruised barley, or peas or bean-meal, in their ordinary state, and after they had been boiled aud administered either in a hot or cold state, and also between the profits arising from both. IIntil this information is obtained, we may rest content with the results obtained by some very accurate experiments. conducted by eminent farmers, on the same food administered in a $\mathbf{w}$ arm and in a cold state, and which go to prove that food is unprofitably administered to cattle in a cooked state. I shall now lay some statements corroborative of this conclusion before you.

* Prize Essays of the Highland and Agricultural Society, vol. xiv. † Ibid., vol. xiv. $\ddagger$ Jbid., vol. sit.
Warnea's suggestion on Fattening Caule. (996) 
(1266.) The first I shall notice, though not in detail, are the experiments of Mr. Walker, Fer. rygate, East Lothian. He selected, in February, 1833, 6 heifers of a cross between country cows and a Short-Horn bull, that had been on turnips, and were advancing in condition, and divided them into 2 lots of 3 heifers each, and put one lot on raw food and the other on steamed, and fed them three times a day-at daybreak, noon and an hour before sunset. The food consisted of as many Swedes as they could eat, with $3 \mathrm{lbs}$. of bruised beans and $20 \mathrm{lbs}$. of potatoes, $\frac{1}{2}$ stone of atraw and 2 ounces of salt to each beast. The three ingredients were mixed together in a tub placed over a boiler of water, and cooked by steaming, and the bruised beans were given to the lot on raw food at noon, and one half of the potatoes in the morning and another half in the afternoon. It was soon discovered that the lot on the cooked food consumed more turnips than the other, the consumption being exactly $37 \mathrm{cwt}$. $16 \mathrm{lbs}$., while, when eaten raw, it was only $25 \mathrm{cwts}$. 1 qr. 14 lbs., the difference being 55 lbs. every day, which continued during the progress of the experiment for 3 months.

(1267.) Steers were experimented on as well as heifers, there being 2 lots of 2 each. They also got as many Swedish turnips as they could eat, but had 30 lbs. of potatoes and $4 \frac{1}{2}$ lbs. bruised beans, 2 ounces of salt, and $\frac{1}{2}$ stone of straw each, every day.

(1268.) The cost of feeding the heifers was as follows:

$\checkmark$ heifers on steamed food: Cwts. qrs. lbs.

Consumed of Swedish turnips, $37 \quad 0 \quad 16$, at $4 \mathrm{~d}$. per cwt................. $£ 0 \quad 12 \quad 4 \frac{3}{4}$

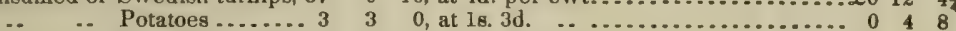

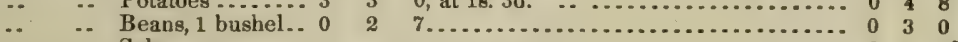

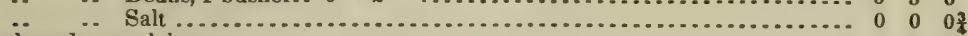

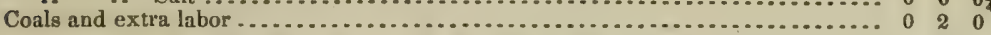

Cost of 3 heifers 1 week, or 7 s. $4 \frac{1}{2}$ d. per week each.................

3 heifers on raw food: Cwts. qris. lbs.

Consumed of Swedish turnips, 25 I 14, at 4 d. per cwt................. £0 $8 \quad 6 \frac{1}{4}$

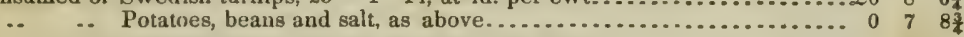

Cost of 3 heifers 1 week, or 5 s. 5 d. each per week................. £0 $16 \quad 3$

2 stots on steamed food : Cwts. qrs. lbs.

Consumed of Swedish turnips, $282_{2} 0$, at 4 d. per cwt................. £0 710

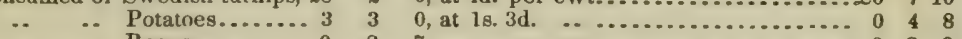

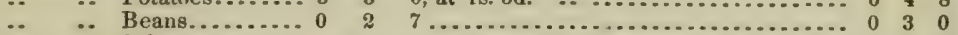

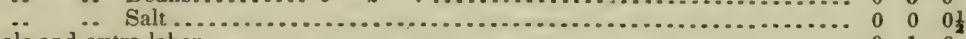

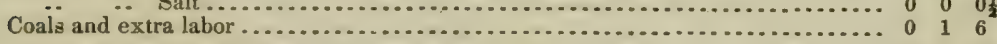

Cost of 2 stots for 1 week, or 8 s. $6 \frac{1}{4} \mathrm{~d}$. each per week ...............

2 stots on rave food: Cwts. qre. lbs.

Consumed of Swedish turnips, $17=20$, at $4 \mathrm{~d}$. per cwt.............................. 510

.. $\quad . \quad$ Potatoes, beans and salt, as above.......................... 0

Cost of 2 stots for 1 week, or 6 s. $9 \frac{1}{4} \mathrm{~d}$. each per week............... £0 $13 \quad 6 \frac{1}{2}$

(1269.) The following table shows the progress of condition made by the heifers and stots :

\begin{tabular}{|c|c|c|c|c|c|c|c|c|c|c|c|}
\hline Cattre. & $\begin{array}{c}\text { Average live } \\
\text { weight of } 3 \mathrm{at} \\
\text { commence- } \\
\text { ment of } \\
\text { feeding. }\end{array}$ & $\begin{array}{l}\text { Aver } \\
\text { live w } \\
\text { of } 3 \mathrm{at} \\
\text { of } \mathrm{feec}\end{array}$ & $\begin{array}{l}\text { age } \\
\text { eight } \\
\text { end } \\
\text { ding. }\end{array}$ & $\begin{array}{l}\text { Averas } \\
\text { creas } \\
\text { live we } \\
\text { in } \\
\text { mont }\end{array}$ & $\begin{array}{l}\text { gein- } \\
\text { e of } \\
\text { eight } \\
3 \\
\text { the. }\end{array}$ & $\begin{array}{r}\text { Aver } \\
\text { de? } \\
\text { weigh } \\
\text { bee }\end{array}$ & $\begin{array}{l}\text { rage } \\
\text { ad } \\
\text { ht of } \\
\text { ef. }\end{array}$ & $\begin{array}{c}\text { Average } \\
\text { weight of } \\
\text { tallow. }\end{array}$ & $\begin{array}{c}\text { Average } \\
\text { weight of } \\
\text { hide. }\end{array}$ & $\begin{array}{l}\text { Aver } \\
\text { weigt } \\
\text { off }\end{array}$ & $\begin{array}{l}\text { rage } \\
\text { tit of } \\
\text { al. }\end{array}$ \\
\hline $\left.\begin{array}{c}\text { Heifers on } \\
\text { steamed food, }\end{array}\right\}$ & $\begin{array}{l}\text { sits. } \\
74\end{array}$ & $\begin{array}{l}\text { Sts. } \\
90\end{array}$ & $\begin{array}{c}1 \text { lbs. } \\
0\end{array}$ & $\begin{array}{l}\text { Sts. } \\
16\end{array}$ & $\begin{array}{l}\mathrm{Ibs} . \\
0\end{array}$ & $\begin{array}{l}\text { Sts. } \\
50\end{array}$ & $\begin{array}{c}\text { Ibs. } \\
0\end{array}$ & $\begin{array}{c}\text { Sts. Ibs. } \\
711\end{array}$ & $\begin{array}{c}\text { Sts. Ibs. } \\
312\end{array}$ & $\begin{array}{l}\text { Sts. } \\
26\end{array}$ & $\begin{array}{c}168 . \\
9\end{array}$ \\
\hline $\left.\begin{array}{l}\text { Heifers on } \\
\text { raw food, }\end{array}\right\}$ & 74 & 89 & 3 & 15 & 0 & 50 & 1 & 84 & 44 & 26 & 10 \\
\hline $\left.\begin{array}{c}\text { Stots on } \\
\text { steamed food, }\end{array}\right\}$ & 84 & 103 & 4 & 19 & 0 & 56 & 19 & 811 & $\begin{array}{ll}5 & 12\end{array}$ & 28 & 3 \\
\hline $\left.\begin{array}{l}\text { Stots on } \\
\text { raw food. }\end{array}\right\}$ & 90 & 106 & 5 & 15 & 0 & 58 & 6 & 88 & 54 & 30 & 4 \\
\hline
\end{tabular}

(1270.) The comparative profits on cooked and raw food stand thus:

Live weight of heifers, when put to feed on steamed food, 74 sts $=42$ sts. 4 lbs. beef, at $5 \mathrm{~s}$. $6 d$. per

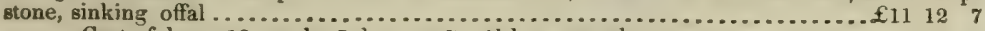

Cost of keep 12 weeks 5 days, at 7 . $4 \frac{1}{2}$ d. per week................... 4190

Total cost. ........................................ $\overline{£ 16} 117$

Live weight of the same heifers, when finished feeding on steamed food, $90 \mathrm{sts}=50$

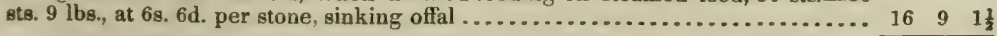

Loss on steamed food on each heifer.......................

Live weight of 1 heifer, when put to feed on raw food, 74 sts. $=42$ sts. 4 lbs. beef, at

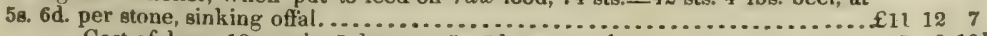

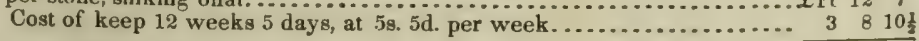

Total cost. ....................................... $11515 \frac{1}{15}$

Live weight of the snme heifer when finished feeding on raw food, 89 sts. 3 lbs. $=50$

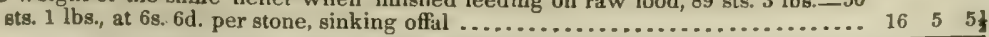

Profit on raw food on each heifer........................ 1140 
Live weight of 1 stot when pat up to feed on steamed food, 84 sts. $=50$ sts. 4 lbs., at

5s. $6 d$. per stone, sinking oflal. ............................... 113 , 0

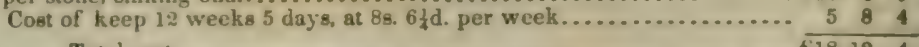

Live weight of the same stot after being feed on steamed food, 104 sts. 7 ibs. $=56$ sts. $10 \mathrm{Jbs}$, at $68.6 \mathrm{~d}$. per stone, sinking offal............................. $18 \quad 8 \quad 7$

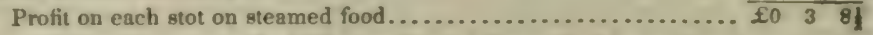

Live weight of 1 stot when put on raw food, 90 sts. $=51$ sts. 6 lbs., at $58.6 \mathrm{~d}$. per stone,

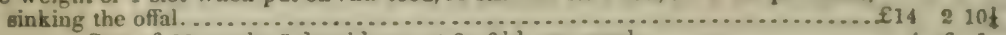
Cost of 12 weeks 5 days' keep, at 6 s. $9 \frac{1}{4}$ d. per week............... $4 \quad 6 \quad 1$

Total cost..................................... $118 \quad 811 \frac{1}{11}$

Live weight of the same stot after being fed on raw food, 106 sts. 7 lbs. $=58$ sts. 6 lbs.,

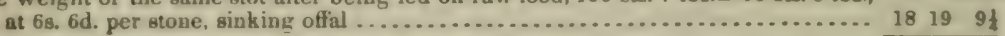

Profit on each stot on raw food....................... t0 1010

(1271.) The facts, brought out in this experiment, are these: It appears that tarnips lose weight on being steamed. For example, 5 tons $8 \mathrm{cw}$ ts. only weighed 4 tons $4 \mathrm{cw}$ ts. 3 grs. 16 lbs. after being steamed, having loat 1 ton $3 \mathrm{cw}$ (s. $12 \mathrm{lbs}$. or 1.6 of weight : and they also lost 1.5 of bulk when pulled fresh in February; but on being pulled in April the luss of weight in steaming decreased to 1.6. Potatoes did not lose above $1-50$ of their weight by steaming, and none of their balk. The heifers on steamed food not only consumed a greater weight of fresh turnips, in the ratio of 37 to 25 , but after allowing for the loss of steaming, they consumed more of the steamed tarnips. Thus, after deducting 15 from $37 \mathrm{cwts} .16 \mathrm{lbs}$ - the weight lost in steaming them-the balance, 29 cwts. 2 grs. 17 lbs. is more than the $25 \mathrm{cw}$ ts. 1 qr. 14 lbs, of raw turnips consumed, by 4 cwts. 1 qr. 3 lbs. All the cattle, both on the steamed and raw food, relished salt: 80 much 80 , that when it was withheld, they would not eat their food with the avidity they did when it was returned to them.

(1272.) Steamed food should always be given in a fresh state-that is, new made ; for, if old, it becomes sour, when cattle will scarcely rouch it, and the eourer it is they dislike it the more. "In sbort," says Mr. Walker, "the quantity they would consume might have been made to agree to the fresh or sour state of the food when presented to them. . . We are quite aware that to have done a large quantity at one steaming would have lessened the expense of coal and labor, and, also, by getting sour before being used, saved a great quantity of food; but we are equally well aware that, by so doing. we never could have fattened our cattle on steamed food.'

(1273.) An inspection of the above table will show that both heifers and stots increased more in tive-weight on steamed than on raw food; the larger profit derived from the raw food arising solely from the extra expense incurred in cooking the food. It appears, however, that a greater increase of tallow is derived from raw food. The results appear nearly alike with heifers and stots of the same age; but if the stots were of a breed possessing less fattening properties than cross-bred heifers-and Mr. Walker does not mention their breed-then they would seem to ac. quire greater weight than heifers, which 1 believe is the usual experience. The conclusion corve to by Mr. Walker is this: "We have no hesitation in saying that, in everv respect, the advantage is in favor of feeding with raw food. But it is worthy of remark that the difference in the consumption of food arises on the turnips alone. We would therefore recomnend every person wishing to feed cattle on steamed food to use potatoes, or any other food that would not lose bulk and weight in the steaming process, as there is no question bot, in doing 10 . they would be brought much nearer to each other in the article of expense of keep. . U Un the whole, we freely give it as our opinion that steaming food for cattle will vever be attended with beneficial results under any circumstances whatever. because it requires a more watchful and vigilant superintendence during the whole process than can ever be delegated to the common run of ecrvants, to bring the cattle on steamed food even upon a footing of equality, far lezs a i periority, to those fed on raw food." "*

(1274.) One of the stots that had been fed on raw and another on steamed food were kept and put to grase. In their external condition no one was capable of judging how they had been fed. They were put to excellent grass on the 20th May, and the stot on raw fuod gained condition until 20 th July, when, perhaps, the pasture may hnve begun to fail. That on steamed food fell off to that time 3 stones live weight. On 20 ih August both were put on cut grass, and both improved, especially the one that had been on steamed food. until the 18 th October, when both were put on turnips. on which both became alike by the 10th November, relatively to what they were at the begimning of the season; that is, the stot that had been on raw food increased from 108 to 120 stones, and the other from 106 to 118 stones, live weight.

(1275.) Similar results as to profit were obtained by the experiments of Mr. Howden. Law. head, East Lothian. "To me," he says, "it has been moat decidedly shown that preparing food in this way [by steaming] is anything but profitable. Local advantages--such as fuel and water being at hand-may enable eome others to steam at less expense: but in such a situation as mine. I am satisfied that there will be an expense of $10 \mathrm{~s}$ a head apon cattle incurred. by the practice. A single horse-load of conls, carriage included, costs me $10 \mathrm{~s}$; and exactly 6 cart.loads were required and used in preparing the food for cattle, equal to $68.8 \mathrm{~d}$. each, and probably as much more would not be an over-estimate for the additional labor in the 3 monthe." A few facts, worthy of attention, have been brought to light by Mr. How den's experiment. It seems that raw potatoes and water will make catsle fat-a point which has been questioued by some of our best farmers. Potatoes, beans and oats, taken together, will feed cheaper, in reference to time, than turnips or potatoes separately ; nnd from this fact may be deduced these, namely; that potatoes, when used alone, to pay their expense, would require the beef fed by them to fetch $4 \mathrm{~d}$. per $1 \mathrm{~b}$.;

" Ir.z." Esans of the Highland and Agricultural Society, vol. $x$. (Y98) 
turnips alone, $3 \frac{1}{3} \mathrm{~d}$. ; and potatoes and corn together, $3 \mathrm{~d}$., and at the same time yielaing beef of finer quality. There is a curious fact to be observed in the table given by Mr. Howden. Of 6 heifers, 1 in a lot of 3 weighed $1022 \mathrm{lbs}$; and another, in another lot of 3, weighed also $1022 \mathrm{lbs}$., on 5th March, when both were put up to be experimented on; and on the 5th June following both were of the same weight, namely, $1176 \mathrm{lbs}$., both showing exactly an increase of $154 \mathrm{lbs}$; both being supplied with the same weight of food, namely, $140 \mathrm{lbs}$. of turnips, to the one given raw, to the other cooked. This is a remarkable coincidence; but here it ends, and the superiority of cooked food becomes apparent; for the beef of the heifer fed on raw turnips weighed 5 sts. 12 lbs. and its tallow 5 sts. 10 lbs. ; whereas, the beef of the one fed on steamed turnips weighed 44 sts. 4 lbs., and its tallow 6 sts. 22 lbs. How is this to be accounted for? Partly, no doubt, in the cooking of the food; but partly, I should suppose, from the state of the animal indicated by its hide, the the thinner one of the heifer fed on steamed turnips weighing 3 sts. $10 \mathrm{lbs}$., showing a greater disposition to fatten-that is, to lay on more rapidly the valuable constituents of beef and tallowthan the thicker hide of the other heifer fed on raw turnips, which weighed 4 sts. 4 Ibs. It is but justice, however, to the raw turnips to mention a fact to which Mr. Howden adverts. The turnips appropriated to the experiment were, it seems, stored against a wall, one store having a northern and the other a western aspect; but whether from aspest, or dampness, or other cause, those intended to be eaten raw had fermented in the gtore awhile before being observed, and thus, becoming unpalatable, of the 18 tons $15 \mathrm{cwts}$. stored, about $2 \frac{1}{2}$ tons were left unconsumed; so that, in fact, the heifers upon raw turnips did not receive so much food. or in so palatable a state as those on the steamed. It seems steaming renders tainted turnips somewhat palatable, while it has a contrary effect on tainted potatoes, the cattle preferring these raw. Turnips require a longer time to steam, and according to Mr. Howden's experience, they lose $\frac{1}{8}$ or $1-10$ more of their weight than potatoes." You may observe, from the state of the turnips in the store, the injudiciousness of storing them against a wall, as I have before observed (1019).

(1276.) Mr. Boswell of Kingcausie, in Kincardineshire, comes to the same conclusion in regard to the unprofitableness of feeding cattle on cooked food. He says, "It appears that it is not worth the trouble and expense of preparation to feed cattle on boiled or steamed food; as, although there is a saving in food, it is counterbalanced by the cost of fuel and labor, and could only be gone into profitably where food is very high in price and coal very low." His experiments were made on 10 dun Aberdeenshire horned cattle, very like one another, and their food consisted of the Aberdeen yellow bullock-turnips and Perthshire red potatoes. The 5 put on raw food weighed alive 228 stones $11 \mathrm{lbs}$., and the other 5 on cooked food 224 stones $6 \mathrm{lbs}$. imperial. When slaughtered, the butcher considered both beef and tallow "to be perfectly alike." Those fed on raw food cost £32 28. Id., and those on cooked $£ 345 \mathrm{~s}$. IUd., leaving a balance of expense of $£ 2$ 3s. $9 \mathrm{~d}$. in favor of the former. The op:nions of feeders of cattle are not alike on all points. Thus, Mr. Boswell says, "The lot on raw consumed much more food than those on steamed," a fact directly the reverse of that stated by Mr. Walker in (1266). "Twice a week, on fixed days," he continues, "both lots got a small quantity of the tops of common heath, which acted in the way of preventing any scouring ; in fact, turnip-cattle seem very fond of heather as a condiment." .. "The dung of the steamed lot was from first to last in the best state, without the least appearance of parging, and was free of that abominable smell which is observed when cattle are fed on raw potatoes, or even when a portion of their food consists of that article. Another fact was observed, that after the steamed lot had taken to their food, they had their allowance finished sooner than the raw lot, and were therefore sooner able to lie down and ruminate." There is a curious fact mentioned by Mr. Boswell regarding a preference and dislike shown by cattle for turnips in different states. "When raw turnips and potatoes were put intu the stall at the same time, the po. tatoes were always eaten up before a turnip was tasted; while, on the other hand, steamed tur nips were eaten in preference to steamed potatoes." $\dagger$

(1277.) Some curious and interesting facts have been arrived at by $\mathbf{M r}$. Stephenson. Whitelaw, East Lothian, in his experience of feeding cattle. They are detailed by him in a paper on feeding different lots of cattle, not with cooked and raw food, but with different sorts of food in a raw state. He divided a number of cattle into 3 lots, containing 6 in each lot, and fed one on oil cake, bruised beans, and bruiscd oats, in addition to whatever quantity of turnips they could eat, and potatoes for the last few days of the experiment; another lot received the same sort of food, with the exception of the oil.cake; and the third lot was fed entirely on turnips. The live weights of the lots varied considerably from 486 to $346 \frac{1}{2}$ imperial stones. I need not detail the particulars of the experiment, which was conducted from November, 1834, to March, 1835, for 17 weeks, as they present nothing remarkable; but their results are worthy of your attention.

(1278.) Each beast in the lot that got oil-cake cost, in 17 weeks, £5 $2 \mathrm{~s}$. $7 \mathrm{~d}$., or $6 \mathrm{~s}$. per week : in the lot fed on corn, $£ 317 \mathrm{~s}$, or $4 \mathrm{~s} .6 \mathrm{~d}$. per week; and in that fed entirely on turnips, $£ 118 \mathrm{~s}$, $7 \frac{1}{4} \mathrm{~d}$., or $2 \mathrm{~s} .3 \mathrm{~d}$. a week. Estimating the value of the fed beef at $6 \mathrm{~s}$. $6 \mathrm{~d}$. per imperial stone, there was a loss of $12 \frac{1}{3}$ per cent. sustained on the lot fed on oil.cake; a gain of $8 \frac{1}{2}$ per cent. on that fed on corn: and a gain of 22 per cent. on that fed entirely on turnips.

(1279.) This was the cost incurred for producing every $1 \mathrm{lb}$. of increase of live weight, the lot fed on oil cake increasing from 486 to 594 stones; that on corn from 443 to 544 stones; and that on turnips from $346 \frac{1}{2}$ to $395 \frac{1}{2}$ stones.

The oil-cake cost $49-10$ pence to produce $1 \mathrm{lb}$. of live weight.

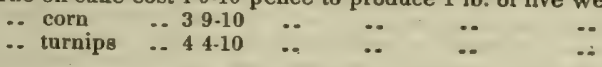

It thus appears that the joint agency of corn and turnips produces $1 \mathrm{lb}$. of live weight at the cheapest rate of the three modes adopted. 
(1280.) Another conclusion come to frum the data supplied by this experiment is, that it took$90 \mathrm{lbs}$. of turups to produce $1 \mathrm{lb}$. of live weight.

$\begin{array}{rlll}40 \mathrm{lbs} \text { of potatoes } & \ldots & \ldots & \text {.. } \\ 87.10 \text { lbs. of corn } & \ldots & \ldots & \ldots \\ 218.10 \text { lbs. of oil-cake } & \ldots & \ldots & \ldots\end{array}$

And the cost of doing this was as iollows:

90 lbs. of turnips, at 4 d. per cwt..................3 2-10d. per $1 \mathrm{lb}$. of live weight.

$40 \mathrm{lbs}$, of potatoes, at 1s.6d. per cwt ...............6 4-10d.

$87.10 \mathrm{lbs}$. of corn at $38,3 \mathrm{~d}$. per bushel of $60 \mathrm{lbs} . . . . .55$ 7-10d.

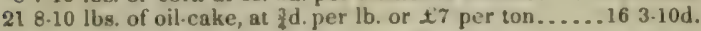

$\begin{array}{lll}\cdots & \cdots \\ \cdots & \cdots\end{array}$

Could these results be proved to be absolutely correct, there would be no difficulty of assigning the degree of profit to be derived from employing any of these subs'ances in the feeding of cattle. Is not the inquiry, however, of as much importance, even in a national point of view, as to deserve investigation at some sacrifice of both cost and trouble?

(1281.) You should not suppose that cattle cousume food of any sort in a uniform ratio; for see actual results. The lot that was fed entirely on turnips increased in the first 32 days of the experiment only 8 stones, wherens the same beasts. in 46 days immediately preceding those on which the experiment began, increased $48 \frac{1}{2}$ stones; and in one 8 days of the 46 they consumed 160 8-10 lbs, each of white globe turnips every day, and increased $1 \mathrm{lb}$. of live weight for every $654.10 \mathrm{lbs}$. of turnips consumed. The $90 \mathrm{lbs}$. Iaken above as the quantity of turnips required to produce $1 \mathrm{lb}$. of live weight is therefore not absolute, but assumed as a medium quantity, for it will happen that $1,000 \mathrm{lbs}$. will not produce $1 \mathrm{lb}$. of live weight. What the circumstances are which regulate the tendencies of cattle to fatten, are yet unknown. The fact is, cattle consume very different quantities of turnips in different states of condition, consuming more when lean, in proportion to their weight, than when fat. A lean beast will eat twice, or perlıps thrice, as many turnips as a fat one, and will devour as much as $\frac{1}{d}$ part of his own weisht every day, while a very fat one will not consume 1-10. I had a striking example of this one year, when 1 bought a very lean 2.year-old steer, a cross betwixt a Short.Horn bull and Angus cow, for $\perp 6$ in April and he was a large-boned, thriving creature, but his bones were cutting the skin. He was immediately put on Swedish turnips; and the few weeks he was on them, before being turned to grass, he could hardly be satisfied, eating three times as much as the fat beasts in the eane hammel. He was grazed in summer, and fed off on turnips and sold in April following for 17 goines. Some stots of Mr. Stephenson's, in November, eat $27.10 \mathrm{lbs}$. for every stone of live weight they weighed; the year after the quantity decrensed to $19.10 \mathrm{lbs}$, and after the experiment was incladed, when their live weights were nearly doubled, they consumed only $15-10 \mathrm{lbs}$

(1282.) The object which Mr. Stephenson had in conducting the experiment the results of which are narrated above, were fourfold: 1 . To compare cattle fed partly on oil-cake with those which had none; 2. To compare those fed partly on corn with those which had none; and 3 . To compare those fed solely on turnips with those which had different sorts of food. The results were, that oil cake is an unprofitable food for cattle, that corn yields a small profit, that turnips are profitable, and that when potatoes can be eold at 18.6d. per cwt. they are also unprofitable. "When any other food than turnips," observes Mr. Stephenson, " is desired for fceding cattle, we would recommend bruised beans as being the most efficient and least expensive ; on this account we would prefer bruised beans alone to distillery offul. As regards linseed-cake, or even potatoes, they are not to be compared to beans." . . "W e give it as our opinion, that whoever feeds cattle on turnips alone will have no reason, on the score of profit, to regret their not having employed more expensive auxiliaries to hasten the fattening process. This opinion has not been rashly adopted, but has been confirmed by a more extended and varied experience in the feed. ing of cattle than has fallen to the lot of most men." 4. Another object he had in these experiments was, to ascertain whether the opinion is correct or othęrwise, that cattle consume food in proportion to their weights. On this subject Mr. Stephenson gays "that cattle consume food something nearly in proportion to their weights, we have very little doubt, provided they have previously been fed in the same manner, and are nearly alike in condition. Age, sex, aud kind have little influence in this respect, as the quantity of food consumed depends much on the length of time the beast has been fed, and the degree of maturity the animal has arrived at-hence the great difficulty of selecting animals to be experimented upon. To explain our meaning by an example, we would say that 2 cattle of the same weight, and which had been previously kept for a censiderable time on similar food, would consume about the same quantity. But, on the contrary, should 2 beasts of the same weight be taken, the one fat and the other lean, the lean beast would perhaps eat twice, or perhaps thrice. as much as the fat one-more especially if the fat one had been for some time previously fed on the same food, as cattle eat gradually less food until they arrive at maturity, when they become stationary in their appetite." . . . "We shall conclude," he says, "by relating a singular fact," and a remarkable one it is, and worth remembering, "that sheep on turnips will consume nearly in proportion to caltle, weight for weight, that is, 10 sheep of 14 lbs. a quarter, or 40 stones in all, will eat nearly the same quantity of turnips as an ox of 40 stones; but turn the ox to grass, and 6 sheep will be found to consume an equal quantity. This great difference may perbaps," say's Mr. Stephenson, and I think truly, "be accounted for by the practice of sheep cropping the grass much closer and ofiener than cattle, and which, of course, prevents ita growing so rapidly with them as with cattle."*

(1283.) Still another question. remains to be considered is reference to the feeding of cattle in winter, which is, whether they thrive best in hammels or in byres at the stake? The determination of this question would settle the future construction of steadings; for, of course, if more profit were certainly yielded to the farmer to feed his cattle in hammels than in byres. not only would

* Prize Esasas of the Highland and Agricultural Society, vol. xii. $(1000)$ 
no more byres be erected, but those in use converted into hammels; and this circumstance would so materially change the form of steadings, as to throw open the confined courts, embraced within quadrangles, to the intluence of the sun, at the only season these receptacles are renuired, namely, in winter. Some facts have alrealy been decided regarding the comparative eflects of hammels and byres upon cattle. Cattle are much cleaner in their persons in hammels than in byres. No doubt they can be kept clean in byres, but not being so, there must be some difticulty incideutal to byre-nanagement, and it consists, I presume, in the cattle-man finding it more laborinus to keep the beasts clean in a byre, than in hammels; otherwise the fact is not easily to be acrounted for, for he takes no specict. care to keep beasts in hamniels clean. Perhaps when cattle have liberty to lie down where they please they may choose the driest, because the most comfortable spot; whereas, in a byre, they must lie down upon what they cannot see behind them. There is another advantage derived from hammels ; the hair of cattle never" scalds oft' the skin. and never becomes short and smonth, but remuins long and mossy, and all licked over, and washed clean by rain, until it is naturally cast in spring, and this advantage is felt by cattle when sent to market in winter, where they can withstand much more wet and cold than those which have been fed in byres. A third advantage is, that cattle from hammels can travel the road without injury to their feet, being accustomed to be so much upon their leet, and to move about. It has been alleged in favor of byres, that they accommodate more cattle on the same space of ground, and are less expensive to erect at first than hammels. That in a given space more beasts are accommodated in byres there is no doubt, and there is as little doubt that more beasts are put in a byre than should be ; but I have great doubts that it will cost more money to accommodate a given number of cattle in the hammel than in the byre system; because hammels can be constructed in a temporary form of wood and straw, and make beasts very comfortable at a moderate charge, whereas byres cannot be formed in that fasbion; and even in the more costly form of roofs and walls, the shedding of hammels requires, comparatively to a byre, but a small stretch of roof; and it is well known that it is the roof and not the bare masonry of the walls hat constitute the most costly part of a steadiog. I have seen a set of hammels, having stone and lime walls, and feed. ing-troughs, and a temporary roof, erected for $£ 1$ for every beast it could accommodate, and no form of byre could be built at that cost. But all these advantages of hammels would be of trifling import, if it can be proved by experience that cattle afford larger profits on being fed in byres; and unless this superiority is established in regard to either. the other is undeserving of preference. How then, stands the fact? Has experiment ever tried the comparative effects of both on anything like fair terms? Mr. Boswell of Balmuto, in Fifeshire, and of Kingcausie, in Kincardineshire, has done it; and it shall now be my duty to make you acquainted with the results.

(1284.) To give as much variety to this experiment as the circumstances would admit, it was conducted both at Balmuto and Kingcausie, and the beasts selected for it were of different ages, namely, 2 and 3-year-olds. At Balmuto 4 three-year-olds were put in close byres, and 4 in open hamriels, and the same number of 2 -vear-olds were accommodated in a similar manner at $\mathrm{K}$ ingcausie. Those at Kingcausie received turnips only, and of course straw : at Balmuto a few potatoes were given at the end of the season, in addition to the turnips. The season of experiment extended from 17 th October, 1834 to 19 th February, 1835. The results were these :-

The 4 hammel-fed 2 year olds at Kingcausie gained of live weight St. $1 \mathrm{~b}$.

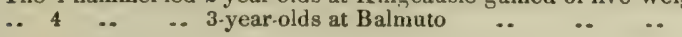

Sts. lbs.

.. 4 byre-fed 2-year-olds at Kingcausie gained of live

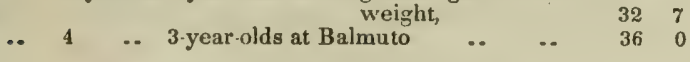

Gain of live weight by the hammel.fed,.................... $\frac{68.7}{23 \quad 1}$

This is, however, not all gain, for the hammel-fed consumed more turnips, the Aberdeen yellow bullock, than the byre-fed.

Those at Kingcausie consumed more by And those at Balmuto ..

Total more consumed,

Tons. cwts. qrs. lbs.

$17 \quad 26$

\begin{tabular}{lrrr}
2 & 4 & 3 & 22 \\
\hline 3 & 12 & 2 & 0
\end{tabular}

In a peruniary point of view, the gain upon the hammel-fed was this:-23 stones $1 \mathrm{lb}$. live weight, $=: 3 \frac{3}{4}$ stones beet, at 6 s. per stone, gives $£_{4} 2 \mathrm{~s}$.. from which deduct the value of the turnips, at 4 d. per cwt., $£ 14 \mathrm{~s}$. 2d., leaving a lance of $£ 27 \mathrm{~s} .10 \mathrm{~d}$.

(1285.) It is a prevalent opinion among farmers, that young cattle do not lay on weight so fast, as old. But this experiment contradicts it; for the 2 year-olds in the hammels at Kingcausie rained 44 stones $22 \mathrm{lbs}$, on their united weights of 320 stones 7 lbs., in the same time that the 3 year-olds in the hammels at Balmuto, weighing together 350 stones, were of gaining 46 stones. Besides. the young beasts in the hammels at Kingcausie gained over those in the byre 12 stones 15 Ibs., while the older cattle in the hammels at Balmuto gained over those in the byre only 10 stones. So that, in tither way. the young cattle had the advantage over the older.

(1286.) Mr. Boswell observes that "hammels ought never to be used unless when the climate is good, and the accommodation of courts dry and well sheltered; and, above all, unless when there is a very large quantity of litter to keep the cattle constantly clean and dry." Shelter is essential for all sorts of stock in any situation, and the more exposed the general condition of the farm is, the more nced there is of shelter; but be the situation what it may, it is, in my opinion, quite possible to render any hammel sheltered enough for stock, not by the distribution of planting, but by temporary erections against its weather-side: and these means will be the more $(1057)$ 
effectual when the howmel is placed facing the meridian sun. which it should be in every caso If these particulars are atteaded to. aud a rain-water spout placed along the eave in front to pro vent the rain from the roof falling into the court, and an open drain. with convenient gratiogs, con nected with all the cuurts, is properly made, the quantity of atraw required will not be inordinate as I have myself experienced when farming dry turnip-soil. Mr. Boswell's testimony in favor of hammels is most satisfactory: it is this. "From the result of my own experiment, as well as the unanimous opinion of every ayriculturist with whum 1 have conversed on the subject, I feel con. vinced that there is no point more clearly established than that cattle inaprove quicker, or, in othet words. Lhrive better in open hamme!s than in close byres." "

(1287.) I have dwelt the longer on the subject of feeding catte. because of its great import. ance to the furmer, and because of the uncertainty sometimes attending its practice to a profitable issue: and there is no loubt that whether it leaves a profit or not depends entirely on the mode in which is prosecuted. Many are content to tatteu their cattle in any way, or because others do so, provided they know they are not actually losing money by it, but if they do not make their cattle in the ripest state they are capable of being made, they are, in fact, losing part of their value. But how are they you may ask, best to be made ripe? There lies the difticulty of the case, and it must be attended with much difficulty before a man of the extensive experience in fattening cattle as Mr. Stephenson, would express hinself in these words: "We have had great experience in feeding stock, and have conducted numbers of experiments on that subject with all possible care, both in weighing the cattle alive, and the whole food administered to them and in every experiment we male we discovered sometheng new. But we have seen enough to convince us that, were the art of feeding better understoud, a great deal more beef and multon might be produced from the same quantity of food than is generally doue." So far ahould guch a declaration deter you from fattening catte, it should rather be a proof of the wideness of the field that is still open for you to experiment in.

(1288.) There are but few diseuses incidental to cattle in a state of confinement in winter, these being chiefly confined to the skin, such as the aftiction of lice, and to accidents in the administration of food, as horen and obstruction of the gullet may be termed.

(1289.) Lice. When it is known that almost every species of quadruped found in the country, and ia a state of nature, is inhabited by one or more pediculidæ, sometimes peculiar to one $k$ ind of animal, at olher times ranging over many, it will not excite surprise that they should also nccur on our domestic ox. Indeed. domestication and the consequences it eutails, such as confinement. transition from a low to a higher coudition, high feeding, and an occasional deviation from a strictly natural kind of food, seem peculiarly favorable to the increase of these parasites. Their occurrence is well known to the breeder of cattle, and to the feeder of fat cattle; and they are not unfrequently a source of no small aunoyance to him. Unless when they prevailed to a treas extent, they are probably not the cause of any positive evil to the aninal, but, as their attacks ure attended with loss of hair, an unhealthy appearance of the skin, and their presence is always more or less unsightly, and a source of personal annoyaue to cattle, they may much impair the animal's look, which, when it is designed to be exhithited in the market, is a matter of no small consequence. As an acquaintance with the appearance and babits of these creatures nust precede the discovery and application of any judicious method of removing or destroying them. I shall describe the species now which are the most common and noxions to the ox. and afterward to the other do. mestic animals of the farm. They may be divided into two sections, according to a peruliarity of structure, which determines the mode in which they attack an animal, namely, those provided with a mouth formed for sucking, and such as have a mouth with two jaws formed for gnaw. ing. Of the former there are 3 species, which are very common. attacking the $o x$, the sow; and the ass.

(1290.) Ox-louse (Hamatopinus surysternus), fig. 268 . It is about 1 or $1 \frac{1}{2}$ lines in length, as seen by the line below the figure, the head somewhat triangular, and of a cliesuat color, the eyes pale brown, antennæ pale ochre-yellow, thorax iarker chesnut than the head, with a spiracle or breathing-bole on each side, and a deep furrow on each side anteriorly : the shape nearly scjuare, the anterior line concave, abdomen bruadly ovate, grayish.white, or very slightly tinged with yellow, with 4 longitudinous rows of dusky horny excrescencer, with 2 black curved marks on the last segment; legs long and strong. particularly the 2 fore-pairs, the color chesnut; claws strong and black. This may be called the common louse that infersts cattle. It is most apt to abound on them when tied to the stall for winter feeding: and a notion prevails in England thut its inerease is owing to the cattle foeding on straw. The fact probably is, that it becomes more plentiful when the animal is tied up, in consequence of its being then less able to rub and lick itself, and the creature is left to propagate, which it does with great rapidity, comparatively undisturbed. It generally concentrates its forces on the mane and shoulders. As the para. site is suctorial, if it is at sll the mesus of causing the hair to fall otf. it can only be by depriving it of the juices by which is nourished, which we can conceive to be the case when the sucker is inserted at the root

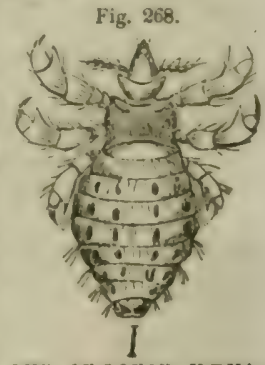

THE OX-LOUSE, HE.MATOPINUS SURYTERNUS. of the hair: but it is more probable that the hair is rubbed off by the cattle themselves, or is shorn off by another louse to be just noticed. The egg or nit is pear-shaped, and may be seen attachod to the hairs.

(1291.) Ox-louse ( Trichodectes scalaris). fig. 269.- This parasite is minute. the length seldom exceediug $\frac{1}{2}$ a line. The hear and thorax are of a light rust color, the former of a romewhat obcordate shape, with two dusky spots in front: the third joint of the antennse longest, and epindle. shaped (in the horse-louse, Trichodectes equi, that joint is clavate; ; abdomen pale, tawny, pubes-

* Prize Essays of the Highland and Agricultural Society, vol. xi. (1058) 
cent, the first 6 segments with a transvere dusky or rust-colored stripe on the upper half, a narrow stripe of the same color along each side, and a large spot at the hinder extremity ; legs, pale tawny. Plentiful on cattle ; commonly found about the mane, forehead, and rump. near the tail-head. It is provided with strong mandibles, with two teeth at the apex, and by means of these it cuts the hairs near the roots with facility. Both these vermin are destroyed by the same means as the sheep-louse (1156).

(1292.) Choking.-When cattle are feeding on turnips or potatoes, it occasionally happens that a piece larger than will enter the gullet easily, is attempted to be swallowed, and obstructed in its passage. The accident chiefly occurs to cattle receiving a limited supply of turnips, and young beasts are more subject to it than old. When a number of young beasts in the same court only get a specified quantity of turnips or potatoes once or twice a day, each becomes apprehensive, when the food is distributed. that will not get its own share, and therefore eats what it can with much apparent greediness, and not taking sufficient time to masticate, swal. lows its food hastily. A large piece of turnip, or a small potato, thus easily escapes beyond the power of the tongue, and, assisted as it is by the saliva, is sent to the top of the gullet, where it remains. Cattle that project their months forward in eating, are most liable to choke. When turnips are sliced and potatoes are broken, there is less danger of the accident occurring even among young cattle. The sight of the obstruction, its consequent effects, and remedial measures for its removal, are thus described by Professor Dick. "The obstruction usually occurs at the bottom of the pharynx and commencement of the gullet, not far from the lower part of the larynx, which we have seen

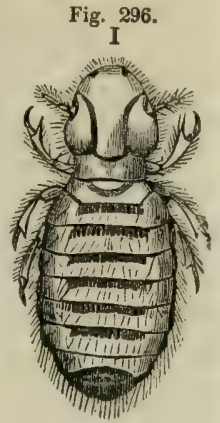

THE OX-LOUSE, TRICHODECTES

SCALARIS. mistaken for the foreign body. The accident is much more serious in ruminating animals than in others, as it immediately induces a suspension of that necessary process, and of indigestion, fol lowed by a fermentation of the food, the evolution of gases, and all those frightful symptoms which will be noticed under the disease hoven. The difficulty in breathing, and the general uneasiness of the animal, usually direct at once to the nature of the accident, which examination bringe under the cognizance of the eye and hand. No time must be lost in exdeavoring to afford relief; and the first thing to be tried is, by gentle friction and pressure of the hand upward and downward, to sce and rid the animal of the morsel. Failing in this, we mention first the great virtue we have frequently found in the use of mild lubricating fluids, such as warm water and oil, well boiled gruel, sc. The gruel is grateful to the animal, which frequently tries to gulp it, and often succeeds. Whether this is owing to the lubrication of the parts, or the natural action superinduced, it is unnecessary to inquire; but the fact we know, that a few pints of warm gruel have often proved successful in removing the obstruction. If this remedy should be ineffectual, the foreign body may perhaps be within the reach of the small hand which a kind dairy-maid may skillfully lend for the purpose. If this good service cannot be procured, the common probang must be used, the cupend being employed. Other and more complicated instruments have been invented, acting upon various princifles-some, for example, on that of bruising the obstructing body ; and the use of these requires considerable skill. Disappointed in all, we must finally have resource to the knife." You may try all these remedies, with the exception of the knife, with perfect confidence. The friction, the gruel, the hand, and the probang, I have successfully tried; but the use of the knife should be left to the practical skill of the veterinary surgeon.

(1293.) The common probang is represented in fig. 271, $a$ being the cup-end, which is so formed that it may partially lay hold of the piece of turnip or potato, and not slip between it and the gullet, to the risk of rupturing the latter, and being of larger diameter than the usual state of the gullet, on pressing it forward distends the gullet, and makes room for the obstructing body to proceed to the stomach. Formerly the probang was covered with cane, but is now with leather, which is more pliab!e. It is used in this manner: Let the piece of wood, fig. 270, be placed over the opened mouth of the animal as a bit. and the straps of leather attached to it buckled tightly over the neck behind the
horns, to keep the bit steady in its place. The nse of the bit is
Fig. 270.
Fig. 27נ

Fig. $270 . \quad$ Fig. 271

(2)

(n)

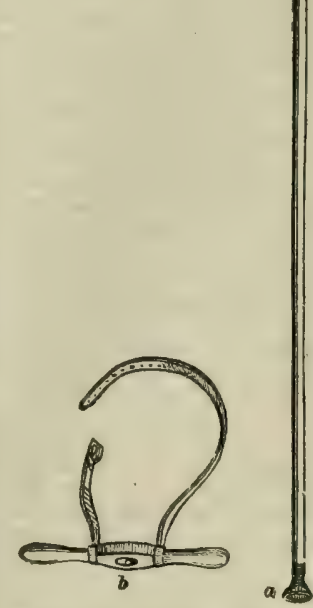
not only to keep the mouch open without trouble, but to prevent the animal injuring the probang with its teeth, and it offers the most direct passage for the probang toward the throat. Let a few men seize the animal on both sides by the horns or otherways, and let its mouth be held projecting forward in an easy position, but no fingers introduced into the nostrils to obstruct the breathing of the animal, nor the tongue forcibiy pulled at the side of the mouth. Introduce now the cup-end $a$ of the probang, fig. 271 , through the round hole $b$ of the mouth-piece, fig. 270 , and push it gently toward the throat until you feel the piece of the turnip obstructing you; push then with a firm and persevering hand, cautioning the men, previous to the push, to hold on firmly, for the

* Dick's Manual of Veterinary Science.

(1059) 
pasage of the instrument may give the animal a little pain, and cause it to wince and even atart away. The obstruction will now most likely give way, eqpecially if the operation bas been performed before the parts around it began to swell; but if not, the jrobang must be used with still more force, while another person rubs with his hands up and down upon the distended thoat of the beast. If these attempts fail, recourse must be had to the knile, and a veterinary surgeon sent for instantly.

(1294.) Hoven.-The loven in cattle is the corresponding disease to the gripes or batts in horses. The direct cause of the symptoms is undue accumulation of gases in the paunch or large stom. ach, which, not finding a ready vent. causes great pain and uneasiness to the animal. and, if not removed in time, ruptures the paunch and death ensues. The cause of accumulation of the gases is indigestion. "Tlie structure of the digestive organs of cattle." Eays Professor Dick. " ren. ders them peculiarly liable to the complaint, while the sudden changes to which they are exposed in feeding prove exciting causes. Thus, it is often witnessod in animals removed from confinement and winter feeding to the luxuriance of the clover field; and in house-fed caule, from the exhibition of rich food, such as peasmeal and beans, often supplied to enrich their milk. We have already mentioned that it sometimes proceeds from obstructed gullet. The symptoms bear so close a resemblance. both in their progress and terminution in rupture and death, to those so fully described above, that we shall not repeat them. The treatment mostly corresponds, and it must be equally prompt. The mixture of the oils of linseerl and turpentiue is nearly a specific." " The recipe is, linseed-oil, raw, $1 \mathrm{lb}$; oil of turpentine, from 2 to $3 \mathrm{oz}$.; laudanum, from 1 to $2 \mathrm{oz}$. for one doze. Or hartshoru, from $\frac{1}{2}$ to $1 \mathrm{oz}$., in 22 pints imperial of tepirl water. In cases of pressing urgency, from 1 to $20 z$. of tar may be added to $\frac{1}{2}$ pint of spirits, and given diluted, with great prospect of advuntage. These medicines are particularly eflective in the early stage of the disease, and should therefore be trient on the first discovery of the animal being affected with it. Should they not give immediate relief. the probang may be introduced into the stomach, and be the means of conveying away the gas as fast as it is penerated; and I have seen it successful when the complaint was produced both by potatoes and clover; but I never saw an instance of loven from turnips, except from obstruition of the gullet. The trial of the probany is useful to show whether the complaint arises from obstruction or otherwise, for should it pass easily down the throat, and the complaint continue, of course the case is a decided one of hoven. Placing an instrument, such as in fig. 270 , across the mouth, to keep it open, is an American cure which is said never to have failed. But the gas may be generated so rapidly that neither medicines nor the probang may be able to prevent or convey away, in which case the apparently desperate remerly of prinching must be had recourse to. "The place for puncturing the paunch," directs Professor Dick, "is on the left side, in the central point between the lateral processes of the lumbar vertebra. the spine of the ileum, and the last rib. Here the trochar may be introduced without fear. If air escape rapidly, all is well. The canula may remain in for a day or two, and, on withdrawal, little or no inconvenience will usually manifest itself. If no gas escape, we must enlarge the opening freely. till the hand can be introduced into the paunch, and its contents removed, as we have sometimes seen, in prodigious quantities. This done, we should close the wound in the divided paunch with 2 or 3 stitchers of fine catgut, and carefully approximate and retain the sides of the external wound, and with rest. wait for a cure, which is often as complete as it is speedy." $\dagger$ To strengthen your confidence in the performance of this operation, I may quote a medical authority on its safe eftects, in the human subject, even to the extent of exposing the intestimes as they lay in the abdomen. "I should expect no immediately dangerous effects from opening the abiloninal cavity. Ir. Blundell has stated that he has never. in his experiments upon the rabbit, ohserved any marked collapse when the peritoneum was laid open, although in full expectation of it. The great danger to be apprehended is from inflammation, and the surgeon, of course, will do all in his power to guard against it." I once used the trochar with success in the case of a Skibo stot which had been put ou potatoes from turnips, and as he was in very high condition, took a litsle bloot from him. and he recovered very rapidly. In another year I lost a fine 1-year old Short.Horn quey by hoven, occasioned by potatoes. Oil and turpentine were used, but as the romplaint had remained too long, before it was noticed by myself, late at night, the medicine had no efiect. The probang went down easily, proving there was no obstruction. The trochar was then thrust in, but soon proved ineffectual, and as I had not the courage to use the knife to enlarge the opening the trochar had made, and withdraw the contents of the paunch with the hand, the animal sank and was immediately slaughtered. The remedies cannot be too soon applied in the case of hoven.

(1295.) The trochar is represented in fig. 272. It consists of a round rod of iron $a, 5$ inches in length, terminating at one end in a triangular, pyramidal-shaped point, and furnished with a wooden handle at the other. The rod is sheathed in a cylindrical cover or case $b$, called the canula, which is open at one end, permitting its point to project, and furnished at the other with a broad. circular flange. The cunula is kept tight on the rod by means of a slit at its end nearest the point of the rod, which, being somewhat ig. 272

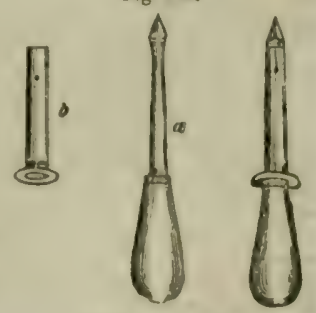

THE TROCHAR. larger in diameter than its own body, expands the slit end of the canula until it meets the body, when the slit collapses to its ordinary size, and the canula is kept sccure behind the enlarged point as at $c$. On using the trochar, in the state as seen by $c$, it is forcel with a thrust into the place pointed out above, through the skin into the paunch; and on withdrawing the rod by its

* Dick's Manual of Veterinary Science.

† Ibid.

\$ Stephens on Obstructed and Inflamed Hernia. (1060) 
handle-which is easily done, notwithstanding the contrivance to keep it on-the canula is left in the opening, to permit the gas to escape through its channel. On account of the distended state of the skin, the trochar may rebound from the throat; and in such an event, a considerable force must be used to penetrate the skin.

(1296.) The fardlebound of cattle and sheep is nothing more than a modification of the disease in horses called stomach-staggers, which is caused by an enormous distension of the stomach. "In this variety, it has been ascertained," says Professor Dick, "that the maniplies are most involved, its secretions are suspended, and its contents become dry, hard, and caked into one solid mass. Though the constipation is great, yet there is sometimes the appearance of a slight purging, which may deceive the practitioner."* The remedial measures are, first, to relieve the stomach by large drenches of warm water, by the use of the stomach-pump. Searching and stimulating laxatives are then given, assisted by clysters, and then cordials.

(1297.) Warts and angle-berries are not uncommon excrescences upon cattle. They are chiefly confined to the groin and belly. I have frequently removed them by ligature with waxed silk thread. Escharotics have great efficacy in removing them-such as alum, bluestone, corrosive sublimate.

(1:98.) Encysted tumors sometimes appear on cattle, and may be removed by simple incision, having no decided root or adhesion. I had a 2-year-old Short-Horn quey that had a large une upon the front of a bind foot, immediately above the coronet, which was removed by simple incision by a veterinary surgeon. What the true cause of its appearance may have been, I cannot say; but the quey, when a calf, was seen to kick a straw.rack violently with the foot affected, and was lame in consequence for a few days; after which, a small swelling made its appearance upon the place, which, gradually enlarging, became the loose and unsightly tumor which was removed.

(1299.) A gray-colored scabby eruption, vulgarly called the ticker, sometimes comes out on young cattle on the naked skin around the eye-lids, and upon the nose between and above the nostrils. It is considered a sign of thriving, and no doubt it makes its appearance most likely on beasts that are improving from a low state of condition. It may be removed by a few applications of sulphur ointment.

(1300.) In winter, when cows are heavy in calf, some are troubled with a complaint commonly called a coming down of the calf-bed. A part of the womb is seen to protrude through the va. ginal passage when the cow lies down, and disappears when she stands up again. It is supposed to originate after a very severe labor. Bandages have heen recommended, but, in the case of the cow, they would be troublesome, and indeed are unvecessary; for if the litter is made firm and higher at the back than the front part of the stall, so as the bind-quarter of the cow shall be higher than the fore when lying, the protrusion will not occur. I had a cow that was troubled with this inconvenience every year, and as she had no case of severe labor in my possession, I did not know whether, in her case, it was occasioned by such a circumstance; but it seemed to give her no uneasiness, when the above preventive remedy was resorted to.

(1301.) It not unfrequently happens to cattle in large courts, and more especially to those in the court nearest the corn-barn, that an oat-chaff gets into one of their eyes in a windy day. An irritation immediately takes place, causing copious watering from the eye, and, if the chaff is not removed, a considerable inflammation and consequent pain soon ensue, depriving the sufferer of the desire for food. To have it removed, let the animal be firmly held by a number of men, and as beasts are particularly jealous of having anything done to their eyes, a young beast even will require a number of men to hold it fast. The fore-finger should then be gently introduced under the eye-lid, pushed in as far as it can go, and being moved round along the surface of the cye-ball, is brought round to its original position, and then carefully withdrawn and examined, to see if the chaff has been removed along with it, which it most likely will be; but if not, repeated at. tempts will succeed. A thin handkerchief around the finger will secure the extraction at the first attempt. Fine salt or snuff have been recommonded to be blown into the eye when so affected, that the consequent increased discharge of tears may float away the irritating substance; but the assistance of the finger is less painful to the animal, and sooner over, and, as it is an operation I have frequently performed with undeviating success, I can attest its efficacy and safety.

\section{DRIVING AND SLAUGHTERING CATTLE.}

"Frisk, dance and leap, like full-fed beasts, and even
Turn up their wanton heels against the Heaven;
Not understanding that this pleasant life
Serves but to fit them for the butcher's knife."
FLAVEL

(1302.) It is requisite that cattle which have been disposed of to the dealer or butcher, or are intended to be driven to market, should undergn a preparation for the journey. If they were immediately put to the roan to travel, from feeding on grass or turnips, when their bowels are full of

\footnotetext{
* Dick's Manual of Veterinary Science.
}

(1061) 
indigested vegetable matter, a scouring might ensue, which would render them unfit to pursue their journey; and this complaint is the more likely to be brought on from the strong propensity which cattle have to take violent exercise on feeling themselves at liberty from a long confinement. They in fact become light-headed whenever they leave the hammel or byre, so much so that they actually "frisk, dance and leap," and their antics would be highly amusing, were it not for the apprehension they may hurt themselves against some opposing object, as they seem to regard nothing before them. I remember seeing a dudded Angus stot let out of a byre running so recklessly about that at length he came at full speed with his head against the wall of the steading, and was instantly felled to the ground. Before any one could run to his assistance he sprang upon his feet and made off again at full speed, holding his head high and tail on end, as if he felt proud of having done a feat which no one else could imitate. With distended nostrils and heaving flanks he appeared dreadfully excited; but on being put into his byre he soon calmed down. On being let out for the first time cattle should be put awhile into a large court, or on a road well fenced with inclosures, and guarded by men, to romp about. Two or three times of such liberty will make them quiet; and, in the mean time, to lighten their weight of carcass, they should get hay for a large proportion of their food. These precautions are absolutely necessary for cattle confined in byres, otherwise accidents may befall them on the road, where they will at once break loose. Even at home serious accidents sometimes overtake them, such as the breaking down of a horn, casting off a hoof, spraining a tendon, bruising ribs, and heating the whole body violently; and, of course, when any such ill luck befalls, the animal affected must be left behind, and become a drawback upon the value of the rest, unless kept on for some time longer.

(1303.) Having been prepared for the road, the drover-who may he your own shepherd, or a hired professional drover-takes the road very slowly for the first two days, not exceeding 7 or 8 miles a day. At night, in winter, they should be put into an open court and supplied with hay and water and a very few turnips; for if the turnips are suddenly withdrawn from them, their bellies will become what is termed clinged, that is, shrunk up into smaller dimensions - a state very much against a favorable appearance in a market. After the first two days they may proceed faster, say 12 or 13 miles a day if very fat, and 15 if moderately so. When the journey is long and the beasts get faint in travel, they should get corn to support them. In frosty weather, when the roads become very hard, they are apt to become shoulder-shaken, an effect of founder; and if sleet falls during the day, and becomes frozen upon them at night, they may become so chilled as to refuse food, and shrink rapidly away. I had a lot of 12 Angus oxen so affected on their ruad to Glasgow, when overtaken in an unexpected storm in May, that I could scarcely recognize them in the market. Cattle should, if possible, arrive the day before in the neighborhood of a distant market, and be supplied with a good feed of turnips and hay, or grass, to make them look fresh and fill them up again; but if the fair is only a short distance, they can travel to it early in the morning.

(1304.) In driving cattle the drover should have no dog, which will only annoy them. He should walk either before or behiud, as he sees them disposed to proceed too fast or loiter on the rond; and in passing carriages the leading ox, after a little experience, will make way for the rest. In other respects their management on the road is much the same as that of sheep, though the rate of traveling is quicker. Accommodation will (1062) 
be found at night at stated distances along the road. On putting oxen in a ferry-boat the shipping of the first one only is attended with much trouble. A man on each side should take hold of a horn, or of a halter made of any piece of rope, should the beast be hornless, and other two men, one on each side, should push him up behind with a piece of rope held between them as a breaching, and conduct him along the plank into the boat, which, if it have low gunwales, a man will require to remain beside him until one or two more of the cattle follow their companion, which they will most readily do. In neglecting this precaution in small ferry-boats, I have seen the first beast leap into the water, and then it was difficult to prevent some of the rest doing the same thing from the quay.

(1305.) Whatever time a lot of cattle may take to go to a market, they should never be overdriven. There is great difference in management in this respect among drovers. Some like to proceed on the road quietly, slowly, but surely, and to enter the market in a placid, cool state. Others, again, drive smartly along for some distance and rest to cool awhile, when the beasts will probably get chilled and have a staring coat when they enter the market; while others like to enter the market with their beasts in an excited state, imagining them then to look gay; but distended nostrils, loose bowels and reeking bodies, the ordinary consequences of excitement, are no recommendations to a purchaser. Good judges are shy of purchasing cattle in a heated state, because they do not know how long they may have been in it, and, to cover any risk, will give $£ 1$ a head below what they would have bid for them in a cool state. Some drovers iave a habit of "thumping at the hindmost beast of the lot with his stick -hile on the road. This is a reprehensible practice, as the flesh, where umped, will bear a red mark after the animal has been slaughtered, the mark getting the appropriate name of blood-burn, and the flesh so affected will not take on salt, and is apt to putrefy. A touch upon the shank, or any tendonous part, when correction is necessary, is all that is required; but the voice, in most cases, will answer as well. The flesh of overdriven cattle, when slaughtered, never becomes properly firm, and their tallow has a soft, melted appearance.

(1306.) A few large oxen in a lot look best in a market on a position rather above the eye of the spectator. When a large lot is nearly alike in size and appearance, they look best and most level on a flat piece of ground. Very large fat oxen never look better than on ground on the same level with the spectator. An ox, to look well, should hold his head in a line with the body, with lively ears, clear eye, dewy nose, a well-licked hide, and stand firmly on the ground on all his feet. These are all symptoms of high health and good condition. Whenever you see an ox shifting his standing from one foot to another, he is foot-sore, and has been far driven. When you observe him hanging his head and his eyes watering he feels ill at ease inwardly. When his coat stares he has been overheated some time, and got a subsequent chill. All these latter symptoms will be much aggravated in cattle that have been fed in a byre. You may discover when a beast has been fed at the stake with the seal or baikie, by observing a fretted and callous mark on the top of the neck immediately behind the ears; by the hoofs being rather overgrown at the points; by marks of dung, or at least much resting, upon the outside of the hams; and very frequently by the remains of lice upon the tail-head and top of shoulder, their scurf remaining, or the hair shorn off altogether.

(1307.) In all customs relating to marliets it is the same with cattle as with sheep (1167). And an ox puts on fat precisely in the same manner as a sheep (1169).

(1063) 
(1308.) In judging cattle the procedure is somewhat different from that of sheep, inasmuch as the hair of cattle not hiding their form so effectually as wool does that of sheep, the eye is more used than the hand; indeed, in the case of ripe fed cattle, the eye alone is consulted. The hand as well as the eye is brought into use in judging of lean cattle to lay on to grass or to fatten on turnips; and when we come to consider that matter in summer and autumn, I shall let you know the use of the hand in determining the qualities essential to a good lean beast. Meantime our business is with fat beasts; and although judging them by the eye is not a difficult thing in itself, it is rather difficult to describe in words. With the assistance, however, of the accompanying figures, I hope you will obtain some useful hints toward acquiring a knowledge of the art. When you look at the near side of a ripe ox in profile-and this is the side usually chosen to begin with-whatever be its size, imagine its body to be embraced within a rectangled parallelogram, as in fig. 273 ; and if the ox is filled up in all

Fig. 273.

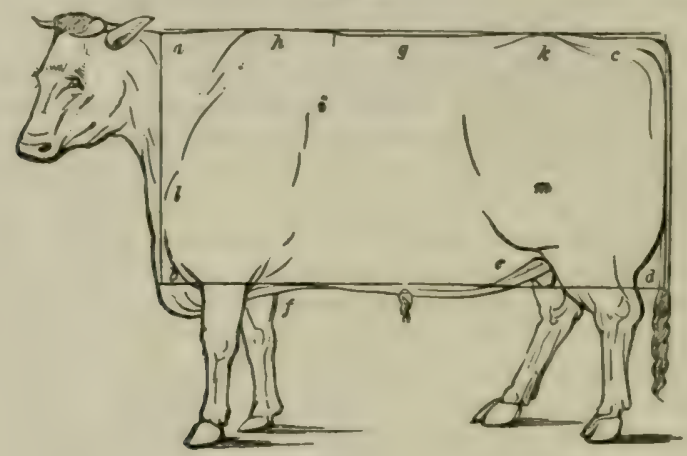

THE SIDE VIEW OF A WELL FILLED-UP FAT $0 X$.

points, his carcass will occupy the parallelogram $a b c d$ as fully as in the figure; but, in most cases, there will be deficiencies in various parts-not that all the deficiencies will occur in the same animal, but different ones in different animals. The flank $e$, for instance, may be shrunk up, and leave a space there to the line; or the brisket $f$ may descend much farther down than is represented; or the rump $c$ may be elevated much above the line of the back; or the milidle of the back $g$ may be much hollowed below the line; or the top of the shoulder $h$ may be much elevated above it; or a large space may be left unfilled in the hams above $d$. Then a similar survey should be made behind the animal; the imaginary line should inscribe it also within it the perimeter of a rectangled parallelogram, though of different form from the other, as represented in fig. 274, where the breadth of the hook-bones, $a$ and $b$, is maintained as low as the points $c$ and $d$; and the closing hetween the legs at $e$ is also well filled up. This figure gives a somewhat exaggerated view of the appearance of a fat ox behind; but still it gives the form of the outline which it should have. Then go in front of the ox, and there imagine the outline of the body at the shoulder, inscribed within a rectangled parallelogram $a b c d$, fig. 275, of exactly the same dimensions as the one in fig. 274. The shoulder, from $a$ to $b$, is apparently of the same breadth as across the hook-bones, fiom $a$ to $b$, fig. 274. The off-side of the animal may of course be expected to be similar in outline to the near side. Having thus (1061) 
obtained an idea of the outline which a fat ox should have, let us now attend to the filling up of the area of the parallelogram.

Fig. 274.

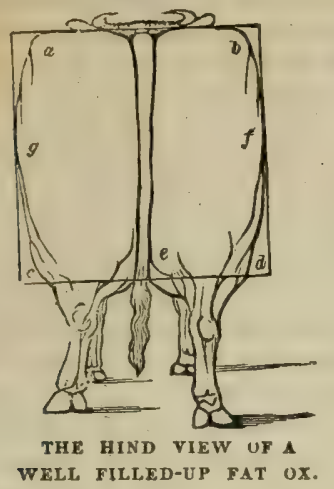

Fig. 275.

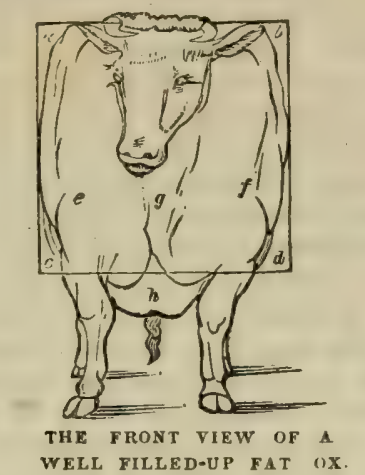

(1309.) On looking again at the near-side view, fig. 271, observe whether the ribs below and on each side of $g$ are rounded, and nearly fill up the space between the more projecting points $h$ and $k$, that is, between the shoulders and the hook. Observe also whether the shoulder $h$ is flat, somewhat in the same plane as $g$, or more rounded and prominent ; and whether the space behind the shoulder, at $i$, is hollow or filled up. Observe, again, whether the shoulder-point $l$ is projecting and sharp, or rounded off; and whether the neck, between $a$ and $l$, is flat and sunk, or sweeps fine'y in with the shoulder. Observe yet more, whether the muscles at $m$ are thin and flat, or full and rounded; and whether the hook-bone $k$ projects or sinks in, or appears to connect itself easily with the rump $c$ on the one hand, and with the ribs $g$ on the other. With all these alternative particulars before you, they should be arranged in the following manner, to constitute points in perfection.

(1310.) The line from the shoulder to the hook, from $h$ to $k$, fig. 273, should be parallel to the back-bone. The space on each side of $g$, along the ribs from $g$ to $h$, and along the loin from $g$ to $k$, does not fall in with the line $h$ and $k$, but should be a little nearer, and almost as high as the back-bone, with a rounding fall of the ribs down the side of the animal. The loin, from $k$ to $g$, should be perfectly flat above, on the same level as the back-bone, and drop down on this side, in connection with the utmost rounding of the ribs. The point of the hook $k$ should just be seen to project, and no more ; and the space between it and the rump $c$ should gradually sweep round to the narrower breadth of the pelvis, as seen from $a$ to $c$ or $b$ to $c$ in fig. 276. $i$ is placed at the utmost bend of the ribs, along which a straight line should touch every point through $i$, from the front of the shoulder to the buttock. The triangular space comprehended within $a, l$ should gradually taper from the shoulder-point to the head. A straight line from $l$, the shoulder-point, should touch every spot from it to $m$. The line of the back should be straight from $a$ to $c$; the tail should drop perpendicularly from $c$ to $d$; and the belly should sweep level, not high at $e$ nor dropping at $f$. There are thus three straight lines along the side of a fat $\curvearrowright \mathrm{x}$, from $a$ to $c$, one through $i$, and from $l$ to $m$. Proceeding behind the animal to fig. 274, the space between the hooks, from $a$ to $b$, should be level, but a little rounded off at both ends, and the bone at the top of the tail only being allowed to project a little upward. The muscles on each side 
below the hooks, at $g$ and $f$, when fuller than the hooks, is no deformuty, but should they be no fuller, they are right. The muscles at $c$ and $d$, down the side of the hams, are allowed to sweep gradually toward the hock joints of the legs. The closing at $e$ should be well filled up to furnish the rounds fully, but freely, for packed rounds prevent easy motion of the hind legs. Sometimes the tail is hid in a channel left by the muscles between $e$ and $f$, but this is not usually the case. On going to the front view, fig. 275, the shoulder-top between $a$ and $b$ should be filled out with a natural round, and the muscles below it upon the shoulder-blades should always project farther than the breadth of the shoulder-top, and in this respect the fore-quarter differs from the hind, where the muscles below the hooks seldom project beyond them. The shoulder-points $e$ and $f$ should not be prominent, but round off with the muscles of the neck toward $g$ where the round of the front of the neck falls from the head to the breast where the upper part of the brisket $h$ meets it, and projecting a little in front, is rounded below and forms the lowest part of the body of a fat ox, and should be well filled out in breadth to spread the fore-legs asunder. The fore-legs are usually farther apart than the hind, but the hind at times, when the shaw or cod is large and fat, is as much and even more apart.

(1311.) The objectionable deviations from these points are as follow's : In fig. 273 , a hollow back at $g$ is bad, showing weakness of the back-bone. A high shoulder-crest at $h$ is always attended with a sharp thin shoulder, and has the effect of bringing the shoulder-tops $a$ and $b$, fig. 275, too close together. A long distance between $g$ and $k$ makes the loins hollow, and gives to a beast what is called a washy appearance, and is always attended with a liability to looseness in the bowels. This washiness is generally attended with an inordinate breadth of hooks, from $a$ to $b$, fig. 274 , and causes them to project much beyond the muscles below. A sharp projecting hook is always accompanied with flat ribs at $g$, fig. 273, and ribs when flat give the animal a hollow side, which bears little flesh, the viscera being thrown down into the cavity of the belly, which droops considerably below the line; but in the event of the muscles of the abdomen having a greater weight to bear, they become thicker and stronger, and, accordingly, the flesh there becomes less valuahle, and it has also the effect of thinning away the thick flank $e$. Flatness of rib is also indicative of hollowness of the space behind the shoulder, so much so, indeed, that the animal seems as if it had been gripped in too firmly there. As the flesh is taken away from the shoulder-blade by a sharp shoulder and hollow ribs, sn the shoulder-joint $l$ projects the more, and causes a thinness of the neck between $a$ and $l$. The rumpbone, at $c$, frequently rises upward, thereby spoiling the fine straight line of the back; and whenever this happens, the rump between $k$ and $c$ wants flesh and even becomes hollow, thereby much deteriorating the value of the hind-quarter. A projecting hook $k$ also thins away the muscles about $m$, and behind it to the rounds; and this again is followed by an enlargement of the

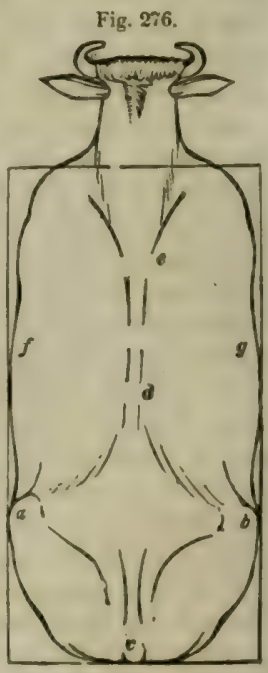

THE BACK VIFW OF A WELL-FILLED FAT OX. openings at the closing $e$, fig. 274. Whenever the shoulder becomes thin and narrow, when viewed in front, as in fig. 275, the shoulder-points $e$ and $f$ are wider than from $a$ to $b$, and while this effect is produced above, the $(1066)$ 
brisket $h$ below becomes less fat, and permits the fore-legs to stand rearer each other. A greatly commendatory point of a fat ox is a level broad back from rump to shoulder, because all the flesh seen from this position, as is endeavored to be represented by fig. 276 , is of the most valuable description; where the triangular space included between $a, b, c$, is the rump; the triangular space between $a, b, d$, the loin; and the space between $d$ and $e$, deflecting on both sides toward $f$ and $g$, the ribs, the value of all which parts are enhanced the more nearly they all are on a level with each other. All that I have endeavored to describe, in these paragraphs, of the points of a fat $\alpha x$, can be judged of alone by the eye, and most judges never think of employing any other means; but the assistance derived from the hand is important, and in a beginner cannot be dispensed with.

(1312.) The first point usually handled is the end of the rump at the tail-head, at $c$, fig. 273 , although any fat here is very obvious, and sometimes attains to an enormous size, amounting even to deformity. 'The hook-bone $k$ gets a touch, and when well covered, is right; but should the bove be easily distinguished, the rump between $k$ and $c$ and the loin from $k$ to $g$ may be suspected, and, on handling these places, the probability is that they will both be hard, and deficient of flesh. To the hand, or rather to the poirits of the fingers of the right hand, when laid upon the ribs $g$, the flesh should feel soft and thick and the form be round when all is right, but if the ribs are flat the flesh will feel hard and thin, from want of fat. The skin, too, on a rounded rib, will feel soft and mobile, the hair deep and mossy, both indicative of a kindly disposition to lay $n$ flesh. The hand then grasps the flank $e$, and finds it thick, when the existence of internal tallow is indicated. The cod is also fat and large, and on looking at it from behind seems to force the hind legs more asunder than they would naturally be. The palm of the hand laid along the line of the back from $c$ to $h$ will point out any objectionable hard piece on it, but if all is soft and pleasant, then the shoulder-top is good. A hollowness behind the shoulder at $i$ is a very common occurrence; but when it is filled up with a layer of fat, the flesh of all the fore-quarter is thereby rendered very much more valuable. You would scarcely helieve that such a difference could exist in the flesh between a lean and a fat shoulder. A high narrow shoulder is frequently attended with a ridged back-bone, and low-set narrow hooks, a form which gets the appropriate name of razor-back, with which will always be found a deficiency of flesh in all the upper part of the animal, where the best flesh always is. If the shoulder-point $l$ is covered, and feels soft like the point of the hook-bone, it is good, and indicates a wellfilled neck-vein, which runs from that point to the side of the head. The shoulder-point, however, is often bare and prominent. When the neckvein is so firmly filled up as not to permit the points of the fingers into the inside of the shoulder-point, indicates a well tallowed animal; as also does the filling-up between the brisket and inside of the fore-legs, as well as a full, projecting, well-covered brisket in front. When the flesh comes down heavy upon the thighs, making a sort of double thigh, somewhat like the shape at $d$ and $e$, fig. 274 , it is called lyary, and indicates a tendency of the flesh to grow on the lower instead of the upper part of the body. These are all the points that require touching when the hand is used; and in a high-conditioned ox, they may be gone over very rapidly.

(1313.) Cattle are marle to fast before being slaughtered, as well as sheep. The time they should stand depends on the state of the animal on its arrival at the shambles. If it has been driven a considerable distance in a proper manner, the bowels will be in a tolerably empty state, so that (1067) 
12 hours may sullici, but if full and just off its food, 24 hours will be required. Beasts that have been overdriven, or much struck with sticks, or are in any degree infuriated-or raised, as it is termed-should not be immediately slaughtered, but allowed to stand on dry food, such as hay, until the symptoms disappear. While such precautions are cerluinly necessary to preserve meat in the best state, we can scarcely credit the luss there must be incurred every year in Smithfield market in London, by the injuries sustained by the animals being driven through the streets of an immensely peopled metropolis. The state of many of the animals in the market on a Monday moning is truly pitiable. "The loss to the grazier," says a writer who advocates the removal of the market to the suburbs, "is in the difference in value of his sheep or cattle, when they arrive in the neighborhood of the metropolis, and when offered for sale in Smithfield after intense suffering from hard blows, driving over the stones, from hunger, thirst, fright, and the compressed state in which they are constrained to be packed; the sheep and beasts the whole time, from their raised temperature, clouding the atmosphere of Smithfield with dense exhalations from their bodies. The London butcher, carrying on a respectable trade, will at all times, when he enters the market, reject such cattle or sheep as are what is termed in a mess; that is, depressed, after excitation by being ovérlaid or overdriven, or such as have been more than usually troublesome in getting into the market, and, consequently, will be in a more worried and exhausted condition. It is to be observed that all animals brought into Smithfield, especially on the Monday's market-day, are more or less in the condition above described." He goes on to state that "a calculation has been made, that 512,000 serious and extensive oelematous bruises are, in the course of one year, discovered on cattle after they are slaughtered. The pain these bruises must occasion to the cattle, and the loss to the butcher or the public, is exclusive of those parts of the animal which suffer most from the conduct of the drovers, namely, the head, especially the nasal organs, and concussions of the lrain hy blows on the horns, besides the more acute suffering from blows on the hocks." The beef consumed in London, in 1836 , amounted to $9 \frac{1}{2}$ millions of stomes, which, at 6 s. a stone, gives a total value of $£ 2, \$ 50,000$; and if its deterioration is taken only at half a farthing per pound, the annual loss sustained by the bruises of cattle alone will amount to $\mathcal{E}(i, 9,27016 \mathrm{~s}$.*

(1314.) Cattle are slaughtered in a different manner from sheep, and the mode differs in different countries. In the great albbatoirs at Montmartre, in Paris, they are slaughtered by bisecting the spinal cord of the cervical vertebræ; and this is accomplished by the driving of a sharppointed chisel hetween the second and third vertebra, with a smart stroke of a mallet, while the animal is standing, when it drops, and death or insensibility instantly ensues, and the blood is let out immeliately by opening the blood-vessels of the neck. The plan pursued in this country is, first to bring the ox down on his knees, and place his uniler-jaw upon the ground, by means of ropes fastened to his head and passed through an iron ring in the flonr of the slaughter-house. He is then stunned with a few blows from an iron ax made for the purpose, on the forehead, the bone of which is usually driven into the brain. The animal then falls on its side, and the blood let out by the neck. Of the two modes the French is apparently less cruel; for some oxen require many blows to make them fall; I once witnessed an ox receive nine blows before he fell. I have beard it alleged by butchers that the separation of the spiual cord pro.

- The Question of the Smithfield Market Fully Considered. (1068) 
ducing a general nervous convulsion throughout the body, prevents the blood flowing so rapidly and entirely out of it as when the ox is stunned in the forehead. The skin is then taken off to the knees, when the legs are disjointed, and also off the head. The carcass is then hung up by the tendons of the hough, on a stretcher, by a block and tackle, worked by a small winch, which keeps good what rope it winds up by a wheel and rachet.

(1315.) Every farm on which sheep are killed should have a proper slaughter-house, such as is seen at fig. 1 , Plate I. at $y$, the ground-plan of which may be seen in fig. 2 , plate II., where it is represented to be 10 feet by 9 feet, a space ton small when cattle are slaughtered, but it is very rare that an ox is slaughtered on a farm, except when one is so that is likely to be lost by some acute disease, in which contingency the animal is slaughtered in the straw-barn and hung up by the baluks; but it is quite easy, when the slaughter-house is fitting up, to have a block and tackle and small winch, erected at 'a convenient corner, to be used on such occasions. The floor should be laid with clean-droved pavement, and have a decided slope to the side at which the drain is made to take away the dirty water occasioned by cleaning, which it should always be thoroughly. The walls should also be plastered, and a ventilator placed on the roof, to maintain a draft of air. The site chosen for the slaughter-house should be in a cool place, away from the sun's influence in summer, for in a heated apartment meat never becomes firm. A locked closet is useful to hold the knives, steel, and stretchers, and the outer door provided with a.good thumb-latch and lock and key; the key, of course, always to remain in the farm-house until needed.

(1316.) It is the shepherd's duty to act the part of butcher on a farm. He should learn to slaughter gently, dress the carcass neatly and cleanly, in as plain a manner as possible, without flourishes, as the figures incised on the membraneous skin are called, and separate the valuable from the worthless purtion of the entrails, keeping the loose fat by itself, and hang up the skin in a suitable place to dry. It is his duty also to keep the slaughter-house neat and clean.

(1317.) After the carcass has hung 24 hours, it should be cut down by the back-bone, or chine, into two sides. This is done eitlier with the saw or chopper; the saw making the neatest job in the hands of an inexperienced butcher, though it is the most laborious, and with the chopper is the quickest, but by no means the neatest plan, especially in the hands of a careless fellow. In London the chine is equally divided between both sides, while in Scotland one side of a carcass of beef has a great deal more bone than the other, all the spinous processes of the vertebra being left on it. The bony is called the lying side of the meat. In London the divided processes in the fore-quarter are broken in the middle when warm, and chopped back with the flat side of the chopper, and this has the effect of thickening the fore and middle ribs considerably when cut up. The Loudon butcher also cuts the joint above the hind knee, and, by making some incisions with a sharp knife, cuts the tendons there, and drops the flesh of the hind-quarter on the flanks and loins, which causes it to cut up thicker than in the Scotch mode. In opening the hind-quarter he also cuts the aitch-bone or pelvis through the center, which makes the rumplook better. Some butchers in the north country score the fat of the closing of the hind-quarter, which has the effect of making that part of both heifer and ox lonk like the udder of an old cow. There is far too much of this scoring practiced in Scotland, and ought to be abandoned, and let the pieces have more their natural appearance.

(1069) 
(1318.) In cutting up a carcass of beef the London butcher displays great expertness; he not only discriminates between the qualities of its different parts, but can cut out any piece to gratify the taste of his customers. In this way he makes the best use of the carcass, realizes the largest value for it, while he gratifies the taste of every grade of customers. A. figure of the Scotch and English modes of cutting up a carcass of beef will at once show you their difference, and on being informed where the valuable pieces lie, you will be enabled to judge whether the oxen you are breeding or feeding possess the properties that will enable you to demand the highest price for them.

(1319.) The scotch mode of cutting up a carcass of beef is represented

Fig. 277.

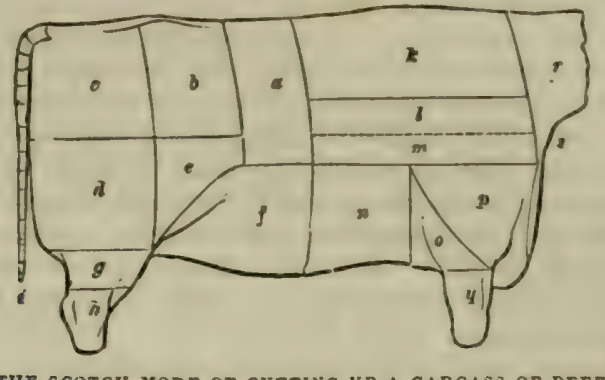

THE SCOTCH MODE OF CUTTING UP A CARCASS OF BEEF.

in $6 \mathrm{~g} .277$, and these are the names of the different pieces of meat:
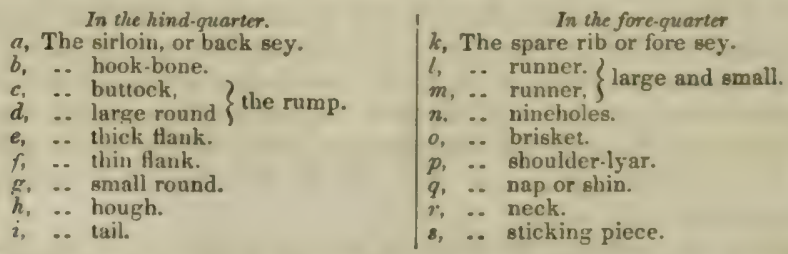

$a$ the surloin is the principal roasting-piece, making a very handsome dish, and is a universal favorite. It consists of two portions, the Scotch and English sides, the former is the one above the lumbar bones, and is somewhat hard in ill-fed oxen; the latter consists of the muscles under these bones, and are generally covered with fine fat, and are exceedingly tender. The better the beast is fed the larger is the under muscle, better covered with fat, and more tender to eat; $b$ the hook-bone and $c$ the buttock are cut up for steaks, beef-steak pie, or minced collops, and both these, along with the sirloin, fetch the highest price; $d$ is the large round, and $e$ the small round, both well known as excellent pieces for salting and boiling, and are eaten cold with great relish; $h$ the hough is peculiarly suited for boiling diwn for soup, having a large proportion of gelatinous matter. Brown soup is the principal dish made of the hough, but its decoction forms an excellent stock for various dishes, and will keep in a state of jelly for a considerable time. The synovial fat, skimmed off in boiling this piece, and poured upon oatmeal, seasoned with pepper and salt, constitutes the famous fat brose for which scotland has long been celebrated. In the making, this brose should not be much stirred, and the oatmeal left among the fat gravy in small, dry lumps. It was of this piece that the old favorite soup of Scotland, called stink, was made. $e$ is the thick and $f$ the thin flank both excellent pieces for salting and boiling; $i$ is the tail, (1070) 
and insignificant as it may seem, it makes a soup of very fine flavor. Hotel-keepers have a trick of seasoning brown soup, or rather beef-tea, with a few joints of tail, and passing it off for genuine ox-tail soup. These are all the pieces which constitute the hind-quarter, and it will be seen that they are valuable both for roasting and boiling, not containing a single coarse piece. In the fore-quarter is $k$, the spare rib or fore-sey, the six ribs of the back end of which make an excellent roast, and when taken from the side opposite to the lying one, being free of the bones of the spine, makes a large one; and it also makes excellent beef-steaks and beef-steak pie. $l$ and $m$ are the two runners, and $n$ the nine-holes, make salting and boiling pieces; but of these, the nine-holes is much the best, as it consists of layers of fat and lean without any bone; whereas the fore parts of the runners have a piece of the shoulder-blade in them, and every piece connected with that bone is more or less coarse-grained; $o$ the brisket eats very well boiled fresh in broth, and may be corned and eaten with boiled greens or carrots ; $p$ the shoulder-lyar is a coarse piece, and fit only for boiling fresh to make into broth or beef-tea; $q$ the nap or shin, is analogous to the hough of the hind-leg, but not so rich and fine, there being much less gelatine in it; $r$ the neck makes good broth, and the sticking-piece $s$ is a great favorite with some epicures, on account of the pieces of rich fat in it. It makes an excellent stew, as also sweet barley broth, and the meat eats well when boiled in it. These are all the pieces of the fore-quarter, and it will be seen that they consist chiefly of boiling-pieces, and some of them none of the finest, the roasting-piece being confined to the six ribs of the spare-rib $k$, and the finest boiling-piece, corned, only to be found in the nine-holes $n$.

(1320.) In some of the largest towns of Scotland a difference of $1 \mathrm{~d}$. per lb. may be made between the roasting and boiling pieces, but in most towns, and in the country villages, all the pieces realize the same prices, and even the houghs and shins fetch $3 \mathrm{~d}$. per $1 \mathrm{~b}$.

(1321.) In the English mode the pieces are cut up somewhat differently,

Fig. 278.

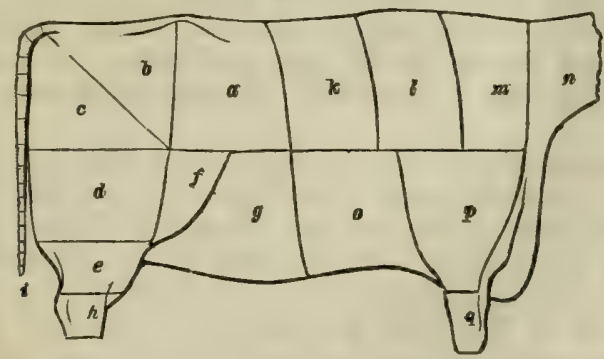

THE ENGLISH MODE OF CUTTIYG UP A CARCASS OF BEEF

especially in the fore-quarter. Fig. 278 shows this mode, and it consist. of the following pieces:

In the kind-quarter.

a, The loin.

b, .. rump.

c, .. aitch-bone.

d, .. buttock.

$e$, .. hock.

f. .. thick flank

$g, \ldots$ thin flank.

$h$, .. shin.

2, .. tail. k. The fore rib.

$l$, .. middle rib.

$m$, .. chuck rib.

$n, \ldots$ clod, and sticking, and neck.

$0, \ldots$ brisket.

$p$, .. leg-of-mutton piece.

q. ... shin. 
$a$, the loin, is the principal roasting piece; $b$, the rump, is the favorite steak-piece; $c$, the aitch-hone, the favorite stew; $d$, the buttock, $f$, the thick flank, and $g$, the thin flank, are all excellent boiling pieces whew corned; $e$, the hock, and $h$, the shin, make soup, and afford stock for various purposes in the culinary art; and $i$ is the tail for ox-tail soup-a favorite English luncheon. In the curious case of assessing damages against the Bank of England for removing the famous Cock eating-house in Threadneedle-street, it was produced in evidence, that, in the 3 years 1837-8-9, there had been 13;359 ox-tails used for soup; and as 36 tails make 10 gallons of soup, there had been served up 59,369 basins, at $11 \mathrm{~d}$. the basin, making the large amount of $£ 2,720$ 13s. $4 \mathrm{~d}$. for this article alone.* These are all the pieces in the hind-quarter, and it will be seen they are valuable of their respective kinds. In the fore-quarter, $k$, the fore rib, $l$, middle rib, and $m$, chuck rib, are all roasting pieces, not alike good; but in removing the part of the shoulder-blade in the middle rib, the spare-ribs below make a good broil or roast; $n$, the neck, makes soup, being used fresh, boiled, and the back end of the brisket $\theta$ is boiled corned, or stewed; $p$, the leg-of-mutton piece, is coarse, but is as frequently stewed as boiled; $q$, the shin, is put to the same uses as the shin and hock of the hind-quarter. On comparing the two modes of cutting up, it will be observed that in the English there are more roasting pieces than in the Scotch, a large proportion of the fore-quarter being used in that way. The plan, too, of cutting the line between $b$ and $c$, the rump and aitch-bone in the hind-quarter, lays open the steak-pieces to better advantage than in the Scotch buttock, $c$, fig. 277. Extending the comparison from one part of the carcass to the other, in both methods, it will be seen that the most valuable pieces-the roasting-occupy its upper, and the less valuable-the boiling-its lower part. Every beast, therefore, that lays on beef more upon the upper parts of its hody is more valuable than one that lays the same quantity of flesh on its lower parts.

(1322.) The relative values of the pieces differ much more in London than in Scotland. The rumps, loin and fore ribs fetch the highest price; then come the thick flank, buttock and middle rib; then the aitch-bone, thin flank, chuck-rib, brisket and leg-of-mutton piece; then the clod, sticking and neck; and last of all the legs and shins. In actual pecuniary value, the last may bear a proportion of only one-fourth of the highest price.

(1323.) Of the qualities of beef obtained from different breeds of cattle, I believe there is no better meat than from the West Highland breed for fineness of grain, and cutting up into convenient pieces for family use. The Galloways and Angus, when fattened in the English pastures, are great favorites in the London market. The Short-Horns afford excellent steaks, being thick of flesh, and the slice deep, large and juicy, and their corned flanks and nineholes are always thick, juicy and well mixed. The Herefords are somewhat similar to the Short-Horns, and the Devons may pernaps be classed among the Galloways and Angus, while the Welsh cannot be compared to the Wost Highland. So that, taking the breeds of Scotland as suppliers of good beef, they seem to be more valuahle for the table than those of England. Any beef that I have seen of Irish beasts is inferior, but the cattle derived from Britain, fed on the pastures of Ireland, afford excellent meat. Shetland beef is the finest grained of all, but the pieces are very small.

(1324.) In regard to the proportion of beef and tallow generally obtained from catte. Dr. Cle. land states that of 14,566 head of cattle sold in the Glasgow market in 1822. averaging exactly

ॠ John Bull, 16th January, 1841.

(1072) 
44 stoncs imperial, each yielded $5 \frac{1}{2}$ stones, which is exactly $\frac{1}{8}$ of the weight of beef* From 4 of the oxen experimented on by Mr. Stephenson, and which were slaughtered at the same time, these results were obtained :

\begin{tabular}{|c|c|c|c|c|c|c|}
\hline CATTLE. & Live weight. & Beef. & Tallow. & Ilide. & Other & oftuls. \\
\hline Nos. & $\begin{array}{l}\text { Sts. } \\
112\end{array}$ & $\begin{array}{lc}\text { Sts. } & \text { lbs. } \\
66 & 2\end{array}$ & $\begin{array}{cc}\text { Sts, } & 16 \mathrm{~b} \\
8 & 10\end{array}$ & Sts. lbs. & Sis. & lbs. \\
\hline 2. & 100 & 58 & 7 & 12 & 29 & 3 \\
\hline 3. & 108 & 62 & 9 & 12 & 26 & 13 \\
\hline 4. & 109 & 62 & 9 & 12 & 31 & 8 \\
\hline
\end{tabular}

The proportion of tallow to beef is here nearer $1-7$ than $\frac{1}{8}$ over the whole beasts; and there is another result worth attending to, which is that of Nos. $\approx$ and 3 , which had the same weight of hide, namely, 4 sts. $12 \mathrm{lbs}$; No. 3 must have had the finest skin and touch, for its superiority in every rexpect is apparent, both in weight of tallow, which was 9 sts. to 7 sts. 7 lbs.; in. weight of beef, which was as $62 \mathrm{sts} .3 \mathrm{lbs}$. to 58 sts. 6 lbs.; and in lightness of other offials, which were as 26 ots. 13 lbs. is to 29 sts. 3 lbs. Besides difference in quality of the same weight of hide, a lighter hide, under similar circumstances, will produce the same results as those above. For example: of two of the heifers fed by Mr. Howden on raw and steamed food, which afforded the sane live weight when put up to feed, namely, $1022 \mathrm{lbs}$, and the same live weight after the experiment was concluded, namely, $1176 \mathrm{lbs}$., one had a light hide, that is, $52 \mathrm{lbe}$. weight, and the other a heavier one, $60 \mathrm{lbs}$, and the light one was accompanied with $620 \mathrm{lbs}$. of beef and $96 \mathrm{lbs}$. of tallow, while the heavier hide was associated with only $572 \mathrm{lbs}$. of beef and $80 \mathrm{lbs}$. of tallow. All these proportions very nearly indicate the tallow at 1.7 of the beef; but sometimes the proportion of tallow is very much greater and much less. I had a young Short-Horn cow which slipped her secoud calf, and was fed when she became dity, which was in November, and in May following was sold to the late Mr. Robert Small, Hesher, Dundee, when she yielded $72 \frac{1}{2}$ stones of beef and 27 stones of tallow, being in the ratio of $2 \frac{2}{3}$ to 1 . On the other hand, Lord Kintore's large ox that was exhibited at the Higbland and Agricultural Society's Show at Aberdeen in 1834 only yielded 16 sts. 7 lbs. of tallow, from 173 sts. 4 lbs of beef; being in the ratio of $10 \frac{1}{2}$ to t.t There are, perhaps, not sufficient data in existence to determine the true proportion of offal of all kinds to the beef of any given fat ox; but approximations have been made which may serve the purpose until the matter is investigated by diret cxperiment, under various circum. stances. The dead weight bears to the live weight a ratio varying between .571 and .605 to 1 ; and on applying one or other multiple to the cases of the live weight, you will find a pretty correct approximation. The tallow is supposed to be $8-100$ of the live weight, so that the multiple is the decimal of .08 . The hide is supposed to be 5-100 of the live weight, so, to obtain its weight, a multiple of .05 should be used. The other offals are supposed to bear a ratio of about $\frac{1}{4}$ of the live weight, so that the multiple of .28 is as near as can be proposed under existing experience $f$

(1325.) Beef is the staple animal food of this country, and it is used in various states-fresh, salt. ed, smoked. roasted, and boiled. When intended to be eaten fresh, "the ribs will keep the best. and with care will keep 5 or 6 days in summer, and in winter 10 days. The middle of the loin is the next best. and the rump the next. The round will not keep long, unless salted. The brisket is the worst, and will not keep longer than 3 days in summer, and a week in winter.'" In cooking, a piece of beef, consisting of four of the largest ribs, and weighing $11 \mathrm{lbs}$. I oz., was sub. jected to roasting by Mr. Donovan, and it lost during the process $2 \mathrm{lbs} .6 \mathrm{oz}$, of which $10 \mathrm{oz}$. were fat. and $1 \mathrm{lb}$. $12 \mathrm{oz}$. water dissipated by evaporation. On dissection, the bone weighed 16 oz., so that the weight of meat fit for the table was only 7 lbs. $11 \mathrm{oz}$. out of $11 \mathrm{lbs}$. $1 \mathrm{oz}$. It appears that when the butchers' price of ribs is $8 \frac{1}{2} \mathrm{~d}$. per lb., the cost of the meat when duly roasted is $11 \frac{1}{2} \mathrm{~d}$. per $\mathrm{lb}$., and the average loss arising trom liquefaction of fat and evaporation of water is 18 per cent. With sirloins, at the price of $8 \frac{1}{2} \mathrm{~d}$. per lb., the meat cost, when roasted. $1 \mathrm{~s}$. 1 1-6 d. per lb., at a loss of $20 \frac{f}{3}$ per cent. A loss of 18 per cent. was also sustained on boiling salted biskets; aud on salted flanks at $6 \mathrm{~d}$. per $\mathrm{lb}$. the meat cost $7 \frac{3}{4} \mathrm{l}$. per lb.. at a loss of $131-5$ per cent. $\delta$ In regard to the power of the stomach to digest beef, that which is eaten boiled with salt only is digested in 2 hours 45 minutes. Beef, fresh, lean, and rarely roasted. and a beef-steak broiled. takes 3 houls to digest: that fresh and dry-roasted, and boiled, eaten with mustard, is digested in 3 hours and 30 minutes. Lean fresh beef fried takes 4 hours to digest, and old hard salted beef boiled does not di rest in less than 4 hours 15 minutes. Fresh beef-suet boiled takes 5 hours 30 minutes to digest. 9

(1326.) The usual mode of preserving beef is by salting; and when intended to keep a long time, such as for the use of shipping, it is always salted with brine: but for family use it should he snlterl dry with good Liverpool salt, without saltpetie; for brine dispels the juice of the meat, aud saltpetre only serves to make the meat dry, and give it a disagreeable and unuatural red color. Various experiments have been made to cure beef, with salt otherwise than by hand-rubbing, and i. a short space of time; and also to preserve it from putrefaction by other means than salt. Thiose of Messrs. Payne and Ellmore, of Loedon, consist in putting meat in a copper which is reutered air-tight, and an air-pump then creates a vacuum within it, thereby extracting all the air out of the meat; then brine is pumped in by pressure, which entering into every pore of the meat formerly occupied by the air, is said to place it in a state of preservation in a few minutes. M. Ganual, of France, preserved the carcass of an ox from putrefaction for 2 years by injecting

* Cleland's Account of the Highland and Agricultural Show at Glasgow in 1828.

1. Quarterly Journal of Agriculture, vol. vii.

Prize Essays of the Highland and Agricultural Society, vol. xii.

The Experienced Butcher. § Donovan's Domestic Economy, vol. ii.

T Combe on Digestion and Dietetica.

(1073) 
4 lbs. of aaline nuxtare into the carotid artery. Whether any such contrivance can be made arail. able for family purposes, seems doubtful. Up to the 10th October, 1812, salted beef imported was subject to a duty of $12 \mathrm{~s}$. per $\mathrm{CWL}$; since that date both salted and fresh pay a duty of 8 . per cwi from foreign countries, and 28. from British possessions. Up to that period the importation of live stock was prohibited, by the anme act; bulls and oxen can now be imported from foreign conntries at $£ 1$ each, and from British possessions, 108. cown, 15s. and $7 \mathrm{~s}$. 6d. ; calves, 10s. and 5a.; sheep. 3s. and 1s. 6i... and lambs, 2s. and 1s. each." Salted beef cured with wood smoke is converted into a ham, and very highly relished. The tierce of salted beef for the navy contains $300 \mathrm{lbs}$. , consisting of 38 pieces of $8 \mathrm{lbs}$. each.

(1327.) Cattle are useful to man in various other ways than affording food from their flesh. their offials of tallow, hides, and horns, forming extensive articles of commerce. Of the hide, the characteristics of a good ove for strong purposes are strength in its middle or butt, as it is called, and light on the edges or offal. A bad hide is the opposite of this, thick in the edges and thin in the middle. A good ride has a firm texture, a bad one loose and soft. A hide improves as the sum. mer advances, and it continues to improve after the new coat of hair in autumn until Novenber or December. when the cont gets rungh from the coldness of the season, and the hide is then in its best state. It is surprising how a bide improves in thickness after the cold wrather has set in. The sort of food does not seem to affect the quality of the hide; bat the better it is, and the better cattle have been fed, and the longer they have been well fed, even from a calf, the better the hide. From what has been said of the effect of weather upon the hide, it reems a natural conclusion that a hide is better from an ox that bas been fed in the open air than from one fed in a byre. Dirt ad hering to a hide injures it, particularly in byre-fed animals: and anything that punctures a hide, such as trarbles arising from certain insects, is also injurious. The best hides are obtained from the West Highland breed of cattle. The Short.Horns produce the thinnest hides, the Aberdeenshire the next, and then the Angus. Of the same breed, the ox affords the stmngest hide; but as hides are applied to various uses, the cows, provided it be large, may be as valuable as an ox's The bull's hide is the least valuable. Hides are imported from Russia and South America; and the number imported in $1838 \mathrm{was} 301,890$. The duty on hides, by the new Tarifl; is $6 \mathrm{~d}$. per $\mathrm{cwt}$ for dried and $3 \mathrm{~d}$. for wet.

(1328.) Hides, when deprived of their hair, are converted into leather by infusion of the astringent property of bark. The old plan of tanning used to occupy a long time: but such was the value of the process, that the old tanners used to pride themselves in producing a substantial arti. cle. More recent discoveries have prompted tanners to hasten the process, much to the injury of the article produced. Strong infusions of bark make leather britile; $100 \mathrm{lbs}$ of skin. quickly tanned in a strong infusion, produce 137 lbs. of leather; while $\&$ weak infusion produces only $117 \frac{1}{2}$, the additional $19 \frac{1}{2}$ lbs. serving only to deteriorate the leather, and cause it to contain much less textile animal solid. Leather thus highly charged with tannin is so spongy as to allow moisture to pass readily through its pores, to the great disconfort and danger of persons who wear shoes made of it. The proper mode of tanning lasts a year or a year and half, acrording to the quality of the leather wanted, and the nature of the hides. A perfect leather is recoguized by its section, which should have a glistening marbled appearance, without any white streaks in the middle.t Leather is applied to many inportant purposes, being made into barness for agricul. tural and other uses. It is used to line the powder magazines of ships-of-war; to make carding. machines for cotton and other mills; belts to drive machinery : to make soles of shoes: and, whea japanued, to cover carriages. Calves' leather is used in bookbinding. The duty on tauned hides is now tixed at $£ 10$ per $£ 100$ value. The bair taken off hides in tanning is employed to mix with plaster, and is surreptitiously put into a hair-mattresses. The duty imposed on foreign cattle hair is $6 \mathrm{~d}$. per cwt.

(1329.) "The principal substances of which glue is made." gays Dr. Ure, "are the paring of ox and other thick hides, which form the strongest article; the refuse of the lenther-dresser; both afford from 45 to 55 per cent. of glue. The tendons, and many other offals of slaughter-honses. also afford materials, though of an inferior quality, for the purpose. The retise of tameriptench as che ears of oxen, calves, shefp, acc.-are better articles: but parings of parchment, old sloves. and in fact animal skins in any form, uncombined with tanning, may be made into glue." +

(1330.) Ox-tallon is of great importance in the arts. Candles and soap are made of it, and it enters large'y into the dressing of leather and the use of machinery. Large quantities are ammually imported from Russia. Of the exports from St. Petersburgh, consisting of $4 \frac{1}{4}$ nuillions uf poods, at least $3 \frac{1}{2}$ millions are exported to this country, at the value of $\pm 2,306,150$. at $\{3.5$ per isu. the quantity imported in $1837,1,294,000 \mathrm{cw}$ ts. were retained for home consumption. Ox rallow consists of 76 parts of stearine and 24 of oleine out of the 100. The daty on tallow by the new Tarift is 3s. 2d. per cwt. from foreign countries, and 3d. per cwt. from the Colonies.

(1331.) The horns of oxen and sheep are used for many purposes. "The horn consists of Iwo parts: an outward horny case, and an inward conical-shaped substance, somewhat intermediate hetween indurated hair and bone." called the flint of the horn. "These two parts are scparated by means of a blow on a block of wood. The horny exterior is then cut into thrce portions by means of a frame-saw. The lowert of these, next the root of the horn, after undergoing keveral processes by which it is rendered flah is made into combs. The midale of the horn, alter being flattened by heat and its transparency improved by oil, is split into thin layers, amd forms a sulsati. tute for glass in lanterns of the commonest kind. The tip of the horn is used by the makers of knife-handles and of the tops of whips, and for other similar purposes. The interior. or core of the horn, is boiled down in water. A large quantity of fot rises to the surface; this is put aside, and sold to the makers of yellow soap. The liquid itself is used as a kind of glue, and is jurchased by the cloth-dresser for stiffening. The bony substance which remains behind is then sent

* The Act to amend the Laws relating to the Custome. Table $A$.

+Ure"s Dictionary of the Arts, art. Leather Tanning.

4 MeCulloch's Dictionary of Cummerce, art. Tallow.

\$ Ibid., art. Glue.

(1074) 
to the mill, and, being ground down. is sold to the farmers for manure. Besides these varions purposes to which the different parts of the horn are applied, the clippings which arise in combmaking are sold to the farmers at about 18. per bushel. The shavings which form the refase of the lantern-makers are sold as manure."* Horn, as is well known, is easily rendered soft and pliant in warm water; and by this, and the property of adhesion like glue, large plates of horn can be made by cementing together the edges of small pieces rendered flat by a peculiar process, as a substitute for glass. For this purpose, the horns of goats and sheep are preferred, being whiter and more transparent than those of any other animal. Imitation of tortoise-shell can be given to horn by the use of various metallic solutions. Horn, also, when softened, can be im. printed with any pattern by means of dies.t The duty on horns is 1s. per ton, and on boofs $£ 1$ per $£ 100$ value.

\section{TREATMENT OF FARM-HORSES IN WINTER.}

"But loose betimes, and through the shallow pond Drive the tired team, and bed them snug and warm; And with no stinting hand their toil reward."

Grahax.

(1332.) With the exception of a few weeks in summer, farm-horses occupy their stable all the year round. It is situate at $\mathrm{O}$, fig. 3 , Plate III., where it is seen with two doors and two windows in front, and surmounted with two ventilators on the roof. Its plan may be seen at $\mathrm{O}$, fig. 4, Plate IV., where it is represented as containing 12 stalls. The fitting-up of the stable in all its particulars of stalls, floor, and accommodation, having already been fully dilated on when treating of the steading, from (23) to $(34)$, more seems unnecessary to be said in regard to these particulars in this place.

(1333.) Farm-horses are under the immediate charge of the plowmen, one of whom works a pair, and keeps possession of them generally during the whole period of his engagement. This is a favorable arrangement for the horses, as they work much more steadily under the guidance of the same driver, than when changed into the hands of different; and it is also vetter for the plowman himselt, as he will perform his work much more aatisfactorily to himself, as well as his employer, with horses familiarized to him than strange ones. In fact, the man and his horses must become acquainted before they can understand each other; and when the peculiarities of each party are mutually understood, work becomes more easy, and of course greater attention can be bestowed upon it. Some horses show great attachment to their driver, and will do whatever he desires without hesitation; others show no particular regard; and the same difference may be remarked of plowmen toward their horses. Upon the whole, however, there seems to be a very good understanding in this country between the plowman and his horses; and, indeed, independently of this, I believe there are few masters disposed to allow their horses to be ill treat ed, because there is no occasion for it; for horses which have been brought up upon a farm, in going through the same routine of work every year, become so well acquainted with what they have to do in every department of work, that should a misunderstanding arise between them and their driver, you may safely conclude that the driver is in the wrong.

(1334.) The treatment which farm-horses usually receive in winter is this: The plowmen, when single, get up and breakfast before daybreak, and by that time go to the stable, where the first thing they do is to take

- Babbage on the Eiconumy of Machinery and Manufactures. † Ure's Dictionary of the Arts, art. Horn. (1075) 
out the horses to the water.* While the horses are out of the stable the rest of the men take the opportunity of cleansing away the lung and soiled litter made during the night, into the adjoining court-yard $\mathbf{K}$, fig. 3 , Plate III., with their shovels (fig. 149), wheelbarrow and besoms. While the horses are ahsent usually one of the jlowmen supplies each corn-box with corn from the corn-chest. It is not an unusual practice (1) put the harness on while the horses are engaged with the corn; but this should by no means be allowed. Let the horses enjuy their fond in peace, as many of them, from sanguine temperament or greed, cannot divest themselves of the feeling that they are about to be taken away from their corn, if worked about during the time of feeding. The harness can be quickly enough put on after the feed is eaten, as well as the horses curried and brushed and the mane and tail combed. A very common practice, however, is to dress the horses while eating, which should not be allowed. A better plan in all respects is to let the hurses eat their corn undisturbed, and then dress and harness them aftcrward, and it has the advantage of allowirg them a little time between eating their curn and going out to work, which, if of a violent nature, undertaken witls a full stomach, may bring on an attack of batts or colic.t The plan which I have just described is intended to apply to single men who live ungether, and who have their own victuals to cook. But should the plowmen be married men the best arrangement for them is to go to the stable when they rise, water the horses, clean the stable, corn the horses, bind them up, and, shutting the door, leave them in quiet to eat their food as long as they themselves are in taking their breakfast, which by that time should be made ready by their wives. On returning to the stable after breakfast the horses should then be dressed, combed and harnessed, when they will come out quite fresh and clean to go to yoke and after their feed has been a little time in their stomachs.

[" It can nowhere, we trust, be unseasonable to exhort the farmer to give attention, habitaally, to the trealment of all domestic snimals, and more especially to those to whose labor he owes the fruits and profits of his indastry. Common humanity, to say nothing of Christian benev. olence, demands, and the more especially as all power of complaint is denied them, that every animal that works should be not only suitably and well fed, but that it should be saved from suffering by thirst; that its skin be kept clean and in good condition, which a few minutes' use of the curry-comb and brush will effect, and that its eyes and feet should be often examined and protected from injury : while a sore back or gall on any part of the body should be deemed a disgrace to master as well as man. Trite and commonplace as this word in their favor may appear. we cannot withhold it, in view of so much neglect in working animals as we see committed on many farms that fall under our observation; for whether we speak of it or not, we never visit or pass a farm without noticing these things. Those whose benevolence does not move them thus to care for the feelings of the humblest beast in their employment should yet be prompted to look after their comfort, as well in the stable as the field-whether in or out of harness-by the consideration that a sufficiency of substantial food, personal care and kind treatment always beget proportionate willingness and efficiency - as much or even more with the brute than with the auman. For ourselves, we take the occasion to reiterate our persuasion that the almost universas preference for the hores over the ox and mule, as a beast of labor and burden, has its origin, in a great measure, in-[alas ] not bygone] ages of war and barharism, which made power and fleetness identical; and that with a vast saving of national wealth these more economical animals might and ought to be substituted for the short lived and perishable horse.

Ed. Farm. Lib]

[t We well remember, when residing in Baltimore, to have been within an ace of killing one of the best geldings we ever straddled, by giving him a brisk eight-mile an-hour canter immediately after he had swallowed his oats. As soon as he took the spur we knew there was something wrong; and, turning back at the end of the first mile, scarcely got him in his stall before be was prostrate and swollen like an inflated bladder. By dint of hard rubbing and the prompt use of enemas he was fortunately saved for some years more of gallant service. Ed. Farm. Lab.] 
(1335.) Men and horses continue at work until 12 noon, when they come home, the horses to get a drink of water and a feed of corn and the men their dinner. Some keep the harness on the horses during this short interval, but it should be taken off to allow both horses and harness to cool, and at any rate the horses will be much more comfortable without it, and it can be taken off and put on again in a few seconds; and, besides, the oftener the men are exercised in this way they will become the more expert. When the work is in a distant field, rather than come home between yokings, it is the practice of some farmers to feed the horses in the field out of the nose-bags; and the men to take their dinners with them, or be carried to them in the field by their own people. This plan may do for a day or two in good weather on a particular occasion; but it is by no means a good one for the horses, for no mode so effectual for giving them a chill could be contrived than to cause them to stand on a head ridge for nearly an hour on a winter day, after working some hours. A smart walk home can do them no harm, and if time is pressing for the work to be done, let the horses remain a shorter time in the stable. The men themselves will feel infinitely more comfortable to get dinner at home. There is a practice in England connected with this subject that I think highly objectionable, which is, doing a day's work in one yoking. For a certain time horses, like men, will work with spirit, but if made to work beyond that time they not only lose strength, but their very spirit is wrung out of them, and in the latter part of the time will do their work in a careless manner. Horses thus kept for 7 or 8 hours upon the stretch at work must be injured in their constitution, or, if able to withstand it, it must be either at the expense of bad work executed at the latter part of the yoking, or of curtailment of hours of a full day's work, or of extraordinary feeding, either of which expedients is no compensation for bad management. Comrnon sense tells a man that it is much better for a horse to be worked a few hours smartly, and have his hunger satisfied before feeling fatigue, when he will again be able to proceed with fresh vigor, than to be worked the same number of hours without feeding. I can see no possible objection that can be offered to horses receiving a little rest and food in the middle of a long day's work, but I see many and serious ones to their working all day long without rest and food. Suppose, then, that men and horses come home at midday, the usual dinner-hour of agricultural laborers, the first thing to be done is to give the horses a drink at the pond on the way to the stable; and there should then be no washing of legs. From the water the horses proceed to the stable, where the harness is taken off; and as the men then have nothing else to do, every man gets the corn from the steward at the corn-chest for his own horses in nosebags, or in a small corn-trough or box which each man keeps for the purpose. Of these two sorts of things for carrying the corn in the stable I prefer the trough, as being most easily filled and emptied of corn. The horses are bound up, the stable door shut, and the men go to their own houses to dinner, which should be in readiness for them. After dinner they proceed to the stable, when the horses will be found to have finished their feed, and when a small quantity of fodder may be thrown before them fresh from the straw-barn, for at this time of year farm-horses get no hay. The men may have a few minutes to converse until 10 minutes to 1 P. M., when they should give the horses a slight wisp down, put on the harness, comb out their tails and manes, and be all ready to put on the bridles the moment 10 'clock arrives, which is announced by the steward.*

[* In our country, in the towns generally, the "ten-hour system," as it is called, prevails, while in the country the practice is to be up by daylight, winter and summer, and to labor until dark, (1077) 
(1336.) The afternoon yoking is short, not lasting longer than sunset, which at this season is before 4 P. M., when the horses are loosened out of yoke and brought home. After drinking again at the pond they are gently passed through it to wash off any mud from their legs and feet, which they can hardly escape collecting in winter. But in washing the men should be prohibited wetting their horses above the knees, which they are most ready to do should there be any mud upon the thighs and belly; and to render this prohibition effectual, I have expressly stated, when speaking of the construction of a horse-pond (125), that it should not be made deeper at any part than will take a horse to the knee. There is danger of contracting inflammation of bowels or colic in washing the bellies of horses in winter; and to treat mares in foal-which they will be at this time of year-in this way is little short of madness. If the feet and shanks are cleared of mud, that is all that is required in the way of washing in winter. On the horses entering the stable and having their harness taken off, they are well strapped down by the men with a wisp of straw. Usually two wisps are used, one in each band; but I am sure the work is much better done with one, shifting the hand as occasion requires, and directing the attention to one place at a time. A couple of wisps may very properly be taken to rub down the legs and clean the pasterns, rendering them as dry as a moderate length of time will admit. All this is done not quite in the dark, for there is still a glimmer of twilight in the western horizon, but too much in the dark to allow its being well done. After the horses are rubbed down, the men proceed to the straw-barn and bundle each 4 windlings of fodder-straw, one to be given to each horse just now, and the other two to be put above the stalls across the small fillets $p$, fig. 7, which run along the stable for the purpose.

(1337.) When 8 P. M. arrives, the steward, provided with light in a lantern, summons the men to the stable to give the borses a grooming for the night and their suppers. The sound of a horn, or ringing of a bell, are the usual calls on the occasion, which the men are ready to obey. I may here remark in passing, that the sound of a horn is pleasing in a calm winter night, and I never hear it without its recalling to my mind the goatherds' horns in Switzerland, pouring out their mellow and prayer-like strains at sunset, the time for gathering the flocks together from the mountain sides, on their way to the folds in the neighboring village. Lights are placed at convenient distances in the stable to let the men see to groom the horses. The grooming consists first in currying the horse with the curry-comb, to free him of all dirt that may have adhered to the skin during the day, and which has now become dry and flies off. A wisping of straw removes the roughest of the dirt loosened by the curry-comb. The legs ought to be thoroughly wisped, not only to make them clean, but dry of any moisture that may have heen left in the evening, and at this time the feet should be picked clear by the foot-picker of any dirt adhering around between the shoe and the foot. The hrush is then used to remove the remaining and finer portions of dust, from which, in its turn, it is cleared by a few rasps of the curry-comb. The wisping and brushing, if done with some force

with the usual intervals for meals. But while mechanics in town, under a vigılant boss, are at work, they keep working all the time; not so with men bired by the day at the public expense to work and to vote! In the country, too, if a stage drives along the rond, you will see a man stop his plow and a whole gang let fall their hoes or axes to look at the passer-by, as if they had never seen a stage or a horseman before.

In the South the slaves "knock off" for two hours at midday in very hot weather, but being almost universally tasked, where the work will admit of it, they generally get through in less than ten hours.

Ed. Farm. Lib.? 
and dexterity, with a combing of the tail and mane, should render the horse pretty clean; but there are more ways than one of grooming a horse, as may be witnessed by the skimming and careless way in which some plowmen do it. It is true that the rough coat of a farm-horse is not easily cleaned, and more especially in a work-stable where there is much dust floating about and no horse-clothes in use; but rough as it is, it may be clean though not sleek; and it is the duty of the steward to see that the grooming is done in an efficient manner. A slap of the hand upon the horse will soon let you know whether there is any loose dust in his hair. Attendance at this time will give you an insight into the manner in which farm-horses ought to be cleaned and generally treated in the stable. The straw of the bedding is then shaken up with a fork such as in fig. 279. This figure has rather longer prongs, and is too sharp for a stable fork, which is most handy for shaking up straw when about 5 feet in length, and least dangerous of injuring the legs of the horses by puncture when blunt. The united prongs terminate at their upper end in a sort of spike or tine, which is driven into a hooped ash shaft, as better seen in fig. 280, which is a steel-pronged fork of the form used in Lincolnshire, and is an excellent instrument for working among straw. This mode of mounting a fork is much better than with socket and nail, which are apt to become lnose and catch the straw. The horses then get their feed of wats, after which the lights are removed Fnd the stable-doors barred and locked by the stewand, who is custodier of the key. In some stables a bed is provided for a lad, that he may be present to relieve any accident or illness that may befall any of the horses; but where the stalls are properly constructed, there is little chance of any horse strangling himself with the collar, or any becoming sick where a proper ventilation is established.

Fig. 279. Fig. 280.

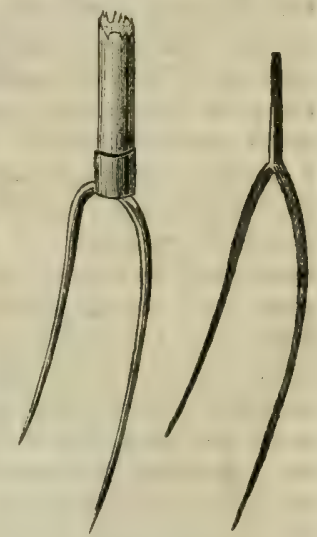

THE COMMON THE LINCOLN FORK.

SHIRE STEET FORK.

(1338.) In winter it is usual to give farm-horses a mash, once, at least, and sometimes thrice a week. The mash consists of either steamed potatoes, boiled barley or oats, mixed sometimes with bran, and sometimes seasoned with salt. The articles are prepared in the boiler $b^{\prime}$ in the hoiling-house U, fig. 4, Plate IV., in the afternoon by the cattle-man or a fieldworker, or any other person appointed to $\mathrm{do}$ it, and put into tubs, into which it is carried to the stable by the men, and dealt out in the troughs used to carry the corn to the horses, with a shovel. It is warm enough when the hand can bear the heat. The quantity of corn put into the boiler is usually as much as that given raw, and in preparation swells out considerably, so that the mash acquires considerable bulk. The horses are exceedingly fnd of mash, and when the night arrives for its being dealt out, show unequivocal symptoms of impatience until they receive it. The quantity of raw oats given to farm-horses, when on full feed, is 3 lippies a day, by measure and not by weight; but taking horse-corn at almust the highest figure of $60 \mathrm{lbs}$. per firlot, each feed will weigh $3 \frac{3}{4} \mathrm{lbs}$., the daily allowance amounting to $11 \frac{1}{4} \mathrm{lbs}$; ; but the lippy-measure, when the corn is dealt out, is most frequently not struck, but heaped, or at least handwaved, so that the full allowance will weigh even more than this. As horses work only 7 or 8 hours a day in winter, their feeding is lessened to perhaps 2 full feeds a day or $7 \frac{1}{2}$ lbs., divided into three portions, namely, a full feed (1079) 
in the morning, $\frac{1}{2}$ feed at midday, and $\frac{1}{2}$ feed at night; and on the nights the mash is giren, the evening $\frac{1}{2}$-feed of oats is saved. One season, as a mash, I tried steamed potatoes, with salt alone, of which the horses were excessively fond, and received three times a week, and on which they became very sleek in the skin and fat, notwithstanding much heavy work; but in spring, when the long day field-work was resumed, they seemed to me to be all affected with shortness of wind. Have cooked potatoes necessarily this effect upon horses? I may mention that oats, when desired to be cooked, must be boiled, as steaming only burns the outside, and does not penetrate into the interior, having somewhat the effect of kiln-drying. Oats, in fact, and barley too, must be macerated to be cooked, and to do this effectually uarm water must be used.

(1339.) I have often thought that the usual careless manner of placing the lights in the stable in the evening is highly dangerous to the safety of the building; and yet, in the most crowded and dirty stables, no accidents of fire almost ever happen. Sometimes the candle is stuck against a wall by a bit of its own melted grease; at other times it hangs by a string from the roof in an open lantern, set apparently on purpose to light straws. A good stable lantern is still a desideratum; and it should be made to hold a candle, and not an oil-lamp, as being the most cleanly mode of light for carrying about; and if the candle could be made to require no snuffing it would be perfect. A common tin lantern, with a horn glass, is what is commonly in use to carry the candle in the air; but when it gets blackened with smoke in the inside, it is of little use to give light outside. I have seen a globe lantern of glass made very strong for use on board of ship, but it has an oil-lamp. I observe Messrs. Palmer and Company, London, advertising a "weather candle-lamp for safet $y$, and for use in wind and rain, and which requires no snuffing." The candle costs $8 \frac{1}{2} \mathrm{~d}$. per lb., $\imath$ nd burns 5 hours for $1 \mathrm{~d}$. I have not seen this lamp, but judging from its figure, and if the glass is made strong enough, it would seem to answer the purpose, and is certainly not dear. If safe, it might be taken into the straw-barn, hammels, \&c. at night.

(1340.) This is the usual routine of the treatment of farm-horses in winter, and when followed with some discernment in regard to the state of the weather, is capable of keeping them in health and condition. The horses are themselves the better of being out every day; but the species of work which they should do daily must be determined by the state of the weather and the soil. In very wet, frosty, or snowy weather, the soil cannot be touched; but then threshing and carrying corn to market may be conducted to advantage, and the dung from the courts may be taken out to the fields in which it is proposed to make dung-hills. This latter piece of work is best done when the ground is frozen hard. When heavy snow falls, nothing can be done out of doors with horses, except threshing when the machine is impelled with horse-power. In a very rainy day, the horses should not go out, as everything about them, as well as the men, become soaked; and before both or either can be again made comfortable, the germs of serious disease may be laid in both. When it is fair above, on the other hand, however cold the air or wet the soil, some of ihe sorts of out-door work mentioned above may be done by the horses; and it is better for them to work only one yoking a day than to stand idle in the stable. Work-horses soon show symptoms of impatience when confined in the stable even for a day, on Sundays, for example; and when the confinement is much prolonged, they even become troublesome. When such occasions happen, which they do in continued snow-storms, with the ground covered deep, the horses should be ridden out for some time every (1080) 
day, and groomed as carefully as when at work. Exercise is necessary to fricuent thickening of the heels, a shot of grease, or a ccmmon cold. Fat horses, when unaccustomed to exercise, are liabie to molten grease.

(1341.) It is an advisable plan for a farmer to breed his own horses; and, on a farm which employs 6 pairs, two mares might easily bear foals every year, and perform their share of the work at the same time, without injury to themselves. The advantage of breeding working stock at home is, that, having been born and brought up upon the ground, they not only become naturalized to the products of its particular soil, and thrive the better upon them, but also become familiarized with every person and every field upon it, and are broken into work without trouble or risk. The two mares should work together, and be driven by a steady plowman; and their work should almost always be confined to plowing, particularly in winter and spring, when they are big with young, for the shaking in the shafts of a cart is nothing in their favor. In driving home turnips, and leading out dung in winter, over most probably not the smoothest of roads, mares in foal should not be employed, their driver rather plowing with them, when that operation can be performed, or assisting the other men at their carts with manual labor.

(1342.) Supposing, then, that one or two mares bear foals every year, the young horses, their produce, consisting of foals, year-olds, and twoyear-olds, should be accommodated in the steading $\mathrm{N}$, figs. 3 and 4, Plates III. and IV., according to age, where there are more than one of the same age, the older being apt to knock about the younger; but where one only of every age is brought up, they may be placed together for the sake of companionship, as horses are very social animals, and they learn to accommodate themselves to one another's tempers. Where blood foals are bred as well as draft, they should have separate hammels, the latter being too rough and overbearing, but the bloods generally contrive to obtain the mastery. Young horses never receive any grooming, and are even seldom handled; but they should all be accustomed to be led in a halter from their youngest period.

(1343.) The food usually given to young horses in winter is oat-straw for fodder, and a few oats; and where they are wintered among the young cattle in the large court $K$, they have the chance of a few pickings of corn from the corn-barn, or the refuse of hay from the litter of the workhorse stable, and then they seldom get corn. The fact is, young horses are generally unjustly dealt with ; they are too much stinted of nourishing frod, and the consequences established by the treatment are a smallness of bone which deprives them of requisite strength for their work, and a dullness of spirits which renders their work a burden to them. I speak of what I have seen of the way in which a large proportion of the furmhorses of this country are brought up when young. Their treatment seems to be derived from the opinion that very little nourishing meat should be given to young horses. Instead of this, they should receive a stated allowance of corn-and if bruised, so much the better-according to their ages; and when a mash is given to the work-horses, the young ones should always have a share. Should a mash be grudged as being too extravagant for young horses, they should get Swedish turnips or potatoes every day; for some moist food is requisite with dry fodder and corn.

(1344.) The names usually given to the different states of the horse are these: The new-born young is called a foal, a male one being a colt foal and a female a filly-foal. After being weaned, the foals are called colt or filly, according to the sex, which the male retains until broken in for work, when he is a gelding or horse, which he retains all his life; and tho 
filly is then changed into mare. When the colt is not castrated. he is an entire colt; which name he retains until he serves mares, when he is a stallion or entire horse. A mare, when served, is said to be covered by or stinted to a particular stallion; and after she has horne a foal, then she is a brood-mare, until she ceases to bear, when she is a burren mare or eill. mare; and when dry of milk, she is said to be yeld. A mare, while bearing a foal, is said to be in foal.*

(1345.) You have seen that though cattle gain weight when fed on cooked food, compared to others fed on the rame substances in a raw state; yet the expense of cooking counterbalances any advantage gained in weight, and it is therefore inexpedient to undertake the trouble of it. These results might have been anticipated from the peculiar functions of the stomach of the ox ; for he chew's the eud, that is to say, he masticates the food, as he takes it into his mouth in a very imperfect manner, rendering it only so snall as to be able to swallow it with some degree of force, in which state it reaches the paunch or first stomach; where. if it decomposes immediately and generates gas, it produces the disease of the hoven, which has been spoken of already (1294:. $\mathrm{But}$ should it not decompose- - which is the usual condition of the foor-it is again brought up to the mouth, and undergoes a thorough mastication, after which it is swallowed and finds its way to the stomach, which contains the gastric juice, there to be digested for the purpose of being as. similated into the system. Now, all that we can do for the $0 x$ in cooking his food, is to save him the trouble of chewing the cud, and to put the food into that atate in which it is at once fit to be acted upon by the gastric juice. In doing this, we attempt to imitate and enter into competition with a complicated,natural process, and, as might be expected in the circumstances. exhibit our inferiority. In the state, however, in which cooked food is presented to the ox, chewing the cud is not aliogether saved him. as the straw which be chooses to eat undergoes that operation, and therefore assists in keeping that important function in exercise. It is doubtul that the ox would retain his wonted good health, were we able entirely to suspend the action of that function in him; and it is therefore questionable policy to attempt it to a farther degree than to reduce his food so small as to render it fit to enter the paunch, with still less mastication than he would havo to give it in its ordinary state.

(1346.) The case, however, of the horse is very different. His is a eingle or simple stomach, which must be filled at once with well-masticated food. before the gastric juice can ant upon it in a proper manner; and should any food which enters it in an insufficiently masticated state, escape beyond the influence of the juice into the bowels, it may decompose there, generate gas, and produce the analogous disease of hoven in cattle, namely, flatulent colic or batts. To render food in such a state at first as shall save the horses the trouble of mastication, is, therefore, to do him 8 good service; and hence, cuoked food is in a proper state for feeding a horse, and it has also been proved to be conomical. Still, the cooking will be carried to an injurious degree, if it shall, by dint of ease of deglutition, prevent the flow of the sufficient quantity of saliva into the stomach which is necessary to complete digestion-" the quantity of which," says Professor Dick, "is almost incredible to those who have not had an opportunity of ascertaining it, but which the fol. lowing fact will testify. A black horse had received a wound in the parotid duct, which became fistulous. When his jaws were in motion in the act of eating hay, I had the curiosity to collect in a glass measure the quantity which flowed during 1 minute, by a stop-watch; and it amounted to nearly 2 drachms more than $2 \mathrm{oz}$. in that time. Now, if we calculate that the parutid gland on the opposite cheek poured into the mouth the same quantity in the same time, and allow that the sublingual and sub-maxillary gland, on each side combined, pour into the mouth a quantity equal to the two parotids, we then have no less than $8 \mathrm{oz}$. of saliva passing into the moutl of a horse in one minute, for the purpose of softening the food and preparing it for digestion." + Yet it is im. possible for any horse to swallow food in alue most favorable state it can be made for swallowing, without moving his jaws to a certain degree, and this insures a certain quantity of saliva entering his stomach.

(1347.) But more than this. cooked food may be presented in ton nutritious a state for the stomach; and there may be, on the other hand, too little nutriment in the food riven ; for", "the digestive organs of the horse, like those of the ox," says Professor Dick, "are very capacious, and are evideatly intended to take in a large proportion of matter containing a small proportion of nutriment; and if the food upon which they are male to live is of too rich a quality, there is, by the excitement produced, an increase of the peristaltic motion, in order to throw off the superabubdant quantity which has been taken into the stomach and bowels. It is necessary to give, there. fore, a certain quantity of lmlk, to separate, perhaps, the particles of nutritions matier; that the bowels may be enabled to act upon it properly. A horse could not live so well on oats, if fed entirely upon them, as when a portion of fodder is given ; with them a certain guantity is required. But this may be carried too far, and the animal may have his bowels londed with too large a quantity of unnutritious food:" as witness the nature of the stepp before alluded to; " and nothing less than such a mass as will render him incapable to perform any active exertion, will be sufticient to afford him even a scanty degrce of nourishment. A horse living on straw in a straw-yard be.

[" Some use the foolish expression, out of such a liorse or stallion, instead of by the stallion and out of the mare; and, again. they say "My horse was sired by Messenger," instead of got by Messenger. As John Randolph once observed, they might as well say he was damm'd by a par. ticular mare. There are propricties and technicalities belonging to every sort of business, which should be learned at least by those who follow, or are immediately interest $\mathrm{d}$ in it.

† Quarterly Journal of A griculture, vol. iii.

Ed. Farm. Lib.] (1082) 
comes pot-belied. Hence it is, that a proper arrangement in the properties and proportions of his food becomes a matter of important consideration." $\rightarrow$ These and the preceding remarks comprehend all the rationale of feeding both cattle and horses, and, if carefully considered, may con. duct you to adopt such an appropriate mixture of materials in your possession as may serve to maintain the strength, good health and condition of your horses, on the one hand, and to do so economically on the other. Meantime, I shall enumerate a few of the attempts that have hitherto been made of making mixtures of food for horses, with the view of ascertaining whether cooked or raw food, in a prepared or natural state, maintains horses in the best order.

(1348.) The most careful set of experiments that have yet been recorded in supporting farmhorses on boiled and raw grain, and on raw grain prepared and in a natural state, was made by Mr. James Cowie, Halkerton Mains, Kincardineshire. He subjected no fewer than 12 horses to the experiment, dividing them into 3 sets of 4 each, and keeping each set on a separate fare. The horses were weighed on 1st March, when the experiment began, and their weights varied from 9 cwts. 3 qrs. to 12 cwts. 1 qr. 4 lbs.; and they were again weighed on lst May, at the end of the experiment, and their weights then ranged from 9 cwts. 2 qrs. 23 lbs. to 12 cwts. 1 gr. 14 lbs. Thus the range of weight did wary much at both the periods, though the individual weights did. Their ages ranged from 4 to 12 years.

(1349.) The facts brought out in this experiment were, that the horses fed on unbruised raw and on boiled grain, gave results so very nearly alike that it seems inexpedient to incur the expense of cooking food for horses, as that costs about $1 \frac{1}{2} \mathrm{~d}$. on two feeds for each horse. This is a rather remarkable result, for one should have expected that the boiled grain would have had the advantage. Bruised raw grain seems the most nourishing, and, in not requiring cooking, of course the most economical, mode of feeding work-horses. For, all the horses that had been on boiled and unbruised rau grain lost $70 \mathrm{lbs}$. each; and that amount of loss in an animal of $10 \mathrm{cwts}$. or $12 \mathrm{cwts}$. is considerable; whereas those which had been on bruised grain, though given raw, either gained weight or lost none. And as to the economy of using grain in this state, besides the cooking, it is alleged that boiled whole grain passes throigh the horse undigested as well as raw grain when whole, and that the quantity which thus escapes is equal to 1-6 of what a horse consumes; whereas, the grain that is briised undergoes a considerable degree of digestion at least, before passing away. If the loss is taken at 1.6 on a horse which gets $12 \mathrm{lbs}$. daily of oats whole, a vearly sav. ing might be effected of about 2 quarters of corn, by giving him 10 lbs. of bruised instead.

(1350.) Many economical forms of mixtures have been recommended for farm-horses, and these are among them:

10 lbs. of chaffed straw, at $£ 1$ per ton.............. 1d.

$10 \mathrm{lbs}$ of oats, at 3s. per bushel ........................ 9

$16 \mathrm{lbs}$ of turnips, at 108 . per ton ..................... 1

Expense of cutting and chaffing ........................ $0 \frac{1}{2}$

Cost of one horse each day................... $\frac{11}{11 \frac{1}{2} \mathrm{~d}}$.

$16 \mathrm{lbs}$. of hay, at 3s. $6 \mathrm{~d}$. per cwt.....................6d.

5 lbs. of oats, at 3 s. per bushel........................... $4 \frac{1}{2}$

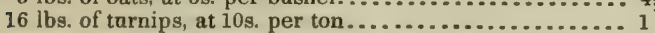

Cost of one horse each day $. . . \ldots \ldots \ldots . . . . . . . . . .11 \frac{1}{2} \mathrm{~d}$.

28 lbs. of steamed turnips......................... $3 \frac{1}{2} \mathrm{~d}$.

7 lbs. of coals, at 1s. per bushel........................ 1

Expenses of steaming................................... $0 \frac{1}{2}$

16 lbs. of straw, at $£ 1$ per ton...............................

Cost of one horse each day ..................... $\frac{1}{6 \frac{1}{2} \mathrm{~d}}$.

This last mixture, containing no corn of any kind, is said to "succeed remarkably well, and although the horses perspired considerably while at work. they kept their condition exceedingly well," and has been adopted hy some farmers in the South of England, and by Mr. Karkeek, the veterinary surgeon, as having been "highly recommended by several practical farmers." $\dagger$ No doubt. horses can live upon turnips, as well as upon grass, without corn, and they may be said to work upon them; but I quite agree with Mr. Stewart, when he observes: "W Wat the owner might call work is not known. In this country, grass alone will not produce workable horses," and the same may more truly be said of turnips and straw. "If food is not given," continues Mr. Stewart, "work cannot be taken. Every man who has a horse has it in his power to starve the animal; but that, I should think, can afford little matter for exultation." $f$ Turnips are frequently given to farm-horses in the evening in lieu of a feed of corn, and even in lieu of a hot mash at night; and horses are very fond of Swedish turnips. which, on being washed, are generally set before them whole, unless'some of the men take the trouble of cutting them into slices with their knives; but the best way would be to have them sliced on purpose by W allace's turnip-slicer, fig. 259, which has been already described. Potatoes are given to horses in a raw state, in the same man. ner as turnips, and they seemed to be relished by them. but not so fondly, in so far as I have observed, as Swedish turnips. But of the sorts of food of the root kind, there is none which gives horses so much delight as the carrot. It is a pity that this root can only be cultivated successfully on very light soil, otherwise it would be worth while to raise as many, at least, as would support the horses, in conjunction with corn, all winter. Stewart says that "for slow-working horses carrots may supply the place of corn quite well, at least for those employed on the farm." $\|$ They would get fat enough on $70 \mathrm{lbs}$. of carrots a day, but would want stamina without corn. $\delta$ Carrots

* Quarterly Journal of Agriculture, vol. iii.

I Prize Essays of the Highland and Agricultural Society, vol. xiv.

$f$ Stewart's Stable Economy.

\|I Ibid.

(10 83) 
are easily and saccessfully grown in the Island of Guernsey; but they are not given to horses on account of an allegation that " when on this food their eyes are injured." The rame writer mentions a similar effect produced by the parsuip at a certain season of the year. "To horses," he says, "parsnips are frequeutly gives, and have the property of making them sleek and fat; but in working they are observed to siveat profusely. If new, and cut sufticiently small. no other ill effect results, exeept, indeed, at one period of the year, toward the close of February, when the root begins to shoot; if then given, both horses and horned cattle are subject, on this food, in an inflammation in the eye, and epiphora or watery eye; in some subjects. perliaps, producing blindness."* Hurses are very fond of biead : a piece of bread, and especially oat.cake, will take a horse in the field when a feed of corn cannot. It is quite common in Holland to see travelers at a village inn, take: a black luaf and slice it down with a bread-knife in a trough for their horse. Upon the principle of economy, M. Longchamp has proposed to feed the cavalry of France with a bread composed of $\frac{3}{4}$ of of boiled potatues and $\frac{1}{4}$ oatmeal, properly buked in an oven. The usual allowance of onts for a horse, at $10 \mathrm{Jbs}$ costs 13 sous: but 10 lbe. of this bread will only cost 5 sous

(1351.) But independent of all surcedanea, which may be given to horkes at times a a treat, and as affording a beneficial change of food, there should be a regular feed prepared for farmhorses, which should be ariministered every day, and any deviation from which should be regarded as a relish or treat. There are two formulae which I shall give, which have been found to make excellent prepared food for furm-horses, and they may be prepared without much trouble, provided the proper apparatus is erected for the purpose. The first is given in quantity of each day for one horse:

$$
\begin{aligned}
& \text { In the morning.... }\left\{\begin{aligned}
3 \frac{1}{2} \text { lbs. of oat and bean meal, } & \text { lbs. of chopped straw, }
\end{aligned}\right\} 214 \frac{1}{2} \text { lbs. } \\
& \text { At midday....... }\left\{\begin{aligned}
3 & \text { lbs. of oat and bean meal, } \\
12 & \text { lbs. of chopped straw, }
\end{aligned}\right\} 15 \ldots . \\
& \text { At night......... }\left\{\begin{aligned}
1 \frac{1}{2} & \text { lbs. of oat and bean meal, } \\
11 & \text { lbs. of steamed potatoes. } \\
2 & \text { lbs. of chopped straw, }
\end{aligned}\right\} \frac{14 \frac{1}{2}}{44} \text { lbs. }
\end{aligned}
$$

This quankity is quite sufficient for the strongest farm-horses, and less will be consumed by ordinary ones, but that can be regulated according to circumstances, by withdrawing a little meal and straw, still retaining the proportions. The usual allowance of oats, as you have scen. weighe $11 \frac{1}{2}$ lbs. a day, when the grain is of the finest quality ; but as horses seldom receive the finest oats, and are nsually supplied with what are called common oats, which do not weigh so heavy, the asual allowance may be taken at $10 \mathrm{lbs}$; and when hay is given to the horses in spring they eat at least $1 \frac{1}{2}$ stones of $22 \mathrm{lbs}=33 \mathrm{lbs}$. every day. This mixture, on the other hand, contains no hay, and only $8 \mathrm{lbs}$. of oats and bean-meal, or $6 \mathrm{lbs}$. of barley-meal instead, if more convenient to be given. and $11 \mathrm{lbs}$. of steamer potatoes. which cannot be estimated at much value on a farm beyond the cost of steaming.t The value of the ordinary and the prepared food can easily be estimated, and it will be found that the prepared is the cheapest, and at the same time better for the horses' health, and equally well for them as to condition and spirit. The mixture is nade in this way: The meal and chopped straw are put and mixed together in a tub, and a little salt sprinkled over it. The steaned pntatoes are then poured hot into the tub over the straw, and the whole is formed into a nash with a shovel, and let stand awhile to acquire an equal temperature throughout, and to stvell the aneal into a pulpy state with the potatoes, before being divided out to the horses.

(1352.) A formula is given by Prof. Low, consisting of chopped straw, chopped hay, bruised or coarsely-ground grain aud steamed potatoes by weight, in equal parts, with $20 z$. of salt; and of this from $30 \mathrm{lbs}$. to $35 \mathrm{ibs}$, or $32 \frac{1}{2} \mathrm{ll}$.s. on an averacr., to be given to a borse every day. $\$$ This mixture, including hay, will he inore expensive than the above; and I am doubtul that 35 lba. of it will satisfy a farm-horse on artive work in spring, when he cau eat $33 \mathrm{lbs}$ of unchopped hay a day, without corn.

(1353.) It appears at first sight somewlat surprising that the idea of preparing fool for farmhorses should only have been recently ucted on ; lut 1 have no donbt that the practice of the turf and of the road. of maintaining lonses on laree inantities of oats and dry rye-grass hay, has had a powerful influence in retuisug it m farms. But now that a more natural treatment has been adopted by the owners of horkes on list work, famers, having now the example of post-horses standing their work well on prepared fint. should ensily be persnaded that. on slow work, the game sort of food should have evers a inore sulutary effict on their horsen. How prevalent was the notion, at one time, that horses embli not be expected in lo work at all miless there was hard meat in them! "This is u very silly and erromens ithen, if we inquire into it." as Prof. Dirk truly observes; "for whatever may lio: the consistency of the food when litken into the stomach, it must, before the borly cun possibly derive ans substantial support or bene fit from it, be converted into chyme-a pultacius mas: and lis. as it passes onward from the stomach into the intertinal canal, is rendered still more thuid, by the mimixtmes of the secretions from the stomach, the liver and the pancreas, when it becomes of u nilky appearance, and is ealled chyle. It is then taken into the system by the lecterals, aur in this flu, th, llis soft stite-und in this stale only-mixes with the blood and passen throukh the circulating vessels for the nourishnent of the system." Actuated by these rational principles. Mr. Juhn Cruall, a lave conch proprietor in Edinburgh, now supports his coach-horsen con 8 lbss. of chnppled hay and $16 \mathrm{lbs}$, of bruised onts; so does Mr. Isaac Scott, a Postmaster, who gives $10 \mathrm{lbs}$, or $12 \mathrm{lbs}$ of chopped hay and $16 \mathrm{lbs}$. of bruised uats to large horses; and to carry the principle still farther into practice, Captain Clscyue found his post-

- Quayle's Agriculture of the Channel Islands.

* Low's Elements of I'ractical Agriculture. (1084)
+ Quarterly Journal of Agriculture, vol. iv. If Quarterly Journal of Agriculture, vol. iii. 
horees work well on the following mixtare, the proportions of which are given for each horee overy day; and this constitutes the second of the formula aliuded to above : In the day .. $\left\{\begin{array}{l}8 \mathrm{lbs} \text {. of bruised oats. } \\ 3 \mathrm{lbs} \text { of bruised beans. } \\ 4 \mathrm{lbs} \text { of chopped straw. } \\ 15 \mathrm{lbs} .\end{array}\right.$

$$
\text { At night .. }\left\{\begin{array}{l}
22 \text { lbs. of steamed potatoes. } \\
1 \frac{1}{2} \text { lbs. of fine barley.dust. } \\
2 \text { lbs. of chopped straw. } \\
2 \text { ounces of salt. } \\
25 \frac{1}{2} \mathrm{lbs} .
\end{array}\right.
$$

Fotimating the barley-dust at 10d. per stone; chopped straw $6 \mathrm{~d}$. per stone ; potatoes, steamed, at 7s. $6 \mathrm{~d}$. per cwt. ; and the oats and beans at ordinary prices, the cost of supper was $6 \mathrm{~d}$., and for daily food 1s. with cooking, in all 1s. $6 \mathrm{~d}$. a horse each day.*

(1354.) [Hay and Straic-Cutters.-Machines for chopping liay and straw form now an important article in the class of implements for preparing food for horses and cattle. In England the straw-cutter or chaff-cutter is held, very properly, in high estimation by the farmer, and its value, in an economical point of view, seems to be fully appreciated by all. In scotland, with all its boasted economy in the various walks of Agriculture, the straw cutter is but partially employed, and it is chiefly among those farmers who, to a well-established experience superadd scientific skill that the employment of the straw-cutter, together with the other members of the class of food preparing machines, are brought to bear upon the establishment in a systematic reform. There can be no doubt that ere long the food-preparing system will become as universal among farmers as the threshing-machine is already, and straw-cutters, corn-bruisers and steaming-apparatus will be seen in every well-regulated steading. To the full development of such a system there exists one especial obstacle, which is that defect, in the minds of many men, which prevents their forming a svstematic arrangement of any given subject. and from being indifferently qualified to draw conclusions from a series of facts, which individually appear isolated and loosely connected, but which, in the aggregate, are capable of bringing out important results. For ex. ample, there are many individuals who may have procured the requisite machinery to have enabled them to follow the,system here alluded to, but, owing to the absence of properly organized methods of procedure in the different processes, and losing sight of the advantages to be derived from a proper combination of effects, by viewing only the results in detail, the well-intended trial ends in disappointment, and the machinery set aside as unprofitable; whereas, under proper direction. it would certainly have achieved the object. In using machinery of this kind it should always be borne in mind that the more constantly and regularly it is kept in operation, so much the more productive it will be in saving expense to its proprietor, provided such machinery be of a kind that can be rendered available as a means of saving expense; and, from the nature of things, no machine will be continued in any practice after it has been ascertained to possess only negative properties.

(1355.) Straw-cutters are of very various construction, rising in the perfection and complication of parts, from the simple knife, jointed at one end to a table and wielded by the right hand, as a lever of the second order, chopping the straw or hay that is presented to it by the left. From this simple and primitive form they rise in gradation to a class of elaborate machines, too numerous to be described individually, but out of which the following varieties are selected as appearing most worthy of attention. I shall pass over some of the early machines, which, however ingenious, were unnecessarily complicated; such as those which enjoyed the advantage of a revolving web to carry forward the substance to be cut, and having also the means of moving the eubstance, not uniformly, but by starts, the progressive action being performed in the interval of the strokes of the cutter, the substance, at the same time, being alternately compressed and relaxed, that is, compressed while the knife is cutting. and relaxed during the progressive stage. Such mechanical appliances are now, for the most part, laid aside, and the machine is proportionally simplified. $\dagger$

(1356.) The straw-cutting machines now in general use may be arranged under three varieties, and in the order of seniority stand as follows: 1. Those having the cutting knife or knives attached on the disk of a $\mathrm{Ar}$-wheel. 2. Those having the knives placed upon the periphery of a skeleton cylinder; and 3 . Those having numerous knives set round the surface of a small solid cylinder. This last being the simplest form of the modern machine I shall place it first in the order of description.

(1357.) The Canadian Strav-Cutfer.-This machine, as the name implies, is an importation from Cauada, a description of it having been sent thence by Mr. Fergusson of Woodhull, now of Fergus, Upper Canada, to the Highland and Agricultural Society, in whose Transactions it was first published; $\neq$ but the present figure is taken from the machine as made by James Slight and Company, who have greatly improved the construction of the cutting cylinder. Fig. 281 is a view in perspective of this machine. It consists, first, of a wooden frame, of which $a$ a $a$ a are the four posts, $2 \frac{1}{4}$ inches square, the front pair 43 inches in hight, and the back pair 36 inches. These are connected by two side-rails, one of which is seen at $b$, and a cross-rail, $c$, which last serves also to support the bottom of the feeding-spout. These rails are $2 \frac{1}{2}$ inches deep by $1 \frac{1}{2}$

[ + Not to bave it said that this great work had been impaired in any of its essential parts, and especially in such engravings as are employed to illustrate it, we give all the cuts of machinery, though well aware that some of them have been well supplanted by more economical invention of our own ingenious countrymen. The presentation of them will be acceptable, too, as we may suppose, to the manufacturers and venders of implements, patrons of this work.

- Quarterly Journal of Agriculture, vol. iii.

\$ Prize Essays of the Highland and Agricul $(1085)$ 
inches in thickness. The posts are farther connected by four light stay-rails below; and the frame, when thus joined, measures 15 inches in width at the front, where the rollers are applied, 22 inches in width behind, and $\mathbf{4 0}$ inches in length at bottom, bat only 36 inches as she rop-rail

Fig. 281.

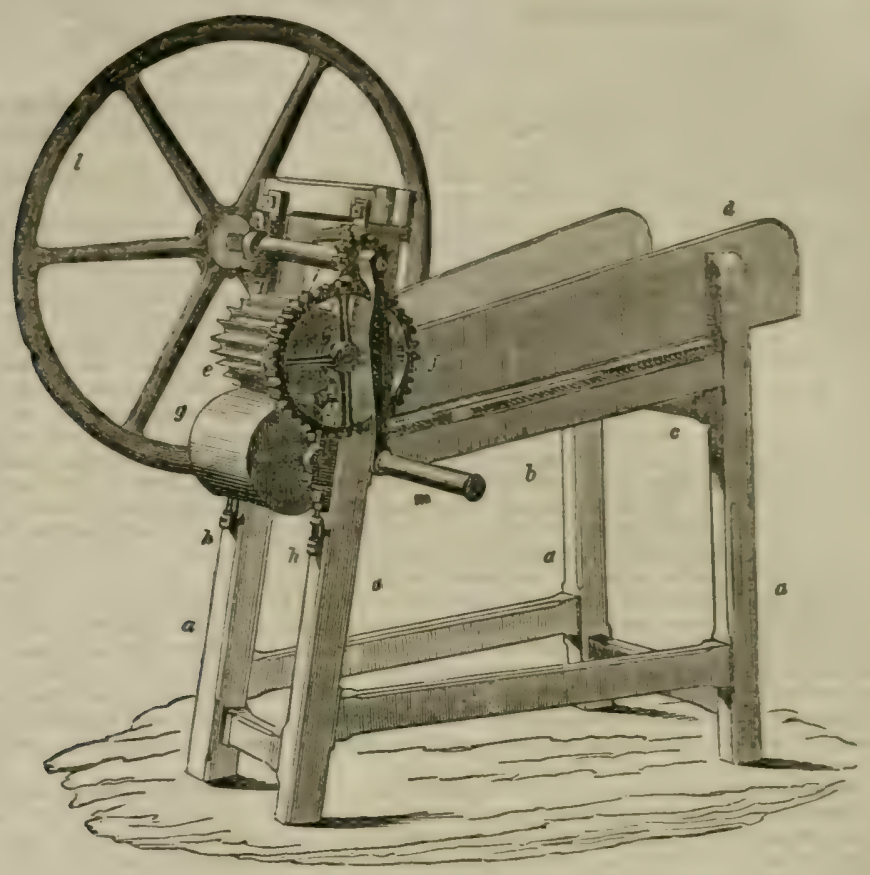

THE CANADIAN STRAW-CLTTER.

measured over all. The feeding-spout, $d$, is 40 inches in length, 9 inches in width within, at the feeding end. and 18 inches behind; the depth is 4 to 6 inches.

(1358.) The acting parts of this straw-cutter consist of the cutting-cylinder $e$ which is 9 inches in length and $6 \frac{1}{2}$ inches in diameter to the edge of the cutters. It is armed with 24 cutters or knives; its axle runs in plummer-blocks, bolted upon the posts, and carries likewise the wheel $f$ of 91 inches in diameter. The pressure cylinder $g$ is a plain cylinder of hard.wood, beech or elm, turned true upon an iron axle. which runs in plummer-blocks similar to the former. The length of the pressure cylinder is 9 inches, and its diameter 7 to 8 inches: it carries no $w$ beel, but revolves by similar contact with the cutting-cylinder. The pressure-cylinder is furmished with a pair of adjusting serews at $h h$, which act upon the plummer blocks of the cylinder, and afford the means of regulating the pressure of the one cylinder upon the other. The sliaft $i$, which has aleo its plummer-blocks, carries at one end a pinion of $3 \frac{2}{2}$ inches in diameter, which acts upon the wheei $f$, while. at the other end, it carries the ty-wheel $l$ of 34 inches diameter and 601 s. weight. The winch baudle $m$ is also attached to the shaft $i$, and serves to put the machine in motion.

(1359.) Fig 282 is a transverse section of the cutting-cylinder, showing the position of the eutters and their insertion into grouves which are planed out of the solid cast-iron forming the bory of the cylinder; $a$ is the axle. and $b$ the body of the cylinder, which is 1 izaches in diameter, and has 24 cutters inserted in its periphery. Fig. 283 is a longitudinal section of the same, for the purpose of exhibiting the nanner in which the cutters are secured in dheir places, $a$ is the axle, and $b$ the body as before. $c c$ being two opposite cutters. The body is 8 inches in length but is furnished with two caps $d d$. which make it up to 9 inches. The caps are cupped out. 0 that their edges e e e e embrace the eade of the body, and at the same time enter into notches cat in each end of the cutter, as seen in fig. 284, which is a cutter detached, and drawn to a larger scale exhibiting the notch $a$ a into which the edges of the cupped ends enter. By tbis arrangement, the numerous cutters are all held firmly in their grooves: for so soon as the caps are applied, and fixed by the keys $f f$, fig. 283. being driven through the axle, the caps are pressed home upon the body and the cutters. On the other hand, when it is found requisite to remove $\mathrm{a}$ cutter, for aharpening or other purposes, it is only necessary to drive ont one of the keys $f$, wo withdraw the cap, and the cutters can be lifter out of their grooves withont trouble.

(1360.) As this machine acts entirely by direct pressure, it will readily be observed that, in workine it, the straw being laid in a trough $d$, fig. 281 , and brought in contact with the cutting (1086) 
cylinder and its antagonist, the hay or straw will be continuously drawn forward by means of the two cylinders; and when it has reached the line of centers of the two, it will be cut through by the direct pressure of the cutting-edges of the one against the resisting surface of the other

Fig. 283.

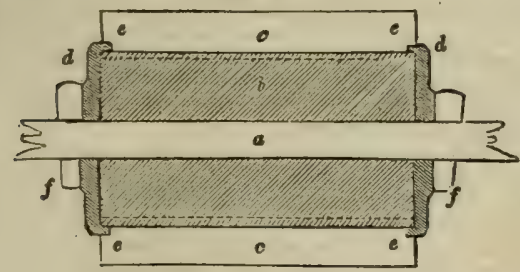

Fig. 282

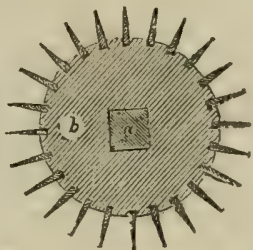

Fig. 284.

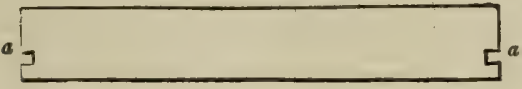

SECTIONS OF THE CUTTING-CYLINDER.

cylinder, and the process goes on with great rapidity. The straw is cut in lengths of about $\frac{3}{4}$ inch, and though it passes in a thin layer, yet the rapidity of its motion is such, that when driven by hand. at the ordinary rate of 44 turns of the handle per minute, the number of cuts made by the

Fig. 285.

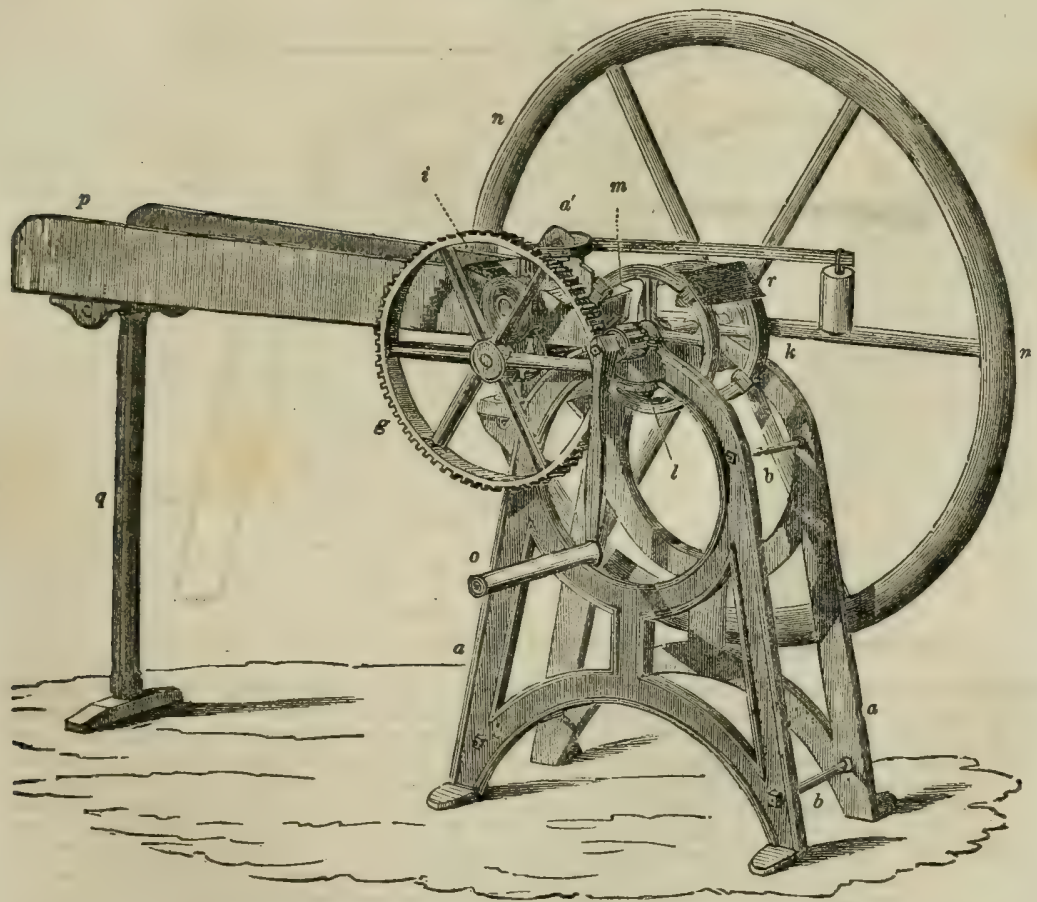

THE CXLINDER STRAW-CUTTER WITH STRAIGHT KNIVES.

cutting-cylinder in that time is 360 ; and the quantity, compared by weight, will be three times, near ly, what any other straw-cutter will produce, requiring the same force to work it, that is to say, a man's power. There is one objection to this machine, which is, the wearing out of the resisting cylinder but this balanced by the excess of work performed, and by the circumstance that the wearing cylinder can be removed at an expense not exceeding 2s., and it will last from 3 to 6 months. The price of the Canadian straw-cutter is $£ 610 \mathrm{~s}$.

(1361.) Cylinder Siraw.cutter, so named here from its having the knives or cutters (generally (1087) 
two, but sometimes four) placed on the periphery of a skeleton cylinder, the knife lying nearly in the plane of revolution. Besides the cutting cylinder, they necessarily have a pair of feeding-rollen, which bring forward the substance to be cut, and nlso. from the velocity of their motion, regulate the length of the cut. Two forms of the machine exist, the essential difference of which is that, in the one. the cutters are placed upon the cylinder with a large angle of obliquity to the axis, generally about 35 , and are therefore bent and twisted until their edges form an oblique section of the cylinder, while the box, or the orifice through which the substance is protruded for being cut, lies parallel to the axis of the feeding-rollers. In the other variety, the knives are placed parallel to the axis of the cylinder, and therefore straight in the edge, while the cutting box is elongated into a nozzle, and is twisted to an angle of $15^{\circ}$ with the axis of the feeding-rollers. To this form of the machine I shall at present chiefly confine myself.

(i362.) The cylinder straw-cutter with straight knives, as constructed by James Slight and Co., Edinburgh, at prices from $£ 710$ s. to $£ 810$ s, is represented by fig. 285 , being a view in perspective of the machine, while fig. 286 is a section of the principal parts; and in the two figures the same letters refer to the corresponding parts of each. The machine is made entirely of iron, chieflv cast.iron. The two side-frames $a a$, are connected together, at a width of from 12 to 15 iuches, by the stretcher-bolts $b$. two of which are seen in the right-hand side of the figure, and a third below on the left: a fourth is formed of the bed-plate $c$, which is bolted to a projecting bracket, and carries the cheeks or frame $d$ of the feeding-rollers $e$ and $f$. The lower roller $e$ carries uyron its axle the driving-wheel $g$, and also the feeding-wheel. indistinctly seen in the figure, but which workg into its equal wheel $i$, fitted upon the axle of the upper roller $f$. In the machine, when adlapted for hand power, the rollers vary from 5 to 8 inches in lenuth, and are $3 \frac{1}{2}$ inches in diameter, and flated. In the apex of the side-frames, bearings are formed for the axle of the cutterwheels $k$, which form the skeleton cylinder, and whose axle carries also the driving-pinion $l$, act ing apon the wheel $g$. The cutter-wheels are 11 inches diameter, and are set at from 10 to 13 inches wide. Intermediate between the feeding-rollers and the cutter-wheels is placed the cutting. box or nozzle $m$, bolted to the roller-frame in the position represented in tig. 286. On the farther end of the cutter-wheel axle the fly.wheel $n$, of 4 feet diameter, is fixed; and on the near end of

Fig. 286.

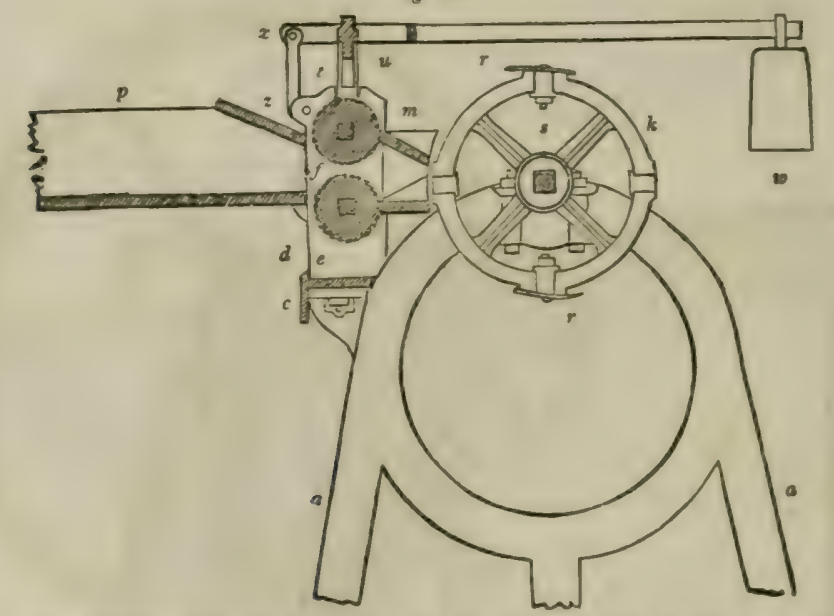

A TRANSTERSE SECTION, SHOWING THE RELATIOS OF THE PRINCIPAL PARTS.

the same, the winch-handle 0 . by which the machine is worked. The feeding-trough $p$ is 4 feet in length, from 5 to 8 inches wide at the feeding end, and 18 inches behind. The depth is 6 inches, and the trough is formed of 3 inch deal. It is hooked to the roller-frame at the mouth, and is sup. ported by the jointed foot $q$. The cutters $r r$, from 10 to 13 inches in length, and 3$\}$ to 4 inches in breadth, are made of the finest steel. backed with iron. The cutters are fixed upon the cylinders, each with two ocrew-bolts, as reen at s, passing through the ring of the wheel, and they are placed slightly eccentric to it; the cutting edge being about inch more distant from the center than the back. To secure the regular feed of the rollers, she lower one turns in fixed bearings; but the other is at liberty to rise and fall in the fork $t$ of the roller-frame. In order farther to aecure a uniform pressure on this roller, a bridge $u$ is inserted on the fork $t$, resting on both journals of the roller. A compensation lever $v$, has its forked fulcra in $x$ through the strap $x z$, which is hooked on to pins in the roller-frame; and it thus bears upon the bridge " at both sides by means of the forked end, as seen at $a^{\prime}$ in fig. 285. A weight to is appended to the extremity of the lever, which, thus arranged, keeps a uniform pressure on the upper mller, while it is always at liberty to rise or fall according to the thickness of the feed which the rollers are receiving.

(1363.) Fig. 287 is a direct front view of the cutting-box detached, on a scale of 2 inches to a foot. $a$ are the ears by which it is bolted to the roller frame; $b c$ and $d e$ are the upper and lower extreme edges of the nozzle, while $f g h i$ is the base, as applied to the roller-frame. The (1088) 
angle $b g f$ or $e i h$ is the obliquity which is given to the nozzle, and is about $15^{\circ}$ with the hori. zontal axis. Fig. 288 is a plan of the same, in which the same letters of reference apply to the corresponding parts. $f g$ is the base, lying on the same plane with the ears $a$. The curve line $b c$ is the contour of the upper edge of the nozzle, and the dotted line $b e$ represents the lower edge $d e$ of fig. 287 .

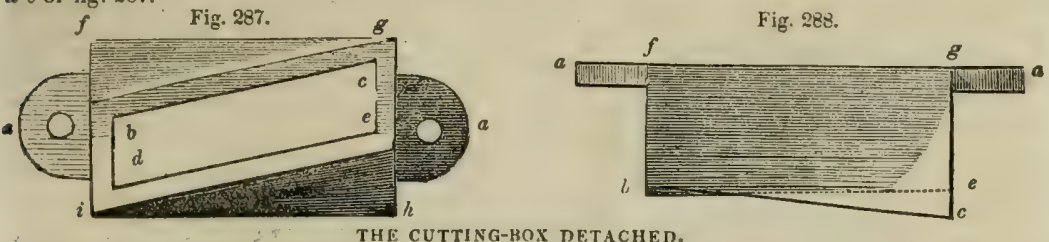

THE CUTTING-HOX DETACHED.

(1364.) The obliquity of the nozzle, as here represented, serves the purpose of causing the knife to make a progressive cut, approaching to the effiet of clipping; thereby preventing the shock that would otherwise arise, were the nozzle and the edge of the tinile parallel at the instant when the cut commences. The action of the machine wonld perhaps be simproved by an increased obliquity of nozzle, as the stroie of the knives would thus be still less felt ; but this conld not easily be done unless the knife were placed oblique also in the opposite direction. But this involves a ditienlty which the present machine was intended to obviate, namely, the preserving a straightedged knife, which, in the hands of an unskilled workmati, is much easieradjusted than a twisted one. And farther, a moderate degree of obliquity is preferable to an excess; in the former, the intervals of the cuts are so considerable as to allow the fly-wheei to exert its natural effert of storing. as it were, a quantity of momentum or force, which it freely gives out to meet the resistance of the next cut; when, on the contrary, the oblicuity is very great, as is frequently the ease in the machines with twisted knives, and more especially when there are four cutters applied to the cylinder. there may, in such cases, be no interval of action in the rutters, for before one has completed its cut, the next has commenced, and the advantages of a $\mathrm{H} y$ - $\mathrm{w}$-heel are, in such cases, nearly, if not altogether, lust; hence we find that some of the machines with twisted knives are extremely heavy to work.

(1365.) There is. however, another cause of increased labor in the working of some straw-cutters, on the principle now before us. In many of the cylinder mactines, the cutter.wheels are of a diameter so large as to render the operation of cutting with them one of great labor. This ariseg from the circumstance of the action of the machine being a combination of the effects of the lever. The winch-handle is a lever, say of 12 inches radius, and the radius of the cutter-wheel, measured to the edge of the cutter, may be taken at 6 inches; here there is a mechauical advantage of two to one in favor of the power. Let the cutter-wheel be increased to 16 inches, or a radius of 8 in. ches, the proportion of the leverage is now materially changed, and the merhanical advantage in favor of the power is only $1 \frac{1}{2}$ to 1 . The power, therefore, suppose it exerts in the first case a force of $30 \mathrm{lbs}$, it will require, in the second case, a forse of $40 \mathrm{lbs}$., to overcome the same resistance, and so on in that proportion. But the fly-wheel, under the like circumstance, loses part of its effect, though not to the same amount; for, suppose its radius to the center of gyration to be 2 feet, the meclsanical advantage of its momentum would be, in the first rase, as 4 to 1 , and in the second, as 3 to 1 . In the construction of all cylinder straw-cutters. therefore, it is of importance to make the cutters of small diameter, that is to say, never to exceed 11 inches. It were, perhaps, better that they should be less than this, but on no account should they exceed it, especially for hand-machines. In the case of steam or water power, any small increase of resistance is less important, provided that a countervailing object is to be attained by it, such as a machine already made, or the like.

(1366.) While on the subject of fly-wheels, it may not be ont of place to make a few remarks, poiuting out where those auxiliaries to machinery may with propriety be applied, and where they ought not. In the first place, it may be asserted that in no case can a fly-wheel act as a generator of power; and under a false impression of this supposed function of fly-wheels, numerous instances occur of their misapplication, or at least a misconception of their effects; and, second$\mathrm{ly}$, the only available function of $\mathrm{Ay}$-wheels is their capability of acting as reservoirs of that power or force that is communicated to them while in motion. Thus a comparatively small force applied to a heavy fly-wheel for a few seconds, will, on the principle of its absorbing and partially retain. ing that power and force, accumulate a momentum that may, through the agency of mechanical means, be discharged on a particular point, and produce an instantaneous effect that the first mover never could accomplish without such means. This is finely exemplified in the machine for punching and cutting thick iron plates and bars; and the principle applies in all cases where fir-wheels can be employed with advantage. The principle of action is this: Fly-wheels may be employed with advantage in every case where the intensity of either the power or the resist. a $\cdots$, is variable; and where both are variable, it becomes still more necessary. On the other hand, where both the power and the resistance are uniform. a fly-wheel may be held as an incumbrance, and can only act as a load upon the first mover. In the steam-engine, for example, of any form in which a crank is used to communicate motion to machinery, the Hy-wheel is indispensably necessary; and such is the requisite governing power of fly to keep up steady motion, that its momentum is sufficient to compensate for considerable variation in the resistance of the machine or machinery upon which it operates. With water-wheels, however, the power is perfectly uniform, and is the resistance is also uniform, as in grist-mills and even threshing-mills, fly-wheels would be worse than useless; but where the resistance is intermitting, such as rolling and tilt-mills, and punching machines, a heavy fly becomes necessary, in which the power of the first mover can be accumalated for a short period and which will be expended during the succeeding short period that the (1089) 
driven machine is in action. In every case where manual labor is applied, fly-wheels are usefol if driven machine is arises from the power itself being variable; for the power of a man working a not essential. This arises from the power winch varies according to the to range in the proportion of $30 \mathrm{lbs}$, and $60 \mathrm{lbs}$. The rationale of this tion, and has beell ascertainition that restricts his exertion to $30 \mathrm{lbs}$, he might not be able to overcome the resistance unless at a very slow rute; but in the pusition where he can exert a force of 60 lbs.. he can do more than overcome the resistance. And here it is that the fly. wheel comes to his aid; for cuppose the resistance requires an actual force of $45 \mathrm{lbs}$, while he is putting forth $60 \mathrm{lbs}$, thene is 8 surplus of $15 \mathrm{lbs}$. This last quantity the ever-ready fly-wheel, whose velocity, from its inertia, he is not able greatly to increase: but it takes up, with a small increase of velocity, the surplus force exerted by the hand, and this is stored up in the mass of the wheel, to be delivered out force exerted by theak point in the revolution of the winch. Hence, a nearly equable force is produced to act upon the machine to which the power of the man is directed. If this power is directed apon an intermitting machine, such as a straw-cutter, the demands upon the thy-wheel are very nuch increased; but as the point of the machine to which the power is applied moves at a much stower velocity than the center gyration in the fiy, and as the intermissions of the resistance are not likely to coincide exactly with the increments or decrements of the power, there ance are not likely compensation going on anong the forces to bring out a uniform result. There is a possibility that a coincidence of the above circumstances may occur; hence, it is sometimes of consequence to observe the placing of the winch, so as to counteract any defect of compensation.

(1367.) The power of horses to impel the machinery being of nearly uniform intensity, requires no regulator in itself; but it comes under the general law, if the resistance is internitting. Thus, in the threshing machine, which is slightly variable in resistance, it would, if worked with horkepower. be considerably improved by the addition of a well proportioned Hy-wheel of which more in another place. In various other machines worked with horse power, where the resistance is frequently-intermitting, such as blowing bellows, pumping, and the like, a fly is indispensable: while in a malt or other mill, whose resistance is uniform. the fly would be an incumbrance. Steam-power applied to a threshing-machine requires, as already observed, no additional fly. wheel: but that of the steam-engine for such purpose, should be above the standard allowed for ordinary purposes.

(1360.) The general theory of the application of fly-wheels may be repeated in a few words They are usefully employed in all cases of intermitting resistance and of variable force, whether in the first mover or in the resistance. Where the motion is uniform and not intermitting, the first mover being also uniform, the $\mathrm{H}_{y}$-wheel is in almost every case unnecessary. and frequently an obstruction.

(1369.) The determination of the weight of a fly-wheel for any given purpose, is a problem not very definite in its results; but approximations to it have been made by men of eminence. Amon these, we find Tredrold statims a rule for the Hy wheels of steam-engines, ${ }^{*}$ which, for practical purposes, is convenicnt, nud comes near to the general practice; though this is to bu practical purporable latitude, seeing that the practice of engineers differs considerably on this point; and the rule, though it applies to heavy $\mathrm{Hy}$ wheels with tolerable exactness, does not agree witl practice in the case of Hy whets for the haint, and other small machines. But the following approximation will be a tolerable yuide in practice fior the weight of small fly-wheels.

(13;0.)Taking the average force that a min will exert in turning a winch of 12 inches radius at $23 \mathrm{lbs}$, when he turns it $4 \overline{3}$ times per minute, the rule will be :

RLCE.-Multiply 20 times the force in pounds r.xerted on the winch by its radius in feet, and divide this product by the cube of the rulius of the ty-wheel in teet, multiplied into the nun ber of the revolutions per minute; the result will be the area of a section of the rim of the fly, in square inches.

Examl't.-The force applied to the winch being $23 \mathrm{lbs}$, its radius 1 foot, and the revolutions per minute 45 ; required the section of the rim of a fly-wheel whose radius is $1 \frac{1}{2}$ feet, or 3 feet diameter.

$$
\frac{20 \times 23 \times 1}{1.5^{3} \times 45}=\frac{460}{151}=3 \text { inches, the area of section of the rim nearly. }
$$

(1371.) Thoush this formula will scrve for small Hy-wheels, whose velocities range from 40 to 80 revolutions per minute, it becomes necessary, in oriler to nake it agree with practice, to change the constant. Thus, for velocities ranging from 80 to 150 , the number 10 will be substituted for 20 ; and from 150 to 300 , the number 5 . In this last case, the fly-wheel cannot exceed 2 feet diameter; and in the former, it is restricted to 5 teet.

(1372.) The Disk S'raic-culler.--()f the disk straw-cutter the varieties are very numernus, and they form a very important order of this machine; being that, also, which is for the most part. employed in Englumb, it is the most mmerous of the class. The principal feature, the cutting-kuife, fixed upon the fy-wheel, is invariable, except that it sometimes carries one, at other times two knives. The machinery or details are exceedingly varied. In some, it is adapted to cut of various lengths by means of ratchet-whecls and lever-ratches applied to the motion of the feeding rollers, and at the same tinze to move the substance furward onity in the intervals of the stroke of the knife: in others, the latter qualification only is attended to: in a third, a continous mo tion of the substance is deemerl sulficient; and these varieties of motion are produced by other and various arrangements of spur, hevel, and screw geerings.

(1373.) The machine selected for illustration is one in which two knives are employed, and which gives to the substance to be cut a continuous motion forward. The figure here represeuting this, is taken from a machine manufactured by John Anderson and Son, founders, Leith Walk

- Tredgold on Steam-Engines.

(1090) 
at a price of $£ 1010 \mathrm{~s}$. Fig. 289 is a view of this machine in perspective. The chief parts of the frame-work are of cast-iron, consisting of a frame $a$ a on each side of the machine, which are sup ported transversely by the truss $b$. The front part of the side-frames extend upward and form

Fig. 289.

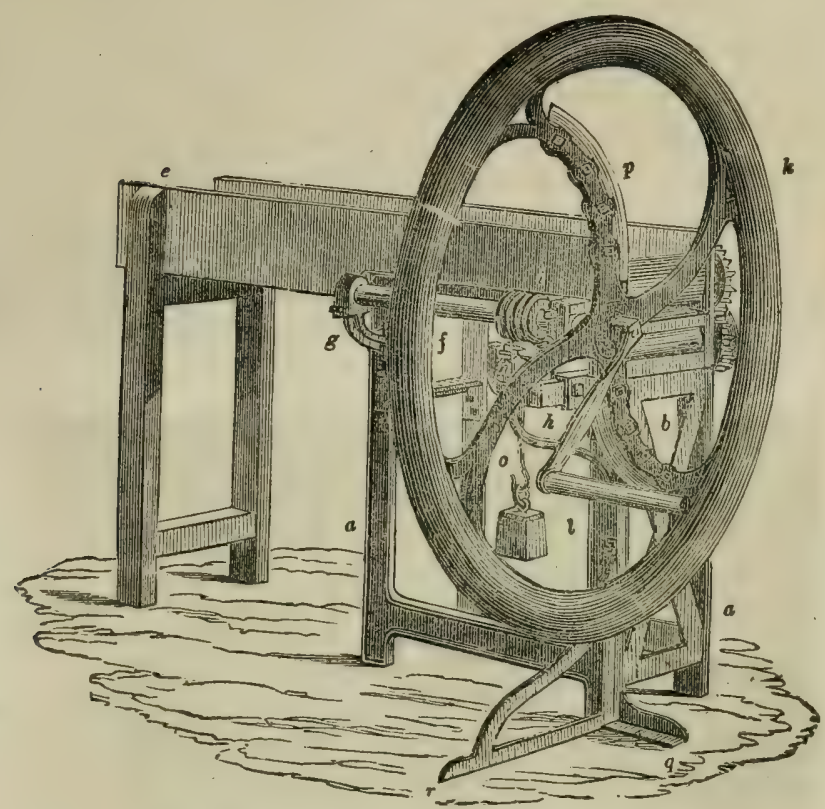

THE DISK STRAW-CUTTER WITH CONVEX KNIVES.

the feeding-roller frame. The cutting plate is attached in front of the latter portion of the framework, and is dressed truly off for the passage of the knife over its face. The feeding-trough $e$ is connected in the fore-part to the roller-frame, and along its bottom to the upper edge of the sideframes. The back end of the trough is supported in a light wooden-frame. The principal shaft $f$ is supported on two projecting brackets $g$ and $h$, and upon it is mounted the single-thread screw $i$, and the fly-wheel $k$; on the extreme end also of the shaft, the winch-handle $l$ is attached. A bracket carries one end of a small shaft, on which the screw-wheel $n$, of 21 teeth. is mounted, and is turn ed by means of the screw, when the fly-wheel is put in motion. On the opposite end of the small shatt $n$, a spur-wheel is also placed, and acts upon another of equal diameter placed on the axle of the lower feeding-roller. This last, as well as the upper roller, are furnished with the usual long-toothed pinions, for admitting of the rise and fall of the upper roller. The upper roller is supported in a light frame that rises and falls in a slide of the roller-frame, and this is acted upon by a lever and weight, of which the hook only is seen in the figure at $o$. The cutting-knife $p$ is 18 inches in length, and 4 inches in breadth. It is firmly bolied upon the arm of the fly-wheel, and its cutting-edge, which is convex, is so formed that every successive point, in passing the edge of the cutting plate, forms equal angles with the edge of that plate. In many of the disk machines, the cutting-edge of the knife is concave, formed on the same principle of equal angles, and, in effect, is the better of the two.

(1374.) The dimensions of the principal parts of this machine are as follows. Width of the frames 14 inches; length of cast-iron frames 30 inches, and hight 3 feet: length of feeding-rollers 12 inches, and their diameter $4 \frac{1}{4}$ inches; length of feeding-trough $5 \mathrm{feet}$, and width 12 inches. The fly-wheel is 4 feet 3 inches diameter, and the hight to its center is 3 feet. From the entire weight of the fly-wheel being supported at one angle of the frame, the spreading brackets $q r$ are attached, to give the machine stability.

(1375.) The Sleaming Apparalus.-The means employed for cooking food for horses and cattle, are either boiling or steaming. In the first, an open vessel is of course employed, in which the roots or other substances are piaced, with a sufficient quantity of water. This method has been found inconvenient in many respects; and when the establishment is extensive, the vessel is required to be incommodiously large, and is withal not economical.

(1376.) Steaming in a separate vessel has been adopted in preference to the former method and has been followed in a variety of forms, but these may be ranked under two distinct kinds. The first is an open vessel, a boiler generally of cast-iron, having a channel or groove of 1 inch wide and 2 inches deep formed round its brim. The vessel is placed over a furnace properly construct. (1091) 
ed, and is partly filled with water. The groove is also filled with water. A sheet-iron cylindrical pan. of 3 to 4 levet in depth, and of a diameter suited to pass into the groove of the water-vesed (which is generally alsout 3 feet diameter), is also provided. The pan has a perforated lottom to admit steam freely from the lower vessel. It is also furnished with an iron tow by which it can be suspended, and by which it can be conveniently tilted while suspended. This is the steam. ing pan; and for the purpose of moviug it to and from the hoiler. u crane, mounted with wheel and pinion and a chain, completes the apparatus. To put this in operation, the pan is filled with the substances to be steamed and covered over either with a deal-cover or with old canvas bags. It is then placed uron the boiler by m:-ans of the crane. and the fire being pretty strongly urged till the water in the boiler gives off its stoam, which, passing up throish the bottom of the pan, and acting upon the contents, proluces in a few loours all the results of boiling. The water in the groove of the boiler serves as a sealing to prevent the escape of steam without passing through the pan. Bus notwithatauling this, it is esident that the steam can hardly ever reach the temperature of $212^{\circ}$; and hence. this apparatus is always found to be very tardy in its effects. When the contents of the pan have been found sufficiently done, the whole is removed from the boiler by means of the craue, and filted into a large trough to be thornughly mixch. and thence served ont to the stork. A general complaint has tieen miged against this constrnction of apraratns, arising from the slow. ness of the procuss of conking by it, and conscquent expense of fuel. Boilers of the form here described are nu well calculated $(0)$ absorb the maximun of caloric that may be afforded by a given quantity of fuet, neither is the apparatus gewerally $2 l_{x}$. hes a alumtion for the application of

Jig. S(4).

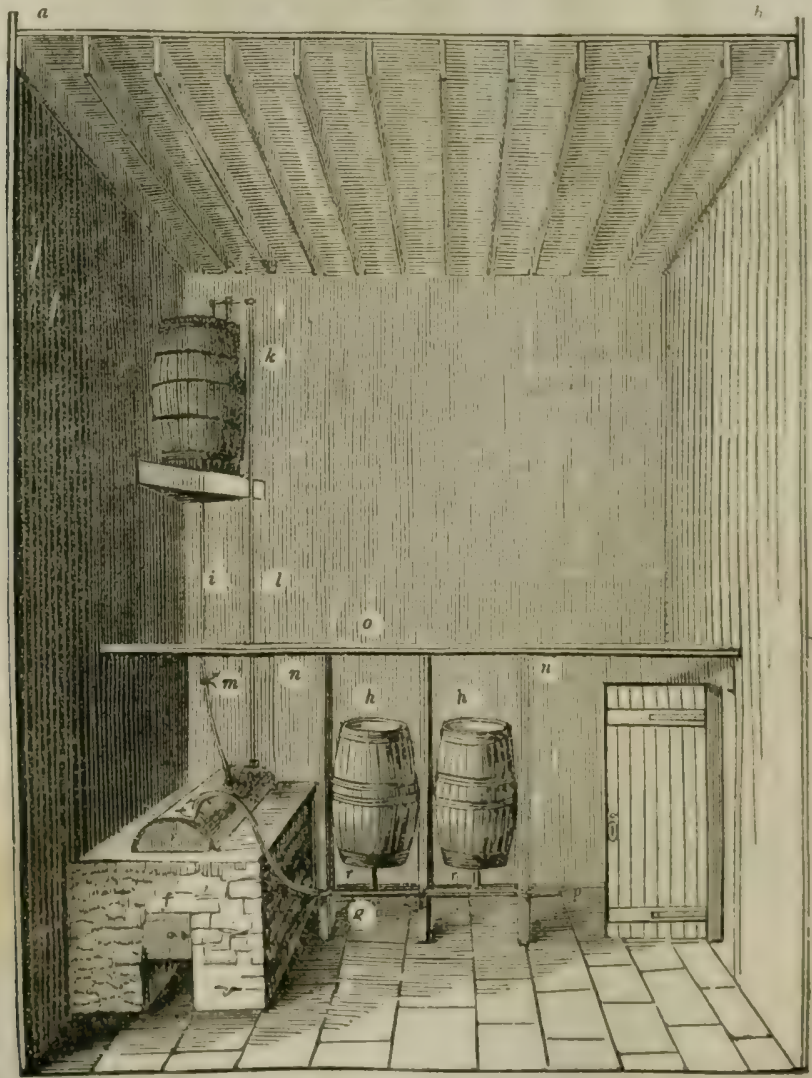

THE CLOSED-BOILER STEAMING APPARATUS.

steam to the substances upon which the steam has to ach. Such boilers, as already observed, can never produce ateam of a higher temperature than $212^{\circ}$. If they did. the shallow water-luting furmed by the marginal groove, would be at once thrown out by the steam pressure ; for it is well known that the addition of $1^{\circ}$ to the temperature of the stean increases its elasticity equal to the resistance of a column of water about 7 inches high. A groove, therefore, of $\gamma$ inches in depth (1092) 
would be required to resist the pressure, which would even then be only $1.5 \mathrm{lb}$ of pressure on the square inch. Under such circumstances, the temperature in the steaming-pan will always be under $212^{\circ}$. Hence the tedious nature of the process by using this apparatus.

(1377.) The apparatus which deserves the precedence of the above mode is here represented in fig. 290. The principle of its construction is that of a closed boiler, in which the steam is produced under a small pressure of 3 to $4 \mathrm{lbs}$. on the inch. It is then delivered through a pipe to one or more separate vessels containing the substances that are to be cooked; and these vessels are so arranged as to be readily engaged or disengaged with the conducting steam-pipe. The outline $a b c d$ of the figure represents a section of the steaming-house, with the apparatus in due order of arrangement, and of the extent that may be capable of supplying an establishment of from 10 to 16 horses. The boiler $e$ is of a cylindrical form, 20 inches in diameter and 4 feet in length. It is set in brick-work $f$, over a furnace of 14 inches in width, with fire-grate and furnace-door. The brick building requires to be 6 feet 6 inches in length, 4 feet 6 inches in breadth, and the hight about 3 feet 6 inches. The furnace is built with a circulating flue, passing first to the farther end of the boiler, then, turning to right or left according as the chimney may be situated, returns to the front of the boiler, and terminates in the chimney on the side opposite to the first turning. The flues should be not less in width at the upper part than one-fourth the diameter of the boiler; and their hight will be about one-third the diameter. The steam-pipe is attached to the boiler at its crown, takes a swan-neck bend downward to within 12 inches of the floor at $g$, and terminates at $p$ : it is furnished with as many branch nozzles as there are intended to be steaming-vessels. The steam-pipe may be either cast-iron or lead, and 2 inches diameter in the bore. The receptacles or steaming-vessels $h h$ are usually casks of from 50 to 100 gallons contents. They are mounted with 2 iron gudgeons or pivots. placed a little above mid-hight; they are besides furnished with a false bottom, supported about 3 inches above the true bottom; the former being perforated with a plentiful number of holes, to pass the steam which is introduced between the two bottoms. The connection between the steam-pipe and the receptacle may be either by a stop-cock and coupling-screw-which is the most perfect connection-or it may be by the simple insertion of the one nozzle within the other, in the form of a spigot and faucet. In this latter case, the nozzle that leads from the steam. pipe is stopped with a wooden plug, when the receptacie is disengaged. Besides the steam-pipe, the boiler is furnished with a pipe $i$, placed in connection with a cistern of water $k$, the pipe entering into it by the bottom. and its orifice closed by a valve opening upward, the lower extremity of the pipe passing within the boiler to within 3 inches of its bottom. A slender rod $l$ passes also into the boiler through a small stuffing-box; and to its lower end, within the boiler, is appended a float, which rests upon the surface of the water within the boiler. The upper end of this rod is jointed to a small lever which has its fulcrum supported on the edge of the cistern a little above $k$; the opposite end of the lever being jointed to a similar but shorter rod, rising from the valve in the bottom of the cistern. This forms the feeding apparatus of the boiler, and is so adjusted by weights that when the water in the boiler is at a proper hight, the float is buoyed up so as to shut the valve in the cistern, preventing any farther supply of water to pass into the boiler, until, by evaporation, the surface of the water has fallen so far as to leave the float unsupported, to such extent as to form a counterpoise to the valve, which will then open, and admit water to descend into the boiler, until it has again elevated the float to that extent that will shut the valve in the cistern. By this arrangement, it will be perceived that the water in the boiler will be kept nearly at a uniform hight; but to accomplish all this, the cistern must be placed at a certain fixed hight above the water in the boiler, and this hight is regulated by the laws which govern the expansive power of steam. This law, without going into its mathematical details at present. in so far as regards this point, may be stated in round numbers as follows: That the hight of the surface of the water in the cistern must be raised above the surface of that in the boiler, 3 feet for every pound-weight of pressure that the stean will exert on a square inch of surface in the boiler. Thus, if it is estimated to work with steam of $1 \mathrm{lb}$. on the inch, the cistern must be raised 3 feet : if 2 inches, 6 feet; 3 inches, 9 feet ; and so on. If the steam is by any chance raised higher than the hight of the cistern provides for, the whole of the water in the boiler may be forced up throngh the pipe into the cistern. or until the lower orifice of the pipe, within the boiler, is exposed to the steam, which will then also be ejected through the pipe; and the boiler may be left dry. Such an accident, however, cannot occur to the extent here described, if the feeding-apparatus is in proper working order; and its occurrence to any extent is sufficiently guarded against by a safety-valve.

(1378.) The safety-valve of the steam-boiler is usually a conical metal valve, and always opening outward; it ought always to be of a diameter large in proportion to the size of the boiler and steam-pipe. so as to insure the free egress of any rapid generation of steam. For a boiler of the size under consideration it should be 2 inches in diameter on its under surface-that being the surface acted upon-this gives an area of fully 3 square inches; and if loaded directly, or without the intervention of a lever, for steam of a pressure of $1 \mathrm{lb}$. on the inch, it will require $3 \mathrm{lbs}$; if $2 \mathrm{lbs}$. on the inch, $6 \mathrm{lbs}$, if $3 \mathrm{lbs}$. on the inch, $9 \mathrm{lbs}$, and so on. With these adjustments, the steam, should it rise above the proposed pressure, will, instead of forcing the water through the feed-pipe, raise the safety-valve, and escape into the atmosphere until the pressure is reduced to the intended equilibrium.

(1379.) Another precautionary measure in the use of the steam-toiler is the guage-cock, of which there are usually two, but sometimes one, a two-way cock; they are the common stop-cock, with a lengthened tail passing downward, the one having its tail terminating about $1 \frac{1}{2}$ inches below the proper water level in the boiler, the other terminating $1 \frac{1}{2}$ inches above that level, which allows a range of 3 inches for the surface of the water to rise or fall. The first, or water-cock, then, when opened, will throw out water by the pressure of the steam upon its surfice, until the surface has sunk $1 \frac{1}{2}$ inches below its proper level, when steam will be discharged, thus indicating the water in the boiler to be too low, and that measures should be taken to increase the supply. When the gecond or steam-cock is opened, it will always discharge steam alone, unless the water shall have risen so high as to come above its orifice, in which case the cock will discharge waler, indi

(1093) 
cating a too large supply of water to the boiler, and that it should be reduced; for this parpose, the feed-pipe $i$ is provided with a stop-cock $m$, whereby the admission of water can be entirely prevented at the pleasure of the attendant.

(1380.) The foregoing description refers to a ateaming-apparatus of the best description, and implies that the water-cistem can be supplied either from a fountain-head, or that water can be pumped up to the cistern. But there may be cases where neither of these are easily attainable. Under such circumstances the feed-pipe may rise to the hight of 4 or $4 \frac{1}{2}$ feet, and be surmounted by a funnel, and under it a stop cock. In this case, also, a float with a wire stem, rising through a stufting-box on the top of the boiler, must be employed-the stem may rise a few inches above the stufting-box, in front of a graduated scale-baving the zero in its middle point. When the water is at the proper hight in the boiler, the top of the stem sliould point at zero, and any rise or fall in the water will be indicated accordingly by the position of the stem. To sapply a boiler mounted after this fashion, the first thing to be attended to, before setting the fire, is to fill up the boiler, through the funnel. to the proper level, which will be indicated by the float pointing to zero ; but it should be raised, in this case, two or three inches higher. In this stage, the gauge.cocks are nun-effective; but when the steam has been got up, they, as well as the float, nust be consulted frequently; and should the water, by evaporation, fall so low as 3 inches below zero, a supply must be introduced through the funnel. To effect a supply, in these circumstances, the steam must be allowed to fall rather low, and the funnel being filled, and the stop-cock opened, the water in the former will sink down through the tube, provided the steam be sufficiently low to adınit its entrance, bat the first portion of wuter that can be thus thrown in will go far to effect this, by sinking the temperature. The sinking of the temperature by the addition of a large quantity of cold water, is the objection to this mode of feeding; but this is obviated to some ex. tent from the circumstance, that unless the stcaming receptacles are large or numerous, the first charge of water will generally serve to cook the mess, when a fresh charge can be put in for the next.

(1381.) In using this steaming-apparatus, it has been noticed that the casks are furnished with gudgeons, which play in the posts $n n$; these are kept in position by the collar-beam $o$ to which they are attached; the casks being at liberty to be tilted upon these gudgeons. They are charged when in the apright position, and the connection being formed with the steam-pipe, as described, they are covered at top with a close lid or a thick cloth, and the process goes on. When the substances are enfficiently cooked. the couplings $r r$ are disengaged, the upper part of the cask is swong forward, and their contents discharged into a trough which is brought in front of them for that purpose.

(1382.) The connections with the steam-pipe are sometimes, for cheapness, formed by a sliding tube of copper or brass, about 4 inches in length, which, after the nozzle of the cask and that projecting from the steam-pipe are brought directly opposite to earh other, is slid over the junction, and as a moderate degree of tightness only is requisite in such joints, a strip of sacking wrapped round the ends of the slider is found sufficient. On breaking the connection, and opening the exit nozzles, the steam will of course flow out, but this is checked by a wooden plug, or even a potato or slice of turnip, thrust into the orifice, may be sufficient. It is advisable, however, that a main stop-cock should be placed in the steam-pipe anywhere between the boiler and the first receptacle.

(1383.) The most perfect connection between the steam-pipe and the receptacles is a stop-cock and coupling-scren. These should be of $1 \frac{1}{2}$ inches bore, they are more certain in their effect, and more convenient in their application, though attended with more expense in the first cost of the apparatus. In this case no main-cock is required. The extremity of the steam-pipe should, in all cases, be closed by a small stop-cock, for the purpose of draining off any water that may collect in the pipe from condensation. A precaution to the same effect is requisite, in the bottom of each cask, to draw off the water that condenses abundantly in it; or a few small perforations in the bottom will effect the purpose.

(1384.) It must be remarked, in regard to steaming, that in those establishments where grain of any kind is given in food in a cooked state. dry grain cannot be cooked, or at least boiled to softness in dry steam, the only effect produced being a species of parching; znd if steam of high temperature is employed, the parching is increased nearly to carbonization. If it is wished therefore, to boil grain by steam, it must be done by one of the two following methods: The grain must either be soaked in water for a few hours, and then exposed to the direct action of the steam in the receptacle; or it may be put into the receptacle with as much water as will cover it, and then by attaching the receptacle to the steam pipe, by the coupling atop-cock, or in the ab. gence of stop cocks, by passing a bent leaden pipe from the steam-pipe, over the upper edge of the receptacle and descending acain inside. to the space between the false and the true bottoms; the steam discharged thus, by either method, will shortly raise the temperature of the water to the boiling point, and produced the deaired effect."

(1385.) The time required to prepare food in this way varies considerably, according to the state of the apparatus, and the principle of its construction. With the apparatus just described, pota. toes can be steamed in casks of from 32 to 50 gallons contents, in 30 to 45 minutes. In casks extending to 80 gallons, an hour or more may be required. Turnips require considerably longer time to become fully ready, especially if subjected to the process in thick masses, the time may be stated at double that of potatoes. When the apparatus is ill construeted, the time, in some cases, required to cook turnips, extends to 5 hours. And, with reference to the apparatus first described (1376), the time is seldom under 5 hours.

(1386.) The prices of steaming-apparatus vary accordingly to quality and extent; but, on an average, the open boiler and pan apparatus, including a power.crane, will range from $£ 7$ to $£ 10$; and the other, fig. 290 , the price ranges from $\mathcal{L} \&$ to $£ 16$. The expense of building the furnace, and supplying mixing-troughs, will add about \pm 2 108. to esch.

* See an article by me in the Quarterly Journal of Agriculture, vol. vi.

(1094) 
(1387.) Corn-Bruisers. In following up an economical system of feeding, the bruising of all grain so applied forms an important branch of the system, and, as might be expected, numerous are the varieties of machines applied to the purpose. These naturally arrange themselves under three distinct kinds. 1st. Machines which act on a principle that partakes of cutting and bruising, by means of grooved metal cylinders, and is applied to those chiefly driven by the hand. 2d. Machines adapted to bruise only by means of smooth cylinders; this is applied exclusively to those driven by steam, or other agency more powerful than the human hand. And, 3d, Breaking or grinding by the common grain millstones, and of course, only worked by power.

(1388.) That variety of the first division which I shall particularly notice. is represented in perspective in fig. 291. It is constructed almost entirely of cast-iron, except the hopper and dischargingspout; but its frame or standard may with propriety be formed of hard-wood, when circumstances render the adoption of that material desirable. In the figure, $a$ a $a$ is the frame-work, consisting of two separate sides, connected by two stretcher-bolts. the screw-nuts of which are only seen near to $a$ and $a$ below. A case $b b$, formed of cast-iron plates, is bolted on the projecting ears at the top of the frame, and contains the bruising cylinders. The cylinders are 4 inches in diameter. and 6 inches in length, of cast-iron or of steel. They have an axle of malleable iron passing through them, having turned journals, which run in bearings formed on the cast-iton side-plates of the case, the bearings being accurately bored out to fit the journals. The spur-wheels $c$ and $d$ are fitted upon the axle of the cylinders, $c$ having 14 teeth, and $d 24$ teeth. The cylinder corresponding to $d$ is perfectly smooth, while that of $c$ is grooved at a pitch of $\frac{1}{4}$ inch, and about $3-32$ inch deep worked to sharp edges. The grooves lie obliquely on the face of the cylinder, being at an angle of $10^{\circ}$ with the axle. The winch-handle $e$ is attached to the axle of the roller $c$, whose bearings are permanent, while those of $d$ are movable, being formed in separate plates, and fitted to slide to a small extent in a seat, for the adjustment of the cylinder to any desired grist.

Fig. 291.

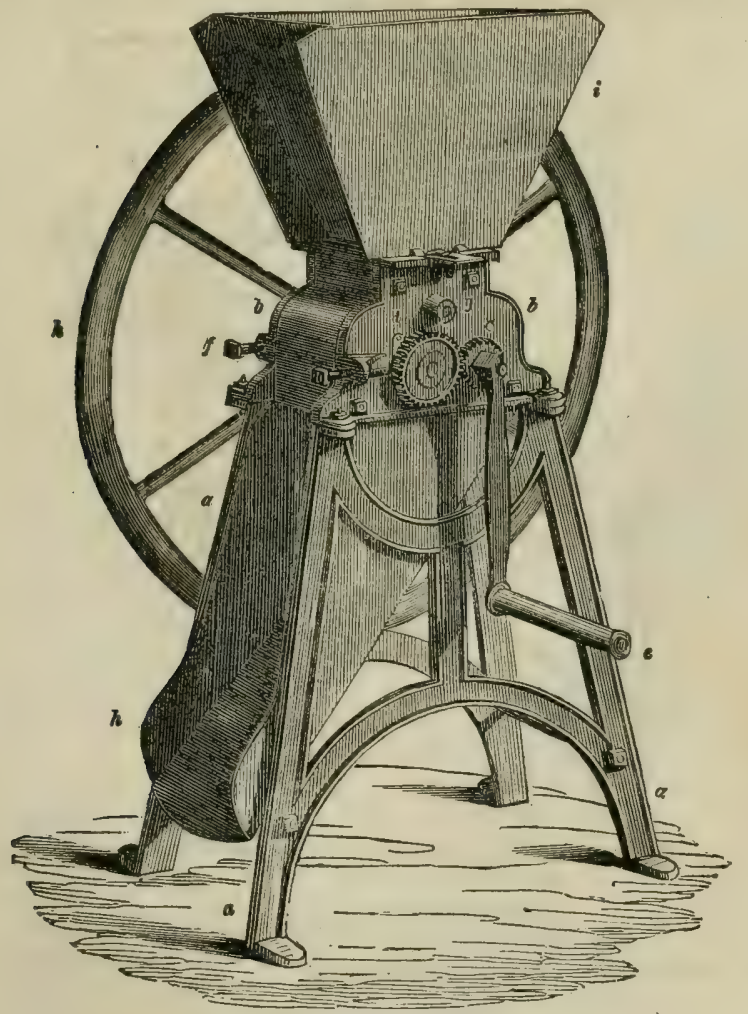

THE HAND CORN-BRUISER.

This adjustment is effected by means of the screws $f$, which act upon the sliding-plates of the bearings. $g$ is one of the bearings of a feeding-roller, placed also within the case; it is turned by means of a toothed-wheel fitted upon the farther end of its axle, and which is driven by another wheel of 24 teeth on the axle of the cylinder $d$. The fly-wheel $h$ is fitted upon the axle of (i095) 
the cylinder $c$, and is $3 \frac{1}{2}$ feet in diameter; $i$ is the feeding hopper, attached to the top of the case by two small hooks; and $k$ is a wooden spout to convey the bruised grain from the case.

(1389.) Fig 292 is a section of the case, and the cylinders, detached from the frame. $b b$ are the two ends of the case cut by the rection; $c$ is the grooved cylinder, $d$ the smooth, and $l$ is the feeding. roller, it is $3 \frac{1}{2}$ inches diameter, and has cylindrical grooves formed on its surface to convey the grain ; $o$ is a cover of cast-iron fixed upon the top of the case; it has two rounds ears $n n$, with eye-holes which serve to steady the hopper, and to which it is screwed by the hooks already mentioned. A hopper-shaped opening $m$ is formed in the cover: it is six inches long, 3 inches wide at top, and 1 iuch at bottom, and the edges fit closely upon the feeding. rollers. Two plate-iron sliders are fitted npon the surface of this little hopper, which serve to enlarge or contract the opening longitudinally, and are fixed by serew.

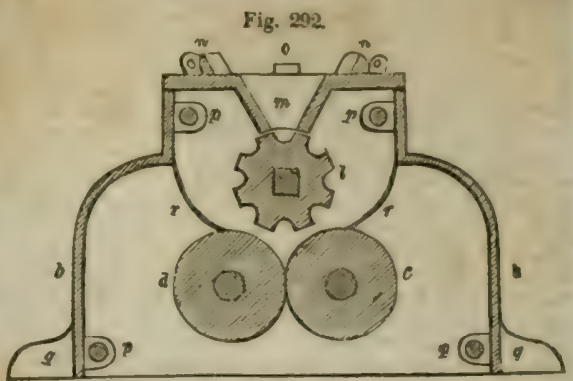

TRANSVEREE SECTLON, SHOWING THE RELATION OF THE PRINCIPAL PARTS.

bolts in cach plate; the head of one of the bolts is seen at $o . \quad p p p p$ are ears by which the case is bolted together, and $q q$ are prolongations of the side-plate of the case ; $r r$ are additional plates of slieet-iron, to prevent the grain from being thrown over the cylinders unbruised.

(1390.) This is a very efficient machine for bruising either oats or beans; the adjustment of the plain cylinder to the requisite distance being easily accomplished by the adjusting-screws; and Fig. 293.

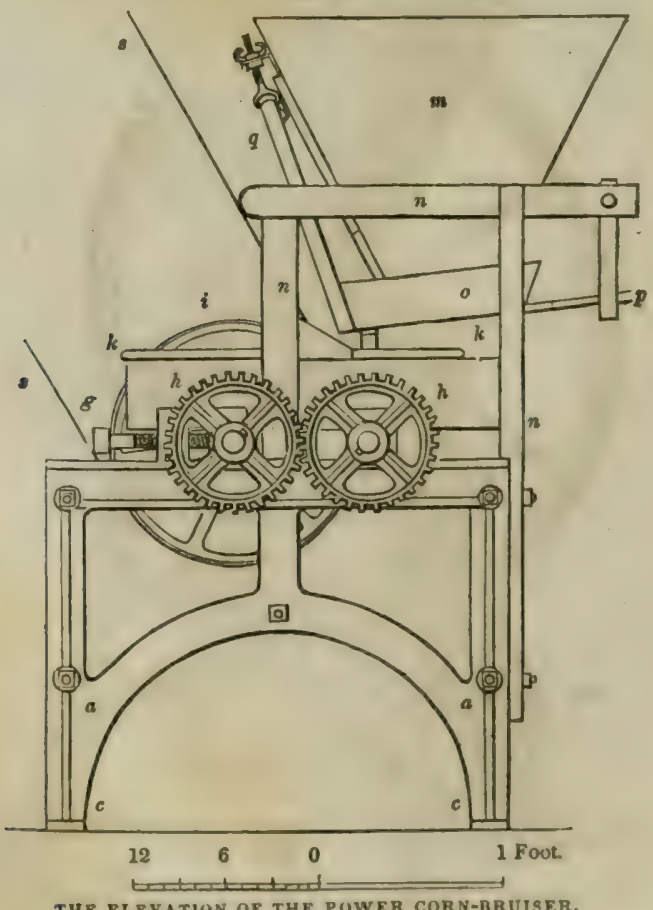

THE ELEVATION OF THE PUWER CORN-BRUISER.

to prevent the abrasion of the grooved cylinder, by coming in too close contact with the other, stopper is applied on ench side, to keep the slides from overreaching the due safety distance. From the different velocities of the two cylinders, the grooved one being the fastest, it produces a cutting as well as a bruising action, which renders its effects on the grain more perfect than simple pressure. It can be worked by one man, who will bruise 4 bushels of oats in an hour. The price of the machine is $£ 610 \mathrm{~s}$.

(1391.) Various other forms of this machine are in use, mone with both cylinders grooved, others with only one grooved cylinder acting against a grooved plate; in this last state it is much used for bruising beans.

(1096) 
(1392.) Among the varieties of the bruising-machine of the $2 d$ division, I may just notice one that is found very efficient. It consists of two plain-edged wheels or pulleys, as they may be termed, usually about 6 inches bruad on the rim or sole; the one ranges from $2 \frac{1}{2}$ feet to 4 feet in diameter, and its fellow only half the diameter of the larger. They require to be truly turned on the rim, and work in contact. The smaller one is always driven by the power, and the larger usually by contact with the smaller. The smaller wheel makes, according to its diameter, from 150 to 200 revolutions per minute. Where plain cylinders are employed for bruising, and their surfaces mor. ing with equal velocity, the effect is to press each grain into a flat, hard cake : but when one of the surfaces is left at liberty to move by simple contact, it is found that the effect is different from the above, for the grain passes, bruised indeed, though not into a hard cake, but has apparently undergone a species of tearing, leaving it in a more open and friable state than as described above. This machine, however, does not answer well for bruising beans, for here, again, they come through in the form of a flat cake. If beans, therefore, are used in an establishment where this bruiser is adopted, a separate one, on the principle of fig. 291 , is required for the beans alone ; that machine though serviceable for a small establishment, being incapable, even with power, to produce the quantity in a reasonable time that would be required in a large one.

(1393.) Plain Roller Corn-bruisers, for power.-A very efficient corn-bruiser, adapted for pow. er, is shown in figs. 293, 294, 295. The first being an elevation, the second a plan, and the third a section of the machine; the same letters apply to such corresponding parts as are seen in all the three figures. In fig. $293 a a$ is one of the side-frames, of cast-iron. which are connected together by stretcher-bolts $b$, and the frame so formed is bolted to a floor through the palms at $c c$. On the top bar of the frames there are two strong snugs $d d$ cast. sufficient to resist the pressure of the rollers, and are formed also to receive the brass bushes in which the journals of the two rollers are made to run. The two rollers $e$ and $f$ are respectively 8 and $9 \frac{1}{2}$ inches diameter, and are 18 inches in length, fitted with malleable iron shafts $1 \frac{3}{4}$ inches diameter; the roller $f$ runs in permanent bearings, but $e$ has its bushes movable, for adjustment to the degree of bruising required, and this adjustment is effected by the adjusting-screws $g$. The shaft of each roller carries a wheel $h$, equal in diameter, which is nine inches. The roller $e$ has also upon its shaft the driving pulley $i$, which by means of a belt $s s$ from any shaft of a threshing-machine or other power baving a proper velocity, puts the rollers in motion. The rollers are inclosed in a square wooden case $k k$, in the cover of which a narrow hopper-shaped opening $l$ is formed to direct the grain betwees the rollers. A hopper $m$ for receiving the grain is supported on the light wooden frame-work $n n$, which also supports the reeding-shoe $o$, jointed to the frame at $p$ and suspended by the straps $q$, which last is adjustable by a screw at $q$ to regulate the quantity of feed. A smooth-edged oblique wheel $r$, fig. 294 , is mounted on the shaft of the roller $f$, and by its oscillating revolutions, acting upon a forked arm which descends from the shoe, a vibratory motion is given to the latter, by which a regular and continued supply of the grain is delivered from the hopper to the rollers. Atter passing the rollers the grain is received into a spout, which either delivers it on the same floor, or through a close spout in the floor below. The velocity of the rollers, which are driven by

Fig. 294.

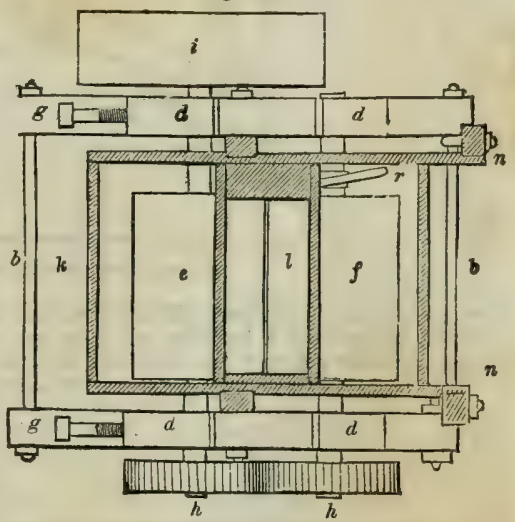

THE PLAN OF THE POWER CORN-BRUISER.

the belt $s s$, may be 250 revolutions per minute. The dimensions of the frame $a$ are 30 in. ches in length and 24 inches in hight; the width over all being also 24 inches. The price of thig machine, as manufactured by James Slight and Co., is $£ 10 .-\mathrm{J}$. S.

(1394.) The horse is an intelligent animal, and seems to delight in the society of man. It is re. marked by those who have much to do with blood-horses, that, when at liberty, and seeing two or more people standing conversing together, they will approach, and seem, as it were, to wish to listen to the conversation. The farm-horse will not do this; but he is quite obedient to call, and distinguishes his name readily from that of his companion, and will not stir when desired to stand until his oun name is pronounced. He distinguishes the various sorts of work he is put to, and will apply his strength and skill in the best way to effect his purpose, whether in the threshing. mill, the cart, or the plow. He soon acquires a perfect sense of work. I have seen a horse walk very steadily toward a feering-pole, and halt when his head had reached it. He seems also to have a sense of time. I have heard another neigh almost daily about 10 minutes before the time of loosening in the evening, whether in summer or winter. He is capable of distinguishing the tones of the voice, whether spoken in anger cr otherwise; and can even distinguish between musical notes. There was a work horse of my own, which, even at his corn, would desist eating and listen attentively, with pricked and moving ears, and steady eyes, the instant he heard the note of low G sounded, and would continue to listen as long as it was sustained; and another, that was similarly affected by a particular high note. The recognition of the sound of the bugle by a trooper, and the excitement occasioned in the hunter when the pack give tongue, are familiar instances of the extraordinary effects of particular sounds on horses.

(1395.) When alluding to the names of horses, I may mention that they should be short and emphatic, not exceeding two syllables in length, for longer words are difficult of pronunciation, and inconvenient to utter when quick or sharp action is required of the horse ; and a long name is almost always corrupted into a short one. For geldings, Tom, Brisk, Jolly, Tinker, Dragon 
Dobbin, seem very good names; for mares, Peg, Rose, Jess. Molly. Beauty, Mettle. keem as gor d and as to the name of stallions, they should be somewhat high-eounding, as indicative of greate: importance of character, as Lofty, Farmer, Plowboy, Matchem, Diamond, Blaze, Bamson, Cham.

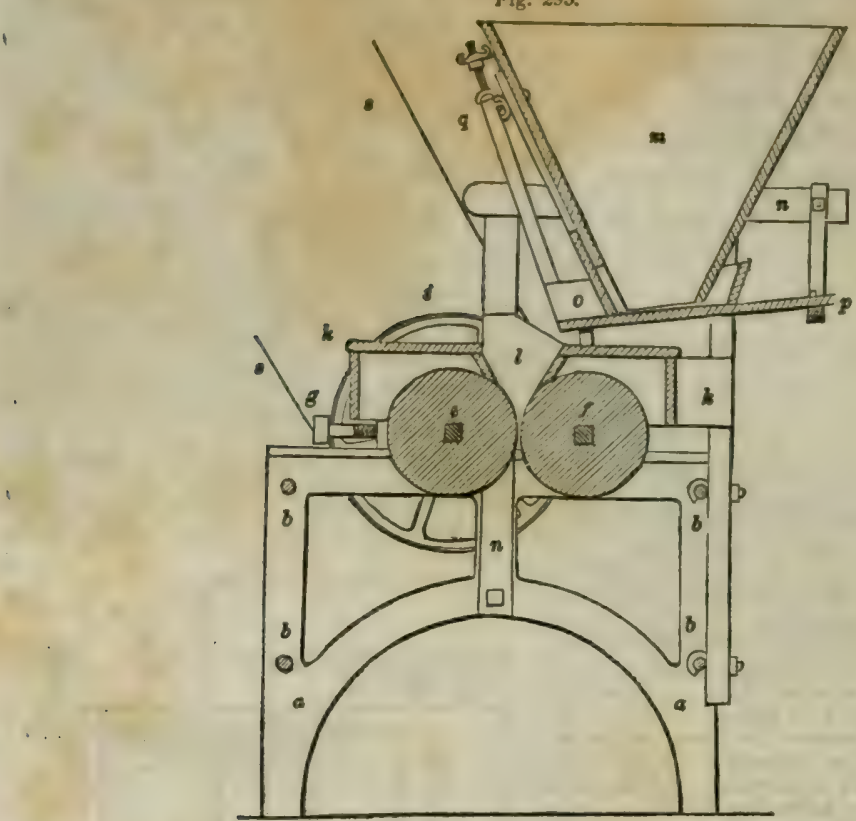

THE SECTION OF THE POWER CORN-BRUISER.

pion, are names which have all distingaished first rate draught horgeg.

(1396.) This seems a befitting place to say a few words on the farmer's riding and harness horses. Usually a young lad, or groom, ia hired to take charge of these, to go errands and to the post-office, and otherwise make himself serviceable in the house. Sometimes the hedger or shep. herd acts the part of groom. My shepherd acted as groom, and his art in grooming is so skillful that many friends remarked to me that they would be glad to see their professed grooms tarn out a saddle-horse or gig in so good a style as he did. Besides being useful in carrying the farmer to market, or other short distances, $\mathbf{a}$ roadster is required to carry him over the farm $w$ hen it is of large extent, and when the work-people necessarily receive pretty constant attention in the important operations of seed-time and harvest. The harness-horse is useful to a family at all times, as well as to the farmer himself, when he visits his friends; and many farmers now prefer riding to market in a gig or drosky, to horseback; and it must be owned to be the pleasanter mode of the two.

(1397.) I have said that the agricultural pupil should have no horse of his own at first, to tempt him to leave bome and neglect his own training. But to know how a riding-horse ought to be kept by a groom, and to be able to correct him when he neglects his duty or performs it in an an. eatisfactory manner, I would advise him to undertake the charge of one himself for some time; not merely to superintend its keeping, but to clean it bimself, to water and corn it at stated times at murning, noon, and night, and to keep the saddle and bridle in proper order. I groomed a new. broke-in blood filly for four months one winter, and got more insight into its form, temper, and management, and wants, than I could have obtained by observation alone in a much longer time. On coming home at night from visiting a friend, I made it a point with myself to make my charge comfortable for the night before thinking of my own rest.

(1398.) A saddle-horse is treated somewhat differently in the stable from a work-horse. The first thing to be done early in the morning is to shake up the litter nearest the strand with a fork, removing the dung and soiled straw to a court-yard, and sweeping the floor clean. Then give the horse a drink out of the pail which is constantly kept full of water in the stable. The usual practice is to offer the water immediately before giving the corn: but I conceive it more conducive to the health of the horse to slake his thirst a while before giving him corn, the water by that time having reached its destined place, and acquired the temperature of the body. Should the horse have to undertake a longer journey than walking about the farm, a stinted allowance of wa. ter before starting on the journey is requisite, say to 10 gluts; but if he is to be at home, then he may drink as much as he pleases. He is then groomed by being, in the first place, gently gone over the whole body with the curry-comb, to loosen the mud that may possibly have been left ad. hering upon the hair from the former night's grooming, and also to raise the scurf from the skin (1098) 
The whole body should be then wisped down with straw, to clear off all the dust and dirt that the curry-comb may have raised to the surface. The brush follows, to clear the hair of its dust and scurf, the curry-comb being used to clean the brash. Of wisping and brushing, wisping is the more beueficial to the legs, where the hair is short and the tendons and bones are but little cover. ed, because it excites in them warmth, and cleans them sufficiently. Both wisping and brushing should be begun at the head and terminated at the other end of the body, along the lie of the hair. whichsoever way that may be, and which, notwithstanding its different swirls, all tends from the upper to the lower part of the body. Many a groom rests content with the brushing just mentioned; but it does not entirely remove the dust raised to the surface, and therefore a wisping is required to do it. The wisp for this purpose is best mads: of Russia mat, first wetted. and then beaten to softness, and rolled up somewhat firmly into the form of a wisp sufficient to fill the hand. A wisp of hair-cloth makes the skin clean, but in dry weather it is apt to excite such a degree of electricity in the hair of the horse as to cause it to attract much dust toward it. On the horse being turned round in the stall, his head, neck, counter, and fore-legs, should be well rubbed down with this wisp, and this done, he should again be tarned to his former position, and the body, quarters, and hind-legs, then rubbed down; and when all this has been accomplished, the horse may be considered clean. All this grooming implies the bestowal of much more labor than most farmers' riding-horses receive. They are usually scuffled over in the morning with the currycomb, and then skimmed down with the brush, and with a hasty combing of the mane and tail, the job is considered finished. The mane and tail ought to be carefully combed out, and wetted over at the time of combing with a half-dry water-brush. The sheet should then be thrown over the horse, and fastened (not too tightly) with the roller. On putting on the sheet, it should be thrown more toward the head of the horse than where it is inteuded to remain, and thence drawn gently down the hair with both hands, to its proper position. while standing behind the horse. The litter is then neatly shaken up with a fork, taking care to raise the straw so far up the travis on each side as to form a cushion for the side of the horse to rest against when he lies down. The feed of corn is then given him, and a little hay thrown into the rack; and on the stable-door being shut, he is permitted to enjoy his meal in peace. At mid-day, he should bave another drink of water from the pail, the dung removed, the litter shaken up, and another portion of oats given him. At 8 o'clock at night, the sheet should again be taken off, the curry-comb and brush used, and the entire dressing finished again with a wisping of the Russia mat. The sheet is thrown over him as in the morning, the litter shaken up and angmented, water given, and the supper of oats, or a mash, finishes the day's treatment of the saddle-horse.*

(1399.) The treatment just described is most strictly applicable to the horse remaining all day in the stable; but when he is ridden ous, a somewhat different procedure is required. When he comes home from a long and dirty ride, the first thing is to get clear of the mud on the belly and legs. A very common practice is to wade the horse through the pond, as the farm-horses are, but such should not be the course pursued with a saddle-horse, because wading through a pond cannot thoroughly clear his legs of mud to the skin, he being clean-shanked and smooth-haired, and there still remains the belly to be cleaned by other means than wading. The plan is, being that adapted for winter, to bring the horse into the stable upon the pavement, and, on taking off the saddle and bridle and putting on a halter, scrape all the mud as clean off the belly and legs as can be done with a knife-a blunt table-knife answers the purpose well. Then, with a pailfull of lukewarm water, wash down the legs, outside and inside, with a water-brush, and then each foot separately, picking out the mud with the foot-picker; then wash the mud clean from the belly. A scrape with the back of the knife, after the washing, will bring out all the superfluous water from among the hair. On going into the stall the horse should be wisped firmly with straw, rubbing the belly first, and then both sides of each leg until they are all thoroughly dry. It is scarce. ly possible to get the belly dry at once; it should, therefore, get another good wisping with dry clean straw after the legs are dry. On combing out the mane and tail, putting on the sheet, and bedding plentifully with dry straw, the horse will be out of danger, and feel pretty comfortable even for the night; but should he have arrived some time before the evening time for grooming,

* In giving these details, and all which follow, we are aware that many of them are too minute, and otherwise ill adapted to American life and management generally; but then the reader must reflect that there are also many patrons of The Farmers' Library who are wealthy men, living in cities, who keep their carriage horses and pet nags for the saddle, with their superfluous grooms and all necessary appliances, to follow out all these directions. And besides, a sensible man never objects to knowing how any department of industry or of pleasure is managed in the country, where such departments have been carried on, as those have in England, to the highest pitch of perfection and refinement. And here we may relate an anecdote of a shrewd Massachusetts man of the world, who was some years since on a tour in England, and on a visit to the Duke of Buccleuch. After showing him many displays of the splendor and laxury of aristocratic living, His Grace took him to his stables, where genius and wealth had combined, to see how much money could be expended, and how much elegance displayed, on such an object. Our Yankee friend perhaps supposing he was expected to be confounded and overcome with astonishment at all he saw, instead of lifting up bis eyes and exclaiming as did the Queen of Sheba when she visited Solomon in all his glory, went peering under and about the troughs and stalls; and, on being ask. ed by the Duke if there was anything deficient in his stable appointment; answered "There is but one thing, your Grace, that is wanting to their completeness. I was looking for a sitver pot de chambre, for each of your Grace's hunters."

[Ed. Farm. Lib. 
the curry-comb and wisp then applied will remove any moisture or duat that may have been over ooked before.

(1400.) Considerable apprehension is felt in regard to wetting the abdomen of horsea, and especially at night, and the apprehension is not ill founded, for if the wet is allowed to remain, even to a small degree, quick evaporation ensues from the excited state of the body conscquent on ex. ercise, and rapidly reduces the temperature of the skin. The consequence of this coldness is ir. ritation of the skin, and likely grease on the legs, and this is the dauger of wetting the bellies of farm-horses, and of any sort of horse, with cold water: for uarm water cleans the hair and makes it dry sooner, even that on the abdomen, which is generally much longer than that of the legs; but, on the other hand, unless as much labor is bestowed as will dry the skin, and which is asual. ly more than can be expected to be given by ordinary country grooms, it is safer for the horse to remain in a somewhat dirty state, than to run the risk of any inflammation by neglected wet limbs and abdomen. At the same time, if the requisite labor shall be bestow ed to render the skin completely dry, there is even less risk in wetting the belly than the legs, inaenuch as the legs, in proportion to their magnitude. expose a much larger surface for evaporation, and are not so near the source of animal hest as the body.

(1401.) Saddle-horses receive oats in proportion to the work they have to perform, but the least quantity that is supposed will keep them in such condition as to enable them to do a good day's work at any time, is three half-feeds a day, one in the morning, another at mid.day, and the third at night. When subjected to daily exercise, riding-horses require 3 feeds a-day, and an extra allowance for extra work, such as a long journey. A mash once a-week, even when on work daily, is requisite; but when comparatively idle, a part of the mash, whenever prepared for the work-horses, may be administered with much advantage. I am no advocate of a bran-mash to a horse in good health. as it serves only to loosen the bowels without bestowing any nourishment. Boiled barley is far better. A riding horse should have hay, and not straw, in winter; and he will eat from $\frac{1}{3}$ to $\frac{3}{4}$ of a stone of $22 \mathrm{lbs}$. every day.

(1402.) On cleaning harness there should be two pairs of girths in use with the saddle, when the horse has much work to do, to allow each pair to be thoronghly cleaned and dried before being again used. The best way to clean girths is first to scrape off the mud with a knife, and then to wash them in cold water, and bang them up so as to dry quickly. Warm water makes them shrink rapidly, and so does long exposure to wet. If there is time, they should be washed in the same day they have been dirtied; but if not, on being scraped at night. they should be washed in the following moning, and hung up in the air to dry, and if the air is damp, let them be hung before the kitchen fire. Girths allowed to dry with the mud on soon become rotten and unsafe. The stirrup leathers should be taken off and sponged clean of the mud, and dried with a cloth. The stirrup-irons and bit should be first washed in water, and then rubbed dry with a cloth immediately after being used. Fine sand and water, on a thick woolen rag, clean these irons well, and a dry rub afterward with a cloth makes them bright. Some smear them with oil on setting them past to prevent rust, but oil, on evaporation, leaves a resinous residuam to which dust readily adheres, and is not easily taken off afterward. The curb-chain is best cleaned by washing in clean water, and then rubbed dry and bright by friction between the palms of both hands. The saddle-flaps should be sponged clean of mud, and the seat sponged with a wrung sponge, and rubbed dry with a cloth. Carriage-harness should be sponged clean of mud, kept soft and pliable with fine oil, and, when not japanned, blackened with the best shoe-black. There should be no plating or brass on a farmer's harness; plain iron japanned, or iron covered witb leather, forming the neatest, most easily kept, and serviceable mounting. Bright metallic mountings of every kind soon assume the garb of the shabby genteel in the hands of an ordinary rastic groom.

(1403.) In regard to the diseases of the horse, if we were to regard in a serious light the list of frightful maladies incident to that animal, which every work on veterinary science contains, we would never purchase a horse; but fortunately for the farmer, his horses are exempt from a large proportion of those maladies, as almost every one relating to the foot, and their consequences, are unknown to them. Nevertheless, many serious and fatal disorders do overtake farm horses in their usual work. with the symptoms of which you should be so far acquainted as to recognize the na. ture of the disease; and as you should be able to perform some of the simpler operations to assist the animal in serious cases until the arrival of the veterinary surgeon, a short account of these operations may prove useful. One or more of them, when timely exercised, may have the effect of soor removing the symptoms of less serious complaints. They consist of bleeding, giving physic and drenches. applying fomentntions, poultices, injections, and the like.

(1404.) Bleeding.- "In the horse and cattle, sheep and dog, bleeding, from its greater facility and rapidity." says Professor Dick, "is best performed in the jugular or neck-vein, though it may also be satiafactorily performed in the plate and saphena veins, the former coming from the inside of the arm, and running up directly in front of it to the jugular; the latter, or thigh-vein, running across the inside of that limb. Either the fleam or lancet may be used. When blood is to be drawn, the animal is blindfolded on the side to be operated upon, and the head held to the other side; the hair is smoothed along the course of the vein by the moistened finger, the point selected being about 2 inches below the angle of the jaw. The progress of the blood toward the heart is to be obstructed, and the vein thus made sufficiently permanent and tense. A large-bladed fleam and a good-sized lancet are preferable, as the benefit of the operation is much increased by the rapidity with which the blood is drawn. From 8 to 10 pints imperial is a moderate bleeding for the horse and ox, regulated. in some degree by the size. From 12 to 16 or even 20 pints is a large one : and sometimes in skillful hands, it is expedient to bleed till fainting is induced, and the animal drops down under the operation. The vessel in which the blood is received should be such that the quantity can be readily ascertained. When this is sufficient, the edges of the wound are to be brought accurately together, and kept 80 by a small sharp pin being passed through them, and retained by a little tow. It is of importance, in closing the wound, to see it quite close, and that no hairs or other forrign bodies interpose. For a time the bead should be tied ap, and cars taken that the horse doen not injure the part."

(1100) 
(1405.) The dangers arising from carelessness in blood-letting are not numerous ; and "the first of which, though it may alarm the inexperienced, is very trifling. It is a globular swelling, thrombus, sometimes as large as the fist, arising immediately around the new-made incision. The filtrating of the blood from the vein into the cellular membrane, which is the cause of the disease, is rarely very copious. Gentle pressure may be used at firet, and should be maintained with a well-applied sponge and bandage, kept cool with cold lotion. Occasionally there is inflammation of the jugular from bleeding. . . . The cause is usually referred to the use of a foul fleam, or fion allowing hairs to interfere with the accurate adjustment of the edges of the wound. The first appearance indicative of the disease is a separation of the cut edges of the integuments, which become red and somewhat inverted. Suppuration soon follows, and the surrounding skin appears tumefied, tight and hard, and the vein itself, above the orifice, feels like a hard cord. After this the swelling of the neck increases, accompanied wich extreme tenderness, and now there is constitutional irritation, with tendency to inflammatory fever. . . In the first stage we must try to relieve by evaporating lotions or by fomentation. If these fail, and as soon as the disease begins to spread in the vein, the appropriate remedy is to touch the spot with the actual cautery, simply to sear the lips of the wound, and apply a blister over it, which may be repeated. Purgatives in full doses must be administered, and the neck, as much as possible, kept steady and upright."

(1406.) Blistering.- "Blistering plasters are never applied to horses. An ointment is always used, of which rather more than half is well rubbed into the part to be blistered, while the remainder is thinly and equally spread over the part that has been rubbed. When there is any danger of the ointment running and acting upon places that should not be blistered, they must be covered with a stiff ointment made of hog's lard and beeswax, or kept wet with a little water. . The horse's head must be secured in such a way that he cannot reach the blister with his teeth. - . . When the blister has become quite dry the head may be freed. Sometimes it remains itchy and the horse rubs it ; in that case he must be tied up again. . . When the blister is quite dry put some sweet-oil on it, and repeat it every second day. Give time and no work, otherwise the horse may be blemished by the process."

(1407.) Physicing.- " Physicing, which, in stable language, is the term used for purging, is employed for improving the condition when in indifferent health. and as a remedy for disease. The medicines chiefly used are-for horses, Barbadoes alves, dose from 3 to 9 drachms; croton bean, from 1 scruple to $\frac{1}{2}$ drachm, or cake, from $\frac{1}{2}$ drachm to 1 drachm, to which may occasionally be added calomel, from 1 to $1 \frac{1}{2}$ drachms. For cattle, aloes in doses somewhat larger than for the horse; Epsom salts, or common salt, dose from $1 \mathrm{lb}$. to $1 \frac{1}{2}$ lbs., with some stimulus, as ginger, anise or carraway-seed; also linseed-oil, dose $1 \mathrm{lb}$, and croton-oil, 15 to $20 \mathrm{drops}$, or the bean or cake, the same as in the horse. For dogs, jalap, dose 1 drachm, combined with 2 grains of calomel ; croton oil, dose 2 drops ; bean, 5 grains; and syrup of buckthorn, dose $1 \mathrm{oz}$. These, it will be observed, are average doses for full-grown animals; in the young and small they may be less, in the large they may require to be greater; but much injury has often been done by too large doses too frequently repeated. To the horse physic is usually administered in the form of a bolue or ball; to cattle by drinking or drenching, though for both either way may be employed. A ball is conveniently made of linseed-meal, molasses and the active ingredient, whether purgative, diuretic or cordial ; it should be softish, and about the size of a pullet's egg. In administering it the operator stands before the horse, which is unbound and turned with its head out of the stall, with a halter on it. An assistant stands on the left side to steady the horse's head and keep it from rising too high; sometimes he holds the mouth, and grooms generally need such aid. The operator seizes the horse's tongue in his left hand, draws it a little out and to one side, and places his little finger fast upon the under jaw; with his right hand he carries the ball smartiy along the roof of the mouth, and leaves it at the root of the tongue; the mouth is closed and the head is beld till the ball is seen descending the gullet on the left side. When loth to swallow, a little water may be offered, and it will carry the ball before it. A hot, troublesome horse should be sent at once to a veterinary surgeon. Instruments should, if possible, be avoided, and adding croton farina to the mash often answers the purpose." Drenches should be given with caution to either horse or ox; "that no unnecessary force be used, that they be never given by the nostrils, and especially that, if the slightest irritation is occasioned in the windpipe, the animal shall immediately be set at liberty, that, by coughing, he may free himself of the offending matter." "The horse must undergo preparation for physic, which is done by gently relaxing the bowels. During the day his food should be restricted to bran-mashes, a $\frac{1}{4}$ peck being sufficient for a feed, and this, with his drink, should be given warm; corr should be withheld and hay restricted. He may have walking and trotting exercise morning and evening. The physic is given on an empty stomach early in the morning; immediately after, a bran-mash is given; that over, the horse goes to exercise for perhaps an hour, and is watered when he returns. The water should be as warm as be will take it; and he should have as much as he pleases throughout the day; bran-mash should be given as often as corn usually is, and better warm than cold; if both are refused bran may be tried, but no corn, and but little hay. Sometimes gentle exercise may be given in the afternoon, and also next day. The physic usually begins to operate next morning, though it rarely takes effect in 12 hours, frequenty not for 30 . When the physic begins to operate, the horse should stand in the stable till it sets, which may be in 12 hours."* The stable should be well littered behind the stall to receive the discharge. "Many practitioners and horse-proprictors," says Mr. Youatt, "have a great objection to the administration of medicines in the form of drinks. - . There are some medicines, however, which must be given in the form of drink, as in colic. : : . An ox-horn, the larger end being cut slantingly, is the usual and best instrument for administering drinks. The noose of a halter is introduced into the mouth, and then, by means of a stable-fork, the head is elevated by an assistant considerably higher than for the deliv. ery of a ball. The surgeon stands on a pail on the off-side of the borse and draws out the tongue

* Dick's Manual of Veterinary Science.

(1101) 
with the left hand. He then with the right hand introduces the horn gently into the mouth and over the tongue, and, by a dextenous turi of the horn, empties the whole of the drink-not mone than about $6 \mathrm{oz}$.-into the back part of the mouth. The horn is now quickly withdrawn and the tongue loomened, and the greater portion of the tluid will be swallowed. A portion of it, however, will often be obstinately held in the mouth for a long tinse, and the head must be kept up until the whule is got rid of, which a quick but violent slap on the muzzle will generally compel the lorse to do. The art of giving a drink consists in not putting too moch in the horn at once, introducing the horn far enough iuto the mouth, and quickly turning and withdrawing it without bruising or wounding the mouth, the tongue being loosened at the aame moment. $\mathbf{A}$ bottle is a disgraceful instrument to use, except it be a flat pint bottle with a long and thick neck." "The near-side horn has the most handy twist for administering a drink with the right hand.

(1408.) Fomentations.- "Clean water is the best fomentation. It should be as hot as the hand can bear it, yet not hot enough to pain the animal. In fomenting the horse the groom has rarely enough water, and he does not coutinue the bathing long enough to do any good. If the leg is to be fumented get a pailfull of water as hot as the hand can bear it; put the horse's foot into it, and, with a large sponge, lave the water well above the affected part, and keep it constantly running down the whole limb. Foment for half an hour, and keep the water hot by adding more."

(1409.) Poultices.- "Poultices should be formed of those materials which best maintain heat and moisture, and they should be applied as warm as possible and can be safely borne. They are usually made of bran-mash, turnips or oat-meal porridge. Linseed-meal alone makes the best of poultices, and some of it should always be added to the other ingredients. Wet bandages act as poultices."

(1410.) Lotions.- " Of cooling lotions cold water is the menstruum. It may be made colder by the introduction of a little salt or ice. Sal-ammoniac and vinegar may be added for the same purpose. The object is to reduce heat and promute evaporation. The addition of a litte spirits is made with the same object."

(1411.) The Pulse.- "Of the horse the natural pulse is from 35 to 45 beats in the minute; under fever it rises to 80,90 and 100 . The most convenient spot to examine it is at the edge of the lower jaw. a little before the angle, where the maxillary comes from the neck to be distributed over the face. The pulse is one of the most important indications in all serious disorders."

(1412.) Injections. - Injections, though easily administered by means of the old ox.bladder and pipe, are still more conveniently given with the syringe. For laxative clysters for the horse or cow, from 1 gallon to 12 pints imperial of warm water or gruel, at the temperature of $96^{\circ} \mathrm{F}$ ahr., with a couple of handfulis of salt or $2 \mathrm{oz}$. of coft soap, prove useful. Stronger ones may be obtained by adding a few ounces of aloes to the mixture. In cases of diarrhcea or over-purging, the injection should consist of a few pints of warm gruel, to which is added $1 \mathrm{oz}$. of catechu electuary, or from $\frac{1}{2}$ drachm to $\mathrm{l}$ drachm of powdered opium. The only art in administering a clyster-where, however, there is often bungling, and even injury by wounding the rectum-is to avoid frightening the animal, anointing the pipe well, and gently insinuating it before the fluid is forced up."

(1413.) "In general, bran-mashes, carrots, green meat and hay form the sick horse's diet, gruel and tepid water his drink." $\dagger$ of the diseases themselves, I shall only notice those at present which usually affect farm-horses in winter.

(1414.) Horse-Louse (Trichodecles equi). - The horse is infested by a louse as well as the ox, and which is represented in fig. 296. Color of the head and thorax bright chesnut, the former very large and somewbat square, the surface with a lon. gituclinal black line toward each side, forming an angle near the middle; antenne with the third joint longest; abdomen pale, tawny yellow, with fine pubescence, the first eight segments having a dusky transverse band on the up. per half, the lateral margins also with a dusky band; legs pale chesnut; length I line. Common in the tail-head and neck of the horse, especially when fresh from pasture in autumn. Found also on the ass. A little oil will deatroy this aninal when first established; but if allowed to remain on for Bome time. mercurial ointment will be necessary, but in small quantities at a time. The ass, however, has a louse peculiar to itself, the Hemalopinus asini; of a rusty red; abdomen whitish, tinged with yellow, with a row of dark horny excrescences on each side; head long, with a deep sinuosity behind the antennas; length 1 to $1 \frac{3}{4}$ lines. It frequents the mane aud neck, and is commont+

(1415.) Balts.-One of the most common complaints among farm-horses is the flatulent colic, gripes or batts. It arises from indigestion, which again is occasioned by various causes, such as hard work immediately after feeding, drinking water largely after a feed of corn, bad atate of the food, fast eating, and, in consequence, a paucity of saliva, an overloaded stomach, a sudden change of food from soft to hard and dry, and more likely to occur after eating

Fig. 296.

I

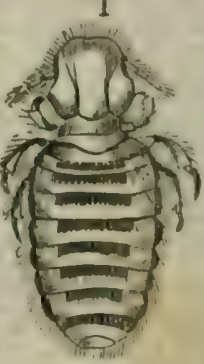

THE HORSE-LOUSE, TRICHODECTES

EQU1. turnips, potatoes, carrots and grass, than hay and oats, and after peas than barley. The indigestion arises in two forms ; the food either undergoing no change, or running rapidly to fermentation. In the former case acule foul founder is apt to arise, aud its treatment is purgatives, drenches and in. jections. In the latter case the eymptoms are most alnrming. The horse falls down. rolls over, starts up, paws the ground with his fore-foot, strikes his belly with the hind foot, perspiration runs down and agony appears extreme. Relief may be obtained from this dose: Linseed-oil, raw. $1 \mathrm{lb}$.; oil of turpentine from $2103 \mathrm{oz}$.; laudanum from 1 to $2 \mathrm{oz}$., or hartshorn from $\frac{\mathrm{z}}{\mathrm{oz}}$. to $1 \mathrm{oz}$. The following tincture may be kept in readiness: In $2 \mathrm{lbs}$, of whisky, digest for 8 days, 3

- Youatt on the Horre, edition of 1842.

\$ Denny's Munographia Anoplururum Britanbia.

† Dick's Manual of Veterinary Sclence. (1102) 
oz. of ginger, $3 \mathrm{oz}$. of cloves, and then add $4 \mathrm{oz}$. of sweet spirits of nitre. Half a pint imperial of this tincture is a dose in a quart of warm water. The abdomen should be rubbed, the horse walked slowly about and supplied with a good bed, and with room to roll about. If there is no relief in half an hour a second dose may be given, and ere long, if still required, a third. Farm. horses that have keen appetites and devour their food greedily; and when they have been long in the yoke, are most apt to take this disease.

(1416.) Inflamenation of the Bomels.-The symptoms of the hatts are very similar, at first, to those of inflatamation of the bowels, and, if mistaken, serious mistakes may arise, as the treatment of the two complaints is very different. The symptoms may be distinguished thus: In batts, the palse remains nearly unaltered, whereas in inflammation it is quickened; all the extremities, the ears and feet, feel cold in batts, hot in inflammation. Whenever inflammation is apprehended, blood nasy be taken; in batts this is not necessary ; but under such an apprehension, the assistance of the veterinary surgeon should be obtained as speedily as possible. I have cured many horses of the batts by administering stimulating drinks with a handy cow's horn. I remember of one horse being seized with inflammation of the bowels, on its arrival home from delivering corn at the market-town; and though the usual remedies of bleeding and blistering were resorted to, they proved ineffectual, no doubt from being disproportioned to the exigencies of the case, and the horse sank in five days in excruciating agony. There was no veterinary surgeon in the district at that time, which was many years ago. Now, however, thanks to the Veterinary College of Edinburgh, through the really practically useful tuition of its indefatigable Principal, Professor Dick, there is not a populous district of the conntry in which a skillful veterinarian is not settled. To the surseon, therefore, in a serious case such as this-and, indeed, in all cases of extensive inflammation, and especially in the interior of the body-recourse should immediately be had. I say immediately, for it is but fair to give the surgeon a chance of treating the case correctly from its comzancement, and not to impose upon him the task of amending your previous bungling. Inflammation of the lungs, as well as inflammation of the kidneys, both of which the farm-horse is subject to, should always be treated by the veterinarian; but tortunately, these formidable maladies may, almost with certainty, be evaded with well-timed working, discrimination of work acoording to the state of the weather, and by gond food, supplied with regularity and in due quantity.

(1417.) Common colds frequently occur among farm-horses at the commencement of winter, and when not entirely unheeded, but treated with due care, seldom leave serious effects. "A cold requires nothing more but confinement in a moderstely warm stable for a few days, with clothing, bran-mashes instead of corn, and a little laxative and diuretic medicine." The evil lies not so much in the complaint itself, as in its ordinary trestment; it is seldom thought seriously of by farmers-" it is only a cold," is the usual remark-and, in consequence, the horse goes out every day, feels fatigued, gets wet, becomes worse, and then the lungs not unfrequently become affected, or a chronic discharge is established from one of the nostrils. One seasun 9 horses out of 12 in one stable were affected, one after another, by a catarrhal epidemic, which required bleeding, poultieing, or blistering under the jaw, besides the medical remedies mentioned above. These I was obliged to take charge of myself, there being no veterinarian in the district, ano all fortunately recovered. The remaining 3 were slightly affected afterward, and easily brought through; but had the cases been unheeded from the first, very serious loss might bave been incurred by death.

(1418.) Grease.- "The well-known and unsightly disease called grease," says Professor Dick, "is a morbid secretion from the cutaneous pores of the heels and neighboring parts, of a peculiar greasy, offensive matter, attended with irritation and increased vascular action. It is most frequently seen in coach and cart-horses, but often also in young colts which are badly cared for; and it is most common in the hind-feet, but occurs in all. Its main cause seems to be sudden changes in the condition of the foot from dry to wet, and from beat to cold, greatly augmented, of course, by eva poration." Hence the evil effects of washing the legs at night, without thoroughly drying them afterward. "The first appearance of grease," continues the Professor, "is a dry state of the heels, with heat and itchiness. Swelling succeeds, with a tendency to lameness; the discharge angments in quantity, the hair begins to fall off. . . . In the early stage the parts should be washed with soap and water, and a solution of sugar of lead and sulphate of zinc applied; this may not be chemically scientific, but we have found it superior to anything else Even in old and aggravated cases it is very efficacious. . . . If the horse be strong and fall of flesh, laxatives sbould be given, followed by dinretics; if weak, tonics may be added to these last. The feeding, too, must be varied with the condition: green-meat and carrots shonld be given, and mashes frequently, as a substitute for corn. During convalescence, exercise should be given, and bandages and pressure basten the care." I have no hesitation in eaying that it is a disgrace for any steward, and in the want of such a functionary, it is so in the farmer himself, to allow his horses to become greasy. There is a complaint called a shot of grease, arising from a different cause from the common grease. "In the horse, plethora," says Professor Dick, "creates a strong disposition to inflammation of the eyes, feet and lungs, and sometimes to an eruption which is called surfeit, or the nettle-rash. The hair falls off in patches, and the skin is raw and pimpled. There is also a tendency to grease, and to what has been designated a $x$ ceed or shot of grease in the heavy draught-horse. One of the legs, generally a hind one, suddenly swells, the animal becomes lame; there is pain in the inside of the thigh-increased upon pressure; and fever supervenes. .... We have seen it occur chiefly during continued rest after hard work and exposure to weather, in animals which were highly fed. The best treatment is large bloodletting, scarifying the limb, fomenting, and applying hay, straw, or flannel bandages, with purga. tives and diuretics. The pressure of a bandage will expedite the reduction of the part to its natural dimensions."

(1419.) Stomach-staggers.- "The most prominent symptoms of this disease are the horse's hanging his head, or resting it on the manger, appearing drowsy, and refusing food; the mouth and eyes being tinged with a yellowish color; there is twitching of the muscles of the chest, and (1103) 
the fore-legs appear suddenly to give way, though the horse seldom falls. In flammation of langs or bowels, or lockjaw, may supervene. Its cause is long fasting and overwork ; but the quality of the food acts as a cause. Its treatment is relieving the stomach and bowels with searching laxatives, such as croton, also aloes and ealomel, with ginger. Clysterg should also be given, and afterwurd cordials. Blood-letting from the jugular vein will be attended with advantace. Finally, steady exercise and careful feeding will prevent a recurrence of the disorder." I I had a yearold draught.colt that was affected with this disense. He was a foul-feeding animal, delighting to eat the moistened litter from the stable and byre. He was bled and physiced by a veterinarian, who had established himself in the neighborhood, and the front of his head blistered. He quite recovered, and having beeu removed from the temptation of foul feeding, he was never again similarly aflected. The practice of keeping he-groals in the stables of inus, and of those persons who have extensive studs, is supposed, by the common people, to act as a charm against the mad staggers; but, as Marshall judiciously observes, the practice may be explained on physiological principles. "The staggers are a nervous disorder," he says, "and as odors, in many cases, operate beueficially on the human nerves, so may the strong scent of the goat have a similar effect on those of the horse. The subject," he adds, "is worthy of inquiry." $\dagger$ And be gives a striking instance of the good effects of the practice.

(1420.) Thrush and Corns,- 1 have said that the feet of the farm-horse are not liable to so many diseases as those of horses subjected to high speed on hard roads. Farm-horses, however, are liable to thrush and corns in the feet. The former is situate at the hind part of the cleft of the frog, originating principally from continued application of moisture and dirt, and hence it may be must expected to be seen in dirty stables, of which there are not a few in the country. After beiug thoroughly cleaned out, the hollow may be filled with calomel, which generally cures; or with pledgets of tow dipped in warm tar, or spirit of tar, applied at night, and retained during the day. The general health of the horse should be attended to. Corns are usually the consequence of the irregular pressure of the shoe on peculiarly formed hoofs; and are mere bruises, generally produced by the heel of the shoe, and which, from the extravasated blood, assume a reddish or dark color. They usually occur only in the fore-feet; and their site is almost invariably in the in. ner quarter between the bar and crust, at the heel. The obvious cure is removal of the pressure of the shoe.

(1421.) Broken wind.-Besides nataral complaints, farm-horses are liable, in the execation of their work, to accidents which may produce serious complaints. Thus overwork, in \& peculiar state of condition, may produce broken wind, which is the common phrase given to all dis. organized affections of the lungs, though the term is defined by veterinarians to be " the rupture of some of the air-cells of the lungs, whereby air-vesicles are produced on the surface, and the expulsion of the air is rendered less direct and easy. It is usually produced by animais being urged to over-exertion when in bad condition, though a horse may become broken-winded in a etrawyard." There are many degrees of broken wind, which receive appellations according to the noise emitted by the horse; and on this account, he is called a piper, trumpeter, whistler, wheezer, roarer, highblower, grunter, and with thick wind, and with broken wind. I had two uncommonly good horses affected in the wind by working much in the traces of a four-horse plow, which were employed to rip up old turf dykes intermixed with large stones, and to break up rougb ground. These serious effects of such work gave me the hint to relinquish it, and take to the spade, which I soon found did the work much better, and in the end cheaper. The horses got gradually worse under the disease, and at length being unable to maintain their otep with the rest, were disposed of as brohen-winded horses.

(1422.) Sprains.- "A sprain, or strain, is violence inflicted, with extension, often rupture and displacenient, upon the soft parts of a joint, including cellular membane, tendons, ligaments, and all uher parts forming the articulation. The dislocation or disruption may be complete, or it may be a mere bruise or stress; and innumerable are the shades of differencue between these extremes. Effusion of the fluids is an attendant consequence. Parts of vital importance, as in the neck or back, may be implicated, and the accident be immediately fatal, or wholly irremediable; on the contrary, they may be to that extent ouly, that, with time and ease, restoration may be accomplished. They constitute a serious class of cases. The marked eymptoms are, pain in the in jured parts, and inability of motion, sometimes complete. The treatment is at first rest, a regulation of the local action and constitutional disturbance, according to circumstances. by venesection. general and local, the antiphlogistic regimen, fomentation, bandages, and other soothing remedies; and when the sprain is of an older date, counter-irritation, friction, and gentle exercise." Farmhorses are not unfrequently subject to strains, especially in doing work connected with building, drainiug, and other heavy work; and they are most apt to occur in autumn. when geldings are generally in a weak state. For rough work of this kind, old seasoned horses are best adapted, and such may often be procured for litile money at sales of stock.

(1423.) Saddle-galls. - When young horses are first put to work, the parts covered by the sad. dle and collar are apt to become tender, heated, and then intlamed, and if the inflammation is neglected, the parts may break out into sores. Washing with a strong solution of ealt in water with tincture of myrrh is a good lotion, while attention should be paid to the packing of both saddle and collar, until they assume the form of the horse intended to wear them. "Tumors, which sometimes result from the pressure of the sadule, go by the nane of warbles, to which when they $\mathrm{ul}$. cerate the name of sitfasts is applied, from the callous sk in which adheres to the center. Goulard water may be ased to disperse the swelling : a digestive ointment will remove the sitfast; and the sore should be healed with a solution of sulphate of zinc."

(1424.) Crib-biting and wind-sucking.-These practices are said to increase the tendency to in. digestion and colic, and to lower condition, rendering the horses which practice them unsound. "A crib-biter derives his name from seizing the manger, or some other fixture, with his teeth, arching his neck, and sucking in a quantity of air with a peculiar noise. ... W ind-sucking 
consists in swallowing air, without fixing the mouth. The horse presses his lip against some hard body, arching his neck, and gathering together his feet." Both vices are said to be prevented by fastening a strap round the neck, studded with one or more sharp points or prickles opposite the lower jaw ; but this means will not avail in all cases, for I had a year-old colt, which first began crib-biting in the field, by seizing the gate or any other object be could find. Being prevented using the gate by a few thorns, he pressed his mouth against any object that would resist him, even against the sides or rumps of his companions, and he then began to be a wind-sucker. A strap of the above form was put on, recommended to me by an artillery officer; bot though it remained upon the colt for more than a twelvemontb, night and day, and as tight as even to affect his appearance, he continued to crib-bite or wind-suck in spite of it, even to the laceration of his skin by the iron studs. Growing largely to the bone, though very thin, he was taken up to work at the early age of two years, solely with the view of seeing if the yoke would drive him from the practice, but it had no such effect. Whenever he came into the stable he set to with earnestness to bite and suck with the strap on, until he would become puffed up as if to bursting, and preferred sucking wind to eating his corn. At length I was so disgusted with the brute that I sold him to a carrier, to draw a heavy single cart, and got a fair price for him, though sold as a cribbiter.

(1425.) Dust-ball.-Millers' horses are most liable to be affected with this disease. It is composed of corn and barley dust, saved in grinding meal, and used as food, and occurs sometimes in the stomach, but more frequently in the intestinal canal. "In an advanced stage no doubt can remain as to the nature of the disorder. The countenance is haggard, the eye distressed, the back up, the belly distended, the respiration becomes hurried, bowels habitually costive, and sometimes the horse will sit like a dog on his baunches. Relief may frequently be afforded. Strong purgatives and large injections must be given, and under their continued action the offending body is sometimes removed." On using barley-dust as food for horses, it would be well to mix it thoroughly with the other prepared ingredients, instead of using it in the dry state."

(1426.) Worms.-Farm-horses are sometimes affected with worms. These are of 3 kinds: the round worm, teres; the thread-worm, ascaris; and the tape-worm, tania. "In the horse the tenia is very rare; in the dog exceedingly common. When the horse is underfed his bowels are full of teres and ascaris; and the appearance of his staring coat, want of flesh and voracious appetite betoken it. They occasion gripes and diarrhœa, but the mischief they produce is not great. The principal habitat of the ascaris is the cœcum, although they are sometimes found in countless multitudes in the colon and rectum. Turpentine is a deadly poison to all these worms; but this medicine, so harmless in man. acts more disagreeably in the lower animals. Hence it must not be given to them pure or in large quantities, but mixed in small proportion with other oils, as linsecd, or in a pill; and, with these precautions, it may be found at once safe and efficacious."

(1427.) Nebula or Specks in the Eye.-Farm-horses are not subject to the more violent diseases of the eye; but, being liable to accidents, the effects of inflammation-nebulæ or specksdo sometimes appear. "The former are superficial, the latter dip more deeply into the substance of the part. Directly in the sphere of vision these, of course, impede it, and cause obscurity of vision. Even here we must proceed gently. These blemishes are the pure consequences of in. flammation, and this subdued, their tendency is to disappear. Time and nature will do much, and the duty of the practitioner consists in helping forward the salutary process where necessary, by gently stimulating washes, while irritating powders should be avoided."* With these sensible remarks of Professor Dick I shall conclude what I have to say of the diseases of the farm. horse at this time.

(1428.) The offals of the horse are not of great value. His hide is of most value when free of blemishes. It tans well and forms a good leather, which, on being japanned, is chiefly used for covering carriages. I was informed by a friend who settled in Buenos Ayres as a merchant, that he once bought a lot of horses, containing no fewer than 20,000, for the sake of their hides alone, and that some of them would have fetched good prices in England. They were all captured with the lasso.

(1429.) Horse-hair is used in the manufacture of damask-cloth for sofas and chair-bottoms. The dyeing of it of various beautiful colors and the manufacture of the damask figures have been much improved of late. Horse-hair is also used for making fish-lines, horse-tails for cavalry caps and stuffing for matresses, for which last purpose it is prepared by being wound up hard and baked in an oven.

(1430.) "Hair, of all animal products, is the least liable to spontaneous change. It can be dissolved in water only at a temperature somewhat above $230^{\circ} \mathrm{Fahr}$. in Papin's digester, but it appears to be partially decomposed by this heat, since some sulphureted hydrogen is disengaged By dry distillation hair gives off several sulphureted gases, while the residuum contains sulphate of lime, common salt, much silica, and some oxides of iron and manganese. It is a remarkable fact that fair hair affords magnesia instead of these latter two oxides. Horse-hair yields about 12 per cent. of the phosphate of lime. Hair also yields a bituminous oil, which is black when the hair is black, and yellowish when the hair is red." $\dagger$

(1431.) "Button-moulds are made of the bones of the horse, ox and sheep. The shavings, saw dust and more minute fragments in making these moulds, are used by the manufacturers of cutlery and iron toys in the operation of case-hardening, so that not the smallest waste takes place." $\ddagger$ The bones of all these animals, when reduced small, make the valuable manure-bone-dustnow well known to every farmer.

* Dick's Manual of Veterinary Science.

+ Ure's Dictionary of the Arts, arts. Hair-Buttons.

† Thomson's Animal Chemistry.

END OF VOLUME I. OF BOOK OF THE FARM.

[The whole to be completed in too volumes.] 
$\sqrt{2}+x^{2}$

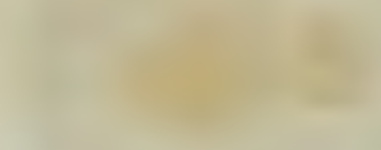







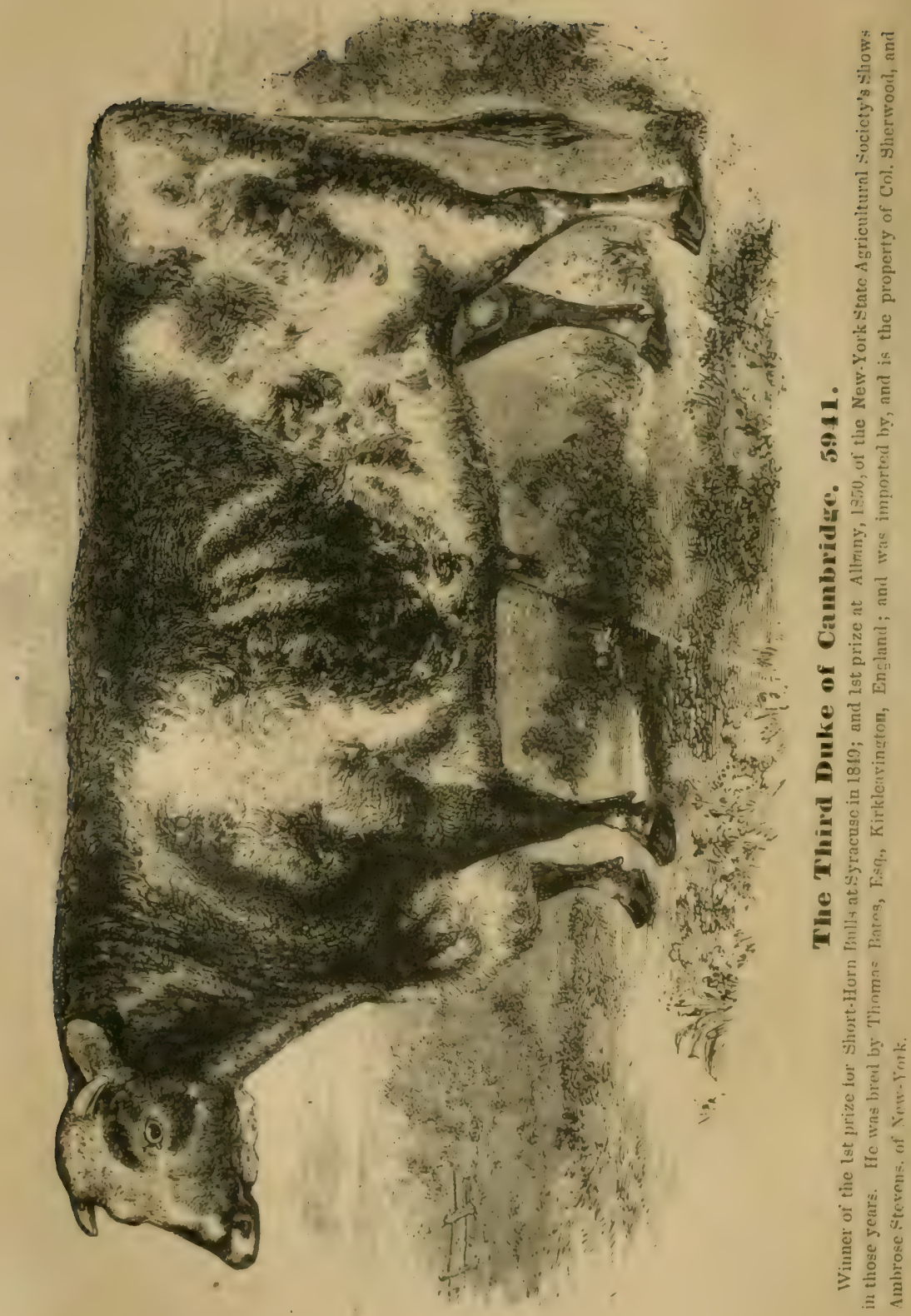




\section{BOOK OF THE FARM :}

DETAILING THE LABORS OF THE

FARMER, STEWARD, PLOWMAN, HEDGER, CATTLE-MAN, SHEPHERD, FIELD-WORKER, AND DAIRYMAID.

\section{BY HENRY STEPHENS.}

WITH FOUR HUNDRED AND FIFTY ILLUSTRATIONS.

TO WHICH ARE ADDED

EXPLANATORY NOTES, REMARKS, ETC.

BY JOHN S. SKINNER,

EDITOR OF THE FARMER'' LIBRARY.

VOLUME II.

NEW YORK :

r. M. SAXTON, AGRICULTURAL BOOK PUBLISHER 



\title{
THE
}

\section{BOOK OF THE FARM.}

\section{FAtTening, DRiving and SlaUghtering siwine.*}

"Where of the swine, from ambush warm and dry. Bolt out, and scamper headlong to their sty."

\author{
BLOOMFIELD.
}

(1432.) That the youngest pigs may receive better treatment, the court and shed at $b$, fig. 3, Plate III., the same as in the plan at $b$, in fig. 4 , Plate IV., and described in (68), are made purposely for them. These pigs consist, probably, of the last litters of the season of as many brood sows as are kept. Here they should be provided daily with turnips as their staple food, of the sort given for the time to the cattle, and sliced as small as for sheep; and they should, besides, have a portion of the warm

[* There are few subjects in regard to which we are in less need of being enlightened by the experience of other countries than in the breeding and management of swine. If, as assuredly it must be admitted, we are, over a large portion of the country, neglectful both as to improvement of the breed and treatment of them in all stages of their growth and existence, it is not that there is any great difficalty in understanding both the one and the other; but mismanagement in this, as in too many other cases, results from sheer listlessness and want of thought. The hog may quickly be brought to the shape that we desire, and which best adapts him to the food at command and the uses designed by the farmer; and common sense tells every one that as the sole purpose of rearing him is for meat, he should be kept alvoays in thriving condition by atten. tion to the necessary warmth and sufficiency of food, so that he may be kept always growing apace, until finally to be fattened. The region of which Indian corn is the staple, and where there is most of it, is the natural habitat of the hog in our country ; nor could he be reared in the Eastern States with that economy which our conntrymen there know so well how to practice, were it not for the essential object which they keep constantly in view, and to which the hog is there made largely subservient, to-wit : the manufacture of manure.

But conversant as we are with swine hosbandry, there may yet be found in this chapter some interesting remarks on the preparation and value of different kinds of food-a subject of importance to every agricultarist who desires, as all should desire, to economize labor and materials in the process of fattening. Useful, too, should be the lesson it teaches, to keep for fattening hogs a constant supply of pure clean water, and to study cleanliness throughout, as far as practicable, in a department where the general impression and practice agree that dirt withont stint is tolerable, if, indeed, it be not medicinal and aseful! The manner of fattening hogs, where Indian corn is used for the purpose, as in the South and West, is to "put them up" in large open pens on the ground, without litter and without shelter. Here they are left to barrow and sleep in mud and mire, exposed to all weathers, consuming, probably, before they get "ripe fat," one-third if not one-half more than would be necessary were they sheltered in a warm pen, with clean litter and with clean water and rich food in abundance at pleasure, free alike from exposure and excitement. Experiment has abundantly proved the truth of Johnson's declaration, that "the 'greater the difference between the temperature of the body and that of the atmosphere in which 'they live, the more food they require to 'feed the lamp of life.'" All this, however, is philosophically and plainly described in our Monthly Journal of Agriculture. Ed. Farm. Lib.' 
mash made for the horses, with such other pickings from the farm-house which the kitchen affords. They should also be provided with a trough of clean water and plenty of litter under the shed every day. The courtyard should be cleaned out every day. Pigs are accused of dirty habits, but the fact is otherwise, and the accusation applies more truly to their owners who keep them dirty, than to the natural habits of the animals themselves. When constrained to lie among dirt and eat food fit only for the dunghill, and even that dealt out with a grudging hand, how can they exhibit other than dirty propensities? But let them have room, choice of clean litter and plenty of food, and it will soon be observed that they keep their litter clean, place their droppings in one corner of the court and preserve their bodies free from dirt.

(1433.) The sties $c$, figs. 3 and 4, Plates III. and IV., are intended for sows about to litter. Whenever the period of their confinement approaches each sow should be put into one of these and supplied with food; but the treatment of sows will better fall to be described in spring. The form of door best suited for securing pigs in their sties may be seen in fig. 23.

(1434.) By direct experiment, which will be found related below, it has been ascertained that pigs fatten much better on cooked than on raw food. This being the case it is only waste of time and materials, and also loss of flesh, to attempt to fatten pigs on raw fond of whatever kind; for although some sorts of food fatten better than others in the same state, yet the same sort when cooked fattens much faster and better than in a raw state. The question, however, simply is, what is the best sort of food to cook for the purpose of fattening pigs? Roots and grains of all kinds, when cooked, will fatten pigs. Potatoes, turnips, carrots, parsnips, as roots ; and barley, oats, peas, beans, rice, Indian corn, as grain, will all fatten them when prepared. Which, then, of all these ingredients should be selected as the most nourishing and, at the same time, most economical? Carrots and parsnips, among roots, are not easily attainable in this country, and therefore cannot be considered as economical food; and as to the other two sorts of roots, when cooked, potatoes doubtless contain much more nourishment than turnips, even in proportion to their price, for it is as easy to obtain $10 \mathrm{~s}$. for a ton of Swedish turnips as $8 \mathrm{~s}$. for a boll of 40 stones of potatoes; and yet potatoes contain 4 times the nutritive matter of Swedes, and 6 times of common turnips.* Steamed potatoes, then, may form the staple ingredient of pig-feeding. As to grains, I have never heard of wheat or wheat-flour being given to pigs; it would certainly not be economical; barley or oat-meal being usually employed. Peas and beans, whether raw or cooked, are proverbially excellent food for pigs. And as to rice and Indian corn, they will both fatten well, if cooked. Amid all these ingredients for choice, regarding the question of economy alone, it may be assumed that entire feeding on grain, of whatever kind, would be ton expensive, so that, as steamed potatoes are of themselves nourishing fond, a proportion, with any of the grains, should form a moderately-priced food which will insure fatness. It has been ascertained in England that upon 2 pecks of steamed potatoes mixed with $9 \mathrm{lbs}$. of barley-meal and a little salt, given every day to a pig weighing from 24 to 28 stones, will make it ripe fat in 9 weeks. Taking this proportion of food to weight of flesh as a basis of calculation, and assuming that 2 months will fatten a pig sufficiently well, provided it has all along received its food regularly and amply, I have no doubt that feeding with

- The Farmers' Almanac and Calendar for 1842. 
steamed potatoes and barley-meal, for the first month, and, in the second, with steamed potatoes and peas-meal (both seasoned with a little salt), and lukewarm water, with a little oat-meal stirred in it, given by itself twice a day as a drink, will make any pig, from 15 to 30 stones, ripe fat for hams. The food should be given at stated hours, 3 times a day, namely : in the morning, at noon and at nightfall. One boiling of potatoes in the day, at any of the feeding-hours that is found most convenient, will suffice; and at the other hours the boiled potatoes should be heated with a gruel made of barley or peas-meal and boiling water; the mess being allowed to stand awhile to incorporate and cool to blood-heat. It should not be made so thin as to spill over the feeding-trough, or so thick as to choke the animals; but of that consistence which a little time will soon let the feeder know the pigs relish best. Washing fattening pigs with warm water and soap rapidly promotes their fattening; and, after the first trial, they delight in the scrubbing. A convenient form of trough for fattening pigs is described below in fig. 297. The swing-door, on being fastened on the side nearest the pigs, serve the purpose of warding them off until the trough is cleaned out or replenished with food. The trough should be thoroughly cleaned every day, and being subdivided into three parts, more than one pig may be fattened in the same sty. But when only one occupies a sty-which is the least troublesome arrangement-one division may be filled with one of the meals daily, thus giving a clean trough every meal; and all the divisions should be cleaned in the morning before supplying the first meal. After every meal is supplied the swing-door is fastened nearest the outside, thus giving the pigs access to their food, as well as preventing them being disturbed at their meals. The quantity of food given at any time should be apportioned to the appetite of the animals fed, which should be ascertained by the person who feeds them; and it will be found that less food, in proportion to the weight of the animal, will be required as it becomes fatter. When pigs are fattening they lie and rest and sleep a great deal, no other creature showing "love of ease" so strongly in all their motions; and, in truth, it is this indolence which is the best sign of their thriving condition. The opposite effects of activity and indolence on the condition of animals is thus contrasted by Liebig: "Excess of carbon," says he, "in the form of fat, is never seen in the Bedouin or in the Arab of the Desert, who exhibits with pride, to the traveler, his lean, muscular, sinewy limbs, altogether free from fat. But in prisons and jails it appears as a puffiness in the inmates, fed as they are on a poor and scanty diet; it appears in the sedentary females of Oriental countries; and, finally, it is produced under the well known conditions of the fattening of domestic animals ;"* and among these last the pig may be instanced as the most remarkable.

(1435.) The denominations received by pigs are the following: When new-born, they are called sucking pigs, or simply pigs; and the male is called boar pig, the female sow pig. A castrated male, after it is weaned, is named a [barrow] shot or hog. Hog is the name mostly used by naturalists, and very frequently by writers on Agriculture; but as it sounds so like the name given to young sheep, I shall always use the term pig and swine, for the sake of distinction. A spayed female is a cut sow pig. As long as both sorts of cut pigs are small and young, they get the name of porkers or porklings. A female that has not been cut, and before it bears young, gets the name of an open sow; and an entire male receives, and retains ever after, the name of boar or brawn. A cut boar is a brawner [barrow],

* Liebig's Animal Chemiatry.

(7) 
and the flesh of both boar and brawner is brawn. A female that has taken the boar is said to be lined; when bearing young she is called a brood sow; and when she has brought forth pigs, she is said to have littered or farrowed, and her family of pigs at one birth are called a litter or farrow of pigs.

(1436.) Of judging of a fat pig, the back should be nearly straight; and though arched a litile from head to tail, it is no fault. The back should be uniformly broad and rounded across along the whole body. The touch all along the back should be firm but springy, the thinnest skin springing most. 'The shoulder, side, and hams should be deep up and down, and in a straight line from shoulder to ham.* The closing behind should be filled up; the legs short, and bone small; the neck short, and thick, and deep; the cheeks rounded and well filled out; the face straight, nose fine, eyes bright, ears pricked, and the head small in proportion to the body. A curled tail is a favorite, because indicative of a strong back [and healthy, thriving condition]. All these characters may be observed in the figure of the brood-sow in one of the Plates; though, of course, the sow is not in the fattened state. A black colored pig is always black of skin, and a white one white, and which latter color gives to the pig a cleaner appearance than the black. A fat pig ought never to be driven, but carried in a cart when desired to be transported from one place to another.

(1437.) As to the breed which shows the greatest disposition to fatten, together with a due proportion of lean, I never saw one to equal that which was originated by Lord Western, in Essex. I received a present of a young boar and sow of that breed from Lord Panmure, and had the breed for 10 years; and such was the high condition constantly maintained by the pigs on what they could pick up at the steading, besides the feed of turnips supplied them daily, that one could be killed at any time for the table as a porkling. They were exceedingly gentle, indisposed to travel far, not very prolific, however, but could attain, if kept on, to a great weight; and so compact in form, and small of bone and offal, that they invariably yielded a greater weight of pork than was judged of before being slaughtered. Though the less valuable offal was small, the proportion of loose seam was always great, and more delicious ham was never cured in Westphalia than they afforded. $\dagger$

["In the United States, where so large a proportion of the hogs slaughtered is made and cured for bacon, and where the ham is much the most valuable part-length from the tail to the hips, or as they are called in cattle the pins, so as to throw their points well forward toward the shoulder is a matter of importance in the formation of the hog; as it insures a greater proportionate weight in that part of the animal. The best bacon in the world, some would except the Westphalia, is to be found in our Middle States, where corn is one of our chief staples, and where the hog is left to run at large, and scuffle for his living, from the time he is weaned until put up finally to be fattened on corn, which is too generally thrown in upon the ground and on the cob. True, where there is a "gang" of turkeys, they are usually fattened on the wasting and leaving of the hog, as the hog is the scavenger to clean up and fatten on the leavings of bullocks fed with corn, on the cob, in open field.

However careless in other things, the salting and smoking of their pork generally conimands the close attention of the husbandman, and not unfrequently of the good housewife. The standard for the best hams, in the region to which we have referred, is where the whole hog weighs from 130 to 160 or 175 at most. W ithout subjecting them to the best of all tests, no one who never compared them, can realize the difference between a Maryland ham of about twelve pounds, properly smoked with hickory wood, and such as one sometimes meets with elsewhere, balf smoked and from a great fat beast of 300 pounds weight.

[ $\uparrow$ We ehould prefer the Mackey breed-if to be had under the sanction of Col. Jaques of Charlestown, Mass. - as to its genuineness. Mr. Webster took great pains to procure, and had at Marsh- 
(1438.) [Pigs'-Troughs.-A very convenient trough for a piggery has been loner manufictured by the Shots Iron Company, of which fig. 297 is a view in perspective from the interior of the court. It is nearly all made of cast.iron, and possesses the great convenience of allowing the troughs to be filled with food from the outside of the building, the feeder being at the aame time free from any annoyance from the inmates. Troughs of this kind are placed in proper sized openings in the external wall of the piggery court, in the manner shown in the figure, where $a$ marks the wall on one side of the opening. that on the hither side being left out of the figure, in order to exhibit the form of the trough. The trough, part of which is seen at $b$, is 4 feet in length, 16 inches wide at top, and 8 inches at bottom, and is 9 inches deep. The two ends $c$ and $d$ rise in a triangular form to the hight of $3 \frac{1}{2}$ feet, and are connected at the top by the stretcher bolt $e$. The lower part of each end extends inward to $f g$, making a breadth of 3 feet 4 inches when complete, but this part of the end $g$ in the figure is broken off, to show part of the trough $b$. Two intermediate divisions $h h$ divide the trough into three compartments; these divisions extend to the same length as the ends $f g$, and are all 21 inches in hight. By means of these divisions, each animal, when there are more than one together, has its own stall, and can take its food undisturbed by its neighbors. A swing-door $i$ is jointed on the pivots $k k$, to complete the form by filling up the opening of the wall. In the figure this door is thrown to the full extent outward, where it always

Fig. 297.

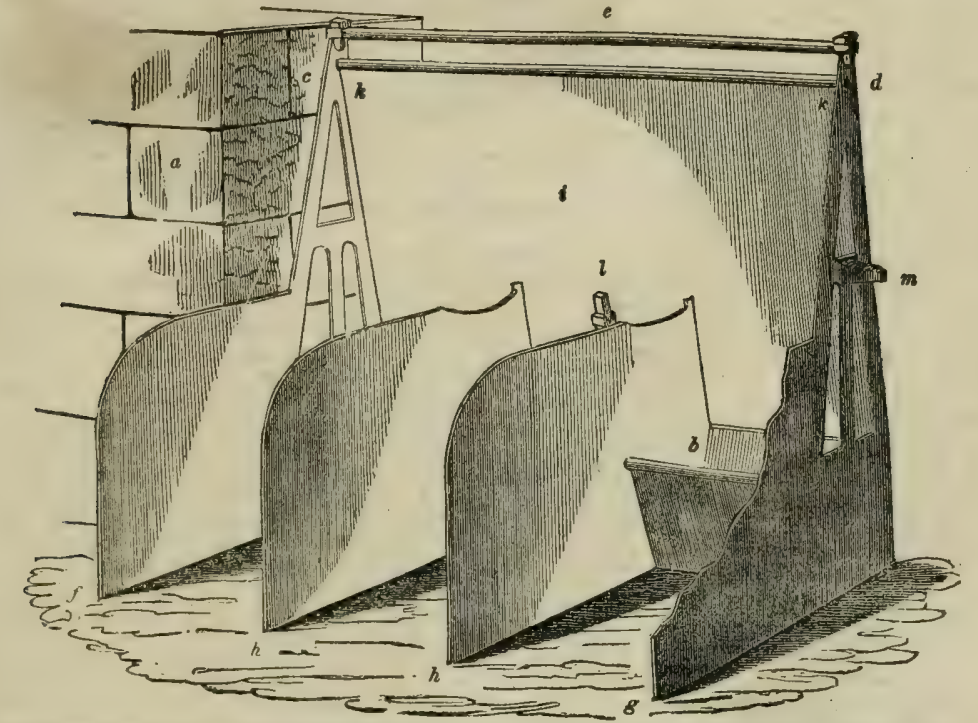

THE PIGS'TROUGH, WITH SEBDIVISIONS, TU STAND IN AN OPENING OF THE OUTER WALL OF THE STY.

stands during the time the animals are feeding, and is fixed there by a slide-bolt on the outside. When food is to be introduced the bolt is withdrawn, and the door moved from that position to $l$, and there bolted until the compartments of the trough are cleaned and tilled, when the door is again swung back to its original position, and the food is placed before the animals. The door has slits formed in it corresponding to the divisions $h h$, to allow of its swinging freely, and yet have depth sufficient to close the entire opening down to the outward edge of the trough. A dowel or stud $m$ is let into the wall at each end, to secure the upper part of the trough. On a late visit to the Duke of Buccleuch's home-farm at Dalkeith Park, which is conducted by $\mathrm{Mr}$ Black, I was much interested with the piggery, where the stock is of the finest quality, and,

field, some time since, the real Simon Pure of that race. But the best breed of hogs that we bave ever seen, according to our judgment, were sent into Maryland from England, in 1823, by Mr. Wright, a brother-in-law of the late Mr. Champion, as a present to the then Editor of the American Farmer. They were black hogs, of which an account may be seen, with a portrait of the sow, in the old American Farmer, vol. 6. They got the name of "Skinner's breed," and some traces of them may yet be found in Virginia. If they conld be bred back to the form and quali. ties of the original stock, they would deserve to be very highly prized. 'Any farmer, however, of common sagacity and attention, may soon modify and shape a breed to suit his own locality and views. From those who have not the spirit and true love of business to do even that, you will be sure to hear the common remark, "say what you will about breeds, but give me the corn house breed." Men without energy or proper ambition are rarely withes: some sucb easy resorh, in the way of self-excuse.] 
among other things of interest, saw what is very probably the original of the trough here de. scribed. The troughs in this piggery are composed of wood, bat precisely on the rame principle, as here figured and described, and their introduction there dates as far back as the time of the late Duke Heary of Buccleuch, whose invention they are supposed to be, and which must be at least of forty or more years' gtanding.

(1439.) The Ring Pigs'-Trough.-I have seen in England a very handsome pigs'-trough adapted for standing in the middle of a court. It is formed also of cast-iron, but in one entire piece, and is here represented in fig. 298. Its external appearance when viewed as it atands on the ground, approaches to that of a hollow hemisphere; but interiorly the bottom parts rise up in the center, forming a central pillar, thus converting the hemisphere into an annular trough, whose iransverse section is a semicircle. and the en. tire section of the two troughs forms two semicircles conjoin. ed. The dismeter $a b$ of this trough is 30 inches, the edge is finished with a round baton, serving both for strength and for comfort to the animals which eat out of it ; the depth is about 9 in. ches, and it is divided into eight compartments by the divisions $c$, which are formed with a convexity on the upper edge to prevent the food being

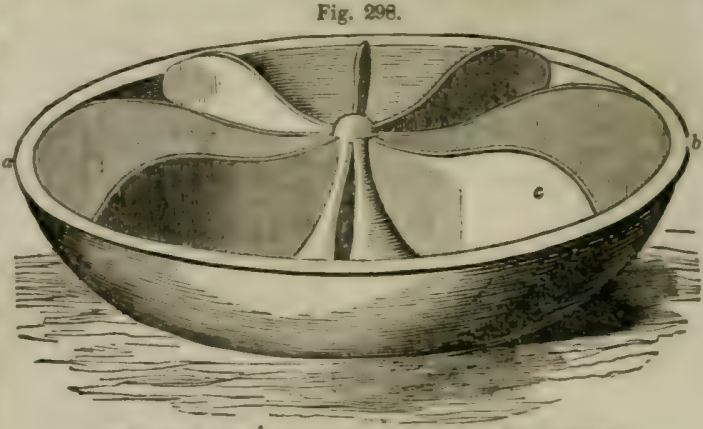

THE RING PIGS'-TROUGH, TO STAND IN A COURT. thrown from the one compartment into another.-J. 8.]

(1440.) In regard to the slaughtering of pigs, they should be made to fast for nearly a day, to clear their bowels of as much food as possible. The season best adapted for the purpose is in the cool months of the year; the flesh in the warm months not becoming sufficiently firm, and is then lia ble to be fiy-blown before it should be cured. For using fresh pork, the season of course does not signify. When you wish to make hams for your own use, Cliristmas is a good time for slaughtering pigs, and, in doing it, great care should be taken that the animals receive no injury by braises before being killed, as the flesh, where bruised, will become blood-burned, and will not take with the salt. When the tinue for slaughtering arrives, the animals should be taken out of their sties gently one by one as slaugbtered, and placed on their back on a considerable guantity of straw, and held in that position by assistants, while a long knife is introduced with a firm hand through the counter near the bottom of the neck. through the opening between the ribs at the sternum into the beart, care being taken that the point of the knife does not miss the opening, and go between the sloulder blade and the ribs. This error is frequently committed in slaughtering pigs; it is called shouldering, and has the effect of collecting a mass of blood under the shoulderblade, where it coagulates, and prevents the whole shoulder from being cured. Before the alangh tering commences, a large quantity of boiling water should be provided, with which to scald off the hair. This is effected either by putting the carcass into a large tub of water, or, should there not be a tub of sufficient size. the hot waier can be poured on the carcass on the straw, and scraped clean of the hair from every part of the body. The hoofs are taken off at this time. The net fat and entrails are separated. and the carcass is dressed in the most sincple manner, without flourishes, and with only a single stretcher to keep apart the flaps of the belly.

(1141.) The carcass hangs in the slanghter-house until nex d day, when it is awn up the back bone into two sides. If it is intended for pickled pork, the sides are cut ap in Scotland in the same way as the Scotch mode of cutting up mutton (fig. 255), namely, $a$, fig. 299, is the leg, and $b$ the loin, in the hind-quarter; $c$ the ribs, and $d$ the breast. in the fore-quarter. The leg $a$ makes an excellent leg of pickled pork, served with pea-pudding; and the loin $b$ a juicy tresh roast. The back-ribs of $c$ are a fine roasting piece, and also for pork-chops, one of the most delicate dishes of the hasty modes of dressing meat. The fore-end of $c$, and the whole of the breast $d$. are fit for pickling. The head, split in two, is also pickled, and considered a delicacy, as the fat upon the cheeke is gristly.

(1442.) The English mode of cutting up pork is different from what has just been described, and, upon the whole, perhaps better adapted for family use. Fig. 300 gives a representation of it, where, in the fore-quarter, $a$ is the spare-rib, so called because the flesh and fat are taken off the ribs for salting; and the ribs are then roasted, and make s savory dish: $b$ is the hand or shoulder, fit for pickling; $c$ the belly or spring, also fit for pickling, or for rolling up, when well seasoned and stuffed, for brawn, and eaten as a relish. In the hind-quarter are $d$ the fore and $e$ the hind loin, both best when roasted, the fore one $d$ also making excellent chops ; and $f$ the leg. which is cut short for pickling. The neck is called a crop of pork, and, when divided into its vertebra, are cut for chops, and called griskins. The head, when divided in two, is again divided at the jaw into an upper part called the face or cheek, and the lower part named the chap. Some times the two chaps are not divided.

(14.43.) According to Mr. Donovan, a hand of salt pork, weighing $4 \mathrm{lbs} .5 \mathrm{oz}$. , lost in boiling 11 oz. The bone weighed $9 \mathrm{oz}$. ; the meat was $3 \mathrm{lbs} .1 \mathrm{oz}$. It the first cost of the pork was $7 \frac{1}{2} \mathrm{~d}$. per lb., the meat alone, when duly boiled, cost $10 \frac{1}{d} \mathrm{~d}$., and with the bone nearly $9 \mathrm{~d}$. per $1 \mathrm{~b}$. The loss in boiling salt pork is consequently $15 \$$ per cent."

- Donovan' Domeatic Economy, rol. li. 
(1444.) Of the time required for digesting pork dressed in various ways, pigs' feet soused and boiled take 1 hour; sucking-pig roasted, $2 \frac{1}{2}$ hours; pork recently salted, raw or stewed, 3 hours; pork-steak, and recently salted pork, broiled, $3 \frac{1}{4}$ hours; pork recently salted, fried, $4 \frac{1}{2}$ hours; pork recently salted, boiled, $4 \frac{1}{2}$ hours; and pork, fat and lean, roasted, $5 \frac{1}{4}$ hours.*

(1445.) Pickled pork derives its name from the mode in which pork is cared in a strong brine or pickle of salt and water. The flesh is first rubbed with salt, then subjected to pressure, then rubbed again, and packed in barrels, and strong brine poured over it. Immense quantities of pork are pickled, for home and foreign consump. tion, by the pieces being simply placed in brine, but is, of course, inferior to what is cured as above described. The largest establishment for the curing of pork I ever saw was in Belfast. A carcass is cut up in a few seconds in this manner: One man stands at the end of a large hackingblock of wood, provided with a long-faced hatchet, and two others stand on each side of the block. A carcass, of whatever size, is placed on the block, on its back, with its head toward the hatchet; a man then seizes each of the limbs, and keeps the carcass open. With three or four strokes of the hatchet, the carcass is divided into two from snout to tail. One chop cuts off each of the balf heads, and one each of the legs. The heads are thrown into one heap, and the legs into another. The two men at the hind-quarter then take their knives and cut off the hams, which are put by themselves, and taken away and rubbed with salt, and placed in rows on the ground, with the Heshy side uppermost, covered with dry salt. The remainder of the carcass gets two or three chops across the ribs, according to its size, and tine pieces are thrown into a large tub of brine. The whole thing is done in far less time than I have taken to describe it. For family

Fig. 299.

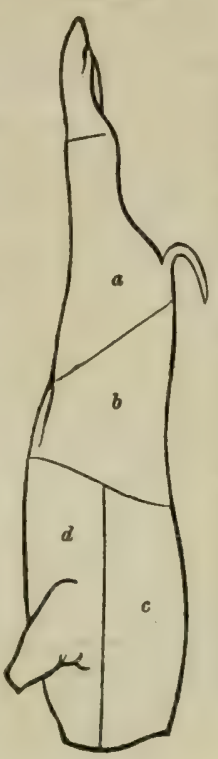

Fig. 300 .

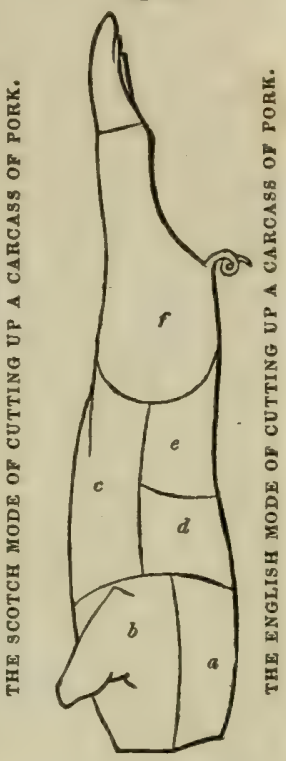

use, no pickle should be used in curing pork, as it extracts the natural juices of the meat; the pieces, cut of a convenient size, should be rubbed with good dry, Liverpool salt, both on the skinny and fleshy parts, and packed in a jar covered with a lid or cloth: and from eight days to a fortight, according to the size or thickness of the pieces, the pork will be ready for use. The navy tierce of pork consists each of 80 pieces of 4 lbs.

(1446.) When the carcasses are meant for ham for family use, they are treated in this manner: After being sawn asunder, the sides should be carefully handled, that the back-bone be not broken, and placed on a table, when all the loose seam or tallow is taken ont, and the kidneys extracted out of it. The muscle lying along the back-bone under the loin is taken out, and, when used fresh, makes an excellent collop for sansages; and the diaphragm or skirt is also cut off. The tongue is cut out, the brains scooped out, the ears extracted by their sockets, the tail cut away, and the four feet disjointed at the knees. Every loose and useless shred of fat, sinew, nerve, flesh, and skin, should be carefully removed.

(1447.) The next process is the salting. Let the sides be placed with the skin side uppermost, and all where there is skin let it be rubbed hard with the palm of the hands, by two persons, for fully half an hour, in a warm place, with good dry salt, taken in indefinite quantity. Thin-skinned uniformly fat pork will feel warm under the rubbing, and the skin become somewhat loose and sweaty, which are the best signs that the flesh is taking in the salt. A hard-skinned side will not exhibit these symptoms, nevertheless it will take in the salt too, though not so kindly. The ends of the shanks should be well rubbed with salt. After this rubbing, the side is turned over, and 4 oz. of saltpetre, finely pounded, are strewed over the inside, and especially over all the fleshy parts that have been cut with the knife, such as along the line of the back-bone, and the inside of the ham. The use of the saltpetre is to give a uniformity to, and highten the color of, the flesh, which. in pork, becomes red on being converted into ham. A layer of salt of about $\frac{1}{2}$ of an inch thick is then laid on the side over the saltpetre. In this state the side is carried carefully, and laid apon a board or wooden floor. Other sides are treated exactly in the same manner, one af ter the other, and laid upon one another, with the skinny sides downmost; but perhaps 4 sides are enough to form one heap, laid alternately, head and tail, to lie compactly. A board is then laid above them, supporting a number of weights; the whole being covered with a woolen cloth, to keep out the frost, should it arrive. In the course of a day or two, brine will run from the heaps. which should be wiped up from the floor. In a fortnight the sides should again be laid on the table, and the brine that may have collected on the ribs poured out, the loose wet salt removed, and the skinny side again rubbed with dry salt for about a quarter of an hour. The loose salt should then be all brashed off by the hand, and the skin wiped dry. To prevent flies blowing the end of the shanks at the joints, a brown-paper bag makes a close enough covering for them; and a wooden skewer being thrust through both shank and bag. and both tied firmly to the leg with twine, the remainder of the twine is formed into a stout loop by which the side is

- Combe on Digestion and Dietetics.

(11) 
anspended from hooks. The inside is then covered with a oniform coating of berley or peas-meal, poshing it well into every crevice with the finger. The dampness of the flesh will make the meal Etick on. but there is none pat on the skinny side. The side is then hung sp from the roof of a warm, dry room, the kitchen being the most appropriate place; and the kitchen roof thus gar. nished conveys an idea of plenty and good cheer. I sent this recipe, through a friend, 10 a lady whom I underatood was at the ime engaged on a work on the calinary art, and it may be found sabstantially in the above shape in her valuable pages.

(1448.) From experiment, it was ascertained by Mr. Donovan that if the first cost of ham be 10d. per lb., the meat. dnly boiled, skinmed and browned, will cost $1 \mathrm{~s}$. 1 $\mathrm{d} d$. per lb.; the lose there by being consequently 33 per cent.

(1449.) Hog's lard is rendered in exactly the same manner as mutton suet (1513); bnt as lard is liable to become rancid. yellow-colored. and acquire a strong stmell when exposed to the air, it is usually tied ap in hladders. For this purpose it is allowed to cool a while, after it is melted. and the bladder (a pig's or calf's) being made ready by being thoronghly cleaned and turned owtside in, is filled with the lard by a fannel, and tied up. Lard "melts completely at $99^{\circ}$ Fahr. and then has the appearance of a transparent and nearly colorless fixed oil. A thermometer placed in it sinks gradually to $80^{\circ}$. The lard then begins to congeal, and the thermometer re. mains at $80^{\circ}$ all the time of congealing. which occupies several minutes. It is clear from this that $80^{\circ}$ is the melting point of hog's lard. Its specific gravity at $102^{\circ}$ is $0-9028$; at $60^{\circ}$. it is 0.9302 . . . It consists of elain 62 parts and of stearine 38 parts out of the 100 parts. . . . When subjected to pressure between folds of blotting-paper, the elain is absorbed, while the stearine remains." For domestic purposes, hog's lard is better than even butter for frying fish; but is quite unfit for pastry, though much ased in that way on the score of economy.

(1450.) Hog's skin is usually thick, and, when tanned, its great toughness renders it valuable for the seats of riding-saddles. Hog's briatles are formed into brushes for painters and artists, and for numeroas domestic usés. Some of the offals of the pig make excellent domestic dishes. such as blood, mealy and sweet paddings; and pork sausages, made of the tender muscle ander the lambar vertebra, are sweeter. higher flavored, and more delicious than those of beef. If it were not for taking ap too mach room, I could give excellent recipes for making these paddings and sausages; because 1 do not.thirk such matter foreign to the pages of a work which professes to make you acquainted with what can be made available on a farm.

(1451.) An experiment on the comparative advantages of feeding pigs on raw and boiled food was made in 1833 by Mr. John Dadgeon, Spylaw, Roxhurghshire. He put ap 6 he pigs in one lot, and 5 she ones in another, and they were all carefally cut, and 9 weeks old. The he pigs were put on bolled food. namely, potatoes and hashed beans; the she ones on raw of the sanie mort. The 6 he pigs increased in live-weight, from $2 d$ Jaly to 12 th October, 38 stones $6 \mathrm{lbs}, 4 \mathbf{e z}_{\text {, }}$ or 6 stones 5 Ibs. $11 \mathrm{oz}$. each; whereas the 5 she ones only increased, in the same time, 17 stones $11 \mathrm{lbs} .8 \mathrm{oz}$, or 3 stones $7 \mathrm{lbs} .14 \mathrm{oz}$. each. Other 3 pigs were fed at the same time on boiled and raw food indiscriminately, as it happened to be left over after serving the other two lots. The facts brought out in this experiment are, that the pigs "fed exclusively upon boiled meat did thrive in a superior manner to the ochers, and even to those which had an oceasional mixtore of $\mathrm{m} w$ and boiled meat; thus shwing that boiled meat is at all times more nutritive than raw." The " pigs were repeatedly washed with soap and water, which refreshed them greatly, and cansen them to relish their food." Those "which got a mixture of food both prepared and raw. approached nearer to those which were fed on boiled to their feeding properties; bat they appeared occasionally shy at having their meat so mixed. It is therefore better, in general, to continue for some time only one description of food; as, whatever the animals become accustomed to, they begin to relish, and thrive upon it accordingly." $\dagger$

(1452.) Mr. Robert Walker, Ferrygate, East-Lothian, also made an experiment on the same subject in the same year. He put 5 pigs on steamed potatoes and prepared broken barley, and other 5 on raw potatoes and raw broken barley. The pigs were $2 \frac{1}{3}$ months old. On the 4th March, 1833, the live weight of the 5 pigs fed on raw food was 7 sts. 10 lbs.; on the Ist June following, it was $16 \mathrm{sts}$. $13 \mathrm{lbs}$, showing an increase of $8 \mathrm{sts}$. $3 \mathrm{lbs}$., or an increase in each pig of 1 st. $9 \mathrm{lb}$. On the 4 th of March, the live weight of those fed on steamed food was 7 at8. $81 \mathrm{bs}$., and on the lst Jane it was 19 sts. 13 lbs., showing an increase over the whole of 12 sts. $5 \mathrm{lbr}$, or an in. crease on each pig of 2 sts. $61 \mathrm{lbs}$. The increase in the time was $67 \mathrm{lbs}$. more than double the original live weight of the pigs fed on steamed food; whereas, in those fed on raw, the increase was only $7 \mathrm{lbs}$. more than the double; "so that there can be very little doubt," as Mr. W alker concludes, "that steamed food is more profitable for feeding pigs than raw food. In fact, I do not think it possible to make pigs fat on raw potatoes, without other food, when confined to them alone."

(1453.) Dairy farms are well suited for rearing pigs on the dairy refuse in summer, but in win. ter the most that can be done is to keep the brood-Bows in pig in fair condition for littering in apring. On carse and pastoral farms, no more pigs can conveniently be reared than to merve the farmer's family. On mixed farms, pigs constitute a portion of the regular stock.

(1454.) With regard to the diseases of swine, they are fortunately not numerous, as it is no easy matter to administer medicine to them. The safest plan, in most cases, I believe, is to slaughter them whenever any symptoms of internal disease show themselves. Bwine are infested with a louse (Homatopinus suis), like all domegticated animals. It is represented in fig. 301 . Head and thorax of a dull, rusty color, the former pear-shaped and narrow, with an angular black line at the apex, and one on each side before the eyes; abdomen large, flat, and oval, of a bluish or yellowish ash gray color, most of the segments with a black homy prominence at each side, surrounding a white breathing hole; legs pale ochre-yellow, the thigh marked with dusky bands;

- Thomson's Animal Chemistr.

+ Prize Eseays of the Highland and Agricultural Society, rol, $\mathbf{x}$. 
length $1 \frac{1}{4}$ to $1 \frac{3}{4}$ lines. This species is generally very plentiful on swine, more partieularly on those fresh imported from Ireland. It appears to abound most on lean animals. "In walking," says Mr. Denny, ${ }^{\Delta}$ it uses the elaw and tibial tooth with great facility (which act as anger and thimb), in taking hold of a single hair; the male is much smaller, sub-orbicular, and the segments lobate. The egg or nit is $\frac{3}{4}$ of a line in length. of a cream color, and ele. gantly shagreened, oblong, and slightly acuminated, surrounded by a lid which, when the young insect is ready to emerge, splits circularly-or, as a botanist would say, has a eircumeisile dehiscenee." $*$ Oil in the first stage, and mercurial ointment in after stages, will destroy this insect.t

(145.) Consumeption is a disease which affects pigs. It is brought on by "neglect and exposure to cold and damp. The animal beoomes thin, the coat staring, the skin appearing as if glued to the ribs; obstinate cough supervenes; discharge is frequent from the nose, and glandular swellings appear about the neek. On dissection, the lungs are studded with tubercles." "It is in the early stage alone of the complaint." seys Professor Dick, "that anything can be done, and the prospect of cure is but faint $\neq$ In allading to the lungs. I may mention a remarkable instance of their state I once observed in a sow of my own. She had barne several litters, and became astamatic, which increasing so as to appear distressing to the animal, sbe was killed; and one lobe of the lungs was found to be so conspletely ossifed that its surface was converted into a shell nearly as hard as the crust of a crab, and it was filled with 2 thick yellow thid. Having understood afterward that this was a remarkable case, I regret that the lobe was not examined by a veterinarian. I take this opportunity of suggesting to every farmer, who may happen to

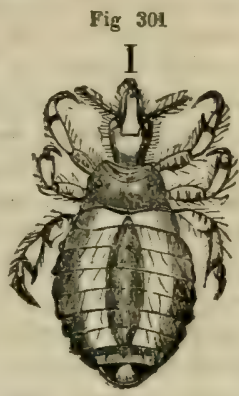

THE SOW-LOUSE (H) MATOPINUS SUIS). meet with any instance of structural disorganization in any part of any aninsal he owns, to have it examined by a competent veterimarian.

(1456.) Pigs are subject to a cutaneous disoase called measles, whieh is supposed to render the flesh un wholesome. "The measles," says a writer, "are very prevalent, though seldom fatal; and if not cheeked, affect the grain of the neat. which may be eovmonly seen in the shops of a faded color, and the flesh punctured, as it were, with small holes, or distensions of the fibre. The commencement of the disease appears iv larguor and decline of appetite, followed by snaall pustules in the throat, together with red and purple eruptions, nore distinet after death than during the life of the animal; but may, it is said, be removed in this stage by giving small ouantities of levi. gated crude antimony in the food. Generally speaking, even if the animals be in health, a small quantity of ritre end sulphur, eccasionally nixed up with their food, besides stimulating their appetite, will frequently prevent disease; neither can we too much ingist on cleanliness, nor upon the punctual regularity of feeding at stated times." $\|$ The injunction contained in the last words, if followed, will do more for the preservation of health in pigs, than the administration of any specific after disease has once shown itself. I can safely say that, with the simple means here enjoined, I never had a pig that was in the least affected in the skin by either diseage or yermin.

\section{TREATMENT OF FOWLS.}

\footnotetext{
"Thither the household feathery tribe crowd, The crested cock, with all his female train, Pensive and dripping;
}

Tromson

(145\%.) Of all the animals reared on a farm, there are none so much neglected by the farmer, both in regard to the selection of their kind, and their qualifications to fatten, as all the sorts of domesticated fowls found in the farm-yard. Indeed, the very supposition that he would devote any of his time to the consideration of poultry, is regarded as a positive affront on his manhood. Women, in his estimation, may be fit enough for such a charge, and doubtless they would do it well, provided they were not begrudged every particle of food bestowed upon those useful creatures. The consequence is what might be expected in the circumstances, that go to most farmsteads and the surprise will be to meet a single fowl of any description in good condition, that is to say, in such condition that it may be

* Denzy's Konographia Anoplurorum Britamiæ. 11 find that the ox-louse (Fendopinus eurgsternus), fig. 268, has been erroneously printed on
page 151 .

tDick's Manuul of Veterinary Scievoe. $\quad$ British Husbandry, vol ii. 
killed at the instant in a fit state for the table, which it might be if it had been treated as a fattening animal from its birth. The usualobjection urged against feeding fowls is that it does not pay, and no doubt the usual price received for lean, stringy-fleshed, sinewy-legged fowls is far from remunerative; but whose fault is it but the rearer of them, that fowls are sent to market in such a state, and why should purchasers give a high price for any animal, be it fowl or beast, that is in under condition? There would be some excuse for the existence of lean fowls at a farmstead were there any difficulty of fattening poultry of every kind at no great expense ; but the idea of expense is a perfect bugbear; and this is one, like all others that seize us through our fears, would vanish were a plan adopted for rearing fowls more consonant to common sense than the one usually pursued. To judge from common practice, the prevalent sentiment seems to be, that fowls cannot be ill off when they get leave to shift for themselves. Such a principle is a grievous error in the rearing of any kind of live stock. Better a man keep no stock at all than allow such a sentiment to influence his conduct to them. Fowls may be considered worthless stock, and so they generally are, but are you sure that it is not your mode of managing them that renders them so? But apart from every consideration of profit to be derived from sales in market-towns, there is the superior one of the farmer having it at all times in his power to eat a well-fed fowl at his own table; and there is no good reason why he should not be able to enjoy such a luxury at any time he choses. There would be economy in it too, in the long run, inasmuch as good poultry, at command, will keep him out of the butcher market, into which he cannot go without cash in hand, and cash he cannot command except by realizing the money value of some commodity or other from the farm. Few farmers kill their own mutton, that is to say, keep fine fat sheep for their own use; lamb, they may kill in the season; but as to beef, it must be purchased; so that, situate as the farmer usually is, the produce of the poultry-yard and pig-sty constitute the principal items of his board. And why should he not have these in the highest perfection?

(1458.) Winter is a season in which no fowls are brought forth in Great Britain. The climate is too severe for them; the cold would either kill chickens outright or prevent their growth so as to render it unprofitable to bestow the great attention which their rearing would require. None of the fowls usually lay eggs in winter. But notwithstanding this natural barrier to the propagation of fowls in winter, both chickens and eggs may, by good management, be obtained in that season.

(1459.) The ordinary fowls on a farm are the cock (Phasianus gallus), the turkey (Meleagris gallopavo), the goose (Anas anser), the duck (Anas domestica), and the pigean (Columba livia), the white-backed or rock dove, which was long ago confounded with the blue-backed dove iColumba anas). In regard to all these $\mathbf{I}$ shall first state the condition in which they are found on a farm in winter, and then describe the mode in which food should be daily supplied them; and as they may all be fed with nearly the same ingredients, the mode of feeding to be described will apply to all.

(1460.) And first, in regard to the condition of the hen. As hatchings of chickens are brought out from April to September, there will be broods of chickens of different ages in winter; some as old as to be capable of laying their first eggs, and others only mere chickens. The portion of those breeds which should be taken for domestic use are the young cocks and the older hens, there being a feeling of reluctance to kill young hens, which will supply eggs largely in the following season. At all events, 
should any hen-chickens be used for the table, the most likely to become good layers next season should be preserved. The marks of a chicken likely to become a good hen are a small head, bright eyes, tapering neck, full breast, straight back, plump ovoidal-shaped body, and moderatelengthed gray-colored legs. All the yellow-legged chickens should be used, whether male or female, as their flesh never has so fine an appearance as the others. As to the color of the feathers, that is not a matter of much importance, some preferring to have them all white, others all black; but I believe there is none better for every useful purpose than the mottled gray. Young fowls may either be roasted or boiled, the male making the best roast and the female the neatest boil. The older birds may be boiled by themselves and eaten with bacon, or assist in making broth, or that once favorite winter-soup in Scotland-cockieleekie. A chicken never eats more tenderly than when killed a short time before being dressed; but if not so soon used, it should hang in the larder for 3 or 4 days in winter. An old fowl will become the more tender on being kept for a week before being used. The criterion of a fat hen is a plump breast, and the rump feeling thick, fat, firm, on being handled laterally between the finger and thumb. A corroborative criterion is thickness and fatness of the skin of the abdomen, and the existence of fat under the wings. White flesh is always preferable, though poulterers insist that a yellow-skinned chicken makes the most delicate roast.

(1461.) Turkeys being hatched in May, will be full grown in stature by winter, and, if they have been well fed in the interval, will be ready for use. Indeed, the Christmas season never fails to create a large demand for turkeys, and it must be owned there are few more delicate and beautiful dishes presented at table, or a more acceptable present given to a friend, than a fine turkey. Young cocks are selected for roasting, and young hens for boiling, and both are most relished with a slice of ham or of pickled ox-tongue. The varieties in common use are white, black and mottled gray; and of these the white yields the fairest and most tender flesh. The criterion of a good turkey is fullness of the muscles covering the breast-bone, thickness of the rump and existence of fat under the wings; but the turkey does not yield much fat, its greatest property being plenty of white flesh. Young turkeys attain to great weights. I have had yearly young cocks weighing, at Christmas, $18 \mathrm{lbs}$. each in their feathers. Norfolk has long been noted for its turkeys, where they are fed on buckwheat, and large droves are annually sent to the London market. A turkey is deprived of life by cutting its throat, when it becomes completely bled. The barbarous practice of cutting out their tongues and hanging them up by the feet to bleed slowly to death, for the alleged purpose of securing whiteness of flesh, ought to be severely reprobated.

(1462.) Geese, having been hatched in the early part of summer, will also be full grown and fit for use in winter. I believe there is very little difference in flavor or appearance, as a dish, between the young male and young female goose, though there may be some difference of size. The criterion of a fat goose is plumpness of muscle over the breast, and thickness of rump when alive; and, when dead and plucked, the additional one of a uniform covering of white fat over the whole breast. It is a very good young goose that weighs in its feathers $12 \mathrm{lbs}$. at Christmas. The goose is as favorite a dish at Christmas as the turkey, but people tire of it sooner, and in consequence it is not so frequently served at table. A green goose at Michaelmas is, however, considered a greater delicacy in England than a turkey-poult. Geese are always roasted; and their flesh is much hightened in flavor by a seasoning of onions as a stuffing, and 
by being served up with apple-sauce. A goose should be kept a few days before being used. It is bled to death by an incision across the back of the head, which completely bleeds it. Large flocks of geese are reared in Lincolnshire, and thence driven to the London market. It is rare to see a gray gander, and as rare to meet a white goose. I remember seeing large flocks of geese on the islands in the Elbe near Hamburg, which were reared chiefly for their quills, their carcasses being salted and sent to Holland. The invention of the steel-pen, however, has much injured the quill-dressing trade, and, in consequence, good quills are now not easily obtained; and their deterioration still farther encourages the use of the steel-pen. Geese have long been proverbially good watchers. I have seen a gander announce the approach of beggars toward the kitchen-door as lustily as any watch-dog.

(1463.) Ducks, being also early hatched, are in fine condition in winter if they have been properly fed. Ducklings soon became fit for use, and are much relished with green peas in summer. I believe there is no difference in flavor and delicacy between a young male and young female duck. They are most frequently roasted and stuffed with sage and onions; though often stewed, and if smothered among onions, when stewed, there are few more savory dishes that can be presented at a farmer's table. A duck never eats better than when killed immediately before being dressed. It is deprived of life by chopping off the head with a cleaver, which completely bleeds it.

(1464.) Hens and turkeys are most easily caught on their roosts at night with a light, which seems to stupefy them; and geese and ducks may be caught in any outhouse at any time they are driven into it.

(1465.) As young pigeons alone are made use of, and as the pigeon does not hatch in winter, they require no other notice at present than what regards their feeding; and to give you an idea of their gastronomic powers, of three rock-doves which were sent to Professor MacGillivray, "The number of oat-seeds in the crop of the second amounted to 1,000 and odds, and the barley-seeds in that of another were 510. Now, supposing," says he, "there may be 5,000 wild pigeons in Shetland, or in Fetlar, which fed on grain 6 months every year, and fill their crops once a day, half of them with barley and half with oats, the number of seeds picked up by them would be $229,500,000$ grains of barley, and 450,000,000 grains of oats-a quantity which would gladden many poor families in a season of scarcity. I am unable," he adds, "to estimate the number of bushels, and must leave the task to the curious." * And the task I have undertaken, and find the result to be 422 bushels of barley and 786 of oats.t

(1466.) The prices of poultry in towns are pretty high. In Edinburgh, for instance, in winter, a couple of chickens are $28.6 \mathrm{~d}$; hens from $1 \mathrm{~s}$. to 1s. 9 d. each; ducks $3 \mathrm{~s}$. per couple; turkeys $3 \mathrm{~s} .6 \mathrm{~d}$. to $8 \mathrm{~s}$. apiece; geese 38. $6 \mathrm{~d}$. to $5 \mathrm{~s}$. each; and eggs are from 1s. $2 \mathrm{~d}$. to $1 \mathrm{~s} .8 \mathrm{~d}$. per dozen. In the country towns the prices are fully one-third below these; but the highest prices in London are not more. In Ruseia fat turkeys are 1s. 10d., geese 28., and fowls and ducks 18. 3d. per couple! In Ireland poultry of all kinds are cheap; but not so much so as in Russia.

(1467.) Farmers usually sell poultry alive, excepting in some parts of

\footnotetext{
- Macfillivmy's Hiatory of Britieh Birde, rol. 1.

+1 ascertained the reeult by weight: and as the facts may be worh recording, I may mention that in an average of 3 deachme, there were 75 grains of chevalier barley in each drachm of a sample weighing $56 \frac{1}{2}$ lbs. per bushel: and 97 grains of Siberian early oat in 1 drachm of ample weighing 46 lbs. per bushel. Of Chidham white wheat, weighing $65 \mathrm{lbs}$. per bushel, there were 86 grains in the drachm.

‡ Venables' Tour in Ruseia, Appendix. 16)
} 
the country, such as the Borders, where geese are killed and plucked for the sake of their feathers before being sent to market. Poulterers in towns, on the other hand, kill and pluck every sort of fowl for sale, so that the purchaser has it in his power to judge of the carcass; and if he buys an inferior article at a high price it must be his own fault. It is easy to judge of a plucked fowl, whether old or young, by the state of the legs. If a hen's spur is hard, and the scales on the legs rough, she is old, whether you see her head or no; but the head will corroborate your observation, if the under-bill is so stiff that you cannot bend it down, and the comb thick and rough. A young hen has only the rudiments of spurs, the scales on the legs smooth, glossy and fresh colored, whatever the color may be, the claws tender and short, the under-bill soft, and the comb thin and smooth. An old hen-turkey has rough scales on the legs, callosities on the soles of the feet, and long, strong claws; a young one the reverse of all these marks. When the feathers are on, an old turkey-cock has a long beard, a young one but a sprouting one; and when they are off the smooth scales on the legs decide the point, beside difference of size in the wattles of the neck, and in the elastic snot upon the nose. An old goose, when alive, is known by the roughness of the legs, the stiength of the wings, particularly at the pinions, the thickness and strength of the bill, and the firmness and thickness of the feathers; and when plucked, by the legs, pinions and bill, and the coarseness of the skin. Ducks are distinguished by the same means, but there is this difference, that a duckling's bill is much longer in proportion to the breadth of its head than that of an old duck. A young pigeon is easily discovered by its pale-colored, smooth-scaled, tender, collapsed feet, and the yellow, long down interspersed among the feathers. A pigeon that can fly has always red-colored legs and no down, and is then too old for use.

(1468.) The hen-houses are placed at $d$ on the plan and view, figs. 3 and 4, Plates III. and IV. They are divided into 3 apartments, each hav ing a giblet-check door to open outward, and all included within a courtyard provided with an outer door and lock. The use of 3 apartments is to devote one of them to the hens and turkeys, which roost high; another to the geese and ducks, which rest on the floor; and the third to a hatchinghouse to accommodate both. When geese are obliged to rest below hens they are made uncomfortable and dirty by the droppings of those which roost above them. The innermost apartment, being the largest, should be occupied by the most numerous body of fowls, namely : the hens and turkeys; the right-hand one by the geese and ducks; and the left-hand one in hatehing, to which access is given by a trap-ladder and opening through the wall at the road, to admit the laying hens. There should be an opening with a sliding-shut in the outer door, as well as one in the doors of the geese-house and hatching-house, to give admittance to the birds when disposed to go to rest in the afternoon; and these shuts should be fastened every night. In the accommodation thus appropriated to every class of fowls, each apartment will be taken up by its own class. The usual practice is to put all kinds of fowls into the same apartment; and the small space occupied by even this single room seems to be grudged, as if any sort of accommodation, however hampered or incommodious, were good enough for poultry. How breeders and feeders of stock can reconcile their minds to such indifference toward any class of their live-stock, while possessing the desire of having a good fowl at their table, is more than I can imagine, unless they believe that quite opposite modes of treatment will produce similar results! In very cold weather the inner apartment, occupied by the hens and turkeys, could be kept sufficiently warm by 
heaping the horse-dung from the work-stable under and upon the feedingtrough in the court $K$, immediately hehind the back wall of the hen-hnuse, as high up against it as is thought desirable; and a quantity of straw could be put on the slated roofs of all the apartments during a continued storm. Snow forms a warm covering on a roof, but the heat from fowls roosting under soon melts it; so that it is better to remove the snow and put on straw, and allow the snow to fall upon the straw. Fowls thrive best where there is a mild temperature, but not a great heat; and such expedients will supply them with a sufficiency of heat during the severity of a winter storm.

(1469.) The pigeon-house is placed in the gable of the boiling-house $U$, fig. 8 , Plate III., to receive warmth in winter from the fire usually kept in that apartment. When pigeons are thus artificially supplied with heat, they not only continue to hatch longer in autumn, but will recommence in spring soner than they would otherwise do. Indeed, by a little management in this way, and taking care to keep the house always pretty full of pigeons to retain heat among themselves, they might be encouraged to hatch all the year, with the exception, perhaps, of two months in the depth of winter, in December and January. Pigeons, like other birds, are most prolific when not too old; and as old cocks are exceedingly tyrannical to the young ones, they should be destroyed as well as the oldest hens. It is no easy matter to get hold of flying pigeons to kill them, as they are always on the alert and make their escape; but there are various ways of destroying them, and a favorite one is shooting, but it is not the best in this case, as young ones may be wounded while aiming at the older birds. The safest plan is to mark the birds yeu wish to destroy daily for some time, in order to recognize them readily, and the old cocks are easily discernible by their forward manner, and the interruption they give at the pigeon-holes to the entrance of others. These remarks apply specially to the recognition of old cocks, but are inapplicable to old hens, as they never conduct themselves so. Other means must, therefore, be taken to recognize them, and the same may be applied to the cocks; and these are those given above for the detection of dead old and young pigeons. The marks are rough, scaly legs, callous soles of the feet, ligh red color of the scales, strong bill, strong wings, thick covering of feathers, and brightness of the play of colors upon the neck. All these marks are most conspicuous in winter, the very season when the process of cocking a pigeon-house, as it is termed, should be performed, as then there are no young to be unknowingly deprived of their parents. The safest way of doing it is to enter the pigeon-house gently, late of a dark night, with a light. On entering with the light, and shutting the door, it will bewilder the pigeons, and the first movements should be to stop up the holes to prevent them escaping, which the old cocks will be the first to attempt; and should the holes be beyond the reach of the floor, a ladder should be taken in to assist in effecting the purpose. Two persons are required to capture the pigeons, as they will endearor to elude every attempt; and one to take special charge of the light, which, if taken out of the lanternand it should be so if the lantern is not of glass-to afford plenty of light, is apt to be blown out by the wind occasioned by the pigeons flying about. Should this be the case, a lucifer match should be in readiness to rekindle it. A light landing net used by anglers is a convenient instrument for entrapping a pigeon, whether sitting or flying. Every hird that is caught should be examined and recognized, and every one exhibiting signs of old age should be destroyed, by pushing the point of the thumb with force into the back of the head, and severing the cervical vertebre, or applying (18; 
the teeth for that purpose; but should these modes be disliked or impracticable, rather than torture the poor devoted animals by abortive attempts, let their heads be cut off at once by a sharp table-knife. When this process of weeding is performing, it should be done effectually at once, and not repeated in the same season, as a nocturnal visitation such as this cannot fail to intimidate the whole flock. Nor should it be done in the season of hatching, though done without fail every year, and the consequence will be that your pigeon-house will be stored with prolific birds, and receive no annoyance from birds which have become barren. Perhaps a dozen of birds, male and female, so destroyed, may suffice at a time. On, removing the stopping from the holes, and the slain birds, and closing the door, the creatures will be left in quietness.

(1470.) The daily treatment of fowls may be conducted in this manner: Some person should have special charge of them, and the dairy-maid is perhaps the best qualified for it. As fowls are very early risers, she should go to the hen-house in the morning, on her way to the byre, and let out all the fowls, giving the hens and turkeys a feed of light corn and cold boiled potatoes, strewed along at some convenient and established place out of the way of the general passage of horses and carts; such as between the hammels $\mathrm{N}$, and the byre-court $l$, fig. 3 , Plate III. The ducks should get the same food either near the horse-pond, or where there is a pond or trough of water, as they cannot swallow dry food without the assistance of water. Geese thrive well upon sliced turnips, a little of which, sliced small, should be left by the cattle-man for the dairy-maid at any of the stores, and given at a place apart from the hens. When stated places are thus established for feeding fowls at fixed hours, they will resort to them at those hours; at least the well-known call will bring the hour to tineir recollection, and collect them together on the spot in a few seconds, and the regular administration of food being as essential for their welfare as that of other stock. Ducks pick up a good deal of what falls about the stable, and near the corn-barn door, as well as in the straw-barn; and geese will help themselves to the turnips that may chance to fall from the troughs of the cattle; and they are also fond of raw potatoes. After her own dinner, say 1 o'clock P. M., the dairy-maid takes a part of the potatoes that have been boiled at that time, and while a little warm, gives them crumbled down, from their skins, with some light corn, to the turkeys and hens. At this time of the day, the spaces below the stathels of the stacks in the stack-yard form excellent dry sheltered places for laying down food, and the stack-yard is a very probable place for their resort after their morning meal, especially when it rains or snows. In laying down food for the fowls, the pigeons should be remembered, as they will feed with the hens, and on the same sort of food. Before sunset the fowls are all collected together by a call, and put into the house, and which they will readily enter; and many will have taken up their abode in it already, especially the turkeys, which go very soon to roost. The ducks are the latest idlers. The floors of the different apartments should be littered with a little fresh straw every day, sufficient to cover the dung, and the whole cleaned out every week. Sawdust or sand, where they are easily obtained, form an excellent covering for the floor of hen-houses. Troughs of water should be placed in the court-yard, and supplied fresh and clean every day.

(1471.) This mode of daily treatment will maintain fowls in a condition for using at any time, and it cannot be said to involve much expense, for the riddlings of potatoes boiled and light corn may be considered as the offal of the farm; but the truth is, food administered to these creatures at 
irregular intervals, though it be of the finest quality, will be comparatively thrown away, when compared to the good effects of food of even inferior nutriment given them at stated hours. This plan contrasts favorably with that which gives them large quantities of food at long intervals, and in an unpleasant state; and also with that which permits fuwls to shift for their meat at the farmstead. Either of these ways will never fatten fowls; for food given in overabundance at one time and restricted at another, can never fatten any animal; nor will they obtain sufficient food at all times when made to shift for themselves, because fowls are like all other animals, some can forage ahout most perseveringly, while others are indolent, and some careless of food when it is not placed before them. A regular plan is recommended, which is, always supply thenı with a certain quantity of food, ascertained by experience, and dependent on the nature of the flock; when this is repeated daily at stated times, their condition must increase, because it cannot decrease, the minimum quantity of food being always sufficient to appease hunger; and this want they can never feel keenly when supplied with food at appointed times. Thus, in the long run, more nutriment will be derived from inferior food regularly administered, than from richer given irregularly. Should it be desired, however, to be particularly indulgent to fowls intended for immediate use, the following materials will render the respective sorts of fowls perfectly ripe in a short time. Boiled potatoes, warm, and light wheat, for hens; boiled potatoes, warm, and firm oatmeal porridge, warm, for turkeys ; boiled potatoes, warm, and oats, for geese ; and boiled potatoes, warm, and boiled barley, warm, for ducks. The potatoes and poridge should be crumbled down in small pieces. But immediate effects, even from superior food, can only be expected on fowls that have been regularly fed as recommended above, up to the time the superior food is indulged in. Let starved fowls receive the same ingredients, and a long time will elapse ere they exhibit symptoms of improved condition, besides the risk they run, in the mean time, of receiving injury from surfeit and indigestion. No doubt, superior feeding would incur cost, if persevered in throughout the season; but I am not disposed to deny that, were proper breeds of fowls only cultivated, and the shortness of time taken into consideration in which a pure breed will ripen upon it, that profit would be derived from its use. The experiment has never been satisfactorily attempted by the farmer, and all the accounts we know of superior feeding, apart from experiments by men of science, are only derived from the establishments of noblemen, whose object is not to obtain profit, but the possession of a superiorly fed animal.

(1472.) Other ingredients may be and are used for the feeding of fowls, among which may be mentioned brank or buckwheat, rice, and Indian corn. Buckwheat is successfully grown in England; not so in Scotland. It is said to fatten poultry well, though not so well as grain. Rice may be given either raw or hoiled; in the former state fowls will pick it as readily as grain after feeding on boiled potatoes, and, when boiled, it will fatten without the aid of potatoes, hut, of course, it is more expensive, as even good damaged rice can seldom be obtained under 16s. or 18s. per cwt., which is nearly 2d. per lb., without the expense of cooking. Fine barley, weighing 56 lhs. per bushel, selling, as it is at present, at $3 \mathrm{~s}$. $6 \mathrm{~d}$. per bushel, is only $\frac{3}{4}$ of a penny per lb. Indian corn is employed in America, in the southern parts of Germany, and in Lombardy, for feeding poultry, and they become very fat upon it. It is too large to be swallowed row, like the horse-hean of this country, but when steeped in water, or boiled, it is easily eaten. If sold at even 8 s. per bushel, its cost would be 
under 2d. per lb. "From a desire to save expense," says Boswell, "the bran of wheat, and sometimes pollard, or middlings, are given to fowls; but these bruised skins, where little if any of the farina of wheat remains, appear to contain a very small portion of nourishment in proportion to the cost price. M. Reamur found by experiment that it is little or no saving to substitute bran for good grain in feeding poultry. Bran is not given dry, but mixed with water to the consistence of paste. Some people boil this; but it does not increase the bulk, except in a very trifling degree, and is, therefore, of small advantage. He found that 2 measures of dry bran, mixed with water, were consumed by fowls in the same time that they would have eaten a single measure of boiled barley, equivalent to $\frac{3}{5}$ of a measure of barley." no use to fowls as food; but it may be made the means of conveying nourishing food to them, in the shape of fat, broth, and other rich liquids from the kitchen, which they could not otherwise avail themselves of but through such an absorbent. Fowls are very fond of bread, and even of butcher-meat, cooked or raw; and they will pick a rough bone very neatly. They sometimes also display carnivorous propensities. Many a time have I observed them watching for a mouse at the casting down of a stack in the stack-yard; and the moment one was seen to escape, away they would run, cocks and hens together, in full chase after it; and on mobbing it, peck it not only to death, but to pieces, and then swallow it.

(1473.) I have said that $\mathrm{eggs}_{\mathrm{g}}$, and chickens too, may be obtained in winter by good management. The young hens of the first broods in April will be old enough to lay eggs in winter. A few of these should be selected for the purpose; and when the period of laying approaches-which may be ascertained by their chaunting a song and an increased redness of the comb-they should be encouraged by better feeding and warmer housing at night. The feeding consists of warm potato and firm oatmeal porridge twice a day-at morning when they are let out, and in the afternoon at 1 o'clock. To give them peace in feeding upon their more tempting fare, they may be fed by themselves in the court-yard of the henhouses, and the door shut upon them after the rest of the fowls have left their night's quarters. And their more comfortable housing consists in directing them into the hatching-house betimes every afternoon, and therein making for them a number of comfortable nests of clean oat-straw, to choose among; and when they have taken to the one each selects for her own, leaving an old egg in it for a nest-egg. These three or four young hens will lay as many eggs every day; and though they are not so large as those of more matured fowls, being only pullets' eggs, still they will be fresh ; and it is no small luxury to enjoy a new-laid egg at breakfast every winter morning - a luxury which I enjoyed for as many years as I lived in the country.

(1474.) With regard to young broods in winter, I believe few people will impose upon themselves the trouble of setting hens on eggs so lifto iu the season for the purpose of rearing chickens in winter; and yet it may be done without difficulty ; but sometimes the task is imposed involuntarily upon one, inasmuch as some hens will secrete their nests in the fields, among corn, or at a hedge-root, or other safe place, and bring out strong broods of chickens on the eve of winter. In such an event, the little innocents, brought into a cold world, cannot be allowed to perish merely for want of care. When such a brood makes its appearance, or is purposely brought forth, it should be kept apart from the rest of the flock, in a warm and

\footnotetext{
* Boswell's Pouitry Yard.
} 
sheltered place; and where no better place presents itself, it may be cumfortably housed in a corner of the boiling-house, (U, fig. 4, Plate IV., ) where a hamper or basket, placed over mother and chickens, or a fence of some kind, erected acruss a corner near the fire, will protect them from ' $\mathrm{x}$ ternal danger. Thence they should be let out in the forenoon, to enjoy the air and bask in the sun, and be returned to their shelter long before sunset. In rainy weather they should be conducted to a shed; and in hard frost they may be kept in the house altogether, as frost soon henumbs their legs, and if they lose the power of which, they will soon droop and die. A nest of straw, elevated some inches above the floor, to keep them above the draft of air that sweeps along the floor, and having a broad base to afford the chickens an easy access to their nest, should be formed, for the hen to brood them on at night; and when fresh litter is given them every evening, a little of the cleanest and warmest to be found under a cow in the adjoining byre, where she has lain, will be most acceptable to the tiny limbs of the active brood. Food should he given them from morning to evening every three hours. It may consist of warm boiled mealy potatoes crumbled down small, picks of oatmeal porridge, mealy boiled potatoes warm, mixed with oatmeal, and a flat dish of clean water. With a little variety of food, daily attention, and temperate housing, they will get on well, and by spring be as plump as partidges and as valuable as ortolans. I am surprised to observe Mr. Mowbray say that "to attrmpt to rear winter chickens in this climate, even in a carpeted room, and with a constant fire, would in all probability be found abortive. I have repeatedly made the experiment," he adds, "with scores, without being able to preserve an individual through the winter."* The difficulty I consider small, though the trouble may be unnecessary, but neither a "carpeted room," nor a "constant fire," will assist much in the rearing of chickens, the whole secret of the art consisting of suitable food, moderate degree of temperature, fresh air and constant attention.

(1475.) Such is the way I would recommend the feeding of poultry on a farm. It is not an expensive mode in a pecuniary point of view, consisting entirely of ordinary fare and regular attention; and therein consists the entire value of the plan. That the plan is valuable and worthy of imitation has been proved beyond doubt, by its supplying fowls of every kind in their respective seasons, in high condition-at any period of the season they were required-and without any previous formal preparation. Thus, a chicken, a young cock, a hen, were at command throughout the year; a duckling throughout the autumn; and a goose or a turkey from Michaelmas to March; and this not for one year, or only in a favorable season, hut year after year for fifteen years, as long as I had opportunity to practice it. In short, a young fat fowl and a fresh egg were never wanting, from January to December; and there is a great deal of truth in Cobbett's remark, where he says, "one thing about fowls ought always to be borne in mind. They are never good for anything after they have attained their full growth, unless they be capons or poullards." $\dagger$

(1476.) In regard to the undue means used for pampering fowls to fatness, I quite agree with Cobbett that "crammed fowls are very nasty things;" and when we reflect on the worse than imprisonment practiced for the purpose, by cooping up fowls in the dark, and tying their feet together, the means used to obtain the end become reprehensible. Liebig explains the rationale of this latter practice. "Experience," he says, "teaches us that in poultry the maximum of fat is obtained by tying the feet and by a

- Mowbray's Practical Treatise on Domeatic Poultry. (22) 
medium temperature. These animals, in such circumstances, may be compared to a plant possessing in the highest degree the power of converting all food into parts of its own structure. The excess of the constituents of blood form flesh and other organized tissues, while that of starch, sugar, $\& c$. , is converted into fat. When animals are fed on fond destitute of nitrogen, only parts of their structure increase in size. Thus, in a goose, fattened in the method above alluded to, the liver becomes three or four times larger than in the same animal when well fed with free motion, while we cannot say that the organized structure of the liver is thereby increased. The liver of a goose fed in the ordinary way is firm and elastic; that of the imprisoned animal soft and spongy. The difference consists in a greater or less expansion of its cells, which are filled with fat."* This practice appears to me the more reprehensible, in that its principal effect is to increase the bulk of offal only.

(1477.) Peacocks may be treated in the same manner as turkeys; and as to guinea-fowls, notwithstanding the deliciousness of their eggs, they should never be tolerated in a farm-yard, both on account of the horrid noise they make, and of the strong propensity they always evince to annoy other fowls.

(1478.) The feathers of the various sorts of fowls used are either disposed of or converted into domestic use. The following directions on sweetening and managing feathers are given by a notable housewife of my acquaintance; and as they very nearly accord with my own experience, I shall transcribe them in her own intelligent words. "Every one is aware that the feathers of cocks and hens are very inferior to those of geese and ducks for the purpose of filling beds and pillows; and, consequently, it is scarcely necessary to mention that the former should be kept separate from those of the latter two fowls. As the birds are plucked, the large feathers should be selected and placed asunder. Paper-bags are the best recipients. The pinion feathers should be stripped from the quill, and added to the other feathers; and, if great caution have not been used in plucking the birds, they should be carefully looked over, that no part of the skin has been torn and adhering to the base of the quills. The bags of feathers should be placed in the bread-oven on the day after it has been heated, and, after some hours, removed to a dry, airy place; and this ought to be done every week." On this part of the subject, I may mention a less troublesome plan than the oven, where the adjoining apartment behind the kitchen fire is not in constant use, which is that in such a situation feathers may be hung up in bags against the wall behind the fire, and there they will soon win. "Notwithstanding," continues our instructress, "every apparent caution shall have been used, the feathers are frequently found to be tainted, either from carelessness in plucking, or by neglecting to attend to them afterward; and no subsequent baking or picking will be found available to restore them. In this case, the only method to render them sweet is to boil them, which is to be effected in the following manner: One or two large canvas or calico bags must be made, into which the feathers from the small paper-bags must be emptied and tied up; a washing-copper must be nearly filled with rain-water, and made to boil. The calico bags then, one at a time, are to be dipped, and, by means of a stick, pushed about, and squeezed and kneaded for the space of four or five minutes, then lifted out and taken out of doors, and being tied together and the openings kept secure, that no feathers may escape; they must be hung over a line and left to drain and dry. Several times a day the bags are to be shaken up and turned over; and as soon as the feathers appear to be

* Liehig's Animal Chemistry. (23) 
light and drying, which will not be the case for nearly a week, the hags must be hung up during dry weather only, and taken in every night. In about a fortnight the feathers will become perfectly sweet and ready for use; and the water in which they were boiled will sufficiently indicate that this plan was not only necessary, but efficacious, in cleansing them from impurities which would else have rendered them useless." As an attestation of the practical efficacy of the plan, the lady adds, "having tried the method ourselves, we can assure our readers of its eligibility."

(1479.) In regard to the discases of fowls, I can safely say that if fowls are attended to in a systematic manner, with wholesome food prepared for them every day, and their roosting place kept clean and airy, very few diseases will affect them at any age.

[The reader will please remember that only Notes are promised to this "Book of the Farm," not dissertations. They are better placed in another part of this journal.

On the subject of Poullry, when a country lad, not unobservant of all such things, our experience covered the whole ground; and who that was thus reared does not retain in his memory, through life, lively associations as connected with this department of his juvenile sports and speculations? We have somewhere seen it said that Mr. Wraster's first investment was in a Dominica cock, which he carried under his arm in a smart journey on foot, stopping to fight hin against every cock that dared crow along the roadside; and this, be it said en passant. is not the only point in which the "Great Expounder" has evinced Southern propensities. On the enb. ject of poultry management generally, our observation agrees, in the main, as to want of care and system, with what is here said.

In this case, as in many others badly conducted, common sense dictates all that is necessary to be borne in mind. In the first place, if the barn-yard, dang-hill and proper range of the poultry do not afford sufficient food to keep them in good, healthy and thriving condition, the deficiency should be supplied with regularity; for in this, as in all otter instances, it should be a cardinal maxim with every farmer, that whatever is worthy of being kept at all is worthy of being well kept. Be it a rule in regard to everything that engages your time and consumes your aubstance, that it be either carcd for or killed! Then, again, as to poultry, vermin and exposure to heat and cold are great obstacles to success in rearing them; and of course too much attention cannot be paid to cleanliness and equable temperature. Farthermore, not one in twenty of husbandmen and housewives keep in their head, or otherwise, a register of the age of their breeding.fowls. Having allowed them to commence breeding. they are usually left to die of age and disense, which must more or less infect the health of the whole flock. With poultry, as with sheep, to keep them in sound condition, none should be allowed to survive a fixed age. When they have passed the period of the highest capacity as breeding-stock, they should be fatted for sale or con. sumption; instead of which, everything is left to chance, and thus some poultry-yards that we have seen, instead of presenting a lively, beantiful scene of varied and splendid plumage, rosy gills, sparkling eyes, and all animate with health, gallantry and courage, are more like hospitals des invalides, a drooping hen in one corner, and a suifting cock in another. But, as we before said, this is no place for a treatise on Rearing Poultry. There is one, however, on Rearing Ducks, published in the June, 1846, number of this journal, written by a very learned clergyman of Charleston, S C., which every good housewife ought to have at her fingers' ends. In the matter of different breeds of fowls, there is much room for indulging the imagination. It may be ranked among the "fancy stocks." We have ourselves been fool enough to give 5 for a hen of the Ostrich breed that would weigh 5 pounds as she sat on her roost; but we agree in one thing with Mowbray, the author of a very cockney sort of a book on "Pigs and Poultry," that

"Small-boned, well-proportioned poultry greatly excel the large-boned, long-legged kind, in color and finenees of thesh and delicacy of Havor; for it is held good that, of all animals of the do. mestic kind, those which have the smullest, cleanest, finest bones, are in general the hest proportioned, and are covered with the best and finest grained meat. besides being, in the opinion of good judges, the most inclined to feed, and fatted with the smallest proportionable quantity of food to the greatest comparative weight and size."

It is agid that the Poland fowl, which is rather under size, jet black with top-knots, are the best layers; but we should be disposed to rely on the true old "game breed." Mr. Colt has this top-

\footnotetext{
* Quarterly Journal of Agriculture, vol. $x$. There is a curious fact given, in Head' Home Tour, of the modes of plucking feathers off fowls of various kinds in a large poulterer's establishment in Lincoln.
} (24) 
knot breed milk-white. We have no doubt of the truth of what the Author asserts, that " chickcus never eat more tenderly than when killed a short time before being dressed; but if not so soon used, they should hang in the larder for three or four days in winter"-or in the ice-house in summer, say we.

This suggestion of cooking immediately on being killed, is probably against the general impression, but is nevertheless correct, as we happen to know by experience; and we are confid:ut the same may be said of butchers' meat. Cook immediately, or keep for some days. After thit unimal gets dead cold, the first tendency of the fibre seems to be to get stringy and tough; the next to relax and break up. The best fried chickens to be met with-what in the Eastern States they call, and esteem a great delicacy, "spring chickens" - are to be had at the old-fashioned, ordinary-looking, but clean, well-kept turnpike-road tavern, 9 miles from Alexandria, D. C., on the road to Fairfax Court-House, kept by Mr. Gooding; and there the process is, when the stage drives up to breakfast, the scullion counts noses, and away he runs to wring off chickens' heads in a given proportion. They are then instantly scalded, picked and washed out clean in warm water; then quartered and thrown into a pan of ready boiling, clean lard; and being in a minute or two "done brown," are served up to the sharp-set passenger, hot and $d r y$, not swimming again, as in most taverns, in dirty grease. In this way the fowl never gets cold, and is truly "as tender as a chicken." The traveler gets his penny-worth, rubs down his abdominals, and in half an hour goes his way, rejoicing that we live in a land of democratic liberty and abundance, surveying as he goes one of the most glorious and the most abused and neglected regions that the sun shines upon.

Mr. Gooding, by the way, is esteemed a trump-card in his line, but in the majority of such cases we have observed that though it be the landlord who is ever foremost to receive the traveler and run away with all the "credit" as well as the change, the good housewife is usually more than "half the battle."

Ed. Farm. Lib.]

\section{WHEAT AND FLOUR.*}

(1480.) Systematic writers on Agriculture, and most others, when treating of the varions plants usually cultivated on a farm, always describe their characteristics in botanical phraseology; and though this way of describing them seems a proper one, when different genera of plants have to be distinguished from each other; yet when more varieties of the same species, and especially when those varieties are numerous, have to be treated of, a more natural method of des. cribing or classifying them seems desirable, so as they may easily be distinguished by other people than botanists. Thus, Professor Low, when treating of wheat, enumerates 11 different subdivisionst which are cultivated, all which doubtless, poseess distinct botanical characteristics; but the distinctions betwixt these are not likely to be apprehended, far less applied, by the majority of farmers; and much less likely still are they to discriminate, with botanical accuracy, betwixt the very numerous varieties that are now cultivated in different parts of the empire. Mr. Lawson has described 83 varieties of wheat, $\neq$ and Colonel Le Couteur mentiuns having in his possession, in 1836, no fewer than 150 varieties:\| and the Museum of the Highland and Agricultural Society in Edinburgh possesses 141 varieties. To distinguish between all these, with botanical exactness, would puzzle any farmer.

(1481.) For this reason, it has occurred to me that some method should be established of recognizing the different kinds of grain in use, by their external characters in the ear and in the grain. Colonel Le Couteur has given a classification of wheat involving the principle I have

[* It may be of some satisfaction to the reader as he proceeds in the perusal of what is here suid in reference to grains which constitute important staples of our own country, to have at hand a memurandum of the amount of each produced in the United States.

Thus, according to the Census of 1839 , a very fallacious authority it is true, but the only one we haw', the crop of Wheat in all the United States was $84,823,272$ bushels. The largest crop in any State was that of Ohio, being put down at 16,571,661 bushels. The second-Pennsylvania, $13,213,077$, and the third on the list is that of New-York, to wit: $12,286.418$.

By a Census of the State of New-York, probably taken with more aceuracy, under an Act of Assembly passed 7th May. 1845. it appears that the whole number of bushels harvested in the State that year was $13,391,757$ bushels, from 595,013 acres, or something less than 14 bushels to the acre.

Ed. Farm. Lib.]

$\uparrow$ Low's Elements of Practical Agriculture.

II Le Couteur on Wheat. Dedication. (25)
† Lawson's Agriculturist's Manual. 5 Catalogue of the Museum. 
mentioned, and he gives a similar reasn for attenyrting it. when he says- "No one has done sow its a brunch of Agriculure, in those plain terms which may be intelligible, not to the botanist or -cientific reuder unly, but to the great mass of farmers." And the principal ubject he considers to he fueld in view, in attempting such a classificatiou. is. that the nature and real gualities of each variety may be ascertained as to their properties for malung bread."

(148.2.) In prosecuting his ideas of a classification. Co m el Le Coutenr divides all the varieties of wheat iuto two classes, namely, beardless and berrdes. In so far he imitates the modern botanists, who divide the cultuvated varieties of when into the two divisions of barbatnm and imberbe. signifying the above characteristics: but, unfortunately fur the stability of this division, the distiuction is immutable, for some bearded wheats lose the ir beards on cultivation, and some beard. l.sw ones are apt to become bearded, when cultivated ou poor solls and exposed situations. Some of the other grains indicate a tenduncy to this sort of degencracy, for even the potato-oat assunzes a beard when suwn a loug time on the sane yround in a poor state. He then subdiviles beardless aheat into white, red, yellow, aud liver-coloved. smosth chafied and velvet chaffed : and the bearde.t he divides under the same colors. Some varietics of wheat are, no doube decidedly downy on the chatl', but others, again, are so linte so that it is diff ent to distinguish them from some of the ronchest varieties of smooth chaffed: and it is well known that the same wheat will be ditsierentIy affected. in that respect, by the soil upon which it has been grown; for a sharp soil has a tend. to produce suft and downs claff and straw. This downiness. therefore, is not so tixed and imunrtant a character as to be adopted to rank one great division of wheat under its denomination. The associatiug together the clsaracters of wheat in grain and in the ear, is also, in my opition, injudicious, inasmuch as neither character separately can positively iudicate the state of the ofler, as I shall soon show, and both are not required to iudicate the flouring properties of any variety of wheat. in respect to its superiority in making bread. A baker will at once distinguish the grain which will afford the fluur best suited for bread, but he could indicate nuthiug of its propereties by an ear of wheat. Colonel Le Couteur puts down a liver-culored wheat. as a distinerive color, along with others. I confess I canuot distinguish this color; for I never remember to have seen wheat of a liver-browa color. I thiuk all the colors of wheat may be classed under two uf the primary colors, yellow and red, for even the whitest wheat has a tinge of yellow in it. and the brownest wheat is deeply tinged with red; but as rthite aud red are the turms by which the co-

Fig. 302.
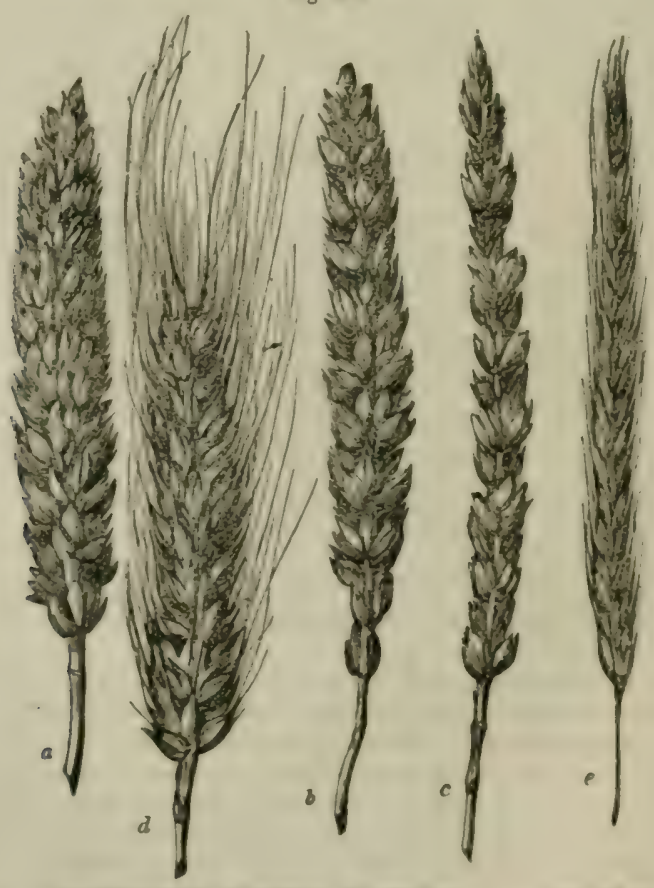

CLASBTICATION OY WHEAT EY THE IAR.

EAR OP 2S:

Inrs of wheat have been longest known, theee should be retained. The variety of whrat w lich should form the standard of each color has never yet been settled : hut judging from the rolluctiun of wheat in the Highland and Agriculturat Socicty's Museum. I should say that the Huntrariau white wheat, $a$, fig. 358 , indicates the purest white, and the blood red wheat the purest red.

- Le Couteur on Whear.

(26) 
(1483.) Were I to attempt to classify wheat by nafneral marks, I would make two classifications, one by the ear and the other by the grain, so that each could be described by its own characteristics, and, if desirable, either could be illustrated by the characteristics of the other. In this way confusion would be avoided between the characters of the ear and of the grain. The farmer who grows the wheat in the ear and sells it in the grain should be acquainted with both; but the baker, who is only acquainted with grain, knows nothing by the ear. Were he, however. to receive an ear of each variety of grain he purchased, he would be able to describe at once to the farmer what particular variety afforded him the flour best suited for his purpose.

(1484.) Wheat.-On examining the ears of wheat that have come under my notice, I think they may be divided into the 3 classes as represented in fig. 302 , and which nay be distinguished thus: $a$ is a close or compact eared wheat. which is occasioned by the spikelets being set near each other on the rachis or jointed stem, and this their position has a tendency to make the chaff short and broad, and the spikelets are so also. This figure, as well as the others, shows the ear half the natural size. This specimen of the close eared wheat is Hickling's Prolific. The second class of ears is seen at $b$, the spikelets being of medinm length and breadth, and placed just so close upon the rachis as to screen it from view. The ear is not so bioad, but longer than $a$. The chaff is of medinm length ared breadth. This specimen is the well known Hunter's white wheat. Thi third class is seen at $c$, the spikelets of which are set open, or so far asunder as to permit the rachis to be easily seen between them. The ear is about the same length as the last specimen, but is much narrower. The chaff is long and narrow. This is a specimen of Le Couteur's Bellevue Talavera white wheat. These three classes of varieties constitute the Triticum sativum im. berbe of botanists, that is, all the varieties of the beardless cultivated wheat. Formerly they were divided by botanists into Triticum hybernum or winter wheat, and Triticum aestivum or sum. mer wheat; but experience has proved that the summer wheat, so called, may be sown in winter, and the winter wheat sown in summer, and both thrive. Paxton says that Triticum is derived from "tritum, rubbed; in allusion to its being originally rubbed down to make it eatable.* It is of the natural order Graminea. and of the third class Triandria, and second order Digynia, of the Linnæan system.

(1435.) In $d$, fig. 302 , is represented a bearded wheat, to show the difference of appearance which the beard gives to the ear. The bearded wheats are generally distinguished by the long shape of the chatf and the open position of the spikelets, and therefore fall under the third class. But cultivation has not only the effect of decreasing the strength of the beard, but of setting the spikelets closer together, as in the specimen of the white Tuscany wheat, slown at $d$ in the cut, which is considered the most compact eared and improved variety of bearded wheat. Bearded wheat constitutes the second division of cultivated wheat of the botanists, under the title of Triticum sativum barbatım. The term bearded wheat is used synonymously with spring wheat, but erroneously, as some beardless wheat is as fit for sowing in spring as bearded, and some bearded may be sown in winter. Figure $e$ is a specimen of rye.

(1486.) In regard to classifying wheat by the grain, on observing a great variety of forms, I think they, as well as the ears, may all be classed under 3 heads. The first class is shown at $a$, fig. 303 , where all the grains are short, round, and plump. with the bosom distinctly enough marked, and well filled up. In the cut, the grain to the left is seen with the median line along its bosom; another, below it, with the round or opposite side lying undernost : and the third and fourth show the germ and radical ends respectively. All fine white wheats belong to this class, and they are enclosed in short, ronend, and generally white choff, which, when ripe, become so expanded as to endanger the falling out of the grain. Very few red. wheats belong to this class. In reference to the ear. this

Fig. 303.
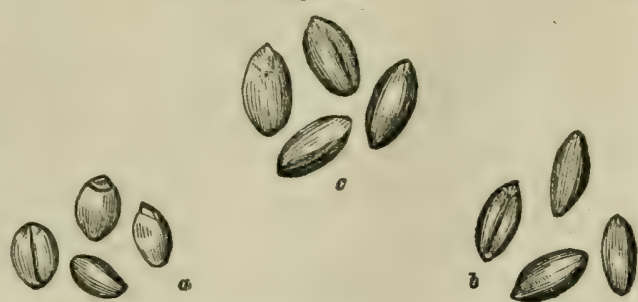

CIASSIFICATION OF WHEAT BY THE GRAIN.

class is found in short-cluaffed and broad spikelets, which are generally compact. The specimen bere is Hungarian white wheat. The second class is represented by $b$, where the grains are long and of medium size, that is, longer and larger than the grains of the first class. The chaff is also medium sized. In reference to the ear, it is of the medium standard, in respect to breadth and closeness of spikelets, though medium sized grain is not confined to this sort of ear: for it is found in the compret ear, as in Hickling's Prolific white and red wheat, as well as in the open ear, such as the red Dantzic creeping wheat. Most of the red wheats belong to this class of grain, though many of the white medinm sized-such as Hunter's white-also belong to it. 'This specimen is the Cancasian red wheat, whose ear is bearded, and belongs to the open-spiked class $c$, fig. 302, The figure at $c$, fig. 303 , represents the third form of grain, which is large and long to a greater degree than the last class. Its chaff is long, and in reference to the ear, the spikelets are generally open, though, in the case of this specimen, the Odessa long white wheat, the ear is mediumsized, though the chatf is long as well as the grain. The three sorts of wheat in the cut are all placed in similar positions, and are of the natural size.

(1487.) It will be seen from what has been stated, that no direct relation exists between the enr and the grain; that the compact ear does not always produce the round grain nor the white wheat; that in the medium ear is not always found the medium-sized grain: and that the open ear does not always produce the large, long grain. But still, there exist coincidents which

\footnotetext{
- Paxton's Botanical Dictionary, Triticum. See also Hooker's British Flora, Edition of 1831.
} 
connect the chaff and the grain. For example, the leng/h of the chnff indicates the length of the grmu, upon whatever sort of ear it may be funnd : and. generally, the color of the chaff determines that of the grnin. As also, the opening spikelet bears grain of coarser quality than the compact. (I) w ishing, therefone, to deternine the sort of grain which any number of ears of dittereus kinds of whent may contais, it is the form and color of the chaff that determines the point. and nus whesther the ear enrries compact, medium, or open spikelets, or whether it be bearded or beardleaw, or whether it be woolly or smooth.

(1488.) But a more important consideration than its classification, in regard to wheas, is the mode of judging it, to ascertain the purposes to which it may be best employed, in the partic. ulur condition in which it may be seen. These purposes are, for seed and and for the making of four: whether the Hour is to be employed in the manufacture of bread or of confections, or in come of the arts, such as starch-making. In its best condition, all wheat, whether red or wlite, emall or large. long or round, should appear plump within its skin. not in the least shriveled or slirunk. The skin should be fine and smooth, not in the least scaly or uneven in its surface. The color, be what tint it may, slrould be bright und tively and uniform. not in the least dull, bleached, or party-colored. The grains should all be of the sane size and form, not short and long, round and long, small and large. The grains should be quite perfeet: there should be no bruises, or holes, or dried motlets banging from the dimpled end, or woolly appendage from the other end. If perfert in all these respects, wheat is fitted for any purpose, and may be purchased by the general merchant. For particular purposes additional properties may be regarded.

(1489.) When wheat is quite opaque, indicating not the least translucency, it is in the best state for yieldiıg the finest Hour. such flour as confectioners use for pastry; and in this state it will be eagerly purcluact by the $\mathrm{m}$ at a large price. Wheat in this state contains the largest proportion of fecula $m$ staveh. and is therefore best suited to the starch.maker, as well as the confectioner. On the other luats. wheu wheat is translucent. [partially transparent,] seemingly hard and flinty, it is best suited to the common baker, as affording what is called strong flour; that is, flour that rises buhlly with yeast into a spongy dough: or in other words, the wheat then contains the largest proportion of gluten. Bakers will. therefore, give more for good wheat in this state than in the opaque; but for bread of first quality the flour should be fine as well as strong, and therefore a mixture of the two conditions of wheat is best suited for making the best quality of bread. Bakers, when they purchase their own wheat, are in the habit of mixing wheats that respectively possess those qualities; and millers who are in the habit of supplying bakers with flour, mix such wheuts and grind them together for the special purpose. Some sorts of wheat, however carefully they may have been preserved pure. naturally possess buth these properties, and on that account are great favorites with bakers, though not so with confectioners ; and I presume, to this mixed property is to be ascribed the great popularity which Hunter's white wheat has so long enjoyed. We hear of "high mixed" Dantzic wheat, which has been 80 mixed for the purpose, and is in high repute among bakers. Generally speaking, the lightest-colored white wheats indicate moet opacity, and of course yield the finest flour, and red wheats are most flinty, and therefore yield the strongest flour: for a translucent red wheat will yield stronger flour than a translucent $\mathrm{w}$ hite wheat. and yet a red wheat never realizes so high a price in the market as white, because it contains a larger proportion of refuse in grinding.

(1490.) For seed, the dimpled end of the grain should be distinctly marked, and the site from which the rootlets issue should be rather prominent; and the end from which the blade springs should be covered with a slight degree of wooliness or hairiness. The protuberances of the :ootlets and woully ends should not have been rubbed off by any process, such as sheeling, as the grain is thereby rentered unfit for seed by being deprived of its vitality. Nor should the grain have been kiln-dried, because that process may also deprive it of vitality, and its effects may partly be detected in the undue hardness of the grain. and partly also from the smoky flavor which the grain has acquired. But hardness alone is not a sufficient criterion, as ome wheats become much harder in ordinary drying than others: and in some parts of the Continent, such as on the shores of the Mediterranean, some wheats are naturaily so hard as to induce that in the ordinary state to be called soft. If no smokiness can be detected in the flavor, the surest test of existing vitality, when time is allowed to apply it, is to germinate the $\mathbf{w}$ heat near the fire, in a glass, among as much water as will swell the graing.

(1491.) Dnmaged wheat may be detected in various ways. If it has been in sea.water, although it may not be enlaryed by moisture. it can never lose the saline taste; and although it may have been washed in fresh water and dried in a kiln, still the washing gives it a bleached appearance, and the subsequent drying may be detected by cither the smell or the taste. Wheat that has been sheeled, to muke it look round and plump, may be detected by the appearance of the ends being rabbed down. Wheat that has been heated in the stack, though not affected in color, will tarte bitter on being chewed. Wheat that has been long in the granary appears dull and dirty, though it may have been passed through the fanners; and although it may not have been injured, it always contracts a musty smell. Wheat is liable to the attacks of insects in the granary, which breed within its shell and eat the kemel. This mode of destruction. orcasioned by the weevil. is easily detected by the grain feeling light in hand, and the boles may easily be seen from which the perfect insect has made its escape. Germinated, swollen. burst, bruised grains, as well as the admixture of other kinds of grain and seeds, are easily detected by the eye.

(1492.) Difference of opinion exist in regard to the best mode of preserving ucheat in granaries. The usual practice is to shovel the heap over from the bottom every few weeks, according to the dryness or dampness of the air, or heat or coldness of the atmosphere. In this mode of treatment, a free ventilation of the air is requisite in the granary, and the worst state of the atmosphere for the grain is when most and warm. Extreme heat or extrene cold are preservatives of grain. The practice of others is not to turn over their wheat at all, but to keep it in very thick masses, reaching from the floor to the ceiling, and quite in the dark. No doube, if air could be excluded effectually from a granary, the grain could be pregerved in it without farther trouble; and a good plan of ex. cluding the air ontirely seems to be to heap the wheat as thick together as poseible. There is as (28) 
little doubt, however, that wheat which has been kept long in heap without turning, retains its color in a fresher state than that which is frequently turned; and a good plan for preserving the color seems to be to keep wheat in the dark. The ancients used to preserve graiu many years, to serve for food when years of famine overtook them. When Joseph was in Eyvpt. wheat was preserved for geven years in the stores; but this might not be a difficult matter in so dry a climate as Egypt; and in Sicily. Spain, and in the northern parts of Africa, pits were wont to be formed in the ground to preserve grain; and the Romans were so impressed with the necessity of preserving grain, that they took great pains in the constraction of their granaries, which are related to have keep wheat for 50 and millet for 100 years.* But as to the farmer, the question how wheat is best preserved in granaries should little affect him, as the best way of keeping his wheat is in the straw in the stack; and when the stacks are threshed for the straw, he should dispose of his wheat immediately, and take the current market prices. In a series of years, during the currency of a lease, this is his safest practice : and besides securing him, in the lung run, of an average price, it saves him a great deal of trouble in looking after the grain, and a great deal of vexation when prices fall below their expected amount. Two friends of mine, farmers; were both great losers by keeping wheat of their own growth on speculation. They each stored three years crop, and though offered $£ 6$ a quarter for it, they kept it with the view of obtaining more, but were never offered so much again; and after prices dropped gradually to 65s. and were not likely to rise immediately, they sold off the whole stock. Such is most likely 10 be the fate of most farmers who speculate in wheat, even of their own growth; but when they venture on purchasing the wheat of others, they forego their proper profession, and become merchants, and thence become involved in the intricacies of trade, of which they must be quite ignorant; and probably only become sensible of their ignorance after feeling the effects of their temerity.

(1493.) Wheat is prepared for the use of man by being ground into flour. The machinery used for griuding wheat, consists of a number of parts, each of which performs its separate work. and they are all strongly constructed. The first process which wheat undergoes in grinding, is in being put through the sheeling cylinder, which rubs off any extraneous matter belonging or adhering to the outer skin of the grain, and separates every foreign matter from the wheat. In this process the wheat is made shorter in length, brighter in color, and freed from every impurity. The quantity of black, suffocating dust which flies off from the cylinder in the process of sheeling, and the seeds and other substances which are separated from the grain, are collected together, surprise every one, who has never witnessed the process, how such impurities can have proceeded from an apparently clenn sample. After the sheeling, the prepared wheat is yut into a large hop-

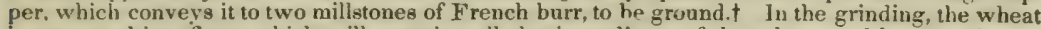
is converted into flour, which still contains all the ingredients of the wheat. and has acquired a high degree of temperature. In order to cool it, which should be done as quickly as possible, it is immediately carried to the well ventilated cooling-room, to be spread upon its wooden floor. and turned frequently over with a wooden shovel. should the grist have been so large as to cause it to be laid thick on the Hoor. After it has been thoroughly cooled, it is made to descend from the cooling-room, by a hopper, into the bolting or dressing cylinder, in which it is separated into its respective parts by being brushed through wire-cloth of different sizes. These parts usually ensist of firets, or fine flour; of seconds, or second flour; of thirds, cr sharps; of broad or coarse bran, and of fine bran. Sometimes the coarse bran only is taken from the flour, which is then said to be ground overhead, and makes good coarse bousebold bread. Sometimes the fine bran is taken out from the overhead flour, and the coarse flour makes a sweet coarse bread. On the other hand. a smaller quantity of the fine is taken out of the bulk of flour, in order to make the finest as fine as possible, and this is used for pastry and fancy bread; and in this case, the seconds flour becomes finer, and makes the seconds loaf of superior quality. More or less of fine flour is taken out in dressing, by merely shifting a hinged board under the dressing cylinder, so as to embrace a larger or smaller space of the upper or finer portion of the wire-cloth of the cylinder. When a large proportion of the bulk is made into first flour, this flour is not fine, and the seconds flour is thereby reduced in quantity, and made coarser. The sharps, or that portion which consists of the heart of the grain, and which is broken and escapes from between the millstones, are used by biscuit-bakers. The first or broad bran is used for bran-mashes, and mixing with horsecorn, and the fine bran is employed to feed poultry and pigs. As you have seen that the butchers of London cut up carcasses of meat in a greater number of pieces than those of this country; so the millers there diess the flour in a greater number-no less than seven distinct-sorts. These sorts are thus divided from the flour of a quarter of wheat of 8 bushels :

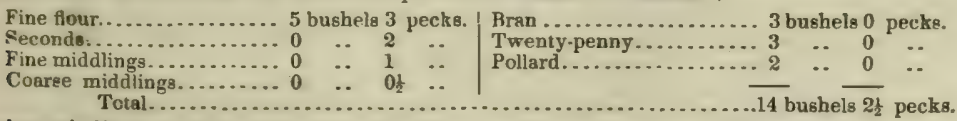

So that grinding nearly doubles the bulk of flour and bran above that of the wheat

11494.) Whether flour is properly ground, is judged of on being taken into the hand as it falls

[ $\$$ Boussingault fonnd as much as $38 \frac{1}{2}$ per cent. of husk or bran on a Winter Wheat, grown in the Botanic Garden of Paris. 'Three lots of good English Wheat, ground at Mr. Robson's mill, in Durham. gave-per cent. respectively :

\begin{tabular}{|c|c|c|c|c|c|}
\hline Fine Flour ............74.2 & $75 \cdot 1$ & $77 \cdot 9$ & Bran & $7 \cdot 0$ & $6 \cdot 9$ \\
\hline Rorings .............. . . 0 & 83 & $6 \cdot 1$ & Waste $. . . \ldots \ldots \ldots \ldots \ldots . \ldots \ldots$ & 30 & 35 \\
\hline Sharps ............... 58 & $6 \cdot 6$ & $5 \cdot 6$ & Total ............. 100 & 100 & 100 \\
\hline
\end{tabular}

* Diekson's Husbandry of the Ancients, vol. it.

t See Ure's Dictionary of the Arts, art. Millstones, for an account of this remarkable substance. (29) 
from the spout leading from millstones. It is rubbed by the thumb against the side of the fore-fiuger, and if it feel pleasantly smooth, without being greasy or rough, it is well. When the outer edges of the nillstones are set too close, the flour fiels greasy, because it has been too much bruised-or killed, as it is termed-and it does not then easily rise with yeast in the making of bread. When the stones are set too tur asunder, the grain accumulates under the eye of the mill. stone, and is there broken, which breakiog prevents the skin of the grain being separated from the substance, and the conequence is, that the bran feels thick, rough, and heavy, and there is nuch wuste of substance. Whether thour is properly dressed, is ascertained in the same way, by rnb. bing the fine flour between the thumb and fore-finger, and if it feel smooth and even. not in the least rongh or gritty, it is well. To judge still farther whether the flour has been perfectly dresked, if, on being pressed with a polished article, such as the back of a plain gold or silver watch, ur the back of a silver spoon, the smooth-pressed surface present no minute brown spots of bran to a good sight, it is clean dreased; and if any such cannot be detected by a good masnifying-glase, it is as perfectly dressed as practicable with the present form of the machinery: When the large bran is inspected, and it is found to be entirely skin and no white substance of the wheat adhering to it. the grinding has been well executed; and in this state the bran. on being thrown upwarl, will fall lightly toward the ground, being in large, thin flakes. The small bran has always a part of the substance of the wheat attuched to it: because it is chiefly derived from the groove which furms the bosom of the grain, and is ouly generated after the large bran has been sloughed off, and a portion of the grain itself ground down to the level of the groove. There is no means of judging whether any parcel of flour will make good bread, the floner of the opaque and flinty wheats being undistinguishable from one another, and it is perhaps this difficulty which induces bakers to buy wheat, and get it made in flour on their own account; otherwise the simplest plan for them would be to buy the sort of flour they want. On account of this practice of the bakers, many of the flour millers in Scotland grind only on hire.

(1495.) Flour is put up in what are called sacks of 280 lbs.. or 20 stones [of 14 poonds] imperia]. It is rendered firm in the sack by the sack being occasiovally beaten against the floor by means of a fork-lever, when filling at the spout leading from the dressing-machine. Of wheat weighing about 64 liss. per bushel, $4 \frac{1}{2}$ or 5 bushels will be required to nake a sack of fine flour. Of the fine crop of 1815 , I remember of the late Mr. Brown. Whitsome Hill, Berwickshire, selling to Mr. Mackay, of Clarabud Mill, in the same county, 800 bolls, or 4,800 bushels of red Dantzic creeping wheit, which weighed 27 stones per boll, or 63 lbs. per bushel, and yielded 24 stones of fine four. and only 3 stones of refuse - that is, only one-ninth of refuse of the entire weight.* I find the fine white wheat used by the bakers of Edinburgh yields $13 \frac{1}{2}$ stones of 14 lbs. of flour from 4 bushels, weighing $18 \mathrm{sts.}$. and 2 stones of odd, seconds, parings, eharps, and waste, and $2 \frac{1}{3}$ sts. of bran.

(1496.) Many devices are practiced to adulterate flour. I remember a miller in Cornwall being fined in very heavy penalties for adulterating his flour with the washed felepar obtained from the disintegration of the granite of his neighborhood. Potato flour and bean flour are mixed with wheat Hour, and though not positively urwholesome, or perhaps unlawful, are frauds when fo used, as being articles of inferior value to the flour of wheat. There are modes, however. of detecting any kind of adulteration. "If potato flour be added," says Dr. Ure, "which is frequently done in France, since a vessel which contains $1 \mathrm{lb}$. of wheat flour will contain $1 \frac{1}{2} \mathrm{lbs}$. of potato tlour, the proportion of this adulteration may be easily estimated. If gypsum or ground bones be mixed wirh thour, they will not only increase its density still more, but they will remain after burning away the meal." "Bean or pea flour may be detected by pouring boiling water upon it, which develops the peculiar smell of these two substances." "Nitric acid has the property of coloring wheat flour of a fine orange yellow, whereas it does not affect the color of potato flour." "Pure muriatic acid colors wheat flour of a deep violet, but diseolves potato fecula." "As fecula absorbs less water than flour, this affords a ready means of detection." "Alum may be detected in bread by treating the bread in water, and pouring a few drops of nitrate or muriate of barytes in it, when a heavy white precipitate will follow, indicating the presence of sulphuric acid." $\dagger$ "Guaiacum," says Dr. Thomson, "is rendered blue by various animal and vegetable substances. It becomes blue, according to Tadei, when rubbed in the state of powder with fluten of wheat, or with the farina which it contains." $\downarrow$ If a little of this gum and water be jut among flour, it is a very good and easy test of its soundness when the flour becomes blue. "It has been found so difficult to detect the adulteration of flour," remarks Mr. Babbage, "and to measure its good qualities, that, contrary to the maxim that Goverument can geuerally pur. chane any article at a cheaper rate than that at which they can manufacture it, it has been consid. cred more economical to build extensive flour.mills, and to grind their own corn, than in verify each sack purchased, and to employ persons in continually devising methods of detecting the new modes of adulteration which might be resorted to." $\mid$

(1497.) Any one may analyze flour in this way: "A ductile paste is to be made with $1 \mathrm{lb}$. of flour and a sufficient quantity of water, and left at rest for an hour; then having laid acrosa a bowl a piece of silken sieve stuff a little below the surface of the water in the bowl, the paste is to be laid on the sieve, on a level with the water, and kneaded tenderly with the hand, so as merely to wash the starchy particles out of it. . . . The water must be several times renewed, until it ceases to become milky. The gluten remains on the sieve."

(1498.) Tle analysis of wheat and flour by the celebrated Vauçuelin gave the following re. sults. It may be observed, however, of the wheat and flour subjected to this analysis, that they were of foreign growth, and the results cannot be adopted for practical purposes in this country. as if they had been obtained from British wheat and flour. "In general," says Davy, "the

As an instance of the grent fuctuation in the price of wheat occasioned by a difference in seasons, I nay mention that part of this tine whent was sold in 1815 for 32 s. per brill of 6 bushels, or 58 . $4 d$. per bushel: and in Altgust. 1816, a very wet season, part was sold for 1058. per boll, or 178, 6d. per bushel.

$\uparrow$ Ure's Dictionary of the Arts, art. Flour of Wheat. † Thomson's Organic Chemistry, Vegetables.

II Labbage on the Economy of Machinery and Manufactures. \& Ure's Dirtionary of the Arte, art. Bread. (30) 
wheat of warm climates abounds more in gluten. and in insoluble parts; and it is of greater spe cilic gravity, harder, and more difficult to grind."**

\begin{tabular}{|c|c|c|c|c|c|c|c|}
\hline COMPONENTS. & $\begin{array}{l}\text { French } \\
\text { wheat. }\end{array}$ & $\begin{array}{c}\text { Odessa } \\
\text { hard } \\
\text { wheat. }\end{array}$ & $\begin{array}{c}\text { Odessa } \\
\text { soft } \\
\text { wheat. }\end{array}$ & Ditto. & $\begin{array}{l}\text { Flour of } \\
\text { Paris } \\
\text { bakers. }\end{array}$ & $\begin{array}{l}\text { Do. of good } \\
\text { quality, and } \\
\text { in public } \\
\text { establish. } \\
\text { ments. }\end{array}$ & $\begin{array}{l}\text { Ditto, } \\
\text { iuferior } \\
\text { kind. }\end{array}$ \\
\hline$\overline{\text { Staril }} . . . .$. & $71 \cdot 49$ & 56.5 & $62 \cdot 00$ & $72 \cdot 00$ & $72 \cdot 8$ & $71 \cdot 2$ & $67 \cdot 78$ \\
\hline Gluten...... & $10 \cdot 96$ & $14 \cdot 55$ & $12 * 00$ & $7 \cdot 30$ & $10 \cdot 2$ & $10-3$ & 9.02 \\
\hline Sneyar........ & $4 \cdot 72$ & $8 \cdot 48$ & $7 \cdot 56$ & 5.42 & $4 \cdot 2$ & $4 \cdot 8$ & $4 \cdot 80$ \\
\hline Gam........ & $3 \cdot 32$ & $4 \cdot 90$ & $5 \cdot 80$ & $3 \cdot 30$ & $2 \cdot 8$ & $3 \cdot 6$ & $4 \cdot 60$ \\
\hline Bran......... & $\ldots$ & $2 \cdot 30$ & $1 \cdot 20$ & $\ldots$ & $\ldots$ & $\ldots$ & $2 \cdot 00$ \\
\hline Water...... & $10 \cdot 00$ & $12 \cdot 00$ & $10 \cdot 00$ & $12 \cdot 00$ & 10.0 & 8.0 & 12.00 \\
\hline Total.... & $107 \cdot 49$ & $98 \cdot 73$ & 98.56 & 100.02 & $100 \cdot 0$ & $97 \cdot 9$ & $100 \cdot 20 t$ \\
\hline
\end{tabular}

It appears that Odessa wheat contains more sugar than French wheat. The gluten mentioned here is a mixture of gluten and albumen. The gum has a brown color, and contains azote. It is the gluten which gives to a mixture of flour and water its tenaciousness, ductility, and elasti. city, and forms the nourishing property of loaf-bread. Gluten has a great resemblance to animal tendon or membrane, containing no less than $14 \frac{1}{2}$ per cent. of azote. When subjected to fermentation, which is of a peculiar character, and has thereby obtained the appellation of panary fermentation, a considerable volume of carbonic acid gas is evolved, but which is retained in the mass of the dough by the tenacity of the gluten. Thus confined during its evolution, the gas expands the dough to nearly double its pristine volume, and gives it its vesicular texture; and it is the infinite number of these cellules filled with carbonic acid gas, and apparently lined with a glutinous membrane of a silky softness, that gives to the well-baked loaf that light, elastic, porous constitution which good bread always possesses. $\neq$

(1499.) Leaven was at first used to produce the fermentation spoken of in dough. It is nothing more than a piece of dough kept in a warm place until it undergoes a process of fermentation, swelling, becoming spongy, or full of air bubbles, at length disengaging an acidulo-spiritous vapor, and contracting a sour taste. A much better promoter of the panary fermentation is yeast. which is the viscid froth that rises on the surface of beer in the first stage of its fermentation.

(1500.) With good wheaten flour, the proportion given by the bakers to make bread is $\frac{3}{4}$ weight of flour and $\frac{1}{4}$ of yeast, water, and salt. The bread loses 1-7 of its weight in baking. With these proportions, a sack of flour of $280 \mathrm{lbs}$. yields 92 loaves of $4 \mathrm{lbs}$. each, [368 pounds.]

(1501.) It is not unusual for farmers to bake their household bread, and it may be done in this way: Take, say $24 \mathrm{lbs}$. of flour, whether fine or ground overhead, and put it in a hollow clay dish. Make a deep hollow in the middle of it; and sprinkle a handfull of salt over it. Then take $\frac{1}{2}$ a pint of thick, sweet, fresh, well washed yeast, about 5 quarts of milk-warm water, from $65^{\circ}$ to $70^{\circ}$ Fahr., and a pint of bran, and stir them together in a pitcher. Too hot water will stop, and ton cold will prevent fermentation. Pour the water and yeast over the flour through a sieve, and, mixing all lightly together, set the mass before the fire, covering it with a cloth. Light the oven fire, and bring it to a due heat. In about an hour the sponge will have risen sufficiently, when it should be kneaded with considerable force for about 15 or 20 minutes. The dough should not be worked too stiff, though it requires to be a little stiffer when the loaves are fired on their own soles than when fired in pans. The kneaded dough is again set before the fire, and covered with a cloth as before, when a new fermentation ensues, which will have proceeded far enough when the dough increases half more in bulk, that is, in about an hour, when the dough is portioned ont into the size of the loaves desired, and placed in the oven to be fired. If the oven is too hot, the dough will be incrusted on the surface too much and too soon, and if too cold. the bread will be heavy, and not rise sufficiently in the firing. Experience must teach these particulars. This quantity will make 31 lbs. of bread.

(1502.) The danger of making the bread sour is incurred between the first and second processes of fermentation. In the first it is the vinous fermentation, which of itself is innocent, but if increased heat is applied, or the sponge allowed to stand too long, it is apt to run into the acetous fermentation. This tendency is checked during the first process by kneading the dough in time. If; however, the second fermentation is allowed to continue longer than it should be, the acetons fermentation will rapidly appear, and then the bread will inevitably be sour unless some conn. teracting expedient is adopted. such as the application of an alkali, as carbonate of soda, or of an alkaline earth, as magnesia or chalk. It is certainly better to employ these neutralizing ingredients than to allow the batch of bread to become sour, but better still to use the means of making the batch into sweet bread than to rectify that acidity in it which ought never to have overtaken it; and the means of avoiding acidity are, to make the sponge fresh in the morning, a short time before the bread is to be fired, and not to allow it to stand over night in the kitchen, in a low temperature. I speak from experience, and can safely aver that with these precautions not a sour

[ Under more appropriate heads, shall we note the results of a great variety of more modern] experiments and analyses, touching this important subject in every light. Professor Johnston is of opinion that the quantity of gluten contained in English Wheat has generally been stated much too high. He concludes, on a view of all that has been said and done, that the quantity of gliteu in English flour is seldom more than ten per cent.]

Ed. Farm. Lib]

- Davy's Lectures on Agricultural Chemistry, Edition of 1839.

$\uparrow$ 'Thoinson's Organic Chemistry, Vegetables.

(:31) 
linf was seen in my house for many years. I do not say that a sponge left over night must becoine suur, but only that it is much mure apt to become so than when fresh made. When the second fernentation is allowed to proceed too far, both the lactic and acetic acids are formed; the tormer most sensibly affiects the taste, and the latter the smell; and both combine to make bread seur.

(1503.) Brewer's barm makes the lightest and best weast for family use, and what of it may not be used at one time may be kept sweet for some weeks in the following manner. "As this substunce works out of the barrels, it should be placed in deep prans, and left to settle for a day or two. The thin fluid should then be poured off, and the pan filled with cold fresh gpring water, etirring the thick yeast well up. Every day this operation is to be repeated, and occasionall! it ought to be strained through a sieve into another vessel. It will thus always be ready for ure." Experience alone can tell whether the scent or appearance of yeast procured at a brewery ure those the most desirable; but these hints may prove useful. "If it be fit for the purpose, it will smell rather fragrant; if stale it will have a strong acid, and slightly putrid scent. In this state, we have known it to be recovered and rendered availatile, by adding a tea-spoonfull of tluur, the same of sugar, a salt-spounfull of salt, and a tea-cupfoll of warm water. 10 a \& pint of yeast, and setting it near the fire to rise, having well stirred it. This should be done about un hour before it in intended to be mixed with the flour; for that time is required in order to watch whether the lermen. tative principle is strong enough to work the bread. In a quarter of an hour, the mass will liave nearly reached its hight, and a fine head will have formed. This must be looked at curefully. If it continue op and appear opaque, it may be trusted; but if it 'go back,' that is, sink, look loollow and watery, and the bubbles break, it will infallibly spoil the batch; it must be thrown away. Bran ought alicays to be used, however fresh and good the ferment mas be found. Bran contains an acid principle which tends to subdue the bitter taste of the hop, and it also possesses much fermentative matter that assists the action of the yeast." In this way, "we have uurselven baked bread that was made with the barn for our own home-brewed beer for six successive weeks; not from necessity, but in order to ascertain the extent of time to $w$ hich yeast might be kept sweet."*

(1504,) It is assumed by some people, that a mixture of potatoes among wheaten flour renders bread lighter and more wholesome. That it will render bread whiter I have no doubt; but I have as little doubt that it will render it more insipid, and more than this, it is demonstrable that its use is less economical than wheaten flour. Thus, take a bushel of "seconds" flonr, weighing $56 \mathrm{lbs}$, at $58.6 \mathrm{~d}$. A batch of bread, to consist of $21 \mathrm{lbs}$., will absorb as much water. and require as much yeast and salt, as will yield 7 loaves, of $4 \mathrm{lbs}$. each, for $2 \mathrm{~g}$ 4d. per loaf. "If, instead of $7 \mathrm{lbs}$. of the flour, the same weight of raw potatoes be substituted. with the hope of saving by the comparatively low price of the latter article, the quantity of bread that will be yielded will be but a trifle more than acould have been produced from 14 ibs. of flour ouly, with. ont the addition of the $7 \mathrm{lbs}$. of potatoes; for the starch of this root is the only nutritive part, and we have proved that but $1-7$ or $t$ of it is contained in every pound, the remainder being water and innutritive matter. Only $20 \mathrm{lbs}$. of bread, therefore, instead of $28 \mathrm{lbs}$, will be obtained; and this, though white, will be comparatively flavorless, and liable to become dry and eour in a few days; whereas, without the latter addition, bread made in private families will keep well for 3 week 8 , though, after a fortnight, it begins to deteriorate, especially in the autumn." The calculation of comparative cost is thus shown:-

$$
\begin{aligned}
& \text { Flour, } 14 \mathrm{lbs.} \text { say at } 1 \frac{1}{\mathrm{~d} d} \text {. per l'b...... = 18. } 5 \frac{1}{2} \mathrm{~d} \text {. } \\
& \text { Potatoes, } 7 \text { lbs., say at 5s. per sack..... }=02 \\
& \text { Yeast and fuel..................... }
\end{aligned}
$$

The yield $20 \mathrm{lbs}$, or 5 loaves of $4 \mathrm{lbs}$ each. will be nearly $5 \mathrm{~d}$. eacb, which is dearer than the wheaten losves, which were 4 d. each, and the bread besides of inferior quality. "There are persons who asten-for we have heard them-that there is no economy in baking at home. An accurate and constant attention to the matter, with a close calculation of every week's nesults for several years - a calculation induced by the sheer love of investigation and experiment-enable us to as sure our readers that a gain is invariably made of from $1 \frac{1}{2} d$. to $2 d$. on the $4 d$. loaf. If all be intrusted to servants, we do not pretend to deny that the waste may veutralize the pmfit; but, $w$ ith care and investigation, we pledge our veracity that the saving will prove to be considerablc." $\dagger$ These are the observations of a notable housewife.

(1505.) The microscope has ascertained the structure of whenten flour. "The largest graius of the feculs of whear." says Raspail, "do not generally exceed .002 of an inch in size. They are spherical, and along with them we see empty and torn membranes, regulting from the bruising of the grains by the mill. They are much smaller, rounder. and better preserved, when they are extracted from the grain while it is greenish, and not ripened on the stalk." "Parification," he observes, "is a process whose object is to burst all the graing of fecula. which are in the farina, associated with a very fermentable substance called gluten. The finest and best baked bread is what is made of farins abounding in an elastic gluten; for this gluten, rising in large blisters by the dilatation of the gases imprisoned within it, allows ench feculent grain to participate in the communication of the heat, and to burst, as it would by boiling. Hence, atter panification. if the paste has been well knended, we do not find a single grain of fecula entire. The bread will be duller and less properly baked, if it contains less of this glaten. This is the rea son why, other circumstances being alike, the bread of rye and barley is less nourishing thau that of wheat. Wheaten bread will likewise be heavier and less perfect, according as the flour has been more or less mixed with other grain or with fecula. It has been observed," he continues, "that the more of foreign fecula we mix with flour the less increase of weight does 
the bread acquire. Thus, $6 \mathrm{lbs}$. of flour produce $8 \mathrm{lbs}$. of bread; but $3 \mathrm{lbs}$. of fecula of the potuto. with $3 \mathrm{lbs}$, of flour, produce only $6 \mathrm{lbs}$. of bread. The reason of this is the folluwing :The grains of fecula do not imbibe the water, but only are moistened by it; in other words, it only adheres to then. The gluten. on the other hand. imbibes it as a sponge would do. and the mure it is kneaded the more it imbibes, and the wa:er thus imbibed adds to the weight of the bread. There are two rea-ons, then, against this sort of mixtures; and this adulteration, though it be not a crime, is still a fraud, because the immediate result of it is to diminish at once the weight and the nutritive quality of the bread." Thus the minutest scientific research corroborates facts evolved by practice.

(1506.) Wheat cortains more gluten than any of the other grains, and it is this substance which confers the relative value on wheat as an article of food. It is most developed when used in the form of bread. "If we prepare two masses of gluten by kneading," says Raspail, "we shall not be able to make them unite by simple contact; but if we tear open the side of each, and bring the edges together, the smallest effort will be sufficient to unite the two masses into one. The ubject of kneading, then, is to press the two edges of the glutinous parcels against each niher. Hence the quantity of gluten will vary according to the mode of kneading employed, Thus Beccaria, who contented himself with placing the farina in a sieve, and keepiug it under a strenm of water, but without stirring it, obtained less gluten than Kesselmeyer, who, in the first place, made a paste of the farins, and then kneaded it cuntinually under a stream of water, till the water ceased to pass off milky. In the former process, the weight of the water falling on the farina brought a few parcels tugether, but kept asunder or disunited the greater number, which consequently passed through the sieve. In the second process, on the contrary, the hand in kneading compressed, turned in every direction, and brought together by every point of contact, the scattered parceis, and scarceiy allowed the water to carry off anvithing but the round and smooth grains of fecula. I have ever found that, in this process, we obtain more or less gluten, according as the paste is pressed in different ways; for when it is merely compressed perpendicularly, we lose a good deal more of the gluten than when it is rolled upon itselt with some force."

(1507.) In regard to the nutrilive properties of glnten, there is no doubt they are of a superior order, thougli not fur the reason ascribed by Magendie, who concluded that glaten is nutritious because sugar, which contains no nitrogen, could not support doge in life beyoud a certain time; while Parmentier was led to infer that gluten remains undigested. "But who does not perceive," juatly asks Raspail, "that animals till then accustomed to live on flesh, must suffer on being all at once deprived of this aliment, just as a horse would suffer from being fed on flesh instead of hay; for as digestion is a complex operation, why should we seck to study it by violating its elemeuts? Sugar will not ferment by itself-why, then, expect that it should ferment without albumen in the stomach? If this mode of experimenting entitle as to erase sugar, oil, and gam from the list of nutritive substances, we must also erase pure gluten and even pure albumen; for if an animal be fed on them alone it will die just as certainly as if it had been fed exclusively on sugar. This is one of these questions," he concludes, "in which both sides are wrong, and the truth lies in blending the opposite opinions together. Neither gluten nor sugar, taken singly, is nutritive; but they become alimentary when united."

(1508.) Wheat is ased in slarch-making. "In starching linen," says Raspail, "the fecula of the putato, of the horse-chestnut, \&c. may be used, as well as that of wheat; and it may be used either hot or cold, in the state of starch or of powder. The effect will be the same, provided the irons used be sufficiently heated. It is sufficient to mix the fecula wish a little water, to dip the linen in it, clapping it with the hand, and to apply the hot iron while the linen is still moist. The grains of fecula will burst from the action of the heat, the membranes will dilate as they combine with a portion of the water that is present, the soluble mass will be freely dissolved in the rest of it, and the linen will be starched and dried by one process." Fecula is used in making size for paper as well as glue; and "it is known that weavers are obliged, in order to preserve the bumidity of the batter used in dressing the threads, to work habitually in low, damp, and consequently unwholesome places. Dubuc, an apothecary at Rouen, proposed to add to the dressing a deliquescent chloride, which, by attracting the moisture of the air, might prevent the drying of the batter, and thus admit of the workman carrying on his labor in drier and more healthy places. Vergnaud recommends the use of the fecula of the horse-chestnut, which contains a proportion of potash sufficient to prevent the batter from drying."* "The wheat of the south of $\mathrm{E}$ urope, in consequence of the larger quantity of gluten it contains, is peculiarly fitwed for making macaroni and other preparations of flour, in which a glutinous quality is considered as an excellence." $\dagger$ The macaroni is formed into different sized tubes, by the dough being pressed from a machine in broad fillets, the edges of which are brought into contact and adhere, while the dough is yet moist. Macaroni makes the finest flavored dish with Parmesan cheese.ł

[* It seems proper to advise the reader here, that this chapter does not embrace, by any means all that is said by the author on the subject of Wheat. It will, hereafter, be treated under the heads-Insects and Diseases affecting-Proper Degree of Ripeness for Cutting-Cutting and Stooking-Carrying in and Stacking-Comparative Weights of Grain, Straw, and Roots-Artumn Sowing. Plowing land for it-various modes of doing this-Importance of Thorough Draining-Preparation of the Seed and Sowing-Best Varieties-Sowing by Dibbling-By Trans. planting-Expenses of this, and Sowing of Seed-Description of the Process and Germination \&c. All these points will be embraced in this volume, and we could wish to introduce them now, in reference to the coming season; but there are obvious reasons why we cannot break in upon the systematic arrangement of the author.]

[Ed. Farm. Lib.

* Raspnil's Organic Chemistry. † Davy's Lectures on Agricultural Chemistry, Edition of 1839

(33) .......3 
(1509.) Barley."-Its botanical position is the 3d class Triandria, 2d order Digynia genus Hor deum of the Linnsean system, and in the natural order of the Graminece. Professor Low divides the cultivated barley into two distinctions, namely the 2-rowed and the 6-rowed, and each of these comprehends the ordinary, the naked, and the sprat or battledore forms.t Mr. Lawson describes 20 varieties of barley : $\$$ while the Museum of the Hichland and Agricultural Society contains specimens of 30 varie ties.|f The natural classification of Barley by the ear is obviously of three kinds, 4 rowed. 6-rowed. and 2-rowed. Fig. 304 represents the three forms, where $a$ is the 4-rowed, or bere or bigg; $c$ is the 6.rowed; and $b$ the 2-rowed; all of which figures represent barley in half its natural size. Of these the bere or bigg was that which was cultivated until a recent period, when the 2 rowed has almost entirely supplanted it, and is now the must commonly cultivated variety; the 6-rowed being rather an objeet of curiosity than culture.

(1510.) In classifying barley by the grain, there are just two kinds, bere or bigg, and barley; and though buth awned, are sufficiently marked to constitute dis. tinct varieties. In the bere, the median line of the bosom is so traced as to give the grain a twisted form, one of its sides appearing larger than the other. In the barley the line passes straight, and divides the grain into two equal sides. They are both represented in fig. 305 , where $a$ is the bigg, with the twisted-like grain, and lengthened point from which the awn has been broken otf; and $b$ is the barley, whose shortness and plumpness give it a character of superiority. Both these clusters of grain are of the natural size. The bigg has long been recognized in Scotland, and even a 2-rowed variety, under the name of common or Scotch barley, has long been in cultivation; but several of the English varieties are now naturalized, and in their new sphere show a brighter and fairer color, plumper and shorter grain, quicker in the property of malting, though less hardy and prolific, than the common bar. ley. The crenulated or shriveled skin across both sides of the median line in the English barleys is a good cri. terion of malting; and as most of the barley raised in
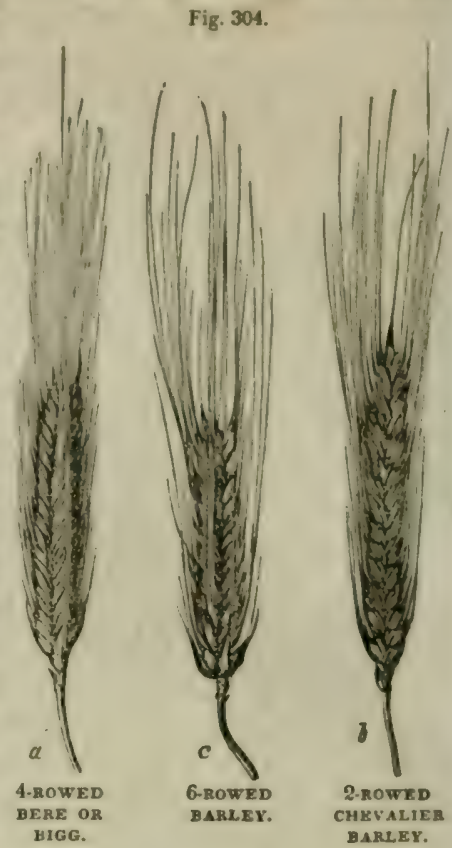

his country is converted into beer or spirits, both of which require malt to produce them of the finest guality, it is not surprising that those varieties which yield the greatest return of malt should always realize the highest prices.

(1511.) A good crop of barley yields a return of from 48 to 60 bushels the imperial acre. Good barley weighs from $55 \mathrm{lbs}$. to $59 \mathrm{lbs}$. per bushel. A crop of 60 bushels per acre will yield of straw, in the vicinity of a town, 176 stones of $14 \mathrm{lbs}$, to the stone, or 11.10 ton, and the weight of the grain of that crop, at 56 lbs. per bushel, will be $1 \frac{1}{2}$ tons. It takes of bigg 111 grains to weigh 1 drachm; of 6-rowed barkey, 93 ; and of Chevalier barley, 80 grains. Of the three kinds, the Chevalier is much the heaviest.

(1512.) By far the largest proportion of the best barley grown in this country is converted into malt for making malt liquor and spirits, and barley is also used for distillation in a raw state. In three years, the following quantities of malt paid duty, viz. :

\begin{tabular}{|c|c|c|c|c|}
\hline \multicolumn{2}{|c|}{ ENGLAND. } & \multirow{3}{*}{$\begin{array}{c}\text { SCOTLAND. } \\
\text { Bushels. } \\
3.580,758\end{array}$} & \multirow{3}{*}{$\begin{array}{l}\text { IUELAND. } \\
\text { Bushels. } \\
1,776,883\end{array}$} & \multirow{3}{*}{$\begin{array}{c}\text { TotAl. } \\
\text { Bushels. } \\
40.307,287\end{array}$} \\
\hline & Bushels. & & & \\
\hline & $34,949,646$ & & & \\
\hline & $f 4,449,745$ & $\mathcal{E} 462.514$ & \&2229.514 & £.5.141.775 \\
\hline \multirow{2}{*}{1835.} & $36,078,855$ & $3.604,816$ & $1,825,300$ & $41,508,971$ \\
\hline & $\mathcal{f}_{4,660,185}$ & $f 465,622$ & f235.767 & $\pm 5,361,574$ \\
\hline \multirow{2}{*}{$1836 \ldots \ldots\}$} & $37.196,998$ & $4,168,854$ & $1,872,104$ & $43,237,956$ \\
\hline & $\{4,804,612$ & $\{538,477$ & 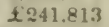 & $£ 5,584,902$ \\
\hline
\end{tabular}

[* The Barley Crop of the U. States, by the last Census, was 4,161,504 bushels much more than half of which was grown in New-York. Maine produced 355,161; Ohio, 212,440; Pennsy]vania, 209.893; Michigan, 127.802; and Virginia only 87,430. Ed. Farm. Lib.]

18 Professor Johnston. in his Table of the nutritive matter of different kinds, from an acre of the usually cultivated crops, puts down Barley thus: Gross produce, bushels 35-pounds 1800Husk or woody fibre, 270-Starch, Sugar, \&c., 1,080-Gluten. \&c., from 210 to 260 -Oil or Fat 36 in $54-$ Saline matter, 50.

Ed. Farm. I,il. ]

† 1.ow's Elements of Practical Agriculture. 34 ;

† Lawson's Manual..

II Catalugue of the \$Lur.um. 
Pot and pearl barley are made from barley for calinary purposes; and both meal and flour are manufactured from barley for the purpose of making unleavened bread, which is eaten by the laboring class in some parts of the country, and barley bannocks are esteemed a luxury by people in towns. Porridge of barley-meal, with rich milk, is accounted a pleasant and light supper, and less heating than that of oatmeal.

(1513.) The barley has received great attention from the chemist, both on account of its importance as a fermentable substance, and partly to discover its constituent parts. "The following are the proportions of the constituents obtained by Einhoff from 3,840 parts of barleycorns :

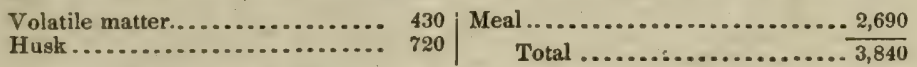

From the same quantity of barley-meal he obtained-

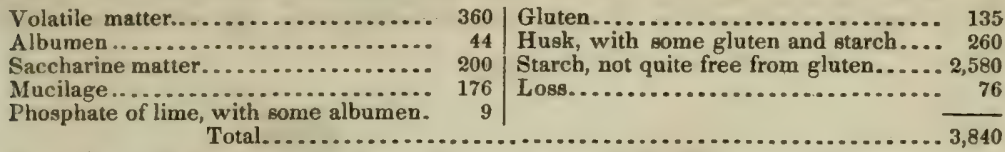

Besiles these substances, Fourcroy and Vauquelin ascertained the presence of phosphates of lime and magnesia, and of silica and iron; and $I$ found in it phosphate of potash and nitrate of soda. Barley-meal, on being macerated, yields an oil. which is supposed to give its peculiar flavor to spirits from raw grain. If this opinion is well founded, the oil must be dissipated or destroved by the process of malting." "*

(1514.) The grains of the fecula of the barley are very fine, not exceeding .00098 of an inch in size. Barley flour only contains 3 per cent of gluten, and is therefore much less nutritive than wheaten flour. The horden, ascribed by Proust to act so important a part in the germination of barley, is asserted by Raspail to be nothing more, under the microscope, than bran. "That this is the case," he says, "is proved by dissection; for if we make a transverse slice of each of the grains of wheat and barley, we shall perceive that the pericarp of the wheat peels off entire like a circular band, while that of the barley can only be detached in very small fragments. Now, what takes place under the edge of the scalpel," he alleges, "wili also happen under the pressure of the millstone ; consequently the bran will be much more minutely divided in the farina of barley than in that of wheat. In bolting flour, therefore, it will remain in the sieve; while, in the other, its almost microscopic fragments will pass through with the fecula and gluten. and will be almost inseparable, by mechanical means, from the farina." Hence, if pearl barley "be ground, we obiain from it a farina as white as that of wheat, and containing only a very minute portion of hordein, equivalent to the amount of those fragments of the pericarp which had been protected by their situation in the posterior groove of the grain." $\dagger$

(1515.) "The meal so highly commended. by the Greeks was prepared from barley. . . . . It was not until after the Romans har learned to cultivate wheat and to make bread, that they gave barley to the cattle. They made barley-meal into balls, which they put down the throats of their horses and asses, after the manner of fattening fowls, which was said to make them strong and lusty. Barley continued to be the food of the poor, who were not able to procure better provision; and in the Roman camp, as Vegetius has informed us, soldiers who had been guilty of any offence were fed with barley instead of bread corn." $¥$

(1516.) Malting.-This process produces a considerable change in the constitution of the grain. The barley is steeped in cold water for at least 40 hours, according to law. Here it imbibes moisture, increases in bulk, and emits a quantity of carbonic acid gas, not exceeding 2 per cent. The moisture imbibed is 0.47 . that is to say, every $100 \mathrm{lbs}$. of barley, when taken out of the steep, weighs $147 \mathrm{lbs}$. The increase of bulk is 1.5 , that is, 100 bushels of grain measures out 120 bushels. The steep-water dissolves from 1-50 to 1-100 of the husk of the barley, and hence barley becomes paler by steeping. The steeped barley is then put on a floor in a heap 16 inches deep, to remain so for 26 hours. It is then turned with wooden shovels, and diminished in depth to a few inches by repeated turnings. In 96 hours the grain becomes $10^{\circ}$ hotter than the air, and then sweats. when it is frequently turned, the temperature being preserved in the grain from $55^{\circ}$ to $62^{\circ}$. The roots now begin to appear, the stem called acrospire springs from the same end, and advances within the husk to the other end of the grain; but the process of malting is stopped by kilndrying before the germ has made much progress. The kiln, at first $90^{\circ}$. is raised gradually to $140^{\circ}$. The malt is then cleaned, and the rootlets removed, as they are considered injurious, and are called comins. Malt is from 2 to 3 per cent. greater in bulk than the barley, and it loses $1-5$ or 20 per cent. in weight, of which 12 per cent. is loss by drying; so the real loss is only 8 per cent. accounted for by the steep-water carrying away $1 \frac{1}{2}$ per cent.. dissipated on the floor 3 per cent., roots cleaned away 3 per cent. and waste $\frac{1}{2}$ per cent. The roots take away the glutinons portion of the grain. and the starch is converted into a sort of sugar.

(1517.) Beer.- Beer is a beverage of great antiquity. "The earliest writer who mentions beer," commences Dr. Thomson in his account of the process of malting, of which the foregoing paragraph is the substance, " is Herodotus, who was born in the first year of the 74th Olympiad, or 444 years before the commencement of the Christian era. He informs us that beer was the common drink of the Egyptians, and that it was manufactured from barley, because wines did not grow in their country. In the time of Tacitus, whose treatise on the Manners of the Germans was written about the end of the first century of the Christian era, beer was the common drink of the Germans. Pliny mentions beer as employed in Spain, under the names of crelia and merit, 
and in Gaul ander the name of cervisia. Almost every species of corn has been used in the manufacture of beer. In Earope it is usually made from barley, in India from rice, in the interior of Africa, according to Park, from the seeds of the Holcus spicalus. But whatever crain is employed, the process is nearly the same, and it is usual in the first place to convert it into malt" +

(1518.) Oats.-Oats are cultivated on a large extent of ground in Scotland, and it is believed that no country produces greater crops of them or of finer quality. The plant belongs to the natu. ral order of Graminea, and it occupies the $3 \mathrm{~d}$ clase Triandria, 2d order Digynia, genus Avena, of the Linnuan system. Ita ordinary botanical name is Avena sativa, or cultivated oac. The term oat is of obscure origin. Paxton conjectures it to have been derived from the Celtic elan, to eat. There are a great number of varieties of this grain cultivated in this country. Mr. Lawson degcribes $37: \|$ and 54 are deposited in the Highlaud and Agricultural Society's Museum. $\$$ The natu$\mathrm{ral}$ classification of this plant by the ear is obvious. One kind has its panicles spreading and equal on all sidea, and tapering toward the top of the spike in a conical form. The other has its panicles shortened, nearly of equal length, and all on the same side of the rachis. Fig. 306 represents both

Fig. 306.

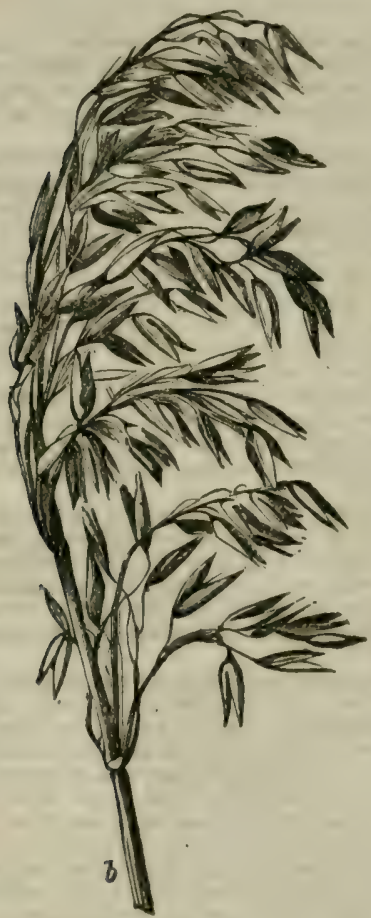

THE TARTAXYN OAT.

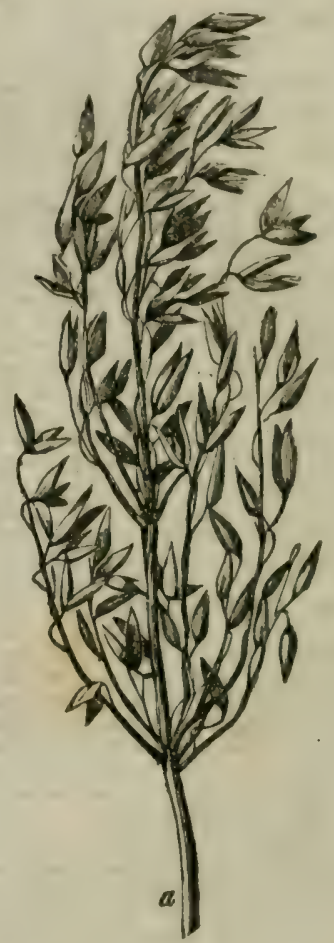

THE POTATO OAT.

the kinds, $a$ showing the first and $b$ the second, where they both appear somewhat confined or aqueezed toward the rachis, the object being to exhibit the grain in the straw as taken from the stack, rather than when pulled green from the field. $a$ is the prolific potato oat, which is beardleas, commonly cultivated in Scotland for the sake of its meal, and $b$ is the white Tartarian oat, which is bearded, and extensively cultivated in England for horse-corn. The natural classi-

[ F For a valuable Easay on the culture of Barley in the United States, from the pen of H. S. Randall. Erq., ace The. Farmers' Librahy and Monthi.y Journal of Agriculture, Vol. 1I., page 233. It will be farther treated in this "Book of the Farm," under the heado-Insects and Disease incident to it-Stooking-Precautions necessary against its Heating in the Stack-Quantity annually Malted in Great Britain-Its Chemical Composition, and that of Barley MealGrinding and Malting-Comparative Weight of Grnin, Straw and Roots-\&c. Ed. Farm. Lib.]

* Thomson's Organic Chemistry, Vegctables.

\|l Lawron's Agriculturist's Manual.
1. Paxton's Botanical Dictionary, art. Avena. Catalogue of the Musuem. 
fication by the grain consists also of two forms ; the one a round, plump grain, like $a$, fig. 307 , and an elongated, thin grain, having a tendency to show awns, as at $b$; the $a$ kind being cultivated on the best lands in the low country, the other on poorer soils and in high districts. The first is tender, and liable to shake with the wind; the other is hardy, and able to resist the tempest. The former is cultivated chiefly for human food, yielding meal largely, the latter being raised chiefly for the food of horses. The straw of the former kind is strong and inclined to reediness; that of the latter is fine, pliable, and makes an ex. cellent dry fodder for cattle and horses, there being a good deal of saccharine matter in the joints; the former is considered late in coming to maturity, the latter early, and is consequently so designated,

(1519.) The crop of oats varies from 40 to 75 bushels per imperial acre, according to the kind and the circumstance of soil and situation. Oats vary in weight from $36 \mathrm{lbs}$. to $48 \mathrm{lbs}$. per bushel, Whiteness, of a silvery hue, and plumpness, are the criterions of a good sample. The potato oat, 47 lbs. per bushel, gave 134 grains to 1 drachm; the Siberian early oat, weighing 46 lbs. per bushel, gave 109 grains; and the white Tartarian oat gave 136 grains. A crop of potato oats, yielding 60 bushels to the acre, at $47 \mathrm{lbs}$. per bushel, will weigh of grain 1 ton $5 \mathrm{cwt}$. $20 \mathrm{lbs}$, and will yield of straw 1 ton $5 \mathrm{cwt}$. 16 lbs., in the neighborhood of a large town; or, in other words, will yield 8 kemples of 40 windlinge each, and each windling 9 lbs. in weight. But $I$ have been made acquainted with a crop of Hopetown oats near Edinburgh of no more than 60 bushels to the imperial acre, yielding 2 tons $18 \mathrm{cwt}$. $16 \mathrm{lbs}$. of straw. The common oats yield more straw in proportion to the grain than the potato variety.

(1520.) The portion of the oat-ciop consumed by man is manufactured into meal. It is never called flour, as the millstones are not set so close in grinding it as when wheat is ground, nor are they usually made of the same material, but most frequently of sandstone. Oats, unlike wheat, are always kiln-dried before being ground; and they undergo this process for the purpose of allowing the thick husk, in which the substance of the grain is enveloped, to be ground off, which it is by the stones being set asunder; and the husked grain is then winnowed by fanners, which blow away the husk and retain the grain, which is then called groats. The groats are ground by the stones closer set, and yield the meal. The meal is then passed through sieves to separate the remaining husk from the meal. The meal is made in two states; one fine, which is the state best adapted for making into bread, in the form called oat-cake or bannocks; and the other is coarser or rounder ground, and is in the best state for making the common food of the country people, porridge, Scoticè, parritch. A difference of practice prevails in respect to the use of these two different states of oatmeal in different parts of the country, the fine meal being best liked for all purposes in the northern, and the round or coarse meal in the southern counties; but as oat-cake is chiefly eaten in the North, the meal is there made to suit the purposes of bread rather than of porridge : whereas, in the South, bread is made from another grain, and oatmeal is there used only in the shape of porridge. There is no doubt that the round meal makes the best porridge when properly made, that is, when boiled as long as to allow the particles to swell and burst, when the porridge becomes a pultaceous mass. So made, with rich milk or cream, there are few more wholesome meals for any man, or upon which a harder day's work can be wrought. Children of all rakss in Scotland are brought up on this diet, verifying the poet's assertion,

"The halesome parritch, chief o' Scotia's food."-BurNs.

(1521.) In regard to the yield of meal from any given quantity of oats, it is considered that when they give what is called even meal they yield half their weight of meal ; that is, supposing that a boll of oats of 6 bushels weighs 16 stones, it should give 8 stones of meal, and, of course, 8 stones of refuse; but the finer class of oats will give more meal in proportion to weight than this, more nearly 9 stones, and some even 12 stones. The market value of oats is thus estimated by the meal they are supposed to yield, and in discovering this property in the sample millers be. come very expert. When oats yield less than even meal they are considered to give ill, and are disposed of for horses, or kept at home for that purpose.

(1522.) The oat has not received that attention from the chemist as the barley or wheat. The principal characteristic of oatmeal is, that it contains a large proportion of starch. "Vogel found that 100 parts of oats consisted of meal 66, and of husk 34. The dry meal yielded

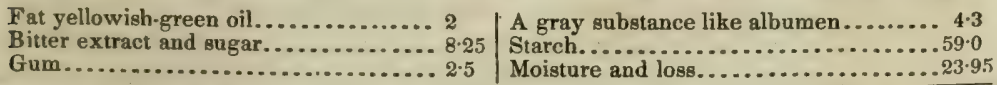

Total $\widehat{100 \cdot 00^{\prime \prime}} *$

"The farina of the oat seems, to the unassisted eye, cottony, or as it were felted, from the presence of an innumerable quantity of hairs with which the seeds are covered. The grains of the fecula have a size of about .00276 by .0018 of an inch. They appear in general yellowish, and strongly shaded. Some of these have the appearance, but not the form, of the fecula of the potato." $\uparrow$

(1523.) "We find no mention made of oats in Scripture," says Phillips, "which expressly states 
that Solomon's horses and dromedaries were fed with barley :" but " the use of oats as a provender for hores appears to have been known in Rume as early as the Chistian Fra. as we find that thut capricious and protligate tyrant Calignla fed Incitalus, his favorite horse, with gill oats out of a golden cup." Oats are mixed with barley in the distillation of spirits from ruw grain; and "the Muscovites make an ale or drink of oats, which is of so hot a nature, and so strong, that it intoxicates sooner than the richest wine." $* \dagger$

(1524.) Rye.-Botanically, this plant occupies the same place, both in the natural and sexual systems, as the other grains which have been described. It is the Secrle cereale of the botanists so called, it is said, à secando, from cutting. as opposed to leguninous plants. whose fruits used to be gathered by the hand. A figure of the spike of rye may be seen at e, fig. 358. It is a uarrow small grain, not unlike shelled outs. There is only one species of this plant, which is said to be a native of Candia. and was known in Egypt 3.300 years ago : but there are several varieties which are raised as food, 4 of which are described by Mr. Lawront and 7 to be seen in the Museum of the Highland and Agricultural Society. II The produce of rye may be about 24 bushels per acre. and the weight of the grain is stated at from $52 \mathrm{lbs}$. to $57 \mathrm{lbs}$. per bushel; the number of grains in 1 drachm weight being 165 .

(1525.) The rye is not much cultivated in this country, particularly in Scctland, where only a patch here and there is to be seen. It is, however, extensively cultivated on the Contineut, especially in sandy countries, and indeed forms the principal article of food of the laboring classes. I have been in many parts of Germany where none but rye bread could he purchased. Rye bread js denser than wheaten bread, and darker in color, and, when baked in the sweet state, is rather agreeable to the palate; but when baked sour, in which state it is commonly used in many places, it requires custom to make one become reconciled to its taste. Honses ou the Continent get it un a journey in lieu of corn, and seem very fond of it.

(1526.) Einhoff analyzed rye-seeds and meal with great care: 3,840 parts of good rye-seeds were conposed of

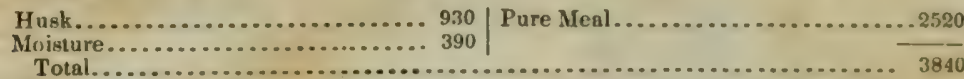

100 parts of good rye-meal contained

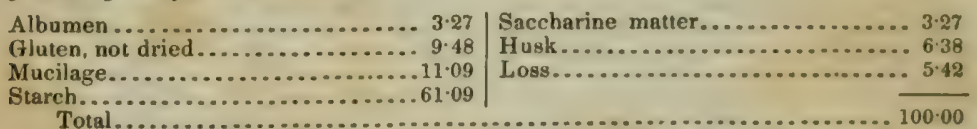

"But the proportion of these substances must vary extremely according to the soil, the climate and the age of the rve. The gluten of rye differs in several particulars from that of wheat. It is less tenacious and more soluble. When it is allowed to ferment, Einhoff perceived a strong smell of nitric acid, which is peculiar to this species of gluten. The starch of rye bears a striking resemblance to that of wheat. Like this last, it does not form a colorless solution with boiling water, and always precipitares at last, when the solntion is left a sutticient time to rest." $\$$

(1527.) The graing of the fecula of rye-meal are peculiarly shaped. "The largest grains of this fecula." says Raspail, "are about 002 of an inch in size; but what distinguishes them from all the other varieties is, that they are flattened, and with sharp edges like disks, and for the most part, marked on one of their sides with a black cross, or three black rays united at the center of the grain." $\mid$ " **

(1528.) Beans. Beans belong to a very different tribe of plants to those we lave heen considering. They belong to the natural order of Legruminose, because they bear their fruit in legumes or pods; and in the Linnæan system they oceupy the class and order Diadelplia decandria

L The oat crop of the United States, as set down in the last Census, was 193,071,341 bushele. A close run between New.York, 20,675,847, and Pernsylvania, 20,641,819. The next largest producer was Ohio, 14,393,103, Virginia being the fourth on the list-13,451,06: bushels. Profes. sor Jok: Nstos may be here quoted, thus:

Speciax Manure For OATs,-To replace 100 pounds of the inorganic matter of the ont, accord. ing to the mean composition of ius as, the following mixture is adapted:

Bone-dust ................... 88$\} 132$ lbs.

Sulphuric acid .............. 44
Carbonate of potash, (pearlash).... $18 \ldots$
Carbonate of soda............. $10 \mathrm{lbs}$. Carbonate of magnesia .......... 14 .

Total .................. 174 lbs.

Five bushels of oats contrin 6 pounds of inorganic matler. A crop of 50 bushels, therefore, will carty oft 60 pounds, and will require 105 pounds of the ubove mixture to replace it.

This grain will be farther discunsed under the heads-Diseases to which subject-Insects attacking it-Weeds to which it is subject-How to remove them-Cutting, Stooking and Stacking-Average Crop yielded by it, and its Value-Ito Straw-Comparative Weight of Straw, Grain and Hoots-ac.

Ed. Farm. Lib.]

["* Rye crop of the United Stases in 1839, 18,645,567. Here Pennsylvania runs far in the lead, growing 6.613,873, while the next on the list, New-York, gives but 2,979,323. Strange to say, the

$\uparrow$ Phillips' Hintory of Cultivated Vegetables.

1. Lwson's Agriculturist'a Manual.

\$.homsun' Organic Chemistry-Vegetables.
II Catalogue of the Museun.

If Raspail's Organic Chemistry. 
Their generic term is Faba vulgaris; formerly they were classed among the vetches and called Vicia Fabr. The common bean is divided into two classes, according to the mode of culture to which they are subjected, that is, the field or the garden. Those cultivated in the field are called Fuba vulgaris arvensis, or as Loudon calls them, Faba valgaris equina, because they are cultivated chiefly for the use of horses, and are usually termed horse-beans. The garden bean we have nothing to do with, though some farmers attempt some of the garden varieties in field culture, but I believe without success. All beans have butterfly or papilionaceous flowers. Mr. Lawson has described 8 varieties of the field bean; and 10 varieties are placed in the Highland and Agriculiural Society's Museum." The variety in common field culture is thus well described by Mr. Lawson. "In length the seed is from $\frac{1}{2}$ to $\frac{5}{8}$ of an inch, by $\frac{3}{8}$ in breadth, generaliy slightly or rather irregularly compressed and wrinkled on the sides, and frequently a little hollowed or flattened at the end; of a whitish or light-brown color, occasionally interspersed with darker blotches. particularly toward the extremities; color of the eye black. Straw from 3 to 5 feet in length. There is perhaps," continues Mr. Lawson, "no other grain over the shape and color of which the climate, soil, and culture, exert so much influence as in the bean. Thus, in a dry, warm summer and harvest, the sample is always more plump and white in color than in a wet and cold season; and these more so in a strong, rich soil, than in a light, and more so in a drilled crop than in one sown broadcast." $\dagger$ I omitted to mention in the proper place, under the head of our subject of barnwork, that, as the bean is easily separated from its pod, the fast motion of the threshing-machine should be put on when beans are to be threshed, and in case, even with the fast motion, the straw, being brittle, should be much broken, the best plan to avoid this effect is to feed the sheaves thin sideroays, instead of lengthways, into the feeding-rollers. The pods being covered with a sort of down. which becomes black on winning the crop, the threshing throws off this down like a thick black, impalpable dust, which entering the mouth and nostrils and blackening the clothes. makes the threshing of beans a disagreeable process; and the noise occasioned by their impinging against the iron lining of the drum-case, is almost deafening, and almost overpowering to human speech.

(1529.) The produce of the bean crop varies from 20 to 40 bushels per imperial acre, much of the prolificacy of the crop depending on the nature of the season. The average weight may be stated at 66 lbs. per bushel. It only requires 5 beans to weigh I drachm. I have not cultivated the bean so much as to enable me to ascertain the weight of a good crop of straw or haulm, in comparison with that of the grain, for it is seldom that the same season gives the largest return of both ; but I bave seen it stated that "it has been known to yield 2 tons per acre." $\ddagger$ A crop of 50 bushels, at $66 \mathrm{lbs}$. per bushel, gives 1 ton $3 \mathrm{cwt}$. $64 \mathrm{lbs}$. per acre.

(1530.) Beans are administered to the borse either raw, whole, or boiled whole or bruised. They are given to cattle in the state of meal, that is, husk and grain ground overhead, and that not very finely. Beans, however, can be ground into fine flour; and in this state are used to adulterate the flour of wheat. Their presence is easily detected by the peculiar smell arising from the flour when warm water is thrown upon it. Beans are of essential service to support horses that have fatiguing work. "If beans do not afford more nutriment," says Stewart, "weight for weight of oats, they at least produce more lasting vigor. To use a common expression, they keep the stomach longer. The horse can travel farther; he is not so soon exhausted. . . . . In the coaching stables, beans are almost indispensable to horses that have to run long stages. They afford a stronger and more permanent stimulus than oats alone, however good. Washy horses, those of slender carcass, cannot perform severe work without a liberal allowance of beans; and old horses need them more than the young. The quantity varies from 3 to $6 \mathrm{lbs}$. per day; bat in some of the coaching stables the horses get more, $1 \mathrm{lb}$. of oats being deducted for every $1 \mathrm{lb}$. of beans. Cart-horses are often fed on beans, to the exclusion of all other corn, but they are always given with dry bran, which is necessary to keep the bowels open, and to insure mastication, and fur old horses they should be always broken." "There are several varieties of the bean in use as horse-corn; but I do not know that one is better than another. The small. plump bean is preferred to the large, shriveled kind. Whichever be used, the bean should be old, sweet, and sound; not mouldy, nor eaten by insects. New beans are indigestible and flatulent; they produce colic, and founder very readily. They should be at least a year old." $\|$

(1531.) Einhoff carefully analyzed the small field-bean. "From 3,840 parts of the ripe beans he obtained the following substances:

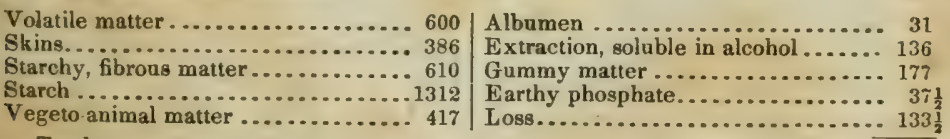

Total. 3840

Vanquelin could detect no sugar in it. He and Cornea de Serra found in the skins of the beans, tannin striking a blue with the persalts of iron, animo-vegetable matter mixed with tannin, insol.

comparatively small State of New-Jersey, with her sandy soil, comes in next, before Virginia. giving 1,665,820 bushels-Virginia, 1,482,799. Kentucky next-1,321,373.

Spectal ManURE Fon Rye.-The following mix. | Carbonate of potash, (dry) 32 Ibs ture is adapted to the composition of the ush of the $\mid \begin{aligned} & \text { Carbonate of potash, (dry) } \ldots \ldots \ldots \ldots \ldots \ldots \ldots \ldots \\ & \text { Carbonate of soda, (dry) } \ldots \ldots \ldots \ldots \ldots \ldots\end{aligned}$ grain of rye :

Bone-dust .................. 190 \}

Sulphuric acid.................... $19095 \% 286 \mathrm{lbs}$ Carbonate of magnesia................. 22 .

- Catalogue of the Museum

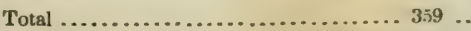

Ed. Farm. Lib.]

+ Lawern's Agriculturist's Manual. (39) 
able in water, but soluble in potash. The cotyledons contained a sweet-tasted substance, starch legumen, albumen, an uncombined acid. with carbonate of potash, phosphates of lime, magnesia and iron. The germen of the bean contained white tallow, legumen, albumen, phosphate of lime and iron." "w

(1532.) The grains of the fecula of the bean "are egg or kidney shaped, often presenting an interiur grain, as if inclosed in the principal one. Some of them are found broken down and empty. They attain the size of 002 of an inch."

(1533.) The ancients entertained some curious notions in regard to the bean. The Egyptian priests held it a crime to look at beans, judging the very sight unclean. But the bean was not everywhere thus contemned, for Columella notices them in his time as food for peasants, and for them only.

"And herbs they mix with beans for vulgar fare."

"The Roman husbandmen had a religious ceremony respecting beans somewhat remarkable: When they sowed corn of any kind, they took care to bring some beans from the field for good lack's sake, superstitiously thinking that by such means their com would retum home again to them. The Homans carried their superstition still farther, for they thought that beans, mixed with goods oftered for sale at the ports, would infallibly bring good luck to the seller." They used them, however, more rationally", when beans were employed "in gathering the votea of the people, and for electing the magistrates. A white bean signified absolution, and a bluck one condemnation. From this practice, we imagine, was derived the plan of black-balling obnoxious persons." + It would appear, from what Mr. Dickson states, that the faba of the Romans, a name by the way, said to be derived from $H a b a$, a town of Etruria, where the bean was cultivated, is the same as the small bean of our fields.ll 8

(1534.) Peas. - The pea occupies a similar position in both the natural and artificial systems of botany, as the bean. The plant is cultivated both in the field and in the garden, and in the latter place to great extent and variety. The natural distinction betwixt the field and garden pea is found in the flower, the field pea always having a red-colored, and the garden pea almost always a white flower; at least the exceptions to this mark of distinction are few. The botanical name of the pea is Pisum sativum, the cultivated pea, and those varieties cultivated in the field are called in addition arvense, and those in the garden hortense. The name is said to have beev given to it by the Greeks, from a town called Pisa, in Elis, in the neighborhood of which this pulse was cultivated to great extent. Mr. Lawson has described 9 varieties of the field pea, and the Highland and Agricultural Society's Museum contains 14 varieties. I Of these there are a late and an early variety cultivated, the late kind, called the common gray field-pea, or cold-seed. is suited for strong land in low situations, and the early, the partridge, gray maple, or Marlborough pea, is suited for light soils and late situations, and it is superseding the old gray Hastings, or hot. seed pea. The gray pea is described as having "its pod semi-cylindrical, long, and well-filled often containing from 6 to 8 pess. The ripened straw indicates 3 varieties-one spotted with s bluish-green ground, one light blue, and one bluish green without spots." The partridge pea has its " pods broad, and occasionally in pairs, containing from 5 to 7 peas, of a medium size. roundish, and yellowish-brown speckled, with light-colored eyes. The ripe straw is thick and soft like, leaves large and broad, and average hight 4 feet."**

(1535.) The produce of the pea crop is either in abundance or a complete failure. In warm weather, with occasional showers, the crop may amount to 46 bushels, and in cold and wet it may not reach 12 bushels the acre. The grain weighs $64 \mathrm{lbs}$. the bushel, and it gives 13 grains to 1 drachm. In threshing it, the feeding-rollers are put on the fast motion, and the sheaf is allowed to be taken in by them, while the feeder holds on by the sheaf, and pulls it thinner and thinner. Peas are as easily threshed out as beans; but the process does not crease such an offensive dast, though the noise attending it is very great. Peas are riddled with the oat-riddle, the refuse generully being small clods of earth and shriveled grains, which are left in the riddle, and given to the pigeons.

(1536.) Chemists have examined the pea, "From ripe peas, by macerating them in water, and employing a mode of analysis similar to that used in ascertaining the constituents of barley, Ein. Loti obtained the following products; the quantity employed was 3,840 parts:

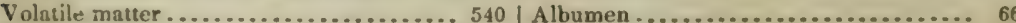

Starchy fibrous matter, with the coats of Saccharine matter................ 81

the peas ......................... 840 Mucilage ......................... 249

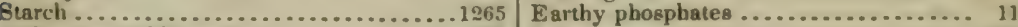

Animo vegetable matter............... 559 Loss ............................ 229

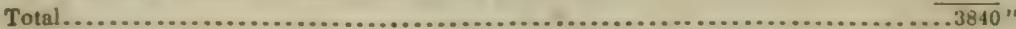

In regard to the substance named animo-vegetable matter, "it approsches most nearly to gluten ;

[ 6 The reader may judge of the dependence to be placed on the Censas as a presentment of our National Industry and the amount contributed to the public wealth by the cultivators of the soil, by noting the fact that no mention is made in it whatever of beans, peas, feathers, flaxseed, corn-fodder, \&c. The corn-fodder, according to the lowest estimate that can be made, may be valued at more than $\$ 50,000,000$. We have no means of estimating the amount of the bean and pea crop, but looking at the returns for the State of New-York alone, taken in 1845 under the State $\mathrm{Law}$, we find the Beans put down at 162,171 bushels from 16,211 acres, being 10 bushels to the acre.

Ed. Farm. Lib.]

* Thomenn's Organic Chemiatry, Vegetables.

I Phillips's History of Cultivated Vegetables, vol. 1

T Catalugue of the Mluseum. $\uparrow$ Raspail's Organic Chemistry

14 Dickson's Husbandry of the Ancients, rol, ii.

* Lawson's Agriculturist's Nanual. 
but as it differs in several particulars from gluten and from all other vegetable constituente, we mnst consirler it as a peculiar principle." "When dried, it assumes a light-brown color, and the semi-transparency of glue, and is easily reduced to powder. Einhoff remarks that he has seen the cluten of wheat assume this appearance. I have observed the same thing," says Dr. ThomF(n) "twice. In both cases the wheat was very inferior in quality, and had been the grow th of a very rainy season."*

(1.33\%.) "The grains of the fecula of the pea are nearly of the same size as those of the bean, and of the form of those of the potato. When fresh they are as strongly shaded at the edges as those of the bulbs of the Alstrameria pelegrina. Their surface is unequal. The largest of them is aluut 002 of an inch." $t$

(1533.) The pea was formerly much cultivated in this country in the field, and even used as food. both in broth and in bread, peas bannocks having been a favorite food of the laboring class ; but since the extended culture of the potato its general use is greatly diminished. It is now chiefly given to horses, but is also split for domestic purposes, such as making pea-soup-a favorite dish with families in winter. Its flour is used to adulterate that of the wheat but is easily detected by its peculiar smell, which is given out with hot water. Peas-meal in brose is administered in some cases of dyspepsia. Peas-pudding is eaten as an excellent accompaniment to pickled pork. It used to be customary in the country to burn a sheaf of peas, by which the peas were roasted, and, when mixed with butter and served up while hot at supper, were eaten as a treat under the name of carolins. In some towns where ancient customs still linger, roasted peas are sold in winter in the hucksters' stalls. Pigeons are excessively fond of the pea, and I have heard it alleged that they can eat their own weight of them every day. "The ancients gave peas to stallion horses, on account of a particular virtue which they were thought to possess." $\neq \|$

(1539.) These are the constituents in $100 \mathrm{lbs}$. of the ashes of the different sorts of grain we have been treating of. Instead of giving the constituents of each separately, I have collected them to. gether, in order to show their comparative proportions:

\begin{tabular}{|c|c|c|c|c|c|c|}
\hline Constituents. & Wheat. & Barley. & OAts. & Rye. & Beans. & Peas. \\
\hline Potash .................. & $\begin{array}{l}\text { Lbs. } \\
19\end{array}$ & $\begin{array}{l}\text { Lbs. } \\
12\end{array}$ & $\begin{array}{l}\text { Lbs. } \\
6\end{array}$ & Lbs. & $\begin{array}{l}\text { Lbs. } \\
19 \frac{1}{2}\end{array}$ & $\begin{array}{l}\text { Lbs. } \\
32 \frac{3}{4}\end{array}$ \\
\hline Soda & $20 \frac{1}{2}$ & 12 & 5 & 51 & $\begin{array}{l}19 \frac{1}{2} \\
38 \frac{1}{4}\end{array}$ & 30 \\
\hline Lime ............... & 8 & $4 \frac{1}{2}$ & 3 & $10 \frac{3}{4}$ & $7 \frac{4}{4}$ & $2 \frac{1}{2}$ \\
\hline Magnesia............ & 8 & 8 & $2 \frac{1}{2}$ & $4 \frac{1}{2}$ & $7 \frac{4}{4}$ & $5 \frac{1}{2}$ \\
\hline Alumina........... & 2 & 1 & $0 \frac{1}{2}$ & $2 \frac{1}{2}$ & $1 \frac{4}{2}$ & $0 \frac{3}{4}$ \\
\hline $\begin{array}{l}\text { Oxide of iron ......... } \\
\text { Oxide of manganese. }\end{array}$ & & a trace. & $1 \frac{1}{2}$ & $\begin{array}{l}4 \\
3 \frac{1}{2}\end{array}$ & & $0 \frac{1}{2}$ \\
\hline Silica.............. & 34 & 50 & $76 \frac{1}{2}$ & $15 \frac{2}{4}$ & 6 & $16 \frac{1}{3}$ \\
\hline Sulphuric acid ....... & 4 & $2 \frac{1}{2}$ & $I_{\frac{1}{2}}$ & $2 \frac{1}{2}$ & $4 \frac{1}{4}$ & $2 \frac{1}{4}$ \\
\hline Phosphoric acid ...... & $3 \frac{1}{2}$ & 9 & 3 & $4 \frac{1}{2}$ & $13 \frac{3}{4}$ & $7 \frac{3}{4}$ \\
\hline Chlorine ............ & 1 & 1 & $0 \frac{1}{2}$ & 1 & $1 \frac{3}{4}$ & $1 \frac{1}{2}$ \\
\hline Total.............. & 100 & 100 & 100 & 100 & 100 & 100 \\
\hline
\end{tabular}

On comparing the numbers in these columns we may observe how much more potash peas contain compared to beans; now beans contain double the quantity of soda to that of potash; how there is as much magnesia as lime in the bean; how large a quantity of the oxides of iron and manganese are found in rye compared to all the rest of the grains; how large a proportion of silica the oat contains in comparison of the rest of the grains; and how large a proportion of phosphoric acid the bean contains to other grains. The following statement exhibits the veight of ashes left by $100 \mathrm{lbs}$. of the sorts of grain spoken of above, according to the analysis of Sprengel :

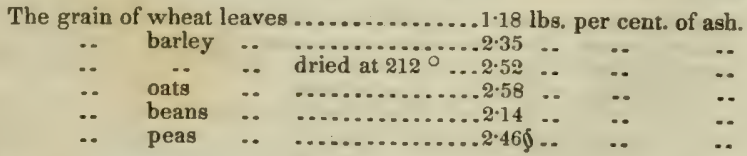

(1540.) Strano.-As the straw of the various kinds of grain which I have just treated of, possess different properties, and as they are best applied to different purposes, a few remarks on their
peculiarities may be useful.

(1541.) Whent-straw.-Wheat-straw is generally long. I have seen it upward of 6 feet in length in the Carse of Gowrie, and it has always strength, whatever may be its length. Of the two sorts of wheat, white and red, the straw of white wheat is softer, more easily broken by the threshing mill, and more easily decomposed in the dunghill. Red wheat-straw is tough. The striw of some sorts of wheat of both kinds possess their respective properties in a greater aud less derree than others. The strength and length of wheat-straw render it useful in thatching, whether luuses or stacks. It is yet much employed in England for thatching houses, and perhaps the $m$ st beautiful thatchers are to be found in the County of Devon. Since the general use of slates in s rnland, the thatching of houses with straw has almost fallen into desuetude in that country.

III This crop, as already stated, is not noticed in the Census. The crop in New.York in 1845 was 1.761,487 bushels, gathered from 113,020 acres, or 15 bushels to the acre. Both this and the bean will be yet much more fully treated hereafter, in other points of view not necessary to particularize.

Ed. Farm. Lib.]

* 'Thnmson's Organic Chemistry, Vegetables.

₹ Phillips's History of Cultivated Vegetables, vol. ii.

+ Raspail's Organic Chemistry.

$\S$ Compiled from Johnston's Elements of Agricultural Chemistry, and Lectures on Ag. Chem.

(4i) 
An existing thatch-roof may yet be repaired in preferénce to the adoption of a slated one, bot in new roof is thatched with straw. Wheat kirnw makes the besi thatrhing for com ataeks, its length and strnichtness insuring safety, neatness, and dispatelo in the proces, in the busy period of sto. curing the fruits of the earth. It forms an admimble botoming to the bedding in every court and hammed of the steading. As littering straw. whent straw possesses superior qualities. It is not so suited for fodder to stock. its hardness and length bejug unfavorable to mastication; yet I have seen farm-horses very fond of it. Horses in general are fond of a hard bite, and were wheat. straw cut for tham by the chaff-eutter of a proper length. I have no doubt they would prefer it to every other kind of atraw as fodder. The chaff of wheat does not seem to be relished by any stock: and is therefore strewn on the dunghill. or uyon the lairs of the cattle within the sheds. When it ferments. it canses a great lieat, and on this account I have supposed that it would be a valuable ingredient in assisting to maintain a heat around the frames of forcing.pits. The odor arising from wheat-stril wat chutf fresh threshed is clutinous.

(1542.) Barley-strau' is always soft, and has a somewhat clammy feel. and its odor, with its chaff, when new thrished, is heavy and malt-like. It is relished by no sort of stock as fudder; on the contrary, it is said to be deleterious to horses, on whom its use is alleged to engender greare in the heels. Barley-chaff, however, is much relished by cattle of all ages, and rough as the awns are, they never injure their month in mastication. Barley-atraw is thus only used as litter, and in this respect it is much inferior to whent strnw either for cleanliness, durability, or comfort. It does not make a good thatch for stacks, being too soft and difficult to assort in lengths. apt to let through the rain, and rot. Barley-chaff' soon beats in the chaff-house, and if not removed in the course of two or three days, dependent on the state of the air, decomposition will rapidly ensue. Barley-straw and chaff seem to contain sone active principle of fermentation.

(1543.) Oat stran.- This straw is nost commonly used as forder, being considered too valuable to be administered in litter. It makes a sweet, soft fodder, and. when new threshed, its odor is always refieshing. Its chaff is not much relished by cattle. Oat-straw is very clean, raising little or ho dust, and so is its cliaff; and on this account, as well as its elasticity, the latter is very commonly used in the country to make b'ds with tickings, for which purpose the chaff is riddled through an oat-riddle, and the larger refuse left in the riddle thrown aside. Sheep are very fond of oat-siraw, and will prefer it to bad hay : and even on the threatening of a coming storm, when on turnips, I have seen them prefer it to good bay. Of the diflerent eorts of oat-straw, that of the common oats is preferred, being softer, sweeter, and more like hay than that of the potato oat. When oats are eut a little green, the straw is much improved as foitder.

(1544.) Rye-stran,-This kind of straw is small, hard, and wiry, quite unfit for fodder, and per. haps would make but uncomfortable litter in a stable, though it would, no doubt, be useful in a court for laying a durable bottoming for the dunghill; but it forms most beantiful thatch for houses, and would, of course. do for stacks, if it were not to expensive an article for the purpose. It is much sought for by saddlers for stuffing collars of posting and coach-horses, and in default of this wheat-straw is substituted. It is also in great request by brick-makers, who, as stated by a writer, gave as much as $\mathcal{E} 5$ per load for it in the neighborhood of London in the winter of $1834-5$, but from what particular reason is not mentioned." Its ordinary price is f2 per load. The plaiting of rye straw for hats was practiced so long ago as by even the ancient Britons, and was certainly not out of use in Shakspeare's days, who thus notices the custom of wearing this elegant head. gear on holidays :

\section{"You sun-burned sicklemen, of August weary, \\ Come hither from the furrow, and be merry: \\ Make holy-day ; your rye-etraw hats put on, \\ And then fresh nymphs encounter every one, In country footing."}

\section{THE TRMPEST.}

I have eeen very useful hats and honnets for field-work made by laborers and field-workers fnom the upper joint of wheat-straw. Bee-hives and ruskies - that is, baskets for supplying the sowers with seed-are beautifully and lightly made of rye-straw; but where that commodity is scarce, which it usually is in Scotland, wheat straw is substituted.

(1545.) Peas and Bean-straw, or haulm. - It is difficult in some seasons to preserve the straw of the pulse crops, but, when properly preserved. there is no kind of straw so great a favurite as fodder with every kind of stock. An ox will eat peas-straw as greedily as he will hay; and a horse will chump bean-straw with more gusto than ill-nade rye-grass hay. Young cattle are exceedingly fond of bean and peas chaff; and sheep enjoy peas.straw as much. These products of the pulse crops are considered much too valuable to be given as litter. Since bean-chatt is so much relished by catte, there is little doubt that bean and pea haulm. cut into chaff, would not only be relished, but be economically admunistered; and were this practice attended to in spring, the hay usually given to horses at that season might be dispensed with on farms which grow beans and peas. It is said that when work borses are long kept on bean-straw their wind becomen atfected.

(1546.) Ot all the different eorts of straw, it appears that wheat. oata, peas, and bean-atraw are used for folder. and that barley straw is fit only for litter; and that where there is a sufficiency of oat and beau straw, wheat-atraw might also be dispensed with as fod Jer. This being the relative positions of the different kinds of straw, their supply should be an arranged as to prevent the waste of fodder-straw in litter, and this may lie easily accomflished by having oat-straw in the strawbarn with barley or wheat straw. The procedure should be in this wise: In the early part of the winter, the grain chiefly in demand is barley. Barley straw should therefore be supplied, stack after stack, until all the stock. with the exception of the seed-corn, is disposed of. During winter, the corn for the horses should be threshed, and laid up in granary, and, as common oats are usually given to horses, the best sort of fodder could thus be supplied simultaneously with the litter-

- Ji itish Husbandry, vol. ii.

(42) 
straw of barley. After the barley is disposed of, toward spring, the demand for wheat commences, and then the wheat-straw should come in lieu of that of the barley for litter. Farther on in spring, the bean-straw comes in lieu of oat-straw for fodder. In this way the time may pass on until grass is ready for stock. See (13).

(1547.) The color of the fodder-straw affects the color of the dung of the various animals ; thus, peas and bean-straw and chaff make the dung quite black, wheat-straw gives a bleached appearance to the dung of horses, and oat-straw gives it a yellow hue.

(1548.) I do not know that the specific gravity of straw has ever been ascertained by experi. ment; but I should say, judging only by surmise, that oat-straw is the lightest, and wheat-straw heaviest.

(1549.) It may be interesting to you to give the constituents of the different sorts of straw spoken of. These consist of organic and inorganic substances. The organic substances resolve themselves ultimately into the four elements of oxygen, bydrogen, carbon, and nitrogen. The inorganic consist of a considerable number, a tabular view of which is here given under each oort of straw, for the purpose of comparison. According to the analysis of Sprengel,

$1000 \mathrm{lbs}$. of wheat.straw leave $35 \cdot 18 \mathrm{lbs}$. of ash. $1000 \mathrm{lbs}$. of rye-straw leave...27.93 lbs. of ash.

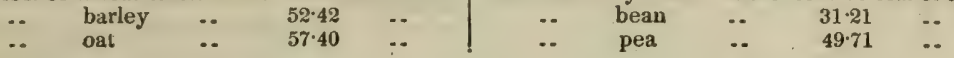

And $100 \mathrm{lbs}$. of the ash of each of these sorts of straw gave the following constituents :

\begin{tabular}{|c|c|c|c|c|c|c|}
\hline Constituents. & $\begin{array}{l}\text { Wheat } \\
\text { Straw. }\end{array}$ & $\begin{array}{l}\text { Rarley } \\
\text { Atruw. }\end{array}$ & $\begin{array}{c}\text { Oat } \\
\text { Straw. }\end{array}$ & $\begin{array}{l}\text { Rye } \\
\text { Straw. }\end{array}$ & $\begin{array}{l}\text { Bean } \\
\text { Straw. }\end{array}$ & $\begin{array}{l}\text { Peas } \\
\text { Straw. }\end{array}$ \\
\hline Potash................. & Ibs, & lbs. & $\begin{array}{l}\text { Jbs. } \\
15\end{array}$ & Jbs. & lbs. & lbs. \\
\hline 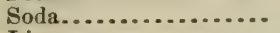 & $0 \frac{3}{4}$ & 1 & a trace. & $0 \frac{1}{2}$ & $1 \frac{1}{2}$ & - \\
\hline Lime................... & $7^{4}$ & $10 \frac{1}{2}$ & $2 \frac{3}{4}$ & $6^{2}$ & $20^{2}$ & $54 \frac{3}{4}$ \\
\hline Mrgnesia.............. & 1 & $1 \frac{1}{2}$ & $0 \frac{1}{2}$ & $0 \frac{1}{2}$ & $6 \frac{1}{2}$ & $6 \frac{3}{4}$ \\
\hline Alumina ................ & $2 \frac{3}{4}$ & 3 & a trace. & \} & $0 \frac{1}{4}$ & $1 \frac{i}{4}$ \\
\hline Oxide of iron ............ & \} & $0 \frac{1}{2}$ & a trace. & & $0 \frac{1}{4}$ & $0 \frac{1}{2}$ \\
\hline Oxide of manganese ... & $\ddot{0}$ & & 80 & 821 & & $0 \frac{1}{4}$ \\
\hline Silica................ & 81 & $73 \frac{1}{2}$ & 80 & $82 \frac{1}{4}$ & 7 & 20 \\
\hline Sulphuric acid......... & 1 & 2 & $1 \frac{1}{2}$ & 6 & 1 & $6 \frac{3}{4}$ \\
\hline Phosphoric acid......... & 5 & 3 & $0 \frac{1}{4}$ & 2 & $7 \frac{1}{4}$ & $4 \frac{3}{4}$ \\
\hline Chlorine............... & 1 & $1 \frac{1}{2}$ & a trace. & $0 \frac{3}{4}$ & $2 \frac{3}{4}$ & $0 \frac{1}{4}$ \\
\hline Total............. & 100 & 100 & 100 & 100 & ] 00 & 100 \\
\hline
\end{tabular}

On comparing the numbers in these columns, we cannot fail to remark how much potash there is in the straw of the bean; how small a trace of soda there is in all the straws; how large a propor. tion of lime there is in the straw of the pea, compared to that of the bean; how large it is com. pared to that in the grain of the pea itself; how much more silica in the straw of the pea than in that of the bean; but how much more phosphoric acid in bean-straw than in that of the pea.

(1550.) "The inorganic matter contained in different vegetable productions varies from 1 to 12 per cent. of their whole weight. The following Table exhibits the weight of ash left by $100 \mathrm{lbs}$. of the dry straw of the more commonly cultivated plants, according to the analysis of Sprengel :

Dry straw of wheat 3.51 lbs. per cent.

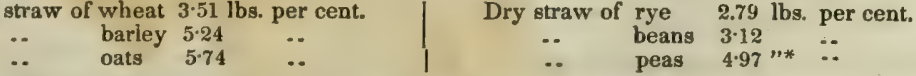

(1551.) Such are the kinds, uses, and constitution of the straw usually found on farms ; and the proper management of them, so as to confer the greatest comfort to stock, and procure the largest amount of manure to the farm, is a matter deserving much consideration. I fear there is too much truth in the observation of Sir Joln Sinclair, when he says on this subject, that "the subject of straw is of greater importance than is commonly imagined; and the nature of that article, taken in the aggregate, entitles it to more attention than has hitherto been bestowed upon it. Farmers are apt to consider it as of little or no worth, because it is not usually salable, and is rarely estimated separately from the yearly produce of the soil. But though seldom salable, except in the vicinity of towns, it has an intrinsic value as a fund for manure, and a means of feeding stock." $\downarrow$

(1552.) The proper management of straw which $I$ allude to, is that the respective kinds shall always be appropriated to their best uses-that is, the straw best adapted for litter shall not be al ministered as fodder, for if it be, the animals will thereby be rendered discontented; if barleystraw, for irstance, is put before cattle that have been, or should have been, accustomed to oatstraw, they will not only not eat the usual quantity of fodder, but eat that which they are obliged to eat with disrelish. On the other hand, if fodder-straw is strown abroad for litter, it is not used to the best advantage, being partly wasted. Again, if more straw is threshed at a time than can be consumed in a few days in fodder, what of it remains to the last becomes dry and brittle, and unfit for the use of stock; and even litter straw, if kept for a long time before it is used, becomes much lighter. and, of course, loses a portion of its value. So far, therefore, as the straw is concerned, it is bad practice to stack up threshed straw for a long time, as some farmers seem fond

* Compiled from Johnston's Lectures on Agricultural Chemistry. $(43)$ 
of doing, for it then certainly wastes some of its properties as foilder or litter. The plan is, to thresh the straw when and as often as it is required, both for fodder and litter, atul it will bes always in the freshest state for use in both ways. But to follow out this plan successfully requireg the previous consideration whether there is a sutticicut uumber of stacks in the stack.yard, for the purposes of fodder and litter throughout the season, and if there is, then those should be selected which are best suited, of the respective kinds. for those purposes, during the winter, when the utility of good straw is most appreciated. The remainder can be used for the inferior purposes of bottoming the courts and stacks of the ensuing crop and season. Should the whole quats. tity of straw, however, seem inadequate to the demands upon it, then it should be threshed only as required, and dealt out with an economical and judicious hand, so that no part of the season should be worse or better supplied than the rest. Do these considerations usually engage the attention of furmers? I fear not. but certainly not so much as they deserve. I am aware that it may here be observed, that it is of much greater import for the interest of the farmer to study the state of the market for grain, than to lose that advantage by not threshing out the straw. This is feasible, but, at the same time, is the farner aware how much injury he may receive by losg ot condition in stock, and deterioration in dung, by being inattentive to the state of his straw ? I suspect the subject has received but little of lis consideration.

(1553.) It was at one time a prevalent notion that straw could not be converted into good manure, unless it were consumed by catte and horses; and the celebrated Bakewell carried this idea to such a hisht that if he had not stock sulficient of his own to consume his straw, he took in those of others for the purpose. But he lived to see his error. Opinion changed to the opposite extreme. so that many farmers persuaded themselves into the belief that straw consumed by stock was wasted, and that it should only be used as litter. This latter opinion is nearer the truth than the former, but goes beyond the truth; for although it is quite correct to say that stock ought to drpend on green crops for food to fatten them, yet it is also true that that food is much assisted in its assimilation into the animal system by a participation of fodder. It is not merely that the stomach requires to be distended by food, but sweet, dry fodder is an agreeable change to the ox after a hearty meal of turnips. Feeding stock really consume very little fodder; and when it is placed betore them at pleasure, they znay either partake of it, or pick out a few choice straws, or let it alone altogether; thus affording crealures as much liberty of choice in their food as their confined situation will admit.

(1554.) The value of straw may be estimated from the quantity usually yielded by the acre, and the price which it usually realizes. Arthur Young estimated the straw yielded by the ditferent crops-but rejecting the weaker soils-at 1 ton $7 \mathrm{cwts}$. per English acre. Mr. Middleton estimated the different crops in these proportions:

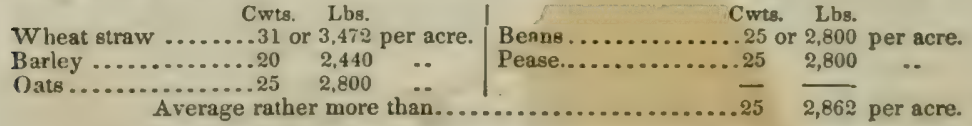

or 1 ton 5 cwts. per English acre. Mr. Brown, Markle, East-Lothian, computed the produce of straw as follows, in stones of 22 lbs. per Scotch acre, which I have contrasted with the imperial:

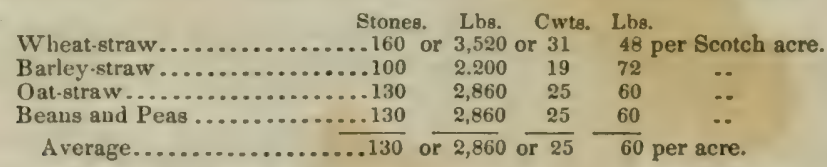

or 1 ton 5 cwts. 60 lbs. per Scotch acre, or 1 ton 0 cwt. 76 lbs. per imperial acre." In the immediate vicinity of Edinburgh, the produce, both in Scotch and imperial measures, per acre, is this:

\begin{tabular}{|c|c|c|c|c|c|c|c|c|}
\hline Wheat-straw. ...99 & kemples & $6 \mathrm{st}$ & 2210 & $\begin{array}{l}\text { Stones. } \\
=144 \text { or }\end{array}$ & $\begin{array}{l}\text { Lbs. } \\
3,168\end{array}$ & $\begin{array}{c}\text { Cwts. } \\
\text { or } 28\end{array}$ & Qrs. & $\underset{4}{L}$ \\
\hline Bariey-straw ....7 & $\ldots$ & .. & . & $=112$ & 2.464 & 22 & 0 & 0 \\
\hline Oat-straw .......8 & $\cdots$ & .. & $\ldots$ & $=128$ & 2,816 & 25 & 0 & 16 \\
\hline Average ......8 & .. & .. & .. & $\overline{=128}$ or & 2,816 & $\overline{\text { or } 25}$ & $\overline{0}$ & $\overline{16}$ \\
\hline
\end{tabular}

or 1 ton 5 cwts. 16 lbs. per Scotch, or 1 ton 0 cwt. 13 lbs. per imperial acre. On comparing this result-from the vicinity of a large town where a large supply of manure can always be ob. tained-with Mr. Brown's general estimate for the whole country, and finding the quantity lese, we must conclude that Mr. Brown's estimate is above the mark as an average one for the country; and unless the production of straw be very much greater in Eneland than in Scotiand, we must also conclude that the estimates of both Arthur Young and Mr. Middleton are above the general average; 1 ton the imperial acre of weight for straw is too hizh an average for Scotand.

(1554.) In regard to the market value of atraw, it being usually prohibited to be sold except in the vicinity of towns where manure can be received in return, it is only from the value received for it in towns that we can form an estimate of its value. In Edinburgh, the usual price for wheat-straw is 128. per kemple of 16 stones of $22 \mathrm{lbs}$, or $9 \mathrm{~d}$. per stone; and for oat-straw $10 \mathrm{~s}$. the keinple, or $7 \frac{1}{2} \mathrm{~d}$. per stone. This statement brings out and contrasts the values in Scotch and imperial measures :

* Sinclair's Code of Agriculture. 
Wheat-straw, 144 sts. of 22 lbs. at $9 \mathrm{~d}$. per st. $=£ 56 \mathrm{~s} .4 \mathrm{~d}$. per Scotch acre of 10 bolls of 4 bushels, $=10 \mathrm{~s} .7 \mathrm{~d}$. per boll.

Cet-straw, 128 sts. of 22 lbs. at $7 \frac{1}{2} \mathrm{~d}$, per st. $=£ 4$ per Scotch acre of 10 bolls of 6 bus. $=8 \mathrm{~s}$. pr boll.

\section{Equivalent to}

Wheat straw, 181 sts. of 14 lbs. at $5 \frac{3}{4} \mathrm{~d}$. per st. $=£ 46 \mathrm{~s} .9 \mathrm{~d}$. per imperial acre of 8 bolls of 4 bushels, $=10 \mathrm{~s} .9 \mathrm{~d}$. per boll.

Oat-straw, 161 sts. of 14 lbs. at $4 \frac{3}{4} \mathrm{~d}$. per st. $=£ 34$ s. per imp. acre of 8 bolls of 6 bushels $=8 \mathrm{~s}$. per boll.

In those parts of the country where straw, with its corn, is allowed to be sold on foot-that is, as it grows in the field-but prohibited from being sold by itself, the price for wheat-straw is $6 s$. per boll of 4 bushels, and $5 \mathrm{~s}$. per boll of oat-straw of 6 bushels. The quantity of straw per boll and per bushel will stand thus :

Wheat-straw, $14 \mathrm{sts} .8 \mathrm{lbs}$. of 22 lbs. per boll of 4 bushels $=3$ sts. 11 lbs. per bushel.

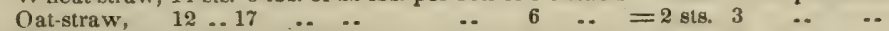

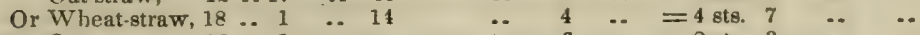

$\begin{array}{lllllllllllll}\text { Oat-straw, } & 16 & \ldots & 1 & \ldots & \ldots & \ldots & 6 & \ldots & & & & \end{array}$

(1556.) The Romans used straw as litter, as well as fodder, for cattle and sheep. They considered millet-straw as the best for cattle, then barley-straw, then wheat-straw. This arrangement is ratber against our ideas of the qualities of barley and wheat-straw; but very probably the hot climate of Italy may improve the quality of the barley-straw by making it drier and more crisp, and render that of the wheat too hard and dry. The haulm of pulse was considered best for sheep. They sometimes bruised straw on stones before using it as litter, which is analogous to having it cut with the chaff-cutter, as has been recommended.

(1557.) Where straw is scarce, they recommend the gathering of fern, leaves, \&c., which is a practice that may be beneficially followed in this country, where opportunity occurs. Varro gays: "It is the opinion of some that straw is called stramentum because it is strewed before the cattle."*

\section{THE WAGES OF FARM-SERVANTS. $†$}

"The husbandman that laboreth must be first partaker of the fruits."

ST, PACL.

(1558.) Winter is the time in which wages in kind are paid to farmservants; and the part of that season chosen for the purpose is about the end of the year. It is requisite that harvest shall be completely over in the latest season, and every preparatory operation connected with the accommodation of stock, either on turnips or in the steading, be gone through, before the business of threshing the crop in a regular order be commenced. In connection with threshing the crop, a plan should be adopted for supplying straw for fodder and litter, as recommended in (1457), as well as for placing a quantity of new oats in the granary, to be drying and to be ready for use by the time the perhaps small stock of old corn shall be consumed. After all these preparatory operations incidental to winter have been accomplished, and before much of the new crop has been disposed of at market, farther than to ascertain its general quality

[ + We need not say that in copying this chapter, we suppose that there is much. if any of it, susceptible of adaptation to our country-still. the system of farm wages is one so obviously and intimately interwoven with the agricultural economy of every country that every gentleman may be presumed to be curious to know how these systems differ in different parts of the world. The high price of wages in this country, and the scarcity of that and capital in their proportions to the price of land, not only prevent the restoration of exhausted lands in the old Atlantic States, but are fruitful sources of exhaustion and abandonment of States comparatively new-as Western New. York for example.

What constitutes of itself a great advantage in favor of laboring people in the United States is, that they are almost invariably "found," or boarded by their employers, and in the Free States in must cases eat at the same table, three times a day, with the farmer and his family. For a head man on a farm, \$12 may be put down as the usual wages, and for hands or "helps" by the month from $\$ 8$ to $\$ 10$.

Ed. Farm. Lib.]

* Dickson's Husbandry of the Ancients, vol. ii. 
and price, the first leisure afforded by them is taken for paying the farmscrvants their yearly wages of corn; and as the quantity distributed is considerable on a large farm, and as all the servants should receive their wages at the same time, to avoid jealousy, there will be a considerable quantity of threshed grain in the barn before the distribution takes plare. The servants receiving a variety of corn, that kind should be first distributed which is found most convenient for the farmer to thresh; and each kind should be delivered, and the barn cleaned out, before another is interfered with.

(1559.) I have already enumerated the different classes of laborers employed on a farm from (241) to (252); and I may here mention generally, that the wages of all may be classed under three heads: 1st, Those consisting chiefly of kind, that is, of the produce of the farm, and but a small sum in cash; 2d, Those consisting of a large proportion of cash and small amount of kind; and, 3d, Those which consist entirely of cash. The recipients of the first and third classes may be engaged on the same farm, and the third class may be found exclusively on a farm, but the first and second classes are never found together; and as all three modes of paying wages coëxist in this kingdom, though in different parts of it, they afford a criterion for judging which is the best mode for all parties, for master and servant; which the most convenient for the master, which the most conducive to the servants' comfort and moral habits. Plowmen or hinds constituting the principal or staple class of laborers on a farm, like the battalion-men in a regiment, the terms of their wages are taken as a standard of comparison for those of the rest.

(1560.) Ploumen's wages.-These are paid in all the three modes enumerated above (1559), the first mode being in general adoption in the border counties of England and Scotland; the second mode being practiced in the midland and northern counties of Scotland; and the third having long been adopted in the southern counties of England.

(1561.) Wages in kind and money differ, in their constituent items, in different counties, but only in a slight degree; the aggregate items affording sufficiency of food to support a plowman and his family. I shall enumerate the particulars received by the plowmen of Berwickshire and Northumberland :

In Berwickshire.

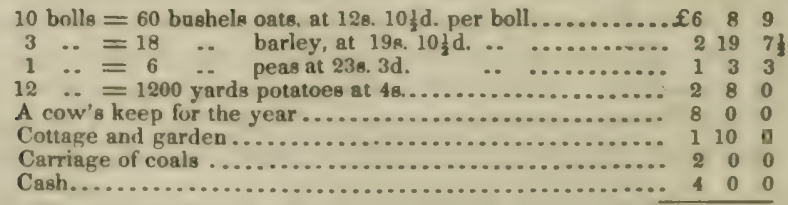

Equal to 108. $11 \frac{1}{d}$. per week....................

In Northumberland.

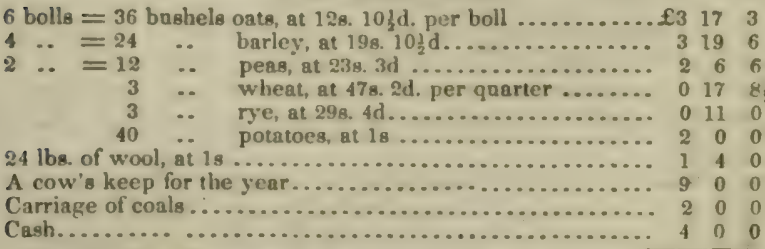

Equal to 11 s. 5d. per week....................

To the money value of both particulars I attach no importance, firt! ir than giving to them a tangible form; for the prices of agricultuml [1w(46) 
duce affect neither master nor servant in their relation to one another, the point simply being, that the master supports the servant in an adequate manner. Any difference, therefore, shown. in the weekly wages between $10 \mathrm{~s} .11 \frac{1}{4} \mathrm{~d}$. and $11 \mathrm{~s} .5 \mathrm{~d}$. as brought out in estimating the money value of the particulars does not in fact exist, because the plowmen of both counties live equally well. Instead of taking an imaginary rate of prices, I have selected the aggregate average, as given in the Universal Corn Reporter of 20th January, 1843. Besides working a pair of horses, the plowman is bound to supply a field-worker, whether a woman or a boy, usually the former, whenever the farmer requires her services, and who receives for her work $10 \mathrm{~d}$. a day, and in harvest $2 \mathrm{~s} .6 \mathrm{~d}$. a day, besides victuals. In harvest-wages there is a difference between the two counties, and it is explained in this way. In Northumberland, it will be observed that the rent of the house and garden is set down at $£ 3$ a year, while the plowman receives 2 s. 6 d. a day, and victuals, for the field-worker in harvest; whereas, in Berwickshire, the plowman is bound to work the harvest as rent for his house and garden, receiving only victuals, which $I$ have estimated at that season at $1 \mathrm{~s}$. a day for 30 days, which is as long a period as harvest may be expected to last, and which should be deducted from $£ 3$ of rent. There is also a difference in the cow's keep. In Berwickshire, the allowance is 60 stones of $22 \mathrm{Jbs}$. of hay in winter in lieu of turnips; but turnips are always preferred, and these are given to the amount of 6 double horse-loads, 3 of white and 3 of Swedes. In Northumberland, 10 cart-loads of white turnips are given, or 5 of white and 3 of Swedes; or, in lieu, 1 ton of hay, or 100 stones of 22 lbs.; so that the Northumberland cow is better off by $£ 1$ in winter than the Berwickshire, and the difference is certainly so far an improvement on the condition of the English hind. Both cows have as much straw as they can use. The grain which the plowman can claim is next in quality to the seed-corn; and in Berwickshire he receives it in advance at the end of the year, which is in the middle of the year's engagement from Whitsunday (May) to Whitsunday. In Northumberland, the corn is paid in advance once a quarter. The corn is ground in any way the plowman pleases, at one of the small mills of the country, for the mere miller's multure; so he saves the profits of the retail dealer. If he cannot consume all his corn, the farmer willingly takes what he has to spare at the current market price. The produce of the cow, over and above what is required to serve the plowman and his family, may be disposed of; and if the cow is a good one, and the season favorable, and the wife a good dairymaid, a considerable sum may be realized from the cow during the year. Her calf, if early and gotten by a wellbred bull, will fetch $£ 2$, and perhaps more; if late, it may still be worth 20s. The refuse of the dairy, of the garden, and the house, enables the plowman to fatten two pigs every year; one for his own use, and the other to dispose of. The cow is the plowman's own property; and to lose her by death is a serious affliction upon him. I have seen men with families much injured by such a loss, and could never refrain from rendering the poor fellows some assistance. To avert so serious a calamity to a poor man, cow-clubs have been established, to purchase cows for the memhers who may have the misfortune to lose them. Farmers subscribe according to their number of plowmen, and each plowman who wishes to enjoy the benefit subscribes 1s. a quarter to the funds of the club.

(1562.) Wages, more in cash than in kind, are more extensively given in Scotland than the plan which I have just described. Those who receive this species of wages are chiefly single men, living either in the farmer's house, or in a house by themselves called a bothy. The practice of

(47) 
allowing farm-servants to take their meals in the farmer's house is falling fast into desuetude, and its abandonment is much to be regretted, for it is a far better plan for the comfort of the men themselves than the bothy system. But married men are also supported in this form of wages, though their condition is not so good as that of the plowmen on the preceding plan, but it is certainly preferable to the bothy system.

(1563.) The portion of wages received in kind consists of oatmeal and milk. The meal amounts to 2 pecks per week for each man, that is, 1 stone of $17 \frac{1}{2} \mathrm{lbs}$., which makes $6 \frac{1}{2}$ bolls per annum, or $65 \frac{1}{2}$ stones of $14 \mathrm{llis}$; and this at 1s. per peck gives a money value of $£ 54 \mathrm{~s}$. a year. The milk is supplied either fresh from the cow or after the cream has been skimmed off, according to agreement. In the former state it is given to the amount of 1 Scotch pint or 2 quarts a day; and in the latter state, 3 quarts are given in summer, and 2 in winter. The value of the milk is usually estimated at $£ 4$ a year. In some cases a cow or cows are supplied to the men, who milk them, and are exchanged for others when they go dry ; but supplying milk is the least troublesome plan for the master. These items of kind, with from $£ 10$ to $£ 14$ a year of cash, varying with the rate of wages in the country, or according to the skill of the plowman, constitute the earnings of a plowman on this system. It is only in the amount of cash that these wages vary at any time, for what is given in kind is considered invariable, being no more food than a stout man can consume; but some cannot consume it all, and save a part of the meal, which they either dispose of to the farmer or to dealers. In strict fairness, the meal should be given to the men every week, but to save trouble, it is dealt out once a month or once a fortnight. The milk, of course, is supplied every day.

(1564.) Besides these principal ingredients, the married men get a house and garden rent free, and coals are driven free to their house. The single men are provided with a room containing a number of beds, which are occupied each by two men; and the bed-cluthes, consisting of a chaff ticking and bolster, blankets, sheets and coverlid, are provided by the master, and replaced clean every month. This room is called the bothy, and it usually forms both the sleeping-chamber and cooking-apartment of all its inmates, which may amount to as many men as there are plowmen employed on the farm. The men are supplied with fuel all the year round, with which to cook their victuals, and which they do for themselves. The fuel consists of wood, brushwood, or coal, according to the supplies of the locality; but in winter, coal is always laid in to the extent of 1 ton each man. Salt is also provided by the master; and he also furnishes a pot for cooking in, a dish for holding milk, and some forms and perhaps a table; but this last article of furniture is often dismissed from the bothy with little ceremony, a form, or the lap, making a much more desirable dinnerboard. A few potatoes are generally given in winter.

(1565.) The oatmeal is usually cooked in one way, as brose, as it is called, which is a different sort of pottage to porridge. A pot of water is put on the fire to boil, a task which the men take in turns; a handfull or two of oatmeal is taken out of the small chest with which each man provides himself, and put into a wooden bowl, which also is the plowman's property; and on a hollow being made in the meal, and sprinkled with salt, the hoiling water is poured over the meal, and the mixture receiving a little stirring with a horn spoon, and the allowance of milk poured over it, the brose is ready to be eaten; and as every man makes his own brose, and knows his own appetite, he makes just as much brose as he can consume. The bowl is scraped clean with the spoon, and the spoon licked (48) 
clean with the tongue, and the dish is then placed in the meal-chest for a similar purpose on the succeeding occasion. The fare is simple, and is as simply made; but it must be wholesome, and capable of supplying the loss of substance occasioned by hard labor; for I believe that no class of men can endure more bodily fatigue, for ten hours every day, than those plowmen of Scotland who subsist on this brose thrice a day.

(1566.) The plowmen who receive cash for wages, are in the same condition as day laborers, who receive their earnings once a week and purchase their subsistence at retail dealers' in country towns and villages. This, I believe, is the condition of most of the plowmen in the southern counties of England. There is one obvious remark, occasioned by this statement, which cannot fail to be considered by every farmer, which is, that unless money wages adapt themselves to the fluctuating prices of the commodities upon which farm-servants subsist, servants so paid must suffer much privation on a rise in the price of provisions; and on the other hand, when prices again fall, they receive higher wages than they are entitled to. They are thus subjected to vicissitudes in their condition, from which the former two classes of plowmen are exempt.

(1567.) The wages of stewards are in all respects similar to those of the plowmen of whom they have the charge, the only difference being in the amount of cash received, which is always greater than that given to the plowmen. Instead of $\mathfrak{£ 4}$, given to the former class of plowmen, they may receive $£ 12$ or $£ 15$, and instead of $£ 12$ or $£ 14$ given in cash to the latter class, they may receive from $£ 20$ to $£ 25$; and if there is any difference in the size or situation of the servants' houses, the best is appropriated to them. In most cases the steward is exempt from attendance on the farm on Sundays, while in others he takes his turn along with the other men, which latter is the better plan for the master, as the steward can then have much better opportunity of observing whether the men fulfill their duties properly.

(1568.) The shepherd receives the same amount of kind and money as the plowman; but as he is accounted a skillful servant, and his hours of attendance extend every day from sunrise to sunset, he has leave to keep a small flock of sheep of his own, which is maintained by his master, and the produce of which he is entitled to dispose of every year. His flock consists of breeding-ewes, which vary in number from half a score, such as of Leicester ewes in the low country, to perhaps twoscore of Blackfaced ewes in the highest districts. About $\frac{1}{5}$ of the number of the ewes being disposed of every year, he is entitled to retain as many ewe-lambs of his flock as will maintain the full number of his breeding-ewes. The shepherd's dog is his own property, often purchased at a high rate, and trained with much trouble and solicitude.

(1569.) The hedger, being considered a day laborer or spadesman, gets a smaller proportion of kind than the first class of plowmen, and more money, and generally no cow's-keep; and where the second class of plowmen exist, no hedger is kept as a hired servant, but is viewed in the light of a day-laborer, and is paid money-wages accordingly. Being a skillful man, the hedger never receives less than $£ 40$ a year in value, and more frequently $£ 1$ a week. He can sow com, build stacks, and do anything that the steward can, and sometimes all that the shepherd can besides.

(1570.) The cattle-man, being viewed as a laborer, receives some of his wages in kind and the rest in cash, and is seldom indulged with a cow. Being generally a person somewhat advanced in life, the rate of his wages is not high-perhaps $9 \mathrm{~s}$. a week; and it is well when such a post as this 
can be given on a farm to an old and faithful plowman or shepherd, whose growing infirmities disable him from undertaking his former active duties.

(1571.) The field-worker is simply a day-laborer, and receives $10 \mathrm{~d}$. a day, without any wages in kind, from the farmer. This person is usually a woman. The first class of plowmen are each bound to supply a fieldworker for the farm during the year, they receiving the wages earned by the workers in that time. They hire the women in the public markets and support them in their houses with bed and board and wages. Should the field-worker obtain constant employment on the farm, the plowman may profit by the arrangement. On large farms field-workers are almost constantly employed. The practice had, no doubt, arisen at a time when few women could be persuaded to work in the fields; and the circum stance of plowmen being bound by agreement to supply such laborers, these latter have long been designated by the odious name of bondagers, an epithet no doubt left us in legacy by our feudal forefathers. The practice has been found fault with, and even represented as a species of slavery, probably because of the odious designation given to the condition of the women; but the truth is, there is no more binding or slavery about the matter than in the case of the plowmen themselves, and even less, for they are bound by agreement to work for a year, whereas the bondager's term is only for six months. The epithet is a nick-name, and should be relinquished for the proper name of field-worker; but the practice is good, because it enables the farmer to command a certain number of hands at all times, and also to accomplish his ends by his own resources, independent of extraneous aid. It is no answer to say that women may be hired out of villages when their services are required, because many large farms are situate far from any village; and even the vicinity of a village will not secure a supply of field-workers, as I have myself experienced to my vexation; for whenever trade is brisk, manufacturers not only pick up all the hands they can procure, but the work which they supply being done by the piece, at which greater wages than at field-work can be earned in long hours of labor, a temptation is presented to women laborers to desert the fields; and to such a degree of stringency is this monopoly of labor carried by manufacturers that they will not allow their people to go and assist at harvest. A resource of labor like the Border system should, therefore, not be yielded by the farmer, until a better, or one as efficient, can be substituted. Its hardship, however, is not imputed to the workers them selves but to the plowmen who must hire them; but if there is any hardship in it to the plowmen, they nevertheless engage in it voluntarily with all its inconveniences, rather than abandon their profession; though, no douht, if a man have no family, and the work is but limited, the support of a field-worker may press hard upon his gains, but there is this alleviating circumstance, even in such a case, that the burden is imposed upon a man who has no family to support; whereas, a family of daughters is a great source of income to a plowman, one doing the bondage work, others being paid for their labor, and all contributing to the support of a common fund. The system has no bad effect on the bondagers themselves; for they are cheerful and happy at work, and are well clad on Sundays. Nor are they ever put to any labor beyond their strength; for as to the alleged "unfeminine practice of females driving dung-carts," the practice is not more unfeminine than helping to fill dung-carts, or turning dunghills; but the fact is, women do not drive carts, in the usual sense of that term; they only walk beside the cart, in the absence of the driver at more laborious work, to and from the dunghill to the place of its destination,

- Report of the Cottage Improvement Society of Narth Northumberland for 1842.

(9z) 
merely to keep the carts clear of one another, and when so employed they have nothing to do with the yoking or loosening of the horse, or filling or emptying of the cart, or turning in or out of the landings. In the northern counties of Scotland no such obligation exists on the plowmen, nor indeed can be, for it would be impossible to coëxist with the bothy system, where a plowman has not a house for himself, far less for any worker; and hence in those parts of the country field-labor, in as far as the manual operations are concerned, is very much inferior to that executed on the Borders, because of its being performed by casual laborers instead of those who have been steadily trained up to it from early youth; and as long as no means are used to initiate young people, especially young women, who are admitted to be more nimble in the fingers than men, in the several varieties of field-labor, so long will they be imperfectly exe- . cuted.

(1572.) Now, on taking a retrospect of the actual condition of all the laborers of the farm, as I have endeavored to represent it, and comparing the condition of the first class of plowmen with the others. the question that naturally occurs to the mind is-Which is the best? I have not the slightest hesitation in expressing my conviction of the superior position of the plowmen in the Borders. Let us look into one of their cottages of an evening. I grant that their cottages might be made much more comfortable and much more convenient, and much better suited to the wants of their inhabitants, than they are; and this I shall endeavor to show in due time; but in the mean time I may say that a determination exists for improvement in this matter evinced by parties most able to do it, namely, the landlords, and its good effects will be seen in the course of a few years; but look into one of their cottages, such as they are, during a winter evening, and "you will probably see," to use the words of Mr. Grey, Dilston. on this subject, in the letter and spirit of whose sentiments I cordially concur, "assembled the family group round a cheerful coal-fire-which, by the way, is an inestimable blessing to all classes, but chiefly to the poor of this country-females knitting or spinning - the father, perhaps, mending his shoes-an art almost all acquire-and one of the young ones reading for the amusement of the whole circle." Contrast this with the condition of those plowmen in England who receive their wages entirely in cash, and who have to go to a distance to purchase the necessaries of life. "Contrast this," continues Mr. Grey, "with the condition if many young men emoloyed as farm-servants in the soutbern counties, who being paid board-wages, club together to have their comfortless meal in a neighboring cottage, with no house to call their home, left to sleep in an outhouse or hay-loft, subject to the contamination of idle companions, with no parent's eye to watch their actions, and no parent's voice to warn them of their errors; and say which situation is best calculated to promote domestic comfort, family affection, and moral rectimde?" Contrast this also with the bothy system, which perhaps Mr. Grey has never witnessed, or no doubt it would have met with his reprobation; contrast this with a system which, although it supplies the necessaries of life in a convenient enough form, presents them in uncomfortable circumstances affording no assistance to cook the food and clean out the chamber; affording no one to admonish thoughtless young men, many of whom are in the practice of wandering at night after a long day's toil, and returning home only in the morning, to begin a day's work, with wearied limbs and depressed spirits. In the winter evenings, too, the bothy is a scene of lewd mirth, excited by the company of females who have come perhaps from a distance to visit their acquaintances, and who are treated most probably with a stolen fowl, entertained with profane jests and songs, and afterward convoyed homeward amid darkness and wet.

(1573.) "One very obvious benefit," observes Mr. Grey justly, in regard to married plowmen, "arising to the hind from this mode of paying in kind, besides that having a store of wholesome food always at command, which has not been taxed with the profits of intermediate agents, is the absence of all temptation which the receipt of weekly wages and the necessity of resorting to a village or a town to buy provisions, hold out of spending some part of the money in the ale-house, which ougnt to provide for the wants of the family; and to this circumstance, and to the domestic employment which their gardens afford in their leisure hours, we are probably much indebted for the remarkable sobriety and exemplary moral conduct of the peasantry of the North." And farther, "this mode of engaging and paying farm-servants is not only more conducive to their welfare and social comfort than the weekly payment of money-wages-which go but a little way in purchasing the necessaries of a family, are injudiciously laid out, and sometimes wastefully squandered-but it has, besides, a strong and apparent influence upon their habits and moral character. it possesses the advantage of giving to the peasant the use of a garden and cow, with the certainty of employment; it gives him a personal interest in the produce of his master's farm, and a desire to secure it in good condition; it produces a set of local attachments, which often lead to a connection between master and servant, of long continuance."

(1574.) Beueficially as this system of paying farm-servants in kind has long operated both for master and servant, it has been stigmatized by persons even in Parliament, as being only another form of the trick-system, which has been made to act so prejudicially against the interests of operatives in England. But what is the truck-system? After hearing the proper answer to this question, we shall be the better able to judge whether the plowman's wages paid in kind can truly receive that appellation. Of the truck-system, Mr. McCulloch says that it is "a name given to a 
practice that has prevailed, particularly in the mining and manafactaring districts, of paying the wages of workmen in goods instead of money. The plan has been for the master to establish warehouses or shops; and the workmen in their employment have either got their wages accounted for to them by supplies of goods from such dep $6 t s$, without receiving any money; or they have got the money, with a tacit or express understanding that they were to resort to the warehouses or shops of their masters for such articles as they were furnished with." If this be anything like a correct account of the properly reprobated system, it is clear that it bas no affinity to the aystem in kind, in which the binds are paid their wages, inasmuch as this has no reference to the moriey value of any article which the hinds receive, and therefore they always receive the same amount of kind, and of course the same rate of wages; whereas the truck-system has undoubted reference to the money value of the articles dealt out to, or purchased by, the operatives; and that money value is fixed by the master whose interest it is, of course, to keep it at as high a rate as practicable, or else to give out articles of inferior quality at the price of those of more value; and hence the artisan does not always receive the same amount of goods, nor the same rate of wages.

\section{CORN MARKETS.}

- Thus all is here in motion, all is life;

The creaking wain brings copious stores of corn."

Drer.

(1575.) The surplus grain of the farm is disposed of to corn-merchants, millers, bakers, distillers, and brewers. These attend on the market-day in the market-town. If the market-town is a seaport, most of the cornmerchants and brewers reside in it permanently, and have their granaries there. When the market-town is situate in the interior of the country, the merchants and brewers attend the market there from the nearest seaport. The purchase of grain is chiefly carried on in winter, when the farmer has his crop to dispose of. Brewers and distillers chiefly buy barley for malting, millers and bakers chiefly wheat and oats, and merchants every species of grain. The market for barley commences the season, wheat and oats being then disposed of according to the demand for them; but after March the demand for both increases, to supply the consumptiou until next harvest. In a corn district, from which most of the produce is carried away to large towns or manufacturing districts, it is most convenient for the shipment of grain that corn-merchants reside in seaport towns.

(1576.) Corn markets are of two kinds, stock or sample markets. A sample-market is that in which farmers bring hand samples of the grain they wish to dispose of, exhibit them to purchasers, and deliver the stock or bulk at an appointed time.

(1577.) A stock market is where farmers bring in the grain they have to sell in bulk upon their carts, exhibit a bagfull of it, sell the quantity brought, deliver it to the purchasers immediately after the sale is effected, and then receive the money for it. A merchant who sells grain in a stock-market does so by sample, and never thinks of bringing his stock, which perhaps consists of granaries-full, to the market-place; and there is nothing to prevent farmers also to sell their grain by sample in a stock-market.

(1578.) When sold by sample, the grain is delivered by the farmer in his own carts in the course of the few days allowed him for the purpose, either at the granaries of the merchant, brewer, or distiller, or at the mill of the miller. Water-proof tarpaulins are required to cover the sacks in the carts when grain is delivered in a a rainy day, but it is better to defer the delivery until fair weather, if not otherwise inconvenient.

* McCulloch's Commercial Dictionary, art. Truck-System.

(100) 
(1579.) When sold in bulk, corn is delivered immediately after the sale at the granaries of the merchants on the spot, or at the brewery, or distillery. or mill in the country, according to agreement.

(1580.) The payment for grain sold by sample is only made on the marketday after the delivery has been effected; but the payment of that sold in bulk is due, and is generally received, on the day it is sold, soon after its delivery at the granaries.

(1581.) Of the two modes of selling grain, each has its advantages and disadvantages to the farmer. It is very convenient to take a quantity of grain to market, sell it, deliver it on the spot, and receive the cash for it immedidiately afterward. It enables the farmer to transact his market business at once, and saves him the trouble of attending next market-day on purpose to receive the cash, when he may have no other occasion to be there. It obliges, in a great degree, merchants to provide granaries for the reception of grain in the interior market-towns; as farmers may refuse to deal with a purchaser who wishes the grain delivered at a distance from the market-town, the fatigue to their horses being thereby probably much increased. This mode of selling grain has also the advantage of securing the farmer against bad debts, because he may deliver the grain and receive the value for it simultaneously. On the other hand, it is attended with this great disadvantage, that in case the farmer does not sell his grain on the day he has brought it to the market-place, be is either obliged to take it home again, or put it into a granary until the next market-day, when, of course, granary-rent must be incurred, and the additional expense also incurred of either hiring carts to deliver the grain next market-day, from the temporary granary to that of his purchaser, or of sending a cart of his own to do it; and as he must keep the grain so accommodated in sacks, he may be deprived of the use of his sacks at a time when he may have a large quantity of corn in his barn to measure up, and which, where lying in a loose state, may be an inconvenience. Or to avoid these manifold and obvious inconveniences he must take the price offered for his grain. Another disadvantage is, that his horses must stand in the market-place, exposed for hours to cold blasts, after perhaps being heated on their way to the market-town. The exhibition of corn in bulk gives power, however, to the purchaser to inspect the cleaning of every sack before purchasing it, and it also gives him the command of a quantity of corn immediately after its purchase.

(1582.) The advantages of a hand sample-market to the farmer are, that he is independent of the rate of price of any market-day; for if it does not satisfy him, he can put his sample into his pocket again. His men and horses cannot lose a day's work, and are not exposed to the weather in waiting in the market-place. He need not, moreover, clean his grain before selling it, and should he be induced to sell more than what is threshed, he has time to thresh more and clean the whole quantity at once, thereby making the stock of uniform quality, and cleaned agreeably to the particular taste of the purchaser. The disadvantages to the farmer are inability to receive cash for the grain he sells until the next market-day after its delivery, and the risk he thereby runs of incurring bad debts with the merchant, to whom the stock is delivered some days before he pays for it. The advantage of a sample-maricet to the merchant is, that should the sample please him, he can purchase as large a quantity of grain as the farmer pleases to dispose of, and thus make up a cargo of uniform quality: and the disadvantage which he experiences, which, by the way, is felt most strongly by the brewer, distiller and miller, is that he cannot obtain possession of the grain immediately after purchase. 
(1583.) Of the two species of corn-markets, I prefer selling by the sample, chicfly because I dislike to see horses standing for hours with a load in the market-place, and most probably in bad weather, for none clse can be looked for in winter. Such a stand cannot be for their advantage, and, in my estimation, the peculiar advantages of a stock-market are insufficient to counterbalance the risk thus incurred in the safety of the horses. This inconvenience is perhaps appreciated by some farmers, and a modification of the plan is followed, such as delivery in the course of a few days of a larger quantity of grain than what was actually presented in the marketplace; but no modification can take place of the sale of grain by sample, in that it is simply the presentation of the hand sample in the market, the sale of the bulk therewith, and its consequent delivery at the specified time. It would be curious to observe the particular diseases to which horses are most liable, that are made to stand in a market-place for hours together, and to ascertain if these are of the class most commonly contracted from exposure to weather.

(1584.) Were all men honest, it would be immaterial which mode were adopted for the sale of grain, in so far as the state of the grain is concerned; but to the shame of the farmer be it spoken, it sometimes happens that the stock is delivered of an inferior quality, or not so well cleaned as the sample that was shown in the market. Some farmers acquire a character for this species of fraud, and so blinded do they become by their cupidity, that they cannot discover the advantage which they thereby confer on the merchant to reduce the price of the bargain made between them. It is curious that men cannot at once believe that ill-cleaned corn cannot be so heavy, bulk for bulk, as well-cleaned. While such people, therefore, think they are taking advantage of the merchant by giving him light corn among the good, they are in fact cheating themselves, for no purchaser will pay the stipulated price of good corn when ill-cleaned corn is delivered to him instead. Many farmers, I apprehend, deliver stock inferior to sample, from no intention of committing fraud, but because they cannot deliver the stock so clean as the sample shown, it having been differently treated from the stock. They are in the habit of pulling out a sample from the stack, rubbing out the grain from the ears, blowing away the chaff with the mouth, and picking out the light corn. Now no winnowing machine can clean corn in this style. Or a sample is taken from the unwinnowed bin on the barn-floor, and treated in a similar manner. Sample and stock can only agree exactly when both are derived from a similar state of the same parcel of grain.

(1585.) On the other hand, I must say, in justice to the farmer, that some corn-merchants are very fastidious on receiving stocks of grain that have been sold them by sample. The stock is objected to at the granary, because it is inferior to the sample; and when this plea cannot be substantiated on comparison, the bulk is declared deficient in measure, which objection cannot be rebutted without measuring over the whole quantity, and on this being done, and this objection also proving groundless, it is rejected because the grain is lighter than that guarantied by the farmer. But the object is to set up the grain anyhow, to give the merchant an opportunity to reduce its price. To show how such a circumstance as this can happen, I may observe that the merchant seldom witnesses the delivery of grain at his granaries, this duty being deputed to the man who has charge of the granaries, and its delivery cannot of course be witnessed by the farmer. So if the merchant's foreman receive the clue to make objections, these are easily made to appear effective to the farm-servants delivering the grain, who of course know nothing of the conditions of the bargain. The (102) 
corn is then set up, that is, set down in the sacks on the floor, and remains there unemptied until an explanation takes place; on which, if the farmet has committed an error, he suffers a considerable reduction in price, but if he can maintain his own rectitude, the merchant concedes the point, and throws the blame on his stupid foreman, who, after all, is justified for the interruption he had given, by the allegation that he had only done his duty to his master. I have heard of both these species of fraud being attempted to be committed, and have also heard a remark connected with one of them, that merchants are most likely to be fastidious in regard to the quality of the grain they receive, when prices happen to fall between the period of purchase and that of delivery. Unfortunately, no such motive can be urged to justify the farmer in his attempts to pass off inferior grain. In a stockmarket no such occurrence can happen. Let me say here, that my sole object in alluding to so painful a subject is to make you aware of the tricks of trade.

(1586.) Every species of grain is directed by the Weights and Measures Act, (5th Geo. IV., c. 74, sec. 15,) to be sold by the imperial bushel, containing 2,218.192 cubic inches, and not $2,150.42$ cubic inches, as erroneously given in that paragraph, this latter number being the contents of the old Winchester bushel, which is now obsolete, and there is no such recognized quantity as a quarter, boll, coom, or load. The practice has settled into measuring grain into half-quarter sacks of 4 bushels, which forms a convenient size of load in the barn, as well for carriage on men's backs as in carts, Plate XVIII.

(1587.) Granaries in town are frequently situate in inconvenient places for access to carts, such as narrow streets and lanes; and some are so inconveniently high that four or five flights of steps have to be surmounted ere the floor be attained which is to contain the corn; and these stairs are not unfrequently too narrow or too steep, or the steps so worn away in front as to endanger the safety of the persons who carry loads up them. But the risk is fully greater to those who have to bring loads down them, when the contents of the granary are emptying for the loading of a ship. For the carriage of corn in such a case, I have seen a convenient form of bag used. It consisted of a short sack, capable of holding rather more than two bushels, drawn together at the bottom, where a short piece of thick pliable rope is attached, the mouth being formed like any other sack. The person who is to carry the bag, folds the mouth together when filled so as to cover the corn, and at the same time leaves a portion of the sack loose, by which he holds firmly with his right hand. On assistance being given him to lift the sack, when filled, he turns himself quickly round with his back to it, and brings the part by which he holds on, over his head; and holding on there with one or both hands, as he chooses and feels most convenient in the circumstances, literally runs with the load to the ship's hold, where, on a man seizing the short rope at the bottom of the sack, the carrier hitches the sack off his back, and the grain is poured into the hold, while the man all the time retains hold of the short rope.

(1588.) For long in Scotland, grain used to be sold by measure alone, and for long it used to be sold in Ireland by weight alone; but both ways are liable to objection. When the measure alone is used, there is a temptation to measure the corn before it is properly cleaned, especially if the corn is sold; and when sold alone by weight, there is also a temptation to retain light corn among the good, with the view, in both cases, of disposing of the inferior grain at as good a price as the fine. But a check has of late years been establisherl against both species of fraud, by a statement of the weight along with the bulk. Merchants know the weight (103) 
of grain by its appearance and feel, and therefore, by trying the weight of a 4-bushel sack, they can easily ascertain whether the grain is in as clean a state throughout the whole bag as at its mouth. But the introduction of the weight has given rise to a species of deceitful dealing as regards the public. The purchaser offers a certain price for every so many pounds weight of grain, without direct reference to the contents of the bushel; and some farmers are induced to sell on this plan, in the vain hope of being able to boast that they have sold their grain at such a price, wishing it to be believed that the price applies to the true quarter, when in fact it is given for so many pounds weight, and to deliver the number of pounds for the specified sum the bushel is heaped. This is pitiful work. The fair and common practice is to ask such a price for the grain per quarter, stating its weight by the bushel; and, of course, the heavier the grain, and better the quality, the purchaser will give the higher price for it.

(1589.) The asual denominations of corn measures, based upon the imperial bushel, the standard of capacity, are these ;

\begin{tabular}{|c|c|c|c|c|c|}
\hline 4 gills & $=1$ pint, & contain & $34 ?$ & cubic & inches. \\
\hline 2 pints & $=1$ quart & .. & $69 \mathrm{k}$ & -. & .. \\
\hline 4 quarts & $=1$ gallon, & . & 277 & .. & .. \\
\hline gallons & $=1$ peck, & $\cdots$ & $554 \frac{2}{3}$ & $\cdots$ & \# \\
\hline cks & $=1$ busbel, & $\ldots$ & 22183 & . & \\
\hline ashels & $=1$ quarter & -. & $10 \frac{1}{4}$ & ॥ & feet. \\
\hline arers & $=1$ load, & . & $51 \frac{1}{4}$ & .. & . \\
\hline
\end{tabular}

(1590.) In regard to the sale of corn, these settled points in law mav prove neeful for you to know. "In sale by sample, the buyer may decline the bargain, if the bulk does not correspond with the sample (Parker, 4 Barn. and Ald., 387). The delivery of the sample does not transfer the property of the bulk (Hill, Jan. 26, 1785, M. 4200). The price must consist in current money, either of Great Britain or some foreign country, which has a determinate value put apon it by the tacit consent of the State; if in goods it will be barter and not sale ; and if illusory, it will be donation. The price must be certain, as well as the subject sold. It is generally tixed by the parties themselves at striking the bargain. Where a purchaser of oats, payable on delivery, temporized with the seller, and delayed to take delivery for a fortnight. during which period the price of oats rose, it was held that he was not entitled to delivery to demand delivery (Craig. May $29,1823,2 \mathrm{~S}$. D. 347). . . . In sales of grain, the price is sometimes fixed by the Sheriff's fiars. In the case of Leslie (Jan. 27, 1714, M. 1419 and 1678), where there was an agreement to purchase grain without a price specified, it was held, inter alia, that fars' prices may be presumed the sale between landlord and tenant; and that merchants are presumed to contract according to the current prices of the country where the bargain is made. As to the risk of the sale after the subject is sold, the loss is to the purchaser, as in the case of Campbell (July 15, 1748, M. 10,071), and in the case of Tarling (1827, 6 Barn. and Cres. 361). But it was held in the case of Milne Feb. 1, 1809, F. C.), that where the seller takes upon himself the delivery of goods at a certain place, it throws the risk of the goods, while in transitu to that place, on the seller. . . Where the seller bas de. layed delivering the subject to the purchaser when bought, he is liable for the risk; but it is not considered delay when the purchaser declines paying the price. Also, when a landed proprietor eells a certain quantity of grain of a particular crop to a merchant, without specifying any particular parcel, and the whole crop is destroyed, the loss is to the seller; but after such quantity of grain is measured, or otherwise prepared for delivery, the risk will be transferred to him: 80 found in the case of Hinde (6 East. 558.) : Erskine, iii. 3. 7." In regard to the landlord "s hypothec over corn, restitution was given in the case of Scot (June 11, 1673. M. 6223.). of corns bought from a tenant while under hypothec. Though, when bought in public market, where they bave been brought in bulk, the purchaser is not liable in restitution; if brought only in samples, the landlord is entitled to restitution. This was held in the case of Smart. Dec. 10, 1793, and Earl of Dalhousie, Feb. $27,1828,6$ B. D. 626 ." * So that a stock-market is safer for a purchaser to buy in. and a sample-market is safer for the hypothec of a landlord.

\section{FORMING OF DUNGHILLS, AND LIQUID-MANURE TANKS.}

"If frost, returning. interrupt the plow,

Then is the time, along the hardened ridge,

To drive manure-"

(1591.) Toward the close of winter, the dung will have accumulated so high in the large courts I and K, figs. 3 and 4, Plate.III. and IV., as to become nearly level with the feeding-troughs $z$, and thereby making them

* The Farmer' Lawyer.

(104) 
inconveniently low for cattle; but before this inconvenience occurs, the dung should be removed and formed into dunghills in the fields intended to he manured in the ensuing season. The court $K$, besides its own litter and the refuse from the corn-barn $C$, contains the litter of the work-horse stable $O$, and the pig-sty $b$; and the court I contains the litter of the servants'-cow byre $Y$, besides its own. The dung from the cows'-court 7 should also be taken away, to save annoyance to cows heavy in calf wading in deep litter; and that from the courts of both the hammels $M$ and $N$, if not from under the sheds, should also be taken away, for the same reason as given above in the case of the courts, that the feeding-troughs become too low, especially in the hammels $\mathbf{M}$ of fattening cattle.

(1591.) I am thus particular in detailing the contents of each court, bccause, differing in their constituent parts, they should be appropriated to the raising of the crop best adapted for each sort of manure. For example, the court $\mathrm{K}$ contains a large proportion of stable-litter, and not a little from that of the pig-sties; so its contents are somewhat of a different nature from those of the court I, which contains nothing but the litter of cattle. If it is desired to raise a large extent of that crop which thrives best with a considerable proportion of horse-dung, the contents of the court $K$ should of course be preferred to that of the other court $I$; and if any crop is best raised with cattle-dung, the contents of the court I and the cows'court $l$ should be used for it. Or should the manure required consist of an average proportion for raising of general crops, then the contents of all the courts should be mixed together. This method of appropriating the dung of a farm is not so much practiced by farmers as it deserves; and it is not urged by me as a mere theoretical suggestion, but as practically being the best mode of appropriating manure to raise each crop to the best advantage. To make my meaning more intelligible, I shall illustrate it in this way. Suppose that carrots were desired tu be raised on a field of light land, then the land should be dunged in the autumn with the contents of the court $K$, because it contains a large proportion of horse-litter. When potatoes are attempted to be raised on heavy soil, which is not their natural one, they most likely to succeed with horse-litter also. Turnips, on the other hand, grow best with cow-dung, and therefore a mixture of the courts $I$ and $l$ would be best for them. Should carrots not be raised, and the soil is naturally favorable to the potato, and therefore horse-dung will not be specially wanted, the best way is to mix all the sorts of dung together, and form dunghills of average properties.

(1592) There is another matter which deserves consideration before the courts are begun to be cleared of their contents; which is the position the dunghill or dunghills should occupy in the field, and this point is determined partly by the form which the surface of the field presents, and partly from the line of access to the field. In considering this point, which is of more importance than it may seem to possess, it should be held as a general rule, that the dunghill should be placed where the horses will have the advantage of going down-hill with the loads from it. Wherever practicable, this rule should never be violated, as facilities afforded to labor in a busy seuson are of the utmost importance. If a field, then, has a uniformly sloping surface, the dunghill should be placed at the upper or highest side, but then the access to the field may only be at the lowest side. And it may be impracticable to reach the upper side by any road. In such a case, the loads should be taken up a ridge of the field; and when a field is so inconveniently placed, frosty weather should be chosen to form the dunghill in it, as the wheels and horse's feet will then have a firm bearing. But should it be found impracticable te lead dung to its upper side, by reason of the 
soft state of the land or steepness of the ascent, then the dunghill should be formed at the side nearest of access. If the field has a round-hacked form, the dunghill should be placed on the top of the hight; and in order to supply the rilges down both slopes from it with manure, a ridge, hy way of head-ridge, should be formed along the crest of the hight, at the time the stubble is plowed. In a level, or nearly a level field, it is immaterial which side the dunghill occupies.

(1594.) The fields to which the dung should be carried, are those to be fallowed the ensuing seasun; that is, set apart for the growth of green crops, such as potatoes and turnips, and for the part which receives more cleaning than a green crop admits of, namely, a bare fallow. The potato culture coming first in order, the land destined for that crop should have its manure carried out and formed into the first dunghill. The turnips next come in hand; and then the bare fallow. The dunghills intended for potatoes and turnips should of course be made respectively of such a size as to manure the extent of land to be occupied by each crop. The manure for bare fallow not being required till much farther on in the sea. son, may be deferred being carried out at present. The proportions and nature of the soils best suited for potato and turnip culture, will be treated when we come to speak of those crops respectively, so that any remarks on these particulars would be irrelevant here.

(1595.) Then the precise spot which a dunghill should occupy in a field is not a matter of indifference. I have seen a dunghill placed in the center of a field which it was intended wholly to manure. From this point, it is obvious, the carts must either traverse every ridge situate between the one that is in the act of being manured and the dunghill, or go direct to a head-ridge, and thence along it to the ridge to be manured. This latter alternative must be adopted if the dung is to be deposited in drills ; for if not, the drills will be much cut up by the passage of the carts across them-a practice which should never be allowed when neat work is iesired. The dunghill should be placed on a head-ridge or a side-ridge of the field; and of these two positions I would prefer the side-ridge, because, when the head-ridge is occupied in the length of a dunghill, the ends of all the ridges abutting against its side camnot be plowed or drilled in their entire length; and if there be more than one dunghill on the same head-ridge, a considerable number of head-ridges may thus be curtailed of their fair proportions. The dunghill on a side-ridge affects only a part of the single ridge which it occupies. Should a field be large and require two dunghills, the one first to be used should be placed along a ridge, at a distance just beyond the space of ground the manure it contains will cover, so that the ridge occupied by it may be plowed to its end hefore it is manured; and the second dunghill should be placed along the farthest off side-ridge. The ridge nccupied by the farthest dunghill can be easily reached at a time when the earth is hard; but should the weather continue fresh, and the ground soft, a dunghill should be made on the sideridge nearest the gateway; and should no frost happen, this dunghill should be made large enough to manure the whole field. A large dunghill in one place will no doubt cause more labor to manure the field at the busy seasun than would two dunghills at different places; hut in soft weather and soil it is better to incur the risk of future inconvenience than allow the horses to drag only a half-load, axle-deep, along a soft headridge. When proper sites can be chosen for dunghills in fields, the losils, in the busy season, will not only be irsured a passage down hill, but 1].e dung be situated at the shortest distance from the place it is wanted, and the plowed and prepared land be uninjured by cart-wheels and horses' feet. (106) 
(1596.) Some consideration is even required in littering the courts, and especially the large courts, I and $K$. No one would believe that any care is requisite in laying down straw in a court; but those who have witnessed the inconvenience and loss of time incurred in removing dung from courts will easily perceive that this may be the case. The courts are usually cleared during frost, when time is erroneously regarded of little value, and when, as our motto implies, the plow is rendered useless; but notwithstanding this common opinion, a loss of a small portion of time, even at this season, may have a material effect upon some future operations. For example: the hard state of the ground may favor the carriage of manure to a distant field, to gain which, most of the time is spent upon the road. Suppose frost continued as long as to allow time to carry as much manure as would serve the whole field, provided ordinary diligence were used, and no interruption met with in the courts. Suppose farther, on manuring the field in summer there was found to be less manure in the dunghills by a small quantity than was wanted, and that half-a-day, or at most a whole day's driving from the steading would supply the requisite quantity, it is clear that the day's driving could have been accomplished in frost at much less trouble than at the season when the manure was wanted. But this sacrifice of time must be made at the instant, or the field be deprived of its just proportion of reanure. This is no hypothetical case; it has occurred in every farmer's experience. Now, what is the primary cause of this dilemma? Either too much time had been spent upon the road in driving the manure, or much interruption had been experienced in the courts. To which of these two causes should the waste of time be ascribed? With regard to driving, farm-horses get into so regular a pace upon the road at all times, that little loss or gain of time can be calculated on in this particular; and besides, when a head of carts is employed at any work, every one must maintain its position in the routine, otherwise it will either be overtaken by the one behind, or be left far behind by the one before. The probability, therefore, is that the loss of time is incurred in the courts, and for this reason. The usual mode of taking away wetted litter from the work-horse stable is to roll it together with a graip, and then to throw it into a barrow, in which it is wheeled into the court, and there emptied on any spot to get quit of it in the shortest time, and left in heaps to be trampled down by the cattle. Back-loads of thatchings of stacks, some of which are not very dry, are carried into these same courts, put down anywhere, and partially spread. Long straw-ropes, which bound down the thatching of stacks, are pulled along the top of the litter. In doing all this, and it is not all done at one time, no plan is followed with the view of facilitating the lifting of the straw afterward, but as if it was to remain there always; but so far from this being the case, it is again lifted before it becomes short by fermentation, and there is considerable difficulty in doing so. Long, damp straw is seized in one part by a graip, and the other parts, being coiled in the heap it was first laid down, cannot be separated without much exertion on the part of the plowman, pulling it this way and that; and it is too soft to admit of its being cut with the dung-knife. Another graip encounters a long straw-rope, which, after much tugging, is broken or pulled out, and thrown upon the cart with its ends dangling over. In short, not a single graipfull is easily raised, and the business is not expedited when a heap of chaff evades the action of the graip. Add to this the few hands generally sent to assist the plowman to fill the carts, and the consequent time spent by the team in the court, and some idea may be formed of the causes which incur much loss of time in this necessary work. It is easy to conceive that in this way as much time (107) 
might be lost in cleaning all the courts as would give all the carts a half or whole day's driving, which was just what was required to remove the inconvenience felt when the field was manuring. The only method of preventing the recurrence of so great delay in carrying out manure is to put down the litter so as it may be easily lifted, and to afford as much assistance in the court as to detain the horses but a short time, and rather keep them moving on the road; for though their walking was constant in a short winter day, it will not overcome them with fatigue.

(1597.) The litter should be laid down in this manner in the large courts $\mathbf{I}$ and $\mathbf{K}$. On fixing on the gate of the court through which the loaded carts should pass to the nearest road to the fields requiring the manure in the ensuing season, and after covering the ground of the court evenly with straw, the litter should be laid above it in small quantities at a time, beginning at the end of the court farthest from that gate. The litter should be spread with the slope of its lower part toward the gate, and carried gradually forward every day until it reaches the gate; and every kind of litter, whether from the work-horse stable, the stack-yard, or straw-barn, should be intermixed and treated in the same manner. The straw-ropes, as I mentioned before, should be cut into small pieces and spread about. Thus layer above layer is laid, until they form a mass of manureof sufficient hight to be carried out and formed into durghills in the fields.

(1598.) When the time has arrived for emptying the carts, the process is begun at the gate through which the loaded carts are to pass, and, on lifting the litter it will come up in sloping layers, having an inclination from the ground to the top of the dung-heap, not in entire layers of the whole depth of the dung-heap, but in successive small, detached layers, one above the other, and succeeding one after the other, from the gate to the farther end of the court. The empty cart enters the court by the other gate, and, without turning, takes up the position of the loaded cart before it, which has just passed through the gate appointed for it. When there is only one gate to a court, and the court not very large, and a large lot of beasts in it, it is better for the empty cart to wait on the outside until the loaded one has gone away. When the court is large, with only one gate, the empty cart should go in and turn round to succeed the one that is being filled. On dropping work at mid-day, it will save time at starting again after dinner, to fill the first cart returning empty from the field, that has not time to reach it again loaded and return before dinner-time, and to allow it to stand loaded, but without horses, until the time for yoking, when the horses are put into it, and the first load thus started for the field immediately at the hour of yoking.

(1599.) On clearing a court, or any part of it, it should he cleared to the ground; because the manure made from a dung-heap that has been simultaneousiy formed, will be more uniform in its texture than that made from a heap composed of new dry straw on the top, and old wet straw at the bottom. Besides, it is much better for the future comfort of the cattle, that the court receive its fresh dry littering from the bottom, than if the wet bottoming were retained.

(1600.) Sometimes cattle get injured by a cart or horse when the court is emptying, and, to avoid this risk, it is not a bad plan to confine them under the shed as long as the people are at work in the court. The mode of confining the $\mathrm{m}$ in the shed I have already alluded to in (18).

(1601.) On forming a dunghill in the field, some art is requisite. One of a breadth of 15 feet, and of four or five times that length, and of proportionate hight, will contain as much manure as should be taken from one spot in manuring a field quickly. Suppose that $\mathbf{1 5}$ feet is fixed upon for (108) 
the width, the first carts should lay their loads down at the nearest end of the future dunghill, in a row across the whole width, and these loads should not be spread thin. Thus load after load is laid down in succession upon the ground maintaining the fixed breadth, and passing over the loads previously laid down. After the bottom of the dunghill has thus been formed of the desired breadth and length, the farther end is then made up with layer after layer, until a gradual slope is formed from its nearest to its farthest extremity. This is done with a view to effecting two purposes, one to afford an easy slope for the loaded carts to ascend, the other to give ease of draught, for horses ard carts to move along the dunghill in all parts, in order to compress it firmly. Every cart-load laid down above the bottom layer is spread around, in order to mix the different kinds of dung together, and to give a uniform texture to the manure. To effect this purpose the better, a field-worker should be employed to spread the loads on the dunghill, as they are laid down. When the farther end has reached the hight the dunghill is thought will contain of the desired quantity of manure, that hight is brought forward toward the nearest end; but the center of the dunghill will necessarily have the greatest elevation, because a slope at both ends is required to allow the carts to surmount the dung. hill and then to come off it. It is an essential point to have the whole dunghill equally compressed, with the view of making the manure of similar quality throughout. After the carting is over, the scattered portions of dung around the dunghill should be thrown upon the top, and the top itself leveled along and across its surface.

(1602.). The object aimed at by the compression of the dunghill by the loaded carts, is to prevent immediate fermentation. So long as the temperature continues at its average degree in winter of $45^{\circ}$, there is little chance of much action in the interior of a dunghill; but toward spring, when the temperature increases, it may be expected to show symptoms of action, but even then a temperature of $65^{\circ}$ is required to begin the second stage of fermentation. Some advocate the covering of dunghills in the field with a thick layer of earth, with the view to exclude the air and check fermentation; but such an expedient is unnecessary in the coldest months of winter, though it would be of service in spring to a dunghill which is not to be turned until the season is still farther advanced. Others lay up the dunghill in a loose manner at once in graipfulls from each cart-load, giring the dung in fact a turning, and then cover it with earth, and trim round the sides with the spade. This form of dunghill looks neat, and, if the manure is to be used early, it is a good plan for obtaining it partially fermented for an early crop, such as beans; but for dung that is to be used at an advanced period of the season, when the temperature will have gradually increased to a considerable hight during the day, the process is too promotive of rapid fermentation.

(1603.) The litter in the courts of the hammels, and especially in those of the hammels $M$, will be found much more compressed than that in the large courts $I$ and $K$, in consequence of heavy cattle being obliged to move over it frequently within a limited space. It is sometimes so compressed as almost to resist the entrance of the graip. To enable it to be easily lifted, it should be cut in parallel portions with an implement called the dung-spade, fig. 308. This consists of a heart-shaped blade of steel thinned to a

Fig. 308.

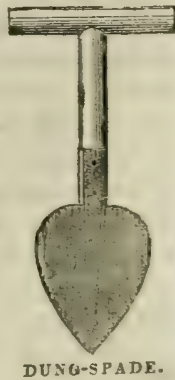
slıarp edge along both sides; and its helve with a cross-head is fastened with nails in a split socket. The hight of the spade is 3 feet, length of (109) 
cross-head 18 inches, length of helve 18 inches, length of blade 16 inches, and breadtb 10 inches. It is kept sharp with a scythe-stone. In using this spade, it is lifted up with both hands by the cross-head, and its point thrust with force into the dung-heap, and it is then used like a common spade while rutting turf, with the foot upon the upper part of the blade. This part, it will be observed, is rounded and not left square with ears like a common spade, because when this spade is used to cut a dung-heap of greater depth than the length of its blade, the round edge is not so apt to catch the litter as square ears, on the instrument being pulled up. A man's strength is required to use this spade effectively, a woman's arms being too weak for the purpose. Another form of instrument for cutting dung is like the common hay-knife, and is used in like same manner, and which will be figured afterward; but it is not so efficient as this instrument, as will be shown when we come to speak of the cutting of hay in spring.

(1604.) It is a practice of some farmers to keep the dung from the cowbyres in a loose state in the court. A space in the center of a court is inclosed with a stout wall 3 or 4 feet in hight, into which the dung is wheeled as it comes from the byre, and the dung-heap is accumulated to the hight of the wall, or even more, by means of a plank as a roadway for the barrow to ascend. The dung managed in this way never requires turning, and soon becomes in a state fit for use for potatoes or turnips. This plan saves the trouble of turning the dung, but this saving is not unattended with a disadvantage, for the dung must be led direct from the court to the field at a season when labor is precious, and when the field to be manured is far off, the extra time spent in leading out the manure to it may more than counterbalance any saving in the cost of turning. This dung, might, it is true, always be reserved for the nearest field, but even the nearest may be at a considerable distance.

(1605.) Of late years the method of carting out a dunghill as described in (1601) has been objected to, because it is alleged that many of the gases useful to vegetation are thereby dissipated. I do not see the strength of this objection in the winter season, when certainly no decomposing process can naturally originate or proceed. The water contained in the dunghill, it is true, may begin to evaporate at a very low temperature, even below $50^{\circ}$, but what harm can accrue from this? But as the fact is, that fermented dung must be prepared for some species of crops, of what avail would means to prevent fermentation be at a period not earlier than would be required to begin to ferment the manure so as it may be sufficiently so. when applied? To obviate waste arising from fermentation, it has been theoretically suggested to make dunghills under sheds instead of in the open air: but how the mere screening afforded by a shed should prevent fermentation, though it may ward off rain, and keep the straw drier, and thereby retard fermentation, I cannot imagine. If the mode is proposed solely with the view to keep the litter dry, its fermentation will no doubt be retarded, but dry litter will never make good manure, as the usual state of litrer under sheds can testify, which is in a state approaching to being fire-fanged, as it is termed, that is, in a smouldering, heated state. Until a better mode of making dunghills in the fields shall prove the present one erronenus, we must continue to follow it, encouraged by the success which has hitherto attended it.

(1606.) An ingenious suggestion has been made by Mr. Kirk, Preston Mains, East-Lothian, to check the spread of the seeds of weeds among manure. His suggestion is founded on the general law of the growth of plants, that certain classes of soils affect certain classes of plants. The suggestion is (110) 
to put the manure of the straw obtained from one kind of soil on another kind of soil. Thus, the straw obtained from clay soil, that is, wheat land, should be made into manure and applied to soil of light quality, that is, turnip soil; and as, according to this law, natural plants, called by farmers weeds, which throve upon the clay soil, would not do so upon the light, it appears to be within the power of the farmer to prevent, or at least to check, the propagation of weeds. Putting this suggestion into practice would be attended with some difficulty, for although Mr. Kirk seems to think it easy "to make all the straw grown on one kind of soil into manure by itself," and which, he conceives, "might be accomplished with very little additional trouble to the farmer, where several hammels are employed in the feeding of cattle,"* yet in large courts it would be almost impracticable to prevent the mixture of straw of one stack off clay land with that of the succeeding one perhaps off light land; and even in the small courts of hammels it would not be easy to devise a plan by which a stack of straw off clay land should be used in them, while straw from light was in use for litter in other courts ; and besides, the best fodder being obtained off light land, the cattle while using it could not be littered with straw off clay land, without running the risk of destroying the object in view. The suggestion, however, being founded on correct theory, might be subjected to experiment, which alone can ascertain its practicability.

(1607.) Immediately after a rainy day, when the land is in such a state of wetness as to prevent any work upon it, and the horses have nothing particular to do upon the road, two or three of the men should each take a mud-hoe or harle, such as in fig. 309 , and rake the loose straws and liquid

Fig. 309.

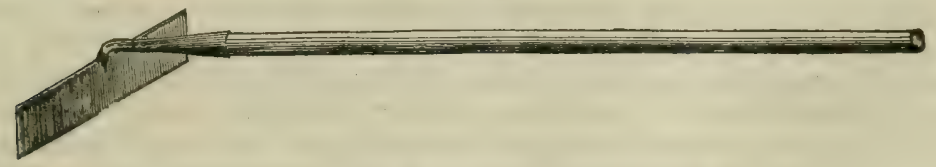

THE MUD-HOE OR HARLE.

mud on all the roads around the steading to the lowest side of the roads, and as much as possible out of the way of carts and people passing along; while the rest should take graips, fig. 257 , and shovels, figs. 149 and 176 , and form the raked matter into heaps, to be led away when it will bear lifting to the compost heap or field, as may best suit the purpose at the time. Where there is plenty of straw, as on carse-farms, some farmers put it upon the roads around the steading, to be trampled down and become wetted with rain, and then lead it away to the dunghill in the field. The object aimed at in so far as wetting the straw is attained, but such a littering makes walking upon the roads very damp and plashy. The best state for roads near steadings in winter is to have their surface hard and smooth, and with such an inclination as to cause the water to run easily away into some ditch hard by. A scraping now and then with the mudhoe will make such a road dry and comfortable.

(1608.) I must now say a few words on tanks, liquid manure, and compost heaps. In fig. 4, Plate IV., may be seen the liquid-manure tank $k^{\prime}$, great in length and in breadth, inside narrow, and its depth under the soles of the liquid-manure drains should not exceed 4 feet, for the reasons given below, its length being only extended to increase its capacity. The

* Quarterly Journal of Agriculture, vol, viii.

(111) 
drains are marked by dotted lines from the tank toward $x$, in all directions, preserving them straight as practicable. Drains in straight lines, for a sluggish liquid, present fewer obstructions in their course than curved or angular ones. The form and dimensions of these drains may be seen in fig. 26, and (75 2d). At $x$, fig. 4, Plate IV., is an opening over the drains to allow the liquid manure to descend into them, and every such opening is protected by a grating such as is figured and described in fig. 25 ind (75 1st). The liquid manure percolates through the grating, passes along the drains, and finds its way into the tank, out of which it is pumped with a cast-iron pump (76) into a liquid-manure cart, described below in fig. 310 , in which it is carried to the field and distributed over its surface.

(1609.) Tanks need not be built on every species of farm. On carse-farms, where there is much straw and little green food, there can be no liquid manure; and on pastoral-farms the stock confined in winter in the steading are too limited in number to afford much of that material. On dairyfarms, on the other hand, where many cows are maintained and much green food consumed by them in byres, tanks might be constructed with advantage to the grass land. The practice of the farmers of Flanders might be usefully followed on such farms by having a small tank constructed under ground in connection with every byre, and the contents of which might be enriched with additions of rape-cake and other valuable ingredients. The enriched contents, employed as a top-dressing on fasture and forage land, appropriated to the support of the cows, might increase their produce very considerably. In collecting liquid manure on farms of mixed husbandry, if the steading is properly furnished with conveniences and the stock well supplied with litter, I do not see much can be done. I had a tank of 12 feet in diameter and 4 feet deep, connected with wellplanned courts by neatly-built drains provided with good gratings; and, at the same time, I had the courts defended from being deluged with rainwater by capacious rain-water spouts, and care taken that the cattle were always provided with a sufficient quantity of litter; having all thesewhich every well-constructed and well-conducted steading should never want-I can say that the tank was not filled in the course of the season above three times, a quantity not worth while providing a liquid-manure cart to take it to the field; and even this small quantity was solely ascribable to heavy rains and melting snows, for a few days, falling directly into the courts, and causing a surplus of water which was readily conveyed into the tank by the drains. The usual supply of the liquid manure came merely in a few drops from the sole of the drain into which all the other drains immerged. The sole was only 4 feet above the bottom, and, except after rain or snow, the liquid manure never reached that hight. I conceive that a small tank might be usefully constructed by a cotter possessing a small piece of ground, or large garden, and a cow, provided the cow were fed within doors in all seasons with green and soft food, as an excellent means of collecting manure that would otherwise be lost. Mr. Milburn, Thorpefield, Thirsk, mentions " an instance of a small receptacle of this kind, where the owner has but one pig; he manages, however, by its aid in his garden to grow astonishing crops, and his garden produce is both earlier and superior to most of his neighbors." There is no quesfion that much may be done in this way at farm-houses, hinds' houses, and villages, to collect matter, both solid and liquid, that would make valuable manure. A necessary might easily be constructed in connection with the liquid-manure tank at a steading to receive the supply.

(1610.) Tanks need not be expensively constructed. Mr. Milburn gives this statement as the expense of constructing a tank dug out of the ground (112) 
$13 \frac{1}{2}$ feet in length, $6 \frac{1}{2}$ feet in width, and 6 feet deep, inside measure, with brick in length and mortar, and plastered with Roman cement :

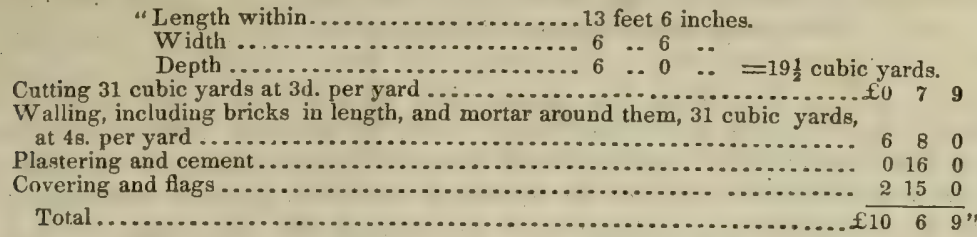

"A tank," continues Mr. Milburn, " might be made under a shed, and composed of clay, and covered with slabs or boarding, or any refuse boarding. The expense of such a receptacle would be somewhere as under, dimensions the same as in the preceding case, viz:

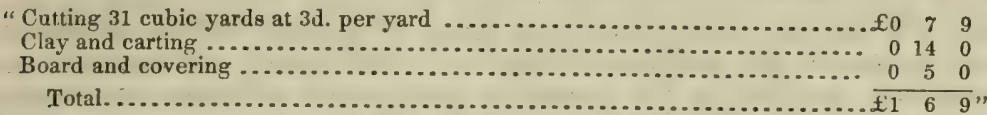

A tank of this nature, Mr. Milburn suspects, would be subject to suffer in frosty and in very dry weather, as well as be liable to be perforated by worms. The frost and drouth are serious objections to this particular construction of tank; but the worms might be prevented perforating the clay, were a little quicklime mixed with it ;* but the true principles on which all tanks should be constructed are stated bclow.

(1611.) Winter is considered a favorable period for the application of liquid manure, both because it is then most abundant, and because the ground is in that loose and moistened state which readily receives and allows the liquid to incorporate with it. Any evaporation at that season is very limited, and is solely confined to the water contained in this liquid, and does not affect its more solid parts. Liquid manure may be applied either to grass or to bare soil, but is preferred for the former. It is distributed over its surface in the manner described under fig. 310 , and the quantity required is from 800 to 1,200 gallons the imperial acre. Its effects are sensibly felt both on old pasture, new grass, and on meadow; but where the quantity of the liquid is small, I would prefer applying it to the small paddocks, which are to be found on most farms, and which are usually in pasture and appropriated as a hospital, breeding-ground, or a place of safety for young stock. The results of the application of liquid manure are best appreciated in summer, in which season we will revert to the subject.

(1612.) The space of ground adjoining the liquid-manure tank is a good site for the formation of composts of various kinds. Winter is not a favorable season for making composts, fermentation being then in a dormant state. I may state here, however, in general terms, that the carriage of mould, as the principal ingredient of a compost, is a laborious piece of work. Such a compost is best made on the spot where the soil is found; but when the foundation of a new building of any kind affords mould which would be removed at any rate, it should be used in compost, and will well repay the trouble of removal. Other materials than mould may, and indeed must, be carried, to form bases for composts, such as saw-dust, spent tanners'-bark, boggy turfing that had been cast in summer and left to dry. These may be mixed with lime, or other fermentable substances, or beneficially watered with liquid manure. The haulm of potatoes, couch-

* Prize Essays of the Highland and Agricultural Society, vol. xiv.
\[ (113) \ldots . . .5 \] 
grass gathered from the fallow-ground in summer, dried leaves, and other vegetable refuse, form valuable and substantial ingredients for composts, and when placed beside the tank may be enriched with liquid manure.

(1613.) On laying down haulms of potatoes or quicken for conopost, it is usual to throw down the loads without the least regard to order, because the excuse is, that when the potato crop is taken up, every hand is too busily employed to do other things; and in summer, every hand is also put into requisition to gather weeds from fallow-ground. In as far as the potato crop is taken up and the weeds gathered in a proper manner, there can be no objection; but these are no reasons why the refuse created by these operations should be neglected and cause future labor and expense. The usual practice is to throw down the haulms and quickens in haste, and leave them in unequal masses to produce unequal decomposition. Instead of this, a field-laborer should be stationed at the compost-stance to throw them up with a graip into a heap of regular shape, when the materials will not only occupy the least space of ground, but be in the best state to receive any additions of liquid or solid matter, and when the most perishable portions of the materials are covered with the more durable, they are placed in the best state to preserve their properties. The neglect I complain of, of apparently unimportant materials, arises from this cause. There is too frequently a great tendency in farmers and stewards, when conducting labor in fields, to do what they consider the least important part of the work in a hasty and unthinking manner, evidently forgetting that correction of hasty work always creates afterward more labor than the part of the work for which it was neglected is probably worth. Many instances might be given of this sort of tuo-handed uork, as it is termed, that is, work which has to be done over again; but I shall confine myself to the case before us. For example, were a field-worker or two placed at the spot where the haulms of potatoes are carried to form a future compost-heap, they could form it according to previous instructions from the cart-loads as they were thrown down; and in this way, when the carritge of the refuse was finished, so would also be the nucleus of the future compost-heap. But if the same materials are laid down at random in a scattered and confused manner by plowmen anxious to get quit of their loads. considerably more labor will be required to place them in the same form of heap; and to do it equally well, more hands and longer time will be required; hecause the materials have not only to be separated from a confused and compressed state, but to be collected together from a distance into the confined space upon which the heap is desired to be formed. Thus, 1 woman, favorably placed, will throw up with a light graip as much loose material, laid down before her in a small quantity at a time, as 3 or 4 women would place the same quantity and in the same position of materials thrown down and scattered as I have described them.

(1614.) Winter is the season which supplies the greatest quantity of scaweed for manure. On farms adjoining the sea-coast, this manure is carefully collected whenever it is thrown upon the shore after a storm, or by a heavy ground-swell of the sea. Sea-weed is very succulent, and feels mucilaginous, and when, exposed to the summer's sun, is easily dried to $\frac{1}{3}$ its bulk, so little solid matter is contained in it. There are 4 species very common on our coast, and these are the Laminaria saccharina, consisting of a single linear elliptic leaf, without any mid-rib : the Laminaria digitata, or common tangle, a cylindrical stem, sometimes as thick as a walkingstick, and about 2 feet long: the Fucus resciculosus, consisting of a double stem with the edges of the leaf entire, and in the disk of which, near the edges, are immersed a number of air-bladders-or crackers, as they are (114) 
vulgarly called-about the size of a hazel-nut, and the use of which seems. to be to cause the leaf to float in water: and the Halidrys siliquosa, consisting of a waved coriaceous stalk about 4 feet long, greatly branched, dark olive when fresh, but quite black when dry; is also furnished with air-bladders or crackers.

(1615.) The constitution of these plants is very complicated, affording no fewer that 21 ingredients. The first species, Laminaria saccharina, afforded the following substances to the analysis of Gaultier de Claubry in 1815 :

A saccharine matter-manna.

Mucilage, in considerable quantity

Vegetable atbumen.

Green coloring matter.

Oxalate of potash.

Malate of potash.

Sulphate of potash.

Sulphate of magnesia.

Muriate of potash.

Muriate of soda.

Muriate of magnesia.
Hyposulphite of soda.

Carbonate of potash.

Carbonate of soda.

Hydriodate of potash.

Silica.

Subphosphate of lime.

Subphosphate of magnesia.

Oxide of iron, probably united with phosphoric acid.

Oxalate of lime.

The composition of the other species, together with the Fucus serratuswhich is like the $F$. vesciculosus, but without air-bladders-and the chorca flum, or thread tangle, is very similar to the one here given.*

(1616.) Sea-weed is applied in a fresh state to grass land that is intended to be plowed up for a crop, and it is laid on as thick as to cover the ground. Being applied in winter it does not soon become dry, and the rain and snow that may happen to fall upon it carries the saline ingredients with which it is accompanied into the ground, or among the roots of the grass. The large quantity of mucilage which sea-weed contains, and the numerous salts which it affords, may be the causes of its utility as a top-dressing and as an active manure. It has been recommended to dry sea-weed for the sake of being easily carried into the interior of the country; but this trouble seems unnecessary, because winter, when it is most abundant, is an unfavorable season to dry it, and because there is no more cast ashore than can easily be used by the farms adjoining the coast. On combustion in a certain way, sea-weed yields an impure alkaline substance called kelp, which is used as a mannre. So long as this substance was used in the arts, it was too expensive for a manure; but its manufacture was stopped some years ago by the introduction of foreign barilla; and its value as a manure is not so well known as to induce the resumption of that manufacture. Many thousands of persons were employed at one time on the shores of the main land and islands of Scotland, in the manufacture of kelp, who are now deprived of that employment. The same substance is manufactured on the coast of Normandy, and sold by the name of varec. Sea-weed, when burned in the open air, leaves ashes, which afford most of the inorganic substances mentioned in the above analysis.

(1617.) [The Liquid-manure Cart, for the economical distribution of this valuable manure, the natural production of the farmstead, is now taking its due place among the machinery of the farm. The water-cart has been very long in use for the conveyance of water, when the supply of that necessary element for household use bas been distant from the steading ; and the liquid-manure cart is its offspring, modified by certain additions to adapt it to this change of purpose. The water-cart is usually the naked bed-frame of a cart, mounted on wheels, and surmounted with a cask of a capacity suited to the demands of the establishment. The cask is furnished with a funnel inserted in or attached immediately over the bung-hole; and it it is likewise furnished with a spigot or with a stopcock, inserted into that end of the cask which hangs over the back of the cart. When the water cart bas been drawn to the fountain or the pond from which water is to be conveyed, it is filled either by means of a common pump, raised so high as to deliver the water which it lifts into the funnel of the cask, or the water is lifted with the hand by means of a scoop, having a helve of sufficient length to enable the workman to reach the pond on the one band and the funnel on the other. The scoop best adapted to this purpose is a small wooden pitcher, about 8 inches in deptt

- Thomson's Organic Chemistry, Vegetables.

(115) 
and 10 inches in diameter. the helve passing through its sides in an oblique direction, and a little above its center of gravity.

(1618.) The liquid-manure cart, as most commonly used, differs very litte from the above, ex cept in its being provided with the distribating apparatus in place of the spigot; but in larce estab. lishmeato the cask is superseded by a covered rectangular cistern or tank, which takes the place of a conmon cart-body. The watering of public streets and highways has induced the necessity of the rectancular tank for the distribution of water over the surface of roads, because of the erse with which, by this constraction, a greater quantity of water can be pat apon one pair of wheela. Here the quantity of water to a given surface is mach greater than in the case of a liquid manure, and bence the propriety of a capacious tank for the distribution of water on streen, while the same principle, (economy in the expense) leads to the propriety of employing a smaller and less expensive vessel for the distribution of liquid manure, which will not in general be super. abundant. For a liquid-manure cart. a cask of 120 or 140 gallons contents will be found more economical in first cost than a rectangular tank, and as these machines can be only occasionally in operation, they will, if not very carefully attended to, become leaky while standing unoccupied. In this respect the cask will have a manifest advantage over the tank, for the tightening of a cask is an operation the most simple, by the act of driving ap the hoops, while, in the case of the tank becoming leaky, no means of that kind can be resorted to, and the alternative is, either soaking it in water till the wood has imbibed as much of the fluid as will expand its substance and close the leaks, or the vessel must be tightened by some more expensive process. As the more econumical of the two, therefore, in point of expense, $\tilde{I}$ bave chosen the cask-mounted cart for the illustration. Fig. 310 is a representation in perspective of this cart, of the simplest and most convenient construc. tion. For the more easy means of filling the cask, it is suspended between the shafts of the cart, and this position requires the bending of the axle to nearly a semicircle. The cart is a mere skeleton. consisting of the shafts $a$ a. which for this purpose may be made of red pine, their length being about 14 feet. They are connected by a fore and hind bar, placed at such distance as will just admit the length of the cask, while the width between the shafts is suited to the diam. eter of it. The axle, as already noticed. is bent downward to nearly a simicircle, to receive the cask, and its length will of course be greater than the common cart-axle; even the distance between the caddy-bolts, in a straight line, will be usually greater, but this will depend on the

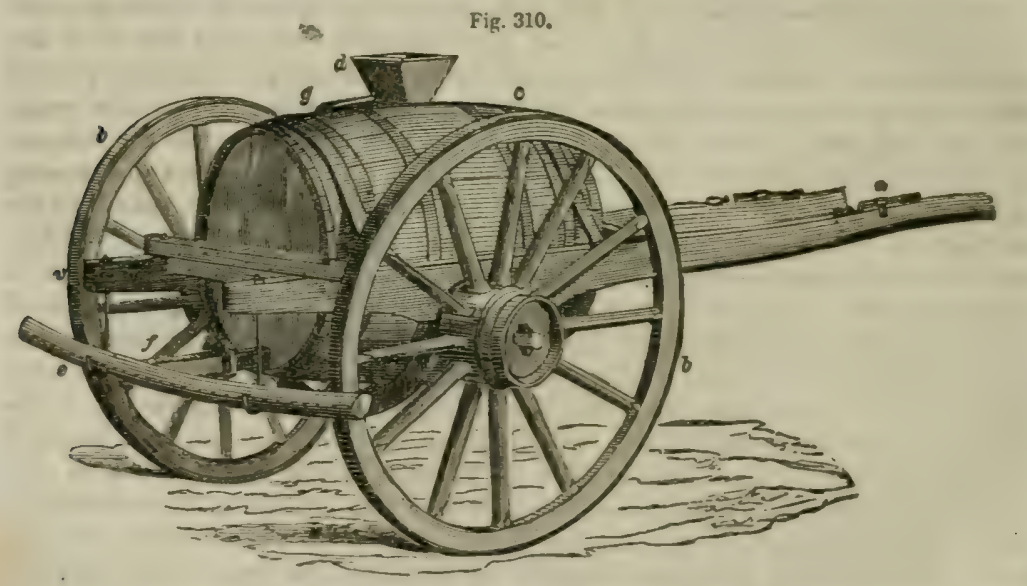

THE LTQUIDMANCRE CART.

diameter of the cask. A pair of common, broad cart-wheels, $b \quad b$, are fitted to the axle. The cask $c$ is suspended on two straps of hoop-iron, 2 inches broad, the ends of which are bolted to the shafts, and the same bolts pass also through the ends of two lighter straps, which pass over, and secure the cask firmly in its place. The funnel or hopper $d$ is asually fixed apon the top of the cask over the bunghole, or it may be inserted therein by means of an attached pipe. The distributor $e$ may be made of sheet-copper, of cast.iron or malleable iron. or even of wood; the copper will be found the most durable, and it should be at least 1-20 of an inch in thickness. The next best is the patent malleable iron tube; enst.iron, thongh sometimes used. is not to be recommended; neither is wood desirable, from its liability to choke. The bore of the distributor should be not less than 2 inches, nor is it required to exceed $2 \frac{1}{2}$ inches, the length from 7 to $7 \frac{1}{2}$ feet, and slightly bent with a uniform curvature, which last property causes it to cover a wider surface of ground than it wonla do if stralkht. But in giving the distributor its carvature, care must be taken to avoid increasing the curvature toward the ends, as is sometimes done, to the prevention of uniform distribution of the manure. The ends of the tube must be closed with movable covers, acrewed or otherwise fixed, that they may be removed at pleasure, for the purpose of sponging out the tube when it happens to get clogged up with any solid matter. A line of perforations is made along the hinder side of the tnbe for the discharge of the fluid: these should be at the distance of 1 inch apart, and their opening aboat $\frac{1}{s}$ inch diameter. As the area of these discharging orifices cannot be altered at pleasure, nor their amount of discharge altered for any given time, it becomes (116) 
necessary, in distributing any given quantity per acre, to regulate that quantity by increasing or diminishing the rate of traveling the cart over the ground. The distributor is attached to the cask by means of a stem $f$ of the same materials and bore as the main tube, and it enters the end of the cask close to the lower chime. A stop-cock is frequently put upon the stem $f$ to regulate the discharge, and for this purpose it is very beneficial, serving in a great measure to regulate the quantity per acre, but for the entire setting off or on of the supply, the stem $f$ opeus into a small chamber inside the cask, which chamber is closed by a flap-valve heavily loaded. This valve when closed stops the discharge, and when lifted the fluid has a free passage to the distributor. The opening of the valve is effected by a small chain attached to the flap, rising to the top of the cask at $g$, where it passes over a emall roller, and onward to the fore-part of the cart on the nigh side, where it hangs at hand for the carter to set off or on at pleasure. Fig. 311 is a section of part of the cask, and showing the chamber and valve; $f$ is again the stem of the distributor, $h$ a stop-cock, $i$ the chamber, and $k$ the valve, which is the common leather flap or clack-valve well loaded with lead, $c c$ is part of the cask, $l$ the chain attached to the valve, and passing over the roller $m$.*

(1619.) When the liquid-manure cart is furnished with a tank, the latter can, with equal facility, be placed low for the convenience of filling; thus the axle may be cracked, as in the Liverpool dray-cart, the tauk resting on the cranked part of the axle; or the axle may remain straight, and the tank appended below the axle. Such a tank may be conveniently built to contain a ton of the liquid, or about $220 \mathrm{gal}$ -

Fig. 311.

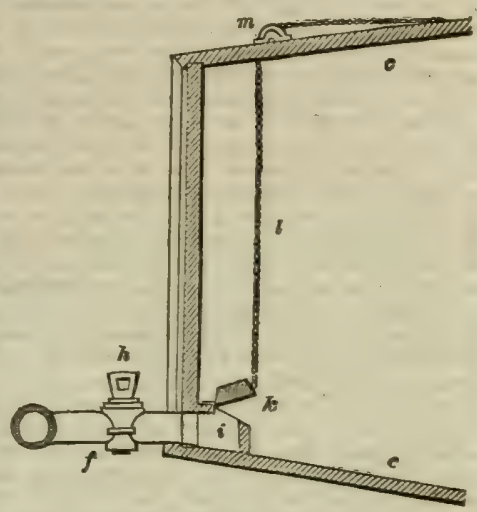

THE APPARATUS FOR REGULATING THE DISCHARGE OF LIQUID MANURE. lons; and the distributing apparatus is the same as for the cask. The prices of these carts vary considerably. partly from construction. and partly from locality. Mr. Crosskil, of Beverley, $£ 25$ as the price of the takk cart. In Scotland the average price may be stated at $£ 18$, and when mounted with a cask $£ 15$ : these prices, of course, including wheels and axle.

(1620.) The cistern for collecting liquid manure in the farmstead, though apparenty simple in its construction, being merely a covered pond or a well, yet serious errors are frequently committec in its formation. The first and most important consideration for the formation of the cistern, is the effect of hydrostatic pressure; inattention to this bas caused the failure of many such cisterns. The liquid we have here to deal with, like all other fluids, acts on the bottom and sides of the vessel or body that contains it, with a pressure directly in proportion to the depth at which the fluid stands, without reference to either length or breadth; that is to say, suppose a cistern whose bottom is 12 inches square, and its depth 10 feet, filled with water, every square inch in the bottom will suffer a pressure equal to the hight of a column of water whose base is one inch square and 10 feet. or 120 inches, in hight. The weight of such a column will be $4 \frac{1}{2} \mathrm{lbs}$. nearly, and this would be exerted on every square inch on the bottom, or the whole pressure on the bottom would be $625 \mathrm{lbs}$. the weight of 10 cubic feet of water. There is a natural law that goverus the pressure of fluids, which shows us that they press equally in all direciions, downward. liorizontally, and even upward, the last arising from the general statical law, that "action and reüction are equal and in opposite directions." It follows, from these hydrostatical laws, that the lowermost portion of each side of our supposed cistern will suffer a pressure from the water equal to that which acts upon the bottom; hence, taking the lowermost inch in the hight of the sides of this cistern, it will be pressed with a force of $52 \frac{1}{2} \mathrm{lbs}$. or thereby, or $4 \frac{1}{2}$ lbs. on the square inch, and each of the four sides will suffer the same pressure. Suppose, now, that the cistern is elongated in one direction to any number of feet, and again filled to the depth of $10 \mathrm{feet}$, the pressure on each square foot of the bottom remains the same as before, and so in like manner does it remain the same upon the sides, for the pressure is not altered in any direction, altbough the proportion of the cistern has been changed. Keeping this in view, it will be seen that length and breadth produce no effect on the pressures that a fluid exerts against the vessel or body that retains it, and that in calculating the resistance to sustain such pressures, depth is the only element requiring to be taken into account. It is also to be kept in view that pressure on the bottom or sides is directly as the depth: thus, if our supposed cistern were reduced to 5 feet in depth, the pressure on the bottom would only be one-half, or $2 \frac{1}{4} \mathrm{lbs}$. on each square inch. $\dagger$

[* As few persons will be at the expense of a cart like this, we recommend the plan of that used at Mr. Wilkinson's Agricultural Institute in Dutchess County, which is found to "work well." Directions for making it.-Make an extra portable bottom to the common horse or ox cart, of $1 \frac{1}{3}$-inch plank, fastened together by battings on the under side, and groove the upper side longitudinally with $\frac{1}{2}$-inch grooves $\frac{1}{2}$ inch deep, every inch and a half over the entire surface. On this set a hogshead on stocks, and tap the front head, and the liquid will spread over the whole grooved bottom, and by having the back end of the cart the lowest, the liquid will be equally distributed over the land.

Ed. Farm. Lib.]

[ + Must it not occur here to every reader that these are principles which ought to be taught at all our country schools, and with which every farmer's son shuuld be familiar? Suppose a dam to be made, and (117) 
(1621.) The conclusion to be drawn from these remarks is that a cistern in the form of a pit or well should be always avoided, unless it can be formed in a natural bed of impervious clay. When such a substratum can be attained, a pit may be adopted, but not otherwise. If such has been found, and the pit dug out, it should be lined with brick, or with stone built in mortar, the bottom being tirst lined with the same material. When the building approaches to the surface, the wall can gradually be reduced in diameter to a small compass, leaving only an opening of 2 to 3 feet square, which is covered in at small expense, and the saving in this last item is the only apparent advantage that seems to attend the practice of pit-cisterns. Deep cisterns are iiable to another inconvenience, of their becoming recipients of spring or of drainage-water; and it is sometimes more difficult to keep such water out than to keep the proper liquid in, for if springs and their origin lay at considerable hights, their hydrostatic pressure may be so great as to render the prevention of access to their products a process of great difficulty.

(1622.) A cistern of moderate depth, not exceeding 4 feet below the out fall of the drains, may be constructed in any situation, whether in gravel or in clay, and its length can be extended so as as to aftiord any required capacity; the breadth being restricted to that for which materials for covering i: can be most easily obtained. which may be from 3 to 4 feet. Whatever be the stratum in which such a cistern is to be formed. (unless it be perfectly impervious clay,) it should be puddled to the thickness of at least 1 foot with the best clay that can be procured. For this purpose the earthy matters are to be dug nut to a depth of $1 \frac{1}{2}$ feet lower than the intended sole, and to a width of four feet more than that proposed fur the cistern. Two or three thin layers of the prepared clay are then to be compactly laid over the whole breadih of the excavation, and beaten firmly together at all points, making up the depth to 1 foot, and the surface of it brought to a uni form level. Upon this the side-walls are to be founded, and these may be of brick 9 inches in thickness, or of flat bedded rubble-stone 14 inches. The wall should be built in successive courses of about 1 foot in hight, the whole being bedded in mortar, and, as each course is completed, the puddle is to be carefully laid and beaten in behind, in layers of 6 inches or thereby, the first layer being properly incorporated with the foundation puddle, and each succeeding layer with the one immediately preceding it. To prevent the side-walls from being pushed inward by the pressure of the puddle or of the bank, tie-walls of brick or of stone should be formed at every 5 feet of the length of the cistern. These may be 9 inches of brick or 14 inches of stone; and they must have conduits formed at the level of the sole, to allow the liquid to run toward the pump. The sole should be laid all over with brick set on edge, or with strong pavement, the whole having a slight declivity toward one end, where a small well-hole of 9 inches in depth is to be formed to receive the bottom of the pump. The brick, or pavement, as the case may be. is to be bedded on the puddle, and grouted flush in the joints with mortar; and when the walls and sole are built up, they should then be pointed in every joint with Roman cement. The covering is to be effected with strong pavement, of length sufficient to rest on the side-walls, laid and jointed with mortar; or with rough found-stones, where such can be procured, and if neither can conveniently be found, a beam of good sound Memel fir may be laid along the middle of the cistern, resting on the tie-walls, and with this bearer, stones of half the length will be sufficient to form a cover. A thin layer of clay may be laid over the stone covers, and upon that a coat of gravel, by which means carts may be allowed to pass over it. To prevent accident, however, it is always desirable to construct the cistern in a situation where it will be as little as possible exposed to the transit of carts; and this may be always obtained at a small additional expense of covered drain to convey the manure from the dunghills to the cistern.

(1623.) The pump for lifting the liquid from the cistern to the cart may be either of wood or cast-iron, but the latter is preferable. A common sucking pump of $3 \frac{1}{2}$ inches chamber is quite sufficient; the chamber should be hored out, and the pump.boxes, for durability, should be also of metal, with leathern flap-valves. The hight of the pump should be such as to deliver the liquid freely into the funnel of the barrel, or tank; but if this hight is found to raise the pump-lever above the reach of a man's hand, it is only necessary to joint a light connecting-rod to the lever. its lower end being furnished with a cross handle, and by these means the pump-man will be able to work the pump in the same manner as the lower end of the common pit-saw. Forcing and lifting pumps have been proposed and even employed for the purpose we have here in view, though with questionable propriety; and here it may be proper to explain, that by the term force-pump is to be understood a pump that raises water to any hight above the point where the power is applied, by the descent of a solid piston acting in the chamber of the pump, sending the liquid into an ascending pipe, which springs from below the piston. The lifting-pump differs from this in having a valved piston through which the liquid passes, as in the sucking-pump, on the descent of the piston; and, on its ascent, the valve being now closed, the liquid is lifted and forced into the ascending pipe, which, in this case, springs from above the piston, the chamber being closed at top with a water-tight stufling-box. From this brief description the simplicity, both in construction and in management, of the sucking or common pump, as compared with the other two, will be obvious; the cost being also in favor of the first.-J. S.]

water to be collected for a mill, or fish, or, as ought to be the case on every farm, for an ice pond ; how prevalent is the common notion that water covering a large surface would require a strong, wide dum! yet here it is seen that if it covered fifty acres, the lateral presare would be no greatur than if it covered but fify superficial yards. What we menn to intimate is, what is suggested by every part of this book, and by common reflection $t o$ every thinking mind-the wonder that the landed interest of the United States does not insiat in the catablishment of institutions by the General Guvernment, similar to that at West Point-not for the inatruction of all directly, for that would be impracticable-but for the instruction of eachers, who might be qualified to reach these plain practical principles to as many boys as the military offices can teach the Manual Exercise to the militin. The knowledge taught by the latter may be highly useful where it should alone be used to repel invasion and to suppress insurection-whereas that tankt by honorable and well instructed civil tutors would greatly augment the best sort of power that any na tion can possess-the civilizing and blesed poner of Knomoledge. We aball wait anxiously to hear the pow. erful voice of Governor W RIGHT on this subject, in his Agricultural Address at Saratoga, in Beptember. 


\title{
7. WINTER IRRIGATION.
}

\author{
"Hence Irrigation's power at first was learnt, \\ A custom ancient, yet but rarely used \\ In cold and watery climes; though even there \\ No mode of melioration has been found \\ of more effect, or with more ease obtained."
}

Grafam.

(1624.) It is not my purpose here to describe the mode of making irrigated meadows; that being a summer occupation, it will be attended to in due time. At present I shall only describe the watering of meadows in winter. Suppose, then, that the meadows have been formed in a proper manner, and every channel cleaned with proper care, let us at once proceed to let on the water, and regulate its duration so as not only to preserve the vitality of the plants, but to promote their vegetation at an earlier period than the natural call of the season would arouse into action. As the late Mr. George Stephens knew the irrigation of land well, I shall use his words in describing the management of water on meadows in winter. I shall only premise that there are two kinds of water-meadows, one called the bed-work, in which the ground is made to decline gently, and the water to flow in the direction of the inclination. The other kind is called catchwork, which is only suited to ground having a considerable declivity, and by which the water is brought across the face of the declivity. The object aimed at in both kinds is the greater production of grass. Irrigation, therefore, is one mode of manuring grass-land.

(1625.) "'The whole works," as Mr. Stephens directs, "being repaired, and there being generally water enough at this season either for the whole or for part, the sluice should be drawn, when, in the course of half an hour, the conductor and the upper part of the feeders will be nearly filled. The first operation of the irrigator is to adjust the water in the conductor; or, if the meadow is in more parts than one, the water in each conductor must be first regulated. Then he commences anew by regulating the stops in the first feeder; but should there not be sufficient water in the feeder, a little more must be let in, by making the aperture wider or deeper, till the water flows regularly over the sides from one end to the other. From the first he proceeds to the second feeder, and so on, until the water in all the feeders is adjusted. Let the beds of a water-meadow be ever so well formed, yet, by some places sinking more than others, or by the ice raising the surface of the ground, although the water along the banks of the feeders has been ever so nicely adjusted, it often happens that there may be some places between the feeders and drains with too little water, when it will be advisable for the manager to make a third round, redressing inequalities of the surface so as to give every spot 1 inch deep of water. Every part of the works being regulated, the water should be allowed to run through the whole of October, November, December and January, from 15 to 20 days at a time without intermission. At the expiration of each of these periods, the ground should be made completely dry for 5 or 6 days, to give it air; for there are few species of the grasses which form the most nutritive part of the herbage of water-meadows, that will long exist under an entire immersion of water. Moreover, if the frost should be severe, and the water begin to freeze, the watering must be discontinued, 
otherwise the whole surface will became one sheet of ice; and, whenever the ice takes hold of the ground, it will undoubtedly draw it into heaps, which is very injurious to plants." "The object of this early watering of the meadows is to take advantage of the autumnal floods, which bring along with them a variety of putrescent matter, which is found very enriching to land. It is the chief object of the irrigator in those months to collect as much of this manure as possible, and at the same time to shelter the land from the severity of frosty nights. It is therefore requisite to use as much water as the land will carry without guttering. I believe it would be difficult to give land, with a dry subsoil and considerable descent, too much water before the weather begins to get warm. It is necessary in those months that the meadows be inspected at least once in 3 or 4 days, to see that the equal distribution of the water is not obstructed by the accumulation of weeds," \&c.

(1626.) Simple as these directions are, yet the actual management of the water of meadows is not unattended with difficulty, but requires the exercise of good judgment and great attention. "The adjustment of water flowing over the surface of land," remarks Mr. Stephens, "for the purpose of improving the herbage, is a very nice operation; it requires a perfect knowledge of levels and the vegetation of grasses, and ought never to be intrusted to an unskillful munager. When the supply of water is, in any state of the stream that supplies it, sufficient for the whole or one-half of the meadow at once, the management becomes pretty easy; for after the works are cleaned, and the water regulated in the autumn, the sluices should be fixed at such a hight as to let in the exact quantity required, when it is allowed to run according to the state of the weather and the season of the year, for $2,6,10$, or 15 days, without any alteration ; and it will be found (unless the water has carried along with it weeds, sticks, or wreck of any kind) to run during that whole period nearly as equally over the surface as when first put on. But when the stream is small, and rising and falling with every shower of rain, the management becomes so much the more difficult that it will require every possible attention of the irrigator to watch and change the water from one part of the meadow to another, or from one bed to another, according to its abundance or deficiency. Such meadows are indeed ill-managed, although half an hour's work in a day would put everything to rights. Indeed, let the formation of the meadow be ever so perfect, and the supply of water constant and uniform, yet it is necessary that the manager should survey the whole every 3 or 4 days, to remedy any defect occasioned by the accumulation of weeds, or by a stop being washed away, and thereby cause some places to have too much water, and others too little; so that, in the former case, the grasses might either be killed or very much injured by the generation of scum, or, in the latter case, there would be little or no produce of grass. Small streams are certainly much more at command than large; but if the manager, as is too often the case with a young practitioner, vainly endeavor to water too much ground at a time, he may give one part too much water, and another too little; for on the alteration of the apertures, and adjustment of the water, greatly depend not only the quality but the quantity of the crop."

(1627.) There are many ways of mismanaging water-meadows, such as retaining a moist subsoil, or allowing the grass to stand too long before cutting; but there is an error committed at this period of the year, to which I wish to direct your attention, and which is thus characterized by Mr. Stephens. "Another great error generally committed is, allowing the water to run too long at a time, without properly drying the ground. I know some instances where the ground is not attempted to be dried from (120) 
the time the water is put on the meadows in autumn till 8 or 10 days be fore the cutting of the hay; the consequence is that the grass is of the coarsest quality, and the ground becomes so very boggy that the whole crop of grass is obliged to be carried by people to some other place to be made into hay. . . . A water-meadow," adds Mr. Stephens, "like a garden, will be good for little without due attention. All dry soils require more attention than moist ones; for if the water in moist soils should not be so nicely regulated as on sandy or dry land, the crop of grass will not be so defective as on porous soils, where the management has been neglected. I presume that all dry land that has been converted into water-meadows, in countries where the art of irrigation is not well known, and the supply of water not abundant or regular, is liable to more injury, from imperfect treatment, than land of a moist nature, for plants must have their food at stated times as well as animals, but this cannot be the case when the water is irregularly applied."

(1628.) The mode in which water acts in producing the effects witnessed in water-meadows, has not yet been completely ascertained. It is not the sediment in the water that alone works the charm, for clear water produces similar results; though, no doubt, enriching ingredients carried by the water encourage the growth of plants more rapidly than clear water, as witness the produce of foul-water meadows in the neighborhood of Edinburgh. Professor Low has these observations on the theory of the process: "The theory of the process of irrigation," says the Professor, "has not been satisfactorily explained. That the effect is not produced by the mere supply of deficient water, appears not only from the period at which the water is admitted, and when in our climate the soil is always saturated with the fluid, but from the circumstance that the effect is not produced when the water is allowed to stagnate, and sink down in the soil, but when it is kept in a current over it. When the water is suffered to stagnate, the soil tends to produce carices, junci, and other sub-aquatic plants; but when it is kept in motion, and drained off at intervals, the finest grasses peculiar to the soil and climate are produced. Neither does the fact of the deposition of mud, or other fertilizing sediment, explain the phenomenon; for however such depositions may increase the effect, it is likewise found that water, without the least perceptible sediment, may be employed with success. It has been supposed that the water acts beneficially by maintaining the soil at a higher temperature. Water, at a temperature of $40^{\circ}$, is of greater specific gravity than at a lower temperature; and hence as the water tends to the freezing point, the warmer portion of it is next the ground. Much, however, cannot be ascribed to this cause, in a current so shallow and constant as that which passes over the watered meadow. It is probable, therefore, that the main effect is produced by a mechanical action of the water, acting upon and bringing nourishment to the fibrous roots of the plants." $f$

(1629.) Although it may be very true, as Mr. Stephens observes, that " however authors may disagree on this interesting subject (the theory of irrigation), I believe all experimentalists acknowledge that early winter wittering is necessary to produce early and abundant vegetation; in what way this operates is, as to practical purposes, less material ;" $\ddagger$ yet it is always satisfactory to man to be able to give a reason for what he does. To this view I shall add another theory of irrigation, that has been suggested by Professor Rennie, late of King's College, London. It is believed by

* Stephens's Practical Irrigator and Drainer.

† Low's Elements of Practical Agriculture, Edition of 1838.

† Stephens's Practical Irrigator and Drainer. (121) 
some vegetable physiologists that plants excrete certain matter from their roots, which proves inimical to the health of other plants of the same kind. Hence it is concluded that grasses do not continue permanently in a healthy state in the same site, because they are in time injuriously affected by their own excretions, which, encouraging the growth of plants of a different nature, such as mosses, spring up and extirpate the grasses. It is supposed to be probable that every species of grass is not alike affected by its oun, or the excrementitious matter firm other grasses, and therefore some species withstand the poison longer than others. Now the water of irrigation, in its descent through the soil and subsoil, washes away or carries off in solution the injurious excrementitious matter exuded by the grasses, and thereby cleanses the soil in which they are growing, free of it. Hence the perennial verdure of irrigated meadows.*

(1630.) In order to arrive at a satisfactory explanation of this subject, and believing that both this theory, as well as the one given by Sir Humphry Davy referred to by Professor Low, contain truth, I proposed some time ago a conjunction of the two theories; and the compound theory certainly explains the four great points of irrigation, namely, that it supplies moisture to the soil in dry seasons and in tropical climates; it affords protection to plants against the extremes of heat and cold; it disseminates manure in the most minute manner to plants; and it washes away injurious matter from the roots of plants. The benefits derived from irrigation I therefore maintained are purely mechanical, and doubted the correctness of Sir Humphry Davy's opinion when he says that "in the artificial watering of meadows the beneficial effects depend upon many different causes, some chemical, some mechanical," $\nmid$ because chemical action only commences after the act of irrigation has ceased, as the nature of the following particulars attending irrigation will show. No doubt, the effects of the sub. stances, whatever they may be, which are deposited by the water of irrigation, may be chemical, as well as those of manure applied to grass by the hand of man. But the act of the water in depositing fertilizing materials, can be no more chemical than that of the instruments used in spreading dung upon the soil. The truth is, that whenever the water of irrigation, or the substances contained in it, act chemically upon the grass or soil, while subjected to the process, that moment irrigation proves injurious to the plants. The chemical action and the injury are both evinced by the same phenomenon, namely, the existence of white scum floating on the water. "If the weather should be mild," observes Mr. Stephens, " and you suffer the water to run over the meadow too long without intermission, a white scum is generated, which is very destructive to the tender grass." + The particulars of irrigation I referred to are these : "The operation of water bringing matter into minute subdivision; the sediment which it contains when used in irrigation being minutely distributed around the stems of the plants; water protecting plants in irrigation against the extremes of heat and cold, by completely covering and embracing every stem and leaf; and the supplying of moisture to the soil and washing excrementitious matter out of it, are all purely mechanical operations." For, "could the hand of man distribute manure around the roots and stems of grass as minutely and as incessantly as turbid water; could it place a covering of woolen texture upon each blade and around each stem of grass, as completely as water can embrace each plant and keep it warm; could it water the grass as quietly and constantly as the slow current of irrigation; and could it wash away hurtful matter from the soil as delicately from the fibres of the

* (2uarerly Journal of Agrieulture, vol, v.

+ Stephens's Pracical Irrigator and Urainer.

$\uparrow$ Davy' Agricultural Chemistry. 123 , 
ruots of grass as irrigating water, there would be no need of irrigation; the husbandman could then command at will verdant pasturage for his flocks and herds, throughout the year, and in the driest season. His mechanical agency would be as effective as irrigation; but constituted as the relative state of things at present are between man and the action of physical laws, he employs irrigation as an instrument of his will, and induces Nature to assist him in maintaining his live-stock by an application of her peculiar mode of acting, under his own guidance, but in which she undoubtedly displays her superiority over him, both in perseverance and dexterity.'

* Eacyclopædia Britannica, seventh edition, art. Irrrigation. 


\section{S P R I N G.}

"Fled now the sullen murmurs of the North,

The splendid raiment of the BPRING peeps forth;

Her universal green, and the clear $6 \mathrm{ky}$,

Delight still more and more the gazing eye."

BLoOMFIEID.

WE have now deliberated upon every topic which the indoor operations of the farm, as they may be called, have suggested; and their consideration, to a minute degree, has extended our lucubrations rather beyond their prescribed limits; and yet, when every subject, as it presented itself in succession, was new, and claimed attention, not only on its own account, but as possessing a controlling influence upon those which are to follow, it was requisite to examine particularly into the principles upon which they were based, that the consequent subjects dependent on similar principles may be the more easily understood, and treated according to their nature. I earnestly hope that this may be the result of the deliberations which we have had hitherto together; and I would feel somewhat confident of that issue, if you have bestowed that attention upon the subjects treated of, which they really require.

Upon the whole, we have seen that winter is the season of repose, of passive existence, of dormancy, though not of death. Spring calls forth the opposite emotions; it is the season of revivification, of passing into active exertion, of hope, nay of confidence in what we do will succeedof hope ripening into fruition as the eamest of prospective plenty is presented in the reproduction of the herds and flocks, and in the world of life which springs into view immediately after the industrious hand has scattered the seed upon the ground. The joy in contemplating such a prospect to the issue of labor is indescribable. I am unequal to the task of describing it, but would not, if I could, in case of giving you an unsuitable idea of the enjoyment. I would rather that you should go and enjoy the pleasure for yourself; because "the chosen draught, of which every lover of Nature may drink, can be had, in its freshness and purity only at the living fountain of Nature; and if we attempt to fetch it away in the clay pitchers of human description, it loses all its spirit, becomes insipid, and acquires an earthy taste from the clay."

The weather in spring, in the zone we inhabit, is exceedingly variable, alternatiug, at short intervals, from frost to thaw, from rain to snow, from sunshine to cloud, very different from the steady character of the arctic spring, in which the snow melts without rain, and the meads are covered with vernal flowers ere the last traces of wiuter have disappeared. The sky is very clear when the air is free of clouds. The winds are very sharp when coming from the N. or N.E. direction; and they are frequent, blowing strongly sometimes from an eastern and sometimes from a western direction. In the former they are piercing, even though not inclining to frost ; in the latter they are strong, boisterous, squally, and rising at times 
into tremendous hurricanes, in which trees only escape being uprooted in consequence of their leafless state; but by which many a hapless mariner is overtaken and consigned to a watery grave, or dashed without mercy on a rocky shore. The air, when dry, evaporates moisture quickly; and the surface of the ground is as easily dried as wetted. Very frequently snow covers the ground for a time in spring. The severest storms and falls have occurred in February. The memorable falls of the 9th February, 1799, and of the 7th February, 1823, are yet fresh in the recollection of many persons alive, when, for weeks together, the internal communication of the country was entirely stopped. Roads opened up in one direction were again blocked up immediately after by a drift from the opposite direction. There is something truly awful among the hills in a storm of snow in spring. Here is a description of one, true to the life. with all its accompanying prognostics. "One evening, after a day of unwonted tranquillity, dense clouds appear like great snowy mountains in the western part of the horizon, while the few clouds which lie in streaks across the setting sun, are intensely deep in their shadows, and equally bright in their lights As the evening closes in, the clouds disappear, the star's are unusually brilliant, and there is not a breath of air stirring. The old experienced farmer goes out to take his wonted nocturnal survey of the heavens, from which long observation on the same spot has enabled him to form a tolerably correct judgment of what will be the state of the weather in the morning. Two or three meteors-brilliant, but of short duration-shoot along a quadrant of the sky, as if they were so many bright lights of the firmament, dropping from their orbits. He returns and directs his men to prepare for what may happen, as there will certainly be a change of the weather. The air is perfectly tranquil when the family retire to their early pillows, to find that repose which healthful labor sweetens and never misses-

'Till rest delicious chase each transient pain, And new-born vigor swell in every vein.

But just at the turn of the night the South gives way, the North triumphs, and the whirlwind, herald of victory, lays hold of the four corners of the house, and shakes it with the shaking of an earthquake. But the house, like its inhabitants, is made for the storm, and to stand secure and harmless; while the wind thunders in the fields around, every gust roaring louder than another among the leafless branches of the stately trees. In a little its sound is muffled, without being lessened, and the snow is heard battering at the windows for an entrance-but battering in vain. Morning dawns; but every lea and eddy is wreathed up; the snow still darkens the air, and reeks along the curling wreaths as if each were a furnace. For two days and two nights the storm rages with unabated violence; but on the third day the wind has veered more easterly, blows rather feebly, and though the snow falls as thickly, it falls uniformly over the whole surface. This continues for two or three days more; and on the coming of the last of these days, the sun, which has not been visible for nearly a week, looks out just before setting, as if promising a morning visit. The night remains clear, with keen frost, and the wind steady at north, and blowing very gently. The sun rises bright in the morning, the storm is over, and the weather remains unbroken for four or five weeks.

"When the appointed days of the snow-storm are numbered, a disturbance again takes place in the atmosphere, but it is of a different kind from the former. There are little sheets of lightning playing momentarily in the lower atmosphere, and the lustre of the stars is diminished; but still there is no cloud. The wind, however, dies away to a dead calm toward (125) 
evening, and all is ready for the breaking storm. That operation is the first performed by the spring, and we shall horrow the words of the "British Naturalist' wherein to describe it: 'As the spring gets the mastery, which is aided by the condensation which takes place during the night, it rises to a wind, the sound of which cannot be mistaken. The rigidity of trees, window-frames and other wooden fabrics through which it passes is relaxed; the withered grass and reeds, when these are exposed, moisterl: and the rattling and thumping are succeeded by murmuring harmony, in which, compared with the other, there is a good deal of music ; and as the morning advances and the animals come abroad, and man begins to be active, the hard metallic sounds are gone, and there is a softness about Nature. There is always a delightful transparency about the atmosphere, because the little spiculce of ice are gone, and the heat of the air is too much occupied in converting the snow and ice into water, for changing much of that into vapor. When the change is accompanied by rain, it is far more pleasant at the time, and there is a danger, almost a certain one, that the spring will be treacherous; and that, in consequence of the great heat required for melting the snow, and the evaporation of the rain together, frosts will return long before the process of thawing, so comparatively slow, s completed. The slow melting of snow by rain, compared by that of a warm atmosphere which is constantly shifting by the wind, can be easily understood, when it is remembered that the water which falls, even if it had the temperature of the greatest summer heat, would be cooled down to the freezing point in melting half its weight in snow. But as the temperature can only be a little above freezing, the water will have the temperature of $32^{\circ}$ before it has cooled perhaps $\frac{1}{10}$ of its weight; and as the water is a bad conductor of heat, and great part of the action of the oblique rays of the sun reflected away from its surface, a rainy breaking of a storm is almost sure to be followed by frost, if it do not happen when the season is far advanced.' In such a situation, and under such circumstances, the storm not unfrequently passes away in what is emphatically termed a gentle thaw; and when this is the case, the spring comes under the most favorable circumstances. The snow is dissolved by atmospheric influence alone, without any rain from the clouds; although there are generally light clouds hovering about, ready to produce rain if a returning first should render a contest of the elements necessary. Besides its rare pleasantness, the gentle thaw is attended with several beneficial consequences. In the first place, there is no flooding of the low grounds, and no washing of the soil from the more elevated ones; but the snow forms a trough for the discharge of the water into which it is melted, and thus the coldest of the snow-water does not reach the surface of the land. In the second place, the water produced by the melting of the snow sinks gradually into the earth, and the earth has been opened to recoive a greater store than if it had heen pelted by rain during winter. This is occasioned by the radiation of the heat from the lower strata of the earth, which is confined by the snow and turned back again to act upon the eartb. In the third place, this last circumstance produces a beginning of the spring under the shelter of the snow, which could not have taken place with free exposure to the atmosphere. The blade of the plant is protected, and the roots have heat and moisture, and the air is excluded from them. They are thus placed under the most farorable circumstances, and they are stimulated accordingly. The difference in this respect is very consideralile; for if, owing to the action of the wind during the fall, or to any other cause, one portion of a field has been exposed to the air while the frost continued, and another covered by the snow, it will be found that vegeta- 
tion upon the part which the snow covered will be fresh, green and vigorous, long before that upon the exposed part shows any decided signs of action. This, by the way, is the real cause why spring is so rapid, and meets with so few reverses, where the winter is firm and decided, but of moderate length, than it does when the winter is variable. In such a place as we are alluding to, the spring wind usually freshens as the snow disappears ; and this latter quickens the melting of the snow, and dries the surface of the ground. When the clods begin to dry, the lark soars aloft at the streak of dawn, calling the plowmen to their labors. Nor are they backward to obey; for they and their teams have been rested during the storm, and then return to their labor with fresh vigor."** I have been the more induced to give this long extract, as, besides containing a true description of a spring snow-storm, it indicates its prognostics, and the peculiar states in which the atmosphere presents itself at this season.

Spring is a busy season on the farm. The cattle-man, besides continuing his attendance on the fattening cattle, has now the more delicate task of waiting on the cows at calving, and providing comfortable lairs for new dropped calves. The dairy-maid commences her labors, not, it is true, in the peculiar avocations of the dairy, but in rearing calves-the supply of a future herd-which, for a time, are indulged with every drop of milk the cows can yield. The farrows of pigs now claim a share in her solicitude. The shepherd, too, has his painful watchings, day and night, on the lambing ewes; and his solicitude and tenderness for the simple lambs, until they are able to frisk and gambol upon the new grass, is a scene of peculiar interest, and insensibly lead to higher thoughts. "When we see the attention of a judicious shepherd upon these occasions, we cannot refrain from thinking of the unspeakable condescension and kindness of Him who 'feeds his flock like a shepherd, gathers the lambs into his arms and carries them in his bosom, and gently leads those that are with young." The condition of the fields demands attention as well as the reproduction of the stock. The day now affords as many hours for labor as are usually bestowed at any season in the field. The plowmen, therefore, know no rest for at least twelve hours every day, from the time the harrows are yoked for the oat-seed until the potato and turnip crops are sown. The beans first demand the plowman's aid, and then the lea ground, turned over at intervals of fresh weather in winter, is ready, with a due degree of drouth, to receive its allowance of oat-seed. The turnip land, bared as the turnips are consumed by sheep, is now plowed across, or ridged up at once for spring wheat, should the weather be mild and the soil dry enough, or else the ridging is delayed for the barley-seed. The fields containing the fallow land now receive a cross-furrow, in the order of the fallow-crops, the potatoes first, then turnips, and lastly the bare fallow. Grass seeds are now sown among the young autumnal wheat, as well as among the spring wheat and the barley. The field-workers devote their. busy hours to carrying seed to the sower, turning dunghills in preparing manure for the potato and turnip crops, and continuing the barn-work to supply litter for the stock yet confined in the steading, and to prepare the seed-corn for the fields. The hedger now resumes his work of watertabling and scouring ditches, cutting down and breasting old hedges, and taking care to release the sprouting buds of the young. quicks from the face of the hedge-bank, fig. 42 , which he planted at the commencement and during fresh weather in winter. The steward is now on the alert, sees to the promotion of every operation, and intrusts the sowing of the

\footnotetext{
* Mudic's Spring. Since I last had occnsion to quote Mr. Mudie's sentiments on the influence of Win ter, death has seized the hand of him who was so capable of wielding the pen.
} (127) 
crops to none but himself, except a tried hand, such as the skillful hedger. Thus every species of laborer has his work appropriated for him at this busy seasun; and as the work of every one is individually defined, it is scarcely possible for so great a mistake to be committed as that any piece of work should be neglected by all.

The farmer himself now feels that he must be "up and doing ;" his mind becomes stored with plans for future execution; and in order to see them executed at the proper time and in the best manner, he nust now forego all visits, and remain at home for the season; or at most undertake an occasional and hasty journey to the market-town to get quit of surplus grain, should the draughts have a leisure day to deliver it. The business of the fields now requiring constant attendance, his mind as well as body becomes fatigued, and, on taking the fireside after the labors of the day are over, seeks for rest and relaxation rather than mental toil. He should at this season pay particular attention to the state of the weather, by observing the barometric and thermometric changes, and make it a point to observe every external phenumenon that has a bearing upon the changes of the atmosphere, and be guided accordingly in giving his instructions to his people.

During a snow-storm in spring, wild-birds, becoming almost famished, resort to the haunts of man. The robin is a constant visitor, and helps himself with confidence to the crumbs cast out for his use. The male partridge calls in the evening within sight of the house in hopes of obtaining a morsel before collecting his covey together to rest for the night upon the snow. In the severe snow-storm of 1823 , several covies used to approach my own door at sunset, and oftentimes, ere putting down the sheat of barley for their nightly meal, at the root of an old beech-tree, the old cocks reminded me of my hospitality, though that was unnecessary in the circumstances, by their loud crisp-like call, before retiring to rest. I believe that, had it not been for this timely supply of nourishing food, they would all have perished in the severity and length of that memorable storm. Hares came to the very door at sunset, and in the moonlight, to receive what food was set down on purpose for them; and so powerful a tamer is hunger of creatures of the most distant habits, that even the wood-pigeons, in large flocks, used daily to frequent an orchard immediately behind the house to pick the curly greens which had grown so tall as to overtop the snow, their favorite food-the Swedish turnip-being then buried out of reach in the snow. The rooks now make desperate attacks upon stacks, and, if allowed, soon make their way through the thatch. Always making their atrack at the top, they seem to be aware of the exact place where the corn can be most easily reached. The sparrows even burrow in the thatch, and the lively tom-tits, with a strength and perseverance, one slould think, beyond their physical abilities, pull out whole straws from the sides of the stucks, to bring the heads of corn within their reach. Farther on in the season the insect world come into active life in myriads, to serve as food for the feathered tribes. Rooks, with sturdy walk and independent gait, diligently search the ground for them, in the wake of the plow, to feed their young therewith. Tom-tits clamber round every spray of trees which indicate an opening of their floret buds. The swallows at length appear, giving animation to the air, and the stream of migration to the northward betokens the approach of genial weather.

"By the time the season is fairly confirmed, the leisure hours of the cottagers," and of plowmen, who are in fact cottagers of the best condition, are spent, in the evening, " in the pleasing labor, not unaccompanied with amusement, of trimming their little gardens, and getting in their early (128) 
crops. There is no sort of village occupation which men, women, and children set about with greater glee and animation than this; for, independently of the hope of the produce, there is a pleasure to the simple and un. sophisticated heart in 'seeing things grow,' which perhaps they who feel the most are least able to explain. Certain it is, however, that it would he highly desirable, that not only every country laborer, but every artisan in towns, where these are not so large as to prevent the possibility of it, should have a little bit of garden, and should fulfill the duty which devolved on man in a state of innocence, to 'keep it and to dress it.' It is impossible for any one who has not carefully attended to the subject, to be at all aware how strong the tie is which binds man even to a little spot of his native earth, if so be that he can consider it as his own, and that he himself, and those on whom he loves to bestow it, are to enjoy the fruit. This is the very strongest natural hold which binds a poor man to his country, and to all those institutions established for the well-being of society. Show me the cottage, the roses and the honeysuckles on which are neatly trimmed and trained, and the garden behind is well stocked with culinary herbs and a few choice flowers, and I will speedily find you a cottager who never wastes his time or his money, or debases his mind, and learns the broad road which leadeth to destruction,' in the contamination of an ale-house. If the garden is neat, one may rest assured that the cottage, however humble it is, is the abode of contentment and happiness; and that however simple the fare may be, it is wealth and luxury in full store to the inmates, because they are satisfied with it, and grateful for the possession of it."* I believe that the contentment of the lot of the scottish married plowmen, and of the attachment to the farm upon which they serve, may be traced t) the principles evolved in these remarks. No doubt, much yet remains to be done to inculcate on them and their families the advantages of practicing habits of personal and domestic cleanliness. Hinds' houses, in this respect, might be much improved, and which, if they were, an air of tidiness and comfort would attend their dwellings, which at present is generally wanting. A great deal depends on the example of the farmer himself; for while he keeps his garden and shrubbery and little avenue in a slovenly manner, it is not to be expected in servants to evince a desire to excel their master. A farmer's garden gets a trimming twice or thrice ayear, and in the mean season, weeds may riot in it without molestation, and its produce may be plucked as best suits the convenience or caprice of the kitchen-maid. Doubtless, considerable crops of vegetables are raised in these gardens, but more through strength of manure than skill of culture. It is, I am aware, inconvenient to obtain the assistance of the professional gardener in the country when his services may be most wanted; but on a farm on which a hedger is employed, he should be taught as much of gardening as to be able to keep the garden in decent order in the absence of the gardener, whose principal duty should be to crop the ground. A fieldworker now and then would keep the weeds in subjection, and allow both the sun and air a freer access to the growing plants.

Toward the end of spring, the farmer thinks of disposing of his fat cattle; but, should he not be offered the price he considers them to be worth, he keeps them on, and even threatens to put them to grass. The dealer and butcher affect to be shy purchasers at this season, knowing there is plenty of fat stock in the country; but, nevertheless, are unwilling to allow - a prime lot to slip through their hands, and therefore keep a sharp look-out on all the best lots for disposal. The ready means of steam conveyance to

* Mudie's Spring.

(129) .....6 
London for fat stock, gives the farmer a vantage ground in his dealings with the butcher, which the latter now knows well to avail himself of by closing a ready bargain on the best conditions he can make.

This is the season, too, for the letting of grass-parks. These usually helong to landed proprietors, and form a portion of their park and lawn. The ready market which these parks meet with, induces the retention of snch ground in permanent grass, while it places their owners beyond the risk of speculation in the purchase of grazing cattle on their own account. It is not customary for farmers to let their grass-parks, except in the neighborhood of large towns, where cow-feeders and butchers tempt them with high offers, which they except rather than purchase cattle whose feeding may not be repaid. Pasture for grass is, in truth, so convenient for the stock of those classes of people, that they will almost give any rent rather than be deprived of the convenience. In regard to the effect which letting of grass-parks by tenants has on the rights of the landlord, I may mention that his "hypothec extends over the crops and live stock of the tenant, in. cluding horses, cows, sheep, cattle, and every description of stock raised on the farm, but it does not extend to the cattle of others taken in to graze. On this ground, it has been held an irritancy of the lease, should the tenant, instead of stocking the farm, take in cattle to graze, and thereby give the landlord no security for his rent. (Mackye, December 4, 1780, M. 6214)" Facility of obtaining grass-parks in the country is at times useful to the farmer who raises grazing stock, in one of which, at least, he may give them a better bite or warmer shelter than he can perhaps offer on the division of his farm which happens to be in grass.

The landed proprietor has to seek another market in spring, one for his timber, which he annually fells in thinning out his plantations. These sales afford convenient supplies to farmers who may be in want of paling for fencing new hedges, wood for sheep-flakes or stabs, or timber for the erection of shedding for animals, or for implements. They are also serviceahle to country joiners and implement-makers, in supplying them with necessary materials nigh at band. The timber is felled by the owner, and assorted into the sizes and kinds of lots which he knows will best suit the local demand. Prunings and small thinnings are sold as fire-wood, and purchased by villagers who cannot afford to purchase coal, and by farmers who have to supply fuel to bothies. After this resumé of spring-work, let us now particularly consider each operation in its proper order

\section{COWS CALVING AND CALVES.}

"When she has calved, then set the dam aside, And for the tenuer progeny provide."

DETDEN's Vinom.

(1631.) The first great event in spring, on a farm of mixed husbandry, is the calving of the con's; not that this event should not occur till springthough most breeders of farm-stock are anxious to have calves early, particularly bull calves, (1238,) and on that account calves are born as early . as December and January - but by far the greater proportion of the stock of cows are not desired to begin to calve till February, and the season of calving continues in good time till the middle of April; after which, as 
in May, the calves are accounted late, and then seldom retained as a part of the breeding-stock, namely, that portion which is specially set aside to propagate its kind. Reluctance to late calves arises from no objection to their purity of breediug, for earliness or lateness of birth can have no effect in that respect; but chiefly because an early calf possesses the advantage of having passed through its period of milking in time to be supported on grass, as soon as it affords a plentiful supply of food. From 8 to 10 weeks at this season is a period of great anxiety for the state of the cows; and, indeed, till her calving is safely over, the life of the most valuable cow is in jeopardy. Every solicitude, therefore, that can conduce to her passing in safety over this critical period, ought to be cheerfully bestowed.

(1632.) You may remember the treatment which I recommended some time ago for cows in winter, in reference to food and exercise, in (1215) and (1218.) When the cow first shows heavy in calf, which is usually after her sixth month, the litter in the court should not be allowed to become too deep, as over-exertion in walking over soft, loose litter and dung may cause such an excited action of the animal's system, and most probably of the womb, as to make her slip calf-or to slink the calf, as it is usually termed. The litter in a court which is constantly trampled by cattle at freedom, becomes so firm as to afford a good footing; but the case is different in a cows'-court, which is usually filled with loose litter wheeled from the byre; and as it is walked upon only for a short time every day by cows, which, when in calf, are not disposed to roam much about, it never becomes firm. To render the litter as firm as may be under the circumstances, the cattle-man should spread each barrowfull as he wheels it out, taking care to mix a due proportion of the straw with the dung.

(1633.) Cows, as they calve, and after it is considered safe for them to go out in the air again, should not be allowed to go into the court at the same time with those yet to calve; because calved cows soon come into season, as the phrase has it, that is, soon become desirous of the bull; and when they approach this condition there is a very prevalent desire on the part of the other cows to ride upon them, and, what is remarkable, especially of those yet uncalved. As may be supposed, such violent exertions, made on soft litter, are likely to produce injurious results on the uncalved cows, by even causing inversion of the calf in the womb, by bringing on febrile action, or by causing the slipping of the calf. The time of the day at which cows in these different conditions should go out, may be left to the discretion of the cattle-man, who should, however, keep this consideration in view, that as cows, after having calved, become more tender in their habit than before, they should enjoy the best part of the day; for instance, from 12 to 2 o'clock.

(1634.) Cows may be ascertained to be in calf between the fifth and sixth months of their gestation. The calf quickens at between 4 and 5 months; and up to that period no disagreeable change has been caused in the constitution of the cow ; but from this period she becomes subject to several diseases. The calf may be felt, by thrusting the points of the fingers against the flank of the cow, when a hard lump will bound against the abdomen, and the feeling will be communicated to the fingers. Or when a pailfull or two of cold water is drank by the cow, the calf kicks, when a convulsive sort of motion may be observed in the flank, by looking at it from behind, and, if the open hand is then laid upon the space between the flank and udder, this motion may be most distinctly felt. But it is not in every circumstance that the calf can be felt at so early a period of its (131) 
existence; for when it is lying in a natural position in the interinr of the womb it cannot be felt at all; and when it lies near the off or right side of the cow, it is not so easily felt as on the opposite side. So that, although the calf cannot be felt at that early stage, it is no proof that the cow is not in calf. Some cow-dealers show great acuteness in ascertaining whether a cow is in calf. One, whom I knew, that was bred a tailor, told me that when a resinous-looking substance could be drawn from the teats by stripping them firmly, the cow is sure to be pregnant. After this period the flank in the near side fills up, and the general enlargement of the under part of the abdomen affords an unequivocal symptom of pregnancy.

(1635.) The vomb of the cow is a bag of irregular form, having a chamber or division attached to each side called the horns of the womb, and so called, perhaps, because of the form they present in an unimpregnated state, of the large curved horns of a black-faced tup. The womb consists almost entirely of muscular fibres, with a large proportion of blood-vessels, and of cellular matter, which admits of contraction and extension. Its ordinary size in a large cow is about $2 \frac{1}{2}$ feet in length, but when containing a full-grown foetus it is 7 feet in length. This is an extraordinary adaptation to circumstances which the womb possesses, to bear an expansion of 7 feet from about $\frac{1}{3}$ of that length, and yet be capable of performing all its functions. The use of the horns seems to be to form a lair for the calf, and each is occupied by the calf according to its sex. The quey-calf occupies the near, and the bull-calf the off-side horn. So that a quey-calf is more easily felt in the younger stage than the bull-calf; and indeed the latter is frequently not felt at all until the seventh month, when other symptoms afford proofs of pregnancy.

(1636.) The exact time of the cow's calving should be known to the cattle-man as well as by the farmer himself, for the time when she was served by the bull should have been marked down. Although this last circumstance is not a certain proof that the cow is in calf, yet if she passes the period when she should take the bull again without showing symptoms of season, it may be safely inferred that she became in calf at the last serving, from which date should then be calculated the period of gestation, or of rectioning, as it is called. A cow generally goes 9 months, or 273 days, with calf, although the calving is not certain to a day. Nay, she sometimes goes as much as 3 weeks, over her time, but far more fiequently only 9 or 10 days. When a cow passes her reckoning for a number of days, she will be found most commonly to bear a bull-calf.

(1637.) Cows are most liable to the coming down of the calf-bed, to which I formerly referred, $(1300$,) when near the period of calving, between the eighth and ninth months, and, from whatever cause it may originate, the position of the cow in which she lies in her stall should be attended to, by keeping her hind part as high as the fore, by raising the litter. The immediate cause of the protrusion of a part of the womb, is the pressure of the calf's fore-feet and head against that part of it which is opposite to the vaginal passage, and the protrusion mostly occurs when the calf is in its natural position; so that no great danger is to be apprehended from the protrusion, although it is better to use means to prevent its recurrence, which is an unnatural occurrence, than to trust to consequences by over-confidence.

(1638.) Much more care should be bestowed in administering fond to cows near the time of their reckoning, than is generally done; and the care should be proportioned to the state of the animal's condition. When in high condition, there is much risk of inflammary action at the time (132) 
of parturition. It should, therefore be the farmer's care to check every tendency to obesity in time. This may be effected by giving fewer turnips and more fodder than the usual quantity; but some cows when in calf, and have been long dry, will fatten on a small allowance of turnips; and there is this disadvantage of administering food in too dry a state, that it tends to aggravate one of the tendencies of the system you are attempting to check, namely, the inflammatory. Other means must therefore be used, along with a limited allowance of food, and, in as far as medical treatment can be applied to the case, there is nothing so safe as bleeding and laxatives. "Every domestic animal like the cow," observes a very sensible writer on this subject, "is to be considered as by no means living in a state of nature. Like man himself she partakes of civilized life, and of course is subjected to similar infirmities with the human race. The time of gestation is with her a state of indisposition, and every manager of cattle should should be aware of this, and treat her with every attention and care during this time. The actual diseases of gestation are not indeed numerous, but they are frequently very severe, and they occasion always a tendency to slinking, or the cow slipping her calf, As the weight of the calf begins to increase, it will then be necessary to take some precautions, and these precautions will consist in an attention to her diet, air and exercise." "*

(1639.) It is the 8 th and 9 th months that constitute the critical period of a cow in calf. The bulk and weight of the foetus cause disagreeable sensations in the cow, and frequently produce feverish symptoms, the consequence of which is costiveness. The treatment for this is bleeding once or twice, in proportion to the strength and condition of the cow, and the administering of laxative medicine and emollient drinks, such as a dose of $1 \mathrm{lb}$. of Epsom salts with some cordial mixture of ginger and carraway and treacle, in a quart each of warm gruel and sound ale. Turnips, of course, are given, and they have a laxative tendency. Potatoes, too, are recommended ; but I confess I entirely object to giving potatoes to cows at any time, because of their great tendency to produce hoven, of which, if an attack were to overtake a cow far advanced in calf, would either kill the calf in the womb, or cause the cow to slip it. Turnips, though perhaps not of so laxative a nature as potatoes, are yet much safer; though it is quite true that Swedish turnips, at the season of the year when cows calve, are solid in their texture, and have less sap in them, and are therefore more binding in their nature, but on account of these properties they are the better adapted for feeding. In cases of indigestion, consequent on inflammatory action, I have seen the substance of this turnip in the maniplies, or third stomach, squeezed flat like the husks of apples from a ciderpress.

(1640.) Having suffered the loss of two or three cows by costiveness, immediately after calving, I was induced to try oil-cake as a laxative along with the Swedish turnip. The cake was given to the cows for 2 months, one before and one after calving, and its valuable property of keeping the cows in a fine laxative state, and at the same time in high health, was truly satisfactory ; and on continuing the practice every year afterward, a similar mishap never overtook my cows. The quantity given to each cow daily was 4 lbs., at an intermediate time between the feeds of turnips. The time of giving it was as regularly adhered to as that of the turnips, and when the hour arrived, at 10 o'clock in the forenoon, for its distribution, every cow expressed the greatest anxiety for the treat. It was broken to them in

* Skellett on the Parturition of the Cow. (133) 
small pieces with a hammer, which is a tedious manner of breaking it when a number of cattle are supplied with it at a time; but the process can be easily and expeditiously performed by the use of the oil-cake breaker, fig. 264.

(1641.) But the opposite state to obesity is also to be avoided in cows in calf, namely, that of weakness and impoverishment of condition. In such a case, bleeding of course is improper, and the cow should rather have good and nourishing food, such as mashes of boiled barley, and turnips and oilcake, not given in large quantities at a time, but frequently and moderately, with a view of laying on flesh in a gradual manner, and of avoiding the fatal tendency to plethora. I helieve he who gives oil-cake to his cows before and after their calving, as I have recommended, need entertain no apprehension of their safety in as far as regards their calving, in whatever condition they may happen to be, because it proves a laxative to the fat, and a nourishing article of food to the lean cow, and in both secures a proper state of all the parts connected with calving.

(1642.) Slinking, or slipping calf, is both a vexatious occurrence and a great loss to the breeder of stock. It is not only a loss of the calf itself, but the want of it makes a blank in the number of the lot to be brought up in the season, and which must be made up by purchase. And it is a very vexatious occurrence in a cow that is desired to be kept as a brood cow, inasmuch as she never can again be depended upon to bear a living calf, the probability being that she will slip every calf afterward at one time or another of her gestation. Why this should be, has never been satisfactorily explained, though the fact is undoubted. The only plan for the farmer to avoid a future disappointment by such an untoward event, is to draw the milk from the cow as long as she gives it, and then fatten her for the butcher. I had a very fine Short-Horn cow, bred by myself, that slipped her second calf; and not being disposed to trust her again, fed ber off, when she became extraordinary fat, and yielded very superior meat; and this was the only cow I ever had which was a victim to the complaint we are speaking of. This is the same cow that I referred to before, as having yielded so great a quantity of tallow. (1324).

(1643.) The causes of this troublesome complaint are various, arising chiefly, however, from violent exercise, the effect of frights, bruises, and knocks; "but," says Skellett, "a more common cause of slinking than any of them, and which is peculiar on the influence of this animal, is a disagreeable nauseous smell; the cow is remarked to prepossess a very nice and delicate sense of smelling, to that degree that the slinking of one cow is apt, from this circumstance, to be communicated to a great number of the same herd: it has been often known to spread like an infectious disease, and great losses have heen suffered by the cow-feeders from the same." If there is any truth in the last cause mentioned in producing the complaint, and which I believe to be true, as I know that cows are endowed with a very delicate sense of smell, you will require no arguments to convince you of the necessity of keeping everything in a byre occupied by breeding-cows in a clean and wholesome state; to have every particle of filth removed daily from the feeding-troughs before and the urine-gutters behind them; and to have the byre thoroughly ventilated when the cows go out to the court. The same circumstance will show you the propriety of preventing any pig being slaughtered on the litter on which cows are accustumed to walk, and of not allowing any animal to be bled, and of any blood to be spilled near the byre. When any of the cows require bleed

- Skellert on the Parturition of the Cow.

(134) 
ing, the operation should be performed in a different apartrnent from the byre.

(1644.) Whenever a cow shows symptoms of slinking, which may be observed in the byre, but not easily in the grass-field, she should be removed immediately from her companions. The first symptoms are a sudden filling of the udder before the time of reckoning would warrant, a looseness and flabbiness and redness of, and a yellow glairy discharge from, the vagina, and a giving way of the ligaments or couples on each side of the rump. When any of these symptoms are observed, the cow should be narrowly watched, and means of preventing slinking instantly adopted, one of the chief of which is blood-letting. This should be followed by a laxative dose. But these means may prove ineffective if the symptoms made their appearance suddenly, and went through their course rapidly, and the calf be slipped after all.

(1645.) The risk which the cow runs, after slinking, is in not getting quit of the cleaning, or afterbirth, or placenta, because in such a case it is in an unprepared state to separate from the womb. Should it be retained, a certain degree of corruption is apt soon to take place in it, which will produce a very nauseous smell, that may remain for some time, as the cleaning may only pass away by degrees by putridity. Whenever the cleaning does not come away in the course of a few hours, or at most a day, the assistance of the veterinary surgeon should be obtained. The following cordial drink will promote the cleansing; juniper berries $3 \mathrm{oz}$., bay berries $2 \mathrm{oz}$, nitre 1 oz., anise seed $1 \mathrm{oz}$, gentian $\frac{1}{2} \mathrm{oz}$., gum myrrh $\frac{1}{2} \mathrm{oz}$., asafetida $\frac{1}{2} \mathrm{oz}$., well pounded together, for 1 dose, and given in 1 quart of mild ale made warm in 1 quart of pennyroyal tea. This drink should be given fasting, and repeated every day till the cleansing is evacuated.*

(1646.) After such a mishap the cow should be kindly treated in her diet, by the administration of mashes, gruels, and cordials, and her bowels kept in an open state at the same time, until her system recover its tone.

(1647.) As to the prevention of the recurrence of this vexatious complaint, though I believe that the best thing for the farmer is not to attempt any, but just to milk and fatten the cow, yet as a natural desire may be felt to retain a valuable and favorite cow, I shall mention some means which may be used, and which may have the effect of enabling the cow again to bear a living calf; and there is certainly this inducement to try means, that after the womb has again assumed its healthfull tone, so as to retain the foetus till the proper time, there is a probability of the complaint not returning, provided the following means are used every season during the period of gestation. Skellett mentions these preventive measures: "When a cow has slipped her calf, in the next gestation she should be early bled, her body should be kept open by cooling physic; she should not be forced to take any more exercise than what is absolutely necessary for her health, and her interfering with other cattle guarded against by keeping her very much by herself. At the same time," he adds, "it must be observed that, though it is necessary to preserve a free state of the bowels, a laxity of them will often produce this accident; cows fed very much upon potatoes, and such other watery food, are very apt to slink, from their laxative effects. In the food of the cow, at this time, a proper medium should be observed, and it should consist of a due proportion of other vegetable matter mixed with the fodder, so as the bowels may be kept regularly open, and no more." Our author, however, does not see that these remedial measures can be very useful. If the cow is in high condition indeed, she should be reduced in

* Skellett on the Parturition of the Cow. (135) 
condition; if she is very low, she ought to get nourishing food and streeg?hening medicines, and if she is much annoyed by nauseous smells, these should either be counteracted, or the cow withdrawn from them. Tocounteract bad smells, Skellett recommends the following mixture to be formed, and rubbed a little every day on the parts the cows commonly smell each other: Barbadoes tar, $3 \mathrm{oz}$., balsam of sulphur, $3 \mathrm{oz}$, rectified oil of az: ber, $1 \mathrm{oz}$., fine oil of thyme, $1 \mathrm{oz}$; and animal oil, $1 \mathrm{oz}$. "Of what nature that odor is," continues Skellett, "which gives offence, we cannot aito" gether be certain; but the author has remarked that its effects occur at one season more than at another, and particularly when the weather has been wet, and the cows have long been kept at grass. From this fact," he concludes, "it will appear that the smell is of a vegetable nature, and connected with their feeding at that time."* It is understood that cows that are fed in the neighborhood of and in woods, and that live on coarse, rank pasture in autumn, are most liable to this complaint. In Switzerland, the complaint increases after the cows are put on rank pastures in autumn.

(1648.) Though slinking is spoken of as an infectious complaint, it has no property in common with any contagious disease; but sympathetic influence being a main cause of it, its result is as fatal as if direct contagion had occasioned it.

(1649.) About a fortnight before the time of reckoning, symptoms of calving indicate themselves in the cow. The loose skinny place between the vagina and udder becomes florid; the vagina becomes loose and flabby ; the lower part of the abdomen rather contracts; the udder becomes larger, harder, more florid, hotter to the feel, and more tender-looking; the milkveins along the lower part of the abdomen become larger, and the coupling on each side of the rump-bones looser; and when the couplings feel as if a separation had taken place of the parts there, the cow should be watched day and night, for at any hour afterward the pains of calving may come upon her. From this period the animal becomes easily excited, and, on that account, should not be allowed to go out, or be disturbed in the byre. In some cases, these entire preparatory symptoms succeed each other rapidly, in others they follow slowly; and the latter is particularly the case with heifers with the first calf. These symptoms are called springing in England, and the heifers which exhibit them are springers.

(1650.) In different parts of the country, different practices exist in regard to attending on cows at calving. In the southern counties of Seotland, the shepherd conceives it to be his duty to attend on the occasion, assisted by the cattle-man, and other men if required. In the northern counties, in the contrary, the calving is left to women to manage. I think this difference in practice must have arisen from the degree of assistance required at the operation. In the southern counties, the large class of cows almost always require assistance in parturition, the veglect if which might cause the cow to sink from exhaustion, and the calf to be strangled or drowned at its birth. Puwerful assistance is sometimes required and can ouly he afforded by men, the physical ahility of women heing unequal to the task. Indered, I have witnessed the assistance of 8 men, in one way and another, given in the extraction of a calf coming even in a natural position. The calf was the first of twins, was very large, and this was the first labor of the heifer. I shall never forcet the distressing cries of the poor creature when racked with pain, nor the patience and sympathy evinced by all the men who were summoned to assist. It was an interesting case, conducted by an experienced shephercl, and lasted altugether

\footnotetext{
- Skellett on the Parturition of the Cow.
} 
about five hours. The cow and calves were much exhausted; but all recovered in the course of a few days. In the northern counties cows are not only smaller, but their calves are smaller in proportion, so that most cows calve without assistance; and, therefore, women may manage both cow and calf without difficulty. Of the two modes of conducting this delicate and ofttimes tedious operation, I should say that it falls most legitimately under the guidance of the shepherd, who seems to be the natural guardian of all the young stock brought forth on a farm; and where there is no shepherd, the cattle-man should take the charge, the farmer himself, in all cases, giving his sanction to the means about to be used, as it is but fair that he himself should bear the heaviest portion of the responsibility connected with this dangerous procedure.

(1651.) There are a few preparatory requisites that should be at hand when a cow is about to calve. Two or three rein-ropes are useful, to fasten to the calf if necessary-a flat, soft rope being the best form, but common rein-ropes will answer. A mat or sheeting, to receive the calf upon in dropping from the cow, should she be inclined to stand on her feet when she calves. The cattle-man should have a calf's crib in R, fig. 3 , Plate III, well littered. The shepherd should pare the nails of his hands close, in case he should have to introduce his arms into the cow to adjust parts; and he should supply himself with goose-grease or hog's lard to smear his hands and arms. Goose-grease is best for making the skin smooth, and withstanding evaporation. It may be that a few sacks may have to be put under the cow to elevate her hind-quarter, and even block and tackle may be used to hoist her up by the hind legs, in order to adjust the calf in the womb. These last articles should be ready at hand if wanted. A little straw should be spread on the floor of the byre, to place the new-dropped calf upon.

(1652.) All being thus prepared, and the byre-door closed to keep all quiet, the cow should be attended to every moment. The symptoms of calving are thus exactly described by Skellett, as they occur in an easy and ordinary case. "When the operation of calving actually begins," he says, "then signs of uneasiness and pain appear; a little elevation of the tail is the first mark; the animal shifts about from place to place, frequently getting up and lying down, not knowing what to do with herself. She continues some time in this state, till the natural throes or pains come on; and as these succeed each other in regular progress, the neck of the womb, or os uteri, gives way to the action of its bottom and of its other parts. By this action the contents of the womb are pushed forward at every throe; the water-bladder begins to show itself beyond the shape, and to extend itself till it becomes the size of a large bladder, containing several gallons; it then bursts, and its contents are discharged, consisting of the liquor amnios, in which, during gestation, the calf floats, and which now serves to lubricate the parts, and render the passage of the calf easier. After the discharge of the water, the body of the womb contracts rapidly upon the calf; in a few succeeding throes or pains, the head and feet of it, the presenting parts, are protruded externally beyond the shape. The body next descends; and in a few pains the delivery of the calf is complete."* The natural and easy calving now described is usually over in 2 hours, though sometimes it is protracted 5 or 6 , and even so long as 12 hours, particularly when the water has been easily evacuated, or the waterbladuler has broken before being protruded beyond the shape or vagina.

(1653.) But although the calf may present itself as here described in its natural position, with both its fore-feet projecting, its chin lying on both

* Skellett on the Parturition of the Cow.

(137) 
fore-legs, and the point of the tongue sticking out of the side of the mouth, it may not be extracted without assistance; and as the feet of the calf are too slippery to be retained hold of by the hands, a rein-rope is doubled, and a folding loop at the double is passed up above each fetlock joint, whence the double rope from each leg is ready to be taken hold of by the assistants. The pull should only be given at each time the cow presses to get quit of the calf, and it should be steady but firm, in a direction down from the back of the cow, and a little more than sufficiently strong to keep good whatever advance the calf may have made. Meantime the shepherd endeavors to relax the skin of the cow around the calf's head, by manipulation, as well as by anointing with goose-grease, his object being to pass the skin over the cantle of the calf, and when this is accomplished, the whole body may be drawn gently out. In obstinate cases of this kind, a looped rope may be passed across the mouth of the calf round the underjaw, which will facilitate the passage of the head; but this should not be resorted to but on necessity, the cord being apt to injure the tender mouth.

(1654.) On the extrusion of the calf, the first symptom it shows of life is a few gasps which set the lungs in play, and then it opens its eyes, and tries to shake its head, and sneer with its nose. The breathing is assisted if the viscid fluid is removed by the hand from the mouth and nostrils; and the thin membrane which envelops the body in the womb should now be removed, much torn as it has been in the process of parturition. The calf is then carried by two men, suspended by the legs, with the head held up between the fore-legs, and the back downward, to its comfortably littered crib, where we shall leave it for the present to attend still farther on its mother.

(1655.) The presentation is sometimes made with the hind-feet foremost. At first the hind-feet are not easily distinguished from the fore, but if a hind presentation is made in the natural position of the body, that is, with the back uppermost, the hind-feet will be in an inverted position to the fore, that is, the soles will be found uppermost instead of the hoofs. There is no difficulty with a hind presentation, only it should be ascertained that the tail is in its natural position, and not folded up, before the legs are pulled out. The first obstructing point is the rump, and then the thickest part of the shoulder. On drawing out the head, and coming last, it should be pulled away quickly, in case the calf should give a gasp for air at the moment of leaving the cow, when it may inhale some of the water instead of air, and run the risk of choking. The mouth and nose should be wiped immediately.

(1656.) Sinme have a custom, which is particularly practiced by women, to rub the skin of the new-dropped calf with a wisp of straw, but such a species of dressing should not be allowed, as it serves only to agglutinate. the hair with the liquor amnios which is brought along witb it. If left to itself, the liquor evaporates in a short time and leaves the hair dry; but while the evaporation is proceeding the calf trembles, no doult from feeling it cold, and on this account, if for $\mathrm{no}$ other, the litter in which it is first laid should he soft, clean, and amply sufficient to bury its body out of sight. I may mention, however, that the trembling is considered a happy symptom of the strength of the calf.

(1657.) All yet has been easily managed, when the cow lies still in her stall, with plenty of straw around and hehind her hind-quarter; but some cows are of so restless a disposition that they will not lie still to calve, and whenever the pains seize them, up they start to their feet, and when they cease lie down again. Such a cow is troublesome to deal with, as it is scarcely possible, by reason of her risings up and lyings down, to ascertain (138) 
the true position of the calf, especially when it does not present itself in the natural position. In such a case, it is the more necessary to extract che calf energetically, and remove the uneasiness of the cow, for, till she gets quit of it, she will not settle in one position or another. When the calf is so near the external air as to enable the operator to get the ropes round its legs, whether fore or hind, and a gentle pulling commenced, to fix her attention to the object in view, she will press with great force, the standing position giving her additional advantage, so that the extraction of the calf, in such a case, is generally the most expeditious. As in this position of the cow the calf will have to fall from a considerable hight to the ground, and may thereby be hurt, it is necessary to be provided with a mat or chaff-sheet, which two men hold below the body of the calf, ready to receive the body upon it when it leaves the cow. I had a ShortHorn cow that was very troublesome at calving, remaining but a short time up or down, and being the whole time in the greatest state of excitement. She always stood to calve, but when the process was actually begun she pressed with so much vigor that she got quit of it in a few minutes. Upon one occasion, after the water had come from her, the shepherd was preparing the ropes to be in readiness in case they should be required; but while employed at them, and within a couple of yards from the cow. in her stall, she gave such a powerful press as to project the calf from her, and it fell upon the floor, but luckily upon the very straw that had been laid down to receive it. This instance shows the necessity of careful watchfulness on cows after symptoms of actual calving have begun, as in such a case as I have just narrated, entire neglect might afterward have found the calf killed or injured by the heavy fall it had received.

(1658.) Some calves, though extracted with apparent ease, appear as if dead when laid upon the straw after birth. When such a case occurs, the hand should be placed against the side of the breast, to ascertain if the heart beats ; which, if it does, there is of course life, and all that is wanted is to inflate the lungs. To accomplish this, the mouth and nose should be cleaned, the mouth opened, and if there still be no breathing, some one should blow steadily into the open mouth, a device which I have seen answer the purpose; as also a hearty slap of the open hand upon the buttock of the calf, which starts it, as it were, into being. Perhaps a bellows might be usefully employed in such a case, to inflate the lungs. Should no beating of the heart be felt, and yet consciousness of life seem to be there, the calf should be carried without delay to its crib, and laid down and covered up with the litter, leaving the mouth free to breathe, and it may survive; but even after giving a few gasps, it may die. Most probably the cause of its death may be from injury it had received in calving, such as long detention in the vaginal passage, or an undue squeeze in passing through the mouth of the womb, or by some rashness of the operator. The body of the calf when thus lost should be skinned while warm; it should be cut in pieces, and buried in compost for manure, and the skin sold.

(1659.) The difficult cases of presentation which usually occur are with one foot and the head, and the other foot drawn back, either with the leg folded back altogether, or the knee doubled and projecting forwará. In all of these states the missing leg should be brought forward. To effect this, it is necessary to put round the presented foot a cord to keep it within the power of the operator when the head is pushed back to get at the other foot, and the greased arm of the operator introduced, and the foot brought forward into the passage beside the other. A calf may be extracted with one leg folded entirely back alongside the body, and on feeling 
this to he the case, it is perhaps better to extract the calf at cnce, than to delay the parturition in attempting to bring forward the leg. The presentation may be of the head alone without the feet, which may be knuckled forward at the knees, or folded back along both sides. In the knuckled case both legs may be brought forward by first pushing the head back, but, in case of losing hold of the calf altogether, a loop should be put in the calf's mouth. In the folded case, one leg at least, but both if possible, should be brought forward. A worse case is, when one or both legs are presented and the head folded back into the side. In this case the calf will most likely be dead. The head should be brought forward, and both legs, if possible. It may be beyond the strength of the operator to bring forward the head; then he should put a loop into the calf's mouth, by which his assistants will pull forward the head. Still worse cases may occur, such as a presentation of the shoulder, with the head lying into the side; a presentation of the buttock, with both the hind legs stretched inward. Or the calf may be on its back, and making presentations in all the worst features now enumerated. In whichever of these states the calf may present itself, no extraction can safely take place until it is placed in a position by which the head and one of the legs, with the other folded entirely back, or both the hind legs, with the back turned uppermost, are secured. In no case, however, should a fore or hind leg be left so as not only to obstruct the body in leaving the mouth of the womb, but a foot left so much at liberty as to tear the womb. The safest practice, therefore, is to secure both legs as well as the head. This may cause the operator considerable trouble, but by retaining hold of what parts he can with cords, and dexterity in handling the part missing, so as to bring it forward to the passage, while the assistants pull as he desires, his ohject will in most cases be attained; but it should be borne in mind that none of all these objects can be attained but by the assistance of the cow herself; that is to say, they should only be attempted when seconded by the throes of the animal. If this circumstance is not attended to and patiently watched by the operator, the muscular grasp of the womb will render his arm powerless. Another facility that should be taken advantage of by the operator is, that when the hind-quarters of the cow have an inclination downward she has the power to press the stronger, and of course to counteract his efforts the more easily. What should be done, therefore, is to raise that quarter of the cow with bundles of straw fully higher than the fore-quarter, until he has got the calf in the position he desires, and then, by letting the cow down again, and watching her pressings and assisting her at the same time, but not otherwise, the extraction may be accomplished in a reasonable time. As to block and tackle, the expedient should never be resorted to but to save the life of the cow, and as to turning the calf in the womb, there is far more danger in the attempt of injuring the womb than the value of the calf is worth. Much rather destroy it and cut it away in pieces, than run the risk of losing the cow. When the head only of the calf has found its way into the mouth of the womb, and cannot he protruded through the vagina, by reason of the unfavorable and obstructive position of the fore-legs, an inspection should immediately be made of the position of the calf, by first throwing the head back with a loop in the mouth, and bringing the legs forward. When this inspection has been too long delayed, and the head kept confined in the passage, the violent throes of the cow will certaiuly strangle the calf, and its head will swell to an inordinate degree. In such a case, as the swelling will prevent the calf's head heing pushed back to get at the legs, it must be taken off, the legs brought forward, and the body then extracted. One of the (140) 
most difficult cases is, when the fore-feet are presented naturally, and the head is thrust down upon the brisket between the legs. 'The feet must first be pushed back, and then the head brought up and forward, and the extraction will then become natural.

(1660.) A skillful shepherd may be able to manage all these difficult cases within a reasonable time; but unless he is particularly dexterous at cases of parturition, it is much safer to obtain the advice of a veterinary surgeon, even although he should not be required to put a hand to the operation himself. In the ease of extracting monstrosities, his assistance is indispensable.

(1661.) In regard to extracting twin calves, before rendering the cow any assistance, it is recessary to ascertain that the calves have made a proper presentation; that they are free of each other; that one member of the one is not interlaced with, or presented at the same time with, that of the other. When they are quite separated, then each can be treated according to its own case.

(1662.) Calving in a byre does not seem to produce any disagreeable sensations in the other cows, as they express no surprise or uneasiness in regard to what is going on beside them. When the cow gives vent to painful cries, which is rarely, the others no doubt express a sympathy; and when the calf is carried away, they may exhibit some restlessness; but any commotion arising from these circumstances soon subsides. But if a difficult labor is apprehended, it is better for the cows, and also for the cow herself, that she be delivered in another apartment, well littered, where the operator and his assistants can have tree access to her.

(1663.) A notion exists in some parts of England, that a cow, when seized with the pains of labor, should be made to move about, and not allowed to lie still, though inclined to be quiet. "This proceeds from an erroneous idea," Skellett well remarks, "that she will calve much easier, and with less danger; but so far from this being the case, the author has known a great many instances where the driving has proved the death of the animal by overheating her, and thus producing inflammation, and $a f^{\circ}$ its bad consequences. Every rational man will agree in opinion with the author, that the above practice is both cruel and inconsistent in the extreme; and this is confirmed by what he has noticed, that the animal herself, as soon as the pains of calving come on, immediately leaves the rest of the rest of the herd and retires to some corner of the field, or under a hedge, in order to prevent the other cows, or anything else, coming near, that may disturb her in bringing forward her young."* " In short, too much gentleness cannot be shown to cows when calving, and they cannot be too strictly guarded against every species of disturbance. The shepherd will not allow even his dog to enter the byre when calving is going on.

(1664.) The afterbirth, or placenta, does not come away with the calf, a portion of it being suspended from the cow. It is got quit of by the cow by pressing, and, when the parturition has been natural and easy, it seldom remains with her longer than from 1 to 7 hours. In bad cases of labor it may remain longer, and may only come away in pieces; but when it remains too long and is sound, its separation will be assisted by attaching a small weight to it, say of 2 lbs., which, with its continued force, and occasional pressing from the cow, will cause it to drop. The usual custom is to throw the afterbirth upon the dunghill, or it is covered up with the litter ; but it should not be allowed to lie so accessible to every dog and pig that may choose to dig it up. Nay, pigs have been known almost to choke themselves with it. Such a custom is disgusting, and should be put an

* Skellett on the Parturition of the Cow.

(141) 
end to. Let the substance be buried in a compost-heap, and if there is none such on the farm, let it rather be buried in the earth than exposed to be used in that manner. The umbilical cord or navel string breaks in the act of parturition.

(1665.) Should the cow seem exhausted by the protracted state of calving, she may be supported with a warm drink of gruel, containing a bottle of sound ale; and should she be too sick or indifferent to drink it herself, it should be administered to her with the drinking-horn, (1407.) After the byre has been cleansed of the impurities of calving, and a supply of fresh litter introduced, the cow, naturally feeling a strong thirst upon her from the exertion, should receive a warm drink. I don't know a better one than warm water, with a few handsfull of oatmeal stirred in it, and seasoned with a handfull of salt, and this she will drink up greedily; but a pailfull is enough at a time, and it may be renewed in a short time after, should she express a desire for it. This drink should be given her for two or three days after calving, in lieu of cold water, and mashes of boiled barley and gruel should be made for her, in lieu of cold turnips; but the oil-cake should not be forgotten, as it acts at this critical period as an excellent emollient. A very com mon practice is to give a cow barley in the sheaf to eat, and even raw barley, when there is no barley in the straw, and sometimes a few sheaves are kept for the express purpose; and barley-chaff is given where people grudge to part with good barley. Though so very common, the practice is a very objectionable one, for nothing could be proposed that would cause indigestion so readily as raw barley or barley-straw at the time of calving, when the tone of the stomach is impaired by excitement, and it may be by fever. Boiled barley, or any other mucilaginous drink, is quite safe, but a substance that can hardly fail to irritate and inflame the stomach is most injudiciously applied in the circumstances. In fact, nothing should be given to a cow at this time of an astringent nature, but rather everything of a laxative quality.

(1666.) It is desirable to milk the new-calved cow, as soon as convenient for her, as, whether the labor has been difficult or easy, the withdrawal of milk affords relief. It not unfrequently happens that an uneasiness is felt in the udder before calving, and should it increase while the symptoms of calving are long delayed, the cow may experience considerable inconvenience, especially if the flush of milk has been sudden. The causes of uneasiness are an unequal hardness in the udder and there is a heat, floridness and tenderness all over it. Fomentation with warm water twice or thrice a day, continued for half an hour at a time, followed by gentle rubbing with a soft hand, and anointing with goose-grease, will tend to allay irritation. In the case of heifers with the first calf, the uneasiness is sometimes so great during the protracted symptoms of calving, as to warrant the withdrawal of milk before calving. Should the above remedial measures fail to give relief, the great heat in the udder may cause direct inflammation, and consequent suppuration. To avert such an issue, the uneasiness should not be neglected from the first moment it is observed, as neglect may allow the complaint to proceed so far as to injure the structure of a portion if not the whole of the udder.

(1667.) Milking is performed in two ways, stripping and nievling. Stripping consists of seizing the teat firmly near the root between the face of the thumb and the side of the fore-finger, the length of the teat passing through the other fingers, and in milking the hand passes down the entire length of the teat, causing the milk to flow out of its point in a forcible stream. The action is renewed by again quickly elevating the hand to the root of the teat. Buth hands are employed at the operation, each having (142) 
hold of a different teat, and moved alternately. The two nearest teats are first milked and then the two farthest. Nievling, or handling, is done by grasping the teat round at its root with the fore-finger like a hoop, assisted by the thumb, which lies horizontally over the fore-finger, the rest of the teat being also seized by the other fingers. Milk is drawn by pressing upon the entire length of the teat in alternate jerks with the entire palm of the hand. Both hands being thus employed, are made to press alternately, but so quickly following each other that the alternate streams of milk sound to the ear like one forcible, continued stream. This continued stream is also produced by stripping. Stripping, then, is performed by pressing and passing certain fingers along the teat; nievling by the whole hand doubled, or fist, pressing the teat steadily at one place. Hence the origin of both names.

(1668.) Of the two modes, I prefer the nievling, because it appears to me to be the more natural method, inasmuch as it imitates the sucking of a calf. When a calf takes a teat into its mouth, it makes the tongue and palate, by which it seizes it, play upon the teat by alternate pressures or pulsations, while retaining the teat in the same position. It is thus obvious that nievling is somewhat like sucking, whereas stripping is not at all like it. It is said that stripping is good for agitating the udder, the agitation of which is conducive to the withdrawal of a large quantity of milk; but there is nothing to prevent the dairy-maid agitating the udder as much as she pleases, while holding the teats in nievling. Indeed a more constant agitation could be kept up in that way by the vibrations of the arms than by stripping. Stripping, by using an unconstruined pressure upon two sides of the teat, is much more apt to press it unequally, than by grasping the whole teat in the palm of the hand; while the friction occasioned by passing the finger and thumb firmly over the outside of the teat, is more likely to excite heat and irritation in it than a steady and full grasp of the entire hand. To show that this friction causes an unpleasant feeling even to the dairy-maid, she is obliged to lubricate the teat frequently with milk, and to wet it at first with water; whereas nievling requires no such expedients. And as a farther proof that stripping is a mode of milking which may give pain to the cow, it cannot be employed when the teats are chapped, or when these and the udder are affected with the cow-pox, with so much ease to the cow as nievling. This difference I saw strikingly exemplified one summer, when all my cows were affected with the cowpox, and when the assistant, who could only milk by stripping, was obliged to relinquish her duty till the cows were so far recovered as to be again able to endure her mode of milking.

(1669.) Milking should be done fast, to draw away the milk as quickly as possible, and it should be continued as long as there is a drop of milk to bring away. This is an issue which the dairy-maid cannot too particularly attend to herself, or see it attended to by those who assist her. Old milk left in the receptacle of the teat soon changes into a curdy state, and the caseous matter not being at once removed by the next milking, is apt to irritate the lining membrane of the teat during the operation, especially when the teat is forcibly rubbed down between the finger and thumb in stripping. The consequence of this repeated irritation is the thickening of the lining membrane, which at length becomes so hardened as to close up the small orifice at the point of the teat. The hardened membrane may easily be felt from the outside of the teat, when the teat is said to be corded. After this the teat becomes deaf, and no more milk can afterward be drawn from the quarter of the udder to which the corded teat is attached.

(1670.) The milking-pail is of various forms and of various materials. (143) 
The Dutch have brass ones, which are brilliantly scoured every time they are in use. Tin pitchers are used in some parts, while pails of wood in cooper-work are employed in other parts of the country. A pail of nak having thin staves bound together with bright iron hoops, with a handle formed by a stave projecting upward, is convenient for milking in, and may be kept clean and sweet. One nine inches in diameter at the bottom, 11 inches at the top, and ten inches deep, with an upright handle or lug of 5 inches, has a capacious enough mouth to receive the milk as it descends; and a sufficient hight, when standing on the edge of its bottom on the ground, to allow the dairy-maid to grasp it firmly with her knees while sitting on a small three-legged stool. Of course the pail cannot be milked full; but it should be as large as to contain all the milk that a single cow can give at a milking; because it is undesirable to rise from a cow before the milking is finished, or to exchange one dish for another while the milking is unfinished.

(1671.) The cow being a sensitive and capricious creature, is so easily offended that if the dairy-maid rise from her before the milk is all withdrawn, the chances are she will not again stand quietly at that milking; or if the vessel used in milking is taken away and another substituted in its place, before the milking is finished, the probability is that she will hold her milk-that is, not allow it to flow. This is a curious property which cows possess, of holding up or keeping back their milk. How it is effected has, I believe, never been ascertained; but there is no doubt of the fact that when a cow becomes irritated, or frightened by any cause, she can withhold her milk. Of course, all cows are not affected in the same degree, but as a proof how sensitive cows generally are, I believe that very few will be milked so freely by a stranger the first time as by one to whom they have been accustomed.

(1672.) There is one side of a cow which is usually called the milking side-that is, the cow's left side-because, somehow, custom has established the practice of milking her from that side. It may have been adopted for two reasons: one, because we are accustomed to approach all the larger dornesticated animals by what we call the near side-that is, the animal's left side-as being the most convenient one for ourselves; and the other reason may have been, that, as most people are right-handed, and the common use of the right hand has made it the stronger, it is most conveniently employed in milking the hinder teats of the cow, which are often most difficult to reach because of the position of the hind legs, of the length of the hinder teats, or of the breadth of the hinder part of the udder. The near side is most commonly used in Scotland, but in many parts of England the other side is preferred. Whichever side is selected, that should always be used, as cows are very sensitive to changes.

(1673.) It is a rare thing to see a cow milked in Scotland by any other person than a woman, though men are very commonly employed at it in England. For my part, I never see a man milking a cow without heing impressed with the idea that he is usurping an office which does not befit him; and this sense seems to be expressed in the terms usually applied to the persons connected with cows-a dairy-maid implying one who milks cows, as well as performing the other functions of the dairy-a dairy-man meaning one who owns a dairy.

(1674.) Cows are easily rendered troublesome on being milked; and the kicks and knocks which they usually receive for their restlessness, only render them the more fretful. If they cannot be overcome by kindness, thumps will never make them better. But the fact is, restless habits are continued in them by the treatment which they receive when first taken in(141) 
to the hyre, when, most probably, they have been dragooned into submission. Their teats are tender at first; but an unfeeling horny hand tugs at them in stripping, as if they had been accustomed to the operation for years. Can the creature be otherwise than uneasy? and how can she escape the wincing but by flinging out her heels? Then hopples are placed on the hind fetlocks, to keep her heels down. The tail must then be held by some one while the milking is going on ; or the hair of its tuft be con verted into a double cord, to tie the tail to the creature's leg. Add to this the many threats and scolds uttered by the dairy-maid, and you will get not a very exaggerated idea how a young heifer is broke into a byre. Some cows, no doubt, are very unaccommodating and provoking; but nevertheless, nothing but a rational course of conduct toward them, administered with gentleness, will ever render them less so. There are cows which are troublesome to milk for a few times after calving, that become quite quiet for the remainder of the season; others will kick pertinaciously at the first milking. In this last case, the safest plan, instead of hoppling, which only irritates, is for the dairy-maid to thrust her head against the flank of the cow, and while standing on her feet, stretch her hands forward, and get a hold of the teats the best way she can, and send the milk on the ground; and in this position, it is out of the power of the cow to hurt her. These ebullitions of feeling at the first milking after calving, arise either from feeling pain in a tender state of the teat, most probably from inflammation in the lining membrane of the receptacle; or they may arise from titillation of the skin of the udder and teat, which become the more sensible to the affection, from a heat which is wearing off. Be the cause of irritation what it may, one thing is certain, that gentle discipline will overcome the most turbulent temper.*

(1675.) Cows, independently of their power to retain their milk in the udder, afford different degrees of pleasure in milking them, even in the quietest mood. Some yield their milk with a copious flow, with the gentlest handling that can be given; others require great exertion to draw the milk from them in streams no larger than threads. The udder of the former will be found to have a soft skin, and the teats short; that of the latter will have a thick skin, with long, tough teats. The one feels like velvet, the other no better than untanned leather.

(1676.) The heifers that are to be transferred to the cow-stock should be taken from the hammels $\mathrm{N}$, fig. 3 , Plate III., in which they have been confined all winter, into the byre, about three weeks or a fortnight before their reckoning, at once into the stalls they are to occupy. If they had been accustomed to be tied by the neck when calves, they will not feel much reluctance in going into a stall; but if not, they require some coaxing to do it. When taking them to a byre, it should be remembered that a fright received at this time may not be forgotten for a long time to come. To avoid every chance of that, let them go in quietly of their own accord; let them smell and look at everything they wish; and let them become acquainted with them before driving them on; and having plenty of assistants to prevent any attempt to break away, let the cattle-man, with the shepherd, allow them to move on bit by bit, until they arrive at the stall. Here will be some difficulty ; but a little favorite food in the manger will entice them to go up, especially if the time is chosen, which it should be,

[* This caution cannot be too strongly impressed on the mind, as applicable to the breaking in of domestic animals for all purposes. To conciliate and reconcile them to any operation or service, assuredly it is more rational and efficient to bave them connect with it agreeable recollections of kind treatment and gentle usage, than anticipations of harshness and violence. 
when they are hungry. Another difficulty will be experienced in putting the seal, fig. 11 , round the neck. It should hang, when not in use, on a nail upon the stake; and on quietly taking it down, without clanking the chain, and while the creature is eating, let the cattle-man slip one hand helow the neck, while the other supports the seal over it, and then bring the loose end of the seal round the neck, and hook it into whatever link he can first get.

(1677.) The milk that first comes from the cow after calving is of a thick consistence and yellow color, and is called biestings. It has the same coagulable properties as the yolk and white of an egg beat up. After three or four days the biestings is followed by the milk. That which comes last, the afterings or strippings, as it is commonly called, is much the richer part of new milk, being not unlike cream. Being naturally thick, it is the more necessary to have it drawn clean away from the udder.

(1678.) The structure of a cow s udder is remarkable. It consists of 4 glands, disconnected with each other, but all contained within one bag or cellular membrane; and the glands are uniform in structure. Each gland consists of 3 parts, the glandular or secreting part, the tubular or conducting part, and the teat or receptacle or receiving part. The glandular forms by far the largest portion of the udder. It appears to the naked eye composed of a mass of yellowish grains, but under the microscope these grains are found to consist entirely of minute bloodvessels forming a compact plexus. These vessels secrete the milk from the bload. "Thus, then," says a writer, "we perceive that the milk is abstracted from the blood in the glandular part of the udder; the tubes receive and deposit it in the reservoir or receptacle; and the sphincter* at the end of the teat retains it there till it is wanted for use. But we must not be understood to mean that all the milk drawn from the udder at one milking, or meal, as it is termed, is contained in the receptacie. The milk, as it is secreted, is conveyed to the receptacle, and when this is full, the larger tubes begin to be filled, and next the smaller ones, until the whole become gorged. When this takes place, the secretion of the milk ceases, and absorption of the thinner or more watery part commences. Now, as this absorption takes place more readily in the smaller or more distant tubes, we invariably find that the milk from these, which comes the last into the receptacle, is much thicker and richer than what was first drawn off. This milk has been significantly styled ufterings; and should this gorged state of the tubes be permitted to continue beyond a certain time, serious mischief will sometimes occur; the milk becomes too thick to flow through the tubes, and soon produces, first irritation, then inflammation, and lastly suppuration, and the function of the gland is materially impaired or altogether destroyed. Hence the great importance of emptying these smaller tubes regularly and thoroughly, not merely to prevent the occurrence of disease, but actually to increase the quantity of milk; for so long as the smaller tubes are kept free, milk is constantly forming; but whenever, as we have already mentioned, they become gorged, the secretion of milk ceases until they are emptied. The cow herself has no power over the sphincter at the end of the teat, so as to open it and relieved the overcharged udder; neither has she any power of retaining the milk collected in the reservoirs when the spasm of the sphincter is overcome." $\dagger \ddagger$

* The teat does not terminate in a true sphincter, there being no muscle in connection with it. A sphincter ect by the power of four muscles, which are contracted or expanded at will, and close or open the oritice eround which they are placed. + Blurton's Practical Essay on Milking.

I Observations such as these, on the anatomy and functions of the udder, may appear superftuous to some, but not 80 to him who would desire, for himself or his son, a sort of knowledge which (194) 
(1679.) You thus see the necessity of drawing away the last drop of milk at every milking, and the better milker the cow is, this is the more necessary. You also see the impropriety of hefting or holding the milk in cows until the udder is distended much beyond its ordinary size, for the sake of showing its utmost capacity for holding milk, a device which all cow-dealers, and indeed every one who has a cow for sale in a market, scrupulously use. It is remarkable that so hackneyed a practice should decesve any one into its being a measure of the milking power of the cow, for every farmer is surely aware, or ought to be aware, that the person who purchases a hefted cow on account of the magnitude of its udder exhibited in the market, gains nothing by the device; because, when the cow comes into his possession, she will never be hefted, and, of course, never show the greatest magnitude of udder, and never, of course, confer the benefit for which she was bought in preference to others with udders in a more natural state. If, then, purchasers derive no benefit from hefting, because they do not allow hefting, why do they encourage so cruel and afterward injurious practice in dealers? Would it not be better to select cows by udders in the state in which it is desired by purchasers they should be in their own possession? Were purchasers to set their face against the barbarous practice, the dealers would soon be obliged to relinquish it.

(1680.) Having spoken of the internal structure of the udder, its external form requires attention, because it indicates different properties. Its form should be spheroidal, large, giving an idea of capaciousness; the bag should have a soft, fine skin, and the hind part upward toward the tail be loose and elastic. There should be fine long liairs scattered plentifully over the surface, to keep it warm. The teats should not seem to be contracted or funnel-shaped at the onset with the bag. In the former state, teats are very apt to become corded or spindled, as another phrase expresses it, and in the latter too much milk will constantly be pressing on the lower tubes or receptacle. They should drop naturally from the lower parts of the bag, being neither too short, small, or dumpy, or long, flabby and thick, but perhaps about 3 inches in length, and as thick as just to fill the hand. They should hang as if all the quarters of the udder were equal in size, the front quarters projecting a little forward, and the hind ones a little more dependent. Each quarter should contain about equal quantities of milk, though I have always believed that the hind contain rather the most.*

it becomes every man to possess who has leisure to acquire it, and which every farmer should regard as being within the purview of his parsuit and position in society-just as much so as it is befitting in a scholar to be familiar with history, or a diplomatist with living languages and the laws of nations. There is, in fact, not a word in this section, nor in the work to which it belongs, that should not be made a part of the course of instruction for all youths who are to gain their living and maintain their standing in society by the practice of Husbandry and a knowledge of its principles. This Note would apply almost as well anywhere as here; we only seize the oc casion to urge an impression which we believe cannot be too often suggeated or too widely acted on, as to the variety of knowledge and of studies that ought to embellish the profession of the practical agriculturist, as well as augment its profits.

Ed. Farm. Lib.]

[ As this number or volume of THE FARMERs' LIBRARY may fall into the hands of persons who do not possess the Monthly Journal of Agriculture in which it was published, it seems proper to refer here to that extraordinary "Treatise on Milch Cows," by M. Guenon. Of the validity of that work the strongest proof has been adduced, not only by the unanimous doclaration of Commitlees of French Societies; but in the testimony of American agriculturists of undisputed judgment, and of the highest respectability. Of these we will take room only for the following statement at a Farmers' Club meeting in Boston: "Mr. Denny fully accorded with Mr. Brooks in his estimate of the treatment of cattle by Guenon. He had tested its value by. (195; 
(1681.) Largely developed milk-veins, as the subcutaneous veins along the under part of the abdomen are commonly called, are regarded as a source of milk. This is a popular error, for the milk-vein has no connection with the udder; but "although the subcutaneous or milk-rein has nothing to do with the udder," says Mr. Youatt, "but conveys the hlood from the fore part of the chest and sides to the inguinal vein, yet a large milk-vein certainly indicates a strongly developed vascular system-one favorable to secretion generally, and to that of the milk among the rest."*

(1682.) Let us now attend to the young calf. The navel-string should be examined that no blood be dropping from it, and that it is not in too raw a state. Inattention to this inspection may overlook the cause of the navel-ill, the treatment of which is given below; and insignificant as this complaint is usually regarded, it carries off more calves than most breeders are aware of.

(1683.) The first food which the calf receives consists of what its mother first yields after calving, namely, biestings. Being of the consistence of egg, it seems to be an appropriate food for the fotus just ushered into the world. On giving the calf its first feed by the hand, in a crib in $\mathbf{R}$, fig. 3 , Plate III., it may be found to have gained its feet, or it may be content to lie still. In whichever position it is found, let it remain 80 , and let the dairy-maid take a little biesting in a small dish-a handy, formed like a miniature milk-pail, and of similar materials, will be found a convenient one-and let her put her left arm round the neck of the calf, and support its lower jaw with the palm of the hand, keeping its mouth a little elevated, and open, by introducing the thumb of the same hand into the side of its mouth. Then let her fill the hollow of her right hand with biestings, and pour it into the calf's mouth, introducing a finger or two into it for the calf to suck, when it will drink the liquid. Thus let her supply the calf, in handfull after handfull, as much as it is inclined to take. When it refuses to take more, the creature should be cleaned of the biesting that may have flown over. Sometimes, on a calf being begun to be fed, when lying, it attempts to get upon its feet, and, if able, let it do so, and rather assist it up than prevent it. Some people are afraid to give a calf as much biestings at first as it can take, because it is said to produce the navel-ill. This is nonsense; let the creature take as much as it pleases, for biestings never harmed a calf, and certainly never produced navel-ill, though it has been accused of it; but if the truth were investigated, the illness would be found to have proceeded from neglect of proper inspection in due time, arising from ignorance of the danger. I have minutely detailed the primary and simple process of feeding a new dropped calf by hand, because very absurd ways are adopted in doing it. Nothing is more common than to plunge the calf's head into a large quantity of biestings, and because the liquid bubbles around its mouth with the breath of the nose, and it will not attempt to drink it, its head is the more forcibly thrust and kept down into the tub. How can it drink with its nose immersed among the fluid? And why should a calf be expected at first to drink with its head

distributing a number of copies among intelligent practical farmers, and their united report was in favor of the high value of the work. One of them went so far as to say that a farmer keeping twenty cows could well afford to give 100 for this treatise of Guénon, if it could not be obtained at a less cost." According to this treatise, the quality and quantity of milk which any cow wi give may be accurately determined by observing natural marks or external indications alone These marks have been fully illustrated by engravings designed to explain the gystem as already published in The Monthly Joursal of Agriculture, connected with The Farmerg' Li. BRART.

Ed. Farm. Lib.]

- Youatt on Cattle. 
down, when its natural instinct should lead it to suck with its head up? 1t should always be borne in mind that feeding calves by the hand is an unnatural process; nevertheless, it is a convenient, practicable and easy one, provided it is conducted in a proper manner. The creature must be taught to drink, and a good mode of teaching it I have described above. In this way it is fed as often as the cow is milked, which is three times a day. After the first two or three days, however, another plan should be adopted, for it should not be accustomed to suck the fingers, as then it will not drink without their assistance. The succeeding plan is to put a finger or two of the right hand into its mouth, and holding the small pail of milk with the left under its head, bring the head gradually down into the pail, where the fingers induce it to take a few gluts of the milk; but in doing this, the fingers should be gently withdrawn while the head is kept down in its position with the hand, taking care to keep the nostrils above the milk. In a few days more the fingers will not be required, and in a few days more still you will see the calf drink of its own accord.

(1684.) For the first month the calf usually has as much sweet milk warm from the cow as it can drink. It will be able to drink about 3 quarts at each meal, and in three meals a day, in the morning, noon and evening, it will consume 8 quarts. After the first month it gets its quantity of milk at only 2 meals, morning and evening. It is supported 3 months in all on milk, during which time it should have as much sweet-milk as it can drink. Such feeding will be considered expensive, and no doubt it is, but there is no other way of bringing up a good calf. Some people grudge sweet-milk after a few days, and take the cream off it, and give the skimmed to the calves. This is considered thrifty management; but its result does not insure immediate gain, because it is not possible to extract double advantage from a given quantity of sweet-milk. If butter is preferred to calves, or good beasts at an after period, the wish is attained, and the farmer has had his preference; but he must know-at least ought to know-that he cannot obtain butter and good beasts from the same milk. Others, more generous, give half sweet and half skimmed milk to their calves; while some provide a substitute for a part of the milk, by making gelatine of boiled linseed or sago, and give it with no milk. When milk is actually scarce, such expedients are permissible; but when it is plentiful, and is used for other purposes than merely to serve the farm-house, the adoption of expedients is a practical avowal that the farmer does not wish to bring up his stock as he might do.

(1685.) The jelly from linseed, or lythax, as it is called, is easily made by boiling good linseed in water, and while it is in a hot state to pour it in a vessel to cool, when it becomes a firm jelly, a proportion of which is taken every meal, and bruised down in a tubfull of warm milk, and distributed to the calves. They are very fond of it, and in the third month of the calf's age, when it can drink a large quantity of liquid at a time, and during a day, it is an excellent food for them. Sago may be prepared in the same way. But a better substance for calves than either is, in my opinion, pea-meal. It should not be boiled, but made into brose, by pouring hot water upon it, and stirring the mixture till it is fine. It becomes gelatinous on cooling; and when cold, a portion of it is put into new warm milk, and mixed so intimately with the hand that not a lump of the meal can be felt; and the mixture is made of a consistence which a calf can easily drink.

(1686.) Another mode of bringing up calves by breeders of stock is to allow them to suck their mothers, and the plan is arranged in this way: Either a large crib is erected at a convenient part or parts of the cow's (197) 
hyre, to contain a number of calves each, in a loose state, and when the hours arrive at which they are fed, they are let out of the cribs, whence they each proceed forthwith to the cow that supports it ; or the calves are tied by the neck in stalls erected for the purpose against the wall of the byre, immediately behind the cows, and when the hours of the respective meals arrive, they are loosened from the tyings, and pass across the byre to the cows. Generally, in both cases, one cow suckles two calves; and a cow that has calved early may suckle two sets, or four calves, or at least three, in the season.

(1687.) With regard to the merits of this plan, I must remark that I am averse to tying calves by the neck. It cramps their motions and deprives them of that freedom of action which is so conducive to health. By preventing motion they will no doubt sooner acquire condition ; but for stockcalres, kept for the formation of a herd, this is of less importance than strength acquired by moderate exercise within a limited size of crib. As to having a number of calves within the same crib, though they all have liberty of motion, they are so commixed as to have liberty to suck at one another. The ears, navel, scrotum and teats, suffer by this dirty habit; and there is no preventing it after it has been acquired, so long as two remain together. Upon the whole, therefore. I much prefer the separate crib to each calf, so formed of spars as to allow every calf to see its neighbors, and so sensibly in company, as to remove the idea of loneliness. The separation prevents the abominable habit of sucking being acquired; and the crib is as large and no larger than to allow them to move about for exercise, without fatigue.

(1688.) In regard to suckling calres, there is no question it is the best way of bringing them up, provided the calf has free access to its mother or the cow which is supporting it; but I am doubtful of the superiority of suckling over feeding by hand, in the case where the calf is only allowed to go to the cow at stated times. It saves the trouble of milking the cows and giving milk to the calves; but the saving of trouble is not so import. ant a consideration in the rearing of young stock as the promotion of theit welfare. There is one objection to suckling where one cow brings up two calves-that the quantity of milk afforded to each is unknown; and the stronger or more cunning calf may steal the larger share. True, they are both brought up; but are they brought up as well as they might be, with the assistance of nourishing food, when the milk becomes scarcer, which it will be to each calf the older it grows. Another objection to suckling is, that a cow which suckles calves at one period of the season does not take kindly afterward to milking with the band; and a cow will always prefer to be sucked to being milked by the hand. Unless, therefore, cows ara kept for the purpose of suckling, they become troublesome to milk after the calves are weaned.

(1689.) At a month old the male calves that are not intended to be kept for bulls are castrated. Though the operation is very simple and safe, yea it should not be performed at a time when there is any affection of the navel-string, or indication of costiveness or dysentery ; these exciting canses of the system should first be removed ere another is voluntarily superadded. Supposing the calf is in good health, the castration is performed in this manner: An assistant places the calf upon its rump on the litter, and, sitting down himself, takes it between his outstretched limbs on the ground, with its back against his breast. Then seizing a hind-hock of the calf in each hand, he draws a hind leg up to each side of its body, and holds both in that position as firmly as he can. The operator makes the testicles keep the scrotum smooth and stretched with his left hand, and then cuts with a (198) 
sharp knife through all the integuments till he reaches one testicle, which he seizes, pulls out as much of the spermatic cord as he can, and there divides it. The same operation is performed on the other testicle, and the castration is finished in a minute or two. The calf feels stiff in the hind quarter for a few days, and the scrotum may swell; and if the swelling appear to become serious, fomentations of warm water should be frequently applied; and should suppuration ensue, the incisions made in the scrotum should be opened to give it vent; but the probability is that the cut will heal by the first intention, and give no farther uneasiness to the calf than a feeling of stiffness in the hind quarter for a few days.

(1690.) When the air becomes mild, as the season advances, and when the older calves attain the age of two months, they should be taken out of the cribs, and put into the court $k$, fig. 3 , Plate III., during the day; and after a few days' endurance to the air, should be sheltered under the shed in the court at night, instead of being again put into the cribs. Some sweet hay should be offered them every day, as also a few sheep-slices of Swedish turnips to munch at. Such a change of food may liave some effect on the constitution of the calves, causing costiveness in some and looseness in others; but no harm will arise from these symptoms, if remedial measures are employed in time. Large lumps of chalk to lick at will be found serviceable in looseness. The shed of the court should be fitted up with small racks and mangers to contain the hay and turnips, and chalk. Should a very wet, snowy, stormy, or cold day appear after the calves have been put into the court, they should be brought back to their cribs till the storm pass away.

(1691.) At three or four months old, according to the supply of milk and the ready state of the grass to receive them, the calves should be weaned in the ordinary seniority, due regard being at the same time had to their constitutional strength. If a calf has been always strong and healthy, it may be the sooner weaned from milk, if there is grass to support it; but should it have ailed, or be naturally puny, it should be remembered that good, sweet milk is the best remedy that can be administered to promote condition or recruit debility, and should be given with an unsparing but judicious hand. Calves, on being weaned, should not be deprived of milk at once; it should be lessened in quantity daily, and given at longer intervals by degrees, so as that they may not be sensible of their loss when it is entirely withheld. I have frequently observed that when calves are stinted of milk preparatory to weaning, means of supplying them with a sufficient quantity of food of an enticing nature are not so well attended to as they ought. Fresh bundles of the most clovery portions of the hay, turnips fresh sliced, pure fresh water at will, a little pounded oil-cake, if presented at times when they used to get their milk, will induce them to eat those substitutes with contentment; whereas, when these are entirely neglected, or the trouble grudged in supplying them, and the creatures left to pick up what they can find for themselves in a court or bare lea, they cannot but suffer from hunger, and vociferate for the loss of what they had enjoyed till then. Thus treated, they evidently fall off in condition; and which if they do at the critical period of weaning, the greater portion of the ensuing summer will elapse ere they regain their former condition, strength, and sleekness of coat. A small paddock near the steading is an excellent place for weaning calves, before turning them out to a pasture field; but then it should afford a full bite of grass to support them as the milk is taken from them, otherwise they will be more injured than benefited in it.

(1692.) When bull calves are brought up, they should be early calved, 
and receive as much new milk as they can consume; and they should not be weaned till the grass is fully ready to support them. The olject of this high keeping is not to fatten them, but to give strength to their bones and vigor to their constitution, these being much strengthened by the quality and quantity of food given to calves at the earliest period of their existence. The valuable impulse thus given in calfhood to these very essential properties in bulls, is evinced in the vigor of succeeding life, and it is sure to lay a foundation upon which a durable superstructure may be raised, and, what is more, no durable structure can be raised on any other. Even in ordinary cases push a calf forward in the first month of its existence, and the probability will be that it will evade every disease incident to its age.

(1693.) The following Table, containing the dates at which cows should calve from those at which they are bulled, will be found useful to you for reference. It is unnecessary to fill up the Table with marking down every day of the year, as within the short period between each fortnight you can easily calculate the particular reckoning of each cow. The period of gestation is taken at 273 days, or 9 calendar months, which is the minimum time, and from wbich the symptoms of calving should be narrowly watched till the event of calving actually takes place.

A RECKONING-TABLE FOR THE CALVING OF COWS.

\begin{tabular}{|c|c|c|c|c|c|}
\hline When Bulled. & Will Calve. & When Bulled. & Will Calve. & When Bulled. & Will Calve. \\
\hline$\overline{\text { January..... } 1}$ & October & May. & Febr & Septemb & June .. \\
\hline$\ldots \quad \ldots 15$ & $\ldots .15$ & $\ldots .21$ & & & 21 \\
\hline 29 & .29 & June...... & March... & October & Iuly. \\
\hline February... 12 & November. 12 & $\ldots . .18$ & .18 & & .21 \\
\hline$\ldots .26$ & & -2 & A pril. & November.. 5 & August. \\
\hline March......12 & December .10 & $\ldots \ldots 16$ & $\ldots .15$ & .19 & 18 \\
\hline$\ldots-26$ &. .24 & .30 & .29 & Decembe & Septemb \\
\hline$\ldots 9$ & January ... 7 & Auguet. & May. & $\ldots .17$ & $\ldots \ldots 15$ \\
\hline$\ldots .23$ & $\ldots .21$ & .27 & $\ldots \ldots 27$ & $\ldots .31$ & ...29 \\
\hline
\end{tabular}

(1694.) The usual modes of determining whether the cow is in calf are deceptive : she may not hold when bulled; she may take the bull again in a few days; and she may not show evident symptoms of calving but for a few days only before she actually calves. The most certain sign of preguancy is the enlargement of the abdomen and filling of the flanks in the third or fourth month. A more philosophical method of determining whether a cow is in calf at all, has been discovered by medical men by the application of the ear to the flank of the cow, suggested by the curious and valuable discoveries brought to light by the stethescope. "That greatest of improve. ments in veterinary practice." observes Mr. Youath "the application of the ear to the chest and belly of various animals, (in order to detect by the different sounds-which, after a short time, will be easily recognized-the state of the circulation through nost of the internal oreans, and consequently the precise seat and degree of inflammation and danger, has now enabled the breeder to ascertain the existence of pregnancy at as early a stage of it as six or eight weeks. The beating of the heart of the calf will be distinctly heard, twice or more than twice as frequent as that of the mother; and each pulsation will betray the singular double-beating of the fotal heart. This will also be accompanied by the audible rushing of the blond through the vessels of the placenta. The ear should be applied to the right flank, beginning on the superior part of it, and gradually shifted downward and backward. These sonnds will soon be heard, and cannot be misiaken."*

(1695.) Strathaven in Scotland has long been famed for rearing good veal for the Glasgow and Edinburgh markets. There the dairy farmers retain their quey-calves for maintaining the number and vigor of their cow stock, while they feed the male calves for veal. Their plan is simple and efficacious, and therefore may be followed anywhere. They give the calves milk only, and seldom any admixtare, and they do not allow them to suck their dams. Some give milk but eparingly at first, to whet their eppetite, and all take care not to produce surfeit by giving too much at a time. The young calves get the first drawn milk, or fore-broads, as it is termed, and the older, less of the fore-broads and more of the afterings, and frequently that of two or three cows, as being the richest portion of the milk. After they are three or four weeks old they get abundance of milk, but only twice a day. They get plenty of dry litter, freeh air, moderate warmth, and are kept nearly in the dark to check sportiveness. They are not bled during the time they are fed, and a lump of chalk is placed within their reach. They are fed from 4 to 6 weeks, when they fetch frgm $£ 3$ to $£ 4$ apiece; and it is found more profitable to fatten a number of calves for that time, to succeed each other, than to force then beyond the state of marketable veal, of from 25 lbs. to 30 lbs. per quarter. ${ }^{\prime}$

(1696.) Diseases of Young Calves.-While speaking of the calf, I may here notice the diseases to which it is subject at this period of its existence, and in this sesson of the year. The young calf should get quit of the black and glutinous freces that had been accumulating in its intestines during the latter perior of its fotnl existence: and there is no aperient better suited for the purpose than biestings. The farmer, therefore, who throws it away, does not know the jeopardy in which be places the lives of this branch of his young stock. Should there not be enough of biestjgg to remove the frece, 2 or $3 \mathrm{oz}$. of castor-oil, beat up with a yolk of an egg, or in thick gruel,

- Youatt on Cattlo. (200) 
should be administered, and a scruple of powdered ginger, to act as a carminative. In cases of (ostiveness, which young calves are very liable to contract. and inattention to which, at first. is tic cause of the loss of many of the best young stock, arising partly from repletion of milk at times when calves are permitted to suck their dams, or when they eat too much hay at one tine after the milk has been too suddenly removed from them at weaning, active measures should be adopted to prevent its confirmation. for then the case becones hopeless, as fever will inevitably ensue aud the food harden into a mass in the muniplies. Doses of warm water, containing a solution of 2 u. $3 \mathrm{oz}$. of Epsom salts. should be frequent; arministered, both to dissolve the matter in the stoinach, move the bowels, and wash out the stomach. Calves are liable to a disease of an opposite nature from this, namely, looseness, sconring or diarrhea. They are most subject to it when put to gruss, though still on milk, at too early an age. I should say that if so treated before attaining 2 months, they are certain of being affected with it. One means of prevention is, to retain the calves in the house or shed till they are at least 2 months old, and if a lithle older so much the better. Of course, it is only the latest calves that are likely to be thus treated, the earlier having attained mature age for weaning before the grass is ready. In the house, scouring may be brought on by starvation and excess, and on grass by a sudden change of food. So long as the calf is lively and takes its milk. there need be no appreheusion from a thin discharge of iæces, but dullness and loathing of food. accompanied by discharge, should create alarm. The first application of a remedy should be a mild purgative, to remove, if possible, the irritation of the bowels, and then should folluw anodynes, astringents, and alkalies, with carminatives, the withdrawal of every sort of green fooil, and the administration of flour or pea-meal gruel. The following mixture the farmer is called to "rely on, and it is recommended that he should have it always by him, as it will do for all suckling animals, namely, $4 \mathrm{oz}$. of prepared chalk, $1 \mathrm{oz}$. of Winters' bark, powdered, $1 \mathrm{oz}$. of laudaum, and 1 pint of water. Give 2 or 3 table-spoonsfull, arcording to the size of the animal, 2 or 3 times a day." Another recipe is: "Take from $\frac{1}{2} \mathrm{oz}$. to $\frac{3}{4} \mathrm{oz}$. of tincture of rhubarb, with an equal quantity of water, according to the age and strength of the caif. To be given every alternate day in case one dose is not sufficient. I have used the remedy for several years," says a writer, " and have not lost a calf." $\dagger$ Mr. E. E. Dawson, Ingethorpe, Granthan, recommends this: "For young calves boil $\frac{1}{2} \mathrm{oz}$. of ground black pepper in half a pint of ale; add a tea-spoonfull of ginger; mix together; to be given lukewarm every morning until the calf recovers of its weakness; to have its milk as usual. Older calves will require $\frac{1}{3}$ more for a complete cure. Great care should be used in making use of the above recipe, that the animal does not receive the mixture too fast; for want of uttention mischief may be done." $\ddagger$ I have given all these remedies for the scour in calves, for it would appear that it may be removed by various means, and one may be more efficacious in one locality than in any other. I never experienced among iny calves but one instance of serious scouring. It was a Short-Horn quey-calf, and the recipe which effected a cure, after trying many, was very like the first, though I now forget the exact ingredients, with the exception of the pint of water, for which flour-gruel was substituted.

(1697.) Calf-lonse.-It is not a little singular, in a physiological point of view, that there should be a peculiar pedicular parasite approprialed to the calf, yet such appears to be the case, although the creature is by no means common. It is very like the ox-louse. Homatopinus enrysternus, fig. 208 , but comparatively narrower, and having two rows of dusky spots on the abdomen. It is termed Hamalopinus vituli, or louse of the calf. $\|_{i}$

(1698.) "Although parturition is a natural process," as well observed by Mr. Youatt, "it is accompaned by a great deal of febrile excitement. The sudden transferring of powerful and accu. mulated action from one organ to another-from the womb to the udder-must cause a great deal of constitutional disturbance, as well as liability to local inflammation." $\delta$ One consequence of this constitutional disturbance of the system is milk-fever. "The cause of this disease," says Skellett, " is whatever obstructs perspiration, and accumulates the blood internally ; hence it may be produced by the application of cold air, by lying on the cold ground, or by giving cold water after calving; and these causes will naturally produce this effect from the open state of the pores at this time, and from the external parts being so wide and relaxed after the operation. Cows in high condition are more subject than others to this complaint, and especially if they have been kept up for some weeks before calving." $/$ The complaint may seize the cow only a few hours after calving, or it may be days. Its first attack is probably not observed by those who have the charge of the cows, or even by the farmer himself, who is rather chary in looking after the condition of his cows, in case of offending his female friends, to whose special care that portion of his stock is consigned. The symptoms are first known by the cow shifting about in the stall. or from place to place if loose, lifting one leg and then another, being easily startled, and looking wildly about her as if she had lost her calf, and blaring for it. Then the flanks begin to heave, the mouth to upen and issue clear water, she staggers in her walk. and at length loses the use of her limbs and lays her head upon ber side. The body then swells, the extremities feel cold and clammy. Stivering and cold sweats follow, the pulse becomes irregular and death ensues. The promptest remudy to be used, after the first symptom has been observed, is to bleed to the extent of 3 or 4 quarts; and the next is to open the bowels, which will be found to have a tendency to constipation. From $1 \mathrm{lb}$. to $1 \frac{1}{3} \mathrm{lbs}$. of Epsom salts, according to the strength of the cow, with a little ginger and carraway, should be given as a purge; and if the dose does not operate in due time, $\frac{1}{2} l b$. of Epsom salts should be given every 6 hours until the bowels are opened. This result will be much expedited by a clyster of warm thin gruel and soap or oil. After the opening medicine has operated, a cordial drink will be necessary, by which time the cow may show symptoms of renovering in expressing an inclination to eat, with which she should be gratified.. but with precaution. ${ }^{* *}$

* Juhnson's Farmer's Encyclopædia, art. Diarrkea.

* Mark-Lane Express for November, 1842.

[ ${ }^{* *}$ The more artificial treatment of cattle in England probably produces diseases and casualties
"

† Bell's Weekly Messenger for March, 1842. to which they are far less subject in our country, where they are left in a more natural and unre. (201) 
(1699.) Red-vater. - The vinth day after a cow has calved, an uterine discharge should take place and coutinue for a day or two, after which the cow will exhibit all the sy mptoms of good health. I have observed that when this discharge does not take place the cow will soon after show symptoms of red.water. She will evacuate urine with difficulty, which will come away in amall streum, and be highly tinged with blood, and at length appear like dark grounds of coffee. "The nature and cuuse of the diseane are here evideut enough," as Mr. Youalt well ob. serves. "Daring the period of pregnancy there had been considerable determinatiun of blood to the womb. A degree of suscepribility, a tendency to iuflummatory action, had been set up, and this had been increaned as the period of parturition approached, and was aggravated by the state and general fullness of blood to which she had incuutiously been raised. The neightsoring orrang necessarily participated in this, and the kidueys, to which so much blood is sent for the proper discharce of their function, either quickly shared io the inflammation of the womb, or first took an intlammation, and suffered most by means of it." "The prevention of this disease is recommeniled in purgative medicine after calving; but as such an admiristration, in the circunstance, never fails to affect the quantity of milk given by the cow for some time after, a better plan is to administer food which will operate as a laxative at the same time, for some time before as well as after calving, and the substance which possesses these two properties is oil-cake. I have proved this from experience. I lost two cows in Forlarshire by red.water, one a ShortHorn and the other an Angus, and one of the hinds lost one also-all in different but successive years. B3y examination of the stomach and bowels after death, I became satisfied that the determination of the blood to the womb during pregnancy bad caused a tendency to intammation in the howels and stomach, and that indigestion and cunstipntion were the consequences, and tbese were aggravated by the state of the food, which consicled entirely of Swedish tarnips, which, at that season, in April, are fibrous and sweet, by the juice becoming concentrated in the bulb, and which the more readily induce cattle to eat them. The remedy wus an ubvious one: give lax a. tive diet, and as that cannot readily be effected by turnips, particularly in cuws which do nut re. ceive so many as they can eat, nor by raw potatoes which incur the risk of hoven (1294), and to the giving of potatoes to cows 1 have always had an utter aversion-call it prejudice, if you will : and as potatues boiled have no laxative effects, the only alternative was oil-cake, and, fortunately, from the period I employed it medicinally to the cows, for a month before and a month after calving, to the extent only of $4 \mathrm{lbs}$. a day to each cow, and which quantity was also given to the hind's cow's about the time of their calving, the complaint was never mure seen or dreaded.

(1700.) I may here mention an unaccountable fatality which overtook a Short-Horn cow of mine, in Forfarshire, immediately after calving. She was an extraordinary milker, giving not less than 30 quarts a day in summer on grass; but what was more extraordinary. fur two calvings the milk never dried up, but continued to How to the very day of calving, and after that event returned in a flush. In the third year she went naturally dry for about a month previous to the day of reckoning : every precaution, however, was takeu that the milk should dry up without giving her any uneasiness. She calved in high health, the milk returned as usual in a great Husb after calving, but it proved an impossibility to draw it from the udder; not a teat would pass the milk, all the four being entirely corded. Quills were introduced into them at first, and then tubes of larger size were pushed up to the root of each teat. A little milk ran out of one of them-hope revived; but it stopped running, and ali the art that could be devised by: a skillful shepherd proved of no avail to draw milk from the udder; rubbing and softening the udder with goosegrease, making it warmer wi:h warm water-all to no purpose. To render the case more distressing, there was not a veterinary surgeon in the district. At length, the udder inflamed, mortified, and the cow died in the most excruciating agony on the third day, from being in the high. est state of health, though not in high condition; for her milking propensity usually kept her lean, but still she was always spirited. No loss of the kind ever stfected my mind so much-to think that nothing could be done to relieve the distress of a creature that could not help itself. I was told afierward by a shepherd to whom I related the case, that I should have cut off all the teats by the roots; which horrid operation would, of course, have destroyed her for a milch cow, but, he conceived, would have saved her for feeding. He had never seen that operation performed on a corn ; but it saggested itself to him in consequence of having been obliged at times to cut off a ewe's teat or teats to save her life. The suggestion I think good; and I mention it that it may occur to you in similar circumstances. I purchased this cow when a quey in calf, along with another, from Mr. Currie, then in Brandon, Northumberland.

(1701.) Cows differ very much in the time they continue to give milk, some not continuing to yield it more than 9 month", while others afford it for years. The usual time for cows that bear calves to give milk is 10 months. The cow that died in consequence of the corded teats mentioned above, (1700,) gave milk for 3 years, and bore a calf every year. A cow of mine that olippeil her calf, and was not again served by the bull, gave milk for 19 months. But many re-

strained condition. Hence with us the parturition of cows is very rarely attended with any difficulty or danger-so ranely as acarcely to make it an object of attention or solicitude; thus all the precautions, descriptions of symptoms and remedies, \&c. laid dow $n$ here, may scem to be almost unnecessary. It is with domestic animals as with the human family-ton much care and manage. ment seem to beget difficulties. The fine lady is watched willa intense solicitude; the family physician is on the quivive for weeks before the event; and she sometimes falls a victim to the contagious sympathy and apprehensions of her friends, and to that delicacy of frame and constita. tion which is the fruit of too much refinement in her rearing and physical education. The poor laboring man's wife bas no such fear, and no such difficulties. The misfortune in his case is that children come too easy and too fast.

Ed. Farm. Lib.]

- Youatt on Cattle. 
markable instances of cows giving milk for a long time are on record. "The immense length of time for which some cows will continue to give milk," says a veterinary writer, " if favorably treated, is truly astonishing; so much so as to appear absolutely incredible. My own observation on this subject extends to four most remarkable cases: 1. A cow purchased by a Mr. Ball. who resided near Hampstead, that continued to give milk for 7 years, subsequently to having her first and only calf. 2. A large dan Suffolk cow, shown to me as a curiosity by a Yorkshire farm. er. This aninal, when I saw her, had been giving milk for the preceding 5 years, daring which period she had not any calf. The five-years' milking was the result of her second calving. During that period, attempts had been made to breed from her, but ineffectually. 3. A small aged cow, belonging to a farmier near Paris, that gave milk for 3 years subsequent to her last calf. 4. A cow in the possession of Mr. Nichols, Postmaster, Lower Merion-street, Dublin. This animal was in Mr. Nichols's possession for 4 years, during the entire of which time she continued to give an uninterrupted supply of milk, which did not diminish in quantity more than 3 pints per diem, and that only in the winter months. . . . . He disposed of her for butchers' meat, she being in excellent condition. The morning of the day on which she was killed, she gave her usual quantity of milk." *

(1702.) The same writer enters fully into a subject with which I was not previonsly acquainted, namely, the possibility of securing permanency of milk in the cow. This is effected, it seems, by simply spaying the cow at a proper time after calving. The operation consists in cutting into the tlank of the cow, and in destroying the ovaries of the womb by the introduction of the hand. The cow must have acquired her full stature, so that it may be performed at any age after 4 years. $f$ She should be at the flush of her milk, as the future quantity yielded depends on that which is af. forded by her at the time of the operation. The operation may be performed in ten days after calving, but the most proper time appears to be 3 or 4 weeks after. The cow should be in high health, otherwise the operation may kill her or dry up the milk. The only preparation required for the safety of the operation is, that the cow should fast 12 or 14 hours, and the milk taken away immediately before the operation. The wound heals in a fortnight or three weeks. For two or three days after the operation, the milk may diminish in quantity; but it regains its measure in about a week, and continues at that mark for the remainder of the animal's life, or as long as the age of the animal permits the secretion of the fluid; unless, from some accidental circumstancesuch as the attack of a severe disease-it is stopped; but even then the animal may be easily fattened.

(1703.) The advantages of spaying milch-cows are thus summed up: "1. Rendering permanent. the secretion of milk, and having a much greater quantity within the given time of every year 2. The quality of the milk being improved. 3. The uncertainty of and the dangers incidental to breeding being to a great extent avoided. 4. The increased disposition to fatten, even when giving milk, or when, from excess of age, or from accidental circumstances, the secretion of milk is checked; also, the very short time required for the attainment of marketable condition. 5 . The meat of spayed cattle being of a quality superior to that of ordinary cattle." $\ddagger$ With these advantages, of course, breeders of stock can have nothing to do; but since the operation is said to be quite safe in its results, it may be presented to the notice of cow-feeders in towns.

(1704.) A cow will desire the bull in 4 or 5 weeks after calving. The symptoms of a cow being in season are thus well described by Skellett: "She will suddenly abate of her milk, and be very restless; when in the field with other cows she will be frequently riding on them, and if in the cow-house, she will be constantly shifting about the stall; her tail will be in constant motion; she will be frequently danging, stalling and blaring; will lose her appetite; her external parts will appear red and inflamed, and a transparent liquor will be discharged from the vagina. In old cows these symptoms are continued 4 or 5 days, but in general not more than 24 hours, and at other times not more than 5 or 6 hours. Therefore. if a cow is intended for procreation, the earliest opportunity should be taken to let her have the bull; for if it be neglected then, it will often be two or three weeks before the above symptoms will return. These instructions," adds Skellett, " are necessary to be given only to the proprietor of a small number of cows, where a bull is not always kept with them. . . . If a cow, after calving, shows symptoms of season sooner than 4 or 5 weeks, which is sometimes the case, she should not be permitted to have the bull sooner than 4 or 5 weeks from that period, for the womb, before that time, is generally in so re. laxed a state as not to be capable of retaining the seed; consequently she seldom proves with calf, if she is suffered to take him sooner." $\|$ This last remark I consider of great value. for 1 am persuaded that most cases of cows not holding in calf the first serving after calving, arises from the want of consideration on the part of breeders, whether the cow is in that recovered state from the effects of calving as to afford a reasonable hope that she will conceive; and this is a point more to be considered than the mere lapse of time after calving, for a cow after a severe labor, may be in a much worse state for conception, even at double that length of time, than another which has

[ $t$ It is not, of course, meant to say that cattle may not be spayed earlier. On the contrary, it is quite common, especially in our western country, to spay heifers, and where the operator has some experience there is little danger. Should the system of M. GunNon, by which it may at a very early age be pronounced whether a calf will make a good or a very indifferent milker, be fully established, it will undoubtedly become expedient for farmers to sell to the butcher for veal. or to have spayed all that are found to be devoid of the marks or escutcheons. Being spayed, they have a greater tendency to fat, and cases might happen, we should think, where the farmer has few cattle that it might be economical to bring such condemned and spayed heifers under the yolke.

Ed. Farm. Lib.]

* Ferguson on Distemper among Cattle.

† Ferguson cn Distemper among Cattle. (203) 
passed the calving with ease, thourls the former may come as regularly into meanon as the latter. The state of the body. therefore, as well as the tength of time, should be taken into consideration in deternining this point.

(170i.) There nre still other considerations connected with the serving of cows which deserve your attention. The usual practice, in places where there is no bull, is to take the cow to the bull it a convenient time for the cattle man to go with her: and should she have passed the bloom of the seasun before her arrival at the bull the issue is of course doubtful. The row may have traveled a long distance and become weary, and yet no rest is allowed her, and she must undergo the still farther fatigue of being served. Some people cannot be satisfied with the gervice which their cows receive, until both cow and bull are wearied out. Others will force either the cow or bull, or both together, against their inclination, she being held by the nose, and he goaded on with chreats and thumps. In all such cases the chances are much against conception. There is, to be sure, the difficulty of not having the bull on the spot, but, when he is reached, he may have been worn out for the day by previous service. No such difticulty is felt when there is a bull at home; but even then. when the cow has to be taken to him out of the byre, for example, some judgment is requisite of the proper time at which she should be taken out : and this can only be ascertained by studying the idiosyncracy of every cow, and remembering each case. It appears to me to be as essential a matter to keep a record of the characteristics of each cow, in regard to her state of season, as of her reckoning to calve; and this remark is strengthened by the great differences, in this respect, evinced by diflerent cows under the same treatment. For example, one arrives soon at mature seaton after the symptoms are exhibited; another requires a few hours to arrive at the agme point, and the season continues for some time longer in a languid state. A third runs through the course of season in a few hours, while a fourth is only prepared to receive the bull at the last part of her season. A fifth may exhibit great fire in her desire, which induces her keejer to have her served at once, when too soon; while another shows comparative indifference, and in waiting for an exhibition of increased desire on her part, the scason is allowed to pass off; aud when this is the case, some cattle-men. conscious of nerlect, and aftuid of detection, will persist in the bull serv. ing her, though she may be very much disinclined for the embrace, and does everything in her power to avoid it. There is no way so natural for a bull serving a cow, as when both are in the field together, and understand one another. The most proper time is wisely chosen by both, and failure of conception will be rare in the circunstance. But it is possible that the bull may be unable to obtain possession of the cow in the field, by reason of disparity in hight and of corporeal conformation; in which case he will require to be taken to a part of the ground which will favor his purpose. Two or three thorough skips are quite sufticient for the purposes of conception. The cow should be put into and kept quiet in the byre, after being served until the desire leave her, and she should get no food or water for some hours after, as any encouragement of discharges from the body at thistime, by food and drink, is inimical to the retention of the semen.

(1706.) "When nature is satisfied," says Mr. Skellett, who is a great authority in the vaccine department of veterinary practice, "or the symptoms of season disappear in the animal, conception has taken place. The reck of the wonb becomes then completely closed by a glutinous sub. stance which Nature has provided for that purpose, being perfectly iransparent, and with diffculty separated from the parts. This matter is for the purpose of exclading all external air from the mouth of the womb during gestation, which, if admitted to the fotus, would corrupt the membranes and the pellucid liquor in which the foctus floats, and would undoubtedly cause the cow to slink. This glutinous substance slso prevents the lips of the mouth of the womb from growing together; and when the cow comes into season it becomes fluid-in the act of corjulation serving to lubricate the parts and prevent inflammation." *

\section{THE ADVANTAGES OF HAVING FIELD-WORK ALWAYS IN A} FORWARD STATE.

\footnotetext{
a Who breakesh timely his fallow or ley, Sets forward his husbandrie many a waye. This, timely well ended, doth forwardly bring Not only thy tillage, but all other thing."
}

Tosser.

(1707.) The season-early spring-having arrived when the laboring and sowing land for the various crops cultivated on a farm of mixed husbandry are about to occupy all hands for several months to come, the injunction of old Tusser to undertake them in time that each may be finished in its proper season, should be regarded as a sound advice; for whenever your field labor is advanced ever so little at overy opportunity of

* Skellett on the Parturition of the Cow. 
weather and leisure, no premature approach of the ensuing season can come upon you unawares; and should the season, on the other hand, be delayed beyond its usual period by natural causes, you will be ready to proceed with your work whenever the weather proves favorable. When work advances little by little, there is time to do it effectually; or, if it be not then executed in an effectual manner, you have yourself to blame for not looking after it. When I say, however, that work may be advanced little by little, I do not mean that it should be done in a slow, careless manner, as if the work-people were unimpressed with the importance of what they were doing. 'The advantage of doing even a little is that whatever is done is not to do afterward; and that a little may be done as well, and in as short a time, as if it had been done as a part of a great operation. In this way, even if only one man is kept constantly at the plow, he would turn over, in the course of a time considered short when looked back upon, an extent of ground almost incredible. He will turn over an imperial acre a day, that is, 6 acres a week, 24 acres in a month, and 72 acres in the course of the dark and short days of the winter quarter. All this he will accomplish on the supposition that he has been enabled to go at his plow every working day; but as that cannot probably happen in the winter quarter, suppose he turns over 50 acres instead of 72 , these will still comprehend the plowing of the, whole extent of ground allotted to be worked every year by each pair of thorses when the farm was taken. In fact, here is a large proportion of a whole year's plowing done in a single, and in the shortest quarter of the year.

(1708.) Now, a week or two may quickly pass in winter in doing things of little moment, and which, in fact, amount to time being thrown away; such as sending away a rake of all the draughts to a stock corn-market, on a day when there is little prospect of disposing of the grain, and when they would have been better employed at home at the plow; or driving some material on the farm which would better and easier be done when the plows are laid idle at any rate by frost; or in setting men to the corn-barn to thresh or clean corn, and laying the horses idle for the time; or in contriving some unimportant work to fill up the time for half a day, until the frost thaws a little on the lea, because it would give too much trouble to take the plows from the lea to the stubble field, if there be any such at the time. Sharpening and setting irons differently may form a reasonable excuse for shifting the plows from a stubble to a lea field, but no such excuse is available in neglecting to make the opposite transference. Such omissions and instances of misdirected labor are too much regarded as trifles in winter; but is undeniable that they occupy as much time as more important work; and in a season, too, when every operation of the field is preparatory to one at a more busy season. Occasionally the state of the work will force the consideration on the farmer, that it is not so far advanced as it should be, or even as he could wish; still, instead of pursuing a different course from that which has given rise to the reflection occasioned hy the delay, his unsatisfied mind consoles itself with the assurance that when the season for active work actually arrives, the people will be able to make up for the lost time. This is, however, mere delusion; for if work can be made up, so can time, the two being inseparable; and yet how can lost time be made up, when every moment of the year has its work to perform, and when that period, long as it is, is usually found too short in which to do everything as it ought to be done? "There's the rub." For time eludes pursuit, and brooks no interruption; but neglected work, though attempted to be overtaken-and it may be overtaken before its issue-still the race will never terminate in a satisfactory manner. The 
neglected work may, no doubt, be done in a short time-in an unprecedentedly short time; but in that case, it is the time in which the work is done that is boasted of, not the work itself-the measure, and not the thing measured, which is held up to view; and yet, time being the standard by which all well-executed labor is measured, it cannot be deprived of that property, whatever devices may be used to make it go beyond its steady pace. You should remember that its pace is the same in winter as in summer, and the extent of labor, measured by the length of its tread, ought to he as great in winter as in summer, otherwise an irreclaimable error is assuredly committed in that season.

(1709.) Convinced that field-labor should be perseveringly advanced in winter, whenever practicable, I am of opinion that plan is good which appoints plowmen to different departments of labor; some to work constantly on the farm, others occasionally to go from home; some to be constantly, or nearly so, at the plow, others frequently at the cart. Thus the henefits of the subdivision of labor may be extended to the farm. When a certain proportion of the draughts are thus set aside for plowing, that most important of all operations will not only be well done by those whose special duty it is to do it, but perseveringly and judiciously done. This proportion is only legitimately employed at any other work when there is no plowing for them to execute. Plowing being a steady occupation, not subject to the irregular action of the cart, can be performed by the older men and horses, who cannot so well bear the shocks of carting as younger men and horses.

(1710.) It may be proper to give some familiar examples of what I mean when I say that field-labor should be advanced at every opportunity. The order of work in spring is well understood; it should therefore be the study of the farmer to conduct the operations of winter so as to suit those of spring in their natural order. If the weather seems tempting to sow spring wheat, then a portion of the land cleared of turnips by the sheep, best suited to that species of crop, should be so plowed as to answer wheat instead of barley. If beans are desiderated as a crop, and there is land suitable for their culture, then, in autumn or in early winter, the stubble land, in its particular state should be so plowed as to suit their growth; and in whatever mode beans are to be afterward cultivated, care should be taken to have the land particularly dry, by letting off water in winter by additional gaw-cuts, where necessary, or by deepening those already existing, where they seem to require that amendment. Beans being an early crop, such precautions to render land dry on the surface are requisite. If common oats are to be sown in spring, they being sown earlier than other sorts, the lea intended for them should be plowed first, and means taken to keep it dry in winter, so that the most unpropitious weather in spring may not find the land in an unprepared state. What land is intended for potatoes, what for turnips, or tares, or bare fallow, should be prepared in their respective order; and when every one of all these objects have been promoted, and there is found little or nothing to do till the burst of spring-work comes, both horses and men may enjoy a day's rest now and then, without incurring the risk of throwing work back; but before such recreations are indulged in, it should be ascertained that all the implements, great and small, have been repaired for workthe plow-irons all new laid-the harrow-tines new laid and sharpened, and fastened firmly into the bulls of the harrows - the harness all tight and strong-the sacks new patched and mended, that no seed-corn be spilled upon the road-the seed-corn threshed, measured up, and sacked, and what is last wanted put into the granary-the horses new shod, that no (206) 
casting or breaking of a single shoe may throw a pair of horses out of work for even one single hour-in short, to have everything prepared to start for work when the first notice of spring shall be heralded in the sky.

(1711.) But suppose the contrary of all this to happen; suppose that the plow-irons and harrow-tines have to be laid and sharpened, when perhaps to-morrow they may be wanted in the field-a stack to be threshed for seed-corn or for horses'-corn in the midst of a sowing of a field-suppose, too, that only a week's work has been lost, in winter, of a single pair of horses, and the consequence is that 6 acres of land have to be plowed when they should be sown, that is, a loss of a whole day of 6 pair of horses, or of 2 days of 3 pair-suppose all these inconveniences to happen in the busy season and the provoking reflection occurs that the loss incurred now was occasioned by trifling offputs in winter. Compare the value of these trifles with the risk of finding you unprepared for sowing beans or spring wheat. Suppose, once more, that instead of having turnips in store for the cattle, when the oat-seed is begun in the fields, and that, instead of being able to prosecute that indispensable piece of work without interruption, you are obliged to send away a portion of the draughts to bring in turnips, which must be brought in, and brought in, too, from hand to mouth, it being impossible, in the circumstances, to store them. In short, suppose that the season of incessant labor arrives and finds you unprepared to go along with it-and what are the consequences? Every creature about you, man, woman, and beast, is then toiled beyond endurance every day, not to keep up work, which is a lightsome task, but to make up work, which is a toilsome task, but which you said you could easily do, when you were idling your time in a season you consider of little value; and, after all, this toil is bestowed in vain to obtain the end you wish, namely, to prepare your crop in due season. You who are inexperienced in the evils of procrastination may fancy this to be an overdrawn picture-even an impossible case; but unfortunately for that supposition, it is drawn from the life. I have seen every incident occur which I have mentioned, both as to work being in a forward and in a backward state, not, it is true, in any one year; but some instances in one, and some in another year, but what may occur in different years may all occur in one, and such a result may easily be realized by indulgence in increased negligence.

\title{
10. CROSS-PLOWING, DRILling, AND RIBBiNg LAND.
}

The new-gained field laid down in seemly drills."

\author{
Gramaur.
}

(1712.) I have already described the various modes of plowing land at the commencement and during winter. It remains for me to describe other modes of plowing, which were deferred from that time until the season in which they are usually begun to be executed, namely, spring. These modes are cross-plowing, drilling, and ribbing.

(1713.) And, first, as to cross-plowing. I have alluded to this mode of plowing, not so much to describe it minutely, as to deprecate its practice before winter. "Its object is to cut across the existing furrow-slices into small pieces, that the land may be the more easily pulverized and prepared for the future crop." Fig. 312 represents a field to be cross- 
plowed, and it is purposely formed of an irregular shape, as most fields are, to show the side from which the cross-furrows should be feered, and the mode of plowing the last, or irregular feering, according to the circumstances of the case.

(1714.) The first thing to be done in preparing any field for cross-plowing is to render its surface as free of large clods as possible; and this is effected by harrowing, an operation which is executed by an implement that will be particularly described when it comes to be spoken of in seedtime. The winter's frost may have softened the clods of the most obdurate clay-soil, and the mould-board of the plow may be able to pulverize them fine enough, and the lighter soils may have no clods on them at all; from all which circumstances it may be regarded as a loss of time to harrow the ground before cross-plowing it in spring; and, for these reasons, I believe, some farmers do not practice harrowing; but it appears to me to be always the surest plan of pulverizing the soil to harrow it before cross-plowing the winter furrow; because you cannot be sure that, in the strongest land, all the clods have been softened to the heart by frost; and should they happen still to be hard there, and become buried by the cross-furrow, they will not be so easily pulverized as when lying exposed upon the surface of the ground to the action of the harrow; and even in the lightest soils, the harrows not only make a smoother surface, but assist in intermixing the dry frost-pulverized soil of the surface with the moister and firmer soil below, at least as far as the tines of the harrows reach.

(1715.) There is not much time lost in harrowing before cross-plowing; for although the harrowing should be given a double-tine, that is, backward and forward upon the same ground, to pulverize the clods, or equalize the texture of the ground; and although it should be given across instead of along the ridges, that the open furrows may be filled up with soil as much as possible, whether the land had been plowed with gore-furrows, fig. 136, or not-that which has been cloven down with gore-furrows, fig. 141, or twice gathered up, fig. 139, being the most difficult to cross-harrow, not only on account of the numerous open furrows of the former method, and the inequality of the ground, occasioned by the latter, but because both these methods are adopted for winter furrows on strong land, which is the most difficult to be labored even in the most farorable forms-yet the worst form of plowed land can be harrowed in a short time.

(1716.) Two pairs of harrows should be set to cross-harrow together, as being the best mode of accomplishing effective harrowing in all cases, as will be shown afterward; and that number of harrows, when unconfined by ridges, will cover at least 16 feet in breadth, and proceeding at the rate of 2 miles per hour for 9 working hours, will give 19 acres of ground a double tine, on the supposition there have been no interruptions; but as time must be lost in turnings, as you have already seen in plowing (930), and a breathing occasionally given to the horses, that quantity of land cannot be harrowed a double tine at that rate of traveling, in the ordinary mode of conducting labor; but say that 16 acres are thus cross-harrowed in the course of a day, a half day's hartowing will make room for a number of plows.

(1717.) If time presses, the feerings for cross-plowing can be commenced almost immediately after the harrows have started; and if these cannot get way before the plow, it can either take a bout or two in each feering, till the harrows have passed the space for the next feering, or the harrows can pass along the lines of each feering before the plow, and return and finish the barrowing of the ground between the feerings. Thus in fig. 312, after the line of feering $e f$ has been harrowed, the plow can either take a bout (208) 
or two around it, till the harrows have passed the next line of feering $g h$; or the harrows can go along each line of feering, first $e f$, then $g h$, then $i k$, aild so along $l m$ and $n o$, in succession, to prepare the ground for feering, and then return and harrow out the ground between $e$ and $g, g$ and $i$, $i$ and $l$, and $l$ and $n$. In this way the harrowing, and feering, and the plowing of the different feerings can be proceeded with at the same time. But if time is not urgent, the systematic mode is to harrow the field

Fig. 312 .

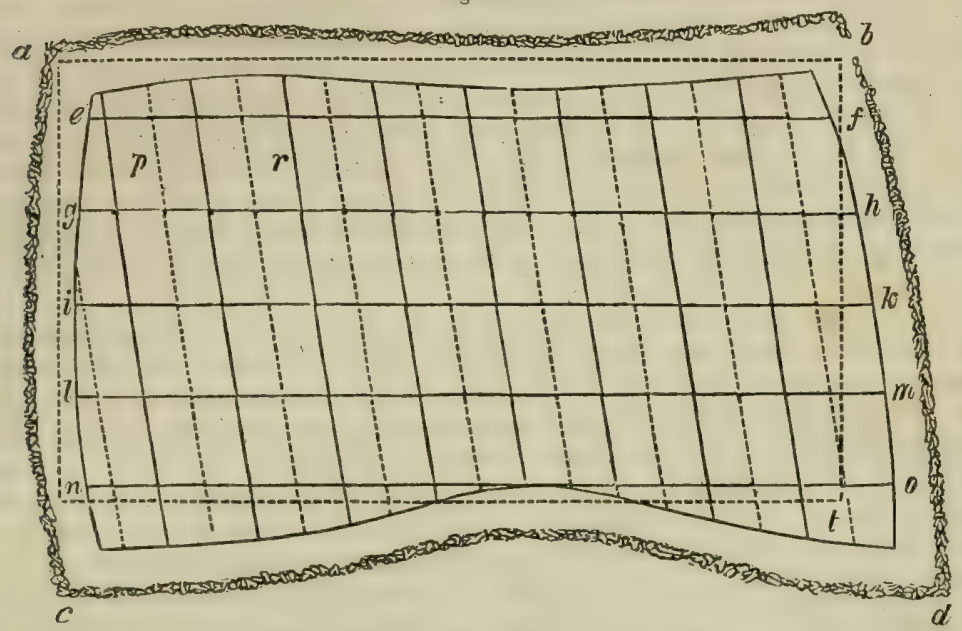

A FIELD FEERED FOR BEING CROSS-PLOWED

in a continuous manner, beginning along the fence $a b$ from the gate at $b$, and proceeding by breadths of the harrows across the field till the other side of it, $c d$, is reached; or another equally effective mode is to step off feerings from $a b$, in breadths of 30 yards in succession, along the field, in the manner I am about to describe, for cross-plowing; and this mode has the advantage of giving an easier turning to the horses at the landings.

(1718.) Suppose, then, that all or as much of the field to be cross-plowed has been harrowed as will give scope to a single plow to make the feerings without interruption. In choosing the side of the field at which the feerings should commence, it is a convenient rule to begin at the side farthest from the gate, and approach gradually toward it, and its convenience consists in not having to pass the finished feerings, and so to avoid the risk of trampling on the plowed to get at the unplowed land. The convenience of this rule is felt not only in cross-plowing, but in prosecuting every species of field-work; and besides avoiding the risk of damage to finished work, it is gratifying to the minds of laborers to think that, as their work proceeds, they approach the nearer home; while it conveys to others the idea of a well-laid plan, to witness the operations of a field which have commenced at its farthest end, and are finished at the gate, where all the implements employed meet, ready to be conveyed to another field. The gate in this instance is like home, and in most instances it is placed on that side or corner of the field nearest the steading. In the particular case of the field represented by fig. 312, these conveniences are not all available, owing to its form, which is a very common one ; and peculiarities of form involve considerations in regard to conducting field operations of more importance than mere convenience, and one of these is the most

$(209) \ldots . . .8$ 
important one of loss of time. It is always desirable to commence a feeriug at a straight side of a field, whence there is little risk of error in ing off the feerings to include parallel spaces of ground; and wher estrikthis particular is not attended 10 , much time is needlessly spent in plowing a number of irregular pieces of ground. It is hetter to leave any irregu. larities in plowing to the last; and, as an irregularity must occur, at all events, along the side of a crooked fence, it is saving of time to throw any irregular plowing to that side. In fig. 314 it so happens that the straightest side of the field is nearest the gate at $b$, and the crooked fence, $c$ to $d$, farthest from it. In pursuance of the rule just announced, the feering should begin along the side of the straight fence $a b$, and terminate in an irregular feering, along the crooked fence $c d$. A straight feering could, no doubt, be made at first along $c d$, leaving any irregularity between it and the fence; but the setting off of that feering parallel with the straight fence $a b$, in order to avoid making an irregularity there also, would in pose considerable labor, and take up more time than the advantage would compensate of avoiding the inconvenience of having to pass plowed ground.

(1719.) Let the first feering, then, be made about 7 or 8 yards from the fence $a b$, or from the ditch-lip of that fence, if there be a ditch there. Some farmers neglect the head-ridge in the cross-plowing, and measure the feering from the open furrow between it and the ends of the ridges. I maintain that the head-ridges should be plowed at this time, as well as the rest of the field, for if they are neglected now, the busy seasons of spring and of early summer will prevent attention being paid to them till, what with the trampling of horses in working the land for green crop, and the probable drouth of the weather in those seasons, will render them so very hard that it will be found impracticable 10 plow them, and they will thus be deprived of the ameliorating effects of the sun and air during the pest part of the year. Let them, therefore, be included in the cross-plowing, although they cannot be cross-plowed themselves. But if it is desired to plow them with the side-ridges, which form the head-ridges to the cross-plowing, and which side-ridges must be plowed before the crop, whatever it may be, can be sown upon them, then the head-ridges may he left out of the feering, and the first feering be struck at 7 or 8 yards from the - head-ridge open furrow. Suppose that this line of feering is $e f$; and as it is executed in the same way as that already described in feering ridges in (646), I refer you to that paragraph, as well as to fig. 132 , where the furrow-slices $m n$ are shown to be thrown out right and left from the line of feering $k l$. The next line of feering is $g h$, at 30 yards' distance from ef, and so there is a feering at every 30 yards' distance, to the last feering, $n o$.

(1720.) After as many feerings are struck as there are plows to be employed in cross-plowing, each plow enters a feering, and first lays the furrow-slices of the feering together, to form the crown of the future cross-plowed break of land. The horses are hupped around each feering, $e f, g h$, \&c., till about $\frac{1}{4}$ of each break of land is plowed, that is, $\frac{1}{4}$ from $e$ toward $g$, and $\frac{1}{4}$ from $g$ toward $e$, thus plowing $\frac{1}{2}$ the hreak between $e$ and $g$ by hupping the horses. The remaining $\frac{1}{2}$ of the break, between $e$ and $g$, is then plowed by hieing the horses (901) from $e$ to $g$, and from $h$ to $f$, till the middle, between $e$ and $g$, is gained by an open furrow. No open furrows, however, are left in cross-plowing, these heing plowed together again by 2 or 3 bouts, lessening the size of each furrow in every bout, till the last one is closed up by the mould-board of the plow, whick is laid over on its side, and dragged forward while the plowman holf (210) 
only by the large stilt. The obliteration of the open-furrow is necessary to avoid any hollow that would be left there across the ridges, when they are again plowed into form. I have' alluded to this subject before in (667.)

(1721.) The plowing of the complete feerings is all plain work, and, indeed, the only difficulty encountered in cross-plowing is when the last or irregular feering, such as $n o$, is reached. This feering is begun to be plowed like any of the rest, till the nearest point to the open furrow of the head-ridge is attained, and if the head-ridges have been included in the feerings, then the plowing proceeds till the ditch-lip or hedge-root stops the plow; but if left to be plowed with the side-ridges, a small feering should be made at the lowest points of the ridges at the head-ridge furrow, and the break included between these points and the feering should be plowed out by hieing the horses with a long furrow on the one side and a short one on the other, till the middle is gained, where the open furrow is closed up like the others. . This feering will take longer time to plow than any of the rest, in proportion to the quantity of the ground turned over in it, on account of the plow having to go empty from the bend of the fence to the points on both sides.

(1722.) Had the field been a true rectangle, like the space included within the dotted lines $a n b t$, the feering might have been struck from either fence, and there would have been no loss of time in plowing alternate long and short furrows. Scarcely a more striking comparison can be made of the loss of time in plowing land of the same extent than be tween a field of regular and irregular form at a busy season. The letters $p$ and $r$ indicate single and double ridges.

(1723.) The furrow given at cross-plowing is always a deep one, deeper than the one given at the commencement of winter; and this is easily ac. complished, as the land, not having had time to consolidate, nor any labor executed upon it to consolidate it, the plow passes easily under the old furrow, and not only turns it over again, but raises a portion of the land below it. Indeed, it is requisite to make the plow take hold of this firm substratum in order to keep it steady, otherwise the formerly turned-over furrows, which are still cloddy, or the unrotted stubble which has been buried by the plow, may form obstacles under and on both sides of the plow, so as to throw it out of operation altogether, or at least so affect its motion as to prevent its maintaining an equal depth of furrow. Perhaps 9 inches may be considered a good average depth in cross-plowing with a pair of horses.

(1724.) But means are frequently used at this season to cross-plow with a deeper furrow than can be reached by a plow drawn by a pair of horses, 3 or 4 horses being employed for the purpose. The third horse is very commonly yoked in front of the furrow-horse of the plow, and harnessed in cart-traces, as represented in the trace-horse of the cart in Plate XVIII., the hooks of the trace-chain being passed into a link of the plow-chains, behind the haims, of the rear horse. A simpler plan still is adopted by only using the plow-harness, and lengthening the plow-chains by shortends, that is, short pieces of chain, which are hooked in a similar manner to that just described. Neither of these methods, however, will bear a comparison, in point of draught, with the yoking of 3 horses, as represented in fig. 201, and described in (909). I have an objection, however, to this mode of yoking, which is founded, not on its principles, which are faultless, but on account of an inconvenience to one of the horses. When so yoked, the three horses work nearly abreast, the middle one being only a little in advance of those on either side; and the objection is, that the (211) 
middle horse will become more heated in the work, in that position, than either of the other two. This inconvenience may not be much felt in early spring-work, but at the time when the largest proportion of crossplowing is usually executed, or in summer, the middle horse must suffer considerably more than the others, and this result I have frequently witnessed in places where three horses are still yoked abreast to the harrows. Ther are various modifications of yoking three horses practiced in different parts of the country, to which reference has already been made in (910), (911) and (912), and where will also be found methods of compensaing the labor of any individual horse by an alteration of the swingtree, when unequally yoked, which one of the horses is, when three are made to work together, as they are usually yoked in tandem fashion. Three horses will take a depth of furrow of 11 or 12 inches, according to the texture and depth of the soil.

(1725.) A still greater depth may be attained, and is frequently desirable in cross-plowing, and there is no other sort of plowing which affords suct: facilities for obtaining a deep furrow. This greater depth is attained by yoking four horses to a plow, 2 leading and 2 following, the 2 off ones walking in the furrow, and the 2 near ones on the firm land. Two very convenient and efficient modes of yoking 4 horses may be seen in figs. 202 and 203, and a description of them is given in (913) and (914). Yoked as in fig. 202, the leading horses are best harnessed, as in the traces of the cart, Plate XVIII; but, as in fig. 203, they may be in their usual plowharness, with the exception of the chains, which are made for this particular mode of yoking. The depth reached by a 4-horse plow is, on an average of soils, 14 inches. I have used the 4 -horse plow much, and with stout, well-matched horses have never reached less than 14 inches in obdurate subsoils; while in freer soil and substratum, not properly a subsoil, but rar ther an undisturbed soil, the plow went to 16 inches of perpendicular depth, and the work was most satisfactory,

(1726.) An ordinary stout plow will answer for 3 horses, and so it may for 4 , where there are no bowlder-stones in the land; but where a considerable quantity of 4-horse plowing is desired to be executed, it is better to have a plow made for the purpose a little stronger than the ordinary 2horse plow.

(1727.) In a 3-horse yoke, one man may drive all the horses by means of reins or by the voice, though a boy to assist at the turnings will save as much time in that matter as will compensate for his wages. Where 3 horses are yoked abreast, one man may as easily manage them as 2 horises. In the case of 4 horses, however, there should be a man to drive the horses, and this is usually done with the whip instead of reins, though the near leader should have a rein. The second man, in this case, is no loss, as the 4 horses just constitute 2 pairs of the ordinary draughts. Even if the second man were taken away from his horses-which should never be the case-and set to other work, he would be of little service, as his mind would be constantly occupied with the desire to know how his horses are getting on under the guidance of another man. But the fact is, that no man can manage 4 horses at the plow with advantage to the work. Fig. 206 shows how a 4 -horse plow may he yoked and driven.

(1728.) This deep cross-plowing with a 3 or 4 -horse plow should not be confounded with trench-plowing, which is hest and usually performed as represented in fig. 206. Trench-plowing only deserves the name when a common plow goes before and turns over a furrow-slice, and in the bottom of which the 4-horse plow follows and goes as deep as it can. In deepplowing, the 4-horse plow goes as deep as it can of itself, and it is rare that (212) 
it meddles with the subsoil, which it is the special object of trench-plowing to disturb. Deep-plowing will be very well executed by one common plow following another in the same furrow; and when the substratum is free, this is a very good way of stirring up the soil to the moderate depth of 10 or even 12 inches.

(1729.) The 3 and 4-horse plows should not be inconsiderately employed in cross-plowing in spring, because, either mode of plowing occupying a considerably longer time with the same number of draughts, and employing more horses than ordinary plowing, it cannot be prudently employed on land that is immediately to be occupied by an early spring crop, such as beans, though the time in which potatoes, turnips, and fallow are respectively finished, will afford plenty of leisure to have the land appropriated to them deeply cross-plowed in the best manner.

(1730.) Next as to drilling. This is a form of plowing very different from the ordinary, but it is not unlike that mode of plowing stubble in some

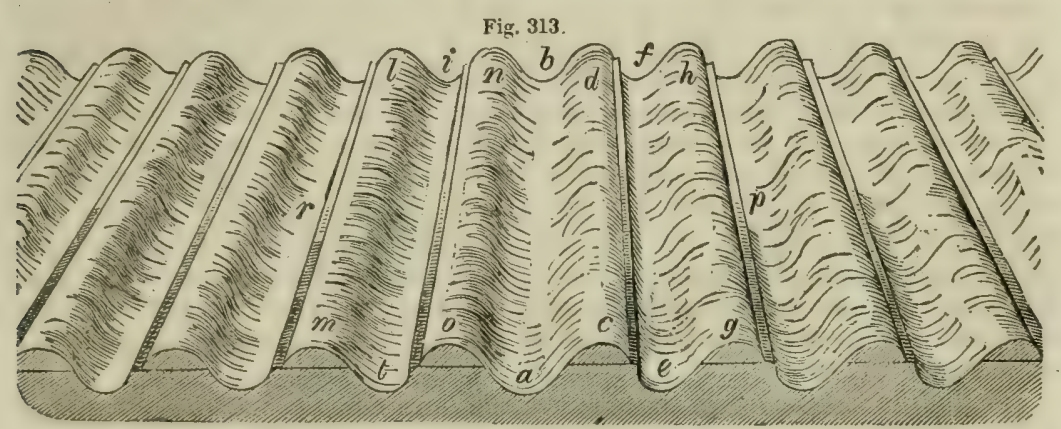

THE MODE OF PLOWING SINGLE DRILLS.

parts of the country which is represented by fig. 142, and which I alluded to only to condemn. The principal reason for my condemnation of it was that, while it professed to turn up the soil to the action of the atmosphere, it buried more than half of it untouched by the plow, thus in a great measure running counter to its own avowed object. On comparing fig. 313 , with fig. 142, the form of the two modes of plowing are somewhat similar, but their structure, that is, the state of the soil within and without, they are very different. In fig. 142 , the ground $b$ is quite solid and unmoved from the state in which it had borne crops, and the moved parts $a$ are full of stubble and weeds. The lines of the drills $c$ are quite irregular, having no reference to the quarters of the compass, the direction of the ridges, or in parallelism with themselves. The regular drill, on the other hand, is formed of deep loosened soil, plowed and harrowed on purpose, and made as clear of weeds as the time allotted to prepare the soil will allow. Drilling is a finished piece of work. the nther only confessedly a preparatory one. Drilling is essential to the proper cleaning of the land at a future period of the season, the other a very questionable mode of attaining any good object.

(1731.) I have said that before land is drilled it should be well pulverized, well cleaned, at least as well as the time when it should be drilled will allow; and the ground should be in a soft state by labor when drilling is to be executed, otherwise the drills will not have their proper form and structure. Drills should not be formed on hard land, nor ought they to be attempted to be formed on hard land, as the object of making them at all is, in the first place, 10 affurd a sufficient quantity of loose soil to 
cover the manure deposited in them; in the next place, to afford the roots of plants sufficient freedom to roam in search of food; and, in the last place, to afford opportunity, notwithstanding the presence of a crop, to free the land of weeds, by stirring it occasionally with proper implements. There is no way of effecting all these objects so effectually as by drilling. Accordingly, all crops intended to meliorate and clean the ground are cultivated in drills, and these are what are called green crops, namely, pritatoes, turnips, mangel-wurzel, beans, \&c.

(1732.) After land has been much plowed and harrowed, and even rolled to render it friable, it is usually in a flat state, whatever may have been the form in which it had been before plowed; and when flat, it is in the best state for being plowed into drills. Yet strong land that is constantly retained in ridges of a rounded form, that is, twice gathered up, fig. 139 and (656), will exhibit the form of ridges, even after it has been well pulverized by plowings, harrowings, and rollings; it will still appear as if gathered up from the flat, fig. 133, and it had been harrowed and rolled fine on the surface. Lighter soil with the same work will appear quite flat, that is, of a uniform surface throughout, not as if it were level. 'This distinction in the appearance of the ground of being ridged or not ridged, should be kept in view, as it will in great measure determine the width of space that should be left between the drills : and it is entirely occasioned by the difference of the form in which the different sorts of soils had been previously plowed. Strong soil is always kept round by repeated gatherings up, or gatherings-up based on casting with gore-furrows, figs. 135 and 136 ; whereas the lighter soils are usually only once gathered up, fig. 133, cast together without gore-furrows, fig. 135, or plowed two-outand-two-in, fig. 138.

(1733.) In whichever of these states the land may be, whether completely flat or exhibiting a slight indication of rounded ridges, the drills are made of the same form; and they are formed in the following various ways. They are made by one landing of the plow, when they are said to be single, or they are made with a bout of the plow when they are called double; and both single and double drills are made cither touard or from the feering. The ultimate forms of the two different modes are apparently the same, but that which makes them from the feering is nevertheless the best, as I shall show in the sequel.

(1734.) In beginning to make diills, let us take one of the simplest cases that present themselves, namely, a field having a straight side at its farthest end, and having the forms of ridges still visible; and as it is requisite in strong land to preserve a form that will keep it as dry as possible, the drills should be so formed upon the ridges as to be accommodated between their open furrows. If the ridges are 15 feet in width, 6 drills of 30 incles apart will fill up that space between the open furrows; and if 18 feet wide, 8 drills of 27 inches will answer the same end. When the ground is flat, any width of drills previously determined on may be executed. have seen it stated in cases of drilling land for turnips in England, that only 18 inches was a good distance to be preserved between drills; but what object is gained by adopting a distance which is too narrow for the free operation of the implements required to keep the ground clean, I cannot imagine.

(1735.) Suppose, then, that the ridges present a form of 15 feet in width on strong land, they should be made 30 inches wide, and they are made in this way: Begin at the end of the field farthest from the gate, and where the fence runs in a straight line; and set up 3 feering-poles (446) in a straight line upon the nearest furrow-brow of the third ridge from the (214) 
fence, and 15 inches from the middle of its open furrow. Split out the feering along the line of the poles, turning over the furrow-slices first to one side and then to the other, like the furrow-slices $m$ and $n$, along the feering $k l$, fig. 132. The reason that the first feering is made on the furrow-brow is, that when the drills are split to cover the dung, or whatever else is put in them, the place which the hollow now occupies will then be filled up by the drill, and the open furrow will then be the hollow between the drills upon the furrow-brow of both ridges. In fig. 313, suppose $a b$ to be the feering in the furrow-brow of the ridge. On passing up from $a$ to $b$, the plow lays over the furrow-slice $c d$, and the soil having been pulverized, it crumbles down in a continuous heap upon the firmer land under it. On gaining the head-ridge at the other end of the feering, the horses are hied, and the plow comes down from $b$ to $a$, laying over a similar furrow $n o$ upon the firm land. A similar feering is made in the furrow-brow of the 6 th ridge from the last, and so on upon every 6 th ridge across the field; but ere the field is all feered for drilling, some of the drills are formed between the feerings, that the land may be proceeded with for the purpose it has been drilled, while the feering and the drilling of the remainder are proceeded with. To proceed, then, with the drilling at the first feering, at a distance of 30 inches, this previously determined width of the drills is measured off from $a$ to $e$, and this the plowman does with his plow-staff, or shaft of his plow-spade, as that implement is call in some parts of the country, upon which the various breadths of drills executed on the farm are notched off. The plow then proceeds from $e$ to $f$, preserving a parallelism with the feered furrow $a b$, laying over the furrow-slice $g h$ upon the firm ground, upon which it crumbles down in a continuous heap. On hieing the horses at the other end of the drills, a similar distance of 30 inches is marked off from $b$ to $i$, the plow passes down from $i$ to $t$, laying over the furrow-slice $l m$ upon the firm ground. Hieing the horses again, the plow passes on to $p$, and goes by $p$, forming another drill like the others. The plowman does not measure off the width of every drill he makes in this manner, his eye being able to keep him right for a number of drills, across which he then lays his plow-staff, to ascertain how he has been proceeding, whether the drills he has made be too narrow, or too wide, or quite the proper breadth, and then again proceeds with his work. It will be observed, from the description of this process, that one drill has been formed every time the plow has gone up in the direction of $e f$, and another every time in coming down in the direction of $i t$, with the exception at striking the feering, when the plow both went up and came down $a b$. In this way the horses are made to hie round $a b$, and the plow to make 2 drills every bout till 2 ridges on each side of the feering $a b$ are drilled up, and the last drill will be made close behind the fence. When this takes place, the plowman goes to the next feering, when two furrows were split out as at $a b$, and forms drills around it in the same manner till 2 ridges also on each side are drilled. Two ridges having thus been drilled to the right of the first feering and two to the left of the second, and six ridges intervening between the feerings, two ridges of the six have yet to be drilled, upon which the drills are formed by hupping the horses from the one set of drills to the other; but in doing this, caution is requisite to make all the drills of the exact width of 30 inches, and particularly the last two formed at the junction of the two feerings. The caution is exercised by the plowman applying his plow-staff frequently to ascertain the breadth of the ground to be drilled, and the width of the drills themselves; and should he find that he has more or less ground than he should have for the number of drills he has yet to make, he must modify the width of each (215) 
drill, so as the whole number may bo very near the width, and not reserve any surplus or deficient ground to be added to, or substracted from, the last drill alone. Another caution of not less importance is to ascertain if the ground to be last drilled is of the samo breadth at both onds at the head-ridges, for if this point is not attended to, the last drill may run out to a point at one end, and be too broad at the other. In closing every feering, therefore, the greatest caution is required to preserve the breadth of the drills.

(1736.) This is one way of forming single drills, and the following is another. Instead of splitting out the feering $a b$, fig. 313 , as just described, the plow lays two furrows together, and forms a finished drill with an elevated ridge, in the place of the hollow furrow $a b$; and this is done by hupping the hoises instead of hieing them, as in the other case. Still hupping the horses and measuring off the width of the drills as formerly, the next drill is made in the direction of $f e$, laying the furrow-slice upon the firm ground, toward the open track of the plow left in making the previous drill in the same direction. The next drill is made in the direction of $t i$, again laying the furrow-slice toward the plow-track left open in furming the previous drill. The drills are thus formed around the first feering over the 2 ridges on each side, then over the 2 ridges on each side of the second feering, and the drills are closed up between them, with the precautions noticed above (1735), by hieing the horses.

(1737.) The essential difference betwixt these two methods is this. In the first, the furrow-slices are all laid over from the feerings toward the unplowed land, and the horses are first hied and then hupped in finishing the feerings. In the second method, the furrow-slices are all laid over toward the feerings and the plowed land, and the horses are first hupped and then hied. As to the treatment of the horses, there is no difference in regard to them, being hupped and hied in both cases, but there is a consid. erable difference in regard to the treatment of the land. In the second method, the furrow-slice being laid over toward the open track which the plow has made in making the previous drill, should the land be at all cloddy, and it is impossible to reduce every clod on strong land at all times, clods or stones may roll down the crumbling furrow-slice, acquiring an impetus by the action of the ear of the mould-board, into the hollows between the drills; and this is no imaginary inconvenience, for clods and stones actually roll down into the said hollows, when they happen to be numerous, or when the soil is so firm as to acquire a considerable force of the plow to elevate it into drills, and when it is apt to rise in large masses before crumbling down in its fall from the mould-board. When the width of the drills is as much as 30 inches, this inconvenience is less likely to happen, but when the more usual width of 27 inches is adopted, I have seen it occur to a considerable degree. The immediate inconvenience occasioned by these clods is, that they interrupt the progress of the beanbarrow when the land is drilled up in this way for the bean-crop; and when the land is dunged, they occupy the best part of the drill, and being there covered up with the dung, they remain among it, and form obstructions to those roots of plants that may be pushing through the manure in search of farther sustenance. At all events, they can do no good.

(1738.) In the first method, on the other hand, this inconvenience is entirely avoided, and no other is substituted in its stead; for should clods and stones roll away from the furrow-slice when the drill is making, and which they will inevitably do when present, upon the open and firm land, they remain there only to the next passage of the plow, which sweeps them (216) 
away, and at the same time leaves a small space of ground between the former furrow-slice and its track, as from $t$ to $o$, \&c., and which track is clear and open, ready for the bean-barrow, or the dung that may be deposited in it. The advantage possessed by the first over the second method of drilling in these respects is so obvious, that any argument in support of it appears unnecessary, and being so obvious, you should not fail to adopt this method as your invariable practice.

(1739.) When the ground is flat, that is, when the ridges are not remarkably prominent, the drills are made the common width of 27 inches, some make them 28 inches, and the feering is conducted in the same way; but in setting off any feering from the last one, when there is no such guide as the breadth of ridges to measure the proper distances, care should be taken to set off such distances as will contain a determinate number of drills of the fixed width, otherwise an error will inevitably occur at the closings of the feerings. Thus, if the drills are 27 inches in width, in a feering of 30 yards broad, 6 ridges of 15 feet, each making a very convenient breadth of feering, the number of drills will be exactly 40 .

(1740.) So much for single drilling; now for double. For this mode the feering is made in a different manner from that for the single mode of drilling. Supposing, again, that the ridges are visibly marked in the ground, the feering is takeu from the furrow-brow of the ridge nearest the fence, at 15 inches from its extreme outer edge, and there setting up a straight line of poles, split out the feering as before by the plowing passing up and down in the same furrow. Suppose this furrow to be represented by the line in $e f$ in fig. 132, then set up a square table at $d$, and mark off therefrom a line with poles at right angles in the direction of the arrow through $s$ to $t$. Removing the square table to $g$, set off a similar and a parallel line in the direction of the other arrow through $u$ to $v$. Split out both these lines with the plow as straight as the plowman can, and the bottom of the furrow in them will form a guide to set off the requisite widths of drills at right angles to the feering, at least they will serve to check the plowman in his making the drills correct. Plowmen expert at drilling are apt to contemn such guides in forming double drills, because they conceive they can preserve the widths sufficiently well by the eye, and no doubt plowmen are to be found who drill with precision, and I have met with such; though very few in number, but the generality of them cannot be intrusted in this delicate task without a guide of some sort, and there is none more simple and more effective than the one I have described and recommended. And where single drilling is to be executed on land on which no vestige of a ridge is seen, it is quite impossible for the most expert driller to set off the feerings with sufficient accuracy. Plowmen, I know, try to do it, and I have seen good ones nearly succeed in it, but never witnessed one who was not obliged to modify the widths of the drills at the closings. Strict accuracy in regard to drills is not required in some crops, such as in the hean and potato; but with regard to the turnip, which is sown with a machine set to a given width, unless the drills are very nearly alike in breadth at both ends, the sowing will be very imperfectly performed. The means, too, of attaining accuracy are so simple-merely drawing two or three furrows across the field-that it is culpable to neglect it. There will be, I am certain, more time spent by the plowman in measuring the widths of drills with his plow-staff at every closing, than he would spend in drawing a few cross-furrows at first; and after all his adjustments, his mind is not satisfied that he has done the work in the most accurate manner. It is true that with all the assistance cross-furrows can afford him, he will still have to measure the widths of drills with his plow-staff at every closing, 
but he is much less likely to err in his measurements while having the cross-furrows to guide him at right angles to the direction of the drills, than in measuring at random in a supposed right direction. This is so self-evident that your mind must assent to the facilites afforded by crossfurrows.

(1741.) The double drills are formed in this way, on the supposition that ridges are visible at 15 feet asunder; and this method is analogous to the first method of feering single drills. After the furrow-slice $c d$, fig. 313 , is laid over at the feering of $a b$ along the furrow-brow of the ridge nearest the fence, the horses are hupped, and the plow is made to come down at the prescribed width of the drills, namely, 30 inches, along the line $f e$, and to put a furrow-slice against the other furrow-slice $c d$, which had just been tumed over upon the firm ground, and in doing this the drill receives a somewhat sharp-pointed crest. At 30 inches this crest is never very sharp, but at 27 inches it may be made as sharp as you please, by making the plow go a little deeper. Then hieing the horses, the plow again goes along $e f$, but in the opposite direction, and lays over the furrow-slice $g h$ on the open ground. Hupping again, the horses come down $p$, and form the other side of the drill $h \mathrm{~g}$; and so on, one drill after another. No breaks of feerings are required in this mode of drilling, as every drill is finished as it is formed, and the precautions required are, that the proper widths of the drills are preserved throughout their lengths, in which they may be easily checked by the assistance of the cross-furrows.

(1742.) The other mode of double drilling is analogous to the second mode of single drilling. After the feering-poles are set up, as in the former case, the plowing is commenced from the other head-ridge, and the first furrow-slice $n o$ is laid over while coming down $b a$. The horses are then hied, and the plow is passed up the same furrow in the opposite direction $a b$, and having little earth to lay over, but a small furrow-slice is laid toward $c d$. Hupping the horses, the plow is then brought down $f e$, which being a fresh furrow, the furrow-slice $d c$ is large, and completes the drill $d c$. Hicing the horses, the plow again passes along the last furrow in the opposite direction $e f$, and having little earth to take lays over the small furrow-slice $g h$; and then hupping again, a large furrow-slice is laid orer from $q$ and cumpletes the drill $h g$, and so on, one drill after another, at the requisite width.

(1743.) The same difference exists in the two modes of making these double drills, or in making the single. Thus, in the first method the large furrow-slice is laid over upon the open and firm ground, and the drill is finished by the second and smaller furrow-slice; whereas in the second method the larger furrow-slice is laid toward the already drilled land, and upon the smaller furrow-slice which was first turned over.

(1744.) On considering carefully both modes of drilling, it will be observed that the two sides of a double drill are not equal, that side which receives the furrow-slice raised from the firm land receives a larger quantity of earth than the side which receives the small furrow-slice derived from the same track out of which the former large slice had been taken. The immediate consequence of this inequality of earth upon the two sides of a drill is to give it the form of an unequal triangle, and its effect on the growth of any seed deposited within the drill, is to cause the germ of the plant to grow out of the side at the upper part instead of the top of the drill. This effect is particularly shown by the sloping direction which a strong growing stem of beans or potatoes takes, and to obviate which the tops of the drills are always, in practice, harrowed down as much as to allow the stems to grow upright.

(218) 
(1745.) This inconvenience of the unequal form of the double drill attends both modes of making them; but, of the two modes, that which lays the large furrow-slice upon the open side of the firm land possesses two advantages over the other; the first of which is that no clods, large or small, can roll from the top of the drill into the hollow; and the other advantage is still greater, that of the finished drills being less trampled by the horses in making the succeeding ones. This last circumstance may be explained by referring to fig. 313. When the plow, for instance, goes up $e f$ to commence a new drill, it cuts the firm ground along that line, laying the furrow-slice $g h$ upon the open unoccupied ground to the right, and leaving on the left a small space of firm ground $c e$ and $d f$, between the line of the plow $f e$ and the crumblings of the previous large furrow or unfinished drill $c d$. In doing this, the furrow-horse walks up the hollow of the former rnade drill $a b$ to guide him in the exact line he should go, and the other goes on the firm ground by the side of $e f$. On returning, the furrow-horse comes down $f e$, while the other comes down $p$, while the plow is making up the small side of the drill $d c$; but in doing this the footsteps of the horse that went up the finished drill $a b$ are left untouched. This may be considered a matter of little importance, and from the generality of the practice, one would be led to conclude it of little importance; and in case of some horses which walk neatly and narrowly in a drill, the impressions of their footsteps may be almost unobserved in its bottom; but in the case of a horse which walks wide behind, and in that of all weak horses which stagger under their draught, both sides of the drills are frequently much trampled; and in the case of drilling strong land, footprints injure the soil by holding water. These may be obliterated in this way: instead of perfecting the drills one by one in succession, let an intermediate drill remain unfinished between one that is finishing and another that is forming. For example : instead of finishing the second side of the drill $h g$ by returning down the hollow $b a$, let the drill remain unfinished until the new drill $p$ is formed so far as to lay over its furrow-slice on the firm ground. Then let the plow come down $b a$, having the furrow-horse before it, and it will obliterate its footmarks, and let the other horse come down the intermediate open furrow $f e$, because in going up and down, it is necessary in drilling that one of the horses shall go in a hollow of a drill formerly made to guide it in the proper line. With regard to the mode which lays the large furrow-slice toward the drilled land, it seems impossible but to leave the finished drills trampled. For example: on finishing the drill $h g$, on the plow coming down $b a$, the furrow-horse walks down the finished drill $i t$, and the other walks on the firm ground down $d c$; and the same ground is gone over by the horses on the plow laying over the small furrow toward $c d$ on passing up the hollow $a b$. When the plow comes down $f e$ to lay over the large furrow toward and to finish the drill $d c$, the furrow-horse comes down $b a$, and the other upon the firm land alongside $f e$; and thus the finished hollow $a b$ is twice trampled, first in guiding the furrow-horse while the plow is forming the drill $\bar{d} c$ when coming down $f e$, and again on the plow passing up $e f$ to lay the small furrow toward $h g$ for the next drill, which is completed in its turn when the plow comes down $p$, and the furrow-horse tramples the finished hollow $f e$.

(1746.) When the ground is quite flat, double drills may be made 27 inches wide, and the same width may be adopted when ridges of 18 feet are visible, for 8 drills of 27 inches just cover an 18-feet ridge. A feering of 6 ridges of 18 feet just includes 64 drills of 27 inches, so that where drills are desired of 27 inches in width, and no more, the land should bo 
in 18-feet ridges, if ridged, or it should be flat-otherwise some of the 27-inch drills on 15 -feet ridges will be left in the open furrow, a pusition which in strong land cannot fail to prove injurious to that part of the turnip crop in winter. When the soil is thorough-drained, it is of no importance where the drills are situated; hut till that operation is performed, it is necessary to attend to the safety of the crop in the must unfavorable circumstance of soil by judicious management.

(1747.) It may have occurred to you to inquire that, if a perfect drill is formed by a bout of the common plow, why it is that perfect drills are not formed by one landing with a double mould-board plow? The inquiry is a natural one, and it can receive a satisfactory answer. Were a drill perfectly formed, a rertical section would give a triangle whose hight is equal to half the length of the base. The hight to which a common plow can elevate the crest of a drill is that of the ear of its mould-board, which, in the common (Small's) plow, Plate X., is 12 inches; and this hight is conformable to a drill of only 24 inches in width. Such a plow, therefore, to make a drill of the usual width of 27 inches, will either leave a flat space on its tops of 3 inches in breadth, or it will leave a sharp crested ridglet of 3 inches in breadth at the bottom of the hollow of the drill. A common plow varies in width from the ear of the mould-board to the land-side from 18 inches (Wilkie's) to 20 inches (Small's). A bout of Wilkie's plow could thus make a drill 36 inches, and that of Small's 40 inches in width in a bout, were it plowed to the full breadth either was capable of; but as drills are only made 27 inches in width, the second furrow is taken by the plow going nearer the side of a drill than in the middle of the hollow between two drills, and it is this expedient which gives to drills one sloping and another more perpendicular side. A double mould-board plow, constructed of similar dimensions of an ordinary one, would make drills much wider than are required; but even if its mould-boards were set as narrow as to make a 27 -inch drill, it is found that on account of the width of double mould-board plows below, they cannot go so deep as to give drills their proper elevation of $13 \frac{1}{2}$ inches, required to bury the requisite quantity of manure deposited in them.

(1748.) There is a species of drilling executed by the small plow, fig. 314 , which has received the appellation of ribbing. In executing this mode

Fig. 314.

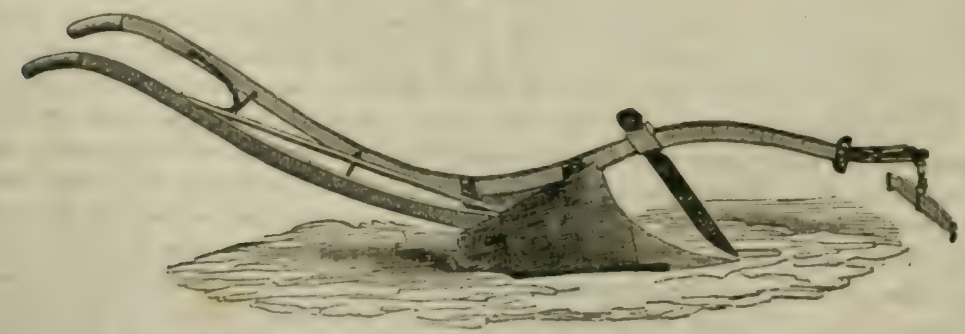

THE SMALL, OR RIBBING OR PARING PLOW.

of plowing, it exactly follows the mode of making single diills; and of the two modes of making these, it is necessarily restricted to that which lays the furrow-slices toward the unplowed ground, because the ribs being necessarily narrow, were clods and stones to fall into the hollows, which the other method would infallibly cause, the purposes of the ribs forming a kindly seed-bed would in a great measure be frustrated. The ribs, with 
great pains, can be formed as narrow as 9 inches, and by careless plowmen they are made as wide as 14 inches, so that 12 inches may be considered a grod medium width. They are always formed on ridges, never on a flat, and only used in seed-furrowing. The best width of feering for making them is 2 ridges, beginning on the furrow-brow of the ridges, and laying the furrow-slices into the middle of the open furrows between the two ridges; by hupping the horses the seed is kept out of the open furrow, and retained upon the best land of the ridges. Ribs are formed in the length of the ridges. Supposing them to be 12 inches asunder, there will just be 30 ribs in every feering of 2 ridges of 15 feet each. Another implement which makes a number of ribs at once is described below.

\section{SOWING SPRING WHEAT AND GRASS-SEEDS.}

"When winter frosts constrain the field with cold, The fitinty root can take no steady hold."

DRYDEN'S VIRGIL.

(1749.) Wheat cannot be sown in spring in every sort of weather, and upon every variety of soil. Unless soil possess a certain degree of firmness, that is, contains some clay, it is not considered adapted for the growth of wheat, at least it is more profitable to sow barley upon it; and unless the weather is as dry as to allow strong soil to be plowed in the proper season, it is also more profitable to defer the wheat, and sow barley in due season. The general climate of a place affects the question of sowing wheat there in spring, and it is a curious problem in climate why wheat sown in autumn should thrive at a place where spring wheat will not. Elevation of position, even in a favorable latitude, produces the same effects. Experience in these well-known circumstances renders the farmers of Scotland chary of sowing wheat in spring, unless the soil is in excellent condition, and the weather very favorable for the purpose.

(1750.) When wheat is sown in spring, it is usually after turnips, whether these have been entirely stripped from the land, or partly consumed on the ground by sheep. In whichever of these states of the turnip crop may be chosen to be followed by wheat, it is not sufficient merely to raise a crop of turnips by dint of a plentiful supply of manure at one time upon an otherwise exhausted soil that will insure a good crop of springwheat; the land itself should be and have been for some time in good heart, otherwise the attempt will inevitably end in disappointment.

(1751.) On a farm possessing the advantages of favorable soil and climate, and on which it is the custom to sow spring wheat every year, the turnip-land is plowed with that view up to a certain period of the season, not later than the beginning of March; and even on a farm on which spring wheat can only be sown occasionally, when a favorable field comes in the course of rotation, or the weather proves tempting, the land should be so plowed as that the advantage may be taken to sow wheat. Should circumstances warrant the attempt, or matters take an unfarorable turn for the purpose, there will be no harm, as the soil can afterward be worked for barley.

(1752.) Land should only receive one furrow, the seed-furrow, for spring wheat, for if it is plowed oftener after a manured green crop, and in spring, (221) 
when it has become tender by the winter frost, it would want that firmness which is essential for the growth of wheat. The nature of this seed-furrow depends upon circumstances. If the land presents a visible form of ridge, and if it soon hecomes wet, the best way to plow it is to gather it up, and then it will have the appearance of being twice gathered up, as in fig. 139. If it is flat, and the subsoil somewhat moist, gathering up from the flat will answer best, as in fig. 133. If the soil has a dry subsoil, though of a pretty strong clay itself, it may be cast with gore-furrows, (663). And should it be fine loam resting on an open bottom, the ridges may be cast together without gore-furrows, as in fig. 135. It is probable that a whole field may not be obtained at ence to plow up in either of these ways, and indeed such an event rarely happens in regard to preparing land for spring wheat; but when it is determined to sow it, a few ridges should be plowed up as convenience offers, and then a number of acres sown at one time. In this way a whole field may be sown by de. grees, whereas to wait until the sowing of the whole field at once can be obtained, may prevent the sowing of any part of it in proper season. Nay, bad weather may set in and prevent the sowing after the land has been plowed; still a favorable week may occur, and at the worst, at the latter end of the season the land may be ribbed with the small plow, in the manneI I have described in (1758), and which will move as much of the tender part of the soil on the surface as sufficiently to bury the seed, and the greater part of the former furrow will still remain in a firm state to sup. port the wheat plant.

(1753.) The land being plowed, it should be sown as quickly as possible; for which purpose the seed-wheat should be measured up in the sacks, or ready to be measured up in the corn-barn or granary, and the means of pickling it also ready when wanted. Wheat should be sown thick in spring, because there is no time for the plant to stool or tiller, that is, to throw out young shoots from the roots, as in the case of autumnal-sown wheat. About 3 bushels per imperial acre will suffice for seed.

(1754.) Seed-wheat should be pickled, that is, subjected to a preparation in a certain kind of liquor, before it is sown, in order to insure it against the attack of a certain disease in the ensuing summer called smut, which renders the crop comparatively worthless. Some farmers affect to laugh at this precaution, as originating in a nonsensical faith in an imaginary specific: but the existence of smut and its baneful effects upon the wheat crop are no imaginary inventions, and when experience has proved, in numberless instances, that the application of a steep has the effect of warding off the evils of smut, the little trouble which pickling imposes may surely be undertaken, rather than the whole crop be put in jeopardy. Why pickling now should have the effect of preventing the smut at a future period is a different question; and it is perhaps because this question has not hitherto been satisfactorily answered, that pickling is thought lightly of by some farmers, rather than because any valid objection can be urged against its practice. Indeed there cannot, for the palpable fact stands obvious to conviction, that one field sown with pickled wheat, and managed in the usual way, will escape the smut, while an adjoining one, managed in exactly a similar manner, but sown with plain wheat, will be almost destroyed with the disease. I have seen this identical case tried by two neighboring farmers, the Messrs. Fenton, late tenants of Nevay and Eassie, in Forfarshire. It is true that, on some farms, wheat sown in a plain state escapes the disease, as I have heard Mr. Oliver, Lochend, near Edinburgh, state is the case with his farm; and it is also true that pickling does not entirely prevent the recurrence of the disease on other farms; but such cases are ex$(222 ;$ 
ceptions to the rule, which is, if wheat is not pickled it may be smutted; at least no one can aver beforehand that it shall not be so; and while uncertainty exists in the recurrence of a serious disease, the safer practice is to bestow the trouble of pickling, the expense being very trifling, rather than incur the risk of disease. It is now a well-ascertained fact that inoculation will not insure immunity from small-pox, yet it will certainly modify the attack when it occurs, and so it is with the case of pickling wheat; and as long as means are used to ward off small-pox, so long also, from analogy, ought wheat to be pickled.

(1755.) Wheat is pickled in this way. For some days, say 2 or 3 weeks, let one of the tubs referred to in (1229) be placed to receive a quantity of chamber lye, and whenever ammonia is felt to be disengaging itself freely from the lye, it is ready for use. It is better that the effluvium be so strong as to smart the eyes, and water added to dilute the liquor, than that the lye be used fresh. This tub should be removed to the straw-barn, as also the wheat to be pickled, and part of the floor swept clean, to be ready for the reception of the wheat. Let 2 baskets be provided, capable of holding easily about $\frac{1}{2}$ a bushel of wheat each, having handles raised upright on their rims. Pour the wheat into the baskets from the sacks, and dip each basketfull of wheat into the tub of lye as far down as completely to cover the wheat, the upright handles of the baskets preventing the hands of the operator being immersed in the lye. After remaining in the liquor for two or three seconds, lift the basket up to drip the surplus lye again into the tub, and then place it upon two sticks over an empty tub, to drip still more till another basketfull is ready to be dripped. Then empty the dripped basket of its wheat on the floor, and as every basketfull is emptied, let a person spread by riddling through a barn wheat-riddle, a little slaked caustic lime upon the wheat. Thus basketfull after basketfull of the wheat is pickled till it is all emptied on the floor, when the pickled and limed heap is turned over and over again till the whole mass appears uniform. The mixing by turning is most surely managed in this way. Let two men be each provided with a barn shovel, and let one stand on each side of the heap, one with his shovel in the right and the other with his in the left hand; let both make their shovels meet in their edges upon the floor, under one end of the heap of wheat, and each, on lifting his shovelfull, turn it over behind him, and thus proceed, shovelfull after shovelfull, to the other end of the heap. Let them return in a similar manner in the opposite direction, and aye till the heap of wheat is completely mixed with the lime and lye. The pickled wheat is then sacked up and carried to the field in carts. Other substances beside chamber lye are used for pickling wheat, such as brine of salt, sufficiently strong to float an egg; solution of blue vitriol-all good enough, I dare say, but when so simple and efficient and easily-obtained an article as lye can be had, it appears to me unnecessary to employ anything else. It is a powerful ingredient, destroying vegetable life in the course of a few hours, and it is perhaps to this property that is to be ascribed its efficacy as a protection against the attack of that vegetable enemy of the wheat-crop -the smut. The wheat pickled with it should therefore be used immediately after the process; and as danger may be apprehended to pickled wheat being kept over night, the quantity pickled should be sown at once, and no more should be pickled at one time than can immediately be sown. The use of the quicklime seems to be to dry the lye quickly, so that the grains may be easily separated from one another in the act of sowing; but there may some chemical change arise between them in the circumstances, which may be serviceable to the purpose for which both are em(223) 
ployed. Can it be that the lime fixes the ammonia of the lye, and preBerves it for use until wanted by the plant or seed?

(1756.) There is some art in setting down sacks of seed-corn on the field. It should be ascertained how many ridges of the field to be sown are contained in an acre, so that the sacks may be set down at so many ridges as each sack contains seed to sow the ground, allowing the specified quantity of seed to the acre. This instruction should be given to the plowman before he proceeds to the field with the sacks, otherwise he roay set them down either too close or too wide. When one row of sacks is sufficient, and the ridges just long enough for the sower to carry as much seed as will bring him back again to the sack, the sacks should be set down in the middle; when the ridges are short they may be set down on the headridge, and when of such a length as to require two rows of sacks, each row should be set on the same ridges, and the distance between them made to suit the circumstances of the case. The setting down of the sacks should be begun from the side at which the sowing commences, and this again depends on the nature of the surface of the field. If the surface is level, it matters not which side is selected for commencing operations; but if it has an inclination, then that side which lies to the left while looking down, or to the right on looking up the inclination, should be begun to be sown. The reason for this preference is that breaking in the surface with the harrows-that is, the first stroke of them over the ground, along the ridge-is most difficult for the horse to draw; and to ease their draught the breaking should be executed down hill. The sacks are always placed on the furrow-brow of a ridge, that the hollowness of the open furrow beside it may give advantage to the person who carries the seed to take it out more quickly and easily when it sinks near to the bottom of the sack.

(1757.) The carrier of the seed is a field-worker, and the instant the first sack of seed is set down, she proceeds to untie and fold back its mouth, and fill the rusky, fig. 315 , with seed, and carries the first quantity to the sower, who should be ready sheeted awaiting her arrival on the head-ridge at the side of the field. Her endeavor should be to supply him with such quantities of seed as will bring him in a line with the sack when he wants more; and as the sacks are placed about half-way down the ridges when only one row is wanted, this may easily be arranged; or should there be two rows, she must go from row to row on the same ridge, and endeavor to form the same arrangement. This regular plan will give her the least trouble, and supply the sower always with the requisite quantities of seed; and it should be borne in mind that nothing can be more annoying to a sower than to have his sheet brimfull at one time and at another stinted; and it is also very annoying to him to be obliged to wait the arrival of the seed-carrier, whereas she should rather wait on him. If the sacks of seed are conveniently placed, one active seed-carrier will serve two sowers, at $e$, fig. 322 ; but where the sacks are set down in more than one row, and there are more than one sower, there should be a carrier at each row.

(1758.) The rusky, fig. 315 , or seed-basket, is usually made of twisted straw laid in rows above each other, and fastened together by means of withes of willow. It is provided with a couple of handles of the same material, sufficient to admit Fig. 315.

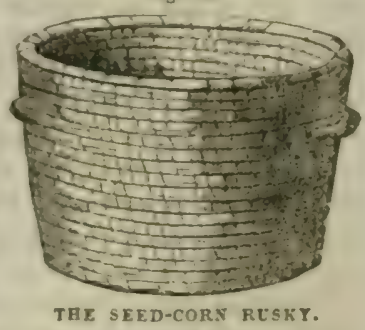
the points of the fingers, and also a rim around the bottom, upon which it stands. In the Border counties it is carried on the bead or the seed-carier (224) 
whon full, in other parts it is carried in the arms with the bottom rim supported by the haunch. It should be filled each time with just the quantity of seed, and no more, which the sower requires at one time. The mouth of the sack should be rolled round upon itself, that the seed may be easily and quickly taken out, for there is usually no time to lose when seed is sowing. As one sack becomes empty it should be taken by the carrier to the nearest sack, and as they accumulate they should be put into one, and thus taken forward out of the way of the harrows. It is not unusual to see the sacks lying upon the ground where they are emptied, and only removed when the harrows come upon them, and not unfrequently tear them, and they are then cast away to be in the road again when the field is harrowed in another direction. The carrier should be careful not to spill the seed upon the ground on taking it out of the sack.

(1759.) The sower is habited in a peculiar manner; he puts on a sowing-sheet. The most convenient form of sowing-sheet is that of a semispheroid, having an opening at one side of its mouth large enough to allow the head and right arm to pass through, and by which it is suspended over the left shoulder. On distending its mouth with both hands, and on receiving the seed into it, the superfluous portion of the sheet is wound over the left arm and gathered into the left hand, by which it is held tightly, while the load of corn is securely supported by that part of it which passes over the left shoulder, across the back and under the right arm. The right arm, which throws the seed, finds easy access to the corn from the comparatively loose side of the mouth of the sheet, between the left hand and the body of the sower. A square sheet, knotted together in three of its corners, and put on in a similar manner, is sometimes used as a sowing. sheet; but one formed and sewed of the proper shape, and kept for the purpose, is a much better article. Linen sheeting makes an excellent material for a sowing-sheet, and when washed at the end of the sowing season will last many years. The difficult point is to make the sowing-sheet fit the sower on the top of the left shoulder, where the greater part of the weight of corn is felt; and, in attempting this, the principal thing to be considered is to make the plain part which goes over the shoulder broad enough, and to slope with the shape of the shoulder. The gatherings of the cloth on each side of the shoulder-top should be neatly executed, and a couple of tapes drawn tight in a slot-hem in front of the sheet across the breast.

(1760.) A basket of wickerwork, such as in fig. 321 , is very commonly used in England for sowing seed. It is suspended by girthing, fastened to the two loops shown on the rim of the basket, and passed either over the left shoulder and under the right arm, or round the back of the neck; and the left hand holds it steady by the head of the wooden stave shown on the other side of the basket.* No doubt such an instrument answers the purpose of the sower, or it would not have been so

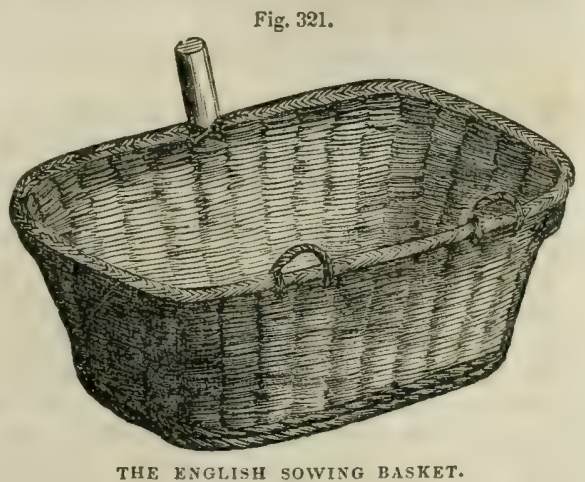
long in use; but, for my part, I much prefer the comfortable feel of the linen sheet to the hard rubbing of the willow basket.

[- Wilkinson says the handle ought to be at the bottom instead of top, projecting forward. Ed. Farm, Lib.] $(225) \ldots . . .99$ 
(1761.) Both these forms of utensils for sowing seed are intended for the use of one hand only; but some sowers throw the seed with both hands, and then the instrument must be made to suit the practice. In this case a linen sheet will not answer; a basket or box, made of thin deal, having a curved form to suit the front of the body, should be used. It is fistened round the body by a strap and buckle, and is suspended besides by girthing fastened to loops on the side next the sower, and passed round the back of his neck; and the further side is suspended by a strap passing upward toward the chin of the sower, where it divides into two, and passes over both shoulders, and is made fast to the strap buckled round the body. A more simple form of sowing-sheet for both hands, is a linen bag attached to a hoop of wood or iron-rod, made to suit the form of the body, buckled round it, and suspended in front in the manner just described. Both hands are thus at liberty to cast the seed.

(1762.) In sowing with one hand, the sower walks on the third and fourth furrow-slices from the open-furrow, which he keeps on his right hand. Taking always as much seed as he can grasp in his right hand, he stretches his arm out and back, with the clenched fingers looking forward, while the left foot is making an advance of a moderate step, as represented by $a$, fig. 322. When the arm has attained this position, the seed is begun to

Fig. 322.

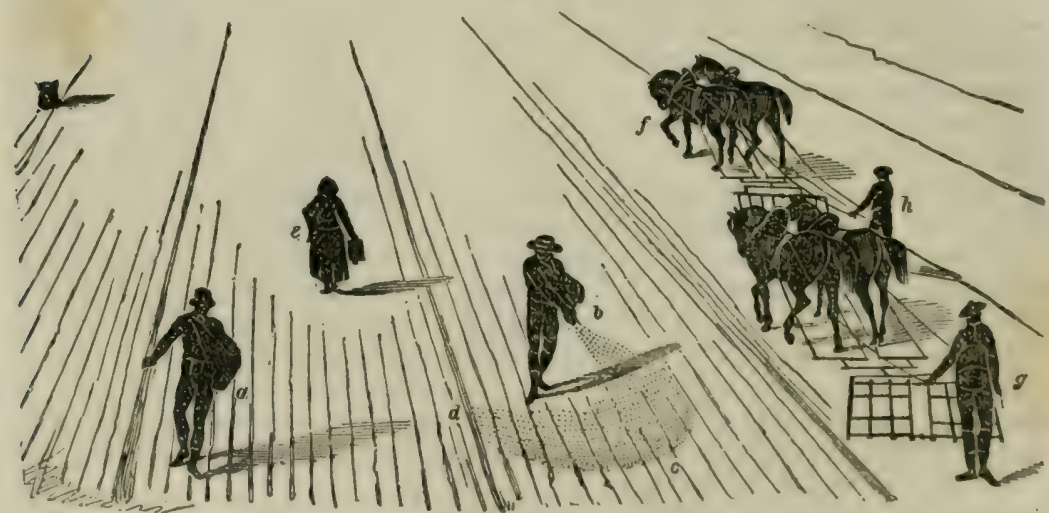

THE SOWING OF CORN BY HAND

be cast, which is done with a quick and forcible thrust of the hand forward. At the first instant of the forward motion, the fore-finger and thumb are a little relaxed, by which some of the seed drops upon the furrowbrow and in the open furrow, and while relaxing the fingers grachally, the back of the hand is turning upward till the arm is stretched forward, when the fingers are all thrown open, with the back of the hand uppermost. The forward motion of the hand is accompanied by a corresponding forward advance of the right foot,* which is planted on the ground the moment the hand has cast forward the most of the seed. This position is attempted to be represented by the figure at $b$. The figure which the seed describes on the ground, in being thus cast forward, is sumething like the area of a section of the extreme end of the larger axis of a very eccentric ellipse, having one corner of the section at the open furrow, and

[ Mr. Wilkinson, of Dutchess County, says this is unnatural; that it should be the lef foot in conce with the right hand.

Ed. Farm. Lit: 
the other stretching 2 or 3 feet beyond the crown of the ridge, and its broadest part spread over that side of the ridge on which the sower walks; this figure is attempted to be shown by $b c d$. The moment the seed is got quit of, the hand is brought back to the sowing-sheet and, thence replenished, is stretched back for a fresh cast, while the left foot is made to advance simultaneously. Thus the right hand and right foot play into each other with a regular simultaneous motion, while the same hand and the left foot play with an alternate motion.

(1763.) Many points require consideration to enable the sower to cast the seed equally over the ground. If the hand and feet do not correspond in their motions, the ground will not be equally covered, but a strip between the casts left almost bare. When the braird comes up, the omission shows itself like the steps of a ladder, and hence it is named, in some parts of the country, laddering, in others, happergain', as if the seed had been cast in hopping. This error is most apt to be committed by a sower with a stiff elbow. The arm should always be thrown well back and com pletely stretched out, though in continuing this action it will become painful in the inner fold of the elbow-joint. If the hand is opened too soon, a larger portion of the seed than necessary will fall upon the furrow-brow, and the crown will receive less than its proportion. This fault young sowers are very apt to commit, from the apprehension that they will retain the seed too long in the hand. If the hand is brought too high in front, the seed will be apt to be acted on by the wind, and tossed to a different direction to that intended by the hand. High casting is a very common error with sowers, and is an unsafe practice in windy weather. In strong wind the sower is sometimes obliged to walk on the adjoining ridge to the windward, to sow the one he wishes; and a sower who casts high will never make good work in such a case. In casting high, the hand is sure to be elevated above the level of the elbow, whereas it should always be below it. The hand should be kept low, the arm stretched out, and the seed made to fly in a curve in front, by a sharp turn of the hand, and a free opening of the fingers near the end of the action, the nearest edge of the cast falling within two paces of the sower. Seed when so cast will be little affected by even a strong wind. Some sowers take long steps, and fill their hand with the seed as if in a shovel, and of course make long casts, reaching across the ridge from open furrow to open furrow. Such a sower will spill the seed behind the hand, and make bad work in wind. The step should be short, the casts frequent, and the seed held firmly in the hand, when a complete command of the whole work will be obtained.

(1764.) A sower with both hands must make high casts, otherwise the seed will not reach the furrows as he walks along the crown of the ridge, which he must do. I can see no advantage attending this mode of sowing over the other, but, on the contrary, a considerable risk of scattering the seed unequally, for however dexterous an ambidexter sower may become, his left arm will not make so perfect a cast as his right, if he is a right-handed person. In calm weather he may get on tolerably well, as also with the wind direct in his face or in his back; but a side-wind would puzzle him, for while adjusting himself to it for one of the hands, the other is immediately placed in a disadvantageous position. In short, he should not sow with both hands in wind. An Irish sower usually makes a. step, stands still, and scatters one handfull of seed with two short and one long cast of the arm. This is slow work.

(1765.) A single-handed sower makes a bout to sow a ridge. When the ridge is single, fig. 133, he always keeps the open furrow on his right (227) 
hand; when it is double, that is, cast together, fig. 135 , he must go a bout round the crown, as well as by the open furrows; and where the land is plowed two-out-and-two-in, fig. 138, a mark of some sort will be required to keep him in the proper place between the crown and open furrows.

(1766.) It is obvious that in sowing with the hand the corn is scattered promiscuously, and, in whatever arrangement it may come up, depends on the form of the ground, whether it had been plowed in common furrows or in ribs; for, in the latter case, the corn comes up in rows or drills, the corn having fallen into the hollows of the ribs when sown; and in the former, broadcast, that is, equally over the surface of the ground.

(1767.) The harrous follow the sowers, each sower keeping 2 pair of harrows employed when the land receives a double tine, that is, backward and forward on the same ground, which a breaking in of the seed should always be. To draw harrows as they should be drawn is not so light a work for horses as in appearance it is; and, indeed, when the tines are new sharpened and long, and take a deep hold on the ground, the labor is considerable. To harrow the ground well, that is, to stir the soil over the seed, and bring to the surface and pulverize all the larger clods, requires the horses to go at a smart pace; and, indeed, harrows should always be employed with a quick motion. If the men owe the steward a grudge for his sharp discipline, spring-wheat sowing is a favorable time to take advantage of him, when the land is naturally friable and easily pulverized, and the horses are quite fresh, and when, on the other hand, the lime of the pickle annoys the sower's face, and the land is rather soft for quick walking. If they keep the harrows hard at his heels, for very shame he must sow hard to keep out before them; and if he is a slow sower, he must get a good heating. I never see a man sowing with his coat on below the sowingsheet, than a wish arises to see the harrows close at his heels to punish him for the lazy-looking trick.

(1768.) After the appointed piece of ground, whether a whole field or part of one, has been sown and broken in, the land is cross-harrowed a double tine, but as, in this, the ground is not confined within the breadths of ridges, the harrows cover as much of the ground as they can, and get over it in less time than in breaking in; and, besides, the second harrowing being easier for the horses, they can walk faster.

(1769.) In regard to harrowing ribbed land, a double tine of breaking in is all that it receives to place it in the same position as the common mode of seed-furrowing is placed after the cross-harrowing-ribbed land never being cross-harrowed, as that would derange the drilled-like state of the seed, and bring a large proportion of it again to the surface.

$(17 ; 0$.$) To judge of the harrowing of land, the sense of feeling is re-$ quired as well as that of sight. When well done, the firable portion of the soil seems uniformly smooth, and any clods that are seen should lie free upon the surface. The ground, too, should feel uniformly soft under foot. When the land is not enough harrowed, the surface appears rough, and the clods are still half immersed in the soil, and the ground feels une qually soft under foot, in some parts resisting pressure, in others giving way too easily.

(1771.) The well harrowing of land is a point of more importance than seems generally to be imagined. Its object is not merely io cover the seed, but to pulverize the ground, and render it of a uniform texture. Uniformity of texture keeps the soil in a more equal state of temperature, not absorbing rain so fast, nor admitting drouth so easily, as when the soil is rough and the clods keeping it open. Whenever the texture is made uniform, the harrowing should cease, for it is a fact, especially in light. (228) 
soft soils, that more harrowing than necessary brings part of the seed up again to the surface.

(1772.) Spring wheat following a green crop is always sown down with grass-seeds, and the land is in a fit state to receive them when it is in the above condition of its harrowing; but as grass-seeds are also sown at this time among the wheat that was sown in autumn, it is requisite to consider, in the first place, the state of that crop before proceeding to sow them among the spring wheat, especially when both kinds of crop are in the same field. The state of the winter wheat depends entirely on the sort of weather it had to encounter in winter and early spring. If the winter has been open and mild, the autumn wheat plant will have grown luxuriantly, indeed so much so that it may have become proud, that is, in a precocious state of forwardness for the season. When it is in this state in spring, which is rarely the case in Scotland, though not unfrequent in England, a heavy fall of snow in spring, that happens to lie for some weeks, will rot a great many of the plants; and, instead of the rest retaining their green color under the snow, they will become blanched at the roots, pressed flat to the ground, and will probably never rise again. Blanks will in consequence be formed where this catastrophe has happened; but unless these be of large extent, or the season be far advanced before the wheat has been liberated from its snowy covering, the plants will tiller out with new runners from the roots of the surviving old plants, and occupy the blank spaces. When snow falls upon wheat in the early part of winter, and covers it for a considerable time, it protects the crop from injury from the atmosphere, and prevents the earth from cooling below $40^{\circ} \mathrm{Fahr}$. In this position the young plant retains its healthy green color, though it does not grow much; and whenever it is relieved from the snow, it grows rapidly, unless it happen to encounter black frost, which changes its greenness into a brown, and may kill some of the plants; but should there be no black frost, there is no state of the young wheat plant in spring in which it tillers so closely, and afterward grows so equally, as after emerging in favorable circumstances from snow. The most trying time, however, for winter wheat is in March, when sharp frosts frequently occur at night, and bright sunshine in the day. The frost draws the moisture of the ground to the surface, and there freezes it; when the sun shines upon the ice it melts, and most frequently very rapidly, and the consequent evaporation produces such an intense degree of cold as even to kill the plants suddenly; and if they escape destruction in this way, the damp ground that had been raised up by means of the expanded condition of the ice suddenly contracts by its melting, leaving the plants with their roots half drawn out of the earth, in which state many. perish. It must be owned, however, that this particular effect is most commonly produced on loamy soils which rest on impervious clay subsoil and not on a dry subsoil, so that draining may be reasonably expected to prevent this injury. Continued rains upon winter wheat make it change its color to a bluish hue, and if the air is temperate the plant becomes tender, and at length sets up with red-pointed leaves, as if it would grow no more. Continued drouth in spring, on the other hand, makes winter wheat of a vivid green, especially in fresh weather; but should it be cold and inclined to frost, the points of the leaves become brown, which latter effect is invariably induced by the cold east winds so prevalent in spring in this country. Drouth and heat combined always promote the vigor of the wheat plant.

(1773.) Although I have said that double harrowing across prepares the land on which spring wheat has been sown for grass-seeds, it should not be imagined these are sown whenever wheat-seed is sown, because the lat(229) 
ter may be sown at any time during winter or early spring that the state of the weather and soil will allow; but when spring wheat is sown at the latest period of the season, then grass-seeds may not onty be sown among this, but among all the spring wheat that had been previously sown: and at the same time among the winter wheat, if the land that has stood all winter is dry enough to bear harrowing at the time. Frost injures cloverseeds, and will even kill them when exposed to it, so that they cannot safely be sown very early in the season; hut there is not much risk of frost being so powerful in March as to injure seed that is harrowed in. Many farmers used to sow grass-seeds without harrowing, trusting to so small seeds finding their way into the soil among the clods, and of being covered by their mouldering, and this practice is, I believe, not yet relin. quished; but the safer and more correct practice is to cover every kind of seed when it is sown by harrowing. It may happen that in the same field in which the latest spring wheat has been sown, may be found some that had been sown at a former period, and even winter wheat may occupy another part of it. When this is the case, and especially if the last sown completes the cropping of the field, then the grass-seeds should be sown over the whole field at one time, beginning with that part which has just been sown, continuing it over that which was the next last, and finishing upon the winter wheat; because it is desirable first to finish the land that has been most recently worked, in case the weather should change, and prevent the finishing of the whole field. Should barley, however, have still to be sown on that field, it will be better to defer the sowing of the grass-seeds upon the wheat until the whole field is sown at one time; and in this case the new-sown spring wheat can he water-furrowed and put past danger for the time. If the winter wheat in the same field is, on the other hand, far advanced, and the weather still favoralle to its growth, the grass-seeds should be sown among it, for, if delayed too long among strong plants, part of the seed may not find its way to the soil, and the subsequent harrowing may injure the progress of the already forward plant. In such a case the spring wheat should be sown with the grass-seeds at the same time, and the barley-land can be sown by itself, when the barleyseed is finishing.

(1774.) The grass-sowing machine is a most perfect instrument for the sowing of grass-seeds, distributing the seeds with the utmost precision, and to any amount, and scattering them so near the ground as to render their sowing a matter independent of windy weather. This machine will be found in Plate XXVI., fig. 316, and a detailed description of it by Mr. Slight will be found below. Its management is easy, when the ground is plowed in individual ridges; the horse which draws it walking in the open furrow, as in $a$, fig. 133, and the machine reaching in length to the crown of the ridge on each side, to $b$ and $b$, sows the width of a ridge at once, the length of the machine being made to suit the breadth of the ridges adopted on the farm. The gearing is put out of action till the horse enters the npen furrow from the head-ridge, when it is put on and it is again taken off when the machine reaches the opposite head.ridge. The seed is supplied at nne of the head-ridges, and the head-ridges are sown by themselves. When ridges are coupled together, the horse walks down in the middle between the crown and the open furrow, taking the furrow-brow as a guide for the line he should keep. Where ridges are plowed in breaks, as two-out-andtwo-in, fig. 138 , it is necessary to use some marks on the spaces of the ridges between the crown and open furrows, to guide the line of the machine. The driver ought to be provided with double-reins. Were this machine to proceed onward, sowing without interruption for 10 hours at (230) 


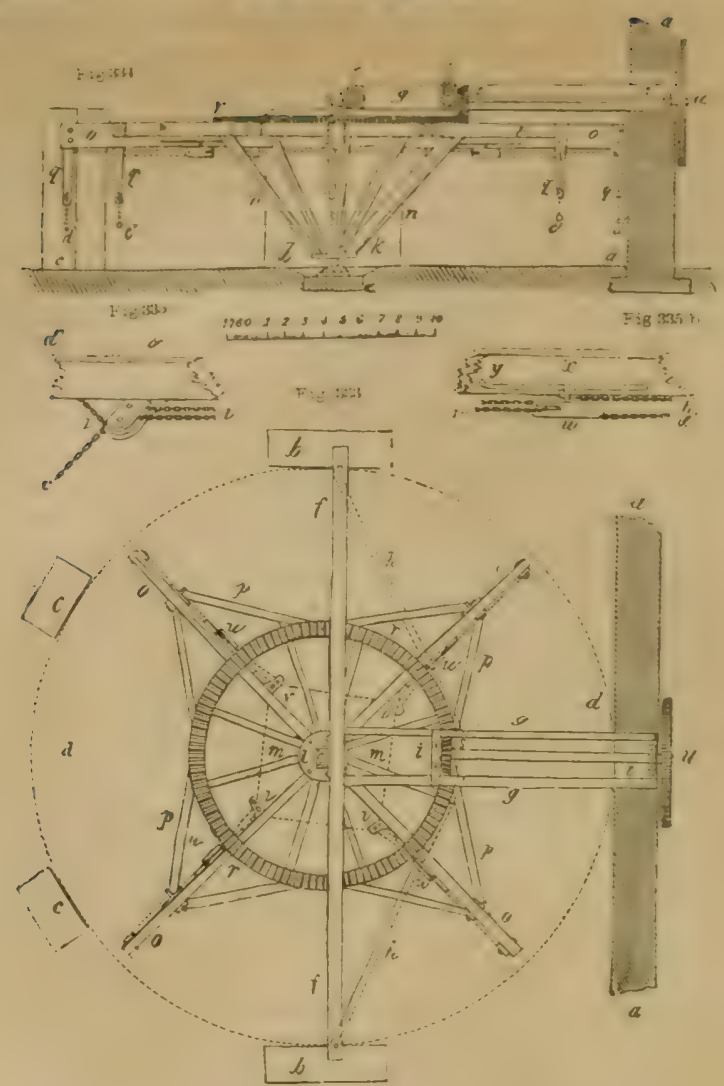

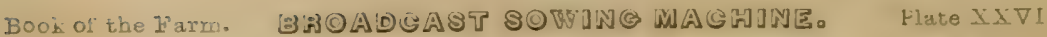
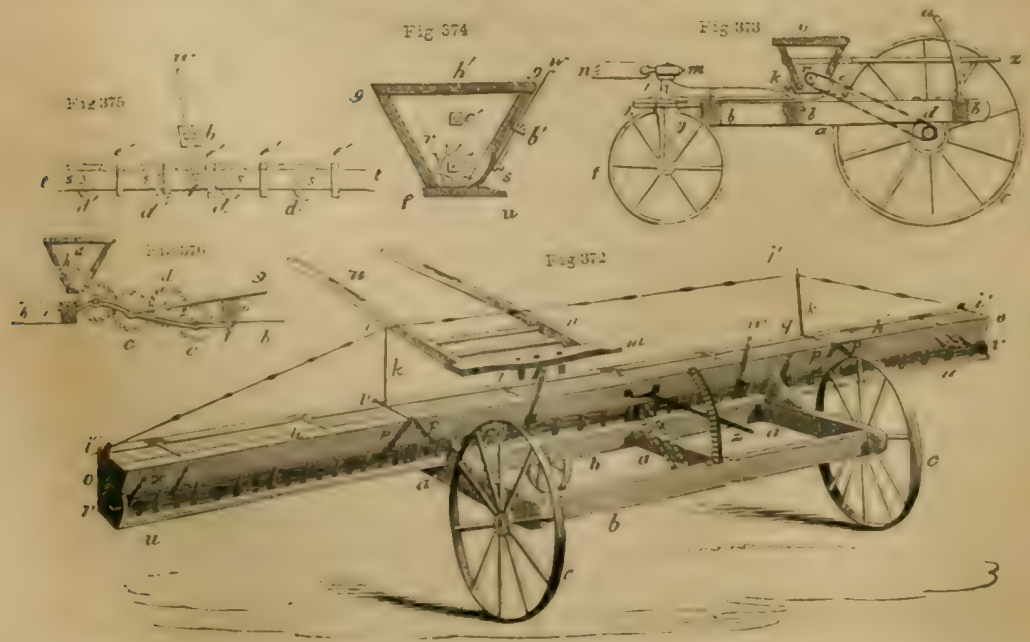
the rate of $2 \frac{1}{2}$ miles per hour, it would sow 54 acres of ground; but, of course, the turnings of the landings, and the time spent in filling the machine occasionally with seed, cause a considerable deduction from that quantity. The machine is also used to sow corn in broadcast, and it answers the purpose very well, but not perhaps in so superior a manner to the hand as it does the grass-seeds, nor is it so generally employed to sow corn as grass-seeds, but for what reason I cannot say. There was a reason for this before the introduction of the third or front wheel, the weight of the box when full of corn being too heavy for the horse's back, especially in going down hill. I cannot refrain from pointing out the superior construction of this machine, as represented in Plate XXVI., in putting it in the power of the person who drives it to contract its length, so as to admit the machine easily into a field-gate, and thereby to dispense with removing it, at any time, from its carriage.

(1775.) After the grass-seeds are sown, the ground is harrowed to cover them in ; and for this purpose lighter harrows are used than those for ordinary harrowing; and being light, are not unfrequently provided with wings, to cover a whole ridge at a time, so that in following the sowingmachine, the process connected with the grass-seed sowing may be finished at once. There is some dexterity required in driving winged grassseed harrows. It is not convenient to move them from one ridge to another immediately adjoining, as a part of the implement will have to turn almost upon a pivot; in doing which, unless conducted with great care injury is apt to be done to it. And, besides, it is a particularly awkward movement to hup the horses with these harrows. The plan to avoid the inconvenience alluded to, is to hie the horses at the end of all the landings, and leave an intermediate unharrowed ridge at every turning, which will be greatly facilitated if the plowman lifts up the near wing from the ground with a hooked stick when the turning is to commence, and lets it drop down again when it is finished.

(1776.) The land may be rolled or not, accoicing to circumstances, before the grass-seeds are sown. If it is dry, even strong land would be the better, at this season, to be rolled, to reduce the clods before they become very hard, and to form a kindlier bed for the small seeds. Should it, however, be in a waxy state, between the wet and the dry, the rolling had better be deferred until afterward. When it is in a proper state for rolling at the time of sowing the grass-seeds, it should be rolled before the sowing, and, of course, before the harrowing of the grass-seeds; because, were the land left with the smooth rolled surface, and rain come after, and this succeeded by drouth, which is not an unfrequent state of the weather at this season, the smooth ground would become so battered and hardened as to curb the wheat braid considerably; whereas, were it rolled before it was sown, and then harrowed, the harrowing would again raise a small, round clod, which would prevent the battering by rain, and consequent incrustation of the land, while the smooth ground would offer a fine surface for the small grass-seeds to spread themselves upon. On lighter soils, such as hazel loams and turnip soils, it is better not to roll until the land has been sown and harrowed, because the smooth rolled surface assists in repelling the drouth for a considerable time, and rain cannot injure such a soil in any way.

(1777.) The roller is represented below, where it is particularly described by Mr. Slight in its principles and action. It is most conveniently formed of cast-iron, and in two pieces, and mounted with shafts and framing. The cast-iron gives weight, which a roller should always have, and being in two pieces, gives a facility to turn on little space. In driving it, the plowman (231) 
may sit on the front of the framing, if he wishes, and urge the horses with whip and reins. The framing sometimes supports a box, into which stones are placed to render the roller heavier, and this device may be necessary when reducing hard clods of clay, in summer. Whether used for this purpose or not, the box is useful in carrying any stones that may be found on the land to either side of the field. It has often seemed to me ridiculous to see a small stone-roller, or one lightly constructed of wood, used to crush clods on new plowed heavy land. Instead of breaking them, a light roller only presses them into the softer soil upon which they are lying. The roller is found to do its work in the best manner when drawn across the ridges, at right angles to the open furrows, which are thus easily passed over.

(1778.) The finishing process consists of water-furrowing, that is, making a plow-furrow in the open furrows, for the purpose of affording facilities to rain-water to flow off the surface of the land. It is executed with a common plow and one horse, or with a small double mould-board plow and one horse ; and in the execution, the plow obliterates the horse's footmarks. When the land is harrowed after the rolling, as in the case of heavy land, the water-furrowing is done after the harrowing, and finishes the work of the field; but when rolling is the finishing operation, as in the case of light soils, the water-furrowing is executed immediately after the harrowing and before the rolling. Water-furrowing after rolling gives a very harsh-looking finish to a field.

(1779.) The presser-roller, used to give consistency to light soils, is seen below, where Mr. Slight's description of it will be found. Like the best of our agricultural implements, it is of English origin, where it has long been employed to compress light soils. It is used in this manner in compressing the soil. Driven by one horse, it follows the last of 2 plows, after they have laid over their furrow-slices; and on passing along these furrow-slices, not only compresses them into less bulk, but leaves a groove on each of them to receive the seed when the land is sown. With 1 presser, 2 acres of ground can only thus be compressed in the course of a day; and, where a considerable extent of spring wheat may be sown, this rate of sowing would be too slow. Either the number of pressers should be increased, nr a considerable extent of land be pressed before it is sown; for it would be tiresome work to sow only 2 acres a day of a large field, which might require a fortnight of 2 plows to plow. Perhaps the most convenient plan for most farmers would be to have 2 pressers in operation, and sow the ground compressed every two days, that is, 8 acres, which would be a large enough sowing of spring-wheat in one day upon a farm that worked 4 pair of horses; and this plan may be followed, with perfect safety to the wheat crop, for a double tine along of the harrows is quite sufficient to cover pressed spring wheat; and, indeed, it should receive no more, unless perhaps a single tine along, in case the surface is considered not sufficiently fine, for crossharrowing would discompose the seed that had fallen in rows into the grooves made by the pressers. Another plan is to plow and press the lea early in winter, allow it to consolidate still more, and then sow an entire field with wheat in spring, if the weather be favorable, and if not, it will be ready for oats. This, I conceive, would be an excellent plan to follow on light soils, that are in a rich enough state for spring wheat.

(1780.) This same instrument may be beneficially employed in compressing light turnip-land as it is plowed into ridges, and rendering it more fit for spring wheat; and in effecting this purpose it is employed in the same manner as on lea.

(1781.) But the presser may be employed on even strong lea, and the crop of wheat consequent thereon increased to a sensible degree, as the (232) 
following case will testify : "A very striking instance of the utility of this machine," says Mr. Hugh Watson, a gentleman whose name is well known in this country as an erninent farmer, "was exhibited on a field belonging tc my friend Captain Barclay Allardyce of Ury, who last season (1832) broke up a piece of grass land near his mansion-house, supposed to have lain out a! out one hundred years. It was a strong soil, and required 4 horses to work the plow, and it was followed by the presser, leaving the work in such a finished state that, although Captain Barclay's intention was to sow the field with oats after the preparation of a winter's exposure, he was incluced to try a crop of wheat, and succeeded beyond his expectation, having reaped 50 bushels per imperial acre, while the probability is that if the field had been sown in spring with oats they would all have rotted." "I have used the presser," continues Mr. Watson, "for two seasons, and can with confidence recommend it on all light soils with every sort of corn crop." * It would thus appear that the use of the presser is almost of general application, and that the ground may be plowed a considerable time before it is sown, which renders it of use even on a winter furrow. Several farmers in Forfar and Fife shires, I am aware, have used this instrument for several years, but I have not learned with what success.

(1782.) With regard to the varieties of wheat which you should sow in spring in preference to others, is a subject in which I feel I cannot advise with confidence. The erroneous classification of wheat by botanists, in as far as it affects Agriculture, into beardless or winter and bearded or spring wheat, is apt to mislead the farmer; and were he so far to rely on the opinions of botanists as to try these two distinctions of wheat in the season said to be suitable to each, he would certainly be disappointed, for the results would probably be the very opposite anticipated. For this reason I quite agree with Mr. Lawson in what he has said on the subject. "Botanists," he states, "generally divide the common beardless and bearded wheats into two distinct species, terming the former Triticum hybernum, or winter wheat, and the latter Triticum astivum, or summer wheat. But the propriety of the distinction may well be questioned, more particularly as the chief distinguishing character between them consists in the varieties of the former being beardless, or nearly so, while the awns of the latter are generally 2, 3 or more inches in length; and it being an established fact that the awns or beards in grasses form by no means a permanent specific distinction, and that in many cases they do not even constitute a variety, so much does their presence or absence depend upon the effects of climate, culture, soil, \&c. . . . But the principal objection to the names commonly used is that they make no proper distinction between the two great classes-winter and spring wheats; for instance, under Triticum hybernum are included several of the earlier, and, without doubt, the best sorts of spring wheat; and under Triticum astivum are included several bearded wheats, equally hardy, and requiring as long time to arrive at maturity as our common winter sorts." $\dagger$ Colonel Le Couteur falls into the same error when treating of the classification of wheat, by dividing all wheats into the two distinctions of "beardless or winter wheats," and "bearded, or spring wheats." $\ddagger$

(1783.) Although the subject is thus rendered by botanists and writers on the cultivated varieties of wheat sufficiently puzzling to the farmer, yet there are a few considerations which may direct you in the choice of your spring wheat. I may premise that you cannot make a mistake in regard to a winter wheat; for however early may be the habit of the variety

* Quarterly Journal of Agriculture, vol. iv.

† Lawson's Agriculturist's Manual. (233)

† Le Couteur on Wheat. 
sown, the very circumstance of having sown it in autumn, when there is not sufficient time to mature the plant before winter will convert it for a time into a winter variety. The wheat plant is a true annual, but when sown late, and the progress of its growth retarded by depression of temperature, it is converted for a time into a biennial. It is therefore highly probable that as the nature of all wheats is to bring their seed to maturity in the course of one season, that any variety sown in spring would mature its seed in the course of the ensuing summer and autumn. I suppose there is no doubt of this being a fact; nevertheless, circumstances concur to render the fact of doubtful application in this climate. A variety of wheat, for instance, that has long been cultivated in winter in the same latitude, on being sown in spring will not mature its seed that season in the same latitude, should the temperature fall below its usual average, or should it be cultivated on very inferior soil to what it has been accustomed; so that in practice it is not safe, in a precarious climate, to sow every variety of wheat in spring. One criterion, however, may safely be applied to any variety of wheat in order to ascertain its character, provided its history is known, which is, that a wheat brought from a warmer to a colder climate will prove earlier in the latter locality than the native varieties, and, in so far, is better suited for sowing in spring in that latitude than the native varieties, and if you can ascertain, besides, that the same variety is an early one in the warmer latitude-bringing its seed to maturity in a short period, perhaps not exceeding 4 months-then you may safely sow it as a spring wheat, whether it be a red or white colored variety.

(17S4.) In my own experience of spring wheat the old Lammas red, and another old variety which $I$ have not heard of for many years, the Cobham red, were at one time considered excellent varieties of spring wheat. Of the Lammas red, I have seen a field of 35 imperial acres sown on the 8 th March, and cut down, an excellent crop, on 26th August. This was, however, in the memorable year for all kinds of good crops, 1815. The variety, I believe, exists to the present day, and is still a favorite with may farmers, and in my opinion deservedly so.

(1785.) [The harrono, considering the operation it has to perform, in covering the seeds that have been cast upon the surface of the soil, is an implement of no small importance; and yet its effects are apparently rude and uncertain. while its construction is of the simplest order. So simple, indeed, is this construction, that at a very remote period it appears to have taken that form which, in so far as the simple principles of the action are concerned, is almost incapable of farther improvement. Variations in size, in weight. in materials, and slight changes of form, have from time to time been proposed and effected ; but yet no important change has been made in the astion of the implement, though among these changes a more uniform distribution of its effects over the surface of the soil has been attained. The only important improvement on the harrow of which we have any historical data, was achieved abont fifty years ago by, I believe, the late Mr. Low, Gordonbank. Berwickshire, father of Professor Low. of the University of Edinburgh ; and this improvement lay ebietly in the form. but which also afforded a more uniform distribution of effect. Previous to the period just alluded to. the seed harrow was always constructed in the form of a rectantular frame of wood. consisting, as it still does, of four longitudinal bars. know $n$. in the language of the agricultural mechanic. by the term bulls, which are framed together by mortising, with four lighter transverse bars, or slots. The dimensions of the rectangular harrows are, on an average, 3 feet 9 inches in breadth, measuring over the bulls, and 3 feet 10 inches in length over the slots. The bulls are generally about 4 feet 6 inches of extreme length, 3 inches in breadth, ard 3 to $3 \frac{1}{4}$ inches in depth; the slots are 3 inches in breadth, and $\%$ to 1 inch in depth. Each bull is armed with 5 tines or teeth of malleable iron, about 10 inches in length. They are fixed in the bull by being driven into an auger-hole bored through it, and project downward from 6 to 7 inches.

(1786.) The improved form given to the harrow, as above alluded to. changes the rectangle into a rhomboid, and this, when duly proportioned, gives to the implement as has been supposed, as high a degree of perfection, in point of form, as it appears capable of attaining. Fig. 323 represents a pair of the rhomboirlal harrows in the working position. The frame of thege harrows consists of the eame number of parts as the common sort already alluded to. Four bulls $a$ a $a$, and four slots $b$ $b b b$, the breadtli of the frame over the bulls, at right angles to them, is 3 feet 6 inches; and in the anme manner, over the slots the length is the same, but the bulls extend at each end inches beyond the slots, making their entire length. including the obliquity. about 4 feet 6 inches. The dimensions of the parts vary a tittle. according to the quality of the material employed, from $2 \frac{1}{3}$ to 3 inches in breadth by 3 to $3 \frac{1}{2}$ inches in depth, for the ball. The slots are from $2 \frac{1}{3}$ inclies in (234) 
breadth, and from $\frac{3}{4}$ to 1 inch in depth, the bulls being mortise 1 , and, when the slots have been inserted, are fixed with wooden pegs driven through the bulls. In each harrow an iron bar $c c$, having a number of holes punched in it, is likewise fixed into mortises in the two outer bulls on the left side. for the attachment of the yoke. Each bull is divided into four equal parts, the extreme division being about 1 inch clear of the mortise of the slot, and at each division the

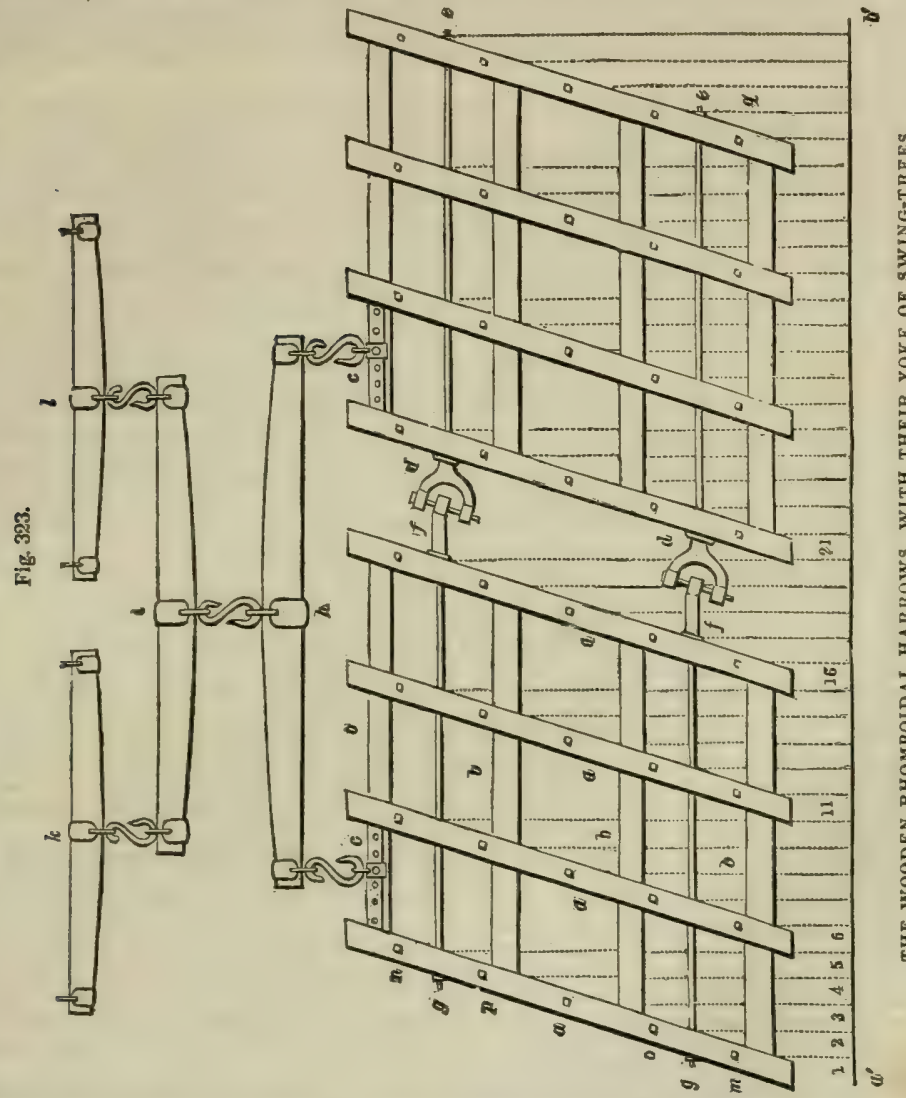

bulls are bored with an anger for the reception of the tines, and in thus boring, a slight inclinatuon forw ard below is given to the tines, though this, it must be admitted, is not of very great import. ance. The length of the tine is about 10 inches, of which 6 or 7 inches project below the bulls; and it has been recommended that the front row should be 7 inches. the succeeding rows diminishing gradually to 6 inches, to compensate for the effect of draught of the horses tending to ele. vate the fore-parts of the barrows. This tendency to rise in front is not so great as has been supposed, for the weight of the swing-trees and whole yoke will nearly compensate for the effect of the angle of draught. In all cases of this kind, the yoke, consisting of chains, hooks and swingtrees, of which the latter, in the harrows-yoke, forms a portion of considerable weight, the system. resolves itself into a catenarian curve, more or less perfect, of which the point $c$, where the yoke is attached to the harrow, will approximate to the apex of the curve, and consequently to a horizontal line, thereby neutralizing the tendency to rise in the front of the harrows.

(1787.) There is one point in the improvement of this harrow that appears to me of even more importance than the rhomboidal shape; it is the joints or hinges $d d$. In the one harrow, fig. 323 , the tail of the double joints of the hinge is prolonged into a bolt $d e, d e$, passing through all the bulls, and secured with screw-nnts at $e$. The single joints are in like manner-prolonged into the bolts $f g, f g$, thus serving to add greatly to the strength as well as to the efficiency of the harrows. The loose joints $d f, d f$ have been found to answer their purposes much better than the well-fitted joints originally given to them, by their allowing of a great freedom of action, and the double joints $d d$ are therefore now usually made as in the figure, the span of the bow $d$ being about 6 inches, with a small eye at each end to fit the joint-bolt. The eve of the single joint $f$ is about $1 \frac{1}{2}$ or 2 inches diameter, having thus great freedom to play upon the joint-bolt.

(1788.) From the figure of the rhomboidal harrow, when daly constructed, it can only perform its maximum of effect when drawn forward with its slots at right angles to the direction of its mo- 
tion, and this is effected by the master swing-tree $h$. This tree, for barrows of the dimensions bere described, reyuires to be 4 feet 8 inches in length between the points of attacbment, and it is connected to the harrow: by means of the $\mathrm{S}$ hooks and shackles at $c$. The balance of draught of the harrows is adjusted by shifting the shackles into the different holes of the bars $c c$, until the harrows are found to lie at right angles to the draught when in motion; and this, be it observed, is not attained by having an equal number of tines on each side of the center of the swing-tree $h$, for there is found to be a greater resistance to the forwari motion of the implement on the left than there is upon the risht side, arising, it is supposed, from the tines presenting a broader surface to resistance on that side than on the other. The other parts of the yoke $i, k, l$, are the cummon plow swing-trees.

(1783.) The objects to be attained on the construction of the rhomboidal harrow are rhiefly uniformity and equal distribution of effect from the tines, and to cover the greatest breadth of surface, with such effects. In these respects, it has been supposed that the rhomboidal affords advantages over the rectangular form. but such advantages seem to fall only within certain limits; for the rectansular harrow, if due attention is paid to its construction and position of yoking. and if mounted with the hinge-joints, will perform all the functions ascribed to the rhomboidal harrow with equal eftect. Though the rectangular form presents no advantage in point of expense, there would be this advantage in construction, that, by keeping simply to one dimension of breadth. no mistake could occur with the maker to mar the attainment of the objects in view; whereas we find rhom. boida! harrow's made at all angles of obliquity, though the length and breadth may be the same in all ; and such being the crse, many of them must be defective in some, if not in all the points sought for. Toexhibit this more clearly, and to render the basis of construction of this simple im. pleme'nt practically intelligible, let us suppose that a pair of harrow's carrying forty tines are to be so constructed as to cover 9 feet in breadth, we shall have 39 spaces between the extreme tines, which are to form equal intervals. Draw a base-line $a^{\prime} b^{\prime}$, fig. 323, and having set from a scale or at full size, a distance $a^{\prime} b^{\prime}$ equal to $9 \mathrm{feet}$; divide this into 39 equal parts and, from the points of division draw the dotted lines at right angles to $a^{\prime} b^{\prime}$, the distance between the divisions will be 276 inches, or say $2 \frac{3}{4}$ inches, which represents the distance at which the tines will pass throu h the ground. Having determined, also, the distance between the times as they stand in the bulls to be $9 \frac{1}{2}$ inches: set off, on the firat dotted line 1 , any distance $a^{\prime} m$, which last point $m$ will be the place of the first tine. With a length of 38 inckes, or 4 tine spaces as before fixed, set off from the point $m$ a distance $m n$, cutting the fifth dotted line in $n$, which last point will be the place of the 5 th tine, or the foremost in the first bull. If a line is then drawn through the points $m n$, it will cut the divisions $2,3,4$, in the points 0 a $p$, indicating the three intermediate tines of the first bull, and the line $m n$ is the true position of the central line of the bull, forming an angle of $73^{\circ}$ nearly with the base-line. A line drawn through $m$ to $q$, and parallel to $a^{\prime} b^{\prime}$, will deter. mine the position of the first tine on each succeeding bull, where the line intersects the 6 th, 11 th, 16th, 21st. \&c., of the dotted lines of division, and lines drawn through those last points of intersection parallel to the first line $m n$, will determine the central line of all the bulls in the pair of harrows. It is then only necessary to extend the length of the bull requisite to contuin the mortise for the slot, with a sufficient extent beyond to prevent the bursting of the wood; this, as already sta. ted, may be about 4 inches, or the bulls will be about $4 \frac{1}{2}$ feet in length.

(1790.) Were it desired to have the tines so placed as to follow in the ground at equal dis. tances of $2 \frac{1}{2}$ inches instead of $2 \frac{3}{4}$ inches, in this case the distance between the extreme tines would be 39 times $2 \frac{1}{2}$ inches, or 8 feet $1 \frac{1}{2}$ inches. The line $a^{\prime} b^{\prime}$, fig. 323 , would now be made 5 feet $1 \frac{1}{2}$ inches, and being divided into 39 equal parts, and the lines of division drawn as before, a repetition of the process described in (1789) will give the true form of the rhomb for this particu. lar breadth, and so of any others; and it should be particularly observed that in any case where the rhomb has been correctly laid down, the harrows should progress with the front row of tines at rizht angles to the line of direction in which they are drawn forward. Attention to this will insure the best possible effects from the harrow, and at the same time cover the greatest breadth of surface that it is capable of harrowing, to the best advantage.

(1791.) I have eaid that the common rectangular harrow is capable of producing equal effects with those of the rhomboidal; and though this cannot be said of all common harrows, the construction of such as will do this is not more difficult, while it is, perhaps, a little less expensive. The chief difference lies in the mode of applying this harrow, for, when duly constructed. it is only necessary. in order to produce equal intervals of the tines, to yoke the harrows in such posi. tion as will make the bulls lie upon the ridge with the same degree of obliquity that those of the rhomboidal shape occupy when they are drawn in the position due to the angle of their respective rhomb. It is necessary, however, in order to secure the due performance of the rectangular har. row, to pay attention to its construction as regards the distanee between the bulle, and the rule is aimply this: Whatever breadth the pair of harrows are intended to cover, divide the whole breadth into a number of divisions, one less than the whole number of tines in the pair, and the distance from center to center of the bulls must be made equal to as many of these divisions as there are tines in each bull. Thus, taking the first case of the rhomboidal harrow (1789) we have 5 times $2 \frac{3}{2}$ inches nearly, or $13 \frac{3}{3}$ inches for the distance between the centers of the bulls, or 3 feet 8 inches in breadth overall. To complete the arrangement, the harrows must be jointed as in the rhomboidal form, and mounted with iron draught-bars, as at $c c$, fig, 323, so that the point of draught can be adjusted to bring the harrows to their proper position; and here it may be remarked that they should never be drawn by the extreme angle: but if not hinge-jointed, the angle with the second bull, and the fore slot, will be tolerably near to the true point of draught. A common and a very useful practice has long existed, of coupling two harrow's together by a bar of wood or iron, called a rider. This oar falls loosely at each end upon a stud projecting upward from the second bull of each harrow, and the bar being adjusted to that length which keeps the two harrows at their proper distance, serves to prevent them from riding over one another, and to make them cover their full extent of surface. The introduction of the rider was an evident approsch to the more perfect modern improvement of the hinge-joints. 
(1792.) The extensive application of iron has of late years brought the use of that material to the formation of the harrow as well as of the plow, and iron barrows are now coming very generally into use, both in the rectangular and the rhomboidal form. Fig. 324 represents the malleable-iron rhomboidal harrow, as commonly constructed, and its dimensions are the same as already given for those of wood. The arrangement of the parts are somewhat different, and, from the nature of the materials, the dimensions of the parts differ also more materially. Thus, the bulls $a$ a $a$ are $\frac{1}{3}$ inch in breadth and 1 inch in depth, swelled out where the mortises for the slots are formed, and also for the tines, their ends projecting only 2 inches beyond the slot. The slots $b \quad b \quad b$ are 2 inches

Fig. 324.

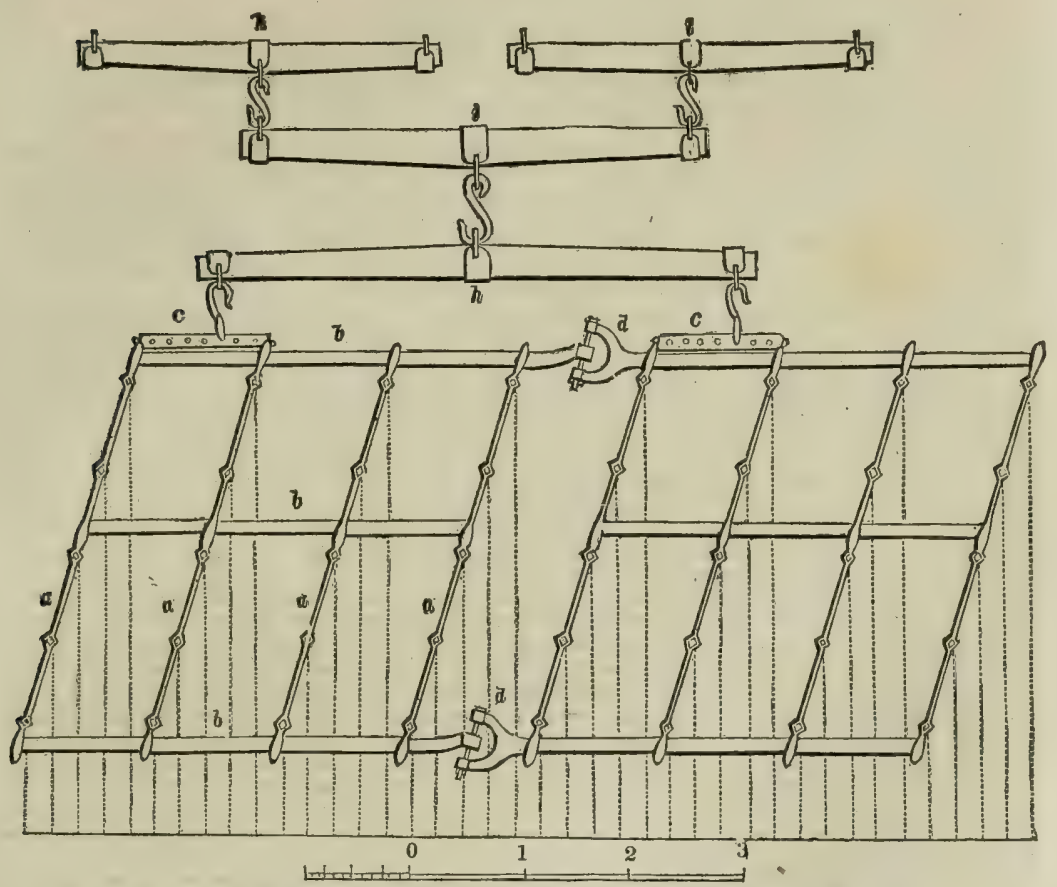

THE IRON RHOMBOIDAL HARROWS, WITH THEIR YOKE OF SWING-TREES.

in breadth. $\frac{3}{8}$ inch in depth, and there being only three of them, the middle one is so placed as to be free of the middle row of tines; while the end slots are elongated toward the meeting sides of the pair, and are there formed into the hinge-joints $d d$, as formerly described for the wooden harrows. The draught-bars $c c$ are inserted in the projecting ends of the first and second bulls, and retained in round pivot-holes; the swing-trees $h i k l$ are the same as described for the wooden harrows. The construction of the iron harrow is so similar to the others that it is unnecessary to enter into farther details regarding it; but it may be remarked that, from the almost imperishable nature of the materials, as compared with wood, there seems every reason to expect the iron implement will entirely supersede the wooden; and though the price of the iron harrows is considerably above that of wood, the additional first cost is more than repaid by the greater durability of the iron. There is good reason also to believe that by a construction more adapted than the present to the nature of the material, the price may yet be considerably reduced.

(1793.) The form of the tines of the harrow, as regards their effects in stirring the soil and covering the seed, is deserving of inquiry. In the wooden implement, we are, from the nature of the material, confined to one form of tine; that which has for its horizontal section an oblong square; the tines in these cases being $\frac{7}{8}$ inch broad by $\frac{5}{8}$ inch thick, must, for the safety of the wood, have the greatest dimension lying in the direction of the fibres of the wood. Another and a better form, for the purpose of stirring the soil, is that which has its cross-section forming an exact square of $\frac{3}{4}$ inch on each side, and inserted in the bull with its diagonal pointing in the direction of the progressive motion. This form and position of the tine, however well adapted to the soil, cannot, with propriety or safety to the implement, be used in the wooden harrow, from the powerful tendency it has to split the wood. In the iron implement this difficulty does not exist; and as this form of tine is in every respect best adapted to the intended purpose, it should never be omitted in the iron harrow. Whatever be the cross-section of the tine, in that part which passes through the bull, the projecting part is tapered toward the point, not uniformly, bat a little barreled, and terminates in an obtuse point. In all wooden barrows the tines are simply driven firmly into the 
wood after it has been boned. In most iron harrows they are fixed in the same manner; but as the tines are sometimes liable to become loose, when simply inserted and driven down by the hammer, they are, when a more perfect construction is followed, fixed by being driven from below, and secured by" a screw.nut above.

(1794.) Girass-sced Harrotes. or those that are employed for giving a light covering to grassseeds when sown, differ from the common harrow in no respect except in dimensions and weigbt. They have generally the same number of tines, bulls and slots. The breadth over all is about 3 feet, or from that down to 33 inches, snd the distance between the tiacs about 7 inches, giving a length of bull $3 \frac{1}{2}$ feet, and the tines vary from 5 to 6 inches in length. Harrow 8 of this descrip. tiun are frequently used by English farmers to give the last turn of harrowing in grain, and a fine finish to the surface. Grass-seed harrows are made of iron as well as of wood, but withal it is rwit held as an essential implement, the commou harrows being more frequently used for the purpose to which the grass-seed harrow is more especially and almost exclusively adapted.

(1795.) Various other forms of harrows are adapted for special purposes, such as the bush-harrour, which is a frame of wood interwoven with the smaller branches or croppings of trees, and in this maner employed instead of the grass-seed barrow described above, and it is also employed for harrowing in top-dressing upon grass.

(1796.) The Iron-web Harrove is a late invention by the ingenious and indefatigable Mr. Smith, late of Deanston, for the same parpose. It is formed of an assemblage of annular disks of castiron, of the size and shape of the common playing-quoit; and these are interwoven with iron wire of about 1 inch diameter, in a certain regular form, until the whole forms a flexible web, in which the disks have liberty to play and roll about within small limits. The web may be 2 yards in length by $l$ in breadth, and is simply dragged over the ground, when it is said to give the tur. face a finish superior to anything hitherto proposed or introduced.

(1797.) The Brake-harron is only an enlargement of the common implement, wherein every part is iucreased in size and weight for the purpose of breaking down and pulverizing rough and stubborn land. Brakes are made of various forms, such as rectangular, rhomboidal, and triangalar: aml every form has its advocates, the preference being given frequently to that which accident had thrown in the way of the experimenter; and without taking measures to compare its effects with those of other forms, the implement is marked as the most perfect of its kind. There appears no good reason for concluding that any one of the above forms is better than another. provided proper weight is put in the implement, and the tines of proper length and number, and disposed in a manner that, with a duly applied draught, will make an equal distribution of its pul. verizing effects over the surface which it covers. The extended application of draining, and the increasing employment of the grubber, which I shall shortly bave to notice, appear in some mcas. ure to be superseding the brake-harrow.

(1798.) The Broadcast. Sonving-machine has now come into pretty general nse, especially in those districts where the arable system is under the best management. and on large farms is nearly superseding the process of hand-sowing. It not only sows all the white grains, wheat, barley, oats, when eown broadeast, in a very uniform manner, and with any desired allowance per acre; but it serves in a superior manner for grase-seeds, in point of distribution, and, in the case of windy weather, is greatly superior to band-sowing. This last advantage arises cbiefly from the low position of the discharging orifices, as compared with the hight of the hand in sow. ing; but partly also from the more direct discharge of the seed from the machine; its velocity of discharge, likewise, and the distance it has to fall, being always uniform. The nice gradation of the discharge is one of its chief qualifications, for it may be adjusted to sow any required quantity per acre, between the lowest and the highest, that may be judged expedient, and in all cases, from the unifornity of the distribution, a considerable saving in seed may be effected.

(179y.) I have on previons occasions had to notice the rather curions facts of the introduction of certain practices from England into the Scottish system of farming. Such practices have remained either stationary in the former country, or bave been but partialiy extended, whereas the practices thus borrowed by the latter bave been improved on and widely extended. The machine now under consideration is anotber example of this; for though it appears to have bcen originally brought into Scotland from Yorkshire, I believe it is even now but sparingly used in England, while here it is in extensive use in the best arable districts, and still rapidly extending. In the course of some inyuiries as to the perind when this machine was first adopted in Scotland, I have been enabled. through the kindness of Mr. Scouler, Haddington, to fix the ume of its introdaction to the year 1817, and the first machine so made appears to have been by Mr. Robert Lowrie, Edington, who makes the following statement: "The first broadcast Bowing-machine that came into this county (Berwickshire) was ordered by myself from England from Mr. Short of Cliver. ton by Hackhill: it was a smart thing. wheeled by a man, and was about 8 feet long; it is still in the possession of Mr. Wilson of Edington Mains. I got that machine in 1816, and in the fullow: ing year I made one from it for Mr. Wright, late tenant in Prenderguest, which was 15 feet long, and was drawu by one horse. So far as I know, this was the first sowing-machine made in Scotland; and after it harl sown Mr. W right's crop of that season, I exhibited the machine at the Agricultural Shows of Coldstream and Kelso, and received premiums for it at both places; this was in 1817 ; and in the following year I made one of the same dimensions for Mr. Wilson's father. the lnte Mr. Abraham Wilson." From Berwickshire the machine made its way immediately into East-Lothian. where the manufacture of it was taken up by the late Mr. Adam Scouler after the machines of Mr. Lowrie above referred to, and has been successfully carried on by his successors, Messrs. Scouler and Company of Haddington. The machine here referred to as having been brought from Chiverton. is the same as are yet to be found in the nurthern and eastern counties, and ascd cbiefy for sowing grass-seeds; its application to the sowing of grain having made little progress, or it may rather be considered as baving been superseded by the drill system of eowing, so much practiced in these counties of England.

(1800.) In the early application of the broadcast nachine, it was mounted on two wheels: bat a few years experience pointed out the advantages of a third wheel, which was applied to it by \{238\} 
Messrs. Scouler about the year 1830, the third wheel being applied as a swivel or fore-carriage. The carriage is still subject to considerable variety of construction, but these varieties are not of a nature to alter its general character. A carriage of a nearly triangular form is very generally adopted, the apex being in front over the swivel-bar. A rectangular carriage is also very much employed, and this is the most workmanlike construction, though perhaps not the cheapest, but it is withal the most convenient and useful form. As regards the general construction, an important improvement has been introduced within the last six years; this is the cutting of the seedchest into sections. The chest is usually made 18 feet long, which being far beyond the width of any field-gate, produced a necessity for changing the position of the chest when passing through a gateway. It was therefore the practice to lift the chest from its working position parallel to the axle of the machine, and deposit it parallel to the horse-shafts until it had passed through the gate. This was clearly both imperfect and inconvenient, and these defects gave rise to the cutting into sections, the middle part being 9 feet, and the extremes each $4 \frac{1}{2}$ feet, so that when the latter are folded up, the extreme length of chest is 9 feet.

(1801.) The illustrations of this machine which I have here given in Plate XXVI. are taken from those manufactured by James Slight and Co., Edinburgh, and they exhibit the machine in its most complete state, embracing the chest in sections, with the mode of supporting the same; this last improvement having, it is believed, been first introduced by the above-named house. In Plate XXVI., fig. 316, is a view in perspective of the entire machine, as it appears when in work, and fig. 317 a section, on a scale of $\frac{1}{2}$ inch to a foot, taking the chest transversely through its center, the carriage being cut in the same line, or parallel to the horse-shafts. In these two figures the same letters mark corresponding parts. The carriage is marked $a b a$, fig. 316 , and is a frame of hard wood, the bars of which are from 4 to 5 inches in depth, and $2 \frac{1}{2}$ inches in thickness; the dimensions of the frame being 7 feet in breadth over all, and 4 feet in length over the rails, of which there are three, as seen at $b b$. The hind wheels $c c$ are 34 inches in bight, generally formed with cast-iron naves, wooden spokes and felloes; or, as in the figure, the felloes are superseded by a simple hoop of malleable iron $2 \frac{1}{2}$ inches by $\frac{3}{8}$ inch, which, for light carriages of this description that never travel on hard roads, is found sufficiently serviceable. The axle of these wheels is $1 \frac{1}{4}$ inches diameter, seen at $d$, in fig. 317 , and is in two lengths supported in pillow. blocks bolted to the lower edge of the bars $a$ a $a$ of the frame, and meeting in the middle bearing. The nigh-side wheel is fixed dead upon the axle, carrying the axle round with it to give motion to the pitch-chain $d e$ of fig. 317 , and which is seen also at $a$, in fig. 316 , where it is seen as en. tering the chest. The off-side wheel may in this case be also fixed dead upon the other half of the axle, or it may run loose. But the axle may also be made in one piece, the off-side wheel being left loose, which is necessary for the convenience of turning round, this wheel being disengaged from turning with the other. The front wheel $f$, fig. 317 , and seen also partially in fig. 316 , is 24 inches diameter, usually of cast-iron. and is supported on the cast-iron sheers $g$, which are 4 inches wide between the arms, and terminates upward in the lower half of the swivel-plate $h$, and this, again, is furnished with a strong pivnt, passing upward through the head $i$ of the cast-iron forebeam $i k$. The head of the fore-beam is formed into a swivel-plate corresponding to that of the sheers $g$. and is bolted to the two foremost bars $b b$ of the carriage. Two small pillars $l$ are cast upon projecting ears of the swivel-plate of the sheers $g$, and bolts passing through these pillars and the splinter-bar $m$, bind these parts firmly together, producing an effective swivel-carriage. The horse shafts $n n$, broken off in fig. 317 , are attached to the splinter-bar $m$ by means of a long draft-bolt passing through the ends of the shafts, and through eyes fixed in the splinter-bar.

(1802.) The seed-chest $o o$ is 18 ieet in length, formed of $\frac{7}{8}$-inch deal. The breadth of the bottom board is $6 \frac{1}{2}$ inches, projecting on one side $2 \frac{1}{2}$ inches, forming an apron, on which the seed falls from the orifices. The sides of the chest are $10 \frac{1}{2}$ inches in depth, and the cover 14 inches in breadth, 9 inches of which form a hinged flap, as seen in the figure. The chest is bound together upon ends and partitions of hard-wood $1 \frac{1}{4}$ inches thick; when in sections as here described, each section has two such ends, and the middle section has swo partitions in the middle, set at $2 \frac{1}{2}$ inches apart. When the chest is in one length, two ends and the two middle partitions only are required. The joints or hinges of the sections are formed of the iron straps $p p$, two of which are securely riveted on each side of the chest, having eyes formed at the apex $q q$, and through these eyes a small bolt, $q$, passes from side to side, which completes the hinge; and by withdrawing the bolt the parts of the chest are at once disengaged. For the better connection of the segments, however, when the machine is in action, the contiguous ends are held in contact by a bolt and nut, as seen at $c^{\prime}$ in fig. 318, which, together with fig. 319, are on a scale of 1 inch to a foot. The two extreme segments. also, are supported by the light tension chain $i^{\prime \prime} i^{\prime} i^{\prime} i^{\prime \prime}$, which passes over the two upright iron stanchions, $k k^{\prime}$ the tops of which, $i^{\prime} i^{\prime}$ form the suspending fulcra for the chain, while its extremities are secured at the points $i^{\prime \prime} i^{\prime \prime}$ with adjusting nuts.

(1803.) The sowing-geer of the machine consists of the following parts: The main axle of the carriage is mounted with a pitch chain-wheel 4 inches diameter, placed upon the axle close to the middle bar $a$ of fig. 316 , and seen in full at $d e$, fig. 317 ; a corresponding wheel $r$ is placed upon a short axle within the seed-chest, and between the two middle partitions of the chest. In this way motion is communicated from the carriage-wbeels $c$, and their axle, to the axle of the small wheel $r$, fig. 317. A light shaft, $\frac{1}{2}$ inch square, is coupled to the ends of the axle of the wheel $r$, extending to each end of the chest; when the chest is entire, each of these shafts is also entire ; but in the present case each shaft is in two pieces, coupled at the junction of the segments of the chest by means of small clutch couplings attached to the ends of the shaft, and these engage or disengage of themselves when the segments of the chest are let down or folded up. These lastmentioned shafts are supported in bearings of hard-wood laid in the bottom of the chest, at distances of from 2 to $2 \frac{1}{3}$ feet, and the journals, which are $1 \frac{1}{2}$ inches long, covered with straps of stout hoop-iron. The shafts are armed with the seed-wheels of the form as shown at $r$ in fig. 318 , which are placed upon it at distances of $6 \frac{1}{2}$ inches, 32 wheels being required for an 18 -feet chest. The seed-wheels have suffered a variety of changes : originally circular brushes were employed. then came wooden naves, of about 3 inches in length and $2 \frac{1}{2}$ inches in diameter; and into these

(239) 
were inserted leaves or teeth of hoop-iron, about 1 inch broad and 1 inch long, and this form of wheel is atill much employed. In the progressive stages of the machine it was farnished with one set of these smalk shafis, carrying brushes, and another set carrying wheels, as above described : the former being then thought necessary for sowing grass-seed. and the latter were $\mathrm{cm}$. ployed for grains: observation sbortly pointed out that the toothed wheels were cqually well adapted for either grass-seeds or grain, and the brashes have consequently been laid aside. The wheels represented by $r$, fig. 318 , are of cast-iron. of very light fabric; they are ten-toothed, and are $4 \frac{1}{1}$ inches in diameter, measuring to the extreme points in the cross-eection: the points of the teeth are slightly rounded, to adapt them to the concave groove or cup that is formed in the back of the chest around each discharging orifice : the wheels are cast with a square eye, and fixed upon the shaft by barbing the angles of the shaft round the eye of the wheel.

(1804.) Corresponding to each eeed.wheel, a discharging orifice $s$ is formed in the back of the chest ; these are $\frac{7}{8}$ inch diameter, and their center is $1 \frac{1}{1}$ inches above the apron-board $f x$. On the inside of the back-board oval excavations are made in the wood around the orifices, leaving the botton of the cops or edges of the orifice not exceeding 1-16 inch thick: and in this oval cup the seed-wheel sinks antil the points of the teeth are only $t$ inch clear of the bottom of the cup or the edges of the orifice as seen at s. The position of the seed-wheels in relation to the bot. tom $f u$ of the chest is such as to make the teeth turn at about $\frac{1}{t}$ inch clear of the bottom. The eeed orifices are deferded by the iron plates $d^{\prime}$, fig. 319, of a triangular form. the apices $d^{\prime}$ are driven into the apron, which secures that point of the plates, and the other two points are fixed by nailing. The fixing of the plates requires some attention, in order that the orifices may exactly coincide with those of the slide $t t$; without perfect coincidence in these two parts the sowing will be unequal.

(1805.) The slide is a bar of boop-iron 2 inches in breadth, and abont 1.12 inch in thickness; it is perforated at the regular distance by means of a punching instrument, and gauged to determine the precise intervals. In the entire chest the slide is in two lengtbs, but in that now described each half is again cut in two at the junction of the sections, and connected by a slip binge-joint. The slide is beld in its place by the small clasps $e^{\prime} e^{\prime}$, and a clamp $f$ is riveted opon it at any con. venient point; the short arm of the lever $v$ enters an opening in this clamp, while its fulcrum lies in the plate $b$, which carries a perforated stud, and is fixed on the back of the chest as in fig. 318, forming the fulcrum of the lever, by means of which the slide is moved over the seed. orifices. To effect the precise adjustment of the orifices, the slide is made in two halves, and at each end of the chest an adjusting-Bcrew $v$ acts in a nut attached to the end of the chest. the point of each screw being brought to bear against the end of the slide, which is here thickened to meet the point of the screw. The adjustment will be anderstood by reference to fig. 319 , which represents a portion of the slide of the left-hand half of the chest. The slide is here supposed to have been pushed toward the right hand by means of the adjusting-serew $v$, fig. 316 , till the orifices have been reduced to the desired size, as here shown in fig. 319 about balf shut; in this state the machine is supposed to be fit for sowing, and that it has reached the end of the field. when it becomes necessary to shut while turning; the shutting is effected by moving the slide still farther, to the right hand, by means of the lever, until the orifices are entirely closed. Both ends of the chest having undergone this operation, which is done in an instant, but in reverse directions, the machine may go to any distance without discharging a grain; but whenever it bas been turned into the next ridge, the levers $w$ are thrown in the opposite direction, moving the slide toward the adjusting-screw $v$, and this being done at both ends, the orifices will bave attained precisely the same area as before. and thus the shutting and opening again to the same area : and of course the same discharge is effected for any number of turns without the smallest variation, so long as the screw $v$ remains unaltered.

(1806.) For the purpose of equalizing the distribution of the seed over the surface of the ground after it has left the discharging orifice, the bottom-board $f x$ of the seed-chest is made to project beyond the back of the chest about $2 \frac{1}{2}$ inches, as at 20 , fig. 318 . forming an apron on which the seed is first received from the orifice, and being thus checked in its descent, is thereby more uniformly scattered over the surface. Another precaution is taken, the better to secure a uniform discharge in the case of enwing on ground that has a high incliastion. In sowing up-hill, in sach situations the weight of the basket is thrown more apon that side of the chest from which it is discharged. tending thereby to iucrease the discharge. On sowing down-hill. on the other band, the effert of pressure is reversed, and the discbarge will be less. To avoid these inconveniences, Messrs. Scouler, among their other jmprovements in this machine, introduced a tilting motion :0 the secd-chest in the following manner: on the two outward bearers $a$ a of the carriage-bolsters $y y$, having a semi-circular seat of about 8 inches diameter, and corresponding to these, on the bottom of the chest, are formed two circular bearing or journals $y$ y $e$ on the bottom of the chest and concentric with the shaft of the seed.wheels $r$, figs. 317 and 318 . Upon these journals the chest can be tilted to a certain extent backward or forward, and this is effected by the lever $z$. which may be variously attached to the chest. In the present case it is a fork thrust into two apertures in the chest. forming a lever, whose arm is retained in the sbeers of the quadrant $a^{\prime}$, and by raising or depressing the lever $z$ the chest is tilted backward or forward as the sower sees it necessary ; the lever being retained in the required position by a bolt passed through the lever and the then corresponding bole in the quadrant.

(1807.) As the seed-chest is 18 feet in length, and it may sometimes be desirable to reduce its breadth of sowing to 16 or to. 15 feet, suiting ridges of these breadths, the reduction is effected by stopping two, three, or more of the seed-orifices at each end. For this purpose the orifices intended to be stopped are provided with a flat swing-clasp, turuing upon a pin to which it is riveted, and having a flat tail which is brought over the orifice that is to be stopped. Two of these clasps are seen at each end of fig. 316, under $x$, where they are in the position that leaveg the orifice open.

(1808.) The sowing-geer of this machine has undergone a variety of changes. In the example before ns. the pitch-chain is employed to communicate motion from the first mover-the carriage (240) 
axle-to the seed-wheels. It has the property of great simplicity, but has been objected to on the score of its keeping the seed-wheels constantly in motion, whether sowing or not, which has been sipposed to bave a tendency to injure the grain which lies in contact with the wheels. Perhaps there may be grounds for this supposition; but if it do exist, the deterioration must be very trifling. Be these surmises what they may, they have given rise to the means of prevention, by employing a gearing that disengages the seed-wheels from the first mover when the machine is being moved and no discharge of seed required. Fig. 320 represents a very perfect and convenient arrangement of this kind, and which has been very successfully employed, but is a little more expensive than the chain-gearing. $a$ is the seed-chest, $b b$ a part of the carriage, and $o o$ the middle and back transverse.bars of the same (corresponding to $b b$, fig. 316.) The bar $f e$ is one side of a light castiron sheers, which is bolted to the bars $o o$ (standing in the place of the middle longitudinal bar $a$ of fig. 316 ;) and the three equal wheels $c c c$ are set in the sheers-the first of the three being upon the carriage-axle, which is in halves as before, and the meeting-ends supported on the sheers $c$. The last of the three wheels takes into the wheel $h$, mounted on the central portion of the seed-wheel shaft, as before described in (1805); and $d$ is a fourth wheel, of equal size with $c c$. mounted on the lever $g$ : which is forked to receive the wheel $d$, and to embrace the sheers $f e$ at $e$, upon which last point the lever turns as a fulcrum. It will be evident that by lifting the lever $g$, and throwing it forward upon the seed-chest, the wheel $d$ will be ungeared from the first wheel $c$; and though it remains in contact with the middle wheel $c$, no motion will be communicated to the seed-wheels until the lever is returned to its original position.

(1809.) In using the broadcast machine, it is frequently drawn by one horse; but it forms a rather heavy draught, and is, therefore, more frequently the work of two horses. The chest is filled from end to end with the seed-corn, and, the horses walking in the furrow, the machine sows the half ridge on either side. When the chest has been filled, and the machine brought to that position which places the horses in the furrow-the sower having previously determined the degree of opening in the orifices that will deliver the desired quantity per acre, he throws each slide outward against ite graduating serew, which will produce the proper opening, (1807); and this done, the horses are driven forward. On arriving at the farther end of the ridge, and before entering upon the head-ridge, the slides are withdrawn toward the center, closing up the vents; the machine is then turned round on the head-ridge, and takes up a position on the next farrow, when the process is repeated, and so on till the field is sown all over, the head ridges being the last portion of the work, and here the blinding of the extreme orifices come frequently into play, if the head-ridges are of less breadth than those of the field.

(1810.) It has often been suggested that a register screw or index would be a useful appendage to the machine, by which the sower could at once fix upon the extent of opening in the seedvents. This addition, however well it may appear in theory, appears, in the practical application of the machine, to be of little value; for the eye of an experienced sower will, on passing over a $\mathrm{f} \in \mathrm{w}$ yards with the machine, by simple ocular inspection, be able to judge of the quantity of seed he is bestowing upon the soil. If experimental accuracy is required, the sower may then put into the chest as much grain as will just cover the seed-wheels, and then measure in one or two bushels, and proceed to sow this until as much remains as will just cover the wheels again, so that the measured quantity is found to have been discharged. By now measuring the number of yards in length that have been sown with two bushels, he will ascertain by calculation the proportional quantity required for an acre. Thus, let the intended quantity to be sown upon an acre be 5 bushels, and that one bushel has been sown in the experiment which has covered 140 yards of the 18 -feet ridge, or two half-ridges equal to $18 \mathrm{feet}$, or 6 yards. The imperial acre contains 4,840 square yards, and this divided by 6 , the yards in the breadth of the ridge, we have $806 \frac{?}{3}$ as the number of lineal yards in length of an 18-feet ridge to make up an acre; and 1.5 of this, or 161.2 lineal yards, is the extent that should have been covered by 1 bushel of seed-corn. The machine having, as supposed, covered only 140 yards, it follows that the sowing is about $\frac{1}{s}$ part of the bushel too thick; the graduating screws, therefore, must be turned forward about half a turn, and the experiment repeated if thought necessary. It is seldom, however, that such experiments will be required in the hands of a practical sower.

(1811.) In reference to the inconvenience attending the great length of the seed-chest as taken notice of at $(1800)$ when it is in one length, there remains to be observed that the method by which it is shifted is this : in its working state the chest is kept in its bolsters by means of two quadrants attached to the lower part of the chest, one being on each side of the carriage ; these are formed concentric with the curvature of the bolster $y y$, fig. 317 , and a bolt, over which the quadrant slides, is screwed into the side of the carriage, and this retains the chest in its place. When it is found necessary to move the chest, the two bolts are unscrewed. which sets the chest at liberty ; it is then lifted from its bolsters and laid longitudinally on the carriage. In this operation, however, the pitch-chain, when that medium of power is employed, has to be disengaged by withdrawing a coupling-link from the chain; but when the medium, fig. 320 , is employed, there is nothing required but the unscrewing of the quadrant-bolts to set the chest at liberty. It is then lifted and laid longitudinally on the carriage as before. The price of these machines ranges from $£ 10$ to $£ 12$.

(1812.) The Presser-Roller is an implement of very recent introduction to the operations of the farm, and, like many others of the useful class of agricultural machines, its origin is to be traced to England. Although the presser does not take its place in the first rank, yet it possesses qualities whose effects on the soil give it a position by no means low in the scale of usefulness. The chief object of its application is to produce consolidation in the soil over a narrow space, in which space the seeds of plants are to have root; hence its effects are applicable only to the drill system of culture, and that only under particular circumstances, namely, consolidating soils whose texture is too loose and friable for the continued support of wheat plants, and to produce close contact in the furrow-slices of lea when plowed for a seed-furrow.

(1813.) The Presser-Roiler is represented in its most common form by fig. 325 , which is a view of the machine in perspective, and is of extremely simple construction. The carriage consists of a (289) ......10 
rectangular frame $a$; its length over the front and back bars is 3 feet 8 inches, and its breadth over the siden 4 feet 8 inches; a third longitudinal bar is introduced between those of the back and front solely to increase the rigidity of the carriage-frame. A pair of horse-shafts $b$, are bolted

Fig 325 .

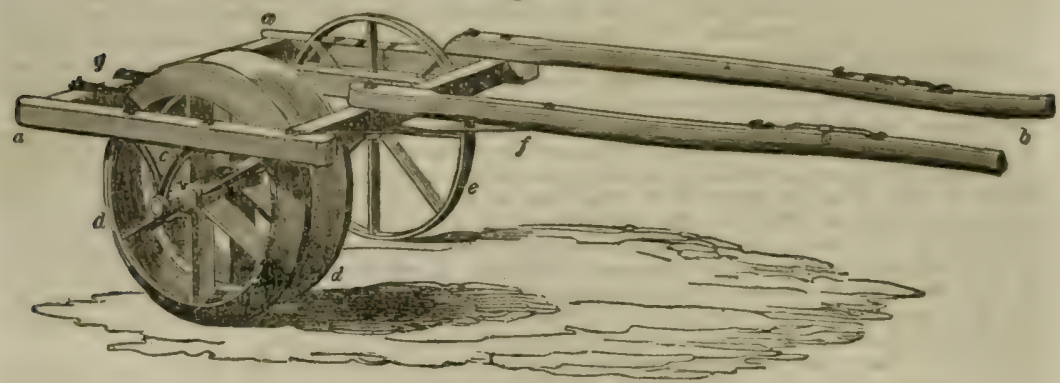

THE PRESSER-ROLLER.

apon the frame, the nlgh-side shaft being laid upon the side-rail, and the other at the usual distance, to afford space for a horse to travel. A cast-iron bracket is appended by bolting to each side-rail; one of these is seen at $c$; its eye or center descends to a distance of 8 inches below the bottom of the rail; an axle of 2 inches square extends between, and is supported in the eye of the bracket in which it turns upon its journals; this nxle carries the two pressing-wheels $d$, which are fitted to turn with the axle, but are movable in the transverse direction, and provided with the means of being fixed at any desired distance apart, though 9 to 10 inches is the usual space. The axle carries also the light carriage-wheel $e_{+}$of 2 feet 10 inches diameter, which may be placed either outside or inside of the carriage-frame, and is usually made of castiron, turning upon the axle, this being requisite for the more convenient turning round of the machine. The off-side shaft $b$ having but an imperfect connection to the carriageis supported by the iron stay-rod $f$; and two iron scrapers $g$ are attached to the hind bar for the purpose of throwing off any soil that may adhere to the wheels. Fig. 326 is an edge. view of the two pressing wheels detached from the carriage, in which $a a$ is the axle broken off, $b b$ are the two pressing. wheels as they appear edgeway'; they are 2 feet 10 inches of extreme diameter, and their breadth $5 \frac{1}{3}$ inches, their weight being about 2 cwts. each; the rim or periphery of the wheel is sloped off on both sides to an angle of about $70^{\circ}$, forming two opposite conical frusta, but a cylindrical band is left in the middle of about $1 \frac{1}{2}$ inches in breadth. 'The pressing-wbeels are held at the required distance by the square collars $c$ c $c$ fitting round the axle and sliding upon it to the proposed distance apart, where they are fixed by the pinching-screws $c c c$. $d d$ represevts a transverse section of ground undergoing the pressing process; the shaded part of the section exhibits the state of a soft. loose soil, when

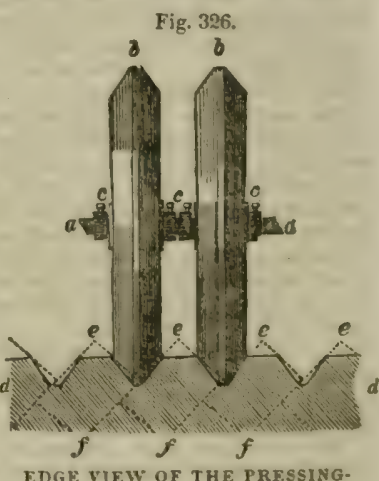

EDGE VIEW OF THE PRESSING.

WHEELS. pressed by the roller, and the dotted lines $f f, e f$, that of newly plowed lea nndergoing the operation of consolidation.

(1814.) As explained in the text above, and with reference again to fig. 325 , the pressing. wheels are to be understood as running always upon the last turned up furrows but one; while the carriage-wheel runs always upon the solid land, where the horse also walks, the shafts being placed at that side. But the presser is now being more advantageously used as to time. in the consolidation of soft soils, by being constructed with four, six, or more pressing-wheels : and in this form the carriage-wheel is not required. In using the presser of this construction, the field must be plowed for the sced-furrow all over, either entirely or in part, before the pressing is begun; and the field is regularly gone over by the presser, which. from its now increased weight, will require two horses. In this form, with six pressing-wheele, and with two horses, the machine will press roll from eight to nine acres in a day. There remains to be observed, in regard to the last form of the machine, that, in order to eccure facility of turning about, the wheels must eisher be all set upon a round axle, or they must be set upon an axle in two lengths, if it is continued of a square form; and there is consequently required a middle bearing for the meeting ends of the axle. For this purpose, a third tiracket is appended to the middle rail of the frame, fig. 325. I have found both of these modes of construction perfectly suitable in practice; and the ontire weight of the aix.wheel rollers amounts to about 12 or $13 \mathrm{cwts}$. The price of the two. wheeled presser is $£ 610 \mathrm{~s}$, and for each additional wheel, with its mounting. $f 112 \mathrm{~s}$.

(1815.) The common Land-Roller is an implement of great simplicity of constraction, the acting part of it being a cylinder of wood, of stone or of metal, and in many cases its only append age is a rectangular frame of wood, consisting of two strong end-bars, selected for baving curvature to keep clear of the ground. In these the gudgeons of the roller are borne, and whin 
are connected by two transverse rails, to one of which the horses are yoked. Simple as this implement appears, there is hardly an article in the establishment in which the farmer is more liable to fall into error in his selection. From the nature of its action, and its intended effects on the soil, there are two elements that should be particularly kept in view-weight and diameter of the cylinder. By the former alone can the desired effects be produced in the highest degree, but these will be always modified by the diameter. Thus, a cylinder of any given weight will produce a greater pulverizing effect if its diameter is one foot, than the same weight would produce if the diameter were two feet; but then the one of lesser diameter will be much worse to draw; hence it becomes necessary to choose a mean of these opposing principles. In doing this, the material of the cylinder comes to be considered. In the first place, wood, which is frequently employed for the formation of land-rollers, may be considered as least adapted of all materials for the purpose ; its deficiency of weight and liability to decay render it the most objectionable of all other's. Second, stone, though not deficient in weight, possesses one marked disadvantage, liability to fracture; this of itself is sufficient to place stone rollers in a doubtful position as to fitness. This brings us to cast-iron, which is undoubtedly the most appropriate of all materials for this purpose. It is unnecessary here to enter into the inquiry as to the most advantageous diameter for a land-roller; the subject has already been elaborately discussed ; * let it suffice to say that experience has proved that a diameter of 2 feet is, under any circumstances, the one that will produce the best effects with a minimum of labor from the animals of draught; the weight being of course proportioned to the force usually applied, which is in general two horses. The weight of roller, including frame corresponding to this, is from 12 to $15 \mathrm{cwts}$; but it is better that the roller itself be rather under the weight, and that the carriage be fitted up with a box, in which a loading of stones can be stowed, to bring the machine up to any desired weight. In a large and heavy roller, in one entire cylinder, the inconvenience of turning at the headlands is very considerable, and has given rise to the improvement of having the cylinder in two lengths; this, with a properly constructed carriage, produces the land-roller in its most perfect form.

(1816.) Fig. 327 is a perspective of the land-roller constructed on the foregoing principles, $a$ a is the carriage-frame, consisting of two semi-circular ends of cast-iron, connected by two trans-

Fig. 327.

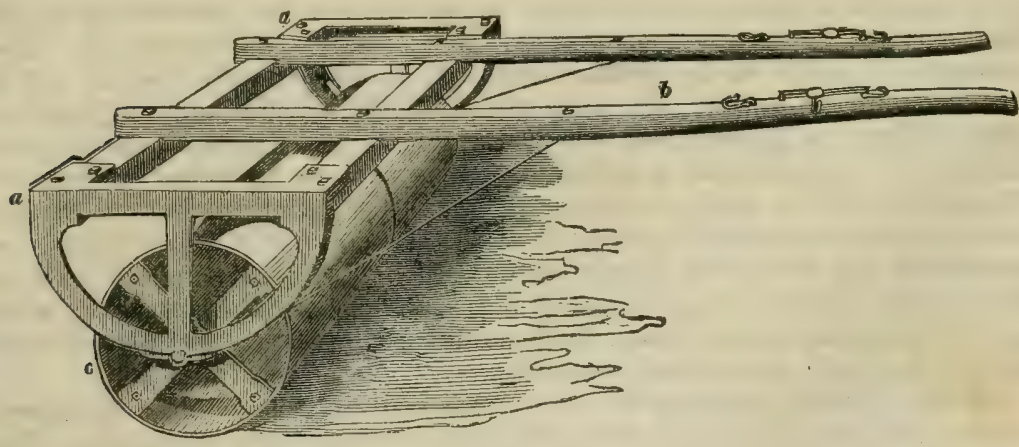

THE LAND RULLER.

verse bars of hard wood, and these last are crossed by the horse-shafts $b$. The cylinder $c$ is in two lengths of 3 feet to 3 feet 3 inches each, and 2 feet in diameter; the thickness of the metal is from $\frac{3}{4}$ of an inch to $1 \mathrm{inch}$, according to the weight required; and each half length of the cylinder has a cross fitted into each end, through the centers of which the axle passes. The axle, in consequence of the cylinder being in two lengths, requires to be of considerable strength, usually $2 \frac{1}{4}$ inches diameter, and of malleable iron; upon this the two sections of the cylinder revolve freely, and the extremities of the axle are supported in bushes formed in the lower part of the semi-circular end-frames. Two iron stay-rods pass from the end frames to the shafts as an additional support to the latter. The price of the land-roller, fitted up as here represented and described, is, according to weight, from $£ 10$ to $£ 14 . \dagger$

[ $\uparrow$ We cannot forbear recommending here the use of a machine invented by, we think, a Mr. Gray, of Lower Virginia. It was brought to our notice by one of those too rare men among farm. ers-one who thinks-Hon. W. Carmichael, of Queen Anne's Connty, Maryland. The simple name of this implement indicates the simplicity of its construction, being called the $d r a g$ - $l o g$. It is made of a log of wood say 5 feet long, more or less, and 12 or 14 inches square, with the tongue of a common ox-cart pinned down in the middle on the top of it, instead of a pair of shafts, as in the land-roller here represented. To this tongue is to be hitched a span of oxen and the log thus dragged over the surface of cloddy plowed land. It will be found to pulverize the land more at one operation than rolling at two. Instead of burying the clods it mashes and grinds them to powder as it proceeds.

Ed. Farm. Lib.]

* Quarterly Journal of Agriculture, vol. i.

(291) 


\title{
12. SOWING OAT-SEED.
}

\author{
" Though ley land you break up when Christmas is gone, \\ For sowing of barley or oats thereupon, \\ Yet haste not to fallow till March be begun, \\ Lest afterward wishing it had been undone." \\ TUsser
}

(1817.) After what has been said of plowing lea ground (919), and of tne mode of sowing seed upon the land by hand, fig. 322, and of the properties of different kinds of oats cultivated in this country (1519), little requires to be added here on the sowing of oats, except the manner in which that operation is finished.

(1818.) Beans and spring wheat are not sown upon every species of farm, the former being most profitable in deep, strong soils, and the latter is only to be commended after turnips, on land in good heart, situate in a favorable locality for climate, and the crop eaten off by sheep; but oats are sown on all sorts of farms, from the strongest clay to the lightest sand, and from the highest point to which arable culture has reached on moorland soil, to the bottom of the lowest valley on the richest deposit. The extensive breadth of its culture does not, however, imply that the oat is naturally suited to all soils and situations, for its fibrous and spreading roots indicate a predilection for friable soils; but its general use as food among the agricultural population has caused its universal culture in Scotland, while its ability to support the strength of horses has induced its culture to be extended throughout the kingdom; and it is certainly a remarkable fact with what admirable effect this plant has adapted itself to the various circumstances in which it is cultivated, and this result is, most probably, owing to the same food, namely, the decomposed grasses with which this plant is uniformly supplied.

(1819.) All the varieties of oats cultivated may be practically classed under three heads, the common, the improved, and the Tartarian. The common varieties include all those having a pyramidal spike, soft straw, long grains possessing a tendency to become awny, and which are late in reaching maturity. Among the named varieties are the following in common use : early and late Angus, Kildrummie, Blainslic, white Siberian, fig. 307, Cumberland, sandy, and Dyock, which last two are recent varieties, and others. It is unnecessary to point out the superior characteristics of each variety, for in the respective districts in which they are sown, each is considered best suited to the locality in which it is cultivated-an. opinion which may safely be disputed. The four last named are in high repute at present, owing to their recent introduction; and it is probable that any recent variety will answer best for a shorter or longer period. All common oats are sown on the inferior soils, and in the most elevated fields of farms, and the season for sowing them is the beginning of March. Of the improved varieties are the potato oat, which has long been cultivated as the only variety; but of late years the Hopetoun oat has been added to the short list. Before it the Georgian was introduced, but did not succeed. Both the potato and Hopetoun oats have long, strong straw, large spikes, come early to maturity, and are chiefly cultivated on the best and lowest lying ground. The grains are very similar, the Hopetoun being distinguished by a tinge of red on the bosom, fig. 306. These oats (292) 


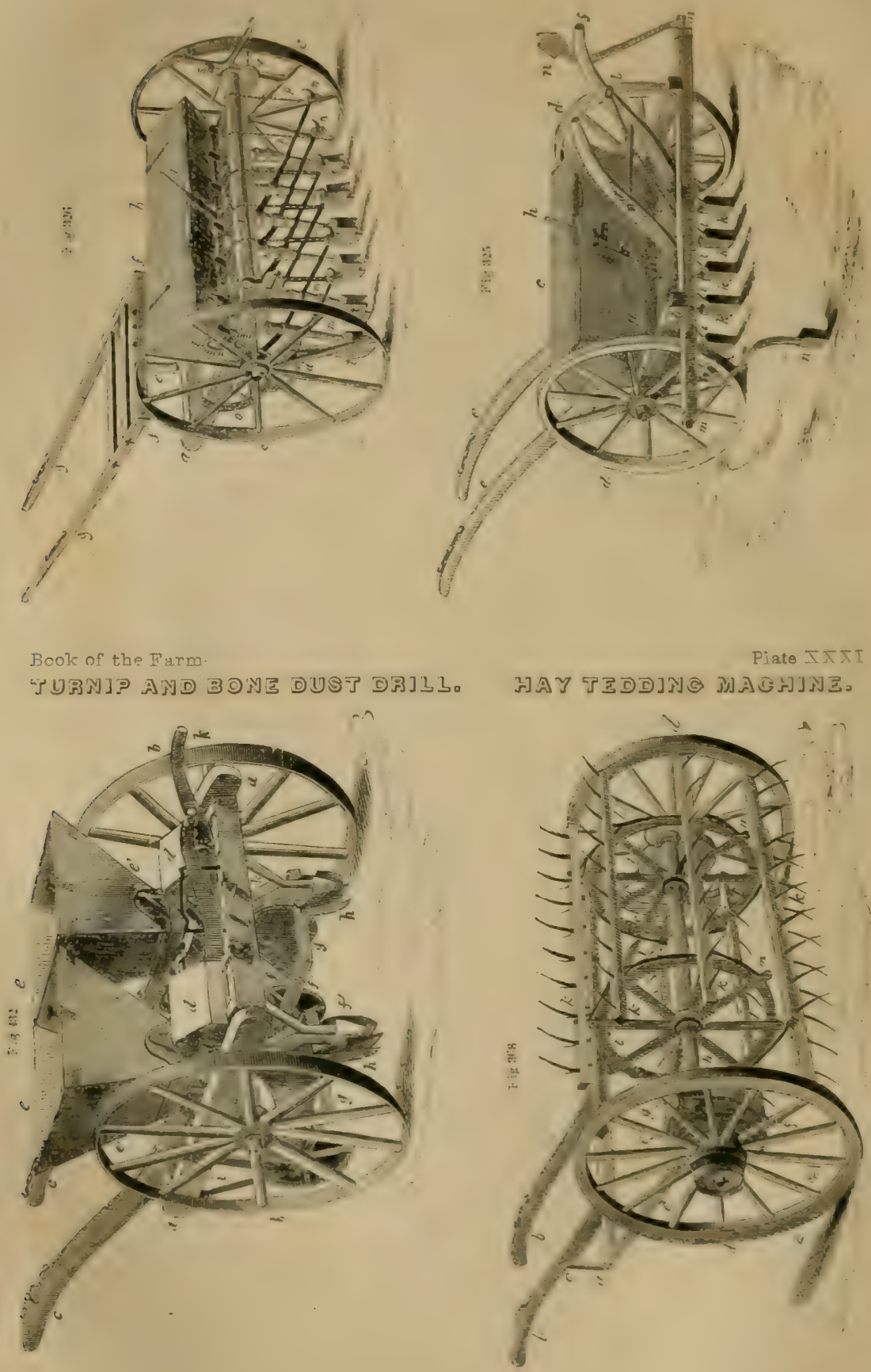
are sown a fortnight after the common. The cultivation of the Tartarian varieties, both black and white, is chiefly confined to England, for the use of horses, and are there called feed oats. I am surprised that this oat sirould be cultivated at this time of day, both on account of its coarseness, as well as the disagreeable work which it occasions in the barn by its long liygrometric awns.

(1820.) The plowed lea-ground should be dry on the surface before it is sown, as otherwise it will not harrow kindly; but the proper dryness is to be distinguished from that arising from dry, hard frost. It will not be proper to wait until every spot of the field is dry alike, as even thorough-draining will not insure that; though spottiness shown in spring is a good criteI Ion whether land has been enough drained, or where it most requires it. Should the lea have been plowed some time before, and from young grass, the furrow-slices will be found to lie close together at seed-time; but should it have been recently plowed or from old lea, or on stiff ground in a rather wet state, the furrow-slices will not lie close together, but be as far asunder as to allow a good deal of the seed to drop down between them, and where this happens the seed will be lost, as oats will not vegetate from a depth of 6 or 7 inches. In all cases of lea where the furrow-slices are not close, in order to save a part of the seed, and avoid a thin crop, the ground should be harrowed a single tine before being sown. The tines of harrows should be particularly sharp when used for covering in seed upon lea. When oats are sown by hand upon dry lea-ground, the grains rebound from it and dance about before depositing themselves in the hollows between the crests of the furrow-slices, and thus accommodating themselves to the form of the ground, are not so liable to be happerga'ed in sowing as other grains. Were the ground only harrowed in along the ridges, so as not to disturb the seed along the furrow.slices, the germs of the crop would come up in as regular rows as if sown by drill; but as the land receives crossharrowing as well as along, the braird comes up broadcast, notwithstanding the position the seed assumes when it settles on the ground. The quantity of common oats sown is usually 6 bushels to the imperial acre; and in deep friable land in good heart, 5 bushels of potato oats suffice. A man does a good day's work if he sows broadcast 16 imperial acres of ground in 10 hours, that is, scatters 80 bushels of potato oats and 96 bushels of common oats in that time. Some men can sow 120 bushels of common and 100 of potato in that time, that is, 20 acres; and double-handed sowers can sow more than this latter quantity. Two sowers keep one seed-carrier fully employed, and indeed if the sacks are not conveniently placed (1756), one will not be able to supply them both, but 2 seed-carriers will easily supply 3 sowers; and every sower employs 2 pairs of harrows breaking in after him, with a double tine. So that the number of sowers is regulated by the number of pairs of harrows that a farm can furnish. The arrangement of the labor for sowing an oat-field may be seen in fig. 322 , where 2 sowers and 1 seed-carrier are represented, but the harrows of 1 sower only are shown in view. See from (1762) to (1766) inclusive. After the land is broken in with a double tine, it is harrowed across with a double tine, which cut across the furrow-crests, and then along another double tine, and this quantity generally suffices. At the last harrowing the tines should be kept clean, and no stones should be allowed to be trailed along by the tines, to the manifest ribbing of the surface. On old lea, or on hard land, another single turn across or angle-ways may be requird to render the land fine enough; and, on the other hand, on a free soil a single tine along after the double one cross may suffice. In short, the harrowing should be continued as long and no longer than the ground feels uni(293) 
formly smooth and firm under the font, having no hard places, or others sinking into hollows by the pressure of the foot $(1770)$. The head-ridges are harrowed round by themselves at last. See (1771). The land, after the oat-seed is sown, is always water-furrowed in every open furrow (1778); and it should also be rolled (1777), according to circumstances; that is, the young braird on strong land being retarded in its growth, when the earth is incrusted by rain after rolling, it is safe to leave the rolling of such land until the end of spring, when the crop has made a little progress, and when the weather is usually dry. Light friable land should be rolled immediately after the seed is sown and harrowed, if there is time to do it; but the rolling of one field should cause no delay to the sowing of others in dry weather. There will be plenty of time to roll the ground after the oatseed and other urgent operations at this season are finished, and especially as rolling may be speedily performed. The cutting of gaws should never be neglected in finishing of an oat-field, to carry off water along hollows or in the open furrow beside the lowest hedge-ridge, as particularly described in (918). Oats are sown broadcast by machinery as well as by hand. The machine is the same as is used for sowing grass-seeds, and figured at fig. 316, Plate XXVI., and already described by Mr. Slight in (1798) to (1811). As constructed at first upon two wheels, this machine, when loaded with a full complement of oat-seed, was too heary for a horse's back, especially on going down hill; but the addition of the third wheel disposes of that objection, and I believe it is now pretty extensively employed in sowing corn.

(1821.) But oats are also sown in rows by such drill-machines as are represented in figs. 325 and 326 , Plate XXVII., and described below by Mr. Slight. In using drill-machines, the land should first be harrowed a double tine along, and then a double tine across the ridges, and again a single tine along. The drill then sows the oats across the ridges, and the land is finished by harrowing a single tine also across the ridges. The water-furrowing and rolling should be executed in the manner described (1820) for broadcast sowing. The drill seems to me not well adapted for sowing corn on lea ground. It cannot pass through it, even after it has been well cut with the harrows, with the facility it does through ground in a soft state; and on hard ground and upon old lea it is questionable whether the coulters can penetrate so far as to deposit the seed at a depth to be out of reach of birds and drouth; and every stone in such ground being rather firmly imbedded, will be apt to cause the drill to go out of its proper course, while at the same time the risk at least of partially displacing the old, uncorrupted turf will be imminent. In these latter cases 1 would recommend the broadcast machine or the hand in preference to the drill; and I would confine the drill in sowing oats to tender land as in the neighborhood of towns, where it is made tender by the application of large quantities of street-manure, and where drilling is advisable as affording a facility for cleaning the land of surface-weeds, a multitude of which, and especially wild mustard, Sinapis artensis, are apt to spring up from the use of street-manure. In England, however, where the drilling of grain is followed out, it must be owned that their plowing with the wheel-plow and sowing with the drill-machine are so perfect in their operation that the seed is laid in the furrows with certainty, and without at all disturbing the furrow-slice.

(1822.) At a time when a less rational system of husbandry was puraued than now happily pre. vails - that is, when land was allowed to be overrun with surface-water; when lea was plowed, out of choice, in a wet state, because the labor of doing it was easier for haif-starved, jaded horses ; when land was harrowed with small, light, loose harrowe, furnished with short, blunt tines; when the lea-turf consisted chiefly of the tough roots of perennial weeds-in these circumstances les (294) 
ground required a great deal of harrowing to bring it to a tolerable degree of tilth, eight or nine double tines being considered no more than necessary. The great length of time required to do this, obliged the oat-seed to be begun early, so early indeed as Tusser recommends it to be begun in January :

\section{"In January, husband that poucheth the groats,}

Will break up his ley, or be sowing of oats ;"

if the husbandman desires to pocket the gain of a good crop; and by the time the crop was finished, every creature, man and beast, were almost worn out with fatigue. The land being now made tender and fertile by draining, cleaning and manuring, oats have time to come to maturity when sown long after January, and its harrowing is now finished in one-third of the time, and with one-fourth the labor it was then.

(1823.) The oat crop, when very young-that is, when the plant has not pushed its leaves more than 2 inches above the ground-is subject to a very serious disease called the grub, a name derived from the grub or larva of a particular insect, the Tipula oleracea, Meadowo-crane-fly, attacking its roots, and causing the plant to decay, and even to die when seriously injured by this insect. The perfect female insect is represented of the natural size at $\alpha$, fig. 328, and which will at once

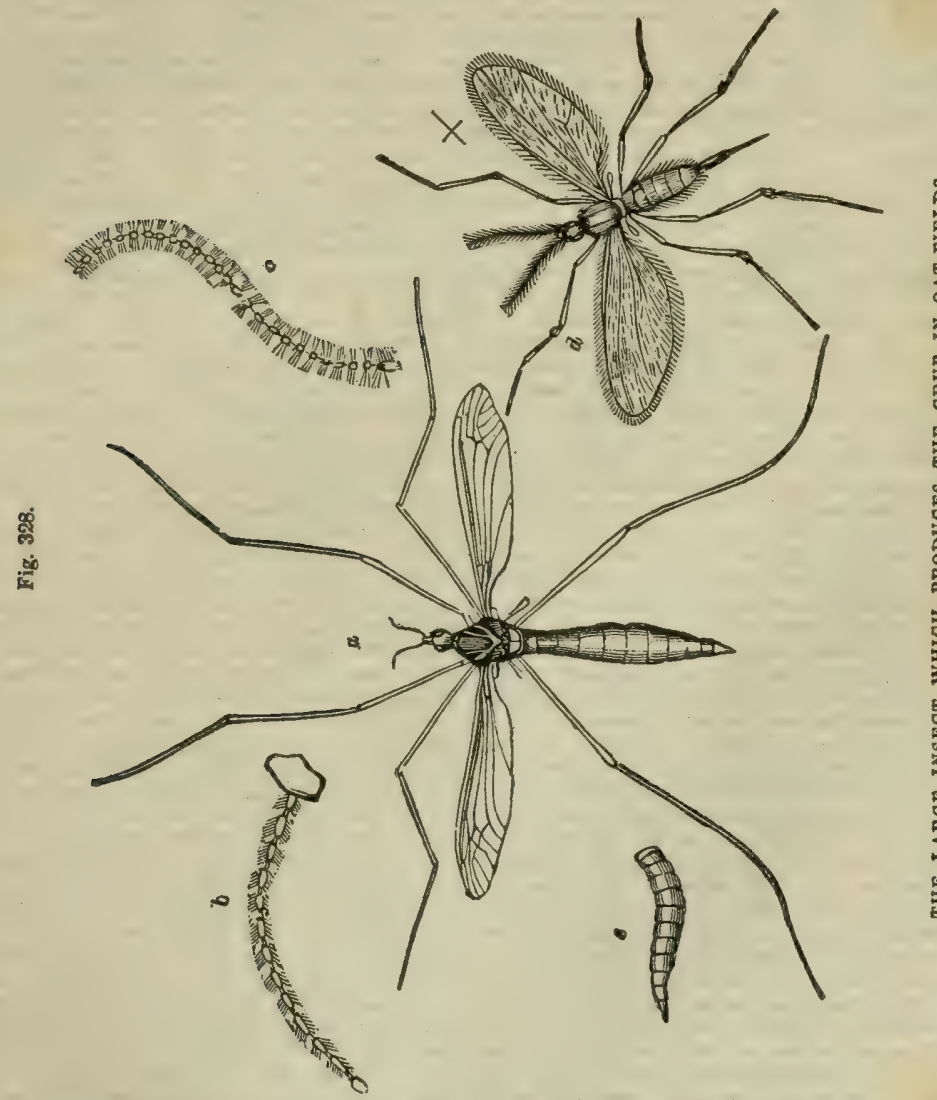

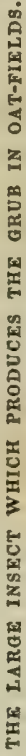

be recognized as that well known by the familiar names of Long-legs, Tailors, Jenny-the-spinner. Its body is near 1 inch long, of a brownish-gray color, and its wings pale-brown. In the female the abdomen is thickest near the middle, from which it tapers to a point at the hinder extremity; that of the male is thicket at the hinder extremity, which forms a kind of club. "This insect," says $\mathrm{Mr}$. Duncan, " is very plentiful during the summer months in all parts of the country. Its long legs are of great advantage to it in places it frequents, as they enable it to skip over the grass as if on stilts; and it still farther facilitates its motions while so doing, by keeping the wings expanded, to render it buoyant. The female lays a great number of eggs, which are very small in proportion to the size of the insect, and of a black color. These she places at some depth in the earth, which she pierces for the purpose with her ovipositor. The insects may easily be seen performing this operation, and it will at once be known that they are so employed by the singular position they assume. The body is placed in a perpendicular direction, supported on the hinder feet and extremity of the abdomen. while the wings are expanded, and the anterior legs (295) 
rest on the surrounding plants. When a sufficient number of eggs have been laid in one spot, the insect moves on to another, without changing the vertical posture of her body, merely dragging herself forward by her fore-legs, aiding her movements with her wings." It is in the larva etate that these insects injure crops, meadow-grass not being their only food; they attack dif. ferent kinds of corn, especially oats, the effects of grubbing in which are well known to every farmer. When full grown, the larvo are in the shape of an elongated cylinder, somewhat saddenly attenuated at hoth extremities, and are of a dull grayish color. and without feet. The head is farnished with two hooks, one on each side. The pupa is not unlike the chrysalis of some kinds of moth; and it is nearly of the same color as the larvw, the edges of the segments being formished with pretty strong hairs. The larve reside generally about 1 or 2 inches beneath the surface. mining their way among the roots of the herbage, and causing it to wither for want of nourishment. They prefer a soil which has been long undisturbed by the plow ; and if it cuntains some portion of peat earth, it seems thereby better adapted to their tastes. "In the rich district of Sunk Island, in Holderness, in the spring of 1813," suy Messrs. Kirby and Spence, "hundreds of acres of pastures have been entirely destroyed by them, being rendered as completely brown, as if they had suffered a three month' drouth, and destitute of all vegetation, except a few thistles. A square foot of the dead turf being dug up, 210 grubs were counted ir it; and what furnishes \& striking proof of the prolific powers of these insects, last year it was difficult to find a single one." "Af. ter mentioning their extensive devastations, it may occasion surprise," as Mr. Duncan well remarks, "to be told that many eminent observers are of opinion, that these maggots eat nothing but the fine mould they find at the roots of plants, and that the injury caused to the latter arises solely from their disturbing the soil, and preventing the rootlets fixing themselves. Such was the opinion of Reaumur : and the generality of subsequent writers on the subject have yielded to his authority. . Mr. Stickney, who has published 'Obsercations on the Grub.' made some experiments for the express purpose of determining this point, and they convinced him that the larva devonr the ronts of grasses. Indeed, unless this were the case, it would be impossible to account for the herbage withering to such an extent in places where the maggots prevail ; for this could never arise from such small creatures, even though very numerous, burrowing in and loosening the soil. When earth-worms are plentiful, they must produce a considerable disturbance in the soil by their winding galleries; but these so far from retarding, have always been regarded as promoting the growth of plants. 'The grub of this tipula,' says Mr. Stickney, as quoted by Mr. Duncan, 'commits its ravages chiefly in the first crop, after the breaking up of the grass-land, also after clover and beans; the fly from which the insect is produced having depesited its eggs in the soil among the grass, clover, or beans. . . On investigating the habis of this insect, I found that it took the fly-state about the beginning of the month of August; I therefore concluded, as we got our clover-hay from the land a little after mid-summer that, if we plowed the clover stubble any time after that, and before the month of August, it would be nearly free from the grub, as instinct has directed the fly nut to leave its eggs upon the naked soil where no vegetable is growing. I knew of no application to the land,' adds Mr. Stickney, 'that will in any way destroy the grub: but we are much indebted to the rook, and a variety of other birds, for keeping its depredations within limited grounds.' $\dagger$ The saturation of the soil," concludes Mr. Duncan, "with some caustic fluid, seems the only way by which this maggot can be destroyed. The perfect insects are easily caught; but they are so generally distributed, and usually so plentiful, that their destruction in this way would be a hopeless task." $\$$ The rook (Corvus frugitegus) may be seen busily engaged in turning over every loose turf clod on a grubbed field of oats, after the young crop has evidently assumed an unhealthy hue. This bue should not be mistaken for the yellowish tint exhibited by the plant when the support derived from the seed is exhaust. ed, and before the rootlets have obtained sufficient scope in the ground to maintain the plant. The grub taint is of a bluish and reddish tint, and many of the plants evidently appear to be dy. ing, and the consequence is, that large spaces are left without a plant. The usual expedient em. ployed by the farmer is rolling the ground, especially in the night; but this is a useless remedy. Holes have been recommended to he made a few inches asunder with the dibble, into which the grubs, it is said will fall and perish; but why they should thas die when they can penetrate the ground, is what I cannot conceive. The ravages are generally committed in dry weather with an easterly wind, and when rain falls they cease. It is sarprising how a field will recover from the effects of grubbing. One seasnn a field of mine, of fine deep hazel loam, after two years grass, was dreadfully grubbed, and after trying the usual remedies to get quit of the insects withont effect, a rainy night silenced them. Most of the field appeared bare after having exhibited a beautiful braird, but on the plants requiring renewed growth, they tillered out with great force, and covered the ground almost as thickly as desirable. At harvest the crop was a very strong onn the straw being difhicult for women to cut with a common sickle; the spikes were very large and full; the stooks, when set without hood-sheaves, stood about 6 feet in hight, and the yield was not less than 60 bushels to the imperial acre. On good soil I wonld have no fear of potato oats tillering out after being severely grubbed, sufficiently to afford a good crop; but such a result should not be expected of common oats upon inferior soil.

(1824.) [Grain Drilling-Machines.-The introduction of the drill-system into the agricultural practice of any country, will always form an era in the annals of its Agriculture : but it is often a difficult matter to define the precise time of its introduction, more especially when we find that. by tracing backward into the history of man in his social capacities, the practice of drilling grain extends backward to the most remote antiquity. A curious and interesting example of this, in 8 n antiquarian point of view, is to be seen in the series of Hindoo models of agricaltural implements in the Museum of the Highland and Agricultural Society in Edinburgh. Among them is to be seen a correct model of a rudely constructed drill-machine posseseing all the essential points of the more elaborate modern implement; and among a people so litile liable to change, there

* Kirby and Spence's Introduction to kintomology, vol. i.

† British Farmer's Magazine, vol. vi. $\quad$ †Quarterly Journal of Agriculture, vol. xh. (296) 
can be no doubt that the machine is of very remote origin, compared with which, the earliest of our modern drills are but things of the moment : and all of them, of whatever degree of merit, are but improvements on the Hindoo original. Among the early notices of the introduction of the system in England, we find Amos* recommending it as early as 1783 as the result of numerous comparative experiments; and the figures which he gives of the drill sowing-machine, which he recommends not as an original invention, but an amplification of that given by Duhamel, is almost identical in every essential point with the most approved drill sowing-machine used in the present day in England, and which may be held as the most perfect machine of its kind; but from the excessive elaboration employed in its construction, its high price lays an interdict upon its introduction into the economical practice of Scotch farming, the price being at least six times that of the common drill used in Scotland.

1825.) The mode of distributing the seed adopted in the broadcast sowing-machine, from the simplicity of the principle, opened a ready means of acquiring a drill sowing-machine at a mode rate price; it accordingly quickly followed the introduction of the broadcast-machine, and until very lately nochange of importance bas been made upon the common Scotch drill. Slight modi fications, however, had been effected occasionally, such as varying the distance between the rows, the machine always covering the same breadth, but varying in the number of coulters. Thus, a machine to cover $7 \frac{1}{2}$ feet in breadth, could change the number of its coulters from 11 to 10,9 or 8 , the spaces between the rows being respectively $8,9,10$, and 11 inches, or thereby.

(1826.) The Common or East Lothian Drill Sowing-Machine, has been here taken to illustrate the principles of the machine. Though it may be deficient in some points as compared with those of Berwickshire and Roxburgshire, yet its extreme simplicity and cheapness has brought it into

Fig. 329.

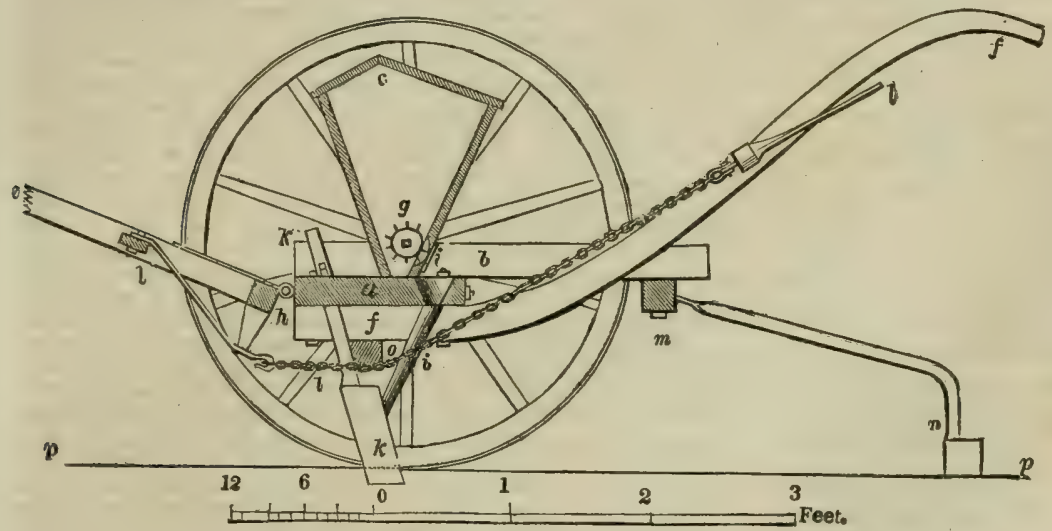

SECTION OF THE COMMON DRILL SUWING-MACHINE.

very extensive adoption, not only in East Lothian, but in other districts where the drill-system is followed. Fig. 325, Plate XXVII, is a view in perspective of this machine, and for the better elucidation of its construction, the annexed cut, fig. 329 , shows the arrangement of the parts in longitadinal section, and for convenience of reference the letters mark corresponding parts in both figures. The figures represent a machine of six rows, which is the size most generally used, chiefly because it can be drawn by one horse; but also in the event of its being employed along swelling ridges, its covering but a small breadth secures a nearly equal depth for the depusition of the seed, which cannot be easily done under the same circumstances if the machine is mounted with a greater number of coulters. But it follows from the peculiarity of structure, the coulters being permanently fixed in position for the depth to which they penetrate the soil, that the machine is best adapted for sowing across the ridges, and hence it is almost invariably worked in that direction. though when worked in the direction of the ridge the breadth covered by the machine is equal to one-fourth of an 18-feet ridge.

(1827.) In the construction, $a$ is a bed-plank 5 feet 1 inch in length, 14 inches in breadth, and $2 \frac{1}{2}$ inches in thickness. Across the ends of this are bolted the two side-bars $b b$. each 33 inches iu length, $2 \frac{3}{4}$ inches in depth, and $2 \frac{1}{4}$ inches in breadth. These last are crossed by the bar $m m$, bolted to the side-bars, serving a special purpose, to be afterward noticed; and these four parts form the simple frame-work of the machine. The seed-chest $c$ is 4 feet 8 inches in length. placed between the side-bars $b$, and attached to these and the bed-plank. The chest may be about 10 inches in depth, $2 \frac{1}{2}$ inches wide at bottom, and 15 inches at top, with a hinged cover. The chest, so mounted with the seed-wheels and axle $g$, fig. 329 , and with side-plate, lever, and adjusting screw in all respects similar to the broadcast-machine (1801), except that, in place of the apron on which the seed falls in the broadcast, the orifices deliver the seerl directly into a small hoppershaped aperture formed in the bed-plank, immediately under the orifice $i$, fig. 329. The carriagewheels $d d$ are 3 feet 1 inch in diameter; the axle of one of them is seated in a strong bush or plummer-block, and coupled to the small shaft of the seed-wheels, thereby giving them the requisite motion, their revolution coinciding with that of the wheels, and the opposite wheel $d$ turns

\footnotetext{
* Theory and Practice of Drill-Husbandry. By William Amos, 1802.
} 
upon an axle fixed permanently upon the bed frame. The horse-shafts $e$ are jointed to the bed plank at $h$, and appear broken off at $e$, fig. 329, by atrap-and hook hinges, and the bandles $f f$ are bolted to the lower side of the bed-plank. The coulters $k k$ consist of an iron shank 1 inch square, farnished at the lower end with a pointed sheath of sheet-iron about 1-10 inch thick; the sides of this sheath, being about 3 inches broad, and 5 inches or more in hight riveted upon the bottom of the shank, which at this place is forged into a wedge shape, to receive the sheath. The coulters are fixed at top in mortises cut in the bed-plank, and fenced with plates of iron above and below, where they are secured by means of wedges; and they are farther supported by the coulter-bar $o$, seen in section in fig. 329 . This bar is bolted under the heel of the handles, and to it the coulters are attached by eve-bolts. The seed on leaving the orifices, falla into the funuel-shaped receptacle $i$ in the upper side of the bed-plank, from which it passes down the tube $i$ into the sheath of the coulter. by which it is deposited into the rut formed by the sheath.

(1828.) From the construction and action of this machine, and the resistance of the soil to the passage of the coulters through it, there is a constant tendency; produced by the traction of the horse when the machine is in action, to elevate the extremity of the nandles; and by thus awing. ing upon the axle of the wheels the coulters are withdrawn from their action on the soil, and from forming the rut for the reception of the seed. The tendency thus produced being greater than a man is capable of continuing to contend with, is counteracted by the application of the balance-chain $l l$, as shown in fig. 329, producing a change of direction in the line of draught, and of the point of attachment of the draught. In this macbine the Irue point of attachment is in the hinge $h$, fig. 329 ; and the tendeacy of the draught, when applied simply to this point, is to cause the point $h$ to approach an imaginary straight line lying between the horse's shoulder and the point of resistance at lower $k$ in the figure, and the effect of this is to bring $h$ forward and downward. or to throw lower $k$ backward till it loose hold of the soil, thereby destroying the intended effect of the coulter. The counteraction of this is effected by the position of the balance chain, and its attachments to the machine. The first part of it is a simple rod, fixed to the shafts at $l$, and to the extremity of a pendant attached to the hind bar of the shafts at $h$; the chain then passes under the coulter-bar 0 , and on to the cross bar of the han. dles, as seen in fig. 325 , Plate XXVII., where it terminates in a handle furnished with a spring. catch. by which it can be hooked under tension, to the cross-bar of the handles, or by disengaging the catch, the chain hangs loose. When the chain is brought under tension, and the shafts borne up by the horse, the resistance to the coulters is transferred to the back of the horse, through the medium of the chain acting on the shat at the point $l$, and on the pendant $h$, the point of which being bejow the plane of the shaft, changes the direction of the tractive force from $e h$ to $c$ middle $l$, and leaves the handles in a nearly quiescent state. The marker $m n$ is another appendage to the machine, which, although not so necessary as the balance-chain, is generally applied to this drill-machine, especially when sowing across the ridges. It consists of the bar $m m$. and the marking $\operatorname{rod} m n$. The latter is swing-jointed on a stud fixed in the ends of the marker-bar $m m$, and having a stop on the joint, by which either of the markers can be retained in the position of that on the farther side of fig. 325, or let down, as in that of the nigh side. The use of the marker is to trace a line on the surface of the ground parallel to the direction in which the machine trav$\mathrm{els}$, and at a distance from the middle point of the surface covered by the machine, equal to the entire breadth, so covered; hence, on returning to sow the next breadth, the horse should walk exactly upon the line drawn by the marker. In sowing with the machine here described, the distance from line to line will be 4 feet 6 inches; the distance between the rows being 9 inches. The wheels are usually set 54 inches apart, measuring at the point where they rest on the ground; or their distance in any machine may be found by multiplying the number of coulters by the number of inches given to the interval between the rows or coulters; thus six coulters of 9 inches interval, give $6 \times 9=54$ inches. From the construction of the machine it is found, that when the balance-chain is under tension, the coulters are drawn to the ground, and the handles also drawn downward; but on releasing the chain, which is done at the land-ends and turnings, the condurtor must support the handles to keep the coulter from the ground. and in this state, if the handles are let go when the machine is standing, the coulter will pass forward and the han. dles will fall to the ground. To prevent this last inconvenience, a crutch is usually appended to the marker-bar, which, on stopping, is allowed to drop to a perpendicular position, resting on the ground, and thus keeps the machine upon a level. This appendage not being of much importanes, is left out of the figure.

(1829.) This sowing-machiue has been long and successfully manufactured by Scouler and Com. pany of Haddington; and with slight variations by various other implement makcrs, as Morton, Leith Walk, Edinburgh; James Slight and Company, Edinburgh, \&c. The price varies accord. ing to the number of coulters, from \pm 6 to $£ 10$.

(1830.) To reuder the expensive English drillmachines [which we bave omitted, and which cost in England from $\$ 50$ to $\$ 90$,$] more generally useful, it is not an uncommon practice in Eng.$ land for the owner of one to travel the country with it at seed-time, and undertake to sow the fields of any tarm, where the farmer may choose to employ him. The charge is usually $29.6 \mathrm{~d}$. per imperial acre. the farmer supplying the requisite number of borses to work the drill, and undertaking to deliver it at the farm on which it is to be next employed. 


\title{
13. THE LAMBING OF EWES.
}

\author{
"Ah gentle shepherd, thine the lot to tend, \\ Of all that feel distress the most assailed, \\ Feeble, defenceless ; lenient be thy care; \\ But spread around thy tend'rest diligence \\ In How'ry spring-time, when the new dropt lamb, \\ Tutt'ring with weakness by his mother's side, \\ Feels the fresh world about him; and each thorn, \\ Hillock, or furrow, trips his feeble feet: \\ $O$ guard his meek sweet innocence from al \\ Th' num'rous ills that rush around his life."
}

DYER.

(1831.) The lambing season of Leicester and other heavy breeds of sheep, reared in the arable part of the country, commences about the 11th of March, and continues for about the space of 3 weeks. There is no labor connected with the duties of the shepherd which puts his attention and skill to so severe a test as the lambing season; and a shepherd whose unwearied attention and consummate skill become conspicuous at that critical period of his flock's existence, is an invaluable servant to a stock farmer-his services, in fact, are worth far more than the amount of wages he receives; for such a man will save the value of his wages every year, in comparison with an unskillful shepherd, and especially in a precarious season, by so treating both the ewe and lamb, during the time, and for some time after the lambing season, that the lives of many are preserved that would otherwise have been lost. To make my meaning more plain, suppose a shepherd that has attentively observed the tupping, and marked the reckoning of every ewe, and who has put the ewes in proper time in a suitable place to lamb in-that renders them requisite assistance, and no more, at the proper instant of lambing, and treats them afterward according to the circumstances of the weather-that sees the lamb supplied with milk by day and night, when its mother happens to be unkind to it, or feeds it with milk obtained elsewhere, when the ewe has too scanty a supply to support it-that knows how to afford relief to the ewe in case of sickness and inflammation after lambing, and who castrates the lamb at the proper period of its strength, and in the proper state of the weatherthat knows the manner how, and the time when, to put an additional lamb to a ewe that has abundance of milk, and to take it from another which has too little for a pair-suppose that by doing all this in a skillful manner, night and day, until the lambing is not only entirely completed, but the lambs. reared beyond danger, he saves the lives of 10 ewes worth $40 \mathrm{~s}$. each, and of 20 lambs, that will come to be worth $20 \mathrm{~s}$. each, and this is no extravagant supposition in a large standing flock of fifteen scores of ewes, it is clear that, in so doing, he will save his wages of $£ 40$. Few shepherds are so successful, although I have known two instances of such success; and no better proof need be adduced of the fewness of skillful shepherds, than the loss which every breeder of sheep sustains every year, especially in bad weather. I knew a shepherd who possessed unwearied attention, but was deficient in skill, and being over-anxious, always assisted the ewes in lambing before the proper time; and as he kept the ewes in too high condition, the consequence was, that every year he lost a number of both ewes and lambs, and in one season of bad weather the ioss amounted to the large number of 26 ewes, and I forget of how many lambs, in a (299) 
flock of only 10 scores of ewes. I knew another shepherd who was far from being solicitous about his charge, though certainly not careless of it, yet his skill was so undoubted that he chiefly depended upon it, and his success was so eminent that the loss of a ewe or a lamb under his charge was matter of surprise. Of these two sorts of shepherds-the attentive and the skillful-it would appear that the skillful is the safer, and of course the more valuable, though it must be owned that it is better to prevent evils by skillful attention, than to cure them by attentive skill; yet it is only by the union of both these qualities that a perfect shepherd can be formed. In contradistinction to a skillful shepherd, whose qualifications have been just noticed, let me advert to a few particulars mentioned by Mr. Price as occurring, apparently as a matter of course, at the lambing season. He says that in preparing ewes for lambing. "the ewes are driven into a pound, and the looker takes them singly, throws them down, and removes with the shears the wool on their tail, udders, and inside of their thighs." If this is a common practice, think of its harbarity, of throwing down a ewe on the ground big with lamb, nay, on the eve of lambing, in order to remove a trifling impediment to the lamb's sucking, which can be removed at any time after lambing. But there is a reason, it seems, for this treatment, called clatting, and it is this: "The removal of the wool renders the part much neater," - neatness of appearance being preferred at this particular time to the comfort and ease of the animal_- "and enables the lamber to see when the ewe has lambed, from a stain which generally appears on the hack part of her udder. Were not this appearance to take place, the lamber would sometimes be at a loss, as the young ewes frequently desert their young, and endeavor to escape along with the other ewes grazing with as much unconcern as if nothing had happened." Observe here the great skill and attention of a shepherd who is at a loss to know whether a ewe has lambed or not; and who, it seems, does not even know whether a ewe is in lamb or not, until he has thrown her down to remove the wool; for" "the barren ewe, or those which are not pregnant, are distinguished at the time of clatting by not having any swelling in their udder or belly, and by their skipping about nimbly." "Think also of what sort of care is bestowed on a newly lambed flock in a low country, when such losses as these are incurred: "I have known thousands of lambs lost from being drowned in a wet stormy night; I once beheld 30 or more lying together drowned in a ditch. The ewes and lambs seek the corners of pasture-fields during the continuance of severe weather, and when the lambs get under these high shores and fall in, it is utterly impossible for them to extricate thernselves; besides, as there are many huddled together, they often push one another in." That lambing paddock must be strangely managed which presents such a scene as this: "Lambing presents a scene of confusion, disorder and trouble, which it is the lamber's business to rectify, and for which he ought always to be prepared: some of the ewes perhaps leave their lambs, or the lambs get intermixed, and the ewes which have lost their lambs run about bleating, while others want assistance." It seems a shepherd cannot recognize the lambs of ewes, and so they must be marked. "The twins are marked with a mixture of tar and lampblack, by means of small figures fixed in an iron handle about 8 inches long;" "and the twin lambs are easily separated, for the ewe very frequently walks away with one lamb, leaving the other in the field, to the confusion of the lamber; therefore they should be marked as early as possible to prevent this confusion." "The lamber must take the lamb to its mother, which he will find out by its number ;" and yet the number, it seems, will not always enable the lamb to find out the mother; for "if the lamber (300) 
finds a young lamb, and is not certain which may be its mother, a circumstance which sometimes occurs when ewe's drop twins, and leave one of them, he may readily discover her by taking away the lamb she is fostering, and putting the doubtful one on in its stead, when she will display evident tokens whether it belongs to her." This method of trial and error the shepherd may have, of course, to put to every ewe before he discovers the true mother; for as he knows neither the mother nor the lamb, the lamb may chance to belong to a ewe which has a single lamb as well as to one which has twins, unless the single lambs are left unmarked; or, at any rate, he may present the marked and known-to-be-a-twin lamb w a ewe that has a single one, as readily as to one that has twins. It will excite no surprise to learn that with shepherds so wretchedly qualified for their profession as the above particulars show, in "most years not more lambs than one to each ewe" were obtained; and that out of 800 ewes of a certain flock only 100 pairs were saved, though it is stated by Mr. Price that with more skill afterward the number of pairs increased to 200. Here, then, is an instance where the improved skill of one man saved the lives of $200 \mathrm{lambs,}$ which would come to be worth $£ 200$, equaling the wages of at least 4 good shepherds.* I would not have noticed these egregious blunders, said by Mr. Price to be committed by shepherds in a low country like Romney Marsh, in Kent, so prominently, had not Mr. Youatt adopted the sentiments of $\mathrm{Mr}$. Price in the very particulars quoted above, in his excellent treatise on the history and diseases of sheep.t Were a shepherd of a Leicester flock in Scotland made aware that he was sus pected of such ignorance of the nature of sheep he would be quite ashamed; and so would shepherds even of the hill country, who cannot have so inti mate a knowledge of every individual of their flock, usually occuying a wide range of mountain land, as their brethren of the profession tending flocks within much more limited bounds.

(1832.) Before the season of lambing arrives, the shepherd should have a small field of 1 or 2 acres or a sheltered corner of a grass-field of like size, conveniently situated as near the steading as possible, fenced round with nets, and fitted up with sheds made of hurdles set up in the most sheltered part, against a wall or hedge, and lined in the inside and comfortably roofed with straw. Such straw-sheds form most comfortable places of refuge for ewes that may lamb in the night, or that have lambed in the day, and require protection from frost, snow, rain, or cold in the night, until the ewes are perfectly recovered from lambing, and the lambs sufficiently strong to bear the weather in the open field. The small hand turnip-slicer, fig. 245 , will be found on such occasions a very convenient instrument, for cutting turnips in such turnip-troughs as fig. 225, for the ewes in the paddock, or in small boxes for them in the shed. Common kale or curly-greens is excellent food for ewes that have lambed, the nutritive matter of which; being mucilaginous, is wholly soluble in water, and beneficial in encouraging the necessary discharges of the ewe at the time of lambing. According to the late Geo. Sinclair, 1 lb., or 7,000 grains of green curled kale, (Brassica oleracea viridis, ) yields 5,680 grains of water, 880 grains of wood fibre, and 440 grains of nutritive matter, which last is all soluble in water $\frac{t}{+}$ In these respects kale is better food for ewes after lambing than Swedish turnips, which become rather too fibrous and astringent in spring for the secretion of milk. A large lantern which sheds plenty of light is an essen tial article of furniture at night to a shepherd. As foxes are apt to snatch away young lambs at night even close to the lambing-houses, I have found

* Frice on Sheep.

‡ Sinclair's Hortus Gramineus Woburnensie, edition of 1824 . (301) 
an effectual preventive to their depredations in setting a shep-net, as in fig. 217 , in front of the lambing-houses, leaving a sufficient space for a few ewes with their lambs taking up their lair within the net. When thus guarded, the foxes are afraid to enter the net, being apprehensive that it is set as a trap to ensnare them. Such an expedient is even more necessary in the corner of the field chosen for the lambing-ground. A large lantern fixed on a stake within the lambing-ground, and so placed as to throw light upon the whole ground, will be found a useful assistance to the shepherd in showing him the ewes that evince symptoms of lambing. A net and lantern are also good safeguards against foxes at night in the grass-field where the recovered ewes with their lambs should be gathered for the night. This expedient of net and lantern I was induced to try after losing, for a year or two, several lambs by the fox; and such was its efficacy in deterring that nightly prowler from visiting the lair of ewes and lambs, that not a lamb was lost ever after. A fox will not meddle with a lamb above a month old.

(1833.) Being thus amply provided with the means of accommodation, the shepherd, whenever he observes the predisposing symptoms of lambing in as many ewes as he knows will lamb first-and these symptoms are, enlargement and reddening of the parts under the tail, and drooping of the flants-he places them of an afternoon, within the enclosed lambingground in the paddock or field, as described above, and provides them with cut turnips. The more immediate symtoms of lambing are when the ewe stretches herself frequently; separating herself from her companions; exhibiting restlessness by not remaining in one place for any length of time; lying down and rising up again, as if dissatisfied with the place; pawing the ground with a fore-foot; bleating as if in quest of a lamb; and appearing fond of the lambs of other ewes. In a very few hours, or even shorter time, after the exhibition of these symptoms, the immediate symptom of lambing is the expulsion of the bag of water from the vagina, which, when observed, the ewe should be narrowly watched, for the pains of labor may be expected to come on immediately. When these are felt by her, the ewe presses or forces with earnestness, changing one place or position for another, as if desirous of relief. Up to this time, not a hand should be put upon her, nor until the hoofs of the fore-feet of the lamb, and its mouth lying upon them, are distinctly seen to present themselves in the passage.

(1S34.) The natural presentation of the lamb is the same as that of the calf, described in (1653). When time has been given to observe that the ewe is not able to expel the lamb by her own exertions, it is the duty of the shepherd to render her assistance, before her strength fails by unavailing pressing. The exact moment for rendering assistance can only be known by experience; but it is necessary for a shepherd to know it, as there is no doubt that hasty parturition often superinduces inflammation, if not of the womb itself, at least of all the external parts. When assistance should be rendered, the ewe is laid gently over upon the ground on her near or left side, and her head a little up the hill; and to prevent her being dragged on the ground when the lamb is being extracted, the shepherd places the heel of his left foot against the belly of the ewe, and kneels on his right kuee on the ground across the body of the ewe, which lies between his heel and knee, with his knee pressing against her rump. Having both his hands free, and his face toward the tail of the ewe, he first proceeds to push out from him, with both hands, one leg of the lamb and then the other, as far as they will go; then seizing both legs firmly, above the fetlock joints, between the fingers of his left hand, he pushes them from him downward from the ewe's back, with considerable force, while by (302) 
pushing in the space between the tail of the ewe and the head of the lamb toward him, with the side of his right hand, he endeavors to slip the the vulva of the ewe over the cantle of the lamb. These pushes are only given simultaneously with the pressing of the ewe, merely to assist her, and keep good what is obtained at each pressing, and not, as it were, to tear the lamb from her per force. Whenever the head is cleared, the shepherd seizes the neck of the lamb behind the head with the right hand, and pulls out the body. The lamb is then placed at the ewe's head, for her to lick and recognize, which she will instantly do, if her labor has not been severe; but if it has she will likely become sick, and be careless of the lamb as long as the sickness continues, which is evinced by quick breathing. If the pains have been very sharp, and thisher first lamb, and she is not overcome by sickness, she may start to her feet, and run away from the lamb. The attempt should, of course, be prevented, and the tail of the lamb put into her mouth to make her notice it. While still lying on her side, her abdomen should be felt, to ascertain if there is another lamb to come; and if there is, the pains accompanying its passage may have been the cause of her carelessness for the first lamb; and if the second one is in natural position, it will most probably by this time be showing itself in the passage, and if this be the case, the best plan is to take it away in the same manner as the first, and the ewe feeling the attempt, will at once assist on ber part by pressing. The existence of a second lamb is worth attending to on another account, inasmuch as some ewes become so engrossed with the first lamb, that the pains attending the second are neglected by them, and they will indicate no signs of it for a time. When a second is found in her she must be watched, that whenever it comes into the passage, it may be takın away; but unlesss it actually makes its appearance there, it should not be attempted to be taken away. Should it not make its appearance in a reasonable time, it may be suspected that the lamb is either dead, or not in a natural position, and examination should be made by the fingers into the state of the case. A dead lamb is easily known by the feel, and should be extracted immediately, as it can afford no assistance of itself; but should the lamb be alive, it may be necessary to introduce the hand to ascertain its position. Before the hand is introduced, it should be smeared over with goose grease. If the head is bent back, it must be placed straight, or if one leg or both be folded back, they must be brought forward, one by one, into the proper position. In short, all the presentations offered by a lamb require the same means to be used to place them in a proper position, as in the case of a calf; but with a Leicester ewe there is the additional difficulty of two, and even more, lambs at a birth, and mistaking a leg of one lamb for that of another. The method of extracting a lamb as described above, is adopted by a shepherd who has no assistants; but when he has assistance, he adopts another and more easy plan for himself. The assistant holds the ewe in any way the most easy for her and himself, so as to prevent the body being dragged along the ground while the shepherd is extracting the lamb, which he does by placing himself behind the ewe, and performs the extraction by pulling the legs toward him, while the assistant endeavors to make the vaginal skin pass over the lamb's head, which, when accomplished, the shepherd seizes the neck by his left hand, and holds the legs still in his right, takes away the lamb as quickly as he can, and places it before the ewe. There is a great difference in the disposition of ewes to assist in lambing. Some, when they find they are assisted, give themselves little trouble; while others press with vigor from first to last; and others only press at long intervals. A ewe that presses strongly and continuously, will become sooner exhausted than one that 1303) 
takes more leisure, and in the former case there is mure danger in neglect ing to make examination of the presentation in time, that is, before the ewe has become exhausted. I remember of seeing a lamb's head without any of the legs protruded by the ewe, and, being allowed to remain in that state too long, the lamb was found strangled to death by the force of pressing. This was a case of neglect, as the head should not have been allowed to come out without one accompanying leg at least. I remember of another case in which there was no appearance of a lamb, though the ewe had pressed for a considerable time. On examination it was found that the mouth of the womb was closed up. Inflammation had no doubt at one time existed, and a discharge of lymph had caused adhesion. The shepherd, nothing daunted, very ingeniously introduced, in his smeared hand, a pen-knife, between the middle and fore-finger, and cut an incision across the pursed mouth of the womb, and thereby liberated two lambs, and the ewe was not at all the worse for the operation.

(1835.) When lambing has taken place in the day, the ewe with her lambs are best at liberty within the inclosed area of the lambing ground, but in rain or snow, she should be taken under shelter to lamb, and kept there for some time until the weather prove better, or she be completely recovered from the effects of parturition. Should she lamb at night, it should be under cover, whatever may be the state of the weather. In the day, it matters not for lambs how cold the air is, provided it is dry. The cleaning or placenta generally drops from the ewe in the course of a very short time, in many cases within a few minutes, after lambing. It should be carried away, and not allowed to lie upon the lambing ground. The lamb is fondly licked by the ewe at flrst, and during this process makes many fruitless attempts to gain its feet, but it is surprising how very soon after an easy birth it can stand; and the moment it does so, its first effort is to find out the teat, expressing its desire for it, by imitating the act of sucking with its lips and tongue, uttering a plaintive cry, and wagging its long tail. It is considered a good sign of health when a lamb trembles after birth. There are various obstacles to its finding the teat at first; the long wool on the ewe's flank hides it, the wool on the udder interferes with it, and what is still more tantalizing to the anxious toper, the intense fundness of its own mother urges her to turn herself to fondle it with her mouth-uttering affectionate regards-but the motion has the effect of removing the teat, the very object of its solicitude. When at length a hold of what it wants is attained, it does not easily let it go until satisfied with a good drink. When a fond ewe has twin lambs, one can easily obtain the teat, while she is taken up in caressing the other. This is the usual conduct of strong lambs; and on once heing filled with warm milk, progress rapidly to increasing strength, and are soon able to bear very rough weather. But lambs after a protracted labor, or the first lamb of young ewes, are so weakly at first as to be unable to reach the teat by their own strength, when they must be assisted, and the assistance is given in this way. Turning the ewe over upon her rump, the shepherd reclines her back against his left leg, which is bent, while he supports himself kneeling on the right one. Removing any wool from the udder by the hand, and which is all that is necessary, without clatting or doddering, as it is called in Scotland, he first presses the wax out of the teats, and then takes a lamb in each hand, by the neck, arid opens the mouth with a finger, and applies the mouth to a teat, when the sucking proceeds with vigor. A young ewe or gimmer is apt to be shy to her first lamb; but after she has been suckled, either in this or in the natural way, she will never forsake her offspring. Indeed, it is a good plan for a shepherd to give every lamb its first suck 1304) 
in this way, as it not only saves it much trouble, and puts it in the way of gaining strength rapidly, but affords bimself a favorable opportunity of examining the state of the udder, whether it is in a proper state for yielding milk, or feels hard, or is inflamed. The proper treatment of the udder when in an inflamed state will be found below. Gimmers have so scanty a supply of milk that it is expedient for the shepherd to support their lambs partially on cow's milk, until they can afford the requisite supply, which will be induced partly by suckling, and partly from new grass. When the shepherd has lambs to support for a short time, he should supply them with milk at regular times, such as in the morning and evening, and see that the lambs are suckled by their mothers during the day, and thus endeavor to bring on a sufficiency of milk. The dairymaid should put the cow's milk for the shepherd in bottles, at the hours when the cows are milked, in the morning and evening, and he administers it to young lambs while warm from the cow, and it is done in this way: Sitting down, let him take a mouthfull of milk from a bottle, and holding up the open mouth of the lamb, he pours the warm milk into it in a small stream from his mouth; and thus mouthfull after mouthfull until the lamb is filled. This auxiliary supply of milk should be witheld the moment the ewe can support her lambs herself, for cow's milk is not so congenial to a lamb's constitution as that of its own mother. The ewes are kept on the lambing ground till they have completely recovered from the effects of lambing and the lambs have become strong, and the ewes and lambs have become well acquainted with each other. The time required to accomplish this depends on the nature of the lambing, and the state of the weather. The ewes, with their lambs, are then put into a field of new grass, where the milk will flush upon the ewes, much to the advantagre of the lambs. It is generally a troublesome matter to drive ewes with young lambs to any distance to a field, because of the ewes always turning round and bewildering the lambs. A dog more frequently irritates the ewes than assists the shepherd in this task. I believe the best plan is to lead the flock instead of driving it, by carrying a single lamb, belonging to an old ewe, by the fore legs, which is the safest mode of carrying a lamb, and walking slowly with it before the ewe, while she will follow bleating close at the shepherd's heels, and the rest of the ewes will follow her of course. If the distance to the field is considerable, the decoy lamb should be set down to suck and rest. With plenty of food, and a safeguard of net and lantern at their lair at night, to keep off the foxes, the flock will not fail to thrive apace. In case this safeguard is not adopted, and which I believe is rare, it may be proper to tell you the distinctive marks of the attacks of a dog from that of foxes on a lamb flock. The fox always attacks a lamb on the neck behind the head, and, if scared from his purpose, distinct holes made by the teeth will be found on each side of the neck, whereas a dog seizes any part of the body, and worries by the under part of the neck. Some ewes will fight off either dog or fox, and be able to protect a single lamb; while others become so frightened at once from an attack, that they do not know whither to flee for refuge. After such an attack, the bleatings of the ewes and lambs in search of each other, which is an unusual occurrence at night, will soon acquaint the shepherd that some disaster has happened to his flock. The fox, if not immediately disturbed, carries off his prey, while the dog worries and leaves behind him what he does not eat.

(1S36.) All the preceding cases of lambing are easy to the shepherd, but others usually occur which put his skill to the test. Malformations of the body of the lamb create difficult parturition, and endanger the life of 
the ewe. It is almost impossible to bring the head of a wry-necked lamb into the passage of the womb, but it must be done before the entire body can be extracted, and if not, the head of the lamb should be taken off rather than the ewe should lose her life. Sometimes twin lambs die in the womb several days before the period of lambing, and as they cannot present themselves to the birth, they must be extracted by force, or even cut away in pieces, or they may be pulled away in pieces. In such a case the placenta will be corrupted, and it may be a considerable time before it is entirely got rid of by the ewe by pressing. I have seen it so corrupted that it came away in discharges from the ewe as black and as riscid as tar. When twins are about to be lambed, the only care required is to ascertain that each is presented separately. A breech presentation is a difficult one, and the extraction is impracticable until the hind-legs are first brought out; and in extracting by the breech, the operation should be done quickly at the last to prevent the lamb drowning in the liquor amnii. In all cases of extraction, it should be made a point to have the back of the lamb next to the back of the ewe.

(1S37.) Much trouble is experienced by shepherds when ewes will not take their own lambs. A ewe that beats off her own single lamb and endeavors to purloin one from another ewe, should be immediately put into the shed and confined to a spot by a short string tied above the fetlock joint of one of her fore-legs to a stub driven into the ground. When she endeavors to leave her lamb, the string pulls her foot off the ground, and while her attention is taken up with the string, the lamb seizes the teat and sucks in the mean time. The stratagem often repeated takes the courage from her, and makes her take with the lamb. In every case of a ewe refusing to let her lamb suck, the shepherd should particularly examine the udder, and see there is no inflammation or uneasiness in it; and if there is, he should endeavor to remove it before putting the ewe under discipline. It is surprising how soon a lamb learns to steal a suck from a ewe; if it cannot approach by the flank, it will seize the teat from behind between the hind legs. When a ewe will allow but one of her twins to suck her, she should be held till both suck her, and in a little time she will take with both. It is not sujprising that one ewe should refuse to take the lamb of another; and yet it is necessary when a lamb is left an orphan, or is a supernumerary, to mother it, as it is termed, upon another ewe. For example, when a gimmer that has little milk has twins at a time when another ewe that has plenty of milk produces a single lamb, it is for the benefit of both ewe and lamb that the ewe which has plenty of milk should bring up two lambs; and the transference is easily enough accomplished while all the lambs are still wet, and two of them are placed before the ewe at once; but when a ewe does not die till two or three days after she has lambed, it will be difficult to make another ewe that lambs a single lamb, as the other ewe dies, take the older lamb along with her own. The usual plan in such a case is to rub the body of the older lamb with the new dropped one, before the new lambed ewe has had an opportunity of recognizing her own lamb, and to place both before her at the same time; and she may take both without scruple; but the probability is that she will reject the older one, when she should be put into a dark cormer of the shed and confined in it by a board placed across the corner, only giving her room to rise up and lie down, and to eat, but not to turn quickly round upon the stranger lamb, which, rubbing against her wool, and sucking her against her inclination, will soon acquire the odor of her own lamb, and ingratiate itself in her favor. Another case of difficulty is when a twin lamb dies at birth from a ewe that has plenty of milk, while (306) 
another ewe has had twins and is unable to support them; and the expedient is to strip the skin immediately off the new-born dead lamb and sew it on the body of one of the lambs belonging to the other ewe, and present both the foster-lamb and her own at the same time to the ewe that has plenty of milk. It is probable that the dark corner will require to be used before a cordial reception is given to the foster-lamb. Should all the above expedients fail to mother the lambs upon the ewes-and they may fail, though under the guidance of a skillful shepherd they seldom dothe lambs should be taken away and brought up as pets on cow's milk.

(1838.) The lamb of a fat ewe is always small when lambed, and is plump and lively, but the ewe in that state runs a great risk in lambing of inflammation in the passage of the womb. A lean ewe bears a lamb large in the extremities, and thin and weak in the body. A very old ewe's lamb is both small and weak. The lamb of a gimmer is small, and she not having sufficient milk to rear it, continues small; and the lamb of a hogg is still worse off. The best plan of managing ewes for rearing good lambs, is to keep them always in fair condition in winter, and until they have lambed, after which event they should have the best grass the farm can afford. New grass always produces abundance of milk, and it springs earlier than old. In case of snow covering the ground in spring, when the ewes are heavy in lamb, they should get a few turnips and plenty of hay, and clover-hay if possible, until the ground is again clear; but in open weather in winter, there is nothing better for them than grass which had been kept rough for the purpose in autumn. While confined on the lambing-ground, ewes should have turnips and hay to support them; and after lambing there is nothing better for them than cabbage or kale, in defau't of which a little oil-cake will encourage, at that time, the necessary discharges and purify the body. New grass also operates medicinally on the system.

(1839.) It is necessary to say a few words on the rearing of pet lambs. Wherever these are there must be orphans or supernumeraries in the flock, and, in either case, the deserted creatures would die were they not reared by hand. As a remarkable instance of lambs being obliged to be made pets from supernumerary births, I remember one season, in a small flock of Leicester ewes, 50 in all, 48 having twins, and two trines. The two lambs which constituted the trines were properly taken away to relieve the ewes, and brought up by hand as pets. When ewes die it is scarcely possible avoiding having pets, on account of the improbability of ewes lambing single Jambs just in time to receive those that have become orphans. Pet lambs are supported on cow's milk, which they receive warm from the cows each time they are milked, and as much as they can drink. In the intervals of meals, in bad weather, they are kept under cover, but in good weather they are put into a grass paddock during the day, and under shelter at night until the nights become warm. They are fed by hand out of a small vessel, which should contain as much milk as is known each can drink. They are first taught to drink out of the vessel with the fingers like a calf (1683), and as soon as they can hold a finger steady in the mouth, a small tin tube, about 3 inches in length, and of the thickness of a goose quill, should be covered with several folds of linen, sewed tightly on, to use as a substitute for a teat, and by which they will drink their allowance of milk with great ease and celerity, A goose quill would answer the same purpose, were it not that it is easily squeezed together by the mouth. When the same person feeds the lambs-and this should be the dairy-maid-the lambs soon become attached to her, and would follow her everywhere; but to prevent their bleating, and to make them (307) 
contented, an apron or a piece of cloth, hung on a stake or bush in the paddock, will keep them together.

(1840.) A very common method practiced by shepherds of Leicester sheep, when they wish to catch a ewe to give a weakly twin lamb a suck, or to examine the state of her udiler, is to stoop down and run in upon her from behind and seize her by a hind leg. This is a safe enough mode of catching a sheep when dexterously done; but when it fails, that is, when the captor cannot keep himself out of view until he seizes the ewe, she will start and run off, and alarm the other ewes beside her, and every alarm to a ewe, whether lambed or about to lamb, is injurious, and at any rate cannot do any good. In these circumstances, a crook does the same thing more quietly and as securely. It consists of a round rod of iron, bent in the form shown in fig. 325 , furnished at the point with a knob, that the animal may not be injured by a sharp point, and at the other end with a socket, which receives a long shaft of wood, 5 or 9 feet long, according to fancy. The hind-leg is hooked in at $a$, from behind the sheep, and it fills up the narrower part beyond $a$, while passing along it until it reaches the loop, when the animal is caught by the hock, and when secured its foot easily slips through the loop. Some caution is required in using the crook, for should the sheep give a sudden start forward to get away, the moment it feels the crook, the leg will be drawn forcibly through the narrow part, and strike the bone with

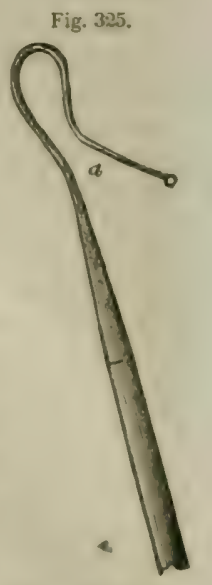

THE SHEPHERD'S cruox. such violence against the bend of the loop as to cause the animal considerable pain, and even occasion lameness for some days. On first embracing the leg, the crook should be drawn quickly toward you, so as to bring the bend of the loop against the leg as high up as the hock, before the sheep has time even to break off, and being secure, its struggles will cease the moment your hand seizes the leg.

(1841.) When those male lambs which are not to be kept as tups attain the age of from 10 days to a month, they are castrated. Some breeders advocate castration in a day or two after birth, while others will not allow the operation to be performed until the lamb is one month old. My opinion is, that both these periods are extremes. A lamb of a day old cannot be confirmed in all the functions of its body, and indeed in many instances I question whether the testicles can then be found. At a month old, on the other hand, the lamb may be so fat and the weather warm, that cutting may be attended with febrile action. I prefer the operation being performed at from 10 to 15 days, when the creature has attained some strength, and yet its parts have not yet become rigid. Castration is performed in this way. Let the assistant hold the body and both legs, one in each hand, as represented in fig. 326. The shepherd then causes the testicles to press the scrotum $a$ smooth; and making an incision through the integuments of the scrotum to the testicles, he pushes out one testicle farther than the other, seizes it with his teeth and draws out the spermatic cord until it breaks, and does the same with the other testicle, when the operation is finished. Advantage is taken of the opportunity to dock the tail, which is left at $c$ as long as to reach to the meeting of the hams. In performing docking, the division should be made in a joint, otherwise the portion of the vertebra which has been cut through will have to be sloughed off before the wound can heal. Ewe lambs are also docked at this time, but they are not held up for the operation, being merely caught 
and held until it is done. In England, docking is performed at the third joint, which leaves a mere stump of a tail. The male lamb, after being docked, is let down to the ground by the tail, which has the effect, it is said, of righting the parts about the scrotum after castration. The same opportunity is taken to mark the ears of lambs, and in the case of stock in hill farms, where it is not easy to gather flocks frequently, the operation is now easily performed; but as Leicester lambs are not marked in the ear at this time, I shall defer describing that operation until its proper season in summer. The scrotum does not bleed in castration, but the tail sometimes bleeds for a long time in two minute and forcible streams, though usually the bleeding soon stems. Should it continue so long as to sicken the lamb, a small cord should be tied firmly round the end of the tail, but this must not be allowed to remain on above 24 hours, as the point of the tail would slough off. The object of docking is to keep the sheep behind clean from filth

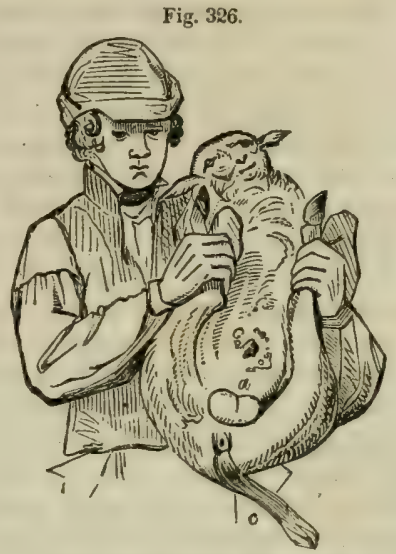

THE CASTRATION OF LAMBS. and vermin; but as the tail is a protection against cold in winter, it should not be docked too short, as is the case in England. Tup-lambs are allowed to retain their full tails until a year old, in order to strengthen the back. Great caution is required in castrating larnbs; it should not be done in rainy weather, nor in very cold weather, nor in frost; nor should the lambs be heated before the operation. It is best performed early in the morning, in fresh weather, with a westerly breeze. The ewes and lambs should be driven gently to a corner of the field, but not by the dog, whose duty is only to prevent a ewe breaking away. One assistant should catch the lambs, and another hold them while the shepherd operates. It is not easy to catch a lamb with a sheep's crook, their small, active limbs easily escaping from the loop, but it may be effectually used in hooking the neck, when the captor runs in upon the lamb and secures it. Where there is a bught or open shed in a field, the lambs and ewes may be driven loosely in, and the lambs captured there. The old-fashioned mode of castrating lambs is to cut off the point of the scrotum and extract both testicles by the large incision; but the extensive wound thus made takes a considerable time to heal, whereas the simple incision now made heals almost always by the first intention. In some cases, however, inflammation ensues, and the scrotum swells, and even suppurates, when the wound should be carefully examined, the matter discharged, and the wound soon heals up. The operation should always be done in the morning, that the several cases may be observed during the day; and should the weather have changed for the worse toward the afternoon, the ewes, with the lambs that have just been cut, should be brought into shelter all night. Besides the state of the weather, one cause of inflammation is the scratching of the wound of the scrotum by the points of the stubble among the new grass, and this irritation is most likely to be induced when the castration has been performed by cutting off the point of the scrotum. To avoid this source of irritation, the new cut lambs should be put into a field of new grass where the stubble is short, or into a field of old grass for a few days. Hill lambs should be diven the night before being castrated into a bught or inclosure where they will be ready and cool for the operation in the (309) 
morning. The practice of applying turpentine to the incision on the scrotum gives unnecessary pain and serves no good purpose. Sometimes one of the testicles does not descend into the scrotum, in which case the lamb becomes what is called a chaser, that is, one who constantly chases the females of the flock, when near him, from morbid desire.

(1842.) These are the various risks which ewes and lambs are suhject to, until they may be said to be beyond danger; and when they have passed through these several trials in safety, the shepherd may calculate on the result of his success- he may then endeavor to ascertain whether he has increased the breeding part of his flock in the proportion it should have increased. He should not be satisfied with his exertions, unless he has preserved one-half the number of ewes with twin-lambs, nor should he congratulate himself, if he has lost a single ewe in lambing. I am aware these results cannot always be commanded, but I believe an attentive and skillful shepherd will not be satisfied for all his toil, night and day, for three weeks, if he has not attained these results. The ewes may have lambed twins to greater number than the half, and yet many pairs may have been broken to supply the deficiencies occasioned by the deaths of single lambs. The death of single lambs is a vexatious matter to a shepherd, as it not only breaks his pairs, but imposes very considerable trouble on him in mothering the severed twins upon other ewes; and yet the trouble must be undertaken to retain the ewes that have lost their lambs in milk, and so maintain them in proper condition for future years. In fine, steady weather, the shepherd proceeds with his labor in comparative ease; but when stormy or wet weather prevails, or comes at unexpected intervals, the number of lambings are not only accelerated, but every ewe most probably creates some trouble even in the day time. True, "daylight has many eyes," and permits him to observe many casualties in time to remedy their effects; but at night, in bad weather, with glimmering light, difficulties increase tenfold, and so sensibly have I witnessed these difficulties myself, I am convinced every farmer of a large flock would find it repay it at the end of the lambing season, in the increased number of preserved lambs and ewes, to afford the shepherd assistance at night in the most busy period of the lambing season, according to the circumstance of the case. In regard to Cheviots, it is considered a favorable result to rear a lamb for each ewe; and with Black-faced ewes, 18 lambs out of the score of ewes is perhaps one as favorable. Cheviots yield a few pairs, Black-faced very few. The former sometimes require assistance in lambing, the latter seldom.

(1843.) The state of the new grass-fields occupied by ewes and lambs requires corsideration. Ewes bite very close to the ground, and eat constantly as long as the lambs are with them; and as they are put on the new grass in the latter part of March, before vegetation is usually much advanced, they soon render the pasture bare when overstocked, and the weather is unfavorable to vegetation. In cold weather in spring, bitten grass soon becomes brown. Whenever the pasture is seen to fail, the ewes should be removed to another field, for if the plants are allowed to be bitten into the heart in the early part of the year, the greater portion of summer will elapse ere they will recover from the treatment. In steady growing weather there need he little apprehension of failure in the pasture. The sown pastures consisting chiefly of red clover and rye-grass, the clover is always acceptable to sheep; and in the early part of the season young shoots of rye-grass are much relished by ewes. On removing the stock from the first to the second field, it is better to eat the first down as low as it safely can be for the plants, in order to hain it, that is, to leave 
it for at least a fortnight, to allow the young plants to spring again with vigor, and which they will do with a much closer bottom than if the field had been pastured for a longer time with fewer stock. Such a field eaten down to the end of May or beginning of June, and allowed to spring afterward in fine growing weather, will yield a much heavier crop of hay than if it had not been depastured in spring at all. Although the whole breadth of young grass on a farm pastured lightly with ewes and lambs in the spring were to grow, as the season advances more rapidly than the ewes could keep it down, it will never produce the fine, sweet, fresh pasture which field after field will yield that has been eaten down in succession, and then entirely hained for a time. But in removing ewes and lambs from a short to a full bite of grass, considerable caution is requisite in choosing the proper time for the removal. It should be accomplished in dry weather, and in the afternoon; because, continued damp or rainy, or cold wet weather, renders new grass so succulent and fermentable as almost certain to produce the green skit in lambs that are put upon it, although the damp weather should increase the ewes' milk.

(1844.) Carse farms have neither a standing nor a flying stock of ewes, and consequently, have no lambing season; neither have farms in the neighborhood of large towns, nor dairy farms, nor pastoral ones for the breeding of cattle; so that ewes and lambs are only found on pastoral farms that are devoted to the breeding of sheep, or on farms of mixed husbandry. But pastoral farms rear breeds of sheep very different in their nature from the breed, the management of which, I have described. On our hills, the Cheviot and Black-faced, or Heath sheep, were long the only inhabitants, but now the valuable Southdowns are added to the list. The cheviot and Southdown range along semi-upland green mountain pastures, such as the Downs and the green hills of Cheviot, in England, and the green hills of Ochils. Sidlaws and the Lammermuir group, which stretches across the south of Scolland; while the Black-faced roam on the highest mountains, not only as far as a plant of heath can grow, but even beyond it, in the regions of the cryptogamiæ.

(1845.) In as far as the assistance of the shepherd is required to be given to ewes in the act of lambing, the observations $\mathbf{I}$ have made in reference to the lambing of Leicester ewes will apply to those of the Cheviot, Southdown and Black-faced breeds; but the ewes of these breeds do not require assistance nearly to the same extent as Leicester ewes, the lambs of the latter being gen. erally larger in proportion to the ewes, and they are more square-built in form. Single lambs of the other breeds are generally brought forth without any assistance, and twin-lambs are so few that the ewes bearing them may be singled out for remarkable attention. A Cheviot single lamb soon gets on foot after being lambed, and its acute instinct as soon directs it to the teat. The Black-faced lamb is fully more active after being dropped, gaining its feet in a few minutes, and its rough coat of wool serves to protect it at once from the weather. Placed in shelter derived from one of the many natural inequalities of the ground common in a pastoral country, both these breeds may easily be tended in the lambing during the day; but the constant attention required of the shepherd limits his ability to superintend, at this particular period, a lambing flock beyond a certain number; 400 ewes are as many as one shepherd can superinted in the course of the day, to render them the assistance they may stand in need of; to see that the new lambed ewes and lambs are placed in shelter until they have both perfectly recovered, and are able to take to the pasture; and, in case of bad weather, to see that the ewes are supplied with some turnips and hay, to enable them to support their lambs until the weather becomes favorable. If one shepherd fulfills these duties in the day, he does quite enough, so that it will be necessary to have an assistant for him in the night, to see that the ewes are gathered into the shelter at nightfall, and to take a weakly lamb, or all the lambs that have dropped during the night. into sheds erected on purpose as a protection against bad weather. To ascertain the state of his flock, he should go through them with a lantern, at least every two hours, and oftener if necessary. Lord Napier recommends the construction of a "lambing park," for the use of ewes, and gives the cost of making one to comprehend 25 acres of ground, which shall accommodate 200 ewes, with 2 stells and 2 stell-houses, and hay-racks, at $£ 90$, which, at 7 per cent. interest, with repairs of racks, \&c., will incur an annual cost of $£ 75 \mathrm{~s}$. 8d. for sheep.* Such a place of shelter and of inclosure would, no doubt, be useful to a certain extent, but only to a limited extent: for such a park can only be in one part of the grazings, where at times it will no doubt be exposed to the weather, and as 25 acres would only contain I-5 of the flock at a time, in stormy weather the rest of the flock, whether already lambed or yet to lamb, require shelter as well as ewes expected to lamb; and the dividing of the flock every day to get the 200 ewes with their lambs out, and other 200 driven in, would make a serious commotion among them at a very critical period of the ewes. I cannot help thinking that a chosen spot selected to afford shelter, according to the circumstances of the weather, to all the ewes yet to lamb within a given time, and where they could be partly supported on artificial food, while those which have lambed could occupy at night a sheltered part of the best portion of the pastures, would disturb lambing ewes far less than a lambing park which was not corstantly occupied by all the ewes. It should be remembered that hill sheep cannot be so easily shifted from one place to another as Leicester sheep, and especially in a grazing which has few or no inclo-

* Napier on Practical Store Farming.

(311) 
sures. Small pieces of English blanketing, to be kept dry when not in use, to wrap round and keep warm a weakly lamb in the shed, until it has recovered by the eflect of its mother's milk, or by warm cow's milk aúministered by the shcpherd, will be found a useful article by every shep. herd, and may be the meane of preserving the life of many a lamb. Many a lamb I have aeen recruited by ilis means, when it would have otherwise perished of inanition. The period of lambing, in hill sheep, is longer than that of Leicester, because the gimmers are not tupped in the autumn until a fortnight after the ewes, and, of course, do not begin to lamb in the spring until a fortnight later. The ewes begin to lamb about the 20 th April, and the gimmers a fortnight after. To otrengthen the gimmers, and to bring a flush of milk upon them, they are separated frum the ewes about a month before their lambing time, and are supplied witb turnipo to the amount of a double horse. load, say 15 ewto., to every 100 or 120 gimmers. A bout a fortuight be. fore the ewes lamb, they get the same quantity of turnips for every 160 ewes. In mountain farms, where there are no turnips, hay should be supplied in the same manner to gimmers and ewes. A quantity of hay, expended at this time, will be more than repaid in the safety of lambs and vigur of ewes, especially in unfaverable weather.

(184ti.) These few observations of Mr. Little on the qualifications of a hill shepherd, are worth your attention, as containing much good practical sense and truth. "Much," he truly says, "of the success in sheep-farming depends on the skill and application of shepherds, as well as on the judgment of farmers. As the situation of a shepherd is one of considerable trust, he ought to be honest, active, useful, and of a calm temper; for if at any time a shepherd gets into a passion with his streep, it is attended with great disadvantage in herding, or in working among them. I have knowu a hasty, passionate man, with a rash dog. give himself double the trouble in managing a hirsel of sheep, besides abusing the sheep, that a calm, guod-tempered man, with a sagacious, close-mouthed dog, would have had in the same circumstances. The qualification required in taking care of a hirsel of sheep, is not in running, hounding and training doge, nor in perforning a day s work of any other kind; but to direct them according to the soil, climate, and situation of the farm, in such a manner as to obtain the greatest quantity of food at all seasons of the year. Their health and comfort should be carefully looked after by the shepherd; and if his exertions are made with judgment, they are of very great consequence to the farmer. It is not by walking much, and doing a great deal, that a shepherd is a good one; but it is knowing where to waik, so as to disturb the sheep the least, and by doing at the time whatever is necessary to be done. There is not an experienced shepherd who has been any length of time on one farm, who does not, as soon as he rises in the morning, and observing the state of the weather, know almost to a certainty where to find every sheep on the hill, and will accordingly take his course to the places he knows his presence is most wanted. The object in looking over a hill every evening and morning is to ascertain if there be no trespassers nor diseases among the sheep which require looking after. If any of your own or neighbor's sheep have tresspassed, it is very foolish to dog or abuse them, for the more gently you can turn them back the better. If the boundary should be on the top of a hight, to which sheep are apt to draw at night, it is better to turn your own a little closer to the boundary in the afternoon, than to turn back your neighbor's; and it will answer the same purpose; and if the two Hocks are gently divided in the morning without dogs, they will become so well acquainted with their own side that at the very sight of the shepherd they will take to it without farther trouble. Those shepherds who dog, force and shed much about a march, I consider them as bad herds for their masters as for the neighboring farmer. If the boundary be a brook or low ground, where the sheep graze in the middle of the day, and if trespassers are likely to be considerable, the same plan of turning the sheep should be taken as on the hight, except that they are to be turned down in the morning, and set out in the afternoon. When a sheep dies on the hill, or any disease appears among them, the dead or diseased sheep should be removed immediately, but particularly so if the disease appears of an infectious nature. Looking regularly over a hill is of great consequence, also, in case of any sheep falling into a ditch, or lamb losing its mother, or when they are annoyed by flies or maggots, or by foxes or dogs worrying them, or when they fall on their backs and cannot get up again. All these incidents an active shepherd with a good eye will soon discover. however much a flock may be scattered over a farm. .... In good weather the shepherd may possibly do all that can be done among the ewes in the lambiug season; but in bad weather it is the farmer's interest to afford every necessary assistance, for the want of which serious losses have often been incurred.

Knowing sheep by head-mark often saves a shepherd much trouble, particularly in the lambing season, and at all sortings of the sheep; yet there are many good shepherds who do not know sheep by head-mark, and there are some very ordinary ones who have a talent in that way. Every individual may be known by the stock mark. To possess the knack of conenting sheep readily is of no small service to the shepheri, for he ought always to be able to count his flock when he makes his rounds on the hills. There are few shepherds who accustom themselves to count sheep, who cannot, wherever they meet with them on a hill, count 100 going at large, or even 200, and it seldom bappens that a greater number than 200 will be found together in an open hirsel. To know the number in the different lots is of great nse in case of a hasty blast, as you can in that event know, almost to a certainty, whether or not any sheep are wanting, and from what part of the farm. A shepherd ought likewise to be able to do any kind of work about a sheep farm, such as cutting lambs, smearing, slanghtering. dressing for the market, repairing stone-dykes, cleaning out drains, mowing grass, making hay, casting and winning peat-lurf for fuel, \&c. ; but he ought at no time to noglect the sheep for such work. Shepherds are generally accounted lazy, but those who really care for their sheep will not be so. Much walking unfits a man for hard labor, as much as hard labor unfita a man for much walking; but laborers will generally be found more lazy in a hill, or atmong sheep, than shepherds will be found at field work."

(1847.) Ewes in lambs are liable to abortion, or slipping of the ?amb, as it is usually termed, as well as the cow, but nut so much so, nor is the complaint considered epidemical in the sheep.

- Little's Practical Observations on Mountain Sheep. 
Various canses produce it, such as severe weather in winter, having to endure much fatigue in snow, leaping ditches, being frightened by dogs, over-driving. It is stated by Mr. Youatt, that too liberal use of salt will produce abortion. The wool is apt to come oft in spring after abortion. It is scarcely possible to predicate abortion in sheep on account of their wcolly covering; but its immediate efiects of duliness in the ewe, and of a redness under the tail, will be symptoms noticed by an observant shepherd. "The treatment after abortion," ubserves Mr. Youatt, "will depend entirely on the circumstance of the case. If the foetus had been long dead, proved by the fetid smell of it, and the vaginal discharge, the parts should be washed with a weak solution in water (1 to 16) of the chloride of lime, some of which may also be injected into the uterus. If fever should supervene, a dose of Epsom salts, timeously administered, will remove the symptoms. If debility and want of appetite should remain, a little gentian and ginger, with smali doses of $\mathbf{E} p$ som salts will speedily restore the animal. Care should be taken that the food shall not be too nutritive or too great in quantity." In protracted labor when the ewe is becoming weak. she will be much relieved by receiving a table-spoonfull of brandy and sweet spirit of nitre in equal parts, with a drinking horn. To produce pains in a ewe when she becomes apathetic in lanbing, 2 table-spoonstull of a strong infusion of the ergot of rye, repeated in a second dose in a quarter of an hour, will produce pains and ease the labor. In cases where it is impossible to extract the lamb, and the life of both lans and ewe are in danger, the Cæsarian operation, that is, extracting the lamb from the womb by an incision made in the side and the womb of the ewe, has been performed with success. "In some lambs that are born apparently dead, the vital principle is not extinct, but it would soon be so if the little animal were suffered to remain on the cold damp grass. Every lamb that is tound in this situation should be carefully examined, and if there is the slightest degree of warmth remaining about it, the shepherd should blow into its mouth in order to inflate the lungs: many a little one has thus been saved. The shepherd need trouble himself very little about the expulsion of the placenta or cleansing, although a day or two may pass before it is detached. A couple of ounces of Epsom salts, with a little ginger, may be given if there should be a longer delay, or if symptoms of fever should be exhibited : but the farmer would do well to avoid the rough barley or the misletoe, or in fact any stimulant, for there is at this time sufficient disposition to fever, without its being artificially set up." "The inflammation of the womb, after parturition, usually comes on between the first and the fourth day, and especially when any violence has been used in extracting the lamb. It is a most fatal disease, and speedily runs its course. The treatment should be bleedings and purgatives of Epsom saits. Connected with this disease are after-pains or heaving, to which ewes are subject, and which are frequently severe and destructive. They are apparently the same pains, but considerably stronger, which Nature uses to expel the lamb. It is evidently produced-by the ewes being too well kept during their pregnancy. It canuot be too often repeated, that it is a fatal error to overfeed the ewes at this period with a view of giving them strength to support their approaching labor. It is an unscienlitic and injurious practice, and severely does the farmer suffer for it. But there is some epidemic influence at work, or the constitution of the sheep is at that time irritable almost beyond belief." Young lambs, as long as they are dependent on their mother for food, are subject to a few diseases. A change to new Juxuriant grass in damp weather may bring on the skic or diarrhoa, and exposure tocold may produce the same effect. As long as it feeds and plays there is little dan. ger; but should it appear dull, its eyes watery and heavy, and its joints somewhat stiff; remedial means should immediately be used. "A gentle aperient is first indicated in order to carry off any offensive matter that may have accumulated in and disturbed the bowels : halt an ounce of Epsom salts, with half a drachm of ginger, will constitute the best aperient that can be administered. To that must be added a table-spoonfull of sheep's cordial. consisting of equal parts of brandy and sweet spirit of nitre, housing and nursing." But there is a species of apparent purging, which is a more dangerous disease than the skit. "In the natural and healthy state of the milk and the stomach, curd produced by the gastric juice gradually dissolves and is converted into chyme; but when the one takes on a morbid hardness, and the other may have lost a portion of its energy, the stomach is literally filled with curd, and all its functions suspended. The animal labors under seeming purging, from the quantity of whey discharged, but the actual disease is constipation. It is apt to occur about the time when the lamb begins to graze, and when the function of the stomach is naturally somewhat deranged. Chemistry teaches us, that while a free acid produces coagulation of the milk, an alkali will dissolve that coagulum. Magnesia, therefore, should be administered, suspended in thin gruel, or ammonia largely diluted with water, and with them should be combined Epsom salts to hurry the dissolved mass along, and ginger to excite the stomach to more powerful contraction. Read's stomach-pump will be found a most valuable auxiliary here. A perseverance in the use of these means will sometimes be attended with success, and the little "patient being somewhat relieved, the lamb and the mother should be moved to somewhat better pasture." Besides looseness, lambs are at times subject to costiveness in the bowels. In the first few days of its existence the frees they void has a very viscid consistence, which, when it falls on the tail, has the effect of gluing it to the vent and of stopping up that passage. On the removal of the obstruction by scraping with a knife, the sympton will also be removed. A worse species of costiveness is, when a few drops of liquid fæces fall occasionally to the ground accompanied by straining, as it is generally accompanied with fever that may be dangerous. Half-ounce doses of Essum saits should be administered every six hours until the bowels are evacuated, after which both ewe and lamb should be turned into more succulent pasture, as the cause of the complaint is to be found in bare pasture and dry weather. In cases of fever, which may be observed from the dullness of the lamb and its quick breathing, the administration of tolerable doses of Epsom salts will generally avert the malady at its commencement. After recovery from lambing, the only complaint the ewe is subject to is inflammation in the udder, or udder-clap, or garget, Of this complaint Mr. Youat gives a good idea of its origin and of its treatment in these words : "The shepherd, and especially in the early period of suckling, should observe whether any of the ewes are restless and exhibit symptoms of pain when the lambs are sucking, or will not permit them to suck at all. The ewe, like the cow, or oftener than that animal, is subject to in. (n)13! 
flammation of the udder during the time of suckling, caused either by the hardnegs or dryness of the soil on which the lies; on the nther hand, by its tno great moisture and filth, or by some tendeney to general inflammation, anul determined to the udder by the bumps and braises, sometimes not a little severe, from the lhead of the lamb. If there is any refusal on the part of the ewe, or even disinclination. to permit the young one to suck, she must be caught and examined. There will generally be found redness and enlargement and tenderness of one or both of the teats, or some. times the whole of the udder, and meveral small distinct kernels or tumors on ditferent parts of the bag. The udder should be cleared of the wool which surmunds it, and ahould be well fumented with warm water, a dose of Ensom salts administered, and then, if there are no large distinct knots or kcrnels, she should be returned to her lamb. whose sucking and knocking about of the udder will contribute more than by any other means, to the dispersion of the tumor and the regular flow of milk. It may occasionally be necessary to confine her in a pen with her little one, in order that he may have a fair chance to suck. A day, however, having passed, and she not permitting it 10 suck, the lamb must be taken away, the fomentation renewed, and an ointment com. posed 1 irachm of cumphor rubbed down with a few drops of spirit of wine, 1 drachm of merca. rial ointment, and $1 \mathrm{oz}$. of elder ointment. well incorporated together, must be rubbed into the affected part. or the whole of the uilder, two or three times a day. She must also be bled, and the physic repeated. If the udder should continue to enlarge, and the heat and tenderuess should increase. and the knots and kernels become more numerous and of greater size. and some of them should begin to soften or evidently to contain a fluid, no time must be lost, for this disease is abondantly more rapid in its progress in the sheep than in the cow. A deep incision must be made into that part of the udder where the swellings are ripest, the pus or other matter squeezed out, and the parts well fomented again. To this should succeed a weak solution of the ehluride of lime with which the ulcer should be well bathed two or three times in a day. When all fetid smell ceases and the wound looks healthy, the friar's balsam may be subtituted for the chloride of lime. The progress of dis organizition and the process of healing are almost incredibly rapid in these cases, and the lamb may sometimes be returned to the course of a few days. There are particular seasons, especially damp and warm ones. when there is a supertuity of grass in which garget is peculiarly frequent and fatal. Withous warning, the udder swells universally with hardened teats, which sometimes brings on great inflanmation. and if it has not stopped in the course of 24 hours. part, if not the whole, of the udder morti-

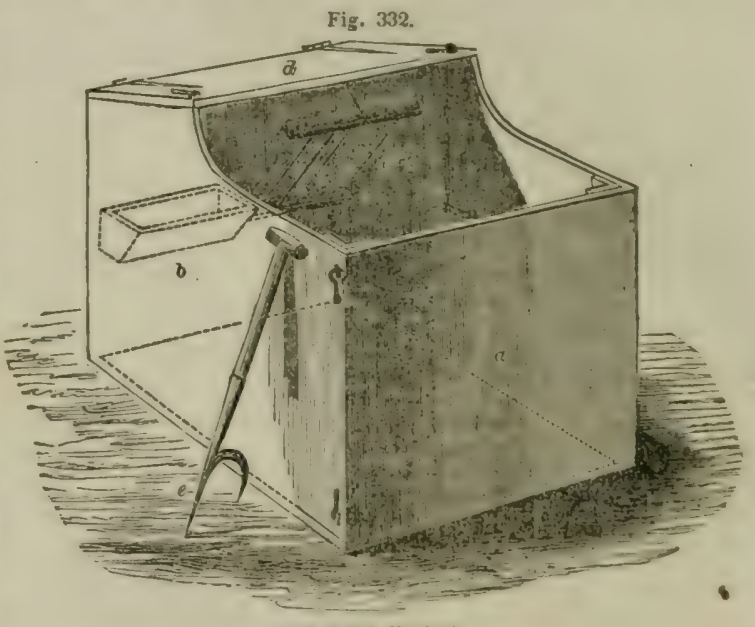

THE EWE-HOUSE.

fies, and the mortification rapidly spreads, and the sheep dies." *

(1848.) In case of an individual ewe, of a large flock of a pastoral farm, straying a considerable distance from the shed erected to afford shelter to ewes, or has suffered in hard labor, or bas a weakly lamb, or has twing which are apt to stray from her or she from them, or has been over. taken by a rude blast immediately after lambing, a contrivance w aftord such ewes temporary shelter, especially under night. liaving been used by Mr. Nicholas Burnet,. Blaik Hedley, near Gates-head, with suecess, seema to deserve attention. It consists of an inclosure of boards. or a box, as seen in fig. 332, whereof $a$ is the front, which removes by hooks at the sides to admit the ewe and her lamb within. and where whe is provided with a manter $b$ to contain sliced turnip or oil.cake, and a rack $c$ for hay, to fill both of which access is obtained by the lid $d$, movabte on its hinges. I have been assured by Mr. Burnett, that in using this contrivance, which. being a light implement, can be easily carried to any spot, he has had the satisfaction of using it as a means of saving the lives both of ewes aud lambs which would have otherwise perished from exposure. The size of the ewe-house, as it is called, may be made to suit that of the sheep brert on the farm and as it is not costly, any number can be made to be used at a time. The fork $e$ leaning against the side of the ewe house may be used to grasp a cwe's neck. while lying on the eround, and to fasten it down, while the shepherd is lambing her without other assistance; but the method of holding a ewe between the heel and the knee, which I have before described, renders such an instrument of little use.

(1849.) One of the grentest sourres of loss among lambs on hill farms is a fall of snow at the lambing season or a continuance of anow to that period. Ground rendered wet by the melting of new fallen snow, is in a worse state for lambs than when made wet by rain, as in the latter case the temperature of the air is higher, though, of course, wet ground of any kind is inimical to the

* Youatt on Sheep. 
safety of new-dropped lambs. In such a case, the driest part of the farm combined with shelter should be chosen for the lambing ground, though it may be inconvenient in some other respects bat should the best lambing ground be covered with old snow, especially in sheltered spots, and the temperature of the air be generally above the freezing point, could the snow be stirred by any
means, it would melt much faster than it would of itself. A snow-harrow or snow. plow will be found a useful implement for the purpose, and those recommended by Mr. Hepbarn of Culqubalzie seem to possess every requisite. The snow-harrow is represented by fig. 333 . It consists of a single bull $a b, 4 \frac{1}{2}$ inches square, and 6 feet long; and in the middle of which, on the under side, a piece of $1 \frac{1}{4}$ inch plank $c d, 3$ feet long, is sunk flush transversely, for the attachment of the

Fig. 333.

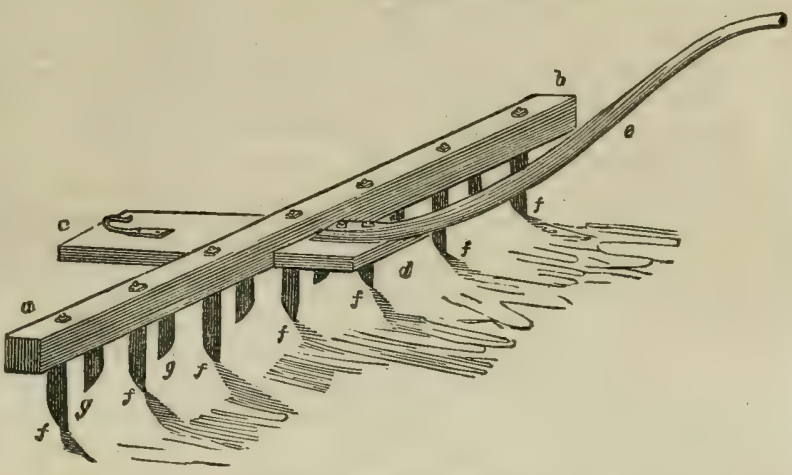

THE MOUNTAIN SNOW-HARROW. draught-hook $c$, and the stilt $e$ to steady the motion of the implement. In the bull are fixed by screw-nuts at intervals of 10 inches, 7 cutters $f f, \& c . .9$ inches long and $1 \frac{3}{8}$ inches broad, sabre-shaped, with their points turned backward, so as to be less liable to be arrested by obstacles on the surface of the ground Between these cutters are fixed 6 shorter ones $g g$, \&c.. 3 inches long, having their point turned forward. This implement. dragged by one horse ridden by a boy, and the stilt held by a man, cuts the frozen snow into strips of 5 or 6 inches broad, which are easily pulverized by the feet of the sheep, or divided by the snow-plow. The severe snow-storm of 1823 lay on the hills from February to May; and the protracted snow-storms of 1837-8, with repeated falls and alternations of frost and thaw, caused the death of many a sheep before and at the lambing season. The snow became so compacted in the latter year, that the common snow-plow was unable to penetrate the snow, and the common harrow to break its glazed surface. With the view of obviating both these inconveniences, Mr. Hepburn contrived the snow.harrow described above, and also the snow. plow, of which the following is a description in Mr. Hepburn's own words: "The severity of the winter of 1837-8 in mountain sheep pasture, led me to attempt the snow-plow, with or without the aid of the snow-harrow, for being applied in such situations. To enable the plow to clear tracks for the sheep along the bill-sides, it is necessary it should be made to throw the snow wholly to the lower side. To effect this I caused to be fitted to the plow $a a_{0}$ fig. 334, the body of which forms an isoceles triangle whose sides are $7 \frac{1}{2}$ feet, and its base 6 feet in length, the depth of the sides being 15 inches, a shifting head $b c d$, with unequal sides, one $b c$, being 18 inches, the other $b d, 30$ inches long, fixed by iron pins passing through to pairs of eyes as seen at $c$, attached to the head and to the sides of the plow respectively, so as to bring the point of the attached head of the plow nearly into the line of its upper side, or next the hill. The stilt $e$ at the same time was made movable by a hinge-joint at its anterior extremity, fixed to the bottom of the head from the post $f$, so as to be capable of being fixed to the cross-bar or stretcher $g a$, either in a line bisecting the angle, as at $h$. which is the position for level ground, or in the line alternately, of either of the sides $b a$ or $b g$, when to be used on a declivity. The draught-chain is fixed, not to the shifting head, but to the upright frame-post $f$, in the nose of the plow, which rises 10 or 12 inches above the mould-boards. When a plow so constructed is to be worked along a declivity, with the left hand toward the hill, the shorter limb of the shifting head is fixed on the left side of the plow, near the point, and the longer

Fig. 334.

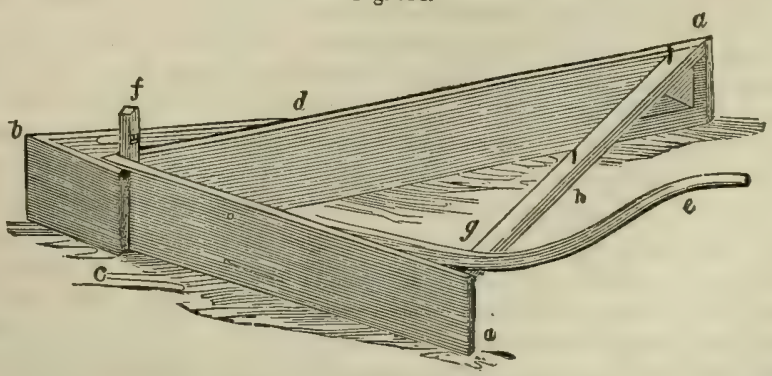

THE MOUNTAIN TURN-WRIST SNOW-PLOW.

limb on the right side, toward the middle : and the stilt being fixed in the left extremity of the cross-bar, nearly in a line with a temporary point, the plow is necessarily drawn in the direction of its left side, so as to throw the snow wholly to the right down the hill. When the plow is to return across the declivity, with its right side to the hill, the movable head is detached by drawing $(315$ j 
out the linch-pins, is tumed ap side down, and fixed in the reveree position; the shorter limb being attached to the right side. and the longer to the left side of the plow, while the stilt is brought to the right extremity $a$ of the eross-bar. The plow is then drawn into the direction of the right side, and the snow is turown wholly to the left, near the lower side. Should the lower side of the plow show a tendency to rise, it may either be held down by a second movable stilt, fixed to the middle $b$ of the cross-bar, or a block of wood, or other ballast weight may be placed on that gide of the plow. The plow will be found to remove considerably more than its own depth of snow. When a plow of 1 foot hish passes through snow 18 inches or 2 feet deep, very little of snow falls back into the track, and what does so fall is easily cleared out by the plow in returning." In lowland farms the snow remains around the fences long after the middle of the fields are clear. A speedy means of getting rid of the snow is to plow it with the common plow repeat. edly. Had I not adopted this expedient in the spring of 1823 , the oat-seed would not have been begun for a fortnight later than it really did.

(1850.) In regard to the treatment of sheep on turnips in spring, they are managed in the same way as in winter, until removed to grass, which they are, whenever the turnips fail, and are kept on for a short time, until the weather becomes mild enough to have them shoru of their wool. and then they are sold to the butcher : but other farmers prefer selling them fat, in a rough state off the turnips - that is, before the wool is clipped off them. The circumstances which regulate these different cases will be explained in a short time.

\title{
14. TRAINING AND WORKING THE SHEPHERD'S DOG.
}

\author{
"He was a gash an' faithful tykè, \\ As ever lap a sheugh or dyke, \\ His honest, sonsie. baws'nt face, \\ Aye gat him freenủs in ilka place. \\ His breast was white, his touzie back \\ Weel clad wi' coat o' glossy black: \\ His gawcie tail, wi" upward curl. \\ Hung o'er his hurdies wi' a swirl."
}

(1851.) The natural temper of the shepherd may be learned from the way in which he works his dog among sheep. When you observe an aged dog making a great noise, bustling about in an impatient manner, running fiercely at a sheep and turning him quickly, biting at his ears and legs, you may conclude, without hesitation, that the shepherd who owns him is a man of hasty temper. Most young dogs exhibit these characteristics naturally, and they generally overdo their work; and if you observe a shepherd allowing a young dog to take his own way, you may conclude that he also is a man who loses his temper with his flock. If you observe another shepherd allowing his dog, whether old or young, to take a range along the fences of a field, driving the sheep within his sight as if to gather them, you may be sure he is a lazy fellow, more ready to make his dog bring the sheep to him, than he to walk his rounds among them. Great harm may accrue to sheep by working dogs in these ways. Whenever sheep hear a dog bark that is accustomed to hound them every day, they will instantly start from their grazing, gather together, and run to the farthest fence, and a good while will elapse ere they will settle again. And even when sheep are gathered, a dog of high travel, and that is allowed to run out, will drive them hither and thither, without an apparent object. This is a trick practiced by lazy herds every morning when they first see their flock, and every evening before these take up their lair for the night, in order to count them more easily. When a dog is allowed to run far out, he gets beyond the control of the shepherd; and such a style of working among wether sheep, puts them past their feeding for a time; with ewes it is very apt to cause abortion; and with lambs after they are

* Prize Essays of the Highland and Agricultural Societv, vol. xiii.

(316) 
weaned, it is very apt to overheat them, and a considerable time will elapse before they recover their breath. Whenever a sorting takes place among the sheep with such a dog they will be moved about far more than is necessary; and intimidated sheep, when worn into a corner, are far more liable to break off than those treated in a gentle manner. A temperate herd works his dog in quite a different manner. He never disturbs his sheep when he takes his rounds among them at morning, noon and night, his dog following at his feet as if he had nothing to do, but ready to fulfill his duty, should any untoward circumstance require his services, such as breaking out of one field into another. When he gathers sheep for any purpose of sorting, or of catching particular ones, the gathering is made at a corner, and to gain which he will give sheep the least trouble, making the dog run out to the right and left, to cause the sheep to march quietly toward the spot, and after they are gathered, he makes the dog to understand that it is his chief duty to be on the alert, and with an occasional bark prevent any of the sheep breaking away. When a sheep does break away and must be turned, he does not allow the dog to bite it, but only to bark and give a bound at its head, and thus turn it. In attempting to turn a Black-faced wether in this way, the dog runs a risk of receiving an injury fiom its horns, and to avoid this I have seen him seize the coarse wool of of the buttock, and hang by it like a drag, until the sheep was turned round in the opposite direction, when he lets it go. In short, a temperate herd only lets his dog work when his services are actually required, he fulfilling his own duties faithfully, and only receiving assistance from his dog when the matter cannot be so well done by himself, and at no time will he allow his dog to go beyond the reach of his immediate control. Dogs, when thus gently and cautiously trained, become very sagacious, and will visit every part of a field where sheep are most apt to stray, and where danger is most to be apprehended to befall them, such as a weak part of a fence, deep ditches or deep furrows into which sheep may possibly fall, and lie awalt or awkward-that is, lie on the broad of their back and unable to get up, and they will assist to raise them up by seizing the wool on one side and pulling the sheep over upon its feet. Experienced dogs will not meddle with ewes having lambs at foot, nor with tups, being quite aware of their disposition to offer resistance. They also know full well when foxes are on the move, and give evident symptoms of uneasiness on their approach to the lambing ground. They also bear footsteps of strange persons and animals at a considerable distance at night, and announce their approach by unequivocal signs of displeasure, short of grumbling and barking, as if aware that those noisy signs would betray their own presence. A shepherd's dog is so incorruptible that he cannot be bribed, and will not permit even a known friend to touch him when intrusted with any piece of duty. So far as my observation extends, I think there are two varieties of the shepherd's dog-one smooth, short-haired, generally black-colored on the back, white on the belly, breast, feet and tip of the tail, with tan-colored spots on the face and legs; the other is a larger and longer-bodied animal, having long hair of different colors, and long, flowing tail. In their respective characters I conceive them to be very like the pointer and the setter. The small, smooth kind, like the pointer, is very sagacious, slow, easily broke and trained, and admirably suited to work in an inclosed and low country; the other, like the setter, is more swift, bold, ill to break, and requiring coercion, and fitter for work on the hills. The former answers the habits of Leicester sheep, the latter those of the Cheviot and Black-faced. The latter requiring a great range to work in, on account of the nature of the sheep and of the ground which (317) 
they frequent, are bold and rough in action; still they should be trained to work with judgment and caution, and not with recklessness and fury. Most shepherds profess to be able to train young shepherds' dogs, and therein many display much ignorance of the nature of the animal, and of the aptitude of the particular animal for the peculiar work, and the consequence is, many dogs are rendered unfit for their work. Every shepherd's pup has a natural instinct for working among sheep, nevertheless they should always be trained with an old dog. Their ardent temperament requires subduing, and there is no more effectual means of doing so than keeping it in company with, and making it imitate the actions of, an experienced, sober dog. A long string attached to the pup's neck, in the hands of the shepherd, will be found necessary to make it acquainted with the language employed to direct the various evolutions of the experienced dog while at work. With this contrivance it may be taught to "hold away out by," to "come in," to "come in behind," to "lie down," to "be quiet," to "bark," to "get over the dike or fence," to "wear," that is, to intercept, to "heel," that is, to drive on, to "kep," that is, to prevent getting away; it will learn all these evolutions and many others in a short time, in imitation of its older companion and guide. It is supposed that the bitch is more acute than the dog, though the dog will bear the greater fatigue. Of the two, I believe that the quietly disposed shepherd prefers a bitch, and is careful in working her as little as he can when in pup. I may mention that the shepherd's dog claims exemption from taxation; and I believe that a well-trained one costs at least $£ 3$.

\section{SOWING BARLEY-SEED.}

"Such land as ye break up, for barley io sow,

'Two earths at the least, ere you sow it bestow,

If land be thereafter set oating apart,

And folluw this lesson to comfort thine beart."

TUSSER.

(1852.) It may be laid down as an axiom, that land which has borne turnips which have been eaten off by sheep should receive two plowings of some sort before it is sown with barley. I have seen the experiment tried of sowing barley on a single furrow on land ranging from clay to gravelly, and the invariable result was a manifest deficiency of crop compared to what had received two furrows; and this result is not surprising, when it is considered that barley requires a deep, well-pulverized soil to its perfect development, and that it is impossible to render any land so with a single furrow, that has been trampled firm by sheep, after carrying a heavy crop of turnips. Strong land yields, with a single furrow, a tough, waxy clod, very inimical to the growth of barley; and light turnip suil, when ridged up with a single furrow, exhibits the growth of barley in drills corresponding exactly with the drills which had been manured for turnips. The least difference of crop with one and two furrows is observed on fine hazel loam, still the superiority is to be found with the two furrows. Lay it, therefore, down as a rule, that barley land shall receive two furrows; and the only question is in what form these should be given, bearing in mind, at the same time, that the land must be deep and well pulverized, and to settle what that form should be shall be our present endeavor. 
(1853.) On clay loam in good heart it is possible that some of the turnip land that had been ridged up for spring wheat had been, from some cause, prevented from being sown with that grain, and, of course, it must be sown with barley. The land had likely been gathered up from the flat, as in fig. 133, or it may have been cast, as in fig. 135; in either case the barley land will be desired to be seed-furrowed in the same manner, that the ridging of the whole field may be uniform. Since the furrow for the spring wheat was the seed-furrow, and its ridges had been formed with a view to make the surface of the field uniform from side to side, it will be impossible to re-plow those ridges with one furrow of the common plow, without disturbing their form. Such ridges must either be plowed twice with the common plow, to bring them back to their preseut form, for which repetition of work there máy not be sufficient leisure, or they may be stirred with the grubber, a class of instruments with the importance of which you will be made acquainted below by Mr. Slight, or ribbed with the small plow, fig. 314 , without affecting their form. The choice of these various modes of stirring the ground may be taken according to circumstances. If the ridges have become much consolidated in consequence of being plowed a considerable time, or of much rain having fallen, and if the soil itself be naturally firm, two furrows with the common plow will best put the land into a state for receiving barley; but should they be in a somewhat soft state, with perhaps rather too much moisture below, though with a kindly state of the surface, capable of affording a fine tid with the harrows, then the grubber is the most proper implement for making a deep bed for the barley-seed, while it at the same time retains the dry surface uppermost; and should the soil be naturally free while it is desired to retain the upper stratum of soil still uppermost, it may be ribbed with the small plow. Putting these ridges thus into the best state for the barley-seed, there will be no difficulty with the remainder of the land. The first furrow given to barley land, which is at the same time in the best direction, is the cross-furrow, as in fig. 312 , because being plowed in an opposite direction to the seed-furrow to be afterward given, the best means are taken to pulverize it. I need not here repeat what has already been said so fully on cross-plowing in (1718) to (1723) inclusive. Although the land may not be all so cleared of turnips as to allow the cross-plowing to extend from one side of the field to the other, it should be divided into two portions, one of which should be plowed and sown while the other is clearing, and which may perhaps be cleared by the time the sowing of the first part is completed. After a passage of the harrows a double tine over the cross-plowed land, the ridges should be feered and plowed up for the seed-furrow, and the usual form of seed-furrow is either gathering fiom the flat, as shown in fig. 133, or yoking two ridge-breadths together, as in fig. 135. Every plow should be employed in ridging up the seed-furrow for the barley-seed, for it is essential to the success of that crop that the seed be sown on the soil fresh turned-up, or on a hot-furrow, as it is termed. Both the cross-plowing and seed-furrow should be deep. The former may be turned up with a broad, stout furrow-slice, but the latter should be plowed with a deep, narrow furrow-slice, in order to pulverize the soil as much as possible, and to make the crests of the furrow-slices numerous and narrow, so as to disseminate the seed more equally when sown by hand; for the sowing of seed on a fine pulverized surface requires assistance of this sort to cause it to be equally disseminated, inasmuch as on whatever spot every seed falls, there it lies, the soft earth having no elasticity like the firm furrow-slice of lea, and hence, of all the sorts of grain, barley is the most likely to be happerga'ed in the sowing, and on that ac: (319) 
count every handfull requires to be cast with greater force than other sorts of grain. The walking on soft ground in sowing barley is attended with considerable fatigue, and as short steps axe most suited for walking on soft ground, so small handsfull are best for grasping plump, slippery barley. Barley may be sown any time that is proper for spring wheat, and it may be sown as late as the end of May; but the earlier it can be sown, the better will the crop be in quality and uniformity, though the straw will be less. The average quantity of seed sown broadcast is 3 bushels to the imperial acre; when sown early less will suffice, and when late, more; because the later it is sown there is less time for so quick a growing grain as barley to tiller and cover the ground. Mr. Brown has some judicious remarks on this subject: "Among the farmers," he says, "it seems a disputed point whether the practice of giving so small a quantity of seed ( 3 bushels per acre) to the best lands, is advantageous. That there is a saving of grain there can be no doubt; and that the bulk may be as great as if more seed had been sown, there can be as little question. Little argument, however, is necessary to prove that thin sowing of barley must be attended with considerable disadvantage ; for, if the early part of the season be dry, the plants will not only be stinted in their growth, but will not send out offsets; and if rain afterward falls-an occurrence that must take place sometime during the summer, often at a late period of it-the plants then begin to stool, and send out a number of young shoots. These young shoots, unless under very favorable circumstances, cannot be expected to arrive at maturity; or if their ripening is waited for, there will be great risk of losing the early part of the crop-a circumstance that frequently happens. In almost every instance an unequal sample is produced, and the grain is for the most part of inferior quality. By good judges it is thought preferable to sow a quantity of seed sufficient to insure a full crop, without depending on its sending out offsets. Indeed, when that is done, few offsets are produced, the crop grows and ripens equally, and the grain is uniformly good."* There is no grain so easily affected by weather at seed-time as barley; a dash of rain on strong land will cause the crop to be thin, many of the seeds not seemingly germinating at all, while others burst and cannot germinate; and in moist, warm weather the germination is certain and very rapid. Indeed, it has been observed that unless barley germinate quickly, the crop will always be thin. I have seen the germ of barley penetrate the ground only 36 hours after I had sown it myself, and when it took place, the ground was smoking by the evaporation of moisture, caused by a hot sun in a calm atmosphere. I have also traced the germ of barley to the depth of 9 inches below the surface. The harrowing which barley-land receives after being sown is less than oat-land, a double tine being given in breaking in the seed, and a double tine across immediately after. Then the grass-seeds are sown with the grass-seed sowing-machine, formerly described in (1774); the land is harrowed a single tine with the light grass-seed harrows (1775); water-furrowed (1775); and finished by immediate rolling. On strong soil, apt to incrust on the surface with drouth, after rain the rolling precedes the sowing of the grass-seeds, and the process is finished with the light grass-seed harrows; but on all kindly soils the other plan is best for keeping out drouth, and giving a smoother surface for harvest-work. The head-ridges are plowed and sown by themselves. Barley may be sown with the broadcast machine as well as oats, and it is admirably suited for sowing with the drill sowing-machine, which deposits the seed at a uniform depth and breadth between the rows, with about two bushels of seed to

- Brown on Rural Affairs, vol. ii.

$(320)$ 
the acre; and such an arrangement affords opportunity for the exercise of the draw-hoe, to remove the wild mustard, which is apt to spring up among the spring crops in the vicinity of large towns, where street-manure is used to a large extent.

(1854.) Barley is sown after potatoes and beans, but never when the weather will permit the sowing of wheat. When intended for barley, the land is gathered up for the winter, water-furrowed and gaw-cut, to prevent water standing upon it; and in spring it is cross-plowed and ridged up with the seed-furrow. Barley is sown also at times after wheat or oats, and the sample in such a case is always fine colored, but the practice is bad farming, and should never be pursued. It is never sown in Scotland after lea, but might be after the land had received a partial fallowing in spring. When sown in autumn, it does not stand the winter well in Scotland, though it does in England. Winter barley is always early ripe, but is seldom a prolific crop, and when it tillers late in spring to cover in the ground, the produce is apt to contain a large proportion of light grain. As an instance of late sowing of barley, I may relate what has fallen under my own observation. The late Mr. Guthrie, of Craigie, near Dundee, had early plowed the greater part of a field of strong soil after turnips, and much rain had afterward consolidated. Being desirous of giving the land another furrow before sowing it with barley, he found the plow bring up large waxy clods, unfit to form a seed-bed for barley. He consulted me, and I advised him to rib the land with a small plow, fig. 314 , instead of plowing it. His men never having seen land so ribbed, I showed them the way, and saw the ground sown and harrowed with one double tine along. The sowing took place on 26th May, 1819, and the ribbed land produced 12 bushels the Scotch acre more than that which was plowed with the common plow, because all the tender part of the land had been kept uppermost.

(1855.) Now that you have seen the termination of the sowing season of the various sorts of grain usually euitivated on a farm, it may prove useful to you to give you an idea of the principles of the germination of seeds, and which you will find given here in the words of Dr. Madden. [The process of germination consists chiefly of various chemical changes in the composition of the seed, by which its substance is rendered soluble, and in this state furnishes nourishment for the young plant. This change is effected by means of a highly azotized principle present in all seeds, and which, under the joint influence of air, moisture and a certain temperature, undergoes various chemical changes, during the occurrence of which it is capable of exciting similar changes in other substances with which it may be in contact. Seeds are for the most part composed of starch, gum, sugar, albumen, and various saline matters; of these the starch is in general the most abundant, and the most important change produced during germination is the conversion of this starch into sugar. I bave stated that the necessary conditions for effecting this change are, independently of the vitality of the seed itself, air, moisture and a certain temperature; these three points are sufficient to regulate all the practical details of the sowing of seed, both as regards the weather and the condition of the soil in respect of water and tillage.* If the season. for example, be not far enough ad. vanced, then germination is either retarded by the lowness of the temperature, or the vitality of the

Fig. 335.

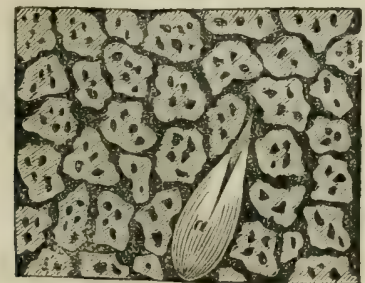

SOIL WITH WATER AND WITHOUT AIR.
Fig. 336.

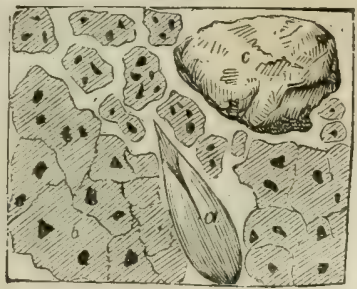

CLODDY AND STONY SOIL.

seed is altogether destroyed by the continuance of hard frost. If, again, the soil be too wet, the seed does not obtain a sufficient supply of air, owing to the interstitial canals already mentioned-

- See a paper by me on this subject in the Prize Essays of the Highland Agricultural Society, vol. xiv.

(321) ......12 
(884) to (886)-being filled with water. To give you a better idea of this condition, you will perceive, in fig. 335 , that the seed $a$ is not supplied with any air beyond what reaches it in the state of solution in water. Again, if the soil be not properly pulverized, it is very possible that the seed may be badly situated for the purposes of germination, owing to the obliteration of the interstitial canals by pressure, as is shown in fig. 336. where $b$ represents a clod of earth, and $c$ a ftone, between which the seed $a$ is placed. I need scarcely mention the remaining cause of imperfect germination, viz., the absence of moisture, as represented in fig. 337, where $a$ is the seed, as this is far too rare an uccurrence, under ordinary circumstances, to require notice. Lasily, the proper condition of soil for germination is, as before noticed. $(885$,$) where the pores of each$ particle are filled with water. while the interstitial canals are filled with air. This condition is shown in fig. 338 , and it will at once be observed that while the seed $a$ obtains moisture by

Fig. 337.

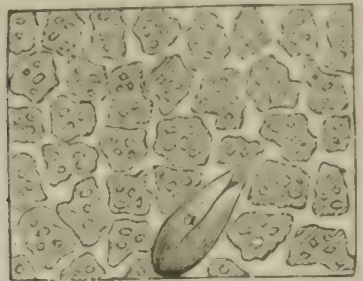

SOLL WITH AIR AND WITHUUT WATER.
Fig. 338 .

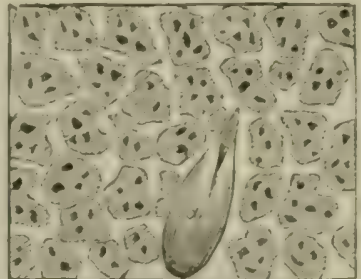

SOIL WITH WATER ASI ALR.

contact with the dark saturated particles of soil. it receives a continuous supply of fresh air from that circulating constantly through the interstitial canals. "Lest any oue should suppose that the contents of these interstitial canals are so minute that their whole amount can be of little cunsequence, we may here notice the fact that in moderately well pulverized soil they amount to no less than the whole bulk of the soil itself. For example, 100 cubic inches of moist soil-that is. of soil in which the pores are filled with water, while the canals are filled with air, as fig. 337 -con. tain no less than 25 cubic inches of air. According to this calculation, in a held pulverized to the depth of 8 inches, a depth perfectly attainable on most soils by careful tillage, every imperial aere will retain beneath its surface no less than $12,545,280$ cubic inches of air. Taking into the calculation the weight of soil, we shall find that every additional inch you reduce to powder by plowing, you call into activity $235 \frac{1}{3}$ tons of soil. and render it capable of retaining beneath its surface $1,568,160$ additional cubic inclies of air.-H. R. M.]

(1856.) The subject of the condition in which seed is usnally found deposited in tle ground may be pursued a little further, from the paper alluded to by Dr. Madden, and the first conditions that strike one are bad plowing and bad sowing. In fig. 339, the furrow-slices under $a, b$ and $c$ are all ill plowed, as you nay easily perceive; and the soil being an arranged. of course the seed will be irregularly deposited, as seen at $a, b$ and $c$, in fig. 340 , where some are too deep, as under $b$, to

Fig 339.

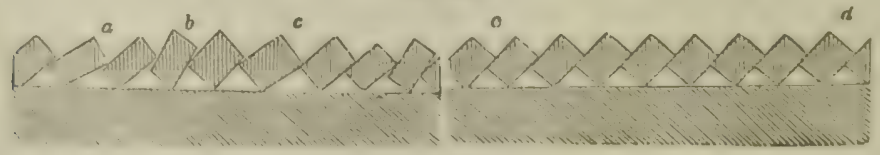

Fig. 340.

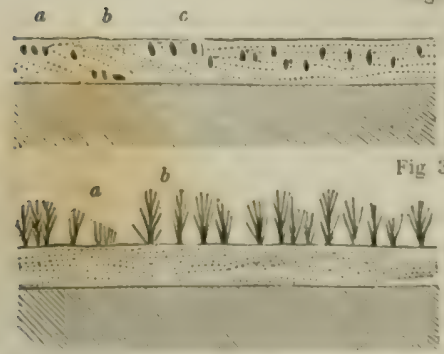

THE EFFETS OF BAD PLOWISG ON SEED.

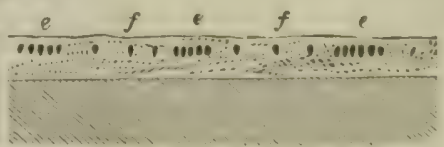

Fig $3+1$

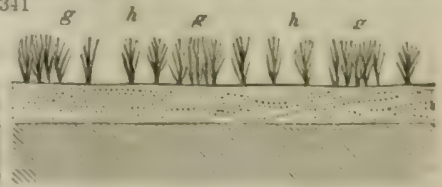

THE EFFECTS OF BAD SOWIXG ON SEED.

germinate quickly, if at all, and others much nearer the surface, as at $c$. In these various positions in which the seed is placed, it is obvious that the plants springing from them will appear and grow as irregularly, as seen in fig. 341. where the plants at $b$ are much farther advanced than those at $a$. In regard to bad sowing, althongh the fiarrow slices are reguar and well plowew in the right-nand side of fig. 339 , from $c$ to $c$, yet the secd having been irregularly deposited on tie $(322)$ 
surface, they have arranged themselves in one place too thick, as at $e e e$, fig. 340 , and too thin at $f f$; and the consequences are visible in the position of the plants in fig. 341 , where they are too thick at $g g g$, and too thin at $h h$. Where such irregularities exist-and every farmer is liable to their consequences by the carelessness of their work-people, it is clear that the crop cannot be uniform; and it is a fact which cannot be disputed however it may be explained, that the more uniform a crop is, it is the greater, and affords better grain. If, on the other hand, you observe fig. 342 , you will perceive that the seed has been deposited at uniform depths and intervals from $a$

Fig. 342.

a

$a$
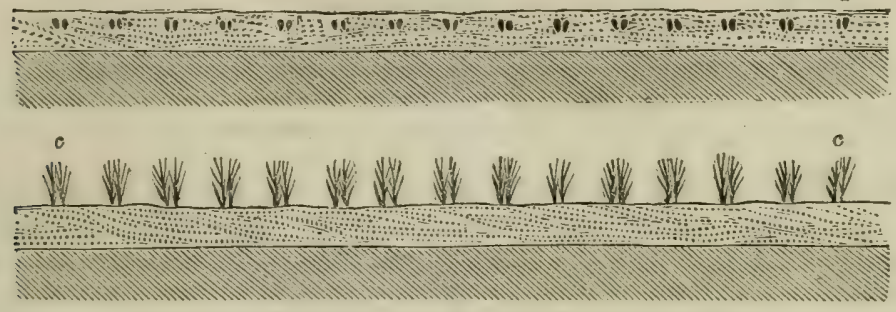

THE GOOD EFFECTS OF THE EQUAL DEPOSITION OF SEED.

to ${ }^{\circ}$, and the consequence is that the plants grow at uniform hights and strength, as from $c$ to $c$. Although the favorable result is obtained by drill-machines depositing every seed at a regular depth, which is not the case of broadcast by band, yet there are objections against sowing corn in rows, which all drill-machines do; but could they be made to deposit seed at a uniform depth, and at the same time disperse it broadcast, the objection would be disposed of. The objection to all crops placed in rows is that the air, having free access along the rows, while it encourages the growth of the cultivated, so also it does of wild plants, and to destroy the latter, certain implements are used to stir the ground, while the former are, of course, allowed to grow; but as in their progressive growth the plants throw out innumerable root-fibres in every direction in search of food, the fibres which occupy the open space between te rows are destroyed in common with the weeds; and though no estimate can be formed of the amount of injury which plants sustain in the destruction of their root-fibres, yet it is consonant to reason that these fibres nust be essential to the welfare of the plant, otherwise they would not be sent forth. It would therefore be worth while to ascertain, by experiment, the comparative results derived from depositing seed broadcast at a uniform depth with ordinary broadcast, and with rows.

(1857.) I have amused myself at times in calculating the quantity of seeds of different grains sown in an acre, and on comparing the amount of crop actually received, with what ought to have been their produce, and the deficiency which the results bear out appears incredible. Thus, Hunter's wheat gives 84 grains to 1 drachm weight; and taking it at 65 lbs. per bushel, the num. ber of grains in a bushel is $698,8 \% 0$, and giving three bushels per acre for seed, there will be sown on an imperial acre, 2,095,510 grains, or 48 grains in the square foot. Now, I have counted ears of wheat to contain as high as 61 , and as low as 24 grains each, the average thus being 44 grains ; and allowing no more than one ear of produce from each grain sown, and allowing nothing for the tillering of the crop, the preduce ought to be 44 fold; but the largest produce of wheat in the Carse of Gowrie is 52 bushels per imperial acre, or only 17 fold for the seed sown: what then becomes of the other 27 fold? Again, 80 grains of Chevalier barley, at 69 lbs. per bushel, weighs I drachm, or affords 604,160 grains to the bushel, and at 3 bushels to the acre, 1,812,480 grains per acre, or 41 grains to the square foot. Now barley yields from 32 to 21 grains in the ear, the average being 28 , and allowing 1 ear from each grain sown, the produce should be 28 fold; but 60 bushels per acre is the best crop. or 20 fold of the seed: what then becomes of the 8 fold which is wanting? Once more : Potato oats give 134 grains to 1 drachm, at $47 \mathrm{lbs}$. per bushel, or 806,144 grains to the bushel, and at 6 bushels an acre for seed, $4,836,864$ grains per acre, or 111 grains per square foot. Now, potato oats differ in the yield of grains in the ear from 182 to 20 , the average being 64 , or 64 fold, allowing 1 ear from each grain sown without tillering. Now 72 bushels is a good crop per acre, or 12 fold of the seed: what then becomes of the 52 fold wanting ? These are incredible discrepancies, and how can they be accounted for? Can the attacks of insects and vermin, or the effects of soil and weather, account for the loss? The subject is worth investigation, and were the result of investigation the discovery of the means to protect the seed while it is in the ground, the produce would either be greatly increased, or the quantity of seed to be sown would require to be much lessened.*

* See some speculations of mine on this subject in vol. iv. of Quarterly Journal of Agriculture. 


\title{
16. TURNING DUNGHILLS AND COMPOSTS.
}

\author{
"The compost pile exnmine now and turn, \\ And if 'tis nut completely decomposed \\ Into one mass of vegerable mould. \\ With an unsparing hand throw in more lime. \\ When unremitting cold retards the stage \\ of fermentation, heat, then, genial heah \\ Must be applied.
}

GRAнAM

(1858.) The ordinary mode of treating dunghills of farm-yard manure is very simple-the principle upon which it is founded is quite consonant to reason-and the results of the application of the manure so treated is also satisfactory. The treatment is, to spread every kind of straw used in litter, and every kind of dung derived from the various sorts of animals domiciled in the steading uniformly in layers, as it is supplied, over the area of the respective courts; to take this compound of straw and dung out of the courts at a proper period, and form it into a heap in the field where the manure derived from it shall be needed, with as much care as to mix the different ingredients of the heap together as they were in the courts, and to prevent the fermentation of the whole until the manure is used; and to turn this heap over in such a way, and at such a time, as the manure it contains shall be ready to be applied to the soil when wanted. The principle of this treatment is the simple one of commixing the various ingredients of straw and dung so intimately together, first in the courts, then in the dung-heap, when led out, and lastly in the same dung-heap when turned over to be duly fermented, as that the fermented manure shall be as uniform a compound as the nature of the materials of which it is composed will admit. And the result is, when the manure so treated is applied to the soil, it is found to be the most valuable of any known manure for every purpose of the farm. You have already been told how the courts should be littered, and been shown the advantages of attending to this simple yet important part of rural management in (1596) and (1597). You have also seen how those courts are emptied of their contents, and the proper time when they should be so emptied, in (1598) and (1599). And you have witnessed how their contents are disposed of in heaps in the fields in which they shall be required, (1601), and the reasons why they are formed in the manner recommended, (1602). My present purpose is to inform you how these heaps should be turned in order to bring them into the degree of fermentation best suited for making them into good manure; and the mode of actually applying that manure will be. shown to you when we come to consider the culture of the potato and turnip crops.

(1859.) Potatoes are the first crop which require a large quantity of farm lung. It is the practice of some farmers to drive the dung for potatoes direct out of the court, in its compressed state, and before it has been fermented at all. On strong soils, naturally unsuited to the growth of this plant, by reason of their heavy and tenacious character, long dung may be successfully used, because it assists to relieve the pressure of the soil upon the young plant. Indeed, on such soil, I have seen a drill of potatoes manured with dry twisted straw-ropes obtained from the coverings of the stacks in the stack-yard, and which was so manured for the purpose of ascertaining the difference, if any, betwixt it and the best made dung, pro(324) 
duce as good potatoes as the dung. In like manner, potatoes may be raised well on soils of that character with horse-dung which has reached that state of worthlessness called fire-fanged. In all other sorts of soils the use of long-dung incurs imminent risk of a deficiency of crop, and therefore dung should generally be fermented for potatoes. Dung, when laid up in an uncompressed state in the court, as noticed in (1604), becomes sufficiently fermented for potatoes, and may be driven out at.once without farther preparation. There is one objection to the use of unfermented dung for potatoes, which seems to me insuperable, and it is, that where grains of every kind find their way among the litter of courts, and it is impossible to have the straw threshed by the mill absolutely clean, or the seeds of weeds that may have been sifted out of the corn when cleaned, thrown upon the litter in the courts, though they ought to have been thrown away elsewhere; so long as these grains and seeds possess all their vitality, and that will escape destruction in unfermented dung, they will spring up among the potatoes, not in the intervals between the drills, where they might be removed by the horse-hoes in the process of cleaning the land, but actually among the potato-plants, having vegetated and grown along with them, and deriving as much nourishment fiom the dung as the potatoes themselves. I have frequently seen such an intermixture with potato plants at various places, and a very dirty and slovenly farming it makes. Having a piece of ground trenched from an old plantation, and being comparatively pretty clean, I was desirous of trying potatoes upon it for the first crop, and having no dung ready prepared for this extra space of ground, what was required was taken out of the court in which the cornbarn was situated, and the result was as I have just described. No doubt, the weeds thus sprung up. among the potatoes can be removed by the fieldworkers with the draw-hoe, when they are cleaning the crop, but the labor of removing large plants from that position, and especially when forced in growth by powerful manure, is considerable, and the weeding cannot be accomplished but by removing a considerable portion of the useful soil around the young potato plant. It is clear that it is much better farming to have no plants in this position to take away, than to have to remove them.

(1860.) On commencing the turning of a dunghill, it should be considered from which end it will be most convenient to take the dung and lay it on the land. On the supposition that the dunghill occupies the position explained in (1595), the end from which the dung will be carted away will be the head-ridge. After determining this point, the next subject for consideration is, whether the dunghill will be once or twice turned before it is applied, and this point is determined by the crop for which the dunghill is preparing-if for potatoes, only one turning is requisite, and two for turnips. As the first dunghill is intended for potatoes, it receives one turning, and it should be begun to be turned at the end farthest from the headridge. The unturned dung-heap slopes at both ends, as observed in (1601), but the turned dunghill should be made of the same hight throughout. To attain this end, the space occupied by the workers at the commencement, between the turned dung and the dung-heap, should be wider than at the middle of the heap, and the dung should be thrown to a greater hight than the side from which it is taken. The usual width marked off on the dungheap is 3 feet, which affords sufficient room for people to work in; but the first few spaces upon which the first divisions of the heap are laid, should be held narrower than 3 feet, until the desired hight of the turned dunghill is attained at the end. The effect of this arrangement is, as the turning approaches the middle of the dung-heap, where it is of the greatest $(325)$ 
hight, the space upon which the dung is turned upon will be more than 3 feet in width, and the additional width will be required near and at the middle, that the extra hight of the dung-heap there may be reduced to the level of the end. After the middle has been passed, the spaces turned upon should be gradually lessened in width toward the end at which the turning is finished, where, as at the commencement, the turned dung will have to be thrown to a greater hight than the dung-heap, to attain the medium hight of the finished dunghill. There is much more of nice management in following these particulars of turning a dunghill than at first sight may appear necessary, because the turned dunghill will not ferment equally throughout if it is of different hights. The greatest heat will be at the deepest part, where the dung will become comparatively short and compact, while at the shallowest parts it will continue crude and unprepared; and these different states of manure have very different effects on the soil. In ordinary practice, miscalculations are always made as to the uniform hight of dunghills, for they are lower at the ends than at the middle ; and if an endeavor is afterward made to equalize the hight, it is done by throwing high dung of the middle toward the ends, and the effect of this expedient is that no union takes place between the dung which was turned over in the regular way with what is afterward thrown upon it ; they ever after remain in different states, and rise differently to the graip when removed into the cart; and the middle part, besides, becomes trampled down and harder than the ends.

(1S61.) Laying these down as the rules by which dunghills should be turned, the mechanical part of the operation is done in the following manner: The people required to do this work are a man and a few fieldworkers, according to the size of the dunghills; and of this latter class, women are by far the best hands at turning a dunghill, because, each taking a smaller quantity of dung at a time upon a smaller graip than fig. 257 , the dung is much more intimately mixed together than when men are occupied at this work, for they take large graipsfull, and merely lift them from one side of the trench they are working into the other, without shaking each graipfull loose, or scattering it to pieces. Turning dung is not a cleanly work for women, their petticoats being apt to be soiled in the trench by the dung on both sides; but there is a plan which Berwickshire women adopt of keeping the bottom of their dress clean, which is to tie the bottom of the petticoat with the garters just below the knee, as long as they are at work. The man's duty is to cut the dung-heap into divisions of 3 feet wide across its breadth with the dung-spade, fig. 308, in the manner described in (1603). When the edge of the dung-spade becomes dull, it is sharpened with the scythe-stone. The drier portions of the dung are put into the interior of the dunghill, and when different sorts of dung are met with, they are intermingled in small graipsfull as intimately as possible. Each division of the dunghill is cut down and turned over to the ground before another is entered on, and when the ground is reached, the scattered straws, and earth that has been damped by any exudation from the dungheap, are shoveled up either with the broad-mouthed shovel, fig. 149, or the frying-pan shovel, fig. 176, and thrown into the interior. When strawropes are met with, they should be cut into small pieces and scattered among the dampest portions of the dung. Though the dung-heap is cut into parallel trenches, the dung from the top of one trench is not thrown into the bottom of the former, but rather thrown upon the breast of the turned dung, so as the turned dung may slope away from the work-penple. The utility of this form is, that when the dung is carting away it rises freely with the graip. When a dung-heap is thus turned over, and its form (326) 
preserved as it should be, it constitutes a parallelopipedon, and is a well finished piece of work.

(1862.) Unless much rain has fallen from the time the dung was led out of the court until the heap is turned, the dung will not be very moist, and not at all wet, but in a free workable state, with a slight degree of heat in it, and evaporation would be observable from it, were the air cold when it was turning. Very little moisture will be observed as having come from the heap. After this turning over, shaking up and mixing together, which should be finished in the same heap as quickly as possible, that the whole mass may have the same time to ferment, the operation being performed about a fortnight before the time of planting potatoes, in the latter end of April and beginning of May, the ordinary temperature of the atmosphere is then such as a considerable degree of heat may be expected to show itself in the dung in the course of a few days. There is no danger of this first fermentation proceeding to a great degree of heat, as the air is still cool at nights and the largest proportion of the heap consists of the dung of cattle, which is slow of fermentation at all times, and particularly in the early part of the season. The first external symptom that fermentation is proceeding in the heap is subsidence of its bulk, which in the course of a fortnight may contract one foot of hight. A perceptible smell will then arise from the dung, accompanied with a flickering of the air over it, which is occasioned by the escape of vapor and some of the gases, but chiefly, I apprehend, aqueous vapor. By inserting a walking-stick into the heap here and there, a heat considerably more than that of the hand will be felt, and by pushing this stick into different parts of the dunghill, the relative heat of those parts will be ascertained, and the greatest heat may be expected to be felt at the side opposite whence the wind blows, if there be wind, or even a breeze. The substance of the dunghill becomes more consolidated in consequence of the fermentation, and also more uniform; and a blackcolored liquid will be found in some degree to ooze from its sides. If the soil upon which the dunghill stands was soft when the dunghill was formed, the oozing will then be absorbed by it, and exhibit no wetness of surface ; but if the soil be firm, then the moisture will remain on the surface, and form small pools in the ruts of the cart-wheels or open furrows. All the leakage, even if collected in one pool, would afford but a trifling quantity; indeed much moisture cannot exude from a dung-heap derived from courts in which the cattle are duly supplied with abundance of litter to keep them both dry and warm. So much for the potato-dunghill.

(1863.) As to the turnip-dunghill, it receives a somewhat different treatment, but still conformable to the purpose for which it is destined. It is turned twice, and on this account it is begun to be turned at the opposite end from that for potatoes; but the same rules are followed in doing it as just described for the potato-dunghill, and it also is allowed to ferment for about a fortnight. At the second turning, which is given about a fortnight or ten days before the dung is used, the operation is commenced at the end at which the former turning terminated, and it is much more easily performed than the first, inasmuch as the substance is easier cut with the dung-spade, more free to separate and shake with the graip, and less care required to retain the rectangular figure formerly given to the dunghill. The weather at the second turning will be warm, and the fermentation, of course, rapid, so that apprehension may be excited that it will proceed to an injurious extent for the materials composing the dunghill. For raising turnips, however, there is little dread of the fermentation proceeding too far, as it is matter of experience that the more effete the dung is, the more valuable it is for the nourishment of the turnip plant, as is well known to (327) 
every turnip farmer. When in this valuable state heat has almost entirely left it, it has become like soft soap, and rises in lumps with the graip, and would almost cut into pieces with the shovel. It is, moreover, sappy, cohesive, greasy, and of a dark-hrownish black color. The larger the mass in which the dung in this state is found, the more valuable it is for turnips. To check rapid fermentation, a spitfull of earth around the dunghill thrown upon its top, will have that effect to a certain degree. It is supposed by many farmer's who grow Swedish turnips to a large extent, that dung of the same year cannot be transformed into this state in time for Swedish tumips, which ought to be sown before the middle of May; and in the temperature of ordinary seasons in Scotland at that time, the observation, I dare say, is correct. To obviate the want of so valuable an ingredient as old muck, it is the practice of some farmers to keep dung on purpose over the year. This would no doubt be a difficult matter on farms which depend entirely on their own produce for the manure applied on then ; but let the sacrifice be made for one year either to collect farm-yard dung from external sources, and form it into a dunghill for the succeeding year, or purchase other manure to a large extent for one year, to raise a crop of turnips, and reserve the farm-yard dung for the Swedish turnips of the next year, and the object is gained. I have known many farmers attain this object to a partial extent, but no one whom I have observed practice it to so great an extent as Mr. Smith, when he was at Grindon in North Durham, where he possessed the fine stock of Short-Horns that was admired by all who saw them. The dung of the year was made fit for white turnips, which were not sown for a month or so after the Swedes, and when both heat and time combine to bring it to a proper state for use.

(1864.) The subject of composts, when followed out in all its bearings, is an extensive one-for there is not a single article of refuse on a farm but what may form an ingredient of a compost, and be converted into a manure fit for one or more of the cultivated crops. At the same time there is great labor attending the formation of composts of every kind, as the materials cannot be collected together without horse-labor; and in summer, when those materials are most abundant, the labors of the field are most important, and to devote then the time required to collect them, would be to sacrifice part of the time that should be occupied in indispensable fieldlabor. I believe the most economical mode of forming composts is to collect materials at times when leisure offers for the purpose; and when they have accumulated in sufficient quantity in the space allotted for their use, they can be put together by the field-workers when not necessarily engaged in the field. This advice will not suit the temper of those who, wishing to obtain their object at once, would make the forming of composts, or any other thing they have in hand at the time, the principal business of the farm; but you should be very cautious in determining to execute any piece of work that diverts horse-labor from its legitimate pursuits. I speak on this subject in this manner from direct experience, for I was once strongly impressed with the benefits to be derived from using composts; and having plenty of materials at my command for making what I conceived should be good manure for the land, I persuaded myself that manure to any extent might be made on the farm. Having access to an unlimited quantity of rough bog-turf and peat, large quantities of dry leaves in autumn, black mould to some extent, and those usual refuse products of the farm-quicken and potato-haulms, with plenty of shell-marl and a stratum of fine clay associated with it, and, of course, lime-shells from the market-town at all times, I was in these circumstances perhaps fully more favorably situated for making composts than most farmers. But little did (328) 
I anticipate the labor I undertook. Two years convinced me that it was no child's play to collect together bog-turf, marl, lime, dry leaves and rubbish into one focus, and cart them all out again to the field or fields destined to receive the benefits of their composition. I put together the materials in the best manner I could devise or hear of, turned them at proper times with the greatest care, and certainly enjoyed the satisfaction of making a great deal of stuff apparently well adapted for the purpose intended; and in regard to its quality, I invariably found that the oldest made compost looked richest, most uniform in its texture, and most active in its effects, like old rotten muck; but notwithstanding these favorable appearances, unless very large quantities were applied, little benefit was derived from them; and even from 40 to 50 cart-loads to the imperial acre did not produce the good effects of 12 cart-loads of good muck. I could have managed the manual part of the work to any extent, for hired laborers could have been found to do it by piece-work, and the bog-turf was obtained on that condition; but the horse-labor was overpowering, for every acre thus required a cartage of 80 to 100 loads to provide no more than sufficient manure for it. An extra pair of horses could not have overtaken the additional labor thus imposed on the horses, and to incur that expense continually for the problematical good to be derived from the largest source of materials I possessed, namely, grassy-bog-turf, and peat-turf, was more than the most sanguine farmer is warranted in risking.

(1865.) It may, perhaps, prove interesting to relate a few of the composts I made with those materials. 1. The first was a compound of peatturf and lime-shells. The turf was wheeled to the margin of the bog on hard land, and allowed to lie some weeks, to drip the water out of it, and to make it lighter for cartage. The lime was mixed in the proportion of 1 cart of lime to 27 of turf. After the compound was twice turned, the mass became a fine greasy pulp in the course of a few weeks in spring and the early part of summer-so greasy that no one could walk on it without slipping. It was applied to good turnip land, to raise turnips, and the rule adopted to determine the quantity requisite for an acre was, in the first place, to fill the drills with it, and the quantity required to do this was from 30 to 40 double cart-loads per acre. The crop of white turnips was only tolerable, and certainly not nearly equal to what was raised in the same field with 12 loads of farm-yard dung, while the field became troublesomely covered with the bog-thistle, as also the common field-thistle, and a few of the bur-thistle, the lime not having been in sufficient quantity to destroy the vitality of the thistle-seed contained in the turf, though the degree of heat created in the mass to reduce it to a pulp was considerable. 2. Another compost was made of peat-turf and farm-yard dung, with a sprinkling of lime, as directed by the late Lord Meadowbank in his celebrated treatise on that subject, and which you may consult.* The effect produced from this was better than the former compost, but still not equal to the usual quantity of dung. 3. A mixture of lime and black mould, on some headridges that had too much earth accumulated upon them, was only applied before the land was drilled up and dunged for turnips, to thicken the soil ; and labor such as this is not thrown away. 4. I tried a compost of rape-cake and earth, the compound was not proportioned, but enough of the cake was sprinkled on while the earth was turning over, to bring a very brisk fermentation to the mass. After the heat had nearly subsided, it was applied for turnips, and with much success. I may mention that no account

- Meadowbank's Direction for Preparing Manure from Peat, edition of 1842. (329) 
was taken of the exact number of cart-loads per acre of this or any other of the composts that were applied, such particulars being seldom noted by farmers, who are chiefly guided hy judgment in the quantity of manure which any crop should receive. 5. Shell-marl and bog-turf, when mixed, produced no heat, and of course were never reduced into a uniform mass, for without the agency of heat it is impossible to make any compost homogeneous. 6. The bog-turf burnt in the form of kilns, produced ashes which varied much in their specific gravities; those of a white color being light and ineffective as a manure, while the red color were heavy, earthy in appearance, and well suited to raise turnips; but I was unable to distinguish beforehand which turf yielded the white and which the red ashes. The trouble attending the casting of the turf in the bog, wheeling it to the side, exposing it to the air to dry, and afterward either burning it to ashes, or carting it away for compost, was much greater than the quantity of ashes obtained, or the quality of compost formed would remunerate. 'Two years' labor with this concoction of materials were sufficient to give me a distaste for the business, and at length I dropped it, and preferred going into the neighboring towns to purchase street and stable and cow-house manure, and bone-dust. These never disappointed me, and the eating off of the turnips which they raised every year with sheep, soon put the soil in a fertile state. Notwithstanding this resolution, I made a point every year of making up a large compost-heap of the quicken gathered from the fallow land, as it was preparing for the turnips-of the potato-haulms as they were harrowed together-and of the dried leaves in autumn, which would otherwise have blown about the lawn and shrubberies-and of any other refuse that could be collected together on the farm. These with the assistance of a little fresh horse-dung, and such water as the liquid-manure tank, which was situate in the compost court, afforded, a compost was formed every year, which assisted in extending the boundaries of the turnip crop; and if that portion of the crop was not always heavy, the greater or less proportion of the turnips eaten off by sheep enabled it to produce its share of the succeeding corn crops and grass, while, at the same time, the soil was thickened by the mould reduced from the compost. 7. Any of the animals that fall by disease, when their carcasses are subdivided, and mixed in a large quantity of earth powdered with a little quicklime, will make a compost far superior to any of the preceding vegetable materials, for raising turnips, especially Swedes. 8. The produce of privies, and pigeons' dung, as well as the dung of fowls from the hen-houses, form excellent ingredients for putting into the tank of liquid manure to melt, and afterward to distribute it over a compost. 9. Of late years saw-dust, which was long considered a useless article, and which may be obtained in quantity on soine farms where saw-mills are at work, is now rendered useful in compost by being mixed with farm-yard dung, fermented to a considerable degree of heat, and then subdued with water;* and it may also be mixed with $\frac{1}{10}$ of its proportion of lime and road scrapings, and turned and kept in compost for 3 years.t Such a compost has raised crops of turnips, as evidenced by Mr. William Sim, Drummond, Inverness-shire, and Mr. H. H. Drummond of Blair-Drummond, Perthshire. 10. Spent tanner's-bark, when laid down for a time on the road around the steading and trampled under foot and bruised by cart-wheels, and then formed into a compost with either dung or lime, and allowed to stand for a consiclerable time, might be rendered into good manure for turnips. Saw-dust and tanner's bark, or refuse of the bark of fir-trees, will not bear the expense of a long 
carriage; but where a supply of them is near at hand, their decomposition, though occupying a long time to effect, is worth the trouble. 11. In the vicinity of villages where fish are cured and smoked for market, refuse of fish heads and guts, or liver and oil refuse, make an excellent compost with earth. Near Eyemouth and Burnmouth, on the Berwickshire coast, 30 barrels of fish refuse, with as much earth from the head-ridges as will completely cover the refuse, is suffcient dunging for an imperial acre. The barrel contains 30 gallons, and 4 barrels make a cart-load, which sell for 1s. 6d. per barrel. From 400 to 600 barrels may be obtained for each farm in the neighborhood in the course of the season. 12. Whale-blubber when mixed with earth forms a good compost for turnips. As this is a most caustic substance in a fresh state, it should be compounded with a large proportion of earth, and turned over and kept for at least 3 years until the compost becomes inert. I have seen a blubber compost, 2 years old, applied as top-dressing on grass, burn up every plant by the roots, but after it becomes apparently effete it raises excellent turnips. 13. I have heard of a compost being made of whin and broom cuttings and earth, 3 loads of earth to one of the cuttings being mixed together and watered for 2 or 3 days, and to remain untouched for 8 or 10 days more, when it is turned and again allowed to rest for 10 days, when it is fit to be applied as manure. The cost of making this compost was estimated at 2s. per cartload, and it is said to have raised wheat and oats well. But the fish refuse which I noticed before is to be obtained at some places at $2 \mathrm{~s}$. a load, and there can be no comparison in the relative value of it and the cuttings. You thus see how endless is the subject of composts for manure; and it is obvious, from what has been said, that the kind of compost which you may make depends entirely on the nature of the materials which can be supplied in your immediate neighborhood.

(1866.) So numerous are the articles which are now presented to the notice of the farmer in the name of manures, that but to notice each shortly would occupy many pages; nor is it incumbent on me to describe them at present, as the greatest number have yet to establish a character for themselves by repeated experiments in successive years. This will, no doubt, put some of them to too severe a trial; but it will be necessary, inasmuch as they may not be able in the second year to confirm the pretensions they assumed in the first. I remember of a compound which became celebrated some years ago, after one year's trial, for the turnips raised with it were really good, and could have stood a comparison with those grown by the best muck of the farm; but, alas, in the second year, even, the substance was almost a complete failure-not that the original composition would have failed in the second any more than it did in the first year, but the demand for it in the second year had probably increased so much in consequence of the success attending its use in the first, that the manufacturer, to supply the market with the desired quantity, had taken the liberty to injure its quality; and the consequence to him was exactly what he himself might have anticipated: the farmer lost faith in the manure and distrusted the manufacturer. I was induced by a flaming advertisement which appeared constantly in the papers at the time, to try a compound manure; but in this substance I was only once deceived" once and for aye," for in truth it had no better effect. in raising turnips, for which it was specially recommended, than black mould which was tried alongside of it. Such results as these should induce caution in the use of compound manures, the composition of which is unknown to you; still it is right to try them, as some one may turn out to be a really valuable substance; but the trials should be made at first on a small scale, if 
you are among the first to try it; but if you hear of others having succeeded, then, of course, your confidence may be yielded to it with the greater safety. To make known whether any new substance has succeed. ed or not, I think it is incumbent on every farmer to do so for the sake of his brother farmers, and there are now many publications which devote themselves to the promulgation of rural practice. But I have been of opinion for many years that no farmer should purchase any compounded substance advertised as a manure, unless it happens to be a natural substance; for, even in the hands of honest men, compounds may fail to continue to afford the satisfaction they once did, as carelessness in compounding an article that is much in demand, and of which large quantities are made at a time, is a very natural and not an uncommon consequence. Besides, failure in a case of this kind is a very serious matter to the farmer. It is not merely the value of the article itself which constitutes his entire loss, though even that may be considerable, but the consequence to fut ure years. The crop immediately dependent on the manure is not only deficient, but the remaining part of the deficient crop is aluays of inferior quality. This is an invariable effect in every crop; and its converse being equally true, that a full crop is always one of fine quality, and not only this, but every crop in the course of the rotation is affected by the state of the one which directly receives the manure, that is, if the fallow crop, as the turnip crop is called, be deficient and of inferior quality, the succeeding ones will not exhibit that vigor of growth by which a full fallow crop is invariably succeeded. I do not pretend to explain the cause of this result, nor have I ever seen it attempted to be explained, but as a fact it is indisputable, and I have heard the fact noticed by many farmers. You thus see how very much it is for your interest to be assured of the efficacy of every manure that you are to apply. To be assured of their efficacy, it has been recommended to analyze every manure before it is applied, in order to ascertain whether it is really the article it is given out for. $\mathrm{As}$ an instance of the necessity for such analysis, I will quote a case or two adduced by Mr. Madden. He says: "Three different specimens of nitrate of soda were submitted to analysis, when they were found to contain respectively 14, 25 and 26 per cent. of common salt. Now these specimens were purchased from extensive dealers in the article, and were contained in the bags in which it was imported, so that we have no reason for suspecting the honesty of the retailer; and it follows, therefore, that this shameful amount of adulteration must be effected prior to its being shipped for Britain. I would desire that you bear in mind, however, the fact that the presence of common salt, even to this enormous extent, may be natural, but yet the imposition upon the British farmer is equally glaring, whichever be the case, as will be seen by the following statement regarding saltpetre. This article, likewise, contains common salt, though in much smaller quantities; but in this instance the fact is not attempted to be concealed. Every cargo is analyzed at the India House before it is sold, and the per centage of salt marked upon it; and the amount of salt is deducted from the lot purchased. For example, suppose the saltpetre contained 10 per cent. of salt, if the purchaser buys $100 \mathrm{cwts}$. he receives the 100 , but only pays for 90 . Hence, therefore, there is no deception; but we would ask how it happens that the same is not done with the nitrate of soda, and that those specimens containing from 14 to 26 per cent. of salt, should all be sold at one and the same price? Why, if justice were done in this case, the specimen containing 26 per cent. should have sold at 22s. in place of $25 \mathrm{~s}$, if that be the fair price for the lot containing 14 per cent.; and if, on the contrary, 25s. is the proper price for the pure ar(332) 
ticle, these three lots should have sold respectively at $21 \mathrm{~s} .6 \mathrm{~d} ., 18 \mathrm{~s} .9 \mathrm{~d}$, and 18s. 6d. per cwt." I may here mention, casually, in regard to the presence of salt in both the saltpetre and nitrate of soda, that it must be natural, and not placed there by human agents; for common salt in the countries whence these articles are imported, is much higher priced than the articles themselves. Strictly in connection with the purity of manures is the price demanded for them of the farmer. If other articles are charged in the same proportion as saltpetre is, as is shown by the following statement of Dr. Madden, the profits of the manure-dealer must be much greater than those of the farmer, even after all the risk he runs in using manures unknown to him. "Before leaving this interesting subject," continues Dr. Madden, "I would make one other observation, viz., concerning saltpetre. I find by reference to the most extensive purchasers of this article, that it sells at the India House in 5-ton lots at a price varying from $25 \mathrm{~s}$. to $29 \mathrm{~s}$. per cwt. whereas it is retailed to farmers at the enormous charge of from $50 \mathrm{~s}$. to $55 \mathrm{~s}$. For example, I analyzed a specimen sold to a farmer at $55 \mathrm{~s}$. per cwt., and detected 2 per cent. of salt in it; whereas another specimen, purchased at the India House at 28s.6d.per cwt., contained less than $1 \frac{1}{2}$ per cent. of salt; and, be it remembered, the lots were purchased at nearly the same time, during which there had been little or no fuctuation in the market." In a note, Dr. Madden mentions the practice of an extensive dealer in nitrate of soda in England, that he examines whatever he buys, and finds the average amount of salt to be from 8 to 10 per cent., and that he rejects as "useless stuff" any lot containing over 13 per cent.* The purity of so simple a substance as saltpetre or nitrate of soda can at once be ascertained by analysis, but the case is rather different with many of the compounds at present offered to the acceptance of farmers; their analysis can hardly prove so satisfactory. If experiments are to be made with substances extraneous to the farm, I think that chemist would act most judiciously who would suggest a mixture of a few of those simple substances which he conceives would benefit any particular crop, or the whole series of crops usual through a rotation, rather than any compound, however high sounding. A farmer can at once see what he is about when he himself forms a compound of various simple substances, differently proportioned, as suggested to him by an intelligent chemist. He can purchase each of these in as pure a state as they usually are made by practical chemists, who make them on a large scale. He himself does not know what may be the result of their application; he only expects results such as he is led to expect from the information given him by the chemist; but, working as he does, even in the dark, when he works under the guidance of a scientific man, who has no interest in the materials he recommends, he has confidence in what he is about to undertake, because he considers himself as his own agent in the business, purchasing simple ingredients, the nature of which is known to every one, and the commixing of which has been performed under his own eye. Far different is the case when he employs an article the purity or impurity, the efficacy or inefficacy, of which is equally unknown to him, and in the application of which he cannot anticipate a single result. Till some such plan is established for the use of extraneous manures, their results will be determined by mere chance, and the confidence of the farmer in them will fluctuate every year as the result turns out favorably or otherwise, till at length the use of them will be abandoned with contempt. All natural substances used as manure, such as bones, gypsum, guano, nitrate of soda, \&c., are not the objects of the foregoing remarks; but

* Prize Essays of the Highland and Agricultural Society, vol. xiv. 
should it be objected that the substance of the compound manures, being themselves natural compounds, cunnot be sold as simple substances, it may he answered that all the natural compounds which they contain, by being rendered dry or concentrated, could be sold as natural compounds, which may perhaps become equally valuable as others; but as long as they are mixed up with other matter, no one can say whether the valuable or valueless materials in them predominate.

(1S67.) A simple list of the various ingredients at present in the market for the use of farmers will puzzle you as to the choice you should make among them. The names and prices are taken from the Mark-I ane Express of 24th April, and the New Farmers' Journal of 8th May, 1843. They are as follows:

Animalized black, $£ 33$ s, to $£ 35$ s. per ton at Dunbar.

A gricultural salt, 348. per ton.

Chie-fou, $21 \mathrm{~s}$, per cwt.

Clarke's desiccated compost, £3 128. 6d. per hhd., suflicient for 3 acres.

Chloricle lime, $28 \mathrm{~s}$. per cwt.

Daniell's new Bristol manure, 8s. per qr.

Graves, f6 10s. per ton.

Gypsum at the water-side, $32 \mathrm{~s} .6 \mathrm{~d}$. perton: land and housed, $38 \mathrm{~s}$. to $42 \mathrm{~s}$. per ton, according to quantity.

Grimwade's preparation for turnip-fly, 108.6d. per packet, sufficient for 3 acres.

Guano, 10s. to $14 \mathrm{~s}$. per $\mathrm{cwt}$, according to quality.

Hunt's bone-dust, $18 \mathrm{~s}$. per $q \mathrm{r}$.

Hunt's half-inch bone, 16s. per qr.

Hunt's artificial guano, $£ 8$ per ton.

Hunt's new fertilizer, $13 \mathrm{~s}$. 4d. per qr.

Lance's carbon, $12 \mathrm{~s}$. per qr.

Lance's humus, 14s. per qr.

Liverpool Abbattoir Company's animalized manuring powder, $£ 210$ s. per ton.

Muriate of ammonia, $24 \mathrm{~s}$. per cwt.

Muriate of lime, 12s. per cwt.

Nitrate of soda, $18 \mathrm{~s}$, to $18 \mathrm{~s}$. $6 \mathrm{~d}$. per cwt., duty paid.

Nitrate of potash (saltpetre) 26s. 6d. per cwt.

Owen's animalized carbon, 25s. per ton. free on board at Copenhagen.

Potter's artificial guano, 15s. per cwt.

Poittevin's patent disinfected manure, 13s. 6d. per qr.

Poittevini's highly concentrated manure, $30 \mathrm{~s}$. per qr.

Petre salt, 4s. per cwt.

Kape-dust, $£ 7$ to $£ 8$ per ton.

Hape-cake, $£ 610$ s. to $£$ t per ton.

Rags, $£ 4$ to $£ 410$ s. perton.

Soda-ash, 14s. to $16 \mathrm{~s}$.

Sulphuric acid, $2 \frac{1}{2} \mathrm{~d}$. per $1 \mathrm{~b}$.

Sulphur for destroying worms in turnips, 16s. per cwt.

Soap-ashes, 10s. per ton.

Sulphate of soda, 7s, $6 \mathrm{~d}$. per $\mathrm{cwt}$.

Sulphate of ammonia, $18 \mathrm{~s}$. per cwt. at Dundee.

Trimmer's compost for clover, wheat and turnips.

Urate of the London Manure Company, $£ 5$ per ton.

Watson's granulated compost, 10s. per cwt

Wolverhampton imperial compost, (Alexander's,) 12s. per qr., subject to carriage to London, or forwarded from Wolverhampton. Willey dust, $£ 448$. per ton.

Wright's alkalies, $28 \mathrm{~s}$. to $42 \mathrm{~s}$. per cwt.

The following are the weights per bushel of some of the substances enumerated above :

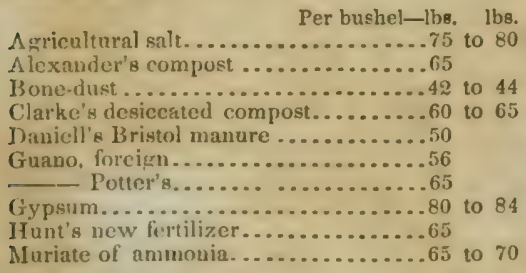

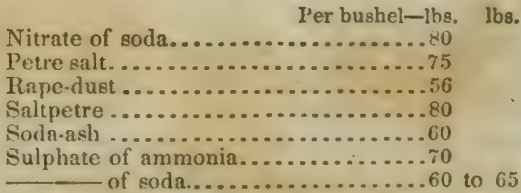

Trimmer's compost for clover, whent

and turnips....................60 to 65

Urate...........................5 50

(1868.) To reduce farm-yard dung to the saponaceous state recommended and described in (1863), is contrary to the theory propounded by non-practical writers; and for the ordinary manuring of the farm, the recommendation, it may be acknowledged, is carried to an extreme; but for the purpose of raising a good crop of turnips, and especially of that invaluable kind the Swe. dish, it is bevond dispate that no manure, of whatever kind, is so congenial to their constitution as well-made old muck. Until, therefore, a substitute is found for this ingredient, equal to it in efficacy, and as attainable, it will be made and applied by every farmer who is desirous of raising a good crop ot Swedish turnips. The recorded opinions of Sir Humplory Davy on this subject, though oft referred to to caution practicul men against hisconclusions, nevertheless deserve examination, because of the common-sense like manner in which he states his views, and on this account these should be the more explicitly refuted; and that they will one day be refuted I have no doubt, for I am persuaded that where practice and theory disagree, theory will be found to be in the wropg. In regard to the general primciple of the action of vegetable manures, he says: "There can be no doubt that the straw of different crops, inmediately plowed into the ground, aflords nourishment to plants. but there is an objection to this method of using straw, from the difficulty of burying long straw, and from its rendering the husbandry foul." You observe at once, bere, that the theory 
of the use of clean straw as a manure is objected to solely on the score of a difficulty of using it in that state in practice. If such an objection may be valid against the use of straw, so may it be against the use of unfermented dung. If practice is to be respected in this instance, why not in the other; but Sir Humphry proceeds to render the straw more manageable when he says"When straw is made to ferment, it becomes a more manageable manure ; but there is likewise, on the whole, a great loss of nutritive matter. More manure is perhaps supplied for a rough crop; but the land is less improved than it would be supposing the whole of the vegetable matter could be finely divided and nixed with the soil." Here the remark suggests itself, that if straw is allowed to be fermented because of its being more manageable in that state for prac. tice, so might dung be allowed to be more fermented for the same reason. If deference is paid to practice in one case, why not in the other? To obviate the inconvenience of burying long straw, Sir Humphry recommends it to be chopped thus: "It is usual to carry straw that can be empioyed for no other purpose to the dunghill to ferment and decompose; but it is worth experiment whether it may not be more economically applied when chopped small by a proper machine, and kept dry till it is plowed in for the use of a crop. In this case, though it would decompose much more slowly, and produce less effect at first, yet its influence would be much more lasting." I have no doubt that chopped straw would raise potatoes on strong clay land, and when applied on summer-fallow a good crop of wheat would also be raised; bat in all free soils, straw, in whatever state, whether long or chopped, would oaly keep the soil so open as to let in drouth. retard vegetation, and it would be found lying at the bottom of the furrow in an inert state, as useless, in short, as fire.fanged straw. In regard to the fermentation of farm-yard dung-which is a composite manure-Sir Humphry admits the propriety of its undergoing a slight fermentation. as thus: "A slight fermentation is uudoubtedly of use in a dunghill; for by mears of it a disposition is brought on in the woody fibre to decay and dissolve, when it is carried to the land or plowed into the soil, and woody fibre is always in great excess in the refuse of the farm." So that fermentation in the dunghill is necessary to the dissolution of woody fibre, and as woody fibre is in great excess in the refuse of farms, it follows that fermentation ought to be generally allowed in dung. hills, so that the question of fermentation here is only one of degree. "Too great a degree of fermentation is, however, very prejudicial to the composite manure in a dunghill; it is better that there shonld be no fermentation at all, before the manure is used, than that it should be carried too far. The excess of fermentation tends to the destruction and dissipation of the most "sefinl part of the manure; and the ultimate results of this process are like those of combustion." If it is here meant to convey the idea that fire-fanged dung is fermentation to excess, the idea is correct, for I suppose no farmer thinks otherwise; bul that the usual degree of fermentation allowed in dunghills renders the manure useless, is inconsistent with experience. It is quite true, as Sir Humphry says, that "it is a common practice among farmers to suffer the farm-yard dung to ferment till the fibrous texture of the vegetable matter is entirely broken down, and till the manure becomes perfectly cold, and so soft as to be easily cut by the spade ;" but so far fiom the most useful part of the manure being dissipated when the dung attains this state, experience assures us that the finest Swedish turnips cannot be raised with dung in a less elaborated state; and this conclusion is inevitable, that if the most valuable part of the manure is dissipated by the fermentation usually allowed in dunghills, that most valuable part is not required for raising the best crop of Swedish turnips, and that being the case, it is unnecessary to trouble ourselves to retain it: But what are the best parts of manure? "During the violent fermentation," says Sir Humphry, "which is nacessary for redncing farm-yard manure to the state in which it is called short muck, uot only a large quantity of fluid, but likewise of gaseous matter, is lost; so much so that the dung is reduced one-half to two-thirds in weight; and the principal elastic matter disengaged is carbonic acid with some ammonia; and both these, if retained by the moisture in the soil, are capable of becoming a useful nourishment of plants." No doubt both the fluid and gaseous products of decomposing vegetables perform important functions in the economy of Nature, but if they escape while dung is preparing in the best state for use according to invariable experience, it follows, as an inevitable consequence, that these products of fermentation are not requisite. in conjunction with short muck, to raise a crop of turnips. They may be useful ingredieuts for other purposes, and at other times, but it is clear that the tarnip crop can be raised to a better state without thau with them. Why, therefore, attempt to retain their presence on the particular occasion? **

(1869.) Whether a more scientific mode of forming dunghills, in consonance with practice, will ever be discovered, I cannot pretend to say; but, as there seem no bounds to the discovery of science in other arts, we should not limit its powers of application to the art of husbandry. Experiments are at this moment in progress on the very subject of the formation of farm-yard dnnghills, in connection with which I may mention the distinguished name of Professor Henslow, of Cambridge, who, in a series of letters addressed to the farmers of Suffolk, and which have appeared in the public prints, suggests the propriety of their performing experiments to ascertain whether the ammonia which escapes in the gaseous state as a carbonate of ammonia may not be retained in dunghills by the instrumentality of gypsum? Should the event prove successful, we may perhaps expect to hear of important improvement in the management of ordinary dunghills. Till the experiments are tried, which time alone can do, I am happy in placing before you the opinion of so distinguished a philosopher as Professor Sprengel on the value of old dung, when he says in his valuable essay on manures, which ought speedily to appear in an English dress, that "the longer the dung is left in the dunghill, the more advantageous will he the preparation of the compost, because the ammonia, disengaged from the dang and arine in it, will become chemically combined with humic acid." It will be observed that these sentiments bear a strong analogy to the subject which engages the attention of Professor Henslow. As a satisfactory conclnsion to the theoretical part of this subject, I give vou the following explanation of the fermentation of manure, and its effects, by Dr. Madden.- [Whenever dead organic matter, either animal

* Davy's Agricultural Chemistry, edition of 1839.

(335) 
or vegetable, is exposed to air in a moist state, it absorbs oxygen, which, by entering into combi. nation with its carbon, destroy's its origjual composition, and gives rise to the production of various new compounds, which in their turn suffer decomposition by means of fresh supplies of oxygen being absorbed, and so on in a continued aeries until the whole mass is reduced to chenical compounds of sach stability as to resist the farther action of oxygen under ordiuary circumstances.During this series of changes, the various solid compounds are converted first into fluid and then into gascous producta : which latter, by escaping into the air. become lost. Chemists are much divided as $t 0$ hat precise anount of decomposition is requisite to render organic matter in a proper state to become food for plants; all agree that decomposition must bave commenced, some maintain that it must be completed. My own belief, founded on extensive observation and not a few experiments, is, that all the mroducts of decomposition, in every stage, are available as food for plants, provided they are cilher liquid or capable of dissolving in water. Theme observations will, of course, regulate $\mathrm{as}$ in the management of the "midden." Whenever any moist organic matter absorbs oxygen, its chenical union with its carbon gives rise to an increase of temperature, which increase enables the surrounding portions to absorb oxygen more rapidly than they otherwise would do; these parts in their turn become heated, and thus the influence extends through the entire mnss-the anoum of heat being proportionable to the size of the mass, its degree of moisture, and quantity of air contained within its interstices. By careful management, you can retard or accelerate the fermentation of your "midden" to almost any extent, from scarcely any change taking place, to so great a rapidity as to endanger the whole taking fire from the heat evolved. The most profitable way for dung to ferment is slowly but steadily, so that by the time it is required for use, it will readily cut with a spade like soft cheese, and exhibit a uniform rich brown color, and emit no smoke unless the air be very frosty. During fermentation, the azote contained in the various constituents of the dunghill unites with bydrogen, and forms ammonia or hartshorn, which, being very volatile, is apt to escape with the watery vapor and other gaseous products of decomposition. Various means have been of late recommended to prevent this, but none of them appear to me at all satisfactory, and I believe have not as yet given very satisfactory results when applied to practice. The best condition for a "midden" to be in is when it contains a sufficiency of water to cut moist, and yield a little liquid by pressure, but not enough to run from it spontaneously; this is easily effected by draining the "midden" etance. if in the court, so that all superfluous moisture runs off into the drains, which, of course, must lead to the liquid manure-tank, from which in dry weather it should be pumped up and scattered uniformly over the "midden"; in this state of moisture, scarcely a perceptible quantity of ammonia is lost, as it all remains in solution; and I believe that this plan will be found in all cases to be superior to every otber bitherto devised for preserving farm-yard dung.-H. R. M.]

\title{
17. Planting potatoes.
}

\author{
"L the potato plat \\ Should now be delved, and, with no sparing hand, \\ Manured: \\ The dibbling done, the dropping of the chips \\ Is left to little hands, well pleased to lend \\ Their feeble help: \\ Graнax.
}

(1870.) The potato crop is cultivated on what is called the fallow-break or division of the farm, being considered in the light of a green or ameliorating crop for the soil. Following a crop of grain, whose stubble is bare in autumn, the soil is plowed early in the season, that it may receive all the advantages which a winter's sky can confer it in rendering it tender; and as potatoes affect a dry and easy soil, the piece of land intended for them may he plowed and even partially cleaned in spring. Time for cleaning is very limited in spring, and on this account the cleanest portion of the fallowbreak should be chosen for the potatoes to occupy. The stubble will either have been cast, fig. 135, in autumn, or clove down without a gore-furrow, fig. 140 , according as the soil is strong or free; and having been particularly provided with gaw-cuts, to keep the land as dry as possible all winter, for a crop which requires early culture in spring, as potatoes do, it is prob. able that the land thus appropriated will be able to be cross-plowed, fig. 312 , soon after the spring wheat and beans are sown, if either is cultivated on the farm, and if not, the cross-plowing for potatoes constitutes the earliest spring work after the lea. After the cross-furrow, the land is thoroughly (336) 
harrowed a double tine along the line of the furrow, and then a double tine across it, and any weeds that may have been brought to the surface by the harrowing are gathered off, along with any isolated stones that would sppear unseemly on the surface. If the land is clean, it will be ready for drilling; if not, it should receive another plowing in the line of the ridges, that is, across the cross-furrow, by being ridged up in casting, and then again harrowed a double tine along and across, and the weeds again gathered off. Should the surface be dry after the harrowing which succeeded the crossplowing, and the weather appear not likely to continue dry, the grubber will be a better implement to give a stirring to the soil than the plow, as it will still retain the dry surface uppermost, and it will also bring up to the surface any weed that would entangle itself about the implement. The two-horse grubber is an excellent implement for stirring the soil when it has become somewhat solid by rain or by lying untouched for a time. The time occupied in doing all this, as the weather will permit, may be about a month, that is, from the middle of March to the middle of April, when the potato crop should be actively preparing for planting. As the land cannot receive more plowing in early spring than it should, to stir the land a little more, and make it still more tender, the drills first made for securing the manure of the potato crop should be set up in the double mode, as particularly described in (1740) and (1741).

(1871.) The state of the potatoes, when taken out of the pit, will depend on the temperature of the weather in spring, and also on the state they were in when pitted in autumn. In cold weather, they will not be much sprouted in the pit by the time they should be planted; but should they have been heated at all, in consequence of the wet state in which they had been pitted, or the unripe state in which they had been taken up ard pitted, they will be sprouted independently of the temperature of the external air. When the sprouts are long, they should be removed, as it will be impossible to preserve them entire; but if the quickening of the tubers be mere buds, these can be preserved; and they are of advantage, inasmuch as they will push above ground several days sooner than sets that are not sprouted at all. It should be kept in mind, however, that sets with long sprouts, and sprouted sets which have been long kept after being taken out of the pit until planted in the field, are apt to set up puny plants. In selecting tubers, therefore, to cut into sets, the middle sized that have not sprouted at all, or have merely pushed out buds, will be found the soundest; and wherever the least softness or rottenness is felt, the tuber's should be entirely rejected, and even the firm portion of these should not be used as seed. The small potatoes should be picked out and put aside to boil for poultry and pigs. Those potatoes which are not required for seed, but are nevertheless firm and of good size, whether intended for sale or for use in the farm-house, should be placed in an outhouse, until disposed of or used-the apartment having, if possible, an earthen floor, and kept in the dark, though with access to the air, and water thrown upon the potatoes occasionally, to keep them crisp, but not at all moist, and turned carefully over by hand, when the sprouts are taken off.

(1872.) To insure the vitality of the sets in the ground, even when planted under adverse circumstances, it has been recommended to dust them with slaked lime immediately on the potatoes being cut; and the sap, on exuding from the incised part, will then be immediately absorbed by the lime, which, on forming a paste, incrusts itself on the incised surface.* Others recommend to dip the sets in a thick mixture of lime and water, which, on drying, envelops them in a coating of plaster. This lat-

* Prize Essays of the Highland and Agricultural Society, vol, xiv.

(385) ......13 
ter plan would be attended with some trouble, and seems to offer no ad. vantage over the former, which is easily done with a riddle, as the sets are cut, and can do no harm at all events. It has also been recommended to sprout the sets prior to planting them, in order to test their vitality. The plan suggested is to spread the sets on the ground, in a part of the field they are to be planted, 2 or 3 inches thick, to cover them with a thin coating of earth, and then to water the earth frequently with a watering-pan, until they are all sprouted, taking care to have them sprouted by the time the land is manured to receive them. They are then to be carefully placed in baskets, and set in the ground with the sprouts uninjured. This process of sprouting is said to accelerate the vegetation of the sets in the drill at least 14 days. If potatoes that have sprouted in the pit are cut into sets and immediately planted, they should be in as favorable a state to grow in the drill as when subjected to this process; and however easily it may be conducted on a small scale-for garden culture, for example-I consider the suggestion as unfit to be practiced on a large scale on a farm; and especially as sets which are in a dry state when planted are found to come up in the drill more equally, provided their vitality has been preserved.Small whole potatoes make good seed. One season, happening to have fewer sets cut than would plant the ground the dunghill allotted to the potato-land manured, some of the small potatoes, which had been picked out for the pigs when the sets were cut, were planted to finish the land with potatoes, and the crop from them was better than on the rest of the field.

(1873.) Having drilled up as much land as will allow the planting to proceed without interruption, and having turned the dunghill in time to ferment the dung into a proper state for the crop, and having prepared the sets ready for planting, let us now proceed to the field, and see how operations should be conducted there, and in what manner they are best brought to a termination. The sets are shoveled either into sacks like corn, and placed in the field at convenient distances, or into the body of close carts, which are so placed on the head-ridges as to be accessible from all points. When the drills are short, the most convenient way to take the sets to the field is in a cart, as the distance to either head-ridge is short; but, when the drills are long, sacks are best suited for setting down here and there along the middle of the land. A small, round willow basket, with a how handle, should be provided for every person who is to plant the sets; and, as a considerable number of hands are required for this operation, boys and girls may find employment at it, over and above the ordinary fieldworkers. A frying-pan shovel, fig. 176, will be found a convenient instrument for taking the sets out of the cart into the baskets. Carts yoked to single horses take the dung from the dunghill to the drills. A dung-hawk or drag, with 2 or 3 prongs, and about 5 feet long in the shaft, such as fig. 343 , is used by the steward for pulling the dung out of the carts. Boys,

Fig. 343.

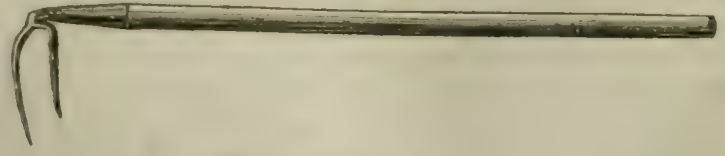

THE DESG-HAWR OR DRAG.

girls or women are required to lead the horse in each cart to and from the dunghill to the part of the field which is receiving the dung. The plowmen, whose horses are employed in carting the dung, remain at the dung(386) 
hill, and, assisted by a woman or two, fill the carts with dung as they return empty. One man, the grieve or steward, hawks the dung out of the carts, and gives the land dung in such quantity as is determined on beforehand by the farmer. Three women spread the dung equally in the drills with the small graips, while a fourth goes before and divides it into each drill as it falls in heaps from the carts. If the drills have all been made before, no plow is employed in that way while the other operations are proceeding; but plows are required to split in the drills and cover in the dung and sets as fast as the planting is finished. All these materials of labor being provided for their respective purposes, let them start to work; and, to render your conception the better of the manner in which they should he arranged relatively to each other, I have contrived the annexed cut, fig. 344, which shows you at once how all the people and horses are employed.

Fig. 344.

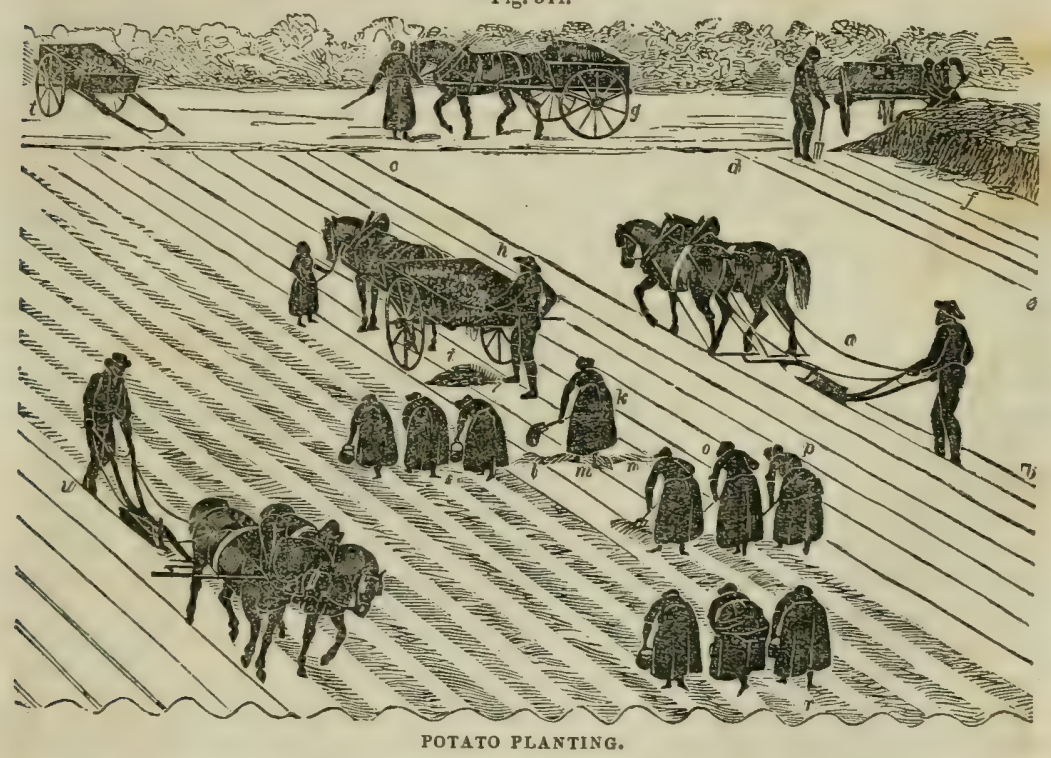

(1874.) The first thing to be done is to back a cart to the dunghill, and fill it with dung; and in doing this the carts are usually not quite filled, and the dung is heaped as near the back end of the cart as is convenient for the draught of the horse, that the man who hawks it out may have the less labor. The carts are filled, and the bottom of the dunghill shoveled clean by the plowmen whose horses are employed in carting the dung; and whose number in the figure is 2 , there being 3 carts employed at the dung: the men are usually assisted by a field-worker or two, in order to keep the carts a shorter time at the dunghill. Whenever the load is ready, the driver $c$ starts with the horse and cart $g$, and walks them along the undunged drills, until the horse meets the steward, who places the horse and cart into their proper place in the drills, and then removes the back-board of the cart. To retain this board within reach, he places it upon its edge on the nave of the near wheel, where it is held from falling off by passing the small coterel, at the end of the chain attached to the back-board, into the slit-eye of the stud, which projects from the hind-end of the side of the cart, and which coterel and stud keep the back-board, when in use, fast in (387; 
its proper place. If the carts are $w$ hole-bodied, the steward proceeds, after the back-board is removed, to hawk out the dung; but if they are tilt or coup-carts, he elevates the front a few inches, by means of the hesp attached there, that the dung may be hawked out the more easily. The wheels of the cart and the horse occupy 3 drills, as at $i$, the horse being in the midule drill between them. The steward $h$, with the hawk in both hands, pulls out a heap of dung $i$ upon the ground, and it invariably falls into the middle drill. The horse is then made to step forward a few paces and to halt again, by the voice of the steward, who then pulls out another heap of dung. An active man, accustomed to this sort of work, does not allow the horse to stand still at all, but to walk slowly on while he pulls out the dung. When the cart is emptied, the steward fastens down the body of the cart, if it is a coup one, puts on the back-board, and the cart again proceeds by its driver to the dunghill. When the distance to the dunghill is short, the carts are as slightly filled as to dispense with the back-board altogether; and when it can be wanted, labor is considerably expedited. After the cart has proceeded a few paces, and deposited a few heaps of dung, the foremost of the band of 4 women who spread the dung, as $k$, divides the heaps, as at $m$, with her small common graip into other two heaps, $l$ and $n$, one in each of the drills beside her; and from $m$ she goes to the next heap $i$ and divides it into other two heaps, and so on with every heap of dung. The 3 field-workers, $n$ o $p$, having each a small graip, fig. 151, then take each 1 of the 3 drills occupied by the horses and cartwheels, and all spread the dung before them equally along the bottom of the drills $l m n$, each taking care to remain in her own drill from the one end of the field to the other, shaking to pieces every lump of dung, and teazing out any that may happen to be ranker than the rest, trampling upon the spread dung as she walks along the bottom, and keeping it within the limits of the drill. Meanwhile the plowman a makes double drills from $b$ to $c$, if they have not been already formed, and proceeds with the making of them toward $e$ and $d$. Immediately that a part of 3 drills are dunged and the dung spread, the potato planters, after having plenished their baskets or aprons with sets from the cart $t$ upon the head-ridge, proceed to deposit the sets upon the dung along the drills, at about 8 or 9 inches apart. Some women prefer to carry the sets in coarse aprons instead of baskets, because they are more convenient. As setting requires longer time than dung-spreading, there should be two sets of planters, as at $r$ and $s$, to one set of spreaders-that is, 6 planters to 4 spreaders. One set of planters, as $s$, go in advance of the other, $r$, till the latter comes up to the place where the former began, and then the set $r$ goes in advance, and so one set after another goes in advance alternately, each set filling their baskets and aprons as they become empty, but all confining their labor to 3 drills at a time. Whenever 3 drills are thus planted, the plowman $u$ commences to split the first and cover in the dung and sets in the double way. 'The drills are split in the same way as they were set upthat is, as the plowman a turns over the first furrow of each drill upon the plain ground, stretching from $a$ to $e$, so the plowman $u$, in splitting the drills, tukns over the first furrow upon the dung toward the planters $r$ and $s$; because the first furrow being the largest, it should have complete freedom to cover the dung and sets. If the land had been sufficiently worked in spring, so as to be tolerably clean and free at the time of planting the potatoes, the plowman a may make up the drills in the single way, that is, making one drill in going away, as he is represented in the cut, from $b$ to $c$, and returuing with another drill in coming from $d$ to $e$, because sin. gle drills will be sufficiently deep to contain the dung within them. Pota-

(388) 
toes always receive a large dunging, they being in the first place a fallow crop, when the ground is entitled to be dunged, and, in the next place, they are considered a scourging crop to the land, that is, taking much nourishment out of it, and returning little or nothing to it-yielding no straw but a few dry haulms, and the greatest proportion of the entire crop being sold and driven away from the farm. A large dunging to potatoes always seems great, for time is wanting to make the dung short, and, of course, to reduce its bulk in the dunghill. About 20 single-horse loads, or 15 tons, to the imperial acre, is as small a dunging as potatoes usually receive of farm-yard dung. In the neighborhood of towns, street-manure, to the extent of 30 tons per imperial acre, is given; but there the crop is forced for an early market, and the street-manure has not the strength of farm-yard dung, and indeed is found to be not nearly so good for them as for turnips. The spreading should be kept up as close to the cart as possible. The plowman $u$ should not leave a single drill uncovered in the evening when he gives up work. If he cannot possibly split all the drills in the double way, he should cover up the dung and sets of a few drills at the last in the single way; or he should receive assistance from the plowman $a$ to split them all completely, if he sees the weather showing symptoms of rain or frost. And even at the loosening from work at mid-day, or forenoon yoking, every drill should be covered in, even though the plowman should work a while longer in the field than the rest of the workpeople ; for which disadvantage he should be as long of yoking after them; and he should make it a point to cover in the drills at the end of the forenoon yoking in a complete manner, when the weather is hot and dry; because dung is soon scorched by the mid-day sun, and its dry state is injurious, not so much on account of the evaporation of any valuable material from it, the material being chiefly water, but because it does not incorporate with the soil so soon and so well as damp dung; and when both soil and dung are rendered hot and dry by exposure, their incorporation is rendered very difficult. If all the plows cannot cover in the drills within a reasonable time after the loosening time arrives, especially at night, much rather give up the dunging of the land and the planting of the sets a little sooner than usual, than run the risk of leaving any dung and sets uncovered.

(1875.) You will observe that the process of planting potatoes, as represented in fig. 344 , is composed of a variety of actions, which, taken individually, are equally important, and none of which can be carried on without the assistance of the rest, and all of which, if not proportioned to one another, would end in confusion. Thus, the plowing of the drills, the dunging of the land, the spreading of the dung, the setting of the potatoes, and the splitting of the drills, are all equally important operations in potato culture. None of them would be of any use without the rest. There would be no use of making drills unless they were to be dunged, nor would the planting of the sets avail unless the dung were spread, nor would the planted sets be safe, even on the spread dung, unless the drills were split to cover the whole from the weather. But if these cornponent operations are not proportioned to each other, the whole operation is thrown into confusion. Suppose, for example, that the plowman $a$, while making double drills, could not keep out before the party that is spreading the dung, it is evident that every other party would be constrained by his tardiness, and made to lose time; and the remedy for this inconvenience obviously is, that the plowman should have as many double drills made before the dunging commences, as that he shall not be overtaken in the drilling; or that the plowman should make single drills, when he finds (389) 
the dunging gaining ground upon him; or that another plowman should be sent to assist him in making double drills. Suppose, again, that more carts are employed in conveying the dung from the dunghill than the steward $h$ can possibly hawk out, or the 4 women $k n$ o $p$ possibly spread; or, the same effect would be produced by employing more people than necessary at the dunghill to fill the carts; the result would be that the steward and women would be overworked, while the horses driving the dung, and the people at the dunghill would be comparatively idle, and of course losing time. Suppose there are fewer planters at $r$ and $s$ than can keep out before the plowman $u$, then time would not only be lost in covering up as many drills as might be, but the dung spread would lie exposed to the desiccating action of the sun and air between the planters of the sets and the spreaders of the dung. Were there, on the other hand, too many planters for those who spread the dung to keep out before them, then the planters would be comparatively idle. Suppose, lastly, that the plowman $u$ cannot keep up with the planters, who, nevertheless, do not proceed on their part faster than the dung is spread, the effect will be that the spread and planted dung will become dry before it can be covered up. The remedy for this inconvenience is either to employ another plowman to split in drills, or to make one plowman cover the dung with one furrow, and let another finish the drills behind him at his leisure.

(1876.) I have dwelt the more fully on these particulars, because potato plauting is one of those great operations which are made up of a variety of constituent operations that are performed simultaneously, and unless they form a harmonious whole, tending in all its parts to a common end, the entire operation cannot be completed in the best manner; but wherever this harmony is seen to exist, it is a satisfactory proof that the person who has so arranged the working materials as to produce it, possesses the knowledge of combining varieties of field-labor. In effecting such an ar rangement as the above, he displays knowledge of a superior order to that which is usually displayed in conducting potato planting. A very common mode of dunging potato-land, for example, is to hawk the dung out of the cart for 5 drills instead of 3, though 3 , or even fewer, women are sent to spread the dung over them. In doing this, each woman's attention is not confined to a single drill, but must be extended over the whole 5 , when each spreads the dung from the heap she takes possession of; and it stands to reason that she cannot spread dung so equally, and of course not so well, over 5 drills as along 1 ; and the work is not done better, though faster, even though the 3 women are all employed to spread from the same heap, as each has still the entire 5 drills to attend to. Besides, when dung is hawked out of the cart for 5 drills, it is usually laid in large heaps at considerable distances, at from 5 to 10 paces apart, thereby increasing the difficulty of spreading; and a large space of the ground being thus heaped over, before the dung is begun to be spread, by the time it is spread, and the sets planted, the dung will have become quite dry. This plan may excusably be adopted on a small farm, where laborers are few, and it is desired to conduct operations with what is considered economy, by the employment of as few hands as possible; but on a large farm it has the appearance of great slovenliness, and it certainly encourages carelessness in work, and evinces confusion of ideas in arranging it. It is no uncommon sight, even on large farms, to see the dung carted out and spread in one yoking, and the sets planted and the dung covered in another, by the same people and horses; doing a great deal of work, no doubt, in each yoking and during the entire day; but the result would be much more satisfactory were the entire work finished as it proceeded. A great (390) 
number of dunged drills are usually begun to be planted with sets at the same time, instead of confining the setting to a few at a time, to get them finished as soon as possible, to be covered with the plow. In short, there is no end to the many ways in which field-work may be done in a slovenly manner; but there is only one best way of doing it.

(1877.) Drills of potatoes are recommended to be made at 30 inches apart, instead of 27 inches, which is the usual width for turnips, because the large stems of the potato-plant growing vigorously require plenty of air. Even 3 feet apart is recommended by some cultivators, and in deep, rich soils this width may not be too great; but I observe that, in the neighborhood of large towns, where the greatest extent of ground is occupied by potatoes, the drills seldom exceed 24 inches, owing partly to the great value of land in that locality, and partly because the earlier varieties of potatoes, which have small stems, are most profitable to cultivate there. The drills for potatoes are usually not made so very regular in width as for turnips, because the seed is not planted by a machine. It is very easy to ascertain whether the exact quantity of manure desired to be given to the potato crop is actually given. Knowing the length of the drill and its breadth, a simple calculation will inform you of the number of drills in an acre, and, by apportioning the number of cart-loads that should be applied on every 3 drills, the requisite quantity per acre can at once be ascertained with great precision ; and this as precisely on the very first 3 drills that are commenced to be dunged, as if the calculation had been made over a large proportion of the field.

(1878.) As to the varieties of the potato I would recommend for fieldculture, I find it impossible to tender an advice, because it would not be generally applicable. I have seen a potato transferced from England, where it was a favorite, to Scotland, another variety transferred from Scotland to England, another from Ireland to Scotland, and in each case produce a very inferior crop in its adopted country to what it ever did in its native one; and even in a transference from one part to another of the same country, I have seen a material effect produced upon the plant, increasing it in one case and diminishing it in another. The general result is found to be an increase of produce and improvement of quality in transferring the potato from inferior to better soil, and from an elevated to a lower situation. The tendency of the potato to improve on being thus transferred, is taken advantage of in its attainment as seed. When I mention that there are upward of 100 varieties of field potatoes described by Mr. Lawson,* and as many experimented on by Mr. Howden, Lawhead, East-Lothian, ${ }^{\prime}$ you will not be surprised that I cannot confidently recommend any particular variety for a particular locality. Nevertheless a good potato has certain characteristics which distinguish it everywhere from an inferior one. A desirable potato is neither large nor small, but of medium size ; of round shape, or elongated spheroid; the skin of fine texture, and homogeneous; and the eyes neither numerous nor deep-seated. The habit of growth of its stem is strong and slightly spreading, and color lightish green. I believe that the intensity of the color of the flower is in some degree an indication of the depth of the color of the tuber; and I believe, also, that white potatoes are generally fit to be eaten when taken out of the ground, but that red ones are the better for being out of the ground for a shorter or longer time, before being used, according to the fineness of their texture. But color is by no means a fixed characteristic of any variety of potato, as it changes by cultivation and other circum -

* Iaw6on's Agriculturist's Manual, and Supplement.

† Prize Essays of the Highland and Agricultural Society, rol. xi. (391) 
stances. Mr. Lawson relates a curious circumstance which gave rise to a permanent difference in the color of the same variety of potato. "In the first report of Messrs. Dickson and Turnbull's Agricultural Museum at Perth," he says, "a remarkable instance is given of a white variety of the Perthshire red potato, being obtained by Miss Bishop, New-Scone, from a red potato with a white eye, which she carefully cut out and planted by itself, the result of which is that the produce has for several years retained the same color as the original eye, without the slightest appearance of change." Before determining the properties of a potato in a locality, it is necessary that it exhibit the same character for 2 or 3 years in the same circumstances of soil, manure and culture, otherwise errors may be committed in your estimation of varieties. The intrinsic value of a potato, as an article of commerce, is estimated by the quantity of starch which it yields on analysis; but as an article of domestic consumption, the flavor of the starchy matter is of greater importance than its quantity. Almost every person prefers a mealy potato to a waxy, and the more mealy it is usually the better flavored. The mealiness consists of a layer of mucilage immediately under the skin, covering the starch or farina, which is held consistent by fibrous matter. Light soil raises a potato more mealy than a strong, and I suppose every one is aware that a light soil produces a potato of the same variety of better flavor than clay. So that soil has an influence on the flavor, and there is no doubt that culture has-for potatoes, whatever may be the variety, raised from soil that has been dunged for some time, are higher flavored than those grown in immediate contact with dung.

(1879.) The most common varieties of potatoes cultivated in the fields in Scotland, are the common or Edinburgh Dons, very plentiful in the Edinburgh market. It is round, and is an early variety; that is to say, the stems are entirely decayed by the time the tubers are fit for use. It produces about 16 -fold of the seed, and yields 576 grains Troy of starch from $1 \mathrm{lb}$. of tubers. The Buff is a mealy and superior-flavored potato, yielding about 15-fold, and 466 grains Troy of starch from $1 \mathrm{lb}$. of tubers. The Perthshire Red, an oblong flat potato, is largely cultivated for the London market. It yields about 15 -fold, and affords as much as 777 grains Troy of starch from $1 \mathrm{lb}$. of tubers. Of the late varieties, that is, those the foliage of which, in ordinary seasons, does not decay until destroyed by frost, and the tubers of which generally require to be kept for some time before being used to the greatest advantage, the Staffald Hall, or Wellington, as it is sometimes called, is to be preferred. It is represented to yield 22-fold, and affords 813 grains Troy of starch from 1 lb. of tubers. The Scotch Black potato has long been cultivated in Scotland; and it seems to suit strong soil better than light, where it yields as high as 16-fold of increase, and affords 522 grains Troy of starch from 1 lb. of tubers. $\dagger$ Of the late varieties for field-culture suited for cattle, the Irish Lumpers and Cups appear prolific. The Lumper is a white, oblong potato of very inferior flavor, but yields 421 bushels, and 3,118 lbs. of starch per Scotch acre, I presume; and the Cups are an oblong red potato? yielding 479 buslsels, and $3,539 \mathrm{lbs}$. of starch per acre.t On recommending any variety of potato, however, it should be understood that potatoes will not permanently maintain their preëminence at all places; on the contrary, a few years may witness their utter decline. The Leather-coats, for example, were a variety in very great esteem and in extensive cultiva-

- Lawson's Agriculturist's Manual.

† Lawson's Agriculturiat's Manual.

I Prize Essays of the Highland and Agricultural Society vol, xi. (392) 
tion snme years ago, and now are hardly known. The small American white potato was extensively cultivated in the midland districts of Scotland about 20 years ago, but has yielded some of its ground to more prolific varieties. For the table, however, when raised in hazel loam-the true potato soil-there are few varieties cultivated superior to it in flavor, richness and beauty as a dish. It is now, I believe, chiefly confined to the garden. The finest flavored and most beautiful potato I ever saw on the table was a light red, small, round variety raised a few years ago in the sandy soil of the parish of Monifieth, in Forfarshire. It had quite the nutty flavor of a fresh Spanish chestnut-a state of that fine fruit unknown in this country.

(1880.) There are other ways of cultivating the potato in the field besides the one I have described. When light soil, in which the potato thrives, is clean and in good heart, it is frequently dunged on the stubble in autumn, and plowed in with a deep, square furrow by casting with or without a gore-furrow, fig. 139. Abundance of gaw-cuts are made to let off superfluous surface-water in winter. It is then cross-plowed in spring, and harrowed a double-tine, when it is ready to be drilled up in the single form, the sets planted, and the drills split in the double form, to complete the operation. In the neighborhood of towns this is an expeditious mode of planting a large breadth of potatoes in spring on light soil, but it requires the land to be in very good heart. I have tried it on good land in middling condition, but could not succeed in raising much more than half the crop produced from dunging the sarne land in spring.

(1881.) There is a modification of this plan which may be practiced with success in very light soil, which is that after the cross-plowing and harrowing in spring, the land is ridged again by casting without gore-furrows in the opposite way it was cast in autumn when the dung was plowed in; and at every third furrow two women follow the plow, and plant the sets in the bottom of the furrow. If the furrows are held 9 inches wide, the distance between the rows of potatoes will be 27 inches; and if they are 10 inches wide, the rows will, of course, be 30 inches apart; so that this plan admits of the rows being made wide enough.

(1882.) There is a sub-modification of this last method, which is, that the dung is spread over the smooth harrowed ground after the land has been cast into ridges in spring, instead of being applied on the stubble in autumn. The dung is raked in and spread evenly along the bottom of every third furrow by a woman with the small graip, fig. 151, following the plow, and immediately preceding the planters, and the plow which follows the planters covers up the sets. In both these modes the potato plants come up in rows upon the flat ground at the same distance they do in drills, and after their stems have grown up in summer, the earth is plowed up toward them, so as to convert the flat ground into a drilled surface by the time the culture is finished.

(1883.) Another mode of the field-culture of the potato is in lazy-beds, a mode more generally practiced in Ireland than in any other part of the kingdom. This system, however, will likely become less general, being much condemned by the good farmers there. Nevertheless, on lea-ground and on undrained bogs the small farmer cannot, perhaps, pursue a better one. "In bogs and mountains," says Martin Doyle, "where the plow cannot penetrate through strong soil, beds are the most convenient for the petty farmer, who digs the sod with his long narrow spade, and either lays the sets on the inverted sod-the manure being previously spread-covering them from the furrows by the shovel; or, as in parts of Connaught and Munster, he stabs the ground with his loy, a long narrow spade pe(393) 
culiar to the laborers of Connaught, jerks a cut set into the fissure when he draws out the tool, and afterward closes the set with the back of the same instrument, covering the surface, as in the case of lazy-beds, from the furrows. The general Irish mode of culture on old rich arable lea (a practice very common in the county of Clare, and elsewhere among the peasantry who pay dearly for old grass land,) is to plow the fields in ridges, to level them perfectly with the spade, then to lay the potato sets upon the surface, and to cover them with or without manure by the inverted suds from the furrows. The potatoes are afterward earthed once or twice with whatever mould can be obtained from the furrows by means of spade and shovel. And after these earthings, the furrows becoming deep trenches, form easy means for water to flow away, and leave the planted ground on each side of them comparatively dry." "The practice in the south of Ireland is to grow potatoes on grass land from 1 to 3 years old, and turnips afterward, manuring each time moderately, as the best preparation for corm, and as a prevention of the disease called fingers and toes in turnips. In wet bog-land, ridges and furrows are the safest, as the furrow acts as a complete drain for surface water; but wherever drilling is practicable, it is decidedly preferable, the produce being greater in drills than in what may be termed, comparatively, a broadcast method." " The spade-culture of potatoes seems an appropriate mode for small farmers and cotters, hut it is by far too expensive a mode to be introduced into a farm where horse-labor is employed.

(1S84.) While speaking of the form of the double drill, I have said that one of its sides was larger or heavier than the other; that is, the first furrow with which it is made is much larger than the second, the effect of which relation of furrows is to make the line of their meeting at the side instead of at the top of the drill, $(1744)$ and fig. 313. The germ of the potato, and of the bean too, in pushing upward, toward the top of the drill, finding the least resistance in the soil along the line of the meeting of the two furrows, finds its way to the day through the side instead of the top of the drill. Were the plants allowed to grow out from that part of the drill, they would not only be bent at the ground, but their stems would interfere with the borse-labor bestowed on the land in the hollows of the drills. To avoid this inconvenient and unnatural position of the plants, the practice is to harrow down the tops of the drills with harrows, so that the drill shall have the lightest part of the earth upon its crown; and, of course, the germ finding the least resistance directly upward, will push out at the top of the drill. The harrowing down of the tops of the drills is executed with the common harrows, or with harrows made for the purpose. The common harrows are passed either along or across the drills, according to the nature of the soil. Strong soil bears the hanrows being driren along the drills, and in very hard land, particularly in dry seasons, they may be passed along a double tine, but a single tine will usually be sufficient. Harrowing across, with tines well worn down, will have the least chance of disturbing long manure when used for dung. ing potatoes, as the drill which first receives the fore part of the harrow supports it and keeps the tines from penetrating too deep at once; but the walking across the drills is irksome both for man and beast, so that the harrowing is most easily performed along the drill. The common harrow, however, is a harsh implement for harrowing drills, compared to a couple of curved ones, figured below, which embrace two drills at a time, and which when pulled along do their work admirably. A modification of this last method has been recommended to be adopted on strong land in

\footnotetext{
* Doyle's Cyclopedia of Practical Husbandry-art. Potato-second edition.
} 
dry weather, after much rain has fallen, and when such land has become very hard and cloddy. A wooden roller, curved so as to embrace two drills, is recommended to be passed along, and by it the clods at top are either crushed or displaced to the bottom of the drills. Two pairs of harrows of a triangular form, suited to work in the hollows between the drills, are then passed along, and they either remove the clods that were too hard to be broken by the roller, or they divide the large clods into a number of small ones, and bring them all, the clods of every kind, into the hollows of the drills. In every one of these modes of rolling and harrowing the drills of bean or potato land, the bean and potato germs are permitted to shoot perpendicularly up through their tops. This harrowing is given to the drills 8 or 10 days after the potatoes have been planted, if the land is dry, but, of course, it must be done before the germs have had time to penetrate the ground, although the weather be not altogether favorable for working heavy land. Of the two sorts of potato-harrows alluded to-the curved and triangular-the latter is best fitted to be used when the germs have appeared above ground, as its outmost tines work between the top of one drill and another, and not over the top of the drill like the curved harrows.

(1885.) The potato is subject to disease at a very early period of its existence, not merely after it has developed its stems and leaves but before the germ has risen from the sets. The disease which affects the plant is called the curl, from the curled or crumpled appearance which the leaves assume when under the influence of the disease. What the immediate cause of the disease is, it is difficult to say; but the puny stem and stinted leaves indicate weakness in the constitution of the plant, and, like weak animals affected with constitutional disease, the small tubers produced by curled potatoes, when planted, propagate the disease in the fu ture crop. The curl is so well known by its appearance, and the curled plant so generally shunned as seed, that the disease is never willingly propagated by the cultivator; still there are circumstances in the management of the tubers which induce the disease therein. The experiments of Mr. T. Dickson show that the disease arises from the vegetable powers of the sets planted having been exhausted by over-ripening, so that sets from the waxy end of the potato produced healthy plants, whereas those from the best ripened end did not vegetate at all, or produced curled plants." It is the opinion of Mr. Crichton, "that the curl in the potato may often be occasioned by the way the potatoes are treated that are intended for seed. I have observed," he says, "wherever the seed-stock is carefully pitted, and not exposed to the air, in the spring the crop has seldom any curl; but where the seed-stock is put into barns and outhouses for months together, such crop seldom escapes turning out in a great measure curled; and if but few curl the first year, if they are planted again, it is more than probable the half of them will curl next season." $\dagger$

(1886.) The other disease alluded to affects the seed or sets, and is called the failure or taint, which consists of the destruction of their vital powers. Many conjectures have been hazarded as to the cause of the failure, and most of them have ascribed it to the fermented state of the dung, to the drouth of the season, to the heating of the sets, to the tuber being cut into sets, and other secondary causes; but all these conjectures leave untouched the principal consideration in the question, how these circumstances should induce failure now, and not in bygone years? Cut sets have been used for many years without causing failure. Farm-yard dung, in various states of decomposition, has been used as long for raising potatoes. The extraordinary drouth of 1826 caused no failure, while in com-

* Memoirs of the Caledonian Horticultural Society, vol.i. (395)

+ Ibid., rol. i. 
paratively cool seasons the disease has made great havoc. Mr. John Shirreff takes a general and philosophical view of the cause of disease in the potato crop, and though, no doubt, his observations are particularIy applicable to the curl, still they will apply equally well to the taint; for the connection between the two diseases is so intimate, that you have seen Mr. Dickson's observation is that some sets "did not vegetate at all," that is, failed, or produced curled plants." Mr. Shirreff adopts the general doctrine broached by Mr. Knight. "The maximum of the duration of the life of any individual vegetable and animal," he says, "is predetermined by Nature, under whatever circumstances the individual may be placed; the minimum, on the other hand, is determined by these very circumstances. Admitting, then, that a potato might reproduce itself from tubers for a great number of years in the shady woods of Peru, it seems destined to become abortive in the cultivated champaign of Britain, insomuch that not a single healthy plant of any sort of potato that yields berries, and which was in culture 20 years ago, can now be produced." Mr. Shirreff concludes, therefore, that the potato is to be considered a shortlived plant, and that though its health or vigor may be prolonged by rearing it in elevated or in shady situations, or by cropping the flowers, and thus preventing the plants from exhausting themselves, the only sure way to obtain vigorous plants, and to insure productive crops, is to have frequent recourse to new varieties raised from seed." "The same view had occurred to Dr. Hunter. The fact ascertained by Mr. Knight deserves to be noticed-that, by planting late in the season, perhaps in June, or even in July, an exhausted good variety may, in a great measure, be restored; that is, the tuber resulting from the late planting, when again planted at the ordinary season, produces the kind in its pristine vigor, and of its former size. It is obvious that all these opinions refer to the possibility of plants indicating constitutional weakness, and why may not the potato? I have all along been of the opinion that the failure has arisen from this cause, nor does it seem to me to be refuted by the fact that certain varieties of potato bave been cultivated for many years in the same locality without fail; because it is well understond that every variety of potato has not indicated failure, and one locality may be more favorable to retention of vigor of constitution than another; at least, we may easily believe this, and discrepancies in the case may arise, since we do not yet know the circumstances which must of necessity produce constitutional weakness. I have no doubt in my own mind that, were seed-potatoes securely pitted, until they were about to be planted-not over-ripened be: fore they were taken out of the ground-the sets cut fiom the crispest tubers and from the waxy end-the dung fermented by a turning of the dunghili in proper time-led out to the field, quickly spread, the sets as quickly dropped on it, and the drills split in the manner represented in fig. 344 , and described in (1874), there would be little heard of the failure even in the driest season-at the same time, the precaution of obtaining seed frequently from an elevated and late district compared to where the seed is to be planted, should not be neglected. I own it is difficult to prove the existence of constitutional weakness in any given tuber, as its existence is only implied by the fact of the failure; but the hypothesis explains many more facts than any other, than atmospheric influence-for example, producing the failure like epidemic diseases in animals, for such influences existed many years ago, as well as now. The longer the cultivation of

- Memoirs of the Caledonian Horticultural Society, vol, i. See also a well-reasoned essay by Mr. Aitken, Castle-Douglas, entiled, "The potato rescued from destruction, and restored to prestine vigor; and who takea the same view of the subject. (396) 
the tuber of the potato, which is not its seed, is persevered in, the more certainly may we expect to see its constitutional vigor weakened, in strict analogy to other plants propagated by similar means; such as the failure of many varieties of the apple and pear, and of the cider fruits of the 17 th century. This very season, 1843, contradicts the hypothesis of drouth and heat as the primary cause of the failure, for it has hitherto (to June) been neither hot nor dry, while it strikingly exemplifies the theory of constitutional weakness, inasmuch as the fine season of 1842 had so much overripened the potato-farmers, still unaware of the cause of the failure, permitting the potatoes they have used for seed to become over-ripened-that the sets this spring, to repeat again the words of Mr. Dickson, "did not vegetate at all," even in the absence of heat and drouth, and in the presence of moist weather. Had the potatoes been a little less over-ripened in 1842 , the sets from them might have produced only curl this season, though it is not improbable that the same degree of over-ripening may cause entire failure now that would only have caused curl years ago ; and as over-ripening was excessive last year, owing to the very fine weather, so the failure is extensive in a corresponding degree in this, even in circumstances considered by most people preventive of its recurrence, namely, in cold and moist weather. And observe the results of both 1842 and 1843 as confirmatory of the same principle, illustrated by diametrically opposite circumstances. The under-ripened seed of the bad season of 1841 produced the good crop of potatoes of 1842 , in spite of the great heat and drouth existing at the time of its planting in 1842; while the over-ripened seed of the good season of 1842 has produced extensive failure, in spite of the coolness and moisture existing at the time of planting in 1843. How can heat, drouth, or fermenting dung account for these results ?

(1887.) As fact, I may mention the effects of comparatively dry and moist soil, on cut sets and whole potatoes, which were brought to light by an experiment of Mr. Howden, and which results obtained no one could have anticipated. "On the 28th June," says Mr. Howden, "I selected from a store which had been repeatedly turned and kept for family use, 70 potatoes of the old rough black variety. I divided this number into 5 lots, sizing them, so as each lot of 14 potatoes weighed exactly $4 \mathrm{lbs}$. I made on that day one lot of 14 into starch, and obtained $9 \mathrm{oz}$. On the same day I put 14 potatoes whole, and 14 cut into 56 sets, into a deep box filled with dry mould. The remaining 14 whole and 14 cut I put into another box filled with moist earth, and which was watered from time to time. At the end of 3 weeks, with the exception of 5 sets, all the plants made their appearance. All this time the dry box had been kept from moisture. On the 21st July, however, I allowed it to be moistened with heavy rain, and on the 28th July I took up and extracted starch from the whole. Before doing so, however, I weighed the several lots, and what seemed to me curious was, that each lot of the whole potatoes had gained 8 oz.; while each lot of the cut ones had lost $6 \mathrm{oz}$. of its weight, and of their number 10 did not vegetate. The sprouts from the whole potatoes weighed $4 \mathrm{oz}$., and those from the cut only $2 \mathrm{oz}$; yet the starch from the 28 cut potatoes was only $2 \mathrm{oz}$., and that from the 28 whole potatoes $9 \mathrm{oz}$., being exactly the produce in starch of half that number, namely, 14, which was made into starch at the commencement of the experiment."*

(1888.) The potato belongs to the nutural order Solanacere, which also comprehends those remarkable but well-known plants, the deadly nightshade, the capsicum, the tobacco, the henbane, the stramonium, the tomato. \&c. "The potato is now considered the most useful esculent that is cultivated, and who," Dr. Neill asks, "could a priori have expected to have found the most use-

* Prize Essays of the Highland and Agricultural Society, vol. xi. (397) 
ful among the natural family of the Solanaceac. most of which are deleterions, and all of which are forbidding in their aspect." The genus Solanum stands in the order Pentandria monogynin. of the Linuman system. "The name is given by Pliny, but the derivatiun is uncer!ain: some derive it from Sol, the sun; others say ut is Sulanum, from Sus, being serviceable in the disorders of swine; and others from Solor. to comfort. from its soothing narcotic effects; all these conjectures are, however. improbable. Solanum tuberosum, the common potato, has roots bearing tubers; stems herbaceous; leaves unequally pinnate; leaflets entire; pedicel articulated. It is a native of South America, on the west coast everywhere. The cultivated potato varies much in the leaves, color of the flowers, shape and color of the tubers, \&c." " "Gerard," says Pbillips, "describes two kinds of potatoes in his Herbal; and as the account is highly interesting I shall copy it verbatim. 'This plant.' saye he, 'which is called Sisarum Peruvionum. or Skyrrits of Peru, is generally of us called potatus or potatoes. . . The roots are many, thick and knobbed. like unto the routs of peonies, or rather of the asphodill, twined together at the top into one bead, in manner of the Skyrrit, which being divided into divers parts and planted, do make great increase, especiaily if the greatest rootes be cut into divers gobbets and planted in good fertill ground. . . O Of these rootes may be made conserves, no less toothsome, wholesome, and domestic, than the flesh of quinces. . . . These rootes may serve as a ground or foundation whereon the cunning confectioner or sugar-baker may worke and frame many comfortable delicate conserves and restorative sweet-meates.' ... . “This was evidently the sweet-potato," continues Phillips, " which was supposed to possess an invigorating property. Kissing-comfits were made of them in Shakspeare's time. Falstaff says in the Merry Wives of W indsor,

\section{Let it rain potatoes, and hail kissing-comfits.'}

Gerard commences his second chapter with the description of the common potato now in use, and says, 'Battata Virginiana sive Virginianorum, et Pappus, potatoes of Virginia.' After an ac. curate description of the plant and flower, he adds, "The roote is thicke, fat, and tuberous; not much differing either in shape, color, or taste from the common potatoes, saving that the rootes hereof are not so great nor long, some of them round as a ball, some ovall or egge fashion, some longer, others shorter.' The potato was introduced into Spain in the early part of the 16 th century, and thence spread over the Continent, first to Italy, then to Flanders, and thence through Germany to Austria in 1598. It found its way to England by a differeut route, being brought from Virginia by the colnnists sent out by Sir Walter Raleigh in 1584 and who returned in 1586 , and probably, according to Sir Joseph Banks, brought with them the potato. This palladium against famine was not cultivated in Scotland until 1683, and was then confined to the gardens. In 1728, Thomas Prentice, a day-laborer, first planted potatoes in open fieldsat Kilsyth. and the success was such that every farmer and cottager followed his example. Potatoes were scarcely known in the Eașt Indies 30 years ago, but they are now produced in such abundance that the natives in some places make considerable use of them. Bombay is chiefly supplied with this excellent root froma Guzerat. And though the cultivation of this root is much increased in France within these last few years, the poor of that country cannot yet be prevailed on to eat it." $\dagger$

(1889.) Rooks are very destructive to the potato crop just as the germs of the plants are penetrating the ground. and they seem to possess an exquisite sense of smelling to find out those which are most palatable to their taste They steal very quietly into potato fields, and are there pretty well hidden among the drills; and in this respect their tactics differ from what they pursue when alighting anoug corn, which they do in large flocks. There is nothing but gunpowder will deter them from a potato-field; they soon find out the innocuous character of a scarecrow, or tattie doolie, as that sorry semblance of hamanity is always misnamed. One cannot always be firing among crows with the gun, but an occasional shot does good, aided by that effectual check to their visitation of any field-the burning of gunpowder matches here and there and now and then along the windward side of the field. the fumes of which sweeping aloag the surface of the ground. being smelt by the rooks, put them in constant trepidation, and at length to flight.

(1890.) It may prove interesting to those of you who may possess a farm in the neighborhood of a large town, to know why it is that the street-manure of towns is not so suitable for raising potatoes as stable or byre manure. A paper on the subject by Dr. Madden enables me to give you an idea of the explanation he gives of the sabject; to enable you, in the first place. to judge of the nature of street-manure. $I$ will insert a part of a Table of his constructun, showing the chemical difference between it and horse and cow-dung.

\begin{tabular}{|c|c|c|c|}
\hline \multirow[b]{3}{*}{ 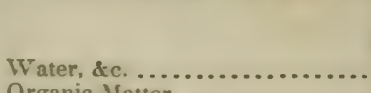 } & \multicolumn{3}{|c|}{ MANURES. } \\
\hline & siable. & Byre. & Street. \\
\hline & $13 \cdot 5$ & 45.7 & 26.4 \\
\hline Organic Matter & & & \\
\hline Soluble in Water............. & $11 \cdot 5$ & $9 \cdot 0$ & $1 \cdot 4$ \\
\hline Soluble in Potassa ............ & $15 \cdot 9$ & $12 \cdot 6$ & $1 \cdot 0$ \\
\hline Destroyed by Heat ........... & $13 \cdot 33$ & $21 \cdot 8$ & $11 \cdot 2$ \\
\hline Saline Matter ................ & $45 \cdot 77$ & 10.9 & $60 \cdot 0$ \\
\hline Tntal ...................... & $100 \cdot 00$ & $100 \cdot 0$ & $100 \cdot 0$ \\
\hline
\end{tabular}

The sum of the chemical nature of these three substances used in raising potatoes is that stabledung is the most heating, but not so durable-that byre dung is cooler, and muob more lastingand that street-manure is very inferior to the other two in every respect, and, in fact, would be little better than soil. were it not for the highly azotized nature of its organic matter. and probably also for the presence of a considerable quantity of chalk. The effect of applying street-manure to the soil is this: "When any quantity of street-manure," says Dr. Madden, "is plowed into good

* Don's General System of Botany and Gardening. vol. iv.-Solanacea.

$+\mathrm{P}$ hillips's History of Cultirated Vegethbles, rol. ii. (398) 



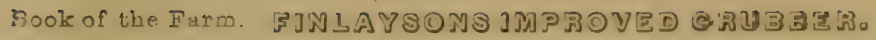

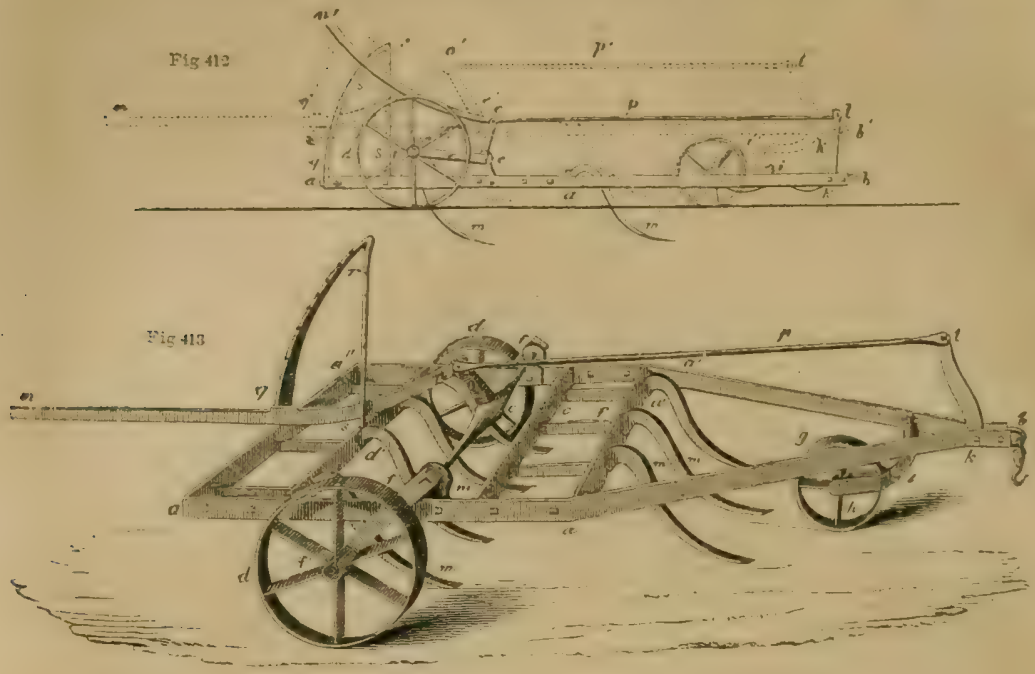

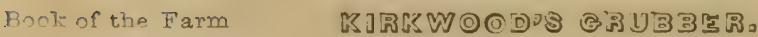
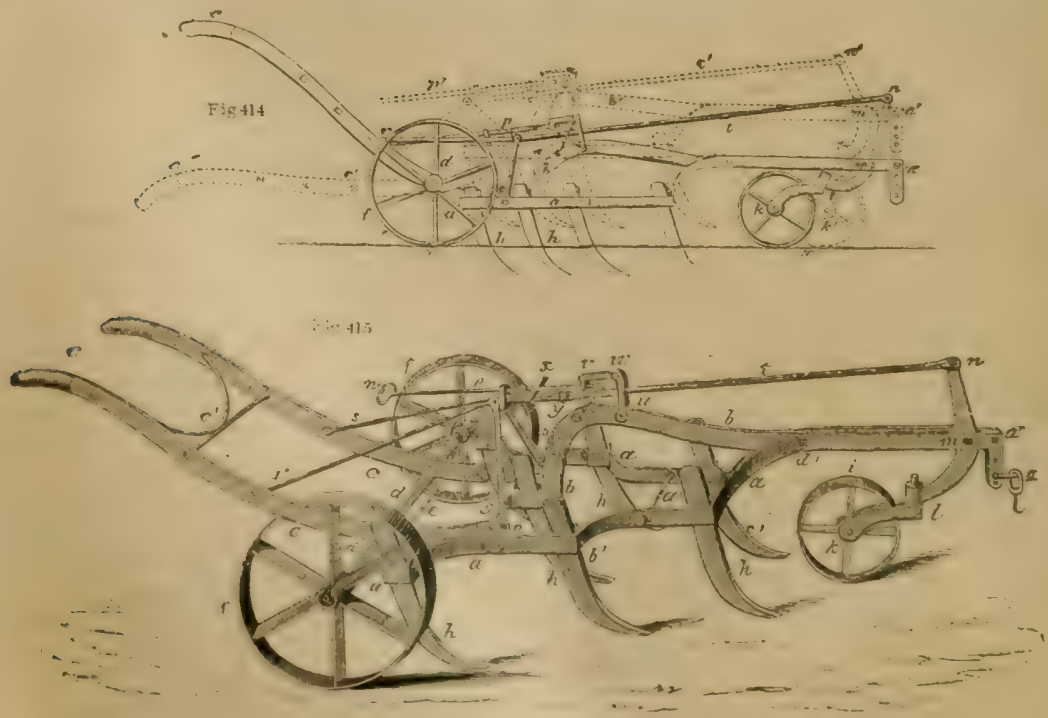
soil, the following changes takes place: The ordure and carbonate of lime, which are evidently the most powerful ingredients of this manure, will reäct upon the less decomposable organic matter, both of the soil and of the manure itself, and thus bring the whole into a state of fermentation, the extent and intensity of which will be regulated by the quality of these active ingredients, es. pecially the ordure. This action depends upon the fact that when any organic substance in a state of fermentation is brought into contact, or mingled with any organic matter capable of fermenting, but not at present in that condition, the whole mass, after a time, undergoes the same series of changes, which are always accompanied with the escape of various gases, and the formation of certain soluble compounds, which latter constitute the chief food of plants. Moreover, it has been long ago proved that substances rich in azote are always the most prone to decomposition, and likewise are capable of exciting fermentation to a far greater extent in others of a less putrescible nature. Again, it is well known to farmers that chalk or carbonate of lime possesses the power of increasing the putrescent tendency of many vegetable substances, so that, when applied to soils, it renders them richer. But what is curious enough, at the same time that it causes the production of suluble matter by promoting putrefaction, it renders less soluble those portions already in a state of solution, by entering into chemical combination with them. On these accounts, therefore. and especially from the ordure being a very highly azotized snbstance, street manure will be capable of exciting putrefaction to a greater extent, considering the small quantity of organic matter which it contains, than one at first sight would be led to suppose. It must, however, be remembered that as the putrescent effect will only be produced in the immediate neighborhood of the active ingredients themselves, and as, moreover, these are mixed with a large quantity of other comparatively inert matters, their action is very liable to be confined to certain spots. Owing. likewise, to the presence of cinders, a certain portion of the soluble organic matter will be absorbed by them, and thus for a time at least, removed beyond the reach of plants. But, on the other hand, it will be observed that, from the highly azotized nature of its organic contents, the fermentation will be rapid at first, and, consequently, the manure will be hot in proportion to the quantity of real manure which it contains." In the actual effect of this manure in raising potatoes being $\frac{1}{3}$ inferior to stable and byre dung, the following explanation of its inferiority is offered by Dr. Madden. "In the account of the culture of the potato, given in Professor Low's excellent work on Practical Agriculture, we find the following expressions: 'Dung will in all cases act most quickly upon young plants when it is well prepared, but extreme preparation of the dnng is not required in the case of the potato. It is enough that it should be in such a state of fermentation as that it may be readily covered by the plow.' Thus proving that this plant does not require an instant supply of a considerable part of soluble matter. And, moreover, it is clear that as the useful part of this plant is produced during the later periods of the growth of the crop, the greatest supply of food will be necessary at that time. But we have already shown that street manure, from the nature of its constituents, ferments very rapidly at first, and, consequently, its greatest effects will be in the very early periods of the growth of the crop. The next sentence in Professor Low's work commences thus: 'The potato requires a large supply of manure.' Bat we have already shown that street-manure does not contain $\frac{1}{3}$ as much real manure as either that derived from dairies or stables. And a little below the above quotation occurs the following sentence: 'Lime does not appear to act in a beneficial manner, and is rarely applied directly to this crop. But our analysis has proved that lime exists in considerable quantities in the streetmanure of Edinburgh ; and as it has been exposed to great heat-for it is evidently derived from the ashes-it will, of course, be in the same state as mil. lime when it is applied, and will, most probably, therefore, have the eame effect, which, according to Professor Low, is 'not beneficial.' The potato possesses a spreading root, and, consequently, must require a uniform manure, in order that all its parts may be equally supplied with soluble organic matter. But we have before shown that street manure is partial. The potato requires the greatest quantity of azote at the later periods of its growth; because the tubers contain considerably more of that substance than the leaves. But street manure, from the nature of its organic constituents, will ferment rapidly, and allow most of its azote to escape during the eariy periods of the cultivation of the crop." As a general rule for the application of manure to potatoes, "We may hence argue," as Dr. Madden remarks, "that a manure to suit well for the potato crop, should possess the following qualities: It must be spread equally through the soil, so that the spongioles, at the termination of all the spread. ing fibres of its roots, may be supplied with nourishment." And surely there is no way of spreading dang so equally as along only three drills at a time, and by spreaders keeping to their own drills. "It must yield azote during the whole period of the growth of the plants : in fact, rather more is required during the later periods than prior to the development of the tubers; for, from M. Boussingault's analysis, it appears that they contain 5-100 per cent more of this substance than the leaves. In an economical point of view, therefore, the best manure for potatoes would be one which contained plenty of azote, but still did not decompose very rapidly-cow-dung, for
example."*

(1891.) Finlayson's Harrono or Grubber.-Fig. 346. Plate XXIX., is a view in perspective of Finlayson's harrow of the improved form. The lrame-work and the active parts are precisely the same as when the implement was manufactured under the patent, the improvement lying in the parts which have been introduced for raising the tine-frame from the ground. The figure represents the implements as carrying seven tines, and consists first of the body-frame. which is formed of two interior oblong frames $a^{\prime} c^{\prime}$ and $d^{\prime} a$, each 4 feet 6 inches in length, and 12 inches in width over all. These frames are welded solid at the angles, and rectangular; the sides $a^{\prime}$ and $d^{\prime}$ are 3 inches in depth, and $\frac{3}{4}$ inch in thickness, and are perforated to receive the tines at their full strength, whether of a square or oblong section; the bars $a^{\prime}$ and $d^{\prime}$ are therefore allowed to swell out on both edges at the perforation, to preserve strength. The sides $c^{\prime}$ and $a$, together with the ends of these frames, are only $2 \frac{1}{2}$ inches in depth, and $\frac{5}{8}$ inch in thickness, and the perforations are only sufficient to pass the screwed tail of the tine. The side-bars $a$ and $a^{\prime \prime} a^{\prime \prime}$ are bolted upon the

"Prize Essays of the Highland and Agricultural Society, rol. xiii. 
ends of the interior frames. as seen in the bar $a^{\prime \prime} a^{\prime \prime}$, and each is prolonged forward from $a$ and $a^{\prime \prime}$ to the point $b$. forming the triangular prolongation $a^{\prime \prime} a^{\prime \prime} b$, aod are connected by a bolt at $b$. These

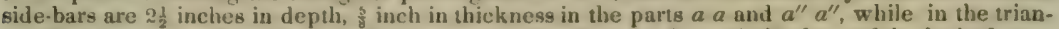
gle they are reduced to inch in thickness. and the distance from $a^{\prime}$, the front of the body frame, to the apex $b$ of the triangle, is 4 feet 6 inches.

(1892.) The tines are always in this machine made of the swan-neck or self-cleaning form. They consist of the shank $f^{\prime}$, by which they are fixed in the interior frame, and of the prong $m$, which penetrates the ground. A cross section of the swan-neck and shavk is either a square of $1 \frac{1}{2}$ inches, or it is an oblong of $2 \frac{1}{4}$ inches by $\frac{7}{8} \mathrm{inch}$, some makers adopting the square, which was Finlayson's uriginal form, while others adopt the oblong. The shank diminishes from the neck toward the tail, which terminate in a $\frac{3}{3}$ inch screw. by means of which and a nut the tine is held firmly in its place. The prong, or forward end of the tine, diminishes gently in depth to the ex. tremity, which terminates in a chisel-shaped point of $1 \frac{1}{2}$ inches broad, having a slight inclination eartbward, without which the implement has a tendency to rise out of the ground.

(1893.) The body frame, with its tines, is supported on the two hind-wheels $d, d$, 20 inches diameter, which are mounted on the cranked-axle $f e f$, and upon the front castor-wheel $g$, of 12 inches, the former turning upon studs in the cranks $f^{\prime}$ and the latter in the sheers $h$. The axle $e$ is supported in brackets, bolted upon the inside of the side-bars $a$ and $a^{\prime \prime} a^{\prime \prime}$, as ceen in fig. 345, where $a$ a is the side-bar, aud $e$ the bracket, the eye of which, for receiving the axle, stands $3 \frac{1}{2}$ jnches above the upper edge of the bar, and its thickness is $\frac{3}{4}$ inch. The sheers $h$, fig. 346 , of the fore-wheel are jointed into the bent lever at $i$. forming a bell crank-lever $i k l$ by which the forepart of the machine is elevated or tepressed. The hind-part is acted upon directly by the lever $n u$, which is also bent at $n$ to nearly a right angle in the $\operatorname{arm} n o e$, the extremity of which passes through the axle at $e$, and is secured with a screw-nut. This form of the lever, $n n e$ is rendered, in its effects upon the hind-wheel and axle, a simple straight lever; but the angle which it forms at $n$ o serves an essential purpose, as it affects the fore-wheels. It will be observed tiat the anm $n o$ e takes a position nearly parallel to the arm $k l$ of the fore-crank, and by the introduction of the connecting rod $n p l$, jointed to the lever $n n e$, and to the crank $i k l$, by this arrangement, whatever motion is communicated through the lever $n n e$, to the cranked-axle of the hind-wheels, a corresponding motion is simultaneously given to the fore-crank and its wheel, whereby the tineframe is uniformly raised or depressed at pleasure. The lever $n n e$ is about $5 \frac{1}{2}$ feet in length, and is under the control of the conductor; its position in the figure indicates the highest position that the tine-frame can attain; and to enable the conductor to retain it in any required position, the quadrant $q r$, with its upright support $s r$, is bolted upon the back frame $d^{\prime} a$; the edge of the quadrant-bar is notched with serratures about $\frac{1}{2}$ inch deep, adapted to receive and retain the edge of the lever, as seen in the figure, occupying the lowest notch, which brings the tines entirely out of the ground. By removing the lever from this notch and putting the machine in motion by the horses, the tines immediately descend into the soil, and when they have attained the required depth the lever is laid into the notch suited to that depth, and the machine proceeds thus until the attendaut sees it necessary to withdraw the tines from the ground, which must be done at every lands-end, or oftener if obstructions are met with.

(1894.) Fig. 345 is a geometrical elevation of the grubber to show more distinctly the relation and actiun of the elevating apparatus, the solid lines exhibiting the machine with the tines $m$ and $m$ nearly at full depth in the soil below the surface line, and the repetition of the figure in the dotted lines show it when the tines are fully raised out of the ground. In the first position, $a \quad b$ is the tine-frame, $e$ the brackets that support the crank-axle, and $f$ the crank carrying the hind-wheel $d$. The fore-crank, including the sheers of the fore-wheel, takes the position $i k l$, and the back lever. which is broken off at $n^{\prime}$, has the position $n^{\prime} \circ e, 0 p l$ being the connecting-rod. It will be easily seen that that $e o l k$ approaches to a parallelogram, and theoretically it ought to be such, but from matters of convenience to suit the diameter of the wheels, the side $o e$ is usually made shorter than the side $l k$, and, to compensate for this difference, the arms $f^{\prime} f$ and $i k$ of the cranks are made proportional to the arms $o e$ and $l k$, and as these are the nembers of the machine by which the clevations and depressions are produced, and being connected by the rod $o p l$, the arms $o e$ and $l k$ will move through equal lengths of arc, but with unequal angles, the proportional arms $f^{\prime} e$ and $i k$ will describe corresponding arcs and angles, and so produce a nearly parallel rise and fall of the tine-frame moving round the centers $f^{\prime}$ and $h$ of the hind and fore wheels, fig. 346. In this complicated combination of levers, it will be observed that the principal lever $u^{\prime} o e_{\text {, }}$ fig. 345 , from its combination with the crank $e f^{\prime}$, is in effect resolved into a simple lever of the first order, whose fulcrum is $f^{\prime}$, its power is in $n^{\prime}$ and the point of resistance in $o$; for though

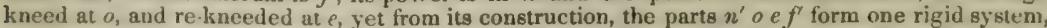
and the result is the same as if a rigid bar were extended from $n^{\prime}$ to $f^{\prime}$, and then from $f^{\prime}$ to 0 , but in which case a jointed bar must fall from $o$ to $e$, to bear up the tine-frame.

(1895.) In this, fig. 345 , the dotted lines represent the changed position of all the parts where the tine-frame has been raised to its utmost limit; the same letters, with an accent annexed, mark the position of the different points : and here it will be farther observed that the change of position takes place by the parts turning about the centers of the hind and fore wheels.

(1896.) This form of Finlayson's harrow or grubber is a very well marked improvement on the original, arising from the facility now afforded of raising the whole of the tines out of the ground. In the oriyinal form, the only provision of this kind that the machines possessed was the elevation of the apex $b$ of the triangle and with it, a partial elevation of the fore tines while those behind remained always in the ground at their working depth. It is true that this depth could be varied, but only by shifting a bracket that carried the axles of the hind-wheels, and the adjustment of them was a work of cousiderable time; a screw in some cases was attached to each bracket, by which it could be raised, but they were at best tedious and inconvenient compared with the new form of the elevating apparatus. The original harrow was, in consequence of this defect. a much less manageable machine, and having four of its tines always in the ground, it was much more liable to accident and to fracture. With the improvement also of the elevating apparatus, the bulk and 
weight of the implement has been reduced, and it is now very frequently ased with five tines, in place of the original seven-tined implement as here figured with the improvements.

(1897.) Kirkwood's Grubber.-Though in point of time, this instrument was introduced prior to that just described, it was several years later than that of Finlayson's original improved harrow, or about $1830 .^{*}$ In this machine the ingenions apparatus for elevating the tine-frame was, I believe, first brought out, and from it has been deduced all the various forms in which this effect is now produced, though, as we shall see, some of them are so much changed from the original as liarlly to be recognizable; still the elentents of the original are there, obtained in some cases at a greater, in others at a smalier expense. The present form, as figured here, differs in some minor poins from the original, but not so much as at all to alter the character of the implement, which is atill essentially Kirkwood's, though the firure is taken from those manufactured by James Slight and Company, Ediuburgh. The chief poiuts of difference are in the length of the axle of the bind-wheels; this, in the original, was so short as to bring the wheels close to the levers: in the figure the axle is extended so far as to place the wheels on the outside of the extreme tines. T'his extension of the axle gives the machine a broader base, and thereby a greater steadiness of motion, and to compensate for, and give support to, the extremities of the axle thus extended, it is supported by a trussed-tie with king-posts.

.(1898.) Fig. 348, Plate XXX., is a view in perspective of this grubber; it may be considered as cousisting of two parts, the tine frame, and the carriage with its wheels and handles, the two being connected by means of the apparatus for elevating the tine-frame, and by a joint-rod which is common to both, the whole being constructed of malleable iron, except the wheels. The tineframe is of an irregular triangalar figure. composed of two sides $a a b$, \&c. ; thege are forged to the peculiar form represented in the figure, and to the following dimensions: from extreme $a$ to $b^{\prime}$ in the oblique straight, the distance is 25 inches, $b^{\prime}$ to $c^{\prime} 21$ inches, and $c$ to $a^{\prime \prime} 39$ inches; and the lengths on the opposite side correspond exactly with these; but the central distance from extreme $a$ to $a^{\prime \prime}$ is 6 feet 6 inches. The breadths measuring from center to center of the tines are at extreme $a 4$ feet two inches: $b^{\prime}$ to $a 2$ feet 19 inches, and $c^{\prime}$ to $a 17$ inches; the fore-part of the bars forming the neck, approach to within $\frac{3}{4}$ inch of each other, between the points $d^{\prime}$ and $m$, and at $a^{\prime \prime}$ they come in contact, and are fixed by the bolt at $a^{\prime \prime}$; the muzzle $a^{\prime \prime} z$ is simply a prolonga. tion of the bars, and is provided with several holes in which the draught-shackle and hook can be attached to regulate in some degree the tendeucy to earth. That part of the frame $d^{\prime}$ to $m$, form. ing the neck, is raised 9 inches above the line of the body, measuring from the upper surface of the one to that of the other. and lies parallel with the body of the frame. The side-bars bere described are $2 \frac{1}{4}$ inches in depth and 1 inch in breadth, till they approach $d^{\prime}$, when they are diminished in breadth $\frac{3}{4} \mathrm{inch}$, and go on diminishing to $\frac{1}{2}$ inch at $a^{\prime \prime} ;$ the slot-holes for the tines are $2 \frac{1}{4}$ inches by $\frac{3}{4}$ inch. Besides the connection at the point $a^{\prime \prime}$, the side-bars are connected by the joint-rod $g$. which is $1 \frac{1}{2}$ inches square at the middle, tapering and rounded toward the end. where it terminates in a screw and nut of about 1 inch diameter: and a light stretcher $a^{\prime}$ is also inserted as a farther support to the fiame. The beam $b b$ is $2 \frac{1}{4}$ by 1 inch from $b$ to $u$, and diminishes from $u$ to $d^{\prime}$ to $\frac{3}{4}$ inch; it is kneed at extreme $b$, so as to leave space sufficient to receive the slot-hole for the middle tine, and it is bent upward at $u$ to the hight of 10 inches above the frame as before for the purpose of receiving the bridle $u u^{\prime}$; at the end $b$ of the beam is notched into the middle of the joint-rod $g$ (which is here spread out to 2 inches in depth.) and fixed by a screw-bolt, tapped into the end of the beam, while its fore-end is secured between the side-bars by a through bolt at $d^{\prime}$. The tines, of which this form of the implement contains seven, $h h$, \&c., are at $1 \frac{1}{d}$ inches by $\frac{3}{4}$ inch, bent at the point as in the figure, with a slight tendency to earth, and are tiattened out at the point to a breadth of $1 \frac{1}{4}$ to $1 \frac{1}{2}$ inches, their length from the level of the point to the top is 20 inches, and they are secured at any required degree of earth by one iron wedge to each tine.

(1899.) The carriage consists of the axle $d d$, on which are mounted the two handles or levers c c 0 , the axle passing through these. and fixed with cotterels on each side. At the distance of $13 \frac{1}{2}$ inches from the center of the axle, the levers are also perforated for the joint-rod $g$, the position of which in the tine-frame is such as just to allow the extremities $a$ to pass the axle when the frame is being raised or depressed. A third perforation is formed in the fore-end of the lever at $n$, 2 inches forward of the joint-rod, for the attachment of the stays. The levers extend backward to a length of $4 \frac{1}{2}$ feet, and terminate in sockets, into which wooden helves are inserted; and they are farther supported by the stay-rod and bow $c^{\prime}$. The carriage is now supported on the hind-wheels $f f$, of 22 inches diameter; and the fore-part of the castor-wheel $i$, of 13 inches diameter, with its sheers $k l$, and crank lever $l m n$. The connections between the carriage and frame, and which also form the elevating apparatus, is arranged in the following matter. The right and left stayrods $o p q$ and $r p s$ are bolted to the levers at $q o$ and $r s$. The perpendicular distance $g p$ being 12 inches, and the like distance from the center of the axle $d$ to $p 18 \frac{1}{2}$ inches, the two stays being brought together upon a stretcher-bolt at $p$, of 1 inch in length, having a screw and rat at each end. The connecting-rod $p t n$ is 5 feet $2 \frac{1}{2}$ inches in length. $\frac{3}{4}$ inch diameter, and is jointed to the carriage by the short stretcher-bolt a: $p$, and to the lever of the front wheel at $n$. which com pletes the arrangement by which the tine-frame is moved up and down in positions always parallel to the horizon.

(1900.) Fig. 347, Plate XXX.. is a geometrical elevation of this grubber, showing in a more distinct manner the relation and action of the elevating apparatus. In this the solid rines represent the machine as with the tines in the ground, the surface being represented by the line $x^{\prime} x^{\prime \prime}$; and the repetition of the figure in dotied lines represents it as when the tines are elevated, and the machine in a traveling condition, the same letters applying in both positions, but. in this with an accent. In the first position, applying the same letters as in the former figure, $a a$. \&c., is the tine-frame, $b$ the beam, $c$ the bandles or levers, $d$ the axle of the carriage, $f$ the hind wheels,

* Prize Essays of the Highland and Agricultural Society, vol. viii. 
$g$ the position of the joint-roil of the tine-frame, and $h h$ are the tines. The front wheel is shown in the sheers $k l$, and $l m n$ is the crank-lever, $g p r$ is the stays, and $t$ the connecting-rod.

(1901.) In the apparatus of the front wheel, the distance from the sole of the wheel, where it touches the line $x^{\prime} x^{\prime \prime}$, to the center at $m$, is 23 inches, and from $m$ to $n 11+$ inches; and as the carriage lever, though in a complicated form, is resolvable into a more simple one. which has the anme proportions as the former, the point where the wheel touches the line $x^{\prime} x^{\prime \prime}$ is the fulcrum. and a line drawn from the point $x^{\prime}$ to the joint at $p$ will be parallel with, and equal to $x^{\prime \prime} m$, and $g p$ will be equal to $m n$; and the point $p, n$ acting simultaneously, by means of the connecting. rod $t$, the point $p$ rises by turning round the fulcrum $x^{\prime}$, while $m$ rises through the same space by the point $x^{\prime \prime}$ turning round the point $m$ in the opposite direction. By these motions the tineframe will rise and fall through equal spaces before and behind, and thus preserve the parallelism of the frame in any position.

(1902.) In working the machine, it is requisite that the condactor have it in his power to regalate and preserve a uniform depth for the tines, and be able to withdraw the tines from the earth. To accomplish this part, the connecting-rod $t$, fig. 348 , has small mortices punched in it, to the uumber of 6 or 8 . at very close intervals between $u$ and $p$, the rod being square at this place. A nut or slide-box $y^{\prime}$ is fitted to slide easily upon it, and having also a mortice punched through it cor. responding to those in the rod, it can be fixed at any point by dropping a pin through this and any required mortice. The bridle $u u^{\prime}$ consists of two similar parts bolted one on each side of the beam; and having the middle parts of its stay widened to adnit the passage of the nut, it receives the folding link $v$ upon the bolt, on which the link turns freely. The handle $v x u$ is made of such length as will bring the eye $w$ within reach of the conductor: it is furnished with a crosshead $x$, and the end $v$ being screwed into the link $v$, the handle can be shortened or lengthened at pleasure : and this is done to make the cross-head fall in behind the end of the connecting.rod when the tines are in the ground, which thus lock them that they cannot rise out of the ground, although, from any malformation of the tines, they might have a tendency to do so were this lock not applied; but while the tines preserve their due form, the lock is not required. A prolonged screw-nut at $p$ is also put upon the handle; it is forked in the prolonged part, and when the tine frame is raised out of the ground for traveling, the nut is adjusted to fall in before the checks of the stays at $p$, and thus keeps up the tine-frame without the continued aid of the conductor.

(1903.) The Drill.Harrow is another implement of recent introduction ; like the other members of its tribe, it is of extremely simple construction, and from its having been first applied to potato culture, it is frequently etyled the potato harrove. This harrow is always worked in pairs; and to render it applicable to its intended purpose, it is made of an arch form, partially embracing the curvature of the ridglet or drill. The two leaves of the pair are connected by two coupling-rods, which are formed to expand or contract to anv required width of drills; and each leaf is furnish. ed with a chain, to which a draught-bar or swiug-tree is attached, and to which again the horse is yoked: the bar and chains. in this mode of yoking, serve by their weight to produce such a catanarian curvature as to make the vertical line of traction leave the harrows nearly in a horizontal line, giving thus the full effect on the drill. Simple though the construction of this implement be, I frequently see a malformation in the placement of its tines; its breadth does not exceed 26 inch$\mathrm{es}$, and. therefore, the number of its tines need not exceed 18 , though a streak at every $] \frac{3}{4}$ inches should be required; notwithstanding this, 'we frequently see these harrows with as many as 24 tines, and with such a number, unless a very careful division is made in their placement. many of them will follow in the track of others, and are hence of no use. In laying out this simple harrow, if the rule laid down in (1789), as applicable to all harrows, is attended to, such useless waste of labor and materials might be saved, and the work for which the implement is intended will be equally well done.

(1904.) Fig. 349 is a geometrical plan of a pair of the rectangular drill-harrc $\mathbf{w}$, in which a regular division of the tines is observed, and as the harrows are 26 inches from center to center of the outside bars or bulls, and the number of tines 15 , they will drav streaks on the surface at equal distances of $1 \frac{7}{b}$ inches nearly: the three bulls $a b c$, and the three cross-bars $d$ ef form the body of the harrow; the breadth over all is 27 inches, and the length 33 inches; the bnlls and bars are all $1 \frac{1}{4}$ by $\frac{3}{8}$ inch. There is no slotting, as in the common barrow, but the bulls and bars are simply crossed, and secured by a small bolt and nut, or they may be riveted together, except where a tine falls in the crossing, when it is secured by the nut of the tine itself. The bulls and cross-bars are simpiy punched for the tines, which are secured by a screw-nut. The middle bull of each harrow is prolonged a little forward at $g$, and punched for the shackle of the draught-chain, which is affixed thereto by a bolt. The bolt which joins it to the cross bar at each end is also prolonged upward 4 inches, having a collar above and nut helow, forming a firm stad. on which the stretcher is placed, and retained by a nut above. The tines are about 4 inches in length below the bars, and are sinch square at the shoulder, tapering to a blunt point.

(1905.) Fig. 350 is a cross aection, at the front-bar, of both the leaves of the harrow, showing the arched form and direction of the tines. The rise of the arch is 5 inches, but this may be varied, and if the arching is flat, the tines toward the apex should be shorter than those toward the sides of the harrow, to prevent injury to the young plants. In the front bar the right-hand tine may be left out, as its place may be taken up by that of the third bar, leaving 5 tines. In the second cross-bar there are also 5 tines, and in the third, 5. The two leaves are connected and kept at due distance by the coupling-rods $k$, which are $\frac{s}{8}$ incl diameter, and flattened at the ends to the extent of 5 inches, and have. 3 perforations made at each end, at $1 \frac{1}{2}$ inches pitch, or clocer if thought necessary; this construction of the coupling-rods affords the means of adapting the harrows to any width of drills. The dranght-chains $i i$, fig. 350 , are about 2 feet long, and are shackled to the draught-bar. to which the horse is yoked by the eyes at $h h$. The pair of harrows are drawn by one horse, walking between the drills : the weight of the pair, with the mounting, is about 90 $1 \mathrm{bs}$, and the price from $30 \mathrm{~s}$, to $35 \mathrm{~s}$. complete.

(1906.) Triangular Drill-Harrows are considered by come agriculturists as superior in effect (402) 

of the hind-end of the mould-board should be cut away, and the plow otherwise formed-that is, of euch size and lenerth as to be worked by a pair of horses instead of one. The double mouldboard, besides aftording expedition, covers the dung equally with both furrows, puts less earth over the sets, permits the germs to grow upright at once, and thereby allows the access of more air to the sets. Still it will be requisite to harrow down the drills before the sets send up their germs to the surface of the ground.

(1908.) Being desirous of ascertaining the true cause of the failure in potatoes, I am ready to recommend to your notice every rational explanation that is offered on the subject. The fol. lowing explanation is, I believe, from the pen of Professor Lindley of Loadon, and therefore deserves attention. At the same time, I must own that the explanation is unsatisfactory to me. insamuch as the tubers in the soil. in regard to their liability of being acted on by chemical agencies, would be the same many years ago, when failure was not so universal as it has been within these few years. "The potato crop." he says, "has of late years been seriously affected by a disease which consists in the production of tubers, instead of stems, when growth first commences after plnnting, and in the loss of all farther power of vegetation consequent upon this malforma. tion. We have examined several specimens of the disease without succeeding in discovering the smallest trace of organic injury, and we feel satisfied that there is nothing in the visible formation of the potato which will account for it. All the tubers, young and old, seem perfect. It is therefore probable that Chemistry must be called upon to explain the source of the mischief, and that some defieiency or excess of the proximate principles lodged in the tuber will be found connected with it. Although we have nothing pusitive to state in confirmation of this suggestion, yet there are some facts which may possibly lead to the discovery. We know all that the potato-shoots, when first produced, are fed by the matter lodged in the tnber from which the shoots proceed. That matter consists largely of starch-an insoluble substance, which only becomes capable of nourishing a young shoot by changing into gum or sugar. Chemists tell us that such change is cffected by a form of matter which they name Diastase, in which nitrogen is an element. Since we know that the quantity of azotized matter found in a potato varies very considerably, it is probable that the quantity of diastase also varies, and that in some cases it may be altogether insufficient to render the starch soluble, except to a small extent. If that were so, the bud, when it springs from a tuber, would be unable to grow into a shoot bearing leaves, but would develop itself in an imperfect way, and remain as a little tuber, without any power of growing farther. This may be the history of the disease in the potato now under consideration; and if so, it would perhaps be removed by adding azotized manure; for the latter, when decomposing in the soil, may furnish the nitrogen that is required. It is true that diastase is a peculiar compound, and that we have no authority for supposing diastase itself likely to be formed in a putato by the addition of azotized matter to soil. On the other hand, we know so little of nitrogen and its action in vegetation, except that its influence is most important, that it is a fair subject of, speculation. If leaves cannot decompose carbonic acid, except in the presence of nitrogen, it may very well be that starch also cannot change into sugar or gum except in its presence, and that in any nascent state it may act just as well as if produced by the decomposition of diastase. We would recommend, then, those whose potatoes are thas affected to manure them at once with water containing ammonia. This can do no harm, and may do good. Experiment, too, is somewhat favorable to the trial; for lately, in the garden of the Horticultural Society, some potatoes which had not made their appearance above ground at the time when others, planted at the same period, were in full vegetation, were, at the desire of $\mathrm{Mr}$. Edward Solly, watered with a weak solution of muriate of ammonia; when in a few days the leaves and stems came up, and are now the most vigorous of all."* This last recommendation, of course, can only be practiced in garden calture.

\title{
18. BREAKING IN YOUNG DRAUGHT-HORSES.
}

\author{
"Thy fattering method with the youth pursue ; \\ Joined with his school-fellowe, by two and two, \\ Persuade 'em trot to lead an empty wheel, \\ That scarce the dust can raise, or they can feel ; \\ In length of time produce the laburing yoke \\ And shining shares, that make the furrow smoke."
}

DRY DEN's VIRGIL.

(1909.) Young draught-horses are never broke in. They are most frequently yoked with an old steady horse at once into the harrows, accompanied with a few restrainers of reins and ropes, or an additional hand or two to assist the plowman, to prevent any attempt at a run away; and, no doubt, when colts have been haltered and led out from the time they were weaned by a steady, quiet-tempered man, they will soon submit to work, and become harmless in the course of a few short yokings. But, notwith-

* The Gardeners' Chronicle for June 24, 1843. 
standing their quietness, they cannot be said to be broke in, in the proper sense of the term; that is, they do not yield to the guidance of the plowman, because they either know or understand what he means, or would subject themselves to his control, but because they feel they are subdued, and are obliged to move along with an older and stronger horse, to which they are attached, as he may choose to lead them. Their mouth is quite intractable to the bit all the time they are apparently subdued; they seize the bit with their teeth, and press upon it, with their head hanging down, their neck arched, and their eyes set back, as if suspicious of harm overtaking them. In this way, day after day, or at least in every yoking they are worked, they look more like objects of oppression and pity than of pride to the farmer, on seeing the young and noble steed he has bred and reared first undertake its work. The rein may be pulled this way and that to no purpose; and in the end the dull, sulky-looking colt is confirmed in his natural temper, and the timid one rendered more afraid. No doubt time, in this as in every other thing, brings about a change; but why should the change, even for the better, be allowed to be effected by a lapse of time, to the discomfort and annoyance of the animal in the mean time, when he can be broke into his work with comparative ease? "Ay, break him indeed, but remember the cost," is the ready rejoinder to the question just asked; and the answer to the rejoinder is as ready. What although it does cost some money to break in a colt to do his work in a proper manner, in the most easy way for himself, and in the shortest time to his master? Is a little cost to be put in comparison to giving trouble to people to teach a colt how to perform his work, who know nothing of the rules of tuition, and who therefore run the risk of spoiling the colt for life? Is one guinea such a deadly sum as to induce any owner of a fine colt to run the risk of spoiling him-for no greater cost need be incurred in breaking in a draught-colt to his work.

(1910.) The easiest plan to make a draught-colt work well soon, is to employ a good horse-breaker to bridle, and handle, and lunge him for a short time-as long as is requisite to make his mouth yield to the bitand then he will obey both voice and rein; and while employing the rein, the horse-breaker should be instructed to use the language that will be spoken to him while at work, the terms of which I have fully explained in (901). The harness required for this purpose is a breaking bridle, a cavesson, and pad for the back, all of which the horse-breaker will supply. I must remark, however, that most of the bits I have seen used in breaking bridles seem to me inefficient for the purpose. They are very thick at the guard, round, and jointed in the middle, a construction which gives the horse an opportunity of seizing the round thick part with his grinders, when folded back by the force of the rein acting on the joint, and of resting his head upon it. A more efficient bit is represerted in fig. 351, which $I$ have seen used many years ago in Berwickshire, by Thomas Middlemiss of Norham, who was reckoned in his day one of the best horse-breakers and grooms that had practiced in that part of the country. It consists of two bits, one twisted and the other square, both $8 \frac{1}{2}$ inches in length. The square bit $c d$ is $\frac{1}{2}$ an inch square, and so is the diameter of the twisted one $a b$, and they both have a play of $\frac{1}{2}$ an inch between the shoulders of the guards $a c$ and $b d$. The guards $e f, g h$, are 7 inches in length. The ring $i$ on each side is $2 \frac{1}{2}$ inches in diameter over all, and at $k$ is a bunch of links to play upon the tongue, and make the horse move his jaws. 'The straps comnected with the bit are, first, the head-stool; the hand-reins, $4 \frac{1}{2}$ feet in length; the check-reins to keep the horse's head in line, when strapped to the pad, and which pass below the neck-strap of the martingale. All

(405) 
these 3 straps are buckled to the rings $i i$. There is, besides, a martingale to prevent the head being thrown forcibly up. The breadth of the straps is 1 inch; that of the counter strap of the martingale $1 \frac{1}{2}$ inches.

Fig. 351 .

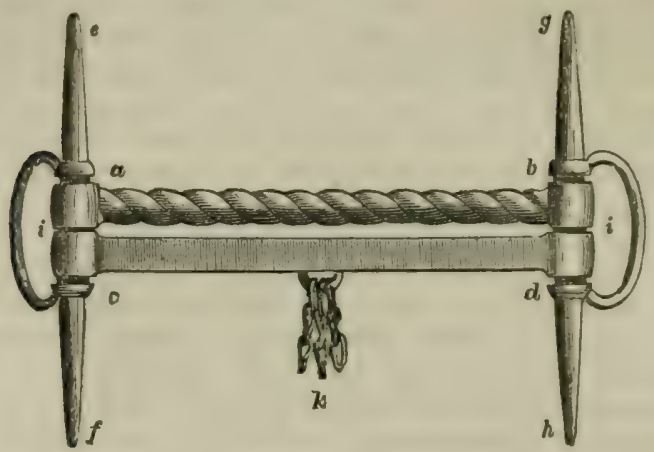

THE BREAKING-BRIDLE BIT.

The bit can be buckled on in the reverse order shown in the cut, having the square bit $c d$ uppermost, and the bunch $k$ is then screwed to the twisted bit $a b$. The cavesson is well known, and requires no particular description, its figure and appointments being uniformly the same.

(1911). It is unnecessary to go through all the discipline of breaking in a draught-colt, as is required in the case of a saddle-horse, but a few preliminary steps are necessary, such as playing the bit in the mouth for 2 or 3 hours in the stable, twice or thrice a day, the colt standing in the reversed position in the stall, which has the double advantage of making the mouth yield to the bit and of keeping up the horse's head. The bit is buckled on slack for this purpose, so as to lie upon the gums, on the bare space of the lower jaws between the front and back teeth, upon which place either the square or twisted bit is felt to rub sharply, while the bunch of links $k$ makes the mouth and tongue play as if desirous of getting quit of the whole concern. When the head is pressed forward to get hold of the bit with the back teeth, the straps being too long, the head finds nothing to rest upon, while the bunch $k$ is brought too far back upon the tongue to be agreeable. After this discipline in the stable for two or three days, according as it is seen that the colt yields to the bit, with occasional walks out of the stable, he should be led out to walk two or three hours at a time by the nose-rein of the cavesson, to learn to step out, and to acquire a good pace; and this is the most essential discipline for a draught-horse. A short lunge or two backward and forward round a circle, on red land, will be useful, not to teach him to trot; but the trotting exercise will make him active, and sooner get the use of his legs in cases of difficulty. He should then be backed, and, while guided by the reins, should be spoken to in the language he will be addressed in the yoke. After that he should be guided along a road with long double-reins, while carrying the plowchains to accustom him to their noise and feel, and addressed in the appropriate language. Now all this discipline may be gone through in the course of a week, or 8 or 10 days, according to the disposition of the animal, the handling he may have received since he was a weaned foal, and 
the genius of the horse-breaker. The horse-breaker should groom the colt immediately after exercise, that the animal may become familiarized with the usages of the stable, and the degree of exercise given should be with a discrimination suited to the condition and physical strength of the animal. The colt's food, too, should be so administered as to harden his condition for labor; with the understanding, however, that, after the busy season of work is finished in the early part of summer, the young tyro shall be allowed to have a run at grass for a few weeks, and then fall into his own share of regular work.

(1912.) After the treatment and discipline received from the horsebreaker, the colt will be easily made to understand work. The sort of harness with which he is first invested is that of the plow, consisting of a bridle, collar, fig. 197, and back-band and chains, or theats, as these are called in some parts of the country. It is quite possible that the discipline received from the horse-breaker will make the colt suffer at once to be yoked with an old horse at the plow; but in case of accidents, and to err on the safe side, it is best to use precaution, even though it should be proved to have been unnecessary. The principal precaution is to attach the colt to a strong, steady horse, that will neither bite nor kick him, and be able to withstand the plunges the colt may choose to make. The attachment is made by a cart-rope being first fastened round the girth of the old horse, and then passed round that of the colt, leaving as little space between their bodies as is required for plowing; and to afford no liberty to advance or retire beyond a step or two before or behind the old horse. Besides the usual rein employed by the plowman, the horse-breaker should have another in his hand from the colt's head. Thus equipped in plowharness, the first yoking of the colt should be to an old cart-wheel, placed on its dished face on plowed land, furnished with a swing-tree, which he should be made to draw, while the horse walks beside him; and, in drawing this, the reins should be used, and the appropriate language spoken, that he may associate the changes of his motions with the accompanying sounds, and which are indlcated by the reins while guiding him. I remark in passing, how curious it is for us to have adopted the Roman method of breaking young horses by the employment of the wheel, as set forth in the motto selected from Virgil. Should the colt offer to wheel round, the gentlest means should be used in putting him again in his proper position, as the start may have been made from fear, or from the tickling of a part of the harness. When a hind-leg gets over a trace-chain, the chain should be unhooked from the swing-tree, and hooked on again after the colt has been put in his right position. Should he offer to rear or kick, from a disposition to break away, the old horse should be urged on to the walk, and be made to pull him along, while a smart tip of the whip will take the courage out of him. According as he evinces a disposition to go on quietly in the work, should the length of time be determined at which he should work at the wheel. When submissive, he should be yoked to the plow, for there is no species of work which calls forth the sympathy of horses to one another in so short a time as when working with this implement; and, after a few landings, it will be seen that he will work with energy and good-will, and then he should be kindly spoken to, encouraged, and even fondled. The probability is that his desire for the draught may be evinced too keenly, but the pace of the old horse should be subdued, and the keenness mitigated by the rein and $t u g$, which the short reins are called that pass from the head of one horse to the collar of the other, and which, in this particular instance, is fastened to the rope round the girth of the old horse. It is interesting to the farmer to see his young horse put (407) 
his shoulder to the first work he has ever tried with a spirit even beyond his strength; and, while he continues at the work until his nostrils distend and flanks heave, his owner cannot help having a regard for him, hightened by a feeling of pity for the unconscious creature acquiring experience of work at which he is about to be doomed to toil for the remainder of his life. It should be mentioned, as a precaution, that all the harness employed about the first yoking of a young horse should be fresh and strong, and not likely to break, even hy violence. The colt should be broke in to the cart as well as the plow. He is yoked into a single horse-cart, but great care should be used on the first yoking, that he get no fright, by any strap rubbing against him, or the shafts falling upon him when raised up to allow of his being backed below them; for, if frightened at the first yoking to a cart, a long time will elapse ere he will stand the yoking quietly. The horse-breaker should stand in the cart using double reins; and a rein should be held by a man walking first on each side of his head, and then at a little distance on the sides of the road. The chief danger is kicking, and thereby injuring the hocks against the front-bar of the cart; to prevent which, a rope should be placed across the top of the colt's rump, and fastened to the harness on the rump, and on each side to the shaft of the cart. There is little danger of his running away while all the reins are good. He will take with the traces of the cart more readily at first than with the trams, as they are so similar to the yoking he has felt at the plow, and he is conscious of having his companion behind him.

(1913.) On the first use of harness by a young horse, the shoulders and back are liable to become inflamed, and even the skin to be broken by the collar and saddle. It should be ascertained, in the first place, that the collar he is to work in fits him properly; and, if it does not, it should be made to do so before he use it, as the first day's use may so injure his skin as to give him pain for weeks thereafter. The usual affection is heated swellings in the line of the collar and seat of the saddle. A good lotion, to be applied to those parts whenever the colt comes out of yoke, is a solution of common salt in warm water, and, when cold, applied as a fomentation with a sponge. The water not only cools the skin, and keeps down the inflammation, but the salt hardens it for use; and in the course of a short time, particularly if the weather be dry, the skin will become inured to the pressure of the harness. A young horse may be broke in for work any time in the course of the spring, from the beginning of working the turnipland to its completion. I can affirm the efficiency of the plan I have recommended by repeated experience, and it is one unattended with the slightest accident in practicing it.

(1914.) It is the usual practice to shoe and dock the young horse before putting him to the yoke. I think he should first be broke in, and then he will suffer himself to be shod the more quietly. At the first shocing it will be useful, in making him stand quietly, and in diverting his attention, to take the old horse he has been working with to the smithy. By nailing a mat against the wall, and making him stand alongside the mat, it will save his skin being ruffled should he rub against the wall, while the wall will form a firm barrier against his retreating farther from the blacksmith. After the fore and hind feet of one side have been shod, these can next be turned to the wall to get his other feet shod. Gentle and coaxing means should be used, though a twitch on the nose has a powerful command over a horse. The first shoes of a young horse should be light, with no heels, and the hoofs should not be pared down much at first. Rather renew the shoes, and pare the hoofs down again in a short time, than incumber a colt at first with heavy shoes with heels, to the risk of tram(408; 
pling himself, as to cure the effects of a severe tramp may cost much more than the price of many sets of new shoes. As to docking a draught-horse, I think it a necessary operation, because a long rump is very apt to get injured when the horse is yoked in the trams, by coming against the body of the cart, and in coup-carts especially it can scarcely escape being nipped when the body of the cart is brought down upon it when lying on the front-bar, and besides a draught-horse has no use for a long tail. A neat swish is all that is requisite at any time, and in winter even that is apt to be loaded with mud on dirty roads. Some writers affect to believe it presumptuous in man to deprive any animal of six of the joints of the vertebral column which Nature has given him; and no doubt were our horses always idle, especially in summer, when a long tail is of essential service in whisking off flies, the vertebræ ought to be kept entire; but surely there is no greater absurdity in docking the tail, than in driving iron nails into the crust of the hoofs of a horse, and yet without iron shoes to protect it, the horny foot of the horse would be beaten to pieces on hard roads at the pace many kinds of horses are driven along them; and there is no necessary cruelty in the act of docking, for it is an operation of the simplest form when properly done, that is, when effected in a joint where the wound is easily healed. As to nicking the tail and cropping the ears, such operations are never performed on draught-horses, and at hest only serve to disfigure the appearance of the animals subjected to such unnecessary torture.*

\section{SOWS FARROWING OR LITTERING.}

"Sows ready to farrow this time of the year,

Are for to be made of, and counted full dear,

For now is the luss of a fare of the sow

More great than the loss of two calves of the cow."

TUSSER.

(1915.) It should be so managed where there are more than one broodsow on a farm, as to have one to bring forth pigs early in spring; but, at the same time, it should be borne in mind that young pigs are very susceptible of cold, and if exposed to it, though they may not actually die, their growth will be so stinted as to prevent them attaining to a large size, however fat they may be made. Even the most comfortable housing will not protect them from the influence of the external air, any more than certain constitutional temperaments can be rendered comfortable in any circumstance in spring, when under the influence of the east wind. From March to September may, perhaps, be considered as the period of the year when young pigs thrive best.

[* The reasoning of the author in this case appears not to be conclusive. There is no reason to suppose there is any sensibility in the horn of the hoof, and the nailing of the shoe is intended to prevent, not to give, pain-whereas docking gives much pain at the time, requires care to heal it up, and deprives the horse of the brash which Nature gave him to keep off the flies from a large portion of his body.

The exposure of the tail to be filled with $\mathrm{mad}$, is an inconvenience, but when occasion requires it (which is generally when there are no flies about, in winter,) the hair may be neatly plaited and tied up, as all good teamsters know how to do. We go against all nicking and docking and cropping, and for saving beasts, as well as our fellow-creatures, from every moment of painful sensation that can be avoided.

(409)

[Ed. Farm. Lib. 
(1916.) Whenever a brood-sow shows symptoms of approaching parturition; that is, when the vulva is observed to eularge and become red, it is time to prepare the sty for her reception, for she will keep her reckoning not only to a day but to an hour. The period of gestation of a sow is 112 days, or 16 weeks. The apartments meant to accommodate brood-sows in the steading are marked by the letter $c$ in figs. 3 and 4, Plates III. and IV. They consist of an outer-court 18 feet long by 8 feet broad, inclosed by a door, as represented in fig. 23, and described at 5 in (68), and an inner apartment 8 feet by 6 , roofed in. This is the usual form of a sty for sows, but others more convenient for overlooking the state of the sow and her pigs is when the outer court and inner apartment are placed under one roof, that is, in a roofed shed, or in a house which may be shut in by a door. The litter allowed to a brood-sow should be rather scanty and of short texture, such as chaff, short straw, or dried leaves of trees, as young pigs are apt at first to be smothered or squeezed to death among long straw, when they get under it. When a sow has liberty before she is about to pig, she will carry straw in her mouth, and collect it in a heap in some retired comer of a shed, and bury herself among it, and the chance is, in such a case, that some of the pigs will be lain down upon unseen and smothered by the sow herself; when seen she will carefully push them aside with her snout before lying down. Some sows have a trick of wandering away to litter in a quiet place, such as in a field of corn, in a plantation among underwood, or in a dry ditch at the root of an old hedge or tree. I remember of a sow being missing for upward of a fortnight, not a person having seen her leave home, or being able to discover where she had gone to ; but she was suspected of having disappeared for the purpose of littering. At length she appeared one day craving for food at the kitchen door, bearing evident signs of having littered, and of having suckled pigs. She was cautiously tracked to her hiding-place, though jealous of being discovered; and it was found that she had formed a nest with the straw gathered from the adjoining field of wheat, in a secluded part of a dry ditch at the root of an old thorn-hedge, about 300 yards from the steading. She had subsisted as long as she could upon the corn, but hunger at length drove her to the house in search of food. Had she been allowed, she would, no doubt, have come to the house every day for food; but means, of course, were used to have the pigs conveyed to the steading, and this was a work of some difficulty, as the sow herself was perfectly savage when any one approached her young ones; and these were so wild in their habits that they eluded capture for a long time among the standing corn. At length, by the assistance of the shepherd's dog, which seemed to enjoy the affair as sport, they were all caught, a large litter, and, on being conveyed home in a large basket, the sow naturally followed her captive young ones. I remember of another sow taking up her abode in the bottom of a pea stack, where a small hole was only left as an entrance, but a large chamber was formed in the interior, and it was found impracticable to dislodge her from this stronghold, she keeping every man and the shepherd's dog at bay, and he was too knowing to ven ture to attack her in single combat; so she was let alone, and she produced her young there, and kept them until they were able to run about, food having been set down for her. I mention these instances of the peculiar habits of some domesticated sows, merely to show you the propriety of securing the brood-sow that is about to farrow, and particularly one that is given to wander abroad in search of a nest, in a proper sty some time before the period of her reckoning.

(1917.) Knowing the day of her reckoning, she should be attended to 
pretty frequently, not that she will probably require assistance in the act of parturition, like a cow or a ewe, but merely to see that all the pigs are safe, and to remove any one immediately that may be dead when pigged, or may have died in the pigging. I have heard, however, of a sow in high condition which died because the second pig, on coming by the breech presentation, had a hind-leg folded back, which could not be put right by the sow herself in pressing, and having been neglected, her parts very much swelled. As an attempt to save her life, the Cesarian operation was performed on her, and the obstructing pig was removed; the animallived, but the others in her womb were dead, and she herself did not survive the operation above an hour, having been completely exhausted before it was attempted. I do not know whether it is generally the case, but I have frequently observed that pigs leave the womb alternately in a reversed order; that is, they are projected by a head and breech presentation alternately, not uniformly so, but most fiequently. There is no doubt, however, of the fact that the first-born pigs are the strongest, and the last the smallest and weakest, in a large litter, such as upward of 12 , though the difference is less or scarcely observable in smaller litters of 6 or 8 . The small, weak pigs are usually nicknamed wrigs, or pock-shakings, and are scarcely worth bringing up; still, if there is a teat for them to lay hold of, they ought not to be destroyed. Sometimes there are more pigs littered than the sow has teats to give to each. I have seen as many as 19 pigs when there were only 12 teats; and I remember of a sow that never littered fewer than 17 , when she had 14 teats, which are two more than the usual number. Extra pigs, can, no doubt, be brought up by hand on cow's milk, but the last ones of a very large litter are usually so small and weak that they generally die off in the course of a day or two to the numker of the teats. A young pig soon gets to its feet after birth, and as soon finds its way to the teat; but it can find no sustenance from it until the sow pleases, so that until the entire parturition is accomplished and the sow recovered from it, there is no chance of the pigs getting a suck. Many sows are very sick during parturition, and for some time after-so much so that the skin of their mouth becomes bleached and parched, and the breathing quick. To those unaccustomed to see a sow in that state, it would seem that she must die; but a little rest recovers her, and she betakes herself fondly to her young. It is necessary, as I have said, to remove the pigs as they die, if any die, as some sows evince the abominable propensity of eating their own pigs when they die, whether the death takes place at the birth, or immediately after, or whether it happens on their being smothered or squeezed to death by being lain down upon by the sow herself, when nestled between her and the wall. I remember of a sow that was never sick at pigging, and such was her propensity to eat every pig that died or was smothered, that even during parturition she would get up as every pig was born, to ascertain whether it was dead or alive, and, if dead, would eat it instantly, provided she was not prevented; and even after they were a week old she would eat them, had they died by accident.* There is a peculiarity exhibited by young pigs, different

[* There is much that is superfluons, in this chapter, for American farmers generally. But although the business of hog-breeding is, perhaps, of all stock-breeding the most simple and the one in which Nature may be generally left unassisted and unattended to, still this inattention may be and is often carried to an extreme; for although generally the pigs will live, how much better would they thrive if, at the time of farrowing, the sow were treated with a more liberal allon. ance of suitable liquid and green food for keeping the system in a better condition, and expressly for producing a greater flow of milk. The growth and ultimate size of all animals depend greatly

(411) 
from the young of other domesticated animals, in each choosing a teat for itself, and ever after keeping possession of it ; and this compact, as it were, is faithfully maintained. Should there be one pig more than there are teats, it must take its chance of obtaining a teat when the rest are satisfied. It is generally olserved that the pigs which are supported at the foremost teats become the strongest; and the fact was noticed long ago by Tusser, who recommends store pigs to be those which are

"Ungelt, of the best keep a couple for store,

Une buar pig and suw pig, that sucketh before."

Pigs require to use coaxing before the sow will give them milk. They make loud entreaties, and rub the udder with their noses to induce her to lie down; which, when she does, every pig takes its own place right earnestly, and nuzzles away at the udder with the teat held in the mouth, whether situate in the upper or lower row. After a good while of this sort of preparation, the milk begins to flow on the sow emitting a fondlike grunting sound, during which the milk is drawn steadily and quietly till the pigs are all satisfied, and they not unfrequently fall fast asleep with the teat in the mouth. Young pigs are lively, happy creatures, and fond of play as long as they are awake, but they are great sleepers. When a week old, their skins are clean, hair soft and silky, and, with plump bodies and bright eyes, there are few more beautiful young animals to be seen about a farm-yard. Those of a white color look the most delicate and fine.

(1918.) As to the food of the sow after she has recovered from parturition-which will be longer or shorter according to her constitutional temperament-she should get a warm drink, consisting of thinnish gruel of oatmeal and lukewarm water, and which serves the double purpose of meat and drink. If she is thirsty-which she is likely to be on recovery from sickness-the gruel may be again offered in a thinner state in an hour or two afterward. The ordinary food may consist of boiled potatoes, with a mixture of barley-meal, among water, administered at a stated hour at morning, noon, and night, with such refuse as may occur from the farmhouse. This food will be found to support her well while nursing; and it should be borne in mind that, as long as she is nursing, she should receive abundance of food, if it is desired she should rear good pigs. Should the weather be frosty, or otherwise cold, the water may be given a little warmed; but in fresh weather, or in summer, cold water is most acceptable to her. The mess should not be made so thin as to be sloppy and take a long time to drink up, or so thick as to be cloggy in the mouth, but in a state of gruel-meat and drink at the same time. Whatever food is given to her should be cooked, and not in a raw state; that is to say, the potatoes should be boiled and not given raw, and the barley-meal should first be made into brose with warm water, and then mixed with the potatoes, and the whole mess made like gruel with cold water. The trough out of

on their being well supplied in their infancy with suitable food. Yet to this it must be confessed that in our country generally too little attention is paid, and in no instance is this the case more than in our neglect to provide properly for the eve and the son during the period of suckling.

As to the propensity of fome sows to eat their pigs, when they die young, it is by no means a rare thing-or rather it sometimes happens, as we know, that they will at once devour the whole litter, though farrowed alive and well! They seem to be animated to this horrible and disgusting act of infanticide by a sort of furor which is said to proceed from a morbid state of the blood, and to be most apt to happen with sows that are in too high condition. To guard againet this monstrous disposition, it was recommended by the late Gunham Pansons, of Massachusetts, (whose memory as a personal friend, and able promoter of the cause of agricultural improvement, we shall ever cherish with grateful recollection, to give, for a week or two before farrowing, a spoonfull of sulphur occasionally in their food, to "cool their blood," as he said.

$(4 i 2)$

Ed. Farm. Lib.] 
which she receives her food should be washed every two or three days in cold, and every day in warm weather. I believe it is the common practice never to give pigs salt among their food, because it is said to encourage the scab. A large quantity of salt may have this effect, but I never saw a relish of salt produce such an effect. When a sow leaves any of the food in the trough, it should not be presented to her again, but given to the young pigs, who will relish it.

(1919.) Most pigs are usually gelded, both male and female-the few that are kept for breeding forming but a small exception. They should be gelded on the milk at from 10 to 14 days old. The males are castrated on being held between the knees, and the scrotum incised down upon each testicle, which is removed by the pressure of the finger and thumb, and the spermatic chord separated by the knife. The she-pigs are treated in a different manner. Being laid on a chair-bottom or table, on its far side, the pig is there held by an assistant; the operator cuts an upright incision into the flank, of about 2 inches in length, and, introducing a finger, brings out the ovaria of the womb, and separates them by the knife. He then closes the incision by a few stitches with a needle and thread, and the operation is finished. There is very little danger attending the operation to either sex. In the case of rupture or hernia in the male-and some breeds of pigs are very liable to this disease when young-it is necessary to stitch up the incision of the scrotum, and the testicle at castration should, in such a case, be removed with care, in case of producing inflammation in the intestines. The incisions in both the male and female generally heal by the first intention. The gelder should use the precaution of cleaning his knife before every operation. The usual charge for gelding pigs is $2 \mathrm{~s} .6 \mathrm{~d}$. the litter, whatever number it may contain. Young pigs are not gelded when intended to be killed for roasting.

(1920.) It is seldom that any complaint overtakes the sow on littering, though she may be carried off by puerperal fever, and I suspect there is no remedy for this disease in her case. The pigs which she leaves may be very well brought up by hand on cow's milk, as they will soon learn to drink out of a dish, in which the milk should be given them warm from the cow, and as often as the cows are milked. It is surprising how small a quantity of milk a pig will drink at a time; and on this account they should get it frequently, and the dish in which it is served should not be easily upset, because there will be a struggle to get first at the milk, and one or more will be sure to jump into it. The diseases incidental to young pigs are luckily few. Their tails sometimes drop off with a sort of canker, and a red eruption sometimes takes place on their skin, and sometimes one in a litter may take a wasting and die. I believe that if the sow is provided with plenty of wholesome food, the pigs kept clean and warm in their sty and litter, and their sire and dam be not too near a-kin, that few diseases will overtake pigs as long as they are on their mother's milk. A sow is not allowed to take the boar until after the pigs are weaned, but as soon after as possible, in a week or two; and, to bring her into season the sooner, she should be fed with oats or oatmeal until she takes the boar.The symptoms of season in a sow are a redness and enlargement of the vulva-which, when observed, the boar should have access to her; and, should there be a boar on the spot, the meeting will be easily accomplished, and one embrace, which is usually a protracted one, is quite sufficient for securing a litter of pigs. When there is no boar on the farm, the sow is sent to him, and she remains a few days with him to secure her impregnation. Pigs are weaned at 6 weeks old, and some keep them on the sow for 2 months; but there is little thrift in such management, as the suckling 
in the last week of a large litter of large pigs brings a sow very fást down in condition, and which must be made up again with extra feeding and a longer time before she farrows the next time. A sow that can bring up 10 pigs, and has 5 such litters in the course of 2 years, is a profitable animal, and deserves to be well maintained and taken care of. Even at 10 s. apiece-which is the lowest sum a farmer should take for a pig, for he should keep it until it is worth that sum, rather than part with it at a lower one-such a sow will return $£ 25$ in the course of 2 years.

(1921.) As it is considered by farmers inconvenient to keep beyond a certain number of pigs on the farmstead, it is necessary to determine what that number should be, and as it is difficult to fix its amount for every particular case, a few hints on different modes of managing litters, after they are weaned. may prove acceptable to yon. Before investigating this point, a few particn. lars may be stated which you may regard in the light of maxims on this subject. A fow should alway be either with young or giving suck, for if allowed to run about in season, or a.breaming. as it is termed, she will lose flesh instead of gaining it. A sow should always be kept in good condition, whether with young or supporting young, because a lean sow never brings forth or can nourish strong pigs. Every breeder and feeder of pigs will find his own advantage in never allowing them to go to bed with a hungry belly. A sow that brings forth the greatest number of pigs of the best quality, proves the best nurse, and is most careful of her young, should always be preferred as a brood-sow. When a sow gets old, she is apt to become careless of her pigs, so that 3 or 4 years may be age enough for a brood.80w. Pigs, though on grass during the day in summer, should, nevertheless, receive a drink of water and meal, or potatoes, or of whey at morning and evening.

(1922.) There are just two ways of rearing pigs on a farm-one is to have a large number of sow's, and sell the pigs when they are weaned at 6 weeks old ; the other is, to have fewer fows, and rear the pigs until they are fit for the pork-curers; and the adoption of either of these plans depends eutirely on the nature of the market of the locality. If there is a demand for joung pigs immediately after being weaned, supporting the larger number of sows will be the most profitable plan for the farmer, because the pigs have not to be maintained on food independently of their mothers; but it is a plan attended with much trouble, inasmuch as food bas to be daily cooked for the sows while supporting their young, and the market for pigs is, moreover, confined to one age. In the latter plan, on the other hand, the sows are only supported on special food as long as they support the pigs, and there is not only the choice of the market for newly weaned pigs, but for pigs of various ages, suited for the tastes of pork-curers. Suppose, then, that 2 Eows are maintained, in pursuance of the latter plan, and that they bring forth 20 pigs twice 8 year. Retaining 4 of these for ham, and other two for pickled pork. for the use of the house, there will be 34 pigs to dispose of every year, and as these meet with a ready market when 4 or 5 stones imperial each, at 68 . a ktone, will make them worth each from 248 , to 308 , or from $£ 40$ to $\mathcal{X} 50$ a year for pigs. It should be borne in mind that these 34 pigs, when running abont the courts in winter, eating a few turuips or jotatoes, or grazing in the grass-field in summer, do not cost much to rear them to the weight most desiderated by the curers of pork, and they are in that state fat enough for the purpose, and make very wholesome meat. On a farm of 500 acres, 2 brood-sows could thus be easily maintained; on a larger farm 3 might be kept, and on a smaller 1 may suffice; but circumstances must regulate the proper number. Where dairy husbandry is more attended to on one farm than on another. and when the mixed husbandry is practiced on both, more sow 8 may easily be kept in summer than where the dairy husbandry is less attended to. There is a remark of Mr. Henderson on this subject which is worthy of attention, in regard to the timing of sows in bearing their litters of pigs. "Whenever," he says, "farmers have an opportunity of eelling pork at all seasons. they do not think it necessary to make the sows bring their litters at a particular season, as they wish to have a lot of a certain age to go off regularly at least every month." in autumn, winter, and spring. " They make them rearly for the market," he continues, "with little expense, only giving them close feeding 2 or 3 weeks previous to their being sold." Pigs intended for pickled pork merely, do not require even this feeding, though those sold for making hams are the better for a little extra and hardening feeding. " They bave very little trouble in selling them," concludes Mr. Henderson, "as there are jobbers continnally traveling drough the country, purchasing swine of all descriptions, who receive them and pay the money at the farms."

(1923) The omnivorous disposition of swine is well known, and it is this disposition which makes them so easily mintained and so serviceable on a farm. "Swine, though exceedingly voracious," remarks Mr. Henderson, "will feed on almost anything. In miry and marshy ground they devour worms, frogs, fern, rush and hedge-roots. In drier and woody countries. they feed on haws, sloes. crabs, mast, chestuuts, acorns, \&c., and on this food they will grow fleshy and fat. They are a kind of natural scavengers; will thrive on the trash of an orchard, the outrasts of the kitchen, the sweepings of barns and granaries, the offals of a market, and most richly on the refuse of a dairy. If near the sea, they will search the shores for shell-fish, in the fields they eat grass, and iu great towns they are supported chicfly by grains. It is evident that the facility of feeding them every where at a small expense is a material benefit. more especially in a country where people are accustoned to eat flesh daily, or, on the other hand, where there is so ready a market for bacon and pork as we have. It is no less observable that, notwithstanding the fa. cility of feeding, and the multitnde of swine maintained, they seldom fail of coming to a good market. Swine ought to have hard feeding two or three weeks previous to their being killed, to give firmness to the flesh. This practice ought to be particularly atended to by those who feed at distilieries on burnt ale and grains, as the fat of piga thas fed melts almost wholly away in boiling or rousting. Peas and beans are excellent for the purpose, and acorns are still better. 
Where oak plantations are near, they will resort to them in autumn, and there remain until this their favorite food is exhausted. The late Sir James Colquhoun of Luss, I have been told, was in the habit of sending his pigs to one of the islunds of Loch Lomond, where there is an oak plantation, that they might pick up the acorns, which is said to have given a surprising degree of delicacy to the flesh. Those who have woods of this kind, and orchards, ought to allow their pigs liberty to range among the trees, to pick up shaken fruit and seeds."* The hoge of Germany enjoy the droppings of the oak and chestnut forests, and it is supposed that it is this species of food that imparts the very superior flavor which the hams of Westphalia are known to possess. That all the hams sold in this country for Westphalian are genuine, I have doubts, after having become acquainted with the true flavor in their own country. I remember of passing through a forest of sweet chestnuts of, I dare say, 3 miles in length, near Bellinzona, in the canton of Ticino, in Switzerland, in autumn, when the fruit was dropping from the trees; and into this forest the peasantry, I was informed, turned their pigs every year to get fattened at the season I allude to.

(1924.) Swine should not be allowed to enter a field of any kind without a ring in the nose. Their propensity to dig for worms and roots makes them turn up the soil with their noses, and when a grass-field is thus treated, it presents a perfect scene of havoc, in so far as the grass is concerned. The best material for making the nose jewels of swine is horse-shoe nails, they being both durable and ductile. As there is no use of retaining the heads of the nails, they are hammered into a point, and the nail is then fit for use. It is inserted into a hole, formed by an awl or other sharp-pointed instrument, through the upper point of the snout, and passing, with a good hold, through the cartilage of the top of the snout to its front, where the points of the nail are twisted firmly together. A new hole can be made in the snout, and another nail substituted, when the old hole and nail have become worn.

\title{
20. THE HATCHING OF FOWLS.
}

\author{
"Calls all ber chirping family rounu, \\ Fed and defended by the fearless cock. \\ Whose breast with ardor flames, as on he walks, \\ Graceful, and crows defiance. In the pond \\ The tinely chequered duck before her train \\ Rowa garrulous. \\ - The turkey nigh, \\ Loud threat'ning, reddens; while the peacock spreads \\ His every-colored glory to the sun, \\ And swims in radiant majesty along. \\ O'er the whole bomely scent, the cooing dove \\ Flies thick in an'rous chase, and wanton rolls \\ The glancing eye, and turns the changefui neck."
}

THouson.

(1925.) Spring is the busy season of the feathered inhabitants of the farm. Thomson well describes the "homely scene," which these happy creatures present while tending their young, and which might be seen at every farmstead in spring, were fowls cared for as they should be. Instead, however, of indulging in unavailing regrets, I shall endeavor, in as few words as the clear elucidation of the subject will admit of, to describe the mode of hatching and rearing every sort of fowl usually domesticated on a farm, and thereby show you that it is not so difficult nor so trouble. some an affair as the practice which generally prevails would seem to indicate. Observation of the habits of domesticated birds, and punctual attention to their wants, are all that are required to produce and bring up plenty of excellent poultry on a farm. $\dagger$

I + As no fitter occasion may offer, we think it best to preserve here the following, which appeared in a late number of the Gardeners' Chronicle, and which applies to disorders of poultry of not unfrequent occurrence. The prescriptions appear to be of a practical character and to be founded on experience :

[Ed. Farm. Lib.

Diseases of Poultry-Disorders of Digestion.-1. Indigestion of or Torpid (full) Crop.-This is a very common ailment, arising from taking cold, unsuitable diet, and other causes. The symptoms are moping, little or no disposition to take food, and hardness of the crop when felt. As a remedy, one or two tea-spoonsfull of English gin, according to the size of the fowl, has almost an immediate effect. It appears to act as a solvent, for the crop soon becomes soft,

* Henderson's Treatise on the Breeding of Swine. 
(1926.) In my observations on the management of hens in winter, I mentioned that the early-hatched chickens of the former spring were the best to treat as laying hens during winter (1473). These same young hens being in fine condition in spring, will prove good layers through the ensuing summer, and should therefore be kindly treated for that purpose, and not encouraged to become sitters on eggs, which they will do, if allowed to wander in search of food, and to find out nests of their own to lay in. I

and maceration soon goes on as usual. Possibly this may be owing to the presence of the essence of the juniper berry, as no otber spirit has the same effect, but is, on the contrary, deleterious to birds. This is infallible.

2. Indigestion of the Gizzard.-It would be difficult to enumerate all the causes for this, as for the former fatal ailment; but it often arises from confinement, locality, exposure to wet, damp and cold, and most frequently from unskillful ireatment in the hands of negligent persons, or those ignorant of the habits or requirements of poultry, such as sheiter, wholesome diet, sweet green food, lime, sand, \&c., which are quite as necessary as grain. In the farm-yard and fields, the more natural state, birds can procure most of these ingredients for themselves, which in towns, pens, coops. or cages, their perfectly artificial ntate, must be administered artificially. Rue and fresh butter, or syrup of rue and barley-meal, or soot and fresh butter formed ioto pellets with barley-meal, with the addition of a little pounded red brick, or pounded dry clay, are excellent remedies; or with the addition of a small pinch of allspice, or a few of the allspice corns. A very few minute grains of Cayenne pepper have been recommended. but with creat caution; indeed, I would scarcely advise anything so powerful and irritating. The best and ouly efficacious remedy, after all, is castor-oil, one or two tea-spoonsfull.

Mechanical Aid, when the crop is overloaded and medicine fails to promote maceration, must be resorted to and be effected by discharging its contents by gentle pressure, with great care and patience, through the mouth.

When, however, the contents swell, and are of a nature impossible to remove in that way without violence, which must never be used on account of the danger of lacerating the throat, an operation by a skillful hand is necessary, but requiring great trouble and attention during the healing process. A small slit must be made in the lower part of the crop, through which the noxious substances can be extracted. One or two entures should then be neatly made with a needle and thread to hold the sides together, which will soon heal.

More sutures than are absolutely necessary would prevent healthy suppuration, which is requisite, in order to encourage the healing process. Care should be taken to keep the wound clean, but without damaging the sutures. The fowl must be kept within doors very quiet, and upon soft diet until recovered. But this sort of operation is often more curious than useful, if nol cruel, unless the patient be one of some value.

3. Oon. or Lush, or Shelless Eggs.-When a hen lays this sort of egg, and not habitually, the occurrence is generally accompanied with hard or full crop. In that case, it is owing to indigestion, to be treated as before with one or two tea-8poonsfull of English gin. One cause is said to be overfeeding when fowls are too fat.

These eggs are generally dropped from the roost, and if it is not too high from the floor, or if they fall on straw, may be saved entire and used for puddings. As to symptoms, experience will make known the indications, and the time when a hen is about to pass one of these eges, by appearing somewhat dull, and uneasy when walking about; when proper precautions should be taken to secure it, and prevent the other hens from gobbling it up. When this occurs from indigestion. the shapes of these eggs are often twofold, either like a fannel, the protuberance being about 2 inches long, ending with a thin thread twisted op at the end, or otherwise twain (two small) eggs, joined by a membrane, about an inch long; one containing the yolk. the other the white. The cause for this curious deviation of shape I have not ascertained. But when this happens habitually, which is not uncommon, the shape is in every respect as usual, and the canse is some derangement or injury of the passages through which the egg has to pasa, after the yolk has detached itself (by its own weight, as it grows from the size of a pin's-head) from the pedicle which attaches it to the egg cluster, before the entire egg reaches the sack, just previous to being laid. The writer has a favorite hen, which always regularly drops these eggg from her roost, and never lays any others, anil has done so for these five years past, although in perfect health.

This circumstance is attributable to the ignorant and cruel practice of "groping." which cannot be too often denounced and reprobated. When these eggs break within, the yolk and the white will pass off, but the skin will olten remain and form a hard "extraneous substance," often becoming putrid. This is the case when the cause is indigestion, of which they often die, if not assisted to get rid of this obstruction. The surest remedy in this case is a dose of castor-oil, which seldom fails to cure the cause and remove the obstruction. Bot a precaution against this occurrence (when possible) is to assist in removing this okin artificially, before it has time to become a fixture, when it is observed to hang from the fowl. Experience and observation alone can teach the extreme nicety of this operation, so as to lead to success. It often occupies a quarter of an hour of time, and requires great forbearance and patience.

4. Egg-lonud.-This is a fatality which is not of unfrequent occurrence, arising from an inactive atate of the organs. When.a fowl does not as usual, in dae time, get rid of an egg, which will remain in the egg-bag for come days, often producing very ill consequences. The gymptoms are moping, awkward gait, enlarged appearance and hanging down of the abdomen. The causes are various; but generally a cold, and often indigestion. The remedy is cometimes opeedy: a few grains of salt put into the entrance, hut without using any violence, will excite an immediate disposition to lay, when the fowl will run off instanter to the nest. If caused by indigestion, the cure must be treated accordingly ] 
also mentioned that there was no great difficulty of bringing up chickens in winter, if it were thought expedient to do it, and should any have been nursed in winter (1474) they will now in spring be in good condition, and be valuable birds, fit to make a handsome dish of roast or boil.

(1927.) As soon as the grass begins to grow in spring, so early will cared-for hens delight to wander into sheltered portions of pasture, in the sunshine, in front of a thorn-hedge, and pick the tender blades, and devour the tiny worms which the genial air may have warmed into life and activity. With such morsels of spring food, and in pleasant temperature, their combs will begin to redden, and their feathers assume a glossy hue; and even by February their chant may be heard, and which is the sure harbinger of the commencement of the laying season. By March a disposition to sit will be evinced by the early laying hens; but every hen should not be allowed to sit; nor can any hen sit at her own discretion where the practice is, as it should be, to gather the eggs every day as they are laid. It is in your option, then, to select the hens you wish to sit to bring out chickens. Those selected should be of a quiet, social disposition, not easily frightened, nor over careful of their brood, nor disposed to wander afar; and they should be large and full feathered, to be able to cover their eggs well and brood their young completely. Those which you may have observed to be good sitters and brooders should be chosen in preference to others; but it is proper to begin one young hen or so every season, to sit for the first time.

(1928.) The eggs intended to be set should be carefully selected. If those of a particular hen are desired to be hatched, they should, of course, be kept by themselves, and set after her laying time is finished. In selecting eggs, they should, in the first place, be quite fresh, that is, laid within a few days; they should be large, well-shaped, truly ovoidal; neither too thin nor too thick, but smooth in the shell; and their substance should almost entirely fill the shell, and should be perfectly uniform and translucent, when looked through at a candle, which is the best light for their examination. It is said that the position of the cell that contains air in an egg determines the sex of the chick that will spring from the egg, that is, if the cell occupies the exact apex of the end, which is always the large end, the chick will be a male, and if on one side of the apex, it will be a female. I believe there is truth in this observation, but to what ex. tent, and what experiments have been made to determine the point, I have not learned; but there is no doubt of this, that the longer an egg has been kept with access to the air, until it becomes addled or dead, this cell increases in size, by the absorption of air through the shell, and, of course, by absorption also of the substance of the egg, which makes room for the air. The matter of the sex of the egg is of no importance on a farm, as a good chicken of one sex is as valuable, as an article of food, as a good one of the other. Either 11 or 13 eggs are placed under a hen; the former number, 11, is more likely to be successful in being entirely hatched than the latter, as few hens can cover in a sufficient manner so many as 13 large eggs. There is a freak, prevalent even at the present day, of the propriety of setting an odd number of eggs under a hen. This may have arisen from the idea that, allowing $1 \mathrm{egg}$ to become rotten, an even number, or so many couples of chickens, will still be obtained in the hatching, and, accordingly, it is considered a good hatching if 10 chickens are brought out of a setting of $11 \mathrm{eggs}$, or a dozen of one of $13 \mathrm{eggs.}$. As essential a matter as selecting the hens and eggs, is the making a proper nest for the sitting hen. This should consist of a circular hassock of soft straw-ropes, or it may be a box, or a basket. The object of this foundation is to raise the 
real nest sufficiently off the ground to keep it dry, and to give the nest such a hollow as that none of the eggs shall roll out by any mischance that may befall the nest. Either a box or a basket is a very convenient thing for the purpose, but in using either it will be requisite to stuff the corners, as well as the bottom, firmly with straw, that the eggs may not drop into the corners, or the young chicks, as they are hatched, fall into them. The nest itself should be made of soft, short straw, sufficiently large to contain the hen, just sufficiently hollow to prevent the eggs rolling out, and sufficiently high above the floor to prevent any draft of air reaching the eggs.

(1929.) Places should be chosen for placing the sitting hens in-for the hen-house, common to all the laying hens, will not answer, the perpetual commotion in it disturbing the sitting hens. A hatching-house should contain one hen at a time, but as many may be accommodated in it as there are partitions to separate the one hen completely from the other, for hens are so jealous of each other, and especially when sitting, that they will sometimes endeavor to take the nest and eggs from one another. Other places can be selected for sitting in, such as an outhouse, a loft, a spare room in the farm-house, or even the back-kitchen. The hen selected for sitting having been accustomed to lay in the hen-house, or elsewhere, will feel annoyed at first on being transferred to her new quarters; she will have to be coaxed to it, and even after all may prove obstreperous, though exhibiting strong symptoms of clucking, in which case she must be dismissed and another chosen, rather than the risk be run of spoiling the whole hatching by her capricious conduct. A couple or so of old eggs should first be put into the nest, upon which she should be induced, by meat and water beside her, to sit for two or three days, to warm the nest thoroughly, before the eggs she is to hatch are placed under her. After she shows a disposition to sit, and the nest has become warm, the eggs are put into the nest, 11, as I said before, being quite enough, and the hen allowed to go upon them in her own way, and to manage the eggs as she chooses, which she will do with her bill and body, spreading herself out fully to cover all the eggs completely. The time chosen for setting the hen should be in the evening, when there is a natural desire for roosting and resting, and by next morning, by daybreak even, it will be found that she has taken to the nest contentedly. It is not an unusual practice to set a hen at any time of the day, even in the daylight, when she is almost certain to come off and desire to wander; and to curb this disposition, a tub, or some such vessl, is placed over her to keep her in the dark, and the consequence is, that the fright consequent upon such treatment prevents her paying any attention to the eggs, and some may even be broken in her attempts to get out of confinement. In such an attempt to keep the creature in the dark, it might suggest itself to a considerate person, one should think, that darkness would be most easily and naturally found at night, and that natural darkness was better than any that could be made artificially. Thus situate, the sitting hen should be looked at occasionally every day, and supplied with fresh food, corn, and clean water. She will not consume much food during the time of incubation, which is 3 weeks. Every 2 or 3 days, the dung, feathers, \&c., about the nest or on the floor should be swept and carried away, and the place kept clean and dry. In about 3 weeks a commotion among the eggs may be expected; and should the hen have proved a close sitter, and the weather mild, it is not unlikely that 2 or 3 chickens will be scen peeping out below her feathers before that period. The hen should not be disturbed during the time the chickens are leaving the eggs, or until they are all fairly out and dry. Any attempt to chip an egg infallibly kills the chick; and every attempt to re- 
move pieces of a chipped egg causes the chick to bleed. A good plan is to give the chickens, when fairly out, a drink, by taking them one by one and dipping their bills in water. Meat is then set down to them on a flat plate, consisting of crumbled bread and oatmeal, and a flat dis: of clean water. The hen's food consists of corn or boiled potatoes and water. The chickens should be visited every 3 hours, and a variety of food presented, so as to induce them to eat it the more frequently and heartily, such as picks of hard porridge, crumbled boiled potatoes, rice, groats, pearl barley -taking care to have their food always fresh, and their water clean, how. ever small the quantity they may consume. The hassock, or box, or basket, should now be removed, and the true nest set down on the floor, with a slope from it, that the chickens may have the means of walking up to the nest to be brooded at night. In the course of 24 hours after all the chickens are on foot, the hen will express a desire to go out, which she should be indulged in, if the weather is dry, and especially when the sun is out; but if it rain, she had better be kept within doors, unless there is a convenient shed near, in which she may remain with her brood for a short time. Visited every 3 hours during the day, and supplied with a change of food such as $\mathbf{I}$ have mentioned, and clean water, for about a fortnight, or until the feathers of the tails and the wings begin to sprout, chickens may then be considered out of danger, and, of course, become less of a charge to her who has the care of them. During the remainder of the season the chickens should receive food 3 times a day, consisting of potatoes boiled as they are used at table, as long as they last, and they might last the greater part of the summer, provided means were used to preserve them for the purpose; and the fact of being able to rear poultry cheaper on potatoes than on any other sort of food, is a sufficient inducement to preserve them as long as possible in a useable state. When potatoes fail, or even along with them, hard-made oatmeal porridge is an excellent food for fowls, when administered in small bits at a time. It is not expedient to set a number of hens at one time, but in succession every 3 weeks or a month; for a few chickens, ready in succession, are of greater value than a large number of the same age. As the season advances in summer, hens, as they become fat by picking up plenty of food in the fields, have a predilection to select places for nests in the fields, lay in them, and bring out chickens from their own eggs; and it must be owned that this is the most natural way of obtaining chickens; but no dependence can be placed for a supply of young fowls in this way, as the weather may not suit hens sitting in the open air; and hens may not be in a state for laying a nestfull of eggs in the most desirable part of the year, namely, the early and late periods of the season. In short, it is impossible to depend on a regular supply of either eggs or chickens, unless provision is made for collecting the one and hatching the other in a systematic manner. Chickens go 6 weeks with their mother. A good hen that has brought out an early brood will become so fat while rearing them that she will in time begin again to drop eggs, and of course again become a clucker, and may then be employed to bring out a late brood. Cockchickens, just out of the egg, are distinguished from hen-chickens by their larger heads and stronger legs.

(1930.) In regard to the hatching and rearing of turkeys, it is universally said to be a very difficult matter to accomplish; an opinion I am by no means inclined to acquiesce in, for I am disposed to maintain that they are as easily reared as chickens, as may be seen in the sequel. When a turkey-hen is seen disposed to lay, a nest should be made for her in the hatching-house. It may consist of the same materials as the hen's nest, but, $f$ 
course, of a larger size to suit the bird. A box or basket is an excellent thing, with every corner filled up. When once the turkey-hen lays an egg, and a nest-egg is placed in the nest, she will use it regularly every time she requires it, which will be once in about 30 hours. As the eggs are laid, they should be removed and placed gently in a basket in the house, in a dry place, and turned with caution every day. When she has done laying, which may not be till she has laid 12 or 13 or even $15 \mathrm{eggs}$, she will be disposed to sit, when the eggs should be placed under her, to the number of 11 or 13 , the former number being the most certain of succeeding, as a turkey cannot cover a greater number of her own eggs than a hen can of hers; and a brood of 10 poults is an excellent hatching. Corn and water should be placed near the nest; but the turkey need not be confined within the apartment she occupies, though she is not disposed to wander, nor is she jealous of another one sitting in the same apartment with her. A turkey sits 4 weeks, and is proverbially a close sitter. During the incubation her fond and water should be supplied to her fresh and clean daily, and all dung and dirt removed from her every two or three days. When the poults are expected to make their appearance, the turkey should be frequently looked at, but not disturbed until all the creatures are fairly hatched. It is, I believe, a common practice to put a peppercorn down the throat of every poult a very short time after it is hatched. How this practice originated I cannot say ; but as turkeys, when at liberty, have a great relish for ants, and seem to possess an instinctive faculty in discovering their hills, it is possible that the peppercorn may operate as a substitute for the ant. It is known that ants yield a peculiar acid called formic acid; and it is not improbable that the pungency of the peppercorn may act as stimulant on the stomach in the same manner as the acid in ants. Dr. Thomson, in speaking of the origin of the formic acid, says that "it is secreted by the Formicn rufa or red ant, and is the liquid that renders the bites of these insects so painful. It was first publicly noticed by Mr. Ray in the year 1670. . . Mr. Fisher had stated to Mr. Ray several years before, that "if you stir a heap of ants so as to rouse them, they will let fall on the instrument you use a liquid which, if you presently smell, will twinge the nose like newly-distilled oil of vitrol.' Mr. Fisher farther stated that "when ants are distilled by themselves or with water, they yield a spirit like spirit of vinegar, or rather like spirit of viride aris. It dissolves iron and lead. When you put the animals into water, you must stir them to make them angry, and then they will spit out their acid juice.' Margraaf obtained this acid in 1749 , by distilling ants mixed with water and rectifying the liquid that came over. The acid obtained had a sour taste and smell."* While considering this acid, I may say a few words on the constitution of pepper. "Piper nigrum is the name of the plant which produces common pepper. It is a shrub which grows in India. The seeds are berries, round, hard, having an aromatic smell and a hot acrid taste. These berries constitute pepper. The unripe berries are the common black pepper; while the ripe berries, deprived of their epidermis, constitute white pepper... In $1821 \mathrm{M}$. Pelletier published an elaborate examination of pepper. He showed that it contained the following constituents :

Piperin.

A solid, very acrid oil.

A balaainic volatile oil.

A gummy-colored matter.

Extract similar to that obtained from leguminous seeds.
Malic and tartaric acids

Starch.

Bassorie.

Lignin.

Earthy and alkaline salts in small quantities.

- Thomson's Chemistry of Animal Bodiea (420) 
M. Pelletier showed that piperin did not possess alkaline characters, as Oestedt had supposed, but that it was a peculiar principle. He found, too, that pepper owed its peculiar taste to a volatile oil. This I had shown many years before," adds Dr. Thomson.* From this account of it, it is not improbable that the solid and very acrid oil in the pepper may operate on turkeys in a similar manner to the formic acid in ants; and this may form an excuse for an old practice for which a sufficient reason cannot be given by those who follow it. After the peppercorn is given, and it may be given or not at the person who has charge may choose, the poults get a drink of water, and are returned into the warm nest, where the mother receives them with characteristic fondness. But before leaving the turkey for that night, the box or basket in which the nest is formed should be taken away, and the nest brought down upon the floor, with a sloping face toward the floor to enable the young poults to gain the nest. For 24 hours the poults will eat nothing, though the turkey herself should be provided with corn or potatoes and water. Next morning the young creatures will be quite astir and ready to eat food, which should now be given them. It should consist solely of hard-boiled eggs, yolks and white shredded down very small, and put on a flat plate or small square board. In one respect turkeypoults differ in their nature from chickens, inasmuch as they are more apt to purge for about the first fortnight of their existence, and when purging does overtake them it is difficult of cure, and indeed generally proves fatal; but hard-boiled eggs, forming an astringent and nourishing food, entirely prevent purging, and are better for them than some other things I have seen tried. For instance, for the sake of experiment, hard-made oatmealporridge was given instead of hard-boiled eggs, and in a short time two poults took the flux and died, the rest having been saved by a return to the egg. With egg, not a single death has occurred among one to two hatchings every year for upward of 20 years, and that is surely sufficient experience to justify the recommendation of any practice. Let the poults be visited every 3 or 4 hours, supplied with hard-boiled egg and clean water. Let their food be removed after the poults are served, otherwise the turkey-hen will devour it, for she is a keen feeder, and not so disinterested a bird as a hen. Let them remain 2 nights and a day in the house, and after that let them go into the open air and enjoy the sun and warmth, of which, it is hoped, there will be a plenty in the month of May. In wet weather, however, they should either be confined to their house, or allowed to go into a shed. When the birds become strong and active, in the course of a few days let the turkey be placed in a coop on the green to curb her wandering propensity, until the poults can follow her, which they will be able to do after they have partaken of the hard-boiled egg for a fortnight. Their meat can be put down on a plate on the green beyond the reach of the coop, and where the poults can help themselves, while the food of the turkey is placed within reach of the coop, consisting of corn, and potatoes, and water. After the feathers in the tails and wings of the poults are beginning to sprout, the egg may be gradually withdrawn, and hard-boiled picks of porridge, with a little sweet milk in the dish, to facilitate the swallowing of the porridge, should be given them at least 4 or 5 times a day at stated hours, and will make wholesome food, until the mother can provide insects and other natural food for them, which will form a desirable variety with the food given them, and then they will thrive apace, and grow amazingly fast as the weather becomes warm. Should the grass be damp, let the coop be placed on the gravel of the road or walk, as dampness is injurious to all young birds of the gallinaceous tribe. After the egg

\footnotetext{
* 'Thomson's Chemistry of Vegetables.
}

(421) 
the poults are fond of a little shredled cress and mustard, and when at full liberty, they will pick the leaves of nettles with avidity. These predilections for ants, cress, and nettles, show that turkeys enjoy stimulating condiments with their food.

(1931.) Turkeys are sometimes extranrdinary layers. One season a henturkey of my own, after bringing up 11 poults till they were 8 weeks old, made a nest in the middle of a large bush of nettles at the edge of a young plantation which she visited, and contrived to slip away unnoticed from her brood to lay an egg in cvery day. The nest was soon discovered, the egg taken away évery day as it was laid, and a nest-egg left in it, and thus she continued to visit it daily until she had laid the extraordinary number of 90 eggs. The consequence of this oviparous fecundity was, that the turkey did not moult till the depth of winter, and the moulting was so very bare that she had to be confined to the house; and whether the catastrophe which befell her before spring was owing to the severity of the late moulting $I$ do not know, but an inflammation and a consequent swelling seized one of her eyes, and she was deprived of its sight. By sping, however, she recovered from the moulting, was furnished with a complete set of new feathers, the wound on the eye healed, but somehow she died in a very short time after. Turkey-hens are most watchful protectors of their young, and are particularly wary of birds of prey, which, whenever observed, even at the greatest hight in the air, they will utter a peculiar cry, and every poult will instantly hide itself among the longest grass and other plants within reach. There is another peculiarity in regard to the turkey-hen; one impregnation from the cock fecundates all the eggs of the ovarium; and on account of this property, I am told it is not uncommon in spring in Ireland to see people carrying about a turkey-cock and offering his services at farmsteads as those of a stallion are proffered. It is perhaps owing to this peculiar constitutional habit of the turkey that makes the cock so regardless of his own progeny; and, indeed, the hen voluntarily shuns his attention when in charge of her brood. The brood goes with her for an indefinite length of time.

(1932.) In regard to geese, they make early preparation for incubation. There are couplets in existence indicative of the period of commencement of their laying, namely,

"Ry Candlemas day.
Good goose will lay."
And,

"By 8L. Valentine's day,

Good and bad goose will lay."

Geese, however, seldom lay in Scotland till the end of February. The goose and gander cannot embrace but in water, and if the pond which they fiequent be covered with ice, it should be broken to allow them to get to the water, and every egg requires a separate impregnation. An attentive observer will know when a goose is desirous of laying, by her picking among straws and placing one on this side and one on that of her, as if making a nest. Whenever this is noticed, or an embrace on the water, a nest should be made for the goose to lay in in the hatching-house, and to which she should have easy access, for she cannot jump up with the nimbleness of either a hen or a turkey, though her nest may be made in a box or basket, in the same manner as that of the hen, but of a size to suit the bird intended to occupy it. It is not proper to confine a goose a long time before laying her first egg; but when symptoms of being with egg are observed, she should be caught in the morning, when let out, and the lower portion of the soft part of the abdomen felt, where the egg may be easily ascertained to be in a state or not, for being immediately laid, and if it feel hard, the goose should be shown her nest and confined to it until she 
lays in the course of the day, after which she is of course let out, the egg taken away and kept dry in a basket, and turned every day, until the whole are placed under her. Every other day after this the goose will visit her nest and lay an egg, and the number she may lay will seldom exceed 12 , though 18 have been known to be laid; so, by the time she is done laying, it will be about the end of March. There is, however, considerable difference in this respect with geese, on some farms they being considerably earlier in hatching than on others. This may arise from the nature of the soil, for it is probable that a dry, sharp, early soil for grass and grain, will also early promote the functions of the animals that live upon it. After the goose has finished laving her eggs she will incline to sit, and then is the time for her to receive the eggs; and the best time for placing her upon them in the nest, as I have said before, is in the evening, that, by the arrival of the morning, the nest being warm and comfortable, the goose will have no inducement to leave it. The number of eggs given to be hatched should be 11, which is as many as a goose can conveniently and easily cover. The goose plucks the down off her body to furnish her nest with the means of its increasing its heat; and one great use of the down is, that when she leaves her nest at any time it serves the double purpose of retaining the heat about the eggs and of preventing the external cold affecting them. A little clean water and a few oats are put beside a goose when she is sitting; but she will eat very little food all the time of her incubation. A feed of good oats, such as is given to a horse, will serve a sitting goose for a month, yet this little handfull is actually grudged the goose, and instead of good corn, only little better than chaff, the lightest corn that is blown from the fanners, is only allowed by many farmers who consider themselves very good managers. Some hen-wives will not allow the goose to go abroad as long as she is sitting; but this is an unnecessary constraint upon her. Let her go off whenever she pleases, and there is no fear but that she will return to her nest in time to retain the heat of the eggs; for she makes it a point to cover every egg with down before leaving the nest. Most people will not allow her to go to the water at all, alleging that if she return wet upon her eggs they will become addled, but this is a mistake. Let her go to the pond if she wills it, and wash herself in it, and, depend upon it, she will not continue long there; she will be cooled and much refreshed by it. The feathers will not become wet; it is not their nature to become so; and after such a relaxation, which she much enjoys, she will sit the closer. Geese are liable to become costive while sitting, and to counteract this tendency, they should be supplied now and then with a little boiled potato in a diy state, which they will relish much, and feel much the better for; and, indeed, every fowl, while sitting, should receive a little of this useful succedaneum at that peculiar juncture. The gander usually takes up with one mate, but if there are only two geese, he will pay attention to both; and his regard for his mate is so strong that he will remain at the door of the hatching-house like a watch-dog, guarding her from every danger, and ready to attack all and sundry who approach her sanctuary. At the end of a calendar month the eggs may be expected to be hatched; and during this process the goose should be left undisturbed, but not unobserved. After the goslings are all fairly out of the shell, and before they are even dry, they may be taken in a basket with straw to a sheltered dry spot in a grass-field, the goose carried by the wings, and the gander will follow the goslings' soft whistle. Here they may remain for an hour or two, provided the sun shines, for in sunshine goslings will pick up more strength in one hour than all the brooding they can receive even from their mother for a day. The goose will rest on the (423) 
grass, the goslings will endeavor to balance themselves on their feet to pluck it, and the gander will proudly protect the whole. Water should be placed beside them to drink. Should the sky overcast, and rain likely to fall, the goslings should be collected, and they and goose carried instantly to their nest; for if goslings get their backs wetted with rain or snow in the first two days of their existence, they will lose the use of their legs. never recover their strength, and inevitably die. Should the weather be wet, a sod of good grass should be cut and placed within their house, with a shallow plate of water. In setting down a common plate to goslings, it should be prevented from upsetting, as they are apt to put their foot upon its edge, and spill the water. After two days' strength, and especially in sunny weather, the goslings may venture to the pond to swim; but the horse-pond is a rather dangerous place for them as yet, so many creatures frequenting it. Some water, or a pond, in a grass-field, would be a better place for them. For the first two or three days after goslings go about, they should be particularly observed, for should they in that time happen to fall upon their backs, or even into a hardened hoof-print of a horse, they cannot recover their legs, will be deserted by their dam and the rest of the flock, and will perish. After three or foumdays, however, in dry sunny weather, and on good grass, they will beceñe strong, grow fast, and be past all danger. It is surprising how rapidly a young gosling grows in the first month of its life. After that time they begin to tire of grass, and go in search of other food; and this is the time to supply them daily with a few good oats, if you wish to have a flock of fine birds by Michaelmas; any other grain will answer the purpose, as rice and Indian corn, let it be but corn, though oats are their favorite food. Even ordinary light corn will be better for them than none; and if they get corn only till harvest, they will have passed the most growing period of their life, and will then be able to shift for themselves, first in the stack-yard and afterward in the stubbles. The sex of the gosling may easily be ascertained after the feathers begin to sprout, the ganders being white, and strong in the leg, head, and neck; the geese are gray and gentler-looking. Goslings go with their parents for an indefinite length of time.

(1933.) Geese are in general close sitters; but sometimes they become so capricious as to forsake some of their eggs after a number of them have been hatched. An instance of this sort of desertion I have witnessed. A goose after hatching 5 goslings, deserted her nest and would no longer sit on the other 6 eggs to bring them nut, though one of them was chipped. Fearing that the deserted eggs would perish from cold, my housekeeper - who took the charge of all the poultry, cows, and calves, besides the duties of the house-brought the eggs into the house, put them in a basket among flannel and wool, caused the oven to be gently heated, placed the basket with the eggs in the oven, and continued the heat in it night and day until all the goslings were hatched, which they were one by one, excepting one in which the bird had died. The young creatures occupied some days in leaving their eggs, and longer than they would have clone under the goose. They were carefully attended to and were taken out to the grass in the best part of the day, kept warm in the house at night, and, when the weather was such that they could noi get out, a grass-sod was brought to them into the house. The goose refused to take her own broken brood when offered to her, after they had gained sufficient strength to go about; and this being the case, they were brought up without her aid, and became as strong birds as those of her own out-bringing. I consider this a remarkable instance of the resources of a ready mind, and of disregard of personal trouble; and it is an encouraging example of perseverance in an 
attempt to preserve the lives of useful annimals under very inauspicious and even provoking circumstances.

(1934.). Ducks begin to lay eggs early in the season, as early as February, so it is possible to obtain an early hatching of ducklings, if desired ; but early ducklings are not desirable, for, during that unnatural period for them, they do not acquire much flesh, even with the utmost care; their bills and bones grow disproportionately large, and altogether the experiment does not succeed. It is early enough to set duck-eggs in Scotland by May, and by April in England. It is customary to place duck-eggs . under hens, owing I believe, to the great difficulty of making a duck take to a nest which she has not herself made. Hens make pretty good fostermothers to ducklings, though in becoming so, the task is imposed upon them of a week's longer sitting than is natural to them, and, after all, the natural plan is for ducks to bring out their own kind; and there is no doubt that when a duck does choose a nest for herself, lines it with her own down, and brings out a brood, the ducklings are better than any reared under the auspices of a hen; the instinct of the duck being more congenial to ducklings in leading them to places in search of food peculiar to their tastes, as well upon land as upon water. Still the entire production of ducklings on a farm shuuld not be left to the chance of ducks setting themselves on eggs, for they are proverbially careless of where they deposit their eggs, and on that account hens must be employed to hatch at least a few broods.

(1935.) As in the case of her own eggs, a hen can only cover 11 duckeggs with ease, and, of course, she requires the same treatment when sitting on them as she receives with her own eggs. A calendar month is required to bring out ducklings; and the hen should be left undisturbed untill all the brood comes out. Ducklings should be kept from water for a couple of days, until their navel-string is healed; and the food which they receive should be of a soft nature, quite the opposite of that given to turkeypoults, such as bits of oatmeal porridge, boiled potatoes, bread steeped in water, barley-meal brose, and clean water to drink in a flat dish in which they cannot swim. On this treatment, 3 or 4 times at least every day, they will thrive apace, and become soon fledged in the body, when they are fit for use; but their quill-feathers do not appear for some time after. In this state wild ducklings, under the name of flaffers, make good sport, and are an excellent dish with green peas, when stuffed with onion and sage shred small, and a little pepper and salt among them, and roasted, and served up in a hot sauce of Port wine seasoned with pepper and mace.

(1936.) A great number of ducklings are bred and reared every year at Aylesbury in Buckinghamshire, for the London market, by people of the poorer class. The eggs are hatched by hens, and 3 or 4 broods are put together into one division; while other divisions contain them in a different state of growth, some half grown; others full fledged, and all are fed alike. In this way one person has 300 or 400 ducklings feeding about his house, and perhaps under the same roof with his own family. A great many are housed in little space, and never allowed to go at large ; but are permitted to wash themselves every day in a pond made on purpose near the house. They are fed three times a day on potatoes, barley-meal, bran, greaves, \&c., and receive as much as they can eat; and it is said that they can eat an incredible quantity of food while thus forced for the market. When full-feathered they are sent to London, where they find a ready sale, at from $6 \mathrm{~s}, 6 \mathrm{~d}$. to $8 \mathrm{~s}$. a pair. As the season advances, prices fall, till they reach $3 \mathrm{~s}$. a pair, when the breeding is given up for the season. These peo. (425) 
ple allege that they are not remunerated for their trouble even at the highest prices.

(1937.) Pea-hens, in their hatching, cannot be subjected to control. The hen selects a secluded spot for her nest, not unlikely in the garden, where she feels herself secure from the attentions of the cock, whom she seems to avoid at this season, with marked assiduity. She takes care that he shall not know, not only where her nest is, but when the pea-fowls come out, because, as is alleged, the cock would destroy them. A pea-hen in this country seldom brings out more than 3 or 4 birds, though usually laying $5 \mathrm{eggs}$; and these she tends with great care, taking them to places where wild food can be found in greatest abundance, such as insects of various kinds and in different states, and grain, while they are fed as young turkeys; and she continues her attentions to them for the greater part of the year.

(1938.) Pigeons, when their dove-cot is favorably situated for heat, begin to lay in February, and will continue to do so until December. They make their own nests, which are of the simplest and rudest construction, and, indeed, the same nest will be used by the same pair season after season, eveh after it has been much elevated with dung. A fine nest is not required by pigeons, which only laying 2 eggs at a time, one of each sex, the hen can easily cover them; and to secure them still more, she pushes thern below her with her bill, among the feathers, to keep them warm. A supply of young pigeons might be found at the farmer's table all summer. To vary their cookery, they can be stewed, roasted, broiled, and mude into pies, one and all of which, when properly seasoned with pepper, salt, onions shred small, and butter, makes a savory appendent to any dinner. While touching on cookery, I may remark, in regard to other poultry, that a young chicken roasted or broiled, when in perfection, at 14 weeks olda young cock especially, or boiled-a young hen being the more delicate -with a slice of ham, is a standing delicacy at a farmer's table. Ducklings and green peas are seen for a short season in the early part of summer, but a roast duck may be had all autumn and the early part of winter. Turkey-poults are never indulged in by the Scottish farmer, probably from the idea that they have too little flesh upon them, and are too similar to boiled chickens; and as chickens are more plentiful, and can be used with less scruple, the poults are spared until they attain full size. Young geese are never seen at a Scottish farmer's table, though a stubble-goose at Michaelmas seems to be prized iu England. With regard to the means of supplying young fowls on a farm, 2 turkey-hens and 2 geese will rear as many turkeys and geese as will be required by a large family ; 3 or 4 broods of ducks will suffice; a brood or broods of chickens may be brought out from March to November; and as to pigeons, it is the farmer's own fault if he has not a supply of them from March to December. Those who do not care for the flesh of fowls may send their poultry to market; and those who breed for the market should provide a person well versed in rearing poultry to undertake the duty.

(1939.) With regard to the feeding of fowls in summer, boiled potatoes and hard-made oatmeal porridge should be their staple food; and so fond are all sorts of birds of potatoes, that there should some pains be taken by farmers to preserve a few of the best of them over the summer, for the express purpose of feeding poultry. I have described a plan of keeping them over a year in a former paragraph (1871). Food, when distributed for poultry, should not be laid down in a large heap in one place, when birds of different natures partake of it, and are therefore almost certain of quarreling and fignting; but st should be scattered thinly along a bare 
piece of ground, or, what is better, upon grass, which keeps it clean, and from which it can easily be picked up, but it should not be laid among straw, as it is easily lost sight of among it. As different sorts of birds have different habits, and firequent different places, the food should be scattered for each kind as near their usual habitats as their natures indicate, and which the person who has charge of the matter can devise-scattering some near water for geese and ducks, upon the margin of grass on the side of the road near the steading, for hens, and at a more retired place, though still upon grass, for the turkeys ; and the food should be thus be laid down for the different sorts of fowls at a fixed hour of morning and afternoon. Cleanliness, attention, regularity, and good food, constitute the grand secret of rearing poultry to the highest perfection.

(1940.) What I have described of hatching the different sorts of fowls usually reared, is suitable to every sort of farm, and may be acquired by any domestic of the farm-house : and that it is a practicable scheme my own experience has demonstrated. Other schemes are recommended in books, and large establishments, consisting of buildings and ponds, and spare ground, are erected in the parks and farm-courts of country gentlemen; but let any other plan be what it may, and the erections and other appliances of whatever magnitude, there is none, I feel confident, will afford poultry at all times in a higher degree of perfection than the simple one I have been describing, and recommending for your adoption-and experience is the true test to which every plan should be subjected. I do not hold it out as a peculiarly cheap plan, that is, that it will supply good poultry for the table at little or no cost, though that is the idea of cheapness entertained by farmers, when they condescend to cast a thought on the poultry of their farms. I will not say, because I do not believe it, that fowls can be reared for nothing, or upon the refuse of the products of a farm; because, when I see that it requires the best oats, the best turnips, and the best grass that a farm can raise, to rear such horses, cattle, and sheep, as purchasers desire to have, I cannot believe that the best poultry can be reared but on the best sort of food suited for them; but this I will say for the plan as a practicable one for an ordinary farm, that it requires no costly buildings, and that it will assuredly yield poultry in good condition at all times in return for the food and trouble bestowed upon them, and what more can any reasonable farmer desire?

(1941.) Fowls are kept in towns in places quite unsuited to their habits; most frequently in a small court, surrounded by a high rail, except on the side in which the hen-house is situated; and this consists of a flattish-roofed outhouse, pervious to rain and redoleut of moisture-a condition the very worst for fowls. The floor of the court is generally covered with dirt, and the small vessel which is intended to contain water is as often dry as plenished with clean water, while the food is thrown upon the dirty court-fioor. Add to these sources of discomfort, the sun, probably, never shines upon the town hen-house, or only for a few minutes in the afternoon, when the fowls are about to retire to roost. Ducks are treated in even a less ceremonious manner than hens; having no water, their feathers become begrimed with dirt, and their food is given them -in a state little else than a puddle. It is, of course, impossible that fowls can thrive in such circumstances, and, indeed, a sight of the poor creatures excites nothing but commiseration for their fate. What can induce people to keep animals in such a state of filth and suffering is what I cannot conceive. One cause of suffering to hens in such situations is the want of sand or gravel to assist the trituration of food in the stomach. It is found that gallinaceous birds require a sapply of quartzy substances, and these they find on any farm, as also calcareous matter, such as lime, to assist in the formation of the shell of the egg, without which hens will lay what are called wind eggs, that is, eggs without a hardened sbell. In the case of the fowls on board a certain East Indiaman getting unwell in their coops, notwithstanding the attention daily bestowed, and the good food allowed them, it was discovered by the surgeon, on dissection of some of the birds which had died, that the cause of death was the wnnt of gravel to assist the digestion of food. A supply of stones to beat down small was obtained at a convenient port, and the fowls became healthy and continued so afterward. A nother source of suffering of a similar nature to hens, is the want of dust to flutter among their feathers in order to destroy the vermin that annoy their skin; and the want of water for the ducks to. wash in and clean themselves.

(1942.) With the diseases of chickens or other young fowls, such as the pip or chip, I am not acquainted, not having seen any such disease after an experience of many years in rearing every

(427) 
species of fowl that is found on a farm, and, of course, I am inclined to maintain that, were others to follow a similar course to the one I have so successfully pursued, they would have equal suc. cess, and witness as few diseases among their poultry as I have. I am corroborated by a writer on the rearing of domestic poultry, whose experience I know is considerable-whose attention I am sure is unremitting-and whose good sense is evident. "Of the diseases to which poultry are liable we are practically ignorant," say's the writer, a lady of my acquaintance, "having been for many years here so fortunate as to experience few or no instances of disease among our stock; and we attribute the health of our various animals in the farm-yard entirely to strict at. tention to cleanlimess, diet, and rational treatment. Those who listen to advice of the ignorant and the prejudiced, nay, they who seek from books remedics for disorders which may appear among their live-stock, will have to contend with monstrous absurdities, excessive ignorance, and barbarous cruelty, in the quackeries recommended. Nature will generally effect a cure, if her efforts are seconded by simple means on our own part. Calomel, sulphur, rue, pepper. and gin, are all absurdities, though all recommended for the ailments of poultry." Another writer thus expresses himself on the same subject: "With regard to medical treatnent applied to the diseases of poultry, but little regarding its efficacy is known. The nostrums and mode of treatment adopted throughout the country, together with the greater part that has been written upon the subject, is a farrago of nonsense and absurdity. If shelter, warmith, food, and cleanliness, congenial to their habits, will not preserve them in health, but little reliance can be placed upon medicne. Most good wives, however possess an insatiable itching to be considered skillful doctors. From among some thousand birds that have come under my observation. $I$ never cmild discover that common and universal disease called the 'pip.' Yet show any farmer's wife a sickly chicken, and she immediately opens its mouth, and with her needle tears off the cartilage from the under part of the bird's tongue, to show it is afflicted with it! When will the light of knowledge banish these absurdities?" " The former writer, however, alludes to un ailment among chickens which I have never seen, arising, it would appear, from their being hatched at a particular period of the year. After adverting to the tender state of chickens superinduced by both early and late hatching, the writer particularizes the yeriod of the year when the disease alluded to makes its appearance: "There is yet another time, during which it is absolutely indispensable that hens be prevented from sitting, and that is the month of June. Close observation (after having suffered at that season numerous failures most unaccountably) enabled us to dis. cover the cause, and thereby verify the truth of an old saying, which we have since met with-

\section{'Between the sickle and the scythe,}

What you rear will seldom thrive.'

We had noticed that chickens which were hatched during the month of July were almost all attacked about the time of their first moulting (a period always attended with much suffering to them) with a fatal disorder, the symptoms of which are unvarying. The chickens appeared to collapse, and moved about with difficulty, as if their joints were stiffened, or rather as if the skin had become tight and tender; their feathers became rough and stood out; their wings drooped and dragged on the ground; they refused sustenance; and becoming more and more weak and torpid. they in a day or two, died off in great numbers. Every rational means was resorted to in order to arrest, or even account for the disorder; at length it was discovered that they were in a high state of fever, and that the extreme redness of the skin was caused by the irritation of hundreds of that minute pest the harvest bug. Some-very few-were recovered by anointing them all over with oil and vinegar (which is also the best, nay the only remedy for the annoyance which human beings experience from the same source); but the receipt is too rough for little delicute creatures already enduring the pain attendant on the season of moulting. It becanie obvious that the period during which harvest-bugs are most numerous and tormenting must be inimical to the rearing of chickens; and that if hens were nut allowed to sit in June, or rather, if the chickens wire either strong enough to cope with the evil, or were not hatched until the season for the pest had passed by, the destruction might be prevented, and so it has proved." $\uparrow$

(1943.) On considering the hatching of fowle, the mind is naturally led to the curious artificial system of hatching which the ancient Eyyptians practiced, and which aftorded them an immense. supply of poultry every year. It is unecessary to detail the ancient mode of hatching. as it is unsuited to this country, our climate being much too unsteady for the purpose; but particular accounts of it may be found detailed by authors. \$ The modern Eyyptians atill practice the sys tem, and the results exhibit sone extraordinary facts, I am tempted to give the following ac. count of it from Mr. Mowbray. "Sicard," he says, "gives an idea of the immense quantities of chickens hatched in his time in Egypt. The number of ovens for hatching the rggs, dispersed in the several cantons of the country, was no less than 386 . The business seems to be monopolized by the Agas or Government. and therefore cannot be varied in extent but by their pernimвion. Each mamal or oven has one managing Bermean, a native of the village of Bermé in the Delta, by whom the art of managing it has been retained, and is taught to his children. There man. agers cannot absent themselves from duty but with leave obtained from the Aga of Bermé. never obtained but at the expense of 6 to 10 crowns. The Ags constantly keeps a register of these fees, which to him is a sort of rent roll. The above number of ovens is kept at work in Egypt annually during 4 to 6 months, allowing more time than is necessary to ha ch 8 successive broods of chickens, ducks, and turkeys, making in the whole, yenrly, 3,088 broods. The number in each hatching is not always equal, from the occasional difficulty of obtaining a sufficieut number of egge, which may be stated at a medium between the two extremes of 40,000 and 80,000 to each oven. The Bermean contracis to return, in a living brood to his employer, $\$$ of the number of eggs set in the oven-all above being his own perquisite in addition to his salary for the sesson, which is 30 to 40 crowns, exclusive of his board. According to report, the crop of poul.

* Bucknellis Eccaleobion.

I Quarterly Journal of A griculture, vol, viii.

+ Wilkinsan's Manners and Custome of the Ancient Egyptians, vol. i., New Serieg.

(428) 
try thus artificially raised in Egypt was seldom or never below that ratio, making the enormons annual amount of $92,640,000$. It is obvious that the apparent grand difficulty of obtaining a sufficient sumber of eggs must subsist chiefly or entirely in the infancy of such an undertaking, and that its progress must infinitely extend that supply, as has been the case in Egypt, where the breeding siock has been so multiplied, and where, in consequence, the commodity is so cheap from its superabundance, that in the tine of Sicard 1,000 eggs were sold for 30 or 40 medims, making 3s. or 4s. English money. Indeed, the chickens were not sold from the stores by tale but by measure; according to Heaumar, by the bushel! And it appears from travelers of the present day, to be the custom in Egypt to purchase chickens by the basketfull." * M. Reaumur, unios the French Academy, instituted experiments to prove that eggs could be hatched in France as well as in Egypt; but it was soon discovered that the two countries were placed in difierent circumstances in regard to climate, and the project was abandoned as being impractica. ble. Plans of artificial hatching were tried with better success by $\mathbf{M}$. Bonnemain, by a system of supplying heat from hot water in pipes; but the French-Hevolution put an end to the experiment. It is worth observing, in passing, how strange it is to hear of the circulation of hot water il pipes, as a steady source of heat, zecommended at the present day as a novelly. $\dagger$ To supply the inhabitants of Great Britain and Ireland with fowls as the Egyptians are, namely, at the rate of $16 \quad 1-5$ fowls to each person every year, the number that would require to be hatched in the relative proportions of the two countries, would be $1,109,000,000$ of fowls!

(1944.) A remarikable machine, exhibited in London some years ago, which $I$ saw in the sum. mer of 1839, was said to have attained the power of supplying the requisite degree of temperature for hatching for any length of time. It was the invention of Mr. William Bucknell, and named the Eccaleobion, derved from two Greek words meaning "I give forth life." "Rationally to hope for success in the artificial hatching of eggs," says Mr. Bucknell, "it becomes necessary to be in possession of a power completely to control temperature, independent of climate, seasons, or changes in the atmosphere, and also uninfluenced by them. These invaluable properties the Ecealeobion possesses, in a perfect and absolute command over temperature, from $300^{\circ} \mathrm{Fahr}$. to that of cold water; 80 that any substance submitted to its influence shall uniformly be acted upon nver its whole surface, at any required intermediate degree within the above range, and such heat maintained unaltered. without trouble and difficulty, for any length of time. By means, then, of this absolute and complete control over temperature, obtained by this machine, the impregnated egg of any bird, not stale, placed within its influence at the proper degree of warmth is. at the expiration of its natural time, elicited into life without the possibility of failure, which is scmetimes the case with eggs subjected to the caprice of their natural parent." $\ddagger$ Without attempting to describe the machine, I may mention that it is capable of containing 2,000 eggs, winich are open to the sight through glazed doors, in different states of incubation, from the day the egg is inserted into it, until the bird is seen to leave it in the act of being hatched. It may be interesting. however, to relate a few of the facts regarding the condition of eggs in different states, as to their vitality, observed by Mr. Bucknell in his experience of the machine.

(1945.) Few eggs are worth the irial of hatching if more than a month old; their condition, however. is greatly infuenced by the season and the state of the weather. An egg retains its frestuness longest in moderately cool weather; very hot weather destroys vitality in \& few days; and an egg having been frozen is also worthless. Failures in hatching arise from want of impregnation in the egg-from age, commonly called staleness, whereby life has become extinctfrom weakness of the vital energy of the eggs, produced by age, lowness of keep, or ill health of the parent, in which cases the chick partially develops jtself, but dies before the full period of incubation. Eggs may be brought to life, but unless the process of incubation be properly executed, the birds will be weakly, ill-conditioned, and die in a short time afterward. To prevent the yolk of weak eggs from settling by its specific gravity, and adhering to the shell, it is useful to pass the hand over them, so as to change their position every 24 hours. The egg of a strong, healthy bird, at the time of its protrusion from the body, is completely filled with yolk and albumen. If examined a few days after, by bolding it toward the light, a small cell of air will be discoverable at the larger end, which increases with the age of the egg. This waste of its internal substance is occasioned by absorption of the atmosphere, through the pores of the shell, of the more volatile parts of its contents. When the cell is large in any egg, it is unfit for incubation; nevertheless, in a good egg, as incubation proceeds, this cell becomes considerable, produced probably both from evaporation by heat and the vital action going on within the shell. It also serves an important purpose in the economy of this mysterious process. An egg will not hatch in vacuo.

(1946.) The progressive series of phenomena daily observable during the process of incubation. in the egg of a comnon fowl, are curious and instructive. In an.impregnated egg, previous to the commencement of incubation, a small spot is discernible upon the yolk, composed of a membraneous sack containing fluid matter in which the embryo of the future chick swims. 1st Day : At the expiration of 12 or 14 hours after incubation has commenced, the matter within the embryo evidently bears a resemblance to a head-vesicles assume the shape of the vertebral bones of the back. 2d Day: In 39 hours the eyes make their appearance-vessels joined together indi. cate the navel-the brain, spinal marrow, rudiments of the wings, and principal muscles-the heart is evidently proceeding. 3d Day: At its commencement the beating of the heart is visible - some hours after, two vesicles containing blood appear, one forming the left ventricle and the nther the great artery - the auricle of the heart is next seen, and polsation is evident. 4th Day : W ings assume a defined form-the brain, the beak, the front and hind parts of the head visible. 5 th Day: Liver seen-circulation of the blood evident. 6th. Day : Lungs and stomach distin-

- Mowbray's Practical Treatise on Domestic Poultry.

† Ure's Dictionary of the Arts and Manufactures, art. Incubation, Artificial.

1 Bucknell's Éccaleobion. (429) 
guishable-full gush of blood from the heart distinct. 7th Day : Intestines, veius, and upper mandible visible-brain becomes consiatent. Bth Day: Besk opens-formation of flesh on the breast. 9th Day: Ribr formed-gall-bladder perceptible. 10th Day : Biil fonned-firat voluntary mo. tion of the chick eeen. Ilth Day : Skull becomes cartilaginous-protrusion of feathers tvident. 12th Day : Orbits of sight appear-ribs perfected. 13th Day : Spleen in its proper position in the abdomen. 14th Day: Lung inclused within the breast. 15:h, 16th, and 17 th Days: Mature state approached-yolk of the egg etill outside of the body. 18th Day : Audible sign of life outside the shell-piping of the click heard. 19th. 20th and 21 st Day : Increase of size and strength -yolk inclosed within the body-chick liberates itself by repeated eftorts made by the bill, seconded by muscular exertion of the limbs.

(1947.) The embryo of the chick is not in every egg placed precisely in the same situation, but varies considerably. Generally it develops itself within the circumference of the broadest part of the egg: sometimes it is found higher, sometimes lower; and when held before a strong light has an appearance, when a few days old, sonewhat resembling the meshes of a spider's web, with the spider in the center. As it increases in sizs, the bulk of the contents of the egg decreasea, so that when the bird is completely matured, it has ample space to move, and to use its limbs with sufficient effect to insure its liberation. The position of the chick in the shell is such as to occupy the least epace. The head, which is large and heavy in proportion to the rest of the body, is placed in front of the belly, with its beak under the right wing; the feet are gathered up like a bird dressed for the spit, yet, in this singular manner and apparently uncomfortable position. the bird is by no means cramped or confined, but performs all the necersary motions and efforts required for its liberation with the most perfect ease, and with that consummate skill which inftinct renders almost infallible. The chicken, when it breaks the shell, is heavier than the wbole egg was at first.

(1948.) "If chickens about 2 months old and npward," say Mr. Bucknell, "are turned in among a brood of young birds that have no mother, they will sometimes take to brooding and tending them with the delight of natural parents. The gratification being quite mutual, the young chicks run after and strive with each other for their favors with the most untiring perseverance. Al. though, probably, it is simply the pleasurable sensation derived from the genial warmth communicated by the young birds nestling under them which induces them to do it, it is nevertheless a striking and highly interesting picture to witness these mimic mothers acting the part of foster parents with so much apparent satisfaction, yet with the awkwardness with which a girl, in similar circumstances, fondles her doll." I never witnessed such an instance of affectionate re. gard, possibly because I never saw a brood of chickens deprived of their mother, but the sentiments conveyed in the following sentence I have frequently seen realized, and can testify to the accuracy of observation and the correctness of the conclusions of Mr. Bucknell: - There is no difficulty," he says, "in teaching the young of the various tribes of gallinaceous fowl to eat and to drink; they verform these operations spontaneously, or from observation, as appetite prompts them. Are not the facts of the extraordinary fecundity of these tribes, their requiring no aseistance in luatching, and their being self-instructed in the manner of taking their food, abundant evidence that an All-wise Providence ordained these peculiarities expressly for man's advantage : as in all those families of birds not so fitted for his use, they do not exist, and consequently cannot be rendered by artificial means available for his benefit? Food is not necessary for the chick until 12 or 24 hours after leaving the shell. Sickly and badly hatched birds seldom can be in. duced to cat, and die from inanition. Birds but a few hours old recognize the person who feeds them, and in a few days evince so many and such pleasing traits of confidence in her as their protector and friend, following her steps, and clamorously repining at her absence, as must induce in the most callous breast a delightful sensation of regard for their welfare."

(1949.) It is of some importance to farmers to have the question answered in a practical sense, Whether the hatching and rearing of chickens is profitable? Hear Mr. Bucknell's answer to this question, as it aftects artificial luatching: "Mr. Mowbray, in his standard work," says Mr. Buck. nell. "gives the consumption of food by birds in the highest state of condition as follows: " $\mathrm{By}$ an experiment made in July, 1806, a measured peck of good barley kept in a high style of condition the following atock, confined, and having no other provision : 1 cock, 3 hens, 3 March chickens, 6 A pril and 6 May chickens, during 8 clear days, and one feed left.' Here, then, are 19 birds, varying in age from 2 months to their full size, consuming 1 peck of corn in 8 days, which, at 18. per peck, gives a cost of 1 t halfpenny per head, which, however, is considerably above the cost of chickens for the first 8 weeks of their existence. But taking it at this high average, it gives an expense of each bird of $9 \mathrm{~d}$. all but a fraction, for 14 weeks' keep, at which age they are in the hicheat perfection, being the moat delicate and easy to digest of all other animal food. Where they can enjoy the advantage of a good run, the expense would still be lessened perhaps $\frac{1}{3}$. Now, what is the price at a poulterer' 8 , or in the London markets, of a fine fat chicken 14 weeks old, or nearly its full size? Never less than 28., and for 6 months in the year, or during the dear season. $4 \mathrm{~s}$, or $5 \mathrm{~s}$. - which, adding to $9 \mathrm{~d}$. an additional $3 \mathrm{~d}$. for the value of the egg and extras, gives the enormous profit of from 100 to 500 per cent. dividend between the trader, the middleman and the retailer. It need not be wondered at that such is the case, nor can it be otherwise while the present system continues. A poulterer whose eale is not more than 10 dozen per week, must keep a man and a horme and cart, and attend the different markets for his purchases. All these things, with incidental expenses, will anount at least to 2 guineas per week, which 2 guineas must be spread over the 10 dozen birds before he derives any profit for himself. Upon any artificial system, these expenses would be saved, and the 2 guineas thus thrown away would keep 1.000 birds, averaging all ages; 1 whole week. Buildings and machinery, and other neceskary appraratus being provided, no objection exista as to the expenses of hatching. An Eccaleobion niachine might be constructed, only requiring regulation once in 24 hours, capable of hatching throushout the year 10.000 eggs per month. (a week being allowed for removing and re-fitting.) while the cost lor hatching during the month would probably be 1 caldron of coke at $f 1$ per caldron, which would be the 1.20 part of 1 farthing per bird. The expense for artificial warmith (430) 
during the time the birds might require it, would be somewhat more-perhaps 1 farthing per bird."

(1950.) I mentioned, in an extract from another writer, that the harveat-bug annoys fowls. This short account of that animal may prove interesting. "You have aiready, perhaps, been satiated with the account given of un enemies of the Acarus or mite tribe," says Mr. Kirby or Mr. Spence; "there are a few, however, which I could not with propriety introduce here, as they do not take up their abode and breed in us. which nevertheless annoy us considerably. One of these is a hexapod so minute that, were it not for the uncommon brilliancy of its color, which is the most vivid crimson that can be conceived, it would be quite invisible. It is known by the name of the harvest-bug (Acarus autumnalis, Shaw), and is so called, I imagine, from its attacking the legs of laborers employed in the harvest, in the flesh of which it buries itself at the roots of the hairs, producing intolerable itching, attended by inflammation and considerable tumors, and sometimes even occasioning fevers." $\dagger$

(1951.) In regard to the original formation of feathers in the chick of a bird, M. Raspail has the following observations: "If we examine," he says, "the epidermis of a sparron, as it comes from the egg, we shall find that we can isolate each of the small bottles, which the vesicles that form the rudiments of hairs assume the shape of, as well as the nerve of which it seems to be the terninal development. It might almost be supposed that the object viewed was the eye of a mollnsca, with its long optic nerve. The summit of this vesicle is open, even at its early period, to afford a passage for a cylindrical bundle of small fibres, which are also cylindrical, and which are nothing else than the barbs, as yet single, of the feather. If, afterward, we examine a feather at a more advanced period, we may, by a little address, satisfy ourselves that its tube is formed and grows by means of spathe, one within another, of which the external ones project over the inner ones, so that the tube seems as if divided by so many diaphragms. The interstices of these diaphragms are filled with a fatty liquid. which condenses in them gradually, as the summits of the spathæ approximate and adhere to each other." $\ddagger$

(1952.) Capons of the common fowl are formed both of the cock and hen chickens, when they are fit to leave the hen, at about 6 weeks old. Chickens are transmuted into capons by destroying the testicles of the male and the ovaries of the female. The testicles are attached by a membrane to what is called the back bone of the carved fowl. They are destroyed by laying the bird on its near side, keeping it down, removing a few feathers, and making an incision through the skin of the abdomen, and, on introducing the fore-finger through the incision, first the one and then the other testicle is obliterated or removed altogether by it. In the case of the hen, the ovary is nipped off by the thumb-nail, or cut off by a knite. The incision is stitched up with thread, and little danger is apprehended of the resalt. The effect of castration is enlargement of the budy of the fowl, an increased delicacy of its flesh, but its flavor is in no way improved, at least in none of the capons I have tasted. Time was when capons were more plentiful at the table than chickens, so that even kain-rent was paid in them; bat the conversion of fowls into capons is now abandoned as an unnecessary and troublesome operation, and will not probably be resumed as long as a well-fed delicate chicken can be procured with little trouble. $\|$

[1] Our poulterers seem to make very slow progress in the art and mystery of caponizing. We are not aware that it is now practiced or understood in Maryland at all, although 50 years ago capons were made by a few old women in Calvert County for carrying chickens. It begins to be done for improving fowls for the table in the neighborhood of Philadelphia, and in New. York it is so little practiced that the botel keepers have "CAPON CHICKENs" announced in large letters on their bills of fare, and some of these probably never felt the knife until it was applied to their throats. It is to be lamented that the practice of caponizing were not more general-surely he who pleases, ought to be able to command what a benevolent monarch said he would have all his subjects enjoy, a fat capon.

* Bucknell's Eccaleobion.

$\ddagger$ Raspail'a Organic Chemistry.

[Ed. Farm. Lib. 


\section{SUMMER。}

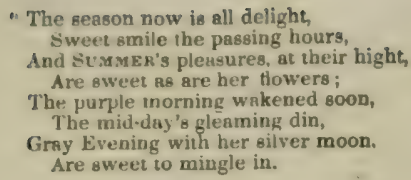

sweet smile the passing hour

And suxMER's pleusures, at thei
Are sweet as are her tiowers;

The mid-day's gleaming din,

Are sweet to miugle in.

"How sweet the fanning breeze is fult
Breathed through the dancing boughs,
How sweet the rural voices melt
From dietant sheep and cows.
The lovely green if wood and bill,
The hummings in the air,
Serenely in my brea-t insti.l,
The rupture reiguing there."
CLars.

I наvе represented Winter, in the agricultural sense, as the season of dormancy, in which everything remains in a state of quiescence. In the same sense I have said that Spring is the season of restoration to life, in which everything again stirs and becomes active. Summer, on the same principle, is the season of progress, in which nothing is begun or endednone of the greater operations of the field are either commenced or terminated, but only advanced a step toward the consummation of all things in Autumn; and, therefore, the mere advancement of the greater operations involves no change of principle, while the smaller ones present so varied an aspect as to excite considerable interest.

The astronomical cause of Summer, as one of the seasons, and the safety in which every living thing-whether animal or vegetable-progresses or grows under its influence, are thus succinctly and well described by Mr. Iudie. "Summer is the bloom of the year-the period during which all the growing and living children of Nature, which wax and wane with the revolving seasons, are in the spring-tide of their activity, and when all those general agencies by which they are stimulated are working to the very top of their bent. Summer is, both in the literal and the metaphorical sense, the scason of blossoms; and as the blossoms make the fruit, the time of them is really the most important of the whole. In our middle latitudes, there is a very beautiful instance of design and adaptation in this. The grand stimulating agent in all is terrestrial action, at least in a natural view of it on the surface of the earth, and the intensity of this action is made up of two elements-the position of the twenty-four hours during which the sun is above the horizon, and the altitude of the sun above that horizon. Both of them, in either hemisphere, increase as the suu declines toward that hemisphere, or rather as the hemisphere inclines to the sun; though, as the first of these is the apparent result of the second as a reality, our using an expression on the other does not affect the result. The increase or decrease of altitude is the same, with the same change of declination, in all latitudes; but the variation in time above the horizon increases with the latitude: consequently the higher the latitude the greater the change of solar action with the same change of declination. The change in declination increases from the solstice to the equinox, and diminishes from the equinox to the solstice. Thus the increase of solar action begins to slarken at the vernal equinox in March, and gradually diminishes till it becomes 0 at midsummer; after this the decrease commences. This, however, only in so far as depends on the altitude of the sun; for the other element, the (432) 
time which the sun is above the horizon, goes on increasing till the longest day, or day of the solstice. Thus, in the advanced part of the summer, there is a diminished increase of the momentary intensity of the solar action, and a lengthening of its daily duration. What is given to the presence of the sun above the horizon is taken from its absence below it; and thus, as the summer advances toward the longest day, all that works by the action of the sun works with his increase of intensity and for a longer time. After the longest day is past, both elements of the sular action diminish, slowly at first, and more rapidly afterward, until the summer merges in the autumn. Near the Equator the changes are comparatively small, and they increase with the latitude; and the differences in this respect are what may be called the celestial differences of the character of summer in different latitudes; but terrestrial causes modify them so much, that the practical results as observed are very different from what the celestial theory would give. Still, any one who thinks but for a moment will not fail to discover how beautifully the season of bloom is secured from violent action either in the one way. or the other. This is enough to convince us that the action which goes on in the production of Nature during the summer is really the most important of the whole year ; for it is performed with the maximum of power in the agents, and the minimum of disturbance in their operation. That resistance of winter, which but too often shrivels the young leaf and blights the early blossom in the spring, is vanquished and completely stayed from making any inroad till the seasonal purposes of $N$ ature are accomplished; and the ardor of the stimulating causes which have vanquished the destructive one, are slackened, so that they may not injure that which during the struggle of the early part of the year they have preserved. All this, too, is accomplished by means so very simple that their simplicity proves the most wonderful part of the whole, for it is nothing more than the planes of the annual and daily motions of the earth intersecting each other at an angle of about $23^{\circ} 28^{\prime}$; and the line of intersection passing through the equinoctial points of the diurnal orbit."*

The atmospherical phenomena of summer are of the most varied and complicated nature. At one time the air is highly elastic, and feels balmy and bracing, indicated by the high position of the mercury in the barometer; at another the mercury descends, and almost always suddenly, to the lowest point, accompanied with gusts of wind and a deluge of rain, forming what is called a tornado in the tropics. The heat of the air at one time is so scorching as to cause us to seek the shade, and the thermometer marks its intensity; at another, a chilling gust, accompanied with a heavy shower of hail, suddenly brings down the thermometer many degrees. The air to-day is so calm and breathless that not a ripple is visible even on the bosom of the great ocean; to-morrow a hurricane raises the waves of the sea to a state of agitation dangerous to the safety of the mariner. Not a cloud is seen at times to stain the purity of the blue vault of Heaven; at others the thunder-cloud hovers over the earth, and blackens its surface with a portentous shadow. These changes, in summer, are usually sudden and of short duration, and they are requisite to preserve the healthy state of the air. Did rain not fall in quantities, the vapor absorbed by the great capacity of heated air for moisture would accumulate beyond due bonds. Were there no colder strata of air moving about to condense the warmer, the warmer portion containing a large quantity of vapor in solution would always be elevated beyond the reach of the earth, and there waste its latent heat. The thunder-storm of sheet-lightning passing from cloud to cloud, the most common display of electric action in summer, re-

\footnotetext{
* Mudie's Summer.
}

$(481) \ldots \ldots 16$ 
stores the electric equilibrium of the air, and the forked lightning relieves both earth and air. Did not the hurricane at times force its way through the calm and inert air, the same portion of the atmosphere would always remain over the same locality, and become vitiated by the breath of animals and the exhalations of vegetables. If the dews failed to descend upon the grass, the pasture would soon become parched by the meridian fervor of the summer sun. Thus, all the agencies of Nature are required tukeep the air in a healthy state for animals and vegetables, and these operate in the most beneficial manner in summer-the season of the intensest action of the solar rays.

As I have already entered very fully into the state of the weather in winter, in Section 18, p. 163 to 197 of the 1st volume, I have less occasion to revert to the subject here; but the consideration of a few of the atmospherical phenomena which only occur in summer was purposely reserved until the arrival at that season; and these phenomena were, thunder and lightning, dew, hail, and easterly winds. The origin of the electricity of the air was indicated at sufficient length from (299) to (312). The presence of electric matter being accounted for, the rationale of a thunder-storm is simple, and it is this: The electric fluid, as the agency of electricity is called, for want of a better name, derived from sources enumerated in the above paragraphs, accumulates in the clouds of vapor. When two clouds, thus provided with electric matter beyond their usual state, are not far from each other, the electricity of the one becomes positive, that is, in an active state; and that of the other, as a necessary consequence, becomes negative, that is, in a passive state. Why these opposite states of electricity always coëxist when near each other, it is impossible to say; but the fact is established as an unvarying law of electric matter. When two clouds thus in these opposite states are near each other, they attract and approach, and when the approach comes within the distance in which the force of the positive electricity is able to overcome the resistance of the air between the positive and negative clouds, the fluid leaves the positive and enters into the negative cloud in such quantity as to restore the equilibrium of both. The forcible passage of the electric fluid causes a concussion in the air between the two clouds, and the vibrations occasioned by the concussion striking against the earth and mountains, cause the noise which is heard in thunder. The time taken by the electric fluid in passing from one cloud to another is inappreciable, but the velocity of sound is calculable. For every $4 \frac{1}{2}$ seconds of time which elapse after seeing the lightning to hearing the thunder, the clouds are situate as many miles from the auditorFar at sea, where there are no objects for sound to be reflected from, thunder is never heard; whereas, in a mountainous country, it inspires terror; though it is obvious that thunder, a mere sound, can do no harm, and lightning, which can do harm, does all the mischief it can do before we are made aware of its danger.

The phenomenon of dew is familiar to every person who lives in the cnuntry. In the hottest day of summer the shoes become wet in walking over a grass-field at sunset, and they may then become as effectually wetted asin wading through water. The late $\mathrm{D}_{\mathrm{r}}$. Wells investigated the phenomena of dew more closely than any other person; and his experiments, as detailed in his instructive essay on that subject, appear to have been very satisfactorily conducted; and the theory which he established on these experiments is the one now embraced by philosophers. From that essay I shall first relate a few of the circurnstances which influence the production of dew; and then give Dr. Wells's theory of its formation, in contradistinction to those of other philosophers. "Aristotle and many other writers," says 
Dr. Wells, "have remarked that dew appears only in calm and serene nights. This remark of Aristotle, however, is not to be received in its strictest sense, as I have frequently found a small quantity of dew on grass, both in windy nights, if the sky was clear or nearly so, and in cloudy nights, if there was no wind. If, indeed, the clouds were high and the weather calm, I have sometimes seen on grass, though the sky was entirely hidden, no very inconsiderable quantity of dew. Again, according to my observation, entire stillness of the atmosphere is so far from being necessary for the formation of this fluid, that its quantity has seemed to me to be increased by a very gentle motion of the air. Dew, however, has never been seen by me on nights both cloudy and windy. If, in the course of the night, the weather, from being calm and serene, should become windy and cloudy, not only will dew cease to form, but that which was formed will either disappear or diminish considerably. In calm weather, if the sky be partially covered with clouds, more dew will appear than if it were entirely covered, but less than if it were entirely clear. Dew probably begins in the country to appear upon grass, in places shaded from the sun during calm and clear weather, soon after the heat of the atmosphere has declined; and I have frequently felt grass moist in dry weather several hours before sunset. On the other hand, I have scarcely ever known dew to be present in such quantity upon grass as to exhibit visible drops before the sun was very near the horizon, or to be very copious till some time after sunset. It also continues to form in shaded places after sunrise; and if the weather be favorable, more dew forms a little before, and, in shaded places, a little after sunrise, than at any other time. The formation of dew, after it has once commenced, continues during the whole night, if the weather remain still and serene. During nights that are equally clear and calm, dew often appears in very unequal quantities, even after allowance has been made for any difference in their lengths. Orse great source of their difference is very obvious, for, it being manifest, whatever theory be adopted concerning the immediate cause of dew, that the more replete the atmosphere is with moisture, previously to the operation of that cause, the more copious will be the precipitation of moisture in the atmosphere, must likewise tend to increase the production of dew. Thus dew, in equally calm and clear nights, is more abundant shortly after rain than during a long tract of dry weather. It is more abundant during $\mathrm{S}$. and $\mathrm{W}$. winds, than during those which blow from the $\mathrm{N}$. and the E. Dew is commonly more plentiful in spring and autumn than in summer; the reason is that a greater difference is generally found between the temperature of the day and the night in the former seasons of the year than in the latter. Dew is always very copious on those clear and calm nights which are followed by misty or foggy mornings; the turbidness of the air in the morning showing that it must have contained, during the preceding night, a considerable quantity of moisture. I have observed dew to be unusually plentiful on a clear morning which had succeeded a cloudy night. For the air having, in the course of the night, lost, little or no moisture, was in the morning charged with more watery vapor than it would have been if the night had also been clear. Heat of the atmosphere, if other circumstances are favorable, which, according to my experience, they seldom are in this country, occasions a great formation of dew. For, as the power of the air to retain watery vapor in a pellucid state increases considerably faster while its temperature is rising than in proportion to the heat acquired, a decrease of its heat in any small given quantity during the night must bring it, if the temperature be high, much nearer to the point of repletion before it (483) 
be acted upon by the immediate cause of dew, than if the temperature were low. I always found when the clearness and stillness of the atmospliere were the same, that more dew was found between midnight and sunrise, than between sunset and midnight, though the positive quantity of moisture in the air must have been less in the former than in the latter time, in consequence of a previous precipitation of part of it. The reason, no doubt, is the cold of the atmosphere being greater in the latter than in the prior part of the night."

Theories of the formation of dew have been proffered by many philosophers, from the days of Aristotle to the time of Dr. Wells. "Dew, according to Aristotle," remarks Dr. Wells, is "a species of rain formed in the lower atmosphere, in consequence of its moisture being condensed by the cold of the night into minute drops. Opinions of this kind, respecting the cause of dew, are still entertained by many persons, among whom is the very ingenious Mr. Leslie, of Edinlurgh." "This view is erroneous, because "bodies a little elevated in the air become moist with dew, while similar bodies, lying on the ground, remain dry, though necessarily from their position as liable to be wetted by whatever falls from the heavens, as the former." Dufay concluded that dew is an electric phenomenon, but it leaves untouched bodies which conduct electricity, while it appears upon those which cannot transmit that influence. All the theories on dew, to the time of Dr. Wells, omitted the important part that the production of dew is attended with cold, and this is a very important omission, since no explanation of a natural phenomenon can be well founded which has been built without a knowledge of one of its principal circumstances. "It may seem strange to many," continues Dr. Wells, " that neither Mr. Wilson nor Mr. Six applied the fact of the existence of cold to its production, to the improvement of the theory of dew. But, according to their view of the subject, no such use could have been made of it by them, as they held the formation of that fluid to be the cause of the cold observed with it. I had many years held the same opinion, but I began to see reason, not long after the regular course of my experiments commenced, to doubt its truth, as I found that bodies would sometimes become colder than the air without being dewed; and that when dew was found, if different times were compared, its quantity and the degree of cold which appeared with it were very far from being always in the same proportion to each other. The frequent recurrence of such observation at length corrected the doubt of the justness of my ancient opinion into a conviction of its error, and at the same time occasioned me to conclude that dew is the production of a preceding cold in the substance upon which it appears." Dr. Wells's theory, therefore, is "that the cold observed with dew is the previous occurrence, and, consequently, that the formation of this fluid has precisely the same immediate cause as the presence of moisture upon the outside of a glass or metallic vessel, where a liquid considerably colder than the air has been poured into it shortly before." As an obvious application of this theory, the experiments of Dr. Wells, which led to its establishment, evince that of all natural substances grass is peculiarly adapted to the exhibition of dew, inasmuch as it becomes, under ordinary circumstances, colder than the air above it, by the radiation of more heat toward the heavens than it receives in any way, and, accordingly, whenever the air is calm and serene, dew may be seen on grass, when it may not be observed on other substances.

But it has been alleged by Dufay that dew is the condensation of vapor rising out of the earth upon the grass on it, because objects removed higher from the surface of the earth, as trees, are exempt frem dew; and this is (484) 
a very popular opinion; but it is an erroneous one, and the phenomen in can be explained on other principles, because the lower air in a clear and calm evening is colder than the upper, and it contains more moisture than the upper; and hence, on all these considerations, it will sooner deposit a part of its moisture. At the same time, it is true that vapor does rise from the earth, and it may be condensed as dew; for we find the grass first becoming moist with dew, then the substances raised above it, while both indicate an equal degree of cold; but all the quantity of dew from this cause can never be great, because until the air be cooled by the substances attractive of dew with which it comes in contact below its point of repletion with moisture, it will always be in a condition to take up that which has been deposited upon grass, or other low bodies, by warm vapor emitted by the earth, just as the moisture formed on a mirror by our breath is, in temperate weather, almost immediately carried away by the surrounding air. Agreeably to another opinion, the dew found on growing vegetables is the condensed vapor of the very plants on which it appears; but this also is erroneous, because dew forns as copiously upon dead as upon living vegetable substances; and "if a plant," as Dr. Wells observes, "has become, by radiating its heat to the heavens, so cold as to be enabled to bring the air in contact with it below the point of repletion with moisture, that which forms upon it from its own transpiration will not then indeed evaporate. But although moisture will at the same time be communicated to it by the atmosphere, and when the difference in the copiousness of these two sources is considered, it may, I think, be safely concluded that almost the whole of the dew which will afterward form upon the plant must be derived from the air; more especially when the coldness of a clear night, and the general inactivity of plants in the absence of light, both lessening their transpiration, are taken into account." Hoarfrost is just frozen dew, but as it only appears when the surface of the earth is sealed with frost, the vapor of which it is formed cannot, of course, at the time, perspire from the earth.*

Another remarkable phenomenon in summer is hail. "The difficulty for accounting for the retention of masses of ice in the free atmosphere," observes Professor Forbes, "is certainly very great. Perhaps no hypothesis more satisfactory, certainly none more ingenious, has followed that of Volta, who conceived, from the highly electric condition of the atmosphere, almost universally attending the production of hail, that the frozen masses were kept in a state of reciprocating motion between two clouds oppositely charged with electricity, until the increase of the mass rendered the force of gravity predominant, or the electric tension of the clouds was exhausted by mutual reäction."' As hail is a very curious and highly interesting phenomenon, a few facts regarding its occurrence and the forms of hailstones may prove instructive. "Hail generally falls in the hottest hours of the day in Spain, Italy and France. It falls in Eu rope generally in the day, and seldom in the night. It seldom falls in winter, though at Plymouth, according to $\mathrm{Mr}$. Giddy, there seems to be an exception. Thus, in the course of 21 years, the recurrence in each month was, in

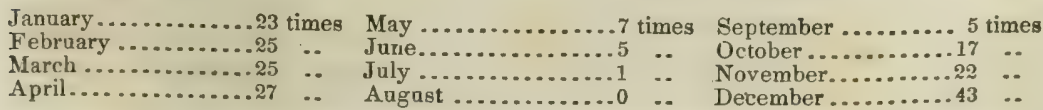

In August is absolute zero, and in December is the maximum. Rain falls in all seasons, snow in winter, hail principally in summer. The appear-

* Wells on Dew, second edition, 1815. (485)

† Forbes's Report on Meteorology, vol. i. 
ance of hail-clouds seems to be distinguished from other stormy clouds by a remarkable shading; their edges present a multitude of indentations, and their surfaces disclose here and there immense irregular protuberances. Hail seldom falls on mountains, which indicates lowness of clouds, which Arago has seen cover the valley with fog, while the mountains were clear above. The form of hailstones varies. They are nearly uniform when they fall on the same level; and in the same storm they have fallen smaller on the tops of mountaius than on the plains. Change of temperature or wind changes the form of hail. On 7th July, 1769, M. Adanson observed 6-sided pyramids fall, but the wind changing to N.E., changed them to convex lenses, and so transparent as to transfer objects without distortion. Hail is sometimes attended with spongy snow, which may have formed the interior of the hailstone, while its exterior was transparent ice. It has been supposed from this, that the different portions have been formed under different circumstances. Leslie imagines the spongy texture to result from an atom of water having been suddenly frozen, and particles of perhaps rarefied air suddenly driven into the center. The pyramidal form fell at Aberdeen on 29th November, 1823. The usual form of hail is a concentric lamellar structure, with a stellular fibrous arrangement. There is great difficulty in accounting for large masses of ice in the atmosphere, as hail cannot take above 1 minute in falling from low clouds."

The forms of the clouds in summer are very distinctly marked. When a deposition of vapor is taking place in the highest part of the atmosphere, the cirrus, or curl-cloud, appears (283), and it sometimes soon disappears, which is a sign of fine weather; but instead of disappearing, it may descend a little lower, and be converted into the cirro-cumulus (2S7), which is the form of that elegant, light, flocculent cloud so often seen in a fine summer day. A farther deposition changes the small cloud into the larger cumulus, called the day-cloud in summer, because it disappears into another form in the evening. The cumulus or heap may may be seen distinctly represented in the plate of the Liecester tup, both above the animal and above the horizon, where it frequently takes up its position for the greater part of the day, resting on the vapor plane. When a large cumulus rises from the horizon in the daytime, and shows white towering heads, it is a sign of a storm or a fall of rain from that quarter; and the wind will change to that direction in the course of the next 24 hours. This threatening cloud, is called cumulo-stratus. In calm, serene evenings in summer, the day-cloud or cumulus descends and spreuds itrelf along the hottom of valleys, or in hollows of the open country, covering the ground like a lake as seen in moonlight, or with a partial sheet of snow. This is the true stratus cloud. Tall objects, such as trees, steeples, and even elevated ground, jut through it like rocks and islands in a lake. The air is then perfectly calm, the temperature is delightfully warm, and the intenseness of the silence is broken only by the snipe drumming in its curious somersets in the air-by the harsh ventrilnquous cry of the corn-craik among the grass-or by the occasional barking of the watchdog at some distant homestead. The morning after such a night is sure to usher in a bright and peerless sun, whose steady heat will soon evaporate the sheet-like stratus-cloud from the valley and hollows, and elevate it, in the form of the beautiful day-cloud, above the mountain-top or the horizon.

The direction of the wind forms an important item in the consideration

- Encyclopedia Metropolitana, art Meteorology.

(486) 
of the weather in summer; for in no other season does the slightest variation of the wind make so decided changes on the weather. If we assent to the general conclusion in regard to the cause of winds, that it is the partial changes of temperature which are their chief general cause, we may expect the winds to be most variable in summer, since changes of temperature are most likely to occur at that season; and the change of the wind is the most ready indication of the change of temperature, especially in the upper portion of the atmosphere. In the torrid zone, while the barometer seldom varies but in a trifling degree, in the temperate zone it is not less fickle than the wind. This indication of a loss of weight in the atmosphere can arise only from a local diminution of its elasticity, most likely from changes of tempexature. But the most remarkable effect in relation to the wind in summer, is the constancy with which it blows from the east in the early part of that season; and so invariable is this phenomenon, that every person who dwells on the east coast of Great Britain is quite familiar with it, as every one feels the keenness of the east wind, and every one knows the aptitude with which catarrhal affections are produced by it. An explanation of this remarkable phenomenon cannot fail to prove interesting; and as a very rational solution of its recurrence has been given by Mr. Samuel Marshall, I shall copy his succinct but satisfactory account of it. After stating that the east winds in early summer usually prevail from the middle of April to the 7th or 8th of May, or even to the 18th of May, and I may add that it continued all June in 1843, Mr. Marshall then proceeds to account for the cause of the phenomenon. "In Sweden and Norway, the face of the country is covered with snow to the middle of May or longer. This frozen covering, which has been formed during winter, grows gradually shallower to the 15th or 16th of May, or until the sun has acquired $170^{\circ}$ or $18^{\circ} \mathrm{N}$. declination; while, on the other hand, the valleys and mountains of England have received an accession of $24^{\circ}$ or $25^{\circ}$. On this account, when the temperature of Sweden and Norway is cooled down by snow to $32^{\circ}$, that of Britain is $24^{\circ}$ or $25^{\circ}$ higher than that of the preceding countries. Because, while the ground is covered with snow, the rays of the sun are incapable of heating the air above $32^{\circ}$, the freezing point. For this reason, the air of England is $24^{\circ}$ or $25^{\circ}$ more heated than that of the before-mentioned countries. The air of Sweden and Norway will then, of course, by the laws of comparative specific gravity, displace that of England, and, from the relative situation of those countries with this country, will produce a N.E. wind. The current is in common stronger by day than by night, because the variation of temperature is at that time the greatest, being frequently from $50^{\circ}$ to $60^{\circ}$ about noon, and sinking to $32^{\circ}$ in the night."* Some of the most obvious prognostics of the wind in summer are, when the wind is variable, rain is not far distant; when it blows low, and raises the dust much, it has the same effect; but when there are small whirlwinds raising the dust along the road or corn-fields, it is a sign of dry weather. I remember of seeing a beautiful whirlwind, in a calm hot day, in the neighborhood of Berlin, raise the sand of a field, the soil being mostly composed of that substance, in a perpendicular direction to a great hight in the air. When currents of air are seen to move in different directions, that which the upper current takes will ultimately prevail. At times in summer, and particularly in the evening, it is hard to say from which quarter the current comes, when a wetted finger held up will tell the quarter, from the cold produced on it by consequent evaporation of the moisture. The pleasant phenomena of the

- Brewgter's Journal of Science, vol. viii.

(487) 
land and sea breezes are distinctly marked in fine warm weather in summer. When winds blow strongly from any quarter, even from the warm west, for two or three days in succession, the temperature of the air is much diminished, sometimes as much as $20^{\circ}$, and seldom less than $10^{\circ}$.

So much for the aërial speculations of summer. Let us now notice the humbler toils of the field. These, as I have already observed, require to be advanced a stage toward their completion in autumn. The first operation which calls for the plowman's attention in summer is the turnip-land, which is now drilled up, dunged, and sown. The culture of the turnip is a most important and stirring operation, affording much interesting work in singling and hoeing the plants for the greater part of the season. In the hight of summer, young stock luxuriate on the riches of the pasture-field, while forage plants, consisting of vetches, rape, or broad clover, are allowed to grow until the general season of want, between the failure of pasture and the premature consumption of turnip. Before stock take possession of the pasture-fields, the hedger makes it a point to put the fences in a complete state of repair, and to second his exertions, the carpenter and smith make the field-gates secure for the season. Fattened stock are seldom allowed to taste the pasture, they being disposed of off the turnips to the butcher or dealer. The fat cattle are almost always then sold. Young cattle and cows are sent to the grazing field of the farm, though turmip sheep are not unfrequently retained on grass until the fleece is clipped from their backs (the season being nigh at hand,) and after that they also are disposed of. The separation of ewe and lamb is now effected; and the respective marks of age, sex, and ownership, are put on each. Horses now live entirely another sort of life, being transferred from the confinement of the collar in the stable to the perfect liberty of the field, and heartily do they enjoy themselves there. The brood mare now brings forth her foal, and receives immunity from labor for a time. Hay-making is represented by poets as a scene of unalloyed pleasure. No doubt lads and lasses are then as merry and chirping as grasshoppers, but, nevertheless, in spite of buoyant spirits, hay-making, in sober truth, is a labor of much heat and great toil-the constant use of the hay-rake and pitch-fork, in hot weather, being no sinecure. Early as the season is, preparations are made in summer for the next year's crop. The bare fallow is worked and dunged, and it may be limed too, in readiness for the seed in autumn.Summer is of all others the season in which the farmer most seriously makes his attacks on those spoilers of his clean fields, and contaminators of the samples of his grain-the weeds. Whether in stocked pastures, upon tilled ground, along drills of green crops, among growing corn, or in hedges, young and old, weeds are daily exterminated, and the extermination is most effectually accomplished by the minute and pains-taking exertions of female field-workers. For these purposes they are provided with appropriate cleaning instruments. This is the season, too, in which his stock and crops are sometimes seriously affected by the attacks of insects. Where building-stones are plentiful, and the risk great from the overflowings of rivulets in winter, summer is also the season for the erection of stone dykes as fences between fields, and of embankments along the margins of rivers. The former afford a substantial fence at once, the latter form insuperable barriers against an element powerful alike whether exerted for or against Man's operations.

Every operation requires constant attention in summer, for, the season being active in its influences, farmers must then put forth their energies to meet its rapid effects, whether these tend to forward or retard his efforts.

(488) 
The long hours of a summer day, of which at least ten are spent in the fields - the ordinary high temperature of the air, which suffuses the body of the working man in constant perspiration-and the fatiguing nature of all field-work in summer, bear hard as well on the mental as the physical energies of the laborer, and cause him to seek for rest at a comparatively early hour of the evening. None but those who have experienced the fatigue of working in the fields in hot weather, and for long hours, can truly appreciate the luxury of rest-a feeling truly described in these simple lines :

\footnotetext{
"Night is the time for rest.

How sweet when labors close

To gather round the aching breast

'T'he curtain of repose-

Stretch the tired limbs, and lay the head

Upon one's own delightful bed!"
}

Montgomerx.

The hours devoted to field-work vary in summer in different parts of the country. On the borders it is the practice to go very early to the morning yoke, as early as 4 o'clock, that the forenoon's work may be over by 9 , and that there may be time to rest in the heat of the day; the afternoon's yoking commences at 1 o'clock, and continues till 6 o'clock. There are thus 10 hours spent in the fields. But in most parts of the country, the morning yoking does not commence till 6 o'clock, and, on terminating at 11 , there are only 2 hours for rest and dinner till 1 o'clock, when the afternoon's yoking begins. In other parts, only 4 hours are spent in the morning yoking, when the horses loose at 10 o'clock, and yoking again from 2 to 6 in the afternoon, only eight hours are spent in the fields, and the men are employed elsewhere by themselves for 2 hours. This is practiced where the plowmen are made to do the work of fieldworkers, and where a large numbers of diaughts are kept. Perhaps the best division of time is to begin the yoking at 5 o'clock in the morning, loose at 10 , yoke again at 1 , and loose at 6 in the evening, affording 3 hours for rest to man and horse at the hight of the day, and 10 hours in the field. Day-laborers, when not dependent on the horses, as well as field-workers, usually work from 7 to 12 , and from 1 to 6 o'clock in the evening, having 1 hour for rest and dinner. When laborers take their dinner with them to the field of their operations, this may be a good enough division of time; but when they have to go home to dinner, 1 hour is too little for the purpose, and affords no time for rest between yokings, which is to be deprecated, as neither men nor women are able to work 10 hours without an interval of quiet rest. It would, therefore, be a better arrangement for field-workers to go to work at 6 instead of 7, and loose at 11 instead of 12 , when they have to go home to dinner; but if they took their dinners with them to the field, then 1 hour is sufficient for rest and dinner at the same time.

Summer is the only season in which the farmer has liberty to leave home without incurring the blame of neglecting his business, and even then the time which he has to spare is very limited. There is only about a fortnight between finishing the fallow, the turnip and potato culture, and haymaking, and the commencement of harvest, in which the farmer has leisure to travel. This limitation of time is to be regretted, because it is proper that he should take a journey every year, and see how farm operations are conducted in other parts of the kingdom. An excursion of this nature is seldom undertaken by a farmer, who is generally a man capable of observation, without acquiring some hints which may induce the adoption of a pratice that seems good, or the rejection of one which is bad. Such a journey exhibits mankind in various aspects, 
and elevates the mind above local prejudices; and as husbandry is a progressive art, a ramble of a week or two, through different parts of the country, cannot fail to enlighten the mind of the most experienced farmer much beyond anything he can observe by always remaining at bome.

\title{
21. THE SOWING OF TURNIPS, MANGEL-WURZEL, RAPE, CARROTS
}

\section{AND PARSNIPS.}

\begin{abstract}
*They require the land to be well broken hy frequent plowings and harrowiugs, and also to be well dunged; this is of great impontance, bot only as the crop of these routs is thereby rendered larger, but as the land is thereby prepared for carrying good crops of corn." COLTMELLA.
\end{abstract}

(1953.) The first great field operation in summer is the completion of the preparation of the soil for the sowing of the turnip crop. This crop commences the rotation of crops, is a substitute of bare-fallowing, and is of the same nature, as regards the amelioration and working of the soil, as the potato crop, and therefore admits of the soil being manured; and, indeed, on account of all these properties, it is regarded and denominated a fallow crop. Being thus a renovator of the condition of the soil, the turnip crop necessarily succeeds the crop which terminates the rotation, and beyond which the exhaustion of the soil is not permitted; and, being a fallow crop, the preparation of the soil for it requires much labor, and should therefore be begun as early as the breaking up of the stubble in the beginning of winter. This fact is indicated in (916); and the different modes of plowing stubble for fallow, according to the nature of the soil, are mentioned in (917), and the due precautions to be used to keep the soil in a dry state all winter are stated in (918). These constitute the winter preparations for the turnip crop; and those in spring are begun by cross-plowing, fig. 312 . Should potatoes have been planted in the same field intended for turnips, the criss-plowing for the potate land should be extended across the turnip land, if there is time for it; but should the time required for this extended cross-plowing encroach upon that which is devoted to potato-planting, the turnip land should be let alone, until there is leisure. From the cross-plowing to the drilling of the land for the reception of the dung, the turnip culture is exactly the same as for potatoes, with perhaps the exception that as there is more time for working and cleaning turnip-land, it receives one or more plowings or stirrings with the grubber than the potato land; and in this cleansing process the grubber will be found a most efficient implement, and will save a plowing, while it keeps the upper soil uppermost and in a fine loose state. When turnip land is manured with farm-yard dung, the drilling is best and most expeditiously done in the single mode, fig. 313 ; but as the drills have to be kept in exact proportions, for the sake of the better operation of the sowing-machine that is to follow, the best plowman should be desired to make them. The position of the plow which makes the single drills is shown at $a$, fig. 344 ; the ground occupied by one feering in drilling is shown from $a$ to $e$; and the process of dunging, buth in carting out and spreading the dung, and in splitting the drills in the double way, are conducted in the manner described for that figure, with the exception of the potato planters at $r$ and s. So far, then, the culture of potatoes and (490) 
turnips correspond, but after this point a considerable difference ensues, which arises from the difference in the nature of the seed. After the soil on the top of the drills has become a little browned with the sun, or rizzared, as it is technically phrased in some, or with a proper tid in other places, the turnip sowing-machine, which sows 2 rows at a time, such as the one described below by Mr. Slight, is then used, with one horse, for sowing the seed. The soil should be dry at the top of the drills before the seed is sown, because damp soil clings to the rollers of the machine, and causes them to make bad work. One of these machines could sow a great breadth of land in a day, but it is seldom that it can be employed throughout a whole day, for two reasons: One is, that the soil is seldom in a dry enough state in the morning to be thus sown; and the other reason is, that a sufficient quantity of land will not be dunged and split in the course of a day to keep a machine going constantly, because one plow can only split $\frac{1}{3}$ more land in a day than it can plow, so that 3 plows will only split 5 acres at most of drills over dung in a day, and thus 1 machine could hold 4 plows splitting drills; and as the dunging is carried on the same time, there are few farms so large as to employ 4 plows splitting drills.

(1954.) The quantity of seed sown need not exceed 3 lbs. to the English acre, nor should the quantity be much less, as thick sowing insures a quick braird of the turnip plant, and the seed is not a costly article, being usually from $9 \mathrm{~d}$. to $1 \mathrm{~s}$. per $\mathrm{lb}$. Fortunately, that the land may receive its due labor, the different kinds of turnips cultivated require to be sown at different times. Swedes, for instance, should be sown by the 15 th of May at latest, and if the land is ready to receive the seed by the $10 \mathrm{th}$, so much the better. Swedes will grow on any kind of soil, except, perhaps, what is in a state of pure peat; but they grow best in rich alluvial sandy loam -best, because largest, and in that state this particular turnip is firmest too. The yellow turnip follows the Swedes, and then the white, which may be sown any time in June. In England, white turnips are sown as late as July, because, if sown earlier, they would come too sonn to maturity. The seeds of Swedish turnips are much larger than those of yellow or white, and require to be sown through a larger hole in the canister of the machine. They will retain their freshness for several years, and may be confidently sown though kept for 3 years; but it would be hazardous to sow yellow or white turnip-seed after the first year; they somehow lose their vitality after that time. The reason why I give the preference to the purple-top Swedish, the Aberdeenshire yellow bullock, and the white globe turnips, will be found in paragraphs from (1022) to (1031) inclusive, and these turnips are figured in fig. 214, at the same place. At the same time, you should partly be guided by the practice of the district in which your farm is situate, what sorts you should sow on your first coming into the district; but you should hear very satisfactory reasons why those kinds will not thrive in that particular district, and should even experience their failure before you determine on preferring the culture of other kinds. When I began to farm in Forfarshire, I was told that the Swedish turnip would not thrive on such soil as my farm, a light turnip soil, and that I would find the red-topped white the best; but a very short trial showed every one that Swedes and the white or green-topped globe throve much better than the favorite red-topped, which is an early turnip, no doubt, but a very spongy one on that soil. For my part, I would have no fears of raising a good crop of Swedes on any ordinary soil by proper culture, that is by giving them plenty of old well-made dung, and sowing them early. Give Swedes 15 tons, or 20 good cart-loads, of dung in that 
state to the imperial acre, and sow them before the 15 th of May, and little fear need be entertained of the crop on the must ordinary soil ; 12 tons of well-marle dung will suffice for yellow turnips, and 10 tons of the same for white globes; but, of course, the more dung each of the kinds receive, the larger crop may be expected.

(1955.) It is not an unusual practice in England to sow turnips broadcast on the flat ground, instead of in rows, and on ridglets or drills, as in Scotland; and the reason I have heard stated in vindication of the broadcast method is, that it resisted the bad effects of drouth on the land in summer. No doubt excessive drouth in summer is inimical to the full development of the turnip, and it is on this account that the turnip crop fails so frequently in Germany; but, for my part, I cannot see how a broadcast crop can escape drouth more certainly than one in rows, since the plants have to grow and be thinned out to proper distances in both cases; and should the ground be foul with weeds it must be stirred to get rid of them in both cases; and as the work of weeding is done by hand instruments in the case of the broadcast crop, it is, of course, not so effectually done as with horse-hoes, in the case with the crop in rows; while I can see, that as the dung must be spread broadcast for a broadcast crop, it will not have the same opportunity of promoting the growth of the crop at its early stage as when it is deposited in rows, so that the means employed defeat its own purpose; because I think it cannot admit of doubt that the same quantity of manure placed in bulk immediately under the seed should promote the growth of the plant more rapidly than when it is spread over a larger surface of ground, and there can be no doubt, also, in regard to the turnip plant itself, that the more rapidly it grows in its early stage, the more certainly it will be free of danger from drouth and from some insects, at least; for it is well known, in regard to the habits of some of those which attack the turnip, that they become innocuous to its leaves after the development of the rough ones. I do not aver that the sowing of turnips in drills will render them invulnerable to the attacks of insects or to the effects of drouth, but these evils being merely seasonal, the drill system places the crop more immediately under the management of the cultivator, inasmuch as it enables him to apply the whole powers of the manure at once, and of cleaning the soil quickly with the assistance of horse-power. Besides all this, the period of sowing the crop should be suited to the climate of the locality. If drouth is too great in July, or the insects too powerful, the crop should be sown earlier, and though it should reach maturity sooner than desired, it can be drawn and stored until the season of its consumption arrives; or it should be sown later, such as in August, when the genial climate of the South of England-where the nights are warm as well as the day, thereby affording every day the growth of two ordinary days in Seotland, where the nights are always cold-is sufficient to mature the crop before the end of October, which is as early as the turnip crop is required for consumption in that part of the country, and where till then the grass continues good. And were the soil properly cleaned before the crop is sown, comparatively little labor would be required to keep it so in the hight of summer, and of course the drouth would not then much affect it. Or, a part of the turnip crop could be taken after winter retches, which, on being cleared off the ground in time by feeding sheep, or by cutting, would enable the land to receive a short fallowing for turnips before the end of July.

(1956.) Nor is a much earlier fallowing and cleaning of the turnip land an impracticable thing in England, since the corn crop is frequently cleared from the fields by the end of August, when the stubble could be broken (492) 
up, harrowed, cross-plowed, cleaned, drilled, and even dunged, before the arrival of winter, as has been proved in Scotland, by the practice of Mr. James Scougall, at Balgone, East-Lothian, the seat of Sir George Grant Suttie, Bart., in the autumn of 1841 , when he drilled and dunged good turnip land, at 32 inches apart in the drill, and otherwise finished its tillage. Purple-top Swedes were sown on the 10th of May, 1842, the plants thinned to 15 inches apart, and the matured crop was drawn and stored by the middle of September following, when the ground was sown with wheat. On comparing the produce of this mode of culture with the usual one of laboring the turnip land in spring, and at the usual distance of 28 inches between the drills and 12 inches between the plants, the ground prepared in autumn yielded, in 429 links measured along one drill, 82 stones of turnips, whereas that worked in spring yielded only 58 stones, though the number of turnips in the former weight was only 238, while that in the latter was 276, thus giving to each turnip a weight of 4 lbs. 13 oz. in the former, and of only 2 lbs. $15 \mathrm{oz}$. in the latter case. A single horse-load of turnips selected from the ground prepared in autumn only numbered 141 roots, and weighed as much as 109 stones, showing the weight of each root to be 10 lbs. $13 \mathrm{oz} . *^{*}$ This instance proves that land for Swedish turnips may be prepared in autumn, and a heavy crop obtained on drills as wide as 32 inches, and from plants 15 inches apart. A somewhat similar success attended the trial of raising turnips on strong clay land, at ordinary distances, by Mr. Peter Thomson, Peffermill, near Edinburgh. So soon as the ground was cleared of tares, he cross-plowed it with a deep furrow, well worked it with harrows and grubber early in October, drilled it in the single way at 28 inches asunder, but, owing to the unfavorable state of the weather, was prevented applying the dung until December and January, which consisted of 32 single horse-loads of street-manure per imperial acre, and which was covered in with the common plow. In March the soil was found in a fine state, but as it was rather foul with weeds, the drills were harrowed a double tine, the ground stirred between them with the single-horse grubber, and set up with the double mould-board plow, and again set up just before sowing the seed of the green-top yellow turnip on the 15th, and of the white globe on the 25 th and 26 th of May. The yield was 32 tons of turnips per imperial acre, including tops, and quite free of mildew. The field had been dunged 5 years before, and twice since top-dressed with 8 bags of 4 bushels each of soot to the imperial acre.t Were such modes of culture adopted in the South of England, I have no doubt certain and abundant crops of turnips would be raised in spite of drouth and insects, and the slovenly practice of broadcast culture would then give way to the more scientific mode of the drill system.

(1957.) Besides farm-yard dung, a great breadth of turnips is raised every year with bone-dust. This manure is not only cheap, but insures a good crop of turnips in ordinary circumstances, and its use expedites fieldlabor very much. When the land is ready to be drilled up from the flat, the drills are made in the double way (1741); and that is all the preparation the land requires for bone-dust, which is then applied by the bonedust sowing-machine, represented in Plate XXXI., and described below by Mr. Slight. This machine deposits the bone-dust and turnip-seed at the same time, and finishes the sowing of the turnip crop. The quantity of bone-dust used is commonly 16 bushels or 2 quarters to the imperial acre. There is something in the action of bone-dust on the soil, and its consequent power to produce a turnip crop, which I do not understand, the

\footnotetext{
- Mark-Lane Expreas, 17th October, 1842.
}

(493)

† Ibid., 21st November, 1842. 
means being apparently so inadequate to produce the results obtained. What I mean is, that up to a certain quantity used, this manure has evidently a beneficial effect, but, beyond that quantity, there is derived from its use no apparent benefit, in as far, at least, as the crop is concerned. I have tried to raise turnips with different quantities of bone-dust, varying from $12,16,20$, and 24 bushels to the imperial acre, and have found the crop improved up to 16 bushels, but any quantity beyund that, even to 24 bushels, produced no greater effect on the turnips in the same field, and on the same sort of soil, than 16 bushels. Nay, more.than this, my late agricultural preceptor, Mr. George Brown, when he farmed Hetton Steads, in Northumberland, raised as good crops of turnips as 16 busbels of bonedust, with only 8 bushels of bone-dust, combined with an indefinite quantity of sifted dry coal-ashes; and yet 8 bushels of bone-dust, or an indefinite quantity of coal-ashes applied separately, produced a very poor crop of turnips. It is, therefore, unnecessary, in so far as the crop of turnips is concerned, to sow more than 16 bushels of bone-dust alone, or 8 bushels with coal-ashes, or perhaps street-manure. Both coal-ashes and streetmanure, when proposed to be used with bone-dust, should be kept dry under cover and sifted free of large lumps. It is truly surprising what an effect on the soil so small a quantity of bone-dust produces. I have raised a portion of the manured soil of a drill with my hand before the turnipseed had germinated, and found it agglutinated together in a lump with a greasy matter, and the lump interspersed partly with white mouldiness, and partly with minute fibres of plants. When the turnip-seed germinates, which it will do in 8 or 10 days, according to the state of the weather, its radicle strikes into the greasy mass of earth, and sends out an immense number of white fibres around and through it. Its cotyledons then expand upward into two rudimentary, smooth leaves, and immediately thereafter two true or rough leaves appear, and these last are called rough leaves, because they feel rough by reason of the small spiculæe which may be observed to occupy the surface of every leaf of the common turnip. The rudimentary leaves of the Swedish turnip are not rough but smooth, because the plant is not a true turnip, but a species of cabbage, which are all smooth-leaved. The smaller bone-dust is ground the more effective it is as a manure, because it then mixes more intimately with the soil, though its action upon it continues for a shorter time; and, on the other hand, large or drilled, or inch-bones, as they are called, remain longer in the soil undecomposed, but produce less immediate effect. On these accounts, bone-dust is the more valuable manure for turnips, and inch-bones for wheat. But even bone-dust has effect beyond the turnip crop; it extends its influence over all the crops of the rotation. I pulled off 4 acres of turnips raised with bone-dust, and 4 acres adjoining these in the same field that had been raised with 15 loads of farm-yard dung; and the crop of turnips was not only better after the bone-dust than after the dung, but all the crops that followed in the rotation, namely, barley, hay, pasture, and oats, were also better in their respective years. Bone-dust, when purchased in that state on shipboard, is almost always adulterated with old plaster, brick-dust, ashes, \&c., and should therefore be purchased direct from the grinder, one who is on the spot. There are now many bonemills scattered over the country. To avoid adulteration, an association of farmers was formel a few years ago in Perthshire to import bones, rapecake, \&c., and grind them at their own mills under the superintendence of a manager in whom they have confidence, and in this way they continue to supply themselves with genuine manures. Bone-dust is best conveyed in sacks, and 40 bushels will fill a double-horse cart and sow $2 \frac{1}{2}$ acres impe(494) 
rial. It weighs $47 \mathrm{lbs}$. per bushel. It should be immediately emptied out of the sacks and kept in small heaps in a cool shed until it is used, as it is very apt to heat, and one consequence of recent heating is to become lumpy and troublesome to sow by the machine, though otherwise it is not injured, but rather improved by it. In some parts of the country, particularly on the Borders, bone-dust is sown by hand either along drills made up in the single way, which are then split in the double way, while this plan imposes the trouble of a second drilling, or it is sown on the flat ground and covered by drilling in the double way. In both cases; the seed is sown afterward by itself with the common turnip-sowing machine. The only reason I have heard in favor of sowing bone-dust by hand inslead of machinery is saving the cost of the machine; but whatever advantage is gained by this saving, it is, I think, evident that the machine must deposit the bone-dust much more regularly than the hand; and as to the cost of a machine the saving must be trifling, as hoppers for containing bone-dust can be attached and made to remove at pleasure from an ordinary sowing-machine. I always used a machine of this form myself. But in a case of this kind accuracy of work is a more potent consideration than the cost of a small machine, even though it should be used but for a few weeks every year. There is another consideration, too, of even greater import, that the nearer bone-dust is placed to the turnip-seed the quicker will the seed vegetate, and experience has proved that turnip-seed may safely be placed among bone-dust. In sowing by hand, the manure is not placed near the seed in as far as the sower knows, and when the seed is sown by itself after the bone-dust has been covered up by the drill, the sowing-machine is as likely to deposit it away from, as near to, the manure, and hence a regular braird cannot be insured by the practice. The ordinary bone-dust sowing-machine, as well as sowing by the hand, deposits the bone-dust in a continuous line along the drill; but a sowingmachine has been lately invented, and is partially in use in Perthshire, which deposits the bone-dust in small portions at regular intervals. The argument in favor of this mode of depositing manure is the comparatively small quantity required by it to produce a full crop; and certainly when bone-dust is either very scarce or very dear, this is a fair argument to use in its favor. If by depositing as much bone-dust at given distances of 12 inches as would be deposited at those distances were 16 bushels per acre sown in a continuous line, and if the quantities so deposited at intervals of 12 inches are found to produce as well-grown turnips as a continuous sowing, then the saving of manure must be as great as from $\frac{1}{2}$ to $\frac{2}{3}$, because the intervals between the distances are not manured at all; and even if a greater quantity than usual were sown on the spots at intervals, still a saving would be effected upon the whole; and if these greater quantities are found to produce a greater crop than the usual mode, then the plumping mode, as this method of sowing by intervals is termed, may be regarded as a valuable discovery. Still more experience of its results is required before implicit faith can be placed in it as a practice fit for general adoption; although it must be owned that the anomalous circumstance regarding the action of bone-dust already noticed, namely, of its maximum effect being produced by a given quantity, and not by indefinite quantities-favors the pretensions of the plumping mode, and renders it deserving of experiment. The very best method of using bone-dust in small quantity, both for increasing the fertility of the soil and rearing a good crop, is to sow the seed along with it in drills already manured with farm-yard dung. The bone-lust secures a good and quick braird of the plant, and the dung supports it powerfully afterward. This plan I would 
recommend to be pursued, particularly in England, on the land prepared for turnips in autumn, and were it practiced we need not despair of raising heavy crops of turnips, especially Swedes, on the strongest soils, and most certainly they would be obtained after thorough-draining. On using bonedust, it should be measured from the heaps in the shed in bushels, and put into the bodies of close carts, which should be left at stated distances upon the head-ridge; it being exceedingly inconvenient to take bone-dust out of sacks. A field-worker should take the charge of replenishing the hoppers of the machine as the steward returns with it to the head-ridge at every bout, with a rusky, fig. 315 , filled by the frying-pan shovel, fig. 176 . As bone-dust is apt to heat in heap, and although it is improbable that you will keep bone-dust over the year, it being more profitable to put it into the ground, yet in case you should have any left over, or in case you should purchase a lot cheap out of season, it may be proper to let you know how to keep it in the best state until it is used for turnips or for any other purpose. The mode of keeping it is this: Whenever you get it you should put it on a dry pavement floor, as a damp one rots it fast away. It will heat again, but not so violently as at first after being made, and would heat again every time it is turned, which it should not be. It should not be kept in bags, as it will soon rot them, as I have experienced, nor should it be kept upon or under a wooden floor, as it will rot them both; nor should it be kept near horses and cattle, as they evince a strong dislike to its smell, on feeling which, horses actually become restive and troublesome. If new bone-dust obtained from the mill is desired to be heated at once, which it should be when it is to be kept, the process is much accelerated by the addition of a little sifted coal-ashes or earth, and as much water as will make the whole mass only damp, and turning it over several times until the entire mass is incorporated; and in 48 hours the heat will be so great as that you cannot hold your hand in it. The heat will gradually subside, the mass become dry and in a good state for passing through the sowing-machine. Heating has the effect of increasing the weight of bone-dust from $47 \mathrm{lbs}$. to $49 \mathrm{lbs}$. per bushel, and this increase is no doubt effected by the heating having taken off the angles of the particles, and allowing them to come closer together in the bushel. The color is also changed to blue and yellow, and on examination by the microscope; the mass will be found full of mites.*

(1958.) The established manures for raising turnips are farm-yard dung, street-manure in the neighborhood of towns, and bone-dust. There are many other substances which have been recommended for the same purpose, such as guano, animalized carbon, \&c.; but as they are only of comparatively recent introduction, and cannot be said to have yet established their characters, I shall decline entertaining their pretensions here, and shall rather notice what promise they hold out when I como to mention the subject of making experiments in Agriculture.

Bone-dust.-The specific gravity of bone, as determined by Dr. Thomson, is as follows:

Os femoris of a sheep...........2.0345

Tibia of a sheep................... 0329

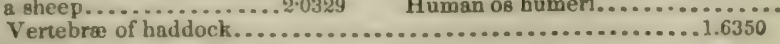

Ilium of an ox................. 1.8353

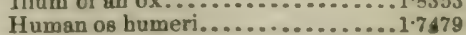

The nature of this remarkable substance, as a manure, demands attention. Bone consists of organic and inorganic matter, and these are found in the following proportion in the bones of those animals which supply the largest quantity for manure, namely, tbe ox and sheep:

* Quarterly Journel of Agriculture, volo xili. 


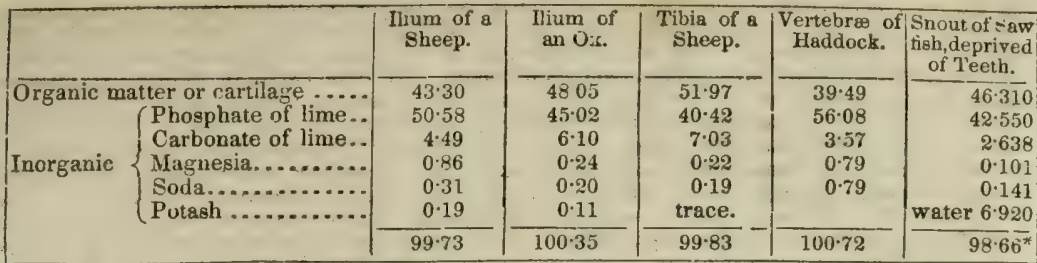

In an analysis made by Dr. Heary $\mathrm{R}$. Madden, to ascertain the relative component parts of bones and farm-yard dung, the following results were obtained, the bone being used in the state it is applied to the soil, and the dung consisting of a proportion of both stable and byre manure :

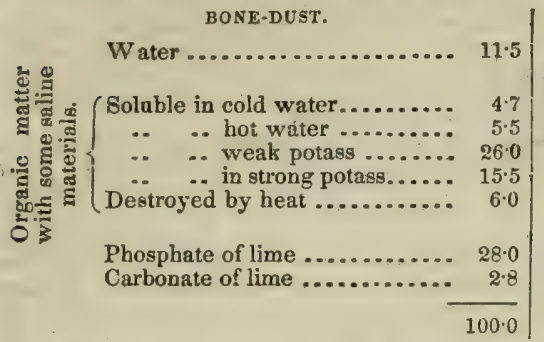

FARM-YARD DUNG.

Water

(Soluble in water ............... 10.750

.. $\quad$.. potass............... 14:250

Destroyed by heat............... 18.565

Salts of potass ................

.. of soda..................

.. of lime..................

$7 \cdot 900$

Silica.................. .6

Earthy phosphates............ 3.000 $100 \cdot 00$

Another analysis gave of azote in bone-dust 1.77 per cent., in farm-yard dung 45 ; so that in this respect these substances stand comparatively thus :

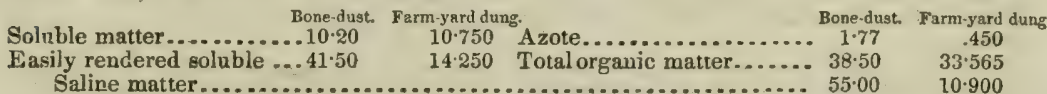

Hence 1 ton bone-dust equals, as regards organic matter...... 1 ton farm-yard dung.

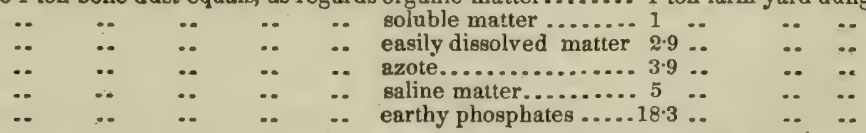

If all the varione degrees in which bone-dust is superior to farm-yard dung be added together, 1 ton of it equals 30 tons of dung, bat as only 16 bushels of bone-dust are applied to the acre, which at 47 lbs. per bushel, weighs 7 cwt., this quantity is equal to $10 \frac{1}{2}$ tons of dung. ${ }^{*}$ It is still a ques. tion, whether the organic or the inorganic portion of bone-manure bestows the greatest benefit on the land, and from its effects extending over more than one crop, some are of opinion, among whom are Liebig and Sprengel, that its principal efficacy is in all cases to be ascribed to the earthy ingredierts, and especially to the phosphate of lime; but it has been brought to light that bones do not lose their organic matter entirely, though they should have been buried for years under ground. Thus the bones of a bear and a stag, after being long buried, were found by Marchand to consist of

\begin{tabular}{|c|c|c|c|}
\hline & \multicolumn{2}{|c|}{ Bones of the bear buried. } & \multirow{2}{*}{$\begin{array}{c}\text { Femur of } \\
\text { a Stag. }\end{array}$} \\
\hline & Deep. & Shailow. & \\
\hline Animal matter................. & $16 \cdot 2$ & $4 \cdot 2$ & $7 \cdot 3$ \\
\hline Phosphate of lime.................... & $56 \cdot 0$ & $62 \cdot 1$ & $54 \cdot 1$ \\
\hline Carbonate of lime............ : ........... & $13 \cdot 1$ & $13 \cdot 3$ & $19 \cdot 3$ \\
\hline Sulphate of lime $\ldots \ldots \ldots \ldots \ldots \ldots \ldots \ldots \ldots \ldots \ldots \ldots$ & $7 \cdot 1$ & $12 \cdot 3$ & $12 \cdot 2$ \\
\hline 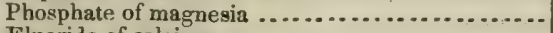 & 0.3 & 0.5 & $2 \cdot 1$ \\
\hline Fluoride of calcium $\ldots \ldots \ldots \ldots \ldots \ldots \ldots \ldots \ldots$ & $2 \cdot 0$ & $2 \cdot 1$ & $2 \cdot 1$ \\
\hline 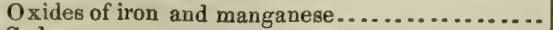 & $2 \cdot 0$ & $2 \cdot 1$ & $2 \cdot 9$ \\
\hline 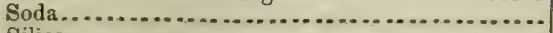 & $1 \cdot 1$ & $1 \cdot 3$ & \\
\hline \multirow[t]{2}{*}{ 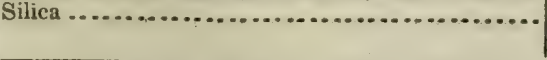 } & $2 \cdot 2$ & $2 \cdot 1$ & \\
\hline & $100^{*}$ & $100^{\circ}$ & $100^{\circ}$ \\
\hline
\end{tabular}

"The most striking change," as Professor Johnston observee, " nndergone by these bones, was the large loss of organic or animal matter they had suffered. The relative proportions of the phosphate and carbonate of lime had been comparatively little altered. The main effect, therefore. produced by bones, when buried at the roots of trees, and their first effect, in all cases, must be owing to the animal matter they contain-the elements of the animal matter, as it decomposes, being absorbed by the roots with which the bones are in contact." Still, it is found that bones, after

* Thomson's Animal Chemistry. † Prize Essays of the Highland and Agricultural Society, vol. xiv.

$(497) \ldots \ldots 17$ 
baving been boiled, and of course deprived of the greater part of their animal matter, make excellent manure; but as they at the same time take up a cousiderable quantity of water, which will cause them to decompose more rapidly when mixed with the soil, they will appear to act as beneficially. Professor Johnston conjectures, as unboiled bones. "He who candidly weighs the considerations above presented, will, I think. conclade," says the Professor, "that the whole eflect of bones cannot in any case be ascribed exclusively either to the one or the other of the prineipal constituests. He will believe, indeed, that in the turmip lusbandry, the organic part performs the most permanent and most immediately useful oflice, but that the earthy part, nevertheless, affords a ready supply of certain inorganic kinds of food. which in mauy soils the plants could not otherwise easi. Iy obtain. He will assign to each constituent its separate and important function, being constrained at the same time to confess that, while in very many cases the earthy part of bones applied alone would fail to benefit the land, there are few caltivated fields in which the organic part opplied alone would not materially promote the growth of most of our artificial crops." "When bones are heated to redness in the open air, the organic part burns away, and leaves the white earthy matter, in the form and nearly of the bulk of the original bone. It is very brittle, and consists chiefly of phosphate of lime, and is sold at the chemical works at 9s. per cwit. Bones of cattle and other animals, and of fisb, except whale-fins, whether burnt or not. or as animal charcoai, pay a duty by the new Tariff of $6 \mathrm{~d}$. per ton. The declared value of bones imported into this country in 1832 was $£ 91,7555 \mathrm{~s}$. $5 \mathrm{~d}$.; and the daty paid thereon was $£ 940 \mathrm{~g}$. 9d.t I sbould suppose there has been a considerable increase in the import since that period. The price of bones at $\mathrm{Hall}$, the great mart of their import, in 1843 , was from $£ 3158$. to $£ 4$ per ton.

(1960.) Turnip-drills, like the other members of the class of implements emplnyed ander the drill-system of cultivation, mark an improved state of the art. for in the early bistory of the turnip culture. we find the broadcast method of sowing generally adopted, and in some paits of England at the present day, where farming is otherwise well understood, we yet see the broadcast system of sowing tarnips not only practiced, but advocated as the most productive. That great aggregate weight of turnip may be produced in broadcast in particular soils and seasons. may be true, bat doubtless a greater certainty of snccess is to be obtained from the drill practice : and it appears now, from the latest English authorities, that the former practice will soon be rooted out by the unflinching hand of experience. In the early stages of the drill practice of turnip culture, the breadth of land sown being but small, a single row band-drill or barrow seens to bave been generally used, but a simpler implement than even this has been employed-the hand ftask sower. As the practice exteuded, machines of two rows were introduced, drawn by one borse, and this in various forms continues to be the chief instrument employed in sowing the seed of this important rool

(1961.j The varieties of the turnip-drill are too numerous to be detailed here in full, nor would it be protitable to follow all the fancies of machine makers. eome of which have produced but cam. brous and inconvenient vehicles, which, when their purpose is considered. are cunabrous not only in their bulk, but in the multiplicity of their parts, and hence are complicated and tender, liable to derangement and failure, and are marked by an absence of that simplicity of construction so desirable in agricultural mechanics. In many of our more modern turnip-drills, however, there is to be seen a marked simplicity of construction, that accords well with the objects in view, and this holds especially with those machines which are employed for sowing the seed alone : and in none more so than the machine wow very generally known as the East Lothian drill. which I shall have occasion more particularly to notice. The recent introduction of numerous granulated maunres has called forth a new class of mrehines, whose object is to deposit the manure along with the seed either in immediate contact, or in close contiguity, and these compound machines liave again invalved a degree of complexity of construction; for whenever a nachine is required to perform compound functions, a necessarily increased complication of structure is entailed upon it to a greater or less extent, proportionate, perhays, to the mechanicai talents of the fabricator. An ad. ditional cause of complication in the compound drills has arisen within the last few years, from a desire to economize the distribution of the modern expensive manures, by depositing small portions of it at the points only where the future root is intended to grow, leaviag the intervals desti. iute of manare. The propriety of thus dealing so niggardly with the soil in withholding those Eubstances in abundance by which it is enabled to continue its fertility, is at least questionable ; but the experiment has effected what I am at present endeavoring to establish-the farther comf.lication of structure in the machines employed. The drill-suwing machines adapted to this purpose are designated in Scotland plumpers, from their dropping their gifts on one point. In England they are better known by the name of dibbling machines, or drop.drills.

Lof tarnip and other drills and complicated machinery used in England, they have either been excluded from use in this conutry on account of their cost and complexity, or they have been great. ly simplified if not improved. The agricultural warehouses everywhere abound in drills of various forms adapted to various purposes.

Although the cheapness of Indian corn and the dryneas of our climate will prevent the general introduction of turnip husbandry on a large scale in this country, the dearness of labor adding another objection, we are strongly persuaded that through all the mountainous ranges of the Southern States, where morning fogs prevails through the summer so favorable to the grasses, they might profitably cultivate the Swedish turnip, to be employed in feeding their cattle, intended to be fattcd on grass the next summer. Turuip crops and sheds for sheltering and feeding their cattle in

* Johnston's Lectures on Aericultural Chemistry.

† McCulloch's Dictionary of Commerce, art. Boncs.

I Journal of the Royal English Agricultural Society, rol. iv. 
winter, would, we think, on trial be found a great improvement on their present system. The extent of the country referred to, the value of its industry, and our partiality for that branch of hos. bandry, and some of those who pursue it, induce us to give what otherwise might have been omitted with prejudice to the mass of American farmers.

Ed. Farm. Lib.]

\title{
22. REPAIRING THE FENCES OF GRASS-FIELDS, AND THE
}

\section{PROPER CONSTRUCTION OF FIELD-GATES.}

\author{
"At neglected gaps \\ Burst scrambling through, and widen every breach. \\ A stake put timely in, or whinny bush. \\ Until the season come when living plants \\ May fill the vacant space, much harm prevents." \\ Grahair.
}

(1962.) The season being almost arrived when the grass is able to support stock, and of course, when the cattle are permitted to leave their winter quarters in the steading, it is necessary to ascertain, in the first place, whether the fences of the grass-fields are in such a state of repair as will offer no temptation to stock to scramble through neglected gaps, much to the injury not only of the fence, but perhaps of themselves, or at least much to their disquietude; and in the next place, to watch the period when the grass is in a fit state to receive them. Sometimes a good deal of work is re. quired to put grass-fields in a proper state for the reception of stock, owing principally to the nature of the soil, and partly to the state of the weather. On every kind of land the small stones lying on its surface should be gathered by the field-workers and carted off for the use of drains, or be broken into metal for roads. It may happen that the throng of other work may prevent the assistance of horses and carts being given for this purpose, in which case the stones should be gathered together in small heaps on the furrow-brow of every other single ridge; but in doing this, it should be remembered that these heaps occupy so much of the ground, and, of course, prevent the growth of so much grass, that, on this account, it is a much better practice to cart them away at once if practicable. When carts are used the stones are thrown directly into them; whereas in making heaps, the stones require some care to be put together, and, of course, waste time, and they have to be removed after all. Some farmers are regardless of gathering the stones from any of their fields, even from grassfields which are to be in pasture; while all acknowledge that fields of grass which are to be made into hay ought to be cleared of stones to save the scythes at hay-time. On clay soils there are very few, or perhaps no stones to clear off, and in wet weather no cart should be allowed to go on new grass. As every field, whether of new or of old grass, should be rolled some time before the stock enter them, it is clear that the ground cannot receive all the benefits of rolling as long as stones are allowed to remain on its surface. The best time for rolling is when the surface is $d r y$ - mark you, not when hard and dry-for when grass, especially young grass, is rolled in a wet state, it is very apt to become bruised and blackened. When dry, grass is elastic and able to bear the pressure of the roller without injury. Light land will bear rolling at any time when the surface is dry; but plants are very liable to be bruised by the roller against the hard clods of clay land, and in a soft state, on the other hand, clay $1-\mathcal{A}$ 
is apt to become hardened or encrusted hy rolling. The rolling of heavy land is thus a ticklish matter; hut a good criterion to judge of its being in a fit state for the roller, is when clods crumble down easily with the pressure of the foot, and not press flat, or enter whole into the soil. 'The rolling is always given across the ridges. The stones should be gathered, and the land rolled at least a fortnight before the stock are put on grass, to allow the grass time to grow after these operations, when it will be found to grow rapidly, if the weather is at all favorable.

(1963.) Besides the fences, the gates of grass-fields require inspection and repairs, so as they may be put in a useable state for the season. When any of the timbers, posts, or bars, are broken or wanting, or the fastenings loose, the carpenter or smith should be made to repair them; and the posts on which the gates hang should be made firm in the ground when luose, or renewed when decayed. In putting up new gate-posts, the firmest mode I have found, is to dig as narrow a hole as practicalle 3 feet deep for the hanging-post, and then to ram the earth, by little and little, firmly around the post without any stones. Charring or pitching the part under ground is a pretty good prevention from rot for some time. The simplest mode I have seen of fastening field-gates is with a small chain attached to the fore stile of the gate, to link on to a hook on the receivingpost. The most convenient position for field-gates is at the ends of head. ridges, which may be regarded as the roads of fields. Field-gates should be made to fold back upon a fence; to open beyond the square; and not to shut of themselves. When they shut of themselves, and are not properly set when opened, and which requires greater care than is usually bestowed on these matters, they are apt to catch a wheel of the cart which is passing, and, of course, to be shivered to atoms, or the post to be snapped asunder; and more than this, self-shutting gates are apt to be left unfastened by most people who pass through them, and are therefore unavailing as a fence to stock, especially to horses when idle, which seem to take delight to loiter about gates, and they not unfrequently find out the mode of opening them. One reason, perhaps, for horses loitering about the gates is to rub themselves, to prevent which, thorns are wattled into the bars: but independent of this casual safety, every pasture-field should be provided with one good rubbing-post at least, standing 6 feet in hight. The proper construction of field-gates is generally very little attended to, if one may judge by those usually to be seen in the country. Some judicious remarks by Mr. Slight, with appropriate figures, in reference to this much neglected subject, will be futund below, and which I hope will tend to the diffusion of an improved form in this necessary portion of farm furniture.

(1964.) The importance of field-gates, whether viewed as the means of security to crops and live stock, or as a portion of the peri hable stock in trade of the farm, is an object deserving of grave consideration. Hitherto, it may safely be averred that very little attention has been paid to principle in the construction of tield-gates : and for the truth of this, we have only to lonk around us, where the eye of the construetive student will detect probably not more than one in a hundred of our field gates that are not glaringly defective as pieces of extremely simple constructive carpentry. Defects in point of eonstruction are not even confined to the field gate : we find them in many of those gates of much higher yretensions, and where the hand of a master having been at work, we might be led to expect something like an approach to the true and simple principle: yot how seldom does the eye, experienced in directing those geometrical and dynamial principles, on which alone a just and permanent system of construction depends, light upon a form that satisfies its discriminating glance. We do, indeed, occosionally meet with examples wherein is evinced a correct knowledge of those arrangements of the parts, in a rectangular frame, whether of wood or iron, that at once secures permanency of form, and stability in the entire structure. In such cases we are sure to find that the proprietor possesses not only an educated mind, but one that has not disiained to atoop to the drudgery of acquiring a competent knowledge of prantical mechanics, leading him also to see the advantage of securing the assistance of mechanics whose education qualifies them to perform their duties in accordance with the laws of that science. It may seem trivial to apply remarks of this kind to such a simple matter as the construction of a field-gate; but assuredly there is no part of our agricultural economy that points out so broadly the $(500)$ 
imnorance of our arisans in those important branches of their education, the elementary truths of Geometry and Mechauics.

(1965.) A gate, generally speakiug, may be described as a rectangular frame; there are excep. tions to this definition applicable to gates as a whole, but to field-gates there are none. A gate, to be permanent, should le immutable or unchangeable in its form; a simple rectangular frame without upfillings, if they are placed at right angles to each other, is the most liable to change of any connected structure of frame-work. The triangle, on the other hand, is the most immutable or least liable to change ; it is, in short, so long as the materials remaiu unchanged, perfectly immu. table. but a gate in a form of a triaugle would, in most cases, be very unserviceable, though a combination of triangles may produce the requisite igure for a serviceable gate. If then we take the rectangular frame so essential to a field-gate, and apply a bar in the position of the diagonal of the parallelogram. we immediately convert the original rectangular figure into two triangles, applied to each other by their hypothenuse, and this gives us the true eleuents of a properly constructed gate, all the other parts being subordinate to these, and adapted solely to the practical purposes of the gate as a defence or for ornament. In many cases depending upon the material employed, an opposite diagonal may be applied. dividing the gate into four triangles; but, in general, this is only uecessary where flexible rods of iron are applied as the diagouals.

(1966.) In looking at the construction generally of tield-gates, we observe traces of an incipient knowledge of the usefulness of a diagonal bar, but in very many cases it is applied with that uncertainty of purpose that marks a doubtful and hesitating knowledge of the subject; we see it, in short, applied in all the possible positions that may be conceived to deviate from the one, true, and simple position-extending from an angle to its opposite-which is the simple and universal rule applicable to gates. Let it, then, be borne in mind that the essentials of a tield-gate, whether of wood or iron, are a rectangular frame.consisting of the heel and head-posts, and a top and bottom bar or rail, which four parts. properly connected at the angles, are rendered of an unchangeable figure, by the application of one or more diagonal bars, and these diagonals should in no case be applied short of the whole length between any two of the opposite angles. The upfilling, whether of rails or otherwise, as may be desired to attain any particular object, are mere accessories, and not in any way tending to the stability or durability of the fabric.

(1967.) The choice of the material for the diagonal is of some importance, and here the maxim of universal application in mechanical construction: "Tie with iron and strut with wood," is es. pecially applicable. The field-gates constructed entirely of wood, the diagonal should invariably be applied as a strut; that is to say, it should rise from the foot of the heel-post. and terminate at the top of the head-post. Placed in this position, the diagonal supports the head or swinging end of the gate, by its resistance to compression, a duty which, from the area of its cross section being considerable, and hence capable of resisting lateral flexure, it is well adapted to perform; while. at the same time, the above sectional property gives it a broad terminal resistance, where it abuts upon the angles of the external frame. The same diagonal bar, if applied in the opposite position, and performing a duty of a tie or stay, its great sectional area would avail but little, for, though woody fibre is capable of resisting very considerable tension, larch.wood having, with equal sectional areas, a power of resistance to tension equal to about $\frac{1}{4}$ that of malleable iron of medium quality: and though this wooden tie might be found to possess in its aggregate section a cohesive force greatly beyond that of an iron bar applied in the same position, for the wooden bar would have a sectional area at least twelve times greater than could be requisite for an iron tie, thus yielding an aggregate force double of the iron; yet as the wooden tie must depend for its connection in the structure, upon nails or bolts only, its ultimate power of resistance to tension depends not on its own sectional area, but on that of the nails or bolts by which it is fastened, and these again, may be very greatly reduced by the rending of the extremities of the wooden tie.

(1968.) The advantages of iron as a tie, and its disadvautages as a strut, are just the converse of the foregoing. From the smallness of sectional area requisite in an iron bar applied in this construction, as compared with its length. it is not capable of withstanding compression even to the smallest extent without suffering lateral flexure, aud this defect unfits it entirely for the purpose of a strut. Applied as a tie the iron bar is perfect; the cohesion is such that a very small sectional area is sufficient for the purpose under consideration; thus, a rod of $\frac{1}{2}$ inch square even of inferior iron will bear a tension, with safety, of two or three tons, while the best quality will bear six tons; a rod of half this sectional area may, therefore. be leld as sufficient for the diagonal tie of a gate, and as it can be fixed by bolts without risk of fracturing its ends, as in the case of wood, its application in principle becomes as perfect as it is possible to approach. But though this construction is in principle completely supported by the tie from any force tending to depress the head-post of the gate, there is yet a defect in practice: for a gate is liable, from various causes, to be forced upward at the head-post. We have seen that a slender and flexible iron rod cannot resist compression without flexure, and, therefore, a gate with only one iron diagonal tie will still be practically imperfect, and it becomes necessary to apply an antagonist placed in the position of a strut, but virtually performing the duties of a tie arising from the antagonist effects of the two, the tendency of the one being to hold the head of the gate up, while the other exerts an equal force to keep it down, whereby a perfect equilibrium is preserved within the structure.

(1969.) In treating of the practical construction of field-gates, it is, perhaps, unnecessary to $\mathrm{d}$ well upon the strains that occur in the individual horizontal bars, because, if the principles inculcated above are attended to, all cross strains in the principal joinings are avoided; and, except when any extraneous force is applied, the strains are resolved by construction into those of direct compression or of tension. Thus, in fig. 352 , which may represent the elements of a fly-gate. applicable to a drive or thoroughfare, and opening either way; if we take the heel-post $a b$ and the bar $a c$ alone, and hinged in any manner at $a$ and $b$; and if the bar $a c$ is 10 feet long, the breadth of the heel-post at $a 5$ inches, and the parts being joined by mortise and tenon : suppose, then, $a$ load applied to the bar at $c$, the mechanical effect of the load would be a cross strain at $h$, tending to break the bar directly across with a force equal to 24 times the load, exclusive of the effect of 
the bar itself, the bar $a c$ forming here a lever of the first order, whose arm $h c$ is to the arm $h a$, or the breadth of the beel-post, as 24 to 1. By increasing the number of bars we do not alter the

Fig. 352

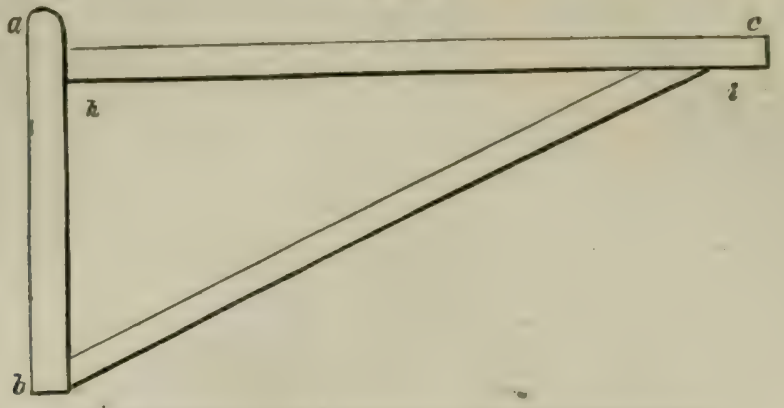

THE ELEMENTS OF THE TRUSS IN A WOODEN FIELD-GATE.

total effect of the load, but simply divide it equally over the superinduced bars, supposing them to be connected with a bead-post at $i$. But reverting again to the single bar $a c$, and applying to it the diagonal $b c$, we have now the triangular figure $a b c$, the parts of which being firmly connected at their points of junction, the form becomes unchangeable, and the effect of the load at $c$ is instantly altered. The effect of the load at $c$ is now recolvable by the parallelogram of forces into two others, the one of tension on the bar $a c$, the other of compression on the diagonal $b c$, and taking the length $a b$ as a representative of the gravitating or direct effect of that load. then the tersion on $a c$ will be to the absolute load as the length of $a b$ is to that of $a c$, and the compression on the diagonal will be as $b c$ to $b a$. In this example the hinges of the gate are not shown, but in actual practice the tails of the upper hinge stretch along part of the top bar, binding it securely to the heel-post, while the buttom hinge may be made to form an abutment to the foot of the diagonal.

(1970.) The practical insertion of the diagonal is also of some importance. Fig. 353 exhibits one mode of performing this, where $a b$ is the strut half lapped upon the heel-post at bottom and apon the head-post at top; it is not an elegant mode of insertion, but it is efficient, in so far that while it acts as a strut, it binds the top of the luead-post to the top-bar, and prevents it from flying off by the thrust of the diagonal.

(1971.) Fig. 354 exhibits another mode of insertion of the diagonal, which is perhaps preferable to the former; here the head of the diagonal is attached to the top bar, half lapped upon it at $b$, and notched into the lower edge as an abutment, forming a very efficient strut, the tension strain being brought entirely upon the top-rail, which is always securely tied to the heel-post by the tails of the hinges at $c$. These examples are applicable to field-gates where the bars are always much thinner than the heel and head-posts, the latter being generally about $2 \frac{1}{2}$ to 3 inches thick, and the former only $1 \frac{1}{2}$ inches. In such cases the diagonal is slightly notched upon all the bars, and deeper upon the heel and head-posts, where the method fig. 353 , is adopted; but in no case should the bars be notched except in the edge of the top bar, where it receives the head of the diagonal.

(1972.) I have hitherto alluded only to the simplest efficient form of wooden field-gates, in the construction of wbich cheapness is al. ways an object, and I have, in order to avoid confusion of ideas, restricted the description to the essential parts, the number of bars, or other means of rendering the gate a sufficient fence, is left to be filled up at discretion. In making these upfillings the maker should studiously keep in mind that no curved bars

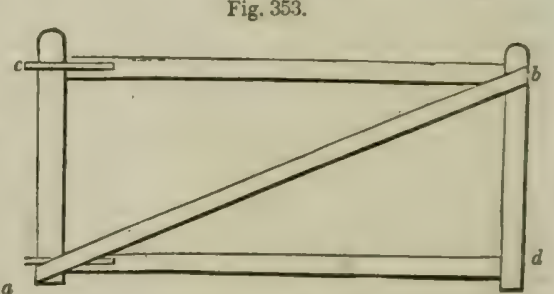

Fig. 354.

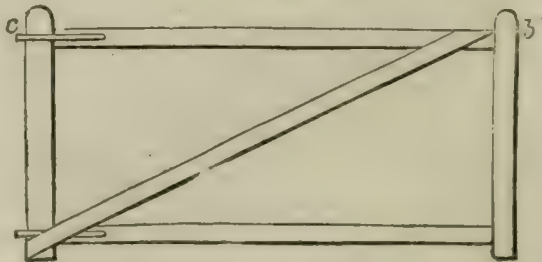

EXAMPLES OF THE APPLICATION OF THE DIAGONAL or timbers, of any descriptiou, should enter into the construction, either for omament or ostensibly for use.

(1973.) In the constraction of wooden gates for drives or approaches, where utility is still the chief object, strict attention should still be paid to the principles of construction, but a little more lati. tude may be admissible in point of finish and expense. For such purposes, the rails and posts of the gate should be all of one.thickness, or at most, the only difference should be a gradual diminution in thickness toward the head, to lessen the effect of gravity on the hinges and gate. post; and for pleasant effect, there should not be more than three horizontal rails, with two diag. $(502)$ 
onals; and if it is necessary to bave a closer upfilling, it should be of an upright light balustrade form. Fig. 355 is an example of this form of gate, which I adopted 26 years ago, and the ori.

Fig. 355.

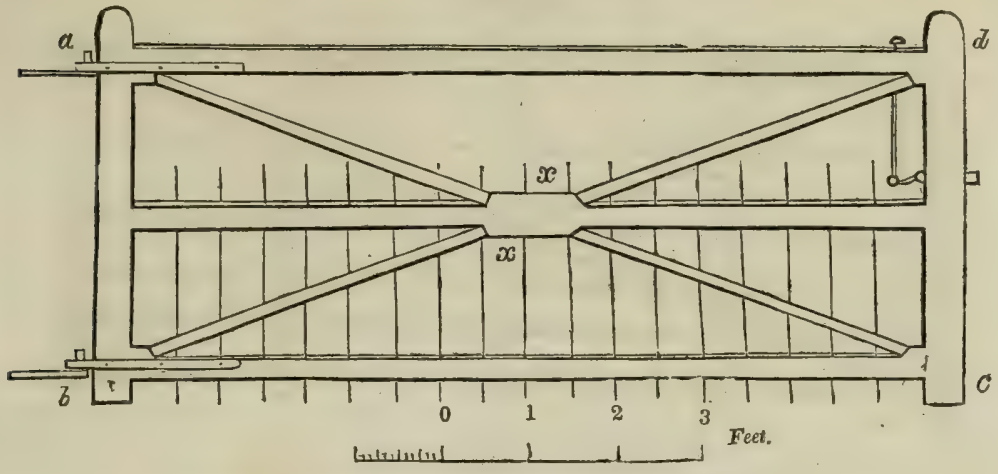

WOODEN GATE SUITED FOR THE APPROACH TO A VILLA.

ginals then constructed are still good and serviceable, but it is considerably more expensive than the common field-gate. The heel-post $a b$ is 5 inches broad and 3 inches thick, while the headpost $c d$ may be reduced to $2 \frac{1}{4}$ inches if thought advisable. The top and bottom bars are formed with abutment pieces at both ends, which are 5 inches broad, the intermediate parts being re. duced to $3 \frac{1}{2}$ inches; the middle bar has the same breadth, but is made up in the middle with corresponding abutments, and the two diagonals, of 2 inches in breadth, are inserted in four pieces, exactly fitted between the abutments of the bars. The hinges are of the common double-tailed form, binding the top and bottom rails firmly to the heel-post, and the gate may be hung upon pillars of stone, or of wood well secured. The best balustrade for a gate of this kind is rods of iron $\frac{1}{2}$ inch diameter, as in the figure, passed up through the bottom and middle bars and the diagonale, the holes for these being easily bored with an auger after the gate is formed; but a simple and cheaper balustrade is formed of light wooden spars sunk into the bars and diagonals.

(1974.) For all wooden gates, the method of bracing with light iron diagonals is to be preferred to wooden struts, but to be effective two diagonals must always be applied. In some cases, they may pass from one angle to its opposite in one length, but in others it is necessary to apply them in four pieces, the connection at the center of the gate being effected either by a ring of iron, in which the four ends are screwed, or by bolting the palmated ends of the four parts, two and two together, through the middle bar, as applied at $x x$ fig. 355 , one bolt securing the four ends, and in either case the rods pass through the top and bottom of the heel and head-posts of the gate, and are there secured by serew-nuts. It is obvious that iron diagonals would apply in this manner to the gate, fig. 355 , instead of wooden braces.

(1975.) Field-gates of wood, from the cheapness with which they may be furnished when imperfectly constructed, have been long in use, and in many localities continue to be more exten. sively used than any other; but malleable iron is gradually taking the place of wood, and, from its greater durability, may be expected to supersede wood entirely. In the construction of malleable iron gates, we as fiequently find malformations as in those of wood, such as placing all the bars on edge except the heel and head-post, misplacing the diagonal, if single, and not unfrequently applying bars variously formed in curves and fanciful figures, to serve the purpose of the diagonals. The field-gate maker should be instructed to hold steadily in view that there is but one position and form for that member of the structure that can be fully efficient, and these are, the straight bar extending from the upper angle at the heel to its opposite angle at the head-post, and, if the materials of the gate are light, to apply an antagonist diagonal crossing the first. 'In framing the gate, also, the top and bottom bars should be set flat-ways, to enable the structure to resist lateral strain from animals rubbing or pushing against it.

(1976.) One of the latest improvements in iron field-gates is the introduction of angle.iron, now so extensively used in boiler-making, ship-building and other porposes. In the application of the angle-iron to the construction of gates, the fabric acquires the rigidity of a massive wooden gate, with all the tenacity and strength of the iron, while its weight is little more than that of wood. Fig. 356 is a form of gate of this construction, which I have lately adopted, with some alteration, from a design of Mr. William Danlop, Edinburgh, and is manufactured by James Slight \& Co., Edinburgh. The external form is composed of four bars of angle-iron, measuring $1 \frac{1}{3}$ inches on each side, and to give security to the joinings at the four angles of the truss, the ends of the hars are riveted upon cast-iron corner-plates, those of the heel-post $a b$ being formed with strong projecting pivots, by which the gate is hinged. Any number of interior bars may be ap. plied to suit the objects of the gate. The figure exhibits the arrangement adapted to retain sheep and lambs. The diagonal $b d$ is contrary to the general rule, for it is apparently a strut, but being a bar of angle-iron, of the same breadth as before, it possesses the stiffness of wood. to resist lateral strains-and is hence properly adapted for a strut; to render the bracing complete, the antagonist diagonal $a c$ is applied, and this, acting as a tie, is only a flat bar 1 inch by $\frac{1}{8}$ inch. The external frame is thus reudered anchangeable in figure by any force that may be applied to the 
head.post in a vertical direction, either upward or downwnrd, short of what will fracture the gate and the point $e$. where the diagonals cross each other at the center of the gate, becomes also immovable in the plawe of the truss; hence the perpendicular bar $f$ e $g$, being riveted to the

Fig 356.

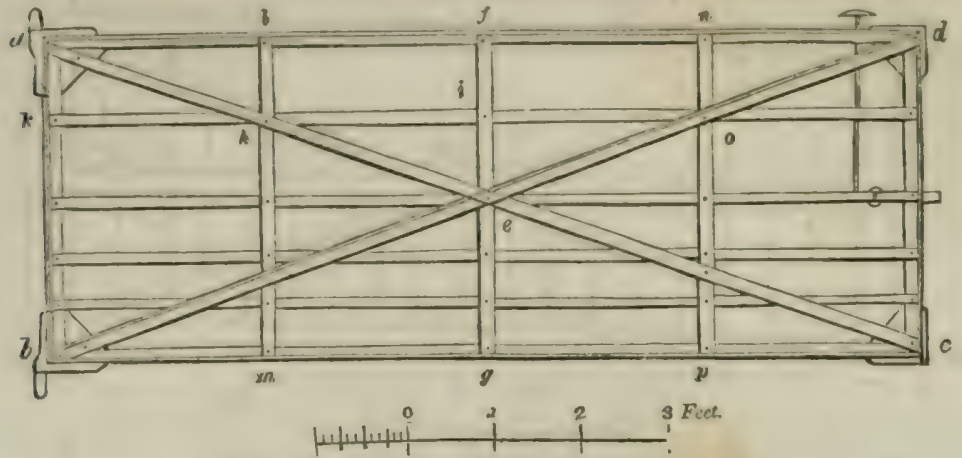

THF. FIELD-GATE WITH ANGLE-IRON FRAME-WORK.

diagonal at $e$, acquires the same property, and by attaching all the horizontal bare to $f e g$ at their several crossings, each of them is rendered permanent in its position at that point, and no force short of breaking down the gate can bend any of the parts upward or dowuward in the direction of the bar $f e g$, so long as this last remains attached to the crossing of the diagonals at $e$. In order to give further support to the horizontal bars by the principle of construction, we have only to take a point where a diagonal crosses a bar, as at $h$, forming the opposite triangles $e h i$ and $a h k$, which, when the bar and diagonal have been connected, become also immutable, and the perpendicular bar $l h \mathrm{~m}$ being secured to the point $h$, and again to the differeat bars at their in. lersection with $l h \mathrm{~m}$, the whole are again rendered immovable as in the middle. The support given to the horizontal bars in the line $l h \mathrm{~m}$. would have been atill more complete if there had been only one intermediate bar below the middle one, as the three parts would then have met in oue point, as they do at $h_{*}$ but two bars are introduced to render the gate fencible for sheep of all ages. The perpendicular bar $n$ o $p$ is applied on the same principle as laid down for $l h m$, the point of support in this case being 0 .

(1977.) In this construction of gates, the greatest possible amount of mutual support among the parts is obtained with a given quantity of materials; hence gates of this construction may be made lighter than any other form where iron is the material employed, and yet bave a greater amount of strength. In this example, the dimensions of the angle-iron are $1 \frac{1}{3}$ inches each way, and about $f$ inch thick; sll the other parts are $1 f$ inches broad by $\frac{1}{8}$ inch thick, the cast-iron corner plates being, of course, stouter, and the eutire weight of the gate is $112 \mathrm{lbs}$. It may be of use to those who make iron gates, but who have not taken time to study the firat priuciples of their construction, to notiee this farther remark. Any number whatever of additional upright bars to those shown in fig. 356 would add strength or support to the horizontal bars only on the principle of superposition, or adding bar to bar, without the advantages which arise from the principle of anchangeableness in the triangle when applied in the construction of frame-work, whether in a sim. ple field-gate, or in the highest branches of constructive carpentry in wood or in iron. In the one case, the stress on the parts continue to act at right angles to the bars, the direction in which they are weakest, while in the other-the principle of throwing the frame into triangles-the whole stress is thrown upon one or more parts in the dircetion of their length, in which position all bars and beams are sirungest.

(1978.) Au example of an ingenious construction of iron gate is given in Parnell's work on RoadMaking, which has been improved npon by Mr. Buist, now of Bombay, and doscribed in the Prize Essny of the Highland and A gricultural Society. These gates consist of a wrought.iron external frame, which is supported by a very perfect system of bracing, with diagonal ties of iron wire, and filled up in a variety of forms with the anme material. Fig. 357 represents Mr. Buist's gate with the fundamental braces and ties, which he thus describes: "The framing a $b c d$ is fasbioned like that of an ordinary gate; $e f, g h$, and $k l$ are three light alips of iron parallel to the ends of the gate, and riveted to the upper and lower rails; $a p b$ is a wire about the thickness of a goose-quill, fastened by a rivet at one end, and a nerew and nut at the other; it passes through holes in the slipe $e f$. $k h$, and $k l$, and serves na a brace to support the bar $a b$. In the same manner $d p c$ serves as a brace to $d c$, while the iwo sides of the gate being conpled together by the slips $e f, g h$, and $k l$, the lower and upper rails have severally the benefit of both braces. The diagonals $a c$ and $d b$ keep the frame in shape, while $a s d$ and $b t c$ are braces to $a d$ and $b c$. by means of the light bar $m n$. It will be meen that all the wires and straps which act as fills-up. are either braces or supports, so that nothing can be more stiff than the gate thus completed. It weighs about $80 \mathrm{lbs}$., and costs $£ 18 \mathrm{~s}$. Its dimensions are 9 feet by $3 \frac{1}{3}$ feet, but may be made of any size, the price varying in proportion. It mas be observed that a gate with one bolt, when shut suddenly, vibrates for some time at the fore-foot; this is obviated by two bolts conpled together, as in the figure, near $b$ and $c$, and acting simultaneously. It is also convenient for gates opening into policy grounds, getting bolted when thrown back by means of a short atump driven into the ground, with catch at the bight of the lower bolt $c . "$ 
(1979.) Fig. 358 represents a gate of this construction filled up with wires in the form of ravs from a center. "The horizontal bar $m n$, and the braces $a s d$, and $b t c$, of fig. 357 ate here omit. ted as supertious. The rays consist of wires of the same thickness as before, and about 9 inches

Fig. 357.

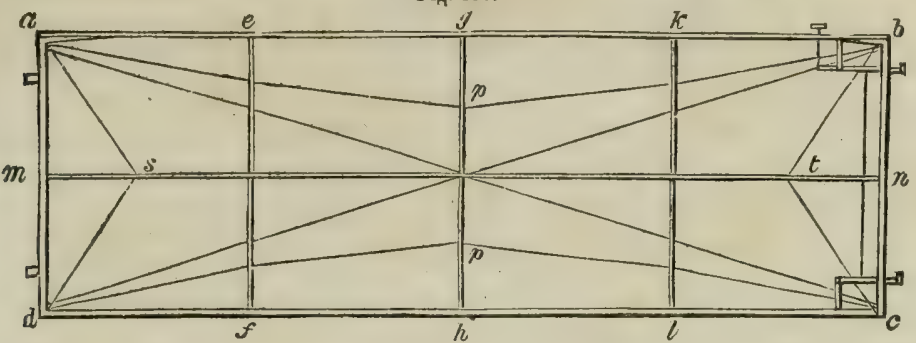

THE ELEMENTS OF THE BRACING OF A WIRE FIELD-GATE.

from each other. Their lower extremities are upset as nail-heads or rivets, and their upper ends are fastened with a nut and screw. For the admission of the screws a strong iron arch is placed in the corner of the gate, and fastened at each end with screw-nuts; its range down the heel-post

Fig. 358.

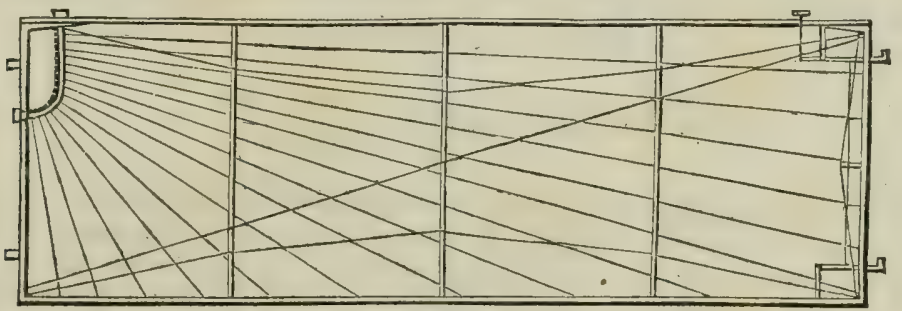

THE WIRE FIELD-GATE WITH RAYED UPFILLINGS,

as compared with that along the upper rail, should be as the length of the gate is to its hight, which in this example, is 18 inches down the heel-post, and 6 inches along the upper rail. A gate of this form, and 9 feet by $3 \frac{1}{2}$ feet, costs $£ 115 \mathrm{~s}$."*

(1980.) The wire-gates above described are admirable examples of the principles of trussed frames, and for gates. So far as that principle gives them firmness and support, they can hardly be excelled; but there is one defect attendant apon the wire upfilling. its too great tenuity, which renders the wires liable to derangement on being loaded with any cross-strain, such as a person attempting to climb over the gate, and setting foot on the wires. A diagonal wire undergoing guch treatment will be liable to stretch, and thereby lose its effect. Could such accidents be effectually guarded against, these gates might be regarded as almost perfect. In regard to the expense of the gates first described, the common wooden field-gates may be considered to range from $15 \mathrm{~s}$. to $25 \mathrm{~s}$. The gate, fig. 355 , about $£ 115 \mathrm{~s}$; and the selling price of the angle-iron-gate, fig. 356 , is about $£ 15$ s.

(1981.) Gate-pillars and fastenings.-For field-gates where hedges form the inclosures, the simplest kind of gate-posts are those of larch or common Scots fir. They may be set in their natural state, or peeled or dressed in any form to the taste and means of the farmer; but in whatever form the body of the post may be, the top should be cut off either in form of a cone or pyramid, or a hemisphere, to prevent the lodgment of water on it. The simplest means of fastening wooden gate-posts is by beating or pinning in the earth around them as described (1963), but the most effectual and permanent mode is to form a pit of at least $2 \frac{1}{2}$ feet square, and of the same depth, and the post being set in it, the pit is filled up with rubble masonry in mortar packed firmly, and grouted round the post. This an expensive mode, but is more permanent, and a greater durability of the timber is effected by contact with the lime.

(1982.) In the Isle of Man, though its agriculturists cannot boast more than ourselves of the perfection of their gates, Nature has supplied them with an admirable material for gate-posts. The transition-slate with which the island abounds is found in one locality, Spanish-head, of a nature that serves all the purposes of beams and planks of wood, and of this many, indeed, most of the gate-posts are formed. In Scotland we have now in abundance a material equally suitable for the same purpose, in the Caithness pavement, which is now applied for gate-pillars, and for which no material can surpass it. They are built into the ground in the same manner as wooden posts, and look very much like a plank of wood, but possessing strength, and especially durability, far beyond wood. The crook-hinges are either fixed into them by passing through them as bolts through a jumper-hole, or they may be put in the form of a hoop, and secured with wedges. For

* Prize Essays of the Highland and Agricultural Society, vol. xiv. 
feld-gateg built pillars of stone are seldom used, and only when the inclosures are formed of stonedykes, and these forms are so various. that it is out of place to describe them here.

(1983.) The kanging of gates has already been sliebtly adverted to: the crook and band hinges are those chiefly employed, and of them it is only necessary to say that the hine should be always donble-tailed. The fastenings of gates are stils more various, and many of them so simple and etfi. cient that it were difficult to point out which is the superior.-J. S.]

(1984.) While treating of fences and iron gates, I may mention a simple plan by which grasslawns or the small plats asnally formed in froot of farm-honses, may be kept short without the use of scythes, or incarring mach trouble and expense. Let a baght be made of wire hurdles of the form of the gate fig. $35 \%$ : and. that it may be movable. let the hurdles be fixer together. If the plat is very small, one inclosure composed of 4 bardles, forming a square of 9 feet, will suffice : if it is larger. any number of such bughts may be be employed. The use of these inclosures is to fence 1 or 2 sheep within each. so that when they have eaten down the inclosed grass, the baghts may be moved forward, or backward, or sideways to a fresh division of grass, until the whole grass.plat is eaten bare. The sbeep may then be removed for a time till the grass grows, and again brought back. Or, since such bnghts would be rather ornamental as otherwise. only as many sbeep may be inclosed wilhin them as will just suffice to keep the grass in good order, and where they may constantly grace the lawn. A few Leicester taps or tup-lambs may thos be kept separate all the summer from the rest of the flock, and be pretty objects on the lawn, while, at the same time, they may be doing good in keeping the grass in order, and top-dressing it.

\section{THE WEANIYg OF CALVES, OF BLLLS, AND THE GRAZING} OF CATTLE TILL WINTER.

"Dissolred in pleasure, crowned with buds of May,
They. for a tione, in their fat pastures play." FLABEL

(1985.) The cattle which were accommodated in their respective places in the steading at the beginning of winter, continue to be treated through the spring months in the same manner as is pointed out in the $32 \mathrm{~d}$ section, p. 495 of the first volume. In fact, their treatment is throughout the same until turned out to grass, which is usually some time in May; unless variety of food may be regarded as difference of treatment. It is found that cattle in a state of confinement in a steading, thrive better on a variety than on the same food; and yet when on grass they require no variety of food, and thrive the better the longer they are kept upon it, except that a change of pasture is desirable when it becomes bare. Grass is thus evidently the natural food of the ox, and his anatomical structure is peculiarly suited for it. Whaterer kind of food he is supplied with in winter partakes of an artificial character, and that being only a succedaneum for grass when it cannot be obtained, the food he receives should be made as palatable to him as circumstances will allow, whether by variety or in in superior quality.

(19S6.) The grass should be ready to afford a bite for cattle whenever the turnips are all exhausted; at which time the cattle will be found to be in this state: The 2-year-olds, now 3-year-olds, will be full fat, and ready to be disposed of to the butcher or dealer. The 1-year-olds and calves will have grown much to hone, and their condition will have improved in proportion to the quantity of nourishing food they have received during the feeding season. The cows will all have calved, or should all inare calved, for a May calf is too late to bring up and form a part of the herd; they will be in milk, and in fresh condition to put to grass. The early calves will hare just been weaned, and in excellent order to put on grass; and the remainder will be in rapid progress toward weaning. These cattle, in their respective states, are treated in summer in a different manner from each other, and different from the way they were treated in winter, and they are treated thus. 
(1987.) The fat cattle are seldom put on grass, being disposed of to the butcher or dealer, either at home or in markets held for the purpose. Breeders of their own stock seldom dispose of their fat cattle until the turnips are nearly consumed, being anxious to keep them as long as possible for the sake of the excellent manure which the turnips afford. Those who purchase oxen to fatten usually buy a larger lot than can be maintained on full turnips till the grass is ready, in order to dispose of them before the season arrives when fat oxen are usually sold. Such fatteners of cattle dispose of their lots in whole, or in part, from the end of the year to April, whenever the market offers them the most profit. As you are supposed to breed and feed your own stock, you are supposed to retain your fat oxen to the end of May, when Swedish turnips are still fresh, sweet and nutritious, though perhaps a little shriveled and even sprouted. There are then plenty of opportunities to dispose of them, such as the weekly markets of large towns, fairs for fat stock, butchers from the neighboring towns, dealers from a distance, and shipment by sea to London, under consignment to a respectable salesman. Before disposing of your oxen, however, you should be acquainted with their weight; otherwise you will not know what to ask for them at the current market prices. Experience will teach you to estimate the weight of an ox by the eye, not the actual liveweight of the animal, but the weight of beef it will yield after deducting the weight of what is called the offal, that is, the weight of every part but the beef and bones, such as the skin, head, entrails, and loose tallow. It is understood that the farmer is entitled to the value of the entire weight of the beef at the current prices, and these are always understood to relate to the prices of the meat alone; and that the profit of the purchaser consists of the value of the offal, subject to the deduction of incidental expenses before the animals are slaughtered. The available parts of the offals are supposed to be equal to the value of $\frac{1}{5}$ of that of the animal, so that an ox of $£ 20$ value should leave the purchaser $£ 4$ profit, subject to incidental expenses. But if the buyer is a good judge of cattle, and knows their exact available weight of beef, which he will know to within a very small fraction, he may make such a bargain with the farmer as will not only cover his expenses, but leave a profit on the carcass over and above the value of the offals; and as dealers are constantly in practice, they generally contrive to make pretty good bargains for themselves, in as far as their judgment is concerned, at the time the bargain is made, but their purchases are subject to fluctuation of price, which may fall without an adequate cause, and occasion them serious loss; or they may rise and leave them a handsomer profit than was anticipated, so that the profession of dealers resolves itself into a speculation, which, if prolonged in its issue, is involved in uncertainty. Dealers formerly made large fortunes when breeders and feeders of stock could estimate the value of even their own stock but indifferently; but nowadays I believe few dealers make fortunes, owing partly to competition, and partly to greater skill on the part of the farmer, and partly to the great expense incurred on driving their purchases to suitable markets, and in leading a roving sort of life.

(1988.) But assistance may be afforded you in ascertaining the weight of your cattle until you are better taught by experience, and this consists in measuring their bulk, or in weighing their live-weight. The live-weight of cattle is easily ascertained by placing the animals upon a steel-yard, of which convenient forms have been recommended for the special purpose; but I am not aware that any of those which have been specially recommended are as accurate or convenient as might be. The rule to determine the quantity of beef by the live-weight is to multiply the gross weight by (507) 
. 605 of a decimal, if the ox is ripe fat, but if not so, by 5 of a decimal ; that is to say, that the uffuls of an ox in ordinary condition weighs abont as much as its beef and hones. An wx should not be weighed immediately after it has fed, as it will weigh too heary, but after it has chewed the cud, and is ready again to feed. Ascertaining the weight by measurement is a more convenient method than by weighing; and when the measurement is properly taken, and the ox of an ordinary size, it is about as accurate, though every person cannot measure an ox, that process requiring judgment to do it properly and accurately. Suppose fig. 358 to represent an ox whose weight, sinking offals, is desired to be ascertained by measurement. The mode is, measure with a tape-line from the top of the shoulder $a$ to the tail-head $c$, and mark this for the length, then measure round the body at $f$, immediately behind the shoulder, and mark this for the girth, and on consulting the tables calculated for the purpose of affording the results, the weight of beef will be found. Upon what principle this rule for measurement is founded $\mathrm{I}$ cannot say, and suspect that it is entirely

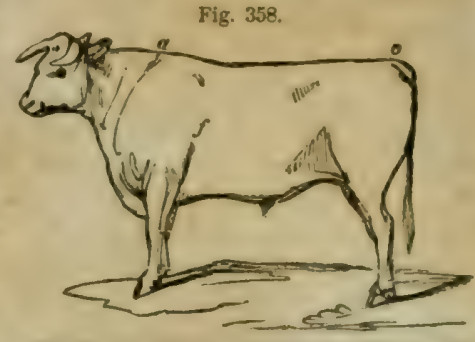

HOW TO MEASURE A FAT OX IN ORDER TO ASCERTAIN HIS WEIGHT, SINKING THE OFFALS. empirical. The rules by which the tables are calculated seem to be these two, namely: multiply the square of the girth in inches by the length in inches, and divide the product by 7344 , and the quotient is the weight in imperial stones. Or, square the girth in feet and multiply it by the length in feet, and multiply again by the decimal 238 , and the sum is the weight in imperial stones. For example: Suppose the girth is 7 feet, or 84 inches, and the length 5 feet, or 60 inches, the weight of beef in imperial stones, according to Strachan's Tables, which are the most recent, is 57 sts. 10 lbs. by the former rule, and by the latter it is 56 sts. 4 lbs. These results show that there is no fixed principle upon which either rule is founded.

(1959.) This seems a very simple process, and so it would always be, were the form of the ox always perfect, which is very seldom the case, the fore and hind-quarters, instead of being equal, being more frequently otherwise; and were the condition always the same. Therefore, the judgment is called into exercise to make allowance for those differences. When the fore-quarter seems heavier of the two, the line should be stretched nearer the head than $a$, the exact top of the shoulder; and so in like manner, when the hind-quarter seems heavier than the fore, the line should be stretched beyond $c$. In regard to the girth, it is no uncommon fault in an ox to have the carcass gripped small behind the shoulder, so that the exact girth of such a shoulder would be below the truth. It is very rare to find the girth too much filled out. You thus see that judgment is required to apply the tape-line to an ox; and as an illustration of the practical effects of misapplying the tape-line, I may state that 1 inch only added to the girth and length given in the ahove example, makes a difference in the above weight of upward of 2 sts. The addition of 1 inch in the length is a mistake which may easily be made by the ox merely standing with his head down and back up; and a similar position may may as easily cause an error in the girth. Experience alone can make you proficient in measuring. I knew a steward in Berwickshire who had so much practice in measuring and so frequent opportunities of verifying his measurements, that he measured any ordinary sized ox, whether fat or half lean, from 1 st. to $\frac{1}{2}$ st. of ite true weight. 
(1990.) To an ox from 40 to 70 stones the rule of measurement applies pretty near, if it is applied with judgment, and it is but fair to the principle that it should be so applied; but in weights both below and above these figures the rule is usually at fault. I have no instances of error in very small weights to adduce, but many of large ones, and shall adduce only two. A Short-Horn white ox belonging to Mr. Boswell of Kingcausie was exhibited at the Highland and Agricultural Society's Show at Aberdeen in October, 1S34. Its measurement was 9 feet 3 inches in girth, and 6 feet 2 inches in length. According to Renton's Tables, the farmer of Dykegatehead, in Berwickshire, the weight should be 126 sts. 9 lbs.; Strachan's Tables, 124 sts. 2 lbs.; Ainslie's Tables, 122 sts. ; and Stewart's Tables, 117 sts. The actual weight of beef yielded by it was 136 sts. 10 lbs., after being slaughtered by Deacon Sparks of Aberdeen, being 10 sts. $1 \mathrm{lb}$. more than the heaviest weight indicated by all these tables. This difference of weight, at $6 \mathrm{~s}$. per stone, would make a loss to the feeder of $£ 3$ upon a single animal! A 2-year-old light-red ox, also belonging to Mr. Boswell, and exhibited at the same time, measured 7 feet 10 inches in girth, and 5 feet in length. Stewart's Tables give a weight of 80 sts. 3 lbs.; Renton's, 73 sts. 8 lbs.; Ainslie's, 73 sts.; and Strachan's, 72 sts. The actual weight obtained by Deacon Sparks was 89 sts. 10 lbs., showing the enormous difference of 17 sts. $10 \mathrm{lbs}$. between the real weight obtained and the lowest weight indicated by Strachan's Tables, and which, estimated at 6 s. per stone, would cause a loss to the feeder of $£ 56 \mathrm{~s}$. $3 \mathrm{~d}$. The rule derived from live weight is also liable to err, or when applied to oxen of inordinate weights. Thus, Lord Kintore's black ox, 7 years off, exhibited on the above occasion at Aberdeen, weighed 28 cwt., or 224 stones. By the rule of multiplying the live weight by the decimal $\cdot 605$, the dead weight should have been 135 sts. 7 lbs.; but when the ox was slaughtered by Mr. Roger, Crown Street, Aberdeen, his 4 quarters weighed 173 sts. 4 lbs., or 37 sts. 11 lbs. more than anticipated, which, at 6s. per stone, made him worth more by $£ 116 \mathrm{~s}$. $8 \mathrm{~d}$.! On the other hand, a small spayed heifer, belonging to Mr. Boswell, weighed 88 sts. live weight, and should have yielded 53 sts. 3 lbs., but her 4 quarters only weighed 49 stones.* In consequence of such discrepancies, it would certainly be desirable were means used to render the rules of measurement, as well as of weight, more correct than they are; and I see no way of effecting this desirable end except by collecting data, by instituting a set of experiments in different parts of the country, to measure and weigh every animal before slaughtering, be it ox, sheep, or pig, be it large or small, for a given period, say 12 months, and see how far the results coincide or differ from the actual weight of meat afforded by the 4 quarters.

(1991.) The fat cattle being disposed of, the pasture should be judiciously distributed among the remaining stock; and first, as to the cows, they should be supplied with the best pasture, the object of keeping them being to breed calves and to afford plenty of milk to bring them up; the more milk they yield the better will the calves prove, and the more profitable they will themselves prove after the calves are weaned. Cows in summer are treated in a different manner by different people, some taking them into the byre at night, and even at all times of milking, whereas others allow them to lie out all night, and milk them in the field. Whichsoever mode is adopted, it should be kept in mind that cows are peculiarly susceptible of sudden changes of temperature, especially from heat to cold and from drouth to rain, so that whenever cold or rain, or both together, which is the most common circumstance, occur, they should be brought

* See paper by me on this subject in the Quarterly Journal of Agriculture, vol. v. 
into the byre. For some time after they are put out to grass they should be brought into the byre at night, where they are milked, and again in the moruing before they are let out to the field, and milked in the field at mid-day. After the nights become warm I have found it conducive to health, and it is both a rational and a natural plan to allow them to lie out in the field all night, and to milk them there at stated hours, three times every day, the shepherd or cattle-man taking it as a part of his duty to bring them to a certain spot of the field to be milked, and which is usually named the milking loan. This mode of allowing them to lie out always in a sheltered field, no doubt impuses a good deal of labor on the dairymaid and her assistant in carrying the milk to the dairy after the calves have been weaned; but I am persuaded it is an excellent system for the health of the cows. Under it cows rise from their lair at daybreak and feed while the dew is still on the grass, and by the time of milking arrives, say 6 o'clock, they are already partially filled with food, and stand contented, chewing the cud, while the milking proceeds. They then roam and fill themselves, and by 9 o'clock lie down in a shady part of the field and chew their cud until milking time arrives at mid-day, when they are again brought to the loan and milked. Again they roam for food, and, when the afternoon is hot, will stand in the coolest part of the field whisking away the flies with their tail and ears. The evening milking takes place about 7, after which they feed industriously, and take up their lair about sunset, and from which they rouse themselves in the morning before being milked. Some people are apprehensive that cows must injure themselves by eating grass which is wet with dew in the morning; but it is a fact, which I believe is not so sufficiently known as it should be, that bedewed grass before sunrise, and grass after it is dried by the sun, are alike uninjurious to animals, and it is only when the dew is in the act of being evaporated, immediately after sunrise, that grass proves injurious to animals. Why it should be injurious at that particular state I do not precisely know, but imagine it to be so, because the grass then becomes suddenly cold by evaporation of the dew. When cows lie out, they have nearly filled themselves by the time the dew is evaporated, and therefore feel less impelled to eat much of the grass in the dangerous state; whereas, cows that are housed in the byre all night are usually milked about sunrise, and put out to grass just at the very time the dew on it is being evaporated, and is, of course, in the most dangerous state ; and it is, moreover, just then that cows feel the greatest hunger, and eai most grass. The effect of this state of grass is to produce hoven (1294), and especially on aftermath in autumn. Be the cause of injury what it may, it is certain that cows let out to grass from the byre are far more liable to be affected with hoven on wet grass than those which lie out all night, and especially on new grass. The lying out at night, too, saves the trouble of providing supper for the cows, which they must have when housed in the byre. But whenever the weather becomes cold and wet, cows should be brought into the byre at night, and supplied with supper, such as cut aftermath or tares.

(1992.) The weaning of calves should not exceed one month after the cows have been on grass, that is, by the end of June, for a calf later weaned than that period has been too late brought into the world to be worthy of belonging to the standing stock of a farm. As cows increase in gift of milk after the grass has fairly passed through them, the late calves should have as large an allowance of new milk, three times a day, as the quantity obtained will allow, reserving a little for the use of the house, The elder calves are off sweet milk by the time the cows go to grass, and (510) 
have received lythax (1685) with a little skimmed milk among it, cut Swedish turnips and hay, until the grass is ready. These calves having been in the court $k$, fig. 3 , Plate III. of the steading, for some time, may be put on grass when the cows are let out. The most convenient first grass field for calves is a contiguous paddock, from which they should be brought into the court for a few nights and receive turnips and hay, until the grass has safely passed through them, and the weather prove mild and dry for them to lie out all night in the paddock. The youngest calves should now leave their cribs $\mathbf{R}$, and pass a few days in the court $k$ until they become accustomed to the air and sun, when they also may be put into the paddock during the day, and there supplied with their diets of milk, and brought into the same court at night until they are able to lie out all night. In weaning the youngest calves, the milk should be gradually taken from them until they 'take with the grass, upon which they must then entirely depend. A little after all this has happened, say by the middle of July, the pasture in the paddock will become rather bare, and the whole lot of calves should then be taken to good pasture, where they will have a full bite, for nothing can be more injurious for calves than to place them on bare pasture to fall away in condition immediately after weaning, and which they will assuredly rapidly do, and from which it will be very difficult to recover them all summer. Calves may be grazed among cows, or in a field by themselves. In their peregrinations through the field, it will be found that those which have been brought up and weaned together will keep together for the greater part of the season. The older calves may be 4 months old before they are weaned; but as the season of grass approaches, the younger ones may be weaned at an earlier age, being seldom indulged with milk for more than 13 weeks, but it should rever be forgotten that the first month's nourishment to a calf is of much greater importance to its future growth and health, than any period beyond 13 weeks, supported on a stinted allowance of inferior milk. There are parts of Ireland where calves are brought up on buttermilk and gruel, after the first 8 days they have received sweet milk, and it is boasted that they thrive well on that beverage. This is possible, but they will thrive far better on sweet milk.

(1993.) Bull-calves should have good milk every day until the grass is able to support them, in order to strengthen their bone, and maintain their condition. When a number are brought up together, they should be grazed by themselves on the best grass the farm affords, or they may go along with the cows, or they may go along with the ox-calves while the quey-calves are with the cows. Under any arrangement, they should not be allowed to accompany the quey-calves. I knew an instance of a quey-calf being stinted at so early an age as to bear a calf at 15 months old ; and I knew another quey-calf, one of my own, that was so injured by a young bull-calf, that she was thereafter rendered incapable of impregnation, though her season recurred periodically. To avoid every such vexatious casualty, it is far better to keep apart young animals of different sexes that are capable of breeding. When there is only a single bull-calt he may go with the cows, or with the young oxen.

(1994.) The young 1-year-old bulls should now be furnished with a ring in their nose.* This instrument is useful not only in leading the animal, but being constantly in use, in keeping his temper in subjection. I have no doubt whatever that such a ring affords the most complete command over the most furious bull. In case of a bull becoming more irritative and troublesome as he advances in years, which many bulls are

\footnotetext{
* The form of this ring will hereafter be given by an engraving.
} 
inclined to be, the ring furnishes the means of curbing him at once, when it would otherwise be impossible to get hold of his nose. It affords also an easy means of suspending a light chain from the nose to the ground, upon which the fore-feet are ready to catch the chain in walking, when the nose receives so sudden a check that whenever the bull attempts to run at any one in the field he pains himself. Even a young bull in a field may follow you at first in sport, and run at you afterward in earnest. The ring is put into a bull's nose in this way: Let a ring of iron be provided of perhaps $2 \frac{1}{2}$ inches in diameter over all, and $\frac{1}{4}$ inch diameter in the rod, when finished. It should have a joint in it, to let the ring open wide enough to pass one end through the nose, and the two sides of the ring, on being closed again after the operation, are kept together with two countersunk screws. An iron rod tapering to the point, and stouter than the rod of the ring, should be provided. Let a cart-rope have a noose cast firm at its middle, and put the noose over the bull's head, and slip it down his neck, with the knot undermost, till it rests upon the breast. Any mortared wall sufficiently low to allow the bull's head to reach over it will answer to put him against; or what is safer for his knees, any gateway with a stout bar of wond placed across it as high as his breast. Place the bull's breast against the wall or bar, and pass the rope from the lowest part of the neck along each side round the buttock like a breeching, and hring one end of the rope over the wall or bar on each side of the bull's head, where a stout man holds on at each end, and it is the duty of both these men to prevent the bull from retreating backward from the wall or bar. A man also stands on each side of the bull's buttock to prevent him shifting his position. The operator having the iron rod given him heated in the fire, just red enough to see the heated part in daylight, he takes the bull by the nose with his left hand and feeling inward with his fingers, past all the soft part of the nostrils, until he reaches the cartilage or sep. tum of the nose, he keeps open the nostrils, so as on passing the hot iron through the septum it may pass clear through without touching the outer skin of the nostrils, taking care to pass the iron parallel to the front skin of the nose, otherwise the hole will be oblique. Immediately after the rod has been passed so far as to make the hole sufficiently large, and the wound has been sufficiently seared, the operator takes the ring, opened, and still keeping hold of the bull's nose with the left hand, passes it through the hole, and on bringing the two ends together, puts in the screws, and secures them firmly with a screw-driver. On being satisfied that the ring turns easily round in the hole, and hangs or projects evenly, the bull is then released. The ring, as it should appear in the nose, is represented in the portrait of the Short-Horn bull. It cannot be too highly finished or polished, and its cost in this state may be $2 \mathrm{~s}$. The ring should not be used until the wound of the nose is completely healed, though it is not uncommon to see the poor animal tormented, in the attempt of being led about by the ring immediately after the operation, when every part of the nose is still tender and sensitive. So alarmed do some bulls become from the operation, that they hang back from the leading rope of the ring with such force as to pull the ring through the nose; but such a use is au abuse of the rope, and rather than such a result shall occur the rope should be slackened, and the animal relieved from pain as often and until he learns to yicld to the rope. The readiest and neatest way to attach a rope to a bull's ring is with a swiveled hook, retained in its place by a spring, and a rope should be kept for the purpose. On first trying to lead a bull by the ring, the drover should not endeavor to pull the animal along after himself, but allow him to step on while he walks by his side, or even (512) 
behind him, with the rope in his hand. While so following, to relieve the animal as much as practicable of the weight of the rope upon the nose, the drover should throw the middle of the rope upon the bull's back, and retain a hold of its end. Should he offer to step backward, a tap on the shank with a stick will prevent him; and should he attempt to run forward, a momentary check of the rope will slacken his pace. On no account should the drover attempt to struggle with the bull on the first occasion; on the contrary, he should sonthe and pacify him, and endeavor to inspire him with confidence in himself and the rope, and to show him that he will receive no hurt if he will but walk quietly along. The animal, in the circumstances, will soon learn the nature of the tuition he is undergoing if he is properly dealt with, but if tormented merely that the drover may show his power over a powerful animal, it may be a long time, if ever, before he will learn to behave quietly when led. A useful instrument for leading a bull by occasionally, when he has not been ringed, or for leading a cow to the bull at some distance; or for taking away any single beast, and the same time retaining a power over it, is what is named the bullock-holder. It consists of iron in two parts jointed, which are brought together or separated by a thumb-screw passing through them. The ends farthest from the joint terminate in a ring having an opening at its extreme side, each end of which opening is protected by a small ball. The arms of this ring embrace the septum of the nose gently between them; and the shank of the instrument being screwed close together, the balls approach no closer than just to embrace the septum, and the nose of the animal prevents them slipping out. The leading rope is attached to the jointed end of the instrument, which is formed for the purpose into a small ring.

(1995.) A bull that is serving cows is never in a better position than when attending them in the field. He knows much better than either the shepherd or the cattle-man when a cow is coming into heat, and he will attend her faithfully until the proper time of service; and I believe it is a fact, that a bull which is constantly among cows in a field never teases or abuses them so much as one that is taken to them for the occasion out of his own house. At any rate, I have seen very striking instances of what I have now stated. But a bull can only be left in the field where he is intended to serve all the cows. It may be necessary, however, in the course adopted by you for the improvement of your stock, that different bulls shall serve the cows, in which case no single bull can have access to all of them alike, and therefore cannot be grazed in the same field with them. When a bull goes among cows he is usually quite safe to approach, and is quiet within the fence; but a bull is always troublesome by himself in a paddock or field, or even among oxen. He is restless, often bellows, and few fences will retain him when he is resolved on breaking through, especially where he can snuff the cows at a distance. In such circumstances, it is much better to confine him in his hammel or byre, and support him on cut forage of some kind, such as clover, lucerne, tares, and the like. When so confined, bulls, like watch-dogs always kept on the chain, dislike the approach of any one but their keeper, and even a keeper has been known to fall a victim to resentment. Some bulls become so prone to mischief when constantly confined, that they will attempt to run on any one, when brought out of the house to serve a cow, the presence or smell of the cow in heat having so maddening an effect upon them as to render them reckless. The air and daylight together have an intoxicating effect upon them. Besides the rope or chain in the ring, a safe precaution for the keeper, in such a case, is to to have a stout stick about 6 feet long, with a swiveled. hook (513) .......18 
on its end to fasten into the ring, and with this he will not only have a better command over the ring than by the rope, but it will enable him to keep the buil off to a certain distance, the animal not being able to run at him without first giving a warning of his intention by pushing the stick. Bulls display a natural fondness for calves. Bulls that have served cows should never be allowed to herd together, as they will inevitably fight, and a serious bull-fight is a terrific thing, seldom terminating before the infliction of serious injury to both parties.

(1996.) The young cattle-the 1-year-old and 2-years-old-may be put on the inferior pasture, that is, on the second and third year's grass; inferior, not because it is insufficient to maintain the stock in full condition, but because new grass is usually considered the most nourishing on a farm for the youngest stock, and most profitable for cows when bringing up calves. Certainly it is the most succulent grass, and stock are fondest of it, and it springs the earliest of any on a farm; but then all the stock cannot have new grass at the same time, and that part of the stock which are not employed in reproduction, should receive the least valuable grazing in summer, though the entire pasture may be very good.

(1997.) Grass land requires peculiar munagement to render it the most available as pasture in every variety of season. The circumstances which most injure grass are overstocking and continual stocking. 'The most obvious plan, of course, of avoiding overstocking is to have no more stock upon the farm than its grass will in summer maintain in good condition, and to avoid continual stocking, the stock should not be allowed to remain too long on the same field. I believe the safest principle upon which each grazing field can be treated, is to stock it at once as fully as that it shall be eaten bare enough in a short time, say in a few weeks, and then it should be left unstocked altogether, hained, as it is technically called, for perhaps a fortnight, in order to allow the grass to grow sufficiently to afford a bite for cattle. One obvious advantage of this plan is, that the stock at periodic times during the grazing season will enjoy fresh grown grass; and another is, that the same growth of grass will not be so long depastured as either to cloy the appetite of the animals, or become foul by being constantly trodden upon. That this is a rational and natural mode of managing grass land is evinced by the fact that all stock delight in consuming fresh grown grass, and all loathe grass which has been long trampled and dunged upon, and the breath passed over it times out of number. There is another important consideration to be borne in mind in conducting the grazing of grass land, which is, the modes in which different kinds of stock crop the grass, one kind biting it close to the ground, while another hites it high. The ox gathers each mouthfill of grass with his tongue before he cuts it with his teeth, and therefore requires the grass to be some inches in length before he can obtain a full bite. Grass which is not sufficiently long for this purpose, either before it is grown, or after it has been eaten down, is in an unfit state for cattle; they may live, but cannot gain condition upon it, and as long as they are confined upon it will lose so much time. Horses and sheep, on the other hand, crop grass in quite a different way; their lips being very mobile and muscular, seize the grass firmly, while the teeth cut it over, and in doing this they bite very near the ground. This is a remarkable peculiarity in regard to the sheep, inasmuch as the arrangement of their teeth being the same as that of the ox, but wanting them in the upper jaw, one would have expected them to employ a similar mode of cropping; but the difference in the form of their lips explains the peculiarity, those of sheep being decidedly prehensile, like those of the horse, while those of the ox are thick and inac(514) 
tive, but the ox's tongue is prehensile, and thus we see that it is the prehensile organs which are the active agents in the collection of food. And this is a wise distinction in the formation of these two classes of ruminants, in as far as it is suited to their respective natures-sheep being suited to mountainous regions, where pasture is always short, and where they are able to erop it with the assistance of their prehensile lips, notwithstanding the want of teeth in the upper jaw; whereas the ox is better suited to the plains and valleys, where grass grows long, and is therefore better suited to be cropped by the scythe-like operation of the ox's tongue and teeth. The practical conclusion to be drawn from these different distinctions in the formation of these animals is, that the horse or sheep should follow the ox in grazing, or graze in company with him, but not precede him. When they follow, the pasture will be eaten barer by the horse or sheep than when the ox left it; and, when in company, it will be eaten barer by the horse or sheep where the ox has eaten hefore, and it may first be topped by them before the ox has touched it. Of the two modes of treating the horse or sheep, the latter is the preferable, because choice is offered them to take the long grass as well as the short. The same reason, however, that should graze the ox with the horse or sheep should cause the separation of the horse from the sheep, and especially in the latter part of the pasture season; both kinds of animals biting close, will render the grass too bare for the maintenance of both. Horses too, work-horses especially, seem to have a greater dislike to sheep than to cattle.

(1995.) There is a difficulty attending the grazing of all kinds of stock on a farm of mixed husbandry which I must mention, that as there is every summer the same number of stock, there may not be the same quantity of grass to support them; for the same number of acres of grass, secured by following a regular rotation of crops, may produce different quantities in different seasons-one year being scanty, another superabundant. The number of stock, therefore, should correspond with the produce of an average year. In such a case, a bad year very much stints the condition, while a good year supplies perhaps even more than the same stock can consume. The stinted condition cannot be alleviated by the sale of any of the stock, as it is impolitic to disturb the equilibrium of the stock of several years' produce which exist on the farm at the same time; and if the stock suffer hunger, as it did in the severe drouth of the summer of 1826 , there is no alternative but to make up the deficiency by hay, even though it should be purchased for the occasion. On the other hand, superabundance of pasture does no harm, for, independent of its maintaining the entire stock in high condition, the rough aftermath will be of essential use to sheep in winter. Of farms whose stock are purchased every year, the number can be regulated by the likelihood of the crop of grass, but even in this case the season may turn out worse than was expected. Seeing, therefore, that no one can foretell the future state of any crop, the prudent plan is, in every case, to keep the number of stock under the mark which a farm can support.

(1999.) One essential requisite in all pasture-fields is an abundant supply of water for stock to drink. Both cattle and horses drink largely, and sheep, grazing early on the dewy grass, do not require so much water to keep them in a healthy condition; still, when there is no dew, they do drink water. The proper construction of a watering-pool is sadly misunderstood in this country. The entrance to it generally consists of poached mud of at least half a foot in depth, and to avoid this, the animals go into the water before they drink, when, of course, it is at once rendered muddy. Not unfrequently there is scarcity of water, and if there is just sufficient sup(515) 
ply to prevent the pool being evaporated to dryness, the water is rendered almost stagnant. So obvious are the objections to this mode of administering so necessary and wholesome a beverage to the brute creation as water, that all that seems necessary to an amendment of the system is to point out its inconveniences. True, in some cases, tanks of wood or stone are provided in fields, which are supplied from some adjoining spring, or even pump-well, and, as far as the quality of the water is concerned, this is a much better mole of supplying it than in pools; but this mode, good as it is as far as it goes, does not provide all the requisites of a good watering-pool. In hot days, a walk though a pool is very wholesome to the feet of cattle, and in dry weather, a stand for some time among water is an excellent preventive of that troublesome complaint, the foot-sore. The external application of water in this manner allays inflammation, and prevents irritation, and permits animals to take their food in peace even in scorching drouth. Besides the tank of a pump-well is not unfrequently neglected to be filled-because in cold and rainy weather it is scarcely visited by the cattle, in hot weather-it is supposed to be viewed with the same indifference; and, even where tanks are duly attended to for cattle, there are none set down at a lower level for sheep. A watering-pool should be securely fenced, as cattle are very apt to push one another about while in it, and for that reason it should also be roomy. It should be of considerable length and narrow, to allow access to a number of animals at the same time, if they choose to avail themselves of it; and I have often observed cattle delight to go to the water in company. Pools are usually made too small and too confined. The access to them should be made firm with broken stones in lieu of earth, and gravel placed on its bottom keeps the water clean and sweet, while the water should flow gently through the pool.

(2000.) The want of sharle in pasture-fields is also a sad reflection on our farmers. Observe, in summer, where the shade of a tree cast itself over the grass, how gratefully cattle resort to it, and where a spreading tree grows in a pasture-field, its stem is sure to be surrounded by cattle. The stirring breeze under such a tree is highly grateful to these creatures; and such a place affords them an excellent refuge from the attacks of flies. In cold weather, also, observe how much shelter is afforded to cattle by a single tree, and how they will crowd to the most wooded corner of a field in a rainy day, even in summer. Ought not such indications of animals - teach us to afford them the treatment most congenial to their feelings ? I am no adrocate for hedge-row trees, even though they should cast a grateful shade into a pasture-field, and still less do I admire an umbrageous plane in the middle of a field that is occupied in course with a crop of grain or turnips; but similar effects as good as theirs may be obtained from different agencies. A shed erected at a suitable part in the line of the fence of a field, would not only afford shade in the brightest day in summer, but comfortable shelter in a rainy day, or in a cold night in autumn. Such an erection would cost little where stone and wood are plenty on an estate, and they could he erected in places to answer the purpose of a field on either side of the fence when it was in grass. But no matter what it may may cost, when the health and comfort of stock are to be maintained unimpaired by its means. The cost of a shed may, perhaps, in this way be repaid in the first year of its existence, and it would stand, with slight occasional repairs, during the currency of a long lease. When such an erection is properly constructed at first, it is surprising how many years it will continue to be useful with a little care. Let it be roomy, and its structure light, as it may be roofed at a moderate cost with zinc, or composition of 
some sort, or tiles, when they are manufactured in the-neighborhood. It may be troublesome to carry straw for litter from the steading to a shed situate at a distance, but there is no occasion for straw for litter in summer; the rough grass from an adjoining plantation or ditch will supply litter, and the dung at any rate should be shoveled up and carried away before it becomes uncomfortable to the animals. I should like to see a farm with such a shed erected in it for every two fields.

(2001.) The teats and udder of cows are at times subject to certain complaints in summer; and these are chapped teats, sore teats, warty teats, and cont-pox. Chapped teats consist of cracks occar. ring across the teats, which when drawn downward, the cracks are forcibly opened, and, of course, inflict pain on the animal; and the cows then become troublesome to milk. The easiest mode of milking them while under this complaint, is that described by nievling in (1667), while stripping aggravates the complaint. I do not know the certain cause of this complaint, but suppose it to arise from leaving the teats in a wet state after milking; and perhaps cows lying upon wet ground may have the same effect. Sore teats are, when blotches of skin come off the teats, and their fleshy substance becomes sores by exposure to the air. This complaint may arise from the milker who strips seizing a particular part of the teat too hard, where an inflammation being set up, terminates in the sloughing of the skin, and consequent exposure of the fleshy substance to the air. Warty teats, I conceive, may originate in the skin of the teats being ruttled by too much force in stripping, or by too long a nail apon the thumbs; and the warts produced in consequence may be exuberances of the skin in covering the injured parts. I am not sure that these conjectures, for they are nothing more. will explain the causes of these complaints, bat I believe when care is used not to abrade the skin or pinch the substance of the teat, but to keep it clean and dry, these complaints seldom or never occur. As to the cow-pox, it is a constitutional disease, and cannot be either induced or retarded. The pock makes its appearance both on the adder and the teats of the cow; and as milkiug must be performed frequently by all the teats, the operation feels very painful to the cow and she of course, becomes very troublesome to milk. Very soon the pustules are rubbed off by the operation, and their sites become skinless sores. Nothing but the utmost gentleness will prevent the cow becoming distracted under the torture. After having run its course, the disease declines, the sores become less acute, and heal up by degrees. The disease fortanately is not of frequent occurreuce; I bave only seen it once in the course of a fifteen years' experience, and it affected all the cows I had at one time-9 in number. I acquainted several of my medical friends of the existence of a disease. inagining that they would have been glad of so favorable an opportunity of obtaining fresh vaccinating matter, but they treated the offer with indifference. There was an ointment I found very efficacious in affording relief to the cows when afflicted with the cow-pox, sore teats, or hacked teats. It consisted of fresh butter melteci and burnt in a frying-pan, and mixed with half its quantity of tar. While hot it was poured into a gallipot. and applied cold to the affected parts. The tar had the effect of keeping off the files, while the burnt butter never became dry. The ointment was washed off with warm water before milking commenced, and the udder and teats dried with a soft linen cloth; they were again bathed with warm water after milking, again dried with the soft linen cloth, and the ointment again applied. Calves, after being weaned, are subject. toward the end of summer, to a disease commonly called the joint-fellon, which, when oxen take it upon the loins, is named the chine-fellon. It is nothing else than acute rheumatism, ending in a resolution to low fever, and so severe is it at times apon calves, that they cannot bear to be moved when lying stretched out all their length upon the ground. Had cattle sheds to retire to whenever a cold dash of rain came in the evening of a cold day, even in summer, this disease would perhaps never occur. Its treatment is removal to the courts and sheds of the steading among straw, bleeding, moderate purging, with fomentation, and embrocations of liquid blister, forcibly and long rubbed in, of the swelled joints. Another effect of the same frebile affection on calves in autumn is the quarter ill or evil. "Its characteristic symptoms are general disturbance of the circulation, and feeble, rapid pulse, weakness, prostration of strength, determination of blood to particular, but in different instances and epidemics, very different parts, producing pain, and manifesting a tendency to in. Hammation, but of a degenerate kind, so that the very texture of the tissue becomes disorganized. The progress of the disease is often rapid, and the result very fatal. In some cases the lungs or heart are attacked. and in others the liver. bowels, or even some external part of the body." Its immediate cause is plethora, or fullness of blood in the system, which shows its effects in this manner: "When the supply of food is greater than the exigencies of the system requires," as Professor Dick observes, "an animal asually becomes fat, but still may be tolerably healthy. When, however, a sudden change is made from poor to rich feeding, not fatness but plethora may be the consequence ; more blood is formed than the system can easily dispose of, and it becomes oppressed. The effect is often witnessed in cattle and sheep, which, after indulging for a time in luxuriant pasture, take what is nalled a shot of blood. All at once they become very ill; some part of the body swells. becomes puffy, as if containing air, and in two or three hours the animal is dead, from the quarter evil already described. Upon dissection a large quantity of black and decom. posed blood is found in the cellular membrane, which during life was distended."* This disease is of frequent occurrence on farms where fine stock are bred, and from the above description of its nature, there is no wouder that the best calves first fall victims to it. As its name implies, the disease attacks the hind quarter, and its effects are as sudden as described. Since its cause is known, calves ahould not be put at once on strong foggage from a comparatively bare pasture, nor, for the same reason, should calves in low condition be put on rank foggage; the transition, both as regards the pasture and the state of the calves, should be gradual. As a preventive, some

* Dick's Manual of Veterinary Science.

(517) 
farmers introduce a seton into the dewlap of all their calves before putting them on foggage in an tumn. The use of the seton is to produce counter-irritation. The seton consists of a piece of tape or soft cord passed under a portion of the skin by a seton-needle: the ends may be tied together. and the cord may be moved every ouher day from side to side, being previously labricated with oil of turpentine or blister-plaster, and in this way the amount of irritation may be regulated. A to the cure, I believe every one is anavailing after the disease has been observed to exust; but as a remedial measure applied by anticipation, large blood.letting with purging of repeated doses will reduce the plethoric tendency of the animal system. Perhaps a cribfull of bay, with some salı, placed in a foggage field, would not be a bad alternative for calves to resort to at times, in order to modify the effects of the succulence of rank aftermath.

\title{
24. MARES FOALING, OF STALLIONS, AND OF HORSES AT GRASS.
}

\author{
"Yet when from plow or lumbering cart set free, \\ They taste awhile the sweets of liberty: \\ E'en sober DOBBIx lifts bis clumsy heel \\ And kicks, disdainful of the dirny wheel "
}

BLOOYTIELD.

(2002.) Whenever field-labor commences in spring, whether with bean or oat-seed, draught-horses are indulged with hay instead of straw, and their allowance of corn is increased. The hay is supplied to them at will, and a strong work-horse is supposed to eat about $1 \frac{1}{2}$ stones, or 33 lbs. a-day, and some will eat even more. The oats are increased to 3 feeds a-day, which at $40 \mathrm{lbs}$. the bushel, will weigh $7 \frac{1}{2} \mathrm{lbs}$, but if the measure is heaped, which some farmers will allow to be done with horsecorn, the feeds will weigh 8 lbs. The quantities of hay and com here specified are supposed to be given in their ordinary state, but when given in a cooked state, I have already described their treatment in (1351) to (1353) inclusive.

(2003.) The hay-stack is seldom broken upon until the horses get hay in spring. Its site in the stack-yard is marked by an $n$ in Plate IV., fig. 4, of the steading, and the hay-house is contiguous to it at $H$, the apartment which also contains the corn-chest $y$, and the whole adjoins the work-horse stable $\mathrm{O}$. When the hay is to be used, as much of the stack is brought in as will fill the hay-house, and thence distributed to the horses. Every portion cut off the length of the stack should be 4 or 5 feet, and they are cut off with a hay-knife, fig. 360 , which represents the usual form of that instrument. It will be observed in the figure, that the line of the back of the blade is not so much as at right angles to the handle, a position which gives the cutting edge of the knife an inclination to the line of section, which, when the knife is used alternately up and down in a perpendicular motion with both hands, causes it to cut a longer space than the breadth of the blade. The person who uses the knife, usually the steward, while it is the field-workers who carry the hay and fill the hay-house, sets himself on his knees

Fig. 360 .

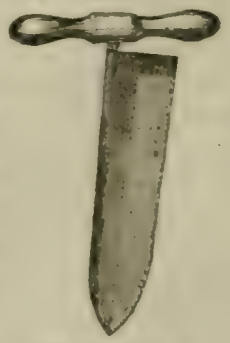

THE HAT-KNITE. upon the part he is cutting off, with his face to the body of the stack. This form of knife requires considerable strength in its use, and unless the edge is kept remarkably keen with a whet-stone, and the hay is firm, it does not make good work. The hay-knife I prefer is of the form of the dungspade in fig. 30 , which, being used when standing, can be wielded with more force and make a deeper cut; and it cuts equally well in both directions, whereas the common knife cuts only in one direction-to the right. 
(2004.) There is considerable waste of hay as it is commonly used in hay-racks $i$, fig. 7. The plowmen stuff the rack not only full, but squeeze the hay firm, from a mistaken notion that they cannot give too much at a time to their horses; but when horses find it in this compressed state, and are unable to select the morsels they want, they toss out a considerable quantity among the litter, with which, after being trampled upon, and refused to be eaten, it is thrown into the dung-yard. True, the cattle there will eat it, and prefer it much to straw, because of its being hay and having a saline taste, so that it cannot be said to be entirely lost, yet the object of supplying the horses only upon hay is frustrated. If it is desired to give hay to cattle also, it should be given them in a direct manner. To avoid waste, therefore, small quantities should be put into the racks at a time, and these frequently; but the best way to prevent waste is to chop the hay and bruise the corn, and the mixture will also go a greater length in feeding the horses. Young horses should also receive hay after the stack has been broken up, straw becoming too hard and dry after March; and hay, besides, serves to improve their condition, and prepare them for grass. They should also get a little corn every day, until grass time, as nothing tends so much to enlarge and strengthen the bone, and confirm the spirit of young horses as corn. So much am I convinced of the truth of such a result, that I entirely agree with the observation of the late celebrated Nimrod (Mr. Apperley), that the belly of the young horse should be the measure of his corn. It is to the niggardly disposition, in regard to corn, which farmers evince toward their young horses, that is to be ascribed the number of weak horses that are met with on farms; for the greatest abundance of corn administered to the adult state, will never compensate for its want when the animal was in the state of adolescence.

(2005.) May is the particular month in which draught-mares usually drop their foals. They continue to work until the immediate symptoms of foaling are observed. These are great loosening of the ligatures on each side of the root of the tail, and the appearance of a waxy-like matter projecting from the point of the teats. As it is impossible to predict a mare's foaling within a few hours, it is proper to put her into a loosehouse or a box by herself, and to watch her every night. Too many farmers contemn such precautions, and allow their mares to foal in their stall in the stable, to the risk of having both them and their foals kicked by the other horses. That watching is necessary at night, even in a loose house, is evinced by a fact mentioned to me by the late Mr. Airth, Mains of Dun, Forfarshire, of a mare of his which, having been neglected to be watched at night, or even removed from the stable, was found in the morning lying on the floor with her womb protruded and the foal smothered in it. The mare shortly after died in great agony. It is a remarkable fact that few people have observed mares to foal, even though watching for the purpose, for somehow they contrive to foal when left by themselves for even a few moments. I have endeavored for successive years to witness the foaling both of blood and draught-mares, and was always disappointed. A mare will eat with heartiness until the pains of labor seize her, when she suddenly lies down, foals easily, quickly, forcibly, requiring no assistance, and starts to her feet almost immediately after parturition, takes up with, though licks but little at her foal, and soon begins to eat again. The foal is not long of gaining its feet after a few staggering attempts on its long legs, but some time elapses before it can steady itself, so as to lay hold of the teat. It should be assisted in this its first attempt, in order to get filled with milk, after which it may lie and sleep among straw until it becomes dry. The placenta soon drops from the mare, and should be imme-

(519) 
diately removed. The thin pellicle which covers the foal is, when dried, very like the finest gut-skin used by gold-beaters, and it forms a very good prutection from the air when applied as a plaster over the surface of a green wound. The mare should have a drink of lukewarm water and oatmeal, and a few handsfull of corn, after parturition, and, on partaking of which, she may be left with the foal. For the sake of increasing her milk she should be put to grass immediately after foaling, if she is not on grass, and should remain there without being put to work for a month; by which time she will have recovered her tone of body sufficiently to bear again the fatigue of labor. The sort of work for a mare having a foal should be of a nature to interfere but slightly with the more important operations of the farm; because having to suckle the foal every half yoking, she should be employed singly, such as at sowing and scuffling turnips, scuffling potatoes, and leading grass or other forage. When the mare is again made to work, the foal should be left by itself to rest in a well-littered apartment of the steading until it become accustomed to be alone, rather than in a court or hammel, out of which it may attempt to escape and injure itself. Should there be two mares with foals, both should be worked together; the treatment of both being alike, little inconvenience will arise to work, from being taken to their foals out of yoke together (3141). A stout mare will be able to perform her own share of summer work, and bring up a foal at the same tirne; but should she be in a weakly state, which she will be when becoming old, or is overworked, she should be put either to very gentle work, or to work only in half yokings, or one yoking a day, or be idle altogether and constantly with her foal. She should not be neglected of corn, however, though idle at grass with her foal. It is seldom that any illness attacks a draught-mare while bringing up a foal, and it is as seldom that anything is the matter with a foal. I had one work-foal, however, which, though safely and easily foaled, and seemed lively enough, could never stand upon its feet, or lay hold of a teat, and it died in the course of a day after it was foaled, though fed on cow's milk. A mare when thus deprived of her foal, should be occasionally milked, and kept un dry food for a few days, until the tendency of the milk to secrete subsides. The mare will be ready to receive the horse in 3 weeks, or a month at faxthest, after parturition, and the first symptom of heat is frequent twitching of the vulva, and emission of a clear fluid. When a mare is touched in this state, she immediately presses toward the object that touches her.

(2006.) In presenting a mare to the stallion, caution should be used to prevent her striking him with her heels when she refuses his attentions; and this consists simply in holding her by the head with a bridle across the outside of the stable door, while the stallion is kept within, and allowed to snuff and pinch her flank. If she takes the teasing kindly, presses closer toward him, twitches the vulva, and emits, she is in proper heat, but if she squeal and kick whenever he touches her, she is in an unfit state for him; but the tickling of the horse for a time not unfrequently confirms the season of the mare when it at first evinces a doubtful issue. If in season, she should be taken to an open piece of level ground, and held by the head as long as the horse covers her, and the time occupied by a stallion in covering is much longer than by the bull or tup, which is instantaneous. A horse which is safe to use requires no encouragement from his leader, but many need some assistance from him. Making a mare stand to the horse by a twitch on her nose is an unnecessary act of cruelty; for if she will not voluntarily receive him she will not become impregnated by any force that can be used against her. One cover is quite (520) 
sufficient at a time. In about 3 weeks it will be seen whether the mare has held to the horse; and should she again exhibit symptoms of season, simple and safe expedients may be used to secure her holding, such as throwing a bucket of cold water upon her rump the moment the horse leaves her, or drawing blood from her neck vein while the horse is covering, or, what is better than all, unless the season is going rapidly off her, retaining the horse all night and offering her a fresh cover in the morning, or, to adopt a different plan altogether, covering her with another horse, or another kind of horse-one or other of which expedients generally secures the holding, unless the mare is past bearing, which casualty befalls mares at very different ages. I was told by a man who led stallions for many years, that the expression of a sigh, from both horse and inare, immediately after an embrace, is an infallible sign of the mare proving in foal. The circumstances which militate against a mare's holding in foal is too high and too low condition. Whenever a mare is seen to eject semen as soon as the horse has left her, she will certainly not hold. Sometimes the fault is as much that of the horse as the mare, for when subjected to much traveling, and is, moreover, not a good traveler, and has undertaken more service than he can easily overtake, he is often so much fatigued when brought to a mare, especially toward evening, as to be quite unfit for effective service. When a horse is observed to be in a state of lassitude, the very best policy for the farmer is to give the horse and his leader a night's quarters, and let him cover the mare in the morning when he is comparatively fresh. Many farmers grudge maintaining a horse and man all night, but much better incur that small expense than run the risk of a mare proving barren. When a mare has been covered 3 separate periods without success, it is needless to persevere with her, as the foal will come too late next season, and a late foal is as objectionable stock to bring up as a late calf.

(2007.) The usual treatment of draught-horses in summer is to allow them to lie out in the pasture-field all night, and give them cut grass between the yokings in the stable. Forage is supplied them, because the time between the yokings is too short to fill themselves with grass on pasture; but on the Borders, where the first yoking is over by 9 or 10 o'clock in the forenoon, the horses are put into the pasture-field until the afternoon yoking at 1 o'clock; and this plan saves all the trouble of cutting grass for the horses. The piece of grass allotted to horses is cut by the plowmen, who each take the duty for a week by turns, and he quits the yoking in time to allow him to cut the requisite quantity and cart it to the stable. It is not his duty to supply the racks in the stable, except his own horse's, but to empty the load of grass on some convenient spot near the stable door-a dirty and slovenly practice. No doubt it is better to keep the fresh cut grass in the open air than to put it into a house; but still a crib or inclosure could be made in a shady place conveniently near the stable, to keep the grass fresh, and place it off the dirty ground.

(2008.) Grass is cut with the common scythe, which is so well known an implement that a particular description of it seems unnecessary. A few words, however, on the choice of scythes and of the manner of mounting them, may be useful to you. The handle, or snead or sneath, fig. 361, $a b$, is made either curved to suit the sweep of the instrument by the hands round the body, as in the figure, or straight, and the suitableness of both for work you shall learn when we come to consider harvest-work. The curved snead is usually made of willow, which, being shaped in hot water, and restrained, on being released when the wood becomes cold, retains the shape. Of scythes there are various kinds: the common kind keeps (521) 
its edge but a short time, and in the long run is, I believe, more expensive than the patent kind, which consists of a steel plate riveted between 2 small rods of iron, and which plate will continue to cut keenly until it is worn to the back-bone. 'The length of the blade of scythes varies fiom 28 inches to 46 inches, and the price of the common kind varies between these lengths from $2 \mathrm{~s} .4 \mathrm{~d}$. to $3 \mathrm{~s} .3 \mathrm{~d}$. each, and the patent from $3 \mathrm{~s}$. $2 \mathrm{~d}$. to $4 \mathrm{~s}$. $8 \mathrm{~d}$. each. There are besides these, other kinds termed crown, labeled, and extra-warranted scythes. Bent sneads cost from 1s. 3 d. to 1s. 6d. each, straight ones $1 \mathrm{~s}$, each. The straight are made of any sort of wood; I have seen good ones of larch. Scythes are sharpened with strickles and stones. The strickles are made of fine sand imbedded in an adhesive medium laid over the surface of a piece of wood of square or flat shape, and cost $6 \mathrm{~d}$. each. They are used to smooth the edge after the stone, and serve of themselves, for a time, to keep the edge keen; and they are always attached to and carried along the upper end of the snead at $d$, by a $\mathrm{T}$ headed nail and spike. Scythestones are either square or round, are formed of the same sandstone as grindstones, and cost $4 \mathrm{~d}$. each. They are only occasionally used to set a new edge on the blade. Ragstones cost $4 \mathrm{~d}$. per $1 \mathrm{~b}$. The blade of a scythe is mounted in this man-

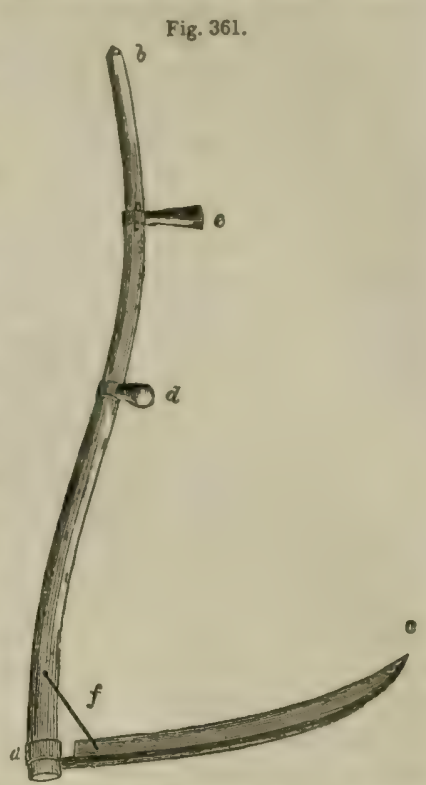

THE PATENT BCYTHE WITH BENT SNEAD. ner: the snead is furnished with an iron ring at the end, to which the blade is attached; the projecting hook at the butt-end of the blade is imbedded flush into the snead by taking away a portion of the wood, and the ring is then slipped over the imbedded hook, and is held tight in its position by an iron wedge as at $a$. The peculiar position which the blade bears to the snead is determined by measuring the length of the blade $a c$ straight along the snead from $a$ to $d$, where is fastened the handle for the right hand, and the same length from $d$ to $c$ fixes the point of the scythe, so that $a d c$ forms an equilateral triangle; and of course the blade stands at an angle of $60^{\circ}$ with the snead. Theory would advise the placing of the plane of the blade parallel with the ground, when the scythe is held as intended for cutting; but practice requires the cutting edge to be a little elevated above the ground, and above the back of the scythe which sweeps along the surface of the ground; and the reason for keeping the edge elevated is, that it would not only be apt to run into the ground if swung parallel with it, but the scythe would be worked with greater labor, as the stems of the plants to be cut would present an obstacle directly at right angles against the blade, whereas the edge set upward cuts the stems in an oblique direction. The blade is still farther secured in its position by the grass-nail $f$, which is hooked by one end into a hole in the blade, and is nailed through an eye by the other to the snead; and a great use of the grass-nail is to prevent any plants cut from being entangled between the blade and snead. The left-hand handle $e$ is placed to suit the convenience of the workman. I shall reserve remarks on the mode of using and sharpening the scythe until we treat of harvest-work. 
(2609.) Objections have been made to pasturing grass at all by any species of stock, inasmuch as the same extent of land will maintain a greater number of animals when cut and given them in houses or yards. To express this proposition shortly, soiling is a more profitable and less wasteful mode of using grass than pasturing. Although there is much truth in the observation, it is too generally expressed to be true in all cases. In the case of mountain-grass it is evidently an impracticable proposition to use it by soiling. Much cattle and sheep must, therefore, be allowed to pasture; and with regard to much of the old grass of the low country a great part of the summer would elapse before it would be fit for the operation of the scythe. What is to become of stock in the mean time? The only other grasses left are the cultivated kinds, such as clover and rye-grass, and that from irrigated meadows. Of these two kinds it is quite possible to procure a supply of cut grass from water-meadows by the time the Swedish turnips are exhausted in the beginning of June; but the cultivated grasses are not fit for cutting by that time except in the neighbor-

- hood of large towns. What, again, is to become of stock in the mean time? Some other plants than clover and rye-grass must be cultivated to support the stock till that period; perhaps lucerne and Italian rye-grass might be cultivated for the purpose, but both cannot be cultivated everywhere, for lucerne will not thrive in Scotland, and before either could be cultivated anywhere for an extensive system of soiling, a different system of husbandry will have to be contrived, and a system to produce early forage in a late climate will not be easily discovered. In regard to the comparative extent of a ground required for soiling and pasturage, it has been alleged to be 3 to 1 in favor of soiling; that is, 33 head of cattle

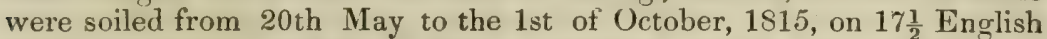
acres, and which number of cattle, it was said, would have required 50 acres to pasture them.* On the face of this statement I would say, that any 33 head of cattle that could be maintained on $17 \frac{1}{2}$ acres of cutting grass, would as easily be maintained on the same land on 33 acres of pasture-1 acre of pasture to an ordinary sized ox being quite sufficient to maintain it from May to October. So that the proportion is reduced from 2 to 1 , which I believe is near the truth in regard to the maintenance of oxen. In regard to work-horses, it is different, for they will certainly require a much greater extent of ground in cutting grass than in pasture. To cut grass, however, for all the cattle on a large farm, to lead it to the steading, and to supply them with sufficient litter in summer, is what I consider an impracticable thing, were it for no other reason than that the crop of grain on any farm that admits of its grass being pastured cannot afford sufficient straw to litter stock the whole year; and if sheep are to be included in the soiling system, where is the steading that could afford them accommodation? Nor is the objection against grazing of the manure of animals being entirely lost, altogether valid, because land that is constantly grazed will support stock to an indefinite time; whereas where grass is cut and rarried off every year, the time will soon arrive when the grass can no longer be cut until manure be applied to the ground. Does not this circumstance of itself show that the dung dropped on pasture is not entirely lost, and that the land derives considerable advantage from being pastured? I have often thought that all the work-horses on a farm might be supported in the steading night and day upon cut grass. I have tried the experiment twice myself, but failed in both cases, at one time for want of cutting grass, the second cutting having entirely failed that year, and the other for want of straw for litter until the arrival of the new crop.

- See Sinclair's Code of Agriculture, and Notes.

(523) 
The straw might have been economized in the stable, but the stable in summer, even with open doors, ventilators, and no hay-loft, is insufferable; and the horses required far more straw to keep them dry in the hammel on cut grass than they did on straw and corn in the stable in winter. Taking all these untoward circumstances into consideration, they led to the conviction that soiling on a large scale is impracticable; and until early growth of grass, as well as a late growth of aftermath, and plenty of straw, are assured to the farmer every year, I cannot see how soiling can be established as a regular practice in husbandry on a farm of even moderate extent. On a small scale where only a few animals of every kind are kept, I conceive that soiling might be practiced with advantage, and it behooves all small farmers to make their grass land go as far as possible.

(2010.) Work-horses, when on grass, are subject to few distempers, the principal being annoyance from a host of insects, and among these the common horse-fly or cleg, and the bot.fy, are the most troublesome. The cleg delights in warm and sultry weather; is most active on the wing during the day, and therefore most troublesome to horses and cattle when they stand most in need of repose. They are particularly excited and eager for blood when the atmosphere is in a warm and humid state, such as it usually is after a thunder shower; and it is this circum. ftance which has obtained the specific name of pluvialis for the cleg. Another pest to the hurse is the great spotted horse-bot, Gasterophilus equi, seen at a. fig. 362. It is about 7 lines in length;

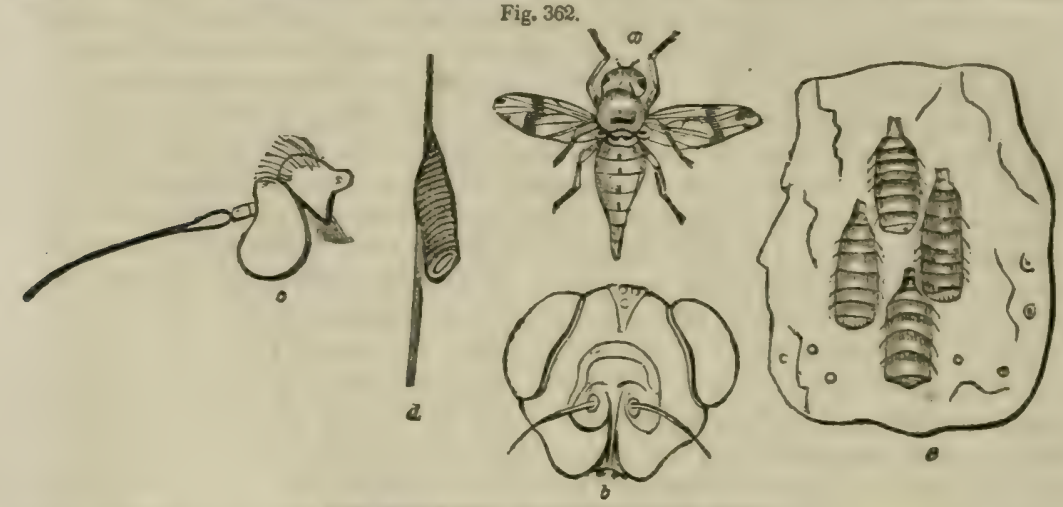

THE HORSE-BOT-GASTERUPHILES EQUT.

general color clear yellowish-brown; thorax inclining to gray; abdomen rust-brown, with a tinge of yellow; wings whitish; and legs yellowish. The antennæ are inserted in the cavity of the face, as seen at $b$, the second joint large and kidney-shaped, the remaining three forming 8 naked bristle as at $c$. The ejes are equally distant in both sexes; mouth either entirely want. ing, or consisting merely of an indistinct line or opening. This insect takes no nourishment of any kind; in fact, the alimentary camal has no opening at its anterior extremity. It flies in compawy, producing a hamming sound. "The fenale having selected the individual to which her treasure is to be intrusted." says Mr. Duncan, "she continues to hover about for a short time till the egg be propelled through the oviduct, and placed in the pincers at the extremity of the anal tabe. Thus prepared, she makes a sudden descent upon the horse-her body carried nearly in a perpendicular direction, and the ovipositor curved forward-and deposits the egg upon a bair, to which it instantly adheres by means of a glutinous matter secreted along with it. This process, which is performed with so much expedition that the fly can scarcely be said to alight on the horse, is reptated at intervals till the whole of the mature eggs are discharged." These egyss, which are very numerous, 400 or 500 being sometimes placed on a single hair, are somewhat pouch-shaped, and shagreened with transverse and longitudinal striæ. as eeen at $d$. Under the guidance of an instinct which cannot be sufficiently admired, the fly almust invariably atiaches her eggs to some part of the fore-quarter of the horse, the inside of the knee and the shoulder being the spots most commonly selected, so as to be within the reach of his mouth, for be is himself to be made the unconscious instrument of conveying them into his stomach. where alone they can be brought to maturity, the temperature of a horse's stomach being as high as $102^{\circ}$ Fahrenheit. Even when beyond the reach of the mouth, the eggs are not necessarily lost, for the horses are in the habit of licking each other, and a horse free from bots may thus receive them from another. "When the eggs are mature." continues Mr. Duncan, "it would seem that the larvæ make their appearance very soon after they are touched by the tongue, the warmth and the moisture both contributing to their immediate development. Indeed, if the larvæ were not disclosed before reaching the stomach, or very shortly after, the eggs would very soon pass into the alimentary canal. The larva fix themselves by hooks to the inner tissue of the stomach, where they remain in security, uninjured by the powerful action of the gastric juice, and enjoying the warmth of a 
tropical climate." A small group of these larvæ adhering to the coat of the stomach are represented by $e$. Their color is pale reddish-yellow. Their only food seems to be the humor secreted by the internal membrane of the stomach, or it may be the chyme, the latter undergoing a farther elaboration to adapt it to their system. Bots take up their quarters in the stomach in the end of summel or autumn; and pass the whole winter and spring months there, without undergoing any change, save gradually enlarging and advancing to matarity. When that is complete, they cease to retain their hold, pass into the intestinal canal, and are ejected by the anus. On accuunt of the many ordeals which this insect has to pass in its transformation, perhaps not 1 in 100 of the eggs ever arrive at the perfect state of fly. The red-tailed horse-bot, Gasterophilus hamorrhoidalss, though only half the size of the preceding, is nevertheless a greater torment to the horse. The female parent fly deposits her eggs on the lips of the horse, and this operation is attended with so much pain, that no sooner does it make him aware of the presence of the fly, than he tosses his bead and gallops off to a different part of the field, or, if he has the opportunity, betakes himself to the water, where his tormentor generally leaves him, having a peculiar dislike to that element. Indeed all the tribe of gad-flies have, and, to avoid them, it is not uncommon to see numbers of cattle lying on the sea-shore antil the approach of tide alone compels them to retire. When this fly succeeds in fixing an egg, the horse rubs his mouth against the ground or upon his fore-legs in great agitation, frequently striking out with his fore-foot, which occasionally comes in contact with the jaw, and serves but to increase his irritation. The larva are taken into the stomach, and fix themselves there, exactly in the same manner as the greater bot. When they reach the intestines, they remain a long time, casting anchor again in the rectum, where they cause great uneasiness to the horse, causing him to kick frequently, and even rendering his movements awkward. These bots should occasionally be looked for in horses that have been out at grass the preceding year, at the extremity of the anus. The only speedy remedy for getting quit of them is in backraking by the anus. The more rare species are the Gasterophilus nasalis, salutiferus, and Clarkii. Mr. Bracey Clark was of opinion that the presence of bots in no way injured the horse, but on the contrary, by stimulating the stomach, they tend to prevent colic, gripes, and other indigestions which affect the head of the horse and produce staggers. "The appearance of exanthemous eruptions on the skin," he says, "and the formation of local abscesses, from the same cause of partial irritation, often relieve a general disorder of the system. The mucous membranes of the skin possess this power, when irritated, in the most eminent degree, and to these the larvæ of the $O$ stri are applied. Irritating the membranes of the stomach in other animals would excite nausea and vomiting; but the horse not possessing this power, his stomach is peculiarly fitted for the stimulus of such animals." * An annoying insect of less importance is the Chrysops coecutiens, which is of a bright color, and though frequent in some parts of England, is not so great a pest there as to horses on the Continent. Another fly, the Stomoxyda calcitirans, is in size and markings not unlike the common house-fly, $M$ usca dom cstica. This insect attacks various animals, as well as man himself, and becomes very troublesome in certain localities. It attacks the legs, and its panctures are attended with great pain, especially in damp, moist weather. Another annoyance to horses is the forest-fly, Hippobosca equina. "The attacks of this insect." says Mr. Duncan, "are principally confined to horses. It occasions no other harm than an extreme degree of irritation, and if the flies are numerous, the animal is apt to become unmanageable. It insinu. ates itself by a sideling, crab-like motion beneath the hair, and anchors itself to the skin by means of its largely-toothed claws. It also runs about among the roots of the hairs with great ease, creating an insufferable titillation, which is still more increased by the frequent insertion of its proboscis into the pores of the skin. The places to which it prefers attaching itself are the under side of the belly, beneath the tail, and on the under side of the jaws. The insect is so flat, tough, and unyielding, that it is by no means easy to kill it by pressure, and it is, moreover, tenacious of life. It is said that horses long accustomed to its attacks become, in some measure, indifferent to them; those which have never experienced this plague, which is enough to render some animals almost frantic, may be saved from it, according to $M$. Kollar, by the following application. Take of mineral earth $8 \mathrm{oz}$. and of lard $1 \mathrm{lb}$, and make them into a salve. Some of this salve is to be rubbed on here and there upon the hair, and worked in with a wisp of straw. After 24 hours the salve is to be washed off with warm water, in which brown soap has been dissolved. Care must be taken that the horse does not catch cold."

\section{SHEEP-WASHING, SHEEP-SHEARING, AND THE WEANING OF LAMBS.}

\footnotetext{
" Gay shearing time approaches. First, howe'er, Drive to the double fold, upon the brim Of a clear river-gently drive the flockAnd plunge them one by one into the flood."
}

(2011.) I have said that as lambs become strong enough to be put to pasture, they always get new grass, in order to increase the milk of the

\footnotetext{
* Clark's Essay on Bots.
} 
ewes (1835). The new grass, to be pastured by ewes and lambs, should be selected with judgment, and that intended for hay should first be stocked, because it is found that new grass, if moderately eaten down in spring, stools out, and affords a thicker cutting at hay-time, than if it had not been so pastured. For the same reason, the new grass intended to cut for horses' forage, should also be earlier pastured than what is to be pastured all the season, not only to give both it and the hay-grass time to attain their growth when they shall be wanted, but to give the pasture-grass time to become Bo strong as to support being pastured. None of the new grass should be eaten too bare, even the part which is to be pastured by the ewes; and rather than commit such a mistake, even in a late season, the ewes should have a hasty run over the best of the older grass for a fortnight ur so, till the hained new grass has revived. After the castration of the lambs (1841), there is nothing to do to them until the ewes are washed preparatory to shearing the wool for them, and which is done about the beginning of June (1843).

(2012.) When the turnips are all consumed, and the time has arrived for the last of the turnip land to be plowed up for barley (1852), the hoggs receive a change of treatment. The wether-hoggs are either sold to the dealer of the turnips, or put to grass till shorn of their wool, and then disposed of ; but the ewe-hoggs are always retained on the farm, because it is they which supply the waste of ewes, and are, of course, clipped of their wool in due time. The circumstance that determines which of these ways the uether-hoggs should be treated, is the state of the wool and mutton markets. If you find, on examination, that the hoggs are so forward in condition as to realize as much money off the turnips, with current prices, as they probably would after being kept for a month on grass, and washed and clipped, it is, of course, more profitable to dispose of them at once; and, independent of this circumstance, should you fear the grass to prove insufficient to support them well till they are clipped, there is a necessity for parting with them immediately off the turnips; but should you find that you have grass to maintain their condition, and that the wool market is likely to be brisk, it would, of course, be advisable to clip them. It is of less importance to increase the condition of the ewe-hoggs off the turnips by putting them on the best grass, nevertheless they should not be allowed to fall. off in condition, for fear of injuring the quality of their wool. If you determine on selling the wether-hoggs, you should first ascertain their value; and in attempting this you will at once perceive, that a sheep wearing its coat of wool cannot be subjected to the ordinary rules of measurement; nor can its true weight be found by weighing it alive, because the weight of the wool enters as a disturbing element into the calculation, and the value of that material depends on very different circumstances from that of mutton. A new clipped sheep, however, may either be measured or weighed, and its value ascertained pretty nearly.The eye and the hand must be employed to judge of the weight of a rough sheep; and there is no more certain way of acquiring a correct judgment of its weight in that state, than by first handling the sheep in the way I have before described, and weighing the 4 quarters after it is slaughtered. An average sized sheep of a large flock thus treated will enable you to form a pretty correct idea of the average weight of the whole, and the market price of mutton per stone is quoted in all the newspapers of the day.

(2013.) The season for wasting sheep having arrived, a fit place should be selected for the purpose. It should consist of a natural rivulet, or, where that is wanting, of a large ditch, having both its banks clad with (526) 
clean sward. The next step is to form a damming across the rivulet, if it is not naturally sufficiently deep of water to conduct the operation of washing. The bottom of the river or ditch should be hard and gravelly, and the water in it pure, or it will not answer the purpose; as a soft and muddy bottom, and dirty water, will injure the wool more than do it good. A damming may be made either entirely of turf-wall built across the stream, though that imposes considerable labor and waste of grass, or with an old door or two or other boarding placed across the bed of the stream, supported by stabs against the weight of water, and the chinks at the bottom and sides filled up with turf; and over which, when the water accumulates, the water falls. In constructing this dam, the overflowing should be as great as to cause such a current in the pool as to carry away quickly all impurities, such as earthy matter, greasy matter, small locks of wool, and scum. One side of the pool is occupied by the unwashed, and the opposite by the washed sheep. They are confined in their respective places by flakes, fig. 216, or nets, fig. 217. To prevent any sheep taking the water of themselves, which they are apt to do when they see others in before them, the fence should be returned along the sides of the pool as far as the men who wash the sheep are stationed. Fig. 363 brings out all these

Fig. 363 .

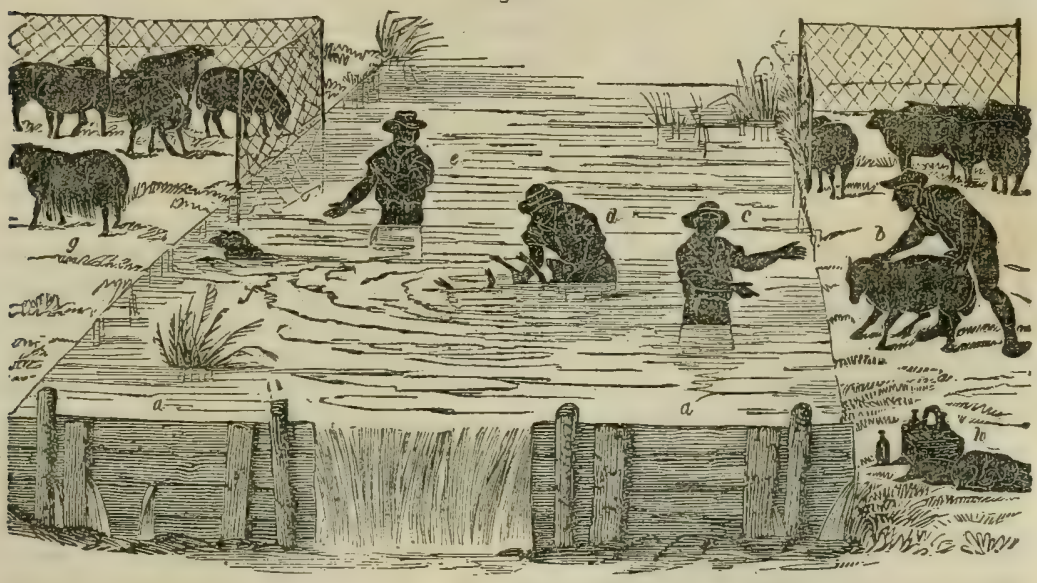

SHEEP-WASHING.

particulars pretty well. The damming $a a$, by means of doors and stabs, and turfing, retain the water until it overflows. The net on each side of the pool is returned so far down both its sides. The depth of the water is seen to take the men to the haunches-the proper depth.

(2014.) Everything being thus prepared at the pool, the sheep are also prepared for the washing. The lambs not being washed, and to save trouble with them at the washing pool, they are separated from their mothers, and left in a court of the steading until the washing is over. The ewes, hoggs and dinmonts are all taken to the pool in a lot. They shonld be driven gently, and not allowed to be at all heated. The ewes will be troublesome to drive, being always in search of their lambs; but, notwithstanding this annoyance, they should not be dogged, and rather give them plenty of time upon the road. They should be driven along the road most free of dust or mud. The men who are to wash also prepare themselves by casting their coats, rolling up the sleeves of their shirts, and putting on 
old trowsers and shoes to stand in the water with. The shepherd and other 2 men are quite enough to wash a large number of sheep thoroughly. but, if the stream is very broad, another may be required to save time in handing the sheep across. These 3 men are represented in the figure, $e$ being the shepherd, and the last man to handle the sheep, and $d$ and $c$ bis assistants. At least 2 men are required to catch the sheep for the washers, of whom 1 is seen at $b$. On an occasion of this kind the men receive a gratuity of bread and cheese, and ale, and also a dram of spirits as a stimulus, as at $h$, where the dog is seen to keep watch. Indeed, some stimulant of this kind is requisite for men who stand for hours in the water, the lower half of their body being chilled by the water, and the upper half being heated by the work. If they were provided with large fishermen's boots, they would less require such a fillip.

(2015.) The washing is performed in this way: While the 3 men are taking up their positions in the water, the other 2 are catching a sheep; and, to render this fatiguing work more easy, the fold should not be made larger than to contain the sheep easily. A sheep is caught, and is being presented by $b$ to the first washer $c$, who takes the sheep into the water, and, allowing its wool to become saturated with it, turns it over upon its back, keeping up its head, and taking a hold of the arm of a fore-leg with either hand, and of the wool on the opposite side of the head with the other. He then dips the sheep up and down, to and fro, and from one of its sides to the other, slowly, causing all the wool to ware backward and forward, as if rubbing it against the water. In doing this the water becomes very turbid about the sheep, and he continues to do it till it clears itself, when he hands the sheep to the next washer $d$, standing in the middle of the stream. Whenever $c$ gets quit of one sheep, another should be ready by the catchers for him to receive into the water. The second washer $d$ holds and manages the sheep in the same manner, and then hands it to the shepherd $e$, and is immediately ready to take another sheep from the first man. It is the duty of the shepherd to feel if the skin of the sheep is clean, and every impurity removed from the wool. The position of the sheep on its back is favorable for the rapid descent of earthy matter from the wool. Wherever he feels a roughness upon the skin, he washes it off with his hand; and wherever any clots are felt in the wool which have escaped the other washers, he rubs them out. The belly, breast, and round the head, he scrubs with the hand. Being satisfied that the sheep is clean, he dips it over the head while turning it to its natural position, when it swims ashore, and gains the bank at $g$. Its first attempts at walking on coming out of the water are very feeble, its legs staggering under the weight of the dripping fleece; in a little after it frees itself from the water entirely by making its fleece whirl like a large mop. It will be observed in the figure that the 3 men do not stand abreast across the water, but in eschelon; and they stand so for this reason, namely: the sheep being in the dirtiest state when in the hands of the first man $c$, his standing farthest down the stream allows the dirtiest water to flow away at once, and not come near the stations of the other men. The sheep being in a comparatively. clean state when it reaches the second man $d$, the water from it cannot render that more dirty which runs past the first man $c$. In like manner, the same sheep, when with the shepherd $e$, can but very slightly render the water impure to those below it, and, being washed higliest up the stream, gets an immediate supply of the cleanest water for finishing its washing. This is the way in which sheep are washed in the Lowlands; and from 2 to 3 scores may be washed in 1 bour, according to the size of the sheep, the activity of the washers, and the supply of water (528) 
Tups are washed 2 or 3 weeks before the rest of the flock, and clipped as long before to allow time to their wool to grow; and, as they are usually in high condition, their new wool rises soonest, and, of course, soonest allows the old fleece to be taken off. After washing, sheep should not be driven along a dirty or dusty road, nor should they be put into any grassfield having bare earthy banks, against which they might rub themselves. In fact, they should be kept perfectly clean until their fleeces are taken off. How long they should be kept depends on the state of the weather; for the wool must not only be thoroughly $d r y$, but the yolk, as the natural oil of the wool is called, must return again into it. Perhaps 8 or 10 days may suffice to produce both these effects. But another circumstance, more important than either, should receive attention before the wool is clipped, which is, that the new wool be risen fiom the skin before the old be attempted to be taken off. Disregard to this state of the fleece will make good clipping very difficult to accomplish, and it will certainly deteriorate the appearance of the fleece. You need be under no apprehension of the wool falling off when the new growth commences, for wool will remain for years upon the sheep's back if not clipped off, and the sheep be in a clean and healthy state. How many years the fleece may continue to grow I do not know, but I have seen a 3-years' fleece. Lord Western showed Anglo-Merinos, at the Show of the Royal English Agricultural Society at Oxford, in 1839, the fleeces of which, when clipped, weighed, I think, 20 lbs. each.

(2016.) A place under cover should be selected for clipping the fleeces. The straw-barn L, fig. 4, Plate IV. of the steading, is a very suitable place for the purpose. The end next the chaff-house $r$, between the two doors, will answer for the clipping process, and the remainder will contain the sheep under cover until they are returned clipped to the fields again. The clipping floor is prepared in this way: Let clean wheat straw be spread equally over the floor 2 or 3 inches thick, and spread over it the large canvas barn-sheet, the edges of which should be nailed down tight to the floor. The use of the straw is to convert the floor into a sort of soft cushion for the knees of the clippers, as well as for ease to the sheep. A hroom should be provided to sweep the cloth clean. A board $2 \frac{1}{2}$ feet above the floor should be provided to wind the fleeces upon, and it may be placed along the wall of the barn opposite to that occupied by the clippers. A space near this should be cleaned, and a sheet spread upon it, for putting the rolled fleeces upon. The remainder of the barn should be cleared of dust both from the floor and walls as high as the sheep can reach, and a little clean straw strewn upon the floor for them to lie upon.

(2017.) The instrument by which the wool is clipped off sheep is named wool-shears, as seen in fig. 364. They require no particular description farther than to explain that the bend or bowl $a$, which connects the two blades, acts as a spring to keep them separate, while the pressure of the hand on each side of the handle $b$ overcomes and brings the blades together. There are wool-shears which

Fig. 364.

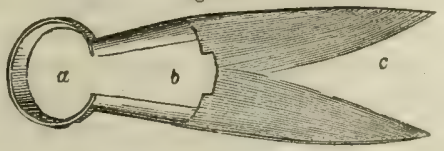

THE WOOL-SHEARS. have additional springs placed between the handles $b$ to separate the blades more forcibly, but are not so agreeable to the hand as the simple bent spring $a$. Sometimes the spring of $a$ is so strong as soon to tire the hand, to relieve which a piece of cord is wound slackly round the handles.Strong shears are more easily worked if held near the blades; but if held upon their sharp edges they will soon hurt the hand. When not in use, 
the blades are held together by their points being passed through a ring of leather. A rag-stone is used to sharpen wool-shears. The cost of the shears is from 2s. $6 \mathrm{~d}$. to $3 \mathrm{~s} .6 \mathrm{~d}$. each. A shepherd requires 2 or 3 pairs to do other jobs, and he makes it a rule to use clipping-shears on no other occasion than at regular shearing.

(2018.) In case of dew or rain in the morning, it is customary to bring into the barn as many dry sheep on the previous evening as the clippers will shear on the ensuing day. About 1 score of Leicester sheep to each clipper is considered a very good day's work. It is a frequent custom for neighboring shepherds to assist each nther; and though the plan does not, perhaps, expedite the entire sheep-shearing of the country, yet a number of men clipping at the same time makes work seem lighter, and it gets the clipping of any individual flock the sooner through. It is seldom that a steward can clip sheep, but it is accomplishment not unfrequently possessed by a hedger; and, if the cattle-man has been a herd, he can lend a hand as far as he is able, and in this way a party of clippers is mustered upon the farm itself. Clipping being both a dirty and heating work, the coat should be stripped, and the oldest clothes worn; and the hat and the vest are commonly thrown aside. Garters or tight knee-breeches will be found very irksome pieces of dress in clipping. There is an order followed in the classes of sheep as they are clipped-the tups are taken first, then the hoggs, and lastly the ewes; and, where there are dinmonts or wethers, they follow the tups. The reason for adopting this order is, that as tups are highest in condition, and having been earliest clipped the season before, their fleece rises earliest in this; and, if they are to be let in autumn on hire, the sooner they are washed and clipped, they will then show in better wool. Hoggs, too, being forward in condition, should be ready before ewes, as the latter lose their flesh by suckling, or require longer time to bring the yolk again into their old wool, and for the new to rise. The object of washing the sheep perfectly clean will be apparent at shearing, for if the shears grate upon anything, they will make had work; and if any dirt is found on clipping, either upon the skin or fleece, the shepherd is alone to blame who had the sheep last through hands, and had the charge of them afterward on pasture.

(2019.) Clipping is done in this way: Whenever a sheep is caught in the barn, every straw or dirt on the wool or hoofs should be taken away before it is laid on the canvas carpeting. Clipping consists of 3 stages, the first of which is represented in fig. 365. After setting the sheep on its rump, and, on the supposition that the clipper is a right-handed man, he goes down on his right knee, and leans the back of the sheep against his left leg $a$. Taking the shears in his right hand, and holding up the sheep's face with his left, he first clips the short wool on the neck, and passes down the throat and breast between the fore-legs to the belly. Then placing the fore-legs under his left arm, as seen at $b$ under $c$, the belly is left exposed to be next shorn across from side to side down to the groins. In passing down here, while the shears $d$ are at work, the left hand $e$ is engaged keeping the skin tight where it is naturally loose. The scrotum $f$ is then bared, then the inside of the thighs $g g$, and then the under side of the tail h. These complete all the parts of this position. For clipping this part of the sheep, small shears, as in the figure, will suffice; and as the wool is short and of a detached character on the under side of a sheep, it is best clipped away by the points of the shears, as by $d$.

(2020.) The shear's are used in a particular manner, to be safe alike to the fleece and the skin of the animal. The essential thing is to keep the points always clear of the skin, for, if held downward, they will inevitably (586) 
run into it; and, should such a prick be made when the hand is about to close, the consequence will be that a large piece of the skin will almost be clipped out before the clipper is aware of what he is about. This is a

Fig. 365.

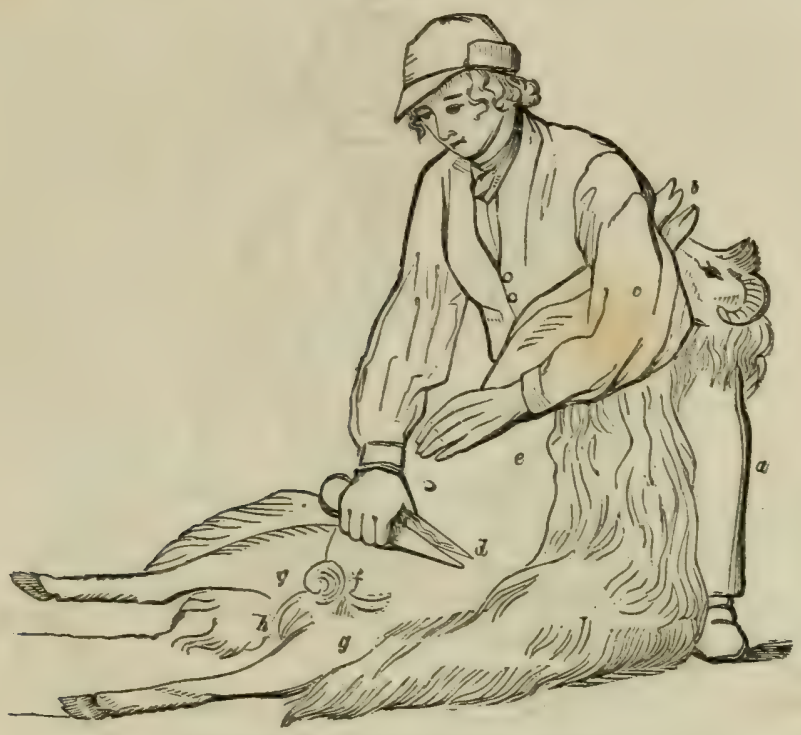

THE FIRST STAGE OF CLIPPING A SHEE

common error committed by new clippers, and it is a great offence in any clipper's hands. The only way to avoid this serious injury to sheep is to rest the broad part of the shears only and always upon the skin. In this position, with the skin drawn tight by the left hand, the shears are made to move forward with a hold of the wool not exceeding 1 inch in breadth, in very short and frequent clips, taking care only to bring together the broad parts of the blades from where they are seen to separate in fig. 364 to as far as $c$, keeping the points always apart. The form of the carcass of a sheep being round, it is clear that the shears cannot make a long clip by bringing the points of the blades together at every stroke, without cutting the wool with the points at a considerable elevation above the skin. Very short clips, no doubt, make slow work, but rather work slow with short cuts than injure the wool with long. Experience will teach you to make longer clips effective when you know how to manage the shears dexterously.

(2021.) Fig. 366 represents the second stage of clipping. Its position is gained by first relieving the fore-legs from the first position, fig. 365 , and, gently turning the sheep on its far side, the fore-legs $c$ are put under the right or clipping arm $f$, while the clipper, going on both knees, supports the shoulder of the sheep upon them, thus giving the animal an easy reclining posture. You may rely upon this fact, that the more at ease the animal feels, the more readily will it lie quiet to be clipped. Supporting the head of the sheep with his left hand, the clipper first removes the wool from behind the head, then around the entire back of the neck to the shoulder-top. He then slips its head under his left arm, as $a$ under $g$. Having the left hand thus at liberty, he keeps the skin tight with it, while he clips 
the wool with the right, from where the clipping in the first position was left off to the back-bone. In the figure the fleece appears to have been removed about half way down the carcass; the left hand $b$ is laid flat,

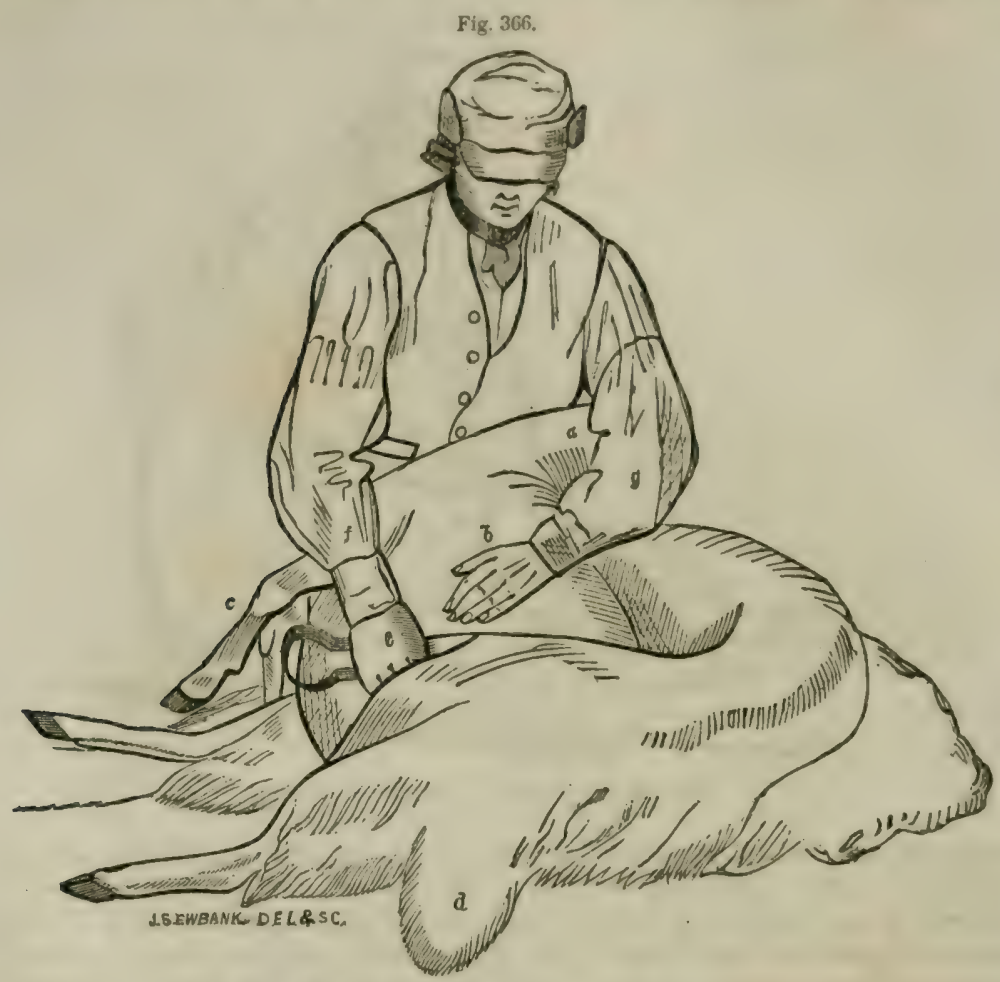

THE SECOND STAGE OF CLIPPING A SHEEP.

keeping the skin tight, while the right hand $e$ holds the shears at the right part and in the proper position. The clipper thus proceeds along the thigh and the rump to the tail $d$, which is entirely bared at this time.

(2022.) Clearing the cloth of the loose parts of the fleece, the clipper, holding by the head, lays over the sheep on its clipped side, and still continuing on his knees, slips his left knee $a$, fig. 367 , over its neck to the ground, while his left foot $b$, resting on the toe, supports the left leg $c$ over the neck of the sheep, and keeps its head $d$ down on the ground. This is the third position in clipping. The wool having been bared to the shoulder in the second position, the clipper has now nothing to do but to commence where it was left off in the first position, and clear the fleece entirely to the back-bone, meeting the clips where they were left off in the second position, the left hand $e$ being still at liberty to keep the skin tight, while the right hand $f$ uses the shears along the whole side of the tail. The fleece $g$ is now quite freed from the sheep. In allowing the sheep to rise, care should be taken that its feet do not become entarigled in the fleece, for in its eagerness to escape from the unusual treatment it has just received, its feet will tear the fleece to pieces. Immodiately that the lot of sheep in the barn is clipped, it is taken to the field, and another brought in its place. 
(2023.) A new clipped sheep should have the appearance of fig. 368, where the shear-marks are seen to run in parallel bands round the carcass, from the neck and counter $a$, along the ribs $b$, to the rump, and down the

Fig. 367.

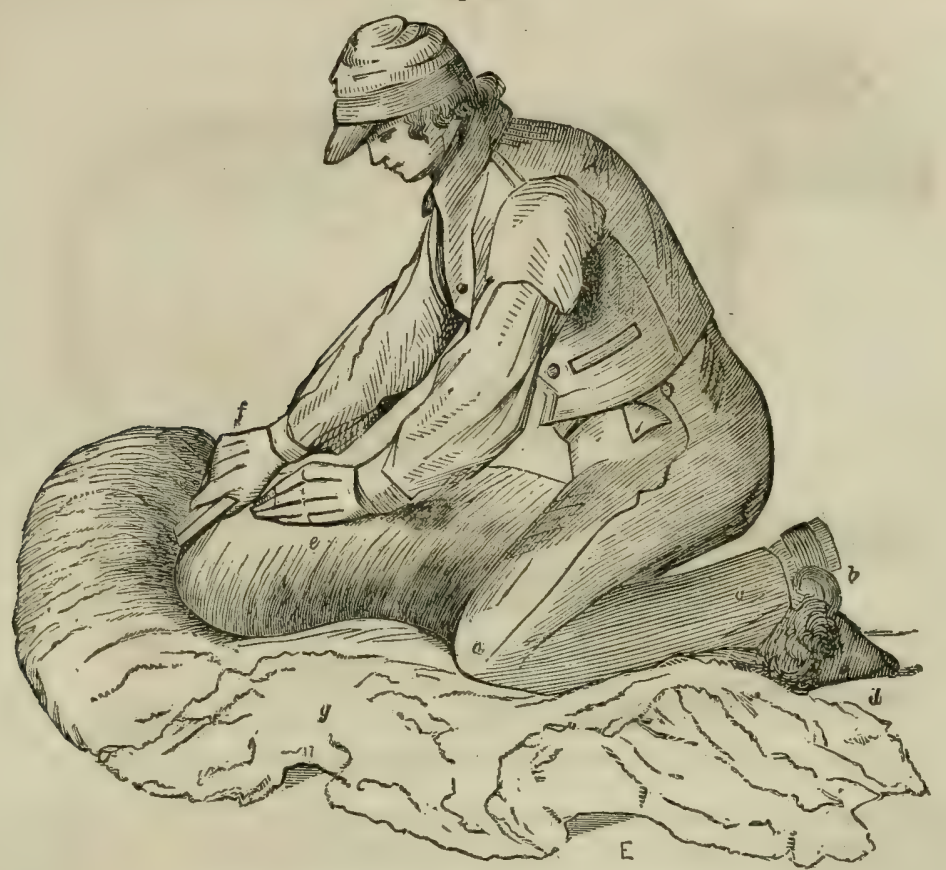

THE THIRD AND LAST STAGE OF CLIPPING A SHEEP.

hind $\operatorname{leg} c$. When pains are taken to round the shear-marks on the back of the neck $d$; to fill up the space in the change of the rings between the counter and the body at $e$; to bring the marks down to $f$ to the shape of the leg; and to make them run straight down the tail, a. sheep in good condition so clipped forms a beautiful object. A sheep clipped to perfection should have no marks at all, for they are formed of small ridglets of wool left between each course of the shears; but such nicety in clipping with shears is scarcely possible, and, at any rate, the time occupied in doing it would be of more value than all the wool that would be gained. It should be borne in mind, however, that the closer a sheep is clipped, it is in a better state for the growth of the next year's fleece.

(2024.) I have introduced so many illustrations on this subject, in order to show the most easy positions that can be assumed in clipping, both to man and animal, that those positions may easily be compared with the common ones. On making this comparison, it is necessary to look again at the first stage of the process, fig. 365 , the common practice being to place the sheep upright on its tail, and the clipper to stand on his feet, supporting its back against his legs-an insecure and painful position for the sheep, and an irksome one for the man when he bows down to clip the lower part of the animal. Again, in the second stage, fig. 366 , it is customary for the man still to remain on his feet, and the sheep upon its rump, while he secures its head sideways between his legs, in order to (589) 
tighten the skin of the entire side which is now bent outward. The skin is thus certainly tightened, but at the expense of the personal ease of the animal; for the hand can tighten the skin as well, as shown in figs. 366 and 367 , by $b$ and $e$, while the bowing down so low, and as long, until he

-

Fig 368 .

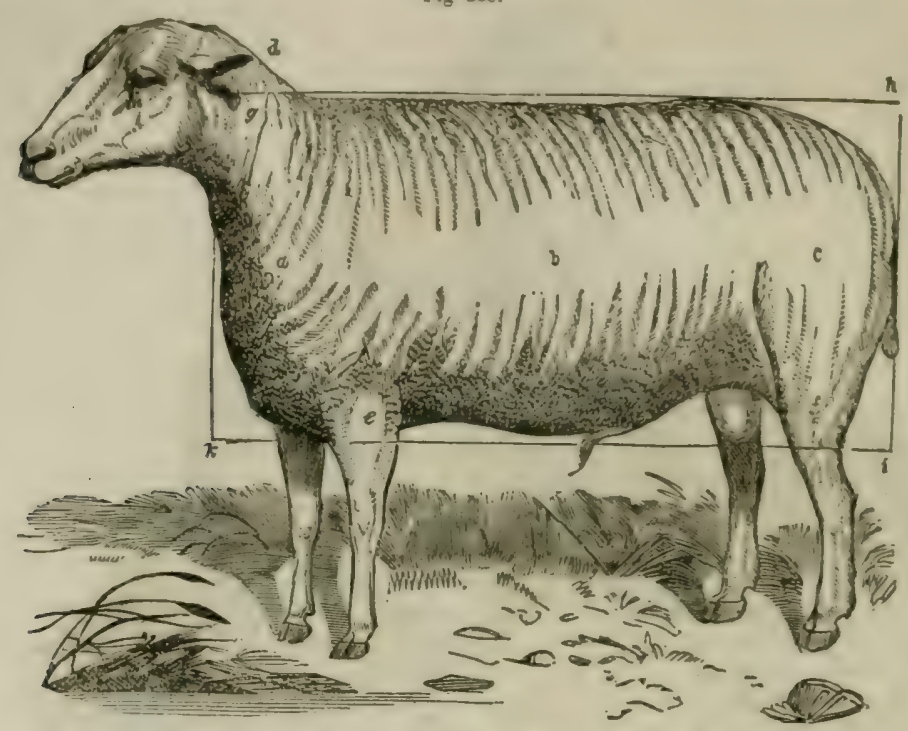

A NEW-CLIPPED SHEEP-THE PARALLELOGRAM SHOWING ITS SYMMETRY.

clips the entire side, cannot fail to pain the man's back. The third position is nearly the same in both plans, with this difference in the old one, which keeps the right leg bent, resting on its foot-a far more irksome position than kneeling on both knees. The treatment of the fleece I shall consider in a separate section; and the mode of washing and clipping Highland sheep will be found below. I may here remark that sheep. shearing is usually held as a merry season, a sort of harvest in which an allowance of good victuals-beef and broth and beer-is usually awarded to clippers engaged at their fatiguing task.

(2025.) Clipping makes such a change on the appearance of sheep that many lambs have difficulty at first in recognizing their mothers, while a few forget them altogether, and wean themselves, however desirous their. mothers may be to suckle them; but as the ewe is content with one lamb, many a twin which does not follow her is weaned on this occasion. It should be the shepherd's particular care to mother the lambs frequently after clipping; but I am aware of the difficulty of bringing an old lamb and ewe together, without much disturbance to the rest of the flock; and besides, the shepherd cannot attend constantly on the clipped portion of his flock while engaged with clipping the rest, and this being the case constitutes another reason, besides those previously given (2018), for clipping the ewes last. Leicester lambs are weaned at the end of June or beginning of July ; and the process is simple and safe, as most of them by that time chiefly depend upon grass for support. All that is required is to separate the lambs from the ewes, in fields so far lying asunder as to be beyond the hearing of the bleatings of each other. Where there is the convenience, lambs should be put on hilly pasture for some weeks at this (590) 
time, the astringent quality of which gives an excellent tone to their system, and renders them more hardy for winter. Some farmers even hire rough hill pasture for their lambs, but where such cannot be had, they are put on the oldest, though good pasture, for a few weeks before the aftermath is ready to receive them.

(2026.) The ewes, when separated from their lambs, should be kept in a field of rather bare pasture, near at hand, until their milk be dried up. They must be milled by the hand, for a few times, till the secretion ceases -once, 24 hours after the lambs are taken away-again, 36 hours thereafter-and the third time perhaps 2 days after that. Even beyond that time a few may feel distressed by milk, which the shepherd should relieve at intervals until the udders become dry. Indeed, milking after weaning of lambs, is essential to the safety of ewes, and I fear it is not so effectually performed as it should be until the udders go dry. The danger to be apprehended from its neglect is the plugging up of the teats with caseous matter, deposited therein by the milk which should have been drawn away; and which plugging, in the next lambing-season, will probably prevent the natural flow of the new milk; and the consequence will be that inflammation will be set up in the udder, and the ewe either take puerperal fever, that is, udderclap, or garget (1847), and die, or her lambs be so restricted of milk as to be half starved. Ewes are milked in a very different manner from cows. A long, narrow bught, formed of hurdles on both sides is erected along a fence close to the gate of a field near the steading or dairy, and it should be no larger than to contain all the ewes in a crowded state. The ewes being driven into the bught head inward, women proceed with the milking, which is accomplished by holding a small handy, that is, a small vessel formed like a milking-pail, in the left hand, and, squatting down behind the ewe, the milk is stripped clean from the teats alternately, with the right hand into the handy. The milker requires to be always on her guard, and remove the handy the instant she sees the ewe showing the least symptom of voiding either water or fæces, and a ewe is very apt to void the former whenever she is touched behind for the first time. Every ewe is turned out of the bught by the shepherd as it is milked, to prevent its coming in hand again. Time was when ewe-milking created a great stir in the farm-house for the making of ewe-milk cheese, and so much anxiety did housewives evince to make it, that the ewes were milked till they were perfectly lean to supply a sufficiency of this sort of milk. Better ideas now prevail, and farmers very properly will not allow their ewes to be milked oftener than is requisite to render them completely dry. It was misplaced economy to reduce the condition of the entire ewe flock for the poor boast of making a few strongtasted cheeses.

(2027.) When lambs cease to bleat for their mothers, they should be marked and buisted, not only to identify them with the flock of the farm on which they are bred, but ss a repord of the particular blood from which they are descended. The markings are rnntined to the ears, and consist of small pieces being cut out, or slits made in the tips, with a knife, from the fore or back margin, or of holes made with punching-nippers, or of a combination of both sorts of marks. The female stock are always marked on the near ear, and the male on the far one. Thus, a single round hole is punched through the near ear of all the ewe-lambs, and a similar hole through the far ear of the wether-lambs; and should any of the ewe-lambs be considered fit for breeding tups, they either receive an additional hole through the near ear, or a bit cut out from a margin of the same ear, corresponding to a similar mark on their dams or sires, to distinguish their (591) 
particular blood from the rest of the flock. Twin ewe-lambs receive a hole through both ears. Tup-lambs receive no ear-marks, their long tail serving the purpose till they are weaned, when they are at once transferred to the tups. Indivilual tups are so easily identified, and their descent so well known by the shepherd, that they require no marking. Fig. 369 are the punching-nippers, of which the inverted hollow cone $a$, having its small end sharpened, is employed to cut the hole out of the ears; and, to save the ears from being unduly pinched, a pad of horn $b$ is inserted into the straight under-arm of the nippers, the pieces nipped out rising out of the orifice $c$. The figure at once shows how the instrument is used, being sim-

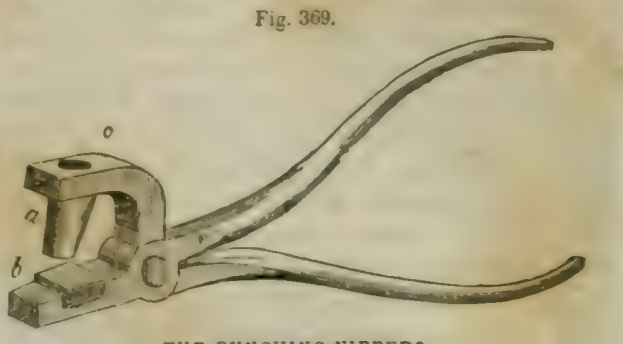

THE PUNCHING-NIPPERS.

ilar to the one used by shoemakers to punch holes into the lappets of shoes, through which the shoe-strings are passed, and it costs $2 \mathrm{~s} .9 \mathrm{~d}$. Buisting consists of stamping a letter or letters, expressive of the initials of the name of the owner or of that of the farm, or of both. The buist or mark is effected by a simple instrument $a$, fig. 370 , which carries the capital letter $\mathrm{S}$. This mark is made on the same principle as the ear-marks, the near side indicating the female, and the far side the male sheep. The material of which the buist is made is boiled tar, made viscid by a little pitch. The sheep to be buisted are put into a convenient apartment of the steading, and handed out one by one, and kept steady by holding the head and rump by the hands; and a knee being placed against the opposite side causes the side to be marked to project. The buist is then dipped lightly into the melted tar, to prevent its dripping; and, to make the mark vivid, it should be applied with some force, and with the entire surface at once, to compress the wool equally, and then quickly withdrawn. The wool must be quite dry, or the tar will not adhere to it. All newclipped sheep are buisted in this manner; and though but a temporary mark, being in time obliterated, though not on short wool, it serves the present purpose well. To my taste, the buist looks best on that point which is the roundest part of the rib, but others prefer it on the shoulder, the rump, or the loins. In fig. 370 is another instrument $b$, the branding-iron, also bearing

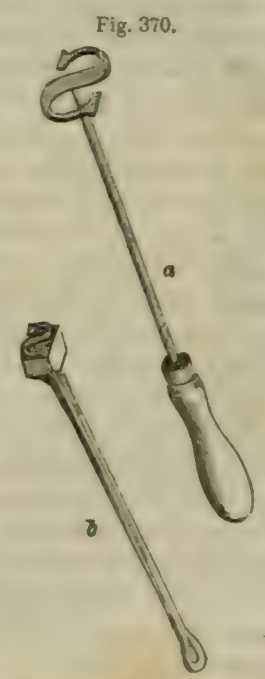

THE BCISTING-IR() A ND BRA NDING-IRON. the capival letter S. It is sometimes used, and, on being heated in the fire, is applied to brand the letter on one side or other of the nose, or on one of the horns, of Black-faced sheep, or on the horns of Highland cattle, in lieu of the punching-nippers or knife, and it makes an indelible mark. To save twice handling of the lambs, they should be marked and buisted at the same time-one person making the marks, another applying the buisting-iron. The buist costs 3 s., and the brand $4 \mathrm{~s}$., though a smaller instrumert, as the letter has to be cut out of the brand like that of a die, and it must be made of the best iron to stand frequent heating. These are all the operations to which sheep are subjected in summer. 
(2028.) Scalded Heads.-Sheep are much infested in sunmer with flies. As a protection to the head against them, the simple cap, or hood, as seen in fig. 371 , is effectual. It may be made of stout linen, and fastened with 4 tapes tied crosswise under the chin, or of leather, and buckled at the same place.Leicester tups should not be without these caps in summer, especially when grazing near woods; and, as tups are occasioually apt to box each other, any little portion of skin which may thereby be abraded on the head will receive immediate protection from the cap.

(2029.) Doddering.-One great means of warding off the attack of the fly on hoggs is doddering, especially in localities obnoxious to flies. This operation consists of clipping away all the wool off the tail and between the hind-legs.Should hoggs scour, which they are not unapt to do when put on foggage immediately after being weaned, and when there

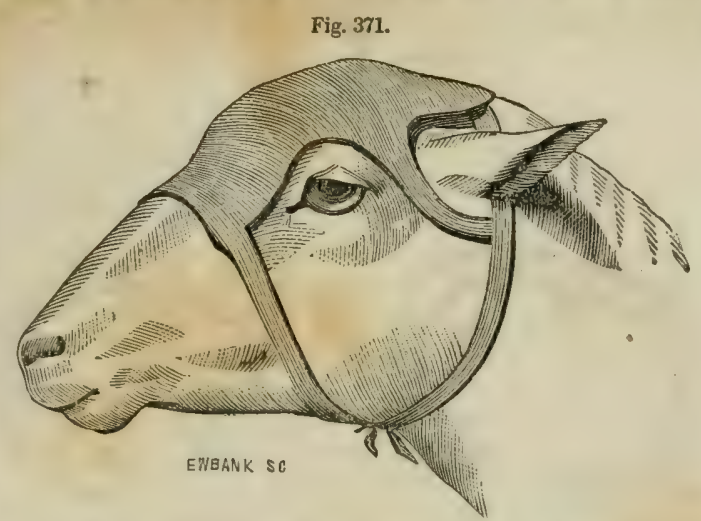

THE HEAD-CAP, OR HOOD, FITTED ON THE SHEEP.

is no rough moory or hilly pasture to put them upon previously for some weeks, the removal of the wool will prevent the discharge remaining about the animal, and, of course, deprive the fly of one object of attraction. The use of docking the tails of sheep is now made obvious (1841).

(2030.) Those who have many horse-chestnut trees, Asculus hippocastanum, may be pleased to learn that their fruit, which is considered worthless, and even poisonous in this country, though both opinions are erroneous, may be asefully employed in feeding sheep. "While I was at Geneva in the autumn of 1837," says a correspondent, "I observed every one collecting carefully the fruit of the horse-chestnut, and on inquiry I learned that the butchers and holders of grazing stock bought it readily at a certain price per bushel. I inquired of my butcher, who himself kept a very extensive grazing farm, and he told me it was given to those sheep in particular that were fattening. The horse-chestnuts were well crushed-something in the way, so I understood, that apples are-previous to cider being made. In Switzerland, they are crushed or cut up in a macbine kept solely for that purpose; then about 2 lbs. weight is given to each sheep, morning and evening. Sheep eat it greedily; it must be portioned out to them, as too much would disagree with them, it being of a very heating nature. The butcher told me that it gave an excellent rich flavor to the meat. The Geneva mutton is noted for being as bighly flavored as any in England or Wales."*

(2031.) Sheep on hill-pasture delight in summer to spread themselves over, and to go to the highest point of their range. Ewes are restricted in their range by the lambs, which, when young, show little inclination to wander afar, but rather to lie down and sleep after being satisfied with milk. Hoggs keep much together, and on that account do not wander far from their morning lair, wherever that may be. Wethers, on the other hand, attain the hight of their pasturage at an early period of the day, and remain till dusk. You thus see, when sheep of different ages are brought up together, how usefully they distribute themselves over their entire pastare; and where only one class of sheep are reared, they extend their range according as their age increases, or their food becomes bare. On contiguous estates, where there is no march dyke to define their common boundary, it is quite possible that the flock of one property may occasionally trespass on the pasture of another. Should this bappen in the early part of the day, the shepherds should not dog off the strange sheep, as that may render them restless even for days; but wait till nightfall, and then point them gently over the march to their own ground, where they will take to their usual lair. Sheep usually select a spot for resting at night, and it will mostly be that which is safest for them, especially if the sheep are aged, and well acquainted with the ground. In fine weather they should not be disturbed in thus selecting their lairs, but in case of threatening storm they had better be directed to the sheltered side of the pasture, or even near the stells, if need be. Within inclosed fields in the Lowlands, sheep can hardly go wrong in summer in selecting their lairs for the night.

(2032.) The figures of the bull's ring and bullock-holder not having reached me when their use was described in (1994), I here give them before concluding the account of the treatment of stock in summer. Fig. 372 represents the-bull's ring in an open state, ready to be inserted into the bull's nose, the joint $a$ allowing the two sides of the ring to open as wide as the end $b$ may be inserted into the hole burned into the septum of the nose. Fig. 373 shows the ring closed, after it has been fastened into the nose, $a$ being the joint, and $b$ the two ends of the ring lapped over and secured together by 2 countersunk screws. The ring is formed of $\frac{1}{4}$.inch rod-iron, and its diameter over all is $2 \frac{1}{2}$ inches, and it should be highly finished.

* The Gardener's Chronicle, 21at October, 1843. 
(2033.) The Bullock-holder is well represented by fig. 374. where $a$ is the joint which allows its two parts to open 80 far as each to enter a nostril of the animal. The lever nut $c$ brings the two knobbed points $b$ as close as to embrace and hold firm the septom of the nose. The leading rein is fastened to the ander ring $e$. This form of bullock-holder would allow the points $b$ to be

Fị̣. 372

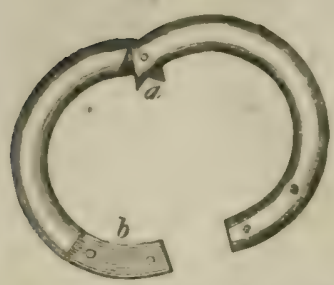

THE BELL'S RTSG IN A STATE TO BE INSERTED INTU THE BULL'S NUSE.
Fig. 373.

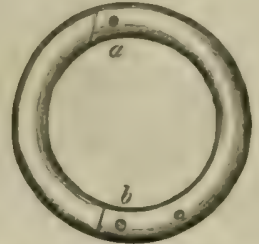

THE BLZL'S RING AS FASTENED IN THE BULL's NusE.

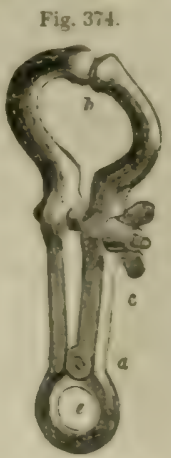

THE BITLOCKHOLDER.

screwed to any degree of tightness, nutil they meet each other; and it is, in my opinion, so far objectiunable, as the screwing may be carried as far by a rash hand as to hurt the animal when the instrumeut was moved in the least derree to either side. Another form which I have seen and approve of, never allows the two knobs $b$ of the instrument to be screwed closer than just to embrace the septam of the nose, allowing the holder to swing from the nose at ase while it holds the nose firmly whenever the animal attempts to move away. The cost of a bullock-bolder of either of these forms is 48 . each.

\title{
26. ROLLING THE FLEECE, AND THE QUALITIES OF WOOL.
}

\author{
"Come, gentle swains, the bright unsullied locks \\ Collect: \\ Be faithful; and the genuine locks alone \\ Wrap round; nor alien fake, nor pitch enfold; \\ Stain not your stores with base desire to add \\ Fallacious weight." \\ DYRR.
}

(2034.) Whenever a fleece is clipped from the sheep, a field-worker should be ready to roll it up. I have already said that a board should be provided to roll the fleeces upon, and it may be erected either in the clipping-barn, or any other adjoining apartment, such as the corn-barn; but the most convenient place for it is beside the clippers, as is also the stance for the rolled-up fleeces to lie upon till the end of the day's work, when they are removed to the wool-room. Suppose the board to be placed in the clipping-barn, the fleece, whenever separated from the sheep, is lifted unbroken from the cloth, and spread upon the board on its clipped side. The winder examines the fleece that it is quite free of extraneous substances, such as straws, bits of thorn, of whin, or burs, and removes them, and she also removes, by pulling off, all locks that have lumps of dung adhering to them, and which have escaped the notice of the washers. The farmer should be very particular in giving instructions on the purity of the fleece, as the purchaser cannot unloose every fleece he buys; and should he find as much filth in the fleeces after purchase as to warrant the helief that it had been purposely left in them, he may either relinquish his bargain, or make a large deduction from the price-in the former case imply- 
ing fraud on the part of the farmer, and in the latter diminishing his profits. And besides the disgrace, any person who attempts to commit fraud in the case of wool is liable to be merced in heavy fines when informed against, which he puts in the power of the purchaser of the wool to do. The winder being satisfied that there are no impurities in the fleece, folds in both its sides, putting any loose locks of wool into the middle, and making the breadth of the folded fleece from about 24 to 30 inches, according to its size. She then begins to roll the fleece from the tail toward the neck as tightly and neatly as she can, and when arrived at the neck, draws the wool there as far out, twisting it into a sort of rope, as will go round the fleece, hold its own end firm, and make the entire fleece a tight bundle. The fleece is then easily carried about, having the clipped surface outside, which, being composed of wool saturated with yolk, exhibits a shining, silvery lustre. Fleeces are by no means all alike either in structure or color. Those of ewes, for instance, will be found thin and open in the locks, of pale color, and feel light in hand; those, again, of hoggs will be close and long in the pile, of a rich color, and the rolled fleece will feel heavy and be bulky in hand. Neither will all the fleeces be alike entire and in proper condition. An occasional fleece may want some part, having been shed off; and another may be coated, that is, have its wool felted together like a piece of very thick cloth; while another may be a black fleece. Whenever any such difference is observed in a fleece, it should be laid aside. The inferior stray locks, and those clotted with dirt, should be put into a basket by themselves, to be afterward washed, dried, and used at home for various purposes, such as in repairing of saddlery. Every day's.clipping is carried into the wool-room, at $W$ in the steading, fig. 4, Plate IV., which enters by a stair from the straw-barn. Previous to being occupied, the room should be completely swept of all dust from its floor and plastered walls, and washed clean and dried. The fleeces are built up on the floor at a little distance from the wall, putting the hogg and ewe fleeces in separate divisions. The whole are covered with clothes, and the shutters of the window closed. The reason for these precautions, which are too seldom attended to by farmers, is, that the cloths keep off dust, prevent too quick evaporation of the yolk of the wool, which, if allowed, will diminish its weight, and the window-shutters being closed excludes the light, which obscures the bright lustre of clipped wool. The odd fleeces and locks should not be brought into the woolroom at all, but the former sold, and the latter prepared for use immediately, as their unclean state creates an effluvium which induces the woolmoth, the Tinea sarcitella of Linnæus, to come into the wool-room.

(2035.) Wool is a ticklish article for a farmer to keep long. If the wool-room is too dry, the natural moisture, occasioned by the yolk, evaporates, and the fibres become curled, and feel harsh; and on the other hand, if it is too damp, which is its usual condition, the fleeces become compressed, feel clammy, and affected with green and yellow mould. The wool-moth then takes up its residence, in summer, among such fleeces, and breeds numerous larvæ, which subsist on the very fibres of the wool, and of course entirely destroy their character. There are farmers who have no wool-room, but keep their wool in the granary or an outhouse, where, of course, either of these effects are aggravated. The best means that I know of preserving wool for a length of time in the fleece, is to keep it in a wool-room with a wooden floor, packed in the pack-sheet, in which it will be out of reach of dust, light, and moths, and where no more air and light need be admitted than is desirable. If it is meant to keep wool only for a fow weeks, the means spoken of in the last paragraph are all that 
are requisite. The safest plan for the wool-grower is so sell it every year at the current prices, which are determined at the great wool fairs that take place in summer in many parts of the country, where wool-dealers attend, and whose proceedings are duly reported in the newspapers.

(2036.) When a wool-dealer purchases wool from a farmer, he sends his own people to pack it in his own pack-sheets. Wool is weighed and packed in this way: wool is sold in Scutland by the wool-stone of $24 \mathrm{lbs}$. avoirdupois, and it is weighed out in double stones of $45 \mathrm{lbs}$, each being called a wigh. Usually 7 Leicester hogg and 11 ewe fleeces make 1 weigh. In England, wool is sold by the $\mathrm{lb}$. and weighed out by the tod of 2 stones of $14 \mathrm{lbs}$. each, or $28 \mathrm{lbs}$. In weighing out, the above number of fleeces may not exactly weigh the double stone; and, as fleeces are never broken to equalize the scales, a few small weights are used to balance the scale either on the side of the wool or of the weights, at each weighing. In this way the weight of the number of scalefulls required to fill each pack are correctly ascertained, a memorandum being taken of the number of weighings. While a simple and large beam and scales for weighing the wool is erecting, the pack for containing the fleeces is also making ready, so that they may be packed immediately from the scales, and save much handling. Pack-sheets are made of thin canvas, of the shape of an oblong rectangle, about 8 feet long when empty, and open along one side. A small stone being placed in each end of the opening of the sheet, a rope for each end being suspended from the ceiling, the stones form knobs which prevent the corners of the sheet slipping through the ropes, as at $a a$, fig. 375 . The sheet $d$ is suspeuded just

Fig. 375.

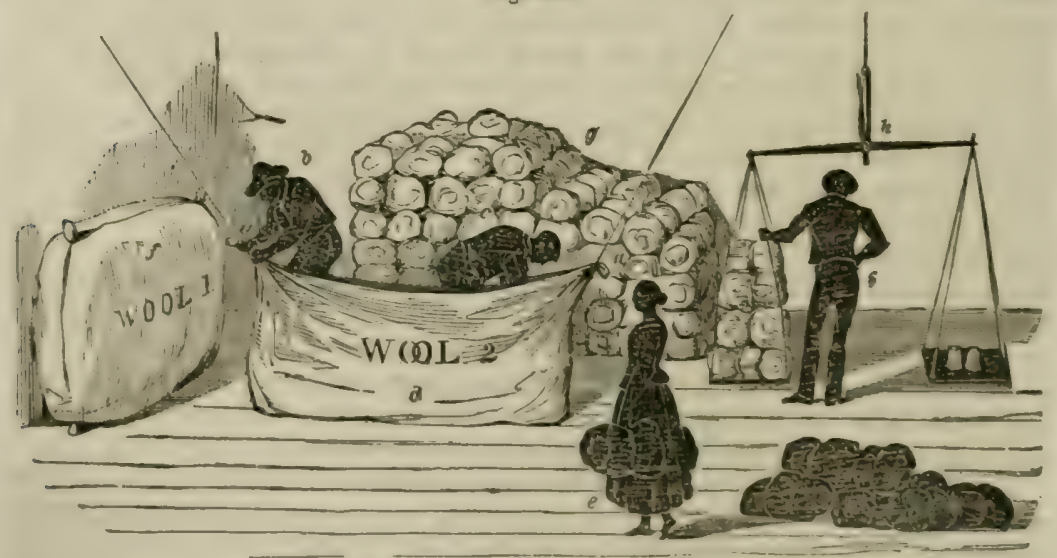

THE WEIGHING AND FACKISG OF WOOL.

to swim above the floor. Two men, $b$ and $c$, then get into the sheet, anc placing the fleeces, as handed to them by the woman $e$, in regular order lengthways across its bottom, trample them down with considerable force especially at the corners, where they are pushed down with both feet set together, while both hands are holding firm by the outside of the corner of the sheet immediately under the tying, as shown in action by the man $b$ The second layer of fleeces is laid contrary to the first, that is, in length along the sheet, placing 2 or 3 fleeces parallel in the breadth of the sheet; but the fleeces at the ends are always placed across the length of the sheet, in the same position as before, and pressed down in the same manner. The sheet is thus filled with alternate layers of fleeces to the top, when (596) 
the packers leave it, and then loosening the ropes, and reserving the small stones for the next sheet, immediately close the mouth of the pack; for if left open, the elasticity of the wool will cause the fleeces to rise so far as to render the closing afterward impracticable, and a pack is difficult to close at any time. With the aid of hand-cramps, inserted into the opposite sides of its mouth, the edges are brought together, and are so held by iron skewers being passed through both edges. When a farmer is packing wool on his own account, it is as well to know that common tableforks answer as well as hand-cramps for pulling the edges of the packsheet together, and for keeping them as close as skewers. The edges being thus brought together, they are permanently secured by sowing with packing-needle and stout twine, and the skewers are removed as the sewing proceeds. Thus, one pack is filled after another. A pack of wool $f$ contains 10 stones, that is, 240 lbs. Any wool I have seen packed in the Highlands, was not put so regularly into the sheet as I have described; the fleeces were crammed in and trampled down in the most irregular and promiscuous manner. I once had an opportunity of seeing merino wool packed on a large scale at Leipsic. The sheets were made of horse-hair, and, during the packing, were occasionally subjected to the pressure of a long pole of wood acting upon them as a lever. The pole was fastened at one end by a ring to the ground, and heavy weights were suspended, and a rope passed from the other through a ring in the ground, to keep good what the lever had gained. The wool was packing for Great Britain, and was to be conveyed in large wagons, each drawn by 8 stallions, to be shipped at Rotterdam. In the rest of the cut the wool is seen piled up at $g$, and the man $i$ is in the act of weighing a scalefull with the large beam and scales $h$.

(2037.) Even on the slightest inspection of a fleece on the sheep's back, one can perceive that it contains wool of different qualities; the coarser is evidently below and the finer above; but none but wool-staplers would discover 10 different qualities of wool in the same fleece. As a general description of a fleece, I may mention that the finest wool is upon the shoulder and along the top of the back to the rump; the next best is below the shoulders, along the ribs to the rump-the coarsest being on the haunches-and that below the belly is short and detached, and cannot be classed with the rest. Each of these parts have their respective qualities, which wool-staplers classify, in order to satisfy the wants of their customers, the manufacturers. The subdivision of the fleece by wool-staplers, after they have purchased the wool from the farmers, is technically in these terms: Prime-choice-super-head-downrights-seconds-fine abbcoarse abb-livery-short coarse or breech-wool. It would be well for wool-growers to receive lessons from wool-staplers on the essential properties which constitute good wool, that they may be able to judge whether the wool which they grow be intrinsically good or bad, comparatively improving or deteriorating, or to what species of manufacture it is best suited. According to present practice, wool-growers, I believe, demand prices for their wool on the faith of markets, without knowing whether their wool is really worth a high or low price.

(2038.) Good wool should have these properties: The fibre of the staple-a staple being any lock that naturally sheds itself from the restshould be of uniform thickness from root to point; it should be true, as the phrase has it: the finer the wool, the smaller is the diameter of the fibre; the fibre should be elastic, and not easily broken; its surface should have a shining silvery lustre; and it should be of great density or specific gravity. Of a staple, all the fibres should be of the same length, otherwise the (597) 
staple will have a pointed character; the end of the staple should be as bright as its bottom, and not seem as if composed of dead wool ; the entire staple should be strong, and its strength is tested in this manner: Take the bottom of the staple between the finger and thumb of the left hand, and its top between those of the right; and, on holding the wool tight between the hands, make the third finger of the right hand play firmly upon the fibres, as if in staccato on the strings of a violin, and if the sound produced be firm and sharp, and somewhat musical, the wool is sound; if the fibres do not break, on repeatedly jerking the hands asunder with considerable force, the staple is sound; if they break, the wool is unsound, and, what is remarkable, it will break at those places which issued from the felt of the sheep when the sheep was stinted of meat or had an ailment; though it will not break at every place simultaneously, because the weaker part, occasioned by the greater illness, will first give way. A good flecce should have the points of all its staples of equal length, otherwise it will be a pointy one; the staples should be set close together; and it should be clcan. One essential good property of wool is softness to the feel like silk, which does not depend on fineness of fibre, but on a peculiar property of yielding to the touch at once, and readily returning to the hand. There should be no hairs in wool-neither long ones, which are easily distinguishable from wool, and give the name of bearded to the fleece; nor short

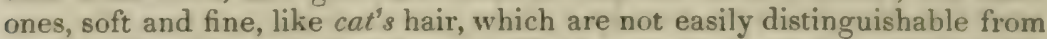
wool, and are denominated kemps. The long hairs are frequently of a different color from the wool, but the kemp hairs are of the same color; and, of the two, the latter are much the more objectionable, as being less easily detected.*

(2039.) Keeping all these properties in view, it is clear that a farmer who breeds sheep having fleeces with pointy staples, thinly set on, and of unequal lengths - who stints his sheep of food at one time, and overfeeds them at another, thereby producing wool of unequal size, and therefore untrue-who, moreover, does not wash his sheep clean, or, having so washed them, allows their wool to be again dirtied before being clipped, therehy creating much waste to the manufacturer to bring the wool again to a clean state-the farmer who manages his sheep and wool so as to produce these effects, injures himself to an incalculable extent.

(2040.) It is remarked by Mr. Culley that "the Herefordshire sheep that have the finest wool are kept lean, and produce $1 \frac{1}{3}$ lbs. each; if better kept, they grow larger, and produce more wool, bat inferior in quality." $\nmid$ This is true of every breed of sheep, and particularly of the Merino, whose propensity to learness caused their culture to be abandoned in Great Britain, as be. int unprofitable. Their wool did not so much deteriorate in this cold climate, as there was no possibility of getting mutton apon their carcass. But, though leanness produces wool of finer quality than high condition, yet the remark is only strictiy true when applied to breeds which yield fine wool in every state of condition; for no degree of leanness will cause a coarse-wooled breed of sheep, such as the Black-faced, to produce fine wool. To obtain any given quality of wool. therefore, it is necessary to possess the breed that produces it. and then the wool will be finer or coarser in comparison as the sheep are kept in low or bigh condition. There is no doubt that the geaeral quality of wool in this country has become coareer than it was years ago; not because the breeds of sheep have deteriorated-for, on the contrary, they have all improved-but because the animals are now kept throughout the year in much hifher condition: and this result might bave been anticipated, for, if there is any analogy between the vegetable and animal econ. omy: we know that well manured soil will produce flax of thicker and longer fibre than the same eoil in poor condition: $e_{0}$, in like manner. sheep when in bigh condition produce wool of thicker and longer fibre than when lean. Daring the improvement that bas taken place in the breeds of sheep, a counteracting influence, as I conceive, bas been at work to retain the wool of finer qrality than the bigh condition would produce-1 mean the infuence of shelter; and though it may only be of a negative character, preventing anequal evaporation of the yolk of wool. by warding off cold and drying winds, yet, in preventing these, its effects are positively beneficial, inasmuch as Mr. Luccock observes that "the silky softness, like most other good qualities of the fleece, depends very much apon the breed of the sheep, and the quality of yolk wrich they consiantly af. ford." It is difficult to eay whether the density of the fibre of wool, that most desirable property, depends on some general law connected witb the breed, or the circumstances in which the fibre

- See Luccock on Wool; Ed. 1805.

† Culley on Live-Stock-Note. 
is produced ; for the mere coarseness or fineness of the fibre does not affect its specific gravityas, for instance, the close full-grown wool off the shoulder of a sheep does not differ materially in density from that from the thin and hairy breech; and hence, perhaps, the density does not depend on the breed. I am inclined to believe that soil and climate very much affect the geveral condition of fleeces, for we find wool grown in the chalky districts of England much drier and coarser than that which is produced on fine, soft hazel loam; and wool grown upon turnips ap. pears to me coarser than when grown on grass in the same soil in similar condition. This fact is undeniable, that fleeces from the same breed. reared even in similar circumstances, differ much in density. The conclusion to be inferred from all these considerations seems to be, that whatever induces the greatest secretion of yolk, whether it be breed, condition of animal, nature of soil, or climate, will produce fibre of the greatest specific gravity; and hence on grass on a deep mellow soil in good heart, and in a sheltered situation, a breed of sheep, capable of continuing in good condition throughout the year, should produce the densest and the finest quality of fibre of wool. If these views be at all correct, you can easily perceive how much depends on the judgment of the farmer himself, to produce wool that will possess the greatest number of good qualities.

(2041.) Chemically, "wool has not yet been subjected to a rigid examination," says Dr. Thom. son; "but, from the experiments made on it by Berthollet, there is reason to conclude that its chemical qualities do not differ much from those of hair. When growing upon the sheep, it is enveloped in a kind of soapy matter, which protects it from the attacks of insects, and which is afterward removed by scouring. Vauquelin has examined this matter, and found it to consist of the following ingredients: A soap of potash-carbonate of potash-a little acetate of potashlime-a very little muriate of potash-and an animal matter."**

(2042.) Mr. Yonatt has examined the external structure of wool with the microscope, and has ascertained that the surface of the fibre is covered with a sort of scale which forms a series of serrations along the entire length. The general outline of the woolly fibre consists of a central stem or stalk, probably hollow, or at least porous, and possessing a semi-transparency not found in the fibres of hair. From this central stalk there springs at different distances, in different breeds of sheep, a circlet of leaf-shaped projections. It is thus ascertained that wool possesses a property common to all independent horny fibres which issue from the felt of animals-namely, an irregularity which constitutes a certain degree of roughness upon their surface from the root to the point. Hence, both physically and chemically, wool and hair are analogous substances. Some of the results of Mr. Youatl's investigations with the microscope, in conjunction with the micrometer, were these :

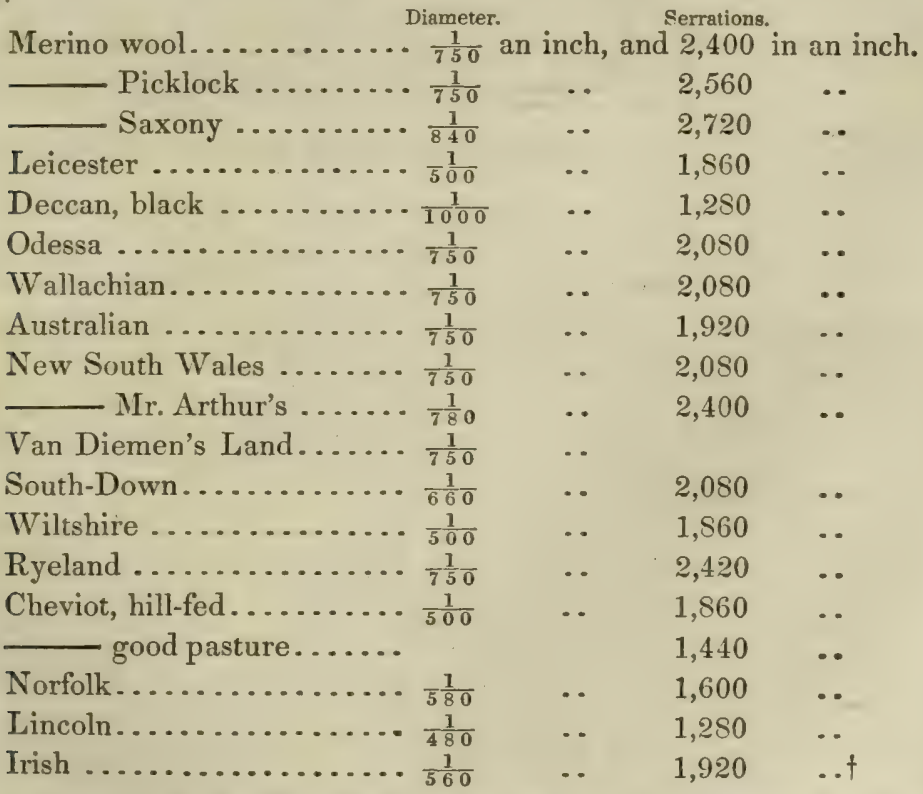

Another instrument besides the micrometer, named the eirometer-the invention of the late celebrated optician, Dolland, of London, and which reads off diameters to a very minute fraction of an inch, is used for measuring the diameters of wool, and it may be employed by an inexperienced hand with less chance of error than a micrometer. It produces a double image of the fibre which are brought in contact, and the result is then read off from a circular index.

(2043.) Wool is well known to have a felting power, but it is unknown in what that power consists. A coated fleece is a natural instance of the felting tendency of wool. Mr. Youatt seems to believe that the discovery of the serrations on the fibre of wool accounts for its felting property.

* Thomson's Animal Chemistry. (599) 
"It is a carious and interesting point that bas been established," he says, "the existence of an irregularity of form in the wool. accounting for and necessarily giving it a felting power-is there a variation in this structure corresponding with the degree of felting power?" Mr. Boyd, of Innerleithen, Peeblesshire, is much disposed to question Mr. Youati's views. "Mr. Youatt asserts with mach confidence," he remarks-and in this remark Mr. Boyd is supported by Mr. Luccock - "that the felting properties depend entirely on the structure of the wool. During an experience of many years I have found this not to be the fact and therefore state, without fear of contra. dietion, that in many instances it is impossible to estimate the extent of the felting properties in a variety of wools, until they have been submitted to the actual test of experiment; and I am decidedly of opinion," he adds. "that however perfect the structure of wool may be, if prodaced in the absence of an oily or saponaceous substance, it cannot possess the reguisite properties of a clothing material." Mr. Boyd is again supported by Mr. Luccock, when the latter says, "If the wool-grower be anxious to promote the growth of Heeces in which the felting quality greatly prevails, I should recommend. from the litle knowledge at present possessed, that he attend closely to the supply of natural, rich, and nutritions yolk, which the pile receives while growing." I confess that Mr. Youatt's theory to account for the felting property of wool, in reference to the action of the serrations on the surface of the fibre upon one another, appears to me unsatisfactory. On the authority of $\mathrm{Mr}$. Luccock, the application of moisture, warmth and pressure are necessary to bring the felting property of wool into action. "I "ithout the aid of moisture," he affirms, "it remains perfectly dormant; the warmth and pressure are required to quicken the process." And he adds " the degree of heat required to make the felting property act with the utmost force is considerably below the boiling point of water," and that "a higher temperature loo:ens the text. ure of the thread. and increases the elasticity of the hair, thus giving it a disposition to start from the substance of the cloth and spoil its surface." $\dagger$ If the action of the serrations on the fibres is the primcipal means of felting wool, it must be proved that they change their structure on being immersed in water of a temperature near the builing point, which has not yet been done. It is also known that wool, after being combed with heated iron combs, will not felt; and yet the fig. ures given by Mr. Youatt, of combed and uncombed wool of different varieties, indicate no such decided change by combing, on the structure of the serrations, as to warrant us in believing that in the one state wool shall felt, and in another it slall not.

(2044.) Having mentioned the application of the microscope to the structure of wool, it may prove instructive to show, by the same instrument, in what manner wool grows. "If the foetus of a sheep," says M. Raspail. " taken when it is of the length of about $4 \frac{1}{2}$ inches, and preserved in alcohol. be examined, it will be found studded with globules of uniform size, elegantly arranged, and almost at equal distances, round certain white spots disposed in quincunxes, which seem, even at this early period, to indicate the places where the hairs are to grow. On the epidermis of the temple, instead of thin white spots, we find vesicles projecting in the form of bottles, or rather of urns, whose sides are granulated in the same manner as the epidermis. These vesicles are the rudiments of hairs." $\neq$

(2045.) The number of sheep in the empire, estimated by Mr. Macculloch, from different sources of information, is the following:

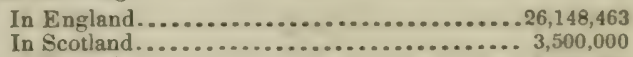

In Ireland........................... 2,000,000

Total. $\overline{.31,648,463 \mid}$

By a statement made by the late Mr. Hubbard, an eminent wool-stapler in Leeds, the number of packs of wool grown every year in England is 463,169, of $240 \mathrm{lbs}$. each, or of $111,160,560 \mathrm{lbs}$, which gives an average weight to each fleece, including those of lambs, of $4 \$ 1$ bs.

(2046.) The term Merino, applied to a particular breed of sheep and variety of wool, is of obscure origin. Mr. Southey informs as that "Merino is an old Leonese title, still preserved in Portugal, though long since obsolete in the other kingdoms of Spain. Perhaps it is a mongrel diminutive of the Arabic title mir or emir, likely enough to have been formed when the two lan. guares, Spanish and Moorish, were, as it were, running into each other. Mirquebir, the augmented title, was in use at Ormuz. Merino would be sufficiently explained by supposing it a dimin. utive grade. The old laws of Spain define it thus: ' He is a man who has authority to administer justice within a certain district." The first mention of this office is in the reign of Bermudo II. The Merinos then commanded the troops of their respective provinces in war: but. before the time of Henrique II., it was become wholly a civil office, and the title was gradually giving place to that of Alguacil, mayor. Most probably the judge of the shepherds was called the Merino. and hence the appellation extended to the flocks onder his care." It is the general opinion that Me rino sheep came to this country from Spain, and so they did at the end of the last century; but it appears that fine-tcooled sheep were sent from England to Spain a very long time ago. That sheep were sent from England to Spain at a known period is certain, for Mrr. Youatt quotes from the chronicles of Stowe, that " this yere (1464) King Edward IV. gave a license to pass over certain Colteswolde sheep into Spain." And he quotes Baker also, who says: "King Edward IV. enters into a league with John, King of Arragon, to whom he sent a score of Costal ewes and four rams-a small present in show, but great in the event, for it proved of more benefit to Spain. and more detrimental to England, than could at first have been imagined." The wool of the Cotteswolte sheep of the present day is long, and not remarkable for fineness. Perhaps the old Cotteswolde wool was finer than the present, becanse the latter has been much crossed with the Leicester. But if the old Cotteswolde conferred so much benefit on Spain, it may be fairly in.

[II Recent estimates make the number from 50 to $70.000,000$.

- Prize Essays of the Highland and Agricultural Society, vol. xiv. †uccock on Wool.

$\ddagger$ Raspail's Organic Chemistry, \$ Dlacculloch's Dictonary of Commerce, art. Wool. $(600)$ 
ferred that the wool of Spain was not so fine as that of England at the time. But sheep were exported from England to Spain prior to the reign of Edward IV., as Mr. Southey intimates that "Fernan Gomez de Cibdareal, in one of his letters (Epist. 73), mentions a dispute between two Spaniards concerning rank in the presence of Juan II., 1437. It was objected tauntingly to one of them, that he was descended from a judge of the shepherds. The reply was, that this office had always been held by hidalgos of great honor, and that ' King D. Alforso had instituted it in the person of Inigo Lopez de Mendoza, when the English sheep were first brought over to Spain." This dispute occurring in 1437, and referring to an ancient title of honor which had been conferred as far back as the time of the introduction of English sheep into Spain, and a taunt being given in 1437 to a descendant of a judge of the shepherds-that is, of a Merino-thereby implying that he, the descendant, was at least of the second or third generation, it is clear that the English sheep referred to could have no reference to the Cotteswoldes exported in 1464 , as mentioned by Stowe. "How long was it before the Merino fleece became finer than that of the original stock ?" asks Mr. Southey; and he replies, "Brito, who wrote toward the close of the 16th century, says, in praise of the wool grown about Santarem, it is so fine that it may vie with that of England. (Monarchia Lusitania, f. i., p. 93.) If the Spanish wool had been as fine then as it is now, he would hardly have drawn his comparison from the English." "* While these facts are recorded in Spanish literature regarding the origin and ancient quality of the wool of Spain, the opinion of Mr. Youatt seoms much too strongly expressed, when he says that "Europe and the world are originally indebted to Spain for the most valuable material in the manufacture of cloth." And. again, "The chunahs, therefore, may be descendants of the English sheep," namely, those sent to Spain in 1464, "mixed with the common breed of the country ; but farther than this England cannot, with any degree of justice, urge the claim which some have done, of being instrumental in producing the invaluable Spanish wool." $\dagger$ And yet, as we have seen, sheep were probably sent from England to Spain long before that date, or even long before 1437; for if the King Al. phonso, mentioned above as having instituted the order of judge of the shepherds, be Alfonso the Wise, King of Leon and Castile, who is stated to "have digested a code of excellent laws, and readered his name famous in history by his patronage of the arts and sciences," $\ddagger$ he reigned at the early period of from 1252 to 1284 . And another fact mentioned by Mr. Southey-when Catherine. daughter of John of Gaunt, was espoused to Henrique III., she took English sheep with her as her dowry - fixes another exportation of sheep to Spain about 1390, a considerable while prior to the Cotteswolde exportation of 1464; and, if the English sheep had been of an inferior descrip. tion to those of Spain, it is not likely that the future Queen of Castile would have taken them with her as her own dowry. In concluding this subject, Mr. Southey puts this donbting query: "Can there possibly be any truth in the remark of Yepes (t. 7, $\delta 134$ ), who says: 'Daily experience shows us that, if a lamb is suckled by a goat, the wool becomes hard and hairy; and, on the contrary, if a kid is suckled by a ewe, the hair becomes soft?"

\section{THE MAKING OF BUTTER AND CHEESE.\|}

"And now the DaIRY claims her choicest care,

And half her household find employment there :

Slow rolls the churn-its load of clogging cream

At once foregoes its quality and name :

From knotty particles, first floating wide,

Congealing butter's dashed from side to side;

Streams of new milk through flowing coolers stray,

And snow-white curds abound, and wholesome whey."

BLOOMFIEL D.

(2047.) THE dairy operations on a farm of mixed husbandry are limited, both in regard to the season in which, and the quantity of materials by which, they can be prosecuted. Until the calves are all weaned, which can scarcely be before the end of June, there is no milk to spare to make butter or cheese, but what of the former may suffice for the inmates of the farm-house; and as some of the cows, at least, will have calved 4 months before all the cows are free to yield milk for the dairy, a full yield of milk cannot be expected from them even when entirely supported on grass.But though thus limited, both in regard to length of time and amount of milk, there is ample opportunity for performing every dairy operation, according to the taste and skill of the dairy-maid. For example: Butter

[II The dairy products of the United States in 1840 were put down at $\$ 33,787,008$.

Ed. Farm. Lib.]

* Southey's Omniana, vol. ii.

(601)......20

† Youatt on Sbeep.

‡ Bigland's View of the World, vol. ii. 
may be made from cream, or from the entire sweet milk. It may be made up fresh for market, or salted in kits for families or dealers. Cheese may also be made from sweet or skimmed milk, for the market; and any rariety of fancy cheese may be made at a time-such as cream-cheese, imitation Stilton, Gloucester, or Wiltshire. With all these means at command, to a moderate, indeed, but available extent, it is quite possible for the dairy-maid to display as much skill and taste in her art on a mixed as on a dairy farm-not only in these respects, but in the endless forms in which milk may be served on the table of the farmer. In short, the only advantage a dairy-farm possesses over one of mixed husbandry is, that all its dairy operations are conducted on a larger scale.

(2048.) The milk-housc, large enough and otherwise convenient and suitable for a farm of mixed husbandry, may be seen represented in plan at $m$, fig. 32 ; and the cheese-room adapted to the same is seen in plan at $h$, fig. 33. The mode in which a milk-house should be fitted up, is described in (231), as well as a cheese-room in (237).

(2049.) The utensits with which a dairy should be supplied, comprise a large number of articles, though all of simple construction. The mill: dishes are composed of stone-ware, wood, metal, or stone.* The stoneware consists of Wedgewood and common ware; the wooden of copperwork, "of oak-staves bound with hoops of iron; the metal of block-tin, or of zinc; and the stone are hewn out of the block, and polished. Besides these, utensils formed of a combination of materials are used, such as wooden vessels lined with block-tin or zinc, and German cast-iron dishes lined with porcelain. Of the whole variety, the stone and wooden ones lined with metal, are stationary, and the rest movable. All milk-dishes should be of a broad and shallow form, for the purpose of exposing a large surface with a shallow depth of milk, in order to facilitate the disengagement of the several parts of the milk. There seems to be a difference of opinion, which of those substances have the greatest influence in disengaging the greatest quantity of cream from the milk. I have heard it maintained at one place that stone is much the best; at another, that wood is the best; at another, that stone-ware is preferable to all others, and of the two kinds of stone-ware that of the common ware is better than Wedgewood's; and at another, that zinc is by far the best ; from all which difference of upinion I would infer that the subject has not been satisfactorily ascertained by comparative experiment, and which I believe to be the case; but I am sure that different management, even in the same circumstances, will produce very different results in this product of milk. Independently of the consideration of cream, however, other circumstances should be regarded in making choice of milk-dishes. Wooden ones require much labor to keep them thoroughly clean, though they are the least liable to injury in the use. Metal ones also require much cleaning, and are liable to be bruised; and it is not questionahle that they are unwholesome for milk, if not kept thoroughly clean. Tin produces no injurious salt with the acid of milk; but the salt produced by the action of lactic acid upon zinc, is believed to be in a slight degree poisonous to the human stomach. At all events, the thought of keeping milk in metallic dishes is unpleasant to the mind. Stone-ware is easily frangible, but is, nevertheless, so cheap, so easily cleaned, and so safe in use, that it forms the most convenient material for milk-dishes to every class of country people. The advantage of Wedgewnod ware consists in its hardness, and the durability of its glazing. The price of dishes of common ware, of 15 inches in di-

[" Better if made of glass, with their capacity stamped in the making. (602)

Ed. Farm. Lib.] 
ameter, is $9 \mathrm{~d}$. each; of Wedgewood's ware, from 12 inches to 24 inches, from 2s. to 8s. each; of wood, 16 inches diameter and 4 inches deep, $2 \mathrm{~s}$. each, and of zinc, 18 inches in diameter, $3 \mathrm{~s} .9 \mathrm{~d}$. each, and others are $3 \mathrm{~d}$. per inch more or less, as the diameter increases or diminishes from this size.

(2050.) The other utensils are : Creaming scallop, for taking the cream off milk; a jar for containing the cream until it is churned; a Wedgewood one, with top and opening in it to be covered with muslin, to keep out dust and let in air, costs from 6s. to 7s. 6d.; a chum, of which there are many forms, all of which will be found described below by Mr. Slight; a flat wooden kit, to wash butter in; scales and weights for weighing butter, whether in pounds, fractional parts of a pound, or in the lump; jars or firkins for packing salted butter; moulds for forming prints of butter for the table; covered dishes for holding fiesh butter in pounds; a tub for earning the milk in when about to make cheese; a curd-cutter, and a curd-breaker; a drainer to lay across the cheese-tub while the whey is straining from the curd; cheese-vats for giving the form to cheese; a cheese-press, a figure of the most convenient and powerful form of which is given below; a furnace and pot for heating water and milk; and a supply of spring-water is an essential concomitant to a dairy.

(2051.) A word or two on churns. The old-fashioned upright handplunge-churn is now confined chiefly to the use of small farmers and cotters; but, when inanimate power is applied to the making of butter, the upright churn is yet used by many dairy farmers who conduct their operations on a large scale. About 20 years ago the barrel-churn was much in vogue, and it was very well suited for making butter, as it kept all the cream in constant agitation; but the trouble required to keep it clean, from its inconvenient form to get within it, has tended to bring it into disrepute. It is now superseded by the box-churn, whose construction admits of its being easily taken to pieces and cleaned. Of the two forms of box-churn, I prefer the one in which the agitators move horizontally, because it can be filled to any degree of fullness, without danger of the cream or milk working out of the journal-holes of the axle. Long ago, small churns were in repute; though they fell into desuetude, but lately have again come into use, and for making small quantities of butter they are admirably adapted. Various constructions of small churns, intended to regulate the temperature of the cream, have of late been proposed, some of which are noticed below.

(2052.) A word or two also on cleanliness. Unless the milk-house is kept thoroughly clean, in its walls, floors, and shelves, the milk will become tainted; and in order to keep them clean, the floor and shelves should be of materials that will bear cleansing easily and quickly. In most farm-houses the shelving is of wood, and the floor of pavement or brick. Wooden shelves can be kept clean, but are too warm in summer. Stone shelving is better, but must be polished, otherwise cannot be sufficiently cleaned; and to be kept clean, requires at times to be rubbed with sandstone. Marble shelving is the best of all for coolness and cleanliness, and they are not so expensive as many imagine. Polished pavement makes a more durable, easier cleaned, and cooler floor than brick. There should be ample means of ventilation in the dairy when required; the principal object, however, not being so much a constant change or a larger quantity of air, as an equality of temperature through summer and winter. To obtain this desideratum, the windows, which should face the $\mathbf{N}$. or E., should not be opened when the temperature of the air is above or below the proper one, which, on an average, may be stated at $50^{\circ}$ Fahren(603) 
heit. The milk-house should be thoroughly $d r y$; the least natural damp in the walls and floor will emanate a heavy fungus-like odor, very detrimental to the flaror of milk and its products. The utensils should all be kept thoroughly clean, and exposed to and dried in the air. Some dairy-maids are so careless in this respect, that $I$ have seen seams of green and yellow rancid butter left in the corners and angles of churns, and a heary smell of dirty woolen rags pervading wooden utensils. However effectual woulen scrubbers may be in removing greasiness lett by milk and butter on wooden articles, they should never be employed in a dairy, but only coarse linens, which should always be washed clean in hot water without soap, and dried in the air. All the vessels should be quickly dried with linen cloths, that no feeling of clamminess be left on them, and then exposed to the air. In washing stone-ware dishes, they should not be dried at that time, but set past singly to drip and dry; and they should be rubbed bright with a linen cloth when about to be used. If dried and set into one another after being washed, they will become quite clammy. The great objection to using stone milk-coolers is the difficulty of drying them thoroughly before being again used. No milk-house should be so situate as to admit the steam 1ising from the boiler which supplies hot water for washing the various utensils; nor should the ground before its windows contain receptacles for filth and dust, but be laid out in grass, or furnished with evergreens. It is said that the odor from the blossom of the cummon elder, Sambucus nigra, in summer is a complete muscafuge, if I may be allowed to coin a word.

(2053.) The articles which engage the dairy-maid's attention within the dairy are milk, butter, and cheese; and, first, as to milk. I have already said that the milk is drawn from the cow into a pail (1670), the most convenient form of which is given in fig. 376 , and the size of which may vary to suit the pleasure of the dairy-maid. It is made light, of thin oak staves bound with iron hoops, and costs from 2s. $6 \mathrm{~d}$. to $5 \mathrm{~s}$, , according to the size. The milk, in being drawn from the cows, is put into a tub, and left to cool; but not to become so cold or stand so long as to separate the cream. The tub should be placed in the air, and out of reach of animals, such as cats and dogs. After it has cooled, the milk is passed through the milksieve into the milk-dishes, and as much only is put into each dish as not to exceed 2 inches in depth. Tn know at once the age of milk in the dishes, one mark or score should be made with chalk on the dishes just filled, to show that they contain the

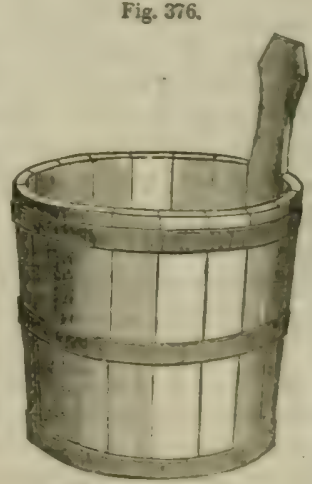

THE MILKING-PAIL. last drawn milk, or freshest meal; a second mark is made, at the same time, ol the dishes containing the meal before this; and a third is put on the dishes containing the milk drawn before the second meal, and which constitutes the third meal, or oldest milk. If the cows are milked three times a day, when the first mark is put on the dishes of the evening meal, those of the morning meal of the same day will have 3 marks, to indicate its being the third meal previous, and the dishes of the mid-day or second meal will have 2 marks. At every meal all the utensils that have been used should be thoroughly cleaned, and set past dry, ready for use when required.

(2054.) The next care of the dairy-maid is taking the cream off the rnilk. In ordinary weather in summer the cream should not be allowed to remain (604) 
longer on the milk than 3 meals-that is, when a fresh meal is brought in, the cream should be taken off the dishes which have 3 marks, when the milk will be 20 or 22 hours old; but, should the weather be unusually warm, the milk should not be allowed to be more than 18 hours old, or that having 2 marks, before the cream is taken off it. For example: in ordinary routine, the cream of the previous mid-day's milk should be taken off in the morning, and at mid-day the milk of the previous evening would be creamed, and so on; but, when the weather is very warm, it would be well to anticipate the creaming of one meal, and take the cream of the two oldest meals at one time, and in this way take off all the cream that can be got every 18 hours. The reason for using this precaution in taking off cream is, that the milk should on no account be allowed to become sour before the cream is taken off, because the cream of sour milk makes bad butter. Let sweet cream become ever so sour after being taken off the milk, and no harm will accrue to the butter. Not that sour cream off sour milk is useless, or really deleterious, for it may be eaten with relish by itself, as a dessert, or with porridge. The cream is skimmed off milk with a thin, shallow dish, called a stimmer or creamer. It may be made of wood or of stone-ware; and, of the two substances, the ware is preferable for cleanliness; and, of ware, Wedgwood's or porcelain is the best, being light, thin, hard, highly glazed, and smooth. There is no other way of taking cream off dishes but with a skimmer; but in stationary coolers, of metal or of stone, a spigot is drawn cautiously from a hole in the bottom, through which the milk runs slowly down into a vessel, and the cream is left on the bottom of the vessel; and this manner of separating the cream from the milk is said to be the most effectual; but, of course, the skimmer can be used for creaming the milk in coolers, as well as other dishes. The cream, when taken off the milk, is put into a cream-jar, in which it accumulates until churned into butter. Every time a new portion of cream is put into the jar, the cream should be stirred, in order to mix the different portions of crearn into a uniform mass. The stirring is usually done with a stick kept for the purpose, but spoons of Wedgwood ware are made for doing it. The cream soon becomes sour in the jar, and it should not be kept too long, as it is apt to contract a bitter taste. Twice a week it should be made into butter, however little the quantity may be at a time. The skimmed milk is put into a tub and made into cheese; but, if a cheese is only made every other day, the milk kept for the following day should be scalded before it is put into the tub.

(2054.) On cunverting cream into butter, the first act is to put the chum into a proper state. It is assumed that the churn when last used was put aside in a thoroughly clean and dry state. This being the case, a little hot water, about 2 quarts, should be poured into it to scald and rinse it. In summer it should be rinsed with cold water after the hot, but not in winter. Some people sprinkle a little salt into the churn before the cream is put into it, but whether it does any good or not I cannot say. The churn being thus prepared, the cream is strained into it through a bag of coarse, open sort of linen cloth, well known under the name of cheese-cloth. This cloth is always kept in a sweet state, no soap ever being employed to wash it. It is dipped in water, and then held over the churn; and, on the cream being slowly poured into it from the jar, the greater proportion will run through into the churn; but the clotted part, which will contain in it dust, drowned flies, moths, and spiders, and other impurities, which it is impossible to keep out of an open cream-jar, the cloth will keep back, on being gently pressed. In the small hand plunge-churn, and in a barrel-churn, a churn-cloth is required to be put round the mouth of the former, and un(605) 
der the bung of the latter, to prevent the cream being thrown out in churning. The temperature at which cream is put into the churn has a considerable influence on the time which the butter will take to make, and also on the weight of butter oltained from a given quantity of cream. It has been found that $55^{\circ}$ Fahrenheit is the temperature which best attains these ends, and it is one easily attained in a cool apartment early of a summer's morning. The churning should be done slowly at first, until the cream has been completely broken-that is, rendered a uniform mass-when it becomes thinner, and the churning is felt to be easier. During the breaking of the cream a good deal of gas is evolved, which is usually let off by a small spigot-hole, if the churn be tight, such as a barrel-churn; but in other churns, which have a cover, the air escapes of itself. When the motion of churning is rotatory, it should be continued in the same direction, and not changed backward and forward. I am not sure that a satisfactory reason can be given for continuing uniform motion, but the opinion is that the butter is formed more simultaneously, and that the backward and forward motions are apt to make the butter soft. It is certain, at all events, when the motion is uniform and rather slow, the butter, whenever it is formed, is felt to stop the motion of the agitators at once. After the cream has been broken, the motion may be a little increased, and continued so until a change is heard in the sound within the churn, from a smooth to a harsh tone, and until an unequal resistance is felt to be given to the agitators. The butter may soon be expected to form after this, and, by increasing the motion a little more, it will form the sooner, and, the moment it is formed, the motion should cease. The rate of motion in churning butter is of some importance, for, when performed too slowly, a longer time will be spent in churning than is necessary, and the butter will be strong-tasted; and, on the other hand, when the motion is too rapid, the butter will be soft and frothy, when the churning is said to have burst. In very warm weather, and when the cream is put in too warm, the churning is liable to burst with any degree of fast motion, and hence the judgment is required to be exercised in the circumstances. I suppose that the most proper motion in churning has never been ascertained by experiment, and to determine which would probably be tedious, but it would be worth while being tried. When butter forms from cream in $\frac{3}{4}$ of an hour to 1 hour churning, it is satisfactory work; when it comes much sooner it will he soft, and when much later it will be strong-tasted. The temperature, by agitation during churning, rises $3^{\circ}$ or $4^{\circ}$.

(2055.) Immediately on being formed, butter should pe taken out of the churn and put into the butter tub, one of a broad and shallow form, to be worked up. A little cold water being first put into the tub, and the tub set in an inclined position, the butter is spread out, rolled up round the edges, and pressed out by the palm of the hand, in order to deprive it of all the buttermilk-for the least portion of that ingredient retained in it would soon render it rancid. The milky water is poured off, and fresh poured in, and the butter is again washed and rubbed as often as the water becomes milky. If intended to be kept or disposed of in a fresh state, the large lump is divided and weighed in scales in $1 \mathrm{lb}$. or $\frac{1}{2}$ lb. lumps each, and placed separately in the tub among water. Each lump is then clapped firmly by the hand and formed into the usual form in which pounds and half-pounds of butter are disposed of in the part of the country in which your farm is situate. For the table any requisite number of the pounds should be moulded from the lump into prints according to taste, or rolled into forms with small wooden spades, figured or plain. The (606) 
made-up butter is then floated in jars with covers, in a clear, strong brine of salt and water, fit to float an egg, made ready for the purpose.

(2057.) Objections have been urged against the use of the hand in making up butter, and small wooden spades recommended to be employed for the purpose; and the use of water has also been objected to making up of butter, as it is said to deprive the butter of its pleasing aroma. A woman who has hot, clammy hands, should never become a dairy-maid, for, butter being very susceptible of taint, its flavor will, no doubt, be injured by the heavy smell of sweaty hands; but clean, cool hands-rendered so by washing in warm water and oatmeal, not soap, and then rinsed and steeped in cold water-hands so prepared will make up butter far cleaner and more solid than any instrument, whether of wood or of any other material ; and as to cold water injuring butter, there can be no such strong affinity between a fatty matter like butter and cold water, as that the latter shall dissolve any essential ingredient out of the former; at all events, water will more effectually take away any milky substance from butter than any dry instrument that can be used, or even all the art the hand alone can accomplish. Let the trial be made both ways, and their comparative efficacy be tested by keeping the butter fresh, and seeing which will keep the longest sweet.

(2058.) If the butter is intended to be salted, it is somewhat differently treated. After being washed clean, as above described, it is weighed in the scales, and salt is immediately applied. Practice varies much in the quantity of salt given to butter, so much as from $1 \mathrm{oz}$. of salt to $1 \mathrm{lb}$. of butter, to $\frac{1}{2} \mathrm{oz}$. of salt to $1 \frac{1}{2} \mathrm{lbs}$. of butter : $1 \mathrm{oz}$. to $1 \mathrm{lb}$. is too much-it is like curing butter with as little art as a salt herring $-\frac{1}{2} \mathrm{oz}$. of fine pure salt being quite sufficient; and this quantity is intended for keeping-butter, for as to powdered butter for immediate use, $\frac{1}{2} \mathrm{oz}$. to $2 \mathrm{lbs}$. is quite sufficient. In the process of salting, the butter is spread out in the tub, and the salt, ground fine, is sprinkled over it by little and little, and the butter rolled up and rubbed down with the side of the hand until the whole mass appears uniform, and is considered to be incorporated with the salt. To insure uniform salting, only half the salt should be applied at once, and the butter lumped and set aside until next day, when the other half of the salt should be rubbed in. Whatever of brine or milk may have subsided from the lump, in the mean time, should be poured off. The salted lump is then put into the jar or firkin on the second day. One great advantage of deferring the making up of butter until the second day is that, without it, the butter will not assume that firm, smooth, waxy texture, which is so characteristic a property of good butter. Butter when kitted is pressed firmly down in all points, and great care taken that it be particularly pressed with the side of the finger round the circumference of the jar, and its substance made solid, and its surface flat and smooth. If a former churning of butter had been put into the jar, its surface should be raised up into regular furrows, that the new lump of butter may be commingled with what was put into the kit before. The compressing of butter, then, into the kit, is of great importance, inasmuch as, if the least cell of air be left in its mass, or get access by the side of the kit, it will wind the butterthat is, impart to it a rancid taste. After the kit has been filled within an inch of the top, the butter is made smooth, and covered with a new piece of wetted white linen or cotton cloth. To secure its goodness, butter should be salted immediately on being made.

(2059.) The state of the kit should be particularly examined before it is used for packing butter. If composed of stone-ware, it is easily cleansed and rendered sweet. A wooden kit that has been used before should be (607) 
filled with water for some time, to render it water-tight by the swelling of the edges of the staves. It should then be repeatedly scalded with hot water, and exposed to the air, and, just before being used, should be rinsed with cold water, and a slight sprinkling of salt scattered over its bottom. A new wooden kit requires somewhat different treatment, because the odor from the new wood will impart a disagreeable flavor to the butter. It should be filled with water mixed with garden mould, or with lime-shells and water, for some days, and the mixture occasionally stirred; after which it should be thoroughly scrubbed and cleansed with hot water, and rinsed with cold water, and salted before being used.

(2060.) The quality of the salt has a material effect on the taste of the butter that has been salted with it. Ordinary sea-salt contains a considerable proportion of other salts which are bitter, and, of course, they will have effect upon the butter as well as the true salt. "It is easy, however, to purify the common salt of the shops from these impurities," says Professor Johnston, "by pouring 2 quarts of boiling water upon 1 stone or 2 of salt-stirring the whole well about, now and then, for a couple of hours, and afterward straining it through a clean cloth. The water which runs through is a saturated solution of salt, and contains all the impurities, but may be used for common culinary purposes, or may be mixed with the food of the cattle. The salt which remains in the cloth is free from soluble salts of lime and magnesia, and may be hung up in the cloth till it is dry enough to be used for mixing with the butter or with cheese."

(2061.) Butter assumes a texture according as it has been treated. When burst in the churning, it is not only soft but frothy, and, on being cut with the knife, seems as if it could be compressed into much less bulk. When churned too rapidly, especially in warm weather, the churning may not advance to the degree of bursting, but the butter will always continue soft; and never assume a firmness, though worked up with ever so much care, and in the coolest manner; and, when one piece is separated from another, they are drawn asunder with a jagged surface, and stick to the knife that cuts them. Soft butter will not keep long, whether salted or fresh. When over-churned-that is, when the cliurning has been continued after the butter had been formed, it becomes soft, not unlike the state when it is too rapidly churned. When properly churned, both in regard to time and temperature, butter becomes firm with very little working, and is tenacious; but its most desirable state is that of waxy, when it is easily moulded into any shape, and may be drawn out a considerable length hefore breaking. It is only in this state that butter has the rich nutty flavor and smell, which impart so high a degree of pleasure in partaking it. To judge of butter, it is not necessary to taste it - the smooth, unctuous feel, on rubling a small piece between the finger and thumb, expresses at once its richness of quality; the nutty smell indicates a similar taste; and the bright, glisteniing, cream-colored surface shows it to be in a clean state.

(2062.) What I have stated in reference to the making of butter, applies especially to that obtained from cream alone, and from cream in the usual state for butter-namely, after it has become sour by keeping but butter can be obtained from sweet cream as well, though chuming enders its buttermilk sour, as well as that always is from sour cream. To have hutter in perfection from sweet cream, it should be chumed every day; and, as the supply of cream daily is usually very limited, a smaller churn than usual is most convenient to be used; and for this purpose there is, perhaps, none better than the table-churn figured hereafter-by tlue peculiar

- Johnston's Lectures on Agricultural Chemistry.

(608) 
construction of which, being placed in a ressel, the temperature of the cream can be regulated in all seasons. I see it alleged in adrertisements of chums of similar construction to this, that butter may be made from cream in 10 or 12 minutes. I have made several experiments with such a table-chuin, in churning cream at different temperatures, and with different velocities, but nerer obtained good butter in less than 30 minutes : and, when formed so quickly as in 15 minutes, the butter was as soft as froth. I hare heard it alleged that butter of the finest quality cannot be obtained from sweet cream; but the allegation, I suspect, is made by persons who have little experience of butter from sweet cream. So far am I from coinciding in this oplnion, that I know butter of the richest quality, and of the finest flaror and appearance, can be made from sweet cream. Were this butter not necessarily good, would the nobles of the land have it upon their tables every morning? It is true that sweet cream requires longer chuming than sour-still, butter is obtained from it in from 30 to $40 \mathrm{~min}$ utes; and, if it is an unprofitable mode of using cream, that is a different question. For my own taste, I would nerer desire better butter, all the year round, than that churned every morning in a small churn from sweet cream. Such butter, on new baked oat-cake, cooled, with a little virgin flower-honey, and a cup of hot, strong coffee, mollified with crystalized sugar and cream, such as the butter had been made from, is a breakfast worth partaking of, but can seldom be obtained.

(2063.) Besides cream, butter is made from sacet milt; but, to obtain which, a large churn is required, and the churning continued for a long time, seldom less than 3 hours. When the quantity of mill- is large, power other than human, whether of steam, water, or horse, is employed to more the churn. The butter obtained from this rothod is rery good. The obvious objection to this method is, the labor imposed in agitating a great quantity of milk, and in consequently having a large quantity of buttermilk; which, however, raay easily be disposed of in towns, and may eren be converted into very good cheese. The method has its advantages in the uniform character of the butter which it affords in all seasons, from the certainty of obtaining a churning at the proper temperature, which is required to be higher than that of cream, being $65^{\circ}$ Fahreaheit, and easily obtained, in winter and summer, by the addition of hotter or colder water among the milk. Churning fiom sweet milk is thus a comparatirely simple process. The milk is poured into coolers at first, and from them it is drawn off by siphons into rats sufficiently large to contain both the erening and morning meals; and the rats are then put by, to stand totally undisturbed, till the whole acquires a sufficient degree of acidity. The time required for this purpose varies a little according to the heat of the weather and the temperature of the milk-house. The point is ascertained by the formation of a strong, thick brat or scum on the surface, when this becomes uneven." All the milk is not of the same age, but this does not affect the quality of the whole. The times of churning are these : "The milk of Sunday and Monday is churned on the Thursday morning ; that of Tuesday, Wednesday, and Thursday mornings, on the Saturday erening: and that of Thursday evening, Friday and Saturday, on the Monday morning."*

(2064.) In churning either ingredient the residuum is buttermilh, which, when obtained in large quantity from milk, may be disposed of in towns. or converted into cheese ; and, when derived in small quantity from cream, a part may be used for domestic purposes, and the remainder mixed with the food given to the brood-sow.

- Transactions of the Highland and Agricultural Society, for July, 1343. $(609)$ 
(2065.) It is now time to say something on the making of cheese. On a farm of mixed husbandry, as much skimmed milk cannot be procured every day as to make a cheese of ordinary size, but there may be one made every other day. To save skimmed milk from souring in warm weather till the next day, it is necessary to scald it-that is, to put it into a furnace pot, and heat it sufficiently, and then let it cool. The fire should be a gentle one, and the milk should be so carefully attended to as neither to burn nor boil, nor be made warmer than the finger can bear. After being thus heated in the morning, the milk should be poured into a cheese-tub, to await the cheese-making of the following day. The skimmed milk of next morning is poured into the same tub, except about $\frac{1}{3}$ of it, which is put into the furnace or another pot, and made warm for the purpose of rendering the entire milk of the tub sufficiently warm. The heat is applied slowly to the pot; the milk occasionally stirred with a stick, and made as warm as the finger can hardly bear. This warm portion is then poured into the tub, the contents of which are thereby made as warm as new milk - that is, about $110^{\circ}$ or $112^{\circ}$. The various degrees of heat here referred to are in rather vague terms, but $I$ believe no specific degree of heat is required in scalding, provided the milk is not allowed to burn at the hottom of the pot, and is prevented from boiling; for, if it boil, the milk will coagulate instantly, and be useless for cheese-making, because the cheese will then be hard or flinty; and, so far as these two points are concerned, the ready and practical test of the finger is sufficiently accurate. On the contents of the tub being mixed by stiming, the rennet or earning is added to the milk, which is allowed to stand some time to coagulate, with a cloth thrown over it, to keep the proper heat.

(2066.) In the meanwhile, I shall describe the method of preparing the rennet, or reed, or earning. A calf's stomach is usually recommended for this purpose; but as calves' stomachs are not easily obtained in districts where calves are reared, a pig's stomach, which can be easily obtained on every farm, will answer the purpose equally well-and, indeed, many believe that it makes the stronger earning of the two. When the pigs are killed for hams in winter, their stomachs should be preserved for rennet, and they are preserved in this manner: Let the inside skin of the stomach be taken out; the operation is somewhat troublesome, but may easily be done by an experienced dairy-maid. Any curdling in it is thrown away, as being unnecessary, and tending to filthiness; and the skin is then wiped clean with a cloth, not washed. It is then laid flat on a table, and rubhed thickly over with salt on both sides, and placed on a dish for 4 days, by which time it has imbibed sufficient salt to preserve it. It is then hung stretched over a stick near the fire to dry and won, and in the dried state is kept for use as rennet by the next season. Some people place a layer of clean wheat straw on the skin, after it is salted, and roll the skin over it to keep it open-tie a piece of paper around it, and then hang it up near the kitchen-fire to dry and won. This plan is good enough, but not better than the other. When the rennet is to be used, a strong brine of salt and boiling water, sufficient to float an egg, is made and sieved through a cloth, and allowed to cool, to the amount of 3 imperial pints to each skin. One skin is allowed to remain in that quantity of brine in a jar, with its mouth covered with bladder, for 3 or 4 days, when the coagulating strength of the brine is tested by pouring a drop or two into a teacupfull of lukewarm milk; and, when considered sufficiently strong, the brine is freed of the skin, hottled and tightly corked for use. The skin is again salted as before, and spread over a stick to dry and won, and is (610) 
again ready for use when required. Half a tea-cupfull of this rennet will coagulate as much milk as will make a $15-1 \mathrm{~b}$. cheese.

(2067.) When the milk is sufficiently coagulated, which it will be in half an hour, the curd is cut in the tub with the curd-cutter, fig. 377, which consists of an oval hoop of copper $a b, 9$ inches long and 6 inches wide, and $1 \frac{1}{2}$ inches deep, embracing a slip of copper, of the same depth, along its longitudinal axis $a b$. The stem $c$ of round copper rod rising from each side of the oval hoop unites at $c$, and after attaining in all 18 inches in length, is surmounted by a wooden handle $d, 9$ inches in length, but 6 inches would be enough, by which it is held either by one or both hands, and on the instrument being used in a perpendicular direction, cuts the curd into pieces in the tub. Some people break the curd at first with the hand, but this instrument cuts it more effectually. On being cut, the curd lets out its whey, which is drained off by means of a flat dish being pressed against the curd-cloth, linen of open fabric, spread upon the curd. As much of the whey. is removed in this way as practicable, and the curd will be left comparatively dry, when it receives another cutting with the cutter, and the whey again

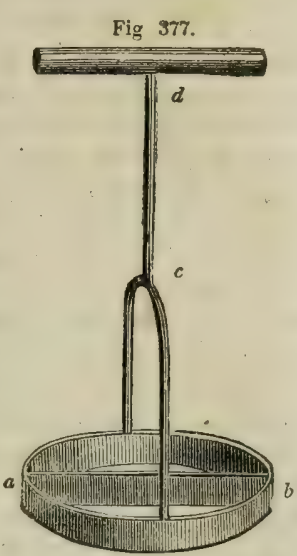

THE CURD-CUTTER. expressed from it. The curd is then lifted out of the tub, and wrapped into the curd-cloth, which, in the form of a bundle, is placed upon a drainer lying across the mouth of the tub, and the whey is pressed out of it by main force. This is the laborious part of the operation, and to save both time and labor in large cheese dairies, the bundle of curd is placed in a large cheese-vat, and subjected to pressure in the cheese-press to get quit of the whey. The curd becomes very firm after this pressing, and must be cut into small pieces by some instrument before it can be put into the cheese-vat. In most small dairies, I believe that the hand alone, or a tableknife, is employed to divide the curd, but a simple implement, such as represented and described below, effects the purpose with comparative ease and sufficient minuteness. The curd, being made small enough, is salted to taste with salt ground fine. In some parts of the country, such as in Cheshire, and in Holland, cheeses are salted by being floated in a strong solution of salt in water, which no doubt penetrates the new formed cheese, but it seems an uncertain mode of giving any desired degree of saltness. After being salted, the curd is put into a cheese-cloth, spread over a cheesevat, and firmly packed into the vat higher than its edge, and on the curd being covered with the cloth, the vat is placed in the cheese-press and subjected to pressure, upon which a quantity of whey will probably exude by the holes in the bottom of the vat. In a short lapse of time, 2 hours or more, the cheese is turned out of the vat, a clean and dry cheese-cloth put in, the cheese replaced into it upside down, and again subjected to increased pressure in the press. Should whey continue to exude, the cheese must again be taken out of the vat, and a clean cloth substituted; in short, a clean cloth should be substituted, and the pressure increased, as long as any whey is seen to exude; but if the prior operations have been properly performed, the exudation should cease in about 12 hours, after which the pressure is continued until the press is wanted for a new cheese on the second day. Fig. 378 shows the common cheese-vat or chessart, as it is called, the form being varied according to that adopted for the cheese. This vat is built in elm staves, as being less liable to burst with pressure, and (611) 
strongly hooped, and is furnished with a sub. stantial bottom, pierced with holes, to allow the whey expressed to flow away, and a strong wooden cover cross doubled. It is of advantage that the cover fit the vat exactly, and that the vat have as little taper interiorly as possible. In some parts, as in Cheshire, cheese-vats are made of tin, with holes in the bottom. The old and inconvenient form of cheese-press, as well as the new and convenient one, are both found figured and described below by $\mathrm{Mr}$. Slight. In some dairy districts large cheeses

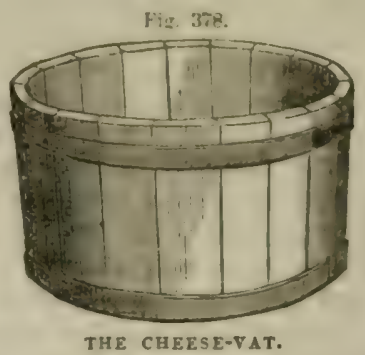
are subject to immense pressure. In Cheshire the cheese is subject to three presses, the first giving a pressure of $\frac{1}{4}$, a second of a $\frac{1}{2}$, and a third of 1 ton weight. There the cheeses being unusually large, are bound round with fillets of linen until their form attains consistency.

(2068.) After the cheeses have been sufficiently pressed, they are put into the cheese-room $h$, fig. 33 , which should not be exposed to too much heat, drouth, or damp, as heat makes cheese sweat; drouth dries them too quickly, and causes them to crack; and damp prevents them bardening and wonning, and causes them to contract a bitter taste. Cheeses being exposed to a cool, dry, and calm air upon the shelres $m$, will dry by degrees, and obtain a firm skin. The skin becomes harder by being dip. ped in hot water, but I see no benefit to be derived from such a practice. They should be wiped with a dry cloth, to remove any moisture that may have exuded from them, and turned daily. To expedite the process of turning and rubbing, a cheese-rack, such as is figured below, has been in use in England, and found to answer the purpose. New cheeses, as they are made, are set in the rack, while as many of the oldest are removed from it and placed upon the shelves. Some cheeses burst, and throw out a serous-like fluid, which accident happens in consequence of the whey which was left in it fermenting, and which should have been pressed out. Any cheese that changes the shape which the cheese-vat gave it, should be suspected of some organic change taking place within it; but if such a cheese does not crack, so as to admit the air into it, it may soon become ripe and mould, and prove of fine flavor. The inconvenience of cracks in cheese, is the facility afforded to the cheese-fly to enter and deposit its eggs; and to prevent their egress, the cracks should be filled up every day with a mixture of butter, salt, and pepper, made to a proper consistency with oatmeal.

(2069.) But the casualties which I have mentioned are less likely to befall skimmed-milk cheese, the making of which I have been describing, than new or sweet-milk cheese. These are made exactly in the same manner with the milk as it comes from the cow. One day's milk being insufficient for a cheese, the fresh morning's meal is mixed with the meals of the previous day, the oldest part of which will have thrown up a covering of cream, which is mixed througb the milk, and the entire gatherings are heated with a portion of the morning's milk. The rennet is applied in the same manner, but in rather larger quantity. Greater difficulty will be found to squeeze the whey entirely from the curd than with the skimmed milk, and it is the difficulty of expressing all the whey out of them which renders sweet-milk cheeses more liable to ferment, and burst and lose their shape.

(2070.) I have said nothing of employing annotto or arnotto for dyeing cheese, because I think it a very useless piece of trouble which cheese(612) 
farmers impose upon themselves. It is employed in Gloucestershire to the extent of $1 \mathrm{oz}$. of arnotto to $1 \mathrm{cwt}$. of cheese; and in Cheshire, $8 \mathrm{dwts}$. to $60 \mathrm{lbs}$. of cheese, and it costs from 1s. to 1s. $6 \mathrm{~d}$. per lb. Arnotto is a precipitate from maceration of the pulp which covers the seeds of the Bixa orellana of Linnæus. It is manufactured in two forms, one in flags or calies of 2 lbs. or 3 lbs. each, of a bright yellow color, soft to the touch, of good consistence, and comes from Cayenne wrapped in banana leaves, and is much used in giving an orange tint to silk and cotton goods, but which is not permanent; and the other kind is called roll arnotto, which is small, not exceeding $2 \mathrm{oz}$. or $3 \mathrm{oz}$. each, hard, dry, and compact, of a brownishcolor outside and red within, is brought from Brazil, and is the kind used in the dairies. The duty on the roll kind used to be $£ 512 \mathrm{~s}$. per cwt., and is now 4s.* When employed it is put into the milk before the earning, and it is prepared by rubbing down the requisite quantity in a bowl of warm milk. All the quantity employed is said to impart no peculiar flavor to the cheese, and this being the acknowledged case, of what utility is it? for as to the appearance of cheese, I suppose it will be allowed that Stilton and Dunlop cheese look as well on a table as that of Gloucester and Cheshire. Marigold flowers, saffron, and carrots, are also employed to give color to cheese.

(2071.) The yield of dairy-cows varies so much, even in the same circumstances, that no average result can be depended upon. I have had cows of the same breed give from 8 to 17 Scotch pints a-day, that is, from 16 to 34 quarts; and I have known a cow of a cross-breed give 60 quarts a-day. So is the variation in respect of the quality of the milk. I have had cows whose milk would only yield a thin film of cream in the course of 24 hours, while that of the others wonld almost admit of its cream of the same age being lifted off with the fingers. But though I can say nothing satisfactory on this head, I may state a few of the circumstances which are supposed to have a controlling influence on the quantity and quality of the inilk of cows.

12072.) The circumstances which affect the quantity of milk are the breed; the smaller breeds yield the smaller quantity, and the yearly quantity of the large and small breeds may vary from $4900 \dagger$ to $240 u_{\dagger}^{\dagger}$ quarts; the kind of food, cows fed on succulent food, such as moist meadow.grass, brewers' and distillers' refuse, and new sown grass, will yield a larger quantity of milk than when fec' on hay and roots, and old pasture: and the time from calving, which, according to a state. ment of Mr. Aiton, causes a variation from 1200 quarts in the first 50 days, to 300 quarts in the sixth 50 days after calving. H

(2073.) The circumstances which affect the quality of milk are more various. The breed has an effect; the small ones yield richer milk than the large, in which respect the small Kerry cow is superior to the large Yorkshire. The kind of food, hay, corn and oil-cake, produce richer milk than turnips and straw, and yield more butter; and bean-meal and tares afford more cheese than oil.cake, corn, potatoes and turnips. In the time from calving, it is well known that the first milk of a cow, called the biestings (1677), is much richer than the ordinary milk which the cow afterward gives. It has a different composition from milk, and acts as a purgative to the newborn calf, which is of essential use to it at that period of life, in removing the sticky sort of dung called the meconium, from its bowels. You thus see how erroneous is the practice of those breeders of calves who throw away the biestings as injurious. In wet and cold weather the milk is less rich than in dry and warm; and on this account more cheese should be obtained in cold, and but. ter in warm weather. The season has its effect; the milk in spring is supposed to be best for drinking, and hence it is then best suited for calves; in summer it is best for cheese, and in au. tumn for butter; and hence, perbaps, autumn butter keeps better than that of summer, because it contains less of the caseous principle. Cows less frequently milked than others will give richer milk, and consequently more butter; morning's milk is richer than the evening's; and the last drawn milk of each milking, at all times and seasons, that is, the afterings or strokings, are well known to be the richest part of the milk, and the first drawn the poorest. A cow, before she is again in calf, gives richer milk than when she is pregnant, a portion of the secretion which sup. plies the richer milk being. no doubt, withdrawn to support the foetus. A well-formed cow will give more and better milk than an ill-formed one. Old pasture will produce richer butter than new. Cows kept constantly in the byre are said to give richer milk than those allowed to go at large at pasture, but the latter are supposed to yield more cheese;-the exercise, perhaps, preventing the due proportion of the richer secretion. Many other circumstances may be known in different localities to affect the quantity and quality of the milk of cows; but a sufficient number are here related to show how perplexing a thing it is to conduct a dairy in the most profitable way.

(2074.) The phenomena accompanying the changes in milk are well known to every dairy-maid, but few of them know that the constituent parts of milk are only mechanically commixed; and thie must be their state even in the udder of the cow, otherwise the afterings, which had occupied the upper part of the udder. would not be the richest portion of the milk, nor the first drawn the

* McCulloch's Dictionary of Commerce, and Ure's Dictionary of the Arts, art. Annatto.

† Dickson on Live Stock, vol. i.

$\ddagger$ Aiton's Treatise on Dairy Hubbandry. If Ib. (613) 
poorest. All. therefore, that is required to separate the different parts of milk is rest and time. The cream or fatty part floats to the surface in the course of a few hours; in a little longer time, according to the state of the temperature, the cascous portion becomes sour, and in a still greater lensth of time the acidity becomes so powerful as to coagulate the milk in one mass, and in a still greater lapse of time the coagulated mass separates into two parts, one becoming firmer, or cheese, the other again fluid, or whey. The rationale of this natural process is thus well given by $\mathbf{M}$. Raspail :- "Milk, when viewed by the microscope with a power of only 100 diameters, exhibits spherical globules, the largest of which are not more than 0004 of an inch in diameter, and which, from their smallness, appear of a deep black at the edees. These globules disappear on the addition of an alkali, such as ammonia. and the milk then becomes transparent. If the proportional quantity of milk be more considerable, it forms a coagulum of a beautiful white color, on the ad. dition of concentrated sulphuric acid. This cosgulum does not arise simply from the adhesion of the globules to each other, but it may be plainly seen by the microseope, that the globules are evolved in a transparent albuminous membrane, which has no appearance of a granular structure. Milk, then. is a watery fluid, holding in solution albumen and oil, by the ageney of an alkaline salt or a pare alkali, and having suspended in it an immense number of globales which are in part albuminous and in part oily. The albuminous globules must tend to subside slowly to the bottom of the vessel by their specific gravity, while the oily globules must have a tendency to rise to the surface. But the oily globules being dispersed in myriads amid equally numerous albuminous globules, they cannot rise to the sarface, without taking with them a greater or less number of the globules of albumen. Hence, at the end of 24 hours, we find on the surface of the milk a crust composed of 2 layers, the apper one of which contains more butter than milk, wbile the lower contains more milk than butter. This separation will take place equally with or withont the contact of the air. The liquid part which lies under the crust contains the dissolved albumen and vil, with a portion of the sugar, the solable salts, and a certain quantity of the albumen and oily globules."* Cream cannot rise throngb a great depth of milk. If milk is, therefore, desired to retain its cream for a time, it should be pat in a deep narrow dish; and, on the other hand, if it is desired to free it most completely of its cream, wit slionld be poured into a broad flat dish, not much exceeding 1 inch in depth. The quantity of cream which any given milk contains can be easily measured by the Galactometer. which consists of a narrow tube of glass not more than 5 inches in length. 3 of which are divided into 100 parts, and on being filled with milis to the top of the graduated scale, whatever number of degrees the thickness of the cream embraces, will be the per centage of cream yielded by the milk. For example, if the cream covers 4 lines of the scale. it is 4 per cent., if 8 lines. 8 per cent. The evolution of cream is facilitated by a rise, and retard. ed by a depression, of temperature. At the usual temperature of the dairy at $50^{\circ}$ Fabrenheit, all the cream will probably rise in 36 hoars, and at $70^{\circ}$ it will, perhaps, all rise in half that time; and if the milk is kept near the freezing point, the cream will rise very slowly, because it becomes partially solidified. Milk boils and freezes about the same temperature as water. Milk may be prevented becoming sour by being kept in a low temperature; in a higb temperature, on the other hand. it rapidly becomes sour, and. at the boiling point, it curdles immediately. The acid os milk is called the lactic acid, and, in its nature, resembles acetic acid, the acid of vinegar.

(2075.) Milk contains many very different substances in its composition, to each of which may easily be traced the origin of its various properties. I sball give the composition of biesting, along with that of milk, from the analyses of MM. Henri and Chevalier, in order to shew the great difference between them. It appears that biesting contains nearly 3 times more casein than milk, and only a trace of sugar of milk. no salts, and a large proportion of mucus; and more tban 9 times more casein than mare's milk:

\begin{tabular}{|c|c|c|c|c|c|c|c|}
\hline & \multicolumn{6}{|c|}{ According to Henri and Chevalier. } & \multirow{2}{*}{$\begin{array}{l}\text { According } \\
\text { to Lutiecints } \\
\text { and Bondt. } \\
\text { Mare. }\end{array}$} \\
\hline & Biestings. I & Mik. & Ass. & Goal & Ewe. & Woman & \\
\hline \multirow{7}{*}{ 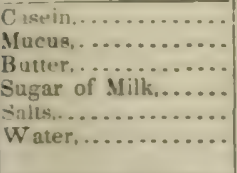 } & 150.7 & 44.8 & 18.2 & 40.2 & 45.0 & 15.2 & 16.2 \\
\hline & 20.0 & $\because$ & $\because$ & $\ddot{\theta}$ & $\ddot{0}$ & 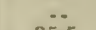 & .. \\
\hline & 26.0 & 31.3 & 1.1 & 33.2 & 42.0 & 35.5 & trace. \\
\hline & trace. & 47.7 & 608 & 52.8 & 50.0 & 65.0 & 87.5 \\
\hline & $\ddot{0}$ & 6.0 & 3.4 & 5.8 & 6.8 & 4.5 & $\{896.3$ \\
\hline & 803.3 & 870.2 & 916.5 & 868.0 & 856.2 & 879.8 & \\
\hline & 1000 & 1000 & 1000. & 1000 & 1000. & 1000 & 1000 \\
\hline
\end{tabular}

Butter gives its richness to milk. sugar its sweetness, casein its thickness, water its refreshing property as a drink, and sales its peculiar tlavor. Of the different kinds of milk enumerated above, the superior sweetness and thinness of mare's milk are accounted for by the large proportion of sugar and the small quantity of casein it contains. "The change which takes place when milk becomes sour, is, therefore, easily understood," as well observed by Professor Johnston. "Under the intluence of the casein the elements of a portion of the milk-sugar are made to assume a new arrangement. And the sour lactic acid is the result. There is no loss of matter, no new ele. ments are called into play, nothing is absorbed from the air, or given off into it, but a simple transposition of the elements of the sugar takes place, and the new acid compound is produced. These changes appear very simple, and yet how difficult it is to conceive by what mysterious influence the mere contact of this decaying membrane, or of the casein of the milk, can cause the elements of the sugar to break up their old connection, and to arrange themselves anew in another prescrib.

* Raspail's Organic Chemistry.

(614) 
ed order, so as to form a compound endowed with properties so very different as those of lactic acid."

(2076.) "Cream does not consist wholly of fatty matter (butter)," observes Professor Johnston, " but the globules of fat, as they rise, bring up with them a variable proportion of the casein or curd of the milk, and also some of the milk-sugar. It is owing to the presence of sugar that cream is capable of becoming sour, while the casein gives it the property of curdling when mix. ed with acid liquids, or with acid fruits. The proportion of cheesy matter in cream depends apon the richness of the milk, and upon the temperature at which the milk is kept during the rising of the cream. In cool weather the fatty matter will bring up with it a large quantity of the curd, and form a thicker cream, containing a greater proportion of cheesy matter. The composition of cream, therefore, is very variable-much more so than that of milk-and depends very much upon the mode in which it is collected." In warm weather, therefore, the cream should be rich though thin. Cream, at a specific gravity of 1.0244, according to the analysis of Berzelius, consists of

Butter, separated by agitation, ......................... 4.5

Curd, separated by coagulating the buttermilk,.................. 3.5

Whey, ..............................................

100.

(2077.) "Butter," says Professor Johnston, "prepared by any of the usual methods, contains more or less of all the ingredients which exist in milk. It consists, however, essentially of the fat of milk, intimately mixed with a more or less considerable proportion of casein and water, and with a small quantity of sugar of milk. Fresh butter is said to contain about 1-6 of its weight (16 per cent.) of these latter substances, and 5.6 of pure fat. according to Chevreul. How much of the 16 per cent. usually consists of cheesy matter," may be seen by this statement :- "two samples of fiesh butter from cream, examined in my laboratory, have yielded only 0.5 and 0.7 per cent. respectively. This is certainly a much smaller quantity than I had expected. Does butter from the whole milk contain more ?"* The proportions of butter yielded by milk varies considerably, from $1 \mathrm{lb}$. of butter to 15 quarts of milk, as in Holstein, to 8 quarts of milk of the Kerry cow. $\dagger$

(2078.) Curd in a state of purity is named casein. "Casein has many properties in common with the albumen of blood," says Dr. Thomson, "and, like albumen, may be obtained in two states, namely, uncoagulated, when it is soluble in water, and coagulated, when it is insoluble in that liquid. It is precipitated from its aqueous solution by acetic acid, which is not the case with albumen. It is coagulated by a boiling heat, but slowly; separately in films, which collect upon the surface of the liquid. Coagulated casein subjected to pressure to free it from the whey conetitutes cheese. If cheese consists of nothing but casein, it has a bluish-white color, is very hard, almost like horn, and is quite insipid. Good cheese is always made from milk still retaining its cream. It is impossible to state the proportion of casein which exists in milk, because it varies so much, not only in the milk of different animals, but also in that of the same animal at different times. According to Berzelins, 100 parts of skimmed milk, which he analyzed, contained 2.8 of casein." The average proportion of curd to milk is thus given by Dr. Dickson,- "Exact and repeated trials have shown that about 15 gallons of milk are necessary for making about 11 lbs. of 2 . meal cheese, and that $1 \mathrm{lb}$. of curd is produced from 1 gallon of new milk. And as the food af forded by the extent of from $2 \frac{1}{2}$ to $3 \frac{1}{2}$ acres of land is commonly supposed sufficient for the sup. port of 1 cow the year round, by taking the medium of 355 lbs. of cheese for each cow, the quan. tity of cheese produced by 1 acre will be $118 \mathrm{lbs}$., which is supported by the authority of many statements. But during the summer season, cows will afford from $14 \mathrm{lbs}$. to $20 \mathrm{lbs}$. of cheese, or more, in the week, when no butter is made." $\neq$

(2070.) Whey has a yellowish-green color, and an agreeable and sweetish taste, in which the flavor of milk may be distinguished. Almost the whole curd may be separated by keeping the whey for some time at a boiling temperature. "It still retains its sweet taste" says Dr. Thomson, "but much of the milky flavor is dissipated. If it be now evaporated over the steam-bath, it deposits a number of crystals of sugar of milk. Toward the end of the evaporation, some crystals of chloride of potassium, and some of common salt, make their appearance. According to Scheele, it contains also a little phosphate of lime, which may be precipitated by ammonia." "The sugar of milk constitutes, at an average, about 3.5 per cent., while the saline ingredients do not exceed 0.22 , or $2-9$ of a per cent. of whey. The water, of course, constitutes about 93.3 in the 100 parts."

(2080.) Schwartz found that 1000 parts of cows' milk left 3.697 of ashes, and of woman's milk 4.407 , composed of

\begin{tabular}{|c|}
\hline 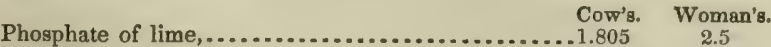 \\
\hline 0.5 \\
\hline of iron,.... \\
\hline of soda,..... \\
\hline 0.7 \\
\hline Soda, combined with lactic acid,...................... 0.115 \\
\hline
\end{tabular}

(2081.) There are a number of other facts given by Dr. Thomson connected with milk in various states, worth mentioning. The constituents of skimmed milk, for example, according to the analysis of Berzelius in 1808, are-

\footnotetext{
* Johnston's Lectures on Agricultural Chemistry.
}

† Journal of the Royal English Agricultural Society, vol. i. $\quad \ddagger$ Dickson on Live Stock, vol. i. 


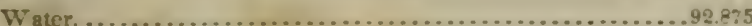

Card, not free from butter, ....................... 2.800

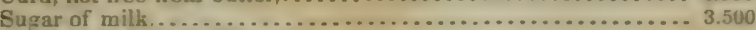

Lactic acid, and the lactate of potasb,................. 0.600

Chloride of potassium............................. 0.170

Phosphate of potash............................. 0.025

Phosphate of lime and magnesia, with a trace of iron,......... 0.030

100.000

Brisson states the specific gravity of varions milks: but it is important to remark, that it varies so much even in the milk from the same animal. that it is impossible to give a correct mean. The specific gravity of cows' milk is the lowest. being 1.0324 ; its whey is, of course, still lower. 1.0193 ; nnd that of ewes' milk is the highest, being 1.0409. Lassaigne examined the specific gravity of cows' milk at various distances of time before and after partarition, at a temperature of $46^{\circ}$ Fahrenheit. and the results were generally, that at 21 days before parturition it was highest, beine 1.064 ; and lowest at 6 days after parturition, being 1.033. The cow, from 42 days before to 30 days after parturition. was fed on the same kind of food, namely, beet-root, hay, and straw. Lassaigne also ascertained the quantity of cream yielded by the same animals at difierent times. There was no difference in the ratio between the bulks of cream and whey from the same cow, fed on beet-root, hay, and straw, from 42 days before 104 davs after parturition, when the quantities were 200 volumes of of cream to 800 of whey; but by 30 days after parturition, the volume of cream had decreased to 64 . and that of whey had increased to 936, and by that tme the water in 100 parts of milk had also increased to 90.0. Lassaigne made a curious remark respecting the milk of a cow. which he examined at 10 different periods, 4 of these before and 6 alter parturition. The milk examined daring the first tbree of the former periods, namely, 42 days, 32 day.8, and 21 days before parturition, contained no casein at all, but in place of it albumen : no sugar of milk and no lactic acid, but a sensible quantity of uncombined suda. The milks examined 11 days before and just after parturition, contained both albumen and casein, while milk 11 days before parturition, and always after it, contained free lactic acid and sugar of milk. but no free soda. The milks examined 4 days, 6 days, 20 days, 21 days, and 30 days after parturition, contained casein and no albumen. It would appear from these observations that the milk of the cow is at first very similar to the serum of blood, and that the casein, sugar of milk, and lactic acid, 10 which it owes much of its distinguishing characters, begin first to make their appearance in it about 11 days before partarition.

(2082.) A great deal more might be given in detail of experiments made in different parts of the country on churning butter at different temperatures, and of the various recipes for making the innumerable variety of cheeses to be found in this country: but as those experiments are merely so many isolated attempts to illustrate particular points, without reference to general principles, their results are unsatisfactory. In like manner the numerous experiments in the laboratory on milk and its constituents have as yet led to no improvement in practice. The field, therefore, to the practical and chemical experimenter is still open, and it might be usefully explored by their combined labors, with a view to the establishment of general principles on the best mode of keeping dairy stock, and of evolving their products, in a superior degree than hitherto attained. As one instance of a want of common understanding on this snbject, I may adduce the nu. mernos forms in which the cheeses of Scotland are made, whether in the homely kebbuck, or in the finished new-milk cheese intended for city epicures. Everywhere else but in Scotland the place of origin of a cheese may be told by its form. A Parmasan. a Gruyére, a Gonda. a Kanter. an Edam, a Cheshire, a Gloucester. whether double or single, a Wiltshire, a Cheddar, or a Stilton, can be named at sight, but who can tell where a Scotch cheese, whether of skimmed milk or new, whether poor or rich, comes from, until examined by a connaisseur? for its Stilton or W iltaire form would not necessarily imply an imitation of those celebrated substances. There should be some settled conventional forms adopted for the identification of the respective classes of cheese of this country, that they may pass current in commerce without suspicion and challenge. I shall finish this interesting subject with recipes for making a number of pleasant dishes from milk, all of which are in the power of every farmer to have in summer as a cool diet. Curds are obtained by simply earning a dishfull of new milk. When served up with grated loaf-sugar, sprinkled over the cord deprived of whey, it has the appearance of a prepared dish, and is eaten with sugar and cream. A sour $\operatorname{cog}$ is a dish of milk allowed to stand with its cream until the milk becomes thoroughly coagulated by sourness, and the sour cream and milk are eaten together. Plain cream, whether sweet or sour, is an excellent accompaniment to oatmeal or barley-meal porridge, or to sowens. The clouted cream of Devonshire is prepared by straining the new milk into s shallow dish, into which a little warm water has previously been put; and after allowiug it to stand from 6 to 12 hours, it is carefully heated over a slow fire or bot plate till the milk approaches to the boiling point, but it must not actaally boil, or the skin of cream be broken. The dish is then removed to the dairy, and the cream allowed to cool, when it may be used as cream or made into butter. Milk oatmeal porridge is more agreeable to the palate than water porridge. and when eaten with cream formas a rich diet. Half churned cream is better with oatmeal porridge than plain cream, having a slight taste of acidity. Nen untcashed butfer is a great treat to breakfast. Hatled kit is one of the pleasantest preparations of milk. Make 2 quarts of new milk scalding hot, and pour upon it quickly 4 quarts of fresh buttermilk, and let it stand, withont stirring. till it becomes cold and firm. Then take off the hat or upper part, drain it in a bair-seive, and pat it into a shape for balf an hour, and servo with cream. The alight acidity of this dish, with the rich sweetness of the cream, and the addition of a little sugar, combine to make this a verv delicious dessert. Float-whey is another preparation equally good as hatted kit. and more delícate. Pour in all the whey drained from the new-milk cheese that bas just been made, into a small furnace pot; apply a slow fire, and raise the whey near the boiling point, but not to let it boil, else the card will fall to the bottom. During the beating, a scum of curd forms apon the 
surface of the whey. Take, then, 1 quart of fresh buttermilk, and pour it gently over the scum, and pour as much more buttermilk till the scum has attained some thickness and consistency. After pouring in some cold water to lower the temperature of the whey, thereby rendering the scum more consistent, skim off the scum upon a hair-sieve, put it into a mould, and on turning it out a short time after, serve with sugar and cream. A treacle posset is made by boiling a little milk in a pan and putting a table-spoonfull of treacle or molasses into it. On removing the curd the whey is ready for use for a sore throat or cold. White-wine whey is made exactly in a simi. lur manner, but is sweetened in addition. To make Irish two-milk whey, put $\frac{2}{3}$ of sweet milk into a saucepan, and make it boiling hot, then pour in $\frac{1}{3}$ of buttermilk, gently stirring it round the edges of the pan. Let the whole come to a boil; take it off the fire, let it settle, and strain off the whey, which is an excellent drink in fever. Cream may be used as an emul. sion with all sorts of preserved fruits, and it enhances the flavor of every kind of fruit used with it; and there is, perhaps, no form of cream more agreeable or more generally admired, than blanc mange thavored with almonds. Iced-cream flavored with pine-apple is a delightful cooler in warm weather. I conclude with a recipe for making cream-cheese. "One pint of cream being mixed with 12 pints of noonday milk, warm from the cow, a little rennet is added, and when the curd is come the whey is poured out gently, so as to break the curd as little as possible. It is then laid in a cloth, and put into a small sieve; the cloth is changed every hour during the day, and in 24 hours it will be fit for use. It may be served on a breakfast-plate with vine-leaves under it, and it will keep perfectly good only one day."*

(2083.) Notwithstanding the immense quantity of cheese made in this country, a large importation of foreign takes place every year, not less than $132,000 \mathrm{cwt}$. chiefly from Holland. The old duty of 20s. per cwt. is retained by the New Tariff.

(2084.) Cheese is liable to many casualties besides those already alluded to as arising from fermentation, chiefly from the attacks of animals. When yet quite fresh, the cheese-fly (Pio. phila casei), a, fig. 379 , is ready to deposit its eggs in the deepest crack it can find by means of

Fig. 379.

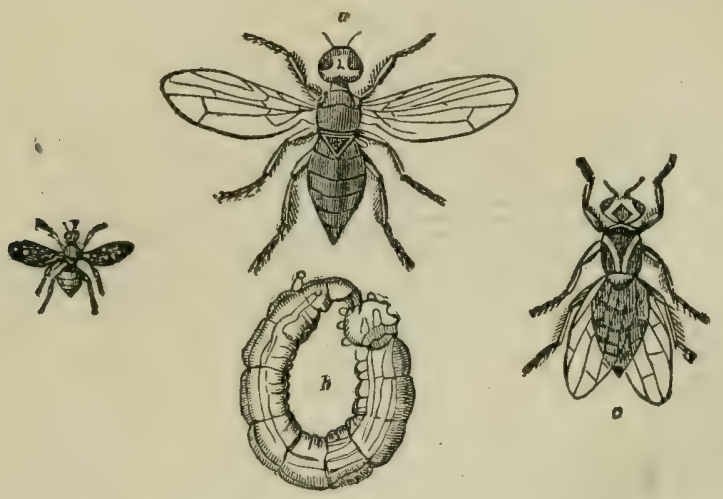

CHEESE-FLY AND MAGGOT-PIOPHILA CASEI ; AND WHEAT-STEM-TLY-CHLOROPS PUMILIONIS.

an extensile abdominal tube. The specific distinguishing characters of this insect are, in the words of Mr. Duncan, " about 2 lines in length, the whole body of a greenish-black color, smooth and shining; front of the head reddish-yellow, paler yellow on the under side; thighs ochre yellow at the base and apex; tibiæ deep ochre. the first and last pair black at the anex; anterior tarsi black, the others ochrey. with 2 last joints and the claws black; wings clear and iridescent, slightly tinged with rust-color at the base; balteres ochrey." $\neq$ The cheese-maggots produced from this fly are commonly called jumpers, and it prepares itself for jumping as seen at $b$. "When it prepares to leap, our larva first erects itself upon its anus, and then bending itself into a circle, by bringing its head to its tail, it pushes forth its unguiform mandibles, and fixes them in 2 cavities in its anal tubercles. All being thus prepared, it next contracts its body into an oblong, so that the two halves are parallel to each other. This done, it lets go its hold with so violent a jerk that the sound produced by its mandibles can be easily heard, and the leap takes place. Swammerdam saw one, whose length did not exceed the fourth part of an inch, jump in this manner ont of a box 6 inches deep, which is as if a man 6 feet high should raise himself in the air by jumping 144 feet! He had seen others leap a great deal higher." When cheese passes its stage of ripeness, it is liable to become mouldy, if kept in a damp situation, which all ripe cheeses should be to retain their moisture and flavor, and where the latter is much enhanced by the production of blue mould. It is possible to inoculate new cheese with the blue mould of old, and thereby at once impart the flavor of ripeness. This process is easiest done by inserting rolls of moulded cheese, extracted by the scoop or spyler, into holes previously made in the new cheese by the same scoop, an instrument usually employed by cheesemongers to taste cheese. 5 Toward

* Dalgairn's Practice of Cookery.

t McCulloch's Dictionary of Commerce, art. Cheese.

† Quarterly Journal of Agriculture, vol. ii. II Kirby and Spence's Introduction to Entomology, vol. i.

Prize Essays of the Highland and Agriculturai Society, vol. ix (681) 
a still farther period of decay, cheese is attacked by the well-known, and, by some, the highly. prized cheese-mite (Acarus siro of Linnmus). "We often wonder how the cheese-mite is at hand to attack a cheese wherever deposited; bat when we learn from Leewenhock that one lived 11 weeks gummed on its back to the point of a needle without food, our wonder is diminished," say Kirby and Spence. Both cheese-maggots and mites, when numerous, destroy cheeze rapidly, by crumbling it into small pieces, and by emitting a liquid substance, which causes the decayed parts to spread speedily. They may easily be killed, however, by exposure to strong heat. or by plunging the cheese in some liquid capable of destroying the larve, without conmunicating any disagreeable flavor, such as whisky. Rats and mice are remarkably fond of, and commit aad havoc among, old cheese. Nothing but a cat can deter them from a cheese cellar, where poison cannot be employed with impunity.

(2085.) (The process of churning, or agitating milk and crean for the production of butter. is performed in such a variety of machines, and in vessels so varionsly formed, each of which has its advocates, and, probably, with bnt little difference in the principal results, that it becomes a question of no small difficulty to answer, which of these numerons forms is the best. That there will be slicht differences is at the same time sufficiently apparent. but these will arise more from the capacity of the vessel, as affecting temperature, than from peculiarity of structure, and probably; also, from other conditions aftecting the chemical changes that take place during the process. It will also be obvious. on a full consideration of the subject, that causes of difference will arise. to some extent from the circumstances attending the more or less perfect nature of the agitation produced, as arising from the peculiar formation, and the motions, whether of the containiug vessel or of the agitators.

(2086.) The peculiarities of form may be viewed nnder four distinct classes. 1. Those in which both the fluid and the containing vessel, with its agitators, are in rotative motion; 2 . In which the containing vessel is at rest, und the agitators in rotative motion horizontally; 3 . In which the containing vessel is at rest, and the agitators in rotative motion vertically; and 4 . Wherein the containing vessel is still at rest, and the agitator having a rectilineal vertical motion.

(2087.) In the first class are to be noticed those machines acting by their gyration on a center, such as the old barrel-churn, wherein the contained fluid will have a tendency to acquire a motion of rotation approaching to that of the vessel; and if this rotation were continued always in the same direction, the process would be very much retarded from a deficiency of agitation; hence, in such machines, very frequent changes in the direction of the rotative motion is absolutely necessary to the cornpletion of the process.

(2088.) The second class embraces those in which the vessel is permanent. and an agitator of two or four arms revolves horizontally within it. If the vessel is cylindrical the agitation will be imperfect, for the Huid will very acon acruire a motion en masse, and will be carried forward by the arms of the agitator, nuclergoing such agitation only as will arise from the central portion. acting by the centrifugal force. haviug aiways a tendency to fly toward the circumference of the revolving mass. This will no doubt ultimately, though slow $1 \%$, produce the requisite ettect, but it will be more speedily accomplished if the vessel is of a square form; for in that case the rota. tion of the mass will be interrupted at every angle, and eddies formed therein of such force as will not only cause disturbance of the tluid in these angles, but in doing so will produce corre. sponding counter-motions in the entirt mass. From such causes, churns of this class and of the square form are found, especially on the large scale, to be very efficient, though, from the inconvenience of adapting manual power 10 a horizontal motion, it is seldom resorted to in the small scale.

(2080.) In the third class of machines, where the vessel is also permanent, but having the agitators revolving in a vertical direction, the agitation is regular, and pervades at all times the entire mass of fluid; and in this respect there is little if any difference in effect. whether the bottom of the vessel be Hat or cylindrical, nor is there any necessity for changing the direction of motion. We accordingly find that whether on the large or small scale, churns of this class find favor in almost all localities.

(2090.) The fourth class of this useful machine is the upright or plunge charn. The ressel in this is also permanent, and its hight, unlike all the others, is considerable, as compared with its breadth. As a matter of convenience, it is always made cylindrical, or rather slightly conical, which last property is given to it for the convenience of boping, for in every other respect its tapering form is a defect. The plunger nus necessarily always move vertically, without guy rotative motion, and, when extended throughout the entire column of flaid, the agitation must be as complete as it is possible to attain. Plunge or vertical churus, therefore, are by many held as the most perfect for the production of butter, as well as for saving time in the operation: but there are objections to it as regards fitness for the adaptation of manual power. It-is obvious to even a careless observer, that the human arm, if applied directly to the upright staff of this churn, the body being also upright, will be employing that power under the gneateat possible disadvan. tages. The muscles of the arm acting, as they do, in all eases under great natural disadvantages in respect of their leverage, will, in their peculiar position, be deprived of nearly all aid which the muscles of the trunk in many positions are calculated to give out to assist those of the arm; hence it is that the lahor of working these churns by haud, is found so oppressive that the operator is unable to keep up a constant action; and the principle on which the churn is based is blamed for that delay in the operation, that ought rather to be attributed to the defect in the medinm through which the power is applied. In proof of this, we find that when animal. or any of the inanimate powers, are applied to the vertical clum. it attains a character superior to all oth. ers, both as to ime and production. and this character is sastained throughout some of the best dairy districts in Scotland. The advantages of applying hand-power through a proper medium are also observable in the case of this churn, when such power is applied through a winch-liandle with a fly-wheel. Examples of this arrangement have been attended with the best effects, and with inuch ease, as compared with the direct applicatlon of the power to the plunger-rod.

(2091.) In proceeding to the details of the cburning machinery, the first class embraces those (682) 
machines that act by their gyration round a center, the fluid and the containing vessel revolving together, or partially so; of which the common barrel-churn may be taken as the type. The barrel, which is of capacity suited to the dairy, is sometimes provided only with a large square bung-hole, secured by a clasped cover. by which it is charged and emptied; while in other cases one of its ends is movable, aud made tight by screwing it down on a packing of canvas cloth. In all cases it is necessary that the interior of the barrel should be armed with three or more lon. gitudinal ribs of woud standing as radii toward the center, and perforated in various forms; these constitute the agitators of the churn. Each end of the barrel is furnished with an iron gudgeon or journal strongly fixed to it, and to one of them is applied the winch-handle by which the machine is turned; while it is supported on a wooden stand, having bearings for the two journals. More than one imperfection attends this construction of churn; from the circumstance of its rotatory motion. it will always have less or more of a tendency to carry the fluid round with the barrel and the agitators, more especially if a rapid velocity of rotation is given to it; and to counteract this tendency, it becomes necessary to reverse the motion at every few turns, which is of itself an inconvenience. There is, besides, the great inconvenience of getting access, either to remove the butter that may adhere to the agitators, or to cleanse the interior of the barrel. This is especially the case where there is no movable end; and even with this convenience for cleaning, the trouble of opening and closing the end is considerable. To those imperfections it is, no doubt, chiefly owing that this churn, once in high repute in East.Lothian and Berwickshire, has gradually fallen into comparative disiepute ; and from these circumstances, it has been deemed necessar to give figures of this class of churn.

(2092.) The machines to be here noticed under the second class, are of a less varied character than any of the others, are seldom, if ever, used with hand-labor, but are generally worked by horse-power, and chiefly in town-dairies, or in those around Edinburgh. From the comparatively small importance of this churn, it has been deemed necessary to give a figure of it; but its structare is so simple, that the following description will convey a tolerably correct knowledge of its construction to the mechanical reader. The horse-path, especially in towns, where space is valuable, seldom exceeds 16 feet: the horse-beam, with yoke, is fixed to an upright central shaft, which carries a spur-wheel placed at a hight of about $3 \frac{1}{2}$ feet from the floor, the wheel being about 4 feet diameter. One, or sometimes two, churning vessels are attached to the machine; their dimensions vary with the extent of the dairy, but for one of 25 or 30 cows, where much of the produce is sold as sweet milk, the vessel may be 2 feet 8 inches square and 2 feet 8 inches deep; they are placed securely on the floor at a proper distance from the central shaft, to suit the spur-wheel. A foot-step of metal is placed in the center of the bottom, and a cross head is attached to two uprights fixed on opposite sides of the vessel. The foot-step and cross-head serve as the two bearings for an upright spindle, which carries the four-armed agitator, and a pinion of $3 \frac{1}{2}$ inches diameter adapted to the spur-wheel. These parts, and a close cover for the vessel, complete the machine, which is, therefore, extremely simple, and in a dairy which is too extensive for manual power being applied effectually to churning, while want of space may preclude the adoption of more bulky machines, the one here described may be resorted to with advantage.

(2093.) In the same class stands the table churn, remark. able for its elegance and cleanliness, and which, though adapted only for the lighter purposes of the butter-dairy, I have considered as deserving a place here. This utensil is represented in fig. 380 in perspective, exhibiting it in the most recently improved form, with onter case to contain hot or cold water. This churn has for the last few years been brought prominently before the public as a recent invention; but on close inquiry, I find that the merit of its original introduction is due to the late celebrated $\mathrm{Mr}$. Werlgewood, and that it has been in use for a period of 30 or 40 years. The containing vessel is still formed of the Wedgewood stoneware; and, as I am informed by $\mathrm{Mr}$. Child of Edinburgh, the indefatigable purveyor of elegance, ntility, and comfort, in the china, stoneware, and ylass trade, it. was in great request about 30 years ago. its lately extended appearance being merely a revival. The chief part of the utensil is the W edgewood receptacle $a$, formed of the finest and strongest white glazed ware of that manufacture; they are of various sizes. from 1 to 4 gallons capacity ; it is furnished with a varnished wooden cover $b$.The outer case $c$ is made of zinc or of tin plate; it is 2 inches wider than the charn, furnished with handles $d$. and two ears to which the iron cross-bar $e$ is attached by two thumb-screws $e$ and $d$, serving to secure the cover to the top of the vessel. A brass socket $f$ is fixed in the cover, and an iron spindle armed with three vanes is fitted to turn in the socket, a wooden pulley is usually placed in the position of the wheel $g$ on the top of the spindle, and when secured there it holds the spindle and cover in constant connection. The common drill-bow is the asual medium of power, the string of which being held in tension by the

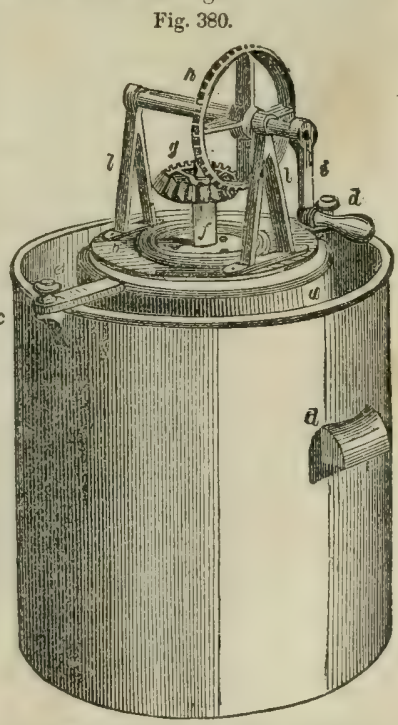

THE WEDGEWUOD TABLE CHURN. elasticity of the steel-back or bow, any movement backward or forward of the instrument will cause the pnlley and spindle to revolve, and the movements are effected by applying the hand to the handle of the drill-bow. When the cover and spindle have been secured by the screws $e d$, and the bow-string applied as above, which is effected by bending the bow until the string is sufficiently relaxed to allow of its being laid once round the pulley, the bow is then allowed to ex(683) 
pand, and the operation proceeds. It has been stated (2087) that vessels in this class, if cylindrio. al, do not produce the effiects of churuing so speedily as if the form were square, to obviate which the motion of the agitator must be frequently reversed in the cylindrical vessel. The drill-bow motion is admirably adapted to the reversing process; for in pushing the bow furward by the hand. the agitator will be made to revolve 2 or 3 times, the number being in the proportion of the length of the string to the proportion of the pulley; and in drawing them back the name number of revolutions will be performed in the opposite direction, and so on till the process is completed, $F$ ig. 381 is a view of the agitator, $a$ a a are the vanes of strong tin-plate with perforations, $b$ is that part of the spindle that falls within the socket. and $c$ that on which the pulley or the wheel is fastened. (2094.) The drill-bow being rather an awkward medium of power, especial. Iy in non-mechanical hands, an attempt has lately been made to substitute for it, in this case, the common winch handle turning horizontally. This arrangement is exhibited also in fig. 380 , where $h$ is a toothed beveled wheel of 4 inch. es diameter, on the axle of which the handle $i$ is fixed, and it works into the wheel $g$ fixed on the top of the agitator spindle in the place formerly occupied by the pulley, the two standards $l l$ being fixed on the cover $b$, to carry the axle of the wheel $h$. By this arrangement two turns of the handle $i$ produee the same result in the agitator as was doue by one stroke of the bow, and the motion of the handle being reversed at every second revolution, the ultimate effect is the same as before, and the manual operation is more easily effected in the one case than in the other. W ith a view to determine whether the alter-

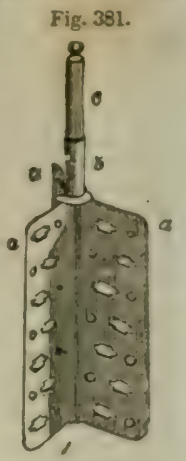

THE AGITATOR. nate motion may not be dispeused with even in a cylindrical vessel, I have instituted experiments in which the interior of the vessel is armed with combs, and the agitator being converted to a like form, but having its prongs or teeth adjusted to the intervals of those of the vessel; with this apparatus I have found that like quantities of milk and cream, and with the same temperature, yield their butter in the fullowing times:

In the plane cylindrical vessel, with the agitator always moving in one direction, butter was not obtained in 55 minutes. In the same vessel, with the agitator moving alternately right aud left, at every two revolutions, butter was obtained in 25 minutes. In this same vessel, fitted as above described, with counter-agitators, but with the agitator moving in one direction only, butter was obtained in 20 minutes. From these results it appears, that, even with a cylindrical vessel, if prop. erly armed, the process is performed in a shorter time than with the inconvenient reversed motions.

(2095.) It is well knowis that a certain elevation of temperature is acquired by the fluid in the process of butter-making, and that the process is accelerated by producing this temperature arti. ficially, from the application of heated water. For this purpose also, a practice is becoming prevalent to apply the water externally to the vessels containing the milk and cream, and not in mix. ture with them. Fig. 380 exhibits the application of this process to the utensil now under consideration, where $c$ is the water case formed of tin plate, zinc, or of wood, at the bottom of which is fixed a circular stand to place the receptacle $a$ upon, that the water may be under as well as around the receptacle. Wood, from its non-conducting quality, is perhaps better adapted than any metal for a water-case. Water brought to the proper temperature is poured into the space between the case and the retaining vessel, and if found necessary to increase or diminish the temperature, part of the contained water is drawn off below by a spigot, and hot or cold added to restore the requisite degree of heat. Experience seems to point out. that, in operating on the large scale ir wooden vrssels, no extraneous heat is required, the naturally acquired heat appears to be sufficient, especially if aided in winter by the admixture of a small quantity of moderately heated water, and the non-conducting quality of the wooden vessel retains it; whereas the stoneware vessel will be continually abstracting heat, and giving it off by radiation, if not surrounded by a medium of equal temperature.

(2096.) Churus of the third class are much more numerous than the two former, and though in themselves not differing much in the essential points, they yet exhibit a variety of struc. ture in their details. They are usual. ly distinguished by the name of bnx. churns, though the class embraces not only the cubical and oblong box, but also the cylinder or barrel, the dis. tinctive character being an ngitator revolving in the vertical direction within a stationary case of any form.

(2097.) To illustrate this class, I have selected, first, the box hand. churn, in very general ase. Thes present example, fig. 382 . is 18 inches in length, 11 inches in width, and 20 inches in depth, inside mensure. Birch or plane-tree are the best nate. rial for the purpose, and it requires to be very carefully joined so as to be water-tight. As before noticed (2088) it is of very smail moment whether the bottom is formed to the circle of the ag itator, or remains flat, in as far as the

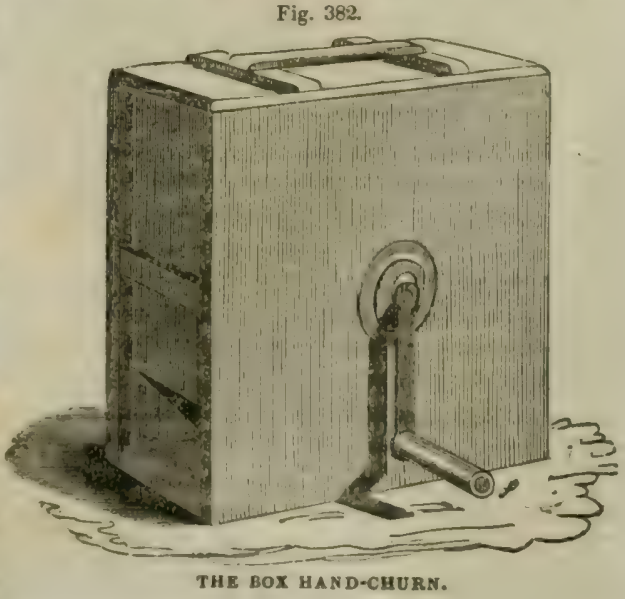


production of the butter is to be considered; but for the process of cleansing, the curved bottom will present some little advantages; a cover of the same material is fitted close in the top of the box. with convenient handles. The agitator, fig. 383 , is of the usual form; the dimensions of its parto are unimportant, except that they have sufficient strength, and present sufficient surface to produce the requisite degree of agitation in the fluid. The two pairs of arms are half lapned at the center, and the cross-bars mortised into them; the dimensions in length and breadth being such as to allow it to move with freedom within the box. At the center a perforation is made through the sides to admit the iron spindle, which. at this part, is a square bar, fitting neatly into socketplates of iron let into the agitator on each side, as seen in the figure as $a$. The farther end of the spindle projects about an inch beyond the agitator. and is rounded to form a journal, which has its bearing in a close brass plate-bush or socket, which is sunk into the side of the box, and fixed with screws. The outward end of the spindle is furnished with a conical journal. the smallest diameter of which is equal to the diagonal of the square part of the spindle, and is furnished with a raised collar or ruff; the conical journal lying in a thorough brass plate-bush, leaving the collar outside, but embraced by a cup of the bush, upon which a coupling-ring is screwed, covering the collar, and. pressing home the conical journal, preventing thas the spindle from being withdrawn until the coupling-ring is removed. The spindle extends beyond the collar about $2 \frac{1}{2}$ inches, and is here formed into a square stud, upon which the eye of the winch-handle $f$ is shipped when in work. In rigging this apparatus, the agitator is placed within the box, and the spindle is pushed through the outer bush and the agitator, until its two journals rest in the bushes; the coupling-ring is then screwed on to the outer bush, until the spindle with the agitator just turns round with freedom in the conical bush. To prevent the ring from turning round by the motion of the spindle, a smooth ring or washer of steel may be interposed between the collar and the brass ring. Various other modes of securing the spindle are em. ployed, but in all, the object is to prevent leakage at the bush. To prevent taint from galvanic influence also, it is not uncommon to apply bone or other animal substance for the bushes.

(2098.) Churns of this kind are made of all sizes. without any change in the principle of their construction. They are applied to all kinds of power, and the capacity is proportioned to the extent of the dairy : but the entire capacity of the churn

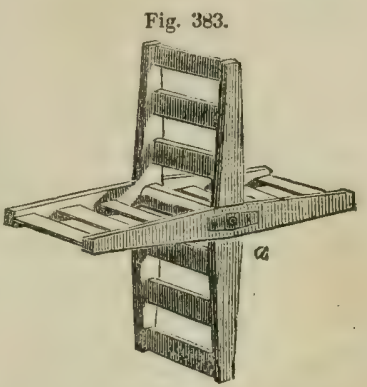
must be in general about double the quantity iu gallons. of the fluid intended to be acted upon. In operating with the box-churn, it may be filled to the hight of the spindle, or, if that member is well fitted, the milk may rise considerably above it, though in general practice it rises but little above. To adapt the churn to power, it is only necessary to put a pulley for a strap, or a chain, upon the end of the spindle, in place of the handle; or the spindle may be attached to another shaft, having the proper velocity, by means of a slip-coupling. The velocity of the agitator must depend upon the size of the churn; one of 24 inches diameter may make 60 revolutions per min. ute on the average, but may be higher or lower in different stages of the process.

(2099.) A new churn of this third class has been lately introduced, and meets with much favor in the north of Ireland. It is believed that its introduction from France is due to Mr. Blacker of

Fig. 384.

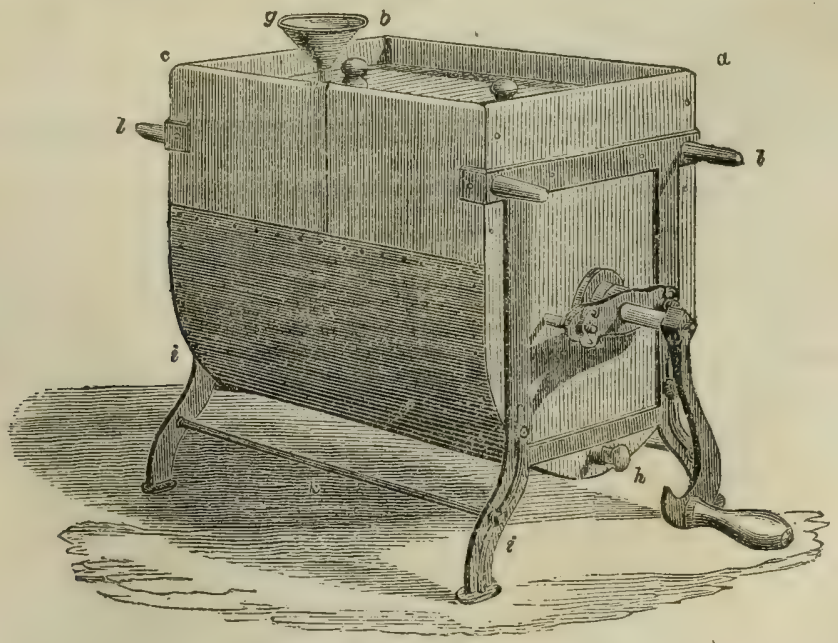

THE IRISH BOX-CHURN.

Armagh, who is ever zealous in the advancement of objects tending to the improvement of bis country; but the manufacturing of it is conducted by Mr, R. Robinson, Lisburn. This churn is (685) 
represented in figs. 384 and 385 ; the firat a perspective of the machine as it appears when in work, the second a cross section. showing the chief peculiarity of its construction. In the principle of its operation, this charn is the same as the one last described, but, like that alluded to under our second class, it is fumished with a case for containing water to reeulate the temperature. It differs also from the common box-churn, in having the spindle or axis of the agitator passing through the length, instead of the breadth, of the containing vessel.

(2100.) In constroction, fig. 384 represents a hand-churn of ordinary size; the containing vessel is of an oblong form. with a semi-cylindrical botton, its length $a b$ is $22 \frac{1}{2}$ inches, the breadth $b c$ 14 inches, and the depth to the axis of the semi-cylinder $11 \frac{1}{2}$ inches, the entire depth being 21 inches, all inside measure. The sides and ends are formed of birch or plane-tree, $1 \frac{1}{4}$ inches in thickness, securely joined at the angles; the ends of the vessel thas constructed descend to the foll depth of the semi-cylinder, while the sides are only 12 inches in slepth. The botton is form. ed in two plates of zinc, the edges of which are secured to the outer and imner faces of the sides, by means of close nailing, and also to the ends. making water-tight joinings all round. in the manner seen in section at $d$ and $e$, fig. 385 , where the space $d f e$. between the outer and inner plates, form the receptacle for the water. In the edge of one side there is inserted a funnel $g$, by which the water is introduced into the receptacle by passing down through a small bore in the side of the vessel, and the spigot $h$ serves to draw off the water when required. A wooden cover is fitted into the opening in the top, with knobs for the convenience of lifting it ont. The chamber thus con. structed is get in the iron frames $i i i$, which are attached to each end of the box, with screw nails; and are farther secured by the stretcher-bolts $k$, and furnished with atad-handles $l l$. for the convenience of lifting the churn.

(2101.) In fig. 385 the agitator is also seen in section, whereof $m m$, sc., are the four arms, the three transverse bars in each arm being in this case round rods, which are here shown cut across by the section, as is likew ise the square spindle passing through the center. The spindle is formed and inserted in the same manner as described for the box-churn (2097), and differs only from it in the mode of securing it in place. In this machine the spindle is pressed home by a perforated oblong plate, as seen in fig. 384 , which passing upon the outward end of the spindle till it rest against the collar. it is then passed apon two stad.bolts fixed in the end of the vessel, having a screw.nut on their point. which presses the plate and the spindle, by means of the collar, bome to the conical bosh with any degree of tightness; and the winch-handle is then applied to the extreme end. It will be observed that both this and the last described charn require being placed apon a stand or table about $2 \frac{1}{2}$ feet high when worked by the hand, in order that the handle may be brought to a proper hight for the full effect of the hand. When either of them are worked by power, they are then most conveniently set on the floor of the dairy.

(2102,) In the fourth class of our subdivision. there is only to be considered the plunger churn; for in this class there is no variety, ex-12 cept as to the dimensions. The means of working the plunger, and the different media through THANSVERSE SECTION OF THE IRISH CHERY.BOX. which the power is applied, whether of man or

of animals, are of a character much mure varled than in all the others put together : and all these varieties seem to have been suggested with a view to overcome the very unfavoratile position in which a man applies his force directly to the planger.rod of this charn. Among these varietiea of construction in the mechanical media throngh which power, of whatever kind, may be applied, we find all possible varieties of the lever and its combinations. the loaded pendulum, with com. binations of the lever and of rack-gearing, crank and lever, and crank with connecting-rods; but it would be profitless to enumerate all the forms that have been devised for the improvement of this paricuiar kind, and much more so to attempt to describe them. I will, therefore, rest satisfied with one that bas long been in extensive use, and is equally well adapted to the hand or to power of any kind.

(2103.) The upright or plunge churning-zessel, is always a piece of cooper-work varying in capacity, according to the extent of the dairy in which it is to be employed, from 10 to 130 gallons. It is built slightly tapering upward for the convenience of being tightly looped, having a surong bottom and a movable cover. which may be fastened down with an iron clasp-hoop; a perforation is formed in the center of the cover for the passage of the churn-staff or plunger-rod, and this is surrounded by a wooden eup, to prevent the lashing over of the fluid in the act of charning. The plunger or agitator, which is attached to the bottom of the plunger-ron, is a circular reticulated frame of wood: the meshes may be from $1 \frac{1}{3}$ to 2 inches square, and the bars forming the reticulation about inch thick and $1 \frac{1}{2}$ inches deep, the whole embraced by a wooden hoop, whose diameter will just enter the top of the chura. The structure of the planger is by no means important, the only essential point being, that it shall not present loo much resistance to the passage of the fluid through its interstices. nor too little to give it a too easy passage, which might render the agitation so slight as to be ineffectual; a good medium is to make the horizon(686) 
tal area of all the interstices 1.5 times the area of the solid parts, and this rule will apply to the agitators of all churns. Such is the simple construction of this churning vessel, which is capable of adaptation to any kind of power, and to any extent of dairy.

(2104.) As an example of the application of power to the plunge-churn, the acconpanying illustrations are taken from those extensively used in Lanarkshire and the neighboring counties, where they are usually worked by one horse. It will suffice at present to show the internal mechanism, leaving the horse-wheel and intermediate gearing for another occasion. Fig. 386 is a

Fig. 386.

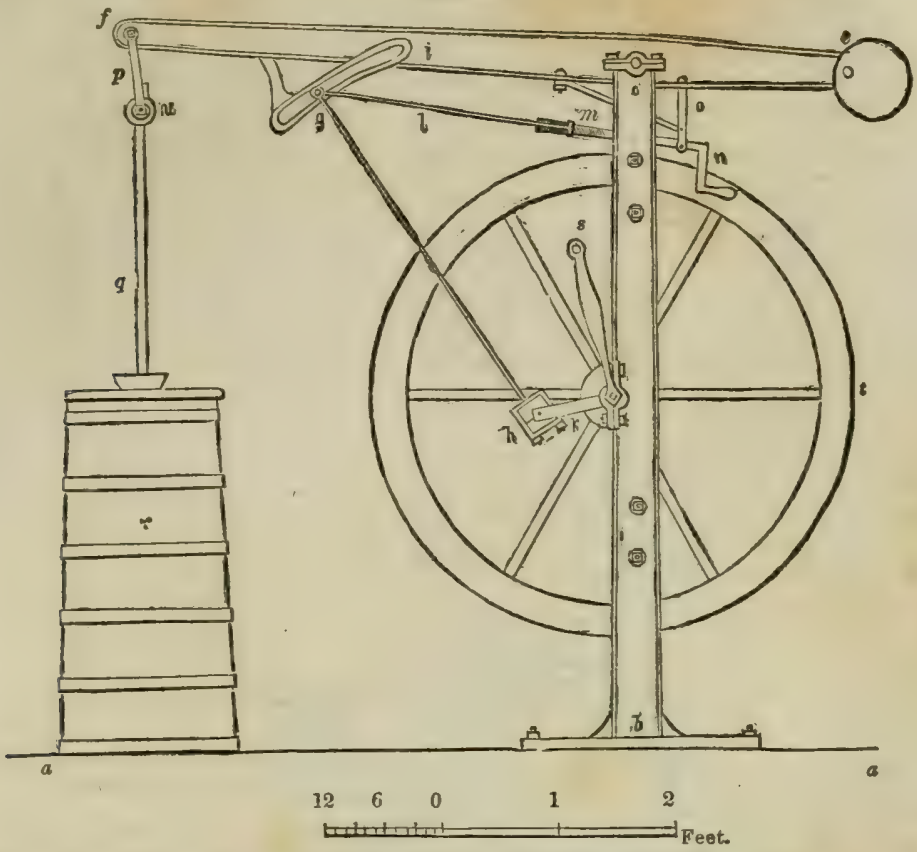

THE PLUNGE-CHURN WITH POWER-MACHIXE.

side elevation of the charn, and the mechanism required within the churn-room of the dairy. It is here represented as being for hand-power, but the arrangements of the machine, so far as here exhibited, are the same whether for man or horse. Fig. 387 is a back view of the same, and the same letters apply to the corresponding parts in each figure. The floor-line of the churning-room is represented by the line $a a$, and $b c$ is an upright frame of cast-iron, which is bolted to the floor. The frame consists of two cheeks, which are bolted together on the flanged bars $d, d$ : it is 5 feet 9 inches bigh, and 16 inches wide. The reciprocating cast-iron lever $e f$ is supported by its ful. cra on the top of the frame, by means of a center-shaft-passing throngh the lever. The length from the fulcrum to the head $f$ is 4 feet 2 inches, and from the same point backward to the ex. tremity is 2 feet 3 inches; a counterpoise is here placed upon the lever to bring it nearly to an equilibrium. The connecting-rod $g h$ is jointed upon a bolt that is fitted to move along the oblique groove $g i$ formed in the lever, and the crank $k$ is formed on a shaft that tnrns in bearings in the upright frame; its throw is 8 inches, less or more, proportioned to the hight of the churning-vessel, and the foot $h$ of the connecting-rod is fitted to the crank-pin. $l$ is a light sheens of malleable iron, whose forked ends embrace the head of the connecting-rod, which is also forked at the head $;$ and the pin of the groove passes through all the three. The adjusting-serew $m$, with its winch handle $n$, is supported in a swivel socket in the bracket $o$; while its screwed end $m$ works in the bend of the sheers $l$, which is screwed as a nut to receive it, for the purpose of shortening or lengthening the distance $m g$, and so changing the position of the head of the connecting-rod. The head $f$ of the lever is mounted with a pair of side-links $p p$, jointed on a cross-head in $f$; the links are again jointed on a wooden cross head $u$, into which the head of the planger-rod $q$ is in serted, and fixed by a pin or key ; these side.links, jointed as they are at top and bottom, produce a very imperfect parallel motion, but sufficient to answer the rise and fail of the plunger-rod. The handle $s$ is fixed on one end of the crank-shaft, and on the other is placed the fly-wheel $t$, to equalize the motion of the lever, and compensate the inequality of the resistance to the plunger in its ascent and descent. The churning-vessel $r$ is 3 feet high. with an average diameter of 15 inches, and its capacity about 23 gallons. In extensive dairies, it is common to have two churn. ing-vessels attached to the machine, in which case the wooden cross-head $u$ is elongated so as to receive the head of the plunger-rods of both vessels, the vessels standing side by side during the operation.

(2105.) When this machine is in operation, the revolutions of the crank produce a reciprocating (687) 
nction in the connecting-rorl, which is communicated to the lever, and thence to the plungers; and it will be neen that, by moving the head $g$ of the connecting-rod in the oblique groore of the lever, the strokes or reciprocations of the plunger will be long or short as the juint at $g$ is moved upward or downward in the croove $g i$. It is found from experience that there are advantages to the process deriva. ble from this; hence, at the commencement of the operation, the head of the rod $g h$ is kept at the lower ex. tremity of the slit, producing the shortest stroke: as the fluid becomes heated, and from the consequeat effervescence, its bulk is increased. the stroke is grad. ually lengthened by turning the handle $n$ of the screw; and by thus shorteniag the distance $g m$, the pin at $g$ is brought to the bead of the slit, producing a stroke of the greatest length ; and when the effervescence ceases. and the butter has beeun to forma, this state is reversed, the stroke is gradually shortened, till the process is finished with the shortest siroke.

(2106.) The application of power to this machine is easy and commodious. It may be effected by a pulley placed on the crank-shaft instead of the haudle $\delta$, and so driving with a strap or a chain; or it may be driven by a spur-wheel placed on the same point, calculated to the speed that may be afforded by the power, $w$ hether horse, water, or steam. The usual rate of the pluager in these churns is about 50 to 55 donble strokes per minute. subject to the usual variation that is required in the different stages of the process. The price of the hand-machine. as in the figure, is from $£ 6$ to $f 8$; and, when completed with horse-wheel and gearing, it is from $£ 15$ to $£ 18$.

(2107.) Besides the four established classes of churns now described. there are a few other anomalous cases which bave of late years been brought forward by in. ventors, and though they ultimately may be found to possess merit. they cannot jet be received as of eatablished character. The machines to which I here allade may be named "oscillating chums." They possess no distinct agitator, but produce their effects by a species of oscillation produced in the fluid. Among these may be mentioned a vessel of an oblong form, placed upon skids, curved in a manner that when the vessel is toached with even a sentle force, it will assume a mo-

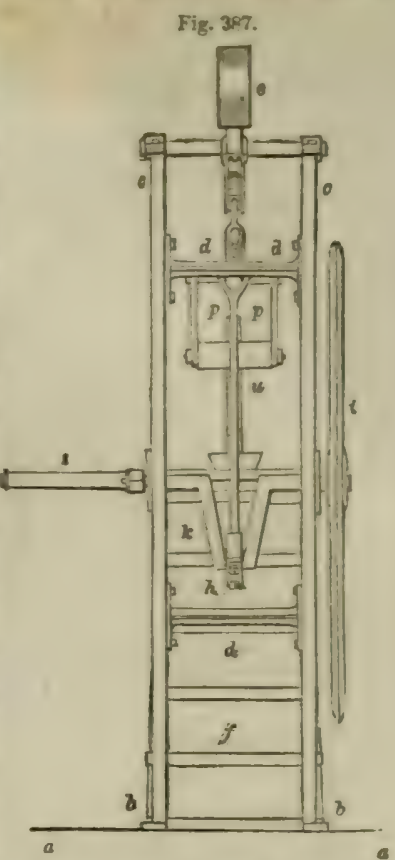

BACK VIEW OF THE PLCNGR.CHERN WITH POWER-MACHISE.

tion resembling the well-known \&wing of a child's cradle, which will thereby prodace a cunstant succession of irregular oscillatory motions in the contained Huid, which will produce the effect of charning.

(2108.) Another of these forms is an upright cylindrical vessel containing the fluid, and which is attached by its bottom to a crank revolving horizontally. The veseel is restrained from revolving on its own axis, but is made to describe a small circle, and every point in its base will virtually describe that circle which will be equal to that described by the crank that gives it mo. tion. The effect of this oscillating motion in the vessel is to prorluce oseillation in the fluid. which will altimately make gyrations within the vessel. combined with an undulatory motion, that will again produce the effect of the chura. In the first of these proposed machines, the motion would be so easy and equable that there appears no mechanical difficalty in the acheme: but in the second. when we consider the mass of fivid that may be contained in the ves sel, and then the whole pat in that kind of motion that may be de scribed as reciprocating-circular. which, when combined with the unequal effects of the undulatory motion on the fluid within. would, it is ferred. require either a much stronger fabric than is usually allotted to such operations, or oth. erwise the machine would be very liable to derangement and to fracture. A charning-ma. chine, on this principle, was ex.

hibited at the Show of the
Royal A gricultural Improvement Society of Ireland, beld at Belfast in Augast, 1843, and excited

Fig. 3e8.

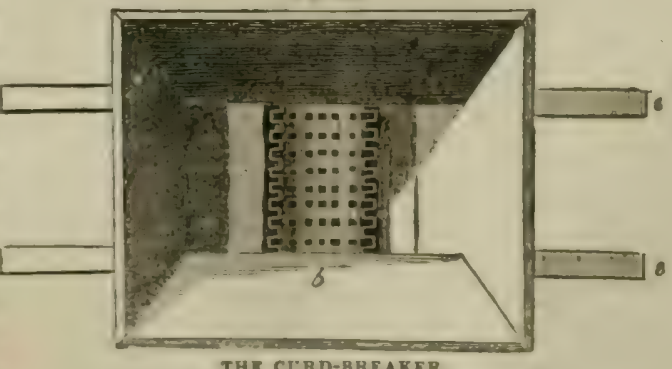
considerable interest from its apparent novelty.

(2109.) The utensils and machines yet remaining to be described in the cbeese-making department of the dairy, consist principally of the curd-breaker, cheese-press and cheeseturner. 
(2110.) The curd-breaker, ${ }^{*}$ of which fig. 388 is a plan, and fig. 389 a transverse section, consists of a hopper-shaped vessel $a b$, 17 by 14 inches at top, and 10 inches deep. It is fixed upon two bearers $e e$, which are set upon a stand or tub when in operation. A wooden cylinder $f$, having an iron axle, which passes through the bearerg $e$, and is turned by a winchhandle $d$. The axle is kept in its bearings in $c$ by means of slots $h$ on each side, which slide in grooves in the bearers, and are held in their place by a slider at $h$. The cylinder is 7

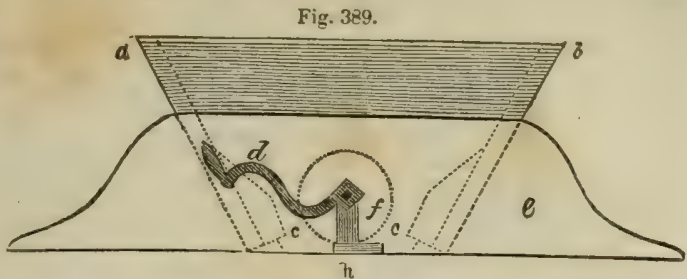

THE SECTION OF THE CURD-BREAKER.

inches long and $3 \frac{1}{2}$ inclues in diameter, studded all over with pegs of hard wood $\frac{1}{4}$ inch square. and projecting $\frac{3}{8}$ inch. These pegs or teeth are set in eight regular zones round the cylinder, each zone containing 18 teeth. Two wedge-shaped pieces $c c$ are attached to the sides of the hopper below, serving at the same time to reduce the opening between the cylinder and the hopper, and to carry a row of pegs similar to those of the cylinder, but falling into the spaces between the zones of pegs, as seen in fig. 389. In using this machine, it is placed over the tub or other recipient for the broken curd; the hopper is filled with the curd that requires to be broken; and while one hand is turning the winch-handle, which may be turned either way, the other hand may occasionally be required to press the eurd down upon the cylinder. To prevent the curd being passed beyond the ends of the cylinder, it is covered at each end, to the extent of $\frac{1}{2}$ inch, with an overlap of the sides of the hopper.

(2111.) The cheese-press comes next in the order of business, and of that machine the varieties are very numerous, though they may be ail resolved into three kinds, namely, the common old stone-press; the combined lever-press, of which the varieties are the most numerous, embracing from the single lever, through the various combinations of simple levers, to the more elaborate

Fig. 390.

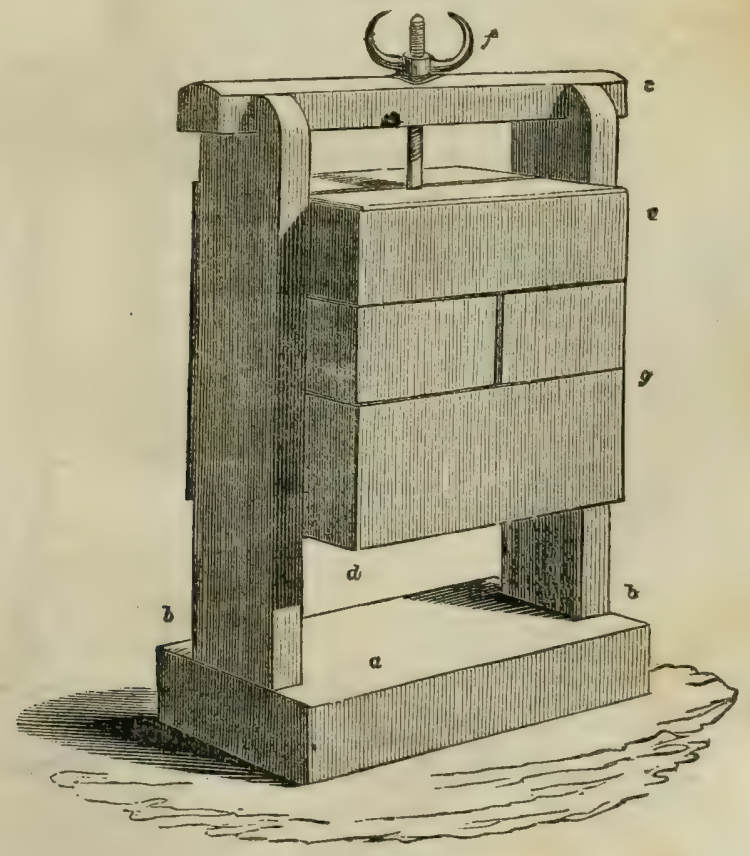

THE STONE CHEESE-PRESS.

one of the rack and levers; and the atmospheric or pneumatic press. An essential characteristio of these presses must always be, that the load, in whatever way produced, shall, when left to itself bave the power to descend after the object being pressed, as that may sink by the expression of the whey from the curd.

* Quarterly Journal of Agriculture, vol. iv. 
(2112.) An example of the first of these is shown in fig. 390 ; it consists of a strong frame of wood, of which $a$ is the sill, 2 feet long, 18 inches broad, and 4 inches thick; two uprights $b l$ are mortised or dovetailed into it ; these are ench 6 inches broad by $2 \frac{1}{2}$ inches thick, and 3 feet high, and are connected at top by the cross-head $c$ mortised upon the posts. A cubical block of stone $d e$ is squared to pass freely between the posts; an iron stem of 1 inch diameter is fixed into the upper surlace of the block, and the upper end of it being screwed, is passed through the centre of the top bar. and the lever-nut $f$ is applied to it for raising or lowering the block. In each end of the block a vertical groove is cut corresponding to the middle of the posts; and a baton of wood is uailed ufron the latter, in such form and position as will admit the block to rise and fall freely, while it is prevented falling to either side. When put in operation, the block is raised by means of the serew until the cheese-mould, with its contents can be placed upon the sill $a$ under the block. This bring done, the nut is screwed backward till the block rests lightly on the cover of the monld ; it is let down by small additions, as the curd consolidates, until it is thought safe to let the entire weight press upon the mould, which is done by withdrawing the nut $f$. Iustead of the solid block of stone $d e_{r}$ which, when left to itself, will always produce the same pressure, it is better to lave one block $d g$ into which the suspending bolt is fixed, and the renainder of the mnss made up of smaller pieces, as shown in the figure, by which means the amount of free pressure can be rezulated to the particular size and state of the cheese; or blocks of cast-iron are sometimes used in the form last described, which are more commodious, and less liable to be broken.

(2113.) The next class of this machine, the lever-press, to speak in general terms, possesses the sill of the former in some shape or other, but generally of wood, with two uprights as before; but instead of a heavy block of stone, a simple movable sill of plank is employed, having an iron or a wooden stem attached to it, upon which simple or compound levers are made to act in producing the pressure. An improved form of this lever-press was brought out by the Shotts Iron Company, ${ }^{*}$ made entirely of iron, of a more commodious and compact construction than had hitherto been attempted. and, with slight alterations, is bere presented as the type of the class.

(2114.) The combined lever cheesepress of iron is represented in the perspective view, fig. 391 , and is constructed in the following manner : $a$ a are a pair of cast-iron feet, on which the machine is supported; they have a socket formed at the crown to receive the malleable iron pillars $b$ b. The sill.plate $c$ is 18 inches in diameter, cast with two perforated ears, through which the feet of the pillars $b b$ also prass, amd secure the sill to the feet-ihe cross lines in the sill indicate chamnels for the escape of the expressed whey. The movable sill $d$ is of the sume size as the one below, with corres. ponding ears perforated and fitted to slide on the pillars, and having the rack-bar $f$ fixed in it centre. A top frame $e, 18$ inches by 9 inches, and 3 inches decp. is seated upon the top of the pillars, where it is tixed by two screw-nuts, and aulapted to carry the gearing of the machine. The action of the rack and its sill is effected in the following manner: The ratchet wheel $g$ is fixed upon an axle that has itg bearings in the top frame; on the same axle is fix. ed a pinion of eight teeth, not seen in the figure, which works in the wheel $i$ of twenty four tecth, fixed upon an axle which has its bearing also in the top frame; and this axle carties also a pinion of eight teeth, which acts upon the rack, but is also hid from view in the figure. The ratchet-wheel $g$ stands clear of the top frame abuut an inch, and its axle is prolonged beyond the wheel double that extent. The lever $k$ is forked at the extremity $R$, and the terminations of the furcation are received upon the axle of the wheet $g,-$ the wheel being embraced by

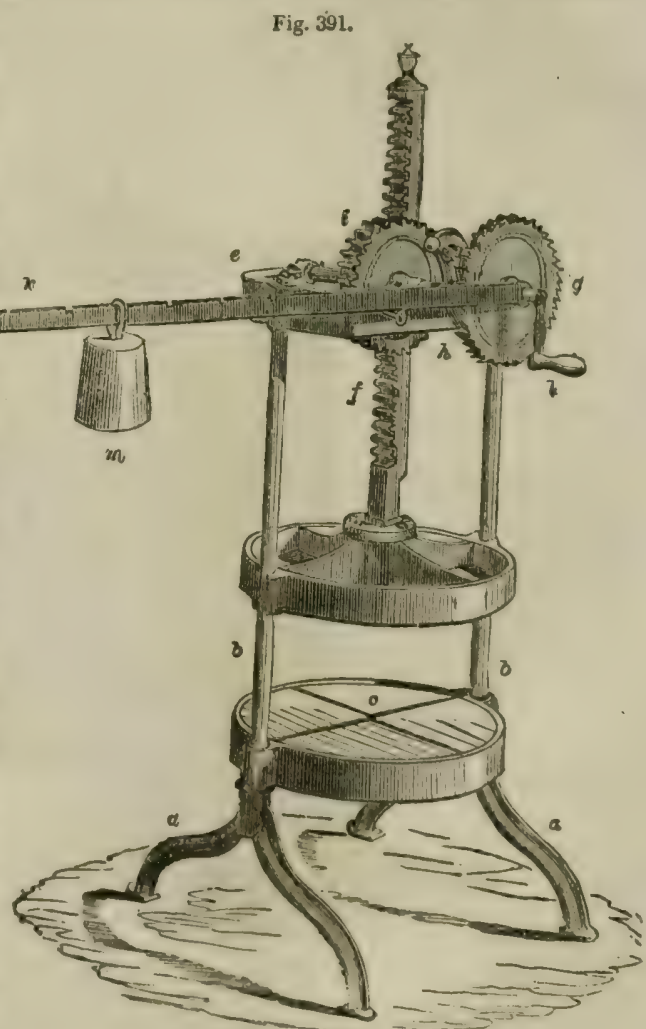

THE COMHNED LEVER CHEESE-PRESS,

the fork of the lever, but the lever moving freely upon the axle. The furcation is also lengthened toward $k$ to an extent that receives a pall at $h$; between and in the throat of the fork, the pall is jointed upon a pin that passes through both, - the edge of the pall pointing downward to catch

* Prize kssays of the Highland and Agricultural Society, vol, $\mathbf{x}$. 
the ratchet, while it has a knob-handle standing upward, by which it can be conveniently disengag. ed from its wheel. A small winch-handle $l$ is also fitted upon the axle of the ratchet-wheel, and a pin scen near $h$ is adapted to a perforation in the top frame, by the insertion of which the descent of the lever is checked, when such is required, and this completes the mechanism of the press.

(2115.) In pressing with this machine, the cheese-mould is placed upon the lower sill, and the lever being supported on the pin at $h$, the winch-handle is turned to the left, depressing the rack and its sill till the sill presses upon the cover of the mould. The lever is now lifted by the hand, and the pall allowed to take into the ratchet; while the lever, being loaded by the weight, will cause the ratchet to turn, and produce the descent of the rack. If necessary, this is repeated again and again, till a considerable pressure is produced; and if it wished that a continued pressure is to go on, the lever is again raised considerably above the horizontal line, and left to descend gradually, following the consolidation of the cheese. If it is wished that the load shall not follow the shrinking of the cheese, the pin $h$ is inserted, which, when the lever comes to rest upon it. checks farther descent. The amount of pressure is also regulated by the disposal of the weight $m$ in the difterent notches of the lever. The usual selling price of this machine is $f 4$, when constructed of iron. as in the figure; but with wooden framework, and the rack and other gearing of cast-iron, the price is $£ 35$ s.

(2216.) In the third division of the cheese-presses there is not such a variety as in the others. aud what does exist is of recent introduction. I have to notice only one-the pnenmatic cheese. press of the late Sir John Robison of Edinburgh-as an elegant application of Science to a homely though important domestic purpose. The principle here applied is the pressure of the atmosphere, brought to bear, with any degree of force compatible with that natural pressure, upon the curd when placed in the mould, by exhausting a vessel placed below and in communication with the mould, by means of a pipe descending from the bottom of the mould to a receivingvessel. To this pipe of communication a small air-pump is attached. and the mould having, be. sides its true bottom, a movabie one of wire or of wicker-work, the curd, wrapped in a cloth, is laid upon the pervious bottom, and gently pressed with the hand till it fili the vessel all round. The pump is worked a few strokes to produce a partial vacunm in the receiver and below the curd, when the atmosphere, by its pressure on the surface of the curd, causes the whey to separate and descend into the receiver. The pressure may be continued or increased at pleasure by a few more strokes of the pump, until the cheese has acquired sufficient consistency to allow of its being handled. when, as recommended by Sir John, it is to be removed from the mould and placed within another of close wire-work, with a weight placed over it to complete the consolidation.* The whey that is discha"ged from the curd while under the atmospheric pressure, being collected in the receiver, is drawn off by means of a stop-cock.

(2117.) There falls yet to be taken notice of an important article in the cheese department of the dairy machinery - the tumbling cheese-rach, or cheese-turner. This machine is the invention of Mr. IVilliam Blurton, of Fieldhall. Uttoxeter, and its merits are believed to be sufficient to warrant its adoption on dairy-farms. The object of the machine is to save much of the labor required in the daily turning of a large number of cheeses in the drying-room. and this it dues very fffectually, for with a rack containing 50 cheeses, they are turned over in very little more time than would be required to turn a single one.

(2118.) Fig. 392 is a view of the cheese-turner, as constructed to stand alone, and on its own feet: though this is not the best mode of constructing the machine. It consists, first, of an external frame $a b c d$. of which the two parts $a b$ and $c d$ are $6 \frac{1}{3}$ feet high, and 7 inches by $2 \frac{1}{2}$ inches; they are here represented each with a cross foot $a$ and $c$, and connected at top by a top-rail $b d$. It constructed in a cheese-room, the posts should be at once fixed to the floor at bottom, and to the joisting or tie-beams overbead, becoming thus a fixture in so far as regards the external frame. The second part of the machine is a movable frame or rack, formed by the two interior posts $e$ and $f$, which are framed upon the 12 shelves $g h i, \& c$.; the posts are 6 feet high, and are again 7 by $2 \frac{1}{2}$ inches, the shelves being 7 feet long and 14 inches broad, or more, according to the size of the cheeses manufactured, by 1 inch thick. The shelves extend to $5 \frac{1}{2}$ feet in hicht over all, and are tenoned into and lipped over the posts, and each shelf is finished on both sides with a knife-edged lath, nailed along the back edge: these laths are 2 inches broad, and $\frac{1}{4}$ inch thick at the back, thus increasing the thickness of that edge of the shelves to $1 \frac{1}{2}$ inches. As the figure represents a rack that will contain 5 cheeses on each shelf. a corresponding number of pairs of vertical laths, $k, k$, \&c., are nailed upon the back edge of the shelves. These laths are $1 \frac{1}{2}$ inches broad and 1 inch thick, chamfered off to one side to the thickness of $\frac{3}{8}$ inch or thereby at the edges, against which the cheeses are laid, and are checked upon the shelves, and securely nailed. The shelf-frame thus formed is provided with two strong iron gudgeons or pivots fixed in the sideposts at mid-bight, and these are received into corresponding holes in the outer or bearing-posts, so that the shelt-frame swings poised upon the two pivots; and it is farther provided with an iron latch at top and bottom on one end, by which it may be tilted and secured with either the sheif $g$ or $e f$ uppermost. The catches of the two latches are both placed at top on the external post at one side, suited to the motion of the shelf-frame, and to prevent its being turned with the back edge of the shelves upward.

(2119.) When cheeses are placed upon the shelves, it will be found that the knife-edge laths keep them free of the body of the shelf, and thus permit air to pass under them, while the pair of vertical laths keep the cheese in its proper position on the shelf. The hight between the shelves is such as to leave a free space of 1 inch between the cheese and the shelf above it; and whatever number of cheeses may be lying upon the shelves, the simple act of tilting the frame will place every cheese which vas resting on a shelf, on its opposite side, upon that shelf which im. mediately before was above the cheese, but by the tilting is now below it. It will be observed that the vertical laths serve to prevent the cheeses from falling out while the frame is tilting, and

* Prize Essays of the Highland and Agricultural Society vol. $x$. 
each cheese has only to fall one inch in tbat operation, or from the one shelf to the other, in a reversed position.

(2120.) It will be also observed that the fixed external frame is best adapted for an extensive

Fic. 392

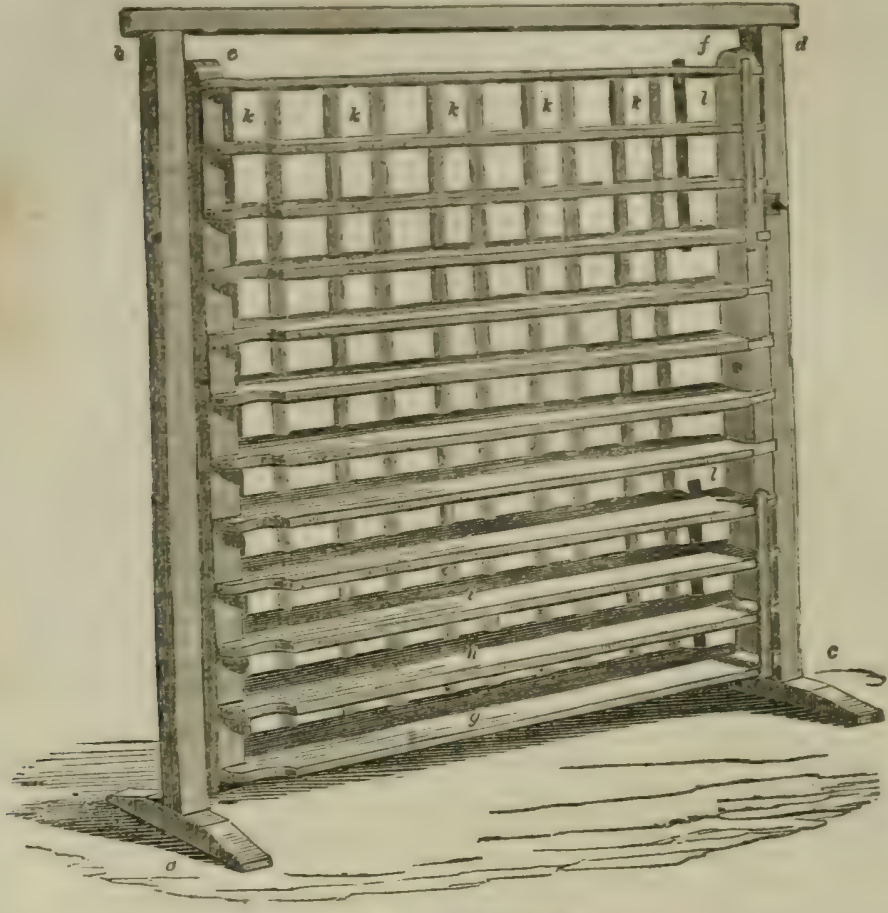

THE CHEESE-TVRNER.

cheese-room, where the rack 8 may he placed in rows extending the length of the room, leaving free passage between the rows. The width of the passages requires to be equal to half the hight of the shelf-frame, or 3 feet; a room, therefore, 20 feet wide would contain 4 rows of snch racks ; and if the length were equal to 10 diameters of the cheeses, or containing that number in the length. the room would contain in all 440 cheeses in the best possible condition for their being prepared for market, having free ventilation, and access for the dairy-maids to handle and wipe any cheese at any time. We have no experience of this cheese-rack in Scotland; but, judging trom its apparent capabilities, there is much reason to think that it might be employed with excellent effect in the extensive cheege-dairies of Ayrshire and Galloway. The price of a portable rack, as bere figured, capable of holding 55 cheeses, is $14 .-J .8$.]

\section{THE DOUBLE MOULD-BOARD PLOW.}

(2121.) (The double mould-board plore, is an implement essentially requisite in the cultivation of the turnip and potato crop. When duly constructed, it is highly efficient in the formation of the drills or ridgelets for either of these crops, setuing up at each tura the half of a ridgelet on each side, while the conmon plow, or one-horse plow so much employed for this purpose, sets up only a balf ridgelet at each turn, doing, therefore, but half the work. In a variety of forms also, it is much employed in the earthing-up of the potato crop; for this porpose it is frequently made of wood, but in all cases the iron plow is to be recommended.

(2122.) Fig. 393 is a representation of a common double monld-board iron plow equipped for the purpose of earthing-up. The framework of it is pretty much in form of the common plow, except that the beam $a$ lies right in the centra! line of the whole plow. The bridle $b$ is variously formed according to the taste of the maker, but always possessing the properties of varying the (692) 
point of dranght upward and dowuward, as well as right and left. The breast $d$ is a shield form. ing part of the cast-iron body-frame afterward described. The share $e$ is plain on both sides, spear-pointed, and set upon the head of the cast-iron body-frame. The right and left mould-boards

Fig. 393.

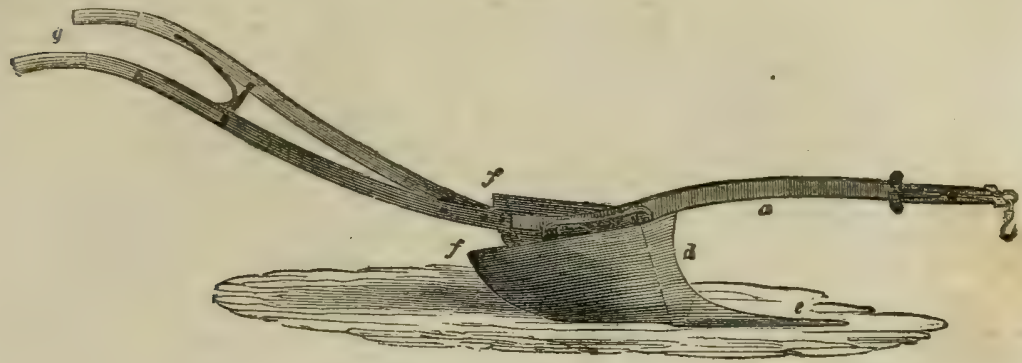

THE DOUBLE MOULD-BOARD PLOW.

$f f$ are hinged to the edge of the shield $d$ with drawing hinge-pins, and they are supported behind by a jointed iron-strap affixed to the back of each mould-board, and which slide through a socket in the body-frame, where the tails of both straps are secured by means of a pinching-screw, setting the mould-boards at any required width behind. The handles $g$ are bolted on each side of the beam, as seen at $f f$, and are supported near the helves by the usual stretcher and bow. The dimensions of the plow are : from the breast $d$ to the point of the beam 3 feet, 6 inches, from $d$ to extremity of mould-board $f, 2$ feet 6 inches, and from $d$ to end of helve 6 feet 6 inches. The hight of the mould-board, where it joins the shield, is 12 inches, and at the point $f 10$ inches; length of share 16 inches. The mould-boards of such plows are liable to great variation in their form; some of them have little or no twist, and others variously contorted. Those of the present figure hnve been selected as possessing all the requisite qualifications for an earthing-up plow. At the fore-edge, where they join the shield, the surface is nearly in a straight line, and along the upper edge they are slightly convex; from these two lines they twist gradually, rounding away below toward the tail, so as to leave the furrow of a round-bottomed trough shape. Where the double mould board is employed for forning tho ridgelets, the mould-board is made to fit the shield $d$, as in the figure; it then stretches away to a length of 2 feet 6 inches along the upper edge, the point $f$ being at a hight varying from 11 to 14 inches above the sole-line. At this point the depth of the mould-board is only 6 inches, so that the lower edge runs off at a considerable elevation, and the surface having not more than 3 inches of twist, it is the lower edge only of the board that effects the parpose of laying up the earth to form the ridgelet. In working the plow, tor the purpose of forming drills, there is frequently a marking-bar jointed to the beam immediately before the breast $d$; the bar folds to either side, and having an adjustable donble-edged scraper fitted to it, a rut is drawn on the surface at the proper distance for the centre of the next furrow.

(2123.) The plow just described and represented, is convertible into a scuffling or cleaning plow, or horse-hoe. To effect this, the hinge-pins of the mould-boards are withodrawn, and the mouldboards removed, when we have an implement represented by fig. 394 , which exhibits the body-

Fig. 394.

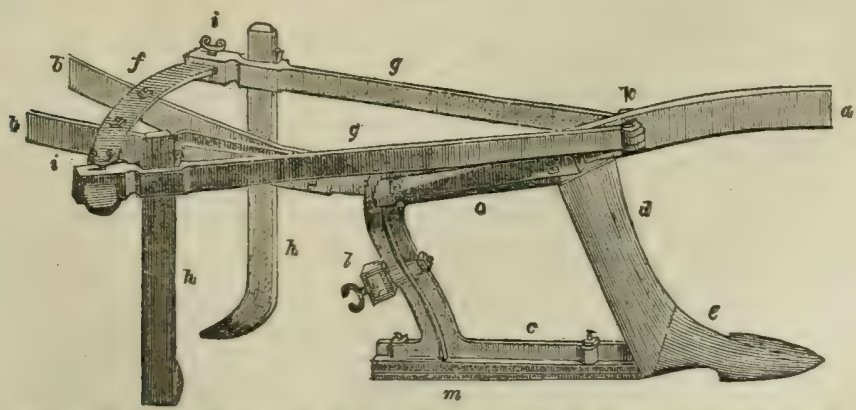

THE BODY OF THE DOUBLE MOULD-BOARD ALTERED TO A SCUFFLING PLOW.

parts of the same plow upon an enlarged scale, and from which portions of the beam and han. dles are cut off. Here $a$ is the remaining portion of the beam, and $b b$ those of the bandles, ex. hibiting also their junction with the tail of the beam. The body-frame $c c$, is of an irregular rhomboidal form, whereof the front bar forms the shield; its breadth from right to left bebina is 3 inches, running off forward to a sharp edge, and is hollowed out behind. The top bar $c$, by which it is bolted to the beam, is $2 \frac{1}{2}$ inches broad, and $\frac{1}{2}$ inch thick; the sole-bar $c$ is formed flat below, 
to receive the plain eole-shoe $m$, and the hind bar is formed to receive the malleable iron socket $h$ through which the tails of the mould board straps are passed, and secured by the pinching serew $l$, when these are in use. To complete the implement for the purpose of scuffing. the two wing bars $g g$ are jointed to a etud that projects frnm the beam on each side at $k$. A quadrant bar $f, a$ feet long. and $1 \frac{1}{2}$ by $\frac{1}{3}$ inch is attached by bolts to the two stilts at $f$, and the ends of the wing. bars having a mortise formed to receive the quadrant, are moved apon this to any required width, and secured by the screws it. A second mortise is punched in each wing-bar to receive the scuffling coulters $h h$; these are 2 inches broad by $\frac{1}{2}$ inch thick, thinned off to a knife-edge in front, and bent inward below till the points stand 6 inches to the right and left of the shanks. A double-feathered share $e$ is now fitted to the head of the body-frame, which completes this simple borse-hoe, and the change from the one state to the other is eflected in a few minutes, for, in returning it to the double mould-board state, it is only necessary to remove the scufflers and the feathered share. The dimensions of the body are, hicht at the breast from the sole to the top of the beam 14 inches, length of sole 2 feet 6 inches, iucluding the feathered share. The effect of this horse-hoe in the soil is to loosen the earth between the rows of drills, or if fool, to under-cut all the weeds that exist in that space, or to such breadth as the two scufflers may be set; the uprizlst part of these coulters performing a species of paring aloug the aides of the two contiguous rows. If the land is in good order. and tolerably clean, stirring it with this scuftler will be sufficient; but if overrun with weeds, one or other of the drill-harrows or grabber will be found necessary to prevent a re-vegetation of the weeds, and the following will be found to answer this purpose well.

(2124.) The common drill-grubber, fig. 395, is a light and convenient implement drawn by one horse. It consists of a central bean $a b c$, the neck part of which $a b$ is 18 inches loug, the body

Fig. 395.

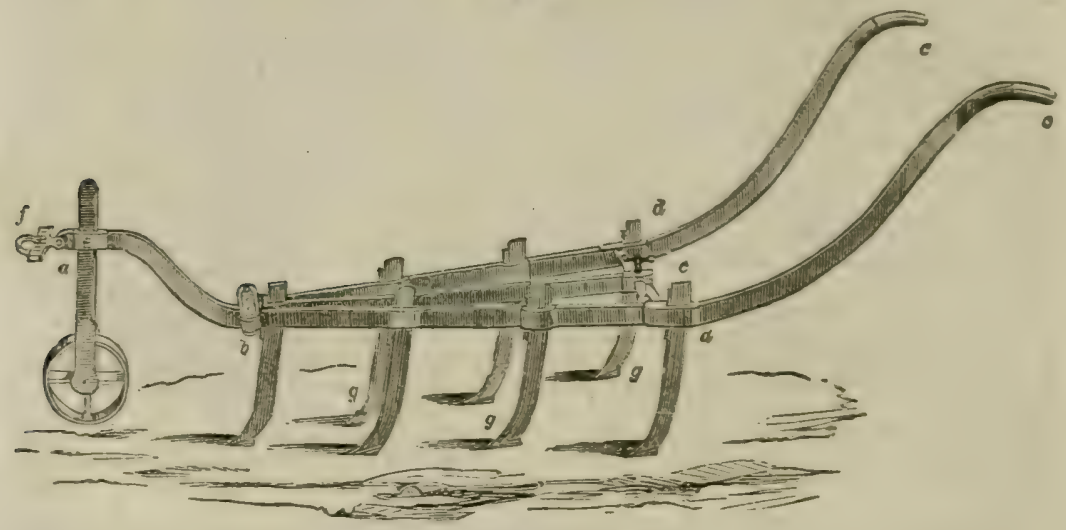

THE COMMON DRILL-GRUBBER.

part 3 feet 6 inches; and of the two wings $b d$. which are extended to $c c$ forming the handles, the length from $d$ to $c$ is 3 feet 4 inches. The neck part of the beam is $1 \frac{1}{2}$ iuches square, and peened. or rounded, and this strength is carried past the tirst tine : the remainder of this bar, as well as of the wines, is $1 \frac{1}{2}$ inches deep by $\frac{1}{2}$ inch thick, the handles becoming lighter backward. The beam is punched at the front for the passage of the stem of the wheel, and at $b$ for the fixing of the two joint-plates for the wings, as well as for the front tine; and it is also perforated horizontally at the end $c$, for the guadrants of the wings. The wing.bars reguire to be verr neatly forged in forming the swells, in which the tine boles are to be panched, and also for the joint at $b$. where they are hinged to the beam, between the two joint-plates, which, being riveted dead upon the beam. leave a chamber on each side for the reception of the ends of the wing-bars, and through these their joint-bolts are passed. The wing-bars are each furnished with a quadrant-bar rjeted into the wings at $d d$; the tail of the quadrants passing through the mortise at $c$ are secured by a pinching-screw fixing the wings at any reyuired width. To the point of the beam is affixed a simple bridle $f$ with a cross-web and shackle, giving a small range of yoke right and left : the rise of this point is 10 inches above the line of the body of the beam. The front wheel, whose office is to regulate the depth of the grubbing. is usually 8 or 9 inches diameter, set in the sheers of the stem, which may be 20 inches long, and is $1 \frac{1}{2}$ inches broad by $\frac{1}{2}$ inch thick. The tines $g$ are 15 inches long, the body being $1 \frac{1}{2}$ inches broad by $\frac{1}{5}$ inch thick, forged with duck-feet not exceeding $2 \frac{1}{2}$ inches broad and pointing slightly forward. In many localities this implement is used for all the purposes of horse-hoeing, except the process of paring or of eartbing-up, and having cheapmess as well as utility as a recommendation, it is very generally approved of. It is, however, subject to variety in the different districts where it is employed : in some it is shortened to fire tines, in others lengthened out to nine, and in many cases the tines are plain-pointed, or not exceetling 1 inch broad. It is frequently also made with the tiues standing in zigzag position; but except in the second pair of tines, this is of little importance, as those behind the second are sufficiently far apart to prevent them gettiog choked with weeds. The price of this grubber is about $\mathrm{fi}_{2} 10 \mathrm{~s}$.

(2125.) In this class of implements, we find a very bandsomely constructed one, known as 
Wilkie's drill-grubber and harrow, which is here represented in fig. 396. The implement is. however, of older date, and seems to have been invented by a Banffshire farmer, ${ }^{*}$ the original having been constructed with wooden framing until Mr. Wilkie adopted the iron instead of wood.

Fig. 396.

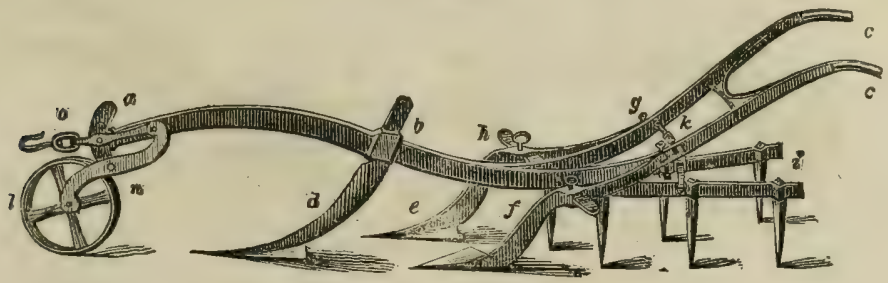

WILKIE DRILL-GRUBBER AND HARROW

This implentent is constructed with a beam $a b$, and a pair of handles $c c$ attached to the tail of the beam, one on each side, in the way tormerly shown in fig. 394 . It has no proper body-frame, but is merely a skeleton, the grubbing parts of it being the three tines or coulters $d, e, f$. The foremost of them, $d$, is set in a coulter-box in the beam, the two others, $e$ and $f$, are continuations of the two wings, which are hinge-jointed to the side of the handles as at $g$, and where they are kneed downward at $h$, they are perforated for a quadrant bar, on which they are moved outward or inward, and are secured by the pinching-screws at $h$. The front tine terminates in a double spreading feather or duck's-foot point of about 11 inches in length, and 8 inches in breadth at the heel; the two back tines are flat on the outward sides, and feathered inward; their effect on the soil is therefore somewhat similar to that of the scuffler, fig. 394, paring and undercutting; but the implement is furnished with an appendage in the attached harrow $i$, which completes the operation at one turn. The harrow consists of two bars jointed to the middle of the quadrantbar which sustains the back grubber tines, and are suspended by a small quadrant attached to each of the bars $i$, from the first stretcher of the bandles at $k$, and each of the harrow-bars carries three common harrow-tines, but somewhat longer than usual. The harrow is, besides, capable of adjustment to depth by means of its suspenders, and to breadth by means of its two small quadrant-bars. The regulation of depth is aided by the wheel $l$, which may be from 8 to 10 inches in diameter, hung in the sheers $n$, which is jointed to the beam at $a$, and is capable of being shifted up or down upon the cross-head 0 of the beam, and fixed by a bolt at $n$, passing through the perforations of the cross-head, to which also a shackle and hook are attached for the dranght.

(2126.) It requires no demonstration to show that the principle of this instrument is good-grubbing or scarifying to undercut all weeds, which are immediately brought to the surface by the action of the harrow, to wither and die-but it is believed that defects of construction exist in it that in some measure mar its utility. In stiff soils the broad-feather shares will with difficulty be kept in the ground; and. from their great length and brearlth, will have the effect of consolidating that part of it which they pass over, into a hard crust. The harrow is an important part of the implement, but adds considerably to the draught; and the implement, upon the whole, is too heavy for one horse being able to produce efficient work with it; by lightening the entire structure, and altering the form of the tine, it might be rendered a very useful horse-hoe. Its general dimensions, as constructed by Mr. Wilkie, may be shortly stated. Length of beam from crosshead to coulter-box 2 feet 10 inches; thence to quadrant of the bark tines 1 foot 10 inches, and thence to end of handles 4 feet 6 inches; hight of beam at coulter box 16 inches, at quadrant 14 inches, and at the point 18 inches. The depth of the beam at the coulter box is $2 \frac{1}{2}$ inches, and its breadth 1 inch, from which point it tapers off forward and backward; the handles are $1 \frac{3}{4}$ inches in depth by $\frac{3}{8}$ inch in breadth. The length of the harrow-bars is 2 feet 9 inches, and the length of the tines 10 inches; the weight is $145 \mathrm{lbs}$; and the price of the implement is $£ 415 \mathrm{~s}$.

(2127.) The foregoing constitute a series of green-crop horse-hoeing implements, that possess all the principal points requisite for this operation; but there are numerous varieties of all the types here exhibited, though all are referable to one or other of them. It is, or ought to be, an essential point in all implements of this kind, that they possess a principle of expansion and contraction, to suit the different widths of drills; and, with few exceptions, this is the case. In many of those in use, however, the mode of expausion is attended with an inconvenience arising from the shortness of the expanding wings, which throws the coulters or tines ont of parallelism. and thus proves detrimental to their perfect working in the soil. This inconvenience is more felt in those implements which have their tines formed like those of fig. 396, and least of all when the scuffling-tines are employed as in fig. 394. Mr. Wilkie, with his usual ingenuity, has invented, some years ago, an implement of this class, in which the expansions and contractions are effected by means of a parallel motion applied to the tines, as exhibited in the following figure.

(2128.) Fig. 397 exhibits Mr. Wilkie's horse-hoe with parallel motion; it is very similar in figure to the last, but the two back tines have their tails jointed at $a, b, c, d$, to two transverse parallel bars, which traverse, to a small extent, upon pivots placed in the middle of their length, attached to the tail of the beam. By moving these bars upon their pivots, from the position of a right angle with the central line of the beam, the one tine is pushed forward and the other backward, which must cause the points $a, b, c, d$, to approach the central line, and along with these the points of the tines, preserving a perfect paralielism, and capable of being secured at any required

- Agricultural Report for Banffishire. 
width by pinching-screws. This is the most perfect mode of adjustment for the tines of a hoe of this construction-three-tined-but it does not apply to those with more than three, and if, withal. perhaps, too refined for a field implement. The self-cleansing form of the tine which is exhibited

Fig. 397.

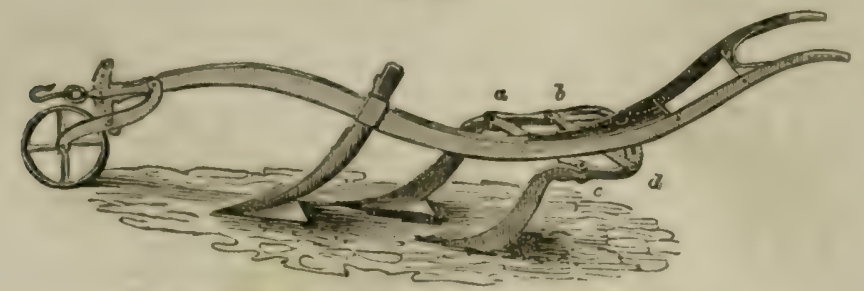

WILKIE'S HORBE-HOE WITH PARALLEL MOTION.

bere, and in fig. 396, in the two back tines of each, has been often dwelt upon as of much im. portance; but the truth of the matter seems to be, that though that particular form is beneficial in the great field-grubber, it seldom occurs, and ought never to be the case, that a drilled field-crop is so overrun with weeds as to require a self-cleansing tine.-J. S.]

\section{HAY-MAKING.}

"As they rake the green appearing ground,

The russet hay-cock rises thick behind,

In order gay."

THoMson.

(2129.) Hay is made both of sown and of natural meadow-grasses. The sown grasses are employed for hay in Scotland, and of these the hay consists of red clover (Trifolium pratense), and rye-grass (Lolium perenne); for although the white clover (Trifolium repens) is sown along with the seeds of the other two, it scarcely forms a part of the first year's grass, and constitutes no part of the hay, which is always taken from the grass of the first year. As hay is thus taken from the first year's grass, it matters not whether the rye-grass made into hay is annual or perennial. The annual yields the heavier crop, but the perennial the finer quality of hay. The natural grasses constitute the hay of England and Ireland. These two sorts of hay are certainly very different in appearance, the sown grasses showing the strong and stiff stems of the red clover and rye-grass, and especially when the rye-grass is annual, while the hay from the natural grasses is soft and woolly to the feel, and more odorous to the scent, because the sweet-scented vernal-grass (Anthoranthum odoratum) always forms a component part. In so far as their nutritive properties are concerned, if both are equally well made, there will probably be no material difference; but this fact has been established in Scotland, that the sown grasses are more nutritive for young stock, both sheep and cattle, than natural grasses, and for that reason we may hold it as true that their hay will also be more nutritious for young stock; and in like manner the hay of natural grass should be more nourishing to old stock than from that which is sown; and hence natural hay is best for cows.

(2130.) I have heard farmers express the opinion that sown grasses require a different treatment on being made into hay than natural grasses. If the object is to obtain rye-grass seed while hay is being made, then, of course, the two processes should be different; but if the object is to make (696) 
the best hay from both the substances, then I cannot see why the processes should be different. On the contrary, the nature of all the plants employed being the same, the same treatment should produce in all the same results; and as the art of hay-making is merely to expel the water which the plants contain without injury to their texture, the only danger to be apprehended is excessive fermentation, which is easily excited in warm weather, and will proceed to a destructive extent, if not subjected to control. Still hay-making varies according to the means used for conducting it; for if manual labor alone is employed, one process should be adopted, but when mechanical assistance is received, the process should be modified accordingly.

(2131.) First, then, as to hay-making with manual labor alone. The implements required for the purpose are few and simple. The grass is cut with the common scythe, fig. 361 ; and the cutting is either let to laborers by the piece, or the plowmen of the farm do it, should there be spare time from horse-labor between the sowing of the turnips and the hay-harvest. The grass will be better and more expeditiously cut down if let by the piece, as the contractors will exert themselves more, and work more hours, than plowmen who have charge of horses can be expected to do. The usual cost of cutting grass for hay is $2 \mathrm{~s}$. $6 \mathrm{~d}$. or $3 \mathrm{~s}$. per imperial acre. On commencing to cut a field, the direction toward which the clover leans, or, should it be thin and upright, the quarter of the wind, which always influences the direction of thin grass, should be attended to; and in both cases the grass should lean away fiom the mower. It always makes the best work for the grass to be mowed across the ridges. It is fair work for 1 man to mow 1 acre every day; and I may here remark, it is no good sign of the weight of the crop if the mowers go over more ground every day. The other implements used in manual hay-making are forks and rakes. Forks are shown in fig. 279, and rakes are figured and described below; and of the two kinds I prefer the right-hand figure, as being the neatest and lightest.*

(2132.) Let us next consider the making of hay with the aid of horselabor and suitable implements, the employment of which makes a considerable difference in the process. The tedding-machine, represented in Plate XXXI. fig. 368, is used to ted hay, and which it best does by passing across the swathes, taking up and teasing and scattering them on the ground in the most regular manner. It is alleged that this machine is only suited to ted natural grass, but why so is not obvious, for its structure is capable of laying hold of any kind of grass. It would indeed shake rye-grass too much that is intended for seed; but I have already said it is impossible to obtain good hay and good seed from the same crop. If the object be merely to ted grass, this machine will doubtless ted sown grasses as well as natural, when they are cut at the proper age. After the grass has thus been tedded, it is allowed to dry in the sun and wind all the forenoon. In the afternoon the bay-rake, whether the common horse-rake or American hay-rake, both of which are represented and described below by Mr. Slight, is employed to rake the tedded grass into a windrow across the 4 ridges which intervene between every fifth ridge which contains a row of cocks. Where the crop of grass is very thin, the horserake might carry the grass into a windrow over more than 4 ridges upon the fifth ridge; but with an ordinary crop it could not, perhaps, accomplish this, and much less with a heavy crop. After the grass, therefore,

L*Here follow minute directions for hay-making, not applicable to our country, from various circumstances, which the reader can imagine. The difficulty with us is to get the grass or the ground. The process of curing is simple enough.

Ed. Farm. Lib.] 
has been withdrawn across the 4 ridges, manual labor is employed to put it into grass-cocks, as in the case with manual labor. It will be observed that few people, and especially women, are required to conduct haymaking in this way, the heavy part of the duty consisting of making the cocks as often as requisite, which is best done by men.

(2133.) A large oblong hay-stack should be built in this way: In the first place a dry stance should be chosen, for a damp one will cause the destruction of several stones of hay at the bottom of the stack. The stance should be raised 1 foot above the ground with large stones inscribing the circumference, and the interior filled up with stone shivers or gravel beat firmly down. Upon this space the stack sliould be built by 2 men, who are supplied with armsfull of hay by a number of field-workers, whose duty is not merely to carry the hay but to tramp it under foot in a regular manner from one end of the stack to the other. The 2 men, each occupying a side of the stack, shake and build up what is called a dace of the hay before them as high as their breast, from one end of the stack to the other; and after half its length is built up in this manner, the women go upon it and trample it, and if they hold by one another's hand in a row their walking will prove the more effective. The breadth of the stack is a little increased to the eaves. The hay is forked from the ground by 2 or 3 men, and when the stack lias attained an incourenient hight for this purpose, there are 2 or 3 modes by which hay may be carried to greater hight; one is by placing short ladders against the stack, and a nin on each, some way above the ground, with his back to the laddor, where he receives the forksfull of hay from the forker on the cround, and raises the load above his head upon the stack. Anotlier mode is for men to carry back-loads of hay up long laduers, and emply them on the stack. A third is to erect a scaffolding of planks upon a couple of tresses of 6 feet in light, and to fork the hay oft' the scaffolding to the stack as it is forked upon it from the ground. Of the 3 modes, the last of the scaffold affords the most secure footing to the men at an elevation from the ground, and in the end is the most expectitious; and in all the modes 4 men will be amply employed in forking up the hay to keep 2 builders in work. The hay is forked off the ground instead of the cart, as the latter mode would hinder the horses too long to make them stand till the cart is cleared of its hay by forking. The hay is, therefore, thrown down upon the ground from the cart, and if the cart is constructed to tilt up, the deposition of hay is easily effected ; and even from a whole-bodied cart hay is easily thrown off by the forkers sticking their forks under the load along one side of the cart, and pushing upward and from them to the other side, one person holding by the wheel nearest the men to prevent the cart upsetting. The position in which the load is thrown upon the ground requires to be considerately chosen. The load should be thrown away from the spot upon which the men stand to fork, when the hay will easily come away with the fork, because each stratum of hay, as it was forked on the cart, then lies toward the men; whereas, when the load is thrown toward the forkers, the inclination of the hay abuts against them, and every forkfull must then be pulled away by main force. A hight of 12 feet is enough for the body of the stack, and a breadth of 15 feet is convenient for a hay-stack, and with these fixed dimensions, the length may be made more or less, according to the quantity of hay to be stacked. With these dimensions a new-built stack of 40 feet in length will contain about 2,000 imperial stones. After the body of the stack has attained 12 feet in hight, the heading is commenced by gradually taking in the breadth on each side to the ridging, which is elevated half the (698) 
breadth of the stack above the eaves, and the ends are built perpendicular. One man and one woman will only find room at the finishing of the top of the stack. A few straw ropes are thrown over the stack to prevent the wind blowing off its new-made top. The stack is left for several days to subside, and unless it has been slowly built and firmly trampled, it may subside in the body to the extent of 2 feet. Very probably heat may be indicated in some part of the stack a few days after it is built, by a leaning toward that part, because heating causes consolidation of the hay. A prop of wood placed against the place will prevent the stack subsiding much farther, and the handle of a rake pushed in here and there into the stack, will indicate whether the heating is proceeding upward or to a dangerous extent. A gentle heating will do no harm, but rather good, by rendering the quality of the hay uniform, and horses do not dislike its effect. Salt has been recommended to be used in hay, and when hay is in a damp state in consequence of the weather, it is an excellent remedial measure against mouldiness, and it may be sown by hand upon every dace of hay laid down by the two builders. The proper quantity of salt is to be used, according to the state of the hay, has never been correctly ascertained, and must, therefore, be left to your own judgment according to circumstances. Salted hay is very much relished by all kinds of stock, and especially by cattle.

(2134.) When the hay has fairly subsided, and the heat, if any, is no longer felt, the stack should be thatched, and as a preparatory operation, the sides and ends are neatly pulled straight from angle to angle of the stack, with a small increase of breadth to the eaves. This operation sim. ply consists of pulling out the straggling ends of the hay, which give a rough appearance to the sides and ends, in order to render them smooth; and its use is to save the hay pulled out which would otherwise be bleach ed useless by exposure to rain, and to prevent rain hanging upon then about the stack. The heading or thatching consists of straw drawn straight in bundles, held on by means of straw-ropes. When a hay-stack is to be thatched, the drawn bundles of straw, and the straw-ropes, should, of course, be prepared in time; and yet it is a matter not of unfrequent occurrence for farmers to allow the hay-stack to stand unthatched until the corn harvest, for want of straw ; or even to allow the hay to be left in ricks on the field till just on the eve of harvest. Straw, in some instances, may indeed be scarce, but in that case rushes and other tall-grown wild plants form an excellent substitute, both for thatch and ropes. Ferns and heath are good materials for thatch. The thatching should be carried on both sides of the stack simultaneously by 2 men, and begun at the same end. The men being mounted on the head of the stack, the bundles of straw are handed up to them on a fork one by one as they are needed, and each bundle is retained in its place on the roof, beside the thatcher, by leaning against a graip stuck into the hay. The straw is first placed over the eaves, handfull after handfull from the eave to the top of the stack, each length of the straw being overlapped by the one immediately above it. When the thatcher feels a hollow or soft part with his feet in the head of the stack, he makes up the part by some of the hay that was pulled out of the stack, to save the wasting of thatch straw in filling up such hollows. The straw is thus laid from the eaves to the ridge of the stack to a breadth as far as the thatcher can reach at a time with his arms. When the men on both sides meet at the ridge, straw is laid along the stack upon the ridge, to cover the terminal ends of the thatch on the sloping roof, and to support the ropes which keep down the thatch. When this breadth, of perhaps 3 feet, or a little more, of the thatch is laid down, its surface is (699) 
switched down smooth by the thatcher with a supple willow rod, and then a rope is thrown across the stack at its very end, and another parallel to it at 18 inches apart, and made fast at both ends, in the mean time, to the sides of the stack. Other ropes, at right angles to the first, are fastened Is inches apart to the hay at the end of the stack, and supposing the side of the roof to be 11 feet along the slope, 6 ropes running horizontally will be required to cover the depth of the slope, leaving a space of " 9 inche: from the ridge for the place of the uppermost rope, and the rope at eacl eave is put on afterward. Each of these horizontal ropes is twisted once round every perpendicular rope it meets, so that the roping when completed has the appearance of a net with square meshes. As every subsequent breadth of thatch is put on, the roping is finished upon it, the advantage of which is, that the thatching is finished as it proceeds, and placed beyond danger from wind or rain, or disturbance from after work. If the stack stands $\mathbf{N}$. and $\mathbf{S}$, the $\mathrm{E}$. side should have a thicker thatching than the $W$., as being most liable to damp, and the thatching of both sides should he thicker toward that end of the stack which is farthest from the steading, as it will stand longest, and the process of thatching should terminate at the end which will be first broken upon, that is, nearest the steading, because the thatch will come away more freely when removed in the opposite direction from which it was put on. The horizontal ropes at their termination are fastened into the hay at the end of the stack. The eave is finished by laying a stout rope horizontally along the line where the roof was begun to be taken in, and twisting it round each perpendicular rope as it occurs; when each perpendicular rope is broken off at a proper length and fastened firmly to the hay immediately under the eave, and after the eave-ropes have thus been fastened down, the projecting ends of the thatch over the eave are cut straight along the stack, and give to the heading a pretty finish. Another mode of roping the thatch is to place the ropes in a diagonal direction across the stack, and when one set of ropes cross the other diagonally, the effect is lozenge-shaped, which looks well; but roping in this fashion requires the thatcher to place all the straw upon the roof before he guides the ropes over the ridge of the stack, to do which he must stand upon the ridge and step backward upon it-a plan which allows the wind to have liberty to blow off the thatch before it is roped at all, and also obliges him to trample down the ridge straw to a certain degree.

(2135.) On the other hand, when the stack is built under corer of a rickcloth or shed, the hay may be led in by a cart-load at a time, employing only 3 hands, for the builder forks the hand-cocks in the field to the cart, and the carter forks the hay to the builder off the cart, while the same field-worker who rakes the bottoms of the hand-cocks in the field carries the hay to the builder on the stack, each forkfull of hay, in this case, being thinly scattered over the stack, is easily trampled down, and has time to subside before another load is put over it on the following day. Where the rick-cloth is used, the stack should be thatched on its removal; but where a shed is erected, no thatching is required.

(2136.) Hay is sometimes built in round stacks, which are kept of a cylindrical form for 7 or $S$ feet from the ground, and then terminated in a tapering conical top, and thatched. Such stacks contain from 300 to 500 stones of hay. This form of stack is convenient enough when a whole one can be brought at once into the hay-house, but should the stack be of such a size as to be necessary to bisect it perpendicularly, the remaining half is apt to be blown over; or should its upper half be brought into the (r00) 
lay-house, the under part must be protected by a quantity of straw kept lown by some weighty articles, and in such a case it is seldom that these are put on with sufficient care to keep out rain and resist wind. Upon the whole, the oblong form of stack admits of being most conveniently cut for lise, and left at all times in safety; because a section of any breadth can he: cut fiom top to bottom to fill the hay-house.

(213\%.) The rule for ascertaining the number of stones of hay in oblong stacks is simple enough, hint 101 so for conical stacks. To find the weight of hay in an oblong stack:-To the hight from the srounl to the eaves add one-half of the hight of the top above the eaves for the mean hight, then multiply the mean hight by the breadth, and then multiply the product of both by the length. Divide the Linss product by 27 . and the dividend will give the number of cubic yards in the stack, and that number of yards multiplied by the number of stones of hay in a cubic yard, will give the weirht of the stacks in stones imperial. It is not easy to state the exact number of stones of hay in a cubic yard, as that must vary according to the compressed state of the hay, the weight actually varying from 5 stones to 9 stones per cubic yard, according to the age and size of the stack, and the part of the stack from which the hay is taken; but perhaps 6 stones may be near enough the mark of the weight in a new stack, 7 stones in one that has stood for some months, and 8 stones in one that has stood over years. The contents of a round stack with a conical top may be ascertained in this way:-Take the hight of the round part from the ground to the eaves, and add to it one-third of the perpendicular hight of the covical top above the eaves for the mean hight of the stack. Take then the mean girth, which, if the stack is wider at the eaves than at the ground, is ascertained by taking the girth at the eaves, aud also at the ground. and dividing their sum by 2. Square the mean girth, and multiply the product by the decimal .0795 , which will give the area of the base of the stack. Then multiply the area by the mean bight, which will give the contents of the stack in cubic feet, divide the contents by 27 , which will reduce them to cubic yards, and then multiply the yards by the supposed number of stones of hay in the yard, and the capacity of the stack will be found in stones. To know the contents of a conical stack or coll, take the girth at the ground in feet, find the area of the circle in the ordinary way, and multiply the area by one-third of the hight. The contents thus found in feet reduce to yards, and then multiply by the number of stones in a cubic yard. But the simplest plan in all such cases is to use any of the Tables which are published for the purpose of saving tedious calculations, such as those of Anslie or Stracban, the latter of which, however, are not extended far enough to comprehend stacks of the largest dimensions.

(2138.) A crop of hay varies from 150 to 300 stones per acre, according to the season and the nature of the soil. On light gravelly soils the crop is never heavy, but its quality is generally fine, and on good clay it is usnally heavy, and the plants large and strong, the clover predominating. For quantity and quality combined, a deep mellow clay loam may be regarded as the best texture of soil. On thin clay, and on thin light soil resting on retentive clay, the clover is frequently thrown out by frost in spring, and the hay then cunsists chiefly of rye-grass, and on the same soil the same effect is produced by severe drouth in May. Good hay should consist of equal quantities of clover and rye-grass, teel pleasant to the hand, and smell fragrantly, and, when well prepared, possess a light brownish-green color; but as it is commonly prepared, the color is usually light brownish-yellow. Hay of natura] grass, when well prepared, is darkish green in color, feels soft, is generally of fine quality, and highly fragrant. Grass usually loses two-thirds of its weight on being made into hay.

(2139.) Of 3060 grains of white clover, as much as 2430 grains were water. 100 grains nutritive matter, and the remaining 470 grains were iusoluble matter. The nutritive matter in the 100 grains consisted of 77 of starch, 2 of sugar, 7 of gluten, and 14 of bitter extract and saline matter.* "When green grass or clover, approaching to maturity," say Professor Johnston. " is first cut down, it contains a considerable proportion of starch, sugar, and gum still unchanged into woody fibre, as it would mostly be were the plant allowed to become fully ripe." Here you see the propriety of cutting down grass for hay before any of its seed approaches to maturity, because latterly it contains woody fibre instead of the nutritive ingredients just mentioned. But even when sueculent grass is "left to dry in the open air, the circulation proceeds to a certain extent, and, under the influence of light, woody fibre continues to be formed in the upper part of each stem, until it becomes completely dry." And "it may even be a matter of doubt whether the process of change does not often proceed after the hay has been carried off the field and stacked." $\dagger$ All which considerations tend more and more to prove that the longer grass is allowed to stand after the plant has attained its full stature, the less digestible or nutritious the hay will become; and more than this, the longer the process of making the grass into hay is delayed, the more woody, and, of course, the less nutritious the hay will be. Every quick process of converting grass into hay is, therefore, better than any slow one. There is a very quick mode practiced in Saxony, which is this:-The grass that has been cut down during the day is put into large cocks late in the afternoon. A very strong fermentation soon ensues. which continues all night until the morning. when the work-people return to the field, by which time the cocks have contracted much in bulk, and the steam rises briskly from them. They are then thrown down and scattered on the ground, and their contents allowed to remain all day exposed to the sun and air. and by the afternoon the hay is so dry and won as to be fit to be stacked, and accordingly it is gathered from the ground and carried to the stack. The new-mown grass of the day is put into large cocks in the evening, to be treated the next day in the same manner. This mode of hay-making might be followed in this country, provided we could trust our climate; but should the next morning prove a rainy or even a damp one, the contents of the cocks would inevitably be rotted. The modes of

* Sinclair's Hortus Gramineus Woburnensis.

+ Transactions of the Highland and Agricultural Society for October, $18 \$ 3$. (701) 
hay-making, both manually and mechanically, which I have described above, are both expeditions, as are also the modes described by Mr. Little, Carlesgill, and Mr. Miller of Forest, both in Dom. friesshire."

(2140.) As hay is usunlly made in a thriftless manner, and as grass is more nourishing to atock than hay, and as good food can be cooked for horses in winter withont hay. I bave often thought it a losg to farmers to make hay at all. The grass would pay better on being grazed, and the land would be retained in better lieart. In the vicinity of large towns, it may be expedient to make hay, and yet when the crop proves heavy the price is low-the average may be atated from the tramp-rick at $8 \mathrm{~d}$. per stone of $22 \mathrm{lbs}$. I have seen the price as low as $4 \mathrm{~d}$. and as bigh as 18. 4d. per stone; but when the price is bigh, the crop is deficient, and the quality of the hay bad. Taking the heaviest crop of 300 stones at $8 d$., it will jield $f 10$ an acre, but 220 stones is nearer the mark; and yet grass lets for cutting \pm 12 or $£ 14$ per acre in the neighthorhood of Ellinburgh, withont incurring any trouble to the farmer. I am sure if half the labor spent in making hay were bestow. cd in winter in cooking food for the horses. tarmers would derive a profit from the exchange.t

(2141.) (Of the hay-making implements, the scythe (2615), and fig. 361 , and the hay-fork, fig. 279 , having been already alluded to, I have now to notice a machine which is extensively employed by the English farmers in the preparation of meadow-hay, or hay prepared from the mix. ed natural grasses, in contradistinction from the artificial, or rye-grass and clover hay.

(2142.) The English hay-tedding machine, which is represented in perspective in Plate XXXI. fig. 368, consists of a skeleton carriage, having a series of revolving rakes occupying the place of the body. The carriage is composed of the transverse bar $a, 6$ feet in length, into which the horse-shafts $b \quad b$ are tenoned. An iron stay bar $c c$ on each side connects and supports the shafts, and the atays are continued backward. and attached to the center of the box that curries the axle of the carriage-wheel on each side. The length of the bars $c$ from $a$ to the center of the axle-box is 3 feet 10 inches, and the bars are $2 \frac{1}{2}$ by $\frac{1}{2}$ inch. The carriage-wheels $d d$ are 3 feet 10 inches diameter, and turn upon arms cast on a circular box, into which the nave of the wheel, armed with a ratchet $e$, is received. The ratchet wheel $e$, thus attached to the nave of the carriage wheel, takes hold of the spur-wheel $f$ by means of a pall, and carries it round when the machine advances, but slips hold on backing or turning. The spur-wheel $f$ works into the pinion $g$. which is mounted on the end of the hollow shaft $h$, extending from side to side of the machine; and though in the figure, for the sake of distinctness, the spur-wheel and pinion are exposed to view. they are in the machine closely boxed up in a caet-iron casing, which, for perfect and safe working is necessary to prevent entanglement from the hay falling between the wheel and pin. ion. A bar of $1 \frac{1}{2}$-inch round iron passes through the hollow shaft $h$, and has its end fitted tightly into the outward side of the case that contains the pinion $g$, and there fixed firmly with a sirewv. nut on the outside of the case; and the hollow shaft and pinions being firmly connected by thin flanges (which are left out of the figure), they revolve round the central rod or shaft as one body, the rod having turned bearings where the pinion embraces it. The two rake-whecls $i$ i are 2 feet 8 inches diameter, and of very light construction; they have eyes sufficiently large to pass over the end flanges, of about 7 juches diameter, of the hollow shaft, to which the pinions g are attached by means of their Hanges; and, to fill up the large eyes of the rake-wheels, the shaft $h$ is swelled ont at the points of bearing. The rake.wheels, fixed dead upon the shaft $h$, are now armed with the eight rakes $k k$; these are wooden bars 5 feet 6 inches long, and $2 \frac{1}{4}$ inches square, each carrying 10 light iron teeth about 7 inches in length. The rakes are attached to the wheels by a tumbling joint $m m$, dc., and are held to the work by the springs ? only ; by which arrangement, when any undue resistance is opposed to a rake, such as a stone or other obstruction, the rake falls back till the obstruction has been passed, when the springs immediately return it to its working position.

(2143.) It will be observed that there is no thorough axle in the machine, as the revolution of the rake occupies the place where that member should exist; hence the axle-arms or heads are simply studs projecting from the box which contains the machinery $e, f, g$, and hence also the necessity for the connecting-bar which passes through the hollow shaft; that, together with the

* See Prize Essays of the IIighland and Agricultural Society, vol. xiv.

[ $\dagger$ We have before us a letter from Henry Ancrum, of Ashley, Missouri, in which he says :- "I have tried a great many experiments on animals. I have kept 20 Durham cows, 7 horses, and other stock. in a situation where hay was $\$ 25$ a ton, in the highest health and condition without a blade of hay; and the result of my investigations and trials is, that cooked food in winter is the cheapest and most wholesome.

I have found that it is pretty indifferent as to the quality of the food by which the alimentary canal is filled, if ample, provided a certain quantity of concentrated food is given containing uitrogenous substances, and a small quantity daily suffices. No animal can be brought easily and read. ily to his highest pitch of perfection on one kind of food alone. The great secret is to keep up the animal heat in the winter. Where this is strictly attended to, any inferior food at discretion. and given with stated regularity, will make an animal fat. I have seen oxen of the largest size made completely fat with a moderate allowance of hay, with cabbages of the Anjou kind; but these animals were fed with the greatest regularity, curricd, kept extremely warm, and the chill taken off the water in cold weather. How many millious are lost in the United States by not keeping up the animal heat in the winter ?"

These suggestions, sustained by modem experiments on the nature and action of food, we consider important, as going to show that good hay is not so indispensable as may be imagined by those who have it not within their reach or to whom it would be very costly. Ed. Farm. Lib.] 
bar $a$ and the longitudinal bars $c c$, being the only parts which constitute the framework of the machine. Besides the capability of backing, without turning the rakes, there is provision for dis. engaging them when the machine is advancing. To effect this, the pall which is attached to the spur-wheel $f$, for the purpose of deriving its motion from the ratchet-wheel of the nave, is held in action by means of a spring pressing on the tail of the pall, and the disengagement of the whole machinery from the carriage-wheel or first mover, is effected by a small tumbling lever affixed also to the spur-wheel, and fitted to bear upon and throw the pall out of gear with the ratchet of the carriage-wheel nave. The machine is also furnished with the means of elevating and depressing the center of the revolving-rake. and, of consequence, bringing the rake-teeth nearer to, or farther from the ground, and this is effected by turning round the circular boxes that contain the gearing to the extent required, which is then fixed by means of a quadrant bolted to the bars $c, c ;$ a small portion of this quadrant, which is a part or flange of the gearing-box, is seen with its bolt-holes at $e$ on the left, and at $i$ on the right of the figure. When in operation the machine is drawn by one horse, or sometimes two horses, and the result of the combination of the gearing is that the revolving-rake makes $4 \frac{1}{2}$ revolutions for one of the carriage-wheel. The latter being 3 feet 10 inches diameter, will pass over 12 feet or thereby in one revolution. and the rakes being 4 feet 6 inches diameter over the extreme points of the teeth, will describe a circle of about 14 feet in circumference, and this revolving $4 \frac{1}{2}$ times for one of the other, the points of the teeth, will pass through 63 feet while the carriage has moved over 12 feet, and as there are 8 rake-heads, there will be $8 \times 4.5=36$ contacts with the substance which is to be lifted, in a space of 12 feet, or one at every 4 inches. From this calculation it will be seen that the hay under the operation of this machine will undergo a process of teazling or tedding of the most perfect description; it will be separated and tossed about until no two stems of the plants will be left in contact. and by this exposure the drying process is effected in a period greatly shorter and more effectually than could be done by any number of hands. Thus, if we suppose the horse to walk $2 \frac{1}{2}$ miles per hour, and the machine to cover 6 feet in breadth, we have a surface of $1 \frac{1}{2}$ acres nearly covered in an hour.

(2144.) The following machines, though not confined to the hay-field alone, but are also employed in the grain harvest, are very frequently employed in hay-making, for the sole purpose of collecting the bay into heaps after the tedding process has been gone through.

(2145.) The hand hay rake is an implement of great simplicity, but though almost elementary in its construction, it has been subjected to numerous variations, chiefly in one point, with a view to improve its construction. It covsists of a head $c d$, fig. $399, g h$, fig. 398 , of from 24 to 27 inches in length, made of lard wood $1 \frac{1}{2}$ inches broad in the middle, tapering a litule to each end, and from 1 to $1 \frac{1}{4}$ inches thick. The head is armed with twelve or thirteen wooden teeth $a$ or $e$, made of oak or ash $\frac{3}{8}$ inch in diameter, and. when first made, about $3 \frac{1}{2}$ inches long. They ought to be formed

Fig. 398.

Fig. 399.

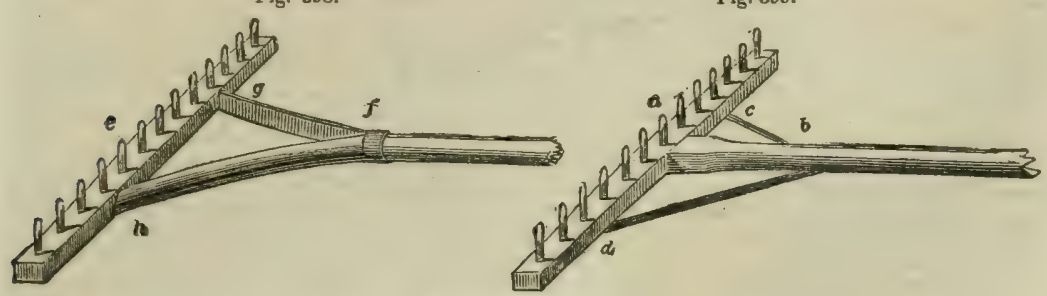

THE HAND-RAKES.

with a slight swelling in the middle, or rather towards one end. the shorter end being adapted to fit into holes previously bored at 2 inches apart centres; and when the teeth are driven into their holes the swell on the tooth fills up the hole tightly. giving the tooth much greater strength than if it were quite cylindrical. The teeth are then properly secured by wedging, and the wedges and ends dressed off; the points of the teeth are likewise dressed off to a unitorm length, $2 \frac{1}{4}$ inches or thereby, and sharpened off from the back. The shaft or helve, which is $5 \frac{1}{2}$ feet loug, is usually made of ash, but as lightness is an object, its thickness ought not to exceed $1 \frac{1}{4}$ inches, dressed neatly smooth and round except where it enters the head; here, and for a length of 12 inches, it is usually kept square. This part of it is either let into the middle of the head by a tenon, as in fig. 399, or it is split as in fig. 398, and enters it by two tenons. It is in this point of the construction that the variations have occurred, and from the slightest consideration it will be evident that the single tenon alone, as in fig. 399, is defective and weak; hence the grounds for the variation, to afford some additional support to the simple tenon, and fig. 398 exhibits one mode of accomplishing the object; the helve is split with a saw from the end backward to $f_{0}$ at which point it is prevented from splitting farther by the application of a rivet put through the termination of the split part, or, what is much better, an iron ferule, as in the figure, is drawn tight upon it ; the fork is then opened, the ends adapted to the respective mortises and secured into the head of the rake. This is apparently a very simple mode of accomplishing the object, but it is not by any means a perfect one. Were it possible to make the two parts $f g$ and $f h$ free of curvature, the object wonld be attained; but as this cannot under the circumstances be done, the head and the helve will have a very unstable attachment to each other, and a consequent weakness of parts; neither is it less expensive than other and better methods, though the rake of this form is always light in hand, which is its only commendation. A semi-circular bow of bent ash wood bas been often applied, passing through a hole at $b$, fig. 399 , and entering the head at $c$ and $d$, but this, by reason of its curved figure, is also especially defective, besides weakening the helve. Equally so is a light iron bow of the same curvatare, but, instead of passing through the helve, it is simply attached to

(703) 
it, and to the hend with a nail at each of these points. This will be better in degree than the last. from the greater rigidity of the iron. but is not better in principle. The true and only mode of applying the bow is that exhibited in fig. 399, where the parts $b c$ and $b d$ are perfectly straight, and formed of very licht iron rod; it need not exceed t inch diameter, tlattened at the two extrem. ties and at the noint $b$ into a small flat palm, and fixed to the helve and the head by a serew-nail at each point. This part of the rake is called the stay or brace, and in the last described form is as perfect as the case will admit of.

(2148) To have said so mach on an implement so simple and of such small intrinsic value may appear trifing, but the hay-rake is not so much the object here as the development of the principle, on which depends the strengthening and supporting the parts of any form of frame-work. whether of woou or iron, by the nid of diagonal stays or braces. This single member in all constructions is of such importance that no opportunity should be lost in impressing the principle on the mind of all, whose busiuess or interest lies in those departments of Mechanics where its applieation is required.

(2147.) The American hay-rake, is on called from its luaving becn an importation from America. This implemeut is represented in fig. 400 , in perspective, and lying in the working position. It

Fig. 400.

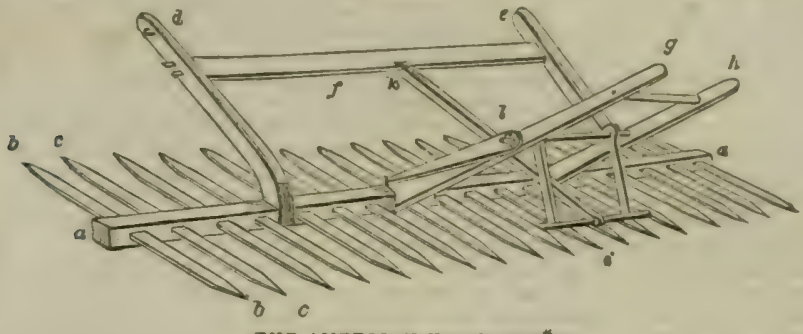

THE AMERICAN HAT·RAKE.*

consists of a beam or head $a a, 9 \frac{1}{2}$ feet long and about 4 inches square; it is perforated with 18 square mortises, into which the transverse bars or teeth $b b, c c$, $c c$. are firmly fixed. These teeth are about 3 feet 10 inches long, or 21 inches on each side of the head $a a$, and are about $1 \frac{1}{4}$ inches square on the body, slightly tapering to each end, where they are rounded off to a blunt point, but chiefly upon that side which is to lie next the ground, and this constitutes the body of the rake. It is drawn by a horse yoked to the draught-frame $d e$, of which $d$ and $e$ are two naturallybent bars of wood about $3 \frac{1}{2}$ feet long and 4 inches by $2 \frac{1}{2}$ inches at the butt.end; at the but they are worked out to the end in a semi-circle half embracing the head $a$ a. which is here dressed into a cylindrical journal, and the bars $d e$ are secured to the journals by a strap of iron passing ronnd each and nailed or bolted upon the bars. leaving them freedom to traverse upon the journals. The stretcher-bar $f$ is mortised into $d$ and $e$ at a distance of not less than 2 feet from the bead $a$ a. The handle-frame by which the implement is guided has the two bars $g$ and $h 4 \frac{1}{3}$ feet long and is $2 \frac{1}{2}$ feet apart; the bars being attached to the head in the same manner as described for $d e$. The two bars $g, h$, are also connected by 2 stretchers, and upon the lower one is appended the light pendent and movable frame $i$, the depth of which from the stretcher, to which it is appended, to the bar $i$ is 10 inches, and is jointed to swing freely on the stretcher. The bar $i$ of this last frame is put in counection with the draught-frame, by neans of the connecting-rod $i k$, which is jointed movable at both ends on round journals, and strapped as before. The stretcher on which the frame $i$ is appended is prolonged at each end to receive the catch-bars $l$, on the outside of the frame $g h$, one of which bars is seen at $l$, jointed on the prolonged stretcher. the position of which is 2 feet 3 inches from the journal of the head $a$. The catch-bars are $3 \frac{1}{3}$ inches by $1 \frac{1}{2}$ inches at $l$, but diminish forward to $1 \frac{1}{2}$ inches square at the point, where they abut upon an iron stud, which is presented at two of the opposite curners of the rake-head. at each side of the haudle-frume, serving an esseutial purpose in the management of the implement.

(2148.) In the working of this rake, it lies nearly flat on the ground, and when the draughtframe is at its proper hight, the connecting-rod $i k$ keeps the hanging frame just wishin the extremity of the teeth that are then behind, and nearly bearing upon them. In this position also, the point of the catch-bars $l$ is quite free of the studs of the head or beam, and by pressing down the handle-frame, the pendent $i$ will come down upon and depress the teeth that are looking back. ward, raising at the same time those in front, such as for the purpose of passing over any ohstruc. tion. When, on the contrary, it is wished to depress the front teeth. the handle-frame is raised till the points of the catch-bars press against their atuds, which will depress the front-teeth; and by continuing to elevnte the handle-frame, the connecting-rod, from change of position in the hars $i k$, $i l$, and $l f$, will push the pentent $i$ beyond the extremity of the teeth behind, when, the front teeth taking the ground, and nothing to resist the rising of those behind, the rake will immediately tilt over, the fore and hind teeth changing places: but. in other respects, everything will be the same as before. The effects of the motion and tilting, it is evident, will be, that in the progressive state the rake collects the hay or straw upon it chiefly in the front part; and when the attendant sees that the rake is filted, he raises the handles and tilts the rake as above described, lesving the collected mass at the spot where the tilt occurs.

[* Invented by Moses Pennock of the Society of Friends, in Delaware. Men's names have been immortalized by acts of mach less public service. (704) 
(2149.) A slight consideration of this implement will show the effectual and convenient manner in which its work is performed; but it will also probably occur to the observer, that, for progressive motion, it is by no means so well adapted as for collecting and depositing the products. The heavy transverse bar, or head of the rake, is drawn forward in the worst possible position, or what is called broad-side on; and it appears very obvious that this defect could be removed by simply applying a pair of low light wheels to the ends of the head; their diameter need not exceed 8 inches, aud they should be very light. Perhaps it may be owing to this defect that the Americau hay-rake has of late years not been in such high repute as formerly.

(2150.) The Flail, fig. 401, is an implement of considerable antiquity, and of very extended application. Till about 80 years ago, it was the sole implement employed in Britain, and to this day is nearly so over a great part of Europe, for threshing out the grain from the straw. Though falling rapidly into disuse in England, it is nevertheless an important implement in many others, and therefore claims our attention in common witb those of higher pretension. The flail con. sists of two parts, the hand-staff or helve $a b$, and the supple or beater $b c$; the first is a light rod of ash about 5 feet in length, slightly increased in breadth at the lower extremity, where it is per-

Fig. 401.

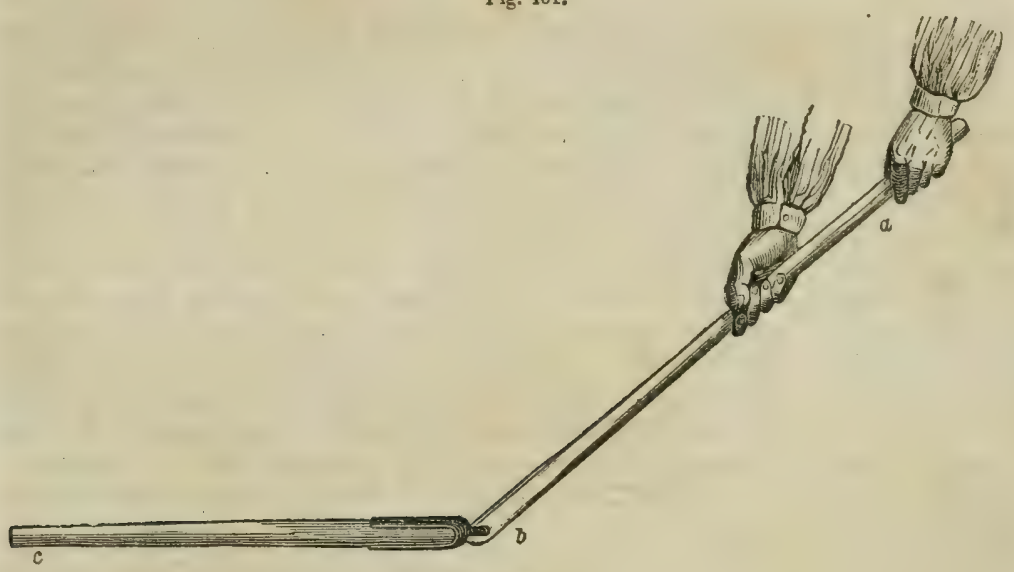

THE FLAIL.

forated for the passage of the thongs that bind the beater to it. The beater is a rod of from 30 to 36 inches in length, frequently also made of ash, though a more compact wood, such as thorn, is better adapted for it. If not properly applied, the ash beater will very soon separate into thin plates, which are portions of the concentric layers of the wood, and their separation arises from the beater falling upon the flat or convex side of these annular layers-or the reed of the wood, as valgarly called. To prevent this disintegration of the wood, the beater should be constructed to fall upon the edge of the segmental portions of the reed, which is easily accomplished in its formation. The usual form of the beater is cylindrical, but frequently thickened a little toward the extreme end, the diameter being from $1 \frac{1}{4}$ to $1 \frac{1}{2}$ inches. For the most part, it is attached to the hand.staft by a strap of leather, or more frequently of hide untanned; when mounted in this manner, the beater is formed with two projecting ears, standing at right angles to the side on which it is intended to fall, and about $1 \frac{1}{2}$ inches from the end by which it is attached, serving the purpose of retaining the end of the beater within the strap. The strap is about 8 inches long and $1 \frac{1}{2}$ inches broad; it is bent over the end of the beater, and the tails brought to embrace the sides of it beyond the ears. The strap being previously perforated with four holes in each tail, it is bound by a thong of leather laced through the holes and round the neck of the beater; the upper turn of the lacing thong catching the ears, prevents the strap from slipping off. The strap, thus applied, forms a loop standing about 1 inch beyond the end of the beater; and through that, and the perforation in the end of the hand-staff, another and stronger thong is passed several turns and secured, forming thus a kind of loose swing-joint that allows free action to the beater in its gyration round the bead of the thresher, and its descents upon the threshing-foor. Another mode of mounting the beater is by applying a strap of iron in place of leather, which is fixed to the wood by riveting, leaving a loop as before, which must be nicely rounded and smooth, to prevent the too rapid chafing of the thong by which it is bound to the hand-staff, in the same manner as described above. The figure here described exhibits the iron strap. In constructing a flail, a very general practice prevails, which is, to have the beater club-shaped, or thickest at the farthest extremity c-intended, no doubt, to give the better effect to the blows; but when we consider the effects arising from the manner of wielding the instrument, any additional weight at the extremity seems misapplied.The greatest amount of useful effect will be produced by the beater when every point in its length strikes the floor with an equal amount of momentum or force; but there will be a constant tendency to a larger amount of momentum at the extremity $c$ than at any.other point, and a clubshaped beater will always angment this tendency, for the greater velocity of the extreme end, during the gyration of the instrument, multiplied by its greater weight, must give an undue preponderance of effect to that part of the beater, thereby lessening the general effect upon the work 
ander performance. The opposite mode, which is also practiced, to make the beater thinner to. ward the extremity, as exbibited in the figure, is more consonant to the laws of dynamics, and there can be no doubr that its practical effects will be equally favorable as compared with those of the club-shaped beater." -J. S.]

\section{SUMMER-FALLOWING, AND LIMING THE SOIL.}

"The bare fallow brings to teeming foyson."

Meastar for Meastar.

(2151.) Although summer-fallow occupies the same division of the farm as green crops-turnips, potatoes, tares-yet it may most characteristically be regarded as the first preparation for the crop of the following year; it is a transferrence of a portion of the land, with the labor bestowed upon it, from one year to another; it forms the connecting link between one crop and another. But although the preparation of the soil for a part of the crop of two consecutive years are conducted simultaneously by means of summer-fallow, yet the crops which occupy the soil thus simultanenusly prepared are committed to it at very different periods-the green fallow crops being sown early in summer, while the sowing of the fallow crop on the summer-fallow is delayed to autumn; so that before the latter makes its appearance above ground, the former have almost advanced to maturity. Since the crop on summer-fallow is delayed to autumn-till the eve of commencing another agricultural year-the practical effect of the delay is to dispense with a crop for a whole year on that part of the fallow-break which is summer-fallowed, and, on this account, such a fallowing is commonly called a bare-fallow. As an entire crop is dispensed with, bare-fallowing should impart such advantages to the land as to compensate for the rest and indulgence which it receives; and so, in fact, are its advantages felt on some sorts of soils. But the truth is, after all, that bare-fallowing is a necessitous operation in soils that will not carry green or summer crops; and if such soils will not carry them, they must be operated on so as to be made suitable for a crop which they will not only bear to perfection, but will pay the expense of the operation. The sort of soils alluded to are heavy clays; and why will they not bear green summer-crops? A satisfactory reason cannot be given; but the fact, as developed by experience, is, that their nature is unkindly to the growth of plants commonly used in a green state; and their heavy, wet and obdurate nature prevents them, at any rate, from heing prepared in time for sowing such plants:Could clays be altered in their nature by any means, they might be employed in raising summer crops as well as the naturally more kindly soils; and such a change has been effected on many clay soils which were formerly incapable of rearing them; and the change has been effected by ameliorating their texture by thornugh-draining, skillful tillage, and liberal manuring and liming. In this way the bounds of bare-fallow have been much circumscribed, and those of green crops as much extended. Still the heavier class of clays - the deep alluvial clays-have not yet been ameliorated to the degree of bearing green crops profitably, so they must continue to be bare-fallowed; but more than this, part of even the ameliorated

[* This implement is still mach used in the Eastern States. Col. Chapman, President of the Saratoga Agriculturai Society, still uses it on the ground of employment to the poor men who do the work.

Ed. Farm. Lib.] 
soil of almost every farm is necessitated to be bare-fallowed, for want of an adequate supply of farm-yard manure. Farms in the vicinity of large towns may be amply supplied with extraneous manure, to make up for the deficiencies of the farm-yard; but as most farms are beyond the reach of such assistance, it may be alleged that bare-fallowing, to some extent, is practiced every year upon every farm; though the limits of compulsory fallowing have been much circumscribed of late years by the purchase of extraneous manure from distant sources, which are easily conveyed, and sold at prices that afford a profit. Those manures-and I only allude to them here-are bone-dust and guano. These, superadded to draining and deep-plowing, have afforded the power to cultirate green crops upon soils which were naturally unfit for them; and, without such auxiliaries, soils suitable for their growth would be obliged to be bare-fallowed, to allow time to collect the requisite quantity of manure to support their fertility. Until manure is, therefore, obtained in sufficient quantity, bare-fallow must exist ; but whenever that desideratum shall be accomplished, many farms will dispense with bare-fallow altogether. But there is a natural obstacle to the increase of manure in farms themselves; for it so happens that the greatest quantity of straw, which is the great source of fertilizing manure, is afforded by land the least fitted for green crops; and, on the contrary, land best fitted for green crops affords the least quantity of straw. Turnip-soils cannot supply as much straw as to manure, to the degree and in the state it should be applied to green crops, little more than $\frac{1}{2}$ of the fallow-break; whereas clay soils afford as much straw for manure, in the state in which it may be applied to them in bare-fallow, as sufficiently to manure the fallow-break.

(2152.) The land subjected to bare-fallowing should have the strongest texture ; be foulest of weeds, if any there be ; and be situate farthest from the steading, that the carriage of turnips may be'rendered as short as practicable. The winter treatment of the fallow land is the same as that for the summer crops, and this has already been described in preparing the soil for potatoes (1870) and turnips (1953). If one furrow-that of twoout-and-two-in, or of four-out-and-four-in-has been given to the fallowbreak after cross-plowing, it will be as much as time can afford from working the potato and turnip land; and when it is found that the fallow-break will not likely be worked for some time to come, it is better to let it lie in the rough state left by the plow, than to render it smooth with the harrow ; because, should dry weather ensue, the air will more easily affect rough than smooth land; or should it prove wet, the rain will less likely render rough land tough, than land in a compact and smoothened state; and, in strong soil, rain most advantageously moulders down rough clods.

(2153.) When leisure is again afforded to pay attention to the fallowbreak from the advanced working of the turnip-land, the state of the fallow-soil should be particularly examined. Should the weeds in the soil consist principally of fibrous and fusiform-rooted plants, they will be easily shaken out by the harrows in dry weather; but should the running roots of weeds be found to have threaded themselves through hard, round clods, these will not be so easily detached, and it requires considerable skill in the farmer to conduct his operations so as to detach them with the least application of labor. It is inattention to these states of the weeds which causes so much unnecessary work in the subsequent part of summer in cleansing fallow land. If clods containing portions of the running roots of plants are knocked ever so much about in dry weather, they may be broken into smaller fragments; but the roots in them will be subdivided into as many pieces as there are broken clods, and the land will be as far (707) 
from being cleaned of weeds as ever; nay, the greater number of parts in which the roots are divided, so many more chances have the weeds of being disseminated over the land.

(2154.) In such a case, which is of frequent occurrence on strong land, the best plan is to allow the roots to grow for a time, and the force of vegetation will have sufficient power to break the clods, or will render them easily so by the roller, to reduce the clods by rolling after such a shower of rain as shall have nearly penetrated them. A precaution in the use of the roller should, however, be here observed. When most of the soil is in a mouldy state, rolling the hard clods found on it, will only bury, not break them. Rolling, with a view to breaking large clods, should therefore be performed when the soil is in a firm state, against which the clods will be reduced to powder. After such a rolling, the land should be harrowed a double tine, first one way and then across another way. The weeds and weed-roots will then be seen upon the surface. It is not expedient to gather weeds immediately on their being collected by the harruws, as a gnod deal of fresh soil adheres to them. A day or two of drouth should intervene, and the weeds will then be easily shaken free of soil by the hand. It has been recommended by writers to gather the weeds of fallow land by a raking implement, such as the American hayrake, fig. 400 ; but every instrument of the kind will rake together clods as well as the weeds adhering to them, and if these are carried away with the weeds, the land will be imporerished by the loss of its finest soil; whereas the hand which throws the weeds into convenient heaps, can at the same time shake them free of soil. In collecting weeds, the fieldworkers should be ranged in a row as when weeding corn, every two throwing the weeds into the same heap; and the rows of heaps should be placed as far asunder as to allow a cart to pass between them, and take away 2 rows at a time. Many writers recommend the weeds to be burnt on the ground. No doubt, weeds will burn readily enough when dry, and the ashes of weeds constitute good manure, but, for my part, I nerer saw heaps of weeds thoroughly burned, and have seen their remains scattered, again to render the land foul. I agree with Lord $\mathbf{K}$ ames, that it is better to make a vegetable compost with weeds, than to destroy them by incineration, and with him readily demand, "What better policy than to convert a foe into a friend ?" It is impossible to determine beforehand how many times fallow land should be plowed, harrowed, grubbed, and rolled, to render it clean; but it should be borne in mind, to incur the least expenditure of labor in accomplishing the object fully. It was once the practice to work fallow land until it was reduced to the state of meal; but experience has long established it as a fact, to be better for the ensuing crop of wheat to preserve a good-sized clod upon the surface of the ground in winter, however much the ground may be otherwise pulverized. The land must have been very foul, the weather very unpropitious, or much time wasted, if the fallow land is not ready for the manure by the beginning of August, before the chance of harvest interfering with the process of manuring.

(2155.) The usual mode of laying dung on fallow land is to feer the ridges (660), cart on the manure in heaps, spread them, and plow the manure in. So far as I have observed, the manure is spread over a large portion of the surface some time before it is plowed in, when, of course, much of its moisture will be evaporated. I very much prefer another mode of plowing in the dung, which is, to angle-drill the land in preparation for the dung ; that is, to set up the land in single drills (1735), and fig. 323, from the flat without any feering, beginning at one corner of the field, (708) 
and terminating at the opposite one: the plow making the drill in one bout, the cart depositing the manure for 3 drills, 4 women spreading it immediately after the cart, and the plow following and covering up the dung in one drill in another bout (exactly as represented in potatoplanting, fig. 344), is a process which so quickly and completely covers in the dung, while in possession of its moisture, that it should be universally adopted. The land remains in the drilled state until prepared for the wheat seed in autumn.

(2156.) Fallow land is not dunged so heavily as that for green crops, not so much from fallowed soils not bearing heavy manuring, as from want of manure. From 12 to 15 tons the imperial acre is an ordinary manuring for fallow. The manure need not be so well fermented as for green crops, as there is usually sufficient time for its fermentation in the ground before the wheat is sown. If there is not sufficient time, it should be fermented before its application, as it is not expedient to sow wheat to stand the winter in soil rendered hollow by rough dung. In strong carse clay, the manure is often applied in a state little removed from wet straw, and yet it seems to answer well in such a soil.

(2157.) While treating of fallow, it is necessary to notice the liming of land, as lime is commonly applied at that period of the rotation of crops, though by no means applied every time the land is fallowed. It has always been a favorite practice with farmers to apply lime in as caustic a state as practicable; because, perhaps, it is then in the state of finest powder, and easily commixes with every species of soil. When obtained from the kiln or from shipboard, it is in lumps, light in weight, and is technically called lime-shells. There is a difference in the practice of disposing of lime-shells while in preparation for the soil. Some lay down the shells in small heaps upon the feered ridges, while others lay them in large heaps along a head-ridge. It is clear that shells cannot be laid at once upon the land, unless the land had previously been sufficiently fallowed; and as land occupies a considerable time in being fallowed in a proper manner, it is also clear that no considerable quantity of lime can be driven, after the fallow is ready, unless the kilns are situate very near; and, at any rate, it is unnecessary to lay the lime upon the land, but at a short period before the wheat is sown. Besides, when shells are placed in heaps on the ridges, they must remain a considerable time there till reduced to powder by the air, when the lime will have lost a considerable portion of its causticity by union with the carbonic acid of the air, unless a good deal of rain shall have fallen to hasten its slaking. To preserve the shells intact, till needed, they should be put in large heaps, the outer surface of which may become neutralized by the action of the air, but the interior of which will not be so affected. Meantime the land is worked as opportunity offers, while the heaps occupy a head-ridge.

(2158.) A week or so before the lime is applied, water is poured on the large heaps of shells, in order to reduce them to a state of impalpable powder. The water will all be absorbed by the lime, which will, nevertheless, continue quite dry, thereby indicating that the water has disappeared by reason of its chemical union with the lime. A great quantity of heat is evolved during the time the lime takes to fall to powder; and when that last has been accomplished, the heaps will have swelled to more than three times their former size, when the lime is said to be slaked, and is then in its most caustic state. While the slaking is proceeding, the land that was manured in drills is cross-harrowed a double tine, to make it flat; after which the ridges are feered; and the lime is then spread along the feered ridges. The lime is spread in this way: The frying-pan 
shovels, fig. 176, are the best implements fur filling carts with, and spreading lime on land. A calm day should be chosen for the purpose, but should there be an air of wind, the single-horse carts should be so placed at the heaps as that the lime-powder which floats in air should be blown away from the horses and men. Powdered lime is heavy, but all that can lie upon a shovel is so light that one plowman takes a heap, and with one of his horses in a cart, for a yoking at a time, fills his own cart, and spreads the lime from it upon the land, with the shovel. The liming should be conducted against the wind; and when a number of men take from different heaps, they should so arrange themselves along the feered ridges as that the cart farthest down the wind takes the lead in spreading. In spreading lime, the man walks along the middle of the feered ridge, and casts the shovelsfull right and left from the middle toward the feering furrows, which will, of course, become, by plowing, the crowns of the future ridges. The man who can cast the shovelsfull with either hand will spread lime better than one who is right or left handed only. The lime should be spread evenly orer the surface, but it may be spread thicker on one part of the field than another, according to the vature of the soil. On light knolls it may be spread thinner than in hollows, where the soil is either deeper or stronger. Progressively as the lime is spread, ridge after ridge, it is harrowed in and mixed with the soil; and immediately on the entire field being limed, the ridges are plowed with a light furrow, to bury the lime as little as possible, and which constitutes the seed-furrow of the future crop. It will be observed, from what has been said on the manuring and liming of fallow land, that the lime is spread above the dung, and some time after its application. This relation between the two substances is held, because it is conceived that, as dung has a natu$\mathrm{ral}$ tendency to rise to the surface, and lime to descend, this is the proper relation they should bear in the soil. Whenever rain falls, the liming should be discontinued.

(2159.) It is proper to put a cloth over the horse's back and the harness, and the men may cover their face with crape, to save its orifices being cauterized by the quicklime. The horses, when loosened from work, should be thoroughly wisped down and brushed, to free them of every particle of lime that may have found its way among the hair; and, should the men feel a smarting in their eyes or nose, a little sweet thick cream will be felt as an agreeable emollient; and the same application will prove useful to the horses' eyes and nose.

(2160.) The quantity of lime that should applied depends on the nature of the soil, the lighter soils requiring the less, and the stronger soils the greater quantity. On light turnip-soils, some think 120 bushels to the imperial acre sufficient, while I have used 150 bushels with benefit. I have seen as much as 510 bushels applied to the imperial acre, wheat-land, with manifest advantage. But perhaps from 150 to 240 bushels may be considered fair average quantities, according to the nature of the soil. On weak moory soils, 75 bushels are, perhaps, enough to commence its im. provement with. The sort of lime should determine the quantity applied, the stronger being used in less quantity than the weak. The English lime is much more caustic than the Scotch. It is not customary to apply lime often to land, a farmer not thinking it expedient to apply it oftener than once in a lease of 19 years, on account of its expense. Its common price is $3 \mathrm{~s}$. per boll of 6 busbels; consequently its entire cost, at those quantities, will be from $£ 315$ s. to $£ 6$ per acre for the best sea-borne English lime, exclusire of carriage; the Scotch sells for $10 \mathrm{~s}$. per cart-load of 4 bolls, including carriage for 10 miles.

(i10) 
(2161.) Lime is applied at different periods of the year, according to the state of the land. On summer-fallow it is applied immediately before the wheat is sown in autumn. It is also used immediately after taking up the potato crop in autumn. It is applied to the land cleared of turnips by sheep, just before the sowing of the barley-seed in spring. It is also applied before the turnip-seed is sown in the beginning of summer; and it may be applied to lea immediately before being plowed for oats in early spring. I do not say that it is immaterial to the proper use of lime to choose the season in which it is applied, convenience often determining that point as much as propriety; but experience has taught that it is used to manifest advantage when spread on land in summerfallow, and for barley-seed immediately after the ground has been cleared of turnips by sheep.

(2162.) Lime is usually procured in summer and autumn, as the kilns are only kept in activity in those seasons, so when it is intended to apply it in spring, it is necessary to procure it in autumn, and keep it all winter; and to preserve it in the desirable state in winter, the heaps of shells should be covered with a thick coating of earth, and every crevice that appears in it should be immediately filled up. I am quite aware of the opinion of some farmers that lime is equally efficacious in the soil in the effete as in the caustic state, and Lord Kames was of that opinion; and, therefore, precautions to preserve it in a caustic state in winter may, by them, be deemed unnecessary; but as the general opinion runs in favor of quicklime, and which opinion I support, I have treated the subject accordingly, until experience shall instruct us better. There is this advantage, however, in using quicklime, that it is much more easily spread upon, plowed into, and mixed with the soil than effete lime.

(2163.) It is supposed that light and heat, together with cleansing and working, have a beneficial effect upon soil. That these agencies promote fertility in some way, perhaps hy affording facilty to the union of oxygen with the soil, appears certain, for a smaller quantity of manure will raise as large a crop with bare-fallow as a greater quantity without it; and yet this particular result is only obtained from a peculiar class of soils-namely, the strong clavs, for all turnip-soils actually become more fertile by the overshadowing of a luxuriant crop of leaves than by barefallowing.

(2164.) The action of lime upon land seems generally well understood by farmers. They conceive that lime operates in two ways upon soil, namely, mechanically and chemically. Mechanicall $y$, it subdivides the adhesive portions of obdurate clay; hence it was castomary in the Carse of Gowrie, when the high price of grain remunerated the outlay, to apply lime to the land every time it was bare-fallowed, that is, every 6 or 8 years, according to the rotation of crops pursued. I suspect that liming is not now so frequent there as it was wont to be. Chemically, lime unites with vegetable matter, and assists in its decomfosition; hence it has been found to act very beneficially on all deaf soils. It renders lòse soils more firm. In strictly chemical language, quicklime acts as an alkali, and this property has led some writers to assert that green vegetables are not decomposed, but rather preserved, by caustic lime-a result which cannot be experienced by the practical farmer in the soil ; because, as caustic lime very soon becomes a compound of a hydrate and a carbonate in the soil, the property of this latter state is to accelerate rather than retard the decomposition of vegetable matter. As the consideration of this subject would lead us into a long discussion, I must content myself with quoting only a part of the account of the theory of its action by Professor Johnston, in order to show that the opinions of farmers is not far astray on this subject, which, in some respects, is yet but obscurely understood. "Lime acts in two ways on the soil," says the Professor. "It produces a mechanical alteration, which is simple and easily understood, and is the cause of a series of chemicrl changes, which are really obscure, and are as yet susceptible of only partial explanation. In the finely divided state of quicklime, of slaked lime, or of soft and crumbling chalk, it stiffens very loose soils, and opens the stiffer clays; while in the form of limestone gravel, or of shell-sand, it may be employed either for opening a clay soil, or for giving body and firmness to boggy land. These effects and their explana. tion are sn obvious to you that it is unnecessary to dwell upon them. The purposes served by lime, as a chemical constituent of the soil, are at least of four distinct kinds. 1. It supplies a kind of inorganic fond, which appears to be necessary to the healthy growth of all our cultivated plants. 2. It neutralizes acid substances which are naturally formed in the soil, and decomposes, or renders harmless, other noxious compounds which are not unfrequently within reach of the roots of plants. 3. It changes the inert vegetable matter in the soil, so as gradually to render it useful to vegetation. 4. It causes, facilitates, or enables other useful compounds, both organic and inorganic, to be produced in the soil, or so promotes the decomposition of existing compounds as to 
prepare them more speedily for entering into the circulation of plants." In conclusion on this subject. when we consider that 1 ton of limestone is reduced in weight to a little more than $11 \mathrm{cw} t \mathrm{~s}$. of shells by burning, we cannot but admire the simple art which renders so valuable a material avail. able to the purposes of the farmer, even when it is situate at a considerable distance from his farm.

(2]65.) As fallowed land is usually manured along the feered ridges by depositing the loads into heaps. I might here give a Table showing the number of heaps each cart should afford in manuring an acre with a given number of cart-loads; but as heaps of manure are so indefinite a standaril of measure, such a table would practically prove of little service. A much more accnrate plan is to number the ridges on an acre in each field. and at every part of a field where the ridge日 are changed in length, as I have recommended before $\{386\}$, and try and lay down the manure on the first ridse in the proportion it is proposed to manure the acre, and by the time the second ridge is gained, the man who hawks out the dung, fig. 343 , will have found out how close the hawksfull should be laid down, and how large the heaps, if any, should be made.

(2166.) [Of the pulverizing implements used at all seasons, there have been already deacribed the grubber, Plates XXIX and XXX, brake (1797), and the common land roller, fig. 327 ; but there remains a class of implements of the same nature, which, though not numerous, are yet of considerable importance : they come also under the denomination of rollers, but are peculiar in their construction. and are particularly adapted for being used in summer-fallowing. The object of these machines being to break down the more indurated clods in clay soils, they are fitted in act either by abrasion, or by disintegration, or both combined. One of the simplest of them is the common plain roller, armed with strong and broad iron spikes, the latter splitting the clods, while the weight of the roller produces their farther abrasion: this implement, however, stands low in the scale of efficiency when compared with others which I have to notice.

(2167.) Crosskill's clod-crushing roller is one of the most efficient implements of this class, and is here represented in fig. 402 , which is a viev of the machine in the working state; but to con-

Fig. 402

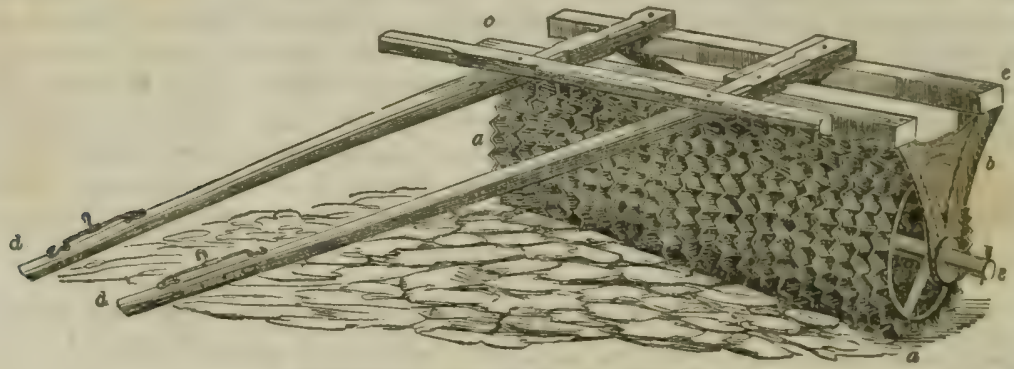

CROSSKILL'S CLOD-CRUSHING ROLLER.

vey any idea of its construction we must exhibit it somewhat in detail. With this view, fig. 403 is a side elevation of one of tho individual wheels or plates that go to form the body of the roller. and consists of a ring or web of 30 inches diameter over the extreme points; the web is $2 \frac{1}{2}$ inches broad and $\frac{5}{8}$-inch thick, formed into angular-pointed teeth. The ring is supported on the four feathered arms, and an eye formed in the center 3 inches in depth and $2 \frac{1}{3}$ inclies diameter, titted to nove easily on the axle of the roller. Corresponding to each touth of the wheel, studs are cast on each side of the web, which project 1 inch from it, as scen in fig. 404, an edge view of the wheel, where $a$ a $a$ are the projecting studs, and $b$ the eje, show. ing also the feathers of the arms. The wheels thus former? are threaded, to the number of 28 , upon round axle, $2 \frac{1}{3}$ inches diameter, upon which they are at liberty to turn separately, making up the body of the body of the roller $a$, fig. 402 , to a length of 6 feet. $\Lambda$ cast-iron end-frame $b$ is then placed on each end of the axle. and these are bolted to the wooden transverse bars $c c$, and to these last also the horeeshafts $d d$ are bolted. The axle is prolonged at each end $e$ to an extent of 4 or 5 inches, forming the arm on which the carriage-wheels are placed for the removal of the roller from one field to another. The carriage-wheels are also of cast-iron, 3 feet diameter, plain of course on the sole: and when these are to be placed or removed, a hole is dug in the soil under each wheel, until the wheel turns freely round and can be moved on or off the axle, the roller then resting on the ground; but when the carriage-wheels are shipt on the axic and brought on level ground, the whole weight is borne by them, while the body is 3 inches clear of the surface. In this state it is traveled from ficld to field, and. when about to be worked. the carriage-wheels are removed by the process just described.

* See the whole of the xvihth Lecture of Johneton's Lectures on Agricultural Chemistry, for a careful exnminatisn of the properties of Lime in reference to its effects on the eoil. This, in my opinion, is the most valuable monograph on Lime, as a material used in Agriculture, that has ever appeared.

(712) 
(2168.) The effect of such a roller upon romch clay land mav be easily conceived, and that where such a great number of points are hrow ht into contact with the indurated clods, the result must be their reduction to a state approachinir to the crramlar, especially if the operation is repeated. The effect is entirely different from that of the plain roller, for with it, if a clod does not crumble at once with its pressure. it is forced downward into the soil in a still solid state; whereas, with the one now described, the numerous points, acting like so many wedges, will almost infallibly split such a clod into numerous fragneuts, and repetitions of the process will produce a well pulverized surface.*

\section{BUILDING STONE-DYKES.}

"It is by artificial calms that fields

Are warmed; and waLLs but slightly check The sweeping blast."

\section{GrahaM.}

(2169.) After the general principles upon which inclosures should be made have heen explained, it is unnecessary to dwell on the subject of field-fences when treating of stone-dykes, but describe at once the best mode of constructing them. It may be premised that many dry stone-dykes in this country are constructed on erroneous principles, the stones being laid in an irregular manner, and more with a view to give a smooth face than a substantial hearting to the wall. The coping, too, is often disproportion. ately large for the body of the wall, which is not unfrequently too narrow for its hight. I suspect that many dry stone-dykes are built by ordinary masons, who, being accustomed to the use of lime-mortar, become regardless of bedding the loose stones of a dry dyke as firmly as they should be, and, of course, are unfitted to build one. It is true that a proper form of stones is a great assistance to the builder of stone-dykes-flat, thin stones being the best: but flatness and thinness are not the only requisites; they should also have a rough surface, by which they may adhere to one another in the wall ; and no material, on this account, is so well adapted for the purpose as those derived from sandstone-boulders of gravel deposits, which split with the pick into flat stones of requisite thickness when first taken from their matrix, and, on being exposed to the air, become dry and hard. A builder of dry stone-dykes should, therefore, be brought up to the profession; and, when he has acquired dexterity, he will build a substantial wall, at a moderate cost, which will stand upright for many years.

(2170.) Dry stone-dykes are measured by quarters, that is, quarters of a yard of 9 iuches each. A 5-quarter dyke is the usual hight of a fieldfence-that is, 45 inches, or 3 feet 9 inches to the under side of the cover upon which the cope-stones stand-the cover and cope-stones usually measuring 12 inches, so that the dyke stands altogether 4 feet 9 inches in hight. The dyke, when finished, is measured by the rood of 36 square yards upon its face under the cover, so that every 30 yards of a 5-quarter dyke will be 1 rood in length. The usual thickness of such a dyke is 2 feet at the base, and 15 inches under the cover. But the best way to contract for the erection of stone-dykes is by the rood of 36 cubic yards, when every temptation on the part of the builder to contract the breadth, and

[*A very simple and most useful contrivance, not generally known, for pulverizing cloddy land is a "drag-log" of say 12 or 14 inches square, according to the hight of the wood and the work to be done, and 5 feet long, more or less, with tongue or shafts fastened on the top of it. This, dragged over the surface by a yoke of oxen or other suitable force, will at one operation produce a degree of pulverization of which few would have any idea who bad not witnessed its effect. Any, the roughest, carpenter can make it.

Ed. Farm. Lib.] 
make the heart of the dyke hollow, will be removed. A dyke that has 2 plain faces is called a double-fuced dyke; and one with 1 face, as when built against a sunk-fence, is called a single-fnced dyke. A double-faced 5 -quarter dyke requires 1 ton of stones for every square yard of its faceso that 36 tons of stones are required for every rood of 30 yards long.The expense of quarrying that quantity of stones is about 10 s. the rood; the carriage of them at a reasunable distance beyond 1 mile is also $10 \mathrm{~s}$. the rood; and the building is commonly undertaken, when the stones are good, at $10 \mathrm{~s}$. a rood also; so that such a dyke costs 30 s. the 30 yards, $0 r^{\circ}$ 1s. for every yard in length. The tools of a dry-stone dyker are few and inexpensive, consisting only of a mason's hammer, a frame as a gauge for the size of the dyke, and cords as guides for the straightness and thickness of the dyke. A dyker cannot continue to work in wet or in very cold weather, as handling stones in a state of wetness is injurious to the bare hand; on which accounts, dry stone-dykes are commonly built in summer.

(2171.) The line of fence being determined on, it is marked off with a row of stakes driven firmly into the ground. The upper soil, to the depth it has been plowed, is removed from the line to form the foundation of the dyke, and it may be driven away, or formed into a compost with lime near the spot for top.dressing grass. When driven away, it should be so immediately, and not lie to annoy the builder. When the surface consists of old firm sward, especially of moory turf, the dyke may be founded upon it; but, in forming foundations, it should always be borne in mind that dykes are apt to sink into soft earth of every kind to the injury of the dyke, not merely in curtailing its hight as a fence, but in twisting its structure and causing it ultimately to fall : so, when the soil consists of vegetable mould, it slould be removed altogether, and its intrinsic value in a compost will amply repay the trouble of removing it. After the foundation has been formed by the removal of the earth, the stones should be laid down on hoth sides as near the line of foundation as practicable, for it is of considerable importance to the builder that the stones be near at hand. Indeed, when stones are laid even as far as 2 yards from the foundation, the builder incurs loss of time in throwing them nearer; but, on the other hand, no stones should be thrown into the foundation, as they will have to be removed by the builler before he commences operations. Where large boulder-stones exist, they form excellent material for the foundation of stone-dykes, and should be laid close to the foundation before the building stones are brought. The simplest mode of conveying large boulders is upon a sledge, shod with iron; and it is better for putting on and taking out than a common cart, the bottom and sides of which are apt to be injured by such beulders. Indeed, when many stones of ordinary kinds are intended to be driven for buildings, the carts should receive an extra temporary bottoming and lining with deals of common Scots fir, or deals of willow, which are better, as being softer and less liable to split. A pair of horses, yoked as in a plow, will draw a very heavy boulder upon such a sledge.

(2172.) Every preparation being thus made, the builder proceeds to his work-or rather 2 buillers together, as they make the best work, and assist each other with stones which one would be unahle to manage. They begin by setting up the frame $a$, fig. 405 , in the foundation of the proposed line of dyke. The fiame is made of the breadth and hight of the proposed dyke under the cover; and it is set in a perpendicular position by the plummet $c$, attached to it. $A$ corresponding frame should be placed beyond the point at which the dyke commences; or 2 stakes, such as $d$ and $e$, driven into the ground, having the same inclination as the sides of the (714) 
frame, answer the temporary purpose of an auxiliary fiame. In uneven ground, a space of $\frac{1}{2}$ a rood, or $15 \mathrm{yards}$, between the frames, is a sufficient stretch of building at a time; but, on even ground, a rood may safely be

Fig. 405 .

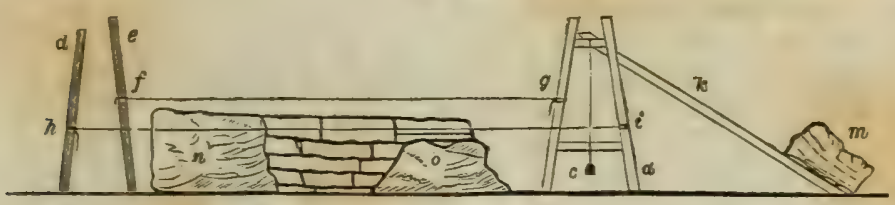

THE FRAME AND COMMENCEMENT OF BLILDING A STONE-DYKE.

taken in. The cords $f g$ and $h i$ are then stretched along the space between the frames, and fastened to each frame respectively, to guide, as lines, the side of the dyke straight, and to gauge its breadth. The frame is held upright and steady by a stiff rail $k$, having the nail projecting through one of its ends $l$, being hooked on to the top-bar of the frame, and a stone $m$ laid upon its other end.

(2173.) When the dyke has a. scuncheon for its end, a large boulder, such as $n$, should be chosen as the foundation-stone; and if no boulders exist, a large stone should be selected for the purpose ; for no better protection can be afforded to the end of a dyke than such a foundation, especially if the scuncheon forms at the same time one side of a gateway to a field. Another boulder, or large stone, should be placed at a little distance from the first, as at $o$, and the smaller stones are used to fill up the space between them, until the space is raised to the hight of the boulders. There is a great art in laying small stones; and it is, in fact, this part of dykebuilding which detects the difference between a good and bad builder.In good dry building, the stones are laid with an inclination downward, from the middle of the dyke, toward each face, as seen at $a$ to $a$, and $b$ to b, fig. 406. This contrivance causes the rain which may have found its way down through the top of the dyke to be thrown off by both sides; and, to susta." the inclination of the stones, small stones mur he packed firmly under their ends in the very heart of the dyke; whereas stones, when laid that, require no hearting to place them so, and may receive none, to the risk of the dyke bulging out in both faces. It tends much to the stabiity of a dyke to have what is called a thorough-band stone $c d$, placed across it at such a hightfrom the ground as represented in the figure. In like manner the cover $e f$ acts as a thoroughband at the top of the dyke; but in laying the cover, the leveling of the dyke to form its bed

Fig. 406.

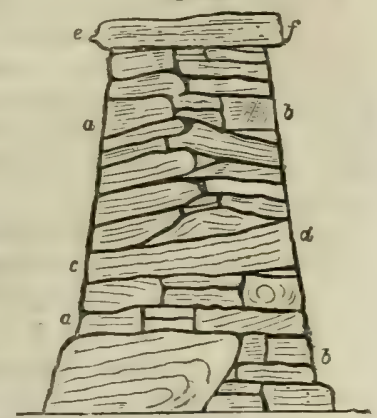

SECTION OF STONE-DYKES, SHOWING HOW THE STONES SHOLLD BE LAJD. should not be made of very small and very thin stones, as is too often the case, as these have little stability, being easily shifted from their position, easily broken, and, of course, constantly endanger the safety of both cover and cope. Thorough-band stones are frequently left projecting from one or both sides of the dyke by some builders, merely to indicate that they are thorough-bands; but the practice is objectionable, inasmuch as projections serve as stepping-stones for trespassers to climb over the dyke. Fig. 407 shows how a scuncheon should be formed of in-band $a a c$, and of out-band stones $b b \vec{b}$, hammer-dressed, (715) 
and firmly bedded upon one another. The covers $c$ should project 1 or 2 inches beyond the face of the dyke, to protoct the top. They should be 2 inches in thickness, and without a flaw throughout their length, which should be 2 feet at least, that their weight may keep them firm, and their size cover a large space of building. In forming the cope, a large stone should be placed at the end, as $d$, in order to keep down the cover, and act as an alutment against which the smaller copestones may be wedged. Other large stones, such as $e$, should be placed at short distances from each other, and upon the joining of two covers, to keep them both secure. Thinner stones should then be pląced between these on edge, and wedged firmly, with small stones driven between them with a hammer; hut the wedging should be delayed until a considerable length of coping is finished, which will be the better able to resist its force. Fig. 407 shows how the stones should be laid in the body of the dyke, those placed uppermost covering the joinings of those beneath them; and small, thin stones are introduced here and there in the finishing to act as wedges be. tween the large ones. The cope-stones should be nearly all of the same bight.

(2174.) In building a stretch of dyke, such as the rood above referred to, it is customary to carry up the building at both ends, as well as at the middle, of the stretch to the leveling of the top, before the intermediate spaces are built up, because those parts being built almost independently, act as pillars in the dyke to support the intermediate building plumb; and they are convenient for pinning the cords into while the intermediate spaces are being built.

(2175.) When a few stretches of a dyke have thus been finished, the surplus stones, if any, should be removed, and laid where they are wanted; but should there be a deficiency, stones should be immediately brought, to allow the builder to finish one stretch before he proceeds to another. The debris of stones caused by the hammer should be removed either to drains or roads.

(2176.) These are all the particulars to be attended to in building dykes for ordinary purposes; but there are a few modifications which require attention in order to render dykes, as a fence, convenient. 1 . The first I shall mention is an opening left for the passage of sheep from one field to another, where the access between them by road is at a distance. Fig. 408, though a mere elevation, obviously shows how such an opening is made. A bunch of thorns or whins, or a board, closes the opening when no longer needed. Such an opening gives sheep access to pasture banks, or to a grass-field from their turnip-breaks in wet weather in winter, and it allows ewes to go to a turnip-break for a few hours every day from the grassfield they are grazing in. For such purposes, an opening of from 3 feet (716) 
to $3 \frac{1}{2}$ feet will suffice. 2. Another convenience is seen in fig. 409, consisting of a gap near the top of the dyke, which map be useful as a stile in the line of a foot-path, or a gap at the side of a cover, for hounds and

Fig. 408.

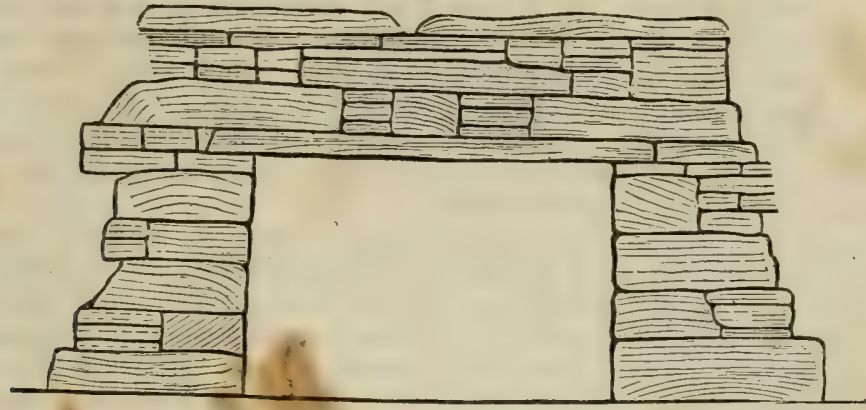

THE OPENING IN DTKES FOR SHEEP.

huntsmen to enter with ease; and here the whipper-in may stand on the out-look for a burst. When not constantly in use, such a gap is easily fenced with a bunch of thorns or whins.

Fig. 409 .

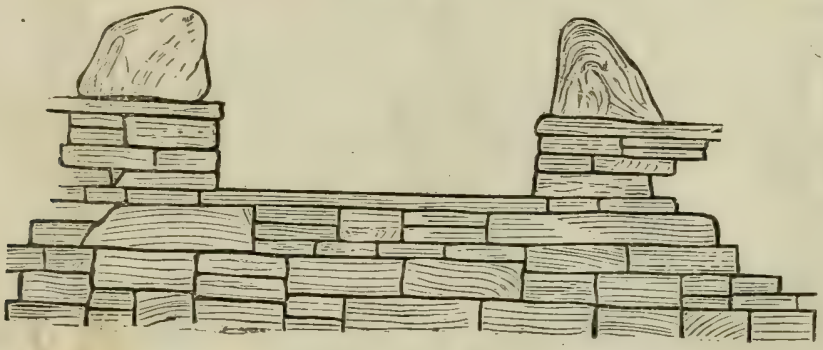

THE STILE OR GAP IN A DYKE.

(2177.) Dykes such as I have been describing, namely, of 5 quarters in hight, will fence horses, and cattle, and Leicester sheep, but will not confine Black-faced sheep? For these, higher walls must be built, or expedients used to make ordinary dykes confine them. Some of these expedients are shown in fig. 410 , where part of an ordinary dyke with its cope

Fig. 410 .

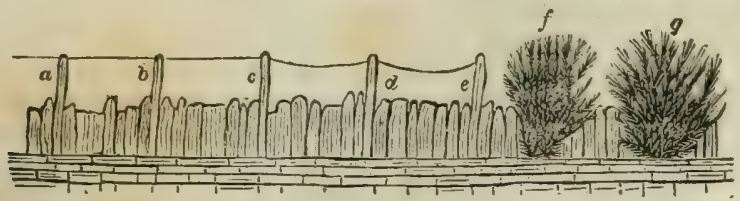

SOME EXPEDIENTS FOR INCREASING THE HIGHT OF STONE-TYKES.

is seen; and the expedients consist, 1 . Of cope-stones $a, b, c, d$, and $e$, set on edge to a considerable hight, say 9 inches or 1 foot, above the ordinary cope-stones. In one case, such as that of the stones $a, b, c$, fillets of wood are laid along notches formed on their top, and wedged into them. In the case of the stones $c, d, e$, a strong rope of straw, laid somewhat loosely over the notches, and dangling occasionally with the wind, form a suffi- 
cient scare to sheep. 2. Another expedient, where the dyke is built against rising ground, consisting of plantation or of cultivated land, is to sow a few seeds of whin or broom in the soil behind the dyke, and cause their shoots to push forth between the cope-stones, and grow into bushes, $f$ and $g$, in front of them. 3. Where good stones for covers are scarce, and where turf is tough and heathery, thick turfs cut of the size of the top of the dyke, and laid firmly and neatly on, make very good covers, and will last a long time. Cope-stones are placed upon the turfs, which afford them a firm bed; and as heath and other wild plants, including the grasses, continue to grow in the turf, they serve to raise the hight of the dyke, and enhance its appearance as a fence.

(2178.) When dykes run at right angles into one another, and are erected simultaneously, they should be built in connection; but where a new dyke comes against an old one, the old one should not be touched, and the new built firmly beside it. Where 2 dykes cross and the place is naturally wet, or water may be easily brought to it, a watering-pool to serve 4 fields may be easily formed; and there are two ways of making such a pond:- When the ground is firm, and the water shallow, the 2 dykes may cross, as in fig. 411 , and allow the water to pass through them, and form a watering-pool in each field, such as $a, b, c$, and $d$ out of a single pond. Where a pond $e$, fig. 412 , already exists, and its water is too

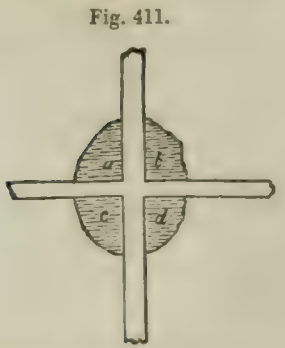

HOW TO FORM A WATERING. POOL TO FOUR FIELDS.
Fig. 412.

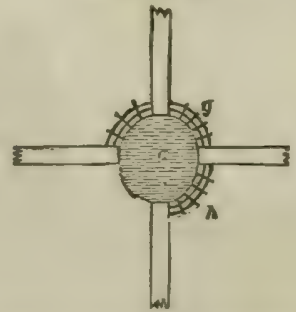

HOW TO FORM A WATERING-POOL COMMON TO FOUB FIBLDS.
Fig. 413.

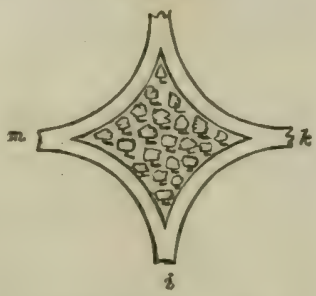

$\triangle$ CLUMP OF TREES AT THE MEETING OF DYKEG.

deep for dykes to traverse, the dykes must terminate at its edge and convert the pond into a watering-pool common to 4 fields. When the pond is used by only 1 field at a time, it should be fenced from the other 3 fields by means of hurdles, as $f, g$, and $h$; but when it is used by more than 1 field at a time, a fence should be run across the pond, beside the hurdles in the fields not occupied by stock. Where the ground is firm, and there is no prospect of obtaining a site for a watering-pool, the dykes should be made to cross, and a well sunk in a comer of one of the fields, with a pump in it of such hight as to supply all the fields with water in tanks by means of a spout. This expedient I used successfully on one occasion. Where the ground is firm, and no water wanted at that spot, the dyke should be built curved, as from $i$, to $k$, from $k$ to $l$, from $l$ to $m$, and from $m$ to $i$, fig. 413 , and the space included hetween them planted with trees for ornament and shelter. There will be here little waste of land, even should it be of the finest quality, as the corners of 4 adjoining fields always contain ground that cannot be reached by the plow, while the plow can pass along such curves as near as to a straight fence. In building curvatures in dykes, builders charge $\frac{1}{2}$ more per rood than for plain work.

(2179.) A stone-dyke is in the highest perfection as a fence immediately from the hands of the builder; but every day thereafter the effect of the atmosphere upon the stones, at all seasons, and the accidents to which (718) 
they are liable by trespasses of individuals, and the violence of stock, render it necessary to uphold their repairs frequently ; and this consideration should cause the best suited materials to be selected for their original erection.

\section{BREAKING-IN YOUNG SADDLE-HORSES.}

"Which with a maffle you may pace easy."

antony and Cleopatra

(2180.) As I have mentioned how your saddle-horse should be groomed (1398), I would wish to say a few words on breaking him in. And, in the first place, I may remark that, judging by the conduct of roadsters one meets with every day on the public roads, we may fairly conclude that the profession of horse-breaking is not well understood in this country; and the conclusion need create no surprise, when we observe those who become horse-breakers to be generally cast-off grooms unable to procure a permanent situation, just as we occasionally see a discarded plowman become a spadesman, to save himself from starving; but it ought to excite even wonder to see farmers, who ought to be somewhat acquainted with the nature of horses, employ such persons to break-in their saddle-horses, merely because they demand a small fee, and undertake to finish a horse in all his paces in the course of 2 or 3 wceks. In fact, the farmer grudges the time, beyond a few days, any horse requires to be broke-in, and acts as if he conceived the animal should know the art of carrying him by instinct, when he himself may have been practicing horsemanship all his days, and never perhaps become a horseman after all. Notwithstanding the folly of employing inexperienced men, I am convinced were men of experience, address, and character to undertake horse-breaking in a perfect manner, they would receive encouragement from the farmer. No miracle is required to break-in a horse; he is naturally docile, and may be taught to do anything, as those who have witnessed the evolutions of the late Ducrow's stud with wonder and delight can believe; but the horse is naturally fearful, and, endowed with an undying memory, he never forgets any circumstance, however trivial, which may have aroused his fears. If the breaker, therefore, proceeds on the principle of subduing what he calls the horse's temper, by a constant endeavor to curb him, he may tame him for a time, but will never break him in ; and even this subjection will only last as long as the horse finds he cannot obtain the mastery over his rider, who, on some occasion, may be a timid one; whereas, were it shown to the horse that no irritation awaits him in the stable, or on being ridden, he will place confidence in his rider, will regard him with attachment, and will take him everywhere, even through danger, by the gentlest touch of the rein, or exhortation of the voice. Why should the Red In. dian of North America never put a bridle on his horse's head, and only have a piece of cord round the under jaw, by which to pull him up in a gallop, and guide him, with the greatest nicety, in the hottest pursuit after buffaloes, by the palm of the hand against the side of the head; as much so as to enable him to point the arrow with unerring aim into the heart of his prey? Why should the Arab's horse come into his tent like one of his family, lie down and rest, and never think of running away from his master when his services are required? Does the horse of the accomplished European display the least degree of such confidence in his rider? 
Is it possible that a savage knows better how to break-in a horse than an European? T!e difference hetween the cases can he explained in a few words; the savage makes his horse his companion and friend, the civilized man treats his as lis slave. And can any doubt, were the same gentleness, kindness, attention io his wants, which secure to the savage the willing assistance of his horse, bestowed by the civilized man on his horse when young, would also inspire lim witı confirlence? Every one has felt the satisfaction of liding a horse one knows thoroughly. It should also be borne in mind as an incentive to liud treatment, that were horses generally well broke-in, they could not he spoiled hy even bad riders, for their paces would be su pleasant the rider would have no inducement to try and mend them.

(21S1.) The age of 3 ycars seems an excellent one for breaking-in a saddle-horse. The colt should be set 10 grass in the end of May, and taken in to break by August at latest, ly which time the grass will have operated beneficially upun him as merlicine, and there wili be sufficient time to teach him his paces and put him in working condition before the fall of the year, when lorses are apt to become soft, and catch cold; but were he kept longer at grass, his condition might become so fat as to endanger his constitution, were it sudlenly reduced to working order.

(2182.) The first thing, in bringing a horse into the stable, to which he should have been accustomed from his foalhood, is to give a gentle dose of medicine to clear the howels of a load of grass. A second dose may be repeated in a week. A little new-made hay with oats is the best food as a transition from grass to hard food. The first treatment with the cavesson and bridle being the same as that described from (1909) to (1911) for breaking-in the draught-horse, I need not repeat it here. I may mention, however, that much lunging in a circle is not advisable for a young riding-horse, though horse-breakers are very fond of giving him this sort of exercise, because it sares themselves a good deal of traveling; the motion round the circle being apt to cause the colt to contract a long step and a short. The circle is of most use in training to canter, when a leading foot is requisite to be used in that sort of action. The first tuition should be a straight-forward pace, as on a lea-field, and the only pace a walk, which should be taught to be both free with an easy head, and short with a tight rein. During the period of the walking-tuition, a great many useful lessons should be taught the colt, such as turning off you and to you-backing, whether quickly or slowly-leading, whether by the side of the head with the hand on the bridle-bit, or in front with a slack reinstanding still, whether for a short or long time-suffering to be tied to any object, such as a gate or tree-passing objects of terror, or of uncertainty, causing the animal to become acquainted with everything it does not seem to recognize-becoming accustomed with the crack of the long, and the touch of the short whip-lifting the fore and hind legs when desired-and suffering the groom to go about him and arrange the breaking-harness. With all these matters the young colt will become much sooner fomitiarized, by the breaker going constantly about with him on foot as a companion on the road and the field, than when mounted on his back. In the stable, too, the same system of tuition should be followed out, such as suffering a person to go up on either side, and in any way-suffering to be groomed, and rather liking it than opposing it, as is ton often the casedrinking out of a pail in the stable and at the pump, or out of a trough or a brook-taking up with a dog in the stable or on the road-bearing, without a startle, the fall of the pail-handle, the broom, or anything else-lifting the feet at the pail to be washed-being led by the forelock to the door, or $(720)$ 
the pump, or anywhere. These and many other things, the colt can be taught to know in and out of the stable before he is mounted at all. Thus familiarized, he will allow himself to be mounted without any trouble; and all the assistance of boys with whips, and of men to hold down the opposite stirrup, recommended by Mr. Youatt, dispensed with.* Tom Middlemiss, the horse-breaker whose name I mentioned before (1910), never required any assistance to mount a young horse, nor did any person ever see him mount one for the first time. The truth is, no fuss should be made about the colt; but when a number of persons are about him when anything is done, there cannot be but fuss, and he cannot fail to become apprehensive. He will soon confide in one person, the breaker who is constantly about him, but he will not confide in a number of persons at the same time, nor will he confide even in his breaker, when others are engaged along with him; and hence no considerate horse-breaker will permit any one to be near him, to distract the attention of the colt, when he is subjecting him to tuition of any kind. When mounted, the colt should bear his rider in standing for some time before he is urged to walk, as it will habituate him to stand at all times when mounted until his rider is ready to move. Every one rnust have felt the annoyance of mounting a horse that will not stand. His first pace should again be a walk, which having accomplished well with a rider, the trot should be taught. It is said that trotting is not a natural pace for a horse, he either walks or starts off at a canter. However this may be, trotting is an indispensable pace on our roads. On teaching trotting, horse-hreakers are very apt to degenerate the pace into a jog, the most dangerous of all paces for a young horse in causing him to trip, and the most difficult to break a horse from, when contracted. A short, hitching walk, ready to break into the jog alluded to, is as bad as the jog itself, and is a favorite pace with horse-breakers in chewing off their wards as fast walkers; but in such a pace a young horse is almost sure to dig a toe into the ground, and if a stumble is not the consequence, it is not the man's fault. Let the walk be a sound walk, and a trot a fair trot, and let no bastard pace be permitted to spoil both. It is not easy to teach a young horse to canter from a trot in a straight line, as he is more apt to start off to the gallop; but a few lessons in the circle will give him an idea of a canter, as he will there learn to point the leading foot. There is some risk at first in making a young horse reduce a canter into a trot, the actions being so very different, he seems at a loss what to do, and would rather halt. The tightening of the rein by degrees is the only way of reducing the pace in safety, as it likewise is from a fast to a slow trot. A sudden halt might throw the colt upon his haunches, and irrecoverably bring him over upon his back, and such an accident as this the colt will never forget, and, in fear of it, may become restive when pulled up suddenly at any time afterward. Every maneuver that may occasion any sort of accident to the colt should be avoided by the rider with care, and counteracted with firmness. Thus day by day the young horse acquires experience in the management of himself on the road, or in the field, but this series of experiences is a work of much time to both man and horse-of much patience and perseverance to the man-of much endurance and irksomeness to the horse; and more than all this, much of the benefit derived from the horse-breaker will be in a manner lost, if the future rider of the horse does not guide him in a similar manner, and with equal care for some time to come. If considerations such as these do not induce the owners of horses to employ only men of skill and character in breaking them in, I do n't know what stronger motive can be placed before them to do it. 


\title{
A U T U M N .
}

\begin{abstract}
"Ye balmy breezes! wave the verdant field;
AUTUMN! adl your bounties, all your lustre yield;

That fruits and berbage may our farms adorn,

And furrowed ridges teem with loaded corn."
\end{abstract}

FERGUSSON.

Iv contemplating the nature of the different seasons, we have seen Winter the season of dormancy, in which all Nature desires to be in a state of repose-Spring, the season of revival, in which the returning power of Nature inspires every created being with new vigor-Summer, the season of progress, in which Nature puts forth all her energies to increase and multiply her various productions-and, now, we see Autumn, the season of completion and of consequent decay, in which Nature, in bringing the individual to perfection, makes provision for the future preservation of the kind. While, therefore, the natural action of spring and summer is single, that of autumn is of a compound character. "Thus, if we follow out the study of the autumn in a proper manner, it leads us to all the revolutions that have taken place in the surface of our planet; and in this way, a plant of which we can, in a few months, see the beginning, the perfection, and the decay, becomes to us an epitome of the system of growing Nature in its widest extent, and through its most prolonged duration. This is the grand advantage while studying the productions of Nature in their connection, and the events and occurrences of Nature in their succession, has over the mere observations of the individual substance and the passing momeut; and it is this which gives to the law of the seasons so high a value above all the beauties of the seasons taken in their individual character."

Autumn brings fruition, in which the toilsome labors of the husbandman, for the preceding twelve months, find their reward. It is the season in which liope is lost in the possession of the thing hoped for, and because of a harvest of plenty, it is the season of gratitude. "It is this which makes the principles of seasonal action thicken upon us as the year advances, and the autumn to become the harvest of knowledge, as well as the fruits of the eaxth. Nor can one help admiring that bountiful and beautiful Wisdom which has laid the elements of instruction most abundantly in the grand season of plenty and gratitude." But grateful as the husbandman must always feel for the bounties of Providence, so much labor is bestowed, so much anxiety is felt by him, as regards the effects of the vicissitudes of the seasons, before "he gathers his wheat into the garner," that the reflections which the consummation of harvest is calculated to give rise to are, I fear, narrow, and even selfish. "Fur as the annual harvest which we obtain from the earth is received by us as resulting from that in which we have a right of property, a merit in labor, or both united, we are apt to forget the part which Nature has in the productiveness of the year, and look upon the whole produce as the return of our own capital and our own skill, just as we do in any mechanical work or mercantile speculation. That this is the true state of the case is proved by the habitually proverbial fact that the cultivators of the ground, for what purpose soever they may cultivate, are always complaining of 
the weather, as the grand enemy by which all their labors are frustrated, and all their products diminished. They are nowise at fault themselves, but the 'weary weather' never will be obedient to their dictates. What with rain, what with drouth, what with heat, what with cold, each thrusting itself forward at the time when its opposite would have been by far the more beneficial, the crop they get is always 'below a fair average,' and what they do get is got in in spite of the weather, and not by means of its coöperation. It is in vain that the fable of the farmer-into whose hands Jupiter gave the management of the weather, and who, by having rain, and drouth, and sunshine, and snow, when and where he wished, brought his land into a state of such utter sterility, that he was fain to plead more earnestly than ever that so dangerous a power might be taken out of his hands-has stood on the record against them from remote antiquity; for the majority contend stubbornly that all the merit is their own, and that all the blame falls upon the weather, which, notwithstanding all the examples which have been set before it, and all the experience it must have had, 'will not understand and obey the rules of good Husbandry.' "*

The colors displayed by the autumnal setting sun are exceedingly rich; one form of the phenomenon not uncommon at that period is attempted to be penciled in Plate XIV; but a far finer picture is to be seen in these words of a revered bard, who can feel intensely as he can describe beautifully :

\footnotetext{
"A cloud lay cradled near the setting sun : A gleam of crimson tinged its braided snow.

Long had I watched the glory moving on O'er the soft radiance of the lake below. Tranquil its spirit seemed, and toated slow;

$E^{\prime}$ 'en in its very motion there was rest ;

While every breath of eve that chanced to blow

Wafted the traveler to the beauteous West. Emblem, methought, of the departed soul,

To whose white robe the gleam of light is given; And, by the breath of Mercy, made to roll

Right onward to the golden gates of Heaven, Where to the eye of Faith it peaceful lies, And tells to Man his glorious destinies."
}

Wirson.

Objects in the horizon-trees, houses, and ruins-are projected in bold relief against the clear, deep sky of a calm autumnal evening at sunset. Such a scene as this-if gemmed, moreover, with the radiant and lustrous evening star-affects the mind to thoughtful meditation, not untinged with melancholy.

The temperature of autumn is high-August, in Scotland, affording the highest average of the year, on account of warmth in the night as well as the day, though the sun is not more hours above the horizon than in March-but Autumn follows the radiance of Summer, while Spring just escapes from the frigidity of Winter. Such is the heat that it is no uncommon occurrence for reapers to be seriously affected by it in the harvestfield.

The labors of the field partake of the compound character of the season itself. Just as one crop is reaped from the ground, part of the succeeding one is committed to the earth; the autumnal wheat of two successive years being sown and reaped about the same time. The toil endured in harvest is almost incredible. Only conceive the entire bread-corn sufficient to support the population of such a kingdom as this to be cut down and carried, in minute portio s, in the course of a single month! The usual season of reproduction among the animals of the farm is spring; but the most useful animal of all, the sheep, forms an exception to the rule, Autumn being the season in which the ewes are drafted, and the tup is allowed to

* Mudie's Autumn. 
go with them. There seems in autumn a tendency in the animal frame to disease; sheep are liable to hepatitis, calves to quarter-ill, the horse to colic and even inflammation in the bowels, and stallions and geldings become dull in spirit. Perhaps the feeding nature of aftermath, on which all animals live in autumn, may cause a tendency, in the animal system, to predominant secretion of one of the fluids, and thereby predispose the sys. tem to particular complaints. If there is probability of truth in this surmise, preventive measures should be sought for and obtained; and oil-cake seems to possess this property. One preventive remedy against annoyance from parasitic insects and from cold to sheep, is bathing or smearing.

The sports of the field all commence in autumn. The long-contemplated gatherings in the hills, on the noted 12th of August, in quest of grouse-game, par excellence, of which our country should be proud as its only indigene-cause every sheiling to afford shelter to many who, at other seasons, indulge in the far different enjoyments of urban luxuries. Partridge-shooting comes in September, sometimes even before the corn is cut down, and is followed by hare-hunting in October; and after all the fields are cleared of their valuable produce, the inspiring "music" of the pack is heard to resound through hill and dale.

The great event of autumn-the harvest-naturally claims a preponderating share of the husbandman's solicitude; and until this important issue of all his toil is secured beyond danger, he cannot rest in quiet. $\mathrm{He}$ looks around him, night and day, regarding the "face of the sky," and acts with circumspection. He sees his whole year's bread at stake, and feels that its safety depends on his own skill; and should he fail to exercise this aright, he would never cease to blame himself. None is more anxious to follow this advice than he:

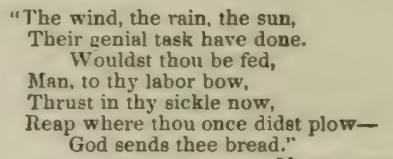

Montgomeny.

When every straw is safe in the stack-yard, and the stack-yard gate closed for the season, then, and not till then, is he satisfied of his task being finished, and enjoys undisturbed repose.

Now that we have surveyed all the seasons as they present themselves in this country, we must own our climate to be anything but genial. The frequent changes to which it is daily susceptible render the culture of the soil always a difficult, and not unfrequently an irksome occupation. Those vicissitudes, no doubt, sharpen the intellect of the farmer, and perhaps have been the chief means of eliciting the high skill which is so universally acknowledged to be exercised in the Agriculture of this kingdom. Such skill will always have a field for exercise, for our insular position will subject our atmosphere to perpetual changes dependent on different conditions of heat and moisture produced by the state of the surrounding ocean. Notwithstanding the farmer is held to his task by a frowning climate, he would rather wish to have a smiling one, and sometimes envies the bright skies which he hears illumine the Continent. There is much truth in the desire expressed in the following observations, lightly as they are put together, for no one but enjuys fine weather, which is, indeed, always the source of gratulation when it occurs: "It may be very well for a lover to declare in the presence of his mistress that 
but to common mortals, occupied with the ordinary affairs of life, there is no truth in it. Who in his senses ever affirmed that the fogs of November were as delightful to him as the balmy breath of May? If any one has, as I have, a horror of icicles, and who would never have the mild temperature of the air interrupted by the presence of a hoar-frost, let him migrate with the climate. Let him spend the month of January in Portugal; February in the Madeiras; March in Spain; April in Sicily; May in Lapland; June in Italy; July in Switzerland; August in France; September in England; October among the forests of America ; November in Crete; and December in the islands of the Cape de Verd. By this rotatory motion he may enjoy a delicious temperature, and revel in honeysuckles and roses all the year round."*

\section{PULLING FLAX AND HEMP, AND THE HOP.}

"Now pluck up thy flax, for thy maidens to spin; First see it dried, and timely got in."

TUSSER.
"Lo! on auxiliary poles, the hops, Ascending spiral, ranged in meet array !"

Phillips.

(2183.) I propose here merely to speak of flax as to its treatment in summer, and the mode of harvesting it; for as to its treatment afterward as an article of manufacture, that is beyond my province. The only care required by the growing crops of flax in summer is weeding, and in its early stage of growth it will be much injured if weeds obtain the mastery. To obviate this inconvenience, and, indeed, to save altogether the trouble of weeding, it has been recommended to sow the land at the time of sowing the flax-seed with grass-seeds, or to sow the flax-seed in drills; but neither expedient is so suitable for flax itself as land kept clean by weeding a broadcast crop; for as equality of fibre is of the utmost importance to the value of flax, sowing it in drills admits the air unequally to the crop, and the fibre of the plants on the outside of the drills would thereby be much coarser than that of those in the interior.And as to sowing grass-seeds, even the low-growing white clover among flax, it should make no difference to the flax-plant whether it was choked by a valuable or a worthless plant, since both would equally be weeds in reference to it.

(2184.) Besides the common weeds which infest the soil, according to its nature, there are others specially found among flax; of these, one is the common gold-of-pleasure, Camelina sativa, the seed of which is imported among flax-seed; and the plant may be known by its attaining from 2 to 3 feet in hight, having small yellow flowers, and very large pouches on long stalks. But a more troublesome weed than this is the flax-dodder, Cuscuta Europoe, inasmuch as it adheres parasitically to the flax plant, and, of course, injures its fibre; while the gold-of-pleasure may be pulled out before the flax is ready. The habits of the flax-dodder are these: "It is a plant which germinates in the ground, and sends up a slender, thread-like stem, which, twisting itself about, soon touches one of the stems of the flax among which it is growing. As soon as this takes place, the dodder twists itself round the flax, and throws out from the side next

- Note-Book of an Oxonian-John Bull, for 5th August, 1843. (781) 
to its victim several small processes, which penetrate the outer coat or cuticle of the flax, and act as suckers, by which the parasitical doda'er appropriates to its own use the sap which has been prepared in the flar, upon which the growth of the flax depends. The dudder then separates itself from the ground, and relies solely upon the flax for its nourishment, producing long, slender, leafless stems, which attach themselves to each stem of flax that comes in their way. Thus large masses of the crop are matted together, and so much weakened as to become almost useless. This plant produces great quantities of seed, which is usually threshed with the flaxseed, and sown again with it in the succeeding year. Several years since I took considerable trouble to ascertain if all foreign flax-seed was mixed with that of the dodder, and was led to the conclusion that the American flax-seed is nearly free from this pest, and that that from Russia, and especially Odessa, is peculiarly infested with it."* The weeds, when very young, are picked out by hand from the flax by field-workers; and, in doing this, the kneeling down upon the flax does it no harm. If weeding be once effectually and timeously done, the weeds will not again much trouble the crop; and, though it should cost several shillings the acre, the increased value of the crop will repay it all. Before leaving the subject of weeding, I may remark that, though the American flax-seed be free from dodderseed, it is far inferior in giving a crop to that imported from Riga, the Riga-kind, which also bears the name of Belgian seed, from the Belgians sowing it. And I may also remark that sowing flax on clean land will save much of the cost of weeding-that is, after a green crop, as turnips and potatoes, the cleansing of which will have rendered the soil comparatively clean for flax. If flax be thus cultivated in lieu of a corn-crop, its culture may be practiced without much deterioration to the land; but if it is determined to regard flax as a green crop, and cause a corn-crop to follow it, the land will in time assuredly feel the scourging effects of such a system, and oblige its cultivators to abandon it altogether.

(2185.) The pulling, steeping and drying of flax are simple enough, and are processes generally well understood; but Mr. Henderson's account of managing the crop, whose sample of Irish flax obtained a gold medal from the Agricultural Improvement Society of Ireland, at their meeting at Belfist, in August, 1843, being the most practical, and at the same time succinct, I have met with, I shall transcribe it. 1. And, first, as to test of ripeness, Mr. Henderson says: "I have found the test recommended by Mr. Boss to ascertain the degree of ripeness that gives the best produce, with the finest fibre, perfect. It is this: Try the flax every day when approaching ripeness, hy cutting the ripest capsule on an average stalk across (horizontally), and when the seeds have changed from the white, milky substance which they first show to a greenish color, pretty firm, then is the time to pull. The old prejudice in favor of much ripening is most injurious, even as regards quantity; and the usual test of the stalk stripping at the root and turning yellow should not be depended on. Where there is one man that pulls too green, five hundred over-ripen." 2. When properly ripened, flax should be pulled in this way: "I use the Dutch method - say, catching the flax close below the boles; this allows the shortest of the flax to escape. With the next landful the puller draws the short flax, and so keeps the short and the long each by itself, to be steeped in separate ponds. It is most essential to keep the flax even at the root end, and this cannot be done without time and care, but it can be done, and should always be done. The beets should always be small, evenly sized, straight,

* Gardenerg' Chronicle and Agricultural Gazette for 10th Fehruary, 1844. (782) 
and even, and should never be put up in stooks or windrows, but taken to the pond the day they are pulled, or the day after at longest, especially in bright weather; for the discoloration produced by the sun on green flax will $n$.ver be removed till it goes to the bleacher, and will give him some trouble also." 3. Next comes the steeping, which is a most important process, and is the one least understood by growers of flax in this country. You, perhaps, require to be informed of the object of steeping the flax-plant.The stem of flax consists of two parts possessing very different properties : the one, the outer, is fibrous, and affords the substance of flax; the other, the interior, is pithy, and is got rid of by fermentation in steeping, loosening its hold of the fibre. There is also much mucilage to be got quit of ; and the sooner flax is put into steep after being pulled, the more mucilage will be dissolved from it. If steeping is so long continued as to affect the texture of the fibrous coating, the flax will be injured; and should it not be as long applied as the pithy matter may be easily loosened, much labor will be afterward incurred in getting quit of it. Proper steeping, then, is an essential and delicate process, and on this account Mr. Henderson's instructions are valuable: "Flax is subject to injury from neglect in every process, but in this especially. The water brought to the pond should be pure from all mineral substances, clean and clear. The water of large rivers is generally to be preferred; but spring-water, which has run some hundred yards, becomes soft, and will have deposited any mineral impurities it contained; immediately from the spring it seldom does well. If the water be good and soft, it is injurious to allow it to stagnate in the pond before steeping. I put in two layers, each somewhat sloped, with the root-end of each downward: one layer at a time is said to be safer, and, perhaps, is so, though I have tried both and seen no difference. The flax should be placed rather loose than crowded in the pond, and laid carefully straight and regular. Having an abundant supply of water, I do not let any into the pond till the first layer is in. I cover with moss-sods (from the turf-banks) laid perfertly close, the shear of each fitted to the other.Thus covered, it never sinks to the bottom, nor is it affected by air or light. It is generally watered in 11 or 13 days. A good stream should, if possible, always pass over the pond-it carries off impurities, and does not at all impede due fermentation; flood and all impure water should be carefully kept off. The Dutch test of being sufficiently watered is certain and perfect ; at least, I never found it otherwise. It is this : Try some stalks of average fineness, by breaking the woody part in two places, about 3 inches apart, at the middle of the length; catch the wood at the lower end, and if it will pull (downward) for those 3 inches freely, without breaking or tearing the fibre, it is ready to take out. This trial should be made every day after fermentation subsides, for sometimes the change is rapid.Flax is more frequently injured by too little than too much of the water. Great care and neatness are necessary in taking it out. Broken or crumpled flax will never reach the market. Spread the day it is taken out, unless it is heavy rain-light rain does little harm; but, in any case, spread the next day, for it will heat in the pile, and that heating is destructive.The most particular cause of injury in steeping is exudation of water from the sides or bottoms of the pond. Stripe and discoloration are mostly imputed to the quality of the water brought to the pond; while, in 9 cases out of every 10 , the water oozing from the sides and bottom of the pond itself is the cause. Even if such water were pure, which it seldom is, it is injurious; but when impregnated with iron or other materials, it does immense harm. If such ponds must continue to be used, the injury may be partially amended by draining around the sides and ends, at 6 or 8 feet (783) 
distance, and 18 inches deeper than the bottom of the pond, and filling the drains with stones. No other thing I know of does such extensive injury as this springing of water within the pond." 4. Flax "should be spread even, straight at its length, not too thick, and well shaken, so that there shall be no clots; indeed, if possible, no 2 stalks should adhere. I have ever found it injurious to keep it long on the grass; it is in the steep the wood is decomposed; on the grass the fibre is softened, and the wood little, if at all, affected. I rarely let it lie more than 5 days, sometimes only 3 ; this year it had only 3 days, and I never had better flax. It should never, if possible, be spread on the ground flax grows on-it claps down, and the clay and weeds discolor it ; clean lea, or lately cut meadow, is the best." 5. "Lifting, like all other operations, requires care and neatness to keep it straight to its length, and even at the roots. This operation is too frequently hurried and coarsely done." 6. If the steeping and grassing have been perfect, flax should require no fire; and, to make it ready for breaking and scutching, exposure to the sun should be sufficient; but if the weather be damp, the flax tough, and must be wrought off, then it must be fire-dried. Such drying is always more or less injurious; but, if it be put on the kiln in a damp state, it is ruinous-it is absolutely burnt before it is dry. All who can afford it should keep such flax over to the ensuing spring or summer, putting it dry into stacks-then it will work freely without fire-heat." 7. In the concluding remarks of Mr. Henderson, there is much good sense: "The proper culture and preparation of flax require more care, exertion and expense than the old, slovenly method; and those who will not give those requisites would do wisely to abstain from growing flax altogether. Any other crop will abide more negligence. So much has been said and written of late of the advantage of flax-culture, that it is to be feared some may be led to carry it to an undue extent, and sow it on land not fitted for it; indeed, this is already often done, and I know of nothing more injurious to the farmer. Flax is proverbially either the very best or the very worst crop a farmer can grow."

(2186.) The crop of flax, after it is dried, is bulky for its weight; and yields from 3 to $10 \mathrm{cwt}$. per imperial acre of dried plants. From 30 to 40 stones, of $14 \mathrm{lbs}$. each, the acre, of dressed flax, is considered a fair crop, and if fine quality, will fetch perhaps $£ 90$ a ton; that is, from 4 to 5 acres are required to furnish 1 ton of flax, and a return obtained of from $£ 18$ to $£ 22$ per acre, exclusive of the expense of preparing it by heetling, scutching, and hackling, and may still leave from $£ 10$ to $£ 15$ an acre of profit, which is a large one; but should the flax prove coarse by improper management, or be injured in drying, much waste will be occasioned in dressing it, and the profit reduced to perhaps $\frac{1}{3}$ of these amounts. So the observation of $\mathrm{Mr}$. Henderson, of flax being either the best or worst crop for the farmer, thus receives corroboration; and it should also be borne in mind that flax, like the potato crop, leaves no straw for manure to the land.

(2187.) Hemp is a crop scarcely cultivated in Scotland, and its culture in England is confined to the southern counties, being a plant indigen. ous to the south of Europe and India. Being tall of growth in comparison to flax, it receives no injury from weeds, but, on the contrary, smothers by overtopping them. This plant is best cultivated in drills. The crop is pulled and watered, and dried like flax, the weight of produce dressed being little more than flax, from 40 to 45 stones the imperial acre, and the profit derived from it, after deducting expenses, seems

* Dublin Farmers' Gazette. $(784 ;$ 
to be from $£ 5$ to $£ 6$ per acre, though Lord Somerville, in sanguine expectation of extending the culture of this plant in England, estimated it at $£ S$. The dried refuse of the stems of hemp, after the fibre has been separated, is used as fuel, and may be converted into charcoal fit for gunpowder. The seed yields about 3 quarters per acre, and from it is expressed an oil " employed with great advantage in the lamp, and in coarse painting. They give a paste made of it to hogs and horses to fatten them; it enters into the composition of black-soap, the use of which is very common in the manufacture of stuffs and felts; and it is also used for tanning nets." The common hemp is raised in India, not for the sake of its fibre, but for the intoxicating quality of its seeds when eaten green and fresh; the hemp of commerce of that country is derived from a different plant.*

(2188.) The hop is not cultivated in Scotland but as an ornamental plant in the shrubbery, because the climate is not sufficiently warm to develop its cones, constituting the ripe fruit, which is its useful part. The culture of the hop is confined to the south of England, where, in 1835, the extent of ground occupied by it was 53,816 acres ; and its culture is very different from that of usual field-crops. When a new hop-garden is formed, the ground is trenched to the depth of 2 feet; and as the plants occupy the ground several years, their roots strike to a considerable depth, where the more of better soil they find near the bottom of the trench, the better they grow, for as to the surface soil, it can be manured at any time, and in many ways. The plants, previously raised from seed, as being more hardy in constitution than raised by cuttings, are placed in quincunx order, at $5 \frac{1}{2}$ feet distance each way, which give 1,440 plants to the imp. acre. The hop-plant being diocious in its nature, that is, having different sexes on different plants, 1 male is planted among every 10 female plants. The female plants only bear fruit, which has the form of solitary cones or strobiles, ovate and pendulous, composed of membraneous scales of a pale-green colour, eack containing one round flattish seed of a bay-brown color, surrounded with a sharp rim, and compressed at the top. Being climbers, as the plants shoot up, they are tied to and trained along poles pushed endwise into the ground beside them; and in the first year's growth of the bine the poles used may be short; but afterward, when shoots spring from the old stock, 3 bines are preserved from each shoot and trained up upon 3 poles placed around each plant-hill, with their upper ends divergent, that the air and sun may find their way into the centre of each cluster of plants; and the poles are, besides, so set as to allow the forenoon sun to reach the plants, and also to receive as little injury as possible from the prevailing wind of the district. The poles are from 16 to 18 feet the longest, and 14 the shortest; and as 3 are required for every hill, 4,320 are wanted for every acre. The best poles are of yew, next of chestnut, then larch, ash, willow, oak cut in winter, Scots fir, birch alder, beech, in the order enumerated. They last from 3 to 5 years, according to the wood, and cost $1 \mathrm{~s}$. per foot per 100 poles; that is, poles 18 feet long will cost $18 \mathrm{~s}$. the 100 , or nearly $£ 39$ per acre; and as about 500 poles are wanted every year to keep up the stock, their wear and tear costs about $£ 410$ s. the acre. In order to lessen this great annual expense, it has lately been suggested to stretch a stout wire along each alley, to which the poles should be fastened. The advantages of this plan are said to be, that poles of much less value than those usually employed may be used, injury from gales of wind avoided, and the alleys being open to the influence of the sun and air, the mould,

* See Wisset's Treatise on Hemp, which contains all that can be said on the subject. Quarto edition, 1808. 
that fatal disease of the hop, prevented; and it is said that a garden of 9 acres at Halling, near Rochester, is cultivated in this way. Poles are carefully laid aside at the end of every hop-season. The bines, as they shoot up, are tied to the poles by women, who use dried rushes for the purpose. The ground receives culture to keep it clean and open till the season of picking or gathering the flowers arrive, which is commonly the first week of September. The hop properly so called, is picked from the bine by the hand; and, to facilitate that process, the bines aire cut over at 3 feet from the ground, aud the poles raised and laid on their side in a convenient position and place for the pickers. Whole families of laborers are employed at picking, receiving $1 \frac{1}{2} \mathrm{~d}$. per bushel, at which rate a family of 5 will earn from $7 \mathrm{~s}$. to $10 \mathrm{~s}$. a-day. There being 1,440 hills in the acre, and allowing 1 bushel of hops to each hill, and $1 \frac{1}{2} \mathrm{lbs}$. to each bushel, the acre will yield $19 \mathrm{cwt} .32 \mathrm{lbs}$; but the crop is sometimes not $\frac{1}{4}$ of that quantity. Indeed, so precarious is the crop of hops, that, at Binstead, in Hampshire, a farmer grew $4 \frac{1}{2}$ cwt. on 10 acres, in the year 1825, and in the following year, 1826, he realized 9 tons from the same land! This diversity of crop is greatly owing to the effects of insects, of which a considerable variety and in great numbers affect the hopplant, and also of blight or mould, occasioned by damp or confined air. When ripe for picking, the hop is of a lightish-green color, and gummy to the feel when in the highest perfection. In a few days longer it becomes brown and strong-tasted. At Farnham, in Kent, the hops are always picked in the perfect state, and every injured flower is put into a separate basket; and, on this account, the Farnham hops always command the highest price in the market. This hop is eagerly sought after by pale-ale brewers; while the brown, stronger-tasted hop is better liked by porterbrewers. After being picked, hops are immediately subjected to artificial heat in a kilu to be dried, so that they may keep; and to show the value of a delicate-colored article in the market, the brown samples are strongly fumigated with sulphur, to give them a fairer and more equal appearance. It is surprising that purchasers who are judges of hops, and aware of such a practice, submit to it, unless they themselres employ it as a means of deceiving customers who never saw hops growing, and know not how they are treated. What would be thought of a corn-farmer, were he to fumigate the barley he had to dispose of with sulphur, in order to make the bright-colored, overripened, and stained samples look all alike? If lightcolored hops are indispensable to the brewer, let him manufacture his commodities as he pleases, but let the farmer deal only in the genuine produce of the soil. If he must have fair-colored hops, let him pick them in due season, and exercise his skill in a legitimate way, and eschew every species of deception. The drying is effected with cobe and some charcoal, the drying heat being $112^{\circ}$ Fahrenheit; and costs, including every expense, 14s. the cwt. After being dried, hops are laid in a heap, to sweat and grow tough, and there they lie longer than merely to cool; for they must feel moist and clammy, and be squeezable in the hand, before they are bagged, when 5 Ihs. of fresh hops will weigh only $1 \mathrm{lb}$. when taken from the kiln. A bag of hops weighs $2 \frac{1}{2}$ cwt. ; and is fixed by statute 4 feet wide, $7 \frac{1}{2}$ feet long, and to contain $5 \frac{1}{2}$ yards of cloth, weighing $5 \frac{1}{2}$ lbs., which usually costs $6 \mathrm{~d}$. per yard. A Kent pocket is 3 feet wide, $7 \frac{1}{2}$ feet long, weighs $4 \mathrm{lbs}$., and contains usually $1 \frac{1}{4} \mathrm{cwt}$., but $2 \mathrm{cwt}$. of Farnham hops. Such a pocket will occupy a man from 3 to 4 hours to tread the hops into firmly; and to tread 4 of them in a day, at $9 \mathrm{~d}$. per cwt., is a very good day's work; and in doing which he becomes covered with yellow dust, to which powder Dr. Ives ascribed the whole virtue of the plant. (786) 
Hops cannot be tread too firmly into the bags, for the more the air is excluded the better; and, for this end, the use of the Bramah hydraulic press is recommended. It is not an easy matter to keep hops when they shrink in the bags, and the air finds admission to them, and they then lose from 5 to $10 \mathrm{lbs}$. per cwt.; but the greater quantity of sulphur and saltpetre employed in the drying, the worse will hops keep. Damp is ruinous to them. In most cases, the price of old hops drops down to the half of that of new. Hops containing the most seed will retain their weight the longest.

(2189.) The [excise] duty on hops is $2 \mathrm{~d}$. per lb., and it amounted to $£ 409,055$ in 1835 , on the produce of 53,816 acres, being $49,086,600$ lbs., or $8 \frac{1}{2}$ cwt. per acre. Small as this impost appears, it made that year a direct tax upon the land on which the hop grew, of $£ 719 \mathrm{~s} .6 \frac{1}{2} \mathrm{~d}$. per acre! I never could understand why hops should be subjected to direct taxation, when all other agricultural productions are exempt fiom it. I can see the plea upon which a duty on malt may be urged, of its truly being a manufuctured article; but the tax ou hops is a direct impost on the produce of the soil. Whatever benefit is derived from this impost to the revenue, from which nearly $£ 4,000$ a year must be deducted for its collection, is more than counterbalanced by the spirit of gambling engendered in speculators, who make purchases solely in accordance with the palpable amount of duty to be exacted. Offers made to farmers, resting on this contingency, lure them also into that vice, and frequently make them suffer; and they cannot avoid the temptation, for the casualties affecting hops are so uncertain, that the prospects of a crop may be blighted or secured in the course of a few days. Thus, in 1834, the hop was so much affected by the aphis, that the whole amount of duty was struck at about $£ 100,000$ over all the districts; but on thunder-showers falling and destroying the insects just in time, and the weather afterward proving very favorable to the growth of the plant, actually raised the duty, which was paid, to $£ 329,936$, thus indicating an increase in the value of the apprehended crop of more than 3 times. Were there no duty, the farmer would dispose of his hops, when he realized them, as he does any other crop. The expense of forming a new hop garden is $\mathfrak{£ 1 5} 13 \mathrm{~s}$. per acre, including a half-year's rent. The yearly expense of maintaining an acre of hops is, up to picking time, including rent, \&c., $£ 17$ 8s.; picking, drying, and including duty on 6 cwts., $£ 152 \mathrm{~s}$. ; together, $£ 3210$ s. It is not an uncommon practice to let the working of the ground, the poling of the hills, and the tying of the bines to the time of picking, to laborers at $£ 310$ s. per acre.*

(2190.) Flax (Jinum usitatissimum), from the Celtic Llin, a thread, in the class and order Pentandria Pentagyura, of Linnæus, and in the natural order of Linea, is a native of many parts of Europe, as well as of Nepaul and North America, in corn-fields, and is said to be originally from Egypt. It has been cultivated for an unknown length of time in Britain, of which it is now considered a naturalized inhabitant; and it is cultivated both for its fibre and oil, and the husk of the seed, after the oil has been extracted from it, is employed in the fattening of live-stock.

(2191.) "Mr. James Thomson and Mr. Bauer," relates Dr. Thomson, "have shown that the fibres of flax are tiansparent cylindrical tubes, articulated, and pointed like a cane; while the filaments of cotton are transparent glassy tubes, flattened, and twisted round their own axis. A section of a filament resembles, in some degree, the figure 8 , the tube, originally cylindrical, having collapsed most in the middle, forming semi-tubes on each side, which give to the fible, when viewed in a certain light, the appearance of a flat ribbon, with a hem or border on each edge. The uniform transparency of the filament is impaired by small irregular fissures, probably wrinkles arising from the desiccation of the tube. In consequence of this difference between the structure of linen and cotton fibres, Mr. Thomson and Mr. Baner were enabled to ascertain that the cloth in which the Egyptian mummies are wrapped is always linen, and never cotton. It is clear from this, that the opinion entertained by some, that what is called in our translation of the Old Testament fine linen of Egypt, ought to be the cotton cloth of Egypt, is erroneous. We have

\footnotetext{
* See Lance's Hop-Farmer, edition of 1838, for a great deal of information regarding the culture of this interesting plant.
} 
no evidence from the cloth wrapped about ancient mummies, that the Egyptians in those early times were acquainted with cotton."

12192.) Large quantities of flax-seed, commonly called linseed, are annually imported into this country. It is imported for the purposes of growing tbe flax-crop, and for crushing into oil. Vitality not being certain in the flax-seed raised in this country, it is necessary to receive a supply from abroad, and of all forcign kinds, that from Holland is the preferable for seed, while our own answers for crushing into oil. "Crushing-seed is principally imported from Russia, but consid. erable quantities are also brousht from Italy and E gypt. Of 2,759,103 bushels of linseed imported in $1831,2,210.702$ were brought from Hussia, 172.099 from Prussia, 106.294 from the L nited States. 105,448 from Italy, 98,847 from Egypt, 53.738 from the Netherlands," $\uparrow$ \&c. By the New Tariff, the duty on forcign linseed. and that from British possessions, is only nominal, being $1 \mathrm{~d}$. per quar. ter. The prices by the quotations in February, 1844, are from 508. to 60s. per quarter for English sowing, and from 25s. to $37 \mathrm{~s}$. for Baltic crashing.

(2193.) Linseed contains a great proportion of mucilage, and, when converted into jelly, constitutes an excellent nutriment for stock. The process of making the jelly is this: "The proportion of water to seed is about 7 to 1 . Having been steeped in water 48 hours previous to boiling, the remainder is added cold, and the whole boiled gently for 2 hours, keeping it in motion during the operation, to prevent its burning to the boiler, thus reducing the whole to a jelly-like, or rather a gluey or ropy consistence. After being cooled in tubs, it is given with a mixture of barley-meal, bran. and cut chaft; a bullock being allowed about 2 quarts of the jelly per day, or somewhat more than 1 quart of seed in 4 days; that is, about 1-16 of the medium allowed of oil-eake."

(2194.) The mucilage of linseed does not belong to any of the genera of gams; but its nature bas not yet been ascertained. Its general composition and elementary constituents were ascertained to be these, by Guerin-Varry :

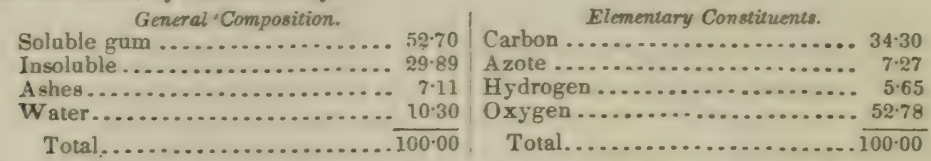

The ashes contaiued carbonates of potash and lime, phosphate of lime, chloride of potassium, sulphate of potash, oxide of iron, alumina, and silica.||

12195.) The oil afforded by linseed is in the proportion of 22 per cent., that is, about 15 gallons of oil from 1 quarter of seed, at a weight of $7 \frac{1}{2} \mathrm{lbs}$. to the gallon; the remainder is oil-cake. The best oil is that which is cold-drawn; and I suppose that the best oil-cake is obtained from this process, as having most oil in it. The warm-drawn oil is obtained by heating the seed by steam to a temperature of $200^{\circ} \mathrm{F}$ ahrenheit; and as the heat liquefies the oil, no doubt more is expressed from the seed, and the oil-cake cannot be so rich. Both the cold and heated seed are pat into woolen bags, and pressed by means of the hydraulic-engine or a wedge, and the cake, on being taken out of the bag. is already quite firm; its weight at most is 8 lbs., and sells for $f 910$ s. to $£ 10$ per 1,000 , or $1 \frac{1}{3}$ farthings per lb., and the foreign from $£ 5$ to $£ 610 \mathrm{~s}$. per ton, or $2 \frac{3}{4}$ farthing» per lb. From this difference in the price, it would appear that the foreign is the more valuable oil-cake. owing, perhaps, to its being manufactured by imperfect machinery, which cannot extract so much of the oil out of it as our own; but be this as it may, I am not aware that any experiments have ever been made on their comparative fattening powers. A substitute for oil-cake. or what is called Hutchinson's patent oil-cake, is compounded, I understand, of $3 \mathrm{cw}$ ts. of linseed-oil and 1 ton of barley-meal, and is sold at 112 per ton. I have given the proportions of Mr. Warnes's compound, which is similar, in (1264).

(2196.) Oil-cake. independently as an article of food, is an excellent medicine for live-stock. preventing constipation in the bowels and giving to the bide a siceetness of cont anattainable by other means. Mr. Wilson of Edington Mains, in Berwickshire, tells me that ever since he bas given oil-cake to his calves after being weaned. they have not been affected with that fatal complaint the quarter-ill, already described in the latter part of (2001), and he has experienced this beneficial effect for 6 years without any external application of setons. By administering oil-cake to my cows after calving. I certainly prevented their being affected with red-water (1699).

(2197.) Hemp (Cannabis sativa) is in the class and order Diocia Pentandria of the Linnæan Bystem, and of the natural order Uricacec, or nettle tribe. Being a diocious plant-that is, having the sexes in different plants it is necessary to have a mixture of both sexes in the same plot of pround, if seed is desired to be raised and collected; though, I presume, for the purpose of raising the fibre merely, that condition is not requisite; but. as apparently similar seed produces plants of different sexes, a mixture of the sexes cannot well be avoided in practice. The male plant is more slender and delicate in appearance than the female, which bears the seed; and, thougb this is the asual distinction of sexes in plants, yet, strange to say that, in speaking of the hemp-plant, most writers denominate the plant which bears the seed the male-owing, perhaps, to its more robust appearance, in comparison of the true male, which is, of course, barren of seed. On this misapplication of the sexes, it has been well remarked : "We are the more surprised that botanical writers should fall into the error, or rather copy this blunder from one work into another. for 80 many ages, without correcting a mistake that inverts the order of Nature." $f$

(2198.) The principal use to which hemp is applied is the making of cordage of all kinds, the fibre being both strong and durable. A first-rate man-of-war is said to require 80 tons of rough

\footnotetext{
- Thomson's Organic Chemistry of Vegetables. \$ McCulloch's Dictionary of Commerce, art. Flex.

\& Don's General Dictionary of Botany and Gardening, art. Linum, vol. i.

II Thomson's Organic Chemistry of Vegetables.

$\$$ Phillips's History of Cultivated Vegetables, vol. i.
} (788) 
hemp to supply her with her necessary tackle. Taking 40 stones the imperial acre as a good crop, 4 acres are required, at that rate, to raise 1 ton; so that a man-of war consumes at least one year's produce of 320 acres of hemp for an ontfit of cordage! "By this cordage," says Coles, quaintly, in his Paradise of Plants. " ahips are guided, bells are rung, beds are corded, and rogues kept in awe." Old cordage is converted into paper, and should, therefore. never be destroyed.

(2199.) The Hop (Humulus lupulus), like hemp, stands in the class and order of Linnæus, Diacia Pentandria, and natural order Crticacece. It is not a native of Britain, nor was its use known in this country till the reign of Henry VIII., in 1524,* when it was used in the composi-. tion of malt liquor-thus franking the truth of an old English distich, that

\title{
"Hops, Reformation, Bays, and Beer,
}

Came into England all in one year."

It had not become a favorite with the people for many years after that period; for Walter Blith records, in 1653 , this remarkable popular error. only 200 years ago-and such errors are rife in all ages of the world - that " it is not many years since the famous city of London petitioned the Par. liament of England agaiust two nuisances; and these were, Newcastle coals, in regard of their stench. \&c., and hops, in regard they would spoil the taste of drink, and endanger the people." $\dagger$ It would appear that this public expression of dislike against hops had prevailed in high quarters, for their use was forbidden by act of Parliament in the reign of James I., though the mandate was little attended to; and, by the time of Anne, public opinion had so entirely changed, that hops were considered so superior to all other bitter principle, that brewers were prohibited from using any other, under a peualty of $£ 20$. Hops had not thriven for some time after their introduction inte England; and, even so lately as 1695 , enough was not grown to serve the country, for 510 cwt. were that year imported from Flanders and Holland. For many years part this conntry has been able not only to supply itself, bnt to export hops, and few foreign hops are imported. In 1832 there were 703,153 lbs. exported, and only 11,167 lbs. foreign imported; but even this small importation was not required for home consumption, for in the same year the much greater quantity of $50,113 \mathrm{lbs}$. of foreign were exported. The English hop is accounted the best in the world. Hops may be used medicinally; a bop-pillow will insure sleep to a patient in fever. when all other expedients will prove ineffective. The tender shoots of the hop in spring may be ased as a pleasant, bitter salad.

(2200.) The yellow powder of hops was named lupulin by Dr. Ives, which Messrs. Payen and Chavallier tound, by analysis, to contain the following substances: Volatile oil 2, bitter principle 12.5, resin 52.5, silica 4, and of di-acetate of ammonia, gnm, bi-malate of lime, traces of fatty matter, and some salts, unascertained portions of each. In another analysis, they found it to contain 13 per cent. of the weight of the cones, but, deducting 4 per cent. of foreign matter, there was left 9 per cent. of lupalin. When distilled with water, it gives about 2 per cent. of its weight of colorless volatile oil, to which hops owe their peculiar smell. This oil dissolves in considerable quantity in water, and it seems to contain sulphur.t

\section{REAPING RYE, WHEAT, BARLEy, OATs, BEANS, AND PEASE.}

\author{
"Here, stretched in ranks, the swelled swarths are found \\ Sheares heaped on sheaves here thicken up the ground. \\ With sweeping stroke the mowers strew the lands- \\ The gatherers follow and collect in bands; \\ The rustic monarch of the field descries. \\ With silent glee, the heaps around him rise."
}

POPE'S HOMER.

(2201.) We are now arrived at the most important of all field operations-that for which every other that has hitherto been described has been merely preparatory - the grand result, to attain which the farmer feels the greatest anxiety, and which, when attained, yields him the greatest happiness, because it bestows upon him the fruit of all his labor; but the fruit will be great or small, in proportion-all other things being alike -to the skill and industry he has displayed during the course of the pre. paratory year; for no adage conveys a stronger truth than this, when applied to the farmer, "As he has sown, so shall he reap." If he have dealt with the land in a penurious spirit, laboring with inadequate means, stinting manure, and grudging seed, he will reap a scanty produce, a deceitful crop, and grievous disappointment; but should he have done all that skill, 
industry and liberality could effect, he will assuredly reap a bountiful reward, for the earth is ever grateful of kindness. Not having yet experienced it, you can hardly conceive the difference between these two positions of the farmer; in the latter case, the very rustling of exuberant straw, while the crop is handling, is delightful to his ear, and his heart is made glad when he sees every one bestowing with heartiness the severe labor required in cutting down and carrying in a heavy crop. In the former case, on the contrary, the honeless straw is easily squeezed in the hand of the reaper-the light, scanty-grained heads are almost disregarded by him, and a single cart-load clears a large space of the field. Such a contrast is indeed lamentable, and unfortunately may be made every harvest; but it is true, nevertheless, that the contrast is becoming less striking yearlyfor it is within my own recollection that 9 bolls, or 54 bushels, barley are now as easily raised as 7 bolls, or 42 bushels, were 20 years ago; and should the present spirit of inquiry continue, and lead to still more amended practice, it is certain that the range of comparison between former and present crops will be still more narrowed; and to the furtherance of this there is, besides, this great stimulus to improvement of poor soils, that the effect of amended practice is far more apparent on them than on better soils.*

(2202.) As harvest-work requires a greater number of laborers than usually live on a farm, it is requisite you should hire beforehand a band of reapers on whom you can rely on remaining with you all harvest, and not trust to the chance of a casual supply. No doubt farms in the immediate vicinity of large towns can obtain a great number of reapers daily, who go to their own lodgings in town at night; and the convenience of obtaining a day's work at good wages, within a few miuutes' walk of their own homes, will tempt most of the inbabitants of towns to prefer farms near them; and this being the case, farms so situate may not require a hired band, but depend on the chance of finding reapers from day to day.When harvest-work goes on in a regular manner through the country, this is an easy and simple mode of conducting harvest-work; but should a great proportion of the crop become sooner ripened than was expected, or the weather endanger the safety of the standing crop everywhere, the general demand for hands renders the farmers near towns no better off than those at a distance, for town reapers will then go anywhere for higher wages. The farmers near towns may, no doubt, then give higher wages as well as others; but the excitement of raising wages renders reapers unsettled, and their chief anxiety then is to inquire where the highest wages are to be obtained, not who the possessor is of the nearest farm. In such circumstances, the farmers near towns must put up with the services of the infirm, the young, and those who are burdened with household cares. The safest plan, therefore, for every farmer to follow, is to hire a band of reapers, proportioned to the extent of work to be performed, to remain with him all harvest, and to olitain auxiliary hands, as he wants them, on any hiring-day in the neighloring town.

(2203.) Reaping-scythes being of different forms, and having to be mounted in a peculiar manner, are figured and described hereafter, and the mode of using them I shall soon describe.

[ The same spirit of inquiry is producing like results in some parts of the United States; but there is no sort of industry that experiences as much difficulty in commanding the use of the cap. ital necessary for its advancement-except it be in the New-England States, where facifities exist for the incorporation and loaning out of capital, and where consumers employed in every trade are close alongside the producers, ready to demand and pay for every species of the fruit of agricultural industry, from an onion to an ox.

$(790)$

Ed. Farm. Lib.] 
(2204.) Before proceeding to employ reapers in the field, it is requisite you should know when corn is fit to be cut; for if cut down too soon, or allowed to stand too long, loss of produce will be incurred. It may be laid down, as a general rule, that corn in a healthy state comes to maturity first in the ear, and then in the straw; and when it does not, that is, when the straw becomes matured first at the root, then, of course, the grain suffers premature decay. Whenever a crop is observed to be in the latter state, it need not be allowed to stand longer on the ground, as it can derive no more benefit from the soil, and its grain will won as readily in the stook as on foot; and so, in like manner, whenever the ear is observed to be sufficiently ripe, the crop should be cut down, as the straw will won more rapidly in the stook than standing on the ground. The only matter of doubt, then, in the case is, when the ear is sufficiently ripe. The most ready way of judging of this, in wheat and oats, is the state of the chaff, and of 2 or 3 inches of the top of the straw under the ear; if all these are of a uniform straw-yellow colour, and feel somewhat hard in the ear, in the oat, and absolutely prickly to the hand, in the wheat, when grasped, they are ripe; or the grain itself may be examined, and should it feel firm under pressure between the finger and thumb, it is ready for reaping; or should the neck of the straw yield no juice when twisted round by the finger and thurnb. Barley should be of uniform yellow color in the grain and awns, and the rachis somewhat rigid; for as long as it moves freely by a shake of the hand, the grain is not sufficiently ripe, nor will it be ot uniform color. It is not equally prudent to reap all sorts of grain in the same degree of maturity. When wheat is reaped before it is sufficiently ripe, it is apt to shrink, and have a bluish tint in the sample; and when too ripe, the chaff opens from the grain, which is apt to be thrown out by the least agitation of the air ; and some sorts of white wheat are very subject to be thrown out by the wind, even before reaching the point of maturity. When very ripe, wheat bends down its ear, opening the chaff, and becomes stiff in the neck of the straw, indicating that Nature intends the grain to be shaken out. Red wheat is less liable to be shaken than white; but any kind will shake out when too ripe, provided the plant is in good health, and the grain of good quality; for as to immature grain, it is difficult to make it leave the chaff even when hardened, and the spelt wheat has so tenacious hold of its capsule, that it is difficult to be disengaged from it even by the blows of the flail, fig. 401. It may be supposed that, whenever the ear and the entire straw are of uniform yellow colour, the plant is no more than ripe, and so it is ; but by the time the straw has fully ripened to the root, the ear will be rigidly bent, and ready to cast its seeds with the slightest violence. The same rule may be applied to barley as to wheat, that is, whenever the neck of the straw is ripe, it is time to cut, for when too ripe, the ear bends -itself down, diverging the outward row of awns nearly at right angles with the rachis, and is apt to be snapped off altogether by the wind. In regard to oats, the same rule also applies; but there is much less risk of cutting oats unripe, in comparison to allowing them to stand till perfectly ripe, as they are easily shaken out by the wind,-the chaff standing apart from the grain. When beanstraw turns black, it is fit to cut, and so is pease-straw, when the pease become firm in the pod. In every case it is much safer for the crop to be cut before it is ripe than after it has become too ripe, as I shall show below.

(2205.) With all these preliminaries arranged, and with your mind satisfied that the crops are in a fit state for reaping, proceed with the reapers to the harvest field, and conduct the reaping in the best manner for each 
respective sort of grain. And, in regard to this, I should remark that the harvest-field will not be properly conducted unless a person is appointed to superintend the reapers; for to none of the reapers can such a task be deputed, as his own occupation is sufficient to occupy all his attention. The steward is the person who shnuld undertake this duty, unless you undertake it yourself. It is his duty to mark the time to commence work, and to leave it, and of the hours of meals and of rest; it is his duty to restrain the impetuous, to urge the slow worker, and to keep every one in the best spirit for work; and it is his duty to see the ground neatly cleared of the crop, and the crop itself judiciously handled. The man who fulfills all these duties as they should be during the entire harvest, accomplishes no easy task, either of body or mind. He should not be mounted on horseback, but be on foot, ready to keep everything right; for it should be remembered that a single minute's loss of work of a large band of reapers, causes a great loss in the gross amount of work. The farmer himself, when not superintending, may move about on horseback; but a horse is a troublesome companion to a man who has to move about close to workpeople in a harvest-field.

(2206.) Reaping with the scythe is a nice operation, and requires considerable skill. The scythes should be mounted as figured hereafter, and made fit for work some time before being wanted in the harvest-field. There should be a number of small articles always ready in the field in case of accident, the procuring of which wastes much time, when not at hand. These are, a small hammer for fastening the wedges of scythe-ferules and of rake-handles; bits of old sole-leather for bedding the tines of the scythes upon; pieces of cord for tying anything; small large-headed nails for fixing the stays to the snead of the scythes; a large coarse file for rubbing down the turned-up point of a scythe, when it happens to come against a stone; a sharp knife for cutting bits of leather, and for removing any raggedness upon the rakes or cradles.

(2207.) The various forms of scythes are the cradle-scythe, the straightsneaded scythe, and that with the bent snead, fig. 361, already described; and the greatest favorite among mowers is the cradle-scythe, because it is easiest to wield by the arms, and does not twist the lumbar region of the body so much as the two common scythes; and I may remark that it is this last effect which forms the great objection against the scythes in ordinary use. And yet it is not easy to see why the use of the cradle-scythe, which is borne by the arms alone, in front of the body, and which does not admit of being balanced in one hand like the other scythes, should be less fatiguing to work with; yet there is no doubt of the fact, and on that account more work is done with it.

(2208.) In commencing to cut a field of corn with the scythe, that side should be chosen from which the corn happens to lie, if it be laid, and, if not, then the side from which the wind blows. The scythe makes the lowest and evenest stubble across the ridges, and then also most easily passes over the open-furrows. Other things being favorable, it is best to begin at that side of a field which is on the left hand of the mowers. If all these conveniences cannot be conjoined, as many as can should be taken ad. vantage of. The ground should have been rolled, and all large stones removed in spring, otherwise the scythes will run the risk of being injured in the face by stones, and even by clods.

(2209.) I have already said that reaping with the scythe is best executed by the mowers being in what is called heads, namely, a head of 3 scythesmen, 3 gatherers, 3 bandsters, and 1 man-raker, or of 2 scythesmen, 2 gatherers, 2 bandsters, and 1 woman-raker. On a large farm the (792) 
heads may consist of the former, and on a small one the latter number. The best opening that can be made of a field for scythe-work, is to mow along the ridge by the side of the fence, which is kept on the left hand, from the top to the bottom of the field ; and while one head is doing this, let another mow along the bottom head-ridge, the whole length of the field, and thus open up 2 of its sides. After this, the first head commences mowing at the lowest corner of the standing corn, across 6 ridges, or 30 yards, which is as far as a scythe will cut corn with one sharpening. Suppose all these preliminaries settled, the scythesman who is to take the lead first sharpens his scythe. In sharpening a scythe for cutting corn, the scythe-stone has to be put frequently into requisition, fur unless the edge is kept keen, the mowing will not only be not easy but bad; and unless a scythesman can keep a keen edge on his scythe he will never be a good mower, and will always feel the work fatiguing to him. The sharpening should always be finished with the straik or strickle. The stone need not be used at every landing, the strickle answering that purpose; but whenever the scythe feels like a drag on the arms, the stone should be used. In mowing, it is the duty of the mower to lay the cut corn or swath at right angles to his own line of motion, and the straws parallel to each other, as at $a, a, a$, fig. 414 , and to maintain this essential

Fig 414.

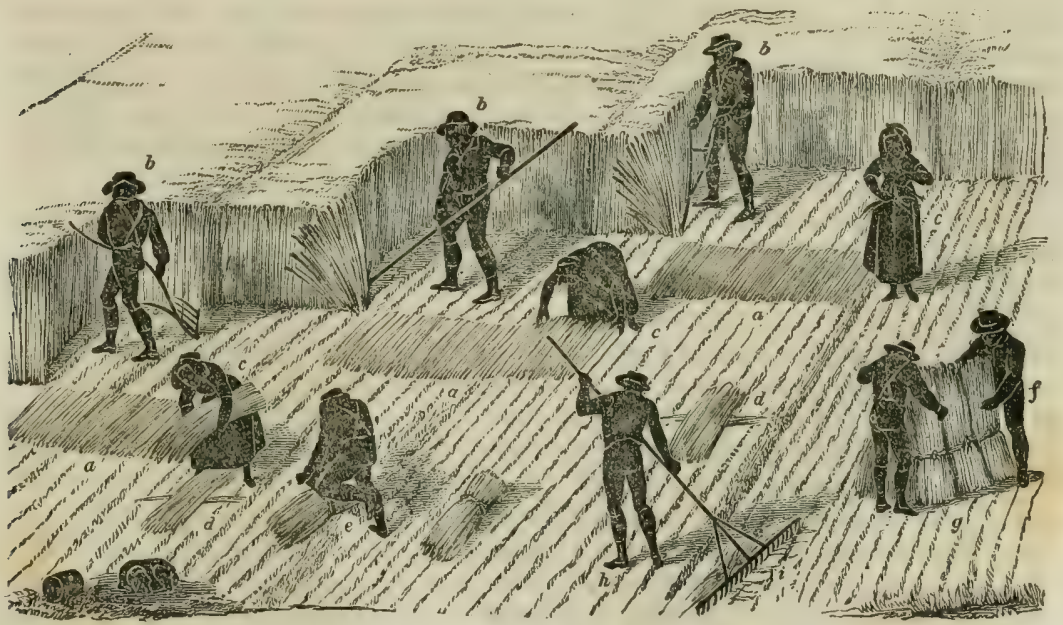

THE MOWING OF CORN WITH THE SCYTHE.

requisite in corn-mowing, he should not swing his arms too far to the right in entering the sweep of his cut, for he will not be able to turn far enough round toward the left, and will necessarily lay the swath short of the right angle; nor should he bring his arms too far round to the left, as he will lay the swath beyond the right angle; and, in either case, the straws will lie in the swath partly above each other, and with uneven ends, to put which even in the sheaf is waste of time. He should proceed straight forward, with a steady motion of arms and limbs, bearing the greatest part of the weight of the body on the right leg, which is kept slightly in advance, as seen at $b, b, b$. The sweep of the scythe will measure about 7 feet in length, and 14 or 15 inches in breadth. The woman-gatherers $c, c, c$, follow by making a band from the swath, and laying as much of the swath in it as will make a suitable sheaf, such as $d, d$. The gatherer (793) 
is required to be an active person, as she will have as much to do as slie can overtake. The bandster $e$ follows her, and binds the sheaves in the manner already described, and any 2 of the 3 bandsters, $f, f$, set the stooks $g$ together, so that a stook is easily made up among them; and in setting them, while crossing the ridges, they should be placed on the same ridge, to give the people who remove them with the cart the least trouble. Last of all comes the raker $h$, who clears the ground between the stooks with his large rake $i$, described below, of all loose straws, and brings them to a bandster, who binds them together by themselves, and sets them in bundles beside the stnoks. This is better than putting the rakings into the heart of a sheaf, where they will not thresh clean with the rest of the corn; and, moreover, as they may contain earth and small stones, and also inferior grain, from straws which may have fallen down before the mowing, it is better to thresh bundles of rakings by themselves. The figure exhibits the 3 kirds of scythes in operation.

(2210.) A scythesman will cut fully more than 1 imperial acre of wheat in a day. Many farmers affect to believe that the scythe is an unsuitable instrument for cutting wheat; but I can assure them, from experience, that it is as suitable as the sickle, and that mown sheaves may be made to look as well as reaped. No doubt mowing wheat is severe work, but so is reaping it. Of oats, 1 scythesman will mow fully 2 acres with ease. The oat crop is remarkably pleasant to handle in every way; its crisp straw is easily cut by the scythe, and being hard and free, and generally not too long, is easily bound in sheaf and set in stook. Nearly 2 acres may be mown of barley; but the gummy matter in the straw, which gives it a malty smell, causes the stone to be frequently used in mowing barley, and the straw being always free, the bands are apt to break when rashly handled in binding the sheaves.

(2211.) One mode of setting up corn to dry quickly is in gaits, that is, the band of the sheaf is tied loosely round the straw, just under the corn, as at $a$, fig. 415 , and the loose sheaf is made to stand upon the lower end of its straw being spread out in a circular form, as $b$ to $c$, and they are set upon every ridge. The wind whistles through the open sheaf, and even the rain passes through, and does not hang upon it. The expedient of gaiting, however, is only practiced in wet weather, and even then only should the crop, if allowed to stand, be endangered by a shaking wind. It is cunfined also to a particular kind of crop, namely, oats-wheat and barley never being gaited, because when wheat gets dry, after being cut in a wet state, it is apt to shake out in binding the gaits; and when barley is subjected to the rough

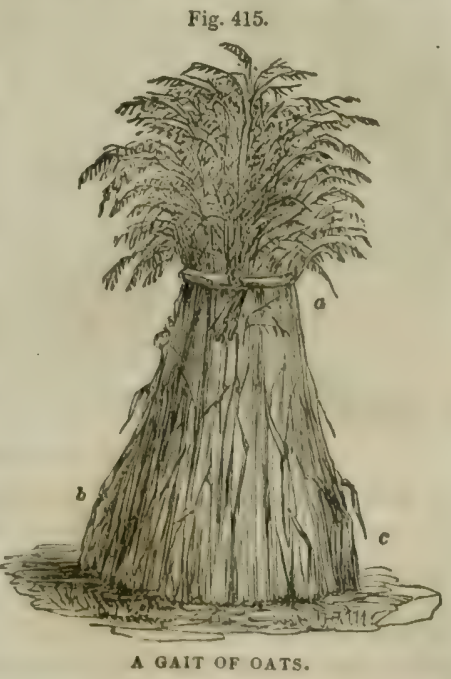
usage of binding, after being won, the heads are apt to snap off altogether, and, besides, exposure in gaits would injure its color, and render it unfit for the maltster. Oats are protected by a thick husk, and the grain is not very apt to shake out in handling, excepting potato-oats, which are seldom gaited, the common kinds only being so treated. But, for my part, I would not hesitate to gait any sort of oats when wet with dew in the morn- 
ing, or even when wetted with rain, rather than lose a few hours' work of reaping every morning, or at nightfall. Gaits, it is true, are very apt to be upset by a high wind; but after having got a set, it is surprising what a breeze they will withstand. After being blown down, however, they set against each other; but whatever trouble the re-setting them should create, they should not be allowed to lie on the ground, and it will be found that a windy day dries them very quickly, and secures their winning.

(2212.) Rye may be reaped or mown in the same manner as the other cereal crops. Its straw, being very tough, may be made into neat slim bands. It usually ripens a good deal earlier than the other grains; and its straw being clean and hard, does not require long exposure in the
field, and on that account the stooks need not be hooded.

(2213.) Beans in drills are reaped only with the sickle, by moving backward, taking the stalks under the left arm, and cutting every stalk through with the point of the sickle. When beans are sowu by themselves strawropes are required for bands; but when mixed with pease, the pea-straw answers the purpose. Beans are always the latest crop in being reaped, sometimes not for weeks after the others have been reaped and carried. In stooking, bean-sheaves are set up in pairs against one another, and the stook may consist of 4 or more sheaves, as is thought most expedient in the circumstances for the winning of the crop, the desire being to have them won as soon as possible, to get the land sown with wheat. Pease are also reaped with the point of the hook, gathered with the left hand, while moving backward, and laid in bundles, not bound in sheaves, until ready to be carried, and are never stooked at all.*

(2214.) It will be observed, from the foregoing statements, that mowing is by much the cheapest mode of cutting down corn, and on that account should be universally adopted; for the item of harvest expenses is a heavy one in the farmer's books, and every legitimate means should be used to lessen it. Any plan that would deprive the inhabitants of a farm of work, I would hesitate to recommend; but when the farmer, as at present situated, is very dependent on the public market of labor to secure his whole year's produce, he is justified in the endeavor to make himself independent in this respect. It is scarcely practicable to render himself entirely independent of the market, without throwing his horses idle for a long time; and, as there is no economy in such a course, the only other left him is to economize on the usual cost of harvest-labor. Now, the scythe offers this advantage, and so efficient is that implement that whoever has tried it fairly, and for a whole harvest, has never relinquished it. I know a prejudice exists against it, on the ground that a mown stook does not look so well as a reaped one, and that is difficult to build a neat stack with mown sheaves. I own there is a roughness in the appearance of mown sheaves, but I can assure every one who has not discovered what I am going to state by his own experience, that that is no detriment to the corn, and the objection disappears as work-people become accustomed to the implement. Such a roughness would not exist were mowers careful to lay the swathes at right angles to their line of motion, and were gatherers to lift the swathes even, and lay them down in armsfull even in the bands; and though it is scarcely possible for work-people to bestow utmost atten-

[* Is there not, in many of the United States, an opening for experiment in an extended cultivation of the bean and pea crops? Indian corn, it is true, profitably supersedes various staple crops much relied on in Europe ; but when we consider the very nourishing quality of beans and peas, we have room for surprise that neither should be even enumerated or alluded to in the decennial return of our agricultural produce.

Ed. Farm. Lib.] 
tion at all times, yet practice makes great proficiency in this matter, which compensates, in a great measure, for want of constant attention. I found this effect produced after employing the same hands at the same work for successive years, and who at length became as neat and clever at their respective works as I could wish them. Besides the actual economy in employing mowers, only conceive the advantage of being able to carry in the corn after it has been exposed in the air to win only half the usual time. Reaped nats require to stand in the stook a fortnight before they will keep in the stack; mown cats, in the same weather, may be carried in a week.* Barley, when reaped, is scarcely fit for leading in less than 3 weeks; when mown, it may be put into the stack in safety in 10 days. And as for mown wheat, ahout 3 days will suffice to win it. It is an error to suppose, as is too commonly imagined, that a mown stook takes in rain: on the contrary, I have frequently ascertained that it takes in rain less than a reaped one. In one instance I remember of a field of potato-oats being finished cutting, that heavy rain fell the next day, and continued without intermission for 3 days, the last of which was very windy, and the wind had changed from E. to W., when it faired. About $\frac{1}{3}$ of this field had been reaped with the sickle, and the reason that implement was used in it all, was to give a little harvest-work at threaving to a few elderly men and women, cotters, and hinds' wives who, having to attend to young children, could not undertake the regular work of a harvest-field. Impressed with the common belief that a mown sheaf must take in rain, I went to the field after the rain had ceased, to ascertain the state the stooks were in, nerer duubting they would be soaked, while the reaped ones would be comparatively dry; but judge of my surprise when the fact was the very opposite, the mown sheaves not being wetted to the heart, while the east side of the reaped sheaves were soaking to the bands. On consideration, 1 accounted for the difference of the phenomena in this way: In reaped sheaves, and especially when cut by threave, the straws are straight and hard pressed, between which the rain finds its way into the heart of the sheaves; while the straws in the mown stooks, being somewhat bent and broken and interlaced on the surface, this texture prevents the rain penetrating, and is rather serviceable in throwing it off. Besides this property, mown sheaves are evidently more pervious to air than reaped.

(2215.) An advantage of another kind obtained in mowing corn should not be overlooked, which is the very short stubble left in the field, and the larger quantity of straw carried to the stack-yard. The following statement may be depended on, as being the result of experiment :

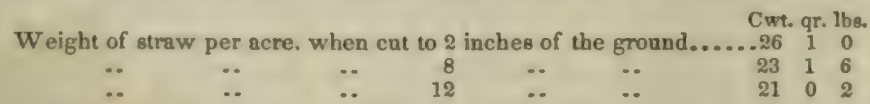

So that $\frac{1}{2}$ cwt. of straw is left per acre on every field by every 1 inch of stubble. When we know that the value of straw is commonly about $28 \mathrm{~s}$. per ton, or $15 \mathrm{~s}$. per load of 36 irusses, we cannot but feel surprised at the barbarous mode of using the wheat-straw in some places of England-in first reaping the ears of corn, and then mowing the straw.

(2216.) It is not easy to state, with sufficient accuracy, the proportion which the straw and grain bear to each other-nor, of course, the ratio realized by the farmer, which must depend on the mode of cutting adopted by him. I have received the following statement of their relative weights in the neighborhood of Edinburgh, from Mr. Andrew Gibson, of

[" Depending, of course, on climate and weather. 
the Dean Farm, whose good farming is well known: From a crop of wheat, of 40 bushels to the acre, or of 2,600 lbs., at 65 lbs. per bushel, the straw will weigh 9 kemples of $440 \mathrm{lbs}$. each, or 3,960 lbs., affording just $\frac{1}{2}$ more weight of straw than of grain. From a crop of barley of 60 bushels, weighing $56 \mathrm{lbs}$. per bushel, or $3,360 \mathrm{lbs}$. per acre, the weight of straw is 7 kemples, or $3,080 \mathrm{lbs}$., being $\frac{1}{10}$ more weight of grain than of straw.From a crop of 60 bushels of oats, at $45 \mathrm{lbs}$. per bushel, or 2,700 lbs. per acre, the weight of straw is $8 \mathrm{kemples,} \mathrm{or} \mathrm{3,520} \mathrm{lbs.,} \mathrm{being} \frac{1}{3}$ more weight of straw than of grain. These are all average quantities. In ordinary crops at a distance from towns, the proportion between the grain and the straw is supposed to be-for, I believe, it has not been satisfactorily ascertained by experiment-the grain $\frac{1}{3}$ and the straw $\frac{2}{3}$ of the entire weight of the crop.*

(2217.) There is another curious inquiry connected with this subjectnamely, the proportionate weight of roots and stubble left in the field after the crop is reaped. In reference to the roots of natural grasses left in the soil acting as manure, Professor Johnston observes that "the same is the case, to a greater or less extent, with all the artificial corn, grass, and leguminous crops we grow. They all leave their roots in the soil; and, if the quantity of organic matter which these roots contain be greater than that which the crop we carry off has derived from the soil, then, instead of exhausting, the growth of this crop will actually enrich the soil, in so far as the presence of organic matter is concerned. No crops, perhaps, the whole produce of which is carried off the field, leave a sufficient mass of roots behind them to effect this end; but many plants, when in whole or in part eaten upon the field, leave enough in the soil materially to improve the condition of the land-while, in all cases, those are considered as the least exhausting to which are naturally attached the largest weight of roots. Hence the main reason why poor lands are so much benefited by being laid down to grass, and why an intermediate crop of clover is often as beneficial to the after-crop of corn as if the land had lain in naked fallow." The remarks here given are not all connected with our present subject, but they show the partial compensation which white crops return to the soil by means of their roots. The Professor then gives the results of some experiments of Hlubek, conducted on a small scale, with a view to ascertain the quantity of roots left in the soil by plants after their parts above ground had been removed; and though the experiments were made with a few of the natural grasses, after they had been made into hay, I shall transcribe them, as the results give the proportion between the roots and stems of gramineous plants.

[* Obvious as is the usefulness of facts thas exactly ascertained, how few farmers in our country have been at the pains to inquire after them for his own government. The relative weight of grain and straw will depend on various circumstances. On the fertile lands of Prince George's and other counties, where the soil is deficient in clay, and yields heavy crops, say from 40 to 60 bushels of Indian corn, you hear them complain that their wheat runs to strav. In such cases the proportion of straw to grain would probably be much larger than is here designated. It is, however, obvious that every farmer should, in the commencement of his career, ascertain these matters for his future government. Every farmer can make a near approach to the quantity of grain he makes on his estate; and having done that he will have the satisfaction to know how much provender he has for his stock, and how much of the fertilizing properties of his land has been carried and sold off in the grain crop, and how much remains to be returned to the land. This relative weight of grain and of fodder needs to be nicely and thoroughly ascertained as to Indian corn.

Ed. Farm. Lib.] 


\begin{tabular}{|c|c|c|c|c|c|}
\hline \multirow[t]{2}{*}{ ENGLISH AND SCIENTIFTC NAME 8 OF GRASSES. } & \multicolumn{2}{|c|}{ Produce in } & \multicolumn{2}{|c|}{$\begin{array}{l}\text { Profure in } \\
\text { Kescis. }\end{array}$} & \multirow{2}{*}{$\begin{array}{l}\text { We chl } \\
\text { of dry } \\
\text { Roozs to } \\
100 \text { ibs. } \\
\text { of } \mathrm{Hay} .\end{array}$} \\
\hline & Grass. & Hay. & Eresh. I & Dry. & \\
\hline Tall fescue-Fesiuca elatior... & $\begin{array}{l}10.8 \\
124\end{array}$ & $\begin{array}{l}16.9 \\
36\end{array}$ & 56 & $\begin{array}{l}1 \text { los } \\
22\end{array}$ & $\begin{array}{r}1 \mathrm{bs}, \\
61\end{array}$ \\
\hline Sheep's fescue-Festuca ovina... & 90 & 30 & .. & 80 & 266 \\
\hline Timothy-Phleum pratense...... & 90 & 25 & 56 & 17 & 60 \\
\hline Rough cock's foot-Dactylus glomerata........... & 202 & 67 & .. & $22 \frac{1}{2}$ & 33 \\
\hline Perennial rye.grass Lolium perenne.............. & 50 & 17 & .. & $50^{2}$ & 300 \\
\hline Meadow fox-tail-Alopecurus pratensis..................... & 106 & 35 & -. & 24 & 70 \\
\hline 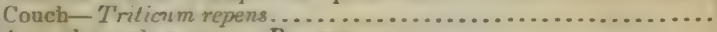 & 120 & 60 & .. & 70 & 116 \\
\hline 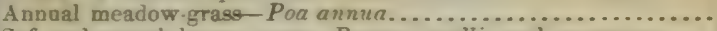 & $\cdots$ & $\cdots$ & .. & .. & 111 \\
\hline Soft and smooth brome-graso-Bromus mollis and racemosus.... & $\ldots$ & $\ldots$ & .. & $\ldots$ & 105 \\
\hline Sweet-scented vernal-grass-Anthoxanthum odoratum.... & $\cdots$ & .. & $\cdots$ & .. & 93 \\
\hline
\end{tabular}

"The fourth column of the above Table," observes Professor Johnston, "shows how large a quantity of vegetable matter some of the grasses impart to the soil, and yet how unlike the different grasses are in this respect. The sheep's fescue and perennial rye-grass-besides the dead roots which detach themselves from time to time-leave at the end of the fourth year a weight of lixing roots in the soil, which is equal to 3 times the produce of that year in hay. If we take the mean of all the above grasses as an average of what we may fairly expect in a grass-field, then the amount of living roots left in the soil when a 4-year old grass-field is plowed up, will be equal to $\frac{1}{6}$ more than the weight of that year's crop." The mean of the Tahle gives a weight of $121 \mathrm{lhs}$. for every $100 \mathrm{lbs}$. of crop; and if we take this as a rule for estimating the weight of roots left in the ground by the cereal crops mentioned above in reference to their weight of straw, and if we take their respective weights of grain and straw as given above, the following will be the entire weights grown of those crops:

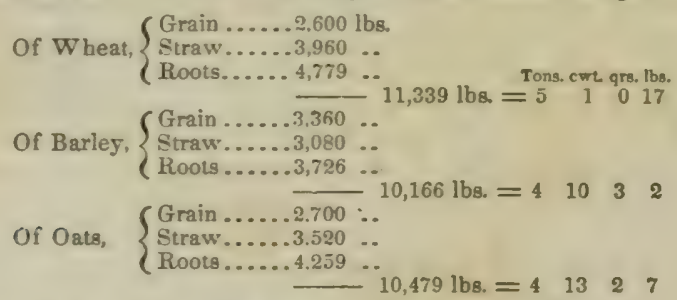

(2218.) Although it is perfectly true what Professor Johnston says in his concluding remarks on this head, that "this burying of recent vegetable matter in the soil, in the form of living and dead roots of plants, is one of those important ameliorating operations of Nature which is always, to some extent, going on where vegetation proceeds : it is one by which the practical man is often benefited unawares, and of which-too often without understanding the source whence the advantage comes-he systematically avails himself in some of the most skillful steps he takes with a view to the improvement of his land,"* it is, nevertheless, of greater benefit to the farmer to cut his crops as near the surface of the ground as possible, thereby putting it in his own power to return the straw to the soil in a state of manure best suited to the wants of the crop, than to cut the stubble high, merely because the soil will derive benefit from it, as an organic substance, when it happens to become decomposed in the soil.

12219.) That one period of their age is better than another for reaping grain crops, has been proved by very careful experiments made by Mr. John Hannam, North Deighton, Yorkshire.Without entering into the details of these experiments, it will be sufficient to give only their results. Of wheat reaped at various times, the following were the advantages and disadvantages derived:

- Jobnston's Lectures on Agricultural Chemistry and Geology.

(798) 
No. 1, reaped quite green on 12th August, and stacked 26th Angust, gave a return of $£ 11178$. per acre.

No. 2, reaped green on 19th August, and stacked 31st August, gave a retarn of f13 6s. per

No. 3, reaped raw on 26th Angust, and stacked 5th September, gave a return of $£ 1418$ s. per acre.

No. 4, reaped not quite so ravo on 30 th Aagust, and stacked 9th September, gave a return of $£ 14$ 17s. 4d. per acre.

No. 5, reaped ripe on 9th September, and stacked 16th September, gave a return of $£ 1311 \mathrm{~s}$. 8d. per acre.

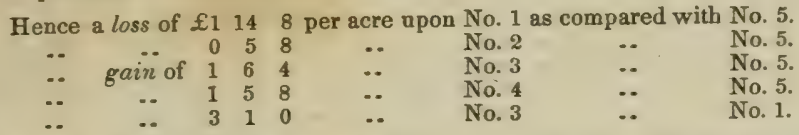

Hence, also, wheat reaped a fortnight before it is npe gives an advantage on every point, viz:

In weight of gross produce, of......................13 1-5 per cent.

.. equal measures, nearly...................

.. equal number of grains, nearly.............. $2_{2}^{\frac{1}{2}} \quad \ldots$

In quality and value, above.................................

Besides these. other advantages are, straw of better quality, a better chance of securing the crop, and a saving in securing it. On the other hand, wheat, reaped a month before it is ripe, gives an advantage of 22 per cent. in weight of straw compared with the ripe. but suffers disadvantage in every other point, namely :

In weight of gross produce.....................11 5-13 per cent.

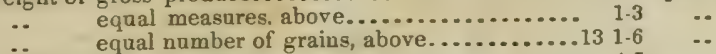

In quality and vajue, above...................... $4-5$

(2220) These may seem trivial advantages and disadvantages, when confined to the area of a single acre; but apply the particulars to the extent of ground under wheat-culture in the king(he truth of the Scottish adage, "mony a little maks a muckle," will be clearly seen; for, as Mr. Hannam observes, "When we consider that there are in England and Scotland about $4,000,000$ acres of wheat grown annually, producing i2,000,000 quarters of grain, of which $\frac{3}{4}$ are allowed to become ripe; when we consider that by cutting this sooner we should produce an increase of 151.7 per cent. of flour, and realize an increased value of $7 \mathrm{~s} .6 \frac{1}{4} \mathrm{~d}$. upon every quarter produced; and that we should produce food for $1,362,857$ persons over and above what we now produce, and an extra annual income of $£ 512,491$ : and when we consider that this increase would be so much added to the wealth of the country, that it is equal to the proceeds, at 3 per cent., of an estate worth $£ 17,083,033$; and that the increase of our population demands an increased supply of food, I would ask, what is our duty in this case?"*

(2221.) Upon one occasion I cut down a few stooks of potato-oats when quite green, though full in the ear, to allow carts to pass to a place destined for the site of a hay-stack; and, after standing till the rest of the field was brought in, they were threshed with the flail by themselves, and the ample they produced was the most beautifully silvery grain I ever saw; but, not having made the experiment with any view to the crop. I pursued the investigation no farther, and cannot say what effect so very early reaping bad produced upon the quantity and quality of meal.

(2222.) [The first and most important operation of the harvest season being the reaping of the crop, I have now to proceed with the description of the machines and implements used in that interesting operation. It is more than probable that, in the dawn of Agriculture, the tiny crop of grain was plucked by the roots from the earth without the aid of any instrument other than that most comprehensive one, the human hand; but the inconveniences attending this mode must have been soon superseded by the adoption of the reaping-hook, or sickle, which is coeval with the most remote history. It is believed that instruments or machines of a more complicated form than the sickle bave been resorted to by some of the nations of antiquity; but of these we have no certain historical information; and when it is considered that, even in modern times, with all our advantages of mechanical knowledge. and the numerous appliances of mechanical experience and skill, we have. as yet, failed in producing a really effective reaping-machine, we are led to the couclusion that nothing of the sort in a perfect form had ever been achieved by the ancients. During the last sixty years, many attempts have been made to produce a perfect reaping-machine. but, with few exceptions, they have proved abortive, and the problem, in its fullest extent, remains yet unsolved; but, nevertheless, several of these attempts have been attended with at lcast partial success-a success which has extended to the reaping of grain when it stands erect, or even slightly inclined, if all in one direction-but have all failed in making satisfactory work when the crop has been lodged by rains, or contorted by winds. The step which has been made in achieving even this much is, however, of importance, and holds out a prospect of the probability that we shall yet see a reaping-machine adapted to the reaping of at least a very large propor. tion of our fields, in the situation in which they are found in general, when ready for the sickle. $\mathrm{But}$ as none of these machines can be considered perfect in their present state, I deem it unnecessary to enter into any minute details of their construction here, and will only give a summary

* See Quarterly Journal of Agriculture, vols. xii. and xiii., for the detailed particulars of Mr. Hannam's interesting experiments.

(799) 
view of their principles, and the leading features of their construction. with a reference to writers whose more detailed information may be obtained by those who desire to prosccute the subject.

(2223.) The first reaping-nachine that cane lefore the public with any claim to efficiency was that of Mr. Smith. of Deanston, about the year 1814-15. when it was tried before a joint-committee of the Highland and Agricultural Society, and of the Dalkeith Farming Society, the latter having previously offered a premium of $£ 500$ for a perfect reaping-machine." On that trial, the machine operated with very considerable effect; but though much approved of, in a general view, was not considered so complete as to warrant the committee to award the premium. Mr. Smith's machine continued for a number of years to be the only one at all effective; but, as it did not possess all the requisite qualities for perfect reaping, it did not come into actual use beyond a very limited extent. The cutting principle in Smith's original machine is beautifully simple, being a plain, smoothedged, annular knife, of about 6 feet diameter, and 6 inches broad, attached by arms to an axle. with which it revolves with a velocity that makes one revolution for every 2 that the machine travels over the ground. The cutter was surmounted by a light sheet-iron drum, or rather frustum, of an inverted cone, about 3 feet in hight, which serves as the collector or gatherer of the machine; and this was attached to, and revolved along with, the cutter and its axle. The motion of the culter and gatherer was derived from a pair of carriage-wheels fixed upon an axle, which carries $₫$ toothed bevel-wheel, and from this last by a piuion and horizontal shaft, ard aecond pair of bevel-wheels, the last of which was fixed upon, and gave motion to, the cutter-shaft. The carriage-wheels, with their axle, bore all the framework and gearing of the machine, with a slight preponderance forward; and this preponderance was borne by a small roller, placed under the fore-part of the framework, near the center of the cutter, serving to preserve the uniform hight of the cutter from the ground-a pole projected backward from the body of the machine, to which two horses were yoked, one on each side, by a splinter bar, pushing the machine before them; and, as the pole projected a few feet behind the horses, it served as a rudder to the machine in the hands of the driver. The circular catter here adopted is, perhaps, the most perfect method of performing the act of cutting the grain, which is doue by it in a very successfal manner-the machine being provided with apparatus for cutting higher or lower, as the crop may require.The gathering process is less perfect-the cat grain is carried round by the motion of the dram to the left side, where, as soon as it is clear of the standing corn in front, it falls outward, forming a continuous swath at one side of the track over which the machine has passed.

(2224.) At a subsequent period. Mr. Smith effected various improvements on his reaping-ma. chine; and in 1837 it was exhibited in operation at Ayr, before a committee of the Highland and A gricultural Society, where it performed to the satisfaction of all present, both in cutting and gatbering; but, at the same time, it showed marks of unwieldiness, especially from its great length, which is about 20 feet, that still rendered its general application doubtful. The chief point of its improve nent. at this trial, lay in the gathering-drum being now adapted to revolve separate from the cutter, with a velocity at its periphery equal to the progressive velocity of the machine: and in the dram also being armed with rakes, or wooden teeth inserted all over its circumference, which supported and carried the cut grain round to the proper point of discharge.

(2225.) The next machine of importance, in the order of time, is that of Rev. Patrick Bell, now minister of the parish of Carmylie, in the county of Forfar. It appeared in operation in $1827-8$, and received the sanction of the Highland and Agricultural Society in 1829 , by a premium of $£ 50 .+$ For several years thereafter this machine retained considerable repute, and a considerable number of them were made. and successfully applied in the counties of Fife and Angus, but after all this apparent success, it has also fallen into disuse, like its predecessor. Mr. Bell's machine acts upon the clipping principle, the cutter being a series of scissors, the upper blades of which are immovable. and of the form of isoceles triangles, whose hights are 10 inches, and bases about 4 inches, adapted to cut on both edges. The lower blades are of a similar form, each jointed upon a pin, in a position corresponding to the space between the upper blades, and their Bhank or handles are all jointed to a traversing bar, put in motion by a crank; there are teu pairs of such scissors, and by the above arrangement, the whole are made to cut simultaneously rigbt or left. The motion of the cutter is communicated from the carriage-wheels, as in Smith's machine, there being two principal wheels for that purpose, and two minor wheels to bear up the cutters and fore part of the machine. The gathering process is accomplished by an endless web, which is placed above and behind the cutter, revolving either to rigbt or left; it receives the grain as it falls from the cutter. and is regularly carried to one side, and dropped in a continuous swatb. as before. To insure the falling of the cut grain upon the web, there is a light four-leaved vane placed in front of the machine, and is made to revolve by means of a band; the leaves of this vane jress gently apon the yet uncut grain, gathering it toward the web, until it is severed below by the scissors, when the web carries it off. For several years this machine bid fair to become 8 favorite; the work was well performed wherever the corn stood apright, and that it would work amoug laid corn was not expected of it ; yet it is now seldom seen in the field, and the only cause to which its failure can be attributed, is the complicated structure of the cutter. A cutter con. sisting of such a number of parts, each of which requires the most perfect adjustment to reuder it effective, being, besides, liable to unequal wear, renders it yet more liable to derangement ; and, farther, as the derangement of a single blade of the cutter is sufficient to destroy the usefulness of the machine: and the rectification of the defective blade requiring a workman of superior talent, it nust have become both troublesome and expensive to effect such repairs; and this. added to the risks of delay in an important season, seem to bave contributed to the gradual disuse of the machine.

(2226.) Soon after the introduction of Mr. Bell's reaping-machine, there appeared another competitor, Mr. Joseph Mann, Raby; near Wigton, Cumberland. Mr. Mann's machine appears to have beeu constructed, after many years' labor, so early as 1826, but it was not exhibited in Scot.

* Prize Fssays of the Highland and Agricultural Society. vol. x. Preliminary Notice.

† Quarterly Journal of Agriculture, vol. i. † Ibid., vol. iv. $(800)$ 
land till 1832, at the Highland Society's Show in Kelso, where it was tried before a Comamittee with a success very similar to those that had gone before it. Though not affording entire satisfaction, it nevertheless possessed some points of considerable importance. In construction it was more compact than some of the previous machines; and, from the simplicity of its movements, mole compact than some. It was drawn by one horse, walking before the machine, and by the would the standing corn, cutting a breadth of from $3 \frac{1}{2}$ to 4 feet, and would, therefore, cut nearly side of the stang hours. The cutter was on the revolving principle. but instead of being circular, it formed a polygon of 12 sides, each side of the polygon being a separate blade, easily removed and changed. The gatherer was the revolving cylindrical drum with rakes, afterward adopted by Mr. Smitb, of Deanston, belore alluded to; but in Mr. Mann's machine the drum revolves at a considerably higher velocity, making 26 revolutions in a minute, while the cutter makes about 200. In this machine, therefore, the velocity of the rake-teeth is 400 feet per minute, or nearly double that in Mr. Smith's improved form. 'This high velocity of the rake carries away the cut grain in a rakes, but it requires the application of a comb to strip the corn trom the rakes, and thus secures its being always dropped at one point in the machine. The motrom the rakes, and rake were obtained from one of the carriage-wheels as in the others; but here they were communicated by pitch-chains, and the front part of the machine was supported by a castor-wheel, to the stem of which the horse-shafts were attached, the castor-wheel running by the side of the standing corn. I am not aware of this machine having ever made farther progress; though I do consider that it possesses some artvantages over any that have yet been tried, and, if fully matured, might bave superseded its competitors.

(2227.) In viewing the subject of the reaping-machine, three things have to be specially considered. The expense of the machine, the expedition it may effect in reaping the erop, and the saving in expense that may be effected by it. The last described machine could certainly be procured at a price not exceeding $£ 30$. The same machine was, perhaps, not capable of reaping an acre per hour consecutively; its effect may, therefore. be restricted to 8 acres per day, being 列 might be requisite, making an outlay of $£ 60$. To qualify this outlay, the expense of reaping (as ascertained, by Bell's machine,) has been estimated, including the expense of binding up the sheaves, at 3s. per acre; while the minimum expense of reaping by the hand is taken at $7 \mathrm{~s}$. per acre, and the maximum may run to $12 \mathrm{s.},{ }^{*}$ but taking the mean at $9 \mathrm{~s}$. , gives three times the expense of machine-reaping. For 100 acres, therefore, cnt by hand, the expense would be $£ 45$, while that by the machine is only $£ 15$, giving a saving of the entire price of the machine in one year. But suppose the price of a machine could be saved even in two years, the advantages would be very great, under the supposition that an effective machine could be procured for $£ 30$. It is deserving of consideration, also, that although no reaping machine is to be expected capable of cutting down the crops in every possible state, yet we may infer that, even on a farm of ordinary extent, such a breadth of crop may be found, in almost any season, capable of heing cat by a machine, as would save half the expense of its purchase. To obtain an effective and durable reaping-machine is, therefore, yet an important object to the farming interest. ${ }^{\prime}$

(2228.) In the present times, it may be safely averred that the only means of reaping is by the sickle and the scythe. The first is a very simple, but, at the same time, so far as it goes, a very efficient instrument. It is employed in various states, not differing much in general form, though exhibiting marked differences in the detail ; but these varieties are confined under two very distinct forms, the toothed and the smooth-edged sickles. Fig. 416 represents the toothed sickle, an instrument so well known that it re quires little description here. The blade, in the common toothed sickle, is principally made of iron, but with an edging of steel; the teeth are formed by striking with a chisel and hammer, in the manner of file-cutting, the cutting being only on the lower side; but when the blade has been bent to the proper form, tempered, and ground on the smooth side, the serratures are brought prominently out on the edge of the blade; and as the striking of the teeth is performed in a position ublique to the edge of the blade, at an angle of about $70^{\circ}$, the serratures on the edge acquire what is called a hook toward the helve, thus causing the instrument to cut keenly in that direction when drawn through the standing corn. When the blade has been thus finished, a wooden helve of the simplest form is fitted upon the pointed tine formed at its root for that purpose. The toothed sickle is made with various degrees of curvature and of weight, but chiefly as represented in the figure, and it has been the subject of several patents, chiefly depending on the formation

Fig. 416 .

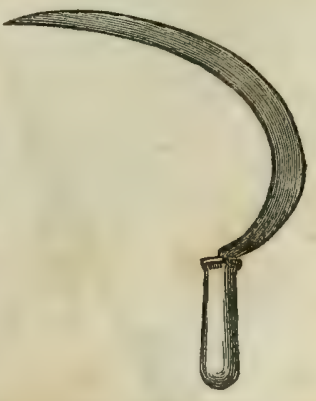

THE TOOTHED SICKLE. the blade. One of these is only of two or three years' standing, and promises to be an important one. Messrs. Sorby \& Son, of Sheffield, are the patentees; and the principle n pon which portant one. Messrs. Sor blade of rolled cast-steel swedged into a form that gives a sufficient de. gree of stiffness to the blade, without the increase of weight that accompanies the thick-backed or the other patent ribbed-back sickles. In the new patent, the advantage of a small quantity of the very best material-cast-steel-is combined with extreme lightness and a due degree of strength and stiffness, the latter arising from the swedged or moulded back.

(2229.) The smooth-edged sickle, or scythe-hook, as sometimes called, differs from the former

If For practical remarks on the two most promising machines in use in the United States, see the letter from Mr. Bowling, of Virginia, in the present (March) Number of the Monthly Journal of Agriculture.

Ed. Farm. Lib.]

* Quarteriy Journal of Agriculture, vol. iv. 
in being broader in the blade, and longer withal, but in curvature it resembles the former ; and its chief difference lies in being ground on both sides, to form a fine and thin sharp edge. Like the toothed sickle, the blade has undergone various improvements; and Mr. Sorby's cast-steel swedge-blade is also extended to the smooth-edged sickle.

(2230.) In the formation of the sickle, the curvature of the blade is a point of more importance than to a careless observer may appear; and though the ordinary reaper is seldom qualified to judge in this matter, he may feel pleased to be informed that there is a certain curvature that will give to the muscles of his right arm the lenst possible cause for exertion. while there are other curves that, if given to the blade of the sickle, would canse him to expend a great amount of un necessary exertion in the arm, and a consequent unnecessary fatigue would follow. Fig. 417 which represents the smooth-edged sickle. has a curvature approaching very near to that which, in this instrument, may be termed the curve of least exertion; and throughout that portion of the sickle that performs the cutting process, it possegses this peculiar property, from the following circumstance, that lines diverging from the center of the lrandle of the sickle at $a$, and intersecting the curve of the cutting-edge, all the diverging lines will form equal angles with the tangents to the curve at the points of intersection. This property gives to the cutting-edge a uniform tendency to eut at every point in its length, without any other exertion than a direct pull upon the helve; were the curvature less at any point, a pressure of the liand would be required to keep the edge to the work, and were the curvature greater at any point, or on the whole, the exertion to make the cut would be grenter, as it would then become more direct, instend of the oblique drawing or sawing cut, which, in all cases, is the most effective, and productive of least resistance.

(2231.) A mode of using the smooth-edged sickle bas of late years come into some repute, known in Scotland by the provincial term dinging-in (striking-in). In this process the sickle is not drawn through the straw, but is struck against it, somewhat in the manner of using a scythe; indeed, the practice originated
in the attempt that was made some years ago to introduce the

Fig. 417.

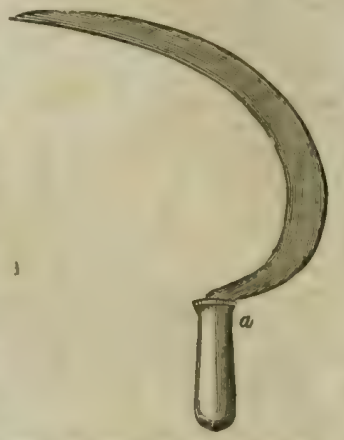

THE SMOOTH-EDGED SICKLE. Hainault scythe in the harvest operations of this country, but without success. In the (dingingin) practice, the left hand is employed, with its back toward the right, in slightly bending down the grain, and holding it to the blow of the sickle. A man practiced in this mode of working will do one-half more work than is usually done in the common way; but the etubble is left less rescular, and, except by very expert hands, there is a want of tidiness in the process.

(2232.) The scythe is also extensively used as a reaping instrument, but more especially in Eng. land, and in some of the northern counties of Scotiand, chiefly for the barley and oat crops, though in some localities, also, for wheat. The common hay-scythe is used for this purpose, in most cases, with the addition only of a very light rail or cradle, sometimes attached to the handle, and in other cases to the heel of the blade, as in the annexed cat, fig. 418 , which is the common

Fig. 418.

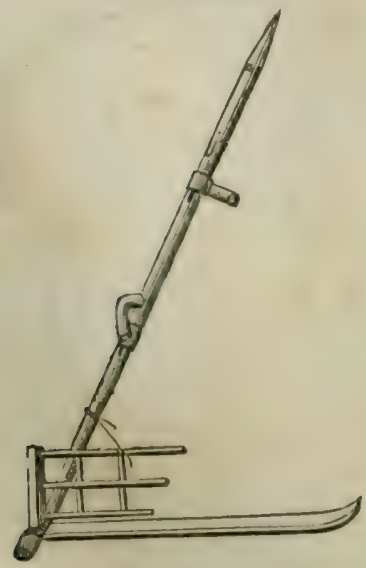

THE COMMON REAPING-SCYTHE.
Fig. 419.

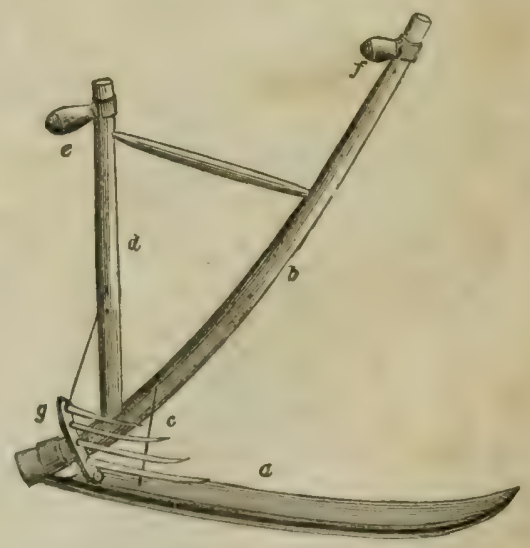

THE CRADLE-SCYTHE FOR REAPING.

scythe, fitted for reaping. In the scythe mounted in this manner, the use of the rail or cradle will be obvious, being the collecting of the swath into a compact body, and depositing the same in as regular a manner as possible, preparatory to the binding of it into a sheaf.

(2233.) For a considerable period, a scythe mounted in a different form has been in ase for the purpose of reaping, and it is believed that its introduction can be traced to Bauffshire or Aber- 
deenshire, where the scythe is rather extensively used for reaping. About ten years ago this form of scythe came more prominently before the public, ${ }^{*}$ and, for a time, gained considerable repute under the name of the Cradle-scythe. Of this form of mounting a reaping-scythe, there are many varieties; but they all agree in one point. that of having two short helves, the one branching out of the other, instead of the common long helve or snead. Fig. 419 is a view of the cradle-scythe in one of its most approved forms, wherein $a$ is the scythe-blade, $b$ the principal helve, to which the blade is attached in the usual way, the hook of the tine being sunk into the wood, and an iron ferule brought down over the tine, binding it firmly to the wood; but the blade is farther supported by the addition of the light stay $c$, termed by mowers the grass-nail. The minor helve $d$ is tenoned into the former, and the two handles $e f$ are adjusted by wedges in the usual way, to the hight and mode of working of the mower. The cradle or rake consists of a little wooden standard $g$, about 8 inches high, jointed to the heel of the blade, so as to fold a little up or down across the blade ; into this are inserted three slender teeth, following the direction of the blade, and may be from 6 to 15 inches long; the head of the standard is supported by a slender rod of iron, which stretches about 18 inches up the handle, where it is secured by a small screw-nut, capable of being shifted up or down to alter the position of the standard and its teeth to suit the lay of the corn. The standard or rake-head was at one time recommended to be made in the segment of a circle, $\dagger$ for which there seems no good reason, either practical or philosophical ; but the idea was seized upon, and the cradle-scythe mounted in that form was widely distributed; but instead of this supposed improvement tending to increase the favorable opinion of scythe-reaping, the practice seems rather on the decline; and there is gond reason to believe that this malformation of the rake may have bad no small share in producing a distaste for scythe. reaping as a practice; whereas, under proper management, and a judicious choice of implements, there can be no doubt of considerable advantages being attainable from scythe-reaping, as compared with the sickle.

(2234.) It is believed by very competent judges, that the figure here given of the cradle-scythe possesses all the advantages that are derivable from using this instrument; and, in addition to the detailsalready given, $I$ may add that the length of the blade is from 3 feet 4 inches to 3 feet 6 inches; the left or principal helve is about 4 feet, the other 3 feet, measuring direct from the heel in both cases; the distance between the helves, where the handles are applied. is 24 inches; and in setting the blade the following rule is to be observed: When the framed helves are laid flat on a level surface, the point of the blade should be from 18 to 20 inches above that surface, and measuring from a point on the left helve, 3 feet distant from the heel of the blade in a straight line, as at $b$, the extremity of the blade should be also 3 feet distant from the point $b$. Iron has, in many cases, been substituted for wood in the construction of the helves; but it does not, by any means, appear to be so well adapted to the purpose as the wooden helves; when constructed of iron, if they are made sufficiently light, there is too much elasticity in the fabric, which is fatiguing to the workman, by reason of the tremor produced at every stroke of the scythe.

(2235.) As essential appendages of the scythe,there must be kept in view the scythe-stone, with which it is kept in proper cutting order: a soft, fine-grained sandstone is the proper material from which it should be selected; and as for applying it. it were difficult in words to describe the proper mode of doing so, but the following may suffice to give the uninitiated some notion of the process. The scythe is placed on the left side of the mower, with the point of the blade resting on a small stone on the ground, the heel of the blade and helve being supported by the left hand; the scythe-stone, which is about 10 inches long, is grasped by one end in the right hand, and is thus applied, crossing the blade. The effect of the sharpening is produced by making sliding strokes with the stone along the blade on each side altemately, upward and downward; but the down. ward strokes only, or those toward the point of the blade, should be the effective ones, the returning stroke of the stone touching the blade but lightly. The object of this mode of treatment is based on the principle that the scythe cuts after the manner of a saw; though the teeth are not very prominent, still the fine serrature is there; and, to make it cut with the best effect, it must be hooked toward the point of the blade, or in the direction of its motion, when cutting; and the application of the stone, as above described, produces this direction of the minute teeth in the cutting. edge. The strokes of the stone cannot conveniently be carried over the whole length of the blade at one throw of the hand, hence the sharpening begins at the heel, and proceeds downward; but, from the position described, there still remain a few inches at the point untouched; and, to reach this part with the stone, the mower lifts up the blade, by seizing it about the middle with the left hand, and bringing it to a horizontal position-the helve still resting partly on the ground. and partly against his body, he is enabled to complete the process of sharpening. Throughout this operation, it is to be specially observed that, in applying the stone, it must always be held flat upon both sides of the blade; if this is not attended to, either the edge will not be improved, or it will be rounded off. and the consequence of this last effect will be that the scythe will speedily be unfit for cutting until it be re-ground.

(2236.) The strike or strickle, which is also used in the sharpening of the scythe, principally for giving it a finer edge-though this is very frequently a mistaken notion-is formed of a piece of hard wood, about 15 inches long, one end of which is shaped into a handle; the body of it is sometimes $1 \frac{1}{2}$ inches square, but in most cases it is about 2 inches broad, by $\frac{3}{4}$ inch thick. It is coated over with granulated emery, imbedded in a cement such as glue; and, to produce the best effects, the emery should be of a medium degree of fineness. The strickle being a light instrunent, it is always attached to the helve of the scythe, and is, therefore, always at hand, ready to be applied in the event of any accidental injury to the edge of the scythe being sustained; while the stone, from its greater weight, can only be resorted to at the landings, where it lies in readiness.

(2237.) The hand stubble-rake. - The gleanings of the stubble is an object of considerable value, and, to secure it for the benefit of the farmer, different implements are employed. 
The principal and the most effective of them is the horse-rake; but in the absence of that machine, the hand-rake is found to serve a very good porpose. Fig. 420 is a representation of this rake, and it is of very aimple conatruction, the form being precisely that of the hay-rake, but of enlarged dimensions. The head, $a b$. is 5 feet long, and should be made of good, tough ash, $2 \frac{1}{2}$ by 2 inches; the helve $c d$ may be 6 feet in hight, of the same material, and furnished with a handle $e$ that can be fixed in any desired position, by means of a ferule and wedge. The helve is tenoned into the head, and supported by the iron brace $f, c, g$. The teeth are of iron, 7 inches in length, and set at 4 inches apart, but formed in the lower part so that the bend rests on the ground, preventing the points of the teeth penetrating and mixing the earth with the gleanings. The best method of fixing the teeth is by a screw-nut, as in the horse.rake, as they are

thereby easily removed in the case of being broken, without risk of injuring the bead. It is also advisable to have the ends of the head hooped, to prevent splitting.-J.S.]

\title{
35. CARRYING IN AND STACKING WHEAT, BARLEY, OATS, BEANS, AND PEASE; AND THE CONSTRUCTION OF CARTS.
}

\author{
"Inwardly smiling, the proud farmer views \\ The rising pyramids that grace bis yard, \\ And counts his large increase; his barns are stored, \\ And groaning staddles bend beneath their load." \\ SOMERVILIR.
}

(2238.) It is necessary that reaped corn remain for some time in stook in the field, before it will keep in large quantities in the stack or barn.The length of time will, of course, depend entirely on the state of the weather; for if the air is dry, sharp, and windy, the corn will be ready in the shortest time-while in close, misty damp, it will require the longest time; but, on an average, for wheat 1 week, and for barley and oats 2 weeks, will suffice. In this respect, the superiority of the mown over reaped corn manifests itself-mown wheat being ready for the stack in 4 or 5 days, and barley and oats in 8 or 10-the chief cause of the difference being the loose and open state in which mowing leaves the straw in the sheaf.

(2239.) Mere dryness to the feel does not constitute all the qualities requisite for making new cut corn keep in the stack. The natural sap of the plant must not only be evaporated from its outside, but also from its interior; and the outside may feel quite dry, while the interior may be far from it; and the knowledge of the latter property constitutes the whole difficulty of judging whether or not corn will keep in the stack. There is one criterion by which whether or not a sheaf is fit to keep may be ascertained with almost certain success, which is, that if the sheaf feel quite dry, the straws be loose and easily yield to the fingers, and the entire sheaf feel light when lifted off the ground by the hand thrust through the middle of the band, the sheaf is ready; for if it present all these qualities at the band, where it is most compressed, the rest will be sure to be won. While win(804) 
ning, it is as probable that the sap of the cereal grains is converted into woody fibre, as that of clover on being converted into hay (2139).

(2240.) The winning of corn is comparatively an easy matter, when the weather is dry; but, in windy and showery weather, the stooks are apt to be blown down and become wet, and incur the trouble of setting up again at the first moment of calm. When the air is calm, dull, damp and warm, every species of grain is apt to sprout in the stook before being ready for the stack. When much rain falls, accompanied with cold, the grain becomes sooner ready than the straw for the stack; and, to win the straw, the bands are not unfrequently obliged to be loosened, and the sheaf spread out to dry in the wind and sun; and in like manner the sheaf should be spread out, even in dry weather, when a large proportion of young grass is mixed among barley-straw. When barley is mown, it is quite practicable to get rid of much of the grass among it, by the gatherers shaking the grass out of the swathes by the corn end, before laying the corn into the bands. This extra process of shaking will, no doubt, lose some time, but. it is probably better to lose a little time in the mowing than subject the corn to perhaps a week longer exposure in the field. It is scarcely practicable to shake out grass in reaping, as the hook would require to be laid aside while both the hands were engaged in shaking every handful; and to cut the stubble as high as the grass would be preposterous. An extra hand, therefore, would be required for this purpose among reapers on every 2 ridges. Corn wins in no way so quickly as in gaits, fig. 415 .

(2211.) While the first reaped corn is winning in the field, the stackyard should be put in order to receive the new crop, by removing everyments, \&c.; but no such use as the latter should ever be allowed of a stack-
mented yard, as implements should be put into their proper places when their respective season for use expires. W'here stathels are used, it should be seen that they are in repair; dry straw should be at hand to form the bottoms of new stacks, where stathels are not used; and, even where they are in partial use, straw is required for the stacks built on the ground, as stathels can only be placed round the utmost limits of a stack-yard, unless an inordinate space of ground is appropriated to it, with a cart-road between every 2 rows of stathels, as already commented on at (70). Straw-ropes should also be provided for covering the barley-stacks, in case of threatened rain.

(224.2.) The description of a stathel or staddle is given in (70), and a perspective view in fig. 24 , which is a framing of wood put together, to remain in a permanent form upon stone props, made up of 3 parts-a sole $b$, a pillar $c$, and bonnet $d$. It has been brought to my notice that a better form of stathel would be to have the frame in 2 pieces, to remove into a shed, and be protected from the weather, when not in use. Such a movable frame would answer the purpose as well as a permanent one; but, when removed, the props should require to be removed also, otherwise they will be driven over, and perhaps broken, or at all events disjointed, and their replacement would create a good deal of trouble when wanted; and this is a species of trouble, perhaps, more serious than the decay of the wood of a fiame 1 year or 2 sooner than it would otherwise be. True, the props could be made of one piece of cast-iron, which they sometimes are; and, where stones are scarce, this material seems indispensable; but, where stones are plenty, they make cheaper props than cast-iron; and, although cast-iron ones would be easily removed, the soles on which they rest would still be liable to be broken, and the setting them again on a level would impose considerable trouble and expense. So that, on the (805) 
whole, such a stathel as is shown in fig. 24 will, in my opinion, answer well for ordinary farms. The framing is made heavy, the scantlings being 9 inches in the side-a size which the Scots fir easily attains, because it is to be permanent in its position, and to last a long time, remaining serviceable for a lease of 20 years; but, of course, where larch is abundant, smaller scantlings will be handier, equally strong, and last perhaps longer. Stathels require no straw to render them fit for building stacks upon.

(2243.) A stool of straw for a stack is made in this way: Stick a fork $a$, fig. 421 , upright in the ground in the center of the intended site of the

Fig. 421.

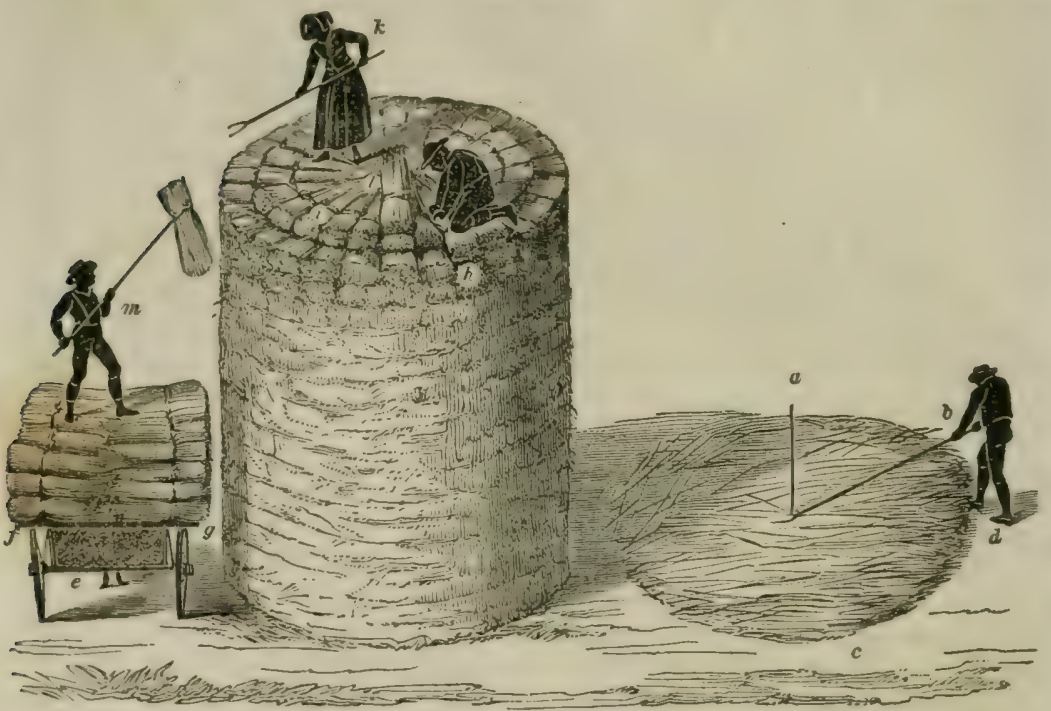

THE FORMING OF A STOOL FOR A STACK; THE LOADING OF A CART WITH SHEAVES; $\triangle N D$ THE BUILDING CF A STACK.

stack. Put a quantity of dry straw around the fork, and shake it up as you would do the litter of a horse, spreading it out to about the size and form the stack should occupy on the ground. Take a long fork $b$, with the radius of the stack marked upon its shaft-embrace the upright fork $a$ between its prongs, and, holding its shaft at the specified distance of the radius, push in or pull out the straw with your feet, as seen from $c$ to $d$, into the shape of the circle described by yourself in walking round the circum. ference of the stool.

(2244.) Having made these preparations, on the supposition that the corn is ready to be carried in and stacked, the first thing is to provide an efficient person to fork the corn in the field to the carts - a man being the best for the work, as he is able not only to wield the sheaves with ease, hut possesses dexterity to place the sheaves in the position most convenient for the plowman to build them on the cart; for, throwing sheaves in any manner upon the cart makes the forking no easier for the forker, while is gives the plowman much additional trouble to turn the sheaves upon the load, where his footing is not very secure. A loss of 2 or 3 minutes incurred in this way in loading each cart makes a considerable loss upon the day's work. The steward should build the stacks, unless he is specially engaged with the reapers in the field, when another man should be hired (806) 
to stack; but on a large farm more than 1 stacker may frequently be required at a time. When more than 1 stacker is employed, each should have the same head of carts leading to him, even when both heads are leading from the same field, that the corn may be regularly supplied to him.

(2245.) The cart is the vehicle employed in carrying in corn. The common cart, mounted with a framing called tops, is used in some parts of the country; while, in others, the corn-cart, different forms of which are represented and described below by Mr. Slight, is employed, the body of which is put on the axle and wheels of the common cart, and provided with ropes to hold on the load. Of the two sorts of carts for this purpose, I prefer the corn-cart, as it carries the load lower to the line of draught; and it is provided with a plank, called the lead-tree, for the plowman to stand upon when forking off the lower part of the load.

(2246.) The horses are usually yoked double in leading time, as there is only one man to each pair of horses; and there may be inequalities in the fields and roads which require the force of 2 horses to surmount. As I have had occasion to mention the price of the harness required for the plow, I may here enumerate those for the cart. In addition to the collar and bridle, there are-

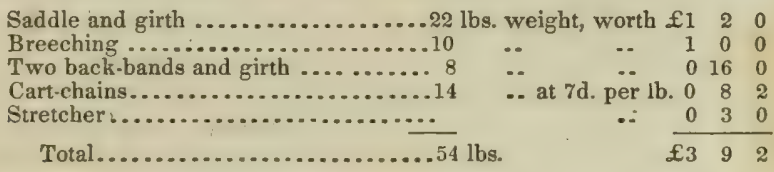

In Forfarshire the trace-horse is harnessed in a different manner. A broad strap is hooked to the back of the upper part of the collar, and terminates at the other end in a crupper, and a haunch-strap passes down in each side to support the trace-chain. This plan supports the stretcher well, and prevents it falling so low as the hocks of the horse in the turnings, but it confines the action of the horse by buckling the shoulder and tail together, and when the bearing-rein is passed over the harness, the horse's head is very much confined. Harness leather is best, in the long run, though dearest at first. Double cart-ropes measure 24 yards, single 12 yards, and cost $4 \frac{1}{2} \mathrm{~d}$. per lb. Hemp and Manilla reins cost $5 \frac{1}{2} \mathrm{~d}$. per lb. There should always be double reins used with the cart, whether the horses be yoked single or double. The double reins are connected at the end with a tie and loop to hang on any hook, or slip below any part of the harness. With the collar and bridle, the shaft-horse carries $58 \frac{1}{2} \mathrm{lbs}$. of harness, and the trace-horse $34 \frac{1}{2}$ lbs.

(2247.) In carrying the crop off the ground, the object is to do as little injury as possible to the land with the cart-wheels, especially to young grass; and for this reason, as well as forming. an excellent guide, the horses should walk in the open furrow between the ridges in every alternate furrow, while the wheels pass along the furrow-brow of the ridge on each side. When corn is cut with band-won reapers, the stooks of 2 ridges being placed on 1 , the cart clears the produce of 2 ridges, and the same may be the case with mown corn, provided the bandsters are instructed to set the stooks in the same manner upon the ridges while working across them. In threaving, the stooks being set on every ridge, the former is obliged to go from one ridge to another to clear 2 ridges, which occasions much loss of time. 
(2248.) A corn-cart is loaded with sheaves in this way: The body $e$, fig. 421 , is first filled with the sheaves lying with their butt-ends toward the shaft-horse's rump at one end, and the back end of the cart at the other. When the corn is on a level with the frame or shilments of the cart, the sheaves are then laid across the body of the cart in a row along both sides of the frame, with the butt-ends projecting as far beyond the frame as the band, as at $f$ and $g$; the sheaf on each corner of the frame being held in its place by being transfixed upon a spike attached to it. Another row of sheaves is placed above the first, and the corner ones kept in their places by a wisp of corn, held fast by the band being placed under the adjoining sheaf. Sheaves are then placed along the cart with their buttends to both its ends, in order to hold in the first laid sheaves, and to fill up the hollow in the middle of the load. Thus row after row is placed, and the middle of the load filled up till as much is built on as the horses can conveniently draw, 12 large stooks being a good load. It should be ascertained that the load is neither back-laden nor too heary upon the horse's back; and, indeed, if the cart has been evenly laden according to its form, there is no risk of either inconvenience being felt by the shafthorse. A load thus built will have the butt ends of all the sheaves on the outside, and the corn-ends in the inside.

(2249.) The ropes are then thrown over the load to keep it from jolting off the cart upon the road, and in necessarily crossing gaw-cuts in the fields. There is usually a ring in the back-bar of the cart to which the rope is fastened by the middle, whence it is wound round each back-stay; but fastening the rope round the back-stays will answer without a ring. The ropes are then thrown across the load diagonally to the opposite angles in the front of the cart, and one end is made fast to each shaft, with as much force as the forker can exert on the ground, with the assistance of the plowman on the top of the load. The crossing of the ropes prevents the load splitting asunder over the sides of the cart, while it is jolted along the road. Some plowmen profess to show their dexterity in building loads of corn, and of bringing them to the stack-yard without the assistance of ropes; but there is no use of running the risk of losing time by breaking the load and strewing the road with sheaves. Such a fate attended the first load I tried to build even with the assistance of ropes. When the corn is mown, a wuman is usually employed to rake the ground on which the stooks stood, because they were set upon the ground at the time of mowing before it was raked.

(2250.) When corn is fit for stacking, the carrying is continued from break of day to twilight, provided there be no heavy dew at morning or night. From a little after sunrise to a little after sunset, the corn may be taken in with great safety. It is customary, in some parts of the country, to keep the horses in the yoke when employed at leading, and feed them with corn from nose-bags, while the carter is taking his cinner, and to give them green food, such as tares, while the cart is unloading at the stack. In other parts the horses are taken out of the yoke, watered, and put into the stable, where they receive their corn while the men are at dinner. This is the best way for the horses, though it usually puts off one hour of the best part of the day before the horses again take the road, whereas half an hour in the other case is quite sufficient for the men to dine, and the horses to eat their feed of corn. Some horses are apt to take fright, owing, no doubt, to the mode in which they had been broke in, when the bridles are temporarily slipped off their head for the purpose of taking the bit out of their mouth, to allow them to eat the tares with freedom; and, to avoid such an accident with a horse known to be easily (808) 
frightened, its bit should be made to fasten with a small strap and buckle to the near side of the bridle.

(2251.) A load of tares is brought to the steading fresh in the morning for the horses. They are not fit for the use of horses until the pods are pretty well filled with grain, prior to which state they are apt to purge and weaken them, when subjected to much work in the cart, as in the time of carrying in corn. For cows it matters not how succulent tares may be, as they yield much milk on them; and, indeed, no other green food is so productive of milk.

(2252.) In setting a loaded cart to the stool or stathel of a stack, it should be studied to let the plowman have the advantage of any wind going in forking the sheaves from the cart. The stack should be built in this way: Set up a couple of sheaves against each other in the center of the stathel, and another couple against them in the other direction. Pile others against these in rows around the center, with a slope downward toward the circumference of the stathel, each row being placed half the length of the sheaf beyond the inner one, till the circumference is completed, when it should be examined, and where any sheaf presses too hard upon another, it should be relieved, and where there is slackness, another sheaf should be introduced. Keeping the circumference of the stack on the left hand, the stacker lays the sheaves upon the outside row round the stack, putting each sheaf with his hands as close to the last set one as he can get it, and pressing each sheaf with both his knees, as represented at $h$, fig. 421 . When the outside row is thus laid, an inside one is made, with the butt end of the sheaves resting on the bands of the outside row, thereby securing the outside sheaves in their places, and at the same time filling up the body of the stack firmly with sheaves, as seen at $i$. A few more sheaves may be required as an inmost row still, to fill up and make the heart of the stack its highest part. It is of immense benefit to a stack to have its center well filled with sheaves, as it is the heart-sheaves which retain the outside ones in their places with an inclination downward from the center to the circumference; and this position of the outside sheaves is necessary to prevent the rain finding a passage along the straw into the very heart of the stack, where, of course, it would find its way easily, were the sheaves to lie with an inclination downward to the center of the stack, and where it would soon spoil the corn. The sheaves are then said to take in pen-wet. The number of rows required to fill the body of a stack depends on the length of the straw and the diameter of the stack. In crops of ordinary length of straw, such as from $4 \frac{1}{2}$ to 5 feet, a stack of 15 feet diameter is well adapted; and 1 inside row, along the bands of the outside one, with a few sheaves laid across one another in the center, will make the stack completely hearted. Where much wheat is raised, and which often reaches from 5 to 6 feet in length, the stack should be 18 feet in diameter, to give room for hearting. In a stack of 15 feet, the breadth is rather too much for the plowman to fork heavy sheaves across to the stacker, when the stack attains a certain hight, and when the load in the cart becomes low; and the stacker should always receive the sheaves within his reach, as he cannot rise from his knees to take them without much loss of time, and risk of making bad work. To expedite the building, a field-worker $k$ should stand on the stack, to pitch the sheaves with a short fork to the stacker in the position they are wanted by him, to save him the trouble of turning them, as the sheaf $l$ is shown in the cut. By a little management, the field-worker may receive every sheaf as the plowman pitches it from his fork upon her fork, and prevent it falling upon the stack until she throws it in its proper position beside the right hand of (809) 
the stacker; and in doing this she should not give him more sheaves than 1 by 1 as he builds them; nor should she receive them faster from the plowman than the stacker can build them, for no time is gained, but lost, in piling more sheaves upon the stack than the stacker can dispose of. The proper relative positions of the plowman $m$ and the field-worker $l$, for thus giving and receiving the sheaves, are endeavored to be represented by those figures in the cut.

(2253.) As every cart is unloaded, the stacker descends to the ground, by means of a ladder, and trims the stack, by pushing in with a fork the end of any sheaf that projects farther than the rest, and by pulling out any that may have been placed too far in. It seems to be considered necessary to make the stack swell out as it proceeds in hight, if we may judge from common practice; but it is not necessary to swell it out in the building, in order to throw off the drops of rain from the eaves-for the spreading of the eares by the stack itself, in settling down after it has been built for a few days, is quite sufficient to throw off the drops. The leg of the stack may, therefore, be carried up nearly perpendicular.

(2254.) As the stack rises in hight with cart-load after cart-load, the trimming cannot conveniently be doue with a fork; a thin, flat board, about 20 inches in length and 10 inches broad, nailed firmly to a long shaft, is an appropriate instrument for beating in the projecting ends of the sheaves, and giving the body of the stack a uniform roundness. A stack of 15 feet in diameter should ultimately stand 12 feet high in the leg; and an allowance of 1 foot, or $1 \frac{1}{2}$ feet, for subsidence, after the top is finished, accord. ing to the firmness of its building, is generally made. The hight is measured with the ladder, and, allowing 2 feet for the hight of the stathel, a 15feet ladder will just give the required measure of the hight of the leg before the top is set on. The eaves of the stack are formed according to the mode in which it is to be thatched. If the ropes are to be placed lozengeshaped, the row of sheaves which forms the eaves is placed a little within the topmost outside row; and, after the top is fully finished, its slope will be the same as that of a roof-namely, 1 foot less of perpendicular hight than half the diameter. In finishing the top, every successive row of sheares is taken as much farther in as to give this requisite slope; and the beveled bottoms of sheaves, as they stand in the stook, answer this purpose well-the hearting being particularly attended to in every row, till the space in the center of the stack is limited to an area upon which 4 sheaves can stand with their tops uniting, and their butt-ends spreading out to give a conical form to the top; and these sheaves are kept firm in their place against gusts of wind with a straw-rope wound round them and fastened to the sheares below. If the thatching is made with heavy ropes, running from the top of the stack to its eaves, the eaves-row of sheaves is made to project 2 or 3 inches beyond the upper row of the body of the stack, and the slope of the top is formed from the point of projection of the eaves, and the top finished as in the other mode. The field-worker remains on the top as long as she has footing to hand the sheaves to the stacker.Thus, as one stack is finished, another is founded on the adjoining stathel, and, as one is finished on a stool of straw, another stool should be ready to have another founded upon it.

(2255.) There is seldom leisure to thatch stacks as long as there is corn to carry in, and the finer the weather the less leisure will be found. A damp day, however, which prevents leading, answers very well for thatching, as the straw is not the worse of being a little damp; but in heary rain it would be improper to thatch and cover up so many wet ends of sheaves as the top of a stack contains. But, before thatching can be carried on, (810) 
preparations should be made for it some time before-that is, straw should be drawn in bundles, and ropes twisted ready to be used; and a rainy day in harvest cannot be better appropriated than to such purposes. The straw is drawn in handsful out of one another, till the individual straws become parallel, when the handsful are carefully laid together till as much as a thick bundle is drawn, and the bundle is then tied in the middle with a piece of straw-rope, which is the quickest mode, or with a thumb-rope.

(2:56.) Straw is twisted into rope with different instruments and in different styles. The simplest instrument is the old-fashioned throw-crook. It is used in this way: The left hand holds by the ring at the end of the shank, and round the point of the head is received a wisp of straw from the person who is to let it out to be spun. The right hand holds the middle of the shank loosely, and causes the head to revolve round an axis, formed by the imaginary line between the head and ring, and the twister walks backward while operating with the instrument. The person who lets out the straw sits still on a stool, or on bundles of straw, and, using the left hand nearly closed, restrains the straw in it till sufficiently twisted, and then lets it out gradually, while the right hand supplies the straw in equal and sufficient quantities to make the rope equal throughout, the twister taking away the rope to the requisite length as fast as the spinner lets it out. The spinner then winds the rope firmly on his left hand in an ovoidal ball, the twister advancing toward him, as fast as the spinner coils the rope, with a hold of the end which secures the ball firm. In the Borders the spinner lets out the straw with both hands, while stooping with his head down and his back turned to the twister; but the rope made in this manner is always thick and rough, compared to the other mode.A woman is usually employed as the twister, and a man as the spinner. It is great ease to the left hand of the twister to have the crook fastened round her middle with a piece of stout straw-rope. The best sort of straw for rope is that of the common or Angus oat, being soft and pliable, and it makes a firm, smooth, small rope. An ordinary length of a straw-rope may be taken at 30 feet. Counting every interruption, a straw-rope of this length may take 5 minutes in the making-that is, 120 ropes in 10 hours: a man's wages $20 \mathrm{~d}$., and a woman's $10 \mathrm{~d}$., making together $2 \mathrm{~s} .6 \mathrm{~d}$., will make the cost of twisting a single rope just 1 farthing. Straw-ropes are twisted in quite a different way, with a machine similar to the one used by rope-makers to twist their cords. In using it the twister sits still, while the spinners carry the straw under their arm, and move backward as they let out the straw. The spinners then wind the rope upon the left hand, and advance, during the winding, toward the machine, where they are ready to begin to spin again. Usually 3 spinners let out to 1 twister, and as they can spin as fast with this machine as with the crook, the cost of making each rope will be less than that given above; but an inconvenience attends the use of this twister-when one of the spinners breaks his rope, he is thrown out of work till the others begin a new rope; and all the spinners must let out with the same velocity, otherwise one will make a longer or a harder-twisted rope than the other.

(2258.) It is the duty of field-workers to fetch bundles of straw and straw-ropes to the thatchers as they are wanted.

(2259.) Having the materials ready-drawn straw and straw-ropes-the covering or thatching of a stack is done in this manner: On the thatcher ascending to the top of the stack by means of a ladder, which is immediately taken away, a bundle or two of straw is forked up to him by his assistant, a field-worker, and which he keeps beside him behind a graip, as 
noticed in covering the hay-stack (2134). The straw is first laid upon the eaves, beyond which it projects a few inches, and then in an overlapping manner upward to the trop. Where a butt-end of a sheaf projects, it should be beaten in, and, where a hollow occurs, it should be filled up with a little additional straw. In this manner the straw is evenly laid all round the top of the stack to the spot where the thatcher began. Suppose he has laid the covering on the top of the stack, fig. 422, all round to the line from $a$ to $b$, before closing up which he makes the top $a$, consisting of a small bundle of well-drawn long straw, tied firmly at one end with a piece of cord; the tied end is cut square with a knife, as shown at $a$, and the loose end is spread upon the covering and forms the finishing to it. To secure the top in its place, a straw-rope is thrown down by the thatcher from $a$ to $d$, the end of which his assistant on the ground fastens to the side of the stack.After passing the other end of the same rope round the top, he throws it down in the same direction, where it is also fastened to the stack. In like manner, he throws down

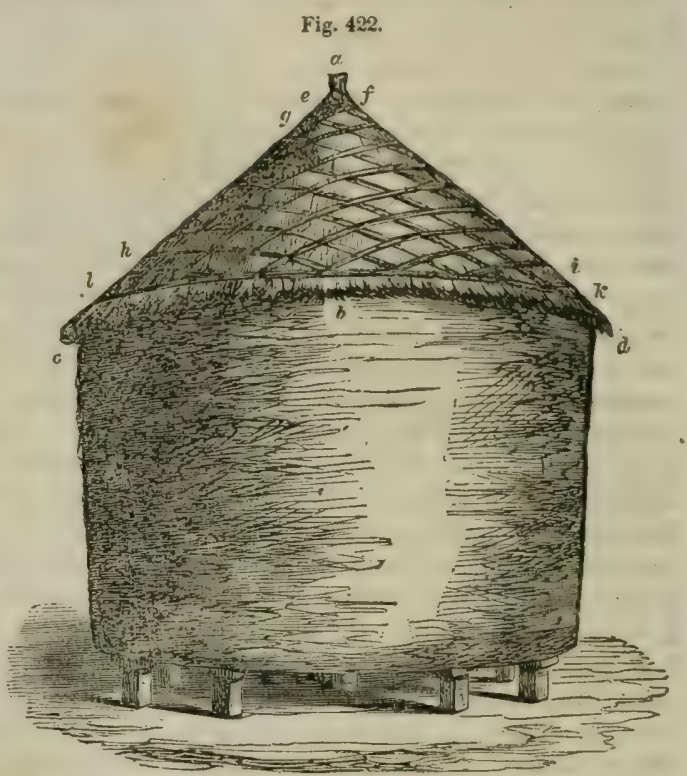

THE LOZENGE MODE OF ROPING THE COVERING OF A STACK. both the ends of a rope from $a$ to $c$, where they are also fastened by the assistant. These 2 ropes are seen at $e$ and $f$. Having thus secured the top, the thatcher closes in the covering from $a$ to $b$, when the ladder is placed to receive him. Taking the ladder to $c$, he inclines its top over the covering of the stack, and secures its lower end from slipping outward by a graip thrust against it into the ground, He then mounts and stands upon the ladder at the requisite hight above the eaves at $c$, and there receives a number of ropes from his assistant, which he keeps beside him, between the ladder and the stack. Holding on by the end of a eoil of rope, he throws the coil from where he stands at $c$ down in the direction of $d$, to his assistant, who, taking it in hand, allows the thatcher to coil it up again upon his hand, without ruffling the covering of the stack, till of sufficient length to be fastened to the side of the stack. The thatcher then throws the other newly coiled end in the same direction of $d$, where, on his assistant taking hold of it, the thatcher retains the rope in his hands by the double, and places it in its position at $g$, a little way below $e$, and keeps it in its place till the assistant pulls it tightly down and makes it fast to the stack like the other end. Thus the thatcher puts on every rope below $g$, till the last one on that side has reached $h$. He then takes the ladder to $d$, where he puts on every rope below $f$, tifl they reach the last one, $i$. Ropes thus placed from opposite sides of a stack cross each other in the diamond or lozenge shape represented in the figure. It will be seen that a windy day will not an(812) 
swer for laying on the covering of stacks. To give the thatch-straw a smoothness, it should be stroked down. with a long, supple rod of willow; and to give the ropes a firm hold, they should receive a tap here and there with the fork, while the assistant is pulling the last end tight. The thatcher is obliged to throw down the rope at first coiled, and to coil up again the second end before it is thrown down, because the loose ends of strawropes would not descend within reach of the assistant. The ends of the ropes are fastened to the stack by pulling a handful of straw from a sheaf a little out of the stack, and winding the rope round it; and the knot thus formed is pushed between the rope and stack, and keeps the rope tight.On such a stack, which is 15 feet diameter at the base, 17 feet diameter at the eaves, 12 feet high in the leg, and $6 \frac{1}{2}$ feet high in the top, 10 ropes on each side are quite sufficient to rope it.

(2260.) It is seldom that the covering of a stack is finished when the straw and ropes are first put on-the stack being placed beyond danger, others are covered to the same state, and the finishing is left till more leisure is found; and, indeed, all the stacks to be early threshed seldom receive the finishing work at all. Many farmers only finish the outside rows of stacks. However, as I am speaking of the subject just now, I shall describe the finishing process at once. An eaves-rope, $k l$, fig. 422 , is spun long and strong enough to go round the stack. Wherever 2 ropes from opposite directions cross at the eaves-rope, they are passed round it, and, being cut short with a knife, are fastened to the stack, immediately below the projecting part of the thatch over the eaves. Thus the 2 ends of all the 20 ropes are fastened to the stack, and the thatch is cut with a knife round the eaves, in the form shown from $d$ by $b$ to $c$.

(2261.) Another mode of roping the covering of a stack is shown in fig. 423 , where the covering being put as described above, ropes are put over the crown of the stack all round, from $a$ to $b, a$ to $c, a$ to $d$, \&c.These ropes, at their crossing over the top, are fastened together by a rope, which is tied above them, and cut off in the form of a rosette, as at $a$. The ropes which cross these are either put on spirally from the top $a$, till they terminate at $d$, or put on separately in bands, parallel to the eaves-rope $e f$. In either case they are twisted round each crown-rope, from the top to the eaves, as $h$ is seen twisted round, $a d, a c$, and $a b$, by $g$, till it reaches the point $h$ again. The crownropes, such as $a b, a c$, and $a d$, are

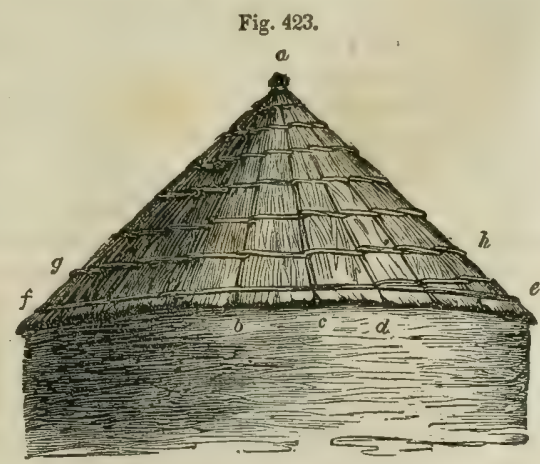

THE NET WORK MODE OF COVERING AND ROPING A STACK.

made to pass round the eaves-rope $e f$, and fastened to the stack under the projecting covering; and the covering is cut short round the eaves, from $e$ to $f$, in the manner described above. This mode of roping, though requiring fully more ropes than the last, perfectly secures the thatch against the strongest winds; though the crown-ropes may be fewer in number than shown in the figure.

(2262.) There is still another mode of roping the covering of a stack, and it is applicable to the heads of all stacks whose eaves are formed of a row of sheaves projecting beyond the body of the stack. It is shown in fig. 424, and is in common use in Berwickshire. The first thing done is 
to put a strong eaves-rope round the stack, below the projecting row of sheaves from $a$ to $b$. The straw is then put on much the same way as before described, but rather thicker, and it projects farther beyond the eaves. The tops of the finishing sheaves of the stack are pressed down, and a rather large, hard bundle of short straw is placed upon them, to serve as a cushion for the ropes to rest upon, and which is put on after most of the covering has been laid on. The thatcher then perches himself upon the top of the hard bundle, where he receives the ropes as they are wanted, and, on being thrown to him, he catches them readily on the point of a long fork. Some dexterity is required to throw a

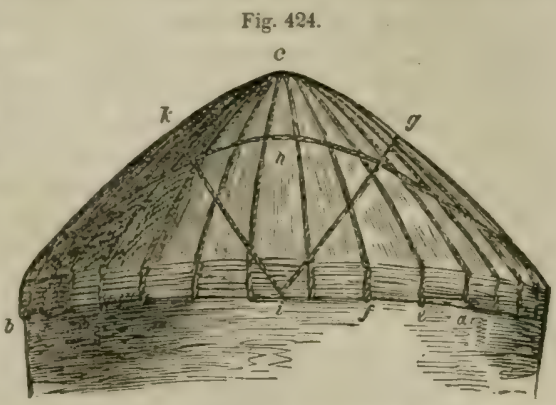

THE BORDER METHOD OF CUVERING AND ROPING A CORN-STACK. coil of straw-rope to the top of a stack. The best position to do it is to stand as far from the stack as to see the thatcher fully in the face, and clear of the head of the stack; then, to take the coil by the small end, pitch it upward with a full swing of the arm toward the thatcher's feet, and he will catch it firmly on the prongs of the fork; if aimed to a higher level, the fork will be almost certain of missing it - the critical position of the thatcher not allowing him to turn his body, but only to move his arms. Uncoiling the half of a rope, the thatcher throws it past the eaves to his assistant, who fastens that end, and while this is doing he throws the other half of the coil down in the opposite direction, across the top of the stack, to another assistant, who fastens it to the stack at the opposite side: 1 assistant may suffice, by tying first one end of the rope, and then the other; but, with 2 assistants, this mode of roping is conducted with great celerity. Thus, rope after rope is thrown, to the number of 30 , before the top of stack is sufficiently roped, as seen in the figure, from $c$ to $d, e, f, \& c$. The rupes, where they cross at the top, are tied together with a piece of straw-rope, to prevent their slipping off. The difficult part of this mode of roping is in finishing the eaveswhich, if well done, looks remarkably neat, but, if otherwise, is apt to have a slovenly appearance. In finishing, the ends of the ropes are loosened from the stack, and passed between the eaves-rope and stack, and, on being brought upward, are passed behind the ropes themselves, about 8 or 9 inches above the eaves-rope. The end of the first rope, suppose $c d$ thus fastened, with the part of the covering which projects beyond the eaves, are brought along the face of the eaves, and the second rope $c e$ is placed over them before it is passed helow the eaves-rope and turned upward, and passed behind itself. The end of the first rope, that of the second, and the projecting covering, are then all brought along the face of the eaves, and the third rope $c f$ is placed over them, and treated like the 2 preceding, and thus all the way round the stack with both ends of the 30 ropes. The last finish is made by bringing the ends of the 2 or 3 last ropes along the face of the eaves, behind the 2 or 3 first ropes. It will be chserved that, while the end of one rope fails to go beyond its length, the end of another rope is gained, so that the band of ropes along the face of the eaves remains about the same breadth round the stack. The ropes between the eaves and top are held down by 4 or 8 ropes, $a h b, g i, k i$, which are so 
thrown across as to quarter the top of the stack, and their ends are fastened to the eaves-rope.

(2264.) There are still other modes of thatching stacks, such as sticking in handsful of straw into the butt-end of the sheaves, and keeping them down with stobs of willow, or with tarred twine, both in imitation of the thatching of cottages; and they are modes in wbich the use of straw-ropes are dispensed with altogether. Whichever may be the plan adopted, the chief object should be to secure the corn in the stack in a dry state, with the least trouble and expense. Of all the modes in practice, I see none more efficient and better-looking than the lozenge-shaped roping of fig.

(2264.) Where rough grass is found on a farm, such as on a bog which is partially dry in summer, I would suggest its being mown and sheafed, for covering stacks. A day or two spent in mowing such grass, after the harvest is over, are well spent, even at the rate of wages and food of ordinary harvest-work. Not only does this stuff save the drawing of gond straw where it is scarce, but of itself forms good covering for stacks which are soon to be threshed; and, by the time it has served the purpose of thatch, it will be dry enough to litter courts, and thereby add to the manure-heap. Reeds might be used in the same way, where they do not find a profitable market as thatch for cottages.

(2265.) These are the usual modes of stacking and covering stacks of wheat, barley and oats, in good weather; but in wet weather many expedients in stacking are tried to preserve the corn from heating, and it is necessary you should be made acquainted with them to put them in practice when required. The most common expedient is to erect a pyramid of 3 small trees or weedings of larch or Scots fir, tied together at the top, and fastened together by the sides with thin fillets of wood. Around this pyramid is the stack built, and its use is to form a hollow space in the center of the stack, into which the air may have access. These structures are commonly called bosses. When placed on a stathel, the air enters them directly from below, but, when on the ground, it is requisite to form an opening from the outside of the stack to the boss, by means of a low tressle; and if a tressle is placed on each side of a stack, and the position of both chosen with regard to the direction from which the wind most prevails, a complete circulation of air may be maintained through the stack. The greatest inconvenience felt in the use of this form of boss is that, on the stack subsiding, its sharp point is apt to pass to one side of the center of the top, and thereby to give a high shoulder to the stack; and it is well known that rain is almost certain of entering a stack by such a shoulder.

(2265.) In wet weather corn is built in small stacks even in the stackyard; and should the weather prove settled wet, a dry moment should be seized to put 2 or 3 stooks into what are called hand-huts in the field, that is, small stacks built by hand, by a person standing on the ground. Sometimes corn is built on a head-ridge of the field, instead of being carried to the stack-yard, as the same strength of men and horses will stack more corn in this way in a single fine day, than carry it to the stack-yard; and the stacks derive more benefit from the air in the field than in the yard. These stacks are also thatched in the field, and carried to the threshingmachine some time during the winter. It is not an uncommon practice of some farmers to build a portion of their crop in the field every year; but the practice is not commendable, for, besides the trouble and dirt created in carrying straw for thatch to the field, as much confusion and dirt are created in carrying the corn to the steading in winter, when some of it cannot fail to be shaken out of the sheaves, and when the stacks 
wanted cannot, perhaps, be brought in for a track of bad weather or through deep snow. A scheme may be justifiable under peculiar circumstances, which would be wrong in ordinary practice; and this is one of them.

(2266.) Of the 3 species of cereal grains, barley is most liable to heat in the stack, partly owing to the soft and moist quality of its straw, and partly because clover is always mixed with it; and, on these accounts, it is advisable, in most seasons, to make barley-stacks smaller than others, both in diameter and hight, and always to support them with prismatic bosses. Much care should be bestowed, not only by the use of these expedients, but on building barley-stacks safely with proper hearting, to prevent heating; for the least touch of heat spoils it for malting purposes, and malting barley always carries the highest price in the market. Besides injuring the grain, heating compresses barley-straw very firmly together, and, in fact, soon rots it. When a single stack only is seen to heat, it may be instantly carried into the barn and threshed, the air attending which will cool both grain and straw; but when a number show symptoms of leaning on one side, about 24 hours after being built, or exhibit a depression in the top, a little above the eaves, you may suspect heating not only to have commenced, but to have proceeded to a serious degree. An incipient symptom of heating is when moisture is observed on any. part of the top of a stack early in the morning, delicately indicated by cobwebs, before the sun has evaporated it; and, when heated air is felt, or steam seen to rise from the top of a stack, the symptom is unequivocal. Heated barley lubricates the parts of the threshing-machine with a gummy matter. Oats are less apt to heat than barley, though their heat is stronger. If there is the least sap remaining in the joints of the straw, oats will be sure to heat in the stalk. Heating gives to oat straw and grain a reddish tinge, and renders the straw quite unfit for fodder, and the grain bitter and unpalatable, both to horses, in the shape of corn, and the people in that of meal. Wheat seldom heats, but, when it does, the heat is most violent. I never saw stacks of wheat heated but once, when it was foolishly led into the stack-yard the day after it was reaped. Partial heating will be induced in stacks by leaning over after being finished in building; when the compressed part may be expected to heat; and to avoid the tendency of a stack leaning to one side or another, a safe practice is to set props loosely round a stack, to guide it in its subsidence, especially if it has been rapidly built; but it should be borne in mind that if one prop is pushed harder in than the others, it will cause the stack to swerve from it. Some stacks begin to sway the moment the top is put on, and such should be supported with props to keep them, right.

(2267.) In filling a stack-yard, respect should be had to the convenience of taking in the stacks to be threshed as they are wanted. As barley is the sort of grain first disposed of in the market, the barley-stacks should be built nearest the barn, except those intended for seed. Wheat, except in very fine seasons, is seldom firm enough to be presented to market till the spring, and on that account may be built on the outside of the stackyard, and wheat-stacks grace a stack-yard well. Oats are wanted at all times, for horses and fodder, and should, therefore, be always at hand, as the stack-yard becomes cleared. Consideration in these particulars saves a great deal of trouble and confusion in bringing in stacks to be threshed.

(2268.) With regard to the carrying of beans and pease, they are usually the last of being brought into the stack-yard, and particularly beans. The bundles of pease are turned in the field till they are won, when they are rolled up in smaller bundles, and tied by a wisp of their own straw.

(816) 
Pease-straw is very apt to compress in the stack, and, of course, to heat, and should therefore be built with bosses, either in round stacks or oblong ones, like a hay-stack. The largest stack of corn I ever saw was one of pease, which was 150 yards in length; but there.was an opening in it, in which any person could have walked upright through the entire length of the stack. When pease become very dry in the field before they are led, the pods are apt to open and spill the corn, particularly in sunny weather; and to avoid this loss, the crop is usually brought quickly into the stackyard, and built in ventilated stacks. Beans are a long time of winning in the field in calm weather. As it is desirable to have the land they grow on plowed up for wheat, they are not unfiequently carried to a lea field and stooked upon it, till ready to be stacked. Being hard and open in the straw, they keep pretty well in small stacks, though not quite won, and the risk of keeping is worth running in dry weather after much rain, when the pods are very apt to burst and spill the corn on the ground. In building pease and beans, the sheaves are not laid with nicety, nor do the stacks receive much trimming, the pease none at all, the beans with the back of a shovel. Thatching pease and bean stacks is conducted in the same manner as described above; but less pains are bestowed in finishing them off. As, however, a good deal of corn is exposed on the outside of those stacks, the thatching is not unfrequently brought down their legs, and kept on by ropes.

(2269.) In connection with this Iatter subject, I may mention that when corn is mown in a slovenly manner, a good deal of heads of grain may be observed exposed to the air on the outside of the stacks ; and to save these, the stacks are shaved down with the blade of a scythe, fastened lengthwise on a shaft, upon the barn-sheet laid upon the ground to receive the shaved-off corn. This process not only saves the grain, but gives a smoothness to the appearance of the stack, and prevents the mixing of sprouted grain among good samples from the body of the stack, and which mixture would inevitably occur were the grain on the outside allowed to be exposed to the weather. The shaving, it is obvious, should be done immediately after the stack has subsided, and even before, if there is appearance of rain; and it is easily done, and does not occupy much time.

(2270.) These are all the particulars which occur to me to say on bringing in the crop. In conclusion, I may advise you not to imitate those farmers who, because they are gratified on having their crop safe in the stack-yard, seem regardless of the state of the stack-yard itself, and leave it for a long time littered with the refuse of the thatching straw, which, when it becomes wetted with rain, is not only useless as litter elsewhere, but soon heats, and causes an unpleasant odor around the stacks. The spare straw should be removed immediately after it is of no use in the stack-yard, either to the straw-barn, if it is drawn and bundled, or, if loose; into the sheds of the hammels, where it will be ready for littering the cattle that may soon be expected to occupy the hammels for their winter quarters. The ground should be raked clean; the air will then become sweet, the stacks have free circulation of it among them, and the poultry will have the opportunity to pick up every particle of grain that had fallen upon the ground. This act of cleanliness being done, the stack-yard gates may be shut, and the labors of the farm, in so far as they concern the crop, may be said to have been brought to a termination.

(2271.) [The throw-crook, fig. 425, is an instrument that has been long in use for the purpose of spinning or twisting straw-ropes, and is one of those primitive inventions that required only the cutting of the first crooked sapling that might come to hand; for though our figure represents an artificially formed implement, any piece of bent material will answer equally well, all that is required being such a form as will give it the character of what we now denominate a crank, and (873).....26 
to have a swivel-joint at the end, to allow it to turn freely and independent of that appendage by which it is attached to the body, or to the left hand of the person who tarns it. The implement represented in fig. 125 is made of a piece of tongh ash, about $3 \frac{1}{2}$ feet long; the bent part is thinned off until it is capable of being bent to the corve, and is there retained by the iron atay $a_{\text {, }}$ the part $b$ being left projecting beyond the stay, for the attachment of the first end of the rope that is to be made. The end $c$ is fornished with ferule and swivel-ring, by which it is attached to the person, by a cord passed round the waist. In using the implement, the rope-maker is ata. tionary, asually sitting beside the straw, and the spinner moves backward as the rope extends.

Fig. 125 .

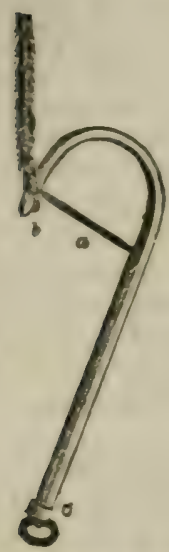

THE THHOW'-CROOK.
Fig. 426.

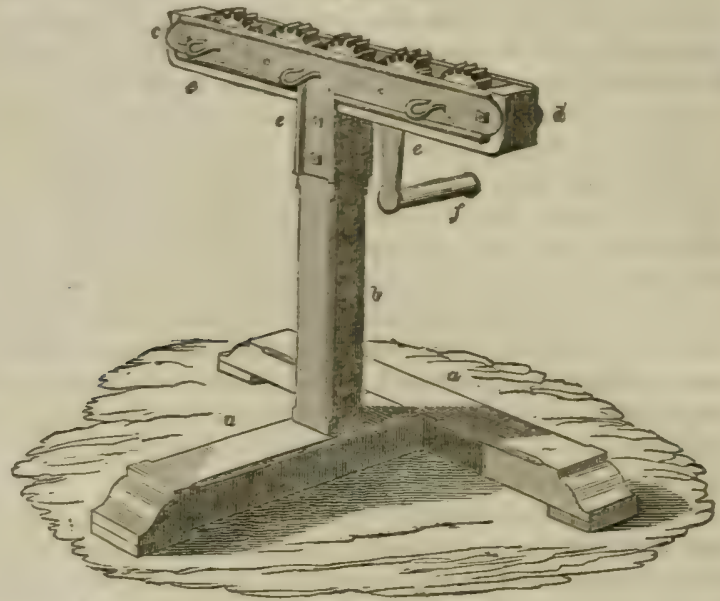

THE STRAW-ROPE SPIXNER.

(2272.) The straw-rope spinner, fig. 426. is a machine of recent introduction to the operations of the harvest season, and is of considerable importance in facilitating the process of straw-rope making. Comparing it with the old instrament, the throuc-crook, the adrantage is considerable; for with that two people must be occupied in the making of one rope, whereas with the spinner four people only are required to make three ropes, being a saving of one-third of the time occapied by the old practice. The spinner bas been constracted in various forms. though exhibiting but two distinct varieties of the machine-the first distinguished by the epinner being stationary, and the rope-maker moving away from it : the second by the rope-maker being stationary, and the epinner moving away from him. The first kind is found to be the best in practice, and I have therefore chosen an example of it for illastration. Fig. 426 is a view of the machine, consisting of a Eole-frame, $a, a$, measuring about 2 feet each way, with an upright post $b$ tenoned into the sole, and carrying the cross-head $c d$. The cross-head is a hollow box or case. adapted to contain the machinery of the spinner, consisting of 5 light spur-wheels, about 6 inches diameter, placed as seen in the case $c d$. Of these. the central and the two extreme wheels are mounted npon axles, which terminate in the hooks $e, e_{,} e$; the other two wheels being merely placed intermediate, to produce revolation in the three principals in one direction. A winch-handle, $f$, is fixed upon the axle of the central wheel, on the side opposite to the books; and, to prevent the machine from moving with the strain of the ropes, \& few stones, or other weighty substances, are laid upon the sole-frame. The machine is tbeu pat in operation by the driver turning the bandle, and the three rope-makers, each with a quantity of straw under his arm. commences his rope by binding a few gtraws round the hook appropriated to himself. He then proceeds backward. letting out the straw as be advances, and the rope takes the twist, antil the length required is completed, when each man coils up his rope into an oval ball.

(2273.) Some machines of this form are monnted on wheels, thereby coming under the charac. ter of the second kind. when the rope-maker is stationary : but great inconvenience must attend any attempt at working in this manner. Another form of the machine adapted to work, as one of the second kind. is that which is strapped to the body of the driver. he moving away from the stationary rope-makers. This method also is attended with inconvenience, especially to the driv. er. who, having the machine strapped in front of his body, the handle being at the end, and the machinery consisting of bevel-gear, baring the external form of the cross-head alone of fig. 426 , the handle is bronght so near to his body that much of the muscular force of the arm is lost by this misapplication. By nsing a well constructed machine for etraw-rope spinuing, not only is there 8 saring of expense effected, but the ropes are much better twisted, and, of course, stronger than those made by the old implement. The price is from 1258 , to $£ 210 s,-J$. S.]

(2274.) Cart-ropes last according to the care bestowed on them. When used with the corncart. they should never be allowed to tonch the gronnd, as earthy matter, of whatever kind, eoon canses them to rot. On being loosened when the load of corn is to be delivered to the stacker, they should be coiled ap before the load is disposed of, and the coil suspended from the back part of the cart quite clear of the ground. A soft rope holds mach more firmly, and is less apt to eat, than a hard one. 

AND SMEARING SHEEP.

"But rather these, the feeble of thy flock. Ranish before the autumnal months: even age Forbear too much to favor; oft renew,

And through thy fold let joyous youth appear."

"The ewes, being rank, In the end of autumn turned to the rams."

(2275.) When last speaking of sheep, the lambs were weaned and buisted. One of the processes among sheep in early autumn, in the beginning of August, is drafting ewes and gimmers-that is, separating those to be disposed of from those to be kept. Drafting, however, applies only to a standing flock of ewes, By a standing flock is meant a fixed number of ewes, which are made to rear their lamb year after year. Instead of having a standing flock, some farmers are in the custom of buying every year a flock of ewes big with lamb, receiving the lambs from them, and disposing of both ewe and lamb at such a season as best suits the market for those respective sorts of stock. The ewes are sold in autumn to be fed on turnips, and the lambs are disposed of, after being weaned, to rearers of sheep who breed none. Such a one is called a flying-flack. Of course, flying-stock require no drafting; where all are disposed of, none obtain the preference of being kept.

(2276.) There are various marks of deterioration which determine the drafting of ewes. Bareness of hair on the crown of the head, which makes them obnoxious to the attacks of fly in summer-deficiency in eyesight, which prevents them keeping with the flock, and choosing out the best parts of pasture and best points of shelter-ill-shaped teeth and jaws, which disable them from masticating their food so well as they should-want of teeth from old age, when, of course, they cannot rope sufficient food to support their lambs-hollow neck, which indicates breeding too near akinhollow back, which implies weakness in the vertebral column, thereby rendering them unfit to bear lambs to advantage-flat ribs, which confine the space for the fotus within the abdominal region-a drooping tait-head, which affects the length of the hind-quarter, a space occupied by superior flesh-bad feet, which prevent traveling with ease along with their companions-round and coarse bone, which indicates coarseness of flesh-thin or short coat of wool, which lessens the clip and the profit of wool-diseased teat or udder, which diminishes the supply of milk for the future progeny-scarcity of milk, by which lambs, not obtaining sufficient nourishment in the early period of their existence, are stinted in growth, and weakened in constitution-carelessness of disposition, which induces neglect of the lamb, particularly one of twins, which is in consequence ill-nursedproducing worthless lamb, by which profits are much diminished-missing being in lamb, a failing which is apt to recur in any future year-casting lamb, a propensity likely to recur every year-rottenness, which is, of course, objectionable in every animal that produces young-shortness of breath, which prevents them seeking their food, and eating so much of it as they should-tendency to scouring, or the opposite, the former imposing. weakness, the latter inducing inflammation-delicacy of constitution, which disables them from wilhstanding the ordinary changes of the weatherdiminutive stature, or inordinate size, which destroys the uniformity of the 
flock. This is a long list of faults incidental to ewes, and yet every one may be observed, and which every breeder of sheep is desirous to get rid of. (2277.) It is not at all probable that any flock of ewes presents all these objectionable qualities in one season; but, notwithstanding this favorable circumstance, it is not in the power of the breeder to draft every ewe having an objectionable property every year, because, the farm supporting a stated number of ewes, the extent of their draft depends on the number of good substitutes which may be obtained from the gimmers; for it is obvious no good object is attained by drafting a bad ewe, and taking in its stead a bad gimmer. The number of gimmers fit to be transferred to the ewe flock should therefore be, in the first instance, ascertained, and a corresponding number of the worst ewes drafted.*

(2278.) In drafting gimmers, many of the above faults may be observed in them also, though every fault arising from lamb-bearing cannot possibly affect young sheep. The faults incidental to gimmers are, bareness of hair on the crown of the head-ill-shaped teeth and jaws-hollow neck-hollow back-flat rib-low tail-head-bad feet-round, coarse bone-thin and short fleece-rottenness-shortness of breath-tendency to scouring, or otherwise-delicacy of constitution-and diminutiveness of stature and inordinate size. These faults are numerous enough, but not likely to be all observed in the same year, and less likely in the same individual.Most of them may be got rid of by rejecting females which have more than one of them, and by employing tups free of them all. When the external form is improved, the constitution is also strengthened. Gimmers, when they become ewes, are moreover likely to be deficient in milk, careless of their young, and produce small lamb; but these faults disappear in the succeeding year-and should this not be the case, the ewe, though young, healthy, and fresh, should be drafted. Thus, ample drafting can alone insure a sound, healthy, well-formed, young, and strong-constitutioned flock of ewes.

(2279.) After being drafted, the ewes and gimmers are buisted [marked] with tar (2027), those to be retained, on the near rib, and those drafted, on the far.

(2280.) Tups require but little preparation on being put among ewes. If their skin is red in the flanks when the sheep are turned up, they are ready for the ewes, for the natural desire is then upon them. Their breast, between the fore legs, is rubbed with keil or ruddle, on being placed among ewes, that they may mark their rump on serving them. It is the duty of the shepherd to mark every ewe so served, that he may observe whether or not the season returns upon her, and to be prepared for the day of her lambing when it arrives. The period of gestation of the ewe is 5 months, and as the tup is usually put among the ewes from the 8 th to the 11th October, the first lambs may be expected to appear on the 8 th or 11th of March following. A young, active tup, a shearling, will serve 60

[" In our Eastern States, where more care and exactness prevail in all branches of husbandry, it is probable that flocks of sheep are periodically overhauled, and all that are defective from age, or disorder of any kind, drafted and in some way disposed of; but, in the Middle and Southern States, very gross neglect is observable, almost universelly on this point. Now, every farmer of true spirit will endeavor to attain all practicable excellence in whatever he undertakes-in the quality of his flocks as well as of his implements-in the purity of bis butter as in the plumpness of his grain; and nothing requires more searching vigilance than the health and condition of his oheep. It is with them, especially, that a single rotten or diseased individual may infect the whole flock; and no inducement, no false calculation of economy, should indace him to retain such an animal, even for a day, after it is discovered. His character, as well as his interest, forbids it. 
ewes, an old one 40 ewes. Tup-hoggs are not used, not having attained maturity in any particular, though one is sometimes put among ewes to make an old tup more active. When tups are too fat, they are apt to become lazy, and will only willingly serve a very few ewes; and when tris is the case, it is better to put him in a field by himself with a few ewes, selected to suit his particular qualities, than to urge him to over-exertion by means of a tup-hogg, because several of the ewes served by him in such case may miss being in lamb. A tup-hogg so employed is seldom allowed by the tup to serve a single ewe, being driven off wherever he is seen to go with one; but as a sure prevention of his serving, a piece of cloth is sewed to the wool on the under part of his belly. Tups, when too heavy, are apt to contract spavin in the hock joints, in consequence of the great weight of the carcass upon the hind legs, in the act of serving ewes. Most of the ewes will be tupped during the second week the tup is among them; and, in the third, they will all be served. It is likely that some of the first served ewes will return in season, and these should be specially noticed by the shepherd, as it is not improbable they will become tup-eild. The ruddle requires to be renewed almost daily, and even oftener, when the tupping is active.

(2281.) Tups are not selected for ewes by mere chance, but according as their qualities may improve those of the ewes. When ewes are nearly perfect, they may be selected for breeding-tups. A good ewe flock should exhibit these characteristics: strong bone, supporting a roomy frame, affords space for a large development of flesh-abundance of wool of good quality, keeping the ewes warm in inclement weather, and insuring profit to the breeder-a disposition to fatten carl $\%$, which enables the breeder to get quit of his draft-sheep readily-and being prolific, which increases the fiock rapidly, and is also a source of profit Every one of these properties is advantageous in itself, but when all are combined in the same individuals of a flock, that flock is in a high state of perfection. Now, in selecting tups, it should be observed whether or not they possess one or more of those qualities in which the ewes may be deficient, in which case their union with the ewes will produce in the progeny a higher degree of perfection than is to be found in the ewes themselves, and such a result will improve the state of the future ewe flock; .but, on the contrary, if the ewes are superior in all points to the tups, then, of course, the use of such tups will only serve to deteriorate the future ewe flock.

(2282.) After 3 weeks have elapsed from putting the tup among the ewes, he should be withdrawn; because lambs begotten so long after the rest, will never coincide with the flock. Tups should, after serving, be put on good pasture, as they will have lost a good deal of condition, being indisposed to settle during the tupping season. The ewes and gimmers may now be classed together, and get such ordinary pasture as the farm affords. During the autumnal months, they will find plenty of food in the pasture fields, but in winter, rather than be fed on turnips, a rough pasture field should be reserved for them. When they have no such pasture, they will require to be put on a break of turnips for 2 or 3 hours every day; but it should be borne in mind that a fat ewe always bears a small lamb, and is very subject to inflammatory fever after lambing, from the recovery of which, if she ever recover, the probable result will be scantiness of milk. Swedish turnips will produce this effect on ewes more readily than other kinds, therefore a few white turnips should be reserved for them as long as practicable, should they receive turnips at all.*

* See paper by me on Drafting Sheep, in the Quarterly Journal of A griculture, vol. iti. (877) 
(2283.) Immediately after the arrangements for tupping the ewes are made, part of the sheep-stock undergo a preparation for being put on turnip, and the preparation consists of bathing them with a certain sort of liquid. Sheep are affected by a troublesome insect, the keb or ked, or sheep-tick, which increase so much in numbers as the wool grows, toward autumn, as to become troublesome to sheep; and were means not taken to remove them, the annoyance they occasion the sheep would cause them to rub themselves upon every object they can find, and in thus breaking their fleece deteriorate its value to a considerable extent. Another reason for bathing sheep is, that on experiencing so great a change of food as from grass to turnips, cutaneous eruptions are apt to appear on the skin, even to the extent of the scab, which would deteriorote the fleece even more than the rubbing occasioned by the ked. The liquid, then, which would be of service, should combine the properties of killing the ked with certainty, and of preventing eruptions on the skin, without injury to the staple of the wool; and these effects are attained by the use of tobacco-liquor and spirit of tar, the former instantly destroying the ked, and the latter acting as a preservative to the skin. The former precaution is necessary to be exercised on all classes of sheep, but the latter is the more necessary on sheep bought to fatten on turnips, as traveled sheep are almost always affected with cutaneous eruptions, and especially Black-faced sheep direct from the hills, after they have been on turnips for some time. As a matter of safety, then, for your own flock, however clean it may be, every sheep that you buy from another flock, whether intended for feeding on turnip or for augmenting your own flock, should be bathed immediately on its arrival on your farm, and before it can possibly have had time to contaminate your own sheep.

(2284.) The materials used in the bath are tobacco, spirit of tar, soft soap, and sulphur vivum. The tobacco is best used in the state of leaf, but I understand it is illegal for tobacconists to sell tobacco in the leaf. Being used in the proportion of $1 \mathrm{lb}$. of tobacco to every 20 sheep, it is put into a boiler with 1 quart of water for every $1 \mathrm{lb}$. of tobacco, and boiled gently for several hours. The tobacco is then wrung out, and returned again into an empty boiler with $\frac{1}{2}$ quart of fresh water for every 1 lb., and boiled as long as any coloring matter can be obtained from it, when it is wrung out and thrown away. The entire water will have boiled in to 1 quart to $1 \mathrm{lb}$. of tobacco. This forms a decoction of tobacco which is much better than an infusion. The soft soap is used in the proportion of $1 \mathrm{lb}$. to every 20 sheep, and is dissolved thoroughly in a sufficient quantity of warm water. The sulphur vivum is pounded fine and mixed with the soap in proportion of $\frac{1}{4} \mathrm{lb}$. to 20 sheep, and it combines with the soap in some degree, but when both are mixed with the tobacco-liquor, the sulphur is apt to be thrown down in the original state of powder. I don't know of what particular use the sulphur vivum is, for the greater proportion of it is certainly precipitated to the bottom before it is used, unless its sulphureous property may serve to prevent the ked breeding again for a time; but if this is its only use, the flour of sulphur should be more efficacious. The tobacco-liquor is put into a tub, and the solution of soft soap and sulphur vivum are intimately mixed with it. The bath thus made is administered by means of a tin flask capable of easily holding 1 quart, and provided with a long spout, by which to pour it along the shedded wool of the sheep. The spirit of tar is poured into the flask of liquor when about to be used, in the proportion of $\frac{1}{2}$ a wine-glass to 1 quart, and stirred. Some people use stale urine over and above these materials, for the professed purpose of making the bath stronger, but I cannot see how (878) 
it can strengthen any of these ingredients; for, as to any caustic effect upon the skin, a small addition of the spirit of tar will have a much greater effect than the urine. If the urine is employed with a view to its ammoniacal vapor destroying the insects, that may be a good plea for its employment in summer to prevent the extension of insect vermin; but in autumn, when the keds are entirely destroyed by the spirit of tar, and will not again appear till spring in a new progeny, the urine seems useless in winter.

(2285.) This is an effectual bath, and is not expensive; the tobacco being $3 \mathrm{s.} 6 \mathrm{~d}$. per lb., a bottle of spirit of tar 1s. $6 \mathrm{~d}$., soft soap $6 \mathrm{~d}$., and sulphur vivum 1s. per lb., give a cost of $5 \mathrm{~s}$. $6 \mathrm{~d}$. for 20 , or $3 \frac{1}{4} \mathrm{~d}$. per sheep. But it should be mentioned, in regard to this bath, that, though in very common use, it tinges the color of the wool, and is more expensive than some other baths to be adverted to hereafter.

(2286.) An useful implement in bathing sheep is the bathing-stool, fig. 427, which is made of the best ash. It consists of a seat $a$, for the shepherd to sit on while bathing the sheep, 1 foot square; the sparred part is 3 feet long, and 30 inches wide in front from $b$ to $c$, its greatest width being across at $d$. The legs $e, e$, \&c., are 18 inches high, attached by means of iron rods passed through their upper part and the frame of the stool, and secured with nut and screw.

(2287.) The bathing is conducted in this way: A sheep is caught and placed on the stool on its belly, with its 4 legs through the spars, and its head toward the Fig. 427.

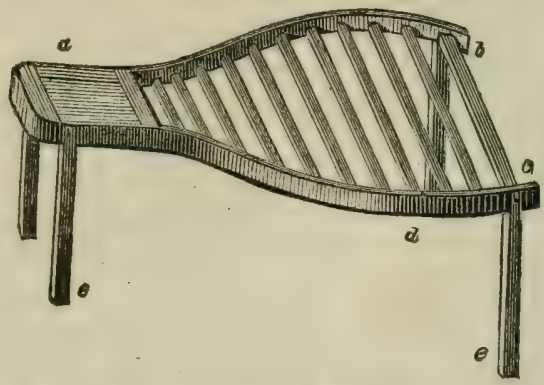

THE BATHING-STOOL FOR SHEEP. seat $a$, on which the shepherd sits astride. The wool is shed by the shepherd, with the thumbs of both hands, from one end of the sheep to the other; and, when he has reached the farthest end of the shed, an assistant, a field-worker, pours the liquor from the flask equally along the shed, while kept open by the shepherd with both hands. The sheds made are 1 along each side of the back-bone, 1 along the ribs on each side, 1 along each side of the belly, 1 along the nape of the neck, 1 along each side of the neck, and 1 along the counter. From these sheds the bath will cover the whole body. The sheep is turned on the sides and back to obtain easy access to all these several parts. Additional liquor is put on the tail, head, scrotum, inside of the thighs, brisket, root of the neck, and top of the shoulder, because these are parts most likely to be affected by scab, and are chiefly the seats of the nidi of insects. The shepherd and his assistant will bathe 40 sheep in a day. Dry weather should be chosen for bathing, else the rain will wash away the newly applied bath; and coarse clothes should be worn by those who administer the bath, as it is a very dirty process. When the sheep are lying on their back on the stool, their legs are not tied, so the assistant should be aware of receiving a kick from the hind feet on the face or on the flask.

(2288.) Shortly after bathing, the keds may be seen adhering to the points of the wool dead; and, when sheep are much infested by this vermin, the fleece may be seen speckled thick with their bodies. Sheep are differently affected with keds; and those which recover from a lean or stinted state to one in better condition, on a change of food, are most liable 
to be overrun with them, as cattle are with lice when improving in condition on turnips. This being the case, the ked may be expected to increase rapidly on sheep that have been some time on turnips, and hence the necessity of bathing sheep before being put on turnips. Hoggs are most liable to their attack, because, perhaps, they get most rapidly into condition after being some time weaned.

(2289.) The diseases incident to sheep in autumn are yellows and rot, both arising from a disor dered state of the same organ-the liver, and pining. The yellors is jaundice, exhibiting yellow: ness of the eye. the mucous membranes, and the urine. Bleeding, and purging with aloes and calomel, are the appropriate remedies. Fat draft ewes which bave fed some time upon aftermath are most liable to the disease. Inflammation of the liver is the cause. in which the pain of the affected part is very obscure, and the natural language of the sufferer not very expressive, nor is the symptomatic fever marked. Here a striking analogy is noted between the lower animals and man. inasmuch as there is generally a sympathetic pain in the right shoulder, so strongly marked as often to be mistaken for the principal disorier, and treated accordingly. Whenever you observe, therefore, a lameness of the right tee of any fat sheep on foggage, you axay suspect the existence of jellows, and examine the inside of the eyelid, and observe whether any yellowness exists there.

(2290.) The rot is a far more zerious disease, causing the death of numbers of a flock in a very short period. Deficient food in summer, and a flush of rank wet grass in autumn, occasion ruin to the health and constitution of sheep. In the wet and cold season of 1817, when sheep could not obtain a mouthful of good food in summer, and when the autumn arrived, accompanied with a flush of wet herbage, I knew a farmer in Cheviot who lost 300 Cheviot ewes in the course of 2 or 3 weeks. The early symptoms of rot are very obscure: a circumstance much to be lamented, as in the first stage alone does it often admit of cure. "The animal is dull," observes Mr. Youatt; " lagging behind his companions, he does not feed so well as usual. If suspicion has been a little excited by this, the truth of the matter may easily be put to the test : for if the wool is parted, and especially about the hrisket, the skin will have a pale yellow bue. The eye of the sheep beginning to sicken with the rot, can never be mistaken; it is injected, but pale. the omall veins at the corner of the eye are turgid, but they are filled with yellow serous fluid, and not with blood. The caruncle, or small glandular body at the corner of the eye, is also yellow. Farmers, very properly, pay great attention to this in their examination or purchase of sheep. If the caruncle is red, they have a proof, which never fails them. that the animal is healthy. If that body is white they have no great objection or fear-it is generally so at grass; but if it is of yellow color, they immediately reject the sheep. although he may otherwise appear to be in the very best possible condition; for it is a proof that the liver is diseased, and the bile beginning to mingle with the blood. There is no loss of condition, but quite the contrary; for the sheep, in the early stage of rot, has a great propensity to fatten. Mr. Bakewell was aware of this, for be used to overflow certain of his pastures, and when the water was run off, turn those of his sheep upon them which he wanted to prepare for the market. They speedily became rotted, and in the early stage of the rot they accumulated flesh and fat with wonderful rapidity. By this maneuver he used to gain 5 or 6 weeks on his neighbors."

(2291.) It is alleged, that when sheep have access to salt, they are never known to be affected with rot; and I have as little doubt that, were oil-cake put freely within their power in such a season as I bave alluded as having occared in 1817, they would escape the malady. Change of pasture from a wet to a dry situation may be the means of even curing the rot, when the change has been effected at an early stage of the disease. All land that has been irrigated in sum. mer, and produces a rank growth of grass in autumn, should be avoided by sheep, as being the very pest-house of rot. Some land, in its natural state, will affect sheep with rot when grazed upon it, such as soft, spongy soil, having a clayey tendency, and never free of moisture. In so far as this last cause of rot is concerned, draining bas bad the effect of rendering land sound which was known to have rotted sheep in a short time. In the prospect of such an evil, when inevitable. sheep cannot be long kept on the same farm, but must be sold in the course of a few months; in short, tenants, in their fear, are obliged to keep a flying-stock, especially of ewes, for these are the most easily affected portion of the flock. The application of lime has rendered land sound which was subject to rot, even after it had been drained. Sudden frost and thaw, alternately, in spring, produce rot, according to the old proverb-

$$
\begin{aligned}
& \text { "Mony a frost, and mony a thow, } \\
& \text { Betakez mony a rotten yow." }
\end{aligned}
$$

(2292.) The liver of rotten sheep always cuntains the well known animal the fuke, so named from its striking resemblance to a lounder. Its nature has not yet been satisfactorily examined. It was named Fasciola by Linnæus, and Distoma hepaticum by Rodolphi. Its inteatinal ducts contain great numbers of grains of a pale red color like sand, which ane supposed to be its eggs; and as no difference of sex has been ubserved, it is believed to be a hermaphrodite. It is sup: posed that its eggs find their way to the grass, from which sheep receive them into their stomach, and thus are supposed to find their way into the liver. The eggs are found in the biliary ducts, in the intestinal cavals, and even in the duug of healthy sheep, and they swarm in the dung of rotten ones. Much more could be said on the subject of rot, but I must refer you to authorities."

(2293.) "Pining," says the Ettrick Shepherd, "is a very descriptive Scotticism, from the verb; for no creature can have a more languishing and miserable look than a sheep affected by this malignant distemper. Well may I describe it, for in the last 9 years I have lost upward of 900 sheep by its ravages. It is quite a new disease on the Border; for I was 20 years a shepherd and never

* Youatt on Sheep, Quarterly Journal of Agriculture, vol. V. and rol. Fi. Parkinson on Live Stock, จol. i. 
saw an instance that I can remember of with certainty, nor did I ever hear its name save from Galloway, where it was called the vinquish, and where it has been prevalent for ages. It was likewise known long ago in some of the districts of the middle Highlands. It is a strange distemper. On the genuine pining farms, the sheep do not take it by ones or twos, but a whole flock at once. It is easily distinguished by a practiced eye, the first symptoms being lassitude of motion, and a heaviness about the pupil of the eye, indicating a species of fever. I wish I had science to describe it in a pathological manner, which I have not, and therefore shall not attempt it : but at the very first the blood is thick and dark of color, and cannot by any exertion be made to spring: and when the animal dies of this distemper, there is apparently scarcely one drop of blood in the carcass. It lives till there does not seem to be a drop remaining: and even the ventricles of the heart become as dry and pale as the skin. This simple fact may, I hope. enable men of science to comprehend its nature. It is most fatal in a season of drouth; and June and September are the most deadly months. If ever a farmer perceive a flock on such a farm having a more than ordinary flushed appearance by rapid thriving, he is gone. By that day 8 days, when he goes out to look at them again, he will find them all lying, hanging their ears, running at the eyes, and looking at him like so many condemned criminals. As the disease proceeds, the hair on the animal's face becomes dry, the wool assumes a bluish cast. and if the shepherd have not the means of changing pasture, all those affected will fall in the course of a month."

(2294.) The rationale and cure of this fatal disease are thus attempted to be given by a writer. "The disease called pining, seems to arise from an enervated and costive habit of the animal, which may be produced by a want of proper exercise, in conjunction with feeding in pastures of an astringent nature. The principal districts in which this disease is found to prevail, are the green pastures of the Cheviot mountains, the chain of hills running through the S. W. parts of Roxbuighshire, the pastoral districts of Selkirk and Peebles shires, and some other districts of Scotland, as Galloway. Under the old practice of keeping the sheep in Hocks, as they are termed, hir. sels, of weaning the lambs in the months of July or August, and afterward of milking the ewes for 8 or 10 weeks, the pining was unknown in most of these districts; but uuder this mode of treatment, the sheep were frequently subject to diarrhea-a disease diametrically opposed to pining. The farmers of those pastoral districts have generally improved upon the older methods of keeping their sheep. They find it to be more profitable to allow the whole flocks to pasture together indiscriminately and undisturbed. The lambs remain unweaned, until they wean themselves, which generally does not take place till the month of December. By this mode of management, the ewes and lambs are found to be of a higher comparative value than all the sum realized by the sale of cheese made from the milk of the ewes; besides, the ewes "are not subject to various accidents arising from so frequently collecting them together for the purpose of milking. But under this undisturbed state of management, in all cases where dry astringent pastures are produced, such as on the sienitic porphyry of the Cheviot range, the pining made its appearance. That such pasture promotes this disease, is farther strengthened by the fact that it is more common in diy than in wet seasons; and most so at that season of the year when, by the influence of the sun, the plants are less juicy: or early in autumn, when the grasses which have pushed to seed become less succulent. The disease is not known on the whole of the clay-slate range of the Lamnermoor Hills, where heath prevails, occasionally interspersed with green pastures, and where the hirseling practice is pursued. Nor is it known to exist in general on greer succulent pastures, or even heaths, growing on calcareous or sandstone grounds, where the nature of the food and the exertion of the animal in procuring it appear to counteract the progress of the disease, arising from the inactivity of the digestive function. If we suppose these to be the predis. posing causes of this disease, the prevention or remedy will suggest itself either under the head of food or treatment. Should it be deemed inexpedient to adopt the mode of keeping the flocks in hirsels, a change of place, and, consequently, of food, is necessary to accomplish this purpose. The salutary effects of a variety of food on the animal system are well known. When sheep affected with this disease are put upon a heath, it has frequently the desired effect; but when the animal is much overcome with the disease, its state of languidness may prevent it from taking such a quantity of food as will produce a reäction upon the animal functions. The most effectual cure, therefore, in all cases, is a change to a more rich and succulent pasture."**

\section{Lifting AND PITTING POTATOES.}

"If planted in fair rows

They marshaled grew, the plow will best perform

The reaping task: amid the tumbling soil

The vegetable mine, exposed to view,

The gatherer's basket fills."

Grahax.

(2295.) The harvest-work of a farm cannot be said to be completed until the potato crop is taken out of the ground and secured against the winter's frost. By October the potatoes may be expected to be ready for lift-

* Quarteriy Journal of Agriculture, vol. ii.

(881) 
ing. The fitness of potatoes for lifting is indicated by the decay of the haulms : for as long as these appear at all green, you may conclude the tubers have not yet arrived at maturity. In an early season potatoes will ripen before October; and though the weather should continue fine, the best plan is to let them remain in the ground till the corn crops are entirely harvested. Immediately after the fields are cleared of corn, the potatoes should he taken up and secured, to allow the land to be plowed up for wheat; indeed it will happen, under all circumstances of weather, that the corn will be ready to be cut down and carried in before the potatoes are fit to be taken up.

(2296.) There are two modes of lifting potatoes, namely, with the plow and with the potato-graip. The plow is the most expeditious, though I believe the ground is best cleared of tubers with the graip. With either instrument a large number of people to gather the potatoes are required, each of whom should be provided with a small semi-spheroidal shaped basket, with a bow-handle, to gather the potatoes into, and then to put them into sacks or close-bodied carts. When a farmer lifts potatoes on his own account, they are usually put into a cart and carried direct to the pits. When he lifts them on account of a purchaser, or a number of purchasers, they are measured on the spot from the basket, and put into sacks, in which they are easily delivered. When lifted for shipment to the London market, they are first riddled into sizes, then measured or weighed on the spot and put into carts, and taken to the ship's side. The potato-riddle is made of wire, with meshes from $1 \frac{3}{4}$ inches to $1 \frac{1}{2}$ inches square, and, if rimmed with oak, costs $2 \mathrm{~s}$. 6d. each. The riddlings, or small potatoes, are used on the farm. Potatoes are usually sold by weight, and a given weight represents the measure of a boll; which boll, again, differs in weight in different parts of the country, thereby rendering the imperial weights and measures act, in this instance, nugatory. A boll is 20 stones of $14 \mathrm{lbs}$. to the stone, in some parts of Scotland, and it is 40 stones in others; and, to contradistinguish them, the small boll is called a single, and the large a double boll. The produce of a crop of potatoes varies amazingly-from 30 to 100 single bolls per imperial acre. It is singular that the price does not vary nearly so much-from $4 \mathrm{~s}$. 6 s. the single boll, being the limits between dear and cheap prices. Taking 60 bolls $[16,800 \mathrm{lbs}$.$] as the medium produce, and 5 \mathrm{~s}$. as a medium price, the gross return from an imperial acre of potatoes will be $£ 15[\$ 75]$. If the expense of lifting the crop is taken at 30 s. per acre, the return will be $£ 13$ 10s.; a large sum, certainly, but then it should be remembered that potatoes leave no straw for manure, and require, on the contrary, a large quantity of manure to raise even a tolerable crop. They incur considerable trouble in their delivery; and, being a perishable commodity, cannot be kept beyond a given time.

(2297.) In employing the plow to take up potatoes, the common one, with 2 horses, answers well; but as the potatoes run the hazard of being split by the coulter when it comes in contact with them, it should be taken out, the sock being sufficient to enter the plow below the drill, and the mould-board to turn them out of it. The plow in going up splits one drill, and in returning splits the next, but no faster than a band of gatherers, or field-workers, if numerous enough, but if not, assisted by hired laborers, can clear the ground of them into the baskets. In free soil, potatoes are easily seen and picked up; heavier soil is apt to adhere to them, in which case it is a good plan to make a stout field-worker shake those portions of the earth turned up by the plow, which still adhere in lumps, with a potato-graip, and expose the tubers. Potato-gathering should not be con$(882)$ 
tinued so late in the evening as that the tubers cannot be easily seen ; nor should it be prosecuted in wet weather, which causes the earth to adhere to them, and renders them undistinguishable from the earth itself. Of course every one, the smallest tuber, should be taken off the ground, not only on the score of economy, to realize the whole crop, but to remove them as a weed from among the succeeding crop. After the field has been gone over in this manner, the harrows are passed a double tine to bring concealed tubers to the surface, when they are gathered by the people, and to shake the haulms free of soil. These after-gathered potatoes. are usually reserved for pigs and poultry. Whenever the field is cleared of the crop, the haulms are gathered by the field-workers and carried to the compost stance, to be converted into manure, and these are the only return which the potato crop makes to the soil.

(2298.) A simple instrument, fig. 428, which may be substituted in the plow for the mould-board for turning potatoes out of the drill was contrived by Mr. John Lawson, of Elgin. It consists of 6 malleable iron bars, the outer ones $\frac{5}{8}$ of an inch square, the inner $\frac{1}{2}$ an inch in diameter, joined together in the form of a brander, 26 inches long from $a$ to $b ; 5$ inches in breadth from $b$ to $c$, at the fore part, where is a plate of iron; 27 inches in length from $c$ to $d$; and 18 inches in breadth from $d$ to $a$. This brander is attached to the right side of the head and stilt of a plow, in lieu of

Fig. 428.

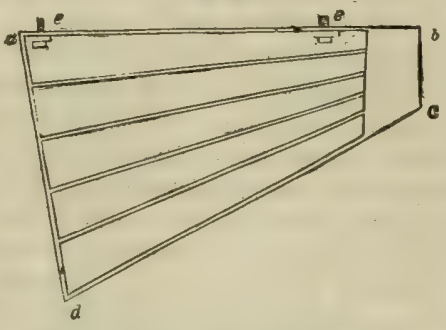

THE POTATO-RAISER OR BRANDER. the mould-board, by the screws $e, e$, and the fore-end, $b c$, being placed close behind the sock, as seen at $a$, fig. 429 , which shows the plow mount-

Fig. 429.

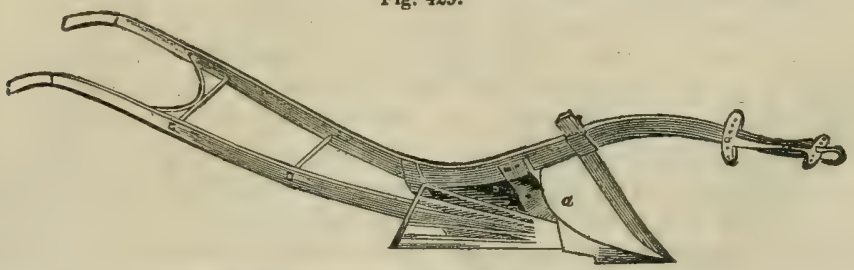

THE POTATO-RAISER ATTACHED TO THE PLOW.

ed with the brander, having its upper angle at $a$, fig. 428, 8 inches, and the plane of its face so bent down as to have the lower angle $d$ only 4 inches above the sole of the plow. The openings between the rods will thus be rather more than $2 \frac{1}{2}$ inches at the widest end of the brander, between $a$ and $d$. The mode of operation of the brander is, that while the earth partly passes through it, and is partly placed aside by it, the potatoes are wholly laid aside, so there are few of them but are left exposed on the surface of the ground.

(2299.) "This plow," says Mr. Lawson, “ is drawn by one pair of horses, in the same manner as the common plow. In working it, the plowman inserts it into the potato-drill so as to have the whole of the potatoes on his right-hand side. He then proceeds along the drill, splitting it up in the common way. The earth is then thrown to the right-hand side, and the potatoes lie scattered on the surface of the ground behind the plow. Women follow, provided with baskets, into which they gather the potatoes, and throw the stems upon the drill which lies to the right hand of the one (885) 
from which they are gathering the potatoes. The reason why the potatostems are thus removed is that as soon as the potatoes which lie on the surface are gathered, the plow returns, and again proceeds as before, through the part of the drill in which the potatoes lay, still turning the earth to the right-hand side. This second operation raises to the surface any stray potatoes which the first may not have turned up, and the potatoes thus raised are gathered by the women who attend for that purpose. The second operation may he delayed till about 12 drills are turned orer by the first operation, and the potatoes gathered. The plow may then be put through these 1: drills the second time. By this there will be a saving of labor, as a smaller number of women will gather the potatoes by the second operation, while the greater number of them may remain with another plow in its first movement. If the stems of the potatoes be very strong and luxuriant, a few of the women might be directed to go along the drill and pull them out of the ground, at the same time plucking off any potatoes that may adhere to and come along with the stems. If this is done, the plow will turn up the greater part of the potatoes by going only once through the drill; but, in going twice, it will do it in the most satisfactory manner. A man with 1 pair of horses will thus pass over the ground as quickly as with the common plow. In light soils this plow performs its work in a very efficient manner. It pulverizes the soil in an extraordinary degree, and scarcely leaves a single potato in the soil. I have never before been able to clear my fields of potatoes so effectually as by this implement, or at nearly so small an expense."*

(2300.) When potatoes are taken up by manual work, it is done with the potato-graip, fig. 430 , the prongs of which are flattened. Being rather severe work to use this graip, men are employed for the purpose, 1 man taking 1 drill, close beside that of his fellow-workmen, while 2 gatherers to every man are ready to pick up the potatoes he turns out into the baskets. In using the graip, it is inserted into the side of the drill, and below the potatoes, with a push of the foot, and the graipful of earth thus obtained is turned on its back into the hollow of the drill, exposing the potatoes to view on the top of the inverted earth, whence they are gathered. The men then pass the prongs of the graip here and there through the inverted graipful and the soil on the drill, to detect and expose to view every tuber lurking beneath the soil. In this manner, 1 man and 2 women will take up, of a good crop of 80 bolls of 20 stones per acre, 20 bolls a day, which will cost $3 \mathrm{~d}$. per boll at the following wages: 1 man 2s., and 2 women at $1 \mathrm{~s}$. $6 \mathrm{~d}$. each per day, without food $=5 \mathrm{~s}$. per day, or 20 s. per acre. Such graips cost 2s. 3d., and when handled 3 s. each.

(2301.) In regard to the storing of potatoes, there is no difficulty in the early part of winter, when a low temperature prevails, and vegetation is lulled into a state of repose. Potatoes

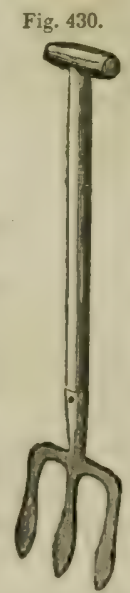

THE POTATO GRAIP. may therefore be kept in almost any situation in the early part of winter; but then, if damp is allowed to surround them for a time, it will inevitably rot them, and if air finds easy access to them at all times, the germ of vegetation will be awakened in them at the first call of spring. To place potatoes beyond the influence of those elements as long as convenience suits, they should be stored in a dry situation, and be covered up from the air; and no mode of storing affords more ready means for both those requisites than the ordinary forms of pits in dry soil.

* Quarterly Journal of Agriculture, vol. viii. $(886)$ 
(2302.) Fig. 431 shows the two different forms of the ordinary potato pits, the one being conical, the other prismatic in shape. The conical form is usually employed for pitting small quantities of potatoes, and is well suited for small farmers and cotters; the prismatic is the form commonly adapted for storing large quantities. For both sorts, a situation sheltered from the north wind should be selected, and the ground should either be so dry of itself as to absorb the rain as it falls, or so inclined as to allow surface water to pass quickly from the site of the pits. The site should be conveniently situated for opening the pits and admitting the carts to them, and so near the corner or side of a field as not to interfere with its being wrought in winter.

(2303.) A conical pit of potatoes is formed in this manner : If the soil is of ordinary texture, and not very dry, let a small spot of its surface be smoothened with the spade. Upon this spot let the potatoes, as they are taken out of the cart, be built by hand in a conical heap, not exceeding 2 feet in hight; and the breadth which a cone of that hight will occupy, so as not to impose much trouble in piling up the potatoes, will not be less than 4 feet, and is more likely to be 5 feet. The potatoes are then covered with a thick thatching of dry, clean straw. Earth is then dug with a spade from the ground in the form of a trench around the pit, the inner edge $a$, fig. 431, of the trench being as far from the pile of potatoes as the thickness of the covering of earth to be put upon it, which is to be considered sufficient at 1 foot. The first spadeful is laid around the potatoes on the ground, and the earth chopped fine and beaten down with the spade, in order to render the earth as impervious to cold as possible, and the drier the earth is, the less effect will frost have upon it, and the less distance will it penetrate through it. Thus spadeful after spadeful of the earth is taken from the trench and heaped on the straw above the potatoes, until

Fig. 431.

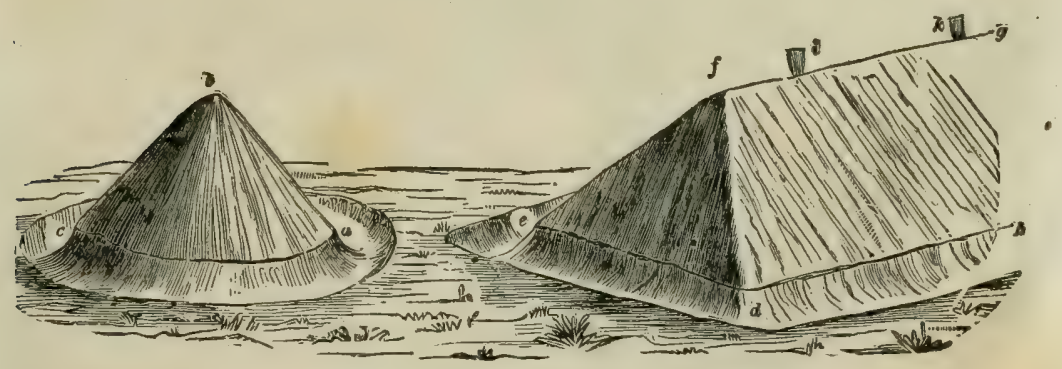

THF CONICAL AND PRISMATIC FORMS OF POTATO-PITS.

the entire cone $a b c$ is formed, which is then beaten smooth and round with the back of the spade. The top of the cone at $b$ will then be about 3 feet 3 inches in hight, and the width of the cone from $c$ to $a$ about $7 \frac{1}{2}$ feet. The trench round by $a c$ should be cleared of earth, that no surface water may lie near the pit, and an open cut should be formed from the lowest side of the trench to allow the water to go away most freely.

(2304.) When the soil is naturally thoroughly dry, the site of the pit may be dug out of the solid ground a spade depth, for storing the potatoes into what would then really be a pit, and then the apparent hight of the pit above the surface of the soil will be small; but unless the soil is as thoroughly dry as sand or gravel can make it, the potatoes should be piled

upon the natural surface of the ground. 
(2305.) The prismatic, or long pit, $d$ e $f g$, fig. 431 , is formed exactly in the same manner, with the exception that the potatoes in it are piled in a straight line along its sides $d h$, instead of round, as in the case of the coni cal pit $a b c$. The hight of the pile of potatoes sbould not exceed $2 \frac{1}{2}$ feet, and its breadth will spread out to about 7 feet, and allowing 15 inches for thickness of straw and earth, the hight of the finished pit will be 3 feet 9 inches, and breadth 9 feet 6 inches. The direction of a long pit should always be $\mathbf{N}$. and $\mathrm{S}_{\text {, }}$ in order to place both its sides within reach of the sun's rays.

(2306.) It is considered that when fresh potatoes are heaped together in large quantities, a certain degree of fermentation ensues, which increases the temperature of the mass so much as to awaken vegetation in the tubers, and the existence of long sprouts so frequently found covering the top of the heap of potatoes when a pit is opened in spring, is adduced as a proof of the effects of such an increase of temperature; and the thick covering of dry straw usually placed above potatoes in pits is also considered a great means of retaining within the bounds of the pit the heat evolved from the potatoes, aud hence a plan has been suggested, of having openings left along the upper parts of pits through which such heated air may escape. The openings are left by drawing small bundles of long straw, tied at one end with a piece of cord, and cut square like a rosette on the top of a corn-stack $a$, fig. 422, and which are placed upright, and project upward at short intervals along the top of the pit, before the earth is thrown upon the straw near its ridging, and the earth is put round, and beaten down, and finished smoothly, beside the projecting part of each bundle. These vents may be seen at $i$ and $k$, in fig. 431

(2307.) It is truly remarked by Sinclair, that " the varieties of the potato are very numerous, and the confusion of their names inextricable." Without attempting to particularize any one variety, I would say generally, that as an article of food. the potato is now universally cultivated, and this, no doubt, chiefly from the facility with which it may be raised. the pleasantuess of its taste, the simplicity of its cookery, and the nourishment which it affords. According to a statement of Sinclair, it appears that in several varieties of potato fit for homan food, the nutritive matter varies from two hundred to two hundred and sixty grains in 64 drachms; that those quantities of natritive matter contained from 169 to 204 grains of starch, and from 31 to 61 grains of albumen, mucilage, and sugar. *

(2308.) As compared with grain, "Cobbett's assertion, that wheat produces more nutritious matter per acre than potatoes, is now completely disproved. Later experiments have ebown that it is very near the truth to estimate the proportion of the nutritive power of wheat to that of potatoes as about 7 to 2 ; or, in other words, 2 lbs of wheat afford as much sustenance as 7 lbs. of potatoes, though it may be doubtful whether they afford so mach nourishment ; for. by caleulating the produce of the two crops, it bas been determined that 1 acre of wheat will produce sustenance for 3 persons as long as 1 acre of potatoes affords it to 6 5-6 persons. This is on the supposition that the power of untrition of a plant is only in proportion to the quantity of farinaceous and glatinous matter contained in it. But this is by no means certain. We have not been able to discover what it is that renders one substance more proper for food than another. . . In estimating the amount of aliment afforded by potatoes and grain, we should rather calculate accoriling to the mass of vegetable matter capable of satisfying a full-grown person. . . . . I may add that potatoes, from some peculiarity in the mixtare or degree of condensation in their nutritive matter, keem to possess an advantage over all grains as constant food. It is well known that potatoes and water alone, with common salt, can nourish men completely; we have hundreds of instances, in many parts of Ireland, where the feople have lived constantly on this diet from necessity, and yet bave been robust. healthy, and long.lived as persons fed plentifully on animal food. Now, I know of nc meal derived from grain ased as the general food of any aation, without being mixed with other kinds of alimentary matter, as oil, fraits, whey, or milk." $\dagger$

- Sinclair's Hortus Gramineus Woburnensis.

$\uparrow$ Quarterly Journal of A griculture, vol. $\nabla_{4}$ a paper enumerating the variong uses to which the Potato may be applied. 
(2309.) The potato has been subjected to careful analysis by different chemists, and these are a few of the results :

\begin{tabular}{|c|c|c|c|c|c|c|c|}
\hline KINDS. & $\begin{array}{l}\text { Starchy } \\
\text { Fibrin. }\end{array}$ & Starch. & \begin{tabular}{|} 
Vegeta- \\
ble Albu- \\
men.
\end{tabular} & Gum. & $\begin{array}{c}\text { Acids } \\
\text { and } \\
\text { Salts. }\end{array}$ & W ater. & Analyst. \\
\hline 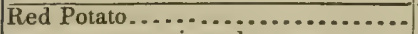 & $7 \cdot 00$ & $15 \cdot 00$ & $1 \cdot 40$ & $4 \cdot 1$ & $5 \cdot 1$ & $75 \cdot 0$ & Einhoff. \\
\hline$\ldots \quad$ germinated $\ldots \ldots \ldots \ldots \ldots$ & $6 \cdot 80$ & $15 \cdot 20$ & $1 \cdot 30$ & 3.7 & & $73 \cdot 0$ & \\
\hline sprouts ...................... & $2 \cdot 80$ & $0 \cdot 40$ & 0.40 & $3: 3$ & & $93 \cdot 0$ & \\
\hline Kidney $\ldots \ldots \ldots \ldots \ldots \ldots \ldots \ldots \ldots \ldots \ldots$ & $8 \cdot 80$ & $9 \cdot 10$ & 0.80 & & & $81 \cdot 3$ & \\
\hline Large Red ........................ & $6 \cdot 00$ & $12 \cdot 90$ & $0 \cdot 70$ & & & $78 \cdot 0$ & \\
\hline Sweet $\ldots \ldots \ldots \ldots \ldots \ldots \ldots \ldots \ldots \ldots$ & $8 \cdot 20$ & $15 \cdot 10$ & $0 \cdot 80$ & & & $74 \cdot 3$ & \\
\hline 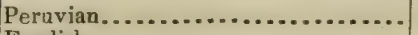 & $5 \cdot 25$ & $15 \cdot 00$ & $1 \cdot 88$ & & 37 & $76 \cdot 0$ & Lampadins. \\
\hline 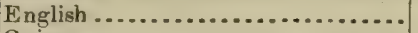 & $6 \cdot 83$ & $12 \cdot 91$ & $1 \cdot 04$ & & 0 & $77 \cdot 5$ & \\
\hline Onion $\ldots \ldots \ldots \ldots \ldots \ldots \ldots$ & $8 \cdot 38$ & $18 \cdot 75$ & 0.90 & & & $70 \cdot 3$ & \\
\hline 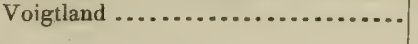 & $7 \cdot 13$ & 15.41 & $1 \cdot 25$ & 1. & & $74: 3$ & \\
\hline Paris . & $6 \cdot 79$ & $13 \cdot 30$ & 0.92 & $3 \cdot 3$ & $1 \cdot 4$ & $73 \cdot 12$ & Henry, Jr. \\
\hline
\end{tabular}

Of these constituents of the potato, it will be observed how large a proportion the water bears, and the remainder is chiefly composed of fibrin and starch. Hence, potato differs essentially from wheat and barley, by containing no gluten. and approaches in some measure to the nature of rye. ${ }^{*}$ Of the dry constituents, starch is frequently used in the manufacture of wheaten bread, the potatoflour giving to the loaf, when stale, a tendency to excessive crumbiness. Potato-flour does not injure bread as an article of food; but still it is an adulteration, and its use constitutes a fraud on the public, when the same price is demanded for the loaf partly made of this cheap material as for one of wheat alone.

(2310.) Potato-starch may be converted into tapioca. The tapioca of commerce is derived from cassava, a preparation made in the West Indies, the tropical regions of America, and on the African coast, from the root of the manioc (Jatropha manihot), an euphrobaceous plunt. "The cas-" sava cakes sent to Europe, which I have eaten with pleasure," says Dr. Ure, "are composed almost entirely of starch, along with a few fibres of the ligneous matter. It may be purified by diffusion through warm water, passing the milky mixture through linen cloth, evaporating the strained liquid over the fire with constant agitation. The starch dissolved by the heat thickens as the water evaporates; but, on being stirred. it becomes granulated. and must be finally dried in a proper stove. Its specitic gravity is 1.530-that of the other species of starch. The product obtained by this treatment is known in commerce uuder the name of tapioca; and being starch very nearly pure, is often prescribed by physicians as an aliment of easy digestion. A.tolerably good imitation of it is made by beating, stirring. and drying potato-starch in a similar way." $t$ An acquaintance of mine, a farmer in Forfarshire, Mr. James Scott, Beauchamp, instead of disposing of his potatoes, of which he used to raise large quantities every year, converted them into tapioca. thereby saving a great deal of carriage which the delivery of potatoes occasions, and retaining the refuse of the manufactured potato, apon which he fed a large number of pigs, and which, moreover, afforded a good mash to the horses.

(2311.) "When potatoes are boiled, they lose from 1 to $1 \frac{1}{2}$ per cent. of their weight. The juice which may be separated from them is sweet tasted. The meal is insoluble even in boiling water, though potato-starch forms a transparent solution with hot water. Thus it appears that by boiling, the albumen, fibrous matter, and starch combine together, and form an insoluble compound." Simple as the matter appears, it is not every cook who can boil a potato voll.

(2312.) "When potatoes are exposed to the action of frost, it is well known that they become soft, and acquire a sweet taste. This taste is succeeded by a sour taste, owing to the rapid evo. lution of acetic acid, and the root soon passes to putrefaction. From the experiments of Einhoff, we learn that the sugar is formed at the expense of the mucilage; for the other ingredients were found in potatoes sweetened by frost, in the usual proportion. He considers this sweetening process as connected with the vegetative powers of the root." "Dr. Peschiez of Geneva has described the presence of mucous sugar and of gum in the potato. This explains why it is capable of undergoing the vinous fermentation." The acids contained in potatoes in the natural state were ascertained by Einhoff to be a mixture of the tartaric and phosphoric acids. He also obtained from 1,820 parts of dried potatoes, 96 parts of a grayish-white ash. Of these, 64 parts were soluble in water, and 35 insolublet. A ninute analysis of the ash of potatoes is given by Professor Johnstou, including that of the haulms. In $10,000 \mathrm{lbs}$. there were found of -

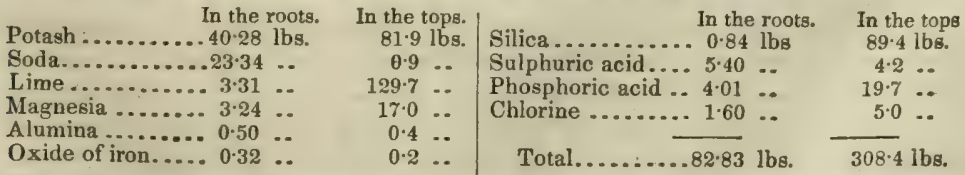

It will be observed what a large proportion of potash, lime and silica the tops of the potato plant yield. "These roots," as observed by Professor Johnston, and the observation applies to turnips, carrots and parsnips, as well as to the potato, "contain very much water, so that, in a dry state, the proportion of inorganic matter presentrin them is very much greater than is represented by

* Thomson's Organic Chemistry of Vegetables

† Ure's Dictionary of the Arts and Manufactures, art. Cassara.

‡ Thomson's Organic Chemistry of Vegetables. (887) 
the above nambers. I have, bowever, given the quantities contained in the crop as it is carried from the field, as alone likely to be of practical atility. The crops of these various sorts vary very much in different localities, being in some places twice, and even thrice as much as in othersevery 10 tons, however, which are carried off the ground, contain about 9 times the weight of saline and earthy matters, indicated by the numbers in the Table."

(2313.) Solunina was discovered by M. Desfosses in the fruit of the common potato, and M. Otto discovered it also in the potato itself. after it had been allowed to germinate, and this substance is an acrid narcotic poison. "Its existence in the potato after germination," says Dr. Thomson, "is an interesting fact, and should lead to the cautious use of that important vegetable after germination has commenced."

(2314.) "It is well known that a spirit can be extracted from potatoes. From this spirit Messrs. Bertillon and Guietand extracted a volatile oil, being a colorless, limpid liquid, having a strong umell. hot. acrid taste, and being very soluble in alcohol." $\uparrow$

(2315.) The particles of potato-starch are irregular ellipsoids, varying in size from 1-300 to 1.3000 of an inch; those of wheat being separate spheres of 1.1000 of an inch: so that it would be an easy matter to detect potato-flour among wheaten flour with the microscope.

\title{
38. SOWING AUTUMN WHEAT, AND THE CONSTRUCTION AND PRINCIPLES OF AGRICULTURAL WHEEL-CARRIAGES.
}

\author{
"How ceaseless is the round \\ Of rural labor! Sonn as on the field \\ The withered haulms and suckers crackling blaze, \\ And with their far-extending volumes load \\ The wings of Autumn's latest lingering breeze. \\ The WHEATEN SEED-TIME all your care demands."
}

Grahor.

(2316.) How ceaseless, indeed, is the round of rural labor! No sooner does the farmer secure his crop, the progress of which toward maturity has excited his most lively solicitude during the course of a whole year, than he begins to sow the succeeding one, and strives to prepare as much land for it before winter sets in as he possibly can secure. The crop usually sown in autumn is wheat, that plant being able to bear the vicissitudes of winter in our latitude, though barley and tares are also sown at the same time in some parts of England, where they stand the winter well, but neither can withstand a Scottish winter.

(2317.) You have just seen (2312) that the constituent parts of the haulm of potatoes consist of large proportions of potash, lime, and silica-ingredients useful to many of the crops which follow in rotation after a summerfallow; and though incineration is the means by which the chemist discov. ered those substances in potato-haulms, yet I would advise you to make a compost of them, as I did before (1613), rather than convert them into a "crackling blaze," as described in the motto, inasmuch as their iuorganic constituents can be secured equally well by fermentation as hy incineration, while their organic constituents are not dissipated, but thereby preserved for use.

(2318.) You will recollect that we left off the working of summer-fallow after the land was dunged (2155), and when the land was to receive no lime. It is now our business to finish the summer-fallow, by the sowing of autumn wheat, the crop for which the land was specially prepared by fallow. The first process is the leveling of the drills which cover the dung, by harrowing them across a double tine; and, unless the land is of very strong clay, 1 double tine will be sufficient for the purpose. After the land has been harrowed level, any root-weeds that have been brought

- Johnston's Lectures on Agricultural Chemistry and Geology.

1 Thomson's Organic Chemistry of Vegetables. (888) 
to the surface should be removed, but the surface-weeds will soon wither in the sun and air. The land should now be feered, to be gathered up $(650)$, fig. 133, into ridges, and if it has been thorough-drained, or is otherwise sufficiently dry, 1 gathering-up will-make a good seed-bed; but should it be too wet for once gathered-up ridges to lie safe all winter, the ridges should be twice gathered-up (665), fig. 139. The second gatheringup, however, should not be done immediately after the first, but after such an interval of time has elapsed between them as to allow the land to subside, and the subsidence will be much hastened by a fall of rain. Should the fallow-land have been dunged in the usual way, that is, the dung spread upon the surface, and plowed in, with feered ridges, the feerings should have been so made as to leave a $\frac{1}{2}$ ridge at the side of the field, that now, when the land is about to be plowed for the seed-furrow, the $\frac{1}{2}$ ridge is converted into a whole one, and the field thereby made fit to be continued in that form.

(2319.) But a practice has come into use since the introduction of the grubber, Plates XXIX. and XXX., which possesses some advantages, on strong land, in certain circumstances, which is to cover in the sown wheat with the grubber, instead of first plowing the land for a seed-furrow, and to finish the work with a slight harrowing. When the grubber is contemplated to be thus used, the land, in summer-fallowing, should be feered in ridges, as if for the seed-furrow, when covering in the dung, as the subsequent grubbing will not alter the form of the ridges farther than to reduce their crowns, and fill the open-furrows a little. When a tough, waxy clod is expected to arise on plowing strong land, rather wet below, for a seed-furrow, or when there is appearance of unsettled weather, the grubber will be found useful in keeping dry the meliorated soil on the surface, and also in getting quickly through with the wheat-seed.

(2320.) Land that has grown beans is usually gathered-up for the seedfurrow at once, and sown immediately, as the season is far advanced by the time the bean-crop is carried in and stacked; but the seed-bed would certainly be in a better state for wheat were the land allowed to subside for a few days before the seed is sown. Where the land is strong, and the ridges are sufficiently rounded, the grubber may be used on beanstubble, as on fallow-land, for covering in the wheat sown broadcast on it, but for this purpose a 4 -inch grubber is required, the surface being finished with a slight harrowing. The grubber will succeed in this very well, in as far as the wheat is concerned, and it has a great advantage in a late autumn in getting through the work expeditiously; but on strong land, not thorough-drained, and in a comparatively flat state, grubbing will not succeed on bean-stubble; at least, the wheat-seed would incur considerable risk of being rotted in that state of the soil all winter, and the land itself of becoming soured; and the land would not escape the effects of such an injury, even though it should be fallowed the succeeding year.

(2321.) The land which has grown potatoes should be plowed for a seedfurrow, because, having been laid flat for the culture of this summer crop, the grubber cannot be employed with advantage in the case, as that implement leaves the land as flat as it found it. The land only receives 1 furrow after potatoes; and it should have time to subside a little, though the usual practice is to sow the wheat upon it as soon as plowed. The reason why I have frequently recommended the subsidence of the land before being sown with seed is, that wheat thrives better in soil having a little firmness in it than in the loose state the plow leaves it.

(2322.) When the land is naturally strong enough to grow wheat, but is $(889) \ldots . . .228$ 
Bomewhat soft, and so wet below as to make it apt to throw out the wheat plant in spring, the best plan is to make a seed-bed by ribbing with the small plow, fig. 320 , and (1748). The wheat is sown broadcast over the ribs, and harrowed in with a double-tine along (1769). The ribbing gives the wheat a deeper bed in the soil than mere harrowing, and a deeper hold of the soil in spring, and it has also the advantage of stirring only the dry surface-soil for the seed-bed. It can only be practiced, however, on land that has been ridged up for a seed-bed for a considerable time, as the small plow does not make good work on new-plowed land, it, small as it is, going ton deep, and making the drills too wide; and it is never employed on land that has not been ridged, being unfit to turn up land in a hardened state.

(2323.) Another mode of preventing the throwing out of the wheat plant in spring on soft land, otherwise well adapted for wheat, is, first, to feer the land into ridges, sow the wheat broadcast between the feerings, and cover it in with a light seed-furrow, leaving the land unharrowed and rough all winter.

(2324.) Whether harrowed or not, it is of great importance to leave wheat land rough all winter, that is, with a round large clod upon the surface. These clods afford shelter from wind and frost to the young plants, and when gradually mouldered by frost, serve to increase the depth of the loose soil, and protect the roots of the plants from frost. Indeed, whenever the land is harrowed as fine as meal with autumn wheat, the rain never fails to batter its surface into a crust, and the frost heaves it up in spring like fermented dough; and this action raising the plants along with the soil, they are exposed on the surface after the frozen earth has subsided, on being thawed by sunshine (1772). Such an effect, however, can only occur where a considerable quantity of moisture exists under the surface of the soil, ready to be acted on by frost. Draining, then, is the only safeguard against the young wheat plant being thrown out of the earth in spring. As the ground is desired to be left in a rough state in autumn, no use is, of course, then made of the roller.

(2325.) Autumn wheat is almost always sown broadcast in Scotland, except, perhaps, in the neighborhood of large towns, where it is sown with the drill, Plate XXVII., figs. 325 and 326 ; and the reason why the drill is used in that particular locality is the facility afforded by the drilled rows to hoe the land free of surface weeds, which invariably make their appearance where the street manure is used. In England wheat is very generally drilled, for the reason just given, and surface weeds seem more generally numerous and troublesome throughout England than Scotland. Sowing broadcast is represented by fig. 322 , and is fully described from (1756) to (1766). The machines for sowing grain in drills will be found fully described by Mr. Slight from (1824) to (1829).

(2326.) Wheat is pickled at this season, as well as in spring, before it is sown, and the reasons for treating it thus, as far as they are known, as well as the best method of doing so, will be found described in (1754) and (1755).

(2327.) Almost every year some new variety of wheat, of great reputation, is offered to public notice, and no doubt a good variety may thus occasionally be obtained. But the safe plan for you to follow is to adhere to that variety, or those varieties, which have succeeded in the district in which you farm; because one variety may succeed well in that locality, and not another. It is right to try experiments in growing new varieties which are well recommended, and you slould give such experiments every justice; but until the fact is proved by yourself or your neighbors, that (890) 
the recommended wheat is a good one for your locality, it should not be extensively cultivated. The good properties of wheat are : heavy weight, fine sample, prolific per acre, and plenty of clean straw. A good weight is from $62 \mathrm{lbs}$. to $66 \mathrm{lbs}$. per bushel; it is now, however, as easy to obtain $65 \mathrm{lbs}$. as it was a few year's ago to get $63 \mathrm{lbs}$. a bushel. Years ago, 24 bushels per acre were considered a fair crop on ordinary wheat land; it is now as easy on the same soil to raise 32 bushels. The greatest difference in these results has been realized in the course of years, from the inferior, not the superior classes of soil.

(2328.) There are other modes than those 1 have mentioned of sowing wheat on fallow ground. One of these is dibling, and there are various ways of dibbling wheat. One is to make a hole not exceeding $2 \frac{1}{2}$ inches deep, with a dibble not so thick as that used for planting potatoes in gardens, to drop 1 seed or 2 into it, and to cover them with earth with the foot; the holes being made 4 inches apart, and 7 inches wide between the rows. But this is a very slow process. A more expeditious plan is to use an implement of a cylinder of wood 6 feet long, 4 inches in diameter, and divided lengthways by the middle, to make into 2 dibbles. Pins of wood of a conical form, 3 inches long, are driven perpendicularly at 4 inches apart into the apex of the curved side of the split cylinder. This implement forms a number of dibbles, by being laid along the ground with the pins downward, which are pushed into the ground with the pressure of the foot, to make as many holes as there are pins. The implement being removed by means of a handle attached to its flat side. boys or girls drop 2 seeds into each hole, and cover them with earth. Arother and more certain plan of dibbling is this: a flat. thin board of wood is provided with holes 4 inches apart in the row, and the rows 7 inches asunder. This is laid flat on the ground, when small dib. bles are pashed through the holes to the requisite depth of $2 \frac{1}{2}$ inches into the soil, the depth being determined by a shoulder on the dibble; 2 seeds are then dropped into the hole as each dibble is withdrawn; and when the board is lifted up from the space it occupies to another space in advance, the earth is brought over the holes and seed by the foot. It is asserted by those who have sown wheat by dibbling, that about one bushel is sufficient seed for one acre, and that the produce will be $5 \frac{1}{2}$ quarters per acte ; that is, the produce bears a proportion of 44 to $I$ of the seed sown. ${ }^{*}$

(2329.) Another mode of sowing wheat has a similar effect in the appearance of the growing crop as ribbing with a small plow, and this is accomplished by using the common plow with a single horse, and depositing the seed, anc along with it, if necessary, any species of manure dust, such as rape-dust, in the furrow. The seed is dropped out of a hopper placed in the bosom of the plow, and the quantity is regulated by a grooved axle, made to revolve by a small wheel, which receives its motion by being carried along the ground with the plow. The immediate effect of this operation is to cover the seed-wheat with the plow-furrow, to prevent its being thrown out by the frost in spring in soft and spongy land, and to cause the crop to grow in rows 9 inches asunder. The pulverized manure is sown at the same time and in the sane manner as the seed, out of the same hopper in which a division is formed to separate the seed from the manure, and both fall through spouts, one placed behind the other. Such a drill has already been described by Mi. Slight in (1770) and (1771). The advantages resulting from this mode of sowing wheat on spongy clay soil are, that the horse does not tread on the seed, and the seed requires no covering in by the harrow. It is necessary, however, to caution you in the use of rape-dust and guano in contact with seed, as both are apt to affect the vitality of seeds, without the intervention of a little soil, or the previous mixtare of a little earth. $\dagger$

(2330.) Another mode recommended for cultivating wheat is transplanting. It is proposed to sow a small portion of ground with seed early in the season, and take up the plants as chey grow, divide them into single plants, and transplant them. By thus dividing the plants as they tiller into single plants at 4 periods of the season, a very small quantity of seed will supply as many plants as would cover a large extent of ground. Though wheat no doubt bears transplanting very well, yet as the scheme implies the use of much manual labor, it is questionable if it will repay the expense. The proposed method has been tested by experiment, and the question of comparative ex. pense stands thus: Suppose 440 graing of wheat are sown on the 1st of July, by the beginning of August each seed will afford 4 plants, or in all.................... 1,760 plants.

At the end of August these will produce...................... 5,280 ...

In September these again. ................................

And in November these last will produce .....................

The time occupied in sowing the 440 grains, and dividing and transplanting the produce of them, stands thus :

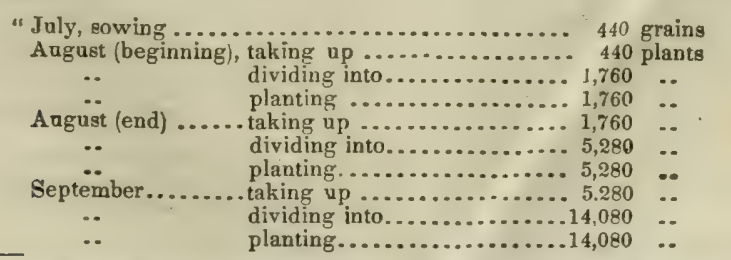

$\begin{array}{rl}\text { Hours. } & \text { Minutes. } \\ 0 & 20 \\ 0 & 20 \\ 1 & 10 \\ 3 & 30 \\ 1 & 28 \\ 3 & 30 \\ 10 & 33 \\ 4 & 24 \\ 9 & 23 \\ 28 & 9\end{array}$

* See Mark-Lane Express for February, 1843. 


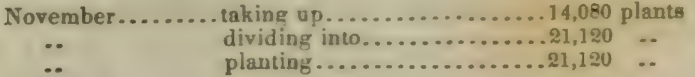

Nearly 13 days.

\begin{tabular}{ll} 
Hours. & Minutes. \\
11 & 44 \\
14 & 4 \\
42 & 14 \\
\hline 130 & $49 .^{\prime \prime}$
\end{tabular}

Of these $13 \frac{1}{2}$ days, $4 \frac{1}{2}$ days may be reckoned for women and boysoccupied in taking ap and dividing the plants, which, at $10 \mathrm{~d}$. per day, will cost $38.9 \mathrm{~d}$. The remaining 9 days are for men trans. planting at 108, per week, 1s. $8 \mathrm{~d}$. a day, which will cost $15 \mathrm{~s}$. more; in all $18 \mathrm{~s} .9 \mathrm{~d}$. per acre. As the saving of seed was estimated at $18 \mathrm{~s}$. 6d. per acre. the expense of transplanting would thas be greater than the saving effected. It appears, besides, from Mr. Palmer's emall but well-conducted experiments, that 10 plants out of 48 died, which is a large proportion, leaving more than 2-5 of the ground blank, while the return of the produce does not warrant the supposition that the remainder would make up the deficiency; the $2 \frac{1}{2} \mathrm{lbs}$ of grain from the space of gronnd experi. mented on is not more than 20 bushels per acre, and still. after adding $\frac{1}{4}$ to this for the destruction of eeeds occasioned by birds, the whole amount, only 25 bushels, would not be a full crop. Taking 2d. an hour as the fair cost of a mau's labor. the cost of transplanting would be $£ 1128$. 9d., to set against the $18 \mathrm{~s}$. $6 \mathrm{~d}$. of seed saved; and supposing the plants to be set as far apart as $1 \frac{1}{2}$ feet, the cost would still be $f_{1} 4 \mathrm{~g}$. 8d. per acre. "In my opinion." says the experimenter. "the only way of executing this plan is to dibble in the seed, 2 grains in a hole, about 4 inches from each other, the plants to be taken up when they are in a proper state, and divided into 5, which would be as many ou an average at that time as could skillfully be made, and then planted out at once. where they are to remain. thus getting rid of all the intermediate dividings. The number of grains of wheat required for 1 rood would be 42,240, which would not exceed 1 pint at fartbest. gr I have ascertained by actually counting that quantity; and, consequently, 1 pint of wheat will plant 21,120 holeg. If each hole gives 5 plants on an average, which may be reasonably expected, there would be at the disposal of the farmer 105,600 plants, a quantity sufficient to plant 5 acres, at $17 \frac{1}{2}$ inches apart. If farmers were to adopt a system of this kind, there is little doubt but it would soon gain ground in the country. Seed for 5 acres, sown in the usual way, would cost about $£ 412 \mathrm{~s}$. 6d., whereas 1 pint of wheat would only cost about 1 penny. The plants may be taken up, separated, and planted again by 50 people in one day; 25 taking up, dividing, and supplying 25 planters, allowing each to plant 4,224 per day, and this might be wholly done by boys and girls at $6 \mathrm{~d}$. per da5; consequently, the farmer's saving, exclusive of the original cost of dibbling 1 rood, would be $£ 37 \mathrm{~s} .5 \mathrm{~d}$. per every 5 acres, as thus:

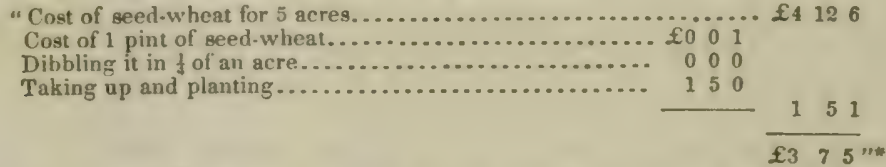

(2331.) The ohject of these various modes of sowing wheat is the saving of seed-a great object vertainly, when it is borne in mind that 1.14 of the whole grain grown in the country is consigned toshe earth in seed. From the statement just given in regard to the transplanting of wheat, it appears that 4 Engliah pints of wheat are capable of supplying a sufficient number of plants for 1 acre. By ordinary drilling, 3 pecks are enough seed for 1 acre, according to a statement of $\mathbf{M r}$. Hewik Davis, whose wheat crops average $4 \frac{1}{3}$ quarters per acre on poor soil, which is manured when the green crops are sown, and by sheep eating green crops off the land. His profits from farming rem to arise solely from the economieal system of managenent he pursues. "The soils I cultivate, he says, "are naturally very poor. Two of my farms are principally gravel, and most of one ha moorish, boggy gravel, exiremely spongy in winter, and very apt to burn in sum. mer, and formerly in the state of, and similar to, the heaths at Bagshot and Blackheath. The other is a very hilly farm. with but few inches of soil, on chalk. These farms have been greatly improved by the ese of the subsoil and trenching plows; but they are only kept in profitable tillage by the general economy of the system."

(2332.) But practice bas always tended against the use of a emall quantity of seed; and the practice is sanctioned by the fact that, though large quantities of seed are usually eown, in many seasons the young plant come up rather scanty. There is a circumstance attending the germin. ation of seed which may account fur nuch of the seed being destroyed by the insect tribe, especially if the weather be such as to cause its germination to he tardy. The circumatance l allude to is the nutritive matter of the seed, which constitutes its largest proportion, speedily becoming fluid after being sown, by abeorption of moistur. then milky in its aspect and sweetish in its taste. In fact, a good deal of saccharine matter is always evolved in the process of germination. Now, as all creatures are known to be fond of sucar, the germinating seeds become a ready prey to hosts of insects constantly existing in the soil; and should the progress of germination be retaried, by auy cause external to the seed, we can t'asily conceive that injury derived from insects may soon render the seed useless fur the purpose $s$ of vegetation; for, if the nutritive matter be extracted, there is nothing to nourish the rudimentary plant, as it is not then sufficiently developed to draw nourishment from the soil.

(2333.) Fig. 432 represents a grain of wheat magnified, and so dissected as to show its component parts. It consists of 2 skins, an outer and an inner- $a$ a the onter, and $b$ the inner, skin; $b$ is where the nutritive matter, called the albumen, is situate, and it constitutes the whole seed, and

- The Gardener's Chronicle for October, 1843.

f Bell's Weekly Measenger for Sept. 1843; and see also Mr. Davis's pamphlot on the same subject. (892) 
is mostly hid beneath the skins; $c$ is the little scale or cotyledon through which the nutritive matter passes in the sweetish state. when the grain is germinating. and by which it is rendered most fit for the nourishment of the little plant; $d$ is the rudimentary plant, at the base of which 3 tubers may be seen, from which as many roots or stens, or both, will afterward proceed; and $e$ is the point where all the 3 -the nutritive matter, the little scale, and the rudimentary plant-are united. All these parts are essential to the growth of the seed; for, when any one of them is absent by accident or design, the seed fails to spring.

(2334.) The seeds of almost every species of plant naturally possess such a structure that only 1 stem can pruceed from them; but in the grasses, and more particularly in the cereal grasses-that is. those which yield corn-there is observed a remarkable departure from this form of parts. In them the embryo plant is usually thickened toward its base, and so organized that, instead of 1 stem. 3 or 4 usually spring fiom 1 grain ; ard. in other cases. a number of stems so great has issued as almost to exceed belief. The peculiarity mentioned may be observed at $d$, fig. 432, which is the rudimentary plant, having 3 projections in the lower part, while in another seed there would have only been 1 ; and from each of these a rootlet or a stem or both. will proceed when the grain is placed in the soil. Fig. 433 represents the grain in a state of germination, 1 shoot $a$ having left the sheath, another $b$ is just evolved, and a third $c$ remains unevolved; and $d d$ are the rootlets. It is this peculiarity of structure which compensates, in some degree, for the loss arising from the destruction of seed. The germination of autumn wheat takes place in about 17 or 19 days. The force of the vegetation of a single seed is so great as to be able to raise a weight of 200 lbs., as has been proved by the process being made to split hollow balls, in the same manner as the Florentine academicians measured the expansive force of freezing water.

(2335.) There is a valuable property in the growth of wheat which I must not omit to mention. which is, that the wheat plant pushes out 2 sets of roots, the one from the seed, and the other from the crown of the plant, from which the leaves originate.The seminal roots as $d$, fig. 433, push out from the seed wherever it may have been sown, provided the depth does not exceed 7 inches: but the coronal roots always push out as at a, fig. 4:33, very near the surface of the soil, not much pxceeding 1 inch below it. The existence of those 2 sorts of tnots clearly indicates the nature of the plant to bear sowing both in winter and spring; and the relative position of the roots indicates the differences of culture which should be given to the plant in winter and spring. In winter, wheat-seed should be pretty well covered with soil, say 4 inches, in order to be placed beyond the influence of frost, but in spring it should be sown nearer" the surface. "The first or seminal root," says a writer in the Georgical Essays, quoted by Colonel Le Couteur, "is pushed out at the same time with the germ-which, together with the farina, nourishes the plant until it has formed its crown." "In the spring, when the crown has become sufficiently large, it detaches a number of strong fibres, which push themselves obliquely downward. These are the coronal roots. A small pipe preserves the communication between them and the seminal roots, and it makes an essential part of the plant; and is observed to be longer or shorter, according to the depth that the seed has been buried. It is remarkable, however, that the crown is always formed just within the surface; its place is the same, whether the grain has been sown deep or superficial. I believe I do not err when I call this vege-

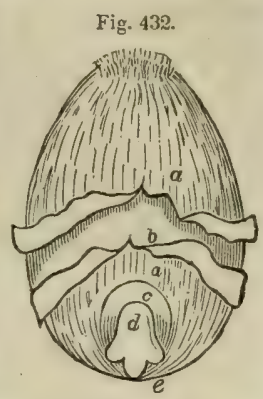

THE COMPONENT PARTS OF A GRAIN OF WHEAT.

\author{
Fig. 433.
}

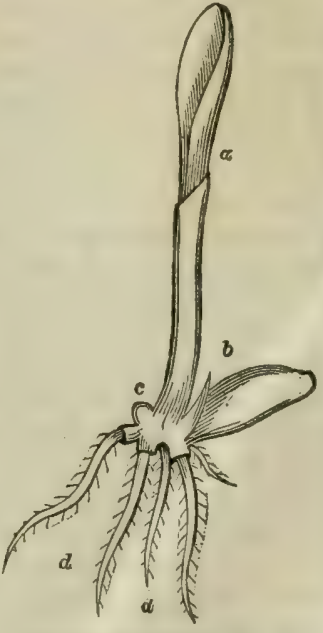

A PLANT OF WHEAT IN THE STATE OF GERMINATION.

table instinct. As the increase and fruetification of the plant depend upon the vigorons absorption of the coronal roots, it is no wonder that they should fix themselves so near the surface, where the soil is always the richest. From an attention to this circumstance, we are led to explain the operation of top-dressings." . . . " Wheat sown superficially." continues the same writer, "must be exposed to the severity of the frost, from the shortness of the pipe of communication. The plant in that situation has no benefit from its double root. On the contrary, when the grain has been perfectly covered, the seminal and coronal roots are kept at a reasonable distance. The crown, being well nourished during the winter, sends up numerous stalks in the spring. On the tillering of the corn, the goodness of the crop principally depends." Spring-sown wheat, having no time to tiller, may therefore be sown rearer the surface. and also thicker than autumn-sown. Viewed in this light. drilled wheat in spring should grow more equally than seed covered in with the harrow ; for, as this writer justly observes, "a field of wheat, dibbled, or sown in equidistant rows by the drill-plow, always makes a better appearance than one sown with the harrow. In the one, the pipe of communication is regnlarly of the same length, but in the other it is orregu. lar, being either too long or too short." "I would say, with Colonel Le Couteur, that the exact depth at which wheat should be sown is a question of local experience, bearing relation to the nature of the soil and climate.

(2336.) As to the natural tillering of wheat, some varieties evince extraordinary powers in that respect. Colonel Le Couteur mentions that "one plant from a single grain of a downy variety, in 1833 , threw out 32 tillers; all prodused ears, with an average of 50 grains to each, or 3600 grains
$(893)$ 
from 1-an enormous produce," as the Colonel regards it, but judicionsly adds, "which no field cultivation could be fairly expected to attain, as it is not the extraordinary quantities which art may produce, either by extreme care. subdivision, and transplantation. that should be brought under the consideration of farmers; but the fair and legitimate mode of husbandry, attainable to all who will devote to its pursuit that industry and inquiry without which their art is a mere mechanical operation, throwing in a little seed into the ground, and leaving Nature to do the rest." *

(2337.) Early sown wheat, when growing luxuriantly in autumn, is eometimes affected by slags in damp weather. Mr. Wentworth. of Harlow, gives this recipe for deatroying them : "Provide, fresh from the kiln, as much lime as will allow 5 bushels to the acre. Slake it 2 days before sow. ing; choose a calm and mild morning; commence sowing early enough to finish before daylight; and 1 man can sow 1 acre per hour, sowing 2 yards at a cast." Turnip-leaves have been recommended to be laili upon wheat, and, as slugs readily take shelter under them, they can thus be collected and destroyed. Of the 2 modes of desuruction, 1 should conceive the quicklime to be the more efficacious, especially in moist weather.

\section{EGGS.}

"Nine honest friend.

Will you take eggs for money ?"

WINTER'S TALE.

(2338.) The treatment which every kind of poultry should receive in autumn is that recommended in spring (1939), to be followed in summer. Geese, ducks and turkeys should only hatch in spring and the early part of summer; for late hatchings of these never produce birds worth rearing, as they cannot attain in the same season a tolerable size and degree of fatness. But common fowls may be hatched throughout the summer, and even to a late period in autumn, and the chicks be reared to a useful state. What can constitute a more delicate dish than a chicken, boiled, roasted or broiled, at any season, but especially when the productions of the garden are in the highest state of perfection, in summer and autumn?

(2339.) Hens are fond of making their own nests and bringing out broods in corn-fields, and at the roots of hedges and shrubs; and uhen hens have their liberty during the duy, it is impossible to prevent their following this inclination, which is common to all, under the best regulated system; and so high a value do I set upon liberty to these creatures, on the score of health and strength of body, and flavor in flesh, that 1 would rather run the risk of losing a few broods in the year, by the fox and polecat making free with a self-set hen or two upon nests of their own seeking in cornfields, than see them cribbed in summer within a court of the largest dimensions.

(2340.) One of the daily cares of the hen-wife in summer and autumn is the gathering of eggs. Whenever a hen is observed to show a desire to lay, a nest should be provided for her in a quiet and convenient place, and if she is directed to it at the commencement of her laying, she will continue to frequent it ever after, if undisturbed; but a nest is not required for every laying hen, as several will lay in succession in the same nest, some hens laying earlier in the day than others; and so tenacious are they of their right to particular nests, that two hens will not unfrequently occupy the same nest at the same time.

(2341.) Every place is not equally suitable for a hen's nest. In other places than the hen-house, hens are not fond of laving their eggs on a level with the ground, though a quiet corner in a shed under some shelter is not unfrequently selected by themselves for the purpose; but they

* Le Couteur on Wheat; and it is but justice to Mr. Lawson, of Elgin, to state that he detected this peculiarity in the germination of wheat, when too deep eown, so long ago as 1827 - as may be seen by referring to No. VI. of the Old Series of the British Farmerg' Magazine.

(894) 
usually prefer to be elevated above the ground, such as in the mangers of stables, or in a trough of a shed or hammel, or upon the top of the wall of a stable, byre, or outhouse, immediately below the roof. When nests are made in such places as hens would themselves prefer, they are much more likely to be frequented than when an opposite determination is taken. One reason, perhaps, for their preference to the manger of the work-horse stable is that in daily picking up morsels of food dropped there by the horses, while the latter are at work in the field, the manger presents a convenient place on the spot when the pressure for laying overcomes them.

(2342.) Ducks are very careless layers, dropping their eggs wherever they seek for food, and these, when discovered by the pigs, are champed up as the most delicate morsels that fall in their way. Common rooks watch for such stray eggs, and carry them off even out of the courts of the steading. To secure the eggs of ducks, the birds should be examined before being let out in the morning, and those indicating hard with egg should be confined in the hen-house till they have laid, and afterward let at large.

(2343.) It should be the hen-wife's duty to visit every nest and collect the eggs from them every day, and the period of creating the least disturbance to the poultry in this duty is the afternoon, say between 2 and 3 o'clock, before the birds begin to retire to roost. A nest-egg should be left in every nest; because it is an old established fact, that all domestic birds, at least, prefer to lay in nests containing eggs to those which are empty. Eggs are most conveniently collected in small hand-baskets; and a short, light ladder will give easy access to all nests elevated above reach from the ground.

(2344.) Whether eggs are retained for use at home, or disposed of to the egg-merchant, it is of importance to keep them in a fresh state for some time. This end may be attained by preventing the air penetrating the pores of the shell, and the yolk coming in contact with its inside. A simple and effectual way of preventing the air penetrating the shell is to rub the egg over with butter when taken warm from the nest; and as simple a way of preventing the yolk adhering to the inside of the shell is to roll the egg from one side to the other every day. This treatment eggs should daily receive, whether kept for your own use or sold to the dealer, and it will preserve them in quite a fresh state for several weeks. But I need hardly inform you that this is not the general mode of treating eggs in farm-houses, whether intended for use at home or for sale, they being commonly kept in promiscuous heaps, and used in the state when taken from the nest; and if they are habitually used on the day they are laid, no unnecessary trouble is required to be taken with them. When trouble is desired to be avoided with eggs, they are sold to the dealers every week in spring and early summer, when most abundant; but the price is then very low, not above perhaps $4 \mathrm{~d}$. per dozen-a price unremunerative for the least degree of care bestowed on fowls. If it is desired to render eggs a remunerative item of farm economy, they should be preserved in a fresh state until the season of scarcity arrives, when, of course, they would realize a fairer price. It is easy to preserve eggs to that season by simply smearing them with butter immediately from the nest, and setting them on their small ends among salt in barrels in a dry room. They may be kept in this manner for 7 months, at least I have found them quite fresh at the end of that period, so much so, that they contained the very milk which constitutes the criterion of an egg being fresh when boiled; and how much longer they would have remained in that state I cannot say, as I never tried the experiment farther. I have heard of an instance (895) 
of eggs packed in salt becoming so salted as to be useless; but in this case the salt might have been damp, and the eggs might not have been greased at all. Both circumstances are material, for without grease air canuot be excluded, and I know that new-laid eggs will soon become salt when floated in brine. Eggs will also keep fiesh in a barrel of limewater; but the dry salt, in a dry chamber, is a much more agreeable material to put the hand among every day. In short, tley may be kept in any way that will exclude the air entering the slıell; but whatever other additional expedient is adopted, that of greasing them with butter immediately from the nest should never be neglected.

(2345.) Hens begin to lay about the begiuning of March, and continae to the beginning of October. They do not lay every day, that is, every 24 hours, some laying every other day, and some missing one day in three. They lay about 2 dozen of eggs at one period, then cease for 2 or 3 weeks. and again lay other 2 dozen, and so on for the number of months mentioned. Of all these months, howerer, they lay most constantly in March and April. After each period of laying they are inclined to sit on the eggs, and when it is not desirable for them to incubate, it is difficult, in most cases, to drive them from their propensity to clucking, as it is commonly called.

(2346.) Many cruel expedients are practiced by country people to prevent hens clucking, such as ducking them in water, dipping them in water for a few seconds, pulling feathers in a particular manner out of particular parts of their body, and such like barbarities - all of which I believe to be ineffectual, at least I never saw a single instance of their success. The only effectual plan I know, without giving bodily pain to the animal-for if it is desired to have hens to lay eggs in preference to hatching chickens, it is requisite to remove from them the desire to sit-is to place them in darkness, and there deprive them of food and water for 2 days and 2 nights, and, in difficult cases, for the third day. The simplest means of accomplishing this is to procure a number of light-made tubs, each just large enough to hold one hen within it when standing on her feet, and to have its top and sides pierced with holes to afford air, but so small as to exclude light, and to give them such an inclination as the hen may not see through them. Such a tub is placed mouth downward over a hen, in a quiet place, such as an out-house, and not in the hen-house. In this position, the desire to sit will be removed from her in 2 days, and in obstinate cases in 3 days. It is not an uncommon practice to whelm an ordinary tub over a number of hens, with one side of its mouth raised a little from ths ground, the effects of which contrivance are to allow as much light to enter the tub as to let the hens see to fight each other, and in many such cases they are removed with their scalps bared to the bone, and even pecked and trampled to death.

(2347.) Neither dogs nor children should be allowed to run after laying hens, as 6uch treatment obliges them to lay their eggs before they are provided with the shell. Guinea fowls are incessant chasers of hens.

(2348.) Ducks are great layers, laying an egg almost every day. They commence at the beginning of April, and cease at the season the bean usually comes in bloom-in July.

(2349.) Autumn is the time to select hens for laying the eggs in the ensuing winter. They should all be young, but of different ages, that a succession of layers may be maintained during the season, as I have mentioned before in (1473), and the food they should receive I have also mentioned in (1939). Like the eggs collected in summer, those dropped in winter should also be smeared with butter when taken from the nest. 
Hens readily taken to the nests made for them at this season, evincing little desire to make them in the fields for themselves. Autumn is the season of moulting with fowls. The only care requisite under this periodic visitation, is to keep the creatures warm at night, for chillness of air may be looked for at nights in October.

(2350.) Pigeons will produce a young brood in every month in autumn, and in this season of heat and abundance of food, both old and young become full-sized and in fine condition. They should be fed in common with other poultry; but though this be regularly practiced, they are fond of going to the fields in search of variety of food. Fields of new-sown peas, oats, barley, and wheat, are eagerly visited by them in quest of grain that has escaped burial by the harrow. Even the turnip-seed is eagerly sought for in a new-sown field; and where the wheat crop is laid by the weather, there they will congregate in flocks, and pick out every kernel within their reach. For wheat and pease they will fly miles to obtain. It is, no doubt, provoking to see corn nearly ready for the sickle destroyed in the field by any kind of animal; but a farmer regards the depredations of his own pigeons in a pardoning mood.

(2351.) Turkeys and geese commit sad havoc in corn-fields situate near the steading, for a week or two before harvest-a sight intolerable to the farmer, not so much on account of the quantity of grain actually consumed, as for that scattered about and trampled down. When corn happens to be growing near the steading, all the poultry should be confined within court-yards for a time, and supported entirely by hand. A few sheepnets stretched over the court-walls of hammels, afford an easy means of confining a large assortment of poultry, and of subdividing them into classes.

(2352.) The egg, being a remarkable object, and produced in such abundance, and so universally esteemed as an article of foud, a few particulars obtained by men of science of its nature and constitution may prove interesting to you.

(2353.) "The eggs of all birds," says Dr. Thomson, "so far as they have been examined, bear a striking resemblance to each other. They consist of 4 parts, first, the shell, which is white in the eggs of the common fowl, and of many other kinds; but it is often colored or spotted of various colors, so as to give it a beautiful appearance; second, the membrana putaminis, a thin, transparent pellicle, immediately within the shell; at the great end of the egg this membrane is detached from the shell, leaving a certain distance between them, which is filled with air; third, the white or albumen, a glairy liquid, consisting of albumen dissolved in water. and contained, like the vitreous humor of the eye, in an extremely thin membrane, divided into cells : fourth, the yolk, a thick and almost solid yellow matter, inclosed in a peculiar membrane ; this membrane, by 2 ligaments, called chalazce, is tied to the membrane of the albumen, and thus the yolk is kept in the center of the egg."

(2354.) In regard to the constitution of these various parts, it appears from an analysis of Dr. Prout, which was later than that of Vauquelin, that the shell of the common fowl consists of

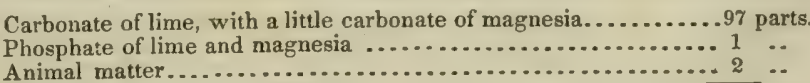

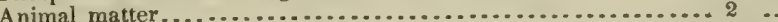

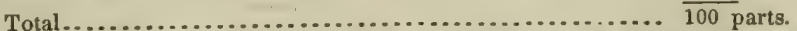

The membrana, according to Hatchett, consists of coagulated albumen. The white, or albumen, coagulates into a firm white solid, when heated to $159^{\circ} \mathrm{Fahr}$.; and when evaporated to dryness, leaves about 14 per cent. of albumen. Dr. Bostock has shown that it contains also a little mucus. The constitution of the white, according to him, is

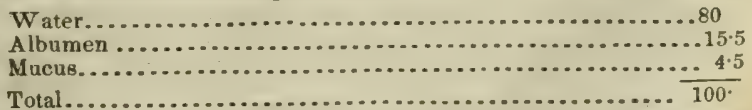

Dr. Prout obtained, by combustion, the following fixed constituents in 1,000 grains of the white of egg, from 3 different eggs:

\begin{tabular}{|c|c|c|c|}
\hline ic acid & 0.15 & 0.18 & grains. \\
\hline acid... & 0.46 & 0.48 & .. \\
\hline ...... & $0 \cdot 93$ & 0.87 & $\ldots$ \\
\hline and & $2 \cdot 93$ & $2 \cdot 72$ & - \\
\hline 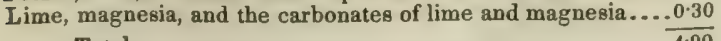 & 0.25 & 0.32 & - \\
\hline
\end{tabular}


M. Mulder has proved that the sulphur and phosphorus are in the state of sulphur and phosphoras, and not in that of acid; and this was to have been expected, from the well known alkaline reaction of the white of an egg. Dr. Prout's analysis of the yolk of an egg wbich was bard boiled in distilled water, and weighed 316.5 grains, gave these rusults:

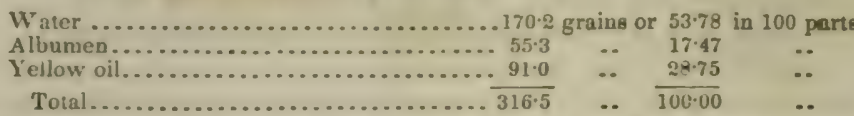

According to Planche, 1,000 parts of yolk of egg furnish, at an average, 180 parts of oil. This oil consists of stearin 10, and of elain 90 parts; the stearin is white and solid, and does not stain paper like oil. He found this stearin and the fat of fowls to agree very nearly. The elain pussesses the character of a fixed oil. Chevreul found a coloring matters in the yolk, the one red, and the other yellore. Lecanu, besides the stearin and elain, extracted from the yolk a crystaline matter, which melted at 29:3 $F$ ahr., and which he considered as of the same nature with cholesterin from the brain. Dr. Prout determined the quantity of fixed constituents in 100 grains of the yolk, by incineration, in 3 different eggs, thus :

\begin{tabular}{|c|c|c|c|}
\hline Sulphuric acid..... & 0.06 & 0.19 & grains. \\
\hline Phosphoric acid..... & 3.50 & $4 \cdot 00$ & $\cdots$ \\
\hline Chlorine...................................... 0.39 & 0.28 & 0.44 & $\ldots$ \\
\hline Potash, soda, and the carbonates of potash and soda..... 0.50 & 0.27 & 0.51 & $\cdots$ \\
\hline Lime, magnesia, and the carbonates of lime and magnesia, 0.68 & 0.61 & 0.67 & $\cdots$ \\
\hline .... 5.34 & $4 \cdot 72$ & $5 \cdot 8$ & Fain8. \\
\hline
\end{tabular}

Whether the sulphur and phosphorus exist in the yolk in the state of acids, or as sulphar and phosphorus, is uuknown. When we compare the fixed constituents of the white and yolk, we cannot avoid being struck with the difference. The white contains a much greater quantity of fixed alkalies than of any other fixed constituent; while in the yolk the most abundant constituent is phosphoric acid. which amounts to from 3.5 to 4 grains; or if we suppose it to exist as phospho. rus, it varies in different yolks from 1.55 to 1.77 grains.

(2355.) The specific gravity o! a new-laid egg varies from 1.080 to 1.090 ; an egg, therefore, is Leavier than sea-water, the specific gravity of which is 1.030. When kept, eggs rapidly lose weight, and become specifically lighter than water. This is owing to the diminution of bulk in the contents of the egg; the consequence of which is, that a portion of the inside of the egg comes to be filled with air. Dr. Prout kept an egg 2 years, and found that it lost weight daily, at an average rate of 0.744 grains. The original weiglit was 907.5 grains, and after 2 years' exposure to the atmosphere, it weighed only 363.2 grains. The total loss amounted to $544 \cdot 3$ grains, or considerably more than half the origival weight. The loss in summer was somewhat greater than in winter, owing, no doubt, to the difference of temperature. When an egg is, therefore, employed as a test of the strength of brine, the newer it is, the stronger is the brine that floats it. The rela. tive weights of shell and membrane, albumen and yolk, are very different. Supposing the original weight of the egg to be 3,000 grains, Dr. Prout found the relative proportions, in 10 different eggs, to be as follows : Shell and nembrane $106 \cdot 9$, albumen $604 \cdot 2$, and yolk 288.9 grains. W ben an egg is boiled in water, it loses weight, particularly if it be removed from the water when boiling, and be permitted to cool in the open air. The water will be found to contain a portion of the saline constituents of the egg. The loss of weight from boiling is not constant, varying from 20 to 30 grains, supposing the original weight to have been 1,000 grains. The quantity of saline matter obtained by evaporating the distilled water in which an egg was boiled, amounts, at an average, to 0.32 grains. It is strongly alkaline, and yields traces of all the fixed principles found to exist in the egg; but the carbonate of lime is most abundant, and is obtained by evaporation in the form of white powder.

(2356.) The source whence are derived the bones of the chick while in the egg, is still an object of research. At the full term of incubation, important changes in the constitution of the egg are completed. "The albumen." as Dr. Thomson observes, "has disappeared, or is reduced to a few dry membranes, together with earthy matter. The yolk is considerubly reduced in size, and is taken into the abdomen of the chick, while the animal has attained a weight nearly equal to tbe original weight of the albumen, together with that lost by the yolk, minus the loss of weight sugtained by the egg during incubation. The alkaline matters and chlorine have diminished in quantity, while the earthy matters have consilerably increased. . . . . . During the last week of incubation, the yoik has lost most of its phosphorus, which is found in the aninal converted into phosphoric acid, and, combined with lime, constituting its bony skeleton. This lime does not exint in the recent egg, but is derived from some unknown cource during the process of incubation. Mr. Hatchett made the curious remark, that in the ova of those tribes of animals the embryos of which have bones, there is a portion of oily matter. and in those ova whose embryos consist entirely of soft parts, there is none. In what way the oily matter contributes to the formation of bone it is impossible, in the present state of our knowledge, to conjecture. Nor can any source of the lime of the bones be pointed out, except the shell; and it would be difticult to determine whether the shell loses lime during the process of incubation."

(2357.) M. Raspail, in investigating the nature of animal albumen by the microscope, as exemplitied in the white of the egg, observes that "the albumen of the pullet's egg is composed of an insoluble and regularly organized texture, which contains in its cells a soluble substance much more susceptible of alteration than the texture is. Chemists had previously acknowledged the existence of an albumen soluble in water, and of another which was insoluble; but they bad not re. marked that these 2 sorts of albumen existed together in the white of eggs, and they had consider-

* Thomson's Chemistry of Animal Bodles.

$(898)$ 
ed this substance as a variety of the insoluble albumen. . . . . But the insolable substance of the white of an egg is rendered apparent only by degrees, and accordingly there is a veriod when it can scarcely be distinguished in this respect from the soluble substance, and this is when the egg is fresh, that is, recently laid. Hence, as I have already pointed out regarding the vegetable textures, the textures are formed by the aggregation of the particles of the soluble substance, or, in other words, the soluble substance is converted by solidification into the parietes of cells. All these circumstances establish a complete analogy between gluten in vegetables and albumen in animals."*

(2358.) Of the nature of egg and seed, the origin of animal and vegetable individuality, and of the natural analogy between them, M Raspail thus expresses himself: "The egg and the seed are cells detached from the texture of the mother, in consequence of an influence of an opposite kind. This influence may proceed from an external body which we call the male, or from an internal cause which we altogether neglect to notice. The egg and the seed may more particularly attract our attention, in consequence of their forms and dimensions; but the slice of a polypus, which becomes an entire animal, and the fragment of a potato, which produces a complete plant, are sufficient to teach us that the generative faculty is preserved by the whole organic system, and that the whole organized being is complete in any one of its cells." $\dagger$

(2359.) The duty on the importation of foreign eggs is fixed by the new Tariff at 10d. per 120, and $2 \frac{1}{2}$ d. from British Possessions. The trade in eggs is carried on to a very great extent in this country. The importation from France is large, and the supply obtained in the west coast of England and Scotland from Ireland is also great. About 20 years ago and upward, £30,000 worth of eggs used to be sent from Berwick-on-Tweed to the London market in the vourse of the year, but since the interference of large importations from France and Ireland, that trade, I believe, has almost dwindled away. The price of eggs is never high in the country, but in towns it is almost always so. In the most abundant season. eggs, that can be relied on as fresh, are never below $7 \mathrm{~d}$. per dozen in Ediuburgh, and in winter, especially at Christmas, when the confectioners use large quantities, they are as high as from $14 \mathrm{~d}$. to 18d. per dozen.

\section{THE POINTS POSSESSED BY THE DOMESTICATED ANIMALS}

\section{MOST DESIRABLE FOR THE FARMER TO CULTIVATE.}

\footnotetext{
"From fairest creatures we desire increase, That thereby Beauty's rose may never die.

But as the riper should by time decrease, His tender heir might bear his memory."
}

SONNETS, BY SHAKSPEARE.

The most difficult branch and the highest aim of farming is the breeding and rearing of live-stock, so as to produce the most perfect animal that shall yield the highest profit. It is very easy to maintain a flock or a herd that will propagate its kind; as the actual condition of many flocks and herds in the country abundantly testifies. It is even easier to do this than to cultivate arable land for the purpose of raising corn ; for the latter demands and must receive more trouble, at all events, if not attention, than a flock or herd of neglected animals, who will keep themselves alive if food be within their reach, and who will propagate their kind even in due season, if the sexes are not kept asunder.

I am not aware that the principles upon which the proper breeding of animals should be based are understood by our farmers ; for I hold that our stock have been brought to their present state of perfection, merely from each farmer exercising his individual taste and judgment-by gratifying his eye and satisfying his mind-and not in pursuance of any fixed principle he is acquainted with on the subject. There can be no doubt, however, that the symmetry, disposition to grow and fatten, and the relative proportions of the different parts of animals, are entirely dependent on laws which govern animal life; 'and could these be understood, so as to render their application easy, the breeder of stock would no longer intrust his success to uncertainty. The botanical physiologist and the chem-

* Raspail's Organic Chemistry. (899)

† Ibid. 
ist have been very dilatory in proposing suggestions to the farmer, but the auimal physiologist has hitherto almost entirely neglected lim. The physician and surgeon, on the other hand, have not; for the veterinarian, now a man of science, administers his prescriptions and performs his operations with the confidence and ease of a proficient. Pity the physiologist should have almost neglected so extensive and fine a field as a breeding and rearing farm presents for his peculiar pursuits, and where the functions of the living and growing structure might so easily be observed, and their effects afterward as easily demonstrated by post-mortem examinations. The results obtained from such investigations would afford invaluable data with which to compare the functions of the human structure; and, fortified by the investigations of the comparative physiologist, the human physician would treat diseases with increased skill. The anatomist acknowl. ed ge's the great importance of Comparative Anatomy to his profession; and the surgeon owns to have received mauy useful hints from the veterinarian, in the treatment of wounds and the conducting of operations of magnitude and difficulty; and so, in like manner, no doubt, would the physiologist also acknowledge the importance of the observations he might make on a breeding-farm, were he disposed to turn his attention to the subject. Meantime the breeder of stock must go on, as he has hitherto done, by the light of his own genius.*

From what I have said of what is known of the principles of breeding stock, you will not expect from me so concise an explanation of them as I have given of the methods of conducting the operations of the field; and were it even possible, I could not find space here for the discussion of so extensive a subject. Suffice it to give you a few of the rules which guide the breeder in the treatment of his stock with a view to its improvement; and for your better ability to follow me in a subject which is yet confessedly in a state of confusion, I have selected a numerous group of illustrations, in whose good points you should have confidence, because they were all faithfully taken from the life, from individuals considered excellent by competent judges.

The great aim of breeders is that their stock shall possess fine symmetry-shape, as it is commonly called-robust constitution-and a disposition to attain early maturity, which insures good quality of flesh, as well as of wool in the case of sheep. Let us consider what each of those properties means, and also the points by which the existence of each is indicated in the animal.

Symmetry or Shape.-The shape is the first object to be attained; for without fine symmetry no animal looks well, however passable it may be in other respects; but, in fact, when symmetry is wanting, so are the other good particulars. In fine symmetry, the outline of the figure viewed, whether on the side or at either end, or from above, should be rectangular. Fig. 273 represents the side view of a fat Short-Horn ox ; and it will be observed that the hody nearly fills up the rectangle $a b d c$ inscribed about it. A fat ox will fill up the rectangle more fully than a lean one; but still a lean ox should have the rectangular outline. But it is not enough for an ox to present the rectangular outline in the side profile only; it should have it in other positions, such as when viewed from behind, as in fig. 274 , where the same sort of outline may be observed within the rectangle $a b d c$. True, this is a different rectangle from the other,

\footnotetext{
* The only physiologists I am aware of who have made observations on breeding atock, were the late Mr. Knight, and his raluable suggestions will be found in the Philoaphical Transactions : and Mr. Walker. whose original views on Physiology have been made public in several works; for as to the value of the experiments of Sir John Eebrighth his scientitic acquirements were not of 80 high an order as to inspire practical men, at lesst, in the accuracy of his observatione, and correctness of his conclusions.
} (900) 
approaching near the square, while the other is oblong. I do not know whether the rectangles of the side and the ends should bear a given proportion to each other, as the outlines of the ox have never, I believe, been subjected to proportional measurement, though these could easily be as. certained by employing an adjusting-frame; but, judging from measurements taken with the view of ascertaining the weight of beef in oxen (1988), it is probable that a fine symmetry gives, on the side profile, a rectangle of double the length of that of the end profile. The end profile, viewed from behind, gives a rectangle equal, of course, to the depth of that of the side profile. Another point of a well-proportioned ox is that the breadth across the hooks from $a$ to $b$, fig. 274 , should be equal to the depth from the hook $a$ to the hook $c$; that is, the hind profile should be inseribed in a square. Now, an ox may be rectangular in its side, and across its rump, and yet be of different shape across its shoulders, when viewed from the front of the animal-it may, for example, be narrow at the top of the shoulder, and wide below at the brisket. In such a case the ribs will be flat, that is, fall quickly downward, and not project square from the back-bone, as they always do in fine symmetry. Fig. 275 shows the front end of a fat round-ribbed ox filling up the rectangle; but though the top of the shoulder fills up the rectangle as well as the lower part of the body across the shoulder-points $e f$, yet the rectangle may not be a square; that is, the ox may be narrower in front than behind; and this is no uncommon case in many breeds of cattle in this country, and many breeders maintain that this form constitutes perfect symmetry, at least for certain purposes, as for milk. This mode of reasoning, however, is not satisfactory; for the idea conveyed by perfect symmetry is an equilibrium of parts. Now, we cannot conceive an equilibrium of parts to exist in an ox whose fore-end is narrower than its hind; and where this disparity is found there is evidently something wrong in the symmetry. For observe fig. 276, which gives the top view of the body of an $0 x-a$ view which is never seen unless sought for on purpose. Here, again, is the long rectangle as of the side; but when an ox is narrower before than behind, this figure would not be a rectangle, but a trapezium-a figure no way associated with symmetryso that, for fine symmetry, it is not enough to have the front outline filling up a rectangle, for that rectangle should be equal to that of the hooks, as may be seen in comparing figs. 274 and 275 ; and as we have seen, in fig. 274 , that the breadth of the hooks is equal to the depth of the hock, and $i t s$ rectangle is therefore a square, so we see, by fig. 276 , that the breadth and length of an ox, when seen from above, forms a rectangle equal to that of its side, as seen in fig. 273. Perfect symmetry in the ox, therefore, implies that all the horizontal, as well as vertical lines inscribing its outlines, are respectively parallel to each other; and that these two sets of parallel lines are at right angles to one another. On dividing the entire area of the side view of an ox into 5 parallel and horizontal parts, $\frac{3}{5}$ will besfound to be occupied by the body, and $\frac{2}{5}$ below the body.

This is the abstract view of symmetry, as applied to the ox; but it is not to be supposed that every ox fulfills these conditions; for, even in the figures referred to above, it will be observed that in the side view of fig. 273 the brisket falls below $b$, and the flank rises a little at $e$. The brisket $h$ may be observed to drop below the horizontal line $\dot{c} d$ in the front view of fig. 275 ; and in the hind-view of fig. 274 , it frequently happens that the hocks, $c$ and $d$, do not descend so far as to constitute a square figure with the hook $a b$. Still the aim of the breeder should be to attain all the points of the abstract model, and he should never rest satisfied until he attain them. (901) 
Nevertheless, it must not be imagined that the configuration of any ox in any view should fill up the angles of the rectangles, inasmuch as the invariable roundness assumed by the animal frame forbids such a form, which would, in fact, destroy the beautiful blending of curved lines abounding in the body, and deprive us of the highest enjoyment in looking at a symmetrical animal.

Of the states of cattle on a farm, that of the full-grown ox approaches nearer than any other to perfect symmetry of form. If you compare the picture of the ox in Plate VI., though that animal was then only 1 year 11 months old, with that of the bull or the cow, by imagining a rectangle inscribed around each figure, you will find his symmetry more correct than that of the others. The bull in Plate XXXII. has the brisket drooping even lower down than the ox, while his neck rises in a crest behind the head. In Plate $\mathrm{XV}$, though the side view of the cow is pretty similar to that of the ox, the hind view is proportionally broader across the hooks, while the front view is somewhat narrower across the shoulders. If the broad hook-bones, with the narrow chest, are not entirely occasioned in cows by calf-bearing, the disproportion between them is, at all events, greatly increased by it.

So far in regard to the symmetry of the outline of the ox; and as to the filling up of the outlines, the remarks offered in (1309) will apply to cattle in all states, though there especially referring to the points of a fat ox. There should be a straight back, round ribs, and full muscles in every state of cattle, and the objectionable deviations from these points, mentioned in (1311), are as much to be deprecated in the bull, the cow, the heifer, and the calf, as in the ox.

Apply the rectangle to the figure of the sheep, and it will fit the more closely the nearer the animal approaches to perfection. In fig. 462, the rectangle $g h i k$ is applied to the new-clipped body of a Leicester tup, and though an old tup, and deviations from correct form may be expected in old age, still the figure fills up the rectangle very well. Apply it over the wool to the picture of the Leicester tup in Plate XXXIII., and it will fit still better; and carry it to the picture of the South Down in Plate $\mathrm{XIV}$, and it will still apply; though in this particular animal the wool grew more than usually rank upon the top of the rump. Even the figure of the lamb in the fig. 444, will bear the application of the rectangle. In regard to the end and top views of the figure of the sheep, the ribs of the Leicester breed are so very much rounded that they form curved lines down the sides of the rectangle, inscribing the hind and fore profiles; and along the sides of the rectangle, inscribing the view of the back from above ; still the flatness across the back, and the straightness across below the chest, fill up the lines of the rectangle. In other breeds, such as the Black-faced and Cheviot, applied.

To the figure of the horse the rectangle may also be applied, as the picture of the draught-gelding in Plate VII. may be imagined to be inscribed, and of this class of stock the gelding is the best state for comparison, as the $(1 \mathrm{x}$ is that of cattle. The picture of the draught-stallion in Plate VII., will hear the same application; though in this, as in all cases of stallions. the neck rises to a high crest. *** But the end views, in the case of the horse, bear different proportions to those of cattle, the hind view being always broader, and broadest in the mare, approaching more to the square, or like that of the ox, than the front view, which is always narrow. The square-like hind view is very well seen in the left-hand dark figure of a (902) 
mare, in Plate XVII., and the narrow front view is as well observed in the right-hand dark figure of a draught-horse, Plate VII. The comparative breadtlis of the hind and front views approach nearer each other in the draught-horse than in any other breed; his drawing powers lying in the shoulders, the muscles there become developed to a great degree, while, in the saddle-horse, the propelling power is in the hind-quarter, where the muscles become developed; as the fore-quarter is only required to support the fore-hand of the animal in action, the muscles there are all light. For these reasons, it is obvious that the view of a horse from above will not form a rectangle but a trapezium. In perfect symmetry the void below the body is of the same depth as the body to the top of the rump; the length of the body from the shoulder-point through the center of gravity of the horse to the hams is two times the depth of the body; the length of the neck to the withers is equal to the depth of the body from the withers; and the distance from the fore-fetlock to the elbow-joint is the same as from the latter point to the withers.

There are peculiarities in some of the points of the horse which deserve to be mentioned. A horse with ears set high on the crown of the head is of lively temperament, but is hasty of temper, and easily made afraid; while a horse with ears set wide apart is dull in action, but sagacious, and easily taught.

Following the same rule, the rectangle will be found to apply to the shape of the pig as to the other domesticated quadrupeds, as may be seen by $a b d c$, in fig. 434. The end views of the best formed pigs are quite

Fig. 434.

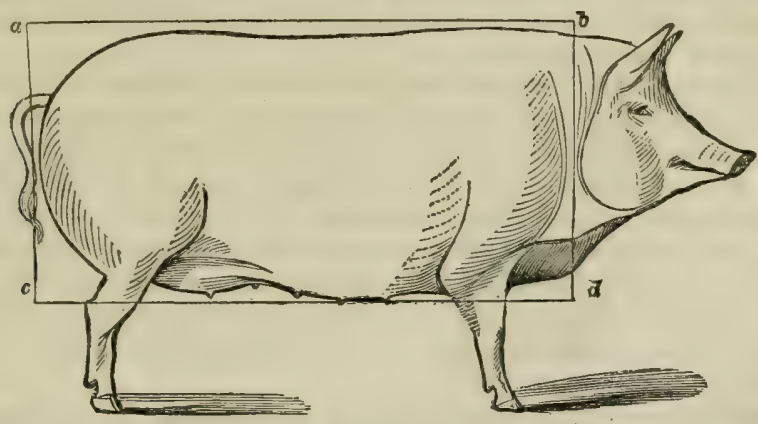

THE RECTANGLE TO ILLUSTRATE THE SYMMETRY OF THF: PLG.

rectangular, though the generality of those met with in the country have a tendency to a larger rectangle in the fore than in the hind view. The view from above is also rectangular, except in the case of the pigs having thick shoulders.

Robustness of Constitution.-Having obtained a good shape, the next object of the farmer with his stock, is to impart to them a strong constitution, that is, to impart to them physical powers to do their work with ease, to eat their food with good appetite, to digest it within a reasonable time, to feel no fatigue with necessary daily exercise, and to withstand the weather, whether hot or cold; in short, always to enjoy good health, and be in a growing condition. The following are indications of robust health which cannot be mistaken: The skin loose upon the body, feeling soft and mellow, and covered thickly with long soft hair. The eyes full and clear, and in the case of cattle, sheep, and pigs, the skin of the nose always bedewed with moisture. The bones of the leg strong, broad, and flat, with the (903) 
sinews thick, strong, and distinctly developod; the whole being closely covered with the skin. This condition constitutes what is termed clean limbs. The horn of the feet and horns smooth and shining, and indicating healthy growth at its junction with the hair. The hair of the tail in cattle, and of the mare and tail in horses, long, shining, and with a tendency to crisp; the wool of sheep waved, greasy, interlaced, and of fine quality.Along with these physical properties, the animal spirits are alive to every passing event, the senses acute, and the instinct sagacious.

All these indications of a sound constitution are obtainable by selecting parents which possess them; and they are sustained by kind treatment, comfortable lodging, and aluundance of good food. Neglect of a proper selection of parents will produce, perhaps, the very opposite results. The skin will become thin and corered with scanty hair and open wool. With such a covering, the animal will easily be affected by the least change of weather, be overcome with the heat of summer, feel uneasy in the cold of winter, and be chilled by every shower that falls. A very small bone, however clean, is always accompanied with reduced size of carcass, though indicative of great disposition to fatten. Should the bone become thick and round, it gives a clumsy form to the limbs and head, and is invariably accompaniel with dullness of spirit, and in the horse, in particular, with want of action. Those conditious of the skin and bone are not so much objectionable in themselves, as hurtful in their consequences. A thinskinned and a thick-boned animal is ill to maintain in condition. Thinskinned animals are easily affected by the weather; a fit of indigestion in consequence frequently overtakes them, and their condition alternates between worse and better; they are, in fact, tender in constitution. Thickboned animals never seem to relish their food, and show carelessness about everything that concerns them.

Disposition to attain early maturity.-But the farmer's aim is not confined to a good shape and robust constitution; there must be a fineness given to every point-every part must be finished off, as it were, with a polish. This fineness can only be superimposed by parents derived from a race which have long possessed all the fine properties-indiriduals whose pedigrees can be traced-whose breeding is accounted pure. No matter whether the breeding be of the plebeian caste of the draughthorse, or of the aristocratic family of the racer,-nor whether the animals be horses, cattle, or sheep; the breeding of all should be pure of its kind.

The immediate effect in employing parents of pure breeding, is not so obvious upon the carcass as upon the extremities. The head and limbs first become finer; the fat disappears from them; the muscles expand into a thin, broad form; the tendons increase in strength; the bone becomes harder and of finer quality; the blond-vessels large and full of blood; the skin thinner, and drawn more tightly orer the bone, so as to exhibit its irregularities, and the tracings of the blood-ressels distiuctly; the hair is smouther and closer; the nostrils more expanded; the eyes more prominent and clear; the ears thinner, more capacious, set higher upon the head, and more quickly moved about; the action of the limbs quickened; and the animal spirits raised. All these changes may take place without materially affecting the shape of the body or the strength of the constitution; but the improvement of the extremities is rapidly followed by that of the body; the skin, though not thinner of itself, floats upon a thicker mass of cellular tissue, which imparts to it the agreeable sensation of the touch. The hair multiplies in numbers, becomes finer in quality, more fixed in color, longer, and softer. The proportion of fiesh to bone increases. (904) 
The fat is more generally and equally diffused over the body. The texture of the muscles is finer and firmer in the fibre, and the tissue between them becomes loaded with fat. In a word, such a total change is effected upon the entire animal, that from being coarse, dull, clumsy, and sluggish, it becomes fine-spirited, handsome, and active ; and as it improves in personal appearance, so it increases in its tendency to grow, and to come sooner to maturity in stature and condition.

Selection of Parents.-You must not imagine, from this uninterrupted description of the improvement of parts in animals, that all those changes are, or can possibly be, effected during the lifetime of one individual parent. The entire of those changes can only be effected in the course of generations; but as all domesticated animals produce rapidly, that is, within the course of every year, it is possible to effect great improvement in the offspring during the lifetime of a female parent, by employing a better male every year. To hasten the improvement more rapidly, better parents of both sexes may be chosen as soon as the points of the progeny show themselves, and which are appreciable in 2 years.

Of the two sexes, the properties of the male are more obviousiy imprinted on the offspring than those of the female; and it is on this account that males are in most request among breeders for the improvement of their stocks. High prices have been given, and high premiums are annually offered, for superior males, whether stallions, bulls, or tups; and it is fortunate for the more rapid extension of the improvement of stock, that the influence of the male thus bears sway in the propagation of his kind, as by permission of polygamy one male may serve many females, and of course extend his infuence in the exact proportion to the number of the latter; whereas a female produces usually 1 in the course of a year. A stallion serves from 60 to 80 mares, a bull 60 cows, and a tup 60 ewes in a season, not once or twice only, but as often until the female prove with young. Generally the female conceives at the first service of the male, and at all events at the second; but should her desire continue beyond that time, it is better to witharaw her from breeding altogether, than run the risk of having a late progeny, or none at all; for a late calf, lamb, or foal, loses 1 year of its progress, compared with its earlier born companions. But the part which the male and female respectively undertake, in the improvement of the progeny, differs widely, and is entirely dependent on their state of breeding-the head and extremities being improved by the highest, and the carcass and procreating powers by the lowest bred. The highest bred imparts the small head, prominent eyes, thin ears, wide nostrils, clean limbs, full blood-vessels, action, spirit, and intelligence; in short, all the parts which go to develop the mental qualities; while the lowest bred improves the shape of the carcass, by straightening the baek and rounding the ribs, extending the muscles, laying on the fat, enlarging the capacity of the pulmonary organs, and decreasing the size of the abdominal. On distinguishing the parts more immediately imprinted by each parent, it is obvious that the effects of the highest bred are more striking than those of the other. Hence, a fine head, well set upon the neck, a lustrous eye, a gay look, an engaging manner, and free action, are more readily appreciated than a fine mould, sound constitution, touch, and disposition to grow.

Few farmers commit a mistake in the choice of the male for improving their stock. Breeders themselves pay particular attention to the production of the male, and farmers who purchase or hire males never grudge paying a high price for them; and hence the male-breeding market is always at a premium. But many mistakes are made by breeders in the 
choice of the females to breed from. In the case of horses particularly, any sort of mare is considered good enough to produce a foal, and if she happen to be unfit for work, or has met with an accident, such as having swung her back, or has a bad leg, she is the one selected for breeding the future labor-stock of the farm. 'The best stallion, it is true, will be put to her, most probably the prize-stallion of the local agricultural show ; but as to the mare herself, it is considered a great sacrifice of physical power to breed from young fresh mares. Now, in acting thus, the farmer commits a fatal blunder; he is depriving himself of the use of superior farm-horses, which would not only work with ease to themselves and satisfaction to him, and at the same cost of keep, but would do him credit wherever they went. Instead of pursuing this system, he should select 1 or 2 of the best mares in his possession to breed from, and if he has none possessing youth and beanty of mould, let him buy 1 or 2 at any price, if such are to be purchased. Let them not he under 5 years of age when the horse is first put to them; for they will not have acquired their full stature until that age. From that period let them bear a foal every year till they attain 12 or 13 years, when they should cease to breed; for old mares, any more than old females of other classes of animals, cannot produce a vigorous progeny. For those 7 years the fresh young mares, stinted to the best stallion that can be secured, will each produce, and bring up, a foal every year, and perform, at the same time, their part of the work with ease. Such foals will be strong in bone and constitution, and be always in high condition, because they are the offspring of young mares themselves, high in condition, and overflowing with milk; and having been brought up together will work better together. I speak not in this tone for the purpose merely of condemning the practice usually followed by farmers in breeding farm-horses, but having myself tried the system I recommend, I can do it with confidence. I purchased from a dealer a very excellent Clydesdale mare in St. John's Market at Perth, for $£ 42$, a large price for the time. She was 5 years old off, and was altogether such a mare, for mould and strength, as is seldom to be found in a market. Next year she was put to a prize stallion, also of the Clydesdale breed, and bore a foal every year till she reached 10 years of age, when, much to my disappointment, she ceased to breed. Her first 2 foals were fillies, and, when 4 and 5 year's old, were sold at the sale, when I declined farming, for $£ 108$, to convert into brood-mares. Her other 2 foals, colts, at 4 years old, realized $£ 38$ and $£ 44$. I had other 2 mares which began to bear foal at 7 years of age, 1 of which bred draught-horses, which realized from $£ 35$ to $£ 40$, and the other was put to a coaching-stallion, and produced excellent harness-horses ; 1 of them, a mare, was purchased by a friend in Ireland, and proved one of the fastest goers in harness I ever saw. I am perfectly certain the same results will be realized everywhere by breeding from excellent young mares; and though 3 mares out of 10 horses, which wrought my farm, bore foals every year, the work never fell behind its season; and they had as rough and heavy work to do for several years, while improvements were in hand, as could be encountered on any farm. The system pursued in regard to the breeding of cattle and sheep is generally much better than that for horses, though I think that cows are not generally so well solected as they should he; and one reason is this: whenever a cow happens to be a good milker, she is kept to breed as long as she is worth keeping for that purpose, without regard to any other point of excellence; and her calves may be good or bad, in proportion as the points of the bull which begot them are so. Those who keep a stock of cows for breeding bulls, of course, do not follow this haz(906) 
ardous plan of producing valuable calves; but I believe by far the greatest number of cattle bred in this country are produced in this careless manner; and the simple recital of the system is quite sufficient to account for the great number of inferior cattle to be met with in all our public markets.

The system of breeding I have recommended is applicable to every kind of stock; but modifications are allowable in it, and in fact expedient, according to the particular object the breeder has in view. If his object is simply to breed cattle and sheep for ordinary markets of fat and lean stock, a useful lot of cows or ewes, with a good tup or bull, are all that are requisite; and once having obtained a desirable stock of either, and not wishing them of finer quality, his solicitude will be confined to sustaining their character by preventing the least tendency to deterioration. In such a case the females are commonly bred by the farmer himself, and the male is purchased from a hreed of superior class to his own. So far the practice is good; but when a good cow, or a lot of good ewes, of the same or superior character as the stock itself can be picked up now and then, the opportunity should not be lost of infusing a fresh strain of blood into the stock. A frequent change of the male is advisable in such a system, as the stock will soon become too near akin to him. On the other hand, those whose professed object is to breed animals to propagate their kind, must bestow great care and skill to sustain their breeding-stock in the highest state of perfection. The least defect in the female, whether arising from accident or inherent weakness, should be the instant signal for her removal from the stock, and as to the male, the very best that can be found should be purchased at any price. The best male in reference to the particular case may not be the best animal of the stock from which it is desired to purchase, because it should preëminently possess points which will either improve or sustain those of the females which he is destined to serve. The properties, therefore, which a male should possess are entirely relative and not absolute; for absolutely good points ought to be possessed by the females before the breeder should attempt to produce breeding-stock from them. To manage this part of his business well is a very difficult task for the breeder; and a single mistake committed in this respect, for a single season, may cause him more trouble to rectify, and incur greater loss than if he had been content with his own stock in the state it was. It must be owned, however, that whenever a breeder discovers a defect in any point in his stock, his desire to remedy it is natural; and whenever he finds an animal superior to his own, it is as natural he should endeavor to possess it. If, for example, he thinks his own stock somewhat slacker behind the shoulder than they should be, the remedy, he conceives, is to use a male which is free of that deficiency. The usual practice is to select a male for this purpose which is rather full behind the shoulder; because, what more natural than to fill up a deficiency with a redundancy? Such an expectation, though natural enough, may lead to unexpected results; for the use of the redundant point may give such an impetus in the strock to rectify their deficiency, that its tendency to fill up may proceed too far, even in one generation, and cause redundancy where there was deficiency before; but this is just the result which ought to have been anticipated, if there is any truth in the breeders' maxim that "like begets like." The employment, therefore, of a symmetrical shoulder to rectify a deficient one is the practice most consonant to reason and principle ; for what morc is wanted than to fill up the deficiency behind the shoulder; and how should that be best attained but by using a model which is exactly in the state which you wish the deficiency to assume? The (907) 
want of forethought to consequences of this sort has been the cause of deterioration to many a good stock. Too many farmers attempt to produce breeding-stock, and they are tempted to proceed with the system as long as they observe the progeny improve upon their parents; and as long as they are observed to improve, purchasers will be found to pay good prices-for they like to purchase from a thriving stock-till a point is reached beyond which improvement does not succeed; and this is considered the point of perfection, though it may be very far short of it. The breeder's skill may be unable to carry him farther; and, on account of his want of skill, will be induced to present his breeding-stock to the attention of other breeders with the greater earnestness. Herein is concealed another source of error; for it is clear, that as long as a stock is itself far short of perfection, its offshoots cannot afford a certain means of improving other stock. Trial may be made of it; but the result may be disappointment to the purchasers, and disgust to the self-sufficient breeder himself. One circumstance alone, I conceive, would justify a breeder in offering imperfect stock for breeding, which is, being situate in a country where crossing with other breeds might be carried on with advantage. The conclusion of the whole matter, then, is that a stock producing offshoots fit to breed from should bave arrived at perfection, at least to such a degree of perfection as the best stocks known; and the object of the owner of such a stock should not be so much to improve its best animals-for that seems impossible-as to improve the inferior, and sustain the quality of the best; and before a stock can be brought to that state of perfection, the pedigree of its best animals-for no stock contains all its animals equally good-might be traced back for many generations. Doubtless this is a severe criterion by which to judge the character of a breeding-stock; but when it is considered that its members are preferred with a view to improve, or at least sustain, the breeding of members of another stock equally well bred as itself, it is necessary to fix a high standard of comparison, and nothing short of this will afford satisfaction. There are many stocks of Short-Horn cattle and Leicester sheep whose character will bear the strictest scrutiny by such a criterion.

Breeding in-and-in.-No wonder high-breeding produces such an improvement in stock as to zender the head small, fine and beautiful, the extremities elegant, the form handsome, and the disposition so accommodating as that the animals grow and fatten without feeling disturbed at what passes around; in short, become so prepossessing as to make their owners mistrust the stocks of others, and employ only their own to increase its own numbers. It was this feeling which actuated Bakewell to breed only from his own stock, after he had brought the Leicester sheep and Long-Hurn cattle to perfection. For a time Mr. Mason, of Chilton, pursued the same course; and there are breeders in England at the preserit time who maintain that it is the best system, and will follow no other. Perhaps a stock brought to the highest state of perfection, and at the same time possessed of sound constitution, may be supported free of deterioration for many years by the peculiar skill of its owner; and I can conceive a high-bred stock, full of young blond, such as Bakewell's was during his whote lifetime, to be increased and supported by its own members though bred in-and-in, that is, supported by near kindred or consanguinity. There was one valid reason for Mr. Bakewell employing only his own stock, which was, that there was no other so good as his own to select from; and it would have seemed extraordinary in him, of all men, to have employed any animal of acknowledged inferiority to his own; but I suspect no such liberty may be taken, with impunity, with a stock as (908) 
highly bred, but not so youthful in blood. At all events, many instances have occurred in which many fine stocks have been ruined in character, and have entailed irreparable loss on their owners simply by being bred in-and-in. The immediate effects of employing parents nearly allied by blood to propagate their kind are remarkable. The bone becomes very small, of condensed texture, and fine quality. The skin is so thin as to receive the appellation of papery, and so open of texture as to be sensible to the least change of temperature; and hence animals bred in-and-in are very susceptible of catarrhal affections, and on which account they are liable to consumption and clyers. The carcass is much reduced in size, and the disposition to fatten increases to such a degree that the animal may be said to be always in a condition to be slaughtered ; and it is, perhaps, this tendency to fatten, which has proved the great inducement with many breeders to tolerate the in-and-in system. The hair is short, smooth, and thin-set, and the wool short, thin-set, and watery; and both hide and fleece lose a large proportion of weight. The body assumes a change of form, the barrel being beautifully rounded, but seems stuffed, as it were, within the skin. The extremities are very fine, the head and hoofs small, the ears thin and broad, and the head of the sheep is almost bare of hair, of a blue color, very liable to be scalded by the heat of the sun, and attacked by the fly. The necks of both cattle and sheep are thin, and droop with a downward curve from the head to the top of the shoulder. The points just enumerated show the unprofitable state into which a stock may be brought by being bred in-and-in. Mr. Mason's fine ShortHorn stock latterly showed symptoms of the bad effects of this system; and Mr. Robertson's stock at Ladykirk, which contained at one time by far the finest Short-Horns in Scotland, suffered after his demise from the same cause, as was apparent on the animals presented at the sale which dispersed them. Only cattle and sheep have been subjected by farmers to be bred in-and-in, for their draught-mares are usually covered by stallions obtained from a distance; and of cattle and sheep, the injurious effects of the system have only been observed in Short-Horn cattle and Leicester sheep. The injurious effects of the system have been felt, it is true, in the racing-stud, and are evinced by the racers of the present day being unable to carry heavy weights, and run the long distances of the horses of old. At present nothing but speed is regarded.

Now, that high-bred stocks exist in every district of the kingdom, there is no excuse for pursuing the in-and-in system of breeding; and the attempt is the more inexcusable from the remarkable fact, brought to light only since the distribution of high-bred stock, that its progeny, after being distributed for a time, may be brought tngether to propagate their kind, and their offspring will exhibit no symptoms of in-and-in breeding. Such a result would seem to indicate that change of soil and situation renovates the animal as well as the vegetable constitution.

It may be proper to mention what relations are considered allied in blood, in breeding in-and-in. Connection of the sire with his grand-dam, dam, and sister, is improper. So it is even with his aunt, niece, and cousingermain. One should imagine that a breeder would feel repugnance at connecting so near a consanguinity as the former; yet the union is too often permitted to take place in the latter cases.

Crossing.-The union of different breeds of the same sort of animal is a favorite scheme with many breeders, and, under certain conditions, produces good results. Those conditions are, that the male employed in the crossing shall have the superior breeding of the 2 parents, and that the situation in which the cross-progeny shall be brought up shall be suitable to (909) 
it. The first condition is usually complied with, but the second is as commonly disregarded; and the cunsequence is, that the crosses attempted to be brought up in situations quite unsuited to their nature have proved a failure.

In the crosses commonly attempted in this country, among cattle the Short-Horn bull, and among sheep the Leicester tup, have been employed to serve the ordinary breeds of cattle and sheep. 'The effects have proved satisfactory; for though the progeny could not but be expected to be inferior to the sire, they are superior to the dam. The effects are: an enlargement of the carcass, a finer skin, longer hair and wool, cleaner bone and finer head, and the disposition to fatten greatly accelerated-all of which are superior to the ordinary points of the breed; but, of course, the better the dam is, the more decidedly improved will those points be. In effecting such a cross, it has been found that the higher bred the male is the finer is the cross; that is, the nearer will it approach his properties; and even an over-bred male, that is, one showing symptoms of having been bred in-and-in, may be used with advantage in crossing. Where a superior cross-male happens thus to be produced, a strong desire is evinced by the breeders to keep him entire for service, and to use him as a sire, instead of expending money in the purchase of a high-bred male. A more short-sighted step than this cannot be taken by a breeder, because from such a male he lias no assurance that the progeny will be superior to the dam. Indeed, he has no guaranty of what the state of the progeny will be at all, for it may be worse than either sire or dam; and if such a disappointment overtakes him, he has himself to blame, having left the whole matter to chance. The employment of a high-bred sire, on the other hand, will never lead to disappointment, as the progeny will assuredly be superior to the dam. It is this assurance which affords much satisfaction to the breeder of high-bred stock, by which he can anticipate the quality of his forthcoming young stock; and it is with high-bred stock alone that the maxim of "like producing like" is realized. Nevertheless, there are situations in which high-bred stock cannot be maintained as a brecding stock, and in which nothing but crossing can be practiced when improvement is desired; but the desire for improvement has been carried by some breeders beyond the bounds of prudence; they have crossed the Black-faced ewe with Leicester tups, in situations where the enlarged lamb has been unable to subsist in winter; and on this account the policy of changing the Black-faced breed of sheep in high localities seems doubtful. In lower situations, the Cheviot ewe, which inhabits the middle range of green pasture, may be crossed with the Leicester tup with advantage. Every crossing, however, should be prosecuted with caution, because the result may overstep the intentions of the breeder. It is clear that if the crossed stock is retained as females, which, in their turn, are served by high-bred males, the time will arrive when the character of the original stock will be entirely changed, and become unsuited to their native climate and pasture, and will, in fact, have become the same breed as their highbred sires. It is quite possible to originate a race of Short-Horns and Leicester sheep any where suited to their nature, by constantly employing a high-bred bull and tup to serve cross-bred heifers and gimmers, generation after generation; and were this practice generally adopterl, the time would arrive when the original breeds which were crossed wuuld disappear altogether. Such a result would prove injurious to the breeder himself, inasmuch as the pasture would be unsuited for the stock he had caused to be produced; so that his best plan is to preserve the original breeds in the higher parts of the country, and take the crosses to the low (910) 
country to be fed off. The temptation of larger profits has already caused the Cheviot to drive the Black-faced breed from the lower pastures to the highest, while the cross-bred Cheviot, with the Leicester, have descended, on the other hand, to the low country, and there have met the true bred Leicester. This result, upon the whole, has done good, as it has increased the quantity of mutton in the market; and the skillful pasturage which the hills have received since a regular system of breeding has been introduced, has caused them to yield z larger quantity of finer grasses. The crossing of the Black-faced sheep has undergone a change; the Leicester tup is too heavy to serve Black-faced ewes on the hills, and to bring those ewes to the tup in the low country is attended with trouble and expense. Instead, therefore, of the Leicester tup being so employed, the Cheviot tup has been substituted; and though the cross is inferior-for nothing can exceed the beauty of the lamb produced between the Blackfaced ewe and Leicester tup-it is a good one, and has enlarged the Blackfaced mutton. So long as crossing is conducted with the breeds in their natural state, it will go on without confusion, but the moment cross-bred tups are employed as improvers of stock, their interference will produce confusion in the crosses, and throw discredit upon crossing altogether.

I purpose giving a short description of the animals whose portraits are given in the Plates illustrative of this work, and shall make such remarks on the form of the animals as to give you an idea of their leading points, whether good or bad. In order to render reference to the figures in the -Plates more easy, wood-cuts of their points have been provided, that they may be more distinctly indicated.

Horses.-Among horses I shall take the draught-horse, fig. 435, and Plate VII., as the standard of comparison. This gelding is of gray color, was bred by Mr. Curry at Brandon, in the county of Northumberland, and is the property of Messrs. Howey and Co., the great carriers from Edinburgh into England. He is not a thorough-bred Clydesdale, having a dash of the coaching blood in him, a species of farm-horse very much in use on the Borders, and admired for their action and spirit. This gelding exhibits such a form as to constitute, in my estimation, the very perfection of what a farm-horse should be. His head $a$ is small, bone clean, eyes prominent, muzzle fine, and ears set on the crown of the head. His neck rises with a fine crest

Fig. 435.

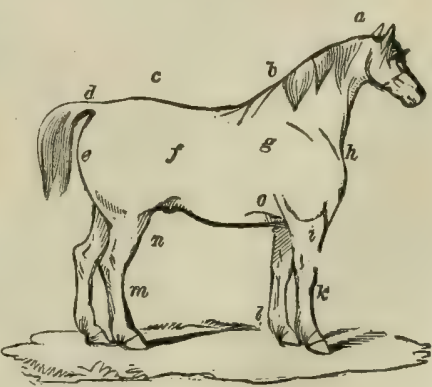

THE DRAUGHT-HORSE along the mane from the trunk $b h$ to $a$, and tapers to the head, which is beautifully set on, and seems be borne by the neck with ease. His limbs taper gradually from the body, and are broad and flat; the knee $k$ is straight, broad, and strong, and the fore-arm $i$ broad and flat-all excellent points in the leg of a draught-horse, giving it strength and action. The back of the fore-leg, from the fetlock-joint $l$ to the body $o$, is straight, indicating no weakness in the limb-a failing here causing the knees to knuckle, and rendering the horse unsafe in going down hill. The hindlegs $m$, as well as the fore ones $k$ and $l$, stand directly under the body, forming firm supports to it. The body is beautifully symmetrical. The shoulder slopes backward from $h$ to $b$, the withers at $b$ being high and thin. The sloped position of the shoulder affords a proper seat for the collar, and provides the muscles of the shoulder-blade $g$ so long a lever as 
to cause them to throw the fore-legs forward in a walk or trot; and with such a shoulder a horse cannot stumble. The back, from $b$ to $c$, is short, no longer than to give room to the saddle. The chest, from $b$ to 0 , is deep, giving it capacity for the lungs to play in, and room for the muscles required in draught. The top of the quarter from $c$ to $d$ is rounded, the flank, from $c$ to $n$, deep, and the hind-quarter, from $f$ to $e$, long. On looking on the side profile of the entire animal, the body seems made up of two large quarters, joined together hy a short thick middle, suggesting the idea of strength; and the limbs, neck and head, are so attached to the body as to appear light and useful. In a well formed horse, I may remark, the line firom the fetlock $l$ to the elbow-joint, at o, is equal to that from the joint $\theta$ to the top of the withers $b$. In a low-shouldered leggy-horse, the line $l o$ is much longer than the line $a b$; but in the case of this horse, the body $b o$ is rather deeper than the leg $l o$ is long, realizing the desideratum in a farm-horse of a thick middle and short legs. The line across the ribs from $g$ to $f$ is, like the hack, short, and the ribs are round. $\mathrm{He}$ is 16 hands high, measures fiom $a$ to $b 35$ inches, from $b$ to $c 33$ inches, from $c$ to $d 19$ inches, being in extreme length 7 feet 3 inches. Length of the face 25 inches, breadth of face across the eyes 10 inches, length of ears $6 \frac{1}{2}$ inches, breadth across the hook-bones 22 inches, girth behind the shoulder 80 inches, girth of fore-arm 23 inches, girth of bone below the fore-knee $9 \frac{1}{2}$ inches; the breadth of this bone shows the strength of the fore-leg of every horse; girth of neck at the onset of the head 32 inches, girth of muzzle 21 inches, width of counter 19 inches, and hight of top of quarter from the ground 63 inches. In a draught-horse the collar causes the muscles to enlarge upon the shoulder, and the neck to become thin. This horse's name is Farmer, his walk is stately, and he can draw 3 tons on level ground, including the weight of the wagon. He is a well known animal in Edinburgh, and is generally admired.

Fig. 436 as here shewn is the portrait of the black draught-stallion Champion, bred by Mr. James Steedman, Boghall, in the county of Mid-Lothian. $\mathrm{He}$ is of the true Clydesdale breed. $\mathrm{He}$ gained the first prize at the Highland and Agricultural Society's Show at Glasgow in October, 1837, and obtained premiums elsewhere. He is a sure foalgetter. He is fully 17 hands high, and though otherwise a large animal, being 8 feet 7 inches in length, his action is high and uncommonly light. On comparing him generally with the gelding just described, though his body is longeh both hind and fore quarters are long and Fig. 436.

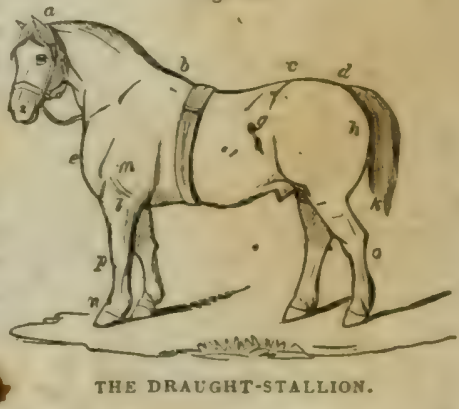
deep, and exhibit a large display of muscle. His middle is somewhat small, as is almost always the case with stallions which have served many mares. Like all stallions, his neck rises beautifully from his body $b c$, in a full crest from $b$ to $a$, evincing that castration has the effect of reducing the size of the muscles of the neck of all geldings. The shoulder slopes well back from $e$ to $h$, giving freedom of action to the fore-legs, while the muscle at $m$ being fully developed, assists in imparting power to that action. The hind-quarter, from $g$ to $h$, is long and deep. The fore-leg is straight, and short from knee to fetlock, $p$ to $n$, the bone under the knee strong, and the fore-arm $l$ flat and broad. The hind-legs $o$ are remarkably handsome. The sweep of line from the crown of the head along the back (912) 
to the tail-head is truly elegant, giving a very fine top to the quarter, and the plenitude of hair in the tail $d k$ indicates great strength of back. His eye is good, though somewhat small, the ratch of white down his face is against his cast of countenance; and having the 2 hind-legs white is also against his general appearance. His disposition is remarkably docile, ano his whole demeanor harmless. His constitution is good, and he is an ex. cellent traveler. These are a few of his dimensions: from $a$ to $b 5$ s inches, from $b$ to $c \cdot 30$ inches, from $c$ to $d 22$ inches; in all 8 feet 7 inches Length of face $26 \frac{1}{2}$ inches, breadth of face across the eyes 11 . inches, lengtb of ears $6 \frac{1}{2}$ inches, breadth across the hook-bones 30 inches, girth behind the shoulder 90 inches, girth of fore-arm 28 inches, girth of bone below the fore-knee 12 inches, hight of top of quarter from the ground 67 inches girth of neck at the onset of the head 39 inches, girth of muzzle 24 inches and width of counter 22 inches.

Fig. 437 as here shewn is the portrait of a brown mare belonging to Mr. George Bagrie, Monkton, near Dalkeith, Mid-Lothian. She gained the first premium at every show of stock she was ever exhibited. The white ratch down her face, and so much white on her legs, detract from her general appearance; but notwithstanding these drawbacks, she is an exceedingly handsome mare. You have only to look at the Plate to observe the beautiful flowing lines of her whole contour, and also the great substance of both fore and hind quarter. The rise and crest of her neck from $b$ to $a$, and from $e$ to $a$, are remarkably fine. The back from $b$ to $c$ is somewhat hollow, and there is a Fig. 437.

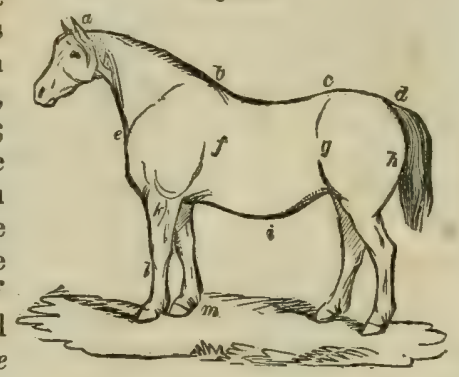

THE DRAUGHT-MARE. corresponding depression of the belly at $i$, both the consequences of foalbearing, as well as a slackness of the flank in front of $g$, the usual deficiency there of brood-mares. The top of the rump from $c$ to $d$ is also very fine. The shoulder slopes well from $e$ to $b$, indicating good action; the muscles are well developed on the fore-quarter from $e$ to $f$ : indicating power in draught; and the ribs are round, and long from $f$ to $g$, a favorable configuration in the brood-mare for giving room for the growth of the fœtus. The hind-quarter from $g$ to $h$ is long. The legs are placed directly under the body, the fore-knee $l$ being broad and strong, the back of the fore-leg from the fetlock $m$ to the body straight, and the fore-arm $k$ broad and flat. I have no measurement of the dimensions of this mare, which I regret, as losing a means of comparison with the gelding and stallion. Beside roundness and length of rib, a brood-mare should be wide across the hook-bones and the pelvis, to afford room for the growth and subsequent egress of the foal.

I have chosen a black stallion, brown mare, and gray gelding, as illustrative of the three colors most commonly seen among farm-horses. A black stallion seems the generally favorite color, and a brown mare is not uncommon, but the gray color is less in vogue than it was 20 years ago; but why I cannot say. It is said that the feet of gray horses are more tender than of horses of other colors; and, for the same reason, whatever that may be, it is alleged that white feet are more tender than any other color. I once corresponded on this subject with the veterinary surgeon of one of the regiments of Life Guards, the horses of which are black, and (969) 
his statement was that he had not observed any remarkable defect in those horses which happened to have white feet; but that his attention had not before been particularly drawn to the subject. It might be worth while to ascertain whether or not it is found that the horses of the Scots Grays are more liable to tender feet than those of other corps of a different color.

Cattle.-I have already said so much on the points of cattle, that nothing more remains to be advanced on that subject; so I shall merely allude to the particular points exhibited by the animals represented in the Plates. And, first, I shall take, as a standard of comparison, the Short-Horn ox, fig. 438 given below. This was an ox from the herd of Mr. Wilson, of Cumledge, in Berwickshire, who has long been known as a successful breeder of Short-Horn steers. His stock comes to maturity and is fattened off at 2 years of age, when they commonly attain 70 stones imperial. The ox in fig. 438 was 1 year 11 months old when his portrait was taken; and he was afterward shown at the Highland and Agricultural Society's Show at Berwick-upon-Tweed, in October, 1841. He was of a roan color, with a good deal of white. His head was remarkably fine, with a pleasant countenance, full eyes, and small, slouching, sharp-pointed horns. Besides a fine head, he had a straight back, round rib, deep flank, and full neck-vein. His principal measurements were, from $e$ to $a 27$ inches, from $a$ to $b 32 \frac{1}{2}$, from $b$ to $c 21 \frac{1}{2}$ inches, in all 6 feet 9 inches; and the girth of the body behind the shoulder at $f 7$ feet 3 inches. His measurement for beef was 4 feet 6 inches in length by 7

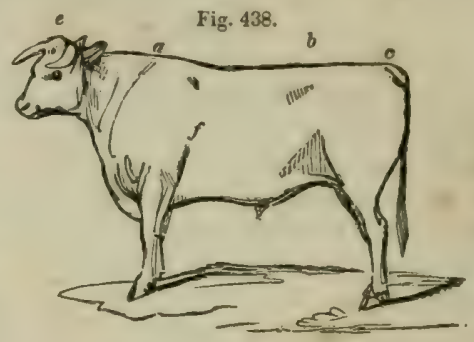

THE SHORT-HORN OX.

feet 3 inches in girth, equal to 56 stones imperial; so $I$ should say from these figures, that this ox was rather too short for a perfectly symmetrical figure.

Fig. 439 given on page 443, is a portrait of a red and white Short-Horn bull. This animal was bred by the late Mr. George Brown at Whitsome Hill, in Berwickshire. He was got by a red and white bull belonging to Mr. Robertson, of Ladykirk, named Valentine.* At that period, Mr. Robertson's stock of Short-Horns was in its glory. The dam of this bull was got by a red bull, never named, bred by Mr. Thomas Smith, now at Buckden, then at Grindon, in Northumberland, and was a son of his old roan bull Duke; and at that period few farmers had so high a bred stock as Mr. Smith. The grand-dam was one of twin quey-calves produced by a heifer, purchased in calf by Mr. Brown from Mr. Mason, of Chilton. One of the twin calves, when a 2-year-old quey, Mr. Brown sold to the late Duke of Buccleuch for 50 guineas, and the other he retained for himself. I purchased this bull when 1 year old from Mr. Brown for 20 guineas, and kept him at Balmadies, in Forfarshire, for 8 years, during which time he proved himself a sure and excellent calf-getter, and evinced a gentleness of disposition to every person who approached him, in a remarkable degree for a bull. He had many good points-small head, lively eye, small, fine, white horn. He was well filled up behind the shoulder, at $f$, fig. 439 , a point in which many bulls are deficient. He had a long quarter from $g$, a difficult point to attain in a bull, carrying the flesh of the hocks $d$; a thick flank $e$; ribs round, forming a straight line from the

- For Valentine's pedigree, see Coates's Herd Book, vol. L. (970) 
shoulder-point in front of $f$, past $g$, to the margin of the round above $d$. His fore-arm $h$ was very strong; neck-vein full; and the crest of his neck $a$ fine and not lumpy, as is too often the case in bulls; his hooks and back were remarkably straight and broad, measuring across the hook-bones at $b 36$ inches; the rump between $b$ and $c$ was full and round, and the tailhead $c$ was remarkably level and fine, showing no undue development of muscle, as is often the case here-a deformity too generally admired, and in so far shows a prevalence of bad taste. His neck and shoulders were

Fig. 439.

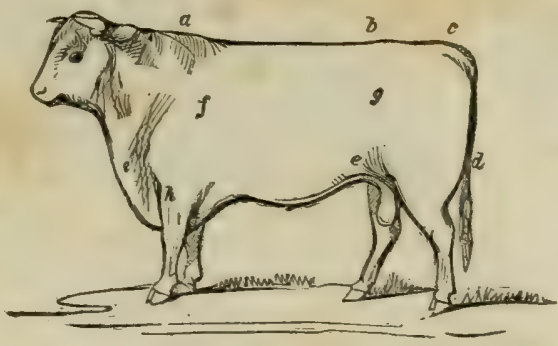

THE SHORT-HORN BULL.

strewed over with curled locks of long hair, the entire body being thickly covered with long soft hair ; the face was garnished with curled hair in a line down in front of each eye; and the roots of the horns were hidden with long hair falling over the forehead. His hide was thick and mellow, and the touch fine. He had a most robust constitution, never having had a day's illness in his life of nine years. Unfortunately I had no measurement taking of him before he was killed fat, when the butcher, Mr. Johnston of Arbroath, informed me he weighed 139 stones imperial, sinking the offals. His flesh was fine, much more like ox than bull beef.

Fig. 440, given below, are the portraits of three Short-Horn cows belonging to the Duke of Buccleuch, at Dalkeith Park, in Mid-Lothian. They are all of pure blood, being descended from Mr. Robertson of Ladykirk's stock, when Mr. John Rennie had a part of them in his possession at Phantassie in East-Lothian. The cow, a roan, whose side view is

Fig. 440.

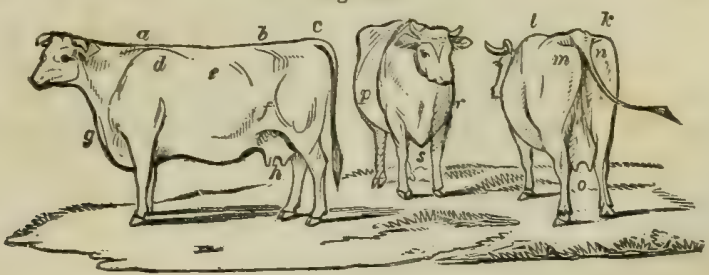

THE SHORT-HORN COWS.

given, was in a lean state when the portrait was taken; but the likeness is the more valuable on that account, in giving an idea of the skeleton, which in her case is very fine. She is the beautiful Kilmeny, got by Match'em. The hook-bone $b$ is finely prominent, and at the same time level; the ribs $e$ round; the shoulder-blade $d$ sloping; the top of the shoulder $a$ broad: the neck-vein at $g$ fine; the muscle at $f$ well developed; the tail-head $c$ level with the hooks; and the udder $h$ hemispherical, the teats being pendant at equal distances. The uncommon half-slouching, half-projecting form of her horns, and a staring of the eyes, give her countenance, though her head is otherwise fine, a somewhat more austere aspect than cows generally have. The front view of the red cow in the middle is intended to show the breadth of the fore-quarter from $p$ to $r$, the roundness of the ribs at $p$, the depth of brisket at $s$, and the width of space upon which the fore-legs stand. The hind view of the white cow, (97L) 
on the right, shows the broad space between the hooks from $l$ to $k$, and the same across the pelvis from $m$ to $n, 2$ points essential in the cow, as a safe breeder of full-grown calves. The form of the udder behind at a shows the proper position of the 2 bind teats, and exhibits the loose, soft skin abore the udder, which is characteristic of good milkers.

The 3 colors, roan, red, and white, were purposely chosen to show the common colors which the Short-Horns bear. Though thus divided into 3 , only 2 colors are, in truth, sported by Short-Horns, namely, red and white, the roan being a mixture of the other 2. The roan is a bandsome color, and is, I beliere, the general favorite now ; the fancy for color baving gone from the red to the white, and is now settled on the roan. Dark-red usually indicates hardiness of constitution, richness of milk, and disposition to fatten; light-red indicates great quantity of thin milk, and little disposition to fatten; but the red in either case is seldom entire, being generally reliered with white on the sides, and the belly, as in the case also of the bull described above. White was considered indicative of delicacy of constitution; and to get quit of it, and at the same time aroid the dullness of red, the roan was encouraged, and now prevails. I think I have observed that white animals show the symptoms sooner than any other color of being bred inand-in.

A single black hair on the body, and particularly on the nose; or the slightest dark spot on the flesh-colored skin upon the nose, or around the eyes, or the horns tipped with black, at once proclaim that a Short-Horn sporting either of these is not pure bred-all attestation to the contrary being of no arail.

To show that careful breeding improres the head of erery breed of cattle, specimens of the heads of 3 celebrated breeds are given, one being the Long-Horns, a breed not confined to England, as it extends over Ireland, though it is only in England that fine specimens of the breed are to be seen. This is the breed which the famous Bakewell improved in Leicestershire, a few years before the Collings improved the Short-Horns, by which they established to themselves a fame which eclipsed that of Bakewell as a breeder of cattle; not because they understood the principles of breeding cattle better than he did, but, fortunately for them, they selected a better subject to deal with-the Short-Horns. Their fame, however, was not established at the cost of that of Bakewell, for he had already acquired an imperishable name as a breeder, in the improrement of the old Leicestershire breed of sheep; but it must be owned that when the Collings advanced beyond Bakewell as breeders of cattle, the adrancement was the more meritorious in being made in competition with so very formidable a rival. The Long-Horns were originally called Leicesters; but having long horns, they were so named in contradistinction to the Durham breed, whose horns were short; and, besides, Bakewell's improved sheep were as often called Leicesters as the Dishley breed.

The Long-Horn bull, a likeness of whose head is here given in fig. 441, belonged to Mr. R. Horton, in Warwickshire, and was shown, and obtained the first prize of his class at the Show of the Royal Agricultural Society of England at Oxford, in July, 1839, when he was 4 years 2 months old. It will be observed that the muzzle is fine, the eye large and ex-

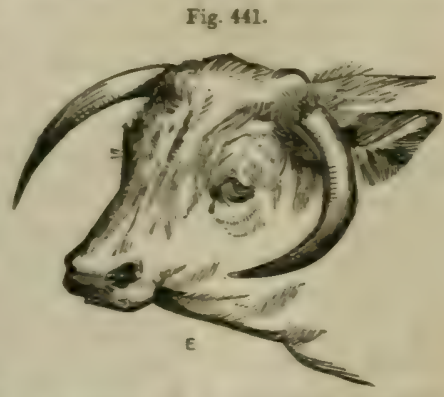

TRI ABAD OF A LOSG-BORF BOLL. (972) 

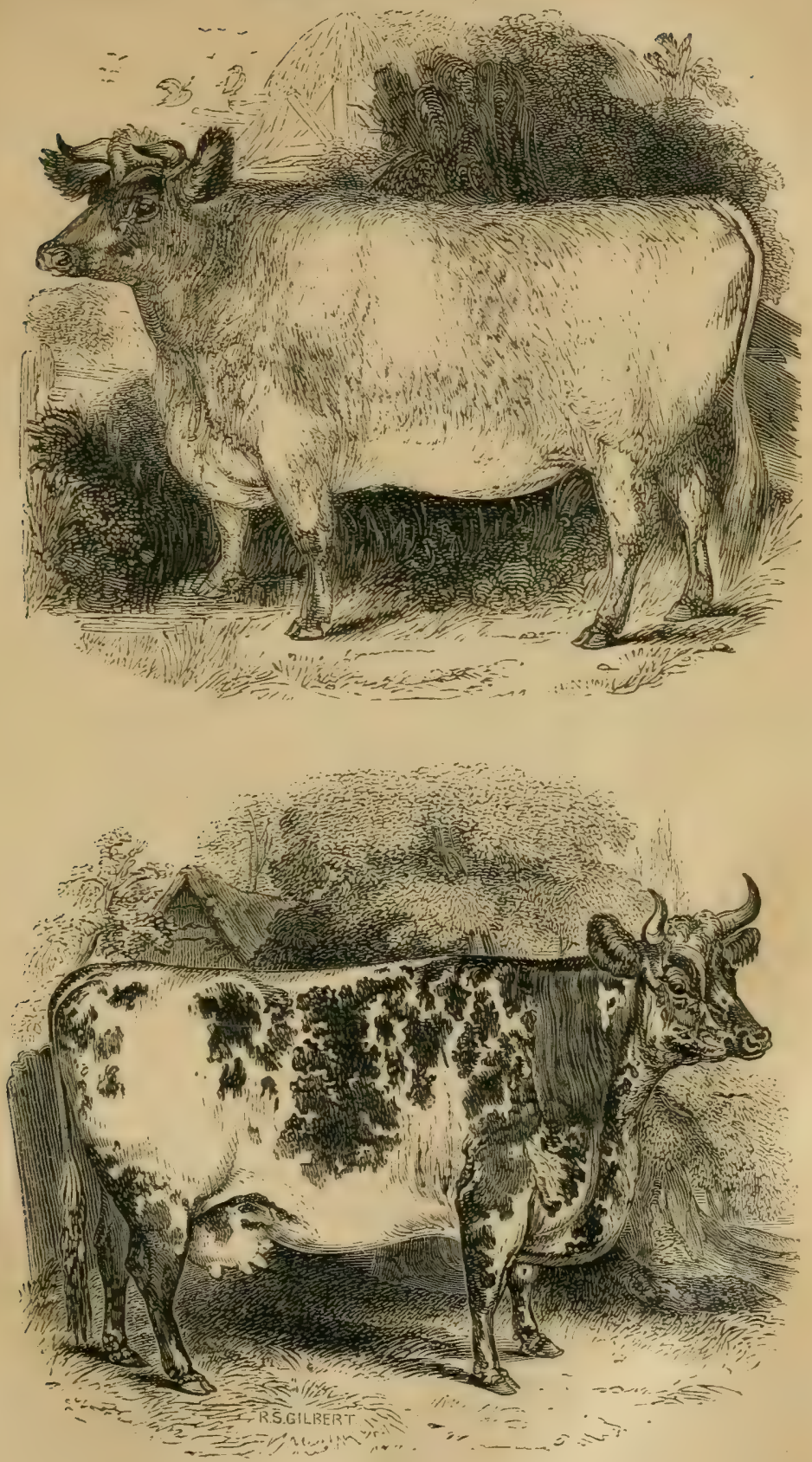

pressive, the horns fine, tapering, and sharp-pointed, and the entire countenance agreeable. His color was light-brown, brindled with black stripes. The skin of the nose and around the eyes dark-flesh color. The slouching position of the horns is very common in the Long-Horn breed; they are brown, with a few reddish streaks, and tipped with brownishblack.

Another breed to which much attention has been paid, is the Hereford, which has long been famed for its excellent steers. Fig. 442 is the portrait of the head of a Hereford ox which belonged to Mr. S. Druce of Ensham, in Oxfordshire, and was shown at $\mathrm{Ox}$ ford, at the Show of the Royal Agricultural Society of England, in July, 1839, when 4 years 4 months old. It will at once be observed that the muzzle is fine, the eye large and full, and the horns small, tapering, and sharp-pointed. A white face is quite common in the Hereford breed, with white horns, and brownish red points. The body is either dark or light-red and white, a common color, or a dark rich chestnut-brown, which is becoming fashionable. The skin on the nose and around the eyes is fine flesh-color.

The West-Highland has long been famed in Scotland as a superior breed of cattle. They have most of the points of

Fig. 442.

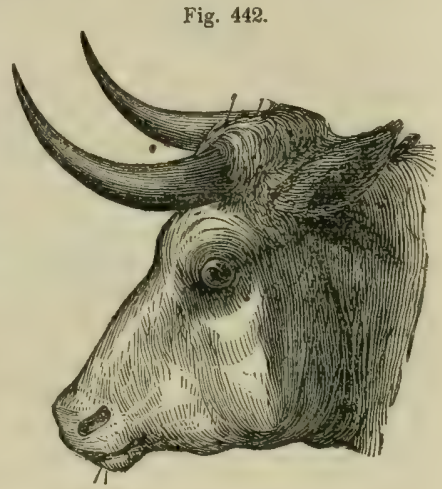

THE HEAD OF A HEREFORD OX.

the Short-Horns in the body, which is covered with shaggy hair, that bids defiance to the keenest blasts and the most drenching rains. Fig. 443 gives an idea of the head of an ox belonging to $\mathrm{Mr}$. Campbell of Jura, which was shown with another, as a pair, at the Highland and Agricultural Society's Show at Inverness, in October, 1839. It will be observed that the muzzle is fine, eye large and full, and the horns small, tapering, sharp-pointed, white, and tipped with black. The color of the body is usually black, sometimes red, and not unfrequently dun. The blackcolored, in my opinion, makes the most profitable animal to the feeder. The skin on the nose, and around the eyes, is always black.

There is a breed of cattle extensively cultivated in Scot-

Fig. 443.

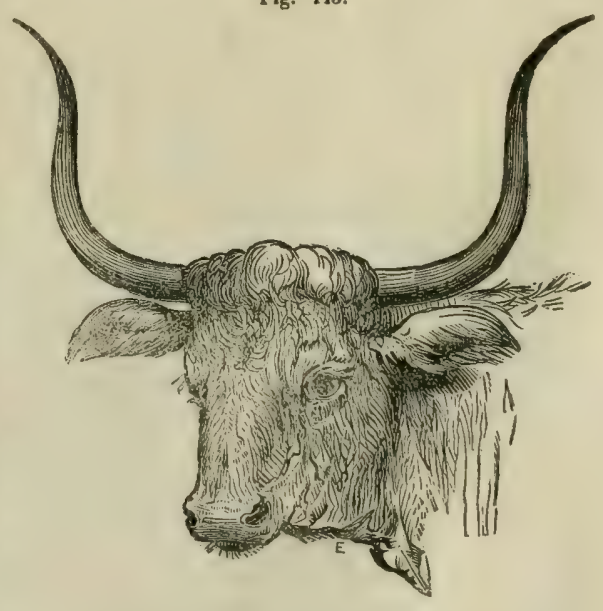

THE READ OF A WEST-HIGHLAND OX. land, the importance of which consists in affording milk for the purposes of the dairy. It is a remarkable circumstance in the history of the breeding of this race for the dairy, that the very opposite points have been cultivated by its breeders, which I have described as being essential in the opinion of the best breeders of every other race. The breed I allude to is the Ayrshire. The points considered good in an Ayrshire bull, by the (973) 
breeders of that species of stock, are a broad, short head, the horns spreading from the side of the head a little in front, and turning upward. The top of the shoulder sharp, back narrow, ribs, of course, flat, hooks confined, hams thin, tail-head somewhat drooping, belly enlarged, and legs very short. These are all points contrary to those of a good ShortHorn; and the points in which they agree are a straight back, loose mellow skin, large eye and small horn. The cows are best liked for a very sharp shoulder and wide hooks and pelvis, in which case the ribs are flat and the belly large. The udder is desired to be hemispherical, well forward, and provided with loose, soft skin behind.

I am satisfied that the points thus desiderated by Ayrshire breeders are not necessarily promotive of the principal object they have in view, namely, a large quantity of milk; for though it cannot be denied that Ayrshire cows are generally good milkers, it is attributable, in my opinion, more to the great length of time they have been devoted to that particular purpose, and which property has now become inherent in the breed, than to the form which the breeders promote; and my reason for thinking so is this: it is well understood, in large dairies in large towns, that the Short-Horns prove the most steady milkers, that is, they continue to yield milk in large quantities for a longer period than any other breed. When they are not allowed to bear calves, they will continue to yield milk un til they are fat enough for the butcher; and when allowed to bear calves, they will give milk to within 5 or 6 weeks of the time of calving. Now it is averred by Ayrshire breeders, that the points cultivated in ShortHorns are for the purpose of yielding flesh; and the averment is quite true; but if the points which yield flesh are also favorable to yielding milk, as the experience of dairymen in towns has proved, and their preference of Short-Horns to others testify, it is clear that it is not in consequence of cultivating points in the Ayrshire breed of entirely an opposite characte to those of the Short-Horns, that the Ayrshire yields so large a quantity of milk; but that it must depend upon some other quality, otherwise the Short-Horns should yield little or no milk, but entirely fleshwhich is found not to be the case. I had a light-red Short-Horn cow, which gave 17 Scots pints of milk at the hight of the grass season, and would scarcely go dry before calving; and have seen another roan cow, which gave 30 pints a day for 3 months, and had to be milked for relief 5 times a day.

Horns of Cattle.-There is much to be observed in the set and form of the horns of cattle. Small, short, slouching horns on a 2 or 3 year old steer give a grave and majestic cast to the countenance. Horns rising outward from the side of the head, and looking up, and bending backward, never fail to impress one with the conviction that their bearer is an illtempered brute, and ready to use them offensively on all occasions. Horns curving laterally and horizontally forward, give a finished appearance to the top of the head, when viewed in front, as exemplified in the figure of the lesser Short-Horn cow in Plate XV. When horns are long, and rise outward, forward, and elevate their points, they impart a very majestic mien to the ox, as shown in fig. 443 of the West-Highland ox. Some horns are set looking backward behind the head, and give an idea of malfurmation. A horn thick at the root never looks well, neither does one that is blunted at the point; and both kinds are associated with dull feeders; nor do those which spring outward and then turn downward, look well, as shown in the left-hand Short-Horn cow in Plate XV. A good horn is small where it emerges from the head, and tapers gradually to a fine point. A white horn is better than a dark-colored, and a finishing of (974) 

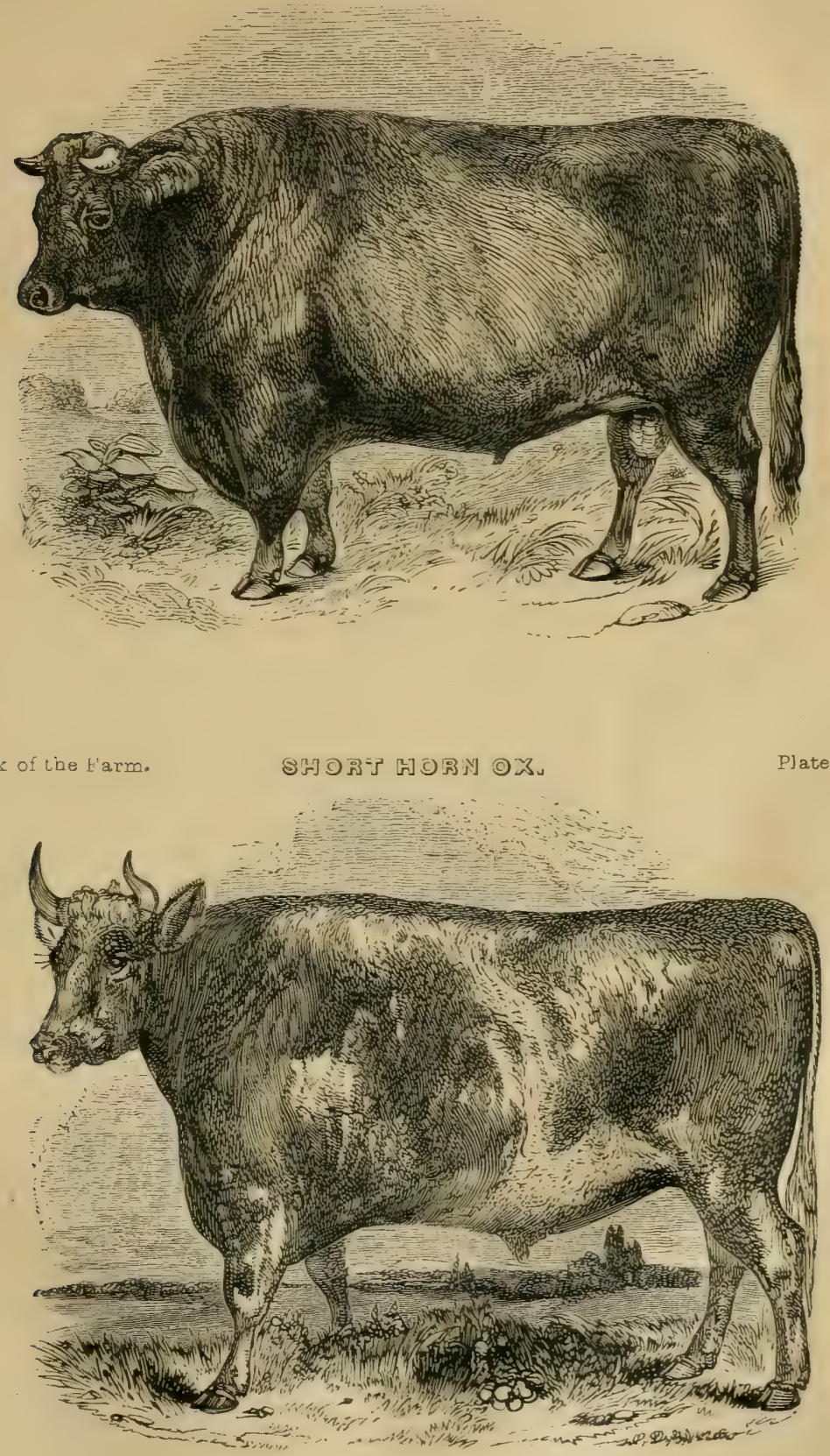

brown or black at the tip, according to the breed, is a good outset, though many Short-Horns, especially of white color, have their horns all white, and being short, do not seem obtrusive-indeed, in most Short-Horns the horns serve more for ornament than purposes of defence. Oxen with spreading horns are better feeders than those which contract toward the front. Horns indicate the age of cattle. At 3 years of age the horn has attained its state of uniform growth; that is to say, it is uniformly smooth from the root to the tip. Every year after the horn is protruded from the head, with a notch on it, so that by counting the number of notches, and adding 3 to the number, the age of the animal may be ascertained. Tricks are practiced by fraudulent dealers, by filing down the notches, to make the animal appear younger than it is ; but a slight inspection of the horn will easily detect the fraud; and the period of the year, whether late or early, in which the animal was born, will have some effect on the notches of the horn.*

Sheep.-Of the numerous varieties of sheep cultivated in Great Britain, 1 have only selected 3 for illustration here, as these include all the breeds hrought up in Scotland, though another has been partially introduced. The three varieties alluded to are the Leicester, the Cheviot, and the Black-faced, and the supplementary variety, as it may be called, is the South-Down. The three varieties are well suited, not only for the climate of Scotland, but also for the peculiar zones, as they may be termed, into which the pasturage of that country is subdivided. The Leicesters are adapted to heavy pastures and sheltered fields in low lands. The Cheviot is equally well fitted for the middle range of green pastures to be found in the pastoral districts of the South and North of Scotland. While the Black-faced derive their chief support from the heathy pastures of the mountains; at least that range of country forms the nurseries of this hardy race.

Plate XXXIII. contains the portrait of a Leicester tup belonging to Mr. Torr of Riby. * * This animal exhibits the peculiar properties of the breed to which he belongs; the principal of which are, a white face and legs covered with hair, homless head, and body enveloped in long wool. The individual characteristics of this tup are, rectangular carcass, round rib, small bone, fine head, small muzzle, large, full eye, and expressive countenance; but his ears are much shorter than usual. The head of the tup is broader across the eyes than that of the ewe or wether, and the skin becomes wrinkled upon the nose when he gets aged. The wool is thick-set, long, of good quality, and the fleece covers the entire body above and below-a mark of sound constitution, and a great means of preserving the animal from the bad effects of the weather above, and of the dampness of the ground below. A level broad back from neck to rump, and across the ribs, is characteristic of the Leicester, and on being turned up, a broad chest and fullness on the inside of the hams. The touch should be equally mellow along the back, a hardness in any part indicating a defect. In ordinary condition, the flesh above the tail-head is nicked, which may be easily felt with the points of the fingers; but when in high condition, which they should be at tuppingtime in autumn, the nicking should extend all the way from the shouldertop to the tail. The rib should also be well covered with flesh and fat, and, indeed, a round rib is almost always so.

Fig. 444, given on page 448, contain the portraits of a Leicester ewe and lumb belonging to Mr. Brodie, Abbey Mains, in the county of Haddington. The Leicester ewe's head is generally long, narrow, and clean,

* See a paper on this subject in the Quarterly Journal of Agriculture, vol, iii. $(975)$ 
with fine muzle, prominent eyes, and long, broad, thin ears. The hone is small and fine. In this particular instance the body is well-wooled and formed. The counter $g$ is full; the shoulder well filled up behind at $a$; the rib at $f$ round and full, and the loin at $e$ not hollow, as is sometimes the case, particularly after ewes have borne a number of lambs. In regard to the wool it is full behind the ears on the top of the neck at $k$, thus

Fig. 444.

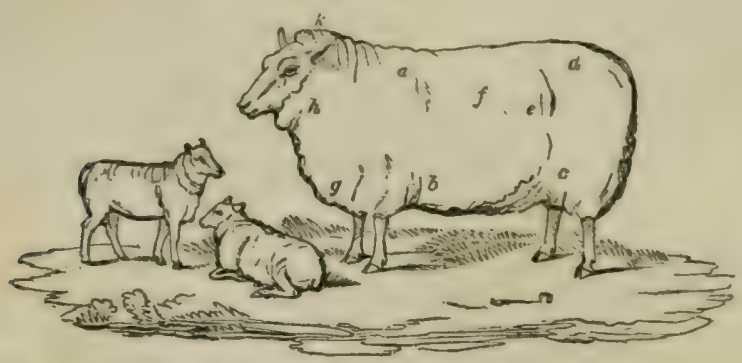

LEICESTER EWE AND LAMBS.

keeping these organs protected; it is also full toward the cheeks at $h$, which keeps the throat warm; the belly is well covered with wool below at $b$; and so is the flank $c$; the rump $d$ has rather a redundancy, and it affects even the shape; but gimmers, that is, ewes of their first lamb, often produce a large quantity of wool on this point, which afterward reduces itself to an equality of the rest of the bndy; but it is a good property in a ewe to have plenty of wool on the rnmp, to protect the anal and vaginal passages below the tail, and it is also an indication that the tail-head is placed nearly on a level with the back. It is no uncommon occurrence in a Leicester ewe to bear twin-lambs, nor is it uncommon to wean twins to the extent of 50 per cent. of the whole flock, some of the ewes bearing twins every year, while others only occasionally.

The Leicester breed of sheep has been cultivated with very great care in Great Britain, since the days of Bakewell, who brought them in his own lifetime to a very high degree of perfection. Many of the flocks in the kingdom can trace their pedigree to that of Bakewell, with as much truth as the purest stud of the race-horse, or the purest herd of Short-Horns, though no Flock-Book has been kept to record the names of the most renowned sheep; a circumstance which excites in me much surprise. The breed is deserving of the utmost attention that can be bestowed upon it, as it possesses many valuable properties. The individuals are in themselves handsome, displaying a beautiful contour, with a pleasant aspect. Their disposition is so amiable that they have no desire to overleap a fence; and this disposition, no doubt, is fostered by their aptitude to fatten. The result of their condition is a large proportion of flesh to bone, and of useful parts to the offal. Many people affect to dislike the mutton, as being too fat and flavorless. The muscle is certainly larger-grained than that of the other 2 breeds, and the fibres are intermixed with fat; but though the mutton may be disliked, for these reasons, by the higher orders, the breed being generally of robust constitution the meat is always wholesome, and acceptable to work-people. Colliers, who eat a large quantity of meat, will have none other. For these reasons, Leicesters are more profitable to the farmer, where they can be reared, than any other breed. The wool is of the most valuable description, not on account of the fineness of its quality, (976) 
for many short-wooled sheep have much finer wool; but its great length, as well as its tolerably fine quality, renders it useful in the manufacture of ail fabrics which require combing wool, and in which worsted is employ. ed. This wool seems peculiar to the British climate; for in no other country have sheep-breeders succeeded in raising it of the same quality; the pile becoming shorter or coarser in warm countries. So long, therefore, as peculiar fabrics are made from Leicester wool, the breeders of Leicesters need not fear the want of a steady, if not a high market for their wool; and it must always be in demand, since no other country can compete in raising it to the same degree of perfection.

Fig. 445 represents the head of a Cheviot tup which gained the first prize of his class at the Highland and Agricultural Society's Show at Aberdeen in 1840, and was shown by Messrs. Craig, Bighouse, Sutherlandshire. It will beobserved that its face is longer than that of the Leicester, muzzle not so fine, eye not so full, ears set not so high and handsomely upon the top of the head, and there is a rugosity of the skin across the bridge of the nose. In the white face, and want of horns, the Cheviot resembles the Leicester. The wool is short, thickset, and of fine quality, fit for the manufacture of inferior qualities of broadcloths. The carcass is usualIy unequal, the fore-quarter being

Fig. 445.

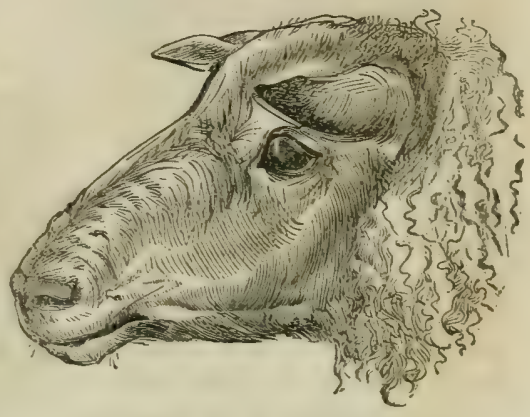

THE HEAD OF A CHEVIOT TUP. lighter than the hind-narrow in front, with the fore-legs set near, and a want of depth and breadth in the counter. The flesh is fine-grained, often well intermixed with fat, and is generally esteemed for the table. The disposition of the Cheviot is somewhat suspicious, with an inclination to rove ; which disposition renders the breed rather unkindly to feed, at least at an early age.

The Cheviots, as their name implies, had their origin in the Cheviot Hills, in Northumberland. They occupy almost all the pastoral hills of the south of Scotland, especially from the center of the country to the eastward. They are localized in some of the best parts of the Grampian mountains, and are to be found as far north as the hills of Caithness and Sutherland. They may, therefore, be regarded as a hardy race, and are well suited, on that account, for the middle green pastures of the mountainous parts of our country.

The South-Downs are little known in Scotland; but what is known of them is favorable to their character. Like the Cheviot, they are covered with short, thick-set, fine wool, which is of a dusky brown colur, and it also affects the hair which covers the face and legs. They are a hornless breed. In symmetry of body they are much superior to the Cheviot, bringing their quarters, like the Leicester, to an equality. Their flesh is fine-grained, and, as high-flavored mutton, is preferred to that of the Cheviot in the London market. They have also a gentler disposition, and are in consequence better feeders. The only doubt with the South-Downs, on their introduction into Scotland, was their ability to withstand the damp climate of our sub-alpine pastures. The experience of several years has proved that they are capable of enduring any climate with the Cheviot; and this being the 
case, with their other superior qualities, they bid fair to rival and perhaps ultimately to displace that breed. Hitherto, however, they have only been tried in a few places. Mr. Hugh Watson has had them at Keillor, in Forfarshire, for more than 20 years, and they have thriven with him upon the pastures of the Sidlaw Hills. The Duke of Richmond has them in Morayshire. Our small flocks are scattered through the country.

Figs. 446 and 447 represent the heads of a Black-faced ram and ewe The ram, fig. 446, was shown by $\mathrm{Ir}_{1}$. Robert M'Turk, Hastings's-Hall, in Dumfriesshire, at the Highland and Agricultural Society's Show at Berwick-upon-Tweed in 1841 , where it obtained the first prize of its class. As indicative of the long period and care with which the breed has been cultivated, we have only to look at the tapering face, small muzzle, and full eye, exhibited by the specimens in the figures. The Black-faced ram has always an arched nose, expressive of boldness and courage. The face and legs are covered witb black or mottled hair, mostly the latter. The head is horned; and the horns are considered as picturesque an object as is exhibited by any animal of this country. The wool is long and coarse, which render it of small value as an article of manufacture, and

Fig. 446.

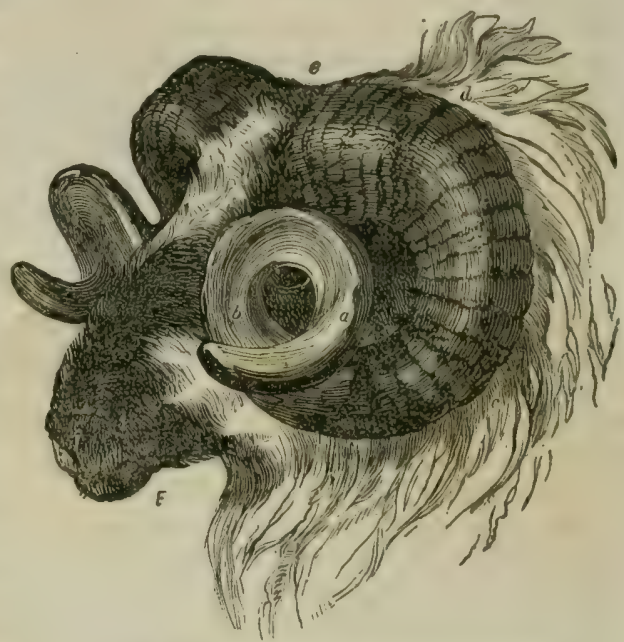

THE HEAD OF A BI.ACK-FACED RAM.

being thin-set exposes the body to the inclemency of the weather" It is to assist the animal for this latter defect in the fleece that the filthy operation of smearing is resorted to. The carcass is well formed, carrying its depth forward to the brisket better than the Cheviot; but still the entire body is narrow, owing to the flatness of the ribs, which gives too much lightness to the whole carcass; or want of substance, as it is commonly called. The flesh is fine-grained, high flavored, greatly esteemed, and can be fed sufficiently fat on the turnips and pastures of the low country. The breed is very havdy, frequenting the highest parts of our heath-clad mountains, ard in summer require little care from the shepherd.

As with cattle, the horns of sheep afford facilities for ascertaining the age of the animal. In fig. 446, the age of the tup is distinctly marked, the 1st year's growth being evidently the space from the point of the horn to the letter $a$; the $2 \mathrm{~d}$ year is from $a$ to $b$, the growth of the dinmont being stronger than that of the hogg; the $3 d$ year's growth is marked from $b$ to $c$; the 4 th, from $c$ to $d$, which great growth shows the vigorous state which the animal had attained at that age; aud this is no doubt the most vigorous period of the life of a sheep; and the 5th year's growth is shown from $d$ to $e$. The respective ages of the ewe, fig. 447, and of the wether, may be traced in like manner, but the horns not attaining the full development in them as in the ram, the yearly marks cannot be discerned 
without minute examination. As to this figure of the ewe it is evidently that of a young one, probably a maiden ewe or gimmer, or at most with the first lamb.

Plate XXVIII. exhibits a group of fat wethers of the 3 native breeds we have been considering and illustrating; but all the animals composing the group are by no means alike favorable specimens of their respective breeds. The Black-faced wether is a good specimen, and many such are brought fat to the Edinburgh market overy winter. They are fed in Forfar, Fife, and Perth shires, on turnips in winter, but the finest fat are those fed on turnips in East-Lothian-that county affording by far the best feeding land for stock in Scotland. The Cheviot is evidently not a wether,

Fig. 447.

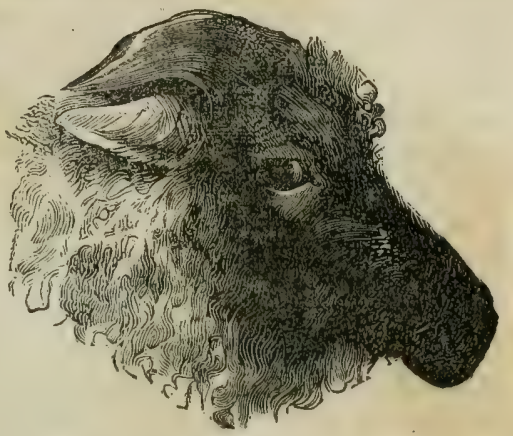

THE HEAD OF A BLACK-FACED EWE. being only a dinmont, and not pure bred; and on both these accounts is not a ripe specimen. The letter $\mathrm{P}$ is left on the rump to show the tar-mark of the farm on which, or the name of the farmer by whom it had been bred. The lightness of the fore-quarter, characteristic of this breed is, however, very well shown in the figure. It is rare to meet with Leicester wethers now-a-days, the dinmonts attaining a sufficient degree of fatness for all useful purposes. The figure in the Plate is a dinmont, and not a favorable specimen, not being pure bred, and too small for the breed. The characteristic distinctions of the three breeds are, however, sufficiently marked in the heads of the figures given in the Plate.

A desire seems to be spreading in this country for the naturalization of the Alpaca from South America. It is the opinion of those who have seen the Alpaca in its native country, that it would thrive well on our highest. mountains, upon the coarsest fare that can be obtained-upon what, in fact, is refused by even Black-faced sheep-and at the same time yield a coat of fine wool, far finer and longer than any grown in this kingdom. Could this opinion be established by experiment, the cultivation of the animal would be worth attempting on a large scale; and no doubt sufficient supplies would be obtained of it in a few years. As yet, the subject is only under discussion.*

Swine.-There are many breeds of swine existing in the country; and whatever denomination they may pass under, if they do not possess the points exhibited in the adjoining fig. 448 , and in the Plate, they may be pronounced defective. Here the same rules apply, not only of symmetry, as we have seen in fig. 431 , but points of breeding. The head $a$ is small, the face tapering to the muzzle or snout $i$, which is short and fine, the ears set on the crown of the head, being broad, thin, long, and so mobile as to indicate quickness of perception. The value of the head, as an article of food, is indicated by the enlargement of the muscle upon the cheek $h$. The neck from $a$ to $b$ is full; the back from $b$ to $c$, broad; the rump from $c$ to

*A little work, named The Alpaca, by Mr. William Walton of Liverpool, published by Blackwood in 1844, gives an interesting account of this animal, both historical and natural. The author seems to know the habits of the animal ; considers that it would thrive to a profitable extent in this country ; and details the particulars of a practicable plan by which a regular and sufficient supply of it. at a remunerative rate, might be obtained.

(979) 
$d$ full and round, and the roundness descends to the hams; the ribs $f$ are round; the space behind the shoulder at $g$ filled up, and so is the flank $e$; the shanks $k$ are small and short, and finely tapered. A pig with these properties is always in a condition for use from the state of a pig sucking milk, through its progress of porkling and shott till it attain the full size for bacon and hams. Such a breed never requires feeding, and as it is always in condition, it must only have time to grow to the size wanted, when a little firming of the flesh by corn is all that is required to prepare it for slaughter.

The slouch-eared breed that pre-

Fig. 448 .

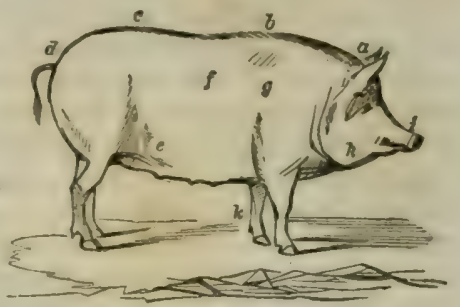

THE BROOD-SOW. vailed in the country is fast being supplanted by the one $I$ have been describing; because, wherever such a character of ear is seen, it is universally accompanied with length of leg, length of nose, narrowness of back, and dilatoriness in feeding. I believe the prick-ears, short snouts, and full cheeks, may be traced to an improvement derived from the Chinese breed, which possess those points even to a deformity. The cross with our old bony breeds has been the means of disseminating through the country a race of beautiful, profitable, delicate-fleshed pigs.

Fig. 449 represents the head of a boar belonging to the Duke of Buccleuch, and the brood-sow represented in the Plate, is also from His Grace's stock. The boar, though evidently full-grown and large, bears the same character of pricked ear, tapering face, short nose, and full cheeks, and the flesh of the neck is seen to be fully able to support the fullness of the head; these pigs are, moreover, strong-constitutioned, and covered with plenty of white hair and valuable bristle. Their temper is generally docile, and the animals seldom wander far from the steading, or engage in mis. chievous pursuits.

Fig. 449.

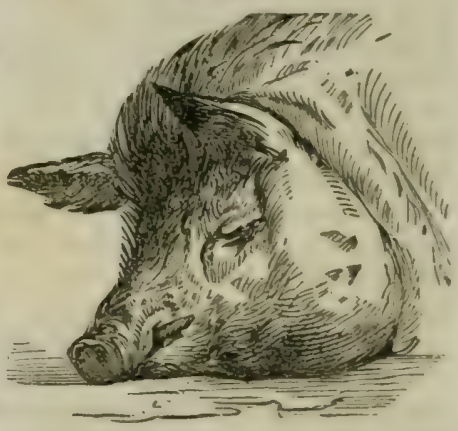

THE HEAD OF A BOAR.

Teeth.-The teeth are far more imperfect organs to the domesticated animals than the horns. The horns are the instruments of defence and of attack; and, in the situation in which those animals are placed, are seldom put in requisition, and the more seldom the better; but the teeth are the instruments by means of which their food is broken and masticated in winter, and cropped and masticated in summer; and this being the case, the condition of the animal mainly depends upon the state of soundness in which the teeth may be preserved. There is one similar property between the horns and teeth of animals; both furnish data by which the age of the animal may be ascertained. You have already seen how the horns are indicative of the age; we shall now advert to the manner in which the teeth may be examined for the same purpose.

Fig. 450 represents the left half of the head of an adult horse, viewed internally, and so figured as to show the origin of the fifth pair of nerves, and the nervous branches which go to the teeth; and for this reason the figure may be consulted with equal advantage for a knowledge of the dis(980) 
tribution of the nervous system and of the teeth. The milk-testh of the horse consist of 12 incisors, 6 in each side of the head; and of molars 16 in number, 8 on either side of the head-in all 28 teeth. The teeth

Fig. 450.

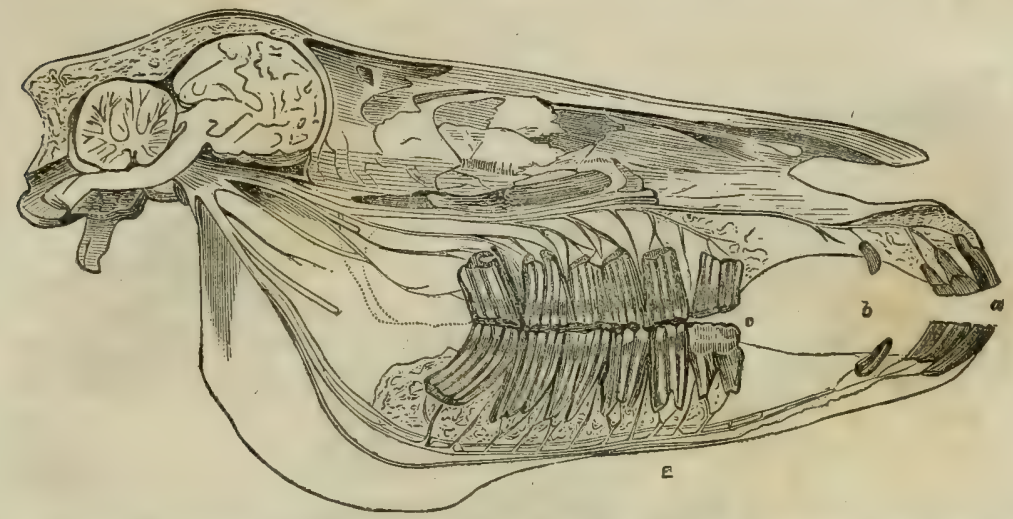

THE VERTICAL SECTION OF THE HEAD OF THE ADULT HORSE, SHUWING THE TEETH AND THE NERYOUS SYSTEM IN CONNECTION WITH THEM.

of the second dentition are 40 in number, of which 28 have replaced the milk-teeth. Those between the incisors and molars, called the canine or tusks, do not appear along with the teeth at an early age. Others complete the arch by occupying the room made by the growth of the jaws; these are new molars which come out of both jaws. The full set consists of 12 incisors, 4 canines, and 24 molars-in all 40 in number. In fig. $450, a$ are the incisors, $b$ the canine or tusks, and $c$ the molars.

"This is the order of coming out of the second or permanent dentition of the horse," observes M. Rousseau. "The first permanent molar, which is situate behind the last milk-molar, presents itself before any of the milkteeth have fallen, and makes its appearance upon the maxillary arch from the 11 th to the 13 th month after birth; it will be, by numerical number, the 4 th persistent molar, when all the milk-molars have fallen. The 5 th permanent molar, which is situate behind the preceding tooth, breaks the edge of the socket from the 14th to the 20th month. During this time the decaying teeth die from their roots, and wear down their crowns to such a degree that the hollow which characterizes the surface of the incisors at certain periods cannot be observed, so that the veterinarians call them lost-mark. The central incisor or pincer is ordinarily of the 9 th or 11 th month; the lesser incisor from the 11 th to 13 th month; and the lateral incisor or corner-tooth, from the 14th to the 20th month. Once these teeth cease to have mark, they bear upon their surface a smooth trace. brown and indelible, which diminishes the more that the teeth approach their fall. The first permanent molar replaces the first and second milkmolars from 2 years to $2 \frac{1}{2}$ years. The central incisor appears upon the edge of the socket after the coming out of the 5 th permanent molar, from $2 \frac{1}{2}$ to 3 years. The $2 \mathrm{~d}$ permanent molar replaces the $3 \mathrm{~d}$ milk-molar a little after the same term, or 1 or 2 months of difference: The $3 \mathrm{~d}$ permanent molar replaces the 4 th decaying molar at 3 years; at this time also appears the 6th and last molar. The lesser incisor from $3 \frac{1}{2}$ to 4 years. The canine or tusks appear from 4 to $4 \frac{1}{2}$ years. At last the second dentition is ordinarily terminated by the lateral incisor or corner-tooth. It must (981) 
not be thought, however, that the coming out, as I have endeavored to indicate as the most ordinary, is without variation; this would be to give to Nature too regular a march. All teeth in general are the more developed that they belong to a large and robust subject."

Fig. 451 gives a similar representation of the dental system of the adult

Fig. 451 .

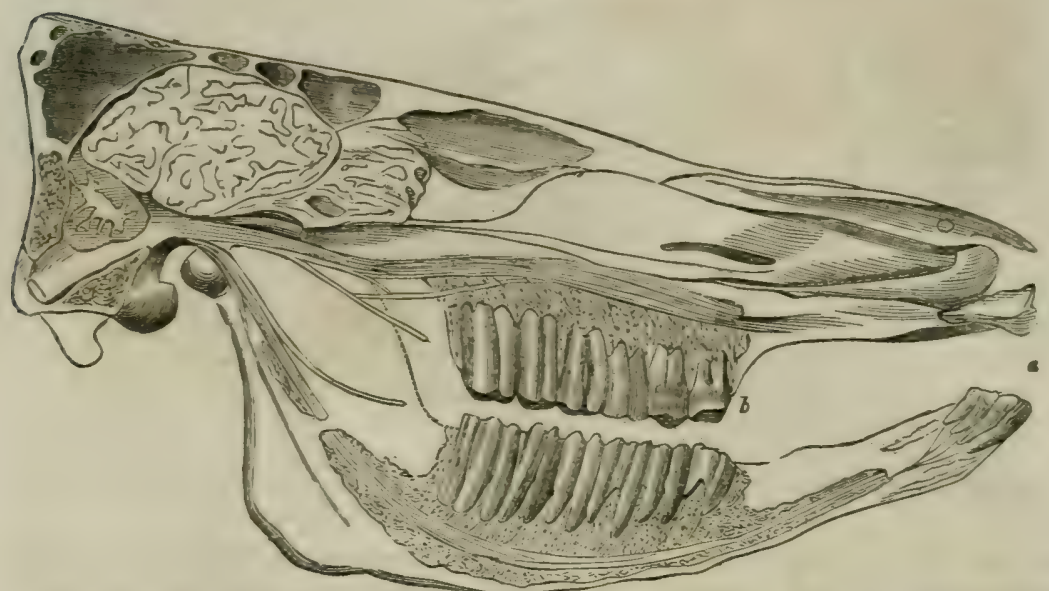

TEE VERTICAL SECTION OF THE HEAD OF THE ADULT OX, SHOWING THE TEETH $\triangle$ ND THE NERVOLS SYSTEM IN CONNECTION WITH THEM.

$0 x$, and of the nerrous system connected with it, that the preceding figure gives of those of the horse. The milk-teeth of the ox are, 8 incisors on the lower jaw, and none on the upper, and 12 molars, 3 on each jaw. In the adult ox are 8 incisors on the lower jaw, and none on the upper; and there are 24 molars, 6 on each jaw. In the figure, $a$ are the incisors, and $b$ the molars, and the same configuration exists in the sheep." "In the second dentition, these teeth show themselres upon the edge of the socket in the following order," says M. Rousseau: "The 4th permanent molar comes out from the 4 th to the 6 th month after birth, and commences the second dentition. The 1 st or central replacing incisor from the 15 th to the $22 \mathrm{~d}$ month. The 5 th or penult molar, from the 18 th to the $22 \mathrm{~d}$ month The second replacing molar, as also the $2 d$ incisor of this order, appear from the 28 th to the $32 \mathrm{~d}$ month. The $3 \mathrm{~d}$ replacing molar, as also the $3 \mathrm{~d}$ incisor, come out very near at the same time, that is, from the 38 th to the 48 th month. The 6 th, or last molar, from the 44 th to the $52 \mathrm{~d}$ month. At length the 4 th permanent incisor tooth terminates the $2 \mathrm{~d}$ dentition, which is ordinarily completed when the animal has not yet attained its 5 th year."

Fig. 452 gives a section of the head of a wild boar, in which the dental and nervous systems are distinctly delineated; $a$ are the superior incisors; $b$ the superior lateral incisor; $c$ the inferior incisors; $d$ the upper canine or defence tusk; $e$ the inferior canine or defence tusk, the origin and form of which may be easily traced; and $f$ are the molars. I have selected the head of the wild boar for illustration, because the character of all the teeth, and particularly that of the tusks, is more strongly developed than in the domesticated boar. The tusks of the sow are comparatively short and weak. The milk-teeth of the ordinary pig are 32 in number, namely, 12 incisors, 4 canines or tusks, and 16 molars half of which numbers are (982) 
on each side of the head. The second dentition is only completed as soon as as all the milk-teeth have fallen; and these are not only replaced, but 3 other molars on each jaw rise up, one after the other, until the whole dental arch

Fig. 410.

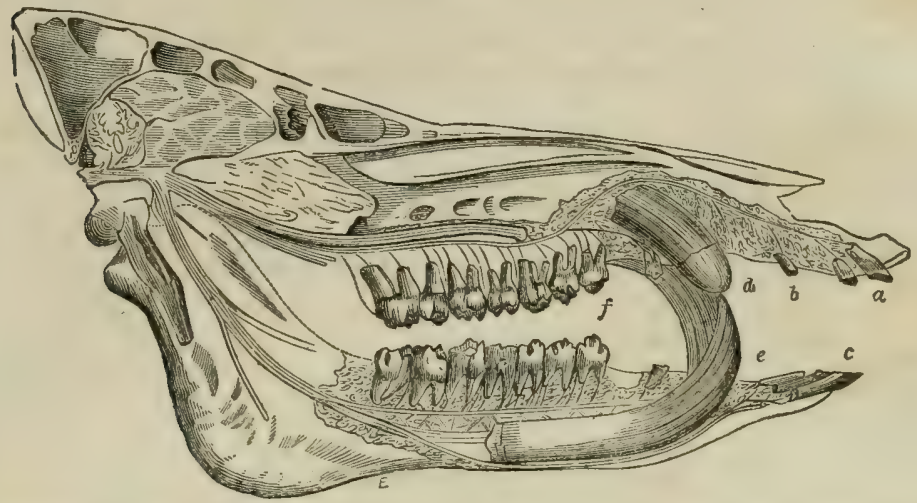

THE VERTICAL SECTION OF THE HEAD OF THE WILD BOAR, SHOWING THE TEETH AND THE NERVOUS SYSTEM IN CONNECTION WITH THEM.

is completed, when the entire complement is 44 teeth, of which 22 are on the upper, and 22 on the lower jaws, and they are divided thus: 12 incisors, 4 tusks, and 28 molars. These teeth are composed of 2 substances, the one bony, the other enameled. "The tusks are each inclosed in a socket, filled with a substance analogous to the marrow of the long bones; it is most remarkable and most abundant in the inferior tusks. These teeth are only provided with enamel upon the external face of the permanent tusks." *

In regard to the indications of age by means of the teeth, in the horse the marks on the crowns of the front teeth on the lower jaw are almost always obliterated, or at least cannot be depended on after 9 years of age. After that period, the only means of judging is by the quantity of matter ground off the top of the teeth, and by the distance between the teeth; the older the horse gets, the wider the space between them becomes. In regard to the grinding down of the teeth, however, you should know that pasturage on sharp land, and support on hard meat, such as unbruised corn and beans, will wear down teeth much faster than pasturage on soft land and prepared food. The same remark applies to cows which have been pastured on sharp or soft land, and been fed on straw and turnips, or on boiled food, and it is only applicable to them; for as to steers, their age cannot be mistaken, from the growth and condition of the body. The teeth of cows also stand wider as they advance in years.

A horse's mouth is easily opened for the purpose of examination, by introducing a finger by the side of the mouth into the space between the incisor and molar teeth, where, in short, the bit of the bridle lies, upon the tongue, when the horse will play with his mouth, to get quit of the finger, and show as much of the lower teeth as to satisfy your curiosity. Some sulky horses require to have their lips held asunder; and vicious ones will even strike out with the fore-feet when their mouth is meadled with. I had a cart-mare, the moment her mouth was attempted to be held for examination, she would wheel round quickly, and kick with the hind-feet at the person attempting it. A cow's mouth cannot be examined without

* Rousseau's Anatomie Compar6e du Systême Dentaire, p. 205-230-a very complete and elegant work. (983) 
first taking loold of her nose, elevating her mouth, and drawing down her under-lip. Some cows will not allow themselves to be taken by the nose, and the thing can only be done in such a case by stratagem. Some, again, have such a power in the nose ly curling up the nostrils when held, that its squeeze against the holder's fingers renders them soon poweriess; but a steady pinch of the thumb.nail against the septum of the nose will make any cow give way, provided the person has strength to hold her firmly at the first burst.

I am strongly tempted to give you an account of the physiological remarks of Mr. Walker on the breeding and crussing of the domesticated animals, hut find that even an epitome of his observations would occupy a considerable space. I must, therefore, content myself by referring to his very curious, instructive, and not less entertaining work.

\section{CARTS AND CARTING.*}

In the ordinary progress of the harvest, having gathered the corn together by the horse-rake, the next step is to carry it to the barn or the stack-yard. This leads us to the question of carts and wagons. The asserted saving in animal power, by the employment of one-horse carts in exchange for the ordinary harvest-wagon, has now, for some years, been the subject of occasional discussion among the farmers of England; the common result of which has been to convince pretty generally the English farmer, that on most soils and in many situations, for the general purposes of Agriculture, there is a very material saving to be accomplished in horse labor, by their employment in preference to wagons. "I early felt convinced," said Mr. Mechi, in the course of some observations he made in 1847 , at a monthly meeting of the London Farmers' Club, " that it was much easier to carry a load upon an implement which weighed $7 \mathrm{cwts}$., running upon one pair of wheels, than upon one which weighed 22 to $24 \mathrm{cw} / \mathrm{s}$. running on two pairs of wheels; my powers of calculation were sufficient to convince me at once that we had been committing a perfect barbarism in the matter of wagons." And he alluded with advantage to a valuable paper by Mr. Hannam, on the use of one-horse carts, which some years since appeared in an early volume of the Journal of the Ruyal English Agricultural Society. In this very excellent paper, Mr. Hannam truly states that the farmers of the counties of Cumberland and Westmoreland have universally, and from time immemorial, used the onehorse cart ; they have no other carriage for any kind of agricultural produce, and never is the addition of another hurse on any occasion seen. 'T'he practice, apparently originating in economy, has long since spread into the neighboring Scotch county of Dumfries, and we have the authority of Mr. Wilkie, the well-

[* For a chapter of 50 pages on the philosophy and the application of Wheel Carriages, which Mr. Stephens says he had bimself at oue time deemed uncalled-for, we venture to substitute this one on Carts and Carting, by Cuthbert W. Johneon, F. R. B. as being more modern and better adapted to common use. We find it in "Modern Agricultural Improvements, intended also as a Supplement to the Farmer's Series of the Library of Useful Knowledge."

By adopting this course we not only present a paper ef more general atility on a subject of very general interest, but it enables us to draw the whole work to a conclusion in this volume, and thus present in two volumes, at a cost of 85 , what would cost 825 if imported.

In reference to this subject of farm transportation, we have no doubt that great waste is com. mitted in the United States in two ways: first, by want of a sufficient number of these and other implements, and next, by the use of heavy, unwieldy wagons in the place of carts, in which the horse may be said to carry a portion of the weight on his back, which in the wagon he must draw, altogether. But we will not presume to go farther, lest we might seem to be anticipating or otherwise taking the subject out of abler hands.

Ed. Farm. Lib.] (984) 
known implement-maker of Addington, near Glasgow, for saying that it is all but universal at the present moment throughout the West of Scotland." As relates to the economy of the cart, it is evident that a considerable saving in the expense for animal labor on a farm may be often accomplished by substituting one-horse carts for wagons. "I had no other object in entering into this practice," adds Mr. Hannam, "than lessening my expenses by reducing the number of my horses, and in this I have succeeded beyond my expectations. My farm (at Burcott, in Oxfordshire) of 370 acres, consisting chiefly of gravelly and ferruginous sandy loams, was some years ago under very able management, with a strength of 12 horses and 6 oxen; and just previous to taking it into my own cultivation, 16 horses had been employed by a very spirited cultivator. 1 have gradually, by the joint operation of two-horse plows and single-horse carts, reduced my number to 8 horses. My system, notwithstanding, is such as somewhat increases my aggregate amount of horse labor beyond that of the surrounding district ; certainly doing a great deal more carting work, although in a few points of tillage it is transferred to the manual labor. For instance, I grow annually about 35 acres of mangel and 20 of potatoes, which necessarily cause much carriage, and, together with the other ridged crops, also a good deal of horse-hoeing." 'l'he general saving of animal power has been thus stated in a tabular form by Mr. Hannam, and $\mathrm{I}$ am always glad when I can avail myself of such condensed statements, since it is general results which are commonly the most practically valuable. Mr. Hannam calculates that the team labor per cent. expended, with four horses, on a farm of 100 acres, is commonly thus apportioned:

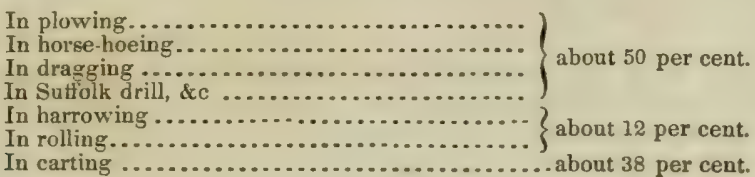

And that the saving capable of being effected is-

By two, and occasionally one-horse plows, and double-ridging plows...........)

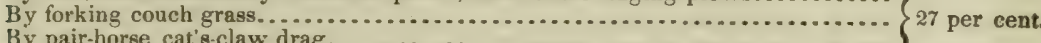

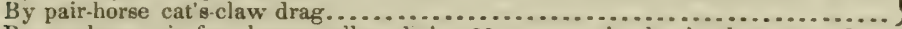

By one-horse six-feet heavy rollers, being 33 per cent. in the implement, and 10 or

12 per cent. on the general labor where heavy rolling is performed............ 1 per cent.

By single-horse-carts.............................................19 per cent.

Being equal to a total saving of............................... $\overline{47}$ per cent.

"Let me now answer the question," continues Mr. Hannam, "which will be asked. In what manner is the saving by single carts of about one-fifth of the usual proportion of horses effected? Bv considering that to move a bulk from one spot to another, in the way that field operations are carried on by a continuous chain of loading at one end and discharging at the other, seldom less than three carts are employed, and that in the usual practice of the Southern Counties one horse occupies the stand-cart or wagon, and three horses each of the other two that are in motion; the work thus going forward with seven horses. If two horses in a cart are used, five will be the number engaged; and if four, the number will be nine. Now, I am prepared to show, not by any series of experiments, but by the routine of my farm for the last ten years, that the same amount of work, when at a moderate distance, may be performed by three horses in separate carts; and that it is only at the greatest distance in which three three-horse carts are able to keep up the chain, that four may be required. And these will keep the same number of (and from low-tilling, somewhat fewer) loaders engaged, and consequently accomplish the moving of an equal bulk. As this may seem a little paradoxical, I will enter into the reasons which combine to effect it. 1st. A horse thus harnessed draws more in proportion with equal ease ; 2d. The misapplication of his strength in the constant draught of a heavy carriage is prevented; $3 \mathrm{~d}$. He moves more briskly and freely, and turns, \&c., with less loss of time, and when any check occurs, the loss is saved that takes place by the hindrance of a large number; and lastly, there is a certain convenience and ready manageableness which can be better felt than calculated or described.

(985) 
"Praclice and general opinion are agreed in assigning a greater power of draught to a horse working singly than to any number harnessed together; but the amount of difference $I$ have never proved by actual experiment. Mr. Culley, in his Report of the three English Border counties, gives an instance in which the advantage is as three to four; and another, in which, with a horse of 16 hands, $24 \mathrm{cw}$ is. was the load, on the hilly* road from Hexham to Newcastle. I am in the regular practice of sending out to any distance, on a turnpike however hilly, 5 qrs. of wheat, which, with the cart, $8 \mathrm{cwts}$, seldom amounts to less than $30 \mathrm{cwts}$. It is also considered, universally, that the nearer a horse is to his load the easier will be the draught, but to what extent I have never proved.

"The misapplication of power caused by a heavy carriage is often enormous, there being sometimes, especially by wagons in harvest, double the weight of timber moved, in going backward and forward, to that of produce brought home; for instance, a common harvest, except at a great distance from the homestead, seldom exceeds one ton, and one ton more or less is the weight of a wagon: at any rate, 1 to 1 is the common proportion of the carriage to the harvest load. It is admitted that there is no perceptible difference between the size of my neighburs? loads and my own; the weight of my harvest-cart I have stated is about $6 \frac{1}{2} \mathrm{cwts}$. : therefore $\mathrm{my}$ proportion is 1 to 3 ; and under less favorable circumstances than mine, it need never, with a similar carriage, be less than 1 to 2 ; and this goes a very considerable way to explain why $I$ am able to perform the same work with half the strength, and without straining the powers of my horses. In the dung-carts the case is not quite so strong in my favor, as there is not so large a disproportion in their weight.

"It is certain that a horse can exert his powers with greater ease and effect by himself than when incommoded by the diverse pulling of companions, and also that a sluggish animal must draw his own share. In turning, one horse is much more handy than a string; and no comparison can be made between the turning of a two and four-wheel carriage. I have never practiced trotting.

"The question," concludes Mr. Hannam, "is not, as is frequently supposed, whether one horse single can draw more in proportion than any number harnessed together, which I believe is generally admitted; it is not altogether which will move the greatest weight; but the question is, which will transport in the most ready and economical manner the materials required to be passed between the field and the homestead, or between one field and another. For in the carrying operations of a farm, with the exception of drawing corn to market, a certain bulk has to be transferred from one point to another, not by one effort, but by a continuous succession of them. Practically speaking, the loading and unloading have to be kept in constant activity by a chain of carriages passing between them. What, then, is the best and most economical intermediate conveyance is not an easy matter for consideration. The best implement and best moving power have to be ascertained; and, among known methods, the selection ranges widely between ihe barrow or pack-saddle and the eight-horse wagon. Our present cunsideration, however, is whether one-horse carts are more ready and economical for the purpose than the methods now generally in use."

'The outlay of capital is certainly in favor of the substitution of carts for wagons. Mr. Bowly, of Siddington, has given the following comparative calculation of the outlay required by the two systems, on 50 acres of arable land :

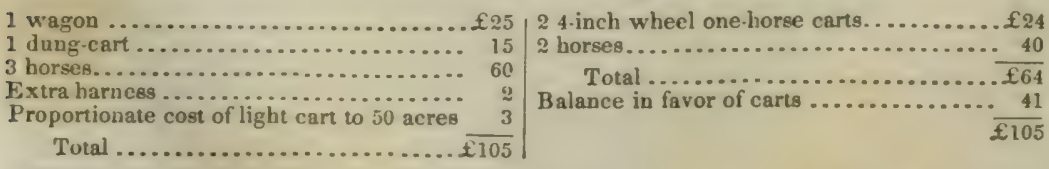

- I had occasion to send my skeleton cart with $15 \mathrm{cwts}$. of hay up the steepest hill (Cuddesden) in this part of the country, and directed a very intelligent laborer to go with it and report: his statement was, that besides observing at a steep descent that the breeching was tightened more than the back-chain, on stopping on the sharpest ascent he found the breat-band tolerably slack, and that the horee drew the linad up this steep point ( 1 in 7 ) without difficulty; and he thought he might have managed a ton. "The horse, however, had a knack of thwarting the road, " a method of easing the ascent horses are very ready at in the North; in a wagon they cannot do It. His opinion also was that four horres, with two tons on a wagon, would have very light work at this part of the bill. (986) 
"In conclusion," says Mr. Bowly, "I may remark that the principle of onehorse carts is quickness of motion ; therefore they must be loaded according to the land to be passed over, so as not to reduce the pace of traveling; and I can assure those who are timid about them that they are much less liable to accidents of every kind than wagons, and that however prejudiced the workman may be against their first introduction, when he becomes acquainted with the system he will prefer it.

"The descriptions of carts I make use of are, five common Scotch carts and one skeleton cart; those of the former, with narrow wheels, cost me 10 guineas each; and with the 4 -inch wheels (which I recommend) $£ 12$, with harvestframe, \&c., complete. The skeleton with narrow wheels cost me $£ 10$; it will carry more hay or straw than the others, its loads being in proportion of four carts to three wagons; it is more convenient for conveying poles, hurdles, \&c. ; and one on a farm may be useful, but it will not answer in dung-carting, and its advantages in harvesting are not sufficient to remunerate for the additional outlay of a double set."

The one-horse carts, then, we perceive, have been successfully tried, and preferred to wagons in the Northern Counties and in Oxfordshire. We have equally satisfactory evidence of their employment on the stiff clays of Gloucestershire and the Weald of Kent, and the deep soils of Huntingdonshire. "My land," observes Mr. T. Baker, of Hardwicke Court, near Gloveester, " is a stiff clay; my carts are on six-inch wheels, and made to hold half the quantity that my neighbors carry in theirs. My land is hilly; my carts generally go with one horse; but up hill, when loaded, another is put on before, which comes down the hill with the next returning cart. Thus, on level ground, with two carts and two, or perhaps three horses, I take out the same quantity of dung that my neighbors carry in their large carts with never less than three horses, and often with four. All my carts have reins; a boy walks and drives them when loaded, but when returning empty he gets into the cart and trots back at the rate of about five miles an hour, which of course saves about half the time in returning. Here, again, I have a manifest advantage in using lighter and more active horses.

"Some time ago I made the following trial. Two heaps of stone, of 32 tons each, were landed from a barge : they were to be taken to the same place, about a mile and a quarter off. A farmer began the first with two large carts and three horses; one cart was being loaded while the other was moving; and the horses were taken off and put on at every load. Finding that he could not do it in the day, he gave over at the end of about six hours, and set to again the next morning; this rest, of course, giving him an advantage, as you will see ; but, anxious for their own credit, both he and his man made the very best use of their time. Their work was completed at eleven loads, (which of course is nearly three tons to each load, or one ton to each horse, ) in nine hours and fifty minutes. I began the other heap with three small one-horse carts, and completed it in one day, at twenty-one loads, (being nearly a ton and a half to each horse,) in six hours and one minute; which was a saving of about three hours and a quarter on nine hours and fifty minutes, or rather more than one-third. In this I had three decided advantages-first, the saving of time by trotting back; secondly, the rest that each of my horses got in his turn while his cart was being loaded ; and thirdly, the ease with which my carts were loaded in consequence of being lower."

"Having," remarks Mr. Jesse French, of Rolvenden, "pursued this plan of carrying corn and hay for two years, and one of my neighbors having followed my example last year, I draw the following conclusion from the observations I have made: that in carrying bound corn, the one-horse cart system has several advantages over that of wagons; and in carrying loose corn or hay, though the loader and he who throws it off may complain, and strong prejudices, the effect of habit, may possess the minds of all the hands employed, there is, upon the whole, no advantage. Three earts will generally be sufficient where the distance does not exceed half a mile, for one cart to be always loading; and for every additional half mile, one additional cart will be about sufficient; but this will depend in a great measure upon the road." It is true, as he very justly adds, that "there certainly are various things which a farmer may have to carry, for which one-horse sarts are not adapted, as timber and hop-poles, which in 
Kent and Sussex are often carried a long distance. In the same district many farmers hring their hay from the marshes, a distance of from three to eight miles. For this purpose small carts are not so cunvenient; and for carrying hay, and particulariy where it has to be carried a considerable distance, a small cart may be enlarged by this expedient. The draught-staples being generally about a foot from the ends of the shafts, by attaching rings to their exireme ends for the horse to draw by, the wheels will be thrown a foot farther behind the horse; consequently the fore-ladder may be fixed a foot forwarder on the shafts. 'Lhis will allow for the tail-ladder to lean farther back, so as the load may balance. By thus lengthening the load, and keeping it a good width, as much hay may be loaded as a horse will be well able to draw."

"And it will be seen," remarks Mr. E. Loomes, of Whittlesea, near Peterborough, "from the following 'Table, (which I have laid down from a careful observation of the capabilities of one-horse carts and wagons,) that one horse in a cart is capable of conveying much more than half what can be carried on a wagon with two horses":

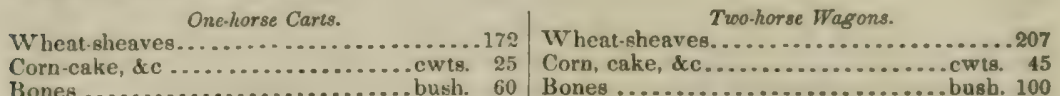

In dung-carting, under ordinary circumstances, one-horse carts appear to have, in ordinary circumstances, a decided advantage. Mr. Love has given the following comparative 'Table of the economy of both one and two-horse carts, in the different distances supposed to be traveled; and each boy driving is counted as the fourth of a man tipping; a man's wages is reckoned as 2s. per day, and the expense of each horse $3 \mathrm{~s}$. per day of nine hours :

\begin{tabular}{|c|c|c|c|c|c|c|}
\hline & $\begin{array}{c}\begin{array}{c}\text { Une-horse } \\
\text { e'arts. }\end{array} \\
\end{array}$ & $\begin{array}{c}\text { Two-borse } \\
\text { carts. }\end{array}$ & $\begin{array}{c}\text { One-horse } \\
\text { carts. } \\
\end{array}$ & $\begin{array}{c}\text { Two-horke } \\
\text { carts. }\end{array}$ & $\begin{array}{l}\text { One-horse } \\
\text { carts. }\end{array}$ & $\begin{array}{l}\text { Two-Lorse } \\
\text { carts. }\end{array}$ \\
\hline 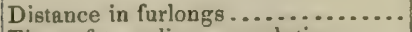 & 3 & 3 & 3 & 3 & 7 & 7 \\
\hline Time of traveling a revolution...... & 15 & 15 & 15 & 15 & 35 & 35 \\
\hline 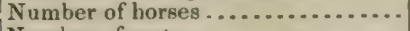 & 3 & 3 & 5 & 5 & 9 & 9 \\
\hline 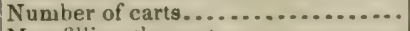 & 3 & 2 & 5 & 3 & 9 & 5 \\
\hline Men filling the carts................ & 2 & 2 & 4 & 4 & 4 & 4 \\
\hline Time of filling $\ldots . . . \ldots \ldots \ldots \ldots$ & 10 & 15 & 5 & $7 \frac{1}{3}$ & 5 & $7 \frac{1}{2}$ \\
\hline Men tipping and driving.......... & $1 \frac{1}{4}$ & 1 & $1 \frac{13}{4}$ & $1 \frac{3}{4}$ & $2 \frac{3}{4}$ & 13 \\
\hline 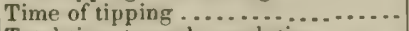 & 3 & $7 \frac{1}{2}$ & 5 & $7 \frac{1}{2}$ & 5 & $7 \frac{1}{2}$ \\
\hline Total time to each revolution....... & 30 & $37 \frac{1}{2}$ & 25 & 30 & 45 & $50^{\circ}$ \\
\hline Number of loads drawn............ & 54 & 29 & 108 & 54 & 108 & 54 \\
\hline Number of yards drawn ............ & 54 & $43 \frac{1}{2}$ & 108 & 81 & 108 & 81 \\
\hline & s. d. & s. d. & 8. $d$. & s. $d$. & s. d. & s. d. \\
\hline Expense of hor & 90 & 90 & 150 & 150 & 270 & 270 \\
\hline Expense of men .................. & 66 & 60 & 116 & 106 & 136 & 116 \\
\hline Total day's expenses ............... & 156 & 150 & 266 & 256 & 406 & 386 \\
\hline Expense of carting thirty yards..... & $87 \frac{1}{2}$ & $102 \frac{3}{4}$ & $74 \frac{1}{4}$ & 95 & 113 & 143 \\
\hline Saving by one horse carts per acre.. & $17 \frac{1}{2}$ & & $20 \frac{3}{4}$ & & 30 & \\
\hline
\end{tabular}

Mr. John Dryden has described a plan for an improvement in single-horse carts, by which the evils of a fixed balance of the load in a cart are avoided; and it is probable that the use of the Welsh drag in hilly countries would materially facilitate the general employment of one-horse carts.

"That the state of the road has a very material influence upcn the animal power required to draw a given weight over it every person is well aware, but few persons regard the difference between the labor of drawing a carriage over a road in good condition and the same road when out of order. This has been, however, experimentally determined, and we commend to every farmer and every overseer the careful and steady consideration of the results thus obtained. In these trials it was found that a light carriage with four wheels, weighing with its load 1,000 lbs., required a force of traction as follows":

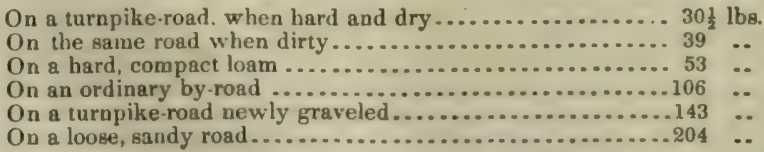

The care with which all drivers avoid the newly graveled portions of a road is 
well known, yet few of even the best whips, I thınk, are aware of the enormous difference of pressure upon the collar shown by the previous Table to exist, when the load is passing over a hard and dry turnpike-road, and the same road when newly graveled, composed of loose, sandy materials. The Farmers' Club, then, we cannot but feel, arrived at a tolerably correct conclusion when they thus gave the preference to one-horse carts for the general purposes of the farm. 'The farmer, however, who resolves to make trial of these advantages, must be firm and resolute, for, like every other alteration, it will hardly fail otherwise of being met by a strong opposition from his servants. To this end a hint or two of Mr. Hannam's will be useful ; he observes, "I market my corn, according to the Nortbern practice. in the dung-cart; it is not so convenient to unload sacks from as a wagon, but the load it carries, viz., 5 qrs. [ 40 bushels at $60 \mathrm{lbs}$. per bushel, $2,400 \mathrm{lbs}$.] of wheat, 6 qrs. of barley, and other grain in proportion, and in back carriage half a wagon-load of ashes compensates for small inconveniences. The only objection that I have heard the carters make to the system in thus carrying out the corn is that they find themselves singular, and making but a bad figure by the side of a wagon and team of horses. They should therefore be indulged with a reserve of the best carts, kept well painted, and washed after being used for manures, and with harness a little ornamented."

of the many excellent carts prepared by various makers, we will only allude to two, those of Mr. Crosskill, of Beverlev, and of Messrs. Stratton, of Bristol.

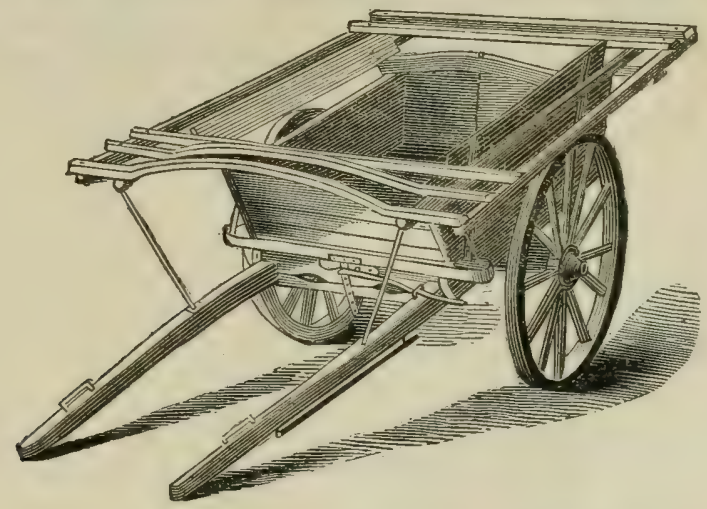

THE ONE-HORSE CART OF CROSSKILL OF BEVERLEY.

"Mr. Crosskill's," said the Judges of the Shrewsbury meeting, "is a thor oughly well made and cheap one-horse cart, having a particularly simple and safe tipping contrivance. The especial reason for awarding to it a premium of $£ 2$ was the introduction of a self-acting tail-board, which opens and shuts as the body is tipped, or brought home, so that no time is lost by having to unship and ship a tail-board, whether the contents of the cart have to be discharged at once or at intervals. At the Newcastle meeting it obtained the prize of $£ 5$.

Of the cart of Messrs. Stratton, and of their other excellent implements of a similar kind, the Judges of the Bristol meeting thus reported: "The show-yard was rich in an assortment of carts and wagons. 'To Mr. Richard Stratton, of Bristol, a premium of $£ 10$ was assigned for the extraordinary variety and good workmanship of his immense collection ; more particularly for the ingenuity displayed in the construction of a cross-lock wagon, which facilitates its turning in a very small space, and permits the use of four large wheels of equal diameter. A tipping-wagon also possessed much mechanical merit, but it is to be recommended as better adapted to commercial than to agricultural use. Mr. Stratton produced an excellent specimen of the low-chested cart, obtained by cranking down the axles, now in such general use by mercantile men and shippers. This disposition, modified to suit farming purposes, well merits the attention of agriculturists, as it would greatly ease the toil of the laborer. Of Mr. Hannam's (of Burcot) unequaled one-horse harvest-cart, more need not be said than that (989) 
it cannot be exhibited too often, and that it ought to be found on every farm To Mr. Robert Law, of Shettleston, near Glasgow, a prize of $£ 3$ was awarded for his Scotch one-horse tipping-cart with a spring-catch to retain it on the

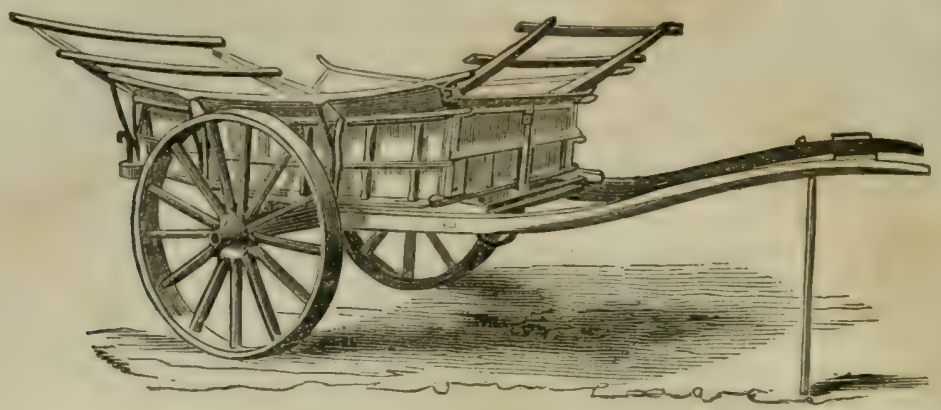

THE CART OF MESSRS. STRATTON \& CO., OF BRISTOL.

shafts. This simple little contrivance is much preferable to pins and cotters; which are apt to shake out, or to be neglected in the fastening, by which the load is not unfrequently let fall." At the Bristol meeting, two prizes wer awarded to Mr. Stratton for his carts and wagons, and three at Southampton. 
The Book of the Farm.

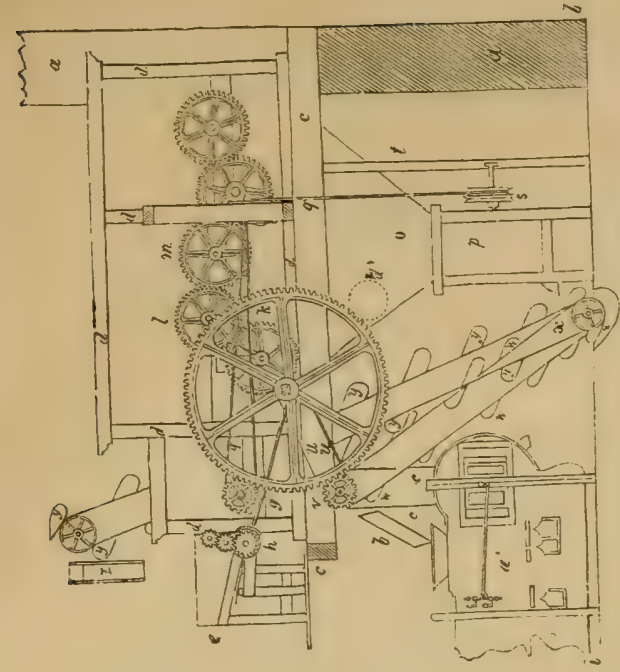

Plate XIX.

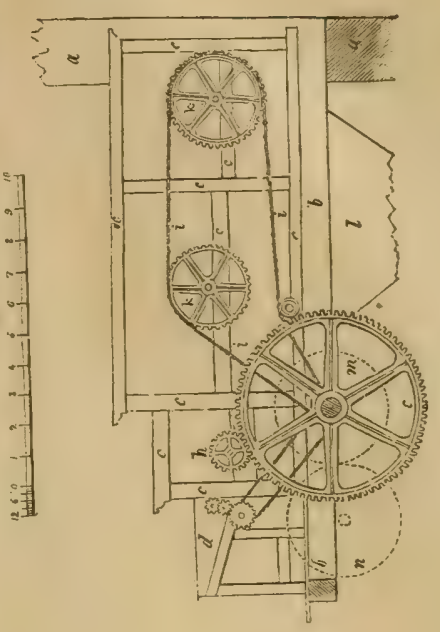

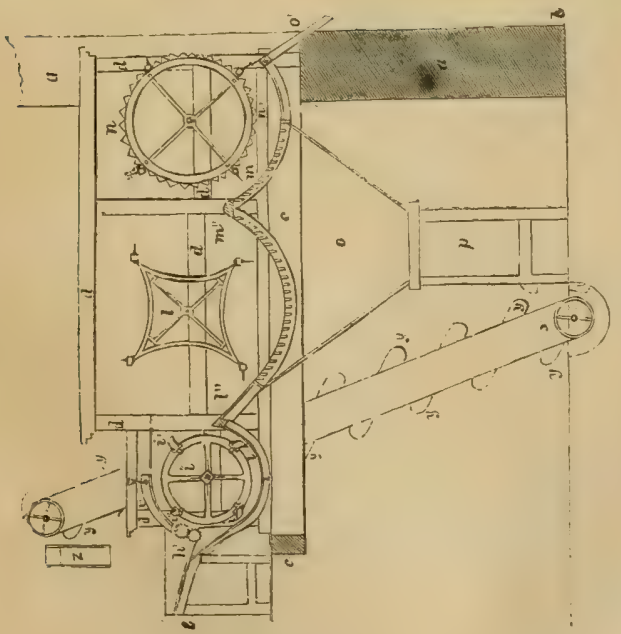

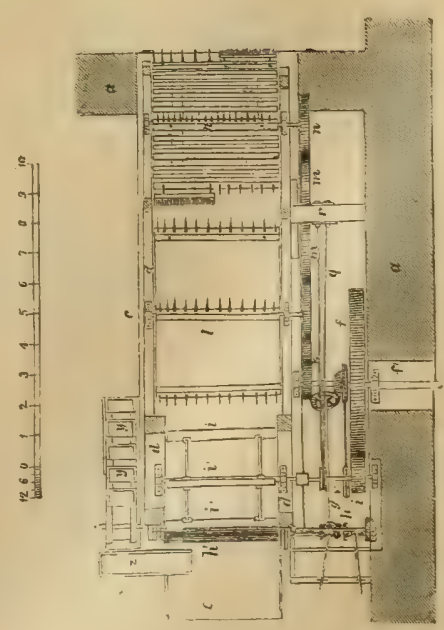





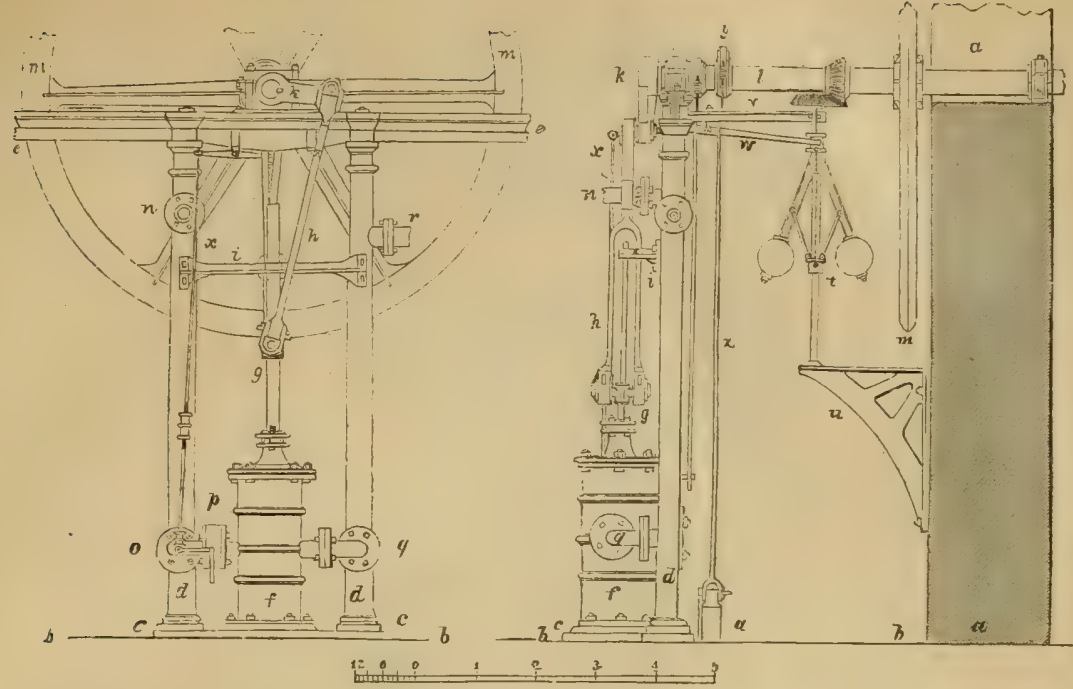

The Book of the Farm.

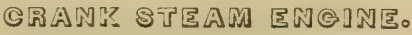

Plate XXII.

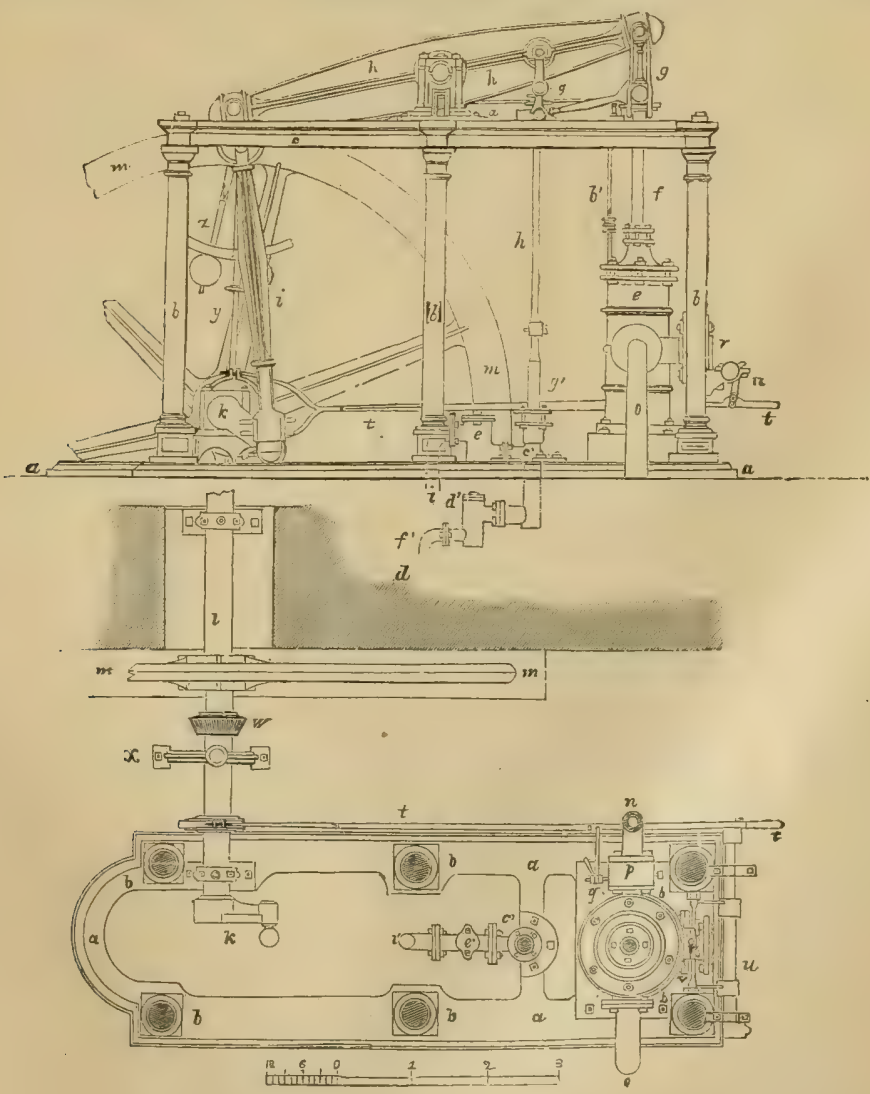


. 


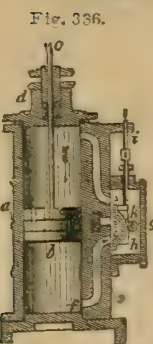
Fig 339
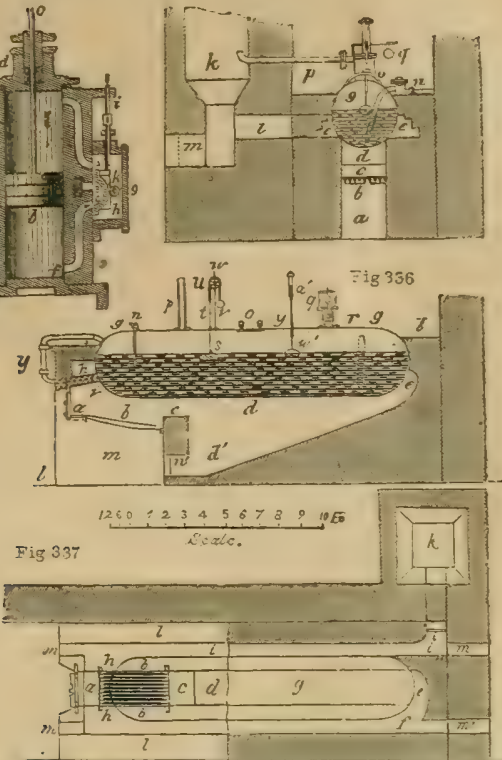

Book of the Farm

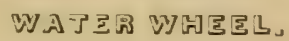

Plate $\Gamma \times \nabla$.
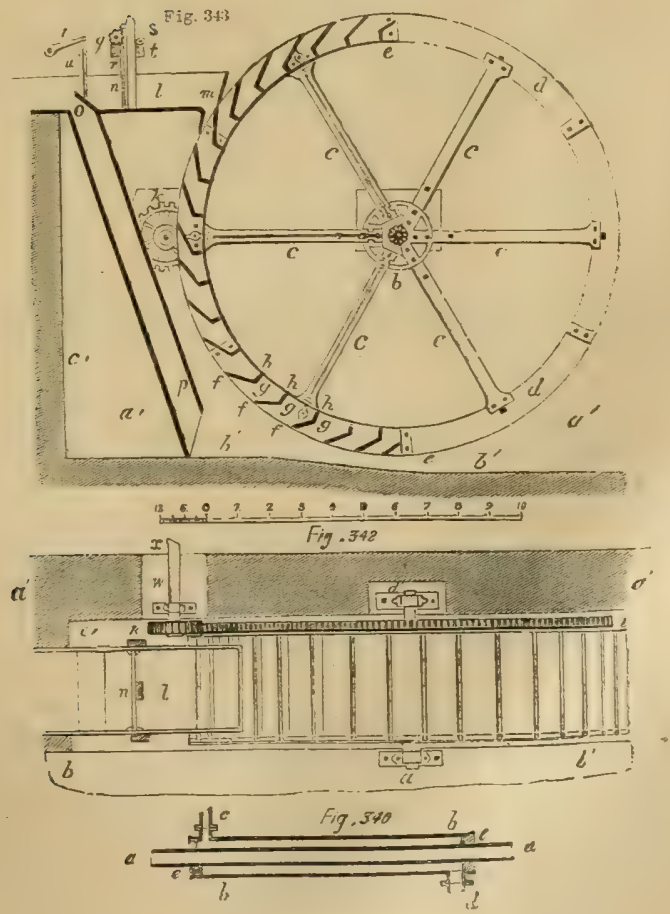



\section{MANURES,}

\section{AMELIORATORS AND STIMULANTS:}

MODES OF MANUFACTURE AND APPLICATION

BY JEAN BAPTISTE DUMAS.

TRANSLATED BY CAMPBELL MORFIT, PRACTICAL AND ANALYTIC CHEMIST.

\section{THE NUTRITION OF PLANTS.}

BY JEAN BAPTISTE DUMAS.

TRANSLATED

BY CAMPBELL MORFIT AND BARNET PHILLIPS.

\section{THE}

\section{ACTION OF SALT UPON VEGETATION;}

AND ITS USE IN AGRICULTURE.

BY

M. BECQUEREL AND J. B. LAWES.

NEW-YORK :

GREELEY \& McELRATH, TRIBUNE BUILDINGS. 



\section{PREFACE.}

Having finished, in the last number of The Farmers' Library Stephens's "Book of THE Farm," we dedicate with pleasure the few remaining pages of this volume of The Library to the following Tract on "Manures, Ameliorators and Stimulants," and on the Action of Salt as a Manure, translated expressly for this work.

The authors are all men of distinguished character as scientific investigators, and have fortunately given their attention, in this case, to subjects of great moment to Agriculture.

The Essay by Dumas will be seen to relate chiefly to the preparation of certain Manures, of which cities supply the materials, and most particularly to nightsoil.

Perhaps nothing could be referred to that would more forcibly illustrate the carelessness of agriculturists in matters that very nearly concern them, than the neglect, in this country, of this, the most wasted of all fertilizers, and the most concentrated and powerful, except the excrement of birds and fowls, which contains more nitrogen. Such are the fertilizing effects of this manure, says an English author of many Prize Essays, that it has been assumed that the excrements of a man, when properly applied, can be made to produce sufficient corn and roots for his own support. Though this may be an exaggeration, a thousand experiments have proved it to be exceedingly nourishing to vegetation, and, it is said, most particularly to potatoes! And yet, what immense quantities of it are carried off and lost, especially from our large towns! What a resource would the privies of the public buildings at Washington afford, if arrangements for preparing their contents were provided according to the directions in this Treatise!

It has been said that nightsoil communicates an unpleasant flavor to plants ; but this objection may be easily obviated by mixing it properly with ashes, or lime, before being applied. In China, where Agriculture is carried to the highest point of productiveness-from the denseness of the population, and the labor being principally manual-nightsoil is the only manure in use, both for the gardens and the fields.

The nightsoil of Paris is exported to Flanders and the low countries, where, after being converted into liquid manure, it is extensively usedbeing considered particularly convenient and valuable as a top-dressing for grass-lands.

We know of but few chances that offer so promisingly of great profit to the manufacturer and to neighboring cultivators, as establishments for (1067) 
the preparation of poudrette, in many large cities where none such havo been provided. It would seem to be superfluous to dwell on the care with which every provident farmer will husband a resource so efficient and valuable. One might as well, it ought to be supposed, exhort a sensible man not to take silver out of his pocket and throw it away!

In appending to the observations of Dumas the remarks of eminent writers and practical agriculturists, on the use of Salt, we had in view to fill with a kindred topic the little space which remained to us and at the same time to show that a Farm is in truth but a Manufactory, and that when so considered it ought to go far in dissipating that prejudice and mistaken apprehenşion of antagonism, which pervade the agricultural community, toward their best friends and customers, to wit: those who (nearest to their own farms) are the manufacturers of their raw materials and the consumers of their produce. 


\title{
MANURES,
}

\section{AMELIORATORS AND STIMULANTS-MODES OF MANUFACTURE, \&C.}

\author{
BY JEAN BAPTISTE DUMAS.
}

Tranelated from the French for The Library, by CAMpBexI Morfrt, Practical and Analytic Chemist.

THE term Manure, in its widest sense, extends to all substances, solid, liquid or gaseous, which are applicable to the nutrition of plants or to the promotion of their growth. Thus generally considered, manures are very diverse. In fact, every substance containing one or more elements of plants, wholly or partially susceptible of assimilation, in the act of vegetation, may be ranked as a manure. Sooner or later, the plants in contact with such substances will assimilate some of its elements - that is, either hydrogen, oxygen, carbon or nitrogen, or the water of combination, or even different calcareous, earthy or metallic salts which enter into the composition of nearly all plants.

An ameliorator (amendment), on the other hand, is a substance designed for the improvement of the physical constitution of the soil; that is, to render it permeable if too compact, and to impart body and consistence when too light and sandy : indeed, to partially change or to modify its nature, if its constitution is either deficient in nutritive power or prejudicial to vegetation. A combination of these valued qualifications of both a manure and an ameliorator is met with in a variety of matters.

Finally, the title of stimulant applies to those substances, solid or liquid, which give an impulse to vegetation, either by imparting a more active energy to the manure, or by stimulating the organs of the plant and thus promoting the assimilation of the elements which constitute it. Sometimes, the stimulants are of a nature totally or partially assimilative by the plant, but their more special object is to augment the activity of manure, particularly those whose which are nitrogenous. In a soil completely deprived of the latter, stimulants are ineffective, and they impoverish the soil if care is not taken to recruit its strength by fresh additions of azotized matters. Gypsum, lime, and common salt, in proper proportions, are powerful stimulants.

Although the term Manure properly refers to every substance capable of furnishing one or more of the elements of a plant, yet custom limits the application of the name to those which furnish the nitrogen, alkaline and earthy phose phates, and other salts requisite for vegetation.

The carbon, hydrogen and oxygen exist abundantly in Nature, and a supreme intelligence dispenses them, in suitable proportions, in the forms of air and water. That which is most wanting and expensive to the agriculturist, as being the most fruitful source of abundant crops, is nitrogenous matter. Since the recogni- 
tion of this great truth, and since modern Chemistry has demonstrated the im. portant agency of nitrogen, real manufactories of manures spring up and prosper, and the offal, detritus and filth which were formerly unavailable, and were even the causes of the insalubrity of cities, are now rendered subservient to Agriculture.

We divide the nitrogenous manures into two classes: the first comprises those which are employed in their natural state, and the second embraces such as shuuld undergo preliminary preparation.

Every nitrogenous substance, liquid or solid, whether from the animal, vegetable or mineral kingdom, when employed in its original state and without previous preparation, constitutes a natural manure.

Among the animal manures are blood, muscular flesh, and the offal of the carcass. All the substances, in their rough state, should be used immediately, otherwise their rapid putrefaction will develop an infectious odor, and consequently render their use impossible in the environs of large cities where they are most abundant. We will see, however, in studying the prepared or manufactured manures, in what manner they can be indefinitely preserved and reduced to a bulk convenient for transportation to a distance, and thus made more uniform and constant in their action.

The herbaceous plants, turned under the soil in a green state, form a natural manure much used, especially in warm countries-for while furnishing nitrogen, they maintain a humidity very favorable to vegetation.

Without recommending this practice, we will merely remark that in the south of France and in Italy, certain plants, (such as the lupines, beans, and even maize) are specially cultivated for this purpose. For moist and cold soils they should be applied in a dry state; and of great advantage in this respect is the employment of rye-stalks and damaged hay. Leaves of trees are also applicable, for analysis has proved them to contain more nitrogen than other portions of the tree: and, moreover, they are not costly, being furnished in abundance and gratuitously by neighboring forests.

The seeds and fruits of plants and trees, are likewise often employed as manure. In Italy, the lupin seeds are successfully used to manure the orange and olive trees; but care is always taken to previously destroy their germinative impulse by turrefaction in a furnace: as the lupin seeds contain 4 per cent. of nitrogen, their activity is readily comprehensible-as is, for like reasuns, the case with clover which is applicable under similar circumstances. So also, the residual matter of malt, of pressed fruits, oleaginous seeds, or of olives, will produce corresponding and frequently even more energetic effects, since, notwith:tanding their loss in weight by expression, they still retain nearly the whole of their nitrogenous and albuminous matter, which constitutes their value and richness as a manure. In fact, the marc of flax-seed, colza, Arachis hypogea, Madic sativa, \&c., contain the enormous quantity of 5 to 8 per cent. of nitrogen, nearly equaling the proportion in dry animal matter.

Finally, among the natural manures of the vegetable kingdom must be classed aquatic plants, growing either in fresh or salt water. The plants which are gathered green from the marshes may be used in that state for the fertilization of the soil, as it sutfices to merely turn them into the groand by plowing.

Sometimes, however, they are previously subjected to incipient fermentation under water, but the resultant peat cannot be used without certain precautions, for its acid reäction renders it hurtful to regetation. To remedy this, and to 
render it suitable for agricultural purposes, the free acid must be saturated with lime--or as well by promoting putrefaction, which destroys these acids, or rather saturates them, by the formation of ammonia.

In some localities they are merely burned, and the ashes spread upon the surface of the fields; but it must be remarked that this process destroys their most fertilizing portion, viz., the ammonia or nitrogenous matters; still, however, the residuum, by reason of its ccnstituent salts, forms a stimulant of much energy.

The marine plants, such as the fucus, sea-wreck, hair-weed, \&c., where they can be procured abundantly and cheaply, make a very advantageous manure, as they contain, in addition to some nitrogen, a certain portion of salt which stimulates their fertilizing power. In Normandy and Brittany they have been used from time immemorial. Sometimes they are applied to the soil in their natural state, and again sometimes in the form of litter. But another practice is to make a compost of them, either by stratification with alternate layers of earth, so as to produce a mould, or by admixture with other mucks. In this last process there is evidently a partial loss of their properties, for the fermentation produced in the mass always eliminates nitrogen, which consequently escapes. As the marine plants decompose with sufficient rapidity in the earth, this previous disintegration, in most instances, is unnecessary.

In France, the use of the varech and fucus creates so extensive a cultivation on the sea-board that a royal ordinance has restricted their time of harvest to a limited period-between the full moon of March and that of April, during which they have expanded their reproducing granules, and are not covered by the spawn of fish.

'The mineral kingdom also furnishes some substances suitable to agricultural purposes. They, too, may be considered as natural manures, and though generally constituted of a certain portion of nitrogen, are, by reason of other properties, powerful stimulants and ameliorators. For example, the black or red pyritous ashes from Picardy, much used in the Northern Departments, may be considered as an energetic stimulant manure.

These ashes, which also are the raw material from which copperas and alum are manufactured, exist in numerous other localities as a black powder, frequently containing shells, vegetable debris, and bituminous wood, more or less decomposed. When heated slightly in a crucible, it intlames and undergoes a slow combustion, which, after two weeks' continuance, partially changes its nature and color, which latter, from the per-oxidation of the iron, becomes red.

According to Girardin and Bidard, they are to be found at the surface of the soil, in the neighborhood of Forges-les-Eaux.

These pyritous earths, after having been leached, are generally mixed with one-fourth of their weight of calcined turf, and applied as a stimulant. They are exactly similar to those from Picardy. According to the analyses of Girardin and Bidard, their composition is as follows:

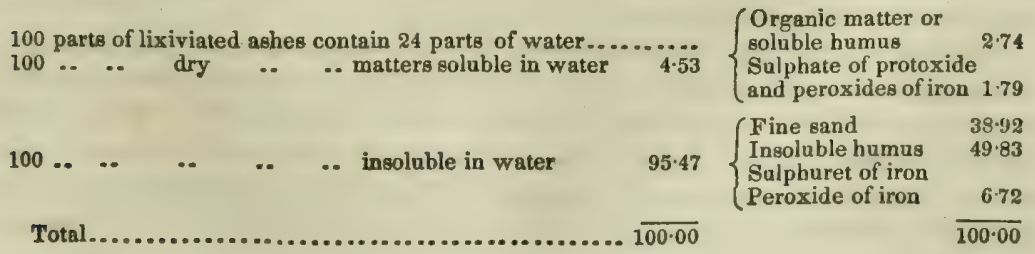

(1071) 
The nitrogen of these ashes equals the considerable amount of 2.72 per cent. The proportion found by Boussingault and Payen in the Picardy ashes, did not exceed 0.65 per cent. - hence, probably it is the humus which they contain that gives them the property of a manure, while the stimulative influence is doubtless due to the presence of salts, especially those of iron. The warmth genera. ted during the slow combustion of the sulphuret may also, and probably does, have some influence promotive and accelerative of vegetation.

The mixed manures which are employed without previous preparation consist of the offal of streets and excrements of animals.

Fecal matters and urine, either pure or diluted with water, are frequently applied in their natural states, merely by distribution on the surface of the soil. This mode enables all parts of such manure to be used, but it is not without inconvenience, for its great bulk renders the expense of transport heavy, and consequently limits its use to the immediate vicinity of its production. As the cities and towns produce more than is requisite for their vicinities, there is a considerable loss when it is not used in its natural state.

There are these objections, however, to fresh fecal matter: they communicate their disagreeable odor to the plants, and emit a pestilential effluvia in the act of being carried to and spread upon the field. A proper treatment previous to their application to the soil, obviates all these disadvantages.

Human excrements constitute one of the best manures. They are employed in a fresh state under the form and name of gadoue, or in a dry state as poudrette.

n China, Tuscany, Holland, Belgium, and many other countries, they are used in a fresh state, being diluted with water and then dispensed throughout the surface of the soil. In China they are kneaded with clay, and the dried mixture is then pulverized or crushed. In Flanders, where they use them for the culture of flax-seed, colza, poppy and tobacco, the farmers have reservoirs expressly for the reception of fecal matters. In these vats they remain for several months, or until transformed by fermentation into a viscid liquid matter. In this state they constitute the Flemish manure. To improve it, the pulverized marc of pressed seeds is frequently added, for the nitrogenous matter therein contained becoming rapidly decomposed, contributes materially to the efficacy of the manure. The addition has other advantages also in decreasing the fluidity of the excrements, and by becoming thoroughly impregnated with it, in facilitating its application and prolonging its beneficial effect. However, this effect is never beyond a year's

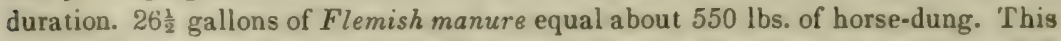
mode, prevalent in Belgium and Flanders, where Agriculture is brought to a full development, and where great care is observed in the preservation and application of all matters promotive of the fertility of the soil, is the one most to be recommended.

The excrements being inclosed and free from exposure, are less subject to sudden changes of temperature and to fermentation, and consequently can be retained unaltered and unimpaired in quality for a long time.

When the liquid manure is to be used, it is drawn portionwise from the reservoir, and then diluted with five or six times its weight of water, in order to modify its energy and prevent injury to the plant. Thus prepared, it is spread upon the fields when they are being sowed, and upon the meadows after having been recently mowed. Sometimes it is dropped, undiluted, by ladles-full at the foot of each plant, when its nature permits the application without too much manual 
labor; but in such instances care must be taken not to touch the stalks, lest they might be injured.

In the environs of Lille, a cask of thirty-five and a half gallons of Flemish manure, costs twenty-four cents, that is, six cents purchase money, six cents for transportation, and twelve for labor in spreading it.

The excrements of birds or fowls form a manure much richer in nitrogen, and consequently much more active than the Flemish manure. They contain, in fact, 8 and even 9 per cent. of nitrogen. 'They undoubtedly are the richest of mixed manures, and, moreover, are among the warmest and most alterable. In the Northern Departments of France, where they are much appreciated, one of themthat most used-is pigeon's dung, $\$ 20$ value of which will fertilize or manure 9,500 square yards of ground. This rich manure is especially used in the culture of flax, tobacco, \&c. It is only necessary to examine the analyses of guano, to see and be convinced of the richness of the excrements of birds and their utility in promoting vegetation. They contain, in fact, independent of accidental portions of feathers and other debris, uric acid, ammonia, coagulated albumen and phosphate of lime.

In Flanders and elsewhere, where pigeon-fanciers are numerous, they collect the dung and engage it to farmers at stipulated rates. At the usual price of $\$ 20$, for the product of 6 or 700 pigeons it will cost $\$ 25$ to $\$ 40$ to manure about three acres.

The excrements of other birds are less valuable than those of the pigeon.Usually, these latter are employed in their natural state, and without any admixture, being in this form specially fitted to assist the growth of the cereals in humid and compact soils. They are, however, of nearly equal service in the culture of clover; but for this purpose they should be mixed with ashes. In Flanders, 4,500 lbs, per three acres is the proportion for a good yield.

As has already been remarked, these manures owe their efficacy, in part, to the urine with which they are impregnated; and furthermore, it is well known that this liquid, by the decomposition of urea, one of its principal constituents, can furnish a notable quantity of carbonate of ammonia, the utility of which to vegetation has been well proved. Independent of the urine absorbed by the litter, a portion which by a little management might be retained, runs off, and is lost.

In Switzerland, it is the custom to collect the urines in cisterns and therein reserve them for some time before spreading them. In Belgium, they are imbibed by straw and then mixed with ordinary manure, and sometimes even with loam, clay, sand or plaster. 'That manure known in commerce under the name of "Urate," is a mixture in equal proportions of urine and plaster. It is dried and powdered, and kept free from moisture.

Whether it is more useful to employ fresh or slightly putrid urines as a manure, is a question which answers the prevalent custom in favor of the latter; but the practice in this, as in many other instances, may lead to error for, for it is not based upon correct principles.

It is known, in fact, that carbonate of ammonia generated during the fermentation of urine is a very volatile salt, and that thus the more active and useful principle is liable to be dissipated when the urine is too long kept. To form an idea of the advantages which may be thus lost, remember, that every $2 \frac{1}{4} \mathrm{lbs}$.of ammonia which evaporates is equivalent to a loss of $150 \mathrm{lbs}$. of grain, and that $2 \frac{1}{4} \mathrm{lbs}$. of urine will produce $2 \frac{1}{4} \mathrm{lbs}$. of wheat.

In all these cases, in order to fix the ammonia, the urine must be mixed with 
plaster, sulphate of iron. or mould. Sulphate of ammonia, a more fixed, but not less efficacious salt than the carbonate, is thus formed.

The advice of some agriculturists to use the fresh urine, properly diluted witb water, we rather hesitate to recommend.

There are many other substances besides bird's dung, which can without previous preparation be advantageously used in Agriculture. 'The excrements from sheep-folds, \&c., are of this number, and this mode of manuring is simple and economical, for there is a saving of both the waste and expense of transportation.

Dung or muck itself, as obtained in most places, may be considered as a mired unprepared manure, since all its preparation consists in receiving the excrements upon straw and stacking it as fast as it becomes impregnated with fecal matter.

The name of dung specially applies to the straw litter impregnated with the urine and fæces of domestic animals. When a mixture of this kind is exposed to air, and moistened occasionally with water, a very active fermentation ensues: carbonic acid and ammonia, among other gaseous products, are disengaged, and the straw itself becomes rotted and disintegrated. It is in this state that the dung is used to manure the land. As to the juices, which serve for irrigation, they hold in solution all the soluble matters of the manures, and owe their deepbrown color to the presence of ulmate of ammonia. Being advantageously serviceable, they should be carefully collected and preserved.

One oircumstance worthy of note is, that the dung during fermentation can lead to the formation of ammonia from the nitrogen of the air and hydrogen of the water. The efficacy and value of manures, then, depend not only upon the nature and relative proportions of the excrements and straw, their bases, but also upon'the processes of their manufacture and modes of preservation and em. ployment.

The dungs obtained from the excrements of herbivorous animals are not equally efficacious. Hog dung is much less valuable as a manure than that of the cow and ox, which latter, in their turn, are surpassed in richness by those of the horse and sheep.

Below are Girardin's comparative analyses of the excrements of the cow, horse, and sheep:

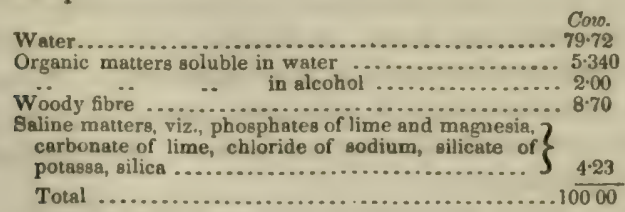

\begin{tabular}{rr} 
Horse. & Sheep. \\
$78 \cdot 36$ & $68 \cdot 34$ \\
$4 \cdot 34$ & $4 \cdot 10$ \\
$2 \cdot 60$ & $2 \cdot 80$ \\
$12 \cdot 16$ & $16 \cdot 26$ \\
& \\
$2 \cdot 34$ & $8 \cdot 15$ \\
\hline $100 \cdot 00$ & $100 \cdot 00$
\end{tabular}

Sheep manure is considered the most preferable of all other species. Being hard and of a shape which prevents a ready admixture with the litter, it is slower to be impregnated with the stable liquor, and consequently is less liable to rapid fermentation. To favor the decomposition of the straw, therefore, it is necessary to arrange it in layers, and to wet it frequently before using it.

It has been calculated that the excrements of a sheep produced in one night, suffice to manure $1 \frac{1}{4}$ square yards of surface, or, according to Boussingault, even one and a third.

In comparing, for different species of animals, the weight of their fæces with that of their food, we find, after Black's experiments, the following relations : 
Experience has, noreover, shown that an ordinary beef of 900 pounds produces, annually, from fifty to sixty metrical quintals of manure. The same quantity is obtained from a hurse and a half, and from ten to fifteen sheep.

The nature of the litter used necessarily exercises a marked influence upon the qualities of the manure. In fact, the different kinds of straw vary, those of the leguminous from those of the cereals, not only in the proportions of their saline contents, but also in their richness in nitrogen.

Sprengel makes the following classification of the straws, ranking each according to its practical value. Annexed, also, is a Table of their relative proportions of organic matters and saline substances:

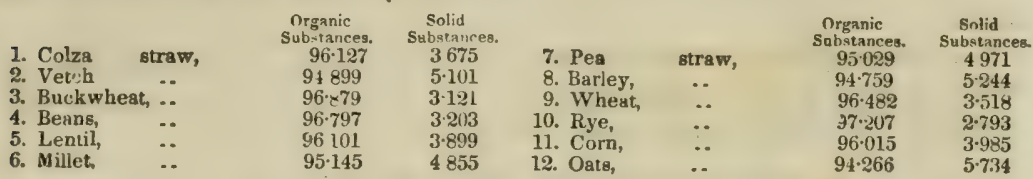

'The following analyses of Boussingault and Payen show the proportion of azote in several straws.

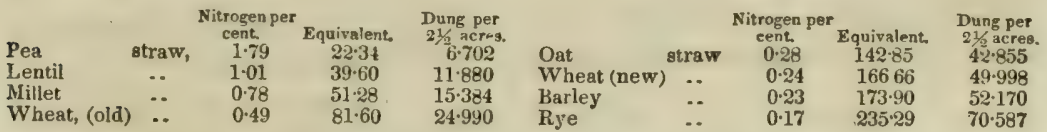

The straw of the leguminous plants is, therefore, richer in nitrogen than that of the cereals, and, moreover, contains larger proportions of potassa salts, and by putrefaction gives more ulmic acid and disengages more ammonia.

The latter are preferable in the manufacture of manures. Cereal straws, poor in nitrogen and alkaline salts, contain a large portion of silica and phosphate of lime. Oat straw is richer in potassa than other cereal straws, and the soil containing this alkali produces good oats. Magnesian earths are particularly applicable to the culture of buckwheat, the straw of which contains a remarkable quantity of magnesia.

The mode of preserving the manure, during the interval between its removal from the stable and application to the soil, has a decided influence upon its fertilizing power. Its action depends upon a carefully managed fermentation, so as to generate ammoniacal salts and other stimulant principles, and at the same time prevent a partial volatilization of the ammonia by a too active evaporation. To this end, therefore, it is requisite to stack the manure in broad heaps, so that a too great hight of the pile may not cause a too high elevation of temperature in the interior of the mass.

To prevent the escape of a part of the ammonia, the manure must be frequently wetted with the juice which runs from the stables, which should be collected and saved for the purpose. It can be pumped up from the reservoir, and thus applied uniformly and regularly.

It is also necessary to protect the manure from the unequal washings by rains.

Some farmers prevent a too active fermentation of manure by stratefying it with earth. It may also be mixed with peat or turf, as experience has shown that a uniform compost of this kind makes an excellent manure.

Manures can be immediately used, fresh from the stable, and without being previously fermented. Under this form they are called long or straw manure. 
Those which have been for some time stacked have the name of short or fat manure. Both the weight and volume of manures are decreased by fermentation. It has been ascertained that 100 volumes of fresh manure are reduced

In 81 days to 73.3 of its original bulk, with a loss of $35 \cdot 7$

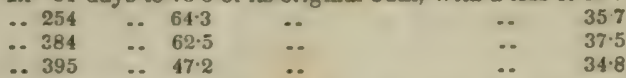

Schattenman, the skillful director of the factories at Bouxwiller, has proposed a simple and economical mode of effecting the fermentation of manures. It consists in adding to saturated waters, or spreading upon the dung, either sulphate of iron or gypsum, the sulphuric acid of which, by forming a fixed salt with ammonia, prevents the volatilization of the latter. With due precaution, a rich manure of great power may after this manner be prepared in two or three months.

As has already been remarked, the different manures vary in properties and fertilizing power. The remarkable difference between the weight of an equal volume of cow and horse dungs, for example, is shown as follows:

A cubic foot of fat manure of the ox weighs 57 1-5 lbs.

$\begin{array}{llllllll}\ldots & \text { fresh } & \ldots & \ldots & \ldots & 47 & 1-4 & \ldots \\ \ldots & \text { fat } & \ldots & \text { horse } & \ldots & 37 & 1-2 & \ldots \\ \ldots & \text { fresh } & \ldots & \ldots & \ldots & 29 & 1-2 & \ldots\end{array}$

The better dung, and that which may be considered as normal, is from horned beasts, and approximates in composition to the following analysis:

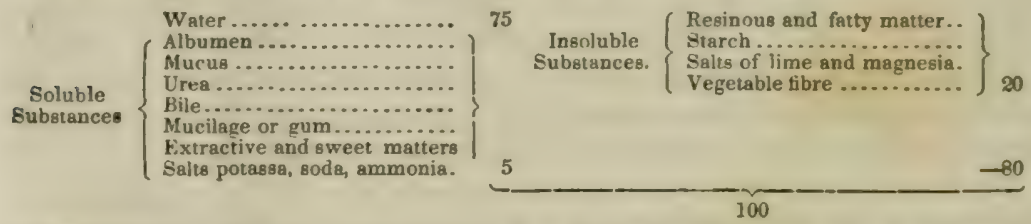

Boussingault gives the composition of a farm manure aged six months, and which he calls normal, as follows :

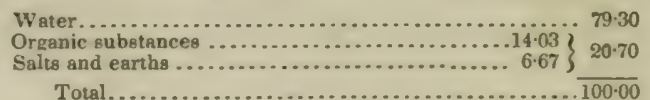

Under the name of street dung is comprised the incongruous mixture of mire and filth which is collected in cities by sweeping the streets. Its composition is complex, and before being used it should undergo fermentation. During this process large quantities of sulphuretted hydrogen gas are disengaged. Lime, which is sometimes added to accelerate decomposition, is apt to cause a partial loss of ammonia.

The mass should be left undisturbed for some time, so that the decomposition may be thorough. If applied while fresh, it will ferment in the soil; and thus, by a too energetic action, will blast the roots of the plants.

The name of compost is given to a mixture more or less similar to street dung. It is formed of alternate strata of manures of different compositions. In this way, a pile of organic debris, the detritus of plants, residual animal matters, and waste juices of dwellings and manufactories, may be manufactured into a profitable manure; but it too often happens that, in large cities, where these matters are most abundant, the profit they would yield the farmer is lost by the neglect in collecting and preserving them,

Jauffret, a Provincial farmer, has proposed the manufacture of manure by a (1076) 
rapid and active fermentation of fern, broom-reeds, and organic residues. To this end, the materials must be finely divided,-heaped up and moistened with lye holding in solution some mineral substances, and putrefied organic matters. The place of manufacture should be convenient to a pool, the water in which can be made foul by additions of fecal matter, urine and sewer filth. Ashes, plaster and nitre, are necessary and advantageous additions.

By wetting the vegetable debris with this lye, a very active fermentation is produced; the confined air of the mass facilitates the reaction, and the tem perature of the interior rises as high as $167^{\circ} \mathrm{Fahrenheit.}$

But this manure is too expensive, for while $4,500 \mathrm{lbs}$. will cost $\$ 480$, that amount of stable manure can be bought for $\$ 2$ to $\$ 3$. Nevertheless, by following the method of Jauffret, a sufficiently economical manure can be made says Lucy, with the following ingredients. The cost of the compost and its application per 11,960 square yards, will be as follows :
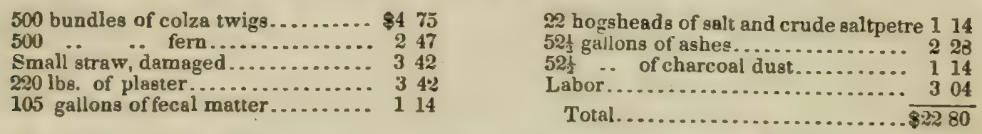

While leaving to agricultural experience the resolution of the problem in a practical and economical point of view, we, on the other hand, cannot too strongly reccommend this system of fabrication, which evidently reposes upon an excel. lent basis.

When the importance of nitrogenous manures in the nutrition of plants becomes fully known and recognized, all matters containing more or less of this element will be turned to account, and everywhere will be erected real manufactories for their proper preparation. Indeed, even now the preparation of manures commences to form a true chemical art-the object of which is to furnish to the land, under the best possible form, the supplement to that nourishment which the farmer cannot supply to soil otherwise well cultivated, and from which it is desired to draw the most advantageous results.

All parts of animals, being rich in nitrogen, form an excellent manure which can be used on the spot in a fresh and unprepared state; but to transport them to a distance, or to preserve them, or to render their effect more constant and uniform, it is requisite to subject them to a certain treatment that will, at the same time, render them less communicative of a bad taste to plants. The slaughter-houses, where sick horses are killed for their fat, possess advantages for the preparation of manures from offal otherwise wasted.

To preserve the blood, indefinitely, it must be coagulated at a temperature of $212^{\circ}$ Fahrenheit, either by a direct application of heat to a caldron containing it, or, more preferably, by the intervention of steam. In the latter case, the blood can be placed in a wooden vat. The coagulated portion is removed by a large skimmer, then pressed until it ceases to yield any more liquid; afterward it is dried either in the open air or in a heated room. Thus dried and pulverized, it can be packed into casks for transportation and agricultural purposes; and being much reduced in bulk forms a very rich manure, containing the large amount of 13 to 14 per cent. of nitrogen.

In the horse butcheries, after having boiled the carcasses in wooden vats or steam tanks, they detach the flesh from the bones and dry it, first in the sun and finally in a dry room, until it becomes friable and pulverulent. When coarsely ground in a mill, this dried flesh makes an excellent manure which decom- 
poses much slower than fresh meat, and at the same time is of more durable fertilizing power. Unfortunately, however, the use of this material in the manufacture of prussiate of potassa and nourishment of animals makes it too expensive except for the most productive vegetables; thus, for instance, it is exported to the Colonies for the culture of the Cant--fur its richness in nitrogen renders it more econonical for transportation than other kinds of manure.

Bones properly prepared constitute an excellent manure which is much used in England. In France, where they are not so plenty, and command a high price for the manufacture of bone-black, they also are used to a limited extent.Before being applied to the soil they must be freed of their grease by a long boiling in water. The fat thus obtained pays the expense of its separation and a small profit additional. The bone, after being buled and dried, must be ground to a coarse powder between channeled iron rollers propelled by steam or horsepower. 'l'hey are first passed through rolls with wide and coarse channels, and finished between a pair with finer grooves and more clusely set.

This manure (bone-dust) is so well appreciated in England that it commands $\$ 3$ to $\$ 350$ per $185 \mathrm{lbs}$; ; and 1,850 to $7,400 \mathrm{lbs}$. are used per $2 \frac{1}{2}$ acres. Its slow decomposition is a peculiar merit of this manure, as its effects are perceptible for many consecutive years. While manures much richer in nitrogen during their rapid decomposition generate fertilizing gaseous matter much faster than it can be assimilated, the bone-dust furnishes them gradually and produces in the end more profitable results.

When the gelatine and glue have been extracted, or when the bones have for a length of time been exposed to the irregularities of the atmosphere, their fertilizing power becomes impaired, and is less than that of new bones proportionably as the organic matter has decreased.

There are mills in various parts of the world for grinding boiled bones and the refuse of the comb and button factories; and the powder thus obtained, when dried, consists, per $220 \mathrm{lbs}$, of

Combustible animal matter........................43-86

Phosphate and carbonate of lime.......................56.14-100.00

This analysis approximates very nearly to the normal coustitution of bone.

The animal matter of bones, doubtless, plays an important part in their application to Agriculture; but it would be false not to recognize the importance, and even absolute necessity, of the phosphate of lime in the bones. The exportation of meat or grain from a farm is equivalent to the exportation of earthy phosphates, because the bony structure of animals is formed of it, and grain contains it in large quantities. In order to revive lands, therefore, these phosphates must be restored to it, for light soils naturally have but very little. Consequently, the most simple method is 10 impregnate the soil with the urine or fecal matters of man, which the consumption of the grain has produced, or with the bones of the animals whose flesh has been exported or otherwise consumed.

The natural phosphate of lime would also make an excellent ameliorator, and its application will doublless be well worth the expense.

Among the economical means of restoring to the soil all the essential ingredients that have been abstracted from it by vegetation, Chemistry enumerates ammonia and the earthy phosphates, as of chief importance. Boussingault, who has also tried the ammonia-magnesian phosphate, recommends its use, as especially advantageous in the culture of a variety of maize known as Mais quarantain. 
The most common and well-known manufactured manure is doubtless the Poudrette, which is prepared from the contents of privies, and contains the earthy phosphates in connection with fecundant animal matters. An extensive factory, established at the very gates of Paris, gives great value to fecal matters by reducing them to a suitable condition for transportation to a distance. Thus a large amount of material, which in other large cities is useless, becomes transformed, by some skill, into a source of profitable revenue.

But it must be remarked, that the mode of preparing the poudrette pursued at Montfaucon is very imperfect, as it not only incommodes the vicinity, but occasions a loss of a great part of the gases most useful to vegetation. As the method is still in prevalent use, we deem it necessary to give a more correct process.It is briefly as follows:

The operation is conducted in six or seven perfectly tight large reservoirs, placed in an elevated position and above the neighboring dwellings. These cisterns are arranged with coupling connections so that they may be united together or disconnected at will. One of them, much more elevated than the rest, is also of a proportionally greater capacity. This is the recipient for all the collected fæces of the City of Paris, which is emptied in from casks specially appropriated for its first reception. The reservoir is of irregular shape, being of 330 feet long, 150 to 175 wide, and 30 deep; and it is in this vessel that the liquid is separated, merely by decantation from the solid portion. It is drawn off through a conduit, and, passing through a wicker sieve, falls into one of the vessels beneath. There should be five or six of these receiving vessels, and each of 50 to 80 square metres capacity; but having to contain less solid matter, they are not necessarily so deep as the upper cistern. As has been remarked, these vats communicate with each other, so that there may be a systematic deposition of the matters suspended in the liquid running from the upper cistern. 'The thin juices then pass consecutively through all the vats, and are again filtered through a fine wicker which catches the solid particles, and allows the free egress of the liquid into a conduit which connects with a sewer emptying into the Seine.

From this it will be readily seen that the lower cisterns are a long time being filled with solid matter; a year or more frequently elapses before one is full. When it is so, after several days' repose it is freed of its liquid with a pump, syphon, or by drawing off. Each vat is emptied in its turn, and again set for the reception of thin juices which are constantly flowing from the large upper cistern. This latter, when sufficiently full of solid matter, must, after the excess of liquid has been drawn off, be worked in the same manner as the lower vessels.

The vats of Montfaucon are so badly arranged as to render it necessary, while working the upper vat, to continue adding the nightsoil. Care, however, is taken to immediately separate the more liquid portion and run it into the lower vessel. The process will be more readily and uniformly conducted if there are two reception reservoirs, so that while one is being worked the other can be filled.

The mode of operating and of managing the vats is very simple. When the matters have been sufficiently drained, open the gangways leading to the bottom of the reservoirs, and then gradually lift out all the matter. The dung. carts empty their contents upon a contiguous field, where it is dried in manner as follows. The fecal matter is first spread uniformly over the whole extent of the lot, and, after some hours, must be harrowed so as to present new surfaces for evaporation, and thus hasten its desiccation. The harrowing is repeated

(1079) 
several times, and until the drying is complete; then the matter must be thrown into piles, and after a proper repose, again spread out into thin layers and crushed to powder. The gravel and other coarse impurities with which it may be contaminated are separated by a riddle or sieve. Thus prepared, the poudrette is ready for use or exportation. In the mean time it is stacked in piles of two or three cubic metres* bulk.

At Montfaucon they receive daily nearly 600 cubic metres of solid and liquid matters, from which are prepared about 100 cubic metres of poudrette.

Of late years, a new art, based upon Jacquemart's experiments, has enabled the useful transformation of the liquid portions previously wasted. A part of the thin juices is thus made into sulphate of ammonia and other ammoniacal salts. There is a factory constructed near this locality, but it consumes at most only 90 to 100 cubic metres of urine; the remainder being thrown into the Seine. A greater perfection of this art will doubtless enable the utilization of all the ammonia and other salts which are contained in the refuse urine.

There is no doubt that, after having withdrawn the ammonia by lime, as is done, the muddy residue will make an excellent manure for the irrigation of artificial meadows, as it contains all the requisite phosphates, much alkaline salt, and even organic matters.

The poudrette prepared as we have directed sells at 80 cents per $26 \frac{2}{2}$ gallons. Of late years the manufacture has been carried on at the Forest of Bondy, M. Mary having constructed a conduit of great diameter for the conveyance thereto of the liquid previously separated from the poudrette vats. The transportation and disinfecting of the solid matters, thus reduced to a fifth, offers comparatively much greater facilities. The arrangement of the vats at Bondy is superior to that at Montfaucon, in having two complete systems; but the difference in levels being less, much more manual labor is demanded. Another conduit conveys the excess of thin juices into a town sewer emptying into the Seine. Thus, as at Montfaucon, the urines will be lost, though they contain nitrogen enough to make them three times as valuable to Agriculture as the poudrette. Future skill will doubtless take advantage of this source of wealth, which is now thrown into the river. They might already use two methods for the purpose. One is indicated by the elevation of the vats at Bondy above the plain of St. Denis, where the thin liquors could be well employed for irrigating and greatly fertilizing the surrounding plains. If it is necessary to dilute the urine with water in order to modify its energy, the proximity of the canal whose level is above that of the cisterns, renders this operation comparatively easy. The quantity of urine thus disposable is, however, much greater than is needed for a field even five times as large as that of St. Denis.

The other method of rendering the urines useful is to convert them into sulphate of ammonia. Since Chemistry has shown the feasibility of using this salt for the fertilization of the earth, a number of experiments have been performed on a large scale in many parts of Europe. In England its use has produced most profitable effects, and in France, where the subject has been investigated, equally favorahle results were obtained. We will cite one essay of many, viz., that on a large scale by Kuhlmann (of Lille) and Schattenmann.

Its large amount of nitrogen (21 per cent.) renders the sulphate of ammonia one of the richest of azotized manures; and hence there will be great economy in transforming the urines of Bondy, Montfaucon and elsewhere into sulphate

\footnotetext{
- A metre is equal to $39 \cdot 37100$ English incher.
}

(1080) 
of ammonia by sulphuric acid. We will prove by figures that under present circumstances, and notwithstanding the interposition of sulphuric acid and the expenses of preparation, that the sulphate of ammonia can be furnished at a cheaper rate than most manures, with which it can successfully compete even at its present prices.

For example, let us compare the sulphate of ammonia with the poudrette of Montfaucon. The pure salt now sells at $\$ 1140$ per $220 \mathrm{lbs}$, and it contains 21 per cent. of nitrogen. The poudrette sells for about 85 cents per $220 \mathrm{lbs}$, and contains, according to Payen and Boussingault, but 1.6 per cent. of nitrogen. Supposing, then, that the value of a manure is exactly proportional to the quantity of nitrogen which it contains, it follows that $220 \mathrm{lbs}$. of sulphate of ammonia will produce the same effect as 2,900 lbs. of poudrette, which amounts to the same as saying that $\$ 1140$ of the first is equal to $\$ 1140$ of the latter. It is true that the action of the poudrette is not limited to its nitrogen, for it contains salts which are excellent ameliorators of moist soils. Moreover, its organic matters have the effect of modifying the properties of water or of the air absorbed by the roots. But as the expense of transporting the sulphate is ten times less, and as the substances which furnish the elements other than nitrogen may be had at a price much lower than that of poudrette, we may hope economical and profitable results from the use of the sulphate of ammonia combined with dung, turf and bone-dust. The price of the sulphate aforementioned is that of the commercial article. If it were extensively used for agricultural purposes, the price would be brought down to $\$ 760$, and lower.

Without dwelling upon the manufacture of sulphate of ammonia, we will only remark that the urines received at Montfaucon would suffice to produce $4,400,000 \mathrm{lbs}$. of that salt, representing in nitrogen $57,200,000 \mathrm{lbs}$. of poudrette, or even $220,000,000 \mathrm{lbs}$. of ordinary manure. It can be inferred from these figures, of what great import to Agriculture is the thorough solution of the question of the availability of the sulphate of ammonia as a fertilizing agent, and how invaluable would be the result, if long experience shall verify the success that some have already attained in its use.

In what manner should the sulphate of ammonia be applied to the soil ? This is a question yet unsolved. Some advise its use in solution of one or two thousandths at least, but under this form it is not applicable in all localities; moreover it requires the expense of additional labor.

It is probable that as good results, with less expense, will follow by sowing it either in a free state or mixed with earth or chalk, provided the time of its application is favorable, so that the too active effect of the manure may not injure vegetation. However, the experiments under this form have, so far, proved less favorable and effective.

The great value of refuse bone-black (from sugar refineries) as a manure, and its advantageous effects, are fully known and appreciated. Unfortunately, however, commerce furnishes a too limited quantity for agricultural purposes, and consequently it has been proposed to form a substitute of similar properties by cornmingling disinfected fecal matters with a cheap charcoal.

This new manure, called animalized black, is made with carbonized vegetable mould and nightsoil, and thus a substance is produced which, in fact, possesses most of the properties of the animal-black from the refineries. Mureover, this compost, by its absorbent power, retains the ammoniacal compounds as they are 
generated, and yields them gradually and in uniform proportions to the growing plant. It is this slow and regular production of ammonia which gives also to the bone-black a fertilizing value so much greater than that indicated by the Table of equivalents.

This effect of retarding decomposition is especially advantageous in the aforementioned instance, for almost the sole inconvenience in the use of fecal matters as manure, in the usual manner, consists in their too sudden and rapid action.

For this manufacture, a mould, as rich as possible in organic debris, should be selected, so that by charring it may furnish a sufficient quantity of coal. It should also be pulverulent, easily divisible, and not liable to become clotted during charring, as will happen when it is too argillaceous.

It must be confessed, however, that even under the most favorable circumstances, the charred mould is far from comparable in absorbent properties to animal charcoal, and perhaps in this respect the processes employed might admit of modification. Still, these plans yield a charred mould sufficiently cheap for an extensive and profitable application. This plan seems to be the best substitute for the manufacture of poudrette. Indeed, by the use of charred mould, we obtain manure, rich in nitrogen, which retains and renders useful all the animal parts of fecal matters, and, moreover, presenis itself in a form convenient for application.

This manure, which is sufficiently rich to be exported, can be made rapidly, that is, in a month during summer, and in two months when the temperature is low. Moreover, in its manufacture there is no disengagement of disagreeable odors, as is the case with poudrette, which in its preparation requires a much longer time, and loses a portion of its ammoniacal components.

As regards the value of the products of these two systems of fabrication, there is but little difference, though the animalized black is generally the richer ; in fact, we might impart to it 3 per cent. of nitrogen, an amount rarely contained in commercial poudrette. It is true that Payen and Boussingault found in the poudrette of Belloni 4.4 per cent. of nitrogen, but that of Montfaucon contains at most but 2.67 per cent. The medium dry poudrettes have but 2 and some only $1 \cdot 6$ per cent. of nitrogen.

It is true that by this mode of preparation and reduction of bulk, the poudrette contains the salts and the phosphates of a large quantity of fecal matter, concentrated in a small bulk, with equal richness in nitrogen, and value greater than that of animalized black, which also contains phosphates, but in a much less proportion.

Nevertheless, I do not consider this a great disadvantage in the black, for by a comparison of the analyses, it is seen that the ratio of nitrogen to phosphorus is almost the same in fecal matters and in a great number of plants; whence it follows that the quantity of animalized black sutficient to furnish the nitrogen requisite for a crop would also yield the amount of phosphorus which the crop should contain. It is true also that the animalized black is not, in this respect, a complete manure, for as its richness in nitrogen is greater than that of other constituents useful to vegetation, it requires, like some other manures, to be as. sisted by a complemental manure.

To facilitate such calculations, it would be useful to make Tables of equivalents for the principal mineral substances which enter into the composition of plants, similar to that which has been made for the most useful element, nitrogen. 
The definite quality of a manure should depend upon the rank that it would have in each of these Tables.

Barronet \& Co. make the animalized black by a process consisting of two steps : first, the extraction of the fecal matters of privies, and then their transformation into manure. Before the removal of the fecal matters from the wells, they are disinfected, and for this purpose two equally good substances are employed : the first is the residue from the manufacture of the proto-sulphate of iron, and may generally be purchased at a low rate. Where there is a choice of residues, those should be preferred which are the least acid and most rich in peroxide of iron, and even sometimes in zinc. The mode of action of these salts is readily comprehensible.

Another substance used for this purpose is a solution of the preceding matter united with an equal quantity of solution of common soap, which is thrown into the trench. A metallic oleate is thus formed, and being of easier decomposition by sulphuretted hydrogen and sulphydrate of ammonia than are the sulphates, the soap and greasy matters are useful in this operation, for protecting the surface of liquids with an oleaginous layer which opposes the diffusion of sulphuretted hydrogen and sulphydrate of ammonia.

The fecal matters are drawn from the privies by dredging buckets attached to an apparatus called a Machine Frédéric. It occupies but little space, and can be conveniently used in any of the houses, as it only requires an opening into the cess-pool of about $1 \frac{1}{4}$ by 1 foot for its entrance. For the convenience of perfectly emptying, the privy wells should be concave at the bottom; it hence follows that the consistency of these matters is not very great. Without these precautions it is necessary to finish their removal in the usual manner. The matter drawn up in the dredges is immediately, and without an instant's exposure, turned into casks, for the wbole apparatus being inclosed with sheet metal, the disengaged gas will be driven into the air through a small apartment containing chloride of lime. By this arrangement, even when operating during the day, there is scarcely any perceptible unpleasant odor, though the material may not have been disinfected previous to its removal from the privies.

These fecal matters transported to the factory, are there converted into manure and mixed with charred soil ; for the disinfection produced by the sulphate of iron will not be permanent. They are consequently turned into vats and therein treated by the shovelfull with nearly their volume of charred soil. After thorough incorporation of the whole, by stirring, the matter is left to deposit, and after having collected about the center of the vat, where the bottom is most elevated, the liquid which remains is run off through gates. The bottom of the vat has a slope of about two-hundredths of a metre.

This compost is spread out, under cover, upon an impermeable soil, and left to dry in the air. To hasten the desiccation, new surfaces should be presented by occasional stirring. When the drying is complete, add to the first mixture, a second time, its volume of fecal matters, and operate as at first. Repeat this process until the soil forms nearly a fourth of the resultant product; this happens about the third mixing, generally, when the operation has been properly conducted, and especially when the fecal matters employed contain a large proportion of solid products.

'This plan of working, during which there is but little disagreeable odor emitted, requires about one month in summer and two in winter. The season 
most favorable to the manufacture is spring, and it is then that the greatest possible number of emplyings should be made.

The charred soil was formerly prepared in pots, but Barronet has substituted an economical furnace.

The soil as it comes from the furnace falls into a sheet-iron extinguisher, wherein it cools, free from exposure to air. It is used as soon as cold in order to obtain the full effect of its absorbent qualities, and should be powdered and sieved as fine as possible. It is better if a little argillaceous, because the coal which it contains is then more divided and absorbent. But if the proportion of clay is too great, the mould becomes clotted.

The addition of a small quantity of carbonate of lime increases its durability and makes it flow more readily. There must be but very little, for if much lime is formed during heating, ammonia will be disengaged at the moment of mixing the soil and fecal matters. It is well also to slightly moisten the soil before carbonization, for the aqueous vapor generated by the heat carries off the air existing in the iuterstices of the soil of the upper apartment. In this way the carbonization is effected almost entirely apart from air, while, if the soil is too dry, it nearly always happens that instead of carbonizing, it burns, although it has only been at a dull red heat.

175 to 200 cubic feet of soil can be carbonized during 24 huurs, in a furnace of 20 feet hight, and under these circumstances the whole expense. of $35 \frac{1}{3}$ cubic feet of charred soil will be about 95 cents.

An establishment for a medium sized city, say of 20,000 inhabitants, will cost $\$ 3,800$ to $\$ 4,750$, that is, for utensils, furnaces and every uther requisite. Such a factory will yield per annum 600 cubic metres of salable manure, which at 95 cents per $3 \frac{1}{2}$ cubic feet, the usual price for manure of 3 per cent. nitrogen, equals $\$ 5,700$.

At the rate of 76 to 95 cents, the animalized black has the advantage orer the dung ; for while the 11,960 square yards of land require of the former but 70 to 80 cubic feet at the gross expense of $\$ 19$ to $\$ 2375$, it needs 22,000 lbs. of manure, which cost $\$ 3420$, and are of more difficult transportation.

If the animalized black is not yet as perfect a manure as could be desired, it is nevertheless one of the best means of wholly using the products of the privies, and offers great advantages with respect to health and Agriculture.

It would be both politic and desirable for the different Municipalities to compel the proprietors to construct their privy-wells perfectly water-tight, and of cement within, so as to avoid infiltration and to protect them from rains. When this measure shall have been generally employed, the vegetable richness of the soil will be completely regenerated, for the immense quantity of manure which it might receive would soon revive its fecundity. Agriculture and hygeine are then equally interested in the success of this new manufacture.

The value of a manure can only be determined by agricultural experience; but the chemist can furnish useful data for the proper management of the experiments. In fact, it is by chemical analysis that we ascertain the precise nature and properties of materials, either organic or mineral, which a given harvest removes from the soil that produces it, and if this determines the absence of earthy phosphates, alkaline salts, potassa and sulphur, these must be restored again before the land can recover its fertility. Chemical researches have also proved that which is now an established fact, the active efficiency of ammonia in manures, and that of nitrogenous matters generally. 
Manures should always contain ammonia or nitrogenous matters capable of yielding it; but as to the collected vegetable or animal offal which contain the requisite nitrogenous matter, as well also in their ashes, the salts necessary for vegetation, a question arises whether it is useful or dangerous to subject them to a prolonged fermentation? Is muck better than the litter which produces it?

I have no hesitation, and I believe no farmer would have any, in declaring that dung is much more eflicacious than the materials which furnish it would be in their natural state. There are two causes contributing to this special efficacy. The first is the formation of ammonia generated during the fermentation of the muck and resulting from the reciprocal action of the hydrogen of the water and the oxygen of the air. Consequently, the muck may be richer in nitrogen than its components, if the fermentation has been properly managed. The second circumstance influencing the special activity of the muck is the presence of brown acids, which evidently have a great affinity for the oxygen of the air contained in the water, converting it into carbonic acid. If the water of the muck contains ammoniacal salts formed by such acids, the action of the oxygen of the air will create the presence of the carbonate of ammonia in the solution.

Now every one knows that it would be very different tor a plant to absorb, by its roots, aërated water containing carbonate of ammonia in solution, or water deprived of air containing carbonic acid and carbonate of ammonia.

Such seems to me to be the part of the muck which gradually supplies the water with very combustible materials, capable of attracting oxygen from the air, and of transforming it into carbonic acid: and which contains, moreover, ammonia, logether with alkaline and earthy salts. If neither meat nor grain is exported, then it becomes the medium through which the ingredients of the soil, abstracted during vegetation, are restored to it. Bone-dust, urines and the like, however, are the most prolific sources of the earthy and alkaline salts and phosphates, and are the best manures for reviving land, exhausted by the removal of grain and live-stock.

But the ulmate of ammonia, as a source of carbonate, which has latterly been too much neglected, is also a manure worthy the particular attention of farners. Its constant presence in muck is a matter for consideration, and indicates plainly the utility of those previous fermentations of the components of muck, to which Jauffet has directed the attention of agriculturists.

Jacquemart, quoted above, has communicated to me the following remarks upon ammoniacal salts as manure:

"In 1832 and 1833, I tried various plans of extracting ammoniacal salts from substances which would furnish liberal proportions, with the view of ascertain. ing whether salts, rich in nitrogen, if cheap and abundant, whould not be of beneficial and profitable applica tion to Agriculture."

"I found that $150 \mathrm{lbs}$. of poudrette are equivalent in nitrogen to $10 \mathrm{lbs}$. of crystalized sulphate of ammonia, and 53 per cent of the nitrogen exists as readyormed carbonate of ammonia, and 47 per cent. is comprised in organic matters."

"This result, and the promptness of the action of poudrette upon vegetation, lead to the idea that the carbonate of ammonia might be very favorable to its development, and that to this salt should be attributed the energetic influence of the poudrette and Flemish manure. In fact, when this manure is employed, all the urea of the urines is transformed into carbonate of ammonia, and this salt is in greater proportion than all others."

"Circumstances did not permit me to continue these researches, and I only pro- 
gressed far enough to prove that the sub-carbonate of ammonia has a very beneficial influence upon vegetation. My essays upon the applicability of ammoniacal salts to Agriculture, were limited to April, 1843. They had for their object,

1st. To determine the value of sub-carbonate of ammonia as a manure or stimu lant, in comparison with the poudrette as the standard.

2d. The use of these matters in small bulk and in convenient form.

The poudrette was applied in the proportion of $2 j$ bushels per acre. As has been said, $150 \mathrm{lbs}$. represent, in nitrogen, $10 \mathrm{lbs}$ of crystalized sulphate of ammonia ; $3,000 \mathrm{lbs}$., therefore, are equivalent to $200 \mathrm{lbs}$. of sulphate."

"The quantities of ammoniacal salts were proportioned so as to contain as much nitrogen as the poudrette, and were, per $2 \frac{2}{2}$ acres.

180 gallons sub-carbonate in solution, formed of 1 equitalent of acid.

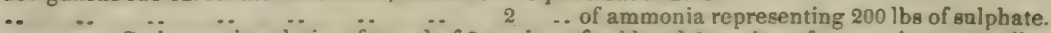
.. .. Carbonate in solution, formed of 2 equivs. of acid and 2 equivs. of ammonia ....200 lbs.

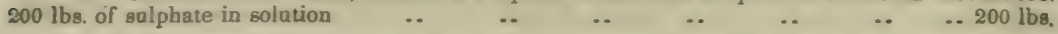

"In order to the ready and easy transportation and distribution of the solutions of ammoniacal carbonate, they should be heated with charcoal, or other porous matters, in quantity sufficient to form a thoroughly impregnated mass. It will be seen in the essays of October, 1843, that the solution of the carbonate can be employed in a reduced volume of one-half, merely doubling the quantity of salt then the bulk of the manure is reduced to that of poudrette."

"The sulphate of ammonia was used in two states:

1st. As solution in six times its weight of water, imbibed by dry calcareous matter in powder.

2d. In the form of powder, and sown similarly as fine seed. To prevent the formation of carbonate of ammonia, the calcareous matter must not be wetted with the solution of sulphate. In fact, a mixture of chalk or marl, and sulphate of ammonia, when placed in a flask, emits an ammoniacal vapor, strong enough to blue a reddened litmus paper. As this reäction, however, is very slow, good effects may be expected from the use of a mixture in which the carbonate of ammonia disengages gradually enough for its assimilation, by the plant, in a nascent state. The first crop derived no benefit, scarcely, but upon the second its good effects were decidedly evident. Unfortunately, I was unable to repeat the experiments in the third year.

"Finally, to approximate as nearly as possible the composition of poudrette, the ammonia of which is partially carbonated and partially free, I made a mixed solution of sulphate and carbonate of ammonia in the proportion of $88 \mathrm{lbs}$. of the first, and 132 pounds of the latter per $2 \frac{2}{2}$ acres. This solution was caused to be imbibed by peat dust, and all the matters employed in this essay were sown on the same day, April 29,1843, simultaneously with the oats, and plowed in with the grain."

"The land was newly cleared, limed and marled ground from which two crops had been taken. Each essay occupied 274 yards of surface, and was separated from the other by intervals of ten feet. The limits were enclosed by cords, the harvest gathered with great care, and the products weighed." 


\begin{tabular}{|c|c|c|c|c|}
\hline RESULTS OBTAINED WITH THE FOLLOWING SUBSTANCES. & 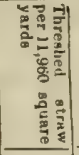 & 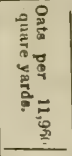 & 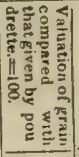 & 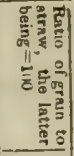 \\
\hline 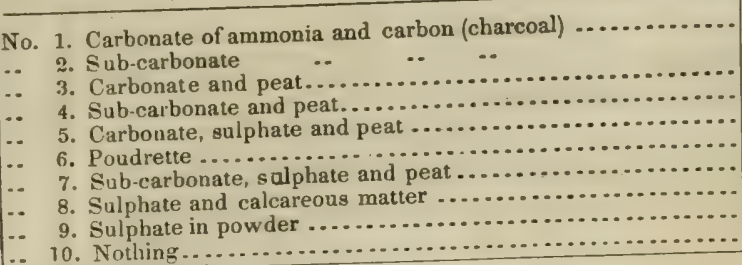 & $\begin{array}{l}4,300 \\
4,640 \\
4,120 \\
4,520 \\
3,960 \\
5,129 \\
4,354 \\
4,060 \\
3,725 \\
3,992\end{array}$ & $\begin{array}{l}3,200 \\
3,120 \\
3,160 \\
3,120 \\
2,750 \\
3,324 \\
2,790 \\
2,634 \\
2,410 \\
2,465\end{array}$ & $\mid \begin{array}{c}\text { Per ct. } \\
96 \cdot 3 \\
94 \\
95 \\
94 \\
38 \\
100 \\
84 \\
79 \cdot 2 \\
72 \cdot 5 \\
74\end{array}$ & $\begin{array}{c}\text { Per ct. } \\
75 \\
69 \\
77 \\
69 \\
69 \\
65 \\
64 \\
66 \\
64 \\
62\end{array}$ \\
\hline
\end{tabular}

"From these experiments it follows:

1st. That the carbonate and sub-carbonate, combined with charcoal or peat, give 94 per cent. of the product of poudrette, containing an equal quantity of nitrogen corresponding to $202 \mathrm{lbs}$. of crystalized sulphate of ammonia per hectare :

2d. That the degree of saturation of ammonia by carbonic acid has no influence :

3d. That the sulphate by itself, and as a salt, furnishes no results :

4 th. That the mixture of carbonate and sulphate of ammonia gives 84 per cent. of poudrette. This number is deduced almost exactly, à priori, from the salts composing the mixture.

5 th. That the calcareous matter imbued with sulphate of ammonia gives 79 per cent., that is to say, 8 per cent. more than nothing. This result, so different from what might have been hoped for, ought probably to be attributed to the mild composition of the sulphate, and to the short time (about four months) that the plant was in the ground. The following experiments seem to show the propriety of farther testing the matter.

These trials were made in October, 1843, upon a crop of wheat, and on the same spot as the before-mentioned experiments.

Having already ascertained that the carbonate and sub-carbonate of ammonia give similar results, the latter only was used in these experiments; but in order to reduce the volume of the mixture, the solution was made of double strength.

The standard of comparison was, poudrette employed in the proportion of about 79 cubic feet, nearly 3 cubic yards, per 11,960 square yards, and representing, in nitrogen, $227 \mathrm{lbs}$. of crystalized sulphate of ammonia.

The ammoniacal salts were used in the proportion of $238 \mathrm{lbs}$. of sulphate of ammonia; that is to say, they contain 5 per cent. of nitrogen more than the poudrette.

"These essays were made in the same spots as the preceding, and the same numbers correspond with the same places: time (October) and other circumstances were likewise corresponding. 


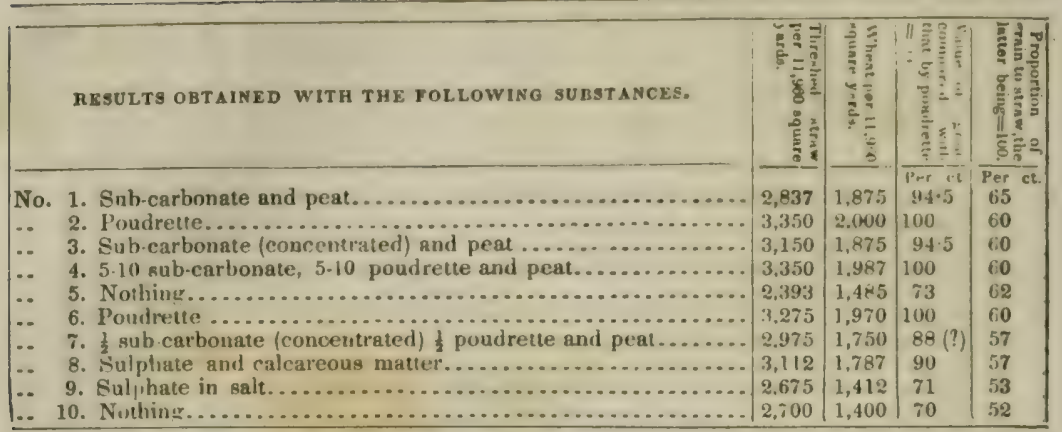

“It follows from these trials as frum the preceding:

1st. That the sub-carbonate of ammonia gives 94 per cent. of the product of the poudrette, as proved by trials Nos. 1, 2, 3, and 6. The 5 per cent. ex. cess of nitrogen that was used produced no effect; probably, because it only served, from the length of the experiment (nine mon!bs) to compensate for the difference of fixity between the principles of the two substances.

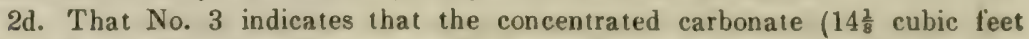
per 11,960 square yards) acts in the same manner as that which is weaker.

3d. That No. 4 apparently proves that a mixture of poudrette and peat in equal proportions, imbued with sub-carbonate, has the same value as poudrette. No. 7 does not confirm this, but it allows the inference that there was some error in the last experiments, for in those of April, Nos. 4 and 7 presented no anomaly.

$4 \mathrm{th}$. It is shown by No. 8 that calcareous matter moistened by sulphate of ammonia yields 90 per cent. of the poudrette, while in the spring it only gave 79 per cent. This difference is doubtless attributable to the difference in time between 9 and $4 \frac{1}{2}$ months. It is difficult to say whether the calcareous matter moistened with sulphate and sown in the spring united its action with that sown in autumn ; for it was buried by the plowing which followed the crop of oats.

"It would have been interesting to have made an examination of the products of a third crop, but circumstances did not permit.

5 เh. The sulphate in salt, as in the preceding case, gave no result.

6 th. Finally, if we compare No. 4 , in which turf imbued with sub-carbonate, was sown in the spring, and no other manure used in autumn, with No. 10, which received no manure, in either season we find the product is nearly the same; hence either the conclusion that the effect of the sub-carbonate of ammonia was not perceptible after the first crop, or that this substance, being on the surface, was plowed in too deeply.

"To conclude, therefore, it seems demonstrated by the experiments of the spring and fall, that the carbonates of ammonia have evidently a very happy influence upon the growth of cereals; that the sulphate of ammonia, in a state of salt, is without influence upon these plants, at least under the aforementioned circumstances. Perhaps better results might be obtained by sowing it in spring upon the cereals, when they cover the soil; that the sulphate of ammonia in solution and absorbed by calcareous matter, produces very favorable effects, especially when the growth of the plant is of some duration. Its action should be studied during many consecutive crops.

"These facts, as is readily observed, are of great importance to Agriculture; for they prove the advantageous applicability of ammoniacal salts. In fact, it results from the experiments that a quantity of sub-carbonate of ammonia equiva(1088) 
lent to $198 \mathrm{lbs}$. of sulphate of ammonia, gave per 11,960 square yards an excess of product as follows:

OATs-680 kilogrammes of grain, say 15.8 hectolitres, of 43 kils. at 6 francs......95 $400 \quad \ldots \quad$ of straw, say 80 bundles, at 10 f. per 100 , net.......... 8

Total .................................................. 103 francs

"That a quantity of the sub-carbonate of ammonia equal to 108 kilogrammes of sulphate of ammonia, gives in excess of products per hectare, as follows:

WHEAT -435 kils. of wheat, say 6 bects. of 73 kils. at 18 francs .......... 108

430 kils. of straw, say 86 bundles at 10 f. per 100 , net ............. 8.60

Total ................................................... $\overline{16.60 f_{0}}$

Or, in English :

OAxs-:, 496 lbs. of grain..................................... $\$ 1900$

880 lbs. straw, say 80 bundles, at $\$ 2$ per $100 \ldots \ldots \ldots \ldots \ldots \ldots \ldots \ldots 160$

Total .................................................. \$20 60

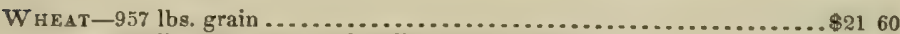

$946 \mathrm{lbs}$. stiaw, say 36 bundles at $\$ 2$ per $100 \ldots \ldots \ldots \ldots \ldots \ldots \ldots{ }_{1} 72$

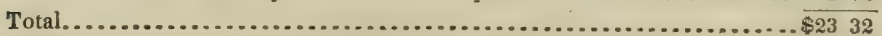

"In the provision market of Paris, where straw is generally of very high price, the revenue would be increased $\$ 152$ to $\$ 190$ per 100 of straw, thus giving as its gross overplus $\$ 2660$ to $\$ 2774$ per 11,960 square yards.

"From these sums must be deducted the expense of the sub-carbonate of ammonia. But the ammoniacal salts are now so low in price, the sub-carbonate being abuudantly extracted from the refuse liquor of gas-works, that its net benefits, the straw being valued as above, may be guarantied at $\$ 950$ to $\$ 1520$ for the crop of oats, and $\$ 1045$ to $\$ 1615$ for the crop of wheat.

"In 1843 I studied the action of ammoniacal salts upon meadows, and of solutions of carbonate and sulphate, with which I cultivated definite portions of a lawn. I also sowed the sulphate in powder, so that two equal surfaces wa. tered with solution, or dusted with powder, should receive the same quantity of ammonia. After thirty-six hours, the wetted surfaces acquired a deep-green tint, and exhibited a striking contrast with the rest of the sward. This effect must be attributed to the salts, for the parts wetted with pure water did not exhibit any change. After the first rain the experiment with the sulphate in powder resulted as favorably as the other.

"This last result made me renounce the use of saline solutions, which to the farmer presents many difficulties. I propose the employment only of sulphate in powder to be sown like the seeds.

"I will remark that when the lawn was reaped and the grass had commenced to re-sprout, it was impossible to observe any difference between the dusted and watered plots, for the action of the salts had been limited to one crop.

"In the latter part of March, 1844, I sowed the meadows with sulphate of ammonia in powder, at the rate of 90 to 100 kilogrammes per hectare, each experiment occupying about one-third of a hectare. After the first rain the parts thus treated were distinguishable from the remainder of the field by their deepgreen color; and subsequently the grass grew luxuriantly, but circumstances did not permit me to accurately estimate the results.

"In 1845, these experiments were repeated, and the plots fenced in. When planting, I also measured off, adjoining these plots, others of equal dimensions, that is, a third of a hectare each, and at the harvest compared the products of 
the sulph-ammoniated parts with those which were cultivated without this treatment :

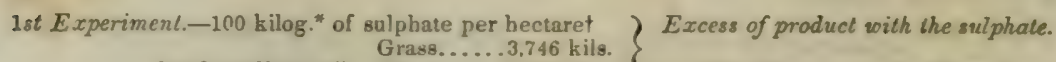

Good medium soil ... Hay .......2,907 kils. $\}$.....839 kilogrammes, or 29 per cent.

$2 d$ Experiment.-100 kilog. of sulphate per hectare Hay ........ 4.956 kils.

Very good soil ...... Hay ....... 3.892 kils. $\}$...1,064 kilogrammes, or 30 per cent. $3 d$ Experiment.-100 kilog. of sulphate per hectare Hay......... 3,970 kils.

Strong soil.........Hay ...........3,450 kils.

520 kilogrammes, or 15 per cent.

"We will rensark that the sulphate apparently has an action much greater pro. portional to the quality of the soil, and its deficiency in strength and argillaceous matter-provided, however, it is not too light. It remains to be determined whether, with a less quantity than 220 lbs. per 11,960 square yards, we would not obtain as good results-whether a stronger proportion would not produce even better effects-in fine, whether the influence of the salt extends beyond a year, especially in argillaceous soils. If the latter is not the case it is probable that the whole influence of the salt is exhausted by the first crop. These queries, however, must be resolved by some future harvest."

The results of the above experiments, such as they are, are nevertheless not without interest to Agriculture.

According to experiment No. 2, sulphate of ammonia costing $\$ 1026$ per 220 lbs., the receipt equals the expense when the price of hay is $\$ 589$ per 100 bundles; and there is a gain of $\$ 342$ to $\$ 570$ per 11,960 square yards, when it brings $\$ \tau$ i 60 to $\$ 836$ per 100 bundles. Again, according to experiment No. 2, where there is an equality between the outlay and return, the hay should be worth $\$ 665$ to $\$ 760$ or $\$ 836$-an advantage of $\$ 143$ to $\$ 247$ per 11,960 sq. yds.

Experiment No. 3 always gave a loss.

But whether a soil annually treated with ammoniacal salts will yield liberal crops for consecutive years, or whether, on the contrary, its fertility is limited to one season only, and requires renewal yearly by fresh additions, are questions for future determination. 


\title{
NUTRITION OF PLANTE.
}

\author{
BY JEAN BAPTISTE DUMAS.
}

Transiated from the French for The Library, by CaMpbeli Morfit and BanNet Phicitrs.

Plants nourish themselves upon animal excretions, that is to say, upon water, carbonic acid, and ammonia : all of which they receive through the medium of the atmosphere. In a general sense, therefore, the study of the nutrition of plants, is, in fact, the examination of their relations to the atmosphere.

A plant, during a growth of some time, presents an evident accumulation of matter in all its tissues; it also acquires carbon, hydrogen, oxygen and nitrogen, together with earthy and mineral matters; but of this more hereafter.

By limiting the examination to the principal phenomena, (discarding all the accidental circumstances which may intervene,) we can readily, by some simple but conclusive experiments, be convinced of the truth of the preceding results. These leave no doubt, either as to the fixation of carbon, hydrogen, and nitrogen by the plants, or the mode in which it is effected during vegetation.

Boussingault proposes to demonstrate this by means of a large bell-glass, with three tubulures. Adapted to the first is a washing apparatus filled with water, for the removal of the dust suspended in the atmospheric air. In the principal tubulure is a funnel, opening and closing at pleasure, through which to introduce distilled water for the irrigation of the seeds and plants placed under the bellglass. These are contained in a capsule or saucer filled with calcined sand.The bell-glass rests upon, and is hermetically cemented to, an earthen pan, so as to prevent the admission of air. The third tubulure communicates with a large flask, by means of two $U$ tubes and a washing apparatus, which retain the water and carbonic acid.

The flask being filled with water, and the apparatus tightly closed, the displacement of the air from the bell-glass is determined by opening the cock in the lower part of the washing-flask. This operation can be repeated as often as desired. By these precautions, it is seen that the plant or seeds under the bellglass receive definitely, as their whole nourishment, only water, air and carbonic acid.

Now if peas be sown in this calcined sand, taking care to water them and frequently renew their atmosphere, they germinate, develop their leaves, and what is remarkable, flower and fructify. Nothing is easier than to estimate the amount of matter lost or gained by the seed in developing itself; a simple comparative analysis of the seed and of the crop suffices. Boussingault has determined by analysis the nature of the elements and their proportions in both the seeds and the crop. The following are his results :

(1091) 
The peas contained:

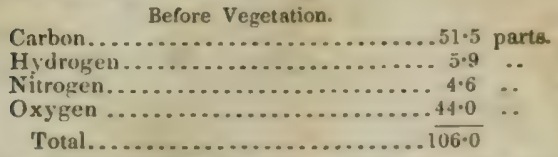

Showing the fixation, during the process of vegetation, of $186 \cdot 1$ parts of Carbon $5 \cdot 5$... Nitrogen

$$
\begin{array}{r}
\text { Afrer Vegetation. } \\
\begin{aligned}
237 \cdot 6 & \text { parts. } \\
28 \cdot 1 & \ldots \\
10 \cdot 1 & \ldots \\
168 \cdot 0 & \ldots \\
\hline 443 \cdot 8 &
\end{aligned}
\end{array}
$$

These results prove in the most evident manner that peas, as well as many other plants, can pass through all their phases of vegetation even when nourished only with water and air. 'The crop thus obtained is, however, very meager and incomparably less than that yielded by manured soil.

'The phenomenon which we are about to study is complex: in fact, a seed, a plant, in certain periods of their growth, present moditications both in their vital functions and in their relations to the atmosphere. To the amount of fixed principles, already considerable, must be added another large portion, which is dissipated after having been momentarily fixed. But if the result, apparently simple, which I am about to give, is the final result of a complex theory, it does not the less fully confirm the fixation of carbon, nitrogen and hydrogen in the plants, besides that of a certain quantity of hydrogen and cxygen, which is fixed as water, or in the proportions which constitute water.

It is not sufficient to have clearly proved that the fixation of the elements constituting plants can be effected by the sole intermediation of the air ; we should investigate farther in order to clearly determine the principal suurces of these elements.

When we reflect upon the enormous quantity of carbon in continual fixation by vegetation, the question naturally arises whether it really does not originate wholly, or at least in part, from the decomposition of the carbonic acid in the air. We know that the atmosphere contains, usually, 4-10,000ths of its volume, or as well, $6-10,000$ ths of its weight of carbonic acid ; an evident proof that this quantity is sufficient.

A very simple calculation will determine this matter. Let us suppose, in fact, that the atmosphere is compressed by a force which would give it the density of water; the column of air at this density, has a hight of about ten metres: in this column of ten metres carbonic acid enters to the extent of four millimetres, and by reducing the carbonic acid to carbon, it will be finally seen that the quantity of carbonic acid in the atmosphere, is sufficient to form a stratum of carbon covering the surface of the whole earth to the thickness of nearly one-third of a millimetre.

The amount of carbonic acid in the air is increased by the torrents emitted from volcanoes, and the supply is constantly kept up by the large quantities emitted during combustion in our fireplaces, by the respiration of animals, and also their decomposition, and by the nocturnal respiration of plants. The quantity is being constantly diminished by the diurnal respiration of plants. We may then ask whether this actual state of the atmosphere has always existed, or if in remote periods, it did not present an entirely different composition.

Ad. Brogniart, relying upon the precise information of Geology, has calculated the cornposition of air before the formation of the coal fields. France, as a fair average of the coal lands of Europe, and perhaps of the whole world, was taken as the standard. It contains 1.200 of coal land, forming a stratum of 
twenty metres thickness, and is poorer in this respect than England and Belgium, but much richer than a large majority of the other countries of the earth.

Estimating by France, we then find that a pro rata apportionment will give to the whole surface of our globe a stratum of coal of a decimetre thickness; by changing the weights into carbonic acid, (for it is incontestable that coal has Its origin from vegetable debris whose carbonic acid must necessarily have been drawn from the atmosphere,) we then have the inference that the air before the formation of the coal-fields must have contained at the very least from 4 to 5 per cent., a medium, and by a little exaggeration, perhaps as much as 8 to 10 per cent. of carbonic acid. Air charged with a like quantity of carbonic acid is injurious to, if not destructive of the warm-blooded animals; and, indeed, we learn from geological fossils that in that epoch there were no animals of that nature. Saussure's experiments have shown that vegetation thrives much better in an atmosphere containing some hundredths of carbonic acid, and we know also that the vegetation of remote periods was much more active than at present, as is well evident in the singular development of fossil debris.

But supposing there were no animals, or at most but a few of them, whence comes this carbonic acid of the air, unless from numberless volcanoes now extinct?

What is the action of the carbonic acid, and what are the conditions requisite for the regular accomplishment of the phenomenon now under study? We will answer by the aid of some historical details. Bonnet first observed that green leares, when placed in aërated water and exposed to the sun's light, disengage a gas which Priestly proved to be oxygen; and Jennevier in his turn showed that this oxygen proceeds from the carbonic acid held in solution by the water, and associates this fact with the nutrition of plants. 'To effect the decomposition of the carbonic acid, the green part of the plants must be exposed to the solar light. A plant which is not struck by the light does not decompose carbonic acid; on the contrary, in the presence of aërated water or air, it generates it, as is unequivocally determined by the following two experiments :

Take a bell-glass containing an atmosphere of carbonic acid, in which plants are also inclosed, and place it under an opaque vessel, and keep it thus secluded from the light for several days. After this time, an examination of the transvased gas shows that it is still unaltered carbonic acid. Again, take a second bell-glass similar to the first, and inclose therein, as before, the green parts of plants; but this time expose it to the sun's light weakened by a gauze sereen or sheet of transparent paper. This precaution is necessary, for though a plant thrives perfectly in the open air even under the direct action of the solar rays, it is requisite, when operating under bell-glasses, to provide against the concentration of light by the lenticles which their surfaces present, else the parts of the plant opposite to the foci become torrefied and the plant perishes. With proper precautions oxygen is obtained nearly pure. Hence the necessity of light in this phenomenon. Without it there would be no action-no durable vegetation upon the surface of the earth.

Let us now examine under what forms the carbonic acid reaches the plant. We can determine a current of air in a bulbed apparatus, with three tubulures, by means of a flacon à ecoulement. A bulbed apparatus, adapted to the first tubulure, serves to wash the air which enters. To the third tubulure is adjusted an $U$ tube containing pumice-stone saturated with sulphuric acid, for the retention of the water. There must be also a second bulbed apparatus, containing a 
concentrated solution of potassa, for the absorption of carbonic acid. Following this is an $\mathrm{U}$ tube again, flled with pumice-stone saturated with sulphuric acid, to retain the little water which may pass over from the potassa solution. The two apparati are accurately weighed before the experiment, and in order to prevent the reentrance of moist air there should be a third $U$ tube filled, as before, with vitriolized pumice-stone.

All the air which passes through this apparatus during exposure to the sun's light is entirely deprived of carbonic acid, without any increase of weight accruing to the apparatus during the experiment. Thus we have evident proof that plants draw carbonic acid directly from the atmosphere. We do not admit, however, that this is the sole source, for it can be conveyed into the plant through its roots, which inbibe it from the soil. The moisture of the soil which is imbibed by the roots is also charged with carbonic acid. Moreover, the slow combustion of the dung deposited around plants is also a continual source of carbonic acid. The arrangement of the apparatus, before noted exemplifies on a small scale, this phenomenon, as also the role of the carbonic acid. The roots of the plant, inclosed in the balloon, being dipped into a vessel filled with water charged with carbonic acid, absorptioh conveys this water to all parts of the plant, and the carbonic acid, as soon as it reaches the leaves or green parts, is decomposed by contact with the light. When the apparatus is to be arranged for this experiment, the first bulbed tube must be filled with a concentrated solution of caustic potassa, in order to arrest the carbonic acid proceeding from the air itself.

To sum up, plants have two sources of oxygen: 1st, the atmosphere, from which they abstract it directly; and, 2dly, the soil, from which they receive it through their roots. They receive it also from dew, but it is the carbonic acid of the air reaching them in an indirect way.

Light is necessary to the decomposition of carbonic acid, as will be proved by a few words. If green twigs or branches are presented to the object-glass of a camera, the light reflected by the green portions of the plant acts very feebly upon an iodinized silver plate, as if all the chemical rays of the light absorbed during the process of life in the plants, when reflected back by their green parts, no longer exercise any chemical action.

Green leaves act nearly in the same manner as those black bodies which are most capable of entirely absorbing the light. This is a matter worthy of deep study, for at the moment the light strikes the leaves, the most mysterious actions of Nature, and the most important to be revealed, are in some way accomplished, while we have no authority for supposing that these actions are produced by any of the methods now known either in Physics or Chemistry.

The decomposition of carbonic acid is effected by the influence of the sun's ray's and the green matter of plants; but is this green matter endowed, in itself, with this property, or does it require the coöperation of vegetable organisms? The thorough experiments of Morren afford a conclusive decision of these questions. 'I'he green matter, when in contact with the solar rays, acts always in the same manner, whether it is or is not coupled with a vegetable organism.

Water sometimes holds in suspension a green matter formed by green animalcules. If this water is analyzed, under different meteorological circumstances, it will be found that the ratio of oxygen in the gas given off during ebullition varies from 16 to 60 per cent., or in the ratio of 1 to 4 . After being some time insulated it shows an excess of oxygen, and the animalcules assume an active life. 
Under the influence of the sun's rays the green matter of the plants decomposes carbonic acid, and sets the oxygen at liberty; but if light is wanting, then the inverse phenomena occur.

The fish of a pond rapidly absorb the oxygen of the air held in solution by the water, and if the green animalcules do not in turn replace this oxygen by the decomposition of carbonic acid, the fish suffer, and gradually suffocate. If, on the contrary, the sun shines, the animalcules quickly restore the oxygen to the air, and the fish become active. These alternatives occur ceaselessly, and are peculiarly remarkable for the strange rapidity with which the resuits become manifest.

This experiment, besides assigning a rôle to the green matter, gives an exact idea of the phenomena occurring in the atmosphere. In fact, in the atmosphere the equilibrium is due to the same causes, but the variations are much more limited. The motion of the air is much more rapid, its mass enormous compared with the causes which tend to modify it; while in the water of the fish-ponds, or preserves, the masses are small and the influential causes enormous.

Independently of the green animalcules which act in the same manner as green plants, Morren has shown that there are those of a red color which produce the same effects. This discovery is of the greatest importance, tor heretofore this action has been, compulsorily, attributed to the green matter of plants, although the foliage of certain vegetables and trees have a purple or nearly red tint, even in their normal state. According to Morren's experiments, there are a number of coloring matters which are capable of decomposing carbonic acid.

Those plants which are not green, the fruits which lose their green color in acquiring the shades peculiar to their maturity, flowers, \&c., do not decompose carbonic acid. As soon as the green matter appears in a plant exposed to light, the decomposition of carbonic acid commences. Is this green matter the instrument or the product of the decomposition? If it is the product, will it be transformed by the successive repetitions which constantly renew themselves into the various products developed by vegetation? We would be disposed to think that the green matter is an instrument, an agent; that it is doubtless but little altered, and that under its influence the other matters are produced and carried from cell to cell by endosmose, even to the vessels which convey them to the different organs of the plant.

There are, however, colorless plants which run through all phases of their existence without being colored. Fungi are of this class, and there are certain kinds which grow in the darkest mines; and hence, very naturally, their absence of color, which, in preventing their action upon light, enables them to dispense with its influence. We will remark, however, that the fungi of the mines are sunny white, while those reared in the light are always diverse-tintecl. But fungi are always parasitical; they thrive upon living or dead animals or plants, and always by means of organic matters which they contain already made.

The life of a fungus is every way comparable with that of animals; their nourishment is the same, and perhaps the analogy between these two beings, apparently so very different, might be much farther traced.

Thus, for our benefit, the vegetable kingdom is particularly characterized by those plants which possess the property of decomposing carbonic acid, and thus it is that it enjoys the full extent of its purpose, and accomplishes its errand upon the earth. The reproductive organs of plants are but a transition. Fungi are too little known, in this respect, to claim our attention longer. It is 
therefore only in the green parts of plants that the great apparatus exists which may exercise a certain influence upon the constitution of the air, and which deserves to be classed among the great instruments which the physics of the world should acknowledge.

Supposing that the plants had ceased the performance of their functions upan the surface of the earth, calculation proves that the amount of oxygen of the atmosphere will suffice for the respiration of the present existent animals for thousands of years. Our knowledge of the nutrition of animals teaches us that the disappearance of plants would on the contrary speedily produce their death by inanition. Hence, from what has been said, the unavoidable conclusion that the carbon of plants proceeds mainly from the decomposition of carbonic acid.

A last consideration compels us to make an important restriction. In citing the beautiful experiments of Boussingaul: upon the complete development in a close vessel of peas nourished by air, water, and carbonic acid, we remarked that the harvest was very poor in comparison with that produced by manured grounds. By manuring the soil, the conditions of growth are augmented, for the dung contains nitrogeneous matters; it moreover surrounds the roots with an incessant source of carbonic acid, which being carried up with the sap of the plant, is decomposed by contact with the green matter of the leaves. The manure contains, also, the mineral salts which are indispensable to the complete development of plants, besides the soluble organic matters which, according to Saussure, in certain cases are equally necessary for the nutrition of plants.

As regards the decomposition of the water, we have to repeat all that has been said relative to the decomposition of carbonic acid by plants, for the hydrogen of plants is derived from water, and besides it fixes water in its natural state.

We have now the certain proof that many fungi disengage hydrogen naturally. Edwards and Colin have shown that the stem of the Polygonum tinctorium, when placed under water, disengages hydrogen. Payen has proved by the analysis of the ligneous parts of vegetables, that the amount of hydrogen is always slightly excessive of that of oxygen. Added to these, also are Boussingault's direct experiments upon the growth of peas, clover, and wheat. Thus:

\section{WHEAT.}

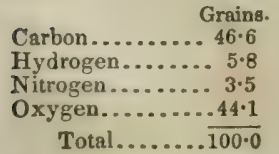

Grains.

Carbon..........5 50.8

Hvdrogen....... $6 \cdot 0$

Nitrogen........7.2

Oxygen......... $36 \cdot 0$

Total...... $\overline{100 \cdot 0}$
After three months vegetation.

\begin{tabular}{|c|c|c|c|}
\hline 88 & $100 \cdot 0$ & $n 81$ & fixed carbon \\
\hline $10 \cdot 0$ & .. & .. & .. nitrogen \\
\hline 3.7 & .. & .. & .. (water) HC $41 \cdot 8$ \\
\hline $81 \cdot 0$ & .. & .. & .. (hydrogen) $\mathrm{H} 0.0$ \\
\hline$\overline{33 \cdot 2}$ & & & 183 \\
\hline
\end{tabular}

CLOVER.

After three months vegetation.

\begin{tabular}{|c|c|c|c|c|}
\hline $131 \cdot 3$ & 100 & ins & fixe & carbon \\
\hline $17 \cdot 1$ & .. & . . & .. & nitrogen 2 \\
\hline $9 \cdot 8$ & .. & .. & $\cdots$ & water 72. \\
\hline $100 \cdot 7$ & .. & .. & .. & hydrogea \\
\hline
\end{tabular}

In the wheat there was no fixation of hydrogen, but much of carbon and water ; while in the clover, carbon, hydrogen, nitrogen and water were all assimilated. If I have insisted upon the decomposition of water, as established by Boussingault, it is because that incident in the life of plants-the fixation of the carbon by the decomposition of the carbonic acid-thus becomes the grand theorem of the general physics of the globe, which forms an equivalent to that other phenomenon so well demonstrated by Lavossier, the combustion of carbon and nitrogen which characterizes the life of anımals. 
Plants decompose water and assimilate its hydroxen; they reduce carbonic acid and appropriate its carbon-they decompose ammonia ; they are, in fact, the reducing apparatus. Animals, on the contrary, burn the carbon and hydrogen, and may be styled oxidizing apparatus.

This property in plants of securing the carbon of carbonic acid, and setting tne oxygen at liberty, has no parallel ia any chemical force. Chemistry at presentise incapable of imitating this phenomenon in the life of plants: Physies must some day afford an explanation. It should be tried whether a daguerreotype in regarding a plant behaves as in the presence of a black plate, if the reflected light is deprived of its chemical rays. Plants certainly absorb a portion of the intensity of the sun's rays, and as all these phenomena are colleagued; if the animal produces heat and electricity, the plants in their turn absorb heat and electricity.

It remains to be inquired how the nitrogen is introduced into plants. It reaches them by two channels: 1st. Through the air. 2d. Through manures. It has already been shown in the experiment upon the growth of peas in a close vessel, that nitrogen is abstracted from the atmosphere. Clover as well as Jerusalem artichokes cultivated under similar circumstances present a similar action. If, however, the experiment is repeated upon the plants, this p!enomenon is not evident ; for instance, the cereals do not abstract their nitrogen from the air, and hence plants, in this respect, are divisible in to two distinct sroups:

1st. Those which abstract their oxygen from the atmosphere, namely, peas, clover, and Jerusalem artichokes.

2d. Those which obtain it through manures, namely, the cereals, and the oleaginous plants.

Though we know that the nitrogen of some plants is borrowed from the atmosphere, we cannot tell the condition or state in which it is assimilated; it may be supposed that it enters directly into their organs, some one of which have the natural property of abstracting it from air. It can be conveyed thither by the water, always aërated, which is imbibed by the roots. The leaves of the plint may convert it into ammonia by means of the hydrogen of the water, which they decompose. Finally, this fixed nitrogen, according to Saussure's experiments, proceeds, certainly in part, from the traces of ammonia contained in the air. If there are any doubts in this respect, doubts removable by experiment, there can be none as to plants which receive their nitrogen through the medium of ma. nures: Manures act by virtue of their urea, uric acid and animal matters, which, by decomposition, are transformed into ammoniacal salts. A single experiment readily proves this fact: Schattenmann (the director of the manufactory at Bouxwiller) observed that by watering a field with the solution of sulphate of ammonia, obtained by treating horse-dung with sulphate of iron, he could readily distinguish the irrigated spots from those which were not watered, by the vigor of their vegetation. Letters traced with the liquid manure were visible at a great distance during the whole term of vegetation. Hence, the evident inportance of its application to Agriculture. In some countries the explanation of this theory has occasioned a profitable practice: for instance, in the Canion of Grisons the dung-liquor is treated with sulphate of iron; the ammonia which is generated decomposes the sulphate of iron, and forms sulphate of ammonia, which, in this state, is potential and not volatile. Elsewhere, the urine or dung-liquor is mixed with sulphate of lime, which is equally efficient in fixing the ammonia: but its application to the dried fæces is not effectual, owing to the generation of carbonate of ammonia, which is wholly volatile : consequently, the efforts to neu- 
tralize the ammoniacal odor in the stables by means of sulphate of lime, have not been successful.

The researches of Payen and Boussingault have removed all doubt both as to the effects of ammoniacal salts as a manure, and the thorough utility of animal matter, or, more generally, nitrogeneous matter, in the dunging of the soils. They have recently shown that all true manures act by virtue of their nitrogen, and are efficient proportional to what they contain of this element. and they have given the following Table, where they are ranked according to their equivalent value.The l'able shows that 100 parts of farm manure can be replaced by 3 parts of dry blood or animal residues, and by 25 parts of grape-cake :

Farm manure......................

Ser weed ........................

Residise of pressed oleaginous seeils .... Grape-cake.......................

Liquor from starch facsuries.........

Jung liquer ........................

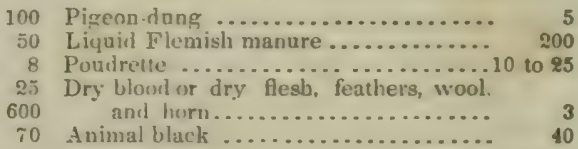

We have too often alluded to the value of urine, in vegetation, to render it necessary again to enforce upon the farmer the policy of carefully collecting the dung juices of his barn yards.

We should, however, recollect that the preceding Table does not give a perfectly just idea, in this respect; for we might be led to think that in the preparation of Flemish manure or animal black, none of the products of the juices are lost. Consequently, though the poudrette presents a greater value, pound to pound, it is nut a thorough proof that this should be preferred in the great econo. my of a country. In fact, during its preparation, a great portion of useful products escape into and infect the atmosphere. The great advantages of liquid ma. nure, with which we cannot be too familiar, may be summed up in a few words :

1st. Man furnishes the air with carbonic acid and water, that the farmer may always have a supply equal to the requirements of his crops.

2d. Man ejects urine and excrements, which constitute liquid manure, after a previous fermentation, all the other products of his alimentation.

$3 \mathrm{~d}$. Consequently, in the liquid manure and the atmosphere, the farmer has all the matters requisite for the culture of those plants suitable to the nutrition of man.

The excrements of animals, which constitute the nourishment of the most useful plants-such as the cereals - are as necessary to their sustenance as bread and meat is to that of Man; and hence the culpable neglect in allowing the waste of sewer juices in large cities. Among the efforts to diminish the miseries of the poor classes, none can take precedence of that to lessen the cost of manures, and as tending 10 this, the collection and preservation of the contents of privies should be provided for by the authorities of all the cities and towns.

One more remark in conclusion of this subject. It is well known with what facil. ity ammonia dissolves in water, which will take up about 430 times its volume, and it is also well known that hydrochloric acid is equally soluble. But let us cumpare the operation of these two solutions. By heating hydrochloric acid of a certain density, it boils at $244.4^{\circ}$ Fahrenheit, without being altered; and it is impossible to separate it from its waters by physical means. At the temperature of $122^{\circ}$ to $140^{\circ}$ Fahrenheit, water no longer retains a trace of ammonia; indeed, in vacuo, it loses all its gas at ordinary temperatures, and even evaporates spontaneously when exposed to air in open vessels. 
This is a wise provision in the natural economy, for this property enables the condensation of the ammonia by the rains, which convey it to the plants, that it may be volatilized anew, and carried to those points where it will be seized upon and rendered available. It is doubtless the final cause of the properties of the aqueous solution of ammonia.

But, as these properties are necessary in the designs of Creation, so that vegetation may not be deprived of that ammonia which it requires; so much the more is it important, as a personal consideration, for they are noxious in the latter respect. It is precisely, this volatility of the ammonia resulting from the decom. position of the animal detritus of a city, which prevents its restoration to the neighboring soil, as might otherwise sowell be done; for it is the whole sum of manure which the soil requires to reproduce the sum of organic matter requisite for its nourishment. We should therefore direct our attention to the elucidation of the mode in which the rejected nitrogenous products, which we regard as lost, can be rendered available. 


\title{
THE ACTION OF SALT ON VEGETATION;.
}

\author{
AND ITS USE IN AGRICULTURE.
}

\author{
BY M. ISECQLEREL.
}

In the Memoir which I presented to the Royal Society of Agriculture in July, 1847, I treated of the state of vegretation in the saliferous soils under the infiuence of water, and laid it down as a principle, that salt and water, when added gradually and in small portions to plants, promoted the growth and excellence of fodder crops, especially in those soils naturally dry. My experience in this respect is based upon observations and analyses made of the old royal salines of the Levant and the surrounding countries. These experiments, it must be told, lowever, are only the heginning of a series which I intend to undertake upon the use of salt as an amendment [ameliorator ?] in Agriculture, commencing, however, with the study of its action in the different phases, of the growth of the cereal and fudder plants. To proceed systematically, we must before passing to the application, determine the principal physiological phenomena induced by the salt during the course of vegetation, so that we may avoid or follow them, accordingly as they are useful or prejudicial to its development.

Those who deny the salutary influence of salt upon vegetation, under certain circumstances, are perhaps too much biased by the idea prevalent among the ancients, that stelility is the inevitable consequence of its application. 'This may be true in those countries which receive but little rain, and where the sun is intensely hot; but the exception is not applicable to humid soils.

The hygroscopic state of the soil being an important element in determining the question, by abstracting it we render it extremely complicated. On the other hand, in sowing salt simultaneously with the seed, it has never been determined how it acts or whether its mode of action is the same:

1st. In germination.

2d. During the development of vegetation, from the extremity of germanation to budding, that is to say, while the plant sprouts.

$3 d$. From the sprouting to the fructitication.

4 th. Finally, from the fructification to the entire cessation of vegetation, or the death of the plant.

If this had been known sooner, the opinion of certain persons as to the action of salt in vegetation would certainly have been moditied, but as the question is very complex, it was necessary to divide it, and study each proposition separately.

From the experiments which I made as to the action of salt upon germination, the following conclusions are to be drawn:

1st. Common salt, in certain proportions, retards and even partially destroys the germination of rye grass and white mustard seeds.

2d. It completely destroys those of wheat and vetch.

$3 d$. It impedes, in a measure, the germination and vegetation of many plants. (1100) 
Thus it is seen that though the salt may not destroy germination, it nevertheless injuriously affects the young plants during vegetation, by inducing a change in their embryo in the initiatory development of life.

Can we not interpret this injurious tendency of the salt in the very first act of vegetable life?

When a seed is subjected to the combined action of water and of heat, it swells, and the starchy matter of the cotyledon passes into gum and sugar, as food for the nutrition of the plantlet. These substances act the same part to young plants that milk does in the nutrition of young animals. Now, as salt is, in general, an antiseptic, being often used to prevent the putrefaction of animal and organic matters, it naturally follows that if its presence will prevent those transformations of the starchy matter of the seed only by which it can be rendered alımentary of the plantlet, the plantlet must necessarily perish. Though the destruction may not be complete, still the plant suffers during its vegetaticn from the ill effects produced by the salt during its germination.

As regards the action of salt in the second phase of vegetation, it may be admitted, à priori, that it should not influence the development of vegetation, from the completion of germination to the moment of blooming, in the same manner as during germination; since, in this case, the salt seems to oppose the decomposition of starchy matter, and its transformation into gum and sugar; while in the other instance, as soon as germination is completed and respiration takes place in the leaves, the salt is carried by water into the different tissues and organs, and should then act only proportional to the quantity introduced, to hasten or retard the phenomena and the different elaborations of the juices designed for the nutrition and development of the plant. The salt, therefore, should not play the same part in both eases. Numerous experiments have effectually confirmed this deduction drawn from facts previously noted.

The facts stated in my Memoir authorize the following conclusions:

1st. That salt in solution is prejudicial to germination, being alterative or destructive of the embryo according to the quantity employed. When the change is very sensible, the development of the young plant is much less perfect than without the action of salt.

2d. That germination is accomplished without the aid of salt, and that when the plant has shot above ground, the application of salt and water even in large doses, causes no alteration of the tissues, nor any disturbance of the vegetation, not even to the budding. As to what are its effects then and afterward, is yet to be determined by the result of some experiments now in progress. The plants usually acquire more vigor than those growing in the natural way, provided the proportions of salt are not excessive. The amount taken up by plants equals, sometimes, eight per cent. of their weight when dried.

3d. 'That the influence of salt upon germination, even in presence of water, may serve, to a certain extent, to explain the conflicting results, as to the action of salt as an amendment [ameliorator ?], of experimenters who kept no record of the time of salting.

4th. That when used as an amendment in soils destined for the culture of the cereals, it should not be spread at the time of sowing, because it is hurtful to germination. The better plan would be to apply it about the month of March, when the earth is moist, and previous to the development of active vegetatiou. In operating at this season, be careful that the winter rains do not carry the salt too deeply into the soil, else it will lose its power of promoting vegetation in the 
spring. The quantity of salt to be used depends upon the nature of the plant under cultivation, as all plants are not equally benefited by its use.

Kuhlmann's experiments have proved that salt, when mixed with nitrogenous manures, is a stimulant of vegetation. It will then be necessary to ascertain whether, as to certain plants which require a substantial nourishment, salt uncombined with these manures would not, by inducing a too vigorous growth, enervate such plants.

5 th. That the large quantity of salt required by the stalk of the cereals, under the circumstances mentioned, may contribute to give them the qualities of fodder.

6th. That all these results determine nothing as to the product in grains, which will only be known when the experiments are completed in the coming year.

7th. That in moist meadows the salt should be sown at the time when vegetation develops. In dry meadows, rain must be waited for before applying the salt.

8 th. That in soils with impermeable bottoms or clayey substrata, the application of salt should not be of ten repeated, for the portion first added suffices for a long time, and sometimes may even injure later germinations. If, on the contrary, the substrata are permeable, it is necessary to renew the salting at each culture. Before taking a definite part in this respect, we should appeal to experiment, the only sure and safe guide.

Salt remains in the soil a shorter or longer time, according as its substratum is permeable or impermeable; and as all plants do not accommodate themselves in the same degree to the salt regime-the vetch, as an example-it is necessary, in the rotation of crops, to plant therein the leguminous and other plants whose growth would be retarded by the salt.

The end proposed in my Treatise is to point out the path to be followed in experiments for the exact determination of the part acted by the salt, as an amendment, either with or without the concurrence of nitrogenous manures.

\section{A FARM BUT A MANUFACTORY,} THE USE OF SALT.

IT was not because we apprehend that Salt is likely ever to be used in our country as a manure to an extent sufficient to make its value for that purpose a question of general interest, that we have selected the following, but because of the philosophical principles which it contains as connected with Agriculture. But the reader can peruse and judge for himself, whether such dissertations are not much more useful, though they may be dryer, for young men wanting to provide for themselves a wider and more solid basis for improvement, in a better knowledge of the principles of their profession, than is to be expected from a relation of the mere details of practice followed in some case where an acre has been made to yield a heavy crop of corn, or a bullock to yield a heavy crop of tallow. Such, at least, is our view of the matter, and such our aims, without any object or desire to deceive or be deceived.

From the London Agricultural Gazette.

THE VALUE OF BALT AS A MANURE.

In your Journal of April 8th I read that Profeseor Damas, who in conjunction with Mr. Milne Fidwards, was engaged by the French Government to examine into the value of common salt as (1102) 
a manure, has recorded in the following terms the conclusions arrived at from their inquiries on the subject in England:

"I quit England with the conviction that the problem of the employment of salt in Agriculture is chimerical We have been sent from county to county without result. Here they send us into the neighborhood of the salt-mines; when we were there we were told that salt was not a prophet in its own country. I am convinced that the most desirable mode of preparing a good manure is by employing the phosphates and ammoniacal salts, rather than sea salt, however cheap the latter." In my opinion the conclusion they have come to, viz,, that salt is of very little value as a manure, is perfectly correct. Opinions unsupported by facts or reasons are, however, not worth much, and as I am aware that many practical agriculturists advocate the employment of salt, I will endeavor to explain the grounds upon which I dissent from them. I am quite willing to admit that numerous experiments have been recorded, wherein a beneficial effect of salt upon the crop was sufficiently evident The question with the French chemists, however, and that to which the remarks I am about to make refer, has not reference to the special, or occasional, but to the general applicability of salt as a manure, and to its importance as such in a national point of view; I shall not, therefore, quote any particular experiments of my own, but sball endeavor to show: 1. That no substance can be nationally or universally useful as a manure, which is not largely exported from the soil. 2. That salt exists to a very small extent in the exported produce of a farm; and that it can never be substituted for those constituents which are largely exported, and in which most soils are more or less deficient. Considering a farm as a manufactory, of which the imported manures represent the purchased raw material, and from which the ex. ported products are corn and meat. it is evident that the nature of the imports which it will be necessary to provide must depend upon that of the exports. The amount of such exports must vary according to climate, soil and cultivation; but assuming the extreme case of an export of 50 bushels of corn from an acre of land one year, and $100 \mathrm{lbs}$. of live-weight of animal the next. let us endeavor to estimate the loss to the land of several of its constituents by sueh means, and especially that of salt. Fifty bushels of grain may be said to contain 50 to $60^{\circ} \mathrm{lbs}$. of mineral matter. In perfectly ripened grain it is doubtful whether either chlorine or sodium, the two constituents of common salt, exists; but the point of perfection in this respect is seldom attained in our climate, and it is probable that it is owing to variations of this kind that the presence and amount of salt in grain ashes are found to be uncertain The average quantity in such asbes may, however, be said to be probably little more than 1 per cent. if even so much as that; so that 50 bushels of grain would contain less than $1 \mathrm{lb}$. of salt. By direct experiment I find that a lean sheep of $100 \mathrm{lbs}$. live-weight, yields about 8 to $10 \mathrm{lbs}$. of bone, $12 \mathrm{lbs}$. skin, and $5 \mathrm{lbs}$. blood ; the flesh, fat and entrails. \&c., comprising the remainder The bone contains no appreciable ameunt of salt, while the total mineral matter of the other parts of the sheep amounts only to a few ounces. of which quantity a very small proportion must be estimated to be common salt. It is evident, then, that the amuunt of salt exported from a farm in corn and meat is exceedingly small; but if we look at the loss of phosphoric acid and of nitrogen which the farm sustains under the same system of sales or export. the case will be found to be very different.

Of the 51 or $60 \mathrm{lbs}$. of mineral matter contained in the 50 bushels of grain, about nine-tenths would be salts of phosphoric acid, and the sheep weighing $100 \mathrm{lbs}$. alive would carry off 3 to 4 ibs. of phosphate of lime in its bones, besides a few ounces of phosphoric acid salts in its other parts Again, the 50 bushels of grain may be said to contain 50 to $60 \mathrm{lbs}$. of nitrogen, and the $100 \mathrm{lbs}$ live-weight of animal $4 \mathrm{lbs}$. of the same substance It is seen, then, that while the soil would be exhausted in two years of 40 to $50 \mathrm{lbs}$. of salts of phosphoric acid, and of a still larger quantity of nitrogen, the amount of salt removed in the same period, and by the same course, would scatcely reach a pound. Some writers have said that farmers do not know their own in. terests when they purchase the expensive foreign guano rather than the cheap salt of home re. source, and employ the bones of distant countries instead of the sulphate of soda manufactured in our own towns; but no one who will carefully consider the statements given above can be at a loss to understand why salt and sulphate of soda cannot be substituted for phosphates and ammo. nia. It is worth consideration, also, that in many parts of England thousands of acres have been brought from a barren waste into the highest state of fertility, by the importation, in some form or other, of phosphates and ammonia, without any direct supply whatever of common salt.

The employment of salt as manure cannot, then, I think, be advocated as providing an im. portant constituent of the ordinary exports of a farm, but only to be of limited necessity, and applicable with economy to a small extent, or in special and occasional cases. It is considered that when corn is used for corn crops the straw is brighter and the grain of finer quality; but perhaps no one will maintain that it would increase the number of bushels upon a corn-exhausted soil ; and if this be the case, but a low rank can be claimed for it by the side of manures which are known to enhance the produce of the land. I fully admit some beneficial influence upon the elaborative actions in the juices of plants under the agency of common salt, but it is probable that such an effect will generally be observed only in highly manured soils, where, under certain conditions of season, vegetation would be too luxuriaut; and it may be doubted, indeed, whether even in these cases an equivalent supply of soluble saline matters, more essential as constituenta of the fixed products of the plants, might not with advantage substitute the salt.

On the other hand, however, the ready solubility of common salt itself, as well as that of compounds which may result from its reanctions on the contents of the soil, is a property which may render it of real service in cases of over-luxuriance, arising from an otherwise too prominent sup. ply of organic constituents to the plant. There are other instances than that afforded in salt, or mineral substances being of apparently great use in the juices of plants, without reeming to constitute portions of the fixed products of the plant; and we must be careful, therefore, not to deny the importance of the presence in the soil of any substance, merely because it does not exist in the exports of the farm; but at the same time it should be borne in mind that unless a substance be either sold off the farm or diminished in quantity by drainage or actual waste, the renewal of a supply once provided can very seldom be needed.

$$
\text { (1103) }
$$


The solubility of salt, already referred to, might be said to be a canse of its rapid exhaustion from a soil by drainage, but such loss will be frequently compensated for by the incidental import of esit for cattle, and by the small amount contained in artificial food. Again, it may be urged that a large proportion of farms export other articles beside corn and meat; but the same local circumstances which lead to such a cause, generally at the same time afford sources of manure not at the command of those circumstanced as our case supposes. Indeed, where towr manures are used, the amount of salt provided must always be considerable. The discrepancies in the accounts that are published of the effects of salt as a manure need not lead us to doubt the correctness but only the completeness of the statement; and if, as I have shown above. this substance is not required in any material quantity as a constituent of the exports of a farm, and if it he also true that when ugeful as an agent it is ao only under particular circumstances of excess of some substances supplied to the plant over others, the differences in result are what we should expect. In illustration of this point I may observe that a few years ago some experiments were carried on upon agricultural plants at the gardens of the Horticultural Society, at Chiswick, under the direction of Mr. Solly, and on comparing the results which be obtained by the application of various substances to a garden soil (probably already in a state of fertility far exceeding that which is nsual under a high condition of field-culture) with those obtained by the same substances upon exhansted land on my farm at Rothamsted, I found that in many important instances the effect seemed to be very beneficial in the one case, and not at all so in the other. Such facts as these plainly show us that upon soils where the essential elements of plants are wanting, no benefit can be derived from the use of salt or any other substance which does not become a constitaent of the produce. Where, however, in the growth of grain, all other essentials are provided, the use of salt may be advantageous by giving a healthy tone to the vital actions of the plant, and thereby improving the quality, and even to a small extent increasing the quantity of the produce also.

The effect of salt is, however, much more marked upon the green produce of a farm than upon corn crops, and the large quantity of it which is found in some plants of the former kind might well lead us to question whether it be not an essential element of sach produce, as well as a useful agent in the processes of vegetation in such cases. Mangel-wurzel, for instance, contains, comparatively speaking, a large amount of salt, and the effect of its application is perhaps more evident in the case of this plant than in that of any other. When. however, we bear in mind the small amount of elective action which is exercised by the roots of plants npon the soluble con. tents of the soil; that in the ash of the mangel-wurzel, as well as in that of all other green produce, we have the saline matter of the juices mixed with those of the parts formed from those juices; and, farther, that this plant, more particularly when fresh gathered, and before fermentation to some degree has taken place in its fluid contents, is known to act as a purgative to animals fed upon it, we cannot fail to admit the presence of a large amount of as yet unorganized matter, and the probability also that some of it is extraneons and annecessary to the growth of the plant; and in this latter supposition the existence of sait in the produce would show an ample resonrce of it in the soil, rather than prove its importance to the plant. Reasons of this kind must not, however, be taken as satisfactorily proving the non-essentialness of salt as a manure to those plants wherein we usually find it, but they should be considered more as pointing out the direc tion and the necessity of farther experiment on the subject, and especially so when we find in the animal economy instances of a very analogous kind. Thus it is found that although the blood of animals, which may be compared to the juice of vegetables, contains a large amount of common salt, which cannot be supposed to be unessential to the healthy actions of the body, yet its presence appears doubtful in any of the resulting products of the processes of the animal. The question, then, of the use and importance of salt to some few plants, and under certain particular cir. cumstances, is still open to investigation, and should it be decided affirmatively, we should yet have to determine whether or not it was necessary in such cases to employ it in any large quan. tities, or even directly as a manure at all. For the reasons I have adduced, I cannot but fully concur in the general opinion expressed by Professor Dumas, more especially as applicable to the state of A griculture in France at the present time, and I will venture to assume the following positions: 1. That sait can never be a substitute for the constituents ammonia and phosphoric acid. 2. That no soils exporting corn and meat can be restored to fertility without the application of these two substances. 3. That much of the money now expended in purchasing salt for agri. cultural purposes would be more profitably employed in procuring ammonia and phosphates. 4. That salt, although apparently essential in the animal economy, and perhaps in that of plants also, is exported from a farm in sach small quantities that many soils will, under an ordinary system of cultivation, never require its direct application, and others will do so seldom, and to a small extent only.

J. B. LAW ES. Rothamated. 


\section{N D E X}

\section{TO THE BOOK OF THE FARM.}

A

Aberdeen, Lectureship on Agricultare in, i. 41. A bortion of the ewe, indications of, ii. 169.

Absenteeism, causes and evils of, i. 53 . .

Adulterations of Flour, ii. 30. detection of, ii. 30 .

Agricultural Year, its divisions, i. 15.

- Readings, i. 421.

Agriculture, difficulties of the first study of, i. 5 . want of schools for teaching, i. 9 .

should be a part of education, i. 10.

Books on, their requisite characteristics,i.7. - errors of arrangement in existing,i.11. their proper arrangement, i. 12. their incompetency, i. 13.

Connection with the physical sciences, i. 19 its present position as a Science, i. 19, 20.

methods of acquiring a knowledge of, i. 28. love for, i. 34 .

practical scientific institutions of, i. 35, 46 . Professorship of, at Edinburgh, 40.

Seminary of, at Templemoyle. i. 41. in England, i. 201.

Agriculturists, American, their resources, i. 152.

Ague, effects of draining on, i. 375.

Air, effect of, on germination, ii. 177.

Allowances of contractors in England, i. 213.

Alpaca, the breeding of, ii. 451.

America, resources of her Farmers, i. 152.

Climate of, i. 226.

- Hedges in, their advantages, i. 226-7.

expensiveness of them, i. 228 .

Draining in, i. 303.

Drafting Sheep in, i. 404.

Horses of, i. 563.

Swine in, and their use, ii. 5, 219.

Farming Industry of, ii. 374.

Experiments in cultivation, ii. $379,381$. see also United States.

Anatomy, value of to the farmer, i. 61 .

Anemometer, the, i. 173.

Animals, geographical distribution, \&c.,i. 77, 207

- domestic, treatment of, i. 540 .

breaking them in, ii. 97 .

experiments in feeding, ii. 342 .

Ancrum, Mr., on feeding stock. ii. 342.

Annatto, coloring cheese with, ii. 316.

Ants, acid yielded by, i. 228.

Arbroath pavement, i. 132.

Artificial hatching of fowls, ii. 236.

Asphaltum pavement, advantages, i. 129

Atmosphere, action of electricity, i. 180.

- its usual electric state, i. 183.

Atmospheric phenomena, i. 163.-Importance of observing, i. 163.--Instruments for, i. 166.

Aurora borealis, appearances of, i. 184 .

Autumn, season of, ii. 362 .

its characteristics, ii. 362-3.

farm-work of, ii. 363-4.

wheat, sowing of, ii. 416 .
Ayr, scholare at, from the U. S., i. 34 .

Ayrshire breed of cattle, ii. 446 .

\section{B}

Bache, Prof., and the Girard College, i 44.

Bacon in the United States, ii. 8.

Baikie, description of, i. 102.

Bailiff. duties of the, i. 159.

Bailey, Mr., mould-board invented by, i. 254.

Baking household bread, ii. 31 .

Bare-fallowing, objects, \&c. of, ii. 346 .

Barley, scientific classification, \&c. of, ii. 34 . Prof. Johnston on, ii. 34

return yielded by, ii. 34

crop in the United States, ii. 34.

quantity annually malted in Great Britain, ii. 34 .

chemical composition, and that of barley. meal, ii. 35 . grinding and malting of ii. 35 .

its straw, ii. 41.

Sowing of, ii. 174.

comparative weight of Grain, Straw and Roots, ii. 382.

Barn, plan of, i. 105 .

Barometer, description and uses of, i. 166.

Tables connected with, i. 167.

Bathing sheep, time for, \&c., ii. 406.

- - composition for, ii. 407.

—— stool for, ii. 407 . how performed, ii. 407 .

Batts in horses, its causes and remedies, i. 566 . Beans, scientific classification of, ii. 38,39 .

uses, and chemical constitution, ii. 39.

- their straw, ii. $43,45$.

reaping of, ii. 379 .

- carrying in and stacking, ii. 400, 401.

Bedfordshire plow, the, i. 404.

Bell's reaping-machine, described, ii. 384 .

Black. James, his thorough drainage, i. 375 .

Black-faced Sheep, ii. 430 .

Bleeding Horses, i. 564.

Blistering Horses, i. 564.

Body-frame of the East-Lothian Plow, i. 258. of the Lanarkshire or Wilkie's, i. 262. of the Mid-Lothian or Currie, i. 267.

Bogs, drainage of, i. 320.-Example of, in Ireland, i. 320.

Boiling-house for food of live-stock, i. 104.

Bondager, origin of the term, ii. 50 .

Bone-dust, use of, for raising turnips, ii. 253.

- Sowing-machine : its advantages, ii. 253-4.

- how to secure from heating, ii. 256.

its chemical composition, ii. 256, 257

- compared with farm-yard dung : their effi. cacy, ii. 257.

- nature of its action in the soil, ii. 257-8.

BooK OF THE FARM, construction of, i. 14. -

Its arrangement, i. 27.-Observations of the

American Editor on, i. 54, 74, 82, 98, 147. 
Books, advantages of tuition by, to the young farmer. i. 7.

- A gricultural, requisite characteristics, i. 9, information contained in existing ones, i.10 their general arrangement, i. 10 .

- their incompetency, i. 11.

Bosweil, Mr., of Kingcausie, on raw and prepared cattle-feed, i. 519.

on hammels and byres. i. 521.

Botany aut botanical physiology, connection of with Agriculture, i. 20.

- value of a knowledge of. to the farmer,i.61

Bothy system, the, condemned, ii. 48 .

Box-churn, ii. 324.

Brake-harrow, description of, ii. 142.

Branding irons for Sheep, ii. 296.

Braxy in sheep, kinds and treatment of, i. 477 .

Breaking-in bridle bit, ii. 214.

-_ domestic animals, ii. 97.

— - young draught horses, ii. 212.

—— young saddle-horses, ii. 359. age for it, ii. 360 .

Bresding live-stock, points of, ii. 427 .

- in-and-in, ii. 436 .

Brick drains, how made, i. 382. their durability, i. 382 .

Bridle of the East Lothian Plow, i. 257.

- of the Lanarksbire, i. 262, 265. of the Mid-Lothian, i. 267 .

Bridle-bit for breaking-in draught colts, ii. 215.

"British Husbandry," arrangement of steading proposed in, i. 125.

Broadenst sowing-machine, ii. 142 .

Brudie, Mr., on feeding cattle, i. 515.

Bruising grain, various machines for, i. 559.

- - by hand, i. 559 .

- by power, i. 560 .

Brushwood drains. how made; not good, i. 382.

Buccleuch, the Duke of, his horses, i. 563.

Bucknell, Mr. on hatching Fowls, ii. 237.

Building stone dykes, ii. 253.

Buisting or marking iron for Sheep, ii. 296.

Bull calves and young bulls, management, ii. 103 ringing them. ii. $272,298$.

trcatment of, while serving cows, ii. 273.

Bullock ring and holder, ii. 298.

Bushel measure. capacity of, ii. 55 .

Bush harrow, description of, ii. 142.

Butter, making of, ji. 305 .

- various forms of churns, ii. 307, 323, 324.

- making of, from sour cream, ii. 310 .

from sweet cream, ii. 312.

from sweet milk, ji. 313 .

- preparation of for market, ii. 310-12. salting and curing of, ii. 311,312 .

- its chemical composition, 319.

Byre, its position in the stcading, size, \&c. i. 99. best floor for, i. 100 .

varioun medes of fixing cattle in, i. 101

window for, i. 105

cleaning of, i. 498.

\section{C}

Cabbage, drawing and storing, i. 421.

- best varieties for cultivation, i. 441 .

the Cow, or Cesarean kale, i. 441.

the Turnip-stemmed, or Kohl-rabi, i. 441.

- the Drumbead, i. 441.

Caithness pavement, i. 132.

Calderwood peat-tile spade, i. 378 .

Calves, description of house for, i, 103

- treatment of, ii. 82.

- extraction of from the mother, ii. 89.

- first feeding, \&c. after birth, ii. 91, 94, 100.

- mode of castrating, and time for it, ii. 102.

- diseases to which subject, ii. 104, 277.

- weaning of, ii. 266.-Proper time, ii. 270.
Calving of cows, reckoning table for, ii. 104.

Canadian straw-cutter, description of, i. 549.

Caponizing fowls, ii. 239.

Carey's wood pavement, i. 130.

Carmichael, Mr. his 'drag log, ii. 147.

Carpenter-work of the steading, specifications

\&c. i. $121,138,148,150$.

Carrick bog, drainage of, i. 320 .

Carrot, cultivation of, i. 442 .

drawing and storing, i. 431.

Carrying cor'u, ii. 391.

- cart for it, ii. 391.

Carse lands, mode of farming on, i. 66 .

— farms, moditied steading for, i. 124.

of Gowrie, mode of draining in, i. 311 .

Carts, liquid manure, ii. $67,69$.

less expensive, for America, ii. 69.

shed, form. size and position of, i. 114

the Corn, ropes, \&c. for, ii. 392.

construction and principles of, ii. 556.

as applied to American Farming, $i b$.

compared with wagons, ii. 557.

- illustrations of different kinds, ii. 561-2. interesting experiments with, ii. 558-560.

Caschrom, of the ancients, i. 253.

- a plow now used in Skye, i. 253.

Castration of the culf, time, age, \&c. for, ii. 102. of the lamb, ii. 165 . of pigs, ii. 221 .

Cattle, the first in New.England, i. 207. in England and America, ii. 105.

Cattle, accommodation of. on the steading, i. 99. sheds for them. i. 69.

- binders for, in the byre, i. 101. court for, i. 104.

- effect of spaying on, ii. 107.

- hammels for feeding them, i. 108.

courts for the young, i. 109.

arrangements for watering, i. 112.

preparing the courts for, i. 495.

littering them, i. 495.

arrangement of, on the steading, i. 496-7.

_ the milking and other treatment of, i. 498. supplying them with food, i. 499, 500

Treatment of the Oxen, i. 500 .

wisping and currying them, i. 501

fattening, in hammels, i. 501.

slicing their Turnips, i. 501.

treatment of the Calves, i. 502.

the servants' cows in England, i. 502.

cleaning their food, i. 503.

quantity of Turnips consumed by, i. 504 .

carrying straw to them, i. 504 .

dress of their attendant, 1. 504.

- dress of their attendant, 1. 504.

- arrangement of time of attendant, i. 505,506

loss by irregularity in fecding, i. 508 .

modes of fattening for exhibition, i. 508 .

- names given them at different ages, i. 509.

- management of, for the Dairy, i. 510.

food given to Dairy Cows, i. 510 .

turnip-slicers for them, i. 511.

effect of different kiride of food on them,i.515

Diseases to which subject, i. 522.

unimals infesting them. i. 523.

Choking, and remedies for it, i. 523 .

the Hoven, i. 524.

the Fardlebound, i. 525.

other diseases of, i. 525.

Driving and Slaughtering them, i. 525, 531 .

precautions on letting them loose, i. 526 .

requisites of their Drover, i. 526.

stripping them, i. 527 .

rate of their traveling, i. 527.

their best stato for the market, i. 527 .

mode of judging of them, i. 528 .

preparations for slaughtering, i. 531-2. 
Cattle. various modes of slaughtering, i. 532 . modes of cutting up, i. 533, 534 .

proportion of offal, \&c. i. 537. loss sustained by modes of Cooking, i. 537 . salting their carcasses, i. 537. uses of the hide, hoofs, horns, \&c. i. 538. Feeding them on Turnips, i. 495. - times of, i. 502.

on Potatoes, i. 510.-On Oil-cake,i.511 on Linseed Oil, i. 516.

on Green Malt, i. 516.

on Linseed Meal and Barley, i. 516. Experiments on the Cost of, i. 517. comparison of, hammels, \&c. i. 520. treatment of in spring, ii. 266.

fattening of, ii. 267

calculating their weight, ii. 268 .

fallacy of these modes of calculation, ii. 269. their distribution over the pasture, ii. 269-70 grazing them during summer, ii. 274. sheds for sheltering them, ii. 276. watering-pool for them, ii. 275.6.

advantages of Pasturage aud Hay, ii. 283. Points to be cultivated by the breeder,ii.42\% examples of the different Breeds :

the Short-Horn, ii. 442.

the Long-Horn, ii. 444

the Hereford and West-Highland, ii. 445. the Ayrshire, ii. 446.

Teeth of; their development, ii, 454. indications of age, ii. 455.

Cattle-man, duties of, i. 504-6.

- suitable dress for, i. 504

necessity of his regularity, i. 505.

arrangement of his time, i. 506.

loss through irregularity, i. 506.

usual wages of, ii. 49 .

Chatf-house, position, \&c. on the steading, i. 89. Charlbury subsoil.plow, description of, i. 412.

Cheese, making of, ii. 314.

- preparation of the Rennet, ii. 314.

— breaking and straining the Curd, ii. 315.

- machine for this purpose, ii. 315.

- vat, the, ii. 316 .

— pressing of, machines for, ii. 316. 329, 330 .

making of, from sweet milk, ii. 316 .

Cream, ii. 321.

drying and coloring, ii. 316-17.

Insects infesting, ii. 321.

Cheese-press, the stone, ii. 329.

- the Compound Lever, ii. 330.

Cheese-rack or turner, ii. 332.

Cheese-vat, description of, ii. 315-16.

Chemical Constitution of Soils : see Soils.

Chemistry, connection of, with Agriculture, i, 22

- its importance overrated, i. 23.

- value of an acquaintance with, to the Farmer, i. 62.

Professor Law on, i. 25.

its true value. i. 25.

Cheviot breed of Sheep, ii. 449.

Cheyne, Captain, mixture of, for his horses, i.548

Chickens, management of, ii. 226.

Childers, Mr., on feeding Sheep on Turnips,i.457

Chine-fellon, a disease in cattle; causes and remedies, ii. 277 .

Choosing the kind of farming, i. 68,-And a Tutor for it, i. 69 .

Churaing of cream, ii. 309-10. of sweet milk, ii. 313.

Churn, various forms of, ii. 322.

— the barrel, ii. 322 .

— Wedgewood's table, ii. 323

the box hand, ii. 324 .

the Irish box, ii. 325 .

the plunger, ii. 326 .

the same, by power, ii. 327.
Churn, the oscillating. ii. 328.

- comparison of the various kinds, ii. 307 .

Cirencester Agricultural Institute, i. 25, 141.

Cistern for rain-water, i. 134.

Classification of corn-plants by the ear, grain \&c. ii. 25.

Clay soil, the pure; characteristics, i. 214.

- effect of sand on it, i. 215.

Clay-loam, i. 215 .

Climates, great varieties of, i. 198.

- general cauees of these, i. 201.

local causes which modify, i. 203.

in Great Britain, i. 204.

- as shown in the distribution of plants and animals, i. 206.

recent change of, in Great Britain, i. 208. causes of this, i. 209.

of the United States, i. 198.

Dr. Forry on, i. 198, 201.

Jefferson on the differences of, i. 203.

geographical distribution of, i. 200.

Closed-boiler steaming apparatus, i. 566 .

Clouds, various forms of, i. 175.

weather indicated $\mathrm{by}, \mathrm{i} .175$.

- prevalent forms of, in summer, ii. 246. in autumn, ii. 362 .

Coach-house, position, \&c. on the steading, i. 98. fireplace in, i. 98.

Collar for the plow-horse, various forms, i. 388.

Culman, Mr. observations of, in Europe, i. 25.

- on Chemistry and its application, i. 25.

Colors of Soils, i. 219.

Comparative Anatomy, valae of to F armers, i. 61

Composts, preparation of, ii. $66,185$.

_ various substances used for, ii. 66-7.

Concrete, for steading floors, i. 129.

Conduits for drains, building of, i. 326.

- varions forms of, in drains, i. 341.

Constitution, importance of attention to, ii. 431.

Contracts for building steadings, i. 122.

Cooked food, advantages of, to the horse, i. 546 .

Corn, quantity consumed by farm-horses, ii. 278.

- advantages of, to yonng horses, ii. 279.

- see Wheat, Oats, and the various Grains.

Corn-barn, position of, on the steading, i. 86 .

- size, form, \&c., i. 86.

- its floor, i. 87,88 .

- its door, i. 87 .

Corn-box for sheep, description of, i. 453. another form of it, i. 476 .

Corn-bruiser for horses, i. 559.

- band, i 559 .

- power, i. 560-1.

Corn-chest, best form of, i. 90 .

Corn-fodder, ii. 40.

Corn-markets, ii. 52.

stock and sample, ii. 52-53.

—— advantages and disadvantages,ii.53,54

- frauds perpetrated in, ii. 54 .

—— measure used in, ii. 55-56.

__ laws relating to them, ii. 56 .

Corona round the Sun, i. 189.

weather indicated by, i. 189 .

Corrosive sublimate, to prevent Dry Rot, i. 141.

Cost of materials, i. 146-7.

Coulter of the East Lothian plow, i. 256, 260.

of the Lanarkshire, i. 262.

of the Mid-Lothian, i. 267.

nature of its action on the soil, i. 271.

Courts for Cattle, position of, i. 109.

their size, \&c., j. 109.

Coventry, Professor, i. 40.

Cow-cabbage, culture of, i. 441.

Cow house, its position, size, \&c., i. 99.

- its floor, i. 100

- mode of fixing cattle in, i. 101.

form and size of window, i. 105 . 
Cow-pox, the, ii. 277 .

Cows, treatment of in Winter, i. 496, 498.

- feeding of. i. 499 ; ii. 84,85 .

_ treatment of, while with calf, ii. 82 .

- to ascertain when in calf, ii. 83, 104.

diseases to which then subject, î. 84 .

danger of slipping the calf, ii. 86.

treatment of, to prevent this, ii. 87. during parturition, ii. 89.

the ndder, ii. 99.

reckoning table for calving time, ii. 104.

diseases after ealving, i 105

$$
\text { their remedies, ii. } 105 .
$$

effects of spaying on them, ii. 107.

Serving them with the Bull, ii. 107.

in Summer, diseases then, ii. 277.

causes affecting their milk, ii. 317 .

Guénon's Treatise on, ii. $99,100$.

Cradle-scythe description of, ii. 386.

Cream, churning of, ii. 310 .

its chemical composition, ii. 318 .

cheese, making of, ii. 321 .

Creaming of milk, the, ii. 309.

Croall, Mr., his mode of feeding horses, i. 548.

Crops: see Wheat, Beans, Pease, Oats, Rye

Crossing live-stock, ii. 437 .

Crosskill's clod.crushing roller, ii. 352.

Cross-plowing, objects, \&c., ii. 111.

Cultivator: see Grubber.

Cunningham's plow: see Mid-Lothian Plou.

Curd of milk, composition of, ii. 319-20.

Curd-cutter, description of, ii. 316 .

breaker, ii. 328 .

Curl in potatoes, causes and prevention, ii. 203.

Currie Plow: see Mid.Lothiun Plot.

Curtis, Mr., modes of feeding cattle, i. 516.

Cylinder straw-cutter, i. 551.

- turnip-slicer, i. 475.

\section{D}

Dairy, general management of, i. 510 . operations in mixed husbandry, ii. 305 .

Dairy-farm, general arrangements, i. 67 .

- modified steading for, i. 124 .

Dairy-maid, duties of, i. 162 ; ii. 308.

Dale's hybrid turnip, culture of, i. 437.-Its origin, i. 440 .

Dalrymple, Mr., on the profit of draining, i. 376 .

Damaged wheat, detecting, ii. 28.

Davy, Sir Humphry, his agri. chemistry, i. 23.

- his theory of irrigation, ii. 74.

- on fermentation of dung, ii. 191.

Deanston subsoil-plow ; its action, i. $408,419$.

Deep plowing. advantages of, i. 402.

Dew, theory of, and its influences, ii. 241.

De Kham on tanks, i. 153.

Dibbling, sowing wheat by, ii. 419.

Dick, Professor, i. 43.

Difticulties of the young farmer, i. 5 .

means of overcoming, i. 7 .

Disk straw-cutter, i. 554 .

Diseases of Sheep, i. 476 ; ii. 408. of Cattle, i. 522.

of Horses, i. 568.69 .

of Swine, ii. 12, 13.

of Calves, and their treatment, ii. 104.

of Cows after calving, ii. 105.

of Potatoes. ii. 203.

of Poultry, ii. 223.

Diatribution of labor, i. $5,17$.

of plants, i. 206.

of animals over the earth, i. 200,207.

Docking draught-colts, how done, ii. 217.

Doddering sheep, ii. 29?.

Dog, the drover' $\mathrm{g}, \mathrm{i} .481$

the shepherd's, training of, ii. 172.
Dog, varieties of the, ii. 173 .

Double mould-board Plow, ii. 332.-A form of, aitered into a Scufter, ii. 333 .

Drafting sheep, \&c., i. 404.

Drag.log, the, ii. 147, 353.

Draining, winter the season for, i. 74.

pastoral farms, importance of, i. 459 of the steading, i. 323.

Drains and draining, definition of, i. 302.

- universal necessity for them, i. 306.

_- indications where wanted, i. 306.

- connection of Geology with i. 308. importance of knowing principles, i. 309

Drains tor the farm-buildings, i. 115 .

grating for them. i. 119

for liquid manure, i. 120.

field, various kinds of, i. 310 .

open ditches and gaw-cuts, i. 311.

old mode of, i. 311.

system introduced by Elkington, i. 312

subsequent modifications, i. 312.

various sources of water, i. 313.

plan of sbeep-drains on a bill, i. 317 .

the open drain in grass, i. $31 \%$.

the closed, i. 318.

application of Elkington's system to a pool, i. 318.

and to bogs and marshes, i. 320 .

example of this, i. 320 .

mode practiced in Ireland, i. 320.

bog-draining, i. 320 .

tools used in making, i. $321,331$.

description of Elkiugtou's sy stem,i.323,331

mode and cost of cutting. i. 324 .

guage for them, i. 326 .

building the conduits, i. 326 .

filling-up, and substances used, i. 327.

section of one, with well and bore, i. 327 .

principles on which founded, i. 331.

Thorough, i. 333.

objects sought to be attained, i. 333.

necessary depth, i. 333

necessity of ducts in, i. 337 .

tile-ducts, i. 338 .

the main drains. i. 340.

regulation of the fall. i. 340 .

position of the small drains. i. 341

their depth, i. 343, 352.-Ascertaining this, i. 344 .

distance between the, i. 345,368 .

evils of too great a distance, i. 346 .

position of, with the main drains, i. 347

proper direction of the run, i. 347 .

mode of cutting. and the tools, i. 351.

filling in, i. 353.- Materials ased for, i. 353.

stones for, i. 353. - Node of preparing them, i. 354 .

Implements for filling-in, i. 354.

view of a stone-drain completed, i. 357.Its dimensions, i. 357.

time required for making a stone, i. 358 .

plan of a thorough-drained field, i. 372.

best period for executing draining, i. 373 .

amelioration of the land by draining, i.374.

its influence in improving health, i. 375 .

examples of the profit of, i. 376.

Draining in America, j. 303.

in the Eastern States, i. 305

letter on, from an Agricultural Inst., i. 306.

Drain, the flat stone, i. 377 .

- the peat tile, j. 377 .

- the clay land shoulder, i. 379.

the plug or wedge, i. 379 .

the sod, i. 380 .

by the mole-plow, i. 381 .

with larch-tabes, i. 382.

with braslawood, i. 382 . 
Drain brick, its durability, i. 382 . employment of the plow in cutting, i 323 various plows for this; McEwan's, i. 383 .

Green's, and Pearson's, i. 383.

scientific principles in draining, i. 384.

Drain-guage, i. 326 .

Drain-plows, various: see Drains,

Drain-tiles for main drains, i. 359.

- necessity for the sole, i. 359 .

- size and form, i. 360 .

-_ number required per acre, i. 361.

- - junction of small and main ones, i. 362 . laying them down, i. 363.

— plumb-level for, i. 365

- joining with the main drains. i. 366 .

—— the sub-main drain, position, \&c.,i.367.

_- size of, for the small drains, i. 368.

- - the soles for, i. 368 -Putting them in, i 368 .

filling up, i 369.

- view of a tile and sole drain, i. 371 .

Drain-stone screen, or harp, i. 354

- rake, beater, \&c., i. 355-6.

Draught of the plow, i 285.

Draught-Horses, breaking them in, ii 212.

_- shoeing. docking, \&c., ii. 216.

_— points desirable to cultivate, ii. 439.

— - - the Horse, ii. 439.

— the Stallion, ii 440 .

the Mare, ii. 441

Drawing turnips, carrots, \&c, i. 421.

Drill sowing-machines, ii. 153

Turnip, ii 258

Grubber, description of, ii. 334 .

- Harrow, ii. 334

unsuited to America, ii. 258-9.

Drilling, single, objects, \&cc., ii. 117 . double, ii. 121

Drive work, or it will drive you, i 17.

Driving and slaughtering cattle, i. 525.-Sheep,

i. 478 . - Swine, ii 5,6

Dryness of American soil, i. 226

Dry-rot in timber, prevention of. i. 141.

Dry-stone dykes, building of, ii. 353

- - their varieties in hight. \&c, ii $\mathbf{3 5 3 - 4}$

__ openings and stiles in, ii. 357 .

- expedients to increase the bight,i.357.

Duck-mire pool, drainage of, i 318.

Ducks, management of, ii. 16, 233

- gathering, \&c., of their eggs, ii. 422, 424.

Dudgeon, Mr., on feeding pigs, ii. 12.

Duug, farm-yard, in the fields, ii 56.

- position of the heaps, ii. 57 .

removal from the cattle-courts, ii. 60 .

laying down the heaps, ii. 60 .

_- spade, for cutting and lifting, ii. 61.

- preparation of for potatoes. ii 180

_- proportion needed for them, ii. 194.

- its distribution, ii. 195

- turning the heaps, ii. 181.

- preparation of for turnips. ii. 183.

necessity of its fermentation, ii. 191.

- usual quantity on fallow land, ii. 349.

Dung-hawk or drag, ii. 193.

Dunghills and composts, management of, ii.180.

Dutch clinkers, pavements of, i 132. plow, description of, i. 253

Dutchess Agricultural Institute, i 306 ; ii. 69.

Dykes, stone, building of, ii. 353 .

- openings for sheep in, ii. 357.

stiles in, ii 357 .

- means to iucrease the hight, ii. 357 .

$\mathrm{E}$

Earning for cheese-making, ii. 314.

East Lothian or Small's plow, i. 255.
East-Lothian drill sowing machine, ii. 153.

Eccaleobion. description of ii 237 .

Edinburgh University, asri chair in, i. 40.

- Veterinary College of. i. 43.

Education, agricultural, i. 9.59.

Egg, changes while batching, ii 237.

Eggs, treatment of, \&c., ii. 422 .

- gathering them. ii. 422 .

modes of keeping them, ii. 423 .

- composition, analyaes of, \&cc, ii. 425-6.

- trade in them, ii. 427

Eqypt, artificial hatching of fowls in, ii. 236.

Electricity, relations of to Agriculture, i. 20.

- value of a knowledge of, to farmers, i. 60

intluence of on the weather, i. 180.

- its sources, i 180, 181.

Electrometer and Electroscope. i. 183.

Elkington, Mr., new system of Draining, i. 312

application of his system, i $312,318$.

— to bogs and marshes, i. 320 .

— detailed description of the system, i. 323.

- principles on which founded, i 332.

- its applicability to Scotland, i 333.

Engine-house, position of, i 89.

England, artificial treatment of stock in, ii. 105 .

- more disease thus induced, ii 105.

- the Agriculture of, i. 201 .

Entomology, value of to the farmer, i 22.

Establishment of Scientific Institutions of Prac.

tical Agriculture, i 35, 46.

Ethrioscope, the, i. 205.

Evans, Mr, plug-drains of, i. 380.

Evaporation as a source of electricity, i. 181.

Evils of not studying Agriculture, i. 49.

Ewe house, Burnett's, ii 170.

Ewes, Drafting of, in Autumn, ii. 403.

- Tupping of, ii. 404.

- Bathing of, ii 4068.

Ewes, lambing of, ii. 155 .

accommodation for, when lambing, ii. 157.

— their delivery, ii. $157,158$.

- their subsequent treatment, ii. 160.

pasturing them, ii. 166.

differences in the treatment of breeds, ii.167

_ Diseases at lambing: Remedies, ii. 170.

- after lambing. ii. 170.

advantages of shearing them last, ii. 294.

mode of milking them, ii. 295.

Experience, advantages of, to the farmer. i. 6 .

Experimental farms, their advantages, i. 55.

\section{F}

Factors, evils of ignorance of Agriculture, i. 52.

Facts, observation of, and its importance, i. 210.

- kind of, to be recorded, i. 211.

Failure of the Potato crop; its causes, ii. 203.

Fallowing, objects of, ii. 346 .

bare, and soils requiring it, ii. 347 .

nature of its action, ii. 351 .

Fallow-land, weeding it, ii. 347 .

- - manuring, ii. 348. - liming, ii. 349 .

Fardlebound, a disease of cattle : remedies,i.525.

Farm, employments on. in winter, i. 74.

duties of various persons employed, i. 158

steward, duties of, i. 159.

plowman, i. 160 .

shepherd, i. 247.

field-worker, i. 162.

dairy-maid, i. 162.

see also Farm Servants.

Farmer, the young, education suited to, i. 59.

Farm-house, form of, i. 153.

- ground-plan of its kitchen. i. 154. the cheese-room, \&c. i. 156.: its position relative to steading, i. 157 .

Farming, different kinds of, i. 64. 
Farming, store, i. 64 .

- carse, or grain, i. 66.

_ in the neighborhood of towns, i. 66 .

dairy, i. 67.

mixed husbandry, i. 68.

choosing the kind of, i. 68 .

selecting a tutor for tenching, i. 69 .

dealing with the details of, i. 71 .

Farm-servants, wages of, ii. 46 .

- the plowman's wages, ii 46.

- in bothies, ii. 47,48 .

—— the steward, ii. 49.

___ the shepherd and hedger, ii. 49.

- the cattle-man, ii. 49.

the field-worker, ii 51 .

comparison of their condition, ii. 51 .

Farm-steading: see Steading

Farm-steward, duties of, i. 159. wages of, ii 49.

Farm-work, modes of describing, i. 15.

Farm-yard dung, for potatoes and turnips, ii 180 . See also Dung.

Farquharson, Dr. on hoar-frost, i 194.

Farrowing of sows, ii 217.

Fattening of sheep, effect on the wool, ii. 302.

Feathers of fowls, uses of, ii. 23 .

- how formed, ii 239.

Feering ridges, how done, i. 290.

- for cross.plowing. ii 113.

- for drilling, ii. 117.

Fellenberg, M. de, agricultural institution, i. 44 .

Felting power of wool, ii 303.

Fermentation of farm-yard dung, ii. 181.

- necessity for it, ii 190 .

opinions relative to, ii 191.

Field-gates, construction of, ii 260 .

- their posts, ii. 260, 261.

__ modes of constructing, ii. 262.

- iron, ii. 264.

- wire, ii. 265 their pillars, and fastenings, ii. 265.

Field-work advantages of forwarding, ii. 108

Field-workers, duties of, i, 162,

Finlayson's grubber, description of, ii. 207.

Fireplace in the coach-house, i. 98.

Flail, description of the, ii. 345 .

Flat stone drain, how made, i. 377

Flax, pulling of, stc. ii. 365 .

- weeding of, ii. 365 .

- steeping and drying. ii. 366 ,

- average value of the crop, ii 368 .

- botanical classification. ii 371 .

- importation of the seed, ii. 372.

Fleeces, rolling, packing, dc. ii. 298.

average wejuht of, ii 304 .

Floor of the corn-barn, i 86,88 .

- materials for, i. 88 .

- of the stables, i 93.

— of the riding-horse stable, i. 98 .

- of the byres, i. 100.

Flottebeck, Flanders, ag. institution at, i. 49.

Flour, grinding wheat into, ii. 29.

- how to judge of its quality, ii. 29.

— various adulterations, ii. 30

- mode of detecting these, ii. 30 .

- analyzing it, ii. 31 .

— its chemical cumposition, ii. 31.

- fermentation of it, ii. 32 .

- mixing potatoes with it, ii. 32 .

Fly, the Hessian, i. 24.

Fly-wheele misapplied, i. 553.

true uses of, i. 554.

Foal, birth of, ii 279 .

Foge causes of, $\mathrm{i} 197$.

Foot-rot, treatment of, $i .47 \%$.
Fure-iuh. urcessity of, i. 6.

Furry, 1)r. (n) C'limate, ii. 209.

Jicowis, ancommoration for, i. 115.

- treatmens of them in winter, ii. $1 \%, 19$

- Eeneral neglect of, ii 13,14 .

- various kinds on a farm, ii. 14.

- Hens, treaiment of. ii 14, 15.

Turkeys, ii. 15.

Geese, ii 15.

- Duck8, ii 16.

— Pigeons, ii. 16.

- Prices in different conntries, ii. 16.

- modes of judging of them, ii. 17.

their hou ses, ii 17

daily treatment. ii 19.

food for them, ii 20

- breeding of, in winter, ii. 21.

cramming, ii. 22.

uses of their feathers, ii. 23.

Hatching of them, ji. 223.

- season for it, ii 223.

by artificial heat, ii. 236.7 .

development of the egg, ii. 237.

Management of hens. ii. 224. - of turkey 8, ji. 227 .

- of geese, ii. 230.

- of ducks, ii. 233.

of pea-fowl, ii. 234.

- of pigeons, ii. 234.

in lowns, their treatment, ii. 235.

Diseases to which subject, ii. 235-6.

castrating them, ii. 239.

Frenchlaw, drainage at, i. 320

Frost, definition of, i. 195.

\section{G}

Gabell's subsoil plow, i. 412.

Gaits, setting up oals in, ii. 378 .

Galactometer, description and uses of, ii. 318.

Garget in ewes, treatment of, ii. 169.

Gates of the steading, i. 120.

- field, construction of, ii. 260.

- their posts, ii. 261

- various kinds of, ii. 262.

iron, ii. 264.

- wire, ii. 265.

- pillars and fastenings, ii. 265.

Gaw-cuts, draining by, i. 311 .

Geese, general treatment of, ii. 15.

management while batching, ii. 230.

Geographical distribution of climate. i. 200. of the Human Family, j. 200.

Geological relations of soils, i. 219.

Geology connected with Agriculture, i. 20.

Germination of reeds, ji. 177 .

effects of water and air, ii. 177.

effects of plowing and sowing on, ii 178.

of wheat, process of, ii. 421.

Gimmers. lambing of, ii. 163.

drafting, for sale, ii. 403.

Glazing of the steading, i. 145, 151.

Gluten, Prof. Johnston on, i. 31 .

Good and bad plowing and sowing, effects of, on germinating seeds : see Germination.

Gore-furrow, mode of forming, i. 295.

Grain, steaming of, for hurses, i. 558. apparatus for bruising it, i. 559. chemical constitution, ii. 41.

disposing of; the markets, ji. 52.

its sale by bulk or sample, ii. 53 .

measures for it, ii 56 .

laws relating to its sale, ii. 56 .

comparative statements, ii. 179.

reaping of, ii. $373-388$.

carrying in, stacking, \&c. ii. 388-400.

see also Barley, Wheat, Oats, \&c. 
Granary, proper position of, i. 80 . plan and description of, i. 106. form of window for, i. 107. securing it from vermin, i. 117 Grass for horses in summer, ii. 281. land, or lea, plowing of, i. 74. - clearing of from stones, ii. 259. summer management of, ii. 274. see also Pastures.

Grass-parks, season for letting, ii. 82.

Grass-seeds, sowing with spring wheat, ii. 132. and by sowing-machine, ii. 134 harrowing, ii. 142.

Grating for drains, i. 119.

Gravelly soils, definition of, i. 216. loams, i. 216.

Grazing cattle, ii. 274.

Gray, Mr. on moor-band pan, i. 418.

Gray slates, not good for roofing, i. 144.

Green, Mr., drain-plow invented by, i. 383.

Green malt, feeding cattle on, i, 516 .

Grieve, or steward, duties of, i. 159.

Grignon, agricultural institution at, i. 47.

Grinding wheat, processes of, ii. 29 .

- barley, ii. 35 .

oats, ii. 37 .

beans, ii. 39 .

Ground plan of an existing steading, i. 83. of a proposed steading, i. 85 .

Grub, the oat : its ravages: preveution, ii. 151. Grubber, Finlayson's, ii. 207.

Kirk wood's, ii. 209.

the common Drill, ii. 335.

Wilkie's ii. 335 .

Guénon's Treatise on Milch Cows. ii. 99. highly esteemed, ii. 99, 100.

\section{$\mathrm{H}$}

Hail, phenomena attending, ii. 245.

Halos around the sun and moon. i. 185. indications of weather from, i. 185 .

Hammels for feeding live-stock, i. 108. their position, size, \&c., i. 108, 125. their advantages over byree, i. 520-2l.

Hams, curing of, ii. 11.

Hand draw hoe for drains, i. 304.

Hand stubble-rake, the, ii. 388.

Hannam, Mr., on wheat, ii. 383.

Harness, position of, in the steading, i. 93.

- of the plow-horse, i. 386.

- its weight and cost. i. 387. cleaning of, i. 564 .

Harrow, various forms of, ii. 138

the wooden, ii. 139

the iron, ii. 141.

the grass-seed and iron-web, ii. 142.

the brake, ii. 142 .

the drill or potato, ii. 210.

Harrowing sowed land, ii. 132, 135. advantages of in spring, ii. 112.

Harvest-bug, the, ii. 239.

Hatching of the various fowls, ii. 223. season for it ii 223.

of Hens, ii. 225 .

of Turkeys, ii. 227.

of Geese ii. 230.

Ducks, ii. 233.

Pea-fowl, ii. 234

Pigeons, ii. 234 .

house for it, described, i. 115.

by artificial heat, ii. 236 .

phenomena of its stayes, ii. 237 .

Hatherton, Lord, results of draining. i. 376.

Haulm, or straw, of the potato, ii. 66 .

— as manure, ii. 66.

Hawthorn for hedges, i. 231.

Hay, for sheep in winter, i. 125.
Hay, cutting, for horses, ii. 278. from different grasses, ii. 336. making, by manual labor, ii. $\mathbf{3 3 7}$ with horse labor. ii. 337 . thatching of the stacks, ii. 339 . calculating their weight, ii. 340-1. average weight per acre, ii. 341 . chemical constitution, ii. 341 . value of the crop, ii. 342 .

Implements in making, ii. 342-4.

Tedding-machine, ii. 342.

Rake, the hand, ii. 342-3. the American horse, ii. 344.

Hay and Straw Cutters, forms of, i. 549. the Canadian, i. 550 .

— the Cylinder, i. 551. the Disk, i. 555.

Hay-house, position, size, \&c.. i. 90

Hay-knife, description of, ii. 278.

Hay-racks, forms of, i. 91. for the riding-horse, i. 96. for sheep, i. 449.

Hav-rakes: see $\mathrm{Hay}$.

Hay-stacks, building, \&c. ii. 338. thatching, ii. 339 . calculating their weight, ii. 341 .

Health, beneficial effect of Draining on, i. 375 .

Hedges in America, i. 226-7.

- Mr. Downing on. i. 227.

the hawthorn for, i. 226 .

the Osage Orange for, i. 228.

expensiveness of, i. 228.

Hedges, Thorn, planting, i. 226, 236. proper season for, i. 227.

- mode of making, i. 228.

- Implements made use of, i. 230. choosing the plants, i. 231 . marking out the line, i. 232 . bed for, i. 233. preparation for planting, i. 234. laying the plants, i. 234 .

- best weather for planting, i. 235.

- dimensions of the ditch, i. 235.

view of a finished hedge-bank, i. 237. obstacles to be encountered, i. 237. water lodging in, i. 238 .

bad effect of the scarsement, i. 240 . planting in shrubberies, i. 242. planting in curves, i. 242. turf fences to them, i. 242-3.

Hemp. steeping and drying, ii. 368 .

- natural history of, ii. 372 . classification of, ii. 372 .

Henderson, Mr., on Swine, ii. 222.

on preparing Flax, ii. 366 .

Hens, management of, ii. 11,12

- houses for them, ii. 17.

- treatment while setting, ii. 17.

Hepburn, Mr., snow-harrow and plow of, ii.171. Hereford ox, the, ii. 445 .

Hessian fly, the, i. 22.

Highland and Agl. Soc.,proposed steadings of, i. 125 .

Hill-shepherd, qualifications of, ii. 168.

Hoar-frost, injurious effects of, i. 193.

Hoe, the hand, i. 364 .

Hofwyl agricultural institution, i. 44 .

Hogs : see Sicine.

Hog's lard, properties of, ii. 12.

Hobenheim agricultural institution, i. 48.

Hop, cultivation of, ii. 369 .

- picking of, ji. 370 .

- drying and packing, ii. 370.

- uncertainty of the crop, ii. 370

duty on the, ii. 371 .

amount of, per acre, ji. 371.

scientific classification, ii. 373 . 
Hop, natural history of, ii. 373 .

- exports and imports of, ii. 373.

Hopetoun oat, the, ii. 148.

Horns of Cattle, ii. 446. of Sheep, ii. 480 .

Horse, the. in New-England, i. 207.

technicalities of, i. 546.

_- development of the teeth, ii. 453. indications of its age, ii. $452 \cdot 3$.

Horses, Farm, accommodation of, i. 90.

- treatment during winter, i. 539.

the stables, i. 99. 539.

day's feeding and work of, i. 539.

cleaning them, i. 542 .

warm mash for them, i. 543.

allowance of oats, i. 543 .

breeding them on the farm, i. 545 .

trentment of the mares, i. 545.

the young, i. 545 .

names of different ages. i. 546 .

cooked food for, i. $5 \pm 6$.

danger of too nutritive food, i. 546.

various mixtures for, i. 547 .

regular allowance of food, i. 548 .

superiority of prepared food, i. 548 .

hay and straw cutters, i. 549.

steaming apparatus, i. 556 .

corn.bruisers, i. 559.

choice of names for, i. 561 .

Riding and Harness, i. 97.

-treatment in winter, i. 562.

before riding out, i. 563 .

cleaning their harness, i. 564.

Diseases to which subject, i. 564.

Bleeding them, i. 564 .

Blistering. i. 565 .

Physicking. i. 565.

Fomentations, other remedies, i. 566.

Pulse of the horse, i. 566.

animals infesting, i. 566.

the Batts, i. 566 .

Inflammation of the Bowels, i. 567 .

Colds, i. 567.

Grease, i. 567.

the Staggers, i. 567.

Thrush and Corns, i. 568.

Broken Wind, i. 568 .

Saddle-Galls and Crib-biting, i. 568.

Wind-sucking. i. 569 .

Dust-ball and Worms, i. 569.

Specks in the eye, i. 569.

uses of its Offals, i. 569.

Grazing them in Summer, ii 274.

Feeding them then, ii 281 .

Diseases, and Insects infesting, i. 566 ; ii. $283-4$.

Breaking in, ii. 212, 359 .

age for this, ii. 360 .

Points to be cultivated, yi. 430,439 .

Horse, Draught, points of. ii. 439.

the Stallion, ii, 440

the Mare, ii 441.

Horse-cloths, the, i. 98.

Horse chesnut, feeding sheep on the, ii. 297

Horse-bot, ii. 284.

Horse-hoe, Wilkie's, description of, ii. 335

Horse-louse, description of, i. 566 .

Horse-ponds, pusition and size of, i 136.

Household bread, baking of, ii. 31 .

Hoven, a disease in cattle, cure of, i. 524.

Howden. Mr, on the protit of Draining, i. 376.

- experiments by, on feeding Cattle, i. 518 .

- on the Potato, ii. 205.

Hurdles for sheep on turnips, i. 466-7.

— implements for making, i. 467-8.

- setting them up, i. 443,469 .

Hasbandry, Mixed, in the United States i. 68
Hydrography, value of a knowledge of, i. 61 .

Hygrometer, description of, i. 171.

\section{I}

Ice. properties of, i. 196

evaporation from it, i. 196.

its cooling powers, j. 196

Imperial bushel, standard capacity of, ii. 55 .

Implement-house, position, \&c., of, i. 90.

Implements of the farmer, i. 18 .

importance of, i. 18.

deficient varieties of, i. 12, 18 .

Importations of cattle, i 207.

Industry in America. ii 374.

Insects infesting Horses, i. 566 ; ii. 284. Cheese, ii. 321.

Institutions of Practica! Agriculture, i 25, 35, 46

Ireland, Agricultural Schools in, i. 25, 42.

- Dr Kune on her Resources, i. 191.

Irish box-churn, ii. 325 .

Iron, its use on farms, i. 97.

Iron field gates, examples of, ii. 263.

Iron web-harrow, ii 142 .

Irrigation, begun during winter, i. 75 .

_. theory of its effects, ii. 73.

Isometrical views of steadings, i, 82, 83.

Italian rye-grass, peculiarities of, i. 22.

\section{$\mathrm{J}$}

Jacob, Mr., on the Moeglin Agl. Inst., i. 46.

Jefferson on ditferences of climate, i. 203, 209.

Joint-fellon, a disease in cattle, ii 277.

- causes and treatment, ii. 277.

Johnston, Prof, on Gluten, ii. 31.

- on Barley, ii. 34.

\section{K}

Kane, Dr., on the Resources of Ireland, i. 191. Kelso. effect of Draining on its health, i. 375.

Kildrummie oat, the, ii 148 .

Kirkwood's grubber, ii. 209.

Kyan's process to prevent dry-rot, i. 142.

\section{L}

Labor, variety of on a farm, i. 5 . distribution of i. 5 .

Laboring population of the United States, ii 45.

Laing, Mr., on subsoil plowing, i 413.

Lamb, extraction of, from the mother, ii. 158.

- treatment of. after birth, ii. 166 .

bringing up by hand, ii. 163 .

- castrating of, ii. 165.

diseases when young, ii. 169

weaning of, ii. 295.

- marking and buisting, ii. 296. instruments for theee, ii. 296.

Lambing ewes, ii, 155.

Lambing-park, proposed, ii. 167.

Lanarkshire or Wilkie's plow, i 255.

detailed description of, i. 262.

Land-owners, evils of their ignorance of Agriculture, i. 49

Land-rollers, various forms of, ii 146.

Lantern for the stable, i 544.

Larch tube drains, i. 382 .

Larne, Ireland, A gricultural School at, i. 25, 42.

Law, Profeseor, on Chemistry, i. 25.

Law of the corn-market, ii. 56.

Lawns. pasturing sheep on, ii. 266.

Lawtown turnip, i, 437

its origin, i. 440

Lead-work of the steading, i. 143. 149, 151.

Lea-ground, plowing of, i. 394.-Modes of plow.

ing, in different soils, i. 395 .

Le Couteur, Colonel, on wheat, ii. 25.

L eicester breed of Sheep, ii. 447.

Lever cheese-press, ii. 330. 
Lever turnip-slicer for sheep, i. 470

Lifting potatoes. time for, ii. 409.

L- by the plow, ii. 410 .

by Lawson's brander, ii. 411.

by the graip, ii. 412 .

Lime, preservation of, i. 137.

preparation of, for the land, i 137 ; ii. 349

quantity for various soils, ii. 350 .

nature of its action, ii. 351.

Liming of land. ii. 349 .

Lind's anemometer, i. 173.

Lindley, Professor, on the Potato, ii. 212.

Linseed, feeding cattle on, i. 516 ; ii. 372 .

- imported into Great Britain, ii. 372.

- expressing the oil, ii. 372.

Liquid-manure drain, i. 120, 152.

- ..- tank. its position, \&c. i. 120 ; ii. 63.

farms where tanks are wanted, ii. 64

expense of the tanks, ii. 65 .

application of, ii 65 .

best cart for, ii. 68 .

cistern and pump for, ii. 69. 70 .

Littering cattle, i. 495.

Littering of sows, ii. 217.

Little, Mr., on the hill-shepherd, ii. 168.

Live-stock, treatment of, i. 13.

importance of attention to, i. 75 .

accommodation for, i. 79 .

their proper position, i. 80 .

providing winter food for, i. 421 . Points of to be culcivated, ii. 427 . symmetry or shape of, ii. 428 . robustness of constitution, ii. 431. early maturity, ii. 432

selection of parents. ii. 433.

breeding in-and-in, ii. 436 .

Crossing, ii. 437 .

examples of Horses, ii. 439.

Cattle, ii. 442 .

Swine, ii. 451

see also Cattle, Horses, Sheep, \&c.

Loam, definition of the term, i. 213.

clay, i 215.

sandy and gravelly, i. 216.

London Veterinary College, i. 43.

Long. Horn breed of cattle, ii. 444.

Loose-box in the stable, i. 96. - its importance, i. 96.

Loudon, Mr., steading arrangement of, i. 125.

Low, Professor, i. 41.

- his arrangement of steading, i. 125.

- theory of irrigation, ii. 73.

\section{M}

M'Ewan, Mr., his drain-plow, i. 383.

Mackey breed of hogs, ii. 8 ,

Machines, reaping, ii. 385 .

Madden, Dr., on the germination of seeds,ii.177.

_ on the nitrate of soda as manure, ii. 189.

- on the fermentation of dung, ii. 191.

- comparison of manures by, ii. 206.

Magnetism, value of a knowledge of, i. 60 .

Malting of barley, ii. 34 .

Man, his susceptibility to social pleasures, i. 77.

Mangel-wurzel, drawing and storing of, i, 431 .

Mangers for cows, form, \&c., i. 100.

supplying with food, i. 100 .

Manures, farm-yard, ii. 180. compost, ii. 184.

artificial and compound, ii. 186-7.

list of these, prices, \&c.. ii. 190.

comparison of various, ii. 206.

bone-dust, ii. 353 .

liquid, i. 152-3.

Mann's reaping-machine. ii. 384 .

Mares, treatment of, i. 545 . management while in foal, ii. 279 .
Mares, treatment after parturition, ii. 280. covering, by the stallion, ii. 280 . points to be cultivated, ii. 441 .

Market, the Cattle, i 527 .

the Sheep, i. 482 .

the Corn, ii. 52.

the Stock, ii. 52.

Sample, ii. 53.

comparison of, ii. 53-4.

frauds in, ii. 54

laws relating to, ii. 56 .

Marketing, winter the season for, i. 76

Marking sheep, and the instruments, i. 479.

Marshall, Mr., on the influence of winds, ii. 247

Marshes, drainage of, i. 320.

Mashes for farm horses, i. 543.

Mason-work of the steading, i. 148,150 .

Mathematics, value of, to the farmer, i. 60 .

Measures for grain, ii. 55, 56.

Mechanics, importance of a knowledge of, i. 60 - application of, to A griculture, i. 18.

Melvin. Mr., on subsoil-plowing, i. 413. on trenching, i. 416 .

Merino sheep, history of, ii. 304.

- ditficuity of fattening them, ii. 302.

Meteorology, value of a knowledge of, i. 61.

Meteorological tables, use of, i. 152.

Mice, prevention of the ravages of, i. $11 \%$.

Mid-Lothian or Currie plow, i. 255.-Detailed description of, i. 267.

Migrations of animals, i. 208.

Milk, churning of, ii. 307

— yield and quality of, ii. 317 .

- its constituents, ii. $317-18$.

___ various kinds, composition of, ii. 318-19.

- coagulation of, for cheese-making, ii. 314 . various preparations for the table, ii. 320 .

Milk-house, situation, \&c. i. 155.

its furnishings, il 306.

- the vessels, and materials, ii. 306. necessity of cleanliness in, ii. 307.

Milking the cow, modes of, ii. 94. vessels for it, ii. 95,96 .

Milking-pail, best form of, ii. 308 .

Mists, phenomena attending, i. 197 .

Mixed farming, i. 68.

in the United States, i. 68.

Moeglin Agricultural Institution, i. 45.

Moisture in land considered, i. 303.

Mole-plow, description of, i 381

formation of drains by, i. 381 .

Moon, effects of its changes, i. 191.

Moor-baud pan, destroying, i. 418. chemical composition of, i. 420 . cause of its injurious effects, i. 420.

Mortar-cart. the Swedish, i 137.

Mould-board of the plow, i. 254 . of the East-Lothian plow, i. 256. Lanarkshire or Wilkie's, i 262 .

- Mid.Lothian or Currie, i. 267

_ nature of its action, i. 274. scientific principles of, i. 278 . formation of, i. 278

- mode of analyzing it, i. 278 .

characters of the various, i. 280 .

mode of constructing, i. 282.

- Slight's new, i 281.

pattern for it, i 284 .

building the block for, i 284 .

Mountain snow-plow, ii. 171

Movable sheds for sheep, i. 456 .

Mucilage of linseed, ii. 372.

Mud-hoe. ii. 63.

Mudie, Mr. Characteristics of Winter by, i. 77 . on Spring, ii. 76 .

on Summer. ii 240

Mutton, modes of cutting up, i, 487. 


\section{N}

Napier, Lord, on the lambing of ewes, ii. 167.

Net for confining sheep, i 444.

tools used in setting up, i. 444

New-Jersey scholars at Ayr, i. 34.

New-England. first catte in, i. 207.

New-York, thermometrical observatiuns at, for 25 vears, i. 209.10. wheat in. ii. 25.

Nitrate of soda as manure. ii. 189.

$\mathrm{O}$

Oats, sowing and culture of, ii. 148 .

varieties of, ii 36,148 .

sowing broadcast. ii. 150 .

drill-sowing, ii. 150.

diseases to which subject, ii. 151.

average crop of: its value, ii. 37 .

weight of straw, grain, \&c ii. 42,382

daily allowance to farm horses, i. 543-4.

quantity consumed, ii 278.

advantage of, to young horses, ii 279 .

grinding, into meal, ii. 37.

natural history of, ii 36 .

classification of. ii. 36 .

chemical constitution, ii. 37

Crop of, in the United States, ii. 38.

Observing and recording facts, i. 210. method to be pursued, i. 211.

Ohio, wheat in, i. 25.

Oil-cake, manufacturing, ii. 372.

feeding cattle on, i. 511 ; ii. 372

machine for breaking, i 514.

advantages, for calving-cows, ii. 85 .

for sheep on turnips, i 452.

box for, i. 453 .

Open ditches, draining by, i. 311.

Osage Orange for bedges, i. 226.

Oxen: see Catlle, of $c$.

Ox-louse, description of, i. 522.

$$
\mathbf{P}
$$

Packing wool, ii. 300.

Painting the steading, i. 146, 151

Parasitic animals infesting cattle, i. 522.

Paring-plow, description of, ii. 124.

Parsnips, drawing, \&c. i. 421.

best varieties. i 441.

Pastoral farming, i. 65.

Pastoral districts of the U. S. i. 65.

Pastoral farms, steading for, i. 123.

importance of shelter, i. 459.

breeds of sheep for, i. 458.9.

drainage of, i. 459 .

management of sheep on, i. 459-60.

stells for, forms of, i. 461-3.

erection of sheep-cots, i. 463

- Hill, i. 464.-Stells for, i. 465,466

Pasturage for cattle, ii. 274

Pasturing and soiling, comparison o ii. 283.

Pea-fowl, treatment of. ii. 23, 234.

Pearson, Mr, drain.plow by, i. 383.

Pea crop in the United States, ii. 41.

Pease, botanical classification of, ii. 40 .

__ average crop, ii. 40 .

- chemical composition, ii. 40.

- uses to which applied, ii. 41.

- their straw, or haulm, ii. 42.

_ reaping and stooking of, ii. 379.

carrying in and stacking, ii. 400-1.

Peat tile drain, how made, i. 377.

Pennock'e improvement on the English sowing. machine, i. 31

- revolving rake, ii. 344 .

Pennsylvania, wheat in, ii. 25.

Pet lambs. rearing, ii. 163.

Physical sciences, importance to Agricalture,i.19
Physickiug horses, i. 565.

Physiology of plants, value of knowledge of, i. 20

Picking hops, ii. 370.

Pickling sced-wheat, objects of, ii 126.

Pigeons, management of, ii. 16, 234.

- houses for them, i. 117 ; ii. 18.

Pigs, management of, ii. 219, 221.

Pig-sties, dimensions, \&c. i. 114.

Pitting Potatoes, ii 413.

_- _ forms of pit, ii. 413-14.

— the conical. ii. 413.

_- the prismatic, or long, ii. 413.

ventilation of these, ii. 414 .

Planting Potatoes, ii. 192

Plants, yeographical distribution of, i. 206.

their respiration, i. 180.

Plaster-work of the steading, i. 145. epecifications, i. 149.151.

Plow, the : its uses. i 245.

- expense of, i. 249

- advantages of iron and wooden, i. 249.

defects of its working, i 249.

remedies for this, $i$ 250.

- proper tempering of the iron, i. 251.

- its early history, i. 253.

- the caschrom. a primitive form of, $\mathbf{i} .253$.

rude kind still in use, i 253.

its gradual improvement, i. 253.

first introduction of Small's, i. 253.

view of its land-side, i. 254.

general description of, i. 255.

its general characteristics, i. 256.

the East-Lothian, i. 255.6.

- the Lanarkshire, i. 255, 262.

its peculiarities, i. 262.

the Mid-Lothian, i. 255.

detailed description of this, i. 267.

its general action, i. 271.

action of the coulter, i. 271.

the share, i. 273

the mould-board, i 274 .

principles and formation of this, i. 279.

its degrees of dranght, i. 285.

Ransome's Bedfordshire, i. 404

the Two-furrow, i. 405.

the Mole, for cutting drains, i. 381.

various others for drain-cutting, i. 382.

the Double Mould-board, ii. 332.

the scuftling or cleaning. ii. 333.

Smith's subsoil, i. 408,418 .

ther subsoil, i. 412

Yoking the horses to, i. 386.

- harness for it, i. 386-7. ordinary weight and cost, i. 387. working with two horses, i. 388. guidance of the horses, i. 389. swing-trees for two horses, i. 390. calculating their strength, \&c. i. 390-1. making the swing-trees of iron, i. 391 swing-trees for three horses, i. 391. and for four, i. 393, 394.

slowness of its improvement. i. 402.

disadvantages of wheeled, i. 402-403.

various makers of, in England, i. 405.

application to lifting potatoes. ii 410.11 .

Plowing, winter the season when done, i. 74.

contrasted effects of good and bad, ii. 178. Ridges, modes of, i. 289, 396

- various breadths of, i 289 .

feering. or striking them, i. 290 .

gathering ap from the flat, i. 292.

casting. yoking or coupling, i. 294.

the gore-furrow, i. 295 .

two-out-and-two-in, i. 297.

inbreak 8, i. 298 .

twice gathering-np, i. 299.

cleaving with and without gore-farrow,, 300 
Plowing, Cross, i. 301.

Angle, how done, i. 301.

Rib, i. 301-2.

Stubble and lea ground, i. 394.

order in which done, i. 395. ways of, and soil, i. 395 .

head-ridges, i. 396.

characteristics of correct, i. 397.

examples of bad, i. 399.

weight of earth turned over, i. 400 .

time occupied by, i. 400 .

Table of time lost in turning, i. 401.

advantage of long ridges, i. 401.

proper length on steep ground, i. 401

chemical changes forwarded by, i. 402.

Deep, advantages of, i. 402.

Shallow, when admissible, i. 402.

Trench and Subsoil, i. 408.

Mr. Smith's plow for, i. $408,418$.

- necessity of previous drainage, i. 410 .

other forms of plows, i. 411.

- advantage derivable from, i. 412. general remarks, i. 419.

Cross, its objects, \&c. ii. 111.

for barley-seed, ii. 174.

for autumn wheat, ii. 416 .

Plowing-matches, advantage of, i. 406. ordinary way of conducting, i. 406. errors in judging, i. 406.

Plowman, duties of, i. 160.

best education for, i. 398 .

wages and allowances of, ii. 46.

Plug-drains, description of, i. 378.

- section of, i. 379.

Plumber-work of the steading, i. 143.

measurement and cost, i. 149, 151.

Plumb-level for the drain-cutter, i. 365 .

Plunger-churn, ii. 326.

Pneumatics, value of, i. 60 .

Poles for hops, ii. 369.

Politics detrimental to the farmer, i. 9.

Pond, the horse, position. \&c. i 136.

- - for sheep-washing, ii. 287.

Pork, pickling of, ii. 10 .

fattening, ii. 8.

see also S'wine.

Posts of field-gates, ii. 260.

Potato, the, mixing with wheat flour, ii. 32.

- - as food for Cattle and Pigs, i. 510,511 ; ii. 6.

Potatoes, preparing dung for, ii. 180, 183.

planting of, ii. 192

plowing, harrowing, \&c. for, ii. 192.

dunging, planting, and plowing in, ii. 194.

width of the drills ii. 199.

best varieties of, ii. 199, 200.

effects of soil on, ii 199.200 .

various modes of cultivating, ii. 201.

harrowing after planting, ii. 202.

Diseases to which subject, ii. 203 .

the curh, ii. 203.

the taint, ii. 203.

natural history of the plant, ii. 205.

classification of, ii. 206.

introduction into Great Britain, ii. 206.

damage done by rooks, ii. 206.

Failure, Prof. Lindley on, ii. 312.

Lifting and Pitting them, ii. 409.

by the Plow, ii. $\mathbf{4 1 0}$.

by the graip, ii. 412 .

storing of, ii. 412.

forms of Pits for, ii. 413-14.

the conical pit, ii. 413.

the prismatic or long, ii. 413 .

necessary precautions against heating,ii.414

comparison with Wheat, ii. 414 .

Cobbett's assertion, ii. 414.

No. persons supported by an acre of, ii. 415 .
Potatoes, Analyses of, ii. 415.

- changes of, by boiling, ii. 415 .

- Starch and Tapioca, manufacture of, ii. 414. average value of the crop, ii. 410 .

Potato-brander, or raiser, li. 411.

Potato-graip, ii. 412.

Potato or drill harrow, the, ii. 210.

Potato haulm, or straw, for manure, ii. 65.

Potato-oat, peculiarities, ii. 148.

Potato-raiser, the, ii. 411.

Potato-8tore, position, \&c. i. 117

Poultry on the steading, i. 115.

_ management of in winter, ii. 13.

- general neglect of, ii. 14 .

- kinds kept on the farm, ii. 14 .

- Hens, ii. 14.

- Turkeys and Geese, ii. 15.

— Ducks and Pigeons, ii. 16.

- Prices of, ii. 16.

how to judge of, ii 17 .

their Houses, ii. 17, 18.

daily treatment, ii. 19,22

food for them, ii. 19, 22 .

— breeding them in winter, ii. 21.

remarks on cramming, ji. 22

uses of their feathers, ii. 23.

Diseases of, ii. 24, 223, 235 .

Indigestion, ii. 223-4.

Shell-less Eggs, ii. 224.

Egg-bound, ii. 224.

Remedies, ii. 224.

Caponizing, ii. 239.

Hatching them, ii. 223, 236.

of Hens, ii. 224:7.

of Turkeys, ii. 227.

of Geese, ii. 230.

of Ducks, ii. 233.

of Pea-fowl and Pigeons, ii. 234.

treatment in towns, ii. 236.

Castrating of. ii. 239.

Poults, management of, ii. 229.

Practical Agriculture, teaching, i. 35, 46.

Practical Husbandry, learning, i. 28.

- necessity of attention, i. 29

- commence in youth, $i .34$.

Presser-roller, objects of, ii. 136. described, ii. 146.

Produce, transporting, by steam, i. 67 .

Profit from draining, i. 375 .

Pulling flax and hemp, ii. 365.

Pulse of the horse, i. 566

Pulse crops: see Beans, Pease, \& $c$.

Punching-nippers, for marking lambs, ii. 296. mode of using, ii. 296.

Pupilage, time for commencing, i. 70.

_ first employments, i. 71.

\section{Q}

Quadrangular steading, origin of, i. 125.

Quarter-ill, a disease of cattle, ii. 277. treatment of, ii. 277 .

\section{$\mathrm{R}$}

Rain, appearances of, i. 186.

_- causes of its fall, i. 186

_ Tables of quantities, \&c. i. 187.

- connection of, with winds, i. 190.

_ effect of the phases of the Moon, i. 191.

- foreign matters brought down by, i. 191.

Rain-water, cistern for, i. 134.

Rain-guage, description of, i 174. mode of using, i. 174

Rake, the hand hay, ii 343 .

— the American horse, ii. 344.

- the stubble, ii. 388 .

- Pennock's revolving horse, ii. 344.

Rams, separate feeding of, i. 45\%. 
Rams, serving the ewes by, ii. 404 .

Kansome, Messrs., plow improvements, i. 403.

- their F F or Bedfordshire plow, i. 403.

Rape, feeding sheep on. i. 455.

Rats, prevention of their ravages, i. 117.

Read ings. agricultural, i, 4\$1.

Reaping of grain, importance, \&c. ii. 373.

proper ripeness of the crop. ii. 375 .

Ur. Hanuam's experiments, ii. 382.3 .

superintendence of the reapers, ii. 376 .

mode of cutting with the scythe. ii. 376 .

arrangement with the workers, ii. 37 7.

Gaits, formation of, ii 378

Rye, Beans, and Pease. ii. 379.

and Mowing contrasted, ii. 379.

greater cheapness of Mowing, ii. 379.

other advantages, ii. 380 .

proportion of straw, grain and roots, ii. 381.

Reaping machines: ii. 384-6.

__ Smith's, ii. 334

—-Bell's, ii. 384.

- Mann' 8 , ii. 384.5 .

- compared with hand-reaping, ii. 385 .

Reaping-sickles, forms of, ii. 3856 .

Reaping-scythes, ii. 386.

Rennet for cheese-making, ii. 314.

Rennie, Prof., on Irrigation, ii. 73.-The proper theory, ii. 74.

Repairing fences, ii. 259.

Respiration of plants, effect on the air, i. 181.

Ribbing, plow for, i. 302.

mode of executing, ii 125.

Ricks, hay, building of, ii. 338 .

Ridges, modes of plowing, i. 289

- different breadths of, i. 289.

- mode of feering. i. 290.

gathering-up from the flat, i 292.

casting, yoking or coupling, i. 294.

the gore-furrow, i. 295 .

two-out-and-two-in, i. 297.

inbreaks, i. 298.

twice gathering-ap. 299.

cleaving with and withont gore-furrow, i. 300 .

cross-plowing, i. 301.

angle-plowing, i. 301.

rib-plowing, i. 302.

Ring for the tull, ii 297 .

the fixing of it. ii. 298.

River-water, peculiarities of. i. 135.

Roberton, Mr., preparing stones for drains, i. 354 .

- on the relative expenses of drainage, i.383.

Robustness of constitution: see Live \$tock.

Roller corn-bruiser, i. 561.

Roller, Crosskill's clod-crushing, it. 352. common, forms, and materials for, ii 146

Rolling after sowing, ii. 132. grass-fields, ii 259.

Rolling, storing and packing fleeces, ii. 298.

Roosting-places for fowls, i. 115.

Ropes, rein, ii 391.

- for the cart, ii 392.

Roping for stacks, varieties of, ii. 396-399.

Rot in sheep, i. 477 ; ii. 408.

alleged cure of, by salt, i. 453

Rotherham plow, i. 253.

Roville agricultural institution, i. 47.

Rusky, or seed-basket, ii 128

Rye, botanical classification of. ii. 38 .

- chemical composition of, ii. 38.

- its straw, ii 42 .

— manure for, ii. 39.

- reaping of, ii 379 .

Rye crop of the United States, ii. 38.

Rye-grass, cultivation for seed, ii 336 .

- Italian, peculiarities of, i. 22.

\section{S}

Saddle-horses, treatment of, i. 562 breaking-in, ii 359 .

proper age, ii. 360

Salt. for the rot in sheep, i. 453 mode of parifying, ii. 312

Salting butter, ii 311 .

Sample grain-market, ii. 52 -Advantages and disadvantages, ii. 52-3.

Sandy soils, definition of, i 215.

- loams, i 216

Scab in sheep, treatment of, i 457 .

Scarsement on hedge-bank, i. 240.

Scarifier or grubber, ii 207.

- Finlayson's ii. 207.

- Kirkwood's, ii. 209.

- the common Drill, ii. 324. Wilkie's, i. 335.

Schools, Agricultural, i. 25. 41, 42.

Sciences, the Physical, and Agricalture, i. 15. _ value of, to the farmer, i. 59.

Scoop, the bog-drain. i. 322.

the earth drain, i. 352.

Scot. Mr., on larch tube draining i. 382.

Scotland, Agricultural Sóciety of, i. 25.

Scott. Mir , on feeding horses, i. 548.

Scuftling.plow, ii 333.

Scythe, the patent, for hay, ii. 282.

cutting grain with the, ii. 376 .

—_ advantages over the sickle, ii. 379 . various forms of, ii. 376.386 .

Seasons, fall of rain in the, i. 189.

- the Agricultural, i. 15, 16.

Sea-ware for manure. ii 66 .

- — its composition, ii. 67.

- way in which applied, ii. 67.

Sea-water, freezing of. i. 196.

Seed-wheat, preparation for sowing, ii. 126.

- choosing, ii. 28.

- marks of good, ii. 28.

_ preparation for autumn-sowing,ii.418. eaving effected by dibbling. \&c..ii.419. process of germination in, ii. 421.

Seed-basket, the English. ji. 128.

Seeds, germination of, ii. 177.

- necessity of water and air, ii. 177-8.

- effects of good and bad plowing, ii. 178 . effects of good and bad sowing, ii. 178.

Selection of parents in breeding live-6tock ii. 433.

Selles. Marcel de, on the Migration of Animale, i. 208 .

Shallow plowing, when admissible, i. 402.

Share of the East Lothian plow, j. 256, 259.

- of the Lanarkshire, i. 262, 264.

- of the Mid-Lothian, i. 267, 269.

nature of its action, i. 273.

Shearing sheep, ii. 289 .

Shed for carts. form. \&c i. 114.

Sheep. providing winter food for, i. 421. cost of feeding on tarnips, i. 436.

Turnip-slicers for, i. $470,472,475$.

Diseases in Winter, i. 476.

in Summer, ii. 297.

in Autumn, ii. 408.

Parging, i. 476.

Parasites, i. 476.

Scab, i. 477 .

Foot-rot, i. 477.

Wildfire, i. 477.

Braxy, i. 477.

Scald.head, ii. 297.

Rot, ii. 408.

Pining, ii. 409

Feeding. on tarnips, i. 442

on rape, i 455 .

the ewes in lamb, i. 454. 
Sheep, Hurdles for confining, i. 443.

Nets, and setting them up, i. 444. precaution to be observed, i. 446. selection for putting on turnips, i. 447. explanation of names given them, i. 448 . straw or hay rack for, i. 449.

turnip-trough for, i. 450 .

mode of arranging, \&c. on turnip-field,i.451.

separate feeding of the tups, i. 452. oil-cake or grain-box for, i. 453,476 .

alleged beriefit of salt, i. 453 .

shelter for, while on turnips, i. 455.

movable sheds for. i. 456-7.

fixed sheds at the steading, i. 457.

advantages of these modes, i. 457.

breeds for different localities i. 458.

on pastoral and hill farms, i. 460 .

various forms of Stells for, i. $461,463,465$.

Driving and Slaughtering, i. 478.

best time for driving, i. 478.

way of marking. i. 479.

proper length of day's journey, \&c. i. 480.

qualifications of the drover, i. 481.

Marketing them, i. 482.

rules of the market, i. 482.

deposition of fat on, i. 483 .

judging of their condition, i. 484.

Slaughtering them, i. 486 .

modes of cutting up, i. 48

merits of the various parts, i. 488.

characteristics of the Hlesh, i. 489.

best age for killing, i. 489-90.

kinds preferred at different markets, i. 490.

shipping them to cities, i. 490 .

superiority of steam conveyance for, i. 491.

Meat and Offal, quantity of, i. 492.

loss sustained in cooking, i. 492.

curing into Hams, i. 492.

preparation of the Suet, i. 493.

uses of its parts, i. 493.

constitution of its skin, i. 494

Grazing of, ii. 274.

Feeding them in Summer, ii. 285.

Washing them, ii. 287. pool for it, ii. 287-8.

Shearing them, ii. 289-93.

appearance of, when new-clipped, ii. 294 .

Weaning the Lamb. ii. 295.

Marking and buisting them, ii. 296.

Management of, in Autumr, ii. 403.

Drafting ewes, \&c. for sale, ii. 403-404.

Tupping of the ewes, ii. 404.

Total number of, in Great Britain, ii. 304.

the Merino breed, ii. 304 .

Points to be cultivated, ii. 447.

examples of these, ii. 448 .

the Leicester. ii. 448.

the Cheviot, ii. 449

the South-Down, ii. 449.

the Black-faced, ii. 450 .

Sheep-cots, disadvantages of, i. 463 .

Sheep-farms: see Pastoral Farms.

Sheep-flakes, making of, i. 466.

Sheep-hurdles, making, i. 443, 467.

- - Betting up. i. 468.

Sheep-nets, working of, i. 470.

Shelter, importance of, i. 243, 458. advantage of, in grazing, ii. 276.

Shepherd, duties of the, i. 161 .

his general qualifications, ii. 168 . ordinary wages and allowances, ii. 49.

duties in the lambing-season, ii. 155. the skillful and the unskillful, ii. 155 . number of ewes he can attend, ii. 167. the Hill, qualifications of, ii. 168.

Shepherd's crook, uses of, ii. 164.

Shepherd's dog, training, \&c. ii. 172.
Shepherd's dog, varieties of, ii. 173.

instruction of, ii. 174.

Shirreff, Mr. on the Potato failure, ji. 204

Shoeing draught-colts, ii. 216.

Shoulder-drain, the, i. 378.

Shovel, the ditcher's. i 231 .

- the broad-mouthed, i. 321.

- the lime or frying pan, i. 356 .

Sickle, forms of, ii. 385-6.

Sinclair, Sir John. breeding stock in his time, i.65

Skinner breed of hogs, the, ii. 9 .

Slating of the steading, i. 143.

- specifications of, cost, \&c. i. 151.

Slaughtering cattle, i. 486.

sheep, i. 532

Slight. Mr., his new mould-board, i. 284.

Slinking or slipping the calf, ii. 86 .

_- its causes, ii. 86.

- prevention of it, ii. 87 .

Small's, or East-Lothian plow, i. 253-256.

Smith. Mr., his subsoil plow, i $408,418$. his reaping-machine, ii. 384 .

Smith-work of the steading, i 149, 151.

Smithy, advantage of, on the steading, i. 121.

Snow, nature of, i. 192 .

- its various forms, i. 192

- storms during spring, ii. 76

Snow-harrow and plow, ii. 171.

Sock of plows: see share.

Sod-draining, i. 380.

—— tools used for. i. 380 .

Soiling and pasturing cattle, ii. 283.

Soils and subsoils, i 213.

- importance of an acquaintance with, i. 213

- Characters of the different, i. 214-216.

the pure clay. $i$. 214.

- the sandy clay, i. 215.

- the clay-loam, i. 215.

— the pure sand, i. 215.

— the gravelly, $\mathrm{i} 216$

- sandy and gravelly loams, i. 216 .

- Definition of, i. 217

- effects of the subsoil on the soil, i. 217 .

- Terms applied to them, i. 218.

—. their colors, i. 219.

- geological relations, i. 220, 221.

- agencies by which produced, i. 220. causes preventing accumulation, i. 221.

scientific definition of, i. 222.

mechanical analysis of. i. 223.

Stones in, their purposes, i 223.

Chemical constituents, i 224.

Liebig's analyses of, i. 225.

Sole-shoe of Small's plow, i 260.

- - of the Lanarkshire, i. 265. of the Mid-Lothian, i. 269

South-Down sheep, ii. 449.

Sow, farrowing, ii. 217.

— sty for her, ii. 218.

- necessity of attending in parturition, ii. 219.

— food for her after it, ii. 220 .

- Diseases of ; treatment, ii. 221.

- number to be kept on the farm, ii. 222. Insects infesting, ii. 13.

Sowing spring-wheat and grass-seeds, ii. 125. of oats ii. 148

of barley seed, ii. 174 .

by drill, i 150 .

by hand, how done, i. 130

effects of good and bad on seed, i. 179

of Turnips, mancel-wurzel, \&c. ii. 252.

Sowing-sheet and basket, ii. 129.

Sowing-machine for grass-seeds, ii. 134.

- for grain, ii 142.

_ - in the United States, i. 31.

Pennock's improved, i. 31 .

Sown and natural grasses compared, ii. 336. 
Spade, the narmw drain, i. 352.

- the dang, ii. 61 .

Spaying, effect of, ij. 107.

Spottiswoode. improvement of by draining,i.3 5

Spirit-level, nses of, i. 362 .

Spring and $W$ inter: contrasted, ii. 76.

the weather during. ii. 77-8.

farm operations of, ii. 79 .

Spring wheat, selection of, ii. 137.

- - sowing with grass seeds, ii. 125.

— preparing the land for. i. 126.

- preparation of the geed, ii. 126.

Spring-water, impurities of, i. 135.

Springe, origin of, i. 313.

- on a uniform surface. i. 313.

- on a varied ditto, i. 314 .

appearances of soil, explained, i. 307.

Stable-forks, i 543.

lantern, i. 544 .

Stables for work-horses, i. 90.

- proper flooring for, i 93.

— roofing and ventilating, i. 95.

for riding-horses, i. 96.

the windowa, i 105.

should be dry, i 98 .

Stacks, thatching of, ii. 393

- roping, modes of, ii. 394.

Covering in wet weather, ii. 399.

Stack-5ard, position, \&c. i. 80.

- - arrangement of, i. 116.

Stacking grain, ii. 389 .

_ stathels for, i 116 .

- stools for, ii 390 .

building the stacks, ii. 390 .

Stallion and the mare, ii. $₫ 80$.

points to be cultivated, ii. 440 .

Stalls for the work-horses, i. 94, 199.

for cows, i. 99.

Starch, manufacture of, ii. 33.

Stathel for stacks, ii. 116.

Steading, description of, i. 78.

- best situation for, i. 78 .

should be complete, i. 79 .

causes of defects, i. 81.

- description of these, i. 82 .

- ground-plan of, i. 83.

- a proposed, i. 84.

- advantages compared, i. 85.

- importance of draining, i. 118.

-. modifications of, i. 121.

- beet mode of contrasting, i. 122.

for pastoral farms, i. 123

- 8 carse farm, i. 124.

- a dairy farm, i. 124.

- origin of the quadrangular, i. 125.

- specifications connected with, i. 126.

- digging its foundations, i. 128.

- the walls. i. 127.

- the doors, corners. \&c. i. 127.

- outside walls, and stairs, i. 129.

the floors, i. 129.

supply of water. i. 134

building-stone for, i. 136.

its wuod-work, i 138.

- kinds of wood employed, i. 140.

- the plumber-work, i. 143.

- slating, i. 143.

- plastering, i. 145.

glazing, i. 146.

—_ measuring, i. 146 ,

Steam, facility of transportation by, i. 67.

Steam-engine, position, \&c. of, i. 89.

Steaming apparatus for turnips, \&c. i. 555.

Steeping flax, ii. 366 .

Stells, various forms of, for sheep-farms, i.461, 465 - with bay-racks, i. 465.
Stephens, Geo on irrigated meadows, i. $\mathbf{7 1 - 7 5 .}$

Stephenson, Mr., on feeding cattle i. $\mathbf{5 1 9}$.

Stew ard, duties of, i. 159.

- wages of, ii. 49.

Stock grain market, ii. 52

- advantages and disadvantages of, ii. 53.

Stone for the steading, i. 136

Stone cheese-press, ii. 329 .

Stone-ducts in drains, i. 333

Stone-dykes, building of, ii. 353.

- openings in, ii 357 .

Stones, removing them from fields, ii. 259.

Etoole for stacks, making, i. 116 ; ii. 390

Store for turnips, i. 111.

- for potatoes, i. I17.

Store-farming: see Pastoral Farms.

Storing potatoes, ii $\mathbf{4 1 2 .}$

— turnips, cabbage, \&c. i. 421, 429. of wool, i. 299.

Stathaven, fattening calres in, ii. 105.

Straw. composition of Wheat, i. 41.

- Barley, ii. 42.

Oat and Rye, ii. 42.

Pease and Beans, ii. 42.

composition of, ii 43.

inattention usually paid to, ii. $\mathbf{4 3 . 4}$.

importance of its right management, ii. 14 .

its value, ii. 44 .

- quantity of different crops, ii. 45.

Straw-barn, position of i. 80 .

Straw-cutter, forms of. i. 549

— the Canadian, i. 550.

— - the Cylinder, i. 551. the Disk, i 555 .

Straw-racks, forms of, i 110.

—— iron, i. 111.

Straw-ropes, twisting, ii. 401-2.

- Implements for, ii. 402.

Street-manure, ii. 207.

- and stable dung, ii. 207 .

Stubble ground, plowing, i. 394. different ways of, i. 395.

Stubble-rake, the hand. ii. 388.

Student, hints to, i. $9,10,17,18,22,74,77,192$.

Sty for gwine, i. 114.

- for the brood-sow. ii. 218

Subsoil, definition of, i. 217.

- effect on the soil, i 217. see also Soils.

Subsoil-plowing, its objects, i. 408.

- Smith's plow for it, i. 408, 418.

—— not always good, i. 410.

- when injurious, i 410.

- other plows for it, i. 412.

- proposed modification, 412.

-

—- compared with trenching, i. 416. general remarks, $i, 419$.

Summer, characteristics of. ii. 240

- phenomena of, ii. $240-1$.

- state of the weather, ii. 255-6.

farm-work during, ii. 248.

Summer-fallowing, ii. 346.

soils requiring, ii. 347 .

nature of its action, ii. 351 .

Surface-draining, i. 315.

Saters for plug-draining, i. 379.

Swedish mortar-cart, i. 137.

Swedish turnips, oowing, \&c. ii. 251.

Swine, driving and slaughtering, ii. 5.

- trestment of the pigs, ii. 6-7.

- cooked vs raw food for, ii. 6 .

— best food for, ii. 6 .

- times to be fed, ii. 7 .

- names at different ages, ii. 7-8. judging of their condition, ii. 8 
Swine, troughs for them, ii. 9, 10. Slaughtering, ii. 10. cutting up, ii. 11.

— loss of flesh in cooking, ii. 11. digesting their flesh, ii. 11. pickling, ii. 11.

curing the hams, ii. 11. composition of the Fat, ii. 12. uses of do., ii. 12.

the skin, bristles, \&c. ii. 12 .

experiments in feeding, ii. 12.

Diseases of, ii 12.

Insects infesting, ii 12, 13.

points to be cultivated, ii. 431,452 .

examples of this, ii. 452 .

in America, ii. 5, 8.

Mackey breed of, ii. 8 .

the Skinner breed, ii. 9.

American treatment of, ii. 219.

their usefulness ii. 219.

food for, ii. 219 .

Swing-trees for the plow, i 390. for two horses, i. 390.

for three, i. 391. for four, i. 393, 394.

Symmetry of live-stock, ii. 428.

Sympiesometer, its uses, i. 168.

\section{$\mathrm{T}$}

Taint in potatoes, ii. 203.

Tank for liquid manure, i. 119.

- cost, \&c. of, i. 119.152; ii. 65.

— farms where required, ii. 64 .

- manure, De Rham on, i. 153.

Tar manufacture, i. 142.

importation of, i. 142.

Tartarian oat, ii. 148.

Tedding-machines described, ii. 337.

- the English, ii. 342.

Teeth of domesticated animals, ii. 452.

- indications of age from, ii. 453.

- of the Horse, ii. 453.

- in the Ox, ii. 454 .

__ in the Wild Boar, ii. 454

Templemoyle, Agricul. Seminary at, i. 41.

Ten-hour system of labor, i. 541.

Thaër, Von, his School at Moeglin, i. 46.

Thatching hay-stacks, ii. 339.

- corn-stacks, ii. 394.9.

Thermometer, the i. 168

- history and uses of, i. 169.

- the self-registering, i. 169.

Thermometrical observations, i. 209.

Thorn-hedges, planting of, i 226.

- season for, i 227 .

— how made, i. 228.

__ implements used for, i. 228-30.

_ choosing the plants, i. 230.

— planting in the shrubberies, \&c. i.๙1:. turf-fences to, i. 242-3. see also Hedges.

Thorough-draining, objects, \&c. i. 322.

- - - depths of drains, i. 333.

—_ necessity of ducts, i. 337. the main drains, i. 339

— - the small drains, i. $342,343,352$.

- distance between drains, i. 345,367 .

_ t the run of the drains, i. 347

—- cutting them, i. 351

—_ tools used for, i 351

—- filling them in, i. 353 .

— materials used for, i. 353-4.

— - preparation of stones for, i. 353

- a stone-drain, dimensions. \&c. i. 357-8.

—— the sub-main drains, i. 367.

—a tile and sole drain, i. 371 .

— plan of a thorough-drained field, i.372.
Thorough-draining, the tiles for, i. 359.

- Examples of profit of, i 375.

the flat stone drain, i. 377.

the peat-tile, i 377 .

the clay-land shoulder, i 378 .

the plug or wedge, i. 379 .

the sod drain, i. 380 .

by the mole plow, i. 381 .

with larch-tubes, i. 382.

with brushwood, i. 382

durability of brick, i. 382 ,

cutting, with the plow, i. 383 .

Principles on which necessary, i.384.

Threshing, by the hand flail, ii 345 .

Threshing-machine, i. 80. position, \&c. of i. 80 .

Throw-crook, ii. 395. description of, ii. 402 .

Thunder-storms, ii. 242.

their prevalence in Summer, ii. 252.

Tile-draining, i. 359.

the ducts. i. 338.

—_ the main drains, i. 339.

the small drains, i 342,352 .

the main-drain tiles, i. 359.

- necessity for the sole, i 359 .

- size and form of tiles, i. 360 .

- number on an acre, i 361 .

- junction of the tiles, i. 362 .

laying them down, i 363 .

fixing and covering i. 365 .

size of the tiles, i. 368 .

soles for small drains, i. 368.

laying these down, i. 368.

flling the drains, i. 369.

—_ view of a tile drain completed, i. 371.

- - - see Draining, Thorough Drain. ing, \&c.

Tiling of roofs, i. 134.

Timber, preserving from dry-rot, i. 141.

proper season for felling, ii. 76 .

Training and working the shepherd dog, ii. 172

Transplanting, sowing wheat by, ii. 419 .

Transporting produce by steam, i. 67.

Treatment of domestic animals, i. $\mathbf{5 4 0 .}$

Trees for hedges in America, i. 227.

Trenching with the spade, i. 408.

- early use of the spade, i. 408

- substitution of the plow, i. 408 .

Trenching, objects, \&c. 1.414.

- with the spade, i. 414.

- expense of it, i. 415 .

with the plow, i. 415.

- effects on the soil, i. 416.

- compared with subsoil-plowing, i. 418. advantage derived from, i. $\mathbf{4 1 9}$.

Troughs for pigs, ii. 9, 10.

- turnip, for cattle, i. 110.

water, i. 111

Trowel, for laying tile-soles, i. 364

Tups, separate feeding of, i. 452 .

serving the ewes by, ii. 404.

Turkeys, management in winter, ii. 15.

- management while hatching, ii. 227.

treatment of the young, ii. 227 .

Turnips, preparing dung for, ii. 183. sowing of, ii. 250-2.

- preparation of the ground for, ii. 250. plowing, dunging, \&c. ii. 250-1.

best varieties of, ii. 251 .

drill and broadcast sowing of, ii. 252.

raising them by bone-dust, ii. 253 .

store for, i. 111

position of the store, i. 111.

proportions to be eaten, i. 423.

- stripping the ground of, i. 424. carting them, i. 427-8. 
Turnips, pulling, topping and tailing, i. 425.

best weather for removing, i. 428 .

the triangular store, i. 430 .

filling and covering it, i. 430 .

other ways of storing, i. 430.

Varieties of. i. 43:2.

the White Globe, i. 432 .

the Yellow, i. 433.

the Swedish, i. 434.

- remarkable Crops, i. 434.

- superiority of the Swedish, i. 43.5 .

- specific gravity of the different kinds, i. 436

- nutritive matter of, i. 436.

—- ordinary prices per acre, i. 436.

hybrid varieties, i. 437 .

protection of during snow, i. 437.

illustrations of badly formed, i. 438.

- Number of roots per acre, i. 439.

examples of heavy crops, i. 440.

their History, i. 440.

introduction and cultivation, i. 440.

feeding sheep on, in winter, i. 440.

best form of picker, i. 442 .

Trough, for sheep-feeding, i. 450.

Slicers, i. 470, 473. 475 .

Feeding Cattle on, i. 495.

- wire-basket for, i. 499.

- slicing and cleaning, i. 503 .

Turnip-drill, history of, ii 258.

Turnip-picker, i. 450 .

Turnip slicers for sheep, i $470,473,475$. for Cattle, i. 511.

Turnip-stemmed cabbage, i. 441.

Turnip-troughs for Cattle, i. 110.

- for Sheep. i. 450 .

Turn-wrest snow-plow, ii 171.

Tutors, agricultural, i 40 : see $\mathrm{Ag}$. Schools.

Two-furrow plow, i. 405.

Twisters of straw-ropes, ii. 402.

U

Udder of the cow, ii. 98.

structure of, ii. 98-9.

Diseases of, in Summer, ii. 277.

United States, mountain ranges of, i. 65. grazing districts of, i. 65 . mixed farming in, i. 68.

iron on farms in, i. 97

climate of, i. 198.9.

Grain produce of, ii. $25,34,38,41$.

Laboring population of, ii. 45 .

Applicability of the Book of тие FARM to: see Book of the Farm, Observations of Am. Ed.

Upper-barn, plan, \&cc. i. 106.

\section{V}

Vapor, quantities of, in the air, i. 187.

Vegetation as a source of electricity, i. 180.

Ventilators for the stable, i. 95.

Vermin, preserving barn-floors from, i. 88.

Veterinary Colleges, i. 43. the London, i. 43. the Edinburgh, i. 43

Von Thaër, M. agricultural institution of, i. 45 .

\section{W}

Waddell, Mr. construction of floors by, i. 129.

Wages of farm-servants, ii. 45.

of the plowman, ii. 46.

when living in bothies, ii. 47-8

of the steward and shepherd, ii. 49.

of the hedger, ii. 49 .

of the cattle-man, ii. 49.

of the field-worker, ii. 50.

W alton, Mr. on breeding the Alpaca, ii. 451 .
Walker, Mr.experiments in feeding cattle, i.517 on feeding pigs, ii. 12

Warnes, Mr. mode of teediug cattle, i. 516 .

Washing sheep, ii. 286-7.

W ater, supply of, for the farm, i. 132.

- causes and cure of its hardness, i. 135.

supplying cattle with, i. 112.

great expansion, when freezing, i. 196.

agency of, in forming soils, i. 219.

- preventing its lodgment, i. 238.

- sources of superfluous, i. 313.

effect on germination, ii. 173.

Water-furrowing, ii. 136 .

Watering-pots for stock, ii. 275 .

$\longrightarrow$ mode of constructing, \&c. ii. 275,358 .

W ater-meadows, management of in winter, i.71

Weaning calves, ii. 266, 270.

Weather, instruments for indicating, i. 165-174

- the Barometer, i. 166.

- Sympiesometer, i. 168.

Thermometer, i. 168

- Hygrometer, i. 171.

Weathercock, i. 172.

Anemometer, i. 173.

Rain-guage, i. 174.

indications from the Clouds, i. 175-80,

agency of electricity, i. 180.

indications of from the Aurora Borealis, i. 185 .

other atmospheric phenomena. i. 185.

- in Winter, general uncertainty of, i. 76 .

- in Spring, ii. 76.

- in Summer, ii. 240.

in Autumn, ii. 363.

Wedge er plug draining, i. 378.

Wedgewood's table-churn, ii. 323.

Weighing wool, ii. 300 .

Weight of fat oxen, rules, ii. 267. fallacy of these rules, ii. 269.

Wells, Dr. his theory of dew, ii. 242 .

Wells, sinking of, on the farm, i. 132.

West Highland ox, ii. 445.

Wheat, spring, sowing of, ii. 125.

classification by the ear, ii. 26 .

by the grain, ii 27.

—_ judging of quality, color, \&c. ii. 28.

kinds for various purposes, ii. 28.9 .

the best for seed, ii. 28 .

detection of damaged, ii. 48-30.

preserving in grauaries, ii. 28.

grinding of, ii. 29.

- flour and bran, ii. 29.

- chemical composition, ii. 31.

- microscopic structure, ii. 32 .

- nutritive matter in, ii. 33 .

__ manufacture of Starch from, ii. 33.

- Straw of, ii. 41.

— Varieties of, ii. 137.

Cutting, i. 17 ; ii. 382.

- Prof. Johnston on the Gluten of, i. 31.

- proper ripeness for cutting, ii. 382 .

— Cutting of, ii. 373.

_ Carrying in and Stacking, ii, 388.

—W eight of Grain. Straw, \&c. ii. 382.

Autumn, sowing of, ii. 416. plowing, dc. the land, ii. 416-17.

— various modes of this, ii. 417 .

- preparation of the seed, ii. 418 .

— sowing by dibbling, \&c. ii. 419

— and by transplanting, ii. 119.

- expense, and saving of seed, ii. 420 .

Wheeled the process of germination, ii. 421.

durnip-slicer, for sheep, i. 473

Wildfire, a disease in sheep, i. 477. trealment of, i. 477 
Wilkie's drill-grubber and harrow, ii. 335. horse-hoe, ii. 336 . plow, i. 255, 262.

Wilson, Dr. on Drainage, i. 375.

W indows for stables, i. 105. for byres, i. 105.

for the granary, i. 107

- Winds, relation of to rain, i. 190. influence on weather in Summer, ii. 246.

Winsboro',Gov., and the cattle of N.Eng'd.i 207 Winter, farm operations in, i. 74.

- importance of these, $\mathrm{i} 74$.

- uncertainty of weather in, i. 76 . arrangement of field-work, i. 301. wheat, sowing, \&c. ii 416.

Wire field-gates, ii. 265. turnip-basket, i 499.

Womb of the cow, the, ii. 84

Wood, Kyanizing, i. 141.

Wood floor for the corn-barn, i. 87. advantages of, i. 87 . preserving it from vermin, i. 88

Wood-paving, advantages of, i. 130.

- various kinds, i. 130.

- comparative expense, i. 131.
W ood-work of the steading, i 138.

Wool, washing, ii. 298 .

clipping, ii. 298

storing, weighing. \&c. ii. 298.

qualities of, ii. 301 .

effects of fattening on its quality, ii. 302.

chemical analysis of, ii. 303 . microscopic examination, ii. 303.

causes of its felting, ii. 303-4.

Wool-room, plan and description of, i. 106-7

Wool-shears, ii. 289.

Working the shepherd's dog, ii. 172. Y

Year, agricultural, divisions of, i. 15.

Yeast for baking, ii. 31.

Yoking horses to the plow, i. 386. the young draught-colt, ii. 215. to the cart, ii. 216

Youatt, Mr., observations on wool, ii. 303

$$
\mathrm{Z}
$$

Zinc, employment for ruofing, i. 143.

Zones of the earth, the. i. 201.

Zoölogy, value of a study of, i. 61 . 





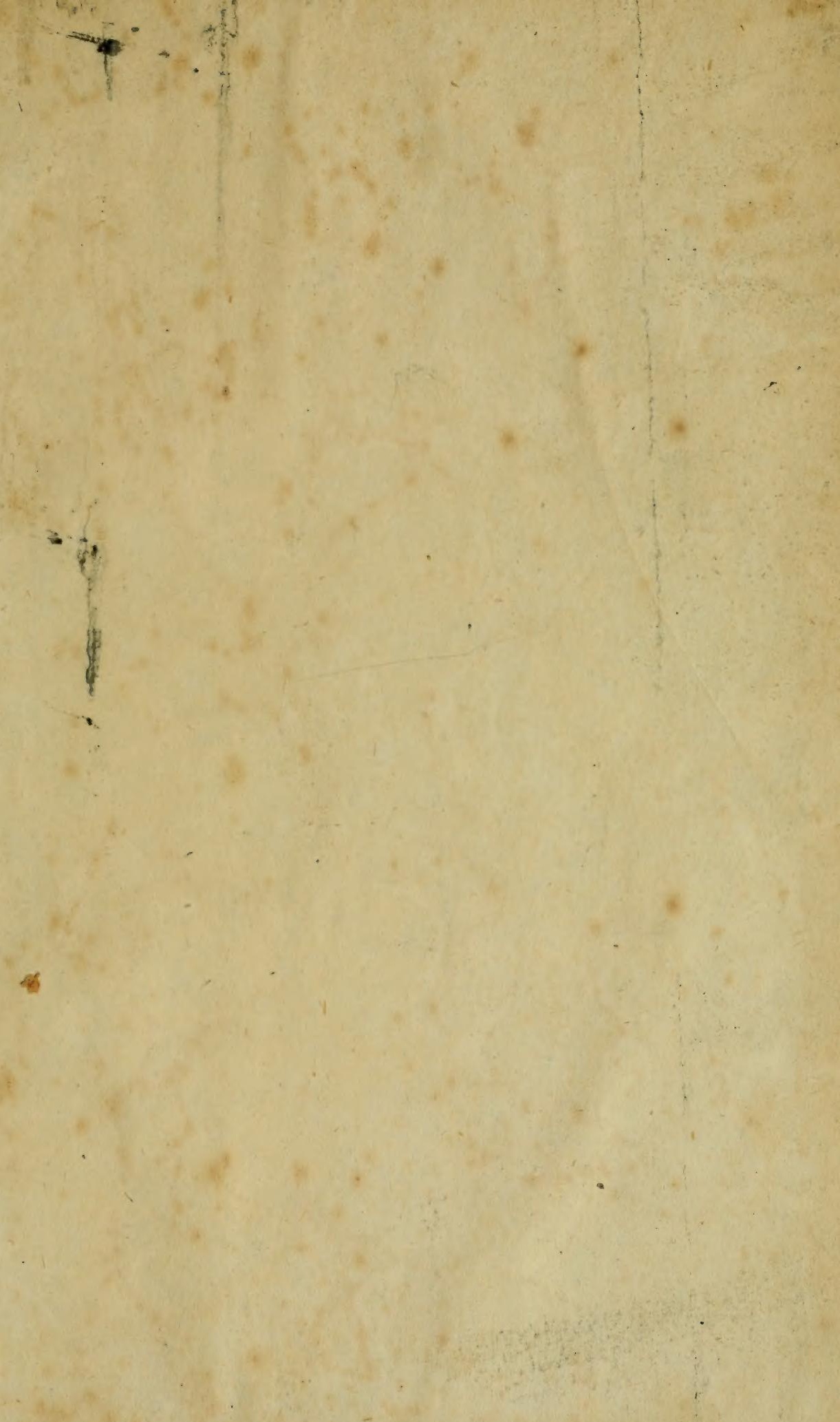




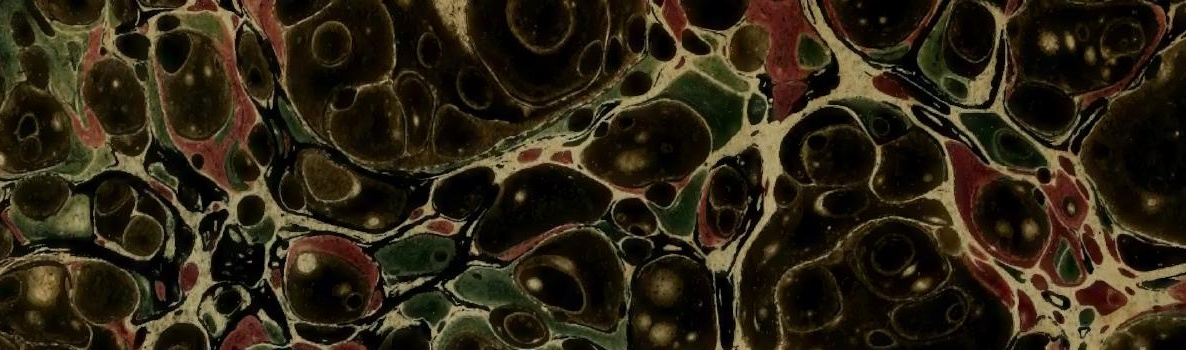

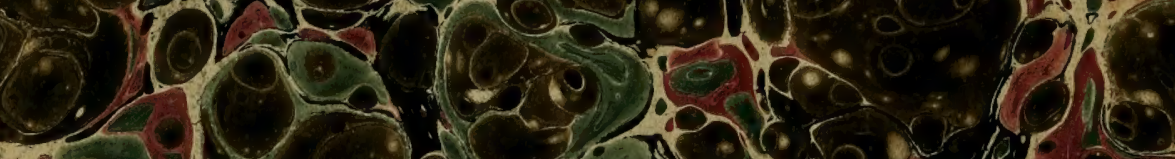
al. al os o 02 (5) 15.

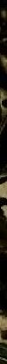

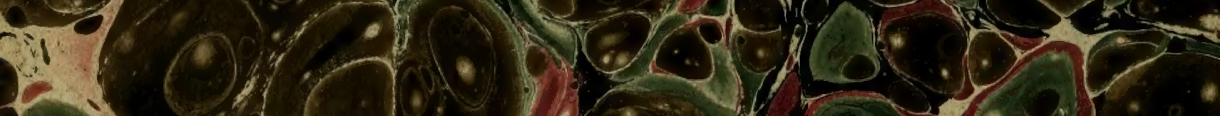
(1) 


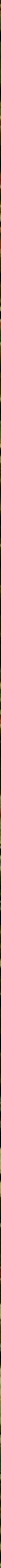



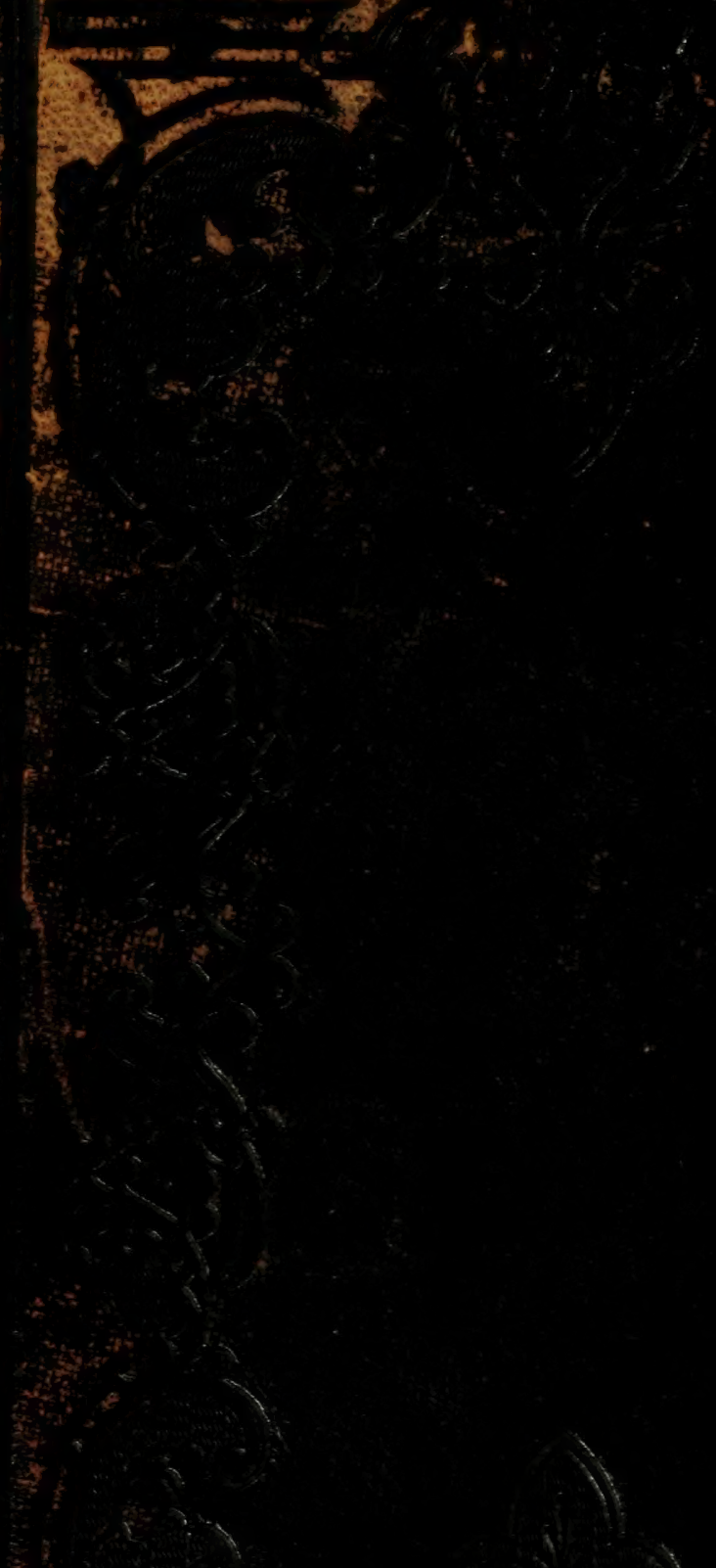